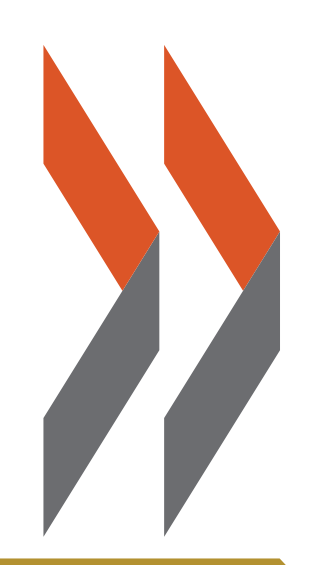

\title{
PISA 2012 Results: What Students Know and Can Do
} STUDENT PERFORMANCE IN MATHEMATICS, READING AND SCIENCE VOLUME I

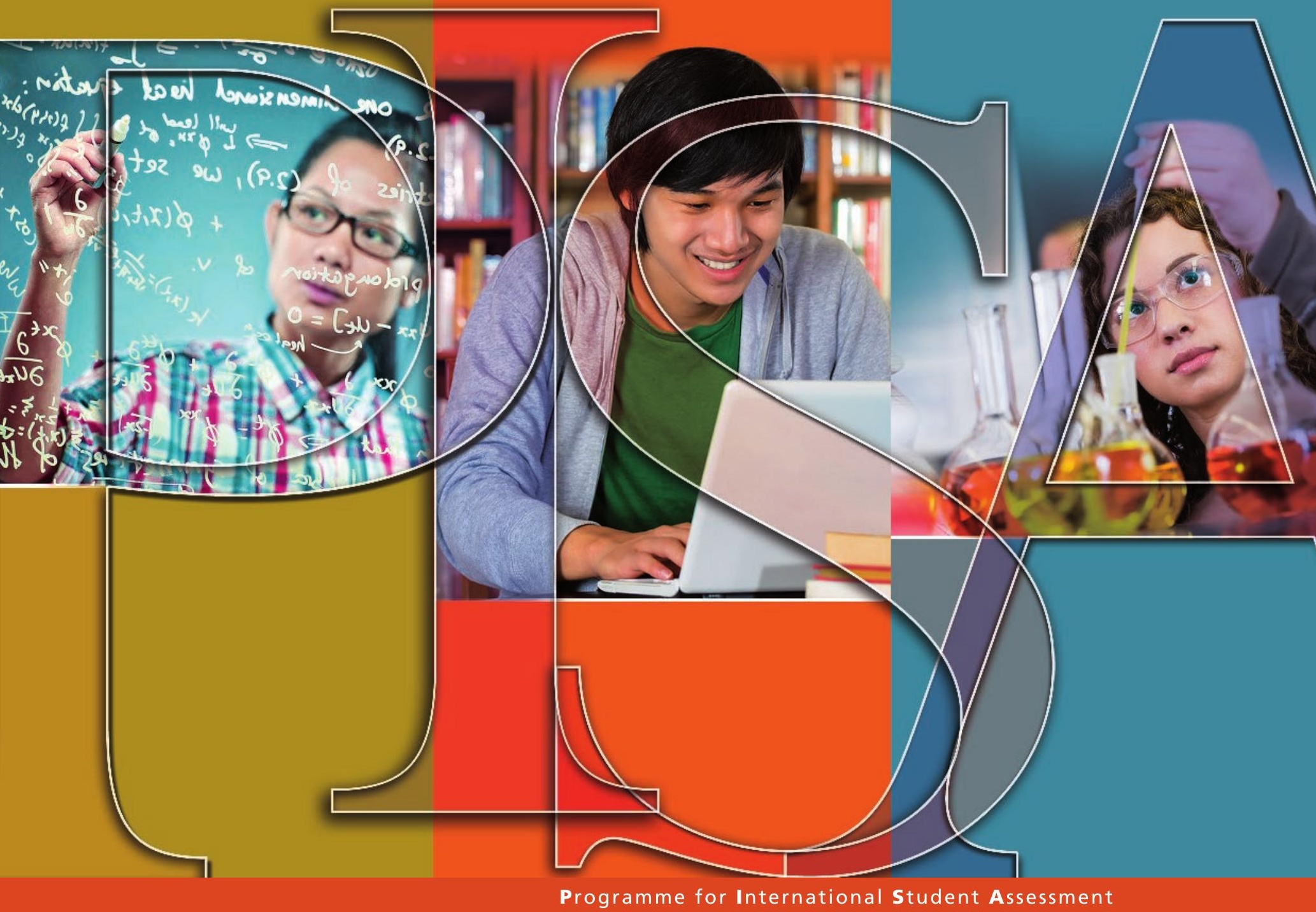

(2)) OECD 



\section{PISA 2012 Results: What Students Know and Can Do}

\section{STUDENT PERFORMANCE IN MATHEMATICS, READING AND SCIENCE (VOLUME I)}

Revised edition, February 2014

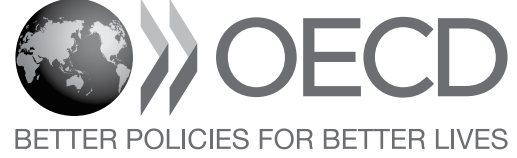


This work is published on the responsibility of the Secretary-General of the OECD. The opinions expressed and arguments employed herein do not necessarily reflect the official views of the Organisation or of the governments of its member countries.

This document and any map included herein are without prejudice to the status of or sovereignty over any territory, to the delimitation of international frontiers and boundaries and to the name of any territory, city or area.

\section{Please cite this publication as:}

OECD (2014), PISA 2012 Results: What Students Know and Can Do - Student Performance in Mathematics, Reading and Science (Volume I, Revised edition, February 2014), PISA, OECD Publishing.

http://dx.doi.org/10.1787/9789264208780-en

ISBN 978-92-64-20877-3 (print)

ISBN 978-92-64-20878-0 (PDF)

Note by Turkey: The information in this document with reference to "Cyprus" relates to the southern part of the Island. There is no single authority representing both Turkish and Greek Cypriot people on the Island. Turkey recognises the Turkish Republic of Northern Cyprus (TRNC). Until a lasting and equitable solution is found within the context of the United Nations, Turkey shall preserve its position concerning the "Cyprus issue".

Note by all the European Union Member States of the OECD and the European Union: The Republic of Cyprus is recognised by all members of the United Nations with the exception of Turkey. The information in this document relates to the area under the effective control of the Government of the Republic of Cyprus.

The statistical data for Israel are supplied by and under the responsibility of the relevant Israeli authorities. The use of such data by the OECD is without prejudice to the status of the Golan Heights, East Jerusalem and Israeli settlements in the West Bank under the terms of international law.

Revised edition, February 2014

\section{Photo credits:}

(c) Flying Colours Ltd/Getty Images

() Jacobs Stock Photography/Kzenon

() khoa vu/Flickr/Getty Images

( ) Mel Curtis/Corbis

( ) Shutterstock/Kzenon

(๑) Simon Jarratt/Corbis

Corrigenda to OECD publications may be found on line at: www.oecd.org/publishing/corrigenda. (c) OECD 2014

You can copy, download or print OECD content for your own use, and you can include excerpts from OECD publications, databases and multimedia products in your own documents, presentations, blogs, websites and teaching materials, provided that suitable acknowledgement of OECD as source and copyright owner is given. All requests for public or commercial use and translation rights should be submitted to rights@oecd.org. Requests for permission to photocopy portions of this material for public or commercial use shall be addressed directly to the Copyright Clearance Center (CCC) at info@copyright.com or the Centre français d'exploitation du droit de copie (CFC) at contact@cfcopies.com. 


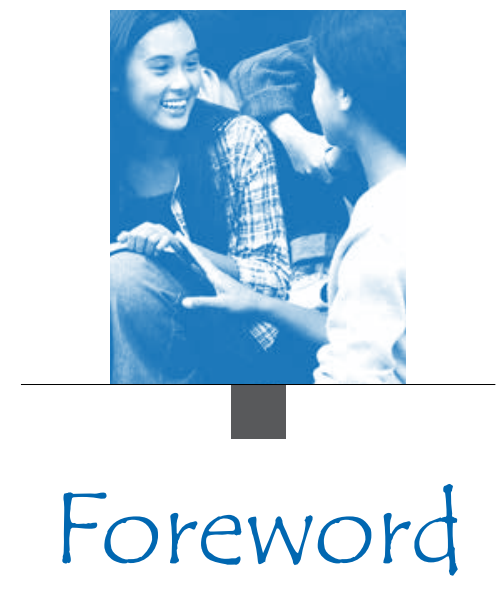

Equipping citizens with the skills necessary to achieve their full potential, participate in an increasingly interconnected global economy, and ultimately convert better jobs into better lives is a central preoccupation of policy makers around the world. Results from the OECD's recent Survey of Adult Skills show that highly skilled adults are twice as likely to be employed and almost three times more likely to earn an above-median salary than poorly skilled adults. In other words, poor skills severely limit people's access to better-paying and more rewarding jobs. Highly skilled people are also more likely to volunteer, see themselves as actors rather than as objects of political processes, and are more likely to trust others. Fairness, integrity and inclusiveness in public policy thus all hinge on the skills of citizens.

The ongoing economic crisis has only increased the urgency of investing in the acquisition and development of citizens' skills - both through the education system and in the workplace. At a time when public budgets are tight and there is little room for further monetary and fiscal stimulus, investing in structural reforms to boost productivity, such as education and skills development, is key to future growth. Indeed, investment in these areas is essential to support the recovery, as well as to address long-standing issues such as youth unemployment and gender inequality.

In this context, more and more countries are looking beyond their own borders for evidence of the most successful and efficient policies and practices. Indeed, in a global economy, success is no longer measured against national standards alone, but against the best-performing and most rapidly improving education systems. Over the past decade, the OECD Programme for International Student Assessment, PISA, has become the world's premier yardstick for evaluating the quality, equity and efficiency of school systems. But the evidence base that PISA has produced goes well beyond statistical benchmarking. By identifying the characteristics of high-performing education systems PISA allows governments and educators to identify effective policies that they can then adapt to their local contexts.

The results from the PISA 2012 assessment, which was conducted at a time when many of the 65 participating countries and economies were grappling with the effects of the crisis, reveal wide differences in education outcomes, both within and across countries. Using the data collected in previous PISA rounds, we have been able to track the evolution of student performance over time and across subjects. Of the 64 countries and economies with comparable data, 40 improved their average performance in at least one subject. Top performers such as Shanghai in China or Singapore were able to further extend their lead, while countries like Brazil, Mexico, Tunisia and Turkey achieved major improvements from previously low levels of performance.

Some education systems have demonstrated that it is possible to secure strong and equitable learning outcomes at the same time as achieving rapid improvements. Of the 13 countries and economies that significantly improved their mathematics performance between 2003 and 2012, three also show improvements in equity in education during the same period, and another nine improved their performance while maintaining an already high level of equity - proving that countries do not have to sacrifice high performance to achieve equity in education opportunities.

Nonetheless, PISA 2012 results show wide differences between countries in mathematics performance. The equivalent of almost six years of schooling, 245 score points, separates the highest and lowest average performances 
of the countries that took part in the PISA 2012 mathematics assessment. The difference in mathematics performances within countries is even greater, with over 300 points - the equivalent of more than seven years of schooling - often separating the highest- and the lowest-achieving students in a country. Clearly, all countries and economies have excellent students, but few have enabled all students to excel.

The report also reveals worrying gender differences in students' attitudes towards mathematics: even when girls perform as well as boys in mathematics, they report less perseverance, less motivation to learn mathematics, less belief in their own mathematics skills, and higher levels of anxiety about mathematics. While the average girl underperforms in mathematics compared with the average boy, the gender gap in favour of boys is even wider among the highest-achieving students. These findings have serious implications not only for higher education, where young women are already underrepresented in the science, technology, engineering and mathematics fields of study, but also later on, when these young women enter the labour market. This confirms the findings of the OECD Gender Strategy, which identifies some of the factors that create - and widen - the gender gap in education, labour and entrepreneurship. Supporting girls' positive attitudes towards and investment in learning mathematics will go a long way towards narrowing this gap.

PISA 2012 also finds that the highest-performing school systems are those that allocate educational resources more equitably among advantaged and disadvantaged schools and that grant more autonomy over curricula and assessments to individual schools. A belief that all students can achieve at a high level and a willingness to engage all stakeholders in education - including students, through such channels as seeking student feedback on teaching practices - are hallmarks of successful school systems.

PISA is not only an accurate indicator of students' abilities to participate fully in society after compulsory school, but also a powerful tool that countries and economies can use to fine-tune their education policies. There is no single combination of policies and practices that will work for everyone, everywhere. Every country has room for improvement, even the top performers. That's why the OECD produces this triennial report on the state of education across the globe: to share evidence of the best policies and practices and to offer our timely and targeted support to help countries provide the best education possible for all of their students. With high levels of youth unemployment, rising inequality, a significant gender gap, and an urgent need to boost growth in many countries, we have no time to lose. The OECD stands ready to support policy makers in this challenging and crucial endeavour.

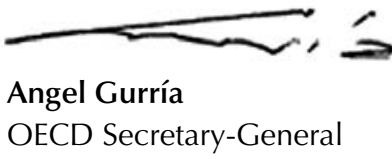




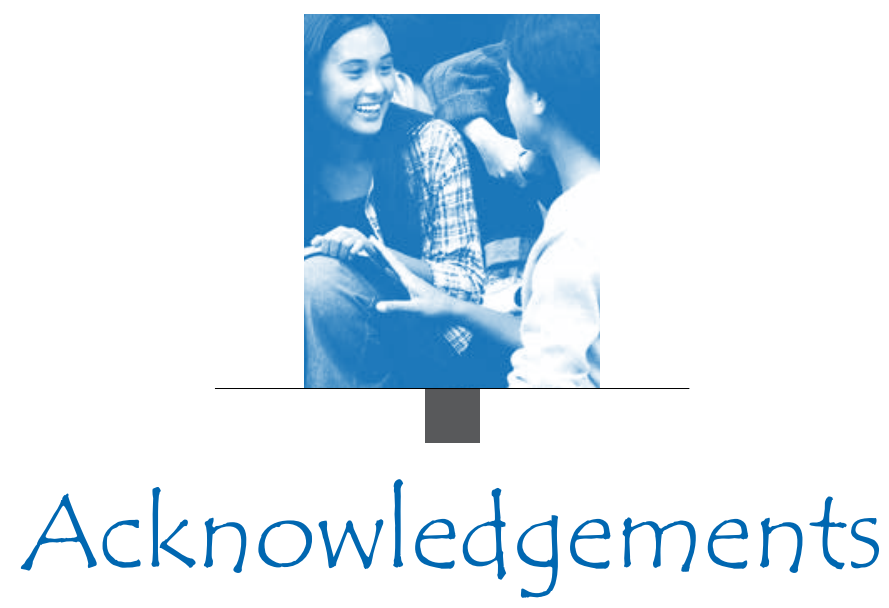

This report is the product of a collaborative effort between the countries participating in PISA, the experts and institutions working within the framework of the PISA Consortium, and the OECD Secretariat. The report was drafted by Andreas Schleicher, Francesco Avvisati, Francesca Borgonovi, Miyako Ikeda, Hiromichi Katayama, Flore-Anne Messy, Chiara Monticone, Guillermo Montt, Sophie Vayssettes and Pablo Zoido of the OECD Directorate for Education and Skills and the Directorate for Financial Affairs, with statistical support from Simone Bloem and Giannina Rech and editorial oversight by Marilyn Achiron. Additional analytical and editorial support was provided by Adele Atkinson, Jonas Bertling, Marika Boiron, Célia Braga-Schich, Tracey Burns, Michael Davidson, Cassandra Davis, Elizabeth Del Bourgo, John A. Dossey, Joachim Funke, Samuel Greiff, Tue Halgreen, Ben Jensen, Eckhard Klieme, André Laboul, Henry Levin, Juliette Mendelovits, Tadakazu Miki, Christian Monseur, Simon Normandeau, Mathilde Overduin, Elodie Pools, Dara Ramalingam, William H. Schmidt (whose work was supported by the Thomas J. Alexander fellowship programme), Kaye Stacey, Lazar Stankov, Ross Turner, Elisabeth Villoutreix and Allan Wigfield. The system-level data collection was conducted by the OECD NESLI (INES Network for the Collection and Adjudication of System-Level Descriptive Information on Educational Structures, Policies and Practices) team: Bonifacio Agapin, Estelle Herbaut and Jean Yip. Volume II also draws on the analytic work undertaken by Jaap Scheerens and Douglas Willms in the context of PISA 2000. Administrative support was provided by Claire Chetcuti, Juliet Evans, Jennah Huxley and Diana Tramontano.

The OECD contracted the Australian Council for Educational Research (ACER) to manage the development of the mathematics, problem solving and financial literacy frameworks for PISA 2012. Achieve was also contracted by the OECD to develop the mathematics framework with ACER. The expert group that guided the preparation of the mathematics assessment framework and instruments was chaired by Kaye Stacey; Joachim Funke chaired the expert group that guided the preparation of the problem-solving assessment framework and instruments; and Annamaria Lusardi led the expert group that guided the preparation of the financial literacy assessment framework and instruments. The PISA assessment instruments and the data underlying the report were prepared by the PISA Consortium, under the direction of Raymond Adams at ACER.

The development of the report was steered by the PISA Governing Board, which is chaired by Lorna Bertrand (United Kingdom), with Benő Csapó (Hungary), Daniel McGrath (United States) and Ryo Watanabe (Japan) as vice chairs. Annex $\mathrm{C}$ of the volumes lists the members of the various PISA bodies, as well as the individual experts and consultants who have contributed to this report and to PISA in general. 



\section{Table of Contents}

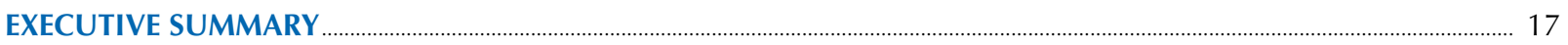

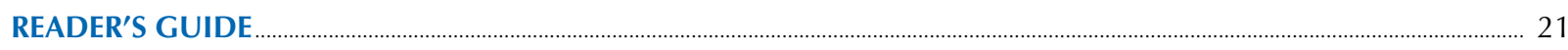

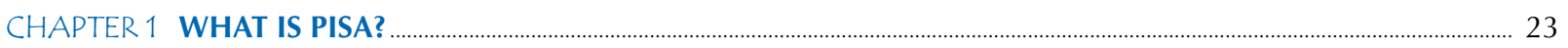

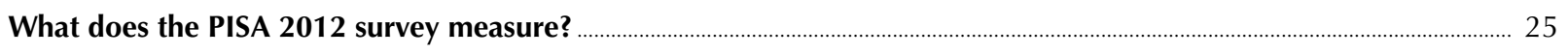

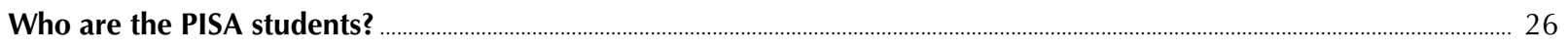

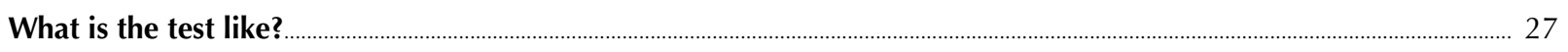

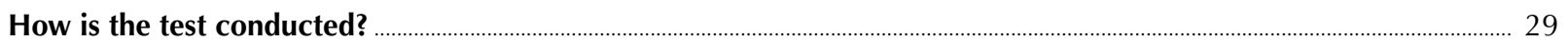

What kinds of results does the test provide? ......................................................................................................................................... 29

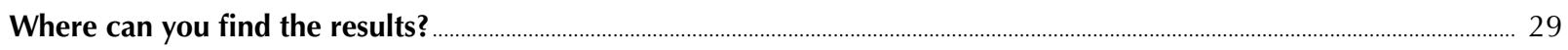

CHAPTER 2 A PROFILE OF STUDENT PERFORMANCE IN MATHEMATICS _.................................................................... 31

A context for comparing the mathematics performance of countries and economies ......................................................... 34

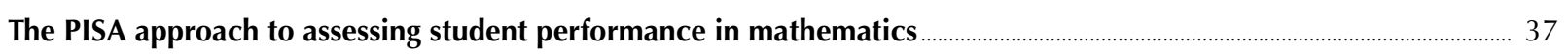

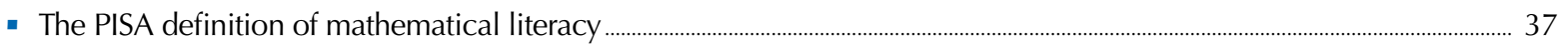

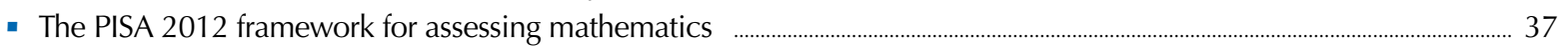

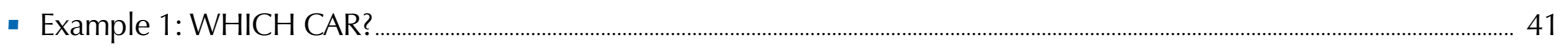

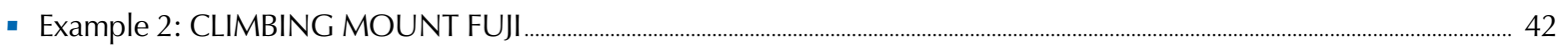

- How the PISA 2012 mathematics results are reported ........................................................................................................................... 44

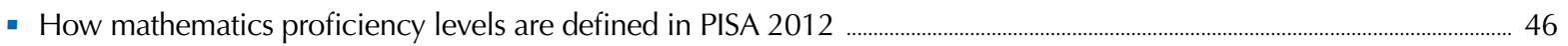

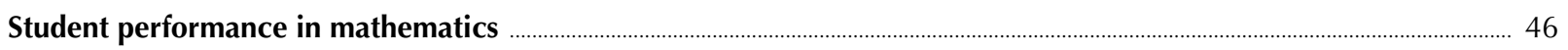

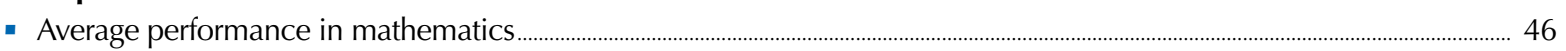

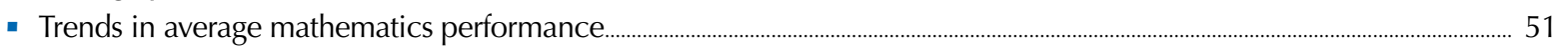

- Trends in mathematics performance adjusted for sampling and demographic changes ........................................................ 58

- Students at the different levels of proficiency in mathematics......................................................................................................... 60

- Trends in the percentage of low- and top-performers in mathematics ......................................................................................... 69

- Variation in student performance in mathematics........................................................................................................................................ 71

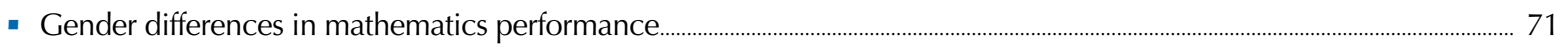

- Trends in gender differences in mathematics performance.......................................................................................................................... 74

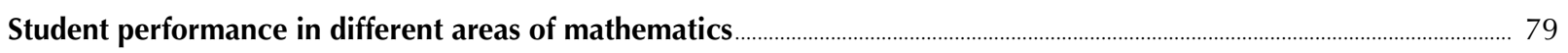

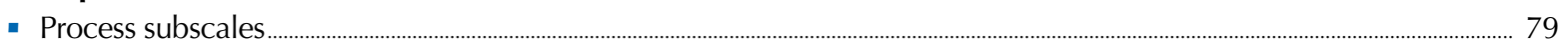

- Content subscales ....................................................................................................................................................................................................... 95

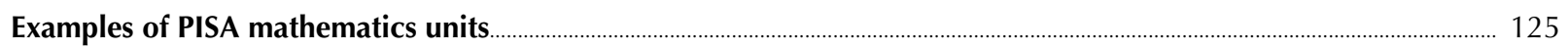

CHAPTER 3 MEASURING OPPORTUNITIES TO LEARN MATHEMATICS ……................................................................ 145

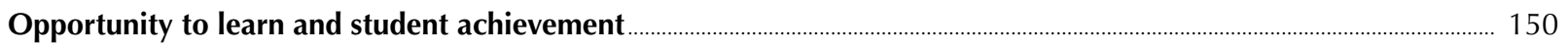

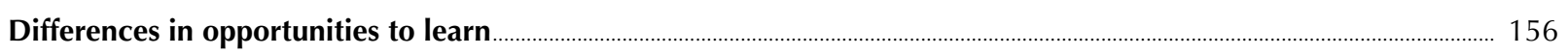

Questions used for the construction of the three opportunity to learn indices ……………..................................................... 170

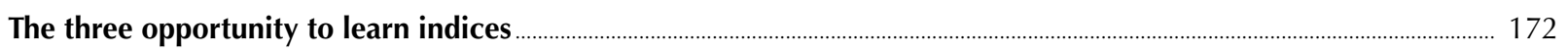


CHAPTER 4 A PROFILE OF STUDENT PERFORMANCE IN READING ……................................................................... 175

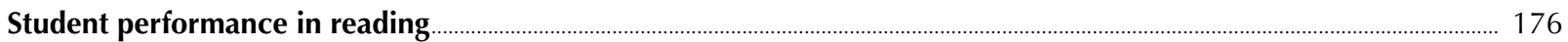

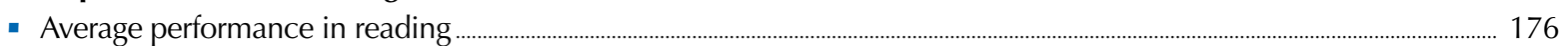

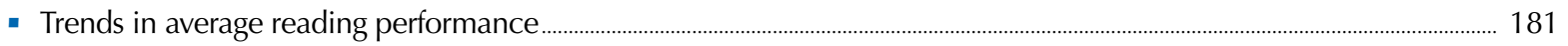

- Trends in reading performance adjusted for sampling and demographic changes................................................................ 187

- Students at the different levels of proficiency in reading ................................................................................................................... 190

- Trends in the percentage of low- and top-performers in reading ................................................................................................... 197

- Variation in student performance in reading .............................................................................................................................................. 199

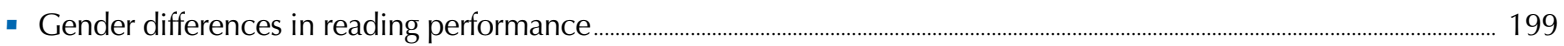

- Trends in gender difference in reading performance ..................................................................................................................................... 201

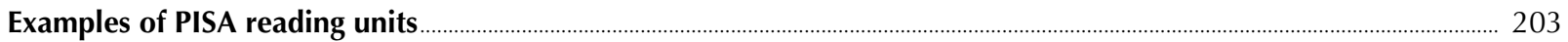

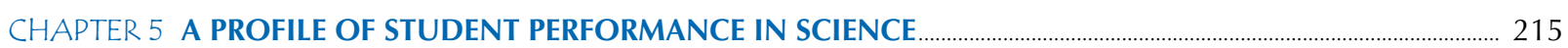

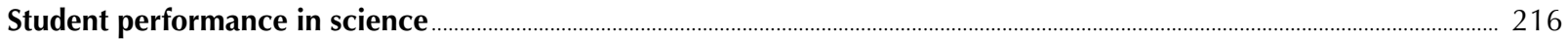

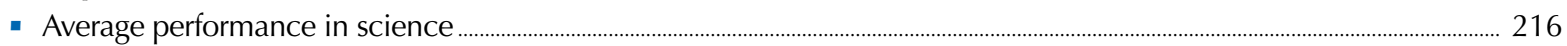

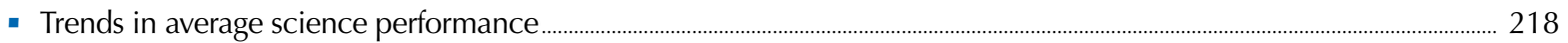

- Trends in science performance adjusted for sampling and demographic changes ......................................................................... 229

- Students at the different levels of proficiency in science ............................................................................................................ 230

- Trends in the percentage of low- and top-performers in science ................................................................................................. 235

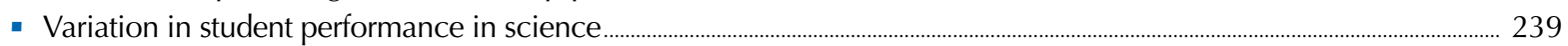

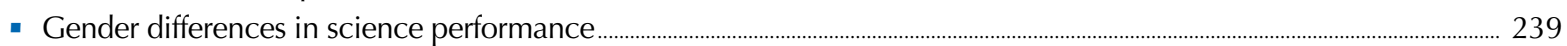

- Trends in gender difference in science performance ............................................................................................................................... 241

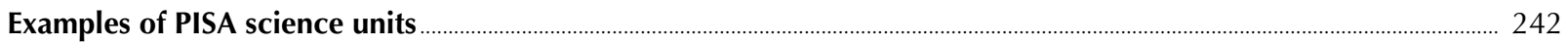

CHAPTER 6 POLICY IMPLICATIONS OF STUDENT PERFORMANCE IN PISA 2012 …............................................... 251

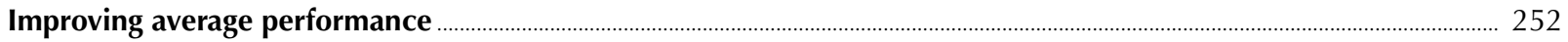

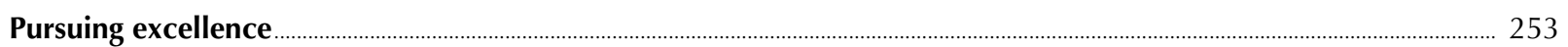

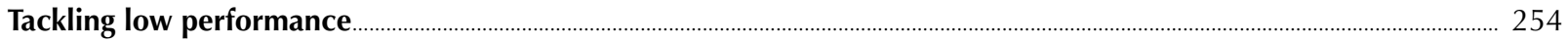

Assessing strengths and weaknesses in different kinds of mathematics ………………......................................................... 254

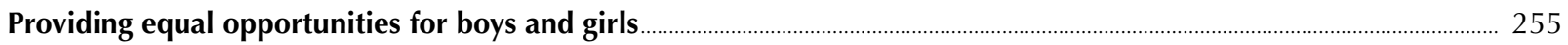

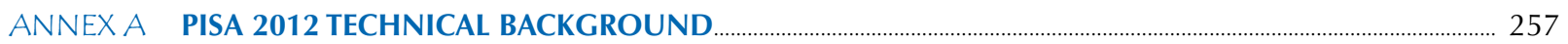

Annex A1 Indices from the student, school and parent context questionnaires ................................................................................................. 258

Annex A2 The PISA target population, the PISA samples and the definition of schools ....................................................................... 265

Annex A3 Technical notes on analyses in this volume....................................................................................................................................... 277

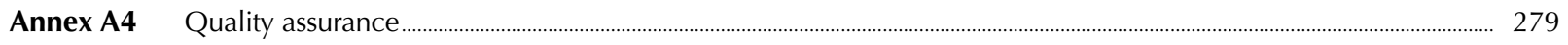

Annex A5 Technical details of trends analyses ………….......................................................................................................................... 280

Annex A6 Development of the PISA assessment instruments .......................................................................................................................... 294

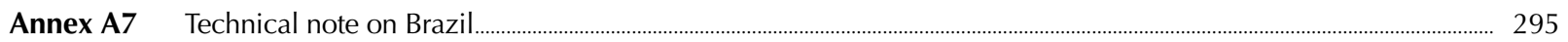

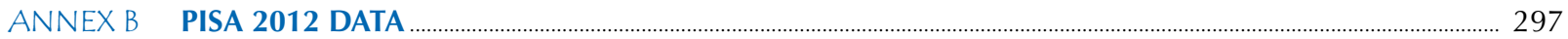

Annex B1 Results for countries and economies ...................................................................................................................... 298

Annex B2 Results for regions within countries .............................................................................................................................................. 405

Annex B3 Results for the computer-based and combined scales for mathematics and reading.................................................... 491

Annex B4 Trends in mathematics, reading and science performance........................................................................................................... 537

ANNEX C THE DEVELOPMENT AND IMPLEMENTATION OF PISA - A COLLABORATIVE EFFORT .......................... 555 


\section{BOXES}

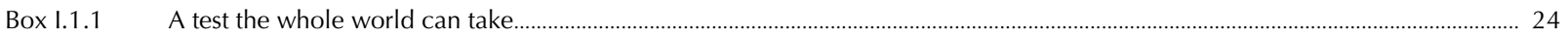

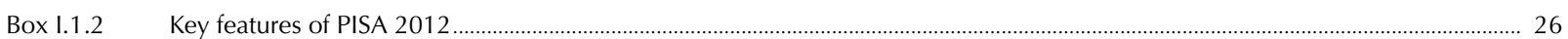

Box 1.2.1 What does performance in PISA say about readiness for further education and a career? .............................................................. 32

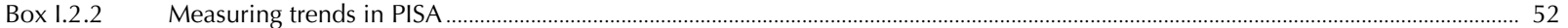

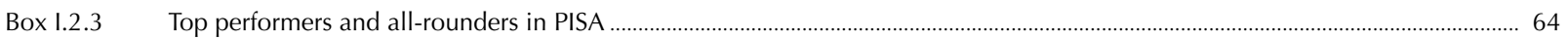

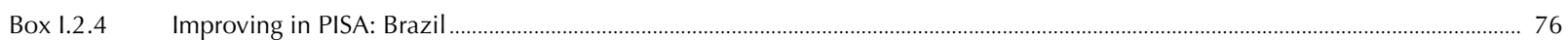

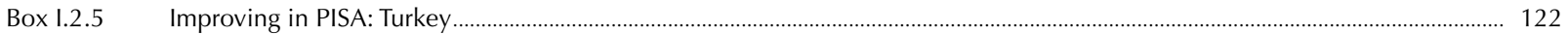

Box I.4.1 Improving in PISA: Korea …

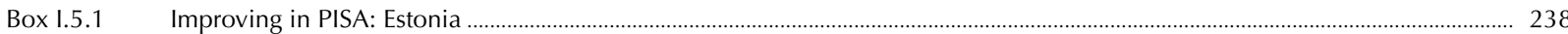

\section{FIGURES}

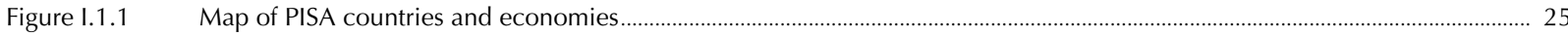

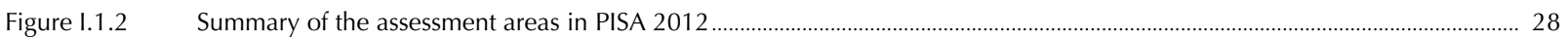

Figure 1.2.1 Mathematics performance and Gross Domestic Product ……................................................................................................... 35

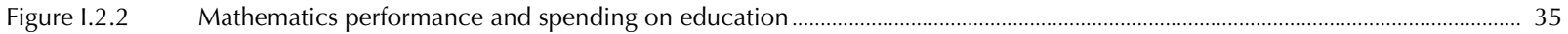

Figure I.2.3 Mathematics performance and parents' education....................................................................................................................... 35

Figure I.2.4 Mathematics performance and share of socio-economically disadvantaged students ................................................................ 35

Figure 1.2.5 Mathematics performance and proportion of students from an immigrant background............................................................ 35

Figure I.2.6 Equivalence of the PISA assessment across cultures and languages............................................................................................. 35

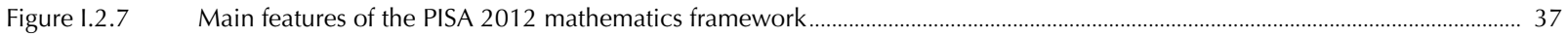

Figure 1.2.8 Categories describing the items constructed for the PISA 2012 mathematics assessment ........................................................ 40

Figure I.2.9 Classification of sample items, by process, context and content categories and response type .............................................. 41

Figure I.2.10 WHICH CAR? - a unit from the PISA 2012 main survey .................................................................................................................. 42

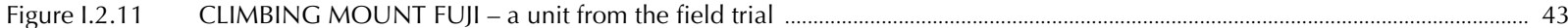

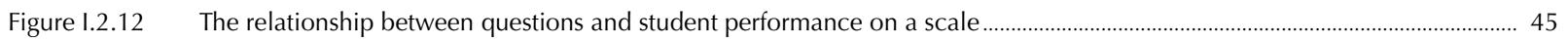

Figure I.2.13 Comparing countries' and economies' performance in mathematics ........................................................................................... 47

Figure I.2.14 Mathematics performance among PISA 2012 participants, at national and regional levels ...................................................... 48

Figure I.2.15 Annualised change in mathematics performance throughout participation in PISA ............................................................... 52

Figure I.2.16 Curvilinear trajectories of average mathematics performance across PISA assessments ....................................................... 55

Figure 1.2.17 Multiple comparisons of mathematics performance between 2003 and 2012 ............................................................................. 56

Figure I.2.18 Relationship between annualised change in performance and average PISA 2003 mathematics scores................................ 58

Figure 1.2.19 Adjusted and observed annualised performance change in average PISA mathematics scores ................................................. 59

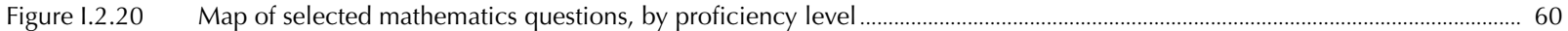

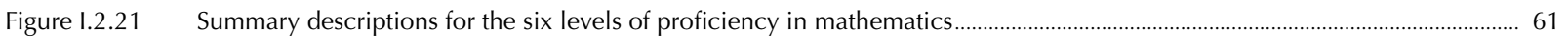

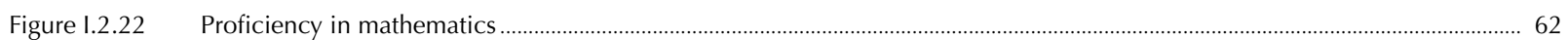

Figure I.2.a Overlapping of top performers in mathematics, reading and science on average across OECD countries.............................. 64

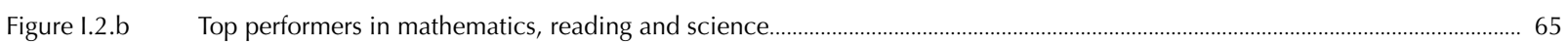

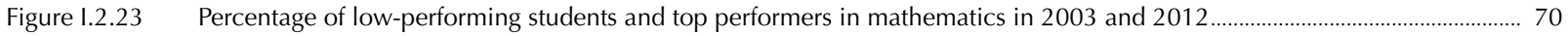

Figure I.2.24 Relationship between performance in mathematics and variation in performance …..................................................................... 72

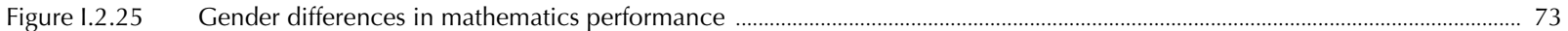


Figure 1.2.26

Figure 1.2.27

Figure I.2.C

Figure I.2.28

Figure 1.2.29

Figure I.2.30

Figure 1.2.31

Figure I.2.32

Figure I.2.33

Figure 1.2.34

Figure 1.2.35

Figure I.2.36

Figure 1.2.37

Figure I.2.38

Figure 1.2.39a

Figure I.2.39b

Figure 1.2.39c

Figure 1.2.40

Figure I.2.41

Figure 1.2.42

Figure I.2.43

Figure 1.2.44

Figure I.2.45

Figure 1.2.46

Figure 1.2.47

Figure I.2.48

Figure 1.2.49

Figure I.2.50

Figure 1.2.51

Figure I.2.52

Figure 1.2.53

Figure 1.2.54a

Figure I.2.54b

Figure 1.2.54c

Figure 1.2.54d

Figure 1.2.55

Figure 1.2.56

Figure 1.2.57

Figure I.2.58

Figure I.2.59

Figure 1.2.60

Figure 1.3.1a

Figure I.3.1b

Figure I.3.1c
Proficiency in mathematics among boys and girls..

Change between 2003 and 2012 in gender differences in mathematics performance _.............................................................. 75

Observed and expected trends in mathematics performance for Brazil (2003-12) ................................................................... 77

Comparing countries' and economies' performance on the mathematics subscale formulating ............................................. 80

Summary descriptions of the six proficiency levels for the mathematical subscale formulating ............................................... 81

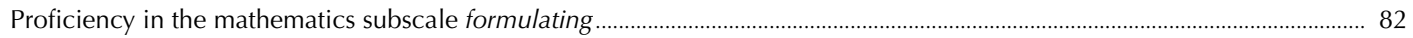

Comparing countries' and economies' performance on the mathematics subscale employing .................................................... 84

Summary descriptions of the six proficiency levels for the mathematical subscale employing ................................................ 85

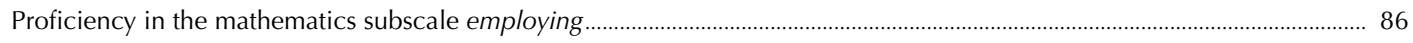

Comparing countries' and economies' performance on the mathematics subscale interpreting ............................................. 87

Summary descriptions of the six proficiency levels for the mathematical subscale interpreting................................................... 88

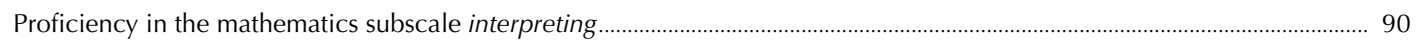

Comparing countries and economies on the different mathematics process subscales.......................................................... 91

Where countries and economies rank on the different mathematics process subscales ............................................................... 92

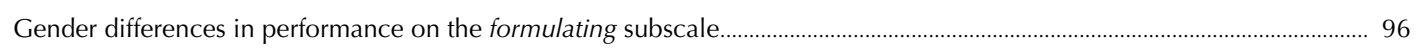

Gender differences in performance on the employing subscale .................................................................................................... 97

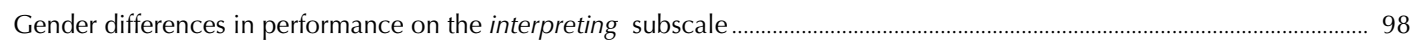

Comparing countries' and economies' performance on the mathematics subscale change and relationships ......................... 99

Summary descriptions of the six proficiency levels for the mathematical subscale change and relationships ........................ 100

Proficiency in the mathematics subscale change and relationships ................................................................................... 101

Comparing countries' and economies' performance on the mathematics subscale space and shape ................................ 102

Summary descriptions of the six proficiency levels for the mathematical subscale space and shape.................................... 103

Proficiency in the mathematics subscale space and shape

Comparing countries' and economies' performance on the mathematics subscale quantity ..................................................... 106

Summary descriptions of the six proficiency levels on the mathematical subscale quantity …............................................ 107

Proficiency in the mathematics subscale quantity ……................................................................................................. 108

Comparing countries' and economies' performance on the mathematics subscale uncertainty and data.............................. 109

Summary descriptions of the six proficiency levels on the mathematical subscale uncertainty and data.............................. 1110

Proficiency in the mathematics subscale uncertainty and data .............................................................................................. 111

Comparing countries and economies on the different mathematics content subscales.......................................................... 113

Where countries and economies rank on the different mathematics content subscales ............................................................. 114

Gender differences in performance on the change and relationships subscale .......................................................................... 118

Gender differences in performance on the space and shape subscale ................................................................................... 119

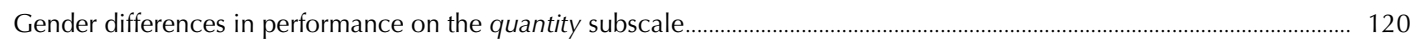

Gender differences in performance on the uncertainty and data subscale ............................................................................ 121

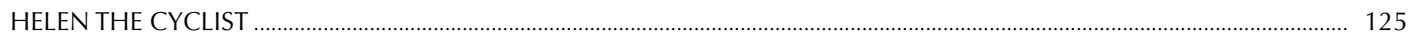

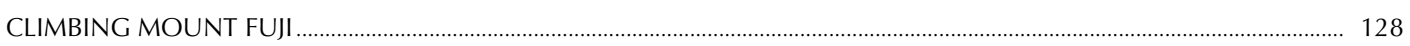

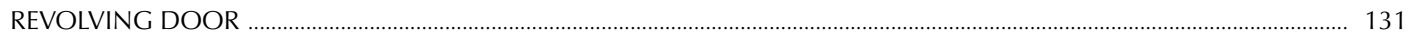

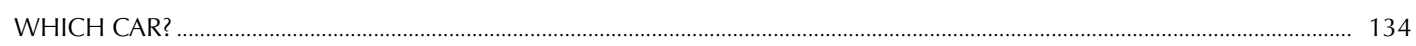

CHARTS

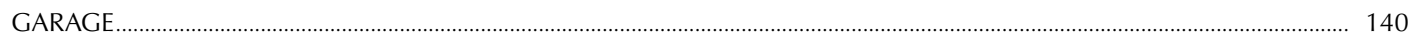

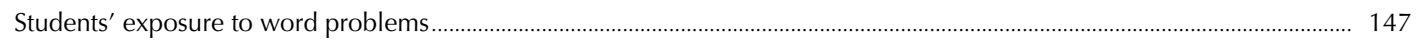

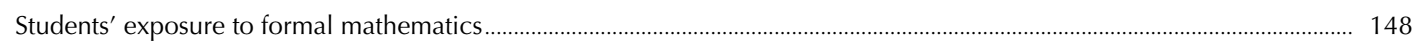

Students' exposure to applied mathematics ..................................................................................................................... 149 
Figure I.3.2 Relationship between mathematics performance and students' exposure to applied mathematics ......

Figure I.3.3 Country-level regressions between opportunity to learn variables and mathematics performance at the student and school levels

Figure 1.3.4a

Relationship between the index of exposure to word problems and students' mathematics performance

Figure $1.3 .4 \mathrm{C}$

Relationship between the index of exposure to applied mathematics and students' mathematics performance.

Figure I.3.6

Percentage of students who reported having seen applied mathematics problems like "calculating the power consumption of an electric appliance per week" frequently or sometimes...

Figure 1.3.7 Percentage of students who reported having seen applied mathematics problems like "calculating how many square metres of tiles you need to cover a floor" frequently or sometimes.....

Figure I.3.8 Percentage of students who reported having seen formal mathematics problems in their mathematics lessons frequently or sometimes.

Figure 1.3.9

Percentage of students who reported having seen word problems in their mathematics lessons frequently or sometimes...

Figure 1.3.10

Percentage of students who reported having seen applied problems in mathematics in their mathematics lessons frequently or sometimes

Figure I.3.11 Percentage of students who reported having seen real-world problems in their mathematics lessons frequently or sometimes.

Figure 1.3.12

Student exposure to mathematics problems

Figure I.3.13

Percentage of students who reported having seen linear equations often or knowing the concept well and understanding it..

Figure I.3.14 Percentage of students who reported having seen complex numbers often or knowing the concept well and understanding it.

Figure I.3.15 Percentage of students who reported having seen exponential functions often or knowing the concept well

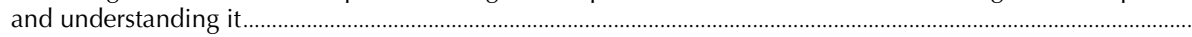

Figure I.3.16 Percentage of students who reported having seen quadratic functions often or knowing the concept well

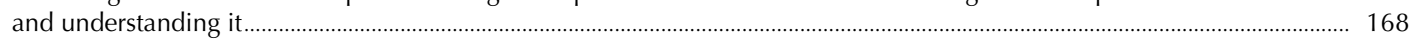

Figure I.3.17 Exposure to applied mathematics vs. exposure to formal mathematics ....................................................................................... 169

Figure 1.4.1

Comparing countries' and economies' performance in reading ......

Figure 1.4.2

Reading performance among PISA 2012 participants, at national and regional levels

Figure 1.4.3

Annualised change in reading performance throughout participation in PISA

Figure 1.4 .4

Curvilinear trajectories of average reading performance across PISA assessments

Figure 1.4.5

Multiple comparisons of reading performance between 2000 and 2012 .....

184

Figure I.4.6

Relationship between annualised change in performance and average PISA 2000 reading scores..

Figure 1.4 .7

Adjusted and observed annualised performance change in average PISA reading scores

Figure 1.4 .8

Summary description for the seven levels of proficiency in print reading in PISA 2012.

Figure 1.4 .9

Map of selected reading questions, by proficiency level...

Figure 1.4.10

Proficiency in reading

Figure I.5.1 Comparing countries' and economies' performance in science........ 
Figure I.5.4 Curvilinear trajectories of average science performance across PISA assessments ............................................................... 223

Figure I.5.5 Multiple comparisons of science performance between 2006 and 2012 .............................................................................. 224

Figure I.5.6 Relationship between annualised change in science performance and average PISA 2006 science scores ......................... 2228

Figure I.5.7 Adjusted and observed annualised performance change in average PISA science scores ...................................................... 230

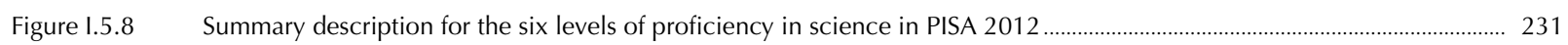

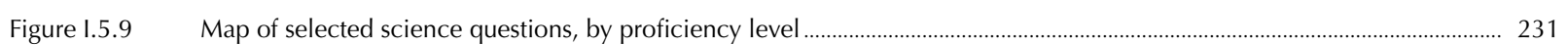

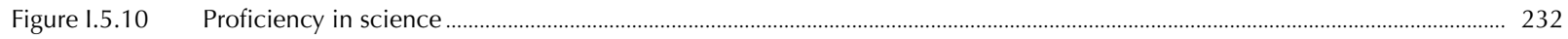

Figure 1.5.11 Percentage of low-performing students and top performers in science in 2006 and 2012 ….......................................... 237

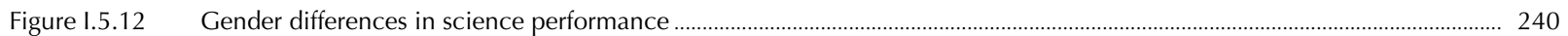

Figure I.5.13 Change between 2006 and 2012 in gender differences in science performance.................................................................... 241

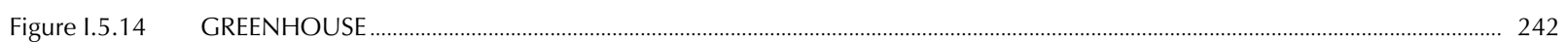

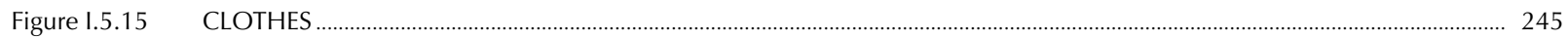

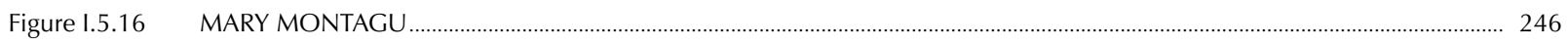

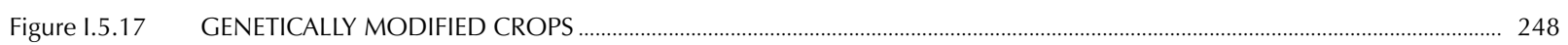

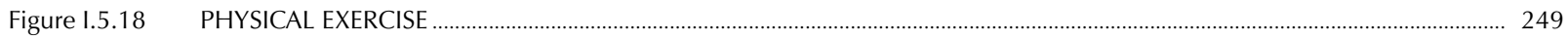

Figure A5.1 Annualised change in mathematics performance since PISA 2003 and observed difference in performance between PISA 2012 and PISA 2003 ............................................................................................................................. 286

Figure A5.2 Annualised change in reading performance since PISA 2000 and observed difference in performance

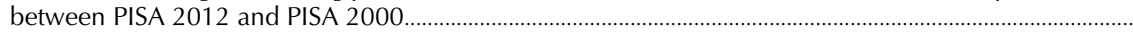

Figure A5.3 Annualised change in science performance since PISA 2006 and observed difference in performance between PISA 2012 and PISA 2006

Figure B4.1 Trends in mathematics, reading and science performance: OECD countries ................................................................................. 537

Figure B4.2 Trends in mathematics, reading and science performance: Partner countries and economies................................................ 546

\section{TABLES}

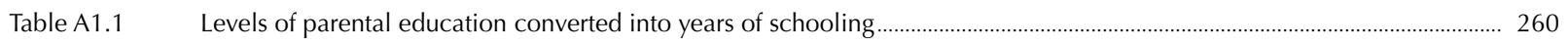

Table A1.2 A multilevel model to estimate grade effects in mathematics accounting for some background variables............................. 262

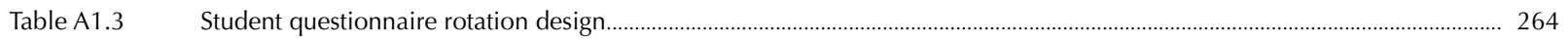

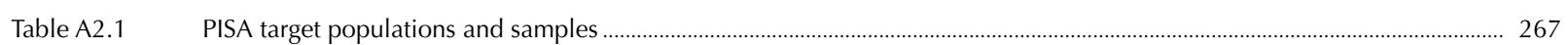

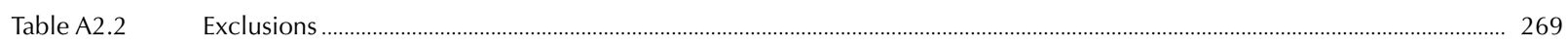

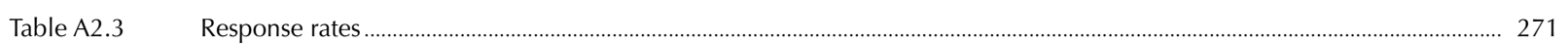

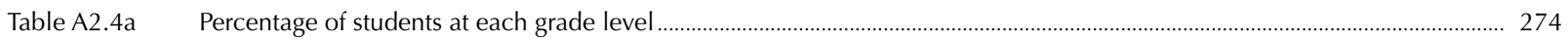

Table A2.4b Percentage of students at each grade level, by gender ……................................................................................................... 275

Table A5.1 Link error for comparisons of performance between PISA 2012 and previous assessments ................................................. 281

Table A5.2 Link error for comparisons of proficiency levels between PISA 2012 and previous assessments................................................. 282

Table A5.3 Link error for comparisons of annualised and curvilinear change between PISA 2012 and previous assessments................ 285

Table A5.4 Descriptive statistics for variables used to adjust mathematics, reading and science scores to the PISA 2012 samples........ 289

Table A7.1 Percentage of Brazilian students at each proficiency level on the mathematics scale

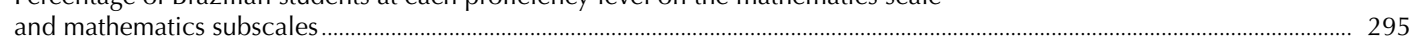

Table A7.2 Percentage of Brazilian students at each proficiency level on the reading scale …................................................................... 295

Table A7.3 Percentage of Brazilian students at each proficiency level on the science scale ................................................................... 296

Table A7.4 Top performers in mathematics, reading and science in Brazil .................................................................................................. 296

Table A7.5 Mean score, variation and gender differences in student performance in Brazil ...................................................................... 296 
Table 1.2.1a

Table 1.2.1b

Table 1.2.2a

Table 1.2.2b

Table I.2.3a

Table 1.2.3b

Table 1.2.3c

Table I.2.3d

Table I.2.4

Table I.2.5

Table I.2.6

Table 1.2.7

Table I.2.8

Table I.2.9

Table 1.2.10

Table I.2.11

Table I.2.12

Table I.2.13

Table I.2.14

Table I.2.15

Table I.2.16

Table I.2.17

Table 1.2.18

Table I.2.19

Table I.2.20

Table I.2.21

Table 1.2.22

Table 1.2.23

Table I.2.24

Table 1.2.25

Table 1.2.26

Table 1.2.27

Table I.2.28

Table 1.2.29

Table I.2.30

Table I.3.1

Table I.3.2

Table I.3.3

Table I.3.4

Table I.3.5

Table I.3.6

Table I.3.7

Table I.3.8
Percentage of students at each proficiency level in mathematics

Percentage of students below Level 2 and at Level 5 or above in mathematics in PISA 2003 through 2012

Percentage of students at each proficiency level in mathematics, by gender...

Percentage of students below Level 2 and at Level 5 or above in mathematics in PISA 2003 and 2012, by gender

Mean score, variation and gender differences in student performance in mathematics............................................................ 305

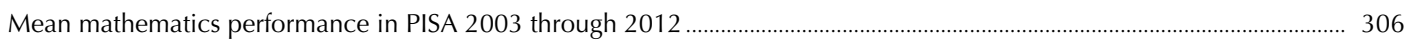

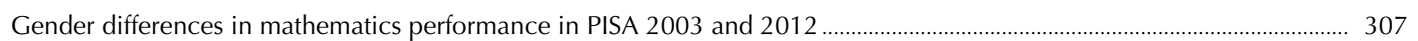

Distribution of scores in mathematics in PISA 2003 through 2012, by percentiles .................................................................... 308

Trends in mathematics performance adjusted for demographic changes ................................................................................... 311

Percentage of students at each proficiency level on the mathematics subscale formulating ..................................................... 312

Percentage of students at each proficiency level on the mathematics subscale formulating, by gender ................................ 313

Mean score, variation and gender differences in student performance on the mathematics subscale formulating ................ 315

Percentage of students at each proficiency level on the mathematics subscale employing .................................................. 316

Percentage of students at each proficiency level on the mathematics subscale employing, by gender .................................. 317

Mean score, variation and gender differences in student performance on the mathematics subscale employing .................. 319

Percentage of students at each proficiency level on the mathematics subscale interpreting................................................. 320

Percentage of students at each proficiency level on the mathematics subscale interpreting, by gender ................................. 321

Mean score, variation and gender differences in student performance on the mathematics subscale interpreting ................ 323

Percentage of students at each proficiency level on the mathematics subscale change and relationships ............................ 324

Percentage of students at each proficiency level on the mathematics subscale change and relationships, by gender ........... 325

Mean score, variation and gender differences in student performance on the mathematics subscale

change and relationships.

Percentage of students at each proficiency level on the mathematics subscale space and shape.

Percentage of students at each proficiency level on the mathematics subscale space and shape, by gender.

Mean score, variation and gender differences in student performance on the mathematics subscale space and shape ..... 331

Percentage of students at each proficiency level on the mathematics subscale quantity ........................................................... 332

Percentage of students at each proficiency level on the mathematics subscale quantity, by gender ................................... 333

Mean score, variation and gender differences in student performance on the mathematics subscale quantity ..................... 335

Percentage of students at each proficiency level on the mathematics subscale uncertainty and data.................................... 336

Percentage of students at each proficiency level on the mathematics subscale uncertainty and data, by gender ................. 337

Mean score, variation and gender differences in student performance on the mathematics subscale

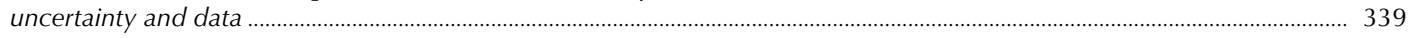

Gender differences in performance in mathematics after taking student programmes into account................................... 340

Socio-economic indicators and the relationship with performance in mathematics.................................................................... 341

Country rankings on preferred questions ..................................................................................................................................... 343

Top performers in mathematics, reading and science.......................................................................................... 344

Top performers in mathematics, reading and science, by gender ............................................................................................ 345

Index of opportunity to learn variables..

Estimated regression coefficients for student and school opportunity to learn variables related to achievement .....

Students' exposure to the mathematics task "using a train timetable"

Students' exposure to the mathematics task "calculating how much more expensive a computer would be after adding tax"

Students' exposure to the mathematics task "calculating how many square metres of tiles you need to cover a floor" ........ 351

Students' exposure to the mathematics task "understanding scientific tables presented in an article”................................... 352

Students' exposure to the mathematics task "solving an equation like $6 x^{2}+5=29$ " ............................................................. 353

Students' exposure to the mathematics task "finding the actual distance between two places on a map with a 1:10,000 scale" 


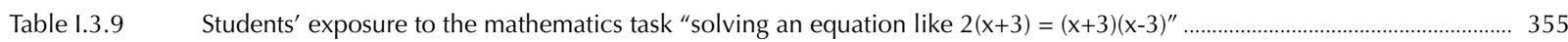

Table I.3.10 Students' exposure to the mathematics task "calculating the power consumption of an electronic appliance per week" ........ 356

Table I.3.11 Students' exposure to the mathematics problem "solve equation; find volume" .................................................................. 357

Table 1.3.12 Students' exposure to the mathematics problem "word problems" ...................................................................................... 358

Table I.3.13 Students' exposure to the mathematics problem "geometrical theorems; prime number" ....................................................... 359

Table I.3.14 Students' exposure to mathematics problem requiring a real-life context (data) ....................................................................... 360

Table I.3.15 Students' exposure to the mathematics concept "exponential function" .................................................................................. 361

Table l.3.16 Students' exposure to the mathematics concept "divisor" ................................................................................................ 362

Table I.3.17 Students' exposure to the mathematics concept "quadratic function" ............................................................................................. 363

Table I.3.18 Students' exposure to the mathematics concept "linear equation" ....................................................................................... 364

Table I.3.19 Students' exposure to the mathematics concept "vectors" ............................................................................................................. 365

Table I.3.20 Students' exposure to the mathematics concept "complex number" ............................................................................................ 366

Table I.3.21 Students' exposure to the mathematics concept "rational number" ...................................................................................... 367

Table 1.3.22 Students' exposure to the mathematics concept "radicals" ...................................................................................................... 368

Table I.3.23 Students' exposure to the mathematics concept "polygon" ..................................................................................................... 369

Table I.3.24 Students' exposure to the mathematics concept "congruent figure" ...................................................................................... 370

Table 1.3.25 Students' exposure to the mathematics concept "cosine" .......................................................................................................... 371

Table I.3.26 Students' exposure to the mathematics concept "arithmetic mean" .................................................................................................. 372

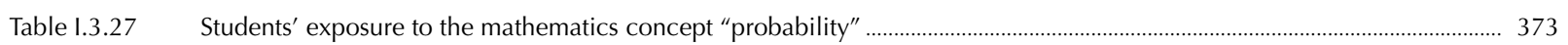

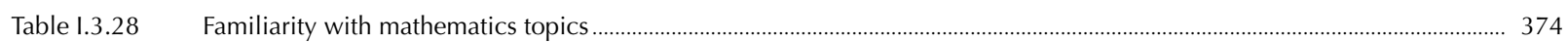

Table l.4.1a Percentage of students at each proficiency level in reading ……............................................................................................. 375

Table I.4.1b Percentage of students below Level 2 and at Level 5 or above in reading in PISA 2000 through 2012 _............................. 376

Table I.4.2a Percentage of students at each proficiency level in reading, by gender...................................................................................... 378

Table I.4.2b Percentage of students below Level 2 and at Level 5 or above in reading in PISA 2000 and 2012, by gender..................... 380

Table I.4.3a Mean score, variation and gender differences in student performance in reading............................................................ 382

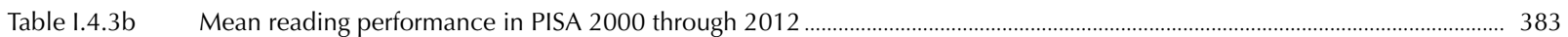

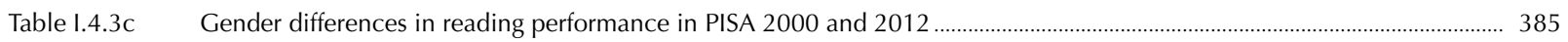

Table I.4.3d Distribution of scores in reading in PISA 2000 through 2012, by percentiles ................................................................... 386

Table I.4.4 Trends in reading performance adjusted for demographic changes ....................................................................................... 390

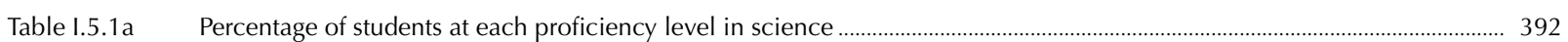

Table 1.5.1b Percentage of students below Level 2 and at Level 5 or above in science in PISA 2006 through 2012 _............................... 393

Table 1.5.2a Percentage of students at each proficiency level in science, by gender....................................................................................... 394

Table 1.5.2b Percentage of students below Level 2 and at Level 5 or above in science in PISA 2006 and 2012, by gender .................... 396

Table I.5.3a Mean score, variation and gender differences in student performance in science _.............................................................. 398

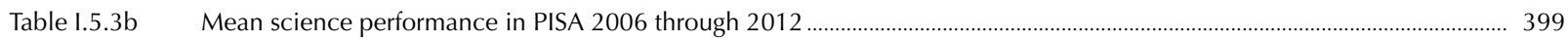

Table 1.5.3c Gender differences in science performance in PISA 2006 and 2012 ............................................................................... 400

Table 1.5.3d Distribution of scores in science in PISA 2006 through 2012, by percentiles ..................................................................... 401

Table I.5.4 Trends in science performance adjusted for demographic changes ...................................................................................... 404

Table B2.l.1 Percentage of students at each proficiency level in mathematics, by region........................................................................... 405

Table B2.I.2 Percentage of students at each proficiency level in mathematics, by gender and region........................................................... 407

Table B2.I.3 Mean score, variation and gender differences in student performance in mathematics, by region ........................................ 411

Table B2.I.4 Percentage of students at each proficiency level on the mathematics subscale formulating, by region ................................ 413

Table B2.I.5 Percentage of students at each proficiency level on the mathematics subscale formulating, by gender and region .............. 415

Table B2.I.6 Mean score, variation and gender differences in student performance on the mathematics subscale formulating, by region 
Table B2.I.7

Table B2.I.8

Table B2.I.9

Table B2.I.10

Table B2.I.11

Table B2.I.12

Table B2.I.13

Table B2.I.14

Table B2.I.15

Table B2.I.16

Table B2.I.17

Table B2.I.18

Table B2.I.19

Table B2.I.20

Table B2.I.21

Table B2.I.22

Table B2.I.23

Table B2.I.24

Table B2.I.25

Table B2.I.26

Table B2.I.27

Table B2.I.28

Table B2.I.29

Table B2.I.30

Table B2.I.31

Table B2.I.32

Table B3.I.1

Table B3.I.2

Table B3.I.3

Table B3.I. 4

Table B3.I.5

Table B3.I.6

Table B3.I.7

Table B3.I.8

Table B3.I.9

Table B3.I.10

Table B3.I.11

Table B3.I.12

Table B3.I.13

Table B3.I.14
Percentage of students at each proficiency level on the mathematics subscale employing, by region

Percentage of students at each proficiency level on the mathematics subscale employing, by gender and region...

Mean score, variation and gender differences in student performance on the mathematics subscale employing, by region .......... 427

Percentage of students at each proficiency level on the mathematics subscale interpreting, by region ............................ 429

Percentage of students at each proficiency level on the mathematics subscale interpreting, by gender and region .............. 431

Mean score, variation and gender differences in student performance on the mathematics subscale interpreting,

by region.

Percentage of students at each proficiency level on the mathematics subscale change and relationships, by region......

Percentage of students at each proficiency level on the mathematics subscale change and relationships, by gender and region

Mean score, variation and gender differences in student performance on the mathematics subscale change and relationships, by region.

Percentage of students at each proficiency level on the mathematics subscale space and shape, by region

Percentage of students at each proficiency level on the mathematics subscale space and shape, by gender and region .......... 447

Mean score, variation and gender differences in student performance on the mathematics subscale space and shape,

by region.

Percentage of students at each proficiency level on the mathematics subscale quantity, by region

Percentage of students at each proficiency level on the mathematics subscale quantity, by gender and region

Mean score, variation and gender differences in student performance on the mathematics subscale quantity, by region... 459

Percentage of students at each proficiency level on the mathematics subscale uncertainty and data, by region

Percentage of students at each proficiency level on the mathematics subscale uncertainty and data, by gender and region

Mean score, variation and gender differences in student performance on the mathematics subscale uncertainty and data, by region.............................................................................................................................................. 467

Percentage of students at each proficiency level in reading, by region.

Percentage of students at each proficiency level in reading, by gender and region ……............................................................... 471

Mean score, variation and gender differences in student performance in reading, by region ................................................... 475

Percentage of students at each proficiency level in science, by region ..................................................................................... 477

Percentage of students at each proficiency level in science, by gender and region.................................................................... 479

Mean score, variation and gender differences in student performance in science, by region ..................................................... 483

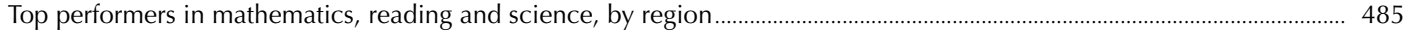

Top performers in mathematics, reading and science, by gender and region …................................................................... 487

Percentage of students at each proficiency level on the computer-based mathematics scale...................................................... 493

Percentage of students at each proficiency level on the computer-based mathematics scale, by gender .............................. 494

Mean score, variation and gender differences in student performance on the computer-based mathematics scale............... 495

Percentage of students at each proficiency level on the combined mathematics scale ......................................................... 496

Percentage of students at each proficiency level on the combined mathematics scale, by gender .......................................... 497

Mean score, variation and gender differences in student performance on the combined mathematics scale.......................... 498

Percentage of students at each proficiency level on the digital reading scale ...................................................................... 499

Percentage of students at each proficiency level on the digital reading scale, by gender .............................................................. 500

Mean score, variation and gender differences in student performance on the digital reading scale ..................................... 501

Percentage of students at each proficiency level on the combined reading scale ........................................................................ 502

Percentage of students at each proficiency level on the combined reading scale, by gender ..................................................... 503

Mean score, variation and gender differences in student performance on the combined reading scale ............................... 504

Percentage of students at each proficiency level on the computer-based mathematics scale, by region ................................ 505

Percentage of students at each proficiency level on the computer-based mathematics scale,

by gender and region 
Table B3.I.15 Mean score, variation and gender differences in student performance on the computer-based mathematics scale, by region

Table B3.I.16 Percentage of students at each proficiency level on the combined mathematics scale, by region .......................................... 513

Table B3.I.17 Percentage of students at each proficiency level on the combined mathematics scale, by gender and region ...................... 515

Table B3.I.18 Mean score, variation and gender differences in student performance on the combined mathematics scale, by region...... 519

Table B3.I.19 Percentage of students at each proficiency level on the digital reading scale, by region ............................................................... 521

Table B3.I.20 Percentage of students at each proficiency level on the digital reading scale, by gender and region.................................... 523

Table B3.I.21 Mean score, variation and gender differences in student performance on the digital reading scale, by region ...................... 527

Table B3.I.22 Percentage of students at each proficiency level on the combined reading scale, by region ..................................................... 529

Table B3.I.23 Percentage of students at each proficiency level on the combined reading scale, by gender and region .............................. 531

Table B3.I.24 Mean score, variation and gender differences in student performance on the combined reading scale, by region................ 535

\section{This book has...}

\section{Statlinks 前政 \\ A service that delivers Excel $^{\circledR}$ files from the printed page!}

Look for the StatLinks at the bottom left-hand corner of the tables or graphs in this book.

To download the matching Excel ${ }^{\circledR}$ spreadsheet, just type the link into your Internet browser, starting with the $h$ ttp://dx.doi.org prefix.

If you're reading the PDF e-book edition, and your PC is connected to the Internet, simply click on the link. You'll find StatLinks appearing in more OECD books. 


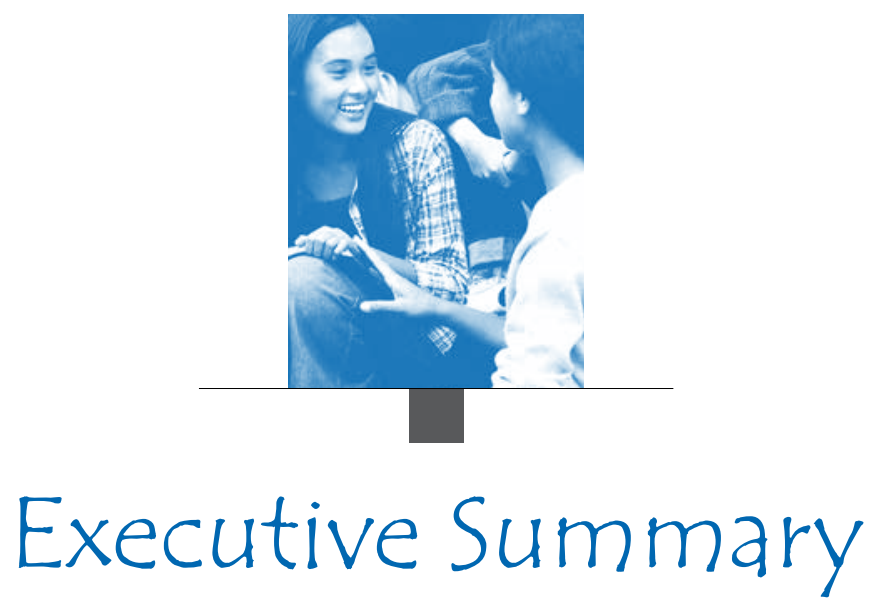

Nearly all adults, not just those with technical or scientific careers, now need to have adequate proficiency in mathematics as well as reading and science - for personal fulfilment, employment and full participation in society. With mathematics as its primary focus, the PISA 2012 assessment measured 15-year-olds' capacity to reason mathematically and use mathematical concepts, procedures, facts and tools to describe, explain and predict phenomena, and to make the wellfounded judgements and decisions needed by constructive, engaged and reflective citizens. Literacy in mathematics defined this way is not an attribute that an individual has or does not have; rather, it is a skill that can be acquired and used, to a greater or lesser extent, throughout a lifetime.

Shanghai-China has the highest scores in mathematics, with a mean score of 613 points - 119 points above the OECD average, or the equivalent of nearly 3 years of schooling.

Singapore, Hong Kong-China, Chinese Taipei, Korea, Macao-China, Japan, Liechtenstein, Switzerland and the Netherlands, in descending order of their scores, round out the top 10 performers in mathematics.

Of all countries and economies with trend data between 2003 and 2012, 25 improved in mathematics performance, 25 show no change, and 14 deteriorated.

Among countries that participated in every assessment since 2003, Brazil, Italy, Mexico, Poland, Portugal, Tunisia and Turkey show an average improvement in mathematics performance of more than 2.5 points per year since 2003. Although countries and economies that improved the most are more likely to be those that had lower performance in 2003, some with average or high performance in 2003 - such as Germany, Hong Kong-China and Macao-China - also improved during this period. Shanghai-China and Singapore, which began their participation in PISA after the 2003 assessment, also improved their already-high performance.

On average across OECD countries, $12.6 \%$ of students are top performers in mathematics, meaning that they are proficient at Level 5 or 6.

The partner economy Shanghai-China has the largest proportion of students performing at Level 5 or 6 (55.4\%), followed by Singapore (40.0\%), Chinese Taipei (37.2\%) and Hong Kong-China (33.7\%). In Korea, 30.9\% of students are top performers in mathematics; and between 15\% and 25\% of students in Belgium, Canada, Finland, Germany, Japan, Liechtenstein, Macao-China, the Netherlands, New Zealand, Poland and Switzerland are top performers in mathematics.

Between 2003 and 2012 Italy, Poland and Portugal increased the share of top performers and simultaneously reduced the share of low performers in mathematics.

Israel, Qatar and Romania saw similar improvements between 2006 and 2012 as did Ireland, Malaysia and the Russian Federation between 2009 and 2012.

Boys perform better than girls in mathematics in only 38 out of the 65 countries and economies that participated in PISA 2012, and girls outperform boys in 5 countries.

In only six countries is the gender gap in mathematics scores larger than the equivalent of half a year of formal schooling. 
Shanghai-China, Hong Kong-China, Singapore, Japan and Korea are the five highest-performing countries and economies in reading.

Shanghai-China had a mean score of 570 points in reading - the equivalent of more than a year-and-a-half of schooling above the OECD average of 496 score points, and 25 score points above the second best-performing participant, Hong Kong-China.

Of the 64 countries and economies with comparable data in reading performance throughout their participation in PISA, 32 improved their reading performance, 22 show no change, and 10 deteriorated in reading performance. Among OECD countries, Chile, Estonia, Germany, Hungary, Israel, Japan, Korea, Luxembourg, Mexico, Poland, Portugal, Switzerland and Turkey improved their reading performance across successive PISA assessments.

Across OECD countries, $8.4 \%$ of students are top performers in reading, meaning that they are proficient at Level 5 or 6 . Shanghai-China has the largest proportion of top performers $-25.1 \%$ - among all participating countries and economies.

More than $15 \%$ of students in Hong Kong-China, Japan and Singapore are top performers in reading, as are more than $10 \%$ of students in Australia, Belgium, Canada, Finland, France, Ireland, Korea, Liechtenstein, New Zealand, Norway, Poland and Chinese Taipei.

Between the 2000 and 2012 PISA assessments, Albania, Israel and Poland increased the share of top performers and simultaneously reduced the share of low performers in reading.

The same trend was observed in Hong Kong-China, Japan and the Russian Federation since PISA 2003; in Bulgaria, Qatar, Serbia, Spain and Chinese Taipei since PISA 2006; and in Ireland, Luxembourg, Macao-China and Singapore since PISA 2009.

Between 2000 and 2012 the gender gap in reading performance - favouring girls - widened in 11 countries and economies.

In Bulgaria, France and Romania, the gender gap in reading performance widened by more than 15 score points during that period. Only in Albania did the gap narrow as a result of a greater improvement in reading performance among boys than among girls.

Shanghai-China, Hong Kong-China, Singapore, Japan and Finland are the top five performers in science in PISA 2012.

Shanghai-China's mean score in science (580 points) is more than three-quarters of a proficiency level above the OECD average of 501 score points. Estonia, Korea, Viet Nam, Poland, Canada, Liechtenstein, Germany, Chinese Taipei, the Netherlands, Ireland, Australia, Macao-China, New Zealand, Switzerland, Slovenia, the United Kingdom and the Czech Republic also score above the OECD average in science, while Austria, Belgium, Latvia, France, Denmark and the United States scored around the OECD average.

Across OECD countries, $8.4 \%$ of students are top performers in science and score at proficiency Level 5 or 6. More than $15 \%$ of students in Shanghai-China $(27.2 \%)$, Singapore $(22.7 \%)$, Japan $(18.2 \%)$, Finland $(17.1 \%)$ and Hong Kong-China (16.7\%) are top performers.

Between 2006 and 2012, Italy, Poland and Qatar, and between 2009 and 2012, Estonia, Israel and Singapore increased the share of top performers and simultaneously reduced the share of low performers in science.

Brazil, Hong Kong-China, Ireland, Japan, Korea, Latvia, Lithuania, Portugal, Romania, Spain, Switzerland, Thailand, Tunisia, Turkey and the United States saw a significant reduction in the share of students performing below proficiency Level 2 between 2006 and 2012.

Boys and girls perform similarly in science and, on average, that remained true in 2012.

However, in Finland, Montenegro, the Russian Federation and Sweden, while there was no gender gap in science performance in 2006, a gender gap in favour of girls was observed in 2012. 


\section{SNAPSHOT OF PERFORMANCE IN MATHEMATICS, READING AND SCIENCE}

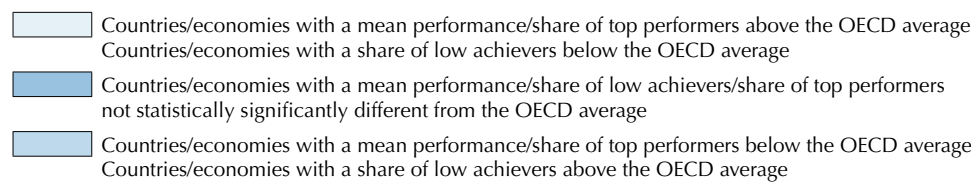

\begin{tabular}{|c|c|c|c|c|c|c|c|c|}
\hline & \multicolumn{4}{|c|}{ Mathematics } & \multicolumn{2}{|c|}{ Reading } & \multicolumn{2}{|c|}{ Science } \\
\hline & $\begin{array}{c}\text { Mean score } \\
\text { in PISA } 2012\end{array}$ & $\begin{array}{c}\text { Share } \\
\text { of low achievers } \\
\text { (Below Level 2) }\end{array}$ & \begin{tabular}{|c|} 
Share \\
of top performers \\
in mathematics \\
(Level 5 or 6$)$
\end{tabular} & $\begin{array}{c}\text { Annualised } \\
\text { change }\end{array}$ & $\begin{array}{c}\text { Mean score } \\
\text { in PISA } 2012\end{array}$ & $\begin{array}{c}\text { Annualised } \\
\text { change }\end{array}$ & $\begin{array}{c}\text { Mean score } \\
\text { in PISA } 2012\end{array}$ & $\begin{array}{c}\text { Annualised } \\
\text { change }\end{array}$ \\
\hline OECD average & 494 & 23.0 & 12.6 & -0.3 & 496 & 0.3 & 501 & 0.5 \\
\hline Shanghai-China & 613 & 3.8 & 55.4 & 4.2 & 570 & 4.6 & 580 & 1.8 \\
\hline Singapore & 573 & 8.3 & 40.0 & 3.8 & 542 & 5.4 & 551 & 3.3 \\
\hline Hong Kong-China & 561 & 8.5 & 33.7 & 1.3 & 545 & 2.3 & 555 & 2.1 \\
\hline Chinese Taipei & 560 & 12.8 & 37.2 & 1.7 & 523 & 4.5 & 523 & -1.5 \\
\hline Korea & 554 & 9.1 & 30.9 & 1.1 & 536 & 0.9 & 538 & 2.6 \\
\hline Macao-China & 538 & 10.8 & 24.3 & 1.0 & 509 & 0.8 & 521 & 1.6 \\
\hline Japan & 536 & 11.1 & 23.7 & 0.4 & 538 & 1.5 & 547 & 2.6 \\
\hline Liechtenstein & 535 & 14.1 & 24.8 & 0.3 & 516 & 1.3 & 525 & 0.4 \\
\hline Switzerland & 531 & 12.4 & 21.4 & 0.6 & 509 & 1.0 & 515 & 0.6 \\
\hline Netherlands & 523 & 14.8 & 19.3 & -1.6 & 511 & -0.1 & 522 & -0.5 \\
\hline Estonia & 521 & 10.5 & 14.6 & 0.9 & 516 & 2.4 & 541 & 1.5 \\
\hline Finland & 519 & 12.3 & 15.3 & -2.8 & 524 & -1.7 & 545 & -3.0 \\
\hline Canada & 518 & 13.8 & 16.4 & -1.4 & 523 & -0.9 & 525 & -1.5 \\
\hline Poland & 518 & 14.4 & 16.7 & 2.6 & 518 & 2.8 & 526 & 4.6 \\
\hline Belgium & 515 & 19.0 & 19.5 & -1.6 & 509 & 0.1 & 505 & -0.9 \\
\hline Germany & 514 & 17.7 & 17.5 & 1.4 & 508 & 1.8 & 524 & 1.4 \\
\hline Viet Nam & 511 & 14.2 & 13.3 & $\mathrm{~m}$ & 508 & $\mathrm{~m}$ & 528 & $\mathrm{~m}$ \\
\hline Austria & 506 & 18.7 & 14.3 & 0.0 & 490 & -0.2 & 506 & -0.8 \\
\hline Australia & 504 & 19.7 & 14.8 & -2.2 & 512 & -1.4 & 521 & $\begin{array}{l}-0.9 \\
\end{array}$ \\
\hline Ireland & 501 & 16.9 & 10.7 & -0.6 & 523 & -0.9 & 522 & 2.3 \\
\hline Slovenia & 501 & 20.1 & 13.7 & -0.6 & 481 & -2.2 & 514 & -0.8 \\
\hline Denmark & 500 & 16.8 & 10.0 & -1.8 & 496 & 0.1 & 498 & 0.4 \\
\hline New Zealand & 500 & 22.6 & 15.0 & -2.5 & 512 & -1.1 & 516 & -2.5 \\
\hline Czech Republic & 499 & 21.0 & 12.9 & -2.5 & 493 & -0.5 & 508 & -1.0 \\
\hline France & 495 & 22.4 & 12.9 & -1.5 & 505 & 0.0 & 499 & 0.6 \\
\hline United Kingdom & 494 & 21.8 & 11.8 & -0.3 & 499 & 0.7 & 514 & -0.1 \\
\hline Iceland & 493 & 21.5 & 11.2 & -2.2 & 483 & -1.3 & 478 & -2.0 \\
\hline Latvia & 491 & 19.9 & 8.0 & 0.5 & 489 & 1.9 & 502 & 2.0 \\
\hline Luxembourg & 490 & 24.3 & 11.2 & -0.3 & 488 & 0.7 & 491 & 0.9 \\
\hline Norway & 489 & 22.3 & 9.4 & -0.3 & 504 & 0.1 & 495 & 1.3 \\
\hline Portugal & 487 & 24.9 & 10.6 & 2.8 & 488 & 1.6 & 489 & 2.5 \\
\hline Italy & 485 & 24.7 & 9.9 & 2.7 & 490 & 0.5 & 494 & 3.0 \\
\hline Spain & 484 & 23.6 & 8.0 & 0.1 & 488 & -0.3 & 496 & 1.3 \\
\hline Russian Federation & 482 & 24.0 & 7.8 & 1.1 & 475 & 1.1 & 486 & 1.0 \\
\hline Slovak Republic & 482 & 27.5 & 11.0 & -1.4 & 463 & -0.1 & 471 & -2.7 \\
\hline United States & 481 & 25.8 & 8.8 & 0.3 & 498 & -0.3 & 497 & 1.4 \\
\hline Lithuania & 479 & 26.0 & 8.1 & -1.4 & 477 & 1.1 & 496 & 1.3 \\
\hline Sweden & 478 & 27.1 & 8.0 & -3.3 & 483 & -2.8 & 485 & -3.1 \\
\hline Hungary & 477 & 28.1 & 9.3 & -1.3 & 488 & 1.0 & 494 & -1.6 \\
\hline Croatia & 471 & 29.9 & 7.0 & 0.6 & 485 & 1.2 & 491 & -0.3 \\
\hline Israel & 466 & 33.5 & 9.4 & 4.2 & 486 & 3.7 & 470 & 2.8 \\
\hline Greece & 453 & 35.7 & 3.9 & 1.1 & 477 & 0.5 & 467 & -1.1 \\
\hline Serbia & 449 & 38.9 & 4.6 & 2.2 & 446 & 7.6 & 445 & 1.5 \\
\hline Turkey & 448 & 42.0 & 5.9 & 3.2 & 475 & 4.1 & 463 & 6.4 \\
\hline Romania & 445 & 40.8 & 3.2 & 4.9 & 438 & 1.1 & 439 & 3.4 \\
\hline Cyprus* & 440 & 42.0 & 3.7 & $\mathrm{~m}$ & 449 & $\mathrm{~m}$ & 438 & $\mathrm{~m}$ \\
\hline Bulgaria & 439 & 43.8 & 4.1 & 4.2 & 436 & 0.4 & 446 & 2.0 \\
\hline United Arab Emirates & 434 & 46.3 & 3.5 & $\mathrm{~m}$ & 442 & $\mathrm{~m}$ & 448 & $\mathrm{~m}$ \\
\hline Kazakhstan & 432 & 45.2 & 0.9 & 9.0 & 393 & 0.8 & 425 & 8.1 \\
\hline Thailand & 427 & 49.7 & 2.6 & 1.0 & 441 & 1.1 & 444 & 3.9 \\
\hline Chile & 423 & 51.5 & 1.6 & 1.9 & 441 & 3.1 & 445 & 1.1 \\
\hline Malaysia & 421 & 51.8 & 1.3 & 8.1 & 398 & -7.8 & 420 & -1.4 \\
\hline Mexico & 413 & 54.7 & 0.6 & 3.1 & 424 & 1.1 & 415 & 0.9 \\
\hline Montenegro & 410 & 56.6 & 1.0 & 1.7 & 422 & 5.0 & 410 & -0.3 \\
\hline Uruguay & 409 & 55.8 & 1.4 & -1.4 & 411 & -1.8 & 416 & -2.1 \\
\hline Costa Rica & 407 & 59.9 & 0.6 & -1.2 & 441 & -1.0 & 429 & -0.6 \\
\hline Albania & 394 & 60.7 & 0.8 & 5.6 & 394 & 4.1 & 397 & 2.2 \\
\hline Brazil & 391 & 67.1 & 0.8 & 4.1 & 410 & 1.2 & 405 & 2.3 \\
\hline Argentina & 388 & 66.5 & 0.3 & 1.2 & 396 & -1.6 & 406 & 2.4 \\
\hline Tunisia & 388 & 67.7 & 0.8 & 3.1 & 404 & 3.8 & 398 & 2.2 \\
\hline Jordan & 386 & 68.6 & 0.6 & 0.2 & 399 & -0.3 & 409 & -2.1 \\
\hline Colombia & 376 & 73.8 & 0.3 & 1.1 & 403 & 3.0 & 399 & 1.8 \\
\hline Qatar & 376 & 69.6 & 2.0 & 9.2 & 388 & 12.0 & 384 & 5.4 \\
\hline Indonesia & 375 & 75.7 & 0.3 & 0.7 & 396 & 2.3 & 382 & $\begin{array}{l}-1.9 \\
\end{array}$ \\
\hline Peru & 368 & 74.6 & 0.6 & 1.0 & 384 & 5.2 & 373 & 1.3 \\
\hline
\end{tabular}

Note: Countries/economies in which the annualised change in performance is statistically significant are marked in bold.

* See notes in the Reader's Guide.

Countries and economies are ranked in descending order of the mathematics mean score in PISA 2012.

Source: OECD, PISA 2012 Database, Tables I.2.1a, I.2.1b, I.2.3a, I.2.3b, I.4.3a, I.4.3b, I.5.3a and I.5.3b.

StatLink 需西 http://dx.doi.org/10.1787/888932937035 



\section{Reader's Guide}

\section{Data underlying the figures}

The data referred to in this volume are presented in Annex B and, in greater detail, including some additional tables, on the PISA website (www.pisa.oecd.org).

Four symbols are used to denote missing data:

a The category does not apply in the country concerned. Data are therefore missing.

c There are too few observations or no observation to provide reliable estimates (i.e. there are fewer than 30 students or fewer than 5 schools with valid data).

$\mathrm{m}$ Data are not available. These data were not submitted by the country or were collected but subsequently removed from the publication for technical reasons.

w Data have been withdrawn or have not been collected at the request of the country concerned.

\section{Country coverage}

This publication features data on 65 countries and economies, including all 34 OECD countries and 31 partner countries and economies (see Figure I.1.1).

The statistical data for Israel are supplied by and under the responsibility of the relevant Israeli authorities. The use of such data by the OECD is without prejudice to the status of the Golan Heights, East Jerusalem and Israeli settlements in the West Bank under the terms of international law.

Two notes were added to the statistical data related to Cyprus:

1. Note by Turkey: The information in this document with reference to "Cyprus" relates to the southern part of the Island. There is no single authority representing both Turkish and Greek Cypriot people on the Island. Turkey recognises the Turkish Republic of Northern Cyprus (TRNC). Until a lasting and equitable solution is found within the context of the United Nations, Turkey shall preserve its position concerning the "Cyprus issue".

2. Note by all the European Union Member States of the OECD and the European Union: The Republic of Cyprus is recognised by all members of the United Nations with the exception of Turkey. The information in this document relates to the area under the effective control of the Government of the Republic of Cyprus.

\section{Calculating international averages}

An OECD average was calculated for most indicators presented in this report. In the case of some indicators, a total representing the OECD area as a whole was also calculated:

- The OECD average corresponds to the arithmetic mean of the respective country estimates.

- The OECD total takes the OECD countries as a single entity, to which each country contributes in proportion to the number of 15-year-olds enrolled in its schools (see Annex B for data). It illustrates how a country compares with the OECD area as a whole.

In this publication, the OECD total is generally used when references are made to the overall situation in the OECD area. Where the focus is on comparing performance across education systems, the OECD average is used. In the case of some countries, data may not be available for specific indicators, or specific categories may not apply. Readers should, therefore, keep in mind that the terms "OECD average" and "OECD total" refer to the OECD countries included in the respective comparisons.

\section{Rounding figures}

Because of rounding, some figures in tables may not exactly add up to the totals. Totals, differences and averages are always calculated on the basis of exact numbers and are rounded only after calculation. 
All standard errors in this publication have been rounded to one or two decimal places. Where the value 0.0 or 0.00 is shown, this does not imply that the standard error is zero, but that it is smaller than 0.05 or 0.005 , respectively.

\section{Reporting student data}

The report uses "15-year-olds" as shorthand for the PISA target population. PISA covers students who are aged between 15 years 3 months and 16 years 2 months at the time of assessment and who are enrolled in school and have completed at least 6 years of formal schooling, regardless of the type of institution in which they are enrolled and of whether they are in full-time or part-time education, of whether they attend academic or vocational programmes, and of whether they attend public or private schools or foreign schools within the country.

\section{Reporting school data}

The principals of the schools in which students were assessed provided information on their schools' characteristics by completing a school questionnaire. Where responses from school principals are presented in this publication, they are weighted so that they are proportionate to the number of 15 -year-olds enrolled in the school.

\section{Focusing on statistically significant differences}

This volume discusses only statistically significant differences or changes. These are denoted in darker colours in figures and in bold font in tables. See Annex A3 for further information.

\section{Categorising student performance}

This report uses a shorthand to describe students' levels of proficiency in the subjects assessed by PISA:

Top performers are those students proficient at Level 5 or 6 of the assessment.

Strong performers are those students proficient at Level 4 of the assessment.

Moderate performers are those students proficient at Level 2 or 3 of the assessment.

Lowest performers are those students proficient at or below Level 1 of the assessment.

Highest achievers are those students who perform at or above the 90th percentile in their own country/economy. High achievers are those students who perform at or above the 75th percentile in their own country/economy.

Low achievers are those students who perform below the 25th percentile in their own country/economy.

Lowest achievers are those students who perform below the 10th percentile in their own country/economy.

\section{Abbreviations used in this report}

\begin{tabular}{ll|ll}
\hline ESCS & PISA index of economic, social and cultural status & PPP & Purchasing power parity \\
\hline GDP & Gross domestic product & S.D. & Standard deviation \\
\hline ISCED & International Standard Classification of Education & S.E. & Standard error \\
\hline ISCO & $\begin{array}{l}\text { International Standard Classification } \\
\text { of Occupations }\end{array}$ & $\begin{array}{l}\text { STEM Science, Technology, Engineering } \\
\text { and Mathematics }\end{array}$ \\
\hline
\end{tabular}

\section{Further documentation}

For further information on the PISA assessment instruments and the methods used in PISA, see the PISA 2012 Technical Report (OECD, forthcoming).

This report uses the OECD StatLinks service. Below each table and chart is a url leading to a corresponding Excel ${ }^{\mathrm{TM}}$ workbook containing the underlying data. These urls are stable and will remain unchanged over time. In addition, readers of the e-books will be able to click directly on these links and the workbook will open in a separate window, if their internet browser is open and running. 


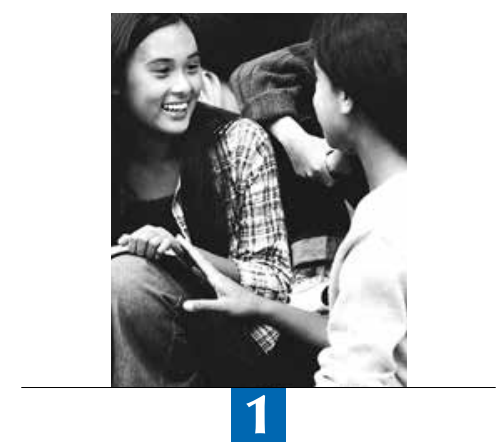

\section{What is PISA?}

The Programme for International Student Assessment (PISA) reviews the extent to which students near the end of compulsory education have acquired some of the knowledge and skills that are essential for full participation in modern society, particularly in mathematics, reading and science. This section offers an overview of the Programme, including which countries and economies participate and which students are assessed, what types of skills are measured, and how PISA 2012 differs from previous PISA assessments. 
"What is important for citizens to know and be able to do?" That is the question that underlies the triennial survey of 15-year-old students around the world known as the Programme for International Student Assessment (PISA). PISA assesses the extent to which students near the end of compulsory education have acquired key knowledge and skills that are essential for full participation in modern societies. The assessment, which focuses on reading, mathematics, science and problem solving, does not just ascertain whether students can reproduce knowledge; it also examines how well students can extrapolate from what they have learned and apply that knowledge in unfamiliar settings, both in and outside of school. This approach reflects the fact that modern economies reward individuals not for what they know, but for what they can do with what they know.

PISA is an ongoing programme that offers insights for education policy and practice, and that helps monitor trends in students' acquisition of knowledge and skills across countries and in different demographic subgroups within each country. PISA results reveal what is possible in education by showing what students in the highest-performing and most rapidly improving education systems can do. The findings allow policy makers around the world to gauge the knowledge and skills of students in their own countries in comparison with those in other countries, set policy targets against measurable goals achieved by other education systems, and learn from policies and practices applied elsewhere. While PISA cannot identify cause-and-effect relationships between policies/practices and student outcomes, it can show educators, policy makers and the interested public how education systems are similar and different - and what that means for students.

PISA's unique features include its:

- policy orientation, which links data on student learning outcomes with data on students' backgrounds and attitudes towards learning and on key factors that shape their learning, in and outside of school, in order to highlight differences in performance and identify the characteristics of students, schools and education systems that perform well;

- innovative concept of "literacy", which refers to students' capacity to apply knowledge and skills in key subjects, and to analyse, reason and communicate effectively as they identify, interpret and solve problems in a variety of situations;

- relevance to lifelong learning, as PISA asks students to report on their motivation to learn, their beliefs about themselves, and their learning strategies;

- regularity, which enables countries to monitor their progress in meeting key learning objectives; and

- breadth of coverage, which, in PISA 2012, encompasses the 34 OECD member countries and 31 partner countries and economies.

\section{Box I.1.1. A test the whole world can take}

PISA is now used as an assessment tool in many regions around the world. It was implemented in 43 countries and economies in the first assessment (32 in 2000 and 11 in 2002), 41 in the second assessment (2003), 57 in the third assessment (2006) and 75 in the fourth assessment (65 in 2009 and 10 in 2010). So far, 65 countries and economies have participated in PISA 2012.

In addition to OECD member countries, the survey has been or is being conducted in:

East, South and Southeast Asia: Himachal Pradesh-India, Hong Kong-China, Indonesia, Macao-China, Malaysia, Shanghai-China, Singapore, Chinese Taipei, Tamil Nadu-India, Thailand and Viet Nam.

Central, Mediterranean and Eastern Europe, and Central Asia: Albania, Azerbaijan, Bulgaria, Croatia, Georgia, Kazakhstan, Kyrgyzstan, Latvia, Liechtenstein, Lithuania, the former Yugoslav Republic of Macedonia, Malta, Moldova, Montenegro, Romania, the Russian Federation and Serbia.

The Middle East: Jordan, Qatar and the United Arab Emirates.

Central and South America: Argentina, Brazil, Colombia, Costa Rica, Netherlands-Antilles, Panama, Peru, Trinidad and Tobago, Uruguay and Miranda-Venezuela.

Africa: Mauritius and Tunisia. 
Decisions about the scope and nature of the PISA assessments and the background information to be collected are made by leading experts in participating countries. Considerable efforts and resources are devoted to achieving cultural and linguistic breadth and balance in assessment materials. Since the design and translation of the test, as well as sampling and data collection, are subject to strict quality controls, PISA findings are considered to be highly valid and reliable.

- Figure I.1.1

Map of PISA countries and economies

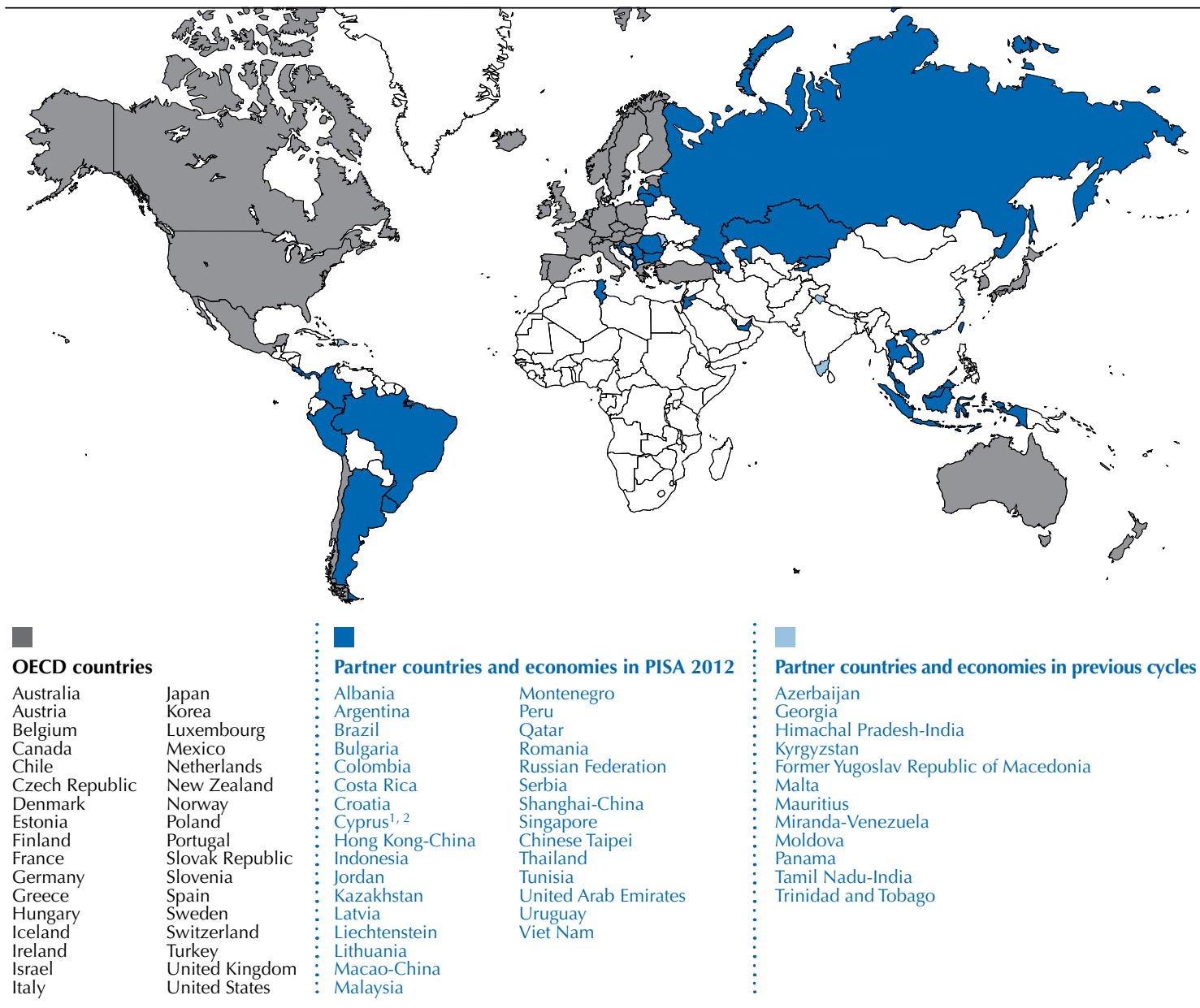

1. Note by Turkey: The information in this document with reference to "Cyprus" relates to the southern part of the Island. There is no single authority representing both Turkish and Greek Cypriot people on the Island. Turkey recognises the Turkish Republic of Northern Cyprus (TRNC). Until a lasting and equitable solution is found within the context of the United Nations, Turkey shall preserve its position concerning the "Cyprus issue".

2. Note by all the European Union Member States of the OECD and the European Union: The Republic of Cyprus is recognised by all members of the United Nations with the exception of Turkey. The information in this document relates to the area under the effective control of the Government of the Republic of Cyprus.

\section{WHAT DOES THE PISA 2012 SURVEY MEASURE?}

The PISA 2012 survey focuses on mathematics, with reading, science and problem solving as minor areas of assessment. For the first time, PISA 2012 also included an assessment of the financial literacy of young people, which was optional for countries.

For PISA, mathematics proficiency means the capacity of individuals to formulate, employ and interpret mathematics in a variety of contexts. The term describes the capacities of individuals to reason mathematically and use mathematical concepts, procedures, facts and tools to describe, explain and predict phenomena. Mathematics literacy is not an attribute that an individual either has or does not have; rather, it is a skill that can be developed over a lifetime. 
The 2012 survey is the fifth round of assessments since PISA began in 2000, and the second, after the 2003 survey, that focuses on mathematics. As such, PISA 2012 provides an opportunity to evaluate changes in student performance in mathematics since 2003, and to view those changes in the context of policies and other factors.

For the first time, PISA 2012 includes an optional computer-based assessment of mathematics. Specially designed PISA questions are presented on a computer, and students respond on the computer, although they can also use pencil and paper as they think through the test questions.

\section{Box I.1.2. Key features of PISA 2012}

\section{The content}

- The PISA 2012 survey focused on mathematics, with reading, science and problem solving as minor areas of assessment. For the first time, PISA 2012 also included an assessment of the financial literacy of young people, which was optional for countries and economies.

- PISA assesses not only whether students can reproduce knowledge, but also whether they can extrapolate from what they have learned and apply their knowledge in new situations. It emphasises the mastery of processes, the understanding of concepts, and the ability to function in various types of situations.

\section{The students}

- Around 510000 students completed the assessment in 2012, representing about 28 million 15-year-olds in the schools of the 65 participating countries and economies.

\section{The assessment}

- Paper-based tests were used, with assessments lasting a total of two hours for each student. In a range of countries and economies, an additional 40 minutes were devoted to the computer-based assessment of mathematics, reading and problem solving.

- Test items were a mixture of multiple-choice items and questions requiring students to construct their own responses. The items were organised in groups based on a passage setting out a real-life situation. A total of about 390 minutes of test items were covered, with different students taking different combinations of test items.

- Students answered a background questionnaire, which took 30 minutes to complete, that sought information about themselves, their homes and their school and learning experiences. School principals were given a questionnaire, to complete in 30 minutes, that covered the school system and the learning environment. In some countries and economies, optional questionnaires were distributed to parents, who were asked to provide information on their perceptions of and involvement in their child's school, their support for learning in the home, and their child's career expectations, particularly in mathematics. Countries could choose two other optional questionnaires for students: one asked students about their familiarity with and use of information and communication technologies, and the second sought information about their education to date, including any interruptions in their schooling and whether and how they are preparing for a future career.

\section{WHO ARE THE PISA STUDENTS?}

Differences between countries in the nature and extent of pre-primary education and care, in the age of entry into formal schooling, in the structure of the education system, and in the prevalence of grade repetition mean that school grade levels are often not good indicators of where students are in their cognitive development. To better compare student performance internationally, PISA targets a specific age of students. PISA students are aged between 15 years 3 months and 16 years 2 months at the time of the assessment, and have completed at least 6 years of formal schooling. They can be enrolled in any type of institution, participate in full-time or part-time education, in academic or vocational programmes, and attend public or private schools or foreign schools within the country. (For an operational definition of this target population, see Annex A2.) Using this age across countries and over time allows PISA to compare consistently the knowledge and skills of individuals born in the same year who are still in school at age 15, despite the diversity of their education histories in and outside of school. 
The population of participating students is defined by strict technical standards, as are the students who are excluded from participating (see Annex A2). The overall exclusion rate within a country was required to be below $5 \%$ to ensure that, under reasonable assumptions, any distortions in national mean scores would remain within plus or minus 5 score points, i.e. typically within the order of magnitude of 2 standard errors of sampling. Exclusion could take place either through the schools that participated or the students who participated within schools (see Annex A2, Tables A2.1 and $\mathrm{A} 2.2$ ).

There are several reasons why a school or a student could be excluded from PISA. Schools might be excluded because they are situated in remote regions and are inaccessible, because they are very small, or because of organisational or operational factors that precluded participation. Students might be excluded because of intellectual disability or limited proficiency in the language of the assessment.

In 28 out of the 65 countries and economies participating in PISA 2012, the percentage of school-level exclusions amounted to less than $1 \%$; it was less than $4 \%$ in all countries and economies. When the exclusion of students who met the internationally established exclusion criteria is also taken into account, the exclusion rates increase slightly. However, the overall exclusion rate remains below $2 \%$ in 30 participating countries and economies, below 5\% in 57 participating countries, and below 7\% in all countries except Luxembourg (8.4\%). In 11 out of the 34 OECD countries, the percentage of school-level exclusions amounted to less than $1 \%$ and was less than $3 \%$ in 31 OECD countries. When student exclusions within schools were also taken into account, there were 11 OECD countries below $2 \%$ and 26 OECD countries below 5\%.

Restrictions on the level of exclusions in PISA 2012:

- School-level exclusions for inaccessibility, feasibility or other reasons were required not to exceed $0.5 \%$ of the total number of students in the international PISA target population. Schools on the sampling frame that had only one or two eligible students were not allowed to be excluded from the frame. However, if, based on the frame, it was clear that the percentage of students in these schools would not cause a breach of the allowable limit, then those schools could be excluded from the field, if at that time, they still had only one or two students who were eligible for PISA.

- School-level exclusions for students with intellectual or functional disabilities, or students with limited proficiency in the language of the PISA assessment, were required not to exceed $2 \%$ of students.

- Within-school exclusions for students with intellectual or functional disabilities, or students with limited language proficiency were required not to exceed $2.5 \%$ of students.

Students who could be excluded from PISA 2012 were:

- Intellectually disabled students, defined as students who are considered, in the professional opinion of the school principal, or by other qualified staff members, to be intellectually disabled, or who have been assessed psychologically as such. This category includes students who are emotionally or mentally unable to follow even the general instructions of the assessment. Students were not to be excluded solely because of poor academic performance or common discipline problems.

- Students with functional disabilities, defined as students who are permanently physically disabled in such a way that they cannot perform in the PISA testing situation. Students with functional disabilities who could perform were to be included in the testing.

- Students with limited proficiency in the language of the PISA assessment, defined as students who had received less than one year of instruction in the language of the assessment.

(For more detailed information about the restrictions on the level of exclusions in PISA 2012, see Annex A2.)

\section{WHAT IS THE TEST LIKE?}

For each round of PISA, one subject is tested in detail, taking up nearly two-thirds of the total testing time. The major subject was reading in 2000 and 2009, mathematics in 2003 and 2012, and science in 2006. As in previous PISA assessments, the paper-based assessment was designed as a two-hour test comprising four 30-minute clusters of test material from one or more subjects. Information was obtained from about 390 minutes worth of test items. For each country, the total set of questions was packaged into 13 linked test booklets. Financial literacy, an option in the paperbased assessment, was allocated two clusters (that is, 60 minutes of testing time) in the 2012 survey. 
Each booklet was completed by a sufficient number of students so that reliable estimates could be made of the level of achievement among students in each country and in relevant subgroups - such as boys and girls, and students with different socio-economic status - within a country. Students also spent 30 minutes answering a background questionnaire. Some questions were answered by all students, as in previous assessments; some were answered by subsamples of students.

In addition to this core assessment, 44 countries and economies participated in a computer-based assessment of problem solving; 32 of them also participated in a computer-based assessment of reading and mathematics. The PISA 2012 computer-delivered assessment lasted 40 minutes. A total of 80 minutes of problem-solving material was organised into four 20-minute clusters. Students from countries not participating in the optional computer-based assessment of mathematics and digital reading completed two of the clusters. Students from countries that did participate in the optional computer-based assessment of mathematics and digital reading completed two, one or none of the four problemsolving clusters. The optional computer-based component contained a total of 80 minutes of mathematics material and 80 minutes of reading material.

- Figure I.1.2 -

Summary of the assessment areas in PISA 2012

\begin{tabular}{|c|c|c|c|}
\hline & MATHEMATICS & READING & SCIENCE \\
\hline Definitions & $\begin{array}{l}\text { An individuals' capacity } \\
\text { to formulate, employ, and } \\
\text { interpret mathematics in a } \\
\text { variety of contexts. It includes } \\
\text { reasoning mathematically and } \\
\text { using mathematical concepts, } \\
\text { procedures, facts and tools to } \\
\text { describe, explain and predict } \\
\text { phenomena. It assists individuals } \\
\text { in recognising the role that } \\
\text { mathematics plays in the world } \\
\text { and to make the well-founded } \\
\text { judgements and decisions needed } \\
\text { by constructive, engaged and } \\
\text { reflective citizens. }\end{array}$ & $\begin{array}{l}\text { An individual's capacity to understand, } \\
\text { use, reflect on and engage with written } \\
\text { texts, in order to achieve one's goals, } \\
\text { to develop one's knowledge and } \\
\text { potential, and to participate in society. }\end{array}$ & $\begin{array}{l}\text { An individual's scientific knowledge } \\
\text { and use of that knowledge to identify } \\
\text { questions, to acquire new knowledge, } \\
\text { to explain scientific phenomena, and } \\
\text { to draw evidence-based conclusions } \\
\text { about science-related issues. It includes } \\
\text { understanding the characteristic } \\
\text { features of science as a form of human } \\
\text { knowledge and enquiry, awareness } \\
\text { of how science and technology shape } \\
\text { our material, intellectual, and cultural } \\
\text { environments, and willingness to } \\
\text { engage in science-related issues, } \\
\text { and with the ideas of science, } \\
\text { as a reflective citizen. }\end{array}$ \\
\hline Contents & $\begin{array}{l}\text { Four overarching ideas that relate } \\
\text { to numbers, algebra and geometry: } \\
\text { - quantity } \\
\text { - space and shape } \\
\text { - change and relationships } \\
\text { - uncertainty and data }\end{array}$ & $\begin{array}{l}\text { The form of reading materials includes: } \\
\text { - continuous texts or prose organised } \\
\text { in sentences and paragraphs (e.g. } \\
\text { narration, exposition, argumentation, } \\
\text { description, instruction) } \\
\text { non-continuous texts that present } \\
\text { information in other ways, such as } \\
\text { in lists, forms, graphs, or diagrams }\end{array}$ & $\begin{array}{l}\text { Scientific knowledge or concepts are } \\
\text { related to physics, chemistry, biological } \\
\text { sciences and earth and space sciences, } \\
\text { but they are applied to the content of } \\
\text { the items and not just recalled. }\end{array}$ \\
\hline Processes & $\begin{array}{l}\text { formulating situations } \\
\text { mathematically } \\
\text { - employing mathematical } \\
\text { concepts, facts, procedures and } \\
\text { reasoning } \\
\text { - interpreting, applying and } \\
\text { evaluating mathematical } \\
\text { outcomes } \\
\text { (referred to in abbreviated form as } \\
\text { "formulate, employ and interpret") }\end{array}$ & $\begin{array}{l}\text { - } \text { - forming a broad general } \\
\text { understanding of the text } \\
\text { - interpreting the text } \\
\text { - reflecting on the content and the } \\
\text { form and features of the text }\end{array}$ & $\begin{array}{l}\text { - describing, explaining and } \\
\text { predicting scientific phenomena } \\
\text { - understanding scientific } \\
\text { investigation } \\
\text { - interpreting scientific evidence and } \\
\text { conclusions }\end{array}$ \\
\hline Contexts & $\begin{array}{l}\text { The situations in which } \\
\text { mathematics literacy is applied: } \\
\text { - personal } \\
\text { - occupational } \\
\text { - societal } \\
\text { " scientific }\end{array}$ & $\begin{array}{l}\text { The use for which a text is constructed: } \\
\text { - personal } \\
\text { - educational } \\
\text { - occupational } \\
\text { - public }\end{array}$ & $\begin{array}{l}\text { The situations in which science } \\
\text { literacy is applied: } \\
\text { - personal } \\
\text { - social } \\
\text { - global } \\
\text { For some applications of science: } \\
\text { - life and health } \\
\text { - earth and environment } \\
\text { - technology }\end{array}$ \\
\hline
\end{tabular}


The material for each subject was arranged in four clusters of items, with each cluster representing 20 minutes of testing time. All material that was presented on a computer was arranged in a number of test forms, with each form containing two clusters. Each student did one form, representing a total testing time of 40 minutes.

\section{HOW IS THE TEST CONDUCTED?}

When a school participates in PISA, a school co-ordinator is appointed. The school co-ordinator compiles a list of all 15-year-olds in the school and sends this list to the PISA National Centre in the country, which randomly selects 35 students to participate. The school co-ordinator then contacts the students who have been selected and obtains the necessary permission from parents.

The testing session is usually conducted by a test administrator who is trained and employed by the National Centre. The test administrator contacts the school co-ordinator to schedule administration of the assessment. The school co-ordinator ensures that the students, who may come from different grades and different classes, attend the testing sessions. The test administrator's primary tasks are to ensure that each test booklet is distributed to the correct student and to introduce the tests to the students. After the test is over, the test administrator collects the test booklets and sends them to the National Centre for coding.

In PISA 2012, at least 13 different test booklets were used in each country. With 13 different booklets for each group of 35 students, no more than 3 students were given the same booklet. Booklets were allocated to individual students according to a random selection process. The test administrator's introduction came from a prescribed text so that all students in different schools and countries received exactly the same instructions. Before starting the test, the students were asked to do a practice question from their booklets. The testing session was divided into two parts: the two-hour test to assess their knowledge and skills, and the 30-minute questionnaire session to collect data on their personal background. Students were usually given a short break half-way through the test and again before they completed the questionnaire.

\section{WHAT KINDS OF RESULTS DOES THE TEST PROVIDE?}

The PISA assessment provides three main types of outcomes:

- basic indicators that provide a baseline profile of students' knowledge and skills;

- indicators that show how skills relate to important demographic, social, economic and educational variables; and

- indicators on trends that show changes in student performance and in the relationships between student-level and school-level variables and outcomes.

Although indicators can highlight important issues, they do not provide answers to policy questions. To respond to this, PISA also developed a policy-oriented analysis plan that uses the indicators as a basis for policy discussion.

\section{WHERE CAN YOU FIND THE RESULTS?}

This is the first of six volumes that presents the results from PISA 2012. It begins by discussing student performance in mathematics in PISA 2012 and examines how that performance has changed over previous PISA assessments. Chapter 3 examines how opportunities to learn are associated with mathematics performance. Chapters 4 and 5 provide an overview of student performance in reading and science, respectively, and describe the evolution of performance in these subjects over previous PISA assessments. Chapter 6 discusses the policy implications based on analyses of the results of the preceding chapters and on the policy-reform experience of some countries that have improved during the participation in PISA.

The other five volumes cover the following issues:

Volume II, Excellence through Equity: Giving Every Student the Chance to Succeed, defines and measures equity in education and analyses how equity in education has evolved across countries between PISA 2003 and 2012. The volume examines the relationship between student performance and socio-economic status, and describes how other individual student characteristics, such as immigrant background and family structure, and school characteristics, such as school location, are associated with socio-economic status and performance. The volume also reveals differences in how equitably countries allocate resources and opportunities to learn to schools with different socio-economic profiles. Case studies, examining the policy reforms adopted by countries that have improved in PISA, are highlighted throughout the volume.

Volume III, Ready to Learn: Students' Engagement, Drive and Self-Beliefs, explores students' engagement with and at school, their drive and motivation to succeed, and the beliefs they hold about themselves as mathematics learners. 
The volume identifies the students who are at particular risk of having low levels of engagement in, and holding negative dispositions towards, school in general and mathematics in particular, and how engagement, drive, motivation and self-beliefs are related to mathematics performance. The volume identifies the roles schools can play in shaping the well-being of students and the role parents can play in promoting their children's engagement with and dispositions towards learning. Changes in students' engagement, drive, motivation and self-beliefs between 2003 and 2012, and how those dispositions have changed during the period among particular subgroups of students, notably socio-economically advantaged and disadvantaged students, boys and girls, and students at different levels of mathematics proficiency, are examined when comparable data are available. Throughout the volume, case studies examine in greater detail the policy reforms adopted by countries that have improved in PISA.

Volume IV, What Makes Schools Successful? Resources, Policies and Practices, examines how student performance is associated with various characteristics of individual schools and of concerned school systems. It discusses how 15-yearold students are selected and grouped into different schools, programmes, and education levels, and how human, financial, educational and time resources are allocated to different schools. The volume also examines how school systems balance autonomy with collaboration, and how the learning environment in school shapes student performance. Trends in these variables between 2003 and 2012 are examined when comparable data are available, and case studies, examining the policy reforms adopted by countries that have improved in PISA, are highlighted throughout the volume.

Volume V, Skills for Life: Student Performance in Problem Solving, presents student performance in the PISA 2012 assessment of problem solving, which measures students' capacity to respond to non-routine situations in order to achieve their potential as constructive and reflective citizens. It provides the rationale for assessing problem-solving skills and describes performance within and across countries. In addition, the volume highlights the relative strengths and weaknesses of each school system and examines how they are related to individual student characteristics, such as gender, immigrant background and socio-economic status. The volume also explores the role of education in fostering problem-solving skills.

Volume VI, Students and Money: Financial Literacy Skills for the 21st Century, examines 15-year-old students' performance in financial literacy in the 18 countries and economies that participated in this optional assessment. It also discusses the relationship of financial literacy to students' and their families' background and to students' mathematics and reading skills. The volume also explores students' access to money and their experience with financial matters. In addition, it provides an overview of the current status of financial education in schools and highlights relevant case studies.

The frameworks for assessing mathematics, reading and science in 2012 are described in PISA 2012 Assessment and Analytical Framework: Mathematics, Reading, Science, Problem Solving and Financial Literacy (OECD, 2013). They are also summarised in this volume.

Technical annexes at the end of this report describe how questionnaire indices were constructed and discuss sampling issues, quality-assurance procedures, the reliability of coding, and the process followed for developing the assessment instruments. Many of the issues covered in the technical annexes are elaborated in greater detail in the PISA 2012 Technical Report (OECD, forthcoming).

All data tables referred to in the analysis are included at the end of the respective volume in Annex B1, and a set of additional data tables is available on line (www.pisa.oecd.org). A Reader's Guide is also provided in each volume to aid in interpreting the tables and figures that accompany the report. Data from regions within the participating countries are included in Annex B2. Results from the computer-based assessment of mathematics and reading are presented in Annex B3.

\section{References}

OECD (forthcoming), PISA 2012 Technical Report, PISA, OECD Publishing.

OECD (2013), PISA 2012 Assessment and Analytical Framework: Mathematics, Reading, Science, Problem Solving and Financial Literacy, PISA, OECD Publishing.

http://dx.doi.org/10.1787/9789264190511-en 


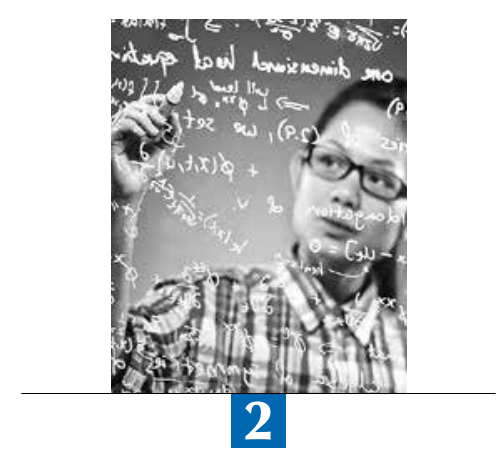

\section{A Profile \\ of Student Performance in Mathematics}

This chapter compares student performance in mathematics across and within countries and economies. It discusses the PISA definition of literacy in mathematics and describes the tasks associated with each PISA proficiency level. The chapter then digs deep into the results of the mathematics assessment, showing gender differences in performance, trends in mathematics performance up to 2012, and differences in students' abilities to handle certain mathematics processes, such as formulating situations mathematically, and certain mathematics contents, such as uncertainty and data, and space and shape. 
All adults, not just those with technical or scientific careers, now require adequate mathematics proficiency for personal fulfilment, employment and full participation in society. To one degree or another, mathematical concepts and processes are intrinsic to many daily tasks: from buying and selling goods and services, to cooking or planning a vacation, to explaining highly complex phenomena. Students about to leave compulsory education should thus have a solid understanding of these concepts and be able to apply them to solve problems that they encounter in their daily lives.

This chapter summarises the mathematics performance of students in PISA 2012. It describes how performance is defined, measured and reported, and then provides results from the paper-based assessment, showing what students are able to do in mathematics. After a summary of mathematics performance, it examines the ways in which this performance varies on subscales representing different aspects of mathematics. Annex B3 provides further results for 32 countries and economies that participated in the computer-based assessment, supplementing the paper-based scale with two others: the computer-based scale and the combined paper- and computer-based scale.

\section{What the data tell us}

- Of the 64 countries and economies with trend data up to 2012, 25 show an average annual improvement in mathematics performance, 25 show no change, and 14 show a deterioration in performance.

- Among countries and economies that have participated in every assessment since 2003, Brazil, Italy, Mexico, Poland, Portugal, Tunisia and Turkey show an average improvement in mathematics performance of more than 2.5 points per year.

- Germany, Hong Kong-China, Macao-China, Shanghai-China and Singapore improved in mathematics performance and their previous scores placed them at or above the OECD average.

- Between 2003 and 2012 Italy, Poland and Portugal reduced the proportion of low performers and increased the proportion of high performers. This was also observed in Israel, Qatar and Romania between 2006 and 2012 , and in Ireland, Malaysia and the Russian Federation between 2009 and 2012.

- Boys perform better than girls in mathematics in 38 out of the 65 countries and economies that participated in PISA 2012, and girls outperform boys in 5 countries.

\section{Box I.2.1. What does performance in PISA say about readiness for further education and a career?}

To what extent is the performance of 15-year-olds in PISA predictive of further education and career readiness and success later in life? The transition from adolescence to early adulthood is a critical time in the social and intellectual development of young people. Once compulsory education is completed, adolescents have to make important decisions about post-secondary education, employment and other life choices that will have a major impact on their future learning and employment prospects as well as on their overall well-being. A decadelong study undertaken in Canada coupled data collected from the PISA assessment of 15-year-olds in 2000 with follow-ups conducted every two years through a national survey of those same students and parents (the Youth in Transition Survey). The results from this study show that having a solid foundation in the kinds of skills that PISA measures makes it much easier to advance in post-compulsory education. Reading scores in PISA, for example, are associated with the likelihood of students progressing from one grade level to another across grades 10 to 16 . Some $37 \%$ of boys with a high reading score, i.e. in the top quintile of reading proficiency, attained grade 16 compared to just $3.4 \%$ of boys with low reading scores (bottom quintile). Similarly, $52.4 \%$ of girls with high reading scores attained grade 16 compared to $14.9 \%$ of girls with low reading scores. The results show that reading scores had a stronger association with grade progression during the post-secondary school years than with schooling up to grade 12 , particularly for boys.

Equally important, the results also show that introducing a uniform increase of one standard deviation in reading scores results in a $17.4 \%$ reduction in the proportion of young men who leave formal education before completing secondary school and a $12.6 \%$ increase in the proportion of young men who attend post-secondary education. 
For girls, the effects of increased reading scores are also substantial. A one standard deviation increase in reading scores is associated with a $31.5 \%$ reduction in the proportion of girls who leave formal education before completing secondary school and an $11.4 \%$ increase in the share of young women who complete at least some post-secondary education. Even after adjusting for socio-economic status, both achievement in PISA and educational attainment are associated with a higher likelihood of continuing in education and a lower likelihood of proceeding to work or to a period of inactivity (OECD, 2010a).

To what extent are the differences in the performance of school systems, as observed in PISA, reflected in the skills of adults who have recently completed initial education and training? The Survey of Adult Skills, a product of the OECD Programme for the International Assessment of Adult Competencies (PIAAC), provides a way to assess this. Most adults aged 27 or under in participating countries correspond to the cohorts assessed in PISA in 2000, 2003, 2006 and 2009, when they were 15 years old.

The results from the Survey of Adult Skills show that, overall, there is a reasonably close correlation between countries' performance across the successive PISA assessments and the proficiency of the corresponding age cohorts in literacy and numeracy in the Skills Survey. Countries performing well in PISA in a given year (e.g. 2000) tend to show high performance among the corresponding age cohort (e.g. 27-year-olds) in the Survey of Adult Skills (PIAAC) and vice versa. This suggests that, at the country level, the reading and mathematics proficiency of an age cohort in PISA is a reasonably good predictor of the cohort's subsequent performance in literacy and numeracy as it moves through post-compulsory education and into the labour market. By implication, much of the difference in the literacy and numeracy proficiency of young adults today is likely related to the effectiveness of the instruction they received in primary and lower secondary school.

Of course, some caution is advised in comparing results of the two studies. The overlap between the target populations of the Survey of Adult Skills (PIAAC) and PISA is not complete; and while the concepts of literacy in the Skills Survey and reading literacy in PISA, and the concepts of numeracy in the Skills Survey and mathematical literacy in PISA are closely related, the measurement scales are not the same. In addition, the skills of 15-27 year-olds are subject to influences that vary across individuals and countries, including participation in post-secondary and tertiary education and the quality of these programmes, second-chance opportunities for low-skilled young adults, and characteristics of the labour market (OECD, 2013a and b). 


\section{A CONTEXT FOR COMPARING THE MATHEMATICS PERFORMANCE OF COUNTRIES AND ECONOMIES}

Comparing mathematics performance, and educational performance more generally, poses numerous challenges. When teachers give a mathematics test in a classroom, students with varying abilities, attitudes and social backgrounds are required to respond to the same set of tasks. When educators compare the performance of schools, the same test is used across schools that may differ significantly in the structure and sequencing of their curricula, in the pedagogical emphases and instructional methods applied, and in the demographic and social contexts of their student populations. Comparing the performance of education systems across countries adds more layers of complexity, because students are given tests in different languages, and because the social, economic and cultural context of the countries that are being compared are often very different. However, while students within a country may learn in different contexts according to their home background and the school that they attend, their performance is measured against common standards, since, when they become adults, they will all face common challenges and have to compete for the same jobs. Similarly, in a global economy, the benchmark for success in education is no longer improvement by national standards alone, but increasingly, in relation to the best-performing education systems internationally. As difficult as international comparisons are, they are important for educators, and PISA goes to considerable lengths to ensure that such comparisons are valid and fair.

This section discusses countries' mathematics performance in the context of important economic, demographic and social factors that can influence assessment results. It provides a framework for interpreting the results that are presented later in the chapter.

As shown in Volume II, Excellence through Equity, a family's wealth influences children's performance in school, but that influence varies markedly across countries. Similarly, the relative prosperity of some countries allows them to spend more on education, while other countries find themselves constrained by a lower national income. It is therefore important to keep the national income of countries in mind when comparing the performance of education systems across countries. Figure I.2.1 displays the relationship between national income as measured by per capita Gross Domestic Product (GDP) and students' average mathematics performance. ${ }^{1}$ The figure also shows a trend line $^{2}$ that summarises the relationship between per capita GDP and mean student performance in mathematics among OECD countries. The relationship suggests that $21 \%$ of the variation in countries' mean scores can be predicted on the basis of their per capita GDP $(12 \%$ of the variation in OECD countries). Countries with higher national incomes are thus at a relative advantage, even if the chart provides no indications about the causal nature of this relationship. This should be taken into account particularly when interpreting the performance of countries with comparatively low levels of national income, such as Viet Nam and Indonesia (Mexico and Turkey among OECD countries). Table 1.2.27 shows an "adjusted" score that would be expected if the country had all of its present characteristics except that per capita GDP was equal to the average for OECD countries (Table I.2.27).

While per capita GDP reflects the potential resources available for education in each country, it does not directly measure the financial resources actually invested in education. Figure 1.2.2 compares countries' actual spending per student, on average, from the age of 6 up to the age of 15, with average student performance in mathematics. ${ }^{3}$ The results are expressed in USD using purchasing power parities (PPP). Figure I.2.2 shows a positive relationship between spending per student and mean mathematics performance among OECD countries. As expenditure on educational institutions per student increases, so does a country's mean performance. Expenditure per student explains 30\% of the variation in mean performance between countries ( $17 \%$ of the variation in OECD countries). Relatively low spending per student needs to be taken into account when interpreting the performance of countries such as Viet Nam and Jordan (Turkey and Mexico among OECD countries). (For more details, see Figure IV.1.7 in Volume IV). At the same time, deviations from the trend line suggest that moderate spending per student cannot automatically be equated with poor performance. For example, the Slovak Republic, which spends around USD 53000 per student, performs at the same level as the United States, which spends over USD 115000 per student. Similarly, Korea, the highest-performing OECD country in mathematics, spends well below the average per-student expenditure (Table I.2.27).

Given the close interrelationship between a student's performance and his or her parents' level of education, it is also important to bear in mind the educational attainment of adult populations when comparing the performance of OECD countries, as countries with more highly educated adults are at an advantage over countries where parents have less education. Figure 1.2.3 shows the percentage of 35-44 year-olds who have attained tertiary education. This group corresponds roughly to the age group of parents of the 15-year-olds assessed in PISA. Parents' level of education explains $27 \%$ of the variation in mean performance between countries ( $23 \%$ of the variation among OECD countries). 
- Figure I.2.1

Mathematics performance and Gross Domestic Product

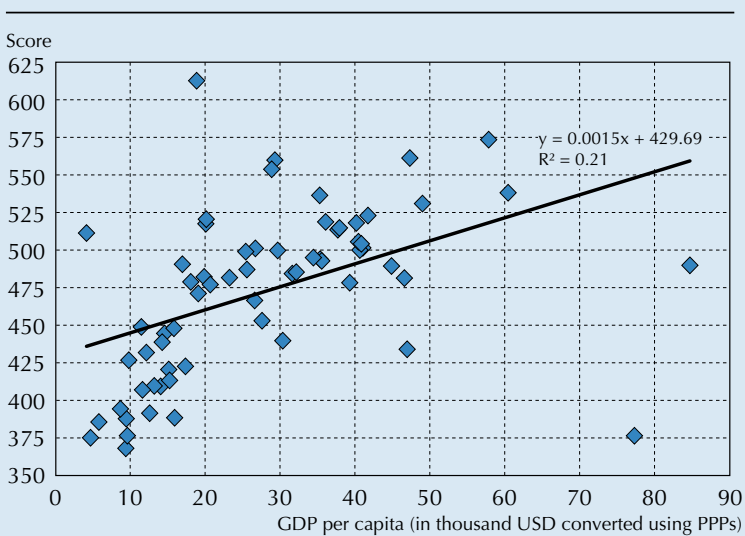

Source: OECD, PISA 2012 Database, Table I.2.27.

StatLink 形)

- Figure 1.2 .3 .

Mathematics performance and parents' education

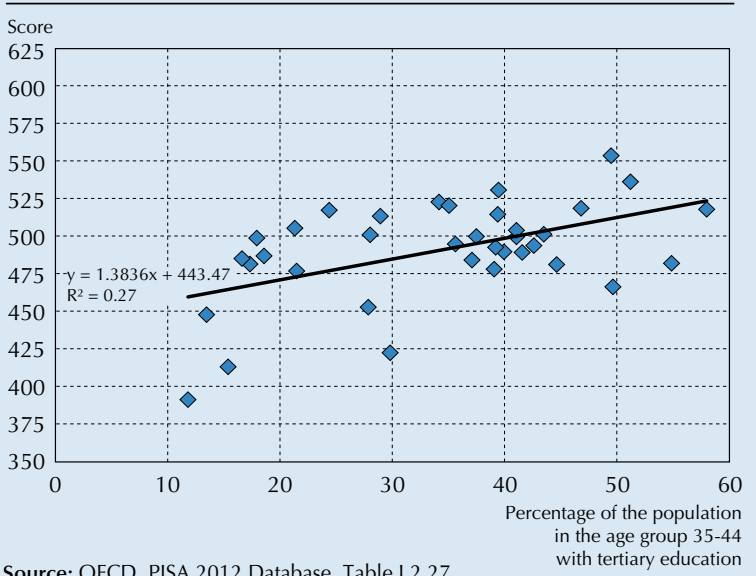

StatLink न्ना15 http://dx.doi.org/10.1787/888932935572

- Figure 1.2 .5 -

Mathematics performance and proportion of students from an immigrant background

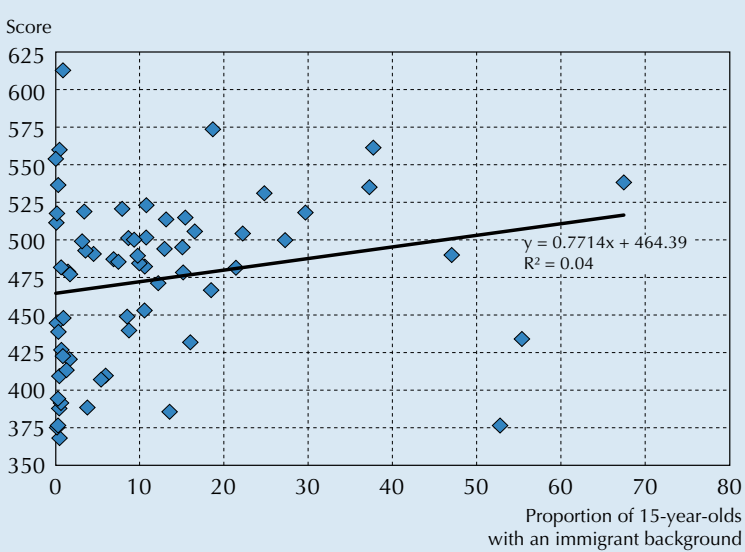

Source: OECD, PISA 2012 Database, Table 1.2.27.

StatLink त्नाज़ http://dx.doi.org/10.1787/888932935572
- Figure I.2.2

Mathematics performance and spending on education

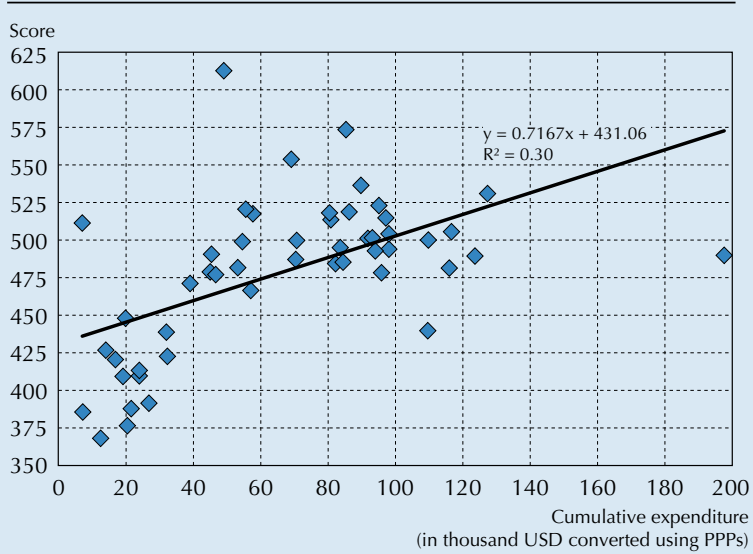

Source: OECD, PISA 2012 Database, Table 1.2.27.

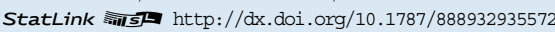

- Figure I.2.4

Mathematics performance and share of socio-economically disadvantaged students

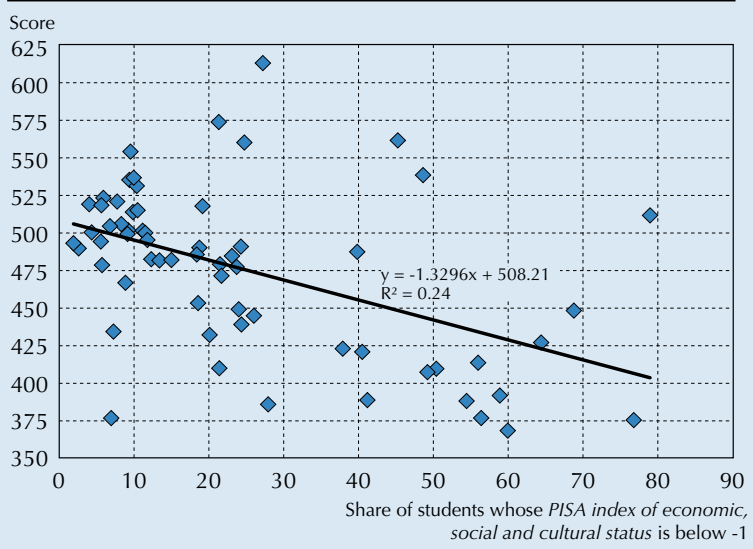

Source: OECD, PISA 2012 Database, Table 1.2.27.

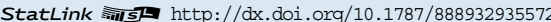

- Figure 1.2.6 =

Equivalence of the PISA assessment across cultures and languages

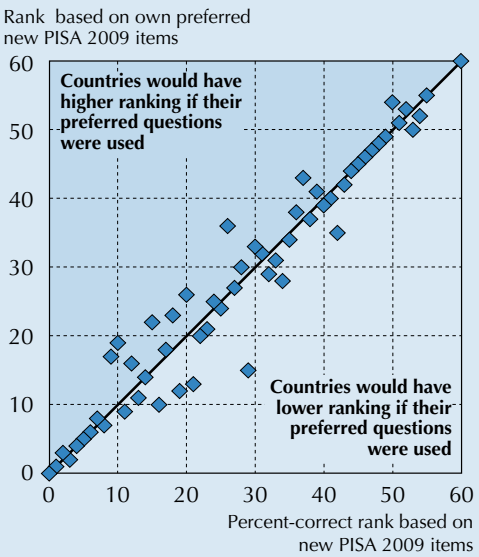

Source: OECD, PISA 2009 Database, Table 1.2.28.

StatLink 部促 http://dx.doi.org/10.1787/888932935572 
Socio-economic heterogeneity in student populations poses another major challenge for teachers and education systems. As shown in Volume II, Excellence through Equity, teachers instructing socio-economically disadvantaged children are likely to face greater challenges than teachers teaching students from more advantaged backgrounds. Similarly, countries with larger proportions of disadvantaged children face greater challenges than countries with smaller proportions of these students. Figure I.2.4 shows the proportion of students at the lower end of an international scale of the economic, social and cultural status of students, which is described in detail in Volume II, and how this relates to mathematics performance. The relationship explains $24 \%$ of the performance variation among countries $46 \%$ of the variation among OECD countries). Among OECD countries, Turkey and Mexico, where $69 \%$ and $56 \%$ of students, respectively, belong to the most disadvantaged group, and Portugal, Chile, Hungary and Spain, where more than $20 \%$ of students belong to this group, face much greater challenges than, for example, Iceland, Norway, Finland and Denmark, where fewer than 5\% of students are disadvantaged (Table I.2.27). These challenges are even greater in some partner countries like Viet Nam and Indonesia where $79 \%$ and $77 \%$ of students, respectively, are socio-economically disadvantaged.

Integrating students with an immigrant background can also be challenging, and the level of performance of students who immigrated to the country in which they were assessed can be only partially attributed to their host country's education system. Figure I.2.5 shows the proportion of 15-year-olds from an immigrant background and how this relates to student performance. This proportion explains only $4 \%$ of the variation in mean performance among countries. Despite having large proportions of immigrant students, some countries, like Canada, perform above the OECD average (Table I.2.27).

When examining the results for individual countries, as shown in Table I.2.27, it is apparent that countries vary in their demographic, social and economic contexts. Table I.2.27 summarises in an index the different factors discussed above. ${ }^{4}$ Among the countries with available data, the index shows Luxembourg, Norway, Japan, Finland, Iceland, Denmark, Ireland and the United States with the most advantaged demographic, social and economic contexts, and Turkey, Brazil, Mexico, Chile, Portugal, Hungary, the Slovak Republic, Poland and the Czech Republic with the most challenging contexts.

These differences need to be considered when interpreting PISA results. At the same time, the future economic and social prospects of both individuals and countries depend on the results they actually achieve, not on the performance they might have achieved under different social and economic conditions. That is why the results that are actually achieved by students, schools and countries are the focus of this volume.

Even after accounting for the demographic, economic and social context of education systems, the question remains: to what extent is an international test meaningful when differences in languages and cultures lead to very different ways in which subjects such as language, mathematics and science are taught and learned? It is inevitable that not all tasks on the PISA assessments are equally appropriate in different cultural contexts and equally relevant in different curricular and instructional contexts. To gauge this, in 2009 PISA asked every country to identify those tasks from the PISA tests that it considered most appropriate for an international test. Countries were advised to give an on-balance rating for each task with regard to its usefulness in indicating "preparedness for life", its authenticity, and its relevance for 15-year-olds. Tasks given a high rating by a country are referred to as that country's most preferred questions for PISA. PISA then scored every country on its own most preferred questions and compared the resulting performance with the performance on the entire set of PISA tasks (Figure I.2.6). It is clear that, generally, the proportion of questions answered correctly by students does not depend significantly on whether countries were only scored on their preferred questions or on the overall set of PISA tasks. This provides robust evidence that the results of the PISA assessments would not change markedly if countries had more influence in selecting texts that they thought might be "fairer" to their students.

Finally, when comparing student performance across countries, the extent to which student performance on international tests might be influenced by the effort that students in different countries invest in the assessment must be considered. In PISA 2003, students were asked to imagine an actual situation that was highly important to them, so that they could try their very best and invest as much effort as they could into doing well. They were then asked to report how much effort they had put into doing the PISA test compared to the situation they had just imagined; and how much effort they would have invested if their marks from PISA had been counted in their school marks. The students generally answered realistically, saying that they would expend more effort if the test results were to count towards their school marks; but the analysis also established that the reported expenditure of effort by students was fairly stable across countries. This finding counters the claim that systematic cultural differences in the effort expended by students invalidate international comparisons. The analysis also showed that within countries, the amount of effort invested was related to student achievement, with an effect size similar to variables such as single-parent family structure, gender and socio-economic background. ${ }^{5}$ 


\section{THE PISA APPROACH TO ASSESSING STUDENT PERFORMANCE IN MATHEMATICS}

\section{The PISA definition of mathematical literacy}

The focus of the PISA 2012 assessment was on measuring an individual's capacity to formulate, employ and interpret mathematics in a variety of contexts. It includes reasoning mathematically and using mathematical concepts, procedures, facts, and tools to describe, explain and predict phenomena. It assists individuals in recognising the role that mathematics plays in the world and to make the well-founded judgements and decisions needed by constructive, engaged and reflective citizens.

The definition asserts the importance of mathematics for full participation in society and it stipulates that this importance arises from the way in which mathematics can be used to describe, explain and predict phenomena of many types. The resulting insight into phenomena is the basis for informed decision making and judgements.

Literacy in mathematics described in this way is not an attribute that an individual has or does not have; rather, it can be acquired to a greater or lesser extent, and it is required in varying degrees in society. PISA seeks to measure not just the extent to which students can reproduce mathematical content knowledge, but also how well they can extrapolate from what they know and apply their knowledge of mathematics, in both new and unfamiliar situations. This is a reflection of modern societies and workplaces, which value success not by what people know, but by what people can do with what they know.

The focus on real-life contexts is also reflected in the reference to using "tools" that appears in the PISA 2012 definition of mathematical literacy. The word "tools" here refers to physical and digital equipment, software and calculation devices that have become ubiquitous in 21 st century workplaces. Examples for this assessment include a ruler, a calculator, a spreadsheet, an online currency converter and specific mathematics software, such as dynamic geometry. Using these tools require a degree of mathematical reasoning that the PISA assessment is well-equipped to measure.

\section{The PISA 2012 framework for assessing mathematics}

Figure I.2.7 presents an overview of the main constructs of the PISA 2012 mathematics framework that was established and agreed by the participating countries, and how the constructs relate to each other. The largest box shows that mathematical literacy is assessed in the context of a challenge or problem that arises in the real world. The middle box highlights the nature of mathematical thought and action that can be used to solve the problem. The smallest box describes the processes that the problem solver uses to construct a solution.

- Figure I.2.7 -

Main features of the PISA 2012 mathematics framework

Challenge in real world context

Mathematical content categories:

Quantity; Uncertainty and data; Change and relationships; Space and shape

Real world context categories: Personal; Societal; Occupational; Scientific

Mathematical thought and action

Mathematical concepts, knowledge and skills

Fundamental mathematical capabilities:

Communication; Representation; Devising strategies; Mathematisation; Reasoning

and argument; Using symbolic, formal and technical language and operations;

Using mathematical tools

Processes: Formulate; Employ; Interpret/Evaluate

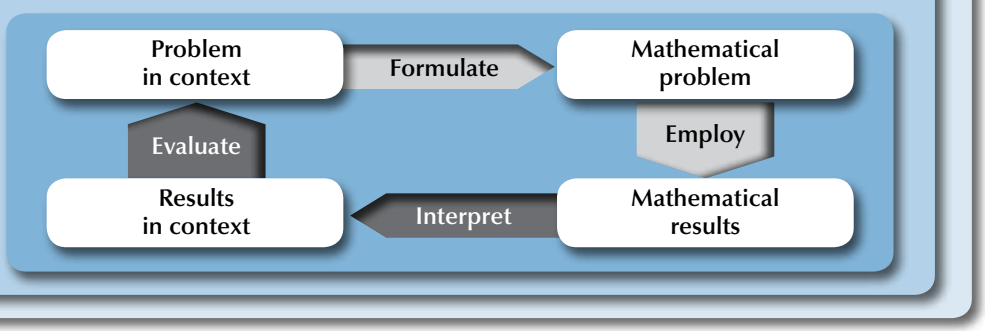




\section{Context categories}

Real-world challenges or situations are categorised in two ways: their context and the domain of mathematics involved. The four context categories identify the broad areas of life in which the problems may arise: personal, which is related to individuals' and families' daily lives; societal, which is related to the community - local, national or global - in which an individual lives; occupational, which is related to the world of work; or scientific, which is related to the use of mathematics in science and technology. According to the framework, these four categories are represented by equal numbers of items.

\section{Content categories}

As seen in Figure I.2.7, the PISA items also reflect four categories of mathematical content that are related to the problems posed. The four content categories are represented by approximately equal proportions of items. For the assessment of 15-year-olds, age-appropriate content was developed.

The content category quantity incorporates the quantification of attributes of objects, relationships, situations, and entities in the world, which requires an understanding of various representations of those quantifications, and judging interpretations and arguments based on quantity. It involves understanding measurements, counts, magnitudes, units, indicators, relative size, and numerical trends and patterns, and employing number sense, multiple representations of numbers, mental calculation, estimation, and assessment of reasonableness of results.

The content category uncertainty and data covers two closely related sets of issues: how to identify and summarise the messages that are embedded in sets of data presented in different ways, and how to appreciate the likely impact of the variability that is inherent in many real processes. Uncertainty is part of scientific predictions, poll results, weather forecasts and economic models; variation occurs in manufacturing processes, test scores and survey findings; and chance is part of many recreational activities that individuals enjoy. Probability and statistics, taught as part of mathematics, address these issues.

The content category change and relationships focuses on the multitude of temporary and permanent relationships among objects and circumstances, where changes occur within systems of interrelated objects or in circumstances where the elements influence one another. Some of these changes occur over time; some are related to changes in other objects or quantities. Being more literate in this content category involves understanding fundamental types of change and recognising when change occurs so that suitable mathematical models can be employed to describe and predict change.

The content category space and shape encompasses a wide range of phenomena that are encountered everywhere: patterns, properties of objects, positions and orientations, representations of objects, decoding and encoding of visual information, navigation, and dynamic interaction with real shapes and their representations. Geometry is essential to space and shape, but the category extends beyond traditional geometry in content, meaning and method, drawing on elements of other mathematical areas, such as spatial visualisation, measurement and algebra. Mathematical literacy in space and shape involves understanding perspective, creating and reading maps, transforming shapes with and without technology, interpreting views of three-dimensional scenes from various perspectives, and constructing representations of shapes.

\section{Process categories}

The smallest box of Figure I.2.7 shows a schema of the stages through which a problem-solver may move when solving PISA tasks. The action begins with the "problem in context." The problem-solver tries to identify the mathematics relevant to the problem situation, formulates the situation mathematically according to the concepts and relationships identified, and makes assumptions to simplify the situation. The problem-solver thus transforms the "problem in context" into a "mathematical problem" that can be solved using mathematics. The downwardpointing arrow in Figure 1.2.7 represents the work undertaken as the problem-solver employs mathematical concepts, facts, procedures and reasoning to obtain the "mathematical results". This stage usually involves mathematical manipulation, transformation and computation, with and without tools. The "mathematical results" then need to be interpreted in terms of the original problem to obtain the "results in context". The problem solver thus must interpret, apply and evaluate mathematical outcomes and their reasonableness in the context of a real-world problem. The three processes - formulate, employ and interpret - each draw on fundamental mathematical capabilities, which, in turn, draw on the problem-solver's detailed mathematical knowledge. 
However, not all PISA tasks engage students in every stage of the modelling cycle. Items are classified according to the dominant process and results are reported by these processes, formally named as:

- Formulating situations mathematically.

- Employing mathematical concepts, facts, procedures and reasoning.

- Interpreting, applying and evaluating mathematical outcomes.

\section{Fundamental mathematical capabilities}

Through a decade of experience in developing PISA items and analysing the ways in which students respond to them, a set of fundamental mathematical capabilities has been established that underpins performance in mathematics. These cognitive capabilities can be learned by individuals in order to understand and engage with the world in a mathematical way. Since the PISA 2003 framework was written, researchers (e.g. Turner, 2013) have examined the extent to which the difficulty of a PISA item can be understood, and even predicted, from how each of the fundamental mathematical capabilities is used to solve the item. Four levels describe the ways in which each of the capabilities is used, from simple to complex. For example, an item involving a low level of communication would be simple to read and require only a simple response (e.g. a word); an item involving a high level of communication might require the student to assemble information from various different sources to understand the problem, and the student might have to write a response that explains several steps of thinking through a problem. This research has resulted in sharper definitions of the fundamental mathematical capabilities at each of four levels. A composite score has been shown to be a strong predictor of PISA item difficulty. These fundamental mathematical capabilities are evident across the content categories, and are used to varying degrees in each of the three mathematical processes used in the reporting. The PISA framework (OECD, 2013c) describes this in detail.

The seven fundamental mathematical capabilities used in the PISA 2012 assessment are described as follows:

Communication is both receptive and expressive. Reading, decoding and interpreting statements, questions, tasks or objects enables the individual to form a mental model of the situation. Later, the problem-solver may need to present or explain the solution.

Mathematising involves moving between the real world and the mathematical world. It has two parts: formulating and interpreting. Formulating a problem as a mathematical problem can include structuring, conceptualising, making assumptions and/or constructing a model. Interpreting involves determining whether and how the results of mathematical work are related to the original problem and judging their adequacy. It directly relates to the formulate and interpret processes of the framework.

Representation entails selecting, interpreting, translating between and using a variety of representations to capture a situation, interact with a problem, or present one's work. The representations referred to include graphs, tables, diagrams, pictures, equations, formulae, textual descriptions and concrete materials.

Reasoning and argument is required throughout the different stages and activities associated with mathematical literacy. This capability involves thought processes rooted in logic that explore and link problem elements so as to be able to make inferences from them, check a justification that is given, or provide a justification of statements or solutions to problems.

Devising strategies for solving problems is characterised as selecting or devising a plan or strategy to use mathematics to solve problems arising from a task or context, and guiding and monitoring its implementation. It involves seeking links between diverse data presented so that the information can be combined to reach a solution efficiently.

Using symbolic, formal and technical language and operations involves understanding, interpreting, manipulating and making use of symbolic and arithmetic expressions and operations, using formal constructs based on definitions, rules and formal systems, and using algorithms with these entities.

Using mathematical tools involves knowing about and being able to use various tools (physical or digital) that may assist mathematical activity, and knowing about the limitations of such tools. The optional computer-based component of the PISA 2012 mathematics assessment has expanded the opportunities for students to demonstrate their ability to use mathematical tools. 


\section{Paper-based and computer-based media}

PISA 2012 supplemented the paper-based assessment with an optional computer-based assessment, in which specially designed PISA units were presented on a computer and students responded on the computer. Thirty-two of the 65 participating countries and economies participated in this computer-based assessment. For these countries and economies, results are reported for the paper-based assessment scale and supplemented with a computer-based scale and a combined paper-and-computer scale (see Annex B3).

The design of the computer-based assessment ensures that mathematical reasoning and processes take precedence over mastery of using the computer as a tool. Each computer-based item involves three aspects:

- the mathematical demand (as for paper-based items);

- the general knowledge and skills related to information and communication technologies (ICT) that are required (e.g. using keyboard and mouse, and knowing common conventions, such as arrows to move forward). These are intentionally kept to a minimum;

- competencies related to the interaction of mathematics and ICT, such as making a pie chart from data using a simple "wizard", or planning and implementing a sorting strategy to locate and collect desired data in a spreadsheet.

\section{Response types}

The response types distinguish between selected response items and constructed response items. Selected response items include simple multiple choice, complex multiple choice, in which students must select correct answers to a series of multiple-choice items, and, for computer-based items, "selected response variations", such as selecting from options in a drop-down box. Constructed response items include those that can be scored routinely (such as a single number or simple phrase, or, for computer-based items, those for which the response can be captured and processed automatically), and others that need expert scoring (e.g. responses that include an explanation or a long calculation).

\section{Examples of items representing the different framework categories}

Figure I.2.8 summarises the six categories constructed to create a balanced assessment. Three of the six - process, content and medium - are reporting categories. As noted before, PISA 2012 reports scores separately for the three process categories. Since PISA questions are set in real contexts, they usually involve multiple processes, contents and contexts. It is necessary to make judgements about the major source of demand in order to allocate items to just one of the categories for process, content and context, even though the items are multi-faceted. The items are allocated to the category that reflects the highest cognitive focus of the item.

- Figure I.2.8 =

Categories describing the items constructed for the PISA 2012 mathematics assessment

\begin{tabular}{|c|c|c|c|c|c|}
\hline \multicolumn{3}{|c|}{ Reporting categories } & \multicolumn{3}{|c|}{ Further categories to ensure balanced assessment } \\
\hline Process categories & Content categories & Medium categories & Context categories & Response types & Cognitive demand \\
\hline \multirow{2}{*}{$\begin{array}{l}\text { Formulating situations } \\
\text { mathematically }\end{array}$} & Quantity & \multirow{3}{*}{ Paper-based } & Personal & \multirow{2}{*}{ Multiple choice } & \multirow{3}{*}{$\begin{array}{l}\text { Empirical difficulty } \\
\text { (continuum) }\end{array}$} \\
\hline & \multirow{2}{*}{ Uncertainty and data } & & \multirow{2}{*}{ Societal } & & \\
\hline \multirow{2}{*}{$\begin{array}{l}\text { Employing } \\
\text { mathematical concepts, } \\
\text { facts, procedures, and } \\
\text { reasoning }\end{array}$} & & & & \multirow[b]{2}{*}{$\begin{array}{l}\text { Complex multiple } \\
\text { choice }\end{array}$} & \\
\hline & \multirow[t]{2}{*}{$\begin{array}{l}\text { Change and } \\
\text { relationships }\end{array}$} & \multirow{3}{*}{ Computer-based } & \multirow[t]{2}{*}{ Occupational } & & \multirow{3}{*}{$\begin{array}{l}\text { Across } \\
\text { fundamental } \\
\text { mathematical } \\
\text { capabilities }\end{array}$} \\
\hline \multirow{2}{*}{$\begin{array}{l}\text { Interpreting, applying } \\
\text { and evaluating } \\
\text { mathematical } \\
\text { outcomes }\end{array}$} & & & & \multirow{2}{*}{$\begin{array}{l}\text { Constructed } \\
\text { response (simple, } \\
\text { elaborated) }\end{array}$} & \\
\hline & Space and shape & & Scientific & & \\
\hline
\end{tabular}

The PISA 2012 mathematics assessment includes the same proportion of items from each of the categories content, context and response type. A quarter of the items in the assessment reflect the process formulating, half reflect the process employing, and a quarter reflect the process interpreting. To measure the full range of student performance, the set of items reflects all levels of difficulty.

Figure 1.2.9 summarises how several sample items (see at the end of this chapter) are categorised. 
Classification of sample items, by process, context and content categories and response type

\begin{tabular}{|c|c|c|c|c|}
\hline $\begin{array}{l}\text { Item/Question } \\
\text { (position on PISA scale) }\end{array}$ & Process category & Content category & Context category & Response type \\
\hline $\begin{array}{l}\text { WHICH CAR? - } \\
\text { Question } 01 \text { (327.8) }\end{array}$ & Interpret & Uncertainty and data & Personal & Simple Multiple Choice \\
\hline $\begin{array}{l}\text { WHICH CAR? - } \\
\text { Question } 02(490.9)\end{array}$ & Employ & Quantity & Personal & Simple Multiple Choice \\
\hline $\begin{array}{l}\text { WHICH CAR? - } \\
\text { Question } 03 \text { (552.6) }\end{array}$ & Employ & Quantity & Personal & Constructed Response Manual \\
\hline $\begin{array}{l}\text { CHARTS - } \\
\text { Question } 01 \text { (347.7) }\end{array}$ & Interpret & Uncertainty and data & Societal & Simple Multiple Choice \\
\hline $\begin{array}{l}\text { CHARTS - } \\
\text { Question } 02 \text { (415.0) }\end{array}$ & Interpret & Uncertainty and data & Societal & Simple Multiple Choice \\
\hline $\begin{array}{l}\text { CHARTS - } \\
\text { Question } 05 \text { (428.2) }\end{array}$ & Employ & Uncertainty and data & Societal & Simple Multiple Choice \\
\hline $\begin{array}{l}\text { GARAGE - } \\
\text { Question } 01 \text { (419.6) }\end{array}$ & Interpret & Space and shape & Occupational & Simple Multiple Choice \\
\hline $\begin{array}{l}\text { GARAGE - } \\
\text { Question } 02 \text { (687.3) }\end{array}$ & Employ & Space and shape & Occupational & Constructed Response Expert \\
\hline $\begin{array}{l}\text { HELEN THE CYCLIST - } \\
\text { Question } 01 \text { (440.5) }\end{array}$ & Employ & Change and relationships & Personal & Simple Multiple Choice \\
\hline $\begin{array}{l}\text { HELEN THE CYCLIST - } \\
\text { Question } 02 \text { (510.6) }\end{array}$ & Employ & Change and relationships & Personal & Simple Multiple Choice \\
\hline $\begin{array}{l}\text { HELEN THE CYCLIST - } \\
\text { Question } 03 \text { (696.6) }\end{array}$ & Employ & Change and relationships & Personal & Constructed Response Manual \\
\hline $\begin{array}{l}\text { CLIMBING MOUNT FUJI - } \\
\text { Question } 01 \text { (464.0) }\end{array}$ & Formulate & Quantity & Societal & Simple Multiple Choice \\
\hline $\begin{array}{l}\text { CLIMBING MOUNT FUJI - } \\
\text { Question } 02 \text { (641.6) }\end{array}$ & Formulate & Change and relationships & Societal & Constructed Response Expert \\
\hline $\begin{array}{l}\text { CLIMBING MOUNT FUJI - } \\
\text { Question } 03 \text { (610.0) }\end{array}$ & Employ & Quantity & Societal & Constructed Response Manual \\
\hline $\begin{array}{l}\text { REVOLVING DOOR - } \\
\text { Question } 01 \text { (512.3) }\end{array}$ & Employ & Space and shape & Scientific & Constructed Response Manual \\
\hline $\begin{array}{l}\text { REVOLVING DOOR - } \\
\text { Question } 02 \text { (840.3) }\end{array}$ & Formulate & Space and shape & Scientific & Constructed Response Expert \\
\hline $\begin{array}{l}\text { REVOLVING DOOR - } \\
\text { Question } 03 \text { (561.3) }\end{array}$ & Formulate & Quantity & Scientific & Simple Multiple Choice \\
\hline
\end{tabular}

\section{Example 1: WHICH CAR?}

The unit, "WHICH CAR?", (Figure I.2.10) consists of three questions. It presents a table of data that a person might use to choose a car and make sure that she can afford it.

Context: Because buying a car is an experience that many people might have during their lifetimes, all three questions were allocated to the personal context category.

Response type: Question 1 and Question 2 are simple multiple-choice questions; Question 3, which asks for a single number, is a constructed response item that does not require expert scoring.

Content: Question 1 was allocated to the uncertainty and data content category. The item requires knowledge of the basic row-column conventions of a table, as well as co-ordinated data-handling ability to identify where the three conditions are simultaneously satisfied. While the solution also requires basic knowledge of large whole numbers, that knowledge is unlikely to be the main source of difficulty in the item. In contrast, Question 2 has been allocated to the quantity content category because it is well known that even at age 15, many students have misconceptions about the base ten and place value ideas required to order "ragged" decimal numbers. Question 3 is also allocated to the quantity content category because the calculation of $2.5 \%$ is expected to require more cognitive effort from students than identifying the correct data in the table. The difficulty for this age group in dealing with decimal numbers and percentages is reflected in the empirical results: Question 1 is considered an easy item, Question 2 is close to the international average, and Question 3 is of above-average difficulty. 
Process: In allocating the items to process categories, their relation to "real-world" problems has been taken into consideration. The primary demand in items in the formulate category is the transition from the real-world problem to the mathematical problem; in the employ category, the primary demand is within the mathematical world; and in the interpret category, an item's primary demand is in using mathematical information to provide a real-world solution. Questions 2 and 3 are allocated to the employ category. This is because in both of these items, the main cognitive effort is made within mathematics: decimal notation and the calculation of a percentage. In Question 1, the construction of a table of data, including the need to identify key variables, is a mathematisation of a real situation. Question 1 is allocated to the interpret category because it requires these mathematical entities to be interpreted in relation to the real world.

- Figure I.2.10

\section{WHICH CAR? - a unit from the PISA 2012 main survey}

\section{WHICH CAR?}

Chris has just received her car driving licence and wants to buy her first car. This table below shows the details of four cars she finds at a local car dealer.

\begin{tabular}{l|c|c|c|c}
\hline Model: & Alpha & Bolte & Castel & Dezal \\
\hline Year & 2003 & 2000 & 2001 & 1999 \\
\hline Advertised price (zeds) & 4800 & 4450 & 4250 & 3990 \\
\hline $\begin{array}{l}\text { Distance travelled } \\
\text { (kilometres) }\end{array}$ & 105000 & 115000 & 128000 & 109000 \\
\hline Engine capacity (litres) & 1.79 & 1.796 & 1.82 & 1.783 \\
\hline
\end{tabular}

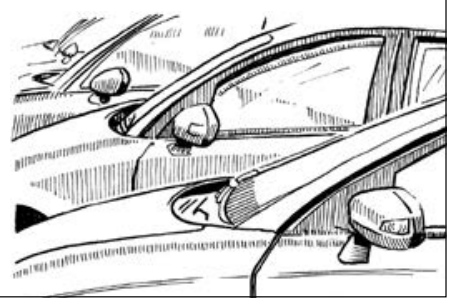

WHICH CAR? - QUESTION 1

Chris wants a car that meets all of these conditions:

- The distance travelled is not higher than 120000 kilometres.

- It was made in the year 2000 or a later year.

- The advertised price is not higher than 4500 zeds.

- Which car meets Chris's conditions?
A. Alpha
B. Bolte
C. Castel
D. Dezal

\section{WHICH CAR? - QUESTION 2}

Which car's engine capacity is the smallest?

A. Alpha

B. Bolte

C. Castel

D. Dezal

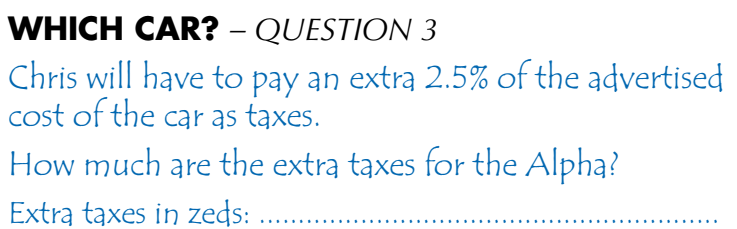

\section{Example 2: CLIMBING MOUNT FUJI}

Context: The unit "CLIMBING MOUNT FUJI", containing three questions, as shown in Figure I.2.11, was allocated to the societal context category. Question 1 goes beyond the personal concerns of a walker to wider community issues in this case, concerns about use of the public trail. Items classified as societal involve such things as voting systems, public transport, government, public policies, demographics, advertising, national statistics and economics. Although individuals can be personally involved in these, the focus of the problem is more on the community perspective.

Response: Question 1 is simple multiple choice (choose one out of four). Question 2 requires the answer 11 a.m. and as such, is a constructed response with expert scoring to ensure that all equivalent ways of writing the time are considered. Question 3 requires the number 40 for full score, or the number 0.4 (answering in metres) for partial credit. It, too, is a constructed response with expert scoring.

Content: Question 1 requires calculating the number of days open using the given dates, and then calculating an average. The question was allocated to the quantity content category because it involves quantification of time and of an average. While the formula for average is required, and this is indeed a relationship, since this question requires use of an average to calculate the number of people per day, rather than focus on the relationship, this question is not allocated to the change and relationships category. Question 3 has similar characteristics, involving units of length. Question 2 is allocated to the change and relationships category because the relationship between distance and time, encapsulated as 
speed, is paramount. From information about distances and speed, the time to go up and the time to come down have to be quantified, and then used in combination with the finishing time to get the starting time. Had the time needed to go up and down been given directly, rather than indirectly through distance and speed, then the question could have been allocated to the quantity category.

- Figure I.2.11 घ

\section{CLIMBING MOUNT FUJ - a unit from the field trial}

CLIMBING MOUNT FUJI

\section{CLIMBING MOUNT FUJI - QUESTION 1}

Mount Fuji is only open to the public for climbing from 1 July to 27 August each year. About 200000 people climb Mount Fuji during this time.

On average, about how many people climb Mount Fuji each day?

A. 340

B. 710

C. 3400

D. 7100

E. 7400

CLIMBING MOUNT FUJI - QUESTION 2

The Gotemba walking trail up Mount Fuii is about

9 kilometres $(\mathrm{km})$ long.

Walkers need to return from the $18 \mathrm{~km}$ walk by 8 p.m.

Toshi estimates that he can walk up the mountain at

1.5 kilometres per hour on average, and down at twice

that speed. These speeds take into account meal breaks and rest times.

Using Toshi's estimated speeds, what is the latest time he can begin his walk so that he can return by 8 p.m.?

\section{CLIMBING MOUNT FUJI - QUESTION 3}

Toshi wore a pedometer to count his steps on his walk along the Gotemba trail.

His pedometer showed that he walked 22500 steps on the way up.

Estimate Toshi's average step length for his walk up the $9 \mathrm{~km}$ Gotemba trail. Give your answer in centimetres $(\mathrm{cm})$.

Answer: $\mathrm{cm}$

Process: Question 1 was allocated to the formulating category because most of the cognitive effort in this relatively easy item requires taking two pieces of real-world information (open season and total number of climbers) and establishing a mathematical problem to be solved: find the length of the open season from the dates and use it with the information about the total number of climbers to find the average number of climbers each day. Expert judgement is that the major cognitive demand for 15-year-olds lies in this movement from the real world problem to the mathematical relationships, rather than in the ensuing whole number calculations. Question 2 was also allocated to the formulating process category for the same reason: the main cognitive effort required is to translate real-world data into a mathematical problem and identify all the relationships involved, rather than calculate or interpret the answer as a starting time of 11 a.m. In this difficult item, the mathematical structure involves multiple relationships: starting time = finishing time - duration; duration = time up + time down; time up $($ down $)=$ distance/speed (or equivalent proportional reasoning); time down = half time up; and appreciating the simplifying assumptions that average speeds already include consideration of variable speed during the day and that no further allowance is required for breaks. 
By contrast, Question 3 was allocated to the employing category. There is one main relationship involved: the distance walked $=$ number of steps $\times$ average step length. There are two obstacles to using this relationship to solve the problem: rearranging the formula (which is probably done by students informally rather than formally using the written relationship) so that the average step length can be found from distance and number of steps; and making appropriate unit conversions. The main cognitive effort required for this question is in carrying out these steps, rather than identifying the relationships and assumptions to be made (the formulating process) or interpreting the answer in real-world terms.

\section{How the PISA 2012 mathematics results are reported \\ How the PISA 2012 mathematics tests were designed, analysed and scaled}

The test material had to meet several requirements:

- Test items had to meet the requirements and specifications of the framework for PISA 2012 that was established and agreed upon by the participating countries. The content, processes and contexts of the items had to be deemed appropriate for a test of 15-year-olds.

- Items had to be of interest and of curricular relevance for 15-year-olds in participating countries and economies.

- Items had to meet stringent standards of technical quality and international comparability.

Items for the assessment were selected from a pool of diverse material with a diverse range of sources (authors in almost 30 different countries, with the contributions from national teams, members of the PISA mathematics expert group and the PISA Project Consortium) that reflected content, context and approaches relevant to a large number of PISA-participating countries and economies. Wordings and other features of the items were reviewed by experts, then the items were tested among classes of 15-year-old students, and finally the items underwent extensive field trials in all countries and economies that would ultimately use the material. Each participating country and economy provided detailed feedback on the curricular relevance, appropriateness and potential interest for 15-year-olds, by local mathematics experts. At each development stage, material was considered for rejecting, revising or keeping in the pool of potential items. Finally, the international mathematics expert group formulated recommendations as to which items should be included in the survey instruments and those recommendations were considered by the PISA Governing Board, in which governments of all participating countries are represented. The final selection of test items was balanced across the various categories specified in the mathematics framework and spanned a range of levels of difficulty, so that the entire pool of items could measure performance across a broad range of content, processes and contexts, and across a wide range of student abilities (for further details, see the PISA 2012 Technical Report [OECD, forthcoming]).

Test items were generally developed within "units" that included some stimulus material and one or more questions related to the stimulus. In many cases, students were required to construct a response to questions, based on their analysis, calculations and mathematical thinking. Some constructed-response items were relatively open-ended, requiring students to present an extended response that may have included presenting the steps of their solution or some explanation of their result, which thus revealed aspects of the methods and thought processes they had used to answer the question. In general, these items could not be machine scored; rather they required the professional judgement of trained coders to assign the responses to defined response categories. To ensure that the response coding process yielded reliable and cross-nationally comparable results, detailed guidelines and training were provided. All the procedures ensuring the consistency of the coding within and between countries are detailed in PISA 2012 Technical Report (OECD, forthcoming).

In other cases requiring students to construct their response, only a very simple response was required, such as a value read from a graph or table, or writing a word, short phrase or the numerical result of a calculation. The evaluation of these answers was restricted to the response itself and did not take into account an explanation of how the response was derived. Responses could often be processed without the intervention of a coding expert. The use of computer-delivered test forms also allowed for a number of response formats such that responses could be captured relatively easily by computer without any additional intervention.

Other items were presented in a format that required students to select one or more responses from a set of given response options. This format category includes both standard multiple-choice items, for which students were required to select one correct response from a number of given response options; and complex multiple choice items, for which students were required to select a response from given optional responses to each of a number of propositions or questions. Responses to these items could be processed automatically, with no intervention by an expert coder needed. 
The final PISA 2012 survey included 36 paper-based items linking to previous PISA survey instruments, 74 new paperbased items and 41 new computer-based items. Each student completed a fraction of the paper-based items - a minimum of 12 items, up to a maximum of 37 items, depending on which test booklet they were randomly assigned from the booklet rotation design. The mathematics questions selected for inclusion in the paper-based component of the survey were arranged into half-hour clusters of 12-13 items. These, along with clusters of reading and science questions, were assembled into test booklets, each containing four clusters. Each participating student was assigned a test booklet to be completed in two hours. In the computer-based survey, students completed a one-hour test composed of two half-hour components selected from a rotated design of mathematics, reading and problem-solving item clusters.

The test design, similar to those used in previous PISA assessments, makes it possible to construct a single scale of proficiency in mathematics, so that each question is associated with a particular point on the scale that indicates its difficulty, and each test-taker's performance is associated with a particular point on the same scale that indicates his or her estimated mathematical proficiency. A description of the modelling technique used to construct this scale can be found in the PISA 2012 Technical Report (OECD, forthcoming).

The relative difficulty of tasks in a test is estimated by considering the proportion of test-takers who answer each question correctly; and the relative proficiency of individuals taking a particular test can be estimated by considering the proportion of test questions they answer correctly. A single continuous scale shows the relationship between the difficulty of questions and the proficiency of test-takers. By constructing a scale that shows the difficulty of each question, it is possible to locate the level of mathematics that the question demands. By showing the proficiency of each test-taker on the same scale, it is possible to describe the level of mathematics that each test taker possesses.

The location of different described levels of mathematical proficiency on this scale is set in relation to the particular group of questions used in the assessment; but just as the sample of students who sat the PISA test in 2012 was drawn to represent all 15-year-old students in the participating countries and economies, so the individual test questions used in the assessment were designed to represent the definition of literacy in mathematics adequately. Estimates of student proficiency reflect the kinds of tasks students would be expected to perform successfully. This means that students are likely to be able to successfully complete questions located at or below the difficulty level associated with their own position on the scale. Conversely, they are unlikely to be able to successfully complete questions above the difficulty level associated with their position on the scale. Figure I.2.12 illustrates how this probabilistic model works.

The higher an individual's proficiency level is located above a given test question, the more likely is he or she to successfully complete the question (and other questions of similar difficulty); the further the individual's proficiency is located below a given question, the less likely is he or she to be able to successfully complete the question and other questions of similar difficulty.

- Figure I.2.12 -

The relationship between questions and student performance on a scale

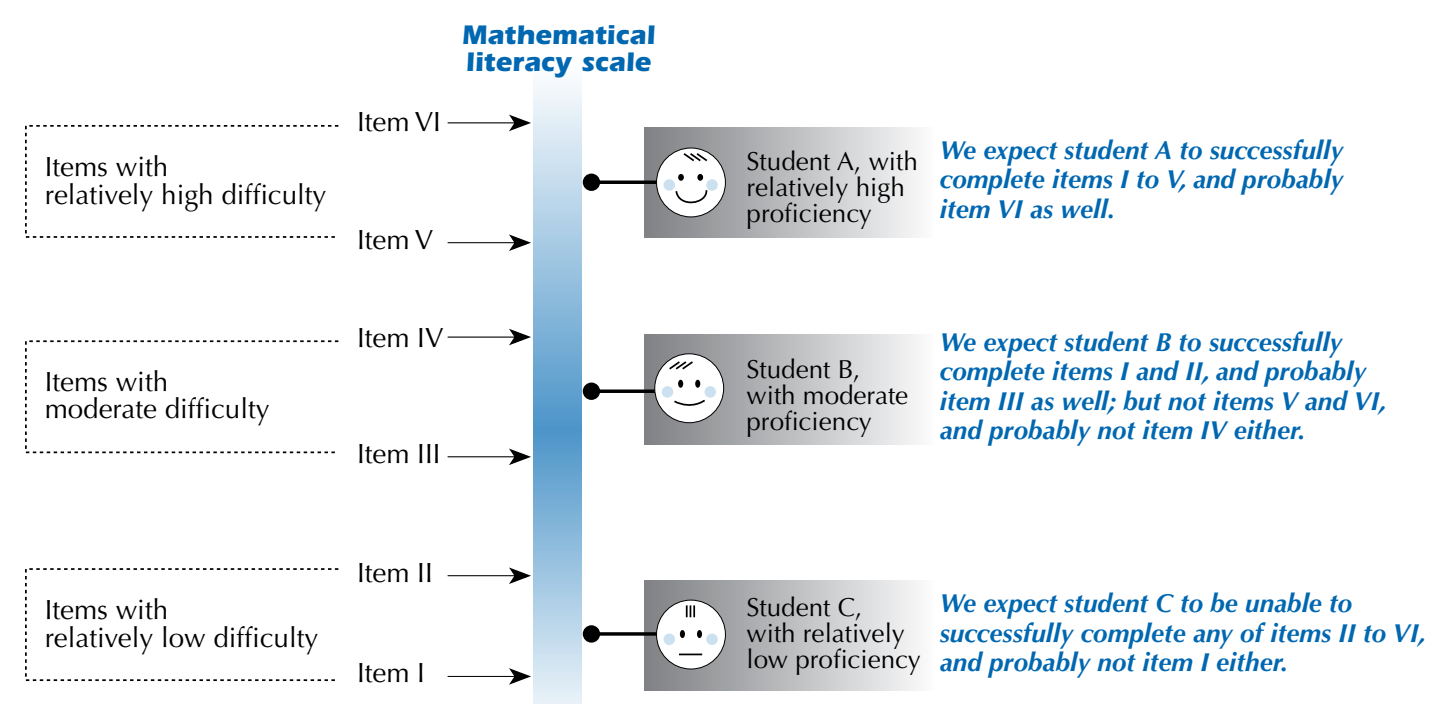




\section{How mathematics proficiency levels are defined in PISA 2012}

PISA 2012 provides an overall mathematics scale, which draws on all of the mathematics questions in the assessment, as well as scales for the three mathematical processes and the four mathematical content categories defined above. The metric for the overall mathematics scale is based on a mean for OECD countries of 500 points and a standard deviation of 100 points that were set in PISA 2003 when the first PISA mathematics scale was first developed. The items that were common to both the 2003 and 2012 test instruments enable a link to be made with the earlier scale. To help users interpret what student scores mean in substantive terms, the scale is divided into proficiency levels. For PISA 2012, the range of difficulty of the tasks is represented by six levels of mathematical proficiency that are aligned with the levels used in describing the outcomes of PISA 2003. The levels range from the lowest, Level 1, to the highest, Level 6. Descriptions of each of these levels have been generated, based on the framework-related cognitive demands imposed by tasks that are located within each level, to describe the kinds of knowledge and skills needed to successfully complete those tasks, and which can then be used as characterisations of the substantive meaning of each level.

Individuals with proficiency within the range of Level 1 are likely to be able to complete Level 1 tasks, but are unlikely to be able to complete tasks at higher levels. Level 6 reflects tasks that pose the greatest challenge in terms of the mathematical knowledge and skills needed to complete them successfully. Individuals with scores in this range are likely to be able to complete tasks located at that level, as well as all the other PISA mathematics tasks (see section Students at the different levels of proficiency in mathematics for a detailed description of the proficiency levels in mathematics).

\section{STUDENT PERFORMANCE IN MATHEMATICS}

PISA outcomes are reported in a variety of ways. This section gives the country results and shows the location of items on the overall PISA mathematics scale described above, how the different levels of proficiency in PISA mathematics can be characterised, and how these proficiency levels are represented by mathematics questions used in the survey. In subsequent sections, mathematical performance will be examined in more detail in relation to: the process categories referred to as formulating, employing and interpreting; and the content categories of space and shape, quantity, change and relationships, and uncertainty and data.

\section{Average in mathematics performance}

This section compares the countries and economies on the basis of their average mathematics scores. In addition, changes in the relative standing of countries since the 2003 survey - the most recent assessment in which mathematics was the major PISA domain - are presented.

The country results are estimates because they are obtained from samples of students, rather than from a census of all students, and they are obtained using a limited set of assessment tasks, not a population of all possible assessment tasks. When the sampling and assessment are done with scientific rigour it is possible to determine the magnitude of the probable uncertainty associated with the estimates. This uncertainty needs to be taken into account when making comparisons so that differences that could reasonably arise simply due to the sampling of students and items are not interpreted as differences that actually hold for the populations. A difference is called statistically significant if it is very unlikely that such a difference could be observed by chance, when in fact no true difference exists.

When interpreting mean performance, only those differences among countries and economies that are statistically significant should be taken into account. Figure I.2.13 shows each country's/economy's mean score and also for which groups of countries/economies the differences between the means are statistically significant. For each country/economy shown in the middle column, the countries/economies whose mean scores are not statistically significantly different are listed in the right column. In all other cases, country/economy A scores higher than country/economy B if country/ economy $A$ is situated above country/economy $B$ in the middle column, and scores lower if country/economy $A$ is situated below country/economy B. Figure 1.2.13 lists each participating country and economy in descending order of its mean mathematics score (left column). The values range from a high of 613 points for the partner economy Shanghai-China to a low of 368 points for the partner country Peru.

Countries and economies are also divided into three broad groups: those whose mean scores are statistically around the OECD mean (highlighted in dark blue), those whose mean scores are above the OECD mean (highlighted in pale blue), and those whose mean scores are below the OECD mean (highlighted in medium blue). Across OECD countries, the average score in mathematics is 494 points (see Table I.2.3a). To gauge the magnitude of score differences, 41 score points corresponds to the equivalent of one year of formal schooling (see Annex A1, Table A1.2). 
- Figure I.2.13

Comparing countries' and economies' performance in mathematics

\begin{tabular}{|c|c|c|}
\hline \multirow[b]{2}{*}{$\begin{array}{l}\text { Mean } \\
\text { score }\end{array}$} & \multicolumn{2}{|c|}{$\begin{array}{l}\text { Statistically significantly above the OECD average } \\
\text { Not statistically significantly different from the OECD average } \\
\text { Statistically significantly below the OECD average }\end{array}$} \\
\hline & $\begin{array}{l}\text { Comparison } \\
\text { country/economy }\end{array}$ & Countries/economies whose mean score is NOT statistically significantly different from that comparison country's/economy's score \\
\hline 613 & Shanghai-China & \\
\hline 573 & Singapore & \\
\hline 561 & Hong Kong-China & Chinese Taipei, Korea \\
\hline 560 & Chinese Taipei & Hong Kong-China, Korea \\
\hline 554 & Korea & Hong Kong-China, Chinese Taipei \\
\hline 538 & Macao-China & Japan, Liechtenstein \\
\hline 536 & Japan & Macao-China, Liechtenstein, Switzerland \\
\hline 535 & Liechtenstein & Macao-China, Japan, Switzerland \\
\hline 531 & Switzerland & Japan, Liechtenstein, Netherlands \\
\hline 523 & Netherlands & Switzerland, Estonia, Finland, Canada, Poland, Viet Nam \\
\hline 521 & Estonia & Netherlands, Finland, Canada, Poland, Viet Nam \\
\hline 519 & Finland & Netherlands, Estonia, Canada, Poland, Belgium, Germany, Viet Nam \\
\hline 518 & Canada & Netherlands, Estonia, Finland, Poland, Belgium, Germany, Viet Nam \\
\hline 518 & Poland & Netherlands, Estonia, Finland, Canada, Belgium, Germany, Viet Nam \\
\hline 515 & Belgium & Finland, Canada, Poland, Germany, Viet Nam \\
\hline 514 & Germany & Finland, Canada, Poland, Belgium, Viet Nam \\
\hline 511 & Viet Nam & Netherlands, Estonia, Finland, Canada, Poland, Belgium, Germany, Austria, Australia, Ireland \\
\hline 506 & Austria & Viet Nam, Australia, Ireland, Slovenia, Denmark, New Zealand, Czech Republic \\
\hline 504 & Australia & Viet Nam, Austria, Ireland, Slovenia, Denmark, New Zealand, Czech Republic \\
\hline 501 & Ireland & Viet Nam, Austria, Australia, Slovenia, Denmark, New Zealand, Czech Republic, France, United Kingdom \\
\hline 501 & Slovenia & Austria, Australia, Ireland, Denmark, New Zealand, Czech Republic \\
\hline 500 & Denmark & Austria, Australia, Ireland, Slovenia, New Zealand, Czech Republic, France, United Kingdom \\
\hline 500 & New Zealand & Austria, Australia, Ireland, Slovenia, Denmark, Czech Republic, France, United Kingdom \\
\hline 499 & Czech Republic & Austria, Australia, Ireland, Slovenia, Denmark, New Zealand, France, United Kingdom, Iceland \\
\hline 495 & France & Ireland, Denmark, New Zealand, Czech Republic, United Kingdom, Iceland, Latvia, Luxembourg, Norway, Portugal \\
\hline 494 & United Kingdom & Ireland, Denmark, New Zealand, Czech Republic, France, Iceland, Latvia, Luxembourg, Norway, Portugal \\
\hline 493 & Iceland & Czech Republic, France, United Kingdom, Latvia, Luxembourg, Norway, Portugal \\
\hline 491 & Latvia & France, United Kingdom, Iceland, Luxembourg, Norway, Portugal, Italy, Spain \\
\hline 490 & Luxembourg & France, United Kingdom, Iceland, Latvia, Norway, Portugal \\
\hline 489 & Norway & France, United Kingdom, Iceland, Latvia, Luxembourg, Portugal, Italy, Spain, Russian Federation, Slovak Republic, United States \\
\hline 487 & Portugal & France, United Kingdom, Iceland, Latvia, Luxembourg, Norway, Italy, Spain, Russian Federation, Slovak Republic, United States, Lithuania \\
\hline 485 & Italy & Latvia, Norway, Portugal, Spain, Russian Federation, Slovak Republic, United States, Lithuania \\
\hline 484 & Spain & Latvia, Norway, Portugal, Italy, Russian Federation, Slovak Republic, United States, Lithuania, Hungary \\
\hline 482 & Russian Federation & Norway, Portugal, Italy, Spain, Slovak Republic, United States, Lithuania, Sweden, Hungary \\
\hline 482 & Slovak Republic & Norway, Portugal, Italy, Spain, Russian Federation, United States, Lithuania, Sweden, Hungary \\
\hline 481 & United States & Norway, Portugal, Italy, Spain, Russian Federation, Slovak Republic, Lithuania, Sweden, Hungary \\
\hline 479 & Lithuania & Portugal, Italy, Spain, Russian Federation, Slovak Republic, United States, Sweden, Hungary, Croatia \\
\hline 478 & Sweden & Russian Federation, Slovak Republic, United States, Lithuania, Hungary, Croatia \\
\hline 477 & Hungary & Spain, Russian Federation, Slovak Republic, United States, Lithuania, Sweden, Croatia, Israel \\
\hline 471 & Croatia & Lithuania, Sweden, Hungary, Israel \\
\hline 466 & Israel & Hungary, Croatia \\
\hline 453 & Greece & Serbia, Turkey, Romania \\
\hline 449 & Serbia & Greece, Turkey, Romania, Bulgaria \\
\hline 448 & Turkey & Greece, Serbia, Romania, Cyprus ${ }^{1,2}$, Bulgaria \\
\hline 445 & Romania & Greece, Serbia, Turkey, Cyprus ${ }^{1,2}$, Bulgaria \\
\hline 440 & Cyprus ${ }^{1,2}$ & Turkey, Romania, Bulgaria \\
\hline 439 & Bulgaria & Serbia, Turkey, Romania, Cyprus ${ }^{1,2}$, United Arab Emirates, Kazakhstan \\
\hline 434 & United Arab Emirates & Bulgaria, Kazakhstan, Thailand \\
\hline 432 & Kazakhstan & Bulgaria, United Arab Emirates, Thailand \\
\hline 427 & Thailand & United Arab Emirates, Kazakhstan, Chile, Malaysia \\
\hline 423 & Chile & Thailand, Malaysia \\
\hline 421 & Malaysia & Thailand, Chile \\
\hline 413 & Mexico & Uruguay, Costa Rica \\
\hline 410 & Montenegro & Uruguay, Costa Rica \\
\hline 409 & Uruguay & Mexico, Montenegro, Costa Rica \\
\hline 407 & Costa Rica & Mexico, Montenegro, Uruguay \\
\hline 394 & Albania & Brazil, Argentina, Tunisia \\
\hline 391 & Brazil & Albania, Argentina, Tunisia, Jordan \\
\hline 388 & Argentina & Albania, Brazil, Tunisia, Jordan \\
\hline 388 & Tunisia & Albania, Brazil, Argentina, Jordan \\
\hline 386 & Jordan & Brazil, Argentina, Tunisia \\
\hline 376 & Colombia & Qatar, Indonesia, Peru \\
\hline 376 & Qatar & Colombia, Indonesia \\
\hline 375 & Indonesia & Colombia, Qatar, Peru \\
\hline 368 & Peru & Colombia, Indonesia \\
\hline
\end{tabular}

1. Note by Turkey: The information in this document with reference to "Cyprus" relates to the southern part of the Island. There is no single authority representing both Turkish and Greek Cypriot people on the Island. Turkey recognises the Turkish Republic of Northern Cyprus (TRNC). Until a lasting and equitable solution is found within the context of the United Nations, Turkey shall preserve its position concerning the "Cyprus issue".

2. Note by all the European Union Member States of the OECD and the European Union: The Republic of Cyprus is recognised by all members of the United Nations with the exception of Turkey. The information in this document relates to the area under the effective control of the Government of the Republic of Cyprus.

Source: OECD, PISA 2012 Database.

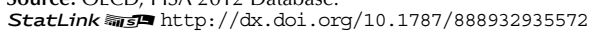


- Figure 1.2.14 [Part 1/3]

Mathematics performance among PISA 2012 participants, at national and regional levels

\begin{tabular}{|c|c|c|c|c|c|}
\hline & & & lathemat & & \\
\hline & & & & & \\
\hline & & & & All c & omies \\
\hline & Mean score & Upper rank & Lower rank & Upper rank & Lower rank \\
\hline Shanghai-China & 613 & & & 1 & 1 \\
\hline Singapore & 573 & & & 2 & 2 \\
\hline Hong Kong-China & 561 & & & 3 & 5 \\
\hline Chinese Taipei & 560 & & & 3 & 5 \\
\hline Korea & 554 & 1 & 1 & 3 & 5 \\
\hline Macao-China & 538 & & & 6 & 8 \\
\hline Japan & 536 & 2 & 3 & 6 & 9 \\
\hline Liechtenstein & 535 & & & 6 & 9 \\
\hline Switzerland & 531 & 2 & 3 & 7 & 9 \\
\hline Flemish community (Belgium) & 531 & & & & \\
\hline Trento (Italy) & 524 & & & & \\
\hline Friuli Venezia Giulia (Italy) & 523 & & & & \\
\hline Netherlands & 523 & 3 & 7 & 9 & 14 \\
\hline Veneto (Italy) & 523 & & & & \\
\hline Estonia & 521 & 4 & 8 & 10 & 14 \\
\hline Finland & 519 & 4 & 9 & 10 & 15 \\
\hline Canada & 518 & 5 & 9 & 11 & 16 \\
\hline Australian Capital Territory (Australia) & 518 & & & & \\
\hline Poland & 518 & 4 & 10 & 10 & 17 \\
\hline Lombardia (Italy) & 517 & & & & \\
\hline Navarre (Spain) & 517 & & & & \\
\hline Western Australia (Australia) & 516 & & & & \\
\hline Belgium & 515 & 7 & 10 & 13 & 17 \\
\hline Germany & 514 & 6 & 10 & 13 & 17 \\
\hline Massachusetts (United States) & 514 & & & & \\
\hline Viet Nam & 511 & & & 11 & 19 \\
\hline German-speaking community (Belgium) & 511 & & & & \\
\hline New South Wales (Australia) & 509 & & & & \\
\hline Castile and Leon (Spain) & 509 & & & & \\
\hline Bolzano (Italy) & 506 & & & & \\
\hline Connecticut (United States) & 506 & & & & \\
\hline Austria & 506 & 10 & 14 & 17 & 22 \\
\hline Basque Country (Spain) & 505 & & & & \\
\hline Australia & 504 & 11 & 14 & 17 & 21 \\
\hline Madrid (Spain) & 504 & & & & \\
\hline Queensland (Australia) & 503 & & & & \\
\hline La Rioja (Spain) & 503 & & & & \\
\hline Ireland & 501 & 11 & 17 & 18 & 24 \\
\hline Slovenia & 501 & 12 & 16 & 19 & 23 \\
\hline Victoria (Australia) & 501 & & & & \\
\hline Emilia Romagna (Italy) & 500 & & & & \\
\hline Denmark & 500 & 12 & 18 & 19 & 25 \\
\hline New Zealand & 500 & 12 & 18 & 19 & 25 \\
\hline Asturias (Spain) & 500 & & & & \\
\hline Czech Republic & 499 & 12 & 19 & 19 & 26 \\
\hline Piemonte (Italy) & 499 & & & & \\
\hline Scotland (United Kingdom) & 498 & & & & \\
\hline Marche (Italy) & 496 & & & & \\
\hline Aragon (Spain) & 496 & & & & \\
\hline Toscana (Italy) & 495 & & & & \\
\hline England (United Kingdom) & 495 & & & & \\
\hline France & 495 & 16 & 21 & 23 & 29 \\
\hline United Kingdom & 494 & 16 & 23 & 23 & 31 \\
\hline French community (Belgium) & 493 & & & & \\
\hline Catalonia (Spain) & 493 & & & & \\
\hline Iceland & 493 & 18 & 22 & 25 & 29 \\
\hline Umbria (Italy) & 493 & & & & \\
\hline Valle d'Aosta (Italy) & 492 & & & & \\
\hline Cantabria (Spain) & 491 & & & & \\
\hline Latvia & 491 & & & 25 & 32 \\
\hline Luxembourg & 490 & 20 & 23 & 27 & 31 \\
\hline Norway & 489 & 19 & 25 & 26 & 33 \\
\hline South Australia (Australia) & 489 & & & & \\
\hline
\end{tabular}

Notes: OECD countries are shown in bold black. Partner countries are shown in bold blue. Participating economies and subnational entities that are not included in national results are shown in bold blue italics. Regions are shown in black italics (OECD countries) or blue italics (partner countries).

1. Note by Turkey: The information in this document with reference to "Cyprus" relates to the southern part of the Island. There is no single authority representing both Turkish and Greek Cypriot people on the Island. Turkey recognises the Turkish Republic of Northern Cyprus (TRNC). Until a lasting and equitable solution is found within the context of the United Nations, Turkey shall preserve its position concerning the "Cyprus issue".

2. Note by all the European Union Member States of the OECD and the European Union: The Republic of Cyprus is recognised by all members of the United Nations with the exception of Turkey. The information in this document relates to the area under the effective control of the Government of the Republic of Cyprus.

Countries, economies and subnational entities are ranked in descending order of mean mathematics performance.

Source: OECD, PISA 2012 Database.

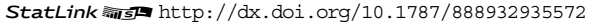


- Figure I.2.14 [Part 2/3] "

\section{Mathematics performance among PISA 2012 participants, at national and regional levels}

\begin{tabular}{|c|c|c|c|c|c|}
\hline & \multicolumn{5}{|c|}{ Mathematics scale } \\
\hline & \multirow[b]{3}{*}{ Mean score } & \multicolumn{4}{|c|}{ Range of ranks } \\
\hline & & \multicolumn{2}{|c|}{ OECD countries } & \multicolumn{2}{|c|}{ All countries/economies } \\
\hline & & Upper rank & Lower rank & Upper rank & Lower rank \\
\hline Alentejo (Portugal) & 489 & & & & \\
\hline Galicia (Spain) & 489 & & & & \\
\hline Liguria (Italy) & 488 & & & & \\
\hline Portugal & 487 & 19 & 27 & 26 & 36 \\
\hline Northern Ireland (United Kingdom) & 487 & & & & \\
\hline Italy & 485 & 22 & 27 & 30 & 35 \\
\hline Spain & 484 & 23 & 27 & 31 & 36 \\
\hline Perm Territory region (Russian Federation) & 484 & & & & \\
\hline Russian Federation & 482 & & & 31 & 39 \\
\hline Slovak Republic & 482 & 23 & 29 & 31 & 39 \\
\hline United States & 481 & 23 & 29 & 31 & 39 \\
\hline Lithuania & 479 & & & 34 & 40 \\
\hline Sweden & 478 & 26 & 29 & 35 & 40 \\
\hline Puglia (Italy) & 478 & & & & \\
\hline Tasmania (Australia) & 478 & & & & \\
\hline Hungary & 477 & 26 & 30 & 35 & 40 \\
\hline Abruzzo (Italy) & 476 & & & & \\
\hline Balearic Islands (Spain) & 475 & & & & \\
\hline Lazio (Italy) & 475 & & & & \\
\hline Andalusia (Spain) & 472 & & & & \\
\hline Croatia & 471 & & & 38 & 41 \\
\hline Wales (United Kingdom) & 468 & & & & \\
\hline Florida (United States) & 467 & & & & \\
\hline Israel & 466 & 29 & 30 & 40 & 41 \\
\hline Molise (Italy) & 466 & & & & \\
\hline Basilicata (Italy) & 466 & & & & \\
\hline Dubai (United Arab Emirates) & 464 & & & & \\
\hline Murcia (Spain) & 462 & & & & \\
\hline Extremadura (Spain) & 461 & & & & \\
\hline Sardegna (Italy) & 458 & & & & \\
\hline Greece & 453 & 31 & 32 & 42 & 44 \\
\hline Campania (Italy) & 453 & & & & \\
\hline Northern Territory (Australia) & 452 & & & & \\
\hline Serbia & 449 & & & 42 & 45 \\
\hline Turkey & 448 & 31 & 32 & 42 & 46 \\
\hline Sicilia (Italy) & 447 & & & & \\
\hline Romania & 445 & & & 43 & 47 \\
\hline Cyprus ${ }^{1,2}$ & 440 & & & 45 & 47 \\
\hline Sharjah (United Arab Emirates) & 439 & & & & \\
\hline Bulgaria & 439 & & & 45 & 49 \\
\hline Aguascalientes (Mexico) & 437 & & & & \\
\hline Nuevo León (Mexico) & 436 & & & & \\
\hline Jalisco (Mexico) & 435 & & & & \\
\hline Querétaro (Mexico) & 434 & & & & \\
\hline United Arab Emirates & 434 & & & 47 & 49 \\
\hline Kazakhstan & 432 & & & 47 & 50 \\
\hline Calabria (Italy) & 430 & & & & \\
\hline Colima (Mexico) & 429 & & & & \\
\hline Chihuahua (Mexico) & 428 & & & & \\
\hline Distrito Federal (Mexico) & 428 & & & & \\
\hline Thailand & 427 & & & 49 & 52 \\
\hline Durango (Mexico) & 424 & & & & \\
\hline Chile & 423 & 33 & 33 & 50 & 52 \\
\hline Morelos (Mexico) & 421 & & & & \\
\hline Abu Dhabi (United Arab Emirates) & 421 & & & & \\
\hline Malaysia & 421 & & & 50 & 52 \\
\hline Coahuila (Mexico) & 418 & & & & \\
\hline Ciudad Autónoma de Buenos Aires (Argentina) & 418 & & & & \\
\hline Mexico (Mexico) & 417 & & & & \\
\hline Federal District (Brazil) & 416 & & & & \\
\hline Ras Al Khaimah (United Arab Emirates) & 416 & & & & \\
\hline Santa Catarina (Brazil) & 415 & & & & \\
\hline Puebla (Mexico) & 415 & & & & \\
\hline
\end{tabular}

Notes: OECD countries are shown in bold black. Partner countries are shown in bold blue. Participating economies and subnational entities that are not included in national results are shown in bold blue italics. Regions are shown in black italics (OECD countries) or blue italics (partner countries).

1. Note by Turkey: The information in this document with reference to "Cyprus" relates to the southern part of the Island. There is no single authority representing both Turkish and Greek Cypriot people on the Island. Turkey recognises the Turkish Republic of Northern Cyprus (TRNC). Until a lasting and equitable solution is found within the context of the United Nations, Turkey shall preserve its position concerning the "Cyprus issue".

2. Note by all the European Union Member States of the OECD and the European Union: The Republic of Cyprus is recognised by all members of the United Nations with the exception of Turkey. The information in this document relates to the area under the effective control of the Government of the Republic of Cyprus.

Countries, economies and subnational entities are ranked in descending order of mean mathematics performance.

Source: OECD, PISA 2012 Database.

StatLink ants http://dx.doi.org/10.1787/888932935572 
- Figure I.2.14 [Part 3/3] "

Mathematics performance among PISA 2012 participants, at national and regional levels

\begin{tabular}{|c|c|c|c|c|c|}
\hline & \multicolumn{5}{|c|}{ Mathematics scale } \\
\hline & \multirow[b]{3}{*}{ Mean score } & \multicolumn{4}{|c|}{ Range of ranks } \\
\hline & & \multicolumn{2}{|c|}{ OECD countries } & \multicolumn{2}{|c|}{ All countries/economies } \\
\hline & & Upper rank & Lower rank & Upper rank & Lower rank \\
\hline Baja California (Mexico) & 415 & & & & \\
\hline Baja California Sur (Mexico) & 414 & & & & \\
\hline Espírito Santo (Brazil) & 414 & & & & \\
\hline Nayarit (Mexico) & 414 & & & & \\
\hline Mexico & 413 & 34 & 34 & 53 & 54 \\
\hline San Luis Potosí (Mexico) & 412 & & & & \\
\hline Guanajuato (Mexico) & 412 & & & & \\
\hline Tlaxcala (Mexico) & 411 & & & & \\
\hline Tamaulipas (Mexico) & 411 & & & & \\
\hline Sinaloa (Mexico) & 411 & & & & \\
\hline Fujairah (United Arab Emirates) & 411 & & & & \\
\hline Quintana Roo (Mexico) & 411 & & & & \\
\hline Yucatán (Mexico) & 410 & & & & \\
\hline Montenegro & 410 & & & 54 & 56 \\
\hline Uruguay & 409 & & & 53 & 56 \\
\hline Zacatecas (Mexico) & 408 & & & & \\
\hline Mato Grosso do Sul (Brazil) & 408 & & & & \\
\hline Rio Grande do Sul (Brazil) & 407 & & & & \\
\hline Costa Rica & 407 & & & 54 & 56 \\
\hline Hidalgo (Mexico) & 406 & & & & \\
\hline Manizales (Colombia) & 404 & & & & \\
\hline São Paulo (Brazil) & 404 & & & & \\
\hline Paraná (Brazil) & 403 & & & & \\
\hline Ajman (United Arab Emirates) & 403 & & & & \\
\hline Minas Gerais (Brazil) & 403 & & & & \\
\hline Veracruz (Mexico) & 402 & & & & \\
\hline Umm Al Quwain (United Arab Emirates) & 398 & & & & \\
\hline Campeche (Mexico) & 396 & & & & \\
\hline Paraíba (Brazil) & 395 & & & & \\
\hline Albania & 394 & & & 57 & 59 \\
\hline Medellin (Colombia) & 393 & & & & \\
\hline Bogota (Colombia) & 393 & & & & \\
\hline Brazil & 391 & & & 57 & 60 \\
\hline Rio de Janeiro (Brazil) & 389 & & & & \\
\hline Argentina & 388 & & & 57 & 61 \\
\hline Tunisia & 388 & & & 57 & 61 \\
\hline Jordan & 386 & & & 59 & 62 \\
\hline Piauí (Brazil) & 385 & & & & \\
\hline Sergipe (Brazil) & 384 & & & & \\
\hline Rondônia (Brazil) & 382 & & & & \\
\hline Rio Grande do Norte (Brazil) & 380 & & & & \\
\hline Goiás (Brazil) & 379 & & & & \\
\hline Cali (Colombia) & 379 & & & & \\
\hline Tabasco & 378 & & & & \\
\hline Ceará (Brazil) & 378 & & & & \\
\hline Colombia & 376 & & & 62 & 64 \\
\hline Qatar & 376 & & & 62 & 64 \\
\hline Indonesia & 375 & & & 62 & 65 \\
\hline Bahia (Brazil) & 373 & & & & \\
\hline Chiapas (Mexico) & 373 & & & & \\
\hline Mato Grosso (Brazil) & 370 & & & & \\
\hline Peru & 368 & & & 64 & 65 \\
\hline Guerrero (Mexico) & 367 & & & & \\
\hline Tocantins (Brazil) & 366 & & & & \\
\hline Pernambuco (Brazil) & 363 & & & & \\
\hline Roraima (Brazil) & 362 & & & & \\
\hline Amapá (Brazil) & 360 & & & & \\
\hline Pará (Brazil) & 360 & & & & \\
\hline Acre (Brazil) & 359 & & & & \\
\hline Amazonas (Brazil) & 356 & & & & \\
\hline Maranhão (Brazil) & 343 & & & & \\
\hline Alagoas (Brazil) & 342 & & & & \\
\hline
\end{tabular}

Notes: OECD countries are shown in bold black. Partner countries are shown in bold blue. Participating economies and subnational entities that are not included in national results are shown in bold blue italics. Regions are shown in black italics (OECD countries) or blue italics (partner countries).

1. Note by Turkey: The information in this document with reference to "Cyprus" relates to the southern part of the Island. There is no single authority representing both Turkish and Greek Cypriot people on the Island. Turkey recognises the Turkish Republic of Northern Cyprus (TRNC). Until a lasting and equitable solution is found within the context of the United Nations, Turkey shall preserve its position concerning the "Cyprus issue".

2. Note by all the European Union Member States of the OECD and the European Union: The Republic of Cyprus is recognised by all members of the United Nations with the

exception of Turkey. The information in this document relates to the area under the effective control of the Government of the Republic of Cyprus.

Countries, economies and subnational entities are ranked in descending order of mean mathematics performance.

Source: OECD, PISA 2012 Database.

StatLink 解田 $\mathrm{http}: / / \mathrm{dx}$.doi.org/10.1787/888932935572 
Figure 1.2.14 shows how participating countries and economies compare in mathematics performance. Since a country's score is based on an estimate of scores obtained from a sample of students, there is some degree of uncertainty associated with the estimates. Thus countries/economies are shown with the range of ranks they could occupy given this uncertainty. A number of countries designed their PISA samples so that it is possible to calculate performance averages for subnational entities as well. These subnational averages are also included in Figure I.2.14.

Shanghai-China ranks first in mathematics performance followed by Singapore. Given the uncertainty inherent in the score estimates, Hong Kong-China could rank third, fourth or fifth among all participating countries and economies. Korea is the top ranking OECD country, but when all participating countries are taken into consideration, it could rank either third, fourth or fifth. Japan is the second listed OECD country (seventh among all countries and economies) with a rank of 2 or 3 among OECD countries (from 6 to 9 among all countries and economies); and Switzerland is the third listed OECD country (ninth among all countries and economies) with a rank also of 2 or 3 among OECD countries (and from 7 to 9 among all countries and economies). For entities other than those for which full samples were drawn, namely Chinese Taipei, Hong Kong-China, Macao-China and Shanghai-China, it is not possible to calculate a rank order; but the mean score provides the possibility of comparing subnational entities against the performance of countries and economies. For example, the Flemish Community of Belgium matches the performance of top-performer Switzerland. Similarly, the performance of the Italian provinces of Trento and Friuli Venezia Giulia, which is similar to that of the Netherlands, a high performer, is higher than the performance of the Italian province of Sicilia, which is similar to Turkey's performance, by the equivalent of almost two full years of schooling.

\section{Trends in average mathematics performance}

Trends in average performance provide an indicator of how school systems are improving. Trends in mathematics are available for 64 countries and economies that participated in PISA 2012. Thirty-eight of these have mathematics performance for 2012 and the three remaining PISA assessments (2003, 2006 and 2009); seventeen have information for 2012 and two additional assessments and nine countries and economies have information for 2012 and one previous assessment. ${ }^{6}$ To better understand a country or economy's trend and maximise the number of countries in the comparisons, this report focuses on the annualised change in student performance. The annualised change is the average annual change in the observed period, taking into account all observations. For countries and economies that have participated in all four PISA assessments, the annualised change takes into account all four time points, and for those countries that have valid data for fewer assessments it only takes into account the valid and available information.

The annualised change is a more robust measure of trends in performance because it is based on all the available information (as opposed to the difference between one particular year and 2012). It is scaled by years, so it is interpreted as the average annual change in performance over the observed period and allows for comparisons of mathematics performance of countries that have participated in at least two PISA assessments since 2003 (for further details on the estimation of the annualised change, see Box 1.2.2 and Annex A5). ${ }^{7}$

On average across OECD countries with comparable data in PISA 2003 and PISA 2012, performance has remained broadly similar, but there have been markedly more countries with increasing than with declining mathematics performance (see Box 1.2.2 for details on interpreting trends in PISA). Of the 64 countries and economies with trend data up to 2012, 25 show an average annual improvement in mathematics performance; by contrast, 14 countries and economies show an average deterioration in performance between 2003 and 2012. For the remaining 25 countries and economies, there is no change in mathematics performance during the period. Figure I.2.15 illustrates that Albania, Kazakhstan, Malaysia, Qatar and the United Arab Emirates, except Dubai (United Arab Emirates, excluding Dubai), show an average improvement in mathematics performance of more than five score points per year. Among OECD countries, improvements in mathematics performance are observed in Israel (with an average improvement of more than four score points per year), Mexico, Turkey (more than three score points per year), Italy, Poland, Portugal (more than two score points per year), and Chile, Germany and Greece (more than one score point per year). Among countries that have participated in every assessment since 2003, Brazil, Italy, Mexico, Poland, Portugal, Tunisia and Turkey, show an average improvement in mathematics performance of more than 2.5 points per year. Box I.2.4 and Box I.2.5 highlight Brazil's and Turkey's improvement in PISA, and provides insight on the education policies and programmes implemented in the last decade. Other chapters of this volume and other volumes of this series highlight other country's improvements in PISA and outline their recent policy trajectories (e.g. Estonia and Korea in Chapters 4 and 5 of this volume, Mexico and Germany in Volume II, Japan and Portugal in Volume III, and Colombia, Israel, Poland and Tunisia in Volume IV). 
- Figure I.2.15 -

Annualised change in mathematics performance throughout participation in PISA

Mathematics score-point difference associated with one calendar year

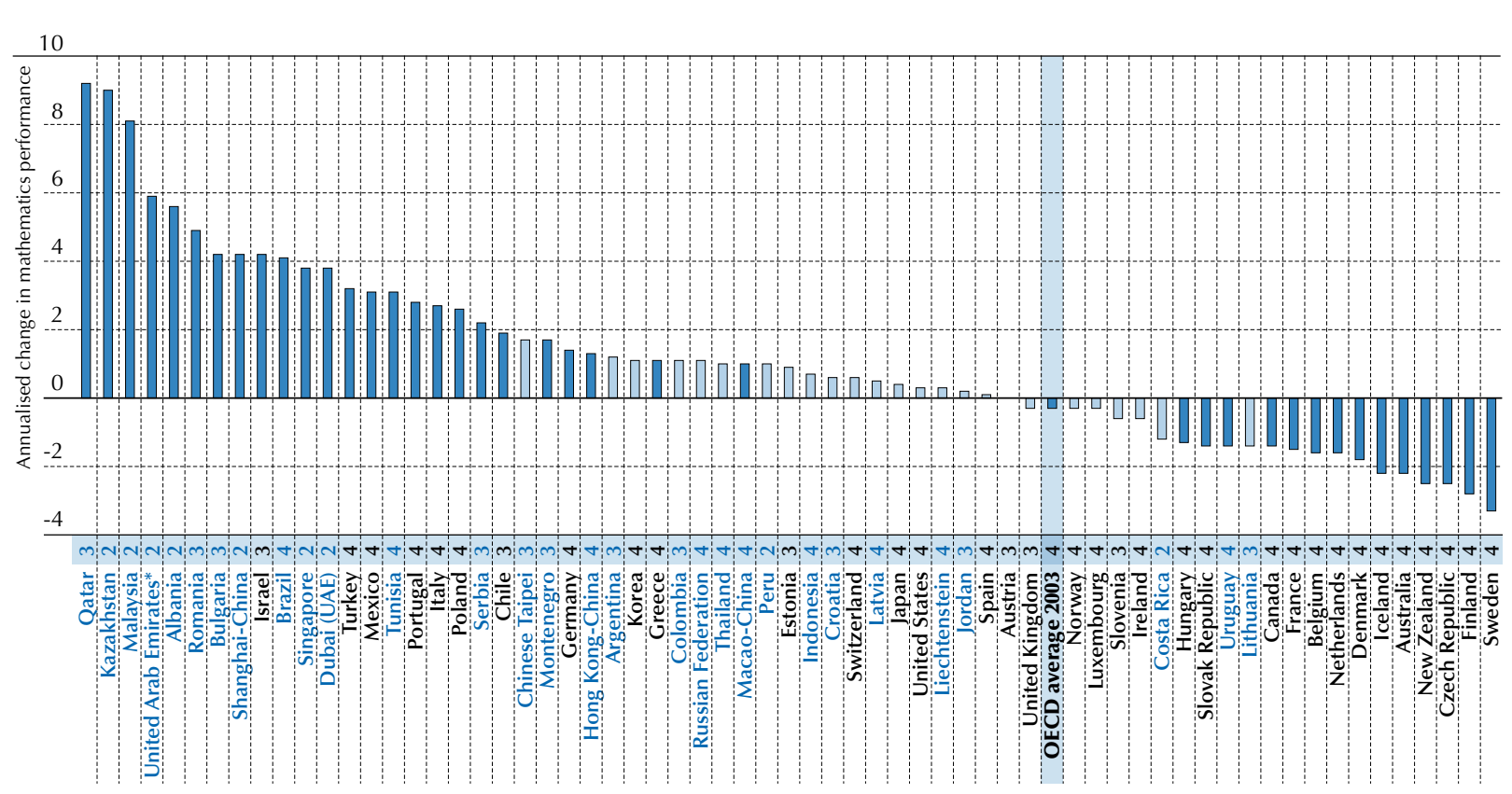

* United Arab Emirates excluding Dubai.

Notes: Statistically significant score point changes are marked in a darker tone (see Annex A3).

The number of comparable mathematics scores used to calculate the annualised change is shown next to the country/economy name.

The annualised change is the average annual change in PISA score points from a country's/economy's earliest participation in PISA to PISA 2012. It is calculated taking into account all of a country's/economy's participation in PISA. For more details on the calculation of the annualised change, see Annex A5. OECD average 2003 compares only OECD countries with comparable mathematics scores since 2003.

Countries and economies are ranked in descending order of the annualised change in mathematics performance.

Source: OECD, PISA 2012 Database, Table I.2.3b.

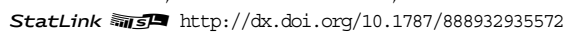

\section{Box I.2.2. Measuring trends in PISA}

PISA 2012 is the fifth round of PISA since the programme was launched in 2000. Every PISA assessment assesses students' reading, mathematics and science literacy, and in each round, one of these subjects is the main domain and the other two are minor domains. The first full assessment of reading was conducted in 2000 (when it was a major domain), while the first full assessment of mathematics was conducted in 2003 and science in 2006. In 2009, the assessment returned to reading as a major domain, which allowed for observations of trends in reading performance since PISA 2000. Mathematics is the major domain of PISA 2012, as it was in PISA 2003, allowing for observations of trends in mathematics performance since PISA 2003. The first full assessment of each domain sets the scale for future comparisons.

The methodologies underpinning performance trends in international studies of education are complex (Gebhardt and Adams, 2007). In order to ensure the comparability of successive PISA results, a number of conditions must be met. First, while successive assessments include a number of common assessment items, the limited number of such items increases measurement errors. Therefore, the confidence band for comparisons over time is wider than for single-year data, and only changes that are indicated as statistically significant should be considered robust. ${ }^{8}$ Second, the sample of students must represent an equivalent population (that of 15-year-olds enrolled in school), and only results from samples that meet the strict standards set by PISA can be compared over time. Third, the conditions in which the assessment is conducted must also remain constant across the rounds that are to be compared. 
Even though they participate in successive PISA assessment, some countries and economies cannot compare all their PISA results over time. For example, the PISA 2000 sample for the Netherlands did not meet the PISA responserate standards, so the Netherland's PISA 2000 results are not comparable to those of subsequent assessments. In Luxembourg, the testing conditions changed substantially between 2000 and 2003, so PISA 2000 results are not comparable with those of subsequent assessments. The PISA 2000 and 2003 samples for the United Kingdom did not meet the PISA response-rate standards, so data from the United Kingdom cannot be used for comparisons including these years. In the United States, no results for reading literacy are available for 2006. In 2009, a dispute between teachers' unions and the education minister of Austria led to a boycott of PISA, which was only lifted after the first week of testing. The boycott required the OECD to remove identifiable cases from the dataset. Although the Austrian dataset met the PISA 2009 technical standards after these cases were removed, the negative reaction to education assessments has affected the conditions under which the PISA survey was conducted and could have adversely affected student motivation to respond to the PISA tasks. Therefore, the comparability of 2009 data with data from earlier PISA assessments cannot be ensured, and data for Austria have been excluded from trend comparisons.

In addition, not all countries have participated in all PISA assessments. Among OECD countries, the Slovak Republic and Turkey joined PISA in 2003. Chile and Israel did not participate in the PISA 2003 assessment, and Estonia and Slovenia began participation in 2006.

When comparing trends in mathematics, reading and science, only those countries with valid data to compare between assessments are included. As a result, comparisons between the 2000 and 2012 assessments use data on reading performance and include only 38 countries and economies. Comparisons between the 2003 and 2012 assessments use data on reading and mathematics performance and include 39 countries and economies. Comparisons between the 2006 and 2012 assessments use data on reading, mathematics and science performance and include 55 countries and economies (54 countries in the case of reading). Comparisons between 2009 and 2012 use data on all domains and include 63 countries and economies. In all, 64 countries and economies have valid trend information when their PISA 2012 data and all their previous valid data are used.

\section{The annualised change in performance}

Trends in a country's/economy's average mathematics, reading and science performance are presented as the annualised change. The annualised change is the average rate of change at which a country's/economy's average mathematics, reading and science scores has changed throughout their participation in PISA assessments. Thus, a positive annualised change of $x$ points indicates that the country/economy has improved in performance by $x$ points per year since its earliest comparable PISA results. For countries and economies that have participated in only two assessments, the annualised change is equal to the difference between the two assessments, divided by the number of years that passed between the assessments.

The annualised change is a more robust measure of a country's/economy's progress in education outcomes as it is based on information available from all assessments. It is thus less sensitive to abnormal measurements that may alter a country's/economy's PISA trends if results are compared only between two assessments. The annualised change is calculated as the best-fitting line throughout a country's/economy's participation in PISA. The year that individual students participated in PISA is regressed on their PISA scores, yielding the annualised change. The annualised change also takes into account the fact that, for some countries and economies, the period between PISA assessments is less than three years. This is the case for those countries and economies that participated in PISA 2000 or PISA 2009 as part of PISA+: they conducted the assessment in 2001, 2002 or 2010 instead of 2000 or 2009.

Annex B4 presents the average performance in mathematics, reading and science (circles) for each country and economy as well as the annualised change (slope of the dotted/solid line). Tables I.2.3b, I.4.3b and I.5.3b present the annualised change in average mathematics, reading and science performance, respectively. Tables I.2.3d, I.4.3 d and $1.5 .3 \mathrm{~d}$ present the annualised change for the 10th, 25th, 75th and 90th percentile in mathematics, reading and science performance. Annex A5 provides further details on the calculation of the annualised change and other trends measures. 
The average improvement over time shows only one aspect of a country's/economy's trajectory; it does not indicate whether a country's/economy's improvement is steady, accelerating or decelerating. To evaluate the degree to which a country's improvement is accelerating or decelerating, only the 55 countries and economies that have participated in PISA 2012 and at least two other assessments have been considered. Annualised linear improvement in mathematics is observed for 18 countries and economies that have participated in PISA 2012 as well as two other assessments. The rate of improvement in the mathematics performance of the average student has accelerated in Macao-China and Poland, meaning that the rate of improvement observed in the 2009 to 2012 period is higher than that observed in the 2003 to 2006 period, for example. In Poland, this means that while scores improved by five score points (not statistically significant) between 2003 and 2006 and maintained that level between 2006 and 2009, between 2009 and 2012 there is a much faster improvement, at 23 points. Similarly, while mathematics scores in Macao-China did not change between 2003 and 2009, they improved by 13 score points between 2009 and 2012. The rate of improvement has remained steady in 13 countries and economies (Brazil, Bulgaria, Chile, Germany, Hong Kong-China, Israel, Italy, Montenegro, Portugal, Romania, Serbia, Tunisia and Turkey); the observed linear annualised change is similar to the rate of change observed throughout a country's/economy's participation in successive PISA assessments. By contrast, Qatar, Mexico and Greece show decelerating rates of improvement: the rate of improvement observed in the first assessments of PISA is slower in the later assessments. In Mexico, for example, between 2003 and 2006 the average mathematics score improved from 385 to 406 score points (a change of more than 20 points), then improved again in 2009 to 419 points, but decreased (not significantly) to 413 points in 2012 (Figure I.2.16 and Table I.2.3b).

Among the 25 countries that have no positive annualised change, 23 have participated in at least two assessments in addition to PISA 2012, and all those that show deteriorating performance participated in at least two assessments prior to PISA 2012. Among these, Chinese Taipei, Croatia, Ireland and Japan show signs of moving from no change to improvement, or from initial deterioration towards no change in mathematics performance. Although Chinese Taipei, Croatia, Ireland and Japan showed no change in mathematics performance during their participation in earlier rounds of PISA, there are signs of improvement in more recent years. Between PISA 2003 and 2006 assessments, France showed a deterioration in its average annual performance, but later assessments did not show any further deterioration (Figure I.2.16 and Table I.2.3b).

At any point in time, countries and economies share similar performance levels with other countries and economies. But as time passes and school systems evolve, some countries and economies improve their performance changing the group of countries with which they share similar performance levels. Figure 1.2.17 shows, for each country and economy with comparable results in 2003 and 2012, those other countries and economies with similar performance in 2003 but higher or lower level performance in 2012. In 2003, Poland, for example, was similar in performance to the United States, Latvia, the Slovak Republic, Luxembourg, Hungary, Spain and Norway; but as a result of improvements during the period, it performed better than all those countries in 2012. In 2003, Poland scored below Finland, Germany, Austria, Canada, Belgium and the Netherlands; but by 2012, its performance was similar to this group of countries. Turkey was similar in performance to Uruguay and Thailand in 2003 but, in 2012, its score was higher than those of these two countries, and was at the same level as that of Greece. In 2003, Portugal scored lower than the United States, Latvia, the Slovak Republic, Luxembourg, the Czech Republic, France, Sweden, Hungary, Spain, Iceland and Norway; but by 2012 the country had caught up to those countries.

Figure I.2.18 shows the relationship between each country and economy's average mathematics performance in 2003 and their average rate of change over the 2003 to 2012 period. Countries and economies that show the strongest improvement throughout the various assessments (top half of the graph) are more likely to be those that had comparatively low performance in the initial years. The correlation between a country's/economy's earliest comparable mathematics score and the annualised rate of change is -0.60 ; this means that $35 \%$ of the variance in the rate of change can be explained by a country's/economy's initial score and that countries with a lower initial score tend to improve at a faster rate.

But this relationship is, by no means, a given. Although countries that improve the most are more likely to be those that had lower performance in 2003, some countries and economies that had average or high performance in 2003 saw improvements in their students' performance over time. Such was the case in the high-performing countries and economies of Hong Kong-China, Macao-China and Germany, all of which saw annualised improvements in mathematics performance even after PISA 2003 mathematics scores placed them at or above the OECD average (results for countries and economies that began their participation in PISA after PISA 2003 are in Table I.2.3b). 
- Figure I.2.16

Curvilinear trajectories of average mathematics performance across PISA assessments

Rate of acceleration or deceleration in performance (quadratic term)

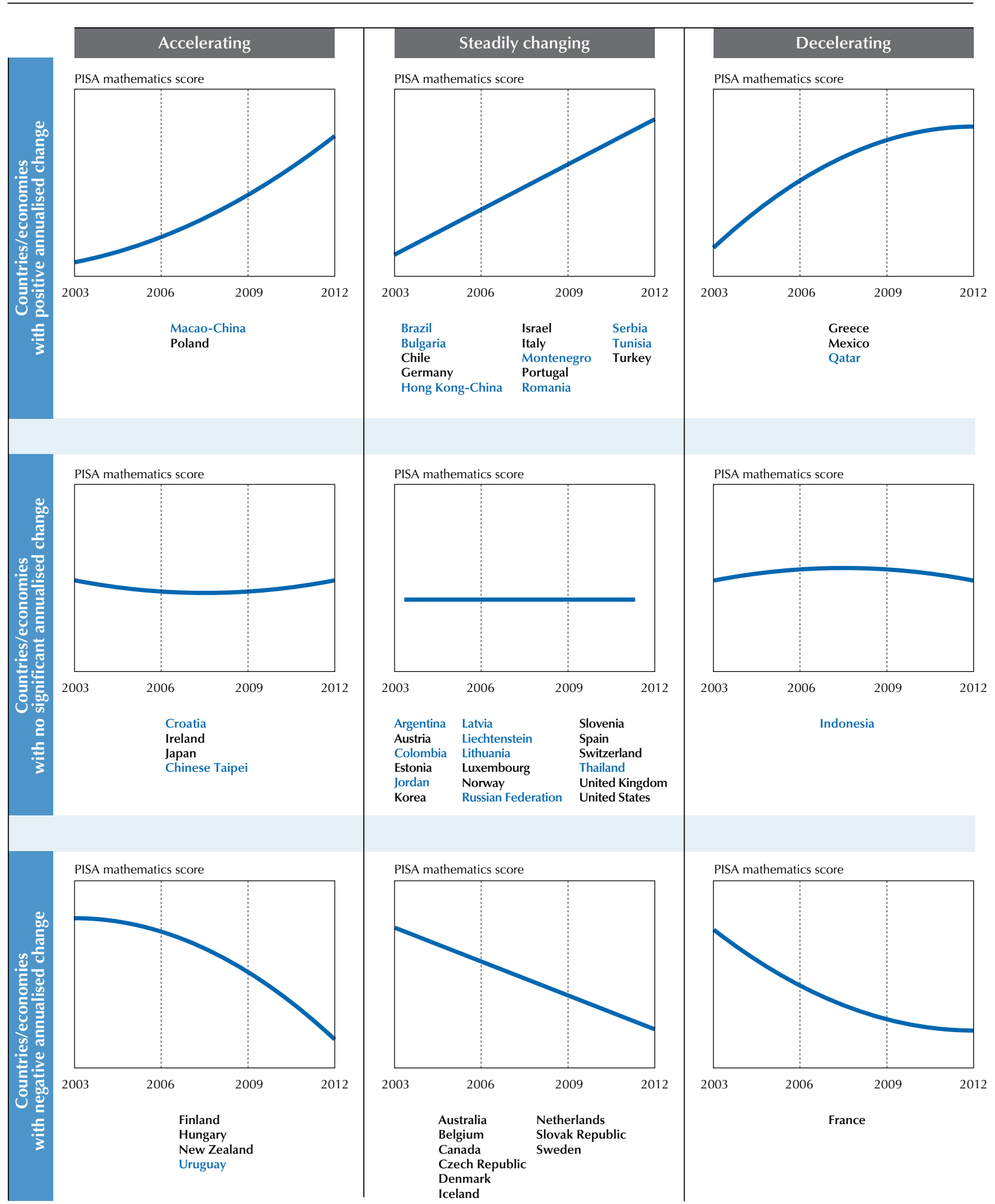

Notes: Figures are for illustrative purposes only. Countries and economies are grouped according to the direction and significance of their annualised change and their rate of acceleration.

Countries and economies with data from only one PISA assessments other than 2012 are excluded.

Source: OECD, PISA 2012 Database, Table I.2.3b.

StatLink त्राजम http://dx.doi.org/10.1787/888932935572 
- Figure I.2.17 [Part 1/2] "

\section{Multiple comparisons of mathematics performance between 2003 and 2012}

\begin{tabular}{|c|c|c|c|c|c|}
\hline & $\begin{array}{l}\text { Mathematics } \\
\text { performance } \\
\text { in } 2003\end{array}$ & $\begin{array}{l}\text { Mathematics } \\
\text { performance } \\
\text { in } 2012\end{array}$ & $\begin{array}{c}\text { Countries/economies with similar } \\
\text { performance in } 2003 \\
\text { but lower performance in } 2012\end{array}$ & $\begin{array}{c}\text { Countries/economies with similar } \\
\text { performance in } 2003 \\
\text { and similar performance in } 2012\end{array}$ & $\begin{array}{c}\text { Countries/economies with similar } \\
\text { performance in } 2003 \\
\text { but higher performance in } 2012\end{array}$ \\
\hline Hong Kong-China & 550 & 561 & $\begin{array}{l}\text { Finland, Japan, Netherlands, } \\
\text { Liechtenstein }\end{array}$ & Korea & \\
\hline Korea & 542 & 554 & $\begin{array}{l}\text { Finland, Japan, Canada, Netherlands, } \\
\text { Liechtenstein }\end{array}$ & Hong Kong-China & \\
\hline Macao-China & 527 & 538 & $\begin{array}{l}\text { New Zealand, Czech Republic, Australia, } \\
\text { Canada, Belgium, Netherlands }\end{array}$ & Japan, Switzerland, Liechtenstein & \\
\hline Japan & 534 & 536 & $\begin{array}{l}\text { New Zealand, Finland, Australia, Canada, } \\
\text { Belgium }\end{array}$ & $\begin{array}{l}\text { Macao-China, Netherlands, Switzerland, } \\
\text { Liechtenstein }\end{array}$ & Hong Kong-China, Korea \\
\hline Liechtenstein & 536 & 535 & $\begin{array}{l}\text { New Zealand, Finland, Australia, Canada, } \\
\text { Belgium }\end{array}$ & $\begin{array}{l}\text { Japan, Macao-China, Netherlands, } \\
\text { Switzerland }\end{array}$ & Hong Kong-China, Korea \\
\hline Switzerland & 527 & 531 & $\begin{array}{l}\text { New Zealand, Czech Republic, Australia, } \\
\text { Canada, Belgium }\end{array}$ & $\begin{array}{l}\text { Japan, Macao-China, Netherlands, } \\
\text { Liechtenstein }\end{array}$ & \\
\hline Netherlands & 538 & 523 & & $\begin{array}{l}\text { Finland, Japan, Canada, Belgium, } \\
\text { Switzerland, Liechtenstein }\end{array}$ & Hong Kong-China, Macao-China, Korea \\
\hline Finland & 544 & 519 & & Netherlands & $\begin{array}{l}\text { Hong Kong-China, Japan, Liechtenstein, } \\
\text { Korea }\end{array}$ \\
\hline Canada & 532 & 518 & & Belgium, Netherlands & $\begin{array}{l}\text { Japan, Macao-China, Switzerland, } \\
\text { Liechtenstein, Korea }\end{array}$ \\
\hline Poland & 490 & 518 & $\begin{array}{l}\text { United States, Latvia, Slovak Republic, } \\
\text { Luxembourg, Hungary, Spain, Norway }\end{array}$ & & \\
\hline Belgium & 529 & 515 & New Zealand, Australia & Canada, Netherlands & $\begin{array}{l}\text { Japan, Macao-China, Switzerland, } \\
\text { Liechtenstein }\end{array}$ \\
\hline Germany & 503 & 514 & $\begin{array}{l}\text { Slovak Republic, France, Sweden, } \\
\text { Ireland, Denmark, Norway }\end{array}$ & Austria & \\
\hline Austria & 506 & 506 & $\begin{array}{l}\text { Slovak Republic, France, Sweden, } \\
\text { Norway }\end{array}$ & $\begin{array}{l}\text { Germany, Czech Republic, Ireland, } \\
\text { Denmark }\end{array}$ & \\
\hline Australia & 524 & 504 & & New Zealand, Czech Republic & $\begin{array}{l}\text { Japan, Macao-China, Belgium, } \\
\text { Switzerland, Liechtenstein }\end{array}$ \\
\hline Ireland & 503 & 501 & Slovak Republic, Sweden, Norway & Austria, France & Germany \\
\hline Denmark & 514 & 500 & Sweden & $\begin{array}{l}\text { New Zealand, Austria, Czech Republic, } \\
\text { France, Iceland }\end{array}$ & Germany \\
\hline New Zealand & 523 & 500 & & Czech Republic, Australia, Denmark & $\begin{array}{l}\text { Japan, Macao-China, Belgium, } \\
\text { Switzerland, Liechtenstein }\end{array}$ \\
\hline Czech Republic & 516 & 499 & Sweden & $\begin{array}{l}\text { New Zealand, Austria, France, Australia, } \\
\text { Denmark, Iceland }\end{array}$ & Macao-China, Switzerland \\
\hline France & 511 & 495 & Sweden & $\begin{array}{l}\text { Czech Republic, Ireland, Denmark, } \\
\text { Iceland }\end{array}$ & Germany, Austria \\
\hline Iceland & 515 & 493 & Sweden & Czech Republic, France, Denmark & \\
\hline Latvia & 483 & 491 & Hungary & $\begin{array}{l}\text { United States, Spain, Norway, } \\
\text { Russian Federation }\end{array}$ & Poland \\
\hline Luxembourg & 493 & 490 & Hungary & Slovak Republic, Norway & Poland \\
\hline Norway & 495 & 489 & Hungary & Latvia, Slovak Republic, Luxembourg & Poland, Germany, Austria, Ireland \\
\hline Portugal & 466 & 487 & & Russian Federation, Italy & \\
\hline Italy & 466 & 485 & & Portugal, Russian Federation & \\
\hline Spain & 485 & 484 & & United States, Latvia, Hungary & Poland \\
\hline Russian Federation & 468 & 482 & & Latvia, Portugal, Italy & \\
\hline Slovak Republic & 498 & 482 & & $\begin{array}{l}\text { Luxembourg, Sweden, Hungary, } \\
\text { Norway }\end{array}$ & Poland, Germany, Austria, Ireland \\
\hline United States & 483 & 481 & & Latvia, Hungary, Spain & Poland \\
\hline Sweden & 509 & 478 & & Slovak Republic & $\begin{array}{l}\text { Germany, Austria, Czech Republic, } \\
\text { France, Ireland, Denmark, Iceland }\end{array}$ \\
\hline Hungary & 490 & 477 & & United States, Slovak Republic, Spain & Poland, Latvia, Luxembourg, Norway \\
\hline Greece & 445 & 453 & & & \\
\hline Turkey & 423 & 448 & Uruguay, Thailand & & \\
\hline Thailand & 417 & 427 & Uruguay & & Turkey \\
\hline Mexico & 385 & 413 & & & \\
\hline Uruguay & 422 & 409 & & & Thailand, Turkey \\
\hline Brazil & 356 & 391 & Indonesia & Tunisia & \\
\hline Tunisia & 359 & 388 & & Brazil, Indonesia & \\
\hline Indonesia & 360 & 375 & & Tunisia & Brazil \\
\hline
\end{tabular}

Note: Only countries and economies that participated in the PISA 2003 and PISA 2012 assessments are shown.

Countries and economies are ranked in descending order of their mean mathematics performance in PISA 2012.

Source: OECD, PISA 2012 Database, Table I.2.3b.

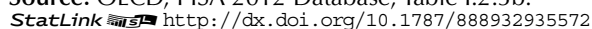


- Figure 1.2.17 [Part 2/2]

Multiple comparisons of mathematics performance between 2003 and 2012

\begin{tabular}{|c|c|c|c|c|c|c|}
\hline $\begin{array}{l}\text { Countries/economies with } \\
\text { lower performance in } 2003 \\
\text { but similar performance } \\
\text { in } 2012\end{array}$ & $\begin{array}{l}\text { Countries/economies with } \\
\text { lower performance in } 2003 \\
\text { but higher performance } \\
\text { in } 2012\end{array}$ & $\begin{array}{c}\text { Countries/economies with } \\
\text { higher performance in } 2003 \\
\text { but with similar performance } \\
\text { in } 2012\end{array}$ & $\begin{array}{l}\text { Countries/economies with } \\
\text { higher performance in } 2003 \\
\text { but lower performance } \\
\text { in } 2012\end{array}$ & $\begin{array}{l}\text { Mathematics } \\
\text { performance } \\
\text { in } 2012\end{array}$ & $\begin{array}{l}\text { Mathematics } \\
\text { performance } \\
\text { in } 2003\end{array}$ & \\
\hline & & & & 561 & 550 & Hong Kong-China \\
\hline & & & & 554 & 542 & Korea \\
\hline & & & Finland & 538 & 527 & Macao-China \\
\hline & & & & 536 & 534 & Japan \\
\hline & & & & 535 & 536 & Liechtenstein \\
\hline & & & Finland & 531 & 527 & Switzerland \\
\hline Poland, Germany & & & & 523 & 538 & Netherlands \\
\hline $\begin{array}{l}\text { Poland, Germany, Canada, } \\
\text { Belgium }\end{array}$ & Macao-China, Switzerland & & & 519 & 544 & Finland \\
\hline \multirow[t]{2}{*}{ Poland, Germany } & & Finland & & 518 & 532 & Canada \\
\hline & & \begin{tabular}{|l|} 
Finland, Germany, Austria, \\
Canada, Belgium, Netherlands
\end{tabular} & $\begin{array}{l}\text { New Zealand, Czech Republic, } \\
\text { France, Sweden, Australia, } \\
\text { Ireland, Denmark, Iceland } \\
\end{array}$ & 518 & 490 & Poland \\
\hline Poland, Germany, Austria & & Finland & & 515 & 529 & Belgium \\
\hline Poland & & $\begin{array}{l}\text { Finland, Canada, Belgium, } \\
\text { Netherlands }\end{array}$ & $\begin{array}{l}\text { New Zealand, } \\
\text { Czech Republic, Australia, } \\
\text { Iceland }\end{array}$ & 514 & 503 & Germany \\
\hline Poland & & $\begin{array}{l}\text { New Zealand, Australia, } \\
\text { Belgium }\end{array}$ & Iceland & 506 & 506 & Austria \\
\hline \multirow[t]{2}{*}{ Austria, Ireland, Denmark } & Poland, Germany & & & 504 & 524 & Australia \\
\hline & Poland & $\begin{array}{l}\text { New Zealand, Czech Republic, } \\
\text { Australia, Denmark }\end{array}$ & Iceland & 501 & 503 & Ireland \\
\hline Latvia, Ireland & Poland & Australia & & 500 & 514 & Denmark \\
\hline $\begin{array}{l}\text { Latvia, Austria, France, Ireland, } \\
\text { Iceland }\end{array}$ & Poland, Germany & & & 500 & 523 & New Zealand \\
\hline $\begin{array}{l}\text { Latvia, Ireland, Portugal, } \\
\text { Norway }\end{array}$ & Poland, Germany & & & 499 & 516 & Czech Republic \\
\hline $\begin{array}{l}\text { Latvia, Luxembourg, Portugal, } \\
\text { Norway }\end{array}$ & Poland & New Zealand & & 495 & 511 & France \\
\hline $\begin{array}{l}\text { Latvia, Luxembourg, Portugal, } \\
\text { Norway }\end{array}$ & $\begin{array}{l}\text { Poland, Germany, Austria, } \\
\text { Ireland }\end{array}$ & New Zealand & & 493 & 515 & Iceland \\
\hline Portugal, Italy & & \begin{tabular}{|l|} 
New Zealand, \\
Slovak Republic, Luxembourg, \\
Czech Republic, France, \\
Denmark, Iceland \\
\end{tabular} & Sweden & 491 & 483 & Latvia \\
\hline $\begin{array}{l}\text { United States, Latvia, Spain, } \\
\text { Portugal, Russian Federation, } \\
\text { Italy }\end{array}$ & & France, Iceland & Sweden & 490 & 493 & Luxembourg \\
\hline \multirow[t]{3}{*}{$\begin{array}{l}\text { United States, Spain, Portugal, } \\
\text { Russian Federation, Italy }\end{array}$} & & $\begin{array}{l}\text { Czech Republic, France, } \\
\text { Iceland }\end{array}$ & Sweden & 489 & 495 & Norway \\
\hline & & \begin{tabular}{|l|} 
United States, Latvia, \\
Slovak Republic, Luxembourg, \\
Czech Republic, France, \\
Sweden, Hungary, Spain, \\
Iceland, Norway \\
\end{tabular} & & 487 & 466 & Portugal \\
\hline & & \begin{tabular}{|l|} 
United States, Latvia, \\
Slovak Republic, Luxembourg, \\
Sweden, Hungary, Spain, \\
Norway
\end{tabular} & & 485 & 466 & Italy \\
\hline \multirow[t]{2}{*}{$\begin{array}{l}\text { Portugal, Russian Federation, } \\
\text { Italy }\end{array}$} & & $\begin{array}{l}\text { Slovak Republic, Luxembourg, } \\
\text { Sweden, Norway }\end{array}$ & & 484 & 485 & Spain \\
\hline & & $\begin{array}{l}\text { United States, Slovak Republic, } \\
\text { Luxembourg, Sweden, } \\
\text { Hungary, Spain, Norway }\end{array}$ & & 482 & 468 & Russian Federation \\
\hline $\begin{array}{l}\text { United States, Latvia, Spain, } \\
\text { Portugal, Russian Federation, } \\
\text { Italy }\end{array}$ & & & & 482 & 498 & Slovak Republic \\
\hline $\begin{array}{l}\text { Portugal, Russian Federation, } \\
\text { Italy }\end{array}$ & & $\begin{array}{l}\text { Slovak Republic, Luxembourg, } \\
\text { Sweden, Norway }\end{array}$ & & 481 & 483 & United States \\
\hline $\begin{array}{l}\text { United States, Hungary, Spain, } \\
\text { Portugal, Russian Federation, } \\
\text { Italy }\end{array}$ & $\begin{array}{l}\text { Poland, Latvia, Luxembourg, } \\
\text { Norway }\end{array}$ & & & 478 & 509 & Sweden \\
\hline $\begin{array}{l}\text { Portugal, Russian Federation, } \\
\text { Italy }\end{array}$ & & Sweden & & 477 & 490 & Hungary \\
\hline \multirow[t]{4}{*}{ Turkey } & & & & 453 & 445 & Greece \\
\hline & & Greece & & 448 & 423 & Turkey \\
\hline & & & & 427 & 417 & Thailand \\
\hline & & Uruguay & & 413 & 385 & Mexico \\
\hline \multirow[t]{4}{*}{ Mexico } & & & & 409 & 422 & Uruguay \\
\hline & & & & 391 & 356 & Brazil \\
\hline & & & & 388 & 359 & Tunisia \\
\hline & & & & 375 & 360 & Indonesia \\
\hline
\end{tabular}

Note: Only countries and economies that participated in the PISA 2003 and PISA 2012 assessments are shown. Countries and economies are ranked in descending order of their mean mathematics performance in PISA 2012.

Source: OECD, PISA 2012 Database, Table I.2.3b.

StatLink intsta http://dx.doi.org/10.1787/888932935572 
- Figure I.2.18

Relationship between annualised change in performance and average PISA 2003 mathematics scores

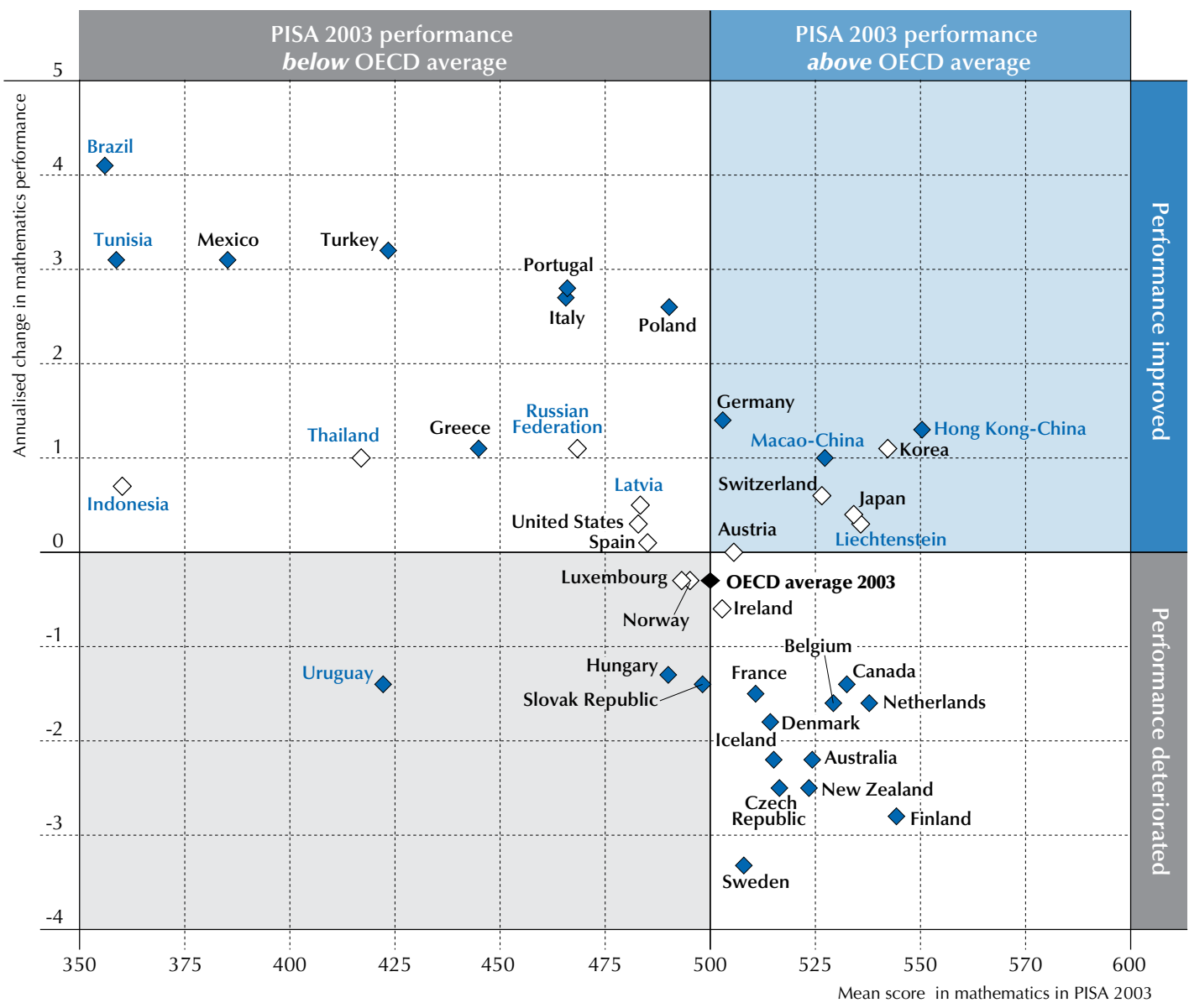

Notes: Annualised score point change in mathematics that are statistically significant are indicated in a darker tone (see Annex A3).

The annualised change is the average annual change in PISA score points from a country's/economy's earliest participation in PISA to PISA 2012. It is calculated taking into account all of a country's/economy's participation in PISA. For more details on the calculation of the annualised change, see Annex A5.

The correlation between a country's/economy's mean score in 2003 and its annualised performance is -0.60.

OECD average 2003 considers only those countries with comparable data since PISA 2003.

Source: OECD, PISA 2012 Database, Tables I.2.3b.

StatLink त्ताज्ञ http://dx.doi.org/10.1787/888932935572

Other high-performing countries and economies that began their participation in PISA after the 2003 assessment, like Shanghai-China and Singapore, also show improvements in performance. In addition, there are many countries and economies that performed similarly in 2003 but evolved differently. As shown in Table I.2.3b, Bulgaria, Chile, Romania and Thailand began their participation in PISA with a mathematics performance of around 410 score points; but while Thailand showed no annual improvement between 2003 and 2012, Chile, Bulgaria and Romania showed an annual improvement between 2006 and 2012 of 1.9, 4.2 and 4.9 score points, respectively (Figure I.2.18 and Table I.2.3b).

\section{Trends in mathematics performance adjusted for sampling and demographic changes}

Changes in a country's or economy's mathematics performance can have many sources. While improvements may result from improved education services, they can also result from demographic changes that have shifted the country's population profile. By following strict sampling and methodological standards PISA ensures that all countries and economies are measuring the mathematics performance of their 15-year-olds enrolled in school; but because of 
migration or other demographic and social trends, the characteristics of this reference population may change. Annex A5 provides details on the calculation of the adjusted trends.

Figure I.2.19 presents annualised changes after adjusting for changes in the age, gender, socio-economic status, migration background and language spoken at home of the population of students in each country or economy. ${ }^{9}$ On average across OECD countries, and assuming that the 2003, 2006 and 2009 population of 15-year-old students had the same demographic profile as the population in 2012, scores in mathematics dropped by around one point per year. The observed trend shows no change since 2006. This difference in trends before and after accounting for demographic changes means that were it not for these demographic and socio-economic changes, average mathematics performance across OECD countries would have deteriorated since 2006.

- Figure I.2.19

\section{Adjusted and observed annualised performance change in average PISA mathematics scores}

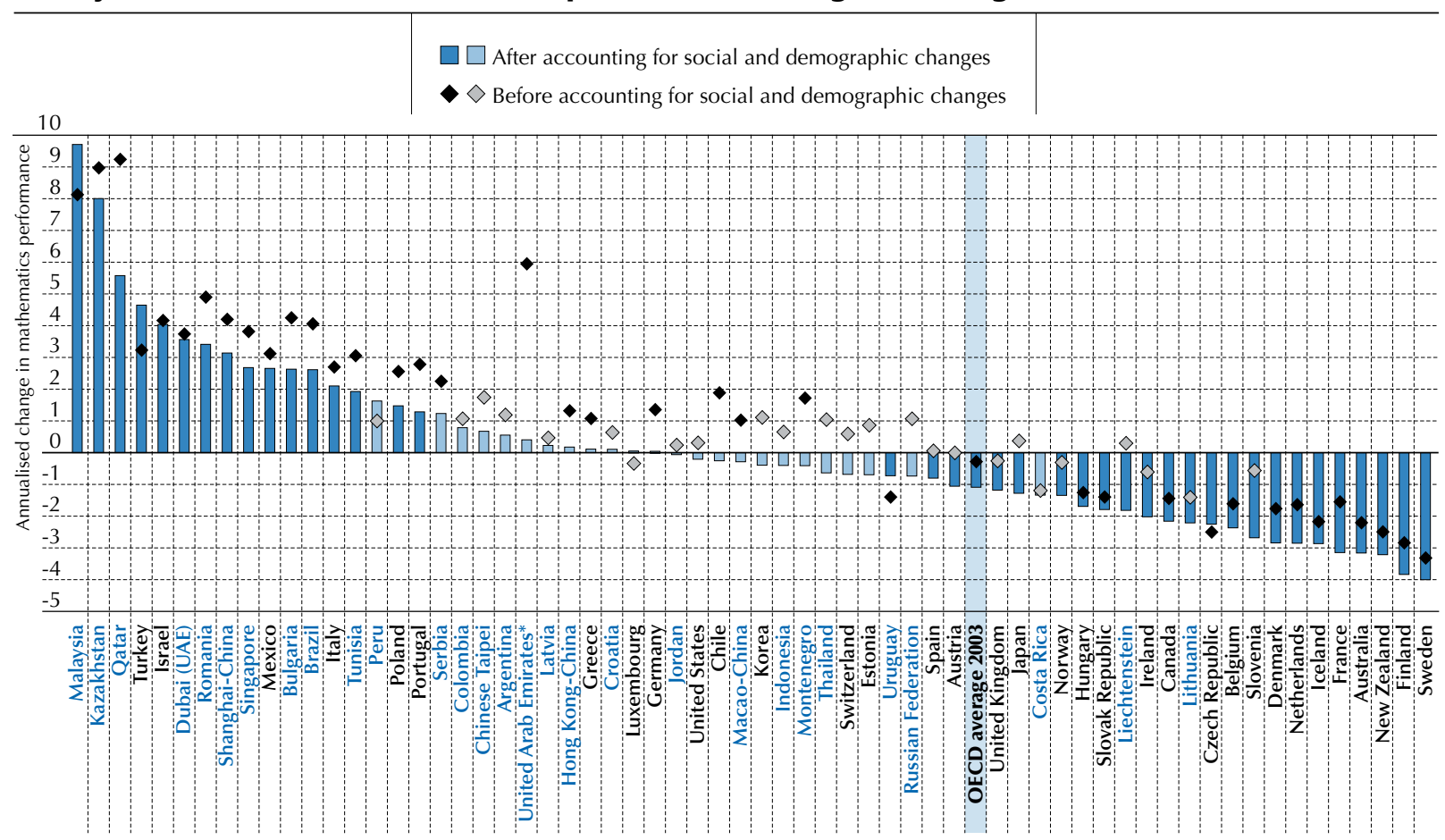

* United Arab Emirates excluding Dubai.

Notes: Statistically significant values are marked in a darker tone (see Annex A3).

The annualised change is the average annual change in PISA score points. It is calculated taking into account all of a country's/economy's participation in PISA. For more details on the calculation of the annualised change, see Annex A5.

The annualised change adjusted for demographic changes assumes that the average age and PISA index of social, cultural and economic status, as well as the percentage of female students, those with an immigrant background and those who speak a language other than the assessment at home is the same in previous assessments as those observed in 2012. For more details on the calculation of the adjusted annualised change, see Annex A5.

OECD average 2003 considers only those countries with comparable mathematics scores since PISA 2003.

Countries and economies are ranked in descending order of the annualised change after accounting for demographic changes.

Source: OECD, PISA 2012 Database, Tables I.2.3b and I.2.4.

StatLink 刑组 http://dx.doi.org/10.1787/888932935572

As shown in Figure 1.2.19, of the 25 countries and economies that saw an overall improvement in mathematics performance, 16 show this improvement after accounting for demographic changes in their student population. ${ }^{10}$ In these countries and economies, changes in the age, immigrant background and language spoken at home of the student population do not explain all of the observed improvement in mathematics performance. Of the 14 countries and economies that show deteriorating performance during their participation in PISA, in no country or economy does this trend lose statistical significance after accounting for demographic changes in the student population. Of the 25 countries and economies that did not see an annualised change in mathematics performance, 9 would show a deterioration in performance had their student populations in previous assessments shared the same profile as students who were assessed in PISA 2012. 
Comparing the results of the adjusted and unadjusted trends in mathematics performance, shown in Figure I.2.19, Costa Rica, the Czech Republic, Dubai (United Arab Emirates), Israel, Kazakhstan, Malaysia and Mexico, have less than a $20 \%$ difference between unadjusted and adjusted annualised trends, meaning that the characteristics of the student population have not changed much between 2003 and 2012, that changes in the characteristics of the student population are unrelated to average student performance, or that education services have adapted to the changes in the student population so that any of those changes that may have an impact on student performance have been compensated for by adaptations made in education service. Similarly, in Colombia, Hungary, Jordan, Latvia, Luxembourg and the Slovak Republic, the difference between the unadjusted and adjusted annualised trends is less than 0.5 score points per year. Large differences in adjusted and unadjusted performance are observed in Chile, Liechtenstein, Montenegro, Qatar, Slovenia and the United Arab Emirates, excluding Dubai. In these countries and economies, the difference between adjusted and unadjusted annualised trends is greater than two score points, signalling that demographic changes have had a considerable impact on trends in mathematics performance.

Informative as they may be, adjusted trends are merely hypothetical scenarios that help to understand the source of changes in students' performance over time. Observed (unadjusted) trends depicted in Figure I.2.19 and throughout this chapter summarise the overall evolution of a school system, highlighting the challenges that countries and economies face in improving students' and schools' mathematics performance. To better understand the observed trends in performance, Chapters 2 and 3 of Volume II analyses in greater detail, how the student population has changed through migration and in socio-economic background, and how these characteristics are related to mathematics performance. Volume III explores students' engagement with and at school, drive and self-beliefs towards learning and mathematics. Volume IV, in turn, explores how attributes of school organisation and educational resources are related to changes in performance, providing further insight into the policies and practices that may explain the trends observed in mathematics performance.

\section{Students at the different levels of proficiency in mathematics}

Figure I.2.20 shows the location of some of these items on the PISA 2012 scale. A selection of items used in the 2012 survey is presented at the end of the chapter. Since PISA is a triennial assessment, it is useful to retain a sufficient number of questions over successive PISA assessments in order to generate trend data over time.

- Figure I.2.20

Map of selected mathematics questions, by proficiency level

\begin{tabular}{|c|c|c|}
\hline Level & $\begin{array}{l}\text { Lower } \\
\text { score } \\
\text { limit }\end{array}$ & Questions (position on PISA scale) \\
\hline \multirow[t]{3}{*}{6} & \multirow[t]{3}{*}{669} & REVOLVING DOOR - Question 2 (840.3) \\
\hline & & HELEN THE CYCLIST - Question 3 (696.6) \\
\hline & & GARAGE - Question 2, FULL CREDIT (687.3) \\
\hline \multirow[t]{3}{*}{5} & \multirow[t]{3}{*}{607} & GARAGE - Question 2, PARTIAL CREDIT (663.2) \\
\hline & & CLIMBING MOUNT FUJI - Question 2 (641.6) \\
\hline & & CLIMBING MOUNT FUJI - Question 3, FULL CREDIT (610.0) \\
\hline \multirow[t]{3}{*}{4} & \multirow[t]{3}{*}{545} & CLIMBING MOUNT FUJI - Question 3, PARTIAL CREDIT (591.3) \\
\hline & & REVOLVING DOOR - Question 3 (561.3) \\
\hline & & WHICH CAR? - Question 3 (552.6) \\
\hline \multirow[t]{3}{*}{3} & \multirow[t]{3}{*}{482} & REVOLVING DOOR - Question 1 (512.3) \\
\hline & & HELEN THE CYCLIST - Question 2 (510.6) \\
\hline & & WHICH CAR? - Question 2 (490.9) \\
\hline \multirow[t]{3}{*}{2} & \multirow[t]{3}{*}{420} & CLIMBING MOUNT FUJI - Question 1 (464.0) \\
\hline & & HELEN THE CYCLIST - Question 1 (440.5) \\
\hline & & CHARTS - Question 5 (428.2) \\
\hline \multirow[t]{2}{*}{$\mathbf{1}$} & \multirow[t]{2}{*}{358} & GARAGE - Question 1 (419.6) \\
\hline & & CHARTS - Question 2 (415.0) \\
\hline \multirow{2}{*}{$\begin{array}{c}\text { Below } \\
\text { Level } \\
1\end{array}$} & & CHARTS - Question 1 (347.7) \\
\hline & & WHICH CAR? - Question 1 (327.8) \\
\hline
\end{tabular}


The six mathematics proficiency levels are defined in the same way as the corresponding levels of the PISA 2003 scale, with the highest level labelled "Level 6", and the lowest labelled "Level 1". However, their descriptions have been updated to reflect the new mathematical process categories in the PISA 2012 framework and the large number of new items developed for PISA 2012. Figure 1.2.21 provides descriptions of the mathematical skills, knowledge and understanding required at each level of the mathematical literacy scale and the average proportion of students at each of these proficiency levels across OECD countries.

Figure 1.2.22 shows the distribution of students on each of these six proficiency levels. The percentage of students performing below Level 2 is shown on the left side of the vertical axis.

Figure I.2.21

Summary descriptions for the six levels of proficiency in mathematics

\begin{tabular}{|c|c|c|c|}
\hline Level & $\begin{array}{l}\text { Lower } \\
\text { score } \\
\text { limit }\end{array}$ & $\begin{array}{l}\text { Percentage of students } \\
\text { able to perform tasks } \\
\text { at each level or above } \\
\text { (OECD average) }\end{array}$ & What students can typically do \\
\hline 6 & 669 & $3.3 \%$ & $\begin{array}{l}\text { At Level 6, students can conceptualise, generalise and utilise information based on } \\
\text { their investigations and modelling of complex problem situations, and can use their } \\
\text { knowledge in relatively non-standard contexts. They can link different information } \\
\text { sources and representations and flexibly translate among them. Students at this } \\
\text { level are capable of advanced mathematical thinking and reasoning. These students } \\
\text { can apply this insight and understanding, along with a mastery of symbolic and } \\
\text { formal mathematical operations and relationships, to develop new approaches and } \\
\text { strategies for attacking novel situations. Students at this level can reflect on their } \\
\text { actions, and can formulate and precisely communicate their actions and reflections } \\
\text { regarding their findings, interpretations, arguments, and the appropriateness of these } \\
\text { to the original situation. }\end{array}$ \\
\hline 5 & 607 & $12.6 \%$ & $\begin{array}{l}\text { At Level 5, students can develop and work with models for complex situations, } \\
\text { identifying constraints and specifying assumptions. They can select, compare, and } \\
\text { evaluate appropriate problem-solving strategies for dealing with complex problems } \\
\text { related to these models. Students at this level can work strategically using broad, } \\
\text { well-developed thinking and reasoning skills, appropriate linked representations, } \\
\text { symbolic and formal characterisations, and insight pertaining to these situations. } \\
\text { They begin to reflect on their work and can formulate and communicate their } \\
\text { interpretations and reasoning. }\end{array}$ \\
\hline 4 & 545 & $30.8 \%$ & $\begin{array}{l}\text { At Level } 4 \text {, students can work effectively with explicit models for complex concrete } \\
\text { situations that may involve constraints or call for making assumptions. They can } \\
\text { select and integrate different representations, including symbolic, linking them } \\
\text { directly to aspects of real-world situations. Students at this level can utilise their } \\
\text { limited range of skills and can reason with some insight, in straightforward contexts. } \\
\text { They can construct and communicate explanations and arguments based on their } \\
\text { interpretations, arguments, and actions. }\end{array}$ \\
\hline 3 & 482 & $54.5 \%$ & $\begin{array}{l}\text { At Level 3, students can execute clearly described procedures, including those that } \\
\text { require sequential decisions. Their interpretations are sufficiently sound to be a } \\
\text { base for building a simple model or for selecting and applying simple problem- } \\
\text { solving strategies. Students at this level can interpret and use representations based } \\
\text { on different information sources and reason directly from them. They typically show } \\
\text { some ability to handle percentages, fractions and decimal numbers, and to work } \\
\text { with proportional relationships. Their solutions reflect that they have engaged in } \\
\text { basic interpretation and reasoning. }\end{array}$ \\
\hline 2 & 420 & $77.0 \%$ & $\begin{array}{l}\text { At Level 2, students can interpret and recognise situations in contexts that require } \\
\text { no more than direct inference. They can extract relevant information from a single } \\
\text { source and make use of a single representational mode. Students at this level can } \\
\text { employ basic algorithms, formulae, procedures, or conventions to solve problems } \\
\text { involving whole numbers. They are capable of making literal interpretations of the } \\
\text { results. }\end{array}$ \\
\hline 1 & 358 & $92.0 \%$ & $\begin{array}{l}\text { At Level } 1 \text {, students can answer questions involving familiar contexts where all } \\
\text { relevant information is present and the questions are clearly defined. They are able } \\
\text { to identify information and to carry out routine procedures according to direct } \\
\text { instructions in explicit situations. They can perform actions that are almost always } \\
\text { obvious and follow immediately from the given stimuli. }\end{array}$ \\
\hline
\end{tabular}


- Figure 1.2.22

\section{Proficiency in mathematics}

Percentage of students at each level of mathematics proficiency

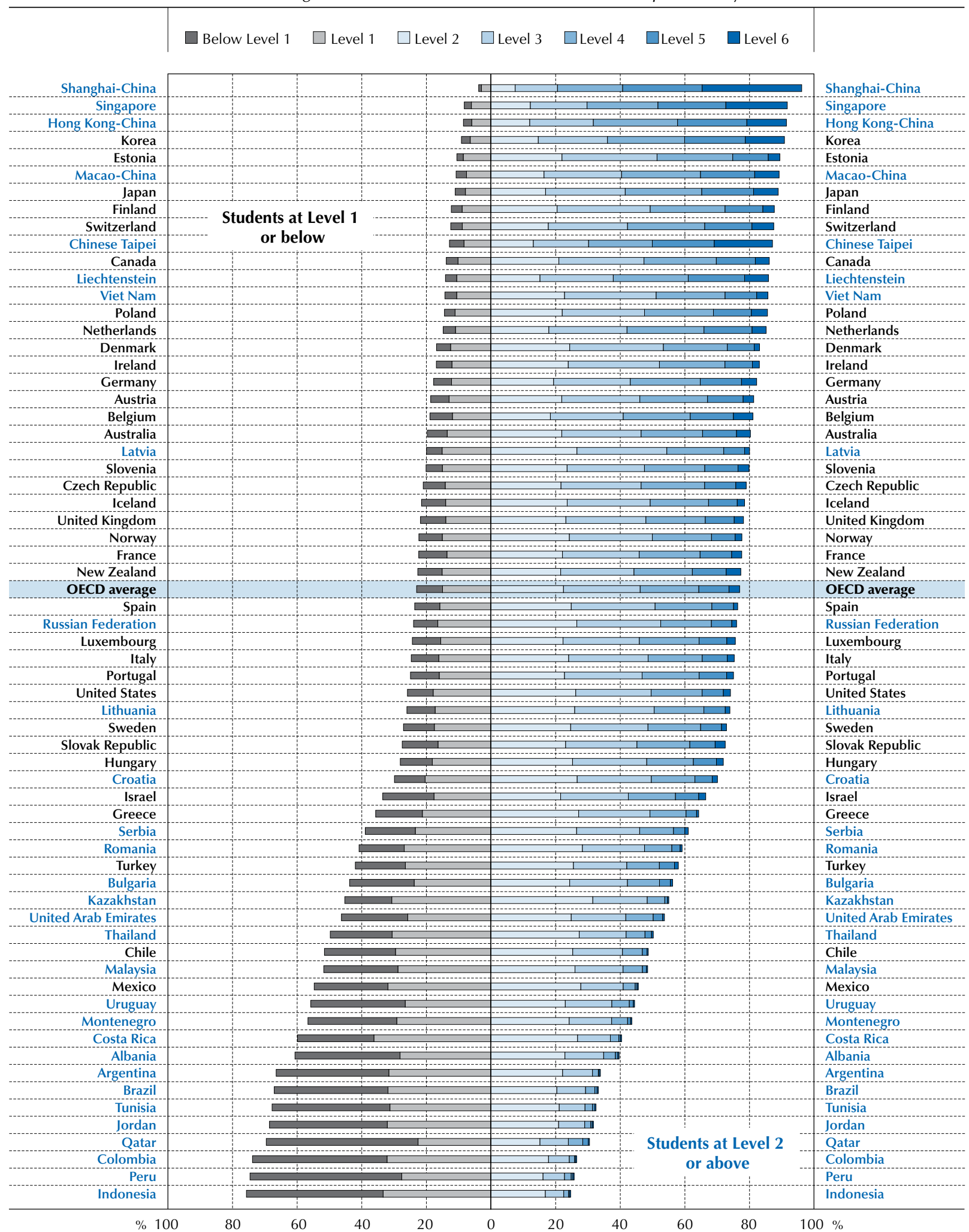

Countries and economies are ranked in descending order of the percentage of students at Levels 2, 3, 4, 5 and 6 .

Source: OECD, PISA 2012 Database, Table 1.2.1a.

StatLink त्राज http://dx.doi.org/10.1787/888932935572 


\section{Proficiency at Level 6 (scores higher than 669 points)}

Students at Level 6 of the PISA mathematics assessment are able to successfully complete the most difficult PISA items. At Level 6, students can conceptualise, generalise and use information based on their investigations and modelling of complex problem situations, and can use their knowledge in relatively non-standard contexts. They can link different information sources and representations and move flexibly among them. Students at this level are capable of advanced mathematical thinking and reasoning. These students can apply this insight and understanding, along with a mastery of symbolic and formal mathematical operations and relationships, to develop new approaches and strategies for addressing novel situations. Students at this level can reflect on their actions, and can formulate and precisely communicate their actions and reflections regarding their findings, interpretations and arguments, and can explain why they were applied to the original situation.

Question 3 in the example HELEN THE CYCLIST (Figure 1.2.55) requires Level 6 proficiency. It requires a deeper understanding of the meaning of average speed, appreciating the importance of linking total time with total distance. Average speed cannot be obtained just by averaging the speeds, even though in this specific case the incorrect answer $(28.3 \mathrm{~km} / \mathrm{hr})$ obtained by averaging the speeds $(26.67 \mathrm{~km} / \mathrm{hr}$ and $30 \mathrm{~km} / \mathrm{hr})$ is not much different from the correct answer of $28 \mathrm{~km} / \mathrm{hr}$. There are both mathematical and real world understandings of this phenomenon, leading to high demands on the fundamental mathematical capabilities of mathematisation and reasoning and argumentation and also using symbolic, formal and technical language and operations.

For students who know to work from total time $(9+6=15$ minutes) and total distance $(4+3=7 \mathrm{~km})$, the answer can be obtained simply by proportional reasoning ( $7 \mathrm{~km}$ in $1 / 4$ hour is $28 \mathrm{~km}$ in 1 hour), or by more complicated formula approaches (e.g. distance / time $=7 /(15 / 60)=420 / 15=28$ ). This question has been classified as an employing process because the greatest part of the demand arises from the mathematical definition of average speed and possibly also the unit conversion, especially for students using speed-distance-time formulas. It is one of the more difficult tasks of the item pool, and sits in Level 6 on the proficiency scale.

On average across OECD countries, 3.3\% of students attain Level 6 . The partner economy Shanghai-China has by far the largest proportion of students (30.8\%) who score at this level in mathematics. Indeed, Shanghai-China has more students at this level of mathematics proficiency than at any other level, and is the only PISA participant where this is the case. Between $10 \%$ and $20 \%$ of students in four other Asian countries and economies - the three partner countries and economies Singapore $(19.0 \%)$, Chinese Taipei $(18.0 \%)$, Hong Kong-China $(12.3 \%)$ and the OECD country Korea $(12.1 \%)$ score at this level. Between $5 \%$ and $10 \%$ of students in Japan $(7.6 \%)$, the partner economy Macao-China (7.6\%), the partner country Liechtenstein (7.4\%), Switzerland (6.8\%) and Belgium (6.1\%) attain Level 6 in mathematics. Thirty-three participating countries and economies show between $1 \%$ and $5 \%$ of their students at this level, while in 22 others, fewer than $1 \%$ of students score at the highest level, including the three OECD countries Mexico, Chile and Greece (Figure I.2.20 and Table I.2.1a).

\section{Proficiency at Level 5 (scores higher than 607 but lower than or equal to 669 points)}

At Level 5, students can develop and work with models for complex situations, identifying constraints and specifying assumptions. They can select, compare and evaluate appropriate problem-solving strategies for dealing with complex problems related to these models. Students at this level can work strategically using broad, well-developed thinking and reasoning skills, appropriate linked representations, symbolic and formal characterisations, and insights pertaining to these situations. They begin to reflect on their work and can formulate and communicate their interpretations and reasoning.

Typical questions for Level 5 are exemplified by Question 3 from the unit CLIMBING MOUNT FUJI (Figure I.2.56). This question has been allocated to the employing category. There is one main relationship involved: the distance walked = number of steps $x$ average step length. To use this relationship to solve the problem, there are two obstacles: rearranging the formula (which is probably done by students informally rather than formally using the written relationship) so that the average step length can be found from distance and number of steps, and making appropriate unit conversions. For this question, it was judged that the major cognitive demand comes from carrying out these steps; hence it has been categorised in the employing process, rather than identifying the relationships and assumptions to be made (the formulating process) or interpreting the answer in real world terms. 


\section{Box I.2.3. Top performers and all-rounders in PISA}

Performance in PISA refers to particular and increasingly complex tasks students are able to complete. A small proportion of students attains the highest levels and can be called top performers in mathematics, reading or science. Even fewer are the academic all-rounders, those students who achieve proficiency Level 5 or higher in mathematics, reading and science simultaneously. These students will be at the forefront of a competitive, knowledge-based global economy. They are able to draw on and use information from multiple and indirect sources to solve complex problems.

Results from the PISA 2012 assessment show that nurturing top performance and tackling low performance need not be mutually exclusive. Some high-performing countries in PISA 2012, like Estonia and Finland, have also low variation in student scores. Equally important, since their first participation in PISA, France, Hong Kong-China, Italy, Japan, Korea, Luxembourg, Macao-China, Poland, Portugal and the Russian Federation have been able to increase the share of top performers in mathematics, reading or science.

Figure I.2.a shows the proportion of top performers and all-rounders across OECD countries. Parts in the diagram shaded blue represent the percentage of 15 -year-old students who are top performers in just one of the three subject areas assessed, that is, either in mathematics, reading or science. The parts in blue show the percentage of students who are top performers in two of the subject areas, while the grey part in the centre of the diagram shows the percentage of 15 -year-old students who are top performers in all three subject areas.

\section{- Figure I.2.a - \\ Overlapping of top performers in mathematics, reading and science on average across OECD countries}

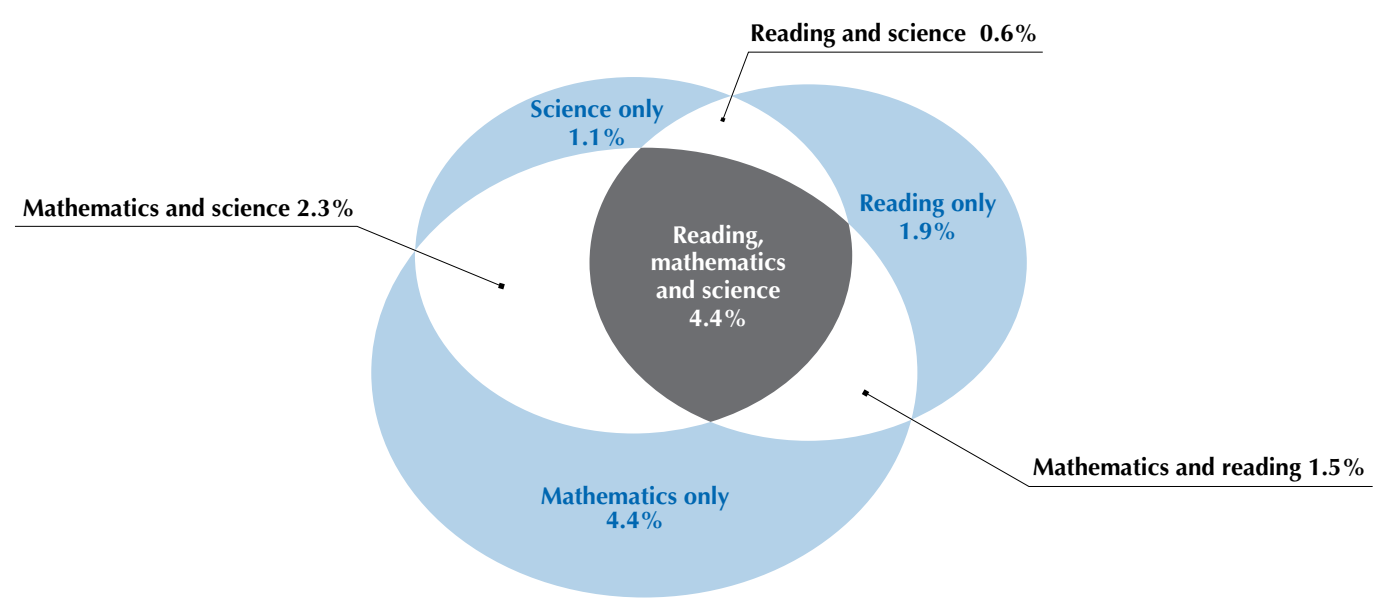

Note: Non-top performers in any of the three domains: $83.8 \%$.

Source: OECD, PISA 2012 Database, Table I.2.29.

On average across OECD countries, $16.2 \%$ of students are top performers in at least one of the three subject areas; but only $4.4 \%$ of 15 -year-old students are top performers in all three. This shows that excellence is not simply strong performance in all areas, but rather that it can be found among a wide range of students in various subjects.

About $1.5 \%$ of students are top performers in both mathematics and reading but not in science, $2.3 \%$ are top performers in both mathematics and science but not in reading, and fewer than $1 \%$ of students $(0.6 \%)$ are top performers in both reading and science but not in mathematics. The percentage of students who are top performers in both mathematics and science is greater than the percentages who are top performers in mathematics and reading or in reading and science.

There is substantial variation among countries in the percentages of top performers in the three subjects (Table I.2.29). 
- Figure I.2.b -

Top performers in mathematics, reading and science

Percentage of students reaching the two highest levels of proficiency

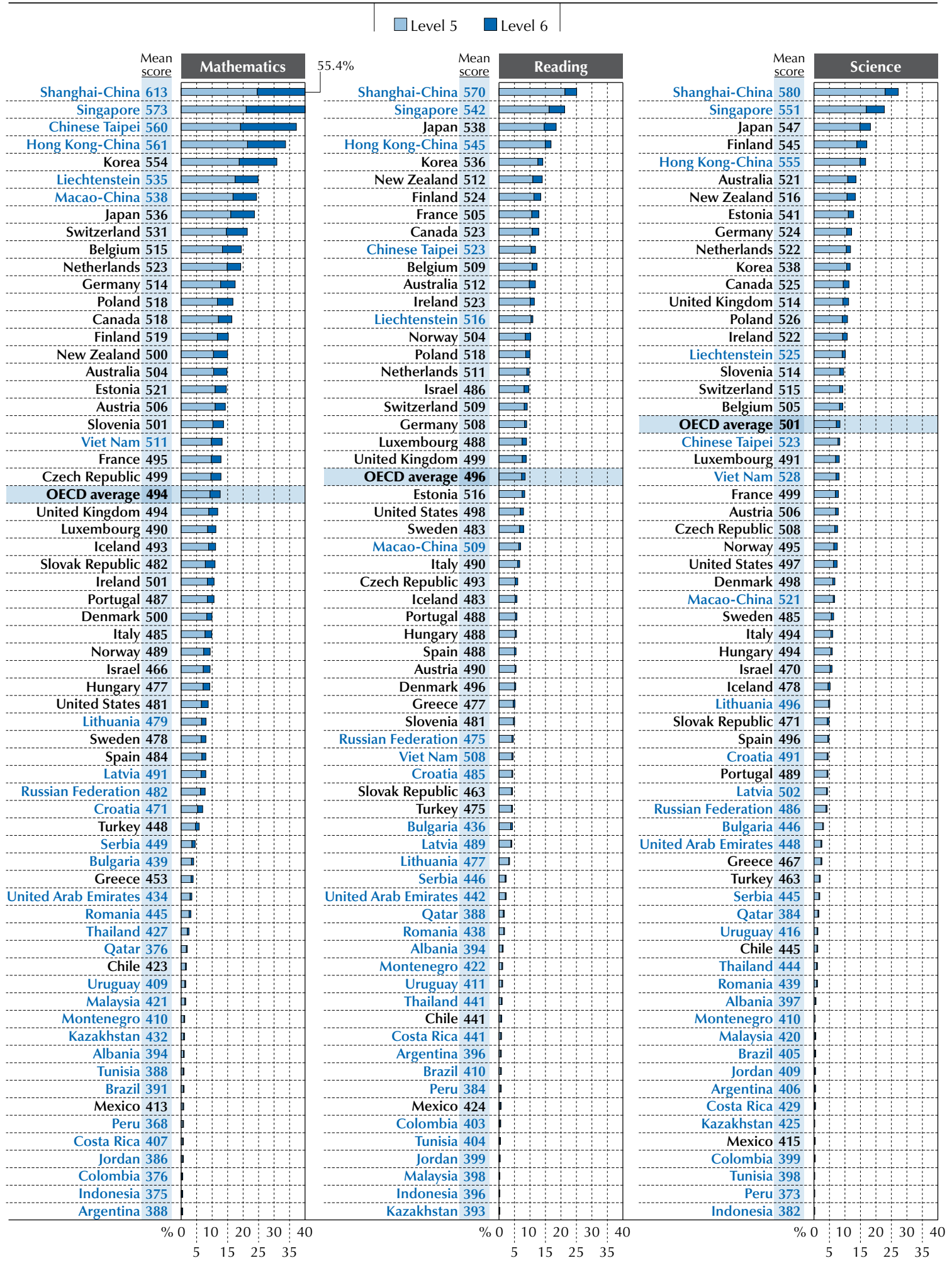

Countries and economies are ranked in descending order of the percentage of top performers (Levels 5 and 6).

Source: OECD, PISA 2012 Database, Tables I.2.1a, I.2.3a, I.4.1a, I.4.3a, I.5.1 a and I.5.3a.

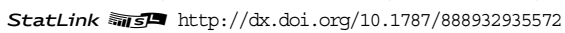


All-rounders, or top performers in all three subjects, comprise between $6 \%$ and just over $8 \%$ of 15 -year-old students in Korea (8.1\%), New Zealand (8.0\%), Australia (7.6\%), Finland (7.4\%), Canada (6.5\%), Poland (6.1\%), Belgium (6.1\%), the Netherlands $(6.0 \%)$ and the partner economy Chinese Taipei $(6.1 \%)$, and even larger proportions are found in the countries and economies Shanghai-China (19.6\%), Singapore (16.4\%), Japan (11.3\%) and Hong Kong-China (10.9\%). Conversely, in two OECD countries and 17 partner countries and economies, fewer than $1 \%$ of students are top performers in all three subjects.

Figure I.2.b shows the proportions of top performers in mathematics, reading and science for each country. Although on average across OECD countries, $9.3 \%$ and 3.3\% of 15-year-olds reach Level 5 and Level 6 in mathematics, respectively, these proportions vary substantially across countries. For example, among OECD countries, Korea, Japan and Switzerland have at least $20 \%$ of top performers in mathematics, whereas Mexico and Chile have fewer than $1 \%$ and $2 \%$, respectively. Among partner countries and economies, the overall proportion of these top performers also varies considerably from country to country; in some countries, no student achieves Level 6 in mathematics. At the same time, Shanghai-China, Singapore, Chinese Taipei and Hong Kong-China have the highest proportion of students performing at Level 5 or 6 . Similar variations are shown in reading and science, with only slight differences in the patterns of these results among countries.

Among countries with similar mean scores in PISA, there are remarkable differences in the percentage of topperforming students. For example, Denmark has a mean score of 500 points in mathematics in PISA 2012 and $10 \%$ of students perform at high proficiency levels in mathematics, which is less than the average of around $13 \%$. New Zealand has a similar mean mathematics score of 500 points, but $15 \%$ of its students attain the highest levels of proficiency, which is above the average. Although only a small percentage of students in Denmark perform at the lowest levels (see Table I.2.1a), these results could signal the absence of a highly educated talent pool for the future.

Having a large proportion of top performers in one subject is no guarantee of having a large proportion of top performers in the others. For example, Switzerland has one of the 10 largest shares of top performers in mathematics, but only a slightly-above-average share of top performers in reading and science.

Across the three subjects and across all countries, girls are as likely to be top performers as boys. On average across OECD countries, $4.6 \%$ of girls and $4.3 \%$ of boys are top performers in all three subjects, and $15.6 \%$ of girls and $16.8 \%$ of boys are top performers in at least one subject (Table I.2.30). However, while the gender gap among students who are top performers only in science is small $(0.9 \%$ of girls and $1.3 \%$ of boys), it is large among top performers in mathematics only (2.9\% of girls and $5.9 \%$ of boys) and in reading only ( $3.2 \%$ of girls and $0.6 \%$ of boys).

To increase the share of top-performing students, countries and economies need to look at the barriers posed by social background (examined in Volume II of this series), the relationship between performance and students' attitudes towards learning (examined in Volume III), and schools' organisation, resources and learning environment (examined in Volume IV).

On average across OECD countries, $12.6 \%$ of students are top performers, meaning that they are proficient at Level 5 or 6 . Among all participants in PISA 2012, the partner economy Shanghai-China (55.4\%) has the largest proportion of students performing at Level 5 or 6 , followed by Singapore (40.0\%), Chinese Taipei $(37.2 \%)$ and Hong Kong-China (33.7\%). In Korea $30.9 \%$ of students are top performers in mathematics. Between $15 \%$ and $25 \%$ of students in Liechtenstein, Macao-China, Japan, Switzerland, Belgium, the Netherlands, Germany, Poland, Canada, Finland and New Zealand perform at Level 5 or above in mathematics. By contrast, in 36 countries, $10 \%$ of students or fewer perform at these levels. These include the OECD countries Denmark (10.0\%), Italy (9.9\%), Norway (9.4\%), Israel (9.4\%), Hungary (9.3\%), the United States (8.8\%), Sweden (8.0\%), Spain (8.0\%), Turkey (5.9\%), Greece (3.9\%) and Chile (1.6\%). In Kazakhstan, Albania, Tunisia, Brazil, Mexico, Peru, Costa Rica, Jordan, Colombia, Indonesia and Argentina, fewer than $1 \%$ of students are top performers in mathematics (Figure I.2.22 and Table I.2.1a).

\section{Proficiency at Level 4 (scores higher than 545 but lower than or equal to $\mathbf{6 0 7}$ points)}

At Level 4, students can work effectively with explicit models on complex, concrete situations that may involve constraints or call for making assumptions. They can select and integrate different representations, including symbolic 
representations, linking them directly to aspects of real-world situations. Students at this level can use their limited range of skills and can reason with some insight, in straightforward contexts. They can construct and communicate explanations and arguments based on their interpretations, reasoning and actions.

Question 3 in REVOLVING DOOR (Figure I.2.57) involves rates and proportional reasoning, and it sits within Level 4 on the mathematics proficiency scale. In one minute, the door revolves 4 times bringing $4 \times 3=12$ sectors to the entrance, which enables $12 \times 2=24$ people to enter the building. In 30 minutes, $24 \times 30=720$ people can enter (hence, the correct answer is response option D). The high frequency of PISA items that involve proportional reasoning highlights its centrality to mathematical literacy, especially for students whose mathematics has reached a typical stage for 15-year-olds. Many real contexts involve direct proportion and rates, which as in this case are often used in chains of reasoning. Coordinating such a chain of reasoning requires devising a strategy to bring the information together in a logical sequence.

This item also makes considerable demand on the mathematisation fundamental mathematical capability, especially in the formulating process. A student needs to understand the real situation, perhaps visualising how the doors rotate, presenting one sector at a time, making the only way for people to enter the building. This understanding of the real world problem enables the data given in the problem to be assembled in the right way. The questions in this unit have been placed in the scientific context category, even though they do not explicitly involve scientific or engineering concepts, as do many of the other items in this category. The scientific category includes items explaining why things are as they are in the real world.

On average across OECD countries, 30.8\% of students perform at proficiency Level 4, 5 or 6 . More than three out of four students in Shanghai-China perform at one of these levels (75.6\%), and more than one in two students in Singapore, Hong Kong-China, Chinese Taipei and Korea do. Countries and economies where more than one in three students are proficient at proficiency Level 4, 5 or 6 are Macao-China (48.8\%), Liechtenstein (48.0\%), Japan (47.4\%), Switzerland (45.3\%), the Netherlands (43.1\%), Belgium (40.2\%), Germany (39.1\%), Canada (38.8\%), Finland (38.4\%), Poland (38.1\%), Estonia (38.0\%), Austria (35.3\%), Viet Nam (34.6\%) and Australia (33.8\%). Yet in 17 participating countries and economies, fewer than $10 \%$ of students attain Level 4 or above. In Indonesia, Colombia, Argentina, Jordan, Peru, Tunisia, Costa Rica, Brazil, Mexico and Albania, fewer than 5\% of students attain Level 4 or above (Figure I.2.22 and Table I.2.1a).

\section{Proficiency at Level 3 (scores higher than 482 but lower than or equal to 545 points)}

At Level 3, students can execute clearly described procedures, including those that require sequential decisions. Their interpretations are sufficiently sound to be the basis for building a simple model or for selecting and applying simple problem-solving strategies. Students at this level can interpret and use representations based on different information sources and reason directly from them. They typically show some ability to handle percentages, fractions and decimal numbers, and to work with proportional relationships. Their solutions reflect that they have engaged in basic interpretation and reasoning.

Question 1 in REVOLVING DOOR (Figure I.2.57) requires Level 3 proficiency. This question may appear very simple: finding the angle of 120 degrees between the two door wings, but the student responses indicate it is at Level 3. This is probably because of the demand arising from communication, representation and mathematisation as well as the specific knowledge of circle geometry that is needed. The context of three-dimensional revolving doors has to be understood from the written descriptions. It also needs to be understood that the three diagrams in the initial stimulus provide different two-dimensional information about just one revolving door (not three doors) - first the diameter, then the directions in which people enter and exit from the door, and thirdly connecting the wings mentioned within the text with the lines of the diagrams. The fundamental mathematical capability of representation is required at a high level to interpret these diagrams mathematically. They give the view from above, but students also need to visualise real revolving doors especially in answering Questions 2 and 3.

On average across OECD countries, 54.5\% of students are proficient at Level 3 or higher (that is, at Level 3, 4, 5 or 6). More than three out of four students in Shanghai-China (88.7\%), Singapore (79.5\%), Hong Kong-China (79.5\%) and Korea $(76.2 \%)$ attain Level 3 or above. More than two out of three students are proficient at these levels in Chinese Taipei $(74.0 \%)$, Macao-China (72.8\%), Japan (72.0\%), Liechtenstein (70.7\%), Switzerland (69.8\%), Estonia (67.5\%), the Netherlands $(67.3 \%)$ and Finland (67.2\%). By contrast, in 22 participating countries, fewer than one in three students attains these levels. In Peru, Colombia and Indonesia, fewer than 10\% of students perform at those levels (Figure I.2.22 and Table I.2.1a). 


\section{Proficiency at Level 2 (scores higher than 420 but lower than or equal to 482 points)}

At Level 2, students can interpret and recognise situations in contexts that require no more than direct inference. They can extract relevant information from a single source and make use of a single representational mode. Students at this level can employ basic algorithms, formulae, procedures or conventions to solve problems involving whole numbers. They are capable of making literal interpretations of the results.

Results from longitudinal studies in Australia, Canada, Denmark and Switzerland show that students who perform below Level 2 often face severe disadvantages in their transition into higher education and the labour force in subsequent years. The proportion of students who perform below this baseline proficiency level thus indicates the degree of difficulty countries face in providing their populations with a minimum level of competencies (OECD, 2012).

Question 1 in the unit HELEN THE CYCLIST (Figure I.2.55) is typical of Level 2 tasks. Question 1, a simple multiple choice item, requires comparison of speed when travelling $4 \mathrm{~km}$ in 10 minutes versus $2 \mathrm{~km}$ in 5 minutes. It is been classified within the employing process category because it requires the precise mathematical understanding that speed is a rate and that proportionality is the key. This question can be solved by recognising the doubles involved $(2 \mathrm{~km}-4 \mathrm{~km}$; $5 \mathrm{~km}-10 \mathrm{~km}$ ), which is the very simplest notion of proportion. Consequently, with this Level 2 question, successful students demonstrate a very basic understanding of speed and of proportion calculations. If distance and time are in the same proportion, the speed is the same. Of course, students could correctly solve the problem in more complicated ways (e.g. calculating that both speeds are $24 \mathrm{~km}$ per hour) but this is not necessary. PISA results for this question do not incorporate information about the solution method used. The correct response option here is B (Helen's average speed was the same in the first 10 minutes and in the next 5 minutes).

Level 2 is considered the baseline level of mathematical proficiency that is required to participate fully in modern society. More than $90 \%$ of students in the four top-performing countries and economies in PISA 2012, Shanghai-China, Singapore, Hong Kong-China and Korea, meet this benchmark. Across OECD countries, an average of $77 \%$ of students attains Level 2 or higher: more than one in two students perform at these levels in all OECD countries except Chile (48.5\%) and Mexico $(45.3 \%)$. Only around one in four students in the partner countries Colombia, Peru and Indonesia attains this benchmark (Figure I.2.22 and Table I.2.1a).

\section{Proficiency at Level 1 (scores higher than 358 but lower than or equal to 420 points) or below}

At Level 1 students can answer questions involving familiar contexts where all relevant information is present and the questions are clearly defined. They are able to identify information and carry out routine procedures according to direct instructions in explicit situations. They can perform actions that are almost always obvious and follow immediately from the given stimuli.

Students below Level 1 may be able to perform very direct and straightforward mathematical tasks, such as reading a single value from a well-labelled chart or table where the labels on the chart match the words in the stimulus and question, so that the selection criteria are clear and the relationship between the chart and the aspects of the context depicted are evident, and performing arithmetic calculations with whole numbers by following clear and well-defined instructions.

Question 1 in GARAGE (Figure I.2.60) is a task that corresponds to the top of Level 1 in difficulty, very close to the Level 1/Level 2 boundary on the proficiency scale. It asks students to identify a picture of a building from the back, given the view from the front. The diagrams must be interpreted in relation to the real world positioning of "from the back", so this question is classified in the interpreting process. The correct response is C. Mental rotation tasks such as this are solved by some people using intuitive spatial visualisation. Other people need explicit reasoning processes. They may analyse the relative positions of multiple features (door, window, nearest corner), discounting the multiple choice alternatives one by one. Others might draw a bird's eye view, and then physically rotate it. This is just one example of how different students may use quite different methods to solve PISA questions: in this case explicit reasoning for some students is intuitive for others.

Question 1 in CHARTS (Figure I.2.59), with a difficulty of 347.7, is a task below Level 1 on the mathematical proficiency scale, being one of the easiest tasks in the PISA 2012 item pool. It requires the student to find the bars for April, select the correct bar for the Metafolkies, and read the height of the bar to obtain the required response selection B (500). No scale reading or interpolation is required.

All PISA participating countries and economies show students at Level 1 or below; but the largest proportions of students who attain only these levels are found in the lowest-performing countries. 
Across OECD countries, an average of $23.0 \%$ of students is proficient only at or below Level 1 . In Shanghai-China, Singapore, Hong Kong-China and Korea, fewer than 10\% of students perform at or below Level 1 . Fewer than $15 \%$ do in Estonia, Macao-China, Japan, Finland, Switzerland, Chinese Taipei, Canada, Liechtenstein, Viet Nam, Poland and the Netherlands. By contrast, in 31 participating countries and economies more than one out of four students perform at these levels. In 15 countries the proportion of students who attain only Level 1 or below exceeds $50 \%$ (Figure I.2.22 and Table I.2.1a).

\section{Trends in the percentage of low- and top-performers in mathematics}

Changes in a country's or economy's average performance can result from changes at different levels of the performance distribution. For example, for some countries and economies, average improvement is driven by improvements among low-achieving students, where the share of students scoring below Level 2 is reduced. In other countries and economies, average improvement is driven mostly by changes among high-achieving students, where the share of students who perform at or above Level 5 increases. On average across OECD countries with comparable data, between 2003 and 2012 there was an increase of 0.7 percentage points in the share of students who do not meet the baseline proficiency level in mathematics and a reduction of 1.6 percentage points in the share of students at or above proficiency Level 5 (Figure I.2.23 and Table I.2.1b).

However, these trends vary across countries. Some countries and economies saw a reduction in the proportion of lowperforming students and a concurrent increase in the proportion of top-performing students. These are school systems that have seen improvements in performance both at the bottom and the top ends of the performance distribution. There are other countries where improvements are limited to reducing the share of low-performing students or increasing the share of top-performing students.

Countries and economies can be grouped into categories based on whether they have: simultaneously reduced the share of low performers and increased the share of top performers between previous PISA assessments and PISA 2012; reduced the share of low performers but not increased the share of top performers between any previous PISA assessment and PISA 2012; increased the share of top performers but not reduced the share of low performers; and reduced the share of top performers or increased the share of low performers between PISA 2012 and any previous PISA assessment. The following section groups countries along these categories, first identifying those that have simultaneously reduced the share of low performers and increased the share of top performers between PISA 2003 and PISA 2012, between PISA 2006 and PISA 2012 or between PISA 2009 and PISA 2012. The remaining countries and economies are categorised as those that reduced the share of low performing students, increased the share of top performing students, or that saw an increase in the share of low performers or a reduction in the share of top performers.

\section{Moving everyone up: Reductions in the share of low performers and increases in that of top performers}

Countries and economies that have reduced the proportion of students scoring below Level 2 and increased the proportion of students scoring above Level 5 are ones that have been able to spread the improvements in their education systems across all levels of performance. Between 2003 and 2012 this was observed in Italy, Poland and Portugal. This reduction in the share of low-performers and increase in the share of high-performers was observed in Israel, Romania and Qatar between PISA 2006 and PISA 2012, and in Ireland, Malaysia and the Russian Federation between PISA 2009 and PISA 2012 (Figure I.2.23 and Table I.2.1b).

Poland, for example, reduced the share of students scoring below Level 2 by eight percentage points while increasing the share of high achievers by seven percentage points between 2003 and 2012. A large part of this change is concentrated in the 2009 to 2012 period. In 2003, 2006 and 2009 about 20\% of students were low-performers and around 10\% were top-performers; by 2012 the share of students scoring below Level 2 dropped to $14 \%$ and the share of students scoring at or above Level 5 increased to 17\%. Similarly, Portugal reduced the share of students scoring below Level 2 by five percentage points and increased the share of students scoring at or above Level 5 also by five percentage points during the period, with most of this change taking place between 2006 and 2009. Italy saw an overall reduction of seven percentage points in the share of students performing below Level 2 and an increase of three percentage points in the share of students scoring at or above Level 5, with most of this change taking place between 2006 and 2009 (Figure I.2.23 and Table I.2.1b).

Annex B4 illustrates, for each country and economy, how mathematics performance at the 10th, 25th, 75th and 90th percentiles has evolved since 2003. Like the trends in the share of low- and top-performing students, it shows that average improvement in Poland and Italy, for example, is observed among low-, average and high-achieving students alike. 


\section{Reducing underperformance: Reductions in the share of low performers but no change in that of top performers}

Other countries and economies have concentrated change among those students who did not meet the baseline proficiency level. These countries and economies saw significant improvements in the performance of students who need it most and who now have basic skills and competencies to fully participate in society. Between 2003 and 2012, Brazil, Mexico, Tunisia and Turkey saw a reduction of more than five percentage points in the share of students scoring below proficiency Level 2 in mathematics. Germany also saw significant reductions in the proportion of students at proficiency Level 2, but no change in the proportion of those scoring at or above Level 5. Similarly, Bulgaria and Montenegro, both of which began participating in PISA after 2003, showed significant reductions in the proportion of students scoring at Level 2 between 2006 and 2012, as did Albania, Dubai (United Arab Emirates) and Kazakhstan between 2009 and 2012 (Figure I.2.23 and Table I.2.1b). Annex B4 shows the performance trajectories of these countries and economies, highlighting how the performance of their lowest achievers (those in the 10th percentile of performance) improved more than that of the highest-achieving students (those in the 90th percentile). By lifting the performance of their lowest-achieving students, these countries and economies have narrowed the gap between high- and low-achieving students and, in some cases, increased equity as well, as many low-achieving students are also from disadvantaged backgrounds (see Volume II, Chapter 2).

- Figure 1.2.23 =

Percentage of low-performing students and top performers in mathematics in 2003 and 2012

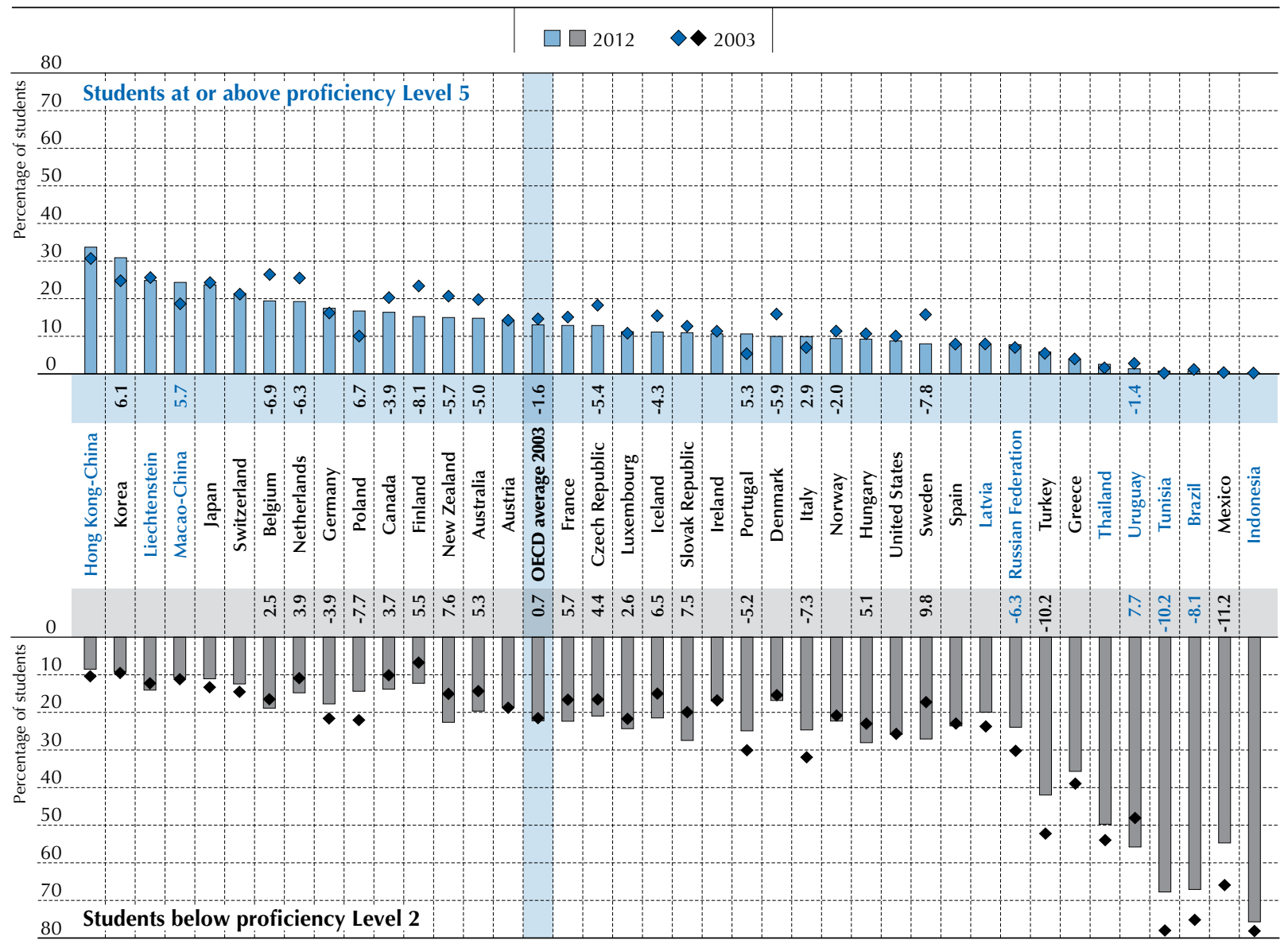

Notes: The chart shows only countries/economies that participated in both PISA 2003 and PISA 2012 assessments.

The change between PISA 2003 and PISA 2012 in the share of students performing below Level 2 in mathematics is shown below the country/economy name. The change between PISA 2003 and PISA 2012 in the share of students performing at or above Level 5 in mathematics is shown above the country/economy name. Only statistically significant changes are shown (see Annex A3).

OECD average 2003 compares only OECD countries with comparable mathematics scores since 2003.

Countries and economies are ranked in descending order of the percentage of students at or above proficiency Level 5 in mathematics in 2012.

Source: OECD, PISA 2012 Database, Table I.2.1b.

StatLink त्राजा http://dx.doi.org/10.1787/888932935572 


\section{Nurturing top performance: Increase in the share of top performers but no change in that of low performers}

Some countries and economies increased the proportion of students performing at or above Level 5. These are students who can handle complex mathematical content and processes. Higher proportions of these students signal a school system's capacity to promote student performance at the highest level. Between 2003 and 2012, Korea and Macao-China saw around a six percentage-point increase in the share of students performing at this level. Other increases in the proportion of students scoring at or above Level 5 were observed in Chinese Taipei, Hong Kong-China, Japan, Serbia and Thailand (between 2006 and 2012) and in Estonia, Latvia, Shanghai-China and Singapore (between 2009 and 2012) (Figure I.2.23 and Table I.2.1b). As shown in Annex B4, the trajectories of these countries' and economies' low- and high-achieving students point to greater increases among the high achievers than among the low achievers. When comparing Korea's mathematics scores in 2012 with those of 2003, for example, students in the 90th percentile improved by 20 scores points, and those at the 75th percentile improved by 18 points; however, there was no change in mathematics performance among those students in the 10th and 25th percentiles. That is, if those students at the bottom of the distribution performed at similar levels in 2003 and 2012, those at the top attained higher levels in 2012 than they did in 2003.

\section{Increase in the share of low performers or decrease in that of top performers}

There are 17 countries and economies, however, where the proportion of students who do not reach the baseline proficiency level increased or the proportion of students who reach the highest levels of proficiency decreased between a previous PISA assessment and PISA 2012. In these countries and economies there were fewer students performing at the top levels and more students who did not show the baseline level of mathematical literacy in 2012 than there were in a previous assessment (Figure I.2.23 and Table I.2.1b).

\section{Variation in student performance in mathematics}

The standard deviation in PISA scores, the difference between the top and bottom 5\% of sampled students and the difference between the top and bottom $10 \%$, or between the top and bottom quarters are all measures of the extent to which student performance varies among 15-year-olds. In fact, each of these measures gives more or less the same picture. Table I.2.3a shows the mean, standard deviation and percentiles of PISA mathematics scores for all participating countries and economies.

As shown in Figure 1.2.24, the ten PISA participants with the widest spread in scores (score-point difference between the top and bottom $10 \%$ of students) are Israel, Belgium, the Slovak Republic, New Zealand, France and Korea as well as the partner countries and economies Chinese Taipei, Singapore, Shanghai-China and Qatar. This group includes four of the highest-performing countries and economies (Chinese Taipei, Singapore, Shanghai-China and Korea), one of the lowest performers (Qatar) as well as two OECD countries that perform close to the OECD average (France, which is at the OECD average, and New Zealand, which is just above the OECD average) (Table I.2.3a).

The ten participating countries/economies with the narrowest spread are Mexico and the partner countries Costa Rica, Indonesia, Kazakhstan, Colombia, Jordan, Argentina, Tunisia, Brazil and Thailand. All of these countries are among the 20 lowest-performing countries; seven of them are among the 10 lowest-performing countries. Less variation in performance is observed among the very lowest-performing countries, largely because there are fewer scores at the highest proficiency levels and, as a result, scores tend to be concentrated at the lower proficiency levels (Figure I.2.24 and Table I.2.3a).

It is noteworthy that the relationship between average performance and the spread in student scores is weak, suggesting that high mean performance does not inevitably lead to large disparities in student performance. It is possible to combine a relatively narrow spread of scores and a relatively high average score, as does, for example, Estonia.

\section{Gender differences in mathematics performance}

Figure I.2.25 presents a summary of boys' and girls' performance in the PISA mathematics assessment (Table I.2.3a). On average across OECD countries, boys outperform girls in mathematics by 11 score points. Despite the stereotype that boys are better than girls at mathematics, boys show an advantage in only 38 out of the 65 countries and economies that participated in PISA 2012, and in only six countries is the gender gap larger than the equivalent of half a school year.

As shown in Figure 1.2.25, the largest difference in scores between boys and girls - in favour of boys - is seen in the partner country Colombia, and the OECD countries Luxembourg and Chile, a difference of around 25 points. In the partner countries Costa Rica, Liechtenstein and the OECD country Austria, this difference is between 22 and 24 points. 
- Figure I.2.24

Relationship between performance in mathematics and variation in performance

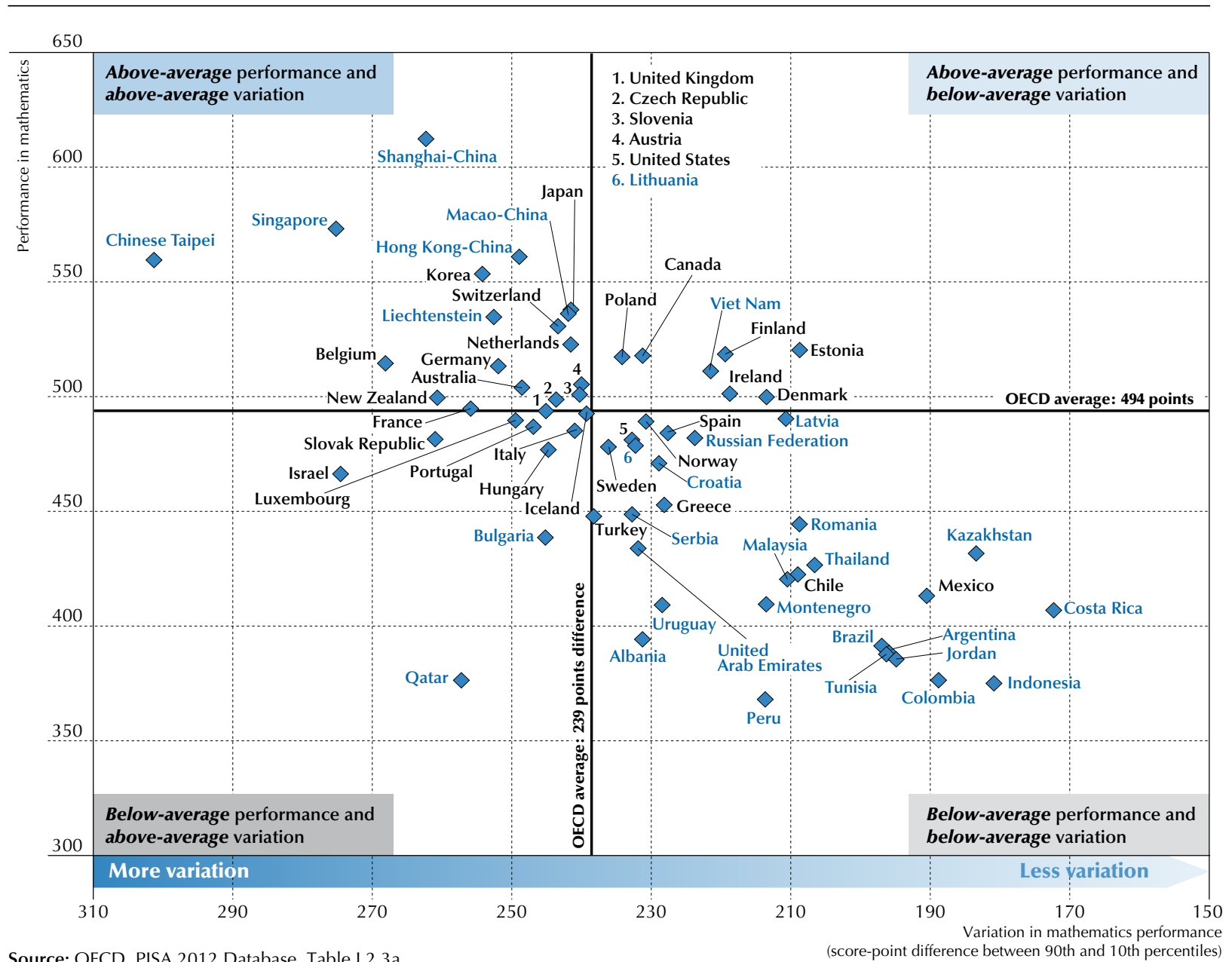

Source: OECD, PISA 2012 Database, Table 12.3a.

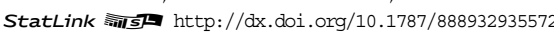

In Korea, Japan and the partner economy Hong Kong-China, all of which are among the 10 top-performing countries, as well as in Italy, Spain, Ireland and New Zealand, and in the partner countries Peru, Brazil and Tunisia, this difference is between 15 and 20 points. In Luxembourg, a larger proportion of boys than girls attains the three highest proficiency levels, and far fewer boys than girls are found in the three lowest proficiency levels, leading to a marked overall gender difference in favour of boys (Tables I.2.2a and I.2.3a).

In contrast, in only five countries do girls outperform boys in mathematics. The largest difference is seen in the partner country Jordan, where girls score around 21 points higher than boys. Girls also outperform boys in the partner countries Qatar, Thailand, Malaysia and in the OECD country Iceland (Figure I.2.25 and Table I.2.3a). In all of these countries more boys score at or below Level 1 than girls. The difference is particularly large in the partner country Jordan, where around $43 \%$ of boys score at or below Level 1, compared to around $30 \%$ of girls. In Iceland, while girls and boys are well-represented at all proficiency levels, far more boys than girls score below proficiency Level 1 (Table I.2.2a).

Figure I.2.26 shows the average proportions of boys and girls in OECD countries within each of the defined mathematics proficiency levels. Larger proportions of boys than girls score at Level 5 or 6 (top performers) and at Level 4 . Conversely, the proportion of girls is larger than the proportion of boys at all other proficiency levels, from Level 3.

In almost all participating countries and economies, a larger proportion of boys than girls are top performers in mathematics (Level 5 or 6). In high-performing countries and economies, where a relatively large share of students performs at these levels, the difference in the proportion of boys and girls scoring at these levels is generally larger. 
- Figure I.2.25

\section{Gender differences in mathematics performance}

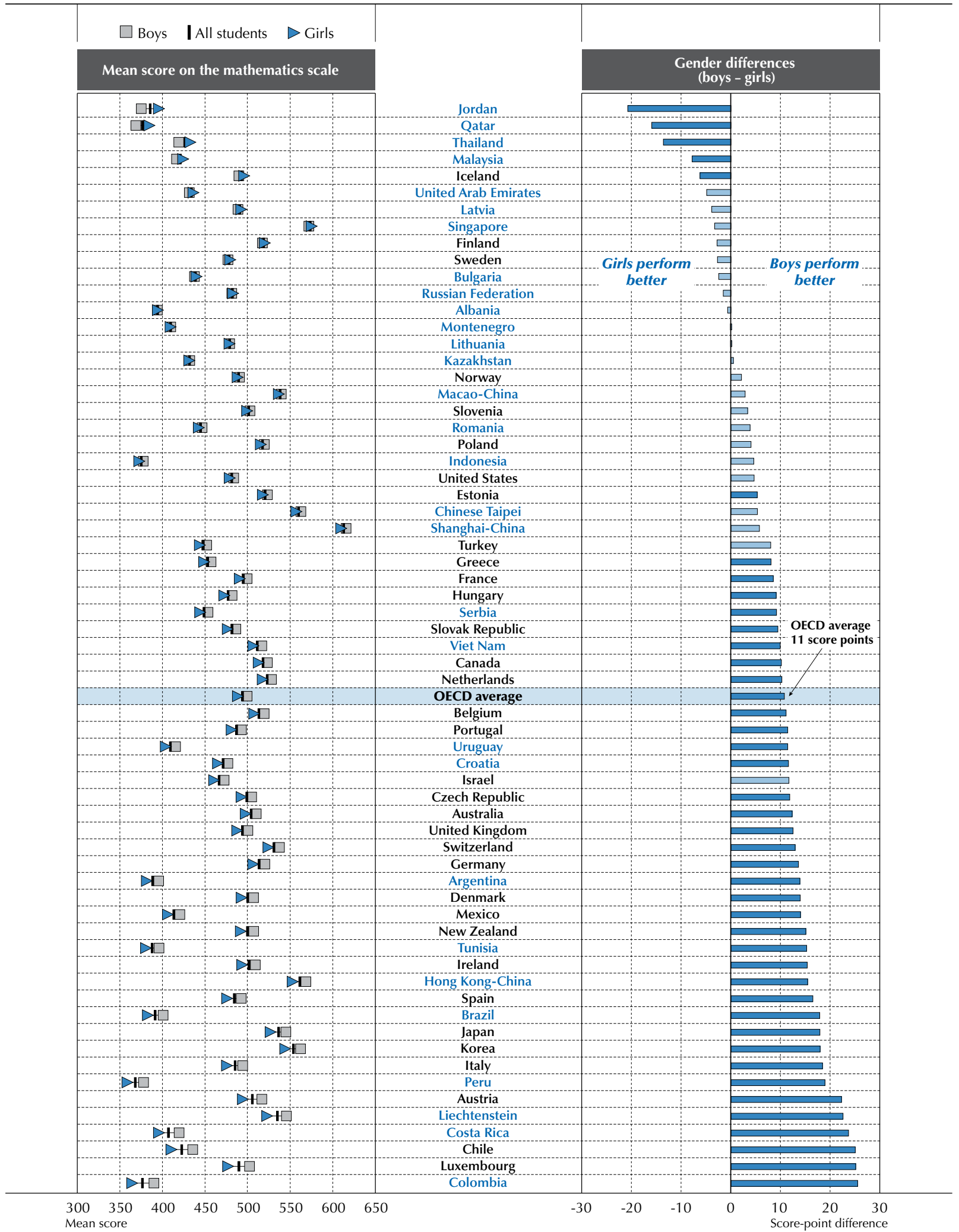

Note: Statistically significant gender differences are marked in a darker tone (see Annex A3)

Countries and economies are ranked in ascending order of the gender score-point difference (boys - girls).

Source: OECD, PISA 2012 Database, Table I.2.3a.

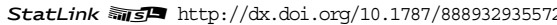


- Figure I.2.26 -

Proficiency in mathematics among boys and girls

OECD average percentages of boys and girls at each level of mathematics proficiency

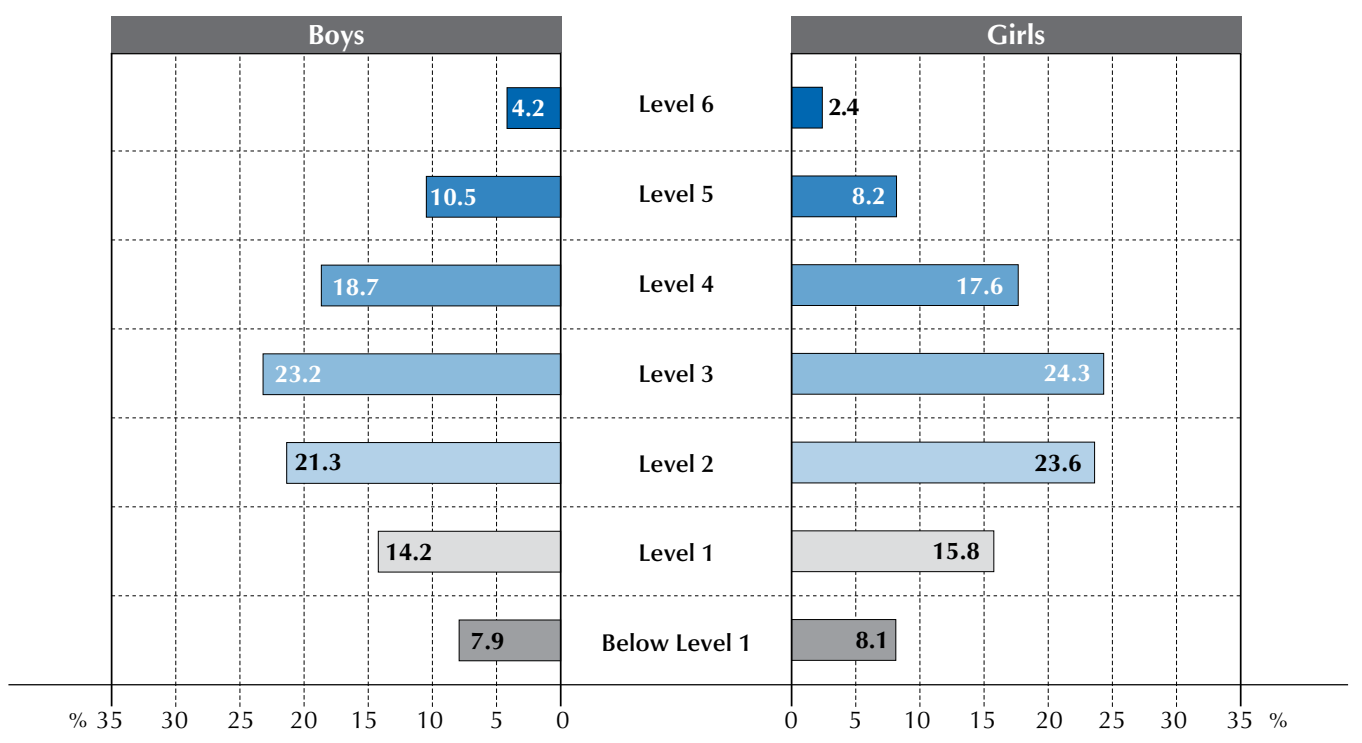

Source: OECD, PISA 2012 Database, Table 1.2.2a.

StatLink 新

For example, in the high-performing OECD countries Korea and Japan, and the partner economy Hong Kong-China, the share of boys who are top performers is around 9 percentage points larger than that of girls. In Israel, Austria, Italy, New Zealand and Luxembourg, which are situated in the middle of the performance distribution, the share of boys who attain at the highest proficiency levels is considerably larger than the share of girls who do, by a difference of 7.7 to 5.8 percentage points. This difference is also larger than 5 percentage points in Belgium, Chinese Taipei, the Slovak Republic, Spain, Canada, Liechtenstein, Switzerland and Germany (Table I.2.2a).

While the proportion of girls is larger than the share of boys at the lower proficiency levels, there is considerable variation among countries and economies. In around a third of participating countries and economies, a higher proportion of boys than girls do not achieve the baseline level of proficiency. In Finland, Iceland and the partner countries Thailand, Jordan, Malaysia, the United Arab Emirates, Lithuania, Latvia and Singapore, a larger proportion of boys than girls perform below Level 2, the baseline proficiency level, and some of these countries, like Finland and the partner country Singapore, belong to the 15 top-performing countries and economies. Yet in many of the 15 lowest-performing countries and economies, including the OECD countries Chile and Mexico and the partner countries Costa Rica, Colombia, Brazil, Tunisia, Argentina and Peru, more girls than boys do not attain that level of proficiency. But in Luxembourg, which scores around the OECD average, and Liechtenstein, which scores well above the OECD average, the share of girls who score at or below Level 1 is considerably larger than that of boys by a difference of 8.6 and 6.1 percentage points, respectively (Table I.2.2a).

\section{Trends in gender differences in mathematics performance}

Among the countries and economies that showed a gender gap in mathematics performance in favour of boys in 2003, by 2012 the gender gap narrowed by nine score points or more in Finland, Greece, Macao-China, the Russian Federation and Sweden. Thus, in Greece, while boys outperformed girls in mathematics by 19 points in 2003 , by 2012 this difference had shrunk to eight score points. In Finland, Macao-China, the Russian Federation, Sweden, Turkey and the United States, there was no longer a gender gap in mathematics performance favouring boys in 2012 compared to 2003. In Austria, Luxembourg and Spain, the gender gap favouring boys widened between 2003 and 2012. For example, in Austria in 2003, there was no observed gender gap in mathematics performance; but by 2012 there was a 22 score-point difference in performance in favour of boys. Iceland was one of the few countries where 
girls outperformed boys in mathematics in 2003; in 2012, girls still outperformed boys, but the gender gap had narrowed (Figure I.2.27 and Table I.2.3c).

Countries seeking to reduce girls' disadvantage in mathematics could examine the experiences of Korea, Latvia, Macao-China, the Russian Federation and Thailand. In Macao-China and the Russian Federation, for example, girls' mathematics performance improved by around 20 score points while boys' performance did not change, resulting in a narrowing of the gender gap in mathematics performance to the extent that the gender gap observed in 2003 lost statistical significance by 2012. In Thailand, boys' performance did not change between PISA 2003 and PISA 2012, but girls' performance improved by 14 score points.

- Figure I.2.27 -

\section{Change between 2003 and 2012 in gender differences in mathematics performance}

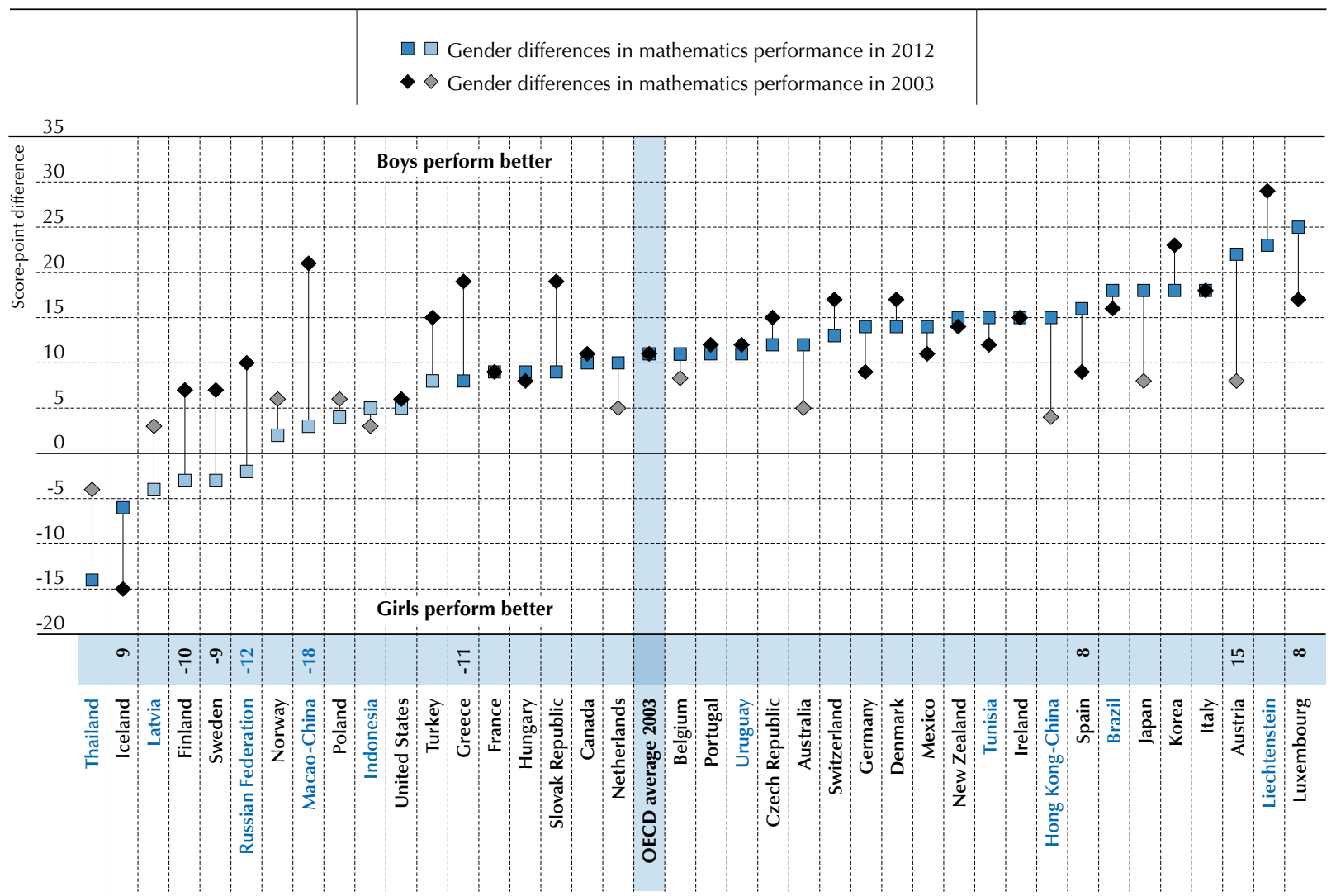

Notes: Gender differences in PISA 2003 and PISA 2012 that are statistically significant are marked in a darker tone (see Annex A3).

Statistically significant changes in the score-point difference between boys and girls in mathematics performance between PISA 2003 and PISA 2012 are shown next to the country/economy name.

OECD average 2003 compares only OECD countries with comparable mathematics scores since 2003.

Countries and economies are ranked in ascending order of gender differences (boys-girls) in 2012.

Source: OECD, PISA 2012 Database, Table I.2.3c.

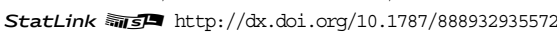

These trends are also reflected in the changes in the proportion of boys and girls who can be considered top performers in PISA (those who score at or above proficiency Level 5) or who are considered low performers in PISA (because they score below proficiency Level 2). Consistent with the fact that the gender gap in mathematics has narrowed or now favours girls in certain countries and economies, in Latvia, Portugal, the Russian Federation and Thailand the share of girls who perform below proficiency Level 2 shrunk between 2003 and 2012 with no concurrent change in the share of low-performing boys. In Macao-China and the Russian Federation during the period, the share of top-performing girls increased with no such increase among boys. In addition, Italy, Poland, Portugal and the Russian Federation show a reduction in the share of girls who perform below Level 2 and an increase in the share of girls who perform at Level 5 or 6 (Table I.2.2b). 


\section{Box I.2.4. Improving in PISA: Brazil}

With an economy that traditionally relied on the extraction of natural resources and suffered stagnating growth and spells of hyperinflation until the early 1990s, Brazil is today rapidly expanding its industrial and service sector. Its population of more than 190 million, which is spread across 27 states in geographic areas as vast and diverse as Rio de Janeiro and the Amazon River basin, recognises the critical role education plays in the country's economic development.

Like only a handful of other countries, Brazil's performance in mathematics, reading and science has improved notably over the past decade. Its mean score in the PISA mathematics assessment has improved by an average of 4.1 point per year - from 356 points in 2003 to 391 points in 2012. Since 2000, reading scores have improved by an average of 1.2 score points per year; and, since 2006, science scores have risen by an average of 2.3 score points per year. Lowest-achieving students (defined as the $10 \%$ of students who score the lowest) have improved their performance by 65 score points - the equivalent of more than a year and a half of schooling. Despite these considerable improvements, around two out of three Brazilian students still perform below Level 2 in mathematics (in 2003, three in four students did).

Not only have most Brazilian students remarkably improved their performance, Brazil has expanded enrolment in primary and secondary schools. While in $1995,90 \%$ of students were enrolled in primary schools at age seven, only half of them continued to finish eighth grade. In 2003, 35\% of 15-year-olds were not enrolled in school in grade 7 or above; by 2012 this percentage had shrunk to $22 \%$. Enrolment rates for 15 -year-olds thus increased, from $65 \%$ in 2003 to $78 \%$ in 2012 . Many of the students who are now included in the school system come from rural communities or socio-economically disadvantaged families, so the population of students who participated in the PISA 2012 assessment is very different from that of 2003.

PISA compares the performance of 15-year-old students who are enrolled in schools; but for those countries where this population has changed dramatically in a short period of time, trend data for students with similar background characteristics provide another way of examining how students' performance is changing beyond changes in enrolment. Figure I.2.c compares the performance of students with similar socio-economic status across all years. The score attained by a socio-economically advantaged/average/disadvantaged student increased by $21 / 25 / 27$ points, respectively, between 2003 and 2012 .

The figure also simulates alternate scenarios, assuming that the students who are now enrolled in schools - but probably weren't in 2003 - score in the bottom half of the performance distribution, the bottom quarter of the performance distribution, or the bottom of the distribution and also come from the bottom half, bottom quarter, and bottom of the socio-economic distribution. Given that they assume that the newly enrolled students have lower scores than students who would have been enrolled in 2003, these simulations indicate the upper bounds of Brazil's improvement in performance.

For example, under the assumption that the newly enrolled students perform in the bottom quarter of mathematics performance, Brazil's improvement in mathematics, had enrolment rates retained their 2003 levels, would have been 56 score points. Similarly, if the assumption is that newly enrolled students come from the bottom quarter of the socio-economic distribution, Brazil's improvement in mathematics between 2003 and 2012 would have been 44 score points had enrolment rates not increased since 2003. Still, it is the observed enrolment rates and the observed performance in 2003 and 2012 that truly reflect the student population, its performance and the education challenges facing Brazil.

Brazil's increases in coverage are remarkable. However, although practically all students aged 7-14 start school at the beginning of the year, few continue until the end. They leave because the curriculum isn't engaging, or because they want or need to work, or because of the prevalence of grade repetition. The pervasiveness of grade repetition in Brazil has been linked to high dropout rates, high levels of student disengagement, and the more than 12 years it takes students, on average, to complete eight grades of primary school. (PISA results suggest that repetition rates remain high in Brazil: in 2003, 33\% of students reported having repeated at least one grade in primary or secondary education; in 2012, 36\% of students reported so.) 
Figure I.2.C

Observed and expected trends in mathematics performance for Brazil (2003-12)

\begin{tabular}{|c|c|c|c|c|c|c|}
\hline & \multicolumn{2}{|c|}{2003} & \multicolumn{2}{|c|}{2012} & \multicolumn{2}{|c|}{$\begin{array}{c}\text { Change between } \\
2003 \text { and } 2012 \\
(2012-2003)\end{array}$} \\
\hline Total number of 15 -year-olds & \multicolumn{2}{|c|}{3618332} & \multicolumn{2}{|c|}{3574928} & \multicolumn{2}{|c|}{-43404} \\
\hline Total 15-year-olds enrolled in grades 7 or higher & \multicolumn{2}{|c|}{2359854} & \multicolumn{2}{|c|}{2786064} & \multicolumn{2}{|c|}{+426210} \\
\hline \multirow[t]{2}{*}{ Enrolment rates for 15 -year-old students } & \multicolumn{2}{|c|}{$65 \%$} & \multicolumn{2}{|c|}{$78 \%$} & \multicolumn{2}{|c|}{$+19 \%$} \\
\hline & Mean & S.E. & Mean & S.E. & Mean & S.E. \\
\hline Mathematics performance & 356 & $(4.8)$ & 391 & $(2.1)$ & +35.4 & (5.6) \\
\hline
\end{tabular}

Comparing the performance students with similar socio-economic backgrounds:

\begin{tabular}{|l|l|l|l|l|l|l|}
\hline Advantaged student in $\mathbf{2 0 0 3}$ & 383 & $(5.2)$ & 404 & $(2.3)$ & +20.5 & $(6.0)$ \\
\hline Average student in $\mathbf{2 0 0 3}$ & 357 & $(4.0)$ & 382 & $(1.6)$ & +24.9 & $(4.7)$ \\
Disadvantaged student in 2003 & 342 & $(3.9)$ & 369 & $(1.7)$ & +27.3 & $(4.7)$ \\
\hline
\end{tabular}

Average performance excluding newly enrolled students assuming that newly enrolled students are at:

\begin{tabular}{|l|l|l|l|l|l|l|}
\hline Bottom half of performance & 356 & $(4.8)$ & 406 & $(2.2)$ & +49.7 & $(5.6)$ \\
Bottom quarter of performance & 356 & $(4.8)$ & 412 & $(2.0)$ & +56.4 & $(5.6)$ \\
\hline Bottom of the distribution & 356 & $(4.8)$ & 415 & $(1.8)$ & +58.6 & $(5.5)$ \\
\hline
\end{tabular}

Average performance excluding newly enrolled students assuming that newly enrolled students come from:

\begin{tabular}{|l|l|l|l|l|l|l|}
\hline Bottom half of ESCS & 356 & $(4.8)$ & 397 & $(2.2)$ & +40.5 & $(5.7)$ \\
Bottom quarter of ESCS & 356 & $(4.8)$ & 399 & $(2.3)$ & +43.5 & $(5.7)$ \\
Bottom of ESCS & 356 & $(4.8)$ & 400 & $(2.3)$ & +44.1 & $(5.7)$ \\
\hline
\end{tabular}

Notes: Enrolment rates are those reported as the coverage index 3 in Annex A3 in Learning for Tomorrow's World: First Results from PISA 2003 (OECD, 2004) and in Annex A2 of this volume. An advantaged/disadvantaged student is one who has a PISA index of economic, social and cultural status (ESCS) that places him/her at the top/lower end of the fourth/first quartile of ESCS in 2003. Average students are those with an ESCS equal to the average in 2003. Average performance in PISA 2012 that excludes newly enrolled students assuming that they come from the bottom half/quarter of performance and ESCS is calculated by randomly deleting $19 \%$ of the sample only among students scoring bottom half/quarter in the performance and ESCS distribution, respectively. Average performance in PISA 2012 that excludes the bottom of the performance or ESCS distribution excludes the bottom 19\% of the sample in the performance and ESCS distribution, respectively.

Despite the fact that primary and secondary education is managed and largely funded at the municipal and state levels, the central government has been a key actor in driving and shaping education reform. Over the past 15 years it has actively promoted reforms to increase funding, improve teacher quality, set national curriculum standards, improve high school completion rates, develop and put in place accountability measures, and set student achievement and learning targets for schools, municipalities and states.

After Brazil's economy stabilised, in the mid-1990s, the Cardoso administration increased federal spending on primary education through FUNDEF (Fundo de Manutenção e Desenvolvimento do Ensino Fundamental) and simultaneously distributed the funding more equitably, replacing a population-density formula that allocated the majority of funds to large cities and linking part of the funding to school enrolments. This was only possible after developing a student and school census to gather and consolidate information about schools and students. FUNDEF also raised teachers' salaries, increased the number of teachers, increased the length of teacher-preparation programmes, and contributed to higher enrolments in rural areas. A conditional cash-transfer programme for families who send their 7-14 year-old children to school (Bolsa Escola) lifted many families out of subsistence-level poverty encouraging their interest that their children receive an education.

In 2006, the Lula administration expanded FUNDEF to cover early childhood and after-school learning and increased overall funding for education, renaming the programme FUNDEB, as it now covered basic education more broadly. The administration also expanded the conditional cash transfers to cover students aged 15-17, thereby encouraging enrolment in upper secondary education, where enrolment is lowest. This expansion means that $6.1 \%$ of Brazil's GDP is now spent on education and the country aims to devote $10 \%$ of its GDP to education by 2020 . Funding for this important increase in education expenditure will come from the recently approved allocation of $75 \%$ of public revenues from oil to education.

Improving the quality of teachers has also been at the centre of Brazil's reform initiatives. A core element of FUNDEF was increasing teacher salaries, which rose $13 \%$ on average after FUNDEF, and more than $60 \%$ in the poorer, northeast region of the country. At the same time, the 1996 Law of Directive and Bases of National Education (LDB) 
mandated that, by 2006, all new teachers have a university qualification, and that initial and in-service teacher training programmes be free of charge. These regulations came at a time when coverage was expanding significantly, leading to an increase in the number of teachers in the system. In 2000, for example, there were 430467 secondary school teachers, and 88\% of whom had a tertiary degree; in 2012 there were 497797 teachers, 95\% of whom had tertiary qualifications (INEP, 2000 and 2012). Subsequent reforms in the late 2000s sought to create standards for teachers' career paths based on qualifications, not solely on tenure. The planned implementation of a new examination system for teacher certification, covering both content and pedagogy, has been delayed. Although universities are free to determine their curriculum for teacher-training programmes, the establishment of an examination system to certify teachers sends a strong signal of what content and pedagogical orientation should be developed.

To encourage more students to enrol - and stay - in school, upper secondary education has become mandatory (this policy is being phased in so that enrolment will be obligatory for students aged 4 to 17 by 2016), and a new grade level has been added at the start of primary school. Giving students more opportunities to learn in school has also meant shifting to a full school day, as underscored in the 2011-2020 National Plan for Education. Most school days are just four hours long; and even though FUNDEB provided incentives for full-day schools, they were not sufficient to prompt the investments in infrastructure required for schools that accommodate two or three shifts in a day to become full-day schools. Although enrolment in full-day schools increased $24 \%$ between 2010 and 2012, overall coverage in full-day schools remains low: only 2 million out of a total of almost 30 million students attended such schools in 2012 (INEP, 2013).

The reforms of the mid-1990s included provisions to improve the education information system and increase school accountability. It transformed the National Institute for Educational Studies and Research into an independent organisation responsible for the national assessment and evaluation of education. It turned a national assessment system into the Evaluation System for Basic Education (SAEB/Prova Brazil) for grades 4, 8 and 11 and the National Secondary Education Examination in Grade 11, which provides qualifications for further studies or entry into the labour market. SAEB changed over time to become a national census-based assessment for students in grades 4 and 8 and its results were combined with repetition and dropout rates in 2005 to create an index of schools quality, the Basic Education Development Index (IDEB). This gave schools, municipalities and states an incentive to reduce retention and dropout rates and a benchmark against which to which monitor their progress. The IDEB is set individually for each school and is scaled so that its levels are aligned with those of PISA. Results are widely published, and schools that show significant progress are granted more autonomy while schools that remain low performers are given additional assistance. Support for schools is also offered through the Fundescola programme. IDEB provides targets for each school; it is up to the schools, municipalities and states to develop strategic improvement plans. In line with Brazil's progress in PISA, national performance as measured by the SAEB has also improved between 1999 and 2009 (Bruns, Evans and Luque, 2011).

Perhaps a result of these reforms, not only are more Brazilian students attending school and performing at higher levels, they are also attending better-staffed schools (the index of teacher shortage dropped from 0.47 in 2003 to 0.19 in 2012, and the number of students per teacher in a school fell from 34 to 28 in the same period), and schools with better material resources (the index of quality of educational resources increased from -1.17 to -0.54). They are also attending schools with better learning environments, as shown by improved disciplinary climates and student-teacher relations. Students in 2012 also reported spending one-and-a-half hours less per week on homework than their counterparts in 2003 did.

\section{Sources:}

Bruns, B., D. Evans and J. Luque (2011), Achieving World-Class Education in Brazil, The World Bank, Washington, D.C.

INEP (Instituto Nacional de Estudos e Pesquisas Educacionais Anísio Teixeira) (2000), Sinopse Estatística da Educação Básica 2000, INEP, Brasilia.

INEP (Instituto Nacional de Estudos e Pesquisas Educacionais Anísio Teixeira) (2012), Sinopse Estatística da Educaçao Básica 2012, INEP, Brasilia.

INEP (Instituto Nacional de Estudos e Pesquisas Educacionais Anísio Teixeira) (2013), Censo da Educação Básica: 2012, Resumo Técnico, INEP, Brasilia.

OECD (2010b), Lessons from PISA for the United States, Strong Performers, Successful Reformers in Education, OECD Publishing. http://dx.doi.org/10.1787/9789264096660-en

OECD (2011), OECD EConomic Surveys: Brazil, OECD Publishing.

http://dx.doi.org/10.1787/eco_surveys-bra-2011-en 


\section{STUDENT PERFORMANCE IN DIFFERENT AREAS OF MATHEMATICS}

This section focuses on student performance on the process subscales of formulating, employing and interpreting; and on the content subscales of change and relationships, space and shape, quantity and uncertainty and data.

In general, the correlation between scores on the subscales and overall mathematics scores is high: students tend to perform as well on the mathematics subscales as they do in mathematics overall. However, there is some variation at the country level in the relationship between subscale performance and overall mathematics performance, which perhaps reflects differences in emphasis in the curriculum.

\section{Process subscales}

The three process categories in the mathematics framework relate to three parts of the mathematical modelling cycle, a key feature of the way PISA assesses mathematics.

As discussed earlier in this chapter, each item in the PISA 2012 mathematics survey was assigned to one of the process categories, even if solving an item often involves more than one of these processes. About a quarter of the items was designed primarily to elicit indicators of the formulating situations mathematically process; about half of them required mainly the employing mathematical concepts, facts, procedures, and reasoning process; and the remaining quarter emphasised the interpreting, applying and evaluating mathematical outcomes process.

\section{Student performance on the mathematics subscale formulating situations mathematically}

In order for individuals to use their mathematical knowledge and skills to solve a problem, they often first need to translate the problem into a form that is amenable to mathematical treatment. The framework refers to this process as one of formulating situations mathematically.

In the PISA assessment, students may need to recognise or introduce simplifying assumptions that would help make the given mathematics item amenable to analysis. They have to identify which aspects of the problem are relevant to the solution and which might safely be ignored. They must recognise words, images, relationships or other features of the problem that can be given a mathematical form; and they need to express the relevant information in an appropriate way, for example in the form of a numeric calculation or as an algebraic expression. This process is sometimes referred to as translating the problem as expressed, usually in real-world terms, into a mathematical problem. For example, in a problem about some form of motion (such as travel on public transport, or riding a bicycle), the student may need to recognise a reference to "speed" and understand that this is referring to the relationship between the distance travelled over a given time period, and perhaps invoke the formula speed = distance/time as an essential step in giving the problem a clearly mathematical form.

Items listed in Figure I.2.9 that have been classified in this category are REVOLVING DOOR Question 2 and Question 3, and CLIMBING MOUNT FUJI Question 1 and Question 2.

Across OECD countries, the average score attained on the formulating subscale is 492 points. A substantially lower score on the formulating subscale compared to average scores in the other processes or in mathematics overall might indicate that some students might find the formulating process more difficult. This would be expected when students have less experience with this process, for example, when most students in school work on mathematics problems that have already been "translated" into mathematical form. Top-performing countries and economies on this subscale are Shanghai-China, Singapore, Chinese Taipei, Hong Kong-China, Korea, Japan, Macao-China, Switzerland, Liechtenstein and the Netherlands (Figure I.2.28 and Table I.2.7).

While across OECD countries, the average formulating score (492) is slightly lower than the average overall score for mathematics (494), this is not the case in the ten highest-performing countries on the overall mathematics scale. For nine of those countries and economies, the average national score on the formulating subscale is higher than the average overall score in mathematics. This is the case in Shanghai-China, Singapore, Hong Kong-China, Korea, Macao-China, Switzerland and the Netherlands, where the mean score in formulating is between 4 and 12 points higher than the overall mathematics average, and is particularly evident in Chinese Taipei and Japan, where it is 19 and 18 points higher, respectively, than the overall mathematics average. This implies that in these countries, students find the formulation process to be a relatively easy aspect of mathematics. The only exception among this highest-performing group is Liechtenstein, where the mean formulating score is similar to the country's mean overall mathematics score (Figure I.2.37). 
- Figure I.2.28

\section{Comparing countries' and economies' performance on the mathematics subscale formulating}

\begin{tabular}{|c|c|c|}
\hline \multirow[b]{2}{*}{$\begin{array}{l}\text { Mean } \\
\text { score }\end{array}$} & \multirow[b]{2}{*}{$\begin{array}{l}\text { Comparison } \\
\text { country/economy }\end{array}$} & $\begin{array}{l}\text { Statistically significantly above the OECD average } \\
\text { Not statistically significantly different from the OECD average } \\
\text { Statistically significantly below the OECD average }\end{array}$ \\
\hline & & Countries/economies whose mean score is NOT statistically significantly different from that comparison country's/economy's score \\
\hline 624 & Shanghai-China & \\
\hline 582 & Singapore & Chinese Taipei \\
\hline 578 & Chinese Taipei & Singapore, Hong Kong-China \\
\hline 568 & Hong Kong-China & Chinese Taipei, Korea \\
\hline 562 & Korea & Hong Kong-China, Japan \\
\hline 554 & Japan & Korea \\
\hline 545 & Macao-China & Switzerland \\
\hline 538 & Switzerland & Macao-China, Liechtenstein \\
\hline 535 & Liechtenstein & Switzerland, Netherlands \\
\hline 527 & Netherlands & Liechtenstein, Finland \\
\hline 519 & Finland & Netherlands, Estonia, Canada, Poland, Belgium \\
\hline 517 & Estonia & Finland, Canada, Poland, Belgium, Germany \\
\hline 516 & Canada & Finland, Estonia, Poland, Belgium, Germany \\
\hline 516 & Poland & Finland, Estonia, Canada, Belgium, Germany \\
\hline 512 & Belgium & Finland, Estonia, Canada, Poland, Germany \\
\hline 511 & Germany & Estonia, Canada, Poland, Belgium, Denmark \\
\hline 502 & Denmark & Germany, Iceland, Austria, Australia, Viet Nam, New Zealand, Czech Republic \\
\hline 500 & Iceland & Denmark, Austria, Australia, Viet Nam, New Zealand, Czech Republic \\
\hline 499 & Austria & Denmark, Iceland, Australia, Viet Nam, New Zealand, Czech Republic, Ireland \\
\hline 498 & Australia & Denmark, Iceland, Austria, Viet Nam, New Zealand, Czech Republic, Ireland \\
\hline 497 & Viet Nam & Denmark, Iceland, Austria, Australia, New Zealand, Czech Republic, Ireland, Slovenia, Norway, United Kingdom, Latvia \\
\hline 496 & New Zealand & Denmark, Iceland, Austria, Australia, Viet Nam, Czech Republic, Ireland, Slovenia, Norway, United Kingdom \\
\hline 495 & Czech Republic & Denmark, Iceland, Austria, Australia, Viet Nam, New Zealand, Ireland, Slovenia, Norway, United Kingdom, Latvia \\
\hline 492 & Ireland & Austria, Australia, Viet Nam, New Zealand, Czech Republic, Slovenia, Norway, United Kingdom, Latvia \\
\hline 492 & Slovenia & Viet Nam, New Zealand, Czech Republic, Ireland, Norway, United Kingdom, Latvia \\
\hline 489 & Norway & Viet Nam, New Zealand, Czech Republic, Ireland, Slovenia, United Kingdom, Latvia, France, Russian Federation, Slovak Republic \\
\hline 489 & United Kingdom & Viet Nam, New Zealand, Czech Republic, Ireland, Slovenia, Norway, Latvia, France, Luxembourg, Russian Federation, Slovak Republic, Portugal \\
\hline 488 & Latvia & Viet Nam, Czech Republic, Ireland, Slovenia, Norway, United Kingdom, France, Luxembourg, Russian Federation, Slovak Republic, Portugal \\
\hline 483 & France & Norway, United Kingdom, Latvia, Luxembourg, Russian Federation, Slovak Republic, Sweden, Portugal, Lithuania, Spain, United States \\
\hline 482 & Luxembourg & United Kingdom, Latvia, France, Russian Federation, Slovak Republic, Sweden, Portugal, Lithuania, United States \\
\hline 481 & Russian Federation & Norway, United Kingdom, Latvia, France, Luxembourg, Slovak Republic, Sweden, Portugal, Lithuania, Spain, United States, Italy \\
\hline 480 & Slovak Republic & Norway, United Kingdom, Latvia, France, Luxembourg, Russian Federation, Sweden, Portugal, Lithuania, Spain, United States, Italy \\
\hline 479 & Sweden & France, Luxembourg, Russian Federation, Slovak Republic, Portugal, Lithuania, Spain, United States, Italy \\
\hline 479 & Portugal & United Kingdom, Latvia, France, Luxembourg, Russian Federation, Slovak Republic, Sweden, Lithuania, Spain, United States, Italy, Hungary \\
\hline 477 & Lithuania & France, Luxembourg, Russian Federation, Slovak Republic, Sweden, Portugal, Spain, United States, Italy, Hungary \\
\hline 477 & Spain & France, Russian Federation, Slovak Republic, Sweden, Portugal, Lithuania, United States, Italy, Hungary \\
\hline 475 & United States & France, Luxembourg, Russian Federation, Slovak Republic, Sweden, Portugal, Lithuania, Spain, Italy, Hungary, Israel \\
\hline 475 & Italy & Russian Federation, Slovak Republic, Sweden, Portugal, Lithuania, Spain, United States, Hungary \\
\hline 469 & Hungary & Portugal, Lithuania, Spain, United States, Italy, Israel \\
\hline 465 & Israel & United States, Hungary, Croatia \\
\hline 453 & Croatia & Israel, Turkey, Greece, Serbia, Romania, Kazakhstan \\
\hline 449 & Turkey & Croatia, Greece, Serbia, Romania, Kazakhstan, Bulgaria \\
\hline 448 & Greece & Croatia, Turkey, Serbia, Romania, Kazakhstan \\
\hline 447 & Serbia & Croatia, Turkey, Greece, Romania, Kazakhstan, Bulgaria \\
\hline 445 & Romania & Croatia, Turkey, Greece, Serbia, Kazakhstan, Bulgaria \\
\hline 442 & Kazakhstan & Croatia, Turkey, Greece, Serbia, Romania, Bulgaria, Cyprus ${ }^{1,2}$ \\
\hline 437 & Bulgaria & Turkey, Serbia, Romania, Kazakhstan, Cyprus 1,2 \\
\hline 437 & Cyprus ${ }^{1,2}$ & Kazakhstan, Bulgaria \\
\hline 426 & United Arab Emirates & Chile \\
\hline 420 & Chile & United Arab Emirates, Thailand \\
\hline 416 & Thailand & Chile, Mexico, Uruguay, Malaysia \\
\hline 409 & Mexico & Thailand, Uruguay, Malaysia \\
\hline 406 & Uruguay & Thailand, Mexico, Malaysia, Montenegro, Costa Rica \\
\hline 406 & Malaysia & Thailand, Mexico, Uruguay, Montenegro, Costa Rica, Albania \\
\hline 404 & Montenegro & Uruguay, Malaysia, Costa Rica \\
\hline 399 & Costa Rica & Uruguay, Malaysia, Montenegro, Albania, Jordan \\
\hline 398 & Albania & Malaysia, Costa Rica \\
\hline 390 & Jordan & Costa Rica, Argentina \\
\hline 383 & Argentina & Jordan, Qatar, Brazil, Colombia, Tunisia \\
\hline 378 & Qatar & Argentina, Brazil, Colombia, Tunisia \\
\hline 376 & Brazil & Argentina, Qatar, Colombia, Tunisia, Peru, Indonesia \\
\hline 375 & Colombia & Argentina, Qatar, Brazil, Tunisia, Peru, Indonesia \\
\hline 373 & Tunisia & Argentina, Qatar, Brazil, Colombia, Peru, Indonesia \\
\hline 370 & Peru & Brazil, Colombia, Tunisia, Indonesia \\
\hline 368 & Indonesia & Brazil, Colombia, Tunisia, Peru \\
\hline
\end{tabular}

1. Note by Turkey: The information in this document with reference to "Cyprus" relates to the southern part of the Island. There is no single authority representing both Turkish and Greek Cypriot people on the Island. Turkey recognises the Turkish Republic of Northern Cyprus (TRNC). Until a lasting and equitable solution is found within the context of the United Nations, Turkey shall preserve its position concerning the "Cyprus issue".

2. Note by all the European Union Member States of the OECD and the European Union: The Republic of Cyprus is recognised by all members of the United Nations with the exception of Turkey. The information in this document relates to the area under the effective control of the Government of the Republic of Cyprus.

Source: OECD, PISA 2012 Database.

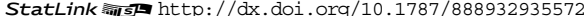


- Figure I.2.29

Summary descriptions of the six proficiency levels for the mathematical subscale formulating

\begin{tabular}{|c|c|c|}
\hline Level & $\begin{array}{l}\text { Percentage of students } \\
\text { able to perform tasks } \\
\text { at each level or above } \\
\text { (OECD average) }\end{array}$ & What students can do \\
\hline 6 & $5.0 \%$ & $\begin{array}{l}\text { Students at or above Level } 6 \text { can apply a wide variety of mathematical content knowledge } \\
\text { to transform and represent contextual information or data, geometric patterns or objects } \\
\text { into a mathematical form amenable to investigation. At this level, students can devise and } \\
\text { follow a multi-step strategy involving significant modelling steps and extended calculation to } \\
\text { formulate and solve complex real-world problems in a range of settings, for example involving } \\
\text { material and cost calculations in a variety of contexts, or to find the area of an irregular region } \\
\text { on a map; identify what information is relevant (and what is not) from contextual information } \\
\text { about travel times, distances and speed to formulate appropriate relationships among them; } \\
\text { apply reasoning across several linked variables to devise an appropriate way to present data } \\
\text { in order to facilitate pertinent comparisons; and devise algebraic formulations that represent } \\
\text { a given contextual situation. }\end{array}$ \\
\hline 5 & $14.5 \%$ & $\begin{array}{l}\text { At this level, students can use their understanding in a range of mathematical areas to } \\
\text { transform information or data from a problem context into mathematical form. They can } \\
\text { transform information from different representations involving several variables, into a form } \\
\text { suitable for mathematical treatment. They can formulate and modify algebraic expressions of } \\
\text { relationships among variables; use proportional reasoning effectively to devise computations; } \\
\text { gather information from different sources to formulate and solve problems involving } \\
\text { geometric objects, features and properties, or analyse geometric patterns or relationships } \\
\text { and express them in standard mathematical terms; transform a given model according to } \\
\text { changed contextual circumstances; formulate a sequential calculation process based on text } \\
\text { descriptions; and activate statistical concepts, such as randomness, or sample, and apply } \\
\text { probability to formulate a model. }\end{array}$ \\
\hline 4 & $31.1 \%$ & $\begin{array}{l}\text { At Level 4, students can link information and data from related representations (for example, } \\
\text { a table and a map, or a spread sheet and a graphing tool) and apply a sequence of reasoning } \\
\text { steps in order to formulate the mathematical expression needed to carry out a calculation } \\
\text { or otherwise to solve a contextual problem. At this level, students can formulate a linear } \\
\text { equation from a text description of a process, for example in a sales context, and formulate } \\
\text { and apply cost comparisons to compare prices of sale items; identify which of given graphical } \\
\text { representations corresponds to a given description of a physical process; specify a sequential } \\
\text { calculation process in mathematical terms; identify geometrical features of a situation and } \\
\text { use their geometric knowledge and reasoning to analyse a problem, for example to estimate } \\
\text { areas or to link a contextual geometric situation involving similarity to the corresponding } \\
\text { proportional reasoning; combine multiple decision rules needed to understand or implement } \\
\text { a calculation where different constraints apply; and formulate algebraic expressions when the } \\
\text { contextual information is reasonably straight-forward, for example to connect distance and } \\
\text { speed information in time calculations. }\end{array}$ \\
\hline 3 & $52.7 \%$ & $\begin{array}{l}\text { At this level, students can identify and extract information and data from text, tables, graphs, } \\
\text { maps or other representations, and make use of them to express a relationship mathematically, } \\
\text { including interpreting or adapting simple algebraic expressions related to an applied context. } \\
\text { Students at this level can transform a textual description of a simple functional relationship into } \\
\text { a mathematical form, for example with unit costs or payment rates; form a strategy involving } \\
\text { two or more steps to link problem elements or to explore mathematical characteristics of the } \\
\text { elements; apply reasoning with geometric concepts and skills to analyse patterns or identify } \\
\text { properties of shapes or a specified map location, or to identify information needed to carry out } \\
\text { some pertinent calculations, including calculations involving the use of simple proportional } \\
\text { models and reasoning, where the relevant data and information is immediately accessible; } \\
\text { and understand and link probabilistic statements to formulate probability calculations in } \\
\text { contexts, such as in a manufacturing process or a medical test. }\end{array}$ \\
\hline 2 & $74.0 \%$ & $\begin{array}{l}\text { At this level, students can understand written instructions and information about simple } \\
\text { processes and tasks in order to express them in a mathematical form. They can use data } \\
\text { presented in text or in a table (for example, giving information about the cost of some product } \\
\text { or service) to formulate a computation required, such as to identify the length of a time period, } \\
\text { or to present a cost comparison, or calculate an average; analyse a simple pattern, for example } \\
\text { by formulating a counting rule or identifying and extending a numeric sequence; work } \\
\text { effectively with different two- and three-dimensional standard representations of objects or } \\
\text { situations, for example devising a strategy to match one representation with another compare } \\
\text { different scenarios, or identify random experiment outcomes mathematically using standard } \\
\text { conventions. }\end{array}$ \\
\hline 1 & $89.7 \%$ & $\begin{array}{l}\text { At this level students can recognise or modify and use an explicit simple model of a contextual } \\
\text { situation. Students can choose between several such models to match the situation. For example, } \\
\text { they can choose between an additive and a multiplicative model in a shopping context; choose } \\
\text { among given two-dimensional objects to represent a familiar three-dimensional object; and } \\
\text { select one of several given graphs to represent growth of a population. }\end{array}$ \\
\hline
\end{tabular}


- Figure I.2.30

Proficiency in the mathematics subscale formulating

Percentage of students at each level of mathematics proficiency

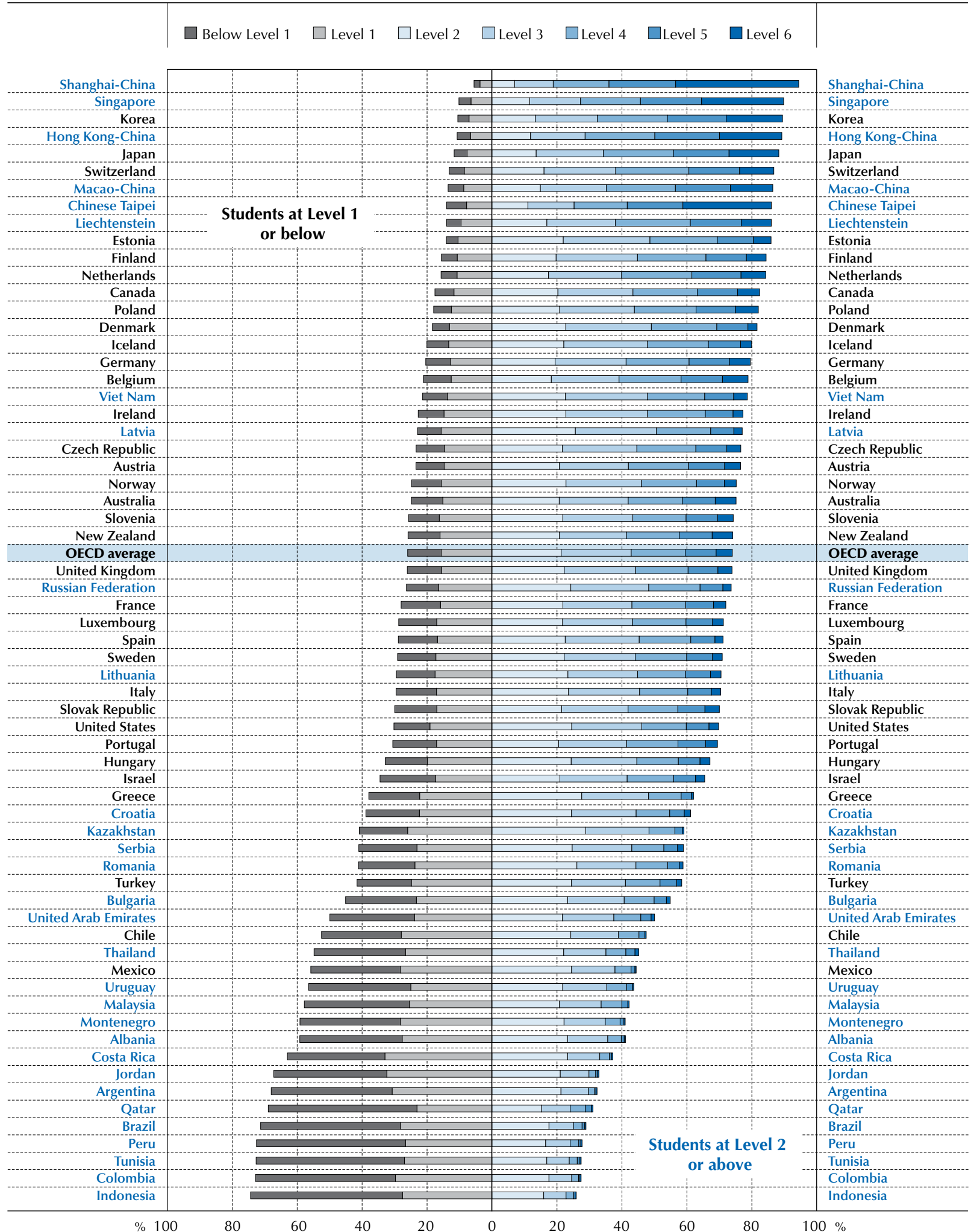

Countries and economies are ranked in descending order of the percentage of students at Levels 2, 3, 4, 5 and 6 . Source: OECD, PISA 2012 Database, Table I.2.5.

StatLink त्नाजा http://dx.doi.org/10.1787/888932935572 
In Croatia, Brazil, Tunisia, Malaysia, Viet Nam, Thailand and the OECD countries France and Italy, there is a difference of at least 10 points between student performance on the formulating subscale and overall mathematics performance. In all these countries, the scores in formulating are lower than the overall mathematics scores. All these countries show an average overall score in mathematics below the OECD average, except France, which is at the OECD average, and Viet Nam, which is above the OECD average.

Descriptions of the six levels of proficiency on the subscale formulating situations mathematically are given in Figure I.2.29 and the distribution of students among these six proficiency levels is shown in Figure 1.2.30.

\section{Student performance on the mathematics subscale employing mathematical concepts, facts, procedures, and reasoning}

To employ mathematical concepts, facts, procedures and reasoning for the PISA assessment, students need to recognise which elements of their "mathematics tool kit" are relevant to the problem as it has been presented, or as they have formulated it, and apply that knowledge in a systematic and organised way to work towards a solution. For example, in a problem about travel on public transport or riding a bicycle, once the basic relationships underlying the problem have been understood and expressed in a suitable mathematical form, the student may need to carry out a calculation, substitute values into a formula, solve an equation, or apply their knowledge of the conventions of graphing to extract data or present information mathematically.

Items listed in Figure I.2.9 that have been classified in this category are REVOLVING DOOR Question 1, WHICH CAR? Question 2 and Question 3, CHARTS Question 5, GARAGE Question 2, CLIMBING MOUNT FUJI Question 3, and HELEN THE CYCLIST Question 1, Question 2 and Question 3.

Across OECD countries, the average score attained on the employing subscale is 493 points - 0.6 score point below the average score in overall mathematics proficiency. This small difference reflects both the centrality of using mathematical concepts, facts, procedures and reasoning in school mathematics classes and the fact that about half of the items in the PISA 2012 mathematics assessment are categorised as predominantly requiring the use of employing processes. Top-performing countries and economies on this subscale are Shanghai-China, Singapore, Hong Kong-China, Korea, Chinese Taipei, Liechtenstein, Macao-China, Japan, Switzerland and Estonia (Figure I.2.31 and Table I.2.10).

The great majority of participating countries and economies have an average employing score that is within about five score points of their average score on the overall mathematics proficiency scale. Only Chinese Taipei has an average score on the employing subscale that is more than 10 points lower than its average score in mathematics (an 11-point difference), indicating that more students have difficulty using this process. By contrast, Viet Nam's average score on the employing subscale is 12 points higher than its average score on the mathematics proficiency scale, suggesting that students in that country find this aspect of problem solving relatively easy (Figure I.2.37).

Descriptions of the six levels of proficiency on the subscale employing mathematical concepts, facts, procedures, and reasoning are given in Figure I.2.32 and the distribution of students among these six proficiency levels is shown in Figure I.2.33.

\section{Student performance on the mathematics subscale interpreting, applying and evaluating mathematical outcomes}

In interpreting mathematical outcomes, students need to make links between the outcomes and the situation from which they arose. For example, in a problem requiring a careful interpretation of some graphical data, students would have to make connections among the objects or relationships depicted in the graph, and the answer to the question might involve interpreting those objects or relationships. In a problem about travel on public transport or riding a bicycle, once the basic relationships underlying the problem have been understood and expressed in a suitable mathematical form, the required mathematical processing has been carried out, and results generated, the student may need to evaluate the results in relation to the original problem, or may need to show how the mathematical information obtained relates to the contextual elements of the problem.

Items listed in Figure 1.2.9 that have been classified in this category are CHARTS Question 1 and Question 2, WHICH CAR? Question 1, and GARAGE Question 1. 


\section{Comparing countries' and economies' performance on the mathematics subscale employing}

\begin{tabular}{|c|c|c|}
\hline & \multirow{2}{*}{$\begin{array}{l}\text { Statistically significantly above the OECD average } \\
\text { Not statistically significantly different from the OECD average } \\
\text { Statistically significantly below the OECD average }\end{array}$} \\
\hline & & \\
\hline $\begin{array}{l}\text { Mean } \\
\text { score }\end{array}$ & $\begin{array}{l}\text { Comparison } \\
\text { country/economy }\end{array}$ & Countries/economies whose mean score is NOT statistically significantly different from that comparison country's/economy's score \\
\hline 613 & Shanghai-China & \\
\hline 574 & Singapore & \\
\hline 558 & Hong Kong-China & Korea \\
\hline 553 & Korea & Hong Kong-China, Chinese Taipei \\
\hline 549 & Chinese Taipei & Korea \\
\hline 536 & Liechtenstein & Macao-China, Japan, Switzerland \\
\hline 536 & Macao-China & Liechtenstein, Japan \\
\hline 530 & Japan & Liechtenstein, Macao-China, Switzerland, Estonia, Viet Nam \\
\hline 529 & Switzerland & Liechtenstein, Japan, Estonia, Viet Nam \\
\hline 524 & Estonia & Japan, Switzerland, Viet Nam, Poland, Netherlands \\
\hline 523 & Viet Nam & Japan, Switzerland, Estonia, Poland, Netherlands, Canada, Germany, Belgium, Finland \\
\hline 519 & Poland & Estonia, Viet Nam, Netherlands, Canada, Germany, Belgium, Finland \\
\hline 518 & Netherlands & Estonia, Viet Nam, Poland, Canada, Germany, Belgium, Finland \\
\hline 517 & Canada & Viet Nam, Poland, Netherlands, Germany, Belgium, Finland \\
\hline 516 & Germany & Viet Nam, Poland, Netherlands, Canada, Belgium, Finland, Austria \\
\hline 516 & Belgium & Viet Nam, Poland, Netherlands, Canada, Germany, Finland, Austria \\
\hline 516 & Finland & Viet Nam, Poland, Netherlands, Canada, Germany, Belgium, Austria \\
\hline 510 & Austria & Germany, Belgium, Finland, Slovenia, Czech Republic \\
\hline 505 & Slovenia & Austria, Czech Republic, Ireland \\
\hline 504 & Czech Republic & Austria, Slovenia, Ireland, Australia, France \\
\hline 502 & Ireland & Slovenia, Czech Republic, Australia, France, Latvia \\
\hline 500 & Australia & Czech Republic, Ireland, France, Latvia, New Zealand \\
\hline 496 & France & Czech Republic, Ireland Australia, Latvia, New Zealand, Denmark, Luxembourg, United Kingdom, Portugal \\
\hline 495 & Latvia & Ireland, Australia, France, New Zealand, Denmark, Luxembourg, United Kingdom, Iceland, Portugal \\
\hline 495 & New Zealand & Australia, France, Latvia, Denmark, Luxembourg, United Kingdom, Iceland, Portugal \\
\hline 495 & Denmark & France, Latvia, New Zealand, Luxembourg, United Kingdom, Iceland, Portugal \\
\hline 493 & Luxembourg & France, Latvia, New Zealand, Denmark, United Kingdom, Iceland, Portugal, Russian Federation \\
\hline 492 & United Kingdom & France, Latvia, New Zealand, Denmark, Luxembourg, Iceland, Portugal, Russian Federation, Norway, Italy, Slovak Republic \\
\hline 490 & Iceland & Latvia, New Zealand, Denmark, Luxembourg, United Kingdom, Portugal, Russian Federation, Norway, Italy, Slovak Republic \\
\hline 489 & Portugal & $\begin{array}{l}\text { France, Latvia, New Zealand, Denmark, Luxembourg, United Kingdom, Iceland, Russian Federation, Norway, Italy, Slovak Republic, } \\
\text { Lithuania, Spain Hungary, United States }\end{array}$ \\
\hline 487 & Russian Federation & Luxembourg, United Kingdom, Iceland, Portugal, Norway, Italy, Slovak Republic, Lithuania, Spain, Hungary, United States, Croatia \\
\hline 486 & Norway & United Kingdom, Iceland, Portugal, Russian Federation, Italy, Slovak Republic, Lithuania, Spain, Hungary, United States, Croatia \\
\hline 485 & Italy & United Kingdom, Iceland, Portugal, Russian Federation, Norway, Slovak Republic, Lithuania, Spain, Hungary, United States, Croatia \\
\hline 485 & Slovak Republic & United Kingdom, Iceland, Portugal, Russian Federation, Norway, Italy, Lithuania, Spain, Hungary, United States, Croatia \\
\hline 482 & Lithuania & Portugal, Russian Federation, Norway, Italy, Slovak Republic, Spain, Hungary, United States, Croatia \\
\hline 481 & Spain & Portugal, Russian Federation, Norway, Italy, Slovak Republic, Lithuania, Hungary, United States, Croatia \\
\hline 481 & Hungary & Portugal, Russian Federation, Norway, Italy, Slovak Republic, Lithuania, Spain, United States, Croatia, Sweden \\
\hline 480 & United States & Portugal, Russian Federation, Norway, Italy, Slovak Republic, Lithuania, Spain, Hungary, Croatia, Sweden, Israel \\
\hline 478 & Croatia & Russian Federation, Norway, Italy, Slovak Republic, Lithuania, Spain, Hungary, United States, Sweden, Israel \\
\hline 474 & Sweden & Hungary, United States, Croatia, Israel \\
\hline 469 & Israel & United States, Croatia, Sweden \\
\hline 451 & Serbia & Greece, Turkey, Romania \\
\hline 449 & Greece & Serbia, Turkey, Romania, Cyprus ${ }^{1,2}$, Bulgaria \\
\hline 448 & Turkey & Serbia, Greece, Romania, Cyprus ${ }^{1,2}$, United Arab Emirates, Bulgaria \\
\hline 446 & Romania & Serbia, Greece, Turkey, Cyprus ${ }^{1,2}$, United Arab Emirates, Bulgaria \\
\hline 443 & Cyprus ${ }^{1,2}$ & Greece, Turkey, Romania, United Arab Emirates, Bulgaria \\
\hline 440 & United Arab Emirates & Turkey, Romania, Cyprus ${ }^{1,2}$, Bulgaria, Kazakhstan \\
\hline 439 & Bulgaria & Greece, Turkey, Romania, Cyprus ${ }^{1,2}$, United Arab Emirates, Kazakhstan \\
\hline 433 & Kazakhstan & United Arab Emirates, Bulgaria, Thailand \\
\hline 426 & Thailand & Kazakhstan, Malaysia \\
\hline 423 & Malaysia & Thailand, Chile \\
\hline 416 & Chile & Malaysia, Mexico, Uruguay \\
\hline 413 & Mexico & Chile, Uruguay \\
\hline 409 & Montenegro & Uruguay \\
\hline 408 & Uruguay & Chile, Mexico, Montenegro, Costa Rica \\
\hline 401 & Costa Rica & Uruguay, Albania, Tunisia \\
\hline 397 & Albania & Costa Rica, Tunisia \\
\hline 390 & Tunisia & Costa Rica, Albania, Brazil, Argentina, Jordan \\
\hline 388 & Brazil & Tunisia, Argentina, Jordan \\
\hline 387 & Argentina & Tunisia, Brazil, Jordan \\
\hline 383 & Jordan & Tunisia, Brazil, Argentina \\
\hline 373 & Qatar & Indonesia, Peru, Colombia \\
\hline 369 & Indonesia & Qatar, Peru, Colombia \\
\hline 368 & Peru & Qatar, Indonesia, Colombia \\
\hline 367 & Colombia & Qatar, Indonesia, Peru \\
\hline
\end{tabular}

1. Note by Turkey: The information in this document with reference to "Cyprus" relates to the southern part of the Island. There is no single authority representing both Turkish and Greek Cypriot people on the Island. Turkey recognises the Turkish Republic of Northern Cyprus (TRNC). Until a lasting and equitable solution is found within the context of the United Nations, Turkey shall preserve its position concerning the "Cyprus issue".

2. Note by all the European Union Member States of the OECD and the European Union: The Republic of Cyprus is recognised by all members of the United Nations with the exception of Turkey. The information in this document relates to the area under the effective control of the Government of the Republic of Cyprus.

Source: OECD, PISA 2012 Database.

StatLink 部实 http://dx.doi.org/10.1787/888932935572 
- Figure 1.2 .32

\section{Summary descriptions of the six proficiency levels for} the mathematical subscale employing

\begin{tabular}{|c|c|c|}
\hline Level & $\begin{array}{l}\text { Percentage of students } \\
\text { able to perform tasks } \\
\text { at each level or above } \\
\text { (OECD average) }\end{array}$ & What students can do \\
\hline 6 & $2.8 \%$ & $\begin{array}{l}\text { Students at or above Level } 6 \text { can use a strong repertoire of knowledge and procedural skills } \\
\text { in a wide range of mathematical areas. They can form and follow a multi-step strategy } \\
\text { to solve a problem involving several stages; apply reasoning in a connected way across } \\
\text { several problem elements; set up and solve an algebraic equation with more than one } \\
\text { variable; generate relevant data and information to explore problems, for example using a } \\
\text { spread sheet to sort and analyse data; and justify their results mathematically and explain } \\
\text { their conclusions and support them with well-formed mathematical arguments. At Level } 6 \\
\text { students' work is consistently precise and accurate. }\end{array}$ \\
\hline 5 & $12.1 \%$ & $\begin{array}{l}\text { Students at Level } 5 \text { can use a range of knowledge and skills to solve problems. They can } \\
\text { sensibly link information in graphical and diagrammatic form to textual information. They } \\
\text { can apply spatial and numeric reasoning skills to express and work with simple models in } \\
\text { reasonably well-defined situations and where the constraints are clear. They usually work } \\
\text { systematically, for example to explore combinatorial outcomes, and can sustain accuracy } \\
\text { in their reasoning across a small number of steps and processes. They are generally able } \\
\text { to work competently with expressions, can work with formulae and use proportional } \\
\text { reasoning, and are able to work with and transform data presented in a variety of forms. }\end{array}$ \\
\hline 4 & $30.7 \%$ & $\begin{array}{l}\text { At Level } 4 \text {, students can identify relevant data and information from contextual material } \\
\text { and use it to perform such tasks as calculating distances, using proportional reasoning to } \\
\text { apply a scale factor, converting different units to a common scale, or relating different graph } \\
\text { scales to each other. They can work flexibly with distance-time-speed relationships, and } \\
\text { can carry out a sequence of arithmetic calculations. They can use algebraic formulations, } \\
\text { and follow a straightforward strategy and describe it. }\end{array}$ \\
\hline 3 & $54.8 \%$ & $\begin{array}{l}\text { Students at Level } 3 \text { frequently have sound spatial reasoning skills enabling them, for } \\
\text { example, to use the symmetry properties of a figure, recognise patterns presented in } \\
\text { graphical form, or use angle facts to solve a geometric problem. Students at this level can } \\
\text { connect two different mathematical representations, such as data in a table and in a graph, } \\
\text { or an algebraic expression with its graphical representation, enabling them, for example, to } \\
\text { understand the effect of changing data in one representation on the other. They can handle } \\
\text { percentages, fractions and decimal numbers and work with proportional relationships. }\end{array}$ \\
\hline 2 & $77.3 \%$ & $\begin{array}{l}\text { Students at Level } 2 \text { can apply small reasoning steps to make direct use of given information } \\
\text { to solve a problem, for example, to implement a simple calculation model, identify a } \\
\text { calculation error, analyse a distance-time relationship, or analyse a simple spatial pattern. } \\
\text { At this level students show an understanding of place value in decimal numbers and can use } \\
\text { that understanding to compare numbers presented in a familiar context; correctly substitute } \\
\text { values into a simple formula; recognise which of a set of given graphs correctly represents } \\
\text { a set of percentages and apply reasoning skills to understand and explore different kinds of } \\
\text { graphical representations of data; and can understand simple probability concepts. }\end{array}$ \\
\hline 1 & $91.9 \%$ & $\begin{array}{l}\text { Students at Level } 1 \text { can identify simple data relating to a real-world context, such as that } \\
\text { presented in a structured table or in an advertisement where the text and data labels } \\
\text { match directly; perform practical tasks, such as decomposing money amounts into lower } \\
\text { denominations; use direct reasoning from textual information that points to an obvious } \\
\text { strategy to solve a given problem, particularly where the mathematical procedural } \\
\text { knowledge required would be limited to, for example, arithmetic operations with whole } \\
\text { numbers, or ordering and comparing whole numbers; understand graphing techniques and } \\
\text { conventions; and use symmetry properties to explore characteristics of a figure, such as } \\
\text { comparin g side lengths and angles. }\end{array}$ \\
\hline
\end{tabular}


- Figure 1.2 .33 .

Proficiency in the mathematics subscale employing

Percentage of students at each level of mathematics proficiency

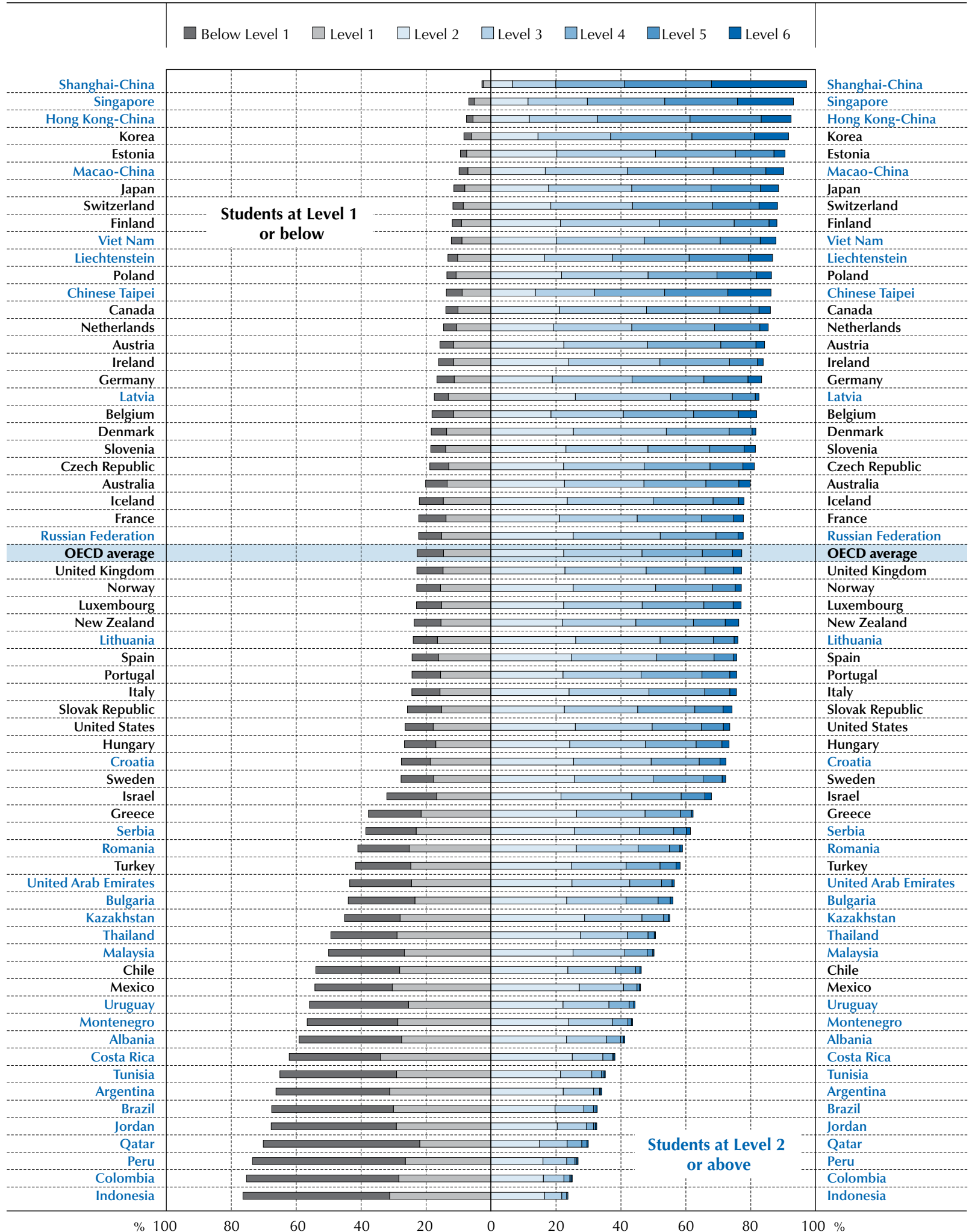

Countries and economies are ranked in descending order of the percentage of students at Levels 2, 3, 4, 5 and 6. Source: OECD, PISA 2012 Database, Table I.2.8.

StatLink त्राज http://dx.doi.org/10.1787/888932935572 
- Figure 1.2 .34

\section{Comparing countries' and economies' performance on the mathematics subscale interpreting}

\begin{tabular}{|c|c|c|}
\hline \multirow[b]{2}{*}{$\begin{array}{l}\text { Mean } \\
\text { score }\end{array}$} & \multirow[b]{2}{*}{$\begin{array}{l}\text { Comparison } \\
\text { country/economy }\end{array}$} & $\begin{array}{l}\text { Statistically significantly above the OECD average } \\
\text { Not statistically significantly different from the OECD average } \\
\text { Statistically significantly below the OECD average }\end{array}$ \\
\hline & & Countries/economies whose mean score is NOT statistically significantly different from that comparison country's/economy's score \\
\hline 579 & Shanghai-China & \\
\hline 555 & Singapore & Hong Kong-China, Chinese Taipei \\
\hline 551 & Hong Kong-China & Singapore, Chinese Taipei \\
\hline 549 & Chinese Taipei & Singapore, Hong Kong-China, Liechtenstein, Korea \\
\hline 540 & Liechtenstein & Chinese Taipei, Korea, Japan \\
\hline 540 & Korea & Chinese Taipei, Liechtenstein, Japan \\
\hline 531 & Japan & Liechtenstein, Korea, Macao-China, Switzerland, Finland, Netherlands \\
\hline 530 & Macao-China & Japan, Switzerland, Finland, Netherlands \\
\hline 529 & Switzerland & Japan, Macao-China, Finland, Netherlands, Canada \\
\hline 528 & Finland & Japan, Macao-China, Switzerland, Netherlands \\
\hline 526 & Netherlands & Japan, Macao-China, Switzerland, Finland, Canada, Germany \\
\hline 521 & Canada & Switzerland, Netherlands, Germany, Poland \\
\hline 517 & Germany & Netherlands, Canada, Poland, Australia, Belgium, Estonia, New Zealand, France, Austria \\
\hline 515 & Poland & Canada, Germany, Australia, Belgium, Estonia, New Zealand, France, Austria, Denmark, Ireland \\
\hline 514 & Australia & Germany, Poland, Belgium, Estonia, New Zealand, France, Austria \\
\hline 513 & Belgium & Germany, Poland, Australia, Estonia, New Zealand, France, Austria, Denmark, Ireland \\
\hline 513 & Estonia & Germany, Poland, Australia, Belgium, New Zealand, France, Austria, Denmark, Ireland \\
\hline 511 & New Zealand & Germany, Poland, Australia, Belgium, Estonia, France, Austria, Denmark, Ireland \\
\hline 511 & France & Germany, Poland, Australia, Belgium, Estonia, New Zealand, Austria, Denmark, Ireland \\
\hline 509 & Austria & Germany, Poland, Australia, Belgium, Estonia, New Zealand, France, Denmark, Ireland, United Kingdom \\
\hline 508 & Denmark & Poland, Belgium, Estonia, New Zealand, France, Austria, Ireland, United Kingdom \\
\hline 507 & Ireland & Poland, Belgium, Estonia, New Zealand, France, Austria, Denmark, United Kingdom, Viet Nam \\
\hline 501 & United Kingdom & Austria, Denmark, Ireland, Norway, Italy, Slovenia, Viet Nam, Spain, Luxembourg, Czech Republic \\
\hline 499 & Norway & United Kingdom, Italy, Slovenia, Viet Nam, Spain, Luxembourg, Czech Republic, Iceland, Portugal, United States \\
\hline 498 & Italy & United Kingdom, Norway, Slovenia, Viet Nam, Spain, Luxembourg, Czech Republic, Portugal \\
\hline 498 & Slovenia & United Kingdom, Norway, Italy, Viet Nam, Spain, Luxembourg, Czech Republic, Portugal \\
\hline 497 & Viet Nam & Ireland, United Kingdom, Norway, Italy, Slovenia, Spain, Luxembourg, Czech Republic, Iceland, Portugal, United States, Latvia \\
\hline 495 & Spain & United Kingdom, Norway, Italy, Slovenia, Viet Nam, Luxembourg, Czech Republic, Iceland, Portugal, United States \\
\hline 495 & Luxembourg & United Kingdom, Norway, Italy, Slovenia, Viet Nam, Spain, Czech Republic, Iceland, Portugal, United States \\
\hline 494 & Czech Republic & United Kingdom, Norway, Italy, Slovenia, Viet Nam, Spain, Luxembourg, Iceland, Portugal, United States, Latvia \\
\hline 492 & Iceland & Norway, Viet Nam, Spain, Luxembourg, Czech Republic, Portugal, United States, Latvia \\
\hline 490 & Portugal & Norway, Italy, Slovenia, Viet Nam, Spain, Luxembourg, Czech Republic, Iceland, United States, Latvia, Sweden \\
\hline 489 & United States & Norway, Viet Nam, Spain, Luxembourg, Czech Republic, Iceland, Portugal, Latvia, Sweden \\
\hline 486 & Latvia & Viet Nam, Czech Republic, Iceland, Portugal, United States, Sweden \\
\hline 485 & Sweden & Portugal, United States, Latvia, Croatia \\
\hline 477 & Croatia & Sweden, Hungary, Slovak Republic, Russian Federation, Lithuania \\
\hline 477 & Hungary & Croatia, Slovak Republic, Russian Federation, Lithuania \\
\hline 473 & Slovak Republic & Croatia, Hungary, Russian Federation, Lithuania, Greece, Israel \\
\hline 471 & Russian Federation & Croatia, Hungary, Slovak Republic, Lithuania, Greece, Israel \\
\hline 471 & Lithuania & Croatia, Hungary, Slovak Republic, Russian Federation, Greece, Israel \\
\hline 467 & Greece & Slovak Republic, Russian Federation, Lithuania, Israel \\
\hline 462 & Israel & Slovak Republic, Russian Federation, Lithuania, Greece \\
\hline 446 & Turkey & Serbia, Bulgaria, Romania \\
\hline 445 & Serbia & Turkey, Bulgaria, Romania \\
\hline 441 & Bulgaria & Turkey, Serbia, Romania, Cyprus ${ }^{1,2}$, Chile, Thailand \\
\hline 438 & Romania & Turkey, Serbia, Bulgaria, Cyprus ${ }^{1,2}$, Chile, Thailand \\
\hline 436 & Cyprus ${ }^{1,2}$ & Bulgaria, Romania, Chile, Thailand \\
\hline 433 & Chile & Bulgaria, Romania, Cyprus ${ }^{1,2}$, Thailand, United Arab Emirates \\
\hline 432 & Thailand & Bulgaria, Romania, Cyprus ${ }^{1,2}$, Chile, United Arab Emirates \\
\hline 428 & United Arab Emirates & Chile, Thailand \\
\hline 420 & Kazakhstan & Malaysia, Costa Rica \\
\hline 418 & Malaysia & Kazakhstan, Costa Rica, Montenegro, Mexico \\
\hline 418 & Costa Rica & Kazakhstan, Malaysia, Montenegro, Mexico \\
\hline 413 & Montenegro & Malaysia, Costa Rica, Mexico, Uruguay \\
\hline 413 & Mexico & Malaysia, Costa Rica, Montenegro, Uruguay \\
\hline 409 & Uruguay & Montenegro, Mexico \\
\hline 401 & Brazil & \\
\hline 390 & Argentina & Colombia, Tunisia, Jordan, Indonesia \\
\hline 387 & Colombia & Argentina, Tunisia, Jordan, Indonesia \\
\hline 385 & Tunisia & Argentina, Colombia, Jordan, Indonesia, Albania \\
\hline 383 & Jordan & Argentina, Colombia, Tunisia, Indonesia, Albania \\
\hline 379 & Indonesia & Argentina, Colombia, Tunisia, Jordan, Albania, Qatar, Peru \\
\hline 379 & Albania & Tunisia, Jordan, Indonesia, Qatar \\
\hline 375 & Qatar & Indonesia, Albania, Peru \\
\hline 368 & Peru & Indonesia, Qatar \\
\hline
\end{tabular}

1. Note by Turkey: The information in this document with reference to "Cyprus" relates to the southern part of the Island. There is no single authority representing both Turkish and Greek Cypriot people on the Island. Turkey recognises the Turkish Republic of Northern Cyprus (TRNC). Until a lasting and equitable solution is found within the context of the United Nations, Turkey shall preserve its position concerning the "Cyprus issue".

2. Note by all the European Union Member States of the OECD and the European Union: The Republic of Cyprus is recognised by all members of the United Nations with the exception of Turkey. The information in this document relates to the area under the effective control of the Government of the Republic of Cyprus.

Source: OECD, PISA 2012 Database.

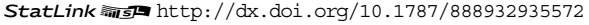


Summary descriptions of the six proficiency levels for the mathematical subscale interpreting

\begin{tabular}{|c|c|c|}
\hline Level & $\begin{array}{l}\text { Percentage of students } \\
\text { able to perform tasks } \\
\text { at each level or above } \\
\text { (OECD average) }\end{array}$ & What students can do \\
\hline 6 & $4.2 \%$ & $\begin{array}{l}\text { At Level 6, students can link multiple complex mathematical representations in an analytic way } \\
\text { to identify and extract data and information that enables contextual questions to be answered, } \\
\text { and can present their interpretations and conclusions in written form. For example, students } \\
\text { may interpret two time-series graphs in relation to different contextual conditions; or link a } \\
\text { relationship expressed both in a graph and in numeric form (such as in a price calculator) } \\
\text { or in a spread sheet and graph, to present an argument or conclusion about contextual } \\
\text { conditions. Students at this level can apply mathematical reasoning to data or information } \\
\text { presented in order to generate a chain of linked steps to support a conclusion (for example, } \\
\text { analysing a map using scale information; analysing a complex algebraic formula in relation } \\
\text { to the variables represented; translating data into a new time-frame; performing a three-way } \\
\text { currency conversion; or using a data-generation tool to find the information needed to answer } \\
\text { a question). Students at this level can gather analysis, data and their interpretation across } \\
\text { several different problem elements or across different questions about a context, showing a } \\
\text { depth of insight and a capacity for sustained reasoning. }\end{array}$ \\
\hline 5 & $14.5 \%$ & $\begin{array}{l}\text { At Level } 5 \text {, students can combine several processes in order to formulate conclusions based } \\
\text { on an interpretation of mathematical information with respect to context, such as formulating } \\
\text { or modifying a model, solving an equation or carrying out computations, and using several } \\
\text { reasoning steps to make the links to the identified context elements. At this level, students } \\
\text { can make links between context and mathematics involving spatial or geometric concepts } \\
\text { and complex statistical and algebraic concepts. They can easily interpret and evaluate a set of } \\
\text { plausible mathematical representations, such as graphs, to identify which one highest reflects } \\
\text { the contextual elements under analysis. Students at this level have begun to develop the ability } \\
\text { to communicate conclusions and interpretations in written form. }\end{array}$ \\
\hline 4 & $33.0 \%$ & $\begin{array}{l}\text { At Level 4, students can apply appropriate reasoning steps, possibly multiple steps, to } \\
\text { extract information from a complex mathematical situation and interpret complicated } \\
\text { mathematical objects, including algebraic expressions. They can interpret complex graphical } \\
\text { representations to identify data or information that answers a question; perform a calculation } \\
\text { or data manipulation (for example, in a spread sheet) to generate additional data needed to } \\
\text { decide whether a constraint (such as a measurement condition or a size comparison) is met; } \\
\text { interpret simple statistical or probabilistic statements in such contexts as public transport, or } \\
\text { health and medical test interpretation, to link the meaning of the statements to the underlying } \\
\text { contextual issues; conceptualise a change needed to a calculation procedure in response to } \\
\text { a changed constraint; and analyse two data samples, for example relating to a manufacturing } \\
\text { process, to make comparisons and draw and express conclusions. }\end{array}$ \\
\hline 3 & $55.9 \%$ & $\begin{array}{l}\text { Students at Level } 3 \text { begin to be able to use reasoning, including spatial reasoning, to support } \\
\text { their interpretations of mathematical information in order to make inferences about features } \\
\text { of the context. They combine reasoning steps systematically to make various connections } \\
\text { between mathematical and contextual material or when required to focus on different aspects } \\
\text { of a context, for example where a graph shows two data series or a table contains data on two } \\
\text { variables that must be actively related to each other to support a conclusion. They can test } \\
\text { and explore alternative scenarios, using reasoning to interpret the possible effects of changing } \\
\text { some of the variables under observation. They can use appropriate calculation steps to assist } \\
\text { their analysis of data and support the formation of conclusions and interpretations, including } \\
\text { calculations involving proportions and proportional reasoning, and in situations where } \\
\text { systematic analysis across several related cases is needed. At this level, students can interpret } \\
\text { and analyse relatively unfamiliar data presentations to support their conclusions. }\end{array}$ \\
\hline 2 & $77.0 \%$ & $\begin{array}{l}\text { At Level } 2 \text {, students can link contextual elements of the problem to mathematics, for example } \\
\text { by performing appropriate calculations or reading tables. Students at this level can make } \\
\text { comparisons repeatedly across several similar cases: for example, they can interpret a bar } \\
\text { graph to identify and extract data to apply in a comparative condition where some insight } \\
\text { is required. They can apply basic spatial skills to make connections between a situation } \\
\text { presented visually and its mathematical elements; identify and carry out necessary calculations } \\
\text { to support such comparisons as costs across several contexts; and can interpret a simple } \\
\text { algebraic expression as it relates to a given context. }\end{array}$ \\
\hline 1 & $91.2 \%$ & $\begin{array}{l}\text { At Level 1, students can interpret data or information expressed in a direct way in order } \\
\text { to answer questions about the context described. They can interpret given data to answer } \\
\text { questions about simple quantitative relational ideas (such as "larger", "shorter time", "in } \\
\text { between") in a familiar context, for example by evaluating measurements of an object against } \\
\text { given criterion values, by comparing average journey times for two methods of transport, or } \\
\text { by comparing specified characteristics of a small number of similar objects. Similarly, they } \\
\text { can make simple interpretations of data in a timetable or schedule to identify times or events. } \\
\text { Students at this level may show rudimentary understanding of such concepts as randomness } \\
\text { and data interpretation, for example by identifying the plausibility of a statement about chance } \\
\text { outcomes of a lottery, by understanding numeric and relational information in a well-labelled } \\
\text { graph, and by understanding basic contextual implications of links between related graphs. }\end{array}$ \\
\hline
\end{tabular}


Across OECD countries, the average score attained on the interpreting subscale is 497 points, 3 score points above the average score of 494 points on the overall mathematics proficiency scale. A substantially higher average score on the interpreting subscale might indicate that students find interpreting mathematical information a relatively less difficult aspect of the problem-solving process, perhaps because the task of evaluating mathematical results is commonly treated as part of that process in school mathematics classes. Top-performing countries and economies on this subscale are Shanghai-China, Singapore, Hong Kong-China, Chinese Taipei, Liechtenstein, Korea, Japan, Macao-China, Switzerland and Finland (Figure I.2.34 and Table I.2.13).

While across OECD countries the average score on the interpreting subscale is slightly higher than the average score on the mathematics proficiency scale, this is not the case in eight of the ten highest-performing countries and economies on the overall mathematics scale. In those countries and economies, the average score in interpreting is lower than the average score in overall mathematics proficiency, with a difference ranging from less than 10 points in Switzerland, Japan, Macao-China and Hong Kong-China, to between 10 and 20 points in Chinese Taipei, Korea and Singapore, to 34 points in Shanghai-China. In the high-performing OECD country, the Netherlands, and the partner country Liechtenstein, the opposite pattern is observed (Figure I.2.37).

In fact, performance on the interpreting subscale does not appear to be related to overall mathematics performance. In eight countries, students score at least ten points higher on the interpreting subscale than they do in mathematics overall, while in eight other countries the interpreting score is at least 10 points lower than the overall score. This latter group of countries includes the four highest-performing countries (Chinese Taipei, Korea, Singapore and Shanghai-China), one high-performing country (Viet Nam), and three countries that perform below the OECD average (Albania, Kazakhstan and the Russian Federation).

Descriptions of the six levels of proficiency on the subscale interpreting, applying and evaluating mathematical outcomes are given in Figure I.2.35 and the distribution of students among these six proficiency levels is shown in Figure I.2.36.

\section{The relative strengths and weaknesses of countries in mathematics process subscales}

Figure 1.2.37 shows the country mean for the overall mathematics scale and the difference between each process subscale and the overall mathematics scale. As the figure makes clear, the levels of performance on the process subscales are somewhat aligned with each other and with the overall mean mathematics performance. However, it is also clear that countries' and economies' strengths in the three processes vary considerably.

Across all participating countries and economies, the average difference between the highest and lowest performance in mathematics processes is around 14 points. Within that variability, 16 countries/economies show the highest mean score in formulating; 21 countries/economies perform best in employing; and 28 countries/economies have the highest mean score in interpreting.

Shanghai-China shows the largest difference (46 points) between its highest (formulating) and lowest (interpreting) performance in processes, followed by Chinese Taipei, which has a difference 30 points between its highest (formulating) and lowest (employing) performance in processes. France shows a large difference (27 points) between its highest (interpreting) and lowest (formulating) performance in processes, the largest among OECD countries, and Singapore shows the same difference as France but its strongest performance is in formulating while its weakest is in interpreting. Viet Nam has a difference of 26 points between its strongest (employing) and weakest (interpreting) process subscales, and both Brazil and Croatia shows a difference of 25 points between their strongest and weakest process subscales. Peru, Turkey, Uruguay and Belgium show a negligible difference (2 to 3 score points) between their highest and lowest performance in processes (Figure 1.2.37).

The OECD average difference between the highest and lowest performance in processes is around 5 points. Switzerland, Iceland, Japan, Korea, the Netherlands and Turkey have the highest mean score in formulating, and four of these countries are the best-performing OECD countries. Austria, Belgium, the Czech Republic, Estonia, Hungary, Israel, Mexico, Poland, the Slovak Republic and Slovenia perform best in employing; and the remaining 18 OECD countries have the highest mean scores in interpreting.

Ten partner countries and economies - Shanghai-China, Chinese Taipei, Singapore, Kazakhstan, Albania, Hong Kong-China, Macao-China, Jordan, Qatar and Peru - have the highest mean scores in formulating; ten other partner countries and economies - Brazil, Colombia, Costa Rica, Thailand, Indonesia, Montenegro, Argentina, Liechtenstein, Bulgaria and Uruguay - perform best in interpreting; and the remaining eleven partner countries and economies have the highest mean scores in employing. 
- Figure 1.2.36

Proficiency in the mathematics subscale interpreting

Percentage of students at each level of mathematics proficiency

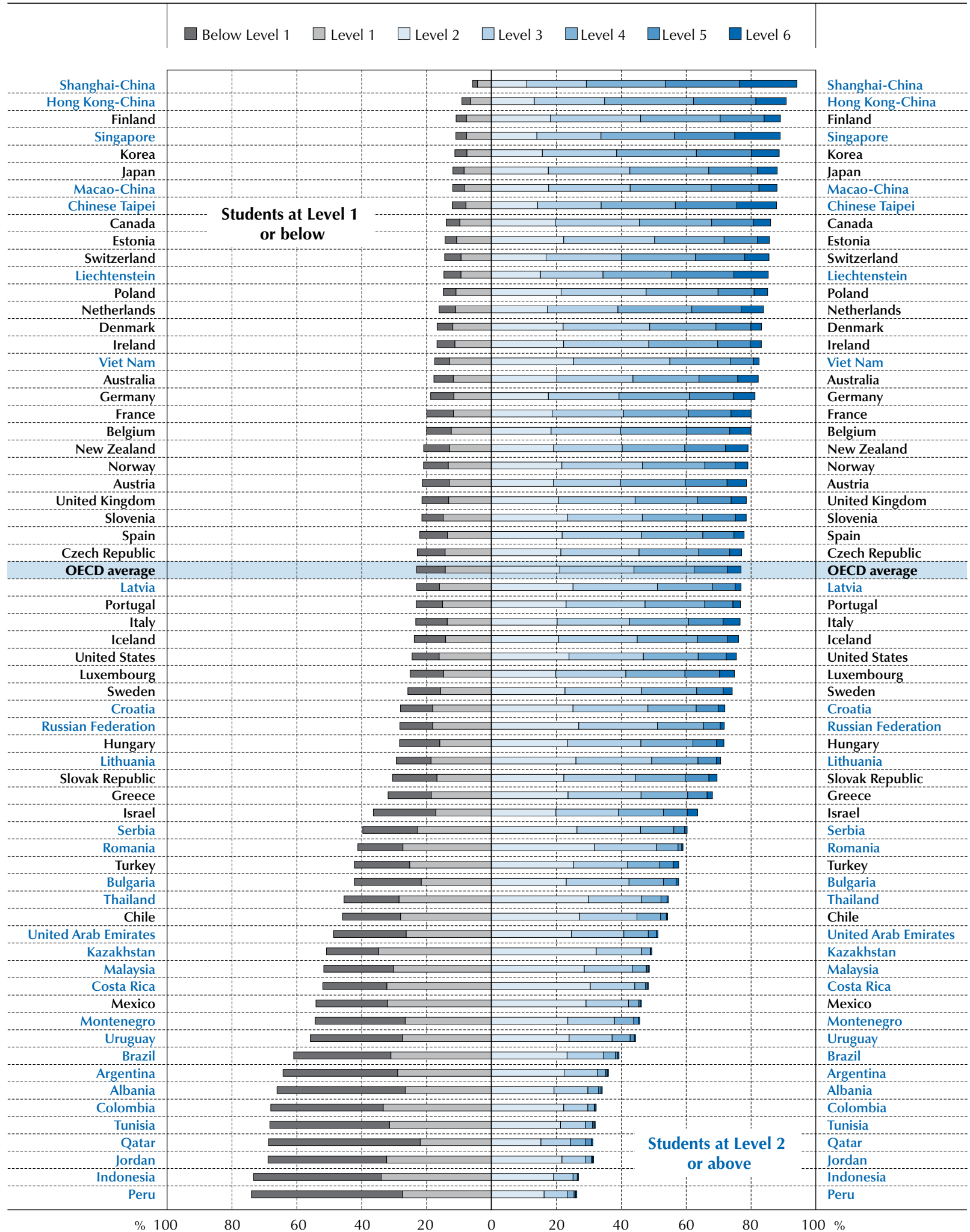

Countries and economies are ranked in descending order of the percentage of students at Levels 2, 3, 4, 5 and 6 . Source: OECD, PISA 2012 Database, Table I.2.11.

StatLink त्नाजा http://dx.doi.org/10.1787/888932935572 


\section{- Figure 1.2 .37}

\section{Comparing countries and economies on the different mathematics process subscales}

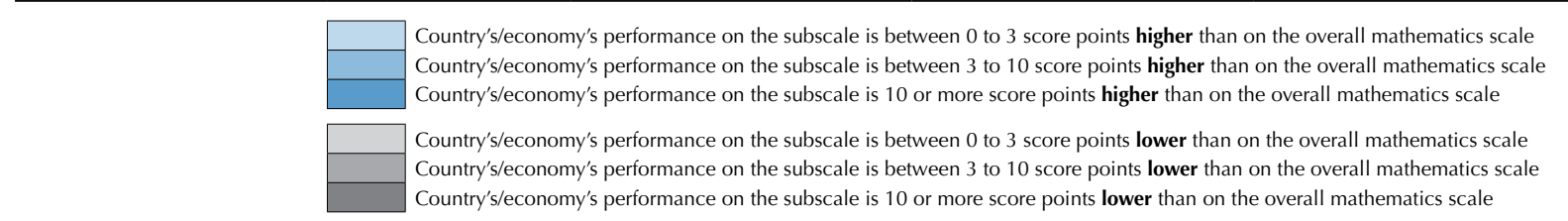

\begin{tabular}{|c|c|c|c|c|}
\hline & \multirow[b]{2}{*}{ Mathematics score } & \multicolumn{3}{|c|}{ Performance difference between the overall mathematics scale and each process subscale } \\
\hline & & Formulating & Employing & Interpreting \\
\hline Shanghai-China & 613 & 12 & 0 & -34 \\
\hline Singapore & 573 & 8 & 1 & -18 \\
\hline Hong Kong-China & 561 & 7 & -3 & -10 \\
\hline Chinese Taipei & 560 & 19 & -11 & -11 \\
\hline Korea & 554 & 8 & -1 & -14 \\
\hline Macao-China & 538 & 7 & -2 & -9 \\
\hline Japan & 536 & 18 & -6 & -5 \\
\hline Liechtenstein & 535 & 0 & 1 & 5 \\
\hline Switzerland & 531 & 7 & -2 & -2 \\
\hline Netherlands & 523 & 4 & -4 & 3 \\
\hline Estonia & 521 & -3 & 4 & -8 \\
\hline Finland & 519 & 0 & -3 & 9 \\
\hline Canada & 518 & -2 & -2 & 3 \\
\hline Poland & 518 & -2 & 1 & -3 \\
\hline Belgium & 515 & -2 & 1 & -2 \\
\hline Germany & 514 & -3 & 2 & 3 \\
\hline Viet Nam & 511 & -14 & 12 & -15 \\
\hline Austria & 506 & -6 & 4 & 3 \\
\hline Australia & 504 & -6 & -4 & 10 \\
\hline Ireland & 501 & -9 & 1 & 5 \\
\hline Slovenia & 501 & -9 & 4 & -3 \\
\hline Denmark & 500 & 2 & -5 & 8 \\
\hline New Zealand & 500 & -4 & -5 & 11 \\
\hline Czech Republic & 499 & -4 & 5 & -5 \\
\hline France & 495 & -12 & 1 & 16 \\
\hline OECD average & 494 & -2 & -1 & 3 \\
\hline United Kingdom & 494 & -5 & -2 & 7 \\
\hline Iceland & 493 & 7 & -3 & 0 \\
\hline Latvia & 491 & -3 & 5 & -4 \\
\hline Luxembourg & 490 & -8 & 3 & 5 \\
\hline Norway & 489 & 0 & -3 & 9 \\
\hline Portugal & 487 & -8 & 2 & 3 \\
\hline Italy & 485 & -10 & 0 & 13 \\
\hline Spain & 484 & -8 & -3 & 11 \\
\hline Russian Federation & 482 & -1 & 5 & -11 \\
\hline Slovak Republic & 482 & -1 & 4 & -8 \\
\hline United States & 481 & -6 & -1 & 8 \\
\hline Lithuania & 479 & -1 & 3 & -8 \\
\hline Sweden & 478 & 1 & -4 & 7 \\
\hline Hungary & 477 & -8 & 4 & 0 \\
\hline Croatia & 471 & -19 & 6 & 6 \\
\hline Israel & 466 & -2 & 2 & -5 \\
\hline Greece & 453 & -5 & -4 & 14 \\
\hline Serbia & 449 & -2 & 2 & -3 \\
\hline Turkey & 448 & 1 & 0 & -2 \\
\hline Romania & 445 & 0 & 1 & -6 \\
\hline Cyprus 1,2 & 440 & -3 & 3 & -4 \\
\hline Bulgaria & 439 & -2 & 0 & 2 \\
\hline United Arab Emirates & 434 & -8 & 6 & -6 \\
\hline Kazakhstan & 432 & 10 & 1 & -12 \\
\hline Thailand & 427 & -11 & -1 & 5 \\
\hline Chile & 423 & -3 & -6 & 10 \\
\hline Malaysia & 421 & -15 & 2 & -3 \\
\hline Mexico & 413 & -4 & 0 & 0 \\
\hline Montenegro & 410 & -6 & 0 & 4 \\
\hline Uruguay & 409 & -3 & -2 & 0 \\
\hline Costa Rica & 407 & -8 & -6 & 11 \\
\hline Albania & 394 & 4 & 3 & -16 \\
\hline Brazil & 391 & -16 & -4 & 10 \\
\hline Argentina & 388 & -5 & -1 & 1 \\
\hline Tunisia & 388 & -15 & 2 & -3 \\
\hline Jordan & 386 & 4 & -2 & -3 \\
\hline Colombia & 376 & -2 & -9 & 11 \\
\hline Qatar & 376 & 1 & -3 & -1 \\
\hline Indonesia & 375 & -7 & -6 & 4 \\
\hline Peru & 368 & 2 & 0 & 0 \\
\hline
\end{tabular}

1. Note by Turkey: The information in this document with reference to "Cyprus" relates to the southern part of the Island. There is no single authority representing both Turkish and Greek Cypriot people on the Island. Turkey recognises the Turkish Republic of Northern Cyprus (TRNC). Until a lasting and equitable solution is found within the context of the United Nations, Turkey shall preserve its position concerning the "Cyprus issue".

2. Note by all the European Union Member States of the OECD and the European Union: The Republic of Cyprus is recognised by all members of the United Nations with the exception of Turkey. The information in this document relates to the area under the effective control of the Government of the Republic of Cyprus.

Source: OECD, PISA 2012 Database, Tables I.2.3a, I.2.7, I.2.10 and I.2.13.

StatLink तitst http://dx.doi.org/10.1787/888932935572 


\section{Where countries and economies rank on the different mathematics process subscales}

\begin{tabular}{|c|c|c|c|c|c|}
\hline & \multicolumn{3}{|c|}{$\begin{array}{l}\text { Statistically significantly above the OECD average } \\
\text { Not statistically significantly different from the OECD average } \\
\text { Statistically significantly below the OECD average }\end{array}$} & & \\
\hline & \multirow[b]{4}{*}{ Mean score } & \multicolumn{3}{|c|}{ Formulating subscale } & \\
\hline & & \multicolumn{4}{|c|}{ Range of ranks } \\
\hline & & \multicolumn{2}{|c|}{ OECD countries } & \multicolumn{2}{|c|}{ All countries/economies } \\
\hline & & Upper rank & Lower rank & Upper rank & Lower rank \\
\hline Shanghai-China & 624 & & & 1 & 1 \\
\hline Singapore & 582 & & & 2 & 3 \\
\hline Chinese Taipei & 578 & & & 2 & 3 \\
\hline Hong Kong-China & 568 & & & 4 & 5 \\
\hline Korea & 562 & 1 & 2 & 4 & 6 \\
\hline Japan & 554 & 1 & 2 & 5 & 6 \\
\hline Macao-China & 545 & & & 7 & 8 \\
\hline Switzerland & 538 & 3 & 3 & 8 & 9 \\
\hline Liechtenstein & 535 & & & 8 & 10 \\
\hline Netherlands & 527 & 4 & 5 & 9 & 10 \\
\hline Finland & 519 & 5 & 8 & 11 & 14 \\
\hline Estonia & 517 & 5 & 9 & 11 & 15 \\
\hline Canada & 516 & 5 & 9 & 11 & 15 \\
\hline Poland & 516 & 5 & 10 & 11 & 16 \\
\hline Belgium & 512 & 7 & 10 & 13 & 16 \\
\hline Germany & 511 & 7 & 11 & 13 & 17 \\
\hline Denmark & 502 & 11 & 14 & 16 & 20 \\
\hline Iceland & 500 & 11 & 15 & 17 & 21 \\
\hline Austria & 499 & 11 & 16 & 17 & 23 \\
\hline Australia & 498 & 12 & 16 & 18 & 23 \\
\hline Viet Nam & 497 & & & 17 & 27 \\
\hline New Zealand & 496 & 12 & 18 & 18 & 25 \\
\hline Czech Republic & 495 & 12 & 19 & 18 & 27 \\
\hline Ireland & 492 & 15 & 20 & 21 & 27 \\
\hline Slovenia & 492 & 16 & 20 & 22 & 27 \\
\hline Norway & 489 & 16 & 21 & 22 & 29 \\
\hline United Kingdom & 489 & 15 & 22 & 22 & 31 \\
\hline Latvia & 488 & & & 23 & 30 \\
\hline France & 483 & 20 & 25 & 27 & 34 \\
\hline Luxembourg & 482 & 21 & 24 & 29 & 33 \\
\hline Russian Federation & 481 & & & 27 & 37 \\
\hline Slovak Republic & 480 & 20 & 28 & 28 & 38 \\
\hline Sweden & 479 & 21 & 27 & 29 & 37 \\
\hline Portugal & 479 & 20 & 28 & 28 & 38 \\
\hline Lithuania & 477 & & & 30 & 38 \\
\hline Spain & 477 & 23 & 28 & 32 & 38 \\
\hline United States & 475 & 22 & 29 & 30 & 39 \\
\hline Italy & 475 & 24 & 29 & 33 & 39 \\
\hline Hungary & 469 & 27 & 30 & 37 & 40 \\
\hline Israel & 465 & 28 & 30 & 38 & 41 \\
\hline Croatia & 453 & & & 41 & 45 \\
\hline Turkey & 449 & 31 & 32 & 41 & 46 \\
\hline Greece & 448 & 31 & 32 & 41 & 45 \\
\hline Serbia & 447 & & & 41 & 46 \\
\hline Romania & 445 & & & 41 & 47 \\
\hline Kazakhstan & 442 & & & 43 & 48 \\
\hline Bulgaria & 437 & & & 45 & 48 \\
\hline Cyprus $^{1,2}$ & 437 & & & 46 & 48 \\
\hline United Arab Emirates & 426 & & & 49 & 50 \\
\hline Chile & 420 & 33 & 33 & 49 & 51 \\
\hline Thailand & 416 & & & 50 & 52 \\
\hline Mexico & 409 & 34 & 34 & 51 & 53 \\
\hline Uruguay & 406 & & & 52 & 56 \\
\hline Malaysia & 406 & & & 52 & 56 \\
\hline Montenegro & 404 & & & 53 & 56 \\
\hline Costa Rica & 399 & & & 54 & 57 \\
\hline Albania & 398 & & & 56 & 57 \\
\hline Jordan & 390 & & & 58 & 59 \\
\hline Argentina & 383 & & & 58 & 61 \\
\hline Qatar & 378 & & & 59 & 62 \\
\hline Brazil & 376 & & & 60 & 64 \\
\hline Colombia & 375 & & & 59 & 64 \\
\hline Tunisia & 373 & & & 60 & 65 \\
\hline Peru & 370 & & & 62 & 65 \\
\hline Indonesia & 368 & & & 62 & 65 \\
\hline
\end{tabular}

1. Note by Turkey: The information in this document with reference to "Cyprus" relates to the southern part of the Island. There is no single authority representing both Turkish and Greek Cypriot people on the Island. Turkey recognises the Turkish Republic of Northern Cyprus (TRNC). Until a lasting and equitable solution is found within the context of the United Nations, Turkey shall preserve its position concerning the "Cyprus issue".

2. Note by all the European Union Member States of the OECD and the European Union: The Republic of Cyprus is recognised by all members of the United Nations with the exception of Turkey. The information in this document relates to the area under the effective control of the Government of the Republic of Cyprus.

Source: OECD, PISA 2012 Database.

StatLink 靖细 http://dx.doi.org/10.1787/888932935572 


\section{Where countries and economies rank on the different mathematics process subscales}

Figure 1.2.38 [Part 2/3]

\begin{tabular}{|c|c|c|c|c|c|}
\hline & \multicolumn{3}{|c|}{$\begin{array}{l}\text { Statistically significantly above the OECD average } \\
\text { Not statistically significantly different from the OECD average } \\
\text { Statistically significantly below the OECD average }\end{array}$} & & \\
\hline & \multirow[b]{4}{*}{ Mean score } & \multicolumn{3}{|c|}{ Employing subscale } & \\
\hline & & \multicolumn{4}{|c|}{ Range of ranks } \\
\hline & & \multicolumn{2}{|c|}{ OECD countries } & \multicolumn{2}{|c|}{ All countries/economies } \\
\hline & & Upper rank & Lower rank & Upper rank & Lower rank \\
\hline Shanghai-China & 613 & & & 1 & 1 \\
\hline Singapore & 574 & & & 2 & 2 \\
\hline Hong Kong-China & 558 & & & 3 & 4 \\
\hline Korea & 553 & 1 & 1 & 3 & 5 \\
\hline Chinese Taipei & 549 & & & 4 & 5 \\
\hline Liechtenstein & 536 & & & 6 & 8 \\
\hline Macao-China & 536 & & & 6 & 7 \\
\hline Japan & 530 & 2 & 4 & 6 & 10 \\
\hline Switzerland & 529 & 2 & 4 & 7 & 10 \\
\hline Estonia & 524 & 3 & 5 & 9 & 12 \\
\hline Viet Nam & 523 & & & 8 & 17 \\
\hline Poland & 519 & 4 & 10 & 10 & 17 \\
\hline Netherlands & 518 & 4 & 10 & 10 & 17 \\
\hline Canada & 517 & 5 & 10 & 12 & 17 \\
\hline Germany & 516 & 5 & 11 & 12 & 18 \\
\hline Belgium & 516 & 5 & 10 & 12 & 17 \\
\hline Finland & 516 & 6 & 10 & 12 & 17 \\
\hline Austria & 510 & 9 & 12 & 16 & 19 \\
\hline Slovenia & 505 & 12 & 14 & 19 & 21 \\
\hline Czech Republic & 504 & 11 & 15 & 18 & 22 \\
\hline Ireland & 502 & 12 & 16 & 19 & 23 \\
\hline Australia & 500 & 13 & 16 & 20 & 23 \\
\hline France & 496 & 15 & 20 & 22 & 28 \\
\hline Latvia & 495 & & & 22 & 29 \\
\hline New Zealand & 495 & 15 & 20 & 22 & 28 \\
\hline Denmark & 495 & 16 & 21 & 23 & 29 \\
\hline Luxembourg & 493 & 17 & 21 & 25 & 29 \\
\hline United Kingdom & 492 & 16 & 23 & 23 & 32 \\
\hline Iceland & 490 & 19 & 23 & 27 & 32 \\
\hline Portugal & 489 & 17 & 26 & 24 & 36 \\
\hline Russian Federation & 487 & & & 28 & 37 \\
\hline Norway & 486 & 20 & 26 & 28 & 36 \\
\hline Italy & 485 & 22 & 27 & 30 & 36 \\
\hline Slovak Republic & 485 & 21 & 28 & 28 & 38 \\
\hline Lithuania & 482 & & & 32 & 39 \\
\hline Spain & 481 & 24 & 28 & 33 & 39 \\
\hline Hungary & 481 & 23 & 29 & 32 & 40 \\
\hline United States & 480 & 24 & 29 & 33 & 40 \\
\hline Croatia & 478 & & & 35 & 41 \\
\hline Sweden & 474 & 28 & 30 & 38 & 41 \\
\hline Israel & 469 & 29 & 30 & 39 & 41 \\
\hline Serbia & 451 & & & 42 & 45 \\
\hline Greece & 449 & 31 & 32 & 42 & 45 \\
\hline Turkey & 448 & 31 & 32 & 42 & 47 \\
\hline Romania & 446 & & & 42 & 48 \\
\hline Cyprus 1,2 & 443 & & & 44 & 47 \\
\hline United Arab Emirates & 440 & & & 45 & 48 \\
\hline Bulgaria & 439 & & & 45 & 49 \\
\hline Kazakhstan & 433 & & & 48 & 50 \\
\hline Thailand & 426 & & & 49 & 51 \\
\hline Malaysia & 423 & & & 50 & 52 \\
\hline Chile & 416 & 33 & 34 & 51 & 53 \\
\hline Mexico & 413 & 33 & 34 & 52 & 54 \\
\hline Montenegro & 409 & & & 54 & 55 \\
\hline Uruguay & 408 & & & 53 & 56 \\
\hline Costa Rica & 401 & & & 55 & 57 \\
\hline Albania & 397 & & & 56 & 58 \\
\hline Tunisia & 390 & & & 57 & 61 \\
\hline Brazil & 388 & & & 58 & 61 \\
\hline Argentina & 387 & & & 58 & 61 \\
\hline Jordan & 383 & & & 59 & 61 \\
\hline Qatar & 373 & & & 62 & 63 \\
\hline Indonesia & 369 & & & 62 & 65 \\
\hline Peru & 368 & & & 62 & 65 \\
\hline Colombia & 367 & & & 63 & 65 \\
\hline
\end{tabular}

1. Note by Turkey: The information in this document with reference to "Cyprus" relates to the southern part of the Island. There is no single authority representing both Turkish and Greek Cypriot people on the Island. Turkey recognises the Turkish Republic of Northern Cyprus (TRNC). Until a lasting and equitable solution is found within the context of the United Nations, Turkey shall preserve its position concerning the "Cyprus issue".

2. Note by all the European Union Member States of the OECD and the European Union: The Republic of Cyprus is recognised by all members of the United Nations with the exception of Turkey. The information in this document relates to the area under the effective control of the Government of the Republic of Cyprus.

Source: OECD, PISA 2012 Database.

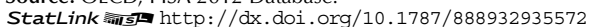


- Figure I.2.38 [Part 3/3]

Where countries and economies rank on the different mathematics process subscales

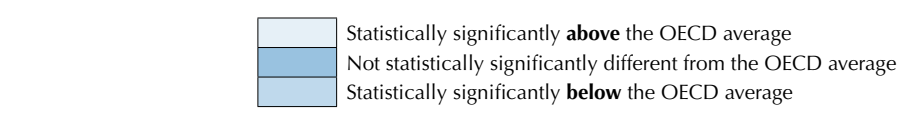

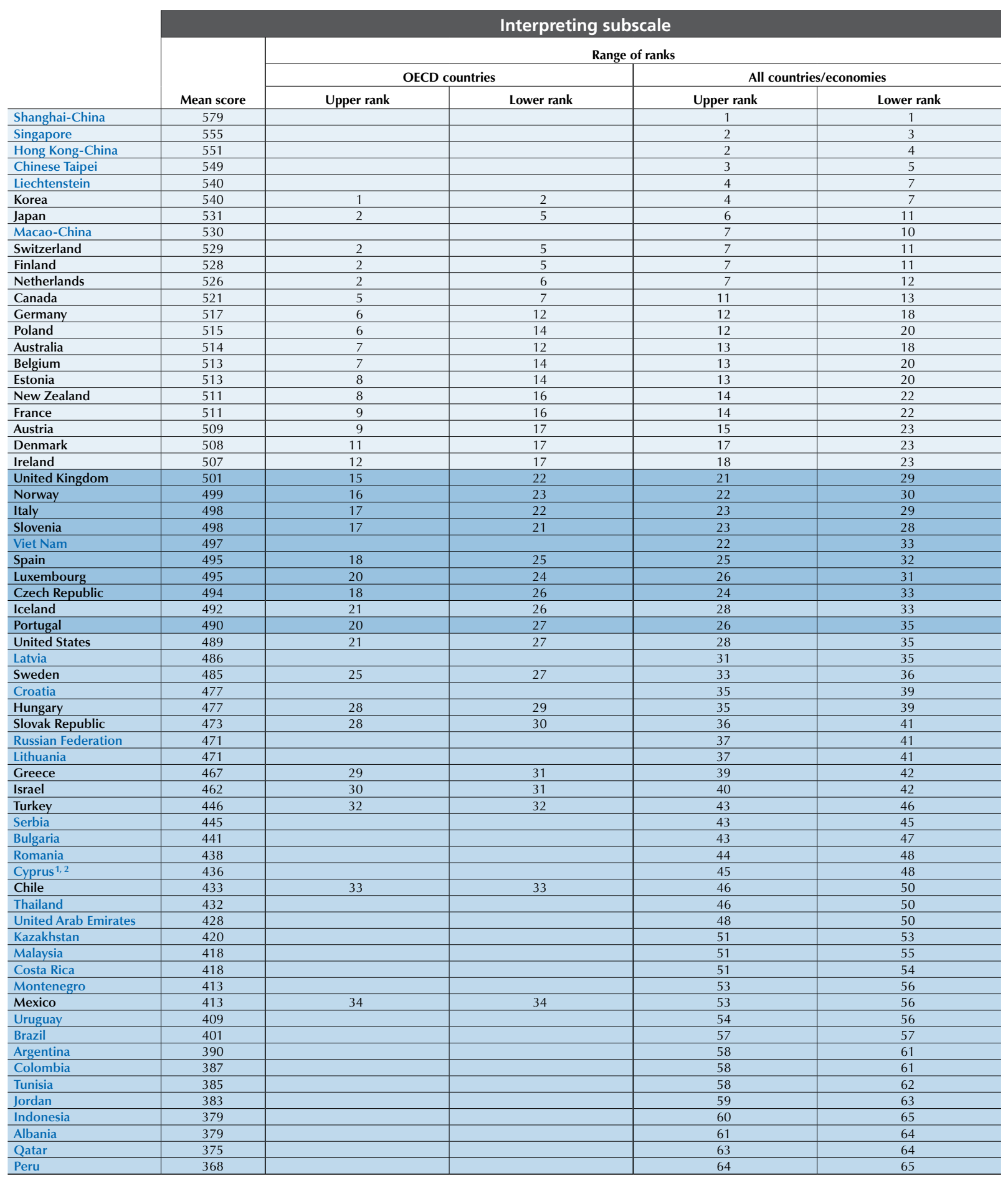

1. Note by Turkey: The information in this document with reference to "Cyprus" relates to the southern part of the Island. There is no single authority representing both Turkish and Greek Cypriot people on the Island. Turkey recognises the Turkish Republic of Northern Cyprus (TRNC). Until a lasting and equitable solution is found within the context of the United Nations, Turkey shall preserve its position concerning the "Cyprus issue".

2. Note by all the European Union Member States of the OECD and the European Union: The Republic of Cyprus is recognised by all members of the United Nations with the exception of Turkey. The information in this document relates to the area under the effective control of the Government of the Republic of Cyprus.

Source: OECD, PISA 2012 Database.

StatLink 靖细 http://dx.doi.org/10.1787/888932935572 


\section{Gender differences in performance on the process subscales}

Figures I.2.39a, b and c show the extent of gender-related differences in performance on the three mathematical processes. In most countries, boys and girls show similar performance on the processes subscales as on the mathematics proficiency scale. Boys also outnumber girls in the top three proficiency levels of the subscales, while girls outnumber boys in the lower levels of the subscales (Tables I.2.6, I.2.9 and I.2.12).

On average across OECD countries, boys outperform girls on the formulating subscale by around 16 points. The largest differences in favour of boys are observed in Luxembourg (33 points), Austria (32 points), Chile (29 points), Italy (24 points), New Zealand (23 points) and Korea (22 points). Ireland, Switzerland and Mexico show a gender difference of 20 points. The difference was less than 10 points in the United States (8 points). Among partner countries and economies, boys outperform girls by 33 points in Costa Rica, and by between 20 and 30 points in Colombia, Liechtenstein, Brazil, Tunisia, Peru, Hong Kong-China, and Uruguay. Several partner countries and economies show gender differences of less than 10 points, including Macao-China (9 points), Shanghai-China (8 points), Kazakhstan (7 points) and Montenegro (6 points). Only one country shows performance differences in favour of girls - Qatar (9 points).

On average among OECD countries, boys outperform girls on the employing subscale by 9 points. In only one OECD country, Iceland, do girls outperform boys - by 7 points. Among partner countries and economies, girls outperform boys on the employing subscale in 6 countries and economies, notably in Jordan (25 points), Thailand (17 points), Qatar (15 points), Malaysia (9 points), Latvia (6 points) and Singapore (6 points). Boys outperform girls by more than 20 points in the partner countries Colombia (28 points) and Costa Rica (23 points).

On average across OECD countries, boys outperform girls on the interpreting subscale by 9 points. The largest differences in favour of boys are recorded in Chile (22 points), Spain (21 points) and Luxembourg (20 points). Among partner countries and economies, large differences in favour of boys are recorded in Liechtenstein (27 points), Costa Rica (21 points) and Colombia (21 points). In Iceland and Finland, girls outperform boys by 11 points, and four partner countries show differences in favour of girls, with measurable differences in Jordan (25 points), Qatar (23 points), Thailand (15 points) and Malaysia (11 points).

\section{Content subscales}

The four content categories in the PISA 2012 assessment - change and relationships, space and shape, quantity and uncertainty and data - aim to capture broad groups of mathematical phenomena that involve different kinds of mathematical thinking and expertise, and that relate to broad parts of the mathematics curriculum found in all countries and economies.

PISA outcomes presented according to this categorisation may reflect differences in curriculum priorities and in course content available to 15-year-olds. For example, in previous PISA assessment, a different profile of outcomes related to the uncertainty and data category compared to the other areas was observed and could be attributed to the fact that the teaching of probability and statistics is not uniform among countries/economies or even within them. Similarly, it might be expected that students who have studied predominantly basic computation and quantitative skills (related most strongly to the quantity category) might have different outcomes from those whose courses emphasised algebra and the study of mathematical functions and relations (which link most strongly to the change and relationships category); and that students in school systems that emphasise geometry can be expected to perform better on the items related to the space and shape category.

\section{Student performance on the mathematics subscale change and relationships}

PISA items in this category emphasise the relationships among objects, and the mathematical processes associated with changes in those relationships. Items listed in Figure 1.2.9 that have been classified in this category are HELEN THE CYCLIST Question 1, Question 2 and Question 3, and CLIMBING MOUNT FUJI Question 2. The questions in HELEN THE CYCLIST relate to the relationships among the variables speed, distance and time in relation to travel by bicycle. CLIMBING MOUNT FUJI also involves thinking about the relationships among the variables distance, speed and time in relation to a walking trip.

The OECD average score on the change and relationships subscale is 493 points. The ten top-performing countries, with a mean score of at least 530 points on this subscale, are Shanghai-China, Singapore, Hong Kong-China, Chinese Taipei, Korea, Macao-China, Japan, Liechtenstein, Estonia and Switzerland (Figure I.2.40 and Table I.2.16). The average score among OECD countries on this subscale is one point lower than the average score on the overall mathematics proficiency scale (Figure I.2.52). 
- Figure I.2.39a

Gender differences in performance on the formulating subscale

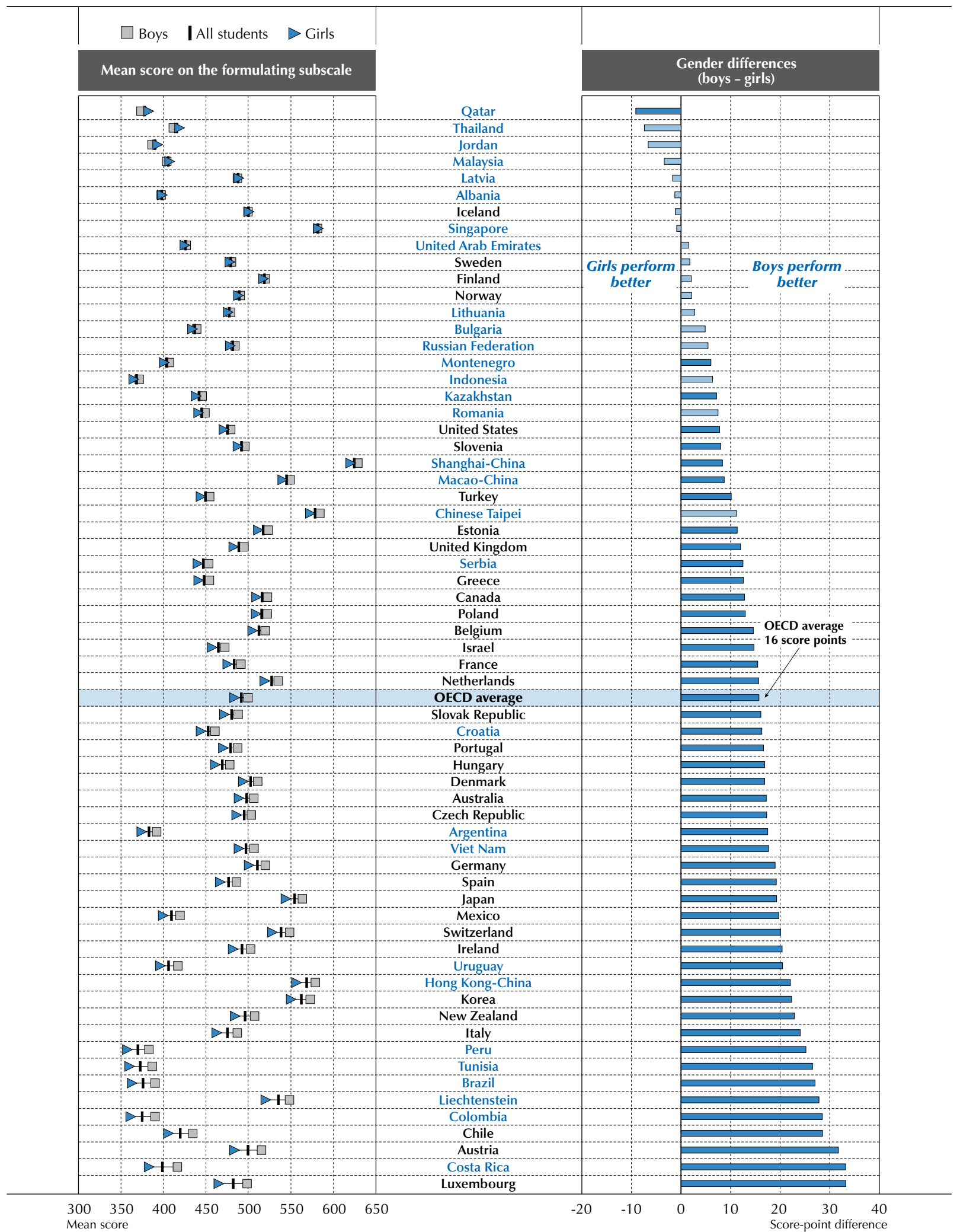

Note: Statistically significant gender differences are marked in a darker tone (see Annex A3).

Countries and economies are ranked in ascending order of the gender score-point difference (boys-girls).

Source: OECD, PISA 2012 Database, Table I.2.7.

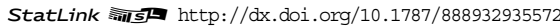


- Figure 1.2.39b

Gender differences in performance on the employing subscale

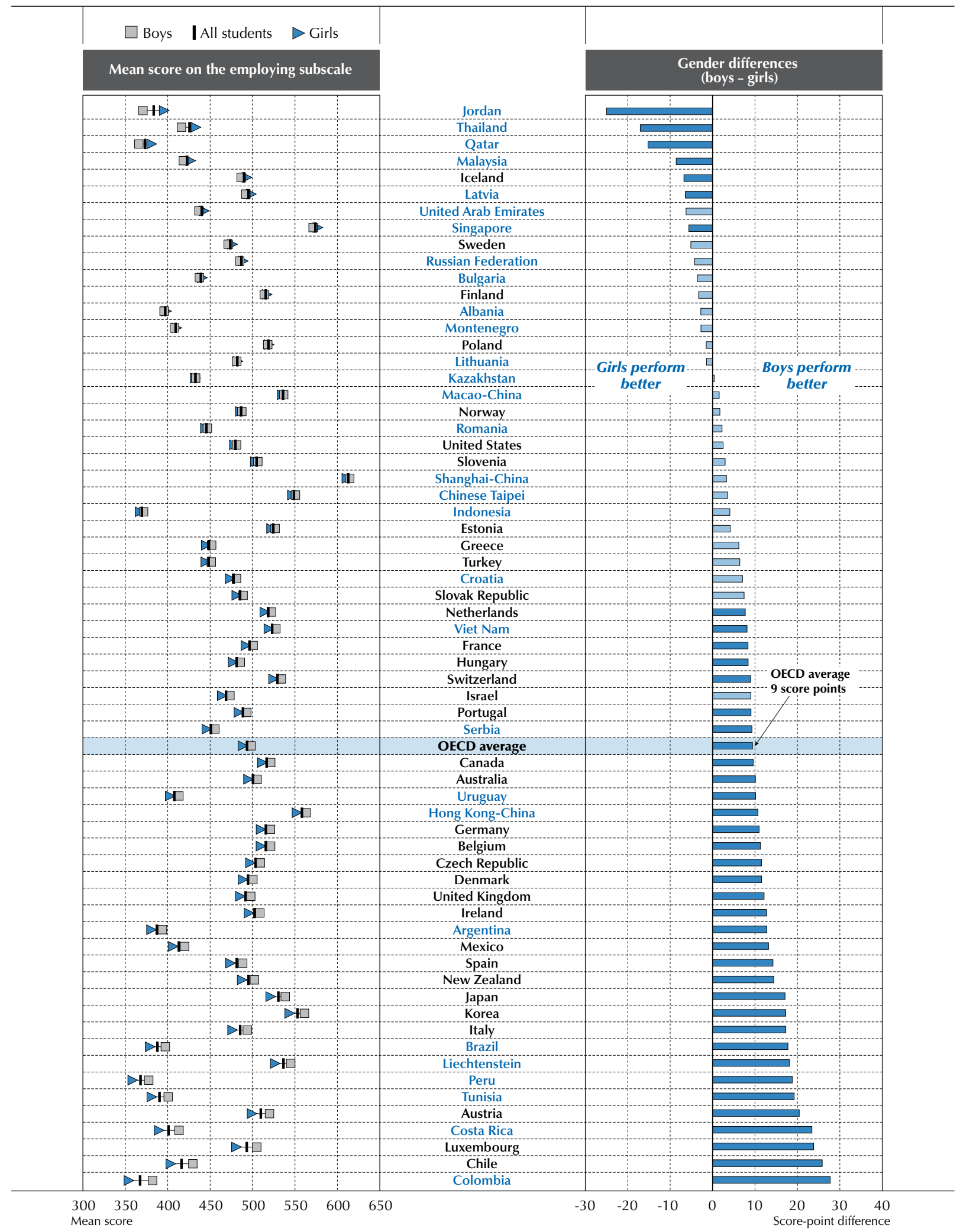

Note: Statistically significant gender differences are marked in a darker tone (see Annex A3).

Countries and economies are ranked in ascending order of the gender score-point difference (boys - girls).

Source: OECD, PISA 2012 Database, Table I.2.10.

StatLink 部鸟 http://dx.doi.org/10.1787/888932935572 
- Figure I.2.39c

\section{Gender differences in performance on the interpreting subscale}

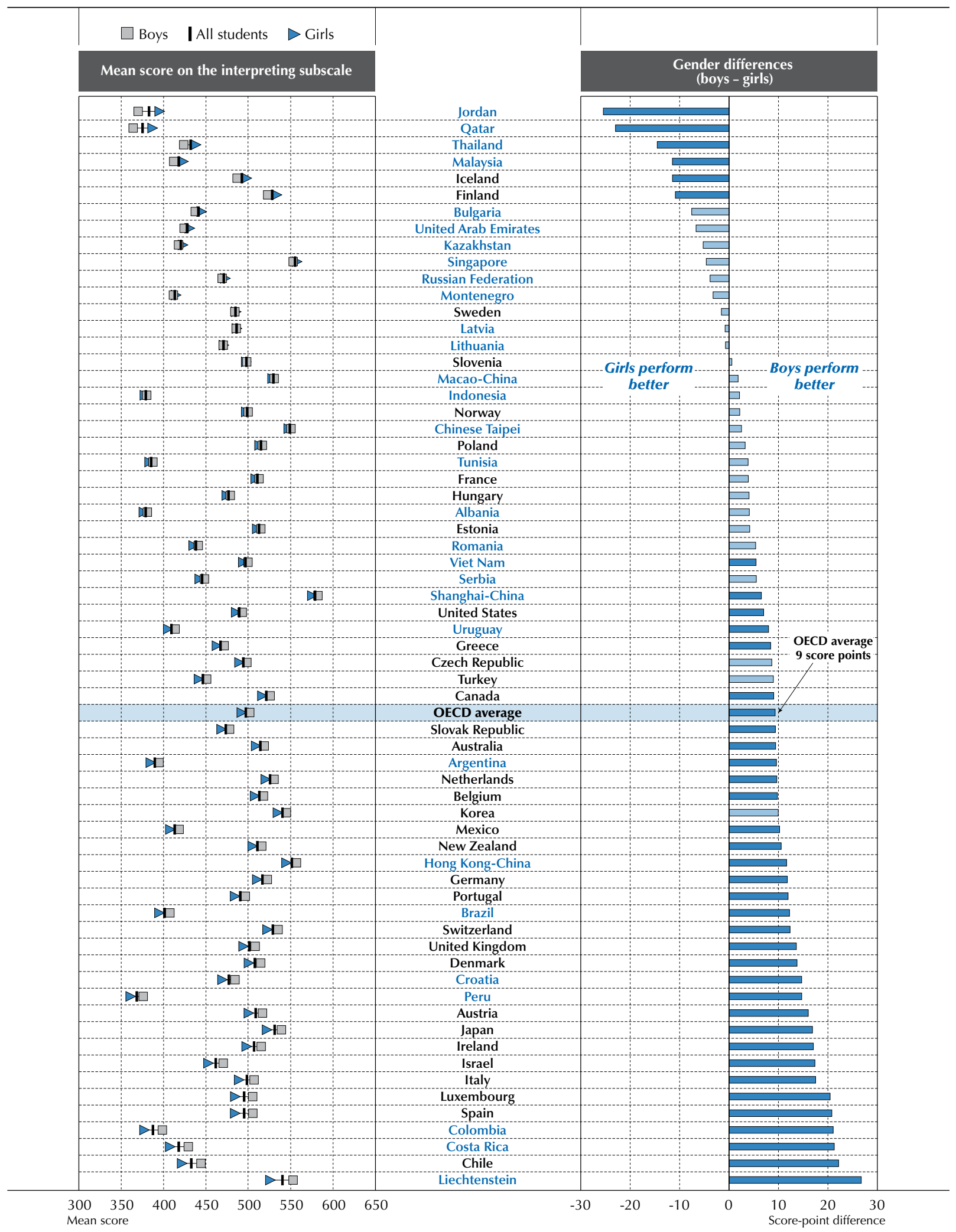

Note: Statistically significant gender differences are marked in a darker tone (see Annex A3).

Countries and economies are ranked in ascending order of the gender score-point difference (boys - girls).

Source: OECD, PISA 2012 Database, Table I.2.13.

StatLink त्राज http://dx.doi.org/10.1787/888932935572 


\section{Comparing countries' and economies' performance on the mathematics subscale change and relationships}

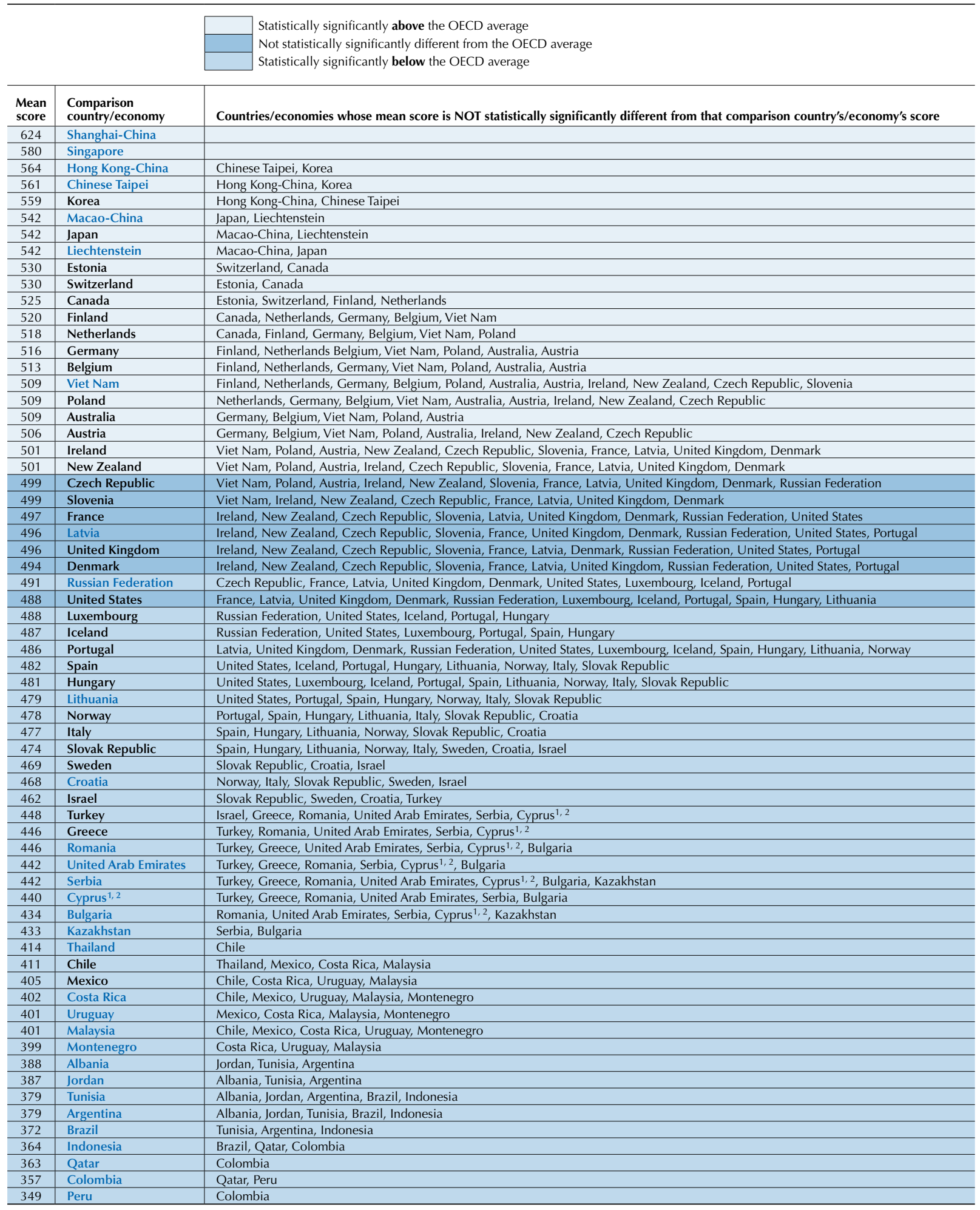

1. Note by Turkey: The information in this document with reference to "Cyprus" relates to the southern part of the Island. There is no single authority representing both Turkish and Greek Cypriot people on the Island. Turkey recognises the Turkish Republic of Northern Cyprus (TRNC). Until a lasting and equitable solution is found within the context of the United Nations, Turkey shall preserve its position concerning the "Cyprus issue".

2. Note by all the European Union Member States of the OECD and the European Union: The Republic of Cyprus is recognised by all members of the United Nations with the exception of Turkey. The information in this document relates to the area under the effective control of the Government of the Republic of Cyprus.

Source: OECD, PISA 2012 Database.

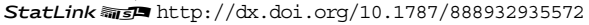


Fourteen countries and economies score more than three points higher on this subscale than on the overall mathematics scale. Eleven of these countries and economies score more than five points above the overall mathematics scale. They include Shanghai-China, which scores 11 points higher (the largest difference) on the change and relationships subscale than on the overall mathematics scale, followed by Estonia, the Russian Federation, the United Arab Emirates, Liechtenstein, Canada, Singapore, the United States, Japan, Latvia and Korea. Seven of these countries and economies score well above the OECD average on the overall mathematics proficiency scale.

At the other end of the spectrum, 28 countries show average scores on the change and relationships subscale that are more than three points lower than the average score on the overall mathematics proficiency scale. Among these countries, Brazil, Colombia, Malaysia and Peru score between 19 and 20 points lower on the subscale than on the overall mathematics proficiency scale; Qatar, Thailand, Norway, Chile, Montenegro and Indonesia score between 10 and 14 points lower; and 14 other countries and economies also score lower on the subscale than on the overall proficiency scale, by a difference of at least 5 points (Figure I.2.52).

Figure 1.2.41 describes the six levels of proficiency on the mathematics subscale change and relationships and the distribution of students among these six proficiency levels is shown in Figure I.2.42.

\section{Summary descriptions of the six proficiency levels for the mathematical subscale change and relationships}

\begin{tabular}{|c|c|c|}
\hline Level & $\begin{array}{l}\text { Percentage of students } \\
\text { able to perform tasks } \\
\text { at each level or above } \\
\text { (OECD average) }\end{array}$ & What students can do \\
\hline 6 & $4.5 \%$ & $\begin{array}{l}\text { At Level } 6 \text {, students use significant insight, abstract reasoning and argumentation skills, and } \\
\text { technical knowledge and conventions to solve problems involving relationships among } \\
\text { variables and to generalise mathematical solutions to complex real-world problems. They } \\
\text { can create and use an algebraic model of a functional relationship incorporating multiple } \\
\text { quantities. They apply deep geometrical insight to work with complex patterns; and they can } \\
\text { use complex proportional reasoning, and complex calculations with percentages to explore } \\
\text { quantitative relationships and change. }\end{array}$ \\
\hline 5 & $14.5 \%$ & $\begin{array}{l}\text { At Level } 5 \text {, students can solve problems by using algebraic and other formal mathematical } \\
\text { models, including in scientific contexts. They can use complex and multi-step problem- } \\
\text { solving skills, and can reflect on and communicate reasoning and arguments, for example in } \\
\text { evaluating and using a formula to predict the quantitative effect of change in one variable on } \\
\text { another. They can use complex proportional reasoning, for example to work with rates, and } \\
\text { they can work competently with formulae and with expressions including inequalities. }\end{array}$ \\
\hline 4 & $31.9 \%$ & $\begin{array}{l}\text { Students at Level } 4 \text { can understand and work with multiple representations, including algebraic } \\
\text { models of real-world situations. They can reason about simple functional relationships between } \\
\text { variables, going beyond individual data points to identifying simple underlying patterns. They } \\
\text { can use some flexibility in interpretation and reasoning about functional relationships (for } \\
\text { example, in exploring distance-time-speed relationships) and can modify a functional model } \\
\text { or graph to fit a specified change to the situation; and they can communicate the resulting } \\
\text { explanations and arguments. }\end{array}$ \\
\hline 3 & $54.2 \%$ & $\begin{array}{l}\text { At Level 3, students can solve problems that involve working with information from two related } \\
\text { representations (text, graph, table, formulae), requiring some interpretation, and use reasoning } \\
\text { in familiar contexts. They show some ability to communicate their arguments. Students at this } \\
\text { level can make a straightforward modification to a given functional model to fit a new situation; } \\
\text { and they use a range of calculation procedures to solve problems, including ordering data, time } \\
\text { difference calculations, substitution of values into a formula, or linear interpolation. }\end{array}$ \\
\hline 2 & $75.1 \%$ & $\begin{array}{l}\text { Students at Level } 2 \text { can locate relevant information about a relationship from data provided } \\
\text { in a table or graph and make direct comparisons, for example, to match given graphs to a } \\
\text { specified change process. They can reason about the basic meaning of simple relationships } \\
\text { expressed in text or numeric form by linking text with a single representation of a relationship } \\
\text { (graph, table, simple formula), and can correctly substitute numbers into simple formulae, } \\
\text { sometimes expressed in words. At this level, student can use interpretation and reasoning } \\
\text { skills in a straightforward context involving linked quantities. }\end{array}$ \\
\hline 1 & $89.6 \%$ & $\begin{array}{l}\text { Students at Level } 1 \text { can evaluate single given statements about a relationship expressed clearly } \\
\text { and directly in a formula, or in a graph. Their ability to reason about relationships, and to } \\
\text { change in those relationships, is limited to simple expressions and to those located in familiar } \\
\text { situations. They may apply simple calculations needed to solve problems related to clearly } \\
\text { expressed relationships. }\end{array}$ \\
\hline
\end{tabular}


- Figure I.2.42 -

\section{Proficiency in the mathematics subscale change and relationships}

Percentage of students at each level of mathematics proficiency

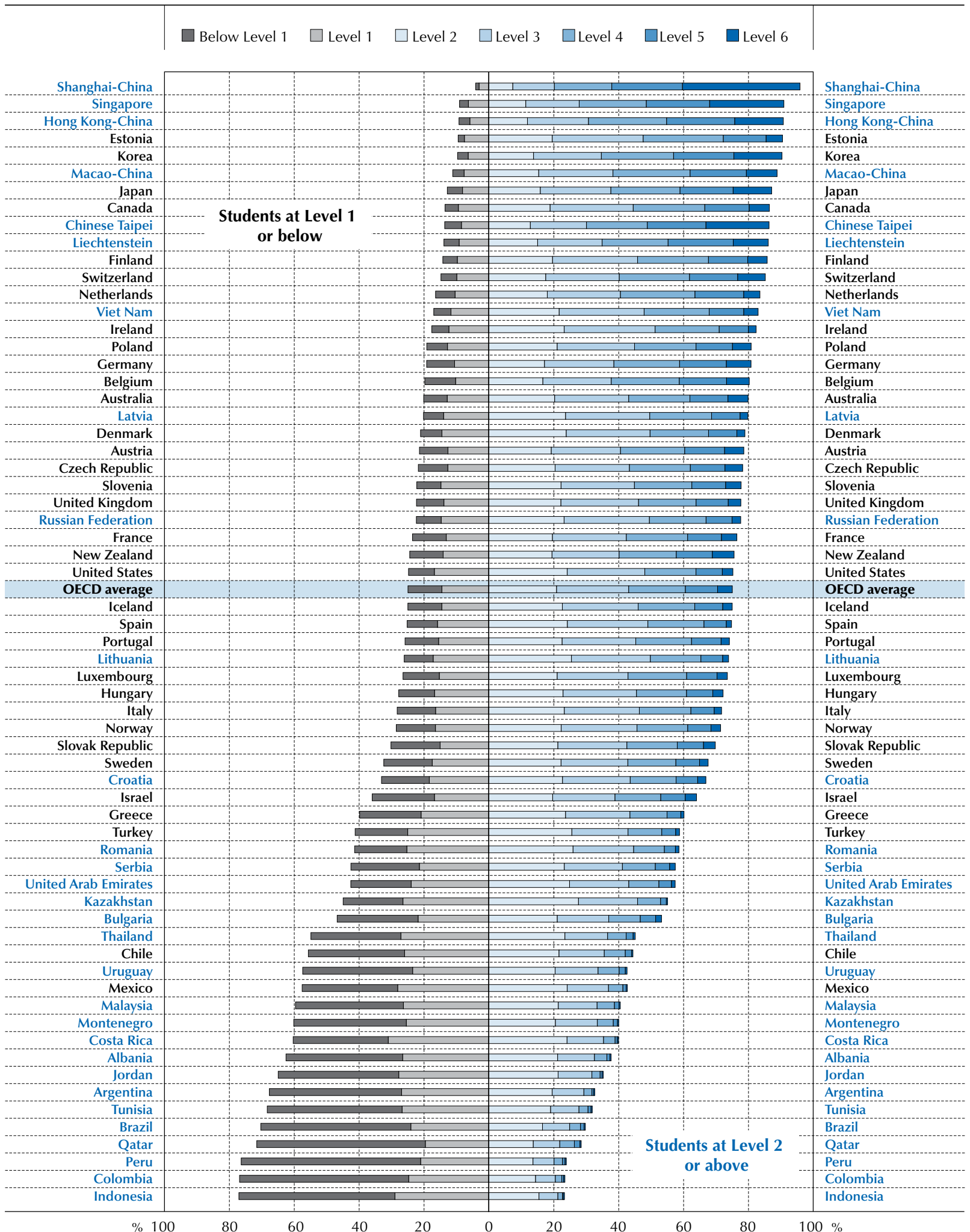

Countries and economies are ranked in descending order of the percentage of students at Levels 2, 3, 4, 5 and 6 .

Source: OECD, PISA 2012 Database, Table I.2.14.

StatLink 解估 http://dx.doi.org/10.1787/888932935572 
- Figure I.2.43

\section{Comparing countries' and economies' performance on the mathematics subscale space and shape}

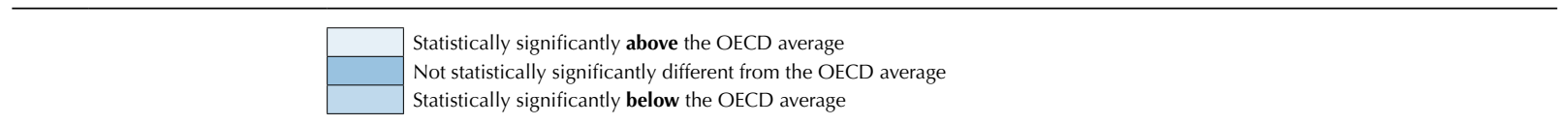

\begin{tabular}{|c|c|c|}
\hline $\begin{array}{l}\text { Mean } \\
\text { score }\end{array}$ & $\begin{array}{l}\text { Comparison } \\
\text { country/economy }\end{array}$ & Countries/economies whose mean score is NOT statistically significantly different from that comparison country's/economy's score \\
\hline 649 & Shanghai-China & \\
\hline 592 & Chinese Taipei & \\
\hline 580 & Singapore & Korea \\
\hline 573 & Korea & Singapore, Hong Kong-China \\
\hline 567 & Hong Kong-China & Korea, Japan \\
\hline 558 & Macao-China & Japan \\
\hline 558 & Japan & Hong Kong-China, Macao-China \\
\hline 544 & Switzerland & Liechtenstein \\
\hline 539 & Liechtenstein & Switzerland \\
\hline 524 & Poland & \\
\hline 513 & Estonia & Canada, Belgium, Netherlands, Germany, Viet Nam, Finland \\
\hline 510 & Canada & Estonia, Belgium, Netherlands, Germany, Viet Nam, Finland \\
\hline 509 & Belgium & Estonia, Canada, Netherlands, Germany, Viet Nam, Finland \\
\hline 507 & Netherlands & Estonia, Canada, Belgium, Germany, Viet Nam, Finland, Slovenia, Austria, Czech Republic \\
\hline 507 & Germany & Estonia, Canada, Belgium, Netherlands, Viet Nam, Finland, Slovenia, Austria, Czech Republic \\
\hline 507 & Viet Nam & Estonia, Canada, Belgium, Netherlands, Germany, Finland, Slovenia, Austria, Czech Republic, Latvia, Denmark, Australia, Russian Federation \\
\hline 507 & Finland & Estonia, Canada, Belgium, Netherlands, Germany, Viet Nam, Slovenia, Austria \\
\hline 503 & Slovenia & Netherlands, Germany, Viet Nam, Finland, Austria, Czech Republic, Latvia, Russian Federation \\
\hline 501 & Austria & Netherlands, Germany, Viet Nam, Finland, Slovenia, Czech Republic, Latvia, Denmark, Australia, Russian Federation, Portugal \\
\hline 499 & Czech Republic & Netherlands, Germany, Viet Nam, Slovenia, Austria, Latvia, Denmark, Australia, Russian Federation, Portugal, New Zealand, Slovak Republic \\
\hline 497 & Latvia & Viet Nam, Slovenia, Austria, Czech Republic, Denmark, Australia, Russian Federation, Portugal, New Zealand, Slovak Republic, France \\
\hline 497 & Denmark & Viet Nam, Austria, Czech Republic, Latvia, Australia, Russian Federation, Portugal, New Zealand, Slovak Republic \\
\hline 497 & Australia & Viet Nam, Austria, Czech Republic, Latvia, Denmark, Russian Federation, Portugal, New Zealand, Slovak Republic \\
\hline 496 & Russian Federation & Viet Nam, Slovenia, Austria, Czech Republic, Latvia, Denmark, Australia, Portugal, New Zealand, Slovak Republic, France, Iceland, Italy \\
\hline 491 & Portugal & Austria, Czech Republic, Latvia, Denmark, Australia, Russian Federation, New Zealand, Slovak Republic, France, Iceland, Italy, Luxembourg \\
\hline 491 & New Zealand & Czech Republic, Latvia, Denmark, Australia, Russian Federation, Portugal, Slovak Republic, France, Iceland, Italy, Luxembourg \\
\hline 490 & Slovak Republic & Czech Republic, Latvia, Denmark, Australia, Russian Federation, Portugal, New Zealand, France, Iceland, Italy, Luxembourg, Norway \\
\hline 489 & France & Latvia, Russian Federation, Portugal, New Zealand, Slovak Republic, Iceland, Italy, Luxembourg \\
\hline 489 & Iceland & Russian Federation, Portugal, New Zealand, Slovak Republic, France, Italy, Luxembourg \\
\hline 487 & Italy & Russian Federation, Portugal, New Zealand, Slovak Republic, France, Iceland Luxembourg, Norway \\
\hline 486 & Luxembourg & Portugal, New Zealand, Slovak Republic, France, Iceland, Italy, Norway \\
\hline 480 & Norway & Slovak Republic, Italy, Luxembourg, Ireland, Spain, United Kingdom, Hungary, Lithuania \\
\hline 478 & Ireland & Norway, Spain, United Kingdom, Hungary, Lithuania \\
\hline 477 & Spain & Norway, Ireland, United Kingdom, Hungary, Lithuania \\
\hline 475 & United Kingdom & Norway, Ireland, Spain, Hungary, Lithuania, Sweden \\
\hline 474 & Hungary & Norway, Ireland, Spain, United Kingdom, Lithuania, Sweden, United States \\
\hline 472 & Lithuania & Norway, Ireland, Spain, United Kingdom, Hungary, Sweden, United States \\
\hline 469 & Sweden & United Kingdom, Hungary, Lithuania, United States, Croatia \\
\hline 463 & United States & Hungary, Lithuania, Sweden, Croatia \\
\hline 460 & Croatia & Sweden, United States, Kazakhstan, Israel \\
\hline 450 & Kazakhstan & Croatia, Israel, Romania, Serbia, Turkey, Bulgaria \\
\hline 449 & Israel & Croatia, Kazakhstan, Romania, Serbia, Turkey, Bulgaria \\
\hline 447 & Romania & Kazakhstan, Israel, Serbia, Turkey, Bulgaria \\
\hline 446 & Serbia & Kazakhstan, Israel, Romania, Turkey, Bulgaria \\
\hline 443 & Turkey & Kazakhstan, Israel, Romania, Serbia, Bulgaria, Greece, Cyprus $^{1,2}$, Malaysia, Thailand \\
\hline 442 & Bulgaria & Kazakhstan, Israel, Romania, Serbia, Turkey, Greece, Cyprus 1,2, Malaysia, Thailand \\
\hline 436 & Greece & Turkey, Bulgaria, Cyprus ${ }^{1,2}$, Malaysia, Thailand \\
\hline 436 & Cyprus ${ }^{1,2}$ & Turkey, Bulgaria, Greece, Malaysia, Thailand \\
\hline 434 & Malaysia & Turkey, Bulgaria, Greece, Cyprus ${ }^{1,2}$, Thailand \\
\hline 432 & Thailand & Turkey, Bulgaria, Greece, Cyprus ${ }^{1,2}$, Malaysia, United Arab Emirates \\
\hline 425 & United Arab Emirates & Thailand, Chile \\
\hline 419 & Chile & United Arab Emirates, Albania, Uruguay, Mexico \\
\hline 418 & Albania & Chile, Uruguay, Mexico, Montenegro \\
\hline 413 & Uruguay & Chile, Albania, Mexico, Montenegro \\
\hline 413 & Mexico & Chile, Albania, Uruguay, Montenegro \\
\hline 412 & Montenegro & Albania, Uruguay, Mexico \\
\hline 397 & Costa Rica & \\
\hline 385 & Jordan & Argentina, Indonesia, Tunisia, Brazil, Qatar \\
\hline 385 & Argentina & Jordan, Indonesia, Tunisia, Brazil, Qatar \\
\hline 383 & Indonesia & Jordan, Argentina, Tunisia, Brazil, Qatar \\
\hline 382 & Tunisia & Jordan, Argentina, Indonesia, Brazil, Qatar \\
\hline 381 & Brazil & Jordan, Argentina, Indonesia, Tunisia, Qatar \\
\hline 380 & Qatar & Jordan, Argentina, Indonesia, Tunisia, Brazil \\
\hline 370 & Peru & Colombia \\
\hline 369 & Colombia & Peru \\
\hline
\end{tabular}

1. Note by Turkey: The information in this document with reference to "Cyprus" relates to the southern part of the Island. There is no single authority representing both Turkish and Greek Cypriot people on the Island. Turkey recognises the Turkish Republic of Northern Cyprus (TRNC). Until a lasting and equitable solution is found within the context of the United Nations, Turkey shall preserve its position concerning the "Cyprus issue".

2. Note by all the European Union Member States of the OECD and the European Union: The Republic of Cyprus is recognised by all members of the United Nations with the exception of Turkey. The information in this document relates to the area under the effective control of the Government of the Republic of Cyprus.

Source: OECD, PISA 2012 Database.

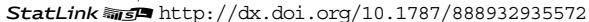




\section{Student performance on the mathematics subscale space and shape}

PISA items in this category emphasise spatial relationships among objects, and measurement and other geometric aspects of the spatial world. Items listed in Figure I.2.9 that have been classified in this category are GARAGE Question 1 and Question 2, and REVOLVING DOOR Question 1 and Question 2. The questions in GARAGE involve spatial reasoning (Question 1), and working with measurements and area calculations with a model of a real-world object. REVOLVING DOOR involves knowledge of angle relationships, spatial reasoning and some calculations with circle geometry.

Across OECD countries, the average score attained on the space and shape subscale is 490 points. Top-performing countries and economies on this subscale are Shanghai-China, Chinese Taipei, Singapore, Korea, Hong Kong-China, Macao-China, Japan, Switzerland, Liechtenstein and Poland (Figure I.2.43 and Table I.2.19). The average score among OECD countries on this subscale is four points lower than the average score on the overall mathematics proficiency scale (Figure I.2.52). However, this difference varies widely among countries.

- Figure I.2.44

Summary descriptions of the six proficiency levels for the mathematical subscale space and shape

\begin{tabular}{|c|c|c|}
\hline Level & $\begin{array}{l}\text { Percentage of students } \\
\text { able to perform tasks } \\
\text { at each level or above } \\
\text { (OECD average) }\end{array}$ & What students can do \\
\hline 6 & $4.5 \%$ & $\begin{array}{l}\text { At Level 6, students can solve complex problems involving multiple representations or } \\
\text { calculations; identify, extract, and link relevant information, for example by extracting } \\
\text { relevant dimensions from a diagram or map and using scale to calculate an area or distance; } \\
\text { use spatial reasoning, significant insight and reflection, for example, by interpreting text and } \\
\text { related contextual material to formulate a useful geometric model and applying it while taking } \\
\text { into account contextual constraints; recall and apply relevant procedural knowledge from } \\
\text { their base of mathematical knowledge, such as in circle geometry, trigonometry, Pythagoras's } \\
\text { rule, or area and volume formulae to solve problems; and can generalise results and findings, } \\
\text { communicate solutions and provide justifications and argumentation. }\end{array}$ \\
\hline 5 & $13.4 \%$ & $\begin{array}{l}\text { At Level 5, students can solve problems that require appropriate assumptions to be made, or } \\
\text { that involve reasoning from assumptions provided while taking into account explicitly stated } \\
\text { constraints, for example, in exploring and analysing the layout of a room and the furniture it } \\
\text { contains. They solve problems using theorems or procedural knowledge, such as symmetry } \\
\text { properties, or similar triangle properties or formulae including those for calculating area, } \\
\text { perimeter or volume of familiar shapes. They use well-developed spatial reasoning, argument } \\
\text { and insight to infer relevant conclusions and to interpret and link different representations, for } \\
\text { example to identify a direction or location on a map from textual information. }\end{array}$ \\
\hline 4 & $29.7 \%$ & $\begin{array}{l}\text { Students at Level } 4 \text { can solve problems by using basic mathematical knowledge, such as angle } \\
\text { and side-length relationships in triangles, and by doing so in a way that involves multistep, } \\
\text { visual and spatial reasoning, and argumentation in unfamiliar contexts. They can link and } \\
\text { integrate different representations, for example to analyse the structure of a three-dimensional } \\
\text { object based on two different perspectives of it; and can compare objects using geometric } \\
\text { properties. }\end{array}$ \\
\hline 3 & $51.9 \%$ & $\begin{array}{l}\text { At Level 3, students can solve problems that involve elementary visual and spatial reasoning } \\
\text { in familiar contexts, such as calculating a distance or a direction from a map or a GPS device; } \\
\text { link different representations of familiar objects or appreciate properties of objects under some } \\
\text { simple specified transformation; and devise simple strategies and apply basic properties of } \\
\text { triangles and circles. They can use appropriate supporting calculation techniques, such as } \\
\text { scale conversions needed to analyse distances on a map. }\end{array}$ \\
\hline 2 & $74.2 \%$ & $\begin{array}{l}\text { At Level 2, students can solve problems involving a single familiar geometric representation } \\
\text { (for example, a diagram or other graphic) by comprehending and drawing conclusions in } \\
\text { relation to clearly presented basic geometric properties and associated constraints. They can } \\
\text { also evaluate and compare spatial characteristics of familiar objects in a situation where given } \\
\text { constraints apply, such as comparing the height or circumference of two cylinders having the } \\
\text { same surface area, or deciding whether a given shape can be dissected to produce another } \\
\text { specified shape. }\end{array}$ \\
\hline 1 & $90.0 \%$ & $\begin{array}{l}\text { Students at Level } 1 \text { can recognise and solve simple problems in a familiar context using } \\
\text { pictures or drawings of familiar geometric objects and applying basic spatial skills, such } \\
\text { as recognising elementary symmetry properties, comparing lengths or angle sizes, or using } \\
\text { procedures, such as dissection of shapes. }\end{array}$ \\
\hline
\end{tabular}


- Figure 1.2.45 -

Proficiency in the mathematics subscale space and shape

Percentage of students at each level of mathematics proficiency

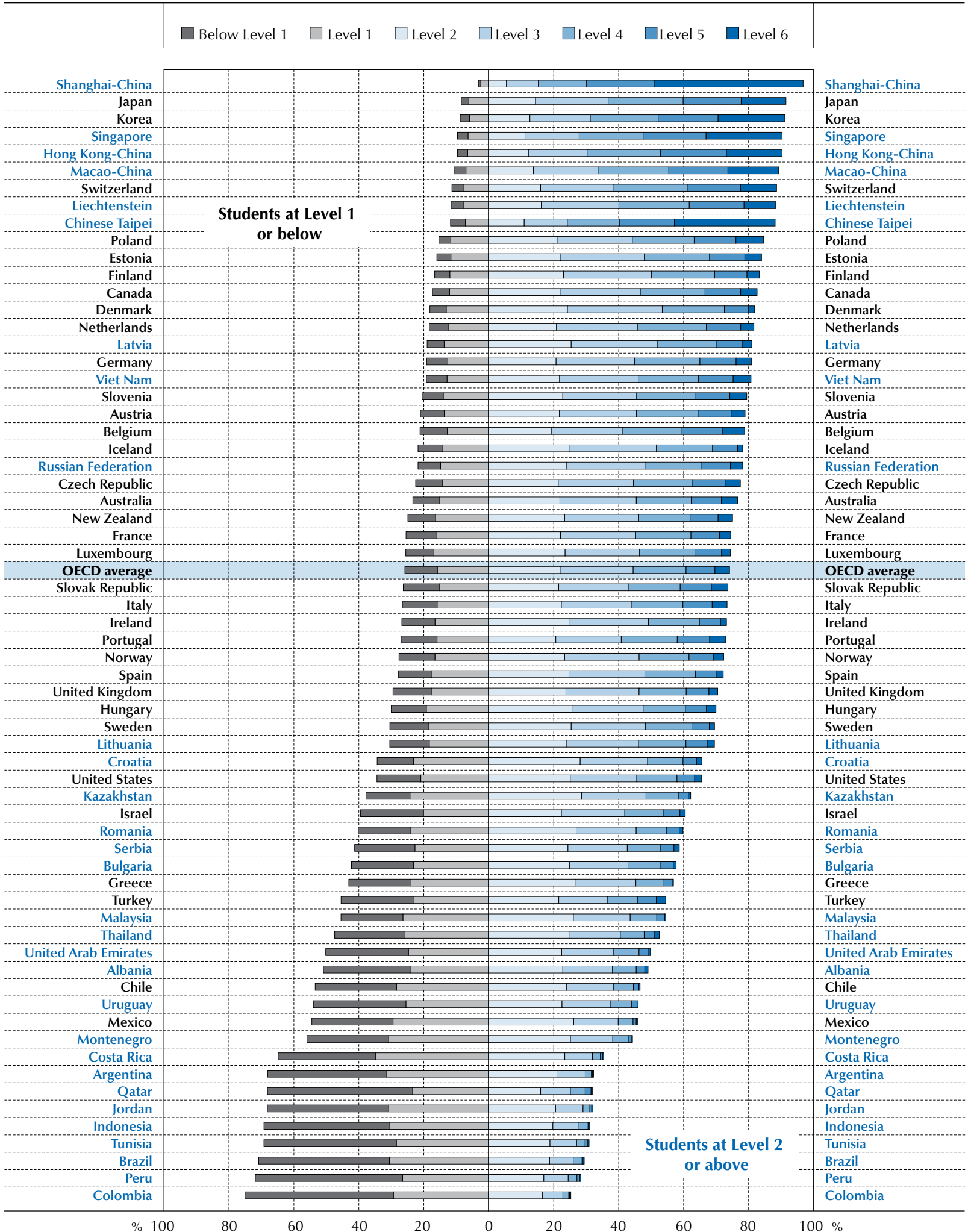

Countries and economies are ranked in descending order of the percentage of students at Levels 2, 3, 4, 5 and 6 .

Source: OECD, PISA 2012 Database, Table I.2.17.

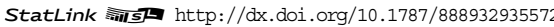


Ten countries and economies score more than 10 points higher on the space and shape subscale than on their overall proficiency scale. These differences are quiet large in some countries, with Shanghai-China showing the largest difference (36 points), followed by Chinese Taipei (32 points), Albania (23 points), Japan (21 points), Macao-China (20 points), Korea (19 points), Kazakhstan (18 points), Malaysia (14 points), the Russian Federation (14 points) and Switzerland (13 points). Five of the best-performing countries and economies on the mathematics scale, Shanghai-China, Chinese Taipei, Korea, Macao-China and Japan, are included in this group.

Conversely, nine countries score at least 10 points lower on the space and shape subscale than on the overall proficiency scale. Ireland shows the largest difference (24 points), while in the eight other countries, differences range from 10 to 20 points: the United Kingdom (19 points), the United States (18 points), Israel (17 points), Greece (17 points), the Netherlands (16 points), Finland (12 points), Croatia (11 points) and Brazil (11 points) (Figure I.2.52).

Figure I.2.44 describes the six levels of proficiency on the mathematics subscale space and shape and the distribution of students among these six proficiency levels is shown in Figure 1.2.45.

\section{Student performance on the mathematics subscale quantity}

PISA items in this category emphasise comparisons and calculations based on quantitative relationships and numeric properties of objects and phenomena. Items listed in Figure I.2.9 that have been classified in this category are $\mathrm{WHICH}$ CAR? Question 2 and Question 3, CLIMBING MOUNT FUJI Question 1 and Question 3, and REVOLVING DOOR Question 3. The questions in WHICH CAR? involve reasoning about quantities of given properties of different objects, and computation with percentages. CLIMBING MOUNT FUJI also involves calculations with given quantities. REVOLVING DOOR Question 3 involves reasoning and calculations using given quantitative information.

The average score on the quantity subscale is 495 points. The ten top-performing countries and economies on this subscale are Shanghai-China, Singapore, Hong Kong-China, Chinese Taipei, Liechtenstein, Korea, the Netherlands, Switzerland, Macao-China and Finland (Figure I.2.46 and Table I.2.22).

The average score among OECD countries on the quantity subscale is one point higher than the average score on the overall mathematics proficiency scale (Figure 1.2.52). Twenty-two countries and economies have an average quantity score that is within about three score points of their average score on the overall mathematics proficiency scale.

Israel scores 13 points higher on the quantity subscale than on the overall mathematics scale, and seven other countries also score higher on this subscale than on the main scale by at least five points: Croatia (9 points), the Netherlands (9 points), Finland (8 points), Serbia (7 points), Spain (7 points), the Czech Republic (6 points) and Italy (5 points).

Shanghai-China scores 22 points lower on the quantity subscale than on the main proficiency scale, and Jordan scores 19 points lower. Japan (18 points), Chinese Taipei (16 points), Korea (16 points), Indonesia (13 points) and Malaysia (11 points) score at least 10 points lower on the subscale than on the main scale.

Figure 1.2.47 describes the six levels of proficiency on the mathematics subscale quantity and the distribution of students among these six proficiency levels is shown in Figure I.2.48.

\section{Student performance on the mathematics subscale uncertainty and data}

PISA items in this category emphasise interpreting and working with data and with different data presentation forms, and problems involving probabilistic reasoning. Items listed in Figure I.2.9 that have been classified in this category are WHICH CAR? Question 1, and CHARTS Question 1, Question 2 and Question 3. The question in WHICH CAR? involves interpreting data in a two-way table to identify an object that satisfies various criteria. The questions in CHARTS involve interpreting a bar chart and understanding the relationships depicted in the chart.

Across OECD countries, the average score on the uncertainty and data subscale is 493 points. Top-performing countries and economies on this subscale are Shanghai-China, Singapore, Hong Kong-China, Chinese Taipei, Korea, the Netherlands, Japan, Liechtenstein, Macao-China and Switzerland (Figure I.2.49 and Table I.2.25). The average score among OECD countries on the uncertainty and data subscale is one point lower than the average score on the overall mathematics scale, but the difference between the two sets of scores varies widely among countries (Figure I.2.52). 
- Figure I.2.46

\section{Comparing countries' and economies' performance on the mathematics subscale quantity}

\begin{tabular}{|c|c|c|}
\hline \multirow[b]{3}{*}{$\begin{array}{l}\text { Mean } \\
\text { score }\end{array}$} & \multirow[b]{3}{*}{$\begin{array}{l}\text { Comparison } \\
\text { country/economy }\end{array}$} & \multirow{3}{*}{$\begin{array}{l}\text { Statistically significantly above the OECD average } \\
\text { Not statistically significantly different from the OECD average } \\
\text { Statistically significantly below the OECD average }\end{array}$} \\
\hline & & \\
\hline & & \\
\hline 591 & Shanghai-China & \\
\hline 569 & Singapore & Hong Kong-China \\
\hline 566 & Hong Kong-China & Singapore \\
\hline 543 & Chinese Taipei & Liechtenstein, Korea \\
\hline 538 & Liechtenstein & Chinese Taipei, Korea, Netherlands, Switzerland, Macao-China \\
\hline 537 & Korea & Chinese Taipei, Liechtenstein, Netherlands, Switzerland, Macao-China \\
\hline 532 & Netherlands & Liechtenstein, Korea, Switzerland, Macao-China, Finland, Estonia \\
\hline 531 & Switzerland & Liechtenstein, Korea, Netherlands, Macao-China, Finland, Estonia \\
\hline 531 & Macao-China & Liechtenstein, Korea, Netherlands, Switzerland, Finland \\
\hline 527 & Finland & Netherlands, Switzerland, Macao-China, Estonia \\
\hline 525 & Estonia & Netherlands, Switzerland, Finland, Belgium, Poland, Japan \\
\hline 519 & Belgium & Estonia, Poland, Japan, Germany, Canada, Viet Nam \\
\hline 519 & Poland & Estonia, Belgium, Japan, Germany, Canada, Austria, Viet Nam \\
\hline 518 & Japan & Estonia, Belgium, Poland, Germany, Canada, Austria, Viet Nam \\
\hline 517 & Germany & Belgium, Poland, Japan, Canada, Austria, Viet Nam \\
\hline 515 & Canada & Belgium, Poland, Japan, Germany, Austria, Viet Nam \\
\hline 510 & Austria & Poland, Japan, Germany, Canada, Viet Nam, Ireland, Czech Republic \\
\hline 509 & Viet Nam & Belgium, Poland, Japan, Germany, Canada, Austria, Ireland, Czech Republic, Slovenia, Denmark, Australia, New Zealand \\
\hline 505 & Ireland & Austria, Viet Nam, Czech Republic, Slovenia, Denmark, Australia, New Zealand \\
\hline 505 & Czech Republic & Austria, Viet Nam, Ireland, Slovenia, Denmark, Australia, New Zealand \\
\hline 504 & Slovenia & Viet Nam, Ireland, Czech Republic, Denmark, Australia \\
\hline 502 & Denmark & Viet Nam, Ireland, Czech Republic, Slovenia, Australia, New Zealand, Iceland, France, United Kingdom \\
\hline 500 & Australia & Viet Nam, Ireland, Czech Republic, Slovenia, Denmark, New Zealand, Iceland, France, United Kingdom \\
\hline 499 & New Zealand & Viet Nam, Ireland, Czech Republic, Denmark, Australia, Iceland, France, Luxembourg, United Kingdom, Norway \\
\hline 496 & Iceland & Denmark, Australia, New Zealand, France, Luxembourg, United Kingdom, Norway, Spain \\
\hline 496 & France & Denmark, Australia, New Zealand, Iceland, Luxembourg, United Kingdom, Norway, Spain, Italy \\
\hline 495 & Luxembourg & New Zealand, Iceland, France, United Kingdom, Norway, Spain, Italy \\
\hline 494 & United Kingdom & Denmark, Australia, New Zealand, Iceland, France, Luxembourg, Norway, Spain, Italy, Latvia, Slovak Republic \\
\hline 492 & Norway & New Zealand, Iceland, France, Luxembourg, United Kingdom, Spain, Italy, Latvia, Slovak Republic \\
\hline 491 & Spain & Iceland, France, Luxembourg, United Kingdom, Norway, Italy, Latvia, Slovak Republic \\
\hline 491 & Italy & France, Luxembourg, United Kingdom, Norway, Spain, Latvia, Slovak Republic \\
\hline 487 & Latvia & United Kingdom, Norway, Spain, Italy, Slovak Republic, Lithuania, Sweden, Portugal, Croatia, Israel, United States \\
\hline 486 & Slovak Republic & United Kingdom, Norway, Spain, Italy, Latvia, Lithuania, Sweden, Portugal, Croatia, Israel, Russian Federation, United States \\
\hline 483 & Lithuania & Latvia, Slovak Republic, Sweden, Portugal, Croatia, Israel, Russian Federation, United States, Hungary \\
\hline 482 & Sweden & Latvia, Slovak Republic, Lithuania, Portugal, Croatia, Israel, Russian Federation, United States, Hungary \\
\hline 481 & Portugal & Latvia, Slovak Republic, Lithuania, Sweden, Croatia, Israel, Russian Federation, United States, Hungary \\
\hline 480 & Croatia & Latvia, Slovak Republic, Lithuania, Sweden, Portugal, Israel, Russian Federation, United States, Hungary \\
\hline 480 & Israel & Latvia, Slovak Republic, Lithuania, Sweden, Portugal, Croatia, Russian Federation, United States, Hungary \\
\hline 478 & Russian Federation & Slovak Republic, Lithuania, Sweden, Portugal, Croatia, Israel, United States, Hungary \\
\hline 478 & United States & Latvia, Slovak Republic, Lithuania, Sweden, Portugal, Croatia, Israel, Russian Federation, Hungary \\
\hline 476 & Hungary & Lithuania, Sweden, Portugal, Croatia, Israel, Russian Federation, United States \\
\hline 456 & Serbia & Greece \\
\hline 455 & Greece & Serbia \\
\hline 443 & Romania & Bulgaria, Turkey, Cyprus ${ }^{1,2}$ \\
\hline 443 & Bulgaria & Romania, Turkey, Cyprus ${ }^{1,2}$ \\
\hline 442 & Turkey & Romania, Bulgaria, Cyprus ${ }^{1,2}$, United Arab Emirates \\
\hline 439 & Cyprus $^{1,2}$ & Romania, Bulgaria, Turkey \\
\hline 431 & United Arab Emirates & Turkey, Kazakhstan \\
\hline 428 & Kazakhstan & United Arab Emirates, Chile, Thailand \\
\hline 421 & Chile & Kazakhstan, Thailand \\
\hline 419 & Thailand & Kazakhstan, Chile, Mexico, Uruguay, Malaysia \\
\hline 414 & Mexico & Thailand, Uruguay, Malaysia, Costa Rica \\
\hline 411 & Uruguay & Thailand, Mexico, Malaysia, Montenegro, Costa Rica \\
\hline 409 & Malaysia & Thailand, Mexico, Uruguay, Montenegro, Costa Rica \\
\hline 409 & Montenegro & Uruguay, Malaysia, Costa Rica \\
\hline 406 & Costa Rica & Mexico, Uruguay, Malaysia, Montenegro \\
\hline 393 & Brazil & Argentina, Albania \\
\hline 391 & Argentina & Brazil, Albania \\
\hline 386 & Albania & Brazil, Argentina, Tunisia \\
\hline 378 & Tunisia & Albania, Colombia, Qatar, Jordan \\
\hline 375 & Colombia & Tunisia, Qatar, Jordan, Peru \\
\hline 371 & Qatar & Tunisia, Colombia, Jordan, Peru, Indonesia \\
\hline 367 & Jordan & Tunisia, Colombia, Qatar, Peru, Indonesia \\
\hline 365 & Peru & Colombia, Qatar, Jordan, Indonesia \\
\hline 362 & Indonesia & Qatar, Jordan, Peru \\
\hline
\end{tabular}

1. Note by Turkey: The information in this document with reference to "Cyprus" relates to the southern part of the Island. There is no single authority representing both Turkish and Greek Cypriot people on the Island. Turkey recognises the Turkish Republic of Northern Cyprus (TRNC). Until a lasting and equitable solution is found within the context of the United Nations, Turkey shall preserve its position concerning the "Cyprus issue".

2. Note by all the European Union Member States of the OECD and the European Union: The Republic of Cyprus is recognised by all members of the United Nations with the exception of Turkey. The information in this document relates to the area under the effective control of the Government of the Republic of Cyprus.

Source: OECD, PISA 2012 Database.

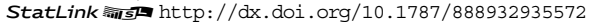


- Figure I.2.47

\section{Summary descriptions of the six proficiency levels on the mathematical subscale quantity}

\begin{tabular}{|c|c|c|}
\hline Level & $\begin{array}{l}\text { Percentage of students } \\
\text { able to perform tasks } \\
\text { at each level or above } \\
\text { (OECD average) }\end{array}$ & What students can do \\
\hline 6 & $3.9 \%$ & $\begin{array}{l}\text { At Level } 6 \text { and above, students conceptualise and work with models of complex quantitative } \\
\text { processes and relationships; devise strategies for solving problems; formulate conclusions, } \\
\text { arguments and precise explanations; interpret and understand complex information, and link } \\
\text { multiple complex information sources; interpret graphical information and apply reasoning } \\
\text { to identify, model and apply a numeric pattern. They can analyse and evaluate interpretive } \\
\text { statements based on data provided; work with formal and symbolic expressions; plan and } \\
\text { implement sequential calculations in complex and unfamiliar contexts, including working } \\
\text { with large numbers, for example to perform a sequence of currency conversions, entering } \\
\text { values correctly and rounding results. Students at this level work accurately with decimal } \\
\text { fractions; they use advanced reasoning concerning proportions, geometric representations of } \\
\text { quantities, combinatorics and integer number relationships; and they interpret and understand } \\
\text { formal expressions of relationships among numbers, including in a scientific context. }\end{array}$ \\
\hline 5 & $14.0 \%$ & $\begin{array}{l}\text { At Level 5, students can formulate comparison models and compare outcomes to determine } \\
\text { highest price, and interpret complex information about real-world situations (including } \\
\text { graphs, drawings and complex tables, for example two graphs using different scales). They } \\
\text { can generate data for two variables and evaluate propositions about the relationship between } \\
\text { them. Students can communicate reasoning and argument; recognise the significance of } \\
\text { numbers to draw inferences; and provide a written argument evaluating a proposition based } \\
\text { on data provided. They can make an estimation using knowledge about daily life; calculate } \\
\text { relative and/or absolute change; calculate an average; calculate relative and/or absolute } \\
\text { difference, including percentage difference, given raw difference data; and can convert units } \\
\text { (for example calculations involving areas in different units). }\end{array}$ \\
\hline 4 & $32.5 \%$ & $\begin{array}{l}\text { At Level 4, students can interpret complex instructions and situations; relate text-based } \\
\text { numerical information to a graphic representation; identify and use quantitative information } \\
\text { from multiple sources; deduce system rules from unfamiliar representations; formulate a } \\
\text { simple numeric model; set up comparison models; and explain their results. They can carry } \\
\text { out accurate and more complex or repeated calculations, such as adding } 13 \text { given times in } \\
\text { hour/minute format; carry out time calculations using given data on distance and speed of a } \\
\text { journey; perform simple division of large multiples in context; carry out calculations involving } \\
\text { a sequence of steps; and accurately apply a given numeric algorithm involving a number } \\
\text { of steps. Students at this level can perform calculations involving proportional reasoning, } \\
\text { divisibility or percentages in simple models of complex situations. }\end{array}$ \\
\hline 3 & $55.4 \%$ & $\begin{array}{l}\text { At Level 3, students can use basic problem-solving processes, including devising a simple } \\
\text { strategy to test scenarios, understand and work with given constraints, use trial and error, and } \\
\text { use simple reasoning in familiar contexts. At this level students can interpret a text description } \\
\text { of a sequential calculation process, and correctly implement the process; identify and } \\
\text { extract data presented directly in textual explanations of unfamiliar data; interpret text and } \\
\text { diagrams describing a simple pattern; and perform calculations, including working with large } \\
\text { numbers, calculations with speed and time, conversion of units (for example from an annual } \\
\text { rate to a daily rate). They understand place value involving mixed 2-and 3-decimal values } \\
\text { and including working with prices; can order a small series of (4) decimal values; calculate } \\
\text { percentages of up to 3-digit numbers; and apply calculation rules given in natural language. }\end{array}$ \\
\hline 2 & $76.5 \%$ & $\begin{array}{l}\text { At Level 2, students can interpret simple tables to identify and extract relevant quantitative } \\
\text { information, and can interpret a simple quantitative model (such as a proportional relationship) } \\
\text { and apply it using basic arithmetic calculations. They can identify the links between relevant } \\
\text { textual information and tabular data to solve word problems; interpret and apply simple } \\
\text { models involving quantitative relationships; identify the simple calculation required to solve a } \\
\text { straight-forward problem; carry out simple calculations involving basic arithmetic operations; } \\
\text { order 2- and 3-digit whole numbers and decimal numbers with one or two decimal places; } \\
\text { and calculate percentages. }\end{array}$ \\
\hline 1 & $90.8 \%$ & $\begin{array}{l}\text { At Level 1, students can solve basic problems in which relevant information is explicitly } \\
\text { presented, and the situation is straightforward and very limited in scope. Students at this } \\
\text { level can handle situations where the required computational activity is obvious and the } \\
\text { mathematical task is basic, such as a one-step simple arithmetic operation, or to total the } \\
\text { columns of a simple table and compare the results. They can read and interpret a simple table } \\
\text { of numbers; extract data and perform simple calculations; use a calculator to generate relevant } \\
\text { data; and extrapolate from the data generated, using reasoning and calculation with a simple } \\
\text { linear model. }\end{array}$ \\
\hline
\end{tabular}




\section{- Figure I.2.48}

Proficiency in the mathematics subscale quantity

Percentage of students at each level of mathematics proficiency

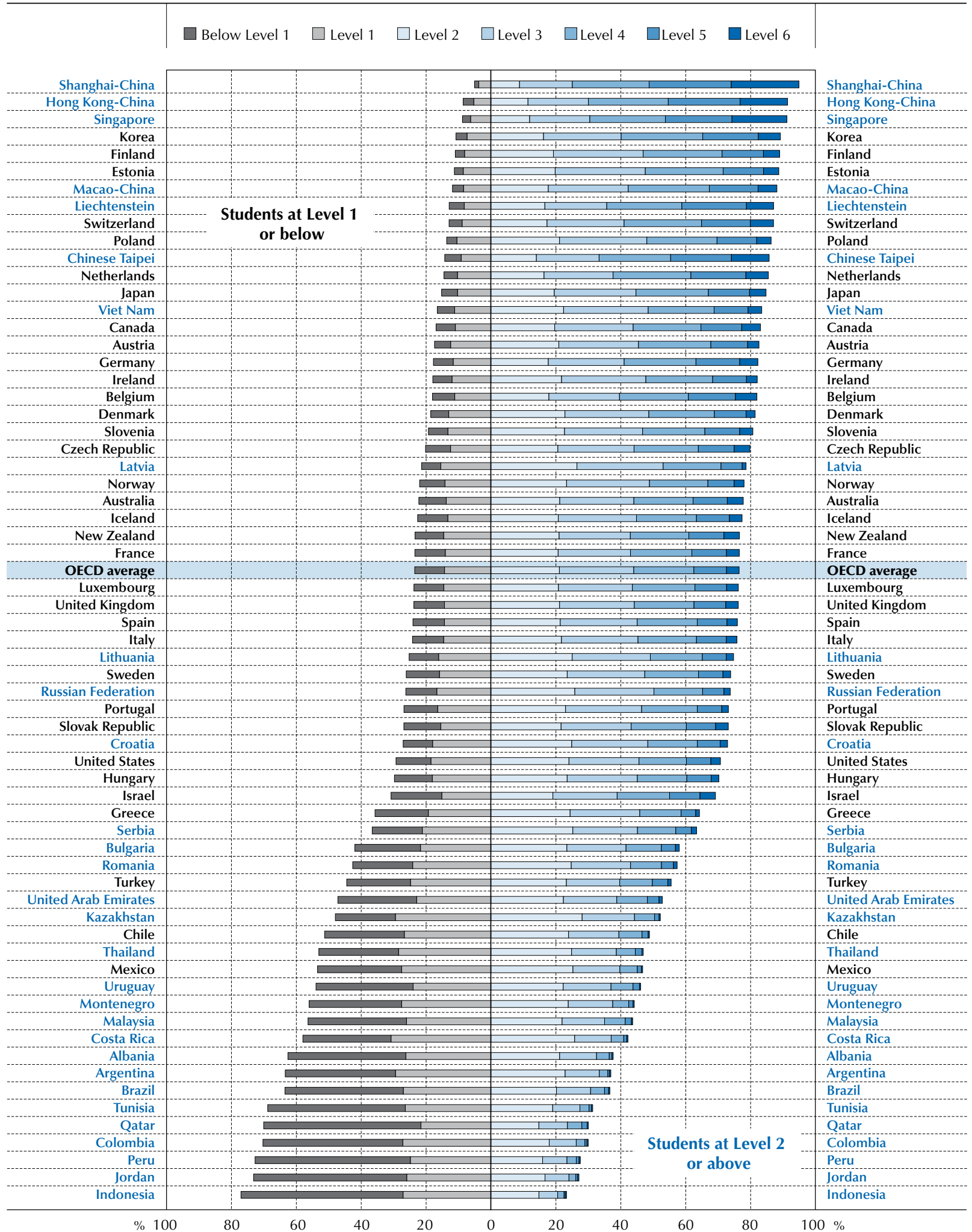

Countries and economies are ranked in descending order of the percentage of students at Levels 2, 3, 4, 5 and 6 . Source: OECD, PISA 2012 Database, Table I.2.20.

StatLink त्नाज http://dx.doi.org/10.1787/888932935572 
- Figure I.2.49

\section{Comparing countries' and economies' performance on the mathematics subscale uncertainty and data}

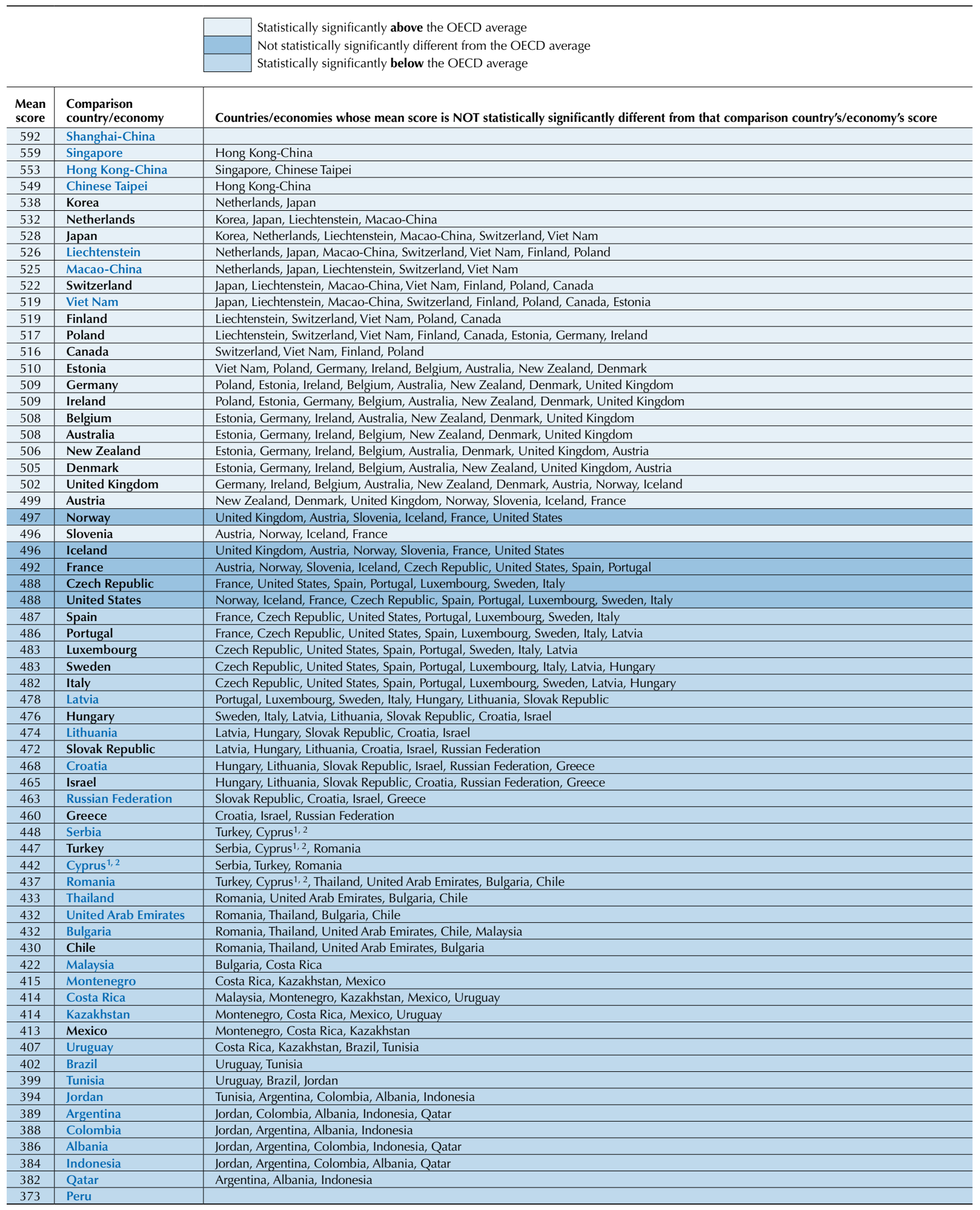

1. Note by Turkey: The information in this document with reference to "Cyprus" relates to the southern part of the Island. There is no single authority representing both Turkish and Greek Cypriot people on the Island. Turkey recognises the Turkish Republic of Northern Cyprus (TRNC). Until a lasting and equitable solution is found within the context of the United Nations, Turkey shall preserve its position concerning the "Cyprus issue".

2. Note by all the European Union Member States of the OECD and the European Union: The Republic of Cyprus is recognised by all members of the United Nations with the exception of Turkey. The information in this document relates to the area under the effective control of the Government of the Republic of Cyprus.

Source: OECD, PISA 2012 Database.

StatLink 新穴 $\mathrm{http}: / / \mathrm{dx}$.doi.org/10.1787/888932935572 
Colombia (12 points), Tunisia (12 points) and Brazil (11 points) score more than 10 points higher on the subscale than on the mathematics proficiency scale. Twenty other countries scores between three and ten points lower on this subscale than on the overall proficiency scale.

Eleven countries and economies score 10 points or more lower on the uncertainty and data subscale than they do on the mathematics proficiency scale. Shanghai-China (21 points lower), the Russian Federation (19 points lower) and Kazakhstan (18 points lower) show the largest differences. Korea (16 points), Singapore (14 points), Macao-China (13 points), Latvia (12 points), Chinese Taipei (11 points), the Czech Republic (11 points), Estonia (10 points) and the Slovak Republic (10 points) complete this group.

Figure I.2.50 describes the six levels of proficiency in the mathematics subscale uncertainty and data and the distribution of students among these six proficiency levels is shown in Figure 1.2.51.

\section{Summary descriptions of the six proficiency levels on the mathematical subscale uncertainty and data}

\begin{tabular}{|c|c|c|}
\hline Level & $\begin{array}{l}\text { Percentage of students } \\
\text { able to perform tasks } \\
\text { at each level or above } \\
\text { (OECD average) }\end{array}$ & What students can do \\
\hline 6 & $3.2 \%$ & $\begin{array}{l}\text { At Level 6, students can interpret, evaluate and critically reflect on a range of complex } \\
\text { statistical or probabilistic data, information and situations to analyse problems. Students at this } \\
\text { level bring insight and sustained reasoning across several problem elements; they understand } \\
\text { the connections between data and the situations they represent and are able to make use } \\
\text { of those connections to explore problem situations fully. They bring appropriate calculation } \\
\text { techniques to bear to explore data or to solve probability problems; and they can produce and } \\
\text { communicate conclusions, reasoning and explanations. }\end{array}$ \\
\hline 5 & $12.5 \%$ & $\begin{array}{l}\text { At Level 5, students can interpret and analyse a range of statistical or probabilistic data, } \\
\text { information and situations to solve problems in complex contexts that require linking of } \\
\text { different problem components. They can use proportional reasoning effectively to link sample } \\
\text { data to the population they represent, can appropriately interpret data series over time, and } \\
\text { are systematic in their use and exploration of data. Students at this level can use statistical } \\
\text { and probabilistic concepts and knowledge to reflect, draw inferences and produce and } \\
\text { communicate results. }\end{array}$ \\
\hline 4 & $30.6 \%$ & $\begin{array}{l}\text { Students at Level } 4 \text { can activate and employ a range of data representations and statistical } \\
\text { or probabilistic processes to interpret data, information and situations to solve problems. } \\
\text { They can work effectively with constraints, such as statistical conditions that might apply in a } \\
\text { sampling experiment, and they can interpret and actively translate between two related data } \\
\text { representations (such as a graph and a data table). Students at this level can perform statistical } \\
\text { and probabilistic reasoning to make contextual conclusions. }\end{array}$ \\
\hline 3 & $54.4 \%$ & $\begin{array}{l}\text { At Level 3, students can interpret and work with data and statistical information from a } \\
\text { single representation that may include multiple data sources, such as a graph representing } \\
\text { several variables, or from two related data representations, such as a simple data table and } \\
\text { graph. They can work with and interpret descriptive statistical, probabilistic concepts and } \\
\text { conventions in contexts such as coin tossing or lotteries, and draw conclusions from data, } \\
\text { such as calculating or using simple measures of centre and spread. Students at this level can } \\
\text { perform basic statistical and probabilistic reasoning in simple contexts. }\end{array}$ \\
\hline 2 & $76.9 \%$ & $\begin{array}{l}\text { Students at Level } 2 \text { can identify, extract and comprehend statistical data presented in a simple } \\
\text { and familiar form such as a simple table, a bar graph or pie chart. They can identify, understand } \\
\text { and use basic descriptive statistical and probabilistic concepts in familiar contexts, such as } \\
\text { tossing coins or rolling dice. At this level students can interpret data in simple representations, } \\
\text { and apply suitable calculation procedures that connect given data to the problem context } \\
\text { represented. }\end{array}$ \\
\hline 1 & $91.7 \%$ & $\begin{array}{l}\text { At Level 1, students can identify and read information presented in a small table or simple } \\
\text { well-labelled graph to locate and extract specific data values while ignoring distracting } \\
\text { information, and recognise how these relate to the context. Students at this level can recognise } \\
\text { and use basic concepts of randomness to identify misconceptions in familiar experimental } \\
\text { contexts, such as lottery outcomes. }\end{array}$ \\
\hline
\end{tabular}


- Figure I.2.51

Proficiency in the mathematics subscale uncertainty and data

Percentage of students at each level of mathematics proficiency

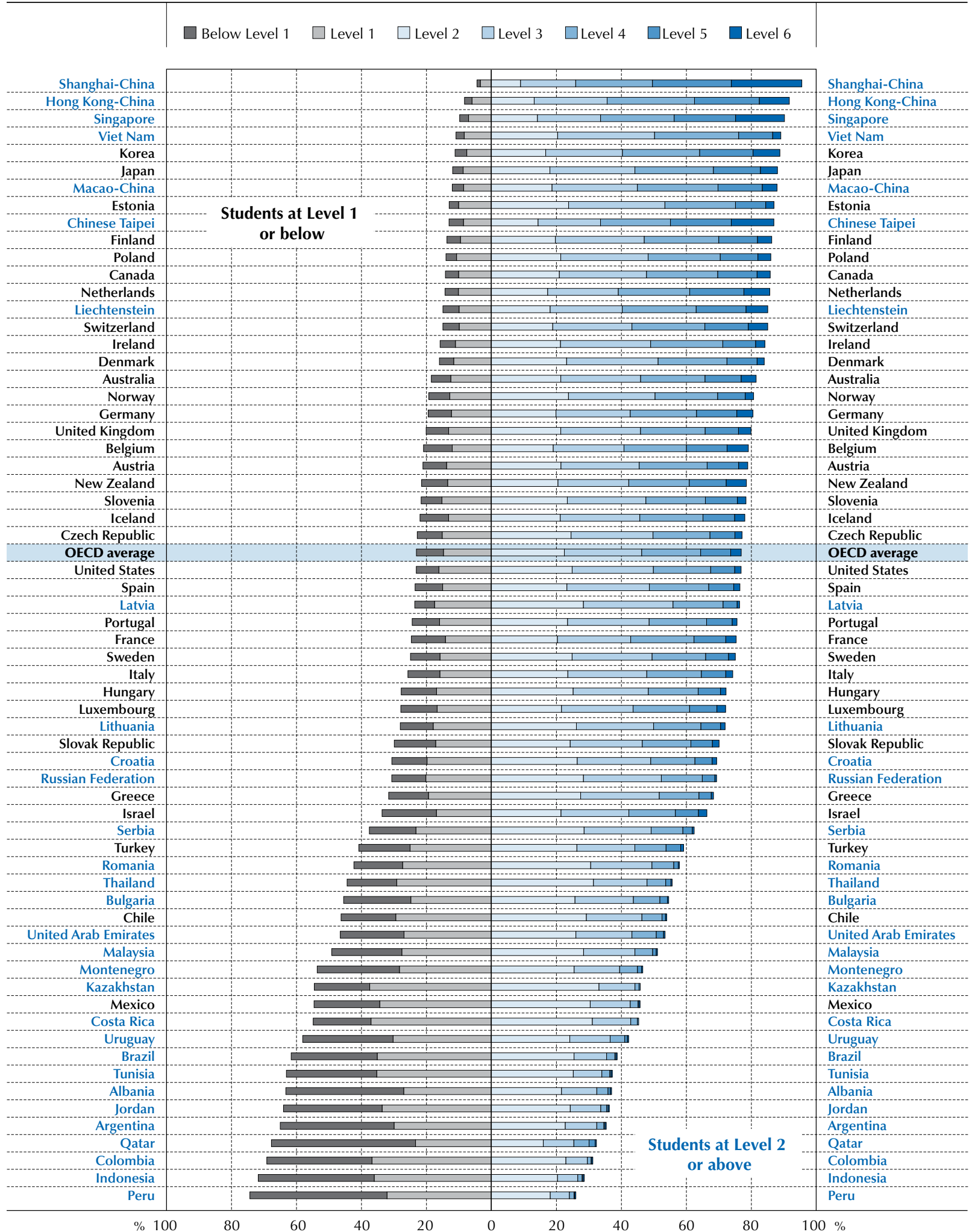

Countries and economies are ranked in descending order of the percentage of students at Levels 2, 3, 4, 5 and 6.

Source: OECD, PISA 2012 Database, Table I.2.23.

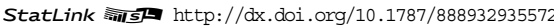




\section{The relative strengths and weaknesses of countries in different mathematics content areas}

Figure I.2.52 shows the country means for the overall mathematics scale and the difference in performance between each content subscale and the overall mathematics scale. As the figure makes clear, the levels of performance on the content subscales are relatively well aligned with each other and with overall mean mathematics performance, as is the case with the process subscales. However, it is also clear that the relative strength of countries in relation to the four content categories varies considerably; in fact, there is even more variability than is the case with the process subscales. It is also evident that while space and shape is frequently the strongest area among some of the higher-performing countries, this is certainly not always the case; and similarly, while change and relationships is the weakest of the four areas in several of the lower-performing countries, this is by no means true for all countries and economies.

Among OECD countries, where the average score on the easiest subscale (quantity) and the most difficult subscale (space and shape), relative to overall mathematical performance, is about 6 points, Japan shows the largest difference between its strongest (space and shape) and weakest (quantity) content areas of 39 points; Turkey has the smallest difference between its strongest and weakest content areas, as it did between its strongest and weakest process areas, this time of about 7 points. Between these extremes there is a great spread, with an average difference between the strongest and weakest performance of about 17 points. Within that variation, six countries had the highest mean score for change and relationships (Estonia, Canada, Australia, Hungary, France and Turkey); six countries performed strongest in space and shape (Japan, Korea, Switzerland, the Slovak Republic, Poland and Portugal); 13 performed strongest in quantity (Israel, the Netherlands, Finland, Spain, the Czech Republic, Italy, Luxembourg, Austria, Belgium, Iceland, Germany, Slovenia and Mexico); and the remaining nine had the highest mean scores in uncertainty and data (the United Kingdom, Chile, Norway, Greece, Ireland, the United States, New Zealand, Denmark, and Sweden).

Among partner countries and economies, Shanghai-China shows the largest difference (about 58 points) between its strongest content category (space and shape) and its weakest (quantity); while the smallest difference between the best and worst performance in the content subscales is around 11 points, seen in Uruguay, Bulgaria, Lithuania and Romania. Once again, between these extremes there is a great spread, with an average difference between the best and worst performance of about 22 points. Within that variation, three countries had the highest mean score for change and relationships; 11 countries performed best in space and shape; five had the highest mean score in quantity; and 12 performed best in uncertainty and data.

Figure I.2.53 shows the mean score on each of the four content scales for all countries, and indicates the range of ranks (highest and lowest) that might apply to each country, taking into account the statistical uncertainty in the estimates of ranks.

\section{Gender differences in performance on the content subscales}

Figures I.2.54a, b, c and d, show the performance differences between boys and girls on the content subscales. On average, a larger proportion of boys than girls attains the top two proficiency levels on all four of the content subscales (Tables I.2.15, I.2.18, I.2.21 and I.2.25).

On the change and relationships subscale, boys outperform girls by 11 points, on average across OECD countries. Differences of more than 20 points, in favour of boys, are seen in Chile (32 points), Colombia (29 points), Luxembourg (25 points), Austria (23 points), Japan (22 points), Korea, Liechtenstein and Costa Rica (21 points each). Twenty-four other countries and economies show significant differences in favour of boys.

Six partner countries and economies show girls outperforming boys on the change and relationships subscale: Jordan (29 points), Thailand (20 points), Qatar (18 points), Malaysia (15 points), Latvia (9 points), and Kazakhstan (8 points). By contrast, in no OECD country did girls outperform boys on the subscale.

On the space and shape subscale, boys outperform girls by 15 points, on average across OECD countries. Differences of more than 20 points, in favour of boys, are seen in 18 countries and economies, with the largest differences in Austria (37 points), Luxembourg (34 points), Colombia (34 points) and Chile (31 points). Twenty-seven other countries and economies show differences in favour of boys. In Iceland, girls outperform boys by a statistically significant 8 points. Statistically significant differences in favour of girls are observed in Albania (10 points), Qatar (15 points) and Jordan (15 points).

Boys outperform girls on the quantity subscale by an average of 11 points across OECD countries. Differences of more than 20 points in favour of boys are seen in Colombia (31 points), Costa Rica (29 points), Luxembourg (23 points), Chile (22 points), Peru (22 points) and Liechtenstein (22 points). Meanwhile, only in four countries do girls outperform boys: Qatar (19 points), Thailand (16 points), Sweden (7 points) and Singapore (6 points). 


\section{- Figure 1.2 .52}

\section{Comparing countries and economies on the different mathematics content subscales}

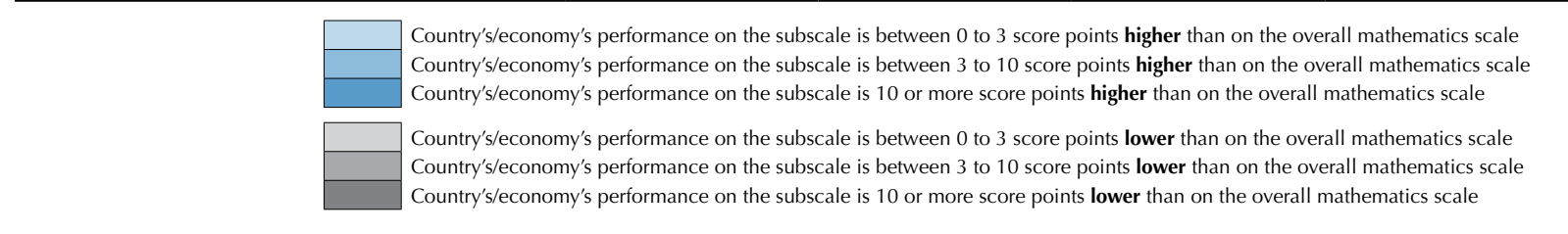

\begin{tabular}{|c|c|c|c|c|c|}
\hline & \multirow[b]{2}{*}{ Mathematics score } & \multicolumn{4}{|c|}{ Performance difference between the overall mathematics scale and each content subscale } \\
\hline & & Change and relationships & Space and shape & Quantity & Uncertainty and data \\
\hline Shanghai-China & 613 & 11 & 36 & -22 & -21 \\
\hline Singapore & 573 & 7 & 6 & -5 & -14 \\
\hline Hong Kong-China & 561 & 3 & 6 & 4 & -8 \\
\hline Chinese Taipei & 560 & 1 & 32 & -16 & -11 \\
\hline Korea & 554 & 5 & 19 & -16 & -16 \\
\hline Macao-China & 538 & 4 & 20 & -8 & -13 \\
\hline Japan & 536 & 6 & 21 & -18 & -8 \\
\hline Liechtenstein & 535 & 7 & 4 & 3 & -9 \\
\hline Switzerland & 531 & -1 & 13 & 0 & -9 \\
\hline Netherlands & 523 & -5 & -16 & 9 & 9 \\
\hline Estonia & 521 & 9 & -8 & 4 & -10 \\
\hline Finland & 519 & 2 & -12 & 8 & 0 \\
\hline Canada & 518 & 7 & -8 & -3 & -2 \\
\hline Poland & 518 & -8 & 7 & 1 & -1 \\
\hline Belgium & 515 & -1 & -6 & 4 & -7 \\
\hline Germany & 514 & 2 & -6 & 4 & -5 \\
\hline Viet Nam & 511 & -2 & -4 & -2 & 8 \\
\hline Austria & 506 & 1 & -5 & 5 & -7 \\
\hline Australia & 504 & 5 & -8 & -4 & 4 \\
\hline Ireland & 501 & 0 & -24 & 4 & 7 \\
\hline Slovenia & 501 & -2 & 2 & 3 & -5 \\
\hline Denmark & 500 & -6 & -3 & 2 & 5 \\
\hline New Zealand & 500 & 1 & -9 & -1 & 6 \\
\hline Czech Republic & 499 & 0 & 0 & 6 & -11 \\
\hline France & 495 & 2 & -6 & 1 & -3 \\
\hline OECD average & 494 & -1 & -4 & 1 & -1 \\
\hline United Kingdom & 494 & 2 & -19 & 0 & 8 \\
\hline Iceland & 493 & -6 & -4 & 4 & 3 \\
\hline Latvia & 491 & 6 & 6 & -3 & -12 \\
\hline Luxembourg & 490 & -2 & -3 & 5 & -7 \\
\hline Norway & 489 & -12 & -10 & 3 & 7 \\
\hline Portugal & 487 & -1 & 4 & -6 & -1 \\
\hline Italy & 485 & -9 & 2 & 5 & -3 \\
\hline Spain & 484 & -3 & -7 & 7 & 2 \\
\hline Russian Federation & 482 & 9 & 14 & -4 & -19 \\
\hline Slovak Republic & 482 & -7 & 8 & 5 & -10 \\
\hline United States & 481 & 7 & -18 & -4 & 7 \\
\hline Lithuania & 479 & 0 & -7 & 4 & -5 \\
\hline Sweden & 478 & -9 & -10 & 3 & 4 \\
\hline Hungary & 477 & 4 & -3 & -2 & -1 \\
\hline Croatia & 471 & -3 & -11 & 9 & -3 \\
\hline Israel & 466 & -4 & -17 & 13 & -1 \\
\hline Greece & 453 & -7 & -17 & 2 & 7 \\
\hline Serbia & 449 & -7 & -3 & 7 & -1 \\
\hline Turkey & 448 & 0 & -5 & -6 & -1 \\
\hline Romania & 445 & 1 & 3 & -1 & -8 \\
\hline${\text { Cyprus }{ }^{1,2}}^{2}$ & 440 & 0 & -3 & -1 & 3 \\
\hline Bulgaria & 439 & -4 & 3 & 4 & -7 \\
\hline United Arab Emirates & 434 & 8 & -9 & -3 & -2 \\
\hline Kazakhstan & 432 & 1 & 18 & -4 & -18 \\
\hline Thailand & 427 & -13 & 5 & -8 & 6 \\
\hline Chile & 423 & -12 & -4 & -1 & 8 \\
\hline Malaysia & 421 & -19 & 14 & -11 & 2 \\
\hline Mexico & 413 & -9 & -1 & 0 & 0 \\
\hline Montenegro & 410 & -11 & 2 & -1 & 5 \\
\hline Uruguay & 409 & -8 & 3 & 2 & -2 \\
\hline Costa Rica & 407 & -5 & -10 & -1 & 7 \\
\hline Albania & 394 & -6 & 23 & -8 & -8 \\
\hline Brazil & 391 & -20 & -11 & 1 & 11 \\
\hline Argentina & 388 & -10 & -3 & 3 & 0 \\
\hline Tunisia & 388 & -9 & -5 & -10 & 12 \\
\hline Jordan & 386 & 2 & -1 & -19 & 8 \\
\hline Colombia & 376 & -20 & -8 & -1 & 12 \\
\hline Qatar & 376 & -14 & 4 & -6 & 5 \\
\hline Indonesia & 375 & -11 & 7 & -13 & 9 \\
\hline $\begin{array}{l}\text { Peru } \\
\end{array}$ & 368 & -19 & 2 & -3 & 5 \\
\hline
\end{tabular}

1. Note by Turkey: The information in this document with reference to "Cyprus" relates to the southern part of the Island. There is no single authority representing both Turkish and Greek Cypriot people on the Island. Turkey recognises the Turkish Republic of Northern Cyprus (TRNC). Until a lasting and equitable solution is found within the context of the United Nations, Turkey shall preserve its position concerning the "Cyprus issue".

2. Note by all the European Union Member States of the OECD and the European Union: The Republic of Cyprus is recognised by all members of the United Nations with the exception of Turkey. The information in this document relates to the area under the effective control of the Government of the Republic of Cyprus.

Source: OECD, PISA 2012 Database, Tables I.2.3a, I.2.16, I.2.19, I.2.22 and I.2.25.

StatLink क्तारा http://dx.doi.org/10.1787/888932935572 


\section{Where countries and economies rank on the different mathematics content subscales}

\begin{tabular}{|c|c|c|c|c|c|}
\hline & \multicolumn{5}{|c|}{$\begin{array}{l}\text { Statistically significantly above the OECD average } \\
\text { Not statistically significantly different from the OECD average } \\
\text { Statistically significantly below the OECD average }\end{array}$} \\
\hline & \multirow[b]{4}{*}{ Mean score } & \multicolumn{3}{|c|}{ Change and relationships subscale } & \\
\hline & & \multicolumn{4}{|c|}{ Range of ranks } \\
\hline & & \multicolumn{2}{|c|}{ OECD countries } & \multicolumn{2}{|c|}{ All countries/economies } \\
\hline & & Upper rank & Lower rank & Upper rank & Lower rank \\
\hline Shanghai-China & 624 & & & 1 & 1 \\
\hline Singapore & 580 & & & 2 & 2 \\
\hline Hong Kong-China & 564 & & & 3 & 5 \\
\hline Chinese Taipei & 561 & & & 3 & 5 \\
\hline Korea & 559 & 1 & 1 & 3 & 5 \\
\hline Macao-China & 542 & & & 6 & 8 \\
\hline Japan & 542 & 2 & 2 & 6 & 8 \\
\hline Liechtenstein & 542 & & & 6 & 8 \\
\hline Estonia & 530 & 3 & 4 & 9 & 10 \\
\hline Switzerland & 530 & 3 & 5 & 9 & 11 \\
\hline Canada & 525 & 4 & 6 & 10 & 12 \\
\hline Finland & 520 & 5 & 8 & 11 & 14 \\
\hline Netherlands & 518 & 5 & 9 & 11 & 16 \\
\hline Germany & 516 & 6 & 10 & 12 & 17 \\
\hline Belgium & 513 & 7 & 11 & 13 & 17 \\
\hline Viet Nam & 509 & & & 13 & 21 \\
\hline Poland & 509 & 7 & 13 & 13 & 20 \\
\hline Australia & 509 & 9 & 12 & 15 & 19 \\
\hline Austria & 506 & 9 & 14 & 15 & 21 \\
\hline Ireland & 501 & 12 & 17 & 19 & 25 \\
\hline New Zealand & 501 & 12 & 17 & 19 & 25 \\
\hline Czech Republic & 499 & 12 & 19 & 19 & 27 \\
\hline Slovenia & 499 & 13 & 17 & 20 & 25 \\
\hline France & 497 & 13 & 19 & 21 & 28 \\
\hline Latvia & 496 & & & 20 & 28 \\
\hline United Kingdom & 496 & 13 & 20 & 20 & 28 \\
\hline Denmark & 494 & 15 & 20 & 23 & 29 \\
\hline Russian Federation & 491 & & & 24 & 32 \\
\hline United States & 488 & 18 & 24 & 26 & 33 \\
\hline Luxembourg & 488 & 20 & 23 & 28 & 32 \\
\hline Iceland & 487 & 20 & 24 & 28 & 33 \\
\hline Portugal & 486 & 19 & 26 & 27 & 36 \\
\hline Spain & 482 & 23 & 26 & 32 & 36 \\
\hline Hungary & 481 & 22 & 28 & 31 & 38 \\
\hline Lithuania & 479 & & & 32 & 38 \\
\hline Norway & 478 & 24 & 28 & 33 & 38 \\
\hline Italy & 477 & 25 & 28 & 34 & 38 \\
\hline Slovak Republic & 474 & 25 & 29 & 34 & 40 \\
\hline Sweden & 469 & 28 & 30 & 38 & 41 \\
\hline Croatia & 468 & & & 38 & 41 \\
\hline Israel & 462 & 28 & 30 & 39 & 42 \\
\hline Turkey & 448 & 31 & 32 & 42 & 47 \\
\hline Greece & 446 & 31 & 32 & 42 & 46 \\
\hline Romania & 446 & & & 42 & 47 \\
\hline United Arab Emirates & 442 & & & 43 & 48 \\
\hline Serbia & 442 & & & 42 & 48 \\
\hline Cyprus ${ }^{1,2}$ & 440 & & & 45 & 48 \\
\hline Bulgaria & 434 & & & 46 & 49 \\
\hline Kazakhstan & 433 & & & 48 & 49 \\
\hline Thailand & 414 & & & 50 & 51 \\
\hline Chile & 411 & 33 & 34 & 50 & 52 \\
\hline Mexico & 405 & 33 & 34 & 51 & 54 \\
\hline Costa Rica & 402 & & & 52 & 56 \\
\hline Uruguay & 401 & & & 52 & 56 \\
\hline Malaysia & 401 & & & 52 & 56 \\
\hline Montenegro & 399 & & & 54 & 56 \\
\hline Albania & 388 & & & 57 & 58 \\
\hline Jordan & 387 & & & 57 & 59 \\
\hline Tunisia & 379 & & & 58 & 61 \\
\hline Argentina & 379 & & & 58 & 61 \\
\hline Brazil & 372 & & & 60 & 62 \\
\hline Indonesia & 364 & & & 61 & 64 \\
\hline Qatar & 363 & & & 62 & 63 \\
\hline Colombia & 357 & & & 63 & 65 \\
\hline Peru & 349 & & & 64 & 65 \\
\hline
\end{tabular}

1. Note by Turkey: The information in this document with reference to "Cyprus" relates to the southern part of the Island. There is no single authority representing both Turkish and Greek Cypriot people on the Island. Turkey recognises the Turkish Republic of Northern Cyprus (TRNC). Until a lasting and equitable solution is found within the context of the United Nations, Turkey shall preserve its position concerning the "Cyprus issue".

2. Note by all the European Union Member States of the OECD and the European Union: The Republic of Cyprus is recognised by all members of the United Nations with the exception of Turkey. The information in this document relates to the area under the effective control of the Government of the Republic of Cyprus.

Source: OECD, PISA 2012 Database.

StatLink 靖细 http://dx.doi.org/10.1787/888932935572 
- Figure I.2.53 [Part 2/4]

Where countries and economies rank on the different mathematics content subscales

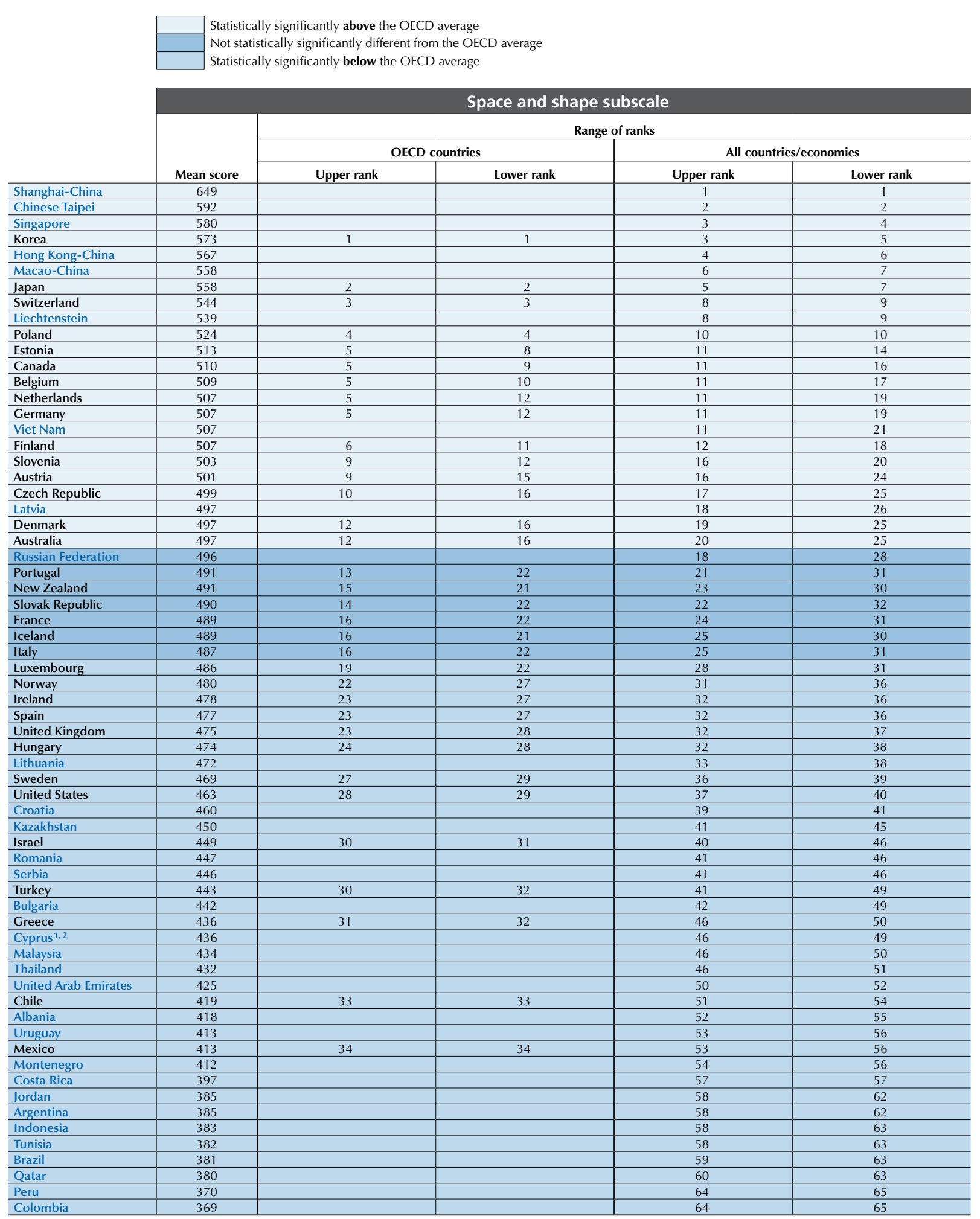

1. Note by Turkey: The information in this document with reference to "Cyprus" relates to the southern part of the Island. There is no single authority representing both Turkish and Greek Cypriot people on the Island. Turkey recognises the Turkish Republic of Northern Cyprus (TRNC). Until a lasting and equitable solution is found within the context of the United Nations, Turkey shall preserve its position concerning the "Cyprus issue".

2. Note by all the European Union Member States of the OECD and the European Union: The Republic of Cyprus is recognised by all members of the United Nations with the exception of Turkey. The information in this document relates to the area under the effective control of the Government of the Republic of Cyprus.

Source: OECD, PISA 2012 Database.

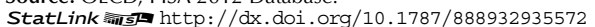




\section{Where countries and economies rank on the different mathematics content subscales}

\begin{tabular}{|c|c|c|c|c|c|}
\hline & \multicolumn{3}{|c|}{$\begin{array}{l}\text { Statistically significantly above the OECD average } \\
\text { Not statistically significantly different from the OECD average } \\
\text { Statistically significantly below the OECD average }\end{array}$} & & \\
\hline & \multirow[b]{4}{*}{ Mean score } & \multicolumn{3}{|c|}{ Quantity subscale } & \\
\hline & & \multicolumn{4}{|c|}{ Range of ranks } \\
\hline & & \multicolumn{2}{|c|}{ OECD countries } & \multicolumn{2}{|c|}{ All countries/economies } \\
\hline & & Upper rank & Lower rank & Upper rank & Lower rank \\
\hline Shanghai-China & 591 & & & 1 & 1 \\
\hline Singapore & 569 & & & 2 & 3 \\
\hline Hong Kong-China & 566 & & & 2 & 3 \\
\hline Chinese Taipei & 543 & & & 4 & 5 \\
\hline Liechtenstein & 538 & & & 4 & 7 \\
\hline Korea & 537 & 1 & 3 & 4 & 8 \\
\hline Netherlands & 532 & 1 & 4 & 5 & 10 \\
\hline Switzerland & 531 & 1 & 4 & 6 & 10 \\
\hline Macao-China & 531 & & & 7 & 9 \\
\hline Finland & 527 & 3 & 5 & 8 & 11 \\
\hline Estonia & 525 & 3 & 6 & 9 & 12 \\
\hline Belgium & 519 & 6 & 10 & 12 & 16 \\
\hline Poland & 519 & 5 & 10 & 11 & 17 \\
\hline Japan & 518 & 5 & 11 & 11 & 17 \\
\hline Germany & 517 & 6 & 11 & 12 & 17 \\
\hline Canada & 515 & 7 & 11 & 13 & 17 \\
\hline Austria & 510 & 9 & 13 & 15 & 19 \\
\hline Viet Nam & 509 & & & 13 & 24 \\
\hline Ireland & 505 & 11 & 15 & 17 & 22 \\
\hline Czech Republic & 505 & 11 & 16 & 17 & 23 \\
\hline Slovenia & 504 & 12 & 15 & 18 & 22 \\
\hline Denmark & 502 & 12 & 17 & 18 & 24 \\
\hline Australia & 500 & 14 & 19 & 21 & 26 \\
\hline New Zealand & 499 & 14 & 20 & 21 & 27 \\
\hline Iceland & 496 & 16 & 22 & 23 & 29 \\
\hline France & 496 & 16 & 23 & 22 & 29 \\
\hline Luxembourg & 495 & 18 & 22 & 25 & 29 \\
\hline United Kingdom & 494 & 16 & 25 & 22 & 32 \\
\hline Norway & 492 & 18 & 25 & 25 & 33 \\
\hline Spain & 491 & 20 & 25 & 27 & 33 \\
\hline Italy & 491 & 21 & 25 & 28 & 33 \\
\hline Latvia & 487 & & & 29 & 36 \\
\hline Slovak Republic & 486 & 22 & 28 & 29 & 37 \\
\hline Lithuania & 483 & & & 32 & 39 \\
\hline Sweden & 482 & 25 & 29 & 33 & 40 \\
\hline Portugal & 481 & 25 & 30 & 32 & 41 \\
\hline Croatia & 480 & & & 33 & 41 \\
\hline Israel & 480 & 25 & 30 & 32 & 41 \\
\hline Russian Federation & 478 & & & 35 & 41 \\
\hline United States & 478 & 26 & 30 & 34 & 41 \\
\hline Hungary & 476 & 27 & 30 & 36 & 41 \\
\hline Serbia & 456 & & & 42 & 43 \\
\hline Greece & 455 & 31 & 31 & 42 & 43 \\
\hline Romania & 443 & & & 44 & 47 \\
\hline Bulgaria & 443 & & & 44 & 47 \\
\hline Turkey & 442 & 32 & 32 & 44 & 48 \\
\hline Cyprus ${ }^{1,2}$ & 439 & & & 45 & 47 \\
\hline United Arab Emirates & 431 & & & 47 & 49 \\
\hline Kazakhstan & 428 & & & 48 & 50 \\
\hline Chile & 421 & 33 & 33 & 49 & 51 \\
\hline Thailand & 419 & & & 50 & 53 \\
\hline Mexico & 414 & 34 & 34 & 51 & 54 \\
\hline Uruguay & 411 & & & 52 & 56 \\
\hline Malaysia & 409 & & & 52 & 56 \\
\hline Montenegro & 409 & & & 53 & 56 \\
\hline Costa Rica & 406 & & & 53 & 56 \\
\hline Brazil & 393 & & & 57 & 58 \\
\hline Argentina & 391 & & & 57 & 59 \\
\hline Albania & 386 & & & 58 & 60 \\
\hline Tunisia & 378 & & & 59 & 62 \\
\hline Colombia & 375 & & & 60 & 62 \\
\hline Qatar & 371 & & & 61 & 63 \\
\hline Jordan & 367 & & & 62 & 65 \\
\hline Peru & 365 & & & 62 & 65 \\
\hline Indonesia & 362 & & & 63 & 65 \\
\hline
\end{tabular}

1. Note by Turkey: The information in this document with reference to "Cyprus" relates to the southern part of the Island. There is no single authority representing both Turkish and Greek Cypriot people on the Island. Turkey recognises the Turkish Republic of Northern Cyprus (TRNC). Until a lasting and equitable solution is found within the context of the United Nations, Turkey shall preserve its position concerning the "Cyprus issue".

2. Note by all the European Union Member States of the OECD and the European Union: The Republic of Cyprus is recognised by all members of the United Nations with the exception of Turkey. The information in this document relates to the area under the effective control of the Government of the Republic of Cyprus.

Source: OECD, PISA 2012 Database.

StatLink 靖细 http://dx.doi.org/10.1787/888932935572 


\section{Where countries and economies rank on the different mathematics content subscales}

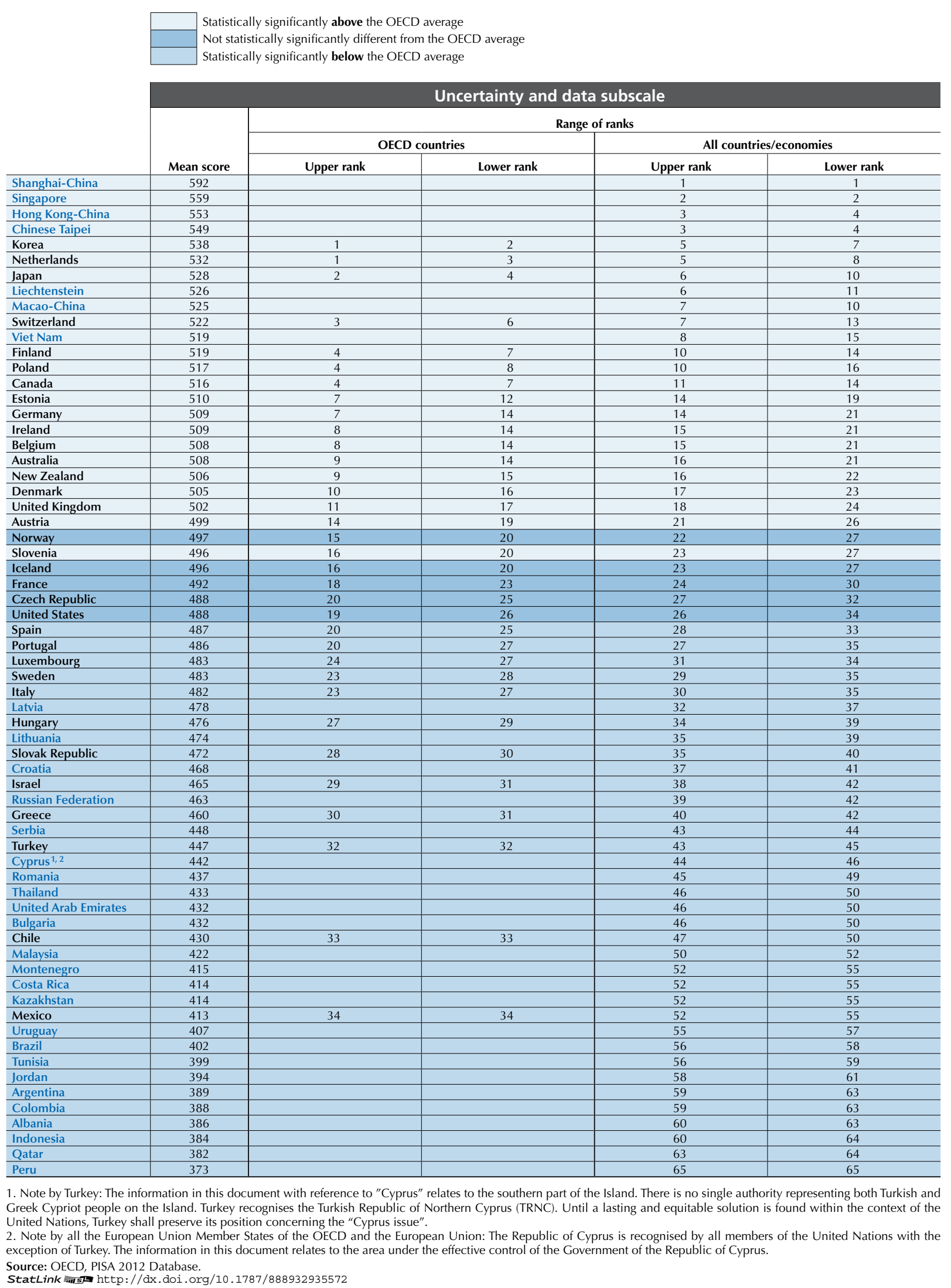


- Figure I.2.54a

Gender differences in performance on the change and relationships subscale

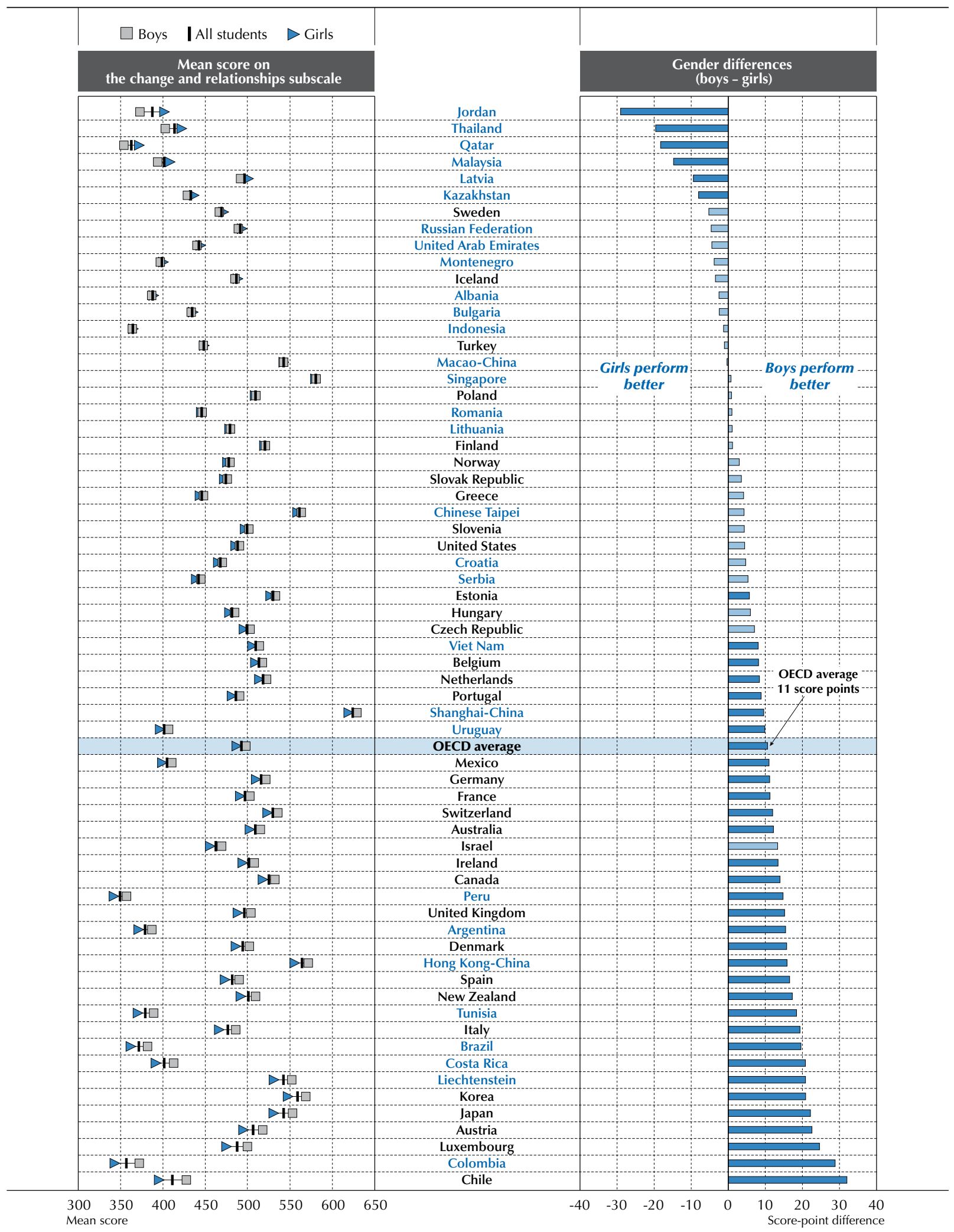

Note: Statistically significant gender differences are marked in a darker tone (see Annex A3).

Countries and economies are ranked in ascending order of the gender score-point difference (boys - girls).

Source: OECD, PISA 2012 Database, Table I.2.16.

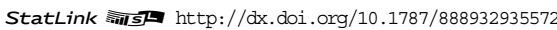


- Figure 1.2.54b -

Gender differences in performance on the space and shape subscale

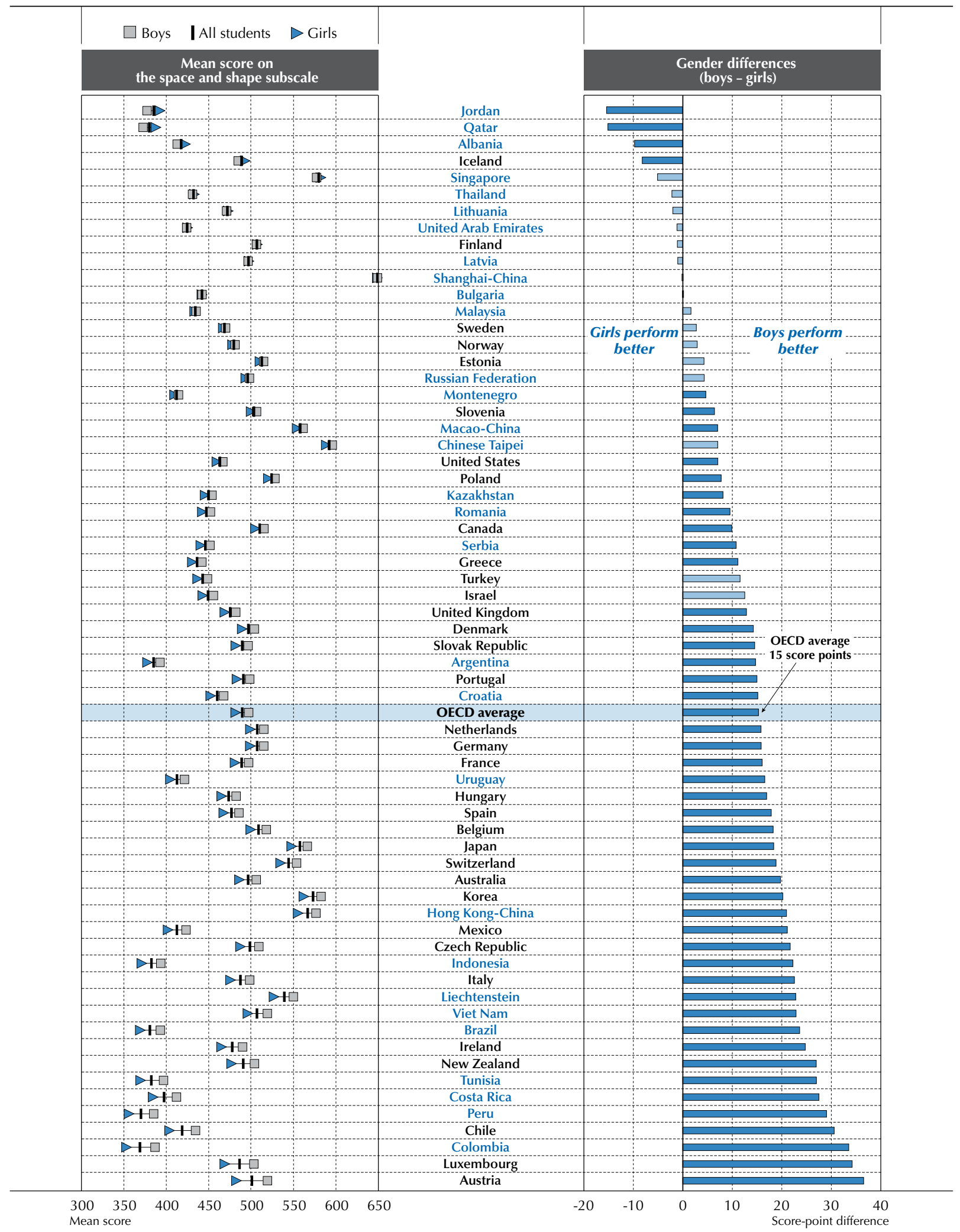

Note: Statistically significant gender differences are marked in a darker tone (see Annex A3).

Countries and economies are ranked in ascending order of the gender score-point difference (boys - girls).

Source: OECD, PISA 2012 Database, Table I.2.19.

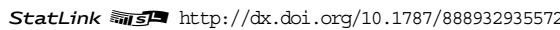


- Figure $1.2 .54 \mathrm{c}$.

Gender differences in performance on the quantity subscale

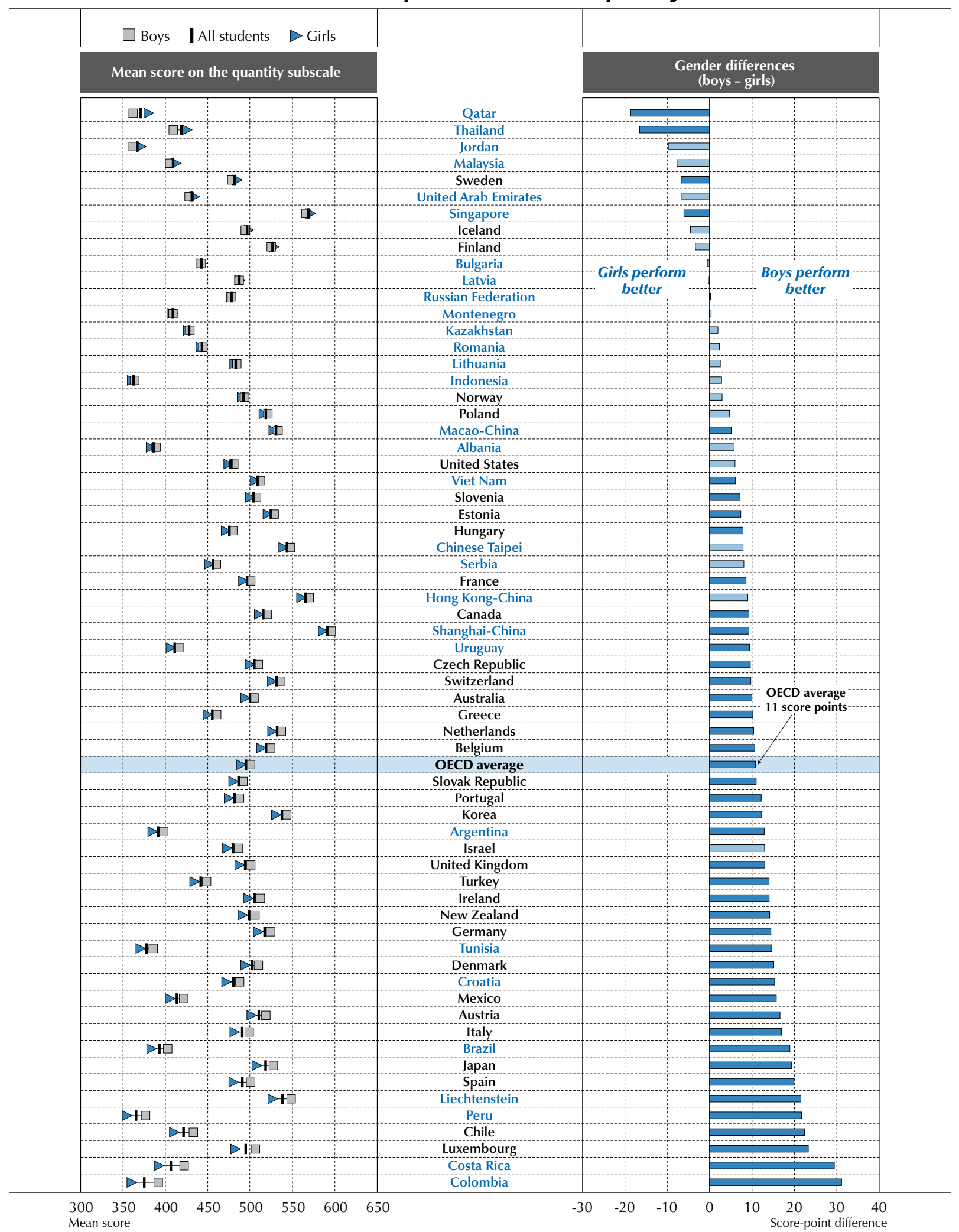

Note: Statistically significant gender differences are marked in a darker tone (see Annex A3).

Countries and economies are ranked in ascending order of the gender score-point difference (boys - girls).

Source: OECD, PISA 2012 Database, Table 1.2.22.

StatLink 尚ISL http://dx.doi.org/10.1787/888932935572 
- Figure $1.2 .54 \mathrm{~d}$

\section{Gender differences in performance on the uncertainty and data subscale}

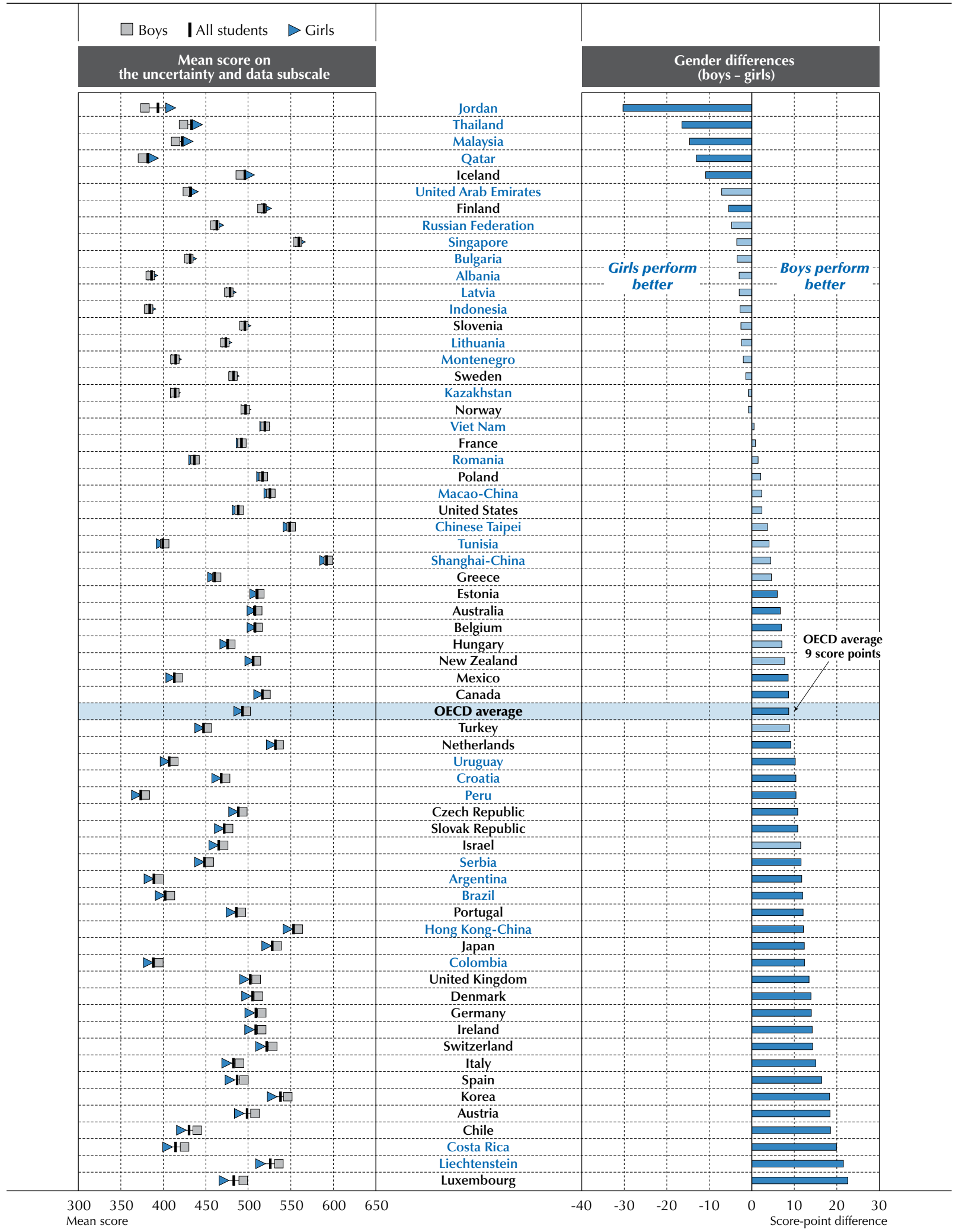

Note: Statistically significant gender differences are marked in a darker tone (see Annex A3)

Countries and economies are ranked in ascending order of the gender score-point difference (boys - girls).

Source: OECD, PISA 2012 Database, Table 1.2.25.

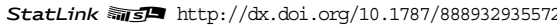


Across OECD countries, boys outperform girls on the uncertainty and data subscale by an average of 9 points - the smallest average difference of the four content subscales. The largest performance difference in favour of boys (23 points) is seen in Luxembourg. In Liechtenstein this difference is about 22 points, and in 31 other countries and economies boys outperform girls on this subscale by less than 20 points. Iceland and Finland are the only OECD countries where girls outperform boys on this subscale ( 11 and 5 points in favour for girls, respectively), but among partner countries and economies, four show substantial differences in favour of girls: Jordan (30 points), Thailand (16 points), Malaysia (15 points) and Qatar (13 points).

\section{Box I.2.5. Improving in PISA: Turkey}

When it first participated in PISA, in 2003, Turkey was among the lowest-performing OECD countries in mathematics, reading and science. Yet Turkey's performance in all three domains has improved markedly since then, at an average yearly rate of 3.2, 4.1 and 6.4 points per year. In 2003, for example, the average 15-year-old student in Turkey scored 423 points in mathematics. With an average annual increase of 3.2 points, the average score in mathematics in 2012 was 448 points - an improvement over 2003 scores that is the equivalent of more than half a year of schooling. Much of this improvement was concentrated among students with the greatest educational needs. The mathematics scores of Turkey's lowest-achieving students (the $10^{\text {th }}$ percentile) improved from 300 to 338 points between 2003 and 2012, with no significant change among the highest-achieving students during the period. Consistent with this trend, the share of students who perform below proficiency Level 2 in mathematics shrank from 52\% in 2003 to $42 \%$ in 2012. Between-school differences in average mathematics performance did not change between 2003 and 2012 , but differences in performance among students within schools narrowed during that time, meaning that much of the improvement in mathematics performance observed between 2003 and 2012 is the result of low-performing students across all schools improving their performance (Table II.2.1b).

The observed improvement in mathematics was concentrated among socio-economically disadvantaged and lowachieving students. Between 2003 and 2012, both the average difference in performance between advantaged and disadvantaged students and the degree to which students' socio-economic status predicts their performance shrank. In 2003, advantaged students outperformed disadvantaged students by almost 100 score points; in 2012, the difference was around 60 score points. In 2003, 28\% of the variation in students' scores (around the OECD average) was explained by students' socio-economic status; by 2012, 15\% of the variation (below the OECD average) was explained by students' socio-economic status. While all students, on average, improved their scores no matter where their schools were located, students attending schools in towns (population of 3000 to 100 000) improved their mathematics scores by 59 points between 2003 and 2012 - more than the increase observed among students in cities or large cities (population greater than 100 000; no change in performance detected).

Turkey has a highly centralised school system: education policy is set centrally at the Ministry of National Education and schools have comparatively little autonomy. Education policy is guided by a two-year Strategic Plan and a four-year Development Plan. The Basic Education Programme (BEP), launched in 1998, sought to expand primary education, improve the quality of education and overall student outcomes, narrow the gender gap in performance, align performance indicators with those of the European Union, develop school libraries, ensure that qualified teachers were employed, integrate information and communication technologies into the education system, and create local learning centres, based in schools, that are open to everyone (OECD, 2007). The Master Implementation Plan (2001-05), designed in collaboration with UNICEF, and the Secondary Project (2006-11), in collaboration with the World Bank, included multiple projects to improve both equity and quality in the education system. The Standards for Primary Education, piloted in 2010 and recently expanded to all primary institutions, defines quality standards for primary education, guides schools in achieving these standards, develops a system of school self-assessments, and guides local and central authorities in addressing inequalities among schools.

One of the major changes introduced with the BEP programme involved the compulsory education law. This change was first implemented in the 1997/98 school year, and in 2003 the first students graduated from the eight-year compulsory education system. Since the launch of this programme, the attendance rate among primary students increased from around $85 \%$ to nearly $100 \%$, while the attendance rate in pre-primary programmes increased from $10 \%$ to $25 \%$. In addition, the system was expanded to include 3.5 million more pupils, average class size was reduced to roughly 30 students, all students learn at least one foreign language, computer laboratories were established in every primary school, and overall physical conditions were improved in all 35000 rural schools. 
Resources devoted to the programme exceeded USD 11 billion. This programme did not directly affect school participation for most of the 15-year-olds assessed by PISA, who are mainly in secondary schools where enrolment rates are close to $60 \%$. In 2012, compulsory education was increased from 8 to 12 years of schooling, and the school system was redefined into three levels (primary, lower secondary and upper secondary) of four years each.

Fifteen-year-old students in Turkey are the least likely among students in all OECD countries to have attended pre-primary education. Several initiatives are in place to change this, but none has yet had a direct impact on the students who participated in PISA 2012. Early childhood education and care is featured in the current Development Plan (2014-18) and other on-going programmes include the Mobile Classroom (for children aged 36-66 months from low-income families), the Summer Preschool (for children aged 60-66 months), the Turkey Country Programme, and the Pre-School Education Project.

New curricula were introduced in the 2006/07 school year, starting from the 6 th grade. The secondary school mathematics and language curricula were also revised and a new science curriculum was applied in the 9th grade for the 2008/09 school year. In PISA 2012 students had already been taught the new curriculum for four years, although their primary school education was part of the former system. The standards of the new curricula were intended to meet PISA goals: "Increased importance has been placed on students' doing mathematics which means exploring mathematical ideas, solving problems, making connections among mathematical ideas, and applying them in real life situations" (Talim ve Terbiye Kurulu [TTKB] [Board of Education], 2008).

The curricular reform was designed not only to change the content of school education and encourage the introduction of innovative teaching methods, but above all to change the teaching philosophy and culture within schools. The new curricula and teaching materials emphasise "student-centred learning", giving students a more active role than before, when memorising information had been the predominant approach. They also reflect the assumption, on which PISA is based, that schools should equip students with the skills needed to ensure success at school and in life, in general.

In 2003, more than one in four students reported having arrived late for school at least once in the two weeks prior to the PISA test; by 2012, more than four in ten students reported having arrived late. By contrast, students' sense of belonging at school seems to have improved during the same period. Students in 2012 also spent one half an hour less per week in mathematics instruction than students in 2003 did, and almost an hour and a half less per week in after-school study.

Students in 2012 attended schools with better physical infrastructure and better educational resources than their counterparts in 2003 did. Throughout 2004 and 2005, private-sector investments funded 14000 additional classrooms in the country. Taxes were reduced for private businesses that invested in education. This was particularly helpful in provinces where there was large internal migration (OECD, 2006).

Several policies had sought to change the culture and management of schools. Schools were obliged to propose a plan of work, including development targets and strategic plans for reaching them. More democratic governance, parental involvement and teamwork were suggested. In 2004, a project aimed at teaching students democratic skills was started in all primary and secondary schools, with many responsibilities assigned to student assemblies. In addition, more transparent and performance-oriented inspection tools were introduced.

Teachers were also the target of policy changes. New arrangements were implemented in 2008 to train teachers for upper secondary education through five-year graduate programmes. The arrangements also stipulated that graduates in other fields, such as science or literature, who wanted to teach would also have to attend a yearand-a-half of graduate training in education. The Teacher Formation Programmes of Education Faculties (2008) links pre-service training courses to the Ministry's curriculum and teacher-practice standards while giving more autonomy to faculties on the courses that should be taught. The New Teacher Programme, introduced in 2011, established stricter requirements for certain subjects.

Several projects implemented over the past decade have addressed equity issues. The Girls to Schools Now campaign, in collaboration with UNICEF, that started in 2003 aimed to ensure that all girls aged 6 to 14 attend primary school. Efforts to increase enrolment in school continue through programmes like the Address-Based Population Registry System, which creates a registry to identify non-schooled children, the Education with Transport programme, which benefits students who have no access to school, and the Complementary Transitional Training 
Programme, which tries to ensure that 10-14 year-olds acquire a basic education even if they have never been enrolled in a school or if they had dropped out of school. The Project for Increasing Enrolment Rates Especially for Girls, in a pilot phase in the 16 provinces with the lowest enrolment rates among girls, addresses families' awareness about the links between education and the labour market. Since 2003, textbooks for all primary students have been supplied free of charge by the Ministry of National Education. The International Inspiration Project, begun in 2011, and the Strengthening Special Education Project, begun in 2010, are designed to promote disadvantaged students' performance.

\section{Sources:}

OECD (2013d), Education Policy Outlook: Turkey, OECD Publishing. http://www.oecd.org/edu/EDUCATION\%20POLICY\%20OUTLOOK\%20TURKEY_EN.pdf

OECD (2007), Reviews of National Policies for Education: Basic Education in Turkey, OECD Publishing. http://dx.doi.org/10.1787/9789264030206-en

OECD (2006), Economic Survey of Turkey: 2006, OECD Publishing.

http://dx.doi.org/10.1787/eco_surveys-tur-2006-en

Talim ve Terbiye Kurulu (TTKB) (2008), Ilkögretim Matematik Dersi 6-8 Sınıflar Öğretim Programı ve Kılavuzu (Teaching Syllabus and Curriculum Guidebook for Elementary School Mathematics Course: Grades 6 to 8), Milli Eğitim Bakanlığı, Ankara. 
- Figure I.2.55 "

HELEN THE CYCLIST

Helen has just got a new bike. It has a speedometer which sits on the handlebar.

The speedometer can tell Helen the distance she travels and her average speed for a trip.

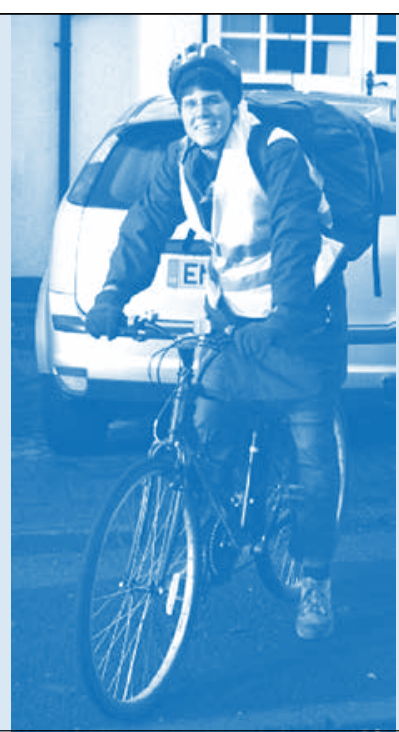

This unit is concerned with journeys by bicycle. Its storyline about an individual person places it into the personal context category. Slight changes in the context of the unit could place these questions into the occupational or scientific categories. These categories are designed to ensure breadth of appeal to students in the contexts used in the assessment and are a checklist to promote inclusion of all aspects of life. They are not reporting categories. The concern with relationships between distance, time and speed puts these questions in the change and relationships content category.

\section{HELEN THE CYCLIST - QUESTION 1}

On one trip, Helen rode $4 \mathrm{~km}$ in the first 10 minutes and then $2 \mathrm{~km}$ in the next 5 minutes.

Which one of the following statements is correct?

A. Helen's average speed was greater in the first 10 minutes than in the next 5 minutes.

B. Helen's average speed was the same in the first 10 minutes and in the next 5 minutes.

C. Helen's average speed was less in the first 10 minutes than in the next 5 minutes.

D. It is not possible to tell anything about Helen's average speed from the information given.

\section{Scoring}

Description: Compare average speeds given distances travelled and times taken

Mathematical content area: Change and relationships

Context: Personal

Process: Employ

Question format: Simple multiple choice

Difficulty: 440.5 -

\section{Full Credit}

B. Helen's average speed was the same in the first 10 minutes and in the next 5 minutes.

\section{No Credit}

Other responses.

Missing. 
Comment

Question 1, a simple multiple choice item, requires comparison of speed when travelling $4 \mathrm{~km}$ in 10 minutes versus $2 \mathrm{~km}$ in 5 minutes. It is been classified within the employing process category because it requires the precise mathematical understanding that speed is a rate and that proportionality is the key. This question can be solved by recognising the doubles involved ( $2 \mathrm{~km}-4 \mathrm{~km} ; 5 \mathrm{~km}-10 \mathrm{~km}$ ), which is the very simplest notion of proportion. Consequently, with this Level 2 question, successful students demonstrate a very basic understanding of speed and of proportion calculations. If distance and time are in the same proportion, the speed is the same. Of course, students could correctly solve the problem in more complicated ways (e.g. calculating that both speeds are $24 \mathrm{~km}$ per hour) but this is not necessary. PISA results for this question do not incorporate information about the solution method used. The correct response option here is $B$ (Helen's average speed was the same in the first 10 minutes and in the next 5 minutes).

\section{HELEN THE CYCLIST - QUESTION 2}

Helen rode $6 \mathrm{~km}$ to her aunt's house. Her speedometer showed that she had averaged $18 \mathrm{~km} / \mathrm{h}$ for the whole trip.

Which one of the following statements is correct?

A. It took Helen 20 minutes to get to her aunt's house.

B. It took Helen 30 minutes to get to her aunt's house.

C. It took Helen 3 hours to get to her aunt's house.

D. It is not possible to tell how long it took Helen to get to her aunt's house.

Scoring

Description: Calculate time travelled given average speed and distance travelled

Mathematical content area: Change and relationships

Context: Personal

Process: Employ

Question format: Simple multiple choice

Difficulty: 510.6 .

\section{Full Credit}

A. It took Helen 20 minutes to get to her aunt's house.

\section{No Credit}

Other responses.

Missing.

\section{Comment}

Question 2 is at Level 3. Again, it is classified in the employing process category and can be solved by simple proportional reasoning, from the understanding of the meaning of the speed: 18 kilometres travelled in one hour. For one third of the distance, the time is one third of an hour, which is 20 minutes (hence the correct answer A: It took Helen 20 minutes to get to her aunt's house). Information about the percentage of students choosing each multiple choice is available for future analysis through the public databases.

\section{HELEN THE CYCLIST - OUESTION 3}

Helen rode her bike from home to the river, which is $4 \mathrm{~km}$ away. It took her 9 minutes. She rode home using a shorter route of $3 \mathrm{~km}$. This only took her 6 minutes.

What was Helen's average speed, in $\mathrm{km} / \mathrm{h}$, for the trip to the river and back?

Average speed for the trip: $\mathrm{km} / \mathrm{h}$ 
Scoring

Description: Calculate average speed over two trips given two distances travelled and the times taken Mathematical content area: Change and relationships

Context: Personal

Process: Employ

Question format: Constructed response manual

Difficulty: 696.6 .

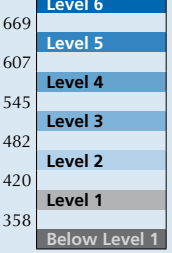

\section{Full Credit}

\section{No Credit}

Other responses.

28.3 [Incorrect method: average of speeds for 2 trips (26.67 and 30)].

Missing.

\section{Comment}

Question 3 requires a deeper understanding of the meaning of average speed, appreciating the importance of linking total time with total distance. Average speed cannot be obtained just by averaging the speeds, even though in this specific case the incorrect answer $(28.3 \mathrm{~km} / \mathrm{hr}$ ) obtained by averaging the speeds $(26.67 \mathrm{~km} / \mathrm{hr}$ and $30 \mathrm{~km} / \mathrm{hr})$ is not much different from the correct answer of $28 \mathrm{~km} / \mathrm{hr}$. There are both mathematical and real world understandings of this phenomenon, leading to high demands on the fundamental mathematical capabilities of mathematisation and reasoning and argumentation and also using symbolic, formal and technical language and operations.

For students who know to work from total time $(9+6=15$ minutes $)$ and total distance $(4+3=7 \mathrm{~km})$, the answer can be obtained simply by proportional reasoning ( $7 \mathrm{~km}$ in $1 / 4$ hour is $28 \mathrm{~km}$ in 1 hour), or by more complicated formula approaches (e.g. distance / time $=7 /(15 / 60)=420 / 15=28$ ). This question has been classified as an employing process because the greatest part of the demand was judged to arise from the mathematical definition of average speed and possibly also the unit conversion, especially for students using speed-distance-time formulas. It is one of the more difficult tasks of the item pool, and sits in Level 6 on the proficiency scale.

\section{General comment on this unit}

Some indication of the increasing difficulty of the three questions of this unit can be appreciated by looking at the overall strategies for the three questions. In Question 1, two rates are to be compared. In Question 2, the solution strategy goes from speed and distance, to time with a unit conversion. In Question 3, the four quantities have to be combined in a way that students often find counter-intuitive. Instead of combining the distance-time information for each trip, the two distances and the two times are combined, giving new distance and time, and so average speed. In the most elegant solutions, all the arithmetic is simple, but in practice students' methods may often involve more complicated calculation. 


\section{CLIMBING MOUNT FUJ}

\section{CLIMBING MOUNT FUJI}

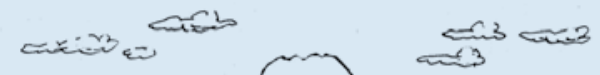

Mount Fuji is a famous dormant volcano in Japan.

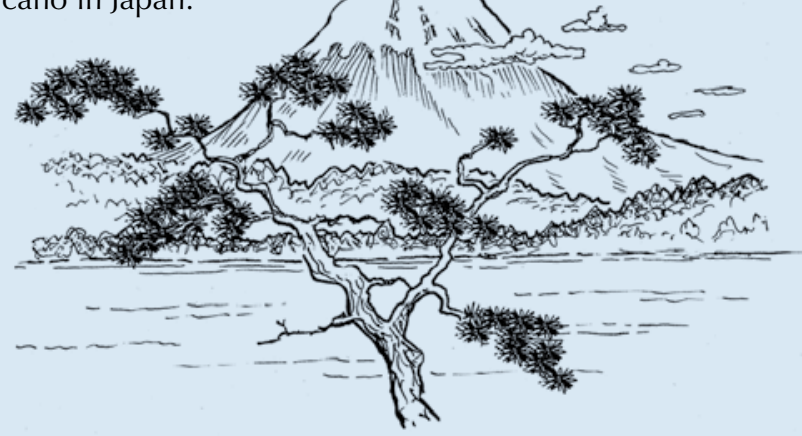

\section{CLIMBING MOUNT FUJI - QUESTION 1}

Mount Fuji is only open to the public for climbing from 1 July to 27 August each year. About 200000 people climb Mount Fuii during this time.

On average, about how many people climb Mount Fuji each day?
A. 340
B. 710
C. 3400
D. 7100
E. 7400

\section{Scoring}

Description: Identify an average daily rate given a total number and a specific time period (dates provided)

Mathematical content area: Quantity

Context: Societal

Process: Formulate

Question format: Simple multiple choice

Difficulty: 464 .

\section{Full Credit}

C. 3400

\section{No Credit}

Other responses.

Missing.

\section{Comment}

Question 1 goes beyond personal concerns of a walker to wider community issues - in this case possibly concerns of use of the public trail. Items classified as societal involve such things as voting systems, public transport, government, public policies, demographics, advertising, national statistics and economics. Although individuals are involved in these things in a personal way, in the societal context category the focus of problems is more on the community perspective. Allocation to the context category is only carried out in order to ensure a balance across the assessment and is not used for reporting. With minor rewording, presenting the challenges from the point of view of the decisions made by park rangers, this unit could have belonged to the occupational category. 
Question 1 is presented in the simple multiple choice format (choose one out of four). Question 2 requires the answer 11 a.m. and so is a constructed response item with expert scoring needed to ensure that all equivalent ways of writing the time are picked up. Question 3, requiring the number 40 for full score, or the number 0.4 (answering in metres) for partial credit, also had expert scoring.

Question 1 requires calculation of the number of days the trail is open using the given dates, and then calculation of an average. It has been allocated to the quantity content category because it involves quantification of time and of an average. The formula for average is required and this is indeed a relationship, but in this question the focus is on its use in finding the number of people per day, rather than inherently about the relationship. For this reason, the question is not in the change and relationships category. Question 3 has similar characteristics, involving units of length. The correct response to Question 1 is C: 3400 .

\section{CLIMBING MOUNT FUJI - QUESTION 2}

The Gotemba walking trail up Mount Fuji is about 9 kilometres $(\mathrm{km})$ long.

Walkers need to return from the $18 \mathrm{~km}$ walk by 8 p.m.

Toshi estimates that he can walk up the mountain at 1.5 kilometres per hour on average, and down at twice that speed. These speeds take into account meal breaks and rest times.

Using Toshi's estimated speeds, what is the latest time he can begin his walk so that he can return by 8 p.m.?

\section{Scoring}

Description: Calculate the start time for a trip given two different speeds, a total distance to travel and a finish time Mathematical content area: Change and relationships

Context: Societal

Process: Formulate

Question format: Constructed response expert

Difficulty: 641.6 .

\section{Full Credit}

11 (a.m.) [with or without a.m., or an equivalent way of writing time, for example, 11:00]

\section{No Credit}

Other responses.

Missing.

\section{Comment}

Question 2 is allocated to the change and relationships category, because here the relationship between distance and time, encapsulated as speed, is paramount. From information about distances and speed, the time to go up and the time to go down have to be quantified, and then used in combination with the finishing time to get the starting time. Had the times to go up and down been given directly, rather than indirectly through distance and speed, then the question could have also belonged in the quantity category. Because PISA questions are set in real contexts, they usually involve multiple mathematical topics and underlying mathematical phenomena, so it is necessary to make judgements about the major source of demand in order to categorise them.

Allocating the process category similarly requires judgement about the major demand of the item. Question 1 has been allocated to the formulating category, because of the judgement that the major demand in this relatively easy item is to take the two pieces of real world information (open season and total number of climbers), and to set up the mathematical problem to be solved: find the length of the open season from the dates and use it with the information about the total to find the average. Expert judgement is that the major cognitive demand for 15-year-olds lies in this movement from the real world problem to the mathematical relationships, rather than in the ensuing whole number calculations. Question 2 has also been allocated to the formulating process category, because again the major demand is judged to arise from the 
transformation from the real world data to the mathematical problem, identifying all the relationships involved, rather than in carrying out the calculations or in interpreting the answer as a starting time of 11 a.m. In this difficult item, the mathematical structure involves multiple relationships: starting time = finishing time - duration, duration = time up + time down, time up (down) = distance / speed (or equivalent proportional reasoning), time down = half time up, and appreciating the simplifying assumptions that average speeds already include consideration of variable speed during the day and that no further allowance is required for breaks.

\section{CLIMBING MOUNT FUJI - QUESTION 3}

Toshi wore a pedometer to count his steps on his walk along the Gotemba trail.

His pedometer showed that he walked 22500 steps on the way up.

Estimate Toshi's average step length for his walk up the $9 \mathrm{~km}$ Gotemba trail. Give your answer in centimetres (cm).

Answer: $\mathrm{cm}$

Scoring

Description: Divide a length given in $\mathrm{km}$ by a specific number and express the quotient in $\mathrm{cm}$ Mathematical content area: Quantity

Context: Societal

Process: Employ

Question format: Constructed response manual

Difficulty: 610 .

\section{Full Credit}

40

\section{Partial Credit}

Responses with the digit 4 based on incorrect conversion to centimetres.

- 0.4 [answer given in metres].

- 4000 [incorrect conversion].

\section{No Credit}

Other responses.

Missing.

\section{Comment}

Question 3 has been allocated to the employing category. There is one main relationship involved: the distance walked= number of steps $\times$ average step length. To use this relationship to solve the problem, there are two obstacles: rearranging the formula (which is probably done by students informally rather than formally using the written relationship) so that the average step length can be found from distance and number of steps, and making appropriate unit conversions. For this question, it was judged that the major cognitive demand comes from carrying out these steps; hence it has been categorised in the employing process, rather than identifying the relationships and assumptions to be made (the formulating process) or interpreting the answer in real world terms. 


\section{- Figure I.2.57 •}

\section{REVOLVING DOOR}

\section{REVOLVING DOOR}

A revolving door includes three wings which rotate within a circular-shaped space. The inside diameter of this space is 2 metres (200 centimetres). The three door wings divide the space into three equal sectors. The plan below shows the door wings in three different positions viewed from the top.
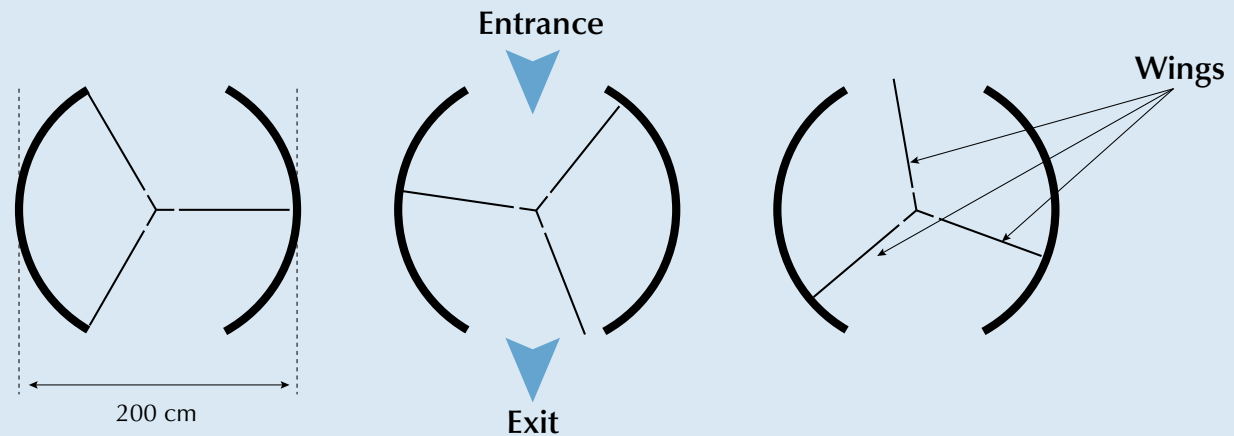

Exit

The stimulus for these three questions concerns a revolving door, which is common in cold and hot countries to prevent heat moving into or out of buildings.

\section{REVOLVING DOOR - QUESTION 1}

What is the size in degrees of the angle formed by two door wings?

Size of the angle: ${ }^{\circ}$

\section{Scoring}

Description: Compute the central angle of a sector of a circle

Mathematical content area: Space and shape

Context: Scientific

Process: Employ

Question format: Constructed response manual

Difficulty: 512.3 -

\section{Full Credit}

120 [accept the equivalent reflex angle: 240].

\section{No Credit}

Other responses.

Missing.

\section{Comment}

The first question may appear very simple: finding the angle of 120 degrees between the two door wings, but the student responses indicate it is at Level 3. This is probably because of the demand arising from communication, representation and mathematisation as well as the specific knowledge of circle geometry that is needed. The context of three-dimensional revolving doors has to be understood from the written descriptions. It also needs to be understood that the three diagrams in the initial stimulus provide different two-dimensional information about just one revolving door (not three doors) - first the diameter, then the directions in which people enter and exit from the door, and thirdly connecting the wings mentioned within the text with the lines of the diagrams. The fundamental mathematical capability 
of representation is required at a high level to interpret these diagrams mathematically. This question is allocated to the space and shape content category because it requires knowledge that there are 360 degrees in a complete revolution, and because of the requirement for spatial understanding of the diagrams.

These diagrams give the view from above, but students also need to visualise real revolving doors especially in answering Questions 2 and 3.

\section{REVOLVING DOOR - QUESTION 2}

The two door openings (the dotted arcs in the diagram) are the same size. If these openings are too wide the revolving wings cannot provide a sealed space and air could then flow freely between the entrance and the exit, causing unwanted heat loss or gain. This is shown in the diagram opposite.

What is the maximum arc length in centimetres $(\mathrm{cm})$ that each door opening can have, so that air never flows freely between the entrance and the exit?

Maximum arc length: $\mathrm{cm}$

\section{Scoring}

Description: Interpret a geometrical model of a real life situation to calculate the length of an arc Mathematical content area: Space and shape

Context: Scientific

Process: Formulate

Question format: Constructed response expert

Difficulty: 840.3

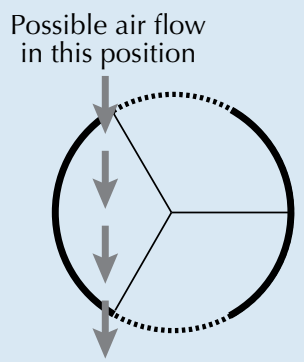

\section{Full Credit}

Answers in the range from 103 to 105 . [Accept answers calculated as $1 / 6^{\text {th }}$ of the circumference $\left(\frac{100 \pi}{3}\right)$. Also accept an answer of 100 only if it is clear that this response resulted from using $\pi=3$. Note: Answer of 100 without supporting working could be obtained by a simple guess that it is the same as the radius (length of a single wing).]

\section{No Credit}

Other responses.

- 209 [states the total size of the openings rather than the size of "each" opening].

Missing.

\section{Comment}

Question 2 was one of the most challenging questions in the survey, lying towards the upper end of Level 6. It addresses the main purpose of revolving doors, which is to provide an airlock between inside and outside the building and it requires substantial geometric reasoning, which places it in the space and shape content category. The complexity of coding such a multi-step response in so many countries led to this item being assessed only as full credit or no credit. For full credit, the complex geometrical reasoning showing that the maximum door opening is one sixth of the circumference needed to be followed by an accurate calculation in centimetres. The item is classified in the formulating process, and it draws very heavily on the mathematisation fundamental mathematical capability, because the real situation has to be carefully analysed and this analysis needs to be translated into geometric terms and back again at multiple points to the contextual situation of the door. As the diagram supplied in the question shows, air will pass from the outside to the inside, or vice versa, if the wall between the front and back openings is shorter than the circumference subtended by one sector. Since the sectors each subtend one third of the circumference, and there are two walls, together the walls must close at least two thirds of the circumference, leaving no more than one third for the two openings. Arguing from symmetry of front and back, each opening cannot be more than one sixth of the circumference. There is further geometric reasoning required to check that the airlock is indeed maintained if this opening length is used. The question therefore draws very heavily on the reasoning and argument fundamental mathematical capability. 
REVOLVING DOOR - QUESTION 3

The door makes 4 complete rotations in a minute. There is room for a maximum of two people in each of the three door sectors.

What is the maximum number of people that can enter the building through the door in 30 minutes?

A. 60

B. 180

C. 240

D. 720

Scoring

Description: Identify information and construct an (implicit) quantitative model to solve the problem

Mathematical content area: Quantity

Context: Scientific

Process: Formulate

Question format: Simple multiple choice

Difficulty: 561.3 *

\section{Full Credit}

D. 720

\section{No Credit}

Other responses.

Missing.

Comment

Question 3 addresses a different type of challenge, involving rates and proportional reasoning, and it sits within Level 4 on the mathematics proficiency scale. In one minute, the door revolves 4 times bringing $4 \times 3=12$ sectors to the entrance, which enables $12 \times 2=24$ people to enter the building. In 30 minutes, $12 \times 30=720$ people can enter (hence, the correct answer is response option D). The question is allocated to the quantity content category because of the way in which the multiple relevant quantities (number of people per sector [2], number of sectors per revolution [3], number of revolutions per minute [4], number of minutes [30]) have to be combined by number operations to produce the required number of persons to enter in 30 minutes. The high frequency of PISA items that involve proportional reasoning highlights its centrality to mathematical literacy, especially for students whose mathematics has reached a typical stage for 15-year-olds. Many real contexts involve direct proportion and rates, which as in this case are often used in chains of reasoning. Coordinating such a chain of reasoning requires devising a strategy to bring the information together in a logical sequence.

This item also makes considerable demand on the mathematisation fundamental mathematical capability, especially in the formulating process. A student needs to understand the real situation, perhaps visualising how the doors rotate, presenting one sector at a time, making the only way for people to enter the building. This understanding of the real world problem enables the data given in the problem to be assembled in the right way.

\section{General comment on this unit}

The questions in this unit have been allocated to the scientific context category, even though they do not explicitly involve scientific or engineering concepts, as do many of the other items in this category. The scientific category includes items that explain why things are as they are in the real world. Question 2 is a good example of such an essentially scientific endeavour. Formal geometric proof is not required by the question, but in answering this item correctly, the highest students will have almost constructed such a proof. 


\section{* Figure 1.2 .58 .}

WHICH CAR?

\section{WHICH CAR?}

Chris has just received her car driving licence and wants to buy her first car.

This table below shows the details of four cars she finds at a local car dealer.

\begin{tabular}{l|c|c|c|c}
\hline Model: & Alpha & Bolte & Castel & Dezal \\
\hline Year & 2003 & 2000 & 2001 & 1999 \\
\hline Advertised price (zeds) & 4800 & 4450 & 4250 & 3990 \\
\hline $\begin{array}{l}\text { Distance travelled } \\
\text { (kilometres) }\end{array}$ & 105000 & 115000 & 128000 & 109000 \\
\hline Engine capacity (litres) & 1.79 & 1.796 & 1.82 & 1.783 \\
\hline
\end{tabular}

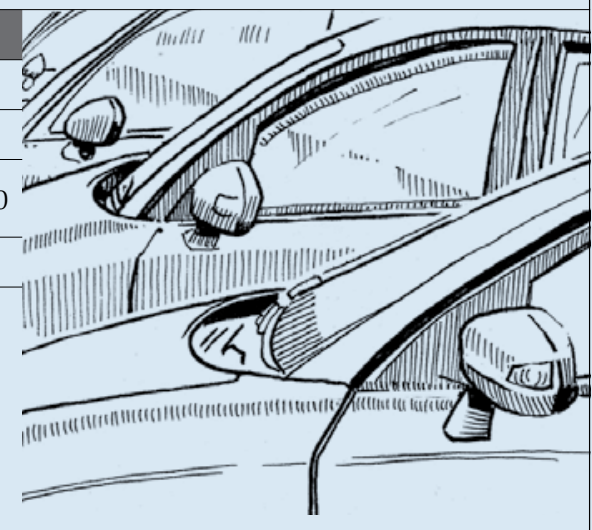

\section{WHICH CAR? - QUESTION 1}

Chris wants a car that meets all of these conditions:

- The distance travelled is not higher than 120000 kilometres.

- It was made in the year 2000 or a later year.

- The advertised price is not higher than 4500 zeds.

- Which car meets Chris's conditions?
A. Alpha
B. Bolte
C. Castel
D. Dezal

Scoring

Description: Select a value that meets four numerical conditions/statements set within a financial context Mathematical content area: Uncertainty and data

Context: Personal

Process: Interpret

Question format: Simple multiple choice

Difficulty: 327.8 -

\section{Full Credit}

B. Bolte.

\section{No Credit}

Other responses.

Missing. 
WHICH CAR? - QUESTION 2

Which car's engine capacity is the smallest?
A. Alpha
B. Bolte
C. Castel
D. Dezal

Scoring

Description: Choose the smallest decimal number in a set of four, in context

Mathematical content area: Quantity

Context: Personal

Process: Employ

Question format: Simple multiple choice

Difficulty: 490.9 .

\section{Full Credit}

\section{Dezal.}

\section{No Credit}

Other responses.

Missing.

\section{WHICH CAR? - QUESTION 3}

Chris will have to pay an extra $2.5 \%$ of the advertised cost of the car as taxes.

How much are the extra taxes for the Alpha?

Extra taxes in zeds:

Scoring

Description: Calculate $2.5 \%$ of a value in the thousands within a financial context

Mathematical content area: Quantity

Context: Personal

Process: Employ

Question format: Constructed response manual

Difficulty: 552.6 •

\section{Full Credit}

\section{No Credit}

Other responses.

- $2.5 \%$ of 4800 zeds [Needs to be evaluated].

Missing.

\section{General comment on this unit}

Because buying a car is a situation which many people face in their everyday life, all three questions have been allocated to the personal context category. Question 1 and Question 2 are simple multiple choice responses, and Question 3, which asks for a single number, is a constructed response item that does not require expert scoring. Question 1 has been allocated to uncertainty and data. The item requires knowledge of the basic row-column conventions of a table, as well as co-ordinated data-handling ability to identify where the three conditions are simultaneously satisfied. The solution also requires basic knowledge of large whole numbers, but the expert judgement is that this knowledge is unlikely to be the main source of difficulty in the item for 15 -year-old students. The correct response is B: Bolte. 
In contrast, Question 2 has been allocated to the quantity content category because it is well known that even at age 15, many students have misconceptions about the base ten and place value ideas required to order "ragged" decimal numbers. Credit is given here for response option D: Dezal.

Question 3 is also allocated to the quantity content category because the calculation of 2.5\% of the advertised cost, 120 zeds, is expected to be a much larger source of cognitive demand than identifying the correct data from the table. The difficulty for this age group in dealing with decimal numbers and percentages is reflected in the empirical results, with Question 1 being an easy item, Question 2 close to the international average and Question 3 above it.

To allocate the items to process categories, it is necessary to consider how the real world situation is involved. Items in the formulating category have their major demand in the transition from the real world problem to the mathematical problem. Items in the employing category have their major demand within the mathematical world. Items in the interpreting category have their major demand in using mathematical information to give a real world solution. Questions 2 and 3 are allocated to the employing category. This is because in both of these items, the major source of cognitive demand has been identified as being within mathematics: the concept of decimal notation and the calculation of a percentage. In Question 1, a table of data is presented, and its construction (with the identification of key variables etc.) represents a mathematisation of the real situation. The question then requires these mathematical entities as presented to be interpreted in relation to the real world constraints and situation they represent. 
In January, the new CDs of the bands $4 \mathrm{U} 2$ Rock and The Kicking Kangaroos were released. In February, the CDs of the bands No One's Darling and The Metalfolkies followed. The following graph shows the sales of the bands' CDs from January to June.

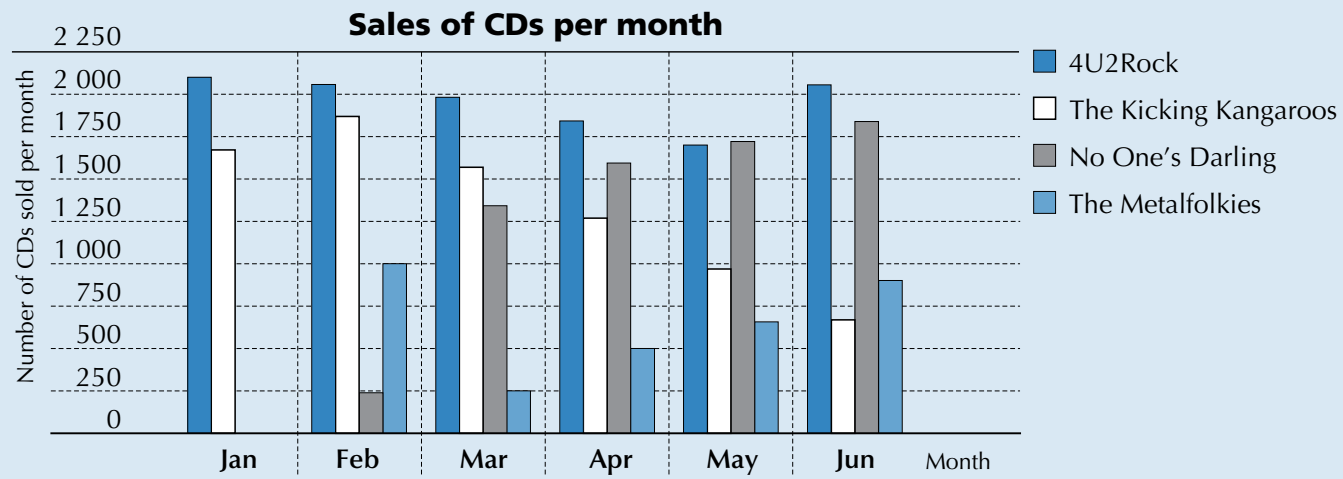

The three questions making up the unit CHARTS are all of below average difficulty in the main survey. All three items are simple multiple choice, so the demand for communication is only receptive. The unit presents a bar chart showing 6 months of sales data for music. The complication of the bar chart is that it displays four separate data series (four different music bands). Students have to read values from the graphical representation of data and draw conclusions. This is a common task type in the content category uncertainty and data. All three items have all been classified in the societal context category because it provides information about community behaviour, in this case, aggregated music choices.

\section{CHARTS - QUESTION 1}

How many CDs did the band The Metalfolkies sell in April?
A. 250
B. 500
C. 1000
D. 1270

Scoring

Description: Read a bar chart

Mathematical content area: Uncertainty and data

Context: Societal

Process: Interpret

Question format: Simple multiple choice

Difficulty: 347.7 .

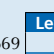

607

Level 4

482

Level 2 Level 1

\section{Full Credit}

B. 500

\section{No Credit}

Other responses.

Missing. 
Comment

Question 1, with a difficulty of 347.7, is below Level 1 on the mathematical proficiency scale, being one of the easiest tasks in the PISA 2012 item pool. It requires the student to find the bars for April, select the correct bar for the Metafolkies, and read the height of the bar to obtain the required response selection B (500). No scale reading or interpolation is required. This question is classified in the interpreting process category.

CHARTS - QUESTION 2

In which month did the band No One's Darling sell more CDs than the band The Kicking Kangaroos for the first time?

A. No month

B. March

C. April

D. May

Scoring

Description: Read a bar chart and compare the height of two bars

Mathematical content area: Uncertainty and data

Context: Societal

Process: Interpret

Question format: Simple multiple choice

Difficulty: 415 .

\section{Full Credit}

C. April.

\section{No Credit}

Other responses.

Missing.

\section{Comment}

Question 2 is a little more difficult, and lies near the bottom of Level 3 on the scale. The bars representing two bands need to be identified and the heights compared, starting from January and working through the year. No reading of the vertical scale is required. It is only necessary to make visual comparisons of adjacent bars against a very simple characteristic (which is bigger), -and to identify the correct response option C (April). In comparison with Question 1, Question 2 is a little more demanding of communication (receptive component), representation, and devising strategies, and similar on the other fundamental mathematical capabilities. It is also classified in the interpreting process category.

\section{CHARTS - QUESTION 5}

The manager of The Kicking Kangaroos is worried because the number of their CDs that sold decreased from February to June.

What is the estimate of their sales volume for July if the same negative trend continues?
A. $70 \mathrm{CDs}$
B. $370 \mathrm{CDs}$
C. $670 \mathrm{CDs}$
D. 1340 CDs 
Description: Interpret a bar chart and estimate the number of CDs sold in the future assuming that the linear trend continues Mathematical content area: Uncertainty and data

Context: Societal

Process: Employ

Question format: Simple multiple choice

Difficulty: 428.2 .

${ }_{420}$

\section{Full Credit}

\section{B. 370 CDs.}

\section{No Credit}

Other responses.

Missing.

\section{Comment}

Question 5 requires identifying the data series for the Kangaroos band and observing the negative trend noted in the lead-in to the item stimulus. It involves some work with numbers and also an appreciation that the correct answer to choose may be an approximation to a calculated answer. There are several ways to continue the trend by one more month. A student might work out each monthly decrease and average them, which involves a lot of calculation. A student might take one fifth of the total decrease from February to June. Another student might place a ruler along the tops of the bars for the Kangaroos and find that the July bar would show something between 250 and 500. The correct response option is B (370 CDs), and the task lies in Level 2 on the mathematics scale. The question has been allocated to the Employing process because it was judged that most students at this level are likely to take the calculation routes, and that carrying these out accurately is likely to present the greatest difficulty for the item. 
A garage manufacturer's "basic" range includes models with just one window and one door. George chooses the following model from the "basic" range. The position of the window and the door are shown here.

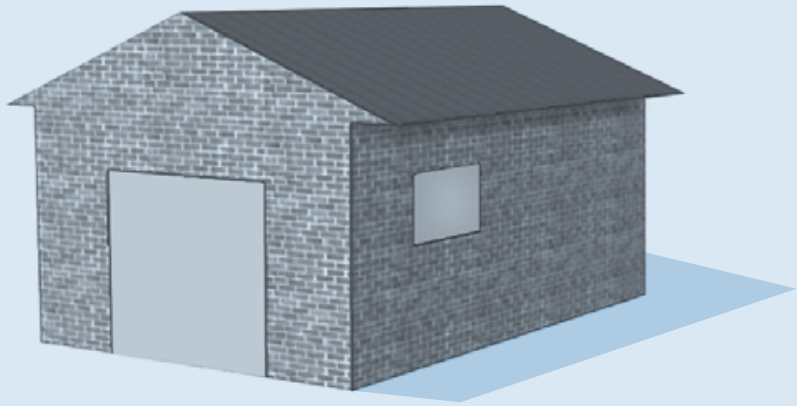

The unit GARAGE consists of two questions, both in the space and shape content category because they deal with spatial visualisation and reading building plans, and both in the occupationa/ context category, because these questions may arise in the construction, painting or other completion of a building project. Because of the need to derive mathematical information from the diagrams, both questions require activation of the representation fundamental mathematical capability.

\section{GARAGE - QUESTION 1}

The illustrations below show different "basic" models as viewed from the back. Only one of these illustrations matches the model above chosen by George.

Which model did George choose? Circle A, B, C or D.

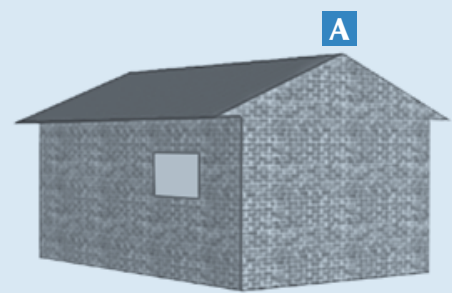

C

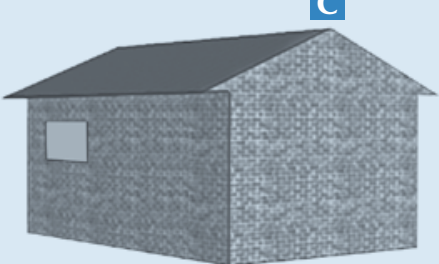

B

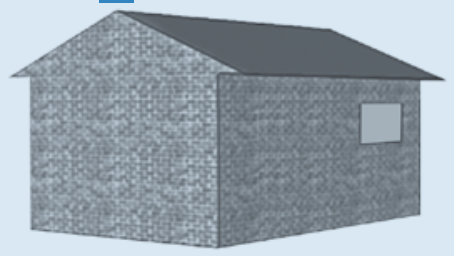

D

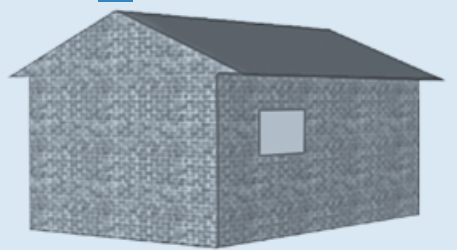

\section{Scoring}

Description: Use space ability to identify a $3 D$ view corresponding to another given $3 D$ view

Mathematical content area: Space and shape

Context: Occupational

Process: Interpret

Question format: Simple multiple choice

Difficulty: 419.6 . 


\section{Full Credit}

C. [Graphic C].

\section{No Credit}

Other responses.

Missing.

\section{Comment}

Question 1 lies very close to the Level 1/Level 2 boundary on the proficiency scale. It asks students to identify a picture of a building from the back, given the view from the front. The diagrams must be interpreted in relation to the real world positioning of "from the back", so this question is classified in the interpreting process. The correct response is C. Mental rotation tasks such as this are solved by some people using intuitive spatial visualisation. Other people need explicit reasoning processes. They may analyse the relative positions of multiple features (door, window, nearest corner), discounting the multiple choice alternatives one by one. Others might draw a bird's eye view, and then physically rotate it. This is just one example of how different students may use quite different methods to solve PISA questions: in this case explicit reasoning for some students is intuitive for others.

\section{GARAGE - QUESTION 2}

The two plans below show the dimensions, in metres, of the garage George chose.

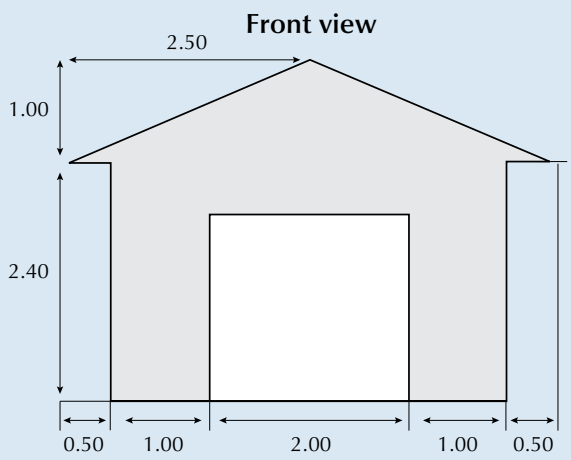

Side view

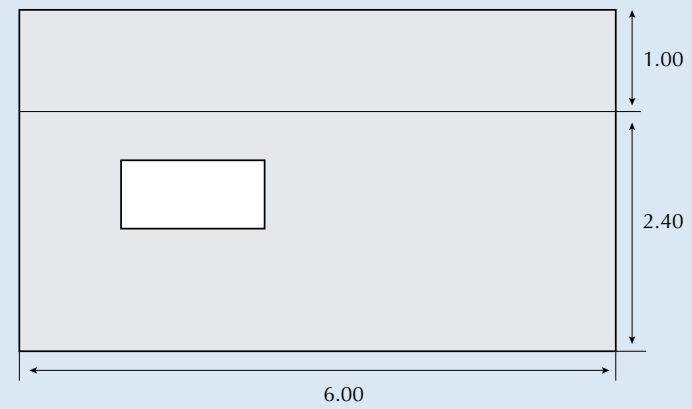

Note: Drawing not to scale.

The roof is made up of two identical rectangular sections.

Calculate the total area of the roof. Show your work.

Scoring

Description: Interpret a plan and calculate the area of a rectangle using the Pythagorean theorem or measurement

Mathematical content area: Space and shape

Context: Occupational

Process: Employ

Question format: Constructed response expert

Difficulty: 687.3 -

\section{Full Credit}

Any value from 31 to 33, either showing no working at all or supported by working that shows the use of the Pythagorean theorem (or including elements indicating that this method was used) [Units $\left(\mathrm{m}^{2}\right)$ not required].

- $12 \sqrt{7.25} \mathrm{~m}^{2}$

- $12 \times 2.69=32.28 \mathrm{~m}^{2}$

- $32.4 \mathrm{~m}^{2}$ 


\section{Partial Credit}

Working shows correct use of the Pythagorean theorem but makes a calculation error or uses incorrect length or does not double roof area.

- $2.5^{2}+1^{2}=6,12 \times \sqrt{6}=29.39$ [correct use of Pythagoras theorem with calculation error].

- $2^{2}+1^{2}=5,2 \times 6 \times \sqrt{5}=26.8 \mathrm{~m}^{2}$ [incorrect length used].

- $6 \times 2.6=15.6$ [Did not double roof area].

Working does not show use of Pythagorean theorem but uses reasonable value for width of roof (for example, any value from 2.6 to 3 ) and completes rest of calculation correctly.

- $2.75 \times 12=33$

- $3 \times 6 \times 2=36$

- $12 \times 2.6=31.2$

\section{No Credit}

Other responses.

- $2.5 \times 12=30$ [Estimate of width of roof lies outside the acceptable range which is from 2.6 to 3].

- $3.5 \times 6 \times 2=42$ [Estimate of width of roof lies outside the acceptable range which is from 2.6 to 3].

Missing.

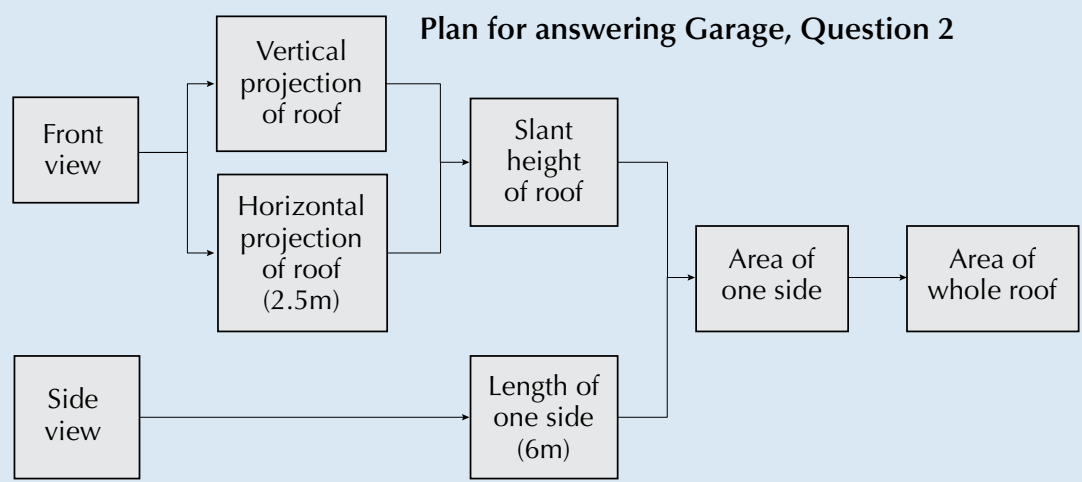

\section{Comment}

Question 2 requires complicated calculation, with multiple calls upon the mathematical diagrams, and knowing to use Pythagoras's theorem. For this reason, it has been classified in the employing process. There are multiple reasons why this item is at Level 5 for partial credit answers and at Level 6 for full credit answers. Question 2 requires a constructed response, although in this case the explanation of reasoning is only used to award partial credit for incorrect answers, rather than being scored for quality of explanation. There is high level demand for the representation capability, in understanding and deriving exact information from the front and side views presented. Mathematisation is also called upon, especially in reconciling the apparent $1.0 \mathrm{~m}$ height of the roof from the side view with the real situation and with the front view. The devising strategies capability is called up at a high level to make a plan to get the area from the information presented. The plan above shows the basic structure of the solution. To carry out such a plan also requires careful monitoring. Future analysis of the data beyond the scope of this first report may show interesting differences between the students who score partial credit. 


\section{Notes}

1. The GDP values represent per capita GDP in 2012 at current prices, adjusted for differences in purchasing power among OECD countries.

2. It should be borne in mind, however, that the number of countries involved in this comparison is small, and that the trend line is therefore strongly affected by the particular characteristics of the countries included in the comparison.

3. Spending per student is approximated by multiplying public and private expenditure on educational institutions per student in 2012 at each level of education by the theoretical duration of education at the respective level, up to the age of 15 . Cumulative expenditure for a given country is approximated as follows: let $n(0), n(1)$ and $n(2)$ be the typical number of years spent by a student from the age of 6 up to the age of 15 years in primary, lower secondary and upper secondary education. Let $E(0), E(1)$ and $E(2)$ be the annual expenditure per student in USD converted using purchasing power parities in primary, lower secondary and upper secondary education, respectively. The cumulative expenditure is then calculated by multiplying current annual expenditure $E$ by the typical duration of study $n$ for each level of education $i$ using the following formula:

$$
C E=\sum_{i=0}^{2} n(i) * E(i)
$$

4. For this purpose, the respective data were standardised across countries and then averaged over the different aspects.

5. For more details, see Butler and Adams (2007).

6. For trend purposes, Dubai (UAE) and the rest of the United Arab Emirates are counted as separate economies. Dubai (UAE) implemented PISA 2009 in 2009 and the rest of the United Arab Emirates implemented PISA 2009 in 2010, as part of PISA $2009+$.

7. As described in more detail in Annex A5, the annualised change takes into account the specific year in which the assessment was conducted. In the case of mathematics, this is especially relevant for the PISA 2009 assessment as Costa Rica, Malaysia and the United Arab Emirates (excluding Dubai) implemented the assessment in 2010 as part of PISA 2009+.

8. Normally, when comparing two concurrent means, the significance is indicated by calculating the ratio of the difference of the means to the standard error of the difference of the means. If the absolute value of this ratio is greater than 1.96, then a true difference is indicated with $95 \%$ confidence. When comparing two means taken at different times, with instruments that have a subset of common items, as in different PISA surveys, an extra error term, known as the link error, is introduced, and the resulting statement of significant difference is more conservative. For more details, see Annex A5.

9. By accounting for students' gender, age, socio-economic status, immigrant background and language spoken at home, the adjusted trends allow for a comparison of trends in performance assuming no change in the underlying population or the effective samples' average socio-economic status, age and percentage of girls, students with an immigrant background or students that speak a language at home that is different than the language of assessment.

10. The PISA index of social, economic and cultural status is unavailable for Albania in PISA 2012. Albania improved throughout its participation in PISA, but it is impossible to calculate adjusted trends for the country.

\section{References}

Bruns, B., D. Evans, and J. Luque (2011), Achieving World-Class Education in Brazil, The World Bank, Washington, D.C.

Butler, J. and R.J. Adams (2007), "The impact of differential investment of student effort on the outcomes of international studies", Journal of Applied Measurement, Vol. 3, No. 8, pp. 279-304.

Gebhardt, E. and R.J. Adams (2007), "The influence of equating methodology on reported trends in PISA", Journal of Applied Measurement, Vol. 8, No. 3, pp. 305-322.

INEP (Instituto Nacional de Estudos e Pesquisas Educacionais Anísio Teixeira) (2000), Sinopse Estatística da Educação Básica 2000, INEP, Brasilia.

INEP (Instituto Nacional de Estudos e Pesquisas Educacionais Anísio Teixeira) (2012), Sinopse Estatística da Educaçao Básica 2012, INEP, Brasilia.

INEP (Instituto Nacional de Estudos e Pesquisas Educacionais Anísio Teixeira) (2013), Censo da Educação Básica: 2012, Resumo Técnico, INEP, Brasilia.

OECD (forthcoming), PISA 2012 Technical Report, OECD Publishing.

OECD (2013a), OECD Skills Outlook 2013: First Results from the Survey of Adult Skills, OECD Publishing.

http://dx.doi.org/10.1787/9789264204256-en 
OECD (2013b), The Survey of Adult Skills: Reader's Companion, PISA, OECD Publishing. http://dx.doi.org/10.1787/9789264204027-en

OECD (2013c), PISA 2012 Assessment and Analytical Framework: Mathematics, Reading, Science, Problem Solving and Financial Literacy, PISA, OECD Publishing. http://dx.doi.org/10.1787/9789264190511-en

OECD (2013d), Education Policy Outlook: Turkey, OECD Publishing. http://www.oecd.org/edu/EDUCATION\%2OPOLICY\%20OUTLOOK\%20TURKEY_EN.pdf

OECD (2012), Learning beyond Fifteen: Ten Years after PISA, PISA, OECD Publishing. http://dx.doi.org/10.1787/9789264172104-en

OECD (2011), OECD Economic Surveys: Brazil, OECD Publishing. http://dx.doi.org/10.1787/eco_surveys-bra-2011-en

OECD (2010a), Pathways to Success: How Knowledge and Skills at Age 15 Shape Future Lives in Canada, PISA, OECD Publishing. http://dx.doi.org/10.1787/9789264081925-en

OECD (2010b), Lessons from PISA for the United States, Strong Performers, Successful Reformers in Education, OECD Publishing. http://dx.doi.org/10.1787/9789264096660-en

OECD (2007), Reviews of National Policies for Education: Basic Education in Turkey, OECD Publishing. http://dx.doi.org/10.1787/9789264030206-en

OECD (2006), Economic Survey of Turkey: 2006, OECD Publishing. http://dx.doi.org/10.1787/eco_surveys-tur-2006-en

OECD (2004), Learning for Tomorrow's World: First Results from PISA 2003, PISA, OECD Publishing. http://dx.doi.org/10.1787/9789264006416-en

Talim ve Terbiye Kurulu (TTKB) (2008), slkögretim Matematik Dersi 6-8 Sınıflar Öğretim Programı ve Kılavuzu (Teaching Syllabus and Curriculum Guidebook for Elementary School Mathematics Course: Grades 6 to 8), Milli Eğitim Bakanlığı, Ankara.

Turner, R., J. Dossey, W. Blum and M. Niss (2013), "Using mathematical competencies to predict item difficulty in PISA", in M. Prenzel, M. Kobarg, K. Schöps and S. Rönnebeck (eds.), Research on PISA: Research Outcomes of the PISA Research Conference 2009, Dordrecht, Springer, pp. 23-37. 


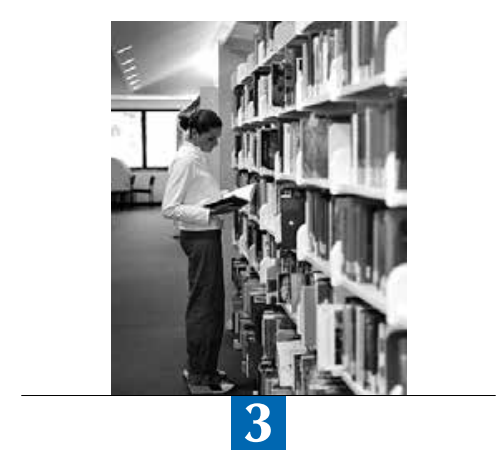

\section{Measuring Opportunities to Learn Mathematics}

This chapter examines whether and how exposure to mathematics content, known as "opportunity to learn", is associated with student performance. The analysis is based on students' responses to questions that appeared in the PISA Student Questionnaire on the degree to which they encountered various types of mathematics problems during their schooling, how familiar they were with certain formal mathematics content, and how frequently they had been taught to solve specific mathematics tasks involving formal or applied mathematics. 
Previous research has shown a relationship between students' exposure to subject content in school, what is known as "opportunity to learn", and student performance (e.g. Schmidt et al., 2001). Building on previous measures of opportunity to learn (Carroll, 1963; Wiley and Harnischfeger, 1974; Sykes, Schneider and Planck, 2009; Schmidt et al., 2001), the PISA 2012 assessment included questions to students on the mathematics theories, concepts and content to which they have been exposed to in school, and the amount of class time they spent studying this content.

\section{What the data tell us}

- Students in the high-performing East Asian countries and economies - Shanghai-China, Singapore, Hong Kong-China, Chinese Taipei, Korea, Macao-China and Japan - are more frequently exposed to formal mathematics than students in most of the other PISA-participating countries and economies.

- Exposure to more advanced mathematics content, such as algebra and geometry, appears to be related to high performance on the PISA mathematics assessment, even if the causal nature of this relationship cannot be established.

- Strong mathematics performance in PISA is not only related to opportunities to learn formal mathematics, such as solving a quadratic equation, using complex numbers, or calculating the volume of a box, but also to opportunities to learn applied mathematics (using mathematics in a real-world context).

Six questions were created in the Student Questionnaire to cover both the content and time aspects of students' opportunity to learn.

Four of the questions focused on the degree to which students encountered various types of mathematics problems or tasks during their schooling, which all form part of the PISA mathematics framework and assessment. Some of the tasks included in those questions involved formal mathematics content, such as solving an equation or calculating the volume of a box (see Question 4 at the end of this chapter). Others involved using mathematics in a real-world applied context (see Question 6 at the end of this chapter). Another type of task required using mathematics in its own context, such as using geometric theorems to determine the height of a pyramid (see Question 5 at the end of this chapter). The last type of tasks involved formal mathematics, but situated in a word problem like those typically found in textbooks (see Question 3 at the end of this chapter) where it is obvious to students what mathematics knowledge and skills are needed to solve them. Students were asked to indicate how frequently they encountered similar tasks in their mathematics lessons using a four-point scale: never, rarely, sometimes, or frequently.

In another question, students were asked how familiar they were with certain formal mathematics content, including such topics as quadratic functions, radicals and the cosine of an angle (see Question 2 at the end of this chapter). Responses to these tasks were recorded on a five-point scale indicating the degree to which students had heard of the topic. Having heard of a topic more often was assumed to reflect a greater degree of opportunity to learn.

In addition, a question asked students to indicate, on a four-point scale, how frequently they had been taught to solve eight specific mathematics tasks (see Question 1 at the end of this chapter). These tasks included both formal and applied mathematics.

All but the last question were used to create three indices: "formal mathematics", "word problems", and "applied mathematics". Values of these indices range from 0 to 3, indicating the degree of exposure to opportunity to learn, with 0 corresponding to no exposure and 3 to frequent exposure. (For more details on how these indices are constructed, see the section in blue at the end of this chapter.). When interpreting these data, it needs to be borne in mind that the 15 -year-olds assessed by PISA are, in some countries, dispersed over a range of grades and mathematical programmes and will therefore be exposed to a range of mathematical content.

On average, 15-year-olds in OECD countries indicated that they encounter applied mathematics tasks and word problems "sometimes" and formal mathematics tasks somewhat less frequently (Figures I.3.1a, b, c and Table I.3.1). 


\section{Students' exposure to word problems}

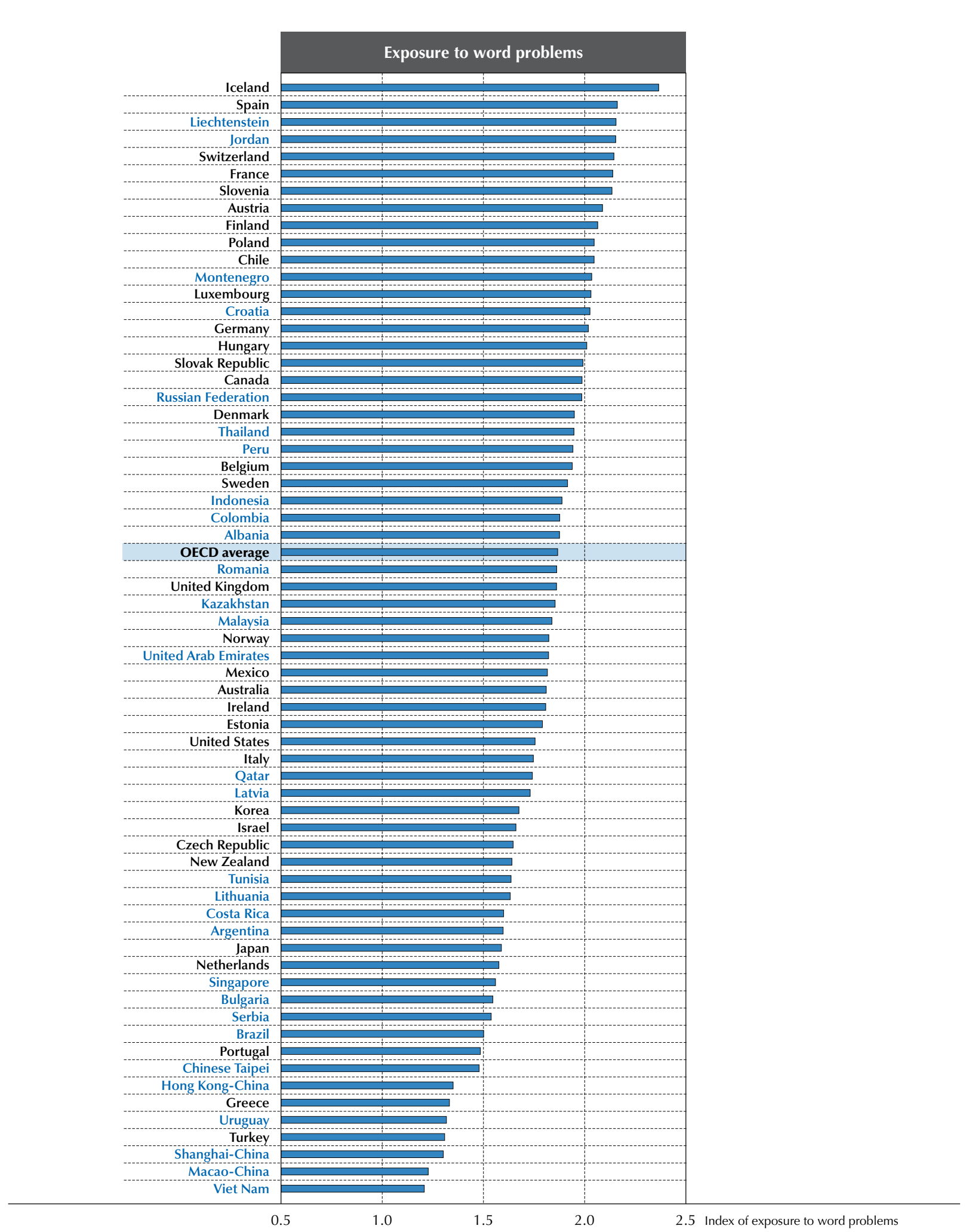

Countries and economies are ranked in descending order of the index of exposure to word problems.

Source: OECD, PISA 2012 Database, Table I.3.1.

StatLink 解估 http://dx.doi.org/10.1787/888932935591 


\section{Students' exposure to formal mathematics}

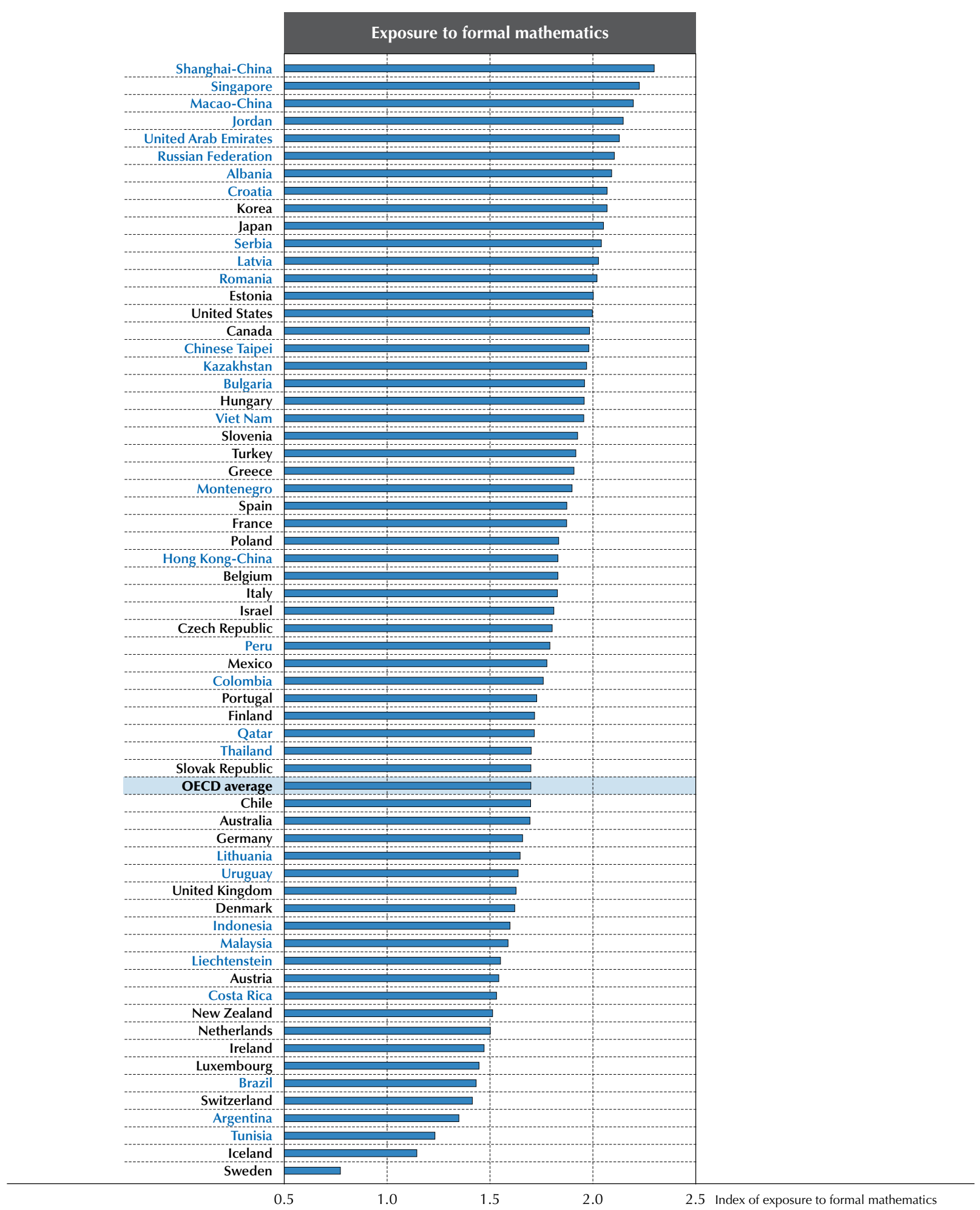

Countries and economies are ranked in descending order of the index of exposure to formal mathematics. Source: OECD, PISA 2012 Database, Table I.3.1.

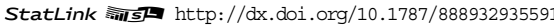




\section{Students' exposure to applied mathematics}

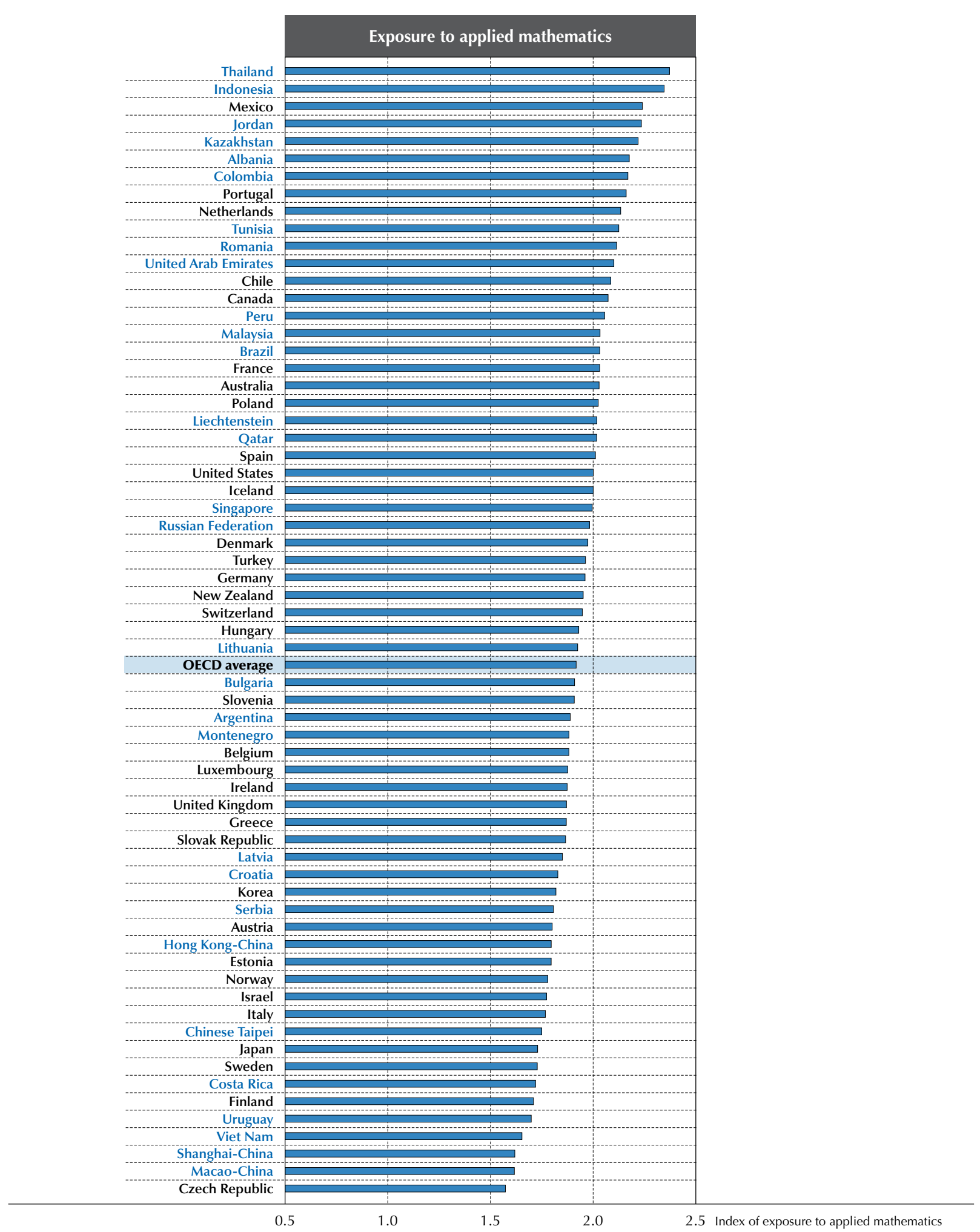

Countries and economies are ranked in descending order of the index of exposure to applied mathematics. Source: OECD, PISA 2012 Database, Table I.3.1.

StatLink त्नाज्ञ http://dx.doi.org/10.1787/888932935591 


\section{OPPORTUNITY TO LEARN AND STUDENT ACHIEVEMENT}

To examine the overall relationship between opportunity to learn and achievement, a three-level model was fitted to the data showing that at all three levels - country, school and student - there was a statistically significant relationship between opportunity to learn and student performance. Therefore, examinations of the relationship between opportunity to learn and achievement can be made at student, school and country levels simultaneously.

For applied mathematics, the relationship at all three levels is curvilinear (e.g. quadratic): on average, the more frequently students are exposed to problems involving applied mathematics, the better their mathematics performance, but only up to a point; after this point, performance declines. Figure I.3.2 graphically portrays the nature of the relationship averaged over the 65 countries, as well as over the OECD countries.

- Figure 1.3.2

Relationship between mathematics performance and students' exposure to applied mathematics

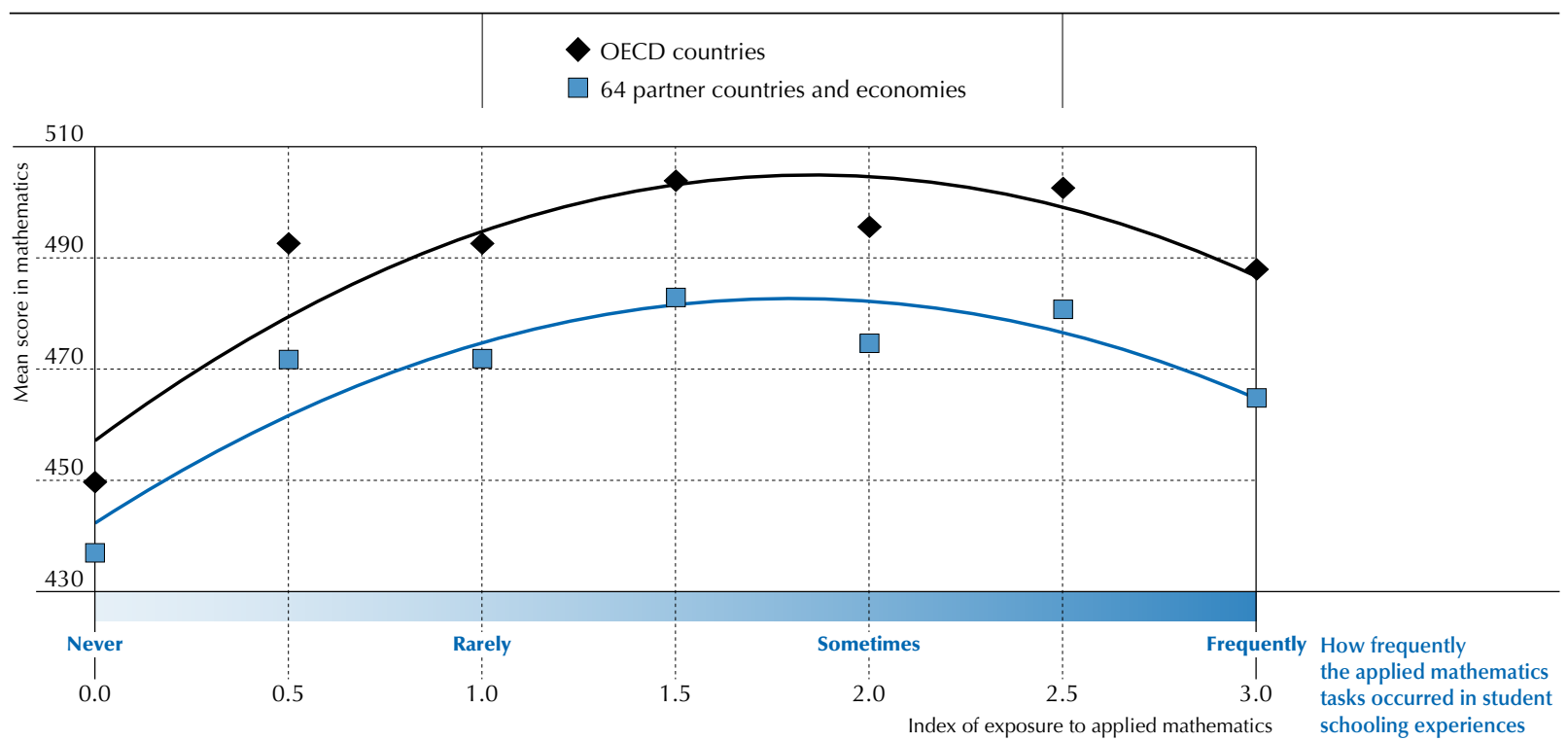

Source: OECD, PISA 2012 Database.

StatLink 而正 http://dx.doi.org/10.1787/888932935591

Among OECD countries, student performance is higher by about 40 points as the frequency of the encounters increased from "never" to "rarely"; but at a point between "rarely" and "sometimes" student performance reached a peak after which more frequent encounters with such problems had a negative relationship to performance. Fifteen-year-olds who frequently encounter applied problems scored about ten PISA score points below students who sometimes encounter such problems.

For both of the other opportunity-to-learn variables, i.e. word problems and formal mathematics - the relationship is linear. Exposure to word problems is positively related to performance at both the school and student levels, but not at the country level; the relationship between exposure to formal mathematics and performance is significant at all three levels.

Within each country the relationship between opportunity to learn and performance can be observed at both the school and student levels. These relationships were analysed using a two-level model. Of the 64 countries and economies that participated in PISA 2012 with available data for the index of opportunity to learn formal mathematics, all but Albania and Liechtenstein show a positive and statistically significant relationship between exposure to formal mathematics and performance at both the student and school levels (Figure 1.3.3). Among the OECD countries, the average impact of the degree of exposure to algebra and geometry topics on performance is around 50 points at the student level (i.e. increase in PISA mathematics score associated with one unit increase in the index of exposure to formal mathematics). The student level impact of the degree of exposure to word problems on performance is more limited, involving 49 countries with an OECD average estimated impact of 4 points (Table I.3.2). 
- Figure I.3.3 -

Country-level regressions between opportunity to learn variables and mathematics performance at the student and school levels

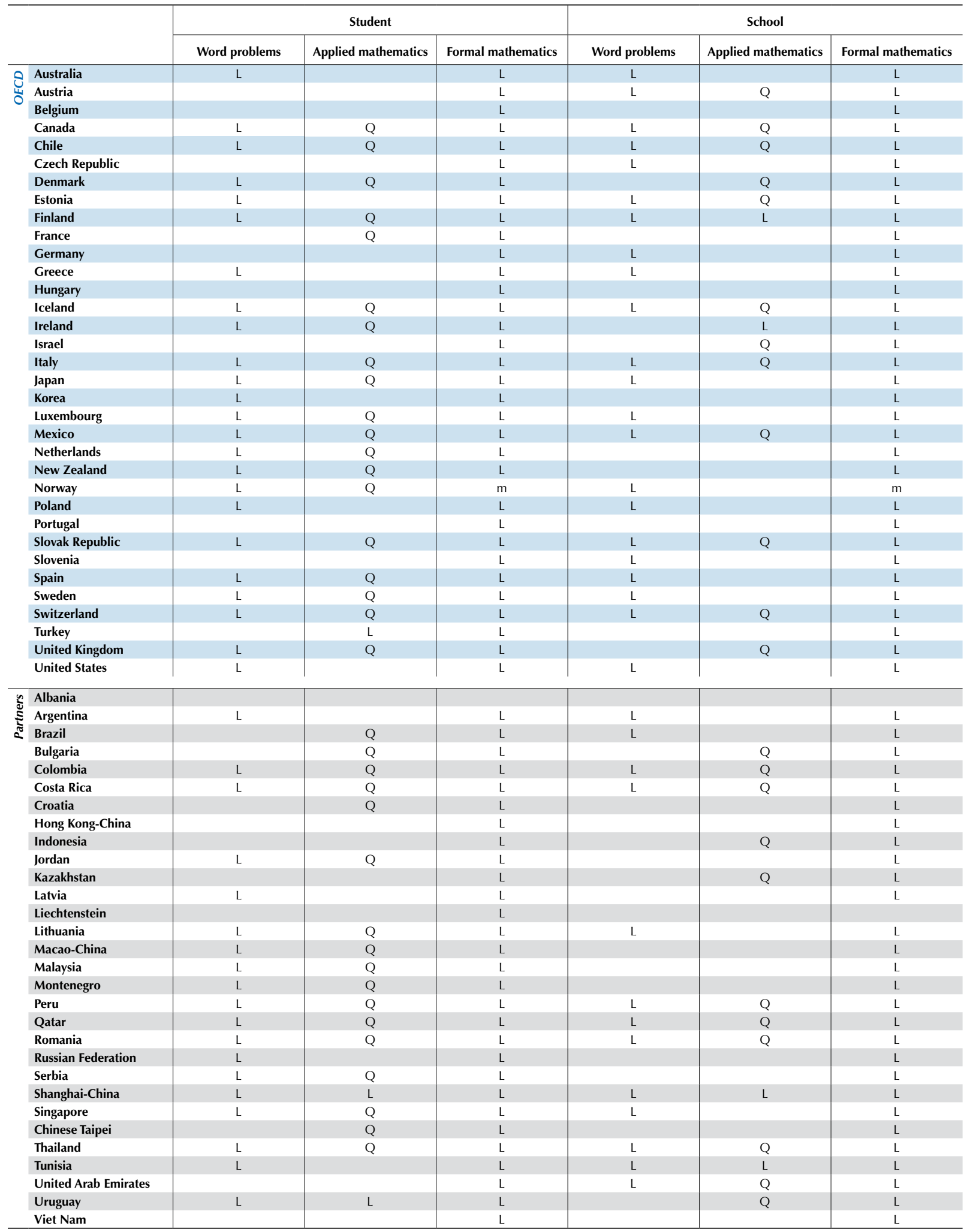

Note: " $\mathrm{L}$ " and "Q" show a statistically significant relationship between the opportunity to learn variables and mathematics performance. " $\mathrm{L}$ " when the relationship is linear and "Q" when it is quadratic.

Source: OECD, PISA 2012 Database, Table I.3.2.

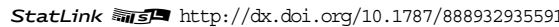


- Figure 1.3.4a

Relationship between the index of exposure to word problems and students' mathematics performance

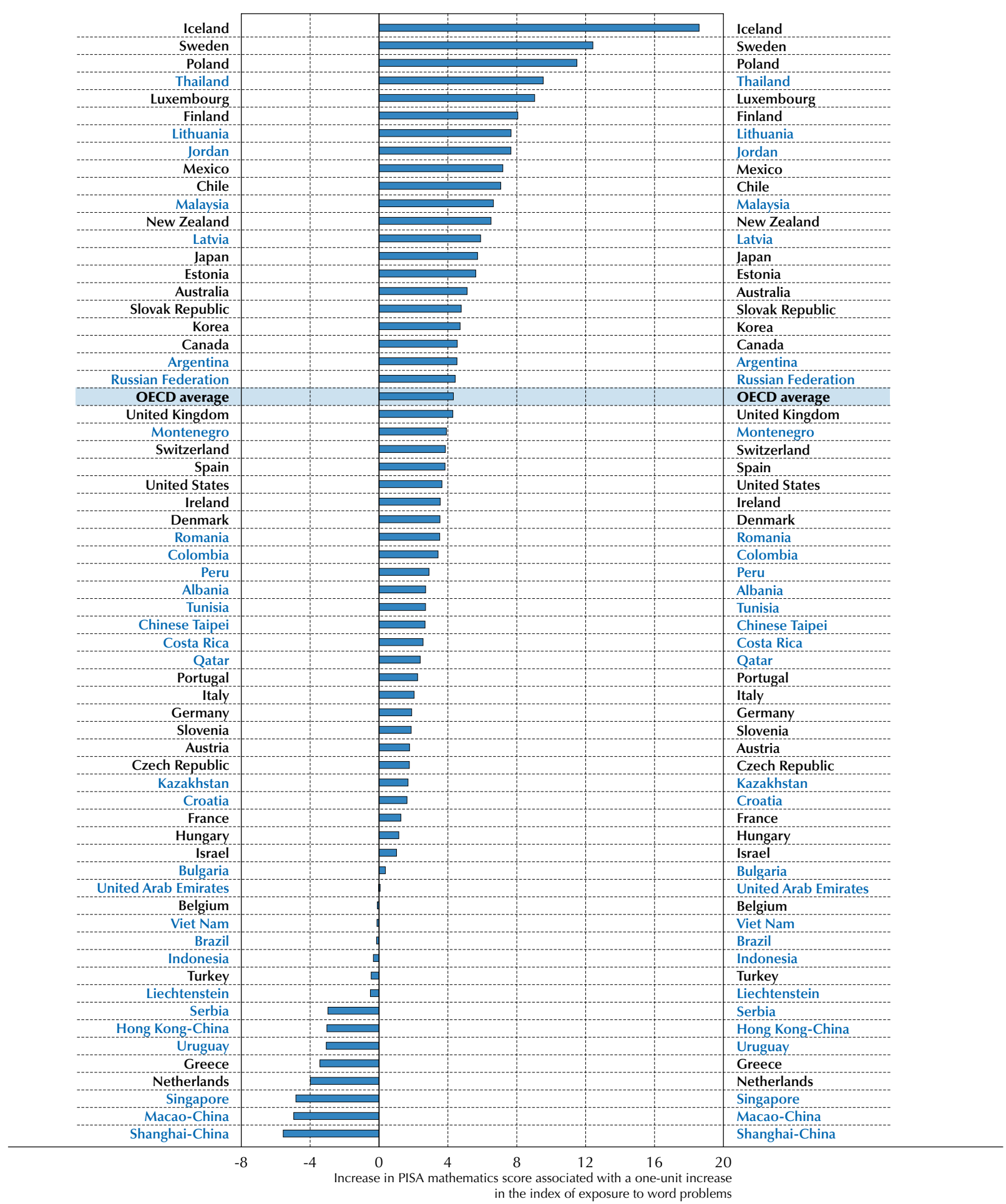

Note: For the index of exposure to word problems the estimates come from a linear regression, positive values thus signal that greater exposure is more strongly associated with students' mathematics performance.

Countries and economies are ranked in descending order of the strength of the relationship between the index of exposure to word problems and mathematics performance.

Source: OECD, PISA 2012 Database, Table 1.3.2.

StatLink त्माजा http://dx.doi.org/10.1787/888932935591 
- Figure $1.3 .4 \mathrm{~b}$ -

Relationship between the index of exposure to formal mathematics and students' mathematics performance

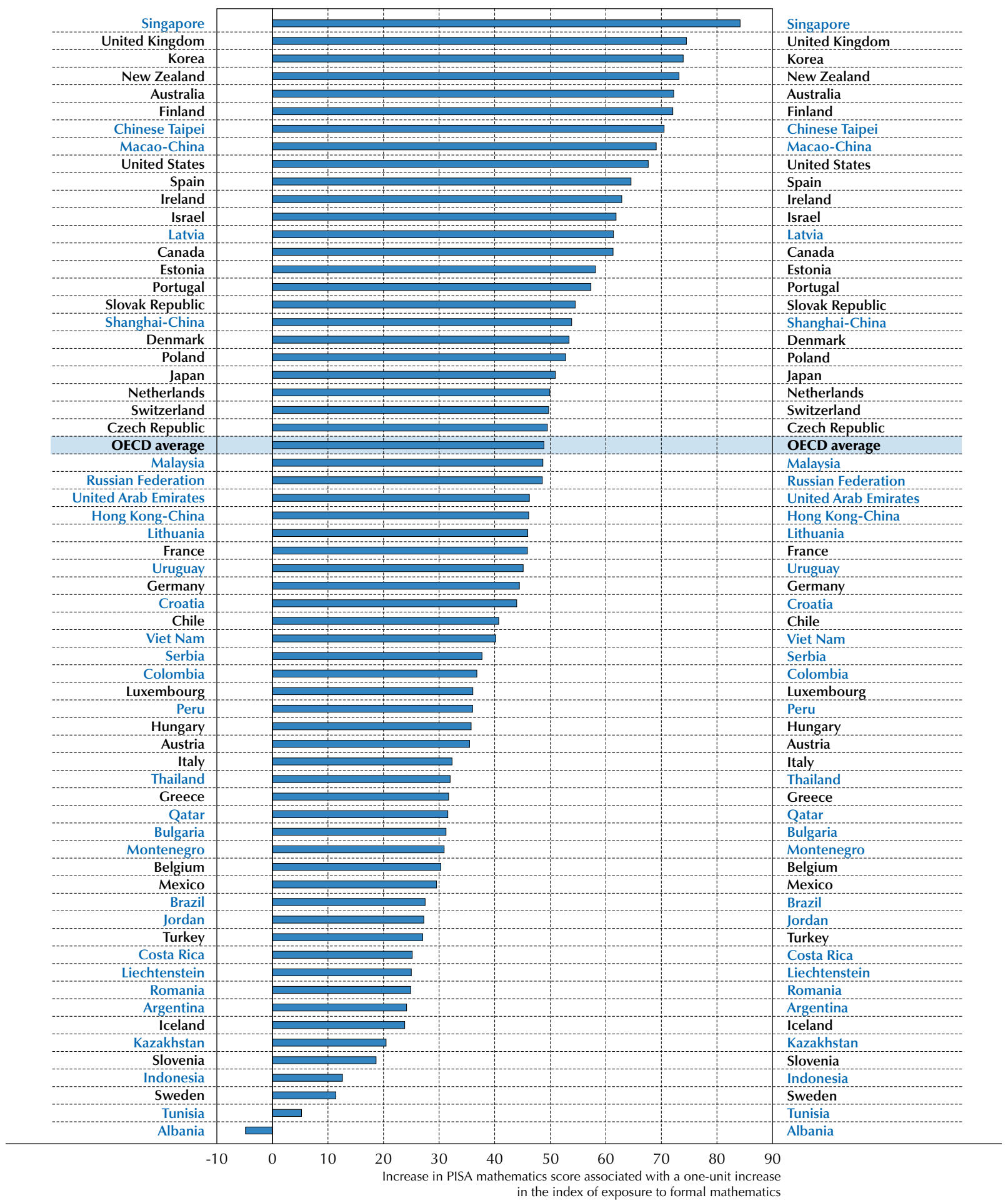

Note: For the index of exposure to formal mathematics the estimates come from a linear regression, positive values thus signal that greater exposure is more strongly associated with students' mathematics performance.

Countries and economies are ranked in descending order of the strength of the relationship between the index of exposure to formal mathematics and mathematics performance.

Source: OECD, PISA 2012 Database, Table 1.3.2.

StatLink न्नाड़ा http://dx.doi.org/10.1787/888932935591 
- Figure I.3.4c

\section{Relationship between the index of exposure to applied mathematics and students' mathematics performance}

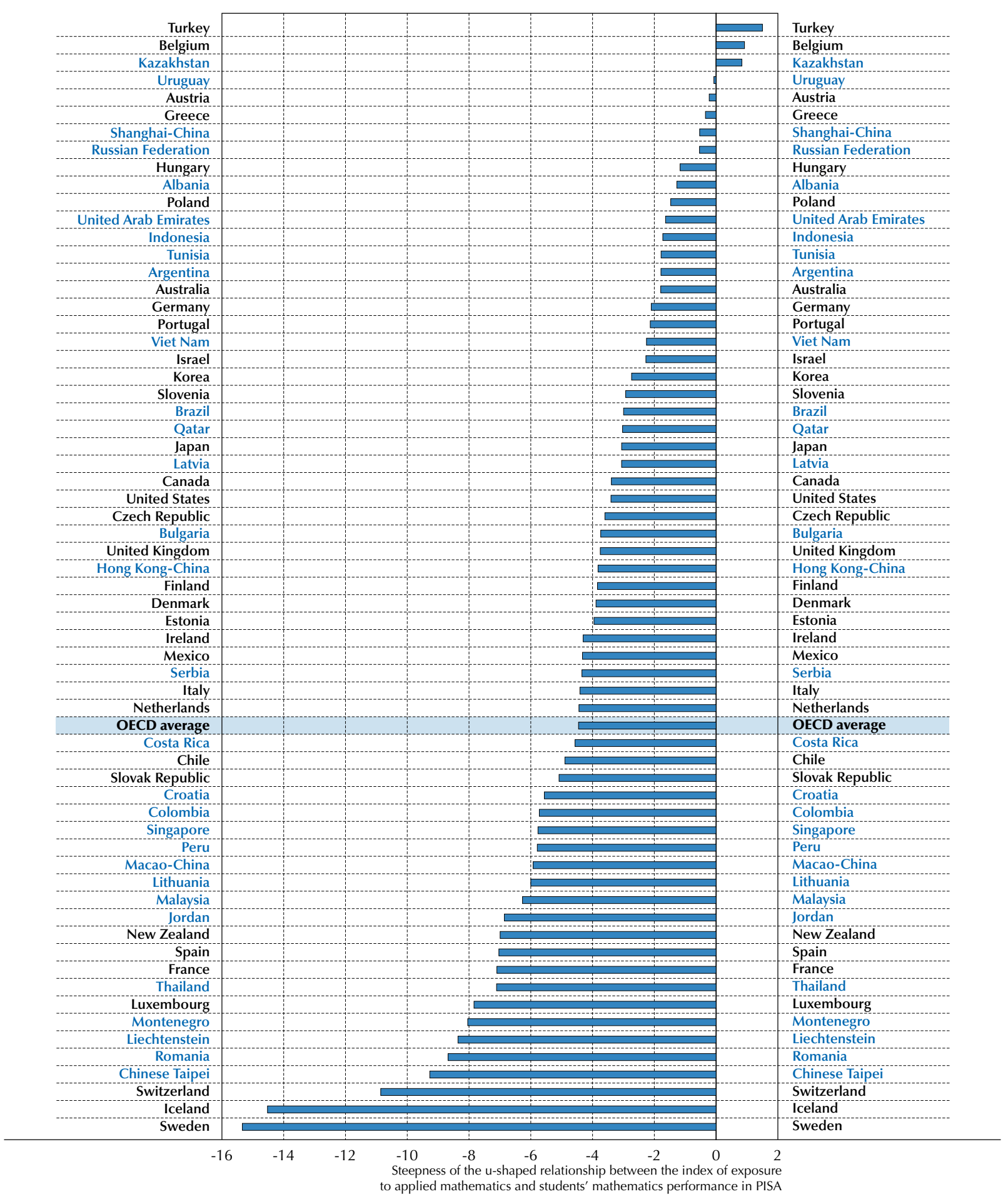

Note: For the index of exposure to applied mathematics the estimates are from a regression with a quadratic term, meaning that negative values indicate an inverted-u shape relationship between the index and students' mathematics performance. Lower negative numbers point to steeper inverted u-shaped relationships. Countries and economies are ranked in descending order of the strength of the relationship between the index of exposure to applied mathematics and mathematics performance.

Source: OECD, PISA 2012 Database, Table I.3.2.

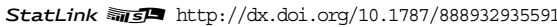


It is noteworthy that in the high-performing East Asian countries and economies on the PISA assessment - ShanghaiChina, Singapore, Hong Kong-China, Chinese Taipei, Korea, Macao-China and Japan - the exposure to formal mathematics is significantly stronger than in the remaining PISA participating countries and economies (2.1 versus 1.7$)$. The exposure to word problems shows the opposite pattern. In this case the exposure to word problems is less strong in the high-performing East Asian countries and economies than in the other countries (1.4 versus 1.8). For the index of exposure to applied mathematics, the difference between high-performing East Asian participants and other countries and economies is about 0.2 points (1.8 versus 2.0) (Table I.3.1).

The results suggest that opportunities to learn formal mathematics are related to PISA performance. Furthermore, exposure to more advanced mathematics content, such as algebra and geometry, appears to be related to high performance on the PISA mathematics assessment, even if the causal nature of this relationship cannot be established.

At the student level, the estimated effect of a greater degree of familiarity with such content on performance is almost 50 points (Figure I.3.4b and Table I.3.2). The results could indicate that students exposed to advanced mathematics content are also good at applying that content to PISA tasks. Alternatively, the results could indicate that high-performing students attend mathematics classes that offer more advanced mathematics content. Exposure to word problems, which are usually designed by textbook writers as applications of mathematics, are also related to performance, but not as strongly (Figure I.3.4a and Table I.3.2).

In 47 of the 65 participating countries and economies, the opportunity-to-learn variable measuring the frequency of student encounters with applied mathematics tasks was related to PISA performance at either the student or school level or both (Figures I.3.3 and 1.3.5). ${ }^{1}$ Again, the causal nature of the relationship cannot be established. In some countries the relationship is likely to be the result of low-performing students attending programmes and tracks that offer more applied mathematics content.

- Figure 1.3.5

Significance of exposure to applied mathematics

Where exposure is related to performance, at the school and student levels

\begin{tabular}{c|l|l|l}
\hline \multirow{2}{*}{\multicolumn{2}{c|}{}} & \multicolumn{1}{c}{ Significant } & \multicolumn{1}{c}{ Not significant } \\
\cline { 2 - 4 } & \multirow{2}{*}{ Significant } & $\begin{array}{l}\text { School } \\
\text { Bulgaria, Canada, Chile, Colombia, Costa Rica, } \\
\text { Denmark, Finland, Iceland, Ireland, Italy, } \\
\text { Mexico, Peru, Qatar, Romania, Shanghai-China, } \\
\text { Slovak Republic, Switzerland, Thailand, } \\
\text { United Kingdom, Uruguay }\end{array}$ & $\begin{array}{l}\text { Brazil, Croatia, France, Japan, Jordan, Lithuania, } \\
\text { Luxembourg, Macao-China, Malaysia, } \\
\text { Montenegro, New Zealand, Netherlands, } \\
\text { Norway, Serbia, Singapore, Spain, Sweden, } \\
\text { Chinese Taipei, Turkey }\end{array}$ \\
\cline { 2 - 4 } & \multirow{2}{*}{ Not significant } & $\begin{array}{l}\text { Austria, Estonia, Indonesia, Israel, Kazakhstan, } \\
\text { Tunisia, United Arab Emirates }\end{array}$ & $\begin{array}{l}\text { Albania, Argentina, Australia, Belgium, } \\
\text { Czech Republic, Germany, Greece, } \\
\text { Hong Kong-China, Hungary, Korea, } \\
\text { Latvia, Liechtenstein, Poland, Portugal, } \\
\text { Russian Federation, Slovenia, United States, } \\
\text { Viet Nam }\end{array}$ \\
\hline
\end{tabular}

Source: OECD, PISA 2012 Database, Table 1.3.2.

In all 40 countries and economies showing a relationship between applied mathematics and performance at the student level, except Uruguay, Turkey and Shanghai-China, the relationship is curvilinear. This means that the positive relationship between applied mathematics and performance at the student level holds until a certain point, and then it becomes negative. The average of the top-achieving East Asian countries on the applied mathematics index (1.76) falls between "rarely" and "sometimes" on the index. As shown in Figure 1.3.2, the average is just at the inflection point as the curve begins its downward slope. The other 58 countries'/economies' mean places them further down the curve where the decline in performance is greater (Table I.3.1). In 20 of them, namely Uruguay, the United Kingdom, Finland, the Slovak Republic, Thailand, Canada, Ireland, Bulgaria, Chile, Denmark, Peru, Costa Rica, Switzerland, Iceland, Qatar, Colombia, Mexico, Romania, Italy and Shanghai-China there is a relationship between applied mathematics and performance at both the school and student levels (Figure I.3.5). 
Educators and education policy makers tend to agree that the capacity of students to apply mathematical content is central to their success later in life, because modern economies tend to pay people not for what they know but for what they can do with what they know. They often debate the extent to which mathematics that is related to real-world problems should be incorporated into school curricula. Some argue that students learn advanced mathematics content best when studying it in an applied context; others contend that contextual material could detract from the content and therefore exposure to advanced mathematics content with as little contextual material as possible will be most effective in helping students learn and apply the content.

PISA results on the opportunity-to-learn measure do not answer the question directly, but they suggest that it is a matter of balance. It appears that strong mathematics performance in PISA is not only related to opportunities to learn formal mathematics, but also to opportunities to learn applied mathematics. Learning formal mathematics is necessary, but not sufficient by itself. Even with a higher level of opportunities related to formal mathematics, a degree of exposure to applied mathematics problems is, up to some point, positively related to performance.

\section{DIFFERENCES IN OPPORTUNITIES TO LEARN}

Decisions on curriculum content, whether taken at the national, regional, local or school level, have direct consequences on students' academic achievement (Schmidt et al., 2001 and Sykes, Schneider and Plank, 2009). As an integral feature of curricula, opportunities to learn thus fall under the purview of education policy. Given the significant relationship between opportunities to learn and performance, as described above, policy makers can learn through PISA how their decisions about curricula are ultimately reflected in student performance.

Students were asked about the frequency with which they had encountered six types of fairly common real-world mathematics problems during their time at school (see Question 1 at the end of this chapter). The average proportion of students across OECD countries who answered "frequently" ranged from 11.2\% (calculating the power consumption of an electric appliance per week, Figure I.3.6 and Table 1.3.10) to 25.4\% (calculating how many square metres of tiles were needed to cover a floor, Figure I.3.7 and Table 1.3.5). The average proportion of 15-year-olds who rarely or never were taught to do these kinds of tasks ranged from $35.9 \%$ to $57.2 \%$.

Countries varied widely on these measures, though some of this variation may be due to differences in what students in different countries and contexts consider to be frequent. For example, in some countries and economies, namely Hong Kong-China, the Czech Republic, Macao-China and Viet Nam, fewer than $10 \%$ of students say they frequently encounter an applied problem like one that requires them to calculate the taxes imposed when purchasing a computer. In Viet Nam, only $3.6 \%$ of 15 -year-olds say they are frequently exposed to such a problem.

By contrast, $60 \%$ to $61 \%$ of students in OECD and partner countries and economies say they frequently encounter formal mathematics tasks like the two items that involved solving quadratic equations (Tables I.3.7 and I.3.9); and there was much less variation between countries.

PISA also categorised mathematics problems into four types - formal mathematics (Figure I.3.8), word problems (Figure 1.3.9), applied problems in mathematics (Figure 1.3.10), and real-world problems (Figure I.3.11) - in order to more finely distinguish between formal and applied mathematics. PISA found that an average of $68.4 \%$ of students in OECD countries said they frequently encounter formal mathematics tasks (e.g. $2 x+3=7$, and finding the volume of a box) in their mathematics lessons. This proportion varies from a high of $85.4 \%$ in Iceland to a low of $49.0 \%$ in Portugal (Figure I.3.8 and Table I.3.11). Among partner countries and economies, the proportion of students who are frequently exposed to these types of tasks ranges from $78.4 \%$ in Croatia to $43.2 \%$ in Brazil. By contrast, only around $6.5 \%$ of students in OECD countries rarely or never encounter this type of problem.

A second category of mathematics problem includes formal mathematics concepts placed in a word problem of the kind often found in textbooks. These types of word problems do have an "applied" component, but they are often perceived by students as contrived real-world problems. Students can often recognise such word problems as requiring the same computations that they are being asked to perform in the lesson, but with verbiage surrounding the computation. The examples given included purchasing furniture with a discount, and finding the age of someone, given his/her relationship to the age of others. 
- Figure I.3.6 "

Percentage of students who reported having seen applied mathematics problems like "calculating the power consumption of an electric appliance per week" frequently or sometimes

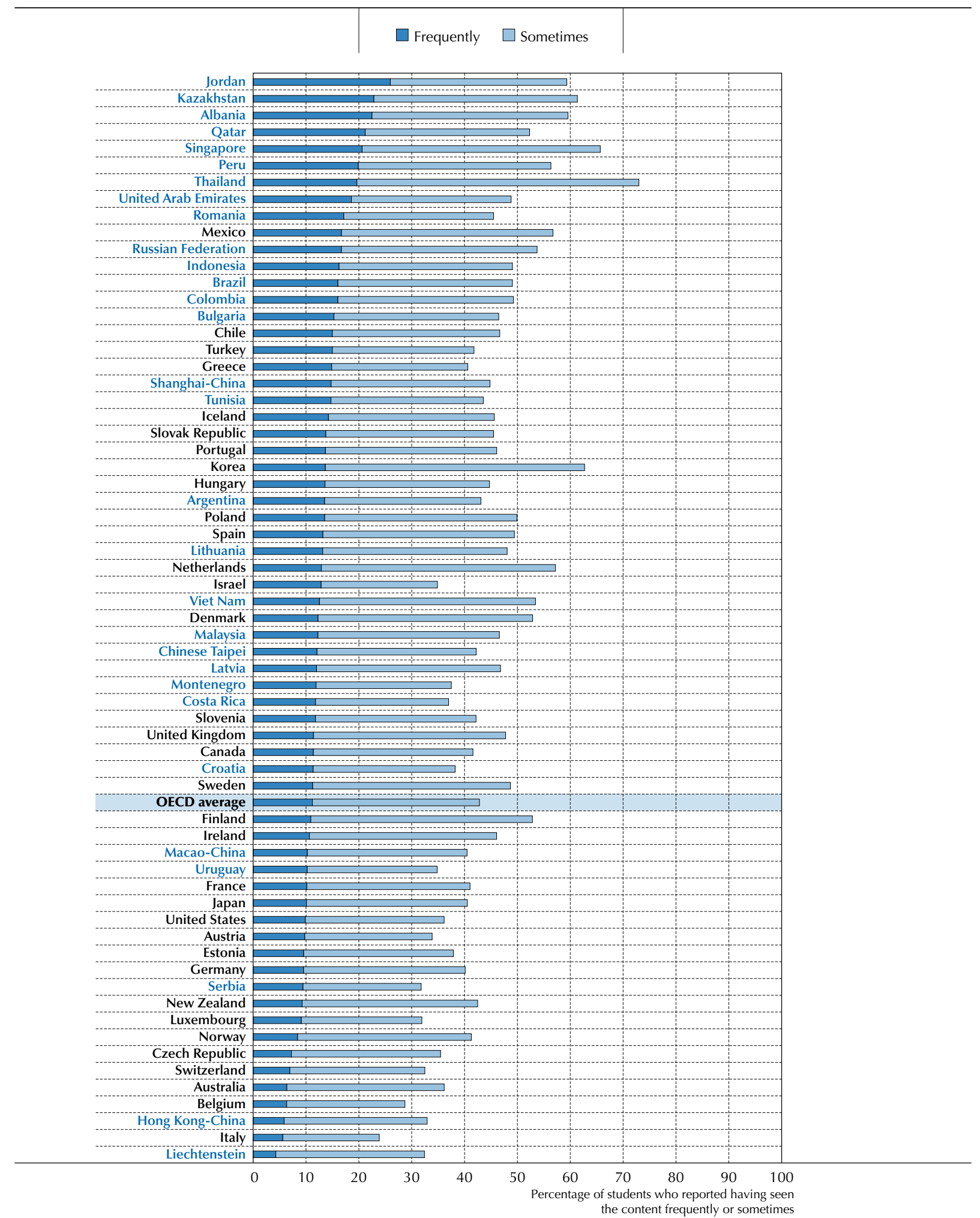

Countries and economies are ranked in descending order of the percentage of students who reported having seen applied mathematics problems, for instance calculating the power consumption of an electronic appliance per week frequently (see Question 1 at the end of this chapter).

Source: OECD, PISA 2012 Database, Table 1.3.10.

StatLink न्ताs $\mathrm{http}: / / \mathrm{dx}$. doi.org/10.1787/888932936427 
- Figure I.3.7

Percentage of students who reported having seen applied mathematics problems like "calculating how many square metres of tiles you need to cover a floor" frequently or sometimes

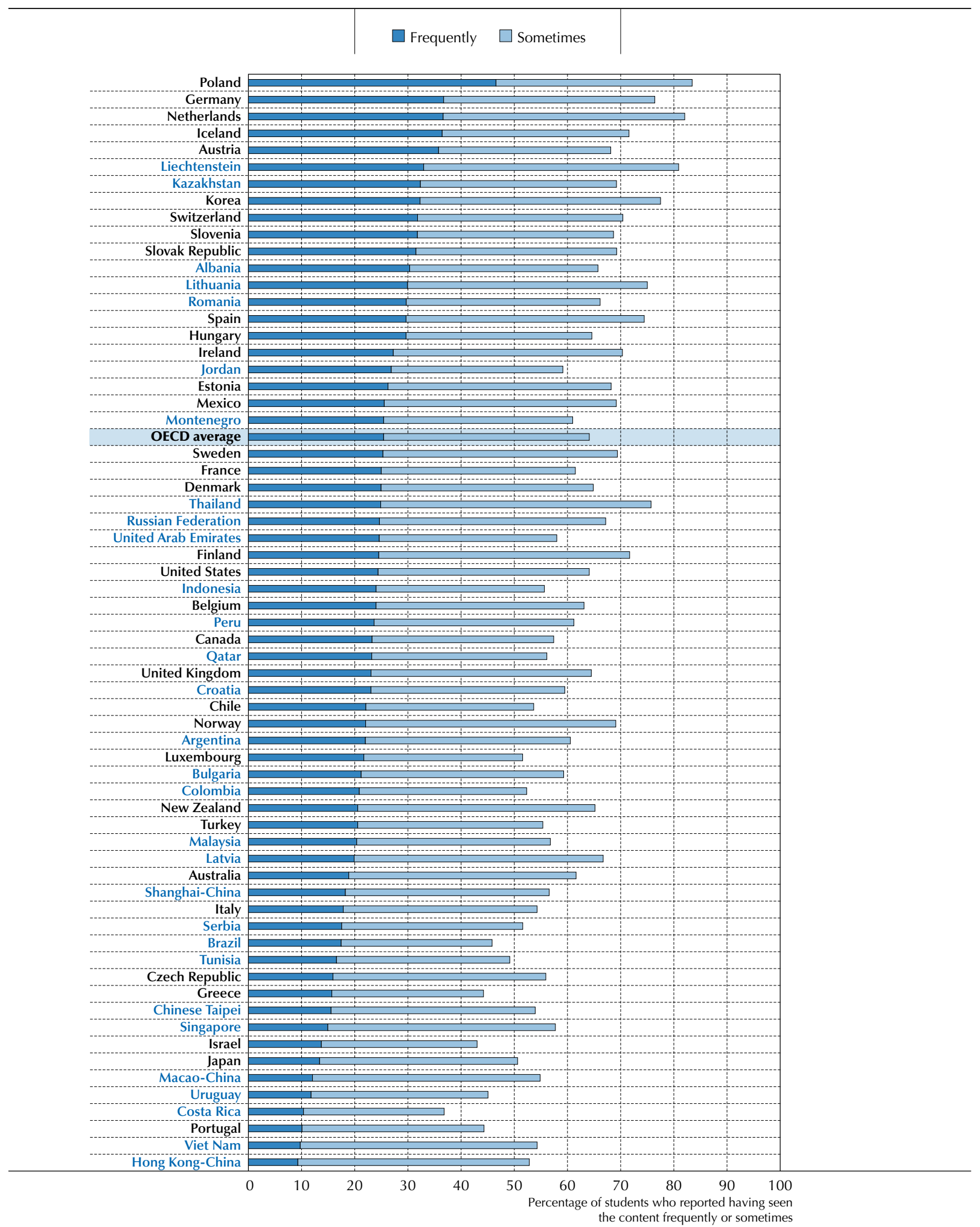

Countries and economies are ranked in descending order of the percentage of students who reported having seen applied mathematics problems, for instance calculating how many square metres of tiles you need to cover a floor, frequently (see Question 1 at the end of this chapter). Source: OECD, PISA 2012 Database, Table I.3.5.

StatLink त्राजम http://dx.doi.org/10.1787/888932936427 
- Figure I.3.8

\section{Percentage of students who reported having seen formal mathematics problems} in their mathematics lessons frequently or sometimes

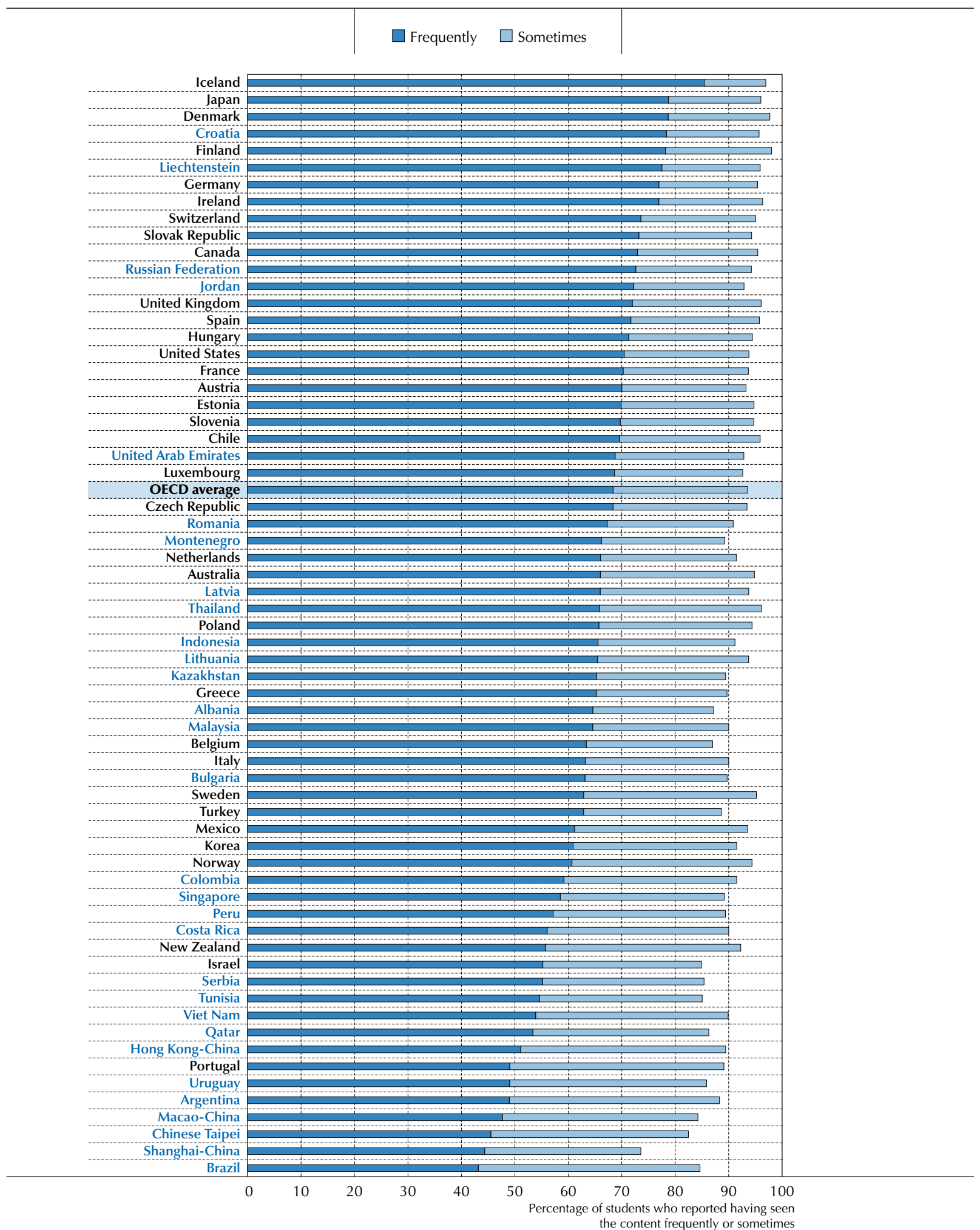

Countries and economies are ranked in descending order of the percentage of students who reported having seen formal mathematics problems, for instance solving an equation or finding the volume of a box, frequently (see Question 4 at the end of this chapter).

Source: OECD, PISA 2012 Database, Table I.3.11.

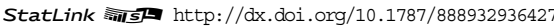


- Figure I.3.9

Percentage of students who reported having seen word problems in their mathematics lessons frequently or sometimes

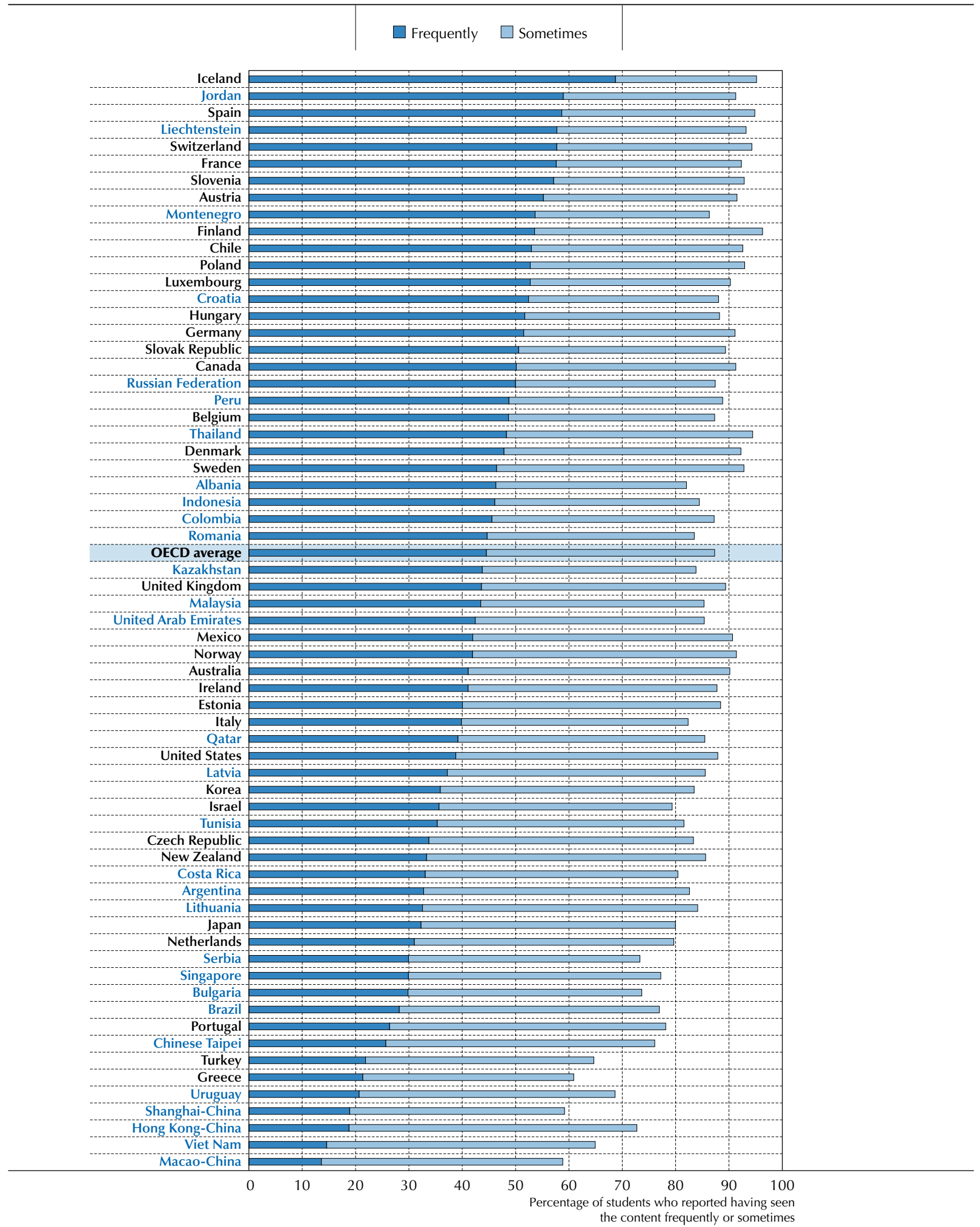

Countries and economies are ranked in descending order of the percentage of students who reported having seen word problems in their mathematics lessons frequently (see Question 3 at the end of this chapter).

Source: OECD, PISA 2012 Database, Table I.3.12.

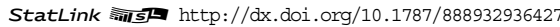


Some $44.5 \%$ of 15 -year-olds in OECD countries say they frequently encounter this type of word problem in their mathematics lessons (Figure I.3.9 and Table 1.3.12), while an average of $12.7 \%$ of students rarely or never encounter such word problems. In France, Spain, Switzerland, Iceland and Slovenia, and in the partner countries Jordan and Liechtenstein, around $60 \%$ of students are exposed to these types of word problems frequently.

In the PISA categorisation of mathematics, two types of applied contexts were studied: mathematics as a context in itself (applied problems in mathematics), and real-world contexts. Across OECD countries, the proportion of students who frequently encounter these two types of problems in their lessons is significantly smaller than the proportion of those who frequently encounter formal mathematics problems and word problems.

Applied problems in mathematics require the use of mathematics theorems, such as finding the height of a pyramid or determining prime numbers - tasks with a primarily mathematical context but that also have more practical applications. Some $34 \%$ of 15 -year-old students in OECD countries say they encounter these problems during their mathematics lessons, but nearly one in four students say they rarely or never encounter these types of problems (Figure 1.3.10 and Table I.3.13). Among OECD countries, only Turkey shows that just over half of its students frequently encounter these types of problems during their lessons. By contrast, in Israel, nearly one in five students never encounters these types of problems in mathematics class.

An average of $21.2 \%$ of students in OECD countries say they frequently encounter mathematics problems that are set in a real-world context; and about $33.6 \%$ of students encounters such problems rarely or never in class (Figure I.3.11 and Table I.3.14). In Mexico, Portugal, Iceland, Chile, Canada, the Netherlands, and in the partner countries and economies Thailand, Jordan, Indonesia, Tunisia, the United Arab Emirates and Colombia, at least 30\% of students frequently encounter these kinds of problems in class.

When looking across the four types of problems in the typology, two observations can be made. First, the typology represents a rough continuum in the percentage of students who are frequently exposed to each type of problem, declining steadily from formal mathematics (68\%) to mathematically-oriented word problems (45\%) to applied problems in mathematics (34\%) to real-world applied problems (21\%) (Figure 1.3.12). At the other end of this distribution, the percentage of students who indicated that they never or rarely have such lessons increased over the same continuum from $7 \%$ to $13 \%$ to $24 \%$ to $34 \%$.

Second, the opportunities to learn the different types of mathematics problems varied greatly among countries - and even more so within countries.

To measure students' familiarity with mathematics content, PISA 2012 asked students how often they had heard of 13 mathematics topics. Tables I.3.15 to I.3.27 show the proportion of students in a country who indicated they had never heard of a particular topic, heard of it once or twice, heard of it a few times, heard of it often, or knew it well. The variation in responses, both across the mathematics topics and across countries, is striking. Considered along with other PISA opportunity-to-learn measures, such as encounters with particular types of problems, these results suggest a wide variation in opportunity to learn - one that is similar to that found in other international mathematics studies, such as the Trends in International Mathematics and Science Study (Mullis et al., 2012).

Assuming familiarity with mathematics topics is related to exposure and by extension to opportunity, the average country results for the 13 topics can be divided into three categories reflecting varying degrees of exposure: the topics with low, medium and high exposure. Fewer than $40 \%$ of students say they "heard often" or "know well" the mathematics topics in the category "low exposure" and more than $60 \%$ in the category "high exposure" do (Table I.3.28). There were clear differences in opportunity to learn different mathematics content.

On average, students identified topics such as linear equations (Figure 1.3.13), radicals and polygons as those that they had heard of often and knew well; other topics, such as complex numbers (Figure I.3.14) and exponential functions, which are typically taught in later grades, were much less well known among 15-year-olds (Figure I.3.15). Only 42\% of students in OECD countries reported that they know linear equations well, but when the category "heard of it often" was included, almost two out of three (64.4\%) 15-year-olds say they have heard of them. However, this varies considerably across countries. In Iceland, only $17.8 \%$ of 15 -year-old students say they either know linear equations well or have often heard about them. By contrast, at least $90 \%$ of students in Japan, Korea and Estonia, and in the partner countries and economies Croatia, Macao-China and the Russian Federation have frequent opportunities to learn about linear equations. In the partner country Viet Nam, less than $10 \%$ of students have a similar exposure to linear equations - the core topic of an elementary algebra course. 
- Figure I.3.10

Percentage of students who reported having seen applied problems in mathematics in their mathematics lessons frequently or sometimes

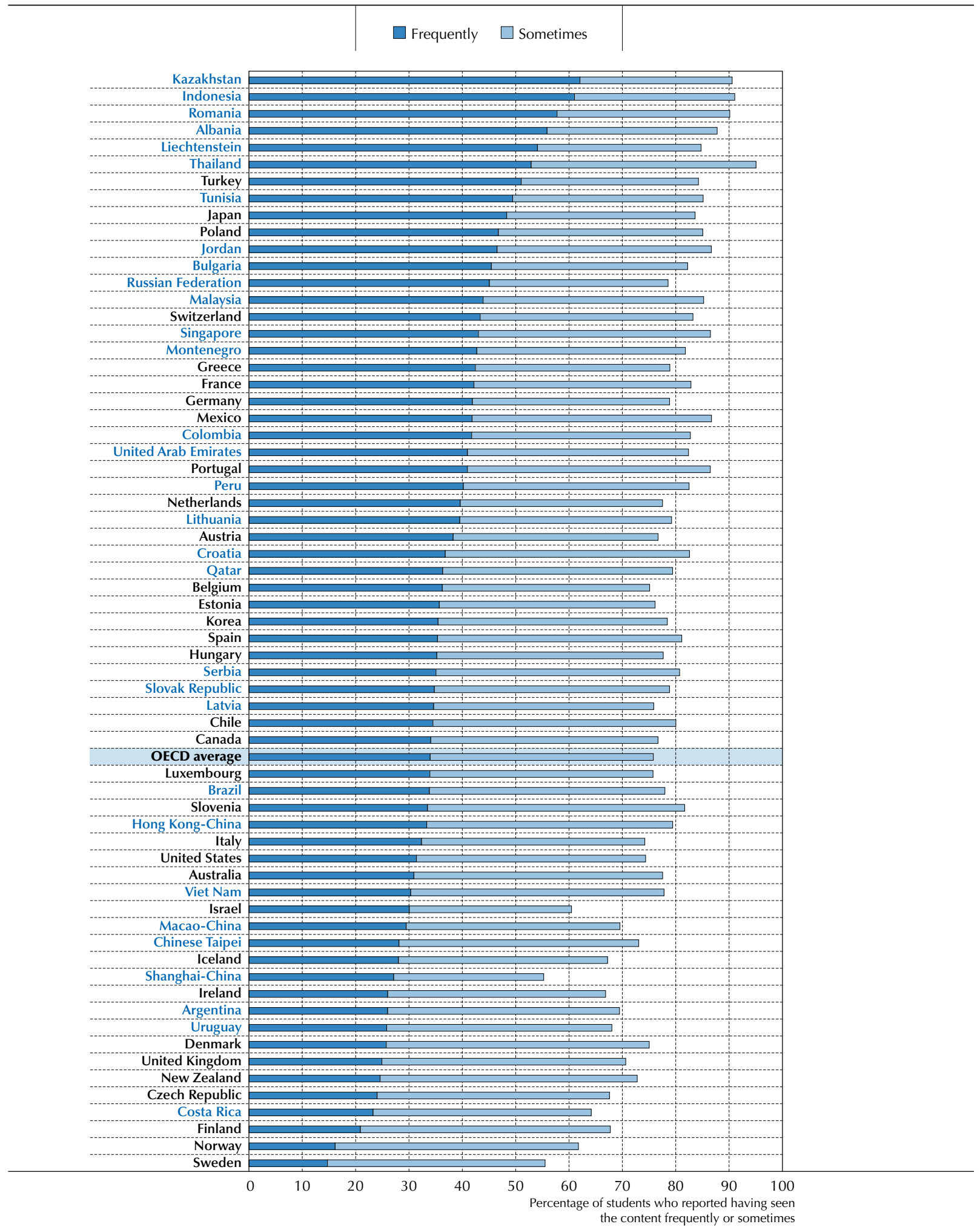

Countries and economies are ranked in descending order of the percentage of students who reported having seen applied problems in mathematics, for instance geometrical theorems or prime numbers, frequently (see Question 5 at the end of this chapter).

Source: OECD, PISA 2012 Database, Table I.3.13.

StatLink तils $\mathrm{\text {http: }} / / \mathrm{dx}$.doi.org/10.1787/888932936427 
- Figure I.3.11

\section{Percentage of students who reported having seen real-world problems in their mathematics lessons frequently or sometimes}

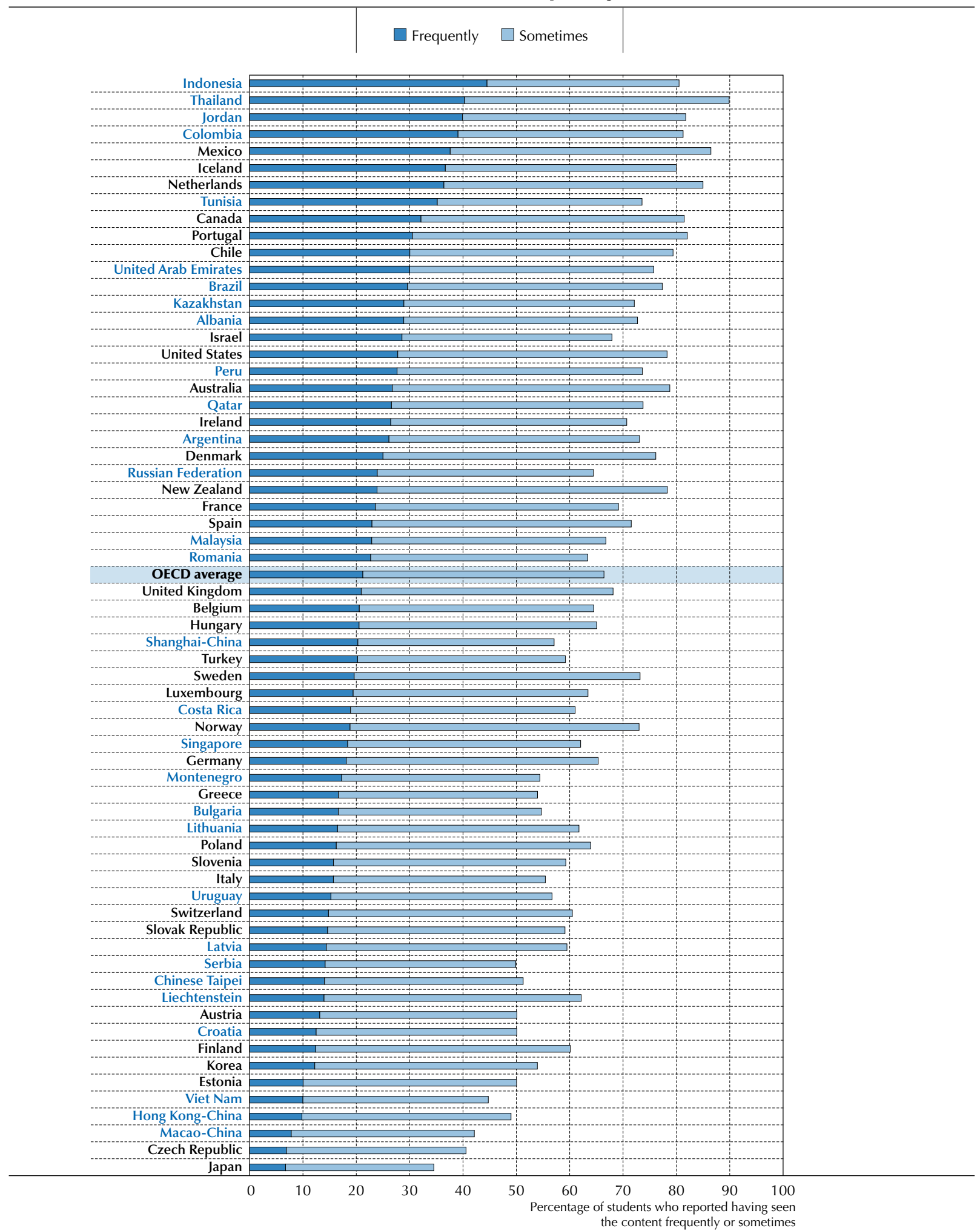

Countries and economies are ranked in descending order of the percentage of students who reported having seen real-world problems frequently (see Question 6 at the end of this chapter).

Source: OECD, PISA 2012 Database, Table I.3.14.

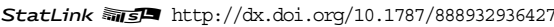


- Figure I.3.12

\section{Student exposure to mathematics problems}

Percentage of students who reported having seen the four types of mathematics problems frequently or sometimes, $O E C D$ average

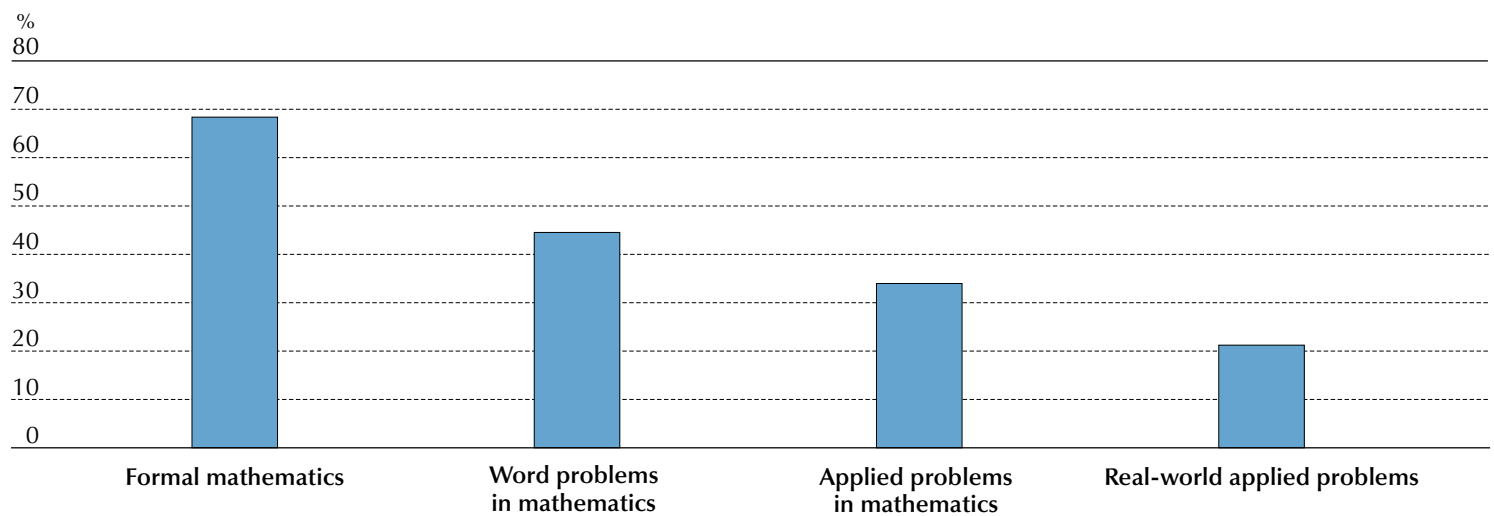

Source: OECD, PISA 2012 Database, Tables I.3.11, I.3.12, I.3.13 and I.3.14.

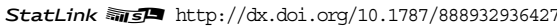

There is also a substantial variation of the familiarity with mathematics topics within some countries, suggesting considerable variability in the implemented curriculum. The point can be illustrated with the algebra topic of quadratic function. For example, in the United Kingdom the distribution of how often students had heard of the topic was almost even across the five response categories (never heard of it, heard of it once or twice, heard of it a few times, heard of it often, or knew it well), with around one in five students self-reporting to fall into each of these categories. A similar type of distribution can be found in Poland, Greece, Colombia and Mexico. For other countries, there is a higher degree of consistency in student reports about their familiarity with mathematics topics. In Shanghai-China, $81 \%$ knew the topic well while fewer than $2 \%$ had never heard of it. Conversely, in Sweden, $63 \%$ of 15 -year-old students had never heard of it while fewer than $5 \%$ knew it well (Figure I.3.16).

OECD countries also show considerable variation on the opportunity-to-learn indices (Figures I.3.1a, b, c and Table I.3.1). The OECD countries Portugal and Mexico had a mean of 2.2 on the applied mathematics index, which implied that, on average, 15-year-old students are sometimes to frequently exposed to these types of problems, while the mean for the Czech Republic was 1.6, between "sometimes" and "rarely". This is a relatively large difference between these countries, given the limited range of the scale. Even larger differences are observed among partner countries and economies: Thailand had a mean of 2.4, indicating that the country's 15-year-olds are between "sometimes" and "frequently" exposed to these types of mathematics problems, while Macao-China shows a mean similar to that of the Czech Republic.

Variations on the formal mathematics index are even larger, with Shanghai-China having a mean of 2.3 (students in these countries encounter such tasks in mathematics class "sometimes" to "frequently") while Sweden shows a mean of 0.8 (meaning students there almost never encounter such problems in their mathematics class).

Using the formal and applied mathematics scales, countries can be categorised into four different groups (Figure I.3.17). The horizontal axis represents the OECD average frequency with which the country's 15-year-olds have the opportunity to learn formal mathematics, while the vertical axis represents the OECD average frequency of the opportunity to learn applied mathematics.

The upper right quadrant shows the countries whose students indicated that, on average, they have more opportunities to learn both applied and formal mathematics. Of the 19 countries in this group, eight of them are OECD countries. Six OECD countries (the United Kingdom, Ireland, Luxembourg, Norway, Sweden and Austria) and three partner countries (Uruguay, Costa Rica and Argentina) are included in the group shown in the lower left quadrant, which includes countries whose students have fewer opportunities to learn both formal and applied mathematics. In partner countries and economies such as Shanghai-China and Macao-China, students reported more opportunities to learn formal mathematics, on average, but fewer opportunities to learn applied mathematics. 
- Figure I.3.13 -

Percentage of students who reported having seen linear equations often or knowing the concept well and understanding it

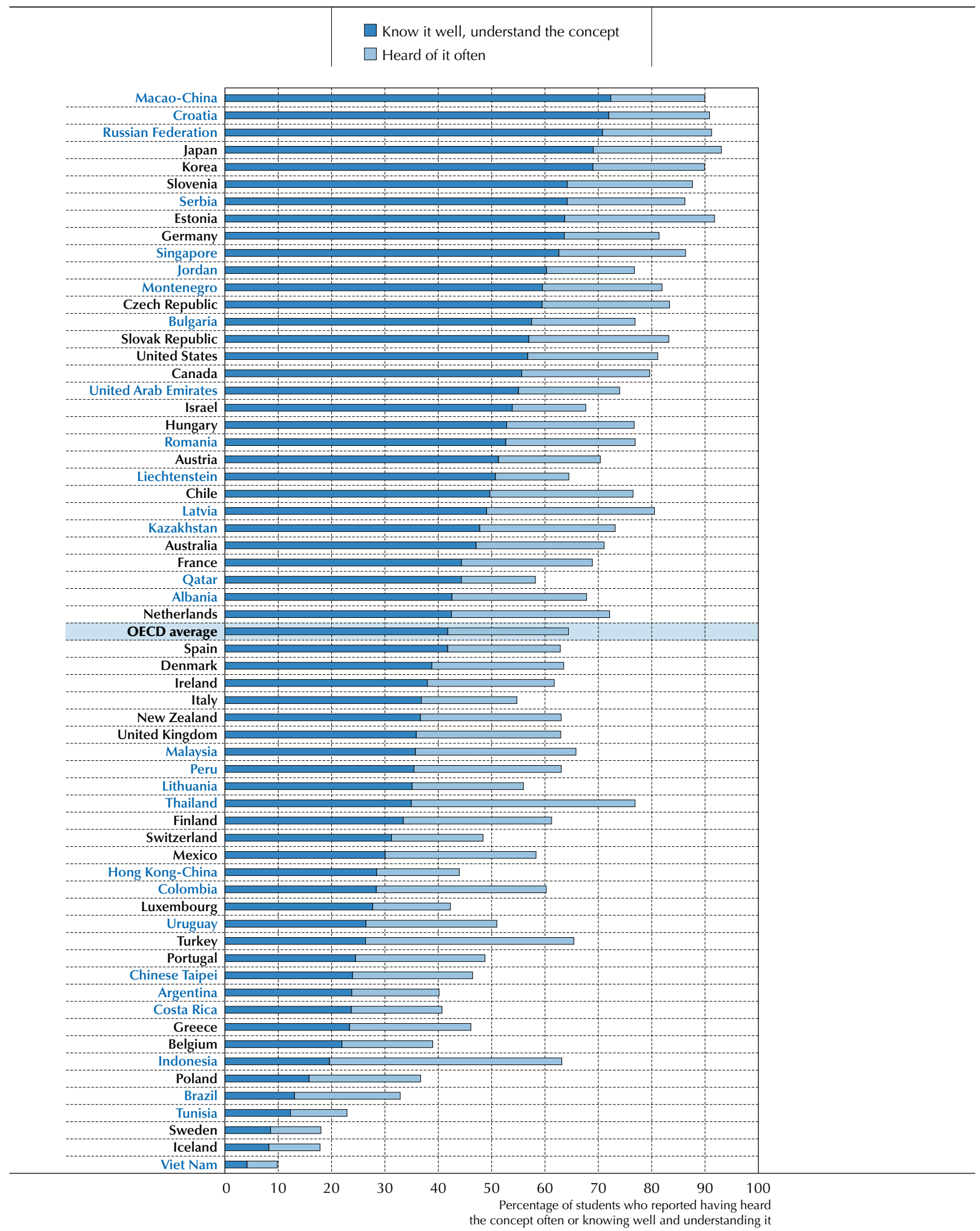

Countries and economies are ranked in descending order of the percentage of students who reported knowing the linear equations concept well and understanding it (see Question 2 at the end of this chapter).

Source: OECD, PISA 2012 Database, Table I.3.18.

StatLink त्नाजम http://dx.doi.org/10.1787/888932936427 


\section{- Figure I.3.14}

Percentage of students who reported having seen complex numbers often or knowing the concept well and understanding it

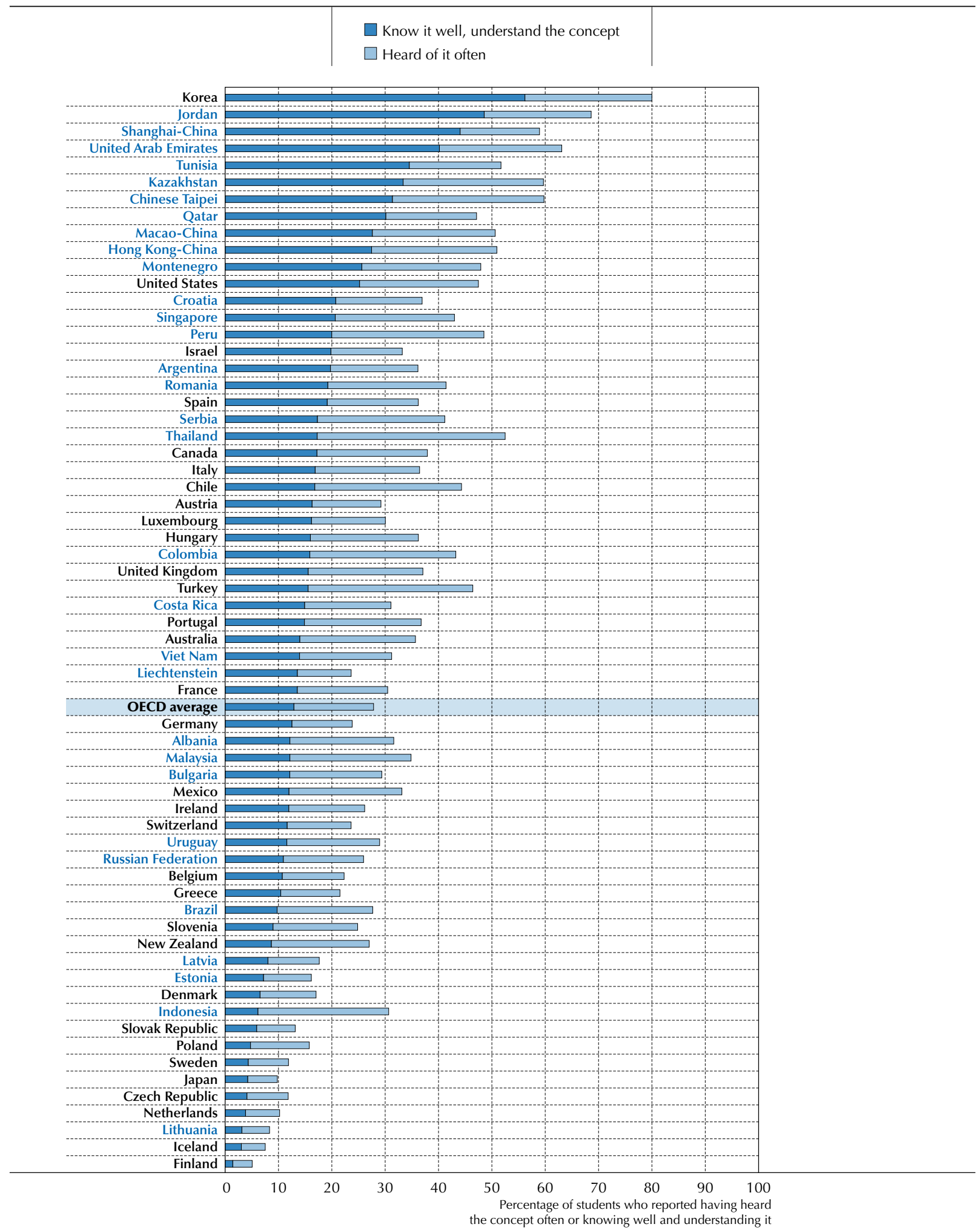

Countries and economies are ranked in descending order of the percentage of students who reported knowing the complex numbers concept well and understanding it (see Question 2 at the end of this chapter).

Source: OECD, PISA 2012 Database, Table I.3.20.

StatLink त्राज्ञा http://dx.doi.org/10.1787/888932936427 
- Figure I.3.15 -

Percentage of students who reported having seen exponential functions often or knowing the concept well and understanding it

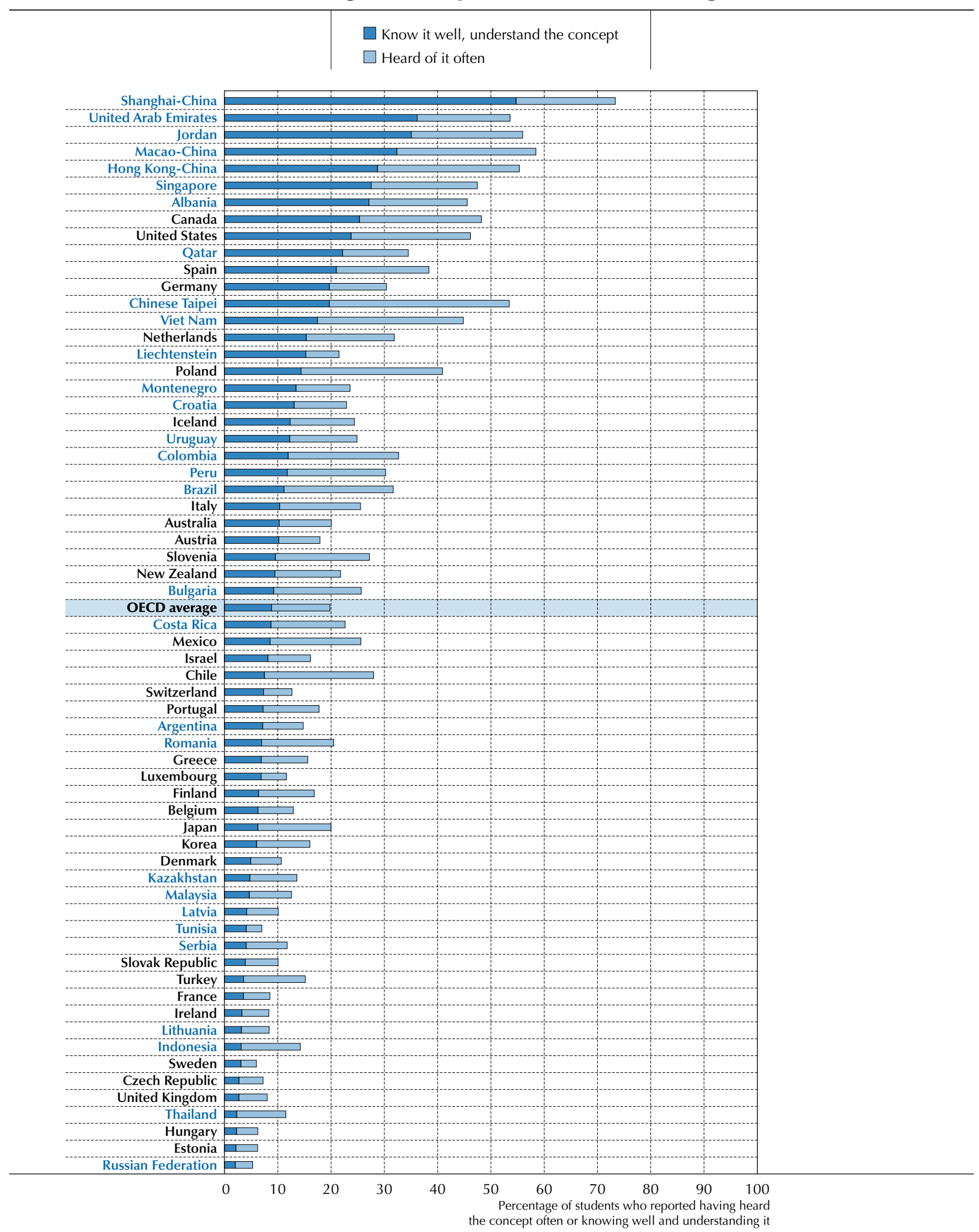

Countries and economies are ranked in descending order of the percentage of students who reported knowing the exponential functions concept well and understanding it (see Question 2 at the end of this chapter).

Source: OECD, PISA 2012 Database, Table I.3.15.

StatLink त्नाls $h t t p: / / d x . d o i . o r g / 10.1787 / 888932936427$ 


\section{- Figure I.3.16}

\section{Percentage of students who reported having seen quadratic functions often} or knowing the concept well and understanding it

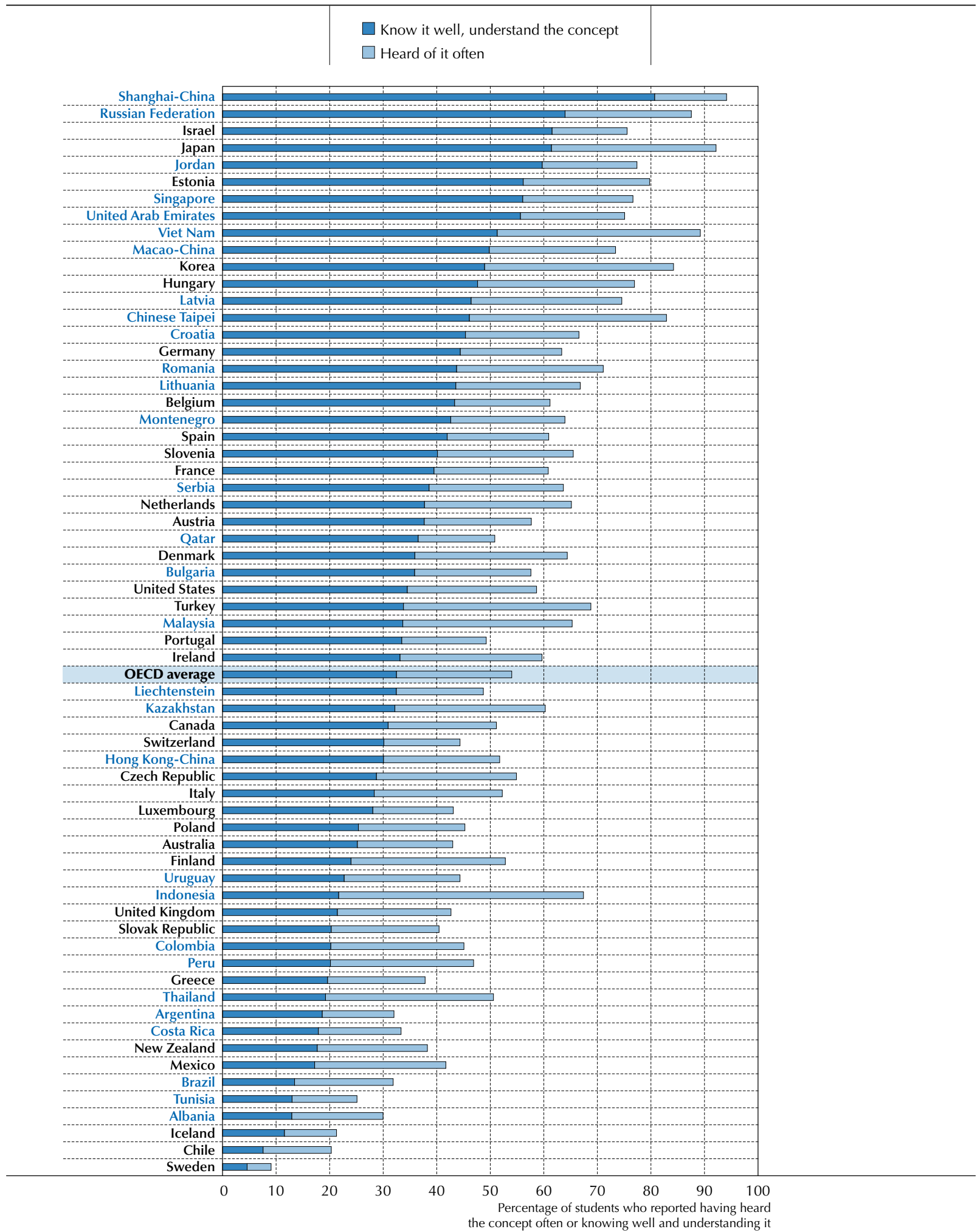

Countries and economies are ranked in descending order of the percentage of students who reported knowing the quadratic functions concept well and understanding it (see Question 2 at the end of this chapter).

Source: OECD, PISA 2012 Database, Table I.3.17.

StatLink त्ञाज http://dx.doi.org/10.1787/888932936427 
- Figure I.3.17

\section{Exposure to applied mathematics vs. exposure to formal mathematics}

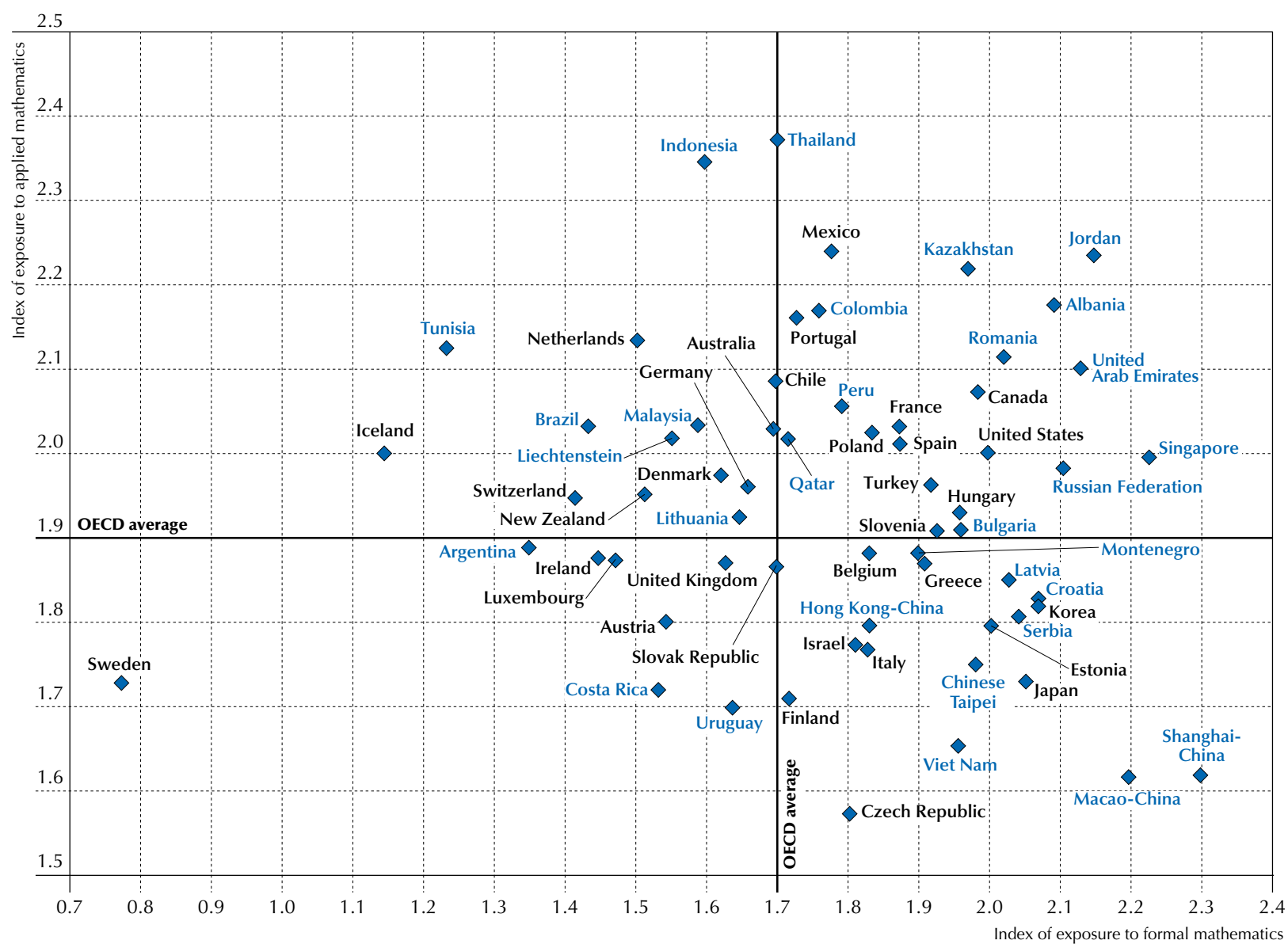

Source: OECD, PISA 2012 Database, Tables 1.3.1.

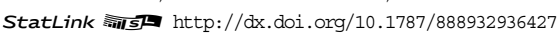




\section{QUESTIONS USED FOR THE CONSTRUCTION OF THE THREE OPPORTUNITY TO LEARN INDICES}

Six questions were used from the Student Questionnaire to cover both the content and the time aspects of the opportunity to learn. These questions are shown below.

\section{Question 1}

How often have you encountered the following types of mathematics tasks during your time at school? (Please tick only one box on each row.)

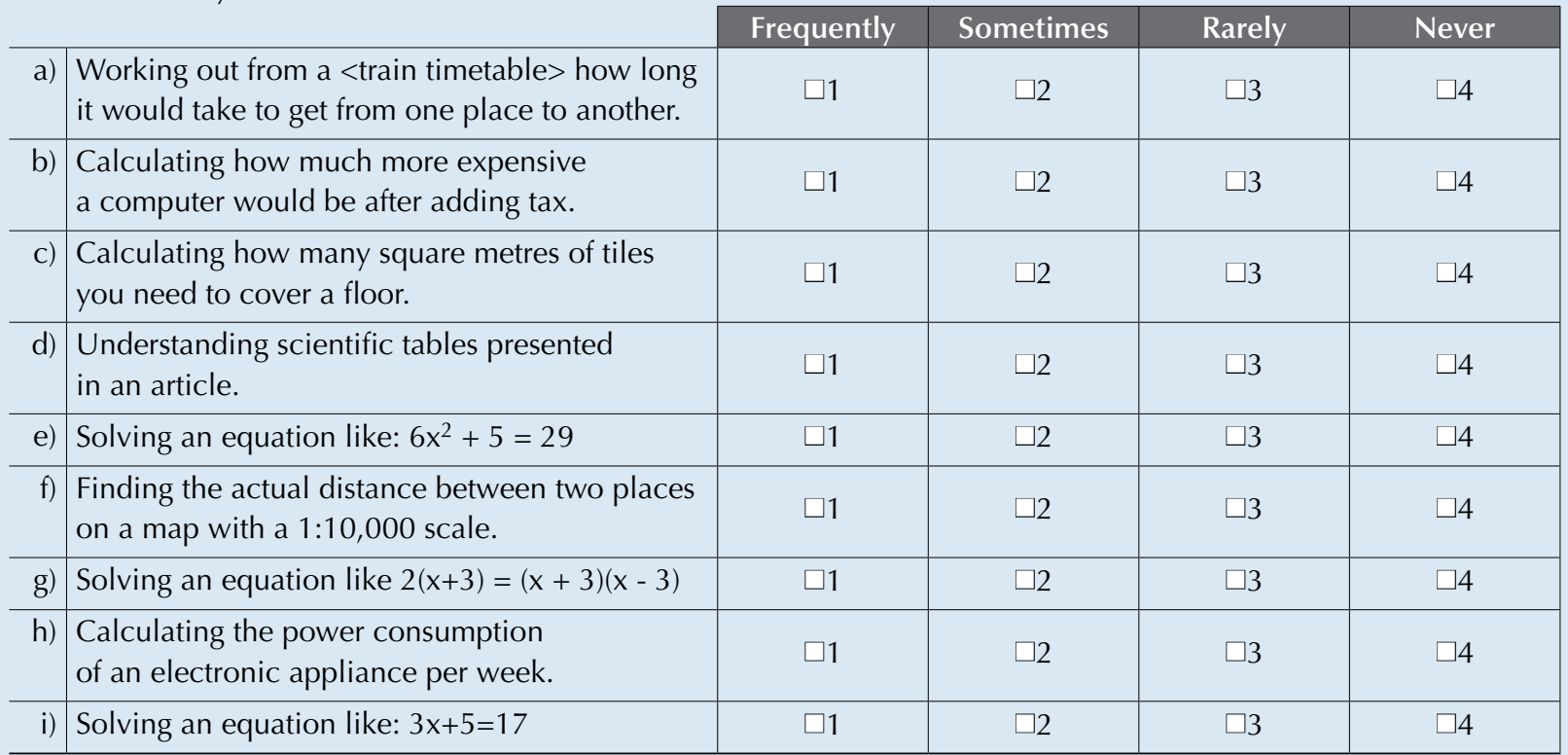

\section{Question 2}

Thinking about mathematical concepts: how familiar are you with the following terms? (Please tick only one box in each row.)

\begin{tabular}{|c|c|c|c|c|}
$\begin{array}{c}\text { Never } \\
\text { heard of it }\end{array}$ & $\begin{array}{c}\text { Heard of it } \\
\text { once or twice }\end{array}$ & $\begin{array}{c}\text { Heard of it } \\
\text { a few times }\end{array}$ & $\begin{array}{c}\text { Heard of it } \\
\text { often }\end{array}$ & $\begin{array}{c}\text { Know it well, } \\
\text { understand } \\
\text { the concept }\end{array}$ \\
\hline$\square 1$ & $\sqcup 2$ & $\sqcup 3$ & $\square 4$ & $\square 5$ \\
\hline$\square 1$ & $\square 2$ & $\square 3$ & $\square 4$ & $\square 5$ \\
\hline$\square 1$ & $\square 2$ & $\square 3$ & $\square 4$ & $\square 5$ \\
\hline$\square 1$ & $\square 2$ & $\square 3$ & $\square 4$ & $\square 5$ \\
\hline$\square 1$ & $\square 2$ & $\square 3$ & $\square 4$ & $\square 5$ \\
\hline$\square 1$ & $\square 2$ & $\square 3$ & $\square 4$ & $\square 5$ \\
\hline$\square 1$ & $\square 2$ & $\square 3$ & $\square 4$ & $\square 5$ \\
\hline$\square 1$ & $\square 2$ & $\square 3$ & $\square 4$ & $\square 5$ \\
\hline$\square 1$ & $\square 2$ & $\square 3$ & $\square 4$ & $\square 5$ \\
\hline$\square 1$ & $\square 2$ & $\square 3$ & $\square 4$ & $\square 5$ \\
\hline$\square 1$ & $\square 2$ & $\square 3$ & $\square 4$ & $\square 5$ \\
\hline$\square 1$ & $\square 2$ & $\square 3$ & $\square 4$ & $\square 5$ \\
\hline$\square 1$ & $\square 2$ & $\square 3$ & $\square 4$ & $\square 5$ \\
\hline
\end{tabular}

The next four questions are about students' experience with different kinds of mathematics problems at school. They include some descriptions of problems and dark blue-coloured boxes, each containing a mathematics problem. The students had to read each problem but did not have to solve it. 


\section{Question 3}

In the box is a series of problems. Each requires you to understand a problem written in text and perform the appropriate calculations. Usually the problem talks about practical situations, but the numbers and people and places mentioned are made up. All the information you need is given. Here are two examples:

1. $<$ Ann $>$ is two years older than $<$ Betty $>$ and $<$ Betty $>$ is four times as old as $<$ Sam $>$. When $<$ Betty $>$ is 30 , how old is $<$ Sam $>$ ?

2. $\mathrm{Mr}<$ Smith $>$ bought a television and a bed. The television cost $<\$ 625>$ but he got a $10 \%$ discount. The bed cost $<\$ 200>$. He paid $<\$ 20>$ for delivery. How much money did Mr $<$ Smith $>$ spend?

We want to know about your experience with these types of word problems at school. Do not solve them!

(Please tick only one box in each row.)

a) How often have you encountered these types of problems in your mathematics lessons?

b) How often have you encountered these types of problems in the tests you have taken at school?

\begin{tabular}{|c|c|c|c|}
\hline Frequently & Sometimes & Rarely & Never \\
\hline$\square 1$ & $\square 2$ & $\square 3$ & $\square 4$ \\
\hline$\sqcup 1$ & $\square 2$ & $\square 3$ & $\square 4$ \\
\hline
\end{tabular}

\section{Question 4}

Below are examples of another set of mathematical skills.

1) Solve $2 x+3=7$.

2) Find the volume of a box with sides $3 \mathrm{~m}, 4 \mathrm{~m}$ and $5 \mathrm{~m}$.

We want to know about your experience with these types of problems at school. Do not solve them! (Please tick only one box in each row.)

a) How often have you encountered these types of problems in your mathematics lessons?

b) How often have you encountered these types of problems in the tests you have taken at school?

\begin{tabular}{|c|c|c|c|}
\hline Frequently & Sometimes & Rarely & Never \\
$\square 1$ & $\square 2$ & $\square 3$ & $\square 4$ \\
$\square 1$ & $\square 2$ & $\square 3$ & $\square 4$ \\
\hline
\end{tabular}

\section{Question 5}

In the next type of problem, you have to use mathematical knowledge and draw conclusions. There is no practical application provided. Here are two examples.

1) Here you need to use geometrical theorems:

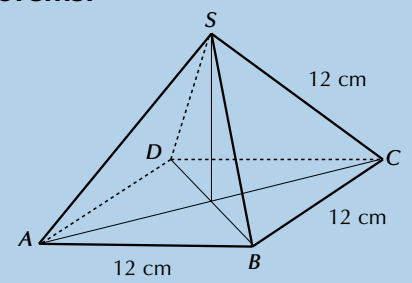

Determine the height of the pyramid.

\section{2) Here you have to know what a prime number is:}

If $n$ is any number: can $(n+1)^{2}$ be a prime number?

We want to know about your experience with these types of problems at school. Do not solve them! (Please tick only one box in each row.)

a) How often have you encountered these types of problems in your mathematics lessons?

b) How often have you encountered these types of problems in the tests you have taken at school?

\begin{tabular}{|c|c|c|c|}
\hline Frequently & Sometimes & Rarely & Never \\
$\square 1$ & $\square 2$ & $\square 3$ & $\square 4$ \\
$\square 1$ & $\square 2$ & $\square 3$ & $\square 4$ \\
\hline
\end{tabular}




\section{Question 6}

In this type of problem, you have to apply suitable mathematical knowledge to find a useful answer to a problem that arises in everyday life or work. The data and information are about real situations. Here are two examples.

\section{Example 1}

A TV reporter says "This graph shows that there is a huge increase in the number of robberies from 1998 to $1999 . "$

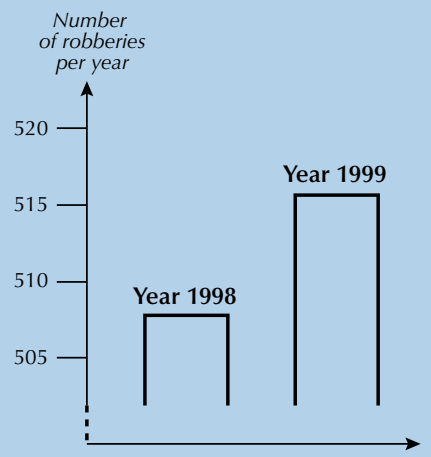

\section{Example 2}

For years the relationship between a person's recommended maximum heart rate and the person's age was described by the following formula:

Recommended maximum heart rate $=220-$ age

Recent research showed that this formula should be modified slightly. The new formula is as follows:

Recommended maximum heart rate $=208-(0.7 \times$ age $)$

From which age onwards does the recommended maximum heart rate increase as a result of the introduction of the new formula? Show your work.

\section{We want to know about your experience with these types of problems at school. Do not solve them!}

(Please check only one box in each row.)

a) How often have you encountered these types of problems in your mathematics lessons?

b) How often have you encountered these types of problems in the tests you have taken at school?

\begin{tabular}{|c|c|c|c|}
\hline Frequently & Sometimes & Rarely & Never \\
$\square 1$ & $\square 2$ & $\square 3$ & $\square 4$ \\
\hline 1 & $\sqcup 2$ & $\square 3$ & $\square 4$ \\
\hline
\end{tabular}

\section{THE THREE OPPORTUNITY TO LEARN INDICES}

From these questions, three indices were constructed:

\section{- The index of exposure to word problems}

This index was coded using the frequency choices for the word-problem type of task (Question 3) as follows:

frequently $=3$, sometimes and rarely $=1$, and never $=0$.

\section{- The index of exposure to applied mathematics}

This index was constructed as the mean of the applied tasks involving both the mathematics contexts (Question 5) and the real-world contexts (Question 6). Each was separately scaled as:

frequently $=3$, sometimes $=2$, rarely $=1$, and never $=0$.

- The index of exposure to formal mathematics

This index was created as the average of three scales.

- Two separate scales were constructed using the item asking for the degree of the student's familiarity with 7 of the 13 mathematics content areas (Question 2). The five response categories reflecting the degree to which they had heard of the topic were scaled 0 to 4 with 0 representing "never heard of it" 4 representing they "knew it well". 
The frequency codes for the three topics - exponential functions, quadratic functions, and linear equations - were averaged to define familiarity with algebra. Similarly, the average of four topics defined a geometry scale, including vectors, polygons, congruent figures, and cosines.

- The third scale was derived from the item where students indicated how often they had been confronted with problems defined as formal mathematics (Question 4). The frequency categories were coded as "frequently", "sometimes", and "rarely" equalling 1 and "never" equal to 0, resulting in a dichotomous variable. The algebra, geometry and formal mathematics tasks were averaged to form the index "formal mathematics", which ranged in values from 0 to 3 , similar to the other three indices. 


\section{Note}

1. The 18 countries/economies that show no relationship between the frequency of student encounters with applied mathematics problems and the performance of 15-year-olds on PISA are the United States, Poland, Hong Kong-China, Greece, Albania, Latvia, Germany, the Czech Republic, Hungary, Australia, Belgium, Argentina, Slovenia, Portugal, Liechtenstein, Korea, the Russian Federation and Viet Nam.

\section{References}

Carroll, J.B. (1963), “A model of school learning", Teachers College Record, 64(8), pp. 723-733.

OECD (2013), PISA 2012 Assessment and Analytical Framework: Mathematics, Reading, Science, Problem Solving and Financial Literacy, OECD Publishing. http://dx.doi.org/10.1787/9789264190511-en

Mullis, I.V.S., et al. (2012), TIMSS 2011 International Results in Mathematics, Chestnut Hill, Boston College, Massachusetts.

Schmidt, W.H., et al. (2001), Why Schools Matter: A Cross-national Comparison of Curriculum and Learning, Jossey-Bass, San Francisco.

Sykes, G., B. Schneider and D.N. Plank (2009), Handbook of Education Policy Research, Routledge, New York.

Wiley, D.E. and A. Harnischfeger (1974), "Explosion of a myth: Quantity of schooling and exposure to instruction, major educational vehicles", Educational Researcher, 3(4), pp. 7-12. 


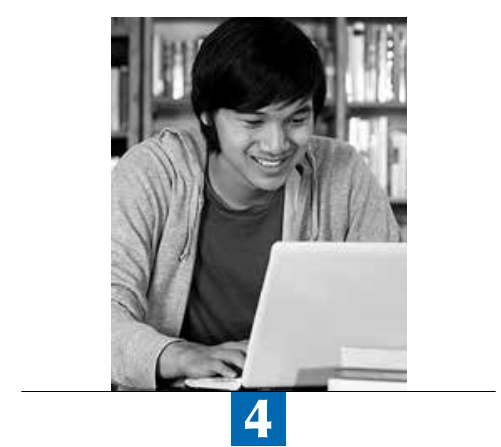

\section{A Profile \\ of Student Performance in Reading}

This chapter examines student performance in reading in PISA 2012. It provides examples of assessment questions, relating them to each PISA proficiency level, discusses gender differences in student performance, compares countries' and economies', performance in reading, and highlights trends in reading performance up to 2012. 
What can 15-year-old students do in reading? This chapter compares countries' and economies' performance, shows some regions' performance, and analyses the changes over the various PISA assessments. It highlights the differences between girls' and boys' performance and provides examples of assessment questions at each PISA proficiency level.

Reading literacy focuses on the ability of students to use written information in real-life situations. PISA defines reading literacy as understanding, using, reflecting on and engaging with written texts, in order to achieve one's goals, to develop one's knowledge and potential, and to participate in society (OECD, 2009). This definition goes beyond the traditional notion of decoding information and literal interpretation of what is written towards more applied tasks. PISA's conception of reading literacy encompasses the range of situations in which people read, the different ways written texts are presented through different media, and the variety of ways that readers approach and use texts, from the functional and finite, such as finding a particular piece of practical information, to the deep and far-reaching, such as understanding other ways of doing, thinking and being.

Reading literacy was the major domain assessed in 2000, the first PISA assessment, and in 2009, the fourth PISA assessment. In this fifth PISA assessment, mathematics was the major domain, thus less time was devoted to assessing students' reading skills. As a result, only an update on overall performance is possible, rather than the kind of in-depth analysis of knowledge and skills shown in the PISA 2009 report (OECD, 2009).

This chapter presents the results of the paper-based assessment in PISA 2012. Thirty-two of the 65 participating countries and economies participated in the computer-based (digital reading assessment). Annex B3 presents results on both the computer-based scale and a combined paper-and-computer scale.

\section{What the data tell us}

- Of the 64 countries and economies that have comparable data in reading performance since 2000, 32 show an improvement in mean reading performance, 22 show no change, and 10 show a deterioration in performance.

- Among OECD countries, Chile, Estonia, Germany, Hungary, Israel, Japan, Korea, Luxembourg, Mexico, Poland, Portugal, Switzerland and Turkey all improved their reading performance across successive PISA assessments.

- Between 2000 and 2012, Albania, Israel and Poland increased the share of top-performing students and simultaneously reduced the share of students who do not meet the baseline level of proficiency in reading.

- The gender gap in reading performance - favouring girls - widened in 11 countries and economies between 2000 and 2012.

\section{STUDENT PERFORMANCE IN READING}

The metric for the overall reading scale is based on a mean for participating OECD countries set at 500, with a standard deviation of 100. These were set when reporting the results of the first PISA reading assessment, administered in 2000 (OECD, 2001). To help interpret what students' scores mean in substantive terms, the scale is divided into levels of proficiency that indicate the kinds of tasks that students at those levels are capable of completing successfully (OECD, 2009).

\section{Average performance in reading}

One way to summarise student performance and to compare the relative standing of countries in reading is through countries' and economies' mean performance, both relative to each other and to the OECD mean. For PISA 2012, the OECD mean is 496, with a standard deviation of 94. This establishes the benchmark against which each country's and each economy's reading performance in PISA 2012 is compared.

When interpreting mean performance, only those differences among countries and economies that are statistically significant should be taken into account. Figure I.4.1 shows each country/economy's mean score and also for which pairs of countries/economies the differences between the means are statistically significant. For each country/economy shown in the middle column, the countries/economies whose mean scores are not statistically significantly different are listed in the right column. In all other cases, country/economy A scores higher than country/economy B if country/ economy $\mathrm{A}$ is situated above country/economy $\mathrm{B}$ in the middle column, and scores lower if country/economy $\mathrm{A}$ is situated below country/economy B. For example: Shanghai-China ranks first and Hong Kong-China ranks second, but the performance of Singapore, which appears third on the list, cannot be distinguished with confidence from that of Hong Kong-China. 


\section{- Figure I.4.1}

\section{Comparing countries' and economies' performance in reading}

\begin{tabular}{|c|c|c|}
\hline \multirow[b]{2}{*}{$\begin{array}{l}\text { Mean } \\
\text { score }\end{array}$} & \multirow[b]{2}{*}{$\begin{array}{l}\text { Comparison } \\
\text { country/economy }\end{array}$} & $\begin{array}{l}\text { Statistically significantly above the OECD average } \\
\text { Not statistically significantly different from the OECD average } \\
\text { Statistically significantly below the OECD average }\end{array}$ \\
\hline & & Countries/economies whose mean score is NOT statistically significantly different from that comparison country's/economy's score \\
\hline 570 & Shanghai-China & \\
\hline 545 & Hong Kong-China & Singapore, Japan, Korea \\
\hline 542 & Singapore & Hong Kong-China, Japan, Korea \\
\hline 538 & Japan & Hong Kong-China, Singapore, Korea \\
\hline 536 & Korea & Hong Kong-China, Singapore, Japan \\
\hline 524 & Finland & Ireland, Chinese Taipei, Canada, Poland, Liechtenstein \\
\hline 523 & Ireland & Finland, Chinese Taipei, Canada, Poland, Liechtenstein \\
\hline 523 & Chinese Taipei & Finland, Ireland, Canada, Poland, Estonia, Liechtenstein \\
\hline 523 & Canada & Finland, Ireland, Chinese Taipei, Poland, Liechtenstein \\
\hline 518 & Poland & Finland, Ireland, Chinese Taipei, Canada, Estonia, Liechtenstein, New Zealand, Australia, Netherlands, Viet Nam \\
\hline 516 & Estonia & Chinese Taipei, Poland, Liechtenstein, New Zealand, Australia, Netherlands, Viet Nam \\
\hline 516 & Liechtenstein & $\begin{array}{l}\text { Finland, Ireland, Chinese Taipei, Canada, Poland, Estonia, New Zealand, Australia, Netherlands, Switzerland, Macao-China, Belgium, } \\
\text { Viet Nam, Germany }\end{array}$ \\
\hline 512 & New Zealand & Poland, Estonia, Liechtenstein, Australia, Netherlands, Switzerland, Macao-China, Belgium, Viet Nam, Germany, France \\
\hline 512 & Australia & Poland, Estonia, Liechtenstein, New Zealand, Netherlands, Switzerland, Macao-China, Belgium, Viet Nam, Germany, France \\
\hline 511 & Netherlands & Poland, Estonia, Liechtenstein, New Zealand, Australia, Switzerland, Macao-China, Belgium, Viet Nam, Germany, France, Norway \\
\hline 509 & Switzerland & Liechtenstein, New Zealand, Australia, Netherlands, Macao-China, Belgium, Viet Nam, Germany, France, Norway \\
\hline 509 & Macao-China & Liechtenstein, New Zealand, Australia, Netherlands, Switzerland, Belgium, Viet Nam, Germany, France, Norway \\
\hline 509 & Belgium & Liechtenstein, New Zealand, Australia, Netherlands, Switzerland, Macao-China, Viet Nam, Germany, France, Norway \\
\hline 508 & Viet Nam & $\begin{array}{l}\text { Poland, Estonia, Liechtenstein, New Zealand, Australia, Netherlands, Switzerland, Macao-China, Belgium, Germany, France, Norway, } \\
\text { United Kingdom, United States }\end{array}$ \\
\hline 508 & Germany & Liechtenstein, New Zealand, Australia, Netherlands, Switzerland, Macao-China, Belgium, Viet Nam, France, Norway, United Kingdom \\
\hline 505 & France & New Zealand, Australia, Netherlands, Switzerland, Macao-China, Belgium, Viet Nam, Germany, Norway, United Kingdom, United States \\
\hline 504 & Norway & Netherlands, Switzerland, Macao-China, Belgium, Viet Nam, Germany, France, United Kingdom, United States, Denmark \\
\hline 499 & United Kingdom & Viet Nam, Germany, France, Norway, United States, Denmark, Czech Republic \\
\hline 498 & United States & Viet Nam, France, Norway, United Kingdom, Denmark, Czech Republic, Italy, Austria, Hungary, Portugal, Israel \\
\hline 496 & Denmark & Norway, United Kingdom, United States, Czech Republic, Italy, Austria, Hungary, Portugal, Israel \\
\hline 493 & Czech Republic & United Kingdom, United States, Denmark, Italy, Austria, Latvia, Hungary, Spain, Luxembourg, Portugal, Israel, Croatia \\
\hline 490 & Italy & United States, Denmark, Czech Republic, Austria, Latvia, Hungary, Spain, Luxembourg, Portugal, Israel, Croatia, Sweden \\
\hline 490 & Austria & United States, Denmark, Czech Republic, Italy, Latvia, Hungary, Spain, Luxembourg, Portugal, Israel, Croatia, Sweden \\
\hline 489 & Latvia & Czech Republic, Italy, Austria, Hungary, Spain, Luxembourg, Portugal, Israel, Croatia, Sweden \\
\hline 488 & Hungary & United States, Denmark, Czech Republic, Italy, Austria, Latvia, Spain, Luxembourg, Portugal, Israel, Croatia, Sweden, Iceland \\
\hline 488 & Spain & Czech Republic, Italy, Austria, Latvia, Hungary, Luxembourg, Portugal, Israel, Croatia, Sweden \\
\hline 488 & Luxembourg & Czech Republic, Italy, Austria, Latvia, Hungary, Spain, Portugal, Israel, Croatia, Sweden \\
\hline 488 & Portugal & United States, Denmark, Czech Republic, Italy, Austria, Latvia, Hungary, Spain, Luxembourg, Israel, Croatia, Sweden, Iceland, Slovenia \\
\hline 486 & Israel & $\begin{array}{l}\text { United States, Denmark, Czech Republic, Italy, Austria, Latvia, Hungary, Spain, Luxembourg, Portugal, Croatia, Sweden, Iceland, Slovenia, } \\
\text { Lithuania, Greece, Turkey, Russian Federation }\end{array}$ \\
\hline 485 & Croatia & Czech Republic, Italy, Austria, Latvia, Hungary, Spain, Luxembourg, Portugal, Israel, Sweden, Iceland, Slovenia, Lithuania, Greece, Turkey \\
\hline 483 & Sweden & Italy, Austria, Latvia, Hungary, Spain, Luxembourg, Portugal, Israel, Croatia, Iceland, Slovenia, Lithuania, Greece, Turkey, Russian Federation \\
\hline 483 & Iceland & Hungary, Portugal, Israel, Croatia, Sweden, Slovenia, Lithuania, Greece, Turkey \\
\hline 481 & Slovenia & Portugal, Israel, Croatia, Sweden, Iceland, Lithuania, Greece, Turkey, Russian Federation \\
\hline 477 & Lithuania & Israel, Croatia, Sweden, Iceland, Slovenia, Greece, Turkey, Russian Federation \\
\hline 477 & Greece & Israel, Croatia, Sweden, Iceland, Slovenia, Lithuania, Turkey, Russian Federation \\
\hline 475 & Turkey & Israel, Croatia, Sweden, Iceland, Slovenia, Lithuania, Greece, Russian Federation \\
\hline 475 & Russian Federation & Israel, Sweden, Slovenia, Lithuania, Greece, Turkey \\
\hline 463 & Slovak Republic & \\
\hline 449 & Cyprus ${ }^{1,2}$ & Serbia \\
\hline 446 & Serbia & Cyprus $^{1,2}$, United Arab Emirates, Chile, Thailand, Costa Rica, Romania, Bulgaria \\
\hline 442 & United Arab Emirates & Serbia, Chile, Thailand, Costa Rica, Romania, Bulgaria \\
\hline 441 & Chile & Serbia, United Arab Emirates, Thailand, Costa Rica, Romania, Bulgaria \\
\hline 441 & Thailand & Serbia, United Arab Emirates, Chile, Costa Rica, Romania, Bulgaria \\
\hline 441 & Costa Rica & Serbia, United Arab Emirates, Chile, Thailand, Romania, Bulgaria \\
\hline 438 & Romania & Serbia, United Arab Emirates, Chile, Thailand, Costa Rica, Bulgaria \\
\hline 436 & Bulgaria & Serbia, United Arab Emirates, Chile, Thailand, Costa Rica, Romania \\
\hline 424 & Mexico & Montenegro \\
\hline 422 & Montenegro & Mexico \\
\hline 411 & Uruguay & Brazil, Tunisia, Colombia \\
\hline 410 & Brazil & Uruguay, Tunisia, Colombia \\
\hline 404 & Tunisia & Uruguay, Brazil, Colombia, Jordan, Malaysia, Indonesia, Argentina, Albania \\
\hline 403 & Colombia & Uruguay, Brazil, Tunisia, Jordan, Malaysia, Indonesia, Argentina \\
\hline 399 & Jordan & Tunisia, Colombia, Malaysia, Indonesia, Argentina, Albania, Kazakhstan \\
\hline 398 & Malaysia & Tunisia, Colombia, Jordan, Indonesia, Argentina, Albania, Kazakhstan \\
\hline 396 & Indonesia & Tunisia, Colombia, Jordan, Malaysia, Argentina, Albania, Kazakhstan \\
\hline 396 & Argentina & Tunisia, Colombia, Jordan, Malaysia, Indonesia, Albania, Kazakhstan \\
\hline 394 & Albania & Tunisia, Jordan, Malaysia, Indonesia, Argentina, Kazakhstan, Qatar, Peru \\
\hline 393 & Kazakhstan & Jordan, Malaysia, Indonesia, Argentina, Albania, Qatar, Peru \\
\hline 388 & Qatar & Albania, Kazakhstan, Peru \\
\hline 384 & Peru & Albania, Kazakhstan, Qatar \\
\hline
\end{tabular}

1. Note by Turkey: The information in this document with reference to "Cyprus" relates to the southern part of the Island. There is no single authority representing both Turkish and Greek Cypriot people on the Island. Turkey recognises the Turkish Republic of Northern Cyprus (TRNC). Until a lasting and equitable solution is found within the context of the United Nations, Turkey shall preserve its position concerning the "Cyprus issue".

2. Note by all the European Union Member States of the OECD and the European Union: The Republic of Cyprus is recognised by all members of the United Nations with the exception of Turkey. The information in this document relates to the area under the effective control of the Government of the Republic of Cyprus.

Source: OECD, PISA 2012 Database.

StatLink 敦到 http://dx.doi.org/10.1787/888932935610 
- Figure 1.4.2 [Part 1/3] "

Reading performance among PISA 2012 participants, at national and regional levels

\begin{tabular}{|c|c|c|c|c|c|}
\hline & \multicolumn{5}{|c|}{ Reading scale } \\
\hline & \multirow[b]{3}{*}{ Mean score } & \multicolumn{4}{|c|}{ Range of ranks } \\
\hline & & \multicolumn{2}{|c|}{ OECD countries } & \multicolumn{2}{|c|}{ All countries/economies } \\
\hline & & Upper rank & Lower rank & Upper rank & Lower rank \\
\hline Shanghai-China & 570 & & & 1 & 1 \\
\hline Hong Kong-China & 545 & & & 2 & 4 \\
\hline Singapore & 542 & & & 2 & 4 \\
\hline Japan & 538 & 1 & 2 & 2 & 5 \\
\hline Korea & 536 & 1 & 2 & 3 & 5 \\
\hline Massachusetts (United States) & 527 & & & & \\
\hline Australian Capital Territory (Australia) & 525 & & & & \\
\hline Finland & 524 & 3 & 5 & 6 & 10 \\
\hline Ireland & 523 & 3 & 6 & 6 & 10 \\
\hline Chinese Taipei & 523 & & & 6 & 10 \\
\hline Canada & 523 & 3 & 6 & 6 & 10 \\
\hline Connecticut (United States) & 521 & & & & \\
\hline Veneto (Italy) & 521 & & & & \\
\hline Trento (Italy) & 521 & & & & \\
\hline Lombardia (Italy) & 521 & & & & \\
\hline Western Australia (Australia) & 519 & & & & \\
\hline Friuli Venezia Giulia (Italy) & 518 & & & & \\
\hline Poland & 518 & 4 & 9 & 7 & 14 \\
\hline Flemish community (Belgium) & 518 & & & & \\
\hline Victoria (Australia) & 517 & & & & \\
\hline Estonia & 516 & 6 & 9 & 10 & 14 \\
\hline Liechtenstein & 516 & & & 7 & 18 \\
\hline New South Wales (Australia) & 513 & & & & \\
\hline New Zealand & 512 & 7 & 12 & 11 & 19 \\
\hline Australia & 512 & 8 & 12 & 12 & 18 \\
\hline Netherlands & 511 & 6 & 14 & 11 & 21 \\
\hline Madrid (Spain) & 511 & & & & \\
\hline Navarre (Spain) & 509 & & & & \\
\hline Switzerland & 509 & 8 & 14 & 13 & 21 \\
\hline Macao-China & 509 & & & 13 & 22 \\
\hline Belgium & 509 & 9 & 15 & 15 & 20 \\
\hline Viet Nam & 508 & & & 12 & 23 \\
\hline Queensland (Australia) & 508 & & & & \\
\hline Germany & 508 & 9 & 15 & 13 & 22 \\
\hline Scotland (United Kingdom) & 506 & & & & \\
\hline Piemonte (Italy) & 506 & & & & \\
\hline France & 505 & 10 & 16 & 16 & 23 \\
\hline Castile and Leon (Spain) & 505 & & & & \\
\hline Asturias (Spain) & 504 & & & & \\
\hline Norway & 504 & 11 & 17 & 17 & 24 \\
\hline Valle d'Aosta (Italy) & 502 & & & & \\
\hline Catalonia (Spain) & 501 & & & & \\
\hline South Australia (Australia) & 500 & & & & \\
\hline England (United Kingdom) & 500 & & & & \\
\hline German-speaking community (Belgium) & 499 & & & & \\
\hline United Kingdom & 499 & 14 & 19 & 20 & 26 \\
\hline Galicia (Spain) & 499 & & & & \\
\hline Emilia Romagna (Italy) & 498 & & & & \\
\hline Basque Country (Spain) & 498 & & & & \\
\hline Northern Ireland (United Kingdom) & 498 & & & & \\
\hline United States & 498 & 14 & 20 & 21 & 28 \\
\hline French community (Be/gium) & 497 & & & & \\
\hline Bolzano (Italy) & 497 & & & & \\
\hline Marche (Italy) & 497 & & & & \\
\hline Denmark & 496 & 16 & 20 & 23 & 27 \\
\hline Aragon (Spain) & 493 & & & & \\
\hline Puglia (Italy) & 493 & & & & \\
\hline Czech Republic & 493 & 16 & 23 & 23 & 31 \\
\hline Umbria (Italy) & 492 & & & & \\
\hline Florida (United States) & 492 & & & & \\
\hline Liguria (Italy) & 490 & & & & \\
\hline La Rioja (Spain) & 490 & & & & \\
\hline Alentejo (Portugal) & 490 & & & & \\
\hline
\end{tabular}

Notes: OECD countries are shown in bold black. Partner countries are shown in bold blue. Participating economies and subnational entities that are not included in national results are shown in bold blue italics. Regions are shown in black italics (OECD countries) or blue italics (partner countries).

1. Note by Turkey: The information in this document with reference to "Cyprus" relates to the southern part of the Island. There is no single authority representing both Turkish and Greek Cypriot people on the Island. Turkey recognises the Turkish Republic of Northern Cyprus (TRNC). Until a lasting and equitable solution is found within the context of the United Nations, Turkey shall preserve its position concerning the "Cyprus issue".

2. Note by all the European Union Member States of the OECD and the European Union: The Republic of Cyprus is recognised by all members of the United Nations with the exception of Turkey. The information in this document relates to the area under the effective control of the Government of the Republic of Cyprus.

Countries, economies and subnational entities are ranked in descending order of mean reading performance.

Source: OECD, PISA 2012 Database.

StatLink 到s http://dx.doi.org/10.1787/888932935610 
- Figure I.4.2 [Part 2/3]

Reading performance among PISA 2012 participants, at national and regional levels

\begin{tabular}{|c|c|c|c|c|c|}
\hline & \multicolumn{5}{|c|}{ Reading scale } \\
\hline & \multirow[b]{3}{*}{ Mean score } & \multicolumn{4}{|c|}{ Range of ranks } \\
\hline & & \multicolumn{2}{|c|}{ OECD countries } & \multicolumn{2}{|c|}{ All countries/economies } \\
\hline & & Upper rank & Lower rank & Upper rank & Lower rank \\
\hline Italy & 490 & 19 & 25 & 26 & 34 \\
\hline Austria & 490 & 18 & 26 & 25 & 34 \\
\hline Latvia & 489 & & & 26 & 35 \\
\hline Hungary & 488 & 18 & 27 & 25 & 36 \\
\hline Spain & 488 & 20 & 27 & 27 & 35 \\
\hline Luxembourg & 488 & 20 & 26 & 28 & 35 \\
\hline Portugal & 488 & 18 & 28 & 25 & 37 \\
\hline Toscana (Italy) & 488 & & & & \\
\hline Israel & 486 & 19 & 31 & 25 & 40 \\
\hline Cantabria (Spain) & 485 & & & & \\
\hline Croatia & 485 & & & 28 & 39 \\
\hline Tasmania (Australia) & 485 & & & & \\
\hline Sweden & 483 & 23 & 30 & 30 & 40 \\
\hline Iceland & 483 & 25 & 30 & 33 & 39 \\
\hline Perm Territory region (Russian Federation) & 482 & & & & \\
\hline Slovenia & 481 & 27 & 30 & 35 & 39 \\
\hline Lazio (Italy) & 480 & & & & \\
\hline Abruzzo (Italy) & 480 & & & & \\
\hline Wales (United Kingdom) & 480 & & & & \\
\hline Lithuania & 477 & & & 37 & 42 \\
\hline Greece & 477 & 28 & 31 & 36 & 42 \\
\hline Andalusia (Spain) & 477 & & & & \\
\hline Molise (Italy) & 476 & & & & \\
\hline Balearic Islands (Spain) & 476 & & & & \\
\hline Turkey & 475 & 27 & 31 & 36 & 42 \\
\hline Russian Federation & 475 & & & 38 & 42 \\
\hline Basilicata (Italy) & 474 & & & & \\
\hline Dubai (United Arab Emirates) & 468 & & & & \\
\hline Northern Territory (Australia) & 466 & & & & \\
\hline Campania (Italy) & 464 & & & & \\
\hline Sardegna (Italy) & 464 & & & & \\
\hline Slovak Republic & 463 & 32 & 32 & 43 & 43 \\
\hline Murcia (Spain) & 462 & & & & \\
\hline Extremadura (Spain) & 457 & & & & \\
\hline Sicilia (Italy) & 455 & & & & \\
\hline Sharjah (United Arab Emirates) & 451 & & & & \\
\hline Querétaro (Mexico) & 451 & & & & \\
\hline Cyprus ${ }^{1,2}$ & 449 & & & 44 & 45 \\
\hline Distrito Federal (Mexico) & 448 & & & & \\
\hline Aguascalientes (Mexico) & 447 & & & & \\
\hline Serbia & 446 & & & 44 & 48 \\
\hline Chihuahua (Mexico) & 444 & & & & \\
\hline United Arab Emirates & 442 & & & 45 & 50 \\
\hline Nuevo León (Mexico) & 442 & & & & \\
\hline Chile & 441 & 33 & 33 & 45 & 50 \\
\hline Thailand & 441 & & & 45 & 51 \\
\hline Costa Rica & 441 & & & 45 & 51 \\
\hline Colima (Mexico) & 440 & & & & \\
\hline Romania & 438 & & & 46 & 51 \\
\hline Mexico (Mexico) & 437 & & & & \\
\hline Durango (Mexico) & 436 & & & & \\
\hline Jalisco (Mexico) & 436 & & & & \\
\hline Bulgaria & 436 & & & 45 & 51 \\
\hline Calabria (Italy) & 434 & & & & \\
\hline Rio Grande do Sul (Brazil) & 433 & & & & \\
\hline Manizales (Colombia) & 431 & & & & \\
\hline Coahuila (Mexico) & 431 & & & & \\
\hline Abu Dhabi (United Arab Emirates) & 431 & & & & \\
\hline Quintana Roo (Mexico) & 430 & & & & \\
\hline Ciudad Autónoma de Buenos Aires (Argentina) & 429 & & & & \\
\hline Baja California (Mexico) & 428 & & & & \\
\hline Federal District (Brazil) & 428 & & & & \\
\hline Mato Grosso do Sul (Brazil) & 428 & & & & \\
\hline
\end{tabular}

Notes: OECD countries are shown in bold black. Partner countries are shown in bold blue. Participating economies and subnational entities that are not included in national results are shown in bold blue italics. Regions are shown in black italics (OECD countries) or blue italics (partner countries).

1. Note by Turkey: The information in this document with reference to "Cyprus" relates to the southern part of the Island. There is no single authority representing both Turkish and Greek Cypriot people on the Island. Turkey recognises the Turkish Republic of Northern Cyprus (TRNC). Until a lasting and equitable solution is found within the context of the United Nations, Turkey shall preserve its position concerning the "Cyprus issue".

2. Note by all the European Union Member States of the OECD and the European Union: The Republic of Cyprus is recognised by all members of the United Nations with the exception of Turkey. The information in this document relates to the area under the effective control of the Government of the Republic of Cyprus.

Countries, economies and subnational entities are ranked in descending order of mean reading performance.

Source: OECD, PISA 2012 Database.

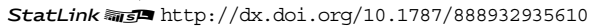


- Figure 1.4.2 [Part 3/3] "

Reading performance among PISA 2012 participants, at national and regional levels

\begin{tabular}{|c|c|c|c|c|c|}
\hline & \multicolumn{5}{|c|}{ Reading scale } \\
\hline & \multirow[b]{3}{*}{ Mean score } & \multicolumn{4}{|c|}{ Range of ranks } \\
\hline & & \multicolumn{2}{|c|}{ OECD countries } & \multicolumn{2}{|c|}{ All countries/economies } \\
\hline & & Upper rank & Lower rank & Upper rank & Lower rank \\
\hline Espírito Santo (Brazil) & 427 & & & & \\
\hline Minas Gerais (Brazil) & 427 & & & & \\
\hline Yucatán (Mexico) & 426 & & & & \\
\hline Morelos (Mexico) & 425 & & & & \\
\hline San Luis Potosí (Mexico) & 425 & & & & \\
\hline Mexico & 424 & 34 & 34 & 52 & 53 \\
\hline Baja California Sur (Mexico) & 423 & & & & \\
\hline Puebla (Mexico) & 423 & & & & \\
\hline Medellin (Colombia) & 423 & & & & \\
\hline Santa Catarina (Brazil) & 423 & & & & \\
\hline Bogota (Colombia) & 422 & & & & \\
\hline Montenegro & 422 & & & 52 & 53 \\
\hline Paraná (Brazil) & 422 & & & & \\
\hline São Paulo (Brazil) & 422 & & & & \\
\hline Tamaulipas (Mexico) & 421 & & & & \\
\hline Tlaxcala (Mexico) & 418 & & & & \\
\hline Nayarit (Mexico) & 418 & & & & \\
\hline Sinaloa (Mexico) & 417 & & & & \\
\hline Fujairah (United Arab Emirates) & 415 & & & & \\
\hline Ras Al Khaimah (United Arab Emirates) & 415 & & & & \\
\hline Ajman (United Arab Emirates) & 414 & & & & \\
\hline Guanajuato (Mexico) & 414 & & & & \\
\hline Hidalgo (Mexico) & 414 & & & & \\
\hline Campeche (Mexico) & 413 & & & & \\
\hline Zacatecas (Mexico) & 412 & & & & \\
\hline Paraiba (Brazil) & 411 & & & & \\
\hline Uruguay & 411 & & & 54 & 56 \\
\hline Veracruz (Mexico) & 410 & & & & \\
\hline Brazil & 410 & & & 54 & 56 \\
\hline Cali (Colombia) & 408 & & & & \\
\hline Rio de Janeiro (Brazil) & 408 & & & & \\
\hline Tunisia & 404 & & & 54 & 60 \\
\hline Colombia & 403 & & & 55 & 60 \\
\hline Piauí (Brazil) & 403 & & & & \\
\hline Umm Al Quwain (United Arab Emirates) & 400 & & & & \\
\hline Rondônia (Brazil) & 400 & & & & \\
\hline Jordan & 399 & & & 56 & 62 \\
\hline Malaysia & 398 & & & 57 & 63 \\
\hline Sergipe (Brazil) & 397 & & & & \\
\hline Ceará (Brazil) & 397 & & & & \\
\hline Amapá (Brazil) & 396 & & & & \\
\hline Indonesia & 396 & & & 56 & 63 \\
\hline Argentina & 396 & & & 57 & 63 \\
\hline Tabasco (Mexico) & 395 & & & & \\
\hline Albania & 394 & & & 58 & 64 \\
\hline Goiás (Brazil) & 393 & & & & \\
\hline Rio Grande do Norte (Brazil) & 393 & & & & \\
\hline Kazakhstan & 393 & & & 59 & 64 \\
\hline Bahia (Brazil) & 388 & & & & \\
\hline Qatar & 388 & & & 63 & 65 \\
\hline Pará (Brazil) & 387 & & & & \\
\hline Peru & 384 & & & 63 & 65 \\
\hline Acre (Brazil) & 383 & & & & \\
\hline Amazonas (Brazil) & 382 & & & & \\
\hline Mato Grosso (Brazil) & 382 & & & & \\
\hline Tocantins (Brazil) & 381 & & & & \\
\hline Roraima (Brazil) & 377 & & & & \\
\hline Pernambuco (Brazil) & 376 & & & & \\
\hline Chiapas (Mexico) & 371 & & & & \\
\hline Maranhão (Brazil) & 369 & & & & \\
\hline Guerrero (Mexico) & 368 & & & & \\
\hline Alagoas (Brazil) & 355 & & & & \\
\hline
\end{tabular}

Notes: OECD countries are shown in bold black. Partner countries are shown in bold blue. Participating economies and subnational entities that are not included in national results are shown in bold blue italics. Regions are shown in black italics (OECD countries) or blue italics (partner countries).

1. Note by Turkey: The information in this document with reference to "Cyprus" relates to the southern part of the Island. There is no single authority representing both Turkish and Greek Cypriot people on the Island. Turkey recognises the Turkish Republic of Northern Cyprus (TRNC). Until a lasting and equitable solution is found within the context of the United Nations, Turkey shall preserve its position concerning the "Cyprus issue".

2. Note by all the European Union Member States of the OECD and the European Union: The Republic of Cyprus is recognised by all members of the United Nations with the exception of Turkey. The information in this document relates to the area under the effective control of the Government of the Republic of Cyprus.

Countries, economies and subnational entities are ranked in descending order of mean reading performance.

Source: OECD, PISA 2012 Database.

StatLink 新 
Moreover, countries and economies are divided into three broad groups: those whose mean scores are statistically around the OECD mean (highlighted in dark blue), those whose mean scores are above the OECD mean (highlighted in pale blue), and those whose mean scores are below the OECD mean (highlighted in medium blue).

As shown in Figure I.4.1, Shanghai-China, Hong Kong-China, Singapore, Japan and Korea are the five highest-performing countries and economies in reading. Shanghai-China has a mean score of 570 points in reading - the equivalent of more than a year-and-a-half of schooling above the OECD average of 496 score points, and 25 score points above the second best-performing participant, Hong Kong-China. Finland, Ireland, Chinese Taipei, Canada, Poland, Estonia and Liechtenstein perform at least 20 score points above the OECD average. Ten other countries and economies - New Zealand, Australia, the Netherlands, Switzerland, Macao-China, Belgium, Viet Nam, Germany, France and Norway - also score above the OECD average. Meanwhile, the United Kingdom, the United States, Denmark and the Czech Republic perform around the OECD average; and 39 countries and economies perform below the OECD average.

Among OECD countries, performance differences are large: 114 score points separate the mean scores of the highestand lowest-performing OECD countries; when the partner countries and economies are considered along with OECD countries, this difference amounts to 185 score points.

Because the figures are derived from samples, it is not possible to determine a country's or economy's precise ranking among all countries and economies. However, it is possible to determine, with confidence, a range of rankings in which the country's/economy's performance level lies (Figure I.4.2). For entities other than those for which full samples were drawn (i.e. Shanghai-China, Hong Kong-China, Chinese Taipei and Macao-China), it is not possible to calculate a rank order but the mean score provides a possibility to position subnational entities against the performance of the countries and economies. For example, Massachusetts shows a score between the performance of top-performer Korea and Finland.

\section{Trends in average reading performance}

The change in a school system's average performance over time indicates how and to what extent the system is progressing towards achieving the goal of providing all students with the knowledge and skills needed to become full participants in a knowledge-based society. Trends in reading performance up to 2012 are available for 64 countries and economies. ${ }^{1}$ PISA 2012 results for 30 countries and economies can be compared with data from all the previous cycles (PISA 2000, 2003, 2006 and 2009); for the other countries and economies, annualised trends can be calculated even if these countries/economies did not begin their participation in PISA assessments in PISA 2000, missed some assesments between PISA 2000 and 2012, or have results from previous assessments that are not comparable over time. The following analyses calculate the average trend using all the available information. Results are presented as the annualised change - the average yearly change in performance observed throughout a country's or economy's participation in PISA. (For further details on the estimation of the annualised change, see Annex A5). ${ }^{2}$

Of the 64 countries and economies with comparable data in reading performance, 32 show a positive annualised trend in mean reading performance across all PISA assessments, 22 show no change, and the remaining 10 countries and economies show a deteriorating annualised trend in average student performance.

Among OECD countries, average yearly improvements (i.e. positive annualised change) in reading performance across successive PISA assessments are observed in Chile, Estonia, Germany, Hungary, Israel, Japan, Korea, Luxembourg, Mexico, Poland, Portugal, Switzerland and Turkey. Figure I.4.3 shows that Montenegro, Peru, Qatar, Serbia and Singapore saw an average yearly improvement of more than five score points in reading throughout their participation in subsequent PISA assessments. Albania, Chinese Taipei, Turkey and Shanghai-China saw an average yearly improvement of more than four score points, and Chile, Israel and Tunisia saw an average yearly improvement of more than three score points. These are significant improvements. Most of these countries and economies, except Shanghai-China and Singapore, have participated in at least three PISA assessments.

Six other countries and economies show a yearly improvement of at least two score points in reading; 11 countries and economies saw a yearly improvement of at least one score point; and three countries and economies saw an annual improvement in performance, albeit of less than one score point.

In 2000, the average 15-year-old in Peru scored 327 points on the PISA reading assessment, 370 score points in 2009 and 384 points in 2012. Improvements over time were also consistent in Turkey, where the average reading performance 
improved relatively steadily from 441 points to 475 points between 2003 and 2012. Poland also saw consistent progress across the five PISA assessments, moving from a below-OECD-average score of 479 score points in reading in 2000 to an above-OECD-average score of 518 points in 2012. Korea's improvement in PISA and recent education policies and programmes are outlined in Box I.4.1.

- Figure I.4.3 =

\section{Annualised change in reading performance throughout participation in PISA}

Reading score-point difference associated with one calendar year

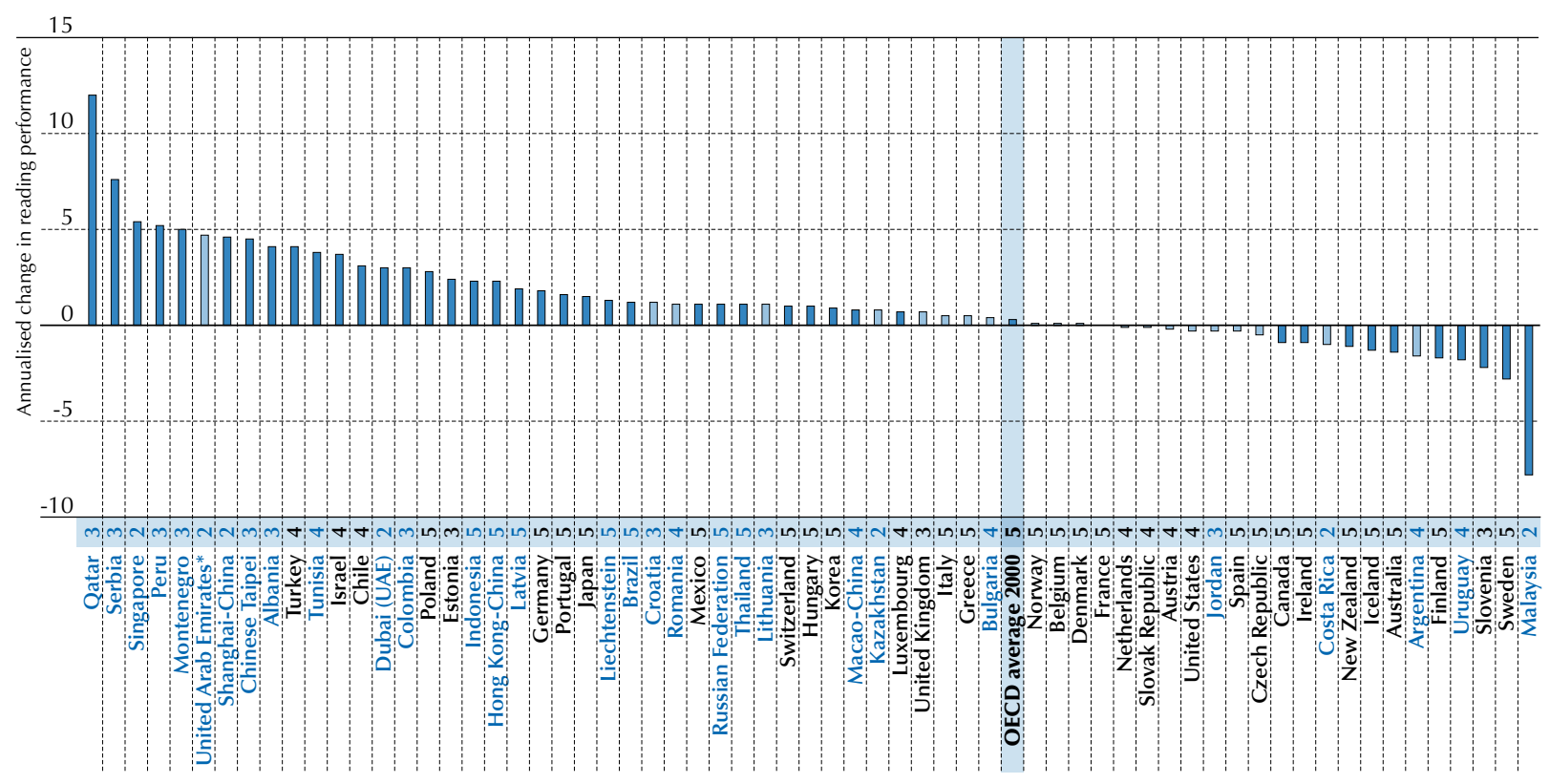

* United Arab Emirates excluding Dubai.

Notes: Statistically significant score point changes are marked in a darker tone (see Annex A3).

The number of comparable reading scores used to calculate the annualised change is shown next to the country/economy name.

The annualised change is the average annual change in PISA score points from a country's/economy's earliest participation in PISA to PISA 2012. It is calculated taking into account all of a country's/economy's participation in PISA. For more details on the calculation of the annualised change, see Annex A5. OECD average 2000 compares only OECD countries with comparable reading scores since 2000.

Countries and economies are ranked in descending order of the annualised change in reading performance.

Source: OECD, PISA 2012 Database, Table I.4.3b.

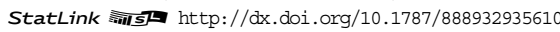

The average change experienced over successive PISA assessments doesn't capture the extent to which this change is steady, or whether it is decelerating or accelerating. Of the 32 countries and economies that show a statistically an annualised improvement in reading performance, 29 participated in at least two PISA assessments in addition to PISA 2012, so it is possible to determine whether their improvement is steady, accelerating or decelerating. The average reading performance in Chinese Taipei, Israel, Japan, Luxembourg, Macao-China, the Russian Federation and Thailand shows an improvement, the rate of which is higher in the later PISA assessments than in the earlier assessments. Improvements in reading have remained relatively steady in Albania, Brazil, Estonia, Germany, Hong Kong-China, Hungary, Indonesia, Mexico, Montenegro, Peru, Portugal, Poland, Switzerland, Tunisia and Turkey, and was slower in the later PISA assessments than the earlier assessments in Chile, Colombia, Korea, Latvia, Liechtenstein, Qatar and Serbia (Figure 1.4.4).

Other countries and economies show no annualised improvement, but this is because of a deterioration between their first two PISA assessments followed by improvements in later assessments. This was observed in Argentina, Bulgaria, France, Italy, Norway, Romania and Spain. Spain, for example, saw a decline in performance between PISA 2000 and PISA 2003 which continued through PISA 2006. But this initially negative trend reversed itself between 2006 and 2009 to the extent that Spain's performance in PISA 2012 was similar to that recorded in PISA 2000. 
- Figure I.4.4

Curvilinear trajectories of average reading performance across PISA assessments

Rate of acceleration or deceleration in performance (quadratic term)

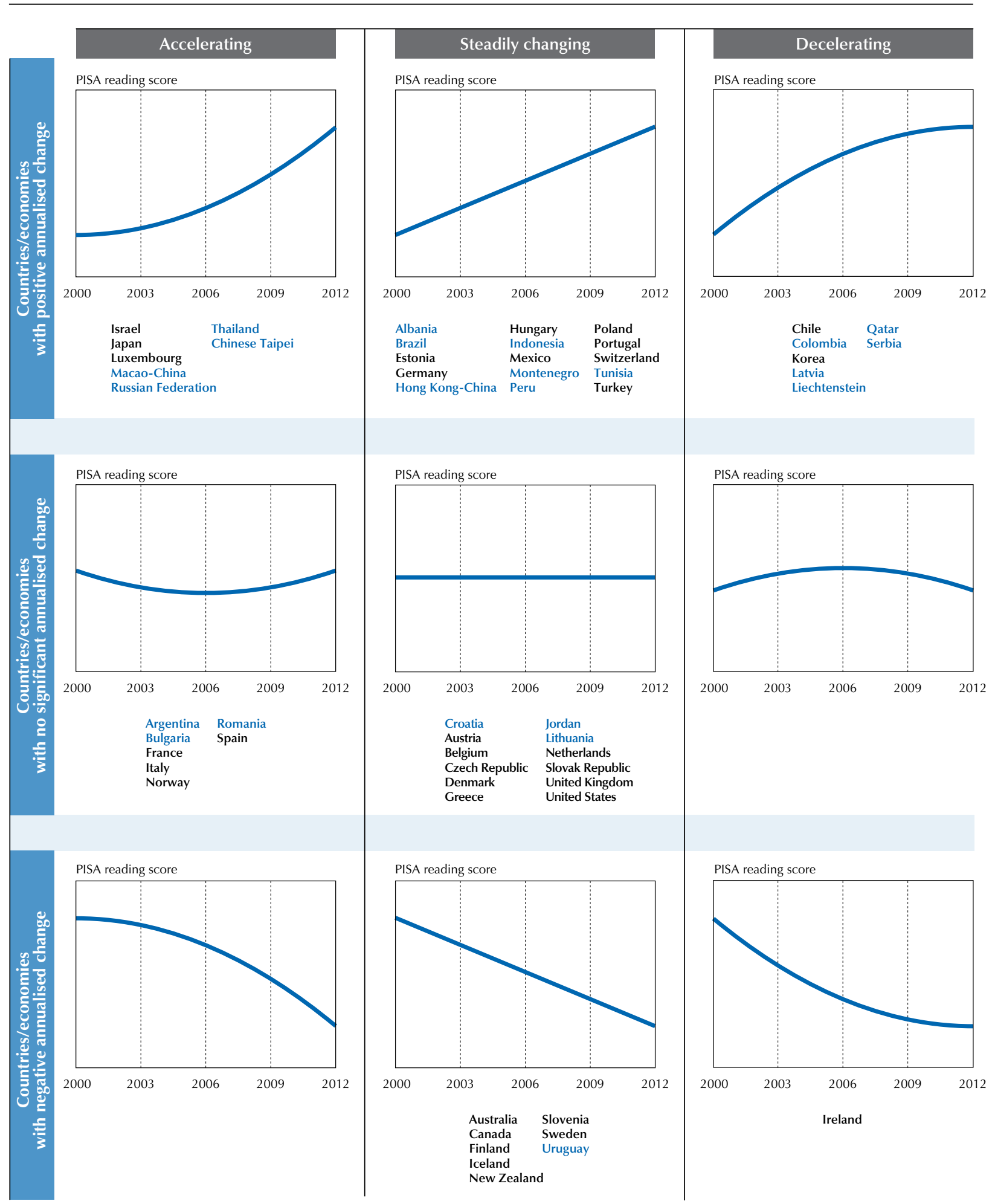

Notes: Figures are for illustrative purposes only. Countries and economies are grouped according to the direction and significance of their annualised change and their rate of acceleration.

Countries and economies with data from only one PISA assessments other than 2012 are excluded.

Source: OECD, PISA 2012 Database, Table I.4.3b.

StatLink त्नाज्ञ http://dx.doi.org/10.1787/888932935610 
- Figure I.4.5 [Part 1/2]

Multiple comparisons of reading performance between 2000 and 2012

\begin{tabular}{|c|c|c|c|c|c|}
\hline & $\begin{array}{l}\text { Reading } \\
\text { performance } \\
\text { in } 2000\end{array}$ & $\begin{array}{c}\text { Reading } \\
\text { performance } \\
\text { in } 2012\end{array}$ & $\begin{array}{c}\text { Countries/economies with similar } \\
\text { performance in } 2000 \\
\text { but lower performance in } 2012\end{array}$ & $\begin{array}{c}\text { Countries/economies with similar } \\
\text { performance in } 2000 \\
\text { and similar performance in } 2012\end{array}$ & $\begin{array}{c}\text { Countries/economies with similar } \\
\text { performance in } 2000 \\
\text { but higher performance in } 2012\end{array}$ \\
\hline Hong Kong-China & 525 & 545 & New Zealand, Sweden, Australia, Ireland & Japan, Korea & \\
\hline Japan & 522 & 538 & $\begin{array}{l}\text { United States, New Zealand, Sweden, } \\
\text { Australia, Canada, Ireland, Belgium }\end{array}$ & Hong Kong-China, Korea & \\
\hline Korea & 525 & 536 & New Zealand, Sweden, Australia & Hong Kong-China, Japan, Ireland & \\
\hline Finland & 546 & 524 & & & \\
\hline Ireland & 527 & 523 & New Zealand, Sweden, Australia & Canada, Korea & Hong Kong-China, Japan \\
\hline Canada & 534 & 523 & New Zealand, Australia & Ireland & Japan \\
\hline Poland & 479 & 518 & $\begin{array}{l}\text { Greece, Austria, Czech Republic, } \\
\text { Hungary, Spain, Portugal, Italy }\end{array}$ & Germany, Switzerland, Liechtenstein & \\
\hline Liechtenstein & 483 & 516 & $\begin{array}{l}\text { United States, Greece, Austria, } \\
\text { Czech Republic, Hungary, Spain, } \\
\text { Portugal, Italy }\end{array}$ & Poland, Germany, Switzerland & \\
\hline New Zealand & 529 & 512 & & Australia & $\begin{array}{l}\text { Hong Kong-China, Japan, Canada, } \\
\text { Ireland, Korea }\end{array}$ \\
\hline Australia & 528 & 512 & & New Zealand & $\begin{array}{l}\text { Hong Kong-China, Japan, Canada, } \\
\text { Ireland, Korea }\end{array}$ \\
\hline Belgium & 507 & 509 & Sweden, Denmark, Iceland & United States, France, Switzerland, Norway & Japan \\
\hline Switzerland & 494 & 509 & $\begin{array}{l}\text { Austria, Czech Republic, Hungary, Spain, } \\
\text { Denmark, Italy }\end{array}$ & $\begin{array}{l}\text { United States, Poland, Germany, France, } \\
\text { Belgium, Norway, Liechtenstein }\end{array}$ & \\
\hline Germany & 484 & 508 & $\begin{array}{l}\text { Greece, Austria, Czech Republic, } \\
\text { Hungary, Spain, Italy }\end{array}$ & Poland, Switzerland, Liechtenstein & \\
\hline France & 505 & 505 & Iceland & $\begin{array}{l}\text { United States, Belgium, Denmark, } \\
\text { Switzerland, Norway }\end{array}$ & \\
\hline Norway & 505 & 504 & Iceland & $\begin{array}{l}\text { United States, France, Belgium, } \\
\text { Denmark, Switzerland }\end{array}$ & \\
\hline United States & 504 & 498 & Sweden, Iceland & $\begin{array}{l}\text { Austria, Czech Republic, France, } \\
\text { Belgium, Spain, Denmark, Switzerland, } \\
\text { Norway, Italy }\end{array}$ & Japan, Liechtenstein \\
\hline Denmark & 497 & 496 & & $\begin{array}{l}\text { United States, Austria, Czech Republic, } \\
\text { France, Spain, Norway, Italy }\end{array}$ & Belgium, Switzerland \\
\hline Czech Republic & 492 & 493 & & $\begin{array}{l}\text { United States, Austria, Hungary, Spain, } \\
\text { Denmark, Italy }\end{array}$ & $\begin{array}{l}\text { Poland, Germany, Switzerland, } \\
\text { Liechtenstein }\end{array}$ \\
\hline Italy & 487 & 490 & Greece & $\begin{array}{l}\text { United States, Austria, Czech Republic, } \\
\text { Hungary, Spain, Denmark }\end{array}$ & $\begin{array}{l}\text { Poland, Germany, Switzerland, } \\
\text { Liechtenstein }\end{array}$ \\
\hline Austria & 492 & 490 & & $\begin{array}{l}\text { United States, Czech Republic, Hungary, } \\
\text { Spain, Denmark, Italy }\end{array}$ & $\begin{array}{l}\text { Poland, Germany, Switzerland, } \\
\text { Liechtenstein }\end{array}$ \\
\hline Latvia & 458 & 489 & Greece, Russian Federation & Israel, Portugal & \\
\hline Hungary & 480 & 488 & & $\begin{array}{l}\text { Greece, Austria, Czech Republic, Spain, } \\
\text { Portugal, Italy }\end{array}$ & $\begin{array}{l}\text { Poland, Germany, Switzerland, } \\
\text { Liechtenstein }\end{array}$ \\
\hline Spain & 493 & 488 & & $\begin{array}{l}\text { United States, Austria, Czech Republic, } \\
\text { Hungary, Denmark, Italy }\end{array}$ & $\begin{array}{l}\text { Poland, Germany, Switzerland, } \\
\text { Liechtenstein }\end{array}$ \\
\hline Portugal & 470 & 488 & & $\begin{array}{l}\text { Greece, Latvia, Hungary, Israel, } \\
\text { Russian Federation }\end{array}$ & Poland, Liechtenstein \\
\hline Israel & 452 & 486 & Thailand, Bulgaria, Argentina & $\begin{array}{l}\text { Greece, Latvia, Portugal, } \\
\text { Russian Federation }\end{array}$ & \\
\hline Sweden & 516 & 483 & & & $\begin{array}{l}\text { United States, Hong Kong-China, Japan, } \\
\text { Ireland, Belgium, Korea }\end{array}$ \\
\hline Iceland & 507 & 483 & & & United States, France, Belgium, Norway \\
\hline Greece & 474 & 477 & & $\begin{array}{l}\text { Hungary, Israel, Portugal, } \\
\text { Russian Federation }\end{array}$ & $\begin{array}{l}\text { Poland, Latvia, Germany, Liechtenstein, } \\
\text { Italy }\end{array}$ \\
\hline Russian Federation & 462 & 475 & & Greece, Israel, Portugal & Latvia \\
\hline Chile & 410 & 441 & Argentina, Mexico & & \\
\hline Thailand & 431 & 441 & Argentina, Mexico & Bulgaria, Romania & Israel \\
\hline Romania & 428 & 438 & Argentina, Mexico & Thailand, Bulgaria & \\
\hline Bulgaria & 430 & 436 & Argentina & Thailand, Mexico, Romania & Israel \\
\hline Mexico & 422 & 424 & Argentina & Bulgaria & Thailand, Chile, Romania \\
\hline Brazil & 396 & 410 & Argentina & & \\
\hline Indonesia & 371 & 396 & & & \\
\hline Argentina & 418 & 396 & & & $\begin{array}{l}\text { Brazil, Thailand, Israel, Bulgaria, Chile, } \\
\text { Mexico, Romania }\end{array}$ \\
\hline Albania & 349 & 394 & & & \\
\hline Peru & 327 & 384 & & & \\
\hline
\end{tabular}

Note: Only countries and economies that participated in the PISA 2000 and PISA 2012 assessments are shown.

Countries and economies are ranked in descending order of their mean reading performance in PISA 2012.

Source: OECD, PISA 2012 Database, Table 1.4.3b.

StatLink त्तारा http://dx.doi.org/10.1787/888932935610 
- Figure I.4.5 [Part 2/2]

Multiple comparisons of reading performance between 2000 and 2012

\begin{tabular}{|c|c|c|c|c|c|c|}
\hline $\begin{array}{l}\text { Countries/economies with } \\
\text { lower performance in } 2000 \\
\text { but similar performance } \\
\text { in } 2012\end{array}$ & $\begin{array}{c}\text { Countries/economies with } \\
\text { lower performance in } 2000 \\
\text { but higher performance in } \\
2012\end{array}$ & $\begin{array}{c}\text { Countries/economies with } \\
\text { higher performance in } 2000 \\
\text { but with similar performance } \\
\text { in } 2012\end{array}$ & $\begin{array}{c}\text { Countries/economies with } \\
\text { higher performance in } 2000 \\
\text { but lower performance in } \\
2012\end{array}$ & $\begin{array}{c}\text { Reading } \\
\text { performance } \\
\text { in } 2012\end{array}$ & $\begin{array}{c}\text { Reading } \\
\text { performance } \\
\text { in } 2000\end{array}$ & \\
\hline & & & Finland, Canada & 545 & 525 & Hong Kong-China \\
\hline & & & Finland & 538 & 522 & Japan \\
\hline & & Finland & Canada & 536 & 525 & Korea \\
\hline $\begin{array}{l}\text { Poland, Canada, Ireland, } \\
\text { Liechtenstein, Korea }\end{array}$ & Hong Kong-China, Japan & & & 524 & 546 & Finland \\
\hline Poland, Liechtenstein & & Finland & & 523 & 527 & Ireland \\
\hline \multirow[t]{3}{*}{ Poland, Liechtenstein } & Hong Kong-China, Korea & Finland & & 523 & 534 & Canada \\
\hline & & \begin{tabular}{|l|} 
New Zealand, Finland, \\
Australia, Canada, Ireland, \\
Belgium \\
\end{tabular} & $\begin{array}{l}\text { United States, France, } \\
\text { Sweden, Denmark, Iceland, } \\
\text { Norway }\end{array}$ & 518 & 479 & Poland \\
\hline & & $\begin{array}{l}\text { New Zealand, Finland, } \\
\text { France, Australia, Canada, } \\
\text { Ireland, Belgium, Norway }\end{array}$ & Sweden, Denmark, Iceland & 516 & 483 & Liechtenstein \\
\hline $\begin{array}{l}\text { Poland, Germany, France, } \\
\text { Belgium, Switzerland, } \\
\text { Norway, Liechtenstein }\end{array}$ & & & & 512 & 529 & New Zealand \\
\hline $\begin{array}{l}\text { Poland, Germany, France, } \\
\text { Belgium, Switzerland, } \\
\text { Norway, Liechtenstein }\end{array}$ & & & & 512 & 528 & Australia \\
\hline \multirow[t]{3}{*}{ Poland, Germany, Liechtenstein } & & New Zealand, Australia & & 509 & 507 & Belgium \\
\hline & & New Zealand, Australia & Sweden, Iceland & 509 & 494 & Switzerland \\
\hline & & $\begin{array}{l}\text { United States, New Zealand, } \\
\text { France, Australia, Belgium, } \\
\text { Norway }\end{array}$ & Sweden, Denmark, Iceland & 508 & 484 & Germany \\
\hline Germany, Liechtenstein & Poland & New Zealand, Australia & Sweden & 505 & 505 & France \\
\hline $\begin{array}{l}\text { Germany, Czech Republic, } \\
\text { Liechtenstein }\end{array}$ & Poland & New Zealand, Australia & Sweden & 504 & 505 & Norway \\
\hline $\begin{array}{l}\text { Latvia, Germany, Hungary, } \\
\text { Israel, Portugal }\end{array}$ & Poland & & & 498 & 504 & United States \\
\hline $\begin{array}{l}\text { Latvia, Hungary, Israel, } \\
\text { Portugal }\end{array}$ & $\begin{array}{l}\text { Poland, Germany, } \\
\text { Liechtenstein }\end{array}$ & & Sweden, Iceland & 496 & 497 & Denmark \\
\hline Latvia, Israel, Portugal & & Sweden, Norway & Iceland & 493 & 492 & Czech Republic \\
\hline Latvia, Israel, Portugal & & Sweden, Iceland & & 490 & 487 & Italy \\
\hline \multirow[t]{2}{*}{ Latvia, Israel, Portugal } & & Sweden, Iceland & & 490 & 492 & Austria \\
\hline & & $\begin{array}{l}\text { United States, Austria, } \\
\text { Czech Republic, Sweden, } \\
\text { Hungary, Spain, Denmark, } \\
\text { Iceland, Italy } \\
\end{array}$ & & 489 & 458 & Latvia \\
\hline Latvia, Israel & & $\begin{array}{l}\text { United States, Sweden, } \\
\text { Denmark, Iceland }\end{array}$ & & 488 & 480 & Hungary \\
\hline \multirow[t]{3}{*}{ Latvia, Israel, Portugal } & & Sweden, Iceland & & 488 & 493 & Spain \\
\hline & & $\begin{array}{l}\text { United States, Austria, } \\
\text { Czech Republic, Sweden, } \\
\text { Spain, Denmark, Iceland, Italy }\end{array}$ & & 488 & 470 & Portugal \\
\hline & & $\begin{array}{l}\text { United States, Austria, } \\
\text { Czech Republic, Sweden, } \\
\text { Hungary, Spain, Denmark, } \\
\text { Iceland, Italy } \\
\end{array}$ & & 486 & 452 & Israel \\
\hline $\begin{array}{l}\text { Greece, Latvia, Austria, } \\
\text { Czech Republic, Hungary, } \\
\text { Israel, Spain, Iceland, Portugal, } \\
\text { Russian Federation, Italy } \\
\end{array}$ & $\begin{array}{l}\text { Poland, Germany, France, } \\
\text { Denmark, Switzerland, } \\
\text { Norway, Liechtenstein }\end{array}$ & & & 483 & 516 & Sweden \\
\hline \multirow{4}{*}{$\begin{array}{l}\text { Greece, Latvia, Austria, } \\
\text { Hungary, Israel, Spain, } \\
\text { Portugal, Russian Federation, } \\
\text { Italy }\end{array}$} & $\begin{array}{l}\text { Poland, Germany, } \\
\text { Czech Republic, Denmark, } \\
\text { Switzerland, Liechtenstein }\end{array}$ & Sweden & & 483 & 507 & Iceland \\
\hline & & Sweden, Iceland & & 477 & 474 & Greece \\
\hline & & Sweden, Iceland & & 475 & 462 & Russian Federation \\
\hline & & Thailand, Bulgaria, Romania & & 441 & 410 & Chile \\
\hline Chile & & & & 441 & 431 & Thailand \\
\hline Chile & & & & 438 & 428 & Romania \\
\hline \multirow[t]{3}{*}{ Chile } & & & & 436 & 430 & Bulgaria \\
\hline & & & & 424 & 422 & Mexico \\
\hline & & & & 410 & 396 & Brazil \\
\hline Albania, Peru & & Argentina & & 396 & 371 & Indonesia \\
\hline Albania, Indonesia, Peru & & & & 396 & 418 & Argentina \\
\hline \multirow[t]{2}{*}{ Peru } & & Argentina, Indonesia & & 394 & 349 & Albania \\
\hline & & Albania, Argentina, Indonesia & & 384 & 327 & Peru \\
\hline
\end{tabular}

Note: Only countries and economies that participated in the PISA 2000 and PISA 2012 assessments are shown.

Countries and economies are ranked in descending order of their mean reading performance in PISA 2012.

Source: OECD, PISA 2012 Database, Table I.4.3b

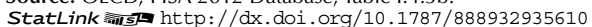


At any point in time, countries and economies share similar levels of performance with other countries and economies. But since the pace of change varies over time and across school systems, the relative standing of countries and economies evolves. Figure I.4.5 shows, for each country and economy with comparable results in 2000 and PISA 2012, those other countries and economies that had similar reading performance in 2000 but whose performance improved or deteriorated in 2012. In 2000, for example, Germany was similar in reading performance to Austria, the Czech Republic, Greece, Hungary, Italy, Liechtenstein, Poland, Spain and Switzerland; but after improvements in performance, it scored higher than Austria, the Czech Republic, Greece, Hungary, Italy and Spain in 2012. In 2000, Germany's score in PISA was lower than those of Australia and New Zealand; but by 2012, the country had reached the same performance level as these two countries. Along the same lines, Chile had similar levels of performance as Argentina and Mexico in 2000. By 2012, Chile showed better performance than these two and attained the same level of performance as Bulgaria, Romania and Thailand- all of which had higher average reading scores than Chile in PISA 2000.

Figure I.4.6 shows the relationship between each country's and economy's average reading performance in PISA 2000 and their annualised change between 2000 and $2012 .{ }^{3}$ Countries and economies that show the strongest improvement in this period are more likely to have had comparatively low performance in PISA 2000 or their earliest comparable PISA score.

- Figure I.4.6

\section{Relationship between annualised change in performance and average PISA 2000 reading scores}

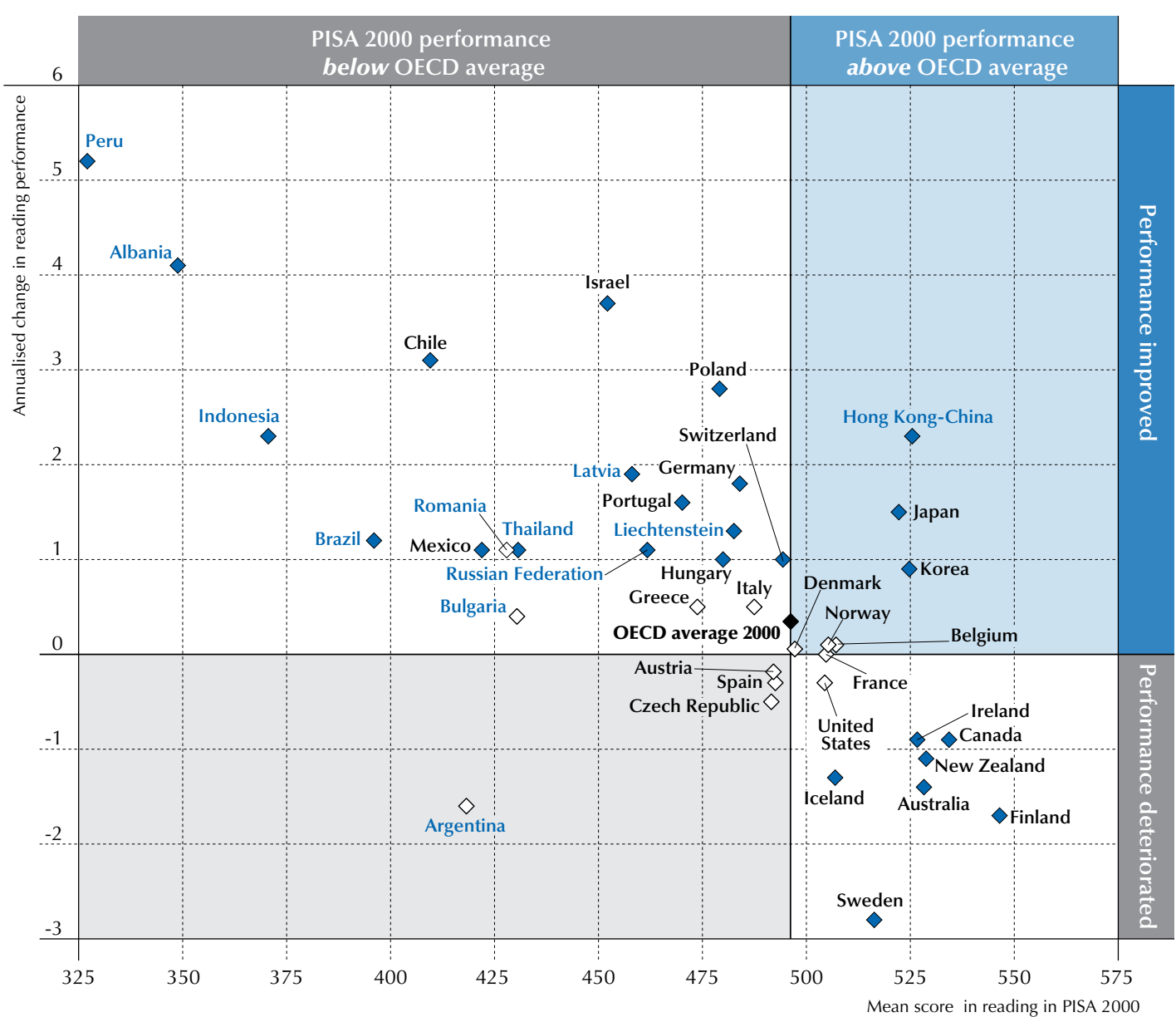

Notes: Annualised score point change in reading that are statistically significant are indicated in a darker tone (see Annex A3).

The annualised change is the average annual change in PISA score points from a country's/economy's earliest participation in PISA to PISA 2012. It is calculated taking into account all of a country's/economy's participation in PISA. For more details on the calculation of the annualised change, see Annex A5. OECD average 2000 considers only those countries with comparable reading scores since PISA 2000.

The correlation between a country's/economy's mean score in 2000 and its annualised performance is - 0.67 .

Source: OECD, PISA 2012 Database, Table I.4.3b.

StatLink 部实 http://dx.doi.org/10.1787/888932935610 
In fact, the correlation between a country's/economy's PISA 2000 reading score and their annualised change in reading is -0.67 . Among other things, this means that $45 \%$ of the variation in the annualised change since 2000 can be explained by a country's/economy's PISA 2000 reading score. Of the 20 countries and economies that showed an annualised improvement in reading performance and participated in PISA in the 2000 assessment, eleven had an average reading performance of 470 points in PISA 2000, well below the OECD average.

It is by no means the case that all low-performing countries improve at a faster pace. Greece, Hungary, Poland and Portugal, for example, had relatively similar levels of performance in PISA 2000 (between 470 and 480 score points in reading), yet by 2012, the degree of improvement, if any, varied among them. Poland improved by 2.8 score points per year, Portugal by 1.6 points and Hungary by 1.0 per year, while no improvement was observed in Greece. Similarly, while Mexico, Argentina and Chile had similar levels of performance in PISA 2000 (between 410 and 422 score points), by 2012 improvements were observed in Chile and Mexico, but no improvement was observed in Argentina.

Indeed, even some of those countries and economies that scored at or above the OECD average in the earlier assessments of PISA showed annualised improvements across their participation in PISA. These include Chinese Taipei, Estonia, Hong Kong-China, Japan, Korea, Macao-China, Shanghai-China, Singapore and Switzerland (Figure I.4.6 and Table I.4.3b).

\section{Trends in reading performance adjusted for sampling and demographic changes}

Improvements in a country's or economy's overall reading performance may be the result of specific education policies; they may also be due to demographic or socio-economic changes that shift the country's/economy's population profile. For example, because of trends in migration, the characteristics of the PISA reference population - 15-year-olds enrolled in school - may have shifted; or, as a result of development, the socio-economic status of students who were assessed in PISA 2012 is higher than that of students assessed in 2000.

Adjusted trends shed light on changes in reading performance that are not due to alterations in the demographic characteristics of the student population or the sample. Figure I.4.7 presents the adjusted annualised changes in reading performance. These adjusted trends assume that the socio-economic status of students and their age, as well as the proportion of girls, students with an immigrant background and students speaking a language at home different from the language of instruction remain intact across PISA cycles, using the PISA 2012 sample as the reference. In short, it assumes that the population and sample characteristics observed in 2012 along these student-level attributes did not change between 2000 and 2012. ${ }^{4}$ If countries and economies see a difference between the adjusted trends and the observed trends, particularly when the observed trend tends lower (or negative) in relation to the adjusted trend (non-negative), that means that changes in the student population are having adverse effects on performance. It is the observed, not the adjusted, trends that measure the quality of education in a school system. Annex A5 provides details on how adjusted trends are calculated.

After accounting for these differences in population and samples, 21 countries and economies experience an average yearly improvement in reading performance. Colombia, Croatia, Dubai (United Arab Emirates), Indonesia, Jordan, Mexico, New Zealand, Costa Rica, the Slovak Republic and Sweden have similar adjusted and un-adjusted trends, meaning that either the PISA samples or the reference population have not changed much during their participation in PISA; that even if the students' characteristics have changed, these have not affected their performance in school; or that improved education services have offset any negative effect on average reading performance related to changes in the population.

After accounting for changes in students' background characteristics, the observed improvements in Japan, Luxembourg, Malaysia, Romania and Turkey are greater. In these countries, improvements in reading performance were unrelated to changes in the student population; had students in the previous assessment shared the same characteristics as students who took the PISA 2012 test, the observed improvements would have been even greater. In Brazil, Estonia, Germany, Hungary, Liechtenstein, Macao-China, Portugal, the Russian Federation, Switzerland and Thailand the overall observed improvement loses statistical significance. In Korea, the observed improvement in reading performance becomes negative after accounting for students' background characteristics. In these countries and economies, a large part of the observed improvement can be attributed to the changes in the student population. Observed improvements in the remaining countries and economies remain, indicating that they are not fully explained by changes in the background characteristics of students. In these cases, changes in other student characteristics, such as students' attitudes towards learning, or the resources, policies and practices implemented in the school system may account for the improvements. Observed improvements remain, but are smaller in magnitude in Chile, Hong Kong-China, Israel, Latvia, Mexico, Montenegro and Poland. In these countries and economies, at least a third of the improvement is the result of a change in the student population - or the sample - towards students whose background characteristics are typically associated with better reading outcomes. 
Informative as they may be, adjusted trends are merely hypothetical scenarios that help to determine the source of changes in students' performance over time. Observed trends depicted in Figure I.4.7 and throughout this chapter summarise the overall evolution of a school system, highlighting the challenges that countries and economies face in improving students' and schools' performance in reading.

- Figure I.4.7

Adjusted and observed annualised performance change in average PISA reading scores

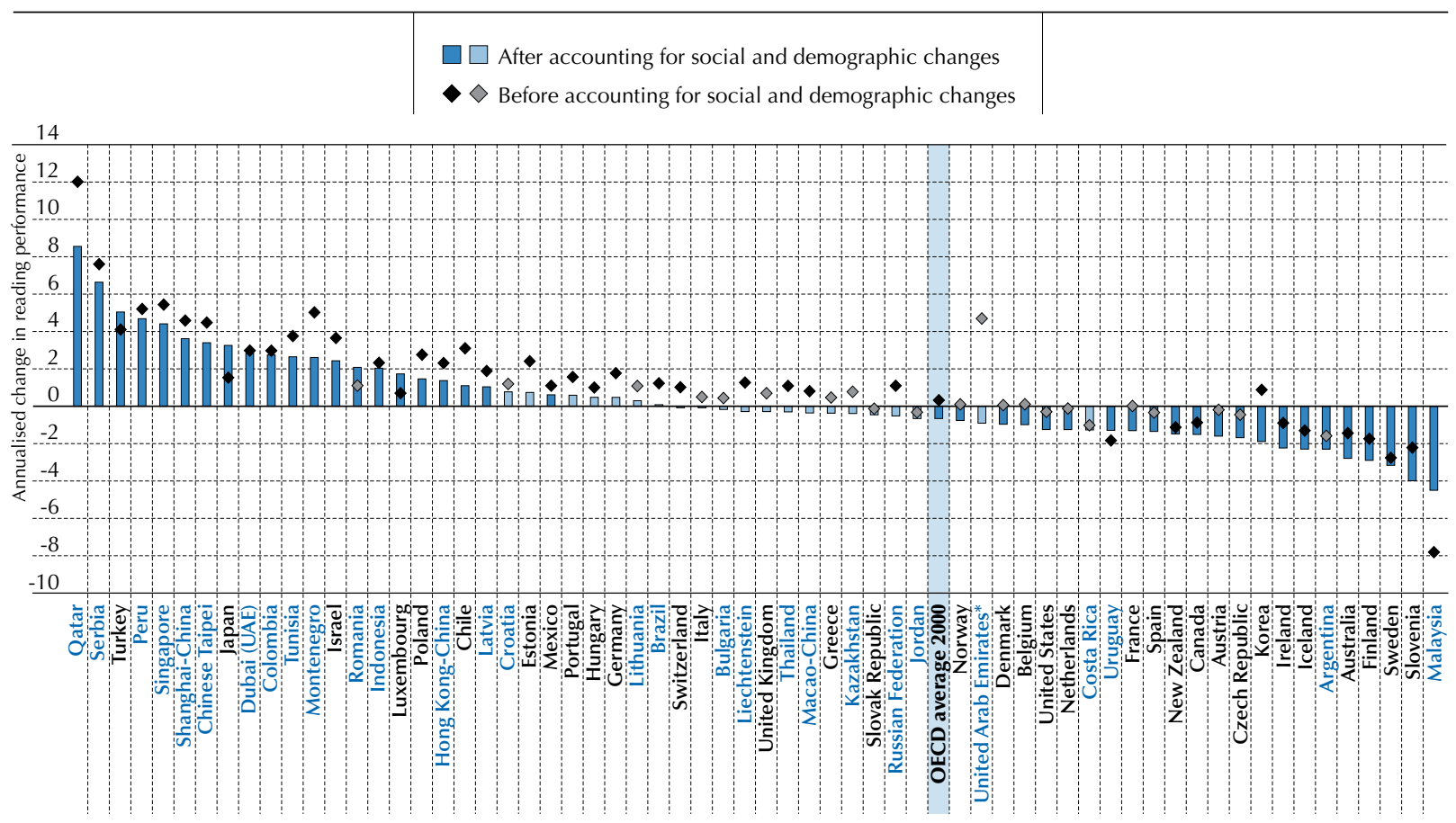

* United Arab Emirates excluding Dubai.

Notes: Statistically significant values are marked in a darker tone (see Annex A3).

The annualised change is the average annual change in PISA score points. It is calculated taking into account all of a country's/economy's participation in PISA. For more details on the calculation of the annualised change, see Annex A5.

The annualised change adjusted for demographic changes assumes that the average age and PISA index of social, cultural and economic status, as well as the percentage of female students, those with an immigrant background and those who speak a language other than the assessment at home is the same in previous assessments as those observed in 2012. For more details on the calculation of the adjusted annualised change, see Annex A5.

OECD average 2000 considers only those countries with comparable reading scores since PISA 2000.

Countries and economies are ranked in descending order of the annualised change after accounting for demographic changes.

Source: OECD, PISA 2012 Database, Tables I.4.3b and I.4.4.

StatLink 部

\section{Box I.4.1. Improving in PISA: Korea}

Korea has consistently performed at the top level in PISA, and has still improved over time. In PISA 2000, Korea performed on a par with New Zealand, Sweden, Australia, Hong Kong-China, Japan and Ireland; by 2012 Korea outperformed the first three. Performance in reading, for example, has improved by an average of almost one score point per year since 2000. As a result, Korea's average score in reading increased from 525 points in 2003 to 536 points in 2012. This improvement was concentrated at the top of the performance distribution: the percentage of students scoring at or above proficiency Level 5 in mathematics increased by more than eight percentage points since 2000 to $14 \%$ in 2012 . While the mathematics scores among the top $10 \%$ of students have improved by more than 30 points during the period, no change was observed among low-achieving students. Korea's performance in science also improved consistently throughout its participation in PISA: science performance increased by an average of 2.6 points per year since 2006 so that average scores in science rose from 522 points in PISA 2006 to 538 points in PISA 2012. 
Korea's improvements in reading were concentrated among high-achieving students. the average improvement of high-achieving students outpaced that of lower-achieving students. Higher standards in language literacy were put in place in the mid-2000s, and language literacy was given more weight in the competitive College Scholastic Ability Test (CSAT), the university entrance examination. This could explain the increase in the share of topperforming students in Korea, as high-achieving students have more incentives to invest in language and reading literacy. Also, and particularly since 2010, programmes for gifted students have been expanded at the primary and secondary levels, and the secondary curriculum has been strengthened to meet the needs of these students (MEST, 2010).

Education policies have been linked to macroeconomic development first through centralised planning (1962-91) then by co-ordinated and strategically oriented approaches through the National Human Resource Development Plans (one for 2001-05 and another for 2006-10, for example). They have followed a sequential approach. Prior to $1975,65 \%$ of the education budget was spent on primary education; in the following decades, secondary education received a greater share of funding and by the late 1990s, public investment in tertiary education was expanded. In the mid-1990s, a comprehensive school reform was launched, introducing school deregulation, choice, a new curriculum and increased public expenditure. Individual schools began to assume more management responsibilities. By 2012, schools had greater autonomy, and programmes were specifically designed to assist school leaders in assuming their new roles (World Bank, 2010).

The National Assessment of Educational Achievement (NAEA) programme was introduced in 1998. NAEA assesses educational achievement and trends among all 6th-, 9th- and 10th-grade students in Korean Language Arts, English, mathematics, social studies and science. Since 2010, the programme changed the grade coverage from 6th-, 9th- and 10th to 6th-, 9th- and 11th. The Subject Learning Diagnostic Test (SLDT) was introduced in 2008 and is implemented by the Nationwide Association of Superintendents of metropolitan/provincial offices of education. The previous Diagnostic Evaluation of Basic Academic Competence (DEBAC), which had tested primary school 3rd grades at the national level since 2002, was delegated to metropolitan/provincial offices of education. The Subject Learning Diagnostic Test measures basic competency in reading, writing and mathematics among 3rd, 4th-, 5th-, 7th- and 8th-grade students. Through these assessment tools, the government and metropolitan/provincial offices can monitor individual student performance levels, establish achievement benchmarks, develop an accountability system for public education, and also identify students who need support. For example, in 2008, the government established the Zero Plan for Below-Basic Students, a national programme to ensure that all students meet basic achievement criteria. The NAEA assessment was converted from a sample-based test to a census-based test to identify and then support low-performing students. Also, MEST introduced a Schools for Improvement (SFI) policy in 2009 to provide support in closing education gaps and improving achievement, also with the aim of reducing the proportion of students who do not achieve basic proficiency. The SFI supports various education programmes, including providing more resources for low-income schools and schools with a high concentration of lowperforming students (Kim et al., 2012).

The national curriculum was revised again in 2009, highlighting reasoning, problem solving and mathematical communication as key competencies in mathematics (MEST, 2011b). In 2012, the government announced a plan for improving mathematics education in keeping with the revised curriculum. The aim is to enhance skills in reasoning and creativity (MEST, 2012). This reform implies a profound change in the way teachers teach mathematics: up until now, teachers have largely taught to the CSAT.

Reforms have also affected the teaching of language and reading. The focus of the Korean Language Arts Curriculum shifted from proficiency in grammar and literature to skills and strategies needed for creative and critical understanding and representation, similar to the approach underlying PISA. Diverse teaching methods and materials that reflected those changes were developed, and investments were made in related digital and Internet infrastructure. Schools were requested to spend a fixed share of their budgets on reading education. Training programmes for reading teachers were developed and disseminated. Parents were encouraged to participate more in school activities and were given information on how to support their children's schoolwork.

In both 2009 and 2012 Korea was among the OECD countries with the largest classes and, since 2003, Korean students have also been more likely to attend schools where the principal reported a teacher shortage. A concerted effort is underway to create more teaching posts. In 2010, more than 53000 new jobs were assigned to the 
education-services sector, including 2000 English conversation lecturers, 7000 intern teachers, who support instruction, 7000 after-school lecturers and co-ordinators, 5500 full-day kindergarten staff, and 5000 special education assistants. The teacher-training system has been expanded to enable outside experts to acquire teaching certificates (MEST, 2010; 2011a).

The school- and teacher-evaluation systems have also been reformed. Since 2010, the teacher-evaluation system, which was developed to improve teachers' professional capacities, was expanded to all schools. Results from the evaluation lead to customised training programmes for teachers, depending on their results. Given the greater autonomy granted to school principals, evaluation information will be made public and regional offices of education will oversee monitoring, focusing more on output-oriented criteria. Schools will use internal assessments to measure the improvement of students who do not meet the national assessment benchmarks. School-based performance-award systems were introduced in 2011 (MEST, 2011).

Fifteen-year-old students in Korea spent an average of 30 minutes less in mathematics classes in 2012 than their counterparts in 2003 did, yet a large number of Korean students participate in after-school lessons. While private lessons are common among those who can afford them, after-school group classes are often subsidised, so even disadvantaged students frequently enrol. For example, in June 2011, 99.9\% of all primary and secondary schools were operating after-school programmes and about $65 \%$ of all primary and secondary students participated in afterschool activities (MEST, 2011c). Many observers suspect that the high participation rates in after-school classes may be due to cultural factors and an intense focus on preparing for university entrance examinations. PISA 2006 data show that Korean students attending schools with socio-economically advantaged students are more likely to attend after-school lessons with private teachers than students in other countries; and disadvantaged students in Korea are more likely to attend after-school group lessons than disadvantaged students in other countries. In both cases, attendance in these lessons, along with other factors, is associated with better performance on PISA (OECD, 2010).

\section{Sources:}

Kim K., H. Kim, W. Roh, K. Sang, J. Shin, H. Jung, S. Woo, J.S. Ryoo, J. Han, S. Lauver, C. McClure, M. Cairns, A. Kanter, B. Fu, D. Yi (2012), Korea-US bilateral study on turnaround schools (CRE 2012-12-2). KICE, Seoul.

Ministry of Education, Science and Technology (2012), Plans for advancing mathematics education (in Korean), MEST, Seoul.

Ministry of Education, Science and Technology (2011a), Major Policies and Plans for 2011, MEST, Seoul.

Ministry of Education, Science and Technology (2011b), Mathematical curriculum (in Korean), MEST, Seoul.

Ministry of Education, Science and Technology (2011c), 2011 Analysis for after school programme (in Korean), MEST, Seoul.

Ministry of Education, Science and Technology (2010), Major Policies and Plans for 2010, MEST, Seoul.

OECD (2011), Quality Time for Students: Learning in and out of school, PISA, OECD Publishing.

http://dx.doi.org/10.1787/9789264087057-en

World Bank (2010), Quality of Education in Colombia, Achievements and Challenges Ahead: Analysis of the Results of TIMSS 1995-2007, World Bank, Washington, D.C.

\section{Students at the different levels of proficiency in reading}

The seven proficiency levels used in the PISA 2012 reading assessment are the same as those established for the 2009 PISA assessment, when reading was the major area of assessment: Level $1 \mathrm{~b}$ is the lowest described level, then Level $1 \mathrm{a}$, Level 2, Level 3 and so on up to Level 6. Figure I.4.8 provides details of the nature of the reading skills, knowledge and understanding required at each level of the reading scale. The tasks related to each proficiency level are described according the three processes that students use to answer the questions. These three processes are classified as access and retrieve (skills associated with finding, selecting and collecting information), integrate and interpret (processing what is read to make sense of a text), and reflect and evaluate (drawing on knowledge, ideas or values external to the text).

Figure I.4.9 shows a map of some questions in relation to their position on the reading proficiency scale. The first column shows the proficiency level within which the task is located. The second column indicates the lowest score on the task that would still be described as achieving the given proficiency level. The last column shows the name of the unit, the question number and, within parentheses, the score given for the correct response to these questions. The selected questions have been ordered according to their difficulty, with the most difficult at the top, and the least difficult at the bottom. 
Figure I.4.8

Summary description for the seven levels of proficiency in print reading in PISA 2012

\begin{tabular}{|c|c|c|c|}
\hline Level & $\begin{array}{l}\text { Lower } \\
\text { score } \\
\text { limit }\end{array}$ & $\begin{array}{l}\text { Percentage of students } \\
\text { able to perform tasks } \\
\text { at each level or above } \\
\text { (OECD average) }\end{array}$ & Characteristics of tasks \\
\hline 6 & 698 & $1.1 \%$ & $\begin{array}{l}\text { Tasks at this level typically require the reader to make multiple inferences, } \\
\text { comparisons and contrasts that are both detailed and precise. They require } \\
\text { demonstration of a full and detailed understanding of one or more texts and may } \\
\text { involve integrating information from more than one text. Tasks may require the reader } \\
\text { to deal with unfamiliar ideas, in the presence of prominent competing information, } \\
\text { and to generate abstract categories for interpretations. Reflect and evaluate tasks may } \\
\text { require the reader to hypothesise about or critically evaluate a complex text on an } \\
\text { unfamiliar topic, taking into account multiple criteria or perspectives, and applying } \\
\text { sophisticated understandings from beyond the text. A salient condition for access } \\
\text { and retrieve tasks at this level is precision of analysis and fine attention to detail that } \\
\text { is inconspicuous in the texts. }\end{array}$ \\
\hline 5 & 626 & $8.4 \%$ & $\begin{array}{l}\text { Tasks at this level that involve retrieving information require the reader to locate and } \\
\text { organise several pieces of deeply embedded information, inferring which information } \\
\text { in the text is relevant. Reflective tasks require critical evaluation or hypothesis, } \\
\text { drawing on specialised knowledge. Both interpretative and reflective tasks require a } \\
\text { full and detailed understanding of a text whose content or form is unfamiliar. For all } \\
\text { aspects of reading, tasks at this level typically involve dealing with concepts that are } \\
\text { contrary to expectations. }\end{array}$ \\
\hline 4 & 553 & $29.5 \%$ & $\begin{array}{l}\text { Tasks at this level that involve retrieving information require the reader to locate and } \\
\text { organise several pieces of embedded information. Some tasks at this level require } \\
\text { interpreting the meaning of nuances of language in a section of text by taking into } \\
\text { account the text as a whole. Other interpretative tasks require understanding and } \\
\text { applying categories in an unfamiliar context. Reflective tasks at this level require } \\
\text { readers to use formal or public knowledge to hypothesise about or critically evaluate } \\
\text { a text. Readers must demonstrate an accurate understanding of long or complex texts } \\
\text { whose content or form may be unfamiliar. }\end{array}$ \\
\hline 3 & 480 & $58.6 \%$ & $\begin{array}{l}\text { Tasks at this level require the reader to locate, and in some cases recognise the } \\
\text { relationship between, several pieces of information that must meet multiple } \\
\text { conditions. Interpretative tasks at this level require the reader to integrate several } \\
\text { parts of a text in order to identify a main idea, understand a relationship or construe } \\
\text { the meaning of a word or phrase. They need to take into account many features } \\
\text { in comparing, contrasting or categorising. Often the required information is not } \\
\text { prominent or there is much competing information; or there are other text obstacles, } \\
\text { such as ideas that are contrary to expectation or negatively worded. Reflective tasks } \\
\text { at this level may require connections, comparisons, and explanations, or they may } \\
\text { require the reader to evaluate a feature of the text. Some reflective tasks require } \\
\text { readers to demonstrate a fine understanding of the text in relation to familiar, } \\
\text { everyday knowledge. Other tasks do not require detailed text comprehension but } \\
\text { require the reader to draw on less common knowledge. }\end{array}$ \\
\hline 2 & 407 & $82.0 \%$ & $\begin{array}{l}\text { Some tasks at this level require the reader to locate one or more pieces of information, } \\
\text { which may need to be inferred and may need to meet several conditions. Others } \\
\text { require recognising the main idea in a text, understanding relationships, or construing } \\
\text { meaning within a limited part of the text when the information is not prominent } \\
\text { and the reader must make low level inferences. Tasks at this level may involve } \\
\text { comparisons or contrasts based on a single feature in the text. Typical reflective tasks } \\
\text { at this level require readers to make a comparison or several connections between } \\
\text { the text and outside knowledge, by drawing on personal experience and attitudes. }\end{array}$ \\
\hline $1 \mathbf{a}$ & 335 & $94.3 \%$ & $\begin{array}{l}\text { Tasks at this level require the reader to locate one or more independent pieces of } \\
\text { explicitly stated information; to recognise the main theme or author's purpose in a } \\
\text { text about a familiar topic, or to make a simple connection between information in } \\
\text { the text and common, everyday knowledge. Typically the required information in } \\
\text { the text is prominent and there is little, if any, competing information. The reader is } \\
\text { explicitly directed to consider relevant factors in the task and in the text. }\end{array}$ \\
\hline $\mathbf{1 b}$ & 262 & $98.7 \%$ & $\begin{array}{l}\text { Tasks at this level require the reader to locate a single piece of explicitly stated } \\
\text { information in a prominent position in a short, syntactically simple text with a familiar } \\
\text { context and text type, such as a narrative or a simple list. The text typically provides } \\
\text { support to the reader, such as repetition of information, pictures or familiar symbols. } \\
\text { There is minimal competing information. In tasks requiring interpretation the reader } \\
\text { may need to make simple connections between adjacent pieces of information. }\end{array}$ \\
\hline
\end{tabular}


- Figure I.4.9

Map of selected reading questions, by proficiency level

\begin{tabular}{c|c|l}
\hline Level & $\begin{array}{c}\text { Lower } \\
\text { score } \\
\text { limit }\end{array}$ & UNITS - Questions (position on PISA scale) \\
\hline $\mathbf{6}$ & $\mathbf{6 9 8}$ & THE PLAY'S THE THING - Question 3 (730) \\
\hline $\mathbf{5}$ & $\mathbf{6 2 6}$ & LABOUR - Question 16 (631) \\
\hline $\mathbf{4}$ & $\mathbf{5 5 3}$ & $\begin{array}{l}\text { BALLOON - Question 3.2 (595) } \\
\text { THE PLAY'S THE THING - Question 7 (556) }\end{array}$ \\
\hline $\mathbf{3}$ & $\mathbf{4 8 0}$ & $\begin{array}{l}\text { MISER - Question 5 (548) } \\
\text { BALLOON - Question 4 (510) }\end{array}$ \\
\hline $\mathbf{2}$ & $\mathbf{4 0 7}$ & $\begin{array}{l}\text { THE PLAY'S THE THING - Question 4 (474) } \\
\text { BALLOON - Question 3.1 (449) } \\
\text { BALLOON - Question 6 (411) }\end{array}$ \\
\hline $\mathbf{1 a}$ & $\mathbf{3 3 5}$ & $\begin{array}{l}\text { MISER - Question 1 (373) } \\
\text { BALLOON - Question 8 (370) }\end{array}$ \\
\hline $\mathbf{1 b}$ & $\mathbf{2 6 2}$ & \begin{tabular}{l} 
MISER - Question 7 (310) \\
\hline
\end{tabular}
\end{tabular}

Figure I.4.10 shows the distribution of students among these different proficiency levels in each participating country and economy. Table I.4.1 a shows the percentage of students at each proficiency level on the reading scale, with standard errors.

\section{Proficiency at Level 6 (score higher than 698 points)}

Tasks at Level 6 typically require the student to make multiple inferences, comparisons and contrasts that are both detailed and precise. They require demonstration of a full and detailed understanding of one or more texts and may involve integrating information from more than one text. Tasks may require the student to deal with unfamiliar ideas in the presence of prominent competing information, and to generate abstract categories for interpretations. Reflect-andevaluate tasks may require the student to hypothesise about or critically evaluate a complex text on an unfamiliar topic, taking into account multiple criteria or perspectives, and applying sophisticated understandings from beyond the text. Access-and-retrieve tasks at this level require precise analysis and fine attention to detail that is inconspicuous in the texts.

Level 6 tasks are illustrated by Question 3 from the unit THE PLAY'S THE THING (Figure I.4.14). The text is long, by PISA standards, and it may be supposed that the fictional world depicted is remote from the experience of most 15 -year-olds. The introduction to the unit tells students that the stimulus of THE PLAY'S THE THING is the beginning of a play by the Hungarian dramatist Ferenc Molnár, but there is no other external orientation. The setting ("a castle by the beach in Italy") is likely to be exotic to many, and the situation is only revealed gradually through the dialogue itself. While individual pieces of vocabulary are not particularly difficult, and the tone is often chatty, the register of the language is a little mannered. Perhaps most important, a level of unfamiliarity is introduced by the abstract theme of the discussion: a sophisticated conversation between characters about the relationship between life and art, and the challenges of writing for the theatre. The text is classified as narration because a story is told through the dialogue of the play.

A high level of interpretation skills is required to define the meaning of the question's terms. The student needs to be alert to the distinction between characters and actors. The question refers to what the characters (not the actors) were doing "just before the curtain went up". This is potentially confusing since it requires recognition of a shift between the real world of a stage in a theatre, which has a curtain, and the imaginary world of Gal, Turai and Adam, who were in the dining room having dinner just before they entered the guest room (the stage setting). A question that assesses students' capacity to distinguish between real and fictional worlds seems particularly appropriate in relation to a text whose theme is about just that, so that the complexity of the question is aligned with the content of the text. 
In addition, the information required to complete the task is in an unexpected location. The question refers to the action "before the curtain went up", which would typically lead one to search at the opening of the scene, the beginning of the extract. But the information is actually found about half-way through the extract, when Turai reveals that he and his friends "have just arrived from the dining room". While the scoring for the question shows that several kinds of response are acceptable, to be given full credit students must demonstrate that they have found this inconspicuous piece of information. The need to assimilate information that is contrary to expectations is characteristic of the most demanding reading tasks in PISA.

Across OECD countries, around 1\% of students performs at Level 6 in reading, but there is some variation among countries. Three percent of students or more perform at this level in Singapore (5.0\%), Japan (3.9\%), Shanghai-China $(3.8 \%)$ and New Zealand (3.0\%). In France, Finland and Canada between $2 \%$ and 3\% of students attain proficiency Level 6 . In contrast, $0.1 \%$ of students or fewer perform at Level 6 in Romania, Albania, Argentina, Thailand, Montenegro, Uruguay, Mexico, Chile, Brazil, Peru, Costa Rica, Jordan, Tunisia, Colombia, Indonesia, Kazakhstan and Malaysia (Figure I.4.10 and Table I.4.1a).

\section{Proficiency at Level 5 (score higher than 626 but lower than or equal to 698 points)}

Tasks at Level 5 that involve retrieving information require the student to locate and organise several pieces of deeply embedded information, inferring which information in the text is relevant. Reflective tasks require critical evaluation or hypotheses, drawing on specialised knowledge. Both interpreting and reflective tasks require a full and detailed understanding of a text whose content or form is unfamiliar. For all aspects of reading, tasks at this level typically involve dealing with concepts that are contrary to expectations.

Question 16 in the unit LABOUR (Figure I.4.15) is an example of a task at Level 5. In fact, this task yields two levels of difficulty: the full-credit response category falls within Level 5, with a PISA score of 631 points; and the partial-credit category falls within Level 3, with a PISA score of 485 points. The full-credit response category illustrates that access and retrieve items, like items from the other two aspect categories (integrate and interpret and reflect and evaluate), can pose a significant challenge.

For full credit (Level 5), students are required to locate and combine a piece of numerical information in the main body of the text (the tree diagram) with information in a footnote - that is, outside the main body of the text. In addition, students have to use this footnoted information to determine the correct number of people who fit into this category. Both of these features contribute to the difficulty of this task.

For partial credit (Level 3), this task merely requires students to locate the number given in the appropriate category of the tree diagram; they are not required to use the information provided in the footnote. Even without this important information, the task is still moderately difficult. The requirement to use information found outside the main body of a text - significantly increases the difficulty of a task. This is clearly demonstrated by the two categories of this task, since the difference between full-credit and partial-credit answers involves applying - or not applying - information from a footnote to correctly identified numerical information in the body of the text. The difference in difficulty between these two categories of response is more than two proficiency levels.

Across OECD countries, $8.4 \%$ of students are top performers, meaning that they are proficient at Level 5 or 6. Shanghai-China has the largest proportion of top performers - $25.1 \%$ - among all participating countries and economies. More than 15\% of students in Singapore, Japan and Hong Kong-China are top performers in reading as are more than $10 \%$ of students in Korea, New Zealand, Finland, France, Canada, Belgium, Chinese Taipei, Australia, Ireland, Liechtenstein and Norway. In 15 countries and economies fewer than 1\% of students perform at Level 5 or 6 . With the exception of Mexico, Chile, Turkey and the Slovak Republic, more than $5 \%$ of students in every OECD country attains at least Level 5 (Figure I.4.10 and Table I.4.1a).

\section{Proficiency at Level 4 (score higher than 553 but lower than or equal to 626 points)}

Tasks at Level 4 that involve retrieving information require the student to locate and organise several pieces of embedded information. Some tasks at this level require interpreting the meaning of nuances of language in a section of text by taking into account the text as a whole. Other interpretative tasks require understanding and applying categories in an unfamiliar context. Reflective tasks at this level require the student to use formal or public knowledge to hypothesise about or critically evaluate a text. The student must demonstrate an accurate understanding of long or complex texts whose content or form may be unfamiliar. 
- Figure I.4.10

\section{Proficiency in reading}

Percentage of students at each level of reading proficiency

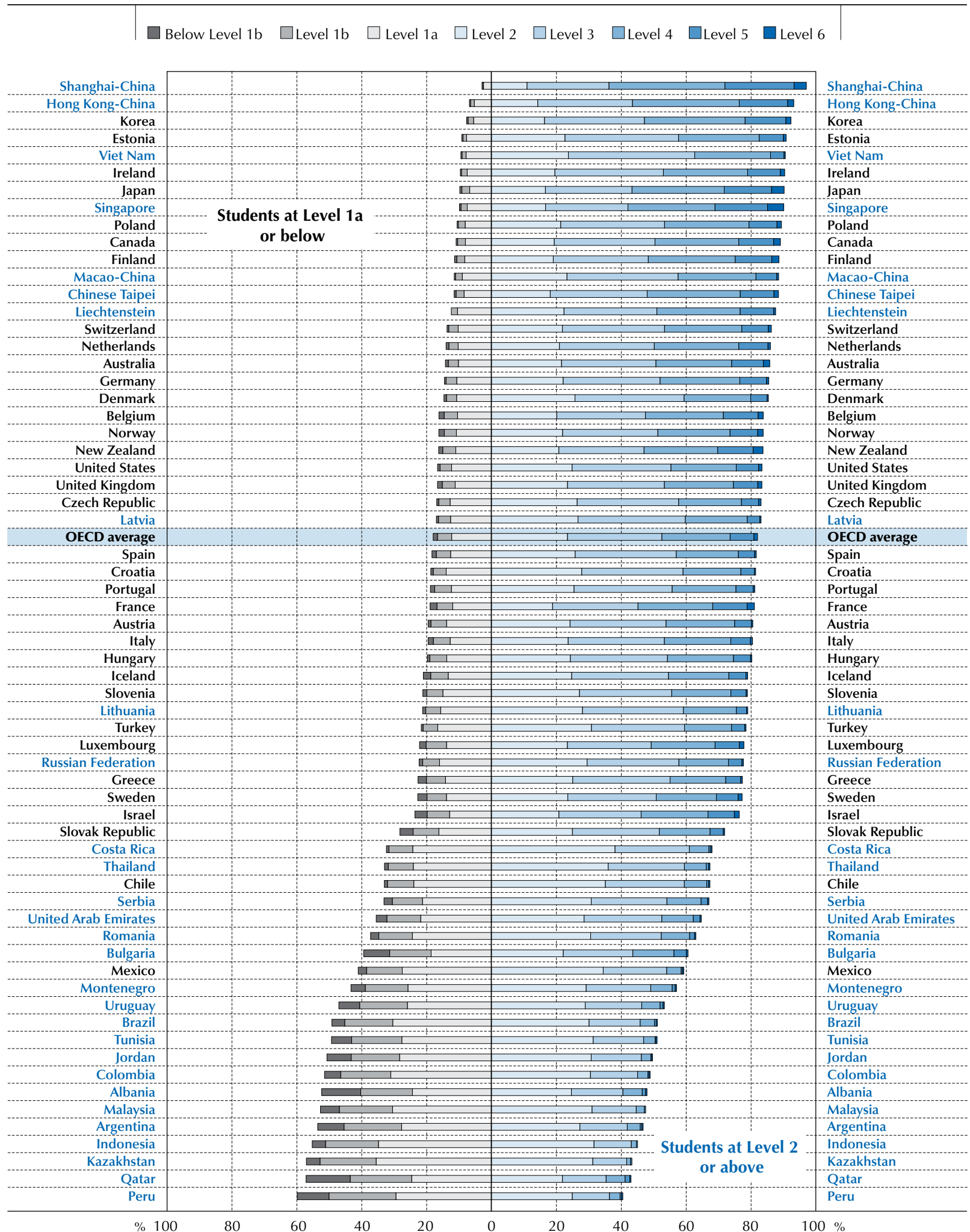

Countries and economies are ranked in descending order of the percentage of students at Levels 2, 3, 4, 5 and 6.

Source: OECD, PISA 2012 Database, Table I.4.1a.

StatLink नillst http://dx.doi.org/10.1787/888932935610 
Question 7 in the example THE PLAY'S THE THING (Figure I.4.14) requires Level 4 proficiency. In this task, the student is asked to take a global perspective, forming a broad understanding by integrating and interpreting the implications of the dialogue in the text. The task involves recognising the conceptual theme of a section of a play, where the theme is literary and abstract. The difficulty of the task largely stems from the abstract nature of the dialogue. A little under half of the students in OECD countries earned full credit for this task, with the others divided fairly evenly across the three other proposed answers.

Across OECD countries, an average of around 30\% of students are proficient at Level 4 or higher (that is, proficient at Level 4, 5 or 6). In Hong Kong-China, Singapore, Japan, Korea, Chinese Taipei and Finland between 40\% and 50\% of students attain these levels; in Shanghai-China, more than $60 \%$ of students do. In more than half of all participating countries and economies, more than one in four students performs at Level 4 or higher. However, in the partner countries and economies Kazakhstan, Indonesia, Malaysia, Jordan, Colombia, Peru, Tunisia, Argentina, Mexico and Brazil, fewer than $5 \%$ of students attain at least this level (Figure I.4.10 and Table I.4.1a).

\section{Proficiency at Level 3 (score higher than $\mathbf{4 8 0}$ but lower than or equal to 553 points)}

Tasks at Level 3 require the student to retrieve, and in some cases recognise the relationship between, several pieces of information that must meet multiple conditions. Interpreting tasks at this level require the student to integrate several parts of a text in order to identify a main idea, understand a relationship or construe the meaning of a word or phrase. The student needs to take into account many features in comparing, contrasting or categorising. Often the required information is not prominent or there is much competing information; or there are other obstacles in the text, such as ideas that are contrary to expectation or negatively worded. Reflective tasks at this level may require connections, comparisons and explanations, or they may require the student to evaluate a feature of the text. Some reflective tasks require the student to demonstrate a fine understanding of the text in relation to familiar, everyday knowledge. Other tasks do not require detailed text comprehension but ask the student to draw on less common knowledge.

Question 5 in MISER (Figure I.4.17), a task at Level 3, requires an open-constructed response. The task sets up a dialogue between two imaginary readers representing two conflicting interpretations of the story. In fact, only the second speaker's position is consistent with the overall implication of the text, so that in providing a supporting explanation, readers demonstrate that they have understood the "punch line" - the moral import - of the fable. The relative difficulty of the task, among the most difficult questions at Level 3, is likely to be influenced by the fact that students need to do a good deal of work to generate a full-credit response. First they must make sense of the neighbour's speech in the story, which is expressed in a formal register. (Translators were asked to reproduce the fable-like style.) Secondly, the relationship between the question stem and the required information is not obvious: there is little or no support in the stem ("What could Speaker 2 say to support his point of view?") to guide the reader in interpreting the task, though the reference to the stone and the neighbour by the speakers should point the reader to the end of the fable.

To gain full credit, students could express, in a variety of ways, the key idea that wealth has no value unless it is used (see examples of answers in Figure 1.4.17). Vague gestures at meaning, such as "the stone had a symbolic value", are not given credit.

Across OECD countries, 59\% of students are proficient at Level 3 or higher (that is, proficient at Level 3, 4, 5 or 6). In Shanghai-China (86.1\%), Hong Kong-China (78.9\%) and Korea (76.0\%) more than three out of four 15-year-olds are proficient at Level 3 or higher, and at least two out of three students attain this level in Japan, Singapore, Ireland, Chinese Taipei, Canada, Finland, Estonia, Poland and Viet Nam. In contrast, in 13 countries and economies (Kazakhstan, Indonesia, Peru, Malaysia, Colombia, Jordan, Argentina, Tunisia, Brazil, Qatar, Albania, Uruguay and Mexico) three out of four students do not attain this level (Figure I.4.10 and Table I.4.1a).

\section{Proficiency at Level 2 (score higher than $\mathbf{4 0 7}$ but lower than or equal to 480 points)}

Level 2 can be considered a baseline level of proficiency at which students begin to demonstrate the reading literacy competencies that will enable them to participate effectively and productively in life. The 2009 Canadian Youth in Transition Survey, which followed up students who were assessed by PISA in 2000, shows that students scoring below Level 2 face a disproportionately higher risk of poor post-secondary participation or low labour-market outcomes at age 19, and even more so at age 21, the latest age for which data from this longitudinal study are available (OECD, 2010a).

Some tasks at Level 2 require the student to retrieve one or more pieces of information that may have to be inferred and may have to meet several conditions. Others require recognising the main idea in a text, understanding relationships, or 
interpreting meaning within a limited part of the text when the information is not prominent and the student must make low-level inferences. Tasks at this level may involve integrating parts of the text through comparisons or contrasts based on a single feature in the text. Typical reflective tasks at this level require the student to make a comparison or several connections between the text and outside knowledge by drawing on personal experience and attitudes.

Question 6 in BALLOON (Figure 1.4.16), a task that corresponds to the bottom of Level 2 in difficulty, uses a multiplechoice format. This task is classified under reflect and evaluate because it asks about authorial intent. It focuses on a graphic element - the illustration of two balloons - and asks students to consider the purpose of this inclusion. In the context of the over-arching idea of the text, to describe (and celebrate) Singhania's flight, the balloon illustration sends the message, "This is a really big balloon!", just as the jumbo jet illustration sends the message, "This is a really high flight!".

Across OECD countries, an average of $82 \%$ of students is proficient at Level 2 or higher. In Shanghai-China, Hong Kong-China, Korea, Estonia, Viet Nam, Ireland, Japan and Singapore more than $90 \%$ of students perform at or above this threshold. In Shanghai-China, fewer than 3\% of students do not attain this level. In 34 participating countries and economies between $75 \%$ and $90 \%$ of students achieve the baseline level of reading proficiency, and in 14 countries and economies between 50\% and 75\% do so. Only in Peru, Qatar, Kazakhstan, Indonesia, Argentina, Malaysia, Albania, Colombia and Jordan, does fewer than one in two students perform at this level. In every OECD country except Mexico (58.9\%), Chile $(67.0 \%)$ and the Slovak Republic $(71.8 \%)$, at least three out of four students perform at Level 2 or above (Figure I.4.10 and Table I.4.1a).

\section{Proficiency at Level 1a (score higher than $\mathbf{3 3 5}$ but lower than or equal to $\mathbf{4 0 7}$ points)}

Tasks at Level 1 a require the student to retrieve one or more independent pieces of explicitly stated information, interpret the main theme or author's intent in a text about a familiar topic, or make a simple connection by reflecting on the relationship between information in the text and common, everyday knowledge. The required information in the text is usually prominent and there is little, if any, competing information. The student is explicitly directed to consider relevant factors in the task and in the text.

Question 8 in the unit BALLOON (Figure 1.4.16) is typical of Level 1a tasks. The main idea of this non-continuous text is stated explicitly and prominently several times, including in the title, "Height record for hot air balloon". Although the main idea is explicitly stated, the question is classified as integrate and interpret, with the sub-classification forming a broad understanding, because it involves distinguishing the most significant and general information from subordinate information in the text.

Across OECD countries, an average of $18 \%$ of students is proficient only at or below Level $1 \mathrm{a}$, and nearly $6 \%$ of students do not even attain Level 1a. Fewer than 10\% of students perform at Level 1a or below in Shanghai-China, Hong Kong-China, Korea, Estonia, Viet Nam, Ireland, Japan and Singapore. In Shanghai-China, fewer than 1\% of students $(0.4 \%)$ do not reach Level 1a. In Estonia, Hong Kong-China, Viet Nam and Liechtenstein fewer than $2 \%$ of students do not reach Level 1a, and in Ireland, Korea, Singapore, Macao-China, Poland and Canada fewer than 3\% of students do not reach this level. By contrast, in 20 participating countries and economies more then one in three students performs at Level 1a or below. In Peru, Qatar, Kazakhstan, Indonesia, Argentina, Malaysia, Albania, Colombia and Jordan more than half of all students are proficient only at or below Level 1a (Figure I.4.10 and Table I.4.1a).

\section{Proficiency at Level $1 \mathrm{~b}$ (score higher than 262 but lower than or equal to 335 points)}

Tasks at Level $1 \mathrm{~b}$ require the student to retrieve a single piece of explicitly stated information in a prominent position in a short, syntactically simple text with a familiar context and text type, such as a narrative or a simple list. The text typically provides support to the student, such as repetition of information, pictures or familiar symbols. There is minimal competing information. In tasks requiring interpretation, the student may need to make simple connections between adjacent pieces of information.

Question 7 in MISER (Figure 1.4.17), a task at Level 1b, requires a short response. This is one of the easiest tasks in the PISA reading assessment. The student is required to access and retrieve a piece of explicitly stated information in the opening sentence of a very short text. To gain full credit, the response can either quote directly from the text or provide a paraphrase. The formal language of the text, which is likely to have added difficulty in other tasks in the unit, is unlikely to have much impact here because the required information is located at the very beginning of the text. Although this is a very easy question, it still requires a small degree of inference: the reader must infer that there is a causal connection between the first proposition (that the miser sold all he had) and the second (that he bought gold). 
Across OECD countries, $1.3 \%$ of students are not proficient at Level 1b, but there are wide differences between countries. In Liechtenstein, Shanghai-China, Viet Nam, Estonia, Hong Kong-China, Ireland, Poland, Macao-China and Korea fewer than $0.5 \%$ of students perform at this level. Across all participating countries and economies, except Malaysia, Tunisia, Uruguay, Jordan, Bulgaria, Argentina, Peru, Albania and Qatar, fewer than 5\% of students are not proficient at Level $1 \mathrm{~b}$ (Figure I.4.10 and Table I.4.1a).

Students with scores below 262 points - that is, below Level 1b - usually do not succeed at the most basic reading tasks that PISA measures. This does not necessarily mean that they are illiterate, but that there is insufficient information on which to base a description of their reading proficiency. Such students are likely to have serious difficulties in benefitting from further education and learning opportunities throughout life (OECD, 2010a).

\section{Trends in the percentage of low- and top-performers in reading}

PISA assesses the reading competencies required for students to participate fully in a knowledge-based society. These range from very complex skills that only a few students have mastered up to the baseline skills that are considered the minimum required for functioning in society. The proportion of students who do not meet this baseline proficiency (Level 2; low-performing students) and the proportion of students who are able to understand and communicate complex tasks (Levels 5 and 6; top-performing students) are important indicators of the needs and challenges faced by each country or economy and benchmarks of the level of skills development.

Changes in a country's or economy's average performance can result from improvements or deterioration of performance at different points in the performance distribution. For example, in some countries and economies the average improvement is observed among all students, resulting in fewer students who perform below Level 2 and more students who are top performers. In other contexts, the average improvement can mostly be attributed to large improvements among low-achieving students with little or no change among high-achieving students; this may results in a smaller proportion of low-performing students, but no increase among top performers. Trends in the proportion of low- and topperforming students indicate where the changes in performance have occurred and the extent to which school systems are advancing towards providing all students with the minimum literacy skills and towards producing a larger proportion of students with the highest-level skills in reading.

Countries and economies can be grouped into categories according to whether they have: simultaneously reduced the share of low performers and increased the share of top performers between any previous PISA assessment and PISA 2012; reduced the share of low performers but not increased the share of top performers between any previous PISA assessment and PISA 2012; increased the share of top performers but not reduced the share of low performers; and reduced the share of top performers or increased the share of low performers between PISA 2012 and any previous PISA assessment. The following section categorises countries and economies into these groups.

\section{Moving everyone up: Reduction in the share of low performers and increase in that of top performers}

Between the PISA 2000 and PISA 2012 assessments, Albania, Israel and Poland saw an increase in the share of students who meet the highest proficiency levels in PISA and a simultaneous decrease in the share of students who do not meet the baseline proficiency level. In Israel, for example, the share of students performing below Level 2 shrank by almost ten percentage points (from 33\% to 24\%) between 2000 and 2012, while the share of students performing at or above proficiency Level 5 grew by more than five percentage points (from 4\% to 10\%) (Figure I.4.11 and Table I.4.1b). The systemlevel improvements observed in these countries and economies have lifted students out of low performance and others into top performance. The same trend was observed in Hong Kong-China, Japan and the Russian Federation since PISA 2003; in Bulgaria, Chinese Taipei, Qatar, Serbia and Spain since PISA 2006; and in Ireland, Luxembourg, Macao-China and Singapore since PISA 2009. In Turkey, the share of low performers shrank when comparing PISA 2003 or PISA 2006 with PISA 2012, and the share of top performers increased when comparing PISA 2009 with PISA 2012 (Table I.4.1b).

For many of these countries and economies, these trends in the share of low and top performers mirror how students at different levels of the performance distribution have changed their performance. Annex B4 shows how, for each country and economy, the 10th, 25th, 75th and 90th percentiles of performance have evolved across different PISA cycles. It shows, consistent with trends in the share of low- and top-performing students, that in Poland, the low-achieving students (those in the bottom 25th percentile) improved their reading performance by 61 score points and the highest-achieving students (those in the 90th percentile) also improved by more than 20 score points. Other countries that saw annualised improvements on average and among both the lowest- and highest-achieving students are Albania, Brazil, Chile, Estonia, Hong Kong-China, Hungary, Indonesia, Italy, Japan, Montenegro, Mexico, Peru, Qatar, the Russian Federation, Serbia, Portugal, Spain, Switzerland, Thailand and Tunisia (Table I.4.3d). The average annual improvement observed in these 
countries is shared by high- and low-achieving students, but not all these countries were able to both increase the share of students performing at or above Level 5 and reduce the share of students performing below Level 2.

\section{Reducing underperformance: Reductions in the share of low performers but no change in that of top performers}

Other countries and economies have seen improvements in the performance of their low-performing students. For example, since PISA 2000, Peru, Indonesia, Chile and Latvia have reduced the share of students performing below Level 2 in reading by more than 10 percentage points with no concurrent change in the share of students who perform at or above proficiency Level 5. Liechtenstein, Germany, Portugal and Switzerland show a reduction of more than five percentage points in the share of students performing below Level 2 between 2000 and 2012. Significant reductions in the proportion of low-performing students are also observed in Italy, Mexico, Thailand and Tunisia since 2003, in Brazil, the Czech Republic, Greece, Montenegro and Norway since PISA 2006 and in Dubai (United Arab Emirates) since PISA 2009 (Figure I.4.11 and Table I.4.1b). In these countries and economies, improvements in performance have reached those students that needed it the most. Annex B4 shows the performance trajectories of these countries and economies, highlighting how the performance of their lowest achievers (those students in the 10th percentile of performance) shows greater improvements than the performance of their highest-achieving students (those in the 90th percentile).

- Figure I.4.11

Percentage of low-performing students and top performers in reading in 2000 and 2012

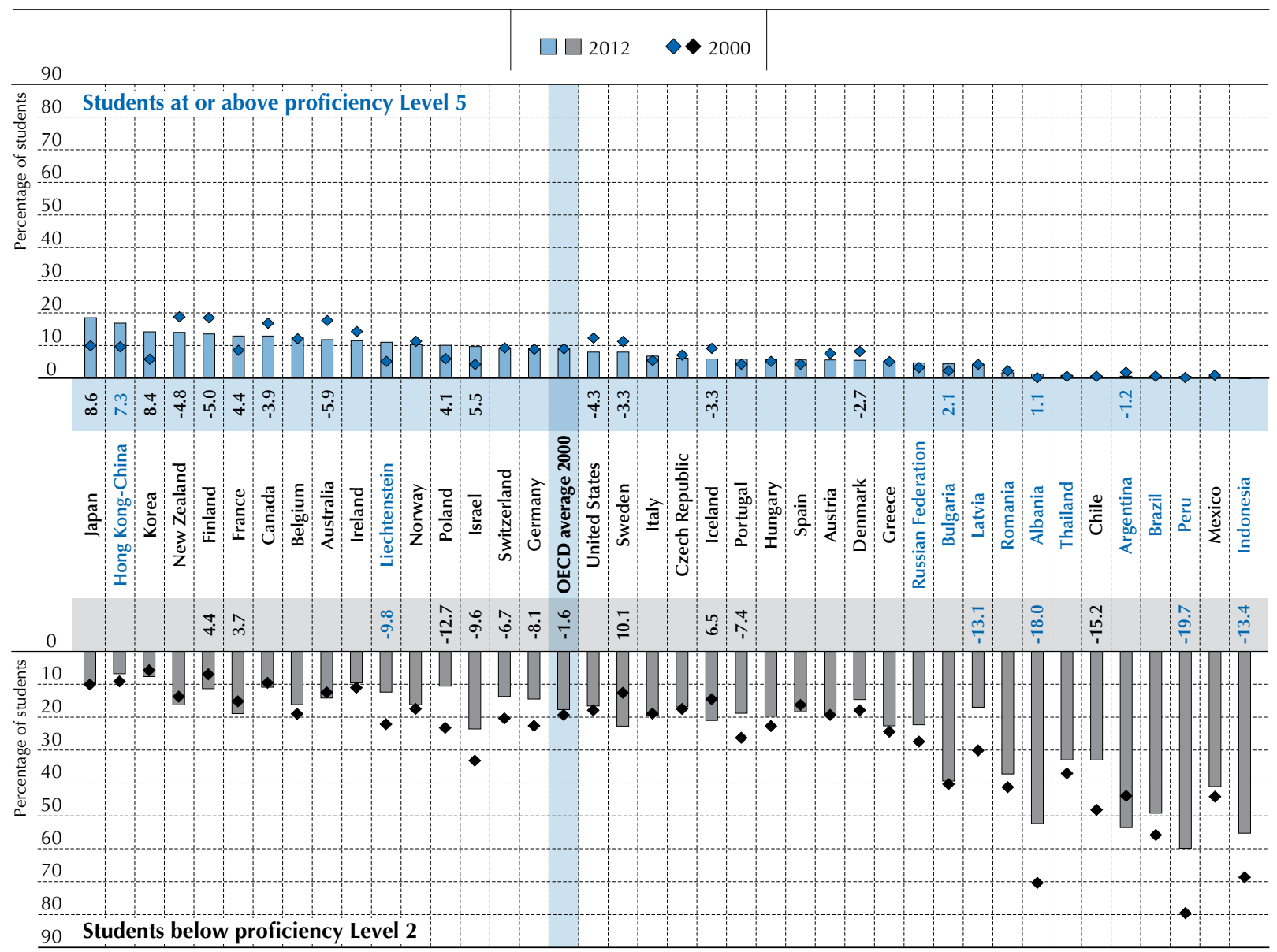

Notes: The chart shows only countries/economies that participated in both PISA 2000 and PISA 2012 assessments.

The change between PISA 2000 and PISA 2012 in the share of students performing below Level 2 in reading is shown below the country/economy name. The change between PISA 2000 and PISA 2012 in the share of students performing at or above Level 5 in reading is shown above the country/economy name. Only statistically significant changes are shown (see Annex A3).

OECD average 2000 compares only OECD countries with comparable reading scores since 2000.

Countries and economies are ranked in descending order of the percentage of students at or above proficiency Level 5 in reading in 2012

Source: OECD, PISA 2012 Database, Table I.4.1b.

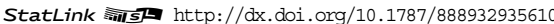




\section{Nurturing top performance: Increase in the share of top performers but no change in that of low performers}

France and Korea saw growth in the share of top-performing students in reading since PISA 2000 with no concurrent reduction in the share of low-performing students. Korea, for example, saw an increase of eight percentage points in the share of students performing at or above Level 5 (from 6\% in 2000 to $14 \%$ in 2012). This trend is also observed in in Shanghai-China since PISA 2009 (Figure I.4.11 and Table I.4.1b). These countries and economies have been able to increase the share of the students who meet the highest-level skills in PISA. France saw an increase of four percentage points in the share of top performers between PISA 2000 and PISA 2012, but also an increase in the share of low performers during the same period. Annex B4 shows how, in these countries and economies, the performance of the highest-achieving students improved to a greater extent than that of the lowest-achieving students.

\section{Increase in the share of low performers or decrease in that of top performers}

By contrast, in some countries and economies the percentage of students who do not meet the PISA baseline proficiency level in reading increased since 2000 - or since later PISA assessments - or the share of students attaining the highest levels of proficiency shrank. This trend is observed on average across OECD countries since 2000, and in 15 countries and economies when comparing results from PISA 2012 and those from previous assessments (Figure I.4.11 and Table I.4.1b).

\section{Variation in student performance in reading}

The range in performance between the highest- (90th percentile) and lowest-achieving students (10th percentile) is shown in Table I.4.3a. Among the ten participating countries and economies that show the narrowest difference between the highest and lowest achievers in reading, this gap ranges between 189 and 211 points. One of the three lowestperforming PISA participants, the partner country Kazakhstan, and the highest-performing PISA participant in reading in PISA 2012, the partner economy Shanghai-China, are in this group of countries. At the other end of the spectrum, among the ten participating countries and economies that show the largest difference between the highest and lowest achievers in reading, this gap ranges from 270 to 310 points. As is true of those countries with a comparatively narrow distribution of scores among students, the group of countries with a wide range in performance is heterogeneous in mean reading proficiency. One of the lowest-performing countries, Qatar, has nearly the same gap between the highest and lowest achievers as the high-performing country, New Zealand, and both countries are included in this group. If this group is expanded to include the country with the 11 th largest difference, it will include one of the five best-performing countries in reading in PISA 2012. Thus, the spread of the performance distribution does not appear to be associated with the overall level of performance. Some countries and economies perform above the OECD average and show only a narrow difference between the highest and lowest achievers in reading.

\section{Gender differences in reading performance}

On average across OECD countries, girls outperform boys in reading by 38 score points. While girls outperform boys in reading in every participating country and economy, the gap is much wider in some countries than in others (Figure I.4.12). As shown in PISA 2009 (OECD, 2010b), these differences are associated with differences in student attitudes and behaviours that are related to gender.

Among the five highest-performing countries and economies, the gender gap in reading performance ranges from 23 to 32 score points - below the OECD average (a difference of 38 score points). Among all participating countries and economies, the narrowest gender gap - 15 score points in favour of girls - is observed in Albania. The gender gap is 25 score points or less in 11 other countries, including both low-performing countries, like Chile, Mexico, the partner countries Colombia, Peru and Costa Rica; and very high-performing countries like Korea, Japan, and the partner countries and economies Shanghai-China, Liechtenstein and Hong Kong-China. The United Kingdom, with a score around the OECD average, is also included in this group. In 14 countries, girls outperform boys by at least 50 score points. All of these countries score below the OECD average, except Finland, which performs above the OECD average in reading. In the partner country Jordan, 75 score points - the equivalent of an entire proficiency level - separate girls' performance from boys'.

With the exception of Denmark, countries in Northern Europe have wider-than-average gender gaps in performance. The most pronounced is found in Finland, where the score difference is 62 points - the largest difference observed in any OECD country. The gender-related differences in performance in East Asian countries and economies tend to cluster just below the average, with Korea, Japan, and the partner countries and economies Shanghai-China, Hong Kong-China, Viet Nam, Chinese Taipei and Macao-China all showing gender gaps of between 23 and 36 points. 
- Figure 1.4.12

\section{Gender differences in reading performance}

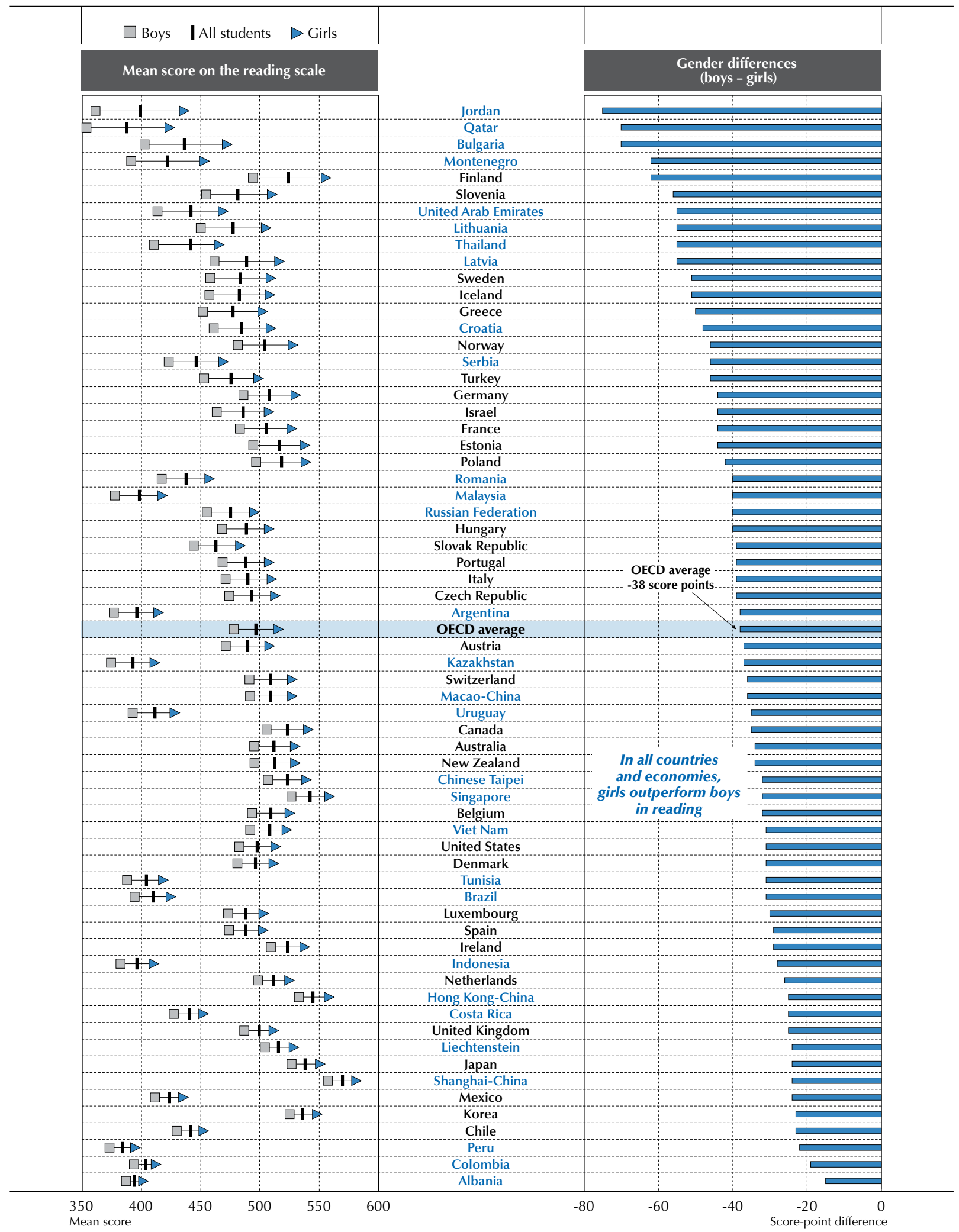

Note: All gender differences are significant (see Annex A3).

Countries and economies are ranked in ascending order of the gender score-point difference (boys - girls).

Source: OECD, PISA 2012 Database, Table I.4.3a.

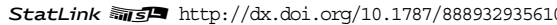


Yet there is no obvious pattern in gender-related differences in performance among groups of countries with lower overall performance. For example, among Latin American countries, the highest-performing country (Chile) and the lowest-performing (Peru) have nearly the same, relatively small, gender gap ( 23 and 22 points, respectively). One of the middle-ranking countries within this group, the partner country Colombia, has the second-smallest gender gap of any country and economy, with a difference of only 19 score points between the mean scores for girls and boys.

How do boys and girls differ in levels of proficiency attained? One way to determine this is to observe the highest level of proficiency attained by the largest group of girls and boys in each country and economy. As can be seen in Table I.4.2a, among all the participating countries and economies, the highest proficiency level attained by the largest group of boys (in 31 countries and economies) and girls (in 37 countries and economies) is Level 3 followed by Level 2 (the highest level attained by most boys in 17 countries and economies, and by most girls in 19 countries and economies). But while in 13 countries and economies the highest proficiency level attained by the largest group of boys is Level 1a - and in one country, Level $1 \mathrm{~b}$ - in only one country is Level 1a the highest proficiency level attained by the largest group of girls. Level 4 is the highest proficiency level attained by the largest group of boys in only three countries, while in eight countries is the highest proficiency level attained by the largest group of girls.

Around the middle of the reading scale, nearly one in two boys (49\%) but only one in three girls (34\%) fails to reach Level 3, which is associated with being able to perform the kinds of tasks that are commonly demanded of adults in their everyday lives. This represents a major difference in the capabilities of boys and girls at age 15 .

This pattern is also seen among students with particularly low levels of reading proficiency. Across OECD countries, $24 \%$ of boys do not attain Level 2, considered as the baseline level of proficiency, while only about half as many girls (12\%) perform at that level. In 14 countries, more than half of all 15-year-old boys perform below Level 2 on the reading scale, but in only one country does the same proportion of girls perform at that level.

Among the ten highest-performing countries in reading, the proportion of girls who perform below Level 2 is only onequarter (in Finland) to one-half that of boys (e.g. Japan, Ireland and Singapore), while in some of the low-performing countries, such as Albania, Peru and Colombia, the proportions of girls and boys performing below Level 2 tend to be similar. Some of the differences in reading performance between boys and girls are closely related to gender differences in attitudes and behaviour, which are discussed in PISA 2009, Volume III (OECD, 2010b).

\section{Trends in gender differences in reading performance}

Girls have traditionally outperformed boys in reading (Buchmann et al., 2008). In PISA 2000 and on average across OECD countries, girls outperformed boys by 32 score points. That year, girls' advantage in reading was significant in the 39 participating countries and economies, except Israel and Peru. It was largest in Albania, Finland and Latvia, at more than 50 score points and exceeded 40 points - more than the equivalent to a year of schooling - in Argentina, Bulgaria, Iceland, New Zealand, Norway and Thailand (Table I.4.3c and OECD, 2001).

By 2012, the relative standing of boys had further deteriorated. In 2012 and on average across OECD countries that have comparable data in PISA 2000, girls outperformed boys by 38 PISA score points, roughly the equivalent of an academic school year. Between 2000 and 2012 the gender gap in reading performance widened in 11 countries and economies. In Bulgaria, France and Romania the gap widened by more than 15 score points. Only in Albania did the gender gap in reading performance narrow, as a result of a greater improvement in reading performance among boys (68 score points) than girls (24 score points) between PISA 2000 and PISA 2012 (Figure I.4.13). ${ }^{5}$

Consistent with this trend, the proportion of low-performing girls shrank significantly in 16 countries and economies between PISA 2000 and PISA 2012, while the share of low-performing boys decreased in only 11 countries and economies. However, the share of low-performing boys increased in seven countries and economies, while the share of low-performing girls increased in only three countries during the period (Table I.4.2b).

At the other end of the performance spectrum, the share of top-performing girls - those who perform at or above proficiency Level 5 - increased significantly between PISA 2000 and PISA 2012 in 11 countries and economies, while the share of top-performing boys increased in only seven of these countries and economies. This increase in top-performing girls was greatest in Hong Kong-China, Japan and Korea where the share of top-performing boys also grew (Table I.4.2b). 


\section{Change between 2000 and 2012 in gender differences in reading performance}

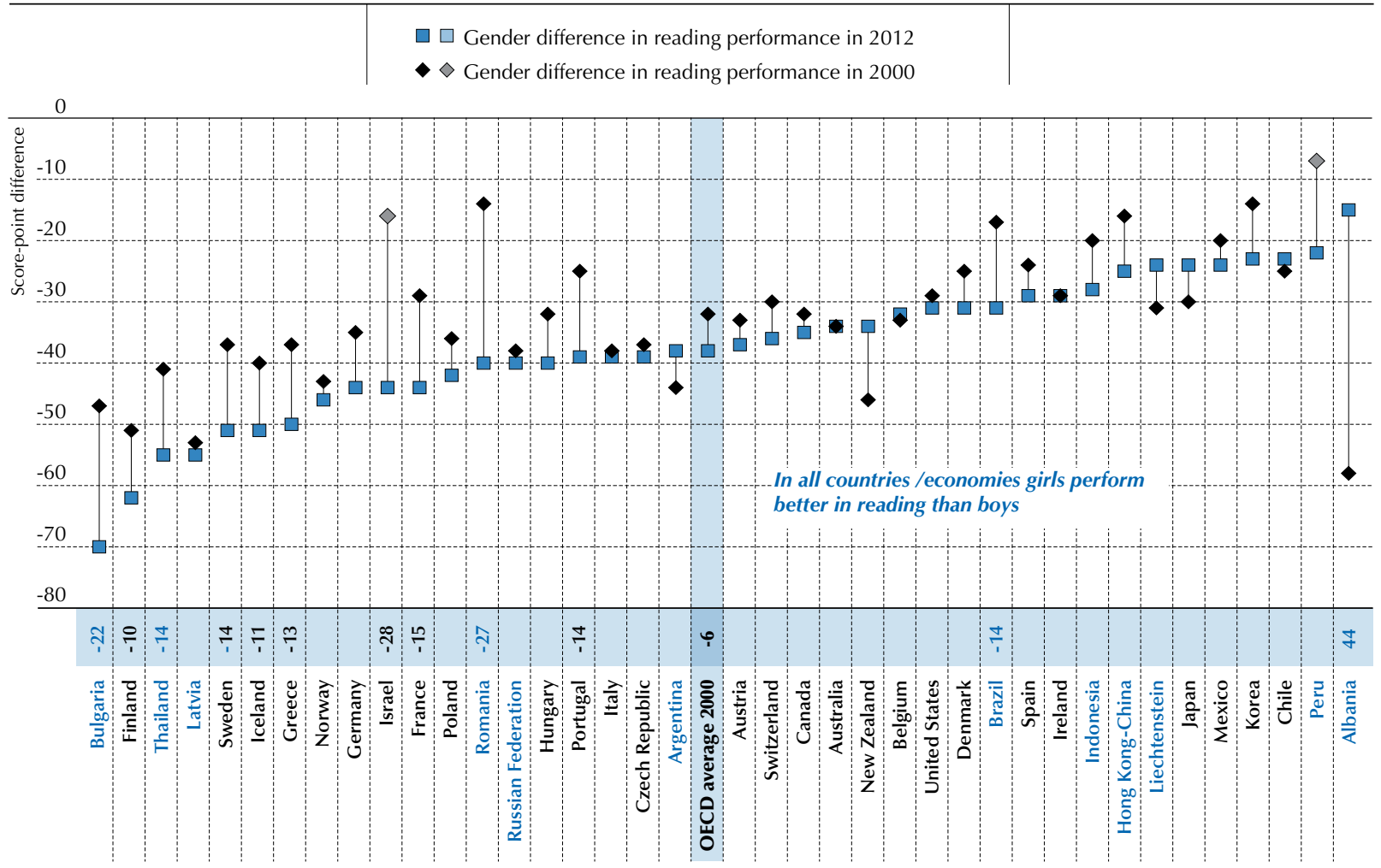

Notes: All gender differences in PISA 2012 are statistically significant. Gender differences in PISA 2000 that are statistically significant are marked in a darker tone (see Annex A3).

Statistically significant changes in the score-point difference between boys and girls in reading performance between PISA 2000 and PISA 2012 are shown next to the country/economy name.

OECD average 2000 compares only OECD countries with comparable reading scores since 2000.

Countries and economies are ranked in ascending order of gender differences (boys-girls) in 2012.

Source: OECD, PISA 2012 Database, Table I.4.3c

StatLink 完开 
EXAMPLES OF PISA READING UNITS

The questions are presented in the order in which they appeared within the unit in the main survey.

- Figure I.4.14

THE PLAY'S THE THING

Takes place in a castle by the beach in Italy.

\section{FIRST ACT}

Ornate guest room in a very nice beachside castle. Doors on the right and left. Sitting

5 room set in the middle of the stage: couch, table, and two armchairs. Large windows at the back. Starry night. It is dark on the stage. When the curtain goes up we hear men conversing loudly behind the door on the left.

10 The door opens and three tuxedoed gentlemen enter. One turns the light on immediately. They walk to the centre in silence and stand around the table. They sit down together, Gál in the armchair to the left, Turai in the one on

15 the right, Ádám on the couch in the middle.

Very long, almost awkward silence.

Comfortable stretches. Silence. Then:

GÁL

Why are you so deep in thought?

20 TURAI

I'm thinking about how difficult it is to begin a play. To introduce all the principal characters in the beginning, when it all starts.

\section{ÁDÁM}

25 I suppose it must be hard.

TURAI

It is - devilishly hard. The play starts. The audience goes quiet. The actors enter the stage and the torment begins. It's an eternity,

30 sometimes as much as a quarter of an hour before the audience finds out who's who and what they are all up to.

GÁL

Quite a peculiar brain you've got. Can't you

35 forget your profession for a single minute?

TURAI

That cannot be done.

GÁL

Not half an hour passes without you

40 discussing theatre, actors, plays. There are other things in this world.

TURAI

There aren't. I am a dramatist. That is my curse.

45 GÁL

You shouldn't become such a slave to your profession.

TURAI

If you do not master it, you are its slave.

50 There is no middle ground. Trust me, it's no joke starting a play well. It is one of the toughest problems of stage mechanics. Introducing your characters promptly. Let's look at this scene here, the three of

55 us. Three gentlemen in tuxedoes. Say they enter not this room in this lordly castle, but rather a stage, just when a play begins. They would have to chat about a whole lot of uninteresting topics until it came out
60 who we are. Wouldn't it be much easier to start all this by standing up and introducing ourselves? Stands up. Good evening. The three of us are guests in this castle. We have just arrived from the

65 dining room where we had an excellent dinner and drank two bottles of champagne. My name is Sándor TURAI, I'm a playwright, I've been writing plays for thirty years, that's my profession. Full stop.

70 Your turn.

GÁL

Stands up. My name is GÁL, I'm also a playwright. I write plays as well, all of them in the company of this gentleman

75 here. We are a famous playwright duo. All playbills of good comedies and operettas read: written by GÁL and TURAI. Naturally, this is my profession as well.

GÁL and TURAI

80 Together. And this young man ...

ÁDÁM

Stands up. This young man is, if you allow me, Albert ÁDÁM, twenty-five years old, composer. I wrote the music for these kind

85 gentlemen for their latest operetta. This is my first work for the stage. These two elderly angels have discovered me and now, with their help, I'd like to become famous. They got me invited to this castle. They got

90 my dress-coat and tuxedo made. In other words, I am poor and unknown, for now. Other than that I' $m$ an orphan and $m y$ grandmother raised me. My grandmother has passed away. I am all alone in this world. I

95 have no name, I have no money.

TURAI

But you are young.

GÁL

And gifted.

100 ÁDÁM

And I am in love with the soloist.

TURAI

You shouldn't have added that. Everyone in

the audience would figure that out anyway.

105 They all sit down.

TURAI

Now wouldn't this be the easiest way to start a play?

GÁL

110 If we were allowed to do this, it would be easy to write plays.

TURAI

Trust me, it's not that hard. Just think of this whole thing as ...

115 GÁl

All right, all right, all right, just don't start talking about the theatre again. I'm fed up with it. We'll talk tomorrow, if you wish.

"The Play's the Thing" is the beginning of a play by the Hungarian dramatist Ferenc Molnár.

Use "The Play's the Thing" on the previous two pages to answer the questions that follow. (Note that line numbers are given in the margin of the script to help you find parts that are referred to in the questions.) 
THE PLAY'S THE THING - QUESTION 3

Situation: Personal

Text format: Continuous

Text type: Narration

Aspect: Integrate and interpret - Develop an interpretation

Question format: Short response

Difficulty: 730 (Leve/ 6).

What were the characters in the play doing just before the curtain went up?

\section{Scoring}

Full Credit: Refers to dinner or drinking champagne. May paraphrase or quote the text directly.

- They have just had dinner and champagne.

- "We have just arrived from the dining room where we had an excellent dinner."[direct quotation]

- "An excellent dinner and drank two bottles of champagne." [direct quotation]

- Dinner and drinks.

- Dinner.

- Drank champagne.

- Had dinner and drank.

- They were in the dining room.

\section{Comment}

This task illustrates several features of the most difficult tasks in PISA reading. The text is long by PISA standards, and it may be supposed that the fictional world depicted is remote from the experience of most 15-year-olds. The introduction to the unit tells students that the stimulus of THE PLAY'S THE THING is the beginning of a play by the Hungarian dramatist Ferenc Molnár, but there is no other external orientation. The setting ("a castle by the beach in Italy") is likely to be exotic to many, and the situation is only revealed gradually through the dialogue itself. While individual pieces of vocabulary are not particularly difficult, and the tone is often chatty, the register of the language is a little mannered. Perhaps most importantly a level of unfamiliarity is introduced by the abstract theme of the discussion: a sophisticated conversation between characters about the relationship between life and art, and the challenges of writing for the theatre. The text is classified as narration because this theme is dealt with as part of the play's narrative.

While all the tasks in this unit acquire a layer of difficulty associated with the challenges of the text, the cognitive demand of this task in particular is also attributable to the high level of interpretation required to define the meaning of the question's terms, in relation to the text. The reader needs to be alert to the distinction between characters and actors. The question refers to what the characters (not the actors) were doing "just before the curtain went up". This is potentially confusing since it requires recognition of a shift between the real world of a stage in a theatre, which has a curtain, and the imaginary world of Gal, Turai and Adam, who were in the dining room having dinner just before they entered the guest room (the stage setting). A question that assesses students' capacity to distinguish between real and fictional worlds seems particularly appropriate in relation to a text whose theme is about just that, so that the complexity of the question is aligned with the content of the text.

A further level of the task's difficulty is introduced by the fact that the required information is in an unexpected location. The question refers to the action "before the curtain went up", which would typically lead one to search at the opening of the scene, the beginning of the extract. On the contrary, the information is actually found about half-way through the extract, when Turai reveals that he and his friends "have just arrived from the dining room". While the scoring for the question shows that several kinds of response are acceptable, to be given full credit readers must demonstrate that they have found this inconspicuous piece of information. The need to assimilate information that is contrary to expectations where the reader needs to give full attention to the text in defiance of preconceptions - is highly characteristic of the most demanding reading tasks in PISA. 
THE PLAY'S THE THING

- QUESTION 4

Situation: Personal

Text format: Continuous

Text type: Narration

Aspect: Integrate and interpret - Develop an interpretation

Question format: Multiple choice

Difficulty: 474 (Level 2).

"It's an eternity, sometimes as much as a quarter of an hour... " (lines 29-30)

According to Turai, why is a quarter of an hour "an eternity"?

A. It is a long time to expect an audience to sit still in a crowded theatre.

B. It seems to take forever for the situation to be clarified at the beginning of a play.

C. It always seems to take a long time for a dramatist to write the beginning of a play.

D. It seems that time moves slowly when a significant event is happening in a play.

Scoring

Full Credit: B. It seems to take forever for the situation to be clarified at the beginning of a play.

Comment

Near the borderline between Level 2 and Level 3, this question together with the previous one illustrates the fact that questions covering a wide range of difficulties can be based on a single text.

Unlike in the previous task, the stem of this task directs the reader to the relevant section in the play, even quoting the lines, thus relieving the reader of any challenge in figuring out where the necessary information is to be found. Nevertheless, the reader needs to understand the context in which the line is uttered in order to respond successfully. In fact, the implication of "It seems to take forever for the situation to be clarified at the beginning of a play" underpins much of the rest of this extract, which enacts the solution of characters explicitly introducing themselves at the beginning of a play instead of waiting for the action to reveal who they are. Insofar as the utterance that is quoted in the stem prompts most of the rest of this extract, repetition and emphasis support the reader in integrating and interpreting the quotation. In that respect too, this task clearly differs from Question 3, in which the required information is only provided once, and is buried in an unexpected part of the text.

\section{THE PLAY'S THE THING - QUESTION 7}

Situation: Personal

Text format: Continuous

Text type: Narration

Aspect: Integrate and interpret - Form a broad understanding

Question format: Multiple choice

Difficulty: 556 (Level 4) .

Overall, what is the dramatist Molnâr doing in this extract?

A. He is showing the way that each character will solve his own problems.

B. He is making his characters demonstrate what an eternity in a play is like.

C. He is giving an example of a typical and traditional opening scene for a play.

D. He is using the characters to act out one of his own creative problems.

Scoring

Full Credit: D. He is using the characters to act out one of his own creative problems.

\section{Comment}

In this task the reader is asked to take a global perspective, form a broad understanding by integrating and interpreting the implications of the dialogue across the text. The task involves recognising the conceptual theme of a section of a play, where the theme is literary and abstract. This relatively unfamiliar territory for most 15-year-olds is likely to constitute the difficulty of the task, which is located at Level 4. A little under half of the students in OECD countries gained full credit for this task, with the others divided fairly evenly across the three distractors. 
The tree diagram below shows the structure of a country's labour force or "working-age population". The total population of the country in 1995 was about 3.4 million.

The labour force structure, year ended 31 March $1995(000 s)^{1}$

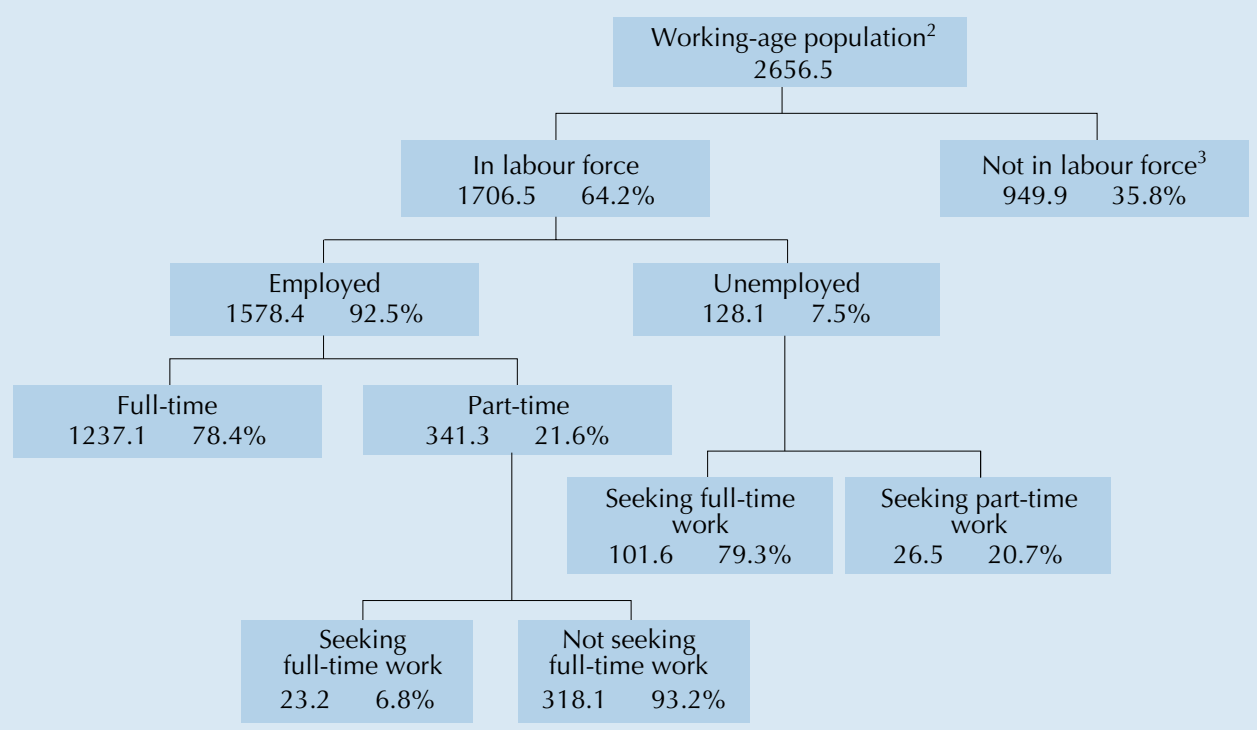

1. Numbers of people are given in thousands (000s).

2. The working-age population is defined as people between the ages of 15 and 65 .

3. People "Not in labour force" are those not actively seeking work and/or not available for work.

Source: D. Miller, Form 6 Economics, ESA Publications, Box 9453, Newmarker, Auckland, NZ, p. 64.

\section{LABOUR - QUESTION 16}

Situation: Reading for education

Text format: Non-continuous

Aspect: Retrieving information

Difficulty: 485 - Percentage of correct answers (OECD countries): $64.9 \%$.

631 - Percentage of correct answers (OECD countries): $27.9 \%$ •

How many people of working age were not in the labour force? (Write the number of people, not the percentage.)

\section{Comment}

The question presented here yields responses at two levels of difficulty, with the partial-credit response category falling within Level 3 with a score of 485 and the full-credit category within Level 5 with a score of 631.

For full credit (Level 5) students are required to locate and combine a piece of numerical information in the main body of the text (the tree diagram) with information in a footnote - that is, outside the main body of the text. In addition, students have to apply this footnoted information in determining the correct number of people fitting into this category. Both of these features contribute to the difficulty of this task, which is one of the most difficult retrieving information tasks in the PISA reading assessment.

For partial credit (Level 3) this task merely requires students to locate the number given in the appropriate category of the tree diagram. They are not required to use the conditional information provided in the footnote to receive partial credit. Even without this important information the task is still moderately difficult. 
BALLOON

\section{Height record for hot air balloons}

The Indian pilot Vijaypat Singhania beat the height record for hot air balloons on November 26, 2005.

He was the first person to fly a balloon 21000 metres above sea level.

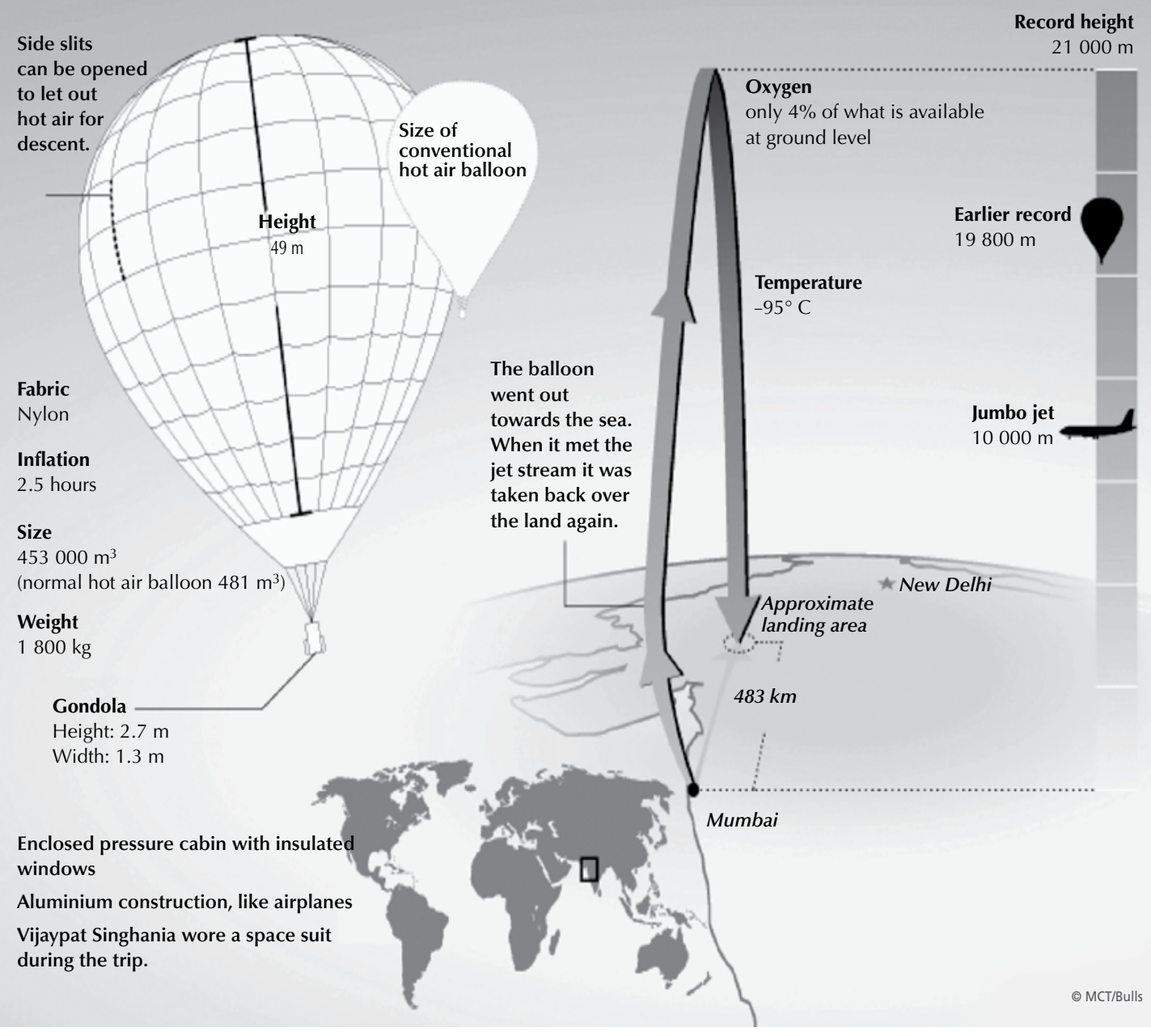

Use "Balloon" on the previous page to answer the questions that follow.

\section{BALLOON - QUESTION 8}

Situation: Educational

Text format: Non-continuous

Text type: Description

Aspect: Integrate and interpret - Form a broad understanding

Question format: Multiple choice

Difficulty: 370 (Level 1a).

What is the main idea of this text?

A. Singhania was in danger during his balloon trip.

B. Singhania set a new world record.

C. Singhania travelled over both sea and land.

D. Singhania's balloon was enormous. 
Scoring

Full Credit: B. Singhania set a new world record.

Comment

The main idea of this non-continuous text is stated explicitly and prominently several times, including in the title, "Height record for hot air balloon". The prominence and repetition of the required information helps to explains its easiness: it is located in the lower half of Level 1 a.

Although the main idea is explicitly stated, the question is classified as integrate and interpret, with the sub-classification forming a broad understanding, because it involves distinguishing the most significant and general from subordinate information in the text. The first option - "Singhania was in danger during his balloon trip" - is a plausible speculation, but it is not supported by anything in the text, and so cannot qualify as a main idea. The third option - "Singhania travelled over both sea and land" - accurately paraphrases information from the text, but it is a detail rather than the main idea. The fourth option - "Singhania's balloon was enormous" - refers to a conspicuous graphic feature in the text but, again, it is subordinate to the main idea.

\section{BALLOON - QUESTION 3}

Situation: Educational

Text format: Non-continuous

Text type: Description

Aspect: Access and retrieve - Retrieve information

Question format: Short response

Difficulty: Full credit 595 (Level 4); Partial credit 449 (Level 2).

Vijaypat Singhania used technologies found in two other types of transport. Which types of transport? 1.

2.

\section{Scoring}

Full Credit: Refers to BOTH airplanes AND spacecraft (in either order, can include both answers on one line). For example:

- 1. Aircraft

2. Spacecraft

- 1. Airplanes

2. Space ships

- 1. Air travel

2. Space travel

- 1. Planes

2. Space rockets

- 1. Jets

2. Rockets

Partial Credit: Refers to EITHER airplanes OR spacecraft. For example:

- Spacecraft

- Space travel

- Space rockets

- Rockets

- Aircraft

- Airplanes

- Air travel

- Jets 


\section{Comment}

In this task full credit is given for responses that lists the two required types of transport, and partial credit is given to responses that listed one type. The scoring rules reproduced above demonstrate that credit is available for several different paraphrases of the terms "airplanes" and "spacecraft".

The partial credit score is located in the upper half of Level 2 while the full credit score is located at Level 4, illustrating the fact that access and retrieve questions can create a significant challenge. The difficulty of the task is particularly influenced by a number of features of the text. The layout, with several different kinds of graphs and multiple captions, is quite a common type of non-continuous presentation often seen in magazines and modern textbooks, but because it does not have a conventional ordered structure (unlike, for example, a table or graph), finding specific pieces of discrete information is relatively inefficient. Captions ("Fabric", "Record height", and so on) give some support to the reader in navigating the text, but the information specific required for this task does not have a caption, so that readers have to generate their own categorisation of the relevant information as they search. Having once found the required information, inconspicuously located at the bottom left-hand corner of the diagram, the reader needs to recognise that the "aluminium construction, like airplanes" and the "space suit" are associated with categories of transport. In order to obtain credit for this question, the response needs to refer to a form or forms of transport, rather than simply transcribing an approximate section of text. Thus "space travel" is credited, but "space suit" is not. A significant piece of competing information in the text constitutes a further difficulty: many students referred to a "jumbo jet" in their answer. Although "air travel" or "airplane" or "jet" is given credit, "jumbo jet" is deemed to refer specifically to the image and caption on the right of the diagram. This answer is not given credit as the jumbo jet in the illustration is not included in the material with reference to technology used for Singhania's balloon.

\section{BALLOON - QUESTION 4}

Situation: Educational

Text format: Non-continuous

Text type: Description

Aspect: Reflect and evaluate - Reflect on and evaluate the content of a text

Question format: Open Constructed Response

Difficulty: 510 (Level 3).

What is the purpose of including a drawing of a jumbo jet in this text?

Scoring

Full Credit: Refers explicitly or implicitly to the height of the balloon OR to the record. May refer to comparison between the jumbo jet and the balloon.

- To show how high the balloon went.

- To emphasise the fact that the balloon went really, really high.

- To show how impressive his record really was - he went higher than jumbo jets!

- As a point of reference regarding height.

- To show how impressive his record really was. [minimal]

\section{Comment}

The main idea of the text is to describe the height record set by Vijaypat Singhania in his extraordinary balloon. The diagram on the right-hand side of the graphic, which includes the jumbo jet, implicitly contributes to the "wow!" factor of the text, showing just how impressive the height achieved by Singhania was by comparing it with what we usually associate with grand height: a jumbo jet's flight. In order to gain credit for this task, students must recognise the persuasive intent of including the illustration of the jumbo jet. For this reason the task is classified as reflect and evaluate, with the sub-category reflect on and evaluate the content of a text. At the upper end of Level 3, this question is moderately difficult. 


\section{BALLOON - OUESTION 6}

Situation: Educational Text format: Non-continuous

Text type: Description

Aspect: Reflect and evaluate - Reflect on and evaluate the content of a text

Question format: Multiple choice

Difficulty: 411 (Level 2).

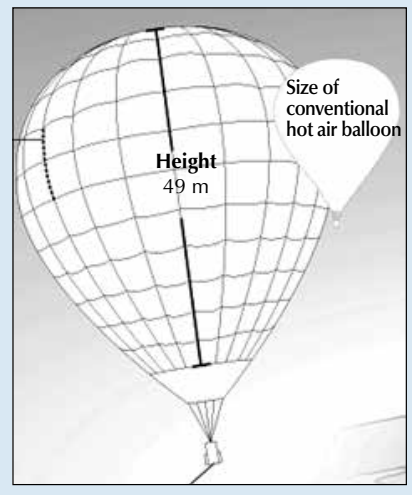

Why does the drawing show two balloons?

A. To compare the size of singhania's balloon before and after it was inflated.

B. To compare the size of Singhania's balloon with that of other hot air balloons.

C. To show that Singhania's balloon looks small from the ground.

D. To show that Singhania's balloon almost collided with another balloon.

\section{Scoring}

Full Credit: B. To compare the size of Singhania's balloon with that of other hot air balloons.

\section{Comment}

It is important for readers to be aware that texts are not randomly occurring artefacts, but are constructed deliberately and with intent, and that part of the meaning of a text is found in the elements that authors choose to include. Like the previous task, this task is classified under reflect and evaluate because it asks about authorial intent. It focuses on a graphic element - here the illustration of two balloons - and asks students to consider the purpose of this inclusion. In the context of the over-arching idea of the text, to describe (and celebrate) Singhania's flight, the balloon illustration sends the message, "This is a really big balloon!", just as the jumbo jet illustration sends the message, "This is a really high flight!" The caption on the smaller balloon ("Size of a conventional hot air balloon") makes it obvious that this is a different balloon to Singhania's, and therefore, for attentive readers, renders options A and C implausible. Option D has no support in the text. With a difficulty near the bottom of Level 2, this is a rather easy task. 


\section{THE MISER AND HIS GOLD}

A fable by Aesop

A miser sold all that he had and bought a lump of gold, which he buried in a hole in the ground by the side of an old wall. He went to look at it daily. One of his workmen observed the miser's frequent visits to the spot and decided to watch his movements. The workman soon discovered the secret of the hidden treasure, and digging down, came to the lump of gold, and stole it. The miser, on his next visit, found the hole empty and began to tear his hair and to make loud lamentations. A neighbour, seeing him overcome with grief and learning the cause, said, "Pray do not grieve so; but go and take a stone, and place it in the hole, and fancy that the gold is still lying there. It will do you quite the same service; for when the gold was there, you had it not, as you did not make the slightest use of it."

Use the fable "The Miser and his Gold" on the previous page to answer the questions that follow.

MISER

- QUESTION 1

Situation: Personal

Text format: Continuous

Text type: Narration

Aspect: Integrate and interpret - Develop an interpretation

Question format: Closed constructed response

Difficulty: 373 (Level 1a).

Read the sentences below and number them according to the sequence of events in the text.

The miser decided to turn all his money into a lump of gold.

A man stole the miser's gold.

The miser dug a hole and hid his treasure in it.

The miser's neighbour told him to replace the gold with a stone.

\section{Scoring}

Full Credit: All four correct: 1, 3, 2, 4 in that order.

\section{Comment}

Fables are a popular and respected text type in many cultures and they are a favourite text type in reading assessments for similar reasons: they are short, self-contained, morally instructive and have stood the test of time. While perhaps not the most common reading material for young adults in OECD countries they are nevertheless likely to be familiar from childhood, and the pithy, often acerbic observations of a fable can pleasantly surprise even a blasé 15-year-old. MISER is typical of its genre: it captures and satirises a particular human weakness in a neat economical story, executed in a single paragraph.

Since narrations are defined as referring to properties of objects in time, typically answering "when" questions, it is appropriate to include a task based on a narrative text that asks for a series of statements about the story to be put into the correct sequence. With such a short text, and with statements in the task that are closely matched with the terms of the story, this is an easy task, around the middle of Level 1a. On the other hand, the language of the text is rather formal and has some old-fashioned locutions. (Translators were asked to reproduce the fable-like style of the source versions.) This characteristic of the text is likely to have added to the difficulty of the question. 
MISER - QUESTION 7

Situation: Personal

Text format: Continuous

Text type: Narration

Aspect: Access and retrieve - Retrieve information

Question format: Short response

Difficulty: 310 (Level $1 \mathrm{~b}$ )

How did the miser get a lump of gold?

\section{Scoring}

Full Credit: States that he sold everything he had. May paraphrase or quote directly from the text.

- He sold all he had.

- He sold all his stuff.

- He bought it. [implicit connection to selling everything he had]

\section{Comment}

This is one of the easiest tasks in PISA reading, with a difficulty in the middle of Level $1 \mathrm{~b}$. The reader is required to access and retrieve a piece of explicitly stated information in the opening sentence of a very short text. To gain full credit, the response can either quote directly from the text - "He sold all that he had" - or provide a paraphrase such as "He sold all his stuff". The formal language of the text, which is likely to have added difficulty in other tasks in the unit, is unlikely to have much impact here because the required information is located at the very beginning of the text. Although this is an extremely easy question in PISA's frame of reference, it still requires a small degree of inference, beyond the absolutely literal: the reader must infer that there is a causal connection between the first proposition (that the miser sold all he had) and the second (that he bought gold).

MISER - QUESTION 5

Situation: Personal

Text format: Continuous

Text type: Narration

Aspect: Integrate and interpret - Develop an interpretation

Question format: Open constructed response

Difficulty: 548 (Level 3).

Here is part of a conversation between two people who read "The Miser and his Gold".

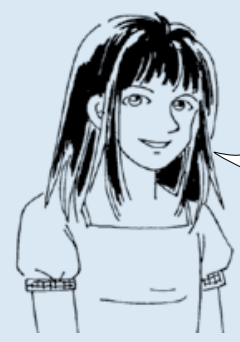

Speaker 1

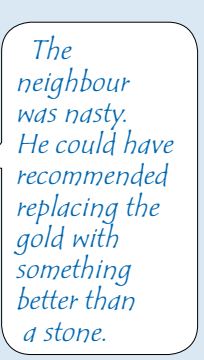

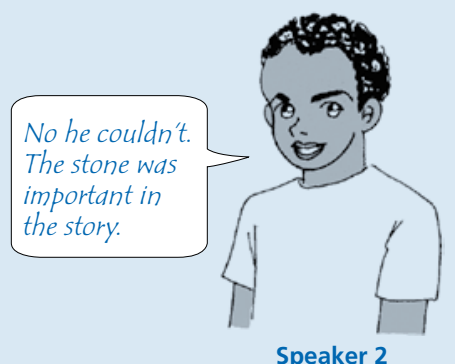

Speaker 2

What could Speaker 2 say to support his point of view? 
Scoring

\section{Full Credit}

Recognises that the message of the story depends on the gold being replaced by something useless or worthless.

- It needed to be replaced by something worthless to make the point.

- The stone is important in the story, because the whole point is he might as well have buried a stone for all the good the gold did him.

- If you replaced it with something better than a stone, it would miss the point because the thing buried needs to be something really useless.

- A stone is useless, but for the miser, so was the gold!

- Something better would be something he could use - he didn't use the gold, that's what the guy was pointing out.

- Because stones can be found anywhere. The gold and the stone are the same to the miser. ["can be found anywhere" implies that the stone is of no special value]

\section{Comment}

This task takes the form of setting up a dialogue between two imaginary readers, to represent two conflicting interpretations of the story. In fact only the second speaker's position is consistent with the overall implication of the text, so that in providing a supporting explanation readers demonstrate that they have understood the "punch line" - the moral import - of the fable. The relative difficulty of the task, near the top of Level 3, is likely to be influenced by the fact that readers needs to do a good deal of work to generate a full credit response. First they must make sense of the neighbour's speech in the story, which is expressed in a formal register. (As noted, translators were asked to reproduce the fable-like style.) Secondly, the relationship between the question stem and the required information is not obvious: there is little or no support in the stem ("What could Speaker 2 say to support his point of view?") to guide the reader in interpreting the task, though the reference to the stone and the neighbour by the speakers should point the reader to the end of the fable.

As shown in examples of responses, to gain full credit, students could express, in a variety of ways, the key idea that wealth has no value unless it is used. Vague gestures at meaning, such as "the stone had a symbolic value", are not given credit. 


\section{Notes}

1. Of the 64 countries and economies that have trend data up to 2012, 30 participated in PISA 2012 and have comparable results for every assessment since PISA 2000; 14 countries and economies have comparable data for 2012 and three other PISA assessments; 13 have comparable data for 2012 and two other PISA assessments; and 7 have comparable data for 2012 and one additional PISA assessment.

2. As described in more detail in Annex A5, the annualised change takes into account the specific year in which the assessment took place. In the case of reading, this is especially relevant for the 2009 assessment as Costa Rica, Malaysia and the United Arab Emirates (excl. Dubai) implemented the assessment in 2010 as part of PISA+ and the 2000 assessment as Chile and the partner countries and economies Albania, Argentina, Bulgaria, Hong Kong-China, Indonesia, Peru and Thailand implemented the assessment in 2001, Israel and Romania in 2002 as part of PISA+.

3. As described in Annex A5, the annualised change considers the case of countries and economies that implemented PISA 2000 in 2001 or 2002 and those that implemented PISA 2009 in 2010 as part of PISA+.

4. By accounting for students' gender, age, socio-economic status, migration background and language spoken at home, the adjusted trends allow for a comparison of changes in performance assuming no alteration in the underlying population or the effective samples' average socio-economic status, age and percentage of girls, students with an immigrant background or students that speak a language at home that is different from the language of assessment.

5. Israel shows a seven percentage-point decline in the weighted percentage of girls assessed by PISA. The sampling design for Israel in the PISA 2000 assessment did not account for the gender composition of schools, despite the different participation rates between boys and girls in Israel due to the fact that some boys' schools refused to take part in the assessment. The gender distribution in the PISA 2000 data for Israel was subject to a relatively large sampling variance due to an inefficient sampling design. The section on adjusted trends takes this into account by adjusting results for 2000 so that the gender distribution is comparable to that observed in 2012 . Nevertheless, trends in the socio-economic status of students and in the percentage of students with an immigrant background - which are also taken into account in the adjusted trends - also played an important role in the observed performance changes in Israel.

\section{References}

Buchmann, C., T. DiPrete and A. McDaniel (2008), "Gender Inequalities in Education”, Annual Review of Sociology, Vol. 34, pp. $319-337$.

OECD (2010), Pathways to Success: How Knowledge and Skills at Age 15 Shape Future Lives in Canada, PISA, OECD Publishing. http://dx.doi.org/10.1787/9789264081925-en

OECD (2010b), PISA 2009 Results: Learning to Learn, Student Engagement, Strategies and Practices (Volume III), PISA, OECD Publishing. http://dx.doi.org/10.1787/9789264083943-en

OECD (2009), PISA 2009 Assessment Framework: Key Competencies in Reading, Mathematics and Science, PISA, OECD Publishing. http://dx.doi.org/10.1787/9789264062658-en

OECD (2001), Knowledge and Skills for Life: First Results from PISA 2000, PISA, OECD Publishing.

http://dx.doi.org/10.1787/9789264195905-en 


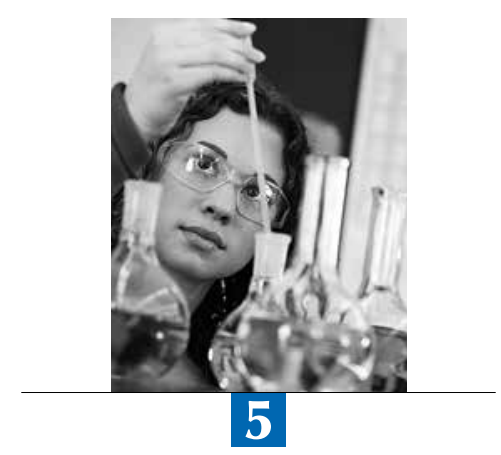

\section{A Profile \\ of Student Performance in Science}

This chapter examines student performance in science in PISA 2012. It provides examples of assessment questions, relating them to each PISA proficiency level, discusses gender differences in student performance, compares countries' and economies' performance in science, and highlights trends in science performance up to 2012. 
What can 15-year-old students do in science? This chapter describes how PISA 2012 measures student achievement in science around the world, at the country and regional levels, among boys and girls, and also compares outcomes of PISA 2012 with those of the previous PISA cycles. It provides a few examples of the questions asked in the science assessment.

An understanding of science and technology is central to a young person's preparedness for life in modern society, not least because it empowers individuals to participate in determining public policy where issues of science and technology affect their lives. PISA defines scientific literacy as an individual's scientific knowledge, and use of that knowledge, to identify questions, acquire new knowledge, explain scientific phenomena and draw evidence-based conclusions about science-related issues; understanding of the characteristic features of science as a form of human knowledge and enquiry; awareness of how science and technology shape our material, intellectual and cultural environments; and willingness to engage in science-related issues, and with the ideas of science, as a reflective citizen (OECD, 2007).

Science was the focus of the PISA 2006 survey and a minor domain in PISA 2009 and 2012. Less time was allocated during these latter two assessments than in PISA 2006. Ninety minutes of the assessment time were devoted to science in the last two cycles, allowing for only an update on overall performance rather than the kind of in-depth analysis of knowledge and skills shown in the PISA 2006 report (OECD, 2007).

\section{What the data tell us}

- Nineteen of 64 countries and economies with comparable data show an average annual improvement, 37 show no change, and 8 show a deterioration in their science performance throughout their participation in PISA.

- Hong Kong-China, Ireland, Japan, Korea and Poland performed at or above the OECD average in science in 2006 and by 2012 showed an improvement in science performance of more than two score points per year. Estonia also performed above the OECD average in science in 2006, and between 2009 and 2012 improved its score by 14 points.

- Estonia, Israel, Italy, Poland, Qatar and Singapore reduced the share of students who do not attain the baseline level of proficiency and simultaneously increased the share of top-performing students in science.

- Boys and girls perform similarly in science and, on average, that remained true in 2012. But in Colombia, Japan and Spain, while there was no gender gap in science performance in 2006, a gender gap in favour of boys was observed in 2012.

\section{STUDENT PERFORMANCE IN SCIENCE}

In PISA 2006 the mean science score for OECD countries was initially set at 500 points (for 30 OECD countries), then was re-set at 498 points after taking into account the four newest OECD countries. To help interpret what students' scores mean in substantive terms, the scale is divided into levels of proficiency that indicate the kinds of tasks that students at those levels are capable of completing successfully (OECD, 2006).

\section{Average performance in science}

One way to summarise student performance and to compare the relative standing of countries in science is through countries' mean performance, both relative to each other and to the OECD mean. For PISA 2012, the mean in science for OECD countries increased to 501 points. This establishes the benchmark against which each country's and economy's science performance in PISA 2012 is compared.

When interpreting mean performance, only those differences among countries and economies that are statistically significant should be taken into account. Figure I.5.1 shows each country's/economy's mean score and also for which pairs of countries/economies the differences between the means are statistically significant. For each country/economy shown in the middle column, the countries/economies whose mean scores are not statistically significantly different are listed in the right column. In all other cases, country/economy A scores higher than country/economy B if country/ economy $A$ is situated above country/economy $B$ in the middle column, and scores lower if country/economy $A$ is situated below country/economy B. For example: Shanghai-China ranks first on the PISA science scale, but Hong Kong-China, which appears second on the list, cannot be distinguished with confidence from Singapore and Japan, which appear third and fourth, respectively. 
- Figure I.5.1

\section{Comparing countries' and economies' performance in science}

\begin{tabular}{|c|c|c|}
\hline \multirow[b]{3}{*}{$\begin{array}{l}\text { Mean } \\
\text { score }\end{array}$} & \multirow[b]{3}{*}{$\begin{array}{l}\text { Comparison country/ } \\
\text { economy }\end{array}$} & \multirow{2}{*}{$\begin{array}{l}\text { Statistically significantly above the OECD average } \\
\text { Not statistically significantly different from the OECD average } \\
\text { Statistically significantly below the OECD average }\end{array}$} \\
\hline & & \\
\hline & & Countries/economies whose mean score is NOT statistically significantly different from that comparison country's/economy's score \\
\hline 580 & Shanghai-China & \\
\hline 555 & Hong Kong-China & Singapore, Japan \\
\hline 551 & Singapore & Hong Kong-China, Japan \\
\hline 547 & Japan & Hong Kong-China, Singapore, Finland, Estonia, Korea \\
\hline 545 & Finland & Japan, Estonia, Korea \\
\hline 541 & Estonia & Japan, Finland, Korea \\
\hline 538 & Korea & Japan, Finland, Estonia, Viet Nam \\
\hline 528 & Viet Nam & Korea, Poland, Canada, Liechtenstein, Germany, Chinese Taipei, Netherlands, Ireland, Australia, Macao-China \\
\hline 526 & Poland & Viet Nam, Canada, Liechtenstein, Germany, Chinese Taipei, Netherlands, Ireland, Australia, Macao-China \\
\hline 525 & Canada & Viet Nam, Poland, Liechtenstein, Germany, Chinese Taipei, Netherlands, Ireland, Australia \\
\hline 525 & Liechtenstein & Viet Nam, Poland, Canada, Germany, Chinese Taipei, Netherlands, Ireland, Australia, Macao-China \\
\hline 524 & Germany & Viet Nam, Poland, Canada, Liechtenstein, Chinese Taipei, Netherlands, Ireland, Australia, Macao-China \\
\hline 523 & Chinese Taipei & Viet Nam, Poland, Canada, Liechtenstein, Germany, Netherlands, Ireland, Australia, Macao-China \\
\hline 522 & Netherlands & $\begin{array}{l}\text { Viet Nam, Poland, Canada, Liechtenstein, Germany, Chinese Taipei, Ireland, Australia, Macao-China, New Zealand, Switzerland, } \\
\text { United Kingdom }\end{array}$ \\
\hline 522 & Ireland & $\begin{array}{l}\text { Viet Nam, Poland, Canada, Liechtenstein, Germany, Chinese Taipei, Netherlands, Australia, Macao-China, New Zealand, Switzerland, } \\
\text { United Kingdom }\end{array}$ \\
\hline 521 & Australia & Viet Nam, Poland, Canada, Liechtenstein, Germany, Chinese Taipei, Netherlands, Ireland, Macao-China, Switzerland, United Kingdom \\
\hline 521 & Macao-China & Viet Nam, Poland, Liechtenstein, Germany, Chinese Taipei, Netherlands, Ireland, Australia, Switzerland, United Kingdom \\
\hline 516 & New Zealand & Netherlands, Ireland, Switzerland, Slovenia, United Kingdom \\
\hline 515 & Switzerland & Netherlands, Ireland, Australia, Macao-China, New Zealand, Slovenia, United Kingdom, Czech Republic \\
\hline 514 & Slovenia & New Zealand, Switzerland, United Kingdom, Czech Republic \\
\hline 514 & United Kingdom & Netherlands, Ireland, Australia, Macao-China, New Zealand, Switzerland, Slovenia, Czech Republic, Austria \\
\hline 508 & Czech Republic & Switzerland, Slovenia, United Kingdom, Austria, Belgium, Latvia \\
\hline 506 & Austria & United Kingdom, Czech Republic, Belgium, Latvia, France, Denmark, United States \\
\hline 505 & Belgium & Czech Republic, Austria, Latvia, France, United States \\
\hline 502 & Latvia & Czech Republic, Austria, Belgium, France, Denmark, United States, Spain, Lithuania, Norway, Hungary \\
\hline 499 & France & Austria, Belgium, Latvia, Denmark, United States, Spain, Lithuania, Norway, Hungary, Italy, Croatia \\
\hline 498 & Denmark & Austria, Latvia, France, United States, Spain, Lithuania, Norway, Hungary, Italy, Croatia \\
\hline 497 & United States & Austria, Belgium, Latvia, France, Denmark, Spain, Lithuania, Norway, Hungary, Italy, Croatia, Luxembourg, Portugal \\
\hline 496 & Spain & Latvia, France, Denmark, United States, Lithuania, Norway, Hungary, Italy, Croatia, Portugal \\
\hline 496 & Lithuania & Latvia, France, Denmark, United States, Spain, Norway, Hungary, Italy, Croatia, Luxembourg, Portugal \\
\hline 495 & Norway & Latvia, France, Denmark, United States, Spain, Lithuania, Hungary, Italy, Croatia, Luxembourg, Portugal, Russian Federation \\
\hline 494 & Hungary & Latvia, France, Denmark, United States, Spain, Lithuania, Norway, Italy, Croatia, Luxembourg, Portugal, Russian Federation \\
\hline 494 & Italy & France, Denmark, United States, Spain, Lithuania, Norway, Hungary, Croatia, Luxembourg, Portugal \\
\hline 491 & Croatia & France, Denmark, United States, Spain, Lithuania, Norway, Hungary, Italy, Luxembourg, Portugal, Russian Federation, Sweden \\
\hline 491 & Luxembourg & United States, Lithuania, Norway, Hungary, Italy, Croatia, Portugal, Russian Federation \\
\hline 489 & Portugal & United States, Spain, Lithuania, Norway, Hungary, Italy, Croatia, Luxembourg, Russian Federation, Sweden \\
\hline 486 & Russian Federation & Norway, Hungary, Croatia, Luxembourg, Portugal, Sweden \\
\hline 485 & Sweden & Croatia, Portugal, Russian Federation Iceland \\
\hline 478 & Iceland & Sweden, Slovak Republic, Israel \\
\hline 471 & Slovak Republic & Iceland, Israel, Greece, Turkey \\
\hline 470 & Israel & Iceland, Slovak Republic, Greece, Turkey \\
\hline 467 & Greece & Slovak Republic, Israel, Turkey \\
\hline 463 & Turkey & Slovak Republic, Israel, Greece \\
\hline 448 & United Arab Emirates & Bulgaria, Chile, Serbia, Thailand \\
\hline 446 & Bulgaria & United Arab Emirates, Chile, Serbia, Thailand, Romania, Cyprus ${ }^{1,2}$ \\
\hline 445 & Chile & United Arab Emirates, Bulgaria, Serbia, Thailand, Romania \\
\hline 445 & Serbia & United Arab Emirates, Bulgaria, Chile, Thailand, Romania \\
\hline 444 & Thailand & United Arab Emirates, Bulgaria, Chile, Serbia, Romania \\
\hline 439 & Romania & Bulgaria, Chile, Serbia, Thailand, Cyprus 1,2 \\
\hline 438 & Cyprus ${ }^{1,2}$ & Bulgaria, Romania \\
\hline 429 & Costa Rica & Kazakhstan \\
\hline 425 & Kazakhstan & Costa Rica, Malaysia \\
\hline 420 & Malaysia & Kazakhstan, Uruguay, Mexico \\
\hline 416 & Uruguay & Malaysia, Mexico, Montenegro, Jordan \\
\hline 415 & Mexico & Malaysia, Uruguay, Jordan \\
\hline 410 & Montenegro & Uruguay, Jordan, Argentina \\
\hline 409 & Jordan & Uruguay, Mexico, Montenegro, Argentina, Brazil \\
\hline 406 & Argentina & Montenegro, Jordan, Brazil, Colombia, Tunisia, Albania \\
\hline 405 & Brazil & Jordan, Argentina, Colombia, Tunisia \\
\hline 399 & Colombia & Argentina, Brazil, Tunisia, Albania \\
\hline 398 & Tunisia & Argentina, Brazil, Colombia, Albania \\
\hline 397 & Albania & Argentina, Colombia, Tunisia \\
\hline 384 & Qatar & Indonesia \\
\hline 382 & Indonesia & Qatar, Peru \\
\hline 373 & Peru & Indonesia \\
\hline
\end{tabular}

1. Note by Turkey: The information in this document with reference to "Cyprus" relates to the southern part of the Island. There is no single authority representing both Turkish and Greek Cypriot people on the Island. Turkey recognises the Turkish Republic of Northern Cyprus (TRNC). Until a lasting and equitable solution is found within the context of the United Nations, Turkey shall preserve its position concerning the "Cyprus issue".

2. Note by all the European Union Member States of the OECD and the European Union: The Republic of Cyprus is recognised by all members of the United Nations with the exception of Turkey. The information in this document relates to the area under the effective control of the Government of the Republic of Cyprus.

Source: OECD, PISA 2012 Database.

StatLink 解出 http://dx.doi.org/10.1787/888932935629 
Moreover, countries and economies are divided into three broad groups: those whose mean scores are statistically around the OECD mean (highlighted in dark blue), those whose mean scores are above the OECD mean (highlighted in pale blue), and those whose mean scores are below the OECD mean (highlighted in medium blue).

As shown in Figure 1.5.1, five countries and economies outperform all other countries and economies in science in PISA 2012 by about half a standard deviation above the average or more: Shanghai-China (580 points), Hong Kong-China (555 points), Singapore (551 points), Japan (547 points) and Finland (545 points). Shanghai-China has a mean score of 580, which is more than three-quarters of a proficiency level above the average of 501 score points in PISA 2012. Other countries with mean performances above the average include Estonia, Korea, Viet Nam, Poland, Canada, Liechtenstein, Germany, Chinese Taipei, the Netherlands, Ireland, Australia, Macao-China, New Zealand, Switzerland, Slovenia, the United Kingdom and the Czech Republic. Countries that performed around the average include Austria, Belgium, Latvia, France, Denmark and the United States. Thirty-seven participating countries and economies have a mean score that is below the OECD average.

The gap in performance between the highest- and the lowest-performing OECD countries is 132 score points. That is, while the average score of the highest-performing OECD country, Japan (547), is slightly more than half a standard deviation above the OECD average, the average score of the lowest-performing OECD country, Mexico (415 points) is more than three-quarters of one standard deviation below the OECD average. But the performance difference observed among partner countries and economies is even larger, with a 207 score-point difference between Shanghai-China (580 points) and Peru (373 points).

Because the figures are derived from samples, it is not possible to determine a country's/economy's precise ranking among all participating countries and economies. However, it is possible to determine with confidence a range of rankings in which the country's/economy's performance level lies (Figure 1.5.2). For entities other than those for which full samples were drawn (i.e. Shanghai-China, Hong Kong-China, Chinese Taipei and Macao-China) is not possible to calculate a rank order but the mean score provides a possibility to position subnational entities against the performance of the countries and economies. For example Western Australia shows a score just below the performance of top-performer Korea.

\section{Trends in average science performance}

The change in a school system's average performance over time indicates how and to what extent the system is progressing towards achieving the goal of providing all students with the knowledge and skills needed to become full participants in a knowledge-based society. PISA 2012 science results can be compared with those from PISA 2009 and PISA 2006, when science was first a major domain. PISA 2012 results for 54 countries and economies can be compared with data from both PISA 2009 and PISA 2006; trends for nine countries and economies can be observed using data from PISA 2009 and PISA 2012; and trends for one country can be observed using data from PISA 2006 and PISA 2012. The following trends in average performance are presented as the annualised change for these 64 countries and economies the average yearly change in science performance observed in a country or economy throughout its participation in PISA. (For further details on the estimation of the annualised change, see Annex A5). ${ }^{1}$

On average across OECD countries, science performance has remained broadly stable since 2006. Among the 64 countries and economies with annualised change, 19 countries and economies saw improvements in their science performance. Figure I.5.3 shows that the annualised change was largest in Kazakhstan (at an annual increase of eight score points per year), Turkey (six score points per year), Qatar and Poland (five and four points per year, respectively), Thailand, Romania, Singapore and Italy (three points per year). For example, the average 15-year-old student in Turkey scored 424 points in the PISA 2006 science assessment; three years later, the average student scored 454 points and, in 2012, he or she scored 463 points. Similarly, in Poland in 2006, the average student scored at the OECD average of 498 points in science, improved to 508 points in 2009, then improved again to score 526 points in 2012 (Table I.5.3b).

Improvements of more than two score points per year were observed in Israel, Korea, Japan, Dubai (United Arab Emirates), Portugal, Brazil, Ireland, Tunisia, Hong Kong-China and Latvia. Annualised improvement in science was also seen in Macao-China.

The average change observed over successive PISA cycles does not capture the extent to which this change is steady, or whether it is decelerating or accelerating. The rate of acceleration of improvement may be steady, in which case the science skills of a country's/economy's students improved at a steady pace between 2006 and 2012. The rate may also be accelerating, in which case the improvement between 2009 and 2012 is greater than that between 2006 and 2009; or the rate could be decelerating, in which case there was less of an improvement observed between 2009 and 2012 than between 2006 and 2009. 
- Figure 1.5.2 [Part 1/3] Ш

\section{Science performance among PISA 2012 participants, at national and regional levels}

\begin{tabular}{|c|c|c|c|c|c|}
\hline & \multicolumn{5}{|c|}{ Science scale } \\
\hline & \multirow[b]{3}{*}{ Mean score } & \multicolumn{4}{|c|}{ Range of ranks } \\
\hline & & \multicolumn{2}{|c|}{ OECD countries } & \multicolumn{2}{|c|}{ All countries/economies } \\
\hline & & Upper rank & Lower rank & Upper rank & Lower rank \\
\hline Shanghai-China & 580 & & & 1 & 1 \\
\hline Hong Kong-China & 555 & & & 2 & 3 \\
\hline Singapore & 551 & & & 2 & 4 \\
\hline Japan & 547 & 1 & 3 & 3 & 6 \\
\hline Finland & 545 & 1 & 3 & 4 & 6 \\
\hline Estonia & 541 & 2 & 4 & 5 & 7 \\
\hline Korea & 538 & 2 & 4 & 5 & 8 \\
\hline Western Australia (Australia) & 535 & & & & \\
\hline Australian Capital Territory (Australia) & 534 & & & & \\
\hline Trento (Italy) & 533 & & & & \\
\hline Friuli Venezia Giulia (Italy) & 531 & & & & \\
\hline Veneto (Italy) & 531 & & & & \\
\hline Lombardia (Italy) & 529 & & & & \\
\hline Viet Nam & 528 & & & 7 & 15 \\
\hline Massachusetts (United States) & 527 & & & & \\
\hline Poland & 526 & 5 & 9 & 8 & 16 \\
\hline New South Wales (Australia) & 526 & & & & \\
\hline Canada & 525 & 5 & 8 & 8 & 14 \\
\hline Liechtenstein & 525 & & & 8 & 17 \\
\hline Germany & 524 & 5 & 10 & 8 & 17 \\
\hline Chinese Taipei & 523 & & & 9 & 17 \\
\hline Netherlands & 522 & 5 & 11 & 8 & 18 \\
\hline Ireland & 522 & 6 & 11 & 10 & 18 \\
\hline Australia & 521 & 7 & 11 & 11 & 18 \\
\hline Connecticut (United States) & 521 & & & & \\
\hline Macao-China & 521 & & & 13 & 17 \\
\hline Castile and Leon (Spain) & 519 & & & & \\
\hline Bolzano (Italy) & 519 & & & & \\
\hline Queensland (Australia) & 519 & & & & \\
\hline Flemish community (Belgium) & 518 & & & & \\
\hline Victoria (Australia) & 518 & & & & \\
\hline Madrid (Spain) & 517 & & & & \\
\hline Asturias (Spain) & 517 & & & & \\
\hline England (United Kingdom) & 516 & & & & \\
\hline New Zealand & 516 & 10 & 14 & 17 & 21 \\
\hline Switzerland & 515 & 10 & 15 & 17 & 22 \\
\hline Slovenia & 514 & 11 & 14 & 18 & 21 \\
\hline Navarre (Spain) & 514 & & & & \\
\hline United Kingdom & 514 & 10 & 15 & 16 & 22 \\
\hline Scotland (United Kingdom) & 513 & & & & \\
\hline South Australia (Australia) & 513 & & & & \\
\hline Emilia Romagna (Italy) & 512 & & & & \\
\hline Galicia (Spain) & 512 & & & & \\
\hline La Rioja (Spain) & 510 & & & & \\
\hline Piemonte (Italy) & 509 & & & & \\
\hline Czech Republic & 508 & 14 & 17 & 21 & 25 \\
\hline Valle d'Aosta (Italy) & 508 & & & & \\
\hline German-speaking community (Belgium) & 508 & & & & \\
\hline Northern Ireland (United Kingdom) & 507 & & & & \\
\hline Marche (Italy) & 507 & & & & \\
\hline Austria & 506 & 15 & 18 & 22 & 26 \\
\hline Basque Country (Spain) & 506 & & & & \\
\hline Belgium & 505 & 15 & 18 & 22 & 25 \\
\hline Aragon (Spain) & 504 & & & & \\
\hline Latvia & 502 & & & 23 & 29 \\
\hline Umbria (Italy) & 501 & & & & \\
\hline Liguria (Italy) & 501 & & & & \\
\hline Toscana (Italy) & 501 & & & & \\
\hline Cantabria (Spain) & 501 & & & & \\
\hline Tasmania (Australia) & 500 & & & & \\
\hline France & 499 & 17 & 22 & 24 & 31 \\
\hline Denmark & 498 & 17 & 23 & 24 & 32 \\
\hline United States & 497 & 17 & 25 & 24 & 35 \\
\hline
\end{tabular}

Notes: OECD countries are shown in bold black. Partner countries are shown in bold blue. Participating economies and subnational entities that are not included in national results are shown in bold blue italics. Regions are shown in black italics (OECD countries) or blue italics (partner countries).

1. Note by Turkey: The information in this document with reference to "Cyprus" relates to the southern part of the Island. There is no single authority representing both Turkish and Greek Cypriot people on the Island. Turkey recognises the Turkish Republic of Northern Cyprus (TRNC). Until a lasting and equitable solution is found within the context of the United Nations, Turkey shall preserve its position concerning the "Cyprus issue".

2. Note by all the European Union Member States of the OECD and the European Union: The Republic of Cyprus is recognised by all members of the United Nations with the exception of Turkey. The information in this document relates to the area under the effective control of the Government of the Republic of Cyprus.

Countries, economies and subnational entities are ranked in descending order of mean science performance.

Source: OECD, PISA 2012 Database.

StatLink 靖血 http://dx.doi.org/10.1787/888932935629 
- Figure I.5.2 [Part 2/3]

\section{Science performance among PISA 2012 participants, at national and regional levels}

\begin{tabular}{|c|c|c|c|c|c|}
\hline & \multicolumn{5}{|c|}{ Science scale } \\
\hline & \multirow[b]{3}{*}{ Mean score } & \multicolumn{4}{|c|}{ Range of ranks } \\
\hline & & \multicolumn{2}{|c|}{ OECD countries } & \multicolumn{2}{|c|}{ All countries/economies } \\
\hline & & Upper rank & Lower rank & Upper rank & Lower rank \\
\hline Spain & 496 & 18 & 23 & 26 & 33 \\
\hline Lithuania & 496 & & & 26 & 34 \\
\hline Norway & 495 & 19 & 26 & 26 & 36 \\
\hline Hungary & 494 & 19 & 26 & 27 & 36 \\
\hline Alentejo (Portugal) & 494 & & & & \\
\hline Italy & 494 & 20 & 26 & 28 & 35 \\
\hline Catalonia (Spain) & 492 & & & & \\
\hline Croatia & 491 & & & 29 & 38 \\
\hline Luxembourg & 491 & 23 & 26 & 32 & 36 \\
\hline Wales (United Kingdom) & 491 & & & & \\
\hline Portugal & 489 & 22 & 27 & 30 & 38 \\
\hline French community (Belgium) & 487 & & & & \\
\hline Russian Federation & 486 & & & 34 & 38 \\
\hline Andalusia (Spain) & 486 & & & & \\
\hline Florida (United States) & 485 & & & & \\
\hline Sweden & 485 & 26 & 28 & 36 & 39 \\
\hline Lazio (Italy) & 484 & & & & \\
\hline Puglia (Italy) & 483 & & & & \\
\hline Northern Territory (Australia) & 483 & & & & \\
\hline Balearic Islands (Spain) & 483 & & & & \\
\hline Extremadura (Spain) & 483 & & & & \\
\hline Abruzzo (Italy) & 482 & & & & \\
\hline Perm Territory region (Russian Federation) & 480 & & & & \\
\hline Murcia (Spain) & 479 & & & & \\
\hline Iceland & 478 & 28 & 29 & 38 & 40 \\
\hline Dubai (United Arab Emirates) & 474 & & & & \\
\hline Sardegna (Italy) & 473 & & & & \\
\hline Slovak Republic & 471 & 28 & 31 & 39 & 42 \\
\hline Israel & 470 & 28 & 32 & 39 & 43 \\
\hline Molise (Italy) & 468 & & & & \\
\hline Greece & 467 & 29 & 32 & 40 & 43 \\
\hline Basilicata (Italy) & 465 & & & & \\
\hline Turkey & 463 & 30 & 32 & 41 & 43 \\
\hline Campania (Italy) & 457 & & & & \\
\hline Sicilia (Italy) & 454 & & & & \\
\hline Sharjah (United Arab Emirates) & 450 & & & & \\
\hline United Arab Emirates & 448 & & & 44 & 47 \\
\hline Bulgaria & 446 & & & 44 & 49 \\
\hline Chile & 445 & 33 & 33 & 44 & 48 \\
\hline Serbia & 445 & & & 44 & 49 \\
\hline Thailand & 444 & & & 44 & 49 \\
\hline Abu Dhabi (United Arab Emirates) & 440 & & & & \\
\hline Romania & 439 & & & 47 & 50 \\
\hline Cyprus 1,2 & 438 & & & 48 & 50 \\
\hline Jalisco (Mexico) & 436 & & & & \\
\hline Nuevo León (Mexico) & 435 & & & & \\
\hline Aguascalientes (Mexico) & 435 & & & & \\
\hline Querétaro (Mexico) & 432 & & & & \\
\hline Ras Al Khaimah (United Arab Emirates) & 431 & & & & \\
\hline Calabria (Italy) & 431 & & & & \\
\hline Colima (Mexico) & 429 & & & & \\
\hline Costa Rica & 429 & & & 51 & 52 \\
\hline Chihuahua (Mexico) & 429 & & & & \\
\hline Manizales (Colombia) & 429 & & & & \\
\hline Espírito Santo (Brazil) & 428 & & & & \\
\hline Distrito Federal (Mexico) & 427 & & & & \\
\hline Fujairah (United Arab Emirates) & 425 & & & & \\
\hline Morelos (Mexico) & 425 & & & & \\
\hline Kazakhstan & 425 & & & 51 & 53 \\
\hline Ciudad Autónoma de Buenos Aires (Argentina) & 425 & & & & \\
\hline Puebla (Mexico) & 423 & & & & \\
\hline Durango (Mexico) & 423 & & & & \\
\hline Federal District (Brazil) & 423 & & & & \\
\hline
\end{tabular}

Notes: OECD countries are shown in bold black. Partner countries are shown in bold blue. Participating economies and subnational entities that are not included in national results are shown in bold blue italics. Regions are shown in black italics (OECD countries) or blue italics (partner countries).

1. Note by Turkey: The information in this document with reference to "Cyprus" relates to the southern part of the Island. There is no single authority representing both Turkish and Greek Cypriot people on the Island. Turkey recognises the Turkish Republic of Northern Cyprus (TRNC). Until a lasting and equitable solution is found within the context of the United Nations, Turkey shall preserve its position concerning the "Cyprus issue".

2. Note by all the European Union Member States of the OECD and the European Union: The Republic of Cyprus is recognised by all members of the United Nations with the exception of Turkey. The information in this document relates to the area under the effective control of the Government of the Republic of Cyprus.

Countries, economies and subnational entities are ranked in descending order of mean science performance.

Source: OECD, PISA 2012 Database.

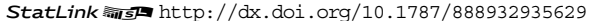


- Figure I.5.2 [Part 3/3]

\section{Science performance among PISA 2012 participants, at national and regional levels}

\begin{tabular}{|c|c|c|c|c|c|}
\hline & \multicolumn{5}{|c|}{ Science scale } \\
\hline & \multirow[b]{3}{*}{ Mean score } & \multicolumn{4}{|c|}{ Range of ranks } \\
\hline & & \multicolumn{2}{|c|}{ OECD countries } & \multicolumn{2}{|c|}{ All countries/economies } \\
\hline & & Upper rank & Lower rank & Upper rank & Lower rank \\
\hline Coahuila (Mexico) & 421 & & & & \\
\hline Mexico (Mexico) & 421 & & & & \\
\hline Ajman (United Arab Emirates) & 420 & & & & \\
\hline Minas Gerais (Brazil) & 420 & & & & \\
\hline Malaysia & 420 & & & 52 & 55 \\
\hline Rio Grande do Sul (Brazil) & 419 & & & & \\
\hline Baja California Sur (Mexico) & 418 & & & & \\
\hline Santa Catarina (Brazil) & 418 & & & & \\
\hline Medellin (Colombia) & 418 & & & & \\
\hline Baja California (Mexico) & 417 & & & & \\
\hline São Paulo (Brazil) & 417 & & & & \\
\hline Quintana Roo (Mexico) & 416 & & & & \\
\hline San Luis Potosí (Mexico) & 416 & & & & \\
\hline Uruguay & 416 & & & 53 & 56 \\
\hline Paraná (Brazil) & 416 & & & & \\
\hline Umm Al Quwain (United Arab Emirates) & 415 & & & & \\
\hline Yucatán (Mexico) & 415 & & & & \\
\hline Mexico & 415 & 34 & 34 & 54 & 56 \\
\hline Mato Grosso do Sul (Brazil) & 415 & & & & \\
\hline Tamaulipas (Mexico) & 414 & & & & \\
\hline Tlaxcala (Mexico) & 412 & & & & \\
\hline Paraiba (Brazil) & 412 & & & & \\
\hline Bogota (Colombia) & 411 & & & & \\
\hline Hidalgo (Mexico) & 411 & & & & \\
\hline Montenegro & 410 & & & 56 & 58 \\
\hline Jordan & 409 & & & 55 & 59 \\
\hline Sinaloa (Mexico) & 408 & & & & \\
\hline Nayarit (Mexico) & 407 & & & & \\
\hline Argentina & 406 & & & 56 & 61 \\
\hline Campeche (Mexico) & 405 & & & & \\
\hline Brazil & 405 & & & 57 & 60 \\
\hline Guanajuato (Mexico) & 404 & & & & \\
\hline Piauí (Colombia) & 403 & & & & \\
\hline Zacatecas (Mexico) & 402 & & & & \\
\hline Cali (Brazil) & 402 & & & & \\
\hline Veracruz (Mexico) & 401 & & & & \\
\hline Rio de Janeiro (Brazil) & 401 & & & & \\
\hline Colombia & 399 & & & 59 & 62 \\
\hline Tunisia & 398 & & & 59 & 62 \\
\hline Albania & 397 & & & 60 & 62 \\
\hline Goiás (Brazil) & 396 & & & & \\
\hline Sergipe (Brazil) & 394 & & & & \\
\hline Tabasco (Mexico) & 391 & & & & \\
\hline Bahia (Brazil) & 390 & & & & \\
\hline Rondônia (Brazil) & 389 & & & & \\
\hline Rio Grande do Norte (Brazil) & 387 & & & & \\
\hline Ceará (Brazil) & 386 & & & & \\
\hline Qatar & 384 & & & 63 & 64 \\
\hline Amapá (Brazil) & 382 & & & & \\
\hline Indonesia & 382 & & & 63 & 64 \\
\hline Mato Grosso (Brazil) & 381 & & & & \\
\hline Acre (Brazil) & 380 & & & & \\
\hline Tocantins (Brazil) & 378 & & & & \\
\hline Chiapas (Mexico) & 377 & & & & \\
\hline Pará (Brazil) & 377 & & & & \\
\hline Amazonas (Brazil) & 376 & & & & \\
\hline Roraima (Brazil) & 375 & & & & \\
\hline Pernambuco (Brazil) & 374 & & & & \\
\hline Peru & 373 & & & 65 & 65 \\
\hline Guerrero (Mexico) & 372 & & & & \\
\hline Maranhão (Brazil) & 359 & & & & \\
\hline Alagoas (Brazil) & 346 & & & & \\
\hline
\end{tabular}

Notes: OECD countries are shown in bold black. Partner countries are shown in bold blue. Participating economies and subnational entities that are not included in national results are shown in bold blue italics. Regions are shown in black italics (OECD countries) or blue italics (partner countries).

1. Note by Turkey: The information in this document with reference to "Cyprus" relates to the southern part of the Island. There is no single authority representing both Turkish and Greek Cypriot people on the Island. Turkey recognises the Turkish Republic of Northern Cyprus (TRNC). Until a lasting and equitable solution is found within the context of the United Nations, Turkey shall preserve its position concerning the "Cyprus issue".

2. Note by all the European Union Member States of the OECD and the European Union: The Republic of Cyprus is recognised by all members of the United Nations with the exception of Turkey. The information in this document relates to the area under the effective control of the Government of the Republic of Cyprus.

Countries, economies and subnational entities are ranked in descending order of mean science performance.

Source: OECD, PISA 2012 Database.

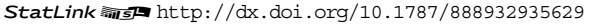




\section{- Figure I.5.3 -}

\section{Annualised change in science performance throughout participation in PISA}

Science score-point difference associated with one calendar year

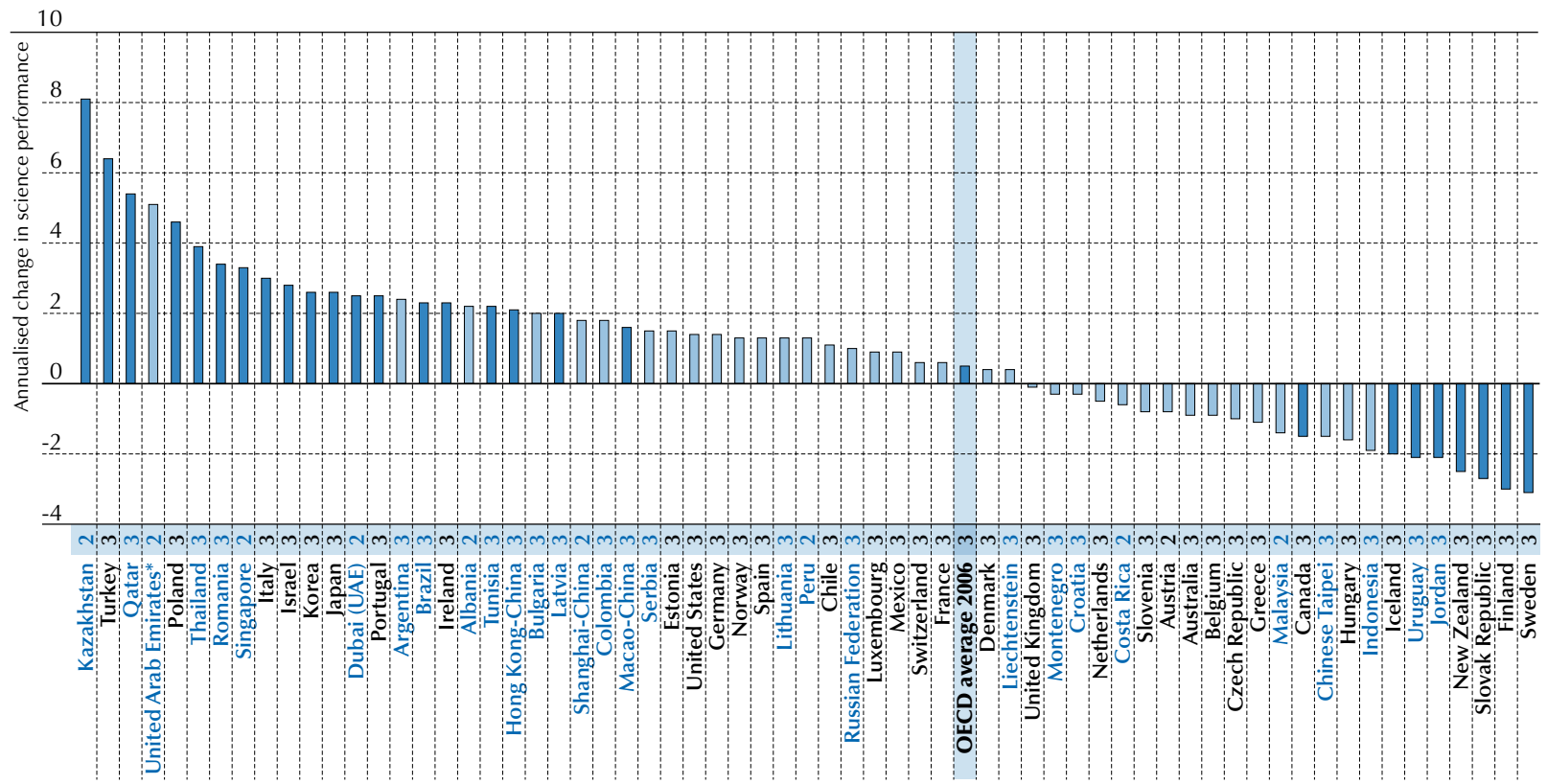

* United Arab Emirates excluding Dubai.

Notes: Statistically significant score point changes are marked in a darker tone (see Annex A3).

The number of comparable science scores used to calculate the annualised change is shown in next to the country/economy name.

The annualised change is the average annual change in PISA score points from a country's/economy's earliest participation in PISA to PISA 2012. It is calculated taking into account all of a country's/economy's participation in PISA. For more details on the calculation of the annualised change, see Annex A5. OECD average 2006 compares only OECD countries with comparable science scores since 2006.

Countries and economies are ranked in descending order of the annualised change in science performance.

Source: OECD, PISA 2012 Database, Table I.5.3b.

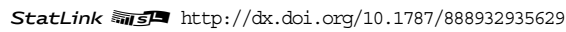

Results on the rate of acceleration of a country's/economy's improvement can be calculated only for the 54 countries and economies that participated in PISA 2006, PISA 2009 and PISA 2012, 16 of which saw an annualised improvement in science performance during the period. Of these 16 countries, Macao-China shows greater improvement between 2009 and 2012 than between 2006 and 2009. Improvements in science performance decelerated in Brazil, Portugal, Qatar, Tunisia and Turkey, where the observed improvement between 2009 and 2012 was smaller than that observed between 2006 and 2009. For the remaining countries, the annualised improvement is relatively similar between the 2006-09 and 2009-12 periods. Other countries and economies show no overall average annual improvement in performance, but do show notable improvements in science performance between PISA 2009 and PISA 2012. Such is the case of Estonia, where science performance improved by 14 score points as well as Luxembourg and Montenegro (Figure I.5.4).

At any point in time, countries and economies share similar levels of performance in science with other countries and economies. But as time passes and school systems evolve, some countries and economies may improve their performance while others may not. Figure I.5.5 shows, for each country and economy with comparable results in 2006 and 2012, those other countries and economies that had similar performance in 2006 but whose performance improved or deteriorated by 2012. For example, in 2006, Japan was similar in science performance to New Zealand, Chinese Taipei, Australia, Canada, the Netherlands, Liechtenstein, Hong Kong-China, Estonia and Korea; but after its annualised improvement of 2.6 score points per year, it scored higher in science than New Zealand, Chinese Taipei, Australia, Canada, the Netherlands and Liechtenstein in 2012. In 2006, Germany had lower scores in science than New Zealand, Chinese Taipei and Canada; but by 2012 , its performance was similar to those countries' performance. Along the same lines, Romania had similar levels of performance as Uruguay, Jordan, Montenegro, Mexico, Thailand and Bulgaria in 2006. By 2012, Romania showed better performance than Uruguay, Jordan, Montenegro and Mexico, and had attained similar levels of performance as Chile and Serbia, both of which had higher scores in science than Romania did in 2006. Estonia's improvement in PISA and recent educational policies and programmes is outlined in Box I.5.1. 
- Figure I.5.4 -

\section{Curvilinear trajectories of average science performance across PISA assessments}

Rate of acceleration or deceleration in performance (quadratic term)

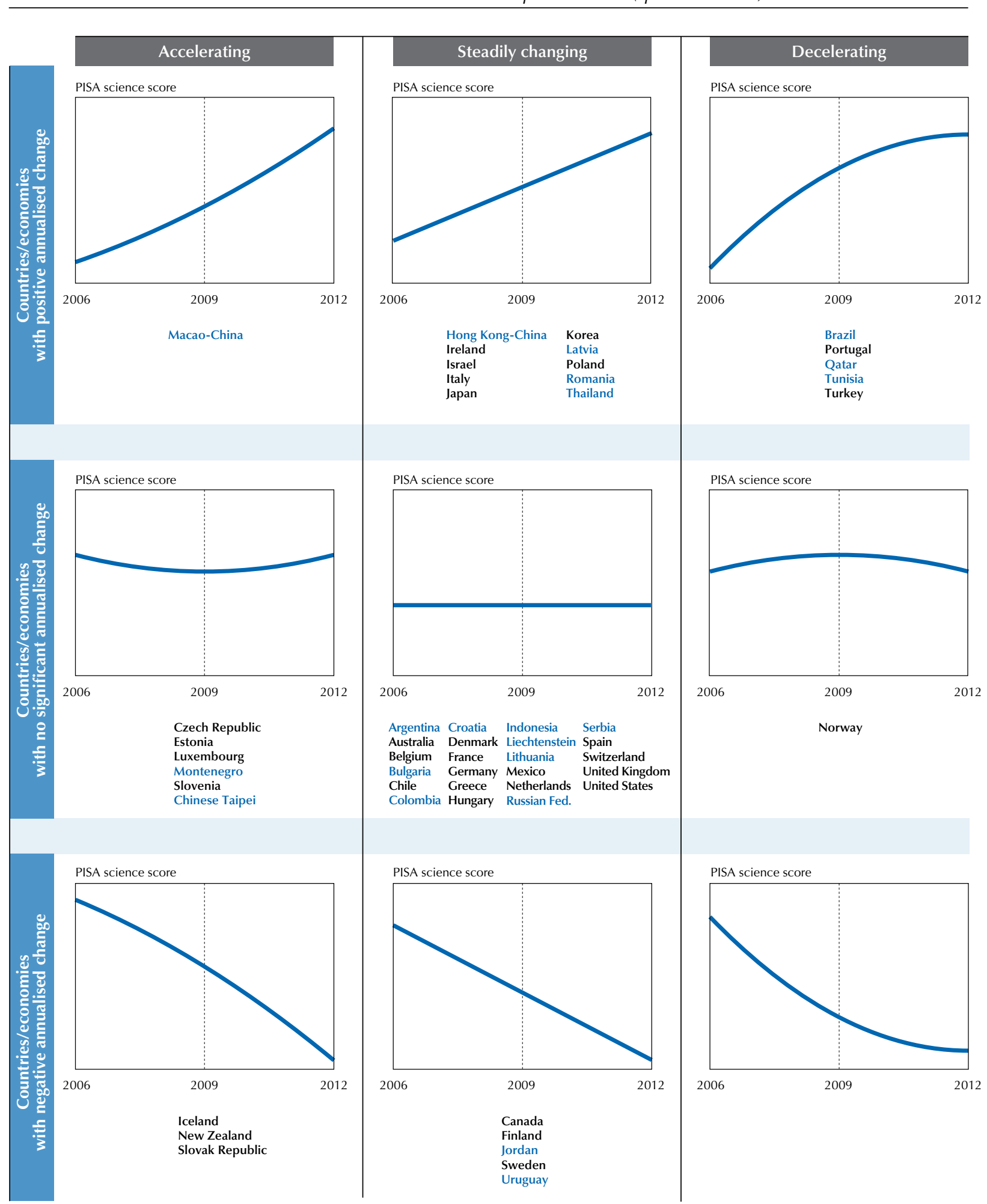

Notes: Figures are for illustrative purposes only. Countries and economies are grouped according to the direction and significance of their annualised change and their rate of acceleration.

Countries and economies with data from only one PISA assessments other than 2012 are excluded.

Source: OECD, PISA 2012 Database, Table I.5.3b.

StatLink त्ता st http://dx.doi.org/10.1787/888932935629 
- Figure I.5.5 [Part 1/4]

Multiple comparisons of science performance between 2006 and 2012

\begin{tabular}{|c|c|c|c|c|c|}
\hline & $\begin{array}{l}\text { Science } \\
\text { performance } \\
\text { in } 2006\end{array}$ & $\begin{array}{c}\begin{array}{c}\text { Science } \\
\text { performance } \\
\text { in } 2012\end{array} \\
\end{array}$ & $\begin{array}{c}\text { Countries/economies with similar } \\
\text { performance in } 2006 \\
\text { but lower performance in } 2012\end{array}$ & $\begin{array}{c}\text { Countries/economies with similar } \\
\text { performance in } 2006 \\
\text { and similar performance in } 2012\end{array}$ & $\begin{array}{c}\text { Countries/economies with similar } \\
\text { performance in } 2006 \\
\text { but higher performance in } 2012\end{array}$ \\
\hline Hong Kong-China & 542 & 555 & Chinese Taipei, Canada & Japan & \\
\hline Japan & 531 & 547 & $\begin{array}{l}\text { New Zealand, Chinese Taipei, Australia, } \\
\text { Canada, Netherlands, Liechtenstein }\end{array}$ & Hong Kong-China, Estonia, Korea & \\
\hline Finland & 563 & 545 & & & \\
\hline Estonia & 531 & 541 & $\begin{array}{l}\text { New Zealand, Chinese Taipei, Australia, } \\
\text { Canada, Netherlands, Liechtenstein }\end{array}$ & Japan, Korea & \\
\hline Korea & 522 & 538 & $\begin{array}{l}\text { New Zealand, United Kingdom, } \\
\text { Germany, Austria, Czech Republic, } \\
\text { Chinese Taipei, Australia, Netherlands, } \\
\text { Switzerland, Slovenia }\end{array}$ & Estonia, Japan, Liechtenstein & \\
\hline Poland & 498 & 526 & $\begin{array}{l}\text { United States, Croatia, Latvia, } \\
\text { Slovak Republic, Lithuania, France, } \\
\text { Sweden, Hungary, Spain, Denmark, } \\
\text { Iceland }\end{array}$ & Ireland & \\
\hline Canada & 534 & 525 & New Zealand & Chinese Taipei, Australia & Hong Kong-China, Estonia, Japan \\
\hline Liechtenstein & 522 & 525 & $\begin{array}{l}\text { Austria, Czech Republic, Belgium, } \\
\text { Slovenia }\end{array}$ & $\begin{array}{l}\text { New Zealand, United Kingdom, } \\
\text { Germany, Chinese Taipei, Australia, } \\
\text { Ireland, Netherlands, Switzerland, Korea }\end{array}$ & Estonia, Japan \\
\hline Germany & 516 & 524 & $\begin{array}{l}\text { Austria, Czech Republic, Hungary, } \\
\text { Belgium, Slovenia }\end{array}$ & $\begin{array}{l}\text { United Kingdom, Australia, Ireland, } \\
\text { Macao-China, Netherlands, Switzerland, } \\
\text { Liechtenstein }\end{array}$ & Korea \\
\hline Chinese Taipei & 532 & 523 & & $\begin{array}{l}\text { New Zealand, Australia, Canada, } \\
\text { Netherlands, Liechtenstein }\end{array}$ & Hong Kong-China, Estonia, Japan, Korea \\
\hline Netherlands & 525 & 522 & Czech Republic & $\begin{array}{l}\text { New Zealand, Germany, Chinese Taipei, } \\
\text { Australia, Slovenia, Liechtenstein }\end{array}$ & Estonia, Japan, Korea \\
\hline Ireland & 508 & 522 & $\begin{array}{l}\text { Austria, Czech Republic, Sweden, } \\
\text { Hungary, Belgium }\end{array}$ & $\begin{array}{l}\text { Poland, United Kingdom, Germany, } \\
\text { Macao-China, Switzerland, Liechtenstein }\end{array}$ & \\
\hline Australia & 527 & 521 & & $\begin{array}{l}\text { New Zealand, Germany, Chinese Taipei, } \\
\text { Canada, Netherlands, Liechtenstein }\end{array}$ & Estonia, Japan, Korea \\
\hline Macao-China & 511 & 521 & $\begin{array}{l}\text { Austria, Czech Republic, Hungary, } \\
\text { Belgium }\end{array}$ & $\begin{array}{l}\text { United Kingdom, Germany, Ireland, } \\
\text { Switzerland }\end{array}$ & \\
\hline New Zealand & 530 & 516 & & $\begin{array}{l}\text { Chinese Taipei, Australia, Netherlands, } \\
\text { Liechtenstein }\end{array}$ & Estonia, Japan, Canada, Korea \\
\hline Switzerland & 512 & 515 & Sweden, Hungary, Belgium & $\begin{array}{l}\text { United Kingdom, Germany, Austria, } \\
\text { Czech Republic, Ireland, Macao-China, } \\
\text { Slovenia, Liechtenstein }\end{array}$ & Korea \\
\hline Slovenia & 519 & 514 & Austria & $\begin{array}{l}\text { United Kingdom, Czech Republic, } \\
\text { Netherlands, Switzerland }\end{array}$ & Germany, Liechtenstein, Korea \\
\hline United Kingdom & 515 & 514 & & $\begin{array}{l}\text { Germany, Austria, Czech Republic, } \\
\text { Ireland, Macao-China, Belgium, } \\
\text { Switzerland, Slovenia, Liechtenstein }\end{array}$ & Korea \\
\hline Czech Republic & 513 & 508 & Sweden, Hungary & $\begin{array}{l}\text { United Kingdom, Austria, Belgium, } \\
\text { Switzerland, Slovenia }\end{array}$ & $\begin{array}{l}\text { Germany, Ireland, Macao-China, } \\
\text { Netherlands, Liechtenstein, Korea }\end{array}$ \\
\hline Austria & 511 & 506 & Sweden, Hungary & $\begin{array}{l}\text { United Kingdom, Czech Republic, } \\
\text { Belgium, Switzerland }\end{array}$ & $\begin{array}{l}\text { Germany, Ireland, Macao-China, } \\
\text { Slovenia, Liechtenstein, Korea }\end{array}$ \\
\hline Belgium & 510 & 505 & Sweden, Hungary & $\begin{array}{l}\text { United Kingdom, Austria, } \\
\text { Czech Republic }\end{array}$ & $\begin{array}{l}\text { Germany, Ireland, Macao-China, } \\
\text { Switzerland, Liechtenstein }\end{array}$ \\
\hline Latvia & 490 & 502 & $\begin{array}{l}\text { Slovak Republic, Luxembourg, Iceland, } \\
\text { Russian Federation }\end{array}$ & $\begin{array}{l}\text { United States, Croatia, Lithuania, France, } \\
\text { Spain, Denmark, Norway }\end{array}$ & Poland \\
\hline France & 495 & 499 & Slovak Republic, Sweden, Iceland & $\begin{array}{l}\text { United States, Croatia, Latvia, Lithuania, } \\
\text { Hungary, Spain, Denmark, Norway }\end{array}$ & Poland \\
\hline Denmark & 496 & 498 & Slovak Republic, Sweden, Iceland & $\begin{array}{l}\text { United States, Croatia, Latvia, Lithuania, } \\
\text { France, Hungary, Spain, Norway }\end{array}$ & Poland \\
\hline United States & 489 & 497 & Slovak Republic, Iceland & $\begin{array}{l}\text { Croatia, Latvia, Luxembourg, Lithuania, } \\
\text { France, Spain, Denmark, Norway, } \\
\text { Russian Federation }\end{array}$ & Poland \\
\hline
\end{tabular}

Note: Only countries and economies that participated in the PISA 2006 and PISA 2012 assessments are shown.

Countries and economies are ranked in descending order of their mean science performance in PISA 2012.

Source: OECD, PISA 2012 Database, Table 1.5.3b

StatLink 凋s http://dx.doi.org/10.1787/888932935629 
- Figure I.5.5 [Part 2/4]

Multiple comparisons of science performance between 2006 and 2012

\begin{tabular}{|c|c|c|c|c|c|c|}
\hline $\begin{array}{c}\text { Countries/economies with } \\
\text { lower performance in } 2006 \\
\text { but similar performance } \\
\text { in } 2012\end{array}$ & $\begin{array}{l}\text { Countries/economies with } \\
\text { lower performance in } 2006 \\
\text { but higher performance } \\
\text { in } 2012\end{array}$ & $\begin{array}{c}\text { Countries/economies with } \\
\text { higher performance in } 2006 \\
\text { but with similar performance } \\
\text { in } 2012\end{array}$ & $\begin{array}{l}\text { Countries/economies with } \\
\text { higher performance in } 2006 \\
\text { but lower performance } \\
\text { in } 2012\end{array}$ & $\begin{array}{c}\text { Science } \\
\text { performance } \\
\text { in } 2012\end{array}$ & $\begin{array}{c}\text { Science } \\
\text { performance } \\
\text { in } 2006\end{array}$ & \\
\hline & & & Finland & 555 & 542 & Hong Kong-China \\
\hline & & Finland & & 547 & 531 & Japan \\
\hline \multirow[t]{2}{*}{ Estonia, Japan, Korea } & Hong Kong-China & & & 545 & 563 & Finland \\
\hline & & Finland & & 541 & 531 & Estonia \\
\hline \multirow[t]{2}{*}{ Poland } & & Finland & Canada & 538 & 522 & Korea \\
\hline & & $\begin{array}{l}\text { New Zealand, } \\
\text { United Kingdom, Germany, } \\
\text { Chinese Taipei, Australia, } \\
\text { Canada, Macao-China, } \\
\text { Netherlands, Switzerland, } \\
\text { Liechtenstein, Korea }\end{array}$ & $\begin{array}{l}\text { Austria, Czech Republic, } \\
\text { Belgium, Slovenia }\end{array}$ & 526 & 498 & Poland \\
\hline $\begin{array}{l}\text { Poland, Germany, Ireland, } \\
\text { Macao-China, Netherlands, } \\
\text { Liechtenstein }\end{array}$ & Korea & & & 525 & 534 & Canada \\
\hline Poland, Macao-China & & Canada & & 525 & 522 & Liechtenstein \\
\hline Poland & & $\begin{array}{l}\text { New Zealand, Chinese Taipei, } \\
\text { Canada }\end{array}$ & & 524 & 516 & Germany \\
\hline $\begin{array}{l}\text { Poland, United Kingdom, } \\
\text { Germany, Ireland, } \\
\text { Macao-China, Switzerland }\end{array}$ & & & & 523 & 532 & Chinese Taipei \\
\hline \multirow{2}{*}{$\begin{array}{l}\text { Poland, United Kingdom, } \\
\text { Ireland, Macao-China, } \\
\text { Switzerland }\end{array}$} & & Canada & & 522 & 525 & Netherlands \\
\hline & & $\begin{array}{l}\text { New Zealand, Chinese Taipei, } \\
\text { Australia, Canada, } \\
\text { Netherlands }\end{array}$ & Slovenia & 522 & 508 & Ireland \\
\hline $\begin{array}{l}\text { Poland, United Kingdom, } \\
\text { Ireland, Macao-China, } \\
\text { Switzerland }\end{array}$ & & & & 521 & 527 & Australia \\
\hline Poland & & $\begin{array}{l}\text { New Zealand, Chinese Taipei, } \\
\text { Australia, Canada, } \\
\text { Netherlands, Liechtenstein }\end{array}$ & Slovenia & 521 & 511 & Macao-China \\
\hline $\begin{array}{l}\text { Poland, United Kingdom, } \\
\text { Germany, Czech Republic, } \\
\text { Ireland, Macao-China, } \\
\text { Switzerland, Slovenia }\end{array}$ & & & & 516 & 530 & New Zealand \\
\hline \multirow[t]{2}{*}{ Poland } & & $\begin{array}{l}\text { New Zealand, Chinese Taipei, } \\
\text { Australia, Netherlands }\end{array}$ & & 515 & 512 & Switzerland \\
\hline & Poland, Ireland, Macao-China & New Zealand & & 514 & 519 & Slovenia \\
\hline Poland, Latvia & & $\begin{array}{l}\text { New Zealand, Chinese Taipei, } \\
\text { Australia, Netherlands }\end{array}$ & & 514 & 515 & United Kingdom \\
\hline $\begin{array}{l}\text { United States, Latvia, France, } \\
\text { Denmark }\end{array}$ & Poland & New Zealand & & 508 & 513 & Czech Republic \\
\hline $\begin{array}{l}\text { United States, Latvia, } \\
\text { Lithuania, France, Denmark, } \\
\text { Norway }\end{array}$ & Poland & & & 506 & 511 & Austria \\
\hline $\begin{array}{l}\text { United States, Latvia, France, } \\
\text { Denmark }\end{array}$ & Poland & & & 505 & 510 & Belgium \\
\hline Italy & & $\begin{array}{l}\text { United Kingdom, Austria, } \\
\text { Czech Republic, Hungary, } \\
\text { Belgium }\end{array}$ & Sweden & 502 & 490 & Latvia \\
\hline Portugal, Italy & & $\begin{array}{l}\text { Austria, Czech Republic, } \\
\text { Belgium }\end{array}$ & & 499 & 495 & France \\
\hline Luxembourg, Portugal, Italy & & $\begin{array}{l}\text { Austria, Czech Republic, } \\
\text { Belgium }\end{array}$ & & 498 & 496 & Denmark \\
\hline Portugal, Italy & & $\begin{array}{l}\text { Austria, Czech Republic, } \\
\text { Sweden, Hungary, Belgium }\end{array}$ & & 497 & 489 & United States \\
\hline
\end{tabular}

Note: Only countries and economies that participated in the PISA 2006 and PISA 2012 assessments are shown.

Countries and economies are ranked in descending order of their mean science performance in PISA 2012.

Source: OECD, PISA 2012 Database, Table I.5.3b

StatLink 刑 st http://dx.doi.org/10.1787/888932935629 
- Figure I.5.5 [Part 3/4]

Multiple comparisons of science performance between 2006 and 2012

\begin{tabular}{|c|c|c|c|c|c|}
\hline & $\begin{array}{c}\text { Science } \\
\text { performance } \\
\text { in } 2006\end{array}$ & $\begin{array}{c}\text { Science } \\
\text { performance } \\
\text { in } 2012\end{array}$ & $\begin{array}{c}\text { Countries/economies with similar } \\
\text { performance in } 2006 \\
\text { but lower performance in } 2012\end{array}$ & $\begin{array}{c}\text { Countries/economies with similar } \\
\text { performance in } 2006 \\
\text { and similar performance in } 2012\end{array}$ & $\begin{array}{c}\text { Countries/economies with similar } \\
\text { performance in } 2006 \\
\text { but higher performance in } 2012\end{array}$ \\
\hline Spain & 488 & 496 & $\begin{array}{l}\text { Slovak Republic, Iceland, } \\
\text { Russian Federation }\end{array}$ & $\begin{array}{l}\text { United States, Croatia, Latvia, } \\
\text { Luxembourg, Lithuania, France, } \\
\text { Denmark, Norway }\end{array}$ & Poland \\
\hline Lithuania & 488 & 496 & Slovak Republic, Iceland & $\begin{array}{l}\text { United States, Croatia, Latvia, } \\
\text { Luxembourg, France, Spain, Denmark, } \\
\text { Norway, Russian Federation }\end{array}$ & Poland \\
\hline Norway & 487 & 495 & Slovak Republic, Iceland & $\begin{array}{l}\text { United States, Croatia, Latvia, } \\
\text { Luxembourg, Lithuania, France, Spain, } \\
\text { Denmark, Russian Federation }\end{array}$ & \\
\hline Hungary & 504 & 494 & & France, Sweden, Denmark & $\begin{array}{l}\text { Poland, Germany, Austria, } \\
\text { Czech Republic, Ireland, Macao-China, } \\
\text { Belgium, Switzerland }\end{array}$ \\
\hline Italy & 475 & 494 & Greece & Portugal, Russian Federation & \\
\hline Croatia & 493 & 491 & Slovak Republic, Iceland & $\begin{array}{l}\text { United States, Latvia, Lithuania, France, } \\
\text { Spain, Denmark, Norway }\end{array}$ & Poland \\
\hline Luxembourg & 486 & 491 & Slovak Republic, Iceland & $\begin{array}{l}\text { United States, Lithuania, Spain, Norway, } \\
\text { Russian Federation }\end{array}$ & Latvia \\
\hline Portugal & 474 & 489 & Greece & Russian Federation, Italy & \\
\hline Russian Federation & 479 & 486 & Greece, Slovak Republic & $\begin{array}{l}\text { United States, Luxembourg, Lithuania, } \\
\text { Portugal, Norway, Italy }\end{array}$ & Latvia, Spain \\
\hline Sweden & 503 & 485 & & Hungary & $\begin{array}{l}\text { Poland, Austria, Czech Republic, France } \\
\text { Ireland, Belgium, Denmark, Switzerland }\end{array}$ \\
\hline Iceland & 491 & 478 & & Slovak Republic & $\begin{array}{l}\text { United States, Poland, Croatia, Latvia, } \\
\text { Luxembourg, Lithuania, France, Spain, } \\
\text { Denmark, Norway }\end{array}$ \\
\hline Slovak Republic & 488 & 471 & & Iceland & $\begin{array}{l}\text { United States, Poland, Croatia, Latvia, } \\
\text { Luxembourg, Lithuania, France, Spain, } \\
\text { Denmark, Norway, Russian Federation }\end{array}$ \\
\hline Israel & 454 & 470 & Chile & & \\
\hline Greece & 473 & 467 & & & Portugal, Russian Federation, Italy \\
\hline Turkey & 424 & 463 & $\begin{array}{l}\text { Uruguay, Thailand, Jordan, Chile, } \\
\text { Serbia, Romania }\end{array}$ & Bulgaria & \\
\hline Bulgaria & 434 & 446 & Uruguay, Jordan & $\begin{array}{l}\text { Thailand, Turkey, Chile, Serbia, } \\
\text { Romania }\end{array}$ & \\
\hline Chile & 438 & 445 & Uruguay & Bulgaria, Serbia & Turkey, Israel \\
\hline Serbia & 436 & 445 & Uruguay & Bulgaria, Chile & Turkey \\
\hline Thailand & 421 & 444 & Uruguay, Jordan & Bulgaria, Romania & Turkey \\
\hline Romania & 418 & 439 & Uruguay, Jordan, Montenegro, Mexico & Thailand, Bulgaria & Turkey \\
\hline Uruguay & 428 & 416 & & Jordan & $\begin{array}{l}\text { Thailand, Turkey, Bulgaria, Chile, } \\
\text { Serbia, Romania }\end{array}$ \\
\hline Mexico & 410 & 415 & Indonesia, Montenegro & & Romania \\
\hline Montenegro & 412 & 410 & & & Mexico, Romania \\
\hline Jordan & 422 & 409 & & Uruguay & Thailand, Turkey, Bulgaria, Romania \\
\hline Argentina & 391 & 406 & Indonesia & Brazil, Tunisia, Colombia & \\
\hline Brazil & 390 & 405 & Indonesia & Argentina, Tunisia, Colombia & \\
\hline Colombia & 388 & 399 & Indonesia & Brazil, Argentina, Tunisia & \\
\hline Tunisia & 386 & 398 & Indonesia & Brazil, Argentina, Colombia & \\
\hline Qatar & 349 & 384 & & & \\
\hline Indonesia & 393 & 382 & & & $\begin{array}{l}\text { Brazil, Argentina, Tunisia, Colombia, } \\
\text { Mexico }\end{array}$ \\
\hline
\end{tabular}

Note: Only countries and economies that participated in the PISA 2006 and PISA 2012 assessments are shown.

Countries and economies are ranked in descending order of their mean science performance in PISA 2012.

Source: OECD, PISA 2012 Database, Table 1.5.3b.

StatLink तोist http://dx.doi.org/10.1787/888932935629 
- Figure I.5.5 [Part 4/4]

Multiple comparisons of science performance between 2006 and 2012

\begin{tabular}{|c|c|c|c|c|c|c|}
\hline $\begin{array}{l}\text { Countries/economies with } \\
\text { lower performance in } 2006 \\
\text { but similar performance } \\
\text { in } 2012\end{array}$ & $\begin{array}{l}\text { Countries/economies with } \\
\text { lower performance in } 2006 \\
\text { but higher performance } \\
\text { in } 2012\end{array}$ & $\begin{array}{c}\text { Countries/economies with } \\
\text { higher performance in } 2006 \\
\text { but with similar performance } \\
\text { in } 2012\end{array}$ & $\begin{array}{l}\text { Countries/economies with } \\
\text { higher performance in } 2006 \\
\text { but lower performance } \\
\text { in } 2012\end{array}$ & $\begin{array}{c}\text { Science } \\
\text { performance } \\
\text { in } 2012\end{array}$ & $\begin{array}{c}\text { Science } \\
\text { performance } \\
\text { in } 2006\end{array}$ & \\
\hline Portugal, Italy & & Hungary & Sweden & 496 & 488 & Spain \\
\hline Portugal, Italy & & Austria, Hungary & Sweden & 496 & 488 & Lithuania \\
\hline Portugal, Italy & & Austria, Sweden, Hungary & & 495 & 487 & Norway \\
\hline \multirow{2}{*}{$\begin{array}{l}\text { United States, Croatia, Latvia, } \\
\text { Luxembourg, Lithuania, } \\
\text { Spain, Portugal, Norway, } \\
\text { Russian Federation, Italy }\end{array}$} & & & & 494 & 504 & Hungary \\
\hline & & $\begin{array}{l}\text { United States, Croatia, Latvia, } \\
\text { Luxembourg, Lithuania, } \\
\text { France, Sweden, Hungary, } \\
\text { Spain, Denmark, Norway }\end{array}$ & Slovak Republic, Iceland & 494 & 475 & Italy \\
\hline $\begin{array}{l}\text { Luxembourg, Portugal, } \\
\text { Russian Federation, Italy }\end{array}$ & & Sweden, Hungary & & 491 & 493 & Croatia \\
\hline \multirow[t]{3}{*}{ Portugal, Italy } & & $\begin{array}{l}\text { Croatia, Sweden, Hungary, } \\
\text { Denmark }\end{array}$ & & 491 & 486 & Luxembourg \\
\hline & & $\begin{array}{l}\text { United States, Croatia, } \\
\text { Luxembourg, Lithuania, } \\
\text { France, Sweden, Hungary, } \\
\text { Spain, Denmark, Iceland, } \\
\text { Norway }\end{array}$ & Slovak Republic & 489 & 474 & Portugal \\
\hline & & $\begin{array}{l}\text { Croatia, Sweden, Hungary, } \\
\text { Iceland }\end{array}$ & & 486 & 479 & Russian Federation \\
\hline $\begin{array}{l}\text { United States, Croatia, } \\
\text { Luxembourg, Israel, } \\
\text { Iceland, Portugal, Norway, } \\
\text { Russian Federation, Italy }\end{array}$ & Latvia, Lithuania, Spain & & & 485 & 503 & Sweden \\
\hline $\begin{array}{l}\text { Israel, Portugal, } \\
\text { Russian Federation }\end{array}$ & Italy & Sweden & & 478 & 491 & Iceland \\
\hline Greece, Turkey, Israel & Portugal, Italy & & & 471 & 488 & Slovak Republic \\
\hline Turkey & & $\begin{array}{l}\text { Greece, Slovak Republic, } \\
\text { Sweden, Iceland }\end{array}$ & & 470 & 454 & Israel \\
\hline \multirow[t]{3}{*}{ Turkey, Israel } & & Slovak Republic & & 467 & 473 & Greece \\
\hline & & $\begin{array}{l}\text { Greece, Slovak Republic, } \\
\text { Israel }\end{array}$ & & 463 & 424 & Turkey \\
\hline & & & & 446 & 434 & Bulgaria \\
\hline Thailand, Romania & & & & 445 & 438 & Chile \\
\hline \multirow[t]{3}{*}{ Thailand, Romania } & & & & 445 & 436 & Serbia \\
\hline & & Chile, Serbia & & 444 & 421 & Thailand \\
\hline & & Chile, Serbia & & 439 & 418 & Romania \\
\hline $\begin{array}{l}\text { Argentina, Montenegro, } \\
\text { Mexico }\end{array}$ & & & & 416 & 428 & Uruguay \\
\hline Argentina & & Uruguay, Jordan & & 415 & 410 & Mexico \\
\hline Brazil, Argentina & & Uruguay, Jordan & & 410 & 412 & Montenegro \\
\hline \multirow{6}{*}{$\begin{array}{l}\text { Brazil, Argentina, } \\
\text { Montenegro, Tunisia, } \\
\text { Colombia, Mexico }\end{array}$} & & & & 409 & 422 & Jordan \\
\hline & & $\begin{array}{l}\text { Uruguay, Jordan, } \\
\text { Montenegro, Mexico }\end{array}$ & & 406 & 391 & Argentina \\
\hline & & Jordan, Montenegro & & 405 & 390 & Brazil \\
\hline & & Jordan & & 399 & 388 & Colombia \\
\hline & & Jordan & & 398 & 386 & Tunisia \\
\hline & & Indonesia & & 384 & 349 & Qatar \\
\hline Qatar & & & & 382 & 393 & Indonesia \\
\hline
\end{tabular}

Note: Only countries and economies that participated in the PISA 2006 and PISA 2012 assessments are shown.

Countries and economies are ranked in descending order of their mean science performance in PISA 2012.

Source: OECD, PISA 2012 Database, Table I.5.3b

StatLink तiा sta http://dx.doi.org/10.1787/888932935629 
Figure I.5.6 shows the relationship between each country's/economy's average science performance in 2006 and their annualised change between 2006 and 2012. ${ }^{2}$ The correlation between performance in PISA 2006 and the annualised change is -0.39 , signalling that countries and economies that had lower performance in their first PISA science assessment are more likely to be those that improve the fastest. To put it another way, 15\% of the variation in countries'/economies' annualised change in science performance can be explained by its initial performance in PISA (Table I.5.3b). Of the 19 countries and economies that saw an improvement in science performance since PISA 2006, nine had an average initial score of 470 score points, well below the OECD average.

- Figure I.5.6

\section{Relationship between annualised change in science performance and average PISA 2006 science scores}

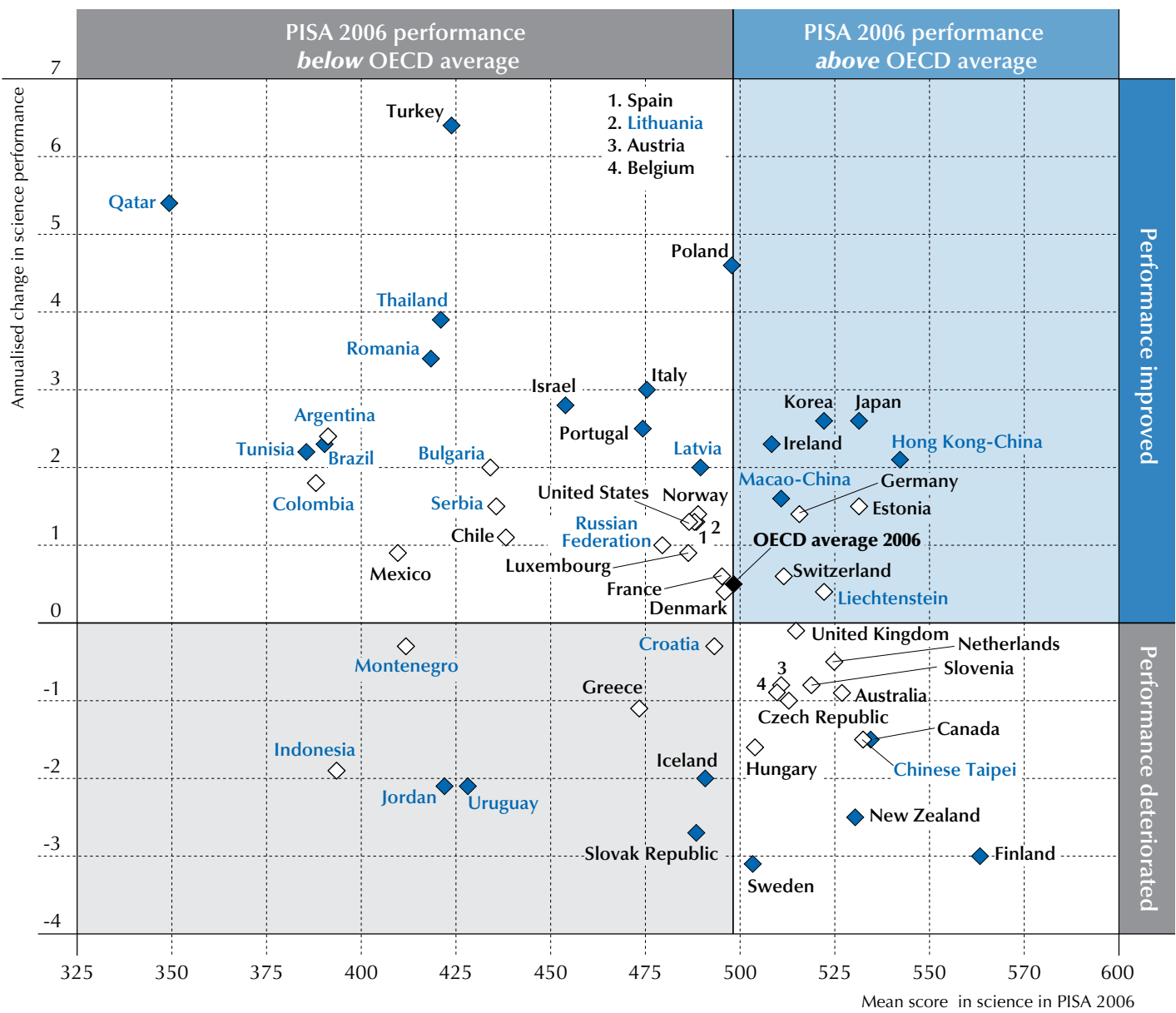

Notes: Annualised score point change in science that are statistically significant are indicated in a darker tone (see Annex A3).

The annualised change is the average annual change in PISA score points from a country/economy's earliest participation in PISA to PISA 2012. It is calculated taking into account all of a country's/economy's participation in PISA. For more details on the calculation of the annualised change, see Annex A5.

OECD average 2006 considers only those countries with comparable data since PISA 2006.

The correlation between a country's/economy's mean score in 2006 and its annualised performance is -0.39.

Source: OECD, PISA 2012 Database, Tables I.5.3b.

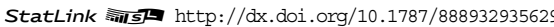

Yet it is not inevitable that only countries and economies that perform below the OECD average show improvements over time. Japan, for example, performed significantly above the OECD average in science in 2006 (at 531 points) and by 2012, shows an annualised improvement in science performance of around two score points per year. Estonia had similar levels of performance to Japan in PISA 2006 and improved, in the three years between PISA 2009 and PISA 2012 by 14 score points. Similarly, among the countries and economies that scored around the OECD average in science in 2006 , 
Poland and Ireland saw improvements by 2012 but Sweden and Hungary did not. The Russian Federation, Italy, Portugal and Greece, for example, all showed similar levels of performance in science in 2006 (around 475 points), but while Italy and Portugal improved their performance by 2012, the Russian Federation and Greece did not. Also telling is that among countries that performed below the OECD average in 2006, eight countries saw no improvement up until 2012. This underscores the fact that all countries and economies can improve their science performance, irrespective of how well they perform in science (Figure I.5.6).

\section{Trends in science performance adjusted for sampling and demographic changes}

There are many reasons why a country's or economy's science performance may change over time. Improvements may be the result of specific education policies or changes in the demographic characteristics of the population. For example, because of trends in migration, the characteristics of the PISA reference population - 15-year-olds enrolled in school may have shifted; or, as a result of economic, cultural and social development, the environments in which students live can better promote student learning. By asking students about their after-school experiences and backgrounds, PISA can identify whether the socio-economic conditions of students have changed and whether more students had an immigrant background in 2012 than did in previous years. These differences in the characteristics of the reference population may be driving the observed trends in some countries but not in others. ${ }^{3}$

Adjusted trends shed light on those trends in science performance that are not due to changes in the demographic and socio-economic characteristics of the student population. Figure I.5.7 presents the adjusted annualised change after assuming that the average age and socio-economic status of students in 2006 and 2009 is the same as that of students who took part in PISA 2012. This adjusted trend also assumes that the proportion of girls, students with an immigrant background and students who speak a language at home that is different from that of the assessment is identical in previous cycles to those observed in PISA 2012. In short, it assumes that the population and sample characteristics observed in 2012 have not changed since 2006. Countries and economies that see a difference between the adjusted trends and the observed trends, particularly when the observed trend is more negative than the adjusted trend (non-negative), can consider these changes in the student population as a challenge that needs to be addressed by the school system, as it is the observed trends, not the adjusted trends, that measure the quality and the real-life outcome of school systems.

After accounting for differences in the sampling and population characteristics, 11 countries and economies show an improvement in science performance. For these countries and economies, the annualised change in performance observed throughout their participation in PISA is not completely attributable to changes in the background characteristics of the students who take part in PISA. This means that, in these countries and economies, either the background characteristic of students haven't changed during the period, that any changes that may have taken place have not brought about differences in average performance, or that improved education services have offset any negative effect on average science performance related to changes in the population.

On average across OECD countries, for example, the observed overall annualised improvement in science performance is no longer observed after changes in students' demographic characteristics are taken into account. This means that, on average across OECD countries, improvements in science performance can be explained by changes in the background characteristics of the student population. Similarly, the annualised improvement observed in Brazil, Hong Kong-China, Ireland, Korea, Latvia, Portugal and Tunisia is no longer apparent when comparing students with similar characteristics across the different PISA assessments.

By contrast, less than $20 \%$ of the improvement observed in Dubai (United Arab Emirates), Israel, Italy, Kazakhstan and Turkey can be attributed to changes in the demographic profile of the student population. In these countries and economies, improvements in science performance remain after accounting for students' background characteristics. Although an important part of the annualised improvement observed in Japan, Poland, Qatar, Romania, Singapore and Thailand is explained by changes in the demographic characteristics of the student population, improvements are still observed when comparing students with similar characteristics in 2012 and previous PISA assessments. In these countries and economies, only part of the observed annualised trend can be attributed to changing country demographics. In Japan, for example, there was an average annual improvement in science performance of 2.6 points; but after accounting for changes in students' background characteristics, this annualised improvement remains but decreases to 2.0 science score points per year. In Macao-China, the observed annualised improvement between PISA 2006 and PISA 2012 becomes negative after accounting for demographic changes in the population. 


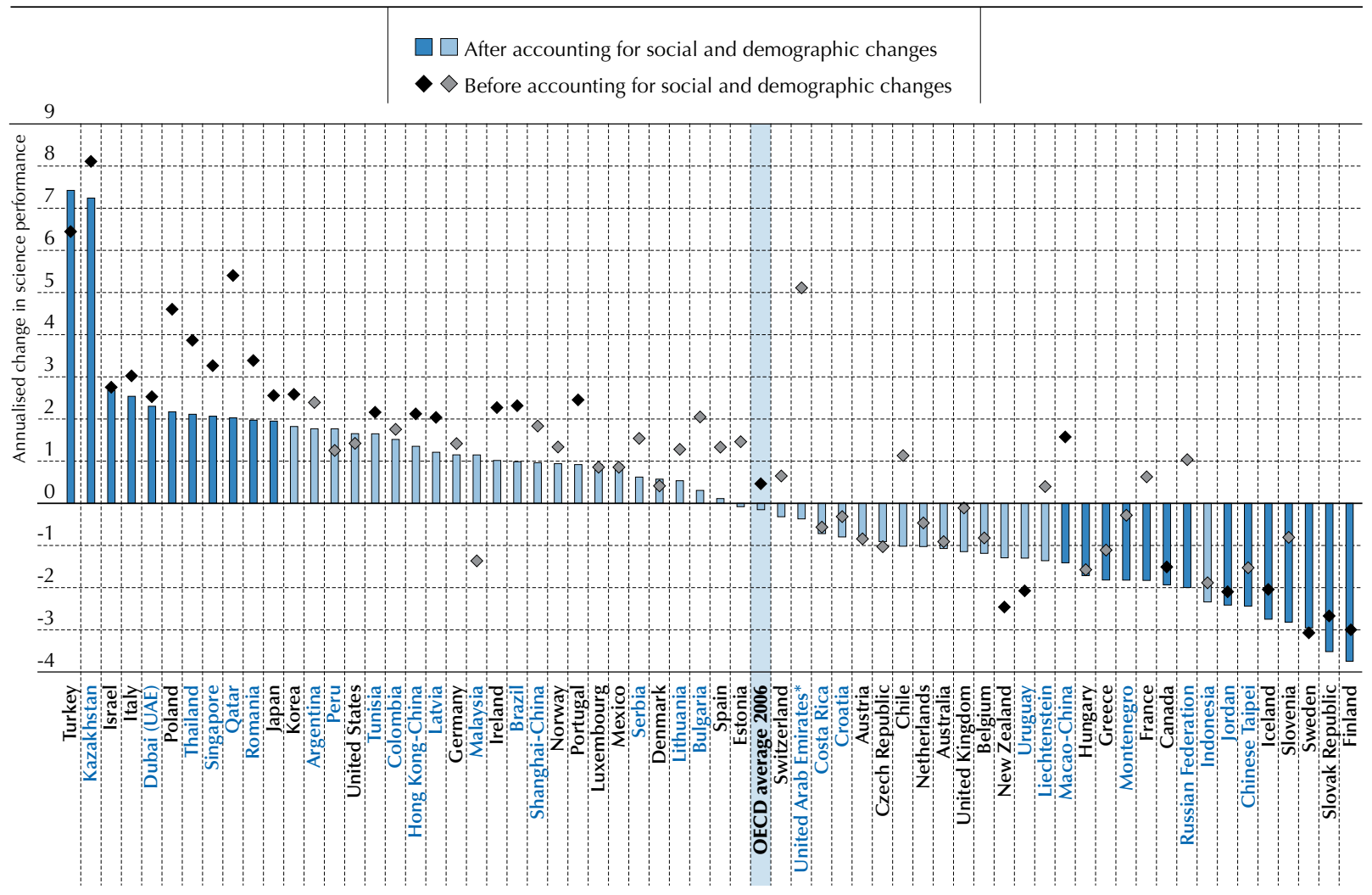

* United Arab Emirates excluding Dubai.

Notes: Statistically significant values are marked in a darker tone (see Annex A3).

The annualised change is the average annual change in PISA score points. It is calculated taking into account all of a country's/economy's participation in PISA. For more details on the calculation of the annualised change, see Annex A5.

The annualised change adjusted for demographic changes assumes that the average age and PISA index of social, cultural and economic status, as well as the percentage of female students, those with an immigrant background and those who speak a language other than the assessment at home is the same in previous assessments as those observed in 2012. For more details on the calculation of the adjusted annualised change, see Annex A5.

OECD average 2006 considers only those countries with comparable science scores since PISA 2006.

Countries and economies are ranked in descending order of the annualised change after accounting for demographic changes.

Source: OECD, PISA 2012 Database, Tables I.5.3b and I.5.4.

StatLink 形IS http://dx.doi.org/10.1787/888932935629

Informative as they may be, adjusted trends are merely hypothetical scenarios that help to understand the source of changes in students' performance over time. Observed trends depicted in Figure 1.5.7 and throughout this chapter summarise the overall evolution of a school system, highlighting the challenges that countries and economies face in improving students' and schools' science performance.

\section{Students at the different levels of proficiency in science}

When science was the major domain in PISA 2006, six proficiency levels were defined on the science scale. These same proficiency levels are used for reporting science results in PISA 2012. The process used to produce proficiency levels in science is similar to that used to produce proficiency levels in mathematics, as described in Chapter 2. Figure I.5.8 presents a description of the scientific knowledge and skills that students possess at the various proficiency levels.

Figure I.5.9 shows a map of some questions in relation to their position on the science proficiency scale. The first column shows the proficiency level within which the task is located. The second column indicates the lowest score on the task that would still be described as achieving the given proficiency level. The last column shows the name of the unit and the task number. The score given for the correct response to these questions is shown between parentheses. The selected questions have been ordered according to their difficulty, with the most difficult at the top, and the least difficult at the bottom. 


\section{- Figure I.5.8}

\section{Summary description for the six levels of proficiency in science in PISA 2012}

\begin{tabular}{|c|c|c|c|}
\hline Level & $\begin{array}{l}\text { Lower } \\
\text { score } \\
\text { limit }\end{array}$ & $\begin{array}{l}\text { Percentage of students } \\
\text { able to perform tasks } \\
\text { at each level or above } \\
\text { (OECD average) }\end{array}$ & What students can typically do \\
\hline 6 & 708 & $1.2 \%$ & $\begin{array}{l}\text { At Level 6, students can consistently identify, explain and apply scientific knowledge } \\
\text { and knowledge about science in a variety of complex life situations. They can link } \\
\text { different information sources and explanations and use evidence from those sources } \\
\text { to justify decisions. They clearly and consistently demonstrate advanced scientific } \\
\text { thinking and reasoning, and they use their scientific understanding in support of } \\
\text { solutions to unfamiliar scientific and technological situations. Students at this level } \\
\text { can use scientific knowledge and develop arguments in support of recommendations } \\
\text { and decisions that centre on personal, social or global situations. }\end{array}$ \\
\hline 5 & 633 & $8.4 \%$ & $\begin{array}{l}\text { At Level 5, students can identify the scientific components of many complex life } \\
\text { situations, apply both scientific concepts and knowledge about science to these } \\
\text { situations, and can compare, select and evaluate appropriate scientific evidence for } \\
\text { responding to life situations. Students at this level can use well-developed inquiry } \\
\text { abilities, link knowledge appropriately, and bring critical insights to situations. They } \\
\text { can construct explanations based on evidence and arguments based on their critical } \\
\text { analysis. }\end{array}$ \\
\hline 4 & 559 & $28.9 \%$ & $\begin{array}{l}\text { At Level 4, students can work effectively with situations and issues that may involve } \\
\text { explicit phenomena requiring them to make inferences about the role of science or } \\
\text { technology. They can select and integrate explanations from different disciplines of } \\
\text { science or technology and link those explanations directly to aspects of life situations. } \\
\text { Students at this level can reflect on their actions and they can communicate decisions } \\
\text { using scientific knowledge and evidence. }\end{array}$ \\
\hline 3 & 484 & $57.7 \%$ & $\begin{array}{l}\text { At Level 3, students can identify clearly described scientific issues in a range of } \\
\text { contexts. They can select facts and knowledge to explain phenomena and apply } \\
\text { simple models or inquiry strategies. Students at this level can interpret and use } \\
\text { scientific concepts from different disciplines and can apply them directly. They } \\
\text { can develop short statements using facts and make decisions based on scientific } \\
\text { knowledge. }\end{array}$ \\
\hline 2 & 409 & $82.2 \%$ & $\begin{array}{l}\text { At Level 2, students have adequate scientific knowledge to provide possible } \\
\text { explanations in familiar contexts or draw conclusions based on simple investigations. } \\
\text { They are capable of direct reasoning and making literal interpretations of the results } \\
\text { of scientific inquiry or technological problem solving. }\end{array}$ \\
\hline 1 & 335 & $95.2 \%$ & $\begin{array}{l}\text { At Level 1, students have such limited scientific knowledge that it can only be applied } \\
\text { to a few, familiar situations. They can present scientific explanations that are obvious } \\
\text { and follow explicitly from given evidence. }\end{array}$ \\
\hline
\end{tabular}

- Figure I.5.9

Map of selected science questions, by proficiency level

\begin{tabular}{|c|c|c|}
\hline Level & $\begin{array}{l}\text { Lower } \\
\text { score } \\
\text { limit }\end{array}$ & UNITS - Questions (position on PISA scale) \\
\hline 6 & 708 & GREENHOUSE - Question 5 (709) \\
\hline 5 & 633 & GREENHOUSE - Question 4.2 (659) (full credit) \\
\hline 4 & 559 & $\begin{array}{l}\text { GREENHOUSE - Question } 4.1 \text { (568) (partial credit) } \\
\text { CLOTHES - Question } 1 \text { (567) }\end{array}$ \\
\hline 3 & 484 & MARY MONTAGU - Question 4 (507) \\
\hline 2 & 409 & $\begin{array}{l}\text { MARY MONTAGU - Question } 2 \text { (436) } \\
\text { MARY MONTAGU - Question } 3(431) \\
\text { GENETICALLY MODIFIED CROPS - Question } 3 \text { (421) }\end{array}$ \\
\hline 1 & 335 & PHYSICAL EXERCISE - Question 3 (386) \\
\hline
\end{tabular}

Figure I.5.10 shows the distribution of students among these different proficiency levels in each participating country or economy. Table I.5.1 a provides figures for the percentage of students at each proficiency level on the science scale with standard errors. 
- Figure I.5.10

Proficiency in science

Percentage of students at each level of science proficiency

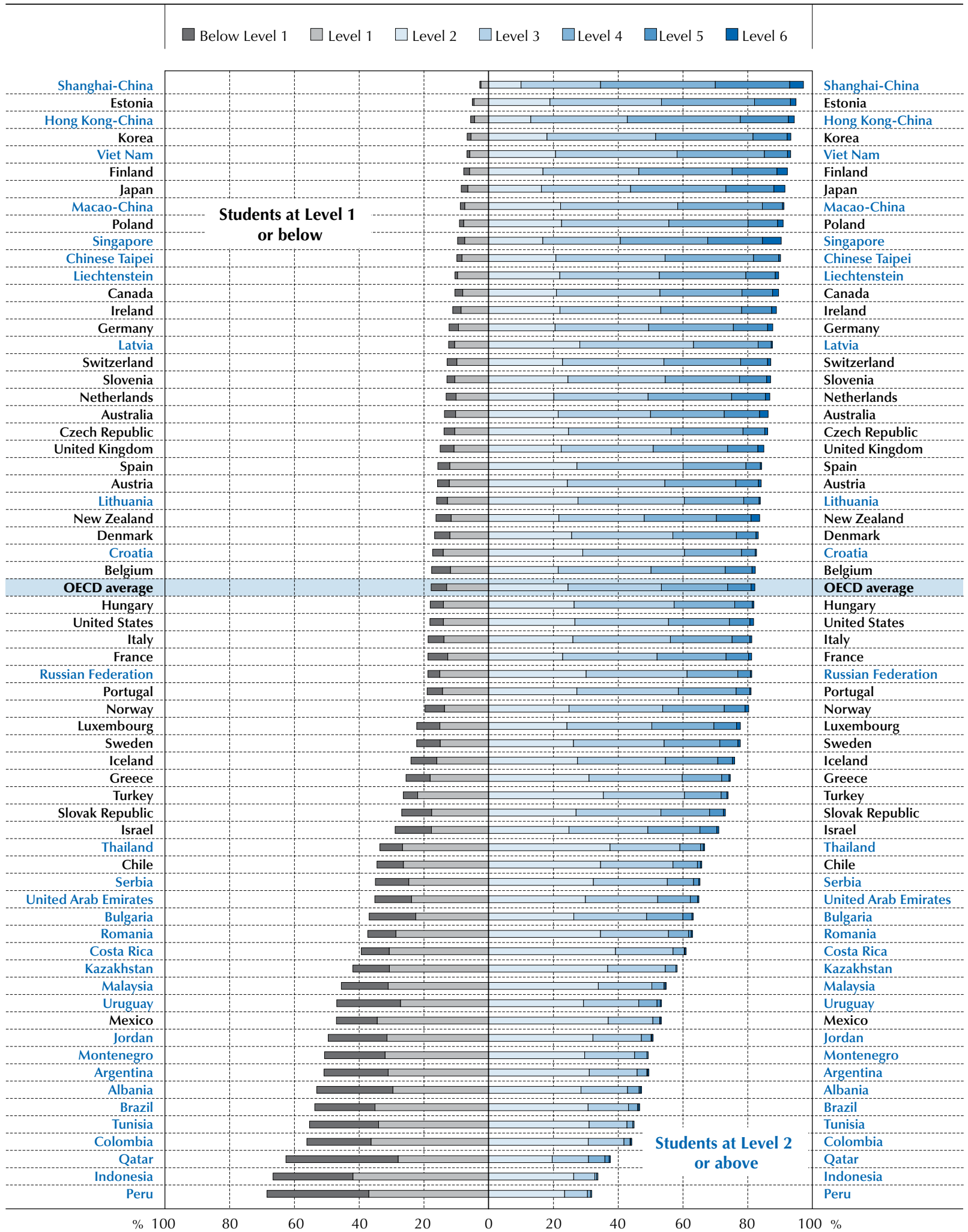

Countries and economies are ranked in descending order of the percentage of students at Levels 2, 3, 4, 5 and 6.

Source: OECD, PISA 2012 Database, Table I.5.1a.

StatLink त्राज http://dx.doi.org/10.1787/888932935629 


\section{Proficiency at Level 6 (scores higher than 708 points)}

At Level 6, students can consistently identify, explain and apply scientific knowledge and knowledge about science in a variety of complex life situations. They can link different information sources and explanations and use evidence from those sources to justify decisions. They clearly and consistently demonstrate advanced scientific thinking and reasoning, and they use their scientific understanding in support of solutions to unfamiliar scientific and technological situations. Students at this level can use scientific knowledge and develop arguments in support of recommendations and decisions that centre on personal, social or global situations.

Question 5 of GREENHOUSE (Figure 1.5.14) is an example of task at Level 6 and of the competency explaining phenomena scientifically. In this question, students must analyse a conclusion to account for other factors that could influence the greenhouse effect. This question combines aspects of the two skills: identifying scientific issues and explaining phenomena scientifically. The student needs to understand the necessity of controlling factors outside the change and measured variables and to recognise those variables. The student must have sufficient knowledge of "Earth systems" to be able to identify at least one of the factors that should be controlled. The latter criterion is considered the critical scientific skill involved, so this question is categorised as explaining phenomena scientifically. The effects of this environmental issue are global, which defines the setting.

As a first step in gaining credit for this question the student must be able to identify the change and measured variables and have sufficient understanding of methods of investigation to recognise the influence of other factors. However, the student also needs to recognise the scenario in context and identify its major components. This involves a number of abstract concepts and their relationships in determining what "other" factors might affect the relationship between the Earth's temperature and the amount of carbon dioxide emissions into the atmosphere. This locates the question near the boundary between Levels 5 and 6 in the explaining phenomena scientifically category. This question requires a short open-constructed response.

Across OECD countries, an average of $1.1 \%$ of students perform at Level 6 . Between $3 \%$ and $6 \%$ of the students are at this level in Singapore (5.8\%), Shanghai-China (4.2\%), Japan (3.4\%) and Finland (3.2\%). In New Zealand, Australia, Canada, the United Kingdom, Hong Kong-China, Estonia, Poland, Germany and Ireland between $1.5 \%$ and $2.7 \%$ of students perform at the highest proficiency level. By contrast, in the majority of participating countries the share of students at proficiency Level 6 is below 1\%. Around zero percent of students on average reach this level in Albania, Argentina, Brazil, Chile, Colombia, Costa Rica, Indonesia, Jordan, Kazakhstan, Malaysia, Mexico, Montenegro, Peru, Romania, Tunisia, Turkey and Uruguay (Figure I.5.10 and Table I.5.1a).

\section{Proficiency at Level 5 (scores higher than $\mathbf{6 3 3}$ but lower than or equal to $\mathbf{7 0 8}$ points)}

At Level 5, students can identify the scientific components of many complex life situations, apply both scientific concepts and knowledge about science to these situations, and can compare, select and evaluate appropriate scientific evidence for responding to life situations. Students at this level can use well-developed inquiry abilities, link knowledge appropriately, and bring critical insights to situations. They can construct explanations based on evidence and arguments based on their critical analysis.

Question 4 of GREENHOUSE (Figure I.5.14), an example of task at Level 5, requires an open-constructed response. This task centres on the skill using scientific evidence and asks students to identify a portion of a graph that does not provide evidence supporting a conclusion. This question requires the student to look for specific differences that vary from positively correlated general trends in these two graphical datasets. Students must locate a portion where both curves are not ascending or descending and provide this finding as part of a justification for a conclusion. As a result, the task involves a greater amount of insight and analytical skill than is required for Question 3. Rather than provide a generalisation about the relation between the graphs, the student is asked to explain the difference in the nominated period in order to gain full credit.

The question is located at Level 5 because it requires the ability to compare the details of two datasets and to criticise a given conclusion. If the student understands what the question requires of them and correctly identifies a difference in the two graphs, but is unable to explain this difference, the student gains partial credit for the question and is identified at Level 4 of the scientific proficiency scale. The skill required is to interpret data graphically presented, so the question belongs in the scientific explanations category.

Across OECD countries, $8.4 \%$ of students are proficient at Level 5 or 6 . Students scoring at Level 5 or 6 are considered as top performers. More than $15 \%$ of students attain one of these levels in Shanghai-China (27.2\%), Singapore (22.7\%), 
Japan (18.2\%), Finland (17.1\%) and Hong Kong-China (16.7\%). In 11 countries and economies between 10\% and 15\% of students are top performers in science. Some countries have virtually no top performers in science: in two partner countries, Indonesia and Peru, fewer than $0.1 \%$ of students reaches Level 5 or 6 , and in Tunisia, Colombia, Mexico, Kazakhstan, Costa Rica, Argentina, Jordan, Brazil, Malaysia, Montenegro and Albania, fewer than $0.5 \%$ of students attains Level 5 or 6 (Figure I.5.10 and Table I.5.1a).

\section{Proficiency at Level 4 (scores higher than 559 but lower than or equal to 633 points)}

At Level 4, students can work effectively with situations and issues that may involve explicit phenomena requiring them to make inferences about the role of science or technology. They can select and integrate explanations from different disciplines of science or technology and link those explanations directly to aspects of life situations. Students at this level can reflect on their actions and they can communicate decisions using scientific knowledge and evidence.

Question 1 in the unit CLOTHES (Figure I.5.15), which typifies a Level 4 question, requires the student to identify the change and measured variables associated with testing a claim about clothing. It also involves an assessment of whether there are techniques to quantify the measured variable and whether other variables can be controlled. This process then needs to be accurately applied for all four claims. The issue of "intelligent" clothes is in the category frontiers of science and technology and is a community issue addressing a need for disabled children; therefore, the setting is social. The scientific skills applied involve the nature of investigation, which places the question in the scientific enquiry category. The need to identify change and measured variables, together with an appreciation of what would be involved in carrying out measurement and controlling variables, locates the question at Level 4 . Students are required to answer in a complex multiple-choice format.

Across OECD countries, an average of $29 \%$ of students is proficient at Level 4 or higher (Level 4,5 or 6 ). In seven countries and economies, at least $40 \%$ of students attain this level, including between $40 \%$ and $50 \%$ of students in Japan, Finland, Korea, Estonia and in the partner country Singapore, slightly more than $50 \%$ in Hong Kong-China, and more than $60 \%$ of students in Shanghai-China. In contrast, fewer than $5 \%$ of students reach Level 4,5 or 6 in Indonesia, Peru, Tunisia, Colombia, Mexico, Brazil, Argentina, Jordan, Kazakhstan, Costa Rica, Albania, Malaysia and Montenegro (Figure I.5.10 and Table I.5.1a).

\section{Proficiency at Level 3 (scores higher than 484 but lower than or equal to 559 points)}

At Level 3, students can identify clearly described scientific issues in a range of contexts. They can select facts and knowledge to explain phenomena and apply simple models or inquiry strategies. Students at this level can interpret and use scientific concepts from different disciplines and can apply them directly. They can develop short statements using facts and make decisions based on scientific knowledge.

An example of a question at Level 3 is Question 4 from MARY MONTAGU (Figure I.5.16). This question requires the student to identify why young children and old people are more at risk of the effects of influenza than others in the population. Directly, or by inference, the reason is attributed to the weaker immune systems among young children and old people. The issue is community control of disease, so the setting is social. A correct explanation involves applying several pieces of knowledge that are well established in the community. The question stem also provides a clue to the groups' different levels of resistance to disease. Students have to answer with an open-constructed response.

Across OECD countries, 58\% of students are proficient at Level 3 or higher (Level 3, 4, 5 or 6 ) on the science scale. In the partner economies Shanghai-China and Hong Kong-China, more than $80 \%$ of students perform at least at this level. In the OECD countries Estonia, Finland, Korea and Japan, more than three out of four 15-year-olds are proficient at Level 3 or higher, and at least two out of three students in Singapore, Viet Nam, Chinese Taipei, Macao-China, Canada, Poland, Liechtenstein, Germany, Ireland and the Netherlands perform at least at this level (Figure I.5.10 and Table I.5.1a).

\section{Proficiency at Level 2 (scores higher than $\mathbf{4 0 9}$ but lower than or equal to $\mathbf{4 8 4}$ points)}

In 2007, following a detailed analysis of the questions from the main study, the international PISA Science Expert Group, which guided the development of the science framework and questions, identified Level 2 as the baseline proficiency level. This level does not establish a threshold for scientific illiteracy. Rather, the baseline level of proficiency defines the level of achievement on the PISA scale at which students begin to demonstrate the science competencies that will enable them to participate effectively and productively in life situations related to science and technology. At Level 2, students have adequate scientific knowledge to provide possible explanations in familiar contexts or draw conclusions based on simple investigations. They are capable of direct reasoning and making literal interpretations of the results of scientific inquiry or technological problem solving. 
Question 3 from the unit GENETICALLY MODIFIED CROPS (Figure I.5.17) is typical of Level 2 tasks. It asks a simple question about varying conditions in a scientific investigation and students are required to demonstrate knowledge about the design of science experiments. To answer this question correctly in the absence of cues, the student needs to be aware that the effect of the treatment (different herbicides) on the outcome (insect numbers) could depend on environmental factors. Thus, by repeating the test in 200 locations, the chance of a specific set of environmental factors giving rise to a spurious outcome can be accounted for. Since the question focuses on the methodology of the investigation it is categorised as scientific enquiry. The application area of genetic modification places this at the frontiers of science and technology and given its restriction to one country, it can be said to have a social setting. In the absence of cues, this question has the characteristics of Level 4, i.e. the student shows an awareness of the need to account for varying environmental factors and is able to recognise an appropriate way of dealing with that issue. However, because of the cues given in three distracters, and the fact that most students will easily eliminate these as options, the question actually sits at Level 2 of the identifying scientific issues scale.

Across OECD countries, 82\% of students, on average, are proficient at Level 2 or higher In Estonia, Hong Kong-China, Korea, Viet Nam, Finland, Japan, Macao-China, Poland, Singapore and Chinese Taipei between $90 \%$ and $95 \%$ of students perform at or above this threshold. In the partner economy Shanghai-China, only 3\% of students are below this level. In every country except the three partner countries Peru, Indonesia and Qatar, at least $40 \%$ of students are at Level 2 or above (Figure I.5.10 and Table I.5.1a).

\section{Proficiency at Level 1 (scores higher than 335 but lower than or equal to 409 points) or below}

At Level 1, students have such limited scientific knowledge that it can only be applied to a few, familiar situations. They can present scientific explanations that are obvious and follow explicitly from given evidence.

Question 3 in the unit PHYSICAL EXERCISE (Figure I.5.18) is an example of task at Level 1. To gain credit for this question, the student has to correctly recall knowledge about the operation of muscles and about the formation of fat in the body, i.e. students must have knowledge of the scientific fact that more blood flows through active muscles and that fats are not formed when muscles are exercised. This enables the student to accept the first explanation of this complex multiple-choice question and reject the second explanation. The two simple factual explanations contained in the question are not related to each other. Each is accepted or rejected as an effect of the exercise of muscles. Since this is common knowledge, the question is located at the very bottom of the explaining phenomena scientifically scale.

Students who score below 335 points - that is, below Level 1 - usually do not succeed at the most basic levels of science that PISA measures. Such students are more likely to have serious difficulties in using science to benefit from further education and learning opportunities and in participating in life situations related to science and technology (OECD, 2010).

Across OECD countries, $18 \%$ of students perform at or below Level 1 - more precisely, $13 \%$ perform at Level 1 and $5 \%$ perform below Level 1. In Shanghai-China, Estonia, Hong Kong-China, Korea, Viet Nam, Finland, Japan, Macao-China, Poland, Singapore and Chinese Taipei, fewer than $10 \%$ of students perform at Level 1 or below. In all of these countries and economies, except in Singapore $(2.2 \%), 2 \%$ of students or fewer score below Level 1 . In OECD countries, the proportion of students performing below Level 1 ranges from $2 \%$ in Japan to less than $13 \%$ in Mexico. In some countries, the share of students at proficiency Level 1 or below Level 1 is substantial, notably in Peru, Indonesia, Qatar, Colombia, Tunisia, Brazil, Albania, Argentina and Montenegro where more than half of all 15-year-olds perform at proficiency Level 1 or below. In the partner countries Qatar, Peru, Indonesia, Albania and Tunisia, more than 20\% of students perform below Level 1 (Figure I.5.10 and Table I.5.1a).

\section{Trends in the percentage of low- and top-performers in science}

PISA's science assessments gauge the extent to which a country's or economy's students have acquired the knowledge and skills in science that will allow them to participate fully in a knowledge-based society. These skills range from basic notions of science (related to proficiency Level 2) to understanding of more complex scientific concepts and processes (related to proficiency Levels 5 and 6).

Changes in a country's or economy's average performance can result from improvements or deterioration at different points in the performance distribution. For example, in some countries and economies the average improvement may be observed among all students, resulting in fewer students performing below Level 2 and more students becoming 
top performers. In other contexts, the average improvement can be attributed to large improvements among lowachieving students with little or no change among high-achieving students; this may result in a smaller share of low-performing students, but no increase in the share of top performers. From a trends perspective, countries and economies succeed when they reduce the share of students who perform below proficiency Level 2 (low performers) or when they increase the share of students who perform at or above proficiency Level 5 (top performers) as they provide more opportunities for students to begin to show scientific literacy or to have the highest level competencies in science.

Countries and economies can be grouped into categories according to whether they have: simultaneously reduced the share of low performers and increased the share of top performers between any previous PISA assessment and PISA 2012; reduced the share of low performers but not increased the share of top performers between any previous PISA assessment and PISA 2012; increased the share of top performers but not reduced the share of low performers; and reduced the share of top performers or increased the share of low performers between PISA 2012 and any previous PISA assessment. The following section categorises countries and economies into these groups.

\section{Moving everyone up: Reduction in the share of low performers and increase in that of top performers}

Between PISA 2006 and PISA 2012, Poland, Qatar and Italy saw a reduction in the share of students who perform below proficiency Level 2 in science and an increase in the share of students who perform at or above proficiency Level 5. In Poland, for example, the share of students who perform below Level 2 in science dropped from 17\% in 2006 to $9 \%$ in 2012, while the share of students who perform at or above Level 5 in science increased from $7 \%$ to $11 \%$. In Italy, 25\% of students were considered low performers in 2006; by 2012, that percentage had decreased to $19 \%$. During the same period, the proportion of top performers in Italy increased from 5\% to 6\% (Figure I.5.11). As shown in Table I.5.1b, the same was observed in Singapore, Estonia and Israel between the PISA 2009 and PISA 2012 assessments.

The reduction in the share of low performers and increase in the share of top performers in these countries and economies mirrors the changes in how students at different points of the distribution have improved since 2006. Annex B4 shows, for each country and economy, the trajectories of the 10th, 25th, 75th and 90th percentiles of science performance. These are the lowest-, low-, high- and highest-achieving students. Consistent with the changes in the shares of low and top performers, it shows how overall average improvements in Poland and Italy are also seen among their low- and high-achieving students. In Poland, for example, the lowest-achieving students improved their science performance by 5.6 score points per year (from 381 points in 2006 to 415 points in 2012), and the highestachieving students also improved their performance by an average of 3.7 points per year (from 615 points in 2006 to 637 points in 2012), resulting in a decrease in the share of students performing below Level 2 and an increase in the share of students performing at Level 5. Similar improvements in science performance among low- and highachieving students are observed in Italy and Portugal.

\section{Reducing underperformance: Reduction in the share of low performers but no change in the share of top performers}

While relatively few countries and economies succeeded in increasing the share of top performers while simultaneously reducing the share of students who do not meet the baseline proficiency in science, many reduced the share of low performers between PISA 2006 and PISA 2012. Turkey, Thailand, Romania, Tunisia, Brazil, the United States, Portugal, Latvia, Korea, Ireland, Lithuania, Spain, Japan, Switzerland and Hong Kong-China saw a reduction in the share of students performing below proficiency Level 2 between 2006 and 2012, thus raising the number of students who demonstrate science literacy. Similarly, the Czech Republic, Slovenia, Dubai (United Arab Emirates) and Kazakhstan reduced the share of low performers between PISA 2009 and PISA 2012. Latvia, Portugal, the United States, Brazil, Tunisia, Romania, Thailand and Turkey, for example, reduced the share of students performing below proficiency Level 2 by more than five percentage points between 2006 and 2012 (Figure I.5.11).

Many of the countries and economies that reduced the share of low-performing students are those that show average improvements in science, and concentrate this improvement among their low-achieving students). Annex B4 shows the trajectories of low- and high-achieving students for all countries and economies, highlighting how, in Turkey, Korea, Romania, Brazil, Chile, Estonia, Switzerland, Spain, Tunisia and Lithuania, for example, while the lowest-achieving students improved their science performance by at least two score points per year between PISA 2006 and PISA 2012, the highest-achieving students saw no change in science performance. 


\section{Nurturing top performance: Increase in the share of high-performers but no change in that of low performers}

Top-performing students in science are those who perform at or above proficiency Level 5. Luxembourg and Serbia saw an increase in the share of top-performing students while the share of low-performing students remained unchanged between 2006 and 2012. Similar improvements were observed in Albania and Macao-China. Between PISA 2009 and PISA 2012. In Luxembourg, for example, the share of top performers increased from 6\% in 2006 to $8 \%$ in 2012 (Figure I.5.11 and Table I.5.1b).

\section{Increase in the share of low performers or decrease in that of high performers}

By contrast, in 13 countries and economies the percentage of students who do not meet the baseline proficiency in science in PISA increased since 2006 - or since more recent PISA cycles - or the share of students who perform at the highest levels of proficiency decreased (Figure I.5.11 and Table I.5.1b).

\section{- Figure I.5.11}

\section{Percentage of low-performing students and top performers in science in 2006 and 2012}

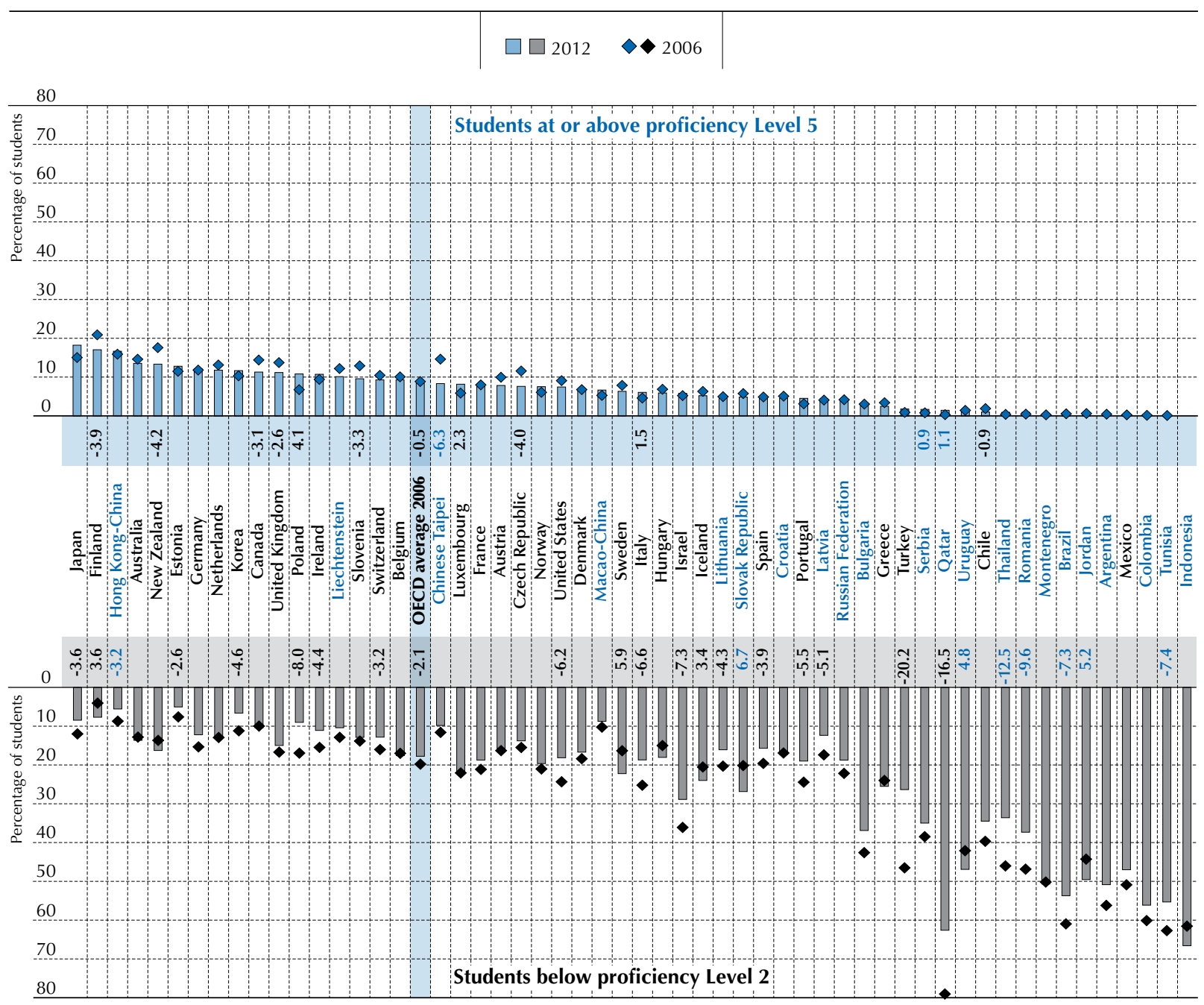

Notes: The chart shows only countries/economies that participated in both PISA 2006 and PISA 2012 assessments.

The change between PISA 2006 and PISA 2012 in the share of students performing below Level 2 in science is shown below the country/economy name. The change between PISA 2006 and PISA 2012 in the share of students performing at or above Level 5 in science is shown above the country/economy name. Only statistically significant changes are shown (see Annex A3).

OECD average 2006 compares only OECD countries with comparable science scores since 2006.

Countries and economies are ranked in descending order of the percentage of students at or above proficiency Level 5 in science in 2012

Source: OECD, PISA 2012 Database, Table I.5.1b.

StatLink त्नाIS http://dx.doi.org/10.1787/888932935629 


\section{Box I.5.1. Improving in PISA: Estonia}

Estonia's performance in PISA improved significantly since it first participated in PISA in 2006: by an average of 2.4 score points per year in reading and and science scores improved 14 points between PISA 2009 and PISA 2012. Its performance in reading improved from 501 points in PISA 2006 to 516 points in PISA 2012, and science performance improved from 531 points in PISA 2006 to 541 points in PISA 2012.

This improvement came in a challenging educational context. A significant demographic shift in Estonia's population of 1.3 million resulted in a $25 \%$ reduction in the number of students in general education between 2004 and 2012. Municipal schools in peripheral areas closed and repercussions are still being felt in teachertraining and retention systems, in higher education and in the labour market. High dropout rates further reduce the number of upper secondary and tertiary-level graduates. In addition, Estonia - as other OECD countries - faces the challenge of encouraging the best teachers to teach in remote and disadvantaged schools.

In response to the changing student population, the government changed its school funding model from a per capita to a per class criteria in 2008, allowing for a more equitable distribution of funds to rural schools, and, to reduce dropout rates, also began to promote vocational training. The change in financing recognises that not all of a schools' operational costs are variable, thus allowing many rural schools to keep functioning because in a per capita financing scheme they would have closed on budgetary reasons (Estonian Ministry of Education and Research, 2008).

To encourage newly qualified teachers to teach in small towns and rural areas, and for teachers with command of the Estonian language to teach in schools where Russian is the language of instruction, new teachers are offered an allowance of more than 12750 EUR during the first three years of teaching. Higher education institutions providing pre-service teacher training have formulated common competency standards for teachers and articulated a development plan for the teacher-training system (European Commission, 2010).

Other policy initiatives have promoted the use of assessments for self-monitoring purposes. In 2006, the Ministry of Education and Research introduced compulsory internal assessments for all pre-primary child-care institutions, general education schools and vocational training institutions, shifting supervisory functions from the state to the individual school level. Schools are offered support from the state to conduct their internal assessment (Estonian Ministry of Education and Research, 2008).

Since 2009, Estonia, through the Tiger Leap Foundation, has been promoting ICT use at all levels of education and in a wide range of study programmes, including science, mathematics, embroidery and robotics. The introduction of ICT equipment is combined with teacher training and new learning materials. For example, for mathematics projects, teachers are taught to use mathematics-learning software and funding is provided to schools to acquire computer-based algebra software (European Commission, 2010).

Based on the "Development Plan for the General Education System for 2007-2013", the national curriculum for basic and upper secondary schools was updated in January 2010 and the Basic Schools and Upper Secondary Schools Act was amended. As a result of these specifications, the volume of compulsory subjects in upper secondary schools was reduced from 72 to 63 courses and more elective courses are offered (Government of the Republic of Estonia, 2011a, 2011b).

The new national curriculum aims to offer more opportunities for a diverse student population in order to reduce grade repetition and dropout (Government of the Republic of Estonia, 2011a, 2011b). It is oriented towards learning, rather than teaching, and recognises the greater role students - and student engagement - take in the learning process. For example, in language-of-instruction classes, composition is emphasised; in natural science classes, research-based learning is promoted; in foreign-language classes, real-life situations are used to prompt responses in the language concerned. Certain topics in science and mathematics have been shifted from primary to secondary schools to ensure that they are taught in appropriate depth (Government of the Republic of Estonia, 2011a, 2011 b).

\section{Sources:}

Estonian Ministry of Education and Research (2008), The Development of Education, Estonian Ministry of Education and Research, Tallinn.

European Commission (2010), National Systems Overviews on Education Systems in Europe and Ongoing Reforms: Estonia 2010 Edition, Eurydice, Brussels.

Government of the Republic of Estonia (2011a), National Curriculum for Basic Schools, Tallinn.

Government of the Republic of Estonia (2011b), National Curriculum for Upper Secondary Schools, Tallinn. 


\section{Variation in student performance in science}

The difference in performance between students within countries and economies is shown in Table I.5.3a. Within countries, the difference in scores between the highest- (90th percentile) and lowest-achieving students (10th percentile) ranges from 174 to 281 points, with an OECD average of 239 points. Some of the lower-performing countries have among the narrowest gaps between the highest- and lowest-achieving students: Indonesia (with a gap of 174 points), Mexico (with a gap of 180 points), Colombia (with a gap of 196 points), Peru (with a gap of 200 points) and Tunisia (with a gap of 201 points). However, Viet Nam performs well above the OECD average and shows one of the ten narrowest gaps (197 points). Shanghai-China shows the best performance in science and a difference of only 209 points between the highest- and lowest-achieving students. At the other end of the spectrum, among the ten participating countries and economies that show the largest difference between the highest and lowest achievers in science, this gap ranges from between 257 to 281 points. One of the lowest-performing countries, Qatar (with a gap of 275 points), has nearly the same gap between the highest- and lowest-achieving students as one of the highest-performing countries, New Zealand (272 points). As in mathematics and reading, some countries perform well without having large differences between their highest- and lowest-achieving students. Among the eight best-performing countries in science, this is the case in Estonia, Korea, and in the partner countries and economies Viet Nam, Shanghai-China and Hong Kong-China, where the differences are around 30 points smaller than the OECD average.

\section{Gender differences in science performance}

Across OECD countries, differences in science performance related to gender tend to be small compared with the large gender gap in reading performance and the more moderate gender differences in mathematics performance. As shown in Figure 1.5.12, in more than half of the countries assessed, differences in the average score for boys and girls are not statistically significant. This indicates that gender equality is more prevalent in science performance than in mathematics or reading performance. In 2006, when science was the main focus of the PISA assessment, gender differences were observed in two of the science processes being assessed. Across OECD countries, girls scored higher in the area of identifying scientific issues, while boys outscored girls in explaining phenomena scientifically. The shorter assessment time for science in 2012 did not allow for an update of this finding.

The largest gender differences in favour of boys are observed in Colombia (18 score points) and in Luxembourg, the United Kingdom, Costa Rica, Japan and Denmark, where there is a 10-to-15 score-point difference between boys and girls. In Spain, Chile, Mexico and Switzerland, boys outperform girls in science by six to seven score points.

By contrast, in Jordan, Qatar, United Arab Emirates, girls outperform boys in science by 43, 35 and 28 score points, respectively. In Bulgaria, Thailand, Montenegro, Finland, Latvia, Lithuania, Greece, Malaysia and Turkey, girls outperform boys in science by from 20 to 10 score points (Figure I.5.12 and Table I.5.3a).

How do boys and girls differ in levels of proficiency? One way to determine this is to observe the highest level of proficiency attained by the largest group of girls and boys in each country and economy. As can be seen in Table I.5.2a, among all the participating countries and economies, the highest proficiency level attained by the largest group of boys (in 36 countries and economies) and girls (in 33 countries and economies) is Level 3 followed by Level 2 (the highest level attained by the largest group of boys in 15 countries and economies and by most girls in 21 countries and economies). But while in nine countries the highest proficiency level attained by the largest group of boys is Level 1 and in one country, below Level 1 - in six countries, Level 1 is the highest proficiency level attained by the largest group of girls. In only four countries is Level 4 the highest proficiency level attained by the largest group of boys and in five countries, the highest proficiency level attained by the largest group of girls.

On average across OECD countries, $18.6 \%$ of boys do not attain the baseline level of proficiency in science, Level 2 , and $16.9 \%$ of girls do not attain this level $-5.3 \%$ of boys and $4.2 \%$ of girls do not even attain Level 1 . The gender gap in the proportion of boys and girls performing below Level 2 is particularly pronounced in Jordan, the United Arab Emirates, Thailand, Qatar and Bulgaria. The share of girls performing below Level 2 is at least 10 percentage points smaller than that of boys. The largest difference is found in Jordan where more than $60 \%$ of boys perform at or below Level 1 compared to $39 \%$ of girls. The opposite pattern can be observed in several countries and economies. The five countries and economies with the largest gender gap, in favour of boys, among students performing below proficiency Level 2 are Colombia, Costa Rica, Liechtenstein, Luxembourg and Mexico. There appears to be no relation between overall science performance and this gender gap as these countries and economies vary considerably in overall science performance. 
- Figure I.5.12

Gender differences in science performance

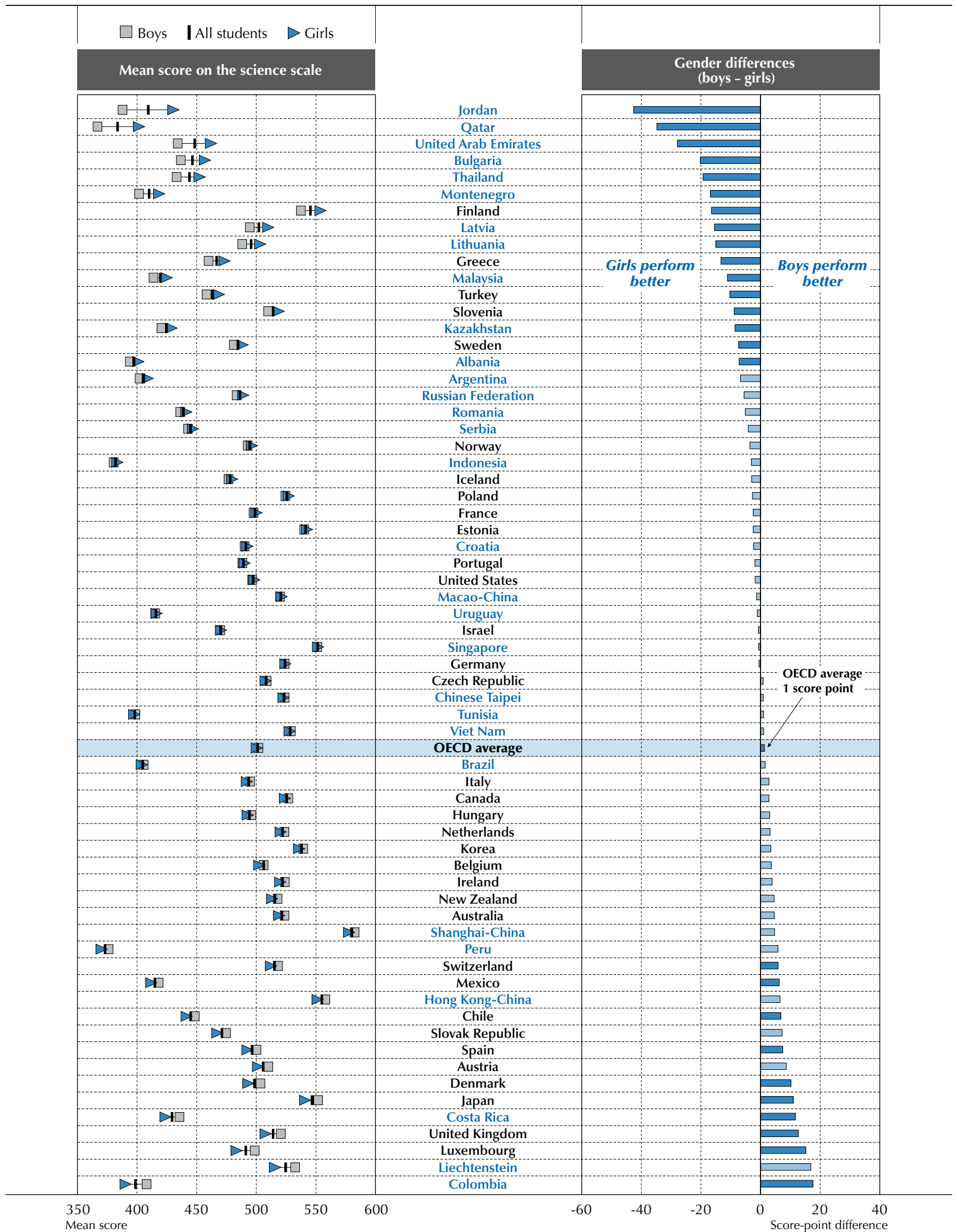

Note: Statistically significant gender differences are marked in a darker tone (see Annex A3).

Countries and economies are ranked in ascending order of the score-point difference (boys - girls).

Source: OECD, PISA 2012 Database, Table I.5.3a.

StatLink 青市D http://dx.doi.org/10.1787/888932935629 
Not only do fewer girls than boys perform at the lowest proficiency levels, but fewer girls than boys perform at the highest proficiency levels on the science scale as well. Across OECD countries, $9.3 \%$ of boys are top performers in science (performing at Level 5 or 6 ), but only $7.4 \%$ of girls are.

In Japan, Liechtenstein, Hong Kong-China and Shanghai-China, all of which are among the highest-performing countries and economies in science and have relatively large shares of students performing at the highest proficiency levels, the share of top performers among boys is at least four percentage points larger than that among girls.

\section{Trends in gender differences in science performance}

In 37 of the 54 countries and economies that participated in PISA 2006 (and also took part in PISA 2012) there was no gender gap in science. A gender gap favouring boys was observed in eight countries (and largest in Chile, at 22 score points), and in ten countries, girls outperformed boys (Table I.5.3c and OECD, 2007).

Between PISA 2006 and PISA 2012, and on average across OECD countries, the gender gap in science performance remained unchanged. However, in those countries and economies where the magnitude of the gender gap in science did change, the change always favoured girls. This was the case in Finland, Montenegro, Sweden and the Russian Federation where, while there was no gender gap in science in PISA 2006, a gender gap in favour of girls was observed in PISA 2012. In the Russian Federation this is the result of an improvement in science performance among girls between PISA 2006 and PISA 2012 that was not observed among boys. In Finland, Montenegro and Sweden, the observed gender gap in science in favour of girls is the result of a greater deterioration in science performance among boys than among girls. In Chile the gender gap that favoured boys in PISA 2006 was weaker in 2012, and was no longer present in Brazil as girls' science performance has improved more rapidly than boys' (Figure I.5.13).

- Figure 1.5 .13 .

Change between 2006 and 2012 in gender differences in science performance

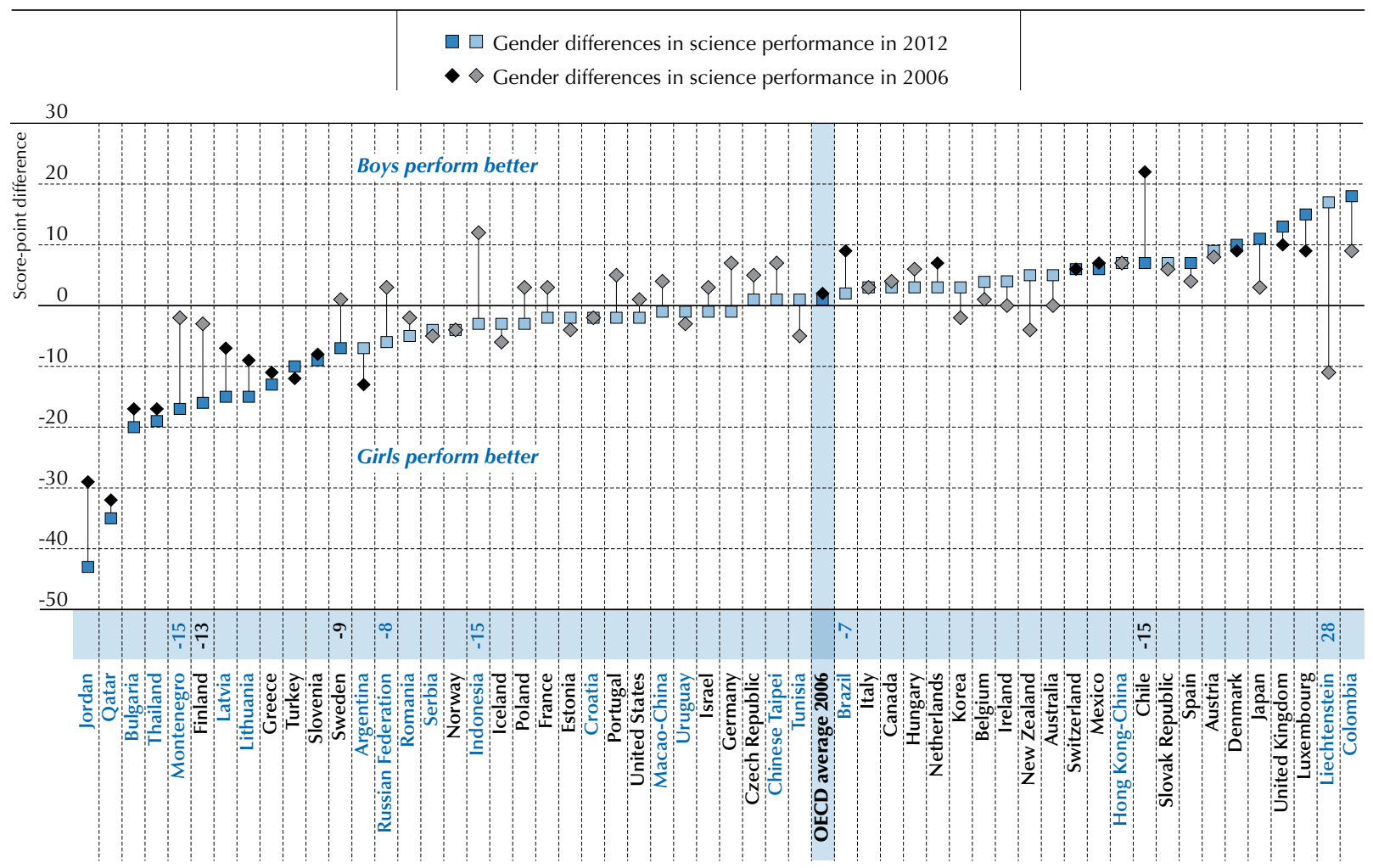

Notes: Gender differences in PISA 2006 and PISA 2012 that are statistically significant are marked in a darker tone (see Annex A3).

Statistically significant changes in the score-point difference between boys and girls in science performance between PISA 2006 and PISA 2012 are shown next to the country/economy name.

OECD average 2006 compares only OECD countries with comparable science scores since 2006. Countries and economies are ranked in ascending order of gender differences (boys-girls) in 2012.

Source: OECD, PISA 2012 Database, Table 1.5.3c.

StatLink त्राज http://dx.doi.org/10.1787/888932935629 


\section{EXAMPLES OF PISA SCIENCE UNITS}

The questions are presented in the order in which they appeared within the unit in the main survey.

\section{- Figure I.5.14}

GREENHOUSE

\section{Read the texts and answer the questions that follow.}

\section{THE GREENHOUSE EFFECT: FACT OR FICTION?}

Living things need energy to survive. The energy that sustains life on the Earth comes from the Sun, which radiates energy into space because it is so hot. A tiny proportion of this energy reaches the Earth.

The Earth's atmosphere acts like a protective blanket over the surface of our planet, preventing the variations in temperature that would exist in an airless world.

Most of the radiated energy coming from the Sun passes through the Earth's atmosphere. The Earth absorbs some of this energy, and some is reflected back from the Earth's surface. Part of this reflected energy is absorbed by the atmosphere.

As a result of this the average temperature above the Earth's surface is higher than it would be if there were no atmosphere. The Earth's atmosphere has the same effect as a greenhouse, hence the term greenhouse effect.

The greenhouse effect is said to have become more pronounced during the twentieth century.

It is a fact that the average temperature of the Earth's atmosphere has increased. In newspapers and periodicals the increased carbon dioxide emission is often stated as the main source of the temperature rise in the twentieth century.

A student named André becomes interested in the possible relationship between the average temperature of the Earth's atmosphere and the carbon dioxide emission on the Earth.

In a library he comes across the following two graphs.
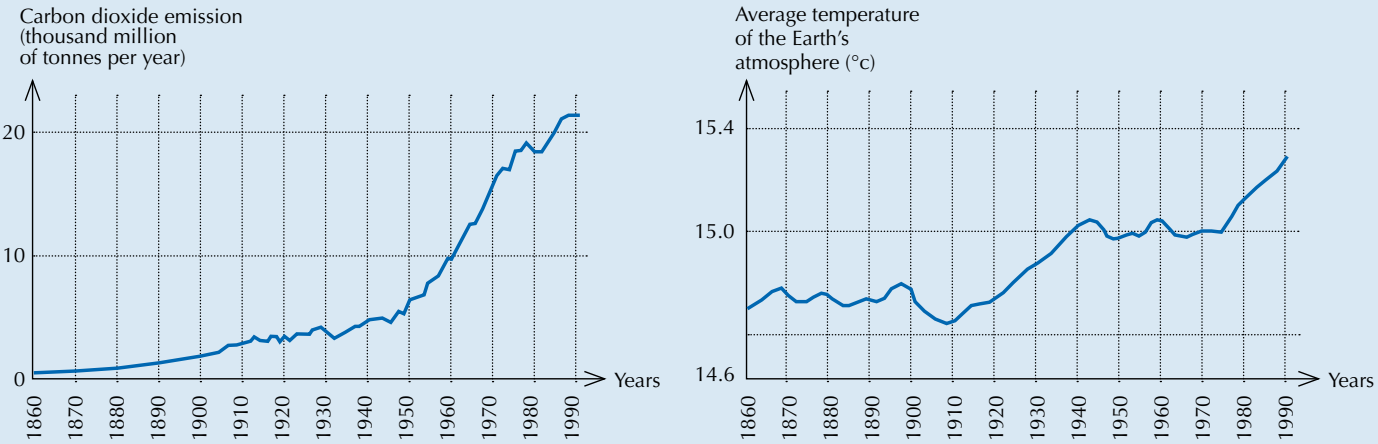

André concludes from these two graphs that it is certain that the increase in the average temperature of the Earth's atmosphere is due to the increase in the carbon dioxide emission.

\section{GREENHOUSE - QUESTION 4}

Question type: Open-constructed response

Competency: Using scientific evidence

Knowledge category: "Scientific explanations" (knowledge about science)

Application area: "Environment"

Setting: Global

Difficulty: Full credit 659; Partial credit 568 .

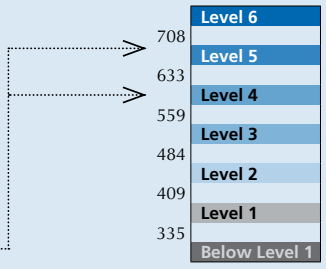

Percentage of correct answers (OECD countries): $34.5 \%$

Another student, Jeanne, disagrees with André's conclusion. She compares the two graphs and says that some parts of the graphs do not support his conclusion.

Give an example of a part of the graphs that does not support André's conclusion. Explain your answer. 
Scoring

\section{Full Credit:}

Refers to one particular part of the graphs in which the curves are not both descending or both climbing and gives the corresponding explanation. For example:

- In 1900-1910 (about) $\mathrm{CO}_{2}$ was increasing, whilst the temperature was going down.

- In 1980-1983 carbon dioxide went down and the temperature rose.

- The temperature in the 1800 s is much the same but the first graph keeps climbing.

- Between 1950 and 1980 the temperature didn't increase but the $\mathrm{CO}_{2}$ did.

- From 1940 until 1975 the temperature stays about the same but the carbon dioxide emission shows a sharp rise.

- In 1940 the temperature is a lot higher than in 1920 and they have similar carbon dioxide emissions.

\section{Partial Credit:}

Mentions a correct period, without any explanation. For example:

- 1930-1933.

- before 1910.

Mentions only one particular year (not a period of time), with an acceptable explanation. For example:

- In 1980 the emissions were down but the temperature still rose.

Gives an example that doesn't support André's conclusion but makes a mistake in mentioning the period. [Note: There should be evidence of this mistake - e.g. an area clearly illustrating a correct answer is marked on the graph and then a mistake made in transferring this information to the text.] For example:

- Between 1950 and 1960 the temperature decreased and the carbon dioxide emission increased.

Refers to differences between the two curves, without mentioning a specific period. For example:

- At some places the temperature rises even if the emission decreases.

- Earlier there was little emission but nevertheless high temperature.

- When there is a steady increase in graph 1 , there isn't an increase in graph 2 , it stays constant. [Note: It stays constant "overall".]

- Because at the start the temperature is still high where the carbon dioxide was very low.

Refers to an irregularity in one of the graphs. For example:

- It is about 1910 when the temperature had dropped and went on for a certain period of time.

- In the second graph there is a decrease in temperature of the Earth's atmosphere just before 1910.

Indicates difference in the graphs, but explanation is poor. For example:

- In the 1940s the heat was very high but the carbon dioxide very low. [Note: The explanation is very poor, but the difference that is indicated is clear.]

\section{Comment}

Another example from GREENHOUSE centres on the competency using scientific evidence and asks students to identify a portion of a graph that does not provide evidence supporting a conclusion. This question requires the student to look for specific differences that vary from positively correlated general trends in these two graphical datasets. Students must locate a portion where curves are not both ascending or descending and provide this finding as part of a justification for a conclusion. As a consequence it involves a greater amount of insight and analytical skill than is required for Question 3. Rather than a generalisation about the relation between the graphs, the student is asked to accompany the nominated period of difference with an explanation of that difference in order to gain full credit.

The ability to effectively compare the detail of two datasets and give a critique of a given conclusion locates the full credit question at Level 5 of the scientific literacy scale. If the student understands what the question requires of them and correctly identifies a difference in the two graphs, but is unable to explain this difference, the student gains partial credit for the question and is identified at Level 4 of the scientific literacy scale.

This environmental issue is global which defines the setting. The skill required by students is to interpret data graphically presented so the question belongs in the "Scientific explanations" category. 


\section{GREENHOUSE - QUESTION 5}

Question type: Open-constructed response

Competency: Explaining phenomena scientifically

Knowledge category: "Earth and space systems" (knowledge of science)

Application area: "Environment"

Setting: Global

Difficulty: 709 .

Percentage of correct answers (OECD countries): $18.9 \%$

André persists in his conclusion that the average temperature rise of the Earth's atmosphere is caused by the increase in the carbon dioxide emission. But Jeanne thinks that his conclusion is premature. She says: "Before accepting this conclusion you must be sure that other factors that could influence the greenhouse effect are constant".

Name one of the factors that Jeanne means.

\section{Scoring}

\section{Full Credit:}

Gives a factor referring to the energy/radiation coming from the Sun. For example:

- The sun heating and maybe the earth changing position.

- Energy reflected back from Earth. [Assuming that by "Earth" the student means "the ground".]

Gives a factor referring to a natural component or a potential pollutant. For example:

- Water vapour in the air.

- Clouds.

- The things such as volcanic eruptions.

- Atmospheric pollution (gas, fuel).

- The amount of exhaust gas.

- CFCs.

- The number of cars.

- Ozone (as a component of air).

\section{Comment}

Question 5 of GREENHOUSE is an example of Level 6 and of the competency explaining phenomena scientifically. In this question, students must analyse a conclusion to account for other factors that could influence the greenhouse effect. This question combines aspects of the two competencies identifying scientific issues and explaining phenomena scientifically. The student needs to understand the necessity of controlling factors outside the change and measured variables and to recognise those variables. The student must possess sufficient knowledge of "Earth systems" to be able to identify at least one of the factors that should be controlled. The latter criterion is considered the critical scientific skill involved so this question is categorised as explaining phenomena scientifically. The effects of this environmental issue are global, which defines the setting.

As a first step in gaining credit for this question the student must be able to identify the change and measured variables and have sufficient understanding of methods of investigation to recognise the influence of other factors. However, the student also needs to recognise the scenario in context and identify its major components. This involves a number of abstract concepts and their relationships in determining what "other" factors might affect the relationship between the Earth's temperature and the amount of carbon dioxide emissions into the atmosphere. This locates the question near the boundary between Level 5 and 6 in the explaining phenomena scientifically category. 


\section{- Figure I.5.15 "}

\section{CLOTHES}

Read the text and answer the questions that follow.

\section{CLOTHES TEXT}

A team of British scientists is developing "intelligent" clothes that will give disabled children the power of "speech". Children wearing waistcoats made of a unique electrotextile, linked to a speech synthesiser, will be able to make themselves understood simply by tapping on the touch-sensitive material.

The material is made up of normal cloth and an ingenious mesh of carbon-impregnated fibres that can conduct electricity. When pressure is applied to the fabric, the pattern of signals that passes through the conducting fibres is altered and a computer chip can work out where the cloth has been touched. It then can trigger whatever electronic device is attached to it, which could be no bigger than two boxes of matches.

"The smart bit is in how we weave the fabric and how we send signals through it - and we can weave it into existing fabric designs so you cannot see it's in there," says one of the scientists.

Without being damaged, the material can be washed, wrapped around objects or scrunched up. The scientist also claims it can be mass-produced cheaply.

Source: Farrer, S., "Interactive fabric promises a material gift of the garb", The Australian, 10 August 1998.

\section{CLOTHES - QUESTION 1}

Question type: Complex multiple choice

Competency: Identifying scientific issues

Knowledge category: "Scientific enquiry" (knowledge about science)

Application area: "Frontiers of science and technology"

Setting: Social

Difficulty: 567 .

Percentage of correct answers (OECD countries): $47.9 \%$

Can these claims made in the article be tested through scientific investigation in the laboratory? Circle either "Yes" or "No" for each.

\begin{tabular}{l|c}
\hline The material can be & $\begin{array}{c}\text { Can the claim be tested through scientific investigation } \\
\text { in the laboratory? }\end{array}$ \\
\hline washed without being damaged. & Yes / No \\
\hline wrapped around objects without being damaged. & Yes / No \\
\hline scrunched up without being damaged. & Yes / No \\
\hline mass-produced cheaply. & Yes / No \\
\hline
\end{tabular}

\section{Scoring}

Full Credit: Yes, Yes, Yes, No, in that order.

\section{Comment}

The question requires the student to identify the change and measured variables associated with testing a claim about the clothing. It also involves an assessment of whether there are techniques to quantify the measured variable and whether other variables can be controlled. This process then needs to be accurately applied for all four claims. The issue of "intelligent" clothes is in the category "Frontiers of science and technology" and is a community issue addressing a need for disabled children so the setting is social. The scientific skills applied are concerned with the nature of investigation which places the question in the "Scientific enquiry" category.

The need to identify change and measured variables, together with an appreciation of what would be involved in carrying out measurement and controlling variables, locates the question at Level 4. 


\section{- Figure I.5.16}

\section{MARY MONTAGU}

Read the following newspaper article and answer the questions that follow.

\section{THE HISTORY OF VACCINATION}

Mary Montagu was a beautiful woman. She survived an attack of smallpox in 1715 but she was left covered with scars. While living in Turkey in 1717, she observed a method called inoculation that was commonly used there. This treatment involved scratching a weak type of smallpox virus into the skin of healthy young people who then became sick, but in most cases only with a mild form of the disease.

Mary Montagu was so convinced of the safety of these inoculations that she allowed her son and daughter to be inoculated.

In 1796, Edward Jenner used inoculations of a related disease, cowpox, to produce antibodies against smallpox. Compared with the inoculation of smallpox, this treatment had less side effects and the treated person could not infect others. The treatment became known as vaccination.

\section{MARY MONTAGU - QUESTION 2}

Question type: Multiple choice

Competency: Explaining phenomena scientifically

Knowledge category: "Living systems" (knowledge of science)

Application area: "Health"

Setting: Social

Difficulty: 436 .

Percentage of correct answers (OECD countries): $74.9 \%$

\section{What kinds of diseases can people be vaccinated against?}

A. Inherited diseases like haemophilia.

B. Diseases that are caused by viruses, like polio.

C. Diseases from the malfunctioning of the body, like diabetes.

D. Any sort of disease that has no cure.

Scoring

Full Credit: B. Diseases that are caused by viruses, like polio.

\section{Comment}

To gain credit the student must recall a specific piece of knowledge that vaccination helps prevent diseases, the cause for which is external to normal body components. This fact is then applied in the selection of the correct explanation and the rejection of other explanations. The term "virus" appears in the stimulus text and provides a hint for students. This lowered the difficulty of the question. Recalling an appropriate, tangible scientific fact and its application in a relatively simple context locates the question at Level 2.

\section{MARY MONTAGU - OUESTION 3}

Question type: Multiple choice

Competency: Explaining phenomena scientifically

Knowledge category: "Living systems" (knowledge of science)

Application area: "Health"

Setting: Social

Difficulty: 431 .

Percentage of correct answers (OECD countries): $75.1 \%$ 
If animals or humans become sick with an infectious bacterial disease and then recover, the type of bacteria that caused the disease does not usually make them sick again.

What is the reason for this?

A. The body has killed all bacteria that may cause the same kind of disease.

B. The body has made antibodies that kill this type of bacteria before they multiply.

C. The red blood cells kill all bacteria that may cause the same kind of disease.

D. The red blood cells capture and get rid of this type of bacteria from the body.

Scoring

Full Credit: B. The body has made antibodies that kill this type of bacteria before they multiply.

\section{Comment}

To correctly answer this question the student must recall that the body produces antibodies that attack foreign bacteria, the cause of bacterial disease. Its application involves the further knowledge that these antibodies provide resistance to subsequent infections of the same bacteria. The issue is community control of disease, so the setting is social.

In selecting the appropriate explanation the student is recalling a tangible scientific fact and applying it in a relatively simple context. Consequently, the question is located at Level 2.

\section{MARY MONTAGU - QUESTION 4}

Question type: Open-constructed response

Competency: Explaining phenomena scientifically

Knowledge category: "Living systems" (knowledge of science)

Application area: "Health"

Setting: Social

Difficulty: 507 .

Percentage of correct answers (OECD countries): $61.7 \%$

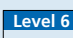

633

559 Level 4

559

Level 2

409

Level 1

335 Below Level

Give one reason why it is recommended that young children and old people, in particular, should be vaccinated against influenza (flu).

\section{Scoring}

Full Credit: Responses referring to young and/or old people having weaker immune systems than other people, or similar. For example:

These people have less resistance to getting sick.

The young and old can't fight off disease as easily as others.

They are more likely to catch the flu.

If they get the flu the effects are worse in these people.

Because organisms of young children and older people are weaker.

Old people get sick more easily.

\section{Comment}

This question requires the student to identify why young children and old people are more at risk of the effects of influenza than others in the population. Directly, or by inference, the reason is attributed to young children and old people having weaker immune systems. The issue is community control of disease, so the setting is social.

A correct explanation involves applying several pieces of knowledge that are well established in the community. The question stem also provides a cue to the groups having different resistance to disease. This puts the question at Level 3. 


\section{- Figure I.5.17 - \\ GENETICALLY MODIFIED CROPS}

\section{GM CORN SHOULD BE BANNED}

Wildlife conservation groups are demanding that a new genetically modified (GM) corn be banned.

This GM corn is designed to be unaffected by a powerful new herbicide that kills conventional corn plants. This new herbicide will kill most of the weeds that grow in cornfields.

The conservationists say that because these weeds are feed for small animals, especially insects, the use of the new herbicide with the GM corn will be bad for the environment. Supporters of the use of the GM corn say that a scientific study has shown that this will not happen.

Here are details of the scientific study mentioned in the above article:

- Corn was planted in 200 fields across the country.

- Each field was divided into two. The genetically modified (GM) corn treated with the powerful new herbicide was grown in one half, and the conventional corn treated with a conventional herbicide was grown in the other half.

- The number of insects found in the GM corn, treated with the new herbicide, was about the same as the number of insects in the conventional corn, treated with the conventional herbicide.

\section{GENETICALLY MODIFIED CROPS - QUESTION 3}

Question type: Multiple choice

Competency: Identifying scientific issues

Knowledge category: "Scientific enquiry" (knowledge about science)

Application area: "Frontiers of science and technology"

Setting: Social

Difficulty: 421 .

Percentage of correct answers (OECD countries): $73.6 \%$

Corn was planted in 200 fields across the country. Why did the scientists use more than one site?

A. So that many farmers could try the new GM corn.

B. To see how much GM corn they could grow.

C. To cover as much land as possible with the GM crop.

D. To include various growth conditions for corn.

Scoring

Full Credit: D. To include various growth conditions for corn.

\section{Comment}

Towards the bottom of the scale, typical questions for Level 2 are exemplified by Question 3 from the unit GENETICALLY MODIFIED CROPS, which is for the competency identifying scientific issues. Question 3 asks a simple question about varying conditions in a scientific investigation and students are required to demonstrate knowledge about the design of science experiments.

To answer this question correctly in the absence of cues, the student needs to be aware that the effect of the treatment (different herbicides) on the outcome (insect numbers) could depend on environmental factors. Thus, by repeating the test in 200 locations the chance of a specific set of environmental factors giving rise to a spurious outcome can be accounted for. Since the question focuses on the methodology of the investigation it is categorised as "Scientific enquiry". The application area of genetic modification places this at the "Frontiers of science and technology" and given its restriction to one country it can be said to have a social setting.

In the absence of cues this question has the characteristics of Level 4, i.e. the student shows an awareness of the need to account for varying environmental factors and is able to recognise an appropriate way of dealing with that issue. However, the question actually performed at Level 2. This can be accounted for by the cues given in the three distractors. Students likely are able to easily eliminate these as options thus leaving the correct explanation as the answer. The effect is to reduce the difficulty of the question. 


\section{- Figure I.5.18 - \\ PHYSICAL EXERCISE}

Regular but moderate physical exercise is good for our health.

PHYSICAL EXERCISE - QUESTION 3

Question type: Complex multiple choice

Competency: Explaining phenomena scientifically

Knowledge category: "Living systems" (knowledge of science)

Application area: "Health"

Setting: Personal

Difficulty: 386 .

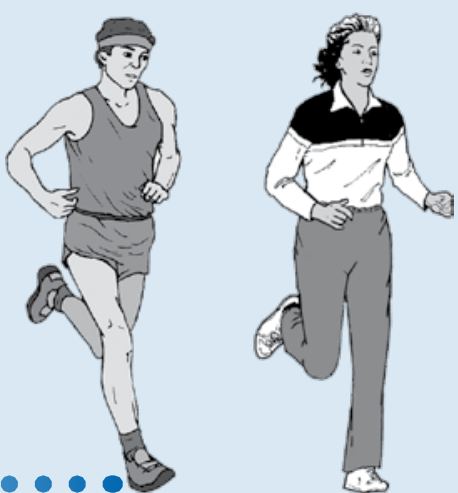

Percentage of correct answers (OECD countries): $82.4 \%$

What happens when muscles are exercised? Circle "Yes" or "No" for each statement.

\begin{tabular}{l|c}
\hline Does this happen when muscles are exercised? & Yes or No? \\
\hline Muscles get an increased flow of blood. & Yes / No \\
\hline Fats are formed in the muscles. & Yes / No \\
\hline
\end{tabular}

Scoring

Full Credit: Both correct: Yes, No, in that order.

\section{Comment}

For this question, to gain credit a student has to correctly recall knowledge about the operation of muscles and about the formation of fat in the body, i.e. students must have knowledge of the science fact that active muscles get an increased flow of blood and that fats are not formed when muscles are exercised. This enables the student to accept the first explanation of this complex multiple-choice question and reject the second explanation.

The two simple factual explanations contained in the question are not related to each other. Each is accepted or rejected as an effect of the exercise of muscles and the knowledge has widespread currency. This question is located at Level 1 , at the very bottom of the scale for the competency explaining phenomena scientifically. 


\section{Notes}

1. As described in more detail in Annex A5, the annualised change takes into account the specific year in which the assessment took place. In the case of science, this is especially relevant for the 2009 assessment as Costa Rica, Malaysia and the United Arab Emirates (excluding Dubai) implemented the assessment in 2010 as part of PISA+.

2. As described in Annex A5, the annualised change considers the case of countries and economies that implemented PISA 2009 in 2010 as part of PISA 2009+.

3. By accounting for students' gender, age, socio-economic status, migration background and language spoken at home, the adjusted trends allow for a comparison of trends in performance assuming no change in the underlying population or the effective samples' average socio-economic status, age and percentage of girls, students with an immigrant background or students that speak a language at home that is different than the language of assessment. See Annex A5 for more details on the calculation of adjusted trends.

\section{References}

Estonian Ministry of Education and Research (2008), The Development of Education, Estonian Ministry of Education and Research, Tallinn.

European Commission (2010), National Systems Overviews on Education Systems in Europe and Ongoing Reforms: Estonia 2010 Edition, Eurydice, Brussels.

Government of the Republic of Estonia (2011a), National Curriculum for Basic Schools, Tallinn.

Government of the Republic of Estonia (2011b), National Curriculum for Upper Secondary Schools, Tallinn.

OECD (2011), PISA 2009 Results: Students On Line Digital Technologies and Performance (Volume VI), PISA, OECD Publishing. http://dx.doi.org/10.1787/9789264112995-en

OECD (2010), Pathways To Success: How Knowledge And Skills At Age 15 Shape Future Lives In Canada, PISA, OECD Publishing. http://dx.doi.org/10.1787/9789264081925-en

OECD (2007), PISA 2006: Science Competencies for Tomorrow's World, PISA, OECD Publishing. http://dx.doi.org/10.1787/9789264040014-en

OECD (2006), Assessing Scientific, Reading and Mathematical Literacy: A Framework for PISA 2006, PISA, OECD Publishing. http://dx.doi.org/10.1787/9789264026407-en 


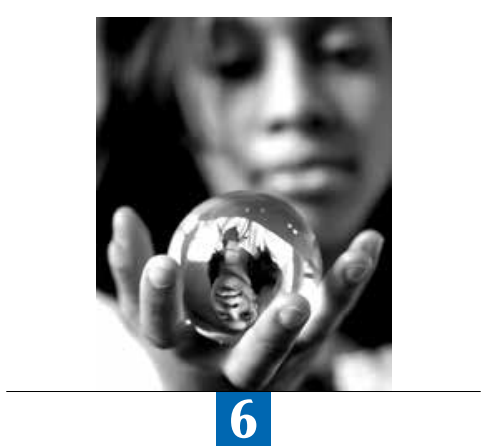

\section{Policy Implications of Student Performance in PISA 2012}

The PISA 2012 assessment dispels the notion that achievement in mathematics is mainly a product of innate ability rather than hard work. Results also suggest that improvement is possible among high performers as well as among low performers. This chapter considers how education policies of school systems and individual schools are associated with student performance and with gender differences in performance. 
OECD countries invest over USD 230 billion each year in mathematics education in schools. While this is a major investment, the returns are many times larger. Countries that have conducted longitudinal studies of student performance, including performance in PISA, have shown that proficiency in mathematics is a strong predictor of positive outcomes for young adults, influencing their ability to participate in post-secondary education and their expected future earnings. The new Survey of Adult Skills (OECD, 2013) also found that foundation skills in mathematics have a major impact on individuals' life chances. The survey shows that poor mathematics skills severely limit people's access to better-paying and more-rewarding jobs; at the aggregate level, inequality in the distribution of mathematics skills across populations is closely related to how wealth is shared within nations. Beyond that, the survey shows that people with strong skills in mathematics are also more likely to volunteer, see themselves as actors rather than as objects of political processes, and are even more likely to trust others. Fairness, integrity and inclusiveness in public policy thus also hinge on the skills of citizens.

PISA 2012 provides the most comprehensive picture of the mathematics skills developed in schools that has ever been available, looking not just at what students know in the different domains of mathematics, but also at what they can do with what they know. The results show wide differences between countries in the mathematics knowledge and skills of 15 -year-olds. The equivalent of almost six years of schooling, 245 score points on the PISA mathematics scale, separates the highest and lowest average performances of the countries that took part in the PISA 2012 mathematics assessment. However, differences between countries represent only a fraction of the overall variation in student performance. The difference in mathematics performances within countries is generally even greater, with over 300 points - the equivalent of more than seven years of schooling - often separating the highest and the lowest performers in a country. Addressing the education needs of such diverse populations and narrowing the observed gaps in student performance remains a formidable challenge for all countries.

The results show that a surprisingly small proportion of the performance variation among countries is explained by the wealth of nations ( $21 \%$ among all countries and economies, $12 \%$ among OECD countries) or expenditure per student (30\% among all countries and economies, 17\% among OECD countries), suggesting that the world is no longer divided into rich and well-educated nations, and poor and badly educated ones.

Even more important, the PISA 2012 assessment dispels the widespread notion that mathematics achievement is mainly a product of innate ability rather than hard work. On average across all countries, $32 \%$ of 15 -year-olds do not reach the baseline Level 2 on the PISA mathematics scale (24\% across OECD countries), meaning that those students can perform at best - routine mathematical procedures following direct instructions. But in Japan and Korea, fewer than $10 \%$ of students - and in Shanghai-China, fewer than $4 \%$ of students - do not reach this level of proficiency. In these education systems, high expectations for all students are not a mantra but a reality; students who start to fall behind are identified quickly, their problems are promptly and accurately diagnosed, and the appropriate course of action for improvement is quickly taken. Everyone knows what is required to earn a given qualification, in terms of both the content studied and the level of performance to be demonstrated. As discussed in Volume III, the observed variation in mathematics performance is closely related to students' beliefs about the importance of self-concept, effort and persistence for their performance in mathematics. The fact that those beliefs vary significantly across schools and countries suggests that they can be shaped by education policy and practice. These findings should inspire education policy makers to move away from the notion that only a few students can achieve in mathematics towards one that embraces the proposition that all students can.

\section{IMPROVING AVERAGE PERFORMANCE}

It is possible to evaluate trends in performance for countries that participated in PISA 2012 and at least one previous assessment. Trends are analysed for 64 countries and economies, 40 of which improved their average performance in at least one of the three subjects. Countries and economies that improve in PISA are diverse: they are countries and economies from all parts of the world, with education systems that organise their schooling in different ways, and that, when they began their participation in PISA, performed below, at or above the OECD average. The diversity of improving countries and economies shows that improvement in performance in all subjects - or in one particular subject - is possible for all school systems.

Some contend that the observed performance differences among countries are mainly the product of culture or socioeconomic status. However, PISA 2012 results show that many countries and economies have improved their performance, whatever their culture or socio-economic status. For some of the countries that improved their performance in one or more of the domains assessed, improvements are observed among all students: everyone "moved up". Other countries concentrated their improvements among their low-achieving students, increasing the share of students who begin to 
show literacy in mathematics, reading or science. Improvement in other countries, by contrast, is concentrated among high-achieving students, so the share of top-performing students grew.

Some of the highest-performing education systems were able to extend their lead, while others with very low performance have been catching up. This suggests that improvement is possible, whatever the starting point for students, schools and education systems.

Brazil, Dubai (United Arab Emirates), Hong Kong-China, Israel, Macao-China, Poland, Portugal, Qatar, Singapore, Tunisia and Turkey improved their average performance in mathematics, reading and science during their participation in PISA, showing that broad improvement in performance is possible, even in a short time span. Improvements in mathematics and reading were observed in Albania, Chile, Germany, Mexico, Montenegro, Serbia and Shanghai-China. Improvements in mathematics and science were observed in Italy, Kazakhstan and Romania, while improvements in reading and science were observed in Japan, Korea, Latvia and Thailand. Improvements in mathematics (but not in reading or science) were observed in Bulgaria, Greece, Malaysia and the United Arab Emirates (ex. Dubai) while improvements in science (but not in mathematics or reading) were observed only in Ireland. Improvements in reading (but not in mathematics or science) were observed in Chinese Taipei, Colombia, Estonia, Hungary, Indonesia, Liechtenstein, Luxembourg, Peru, the Russian Federation and Switzerland.

Even though different countries and economies face significantly different challenges in education and operate in different contexts that privilege certain policies and practices over others, the reform trajectories of improving countries are remarkably consistent with those attributes and policies that, throughout the analyses in Volumes II, III and IV of the PISA results, are related to higher mathematics performance. ${ }^{1}$ Throughout these volumes, case studies examine in greater detail the policy reforms adopted by some countries that have improved in PISA. Poland (see Box IV.2.1 in Volume IV), for example, reformed its education system by delaying the age of selection into different programmes, and schools in Germany (see Box II.3.2 in Volume II) are also moving towards reducing the levels of stratification across education programmes. Estonia (see Box I.5.1), Poland (see Box IV.2.1 in Volume IV), Brazil (see Box I.2.4), Colombia (see Box IV.4.3 in Volume IV), Japan (see Box III.3.1 in Volume III), Mexico (see Box II.2.4 in Volume II) and Israel (see Box IV.1.4 in Volume IV) for example, have focused certain policies on improving the quality of their teaching staff by increasing the requirements to earn a teaching license, providing incentives for high-achieving students to enter the profession, raising salaries to make the profession more attractive and to retain more teachers, by offering incentives for teachers to engage in in-service teacher-training programmes or by changing the criteria and benefits associated with teachers' career advancement. Israel (see Box IV.1.4 in Volume IV), Germany (see Box II.3.2 in Volume II), Mexico (see Box II.2.4 in Volume II), Turkey (see Box I.2.5) and Brazil (see Box I.2.4) have implemented targeted policies to improve the performance of low-performing schools or students, or implemented systems to distribute more resources to those regions and schools that need them the most. Some countries, like Colombia (see Box IV.4.3 in Volume IV), Poland (see Box IV.2.1 in Volume IV) and Korea (see Box I.4.1), have given schools and local authorities more autonomy but have recognised that autonomy works only in the context of collaboration and accountability. Others, like Portugal (see Box III.4.1 in Volume III), have reshaped the organisation of schools to facilitate collaboration and economies of scale between individual schools by creating school clusters. Many low-performing countries that have improved their performance (e.g. Brazil, Box I.2.4, Turkey, Box I.2.5, Colombia, Box IV.4.3 in Volume IV, Tunisia, Box III.3.2 in Volume III and Mexico, Box II.2.4 in Volume II) have focused on ensuring that all 15-year-olds are enrolled and attend school, and have increased the amount of financial resources devoted to the school system. Poland (see Box IV.2.1 in Volume IV), Mexico (see Box II.2.4 in Volume II) and Colombia (see Box IV.4.3 in Volume IV) have expanded the information infrastructure of the education system in support of schools' and local authorities' accountability arrangements. Recognising that a positive learning environment is key to promoting positive attitudes among students which, in turn, promote learning, Japan (see Box III.3.1 in Volume III) and Portugal (see Box III.4.1 in Volume III) have improved their students' attitudes, dispositions and self-beliefs towards school in general, and towards mathematics in particular, by, for example, reforming their curricula so that they are better aligned with students' interests and 21 st century skills.

As described further in Volume II of this series, of the countries that improved, and among those that also participated in PISA 2003, Germany, Mexico, Poland and Turkey also reduced the relationship between students' performance and their socio-economic status, showing that simultaneous improvement in performance and equity is possible.

\section{PURSUING EXCELLENCE}

In most countries and economies, only a small proportion of students attains the highest levels and can be called top performers in reading, mathematics or science. Even fewer are the academic all-rounders, those students who achieve 
proficiency Level 5 or higher in all three subjects. Nurturing excellence in mathematics, reading or science, or in all three domains, is crucial for a country's development as these students will be the vanguard of a competitive, knowledge-based global economy.

Results from the PISA 2012 assessment show that nurturing top performance and tackling low performance need not be mutually exclusive. Some high-performing countries in PISA 2012, like Estonia and Finland, also show small variations in student scores, proving that high performance is possible for all students. Equally important, since their first participations in PISA, France, Hong Kong-China, Italy, Japan, Korea, Luxembourg, Macao-China, Poland, Portugal and the Russian Federation have been able to increase the share of top performers in mathematics, reading or science, indicating that education systems can pursue and promote academic excellence whether they perform at or above the OECD average (e.g. Japan, Korea) or below the OECD average (e.g. Italy, Portugal, the Russian Federation).

Only a handful of countries and economies can promote performance at the highest levels and can claim that more than one in ten students are all-rounders. The fact that some countries and economies have a large proportion of all-rounders, that others attain top performance in one subject, and that yet others achieve excellence among all students, suggests that there is untapped potential - and a need for policies and practices to develop this potential - in all countries and economies.

\section{TACKLING LOW PERFORMANCE}

Countries with large numbers of students who struggle to master basic reading skills at age 15 are likely to be held back in the future, when those students become adults who lack the skills needed to function effectively in the workplace and in society. Among students who fail to reach the baseline level of performance (Level 2) in mathematics, reading or science, most can be expected not to continue with education beyond compulsory schooling, and therefore risk facing difficulties using mathematics, reading and using science concepts throughout their lives. Students who do not reach Level 2 in mathematics, for example, have difficulties with questions involving unfamiliar contexts or requiring information from different sources. The proportion of 15 -year-old students at this level varies widely across countries, from fewer than one student in ten in four countries and economies, to the majority of students in 15 countries. Even in the average OECD country, where more than one in five students does not reach Level 2, tackling such low performance is a major challenge.

Reducing the proportion of students who perform below Level 2 also has an important economic dimension. According to one estimate, if all students attained Level 2 proficiency in mathematics the combined economic output of OECD countries would be boosted by around USD 200 trillion (OECD, 2010). While such estimates are never wholly certain, they do suggest that the cost of improving education outcomes is just a fraction of the high cost of low student performance.

To tackle poor performance and also to increase the share of top-performing students, countries need to look at the barriers posed by social background (examined in Volume II of this series), the relationship between performance and students' attitudes towards learning (examined in Volume III), and schools' organisation, resources and learning environment (examined in Volume IV).

\section{ASSESSING STRENGTHS AND WEAKNESSES IN DIFFERENT KINDS OF MATHEMATICS}

Mathematics performance does not only vary widely among students, but in many countries it also varies between different areas of mathematical processes and content. Now that computer technology is accessible to virtually all and is increasingly capable of carrying out routine processes, jobs that do not require mathematical skills are becoming scarcer. It is now clear that students' mastery of mathematics must include the capacity to formulate problems mathematically and interpret results, as students - and adults - are required to "translate" a real-life situation into mathematical terms and interpret the results as they apply to this real-life situation. For students to succeed in mathematics and use mathematics during their lives, their daily encounters with the subject at school need to involve more than solving of alreadyformulated mathematical tasks; they must learn how to formulate and interpret these concepts and tasks.

Of course, all countries and economies need to make curricular choices based on their national contexts and priorities; but they can use the results of their students' performance in PISA's mathematics subscales to see where their strengths and weaknesses lie to inform policy development in pedagogical orientations and curricular content. Success in mathematics in PISA does not necessarily result in the same level of success in all process and content subscales. For example, within countries and economies there is wide variation in student performance in the space and shape and 
the uncertainty and data subscales: countries that succeed in developing students' ability in space and shape do not necessarily develop their students' ability in uncertainty and data.

These differences in performance are likely a reflection of the different emphases countries and economies give to the mathematics topics related to these scales (such as geometry for space and shape and probability and statistics for uncertainty and data). They also offer an opportunity for countries and economies to reflect on whether their weaknesses result from a lack of exposure to content or the way this content is taught in the classroom.

What content is covered and how it is covered has implications for students', and also for country's/economy's performance in PISA. PISA 2012 measures, for the first time, the relationship between students' opportunities to learn mathematics and students' mathematics literacy. Students who are exposed to formal and applied mathematics perform better in mathematics. PISA finds that exposure only or mostly to applied mathematics is not associated with higher levels of performance. Higher levels of performance are found among those students who are exposed to formal mathematics combined with some exposure to applied mathematics problems. These relationships are strong, which underscores the importance of school in the development of mathematics literacy, and the need for balance in the way mathematics is taught, so that students can master both mathematics concepts and content and how these are applied to real-life problems and situations.

\section{PROVIDING EQUAL OPPORTUNITIES FOR BOYS AND GIRLS}

Boys and girls show different levels of performance in mathematics, reading and science, but performance differences within the genders are significantly larger than those between them. This suggests that the gender gap can be narrowed considerably as both boys and girls in all countries and economies show that they can succeed in all three subjects.

Marked gender differences in mathematics performance - in favour of boys - are observed in many countries and economies, but with a number of exceptions and to varying degrees. Among girls, the greatest hurdle is in reaching the top: girls are under-represented among the highest achievers in most countries and economies, which poses a serious challenge to achieving gender parity in science, technology, engineering and mathematics occupations in the future. Some countries succeeded in narrowing the gender gap in mathematics, but strategies for improving the level of engagement, dispositions, self-beliefs and performance among girls need to be continually reviewed and strengthened, particularly those that promote top performance. At the same time, there is evidence that in many countries and economies more boys than girls are among the lowest-performing students, and in some of these more should be done to engage boys in mathematics.

In addition, the size of the gender gap in mathematics varies, depending on the particular processes and content of mathematics. In general, boys' advantage is most marked in the process subscale formulating and in the content subscale space and shape. Girls' disadvantage in mathematics seems to be narrowest in the process subscale employing and interpreting and in the content subscale uncertainty and data. These gender differences in performance across subscales indicate potential areas for policy development to close the gender gap in mathematics. They also show that overall gender gaps in mathematics can be narrowed, since these are related to particular content and processes. As Volume III in this series highlights, gender differences are also observed in boys' and girls' drive towards mathematics and selfbeliefs in mathematics: even when boys and girls have the same level of performance, girls are more likely to show signs of anxiety towards mathematics and lower levels of mathematics self-efficacy and self-beliefs. Evidence suggest that actions to close the gender gap in mathematics performance should be targeted at youth and, indeed, children, and should include activities to improve students' attitudes and self-beliefs towards mathematics.

By contrast, in almost all countries and economies, girls outperform boys in reading. This gender gap is particularly large in some high-performing countries, where almost all underperformance in reading is seen only among boys. Lowperforming boys face a particularly large disadvantage as they are heavily over-represented among those who fail to show basic levels of reading literacy. These low levels of performance tend to be coupled with low levels of engagement with school and - as observed in PISA 2009 - with low levels of engagement and commitment to reading. To close the gender gap in reading performance policy makers need to promote boys' engagement with reading and ensure that more boys begin to show the basic level of proficiency that will allow them to participate fully and productively in life. 


\section{Note}

1. As PISA is a series of cross-sectional studies, it is impossible to infer which, if any, of these policy initiatives are at the centre of these countries' improvement in PISA. The examples described in the country-specific boxes throughout the volumes of the PISA 2009 report provide a description of the challenges and the policy trajectories of the countries that have improved their PISA performance; they do not provide causal evidence that the performance improvement is the result of any particular policy.

\section{Reference}

OECD (2013), OECD Skills Outlook: First Results from the Survey of Adult Skills, OECD Publishing. http://dx.doi.org/10.1787/9789264204256-en

OECD (2010), The High Cost of Low Educational Performance: The Long-Run Economic Impact of Improving PISA Outcomes, PISA, OECD Publishing.

http://dx.doi.org/10.1787/9789264077485-en 


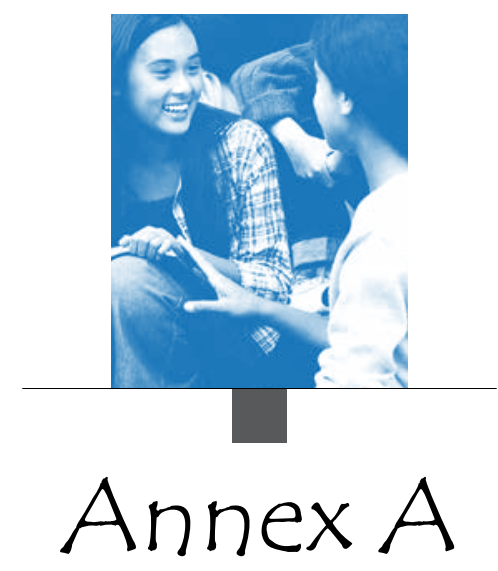

PISA 2012 TECHNICAL BACKGROUND

All figures and tables in Annex A are available on line

Annex A1: Indices from the student, school and parent context questionnaires

http://dx.doi.org/10.1787/888932937073

Annex A2: The PISA target population, the PISA samples and the definition of schools http://dx.doi.org/10.1787/888932937092

Annex A3: Technical notes on analyses in this volume

Annex A4: Quality assurance

Annex A5: Technical details of trends analyses http://dx.doi.org/10.1787/888932937054

Annex A6: Development of the PISA assessment instruments

Annex A7: Technical note on Brazil http://dx.doi.org/10.1787/888932935743

\section{Notes regarding Cyprus}

Note by Turkey: The information in this document with reference to "Cyprus" relates to the southern part of the Island. There is no single authority representing both Turkish and Greek Cypriot people on the Island. Turkey recognises the Turkish Republic of Northern Cyprus (TRNC). Until a lasting and equitable solution is found within the context of the United Nations, Turkey shall preserve its position concerning the "Cyprus issue".

Note by all the European Union Member States of the OECD and the European Union: The Republic of Cyprus is recognised by all members of the United Nations with the exception of Turkey. The information in this document relates to the area under the effective control of the Government of the Republic of Cyprus.

\section{A note regarding Israel}

The statistical data for Israel are supplied by and under the responsibility of the relevant Israeli authorities. The use of such data by the OECD is without prejudice to the status of the Golan Heights, East Jerusalem and Israeli settlements in the West Bank under the terms of international law. 


\section{ANNEX A1 \\ INDICES FROM THE STUDENT, SCHOOL AND PARENT CONTEXT QUESTIONNAIRES}

\section{Explanation of the indices}

This section explains the indices derived from the student and school context questionnaires used in PISA 2012.

Several PISA measures reflect indices that summarise responses from students, their parents or school representatives (typically principals) to a series of related questions. The questions were selected from a larger pool of questions on the basis of theoretical considerations and previous research. The PISA 2012 Assessment and Analytical Framework (OECD, 2013) provides an in-depth description of this conceptual framework. Structural equation modelling was used to confirm the theoretically expected behaviour of the indices and to validate their comparability across countries. For this purpose, a model was estimated separately for each country and collectively for all OECD countries. For a detailed description of other PISA indices and details on the methods, see the PISA 2012 Technical Report (OECD, forthcoming).

There are two types of indices: simple indices and scale indices.

Simple indices are the variables that are constructed through the arithmetic transformation or recoding of one or more items, in exactly the same way across assessments. Here, item responses are used to calculate meaningful variables, such as the recoding of the four-digit ISCO-08 codes into "Highest parents' socio-economic index (HISEI)" or, teacher-student ratio based on information from the school questionnaire.

Scale indices are the variables constructed through the scaling of multiple items. Unless otherwise indicated, the index was scaled using a weighted likelihood estimate (WLE) (Warm, 1989), using a one-parameter item response model (a partial credit model was used in the case of items with more than two categories). For details on how each scale index was constructed see the PISA 2012 Technical Report (OECD, forthcoming). In general, the scaling was done in three stages:

- The item parameters were estimated from equal-sized subsamples of students from all participating countries and economies.

- The estimates were computed for all students and all schools by anchoring the item parameters obtained in the preceding step.

- The indices were then standardised so that the mean of the index value for the OECD student population was zero and the standard deviation was one (countries being given equal weight in the standardisation process).

Sequential codes were assigned to the different response categories of the questions in the sequence in which the latter appeared in the student, school or parent questionnaires. Where indicated in this section, these codes were inverted for the purpose of constructing indices or scales. Negative values for an index do not necessarily imply that students responded negatively to the underlying questions. A negative value merely indicates that the respondents answered less positively than all respondents did on average across OECD countries. Likewise, a positive value on an index indicates that the respondents answered more favourably, or more positively, than respondents did, on average, across OECD countries. Terms enclosed in brackets $<>$ in the following descriptions were replaced in the national versions of the student, school and parent questionnaires by the appropriate national equivalent. For example, the term <qualification at ISCED level $5 \mathrm{~A}>$ was translated in the United States into "Bachelor's degree, post-graduate certificate program, Master's degree program or first professional degree program". Similarly the term <classes in the language of assessment> in Luxembourg was translated into "German classes" or "French classes" depending on whether students received the German or French version of the assessment instruments.

In addition to simple and scaled indices described in this annex, there are a number of variables from the questionnaires that correspond to single items not used to construct indices. These non-recoded variables have prefix of "ST" for the questionnaire items in the student questionnaire, "SC" for the items in the school questionnaire, and "PA" for the items in the parent questionnaire. All the context questionnaires as well as the PISA international database, including all variables, are available through www.pisa.oecd.org.

\section{Scaling of questionnaire indices for trend analyses}

In PISA, to gather information about students' and schools' characteristics, both students and schools complete a background questionnaire. In PISA 2003 and PISA 2012 several questions were kept untouched, enabling the comparison of responses to these questions over time. In this report, only questions that maintained an exact wording are used for trends analyses. Questions with subtle word changes or questions with major word changes were not compared across time because it is impossible to discern whether observed changes in the response are due to changes in the construct they are measuring or to changes in the way the construct is being measured.

Also, in PISA, as described in Annex A1, questionnaire items are used to construct indices. Whenever the questions used in the construction of indices remains intact in PISA 2003 and PISA 2012, the corresponding indices are compared. Two types of indices are used in PISA: simple indices and scale indices.

Simple indices recode a set of responses to questionnaire items. For trends analyses, the values observed in PISA 2003 are compared directly to PISA 2012, just as simple responses to questionnaire items are. This is the case of indices like student-teacher ratio and ability grouping in mathematics. 
Scale indices, on the other hand, imply WLE estimates which require rescaling in order to be comparable across PISA cycles. Scale indices, like the PISA index of economic, social and cultural status, the index of sense of belonging, the index of attitudes towards school, the index of intrinsic motivation to learn mathematics, the index of instrumental motivation to learn mathematics, the index of mathematics self-efficacy, the index of mathematics self-concept, the index of mathematics anxiety, the index of teacher shortage, the index of quality of physical infrastructure, the index of quality of schools' educational resources, the index of disciplinary climate, the index of teacher-student relations, the index of teacher morale, the index of student-related factors affecting school climate and the index of teacher-related factors affecting school climate, were scaled, in PISA 2012 to have an OECD average of 0 and a standard deviation of 1, on average, across OECD countries. These same scales were scaled, in PISA 2003, to have an OECD average of 0 and a standard deviation of 1 . Because they are on different scales, values reported in Learning for Tomorrow's World: First Results from PISA 2003 (OECD, 2004) cannot be compared with those reported in this volume. To make these scale indices comparable, values for 2003 have been rescaled to the 2012 scale, using the PISA 2012 parameter estimates.

These re-scaled indices are available at www.pisa.oecd.org. They can be merged to the corresponding PISA 2003 dataset using the country names, school and student-level identifiers. The rescaled PISA index of economic, social and cultural status is also available to be merged with the PISA 2000, PISA 2006 and PISA 2009 dataset.

\section{Student-level simple indices \\ Age}

The variable AGE is calculated as the difference between the middle month and the year in which students were assessed and their month and year of birth, expressed in years and months.

\section{Study programme}

In PISA 2012, study programmes available to 15-year-old students in each country were collected both through the student tracking form and the student questionnaire. All study programmes were classified using ISCED (OECD, 1999). In the PISA international database, all national programmes are indicated in a variable (PROGN) where the first six digits refer to the national centre code and the last two digits to the national study programme code.

The following internationally comparable indices were derived from the data on study programmes:

- Programme level (ISCEDL) indicates whether students are (1) primary education level (ISCED 1); (2) lower-secondary education level (ISCED 2); or (3) upper secondary education level (ISCED 3).

- Programme designation (ISCEDD) indicates the designation of the study programme: (1) = "A" (general programmes designed to give access to the next programme level); (2) = "B" (programmes designed to give access to vocational studies at the next programme level); (3) = " $\mathrm{C}$ " (programmes designed to give direct access to the labour market); or (4) = " $\mathrm{M}$ " (modular programmes that combine any or all of these characteristics).

- Programme orientation (ISCEDO) indicates whether the programme's curricular content is (1) general; (2) pre-vocational; (3) vocational; or (4) modular programmes that combine any or all of these characteristics.

\section{Occupational status of parents}

Occupational data for both a student's father and a student's mother were obtained by asking open-ended questions in the student questionnaire. The responses were coded to four-digit ISCO codes (ILO, 1990) and then mapped to the SEI index of Ganzeboom et al. (1992). Higher scores of SEI indicate higher levels of occupational status. The following three indices are obtained:

- Mother's occupational status (OCOD1).

- Father's occupational status (OCOD2).

- The highest occupational level of parents (HISEI) corresponds to the higher SEI score of either parent or to the only available parent's SEI score.

\section{Education level of parents}

The education level of parents is classified using ISCED (OECD, 1999) based on students' responses in the student questionnaire.

As in PISA 2000, 2003, 2006 and 2009, indices were constructed by selecting the highest level for each parent and then assigning them to the following categories: (0) None, (1) ISCED 1 (primary education), (2) ISCED 2 (lower secondary), (3) ISCED 3B or 3C (vocational/pre-vocational upper secondary), (4) ISCED 3A (upper secondary) and/or ISCED 4 (non-tertiary post-secondary), (5) ISCED 5B (vocational tertiary), (6) ISCED 5A, 6 (theoretically oriented tertiary and post-graduate). The following three indices with these categories are developed:

- Mother's education level (MISCED).

- Father's education level (FISCED).

- Highest education level of parents (HISCED) corresponds to the higher ISCED level of either parent.

Highest education level of parents was also converted into the number of years of schooling (PARED). For the conversion of level of education into years of schooling, see Table A1.1. 
[Part 1/1]

Table A1.1 Levels of parental education converted into years of schooling

\begin{tabular}{|c|c|c|c|c|c|c|c|}
\hline & & $\begin{array}{c}\text { Completed } \\
\text { ISCED level } 1 \\
\text { (primary education) }\end{array}$ & $\begin{array}{c}\text { Completed } \\
\text { ISCED level } 2 \\
\text { (lower secondary } \\
\text { education) }\end{array}$ & \begin{tabular}{|} 
Completed ISCED \\
levels 3B or 3C \\
(upper secondary \\
education providing \\
direct access to the \\
labour market or to \\
ISCED 5B programmes)
\end{tabular} & $\begin{array}{l}\text { Completed ISCED level } \\
\text { 3A (upper secondary } \\
\text { education providing } \\
\text { access to ISCED 5A and } \\
5 B \text { programmes) and/ } \\
\text { or ISCED level } 4 \text { (non- } \\
\text { tertiary post-secondary) }\end{array}$ & $\begin{array}{c}\text { Completed ISCED } \\
\text { level 5A (university } \\
\text { level tertiary education) } \\
\text { or ISCED level } 6 \\
\text { (advanced research } \\
\text { programmes) }\end{array}$ & $\begin{array}{c}\text { Completed } \\
\text { ISCED level 5B } \\
\text { (non-university } \\
\text { tertiary education) }\end{array}$ \\
\hline \multirow{35}{*}{ 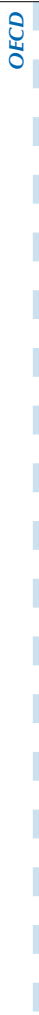 } & Australia & 6.0 & 10.0 & 11.0 & 12.0 & 15.0 & 14.0 \\
\hline & Austria & 4.0 & 9.0 & 12.0 & 12.5 & 17.0 & 15.0 \\
\hline & Belgium ${ }^{1}$ & 6.0 & 9.0 & 12.0 & 12.0 & 17.0 & 15.0 \\
\hline & Canada & 6.0 & 9.0 & 12.0 & 12.0 & 17.0 & 15.0 \\
\hline & Chile & 6.0 & 8.0 & 12.0 & 12.0 & 17.0 & 16.0 \\
\hline & Czech Republic & 5.0 & 9.0 & 11.0 & 13.0 & 16.0 & 16.0 \\
\hline & Denmark & 7.0 & 10.0 & 13.0 & 13.0 & 18.0 & 16.0 \\
\hline & Estonia & 6.0 & 9.0 & 12.0 & 12.0 & 16.0 & 15.0 \\
\hline & Finland & 6.0 & 9.0 & 12.0 & 12.0 & 16.5 & 14.5 \\
\hline & France & 5.0 & 9.0 & 12.0 & 12.0 & 15.0 & 14.0 \\
\hline & Germany & 4.0 & 10.0 & 13.0 & 13.0 & 18.0 & 15.0 \\
\hline & Greece & 6.0 & 9.0 & 11.5 & 12.0 & 17.0 & 15.0 \\
\hline & Hungary & 4.0 & 8.0 & 10.5 & 12.0 & 16.5 & 13.5 \\
\hline & Iceland & 7.0 & 10.0 & 13.0 & 14.0 & 18.0 & 16.0 \\
\hline & Ireland & 6.0 & 9.0 & 12.0 & 12.0 & 16.0 & 14.0 \\
\hline & Israel & 6.0 & 9.0 & 12.0 & 12.0 & 15.0 & 15.0 \\
\hline & Italy & 5.0 & 8.0 & 12.0 & 13.0 & 17.0 & 16.0 \\
\hline & Japan & 6.0 & 9.0 & 12.0 & 12.0 & 16.0 & 14.0 \\
\hline & Korea & 6.0 & 9.0 & 12.0 & 12.0 & 16.0 & 14.0 \\
\hline & Luxembourg & 6.0 & 9.0 & 12.0 & 13.0 & 17.0 & 16.0 \\
\hline & Mexico & 6.0 & 9.0 & 12.0 & 12.0 & 16.0 & 14.0 \\
\hline & Netherlands & 6.0 & 10.0 & 13.0 & 12.0 & 16.0 & 15.0 \\
\hline & New Zealand & 5.5 & 10.0 & 11.0 & 12.0 & 15.0 & 14.0 \\
\hline & Norway & 6.0 & 9.0 & 12.0 & 12.0 & 16.0 & 14.0 \\
\hline & Poland & $\mathrm{a}$ & 8.0 & 11.0 & 12.0 & 16.0 & 15.0 \\
\hline & Portugal & 6.0 & 9.0 & 12.0 & 12.0 & 17.0 & 15.0 \\
\hline & Slovak Republic ${ }^{2}$ & 4.0 & 9.0 & 12.0 & 13.0 & 18.0 & 16.0 \\
\hline & Slovenia & 4.0 & 8.0 & 11.0 & 12.0 & 16.0 & 15.0 \\
\hline & Spain & 5.0 & 8.0 & 10.0 & 12.0 & 16.5 & 13.0 \\
\hline & Sweden & 6.0 & 9.0 & 11.5 & 12.0 & 16.0 & 14.0 \\
\hline & Switzerland & 6.0 & 9.0 & 12.5 & 12.5 & 17.5 & 14.5 \\
\hline & Turkey & 5.0 & 8.0 & 11.0 & 11.0 & 15.0 & 13.0 \\
\hline & United Kingdom (exclud. Scotland) & 6.0 & 9.0 & 12.0 & 13.0 & 16.0 & 15.0 \\
\hline & United Kingdom (Scotland) & 7.0 & 9.0 & 11.0 & 13.0 & 17.0 & 15.0 \\
\hline & United States & 6.0 & 9.0 & a & 12.0 & 16.0 & 14.0 \\
\hline \multirow{31}{*}{ ฐँ } & Albania & 6.0 & 9.0 & 12.0 & 12.0 & 16.0 & 16.0 \\
\hline & Argentina & 6.0 & 10.0 & 12.0 & 12.0 & 17.0 & 14.5 \\
\hline & Azerbaijan & 4.0 & 9.0 & 11.0 & 11.0 & 17.0 & 14.0 \\
\hline & Brazil & 4.0 & 8.0 & 11.0 & 11.0 & 16.0 & 14.5 \\
\hline & Bulgaria & 4.0 & 8.0 & 10.0 & 12.0 & 17.5 & 15.0 \\
\hline & Colombia & 5.0 & 9.0 & 11.0 & 11.0 & 15.5 & 14.0 \\
\hline & Costa Rica & 6.0 & 9.0 & 11.0 & 12.0 & 14.0 & 16.0 \\
\hline & Croatia & 4.0 & 8.0 & 11.0 & 12.0 & 17.0 & 15.0 \\
\hline & Hong Kong-China & 6.0 & 9.0 & 11.0 & 13.0 & 16.0 & 14.0 \\
\hline & Indonesia & 6.0 & 9.0 & 12.0 & 12.0 & 15.0 & 14.0 \\
\hline & Jordan & 6.0 & 10.0 & 12.0 & 12.0 & 16.0 & 14.5 \\
\hline & Kazakhstan & 4.0 & 9.0 & 11.5 & 12.5 & 15.0 & 14.0 \\
\hline & Latvia & 4.0 & 8.0 & 11.0 & 11.0 & 16.0 & 14.0 \\
\hline & Liechtenstein & 5.0 & 9.0 & 11.0 & 13.0 & 17.0 & 14.0 \\
\hline & Lithuania & 3.0 & 8.0 & 11.0 & 11.0 & 16.0 & 15.0 \\
\hline & Macao-China & 6.0 & 9.0 & 11.0 & 12.0 & 16.0 & 15.0 \\
\hline & Malaysia & 6.0 & 9.0 & 11.0 & 13.0 & 15.0 & 16.0 \\
\hline & Montenegro & 4.0 & 8.0 & 11.0 & 12.0 & 16.0 & 15.0 \\
\hline & Peru & 6.0 & 9.0 & 11.0 & 11.0 & 17.0 & 14.0 \\
\hline & Qatar & 6.0 & 9.0 & 12.0 & 12.0 & 16.0 & 15.0 \\
\hline & Romania & 4.0 & 8.0 & 11.5 & 12.5 & 16.0 & 14.0 \\
\hline & Russian Federation & 4.0 & 9.0 & 11.5 & 12.0 & 15.0 & $\mathrm{a}$ \\
\hline & Serbia & 4.0 & 8.0 & 11.0 & 12.0 & 17.0 & 14.5 \\
\hline & Shanghai-China & 6.0 & 9.0 & 12.0 & 12.0 & 16.0 & 15.0 \\
\hline & Singapore & 6.0 & 8.0 & 10.0 & 11.0 & 16.0 & 13.0 \\
\hline & Chinese Taipei & 6.0 & 9.0 & 12.0 & 12.0 & 16.0 & 14.0 \\
\hline & Thailand & 6.0 & 9.0 & 12.0 & 12.0 & 16.0 & 14.0 \\
\hline & Tunisia & 6.0 & 9.0 & 12.0 & 13.0 & 17.0 & 16.0 \\
\hline & United Arab Emirates & 5.0 & 9.0 & 12.0 & 12.0 & 16.0 & 15.0 \\
\hline & Uruguay & 6.0 & 9.0 & 12.0 & 12.0 & 17.0 & 15.0 \\
\hline & Viet Nam & 5.0 & 9.0 & 12.0 & 12.0 & 17.0 & a \\
\hline
\end{tabular}

1. In Belgium the distinction between universities and other tertiary schools doesn't match the distinction between ISCED 5A and ISCED 5B.

2. In the Slovak Republic, university education (ISCED 5A) usually lasts five years and doctoral studies (ISCED 6) lasts three more years. Therefore, university graduates will have completed 18 years of study and graduates of doctoral programmes will have completed 21 years of study.

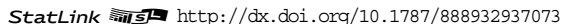




\section{Immigration and language background}

Information on the country of birth of students and their parents is collected in a similar manner as in PISA 2000, PISA 2003 and PISA 2006 by using nationally specific ISO coded variables. The ISO codes of the country of birth for students and their parents are available in the PISA international database (COBN_S, COBN_M, and COBN_F).

The index on immigrant background (IMMIG) has the following categories: (1) native students (those students born in the country of assessment, or those with at least one parent born in that country; students who were born abroad with at least one parent born in the country of assessment are also classified as 'native' students), (2) second-generation students (those born in the country of assessment but whose parents were born in another country) and (3) first-generation students (those born outside the country of assessment and whose parents were also born in another country). Students with missing responses for either the student or for both parents, or for all three questions have been given missing values for this variable.

Students indicate the language they usually speak at home. The data are captured in nationally-specific language codes, which were recoded into variable LANGN with the following two values: (1) language at home is the same as the language of assessment, and (2) language at home is a different language than the language of assessment.

\section{Relative grade}

Data on the student's grade are obtained both from the student questionnaire and from the student tracking form. As with all variables that are on both the tracking form and the questionnaire, inconsistencies between the two sources are reviewed and resolved during data-cleaning. In order to capture between-country variation, the relative grade index (GRADE) indicates whether students are at the modal grade in a country (value of 0 ), or whether they are below or above the modal grade level (+ $\mathrm{x}$ grades, $-\mathrm{x}$ grades).

The relationship between the grade and student performance was estimated through a multilevel model accounting for the following background variables: $i$ ) the PISA index of economic, social and cultural status; ii) the PISA index of economic, social and cultural status squared; iii) the school mean of the PISA index of economic, social and cultural status; iv) an indicator as to whether students were foreign-born first-generation students; $v$ ) the percentage of first-generation students in the school; and vi) students' gender.

Table A1.2 presents the results of the multilevel model. Column 1 in Table A1.2 estimates the score-point difference that is associated with one grade level (or school year). This difference can be estimated for the 32 OECD countries in which a sizeable number of 15-year-olds in the PISA samples were enrolled in at least two different grades. Since 15-year-olds cannot be assumed to be distributed at random across the grade levels, adjustments had to be made for the above-mentioned contextual factors that may relate to the assignment of students to the different grade levels. These adjustments are documented in columns 2 to 7 of the table. While it is possible to estimate the typical performance difference among students in two adjacent grades net of the effects of selection and contextual factors, this difference cannot automatically be equated with the progress that students have made over the last school year but should be interpreted as a lower boundary of the progress achieved. This is not only because different students were assessed but also because the content of the PISA assessment was not expressly designed to match what students had learned in the preceding school year but more broadly to assess the cumulative outcome of learning in school up to age 15. For example, if the curriculum of the grades in which 15-year-olds are enrolled mainly includes material other than that assessed by PISA (which, in turn, may have been included in earlier school years) then the observed performance difference will underestimate student progress.

\section{Student-level scale indices}

For this cycle, in order to obtain trends for all cycles from 2000 to 2012, the computation of the indices WEALTH, HEDRES, CULTPOSS and HOMEPOS was based on data from all cycles from 2000 to 2012. HOMEPOS is of particular importance as it is used in the computation of ESCS. These were then standardised on 2012 so that the OECD mean is 0 and the standard deviation is 1 . This means that the indices calculated on the previous cycle will be on the 2012 scale and thus not directly comparable to the indices in the database for the previously released cycles. To estimate item parameters for scaling, a calibration sample from all cycles was used, consisting of 500 students from all countries in the previous cycles, and 750 from 2012.

The items used in the computation of the indices have changed to some extent from cycle to cycle, thought they have remained much the same from 2006 to 2012. The earlier cycle are in general missing a few items that are present in the later cycles, but it was felt leaving out items only present in the later cycles would give too much weight to the earlier cycles. So a superset of all items (except country specific items) in the five cycles was used, and international item parameters derived from this set.

The second step was to estimate WLEs for the indices, anchoring on the international item set while estimating the country specific items. This is the same procedure used in previous cycles.

A description of the 2012 items used for these indices is given below.

\section{Family wealth}

The index of family wealth (WEALTH) is based on students' responses on whether they had the following at home: a room of their own, a link to the Internet, a dishwasher (treated as a country-specific item), a DVD player, and three other country-specific items; and their responses on the number of cellular phones, televisions, computers, cars and the number of rooms with a bath or shower. 
[Part 1/1]

Table A1.2 A multilevel model to estimate grade effects in mathematics accounting for some background variables

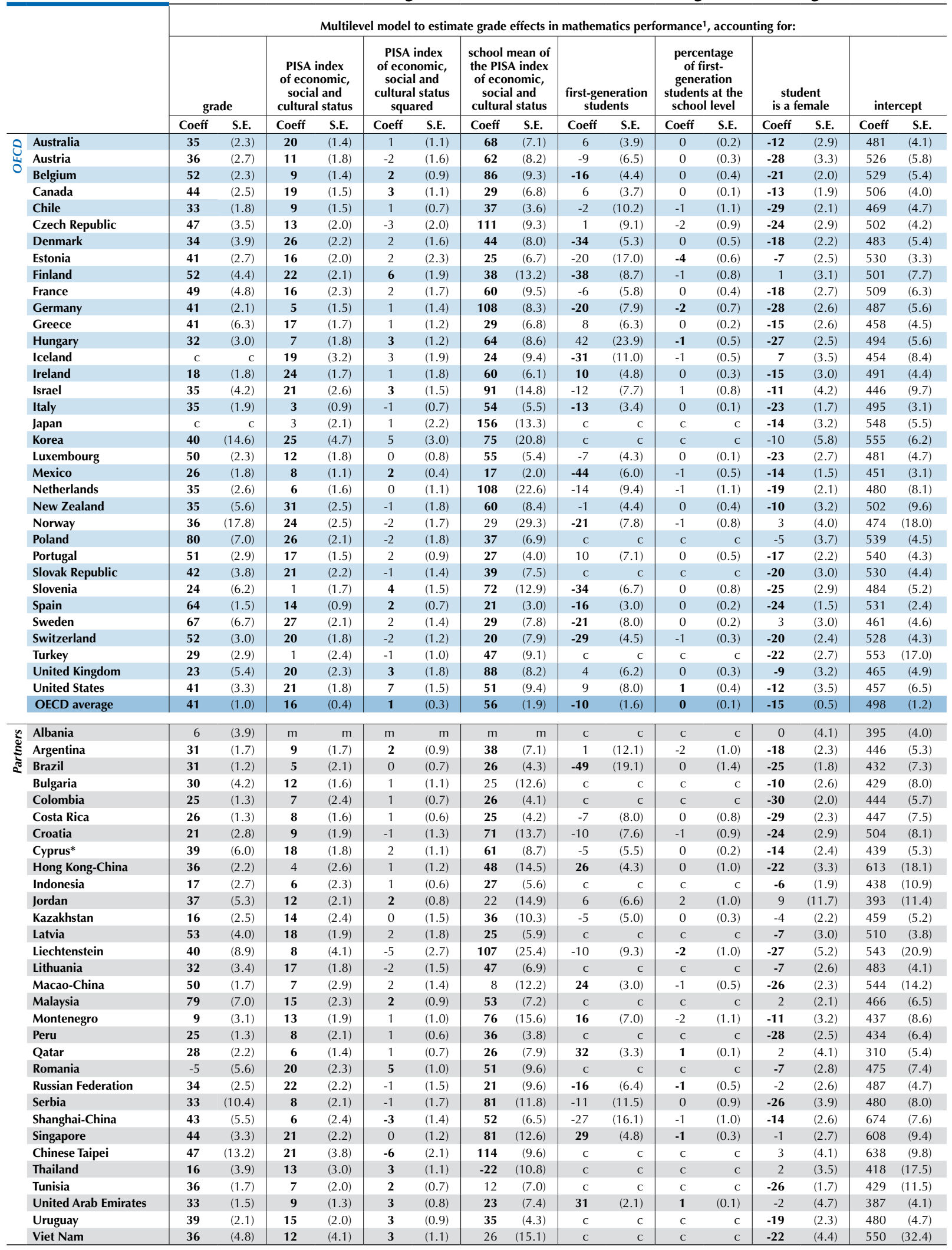

Note: Values that are statistically significant are indicated in bold (see Annex A3

1. Multilevel regression model (student and school levels): Mathematics performance is regressed on the variables of school policies and practices presented in this table.

* See note at the beginning of this Annex.

StatLink 部占 http://dx.doi.org/10.1787/888932937073 


\section{Home educational resources}

The index of home educational resources (HEDRES) is based on the items measuring the existence of educational resources at home including a desk and a quiet place to study, a computer that students can use for schoolwork, educational software, books to help with students' school work, technical reference books and a dictionary.

\section{Cultural possessions}

The index of cultural possessions (CULTPOSS) is based on the students' responses to whether they had the following at home: classic literature, books of poetry and works of art.

\section{Economic, social and cultural status}

The PISA index of economic, social and cultural status (ESCS) was derived from the following three indices: highest occupational status of parents (HISEI), highest education level of parents in years of education according to ISCED (PARED), and home possessions (HOMEPOS). The index of home possessions (HOMEPOS) comprises all items on the indices of WEALTH, CULTPOSS and HEDRES, as well as books in the home recoded into a four-level categorical variable (0-10 books, 11-25 or 26-100 books, 101-200 or 201-500 books, more than 500 books).

The PISA index of economic, social and cultural status (ESCS) was derived from a principal component analysis of standardised variables (each variable has an OECD mean of zero and a standard deviation of one), taking the factor scores for the first principal component as measures of the PISA index of economic, social and cultural status.

Principal component analysis was also performed for each participating country to determine to what extent the components of the index operate in similar ways across countries. The analysis revealed that patterns of factor loading were very similar across countries, with all three components contributing to a similar extent to the index (for details on reliability and factor loadings, see the PISA 2012 Technical Report (OECD, forthcoming).

The imputation of components for students missing data on one component was done on the basis of a regression on the other two variables, with an additional random error component. The final values on the PISA index of economic, social and cultural status (ESCS) for PISA 2012 have an OECD mean of 0 and a standard deviation of one.

ESCS was computed for all students in the five cycles, and ESCS indices for trends analyses were obtained by applying the parameters used to derive standardised values in 2012 to the ESCS components for previous cycles. These values will therefore not be directly comparable to ESCS in the databases for previous cycles, though the differences are not large for the 2006 and 2009 cycles. ESCS in earlier cycles were computed using different algorithms, so for 2000 and 2003 the differences are larger.

\section{Changes to the computation of socio-economic status for PISA 2012}

While the computation of socio-economic status followed what had been done in previous cycles, PISA 2012 undertook an important upgrade with respect to the coding of parental occupation. Prior to PISA 2012, the 1988 International Standard Classification of Occupations (ISCO-88) was used for the coding of parental occupation. By 2012, however, ISCO-88 was almost 25 years old and it was no longer tenable to maintain its use as an occupational coding scheme. ${ }^{1}$ It was therefore decided to use its replacement, ISCO-08, for occupational coding in PISA 2012.

The change from ISCO-88 to ISCO-08 required an update of the International Socio-Economic Index (ISEI) of occupation codes. PISA 2012 therefore used a modified quantification scheme for ISCO-08 (referred to as ISEI-08), as developed by Harry Ganzeboom (2010). ISEI-08 was constructed using a database of 198500 men and women with valid education, occupation and (personal) incomes derived from the combined 2002-07 datasets of the International Social Survey Programme (ISSP) (Ganzeboom, 2010). The methodology used for this purpose was similar to the one employed in the construction of ISEI for ISCO-68 and ISCO-88 described in different publications (Ganzeboom et al., 1992; Ganzeboom and Treiman, 1996; Ganzeboom and Treiman, 2003). ${ }^{2}$

The main differences with regard to the previous ISEI construction are the following:

- A new database was used which is more recent, larger and cross-nationally more diverse than the one used earlier.

- The new ISEI was constructed using data for women and men, while previously only men were used to estimate the scale. The data on income were corrected for hours worked to adjust the different prevalence of part-time work between men and women in many countries.

A range of validation activities accompanied the transition from ISCO-88/ISEI-88 to ISCO-08/ISEI-08, including a comparison of (a) the distributions of ISEI-88 with ISEI-08 in terms of range, mean and standard deviations for both mothers' and fathers' occupations and (b) correlations between the two ISEI indicators and performance, again separately undertaken for mothers' and fathers' occupation.

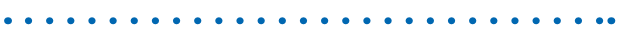

1. The update from ISCO-88 to ISCO-08 mainly involved (a) more adequate categories for IT-related occupations, (b) distinction of military ranks and (c) a revision of the categories classifying different managers.

2. Information on ISCO08 and ISEI08 is included from http://www.ilo.org/public/english/bureau/stat/isco/index.htm and http://home.fsw.vu.nl/hbg. ganzeboom/isco08 


\section{The rotated design of the student questionnaire}

A major innovation in PISA 2012 is the rotated design of the student questionnaire. One of the main reasons for a rotated design, which has previously been implemented for the cognitive assessment, was to extend the content coverage of the student questionnaire. Table A1.3 provides an overview of the rotation design and content of questionnaire forms for the main survey.

Table A1.3 Student questionnaire rotation design

\begin{tabular}{l|l|l|l}
\hline Form A & Common Question Set (all forms) & $\begin{array}{l}\text { Question Set 1 - Mathematics Attitudes / } \\
\text { Problem Solving }\end{array}$ & $\begin{array}{l}\text { Question Set 3 - Opportunity to Learn / } \\
\text { Learning Strategies }\end{array}$ \\
\hline Form B & Common Question Set (all forms) & $\begin{array}{l}\text { Question Set 2 - School Climate / Attitudes } \\
\text { towards School / Anxiety }\end{array}$ & $\begin{array}{l}\text { Question Set 1 - Mathematics Attitudes / } \\
\text { Problem Solving }\end{array}$ \\
\hline Form C & Common Question Set (all forms) & $\begin{array}{l}\text { Question Set 3 - Opportunity to Learn / } \\
\text { Learning Strategies }\end{array}$ & $\begin{array}{l}\text { Question Set 2 - School Climate / Attitudes } \\
\text { towards School / Anxiety }\end{array}$ \\
\hline
\end{tabular}

Note: For details regarding the questions in each question set, please refer to PISA 2012 Technical Report (OECD, forthcoming).

The PISA 2012 Technical Report (OECD, forthcoming) provides all details regarding the rotated design of the student questionnaire in PISA 2012, including its implications in terms of (a) proficiency estimates, (b) international reports and trends, (c) further analyses, (d) structure and documentation of the international database, and (e) logistics have been discussed elsewhere. The rotated design has negligible implications for proficiency estimates and correlations of proficiency estimates with context constructs. The international database (available at www.pisa.oecd.org) contains all background variables included for each student whereby ones that s/he has answered reflecting his or her responses and the ones that $\mathrm{s} /$ he was not administered showing a distinctive missing code by design. Rotation allows the estimation of a full co-variance matrix which means that all variables can be correlated with all other variables. It does not affect conclusions in terms of whether or not an effect would be considered significant in multilevel models.

\section{References}

Ganzeboom, H.B.G. (2010), "A new international socio-economic index [ISEI] of occupational status for the International Standard Classification of Occupation 2008 [ISCO-08] constructed with data from the ISSP 2002-2007; with an analysis of quality of occupational measurement in ISSP", Paper presented at Annual Conference of International Social Survey Programme, Lisbon, 1 May 2010.

Ganzeboom, H. B.G. and D. J. Treiman (2003), "Three Internationally Standardised Measures for Comparative Research on Occupational Status", in Jürgen H.P. Hoffmeyer-Zlotnik and C. Wolf (eds.), Advances in Cross-National Comparison: A European Working Book for Demographic and Socio-Economic Variables, Kluwer Academic Press, New York, pp. 159-193.

Ganzeboom, H.B.G. and D.J. Treiman (1996), "Internationally Comparable Measures of Occupational Status for the 1988 International Standard Classification of Occupations", Social Science Research (25), pp. 201-239.

Ganzeboom, H.B.G., P. De Graaf, and D.J. Treiman (with J. De Leeuw) (1992), "A Standard International Socio-Economic Index of Occupational Status", Social Science Research (21-1), pp. 1-56.

Ganzeboom, H.B.G., R. Luijkx and D.J. Treiman (1989),"Intergenerational Class Mobility in Comparative Perspective", Research in Social Stratification and Mobility (8), pp. 3-79.

ILO (1990), ISCO-88: International Standard Classification of Occupations, International Labour Office, Geneva.

OECD (forthcoming), PISA 2012 Technical Report, PISA, OECD Publishing.

OECD (2013), PISA 2012 Assessment and Analytical Framework: Mathematics, Reading, Science, Problem Solving and Financial Literacy, PISA, OECD Publishing.

http://dx.doi.org/10.1787/9789264190511-en

OECD (2004), Learning for Tomorrow's World: First Results from PISA 2003, PISA, OECD Publishing. http://dx.doi.org/10.1787/9789264006416-en

OECD (1999), Classifying Educational Programmes: Manual for ISCED-97 Implementation in OECD Countries. www.oecd.org/education/skills-beyond-school/1962350.pdf

Warm, T.A. (1989), "Weighted likelihood estimation of ability in item response theory", Psychometrika, Volume 54, Issue 3, pp 427-450. http://dx.doi.org/10.1007/BF02294627 


\section{ANNEX A2}

\section{THE PISA TARGET POPULATION, THE PISA SAMPLES AND THE DEFINITION OF SCHOOLS}

\section{Definition of the PISA target population}

PISA 2012 provides an assessment of the cumulative yield of education and learning at a point at which most young adults are still enrolled in initial education.

A major challenge for an international survey is to ensure that international comparability of national target populations is guaranteed in such a venture.

Differences between countries in the nature and extent of pre-primary education and care, the age of entry into formal schooling and the institutional structure of education systems do not allow the definition of internationally comparable grade levels of schooling. Consequently, international comparisons of education performance typically define their populations with reference to a target age group. Some previous international assessments have defined their target population on the basis of the grade level that provides maximum coverage of a particular age cohort. A disadvantage of this approach is that slight variations in the age distribution of students across grade levels often lead to the selection of different target grades in different countries, or between education systems within countries, raising serious questions about the comparability of results across, and at times within, countries. In addition, because not all students of the desired age are usually represented in grade-based samples, there may be a more serious potential bias in the results if the unrepresented students are typically enrolled in the next higher grade in some countries and the next lower grade in others. This would exclude students with potentially higher levels of performance in the former countries and students with potentially lower levels of performance in the latter.

In order to address this problem, PISA uses an age-based definition for its target population, i.e. a definition that is not tied to the institutional structures of national education systems. PISA assesses students who were aged between 15 years and 3 (complete) months and 16 years and 2 (complete) months at the beginning of the assessment period, plus or minus a 1 month allowable variation, and who were enrolled in an educational institution with Grade 7 or higher, regardless of the grade levels or type of institution in which they were enrolled, and regardless of whether they were in full-time or part-time education. Educational institutions are generally referred to as schools in this publication, although some educational institutions (in particular, some types of vocational education establishments) may not be termed schools in certain countries. As expected from this definition, the average age of students across OECD countries was 15 years and 9 months. The range in country means was 2 months and 5 days ( 0.18 years), from the minimum country mean of 15 years and 8 months to the maximum country mean of 15 years and 10 months.

Given this definition of population, PISA makes statements about the knowledge and skills of a group of individuals who were born within a comparable reference period, but who may have undergone different educational experiences both in and outside of schools. In PISA, these knowledge and skills are referred to as the yield of education at an age that is common across countries. Depending on countries' policies on school entry, selection and promotion, these students may be distributed over a narrower or a wider range of grades across different education systems, tracks or streams. It is important to consider these differences when comparing PISA results across countries, as observed differences between students at age 15 may no longer appear as students' educational experiences converge later on.

If a country's scale scores in reading, scientific or mathematical literacy are significantly higher than those in another country, it cannot automatically be inferred that the schools or particular parts of the education system in the first country are more effective than those in the second. However, one can legitimately conclude that the cumulative impact of learning experiences in the first country, starting in early childhood and up to the age of 15, and embracing experiences both in school, home and beyond, have resulted in higher outcomes in the literacy domains that PISA measures.

The PISA target population did not include residents attending schools in a foreign country. It does, however, include foreign nationals attending schools in the country of assessment.

To accommodate countries that desired grade-based results for the purpose of national analyses, PISA 2012 provided a sampling option to supplement age-based sampling with grade-based sampling.

\section{Population coverage}

All countries attempted to maximise the coverage of 15-year-olds enrolled in education in their national samples, including students enrolled in special educational institutions. As a result, PISA 2012 reached standards of population coverage that are unprecedented in international surveys of this kind.

The sampling standards used in PISA permitted countries to exclude up to a total of $5 \%$ of the relevant population either by excluding schools or by excluding students within schools. All but eight countries, Luxembourg $(8.40 \%)$, Canada (6.38\%), Denmark $(6.18 \%)$, Norway (6.11\%), Estonia (5.80\%), Sweden (5.44\%), the United Kingdom (5.43\%) and the United States (5.35\%), achieved this standard, and in 30 countries and economies, the overall exclusion rate was less than $2 \%$. When language exclusions were accounted for (i.e. removed from the overall exclusion rate), Norway, Sweden, the United Kingdom and the United States no longer had an exclusion rate greater than $5 \%$. For details, see $w w w$.pisa.oecd.org. 
Exclusions within the above limits include:

- At the school level: i) schools that were geographically inaccessible or where the administration of the PISA assessment was not considered feasible; and ii) schools that provided teaching only for students in the categories defined under "within-school exclusions", such as schools for the blind. The percentage of 15 -year-olds enrolled in such schools had to be less than $2.5 \%$ of the nationally desired target population [0.5\% maximum for $i$ ) and $2 \%$ maximum for ii)]. The magnitude, nature and justification of school-level exclusions are documented in the PISA 2012 Technical Report (OECD, forthcoming).

- At the student level: i) students with an intellectual disability; ii) students with a functional disability; iii) students with limited assessment language proficiency; iv) other - a category defined by the national centres and approved by the international centre; and $v$ ) students taught in a language of instruction for the main domain for which no materials were available. Students could not be excluded solely because of low proficiency or common discipline problems. The percentage of 15 -year-olds excluded within schools had to be less than $2.5 \%$ of the nationally desired target population.

Table A2.1 describes the target population of the countries participating in PISA 2012. Further information on the target population and the implementation of PISA sampling standards can be found in the PISA 2012 Technical Report (OECD, forthcoming).

- Column 1 shows the total number of 15-year-olds according to the most recent available information, which in most countries meant the year 2011 as the year before the assessment.

- Column 2 shows the number of 15-year-olds enrolled in schools in Grade 7 or above (as defined above), which is referred to as the eligible population.

- Column 3 shows the national desired target population. Countries were allowed to exclude up to $0.5 \%$ of students a priori from the eligible population, essentially for practical reasons. The following a priori exclusions exceed this limit but were agreed with the PISA Consortium: Belgium excluded $0.23 \%$ of its population for a particular type of student educated while working; Canada excluded $1.14 \%$ of its population from Territories and Aboriginal reserves; Chile excluded $0.04 \%$ of its students who live in Easter Island, Juan Fernandez Archipelago and Antarctica; Indonesia excluded 1.55\% of its students from two provinces because of operational reasons; Ireland excluded $0.05 \%$ of its students in three island schools off the west coast; Latvia excluded $0.08 \%$ of its students in distance learning schools; and Serbia excluded $2.11 \%$ of its students taught in Serbian in Kosovo.

- Column 4 shows the number of students enrolled in schools that were excluded from the national desired target population either from the sampling frame or later in the field during data collection.

- Column 5 shows the size of the national desired target population after subtracting the students enrolled in excluded schools. This is obtained by subtracting Column 4 from Column 3.

- Column 6 shows the percentage of students enrolled in excluded schools. This is obtained by dividing Column 4 by Column 3 and multiplying by 100 .

- Column 7 shows the number of students participating in PISA 2012. Note that in some cases this number does not account for 15 -year-olds assessed as part of additional national options.

- Column 8 shows the weighted number of participating students, i.e. the number of students in the nationally defined target population that the PISA sample represents.

- Each country attempted to maximise the coverage of the PISA target population within the sampled schools. In the case of each sampled school, all eligible students, namely those 15 years of age, regardless of grade, were first listed. Sampled students who were to be excluded had still to be included in the sampling documentation, and a list drawn up stating the reason for their exclusion. Column 9 indicates the total number of excluded students, which is further described and classified into specific categories in Table A2.2.

- Column 10 indicates the weighted number of excluded students, i.e. the overall number of students in the nationally defined target population represented by the number of students excluded from the sample, which is also described and classified by exclusion categories in Table A2.2. Excluded students were excluded based on five categories: i) students with an intellectual disability - the student has a mental or emotional disability and is cognitively delayed such that he/she cannot perform in the PISA testing situation; ii) students with a functional disability - the student has a moderate to severe permanent physical disability such that he/she cannot perform in the PISA testing situation; iii) students with a limited assessment language proficiency - the student is unable to read or speak any of the languages of the assessment in the country and would be unable to overcome the language barrier in the testing situation (typically a student who has received less than one year of instruction in the languages of the assessment may be excluded); iv) other - a category defined by the national centres and approved by the international centre; and $v$ ) students taught in a language of instruction for the main domain for which no materials were available.

- Column 11 shows the percentage of students excluded within schools. This is calculated as the weighted number of excluded students (Column 10), divided by the weighted number of excluded and participating students (Column 8 plus Column 10), then multiplied by 100 .

- Column 12 shows the overall exclusion rate, which represents the weighted percentage of the national desired target population excluded from PISA either through school-level exclusions or through the exclusion of students within schools. It is calculated as the school-level exclusion rate (Column 6 divided by 100) plus within-school exclusion rate (Column 11 divided by 100) multiplied by 1 minus the school-level exclusion rate (Column 6 divided by 100). This result is then multiplied by 100. Eight countries, Canada, Denmark, Estonia, Luxembourg, Norway, Sweden, the United Kingdom and the United States, had exclusion rates higher than $5 \%$. When language exclusions were accounted for (i.e. removed from the overall exclusion rate), Norway, Sweden, the United Kingdom and the United States no longer had an exclusion rate greater than $5 \%$ ". 
[Part 1/2]

Table A2.1 PISA target populations and samples

\begin{tabular}{|c|c|c|c|c|c|c|c|c|c|}
\hline & \multicolumn{8}{|c|}{ Population and sample information } \\
\hline & & $\begin{array}{c}\text { Total } \\
\text { population } \\
\text { of 15-year-olds }\end{array}$ & $\begin{array}{c}\text { Total enrolled } \\
\text { population of } \\
15 \text {-year-olds } \\
\text { at Grade } 7 \text { or } \\
\text { above }\end{array}$ & $\begin{array}{c}\text { Total in } \\
\text { national } \\
\text { desired target } \\
\text { population }\end{array}$ & $\begin{array}{c}\text { Total school- } \\
\text { level } \\
\text { exclusions }\end{array}$ & $\begin{array}{c}\text { Total in national } \\
\text { desired target } \\
\text { population after all } \\
\text { school exclusions and } \\
\text { before within-school } \\
\text { exclusions }\end{array}$ & $\begin{array}{l}\text { School-level } \\
\text { exclusion rate } \\
(\%)\end{array}$ & $\begin{array}{c}\text { Number of } \\
\text { participating } \\
\text { students }\end{array}$ & $\begin{array}{c}\text { Weighted number } \\
\text { of participating } \\
\text { students }\end{array}$ \\
\hline & & $(1)$ & (2) & (3) & (4) & $(5)$ & (6) & (7) & $(8)$ \\
\hline \multirow{34}{*}{ రิ } & Australia & 291967 & 288159 & 288159 & 5702 & 282457 & 1.98 & 17774 & 250779 \\
\hline & Austria & 93537 & 89073 & 89073 & 106 & 88967 & 0.12 & 4756 & 82242 \\
\hline & Belgium & 123469 & 121493 & 121209 & 1324 & 119885 & 1.09 & 9690 & 117912 \\
\hline & Canada & 417873 & 409453 & 404767 & 2936 & 401831 & 0.73 & 21548 & 348070 \\
\hline & Chile & 274803 & 252733 & 252625 & 2687 & 249938 & 1.06 & 6857 & 229199 \\
\hline & Czech Republic & 96946 & 93214 & 93214 & 1577 & 91637 & 1.69 & 6535 & 82101 \\
\hline & Denmark & 72310 & 70854 & 70854 & 1965 & 68889 & 2.77 & 7481 & 65642 \\
\hline & Estonia & 12649 & 12438 & 12438 & 442 & 11996 & 3.55 & 5867 & 11634 \\
\hline & Finland & 62523 & 62195 & 62195 & 523 & 61672 & 0.84 & 8829 & 60047 \\
\hline & France & 792983 & 755447 & 755447 & 27403 & 728044 & 3.63 & 5682 & 701399 \\
\hline & Germany & 798136 & 798136 & 798136 & 10914 & 787222 & 1.37 & 5001 & 756907 \\
\hline & Greece & 110521 & 105096 & 105096 & 1364 & 103732 & 1.30 & 5125 & 96640 \\
\hline & Hungary & 111761 & 108816 & 108816 & 1725 & 107091 & 1.59 & 4810 & 91179 \\
\hline & Iceland & 4505 & 4491 & 4491 & 10 & 4481 & 0.22 & 3508 & 4169 \\
\hline & Ireland & 59296 & 57979 & 57952 & 0 & 57952 & 0.00 & 5016 & 54010 \\
\hline & Israel & 118953 & 113278 & 113278 & 2784 & 110494 & 2.46 & 6061 & 107745 \\
\hline & Italy & 605490 & 566973 & 566973 & 8498 & 558475 & 1.50 & 38142 & 521288 \\
\hline & Japan & 1241786 & 1214756 & 1214756 & 26099 & 1188657 & 2.15 & 6351 & 1128179 \\
\hline & Korea & 687104 & 672101 & 672101 & 3053 & 669048 & 0.45 & 5033 & 603632 \\
\hline & Luxembourg & 6187 & 6082 & 6082 & 151 & 5931 & 2.48 & 5260 & 5523 \\
\hline & Mexico & 2114745 & 1472875 & 1472875 & 7307 & 1465568 & 0.50 & 33806 & 1326025 \\
\hline & Netherlands & 194000 & 193190 & 193190 & 7546 & 185644 & 3.91 & 4460 & 196262 \\
\hline & New Zealand & 60940 & 59118 & 59118 & 579 & 58539 & 0.98 & 5248 & 53414 \\
\hline & Norway & 64917 & 64777 & 64777 & 750 & 64027 & 1.16 & 4686 & 59432 \\
\hline & Poland & 425597 & 410700 & 410700 & 6900 & 403800 & 1.68 & 5662 & 379275 \\
\hline & Portugal & 108728 & 127537 & 127537 & 0 & 127537 & 0.00 & 5722 & 96034 \\
\hline & Slovak Republic & 59723 & 59367 & 59367 & 1480 & 57887 & 2.49 & 5737 & 54486 \\
\hline & Slovenia & 19471 & 18935 & 18935 & 115 & 18820 & 0.61 & 7229 & 18303 \\
\hline & Spain & 423444 & 404374 & 404374 & 2031 & 402343 & 0.50 & 25335 & 374266 \\
\hline & Sweden & 102087 & 102027 & 102027 & 1705 & 100322 & 1.67 & 4739 & 94988 \\
\hline & Switzerland & 87200 & 85239 & 85239 & 2479 & 82760 & 2.91 & 11234 & 79679 \\
\hline & Turkey & 1266638 & 965736 & 965736 & 10387 & 955349 & 1.08 & 4848 & 866681 \\
\hline & United Kingdom & 738066 & 745581 & 745581 & 19820 & 725761 & 2.66 & 12659 & 688236 \\
\hline & United States & 3985714 & 4074457 & 4074457 & 41142 & 4033315 & 1.01 & 6111 & 3536153 \\
\hline \multirow{31}{*}{ ఏँ } & Albania & 76910 & 50157 & 50157 & 56 & 50101 & 0.11 & 4743 & 42466 \\
\hline & Argentina & 684879 & 637603 & 637603 & 3995 & 633608 & 0.63 & 5908 & 545942 \\
\hline & Brazil & 3574928 & 2786064 & 2786064 & 34932 & 2751132 & 1.25 & 20091 & 2470804 \\
\hline & Bulgaria & 70188 & 59684 & 59684 & 1437 & 58247 & 2.41 & 5282 & 54255 \\
\hline & Colombia & 889729 & 620422 & 620422 & 4 & 620418 & 0.00 & 11173 & 560805 \\
\hline & Costa Rica & 81489 & 64326 & 64326 & 0 & 64326 & 0.00 & 4602 & 40384 \\
\hline & Croatia & 48155 & 46550 & 46550 & 417 & 46133 & 0.90 & 6153 & 45502 \\
\hline & Cyprus* & 9956 & 9956 & 9955 & 128 & 9827 & 1.29 & 5078 & 9650 \\
\hline & Hong Kong-China & 84200 & 77864 & 77864 & 813 & 77051 & 1.04 & 4670 & 70636 \\
\hline & Indonesia & 4174217 & 3599844 & 3544028 & 8039 & 3535989 & 0.23 & 5622 & 2645155 \\
\hline & Jordan & 129492 & 125333 & 125333 & 141 & 125192 & 0.11 & 7038 & 111098 \\
\hline & Kazakhstan & 258716 & 247048 & 247048 & 7374 & 239674 & 2.98 & 5808 & 208411 \\
\hline & Latvia & 18789 & 18389 & 18375 & 655 & 17720 & 3.56 & 5276 & 16054 \\
\hline & Liechtenstein & 417 & 383 & 383 & 1 & 382 & 0.26 & 293 & 314 \\
\hline & Lithuania & 38524 & 35567 & 35567 & 526 & 35041 & 1.48 & 4618 & 33042 \\
\hline & Macao-China & 6600 & 5416 & 5416 & 6 & 5410 & 0.11 & 5335 & 5366 \\
\hline & Malaysia & 544302 & 457999 & 457999 & 225 & 457774 & 0.05 & 5197 & 432080 \\
\hline & Montenegro & 8600 & 8600 & 8600 & 18 & 8582 & 0.21 & 4744 & 7714 \\
\hline & Peru & 584294 & 508969 & 508969 & 263 & 508706 & 0.05 & 6035 & 419945 \\
\hline & Qatar & 11667 & 11532 & 11532 & 202 & 11330 & 1.75 & 10966 & 11003 \\
\hline & Romania & 146243 & 146243 & 146243 & 5091 & 141152 & 3.48 & 5074 & 140915 \\
\hline & Russian Federation & 1272632 & 1268814 & 1268814 & 17800 & 1251014 & 1.40 & 6418 & 1172539 \\
\hline & Serbia & 80089 & 75870 & 74272 & 1987 & 72285 & 2.67 & 4684 & 67934 \\
\hline & Shanghai-China & 108056 & 90796 & 90796 & 1252 & 89544 & 1.38 & 6374 & 85127 \\
\hline & Singapore & 53637 & 52163 & 52163 & 293 & 51870 & 0.56 & 5546 & 51088 \\
\hline & Chinese Taipei & 328356 & 328336 & 328336 & 1747 & 326589 & 0.53 & 6046 & 292542 \\
\hline & Thailand & 982080 & 784897 & 784897 & 9123 & 775774 & 1.16 & 6606 & 703012 \\
\hline & Tunisia & 132313 & 132313 & 132313 & 169 & 132144 & 0.13 & 4407 & 120784 \\
\hline & United Arab Emirates & 48824 & 48446 & 48446 & 971 & 47475 & 2.00 & 11500 & 40612 \\
\hline & Uruguay & 54638 & 46442 & 46442 & 14 & 46428 & 0.03 & 5315 & 39771 \\
\hline & Viet Nam & 1717996 & 1091462 & 1091462 & 7729 & 1083733 & 0.71 & 4959 & 956517 \\
\hline
\end{tabular}

Notes: For a full explanation of the details in this table please refer to the PISA 2012 Technical Report (OECD, forthcoming). The figure for total national population of 15-year-olds enrolled in Column 2 may occasionally be larger than the total number of 15-year-olds in Column 1 due to differing data sources.

Information for the adjudicated regions is available on line.

* See note at the beginning of this Annex.

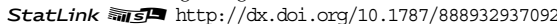


[Part 2/2]

Table A2.1 PISA target populations and samples

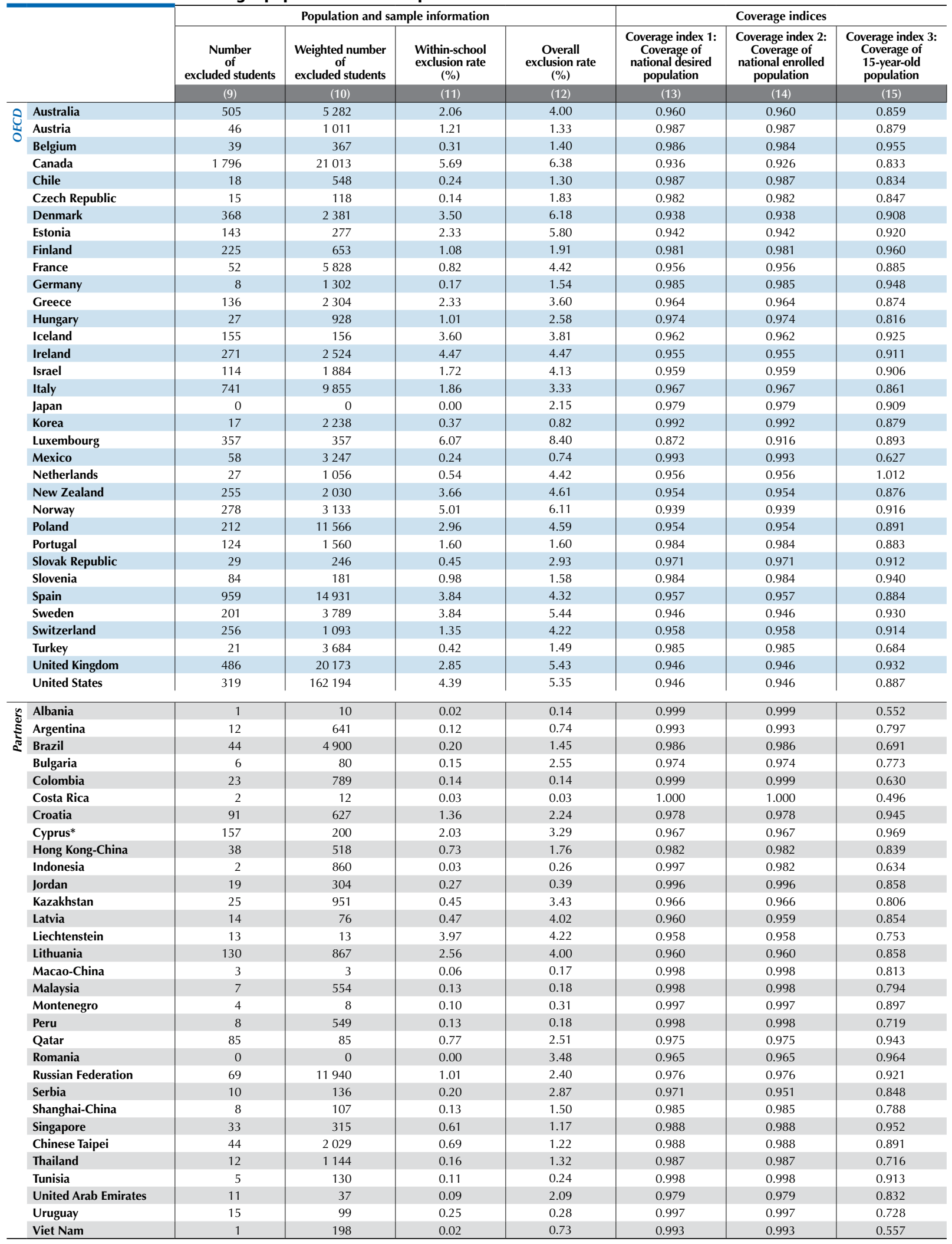

Notes: For a full explanation of the details in this table please refer to the PISA 2012 Technical Report (OECD, forthcoming). The figure for total national population of 15-year-olds enrolled in Column 2 may occasionally be larger than the total number of 15-year-olds in Column 1 due to differing data sources.

Information for the adjudicated regions is available on line.

* See note at the beginning of this Annex.

StatLink 需宁四 http://dx.doi.org/10.1787/888932937092 
[Part 1/1]

Table A2.2 Exclusions

\begin{tabular}{|c|c|c|c|c|c|c|c|c|c|c|c|c|c|}
\hline & \multicolumn{6}{|c|}{ Student exclusions (unweighted) } & \multicolumn{6}{|c|}{ Student exclusions (weighted) } \\
\hline & & $\begin{array}{l}\begin{array}{c}\text { Number } \\
\text { of }\end{array} \\
\text { excluded } \\
\text { students } \\
\text { with } \\
\text { functional } \\
\text { disability } \\
\text { (Code 1) }\end{array}$ & 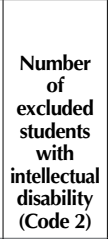 & \begin{tabular}{|c|}
$\begin{array}{c}\text { Number } \\
\text { of } \\
\text { excluded } \\
\text { students } \\
\text { because of } \\
\text { language } \\
\text { (Code 3) }\end{array}$ \\
\end{tabular} & $\begin{array}{c}\begin{array}{c}\text { Number } \\
\text { of } \\
\text { excluded }\end{array} \\
\text { students } \\
\text { for other } \\
\text { reasons } \\
\text { (Code 4) }\end{array}$ & 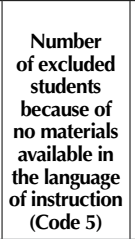 & $\begin{array}{c}\text { Total } \\
\text { number } \\
\text { of } \\
\text { excluded } \\
\text { students }\end{array}$ & \begin{tabular}{|c|}
$\begin{array}{c}\text { Weighted } \\
\text { number } \\
\text { of excluded }\end{array}$ \\
students \\
with \\
functional \\
disability \\
(Code 1)
\end{tabular} & \begin{tabular}{|c|} 
Weighted \\
number \\
of excluded \\
students \\
with \\
intellectual \\
disability \\
(Code 2)
\end{tabular} & $\begin{array}{c}\text { Weighted } \\
\text { number } \\
\text { of excluded } \\
\text { students } \\
\text { because of } \\
\text { language } \\
\text { (Code 3) }\end{array}$ & $\begin{array}{c}\text { Weighted } \\
\text { number } \\
\text { of excluded } \\
\text { students } \\
\text { for other } \\
\text { reasons } \\
\text { (Code 4) }\end{array}$ & 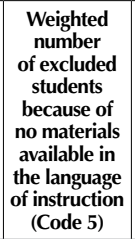 & $\begin{array}{c}\text { Total } \\
\text { weighted } \\
\text { number of } \\
\text { excluded } \\
\text { students }\end{array}$ \\
\hline & & (1) & (2) & (3) & (4) & (5) & (6) & (7) & (8) & (9) & (10) & (11) & (12) \\
\hline \multirow{34}{*}{ త్ } & Australia & 39 & 395 & 71 & 0 & 0 & 505 & 471 & 3925 & 886 & 0 & 0 & 5282 \\
\hline & Austria & 11 & 24 & 11 & 0 & 0 & 46 & 332 & 438 & 241 & 0 & 0 & 1011 \\
\hline & Belgium & 5 & 22 & 12 & 0 & 0 & 39 & 24 & 154 & 189 & 0 & 0 & 367 \\
\hline & Canada & 82 & 1593 & 121 & 0 & 0 & 1796 & 981 & 18682 & 1350 & 0 & 0 & 21013 \\
\hline & Chile & 3 & 15 & 0 & 0 & 0 & 18 & 74 & 474 & 0 & 0 & 0 & 548 \\
\hline & Czech Republic & 1 & 8 & 6 & 0 & 0 & 15 & 1 & 84 & 34 & 0 & 0 & 118 \\
\hline & Denmark & 10 & 204 & 112 & 42 & 0 & 368 & 44 & 1469 & 559 & 310 & 0 & 2381 \\
\hline & Estonia & 7 & 134 & 2 & 0 & 0 & 143 & 14 & 260 & 3 & 0 & 0 & 277 \\
\hline & Finland & 5 & 80 & 101 & 15 & 24 & 225 & 43 & 363 & 166 & 47 & 35 & 653 \\
\hline & France & 52 & 0 & 0 & 0 & 0 & 52 & 5828 & 0 & 0 & 0 & 0 & 5828 \\
\hline & Germany & 0 & 4 & 4 & 0 & 0 & 8 & 0 & 705 & 597 & 0 & 0 & 1302 \\
\hline & Greece & 3 & 18 & 4 & 111 & 0 & 136 & 49 & 348 & 91 & 1816 & 0 & 2304 \\
\hline & Hungary & 1 & 15 & 2 & 9 & 0 & 27 & 36 & 568 & 27 & 296 & 0 & 928 \\
\hline & Iceland & 5 & 105 & 27 & 18 & 0 & 155 & 5 & 105 & 27 & 18 & 0 & 156 \\
\hline & Ireland & 13 & 159 & 33 & 66 & 0 & 271 & 121 & 1521 & 283 & 599 & 0 & 2524 \\
\hline & Israel & 9 & 91 & 14 & 0 & 0 & 114 & 133 & 1492 & 260 & 0 & 0 & 1884 \\
\hline & Italy & 64 & 566 & 111 & 0 & 0 & 741 & 596 & 7899 & 1361 & 0 & 0 & 9855 \\
\hline & Japan & 0 & 0 & 0 & 0 & 0 & 0 & 0 & 0 & 0 & 0 & 0 & 0 \\
\hline & Luxembourg & 6 & 261 & 90 & 0 & 0 & 357 & 6 & 261 & 90 & 0 & 0 & 357 \\
\hline & Mexico & 21 & 36 & 1 & 0 & 0 & 58 & 812 & 2390 & 45 & 0 & 0 & 3247 \\
\hline & Netherlands & 5 & 21 & 1 & 0 & 0 & 27 & 188 & 819 & 50 & 0 & 0 & 1056 \\
\hline & New Zealand & 27 & 118 & 99 & 0 & 11 & 255 & 235 & 926 & 813 & 0 & 57 & 2030 \\
\hline & Norway & 11 & 192 & 75 & 0 & 0 & 278 & 120 & 2180 & 832 & 0 & 0 & 3133 \\
\hline & Poland & 23 & 89 & 6 & 88 & 6 & 212 & 1470 & 5187 & 177 & 4644 & 89 & 11566 \\
\hline & Portugal & 69 & 48 & 7 & 0 & 0 & 124 & 860 & 605 & 94 & 0 & 0 & 1560 \\
\hline & Korea & 2 & 15 & 0 & 0 & 0 & 17 & 223 & 2015 & 0 & 0 & 0 & 2238 \\
\hline & Slovak Republic & 2 & 14 & 0 & 13 & 0 & 29 & 22 & 135 & 0 & 89 & 0 & 246 \\
\hline & Slovenia & 13 & 27 & 44 & 0 & 0 & 84 & 23 & 76 & 81 & 0 & 0 & 181 \\
\hline & Spain & 56 & 679 & 224 & 0 & 0 & 959 & 618 & 11330 & 2984 & 0 & 0 & 14931 \\
\hline & Sweden & 120 & 0 & 81 & 0 & 0 & 201 & 2218 & 0 & 1571 & 0 & 0 & 3789 \\
\hline & Switzerland & 7 & 99 & 150 & 0 & 0 & 256 & 41 & 346 & 706 & 0 & 0 & 1093 \\
\hline & Turkey & 5 & 14 & 2 & 0 & 0 & 21 & 757 & 2556 & 371 & 0 & 0 & 3684 \\
\hline & United Kingdom & 40 & 405 & 41 & 0 & 0 & 486 & 1468 & 15514 & 3191 & 0 & 0 & 20173 \\
\hline & United States & 37 & 219 & 63 & 0 & 0 & 319 & 18399 & 113965 & 29830 & 0 & 0 & 162194 \\
\hline \multirow{31}{*}{ ఏँ } & Albania & 0 & 0 & 1 & 0 & 0 & 1 & 0 & 0 & 10 & 0 & 0 & 10 \\
\hline & Argentina & 1 & 11 & 0 & 0 & 0 & 12 & 84 & 557 & 0 & 0 & 0 & 641 \\
\hline & Brazil & 17 & 27 & 0 & 0 & 0 & 44 & 1792 & 3108 & 0 & 0 & 0 & 4900 \\
\hline & Bulgaria & 6 & 0 & 0 & 0 & 0 & 6 & 80 & 0 & 0 & 0 & 0 & 80 \\
\hline & Colombia & 12 & 10 & 1 & 0 & 0 & 23 & 397 & 378 & 14 & 0 & 0 & 789 \\
\hline & Costa Rica & 0 & 2 & 0 & 0 & 0 & 2 & 0 & 12 & 0 & 0 & 0 & 12 \\
\hline & Croatia & 10 & 78 & 3 & 0 & 0 & 91 & 69 & 539 & 19 & 0 & 0 & 627 \\
\hline & Cyprus* & 8 & 54 & 60 & 35 & 0 & 157 & 9 & 64 & 72 & 55 & 0 & 200 \\
\hline & Hong Kong-China & 4 & 33 & 1 & 0 & 0 & 38 & 57 & 446 & 15 & 0 & 0 & 518 \\
\hline & Indonesia & 1 & 0 & 1 & 0 & 0 & 2 & 426 & 0 & 434 & 0 & 0 & 860 \\
\hline & Jordan & 8 & 6 & 5 & 0 & 0 & 19 & 109 & 72 & 122 & 0 & 0 & 304 \\
\hline & Kazakhstan & 9 & 16 & 0 & 0 & 0 & 25 & 317 & 634 & 0 & 0 & 0 & 951 \\
\hline & Latvia & 3 & 7 & 4 & 0 & 0 & 14 & 8 & 45 & 24 & 0 & 0 & 76 \\
\hline & Liechtenstein & 1 & 7 & 5 & 0 & 0 & 13 & 1 & 7 & 5 & 0 & 0 & 13 \\
\hline & Lithuania & 10 & 120 & 0 & 0 & 0 & 130 & 66 & 801 & 0 & 0 & 0 & 867 \\
\hline & Macao-China & 0 & 1 & 2 & 0 & 0 & 3 & 0 & 1 & 2 & 0 & 0 & 3 \\
\hline & Malaysia & 3 & 4 & 0 & 0 & 0 & 7 & 274 & 279 & 0 & 0 & 0 & 554 \\
\hline & Montenegro & 3 & 1 & 0 & 0 & 0 & 4 & 7 & 1 & 0 & 0 & 0 & 8 \\
\hline & Peru & 3 & 5 & 0 & 0 & 0 & 8 & 269 & 280 & 0 & 0 & 0 & 549 \\
\hline & Qatar & 23 & 43 & 19 & 0 & 0 & 85 & 23 & 43 & 19 & 0 & 0 & 85 \\
\hline & Romania & 0 & 0 & 0 & 0 & 0 & 0 & 0 & 0 & 0 & 0 & 0 & 0 \\
\hline & Russian Federation & 25 & 40 & 4 & 0 & 0 & 69 & 4345 & 6934 & 660 & 0 & 0 & 11940 \\
\hline & Serbia & 4 & 4 & 2 & 0 & 0 & 10 & 53 & 55 & 28 & 0 & 0 & 136 \\
\hline & Shanghai-China & 1 & 6 & 1 & 0 & 0 & 8 & 14 & 80 & 14 & 0 & 0 & 107 \\
\hline & Singapore & 5 & 17 & 11 & 0 & 0 & 33 & 50 & 157 & 109 & 0 & 0 & 315 \\
\hline & Chinese Taipei & 6 & 36 & 2 & 0 & 0 & 44 & 296 & 1664 & 70 & 0 & 0 & 2029 \\
\hline & Thailand & 2 & 10 & 0 & 0 & 0 & 12 & 13 & 1131 & 0 & 0 & 0 & 1144 \\
\hline & Tunisia & 4 & 1 & 0 & 0 & 0 & 5 & 104 & 26 & 0 & 0 & 0 & 130 \\
\hline & United Arab Emirates & 3 & 7 & 1 & 0 & 0 & 11 & 26 & 9 & 2 & 0 & 0 & 37 \\
\hline & Uruguay & 9 & 6 & 0 & 0 & 0 & 15 & 66 & 33 & 0 & 0 & 0 & 99 \\
\hline & Viet Nam & 0 & 1 & 0 & 0 & 0 & 1 & 0 & 198 & 0 & 0 & 0 & 198 \\
\hline
\end{tabular}

Exclusion codes:

Code 1 Functional disability - student has a moderate to severe permanent physical disability.

Code 2 Intellectual disability - student has a mental or emotional disability and has either been tested as cognitively delayed or is considered in the professional opinion of qualified staff to be cognitively delayed.

Code 3 Limited assessment language proficiency - student is not a native speaker of any of the languages of the assessment in the country and has been resident in the country for less than one year.

Code 4 Other reasons defined by the national centres and approved by the international centre

Code 5 No materials available in the language of instruction.

Note: For a full explanation of the details in this table please refer to the PISA 2012 Technical Report (OECD, forthcoming).

Information for the adjudicated regions is available on line.

* See note at the beginning of this Annex.

StatLink 雷 
- Column 13 presents an index of the extent to which the national desired target population is covered by the PISA sample. Canada, Denmark, Estonia, Luxembourg, Norway, Sweden, the United Kingdom and the United States were the only countries where the coverage is below $95 \%$.

- Column 14 presents an index of the extent to which 15-year-olds enrolled in schools are covered by the PISA sample. The index measures the overall proportion of the national enrolled population that is covered by the non-excluded portion of the student sample. The index takes into account both school-level and student-level exclusions. Values close to 100 indicate that the PISA sample represents the entire education system as defined for PISA 2012. The index is the weighted number of participating students (Column 8) divided by the weighted number of participating and excluded students (Column 8 plus Column 10), times the nationally defined target population (Column 5) divided by the eligible population (Column 2).

- Column 15 presents an index of the coverage of the 15-year-old population. This index is the weighted number of participating students (Column 8) divided by the total population of 15-year-old students (Column 1).

This high level of coverage contributes to the comparability of the assessment results. For example, even assuming that the excluded students would have systematically scored worse than those who participated, and that this relationship is moderately strong, an exclusion rate in the order of $5 \%$ would likely lead to an overestimation of national mean scores of less than 5 score points (on a scale with an international mean of 500 score points and a standard deviation of 100 score points). This assessment is based on the following calculations: if the correlation between the propensity of exclusions and student performance is 0.3 , resulting mean scores would likely be overestimated by 1 score point if the exclusion rate is $1 \%$, by 3 score points if the exclusion rate is $5 \%$, and by 6 score points if the exclusion rate is $10 \%$. If the correlation between the propensity of exclusions and student performance is 0.5 , resulting mean scores would be overestimated by 1 score point if the exclusion rate is $1 \%$, by 5 score points if the exclusion rate is $5 \%$, and by 10 score points if the exclusion rate is $10 \%$. For this calculation, a model was employed that assumes a bivariate normal distribution for performance and the propensity to participate. For details, see the PISA 2012 Technical Report (OECD, forthcoming).

\section{Sampling procedures and response rates}

The accuracy of any survey results depends on the quality of the information on which national samples are based as well as on the sampling procedures. Quality standards, procedures, instruments and verification mechanisms were developed for PISA that ensured that national samples yielded comparable data and that the results could be compared with confidence.

Most PISA samples were designed as two-stage stratified samples (where countries applied different sampling designs, these are documented in the PISA 2012 Technical Report [OECD, forthcoming]). The first stage consisted of sampling individual schools in which 15 -year-old students could be enrolled. Schools were sampled systematically with probabilities proportional to size, the measure of size being a function of the estimated number of eligible (15-year-old) students enrolled. A minimum of 150 schools were selected in each country (where this number existed), although the requirements for national analyses often required a somewhat larger sample. As the schools were sampled, replacement schools were simultaneously identified, in case a sampled school chose not to participate in PISA 2012.

In the case of Iceland, Liechtenstein, Luxembourg, Macao-China and Qatar, all schools and all eligible students within schools were included in the sample.

Experts from the PISA Consortium performed the sample selection process for most participating countries and monitored it closely in those countries that selected their own samples. The second stage of the selection process sampled students within sampled schools. Once schools were selected, a list of each sampled school's 15-year-old students was prepared. From this list, 35 students were then selected with equal probability (all 15-year-old students were selected if fewer than 35 were enrolled). The number of students to be sampled per school could deviate from 35, but could not be less than 20.

Data-quality standards in PISA required minimum participation rates for schools as well as for students. These standards were established to minimise the potential for response biases. In the case of countries meeting these standards, it was likely that any bias resulting from non-response would be negligible, i.e. typically smaller than the sampling error.

A minimum response rate of $85 \%$ was required for the schools initially selected. Where the initial response rate of schools was between $65 \%$ and $85 \%$, however, an acceptable school response rate could still be achieved through the use of replacement schools. This procedure brought with it a risk of increased response bias. Participating countries were, therefore, encouraged to persuade as many of the schools in the original sample as possible to participate. Schools with a student participation rate between $25 \%$ and $50 \%$ were not regarded as participating schools, but data from these schools were included in the database and contributed to the various estimations. Data from schools with a student participation rate of less than $25 \%$ were excluded from the database.

PISA 2012 also required a minimum participation rate of $80 \%$ of students within participating schools. This minimum participation rate had to be met at the national level, not necessarily by each participating school. Follow-up sessions were required in schools in which too few students had participated in the original assessment sessions. Student participation rates were calculated over all original schools, and also over all schools, whether original sample or replacement schools, and from the participation of students in both the original assessment and any follow-up sessions. A student who participated in the original or follow-up cognitive sessions was regarded as a participant. Those who attended only the questionnaire session were included in the international database and contributed to the statistics presented in this publication if they provided at least a description of their father's or mother's occupation. 
[Part 1/2]

Table A2.3 Response rates

\begin{tabular}{|c|c|c|c|c|c|c|c|c|c|}
\hline & \multicolumn{5}{|c|}{ Initial sample - before school replacement } & \multicolumn{3}{|c|}{ Final sample - after school replacement } \\
\hline & & $\begin{array}{c}\text { Weighted school } \\
\text { participation } \\
\text { rate before } \\
\text { replacement } \\
(\%)\end{array}$ & $\begin{array}{l}\text { Weighted } \\
\text { number of } \\
\text { responding } \\
\text { schools } \\
\text { (weighted also } \\
\text { by enrolment) }\end{array}$ & \begin{tabular}{|c|} 
Weighted \\
number of \\
schools sampled \\
(responding and \\
non-responding) \\
(weighted also \\
by enrolment)
\end{tabular} & $\begin{array}{c}\text { Number of } \\
\text { responding } \\
\text { schools } \\
\text { (unweighted) }\end{array}$ & $\begin{array}{c}\text { Number of } \\
\text { responding and } \\
\text { non-responding } \\
\text { schools } \\
\text { (unweighted) }\end{array}$ & $\begin{array}{c}\text { Weighted school } \\
\text { participation rate } \\
\text { after replacement } \\
(\%)\end{array}$ & $\begin{array}{l}\text { Weighted number } \\
\text { of responding } \\
\text { schools (weighted } \\
\text { also by enrolment) }\end{array}$ & $\begin{array}{c}\text { Weighted number } \\
\text { of schools sampled } \\
\text { (responding and } \\
\text { non-responding) } \\
\text { (weighted also } \\
\text { by enrolment) }\end{array}$ \\
\hline & & $(1)$ & (2) & (3) & (4) & $(5)$ & (6) & (7) & (8) \\
\hline \multirow{34}{*}{ త్ } & Australia & 98 & 268631 & 274432 & 757 & 790 & 98 & 268631 & 274432 \\
\hline & Austria & 100 & 88967 & 88967 & 191 & 191 & 100 & 88967 & 88967 \\
\hline & Belgium & 84 & 100482 & 119019 & 246 & 294 & 97 & 115004 & 119006 \\
\hline & Canada & 91 & 362178 & 396757 & 828 & 907 & 93 & 368600 & 396757 \\
\hline & Chile & 92 & 220009 & 239429 & 200 & 224 & 99 & 236576 & 239370 \\
\hline & Czech Republic & 98 & 87238 & 88884 & 292 & 297 & 100 & 88447 & 88797 \\
\hline & Denmark & 87 & 61749 & 71015 & 311 & 366 & 96 & 67709 & 70892 \\
\hline & Estonia & 100 & 12046 & 12046 & 206 & 206 & 100 & 12046 & 12046 \\
\hline & Finland & 99 & 59740 & 60323 & 310 & 313 & 99 & 59912 & 60323 \\
\hline & France & 97 & 703458 & 728401 & 223 & 231 & 97 & 703458 & 728401 \\
\hline & Germany & 98 & 735944 & 753179 & 227 & 233 & 98 & 737778 & 753179 \\
\hline & Greece & 93 & 95107 & 102087 & 176 & 192 & 99 & 100892 & 102053 \\
\hline & Hungary & 98 & 99317 & 101751 & 198 & 208 & 99 & 101187 & 101751 \\
\hline & Iceland & 99 & 4395 & 4424 & 133 & 140 & 99 & 4395 & 4424 \\
\hline & Ireland & 99 & 56962 & 57711 & 182 & 185 & 99 & 57316 & 57711 \\
\hline & Israel & 91 & 99543 & 109326 & 166 & 186 & 94 & 103075 & 109895 \\
\hline & Italy & 89 & 478317 & 536921 & 1104 & 1232 & 97 & 522686 & 536821 \\
\hline & Japan & 86 & 1015198 & 1175794 & 173 & 200 & 96 & 1123211 & 1175794 \\
\hline & Korea & 100 & 661575 & 662510 & 156 & 157 & 100 & 661575 & 662510 \\
\hline & Luxembourg & 100 & 5931 & 5931 & 42 & 42 & 100 & 5931 & 5931 \\
\hline & Mexico & 92 & 1323816 & 1442242 & 1431 & 1562 & 95 & 1374615 & 1442234 \\
\hline & Netherlands & 75 & 139709 & 185468 & 148 & 199 & 89 & 165635 & 185320 \\
\hline & New Zealand & 81 & 47441 & 58676 & 156 & 197 & 89 & 52360 & 58616 \\
\hline & Norway & 85 & 54201 & 63653 & 177 & 208 & 95 & 60270 & 63642 \\
\hline & Poland & 85 & 343344 & 402116 & 159 & 188 & 98 & 393872 & 402116 \\
\hline & Portugal & 95 & 122238 & 128129 & 186 & 195 & 96 & 122713 & 128050 \\
\hline & Slovak Republic & 87 & 50182 & 57353 & 202 & 236 & 99 & 57599 & 58201 \\
\hline & Slovenia & 98 & 18329 & 18680 & 335 & 353 & 98 & 18329 & 18680 \\
\hline & Spain & 100 & 402604 & 403999 & 902 & 904 & 100 & 402604 & 403999 \\
\hline & Sweden & 99 & 98645 & 99726 & 207 & 211 & 100 & 99536 & 99767 \\
\hline & Switzerland & 94 & 78825 & 83450 & 397 & 422 & 98 & 82032 & 83424 \\
\hline & Turkey & 97 & 921643 & 945357 & 165 & 170 & 100 & 944807 & 945357 \\
\hline & United Kingdom & 80 & 564438 & 705011 & 477 & 550 & 89 & 624499 & 699839 \\
\hline & United States & 67 & 2647253 & 3945575 & 139 & 207 & 77 & 3040661 & 3938077 \\
\hline \multirow{31}{*}{ ఏँ } & Albania & 100 & 49632 & 49632 & 204 & 204 & 100 & 49632 & 49632 \\
\hline & Argentina & 95 & 578723 & 606069 & 218 & 229 & 96 & 580989 & 606069 \\
\hline & Brazil & 93 & 2545863 & 2745045 & 803 & 886 & 95 & 2622293 & 2747688 \\
\hline & Bulgaria & 99 & 57101 & 57574 & 186 & 188 & 100 & 57464 & 57574 \\
\hline & Colombia & 87 & 530553 & 612605 & 323 & 363 & 97 & 596557 & 612261 \\
\hline & Costa Rica & 99 & 64235 & 64920 & 191 & 193 & 99 & 64235 & 64920 \\
\hline & Croatia & 99 & 45037 & 45636 & 161 & 164 & 100 & 45608 & 45636 \\
\hline & Cyprus* & 97 & 9485 & 9821 & 117 & 131 & 97 & 9485 & 9821 \\
\hline & Hong Kong-China & 79 & 60277 & 76589 & 123 & 156 & 94 & 72064 & 76567 \\
\hline & Indonesia & 95 & 2799943 & 2950696 & 199 & 210 & 98 & 2892365 & 2951028 \\
\hline & Jordan & 100 & 119147 & 119147 & 233 & 233 & 100 & 119147 & 119147 \\
\hline & Kazakhstan & 100 & 239767 & 239767 & 218 & 218 & 100 & 239767 & 239767 \\
\hline & Latvia & 88 & 15371 & 17488 & 186 & 213 & 100 & 17428 & 17448 \\
\hline & Liechtenstein & 100 & 382 & 382 & 12 & 12 & 100 & 382 & 382 \\
\hline & Lithuania & 98 & 33989 & 34614 & 211 & 216 & 100 & 34604 & 34604 \\
\hline & Macao-China & 100 & 5410 & 5410 & 45 & 45 & 100 & 5410 & 5410 \\
\hline & Malaysia & 100 & 455543 & 455543 & 164 & 164 & 100 & 455543 & 455543 \\
\hline & Montenegro & 100 & 8540 & 8540 & 51 & 51 & 100 & 8540 & 8540 \\
\hline & Peru & 98 & 503915 & 514574 & 238 & 243 & 99 & 507602 & 514574 \\
\hline & Qatar & 100 & 11333 & 11340 & 157 & 164 & 100 & 11333 & 11340 \\
\hline & Romania & 100 & 139597 & 139597 & 178 & 178 & 100 & 139597 & 139597 \\
\hline & Russian Federation & 100 & 1243564 & 1243564 & 227 & 227 & 100 & 1243564 & 1243564 \\
\hline & Serbia & 90 & 65537 & 72819 & 143 & 160 & 95 & 69433 & 72752 \\
\hline & Shanghai-China & 100 & 89832 & 89832 & 155 & 155 & 100 & 89832 & 89832 \\
\hline & Singapore & 98 & 50415 & 51687 & 170 & 176 & 98 & 50945 & 51896 \\
\hline & Chinese Taipei & 100 & 324667 & 324667 & 163 & 163 & 100 & 324667 & 324667 \\
\hline & Thailand & 98 & 757516 & 772654 & 235 & 240 & 100 & 772452 & 772654 \\
\hline & Tunisia & 99 & 129229 & 130141 & 152 & 153 & 99 & 129229 & 130141 \\
\hline & United Arab Emirates & 99 & 46469 & 46748 & 453 & 460 & 99 & 46469 & 46748 \\
\hline & Uruguay & 99 & 45736 & 46009 & 179 & 180 & 100 & 46009 & 46009 \\
\hline & Viet Nam & 100 & 1068462 & 1068462 & 162 & 162 & 100 & 1068462 & 1068462 \\
\hline
\end{tabular}

Information for the adjudicated regions is available on line

* See note at the beginning of this Annex.

StatLink त्राजा http://dx.doi.org/10.1787/888932937092 
[Part 2/2]

Table A2.3 Response rates

\begin{tabular}{|c|c|c|c|c|c|c|c|c|}
\hline & & \multicolumn{2}{|c|}{ Final sample - after school replacement } & \multicolumn{5}{|c|}{ Final sample - students within schools after school replacement } \\
\hline & & $\begin{array}{c}\text { Number } \\
\text { of responding } \\
\text { schools } \\
\text { (unweighted) }\end{array}$ & $\begin{array}{c}\text { Number } \\
\text { of responding and } \\
\text { non-responding } \\
\text { schools } \\
\text { (unweighted) }\end{array}$ & $\begin{array}{c}\text { Weighted student } \\
\text { participation rate } \\
\text { after replacement } \\
\qquad \%)\end{array}$ & $\begin{array}{c}\text { Number of students } \\
\text { assessed } \\
\text { (weighted) }\end{array}$ & $\begin{array}{c}\text { Number of students } \\
\text { sampled } \\
\text { (assessed } \\
\text { and absent) } \\
\text { (weighted) }\end{array}$ & $\begin{array}{c}\text { Number of students } \\
\text { assessed } \\
\text { (unweighted) }\end{array}$ & $\begin{array}{c}\text { Number of students } \\
\text { sampled } \\
\text { (assessed } \\
\text { and absent) } \\
\text { (unweighted) }\end{array}$ \\
\hline & & (9) & (10) & (11) & (12) & $(13)$ & (14) & (15) \\
\hline \multirow{34}{*}{ త్ } & Australia & 757 & 790 & 87 & 213495 & 246012 & 17491 & 20799 \\
\hline & Austria & 191 & 191 & 92 & 75393 & 82242 & 4756 & 5318 \\
\hline & Belgium & 282 & 294 & 91 & 103914 & 114360 & 9649 & 10595 \\
\hline & Canada & 840 & 907 & 81 & 261928 & 324328 & 20994 & 25835 \\
\hline & Chile & 221 & 224 & 95 & 214558 & 226689 & 6857 & 7246 \\
\hline & Czech Republic & 295 & 297 & 90 & 73536 & 81642 & 6528 & 7222 \\
\hline & Denmark & 339 & 366 & 89 & 56096 & 62988 & 7463 & 8496 \\
\hline & Estonia & 206 & 206 & 93 & 10807 & 11634 & 5867 & 6316 \\
\hline & Finland & 311 & 313 & 91 & 54126 & 59653 & 8829 & 9789 \\
\hline & France & 223 & 231 & 89 & 605371 & 676730 & 5641 & 6308 \\
\hline & Germany & 228 & 233 & 93 & 692226 & 742416 & 4990 & 5355 \\
\hline & Greece & 188 & 192 & 97 & 92444 & 95580 & 5125 & 5301 \\
\hline & Hungary & 204 & 208 & 93 & 84032 & 90652 & 4810 & 5184 \\
\hline & Iceland & 133 & 140 & 85 & 3503 & 4135 & 3503 & 4135 \\
\hline & Ireland & 183 & 185 & 84 & 45115 & 53644 & 5016 & 5977 \\
\hline & Israel & 172 & 186 & 90 & 91181 & 101288 & 6061 & 6727 \\
\hline & Italy & 1186 & 1232 & 93 & 473104 & 510005 & 38084 & 41003 \\
\hline & Japan & 191 & 200 & 96 & 1034803 & 1076786 & 6351 & 6609 \\
\hline & Korea & 156 & 157 & 99 & 595461 & 603004 & 5033 & 5101 \\
\hline & Luxembourg & 42 & 42 & 95 & 5260 & 5523 & 5260 & 5523 \\
\hline & Mexico & 1468 & 1562 & 94 & 1193866 & 1271639 & 33786 & 35972 \\
\hline & Netherlands & 177 & 199 & 85 & 148432 & 174697 & 4434 & 5215 \\
\hline & New Zealand & 177 & 197 & 85 & 40397 & 47703 & 5248 & 6206 \\
\hline & Norway & 197 & 208 & 91 & 51155 & 56286 & 4686 & 5156 \\
\hline & Poland & 182 & 188 & 88 & 325389 & 371434 & 5629 & 6452 \\
\hline & Portugal & 187 & 195 & 87 & 80719 & 92395 & 5608 & 6426 \\
\hline & Slovak Republic & 231 & 236 & 94 & 50544 & 53912 & 5737 & 6106 \\
\hline & Slovenia & 335 & 353 & 90 & 16146 & 17849 & 7211 & 7921 \\
\hline & Spain & 902 & 904 & 90 & 334382 & 372042 & 26443 & 29027 \\
\hline & Sweden & 209 & 211 & 92 & 87359 & 94784 & 4739 & 5141 \\
\hline & Switzerland & 410 & 422 & 92 & 72116 & 78424 & 11218 & 12138 \\
\hline & Turkey & 169 & 170 & 98 & 850830 & 866269 & 4847 & 4939 \\
\hline & United Kingdom & 505 & 550 & 86 & 528231 & 613736 & 12638 & 14649 \\
\hline & United States & 161 & 207 & 89 & 2429718 & 2734268 & 6094 & 6848 \\
\hline \multirow{31}{*}{ 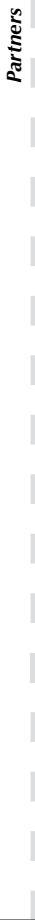 } & Albania & 204 & 204 & 92 & 39275 & 42466 & 4743 & 5102 \\
\hline & Argentina & 219 & 229 & 88 & 457294 & 519733 & 5804 & 6680 \\
\hline & Brazil & 837 & 886 & 90 & 2133035 & 2368438 & 19877 & 22326 \\
\hline & Bulgaria & 187 & 188 & 96 & 51819 & 54145 & 5280 & 5508 \\
\hline & Colombia & 352 & 363 & 93 & 507178 & 544862 & 11164 & 12045 \\
\hline & Costa Rica & 191 & 193 & 89 & 35525 & 39930 & 4582 & 5187 \\
\hline & Croatia & 163 & 164 & 92 & 41912 & 45473 & 6153 & 6675 \\
\hline & Cyprus* & 117 & 131 & 93 & 8719 & 9344 & 5078 & 5458 \\
\hline & Hong Kong-China & 147 & 156 & 93 & 62059 & 66665 & 4659 & 5004 \\
\hline & Indonesia & 206 & 210 & 95 & 2478961 & 2605254 & 5579 & 5885 \\
\hline & Jordan & 233 & 233 & 95 & 105493 & 111098 & 7038 & 7402 \\
\hline & Kazakhstan & 218 & 218 & 99 & 206053 & 208411 & 5808 & 5874 \\
\hline & Latvia & 211 & 213 & 91 & 14579 & 16039 & 5276 & 5785 \\
\hline & Liechtenstein & 12 & 12 & 93 & 293 & 314 & 293 & 314 \\
\hline & Lithuania & 216 & 216 & 92 & 30429 & 33042 & 4618 & 5018 \\
\hline & Macao-China & 45 & 45 & 99 & 5335 & 5366 & 5335 & 5366 \\
\hline & Malaysia & 164 & 164 & 94 & 405983 & 432080 & 5197 & 5529 \\
\hline & Montenegro & 51 & 51 & 94 & 7233 & 7714 & 4799 & 5117 \\
\hline & Peru & 240 & 243 & 96 & 398193 & 414728 & 6035 & 6291 \\
\hline & Qatar & 157 & 164 & 100 & 10966 & 10996 & 10966 & 10996 \\
\hline & Romania & 178 & 178 & 98 & 137860 & 140915 & 5074 & 5188 \\
\hline & Russian Federation & 227 & 227 & 97 & 1141317 & 1172539 & 6418 & 6602 \\
\hline & Serbia & 152 & 160 & 93 & 60366 & 64658 & 4681 & 5017 \\
\hline & Shanghai-China & 155 & 155 & 98 & 83821 & 85127 & 6374 & 6467 \\
\hline & Singapore & 172 & 176 & 94 & 47465 & 50330 & 5546 & 5887 \\
\hline & Chinese Taipei & 163 & 163 & 96 & 281799 & 292542 & 6046 & 6279 \\
\hline & Thailand & 239 & 240 & 99 & 695088 & 702818 & 6606 & 6681 \\
\hline & Tunisia & 152 & 153 & 90 & 108342 & 119917 & 4391 & 4857 \\
\hline & United Arab Emirates & 453 & 460 & 95 & 38228 & 40384 & 11460 & 12148 \\
\hline & Uruguay & 180 & 180 & 90 & 35800 & 39771 & 5315 & 5904 \\
\hline & Viet Nam & 162 & 162 & 100 & 955222 & 956517 & 4959 & 4966 \\
\hline
\end{tabular}

Information for the adjudicated regions is available on line.

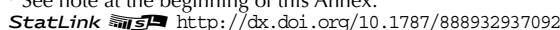


Table A2.3 shows the response rates for students and schools, before and after replacement.

- Column 1 shows the weighted participation rate of schools before replacement. This is obtained by dividing Column 2 by Column 3 , multiply by 100 .

- Column 2 shows the weighted number of responding schools before school replacement (weighted by student enrolment).

- Column 3 shows the weighted number of sampled schools before school replacement (including both responding and nonresponding schools, weighted by student enrolment).

- Column 4 shows the unweighted number of responding schools before school replacement.

- Column 5 shows the unweighted number of responding and non-responding schools before school replacement.

- Column 6 shows the weighted participation rate of schools after replacement. This is obtained by dividing Column 7 by Column 8 , multiply by 100 .

- Column 7 shows the weighted number of responding schools after school replacement (weighted by student enrolment).

- Column 8 shows the weighted number of schools sampled after school replacement (including both responding and non-responding schools, weighted by student enrolment).

- Column 9 shows the unweighted number of responding schools after school replacement.

- Column 10 shows the unweighted number of responding and non-responding schools after school replacement.

- Column 11 shows the weighted student participation rate after replacement. This is obtained by dividing Column 12 by Column 13 , multiply by 100 .

- Column 12 shows the weighted number of students assessed.

- Column 13 shows the weighted number of students sampled (including both students who were assessed and students who were absent on the day of the assessment).

- Column 14 shows the unweighted number of students assessed. Note that any students in schools with student-response rates less than $50 \%$ were not included in these rates (both weighted and unweighted).

- Column 15 shows the unweighted number of students sampled (including both students that were assessed and students who were absent on the day of the assessment). Note that any students in schools where fewer than half of the eligible students were assessed were not included in these rates (neither weighted nor unweighted).

\section{Definition of schools}

In some countries, sub-units within schools were sampled instead of schools and this may affect the estimation of the between-school variance components. In Austria, the Czech Republic, Germany, Hungary, Japan, Romania and Slovenia, schools with more than one study programme were split into the units delivering these programmes. In the Netherlands, for schools with both lower and upper secondary programmes, schools were split into units delivering each programme level. In the Flemish Community of Belgium, in the case of multi-campus schools, implantations (campuses) were sampled, whereas in the French Community, in the case of multi-campus schools, the larger administrative units were sampled. In Australia, for schools with more than one campus, the individual campuses were listed for sampling. In Argentina, Croatia and Dubai (United Arab Emirates), schools that had more than one campus had the locations listed for sampling. In Spain, the schools in the Basque region with multi-linguistic models were split into linguistic models for sampling.

\section{Grade levels}

Students assessed in PISA 2012 are at various grade levels. The percentage of students at each grade level is presented by country and economy in Table A2.4a and by gender within each country and economy in Table A2.4b. 
[Part 1/1]

Table A2.4a Percentage of students at each grade level

\begin{tabular}{|c|c|c|c|c|c|c|c|c|c|c|c|c|c|}
\hline & & \multicolumn{12}{|c|}{ All students } \\
\hline & & \multicolumn{2}{|c|}{ 7th grade } & \multicolumn{2}{|c|}{ 8th grade } & \multicolumn{2}{|c|}{ 9th grade } & \multicolumn{2}{|c|}{ 10th grade } & \multicolumn{2}{|c|}{ 11th grade } & \multicolumn{2}{|c|}{ 12th grade and above } \\
\hline & & $\%$ & S.E. & $\%$ & S.E. & $\%$ & S.E. & $\%$ & S.E. & $\%$ & S.E. & $\%$ & S.E. \\
\hline \multirow{35}{*}{ ৩) } & Australia & 0.0 & $(0.0)$ & 0.1 & $(0.0)$ & 10.8 & (0.5) & 70.0 & $(0.6)$ & 19.1 & (0.4) & 0.0 & $(0.0)$ \\
\hline & Austria & 0.3 & $(0.1)$ & 5.4 & $(0.7)$ & 43.3 & $(0.9)$ & 51.0 & $(1.0)$ & 0.1 & $(0.0)$ & 0.0 & c \\
\hline & Belgium & 0.9 & $(0.1)$ & 6.4 & $(0.5)$ & 30.9 & $(0.6)$ & 60.8 & (0.6) & 1.0 & $(0.1)$ & 0.0 & $(0.0)$ \\
\hline & Canada & 0.1 & $(0.0)$ & 1.1 & $(0.1)$ & 13.2 & $(0.6)$ & 84.6 & $(0.6)$ & 1.0 & $(0.1)$ & 0.1 & $(0.0)$ \\
\hline & Chile & 1.4 & $(0.3)$ & 4.1 & $(0.6)$ & 21.7 & $(0.8)$ & 66.1 & $(1.2)$ & 6.7 & $(0.3)$ & 0.0 & c \\
\hline & Czech Republic & 0.4 & $(0.1)$ & 4.5 & $(0.4)$ & 51.1 & $(1.2)$ & 44.1 & (1.3) & 0.0 & c & 0.0 & c \\
\hline & Denmark & 0.1 & $(0.0)$ & 18.2 & $(0.8)$ & 80.6 & $(0.8)$ & 1.0 & $(0.2)$ & 0.0 & $\mathrm{c}$ & 0.0 & c \\
\hline & Estonia & 0.6 & $(0.2)$ & 22.1 & $(0.7)$ & 75.4 & $(0.7)$ & 1.9 & $(0.3)$ & 0.0 & $\mathrm{C}$ & 0.0 & c \\
\hline & Finland & 0.7 & $(0.2)$ & 14.2 & $(0.4)$ & 85.0 & $(0.4)$ & 0.0 & c & 0.1 & $(0.1)$ & 0.0 & c \\
\hline & France & 0.0 & $(0.0)$ & 1.9 & $(0.3)$ & 27.9 & $(0.7)$ & 66.6 & $(0.7)$ & 3.5 & $(0.3)$ & 0.1 & $(0.1)$ \\
\hline & Germany & 0.6 & $(0.1)$ & 10.0 & $(0.6)$ & 51.9 & $(0.8)$ & 36.7 & $(0.9)$ & 0.8 & $(0.4)$ & 0.0 & c \\
\hline & Greece & 0.3 & $(0.1)$ & 1.2 & $(0.3)$ & 4.0 & $(0.7)$ & 94.5 & (1.0) & 0.0 & c & 0.0 & c \\
\hline & Hungary & 2.8 & $(0.5)$ & 8.7 & (0.9) & 67.8 & $(0.9)$ & 20.6 & (0.6) & 0.0 & c & 0.0 & c \\
\hline & Iceland & 0.0 & c & 0.0 & c & 0.0 & c & 100.0 & $\mathrm{c}$ & 0.0 & c & 0.0 & c \\
\hline & Ireland & 0.0 & $(0.0)$ & 1.9 & $(0.2)$ & 60.5 & $(0.8)$ & 24.3 & $(1.2)$ & 13.3 & (1.0) & 0.0 & c \\
\hline & Israel & 0.0 & $(0.0)$ & 0.3 & $(0.1)$ & 17.1 & $(0.9)$ & 81.7 & $(0.9)$ & 0.8 & $(0.3)$ & 0.0 & c \\
\hline & Italy & 0.4 & $(0.1)$ & 1.7 & $(0.2)$ & 16.8 & $(0.6)$ & 78.5 & $(0.7)$ & 2.6 & $(0.2)$ & 0.0 & $(0.0)$ \\
\hline & Japan & 0.0 & c & 0.0 & c & 0.0 & c & 100.0 & $\mathrm{c}$ & 0.0 & $\mathrm{C}$ & 0.0 & $\mathrm{C}$ \\
\hline & Korea & 0.0 & c & 0.0 & c & 5.9 & $(0.8)$ & 93.8 & (0.8) & 0.2 & $(0.1)$ & 0.0 & c \\
\hline & Luxembourg & 0.7 & $(0.1)$ & 10.2 & $(0.2)$ & 50.7 & $(0.1)$ & 38.0 & $(0.1)$ & 0.5 & $(0.1)$ & 0.0 & c \\
\hline & Mexico & 1.1 & $(0.1)$ & 5.2 & $(0.3)$ & 30.8 & $(1.0)$ & 60.8 & (1.1) & 2.1 & $(0.3)$ & 0.1 & $(0.0)$ \\
\hline & Netherlands & 0.0 & c & 3.6 & (0.4) & 46.7 & $(1.0)$ & 49.2 & (1.1) & 0.5 & $(0.1)$ & 0.0 & c \\
\hline & New Zealand & 0.0 & c & 0.0 & c & 0.1 & $(0.1)$ & 6.2 & $(0.4)$ & 88.3 & $(0.5)$ & 5.4 & $(0.4)$ \\
\hline & Norway & 0.0 & c & 0.0 & c & 0.4 & $(0.1)$ & 99.4 & $(0.1)$ & 0.2 & $(0.0)$ & 0.0 & c \\
\hline & Poland & 0.5 & $(0.1)$ & 4.1 & $(0.4)$ & 94.9 & $(0.4)$ & 0.5 & $(0.2)$ & 0.0 & c & 0.0 & c \\
\hline & Portugal & 2.4 & $(0.3)$ & 8.2 & $(0.7)$ & 28.6 & (1.6) & 60.5 & $(2.1)$ & 0.3 & $(0.1)$ & 0.0 & c \\
\hline & Slovak Republic & 1.7 & $(0.3)$ & 4.5 & $(0.5)$ & 39.5 & $(1.5)$ & 52.7 & (1.4) & 1.6 & $(0.5)$ & 0.0 & c \\
\hline & Slovenia & 0.0 & c & 0.3 & $(0.2)$ & 5.1 & $(0.8)$ & 90.7 & $(0.8)$ & 3.9 & $(0.2)$ & 0.0 & c \\
\hline & Spain & 0.1 & $(0.0)$ & 9.8 & $(0.5)$ & 24.1 & $(0.4)$ & 66.0 & $(0.6)$ & 0.0 & $(0.0)$ & 0.0 & c \\
\hline & Sweden & 0.0 & $(0.0)$ & 3.7 & $(0.3)$ & 94.0 & $(0.6)$ & 2.2 & $(0.5)$ & 0.0 & c & 0.0 & c \\
\hline & Switzerland & 0.6 & $(0.1)$ & 12.9 & (0.8) & 60.6 & $(1.0)$ & 25.6 & $(1.0)$ & 0.2 & $(0.1)$ & 0.0 & c \\
\hline & Turkey & 0.5 & $(0.2)$ & 2.2 & $(0.3)$ & 27.6 & $(1.2)$ & 65.5 & $(1.2)$ & 4.0 & $(0.3)$ & 0.3 & $(0.1)$ \\
\hline & United Kingdom & 0.0 & c & 0.0 & c & 0.0 & $(0.0)$ & 1.3 & $(0.3)$ & 95.0 & $(0.3)$ & 3.6 & $(0.1)$ \\
\hline & United States & 0.0 & c & 0.3 & $(0.1)$ & 11.7 & $(1.1)$ & 71.2 & $(1.1)$ & 16.6 & $(0.8)$ & 0.2 & $(0.1)$ \\
\hline & OECD average & 0.5 & $(0.0)$ & 4.9 & $(0.1)$ & 34.7 & $(0.1)$ & 51.9 & $(0.2)$ & 7.7 & $(0.1)$ & 0.3 & $(0.0)$ \\
\hline$\frac{2}{2}$ & Albania & 0.1 & $(0.1)$ & 2.2 & $(0.3)$ & 39.4 & $(2.4)$ & 58.0 & (2.5) & 0.3 & $(0.1)$ & 0.0 & c \\
\hline 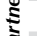 & Argentina & 2.0 & $(0.5)$ & 12.0 & (1.2) & 22.6 & $(1.4)$ & 59.4 & $(2.1)$ & 2.8 & $(0.6)$ & 1.1 & $(0.7)$ \\
\hline & Brazil & 0.0 & c & 6.9 & $(0.5)$ & 13.5 & $(0.7)$ & 34.9 & (1.0) & 42.0 & (1.0) & 2.6 & $(0.2)$ \\
\hline & Bulgaria & 0.9 & $(0.2)$ & 4.6 & $(0.5)$ & 89.5 & $(0.7)$ & 4.9 & $(0.4)$ & 0.0 & $(0.0)$ & 0.0 & c \\
\hline & Colombia & 5.5 & $(0.6)$ & 12.1 & $(0.7)$ & 21.5 & $(0.8)$ & 40.2 & $(0.9)$ & 20.7 & (1.0) & 0.0 & c \\
\hline & Costa Rica & 7.4 & $(0.9)$ & 13.7 & $(0.9)$ & 39.6 & $(1.3)$ & 39.1 & (1.8) & 0.2 & $(0.1)$ & 0.0 & c \\
\hline & Croatia & 0.0 & c & 0.0 & c & 79.8 & $(0.4)$ & 20.2 & $(0.4)$ & 0.0 & c & 0.0 & c \\
\hline & Cyprus* & 0.0 & $(0.0)$ & 0.5 & $(0.1)$ & 4.5 & $(0.1)$ & 94.3 & $(0.1)$ & 0.7 & $(0.0)$ & 0.0 & $(0.0)$ \\
\hline & Hong Kong-China & 1.1 & $(0.1)$ & 6.5 & $(0.4)$ & 25.9 & $(0.7)$ & 65.0 & $(0.9)$ & 1.5 & (1.4) & 0.0 & c \\
\hline & Indonesia & 1.9 & $(0.4)$ & 8.3 & $(0.8)$ & 37.7 & $(2.6)$ & 47.7 & (3.0) & 3.9 & $(0.6)$ & 0.6 & $(0.6)$ \\
\hline & Jordan & 0.1 & $(0.0)$ & 1.1 & $(0.1)$ & 6.0 & $(0.4)$ & 92.9 & $(0.4)$ & 0.0 & c & 0.0 & c \\
\hline & Kazakhstan & 0.2 & $(0.1)$ & 4.9 & $(0.5)$ & 67.2 & (1.9) & 27.4 & (2.0) & 0.2 & $(0.1)$ & 0.1 & $(0.1)$ \\
\hline & Latvia & 2.1 & $(0.4)$ & 14.8 & $(0.7)$ & 80.0 & $(0.8)$ & 3.0 & (0.4) & 0.0 & $(0.0)$ & 0.0 & c \\
\hline & Liechtenstein & 4.9 & $(0.7)$ & 14.2 & (1.5) & 66.3 & (1.3) & 14.6 & $(0.2)$ & 0.0 & c & 0.0 & c \\
\hline & Lithuania & 0.2 & $(0.1)$ & 6.2 & $(0.6)$ & 81.2 & $(0.7)$ & 12.4 & $(0.7)$ & 0.0 & $(0.0)$ & 0.0 & c \\
\hline & Macao-China & 5.4 & $(0.1)$ & 16.4 & $(0.2)$ & 33.2 & $(0.2)$ & 44.6 & $(0.1)$ & 0.4 & $(0.1)$ & 0.0 & $(0.0)$ \\
\hline & Malaysia & 0.0 & c & 0.1 & $(0.0)$ & 4.0 & $(0.5)$ & 96.0 & $(0.5)$ & 0.0 & $(0.0)$ & 0.0 & c \\
\hline & Montenegro & 0.0 & c & 0.1 & $(0.0)$ & 79.5 & $(0.1)$ & 20.4 & $(0.1)$ & 0.0 & c & 0.0 & c \\
\hline & Peru & 2.7 & $(0.4)$ & 7.8 & $(0.5)$ & 18.1 & $(0.7)$ & 47.7 & $(0.9)$ & 23.7 & $(0.8)$ & 0.0 & c \\
\hline & Qatar & 0.9 & $(0.0)$ & 3.1 & $(0.1)$ & 13.8 & $(0.1)$ & 64.8 & $(0.1)$ & 17.1 & $(0.1)$ & 0.3 & $(0.0)$ \\
\hline & Romania & 0.2 & $(0.1)$ & 7.4 & $(0.5)$ & 87.2 & $(0.6)$ & 5.1 & $(0.4)$ & 0.0 & c & 0.0 & c \\
\hline & Russian Federation & 0.6 & $(0.1)$ & 8.1 & $(0.5)$ & 73.8 & (1.6) & 17.4 & (1.8) & 0.1 & $(0.1)$ & 0.0 & c \\
\hline & Serbia & 0.1 & $(0.1)$ & 1.5 & $(0.7)$ & 96.7 & $(0.7)$ & 1.7 & $(0.2)$ & 0.0 & $\mathrm{c}$ & 0.0 & c \\
\hline & Shanghai-China & 1.1 & $(0.2)$ & 4.5 & $(0.6)$ & 39.6 & $(1.5)$ & 54.2 & (1.3) & 0.6 & $(0.1)$ & 0.1 & $(0.1)$ \\
\hline & Singapore & 0.4 & $(0.1)$ & 2.0 & $(0.2)$ & 8.0 & $(0.3)$ & 89.6 & $(0.3)$ & 0.1 & $(0.1)$ & 0.0 & c \\
\hline & Chinese Taipei & 0.0 & c & 0.2 & $(0.1)$ & 36.2 & $(0.7)$ & 63.6 & $(0.7)$ & 0.0 & c & 0.0 & c \\
\hline & Thailand & 0.1 & $(0.0)$ & 0.3 & $(0.1)$ & 20.7 & $(1.0)$ & 76.0 & (1.1) & 2.9 & $(0.5)$ & 0.0 & c \\
\hline & Tunisia & 5.0 & $(0.6)$ & 11.8 & (1.3) & 20.6 & (1.4) & 56.7 & (2.7) & 5.9 & $(0.5)$ & 0.0 & $\mathrm{C}$ \\
\hline & United Arab Emirates & 0.9 & $(0.2)$ & 2.8 & $(0.2)$ & 11.3 & $(0.8)$ & 61.9 & (1.0) & 22.2 & $(0.7)$ & 0.9 & $(0.2)$ \\
\hline & Uruguay & 6.9 & $(0.8)$ & 12.2 & (0.6) & 22.4 & $(1.0)$ & 57.3 & (1.5) & 1.3 & $(0.2)$ & 0.0 & c \\
\hline & Viet Nam & 0.4 & $(0.2)$ & 2.7 & $(0.7)$ & 8.3 & $(1.7)$ & 88.6 & $(2.3)$ & 0.0 & $\mathrm{c}$ & 0.0 & $\mathrm{c}$ \\
\hline
\end{tabular}

Information for the adjudicated regions is available on line

StatLink न्ना st http://dx.doi.org/10.1787/888932937092 
Table A2.4b Percentage of students at each grade level, by gender

\begin{tabular}{|c|c|c|c|c|c|c|c|c|c|c|c|c|c|}
\hline & & \multicolumn{12}{|c|}{ Boys } \\
\hline & & \multicolumn{2}{|c|}{ 7th grade } & \multicolumn{2}{|c|}{ 8th grade } & \multicolumn{2}{|c|}{ 9th grade } & \multicolumn{2}{|c|}{ 10th grade } & \multicolumn{2}{|c|}{ 11th grade } & \multicolumn{2}{|c|}{ 12th grade and above } \\
\hline & & $\%$ & S.E. & $\%$ & S.E. & $\%$ & S.E. & $\%$ & S.E. & $\%$ & S.E. & $\%$ & S.E. \\
\hline \multirow{35}{*}{ 悹 } & Australia & 0.0 & c & 0.1 & $(0.0)$ & 13.1 & $(0.9)$ & 69.2 & $(0.9)$ & 17.5 & $(0.6)$ & 0.0 & $(0.0)$ \\
\hline & Austria & 0.3 & $(0.1)$ & 6.0 & $(0.9)$ & 44.8 & $(1.4)$ & 48.9 & $(1.5)$ & 0.0 & $\mathrm{C}$ & 0.0 & c \\
\hline & Belgium & 1.0 & $(0.1)$ & 7.1 & $(0.6)$ & 33.8 & $(0.9)$ & 57.1 & $(1.0)$ & 1.0 & $(0.2)$ & 0.0 & $(0.0)$ \\
\hline & Canada & 0.1 & $(0.1)$ & 1.3 & $(0.2)$ & 14.8 & $(0.8)$ & 82.7 & $(0.8)$ & 0.9 & $(0.1)$ & 0.1 & $(0.1)$ \\
\hline & Chile & 1.4 & $(0.4)$ & 5.0 & $(0.9)$ & 24.2 & $(1.0)$ & 63.1 & (1.6) & 6.4 & $(0.4)$ & 0.0 & c \\
\hline & Czech Republic & 0.7 & $(0.2)$ & 5.5 & $(0.6)$ & 54.9 & $(2.0)$ & 39.0 & $(2.1)$ & 0.0 & c & 0.0 & c \\
\hline & Denmark & 0.1 & $(0.0)$ & 23.4 & (1.0) & 75.7 & $(1.0)$ & 0.8 & $(0.3)$ & 0.0 & c & 0.0 & c \\
\hline & Estonia & 0.8 & $(0.3)$ & 25.7 & (1.0) & 71.7 & (1.1) & 1.7 & $(0.4)$ & 0.0 & c & 0.0 & c \\
\hline & Finland & 0.9 & $(0.4)$ & 16.2 & $(0.6)$ & 82.8 & $(0.7)$ & 0.0 & c & 0.1 & $(0.1)$ & 0.0 & c \\
\hline & France & 0.1 & $(0.1)$ & 2.3 & $(0.4)$ & 30.8 & $(0.9)$ & 63.5 & (1.0) & 3.2 & $(0.5)$ & 0.1 & $(0.1)$ \\
\hline & Germany & 0.9 & $(0.2)$ & 11.6 & $(0.7)$ & 53.6 & (1.1) & 33.2 & (1.2) & 0.7 & $(0.3)$ & 0.0 & c \\
\hline & Greece & 0.4 & $(0.2)$ & 1.8 & $(0.6)$ & 4.8 & $(1.0)$ & 93.0 & (1.4) & 0.0 & C & 0.0 & c \\
\hline & Hungary & 3.9 & $(0.6)$ & 12.1 & (1.5) & 67.1 & (1.3) & 17.0 & $(0.8)$ & 0.0 & c & 0.0 & c \\
\hline & Iceland & 0.0 & C & 0.0 & c & 0.0 & c & 100.0 & C & 0.0 & c & 0.0 & c \\
\hline & Ireland & 0.0 & c & 2.4 & $(0.3)$ & 63.6 & $(1.0)$ & 21.1 & (1.4) & 13.0 & (1.3) & 0.0 & c \\
\hline & Israel & 0.1 & $(0.1)$ & 0.3 & $(0.1)$ & 18.9 & (1.3) & 79.6 & (1.3) & 1.2 & $(0.5)$ & 0.0 & c \\
\hline & Italy & 0.5 & $(0.2)$ & 2.1 & $(0.3)$ & 19.3 & $(0.7)$ & 75.8 & $(0.7)$ & 2.3 & $(0.2)$ & 0.0 & c \\
\hline & Japan & 0.0 & c & 0.0 & c & 0.0 & c & 100.0 & c & 0.0 & c & 0.0 & c \\
\hline & Korea & 0.0 & c & 0.0 & c & 6.4 & $(1.2)$ & 93.4 & $(1.2)$ & 0.2 & $(0.1)$ & 0.0 & c \\
\hline & Luxembourg & 0.7 & $(0.1)$ & 10.7 & $(0.2)$ & 51.1 & $(0.2)$ & 37.0 & $(0.2)$ & 0.6 & $(0.1)$ & 0.0 & c \\
\hline & Mexico & 1.3 & $(0.2)$ & 6.3 & $(0.3)$ & 33.0 & (1.1) & 57.2 & (1.2) & 2.1 & $(0.5)$ & 0.0 & $(0.0)$ \\
\hline & Netherlands & 0.0 & c & 4.4 & (0.6) & 49.5 & $(1.1)$ & 45.7 & $(1.2)$ & 0.4 & $(0.1)$ & 0.0 & c \\
\hline & New Zealand & 0.0 & c & 0.0 & c & 0.2 & $(0.1)$ & 7.0 & $(0.5)$ & 88.0 & $(0.7)$ & 4.8 & $(0.5)$ \\
\hline & Norway & 0.0 & c & 0.0 & c & 0.6 & $(0.1)$ & 99.1 & $(0.1)$ & 0.3 & $(0.0)$ & 0.0 & c \\
\hline & Poland & 0.9 & $(0.2)$ & 5.7 & $(0.6)$ & 93.0 & $(0.6)$ & 0.4 & $(0.2)$ & 0.0 & $\mathrm{C}$ & 0.0 & c \\
\hline & Portugal & 2.6 & $(0.5)$ & 9.9 & (0.9) & 30.1 & (1.7) & 57.0 & $(2.2)$ & 0.4 & $(0.2)$ & 0.0 & c \\
\hline & Slovak Republic & 1.5 & $(0.3)$ & 5.4 & $(0.8)$ & 40.1 & $(2.0)$ & 51.5 & $(2.1)$ & 1.5 & $(0.5)$ & 0.0 & c \\
\hline & Slovenia & 0.0 & c & 0.4 & $(0.3)$ & 6.3 & $(1.0)$ & 90.2 & (1.0) & 3.1 & $(0.4)$ & 0.0 & c \\
\hline & Spain & 0.1 & $(0.1)$ & 11.8 & $(0.6)$ & 25.8 & $(0.6)$ & 62.2 & $(0.7)$ & 0.1 & $(0.1)$ & 0.0 & c \\
\hline & Sweden & 0.1 & $(0.1)$ & 4.6 & $(0.5)$ & 93.7 & $(0.8)$ & 1.7 & $(0.6)$ & 0.0 & c & 0.0 & c \\
\hline & Switzerland & 0.5 & $(0.1)$ & 13.9 & $(0.9)$ & 60.6 & $(1.7)$ & 24.7 & $(2.0)$ & 0.2 & $(0.1)$ & 0.0 & c \\
\hline & Turkey & 0.3 & $(0.1)$ & 2.6 & $(0.5)$ & 33.2 & (1.5) & 60.3 & (1.5) & 3.2 & $(0.4)$ & 0.3 & $(0.1)$ \\
\hline & United Kingdom & 0.0 & c & 0.0 & c & 0.0 & $(0.0)$ & 1.7 & $(0.4)$ & 94.7 & $(0.4)$ & 3.7 & $(0.2)$ \\
\hline & United States & 0.0 & c & 0.4 & $(0.2)$ & 14.6 & $(1.1)$ & 69.8 & $(1.1)$ & 14.9 & $(0.9)$ & 0.3 & $(0.2)$ \\
\hline & OECD average & 0.6 & $(0.1)$ & 5.9 & $(0.1)$ & 35.6 & $(0.2)$ & 50.1 & $(0.2)$ & 7.5 & $(0.1)$ & 0.3 & $(0.1)$ \\
\hline$\approx$ & Albania & 0.1 & $(0.1)$ & 2.9 & (0.4) & 42.9 & $(2.7)$ & 53.8 & (2.8) & 0.2 & $(0.1)$ & 0.0 & c \\
\hline$\approx$ & Argentina & 2.8 & $(0.8)$ & 15.0 & (1.7) & 25.8 & (1.9) & 52.6 & (2.6) & 3.0 & $(0.9)$ & 0.8 & $(0.5)$ \\
\hline ฮ & Brazil & 0.0 & c & 9.0 & $(0.7)$ & 15.8 & $(0.8)$ & 36.1 & (1.1) & 37.2 & $(1.0)$ & 1.9 & $(0.2)$ \\
\hline & Bulgaria & 1.3 & $(0.3)$ & 5.8 & $(0.7)$ & 88.2 & $(1.0)$ & 4.6 & $(0.4)$ & 0.0 & C & 0.0 & c \\
\hline & Colombia & 7.4 & $(0.8)$ & 13.5 & (1.0) & 22.1 & $(1.0)$ & 38.8 & (1.4) & 18.2 & $(1.2)$ & 0.0 & c \\
\hline & Costa Rica & 9.3 & (1.3) & 16.4 & $(1.2)$ & 38.5 & (1.5) & 35.7 & $(2.0)$ & 0.0 & $(0.0)$ & 0.0 & c \\
\hline & Croatia & 0.0 & c & 0.0 & c & 82.0 & $(0.6)$ & 18.0 & $(0.6)$ & 0.0 & $\mathrm{c}$ & 0.0 & c \\
\hline & Cyprus* & 0.0 & $(0.0)$ & 0.5 & $(0.1)$ & 4.7 & $(0.1)$ & 94.0 & $(0.2)$ & 0.7 & $(0.1)$ & 0.0 & c \\
\hline & Hong Kong-China & 1.2 & $(0.2)$ & 6.9 & $(0.5)$ & 27.5 & $(0.7)$ & 63.0 & (1.0) & 1.4 & $(1.3)$ & 0.0 & c \\
\hline & Indonesia & 2.3 & $(0.4)$ & 10.0 & (1.1) & 38.5 & (3.0) & 45.5 & $(3.7)$ & 3.1 & $(0.6)$ & 0.6 & (0.6) \\
\hline & Jordan & 0.1 & $(0.1)$ & 0.8 & $(0.2)$ & 5.7 & $(0.6)$ & 93.4 & $(0.6)$ & 0.0 & c & 0.0 & c \\
\hline & Kazakhstan & 0.3 & $(0.1)$ & 5.5 & $(0.6)$ & 68.4 & $(2.4)$ & 25.4 & $(2.6)$ & 0.2 & $(0.1)$ & 0.2 & $(0.2)$ \\
\hline & Latvia & 3.6 & $(0.8)$ & 18.0 & $(0.9)$ & 76.4 & (1.3) & 2.0 & $(0.3)$ & 0.0 & $(0.0)$ & 0.0 & c \\
\hline & Liechtenstein & 4.5 & $(1.2)$ & 16.5 & (2.1) & 69.4 & $(2.2)$ & 9.6 & $(0.6)$ & 0.0 & c & 0.0 & c \\
\hline & Lithuania & 0.2 & $(0.1)$ & 7.3 & $(0.6)$ & 82.2 & $(0.9)$ & 10.4 & $(0.8)$ & 0.0 & $(0.0)$ & 0.0 & c \\
\hline & Macao-China & 7.1 & $(0.2)$ & 19.3 & $(0.2)$ & 33.3 & $(0.2)$ & 40.0 & $(0.2)$ & 0.2 & $(0.1)$ & 0.0 & $(0.0)$ \\
\hline & Malaysia & 0.0 & c & 0.1 & $(0.1)$ & 5.1 & $(0.7)$ & 94.7 & $(0.7)$ & 0.0 & c & 0.0 & c \\
\hline & Montenegro & 0.0 & c & 0.1 & $(0.1)$ & 82.0 & $(0.3)$ & 17.9 & $(0.3)$ & 0.0 & c & 0.0 & c \\
\hline & Peru & 3.1 & $(0.5)$ & 9.1 & $(0.8)$ & 19.5 & $(0.7)$ & 46.2 & $(1.0)$ & 22.1 & $(0.9)$ & 0.0 & c \\
\hline & Qatar & 1.2 & $(0.1)$ & 3.6 & $(0.1)$ & 14.0 & $(0.1)$ & 64.6 & $(0.2)$ & 16.1 & $(0.2)$ & 0.4 & $(0.0)$ \\
\hline & Romania & 0.3 & $(0.2)$ & 6.5 & $(0.6)$ & 88.7 & $(0.7)$ & 4.5 & $(0.4)$ & 0.0 & c & 0.0 & c \\
\hline & Russian Federation & 0.7 & $(0.2)$ & 8.9 & $(0.7)$ & 73.7 & $(1.5)$ & 16.7 & $(1.8)$ & 0.1 & $(0.1)$ & 0.0 & c \\
\hline & Serbia & 0.1 & $(0.1)$ & 1.9 & $(0.9)$ & 96.7 & $(1.0)$ & 1.4 & $(0.2)$ & 0.0 & c & 0.0 & c \\
\hline & Shanghai-China & 1.3 & $(0.3)$ & 5.3 & $(0.8)$ & 41.6 & (1.6) & 51.2 & $(1.4)$ & 0.6 & $(0.1)$ & 0.0 & $(0.0)$ \\
\hline & Singapore & 0.4 & $(0.1)$ & 2.0 & $(0.3)$ & 8.3 & $(0.4)$ & 89.3 & $(0.5)$ & 0.0 & $(0.0)$ & 0.0 & c \\
\hline & Chinese Taipei & 0.0 & c & 0.2 & $(0.2)$ & 37.4 & $(1.5)$ & 62.4 & (1.5) & 0.0 & $\mathrm{C}$ & 0.0 & c \\
\hline & Thailand & 0.1 & $(0.1)$ & 0.4 & $(0.2)$ & 22.9 & $(1.3)$ & 74.1 & (1.5) & 2.5 & $(0.5)$ & 0.0 & c \\
\hline & Tunisia & 6.3 & $(0.8)$ & 14.6 & (1.6) & 21.9 & (1.6) & 52.3 & $(3.0)$ & 4.9 & $(0.5)$ & 0.0 & c \\
\hline & United Arab Emirates & 1.3 & $(0.3)$ & 3.1 & $(0.3)$ & 12.9 & $(0.9)$ & 60.3 & $(1.2)$ & 21.8 & (1.0) & 0.6 & $(0.1)$ \\
\hline & Uruguay & 9.4 & (1.3) & 13.1 & $(0.8)$ & 24.0 & $(1.1)$ & 52.4 & (1.9) & 1.2 & $(0.2)$ & 0.0 & c \\
\hline & Viet Nam & 0.7 & $(0.3)$ & 3.5 & $(0.8)$ & 10.5 & $(2.2)$ & 85.3 & $(2.8)$ & 0.0 & $\mathrm{C}$ & 0.0 & $\mathrm{c}$ \\
\hline
\end{tabular}

Information for the adjudicated regions is available on line.

StatLink הतilst http://dx.doi.org/10.1787/888932937092 
[Part 2/2]

Table A2.4b Percentage of students at each grade level, by gender

\begin{tabular}{|c|c|c|c|c|c|c|c|c|c|c|c|c|c|}
\hline & & \multicolumn{12}{|c|}{ Girls } \\
\hline & & \multicolumn{2}{|c|}{ 7th grade } & \multicolumn{2}{|c|}{ 8th grade } & \multicolumn{2}{|c|}{ 9th grade } & \multicolumn{2}{|c|}{ 10th grade } & \multicolumn{2}{|c|}{11 th grade } & \multicolumn{2}{|c|}{ 12th grade and above } \\
\hline & & $\%$ & S.E. & $\%$ & S.E. & $\%$ & S.E. & $\%$ & S.E. & $\%$ & S.E. & $\%$ & S.E. \\
\hline \multirow{35}{*}{$\begin{array}{l}\text { Uิ } \\
\text { Oे }\end{array}$} & Australia & 0.0 & $(0.0)$ & 0.2 & $(0.1)$ & 8.3 & $(0.3)$ & 70.8 & $(0.6)$ & 20.7 & $(0.6)$ & 0.0 & $(0.0)$ \\
\hline & Austria & 0.3 & $(0.1)$ & 4.7 & $(0.7)$ & 41.8 & $(1.3)$ & 53.1 & (1.4) & 0.1 & $(0.1)$ & 0.0 & c \\
\hline & Belgium & 0.9 & $(0.1)$ & 5.7 & $(0.5)$ & 28.0 & $(0.7)$ & 64.4 & $(0.8)$ & 1.0 & $(0.2)$ & 0.0 & c \\
\hline & Canada & 0.1 & $(0.0)$ & 0.9 & $(0.1)$ & 11.5 & $(0.5)$ & 86.4 & $(0.5)$ & 1.2 & $(0.1)$ & 0.0 & $(0.0)$ \\
\hline & Chile & 1.3 & $(0.3)$ & 3.3 & $(0.6)$ & 19.3 & $(1.0)$ & 69.0 & $(1.2)$ & 7.1 & $(0.4)$ & 0.0 & c \\
\hline & Czech Republic & 0.1 & $(0.1)$ & 3.5 & $(0.5)$ & 47.1 & $(2.0)$ & 49.4 & $(2.1)$ & 0.0 & $\mathrm{c}$ & 0.0 & c \\
\hline & Denmark & 0.1 & $(0.0)$ & 13.0 & $(0.9)$ & 85.6 & $(0.9)$ & 1.3 & $(0.3)$ & 0.0 & c & 0.0 & c \\
\hline & Estonia & 0.3 & $(0.1)$ & 18.6 & $(0.8)$ & 79.0 & $(0.9)$ & 2.2 & $(0.4)$ & 0.0 & c & 0.0 & c \\
\hline & Finland & 0.5 & $(0.1)$ & 12.0 & $(0.4)$ & 87.3 & $(0.4)$ & 0.0 & c & 0.2 & $(0.1)$ & 0.0 & c \\
\hline & France & 0.0 & c & 1.6 & $(0.3)$ & 25.1 & $(1.1)$ & 69.4 & $(1.1)$ & 3.8 & $(0.4)$ & 0.1 & $(0.1)$ \\
\hline & Germany & 0.3 & $(0.1)$ & 8.2 & (0.6) & 50.2 & (1.0) & 40.4 & (1.1) & 0.8 & $(0.4)$ & 0.0 & c \\
\hline & Greece & 0.3 & $(0.1)$ & 0.5 & $(0.1)$ & 3.1 & $(0.7)$ & 96.1 & $(0.8)$ & 0.0 & c & 0.0 & c \\
\hline & Hungary & 1.8 & $(0.7)$ & 5.7 & $(0.8)$ & 68.4 & (1.1) & 24.1 & $(0.8)$ & 0.0 & c & 0.0 & c \\
\hline & Iceland & 0.0 & C & 0.0 & c & 0.0 & C & 100.0 & c & 0.0 & c & 0.0 & c \\
\hline & Ireland & 0.1 & $(0.1)$ & 1.4 & $(0.2)$ & 57.3 & $(1.0)$ & 27.6 & (1.4) & 13.7 & $(1.2)$ & 0.0 & c \\
\hline & Israel & 0.0 & $(0.0)$ & 0.2 & $(0.1)$ & 15.5 & $(1.0)$ & 83.8 & $(1.0)$ & 0.4 & $(0.1)$ & 0.0 & c \\
\hline & Italy & 0.3 & $(0.1)$ & 1.2 & $(0.2)$ & 14.0 & $(0.6)$ & 81.5 & $(0.8)$ & 3.0 & $(0.3)$ & 0.0 & $(0.0)$ \\
\hline & Japan & 0.0 & c & 0.0 & c & 0.0 & c & 100.0 & c & 0.0 & c & 0.0 & c \\
\hline & Korea & 0.0 & c & 0.0 & c & 5.4 & (1.1) & 94.4 & (1.1) & 0.2 & $(0.1)$ & 0.0 & c \\
\hline & Luxembourg & 0.7 & $(0.1)$ & 9.7 & $(0.2)$ & 50.2 & $(0.2)$ & 39.0 & $(0.2)$ & 0.4 & $(0.1)$ & 0.0 & c \\
\hline & Mexico & 0.8 & $(0.1)$ & 4.1 & $(0.3)$ & 28.7 & $(1.0)$ & 64.2 & (1.1) & 2.1 & $(0.3)$ & 0.1 & $(0.1)$ \\
\hline & Netherlands & 0.0 & c & 2.7 & $(0.4)$ & 43.8 & $(1.1)$ & 53.0 & $(1.1)$ & 0.5 & $(0.2)$ & 0.0 & c \\
\hline & New Zealand & 0.0 & c & 0.0 & c & 0.1 & $(0.1)$ & 5.3 & $(0.4)$ & 88.6 & $(0.6)$ & 5.9 & $(0.6)$ \\
\hline & Norway & 0.0 & c & 0.0 & c & 0.2 & $(0.1)$ & 99.8 & $(0.1)$ & 0.0 & c & 0.0 & c \\
\hline & Poland & 0.2 & $(0.1)$ & 2.6 & $(0.3)$ & 96.7 & $(0.4)$ & 0.6 & $(0.2)$ & 0.0 & c & 0.0 & c \\
\hline & Portugal & 2.2 & $(0.3)$ & 6.6 & $(0.7)$ & 27.2 & (1.6) & 63.8 & $(2.2)$ & 0.2 & $(0.1)$ & 0.0 & c \\
\hline & Slovak Republic & 1.9 & $(0.5)$ & 3.5 & $(0.5)$ & 38.8 & (1.9) & 54.0 & $(1.9)$ & 1.8 & $(0.5)$ & 0.0 & c \\
\hline & Slovenia & 0.0 & c & 0.2 & $(0.2)$ & 3.8 & $(0.9)$ & 91.2 & $(1.0)$ & 4.7 & $(0.5)$ & 0.0 & c \\
\hline & Spain & 0.1 & $(0.0)$ & 7.8 & $(0.5)$ & 22.3 & $(0.7)$ & 69.9 & $(0.8)$ & 0.0 & $(0.0)$ & 0.0 & c \\
\hline & Sweden & 0.0 & c & 2.8 & $(0.3)$ & 94.4 & (0.6) & 2.8 & (0.6) & 0.0 & C & 0.0 & c \\
\hline & Switzerland & 0.6 & $(0.2)$ & 11.9 & (1.0) & 60.7 & (1.7) & 26.6 & (1.8) & 0.2 & $(0.1)$ & 0.0 & c \\
\hline & Turkey & 0.7 & $(0.3)$ & 1.7 & $(0.3)$ & 21.9 & $(1.2)$ & 70.8 & $(1.1)$ & 4.8 & $(0.4)$ & 0.2 & $(0.1)$ \\
\hline & United Kingdom & 0.0 & c & 0.0 & c & 0.0 & $(0.0)$ & 1.0 & $(0.3)$ & 95.4 & $(0.3)$ & 3.6 & $(0.2)$ \\
\hline & United States & 0.0 & c & 0.1 & $(0.1)$ & 8.8 & $(1.2)$ & 72.7 & (1.3) & 18.3 & $(0.9)$ & 0.2 & $(0.1)$ \\
\hline & OECD average & 0.4 & $(0.0)$ & 3.9 & $(0.1)$ & 33.7 & $(0.2)$ & 53.8 & $(0.2)$ & 7.9 & $(0.1)$ & 0.3 & $(0.1)$ \\
\hline$\frac{n}{2}$ & Albania & 0.1 & $(0.1)$ & 1.4 & $(0.4)$ & 35.7 & $(2.6)$ & 62.5 & (2.6) & 0.3 & $(0.1)$ & 0.0 & c \\
\hline$\stackrel{\Xi}{\underline{\Sigma}}$ & Argentina & 1.2 & $(0.3)$ & 9.1 & $(0.9)$ & 19.7 & (1.3) & 65.8 & (1.9) & 2.7 & $(0.4)$ & 1.4 & $(0.8)$ \\
\hline 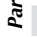 & Brazil & 0.0 & c & 5.0 & $(0.4)$ & 11.5 & $(0.7)$ & 33.8 & $(1.0)$ & 46.4 & $(1.1)$ & 3.3 & $(0.2)$ \\
\hline & Bulgaria & 0.5 & $(0.2)$ & 3.3 & $(0.5)$ & 90.9 & $(0.7)$ & 5.2 & $(0.5)$ & 0.0 & $(0.0)$ & 0.0 & c \\
\hline & Colombia & 3.9 & $(0.6)$ & 10.8 & $(0.7)$ & 21.0 & $(0.9)$ & 41.4 & $(1.1)$ & 22.9 & $(1.1)$ & 0.0 & c \\
\hline & Costa Rica & 5.7 & $(0.8)$ & 11.3 & $(0.8)$ & 40.5 & (1.3) & 42.1 & $(1.7)$ & 0.4 & $(0.2)$ & 0.0 & c \\
\hline & Croatia & 0.0 & c & 0.0 & c & 77.5 & $(0.6)$ & 22.5 & $(0.6)$ & 0.0 & c & 0.0 & c \\
\hline & Cyprus* & 0.0 & c & 0.5 & $(0.1)$ & 4.2 & $(0.2)$ & 94.6 & $(0.2)$ & 0.7 & $(0.1)$ & 0.0 & $(0.0)$ \\
\hline & Hong Kong-China & 0.9 & $(0.2)$ & 6.0 & $(0.6)$ & 24.2 & $(0.8)$ & 67.3 & $(1.0)$ & 1.6 & (1.5) & 0.0 & c \\
\hline & Indonesia & 1.5 & $(0.4)$ & 6.4 & $(0.8)$ & 36.8 & (2.9) & 50.0 & (3.0) & 4.7 & $(0.8)$ & 0.5 & $(0.5)$ \\
\hline & Jordan & 0.0 & $(0.0)$ & 1.3 & $(0.2)$ & 6.3 & $(0.5)$ & 92.4 & $(0.6)$ & 0.0 & c & 0.0 & c \\
\hline & Kazakhstan & 0.1 & $(0.1)$ & 4.4 & $(0.5)$ & 65.9 & (1.9) & 29.3 & $(2.1)$ & 0.2 & $(0.1)$ & 0.0 & c \\
\hline & Latvia & 0.6 & $(0.2)$ & 11.6 & $(0.8)$ & 83.7 & $(1.1)$ & 4.1 & $(0.7)$ & 0.0 & $\mathrm{c}$ & 0.0 & c \\
\hline & Liechtenstein & 5.3 & (1.3) & 11.5 & (1.9) & 62.8 & (1.9) & 20.4 & $(0.8)$ & 0.0 & $\mathrm{C}$ & 0.0 & c \\
\hline & Lithuania & 0.1 & $(0.1)$ & 5.2 & $(0.6)$ & 80.2 & $(0.9)$ & 14.4 & $(0.8)$ & 0.0 & $(0.0)$ & 0.0 & c \\
\hline & Macao-China & 3.5 & $(0.1)$ & 13.3 & $(0.2)$ & 33.1 & $(0.3)$ & 49.5 & $(0.3)$ & 0.7 & $(0.2)$ & 0.0 & c \\
\hline & Malaysia & 0.0 & c & 0.0 & c & 2.9 & $(0.4)$ & 97.1 & $(0.4)$ & 0.0 & $(0.1)$ & 0.0 & c \\
\hline & Montenegro & 0.0 & c & 0.0 & c & 77.1 & $(0.3)$ & 22.9 & $(0.3)$ & 0.0 & C & 0.0 & c \\
\hline & Peru & 2.3 & $(0.5)$ & 6.6 & (0.6) & 16.8 & $(1.0)$ & 49.1 & $(1.2)$ & 25.3 & $(1.0)$ & 0.0 & c \\
\hline & Qatar & 0.5 & $(0.1)$ & 2.7 & $(0.1)$ & 13.6 & $(0.1)$ & 64.9 & $(0.2)$ & 18.2 & $(0.1)$ & 0.2 & $(0.0)$ \\
\hline & Romania & 0.1 & $(0.1)$ & 8.3 & (0.6) & 85.9 & $(0.9)$ & 5.7 & $(0.6)$ & 0.0 & c & 0.0 & c \\
\hline & Russian Federation & 0.6 & $(0.2)$ & 7.3 & $(0.5)$ & 73.9 & $(2.0)$ & 18.1 & $(2.0)$ & 0.1 & $(0.1)$ & 0.0 & c \\
\hline & Serbia & 0.1 & $(0.1)$ & 1.0 & $(0.6)$ & 96.8 & $(0.7)$ & 2.0 & $(0.3)$ & 0.0 & $\mathrm{c}$ & 0.0 & c \\
\hline & Shanghai-China & 0.8 & $(0.2)$ & 3.8 & $(0.5)$ & 37.6 & (1.8) & 57.0 & (1.8) & 0.6 & $(0.1)$ & 0.1 & $(0.1)$ \\
\hline & Singapore & 0.4 & $(0.1)$ & 2.1 & $(0.2)$ & 7.6 & $(0.4)$ & 89.8 & $(0.4)$ & 0.2 & $(0.1)$ & 0.0 & c \\
\hline & Chinese Taipei & 0.0 & c & 0.1 & $(0.1)$ & 35.0 & (1.5) & 64.9 & (1.4) & 0.0 & c & 0.0 & c \\
\hline & Thailand & 0.0 & $(0.0)$ & 0.2 & $(0.1)$ & 19.0 & $(1.2)$ & 77.5 & $(1.2)$ & 3.3 & $(0.5)$ & 0.0 & c \\
\hline & Tunisia & 3.9 & $(0.5)$ & 9.3 & (1.1) & 19.4 & (1.5) & 60.6 & (2.5) & 6.7 & $(0.6)$ & 0.0 & c \\
\hline & United Arab Emirates & 0.6 & $(0.1)$ & 2.6 & $(0.4)$ & 9.7 & (1.1) & 63.4 & (1.7) & 22.6 & (1.3) & 1.2 & $(0.3)$ \\
\hline & Uruguay & 4.6 & (0.6) & 11.4 & $(0.8)$ & 21.0 & (1.1) & 61.7 & (1.5) & 1.4 & $(0.2)$ & 0.0 & c \\
\hline & Viet Nam & 0.1 & $(0.1)$ & 2.1 & $(0.6)$ & 6.4 & (1.5) & 91.4 & (1.9) & 0.0 & $\mathrm{c}$ & 0.0 & $\mathrm{c}$ \\
\hline
\end{tabular}

Information for the adjudicated regions is available on line

StatLink तills http://dx.doi.org/10.1787/888932937092 
ANNEX A3

\section{TECHNICAL NOTES ON ANALYSES IN THIS VOLUME}

\section{Standard errors and significance tests}

The statistics in this report represent estimates of national performance based on samples of students, rather than values that could be calculated if every student in every country had answered every question. Consequently, it is important to measure the degree of uncertainty of the estimates. In PISA, each estimate has an associated degree of uncertainty, which is expressed through a standard error. The use of confidence intervals provides a way to make inferences about the population means and proportions in a manner that reflects the uncertainty associated with the sample estimates. From an observed sample statistic and assuming a normal distribution, it can be inferred that the corresponding population result would lie within the confidence interval in 95 out of 100 replications of the measurement on different samples drawn from the same population.

In many cases, readers are primarily interested in whether a given value in a particular country is different from a second value in the same or another country, e.g. whether girls in a country perform better than boys in the same country. In the tables and charts used in this report, differences are labelled as statistically significant when a difference of that size, smaller or larger, would be observed less than $5 \%$ of the time, if there were actually no difference in corresponding population values. Similarly, the risk of reporting a correlation as significant if there is, in fact, no correlation between two measures, is contained at $5 \%$.

Throughout the report, significance tests were undertaken to assess the statistical significance of the comparisons made.

\section{Gender differences and differences between subgroup means}

Gender differences in student performance or other indices were tested for statistical significance. Positive differences indicate higher scores for boys while negative differences indicate higher scores for girls. Generally, differences marked in bold in the tables in this volume are statistically significant at the $95 \%$ confidence level.

Similarly, differences between other groups of students (e.g. native students and students with an immigrant background) were tested for statistical significance. The definitions of the subgroups can in general be found in the tables and the text accompanying the analysis. All differences marked in bold in the tables presented in Annex B of this report are statistically significant at the $95 \%$ level.

\section{Range of ranks}

To calculate the range of ranks for countries and economies (participants), data are simulated using the mean and standard error of the mean for each relevant participant to generate a distribution of possible values. Some 10000 simulations are implemented and, based on these values, 10000 possible rankings for each participant are produced. For each participant, the counts for each rank are aggregated from largest to smallest until they equal 9500 or more. Then the range of ranks per participant is reported, including all the ranks that have been aggregated. This means that there is at least $95 \%$ confidence about the range of ranks, and it is safe to assume unimodality in this distribution of ranks. This method has been used in all cycles of PISA since 2003, including PISA 2012.

The main difference between the range of ranks (e.g. Figure 1.2.14) and the comparison of participants' mean performance (e.g. Figure 1.2.13) is that the former takes account of the asymmetry of the distribution of rank estimates, while the latter does not. Therefore, sometimes there is a slight difference between the range of ranks and counting the number of participants above a given participant, based on pairwise comparisons of the selected participants' performance. For instance, Canada and Poland have the same mean performance and the same set of participants whose mean score is not statistically different from theirs, based on Figure 1.2.13; but the rank for Canada among OECD countries can be restricted to be, with 95\% confidence, between 5th and 9th, while the range of ranks for Poland is between 4th and 10th (Figure I.2.14). Since it is safe to assume that the distribution of rank estimates for each country has a single mode (unimodality), the results of range of ranks for participants should be used when examining participants' rankings.

\section{Standard errors in statistics estimated from multilevel models}

For statistics based on multilevel models (such as the estimates of variance components and regression coefficients from two-level regression models) the standard errors are not estimated with the usual replication method which accounts for stratification and sampling rates from finite populations. Instead, standard errors are "model-based": their computation assumes that schools, and students within schools, are sampled at random (with sampling probabilities reflected in school and student weights) from a theoretical, infinite population of schools and students which complies with the model's parametric assumptions.

\section{Standard errors in trend analyses of performance: Link error}

Standard errors for performance trend estimates had to be adjusted because the equating procedure that allows scores in different PISA assessments to be compared introduces a form of random error that is related to performance changes on the link items. These more conservative standard errors (larger than standard errors that were estimated before the introduction of the link error) reflect not only the measurement precision and sampling variation as for the usual PISA results, but also the link error (see Annex A5 for a technical discussion of the link error). 
Link items represent only a subset of all items used to derive PISA scores. If different items were chosen to equate PISA scores over time, the comparison of performance for a group of students across time could vary. As a result, standard errors for the estimates of the change over time in mathematics, reading or science performance of a particular group (e.g. a country or economy, a region, boys, girls, students with an immigrant background, students without an immigrant background, socio-economically advantaged students, students in public schools, etc.) include the link error in addition to the sampling and imputation error commonly added to estimates in performance for a particular year. Because the equating procedure adds uncertainty to the position in the distribution (a change in the intercept) but does not result in any change in the variance of a distribution, standard errors for location-invariant estimates do not include the link error. Location-invariant estimates include, for example, estimates for variances, regression coefficients for student- or school-level covariates, and correlation coefficients.

Figures in bold in the data tables for trends in performance presented in Annex B1 of this report indicate that the the change in performance for that particular group is statistically significantly different from 0 at the $95 \%$ confidence level. The standard errors used to calculate the statistical significance of the reported trend include the link error. 


\section{ANNEX A4 QUALITY ASSURANCE}

Quality assurance procedures were implemented in all parts of PISA 2012, as was done for all previous PISA surveys.

The consistent quality and linguistic equivalence of the PISA 2012 assessment instruments were facilitated by providing countries with equivalent source versions of the assessment instruments in English and French and requiring countries (other than those assessing students in English and French) to prepare and consolidate two independent translations using both source versions. Precise translation and adaptation guidelines were supplied, also including instructions for selecting and training the translators. For each country, the translation and format of the assessment instruments (including test materials, marking guides, questionnaires and manuals) were verified by expert translators appointed by the PISA Consortium before they were used in the PISA 2012 Field Trial and Main Study. These translators' mother tongue was the language of instruction in the country concerned and they were knowledgeable about education systems. For further information on the PISA translation procedures, see the PISA 2012 Technical Report (OECD, forthcoming).

The survey was implemented through standardised procedures. The PISA Consortium provided comprehensive manuals that explained the implementation of the survey, including precise instructions for the work of School Co-ordinators and scripts for Test Administrators to use during the assessment sessions. Proposed adaptations to survey procedures, or proposed modifications to the assessment session script, were submitted to the PISA Consortium for approval prior to verification. The PISA Consortium then verified the national translation and adaptation of these manuals.

To establish the credibility of PISA as valid and unbiased and to encourage uniformity in administering the assessment sessions, Test Administrators in participating countries were selected using the following criteria: it was required that the Test Administrator not be the reading, mathematics or science instructor of any students in the sessions he or she would administer for PISA; it was recommended that the Test Administrator not be a member of the staff of any school where he or she would administer for PISA; and it was considered preferable that the Test Administrator not be a member of the staff of any school in the PISA sample. Participating countries organised an in-person training session for Test Administrators.

Participating countries and economies were required to ensure that: Test Administrators worked with the School Co-ordinator to prepare the assessment session, including updating student tracking forms and identifying excluded students; no extra time was given for the cognitive items (while it was permissible to give extra time for the student questionnaire); no instrument was administered before the two one-hour parts of the cognitive session; Test Administrators recorded the student participation status on the student tracking forms and filled in a Session Report Form; no cognitive instrument was permitted to be photocopied; no cognitive instrument could be viewed by school staff before the assessment session; and Test Administrators returned the material to the national centre immediately after the assessment sessions.

National Project Managers were encouraged to organise a follow-up session when more than $15 \%$ of the PISA sample was not able to attend the original assessment session.

National Quality Monitors from the PISA Consortium visited all national centres to review data-collection procedures. Finally, School Quality Monitors from the PISA Consortium visited a sample of seven schools during the assessment. For further information on the field operations, see the PISA 2012 Technical Report (OECD, forthcoming).

Marking procedures were designed to ensure consistent and accurate application of the marking guides outlined in the PISA Operations Manuals. National Project Managers were required to submit proposed modifications to these procedures to the Consortium for approval. Reliability studies to analyse the consistency of marking were implemented.

Software specially designed for PISA facilitated data entry, detected common errors during data entry, and facilitated the process of data cleaning. Training sessions familiarised National Project Managers with these procedures.

For a description of the quality assurance procedures applied in PISA and in the results, see the PISA 2012 Technical Report (OECD, forthcoming).

The results of adjudication showed that the PISA Technical Standards were fully met in all countries and economies that participated in PISA 2012, with the exception of Albania. Albania submitted parental occupation data that was incomplete and appeared inaccurate, since there was over-use of a narrow range of occupations. It was not possible to resolve these issues during the course of data cleaning, and as a result neither parental occupation data nor any indices which depend on this data are included in the international dataset. Results for Albania are omitted from any analyses which depend on these indices. 


\section{ANNEX A5}

\section{TECHNICAL DETAILS OF TRENDS ANALYSES}

\section{Comparing mathematics, reading and science performance across PISA cycles}

The PISA 2003, 2006, 2009 and 2012 assessments use the same mathematics performance scale, which means that score points on this scale are directly comparable over time. The same is true for the reading performance scale used since PISA 2000 and the science performance scale used since PISA 2006. The comparability of scores across time is possible because of the use of link items that are common across assessments and can be used in the equating procedure to align performance scales. The items that are common across assessments are a subset of the total items that make up the assessment because PISA progressively renews its pool of items. As a result, out of a total of 110 items in the PISA 2012 mathematics assessment, 84 are linked to 2003 items, 48 to 2006 items and 35 to 2009 items. The number of PISA 2012 items linked to the PISA 2003 assessment is larger than the number linked to the PISA 2006 or the PISA 2009 assessments because mathematics was a major domain in PISA 2003 and PISA 2012. In PISA 2006 and PISA 2009 , mathematics was a minor domain and all the mathematics items included in these assessments were link items. The 44 items in the PISA 2012 reading assessment are link items (44 are linked to 2009 items and 3 to 2000, 2006 and 2003). Only three items are needed to link PISA 2012 to PISA 2006 because equating is done in two-steps: PISA 2012 reading scores are equated to PISA 2009, which in turn is equated to PISA 2006 through 26 link items. The 53 items in the PISA 2012 science assessment are link items to PISA 2009 and PISA 2006. The PISA 2012 Technical Report (OECD, forthcoming) provides the technical details on equating the PISA 2012 mathematics, reading and science scales for trends purposes.

\section{Link error}

Standard errors for performance trend estimates had to be adjusted because the equating procedure that allows scores in different PISA assessments to be compared introduces a form of random error that is related to performance changes on the link items. These more conservative standard errors (larger than standard errors that were estimated before the introduction of the link error) reflect not only the measurement precision and sampling variation as for the usual PISA results, but also the link error provided in Table A5.1.

Link items represent only a subset of all items used to derive PISA scores. If different items were chosen to equate PISA scores over time, the comparison of performance for a group of students across time could vary. As a result, standard errors for the estimates of the change over time in mathematics, reading or science performance of a particular group (e.g. a country or economy, a region, boys, girls, students with an immigrant background, students without an immigrant background, socio-economically advantaged students, students in public schools, etc.) include the link error in addition to the sampling and imputation error commonly added to estimates in performance for a particular year. Because the equating procedure adds uncertainty to the position in the distribution (a change in the intercept) but does not result in any change in the variance of a distribution, standard errors for location-invariant estimates do not include the link error. Location-invariant estimates include, for example, estimates for variances, regression coefficients for student- or school-level covariates, and correlation coefficients.

\section{Link error for scores between two PISA assessments}

The following equations describe how link errors between two PISA assessments are calculated. Suppose we have $L$ score points in $K$ units. Use $i$ to index items in a unit and $j$ to index units so that $\hat{\mu}_{i j}^{y}$ is the estimated difficulty of item $i$ in unit $j$ for year $y$, and let for example to compare PISA 2006 and PISA 2003:

$$
c_{i j}=\hat{\mu}_{i j}^{2006}-\hat{\mu}_{i j}^{2003}
$$

The size (total number of score points) of unit $j$ is $m_{j}$ so that:

$$
\begin{gathered}
\sum_{j=1}^{K} m_{j}=L \\
\text { and } \quad \bar{m}=\frac{1}{K} \sum_{j=1}^{K} m_{j} \\
\text { Further let: } \quad c_{. j}=\frac{1}{m_{j}} \sum_{j=1}^{m_{j}} c_{i j} \\
\text { and } \quad \bar{c}=\frac{1}{N} \sum_{j=1}^{K} \sum_{i=1}^{m_{j}} c_{i j}
\end{gathered}
$$

then the link error, taking clustering into account, is as follows:

$$
\text { error }_{2006,2003}=\sqrt{\frac{\sum_{j=1}^{K} m_{j}^{2}\left(c_{. j}-\bar{c}\right)^{2}}{K(K-1) \bar{m}^{2}}}
$$


This approach for estimating the link errors was used in PISA 2006, PISA 2009 and PISA 2012. The link errors for comparisons of PISA 2012 results with previous assessments are shown in Table A5.1.

[Part 1/1]

Table A5.1 Link error for comparisons of performance between PISA 2012 and previous assessments

\begin{tabular}{l|c|c|c}
\hline \multicolumn{1}{c|}{ Comparison } & Mathematics & Reading & Science \\
\hline PISA 2000 to PISA 2012 & & 5.923 & 5.604 \\
\hline PISA 2003 to PISA 2012 & 1.931 & 5.580 & 3.512 \\
\hline PISA 2006 to PISA 2012 & 2.084 & 2.602 & 2.006 \\
\hline PISA 2009 to PISA 2012 & 2.294 & & \\
\hline
\end{tabular}

Note: Comparisons between PISA 2012 scores and previous assessments can only be made to when the subject first became a major domain. As a result, comparisons in mathematics performance between PISA 2012 and PISA 2000 are not possible, nor are comparisons in science performance between PISA 2012 and PISA 2000 or PISA 2003.

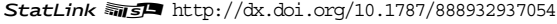

\section{Link error for other types of comparisons of student performance}

The link error for other comparisons of performance does not have a straightforward theoretical solution as does the link error for comparison between two PISA assessments. The link error between two PISA assessments, described above, can be used, however, to empirically estimate the magnitude of the link error for the comparison of the percentage of students in a particular proficiency level or the magnitude of the link error associated with the estimation of the annualised and curvilinear change.

The empirical estimation of these link errors uses the assumption that the magnitude of the link error follows a normal distribution with mean 0 and a standard deviation equal to the link error shown in Table A5.1. From this distribution, 500 errors are drawn and added to the first plausible value for each assessment prior to 2012. The estimate of interest (change in the percentage of students in a particular proficiency level or the annualised change) is calculated for each of the 500 replicates. The standard deviation of these 500 estimates is then used as the link error for the annualised change, the quadratic change, and the change in the percentage of students scoring in a particular proficiency level. The values used to adjust standard errors in the calculation of the change in the percentage of students in each proficiency Level group are shown in Table A5.2 and those used for the adjustment of the linear and quadratic terms in the regressions models used to estimate the annualised change and the curvilinear change are shown in Table A5.3.

\section{Comparisons of performance: Difference between two assessments and annualised change}

To evaluate the evolution of performance, analyses report the change in performance between two cycles and the annualised change in performance. Comparisons between two assessments (e.g. a country's/economy's change in performance between PISA 2003 and PISA 2012 or the change in performance of a subgroup) are calculated as:

$$
\Delta_{2012-t}=P I S A_{2012}-P I S A_{t}
$$

where $\Delta_{2012-t}$ is the difference in performance between PISA 2012 and a previous PISA assessment, where $t$ can take any of the following values: 2000, 2003, 2006 or 2009. PISA 2012 is the mathematics, reading or science score observed in PISA 2012, and PISA $t$ is the mathematics, reading or science score observed in a previous assessment (2000, 2003, 2006 or 2009). The standard error of the change in performance $\sigma\left(\Delta_{2012-t}\right)$ is:

$$
\sigma\left(\Delta_{2012-t}\right)=\sqrt{\sigma_{2012}^{2}+\sigma_{t}^{2}+\text { error }_{2012, t}^{2}}
$$

where $\sigma_{2012}$ is the standard error observed for $P_{I S A_{2012}}, \sigma_{t}$ is the standard error observed for PISA $A_{t}$ and error $2012, t$ is the link error for comparisons of mathematics, reading or science performance between the PISA 2012 assessment and a previous $(t)$ assessment. The value for error $_{2012, t}$ is shown in Table A5.1.

A second set of analyses reported in PISA relate to annualised changes in performance. The annualised change is the average annual rate of change observed through a country's/economy's participation in PISA. The annualised change is the average rate of change for a country's/economy's average mathematics, reading and science scores throughout their participation in PISA assessments. Thus, a positive annualised change of $x$ points indicates that the country/economy has improved in performance by $x$ points per year since its earliest comparable PISA results participated in PISA. For countries and economies that have participated in only two assessments, the annualised change is equal to the difference between the two assessments, divided by the number of years that passed between the assessments. 
[Part 1/3]

Table A5.2 Link error for comparisons of proficiency levels between PISA 2012 and previous assessments

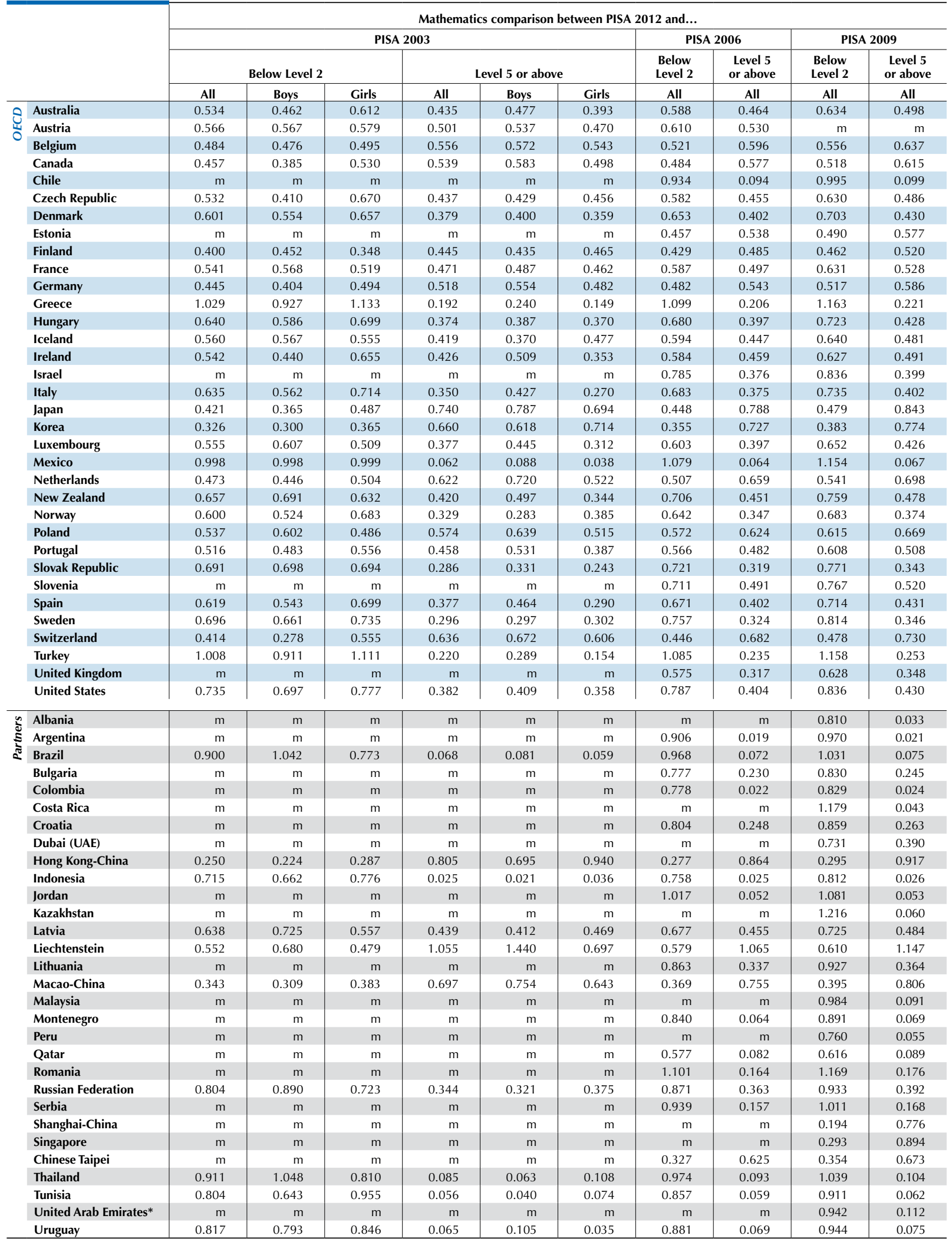

Note: The link error is calculated empirically by adding a random error component from a normal distribution with mean equal to zero and standard deviation equal to those shown in Table A5. 1 to each student's scores in PISA 2000, PISA 2003, PISA 2006 or PISA 2009. Each country's percentage of students in each proficiency level band are then calculated for each of 500 replications. The standard deviation in the observed coefficients is the result of the added error and is the reported link error.

* United Arab Emirates excluding Dubai.

StatLink הinls http://dx.doi.org/10.1787/888932937054 
[Part 2/3]

Table A5.2 Link error for comparisons of proficiency levels between PISA 2012 and previous assessments

\begin{tabular}{|c|c|c|c|c|c|c|c|c|c|c|c|c|c|}
\hline & & \multicolumn{12}{|c|}{ Reading comparison between PISA 2012 and... } \\
\hline & & \multicolumn{6}{|c|}{ PISA 2000} & \multicolumn{2}{|c|}{ PISA 2003} & \multicolumn{2}{|c|}{ PISA 2006} & \multicolumn{2}{|c|}{ PISA 2009} \\
\hline & & \multicolumn{3}{|c|}{ Below Level 2} & \multicolumn{3}{|c|}{ Level 5 or above } & \multirow{2}{*}{$\begin{array}{c}\begin{array}{c}\text { Below } \\
\text { Level 2 }\end{array} \\
\text { All } \\
\end{array}$} & $\begin{array}{c}\text { Level } 5 \\
\text { or above }\end{array}$ & $\begin{array}{l}\text { Below } \\
\text { Level } 2\end{array}$ & $\begin{array}{c}\text { Level } 5 \\
\text { or above }\end{array}$ & $\begin{array}{l}\text { Below } \\
\text { Level } 2\end{array}$ & $\begin{array}{c}\text { Level } 5 \\
\text { or above }\end{array}$ \\
\hline & & All & Boys & Girls & All & Boys & Girls & & & All & All & All & All \\
\hline 0 & Australia & 1.294 & 1.569 & 1.008 & 1.293 & 1.033 & 1.570 & 1.289 & 1.282 & 1.246 & 1.254 & 0.601 & 0.599 \\
\hline 通 & Austria & 1.488 & 1.772 & 1.216 & 0.968 & 0.691 & 1.248 & 1.482 & 0.959 & 1.431 & 0.943 & $\mathrm{~m}$ & $\mathrm{~m}$ \\
\hline & Belgium & 1.177 & 1.243 & 1.114 & 1.392 & 1.162 & 1.627 & 1.182 & 1.380 & 1.143 & 1.350 & 0.551 & 0.656 \\
\hline & Canada & 1.057 & 1.269 & 0.847 & 1.457 & 1.175 & 1.741 & 1.058 & 1.449 & 1.016 & 1.410 & 0.525 & 0.676 \\
\hline & Chile & 2.510 & 2.601 & 2.427 & 0.121 & 0.067 & 0.174 & $\mathrm{~m}$ & $\mathrm{~m}$ & 2.423 & 0.118 & 1.200 & 0.051 \\
\hline & Czech Republic & 1.615 & 1.871 & 1.355 & 0.919 & 0.591 & 1.269 & 1.609 & 0.914 & 1.568 & 0.901 & 0.737 & 0.429 \\
\hline & Denmark & 1.375 & 1.721 & 1.031 & 0.854 & 0.584 & 1.131 & 1.372 & 0.846 & 1.320 & 0.827 & 0.603 & 0.419 \\
\hline & Estonia & $\mathrm{m}$ & $\mathrm{m}$ & $\mathrm{m}$ & $\mathrm{m}$ & $\mathrm{m}$ & $\mathrm{m}$ & $\mathrm{m}$ & $\mathrm{m}$ & 1.011 & 1.194 & 0.391 & 0.602 \\
\hline & Finland & 1.197 & 1.858 & 0.502 & 1.601 & 1.038 & 2.199 & 1.200 & 1.588 & 1.161 & 1.551 & 0.510 & 0.730 \\
\hline & France & 1.119 & 1.282 & 0.968 & 1.326 & 1.121 & 1.526 & 1.115 & 1.321 & 1.077 & 1.288 & 0.485 & 0.603 \\
\hline & Germany & 1.269 & 1.487 & 1.046 & 1.375 & 1.026 & 1.741 & 1.271 & 1.353 & 1.232 & 1.334 & 0.594 & 0.648 \\
\hline & Greece & 1.527 & 1.937 & 1.130 & 0.784 & 0.603 & 0.964 & 1.524 & 0.776 & 1.478 & 0.765 & 0.729 & 0.375 \\
\hline & Hungary & 1.353 & 1.619 & 1.109 & 0.955 & 0.774 & 1.136 & 1.352 & 0.947 & 1.314 & 0.933 & 0.574 & 0.439 \\
\hline & Iceland & 1.588 & 1.826 & 1.348 & 0.889 & 0.603 & 1.210 & 1.576 & 0.882 & 1.537 & 0.865 & 0.755 & 0.466 \\
\hline & Ireland & 1.213 & 1.474 & 0.947 & 1.510 & 1.184 & 1.851 & 1.220 & 1.511 & 1.177 & 1.466 & 0.569 & 0.766 \\
\hline & Israel & 1.355 & 1.274 & 1.447 & 1.145 & 0.950 & 1.338 & $\mathrm{~m}$ & $\mathrm{~m}$ & 1.316 & 1.111 & 0.619 & 0.568 \\
\hline & Italy & 1.468 & 1.630 & 1.295 & 1.040 & 0.816 & 1.281 & 1.463 & 1.032 & 1.418 & 1.011 & 0.678 & 0.482 \\
\hline & Japan & 0.831 & 0.876 & 0.794 & 1.743 & 1.572 & 1.937 & 0.834 & 1.734 & 0.799 & 1.692 & 0.391 & 0.828 \\
\hline & Korea & 0.845 & 1.006 & 0.668 & 1.832 & 1.657 & 2.037 & 0.838 & 1.822 & 0.812 & 1.785 & 0.414 & 0.904 \\
\hline & Luxembourg & $\mathrm{m}$ & $\mathrm{m}$ & $\mathrm{m}$ & $\mathrm{m}$ & $\mathrm{m}$ & $\mathrm{m}$ & 1.460 & 1.130 & 1.415 & 1.112 & 0.663 & 0.543 \\
\hline & Mexico & 2.844 & 2.892 & 2.802 & 0.097 & 0.076 & 0.117 & 2.836 & 0.036 & 2.751 & 0.093 & 1.308 & 0.052 \\
\hline & Netherlands & $\mathrm{m}$ & $\mathrm{m}$ & $\mathrm{m}$ & $\mathrm{m}$ & $\mathrm{m}$ & $\mathrm{m}$ & 1.350 & 1.404 & 1.312 & 1.370 & 0.661 & 0.661 \\
\hline & New Zealand & 1.323 & 1.581 & 1.061 & 1.367 & 1.300 & 1.443 & 1.322 & 1.360 & 1.280 & 1.328 & 0.654 & 0.618 \\
\hline & Norway & 1.259 & 1.569 & 0.945 & 1.236 & 0.840 & 1.658 & 1.254 & 1.231 & 1.210 & 1.204 & 0.514 & 0.526 \\
\hline & Poland & 1.040 & 1.370 & 0.729 & 1.223 & 0.902 & 1.532 & 1.038 & 1.212 & 0.996 & 1.187 & 0.488 & 0.544 \\
\hline & Portugal & 1.410 & 1.671 & 1.147 & 1.064 & 0.746 & 1.391 & 1.408 & 1.059 & 1.353 & 1.036 & 0.666 & 0.506 \\
\hline & Slovak Republic & $\mathrm{m}$ & $\mathrm{m}$ & $\mathrm{m}$ & $\mathrm{m}$ & $\mathrm{m}$ & $\mathrm{m}$ & 1.775 & 0.717 & 1.714 & 0.706 & 0.804 & 0.343 \\
\hline & Slovenia & $\mathrm{m}$ & $\mathrm{m}$ & $\mathrm{m}$ & $\mathrm{m}$ & $\mathrm{m}$ & $\mathrm{m}$ & $\mathrm{m}$ & $\mathrm{m}$ & 1.790 & 0.647 & 0.858 & 0.259 \\
\hline & Spain & 1.539 & 1.682 & 1.400 & 0.824 & 0.641 & 1.016 & 1.532 & 0.815 & 1.483 & 0.803 & 0.669 & 0.380 \\
\hline & Sweden & 1.509 & 1.831 & 1.186 & 1.023 & 0.719 & 1.339 & 1.502 & 1.018 & 1.455 & 0.995 & 0.729 & 0.510 \\
\hline & Switzerland & 1.401 & 1.744 & 1.062 & 1.265 & 0.835 & 1.702 & 1.406 & 1.255 & 1.359 & 1.222 & 0.661 & 0.548 \\
\hline & Turkey & $\mathrm{m}$ & $\mathrm{m}$ & $\mathrm{m}$ & $\mathrm{m}$ & $\mathrm{m}$ & $\mathrm{m}$ & 2.157 & 0.589 & 2.082 & 0.581 & 1.036 & 0.248 \\
\hline & United Kingdom & $\mathrm{m}$ & $\mathrm{m}$ & $\mathrm{m}$ & $\mathrm{m}$ & $\mathrm{m}$ & $\mathrm{m}$ & $\mathrm{m}$ & $\mathrm{m}$ & 1.251 & 1.008 & 0.578 & 0.463 \\
\hline & United States & 1.448 & 1.836 & 1.053 & 1.017 & 0.804 & 1.241 & 1.441 & 1.008 & $\mathrm{~m}$ & $\mathrm{~m}$ & 0.622 & 0.455 \\
\hline$\frac{n}{2}$ & Albania & 2.316 & 2.059 & 2.609 & 0.197 & 0.191 & 0.211 & $\mathrm{~m}$ & $\mathrm{~m}$ & $\mathrm{~m}$ & $\mathrm{~m}$ & 1.104 & 0.080 \\
\hline$\Xi$ & Argentina & 2.544 & 2.469 & 2.624 & 0.139 & 0.113 & 0.175 & $\mathrm{~m}$ & $\mathrm{~m}$ & 2.471 & 0.136 & 1.228 & 0.062 \\
\hline$\Sigma$ & Brazil & 2.716 & 2.627 & 2.800 & 0.124 & 0.068 & 0.178 & 2.707 & 0.123 & 2.633 & 0.121 & 1.285 & 0.063 \\
\hline & Bulgaria & 1.542 & 1.600 & 1.486 & 0.556 & 0.250 & 0.891 & $\mathrm{~m}$ & $\mathrm{~m}$ & 1.505 & 0.539 & 0.682 & 0.275 \\
\hline & Colombia & $\mathrm{m}$ & $\mathrm{m}$ & $\mathrm{m}$ & $\mathrm{m}$ & $\mathrm{m}$ & $\mathrm{m}$ & $\mathrm{m}$ & $\mathrm{m}$ & 2.731 & 0.079 & 1.311 & 0.032 \\
\hline & Costa Rica & $\mathrm{m}$ & $\mathrm{m}$ & $\mathrm{m}$ & $\mathrm{m}$ & $\mathrm{m}$ & $\mathrm{m}$ & $\mathrm{m}$ & $\mathrm{m}$ & $\mathrm{m}$ & $\mathrm{m}$ & 1.237 & 0.065 \\
\hline & Croatia & $\mathrm{m}$ & $\mathrm{m}$ & $\mathrm{m}$ & $\mathrm{m}$ & $\mathrm{m}$ & $\mathrm{m}$ & $\mathrm{m}$ & $\mathrm{m}$ & 1.625 & 0.739 & 0.739 & 0.340 \\
\hline & Dubai (UAE) & $\mathrm{m}$ & $\mathrm{m}$ & $\mathrm{m}$ & $\mathrm{m}$ & $\mathrm{m}$ & $\mathrm{m}$ & $\mathrm{m}$ & $\mathrm{m}$ & $\mathrm{m}$ & $\mathrm{m}$ & 0.987 & 0.295 \\
\hline & Hong Kong-China & 0.758 & 0.837 & 0.673 & 2.017 & 1.723 & 2.366 & 0.762 & 1.996 & 0.734 & 1.961 & 0.364 & 0.886 \\
\hline & Indonesia & 3.255 & 2.874 & 3.652 & c & c & c & 3.230 & 0.023 & 3.151 & 0.023 & 1.559 & 0.008 \\
\hline & Jordan & $\mathrm{m}$ & $\mathrm{m}$ & $\mathrm{m}$ & $\mathrm{m}$ & $\mathrm{m}$ & $\mathrm{m}$ & $\mathrm{m}$ & $\mathrm{m}$ & 2.626 & 0.094 & 1.285 & 0.054 \\
\hline & Kazakhstan & $\mathrm{m}$ & $\mathrm{m}$ & $\mathrm{m}$ & $\mathrm{m}$ & $\mathrm{m}$ & $\mathrm{m}$ & $\mathrm{m}$ & $\mathrm{m}$ & $\mathrm{m}$ & $\mathrm{m}$ & 1.356 & 0.002 \\
\hline & Latvia & 1.591 & 2.138 & 1.043 & 0.689 & 0.327 & 1.066 & 1.585 & 0.681 & 1.532 & 0.664 & 0.749 & 0.302 \\
\hline & Liechtenstein & 1.187 & 1.124 & 1.373 & 1.712 & 1.318 & 2.214 & 1.170 & 1.709 & 1.132 & 1.676 & 0.750 & 0.900 \\
\hline & Lithuania & $\mathrm{m}$ & $\mathrm{m}$ & $\mathrm{m}$ & $\mathrm{m}$ & $\mathrm{m}$ & $\mathrm{m}$ & $\mathrm{m}$ & $\mathrm{m}$ & 1.708 & 0.602 & 0.805 & 0.324 \\
\hline & Macao-China & $\mathrm{m}$ & $\mathrm{m}$ & $\mathrm{m}$ & $\mathrm{m}$ & $\mathrm{m}$ & $\mathrm{m}$ & 1.382 & 1.157 & 1.346 & 1.130 & 0.651 & 0.526 \\
\hline & Malaysia & $\mathrm{m}$ & $\mathrm{m}$ & $\mathrm{m}$ & $\mathrm{m}$ & $\mathrm{m}$ & $\mathrm{m}$ & $\mathrm{m}$ & $\mathrm{m}$ & $\mathrm{m}$ & $\mathrm{m}$ & 1.303 & 0.015 \\
\hline & Montenegro & $\mathrm{m}$ & $\mathrm{m}$ & $\mathrm{m}$ & $\mathrm{m}$ & $\mathrm{m}$ & $\mathrm{m}$ & $\mathrm{m}$ & $\mathrm{m}$ & 2.567 & 0.215 & 1.267 & 0.075 \\
\hline & Peru & 2.488 & 2.406 & 2.571 & 0.132 & c & 0.175 & $\mathrm{~m}$ & $\mathrm{~m}$ & $\mathrm{~m}$ & $\mathrm{~m}$ & 1.161 & 0.058 \\
\hline & Qatar & $\mathrm{m}$ & $\mathrm{m}$ & $\mathrm{m}$ & $\mathrm{m}$ & $\mathrm{m}$ & $\mathrm{m}$ & $\mathrm{m}$ & $\mathrm{m}$ & 1.958 & 0.256 & 0.940 & 0.125 \\
\hline & Romania & 2.498 & 2.587 & 2.417 & 0.330 & 0.230 & 0.431 & $\mathrm{~m}$ & $\mathrm{~m}$ & 2.411 & 0.325 & 1.196 & 0.177 \\
\hline & Russian Federation & 2.090 & 2.393 & 1.791 & 0.666 & 0.447 & 0.895 & 2.088 & 0.659 & 2.031 & 0.643 & 1.069 & 0.314 \\
\hline & Serbia & $\mathrm{m}$ & $\mathrm{m}$ & $\mathrm{m}$ & $\mathrm{m}$ & $\mathrm{m}$ & $\mathrm{m}$ & $\mathrm{m}$ & $\mathrm{m}$ & 2.254 & 0.431 & 1.099 & 0.221 \\
\hline & Shanghai-China & $\mathrm{m}$ & $\mathrm{m}$ & $\mathrm{m}$ & $\mathrm{m}$ & $\mathrm{m}$ & $\mathrm{m}$ & $\mathrm{m}$ & $\mathrm{m}$ & $\mathrm{m}$ & $\mathrm{m}$ & 0.209 & 1.133 \\
\hline & Singapore & $\mathrm{m}$ & $\mathrm{m}$ & $\mathrm{m}$ & $\mathrm{m}$ & $\mathrm{m}$ & $\mathrm{m}$ & $\mathrm{m}$ & $\mathrm{m}$ & $\mathrm{m}$ & $\mathrm{m}$ & 0.375 & 0.985 \\
\hline & Chinese Taipei & $\mathrm{m}$ & $\mathrm{m}$ & $\mathrm{m}$ & $\mathrm{m}$ & $\mathrm{m}$ & $\mathrm{m}$ & $\mathrm{m}$ & $\mathrm{m}$ & 1.034 & 1.575 & 0.544 & 0.744 \\
\hline & Thailand & 2.755 & 3.240 & 2.379 & 0.138 & 0.038 & 0.218 & 2.754 & 0.135 & 2.671 & 0.136 & 1.289 & 0.054 \\
\hline & Tunisia & $\mathrm{m}$ & $\mathrm{m}$ & $\mathrm{m}$ & $\mathrm{m}$ & $\mathrm{m}$ & $\mathrm{m}$ & 2.586 & 0.057 & 2.513 & 0.056 & 1.265 & 0.041 \\
\hline & United Arab Emirates* & $\mathrm{m}$ & $\mathrm{m}$ & $\mathrm{m}$ & $\mathrm{m}$ & $\mathrm{m}$ & $\mathrm{m}$ & $\mathrm{m}$ & $\mathrm{m}$ & $\mathrm{m}$ & $\mathrm{m}$ & 1.190 & 0.084 \\
\hline & Uruguay & $\mathrm{m}$ & $\mathrm{m}$ & $\mathrm{m}$ & $\mathrm{m}$ & $\mathrm{m}$ & $\mathrm{m}$ & 2.506 & 0.176 & 2.431 & 0.172 & 1.261 & 0.097 \\
\hline
\end{tabular}

Note: The link error is calculated empirically by adding a random error component from a normal distribution with mean equal to zero and standard deviation equal to those shown in Table A5.1 to each student's scores in PISA 2000, PISA 2003, PISA 2006 or PISA 2009. Each country's percentage of students in each proficiency level band are then calculated for each of 500 replications. The

StatLink त्नाइड http://dx.doi.org/10.1787/888932937054 
[Part 3/3]

Table A5.2 Link error for comparisons of proficiency levels between PISA 2012 and previous assessments

\begin{tabular}{|c|c|c|c|c|c|c|c|c|c|}
\hline & & \multicolumn{8}{|c|}{ Science comparison between PISA 2012 and... } \\
\hline & & \multicolumn{6}{|c|}{ PISA 2006} & \multicolumn{2}{|c|}{ PISA 2009} \\
\hline & & \multicolumn{3}{|c|}{ Below Level 2} & \multicolumn{3}{|c|}{ Level 5 or above } & \multirow{2}{*}{$\begin{array}{c}\begin{array}{c}\text { Below } \\
\text { Level } 2\end{array} \\
\text { All } \\
\end{array}$} & \multirow{2}{*}{$\begin{array}{c}\begin{array}{c}\text { Level } 5 \\
\text { or above }\end{array} \\
\text { All } \\
\end{array}$} \\
\hline & & All & Boys & Girls & All & Boys & Girls & & \\
\hline \multirow{34}{*}{$\begin{array}{l}\stackrel{\Delta}{0} \\
0\end{array}$} & Australia & 0.702 & 0.699 & 0.708 & 0.816 & 0.779 & 0.855 & 0.419 & 0.486 \\
\hline & Austria & 0.935 & 0.912 & 0.963 & 0.704 & 0.742 & 0.669 & $\mathrm{~m}$ & $\mathrm{~m}$ \\
\hline & Belgium & 0.805 & 0.748 & 0.867 & 0.767 & 0.764 & 0.772 & 0.451 & 0.433 \\
\hline & Canada & 0.584 & 0.585 & 0.584 & 0.856 & 0.933 & 0.783 & 0.338 & 0.478 \\
\hline & Chile & 1.563 & 1.488 & 1.639 & 0.143 & 0.207 & 0.087 & 0.888 & 0.079 \\
\hline & Czech Republic & 0.836 & 0.719 & 0.970 & 0.605 & 0.444 & 0.786 & 0.456 & 0.361 \\
\hline & Denmark & 0.922 & 0.872 & 0.975 & 0.519 & 0.573 & 0.478 & 0.540 & 0.277 \\
\hline & Estonia & 0.506 & 0.560 & 0.456 & 0.933 & 0.929 & 0.941 & 0.310 & 0.518 \\
\hline & Finland & 0.457 & 0.518 & 0.398 & 1.040 & 0.864 & 1.236 & 0.259 & 0.585 \\
\hline & France & 0.830 & 0.761 & 0.899 & 0.634 & 0.718 & 0.562 & 0.489 & 0.326 \\
\hline & Germany & 0.717 & 0.676 & 0.768 & 0.892 & 0.970 & 0.814 & 0.430 & 0.501 \\
\hline & Greece & 1.222 & 1.308 & 1.146 & 0.279 & 0.342 & 0.224 & 0.722 & 0.165 \\
\hline & Hungary & 1.073 & 1.186 & 0.971 & 0.606 & 0.677 & 0.542 & 0.639 & 0.365 \\
\hline & Iceland & 0.940 & 0.930 & 0.957 & 0.484 & 0.496 & 0.476 & 0.486 & 0.288 \\
\hline & Ireland & 0.748 & 0.826 & 0.680 & 0.677 & 0.691 & 0.668 & 0.425 & 0.401 \\
\hline & Israel & 0.957 & 0.877 & 1.038 & 0.557 & 0.736 & 0.388 & 0.537 & 0.337 \\
\hline & Italy & 1.014 & 0.959 & 1.075 & 0.516 & 0.566 & 0.465 & 0.607 & 0.303 \\
\hline & Japan & 0.499 & 0.521 & 0.478 & 1.093 & 1.285 & 0.888 & 0.313 & 0.612 \\
\hline & Korea & 0.499 & 0.586 & 0.404 & 0.976 & 1.129 & 0.809 & 0.293 & 0.584 \\
\hline & Luxembourg & 0.947 & 0.751 & 1.156 & 0.650 & 0.603 & 0.705 & 0.548 & 0.386 \\
\hline & Mexico & 2.072 & 1.952 & 2.190 & 0.022 & 0.028 & 0.017 & 1.195 & 0.014 \\
\hline & Netherlands & 0.879 & 0.668 & 1.106 & 0.911 & 0.968 & 0.856 & 0.541 & 0.548 \\
\hline & New Zealand & 0.796 & 0.677 & 0.923 & 0.803 & 0.900 & 0.707 & 0.433 & 0.451 \\
\hline & Norway & 0.864 & 0.812 & 0.921 & 0.551 & 0.521 & 0.585 & 0.486 & 0.298 \\
\hline & Poland & 0.620 & 0.708 & 0.545 & 0.813 & 0.795 & 0.835 & 0.334 & 0.484 \\
\hline & Portugal & 0.953 & 0.928 & 0.982 & 0.422 & 0.442 & 0.407 & 0.522 & 0.221 \\
\hline & Slovak Republic & 1.013 & 1.100 & 0.924 & 0.424 & 0.463 & 0.386 & 0.566 & 0.253 \\
\hline & Slovenia & 0.918 & 1.222 & 0.600 & 0.758 & 0.832 & 0.685 & 0.542 & 0.414 \\
\hline & Spain & 0.884 & 0.840 & 0.932 & 0.501 & 0.591 & 0.411 & 0.517 & 0.286 \\
\hline & Sweden & 0.973 & 0.918 & 1.033 & 0.454 & 0.447 & 0.466 & 0.560 & 0.254 \\
\hline & Switzerland & 0.740 & 0.725 & 0.760 & 0.712 & 0.665 & 0.765 & 0.443 & 0.389 \\
\hline & Turkey & 1.492 & 1.514 & 1.480 & 0.246 & 0.296 & 0.203 & 0.870 & 0.130 \\
\hline & United Kingdom & 0.718 & 0.648 & 0.790 & 0.808 & 0.862 & 0.768 & 0.411 & 0.452 \\
\hline & United States & 0.938 & 0.946 & 0.938 & 0.507 & 0.546 & 0.476 & 0.527 & 0.288 \\
\hline \multirow{30}{*}{ 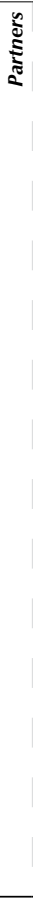 } & Albania & $\mathrm{m}$ & $\mathrm{m}$ & $\mathrm{m}$ & $\mathrm{m}$ & $\mathrm{m}$ & $\mathrm{m}$ & 0.808 & 0.051 \\
\hline & Argentina & 1.800 & 1.660 & 1.941 & 0.053 & 0.066 & 0.047 & 1.025 & 0.027 \\
\hline & Brazil & 1.755 & 1.616 & 1.882 & 0.038 & 0.049 & 0.034 & 1.019 & 0.017 \\
\hline & Bulgaria & 1.207 & 1.248 & 1.169 & 0.264 & 0.249 & 0.286 & 0.723 & 0.149 \\
\hline & Colombia & 1.891 & 2.043 & 1.768 & 0.012 & 0.022 & 0.004 & 1.111 & 0.005 \\
\hline & Costa Rica & $\mathrm{m}$ & $\mathrm{m}$ & $\mathrm{m}$ & $\mathrm{m}$ & $\mathrm{m}$ & m & 1.026 & 0.036 \\
\hline & Croatia & 0.965 & 1.036 & 0.895 & 0.456 & 0.465 & 0.452 & 0.572 & 0.284 \\
\hline & Dubai (UAE) & $\mathrm{m}$ & $\mathrm{m}$ & $\mathrm{m}$ & $\mathrm{m}$ & $\mathrm{m}$ & $\mathrm{m}$ & 0.720 & 0.182 \\
\hline & Hong Kong-China & 0.299 & 0.304 & 0.296 & 1.454 & 1.556 & 1.341 & 0.167 & 0.873 \\
\hline & Indonesia & 1.740 & 1.763 & 1.728 & c & c & c & 0.932 & c \\
\hline & Jordan & 1.669 & 1.530 & 1.808 & 0.051 & 0.057 & 0.053 & 0.936 & 0.028 \\
\hline & Kazakhstan & $\mathrm{m}$ & $\mathrm{m}$ & $\mathrm{m}$ & $\mathrm{m}$ & $\mathrm{m}$ & $\mathrm{m}$ & 1.048 & 0.025 \\
\hline & Latvia & 0.953 & 1.016 & 0.898 & 0.460 & 0.470 & 0.457 & 0.566 & 0.288 \\
\hline & Liechtenstein & 0.597 & 0.867 & 0.380 & 0.728 & 0.928 & 0.584 & 0.269 & 0.423 \\
\hline & Lithuania & 0.869 & 0.924 & 0.819 & 0.501 & 0.382 & 0.628 & 0.489 & 0.320 \\
\hline & Macao-China & 0.685 & 0.640 & 0.742 & 0.656 & 0.820 & 0.494 & 0.434 & 0.383 \\
\hline & Malaysia & $\mathrm{m}$ & $\mathrm{m}$ & $\mathrm{m}$ & $\mathrm{m}$ & $\mathrm{m}$ & $\mathrm{m}$ & 1.058 & 0.026 \\
\hline & Montenegro & 1.689 & 1.595 & 1.793 & 0.067 & 0.071 & 0.070 & 1.035 & 0.042 \\
\hline & Peru & $\mathrm{m}$ & $\mathrm{m}$ & $\mathrm{m}$ & $\mathrm{m}$ & $\mathrm{m}$ & $\mathrm{m}$ & 0.822 & 0.000 \\
\hline & Qatar & 1.126 & 0.940 & 1.328 & 0.132 & 0.124 & 0.143 & 0.657 & 0.071 \\
\hline & Romania & 1.861 & 1.923 & 1.810 & 0.129 & 0.129 & 0.130 & 1.122 & 0.094 \\
\hline & Russian Federation & 1.298 & 1.333 & 1.267 & 0.398 & 0.390 & 0.407 & 0.801 & 0.230 \\
\hline & Serbia & 1.482 & 1.599 & 1.369 & 0.117 & 0.115 & 0.125 & 0.844 & 0.061 \\
\hline & Shanghai-China & m & $\mathrm{m}$ & $\mathrm{m}$ & m & $\mathrm{m}$ & $\mathrm{m}$ & 0.150 & 1.006 \\
\hline & Singapore & $\mathrm{m}$ & $\mathrm{m}$ & $\mathrm{m}$ & $\mathrm{m}$ & $\mathrm{m}$ & $\mathrm{m}$ & 0.307 & 0.650 \\
\hline & Chinese Taipei & 0.751 & 0.742 & 0.763 & 0.764 & 0.788 & 0.747 & 0.480 & 0.426 \\
\hline & Thailand & 1.781 & 1.899 & 1.696 & 0.135 & 0.092 & 0.172 & 1.060 & 0.078 \\
\hline & Tunisia & 1.794 & 1.703 & 1.877 & 0.022 & 0.033 & 0.021 & 1.049 & 0.014 \\
\hline & United Arab Emirates* & $\mathrm{m}$ & $\mathrm{m}$ & $\mathrm{m}$ & $\mathrm{m}$ & $\mathrm{m}$ & $\mathrm{m}$ & 0.758 & 0.075 \\
\hline & Uruguay & 1.352 & 1.225 & 1.468 & 0.096 & 0.157 & 0.049 & 0.760 & 0.052 \\
\hline
\end{tabular}

Note: The link error is calculated empirically by adding a random error component from a normal distribution with mean equal to zero and standard deviation equal to those shown in Table A5.1 to each student's scores in PISA 2000, PISA 2003, PISA 2006 or PISA 2009. Each country's percentage of students in each proficiency level band are then calculated for each of 500 replications. The standard deviation in the observed coefficients is the result of the added error and is the reported link error.

* United Arab Emirates excluding Dubai.

StatLink तilst http://dx.doi.org/10.1787/888932937054 
Link error for comparisons of annualised and curvilinear change between PISA 2012

Table A5.3 and previous assessments

\begin{tabular}{|c|c|c|c|c|c|c|c|}
\hline & & \multicolumn{6}{|c|}{ Comparisons between PISA 2012 and all previous comparable assessments in... } \\
\hline & & \multicolumn{2}{|c|}{ Mathematics } & \multicolumn{2}{|c|}{ Reading } & \multicolumn{2}{|c|}{ Science } \\
\hline & & Linear term & Quadratic term & Linear term & Quadratic term & Linear term & Quadratic term \\
\hline & & Error & Error & Error & Error & Error & Error \\
\hline \multirow{34}{*}{ రి } & Australia & 0.192 & 0.092 & 0.194 & 0.149 & 0.595 & 0.168 \\
\hline & Austria & 0.195 & 0.091 & 0.193 & 0.148 & 0.594 & 0.168 \\
\hline & Belgium & 0.191 & 0.091 & 0.194 & 0.147 & 0.597 & 0.168 \\
\hline & Canada & 0.199 & 0.092 & 0.187 & 0.148 & 0.592 & 0.168 \\
\hline & Chile & 0.305 & 0.185 & 0.292 & 0.169 & 0.605 & 0.168 \\
\hline & Czech Republic & 0.183 & 0.088 & 0.237 & 0.147 & 0.609 & 0.168 \\
\hline & Denmark & 0.205 & 0.094 & 0.187 & 0.149 & 0.588 & 0.168 \\
\hline & Estonia & 0.297 & 0.185 & 0.481 & 0.459 & 0.610 & 0.168 \\
\hline & Finland & 0.195 & 0.092 & 0.193 & 0.148 & 0.593 & 0.168 \\
\hline & France & 0.189 & 0.090 & 0.206 & 0.148 & 0.599 & 0.168 \\
\hline & Germany & 0.189 & 0.084 & 0.305 & 0.145 & 0.635 & 0.168 \\
\hline & Greece & 0.195 & 0.091 & 0.209 & 0.150 & 0.592 & 0.168 \\
\hline & Hungary & 0.194 & 0.092 & 0.193 & 0.149 & 0.594 & 0.168 \\
\hline & Iceland & 0.196 & 0.092 & 0.188 & 0.147 & 0.595 & 0.168 \\
\hline & Ireland & 0.196 & 0.091 & 0.191 & 0.149 & 0.593 & 0.168 \\
\hline & Israel & 0.330 & 0.185 & 0.235 & 0.172 & 0.593 & 0.168 \\
\hline & Italy & 0.191 & 0.091 & 0.200 & 0.148 & 0.597 & 0.168 \\
\hline & Japan & 0.194 & 0.092 & 0.202 & 0.150 & 0.592 & 0.168 \\
\hline & Korea & 0.199 & 0.094 & 0.187 & 0.149 & 0.590 & 0.168 \\
\hline & Luxembourg & 0.203 & 0.094 & 0.184 & 0.148 & 0.590 & 0.168 \\
\hline & Mexico & 0.202 & 0.094 & 0.186 & 0.149 & 0.589 & 0.168 \\
\hline & Netherlands & 0.194 & 0.091 & 0.189 & 0.148 & 0.594 & 0.168 \\
\hline & New Zealand & 0.191 & 0.092 & 0.193 & 0.148 & 0.596 & 0.168 \\
\hline & Norway & 0.199 & 0.092 & 0.186 & 0.147 & 0.593 & 0.168 \\
\hline & Poland & 0.185 & 0.088 & 0.231 & 0.148 & 0.606 & 0.168 \\
\hline & Portugal & 0.203 & 0.093 & 0.187 & 0.150 & 0.587 & 0.168 \\
\hline & Slovak Republic & 0.184 & 0.089 & 0.320 & 0.223 & 0.607 & 0.168 \\
\hline & Slovenia & 0.306 & 0.185 & 0.460 & 0.459 & 0.605 & 0.168 \\
\hline & Spain & 0.194 & 0.092 & 0.198 & 0.148 & 0.595 & 0.168 \\
\hline & Sweden & 0.191 & 0.090 & 0.191 & 0.146 & 0.599 & 0.168 \\
\hline & Switzerland & 0.186 & 0.089 & 0.203 & 0.147 & 0.603 & 0.168 \\
\hline & Turkey & 0.216 & 0.096 & 0.287 & 0.219 & 0.586 & 0.168 \\
\hline & United Kingdom & 0.194 & 0.091 & 0.190 & 0.148 & 0.595 & 0.168 \\
\hline & United States & 0.198 & 0.092 & 0.188 & 0.147 & 0.593 & 0.168 \\
\hline \multirow{30}{*}{ 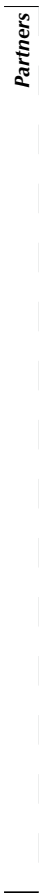 } & Albania & 0.748 & $\mathrm{~m}$ & 0.238 & 0.205 & 0.678 & $\mathrm{~m}$ \\
\hline & Argentina & 0.340 & 0.185 & 0.228 & 0.171 & 0.590 & 0.168 \\
\hline & Brazil & 0.205 & 0.094 & 0.199 & 0.151 & 0.586 & 0.168 \\
\hline & Bulgaria & 0.318 & 0.185 & 0.281 & 0.168 & 0.599 & 0.168 \\
\hline & Colombia & 0.326 & 0.185 & 0.428 & 0.459 & 0.595 & 0.168 \\
\hline & Costa Rica & 0.748 & m & 0.848 & m & 0.678 & m \\
\hline & Croatia & 0.317 & 0.185 & 0.440 & 0.459 & 0.599 & 0.168 \\
\hline & Dubai (UAE) & 0.748 & $\mathrm{~m}$ & 0.848 & $\mathrm{~m}$ & 0.678 & m \\
\hline & Hong Kong-China & 0.195 & 0.092 & 0.201 & 0.177 & 0.593 & 0.168 \\
\hline & Indonesia & 0.234 & 0.095 & 0.262 & 0.176 & 0.581 & 0.168 \\
\hline & Jordan & 0.346 & 0.185 & 0.413 & 0.459 & 0.588 & 0.168 \\
\hline & Kazakhstan & 0.748 & $\mathrm{~m}$ & 0.848 & $\mathrm{~m}$ & 0.678 & $\mathrm{~m}$ \\
\hline & Latvia & 0.184 & 0.086 & 0.255 & 0.148 & 0.614 & 0.168 \\
\hline & Liechtenstein & 0.239 & 0.095 & 0.239 & 0.150 & 0.579 & 0.168 \\
\hline & Lithuania & 0.310 & 0.185 & 0.451 & 0.459 & 0.602 & 0.168 \\
\hline & Macao-China & 0.189 & 0.090 & 0.292 & 0.222 & 0.598 & 0.168 \\
\hline & Malaysia & 0.748 & $\mathrm{~m}$ & 0.848 & m & 0.678 & m \\
\hline & Montenegro & 0.336 & 0.185 & 0.419 & 0.459 & 0.591 & 0.168 \\
\hline & Peru & 0.748 & $\mathrm{~m}$ & 0.245 & 0.205 & 0.678 & $\mathrm{~m}$ \\
\hline & Qatar & 0.358 & 0.185 & 0.411 & 0.459 & 0.584 & 0.168 \\
\hline & Romania & 0.308 & 0.185 & 0.287 & 0.207 & 0.604 & 0.168 \\
\hline & Russian Federation & 0.186 & 0.084 & 0.284 & 0.148 & 0.620 & 0.168 \\
\hline & Serbia & 0.329 & 0.185 & 0.424 & 0.459 & 0.594 & 0.168 \\
\hline & Shanghai-China & 0.748 & $\mathrm{~m}$ & 0.848 & $\mathrm{~m}$ & 0.678 & $\mathrm{~m}$ \\
\hline & Singapore & 0.748 & $\mathrm{~m}$ & 0.848 & $\mathrm{~m}$ & 0.678 & $\mathrm{~m}$ \\
\hline & Chinese Taipei & 0.336 & 0.185 & 0.419 & 0.459 & 0.591 & 0.168 \\
\hline & Thailand & 0.199 & 0.093 & 0.208 & 0.176 & 0.590 & 0.168 \\
\hline & Tunisia & 0.191 & 0.091 & 0.288 & 0.221 & 0.595 & 0.168 \\
\hline & United Arab Emirates* & 1.122 & $\mathrm{~m}$ & 1.273 & $\mathrm{~m}$ & 1.017 & $\mathrm{~m}$ \\
\hline & Uruguay & 0.205 & 0.092 & 0.274 & 0.220 & 0.589 & 0.168 \\
\hline
\end{tabular}

Note: The link error is calculated empirically by adding a random error component from a normal distribution with mean equal to zero and standard deviation equal to those shown in Table A5.1 to each student's scores in PISA 2000, PISA 2003, PISA 2006 or PISA 2009. The linear and quadratic terms of a regression model are then calculated for each of 500 replications. The standard deviation in the observed coefficients is the result of the added error and is the reported link error.

* United Arab Emirates excluding Dubai.

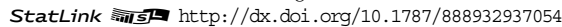


The annualised change in performance is calculated through an individual-level OLS regression of the form

$$
\operatorname{PISA}_{i}=\beta_{0}+\beta_{1} \text { year }_{i}+\varepsilon_{i}
$$

where $P I S A_{i}$ is student $i$ 's mathematics, reading or science score, year $r_{i}$ is the year student $i$ took the PISA assessment and $\varepsilon_{i}$ is an error term indicating student $i$ 's difference from the group mean. Under this specification, the estimate for $\beta_{1}$ indicates the annualised rate of change. Just as a link error is added when drawing comparisons between two PISA assessments, the standard errors for $\beta_{1}$ also include a link error:

$$
\sigma_{\text {link }}\left(\beta_{1}\right)=\sqrt{\sigma^{2}\left(\beta_{1}\right)+\text { error }_{\text {annual }}^{2}}
$$

where error $r_{\text {annual }}$ is the link error associated to the linear term in a regression model. It is presented in Table A5.3.

The annualised change is a more robust measure of a country's/economy's progress in education outcomes as it is based on information available from all assessments. It is thus less sensitive to abnormal measurements that may alter a country's/economy's PISA trends if results are compared only between two assessments. The annualised change is calculated as the best-fitting line throughout a country's/ economy's participation in PISA. The year that individual students participated in PISA is regressed on their PISA scores, yielding the annualised change. The annualised change also takes into account the fact that, for some countries and economies, the period between PISA assessments is less than three years. This is the case for those countries and economies that participated in PISA 2000 or PISA 2009 as part of PISA+: they conducted the assessment in 2001, 2002 or 2010 instead of 2000 or 2009. Figure A5.1 compares the value of the annualised change in mathematics with the difference in mathematics performance observed in PISA 2012 and PISA 2003. Figures A5.2 and A5.3 do the same for reading and science: they compare the annualised change in performance with the difference between PISA 2012 and PISA 2000 and PISA 2006, respectively. In general, and especially in the comparison between science in PISA 2006 and PISA 2012, the annualised change provides a result similar to the difference in performance between two assessments. As more assessments are taken into account, the annualised change begins to differ from the observed trend, providing a more complete picture of a country's/economy's progress in PISA.

- Figure A5.1

Annualised change in mathematics performance since PISA 2003 and observed difference in performance between PISA 2012 and PISA 2003

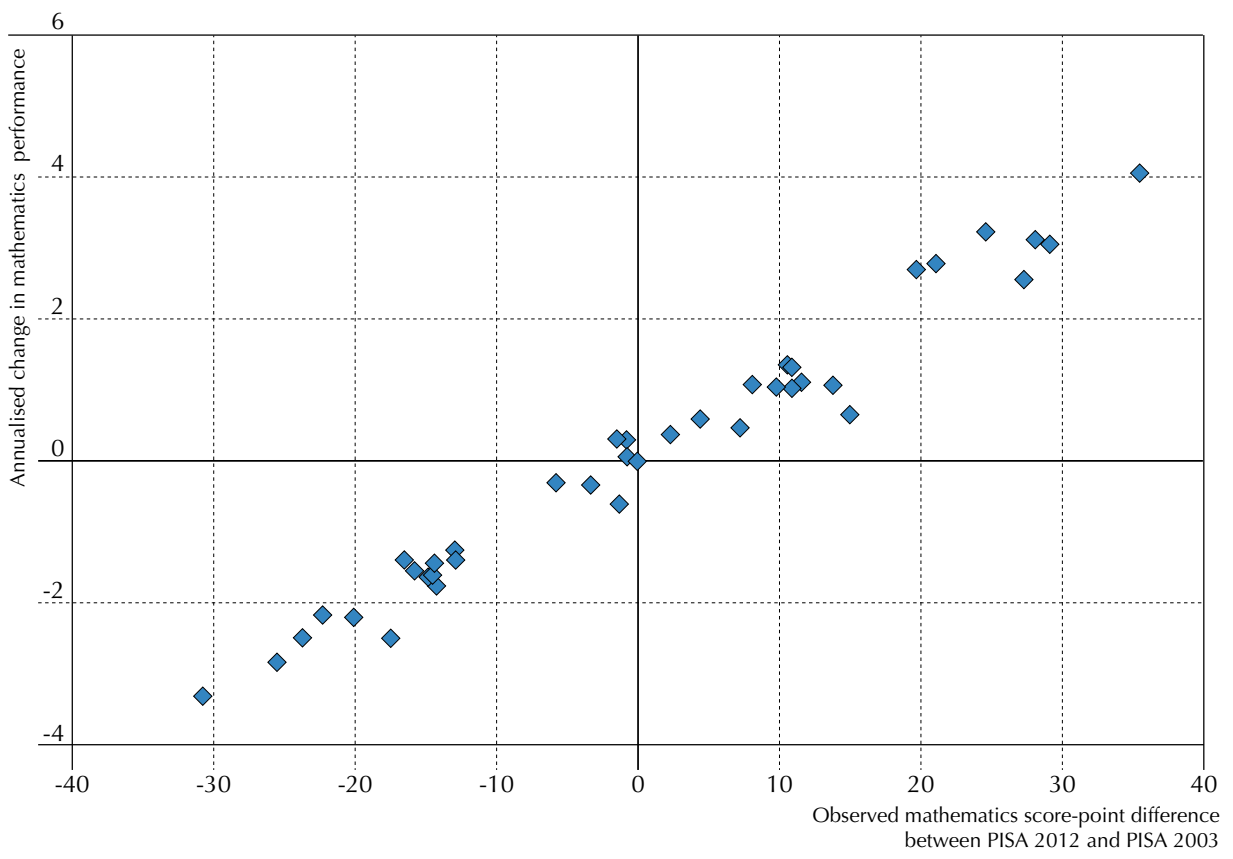

Notes: The annualised change is the average annual change in PISA score points from a country's/economy's earliest participation in PISA to PISA 2012. It is calculated taking into account all country's/economy's participation in PISA.

Source: OECD, PISA 2012 Database, Table 1.2.3b.

StatLink 解古 http://dx.doi.org/10.1787/888932937054 
- Figure A5.2

Annualised change in reading performance since PISA 2000 and observed difference in performance between PISA 2012 and PISA 2000

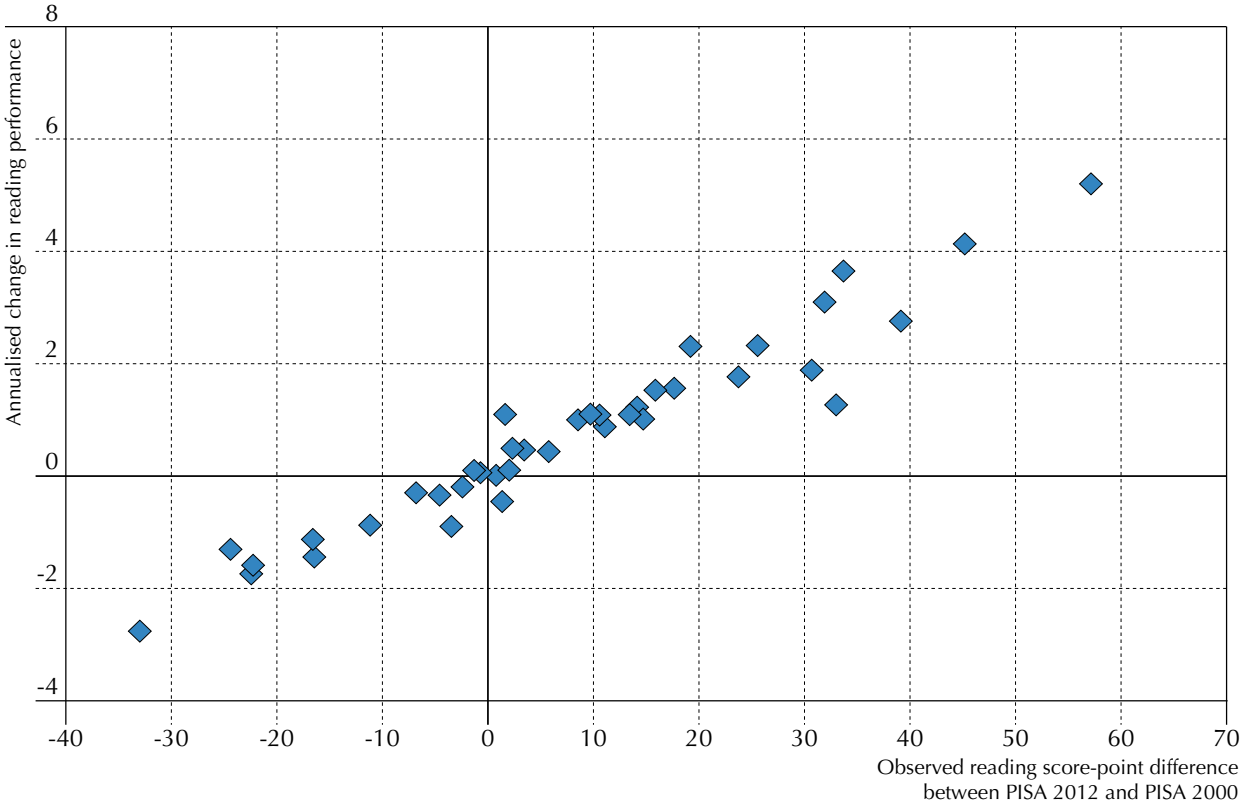

Notes: The annualised change is the average annual change in PISA score points from a country's/economy's earliest participation in PISA to PISA 2012. It is calculated taking into account all country's/economy's participation in PISA.

Source: OECD, PISA 2012 Database, Table I.4.3b.

StatLink त्ता st http://dx.doi.org/10.1787/888932937054

- Figure A5.3

Annualised change in science performance since PISA 2006 and observed difference in performance between PISA 2012 and PISA 2006

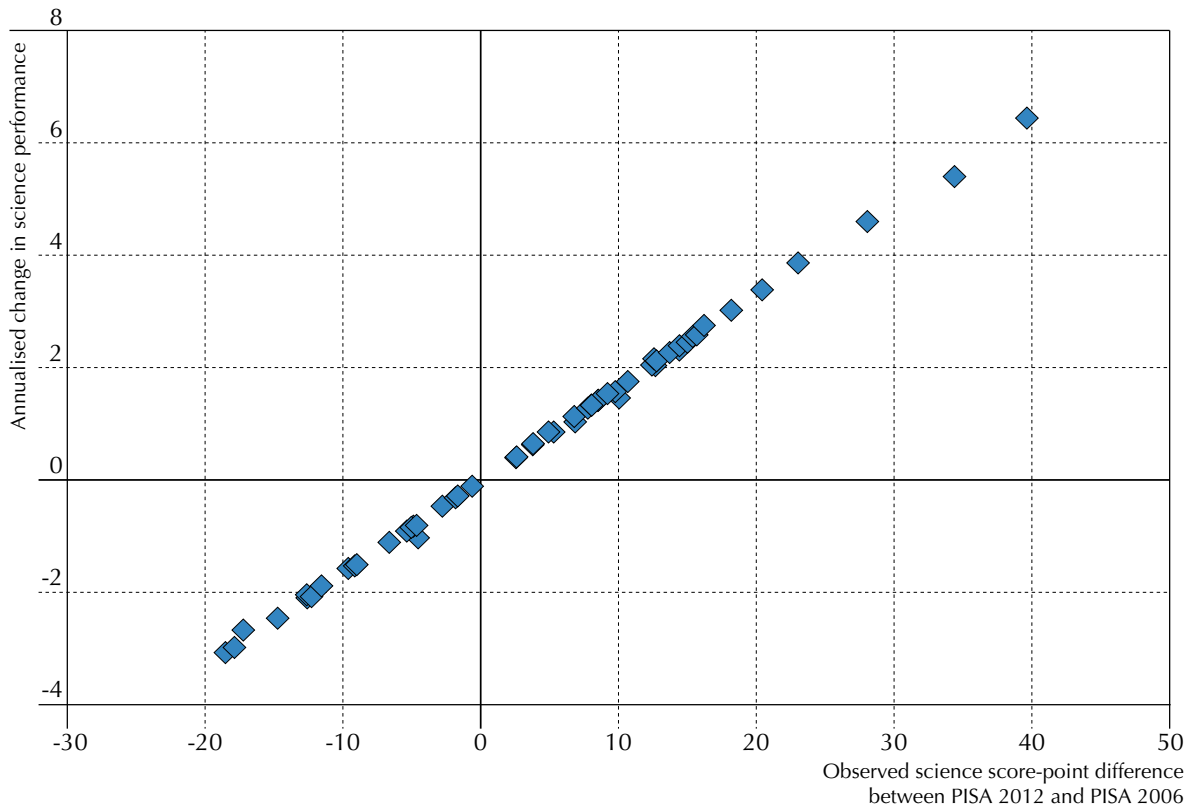

Notes: The annualised change is the average annual change in PISA score points from a country's/economy's earliest participation in PISA to PISA 2012. It is calculated taking into account all country's/economy's participation in PISA.

Source: OECD, PISA 2012 Database, Table I.5.3b.

StatLink त्तार http://dx.doi.org/10.1787/888932937054 
The annualised change assumes that progress in PISA is linear. An extension of the model that yields the annualised change is one that adds the curvature to the estimated annualised change by adding a quadratic term to the regression model (the curvilinear change):

$$
\text { PISA }_{i}=\beta_{0}+\beta_{1} \text { year }_{i}+\beta_{2} \text { year }_{1}^{2}+\varepsilon_{i}
$$

where $y e a r_{i}^{2}$ is equal to the square of year. When year is scaled such that it is equal to zero in $2012, \beta_{1}$ indicates the estimated rate of change in 2012 and $\beta_{2}$ the acceleration/deceleration of the trend. If $\beta_{2}$ is positive, it indicates that the observed trend is $U$-shaped, and rates of change in performance observed in years closer to 2012 are higher than those observed in earlier years. If $\beta_{2}$ is negative, the observed trend has an inverse- $U$-shape, and rates of change in performance observed in years closer to 2012 are lower than those observed in earlier years. Just as a link error is added when in the estimation of the standard errors for the annualised change, the standard errors for $\beta_{2}$ also include a link error:

$$
\sigma_{\text {link }}\left(\beta_{2}\right)=\sqrt{\sigma^{2}\left(\beta_{2}\right)+\text { error }_{\text {quadratic }}^{2}}
$$

where error ${ }_{\text {quadratic }}$ is the link error associated to the quadratic term in a regression model. It is presented in Table A5.3.

The Annualised and curvilinear change assumes a specific type of change: linear or quadratic. This specification may not fit well when a country's/economy's progress in PISA is the result of a one-time change (as can result from targeted policies that shift the performance level but does not create a continuous trajectory of change). Because of the variable nature of a country's/economy's change in performance in PISA, changes in performance must be analysed through the different measures reported in this volume.

\section{Adjusted trends}

PISA maintains its technical standards over time. Although this means that trends can be calculated over comparable populations, in some countries departures in sampling methods were observed. Furthermore, the demographic characteristics and socio-economic background of 15-year-old populations can also be subject to change, for example because of migration, changes in economic conditions or changes in students' and parents' educational attainment over a particular period of time.

Because trend analyses illustrate the pace of progress of successive cohorts of students, in order to draw reliable conclusions from such results, it is important to examine the extent to which they are driven by changes in the demographic and socio-economic condition of students. Two sets of trend results were therefore developed: unadjusted and adjusted trends. Adjusted trends represent trends in performance estimated when controlling for any changes in the average demographic and socio-economic profile of different student cohorts. Linear regression can be used to adjust performance results for differences in student background characteristics. The procedure to adjust performance trends for a single country over time is similar to the adjustment procedure that is used in PISA to derive estimates on between country differences in performance when adjusting for differences in country specific socio-economic and demographic conditions.

PISA reports three sets of results based on adjustments for differences in socio-economic status and demographic characteristics: country-specific estimated mean performances when adjusting for differences across countries in socio-economic and demographic characteristics; country-specific estimated performance change between two assessments when adjusting for differences across countryspecific cohorts in socio-economic and demographic characteristics; and country-specific estimated annualised performance change when adjusting for differences across country-specific cohorts in socio-economic and demographic characteristics. The adjusted mathematics, reading and science performance results reported in PISA Volume I use the 2012 PISA sample as a reference. Thus, the results from previous assessments were adjusted to be comparable to the 2012 sample and population. This was achieved by centring background characteristics on the 2012 average values for each country and then carrying out a regression with centred background characteristics to obtain adjusted trends. In other words, results for 2000, 2003, 2006 and 2009 were adjusted to match the 2012 data.

Table A5.4 provides means for background variables, with the following measures used for the adjustment: student gender and age, as well as indicators for students whose language spoken at home is different from the language of assessment and whether the student has an immigrant background. The last columns show changes in these characteristics. The results were also adjusted for changes in socio-economic status as measured by the PISA index of economic, social and cultural status (variable ESCS). As explained in Annex A1 and below, the ESCS index was re-estimated for 2000, 2003, 2006 and 2009 assessments to be comparable with 2012 results. Mean values, the standard deviation and changes in these statistics for the re-estimated ESCS index between 2012 and 2003 are reported in Table II.2.3b. These statistics could differ from those reported in previous reports, since the re-estimated values of the ESCS index that are comparable with 2012 results can differ slightly from those reported in previous assessments. In both tables, changes that are in bold print suggest that mean values on the respective measure changed between assessments. In this case, the difference between unadjusted and adjusted trends reflects this change, with adjusted trends accounting for it.

Unadjusted performance results are averaged across all students participating in PISA assessments. Thus, adjusted results should be also calculated over all participants in each country. That is not always possible, as in some cases, information on student background characteristics are missing due to non-response or invalid responses. Imputation of missing values was needed prior to the adjustments to sustain sample sizes and comparisons with unadjusted results. This was achieved using multiple imputation models that maintained the relationships between performance and background characteristics when imputing missing information (Rubin, 1987; Royston, 2004). 
[Part 1/3]

Descriptive statistics for variables used to adjust mathematics, reading and science scores Table A5.4 to the PISA 2012 samples

\begin{tabular}{|c|c|c|c|c|c|c|c|c|c|c|c|c|c|c|c|c|c|c|c|c|c|}
\hline & \multicolumn{10}{|c|}{ Students' age } & \multicolumn{10}{|c|}{ Student is a girl } \\
\hline & & \multicolumn{2}{|c|}{2000} & \multicolumn{2}{|c|}{2003} & & 06 & & 009 & & 12 & & 000 & & 003 & & 006 & & 09 & & 12 \\
\hline & & Mean & S.E. & Mean & S.E. & Mean & S.E. & Mean & S.E. & Mean & S.E. & $\%$ & S.E. & $\%$ & S.E. & $\%$ & S.E. & $\%$ & S.E. & $\%$ & S.E. \\
\hline 8 & Australia & 15.7 & $(0.01)$ & 15.8 & $(0.00)$ & 15.8 & $(0.00)$ & 15.8 & $(0.00)$ & 15.8 & $(0.00)$ & 47.5 & (2.18) & 49.2 & $(1.31)$ & 48.9 & (1.39) & 51.1 & $(1.30)$ & 48.5 & (0.59) \\
\hline 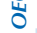 & Austria & 15.8 & $(0.01)$ & 15.8 & $(0.01)$ & 15.8 & $(0.01)$ & $\mathrm{m}$ & $\mathrm{m}$ & 15.8 & $(0.01)$ & 48.8 & $(2.25)$ & 49.9 & (1.56) & 49.1 & (1.82) & $\mathrm{m}$ & $\mathrm{m}$ & 50.1 & (1.52) \\
\hline & Belgium & 15.7 & $(0.00)$ & 15.9 & $(0.00)$ & 15.9 & $(0.00)$ & 15.8 & $(0.00)$ & 15.8 & $(0.00)$ & 47.9 & (1.65) & 47.9 & $(1.36)$ & 47.6 & $(1.40)$ & 48.9 & $(1.22)$ & 49.8 & $(0.91)$ \\
\hline & Canada & 15.8 & $(0.00)$ & 15.9 & $(0.00)$ & 15.8 & $(0.00)$ & 15.8 & $(0.00)$ & 15.8 & $(0.00)$ & 50.1 & $(0.52)$ & 50.7 & $(0.63)$ & 49.7 & $(0.62)$ & 49.7 & $(0.47)$ & 50.1 & $(0.43)$ \\
\hline & Chile & 15.8 & $(0.00)$ & $\mathrm{m}$ & & 15.8 & $(0.00)$ & 15.8 & $(0.00)$ & 15.8 & $(0.00)$ & 53.0 & $(1.82)$ & $\mathrm{m}$ & & 46.0 & $(1.55)$ & 49.0 & (1.12) & 51.6 & (1.28) \\
\hline & Czech Republic & 15.7 & $(0.01)$ & 15.9 & $(0.01)$ & 15.9 & $(0.01)$ & 15.8 & $(0.01)$ & 15.7 & $(0.01)$ & 51.7 & $(1.77)$ & 49.3 & $(1.72)$ & 43.4 & $(1.90)$ & 46.8 & (1.80) & 48.7 & (1.68) \\
\hline & Denmark & 15.7 & $(0.00)$ & 15.7 & $(0.01)$ & 15.7 & $(0.01)$ & 15.7 & $(0.00)$ & 15.8 & $(0.01)$ & 49.7 & $(0.94)$ & 50.9 & $(0.81)$ & 50.3 & $(0.80)$ & 50.5 & $(0.70)$ & 49.7 & $(0.56)$ \\
\hline & Estonia & $\mathrm{m}$ & $\mathrm{m}$ & $\mathrm{m}$ & $\mathrm{m}$ & 15.8 & $(0.01)$ & 15.8 & $(0.00)$ & 15.8 & $(0.01)$ & $\mathrm{m}$ & $\mathrm{m}$ & $\mathrm{m}$ & $\mathrm{m}$ & 48.8 & $(0.86)$ & 48.2 & $(0.70)$ & 50.5 & (0.69) \\
\hline & Finland & 15.6 & $(0.00)$ & 15.7 & $(0.00)$ & 15.6 & $(0.00)$ & 15.7 & $(0.00)$ & 15.7 & $(0.00)$ & 51.4 & $(0.78)$ & 50.1 & $(0.72)$ & 50.4 & $(0.83)$ & 49.9 & $(0.51)$ & 48.6 & $(0.47)$ \\
\hline & France & 15.8 & $(0.01)$ & 15.9 & $(0.00)$ & 15.7 & $(0.01)$ & 15.9 & $(0.00)$ & 15.9 & $(0.00)$ & 51.3 & $(1.32)$ & 52.6 & (1.35) & 51.5 & $(1.28)$ & 51.3 & (1.19) & 51.4 & (1.00) \\
\hline & Germany & 15.7 & $(0.01)$ & 15.8 & $(0.00)$ & 15.9 & $(0.00)$ & 15.8 & $(0.01)$ & 15.8 & $(0.01)$ & 49.7 & $(1.47)$ & 49.7 & (1.04) & 48.4 & $(0.86)$ & 48.9 & $(0.97)$ & 49.1 & $(0.75)$ \\
\hline & Greece & 15.7 & $(0.01)$ & 15.7 & $(0.00)$ & 15.7 & $(0.00)$ & 15.7 & $(0.01)$ & 15.7 & $(0.00)$ & 49.8 & (1.31) & 51.7 & (1.19) & 49.7 & $(1.00)$ & 50.9 & (1.11) & 50.5 & $(0.72)$ \\
\hline & Hungary & 15.7 & $(0.01)$ & 15.7 & $(0.01)$ & 15.7 & $(0.01)$ & 15.7 & $(0.00)$ & 15.7 & $(0.00)$ & 49.6 & (2.11) & 47.3 & (1.58) & 47.9 & (1.87) & 49.6 & (1.51) & 51.8 & (1.43) \\
\hline & Iceland & 15.6 & $(0.00)$ & 15.7 & $(0.00)$ & 15.7 & $(0.00)$ & 15.7 & $(0.00)$ & 15.7 & $(0.00)$ & 50.4 & $(0.84)$ & 48.4 & $(0.82)$ & 49.6 & $(0.75)$ & 50.3 & $(0.26)$ & 49.4 & $(0.33)$ \\
\hline & Ireland & 15.7 & $(0.00)$ & 15.7 & $(0.01)$ & 15.7 & $(0.00)$ & 15.7 & $(0.00)$ & 15.7 & $(0.00)$ & 50.4 & (1.79) & 49.6 & $(0.91)$ & 50.6 & (1.07) & 49.4 & (1.08) & 49.2 & (1.09) \\
\hline & Israel & 15.6 & $(0.01)$ & $\mathrm{m}$ & $\mathrm{m}$ & 15.8 & $(0.01)$ & 15.7 & $(0.00)$ & 15.7 & $(0.00)$ & 58.2 & (2.67) & $\mathrm{m}$ & $\mathrm{m}$ & 50.4 & $(1.40)$ & 50.9 & $(0.93)$ & 50.8 & $(0.81)$ \\
\hline & Italy & 15.7 & $(0.00)$ & 15.7 & $(0.00)$ & 15.7 & $(0.00)$ & 15.7 & $(0.00)$ & 15.8 & $(0.00)$ & 49.3 & $(2.70)$ & 51.9 & (1.71) & 50.4 & $(0.97)$ & 48.6 & (0.93) & 48.2 & (0.91) \\
\hline & Japan & 15.7 & $(0.00)$ & 15.8 & $(0.00)$ & 15.8 & $(0.00)$ & 15.8 & $(0.00)$ & 15.8 & $(0.00)$ & 50.5 & (2.35) & 51.7 & $(2.27)$ & 49.9 & (2.39) & 48.4 & $(1.77)$ & 47.4 & (1.48) \\
\hline & Korea & 15.7 & $(0.00)$ & 15.8 & $(0.00)$ & 15.8 & $(0.01)$ & 15.7 & $(0.01)$ & 15.7 & $(0.01)$ & 44.1 & (3.53) & 40.5 & (3.00) & 49.3 & (2.98) & 47.3 & (1.81) & 46.6 & (1.58) \\
\hline & Luxembourg & $\mathrm{m}$ & $\mathrm{m}$ & 15.8 & $(0.00)$ & 15.9 & $(0.00)$ & 15.8 & $(0.00)$ & 15.8 & $(0.00)$ & $\mathrm{m}$ & $\mathrm{m}$ & 50.8 & $(0.58)$ & 49.4 & $(0.67)$ & 49.3 & $(0.16)$ & 49.2 & $(0.20)$ \\
\hline & Mexico & 15.7 & $(0.01)$ & 15.8 & $(0.01)$ & 15.7 & $(0.01)$ & 15.7 & $(0.00)$ & 15.7 & $(0.00)$ & 50.0 & (1.19) & 51.8 & (0.99) & 51.9 & (0.95) & 50.6 & $(0.44)$ & 51.0 & $(0.36)$ \\
\hline & Netherlands & $\mathrm{m}$ & $\mathrm{m}$ & 15.7 & $(0.01)$ & 15.7 & $(0.00)$ & 15.7 & $(0.00)$ & 15.7 & $(0.01)$ & $\mathrm{m}$ & $\mathrm{m}$ & 49.0 & (1.19) & 49.1 & $(0.92)$ & 50.3 & $(0.70)$ & 48.8 & $(0.67)$ \\
\hline & New Zealand & 15.7 & $(0.00)$ & 15.8 & $(0.00)$ & 15.8 & $(0.00)$ & 15.8 & $(0.00)$ & 15.8 & $(0.00)$ & 49.7 & (2.44) & 50.0 & (1.98) & 51.6 & $(2.10)$ & 49.0 & (1.23) & 48.9 & (1.19) \\
\hline & Norway & 15.7 & $(0.00)$ & 15.8 & $(0.00)$ & 15.8 & $(0.01)$ & 15.8 & $(0.00)$ & 15.8 & $(0.01)$ & 49.0 & $(0.88)$ & 49.6 & $(0.82)$ & 48.3 & $(0.73)$ & 48.9 & $(0.48)$ & 48.7 & $(0.51)$ \\
\hline & Poland & 15.7 & $(0.01)$ & 15.7 & $(0.00)$ & 15.7 & $(0.00)$ & 15.7 & $(0.00)$ & 15.7 & $(0.00)$ & 49.1 & $(2.65)$ & 50.1 & $(0.72)$ & 50.3 & $(0.75)$ & 50.0 & $(0.51)$ & 51.2 & $(0.84)$ \\
\hline & Portugal & 15.6 & $(0.00)$ & 15.9 & $(0.01)$ & 15.7 & $(0.01)$ & 15.7 & $(0.01)$ & 15.7 & $(0.01)$ & 52.0 & $(0.92)$ & 52.4 & $(0.90)$ & 51.7 & $(0.81)$ & 51.1 & $(0.62)$ & 49.4 & $(0.68)$ \\
\hline & Slovak Republic & $\mathrm{m}$ & $\mathrm{m}$ & 15.8 & $(0.01)$ & 15.7 & $(0.01)$ & 15.7 & $(0.01)$ & 15.8 & $(0.01)$ & $\mathrm{m}$ & $\mathrm{m}$ & 48.8 & $(1.71)$ & 48.6 & $(1.71)$ & 50.4 & $(1.57)$ & 47.6 & (1.56) \\
\hline & Slovenia & $\mathrm{m}$ & $\mathrm{m}$ & $\mathrm{m}$ & $\mathrm{m}$ & 15.7 & $(0.00)$ & 15.7 & $(0.01)$ & 15.7 & $(0.00)$ & $\mathrm{m}$ & $\mathrm{m}$ & $\mathrm{m}$ & $\mathrm{m}$ & 50.2 & $(0.74)$ & 49.0 & $(0.45)$ & 48.2 & $(0.44)$ \\
\hline & Spain & 15.8 & $(0.00)$ & 15.8 & $(0.00)$ & 15.8 & $(0.00)$ & 15.9 & $(0.00)$ & 15.9 & $(0.00)$ & 50.8 & $(1.34)$ & 50.8 & (1.09) & 49.4 & $(0.71)$ & 49.2 & $(0.57)$ & 49.2 & $(0.43)$ \\
\hline & Sweden & 15.7 & $(0.00)$ & 15.7 & $(0.00)$ & 15.7 & $(0.00)$ & 15.8 & $(0.01)$ & 15.7 & $(0.00)$ & 49.2 & $(0.86)$ & 49.9 & $(0.90)$ & 48.7 & $(0.76)$ & 49.2 & $(0.53)$ & 49.6 & $(0.57)$ \\
\hline & Switzerland & 15.7 & $(0.01)$ & 15.8 & $(0.01)$ & 15.8 & $(0.01)$ & 15.8 & $(0.01)$ & 15.9 & $(0.01)$ & 49.8 & $(1.00)$ & 48.3 & $(1.62)$ & 48.4 & $(0.83)$ & 49.2 & (1.14) & 49.9 & (1.20) \\
\hline & Turkey & $\mathrm{m}$ & & 15.9 & $(0.00)$ & 15.9 & $(0.01)$ & 15.8 & $(0.00)$ & 15.8 & $(0.00)$ & $\mathrm{m}$ & $\mathrm{m}$ & 45.0 & (1.95) & 45.3 & $(1.92)$ & 48.4 & $(1.71)$ & 49.5 & (1.98) \\
\hline & United Kingdom & $\mathrm{m}$ & $\mathrm{m}$ & $\mathrm{m}$ & $\mathrm{m}$ & 15.7 & $(0.00)$ & 15.7 & $(0.00)$ & 15.7 & $(0.00)$ & $\mathrm{m}$ & $\mathrm{m}$ & $\mathrm{m}$ & $\mathrm{m}$ & 50.5 & $(1.02)$ & 50.9 & (1.61) & 51.0 & $(1.35)$ \\
\hline & United States & 15.7 & $(0.01)$ & 15.8 & $(0.01)$ & 15.8 & $(0.01)$ & 15.8 & $(0.01)$ & 15.8 & $(0.01)$ & 51.6 & $(0.98)$ & 49.6 & $(0.82)$ & 49.4 & $(0.94)$ & 48.7 & $(0.75)$ & 49.0 & $(0.72)$ \\
\hline$\frac{n}{2}$ & Albania & 15.7 & $(0.01)$ & $\mathrm{m}$ & $\mathrm{m}$ & $\mathrm{m}$ & $\mathrm{m}$ & 15.8 & $(0.01)$ & 15.8 & $(0.01)$ & 51.0 & $(1.20)$ & $\mathrm{m}$ & $\mathrm{m}$ & $\mathrm{m}$ & $\mathrm{m}$ & 48.7 & $(0.87)$ & 48.3 & $(1.25)$ \\
\hline$\$$ & Argentina & 15.8 & $(0.01)$ & $\mathrm{m}$ & $\mathrm{m}$ & 15.7 & $(0.01)$ & 15.7 & $(0.01)$ & 15.7 & $(0.01)$ & 56.4 & $(2.52)$ & $\mathrm{m}$ & $\mathrm{m}$ & 52.9 & $(1.39)$ & 53.7 & (1.06) & 51.4 & (1.14) \\
\hline & Brazil & 15.7 & $(0.01)$ & 15.8 & $(0.00)$ & 15.8 & $(0.00)$ & 15.9 & $(0.00)$ & 15.9 & $(0.00)$ & 54.0 & (1.16) & 53.6 & $(0.82)$ & 53.8 & $(0.81)$ & 53.1 & $(0.38)$ & 52.2 & $(0.43)$ \\
\hline & Bulgaria & 15.6 & $(0.00)$ & $\mathrm{m}$ & $\mathrm{m}$ & 15.7 & $(0.01)$ & 15.8 & $(0.01)$ & 15.8 & $(0.00)$ & 48.5 & (1.90) & $\mathrm{m}$ & $\mathrm{m}$ & 48.2 & $(1.83)$ & 48.1 & $(2.24)$ & 48.2 & (1.78) \\
\hline & Colombia & $\mathrm{m}$ & $\mathrm{m}$ & $\mathrm{m}$ & $\mathrm{m}$ & 15.8 & $(0.01)$ & 15.9 & $(0.01)$ & 15.9 & $(0.00)$ & $\mathrm{m}$ & $\mathrm{m}$ & $\mathrm{m}$ & $\mathrm{m}$ & 53.9 & (1.93) & 52.4 & $(1.20)$ & 52.9 & $(0.94)$ \\
\hline & Costa Rica & $\mathrm{m}$ & $\mathrm{m}$ & $\mathrm{m}$ & $\mathrm{m}$ & $\mathrm{m}$ & $\mathrm{m}$ & 15.8 & $(0.01)$ & 15.8 & $(0.01)$ & $\mathrm{m}$ & $\mathrm{m}$ & $\mathrm{m}$ & $\mathrm{m}$ & $\mathrm{m}$ & $\mathrm{m}$ & 53.0 & $(0.61)$ & 53.1 & $(0.72)$ \\
\hline & Croatia & $\mathrm{m}$ & $\mathrm{m}$ & $\mathrm{m}$ & $\mathrm{m}$ & 15.7 & $(0.00)$ & 15.7 & $(0.00)$ & 15.7 & $(0.00)$ & $\mathrm{m}$ & $\mathrm{m}$ & $\mathrm{m}$ & $\mathrm{m}$ & 50.0 & $(1.90)$ & 47.0 & $(1.87)$ & 49.0 & $(0.99)$ \\
\hline & Dubai (UAE) & $\mathrm{m}$ & $\mathrm{m}$ & $\mathrm{m}$ & $\mathrm{m}$ & $\mathrm{m}$ & $\mathrm{m}$ & 15.8 & $(0.00)$ & 15.8 & $(0.00)$ & $\mathrm{m}$ & $\mathrm{m}$ & $\mathrm{m}$ & $\mathrm{m}$ & $\mathrm{m}$ & $\mathrm{m}$ & 48.9 & $(0.14)$ & 48.9 & $(0.25)$ \\
\hline & Hong Kong-China & 15.7 & $(0.00)$ & 15.8 & $(0.01)$ & 15.8 & $(0.01)$ & 15.7 & $(0.00)$ & 15.7 & $(0.00)$ & 49.8 & $(2.12)$ & 49.8 & (2.36) & 50.7 & $(1.92)$ & 47.1 & $(1.76)$ & 46.3 & (1.84) \\
\hline & Indonesia & 15.7 & $(0.01)$ & 15.7 & $(0.00)$ & 15.8 & $(0.01)$ & 15.8 & $(0.01)$ & 15.9 & $(0.01)$ & 51.1 & $(1.84)$ & 50.4 & (1.36) & 48.7 & $(2.05)$ & 50.5 & (1.95) & 49.2 & (1.51) \\
\hline & Jordan & $\mathrm{m}$ & $\mathrm{m}$ & $\mathrm{m}$ & $\mathrm{m}$ & 15.9 & $(0.00)$ & 15.9 & $(0.01)$ & 15.9 & $(0.00)$ & $\mathrm{m}$ & $\mathrm{m}$ & $\mathrm{m}$ & $\mathrm{m}$ & 50.2 & (1.95) & 49.6 & (1.30) & 50.6 & (1.58) \\
\hline & Kazakhstan & $\mathrm{m}$ & $\mathrm{m}$ & $\mathrm{m}$ & $\mathrm{m}$ & $\mathrm{m}$ & $\mathrm{m}$ & 15.8 & $(0.01)$ & 15.8 & $(0.01)$ & $\mathrm{m}$ & $\mathrm{m}$ & $\mathrm{m}$ & $\mathrm{m}$ & $\mathrm{m}$ & $\mathrm{m}$ & 49.3 & $(0.72)$ & 50.2 & $(0.97)$ \\
\hline & Latvia & 15.7 & $(0.01)$ & 15.9 & $(0.01)$ & 15.8 & $(0.01)$ & 15.8 & $(0.01)$ & 15.8 & $(0.01)$ & 51.3 & $(1.56)$ & 52.0 & $(1.22)$ & 51.4 & $(0.69)$ & 50.7 & $(0.87)$ & 49.6 & $(0.89)$ \\
\hline & Liechtenstein & 15.7 & $(0.02)$ & 15.8 & $(0.01)$ & 15.8 & $(0.01)$ & 15.8 & $(0.02)$ & 15.8 & $(0.01)$ & 49.7 & $(2.87)$ & 48.7 & $(2.77)$ & 53.8 & $(2.31)$ & 47.0 & $(1.21)$ & 46.8 & (1.31) \\
\hline & Lithuania & $\mathrm{m}$ & $\mathrm{m}$ & $\mathrm{m}$ & $\mathrm{m}$ & 15.8 & $(0.01)$ & 15.8 & $(0.01)$ & 15.8 & $(0.00)$ & $\mathrm{m}$ & $\mathrm{m}$ & $\mathrm{m}$ & $\mathrm{m}$ & 49.1 & $(0.71)$ & 49.3 & $(0.50)$ & 49.6 & $(0.61)$ \\
\hline & Macao-China & $\mathrm{m}$ & $\mathrm{m}$ & 15.8 & $(0.01)$ & 15.8 & $(0.00)$ & 15.8 & $(0.00)$ & 15.8 & $(0.00)$ & $\mathrm{m}$ & $\mathrm{m}$ & 51.4 & (1.53) & 49.4 & $(0.81)$ & 49.4 & $(0.09)$ & 48.7 & $(0.24)$ \\
\hline & Malaysia & $\mathrm{m}$ & $\mathrm{m}$ & $\mathrm{m}$ & $\mathrm{m}$ & $\mathrm{m}$ & $\mathrm{m}$ & 15.8 & $(0.00)$ & 15.8 & $(0.01)$ & $\mathrm{m}$ & $\mathrm{m}$ & $\mathrm{m}$ & $\mathrm{m}$ & $\mathrm{m}$ & $\mathrm{m}$ & 50.9 & $(0.81)$ & 51.6 & $(1.09)$ \\
\hline & Montenegro & $\mathrm{m}$ & $\mathrm{m}$ & $\mathrm{m}$ & $\mathrm{m}$ & 15.7 & $(0.00)$ & 15.8 & $(0.00)$ & 15.8 & $(0.00)$ & $\mathrm{m}$ & $\mathrm{m}$ & $\mathrm{m}$ & $\mathrm{m}$ & 48.4 & $(0.57)$ & 48.8 & $(0.26)$ & 50.0 & $(0.23)$ \\
\hline & Peru & 15.7 & $(0.01)$ & $\mathrm{m}$ & $\mathrm{m}$ & $\mathrm{m}$ & $\mathrm{m}$ & 15.8 & $(0.00)$ & 15.8 & $(0.00)$ & 49.9 & (2.23) & $\mathrm{m}$ & $\mathrm{m}$ & $\mathrm{m}$ & $\mathrm{m}$ & 49.5 & $(1.21)$ & 51.4 & (1.59) \\
\hline & Qatar & $\mathrm{m}$ & $\mathrm{m}$ & $\mathrm{m}$ & $\mathrm{m}$ & 15.7 & $(0.00)$ & 15.7 & $(0.00)$ & 15.8 & $(0.00)$ & $\mathrm{m}$ & $\mathrm{m}$ & $\mathrm{m}$ & $\mathrm{m}$ & 49.4 & $(0.12)$ & 49.1 & $(0.11)$ & 48.4 & $(0.13)$ \\
\hline & Romania & 14.7 & $(0.01)$ & $\mathrm{m}$ & $\mathrm{m}$ & 15.7 & $(0.01)$ & 15.7 & $(0.01)$ & 15.7 & $(0.00)$ & 52.7 & (1.12) & $\mathrm{m}$ & $\mathrm{m}$ & 50.2 & $(1.77)$ & 50.9 & $(1.41)$ & 51.0 & (1.26) \\
\hline & Russian Federation & 15.7 & $(0.00)$ & 15.8 & $(0.01)$ & 15.8 & $(0.01)$ & 15.8 & $(0.01)$ & 15.8 & $(0.01)$ & 50.1 & $(0.89)$ & 50.3 & $(1.32)$ & 52.1 & $(1.00)$ & 50.4 & $(0.72)$ & 50.0 & $(0.82)$ \\
\hline & Serbia & $\mathrm{m}$ & $\mathrm{m}$ & $\mathrm{m}$ & $\mathrm{m}$ & 15.8 & $(0.01)$ & 15.8 & $(0.01)$ & 15.9 & $(0.01)$ & $\mathrm{m}$ & $\mathrm{m}$ & $\mathrm{m}$ & $\mathrm{m}$ & 49.2 & (1.48) & 49.8 & $(1.21)$ & 50.2 & $(1.07)$ \\
\hline & Shanghai-China & $\mathrm{m}$ & $\mathrm{m}$ & $\mathrm{m}$ & $\mathrm{m}$ & $\mathrm{m}$ & $\mathrm{m}$ & 15.8 & $(0.00)$ & 15.8 & $(0.01)$ & $\mathrm{m}$ & $\mathrm{m}$ & $\mathrm{m}$ & $\mathrm{m}$ & $\mathrm{m}$ & $\mathrm{m}$ & 50.5 & $(0.94)$ & 51.3 & $(0.93)$ \\
\hline & Singapore & $\mathrm{m}$ & $\mathrm{m}$ & $\mathrm{m}$ & $\mathrm{m}$ & $\mathrm{m}$ & $\mathrm{m}$ & 15.7 & $(0.00)$ & 15.8 & $(0.00)$ & $\mathrm{m}$ & $\mathrm{m}$ & $\mathrm{m}$ & $\mathrm{m}$ & $\mathrm{m}$ & $\mathrm{m}$ & 49.2 & $(0.17)$ & 49.0 & $(0.40)$ \\
\hline & Chinese Taipei & $\mathrm{m}$ & $\mathrm{m}$ & $\mathrm{m}$ & $\mathrm{m}$ & 15.7 & $(0.01)$ & 15.7 & $(0.01)$ & 15.7 & $(0.01)$ & $\mathrm{m}$ & $\mathrm{m}$ & $\mathrm{m}$ & $\mathrm{m}$ & 47.6 & (1.45) & 49.5 & $(1.75)$ & 50.9 & $(1.82)$ \\
\hline & Thailand & 15.8 & $(0.01)$ & 15.7 & $(0.01)$ & 15.7 & $(0.01)$ & 15.7 & $(0.01)$ & 15.7 & $(0.01)$ & 58.8 & $(2.04)$ & 54.9 & $(1.31)$ & 57.4 & $(1.45)$ & 56.7 & (1.54) & 56.0 & (1.24) \\
\hline & Tunisia & $\mathrm{m}$ & $\mathrm{m}$ & 15.9 & $(0.00)$ & 15.9 & $(0.00)$ & 15.9 & $(0.00)$ & 15.9 & $(0.00)$ & $\mathrm{m}$ & $\mathrm{m}$ & 50.7 & $(0.76)$ & 52.2 & $(0.92)$ & 52.4 & $(0.48)$ & 53.4 & $(0.61)$ \\
\hline & United Arab Em & $\mathrm{m}$ & $\mathrm{m}$ & $\mathrm{m}$ & $\mathrm{m}$ & $\mathrm{m}$ & $\mathrm{m}$ & 15.8 & $(0.01)$ & 15.9 & $(0.00)$ & $\mathrm{m}$ & $\mathrm{m}$ & $\mathrm{m}$ & $\mathrm{m}$ & $\mathrm{m}$ & $\mathrm{m}$ & 50.4 & $(1.17)$ & 51.8 & (2.71) \\
\hline & Uruguay & $\mathrm{m}$ & $\mathrm{m}$ & 15.8 & $(0.01)$ & 15.9 & $(0.00)$ & 15.9 & $(0.00)$ & 15.8 & $(0.00)$ & $\mathrm{m}$ & $\mathrm{m}$ & 51.2 & $(1.18)$ & 51.2 & $(0.95)$ & 53.0 & $(0.69)$ & 53.1 & $(0.92)$ \\
\hline
\end{tabular}

* United Arab Emirates excluding Dubai.

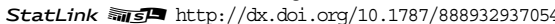


[Part 2/3]

Descriptive statistics for variables used to adjust mathematics, reading and science scores Table A5.4 to the PISA 2012 samples

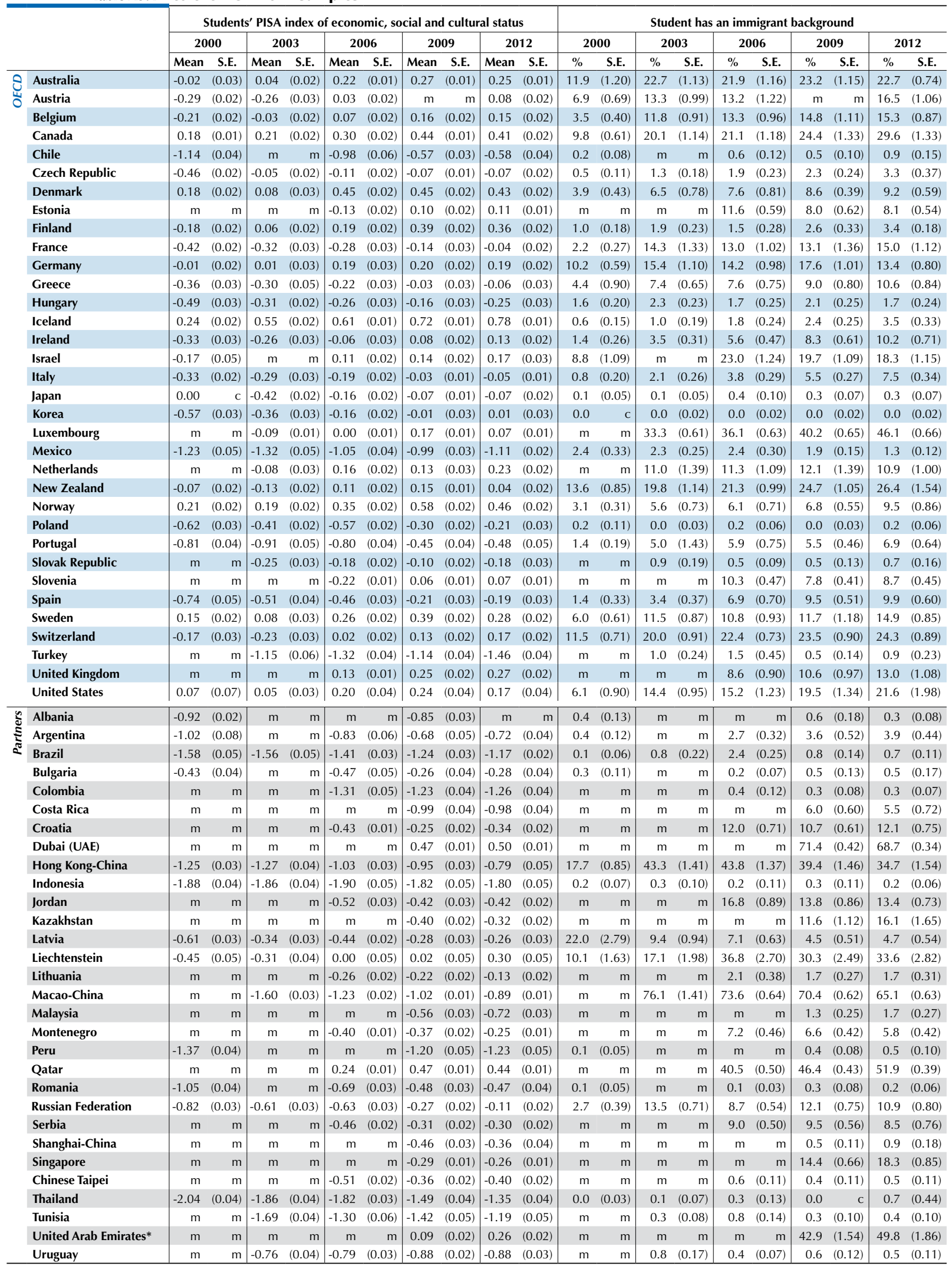

* United Arab Emirates excluding Dubai.

StatLink त्नाls http://dx.doi.org/10.1787/888932937054 
Part 3/3]

Descriptive statistics for variables used to adjust mathematics, reading and science scores Table A5.4 to the PISA 2012 samples

\begin{tabular}{|c|c|c|c|c|c|c|c|c|c|c|c|}
\hline & & \multicolumn{10}{|c|}{ Student speaks a language at home that is different than the language of assessment } \\
\hline & & \multicolumn{2}{|c|}{2000} & \multicolumn{2}{|c|}{2003} & \multicolumn{2}{|c|}{2006} & \multicolumn{2}{|c|}{2009} & \multicolumn{2}{|c|}{2012} \\
\hline & & $\%$ & S.E. & $\%$ & S.E. & $\%$ & S.E. & $\%$ & S.E. & $\%$ & S.E. \\
\hline \multirow{34}{*}{ 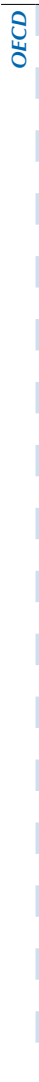 } & Australia & 0.2 & $(0.06)$ & 8.9 & $(0.66)$ & 8.1 & $(0.68)$ & 9.2 & $(0.72)$ & 9.8 & $(0.51)$ \\
\hline & Austria & 0.0 & C & 9.0 & $(0.74)$ & 10.0 & (1.13) & $\mathrm{m}$ & $\mathrm{m}$ & 11.4 & $(0.78)$ \\
\hline & Belgium & 19.0 & $(1.12)$ & 4.8 & $(0.38)$ & 18.0 & $(0.79)$ & 21.6 & (1.14) & 21.6 & $(0.86)$ \\
\hline & Canada & 2.3 & $(0.15)$ & 11.2 & $(0.69)$ & 12.9 & $(0.77)$ & 14.2 & $(0.83)$ & 17.3 & $(0.91)$ \\
\hline & Chile & 0.3 & $(0.10)$ & $\mathrm{m}$ & $\mathrm{m}$ & 0.2 & $(0.06)$ & 0.5 & $(0.10)$ & 0.6 & $(0.13)$ \\
\hline & Czech Republic & 0.0 & c & 0.9 & $(0.19)$ & 1.6 & $(0.21)$ & 1.3 & $(0.17)$ & 2.9 & $(0.37)$ \\
\hline & Denmark & 0.0 & C & 3.9 & $(0.48)$ & 4.5 & $(0.52)$ & 4.5 & $(0.27)$ & 4.6 & $(0.28)$ \\
\hline & Estonia & $\mathrm{m}$ & $\mathrm{m}$ & $\mathrm{m}$ & $\mathrm{m}$ & 4.1 & $(0.75)$ & 2.7 & $(0.40)$ & 5.5 & $(0.52)$ \\
\hline & Finland & 4.6 & $(0.22)$ & 1.8 & $(0.21)$ & 2.3 & $(0.45)$ & 3.7 & $(0.32)$ & 4.5 & $(0.22)$ \\
\hline & France & 1.1 & $(0.20)$ & 6.1 & $(0.72)$ & 7.0 & $(0.58)$ & 7.0 & $(0.62)$ & 8.0 & $(0.69)$ \\
\hline & Germany & 0.0 & $\mathrm{c}$ & 7.7 & $(0.57)$ & 9.0 & $(0.74)$ & 10.5 & $(0.76)$ & 7.4 & $(0.63)$ \\
\hline & Greece & 0.0 & c & 3.2 & $(0.39)$ & 3.9 & $(0.53)$ & 4.8 & $(0.64)$ & 5.1 & (0.58) \\
\hline & Hungary & 0.0 & c & 0.6 & $(0.12)$ & 0.8 & $(0.16)$ & 1.0 & $(0.34)$ & 1.0 & $(0.16)$ \\
\hline & Iceland & 0.0 & c & 1.6 & $(0.22)$ & 2.2 & $(0.26)$ & 3.1 & $(0.30)$ & 3.9 & (0.33) \\
\hline & Ireland & 1.0 & $(0.47)$ & 0.8 & $(0.18)$ & 4.1 & $(0.81)$ & 5.8 & $(0.87)$ & 4.9 & $(0.51)$ \\
\hline & Israel & 1.7 & $(0.37)$ & $\mathrm{m}$ & m & 12.8 & $(1.12)$ & 11.8 & (1.05) & 11.2 & $(0.91)$ \\
\hline & Italy & 17.4 & (1.14) & 1.6 & $(0.23)$ & 14.6 & $(0.54)$ & 14.3 & $(0.42)$ & 14.3 & $(0.39)$ \\
\hline & Japan & 0.0 & c & 0.2 & $(0.07)$ & 0.3 & $(0.10)$ & 0.2 & $(0.06)$ & 0.4 & $(0.08)$ \\
\hline & Korea & 0.0 & $\mathrm{c}$ & 0.1 & $(0.05)$ & 0.1 & $(0.04)$ & 0.1 & $(0.04)$ & 0.1 & $(0.03)$ \\
\hline & Luxembourg & $\mathrm{m}$ & $\mathrm{m}$ & 25.0 & $(0.59)$ & 90.4 & $(0.45)$ & 88.9 & $(0.44)$ & 85.5 & $(0.41)$ \\
\hline & Mexico & 1.5 & $(0.46)$ & 1.1 & $(0.32)$ & 3.4 & $(0.99)$ & 2.8 & $(0.30)$ & 3.2 & $(0.31)$ \\
\hline & Netherlands & $\mathrm{m}$ & $\mathrm{m}$ & 4.6 & $(0.62)$ & 5.9 & $(0.69)$ & 6.4 & $(0.81)$ & 6.4 & $(0.54)$ \\
\hline & New Zealand & 0.8 & $(0.16)$ & 9.0 & $(0.70)$ & 9.0 & $(0.58)$ & 14.5 & $(0.68)$ & 16.1 & (1.08) \\
\hline & Norway & 1.0 & $(0.22)$ & 4.5 & $(0.53)$ & 5.7 & $(0.50)$ & 7.3 & $(0.51)$ & 7.6 & $(0.63)$ \\
\hline & Poland & 0.5 & $(0.15)$ & 0.2 & $(0.07)$ & 0.4 & $(0.17)$ & 0.6 & $(0.13)$ & 0.8 & $(0.26)$ \\
\hline & Portugal & 0.0 & $\mathrm{c}$ & 1.4 & $(0.21)$ & 2.3 & $(0.37)$ & 1.6 & $(0.17)$ & 2.6 & $(0.27)$ \\
\hline & Slovak Republic & $\mathrm{m}$ & $\mathrm{m}$ & 1.4 & $(0.33)$ & 15.1 & (1.38) & 5.4 & $(0.77)$ & 7.4 & $(0.88)$ \\
\hline & Slovenia & $\mathrm{m}$ & $\mathrm{m}$ & $\mathrm{m}$ & m & 6.1 & $(0.36)$ & 5.2 & $(0.34)$ & 5.9 & $(0.42)$ \\
\hline & Spain & 13.6 & (1.45) & 1.7 & $(0.28)$ & 16.1 & $(0.86)$ & 18.1 & (1.04) & 18.6 & (1.11) \\
\hline & Sweden & 0.8 & $(0.17)$ & 6.9 & $(0.67)$ & 8.2 & $(0.89)$ & 8.1 & $(0.86)$ & 10.4 & (0.69) \\
\hline & Switzerland & 6.1 & $(0.50)$ & 9.5 & $(0.70)$ & 15.7 & $(0.64)$ & 15.5 & $(0.72)$ & 16.5 & $(0.82)$ \\
\hline & Turkey & $\mathrm{m}$ & $\mathrm{m}$ & 1.2 & $(0.57)$ & 2.4 & $(0.39)$ & 4.0 & $(0.56)$ & 6.3 & $(0.84)$ \\
\hline & United Kingdom & $\mathrm{m}$ & $\mathrm{m}$ & $\mathrm{m}$ & $\mathrm{m}$ & 4.8 & $(0.81)$ & 6.2 & $(0.59)$ & 7.0 & $(0.67)$ \\
\hline & United States & 0.0 & c & 9.0 & $(0.69)$ & 10.7 & $(1.03)$ & 13.1 & $(1.00)$ & 14.4 & (1.30) \\
\hline \multirow{30}{*}{ 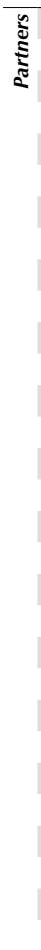 } & Albania & 0.7 & $(0.17)$ & $\mathrm{m}$ & $\mathrm{m}$ & $\mathrm{m}$ & $\mathrm{m}$ & 1.0 & $(0.20)$ & 2.6 & $(0.40)$ \\
\hline & Argentina & 0.4 & $(0.20)$ & $\mathrm{m}$ & $\mathrm{m}$ & 0.9 & $(0.35)$ & 1.4 & $(0.20)$ & 1.6 & $(0.24)$ \\
\hline & Brazil & 0.0 & $\mathrm{c}$ & 0.5 & $(0.12)$ & 0.3 & $(0.09)$ & 0.7 & $(0.09)$ & 1.1 & $(0.13)$ \\
\hline & Bulgaria & 1.2 & $(0.29)$ & $\mathrm{m}$ & $\mathrm{m}$ & 10.5 & $(1.26)$ & 10.9 & (1.74) & 10.7 & (1.16) \\
\hline & Colombia & $\mathrm{m}$ & $\mathrm{m}$ & $\mathrm{m}$ & $\mathrm{m}$ & 0.5 & $(0.17)$ & 0.4 & $(0.09)$ & 0.7 & $(0.19)$ \\
\hline & Costa Rica & $\mathrm{m}$ & $\mathrm{m}$ & $\mathrm{m}$ & $\mathrm{m}$ & $\mathrm{m}$ & $\mathrm{m}$ & 1.5 & $(0.29)$ & 1.2 & $(0.21)$ \\
\hline & Croatia & $\mathrm{m}$ & $\mathrm{m}$ & $\mathrm{m}$ & $\mathrm{m}$ & 1.4 & $(0.44)$ & 1.7 & $(0.44)$ & 1.3 & $(0.27)$ \\
\hline & Dubai (UAE) & $\mathrm{m}$ & $\mathrm{m}$ & $\mathrm{m}$ & $\mathrm{m}$ & $\mathrm{m}$ & $\mathrm{m}$ & 50.1 & $(0.65)$ & 50.2 & $(0.73)$ \\
\hline & Hong Kong-China & 4.2 & $(0.73)$ & 4.5 & $(0.39)$ & 7.1 & $(0.89)$ & 7.2 & (1.08) & 6.8 & $(0.88)$ \\
\hline & Indonesia & 67.4 & $(2.50)$ & 2.1 & $(0.28)$ & 65.8 & $(3.40)$ & 64.4 & $(2.12)$ & 58.9 & (2.35) \\
\hline & Jordan & $\mathrm{m}$ & $\mathrm{m}$ & $\mathrm{m}$ & $\mathrm{m}$ & 2.9 & $(0.29)$ & 3.2 & $(0.31)$ & 4.7 & $(0.32)$ \\
\hline & Kazakhstan & $\mathrm{m}$ & $\mathrm{m}$ & $\mathrm{m}$ & $\mathrm{m}$ & $\mathrm{m}$ & $\mathrm{m}$ & 10.2 & $(0.78)$ & 11.1 & $(0.92)$ \\
\hline & Latvia & 6.9 & $(0.94)$ & 0.5 & $(0.12)$ & 6.0 & $(0.51)$ & 9.4 & $(1.30)$ & 10.5 & (1.40) \\
\hline & Liechtenstein & 7.9 & (1.58) & 18.4 & $(2.25)$ & 12.2 & (1.58) & 15.0 & $(2.24)$ & 11.7 & $(1.82)$ \\
\hline & Lithuania & $\mathrm{m}$ & $\mathrm{m}$ & $\mathrm{m}$ & $\mathrm{m}$ & 3.3 & $(0.89)$ & 4.3 & $(0.83)$ & 3.5 & $(0.51)$ \\
\hline & Macao-China & $\mathrm{m}$ & $\mathrm{m}$ & 4.6 & $(0.72)$ & 99.3 & $(0.07)$ & 11.0 & $(0.16)$ & 13.6 & (0.19) \\
\hline & Malaysia & $\mathrm{m}$ & $\mathrm{m}$ & $\mathrm{m}$ & $\mathrm{m}$ & $\mathrm{m}$ & m & 29.9 & $(2.23)$ & 42.3 & (2.46) \\
\hline & Montenegro & $\mathrm{m}$ & $\mathrm{m}$ & $\mathrm{m}$ & $\mathrm{m}$ & 43.6 & $(0.63)$ & 1.7 & $(0.24)$ & 1.0 & $(0.14)$ \\
\hline & Peru & 5.3 & $(1.22)$ & $\mathrm{m}$ & $\mathrm{m}$ & $\mathrm{m}$ & $\mathrm{m}$ & 5.3 & $(0.86)$ & 6.4 & $(0.89)$ \\
\hline & Qatar & $\mathrm{m}$ & $\mathrm{m}$ & $\mathrm{m}$ & $\mathrm{m}$ & 25.4 & $(0.30)$ & 38.6 & $(0.31)$ & 39.2 & $(0.30)$ \\
\hline & Romania & 1.8 & $(0.44)$ & $\mathrm{m}$ & $\mathrm{m}$ & 2.9 & $(0.77)$ & 3.2 & $(0.57)$ & 1.7 & $(0.38)$ \\
\hline & Russian Federation & 0.0 & c & 5.4 & $(1.26)$ & 9.5 & $(2.02)$ & 9.6 & (1.54) & 8.6 & (1.74) \\
\hline & Serbia & $\mathrm{m}$ & $\mathrm{m}$ & $\mathrm{m}$ & $\mathrm{m}$ & 1.3 & $(0.15)$ & 1.8 & $(0.29)$ & 4.2 & $(0.62)$ \\
\hline & Shanghai-China & $\mathrm{m}$ & $\mathrm{m}$ & $\mathrm{m}$ & $\mathrm{m}$ & $\mathrm{m}$ & $\mathrm{m}$ & 1.5 & $(0.24)$ & 1.4 & $(0.18)$ \\
\hline & Singapore & $\mathrm{m}$ & $\mathrm{m}$ & $\mathrm{m}$ & $\mathrm{m}$ & $\mathrm{m}$ & $\mathrm{m}$ & 59.2 & $(0.80)$ & 54.4 & $(0.87)$ \\
\hline & Chinese Taipei & $\mathrm{m}$ & $\mathrm{m}$ & $\mathrm{m}$ & $\mathrm{m}$ & 23.8 & $(1.40)$ & 21.8 & $(1.24)$ & 16.5 & (1.07) \\
\hline & Thailand & 44.9 & $(2.34)$ & 3.0 & $(1.04)$ & 51.3 & $(1.87)$ & 48.6 & $(1.65)$ & 44.6 & (1.68) \\
\hline & Tunisia & $\mathrm{m}$ & $\mathrm{m}$ & 0.4 & $(0.09)$ & 4.7 & $(0.46)$ & 0.1 & $(0.05)$ & 1.1 & $(0.18)$ \\
\hline & United Arab Emirates* & $\mathrm{m}$ & $\mathrm{m}$ & $\mathrm{m}$ & $\mathrm{m}$ & $\mathrm{m}$ & $\mathrm{m}$ & 25.1 & $(1.25)$ & 27.4 & (1.18) \\
\hline & Uruguay & $\mathrm{m}$ & $\mathrm{m}$ & 1.9 & $(0.40)$ & 1.4 & $(0.27)$ & 2.3 & $(0.23)$ & 2.1 & $(0.35)$ \\
\hline
\end{tabular}

* United Arab Emirates excluding Dubai.

StatLink 部 St http://dx.doi.org/10.1787/888932937054 
The imputation model was carried out once for each plausible value and included all student background characteristics that were listed in the previous paragraph. After the imputation, all calculations were carried out five times, once for each imputed dataset containing one of five plausible values of the performance measures. Final results were obtained by averaging regression outcomes obtained from each imputed dataset and by accounting for imputation error using so-called Rubin's combination rules (Rubin, 1987). The results after imputation differ negligibly from those without the imputation given that for most countries and assessments the number of missing observations was relatively low.

\section{Comparing items and non-performance scales across PISA cycles}

To gather information about students' and schools' characteristics, PISA asks both students and schools to complete a background questionnaire. In PISA 2003 and PISA 2012 several questions were left untouched, allowing for a comparison of responses to these questions over time. In this report, only questions that retained the same wording were used for trends analyses. Questions with subtle word changes or questions with major word changes were not compared across time because it is impossible to discern whether observed changes in the response are due to changes in the construct they are measuring or to changes in the way the construct is being measured.

Also, as described in Annex A1, questionnaire items in PISA are used to construct indices. Whenever the questions used in the construction of indices remains intact in PISA 2003 and PISA 2012, the corresponding indices are compared. Two types of indices are used in PISA: simple indices and scale indices.

Simple indices recode a set of responses to questionnaire items. For trends analyses, the values observed in PISA 2003 are compared directly to PISA 2012, just as simple responses to questionnaire items are. This is the case of indices like student-teacher ratio and ability grouping in mathematics.

Scale indices, on the other hand, imply WLE estimates which require rescaling in order to be comparable across PISA cycles. Scale indices, like the PISA index of economic, social and cultural status, the index of sense of belonging, the index of attitudes towards school, the index of intrinsic motivation to learn mathematics, the index of instrumental motivation to learn mathematics, the index of mathematics self-efficacy, the index of mathematics self-concept, the index of anxiety towards mathematics, the index of teacher shortage, the index of quality of physical infrastructure, the index of quality of educational resources, the index of disciplinary climate, the index of student-teacher relations, the index of teacher morale, the index of student-related factors affecting school climate, and the index of teacher-related factors affecting school climate, were scaled in PISA 2012 to have an OECD average of 0 and a standard deviation of 1, on average across OECD countries. In PISA 2003 these same scales were scaled to have an OECD average of 0 and a standard deviation of 1 . Because they are on different scales, values reported in Learning for Tomorrow's World: First Results from PISA 2003 (OECD, 2004) cannot be compared with those reported in this volume. To make these scale indices comparable, values for 2003 have been rescaled to the 2012 scale, using the PISA 2012 parameter estimates.

To evaluate change in these items and scales, analyses report the change in the estimate between two assessments, usually PISA 2003 and PISA 2012. Comparisons between two assessments (e.g. a country's/economy's change in the index of anxiety towards mathematics between PISA 2003 and PISA 2012 or the change in this index for a subgroup) is calculated as:

$$
\Delta_{2012, t}=P I S A_{2012}-P I S A_{t}
$$

where $\Delta_{2012, t}$ is the difference in the index between PISA 2012 and a previous assessment, PISA 2012 is the index value observed in PISA 2012, and PISA $A_{t}$ is the index value observed in a previous assessment (2000, 2003, 2006 or 2009). The standard error of the change in performance $\sigma\left(\Delta_{2012-t}\right)$ is:

$$
\sigma\left(\Delta_{2012-t}\right)=\sqrt{\sigma_{2012}^{2}+\sigma_{t}^{2}}
$$

where $\sigma_{2012}$ is the standard error observed for PISA 2012 and $\sigma_{t}$ is the standard error observed for PISA $A_{t}$. These comparisons are based on an identical set of items; there is no uncertainty related to the choice of items for equating purposes, so no link error is needed.

Although only scale indices that use the same items in PISA 2003 and PISA 2012 are valid for trend comparisons, this does not imply that PISA 2012 indices that include exactly the same items as 2003 as well as new questionnaire items cannot be compared with PISA 2003 indices that included a smaller pool of items. In such cases, for example the index of sense of belonging trend analyses were conducted by treating as missing in PISA 2003 items that were asked in the context of PISA 2012 but not in the PISA 2003 student questionnaire. This means that while the full set of information was used to scale the sense of belonging index in 2012, the PISA 2003 sense of belonging index was scaled under the assumption that if the 2012 items that were missing in 2003 had been asked in 2003, the overall index and index variation would have remained the same as those that were observed on common 2003 items. This is a tenable assumption inasmuch as in both PISA 2003 and PISA 2012 the questionnaire items used to construct the scale hold as an underlying factor in the construction of the scale. 


\section{OECD average}

Throughout this report, the OECD average is used as a benchmark. It is calculated as the average across OECD countries, weighting each country equally. Some OECD countries did not participate in certain assessments, other OECD countries do not have comparable results for some assessments, others did not include certain questions in their questionnaires or changed them substantially from assessment to assessment. For this reason in trends tables and figures, the OECD average is reported as assessmentspecific, that is, it includes only those countries for which there is comparable information in that particular assessment. This way, the 2003 OECD average includes only those OECD countries that have comparable information from the 2003 assessment, even if the results it refers to the PISA 2012 assessment and more countries have comparable information. This restriction allows for valid comparisons of the OECD average over time.

\section{References}

OECD (forthcoming), PISA 2012 Technical Report, PISA, OECD Publishing.

OECD (2004), Learning for Tomorrow's World: First Results from PISA 2003, PISA, OECD Publishing. http://dx.doi.org/10.1787/9789264006416-en

Royston, P. (2004), “Multiple imputation of missing values", Stata Journal, Vol. 4, No.3, pp. 227-241.

Rubin, D.B. (1987), "Multiple imputation for non-response in surveys", John Wiley \& Sons, New York. 


\section{ANNEX A6}

DEVELOPMENT OF THE PISA ASSESSMENT INSTRUMENTS

Annex A6 is available on line only.

It can be found at: www.pisa.oecd.org 
ANNEX A7

\section{TECHNICAL NOTE ON BRAZIL}

In 2006, the education system in Brazil was revised to include one more year at the beginning of primary school, with the compulsory school age being lowered from seven to six years old. This change has been implemented in stages and will be completed in 2016. At the time the PISA 2012 survey took place, many of the 15-year-olds in Grade 7 had started their education under the previous system. They were therefore equivalent to Grade 6 students in the previous system. Since students below Grade 7 are not eligible for participation in PISA, the Grade 7 students in the sample were not included in the database.

Brazil also has many rural "multigrade" schools where it is difficult to identify the exact grade of each student, so not possible to identify students who are at least in Grade 7. The results for Brazil have therefore been analysed both with and without these rural schools. The results reported in the main chapters of this report are those of the Brazilian sample without the rural schools, while this annex gives the results for Brazil with the rural schools included.

\begin{tabular}{|c|c|c|c|c|c|c|c|c|c|c|c|c|c|c|c|}
\hline \multirow{2}{*}{ Table A7.1 } & & \multicolumn{2}{|c|}{ Below Level 1} & \multicolumn{2}{|c|}{ Level 1} & \multicolumn{2}{|c|}{ Level 2} & \multicolumn{2}{|c|}{ Level 3} & \multicolumn{2}{|c|}{ Level 4} & \multicolumn{2}{|c|}{ Level 5} & \multicolumn{2}{|c|}{ Level 6} \\
\hline & & $\%$ & S.E. & $\%$ & S.E. & $\%$ & S.E. & $\%$ & S.E. & $\%$ & S.E. & $\%$ & S.E. & $\%$ & S.E. \\
\hline \multirow[t]{3}{*}{ Mathematics scale } & All & 36.9 & $(0.9)$ & 31.4 & $(0.7)$ & 19.7 & $(0.7)$ & 8.5 & $(0.4)$ & 2.7 & $(0.3)$ & 0.7 & $(0.2)$ & 0.0 & $(0.0)$ \\
\hline & Boys & 33.0 & (1.1) & 31.3 & $(0.9)$ & 21.1 & $(0.8)$ & 10.0 & $(0.7)$ & 3.5 & (0.4) & 1.0 & $(0.2)$ & 0.1 & $(0.0)$ \\
\hline & Girls & 40.4 & (1.1) & 31.6 & $(0.9)$ & 18.4 & $(0.8)$ & 7.2 & $(0.6)$ & 2.0 & $(0.3)$ & 0.4 & $(0.2)$ & 0.0 & $(0.0)$ \\
\hline \multirow{3}{*}{$\begin{array}{l}\text { Mathematics subscale } \\
\text { formulating }\end{array}$} & All & 44.4 & (1.0) & 27.8 & $(0.6)$ & 17.1 & $(0.6)$ & 7.2 & $(0.4)$ & 2.6 & (0.3) & 0.8 & $(0.2)$ & 0.2 & $(0.1)$ \\
\hline & Boys & 38.1 & (1.1) & 29.0 & $(0.9)$ & 19.3 & $(0.7)$ & 8.6 & $(0.7)$ & 3.5 & $(0.5)$ & 1.1 & $(0.3)$ & 0.2 & $(0.1)$ \\
\hline & Girls & 50.2 & (1.3) & 26.7 & $(0.9)$ & 15.0 & $(0.8)$ & 5.9 & (0.5) & 1.7 & (0.3) & 0.5 & $(0.2)$ & 0.1 & $(0.1)$ \\
\hline \multirow{3}{*}{$\begin{array}{l}\text { Mathematics subscale } \\
\text { employing }\end{array}$} & All & 39.0 & (0.9) & 29.7 & $(0.6)$ & 19.1 & $(0.6)$ & 8.5 & $(0.4)$ & 2.9 & $(0.4)$ & 0.7 & $(0.2)$ & 0.1 & $(0.0)$ \\
\hline & Boys & 35.2 & (1.0) & 29.6 & $(0.9)$ & 20.6 & $(0.9)$ & 9.7 & (0.6) & 3.8 & (0.5) & 1.0 & $(0.3)$ & 0.1 & (0.1) \\
\hline & Girls & 42.6 & (1.1) & 29.8 & $(0.8)$ & 17.8 & $(0.8)$ & 7.3 & (0.6) & 2.0 & $(0.3)$ & 0.5 & $(0.2)$ & 0.1 & (0.1) \\
\hline \multirow{3}{*}{$\begin{array}{l}\text { Mathematics subscale } \\
\text { interpreting }\end{array}$} & All & 31.5 & (0.9) & 30.8 & $(0.7)$ & 22.6 & (0.8) & 10.8 & (0.5) & 3.4 & (0.4) & 0.7 & $(0.2)$ & 0.1 & $(0.0)$ \\
\hline & Boys & 29.5 & (1.1) & 29.7 & $(0.9)$ & 23.4 & $(1.0)$ & 12.1 & $(0.7)$ & 4.2 & $(0.5)$ & 1.0 & $(0.2)$ & 0.1 & $(0.0)$ \\
\hline & Girls & 33.4 & (1.1) & 31.8 & (0.9) & 21.9 & $(0.8)$ & 9.7 & (0.6) & 2.7 & (0.4) & 0.4 & $(0.1)$ & 0.0 & $(0.0)$ \\
\hline \multirow{3}{*}{$\begin{array}{l}\text { Mathematics subscale } \\
\text { change and relationships }\end{array}$} & All & 47.8 & (1.1) & 23.6 & $(0.7)$ & 15.9 & $(0.7)$ & 8.0 & (0.6) & 3.2 & (0.4) & 1.1 & $(0.2)$ & 0.3 & $(0.1)$ \\
\hline & Boys & 44.2 & (1.2) & 23.7 & $(0.8)$ & 17.0 & $(0.8)$ & 9.2 & (0.6) & 4.0 & (0.4) & 1.5 & $(0.3)$ & 0.4 & $(0.1)$ \\
\hline & Girls & 51.1 & (1.3) & 23.6 & $(0.9)$ & 14.9 & $(0.8)$ & 7.0 & (0.7) & 2.5 & (0.5) & 0.7 & $(0.2)$ & 0.2 & $(0.1)$ \\
\hline \multirow{3}{*}{$\begin{array}{l}\text { Mathematics subscale } \\
\text { space and shape }\end{array}$} & All & 41.5 & (1.0) & 30.3 & $(0.7)$ & 18.2 & (0.6) & 7.0 & (0.4) & 2.3 & (0.3) & 0.6 & $(0.2)$ & 0.1 & $(0.0)$ \\
\hline & Boys & 36.0 & (1.1) & 30.4 & $(0.8)$ & 20.9 & $(0.8)$ & 8.5 & (0.5) & 3.2 & (0.4) & 0.9 & $(0.3)$ & 0.2 & $(0.1)$ \\
\hline & Girls & 46.6 & (1.2) & 30.2 & (0.9) & 15.7 & $(0.7)$ & 5.6 & (0.5) & 1.5 & $(0.3)$ & 0.3 & $(0.1)$ & 0.1 & $(0.0)$ \\
\hline \multirow[t]{3}{*}{ Mathematics subscale quantity } & All & 38.1 & $(1.1)$ & 26.6 & $(0.8)$ & 19.6 & $(0.6)$ & 10.1 & $(0.5)$ & 4.1 & $(0.4)$ & 1.2 & $(0.3)$ & 0.2 & $(0.1)$ \\
\hline & Boys & 34.7 & (1.3) & 26.6 & $(1.1)$ & 20.2 & $(0.8)$ & 11.5 & $(0.7)$ & 5.1 & $(0.5)$ & 1.6 & $(0.3)$ & 0.3 & $(0.1)$ \\
\hline & Girls & 41.3 & (1.3) & 26.6 & $(1.2)$ & 19.1 & $(0.8)$ & 8.9 & $(0.6)$ & 3.1 & $(0.4)$ & 0.8 & $(0.2)$ & 0.1 & $(0.1)$ \\
\hline \multirow{3}{*}{$\begin{array}{l}\text { Mathematics subscale } \\
\text { uncertainty and data }\end{array}$} & All & 27.8 & $(1.0)$ & 35.1 & $(1.0)$ & 24.7 & $(0.8)$ & 9.6 & $(0.5)$ & 2.4 & $(0.4)$ & 0.3 & $(0.1)$ & 0.0 & c \\
\hline & Boys & 25.7 & (1.0) & 33.7 & $(1.1)$ & 25.7 & $(1.0)$ & 11.3 & $(0.7)$ & 3.1 & $(0.5)$ & 0.4 & $(0.1)$ & 0.0 & c \\
\hline & Girls & 29.7 & $(1.2)$ & 36.4 & $(1.1)$ & 23.9 & $(0.9)$ & 8.1 & $(0.6)$ & 1.8 & $(0.3)$ & 0.2 & $(0.1)$ & 0.0 & c \\
\hline \multirow{3}{*}{$\begin{array}{l}\text { Computer-based mathematics } \\
\text { scale }\end{array}$} & All & 23.6 & (1.8) & 28.8 & $(1.2)$ & 26.8 & (1.6) & 13.4 & (0.9) & 5.7 & (1.0) & 1.6 & $(0.5)$ & 0.2 & $(0.1)$ \\
\hline & Boys & 20.3 & (1.9) & 27.1 & $(1.5)$ & 27.5 & $(1.7)$ & 15.0 & (1.1) & 7.6 & (1.4) & 2.1 & $(0.6)$ & 0.4 & $(0.2)$ \\
\hline & Girls & 26.6 & (2.2) & 30.3 & (1.5) & 26.1 & $(2.1)$ & 11.8 & (1.1) & 4.1 & (0.8) & 1.1 & $(0.5)$ & 0.1 & $(0.1)$ \\
\hline \multirow[t]{3}{*}{ Combined mathematics scale } & All & 27.8 & (1.7) & 32.7 & (1.3) & 23.4 & (1.3) & 11.3 & $(0.9)$ & 3.9 & (0.7) & 0.9 & $(0.3)$ & 0.1 & $(0.1)$ \\
\hline & Boys & 23.7 & (1.9) & 31.7 & (1.5) & 24.5 & (1.5) & 13.4 & (1.4) & 5.2 & (0.9) & 1.2 & $(0.4)$ & 0.2 & $(0.2)$ \\
\hline & Girls & 31.6 & (2.1) & 33.6 & (1.8) & 22.3 & (1.5) & 9.2 & $(1.2)$ & 2.7 & $(0.7)$ & 0.5 & $(0.2)$ & 0.0 & $(0.0)$ \\
\hline
\end{tabular}

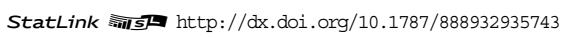

[Part 1/1]

Table A7.2 Percentage of Brazilian students at each proficiency level on the reading scale

\begin{tabular}{|c|c|c|c|c|c|c|c|c|c|c|c|c|c|c|c|c|c|}
\hline & & \multicolumn{2}{|c|}{ Below Level 1b } & \multicolumn{2}{|c|}{ Level 1b } & \multicolumn{2}{|c|}{ Level 1a } & \multicolumn{2}{|c|}{ Level 2} & \multicolumn{2}{|c|}{ Level 3} & \multicolumn{2}{|c|}{ Level 4} & \multicolumn{2}{|c|}{ Level 5} & \multicolumn{2}{|c|}{ Level 6} \\
\hline & & $\%$ & S.E. & $\%$ & S.E. & $\%$ & S.E. & $\%$ & S.E. & $\%$ & S.E. & $\%$ & S.E. & $\%$ & S.E. & $\%$ & S.E. \\
\hline \multirow[t]{3}{*}{ Reading scale } & All & 4.6 & $(0.4)$ & 15.8 & $(0.6)$ & 30.4 & $(0.8)$ & 29.4 & $(0.7)$ & 15.1 & $(0.6)$ & 4.2 & $(0.4)$ & 0.5 & $(0.1)$ & 0.0 & $(0.0)$ \\
\hline & Boys & 6.9 & $(0.6)$ & 20.0 & $(0.9)$ & 31.8 & $(0.9)$ & 25.9 & $(0.9)$ & 11.7 & $(0.8)$ & 3.3 & $(0.4)$ & 0.4 & $(0.1)$ & 0.0 & c \\
\hline & Girls & 2.4 & $(0.3)$ & 11.9 & $(0.6)$ & 29.2 & (1.1) & 32.6 & $(1.0)$ & 18.3 & (1.1) & 5.1 & $(0.5)$ & 0.6 & $(0.2)$ & 0.0 & $(0.0)$ \\
\hline \multirow[t]{3}{*}{ Combined reading scale } & All & 3.4 & $(0.7)$ & 12.8 & (1.1) & 27.6 & (1.4) & 31.5 & (1.5) & 19.0 & (1.3) & 5.3 & $(0.8)$ & 0.5 & $(0.2)$ & 0.0 & $(0.0)$ \\
\hline & Boys & 5.1 & $(1.0)$ & 15.1 & (1.3) & 29.7 & $(1.7)$ & 29.3 & (1.9) & 15.6 & (1.3) & 4.7 & $(0.9)$ & 0.4 & $(0.2)$ & 0.0 & c \\
\hline & Girls & 1.9 & $(0.5)$ & 10.7 & $(1.2)$ & 25.5 & $(1.8)$ & 33.4 & $(2.0)$ & 22.0 & (1.6) & 5.8 & $(0.8)$ & 0.6 & $(0.2)$ & 0.0 & $(0.0)$ \\
\hline
\end{tabular}

\begin{tabular}{|c|c|c|c|c|c|c|c|c|c|c|c|}
\hline & & \multicolumn{2}{|c|}{ Below Level 2} & \multicolumn{2}{|c|}{ Level 2} & \multicolumn{2}{|c|}{ Level 3} & \multicolumn{2}{|c|}{ Level 4} & \multicolumn{2}{|c|}{ Above Level 4} \\
\hline & & $\%$ & S.E. & $\%$ & S.E. & $\%$ & S.E. & $\%$ & S.E. & $\%$ & S.E. \\
\hline \multirow[t]{3}{*}{ Digital reading scale } & All & 39.3 & $(2.1)$ & 29.6 & (1.3) & 21.8 & (1.3) & 7.9 & (1.0) & 1.3 & $(0.3)$ \\
\hline & Boys & 43.9 & $(2.4)$ & 28.4 & (1.9) & 19.7 & (1.7) & 6.9 & (1.1) & 1.1 & $(0.5)$ \\
\hline & Girls & 35.1 & $(2.1)$ & 30.7 & (1.5) & 23.8 & (1.5) & 8.9 & (1.1) & 1.5 & $(0.4)$ \\
\hline
\end{tabular}

StatLink 需可 http://dx.doi.org/10.1787/888932935743 
[Part 1/1]

Table A7.3 Percentage of Brazilian students at each proficiency level on the science scale

\begin{tabular}{|c|c|c|c|c|c|c|c|c|c|c|c|c|c|c|c|}
\hline & & \multicolumn{2}{|c|}{ Below Level 1} & \multicolumn{2}{|c|}{ Level 1} & \multicolumn{2}{|c|}{ Level 2} & \multicolumn{2}{|c|}{ Level 3} & \multicolumn{2}{|c|}{ Level 4} & \multicolumn{2}{|c|}{ Level 5} & \multicolumn{2}{|c|}{ Level 6} \\
\hline & & $\%$ & S.E. & $\%$ & S.E. & $\%$ & S.E. & $\%$ & S.E. & $\%$ & S.E. & $\%$ & S.E. & $\%$ & S.E. \\
\hline \multirow[t]{3}{*}{ Science scale } & All & 19.9 & $(0.8)$ & 35.4 & (0.8) & 29.8 & (0.8) & 12.0 & $(0.6)$ & 2.6 & $(0.3)$ & 0.3 & $(0.1)$ & 0.0 & c \\
\hline & Boys & 20.8 & (1.0) & 34.1 & (0.9) & 29.5 & (0.9) & 12.3 & $(0.8)$ & 3.0 & $(0.4)$ & 0.3 & $(0.1)$ & 0.0 & c \\
\hline & Girls & 19.1 & (0.9) & 36.5 & (1.0) & 30.2 & (1.0) & 11.7 & $(0.9)$ & 2.3 & $(0.4)$ & 0.3 & $(0.1)$ & 0.0 & c \\
\hline
\end{tabular}

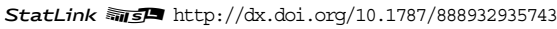

[Part 1/1]

Table A7.4 Top performers in mathematics, reading and science in Brazi

\begin{tabular}{|c|c|c|c|c|c|c|c|c|c|c|c|c|c|c|c|c|c|c|}
\hline & \multicolumn{16}{|c|}{ 15-year-old students who are: } & \multirow{2}{*}{\multicolumn{2}{|c|}{$\begin{array}{c}\text { Percentage of } \\
\text { top performers } \\
\text { in mathematics } \\
\text { who are also } \\
\text { top performers } \\
\text { in reading and } \\
\text { science }\end{array}$}} \\
\hline & \multicolumn{2}{|c|}{$\begin{array}{c}\text { not top } \\
\text { performers in } \\
\text { any of the three } \\
\text { domains }\end{array}$} & \multicolumn{2}{|c|}{$\begin{array}{c}\text { top performers } \\
\text { only in } \\
\text { mathematics }\end{array}$} & \multicolumn{2}{|c|}{$\begin{array}{l}\text { top performers } \\
\text { only in reading }\end{array}$} & \multicolumn{2}{|c|}{$\begin{array}{l}\text { top performers } \\
\text { only in science }\end{array}$} & \multicolumn{2}{|c|}{$\begin{array}{l}\text { top performers } \\
\text { in mathematics } \\
\text { and reading but } \\
\text { not in science }\end{array}$} & \multicolumn{2}{|c|}{$\begin{array}{c}\text { top performers } \\
\text { in mathematics } \\
\text { and science but } \\
\text { not in reading }\end{array}$} & \multicolumn{2}{|c|}{$\begin{array}{l}\text { top performers } \\
\text { in reading and } \\
\text { science but not } \\
\text { in mathematics }\end{array}$} & \multicolumn{2}{|c|}{$\begin{array}{l}\text { top performers } \\
\text { in all three } \\
\text { domains }\end{array}$} & & \\
\hline & $\%$ & S.E. & $\%$ & S.E. & $\%$ & S.E. & $\%$ & S.E. & $\%$ & S.E. & $\%$ & S.E. & $\%$ & S.E. & $\%$ & S.E. & $\%$ & S.E. \\
\hline All & 98.9 & $(0.2)$ & 0.4 & $(0.1)$ & 0.3 & $(0.1)$ & 0.1 & $(0.0)$ & 0.1 & $(0.1)$ & 0.1 & $(0.0)$ & 0.0 & $(0.0)$ & 0.1 & $(0.1)$ & 13.6 & $(7.5)$ \\
\hline Boys & 98.7 & $(0.3)$ & 0.7 & $(0.2)$ & 0.2 & $(0.1)$ & 0.1 & $(0.1)$ & 0.1 & $(0.1)$ & 0.1 & $(0.1)$ & 0.0 & c & 0.1 & $(0.1)$ & 9.8 & $(6.4)$ \\
\hline Girls & 99.1 & $(0.3)$ & 0.2 & $(0.1)$ & 0.4 & $(0.1)$ & 0.1 & $(0.1)$ & 0.1 & $(0.1)$ & 0.1 & $(0.0)$ & 0.0 & $(0.0)$ & 0.1 & $(0.1)$ & 21.6 & (15.2) \\
\hline
\end{tabular}

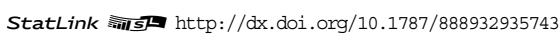

[Part 1/1]

Table A7.5 Mean score, variation and gender differences in student performance in Brazil

\begin{tabular}{|c|c|c|c|c|c|c|c|c|c|c|c|c|c|c|c|c|c|c|c|c|c|}
\hline & \multicolumn{4}{|c|}{ All students } & \multicolumn{6}{|c|}{ Gender differences } & \multicolumn{11}{|c|}{ Percentiles } \\
\hline & \multicolumn{2}{|c|}{ Mean score } & \multicolumn{2}{|c|}{$\begin{array}{l}\text { Standard } \\
\text { deviation }\end{array}$} & \multicolumn{2}{|c|}{ Boys } & \multicolumn{2}{|c|}{ Girls } & \multicolumn{2}{|c|}{$\begin{array}{c}\text { Difference } \\
(\text { B - G) }\end{array}$} & \multicolumn{2}{|c|}{ 5th } & \multicolumn{2}{|c|}{ 10th } & \multicolumn{2}{|c|}{ 25th } & \multicolumn{2}{|c|}{ 75th } & \multicolumn{2}{|c|}{ 90th } & 95th \\
\hline & Mean & S.E. & S.D. & S.E. & $\begin{array}{l}\text { Mean } \\
\text { score }\end{array}$ & S.E. & $\begin{array}{l}\text { Mean } \\
\text { score }\end{array}$ & S.E. & $\begin{array}{c}\text { Score } \\
\text { dif. }\end{array}$ & S.E. & Score & S.E. & Score & S.E. & Score & S.E. & Score & S.E. & Score & S.E. & Score S.E. \\
\hline Mathematics scale & 389 & (1.9) & 78 & (1.6) & 397 & $(2.1)$ & 380 & $(2.2)$ & 17 & (1.8) & 271 & (2.4) & 294 & $(2.1)$ & 334 & (1.9) & 437 & (2.6) & 492 & $(4.2)$ & $528 \quad(5.2)$ \\
\hline $\begin{array}{l}\text { Mathematics subscale } \\
\text { formulating }\end{array}$ & 373 & $(2.4)$ & 88 & (1.9) & 387 & $(2.5)$ & 361 & $(2.7)$ & 26 & (1.9) & 237 & (3.3) & 265 & (2.6) & 314 & $(2.2)$ & 428 & $(3.0)$ & 487 & $(4.9)$ & $527 \quad(6.9)$ \\
\hline $\begin{array}{l}\text { Mathematics subscale } \\
\text { employing }\end{array}$ & 385 & $(2.0)$ & 82 & $(1.7)$ & 393 & $(2.1)$ & 377 & $(2.3)$ & 17 & (1.9) & 259 & $(2.7)$ & 285 & $(2.0)$ & 329 & (1.9) & 437 & (2.6) & 493 & $(4.1)$ & $529(6.2)$ \\
\hline $\begin{array}{l}\text { Mathematics subscale } \\
\text { interpreting }\end{array}$ & 398 & $(2.0)$ & 81 & (1.4) & 404 & $(2.2)$ & 393 & $(2.1)$ & 11 & $(1.7)$ & 268 & $(3.4)$ & 296 & $(2.5)$ & 343 & $(2.2)$ & 450 & $(2.3)$ & 505 & $(3.7)$ & $537(5.1)$ \\
\hline $\begin{array}{l}\text { Mathematics subscale } \\
\text { change and relationships }\end{array}$ & 368 & $(2.5)$ & 100 & (1.9) & 377 & $(2.7)$ & 359 & $(2.8)$ & 18 & $(2.2)$ & 212 & (3.4) & 246 & $(3.2)$ & 300 & $(2.9)$ & 432 & (3.1) & 497 & $(5.0)$ & $540 \quad(6.7)$ \\
\hline $\begin{array}{l}\text { Mathematics subscale } \\
\text { space and shape }\end{array}$ & 378 & $(2.0)$ & 82 & $(1.8)$ & 390 & $(2.1)$ & 367 & $(2.2)$ & 23 & $(1.7)$ & 251 & $(3.0)$ & 279 & $(2.5)$ & 324 & $(2.0)$ & 428 & $(2.4)$ & 482 & $(4.2)$ & $519(6.1)$ \\
\hline Mathematics subscale quantity & 389 & $(2.3)$ & 92 & (1.6) & 399 & $(2.5)$ & 381 & $(2.7)$ & 18 & $(2.2)$ & 246 & $(3.3)$ & 275 & $(3.3)$ & 326 & $(2.5)$ & 449 & $(2.9)$ & 511 & $(4.2)$ & $550 \quad(5.5)$ \\
\hline $\begin{array}{l}\text { Mathematics subscale } \\
\text { uncertainty and data }\end{array}$ & 400 & (1.9) & 72 & $(1.4)$ & 405 & $(2.1)$ & 394 & $(2.0)$ & 11 & $(1.5)$ & 286 & $(2.5)$ & 311 & $(2.4)$ & 352 & $(2.0)$ & 445 & $(2.2)$ & 492 & $(3.5)$ & $522(4.5)$ \\
\hline $\begin{array}{l}\text { Computer-based } \\
\text { mathematics scale }\end{array}$ & 418 & $(4.5)$ & 84 & $(3.0)$ & 429 & $(4.8)$ & 408 & $(4.5)$ & 21 & $(2.4)$ & 289 & $(5.9)$ & 316 & $(4.4)$ & 362 & $(4.9)$ & 471 & $(5.5)$ & 528 & $(8.8)$ & $565(10.6)$ \\
\hline Combined mathematics scale & 406 & $(3.7)$ & 78 & $(2.5)$ & 416 & $(4.1)$ & 396 & (3.7) & 21 & $(2.3)$ & 289 & (4.6) & 312 & (3.7) & 352 & (3.7) & 454 & $(4.8)$ & 510 & $(7.7)$ & $543 \quad(8.7)$ \\
\hline Reading scale & 407 & $(2.0)$ & 86 & $(1.2)$ & 390 & $(2.3)$ & 422 & $(2.1)$ & -32 & $(2.0)$ & 266 & $(3.5)$ & 297 & $(2.8)$ & 348 & $(2.4)$ & 465 & (2.6) & 518 & $(3.1)$ & $550 \quad(3.7)$ \\
\hline Digital reading scale & 431 & $(4.8)$ & 95 & $(2.7)$ & 420 & $(5.4)$ & 441 & (4.6) & -21 & (3.1) & 271 & $(8.0)$ & 308 & $(8.0)$ & 369 & $(6.9)$ & 497 & $(5.7)$ & 550 & (5.5) & $580 \quad(6.1)$ \\
\hline Combined reading scale & 420 & $(4.1)$ & 86 & $(2.3)$ & 407 & $(4.7)$ & 432 & (3.9) & -25 & $(2.8)$ & 277 & $(6.9)$ & 308 & $(6.2)$ & 362 & $(5.1)$ & 480 & $(5.2)$ & 530 & $(5.2)$ & $559 \quad(6.1)$ \\
\hline Science scale & 402 & $(2.1)$ & 79 & $(1.4)$ & 402 & $(2.3)$ & 401 & $(2.2)$ & 0 & $(1.7)$ & 275 & $(3.1)$ & 302 & $(2.4)$ & 348 & $(1.9)$ & 454 & $(2.7)$ & 505 & $(3.5)$ & $536 \quad(4.5)$ \\
\hline
\end{tabular}

Note: Values that are statistically significant are indicated in bold (see Annex A3).

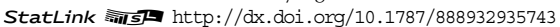




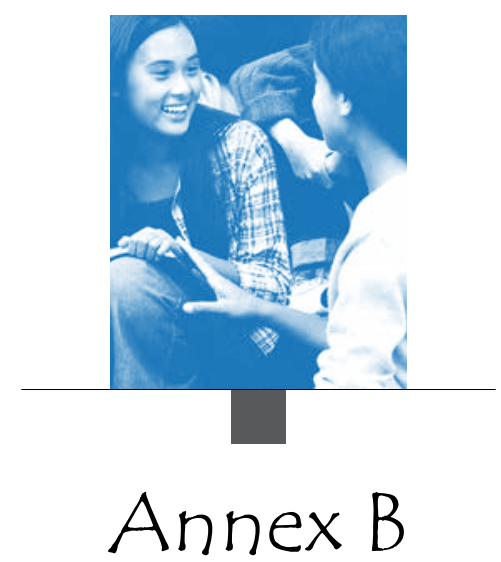

PISA 2012 DATA

All figures and tables in Annex B are available on line

Annex B1: Results for countries and economies http://dx.doi.org/10.1787/888932935667 http://dx.doi.org/10.1787/888932935686 http://dx.doi.org/10.1787/888932935705 http://dx.doi.org/10.1787/888932935724

Annex B2: Results for regions within countries http://dx.doi.org/10.1787/888932935762

Annex B3: Results for the computer-based and combined scales for mathematics and reading http://dx.doi.org/10.1787/888932935781

Annex B4: Trends in mathematics, reading and science performance http://dx.doi.org/10.1787/888932935648 http://dx.doi.org/10.1787/888932936446

\section{Notes regarding Cyprus}

Note by Turkey: The information in this document with reference to "Cyprus" relates to the southern part of the Island. There is no single authority representing both Turkish and Greek Cypriot people on the Island. Turkey recognises the Turkish Republic of Northern Cyprus (TRNC). Until a lasting and equitable solution is found within the context of the United Nations, Turkey shall preserve its position concerning the "Cyprus issue".

Note by all the European Union Member States of the OECD and the European Union: The Republic of Cyprus is recognised by all members of the United Nations with the exception of Turkey. The information in this document relates to the area under the effective control of the Government of the Republic of Cyprus.

\section{A note regarding Israel}

The statistical data for Israel are supplied by and under the responsibility of the relevant Israeli authorities. The use of such data by the OECD is without prejudice to the status of the Golan Heights, East Jerusalem and Israeli settlements in the West Bank under the terms of international law. 


\section{ANNEX B1}

\section{RESULTS FOR COUNTRIES AND ECONOMIES}

[Part 1/1]

Table I.2.1a Percentage of students at each proficiency level in mathematics

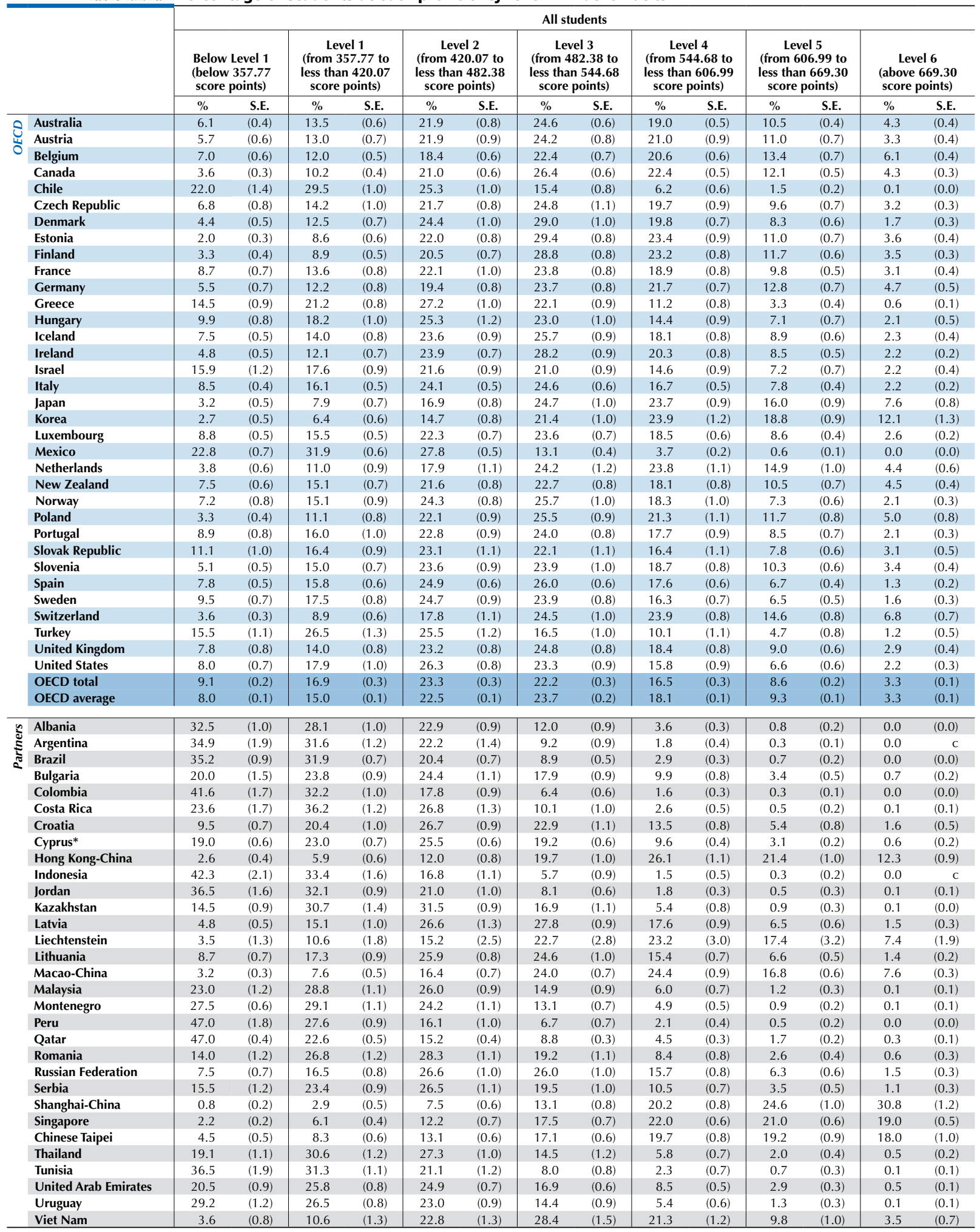

* See notes at the beginning of this Annex.

StatLink त्नाज http://dx.doi.org/10.1787/888932935667 
[Part 1/2]

Table I.2.1b Percentage of students below Level 2 and at Level 5 or above in mathematics in PISA 2003 through 2012

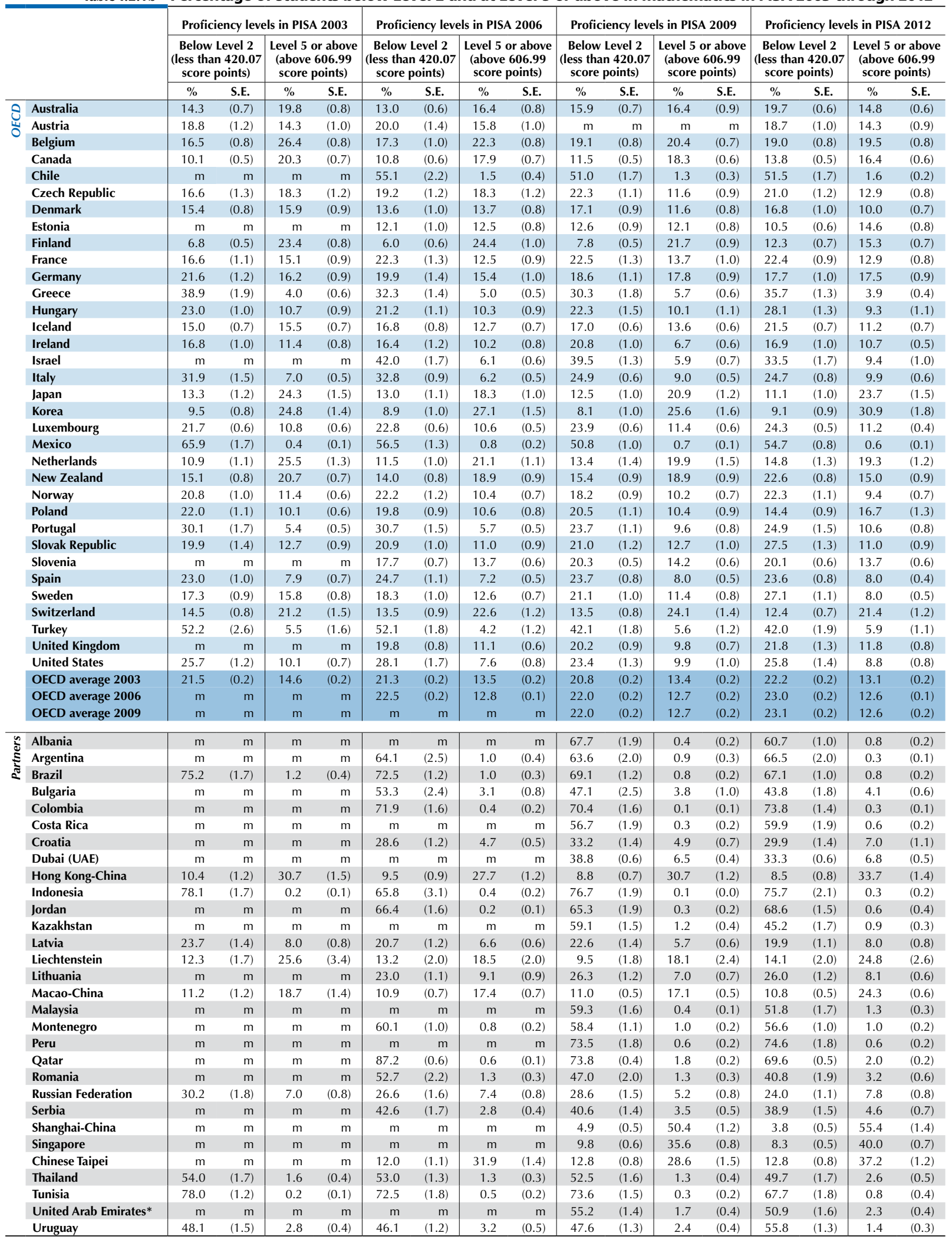

Notes: Values that are statistically significant are indicated in bold (see Annex A3).

In the United Arab Emirates, Dubai took the PISA 2009 assessment in 2009 and the rest of the United Arab Emirates in 2010 as part of PISA $2009+$. Results are thus reported separately.

* United Arab Emirates excluding Dubai (see note above).

StatLink त्नाडs http://dx.doi.org/10.1787/888932935667 
[Part 2/2]

Table I.2.1b Percentage of students below Level 2 and at Level 5 or above in mathematics in PISA 2003 through 2012

\begin{tabular}{|c|c|c|c|c|c|c|c|c|c|c|c|c|c|}
\hline & \multicolumn{4}{|c|}{$\begin{array}{l}\text { Change between } 2003 \text { and } 2012 \\
\text { (PISA 2012 - PISA 2003) }\end{array}$} & \multicolumn{4}{|c|}{$\begin{array}{l}\text { Change between } 2006 \text { and } 2012 \\
\text { (PISA 2012 - PISA 2006) }\end{array}$} & \multicolumn{4}{|c|}{$\begin{array}{l}\text { Change between } 2009 \text { and } 2012 \\
\text { (PISA 2012 - PISA 2009) }\end{array}$} \\
\hline & & \multicolumn{2}{|c|}{$\begin{array}{l}\text { Below Level } 2 \\
\text { (less than } 420.07 \\
\text { score points) }\end{array}$} & \multicolumn{2}{|c|}{$\begin{array}{l}\text { Level } 5 \text { or above } \\
\text { (above } 606.99 \\
\text { score points) }\end{array}$} & \multicolumn{2}{|c|}{$\begin{array}{l}\text { Below Level } 2 \\
\text { (less than } 420.07 \\
\text { score points) }\end{array}$} & \multicolumn{2}{|c|}{$\begin{array}{l}\text { Level } 5 \text { or above } \\
\text { (above } 606.99 \\
\text { score points) }\end{array}$} & $\begin{array}{l}\text { Beloy } \\
\text { (less th } \\
\text { scor }\end{array}$ & $\begin{array}{l}\text { el } 2 \\
20.07 \\
\text { nts) }\end{array}$ & $\begin{array}{l}\text { Level } \\
\text { (abov } \\
\text { scor }\end{array}$ & $\begin{array}{l}\text { above } \\
6.99 \\
\text { nts) }\end{array}$ \\
\hline & & $\%$ dif. & S.E. & $\%$ dif. & S.E. & $\%$ dif. & S.E. & $\%$ dif. & S.E. & $\%$ dif. & S.E. & $\%$ dif. & S.E. \\
\hline 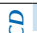 & Australia & 5.3 & (1.1) & -5.0 & (1.1) & 6.7 & (1.0) & -1.6 & (1.1) & 3.8 & (1.1) & -1.6 & $(1.2)$ \\
\hline 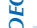 & Austria & -0.1 & (1.6) & 0.0 & (1.4) & -1.3 & (1.8) & -1.5 & (1.5) & $\mathrm{m}$ & $\mathrm{m}$ & $\mathrm{m}$ & $\mathrm{m}$ \\
\hline & Belgium & 2.5 & $(1.2)$ & -6.9 & (1.3) & 1.6 & (1.4) & -2.8 & (1.3) & -0.1 & (1.3) & -0.8 & (1.2) \\
\hline & Canada & 3.7 & $(0.9)$ & -3.9 & (1.1) & 3.0 & (1.0) & -1.5 & (1.1) & 2.4 & (0.9) & -1.9 & (1.1) \\
\hline & Chile & $\mathrm{m}$ & $\mathrm{m}$ & $\mathrm{m}$ & $\mathrm{m}$ & -3.6 & (2.9) & 0.1 & $(0.4)$ & 0.5 & (2.6) & 0.3 & $(0.4)$ \\
\hline & Czech Republic & 4.4 & $(1.8)$ & -5.4 & (1.5) & 1.8 & (1.8) & -5.4 & (1.5) & -1.4 & (1.8) & 1.2 & (1.3) \\
\hline & Denmark & 1.4 & (1.4) & -5.9 & $(1.2)$ & 3.2 & (1.6) & -3.7 & (1.1) & -0.2 & (1.5) & -1.6 & (1.1) \\
\hline & Estonia & $\mathrm{m}$ & $\mathrm{m}$ & $\mathrm{m}$ & $\mathrm{m}$ & -1.5 & (1.3) & 2.1 & (1.3) & -2.1 & (1.2) & 2.5 & (1.3) \\
\hline & Finland & 5.5 & $(0.9)$ & -8.1 & $(1.2)$ & 6.3 & (1.0) & -9.2 & (1.3) & 4.4 & (1.0) & -6.4 & (1.3) \\
\hline & France & 5.7 & $(1.5)$ & -2.2 & (1.3) & 0.1 & (1.7) & 0.4 & (1.3) & -0.2 & (1.7) & -0.8 & (1.3) \\
\hline & Germany & -3.9 & $(1.6)$ & 1.2 & (1.4) & -2.1 & (1.8) & 2.0 & (1.5) & -0.9 & (1.6) & -0.4 & (1.4) \\
\hline & Greece & -3.3 & $(2.5)$ & -0.1 & $(0.7)$ & 3.3 & $(2.2)$ & -1.1 & $(0.7)$ & 5.4 & (2.5) & -1.8 & $(0.8)$ \\
\hline & Hungary & 5.1 & (1.8) & -1.4 & (1.5) & 6.9 & (1.8) & -1.1 & (1.5) & 5.8 & (2.1) & -0.8 & (1.6) \\
\hline & Iceland & 6.5 & $(1.1)$ & -4.3 & (1.0) & 4.7 & $(1.2)$ & -1.5 & $(1.1)$ & 4.5 & $(1.2)$ & -2.4 & (1.0) \\
\hline & Ireland & 0.1 & $(1.5)$ & -0.7 & (1.0) & 0.5 & (1.7) & 0.4 & (1.1) & -3.9 & (1.5) & 4.0 & (1.0) \\
\hline & Israel & $\mathrm{m}$ & $\mathrm{m}$ & $\mathrm{m}$ & $\mathrm{m}$ & -8.5 & (2.5) & 3.3 & $(1.2)$ & -6.0 & (2.3) & 3.5 & (1.3) \\
\hline & Italy & -7.3 & $(1.8)$ & 2.9 & $(0.8)$ & -8.2 & (1.4) & 3.7 & $(0.9)$ & -0.3 & $(1.2)$ & 1.0 & $(0.9)$ \\
\hline & Japan & -2.3 & $(1.6)$ & -0.6 & $(2.2)$ & -2.0 & (1.6) & 5.4 & (1.9) & -1.4 & (1.5) & 2.8 & $(2.1)$ \\
\hline & Korea & -0.4 & $(1.3)$ & 6.1 & (2.4) & 0.3 & (1.4) & 3.8 & (2.5) & 1.0 & (1.4) & 5.3 & (2.6) \\
\hline & Luxembourg & 2.6 & $(1.0)$ & 0.4 & $(0.8)$ & 1.5 & (1.0) & 0.6 & $(0.8)$ & 0.4 & (1.0) & -0.1 & $(0.9)$ \\
\hline & Mexico & -11.2 & $(2.2)$ & 0.3 & $(0.1)$ & -1.8 & (1.9) & -0.2 & $(0.2)$ & 3.9 & (1.7) & -0.1 & $(0.2)$ \\
\hline & Netherlands & 3.9 & (1.8) & -6.3 & (1.9) & 3.3 & (1.7) & -1.9 & $(1.7)$ & 1.4 & (2.0) & -0.6 & $(2.1)$ \\
\hline & New Zealand & 7.6 & $(1.3)$ & -5.7 & (1.2) & 8.6 & (1.4) & -3.9 & (1.3) & 7.2 & (1.4) & -3.9 & (1.3) \\
\hline & Norway & 1.5 & (1.6) & -2.0 & $(1.0)$ & 0.1 & $(1.7)$ & -1.0 & (1.1) & 4.1 & (1.6) & -0.8 & (1.0) \\
\hline & Poland & -7.7 & $(1.5)$ & 6.7 & (1.6) & -5.5 & (1.4) & 6.1 & (1.7) & -6.1 & (1.5) & 6.3 & (1.7) \\
\hline & Portugal & -5.2 & (2.4) & 5.3 & (1.0) & -5.8 & $(2.2)$ & 4.9 & (1.1) & 1.2 & (2.0) & 1.0 & (1.3) \\
\hline & Slovak Republic & 7.5 & $(2.0)$ & -1.7 & (1.3) & 6.6 & (1.8) & 0.0 & (1.4) & 6.4 & (1.9) & -1.7 & (1.4) \\
\hline & Slovenia & $\mathrm{m}$ & $\mathrm{m}$ & $\mathrm{m}$ & $\mathrm{m}$ & 2.4 & $(1.2)$ & 0.0 & $(1.0)$ & -0.3 & (1.1) & -0.5 & $(0.9)$ \\
\hline & Spain & 0.6 & $(1.4)$ & 0.1 & $(0.9)$ & -1.1 & (1.5) & 0.8 & $(0.8)$ & -0.1 & (1.4) & 0.0 & $(0.8)$ \\
\hline & Sweden & 9.8 & $(1.6)$ & -7.8 & (1.0) & 8.8 & (1.7) & -4.6 & (0.9) & 6.0 & (1.7) & -3.4 & (1.0) \\
\hline & Switzerland & -2.1 & (1.2) & 0.2 & (2.0) & -1.1 & (1.2) & -1.3 & (1.8) & -1.0 & (1.2) & -2.8 & (1.9) \\
\hline & Turkey & -10.2 & (3.4) & 0.4 & (1.9) & -10.1 & (2.8) & 1.7 & (1.6) & -0.2 & (2.9) & 0.2 & (1.7) \\
\hline & United Kingdom & $\mathrm{m}$ & $\mathrm{m}$ & $\mathrm{m}$ & $\mathrm{m}$ & 2.1 & (1.6) & 0.7 & (1.1) & 1.6 & $(1.7)$ & 2.0 & (1.1) \\
\hline & United States & 0.1 & $(2.0)$ & -1.3 & (1.1) & -2.3 & (2.4) & 1.2 & (1.2) & 2.5 & (2.1) & -1.1 & (1.3) \\
\hline & OECD average 2003 & 0.7 & $(0.3)$ & -1.6 & $(0.3)$ & 0.9 & $(0.3)$ & -0.4 & $(0.2)$ & 1.6 & $(0.3)$ & -0.4 & $(0.3)$ \\
\hline & OECD average 2006 & $\mathrm{~m}$ & $\mathrm{~m}$ & $\mathrm{~m}$ & $\mathrm{~m}$ & 0.5 & $(0.3)$ & -0.2 & $(0.2)$ & 1.2 & $(0.3)$ & -0.1 & $(0.2)$ \\
\hline & OECD average 2009 & $\mathrm{~m}$ & $\mathrm{~m}$ & $\mathrm{~m}$ & $\mathrm{~m}$ & $\mathrm{~m}$ & $\mathrm{~m}$ & $\mathrm{~m}$ & $\mathrm{~m}$ & 1.2 & $(0.3)$ & -0.1 & $(0.2)$ \\
\hline$\frac{n}{2}$ & Albania & $\mathrm{m}$ & $\mathrm{m}$ & $\mathrm{m}$ & $\mathrm{m}$ & $\mathrm{m}$ & $\mathrm{m}$ & $\mathrm{m}$ & $\mathrm{m}$ & -7.1 & (2.3) & 0.4 & $(0.2)$ \\
\hline 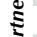 & Argentina & $\mathrm{m}$ & $\mathrm{m}$ & $\mathrm{m}$ & $\mathrm{m}$ & 2.3 & (3.4) & -0.8 & $(0.4)$ & 2.9 & (3.0) & -0.6 & $(0.3)$ \\
\hline$\approx$ & Brazil & -8.1 & $(2.2)$ & -0.4 & $(0.5)$ & -5.4 & (1.9) & -0.3 & $(0.4)$ & -2.0 & (1.9) & 0.0 & $(0.3)$ \\
\hline & Bulgaria & $\mathrm{m}$ & $\mathrm{m}$ & $\mathrm{m}$ & $\mathrm{m}$ & -9.5 & (3.1) & 1.0 & (1.0) & -3.4 & (3.2) & 0.3 & (1.2) \\
\hline & Colombia & $\mathrm{m}$ & $\mathrm{m}$ & $\mathrm{m}$ & $\mathrm{m}$ & 1.9 & (2.3) & -0.1 & $(0.2)$ & 3.4 & (2.3) & 0.2 & $(0.1)$ \\
\hline & Costa Rica & $\mathrm{m}$ & $\mathrm{m}$ & $\mathrm{m}$ & $\mathrm{m}$ & $\mathrm{m}$ & $\mathrm{m}$ & $\mathrm{m}$ & $\mathrm{m}$ & 3.2 & (2.9) & 0.2 & $(0.2)$ \\
\hline & Croatia & $\mathrm{m}$ & $\mathrm{m}$ & $\mathrm{m}$ & $\mathrm{m}$ & 1.3 & (2.0) & 2.3 & (1.3) & -3.3 & (2.2) & 2.1 & (1.3) \\
\hline & Dubai (UAE) & $\mathrm{m}$ & $\mathrm{m}$ & $\mathrm{m}$ & $\mathrm{m}$ & $\mathrm{m}$ & $\mathrm{m}$ & $\mathrm{m}$ & $\mathrm{m}$ & -5.5 & (1.1) & 0.3 & $(0.8)$ \\
\hline & Hong Kong-China & -1.9 & $(1.4)$ & 3.0 & $(2.2)$ & -1.0 & (1.3) & 6.0 & (2.0) & -0.2 & (1.1) & 3.1 & (2.0) \\
\hline & Indonesia & -2.4 & $(2.8)$ & 0.0 & $(0.2)$ & 9.9 & (3.8) & -0.1 & $(0.2)$ & -1.0 & (2.9) & 0.2 & $(0.2)$ \\
\hline & Jordan & $\mathrm{m}$ & $\mathrm{m}$ & $\mathrm{m}$ & $\mathrm{m}$ & 2.2 & (2.4) & 0.3 & $(0.5)$ & 3.3 & (2.6) & 0.3 & $(0.5)$ \\
\hline & Kazakhstan & $\mathrm{m}$ & $\mathrm{m}$ & $\mathrm{m}$ & $\mathrm{m}$ & $\mathrm{m}$ & $\mathrm{m}$ & $\mathrm{m}$ & $\mathrm{m}$ & -13.9 & (2.6) & -0.2 & $(0.5)$ \\
\hline & Latvia & -3.8 & (1.9) & 0.0 & (1.2) & -0.8 & (1.8) & 1.4 & (1.1) & -2.6 & (2.0) & 2.3 & (1.1) \\
\hline & Liechtenstein & 1.8 & $(2.7)$ & -0.8 & (4.4) & 0.9 & (2.9) & 6.4 & (3.4) & 4.6 & (2.8) & 6.8 & (3.7) \\
\hline & Lithuania & $\mathrm{m}$ & $\mathrm{m}$ & $\mathrm{m}$ & $\mathrm{m}$ & 3.1 & (1.8) & -1.0 & (1.1) & -0.3 & (1.9) & 1.1 & (1.0) \\
\hline & Macao-China & -0.4 & $(1.3)$ & 5.7 & (1.7) & -0.2 & (0.9) & 6.9 & $(1.2)$ & -0.2 & $(0.8)$ & 7.2 & (1.1) \\
\hline & Malaysia & $\mathrm{m}$ & $\mathrm{m}$ & $\mathrm{m}$ & $\mathrm{m}$ & $\mathrm{m}$ & $\mathrm{m}$ & $\mathrm{m}$ & $\mathrm{m}$ & -7.6 & (2.5) & 1.0 & $(0.3)$ \\
\hline & Montenegro & $\mathrm{m}$ & $\mathrm{m}$ & $\mathrm{m}$ & $\mathrm{m}$ & -3.4 & (1.6) & 0.2 & $(0.3)$ & -1.8 & (1.7) & 0.1 & $(0.3)$ \\
\hline & Peru & $\mathrm{m}$ & $\mathrm{m}$ & $\mathrm{m}$ & $\mathrm{m}$ & $\mathrm{m}$ & $\mathrm{m}$ & $\mathrm{m}$ & $\mathrm{m}$ & 1.0 & (2.6) & -0.1 & $(0.3)$ \\
\hline & Qatar & $\mathrm{m}$ & $\mathrm{m}$ & $\mathrm{m}$ & $\mathrm{m}$ & -17.6 & $(0.9)$ & 1.4 & $(0.2)$ & -4.2 & $(0.9)$ & 0.2 & $(0.3)$ \\
\hline & Romania & $\mathrm{m}$ & $\mathrm{m}$ & $\mathrm{m}$ & $\mathrm{m}$ & -11.9 & (3.1) & 1.9 & $(0.7)$ & -6.2 & (3.0) & 1.9 & $(0.7)$ \\
\hline & Russian Federation & -6.3 & $(2.3)$ & 0.8 & $(1.2)$ & -2.7 & $(2.2)$ & 0.4 & (1.2) & -4.6 & (2.1) & 2.6 & (1.2) \\
\hline & Serbia & $\mathrm{m}$ & $\mathrm{m}$ & $\mathrm{m}$ & $\mathrm{m}$ & -3.7 & (2.5) & 1.7 & $(0.8)$ & -1.7 & (2.3) & 1.0 & $(0.9)$ \\
\hline & Shanghai-China & $\mathrm{m}$ & $\mathrm{m}$ & $\mathrm{m}$ & $\mathrm{m}$ & $\mathrm{m}$ & $\mathrm{m}$ & $\mathrm{m}$ & $\mathrm{m}$ & -1.1 & $(0.8)$ & 5.0 & (2.0) \\
\hline & Singapore & $\mathrm{m}$ & $\mathrm{m}$ & $\mathrm{m}$ & $\mathrm{m}$ & $\mathrm{m}$ & $\mathrm{m}$ & $\mathrm{m}$ & $\mathrm{m}$ & -1.6 & $(0.8)$ & 4.4 & (1.4) \\
\hline & Chinese Taipei & $\mathrm{m}$ & $\mathrm{m}$ & $\mathrm{m}$ & $\mathrm{m}$ & 0.9 & (1.5) & 5.3 & $(2.0)$ & 0.0 & $(1.2)$ & 8.6 & $(2.0)$ \\
\hline & Thailand & -4.2 & $(2.6)$ & 0.9 & $(0.6)$ & -3.3 & (2.4) & 1.2 & (0.6) & -2.8 & (2.6) & 1.3 & $(0.7)$ \\
\hline & Tunisia & -10.2 & $(2.3)$ & 0.6 & $(0.4)$ & -4.7 & $(2.7)$ & 0.3 & $(0.4)$ & -5.8 & (2.5) & 0.5 & $(0.4)$ \\
\hline & United Arab Emirates* & $\mathrm{m}$ & $\mathrm{m}$ & $\mathrm{m}$ & $\mathrm{m}$ & $\mathrm{m}$ & $\mathrm{m}$ & $\mathrm{m}$ & $\mathrm{m}$ & -4.2 & (2.4) & 0.5 & $(0.5)$ \\
\hline & Uruguay & 7.7 & $(2.2)$ & -1.4 & $(0.5)$ & 9.7 & $(2.0)$ & -1.8 & $(0.6)$ & 8.2 & $(2.1)$ & -1.0 & $(0.5)$ \\
\hline
\end{tabular}

Notes: Values that are statistically significant are indicated in bold (see Annex A3).

In the United Arab Emirates, Dubai took the PISA 2009 assessment in 2009 and the rest of the United Arab Emirates in 2010 as part of PISA $2009+$. Results are thus reported separately.

* United Arab Emirates excluding Dubai (see note above).

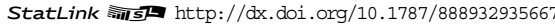


[Part 1/2]

Table I.2.2a Percentage of students at each proficiency level in mathematics, by gender

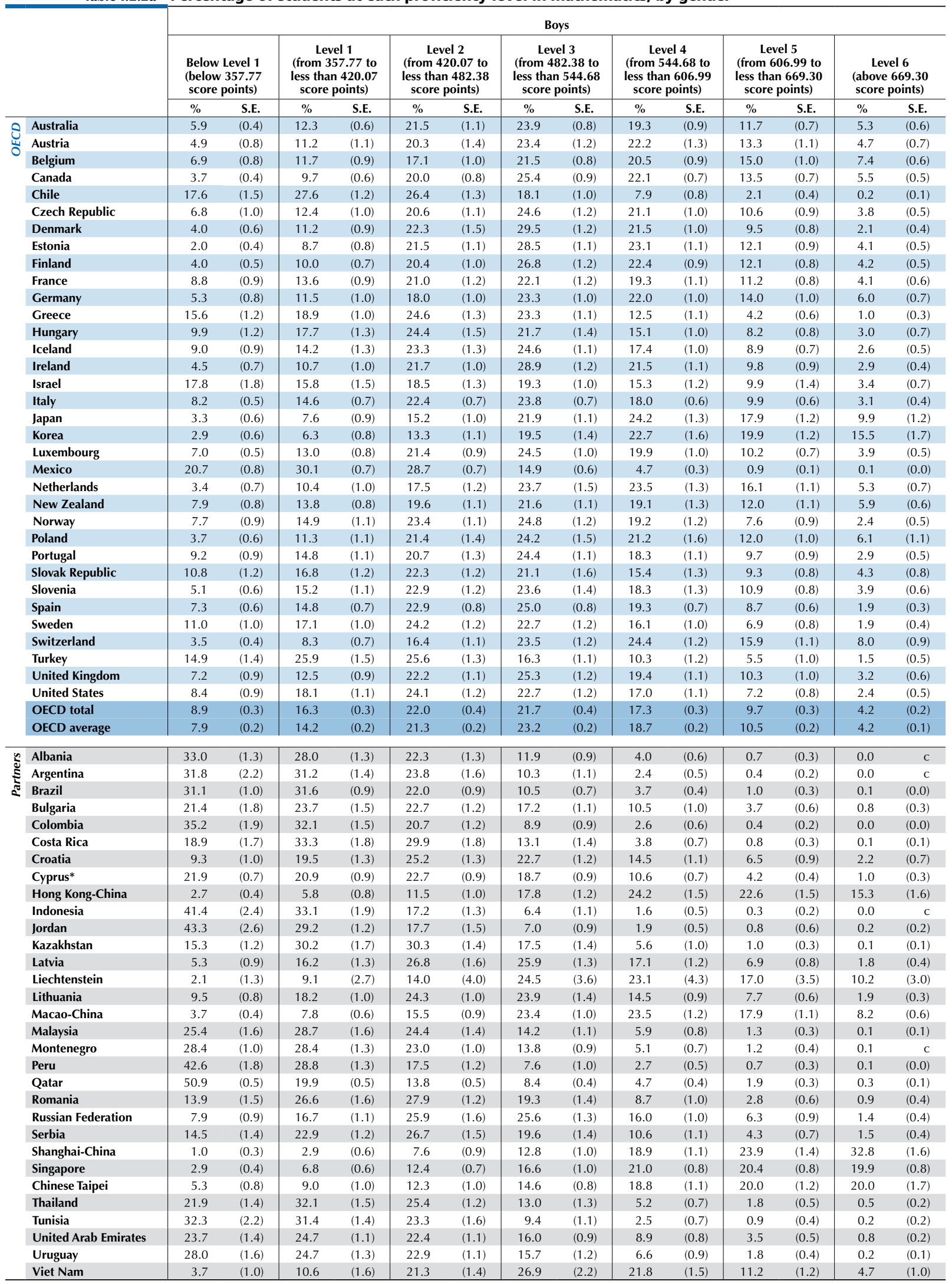

* See notes at the beginning of this Annex.

StatLink 部 St http://dx.doi.org/10.1787/888932935667 
[Part 2/2]

Table I.2.2a Percentage of students at each proficiency level in mathematics, by gender

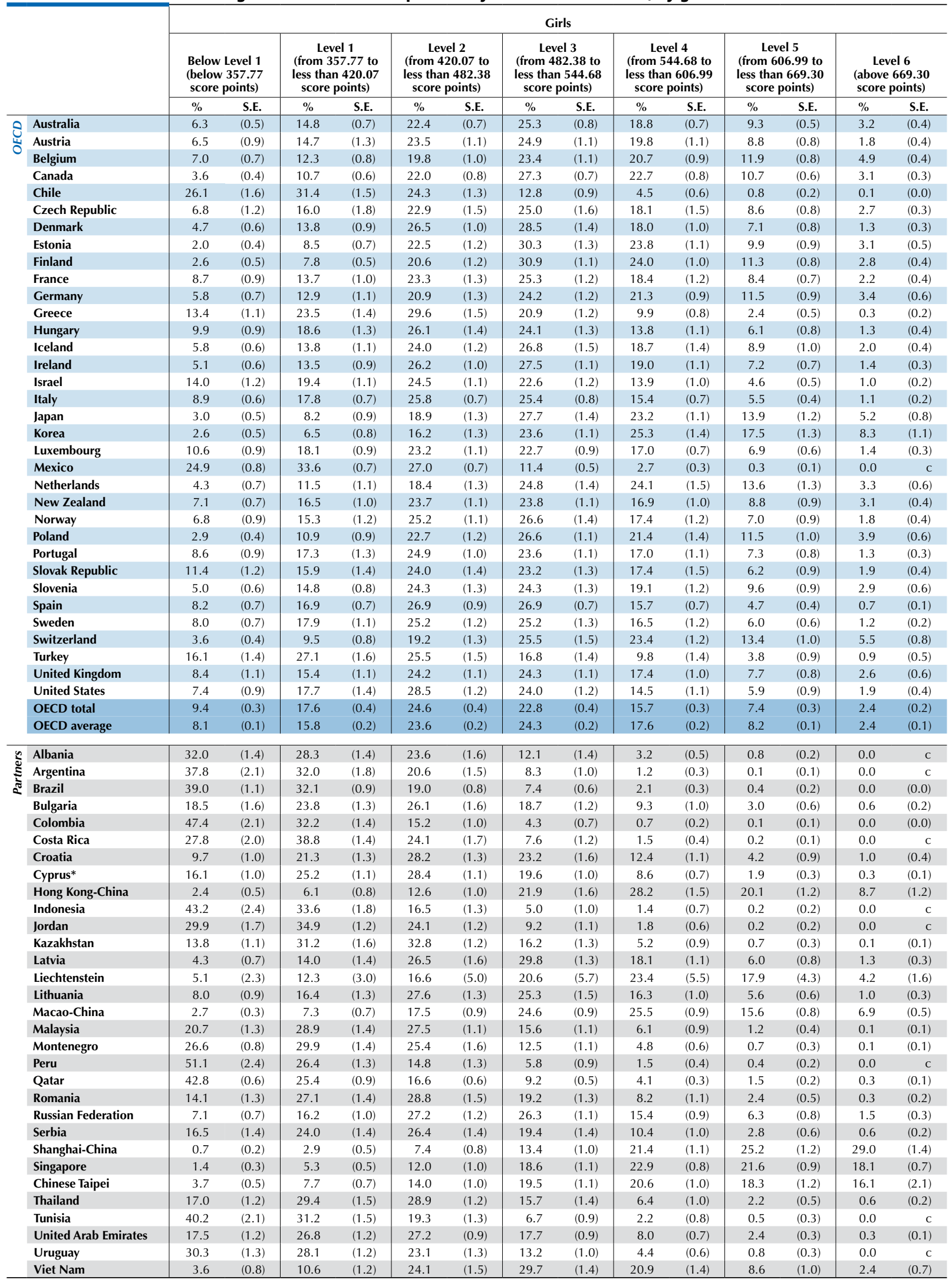

* See notes at the beginning of this Annex.

StatLink 吾Is http://dx.doi.org/10.1787/888932935667 
[Part 1/2]

Percentage of students below Level 2 and at Level 5 or above in mathematics in PISA 2003 and 2012,

\begin{tabular}{|c|c|c|c|c|c|c|c|c|c|c|c|c|c|}
\hline & & \multicolumn{12}{|c|}{ Boys } \\
\hline & & \multicolumn{4}{|c|}{ Proficiency levels in PISA 2003} & \multicolumn{4}{|c|}{ Proficiency levels in PISA 2012} & \multicolumn{4}{|c|}{$\begin{array}{c}\text { Change between } 2003 \text { and } 2012 \\
\text { (PISA } 2012 \text { - PISA 2003) }\end{array}$} \\
\hline & & \multicolumn{2}{|c|}{$\begin{array}{l}\text { Below Level } 2 \\
\text { (less than 420.07 } \\
\text { score points) }\end{array}$} & \multicolumn{2}{|c|}{$\begin{array}{l}\text { Level } 5 \text { or above } \\
\text { (above } 606.99 \\
\text { score points) }\end{array}$} & \multicolumn{2}{|c|}{$\begin{array}{l}\text { Below Level } 2 \\
\text { (less than } 420.07 \\
\text { score points) }\end{array}$} & \multicolumn{2}{|c|}{$\begin{array}{l}\text { Level } 5 \text { or above } \\
\text { (above } 606.99 \\
\text { score points) }\end{array}$} & \multicolumn{2}{|c|}{$\begin{array}{l}\text { Below Level } 2 \\
\text { (less than } 420.07 \\
\text { score points) }\end{array}$} & \multicolumn{2}{|c|}{$\begin{array}{l}\text { Level } 5 \text { or above } \\
\text { (above } 606.99 \\
\text { score points) }\end{array}$} \\
\hline & & $\%$ & S.E. & $\%$ & S.E. & $\%$ & S.E. & $\%$ & S.E. & $\%$ dif. & S.E. & $\%$ dif. & S.E. \\
\hline \multirow{30}{*}{$\begin{array}{l}\text { Ù } \\
\text { ठ }\end{array}$} & Australia & 14.9 & $(0.8)$ & 21.6 & $(1.2)$ & 18.3 & $(0.8)$ & 17.0 & $(1.0)$ & 3.4 & $(1.2)$ & -4.6 & $(1.6)$ \\
\hline & Austria & 19.2 & (1.4) & 16.7 & (1.3) & 16.1 & $(1.4)$ & 18.0 & (1.5) & -3.1 & $(2.1)$ & 1.3 & (2.0) \\
\hline & Belgium & 17.2 & $(1.2)$ & 29.1 & $(1.2)$ & 18.6 & $(1.3)$ & 22.3 & $(1.0)$ & 1.4 & $(1.8)$ & -6.8 & (1.6) \\
\hline & Canada & 10.3 & $(0.6)$ & 25.2 & $(1.0)$ & 13.4 & $(0.7)$ & 19.0 & $(0.9)$ & 3.1 & $(1.0)$ & -6.1 & (1.3) \\
\hline & Czech Republic & 15.1 & (1.4) & 21.6 & (1.5) & 19.3 & (1.4) & 14.4 & (1.1) & 4.2 & (2.0) & -7.3 & (1.9) \\
\hline & Denmark & 13.4 & (1.0) & 18.0 & (1.2) & 15.1 & $(1.3)$ & 11.5 & $(0.9)$ & 1.8 & $(1.7)$ & -6.5 & (1.5) \\
\hline & Finland & 7.3 & $(0.7)$ & 26.0 & (1.2) & 14.1 & $(0.9)$ & 16.3 & (1.0) & 6.7 & $(1.2)$ & -9.7 & (1.6) \\
\hline & France & 16.8 & (1.5) & 17.9 & (1.5) & 22.3 & $(1.1)$ & 15.3 & (1.1) & 5.6 & $(2.0)$ & -2.6 & (1.8) \\
\hline & Germany & 21.4 & (1.5) & 18.3 & (1.3) & 16.8 & (1.1) & 19.9 & (1.2) & -4.6 & (1.9) & 1.6 & (1.8) \\
\hline & Greece & 35.8 & $(2.1)$ & 5.8 & (0.8) & 34.5 & (1.7) & 5.1 & (0.6) & -1.3 & (2.8) & -0.6 & (1.0) \\
\hline & Hungary & 22.2 & (1.3) & 11.9 & (1.0) & 27.6 & $(1.7)$ & 11.2 & (1.3) & 5.4 & $(2.2)$ & -0.7 & (1.7) \\
\hline & Iceland & 18.3 & (1.0) & 15.0 & (1.0) & 23.2 & (1.1) & 11.5 & $(0.9)$ & 5.0 & (1.6) & -3.6 & (1.3) \\
\hline & Ireland & 15.0 & (1.3) & 13.7 & (1.1) & 15.2 & (1.4) & 12.7 & $(0.9)$ & 0.2 & (2.0) & -1.0 & (1.4) \\
\hline & Italy & 29.7 & (2.1) & 9.6 & $(0.7)$ & 22.8 & $(0.9)$ & 13.0 & $(0.8)$ & -6.9 & (2.3) & 3.3 & (1.1) \\
\hline & Japan & 14.2 & (1.5) & 27.5 & $(2.3)$ & 10.9 & $(1.2)$ & 27.8 & (1.9) & -3.3 & (1.9) & 0.3 & (3.0) \\
\hline & Korea & 8.5 & (1.1) & 28.6 & (1.8) & 9.2 & $(1.2)$ & 35.3 & (2.4) & 0.7 & (1.7) & 6.7 & (3.0) \\
\hline & Luxembourg & 20.0 & $(0.8)$ & 13.8 & $(0.8)$ & 20.1 & $(0.8)$ & 14.1 & $(0.7)$ & 0.1 & (1.3) & 0.3 & (1.1) \\
\hline & Mexico & 63.1 & $(2.1)$ & 0.5 & $(0.2)$ & 50.7 & $(1.0)$ & 0.9 & $(0.1)$ & -12.4 & (2.5) & 0.4 & $(0.2)$ \\
\hline & Netherlands & 10.2 & (1.5) & 26.1 & (1.7) & 13.9 & (1.4) & 21.5 & (1.4) & 3.7 & $(2.0)$ & -4.6 & $(2.2)$ \\
\hline & New Zealand & 14.5 & $(0.9)$ & 23.9 & (1.1) & 21.8 & $(1.1)$ & 17.9 & (1.3) & 7.2 & (1.6) & -6.1 & (1.7) \\
\hline & Norway & 20.6 & (1.1) & 13.2 & $(0.8)$ & 22.6 & $(1.2)$ & 10.0 & $(0.8)$ & 2.0 & (1.7) & -3.2 & $(1.2)$ \\
\hline & Poland & 22.7 & $(1.2)$ & 12.1 & (1.0) & 15.0 & $(1.2)$ & 18.1 & (1.6) & -7.7 & (1.8) & 6.0 & (1.9) \\
\hline & Portugal & 28.7 & (2.0) & 7.2 & $(0.8)$ & 24.0 & (1.5) & 12.6 & (1.0) & -4.8 & (2.5) & 5.3 & (1.3) \\
\hline & Slovak Republic & 18.0 & (1.6) & 15.4 & (1.1) & 27.6 & (1.6) & 13.6 & (1.3) & 9.6 & (2.3) & -1.9 & (1.7) \\
\hline & Spain & 22.5 & (1.3) & 9.9 & (1.1) & 22.1 & $(1.0)$ & 10.6 & $(0.7)$ & -0.3 & (1.8) & 0.7 & (1.3) \\
\hline & Sweden & 16.7 & (1.1) & 17.3 & (1.1) & 28.2 & (1.4) & 8.8 & $(0.8)$ & 11.5 & (1.9) & -8.5 & (1.4) \\
\hline & Switzerland & 13.4 & (1.0) & 24.2 & (2.4) & 11.8 & $(0.8)$ & 23.9 & (1.5) & -1.7 & (1.3) & -0.3 & (2.8) \\
\hline & Turkey & 49.3 & (2.9) & 6.5 & (1.9) & 40.8 & $(2.2)$ & 7.1 & (1.3) & -8.6 & (3.8) & 0.5 & (2.3) \\
\hline & United States & 25.2 & $(1.3)$ & 11.7 & (1.0) & 26.5 & $(1.5)$ & 9.6 & $(0.9)$ & 1.3 & $(2.1)$ & -2.1 & (1.4) \\
\hline & OECD average 2003 & 20.8 & $(0.3)$ & 16.8 & $(0.2)$ & 21.5 & $(0.2)$ & 15.1 & $(0.2)$ & 0.6 & $(0.4)$ & -1.7 & $(0.3)$ \\
\hline \multirow{10}{*}{ 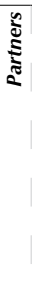 } & Brazil & 72.5 & (2.3) & 1.9 & $(0.7)$ & 62.7 & $(1.2)$ & 1.1 & $(0.3)$ & -9.8 & $(2.8)$ & -0.8 & $(0.7)$ \\
\hline & Hong Kong-China & 11.8 & $(1.7)$ & 33.1 & (2.3) & 8.5 & $(1.0)$ & 37.9 & $(2.0)$ & -3.3 & $(2.0)$ & 4.8 & (3.0) \\
\hline & Indonesia & 78.0 & $(1.7)$ & 0.2 & $(0.1)$ & 74.6 & $(2.4)$ & 0.3 & $(0.2)$ & -3.4 & (3.0) & 0.1 & $(0.2)$ \\
\hline & Latvia & 24.4 & (1.9) & 9.4 & (1.1) & 21.5 & $(1.5)$ & 8.7 & $(1.0)$ & -2.8 & (2.5) & -0.7 & (1.5) \\
\hline & Liechtenstein & 10.2 & $(2.4)$ & 32.3 & $(5.1)$ & 11.2 & $(2.8)$ & 27.3 & (3.3) & 1.0 & (3.8) & -5.1 & (6.1) \\
\hline & Macao-China & 10.8 & $(1.7)$ & 24.0 & (2.7) & 11.6 & $(0.7)$ & 26.1 & $(0.9)$ & 0.7 & (1.9) & 2.1 & (2.9) \\
\hline & Russian Federation & 29.9 & (2.3) & 8.9 & (1.1) & 24.6 & (1.4) & 7.8 & (1.1) & -5.2 & (2.8) & -1.2 & (1.6) \\
\hline & Thailand & 55.0 & $(2.1)$ & 1.7 & $(0.5)$ & 54.1 & $(1.8)$ & 2.3 & $(0.6)$ & -0.9 & $(2.9)$ & 0.7 & $(0.8)$ \\
\hline & Tunisia & 76.3 & $(1.2)$ & 0.3 & $(0.2)$ & 63.7 & $(2.2)$ & 1.1 & $(0.5)$ & -12.7 & (2.6) & 0.9 & (0.5) \\
\hline & Uruguay & 45.6 & $(1.8)$ & 3.8 & $(0.6)$ & 52.8 & (1.8) & 2.0 & $(0.5)$ & 7.2 & $(2.6)$ & -1.7 & $(0.8)$ \\
\hline
\end{tabular}

Notes: Values that are statistically significant are indicated in bold (see Annex A3).

Only countries and economies with comparable results in PISA 2003 and PISA 2012 are presented.

StatLink त्माज्ञा http://dx.doi.org/10.1787/888932935667 
[Part 2/2]

Percentage of students below Level 2 and at Level 5 or above in mathematics in PISA 2003 and 2012 , Table I.2.2b by gender

\begin{tabular}{|c|c|c|c|c|c|c|c|c|c|c|c|c|c|}
\hline & & \multicolumn{12}{|c|}{ Girls } \\
\hline & & \multicolumn{4}{|c|}{ Proficiency levels in PISA 2003} & \multicolumn{4}{|c|}{ Proficiency levels in PISA 2012} & \multicolumn{4}{|c|}{$\begin{array}{l}\text { Change between } 2003 \text { and } 2012 \\
\text { (PISA 2012 - PISA 2003) }\end{array}$} \\
\hline & & \multicolumn{2}{|c|}{$\begin{array}{l}\text { Below Level } 2 \\
\text { (less than } 420.07 \\
\text { score points) }\end{array}$} & \multicolumn{2}{|c|}{$\begin{array}{l}\text { Level } 5 \text { or above } \\
\text { (above } 606.99 \\
\text { score points) }\end{array}$} & \multicolumn{2}{|c|}{$\begin{array}{l}\text { Below Level } 2 \\
\text { (less than } 420.07 \\
\text { score points) }\end{array}$} & \multicolumn{2}{|c|}{$\begin{array}{l}\text { Level } 5 \text { or above } \\
\text { (above } 606.99 \\
\text { score points) }\end{array}$} & \multicolumn{2}{|c|}{$\begin{array}{l}\text { Below Level } 2 \\
\text { (less than } 420.07 \\
\text { score points) }\end{array}$} & \multicolumn{2}{|c|}{$\begin{array}{c}\text { Level } 5 \text { or above } \\
\text { (above } 606.99 \\
\text { score points) }\end{array}$} \\
\hline & & $\%$ & S.E. & $\%$ & S.E. & $\%$ & S.E. & $\%$ & S.E. & $\%$ dif. & S.E. & $\%$ dif. & S.E. \\
\hline \multirow{30}{*}{ তি } & Australia & 13.8 & $(0.9)$ & 17.9 & $(1.0)$ & 21.1 & $(0.8)$ & 12.4 & $(0.6)$ & 7.4 & (1.4) & -5.4 & (1.2) \\
\hline & Austria & 18.4 & (1.5) & 11.8 & $(1.2)$ & 21.2 & $(1.4)$ & 10.6 & $(0.9)$ & 2.8 & $(2.1)$ & -1.2 & (1.5) \\
\hline & Belgium & 15.7 & $(1.1)$ & 23.6 & $(1.0)$ & 19.3 & $(1.1)$ & 16.8 & $(0.8)$ & 3.6 & (1.6) & -6.8 & (1.4) \\
\hline & Canada & 9.4 & $(0.6)$ & 17.8 & $(0.9)$ & 14.3 & $(0.7)$ & 13.8 & $(0.7)$ & 4.8 & (1.0) & -4.0 & $(1.2)$ \\
\hline & Czech Republic & 18.1 & (1.7) & 14.8 & (1.3) & 22.7 & $(1.7)$ & 11.3 & (0.9) & 4.7 & (2.5) & -3.5 & (1.6) \\
\hline & Denmark & 17.4 & $(1.2)$ & 13.9 & (1.0) & 18.6 & $(1.1)$ & 8.4 & (0.8) & 1.2 & (1.7) & -5.5 & (1.3) \\
\hline & Finland & 6.2 & $(0.6)$ & 20.8 & $(1.0)$ & 10.4 & $(0.8)$ & 14.1 & $(0.9)$ & 4.2 & $(1.0)$ & -6.7 & (1.4) \\
\hline & France & 16.5 & (1.3) & 12.6 & (1.0) & 22.4 & $(1.0)$ & 10.6 & (0.8) & 5.9 & (1.7) & -2.0 & (1.3) \\
\hline & Germany & 21.4 & (1.4) & 14.1 & (1.1) & 18.7 & $(1.3)$ & 14.9 & (1.1) & -2.7 & (2.0) & 0.8 & (1.6) \\
\hline & Greece & 41.9 & (2.1) & 2.3 & (0.5) & 36.9 & (1.8) & 2.7 & (0.4) & -5.0 & (2.9) & 0.4 & (0.7) \\
\hline & Hungary & 23.9 & (1.4) & 9.3 & (1.0) & 28.5 & $(1.6)$ & 7.4 & (1.1) & 4.6 & (2.3) & -1.8 & (1.5) \\
\hline & Iceland & 11.5 & (0.9) & 15.9 & (1.0) & 19.7 & (1.0) & 10.8 & (1.1) & 8.2 & (1.5) & -5.1 & (1.5) \\
\hline & Ireland & 18.7 & (1.4) & 9.0 & (1.0) & 18.7 & (1.2) & 8.5 & $(0.7)$ & 0.0 & (2.0) & -0.5 & (1.3) \\
\hline & Italy & 34.0 & $(2.1)$ & 4.6 & (0.4) & 26.7 & $(1.0)$ & 6.7 & (0.5) & -7.3 & (2.4) & 2.1 & $(0.7)$ \\
\hline & Japan & 12.4 & (1.4) & 21.3 & (1.5) & 11.2 & $(1.1)$ & 19.1 & (1.6) & -1.2 & (1.9) & -2.2 & (2.3) \\
\hline & Korea & 11.0 & (1.3) & 19.1 & (2.0) & 9.1 & $(1.1)$ & 25.8 & (2.0) & -1.9 & (1.8) & 6.7 & (2.9) \\
\hline & Luxembourg & 23.4 & $(0.9)$ & 7.9 & $(0.7)$ & 28.7 & $(0.7)$ & 8.3 & $(0.6)$ & 5.3 & (1.3) & 0.4 & (0.9) \\
\hline & Mexico & 68.5 & $(2.0)$ & 0.2 & $(0.1)$ & 58.5 & $(0.9)$ & 0.3 & $(0.1)$ & -10.0 & (2.4) & 0.1 & $(0.1)$ \\
\hline & Netherlands & 11.7 & (1.4) & 24.9 & (1.5) & 15.8 & (1.5) & 16.9 & (1.4) & 4.1 & (2.1) & -7.9 & (2.1) \\
\hline & New Zealand & 15.6 & (1.3) & 17.4 & $(0.9)$ & 23.6 & $(1.1)$ & 12.0 & (1.1) & 7.9 & (1.8) & -5.4 & (1.5) \\
\hline & Norway & 21.1 & (1.5) & 9.6 & $(0.8)$ & 22.0 & $(1.4)$ & 8.8 & $(1.0)$ & 0.9 & $(2.1)$ & -0.8 & (1.3) \\
\hline & Poland & 21.4 & (1.3) & 8.1 & $(0.8)$ & 13.8 & $(1.0)$ & 15.4 & (1.4) & -7.6 & $(1.7)$ & 7.3 & (1.7) \\
\hline & Portugal & 31.3 & (1.8) & 3.7 & $(0.6)$ & 25.9 & (1.8) & 8.6 & $(0.8)$ & -5.4 & (2.6) & 5.0 & (1.1) \\
\hline & Slovak Republic & 22.0 & (1.7) & 9.8 & $(0.9)$ & 27.3 & (1.7) & 8.1 & (1.0) & 5.3 & (2.5) & -1.7 & (1.4) \\
\hline & Spain & 23.4 & $(1.0)$ & 6.1 & $(0.6)$ & 25.1 & $(1.0)$ & 5.3 & $(0.3)$ & 1.7 & (1.6) & -0.8 & $(0.7)$ \\
\hline & Sweden & 17.9 & (1.0) & 14.2 & (1.2) & 26.0 & (1.3) & 7.2 & $(0.6)$ & 8.1 & (1.8) & -7.1 & (1.4) \\
\hline & Switzerland & 15.7 & (1.1) & 18.0 & (1.4) & 13.1 & $(0.9)$ & 18.8 & (1.3) & -2.6 & (1.5) & 0.9 & (2.0) \\
\hline & Turkey & 55.8 & (3.0) & 4.2 & (1.4) & 43.2 & (2.4) & 4.7 & (1.2) & -12.5 & (4.1) & 0.5 & (1.8) \\
\hline & United States & 26.3 & (1.4) & 8.4 & $(0.9)$ & 25.2 & (1.6) & 7.9 & (1.1) & -1.1 & (2.3) & -0.6 & (1.4) \\
\hline & OECD average 2003 & 22.2 & $(0.3)$ & 12.5 & $(0.2)$ & 23.0 & $(0.2)$ & 10.9 & $(0.2)$ & 0.8 & $(0.4)$ & -1.6 & $(0.3)$ \\
\hline \multirow{10}{*}{ 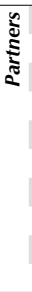 } & Brazil & 77.5 & (1.5) & 0.5 & (0.3) & 71.1 & $(1.2)$ & 0.4 & $(0.2)$ & -6.4 & (2.1) & -0.1 & $(0.3)$ \\
\hline & Hong Kong-China & 9.0 & (1.1) & 28.3 & (2.0) & 8.5 & $(1.0)$ & 28.8 & (1.8) & -0.5 & (1.5) & 0.6 & (2.9) \\
\hline & Indonesia & 78.3 & (2.0) & 0.2 & $(0.1)$ & 76.9 & $(2.2)$ & 0.2 & $(0.2)$ & -1.4 & (3.1) & 0.0 & $(0.2)$ \\
\hline & Latvia & 23.1 & (1.6) & 6.7 & (0.9) & 18.3 & (1.4) & 7.3 & (0.9) & -4.8 & $(2.2)$ & 0.6 & (1.3) \\
\hline & Liechtenstein & 14.4 & $(2.7)$ & 18.6 & $(4.3)$ & 17.3 & $(3.5)$ & 22.1 & $(4.4)$ & 2.9 & $(4.4)$ & 3.5 & (6.2) \\
\hline & Macao-China & 11.5 & (1.7) & 13.6 & (1.6) & 10.0 & $(0.7)$ & 22.5 & $(0.7)$ & -1.5 & (1.8) & 8.9 & (1.9) \\
\hline & Russian Federation & 30.6 & $(2.0)$ & 5.1 & (0.8) & 23.3 & $(1.2)$ & 7.8 & (0.9) & -7.3 & (2.5) & 2.7 & (1.2) \\
\hline & Thailand & 53.1 & (1.9) & 1.6 & $(0.5)$ & 46.3 & $(2.1)$ & 2.8 & $(0.6)$ & -6.8 & (3.0) & 1.2 & $(0.8)$ \\
\hline & Tunisia & 79.6 & (1.5) & 0.2 & $(0.1)$ & 71.3 & (1.9) & 0.5 & $(0.3)$ & -8.3 & (2.6) & 0.3 & $(0.3)$ \\
\hline & Uruguay & 50.5 & (1.9) & 1.9 & $(0.4)$ & 58.5 & (1.6) & 0.8 & $(0.3)$ & 8.0 & $(2.6)$ & -1.1 & $(0.5)$ \\
\hline
\end{tabular}

Notes: Values that are statistically significant are indicated in bold (see Annex A3).

Only countries and economies with comparable results in PISA 2003 and PISA 2012 are presented.

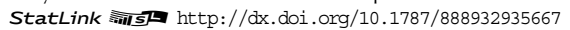


[Part 1/1]

Table I.2.3a Mean score, variation and gender differences in student performance in mathematics

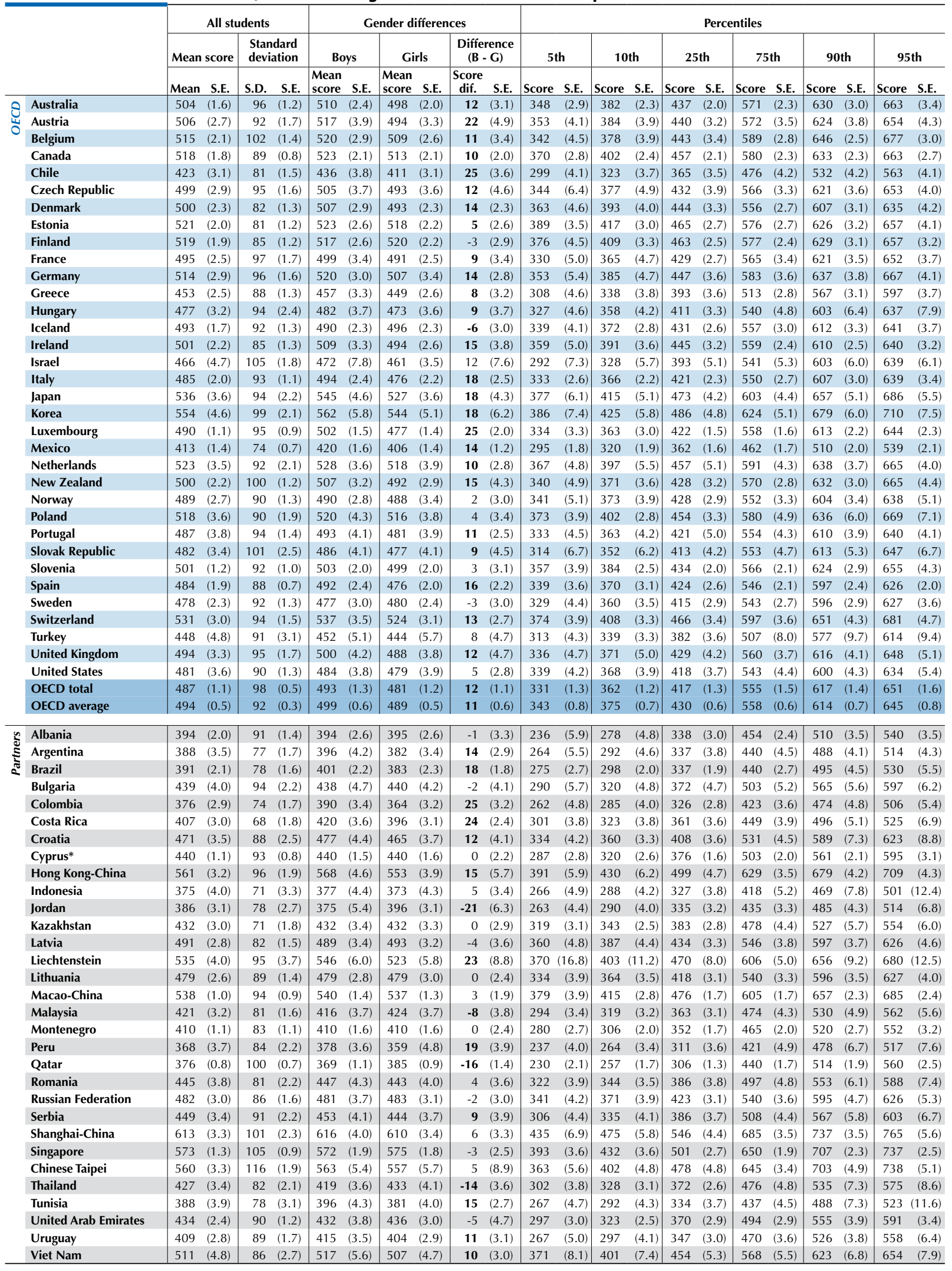

Note: Values that are statistically significant are indicated in bold (see Annex A3).

* See notes at the beginning of this Annex.

StatLink त्ञाज $h t t p: / / d x . d o i . o r g / 10.1787 / 888932935667$ 
[Part 1/1]

Table I.2.3b Mean mathematics performance in PISA 2003 through 2012

\begin{tabular}{|c|c|c|c|c|c|c|c|c|c|c|c|c|c|c|c|c|c|c|c|c|c|}
\hline & \multirow{2}{*}{\multicolumn{2}{|c|}{ PISA 2003}} & \multirow{2}{*}{\multicolumn{2}{|c|}{ PISA 2006}} & \multirow{2}{*}{\multicolumn{2}{|c|}{ PISA 2009}} & \multirow{2}{*}{\multicolumn{2}{|c|}{ PISA 2012}} & \multirow{2}{*}{\multicolumn{2}{|c|}{ 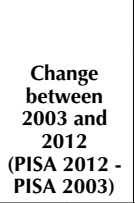 }} & \multirow{2}{*}{\multicolumn{2}{|c|}{$\begin{array}{c}\begin{array}{c}\text { Change } \\
\text { between }\end{array} \\
2006 \text { and } \\
2012 \\
\text { (PISA 2012 - } \\
\text { PISA 2006) }\end{array}$}} & \multirow{2}{*}{\multicolumn{2}{|c|}{$\begin{array}{l}\text { Change } \\
\text { between } \\
2009 \text { and } \\
2012 \\
\text { (PISA 2012 - } \\
\text { PISA 2009) }\end{array}$}} & \multirow{2}{*}{\multicolumn{2}{|c|}{$\begin{array}{c}\text { Annualised } \\
\text { change in } \\
\text { mathematics } \\
\text { across PISA } \\
\text { assessments }\end{array}$}} & \multicolumn{4}{|c|}{$\begin{array}{c}\text { Curvilinear change } \\
\text { in mathematics performance }\end{array}$} \\
\hline & & & & & & & & & & & & & & & & & & \multicolumn{2}{|c|}{$\begin{array}{l}\text { Linear term } \\
\text { (annual change } \\
\text { in 2012) }\end{array}$} & \multicolumn{2}{|c|}{$\begin{array}{c}\text { Rate } \\
\text { of acceleration } \\
\text { or deceleration } \\
\text { in performance } \\
\text { (Quadratic } \\
\text { term) }\end{array}$} \\
\hline & & $\begin{array}{l}\text { Mean } \\
\text { score }\end{array}$ & S.E. & $\begin{array}{l}\text { Mean } \\
\text { score }\end{array}$ & S.E. & $\begin{array}{l}\text { Mean } \\
\text { score }\end{array}$ & S.E. & $\begin{array}{l}\text { Mean } \\
\text { score }\end{array}$ & S.E. & $\begin{array}{l}\text { Score } \\
\text { dif. }\end{array}$ & S.E. & \begin{tabular}{|c|}
$\begin{array}{c}\text { Score } \\
\text { dif. }\end{array}$ \\
\end{tabular} & S.E. & \begin{tabular}{|c|}
$\begin{array}{c}\text { Score } \\
\text { dif. }\end{array}$ \\
\end{tabular} & S.E. & $\begin{array}{l}\text { Annual } \\
\text { change }\end{array}$ & S.E. & Coef. & S.E. & Coef. & S.E. \\
\hline & Australia & 524 & (2.1) & 520 & $(2.2)$ & 514 & (2.5) & 504 & (1.6) & -20 & (3.3) & -16 & (3.5) & -10 & (3.8) & -2.2 & $(0.34)$ & -3.7 & (1.16) & -0.2 & $(0.16)$ \\
\hline & Austria & 506 & (3.3) & 505 & (3.7) & $\mathrm{m}$ & $\mathrm{m}$ & 506 & (2.7) & 0 & (4.6) & 0 & (5.0) & $\mathrm{m}$ & $\mathrm{m}$ & 0.0 & $(0.52)$ & 0.0 & (2.14) & 0.0 & $(0.26)$ \\
\hline & Belgium & 529 & (2.3) & 520 & (3.0) & 515 & (2.3) & 515 & (2.1) & -15 & (3.7) & -6 & $(4.2)$ & -1 & (3.9) & -1.6 & $(0.40)$ & 0.4 & $(1.32)$ & 0.2 & $(0.16)$ \\
\hline & Canada & 532 & (1.8) & 527 & (2.0) & 527 & (1.6) & 518 & (1.8) & -14 & (3.2) & -9 & (3.4) & -9 & (3.4) & -1.4 & $(0.34)$ & -2.2 & (1.05) & -0.1 & $(0.14)$ \\
\hline & Chile & $\mathrm{m}$ & $\mathrm{m}$ & 411 & (4.6) & 421 & (3.1) & 423 & (3.1) & $\mathrm{m}$ & $\mathrm{m}$ & 11 & (5.9) & 2 & (4.9) & 1.9 & $(0.93)$ & -0.8 & (2.44) & -0.5 & $(0.46)$ \\
\hline & Czech Republic & 516 & (3.5) & 510 & (3.6) & 493 & (2.8) & 499 & (2.9) & -17 & (4.9) & -11 & (5.0) & 6 & (4.6) & -2.5 & $(0.54)$ & 0.4 & $(1.66)$ & 0.3 & $(0.21)$ \\
\hline & Denmark & 514 & $(2.7)$ & 513 & (2.6) & 503 & (2.6) & 500 & (2.3) & -14 & (4.1) & -13 & (4.1) & -3 & $(4.2)$ & -1.8 & $(0.43)$ & -2.2 & $(1.40)$ & 0.0 & $(0.18)$ \\
\hline & Estonia & $\mathrm{m}$ & $\mathrm{m}$ & 515 & (2.7) & 512 & (2.6) & 521 & $(2.0)$ & $\mathrm{m}$ & $\mathrm{m}$ & 6 & (4.0) & 8 & $(4.0)$ & 0.9 & $(0.69)$ & 4.6 & $(1.89)$ & 0.6 & $(0.36)$ \\
\hline & Finland & 544 & (1.9) & 548 & (2.3) & 541 & (2.2) & 519 & (1.9) & -26 & (3.3) & -30 & (3.7) & -22 & (3.7) & -2.8 & $(0.34)$ & -9.3 & (1.09) & -0.7 & $(0.15)$ \\
\hline & France & 511 & (2.5) & 496 & (3.2) & 497 & (3.1) & 495 & (2.5) & -16 & (4.0) & -1 & (4.5) & -2 & (4.6) & -1.5 & $(0.44)$ & 1.9 & (1.50) & 0.4 & (0.18) \\
\hline & Germany & 503 & (3.3) & 504 & (3.9) & 513 & (2.9) & 514 & (2.9) & 11 & (4.8) & 10 & (5.3) & 1 & (4.7) & 1.4 & $(0.50)$ & 1.5 & (1.76) & 0.0 & $(0.21)$ \\
\hline & Greece & 445 & (3.9) & 459 & (3.0) & 466 & (3.9) & 453 & (2.5) & 8 & (5.0) & -6 & (4.4) & -13 & (5.2) & 1.1 & $(0.55)$ & -5.8 & (1.62) & -0.8 & $(0.21)$ \\
\hline & Hungary & 490 & (2.8) & 491 & (2.9) & 490 & (3.5) & 477 & $(3.2)$ & -13 & (4.7) & -14 & (4.8) & -13 & (5.2) & -1.3 & $(0.49)$ & -4.8 & (1.62) & -0.4 & $(0.19)$ \\
\hline & Iceland & 515 & (1.4) & 506 & (1.8) & 507 & (1.4) & 493 & (1.7) & -22 & (2.9) & -13 & (3.2) & -14 & (3.2) & -2.2 & $(0.31)$ & -3.2 & $(0.87)$ & -0.1 & $(0.13)$ \\
\hline & Ireland & 503 & (2.4) & 501 & (2.8) & 487 & (2.5) & 501 & $(2.2)$ & -1 & (3.8) & 0 & (4.1) & 14 & (4.1) & -0.6 & $(0.41)$ & 3.2 & (1.38) & 0.4 & $(0.17)$ \\
\hline & Israel & $\mathrm{m}$ & & 442 & (4.3) & 447 & (3.3) & 466 & $(4.7)$ & $\mathrm{m}$ & $\mathrm{m}$ & 25 & (6.7) & 20 & (6.2) & 4.2 & (1.15) & 9.0 & (3.28) & 0.8 & $(0.54)$ \\
\hline & Italy & 466 & (3.1) & 462 & (2.3) & 483 & (1.9) & 485 & (2.0) & 20 & (4.2) & 24 & (3.7) & 2 & (3.6) & 2.7 & $(0.45)$ & 4.3 & (1.19) & 0.2 & $(0.16)$ \\
\hline & Japan & 534 & (4.0) & 523 & (3.3) & 529 & (3.3) & 536 & (3.6) & 2 & (5.7) & 13 & (5.3) & 7 & (5.4) & 0.4 & (0.58) & 5.0 & (1.49) & 0.5 & $(0.20)$ \\
\hline & Korea & 542 & (3.2) & 547 & (3.8) & 546 & (4.0) & 554 & (4.6) & 12 & (5.9) & 6 & (6.3) & 8 & (6.5) & 1.1 & (0.59) & 1.8 & $(2.31)$ & 0.1 & $(0.25)$ \\
\hline & Luxembourg & 493 & (1.0) & 490 & (1.1) & 489 & $(1.2)$ & 490 & (1.1) & -3 & (2.4) & 0 & (2.6) & 1 & (2.8) & -0.3 & $(0.26)$ & 0.6 & $(0.50)$ & 0.1 & $(0.11)$ \\
\hline & Mexico & 385 & (3.6) & 406 & (2.9) & 419 & (1.8) & 413 & (1.4) & 28 & (4.3) & 8 & (3.8) & -5 & (3.2) & 3.1 & $(0.46)$ & -3.2 & (1.17) & -0.7 & $(0.17)$ \\
\hline & Netherlands & 538 & (3.1) & 531 & (2.6) & 526 & (4.7) & 523 & (3.5) & -15 & (5.1) & -8 & (4.8) & -3 & (6.3) & -1.6 & $(0.58)$ & -0.6 & $(1.80)$ & 0.1 & $(0.22)$ \\
\hline & New Zealand & 523 & (2.3) & 522 & (2.4) & 519 & (2.3) & 500 & $(2.2)$ & -24 & (3.7) & -22 & (3.9) & -20 & (3.9) & -2.5 & $(0.40)$ & -7.0 & (1.10) & -0.5 & $(0.15)$ \\
\hline & Norway & 495 & (2.4) & 490 & (2.6) & 498 & (2.4) & 489 & $(2.7)$ & -6 & (4.1) & 0 & (4.3) & -9 & (4.3) & -0.3 & $(0.45)$ & -1.1 & $(1.34)$ & -0.1 & $(0.17)$ \\
\hline & Poland & 490 & (2.5) & 495 & (2.4) & 495 & (2.8) & 518 & (3.6) & 27 & (4.8) & 22 & (4.8) & 23 & (5.1) & 2.6 & $(0.46)$ & 6.8 & (1.73) & 0.5 & $(0.19)$ \\
\hline & Portugal & 466 & (3.4) & 466 & (3.1) & 487 & (2.9) & 487 & (3.8) & 21 & (5.5) & 21 & (5.3) & 0 & (5.3) & 2.8 & $(0.58)$ & 2.7 & (1.62) & 0.0 & $(0.19)$ \\
\hline & Slovak Republic & 498 & (3.3) & 492 & (2.8) & 497 & (3.1) & 482 & (3.4) & -17 & (5.2) & -10 & (4.9) & -15 & (5.1) & -1.4 & $(0.53)$ & -3.5 & $(1.66)$ & -0.2 & $(0.20)$ \\
\hline & Slovenia & $\mathrm{m}$ & & 504 & (1.0) & 501 & (1.2) & 501 & $(1.2)$ & $\mathrm{m}$ & $\mathrm{m}$ & -3 & (2.6) & 0 & (2.9) & -0.6 & $(0.41)$ & 0.3 & (1.04) & 0.1 & $(0.25)$ \\
\hline & Spain & 485 & (2.4) & 480 & (2.3) & 483 & (2.1) & 484 & (1.9) & -1 & (3.6) & 4 & (3.7) & 1 & (3.6) & 0.1 & (0.39) & 1.5 & (1.09) & 0.2 & $(0.15)$ \\
\hline & Sweden & 509 & (2.6) & 502 & (2.4) & 494 & (2.9) & 478 & (2.3) & -31 & (3.9) & -24 & (3.9) & -16 & (4.3) & -3.3 & $(0.40)$ & -5.6 & (1.38) & -0.3 & $(0.17)$ \\
\hline & Switzerland & 527 & (3.4) & 530 & (3.2) & 534 & (3.3) & 531 & (3.0) & 4 & (4.9) & 1 & (4.9) & -3 & (5.0) & 0.6 & $(0.53)$ & -0.9 & (1.53) & -0.2 & $(0.19)$ \\
\hline & Turkey & 423 & (6.7) & 424 & (4.9) & 445 & (4.4) & 448 & $(4.8)$ & 25 & (8.5) & 24 & $(7.2)$ & 3 & (7.0) & 3.2 & $(0.81)$ & 3.2 & (2.64) & 0.0 & $(0.31)$ \\
\hline & United Kingdom & $\mathrm{m}$ & & 495 & (2.1) & 492 & (2.4) & 494 & (3.3) & $\mathrm{m}$ & $\mathrm{m}$ & -2 & (4.4) & 2 & (4.7) & -0.3 & $(0.57)$ & 1.3 & $(2.62)$ & 0.3 & $(0.40)$ \\
\hline & United States & 483 & (2.9) & 474 & $(4.0)$ & 487 & (3.6) & 481 & (3.6) & -2 & (5.0) & 7 & (5.8) & -6 & (5.6) & 0.3 & $(0.57)$ & 1.0 & $(1.88)$ & 0.1 & $(0.21)$ \\
\hline & OECD average 2003 & 500 & $(0.6)$ & 498 & $(0.5)$ & 499 & $(0.6)$ & 496 & $(0.5)$ & -3 & $(0.9)$ & -1 & $(0.9)$ & -3 & $(0.9)$ & -0.3 & (0.09) & -0.6 & $(0.29)$ & 0.0 & $(0.04)$ \\
\hline & OECD average 2006 & $\mathrm{~m}$ & $\mathrm{~m}$ & 494 & $(0.5)$ & 496 & $(0.5)$ & 494 & $(0.5)$ & $\mathrm{m}$ & $\mathrm{m}$ & 0 & $(0.8)$ & -2 & $(0.8)$ & -0.1 & (0.09) & -0.1 & $(0.29)$ & 0.0 & $(0.04)$ \\
\hline & OECD average 2009 & $\mathrm{~m}$ & $\mathrm{~m}$ & $\mathrm{~m}$ & $\mathrm{~m}$ & 496 & $(0.5)$ & 494 & $(0.5)$ & $\mathrm{m}$ & $\mathrm{m}$ & $\mathrm{m}$ & $\mathrm{m}$ & -2 & $(0.8)$ & $\mid-0.1$ & (0.09) & -0.1 & $(0.29)$ & 0.0 & $(0.04)$ \\
\hline
\end{tabular}

\begin{tabular}{|c|c|c|c|c|c|c|c|c|c|c|c|c|c|c|c|c|c|c|c|c|}
\hline Albania & $\mathrm{m}$ & $\mathrm{m}$ & $\mathrm{m}$ & $\mathrm{m}$ & 377 & $(4.0)$ & 394 & (2.0) & $\mathrm{m}$ & $\mathrm{m}$ & $\mathrm{m}$ & $\mathrm{m}$ & 17 & (5.0) & 5.6 & (1.67) & $\mathrm{m}$ & $\mathrm{m}$ & $\mathrm{m}$ & $\mathrm{m}$ \\
\hline Argentina & $\mathrm{m}$ & $\mathrm{m}$ & 381 & (6.2) & 388 & (4.1) & 388 & (3.5) & $\mathrm{m}$ & $\mathrm{m}$ & 7 & (7.5) & 0 & (5.9) & 1.2 & $(1.28)$ & -1.0 & (3.31) & -0.4 & $(0.63)$ \\
\hline Brazil & 356 & $(4.8)$ & 370 & (2.9) & 386 & (2.4) & 391 & $(2.1)$ & 35 & (5.6) & 22 & $(4.1)$ & 6 & (3.9) & 4.1 & $(0.56)$ & 2.0 & $(1.35)$ & -0.2 & $(0.20)$ \\
\hline Bulgaria & $\mathrm{m}$ & $\mathrm{m}$ & 413 & (6.1) & 428 & (5.9) & 439 & $(4.0)$ & $\mathrm{m}$ & $\mathrm{m}$ & 25 & (7.6) & 11 & (7.5) & 4.2 & $(1.34)$ & 2.9 & $(4.66)$ & -0.2 & $(0.83)$ \\
\hline Colombia & $\mathrm{m}$ & $\mathrm{m}$ & 370 & (3.8) & 381 & (3.2) & 376 & $(2.9)$ & $\mathrm{m}$ & $\mathrm{m}$ & 7 & $(5.2)$ & -4 & (4.9) & 1.1 & $(0.89)$ & -4.0 & $(2.82)$ & -0.8 & $(0.50)$ \\
\hline Costa Rica & $\mathrm{m}$ & $\mathrm{m}$ & $\mathrm{m}$ & $\mathrm{m}$ & 409 & (3.0) & 407 & (3.0) & $\mathrm{m}$ & $\mathrm{m}$ & $\mathrm{m}$ & $\mathrm{m}$ & -2 & $(4.8)$ & -1.2 & $(2.26)$ & $\mathrm{m}$ & $\mathrm{m}$ & $\mathrm{m}$ & $\mathrm{m}$ \\
\hline Croatia & $\mathrm{m}$ & $\mathrm{m}$ & 467 & (2.4) & 460 & (3.1) & 471 & (3.5) & $\mathrm{m}$ & $\mathrm{m}$ & 4 & (4.7) & 11 & $(5.2)$ & 0.6 & $(0.78)$ & 6.8 & $(3.02)$ & 1.0 & $(0.49)$ \\
\hline Dubai (UAE) & $\mathrm{m}$ & $\mathrm{m}$ & $\mathrm{m}$ & $\mathrm{m}$ & 453 & (1.1) & 464 & (1.2) & $\mathrm{m}$ & $\mathrm{m}$ & $\mathrm{m}$ & $\mathrm{m}$ & 11 & $(2.8)$ & 3.8 & $(0.91)$ & $\mathrm{m}$ & $\mathrm{m}$ & $\mathrm{m}$ & $\mathrm{m}$ \\
\hline Hong Kong-China & 550 & (4.5) & 547 & (2.7) & 555 & $(2.7)$ & 561 & (3.2) & 11 & (5.9) & 14 & $(4.7)$ & 7 & $(4.8)$ & 1.3 & $(0.58)$ & 3.7 & $(1.66)$ & 0.3 & $(0.21)$ \\
\hline Indonesi & 360 & (3.9) & 391 & (5.6) & 371 & (3.7) & 375 & $(4.0)$ & 15 & (5.9) & -16 & $(7.2)$ & 4 & (5.9) & 0.7 & $(0.63)$ & -5.6 & (2.37) & -0.7 & $(0.26)$ \\
\hline Jordan & $\mathrm{m}$ & $\mathrm{m}$ & 384 & (3.3) & 387 & (3.7) & 386 & (3.1) & $\mathrm{m}$ & $\mathrm{m}$ & 2 & (5.0) & -1 & (5.4) & 0.2 & $(0.84)$ & -1.0 & (2.85) & -0.2 & (0.51) \\
\hline Kazakhstan & $\mathrm{m}$ & $\mathrm{m}$ & $\mathrm{m}$ & $\mathrm{m}$ & 405 & (3.0) & 432 & (3.0) & $\mathrm{m}$ & $\mathrm{m}$ & $\mathrm{m}$ & $\mathrm{m}$ & 27 & (4.9) & 9.0 & (1.54) & $\mathrm{m}$ & $\mathrm{m}$ & $\mathrm{m}$ & $\mathrm{m}$ \\
\hline Latvia & 483 & (3.7) & 486 & (3.0) & 482 & (3.1) & 491 & (2.8) & 7 & (5.0) & 4 & (4.6) & 9 & (4.7) & 0.5 & $(0.54)$ & 1.6 & (1.60) & 0.1 & $(0.20)$ \\
\hline Liechtenstein & 536 & (4.1) & 525 & $(4.2)$ & 536 & (4.1) & 535 & $(4.0)$ & -1 & (6.0) & 10 & (6.1) & -1 & (6.1) & 0.3 & $(0.63)$ & 2.8 & (2.13) & 0.3 & $(0.25)$ \\
\hline Lithuania & $\mathrm{m}$ & $\mathrm{m}$ & 486 & (2.9) & 477 & (2.6) & 479 & (2.6) & $\mathrm{m}$ & $\mathrm{m}$ & -8 & (4.5) & 2 & (4.4) & -1.4 & $(0.81)$ & 2.7 & (1.95) & 0.7 & $(0.37)$ \\
\hline Macao-China & 527 & (2.9) & 525 & (1.3) & 525 & $(0.9)$ & 538 & (1.0) & 11 & (3.6) & 13 & (2.6) & 13 & (2.7) & 1.0 & $(0.36)$ & 4.8 & $(0.77)$ & 0.4 & $(0.14)$ \\
\hline Malaysia & $\mathrm{m}$ & $\mathrm{m}$ & $\mathrm{m}$ & $\mathrm{m}$ & 404 & (2.7) & 421 & (3.2) & $\mathrm{m}$ & $\mathrm{m}$ & $\mathrm{m}$ & $\mathrm{m}$ & 16 & (4.8) & 8.1 & $(2.12)$ & $\mathrm{m}$ & $\mathrm{m}$ & $\mathrm{m}$ & $\mathrm{m}$ \\
\hline Montenegro & $\mathrm{m}$ & $\mathrm{m}$ & 399 & (1.4) & 403 & (2.0) & 410 & (1.1) & $\mathrm{m}$ & $\mathrm{m}$ & 10 & (2.7) & 7 & (3.2) & 1.7 & $(0.45)$ & 3.0 & (1.55) & 0.2 & $(0.31)$ \\
\hline Peru & $\mathrm{m}$ & $\mathrm{m}$ & $\mathrm{m}$ & $\mathrm{m}$ & 365 & (4.0) & 368 & (3.7) & $\mathrm{m}$ & $\mathrm{m}$ & $\mathrm{m}$ & $\mathrm{m}$ & 3 & (5.9) & 1.0 & (2.09) & $\mathrm{m}$ & $\mathrm{m}$ & $\mathrm{m}$ & $\mathrm{m}$ \\
\hline Qatar & $\mathrm{m}$ & $\mathrm{m}$ & 318 & (1.0) & 368 & $(0.7)$ & 376 & $(0.8)$ & $\mathrm{m}$ & $\mathrm{m}$ & 58 & (2.4) & 8 & (2.5) & 9.2 & $(0.41)$ & -4.2 & (0.68) & -2.3 & $(0.21)$ \\
\hline Romania & $\mathrm{m}$ & $\mathrm{m}$ & 415 & (4.2) & 427 & (3.4) & 445 & (3.8) & $\mathrm{m}$ & $\mathrm{m}$ & 30 & (6.0) & 17 & (5.6) & 4.9 & $(1.00)$ & 6.7 & (3.09) & 0.3 & $(0.54)$ \\
\hline Russian F & 468 & $(4.2)$ & 476 & (3.9) & 468 & (3.3) & 482 & (3.0) & 14 & (5.5) & 6 & (5.3) & 14 & (5.0) & 1.1 & $(0.59)$ & 2.1 & $(1.86)$ & 0.1 & $(0.23)$ \\
\hline Serbia & $\mathrm{m}$ & $\mathrm{m}$ & 435 & (3.5) & 442 & $(2.9)$ & 449 & (3.4) & $\mathrm{m}$ & $\mathrm{m}$ & 13 & (5.3) & 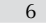 & (5.0) & 2.2 & $(0.93)$ & 2.1 & $(2.68)$ & 0.0 & $(0.45)$ \\
\hline Shanghai-China & $\mathrm{m}$ & $\mathrm{m}$ & $\mathrm{m}$ & $\mathrm{m}$ & 600 & $(2.8)$ & 613 & (3.3) & $\mathrm{m}$ & $\mathrm{m}$ & $\mathrm{m}$ & $\mathrm{m}$ & 13 & (4.9) & 4.2 & (1.69) & $\mathrm{m}$ & $\mathrm{m}$ & $\mathrm{m}$ & $\mathrm{m}$ \\
\hline Singapore & $\mathrm{m}$ & $\mathrm{m}$ & $\mathrm{m}$ & $\mathrm{m}$ & 562 & (1.4) & 573 & (1.3) & $\mathrm{m}$ & $\mathrm{m}$ & $\mathrm{m}$ & $\mathrm{m}$ & 11 & (3.0) & 3.8 & $(0.98)$ & $\mathrm{m}$ & $\mathrm{m}$ & $\mathrm{m}$ & $\mathrm{m}$ \\
\hline Chinese Taipei & $\mathrm{m}$ & $\mathrm{m}$ & 549 & (4.1) & 543 & (3.4) & 560 & (3.3) & $\mathrm{m}$ & $\mathrm{m}$ & 10 & (5.7) & 17 & (5.3) & 1.7 & $(0.91)$ & 9.4 & $(2.91)$ & 1.3 & $(0.52)$ \\
\hline Thailand & 417 & (3.0) & 417 & (2.3) & 419 & (3.2) & 427 & (3.4) & 10 & $(5.0)$ & 10 & (4.7) & 8 & (5.3) & 1.0 & $(0.56)$ & 3.1 & $(1.46)$ & 0.2 & $(0.17)$ \\
\hline Tunisia & 359 & (2.5) & 365 & (4.0) & 371 & (3.0) & 388 & (3.9) & 29 & $(5.0)$ & 22 & (5.9) & 16 & (5.4) & 3.1 & $(0.53)$ & 5.5 & $(1.90)$ & 0.3 & $(0.20)$ \\
\hline United A & $\mathrm{m}$ & $\mathrm{m}$ & $\mathrm{m}$ & $\mathrm{m}$ & 411 & (3.2) & 423 & (3.2) & $\mathrm{m}$ & $\mathrm{m}$ & $\mathrm{m}$ & $\mathrm{m}$ & 12 & (5.0) & 5.9 & (2.55) & $\mathrm{m}$ & $\mathrm{m}$ & $\mathrm{m}$ & $\mathrm{m}$ \\
\hline Uruguay & 422 & (3.3) & 427 & (2.6) & 427 & (2.6) & 409 & (2.8) & -13 & (4.7) & -18 & (4.3) & -17 & (4.4) & -1.4 & $(0.49)$ & -6.8 & (1.41) & -0.6 & $(0.18)$ \\
\hline
\end{tabular}

Notes: Values that are statistically significant are indicated in bold (see Annex A3).

Annualised change is the average change between the earliest available measurement in PISA and PISA 2012. For countries and economies with more than one available measurement, the annualised change is calculated with a linear regression model. This model considers that Costa Rica, Malaysia and the United Arab Emirates (with the exception of Dubai) implemented the PISA 2009 assessment in 2010 as part of PISA 2009+.

The curvilinear change is estimated by a regression of time and time-squared on mathematics performance. The linear term is the estimated annual increase in performance in 2012. The quadratic term is the rate at which changes in performance are accelerating (positive estimate) or decelerating (negative estimate).

In the United Arab Emirates, Dubai took the PISA 2009 assessment in 2009 and the rest of the United Arab Emirates in 2010 as part of PISA $2009+$. Results are thus reported separately.

* United Arab Emirates excluding Dubai (see note above).

StatLink 需可 http://dx.doi.org/10.1787/888932935667 
[Part 1/1]

Table I.2.3c Gender differences in mathematics performance in PISA 2003 and 2012

\begin{tabular}{|c|c|c|c|c|c|c|c|c|c|c|c|c|c|c|c|c|c|c|c|}
\hline & & \multicolumn{6}{|c|}{ PISA 2003} & \multicolumn{6}{|c|}{ PISA 2012} & \multicolumn{6}{|c|}{$\begin{array}{l}\text { Change between } 2003 \text { and } 2012 \\
\text { (PISA 2012 - PISA 2003) }\end{array}$} \\
\hline & & \multicolumn{2}{|c|}{ Boys } & \multicolumn{2}{|c|}{ Girls } & \multicolumn{2}{|c|}{$\begin{array}{l}\text { Difference } \\
(B-G)\end{array}$} & \multicolumn{2}{|c|}{ Boys } & \multicolumn{2}{|c|}{ Girls } & \multicolumn{2}{|c|}{$\begin{array}{l}\text { Difference } \\
\text { (B-G) }\end{array}$} & \multicolumn{2}{|c|}{ Boys } & \multicolumn{2}{|c|}{ Girls } & \multicolumn{2}{|c|}{$\begin{array}{l}\text { Difference } \\
\text { (B-G) }\end{array}$} \\
\hline & & \begin{tabular}{|l|}
$\begin{array}{l}\text { Mean } \\
\text { score }\end{array}$ \\
\end{tabular} & S.E. & $\begin{array}{l}\text { Mean } \\
\text { score }\end{array}$ & S.E. & $\begin{array}{c}\text { Score } \\
\text { dif. }\end{array}$ & S.E. & $\begin{array}{l}\text { Mean } \\
\text { score }\end{array}$ & S.E. & $\begin{array}{l}\text { Mean } \\
\text { score }\end{array}$ & S.E. & $\begin{array}{c}\text { Score } \\
\text { dif. }\end{array}$ & S.E. & $\begin{array}{c}\text { Score } \\
\text { dif. }\end{array}$ & S.E. & $\begin{array}{c}\text { Score } \\
\text { dif. }\end{array}$ & S.E. & $\begin{array}{c}\text { Score } \\
\text { dif. }\end{array}$ & S.E. \\
\hline \multirow{30}{*}{ 岕 } & Australia & 527 & (3.0) & 522 & (2.7) & 5 & (3.8) & 510 & (2.4) & 498 & (2.0) & 12 & (3.1) & -17 & (4.3) & -24 & (3.9) & 7 & (4.9) \\
\hline & Austria & 509 & $(4.0)$ & 502 & $(4.0)$ & 8 & (4.4) & 517 & (3.9) & 494 & (3.3) & 22 & (4.9) & 7 & (5.9) & -7 & (5.5) & 15 & (7.3) \\
\hline & Belgium & 533 & (3.4) & 525 & (3.2) & 8 & (4.8) & 520 & (2.9) & 509 & (2.6) & 11 & (3.4) & -13 & (4.9) & -16 & (4.6) & 4 & (5.7) \\
\hline & Canada & 541 & $(2.1)$ & 530 & (1.9) & 11 & (2.1) & 523 & (2.1) & 513 & (2.1) & 10 & (2.0) & -18 & (3.5) & -17 & (3.4) & -1 & (3.0) \\
\hline & Czech Republic & 524 & (4.3) & 509 & (4.4) & 15 & (5.1) & 505 & (3.7) & 493 & (3.6) & 12 & $(4.6)$ & -19 & (6.0) & -16 & (6.0) & -3 & (6.7) \\
\hline & Denmark & 523 & (3.4) & 506 & (3.0) & 17 & (3.2) & 507 & (2.9) & 493 & (2.3) & 14 & (2.3) & -16 & (4.8) & -13 & (4.2) & -3 & (4.4) \\
\hline & Finland & 548 & (2.5) & 541 & (2.1) & 7 & (2.7) & 517 & (2.6) & 520 & (2.2) & -3 & (2.9) & -31 & (4.1) & -20 & (3.6) & -10 & $(4.0)$ \\
\hline & France & 515 & (3.6) & 507 & (2.9) & 9 & $(4.2)$ & 499 & (3.4) & 491 & (2.5) & 9 & (3.4) & -16 & (5.3) & -16 & (4.3) & 0 & (5.6) \\
\hline & Germany & 508 & $(4.0)$ & 499 & (3.9) & 9 & (4.4) & 520 & (3.0) & 507 & (3.4) & 14 & (2.8) & 12 & (5.4) & 8 & (5.5) & 5 & (5.3) \\
\hline & Greece & 455 & (4.8) & 436 & (3.8) & 19 & (3.6) & 457 & (3.3) & 449 & (2.6) & 8 & (3.2) & 2 & (6.1) & 13 & (5.0) & -11 & (4.9) \\
\hline & Hungary & 494 & (3.3) & 486 & (3.3) & 8 & (3.5) & 482 & (3.7) & 473 & (3.6) & 9 & (3.7) & -12 & (5.4) & -13 & (5.3) & 1 & (5.1) \\
\hline & Iceland & 508 & (2.3) & 523 & (2.2) & -15 & (3.5) & 490 & (2.3) & 496 & (2.3) & -6 & (3.0) & -18 & (3.8) & -27 & (3.7) & 9 & (4.4) \\
\hline & Ireland & 510 & (3.0) & 495 & (3.4) & 15 & $(4.2)$ & 509 & (3.3) & 494 & (2.6) & 15 & (3.8) & -1 & (4.8) & -2 & $(4.7)$ & 1 & (5.7) \\
\hline & Italy & 475 & (4.6) & 457 & (3.8) & 18 & (5.9) & 494 & (2.4) & 476 & (2.2) & 18 & (2.5) & 19 & (5.5) & 19 & $(4.8)$ & 1 & (6.7) \\
\hline & Japan & 539 & (5.8) & 530 & $(4.0)$ & 8 & (5.9) & 545 & (4.6) & 527 & (3.6) & 18 & (4.3) & 6 & (7.7) & -3 & (5.7) & 9 & (7.3) \\
\hline & Korea & 552 & (4.4) & 528 & (5.3) & 23 & (6.8) & 562 & (5.8) & 544 & (5.1) & 18 & (6.2) & 10 & (7.5) & 16 & $(7.7)$ & -5 & (9.4) \\
\hline & Luxembourg & 502 & (1.9) & 485 & (1.5) & 17 & (2.8) & 502 & (1.5) & 477 & (1.4) & 25 & (2.0) & 0 & (3.1) & -8 & (2.8) & 8 & (3.3) \\
\hline & Mexico & 391 & (4.3) & 380 & (4.1) & 11 & (3.9) & 420 & (1.6) & 406 & (1.4) & 14 & $(1.2)$ & 30 & (4.9) & 26 & $(4.7)$ & 3 & $(4.2)$ \\
\hline & Netherlands & 540 & $(4.1)$ & 535 & (3.5) & 5 & (4.3) & 528 & (3.6) & 518 & (3.9) & 10 & (2.8) & -12 & (5.7) & -17 & (5.6) & 5 & (5.6) \\
\hline & New Zealand & 531 & (2.8) & 516 & (3.2) & 14 & (3.9) & 507 & (3.2) & 492 & (2.9) & 15 & (4.3) & -24 & (4.7) & -24 & $(4.7)$ & 1 & (6.2) \\
\hline & Norway & 498 & (2.8) & 492 & (2.9) & 6 & (3.2) & 490 & (2.8) & 488 & (3.4) & 2 & (3.0) & -8 & (4.4) & -4 & (4.9) & -4 & (4.4) \\
\hline & Poland & 493 & (3.0) & 487 & (2.9) & 6 & (3.1) & 520 & (4.3) & 516 & (3.8) & 4 & (3.4) & 27 & (5.5) & 28 & (5.1) & -2 & (4.4) \\
\hline & Portugal & 472 & $(4.2)$ & 460 & (3.4) & 12 & (3.3) & 493 & (4.1) & 481 & (3.9) & 11 & (2.5) & 20 & (6.2) & 21 & (5.6) & -1 & (4.4) \\
\hline & Slovak Republic & 507 & (3.9) & 489 & (3.6) & 19 & (3.7) & 486 & (4.1) & 477 & (4.1) & 9 & (4.5) & -21 & (6.0) & -12 & $(5.7)$ & -9 & (5.3) \\
\hline & Spain & 490 & (3.4) & 481 & $(2.2)$ & 9 & (3.0) & 492 & (2.4) & 476 & (2.0) & 16 & $(2.2)$ & 3 & (4.6) & -5 & (3.5) & 8 & (3.8) \\
\hline & Sweden & 512 & (3.0) & 506 & (3.1) & 7 & (3.3) & 477 & (3.0) & 480 & (2.4) & -3 & (3.0) & -35 & (4.6) & -26 & (4.4) & -9 & (3.9) \\
\hline & Switzerland & 535 & $(4.7)$ & 518 & (3.6) & 17 & (4.9) & 537 & (3.5) & 524 & (3.1) & 13 & $(2.7)$ & 3 & $(6.2)$ & 7 & $(5.2)$ & -4 & $(5.2)$ \\
\hline & Turkey & 430 & (7.9) & 415 & (6.7) & 15 & (6.2) & 452 & (5.1) & 444 & (5.7) & 8 & (4.7) & 22 & (9.6) & 29 & (9.0) & -7 & $(8.0)$ \\
\hline & United States & 486 & (3.3) & 480 & (3.2) & 6 & (2.9) & 484 & (3.8) & 479 & (3.9) & 5 & (2.8) & -2 & (5.4) & -1 & (5.4) & -2 & (3.9) \\
\hline & OECD average 2003 & 505 & $(0.7)$ & 494 & $(0.7)$ & 11 & $(0.8)$ & 502 & $(0.6)$ & 491 & $(0.6)$ & 11 & $(0.6)$ & -3 & (1.0) & -4 & $(1.0)$ & 0 & (1.0) \\
\hline \multirow{10}{*}{ 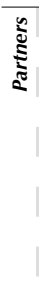 } & Brazil & 365 & (6.1) & 348 & (4.4) & 16 & $(4.1)$ & 401 & (2.2) & 383 & (2.3) & 18 & (1.8) & 36 & (6.7) & 34 & (5.3) & 2 & (4.8) \\
\hline & Hong Kong-China & 552 & (6.5) & 548 & (4.6) & 4 & (6.6) & 568 & (4.6) & 553 & (3.9) & 15 & (5.7) & 16 & $(8.2)$ & 5 & (6.3) & 11 & (8.6) \\
\hline & Indonesia & 362 & (3.9) & 358 & (4.6) & 3 & (3.4) & 377 & (4.4) & 373 & (4.3) & 5 & (3.4) & 16 & $(6.2)$ & 14 & (6.6) & 1 & $(4.3)$ \\
\hline & Latvia & 485 & $(4.8)$ & 482 & (3.6) & 3 & $(4.0)$ & 489 & (3.4) & 493 & (3.2) & -4 & (3.6) & 4 & (6.2) & 10 & (5.1) & -7 & (4.7) \\
\hline & Liechtenstein & 550 & (7.2) & 521 & (6.3) & 29 & (10.9) & 546 & (6.0) & 523 & (5.8) & 23 & (8.8) & -4 & (9.6) & 2 & $(8.7)$ & -6 & (13.9) \\
\hline & Macao-China & 538 & $(4.8)$ & 517 & (3.3) & 21 & (5.8) & 540 & (1.4) & 537 & (1.3) & 3 & (1.9) & 1 & (5.4) & 20 & $(4.0)$ & -18 & (6.4) \\
\hline & Russian Federation & 473 & (5.3) & 463 & $(4.2)$ & 10 & (4.4) & 481 & (3.7) & 483 & (3.1) & -2 & (3.0) & 8 & (6.7) & 20 & (5.5) & -12 & (5.3) \\
\hline & Thailand & 415 & $(4.0)$ & 419 & (3.4) & -4 & $(4.2)$ & 419 & (3.6) & 433 & (4.1) & -14 & (3.6) & 4 & (5.7) & 14 & (5.6) & -10 & (5.4) \\
\hline & Tunisia & 365 & $(2.7)$ & 353 & (2.9) & 12 & (2.5) & 396 & (4.3) & 381 & $(4.0)$ & 15 & $(2.7)$ & 31 & (5.5) & 28 & $(5.4)$ & 3 & (3.7) \\
\hline & Uruguay & 428 & (4.0) & 416 & (3.8) & 12 & $(4.2)$ & 415 & (3.5) & 404 & (2.9) & 11 & (3.1) & -13 & (5.6) & -12 & (5.2) & -1 & (4.9) \\
\hline
\end{tabular}

Notes: Values that are statistically significant are indicated in bold (see Annex A3).

Only countries and economies with comparable results in PISA 2003 and PISA 2012 are presented.

StatLink 完正四 http://dx.doi.org/10.1787/888932935667 
[Part 1/3]

Table I.2.3d Distribution of scores in mathematics in PISA 2003 through 2012, by percentiles

\begin{tabular}{|c|c|c|c|c|c|c|c|c|c|c|c|c|c|c|c|c|c|}
\hline & \multicolumn{8}{|c|}{ PISA 2003} & \multicolumn{8}{|c|}{ PISA 2006} \\
\hline & & \multicolumn{2}{|c|}{ 10th percentile } & \multicolumn{2}{|c|}{ 25th percentile } & \multicolumn{2}{|c|}{ 75th percentile } & 90th $\mathrm{p}$ & centile & 10th pe & centile & 25th pe & rcentile & 75th pe & centile & 90th pe & centile \\
\hline & & Score & S.E. & Score & S.E. & Score & S.E. & Score & S.E. & Score & S.E. & Score & S.E. & Score & S.E. & Score & S.E. \\
\hline$\sqrt{-1}$ & Australia & 399 & $(3.4)$ & 460 & $(2.7)$ & 592 & (2.5) & 645 & (3.0) & 406 & $(2.7)$ & 460 & (2.3) & 581 & (2.5) & 633 & (3.3) \\
\hline 剀 & Austria & 384 & $(4.4)$ & 439 & $(4.0)$ & 571 & $(4.2)$ & 626 & $(4.0)$ & 373 & (6.3) & 438 & (5.5) & 577 & $(4.0)$ & 630 & (3.8) \\
\hline & Belgium & 381 & $(4.6)$ & 456 & $(3.4)$ & 611 & (2.5) & 664 & (2.4) & 381 & $(6.6)$ & 451 & (4.0) & 598 & (2.5) & 650 & $(2.4)$ \\
\hline & Canada & 419 & $(2.5)$ & 474 & $(2.2)$ & 593 & (2.1) & 644 & (2.6) & 416 & (3.3) & 470 & (2.4) & 587 & (2.3) & 635 & $(2.3)$ \\
\hline & Chile & $\mathrm{m}$ & $\mathrm{m}$ & $\mathrm{m}$ & $\mathrm{m}$ & $\mathrm{m}$ & $\mathrm{m}$ & $\mathrm{m}$ & $\mathrm{m}$ & 302 & $(4.3)$ & 350 & (4.4) & 470 & (5.1) & 527 & (6.6) \\
\hline & Czech Republic & 392 & $(5.7)$ & 449 & $(4.5)$ & 584 & $(4.0)$ & 641 & (4.3) & 376 & (4.7) & 441 & (4.3) & 582 & (4.7) & 644 & (4.8) \\
\hline & Denmark & 396 & $(4.5)$ & 453 & (3.7) & 578 & (3.1) & 632 & (3.7) & 404 & $(4.3)$ & 456 & (3.4) & 572 & (2.8) & 621 & (3.4) \\
\hline & Estonia & $\mathrm{m}$ & $\mathrm{m}$ & $\mathrm{m}$ & $\mathrm{m}$ & $\mathrm{m}$ & $\mathrm{m}$ & $\mathrm{m}$ & $\mathrm{m}$ & 411 & $(4.3)$ & 461 & (3.5) & 570 & (3.3) & 618 & (3.2) \\
\hline & Finland & 438 & $(2.8)$ & 488 & $(2.2)$ & 603 & (2.3) & 652 & (2.8) & 444 & (3.4) & 494 & (2.6) & 605 & (2.6) & 652 & (2.8) \\
\hline & France & 389 & $(5.6)$ & 449 & (3.7) & 575 & (3.0) & 628 & (3.6) & 369 & (5.4) & 429 & (4.7) & 565 & (3.8) & 617 & (3.8) \\
\hline & Germany & 363 & (5.6) & 432 & (4.7) & 578 & (3.5) & 632 & (3.5) & 375 & (6.8) & 437 & (4.9) & 574 & (3.9) & 632 & (3.8) \\
\hline & Greece & 324 & $(5.1)$ & 382 & (4.6) & 508 & (4.3) & 566 & (5.3) & 341 & (5.6) & 399 & (3.9) & 522 & $(4.0)$ & 575 & $(4.1)$ \\
\hline & Hungary & 370 & $(4.2)$ & 426 & $(3.0)$ & 556 & (3.9) & 611 & $(4.7)$ & 377 & (3.9) & 431 & (2.9) & 551 & $(4.1)$ & 609 & (5.0) \\
\hline & Iceland & 396 & $(2.7)$ & 454 & $(2.8)$ & 578 & (1.9) & 629 & (3.0) & 391 & (3.6) & 446 & (2.4) & 567 & (2.4) & 618 & (3.2) \\
\hline & Ireland & 393 & $(3.2)$ & 445 & $(3.4)$ & 562 & (3.0) & 614 & (3.6) & 396 & $(4.4)$ & 445 & $(4.1)$ & 559 & $(3.1)$ & 608 & (3.2) \\
\hline & Israel & $\mathrm{m}$ & $\mathrm{m}$ & $\mathrm{m}$ & $\mathrm{m}$ & $\mathrm{m}$ & $\mathrm{m}$ & $\mathrm{m}$ & $\mathrm{m}$ & 304 & (6.9) & 368 & (5.4) & 518 & $(4.7)$ & 581 & (5.0) \\
\hline & Italy & 342 & $(5.9)$ & 400 & $(4.3)$ & 530 & (3.0) & 589 & (3.6) & 341 & $(3.3)$ & 398 & (2.7) & 527 & $(2.8)$ & 584 & $(4.2)$ \\
\hline & Japan & 402 & $(6.3)$ & 467 & $(5.4)$ & 605 & (4.4) & 660 & $(6.1)$ & 404 & $(5.5)$ & 463 & (4.6) & 587 & $(3.0)$ & 638 & (3.6) \\
\hline & Korea & 423 & $(4.5)$ & 479 & $(3.7)$ & 606 & $(4.2)$ & 659 & (5.4) & 426 & (6.1) & 485 & (4.3) & 612 & $(4.4)$ & 664 & (6.9) \\
\hline & Luxembourg & 373 & $(2.7)$ & 430 & $(2.2)$ & 557 & (1.9) & 611 & (3.2) & 368 & (3.5) & 426 & (1.9) & 555 & (1.9) & 610 & $(2.7)$ \\
\hline & Mexico & 276 & $(4.7)$ & 327 & $(4.3)$ & 444 & $(4.5)$ & 497 & $(4.7)$ & 299 & (4.9) & 349 & (3.7) & 463 & $(2.8)$ & 514 & (3.3) \\
\hline & Netherlands & 415 & (5.8) & 471 & (5.4) & 608 & (3.8) & 657 & (3.2) & 412 & (5.0) & 467 & (4.6) & 596 & $(2.7)$ & 645 & (3.3) \\
\hline & New Zealand & 394 & (3.9) & 455 & (2.9) & 593 & $(2.2)$ & 650 & (3.2) & 401 & $(4.1)$ & 458 & (3.2) & 587 & $(3.0)$ & 643 & $(4.0)$ \\
\hline & Norway & 376 & (3.4) & 433 & (2.9) & 560 & (3.3) & 614 & (3.6) & 373 & (3.8) & 428 & (3.9) & 552 & (2.8) & 609 & $(3.3)$ \\
\hline & Poland & 376 & $(3.6)$ & 428 & (3.1) & 553 & (2.9) & 607 & (3.3) & 384 & (3.4) & 435 & (2.8) & 557 & (3.3) & 610 & (3.7) \\
\hline & Portugal & 352 & $(5.3)$ & 406 & $(5.0)$ & 526 & (3.5) & 580 & (3.3) & 348 & $(5.2)$ & 404 & (4.2) & 530 & (3.0) & 583 & (2.8) \\
\hline & Slovak Republic & 379 & $(5.8)$ & 436 & $(4.6)$ & 565 & (3.8) & 619 & (3.5) & 370 & $(5.1)$ & 433 & (3.6) & 558 & (3.5) & 611 & $(4.4)$ \\
\hline & Slovenia & $\mathrm{m}$ & $\mathrm{m}$ & $\mathrm{m}$ & $\mathrm{m}$ & $\mathrm{m}$ & $\mathrm{m}$ & $\mathrm{m}$ & $\mathrm{m}$ & 390 & $(2.1)$ & 441 & (2.4) & 566 & $(2.1)$ & 623 & $(2.7)$ \\
\hline & Spain & 369 & $(3.5)$ & 426 & $(3.0)$ & 546 & (3.1) & 597 & (3.5) & 366 & $(2.8)$ & 421 & (3.2) & 542 & $(2.5)$ & 593 & (2.9) \\
\hline & Sweden & 387 & $(4.4)$ & 446 & $(3.0)$ & 576 & (3.2) & 630 & (3.8) & 387 & $(4.2)$ & 442 & (3.5) & 565 & $(3.2)$ & 617 & (2.8) \\
\hline & Switzerland & 396 & $(4.2)$ & 461 & $(3.6)$ & 595 & (4.9) & 652 & $(5.2)$ & 401 & $(4.7)$ & 464 & (4.1) & 600 & $(3.7)$ & 652 & (3.7) \\
\hline & Turkey & 300 & (5.0) & 351 & (5.3) & 485 & (8.5) & 560 & $(14.2)$ & 316 & (4.0) & 360 & (3.3) & 477 & $(7.2)$ & 550 & (12.4) \\
\hline & United Kingdom & $\mathrm{m}$ & $\mathrm{m}$ & $\mathrm{m}$ & $\mathrm{m}$ & $\mathrm{m}$ & $\mathrm{m}$ & $\mathrm{m}$ & $\mathrm{m}$ & 381 & (3.3) & 434 & $(2.7)$ & 557 & $(2.5)$ & 612 & (3.2) \\
\hline & United States & 356 & $(4.5)$ & 418 & $(3.7)$ & 550 & (3.4) & 607 & (3.9) & 358 & (5.8) & 411 & (4.8) & 537 & $(5.0)$ & 593 & (4.8) \\
\hline & OECD average 2003 & 378 & $(0.8)$ & 436 & $(0.7)$ & 565 & $(0.7)$ & 620 & $(0.9)$ & 379 & $(0.9)$ & 436 & $(0.7)$ & 562 & $(0.7)$ & 615 & $(0.8)$ \\
\hline & OECD average 2006 & $\mathrm{~m}$ & $\mathrm{~m}$ & $\mathrm{~m}$ & $\mathrm{~m}$ & $\mathrm{~m}$ & $\mathrm{~m}$ & $\mathrm{~m}$ & $\mathrm{~m}$ & 376 & $(0.8)$ & 432 & (0.6) & 558 & $(0.6)$ & 612 & $(0.7)$ \\
\hline & OECD average 2009 & $\mathrm{~m}$ & $\mathrm{~m}$ & $\mathrm{~m}$ & $\mathrm{~m}$ & $\mathrm{~m}$ & $\mathrm{~m}$ & $\mathrm{~m}$ & $\mathrm{~m}$ & $\mathrm{~m}$ & $\mathrm{~m}$ & $\mathrm{~m}$ & $\mathrm{~m}$ & $\mathrm{~m}$ & $\mathrm{~m}$ & $\mathrm{~m}$ & $\mathrm{~m}$ \\
\hline$n$ & Albania & $\mathrm{m}$ & $\mathrm{m}$ & $\mathrm{m}$ & $\mathrm{m}$ & $\mathrm{m}$ & $\mathrm{m}$ & $\mathrm{m}$ & $\mathrm{m}$ & $\mathrm{m}$ & $\mathrm{m}$ & $\mathrm{m}$ & $\mathrm{m}$ & $\mathrm{m}$ & $\mathrm{m}$ & $\mathrm{m}$ & $\mathrm{m}$ \\
\hline 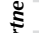 & Argentina & $\mathrm{m}$ & $\mathrm{m}$ & $\mathrm{m}$ & $\mathrm{m}$ & $\mathrm{m}$ & $\mathrm{m}$ & $\mathrm{m}$ & $\mathrm{m}$ & 249 & (9.8) & 316 & (7.9) & 451 & (6.9) & 508 & (7.6) \\
\hline ఏ & Brazil & 233 & $(5.3)$ & 286 & $(4.6)$ & 419 & $(6.2)$ & 488 & $(9.5)$ & 255 & $(4.5)$ & 308 & (3.0) & 427 & (3.7) & 487 & (5.8) \\
\hline & Bulgaria & $\mathrm{m}$ & $\mathrm{m}$ & $\mathrm{m}$ & $\mathrm{m}$ & $\mathrm{m}$ & $\mathrm{m}$ & $\mathrm{m}$ & $\mathrm{m}$ & 287 & $(7.2)$ & 345 & (6.1) & 481 & (6.8) & 543 & (8.4) \\
\hline & Colombia & $\mathrm{m}$ & $\mathrm{m}$ & $\mathrm{m}$ & $\mathrm{m}$ & $\mathrm{m}$ & $\mathrm{m}$ & $\mathrm{m}$ & $\mathrm{m}$ & 258 & (5.6) & 311 & (4.9) & 428 & $(4.6)$ & 482 & (3.8) \\
\hline & Costa Rica & $\mathrm{m}$ & $\mathrm{m}$ & $\mathrm{m}$ & $\mathrm{m}$ & $\mathrm{m}$ & $\mathrm{m}$ & $\mathrm{m}$ & $\mathrm{m}$ & $\mathrm{m}$ & $\mathrm{m}$ & $\mathrm{m}$ & $\mathrm{m}$ & $\mathrm{m}$ & $\mathrm{m}$ & $\mathrm{m}$ & $\mathrm{m}$ \\
\hline & Croatia & $\mathrm{m}$ & $\mathrm{m}$ & $\mathrm{m}$ & $\mathrm{m}$ & $\mathrm{m}$ & $\mathrm{m}$ & $\mathrm{m}$ & $\mathrm{m}$ & 361 & (3.3) & 410 & (3.0) & 524 & (3.3) & 576 & (3.6) \\
\hline & Dubai (UAE) & $\mathrm{m}$ & $\mathrm{m}$ & $\mathrm{m}$ & $\mathrm{m}$ & $\mathrm{m}$ & $\mathrm{m}$ & $\mathrm{m}$ & $\mathrm{m}$ & $\mathrm{m}$ & $\mathrm{m}$ & $\mathrm{m}$ & $\mathrm{m}$ & $\mathrm{m}$ & $\mathrm{m}$ & $\mathrm{m}$ & $\mathrm{m}$ \\
\hline & Hong Kong-China & 417 & $(8.0)$ & 485 & $(6.9)$ & 622 & (3.7) & 672 & $(4.1)$ & 423 & (6.4) & 486 & (4.5) & 614 & (3.1) & 665 & (3.5) \\
\hline & Indonesia & 260 & $(4.8)$ & 306 & (3.5) & 412 & (4.8) & 466 & (6.5) & 293 & (3.9) & 336 & (4.2) & 444 & $(9.3)$ & 498 & (9.4) \\
\hline & Jordan & $\mathrm{m}$ & $\mathrm{m}$ & $\mathrm{m}$ & $\mathrm{m}$ & $\mathrm{m}$ & $\mathrm{m}$ & $\mathrm{m}$ & $\mathrm{m}$ & 279 & $(4.3)$ & 330 & (3.4) & 441 & (3.9) & 489 & (5.0) \\
\hline & Kazakhstan & $\mathrm{m}$ & $\mathrm{m}$ & $\mathrm{m}$ & $\mathrm{m}$ & $\mathrm{m}$ & $\mathrm{m}$ & $\mathrm{m}$ & $\mathrm{m}$ & $\mathrm{m}$ & $\mathrm{m}$ & $\mathrm{m}$ & $\mathrm{m}$ & $\mathrm{m}$ & $\mathrm{m}$ & $\mathrm{m}$ & $\mathrm{m}$ \\
\hline & Latvia & 371 & $(5.1)$ & 424 & (3.9) & 544 & $(4.7)$ & 596 & $(4.4)$ & 378 & $(5.2)$ & 432 & (3.6) & 542 & $(3.2)$ & 590 & (3.4) \\
\hline & Liechtenstein & 408 & $(9.8)$ & 470 & (7.6) & 609 & (7.9) & 655 & (9.5) & 402 & $(11.1)$ & 464 & $(10.0)$ & 588 & $(5.2)$ & 643 & (9.5) \\
\hline & Lithuania & $\mathrm{m}$ & $\mathrm{m}$ & $\mathrm{m}$ & $\mathrm{m}$ & $\mathrm{m}$ & $\mathrm{m}$ & $\mathrm{m}$ & $\mathrm{m}$ & 369 & $(4.3)$ & 426 & (3.3) & 549 & (3.6) & 602 & (4.9) \\
\hline & Macao-China & 414 & $(6.0)$ & 467 & $(4.4)$ & 587 & $(4.0)$ & 639 & (5.5) & 416 & (3.1) & 467 & (2.1) & 585 & $(2.0)$ & 632 & (2.4) \\
\hline & Malaysia & $\mathrm{m}$ & $\mathrm{m}$ & $\mathrm{m}$ & $\mathrm{m}$ & $\mathrm{m}$ & $\mathrm{m}$ & $\mathrm{m}$ & $\mathrm{m}$ & $\mathrm{m}$ & $\mathrm{m}$ & $\mathrm{m}$ & $\mathrm{m}$ & $\mathrm{m}$ & $\mathrm{m}$ & $\mathrm{m}$ & $\mathrm{m}$ \\
\hline & Montenegro & $\mathrm{m}$ & $\mathrm{m}$ & $\mathrm{m}$ & $\mathrm{m}$ & $\mathrm{m}$ & $\mathrm{m}$ & $\mathrm{m}$ & $\mathrm{m}$ & 291 & (3.0) & 342 & (2.0) & 456 & $(2.4)$ & 510 & (2.4) \\
\hline & Peru & $\mathrm{m}$ & $\mathrm{m}$ & $\mathrm{m}$ & $\mathrm{m}$ & $\mathrm{m}$ & $\mathrm{m}$ & $\mathrm{m}$ & $\mathrm{m}$ & $\mathrm{m}$ & $\mathrm{m}$ & $\mathrm{m}$ & $\mathrm{m}$ & $\mathrm{m}$ & $\mathrm{m}$ & $\mathrm{m}$ & $\mathrm{m}$ \\
\hline & Qatar & $\mathrm{m}$ & $\mathrm{m}$ & $\mathrm{m}$ & $\mathrm{m}$ & $\mathrm{m}$ & $\mathrm{m}$ & $\mathrm{m}$ & $\mathrm{m}$ & 212 & $(2.2)$ & 257 & (1.3) & 368 & $(1.7)$ & 438 & $(2.7)$ \\
\hline & Romania & $\mathrm{m}$ & $\mathrm{m}$ & $\mathrm{m}$ & $\mathrm{m}$ & $\mathrm{m}$ & $\mathrm{m}$ & $\mathrm{m}$ & $\mathrm{m}$ & 307 & (7.4) & 358 & (5.5) & 470 & (4.9) & 523 & (7.1) \\
\hline & Russian Federation & 351 & $(5.0)$ & 406 & (4.8) & 530 & (5.0) & 588 & (5.3) & 363 & $(4.8)$ & 416 & (4.2) & 535 & (5.1) & 592 & (5.3) \\
\hline & Serbia & $\mathrm{m}$ & $\mathrm{m}$ & $\mathrm{m}$ & $\mathrm{m}$ & $\mathrm{m}$ & $\mathrm{m}$ & $\mathrm{m}$ & $\mathrm{m}$ & 318 & (5.0) & 375 & (4.4) & 498 & (3.8) & 553 & (3.9) \\
\hline & Shanghai-China & $\mathrm{m}$ & $\mathrm{m}$ & $\mathrm{m}$ & $\mathrm{m}$ & $\mathrm{m}$ & $\mathrm{m}$ & $\mathrm{m}$ & $\mathrm{m}$ & $\mathrm{m}$ & $\mathrm{m}$ & $\mathrm{m}$ & $\mathrm{m}$ & $\mathrm{m}$ & $\mathrm{m}$ & $\mathrm{m}$ & $\mathrm{m}$ \\
\hline & Singapore & $\mathrm{m}$ & $\mathrm{m}$ & $\mathrm{m}$ & $\mathrm{m}$ & $\mathrm{m}$ & $\mathrm{m}$ & $\mathrm{m}$ & $\mathrm{m}$ & $\mathrm{m}$ & $\mathrm{m}$ & $\mathrm{m}$ & $\mathrm{m}$ & $\mathrm{m}$ & $\mathrm{m}$ & $\mathrm{m}$ & $\mathrm{m}$ \\
\hline & Chinese Taipei & $\mathrm{m}$ & $\mathrm{m}$ & $\mathrm{m}$ & $\mathrm{m}$ & $\mathrm{m}$ & $\mathrm{m}$ & $\mathrm{m}$ & $\mathrm{m}$ & 409 & (6.2) & 477 & (6.1) & 625 & (3.3) & 677 & (3.4) \\
\hline & Thailand & 316 & $(3.1)$ & 361 & $(2.9)$ & 469 & (3.8) & 526 & $(4.7)$ & 317 & (3.5) & 362 & (3.3) & 470 & $(2.9)$ & 524 & (3.7) \\
\hline & Tunisia & 256 & (3.5) & 303 & (2.6) & 412 & (3.6) & 466 & (4.8) & 250 & (3.9) & 301 & (3.7) & 427 & (5.5) & 488 & (7.8) \\
\hline & United Arab Emirates* & $\mathrm{m}$ & $\mathrm{m}$ & m & $\mathrm{m}$ & $\mathrm{m}$ & $\mathrm{m}$ & $\mathrm{m}$ & $\mathrm{m}$ & $\mathrm{m}$ & $\mathrm{m}$ & $\mathrm{m}$ & $\mathrm{m}$ & $\mathrm{m}$ & $\mathrm{m}$ & $\mathrm{m}$ & $\mathrm{m}$ \\
\hline & Uruguay & 291 & $(3.8)$ & 353 & $(4.1)$ & 491 & (3.8) & 550 & (4.4) & 296 & (4.4) & 360 & (3.5) & 495 & $(3.5)$ & 551 & (5.5) \\
\hline
\end{tabular}

Notes: Values that are statistically significant are indicated in bold (see Annex A3).

Annualised change is the average change between the earliest available measurement in PISA and PISA 2012. For countries and economies with more than one available measurement, the annualised change is calculated with a linear regression model. This model considers that Costa Rica, Malaysia and the United Arab Emirates (with the

In the United Arab Emirates, Dubai took the PISA 2009 assessment in 2009 and the rest of the United Arab Emirates in 2010 as part of PISA $2009+$. Results are thus reported separately.

* United Arab Emirates excluding Dubai (see note above).

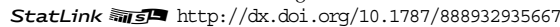


[Part 2/3]

Table I.2.3d Distribution of scores in mathematics in PISA 2003 through 2012, by percentiles

\begin{tabular}{|c|c|c|c|c|c|c|c|c|c|c|c|c|c|c|c|c|c|}
\hline & \multicolumn{8}{|c|}{ PISA 2009} & \multicolumn{8}{|c|}{ PISA 2012} \\
\hline & & \multicolumn{2}{|c|}{ 10th percentile } & \multicolumn{2}{|c|}{ 25th percentile } & 75th pe & centile & 90th pe & rcentile & 10th $p$ & rcentile & 25th $p$ & centile & 75th $p$ & centile & 90th $p$ & centile \\
\hline & & Score & S.E. & Score & S.E. & Score & S.E. & Score & S.E. & Score & S.E. & Score & S.E. & Score & S.E. & Score & S.E. \\
\hline 0 & Australia & 393 & $(2.8)$ & 451 & $(2.5)$ & 580 & (3.1) & 634 & (3.9) & 382 & (2.3) & 437 & $(2.0)$ & 571 & $(2.3)$ & 630 & (3.0) \\
\hline 0 & Austria & $\mathrm{m}$ & $\mathrm{m}$ & $\mathrm{m}$ & $\mathrm{m}$ & $\mathrm{m}$ & $\mathrm{m}$ & $\mathrm{m}$ & $\mathrm{m}$ & 384 & (3.9) & 440 & $(3.2)$ & 572 & $(3.5)$ & 624 & (3.8) \\
\hline & Belgium & 373 & $(4.9)$ & 444 & (3.1) & 593 & $(2.4)$ & 646 & (3.0) & 378 & (3.9) & 443 & (3.4) & 589 & $(2.8)$ & 646 & $(2.5)$ \\
\hline & Canada & 413 & $(2.7)$ & 468 & $(2.0)$ & 588 & $(1.9)$ & 638 & (2.2) & 402 & (2.4) & 457 & $(2.1)$ & 580 & $(2.3)$ & 633 & (2.3) \\
\hline & Chile & 322 & (3.8) & 366 & (3.1) & 473 & $(4.2)$ & 527 & (5.1) & 323 & (3.7) & 365 & (3.5) & 476 & $(4.2)$ & 532 & $(4.2)$ \\
\hline & Czech Republic & 374 & (4.3) & 428 & (3.5) & 557 & (3.8) & 615 & (4.3) & 377 & (4.9) & 432 & (3.9) & 566 & (3.3) & 621 & (3.6) \\
\hline & Denmark & 390 & $(4.0)$ & 445 & $(3.1)$ & 564 & (3.3) & 614 & (3.4) & 393 & (4.0) & 444 & $(3.3)$ & 556 & $(2.7)$ & 607 & (3.1) \\
\hline & Estonia & 409 & (3.5) & 458 & (3.7) & 567 & $(2.7)$ & 616 & (3.6) & 417 & (3.0) & 465 & $(2.7)$ & 576 & $(2.7)$ & 626 & (3.2) \\
\hline & Finland & 431 & $(3.7)$ & 487 & $(3.0)$ & 599 & $(2.5)$ & 644 & (2.6) & 409 & (3.3) & 463 & $(2.5)$ & 577 & $(2.4)$ & 629 & (3.1) \\
\hline & France & 361 & (6.3) & 429 & $(4.8)$ & 570 & (3.7) & 622 & (3.9) & 365 & (4.7) & 429 & $(2.7)$ & 565 & (3.4) & 621 & (3.5) \\
\hline & Germany & 380 & $(4.7)$ & 443 & $(4.4)$ & 585 & (3.1) & 638 & (3.5) & 385 & (4.7) & 447 & (3.6) & 583 & (3.6) & 637 & (3.8) \\
\hline & Greece & 352 & (5.9) & 406 & (4.4) & 527 & (3.6) & 580 & (4.1) & 338 & (3.8) & 393 & (3.6) & 513 & (2.8) & 567 & (3.1) \\
\hline & Hungary & 370 & $(7.1)$ & 428 & $(4.6)$ & 554 & $(4.5)$ & 608 & (5.6) & 358 & $(4.2)$ & 411 & (3.3) & 540 & $(4.8)$ & 603 & (6.4) \\
\hline & Iceland & 388 & (3.5) & 447 & $(2.0)$ & 569 & $(2.0)$ & 623 & $(2.8)$ & 372 & (2.8) & 431 & (2.6) & 557 & $(3.0)$ & 612 & (3.3) \\
\hline & Ireland & 376 & (4.4) & 432 & (3.1) & 548 & $(2.8)$ & 591 & (3.1) & 391 & (3.6) & 445 & $(3.2)$ & 559 & $(2.4)$ & 610 & $(2.5)$ \\
\hline & Israel & 310 & (6.1) & 374 & $(4.6)$ & 520 & $(4.2)$ & 581 & (5.2) & 328 & (5.7) & 393 & $(5.1)$ & 541 & $(5.3)$ & 603 & (6.0) \\
\hline & Italy & 363 & $(2.4)$ & 420 & (1.9) & 548 & $(2.5)$ & 602 & (2.5) & 366 & $(2.2)$ & 421 & $(2.3)$ & 550 & $(2.7)$ & 607 & $(3.0)$ \\
\hline & Japan & 407 & $(5.4)$ & 468 & (4.4) & 595 & $(3.7)$ & 648 & $(4.8)$ & 415 & $(5.1)$ & 473 & $(4.2)$ & 603 & $(4.4)$ & 657 & (5.1) \\
\hline & Korea & 430 & $(6.8)$ & 486 & $(5.3)$ & 609 & (4.3) & 659 & (4.6) & 425 & (5.8) & 486 & (4.8) & 624 & $(5.1)$ & 679 & (6.0) \\
\hline & Luxembourg & 360 & (3.1) & 423 & (1.7) & 560 & $(2.2)$ & 613 & (2.5) & 363 & (3.0) & 422 & $(1.5)$ & 558 & $(1.6)$ & 613 & $(2.2)$ \\
\hline & Mexico & 318 & $(2.6)$ & 366 & $(2.2)$ & 472 & $(2.1)$ & 520 & (2.8) & 320 & (1.9) & 362 & $(1.6)$ & 462 & $(1.7)$ & 510 & $(2.0)$ \\
\hline & Netherlands & 406 & (5.6) & 460 & $(6.8)$ & 593 & $(4.4)$ & 640 & (4.4) & 397 & (5.5) & 457 & $(5.1)$ & 591 & $(4.3)$ & 638 & (3.7) \\
\hline & New Zealand & 392 & $(4.4)$ & 454 & $(2.8)$ & 589 & $(3.1)$ & 642 & (3.9) & 371 & (3.6) & 428 & $(3.2)$ & 570 & $(2.8)$ & 632 & (3.0) \\
\hline & Norway & 387 & (3.6) & 441 & $(3.2)$ & 557 & (2.9) & 608 & (3.4) & 373 & (3.9) & 428 & (2.9) & 552 & $(3.3)$ & 604 & (3.4) \\
\hline & Poland & 380 & $(3.8)$ & 434 & $(3.3)$ & 557 & $(3.2)$ & 609 & $(4.1)$ & 402 & (2.8) & 454 & $(3.3)$ & 580 & $(4.9)$ & 636 & $(6.0)$ \\
\hline & Portugal & 367 & (3.5) & 424 & (3.4) & 551 & (3.4) & 605 & (4.3) & 363 & (4.2) & 421 & $(5.0)$ & 554 & $(4.3)$ & 610 & (3.9) \\
\hline & Slovak Republic & 376 & $(4.7)$ & 432 & (3.7) & 561 & (3.8) & 621 & (5.4) & 352 & (6.2) & 413 & $(4.2)$ & 553 & $(4.7)$ & 613 & (5.3) \\
\hline & Slovenia & 379 & $(2.4)$ & 435 & $(2.5)$ & 569 & $(2.3)$ & 628 & (3.6) & 384 & (2.5) & 434 & $(2.0)$ & 566 & $(2.1)$ & 624 & (2.9) \\
\hline & Spain & 364 & (2.9) & 424 & $(2.5)$ & 546 & $(2.3)$ & 597 & (2.3) & 370 & (3.1) & 424 & $(2.6)$ & 546 & $(2.1)$ & 597 & $(2.4)$ \\
\hline & Sweden & 374 & $(4.2)$ & 432 & $(3.1)$ & 560 & (3.3) & 613 & (3.9) & 360 & (3.5) & 415 & $(2.9)$ & 543 & $(2.7)$ & 596 & $(2.9)$ \\
\hline & Switzerland & 401 & (3.6) & 468 & $(4.2)$ & 604 & (3.9) & 658 & $(4.1)$ & 408 & (3.3) & 466 & (3.4) & 597 & $(3.6)$ & 651 & $(4.3)$ \\
\hline & Turkey & 331 & $(3.6)$ & 378 & $(3.8)$ & 506 & $(6.3)$ & 574 & $(9.0)$ & 339 & (3.3) & 382 & $(3.6)$ & 507 & $(8.0)$ & 577 & $(9.7)$ \\
\hline & United Kingdom & 380 & $(3.1)$ & 434 & $(3.0)$ & 552 & $(3.2)$ & 606 & (3.9) & 371 & $(5.0)$ & 429 & $(4.2)$ & 560 & $(3.7)$ & 616 & $(4.1)$ \\
\hline & United States & 368 & $(4.3)$ & 425 & (3.9) & 551 & (4.9) & 607 & (4.6) & 368 & (3.9) & 418 & $(3.7)$ & 543 & $(4.4)$ & 600 & $(4.3)$ \\
\hline & OECD average 2003 & 379 & $(0.8)$ & 437 & $(0.7)$ & 564 & $(0.7)$ & 617 & $(0.8)$ & 377 & $(0.7)$ & 433 & $(0.6)$ & 561 & $(0.7)$ & 616 & $(0.8)$ \\
\hline & OECD average 2006 & 376 & $(0.8)$ & 434 & $(0.6)$ & 560 & $(0.6)$ & 613 & $(0.7)$ & 375 & $(0.7)$ & 430 & $(0.6)$ & 558 & $(0.6)$ & 614 & $(0.7)$ \\
\hline & OECD average 2009 & 376 & $(0.8)$ & 434 & $(0.6)$ & 560 & $(0.6)$ & 613 & $(0.7)$ & 375 & $(0.7)$ & 430 & $(0.6)$ & 558 & $(0.6)$ & 613 & $(0.7)$ \\
\hline$n$ & Albania & 261 & $(5.0)$ & 317 & $(5.2)$ & 438 & $(4.8)$ & 493 & $(5.7)$ & 278 & $(4.8)$ & 338 & $(3.0)$ & 454 & $(2.4)$ & 510 & $(3.5)$ \\
\hline 0 & Argentina & 271 & $(6.0)$ & 327 & $(4.3)$ & 451 & $(5.0)$ & 509 & $(7.1)$ & 292 & (4.6) & 337 & (3.8) & 440 & $(4.5)$ & 488 & $(4.1)$ \\
\hline ฮั & Brazil & 287 & $(2.7)$ & 331 & $(2.3)$ & 435 & $(3.3)$ & 493 & $(4.7)$ & 298 & $(2.0)$ & 337 & (1.9) & 440 & $(2.7)$ & 495 & $(4.5)$ \\
\hline & Bulgaria & 302 & (5.8) & 359 & (6.2) & 496 & (6.6) & 555 & (9.0) & 320 & (4.8) & 372 & $(4.7)$ & 503 & $(5.2)$ & 565 & (5.6) \\
\hline & Colombia & 286 & $(5.1)$ & 330 & $(4.0)$ & 431 & $(3.4)$ & 479 & $(4.2)$ & 285 & (4.0) & 326 & $(2.8)$ & 423 & $(3.6)$ & 474 & $(4.8)$ \\
\hline & Costa Rica & 319 & (3.3) & 361 & $(2.8)$ & 457 & (3.6) & 502 & $(4.7)$ & 323 & (3.8) & 361 & $(3.6)$ & 449 & (3.9) & 496 & (5.1) \\
\hline & Croatia & 347 & $(4.1)$ & 399 & $(3.5)$ & 521 & $(3.8)$ & 574 & $(5.4)$ & 360 & $(3.3)$ & 408 & (3.6) & 531 & $(4.5)$ & 589 & $(7.3)$ \\
\hline & Dubai (UAE) & 326 & (2.5) & 382 & $(2.3)$ & 523 & $(2.1)$ & 584 & (3.3) & 342 & (2.5) & 396 & $(2.0)$ & 530 & $(2.6)$ & 587 & (3.5) \\
\hline & Hong Kong-China & 428 & $(4.9)$ & 492 & $(3.5)$ & 622 & $(3.1)$ & 673 & (3.9) & 430 & $(6.2)$ & 499 & $(4.7)$ & 629 & $(3.5)$ & 679 & $(4.2)$ \\
\hline & Indonesia & 284 & $(4.6)$ & 324 & $(3.7)$ & 416 & $(4.6)$ & 462 & (6.4) & 288 & $(4.2)$ & 327 & (3.8) & 418 & $(5.2)$ & 469 & (7.8) \\
\hline & Jordan & 281 & $(4.8)$ & 333 & $(3.5)$ & 443 & $(4.4)$ & 490 & (5.5) & 290 & (4.0) & 335 & $(3.2)$ & 435 & $(3.3)$ & 485 & (4.3) \\
\hline & Kazakhstan & 303 & (3.3) & 347 & (3.5) & 458 & (4.3) & 514 & (5.3) & 343 & (2.5) & 383 & $(2.8)$ & 478 & $(4.4)$ & 527 & (5.7) \\
\hline & Latvia & 379 & $(4.5)$ & 427 & $(3.7)$ & 537 & (3.8) & 584 & $(3.8)$ & 387 & $(4.4)$ & 434 & $(3.3)$ & 546 & $(3.8)$ & 597 & (3.7) \\
\hline & Liechtenstein & 421 & (9.4) & 484 & $(7.9)$ & 593 & (5.5) & 637 & $(11.6)$ & 403 & $(11.2)$ & 470 & $(8.0)$ & 606 & $(5.0)$ & 656 & $(9.2)$ \\
\hline & Lithuania & 363 & $(4.2)$ & 417 & (3.0) & 537 & (3.1) & 590 & $(4.0)$ & 364 & (3.5) & 418 & (3.1) & 540 & (3.3) & 596 & (3.5) \\
\hline & Macao-China & 415 & $(2.7)$ & 468 & $(1.5)$ & 584 & (1.3) & 634 & (1.6) & 415 & (2.8) & 476 & (1.7) & 605 & $(1.7)$ & 657 & (2.3) \\
\hline & Malaysia & 312 & (2.9) & 354 & (2.4) & 453 & (3.4) & 500 & $(4.7)$ & 319 & $(3.2)$ & 363 & $(3.1)$ & 474 & $(4.3)$ & 530 & (4.9) \\
\hline & Montenegro & 295 & $(4.4)$ & 346 & (2.8) & 458 & $(2.2)$ & 509 & (2.7) & 306 & (2.0) & 352 & $(1.7)$ & 465 & $(2.0)$ & 520 & (2.7) \\
\hline & Peru & 252 & $(4.0)$ & 303 & $(3.7)$ & 424 & $(5.2)$ & 480 & (6.4) & 264 & (3.4) & 311 & (3.6) & 421 & $(4.9)$ & 478 & $(6.7)$ \\
\hline & Qatar & 255 & $(1.5)$ & 300 & $(1.3)$ & 425 & $(1.5)$ & 506 & $(2.4)$ & 257 & (1.7) & 306 & $(1.3)$ & 440 & $(1.7)$ & 514 & $(1.9)$ \\
\hline & Romania & 326 & $(4.1)$ & 372 & $(4.0)$ & 481 & (3.6) & 530 & $(5.4)$ & 344 & (3.5) & 386 & (3.8) & 497 & $(4.8)$ & 553 & (6.1) \\
\hline & Russian Federation & 360 & (4.5) & 411 & $(4.2)$ & 524 & (3.8) & 576 & (5.3) & 371 & (3.9) & 423 & (3.1) & 540 & (3.6) & 595 & (4.7) \\
\hline & Serbia & 327 & $(4.3)$ & 380 & $(3.7)$ & 504 & $(3.2)$ & 560 & (4.3) & 335 & $(4.1)$ & 386 & $(3.7)$ & 508 & $(4.4)$ & 567 & (5.8) \\
\hline & Shanghai-China & 462 & (5.0) & 531 & $(4.0)$ & 674 & $(3.2)$ & 726 & $(4.2)$ & 475 & (5.8) & 546 & (4.4) & 685 & (3.5) & 737 & (3.5) \\
\hline & Singapore & 422 & $(4.1)$ & 490 & (2.9) & 638 & $(2.0)$ & 693 & (2.5) & 432 & (3.6) & 501 & $(2.7)$ & 650 & (1.9) & 707 & (2.3) \\
\hline & Chinese Taipei & 405 & (3.8) & 471 & $(3.6)$ & 618 & $(4.6)$ & 675 & (5.4) & 402 & (4.8) & 478 & $(4.8)$ & 645 & $(3.4)$ & 703 & (4.9) \\
\hline & Thailand & 321 & $(4.2)$ & 365 & (3.5) & 469 & $(3.7)$ & 522 & (5.4) & 328 & (3.1) & 372 & $(2.6)$ & 476 & $(4.8)$ & 535 & $(7.3)$ \\
\hline & Tunisia & 273 & $(4.3)$ & 318 & (3.7) & 423 & (3.4) & 471 & $(4.9)$ & 292 & (4.3) & 334 & $(3.7)$ & 437 & $(4.5)$ & 488 & (7.3) \\
\hline & United Arab Emirates* & 303 & $(4.5)$ & 352 & (3.5) & 467 & $(3.3)$ & 524 & $(4.7)$ & 318 & (3.2) & 363 & $(3.1)$ & 479 & $(4.6)$ & 538 & (5.9) \\
\hline & Uruguay & 310 & $(4.0)$ & 364 & (3.4) & 490 & $(3.1)$ & 546 & (4.1) & 297 & $(4.1)$ & 347 & $(3.0)$ & 470 & $(3.6)$ & 526 & (3.8) \\
\hline
\end{tabular}

Notes: Values that are statistically significant are indicated in bold (see Annex A3).

Annualised change is the average change between the earliest available measurement in PISA and PISA 2012. For countries and economies with more than one available measurement, the annualised change is calculated with a linear regression model. This model considers that Costa Rica, Malaysia and the United Arab Emirates (with the

In the United Arab Emirates, Dubai took the PISA 2009 assessment in 2009 and the rest of the United Arab Emirates in 2010 as part of PISA $2009+$. Results are thus reported separately.

* United Arab Emirates excluding Dubai (see note above).

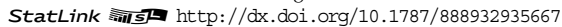


[Part 3/3]

Table I.2.3d Distribution of scores in mathematics in PISA 2003 through 2012, by percentiles

\begin{tabular}{|c|c|c|c|c|c|c|c|c|c|c|c|c|c|c|c|c|c|}
\hline & \multicolumn{8}{|c|}{$\begin{array}{c}\text { Change in percentiles between } 2003 \text { and } 2012 \\
\text { (PISA } 2012 \text { - PISA 2003) }\end{array}$} & \multicolumn{8}{|c|}{$\begin{array}{c}\text { Annualised change in percentiles } \\
\text { across PISA assessments }\end{array}$} \\
\hline & & \multicolumn{2}{|c|}{ 10th percentile } & \multicolumn{2}{|c|}{ 25th percentile } & \multicolumn{2}{|c|}{ 75th percentile } & \multicolumn{2}{|c|}{ 90th percentile } & \multicolumn{2}{|c|}{ 10th percentile } & \multicolumn{2}{|c|}{ 25th percentile } & \multicolumn{2}{|c|}{ 75th percentile } & \multicolumn{2}{|c|}{ 90th percentile } \\
\hline & & $\begin{array}{c}\text { Score } \\
\text { dif. }\end{array}$ & S.E. & $\begin{array}{l}\text { Score } \\
\text { dif. }\end{array}$ & S.E. & $\begin{array}{c}\text { Score } \\
\text { dif. }\end{array}$ & S.E. & $\begin{array}{l}\text { Score } \\
\text { dif. }\end{array}$ & S.E. & $\begin{array}{l}\text { Score } \\
\text { change }\end{array}$ & S.E. & $\begin{array}{c}\text { Score } \\
\text { change }\end{array}$ & S.E. & $\begin{array}{l}\text { Score } \\
\text { change }\end{array}$ & S.E. & $\begin{array}{l}\text { Score } \\
\text { change }\end{array}$ & S.E. \\
\hline \multirow{3}{*}{ తి } & Australia & -17 & (4.6) & -23 & (3.9) & -21 & (3.9) & -14 & $(4.7)$ & -2.3 & $(0.19)$ & -2.6 & $(0.19)$ & -2.1 & $(0.19)$ & -1.4 & (0.19) \\
\hline & Austria & 0 & $(6.2)$ & 1 & $(5.5)$ & 1 & (5.8) & -2 & (5.8) & 0.2 & $(0.33)$ & 0.2 & $(0.21)$ & 0.0 & $(0.20)$ & -0.4 & $(0.22)$ \\
\hline & Belgium & -3 & $(6.3)$ & -13 & $(5.2)$ & -23 & $(4.2)$ & -19 & (3.9) & -0.5 & $(0.75)$ & -1.5 & $(0.75)$ & -2.5 & $(0.75)$ & -2.0 & $(0.75)$ \\
\hline & Canada & -17 & $(4.0)$ & -17 & (3.6) & -13 & (3.7) & -11 & (3.9) & -1.8 & $(0.20)$ & -1.7 & $(0.20)$ & -1.2 & $(0.20)$ & -1.1 & $(0.20)$ \\
\hline & Chile & $\mathrm{m}$ & $\mathrm{m}$ & $\mathrm{m}$ & $\mathrm{m}$ & $\mathrm{m}$ & $\mathrm{m}$ & $\mathrm{m}$ & $\mathrm{m}$ & 3.3 & $(0.50)$ & 2.4 & $(0.56)$ & 1.0 & (1.61) & 0.9 & (3.29) \\
\hline & Czech Republic & -15 & (7.8) & -17 & (6.3) & -18 & (5.5) & -20 & (6.0) & -1.6 & $(0.36)$ & -2.2 & $(0.21)$ & -2.7 & $(0.19)$ & -2.9 & $(0.19)$ \\
\hline & Denmark & -2 & $(6.4)$ & -9 & $(5.3)$ & -22 & (4.6) & -25 & $(5.2)$ & -0.7 & $(0.23)$ & -1.3 & $(0.21)$ & -2.4 & $(0.21)$ & -2.7 & $(0.21)$ \\
\hline & Estonia & $\mathrm{m}$ & $\mathrm{m}$ & $\mathrm{m}$ & $\mathrm{m}$ & $\mathrm{m}$ & $\mathrm{m}$ & $\mathrm{m}$ & $\mathrm{m}$ & 1.0 & $(0.87)$ & 0.7 & $(0.43)$ & 0.9 & $(0.42)$ & 1.4 & $(0.42)$ \\
\hline & Finland & -29 & $(4.7)$ & -25 & (3.9) & -26 & (3.8) & -23 & $(4.6)$ & -3.5 & $(0.20)$ & -3.0 & $(0.20)$ & -3.1 & $(0.20)$ & -2.7 & $(0.20)$ \\
\hline & France & -23 & (7.5) & -20 & $(5.0)$ & -11 & (5.0) & -6 & (5.4) & -2.5 & $(0.32)$ & -2.0 & $(0.19)$ & -0.9 & $(0.19)$ & -0.5 & (0.19) \\
\hline & Germany & 22 & (7.6) & 15 & $(6.2)$ & 5 & (5.3) & 4 & (5.5) & 2.3 & $(0.41)$ & 1.6 & $(0.21)$ & 0.9 & $(0.19)$ & 0.6 & $(0.20)$ \\
\hline & Greece & 15 & (6.7) & 10 & $(6.1)$ & 6 & (5.5) & 1 & (6.4) & 1.7 & $(0.24)$ & 1.1 & $(0.20)$ & 0.6 & $(0.21)$ & 0.2 & $(0.23)$ \\
\hline & Hungary & -12 & (6.2) & -15 & (4.9) & -15 & (6.5) & -8 & (8.2) & -1.5 & $(0.22)$ & -1.6 & $(0.20)$ & -1.4 & $(0.24)$ & -0.8 & $(0.47)$ \\
\hline & Iceland & -24 & (4.3) & -23 & (4.3) & -22 & (4.0) & -17 & (4.9) & -2.5 & $(0.20)$ & -2.2 & $(0.20)$ & -2.1 & $(0.20)$ & -1.6 & $(0.20)$ \\
\hline & Ireland & -2 & $(5.2)$ & 0 & $(5.0)$ & -3 & (4.3) & -4 & (4.8) & -0.7 & $(0.21)$ & -0.3 & $(0.20)$ & -0.5 & $(0.20)$ & -0.7 & $(0.20)$ \\
\hline & Israel & $\mathrm{m}$ & $\mathrm{m}$ & $\mathrm{m}$ & $\mathrm{m}$ & $\mathrm{m}$ & $\mathrm{m}$ & $\mathrm{m}$ & $\mathrm{m}$ & 4.0 & (8.60) & 4.1 & $(2.78)$ & 4.0 & $(2.44)$ & 3.8 & (5.89) \\
\hline & Italy & 23 & $(6.5)$ & 21 & (5.3) & 19 & (4.5) & 17 & (5.1) & 3.2 & $(0.19)$ & 3.0 & $(0.19)$ & 2.8 & $(0.19)$ & 2.7 & $(0.20)$ \\
\hline & Japan & 13 & (8.3) & 6 & $(7.1)$ & -2 & (6.5) & -3 & (8.2) & 1.5 & $(0.32)$ & 1.0 & $(0.23)$ & 0.3 & $(0.24)$ & 0.2 & $(0.42)$ \\
\hline & Korea & 2 & (7.5) & 7 & $(6.4)$ & 18 & (6.9) & 20 & $(8.3)$ & 0.4 & $(0.28)$ & 0.8 & $(0.21)$ & 1.7 & $(0.24)$ & 1.8 & $(0.51)$ \\
\hline & Luxembourg & -9 & (4.5) & -8 & (3.3) & 1 & (3.2) & 2 & (4.3) & -1.0 & $(0.20)$ & -0.9 & $(0.20)$ & 0.2 & $(0.20)$ & 0.3 & $(0.20)$ \\
\hline & Mexico & 44 & (5.4) & 36 & $(5.0)$ & 18 & (5.1) & 13 & (5.4) & 4.9 & $(0.21)$ & 4.0 & $(0.20)$ & 2.0 & $(0.20)$ & 1.5 & $(0.21)$ \\
\hline & Netherlands & -19 & $(8.2)$ & -13 & $(7.7)$ & -17 & (6.1) & -18 & (5.3) & -2.1 & $(0.48)$ & -1.5 & $(0.48)$ & -1.7 & $(0.22)$ & -1.9 & $(0.20)$ \\
\hline & New Zealand & -23 & $(5.7)$ & -27 & $(4.8)$ & -23 & (4.1) & -18 & (4.8) & -2.7 & $(0.20)$ & -2.8 & $(0.19)$ & -2.2 & $(0.19)$ & -1.8 & (0.19) \\
\hline & Norway & -3 & (5.6) & -5 & $(4.5)$ & -8 & (5.0) & -10 & (5.3) & 0.1 & $(0.21)$ & -0.1 & $(0.20)$ & -0.6 & $(0.20)$ & -0.9 & $(0.20)$ \\
\hline & Poland & 26 & $(4.9)$ & 26 & (4.9) & 27 & (6.0) & 29 & $(7.2)$ & 2.4 & $(0.19)$ & 2.5 & $(0.19)$ & 2.8 & $(0.19)$ & 2.9 & $(0.21)$ \\
\hline & Portugal & 11 & (7.0) & 15 & (7.3) & 28 & (5.9) & 30 & (5.5) & 1.8 & $(0.30)$ & 2.2 & $(0.32)$ & 3.6 & $(0.21)$ & 3.8 & $(0.21)$ \\
\hline & Slovak Republic & -27 & $(8.7)$ & -23 & $(6.5)$ & -12 & (6.4) & -6 & (6.6) & -2.5 & $(0.54)$ & -2.2 & $(0.21)$ & -1.1 & $(0.20)$ & -0.4 & $(0.22)$ \\
\hline & Slovenia & $\mathrm{m}$ & $\mathrm{m}$ & $\mathrm{m}$ & $\mathrm{m}$ & $\mathrm{m}$ & $\mathrm{m}$ & $\mathrm{m}$ & $\mathrm{m}$ & -1.1 & $(0.31)$ & -1.2 & $(0.31)$ & 0.1 & $(0.31)$ & 0.1 & $(0.34)$ \\
\hline & Spain & 1 & (5.1) & -2 & $(4.4)$ & 0 & $(4.2)$ & 0 & $(4.7)$ & 0.2 & $(0.20)$ & 0.1 & $(0.19)$ & 0.3 & $(0.19)$ & 0.3 & (0.19) \\
\hline & Sweden & -27 & (5.9) & -31 & $(4.6)$ & -33 & (4.6) & -34 & (5.1) & -3.2 & $(0.20)$ & -3.5 & $(0.19)$ & -3.5 & $(0.19)$ & -3.5 & $(0.20)$ \\
\hline & Switzerland & 12 & (5.7) & 6 & $(5.3)$ & 2 & (6.4) & -1 & (7.1) & 1.2 & $(0.19)$ & 0.6 & $(0.19)$ & 0.2 & $(0.20)$ & 0.1 & $(0.21)$ \\
\hline & Turkey & 38 & (6.3) & 31 & (6.6) & 22 & (11.9) & 17 & (17.4) & 4.3 & $(0.23)$ & 3.7 & $(0.23)$ & 3.1 & (2.13) & 2.5 & (16.74) \\
\hline & United Kingdom & $\mathrm{m}$ & $\mathrm{m}$ & $\mathrm{m}$ & $\mathrm{m}$ & $\mathrm{m}$ & $\mathrm{m}$ & $\mathrm{m}$ & $\mathrm{m}$ & -1.6 & $(0.36)$ & -0.9 & $(0.23)$ & 0.5 & $(0.24)$ & 0.7 & $(0.26)$ \\
\hline & United States & 11 & (6.3) & 0 & (5.6) & -6 & (5.9) & -7 & (6.1) & 1.5 & $(0.24)$ & 0.4 & $(0.21)$ & -0.2 & $(0.22)$ & -0.2 & $(0.22)$ \\
\hline & OECD average 2003 & -1 & $(1.2)$ & -3 & $(1.0)$ & -4 & (1.0) & -4 & $(1.2)$ & -0.1 & $(0.06)$ & -0.3 & $(0.05)$ & -0.3 & $(0.09)$ & -0.3 & $(0.58)$ \\
\hline & OECD average 2006 & $\mathrm{~m}$ & $\mathrm{~m}$ & $\mathrm{~m}$ & $\mathrm{~m}$ & $\mathrm{~m}$ & $\mathrm{~m}$ & $\mathrm{~m}$ & $\mathrm{~m}$ & 0.1 & $(0.26)$ & -0.1 & $(0.09)$ & -0.1 & $(0.11)$ & -0.1 & (0.53) \\
\hline & OECD average 2009 & $\mathrm{~m}$ & $\mathrm{~m}$ & $\mathrm{~m}$ & $\mathrm{~m}$ & $\mathrm{~m}$ & $\mathrm{~m}$ & $\mathrm{~m}$ & $\mathrm{~m}$ & 0.1 & $(0.27)$ & -0.1 & $(0.10)$ & -0.1 & $(0.12)$ & 0.0 & $(0.55)$ \\
\hline
\end{tabular}

\begin{tabular}{|c|c|c|c|c|c|c|c|c|c|c|c|c|c|c|c|c|c|}
\hline & Albania & $\mathrm{m}$ & $\mathrm{m}$ & $\mathrm{m}$ & $\mathrm{m}$ & $\mathrm{m}$ & $\mathrm{m}$ & $\mathrm{m}$ & $\mathrm{m}$ & 5.8 & $(65.52)$ & 6.9 & (35.99) & 5.4 & (25.58) & 5.6 & (55.88) \\
\hline & Argentina & $\mathrm{m}$ & $\mathrm{m}$ & $\mathrm{m}$ & $\mathrm{m}$ & $\mathrm{m}$ & $\mathrm{m}$ & $\mathrm{m}$ & $\mathrm{m}$ & 7.1 & (19.66) & 3.5 & $(5.44)$ & -1.8 & (3.57) & -3.7 & (4.54) \\
\hline & Brazil & 65 & (6.0) & 52 & (5.3) & 21 & $(7.0)$ & 7 & (10.7) & 6.9 & $(0.22)$ & 5.3 & $(0.21)$ & 2.2 & $(0.21)$ & 1.0 & $(0.84)$ \\
\hline & Bulgaria & $\mathrm{m}$ & $\mathrm{m}$ & $\mathrm{m}$ & $\mathrm{m}$ & $\mathrm{m}$ & $\mathrm{m}$ & $\mathrm{m}$ & $\mathrm{m}$ & 5.5 & (6.71) & 4.5 & (3.52) & 3.6 & (7.70) & 3.7 & (16.94) \\
\hline & Colombia & $\mathrm{m}$ & $\mathrm{m}$ & $\mathrm{m}$ & $\mathrm{m}$ & $\mathrm{m}$ & $\mathrm{m}$ & $\mathrm{m}$ & $\mathrm{m}$ & 3.7 & (1.54) & 1.7 & $(0.67)$ & -1.1 & (1.31) & -1.3 & (1.29) \\
\hline & Costa Rica & $\mathrm{m}$ & $\mathrm{m}$ & $\mathrm{m}$ & $\mathrm{m}$ & $\mathrm{m}$ & $\mathrm{m}$ & $\mathrm{m}$ & $\mathrm{m}$ & 2.2 & (75.14) & 0.0 & $(55.91)$ & -3.8 & (119.50) & -3.3 & $(566.82)$ \\
\hline & Croatia & $\mathrm{m}$ & $\mathrm{m}$ & $\mathrm{m}$ & $\mathrm{m}$ & $\mathrm{m}$ & $\mathrm{m}$ & $\mathrm{m}$ & $\mathrm{m}$ & -0.1 & $(0.54)$ & -0.5 & $(0.41)$ & 1.0 & $(0.65)$ & 2.1 & (2.88) \\
\hline & Dubai (UAE) & $\mathrm{m}$ & $\mathrm{m}$ & $\mathrm{m}$ & $\mathrm{m}$ & $\mathrm{m}$ & $\mathrm{m}$ & $\mathrm{m}$ & $\mathrm{m}$ & 5.5 & (2.30) & 4.9 & $(0.92)$ & 2.3 & (1.06) & 0.7 & (7.46) \\
\hline & Hong Kong-China & 13 & (10.3) & 14 & (8.6) & 7 & (5.5) & 8 & (6.2) & 1.5 & (1.58) & 1.6 & $(0.49)$ & 0.9 & $(0.20)$ & 1.1 & $(0.21)$ \\
\hline & Indonesia & 27 & (6.6) & 21 & (5.5) & 7 & (7.3) & 3 & (10.3) & 2.8 & $(0.24)$ & 2.1 & $(0.24)$ & 0.1 & $(0.29)$ & -0.6 & (1.48) \\
\hline & Jordan & $\mathrm{m}$ & $\mathrm{m}$ & $\mathrm{m}$ & $\mathrm{m}$ & $\mathrm{m}$ & $\mathrm{m}$ & $\mathrm{m}$ & $\mathrm{m}$ & 1.9 & (1.02) & 0.8 & $(0.45)$ & -1.0 & $(0.51)$ & -0.8 & (1.51) \\
\hline & Kazakhstan & $\mathrm{m}$ & $\mathrm{m}$ & $\mathrm{m}$ & $\mathrm{m}$ & $\mathrm{m}$ & $\mathrm{m}$ & $\mathrm{m}$ & $\mathrm{m}$ & 13.6 & $(4.52)$ & 11.8 & $(5.67)$ & 6.6 & (22.85) & 4.4 & (96.70) \\
\hline & Latvia & 16 & (7.0) & 10 & (5.4) & 3 & (6.3) & 1 & (6.1) & 1.6 & $(0.22)$ & 0.9 & $(0.19)$ & 0.1 & $(0.20)$ & -0.1 & $(0.21)$ \\
\hline & Liechtenstein & -5 & (15.0) & 0 & (11.2) & -2 & (9.6) & 1 & (13.4) & 0.4 & (5.52) & 0.6 & $(1.22)$ & -0.1 & (2.50) & 0.0 & (1.45) \\
\hline & Lithuania & $\mathrm{m}$ & $\mathrm{m}$ & $\mathrm{m}$ & $\mathrm{m}$ & $\mathrm{m}$ & $\mathrm{m}$ & $\mathrm{m}$ & $\mathrm{m}$ & -0.9 & $(0.80)$ & -1.4 & $(0.61)$ & -1.5 & $(0.55)$ & -0.9 & (0.89) \\
\hline & Macao-China & 1 & (6.9) & 9 & (5.1) & 18 & (4.8) & 18 & (6.3) & 0.0 & (0.19) & 1.1 & $(0.19)$ & 2.5 & (0.19) & 2.8 & (0.19) \\
\hline & Malaysia & $\mathrm{m}$ & $\mathrm{m}$ & $\mathrm{m}$ & $\mathrm{m}$ & $\mathrm{m}$ & $\mathrm{m}$ & $\mathrm{m}$ & $\mathrm{m}$ & 3.6 & $(45.78)$ & 4.5 & (19.46) & 10.8 & (130.86) & 15.1 & $(369.80)$ \\
\hline & Montenegro & $\mathrm{m}$ & $\mathrm{m}$ & $\mathrm{m}$ & $\mathrm{m}$ & $\mathrm{m}$ & $\mathrm{m}$ & $\mathrm{m}$ & $\mathrm{m}$ & 2.6 & $(0.34)$ & 1.7 & $(0.34)$ & 1.4 & $(0.34)$ & 1.7 & $(0.36)$ \\
\hline & Peru & $\mathrm{m}$ & $\mathrm{m}$ & $\mathrm{m}$ & $\mathrm{m}$ & $\mathrm{m}$ & $\mathrm{m}$ & $\mathrm{m}$ & $\mathrm{m}$ & 4.1 & (8.09) & 2.4 & (19.62) & -1.0 & (117.76) & -0.7 & (305.18) \\
\hline & Qatar & $\mathrm{m}$ & $\mathrm{m}$ & $\mathrm{m}$ & $\mathrm{m}$ & $\mathrm{m}$ & $\mathrm{m}$ & $\mathrm{m}$ & $\mathrm{m}$ & 7.1 & $(0.36)$ & 7.8 & $(0.36)$ & 11.4 & $(0.36)$ & 11.8 & (0.36) \\
\hline & Romania & $\mathrm{m}$ & $\mathrm{m}$ & $\mathrm{m}$ & $\mathrm{m}$ & $\mathrm{m}$ & $\mathrm{m}$ & $\mathrm{m}$ & $\mathrm{m}$ & 6.2 & (3.59) & 4.6 & $(1.62)$ & 4.5 & $(1.70)$ & 5.0 & (8.35) \\
\hline & Russian Federation & 20 & (6.6) & 17 & (6.0) & 10 & (6.4) & 7 & (7.3) & 1.9 & $(0.24)$ & 1.6 & $(0.20)$ & 0.7 & $(0.20)$ & 0.2 & $(0.36)$ \\
\hline & Serbia & $\mathrm{m}$ & $\mathrm{m}$ & $\mathrm{m}$ & $\mathrm{m}$ & $\mathrm{m}$ & $\mathrm{m}$ & $\mathrm{m}$ & $\mathrm{m}$ & 2.8 & (1.40) & 2.0 & (1.19) & 1.8 & (1.41) & 2.4 & (2.55) \\
\hline & Shanghai-China & $\mathrm{m}$ & $\mathrm{m}$ & $\mathrm{m}$ & $\mathrm{m}$ & $\mathrm{m}$ & $\mathrm{m}$ & $\mathrm{m}$ & $\mathrm{m}$ & 4.3 & (70.18) & 5.0 & (30.43) & 3.6 & (14.30) & 3.5 & (25.23) \\
\hline & Singapore & $\mathrm{m}$ & $\mathrm{m}$ & $\mathrm{m}$ & $\mathrm{m}$ & $\mathrm{m}$ & $\mathrm{m}$ & $\mathrm{m}$ & $\mathrm{m}$ & 3.2 & (12.71) & 3.5 & $(3.20)$ & 3.9 & (1.01) & 4.6 & (2.16) \\
\hline & Chinese Taipei & $\mathrm{m}$ & $\mathrm{m}$ & $\mathrm{m}$ & $\mathrm{m}$ & $\mathrm{m}$ & $\mathrm{m}$ & $\mathrm{m}$ & $\mathrm{m}$ & -1.2 & (5.10) & 0.0 & $(3.52)$ & 3.0 & $(0.44)$ & 4.0 & $(0.76)$ \\
\hline & Thailand & 12 & (4.8) & 11 & (4.4) & 7 & (6.4) & 9 & (8.9) & 1.3 & $(0.20)$ & 1.2 & $(0.20)$ & 0.7 & $(0.25)$ & 0.8 & (0.84) \\
\hline & Tunisia & 35 & (5.9) & 31 & (4.9) & 26 & (6.1) & 22 & (8.9) & 4.4 & $(0.20)$ & 3.6 & $(0.19)$ & 2.4 & $(0.21)$ & 1.6 & $(0.57)$ \\
\hline & United Arab Emirates* & $\mathrm{m}$ & $\mathrm{m}$ & $\mathrm{m}$ & $\mathrm{m}$ & $\mathrm{m}$ & $\mathrm{m}$ & $\mathrm{m}$ & $\mathrm{m}$ & 7.3 & (171.04) & 5.2 & (66.48) & 5.9 & (219.54) & 7.2 & (753.38) \\
\hline & Uruguay & 6 & (5.9) & -6 & (5.4) & -21 & (5.5) & -24 & (6.1) & 1.0 & $(0.21)$ & -0.6 & $(0.21)$ & -2.2 & $(0.21)$ & -2.4 & $(0.24)$ \\
\hline
\end{tabular}

Notes: Values that are statistically significant are indicated in bold (see Annex A3).

Annualised change is the average change between the earliest available measurement in PISA and PISA 2012. For countries and economies with more than one available measurement, the annualised change is calculated with a linear regression model. This model considers that Costa Rica, Malaysia and the Unite

In the United Arab Emirates, Dubai took the PISA 2009 assessment in 2009 and the rest of the United Arab Emirates in 2010 as part of PISA $2009+$. Results are thus reported separately.

* United Arab Emirates excluding Dubai (see note above).

StatLink त्नाज्ञा http://dx.doi.org/10.1787/888932935667 
[Part 1/1]

Table 1.2.4 Trends in mathematics performance adjusted for demographic changes

\begin{tabular}{|c|c|c|c|c|c|c|c|c|c|c|c|c|c|c|c|c|c|}
\hline & \multicolumn{2}{|c|}{$\begin{array}{l}\text { Adjusted PISA } \\
2003 \text { results }\end{array}$} & \multicolumn{2}{|c|}{$\begin{array}{l}\text { Adjusted PISA } \\
2006 \text { results }\end{array}$} & \multicolumn{2}{|c|}{$\begin{array}{l}\text { Adjusted PISA } \\
2009 \text { results }\end{array}$} & \multicolumn{2}{|c|}{$\begin{array}{l}\text { Adjusted PISA } \\
2012 \text { results }\end{array}$} & \multicolumn{2}{|c|}{$\begin{array}{c}\text { Change between } \\
2003 \text { and 2012 } \\
\text { (PISA 2012 - } \\
\text { PISA 2003) }\end{array}$} & $\begin{array}{r}\text { Change } \\
2006 \text { a } \\
\text { (PISA } \\
\text { PISA }\end{array}$ & $\begin{array}{l}\text { etween } \\
2012 \\
012 \text { - } \\
006 \text { ) }\end{array}$ & $\begin{array}{r}\text { Change } \\
2009 \\
\text { (PISA } \\
\text { PISA }\end{array}$ & $\begin{array}{l}\text { etween } \\
\text { d } 2012 \\
012- \\
009)\end{array}$ & $\begin{array}{r}\text { Ann } \\
\text { adjuste } \\
\text { acro } \\
\text { asse }\end{array}$ & $\begin{array}{l}\text { lised } \\
\text { change } \\
\text { PISA } \\
\text { nents }\end{array}$ \\
\hline & & $\begin{array}{l}\text { Mean } \\
\text { score }\end{array}$ & S.E. & $\begin{array}{l}\text { Mean } \\
\text { score }\end{array}$ & S.E. & $\begin{array}{l}\text { Mean } \\
\text { score }\end{array}$ & S.E. & $\begin{array}{l}\text { Mean } \\
\text { score }\end{array}$ & S.E. & \begin{tabular}{|c|}
$\begin{array}{c}\text { Score } \\
\text { dif. }\end{array}$ \\
\end{tabular} & S.E. & $\begin{array}{c}\begin{array}{c}\text { Score } \\
\text { dif. }\end{array} \\
\end{array}$ & S.E. & $\begin{array}{c}\begin{array}{c}\text { Score } \\
\text { dif. }\end{array} \\
\end{array}$ & S.E. & $\begin{array}{c}\text { Score } \\
\text { dif. }\end{array}$ & S.E. \\
\hline$a$ & Australia & 533 & $(1.8)$ & 521 & (1.9) & 514 & $(2.1)$ & 504 & $(1.5)$ & -29.1 & $(3.0)$ & -16.9 & (3.2) & -10.1 & (3.4) & \begin{tabular}{|l|}
-3.2 \\
\end{tabular} & $(0.3)$ \\
\hline 岕 & Austria & 517 & (2.8) & 505 & $(3.1)$ & $\mathrm{m}$ & $\mathrm{m}$ & 506 & $(2.4)$ & -11.5 & (4.3) & 0.2 & (4.6) & $\mathrm{m}$ & $\mathrm{m}$ & \begin{tabular}{|l|}
-1.1 \\
\end{tabular} & $(0.5)$ \\
\hline & Belgium & 533 & $(1.8)$ & 522 & (2.6) & 514 & (1.9) & 515 & $(1.8)$ & -18.9 & (3.1) & -7.8 & (3.9) & 0.3 & (3.4) & -2.4 & $(0.3)$ \\
\hline & Canada & 539 & (1.6) & 530 & (1.9) & 526 & (1.4) & 518 & (1.6) & -20.5 & $(2.9)$ & -12.1 & (3.3) & -7.7 & (3.1) & -2.2 & $(0.3)$ \\
\hline & Chile & $\mathrm{m}$ & $\mathrm{m}$ & 424 & (3.0) & 420 & $(2.5)$ & 423 & $(2.4)$ & $\mathrm{m}$ & $\mathrm{m}$ & -1.8 & (4.1) & 2.4 & (3.9) & -0.3 & $(0.7)$ \\
\hline & Czech Republic & 514 & $(2.8)$ & 508 & $(3.2)$ & 490 & $(2.6)$ & 499 & $(2.5)$ & -14.9 & (4.1) & -9.4 & (4.5) & 8.8 & (3.9) & -2.3 & $(0.4)$ \\
\hline & Denmark & 527 & $(2.0)$ & 512 & $(2.1)$ & 503 & $(2.3)$ & 500 & $(1.7)$ & -26.5 & $(3.2)$ & -12.3 & (3.5) & -2.9 & (3.7) & -2.8 & $(0.4)$ \\
\hline & Estonia & $\mathrm{m}$ & $\mathrm{m}$ & 524 & (2.5) & 512 & $(2.3)$ & 520 & (1.9) & $\mathrm{m}$ & $\mathrm{m}$ & -3.0 & $(4.0)$ & 8.5 & (3.7) & \begin{tabular}{|l|} 
\\
-0.7
\end{tabular} & $(0.6)$ \\
\hline & Finland & 552 & $(1.7)$ & 553 & $(2.1)$ & 539 & $(2.1)$ & 519 & $(1.7)$ & -33.0 & (3.1) & -34.7 & (3.4) & -20.2 & (3.3) & \begin{tabular}{|l|}
-3.8 \\
\end{tabular} & $(0.3)$ \\
\hline & France & 523 & (2.0) & 510 & $(2.6)$ & 501 & (2.4) & 495 & $(2.2)$ & -27.6 & (3.5) & -14.8 & $(4.2)$ & -6.3 & (3.9) & \begin{tabular}{|l|}
-3.1 \\
\end{tabular} & $(0.4)$ \\
\hline & Germany & 516 & (2.5) & 505 & (3.0) & 515 & $(2.2)$ & 513 & (2.4) & -2.9 & (3.9) & 8.2 & (4.4) & -1.3 & $(4.2)$ & 0.0 & $(0.4)$ \\
\hline & Greece & 453 & (2.9) & 464 & $(2.4)$ & 465 & (3.4) & 453 & (1.9) & 0.2 & $(4.0)$ & -10.7 & (3.7) & -12.0 & (4.4) & 0.1 & $(0.4)$ \\
\hline & Hungary & 492 & (2.1) & 491 & $(2.3)$ & 485 & $(2.7)$ & 477 & $(2.5)$ & -15.1 & (3.7) & \begin{tabular}{|l|}
-14.3 \\
\end{tabular} & (4.0) & -8.4 & $(4.2)$ & $\mid-1.7$ & $(0.4)$ \\
\hline & Iceland & 521 & (1.4) & 510 & (1.9) & 508 & (1.4) & 493 & $(1.7)$ & -27.9 & $(3.0)$ & -17.1 & (3.1) & -15.1 & $(3.2)$ & -2.9 & $(0.3)$ \\
\hline & Ireland & 517 & (1.9) & 509 & $(2.2)$ & 489 & $(2.3)$ & 502 & (1.9) & -15.0 & (3.4) & -7.0 & (3.7) & 12.7 & $(4.0)$ & -2.0 & $(0.4)$ \\
\hline & Israel & $\mathrm{m}$ & $\mathrm{m}$ & 442 & $(4.2)$ & 449 & $(2.7)$ & 466 & $(4.0)$ & $\mathrm{m}$ & $\mathrm{m}$ & 24.1 & (6.1) & 17.9 & (5.3) & 4.0 & $(1.0)$ \\
\hline & Italy & 470 & (2.9) & 465 & $(2.2)$ & 482 & $(1.7)$ & 485 & $(1.7)$ & 15.0 & (3.8) & 20.3 & (3.7) & 3.2 & (3.4) & 2.1 & $(0.4)$ \\
\hline & Japan & 549 & (3.5) & 527 & (3.0) & 529 & (3.1) & 536 & (3.2) & -12.8 & (5.0) & 9.2 & $(4.1)$ & 7.4 & $(4.8)$ & $\mid-1.3$ & $(0.5)$ \\
\hline & Korea & 471 & (20.1) & 554 & (3.4) & 547 & (3.6) & 469 & (20.7) & -1.0 & $(4.9)$ & 0.0 & (5.6) & 6.5 & $(6.2)$ & -0.4 & $(0.5)$ \\
\hline & Luxembourg & 490 & (1.9) & 491 & $(1.2)$ & 486 & $(1.2)$ & 490 & $(1.2)$ & -0.1 & (3.0) & -1.3 & (2.6) & 4.4 & $(2.7)$ & 0.0 & $(0.3)$ \\
\hline & Mexico & 389 & (3.0) & 405 & $(2.3)$ & 417 & $(1.5)$ & 413 & (1.1) & 24.1 & (3.7) & 7.8 & (3.3) & -3.2 & (2.9) & 2.7 & $(0.4)$ \\
\hline & Netherlands & 550 & (2.5) & 534 & (2.2) & 530 & $(4.0)$ & 523 & (3.3) & -27.0 & $(4.7)$ & -10.6 & (4.4) & -7.4 & (5.8) & \begin{tabular}{|l|}
-2.8 \\
\end{tabular} & $(0.5)$ \\
\hline & New Zealand & 531 & $(2.0)$ & 518 & $(2.2)$ & 513 & $(2.1)$ & 500 & $(2.2)$ & -30.8 & (3.6) & -18.3 & (3.6) & -13.4 & (3.8) & $\mid-3.2$ & $(0.4)$ \\
\hline & Norway & 503 & (2.1) & 492 & (2.4) & 494 & (2.3) & 489 & (2.5) & $\mid-14.1$ & (3.9) & -2.9 & $(4.0)$ & -4.4 & (3.9) & $\mid-1.3$ & $(0.4)$ \\
\hline & Poland & 498 & (2.0) & 510 & $(2.3)$ & 499 & $(2.4)$ & 518 & $(3.0)$ & 19.4 & (3.9) & 7.8 & $(4.2)$ & 19.0 & (4.5) & 1.5 & $(0.4)$ \\
\hline & Portugal & 477 & (2.3) & 476 & (2.3) & 485 & $(2.2)$ & 487 & (2.9) & 10.1 & $(4.5)$ & 11.0 & (4.4) & 1.7 & $(4.1)$ & 1.3 & $(0.5)$ \\
\hline & Slovak Republic & 499 & $(2.2)$ & 495 & $(2.3)$ & 492 & (2.8) & 482 & (2.4) & -16.9 & (3.8) & -13.5 & (3.7) & -10.7 & $(4.2)$ & $\mid-1.8$ & $(0.4)$ \\
\hline & Slovenia & $\mathrm{m}$ & $\mathrm{m}$ & 517 & $(1.2)$ & 501 & $(1.2)$ & 501 & $(1.2)$ & $\mathrm{m}$ & $\mathrm{m}$ & -15.6 & $(2.7)$ & -0.3 & (2.9) & -2.7 & $(0.4)$ \\
\hline & Spain & 492 & $(1.7)$ & 488 & $(1.7)$ & 484 & $(1.8)$ & 484 & (1.6) & -7.5 & (3.0) & -3.3 & (3.1) & 0.3 & (3.5) & \begin{tabular}{|l|}
-0.8 \\
\end{tabular} & $(0.3)$ \\
\hline & Sweden & 513 & $(2.0)$ & 501 & (2.3) & 488 & $(2.3)$ & 478 & (2.0) & -35.1 & (3.4) & -23.1 & (3.8) & -10.1 & (3.9) & -4.0 & $(0.4)$ \\
\hline & Switzerland & 538 & (2.9) & 535 & $(2.8)$ & 536 & $(2.7)$ & 531 & $(2.6)$ & -6.6 & (4.5) & -4.1 & $(4.2)$ & -4.6 & (4.4) & -0.7 & $(0.5)$ \\
\hline & Turkey & 408 & (4.5) & 417 & (3.8) & 434 & (3.5) & 448 & $(4.1)$ & 39.5 & $(6.0)$ & 31.2 & (6.0) & 14.4 & (6.0) & 4.6 & $(0.6)$ \\
\hline & United Kingdom & $\mathrm{m}$ & $\mathrm{m}$ & 501 & $(2.1)$ & 493 & $(2.0)$ & 494 & $(2.8)$ & $\mathrm{m}$ & $\mathrm{m}$ & -7.1 & (3.4) & 0.9 & $(4.4)$ & $\mid-1.2$ & $(0.5)$ \\
\hline & United States & 488 & (2.3) & 474 & (3.1) & 486 & (2.5) & 481 & (2.8) & -6.7 & $(4.4)$ & 7.4 & (4.4) & -4.2 & $(4.5)$ & -0.2 & $(0.4)$ \\
\hline & OECD average 2003 & 504 & $(0.8)$ & 501 & $(0.5)$ & 498 & $(0.4)$ & 493 & $(0.8)$ & -10.1 & $(0.7)$ & -4.5 & $(0.7)$ & -2.3 & $(0.8)$ & $\mid-1.1$ & $(0.1)$ \\
\hline & OECD average 2006 & $\mathrm{~m}$ & $\mathrm{~m}$ & 498 & $(0.5)$ & 495 & $(0.4)$ & 492 & $(0.8)$ & $\mathrm{m}$ & $\mathrm{m}$ & -4.0 & $(0.7)$ & -1.0 & $(0.8)$ & -1.0 & $(0.1)$ \\
\hline & OECD average 2009 & $\mathrm{~m}$ & $\mathrm{~m}$ & $\mathrm{~m}$ & m & 495 & $(0.4)$ & 491 & $(0.7)$ & $\mathrm{m}$ & $\mathrm{m}$ & $\mathrm{m}$ & $\mathrm{m}$ & -1.0 & $(0.7)$ & \begin{tabular}{|l|}
-0.9 \\
\end{tabular} & $(0.1)$ \\
\hline$n$ & Albania & $\mathrm{m}$ & $\mathrm{m}$ & $\mathrm{m}$ & $\mathrm{m}$ & $\mathrm{m}$ & $\mathrm{m}$ & $\mathrm{m}$ & $\mathrm{m}$ & $\mathrm{m}$ & $\mathrm{m}$ & $\mathrm{m}$ & $\mathrm{m}$ & $\mathrm{m}$ & $\mathrm{m}$ & $\mathrm{m}$ & $\mathrm{m}$ \\
\hline$\Xi$ & Argentina & $\mathrm{m}$ & $\mathrm{m}$ & 385 & $(4.8)$ & 387 & $(3.2)$ & 388 & (2.9) & $\mathrm{m}$ & $\mathrm{m}$ & 3.5 & (6.1) & 1.4 & $(4.6)$ & 0.6 & $(1.0)$ \\
\hline & Brazil & 368 & (4.3) & 378 & (2.6) & 388 & $(2.0)$ & 391 & $(1.8)$ & 23.0 & $(4.9)$ & 13.2 & (3.7) & 3.3 & $(3.7)$ & 2.6 & $(0.5)$ \\
\hline & Bulgaria & $\mathrm{m}$ & $\mathrm{m}$ & 422 & (4.5) & 428 & (4.6) & 439 & (3.1) & $\mathrm{m}$ & $\mathrm{m}$ & 16.3 & $(6.2)$ & 11.0 & $(6.2)$ & 2.6 & $(1.0)$ \\
\hline & Colombia & $\mathrm{m}$ & $\mathrm{m}$ & 372 & (3.3) & 380 & $(2.7)$ & 376 & (2.4) & $\mathrm{m}$ & $\mathrm{m}$ & 4.8 & $(4.7)$ & -3.3 & $(4.5)$ & 0.8 & $(0.8)$ \\
\hline & Costa Rica & $\mathrm{m}$ & $\mathrm{m}$ & $\mathrm{m}$ & $\mathrm{m}$ & 411 & $(4.1)$ & 407 & $(2.5)$ & $\mathrm{m}$ & $\mathrm{m}$ & $\mathrm{m}$ & $\mathrm{m}$ & -4.0 & (5.9) & $\mid-1.3$ & $(2.0)$ \\
\hline & Croatia & $\mathrm{m}$ & $\mathrm{m}$ & 470 & $(2.2)$ & 457 & (2.9) & 471 & (3.2) & $\mathrm{m}$ & $\mathrm{m}$ & 0.7 & (4.3) & 14.6 & (5.3) & 0.1 & $(0.7)$ \\
\hline & Dubai (UAE) & $\mathrm{m}$ & $\mathrm{m}$ & $\mathrm{m}$ & $\mathrm{m}$ & 453 & $(1.1)$ & 463 & $(1.2)$ & $\mathrm{m}$ & $\mathrm{m}$ & $\mathrm{m}$ & $\mathrm{m}$ & 10.7 & (2.8) & 3.6 & $(0.9)$ \\
\hline & Hong Kong-China & 560 & $(4.2)$ & 553 & $(2.6)$ & 559 & $(2.3)$ & 561 & $(2.6)$ & 0.7 & $(5.2)$ & 7.7 & $(4.2)$ & 2.3 & $(4.4)$ & 0.2 & $(0.5)$ \\
\hline & Indonesia & 368 & $(4.7)$ & 394 & $(5.2)$ & 371 & (3.3) & 375 & (3.4) & 6.8 & (5.6) & -18.7 & (6.7) & 3.6 & $(4.8)$ & -0.4 & $(0.5)$ \\
\hline & Jordan & $\mathrm{m}$ & $\mathrm{m}$ & 386 & (3.1) & 387 & (3.3) & 386 & (2.9) & $\mathrm{m}$ & $\mathrm{m}$ & -0.1 & (4.8) & -1.0 & $(4.8)$ & -0.1 & $(0.8)$ \\
\hline & Kazakhstan & $\mathrm{m}$ & $\mathrm{m}$ & $\mathrm{m}$ & $\mathrm{m}$ & 408 & $(2.8)$ & 432 & (2.9) & $\mathrm{m}$ & $\mathrm{m}$ & $\mathrm{m}$ & $\mathrm{m}$ & 24.0 & (4.5) & 8.0 & $(1.5)$ \\
\hline & Latvia & 484 & (3.4) & 492 & (2.8) & 483 & (2.5) & 491 & (2.3) & 6.7 & (4.6) & -1.2 & (4.1) & 7.9 & $(4.2)$ & 0.2 & $(0.5)$ \\
\hline & Liechtenstein & 556 & (5.5) & 537 & $(4.5)$ & 544 & $(4.2)$ & 536 & $(4.0)$ & -20.3 & $(7.0)$ & -1.1 & (6.2) & -8.7 & (6.1) & \begin{tabular}{|l|}
-1.8 \\
\end{tabular} & $(0.6)$ \\
\hline & Lithuania & $\mathrm{m}$ & $\mathrm{m}$ & 491 & $(2.6)$ & 480 & $(2.4)$ & 479 & $(2.2)$ & $\mathrm{m}$ & $\mathrm{m}$ & -12.4 & $(4.2)$ & -1.5 & (3.8) & -2.2 & $(0.7)$ \\
\hline & Macao-China & 536 & (3.9) & 527 & $(3.6)$ & 527 & $(0.9)$ & 538 & $(1.0)$ & 2.2 & $(4.5)$ & 10.2 & (4.4) & 11.2 & (2.6) & -0.3 & $(0.4)$ \\
\hline & Malaysia & $\mathrm{m}$ & $\mathrm{m}$ & $\mathrm{m}$ & $\mathrm{m}$ & 391 & $(3.4)$ & 421 & $(2.6)$ & $\mathrm{m}$ & $\mathrm{m}$ & $\mathrm{m}$ & $\mathrm{m}$ & 29.1 & (5.4) & 9.7 & $(1.8)$ \\
\hline & Montenegro & $\mathrm{m}$ & $\mathrm{m}$ & 412 & $(2.1)$ & 407 & $(1.7)$ & 410 & $(1.1)$ & $\mathrm{m}$ & $\mathrm{m}$ & -2.1 & (3.1) & 2.8 & (3.1) & -0.4 & $(0.5)$ \\
\hline & Peru & $\mathrm{m}$ & $\mathrm{m}$ & $\mathrm{m}$ & $\mathrm{m}$ & 363 & (2.9) & 368 & $(2.3)$ & $\mathrm{m}$ & $\mathrm{m}$ & $\mathrm{m}$ & $\mathrm{m}$ & 4.9 & $(4.3)$ & 1.6 & (1.4) \\
\hline & Qatar & $\mathrm{m}$ & $\mathrm{m}$ & 339 & $(1.0)$ & 375 & $(0.7)$ & 376 & $(0.8)$ & $\mathrm{m}$ & $\mathrm{m}$ & 37.0 & (2.4) & 0.9 & $(2.5)$ & 5.6 & $(0.4)$ \\
\hline & Romania & $\mathrm{m}$ & $\mathrm{m}$ & 423 & (3.8) & 428 & $(3.0)$ & 445 & $(3.0)$ & $\mathrm{m}$ & $\mathrm{m}$ & 21.1 & (5.3) & 16.7 & (5.1) & 3.4 & $(0.9)$ \\
\hline & Russian Federation & 484 & (3.7) & 492 & (3.3) & 475 & $(2.9)$ & 482 & $(2.9)$ & -2.1 & (5.3) & -10.1 & $(4.8)$ & 7.2 & (4.6) & -0.7 & $(0.6)$ \\
\hline & Serbia & $\mathrm{m}$ & $\mathrm{m}$ & 442 & $(3.1)$ & 443 & $(2.5)$ & 449 & (2.9) & $\mathrm{m}$ & $\mathrm{m}$ & 7.2 & $(5.1)$ & 5.8 & $(4.7)$ & 1.2 & $(0.8)$ \\
\hline & Shanghai-China & $\mathrm{m}$ & $\mathrm{m}$ & $\mathrm{m}$ & $\mathrm{m}$ & 603 & $(2.4)$ & 613 & (2.6) & $\mathrm{m}$ & $\mathrm{m}$ & $\mathrm{m}$ & $\mathrm{m}$ & 9.4 & $(4.2)$ & 3.1 & (1.4) \\
\hline & Singapore & $\mathrm{m}$ & $\mathrm{m}$ & $\mathrm{m}$ & $\mathrm{m}$ & 565 & (1.4) & 573 & $(1.2)$ & $\mathrm{m}$ & $\mathrm{m}$ & $\mathrm{m}$ & $\mathrm{m}$ & 8.0 & (3.0) & 2.7 & $(1.0)$ \\
\hline & Chinese Taipei & $\mathrm{m}$ & $\mathrm{m}$ & 556 & (3.2) & 542 & $(2.8)$ & 560 & (2.4) & $\mathrm{m}$ & $\mathrm{m}$ & 3.6 & (4.5) & 17.8 & (4.4) & 0.7 & $(0.7)$ \\
\hline & Thailand & 432 & $(4.1)$ & 429 & (2.4) & 422 & $(2.7)$ & 427 & (2.9) & -4.8 & (5.8) & -2.2 & $(4.0)$ & 5.0 & (4.4) & -0.6 & $(0.5)$ \\
\hline & Tunisia & 370 & $(2.7)$ & 369 & (3.1) & 376 & (2.6) & 388 & (3.4) & 17.7 & (4.6) & 19.2 & $(5.2)$ & \begin{tabular}{|l|}
11.7 \\
\end{tabular} & (4.6) & 1.9 & $(0.5)$ \\
\hline & United Arab Emirates* & $\mathrm{m}$ & $\mathrm{m}$ & $\mathrm{m}$ & $\mathrm{m}$ & 422 & $(4.6)$ & 423 & (2.5) & $\mathrm{m}$ & $\mathrm{m}$ & $\mathrm{m}$ & $\mathrm{m}$ & 1.2 & $(6.2)$ & 0.4 & $(2.2)$ \\
\hline & Uruguay & 417 & $(2.8)$ & 422 & $(2.4)$ & 426 & $(2.2)$ & 409 & $(2.2)$ & -7.7 & $(3.9)$ & -12.6 & $(4.0)$ & -16.5 & (3.8) & \begin{tabular}{|l|}
-0.7 \\
\end{tabular} & $(0.4)$ \\
\hline
\end{tabular}

Notes: Values that are statistically significant are indicated in bold (see Annex A3).

Annualised change is the average change between the earliest available measurement in PISA and PISA 2012. For countries and economies with more than one available measurement, the annualised change is calculated with a linear regression model. This model considers that Costa Rica, Malaysia and the United Arab Emirates (with the as part of PISA 2009+.

Adjusted scores are obtained by estimating a regression of students' demographic characteristics on math performance with demographic characteristics centred at the 2012 values. Demographic characteristics that entered the model are: students' age, gender, PISA index of economic, social and cultural status, immigrant background (first or second
generation) and whether students speak a language at home which is different from the language of instruction. Adjusted values therefore represent average scores in previous generation) and whether students speak a language at home which is different from the language of instruction. Adjusted values therefore represent
assessment assuming that demographic characteristics remained unchanged. See Annex A5 for more details on the estimation of adjusted trends.

In the United Arab Emirates, Dubai took the PISA 2009 assessment in 2009 and the rest of the United Arab Emirates in 2010 as part of PISA $2009+$. Results are thus reported separately.

* United Arab Emirates excluding Dubai (see note above).

StatLink 需可 http://dx.doi.org/10.1787/888932935667 
[Part 1/1]

Table I.2.5 Percentage of students at each proficiency level on the mathematics subscale formulating

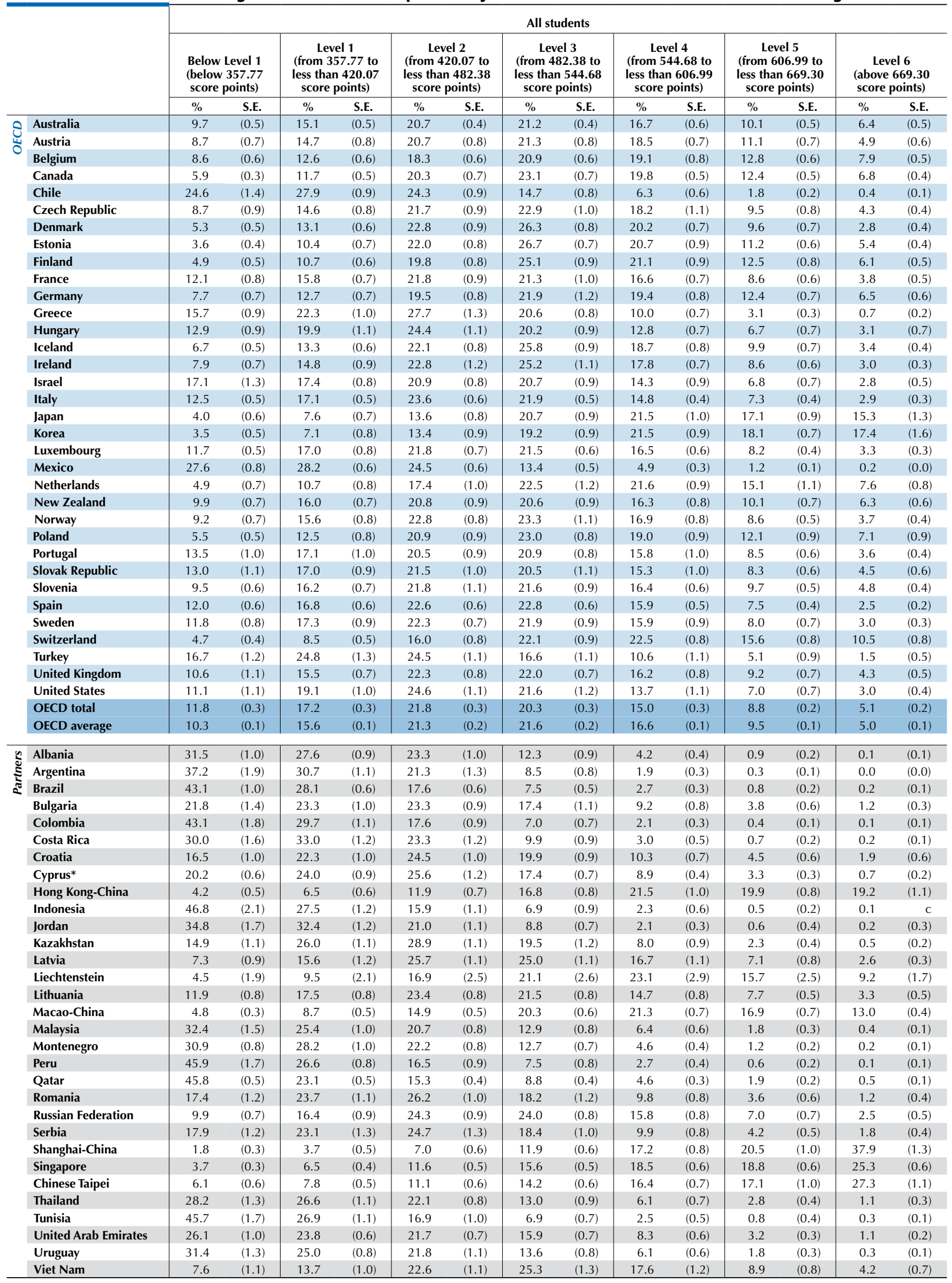

* See notes at the beginning of this Annex.

StatLink 部 SD http://dx.doi.org/10.1787/888932935667 
[Part 1/2]

Table I.2.6 Percentage of students at each proficiency level on the mathematics subscale formulating, by gender

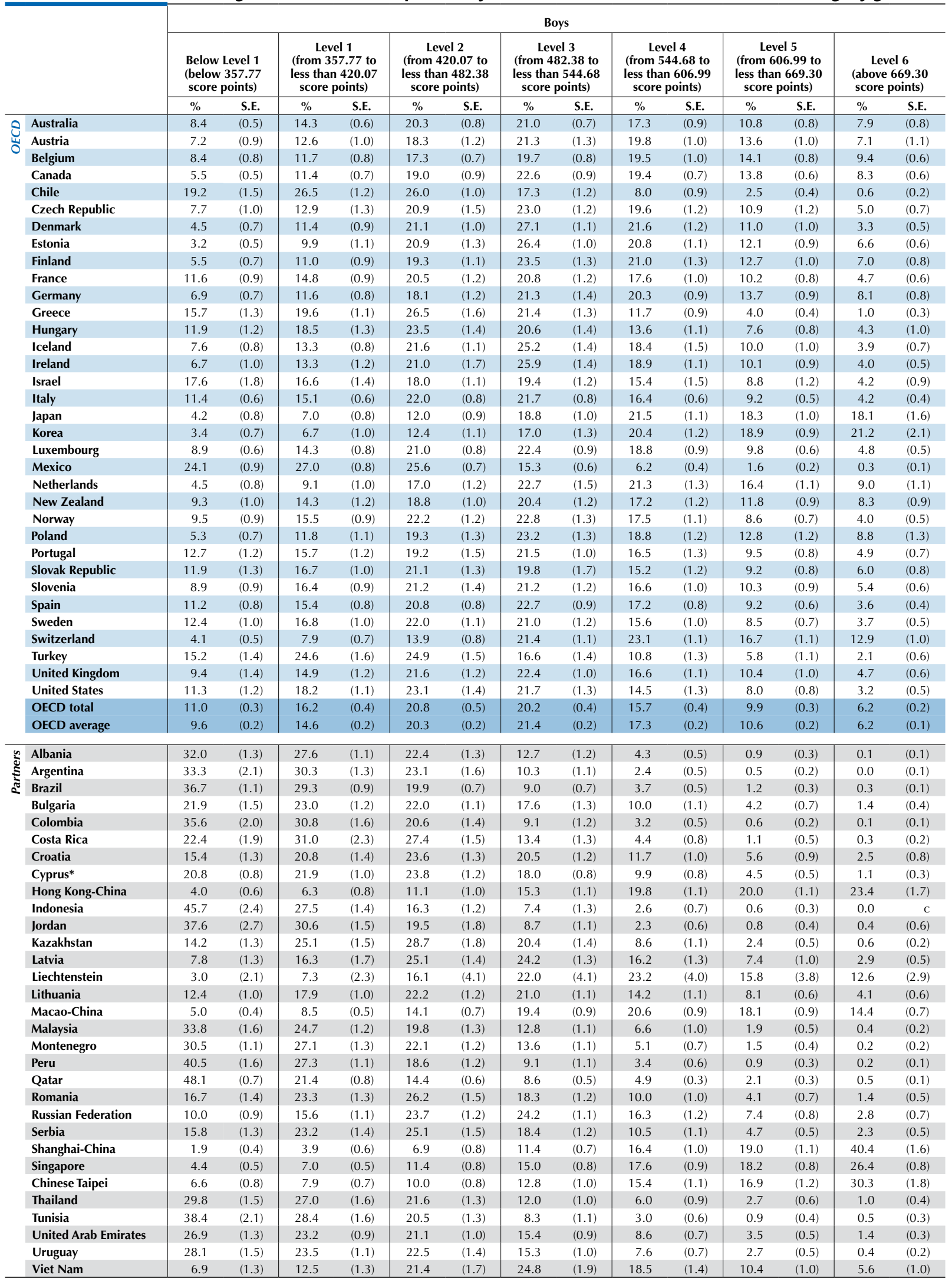

* See notes at the beginning of this Annex.

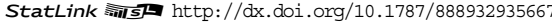


[Part 2/2]

Table I.2.6 Percentage of students at each proficiency level on the mathematics subscale formulating, by gender

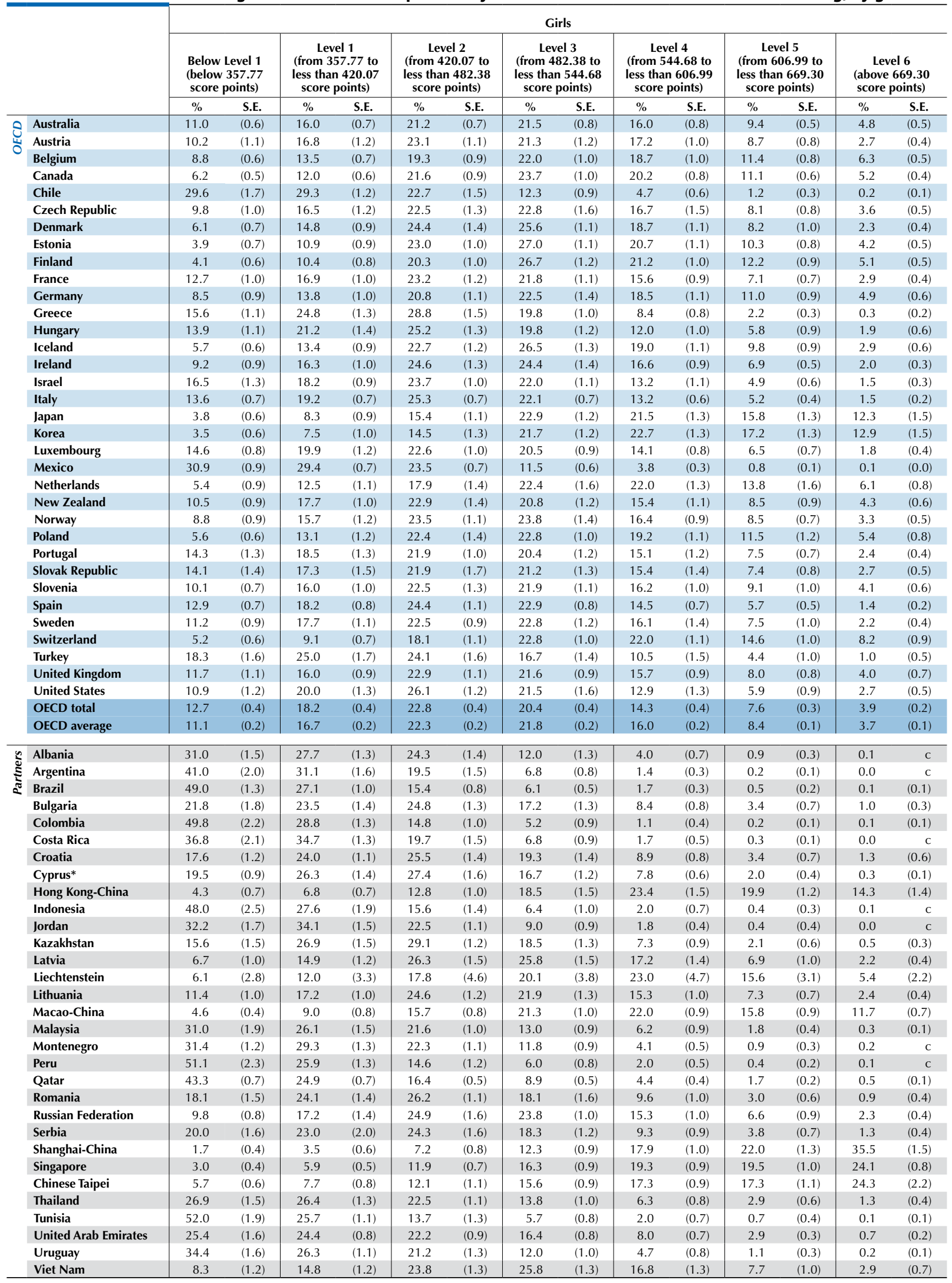

* See notes at the beginning of this Annex.

StatLink 吾Is http://dx.doi.org/10.1787/888932935667 
[Part 1/1]

Mean score, variation and gender differences in student performance on the mathematics subscale Table I.2.7 formulating

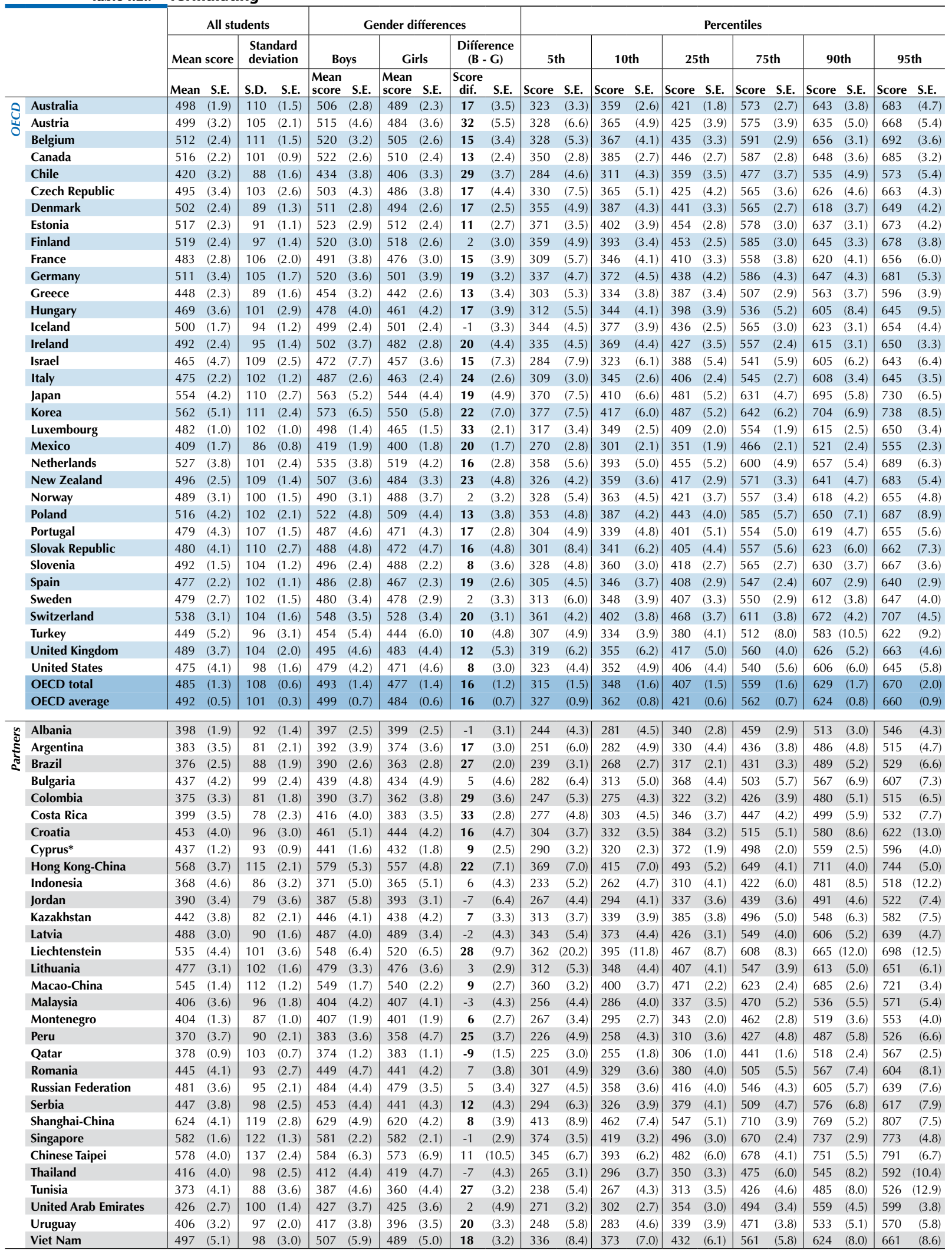

Note: Values that are statistically significant are indicated in bold (see Annex A3).

* See notes at the beginning of this Annex.

StatLink ज्ञाजा http://dx.doi.org/10.1787/888932935667 
[Part 1/1]

Table I.2.8 Percentage of students at each proficiency level on the mathematics subscale employing

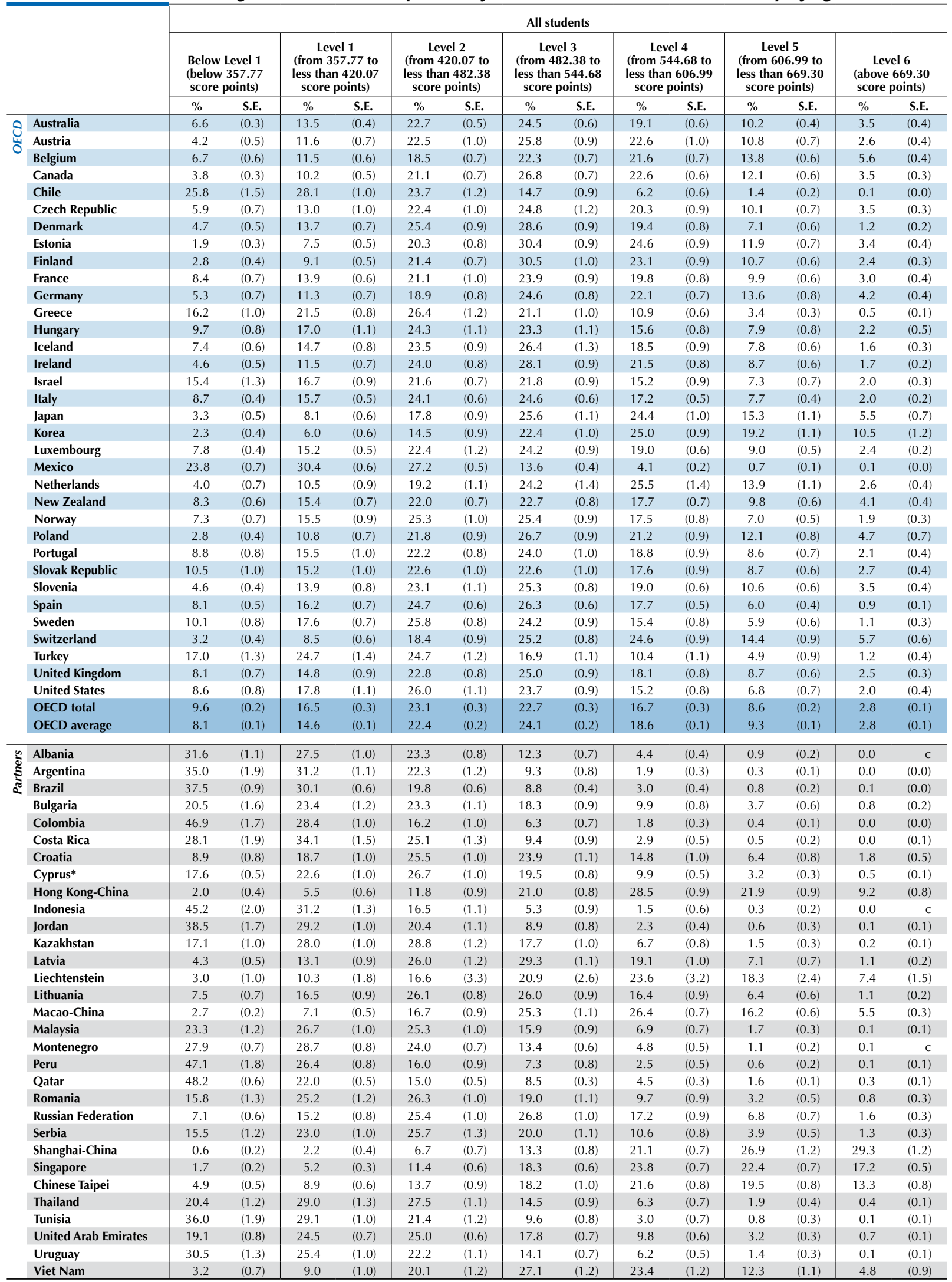

* See notes at the beginning of this Annex.

StatLink त्ञाज्ञा http://dx.doi.org/10.1787/888932935667 
[Part 1/2]

Table I.2.9 Percentage of students at each proficiency level on the mathematics subscale employing, by gender

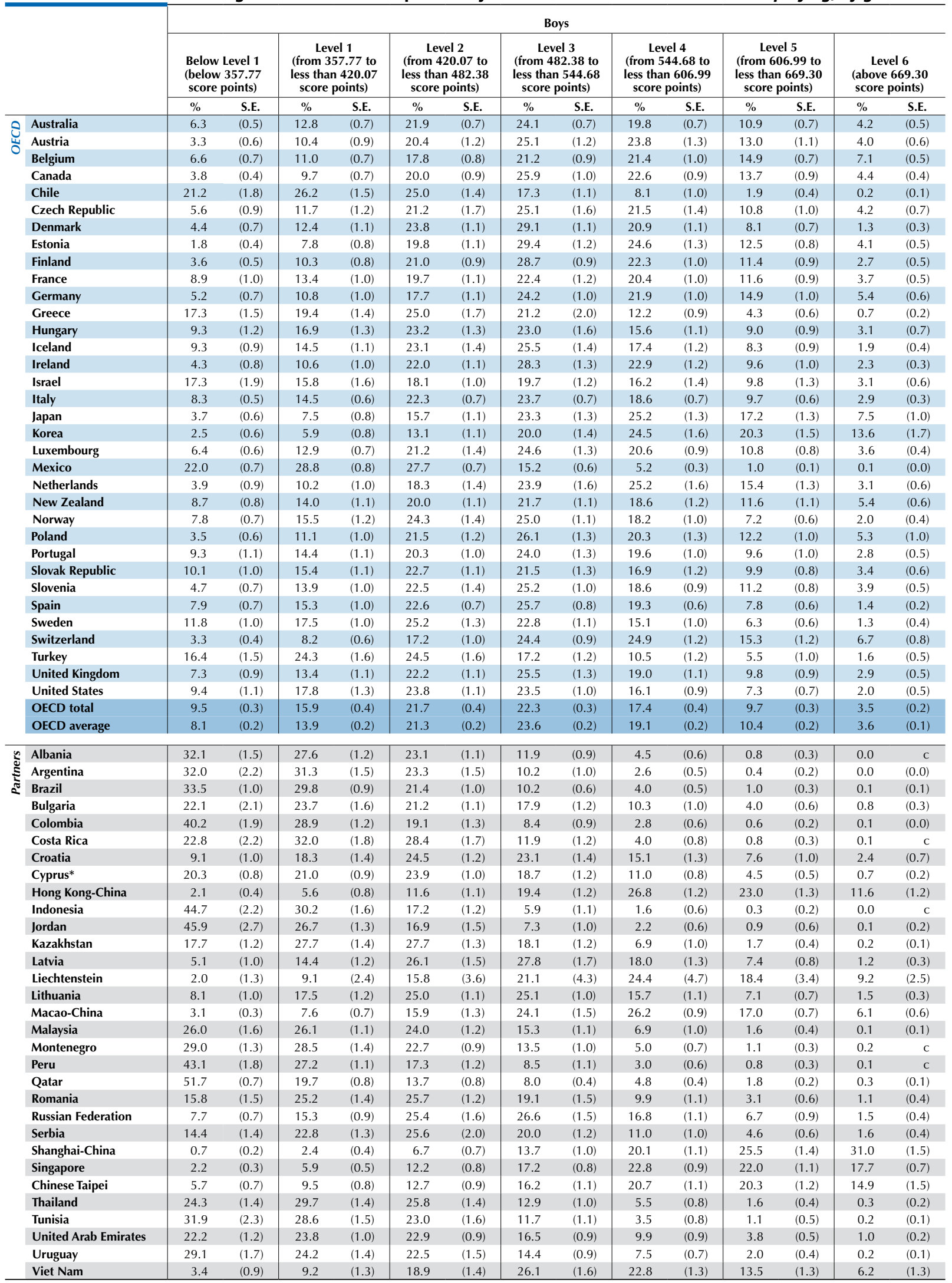

* See notes at the beginning of this Annex.

StatLink त्ताst http://dx.doi.org/10.1787/888932935667 
[Part 2/2]

Table I.2.9 Percentage of students at each proficiency level on the mathematics subscale employing, by gender

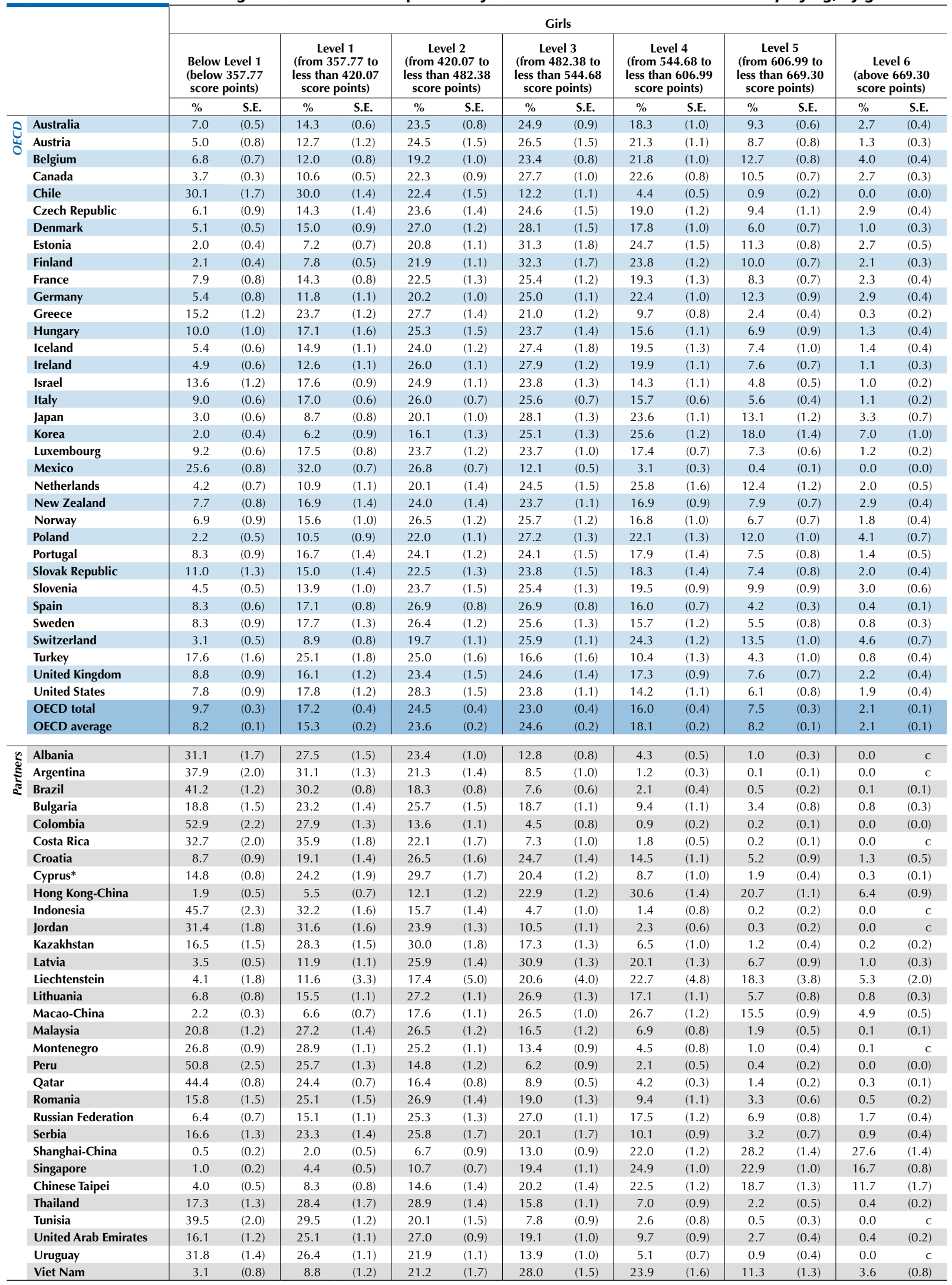

* See notes at the beginning of this Annex.

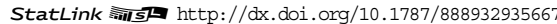


[Part 1/1]

Mean score, variation and gender differences in student performance on the mathematics subscale Table 1.2.10 employing

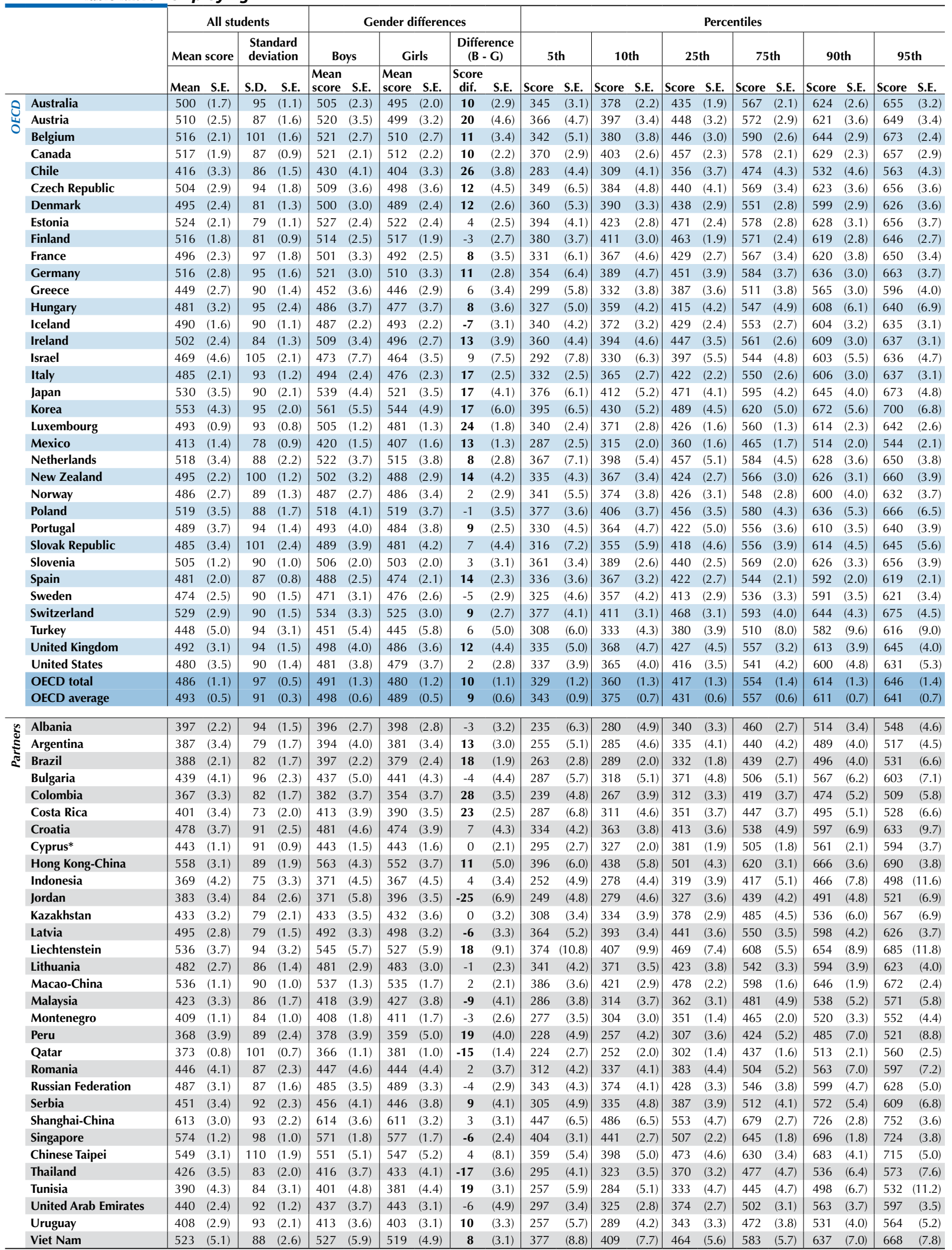

Note: Values that are statistically significant are indicated in bold (see Annex A3).

* See notes at the beginning of this Annex.

StatLink 需SL http://dx.doi.org/10.1787/888932935667 
[Part 1/1]

Table I.2.11 Percentage of students at each proficiency level on the mathematics subscale interpreting

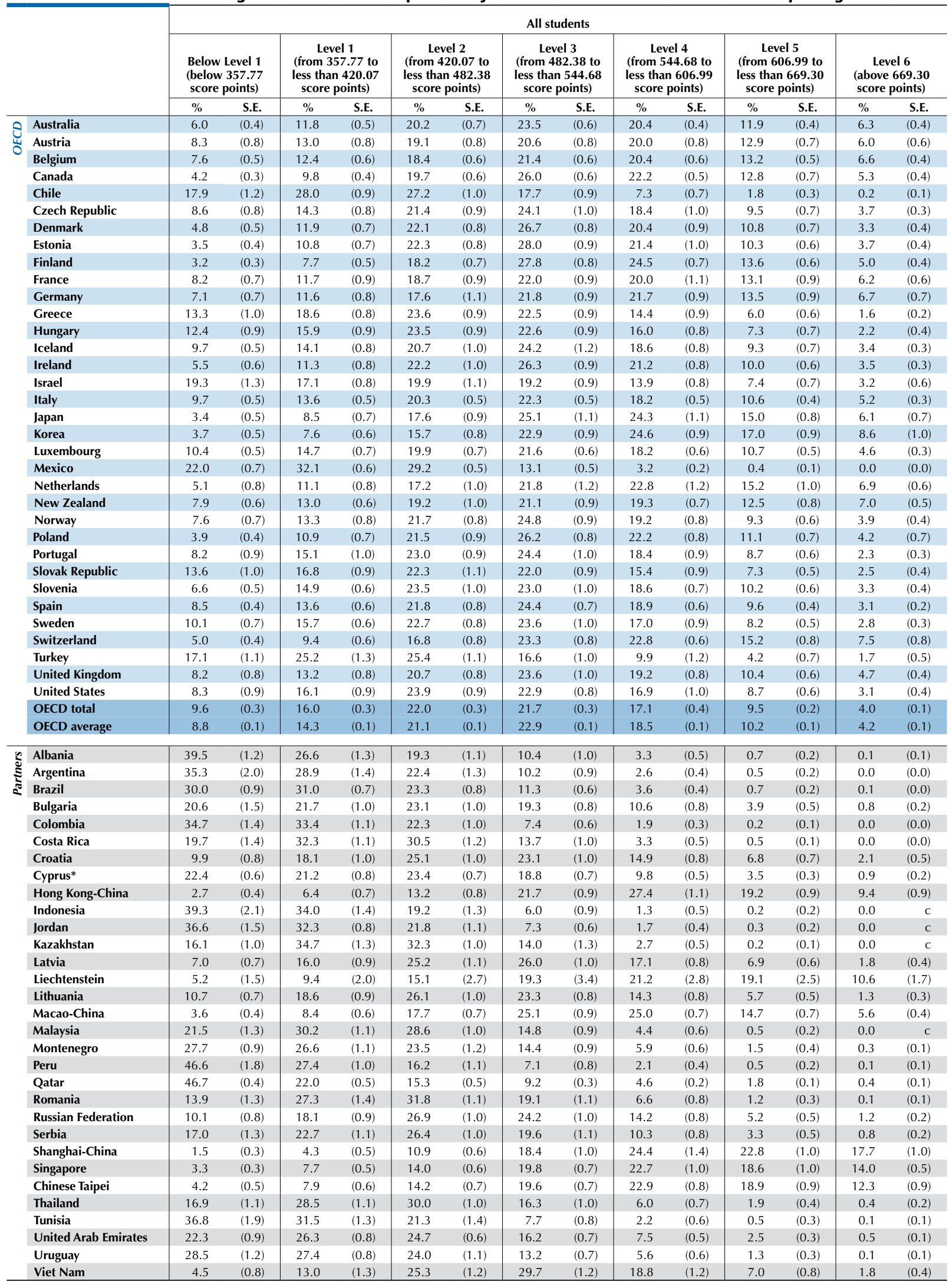

* See notes at the beginning of this Annex.

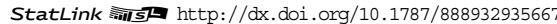


[Part 1/2]

Table I.2.12 Percentage of students at each proficiency level on the mathematics subscale interpreting, by gender

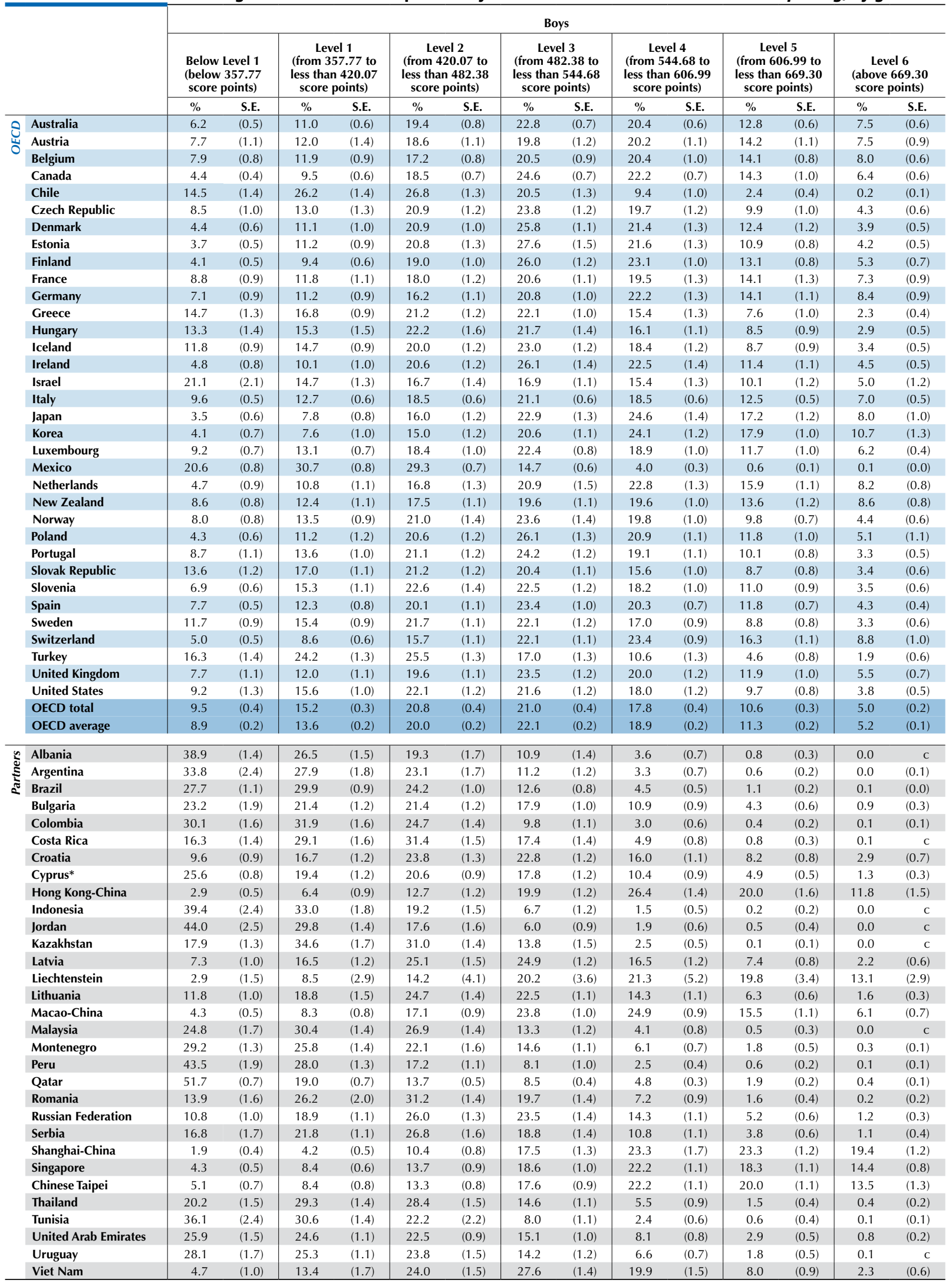

* See notes at the beginning of this Annex.

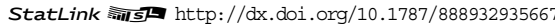


[Part 2/2]

Table I.2.12 Percentage of students at each proficiency level on the mathematics subscale interpreting, by gender

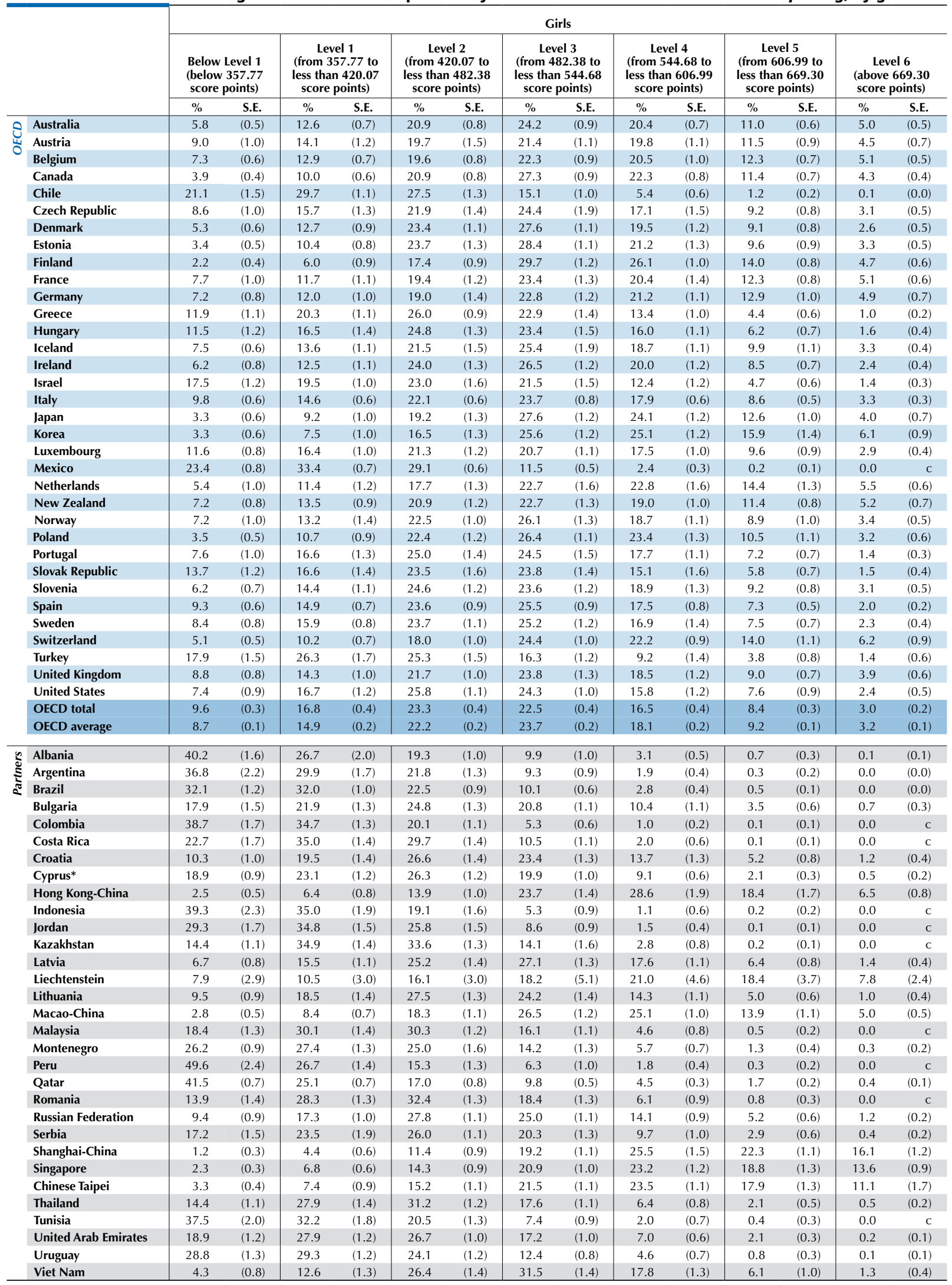

* See notes at the beginning of this Annex.

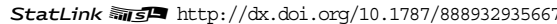


[Part 1/1]

Mean score, variation and gender differences in student performance on the mathematics subscale Table I.2.13 interpreting

\begin{tabular}{|c|c|c|c|c|c|c|c|c|c|c|c|c|c|c|c|c|c|c|c|c|c|c|c|}
\hline & \multicolumn{4}{|c|}{ All students } & \multicolumn{6}{|c|}{ Gender differences } & & & & & & Perce & entiles & & & & & \\
\hline & & Mean & score & $\begin{array}{l}\text { Stan } \\
\text { devi }\end{array}$ & $\begin{array}{l}\text { Idard } \\
\text { ation }\end{array}$ & & oys & Gi & irls & $\begin{array}{r}\text { Diffe } \\
\text { (B }\end{array}$ & $\begin{array}{l}\text { ence } \\
\text { G) }\end{array}$ & $5 t$ & th & 10 & & & th & 75 & th & & 0th & & 5 th \\
\hline & & Mean & S.E. & S.D. & S.E. & $\begin{array}{l}\text { Mean } \\
\text { score }\end{array}$ & S.E. & $\begin{array}{l}\text { Mean } \\
\text { score }\end{array}$ & S.E. & $\begin{array}{c}\text { Score } \\
\text { dif. }\end{array}$ & S.E. & Score & S.E. & Score & S.E. & Score & S.E. & Score & S.E. & Score & S.E. & Score & S.E. \\
\hline 0 & Australia & 514 & $(1.7)$ & 101 & (1.1) & 519 & $(2.4)$ & 509 & $(2.0)$ & 9 & (2.9) & 348 & (3.3) & 384 & $(2.3)$ & 445 & $(2.0)$ & 584 & $(2.2)$ & 645 & $(2.8)$ & 680 & (3.3) \\
\hline & Austria & 509 & (3.3) & 106 & $(2.0)$ & 517 & (4.5) & 501 & (4.1) & 16 & (5.6) & 331 & (5.8) & 368 & (4.9) & 433 & (4.6) & 587 & (3.9) & 644 & (4.6) & 677 & (5.2) \\
\hline & Belgium & 513 & (2.4) & 106 & (1.5) & 518 & (3.2) & 508 & (2.6) & 10 & (3.5) & 335 & $(4.6)$ & 374 & (3.5) & 439 & (3.6) & 590 & (2.8) & 649 & (3.2) & 681 & (2.9) \\
\hline & Canada & 521 & (2.0) & 93 & $(0.9)$ & 526 & (2.3) & 517 & (2.3) & 9 & $(2.2)$ & 366 & (2.9) & 401 & $(2.7)$ & 459 & (2.5) & 585 & (2.6) & 641 & (2.8) & 672 & (3.2) \\
\hline & Chile & 433 & (3.1) & 82 & (1.7) & 444 & (3.9) & 422 & (3.0) & 22 & (3.3) & 305 & (5.1) & 331 & (3.9) & 376 & (3.7) & 488 & (3.9) & 540 & (4.6) & 572 & (4.7) \\
\hline & Czech Republic & 494 & (3.0) & 103 & $(2.5)$ & 498 & (3.9) & 490 & (3.7) & 9 & (4.6) & 327 & $(7.0)$ & 367 & (5.6) & 427 & $(4.1)$ & 564 & $(3.0)$ & 622 & (3.7) & 656 & (3.5) \\
\hline & Denmark & 508 & (2.5) & 90 & (1.3) & 515 & (3.0) & 501 & (2.7) & 14 & (2.5) & 359 & (4.6) & 391 & (3.9) & 447 & (3.1) & 570 & (3.1) & 624 & (3.5) & 653 & $(4.0)$ \\
\hline & Estonia & 513 & (2.1) & 87 & (1.1) & 515 & (2.8) & 511 & (2.3) & 4 & (3.0) & 372 & (3.2) & 401 & (3.4) & 454 & (2.9) & 571 & (2.8) & 625 & (3.2) & 656 & (3.6) \\
\hline & Finland & 528 & (2.2) & 88 & (1.1) & 523 & (3.0) & 534 & (2.1) & -11 & (2.9) & 379 & (3.8) & 415 & (3.7) & 471 & (2.6) & 588 & (2.3) & 639 & (3.0) & 669 & (4.1) \\
\hline & France & 511 & (2.5) & 107 & (2.0) & 513 & (3.7) & 509 & (2.8) & 4 & (4.0) & 329 & (5.9) & 370 & (4.9) & 438 & (3.6) & 588 & (3.7) & 646 & (3.8) & 678 & (4.4) \\
\hline & Germany & 517 & (3.2) & 105 & (2.2) & 522 & (3.4) & 511 & (3.6) & 12 & $(3.0)$ & 338 & (6.5) & 376 & (4.6) & 445 & $(4.2)$ & 592 & (3.5) & 650 & $(4.2)$ & 680 & (4.0) \\
\hline & Greece & 467 & (3.1) & 98 & (1.8) & 471 & (4.0) & 463 & (3.1) & 8 & (3.7) & 304 & (5.6) & 340 & (4.6) & 400 & (4.1) & 536 & (3.6) & 593 & (4.3) & 626 & (4.4) \\
\hline & Hungary & 477 & (3.1) & 100 & (2.2) & 479 & (3.7) & 475 & (3.6) & 4 & $(4.0)$ & 307 & (5.9) & 344 & (5.2) & 410 & (3.7) & 547 & (4.4) & 605 & (4.9) & 638 & (6.4) \\
\hline & Iceland & 492 & (1.9) & 101 & (1.2) & 487 & (2.6) & 498 & (2.5) & -11 & (3.4) & 321 & (5.4) & 360 & (3.8) & 424 & (2.9) & 563 & (3.0) & 619 & (2.7) & 653 & (3.6) \\
\hline & Ireland & 507 & (2.5) & 91 & (1.4) & 515 & (3.5) & 498 & (3.3) & 17 & (4.5) & 353 & (5.3) & 389 & (4.6) & 446 & (3.5) & 569 & (2.6) & 622 & (2.5) & 654 & $(4.2)$ \\
\hline & Israel & 462 & (5.2) & 114 & $(2.2)$ & 470 & $(9.1)$ & 453 & (3.4) & 17 & (8.9) & 272 & $(7.5)$ & 312 & (6.1) & 381 & $(6.0)$ & 542 & (6.1) & 610 & (6.5) & 648 & (7.5) \\
\hline & Italy & 498 & (2.1) & 107 & (1.2) & 507 & (2.7) & 489 & (2.5) & 18 & (3.0) & 321 & (3.1) & 360 & (3.1) & 426 & (2.6) & 573 & (2.7) & 636 & (3.1) & 671 & (3.0) \\
\hline & Japan & 531 & (3.5) & 92 & (2.0) & 539 & (4.5) & 522 & (3.4) & 17 & $(4.2)$ & 375 & (6.1) & 411 & (4.7) & 469 & (4.3) & 595 & (3.9) & 648 & (4.6) & 677 & (5.1) \\
\hline & Korea & 540 & (4.2) & 98 & $(1.8)$ & 545 & (5.4) & 535 & $(4.9)$ & 10 & $(6.0)$ & 373 & (6.9) & 412 & $(5.7)$ & 476 & $(4.5)$ & 609 & $(4.4)$ & 662 & $(4.8)$ & 693 & (5.8) \\
\hline & Luxembourg & 495 & (1.1) & 106 & (0.9) & 505 & (1.6) & 485 & (1.5) & 20 & (2.3) & 322 & (4.3) & 355 & (3.0) & 420 & (1.9) & 571 & (1.6) & 631 & (2.2) & 665 & (3.0) \\
\hline & Mexico & 413 & (1.3) & 73 & $(0.8)$ & 418 & (1.5) & 408 & (1.4) & 10 & (1.3) & 294 & $(2.1)$ & 321 & (1.8) & 365 & (1.7) & 461 & (1.7) & 506 & (1.9) & 533 & (2.3) \\
\hline & Netherlands & 526 & (3.6) & 100 & (2.5) & 530 & (3.8) & 521 & (4.0) & 10 & (2.9) & 357 & (7.4) & 389 & (5.6) & 455 & (5.6) & 599 & (4.1) & 653 & (3.6) & 682 & (4.9) \\
\hline & New Zealand & 511 & (2.5) & 108 & (1.4) & 516 & (3.7) & 505 & (3.1) & 11 & $(4.7)$ & 334 & $(4.7)$ & 370 & $(4.0)$ & 434 & (3.5) & 587 & (3.3) & 650 & (3.6) & 684 & (4.1) \\
\hline & Norway & 499 & (3.1) & 98 & (1.6) & 500 & $(3.2)$ & 498 & (3.7) & 2 & (3.1) & 336 & $(5.8)$ & 373 & $(4.1)$ & 433 & (3.6) & 565 & (3.1) & 623 & (3.9) & 658 & (4.3) \\
\hline & Poland & 515 & (3.5) & 89 & (1.9) & 517 & $(4.2)$ & 513 & (3.7) & 3 & (3.6) & 368 & (4.3) & 400 & $(4.0)$ & 452 & (3.5) & 577 & $(4.2)$ & 630 & (5.4) & 662 & (7.7) \\
\hline & Portugal & 490 & (4.0) & 94 & (1.8) & 496 & (4.5) & 484 & $(4.0)$ & 12 & (2.9) & 333 & $(6.8)$ & 369 & (5.3) & 425 & $(5.2)$ & 557 & (3.8) & 612 & (3.7) & 642 & (3.5) \\
\hline & Slovak Republic & 473 & (3.3) & 103 & (2.1) & 478 & (4.1) & 468 & (3.7) & 9 & (4.2) & 304 & (5.7) & 339 & (5.0) & 402 & (4.6) & 545 & (4.4) & 606 & (4.1) & 639 & (5.1) \\
\hline & Slovenia & 498 & (1.4) & 95 & $(0.9)$ & 498 & $(2.1)$ & 497 & (2.1) & 1 & (3.2) & 347 & (3.5) & 378 & (2.6) & 431 & (2.6) & 566 & (2.5) & 623 & (2.2) & 654 & (4.2) \\
\hline & Spain & 495 & (2.2) & 98 & $(0.8)$ & 505 & (2.5) & 485 & (2.5) & 21 & (2.3) & 330 & (3.3) & 367 & (3.4) & 429 & (2.8) & 564 & (2.6) & 619 & (2.3) & 652 & (2.5) \\
\hline & Sweden & 485 & (2.4) & 99 & (1.3) & 484 & (3.3) & 486 & (2.5) & -2 & (3.4) & 320 & (5.1) & 357 & (3.8) & 418 & (3.1) & 553 & (3.2) & 612 & (3.1) & 646 & (3.1) \\
\hline & Switzerland & 529 & (3.4) & 101 & (1.5) & 535 & (3.9) & 523 & (3.5) & 12 & (2.8) & 357 & (4.9) & 396 & (3.9) & 462 & (3.5) & 600 & (4.3) & 655 & (4.9) & 687 & (5.3) \\
\hline & Turkey & 446 & (4.6) & 95 & (3.0) & 451 & (5.1) & 442 & (5.5) & 9 & (5.0) & 304 & $(4.2)$ & 332 & (3.8) & 380 & (3.1) & 506 & (7.3) & 576 & (9.5) & 616 & (10.3) \\
\hline & United Kingdom & 501 & (3.5) & 102 & $(2.0)$ & 508 & (4.6) & 494 & (3.8) & 14 & $(4.7)$ & 333 & (6.5) & 370 & $(5.2)$ & 432 & $(4.4)$ & 571 & (3.3) & 632 & $(4.0)$ & 666 & $(4.8)$ \\
\hline & United States & 489 & (3.9) & 96 & (1.6) & 493 & (4.4) & 486 & (3.9) & 7 & (3.0) & 336 & (5.1) & 367 & (5.1) & 422 & $(4.3)$ & 556 & (4.6) & 615 & (4.0) & 649 & (5.3) \\
\hline & OECD total & 491 & (1.2) & 102 & $(0.5)$ & 496 & (1.4) & 485 & (1.2) & 11 & (1.1) & 327 & (1.6) & 360 & (1.5) & 418 & (1.3) & 563 & (1.5) & 624 & (1.4) & 659 & (1.6) \\
\hline & OECD average & 497 & $(0.5)$ & 98 & $(0.3)$ & 502 & $(0.7)$ & 492 & $(0.6)$ & 9 & $(0.7)$ & 335 & $(0.9)$ & 370 & $(0.7)$ & 430 & $(0.6)$ & 565 & $(0.6)$ & 622 & (0.7) & 655 & $(0.8)$ \\
\hline$n$ & Albania & 379 & (2.4) & 101 & (1.7) & 381 & (3.0) & 377 & (3.1) & 4 & (3.6) & 202 & (7.2) & 254 & (5.3) & 318 & (3.0) & 445 & (2.8) & 504 & (3.1) & 538 & $(4.1)$ \\
\hline 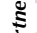 & Argentina & 390 & (4.1) & 83 & (2.1) & 395 & (5.0) & 385 & (3.6) & 10 & (3.2) & 253 & (6.1) & 283 & (5.2) & 334 & (4.7) & 447 & (4.9) & 496 & (5.2) & 526 & (6.0) \\
\hline d & Brazil & 401 & (2.1) & 81 & (1.4) & 407 & (2.2) & 395 & (2.3) & 12 & (1.7) & 273 & (3.1) & 300 & (2.5) & 346 & (2.1) & 453 & (2.6) & 507 & (3.8) & 540 & (5.1) \\
\hline & Bulgaria & 441 & (4.2) & 99 & (2.4) & 437 & (5.1) & 445 & (4.4) & -8 & (4.8) & 282 & (6.6) & 314 & (6.1) & 372 & (5.1) & 510 & (4.8) & 570 & (5.4) & 604 & (6.0) \\
\hline & Colombia & 387 & (2.5) & 74 & (1.6) & 399 & (3.2) & 377 & (2.6) & 21 & (2.9) & 269 & (4.6) & 295 & (3.6) & 337 & (2.8) & 435 & (2.9) & 481 & (3.8) & 512 & (4.8) \\
\hline & Costa Rica & 418 & (2.9) & 70 & $(1.4)$ & 429 & (3.4) & 408 & (2.9) & 21 & (2.4) & 305 & (3.7) & 330 & (3.5) & 370 & (3.3) & 464 & (3.3) & 508 & $(4.2)$ & 535 & (5.6) \\
\hline & Croatia & 477 & (3.5) & 93 & (2.1) & 484 & $(4.2)$ & 470 & (3.8) & 15 & $(4.0)$ & 328 & (4.1) & 358 & $(4.2)$ & 412 & (3.5) & 541 & $(4.5)$ & 600 & (6.1) & 636 & (6.8) \\
\hline & Cyprus* & 436 & (1.3) & 101 & (1.1) & 434 & (1.8) & 438 & (1.8) & -4 & $(2.5)$ & 269 & (3.1) & 305 & (2.7) & 367 & (2.1) & 505 & (2.3) & 565 & (2.8) & 601 & (4.1) \\
\hline & Hong Kong-China & 551 & (3.4) & 93 & (1.9) & 557 & (4.8) & 545 & (3.8) & 12 & (5.5) & 385 & (5.9) & 425 & (5.7) & 492 & $(4.9)$ & 616 & (3.9) & 666 & (4.8) & 696 & (5.1) \\
\hline & Indonesia & 379 & (4.0) & 70 & (3.1) & 380 & (4.5) & 378 & $(4.2)$ & 2 & (3.3) & 270 & (5.9) & 293 & (4.4) & 331 & (3.6) & 424 & (4.8) & 469 & (7.1) & 500 & (9.8) \\
\hline & Jordan & 383 & (3.0) & 77 & $(2.2)$ & 370 & (5.2) & 395 & (2.9) & -25 & (6.1) & 255 & (6.0) & 286 & (3.8) & 333 & (3.2) & 434 & (3.1) & 479 & (4.2) & 508 & (6.3) \\
\hline & Kazakhstan & 420 & (2.6) & 64 & (1.3) & 418 & (3.1) & 423 & (2.8) & -5 & $(2.8)$ & 317 & (3.1) & 339 & (2.5) & 377 & (2.5) & 463 & (3.6) & 504 & (4.8) & 528 & (4.4) \\
\hline & Latvia & 486 & (3.0) & 89 & (1.6) & 486 & (3.6) & 487 & (3.6) & -1 & (3.8) & 340 & (5.7) & 373 & $(4.2)$ & 426 & (3.2) & 547 & (3.6) & 600 & (3.9) & 632 & (4.7) \\
\hline & Liechtenstein & 540 & (4.1) & 107 & (3.6) & 553 & (6.4) & 526 & (6.4) & 27 & (10.1) & 355 & (18.4) & 393 & (9.7) & 466 & (10.1) & 620 & $(7.0)$ & 672 & (10.5) & 706 & (16.9) \\
\hline & Lithuania & 471 & (2.8) & 91 & (1.5) & 470 & (3.0) & 471 & (3.2) & -1 & $(2.6)$ & 322 & (3.7) & 354 & $(4.2)$ & 408 & (3.4) & 533 & (3.8) & 591 & $(4.0)$ & 622 & (4.7) \\
\hline & Macao-China & 530 & (1.0) & 92 & $(0.9)$ & 530 & (1.4) & 529 & (1.5) & 2 & $(2.0)$ & 374 & (3.7) & 409 & (2.4) & 469 & $(2.0)$ & 594 & $(2.0)$ & 645 & (2.5) & 674 & (3.0) \\
\hline & Malaysia & 418 & (3.1) & 75 & (1.5) & 412 & (3.6) & 423 & (3.3) & -11 & (3.4) & 296 & (4.0) & 322 & (3.6) & 366 & (3.4) & 468 & (3.7) & 516 & (4.7) & 544 & (6.0) \\
\hline & Montenegro & 413 & (1.4) & 90 & (1.0) & 412 & (1.9) & 415 & (1.8) & -3 & (2.4) & 271 & (2.8) & 299 & (3.0) & 350 & (2.3) & 474 & (2.5) & 532 & (2.7) & 565 & (3.6) \\
\hline & Peru & 368 & (3.8) & 86 & $(2.2)$ & 376 & (3.8) & 361 & (4.8) & 15 & $(4.0)$ & 233 & (4.8) & 262 & (3.7) & 310 & (3.5) & 423 & (5.0) & 481 & (6.4) & 516 & (7.6) \\
\hline & Qatar & 375 & $(0.8)$ & 105 & $(0.7)$ & 364 & (1.1) & 387 & (1.1) & -23 & (1.5) & 216 & (2.8) & 248 & (1.8) & 301 & (1.4) & 442 & (1.7) & 519 & (2.3) & 564 & (2.8) \\
\hline & Romania & 438 & (3.1) & 74 & (1.9) & 441 & (3.8) & 435 & (3.4) & 5 & (3.4) & 321 & (4.4) & 345 & (3.8) & 387 & (3.4) & 487 & (3.8) & 535 & (4.6) & 563 & (6.4) \\
\hline & Russian Federation & 471 & (2.9) & 89 & (1.6) & 469 & (3.8) & 473 & (3.0) & -4 & (3.4) & 324 & (4.8) & 357 & $(4.0)$ & 411 & (3.7) & 531 & (3.5) & 586 & (3.9) & 618 & (4.6) \\
\hline & Serbia & 445 & (3.4) & 92 & $(2.2)$ & 448 & (4.3) & 443 & (3.5) & 6 & $(4.1)$ & 297 & (6.2) & 328 & (5.6) & 383 & (3.9) & 506 & (4.4) & 566 & (5.0) & 599 & (6.7) \\
\hline & Shanghai-China & 579 & (2.9) & 98 & (2.0) & 582 & (3.5) & 576 & (3.2) & 7 & (3.3) & 412 & (6.2) & 448 & $(4.8)$ & 514 & $(4.2)$ & 647 & (3.4) & 700 & (4.1) & 732 & (6.0) \\
\hline & Singapore & 555 & (1.4) & 106 & $(0.9)$ & 553 & (1.9) & 557 & (2.0) & -5 & (2.9) & 377 & (3.5) & 414 & (2.3) & 482 & (2.1) & 629 & (2.4) & 688 & (2.1) & 721 & (3.4) \\
\hline & Chinese Taipei & 549 & (3.0) & 105 & (1.8) & 550 & $(4.7)$ & 548 & (4.9) & 3 & (7.4) & 366 & (5.3) & 407 & (5.1) & 478 & $(4.0)$ & 625 & (3.4) & 680 & (3.8) & 710 & (4.8) \\
\hline & Thailand & 432 & (3.4) & 80 & (2.0) & 424 & (3.7) & 438 & (3.9) & -15 & (3.7) & 305 & (4.6) & 333 & (3.6) & 379 & (3.2) & 481 & $(4.0)$ & 535 & (5.7) & 571 & (7.6) \\
\hline & Tunisia & 385 & (3.9) & 78 & (2.9) & 387 & (4.4) & 384 & (3.9) & 4 & $(2.7)$ & 261 & (5.6) & 288 & (4.6) & 332 & $(4.3)$ & 435 & (4.6) & 484 & (6.8) & 518 & (8.9) \\
\hline & United Arab Emirates & 428 & (2.4) & 90 & (1.2) & 424 & $(4.1)$ & 431 & (3.0) & -7 & (5.3) & 286 & (3.4) & 315 & (2.7) & 365 & (2.5) & 487 & (3.1) & 548 & (3.8) & 583 & (4.4) \\
\hline & Uruguay & 409 & (2.7) & 88 & (1.8) & 414 & (3.5) & 406 & (2.9) & 8 & (3.3) & 268 & (4.6) & 299 & (3.5) & 349 & (3.1) & 468 & (3.3) & 525 & (4.9) & 559 & (5.7) \\
\hline & Viet Nam & 497 & (4.5) & 81 & (2.3) & 500 & (5.2) & 494 & (4.3) & 5 & $(2.7)$ & 361 & (6.9) & 391 & (6.4) & 442 & (5.6) & 551 & (4.9) & 600 & (5.9) & 631 & (6.6) \\
\hline
\end{tabular}

Note: Values that are statistically significant are indicated in bold (see Annex A3).

* See notes at the beginning of this Annex.

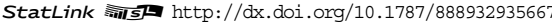


[Part 1/1]

Table I.2.14 Percentage of students at each proficiency level on the mathematics subscale change and relationships

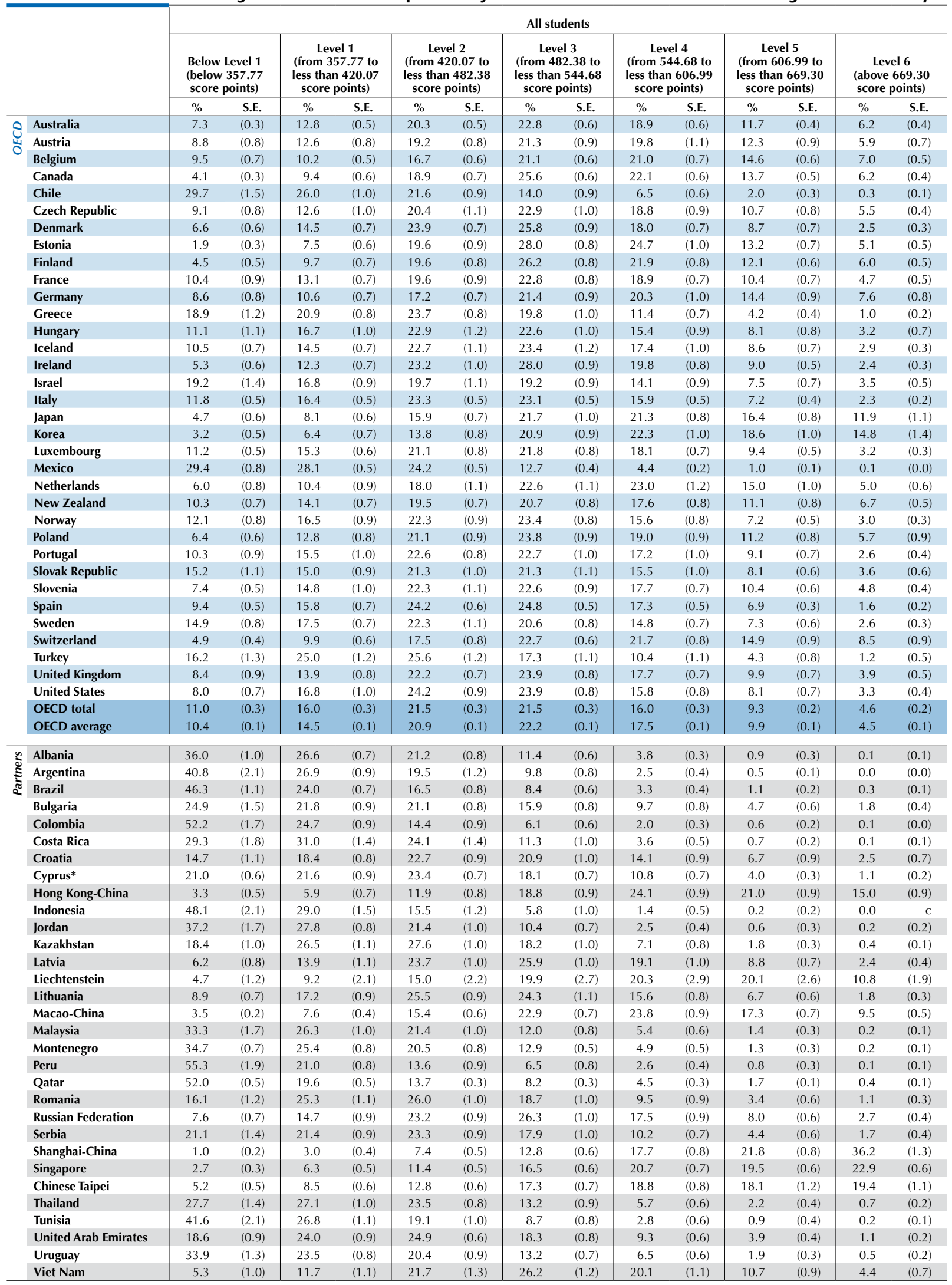

* See notes at the beginning of this Annex.

StatLink 全 Sस http://dx.doi.org/10.1787/888932935667 
[Part 1/2]

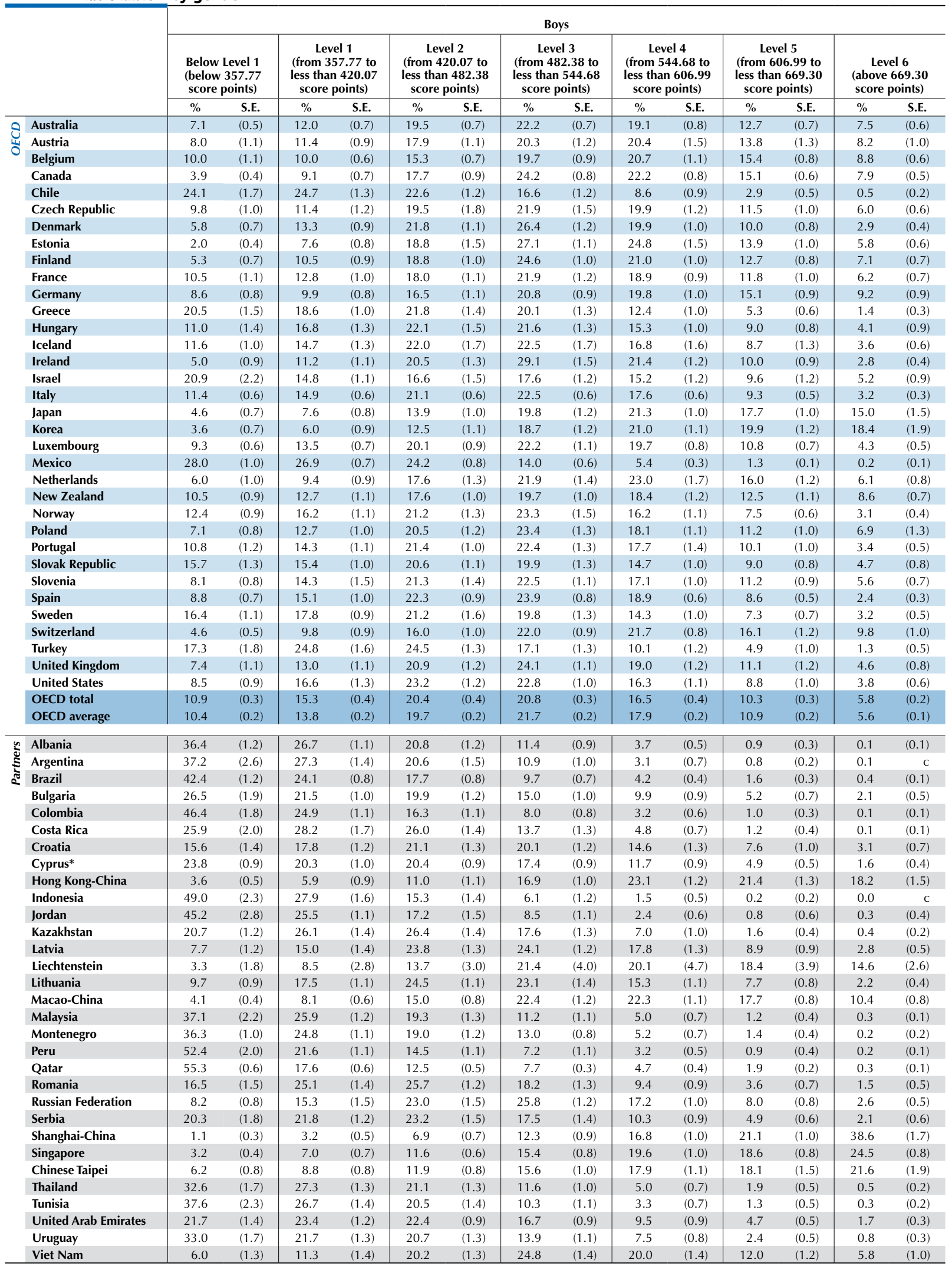

* See notes at the beginning of this Annex.

StatLink त्ताst http://dx.doi.org/10.1787/888932935667 
Part 2/2]

Percentage of students at each proficiency level on the mathematics subscale change and relationships, Table I.2.15 by gender

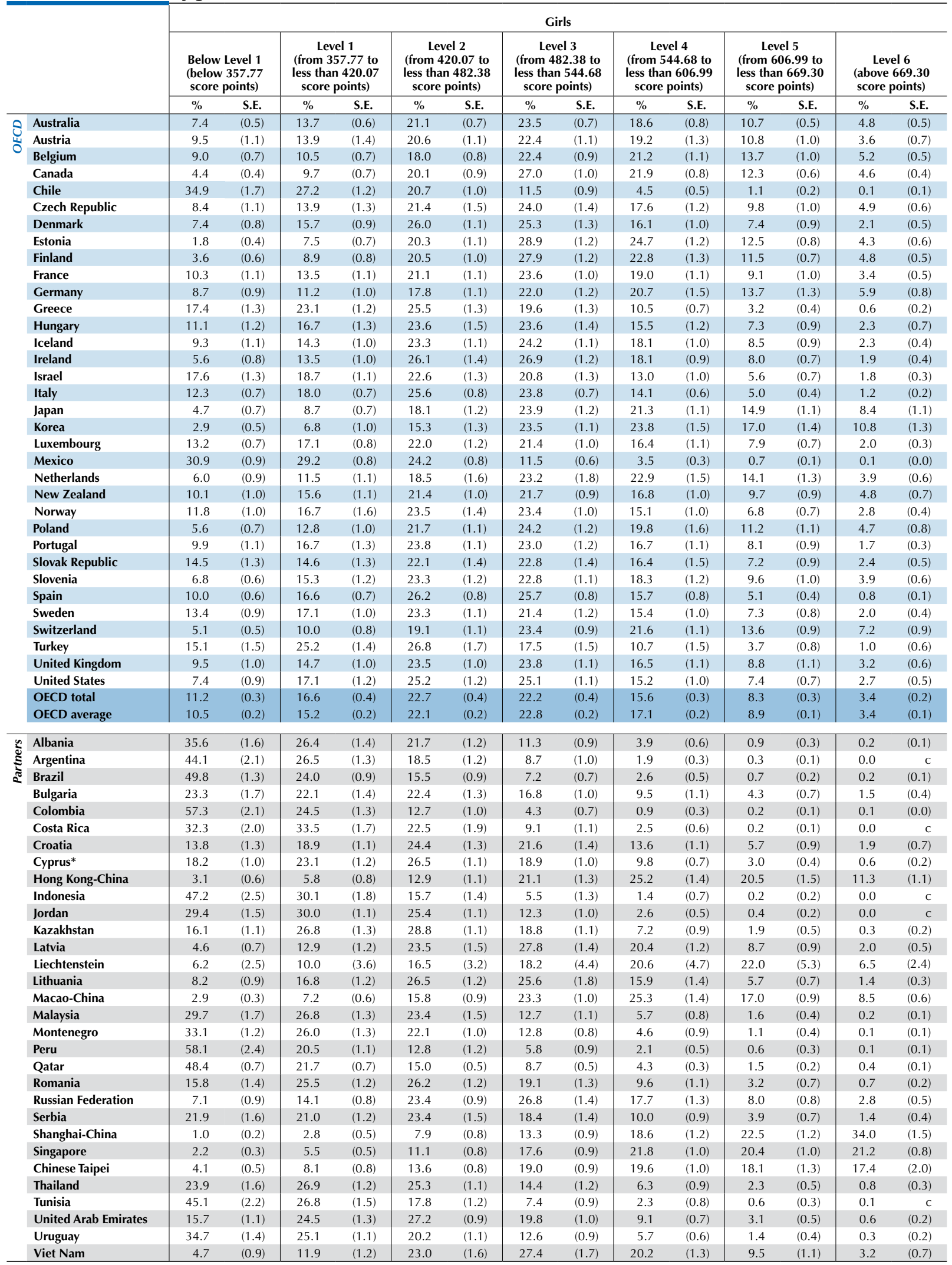

* See notes at the beginning of this Annex.

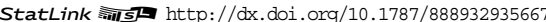


[Part 1/1]

Mean score, variation and gender differences in student performance on the mathematics subscale Table I.2.16 change and relationships

\begin{tabular}{|c|c|c|c|c|c|c|c|c|c|c|c|c|c|c|c|c|c|c|c|c|c|c|c|}
\hline & \multicolumn{4}{|c|}{ All students } & \multicolumn{6}{|c|}{ Gender differences } & & & & & & Perc & entiles & & & & & \\
\hline & & Mean & score & $\begin{array}{l}\text { Stan } \\
\text { devi }\end{array}$ & & & oys & & irls & $\begin{array}{c}\text { Diffe } \\
\text { (B }\end{array}$ & $\begin{array}{l}\text { ence } \\
\text { G) }\end{array}$ & & th & & 0 th & & 5th & 75 & th & 90 & & & 5 th \\
\hline & & Mean & S.E. & S.D. & S.E. & $\begin{array}{l}\text { Mean } \\
\text { score }\end{array}$ & S.E. & $\begin{array}{l}\begin{array}{l}\text { Mean } \\
\text { score }\end{array} \\
\end{array}$ & S.E. & $\begin{array}{c}\text { Score } \\
\text { dif. }\end{array}$ & S.E. & Score & S.E. & Score & S.E. & Score & S.E. & Score & S.E. & Score & S.E. & Score & S.E. \\
\hline 0 & Australia & 509 & $(1.7)$ & 104 & (1.2) & 515 & (2.5) & 503 & $(2.2)$ & 12 & (3.2) & 339 & (2.8) & 375 & (2.4) & 437 & $(2.1)$ & 581 & $(2.4)$ & 645 & (2.9) & 680 & $(3.7)$ \\
\hline & Austria & 506 & (3.4) & 109 & $(2.7)$ & 518 & (4.8) & 495 & $(4.1)$ & 23 & (5.8) & 326 & (7.2) & 365 & (5.2) & 433 & (4.6) & 584 & $(4.7)$ & 643 & (4.6) & 677 & (6.7) \\
\hline & Belgium & 513 & (2.6) & 116 & (3.2) & 517 & (3.6) & 509 & $(2.9)$ & 8 & $(4.1)$ & 312 & (7.9) & 362 & (5.6) & 443 & (3.5) & 596 & $(2.5)$ & 653 & (2.6) & 684 & (2.9) \\
\hline & Canada & 525 & $(2.0)$ & 94 & $(0.9)$ & 532 & $(2.2)$ & 518 & $(2.2)$ & 14 & $(2.0)$ & 367 & (3.1) & 403 & (2.7) & 461 & (2.2) & 591 & (2.8) & 647 & (2.5) & 679 & (2.9) \\
\hline & Chile & 411 & (3.5) & 95 & (1.6) & 428 & (4.5) & 396 & (3.4) & 32 & (4.1) & 263 & (5.2) & 293 & (3.8) & 345 & (3.5) & 475 & (4.6) & 537 & $(4.7)$ & 574 & (5.5) \\
\hline & Czech Republic & 499 & (3.5) & 112 & (3.3) & 503 & $(4.5)$ & 496 & $(4.2)$ & 7 & (5.3) & 317 & (11.2) & 364 & (6.5) & 430 & (4.5) & 576 & (3.6) & 636 & (3.5) & 674 & $(4.2)$ \\
\hline & Denmark & 494 & $(2.7)$ & 91 & (1.3) & 502 & (3.3) & 486 & $(2.7)$ & 16 & (2.8) & 345 & (4.7) & 377 & (3.7) & 432 & (3.1) & 557 & (3.1) & 613 & (3.5) & 643 & $(4.0)$ \\
\hline & Estonia & 530 & (2.3) & 84 & (1.1) & 533 & $(2.8)$ & 527 & (2.4) & 6 & (2.7) & 394 & (4.4) & 422 & (2.6) & 472 & (2.8) & 587 & (2.6) & 639 & (3.7) & 669 & (4.1) \\
\hline & Finland & 520 & (2.6) & 97 & (2.3) & 521 & (3.2) & 520 & (2.8) & 1 & (3.0) & 363 & (5.9) & 400 & (3.5) & 458 & (2.7) & 584 & $(2.5)$ & 643 & (3.4) & 677 & (4.4) \\
\hline & France & 497 & $(2.7)$ & 107 & (2.4) & 503 & (3.7) & 491 & (2.8) & 11 & (3.6) & 313 & (9.6) & 355 & (6.3) & 425 & (3.6) & 572 & $(3.2)$ & 632 & $(4.2)$ & 667 & (4.9) \\
\hline & Germany & 516 & (3.8) & 114 & (3.4) & 521 & (3.9) & 510 & $(4.2)$ & 11 & (3.0) & 321 & (8.4) & 368 & (6.6) & 443 & (4.4) & 597 & (3.7) & 656 & $(4.2)$ & 688 & (5.4) \\
\hline & Greece & 446 & $(3.2)$ & 101 & (1.6) & 448 & $(4.3)$ & 444 & (3.1) & 4 & (3.7) & 278 & (5.6) & 317 & (5.4) & 378 & (4.1) & 515 & (3.7) & 574 & (3.9) & 609 & (4.7) \\
\hline & Hungary & 481 & (3.5) & 100 & (2.7) & 485 & $(4.0)$ & 479 & (4.0) & 6 & (3.8) & 320 & (6.9) & 352 & (5.5) & 411 & (3.9) & 550 & (4.9) & 614 & (7.0) & 551 & (7.3) \\
\hline & Iceland & 487 & (1.9) & 100 & (1.5) & 485 & (2.5) & 488 & (2.5) & -3 & (3.4) & 318 & (5.0) & 355 & (4.4) & 420 & (3.0) & 557 & $(2.7)$ & 614 & (3.2) & 647 & (3.6) \\
\hline & Ireland & 501 & (2.6) & 87 & (1.5) & 508 & (3.6) & 494 & (3.1) & 13 & (4.3) & 355 & (6.1) & 389 & (4.8) & 443 & (3.3) & 561 & (2.6) & 613 & (2.5) & 642 & (3.5) \\
\hline & Israel & 462 & $(5.3)$ & 117 & (2.4) & 469 & (8.9) & 456 & $(4.0)$ & 13 & (8.6) & 266 & (9.1) & 308 & (7.4) & 382 & $(6.3)$ & 545 & (5.5) & 613 & $(6.0)$ & 651 & (6.6) \\
\hline & Italy & 477 & $(2.1)$ & 100 & (1.3) & 486 & (2.4) & 467 & (2.3) & 19 & (2.6) & 310 & (3.3) & 348 & (2.9) & 410 & $(2.5)$ & 546 & (2.5) & 604 & $(2.9)$ & 638 & (3.4) \\
\hline & Japan & 542 & $(4.0)$ & 107 & (2.4) & 553 & (5.0) & 531 & $(4.2)$ & 22 & (4.8) & 362 & (7.0) & 04 & (5.8) & 470 & (4.5) & 618 & (5.0) & 80 & (6.0) & 15 & (7.1) \\
\hline & Korea & 559 & (5.2) & 107 & $(2.7)$ & 569 & (6.6) & 548 & (5.4) & 21 & (6.5) & 382 & (8.4) & 422 & (6.2) & 488 & (5.1) & 633 & (5.7) & 692 & $(7.0)$ & 27 & (9.0) \\
\hline & Luxembo & 488 & $(1.0)$ & 102 & $(1.0)$ & 500 & (1.5) & 475 & (1.3) & 25 & (1.9) & 317 & (3.4) & 352 & (2.6) & 415 & $(2.0)$ & 562 & (1.9) & 619 & $(2.3)$ & 552 & (3.0) \\
\hline & Mexico & 405 & (1.6) & 87 & $(0.8)$ & 410 & (1.9) & 399 & $(1.7)$ & 11 & (1.5) & 264 & (2.6) & 295 & (2.3) & 347 & $(1.9)$ & 462 & (1.9) & 516 & $(2.1)$ & 549 & (2.4) \\
\hline & Netherlands & 518 & (3.9) & 103 & (3.2) & 522 & $(4.3)$ & 514 & $(4.2)$ & 8 & (3.4) & 345 & (10.0) & 388 & (6.5) & 453 & (5.2) & 593 & $(4.0)$ & 642 & (3.7) & 69 & (3.7) \\
\hline & New Z & 501 & (2.5) & 112 & (1. 6 & 509 & (3.6) & 492 & (3.5) & 17 & (5.0) & 319 & (5.1) & 356 & (4.1) & 422 & (3.5) & 578 & (3.7) & 646 & $(4.1)$ & 86 & (4.7) \\
\hline & Norway & 478 & (3.1) & 102 & (1.3) & 479 & $(3.2)$ & 476 & (3.8) & 3 & (3.4) & 306 & (5.2) & 346 & (4.7) & 409 & (3.4) & 547 & (3.4) & 608 & (4.1) & 44 & (4.7) \\
\hline & Poland & 509 & $(4.1)$ & 100 & $(2.1)$ & 510 & $(4.7)$ & 509 & $(4.3)$ & 1 & (3.6) & 347 & (4.4) & 380 & (4.0) & 440 & $(4.1)$ & 578 & $(5.2)$ & 641 & (6.8) & 677 & (9.3) \\
\hline & Portugal & 486 & $(4.1)$ & 98 & (1.4) & 490 & (4.4) & 482 & $(4.1)$ & 9 & (2.6) & 323 & (5.6) & 356 & (4.7) & 417 & (5.4) & 556 & (4.0) & 615 & $(4.0)$ & 645 & (3.9) \\
\hline & Slovak $\mathbf{R e}$ & 474 & $(4.0)$ & 114 & (2.9) & 476 & (4.9) & 472 & (4.5) & 4 & (4.9) & 282 & (9.2) & 327 & (6.9) & 401 & (5.5) & 553 & $(4.6)$ & 617 & (4.8) & 655 & (6.7) \\
\hline & Slovenia & 499 & (1.1) & 100 & (1.0) & 501 & (1.7) & 497 & $(2.2)$ & 4 & (3.1) & 338 & (2.9) & 372 & (2.7) & 429 & (2.3) & 570 & $(2.2)$ & 632 & (3.8) & 67 & (3.7) \\
\hline & Spain & 482 & (2.0) & 93 & (0.8) & 490 & (2.5) & 473 & $(2.1)$ & 17 & (2.2) & 326 & (3.0) & 361 & (3.1) & 420 & (2.9) & 547 & $(2.1)$ & 600 & (1.9) & 630 & (1.9) \\
\hline & Sweden & 469 & $(2.8)$ & 107 & (1.6) & 466 & (3.6) & 472 & (3.1) & -5 & (3.8) & 291 & (5.4) & 331 & (4.1) & 397 & $(4.0)$ & 544 & (3.4) & 606 & (3.8) & 641 & (4.0) \\
\hline & Switzerla & 530 & (3.4) & 103 & (1.6) & 536 & (3.9) & 524 & (3.6) & 12 & (3.0) & 359 & (4.1) & 396 & (3.4) & 459 & (3.7) & 602 & (4.0) & 661 & $(4.8)$ & 695 & (5.3) \\
\hline & Turkey & 448 & (5.0) & 92 & (3.1) & 448 & (5.4) & 449 & (5.7) & -1 & (4.7) & 310 & (4.7) & 336 & (4.9) & 383 & (3.9) & 508 & (7.3) & 575 & (9.1) & 612 & (10.6) \\
\hline & United K & 496 & (3.4) & 99 & (1.8) & 504 & (4.4) & 489 & (3.9) & 15 & (4.8) & 333 & (5.3) & 368 & (5.2) & 429 & $(4.4)$ & 565 & (3.9) & 626 & $(4.4)$ & 659 & (5.2) \\
\hline & United States & 488 & (3.5) & 95 & (1.4) & 490 & (3.9) & 486 & (3.9) & 4 & (3.2) & 339 & (4.2) & 368 & (4.0) & 421 & $(4.1)$ & 552 & $(4.2)$ & 614 & $(4.3)$ & 649 & (5.1) \\
\hline & OECD total & 488 & $(1.2)$ & 107 & $(0.6)$ & 494 & (1.3) & 482 & (1.3) & 12 & (1.1) & 316 & (1.4) & 352 & (1.2) & 414 & $(1.5)$ & 562 & (1.5) & 628 & (1.5) & 665 & (2.1) \\
\hline & & 493 & $(0.6)$ & $\mid$\begin{tabular}{|l|}
101 \\
\end{tabular} & $(0.4)$ & 498 & $(0.7)$ & 487 & $(0.6)$ & 11 & $(0.7)$ & 325 & (1.1) & 362 & (0.8) & 424 & $(0.7)$ & 563 & $(0.7)$ & 622 & $(0.8)$ & 657 & \\
\hline है & Albania & 388 & $(2.1)$ & 98 & (1.4) & 387 & (2.6) & 389 & (3.3) & -2 & (4.0) & 217 & (5.1) & 263 & (4.1) & 327 & (2.9) & 453 & (2.9) & 510 & $3.1)$ & 43 & $(4.7)$ \\
\hline & Argentina & 379 & $(4.2)$ & 90 & (1.9) & 387 & (4.9) & 371 & (3.8) & 15 & (3.0) & 231 & (4.9) & 263 & (4.5) & 318 & $(4.8)$ & 440 & (5.5) & 495 & (5.1) & 525 & (5.2) \\
\hline s & Brazil & 372 & $(2.7)$ & 99 & (1.9) & 382 & (2.8) & 362 & (3.0) & 20 & $(2.2)$ & 217 & (3.5) & 250 & (3.7) & 304 & (2.9) & 435 & (3.3) & 500 & $(5.1)$ & 542 & (6.6) \\
\hline & Bulgaria & 434 & (4.5) & 109 & (2.5) & 433 & (5.3) & 436 & (4.9) & -2 & (5.0) & 263 & (6.7) & 299 & (5.4) & 358 & (4.7) & 507 & (5.7) & 579 & (6.7) & 620 & (7.7) \\
\hline & Colombia & 357 & (3.7) & 91 & (1.8) & 372 & (4.4) & 343 & $(4.0)$ & 29 & (3.8) & 214 & (6.5) & 244 & (4.6) & 295 & (3.8) & 415 & $(4.2)$ & 475 & (5.4) & 513 & (5.3) \\
\hline & Costa Rica & 402 & (3.5) & 81 & (1.9) & 413 & (4.1) & 392 & (3.5) & 21 & (2.9) & 273 & (5.0) & 300 & (4.9) & 348 & $(4.1)$ & 454 & (4.1) & 506 & (5.2) & 538 & (5.6) \\
\hline & Croatia & 468 & $(4.2)$ & 103 & (2.8) & 470 & (5.1) & 465 & (4.6) & 5 & (4.9) & 301 & (5.9) & 336 & (5.5) & 395 & $(4.5)$ & 539 & (5.5) & 602 & (7.3) & 640 & (9.0) \\
\hline & Cyprus* & 440 & $(1.2)$ & 102 & (1.0) & 439 & (1.9) & 441 & (1.8) & -2 & (2.8) & 272 & (3.4) & 310 & (2.8) & 371 & (1.9) & 509 & (2.5) & 572 & $(2.7)$ & 608 & (3.5) \\
\hline & Hong Ko & 564 & (3.6) & 103 & $(2.2)$ & 572 & (5.0) & 556 & (4.3) & 16 & (5.9) & 380 & (7.9) & 426 & (7.1) & 497 & (4.9) & 636 & (3.6) & 691 & (4.0) & 723 & (5.3) \\
\hline & Indonesia & 364 & $(4.3)$ & 79 & (3.4) & 364 & $(4.7)$ & 365 & $(4.7)$ & -1 & (3.8) & 240 & (5.8) & 267 & (4.9) & 311 & $(4.1)$ & 414 & (5.6) & 468 & (8.7) & 501 & (11.3) \\
\hline & Jordan & 387 & (3.7) & 87 & (2.7) & 373 & (6.5) & 402 & (3.0) & $\mid-29$ & $(7.2)$ & 246 & (6.4) & 279 & (5.0) & 330 & $(4.0)$ & 447 & (3.8) & 499 & (4.5) & 529 & (5.9) \\
\hline & Kazakhs & 433 & (3.2) & 84 & (1.9) & 429 & (3.7) & 437 & (3.6) & -8 & (3.6) & 298 & (3.0) & 327 & (3.3) & 375 & $(2.7)$ & 489 & (4.4) & 541 & $(6.1)$ & 573 & (6.4) \\
\hline & Latvia & 496 & (3.4) & 90 & (1.8) & 492 & (4.0) & 501 & (3.6) & -9 & (3.7) & 347 & (6.4) & 381 & (4.4) & 434 & (3.9) & 558 & $(4.2)$ & 613 & (3.9) & 642 & (4.5) \\
\hline & Liechtenstein & 542 & (4.0) & 104 & (3.6) & 552 & (6.3) & 531 & (6.5) & 21 & (10.0) & 363 & (17.8) & 400 & (11.4) & 469 & $(8.2)$ & 621 & (6.4) & 675 & (11.8) & 703 & (11.6) \\
\hline & Lithuania & 479 & (3.2) & 92 & (1.6) & 480 & (3.5) & 479 & (3.3) & 1 & (2.5) & 330 & (5.0) & 364 & (4.2) & 417 & (3.5) & 542 & (3.6) & 599 & $(4.1)$ & 632 & (4.9) \\
\hline & Macao-Ch & 542 & $(1.2)$ & 100 & (1.1) & 542 & (1.7) & 543 & (1.5) & 0 & (2.0) & 375 & (3.5) & 413 & (2.5) & 478 & (1.7) & 612 & (2.1) & 667 & (2.8) & 700 & (3.5) \\
\hline & Malaysia & 401 & $(4.0)$ & 92 & (2.1) & 394 & (4.9) & 408 & (4.3) & -15 & (4.5) & 258 & (5.1) & 287 & (4.2) & 337 & $(4.2)$ & 461 & (5.1) & 524 & (6.5) & 561 & (6.6) \\
\hline & Montenegro & 399 & $(1.3)$ & 93 & (1.0) & 397 & $(1.7)$ & 401 & (1.9) & -4 & (2.7) & 253 & (2.5) & 282 & (2.1) & 333 & (1.9) & 462 & $(2.3)$ & 521 & $(3.1)$ & 556 & (3.6) \\
\hline & Peru & 349 & (4.5) & 101 & (2.6) & 357 & (4.6) & 342 & (5.6) & 15 & (4.5) & 191 & (5.3) & 224 & (4.8) & 280 & $(4.2)$ & 415 & (6.0) & 482 & (7.4) & 525 & (9.1) \\
\hline & Qatar & 63 & $(0.9)$ & 110 & $(0.7)$ & 354 & $(1.2)$ & 372 & (1.2) & \begin{tabular}{|l|}
-18 \\
\end{tabular} & (1.6) & 197 & (2.2) & 230 & (1.9) & 285 & (1.4) & 434 & (1.5) & 514 & $(2.2)$ & 562 & (2.9) \\
\hline & Romania & 446 & (3.9) & 89 & (2.4) & 446 & $(4.7)$ & 445 & (4.1) & 1 & (3.9) & 307 & (4.4) & 336 & (4.6) & 382 & (3.9) & 504 & $(5.0)$ & 566 & (6.8) & 602 & (7.1) \\
\hline & Russian Fe & 491 & (3.4) & 93 & (1.8) & 489 & $(4.0)$ & 493 & (3.5) & -5 & (3.1) & 338 & (5.5) & 371 & (4.7) & 428 & $(4.0)$ & 553 & (3.8) & 611 & $(5.0)$ & 644 & (6.3) \\
\hline & Serbia & 442 & (4.1) & 104 & $(2.7)$ & 445 & (4.9) & 439 & (4.6) & 5 & (4.7) & 274 & (7.6) & 311 & (5.7) & 371 & $(4.9)$ & 512 & (4.4) & 578 & (6.3) & 618 & (6.5) \\
\hline & Shanghai- & 24 & (3.6) & 112 & (2.4) & 629 & (4.4) & 619 & (3.9) & 10 & (3.9) & 431 & (6.7) & 473 & (6.5) & 547 & (5.4) & 704 & (3.6) & 764 & $(4.1)$ & 797 & (5.3) \\
\hline & Singapore & 580 & (1.5) & 114 & $(0.9)$ & 581 & $(2.2)$ & 580 & (1.9) & 1 & (2.6) & 387 & (4.4) & 428 & (3.9) & 502 & $(2.7)$ & 662 & (2.1) & 725 & (2.8) & 759 & (2.8) \\
\hline & Chinese Taipei & 561 & (3.5) & 121 & $(2.2)$ & 563 & $(5.7)$ & 559 & (5.8) & 4 & (9.0) & 355 & (6.4) & 398 & (5.7) & 476 & $(5.0)$ & 648 & (3.7) & 714 & $(5.2)$ & 752 & (5.4) \\
\hline & Thailand & 414 & (3.9) & 93 & (2.3) & 403 & $(4.1)$ & 422 & (4.6) & -20 & (3.9) & 269 & (4.6) & 300 & (3.7) & 350 & (3.9) & 471 & $(5.0)$ & 535 & $(7.0)$ & 576 & (9.3) \\
\hline & Tunisia & 379 & (4.5) & 91 & (3.0) & 389 & (5.1) & 371 & (4.6) & 18 & (3.2) & 234 & (5.7) & 264 & (5.1) & 318 & $(4.4)$ & 438 & (5.0) & 496 & $(7.0)$ & 531 & (11.7) \\
\hline & United & 42 & (2.6) & 95 & $(1.2$ & 440 & $(4.2)$ & 445 & (3.0) & -4 & (5.0) & 294 & (3.9) & 325 & (3.0) & 376 & (2.8) & 505 & (3.4) & 570 & (3.8) & 607 & (4.2) \\
\hline & Uruguay & 401 & $(3.2)$ & 105 & $(2.2)$ & 407 & (4.1) & 397 & (3.4) & 10 & (3.8) & 230 & (5.7) & 267 & (5.0) & 331 & $(4.0)$ & 472 & (3.7) & 537 & (5.4) & 576 & (5.7) \\
\hline & Viet Nam & 509 & (5.1) & 94 & (2.7) & 514 & (5.9) & 506 & (4.9) & 8 & (3.2) & 355 & (8.0) & 389 & (7.1) & 445 & (6.1) & 572 & (5.7) & 631 & (6.6) & 664 & (6.7) \\
\hline
\end{tabular}

Note: Values that are statistically significant are indicated in bold (see Annex A3).

* See notes at the beginning of this Annex.

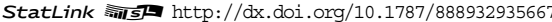


[Part 1/1]

Table I.2.17 Percentage of students at each proficiency level on the mathematics subscale space and shape

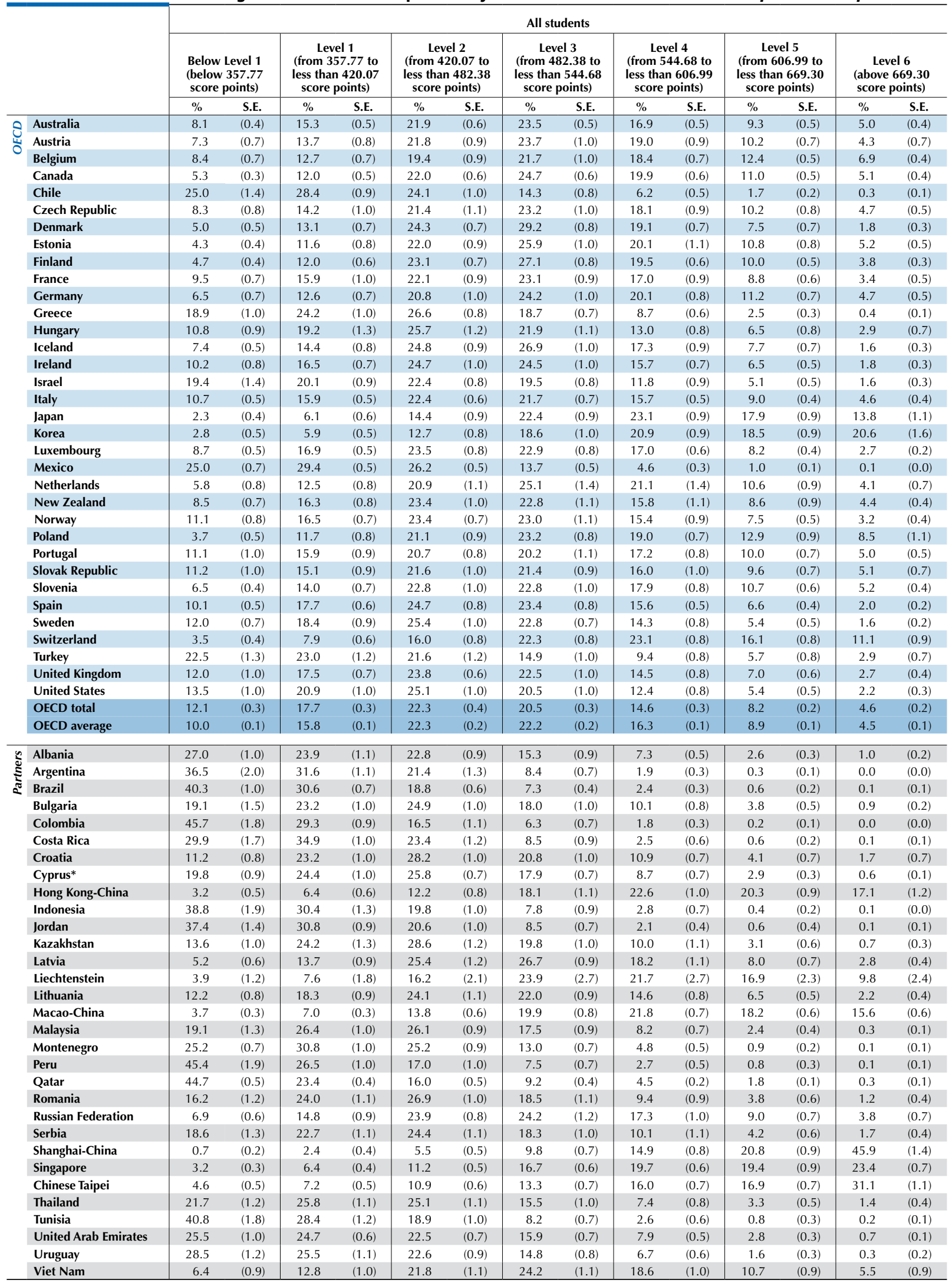

* See notes at the beginning of this Annex.

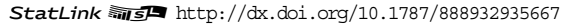


Percentage Table I.2.18 by gender

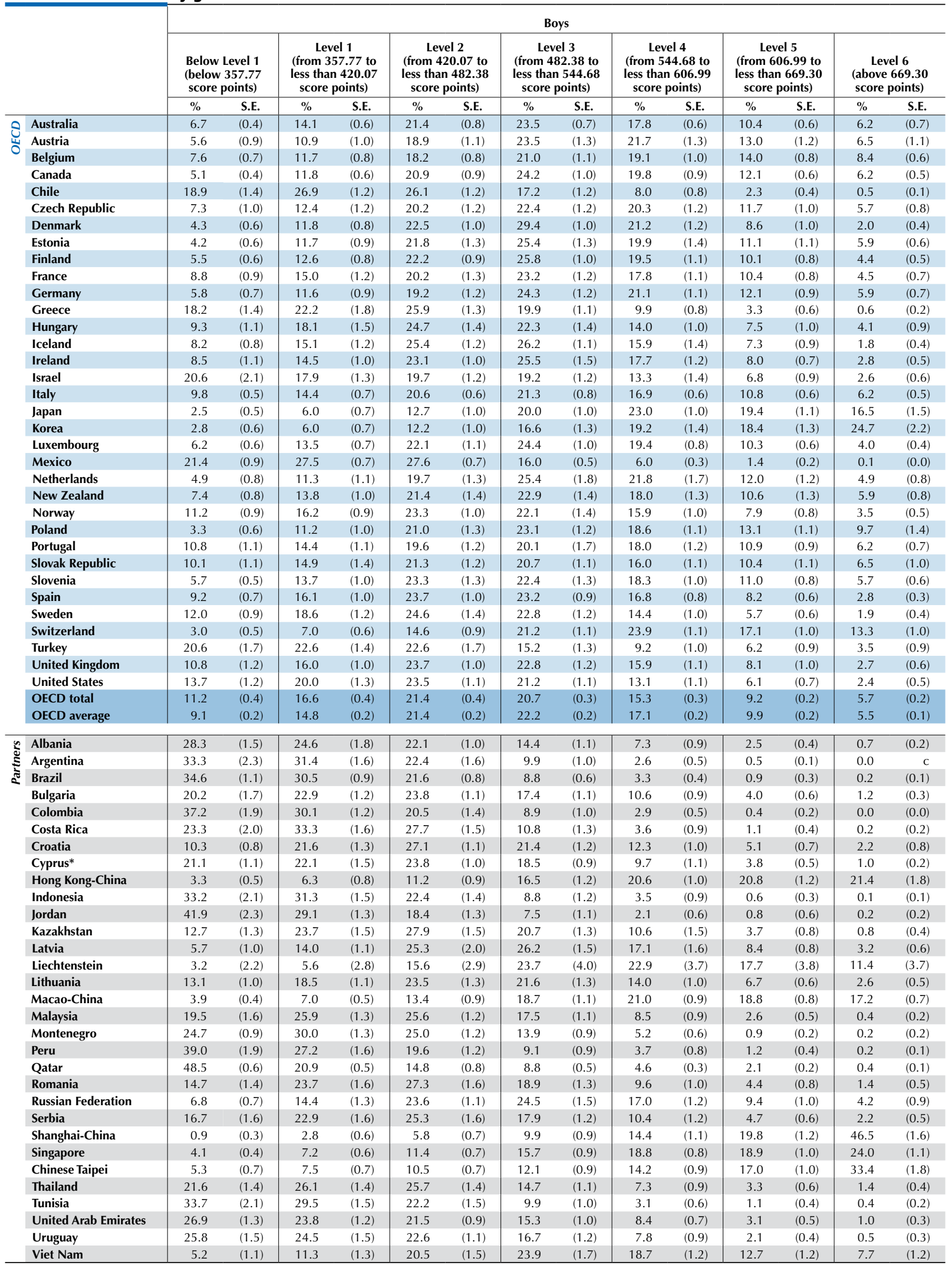

* See notes at the beginning of this Annex.

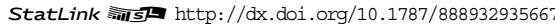


Part 2/2]

Percentage of students at each proficiency level on the mathematics subscale space and shape,

Table I.2.18 by gender

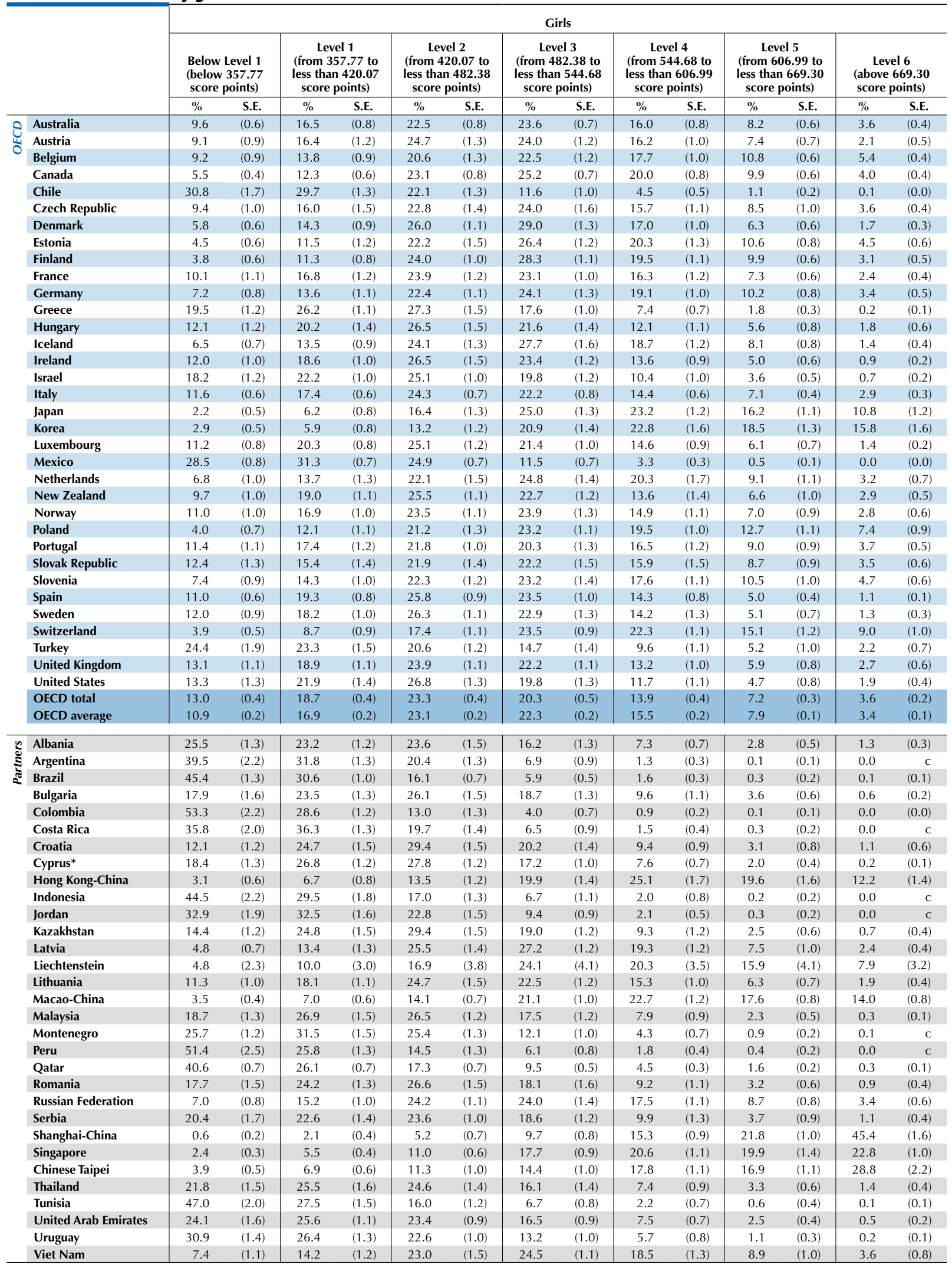

* See notes at the beginning of this Annex.

StatLink 部 St http://dx.doi.org/10.1787/888932935667 
[Part 1/1]

Mean score, variation and gender differences in student performance on the mathematics subscale Table I.2.19 space and shape

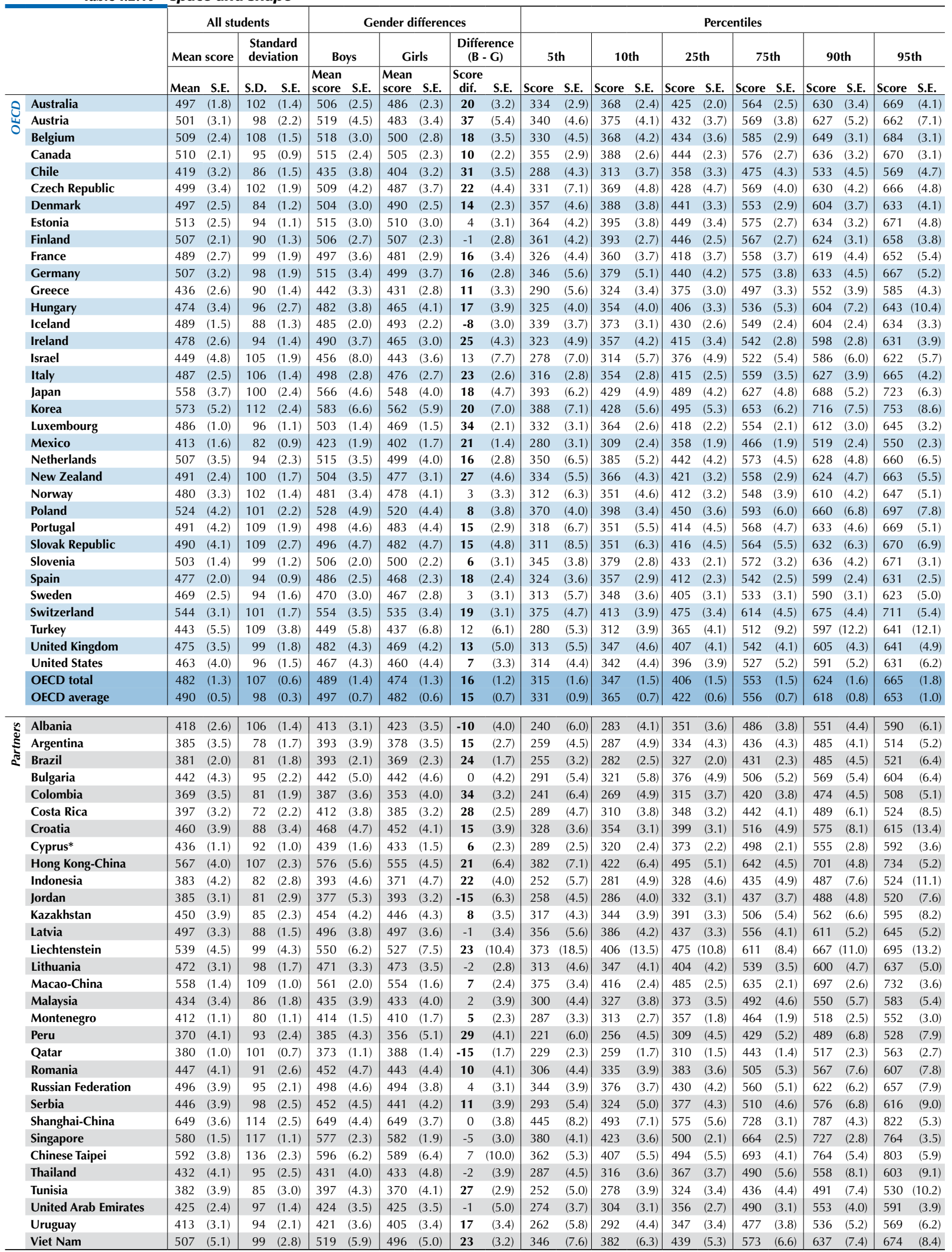

Note: Values that are statistically significant are indicated in bold (see Annex A3).

* See notes at the beginning of this Annex.

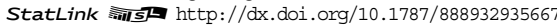


[Part 1/1]

Table I.2.20 Percentage of students at each proficiency level on the mathematics subscale quantity

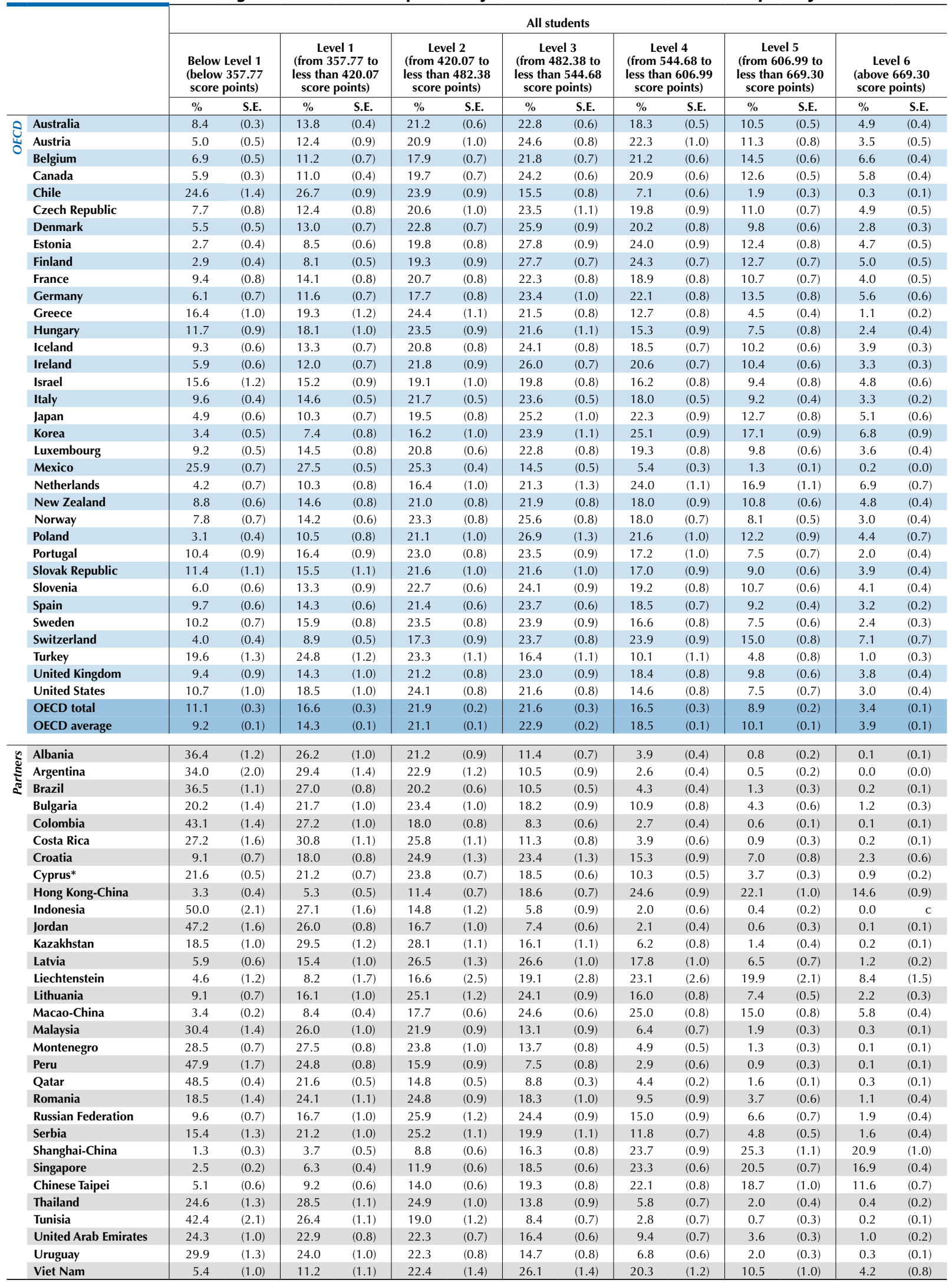

* See notes at the beginning of this Annex.

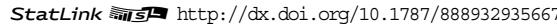


[Part 1/2]

Table I.2.21 Percentage of students at each proficiency level on the mathematics subscale quantity, by gender

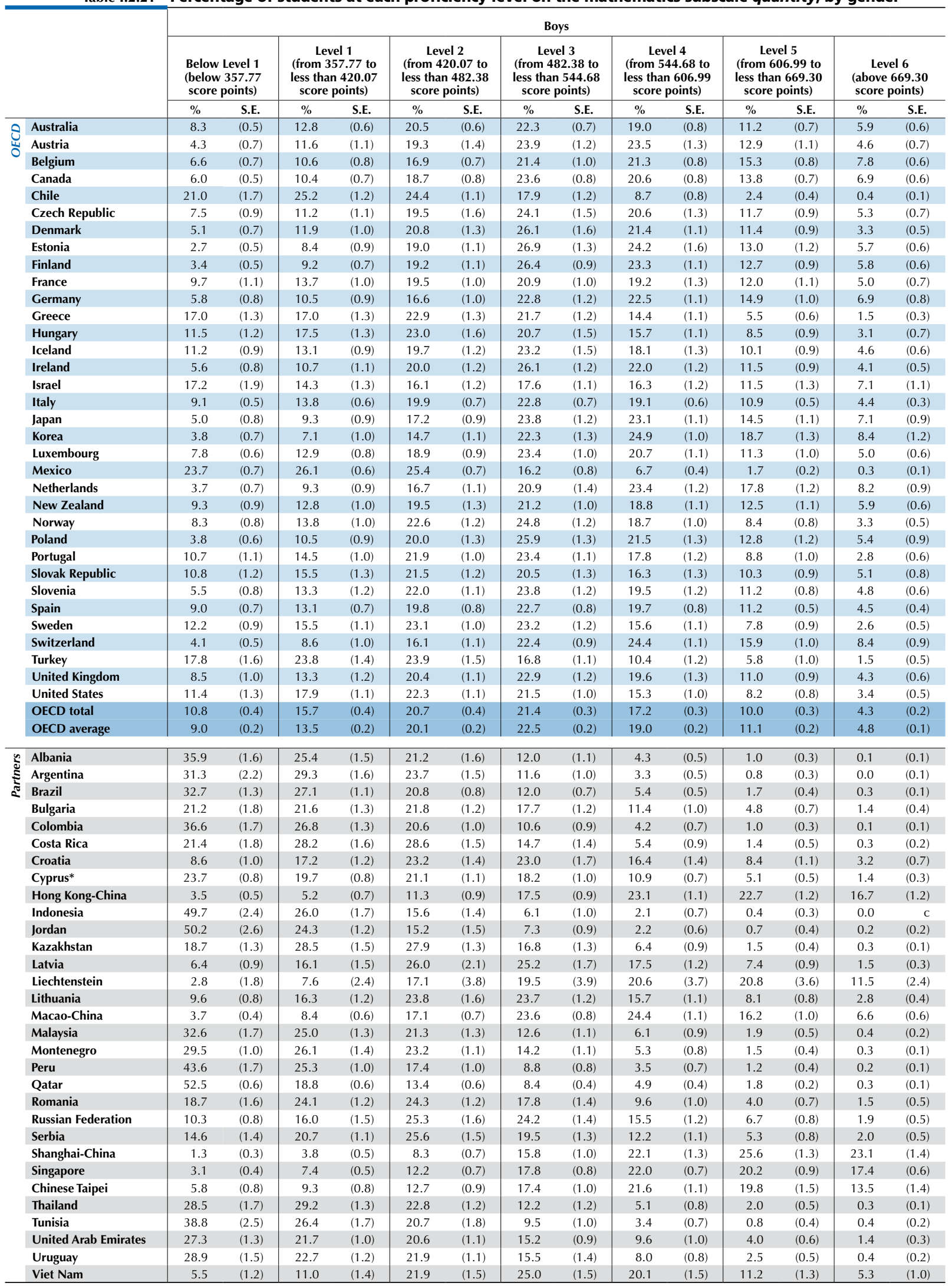

* See notes at the beginning of this Annex.

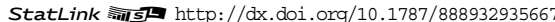


[Part 2/2]

Table I.2.21 Percentage of students at each proficiency level on the mathematics subscale quantity, by gender

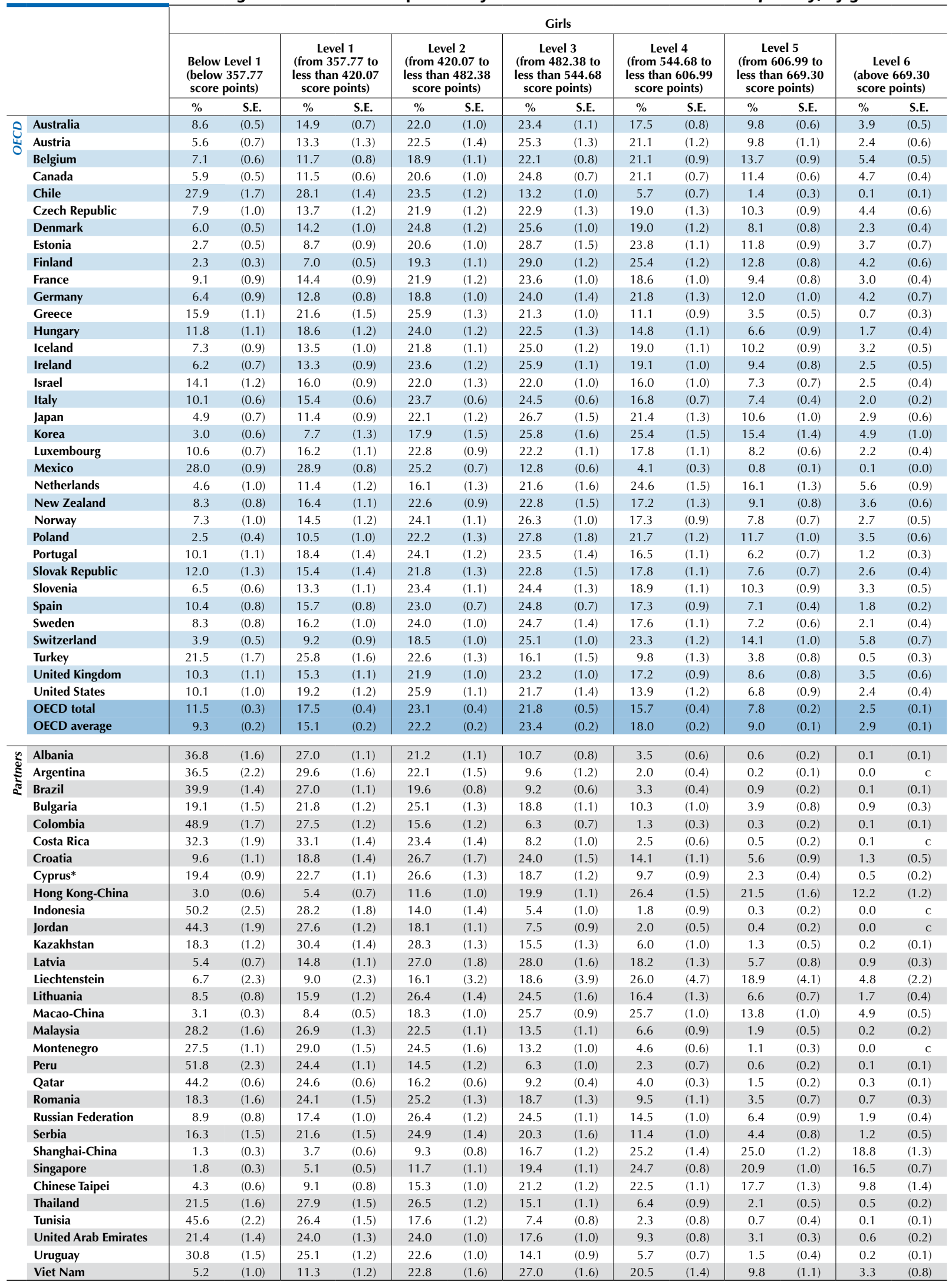

* See notes at the beginning of this Annex.

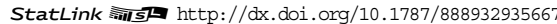


[Part 1/1]

Mean score, variation and gender differences in student performance on the mathematics subscale Table I.2.22 quantity

\begin{tabular}{|c|c|c|c|c|c|c|c|c|c|c|c|c|c|c|c|c|c|c|c|c|c|c|c|}
\hline & \multicolumn{4}{|c|}{ All students } & \multicolumn{6}{|c|}{ Gender differences } & & & & & & Perce & entiles & & & & & \\
\hline & & Mean & score & $\begin{array}{l}\text { Stan } \\
\text { devi }\end{array}$ & $\begin{array}{l}\text { ard } \\
\text { ion }\end{array}$ & & oys & & irls & $\begin{array}{c}\text { Diffe } \\
\text { (B - }\end{array}$ & $\begin{array}{l}\text { rence } \\
\text { - G) }\end{array}$ & $5 t$ & th & 10 & th & 25 & th & 75 & th & & Dth & & 5 th \\
\hline & & Mean & S.E. & S.D. & S.E. & $\begin{array}{l}\begin{array}{l}\text { Mean } \\
\text { score }\end{array} \\
\end{array}$ & S.E. & $\begin{array}{l}\text { Mean } \\
\text { score }\end{array}$ & S.E. & $\begin{array}{c}\text { Score } \\
\text { dif. }\end{array}$ & S.E. & Score & S.E. & Score & S.E. & Score & S.E. & Score & S.E. & Score & S.E. & Score & S.E. \\
\hline 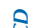 & Australia & 500 & (1.9) & 104 & (1.3) & 505 & $(2.7)$ & 495 & $(2.2)$ & 10 & (3.1) & 330 & $(2.8)$ & 367 & $(2.2)$ & 429 & $(2.0)$ & 572 & $(2.7)$ & 634 & (3.1) & 669 & (3.5) \\
\hline & Austria & 510 & (2.9) & 91 & (1.7) & 519 & (3.6) & 502 & (3.8) & 17 & $(4.8)$ & 358 & $(5.1)$ & 391 & (3.9) & 446 & (3.8) & 576 & (3.6) & 627 & (3.9) & 656 & (5.3) \\
\hline & Belgium & 519 & (2.0) & 104 & (1.4) & 524 & $(2.8)$ & 513 & (2.5) & 11 & (3.4) & 341 & $(4.6)$ & 381 & (4.0) & 447 & (3.1) & 594 & (2.5) & 650 & $(2.4)$ & 681 & (2.5) \\
\hline & Canada & 515 & $(2.2)$ & 99 & (1.0) & 520 & $(2.5)$ & 511 & (2.4) & 9 & $(2.3)$ & 349 & (3.0) & 386 & (3.1) & 448 & $(2.3)$ & 585 & (2.6) & 643 & (3.1) & 676 & (3.2) \\
\hline & Chile & 421 & (3.3) & 90 & (1.6) & 433 & $(4.0)$ & 411 & (3.4) & 22 & (3.6) & 280 & (4.4) & 310 & (4.2) & 359 & $(4.0)$ & 482 & $(4.2)$ & 541 & $(4.0)$ & 575 & (4.3) \\
\hline & Czech Republic & 505 & (3.0) & 101 & $(2.0)$ & 510 & (3.5) & 500 & $(4.0)$ & 10 & $(4.5)$ & 336 & (6.5) & 373 & (5.8) & 438 & $(4.4)$ & 576 & (3.5) & 633 & (3.6) & 668 & (4.5) \\
\hline & Denmark & 502 & (2.4) & 91 & (1.3) & 510 & (3.2) & 495 & (2.4) & 15 & (3.0) & 354 & $(4.3)$ & 387 & (3.8) & 441 & (2.9) & 565 & (2.9) & 619 & (3.7) & 648 & (3.2) \\
\hline & Estonia & 525 & $(2.2)$ & 86 & $(1.2)$ & 528 & (2.6) & 521 & (2.5) & 7 & (2.6) & 382 & (4.6) & 415 & (3.2) & 466 & (2.8) & 583 & (2.6) & 636 & (3.3) & 667 & (4.4) \\
\hline & Finland & 527 & (1.9) & 87 & (1.0) & 525 & (2.6) & 528 & (2.1) & -3 & (2.8) & 382 & $(4.0)$ & 415 & (2.9) & 469 & (2.5) & 586 & (2.3) & 638 & (3.3) & 669 & (3.8) \\
\hline & France & 496 & (2.6) & 103 & (1.8) & 501 & (3.7) & 492 & $(2.7)$ & 9 & (3.8) & 324 & (6.0) & 362 & (4.9) & 425 & $(2.9)$ & 570 & (3.1) & 628 & (3.6) & 661 & (4.5) \\
\hline & Germany & 517 & (3.1) & 100 & (1.9) & 524 & (3.3) & 510 & (3.6) & 14 & $(2.9)$ & 348 & (6.4) & 384 & (5.1) & 449 & $(4.0)$ & 588 & (3.4) & 643 & $(4.1)$ & 674 & $(4.2)$ \\
\hline & Greece & 455 & (3.0) & 97 & (1.6) & 461 & $(4.0)$ & 450 & (3.1) & 10 & (3.8) & 295 & (5.0) & 330 & (4.4) & 388 & $(4.0)$ & 523 & (3.4) & 579 & (3.7) & 613 & (4.6) \\
\hline & Hungary & 476 & (3.4) & 99 & (2.2) & 480 & (3.8) & 472 & (3.9) & 8 & (3.8) & 314 & (5.9) & 350 & (4.3) & 406 & $(4.0)$ & 545 & (5.0) & 606 & (6.5) & 641 & (5.9) \\
\hline & Iceland & 496 & (1.9) & 102 & (1.5) & 494 & (2.6) & 499 & (2.5) & -5 & (3.4) & 322 & (4.9) & 362 & (4.7) & 429 & (2.5) & 567 & (3.2) & 627 & (3.6) & 661 & (3.3) \\
\hline & Ireland & 505 & (2.6) & 92 & (1.4) & 512 & (3.7) & 498 & (3.0) & 14 & $(4.4)$ & 350 & (4.6) & 386 & (4.6) & 443 & (3.2) & 569 & (3.0) & 624 & (3.1) & 653 & (3.6) \\
\hline & Israel & 480 & (5.2) & 116 & (2.1) & 486 & (8.6) & 473 & (3.8) & 13 & $(8.2)$ & 284 & (9.1) & 327 & (6.2) & 398 & (6.1) & 563 & (5.9) & 629 & (6.1) & 667 & (6.5) \\
\hline & Italy & 491 & (2.0) & 101 & (1.0) & 499 & (2.5) & 482 & (2.3) & 17 & $(2.7)$ & 321 & (3.2) & 360 & (2.7) & 423 & (2.2) & 561 & (2.5) & 619 & (2.6) & 652 & (2.8) \\
\hline & Japan & 518 & (3.6) & 94 & (2.2) & 527 & (4.5) & 508 & (3.5) & 19 & $(4.0)$ & 359 & (7.4) & 395 & (5.2) & 456 & (4.2) & 584 & (4.0) & 638 & (4.2) & 670 & (4.7) \\
\hline & Korea & 537 & (4.1) & 94 & (2.0) & 543 & (5.0) & 531 & (5.0) & 12 & (5.9) & 377 & (7.1) & 416 & (6.1) & 477 & (4.6) & 604 & (4.3) & 654 & (4.9) & 682 & (6.1) \\
\hline & Luxembourg & 495 & (1.0) & 100 & $(0.9)$ & 506 & (1.5) & 483 & (1.3) & 23 & $(2.0)$ & 326 & (3.8) & 362 & (2.9) & 424 & (2.0) & 567 & (1.6) & 623 & $(2.2)$ & 656 & (2.9) \\
\hline & Mexico & 414 & (1.5) & 87 & (0.9) & 422 & (1.7) & 406 & (1.7) & 16 & (1.4) & 271 & (2.8) & 304 & (2.2) & 355 & (1.7) & 472 & (1.9) & 526 & $(2.2)$ & 559 & (2.3) \\
\hline & Netherlands & 532 & (3.6) & 97 & (2.3) & 537 & (3.8) & 527 & $(4.0)$ & 10 & (3.1) & 365 & (7.0) & 398 & (6.0) & 463 & (5.0) & 604 & (3.7) & 653 & (3.1) & 682 & (3.4) \\
\hline & New Zealand & 499 & (2.4) & 103 & (1.3) & 506 & (3.3) & 492 & (3.1) & 14 & (4.4) & 331 & (4.3) & 365 & (3.9) & 426 & (3.3) & 572 & (2.8) & 634 & (3.4) & 667 & (4.1) \\
\hline & Norway & 492 & (2.9) & 95 & (1.6) & 494 & (3.0) & 491 & (3.5) & 3 & (3.2) & 335 & (6.1) & 372 & (4.5) & 429 & (3.5) & 556 & (3.2) & 613 & (3.5) & 648 & (4.4) \\
\hline & Poland & 519 & (3.5) & 89 & (1.6) & 521 & $(4.1)$ & 516 & (3.7) & 5 & (3.4) & 375 & (4.4) & 406 & (3.8) & 457 & (3.5) & 579 & $(4.5)$ & 634 & (5.3) & 664 & (6.6) \\
\hline & Portugal & 481 & (4.0) & 96 & (1.5) & 487 & (4.4) & 475 & (4.1) & 12 & $(2.6)$ & 321 & (5.7) & 355 & (5.8) & 415 & (4.9) & 550 & $(4.2)$ & 604 & (3.9) & 636 & (4.2) \\
\hline & Slovak Republic & 486 & (3.5) & 105 & $(2.2)$ & 492 & $(4.1)$ & 481 & $(4.2)$ & 11 & $(4.5)$ & 312 & (7.9) & 350 & (5.8) & 414 & $(4.8)$ & 560 & (4.3) & 621 & $(4.2)$ & 658 & (5.3) \\
\hline & Slovenia & 504 & $(1.2)$ & 94 & $(1.0)$ & 508 & (1.8) & 500 & (2.1) & 7 & (3.0) & 351 & (3.9) & 382 & (2.4) & 438 & (2.3) & 570 & (2.1) & 629 & $(2.7)$ & 661 & (3.8) \\
\hline & Spain & 491 & (2.3) & 101 & (1.0) & 501 & $(2.7)$ & 481 & (2.4) & 20 & (2.3) & 321 & (3.8) & 360 & (4.0) & 423 & (3.3) & 562 & (2.2) & 618 & $(2.0)$ & 651 & (2.9) \\
\hline & Sweden & 482 & (2.5) & 97 & (1.3) & 478 & (3.1) & 485 & (2.9) & -7 & $(3.2)$ & 320 & (4.9) & 357 & (4.0) & 417 & (3.2) & 549 & (3.1) & 607 & (3.1) & 639 & (3.9) \\
\hline & Switzerland & 531 & (3.1) & 96 & (1.4) & 536 & (3.8) & 526 & (3.0) & 10 & $(3.0)$ & 369 & (4.5) & 404 & (3.3) & 467 & (3.3) & 598 & (3.8) & 652 & $(4.8)$ & 684 & (4.5) \\
\hline & Turkey & 442 & (5.0) & 97 & (3.0) & 449 & (5.5) & 435 & (5.7) & 14 & (5.1) & 295 & (5.0) & 324 & (4.0) & 373 & $(4.0)$ & 506 & (8.0) & 576 & (9.3) & 613 & (8.6) \\
\hline & United Kingdom & 494 & (3.8) & 102 & (1.9) & 501 & (4.8) & 488 & $(4.1)$ & 13 & $(4.7)$ & 325 & (7.2) & 362 & (6.4) & 424 & (5.5) & 567 & (3.9) & 625 & (3.7) & 658 & (4.3) \\
\hline & United States & 478 & (3.9) & 99 & (1.7) & 481 & (4.3) & 475 & $(4.1)$ & 6 & (3.1) & 322 & (5.5) & 354 & (5.5) & 408 & $(4.0)$ & 545 & (4.9) & 610 & (5.1) & 646 & (5.5) \\
\hline & OECD total & 484 & $(1.2)$ & 103 & $(0.5)$ & 490 & (1.3) & 478 & (1.3) & 12 & (1.1) & 317 & (1.4) & 352 & (1.5) & 411 & $(1.5)$ & 557 & (1.4) & 619 & $(1.3)$ & 653 & (1.4) \\
\hline & OECD average & 495 & $(0.5)$ & 97 & $(0.3)$ & 501 & $(0.6)$ & 490 & $(0.6)$ & 11 & $(0.7)$ & 334 & $(0.9)$ & 369 & $(0.8)$ & 429 & $(0.6)$ & 563 & $(0.6)$ & 620 & $(0.7)$ & 653 & $(0.8)$ \\
\hline 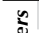 & Albania & 386 & $(2.7)$ & 101 & (1.7) & 389 & (3.2) & 383 & (3.3) & 6 & (3.7) & 206 & (7.0) & 257 & (5.0) & 326 & (3.7) & 453 & (3.0) & 511 & (3.6) & 543 & $(4.2)$ \\
\hline & Argentina & 391 & (3.7) & 84 & $(2.2)$ & 398 & $(4.1)$ & 385 & (3.9) & 13 & (2.9) & 251 & (6.7) & 284 & (5.2) & 336 & $(4.7)$ & 448 & (4.4) & 499 & $(4.2)$ & 529 & (4.6) \\
\hline s & Brazil & 393 & (2.5) & 91 & (1.6) & 403 & $(2.7)$ & 384 & (2.8) & 19 & $(2.3)$ & 250 & (3.4) & 280 & (3.3) & 330 & (2.6) & 452 & (3.1) & 513 & $(4.2)$ & 552 & (5.9) \\
\hline & Bulgaria & 443 & (4.3) & 102 & (2.8) & 442 & (5.1) & 443 & (4.7) & -1 & (4.6) & 280 & (7.1) & 313 & (5.6) & 373 & (4.5) & 513 & (5.7) & 576 & (5.8) & 612 & (8.3) \\
\hline & Colombia & 375 & (3.4) & 90 & (2.1) & 392 & (3.9) & 360 & (3.8) & 31 & (3.5) & 232 & (6.3) & 264 & (4.9) & 315 & (3.2) & 434 & (3.9) & 491 & (5.0) & 527 & (6.4) \\
\hline & Costa Rica & 406 & (3.6) & 81 & (2.4) & 422 & $(4.0)$ & 393 & (3.7) & 29 & (2.6) & 278 & $(6.2)$ & 306 & (5.1) & 353 & (4.0) & 457 & (4.0) & 509 & (5.7) & 544 & (8.4) \\
\hline & Croatia & 480 & (3.7) & 93 & (2.5) & 488 & $(4.6)$ & 472 & $(4.0)$ & 15 & $(4.5)$ & 332 & $(4.3)$ & 363 & (3.8) & 414 & (3.5) & 543 & (5.3) & 603 & (7.4) & 637 & (8.3) \\
\hline & Cyprus* & 439 & (1.1) & 100 & (1.1) & 439 & (1.8) & 438 & (1.8) & 1 & (2.7) & 276 & (3.0) & 310 & (2.5) & 370 & (2.1) & 508 & (3.3) & 568 & (2.4) & 604 & (3.4) \\
\hline & Hong Kong-China & 566 & (3.4) & 101 & $(2.0)$ & 570 & $(4.4)$ & 561 & $(4.2)$ & 9 & $(5.1)$ & 383 & $(7.5)$ & 430 & (6.0) & 501 & $(4.9)$ & 637 & (3.4) & 688 & $(4.2)$ & 718 & (3.6) \\
\hline & Indonesia & 362 & (4.7) & 83 & (3.5) & 364 & $(5.1)$ & 361 & (5.1) & 3 & $(4.0)$ & 235 & (5.6) & 261 & (4.9) & 307 & (4.3) & 414 & (5.6) & 471 & (9.3) & 507 & (12.5) \\
\hline & Jordan & 367 & (3.4) & 90 & (2.3) & 362 & (5.7) & 372 & (3.7) & -10 & $(6.9)$ & 223 & (3.8) & 255 & (4.5) & 307 & (3.3) & 425 & (3.9) & 483 & $(4.8)$ & 518 & (6.8) \\
\hline & Kazakhstan & 428 & (3.5) & 79 & $(2.1)$ & 429 & (3.7) & 427 & $(4.1)$ & 2 & (3.5) & 305 & (3.4) & 331 & (3.0) & 373 & $(2.8)$ & 479 & $(5.0)$ & 533 & (6.3) & 564 & (6.9) \\
\hline & Latvia & 487 & (2.9) & 84 & (1.5) & 487 & (3.5) & 487 & (3.3) & 0 & (3.5) & 350 & (6.3) & 381 & (4.3) & 430 & (3.2) & 546 & (3.5) & 596 & $(4.0)$ & 624 & (4.3) \\
\hline & Liechtenstein & 538 & (4.1) & 100 & (3.6) & 548 & (6.3) & 527 & (6.4) & 22 & $(9.7)$ & 364 & (13.9) & 398 & (13.3) & 467 & $(8.5)$ & 615 & (6.0) & 660 & (9.9) & 686 & (10.9) \\
\hline & Lithuania & 483 & (2.8) & 93 & (1.4) & 484 & (3.1) & 482 & (3.2) & 3 & (2.8) & 331 & (4.5) & 363 & $(4.2)$ & 420 & (3.6) & 547 & (3.4) & 605 & (3.7) & 637 & (4.6) \\
\hline & Macao-China & 531 & (1.1) & 92 & $(1.0)$ & 533 & (1.5) & 528 & (1.4) & 5 & $(1.9)$ & 375 & (2.8) & 411 & (2.7) & 469 & (1.9) & 595 & $(1.8)$ & 646 & (1.9) & 675 & (3.6) \\
\hline & Malaysia & 409 & (3.6) & 94 & (1.9) & 405 & $(4.3)$ & 413 & $(4.3)$ & -8 & $(4.7)$ & 263 & (4.1) & 291 & (3.1) & 343 & (3.4) & 471 & $(4.9)$ & 536 & (6.5) & 572 & (6.1) \\
\hline & Montenegro & 409 & $(1.2)$ & 88 & (1.1) & 409 & (1.6) & 409 & (1.8) & 0 & (2.5) & 269 & (3.0) & 298 & (2.3) & 349 & (1.7) & 467 & $(2.0)$ & 523 & $(2.7)$ & 556 & (4.4) \\
\hline & Peru & 365 & $(4.1)$ & 97 & (2.4) & 377 & (4.1) & 355 & $(5.2)$ & 22 & $(4.3)$ & 211 & (4.8) & 245 & (4.6) & 301 & $(4.0)$ & 427 & $(5.3)$ & 490 & (7.1) & 532 & (9.1) \\
\hline & Qatar & 371 & $(0.9)$ & 105 & $(0.7)$ & 362 & $(1.2)$ & 381 & $(1.2)$ & -19 & $(1.8)$ & 212 & (3.5) & 244 & (2.0) & 298 & (1.1) & 437 & (1.6) & 514 & (2.0) & 559 & (2.7) \\
\hline & Romania & 443 & (4.5) & 94 & (2.5) & 444 & $(5.2)$ & 442 & $(4.8)$ & 2 & $(4.3)$ & 298 & (5.0) & 327 & $(4.7)$ & 376 & (4.6) & 505 & (5.6) & 567 & $(7.2)$ & 605 & (7.6) \\
\hline & Russian Federation & 478 & (3.0) & 93 & (1.6) & 478 & (3.5) & 478 & (3.2) & 0 & (3.2) & 326 & (4.9) & 360 & (3.9) & 417 & (3.7) & 540 & $(4.2)$ & 598 & (5.0) & 632 & (5.8) \\
\hline & Serbia & 456 & (3.7) & 97 & (2.6) & 460 & (4.3) & 452 & (4.3) & 8 & $(4.4)$ & 303 & (6.0) & 334 & (4.9) & 390 & $(4.4)$ & 521 & (4.6) & 582 & (5.6) & 619 & (8.4) \\
\hline & Shanghai-China & 591 & (3.2) & 98 & (2.4) & 596 & (3.8) & 586 & (3.5) & 9 & (3.3) & 419 & $(7.2)$ & 460 & (5.8) & 528 & $(4.5)$ & 658 & (3.2) & 710 & $(4.2)$ & 741 & (6.3) \\
\hline & Singapore & 569 & (1.2) & 104 & $(0.9)$ & 566 & (1.8) & 572 & (1.7) & -6 & (2.4) & 390 & (3.5) & 428 & (2.9) & 500 & (1.9) & 642 & $(2.1)$ & 699 & $(2.2)$ & 731 & (3.6) \\
\hline & Chinese Taipei & 543 & (3.1) & 108 & (1.8) & 548 & (4.8) & 540 & $(5.0)$ & 8 & (7.5) & 357 & (5.9) & 396 & (5.1) & 470 & (4.6) & 622 & (3.2) & 677 & (3.1) & 707 & (3.5) \\
\hline & Thailand & 419 & (3.7) & 88 & (2.2) & 409 & (3.8) & 426 & (4.4) & -16 & (3.9) & 282 & (4.3) & 311 & (3.8) & 359 & (3.1) & 473 & (4.8) & 534 & $(7.1)$ & 573 & (8.6) \\
\hline & Tunisia & 378 & (4.6) & 91 & (3.4) & 386 & (5.4) & 371 & (4.6) & 15 & (3.5) & 233 & $(6.7)$ & 264 & (5.3) & 316 & $(4.8)$ & 437 & $(4.9)$ & 493 & (7.3) & 530 & (11.9) \\
\hline & United Arab Emi & 431 & (2.7) & 101 & (1.2) & 428 & $(4.3)$ & 434 & (3.5) & -7 & (5.5) & 273 & (2.8) & 304 & (3.2) & 360 & (3.0) & 500 & (3.6) & 567 & $(4.0)$ & 603 & (3.9) \\
\hline & Uruguay & 411 & (3.2) & 98 & (1.9) & 416 & (3.9) & 407 & (3.4) & 9 & (3.5) & 250 & (6.1) & 284 & (4.8) & 344 & (3.8) & 478 & (3.4) & 539 & (5.0) & 572 & (5.9) \\
\hline & Viet Nam & 509 & (5.5) & 93 & (2.7) & 512 & (6.2) & 506 & (5.4) & 6 & (3.0) & 354 & (9.4) & 391 & (8.5) & 446 & (5.8) & 571 & (6.1) & 629 & (6.7) & 662 & (8.5) \\
\hline
\end{tabular}

Note: Values that are statistically significant are indicated in bold (see Annex A3)

* See notes at the beginning of this Annex.

StatLink 部实 http://dx.doi.org/10.1787/888932935667 
[Part 1/1]

Table I.2.23 Percentage of students at each proficiency level on the mathematics subscale uncertainty and data

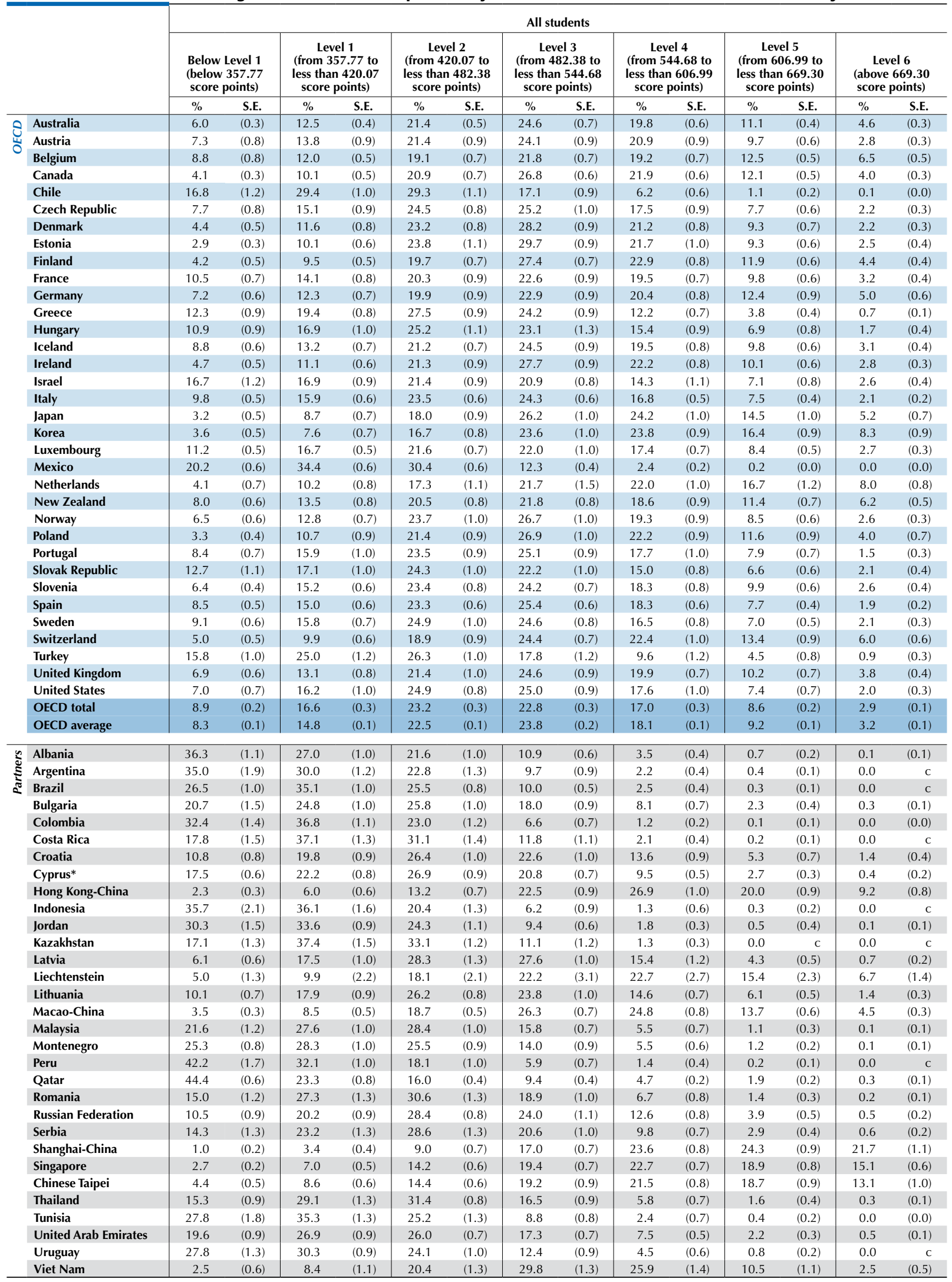

* See notes at the beginning of this Annex.

StatLink त्ञात http://dx.doi.org/10.1787/888932935667 
Percentage Table I.2.24 by gender

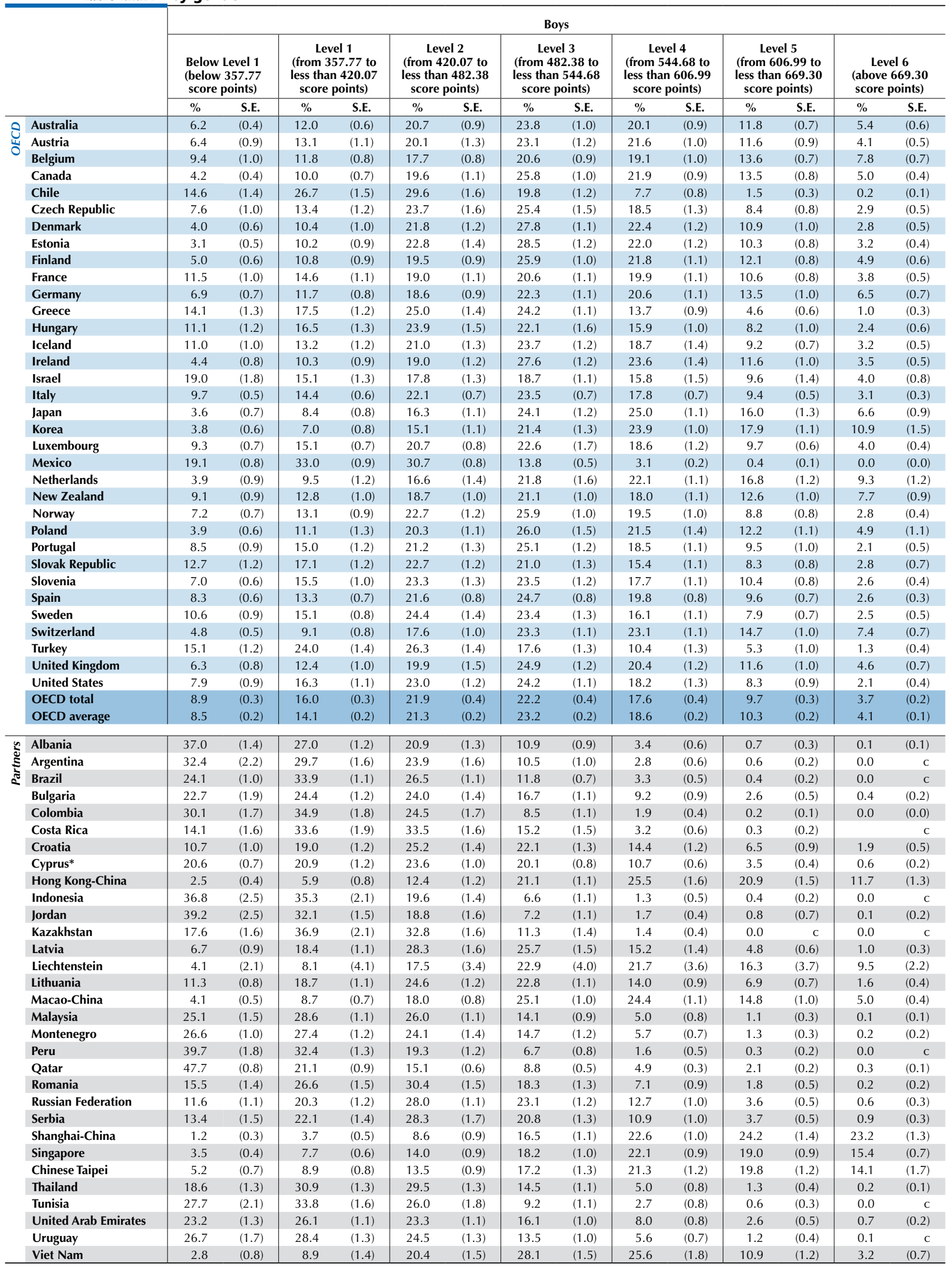

* See notes at the beginning of this Annex.

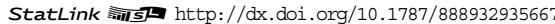


Part 2/2]

Percentage of students at each proficiency level on the mathematics subscale uncertainty and data,

Table I.2.24 by gender

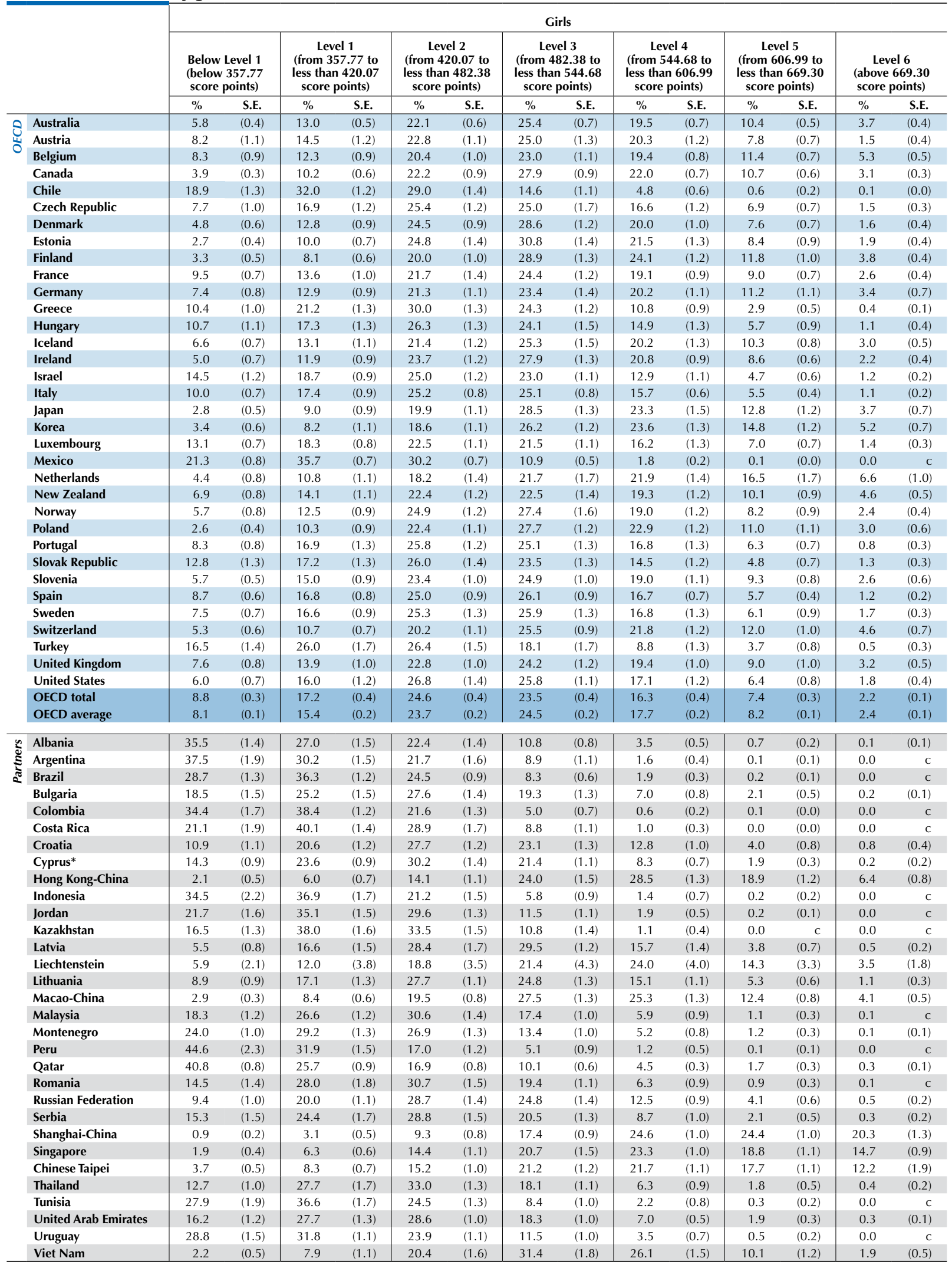

* See notes at the beginning of this Annex.

StatLink 需宁四 http://dx.doi.org/10.1787/888932935667 
[Part 1/1]

Mean score, variation and gender differences in student performance on the mathematics subscale Table 1.2.25 uncertainty and data

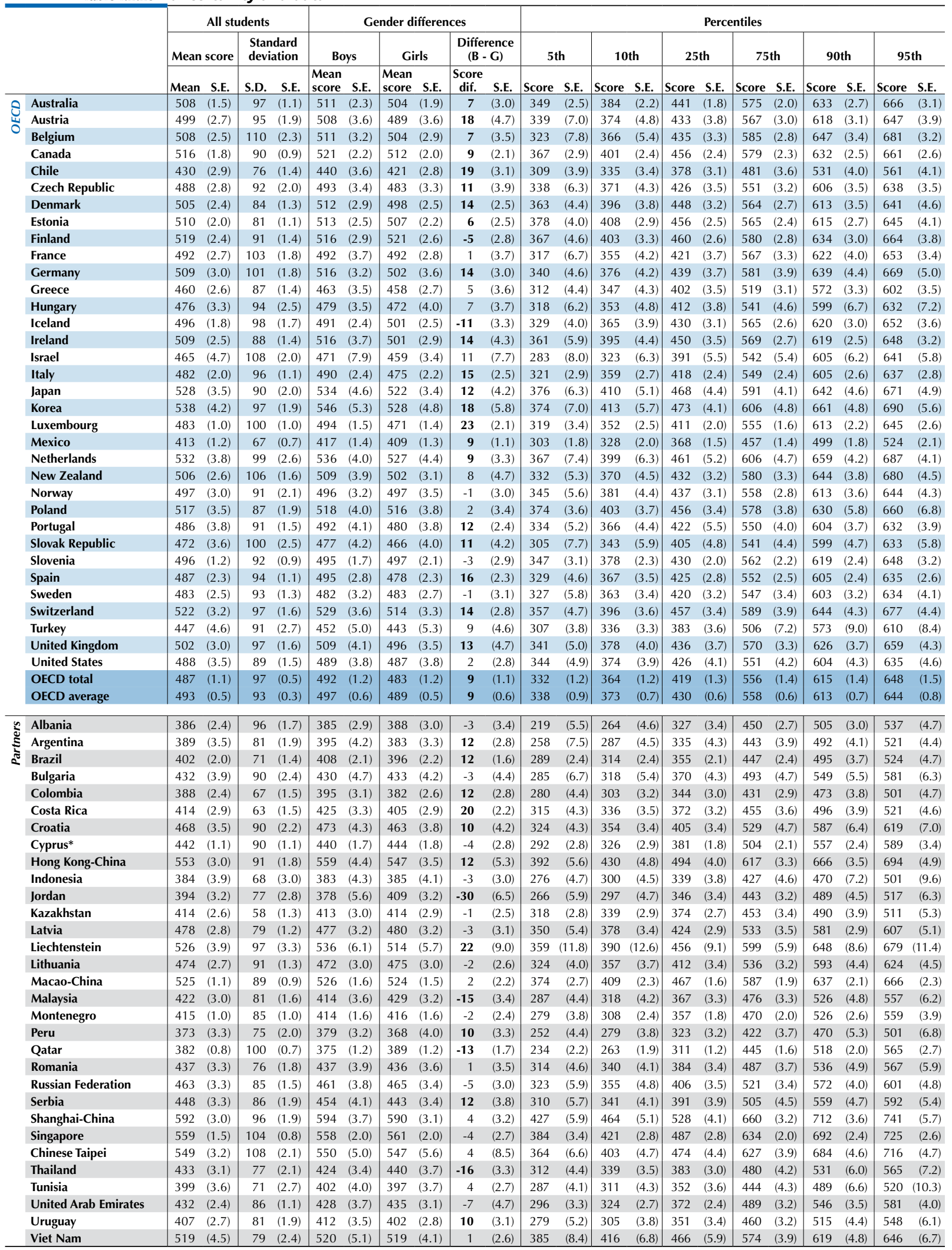

Note: Values that are statistically significant are indicated in bold (see Annex A3).

* See notes at the beginning of this Annex.

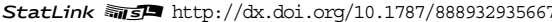


[Part 1/1]

Table I.2.26 Gender differences in performance in mathematics after taking student programmes into account

\begin{tabular}{|c|c|c|c|c|c|c|c|}
\hline & & \multicolumn{6}{|c|}{ Gender differences in mathematics performance (boys - girls) } \\
\hline & & \multicolumn{2}{|c|}{ Observed } & \multicolumn{2}{|c|}{ Within school } & \multicolumn{2}{|c|}{$\begin{array}{l}\text { After accounting for the programme level } \\
\text { and programme designation } \\
\text { in which students are enrolled }\end{array}$} \\
\hline & & Score dif. & S.E. & Score dif. & S.E. & Score dif. & S.E. \\
\hline \multirow{36}{*}{ రి } & Australia & 12 & $(3.1)$ & 14 & $(2.0)$ & 15 & $(2.0)$ \\
\hline & Austria & 22 & (4.9) & 27 & (2.8) & 29 & $(2.7)$ \\
\hline & Belgium & 11 & (3.4) & 20 & (1.9) & 21 & (1.8) \\
\hline & Canada & 10 & $(2.0)$ & 11 & $(1.5)$ & 13 & $(1.5)$ \\
\hline & Chile & 25 & (3.6) & 26 & (2.4) & 27 & (2.3) \\
\hline & Czech Republic & 12 & (4.6) & 24 & $(2.5)$ & 25 & (2.5) \\
\hline & Denmark & 14 & $(2.3)$ & 16 & $(2.1)$ & 16 & $(2.1)$ \\
\hline & Estonia & 5 & (2.6) & 8 & (2.5) & 8 & (2.5) \\
\hline & Finland & -3 & (2.9) & -2 & (2.5) & -2 & (2.5) \\
\hline & France & 9 & (3.4) & 19 & (2.8) & 21 & (2.8) \\
\hline & Germany & 14 & (2.8) & 25 & (2.2) & 25 & (2.2) \\
\hline & Greece & 8 & (3.2) & 21 & (2.7) & 22 & (2.7) \\
\hline & Hungary & 9 & (3.7) & 29 & (2.3) & 29 & (2.3) \\
\hline & Iceland & -6 & (3.0) & -7 & (4.1) & -7 & (4.1) \\
\hline & Ireland & 15 & (3.8) & 18 & (3.5) & 20 & (3.5) \\
\hline & Israel & 12 & (7.6) & 15 & (4.2) & 16 & (4.1) \\
\hline & Italy & 18 & (2.5) & 25 & (1.4) & 26 & (1.4) \\
\hline & Japan & 18 & $(4.3)$ & 14 & (2.4) & 14 & (2.4) \\
\hline & Korea & 18 & (6.2) & 10 & (3.6) & 12 & (3.5) \\
\hline & Luxembourg & 25 & (2.0) & 20 & $(4.2)$ & 24 & (3.4) \\
\hline & Mexico & 14 & $(1.2)$ & 17 & (1.1) & 18 & (1.1) \\
\hline & Netherlands & 10 & (2.8) & 17 & (2.1) & 18 & (2.1) \\
\hline & New Zealand & 15 & (4.3) & 18 & (3.4) & 19 & (3.4) \\
\hline & Norway & 2 & (3.0) & 2 & (2.9) & 2 & (2.9) \\
\hline & Poland & 4 & (3.4) & 7 & (2.9) & 7 & (2.9) \\
\hline & Portugal & 11 & (2.5) & 14 & (2.7) & 24 & (2.5) \\
\hline & Slovak Republic & 9 & (4.5) & 27 & (3.5) & 27 & (3.5) \\
\hline & Slovenia & 3 & (3.1) & 26 & (2.9) & 28 & (2.8) \\
\hline & Spain & 16 & (2.2) & 17 & (1.6) & 17 & (1.6) \\
\hline & Sweden & -3 & (3.0) & 0 & (3.1) & 0 & (3.1) \\
\hline & Switzerland & 13 & (2.7) & 22 & (3.2) & 21 & (3.0) \\
\hline & Turkey & 8 & (4.7) & 22 & (2.3) & 22 & (2.3) \\
\hline & United Kingdom & 12 & (4.7) & 13 & (2.5) & 13 & (2.5) \\
\hline & United States & 5 & (2.8) & 10 & (2.9) & 14 & (2.9) \\
\hline & OECD total & 12 & (1.1) & 17 & (1.0) & 19 & $(0.6)$ \\
\hline & OECD average & 11 & $(0.6)$ & 16 & $(0.5)$ & 17 & $(0.5)$ \\
\hline \multirow{31}{*}{ ఏ } & Albania & -1 & (3.3) & 2 & (3.3) & 2 & (3.3) \\
\hline & Argentina & 14 & (2.9) & 16 & (2.3) & 20 & (2.3) \\
\hline & Brazil & 18 & (1.8) & 22 & (1.5) & 24 & (1.6) \\
\hline & Bulgaria & -2 & (4.1) & 15 & (2.3) & 16 & (2.2) \\
\hline & Colombia & 25 & (3.2) & 26 & (2.1) & 30 & (1.8) \\
\hline & Costa Rica & 24 & (2.4) & 25 & (1.9) & 27 & (1.9) \\
\hline & Croatia & 12 & (4.1) & 28 & (2.8) & 32 & (2.7) \\
\hline & Cyprus* & 0 & (2.2) & 13 & (2.6) & 15 & (2.5) \\
\hline & Hong Kong-China & 15 & (5.7) & 24 & (3.0) & 26 & (3.0) \\
\hline & Indonesia & 5 & (3.4) & 7 & (1.8) & 7 & (1.8) \\
\hline & Jordan & -21 & (6.3) & 0 & (9.4) & 0 & (9.4) \\
\hline & Kazakhstan & 0 & (2.9) & 4 & (2.0) & 5 & (2.1) \\
\hline & Latvia & -4 & (3.6) & 3 & $(3.0)$ & 4 & (3.0) \\
\hline & Liechtenstein & 23 & (8.8) & 17 & $(7.2)$ & 21 & (6.5) \\
\hline & Lithuania & 0 & (2.4) & 10 & (2.7) & 10 & $(2.7)$ \\
\hline & Macao-China & 3 & (1.9) & 17 & (3.9) & 22 & $(2.7)$ \\
\hline & Malaysia & -8 & (3.8) & 0 & (2.5) & 2 & (2.4) \\
\hline & Montenegro & 0 & (2.4) & 15 & (3.5) & 18 & (3.0) \\
\hline & Peru & 19 & (3.9) & 28 & $(2.2)$ & 30 & $(2.1)$ \\
\hline & Qatar & -16 & (1.4) & -6 & (7.3) & -4 & (6.7) \\
\hline & Romania & 4 & (3.6) & 15 & (2.5) & 15 & (2.5) \\
\hline & Russian Federation & -2 & (3.0) & 3 & $(2.7)$ & 4 & (2.6) \\
\hline & Serbia & 9 & (3.9) & 24 & (2.8) & 27 & $(2.7)$ \\
\hline & Shanghai-China & 6 & (3.3) & 17 & (2.8) & 18 & (2.7) \\
\hline & Singapore & -3 & (2.5) & -1 & $(2.7)$ & -1 & (2.7) \\
\hline & Chinese Taipei & 5 & (8.9) & 2 & (2.9) & 2 & (2.9) \\
\hline & Thailand & -14 & (3.6) & 3 & (2.3) & 4 & (2.4) \\
\hline & Tunisia & 15 & $(2.7)$ & 25 & (1.9) & 26 & (1.9) \\
\hline & United Arab Emirates & -5 & $(4.7)$ & 4 & (5.1) & 6 & (4.6) \\
\hline & Uruguay & 11 & (3.1) & 21 & (2.0) & 25 & (1.9) \\
\hline & Viet Nam & 10 & (3.0) & 25 & $(2.2)$ & 25 & $(2.2)$ \\
\hline
\end{tabular}

Note: Values that are statistically significant are indicated in bold (see Annex A3).

1. Programme level indicates whether the student is in on the lower (ISCED level 2) or upper (ISCED level 3) secondary programme. Programme designation indicates the destination of the study programme: A, B or C (see Annex A1)

* See notes at the beginning of this Annex.

StatLink त्ताज http://dx.doi.org/10.1787/888932935667 
[Part 1/2]

Table I.2.27 Socio-economic indicators and the relationship with performance in mathematics

\begin{tabular}{|c|c|c|c|c|c|c|c|c|c|}
\hline & & \multicolumn{8}{|c|}{ Socio-economic indicators } \\
\hline & & $\begin{array}{c}\text { Mean } \\
\text { performance on } \\
\text { the mathematics } \\
\text { scale }\end{array}$ & $\begin{array}{l}\text { GDP per capita } \\
\text { (in equivalent } \\
\text { USD converted } \\
\text { using PPPS) }\end{array}$ & $\begin{array}{c}\text { Cumulative } \\
\text { expenditure per } \\
\text { student between } \\
\mathbf{6} \text { and } \mathbf{1 5} \text { years } \\
\text { (in equivalent } \\
\text { USD converted } \\
\text { using PPPS)1 }\end{array}$ & $\begin{array}{l}\text { Percentage of } \\
\text { 35-44 year-olds } \\
\text { with tertiary } \\
\text { education }^{1}\end{array}$ & $\begin{array}{c}\text { Proportion of } \\
\text { 15-year-olds with } \\
\text { an immigrant } \\
\text { background }\end{array}$ & $\begin{array}{c}\text { Share of students } \\
\text { in their own } \\
\text { country whose } \\
\text { PISA index } \\
\text { of economic, } \\
\text { social and } \\
\text { cultural status } \\
\text { is below -1 }\end{array}$ & $\begin{array}{c}\text { Size of } \\
\text { the } 15 \text {-year-old } \\
\text { student } \\
\text { population }\end{array}$ & Average index \\
\hline \multirow{35}{*}{ త్రి } & Australia & 504 & 40801 & 98025 & 41 & 22.2 & 6.8 & 288159 & 0.22 \\
\hline & Austria & 506 & 40411 & 116603 & 21 & 16.5 & 8.3 & 89073 & 0.07 \\
\hline & Belgium & 515 & 37878 & 97126 & 39 & 15.4 & 10.5 & 121493 & 0.22 \\
\hline & Canada & 518 & 40136 & 80397 & 58 & 29.6 & 5.6 & 409453 & 0.27 \\
\hline & Chile & 423 & 17312 & 32250 & 30 & 0.9 & 37.9 & 252733 & -0.74 \\
\hline & Czech Republic & 499 & 25364 & 54519 & 18 & 3.1 & 9.1 & 93214 & -0.34 \\
\hline & Denmark & 500 & 40600 & 109746 & 37 & 9.3 & 4.3 & 70854 & 0.51 \\
\hline & Estonia & 521 & 20093 & 55520 & 35 & 7.9 & 7.8 & 12438 & -0.20 \\
\hline & Finland & 519 & 36030 & 86233 & 47 & 3.4 & 4.0 & 62195 & 0.57 \\
\hline & France & 495 & 34395 & 83582 & 36 & 15.0 & 11.8 & 755447 & 0.01 \\
\hline & Germany & 514 & 37661 & 80796 & 29 & 13.1 & 9.9 & 798136 & -0.01 \\
\hline & Greece & 453 & 27539 & $\mathrm{~m}$ & 28 & 10.5 & 18.6 & 105096 & m \\
\hline & Hungary & 477 & 20625 & 46598 & 21 & 1.7 & 23.7 & 108816 & -0.57 \\
\hline & Iceland & 493 & 35509 & 93986 & 39 & 3.5 & 1.9 & 4491 & 0.51 \\
\hline & Ireland & 501 & 41000 & 93117 & 43 & 10.7 & 9.2 & 57979 & 0.42 \\
\hline & Israel & 466 & 26552 & 57013 & 50 & 18.5 & 8.9 & 113278 & -0.05 \\
\hline & Italy & 485 & 32110 & 84416 & 17 & 7.4 & 18.4 & 566973 & -0.29 \\
\hline & Japan & 536 & 35238 & 89724 & 51 & 0.3 & 10.0 & 1214756 & 0.64 \\
\hline & Korea & 554 & 28829 & 69037 & 49 & 0.0 & 9.5 & 672101 & 0.40 \\
\hline & Luxembourg & 490 & 84672 & 197598 & 40 & 47.0 & 18.7 & 6082 & 0.83 \\
\hline & Mexico & 413 & 15195 & 23913 & 15 & 1.3 & 56.0 & 1472875 & -1.32 \\
\hline & Netherlands & 523 & 41682 & 95072 & 34 & 10.8 & 5.9 & 193190 & 0.33 \\
\hline & New Zealand & 500 & 29629 & 70650 & 41 & 27.2 & 11.5 & 59118 & -0.28 \\
\hline & Norway & 489 & 44825 & 123591 & 42 & 9.7 & 2.6 & 64777 & 0.74 \\
\hline & Poland & 518 & 20034 & 57644 & 24 & 0.2 & 19.2 & 410700 & -0.37 \\
\hline & Portugal & 487 & 25519 & 70370 & 19 & 6.9 & 39.8 & 127537 & -0.72 \\
\hline & Slovak Republic & 482 & 23194 & 53160 & 17 & 0.7 & 15.0 & 59367 & -0.42 \\
\hline & Slovenia & 501 & 26649 & 91785 & 28 & 8.6 & 11.2 & 18935 & -0.06 \\
\hline & Spain & 484 & 31574 & 82178 & 37 & 9.9 & 23.1 & 404374 & -0.07 \\
\hline & Sweden & 478 & 39251 & 95831 & 39 & 15.1 & 5.7 & 102027 & 0.30 \\
\hline & Switzerland & 531 & 48962 & 127322 & 39 & 24.8 & 10.4 & 85239 & 0.39 \\
\hline & Turkey & 448 & 15775 & 19821 & 13 & 0.9 & 68.7 & 965736 & -1.53 \\
\hline & United Kingdom & 494 & 35299 & 98023 & 43 & 12.9 & 5.6 & 745581 & 0.36 \\
\hline & United States & 481 & 46548 & 115961 & 45 & 21.4 & 13.4 & 4074457 & 0.40 \\
\hline & OECD average & 494 & 33732 & 83382 & 34 & 11.4 & 15.4 & 429020 & 0.00 \\
\hline \multirow{31}{*}{ ఏ } & Albania & 394 & 8631 & $\mathrm{~m}$ & $\mathrm{~m}$ & 0.3 & $\mathrm{~m}$ & 50157 & $\mathrm{~m}$ \\
\hline & Argentina & 388 & 15868 & $\mathrm{~m}$ & $\mathrm{~m}$ & 3.8 & 41.2 & 637603 & $\mathrm{~m}$ \\
\hline & Brazil & 391 & 12537 & 26765 & 12 & 0.6 & 58.8 & 2786064 & -1.43 \\
\hline & Bulgaria & 439 & 14203 & 31944 & $\mathrm{~m}$ & 0.3 & 24.3 & 59684 & $\mathrm{~m}$ \\
\hline & Colombia & 376 & 9555 & 20362 & $\mathrm{~m}$ & 0.3 & 56.4 & 620422 & $\mathrm{~m}$ \\
\hline & Costa Rica & 407 & 11579 & $\mathrm{~m}$ & $\mathrm{~m}$ & 5.4 & 49.2 & 64326 & $\mathrm{~m}$ \\
\hline & Croatia & 471 & 19026 & 38992 & $\mathrm{~m}$ & 12.2 & 21.7 & 46550 & $\mathrm{~m}$ \\
\hline & Cyprus* & 440 & 30307 & 109575 & $\mathrm{~m}$ & 8.7 & $\mathrm{~m}$ & 9956 & $\mathrm{~m}$ \\
\hline & Hong Kong-China & 561 & 47274 & $\mathrm{~m}$ & $\mathrm{~m}$ & 37.7 & 45.2 & 77864 & $\mathrm{~m}$ \\
\hline & Indonesia & 375 & 4638 & $\mathrm{~m}$ & $\mathrm{~m}$ & 0.2 & 76.7 & 3599844 & $\mathrm{~m}$ \\
\hline & Jordan & 386 & 5752 & 7125 & $\mathrm{~m}$ & 13.5 & 27.9 & 125333 & $\mathrm{~m}$ \\
\hline & Kazakhstan & 432 & 12092 & $\mathrm{~m}$ & $\mathrm{~m}$ & 16.0 & 20.1 & 247048 & $\mathrm{~m}$ \\
\hline & Latvia & 491 & 16902 & 45342 & $\mathrm{~m}$ & 4.5 & 24.3 & 18389 & $\mathrm{~m}$ \\
\hline & Liechtenstein & 535 & $\mathrm{~m}$ & $\mathrm{~m}$ & $\mathrm{~m}$ & 37.2 & 9.4 & 383 & $\mathrm{~m}$ \\
\hline & Lithuania & 479 & 18022 & 44963 & $\mathrm{~m}$ & 1.5 & 21.5 & 35567 & $\mathrm{~m}$ \\
\hline & Macao-China & 538 & 60397 & $\mathrm{~m}$ & $\mathrm{~m}$ & 67.4 & 48.6 & 5416 & $\mathrm{~m}$ \\
\hline & Malaysia & 421 & 15077 & 16816 & $\mathrm{~m}$ & 1.7 & 40.5 & 457999 & $\mathrm{~m}$ \\
\hline & Montenegro & 410 & 13147 & 23913 & $\mathrm{~m}$ & 5.9 & 21.4 & 8600 & $\mathrm{~m}$ \\
\hline & Peru & 368 & 9350 & 12431 & $\mathrm{~m}$ & 0.5 & 59.9 & 508969 & $\mathrm{~m}$ \\
\hline & Qatar & 376 & 77265 & $\mathrm{~m}$ & $\mathrm{~m}$ & 52.7 & 7.0 & 11532 & $\mathrm{~m}$ \\
\hline & Romania & 445 & 14531 & $\mathrm{~m}$ & $\mathrm{~m}$ & 0.1 & 26.0 & 146243 & $\mathrm{~m}$ \\
\hline & Russian Federation & 482 & 19811 & $\mathrm{~m}$ & 55 & 10.6 & 12.3 & 1268814 & $\mathrm{~m}$ \\
\hline & Serbia & 449 & 11421 & $\mathrm{~m}$ & $\mathrm{~m}$ & 8.5 & 24.0 & 75870 & $\mathrm{~m}$ \\
\hline & Shanghai-China & 613 & 18805 & 49006 & $\mathrm{~m}$ & 0.9 & 27.2 & 90796 & $\mathrm{~m}$ \\
\hline & Singapore & 573 & 57799 & 85284 & $\mathrm{~m}$ & 18.7 & 21.3 & 52163 & $\mathrm{~m}$ \\
\hline & Chinese Taipei & 560 & 29255 & $\mathrm{~m}$ & $\mathrm{~m}$ & 0.5 & 24.7 & 328336 & $\mathrm{~m}$ \\
\hline & Thailand & 427 & 9748 & 13964 & $\mathrm{~m}$ & 0.7 & 64.4 & 784897 & $\mathrm{~m}$ \\
\hline & Tunisia & 388 & 9410 & 21504 & $\mathrm{~m}$ & 0.4 & 54.4 & 132313 & $\mathrm{~m}$ \\
\hline & United Arab Emirates & 434 & 46916 & $\mathrm{~m}$ & $\mathrm{~m}$ & 55.3 & 7.3 & 48446 & $\mathrm{~m}$ \\
\hline & Uruguay & 409 & 14004 & 19068 & $\mathrm{~m}$ & 0.4 & 50.4 & 46442 & $\mathrm{~m}$ \\
\hline & Viet Nam & 511 & 4098 & 6969 & $\mathrm{~m}$ & 0.1 & 78.9 & 1091462 & $\mathrm{~m}$ \\
\hline
\end{tabular}

1. OECD, Education at a Glance 2013: OECD Indicators.

* See notes at the beginning of this Annex.

StatLink त्राज् http://dx.doi.org/10.1787/888932935667 
[Part 2/2]

Table I.2.27 Socio-economic indicators and the relationship with performance in mathematics

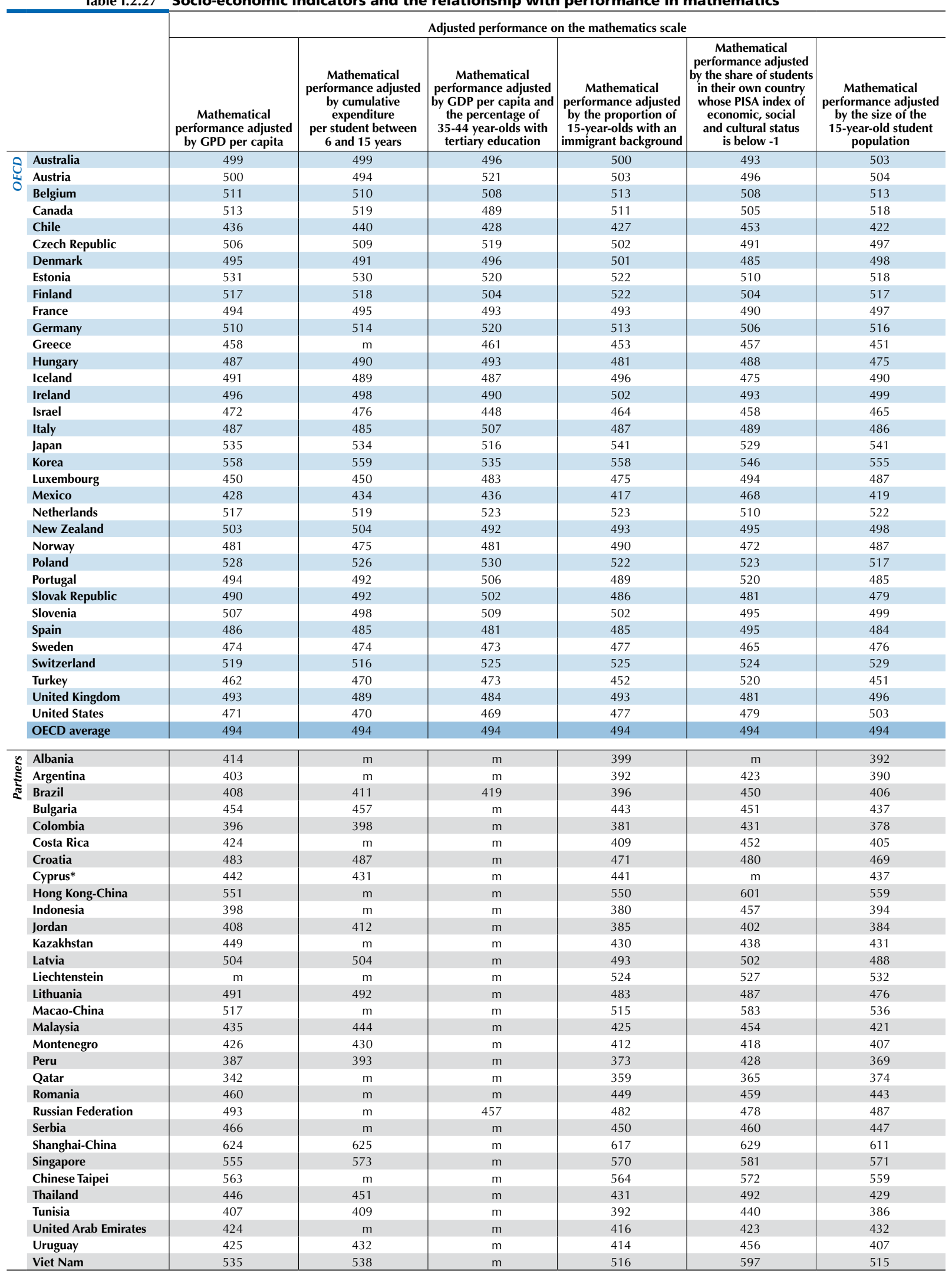

1. OECD, Education at a Glance 2013: OECD Indicators

* See notes at the beginning of this Annex.

StatLink 部 5 Rttp://dx.doi.org/10.1787/888932935667 
[Part 1/1]

Table I.2.28 Country rankings on preferred questions

\begin{tabular}{|c|c|c|c|c|c|c|}
\hline & & $\begin{array}{l}\text { PISA } 2009 \text { initial report } \\
\text { reading performance rank }\end{array}$ & $\begin{array}{l}\text { Percent-correct rank based } \\
\text { on all PISA } 2009 \text { items }\end{array}$ & $\begin{array}{l}\text { Rank on own preferred new } \\
\text { PISA } 2009 \text { items and link } \\
\text { items from previous cycles }\end{array}$ & $\begin{array}{l}\text { Percent-correct rank based } \\
\text { on new PISA } 2009 \text { items }\end{array}$ & $\begin{array}{l}\text { Rank on own preferred } \\
\text { new PISA } 2009 \text { items }\end{array}$ \\
\hline \multirow{34}{*}{ తి } & Australia & 8 & 8 & 7 & 7 & 8 \\
\hline & Austria & 33 & 35 & 26 & 26 & 36 \\
\hline & Belgium & 10 & 10 & 16 & 16 & 10 \\
\hline & Canada & 5 & 5 & 5 & 5 & 5 \\
\hline & Chile & 38 & 30 & 25 & 25 & 24 \\
\hline & Czech Republic & 29 & 31 & 30 & 30 & 33 \\
\hline & Denmark & $\mathrm{m}$ & $\mathrm{m}$ & $\mathrm{m}$ & $\mathrm{m}$ & $\mathrm{m}$ \\
\hline & Estonia & 12 & 14 & 12 & 12 & 16 \\
\hline & Finland & 3 & 3 & 2 & 2 & 3 \\
\hline & France & 19 & 20 & 17 & 17 & 18 \\
\hline & Germany & 17 & 15 & 10 & 10 & 19 \\
\hline & Greece & 27 & 29 & 32 & 32 & 29 \\
\hline & Hungary & 22 & 21 & 23 & 23 & 21 \\
\hline & Iceland & $\mathrm{m}$ & $\mathrm{m}$ & $\mathrm{m}$ & $\mathrm{m}$ & $\mathrm{m}$ \\
\hline & Ireland & 18 & 16 & 19 & 19 & 12 \\
\hline & Israel & 31 & 33 & 31 & 31 & 32 \\
\hline & Italy & 25 & 25 & 27 & 27 & 27 \\
\hline & Japan & 7 & 7 & 6 & 6 & 6 \\
\hline & Korea & 2 & 2 & 3 & 3 & 2 \\
\hline & Luxembourg & 32 & 34 & 35 & 35 & 34 \\
\hline & Mexico & 41 & 40 & 39 & 39 & 41 \\
\hline & Netherlands & 9 & 9 & 11 & 11 & 9 \\
\hline & New Zealand & 6 & 6 & 8 & 8 & 7 \\
\hline & Norway & 11 & 12 & 13 & 13 & 11 \\
\hline & Poland & 14 & 11 & 21 & 21 & 13 \\
\hline & Portugal & 23 & 23 & 20 & 20 & 26 \\
\hline & Slovak Republic & $\mathrm{m}$ & $\mathrm{m}$ & $\mathrm{m}$ & $\mathrm{m}$ & $\mathrm{m}$ \\
\hline & Slovenia & 26 & 27 & 28 & 28 & 30 \\
\hline & Spain & 28 & 28 & 34 & 34 & 28 \\
\hline & Sweden & 16 & 18 & 18 & 18 & 23 \\
\hline & Switzerland & 13 & 13 & 14 & 14 & 14 \\
\hline & Turkey & 35 & 37 & 36 & 36 & 38 \\
\hline & United Kingdom & 21 & 22 & 15 & 15 & 22 \\
\hline & United States & 15 & 17 & 9 & 9 & 17 \\
\hline \multirow{31}{*}{ 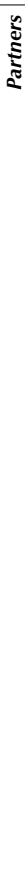 } & Albania & 51 & 49 & 48 & 48 & 48 \\
\hline & Argentina & $\mathrm{m}$ & $\mathrm{m}$ & $\mathrm{m}$ & $\mathrm{m}$ & $\mathrm{m}$ \\
\hline & Azerbaijan & $\mathrm{m}$ & $\mathrm{m}$ & $\mathrm{m}$ & $\mathrm{m}$ & $\mathrm{m}$ \\
\hline & Brazil & 45 & 45 & 44 & 44 & 44 \\
\hline & Bulgaria & 39 & 39 & 42 & 42 & 35 \\
\hline & Colombia & 44 & 44 & 45 & 45 & 45 \\
\hline & Croatia & 30 & 32 & 33 & 33 & 31 \\
\hline & Dubai (UAE) & 36 & 26 & 29 & 29 & 15 \\
\hline & Hong Kong-China & 4 & 4 & 4 & 4 & 4 \\
\hline & Indonesia & 49 & 54 & 50 & 50 & 54 \\
\hline & Jordan & 47 & 46 & 46 & 46 & 46 \\
\hline & Kazakhstan & 50 & 48 & 49 & 49 & 49 \\
\hline & Kyrgyzstan & 55 & 55 & 55 & 55 & 55 \\
\hline & Latvia & $\mathrm{m}$ & $\mathrm{m}$ & $\mathrm{m}$ & $\mathrm{m}$ & $\mathrm{m}$ \\
\hline & Liechtenstein & $\mathrm{m}$ & $\mathrm{m}$ & $\mathrm{m}$ & $\mathrm{m}$ & $\mathrm{m}$ \\
\hline & Lithuania & 34 & 36 & 38 & 38 & 37 \\
\hline & Macao-China & 24 & 24 & 24 & 24 & 25 \\
\hline & Montenegro & 46 & 50 & 51 & 51 & 51 \\
\hline & Panama & 53 & 53 & 54 & 54 & 52 \\
\hline & Peru & 54 & 52 & 52 & 52 & 53 \\
\hline & Qatar & 52 & 51 & 53 & 53 & 50 \\
\hline & Romania & 42 & 42 & 40 & 40 & 39 \\
\hline & Russian Federation & 37 & 38 & 37 & 37 & 43 \\
\hline & Serbia & $\mathrm{m}$ & $\mathrm{m}$ & $\mathrm{m}$ & $\mathrm{m}$ & $\mathrm{m}$ \\
\hline & Shanghai-China & 1 & 1 & 1 & 1 & 1 \\
\hline & Singapore & $\mathrm{m}$ & $\mathrm{m}$ & $\mathrm{m}$ & $\mathrm{m}$ & $\mathrm{m}$ \\
\hline & Chinese Taipei & 20 & 19 & 22 & 22 & 20 \\
\hline & Thailand & $\mathrm{m}$ & $\mathrm{m}$ & $\mathrm{m}$ & $\mathrm{m}$ & $\mathrm{m}$ \\
\hline & Trinidad and Tobago & 43 & 43 & 43 & 43 & 42 \\
\hline & Tunisia & 48 & 47 & 47 & 47 & 47 \\
\hline & Uruguay & 40 & 41 & 41 & 41 & 40 \\
\hline
\end{tabular}

Source: OECD, PISA 2009 Database.

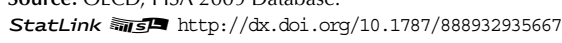


[Part 1/1]

Table I.2.29 Top performers in mathematics, reading and science

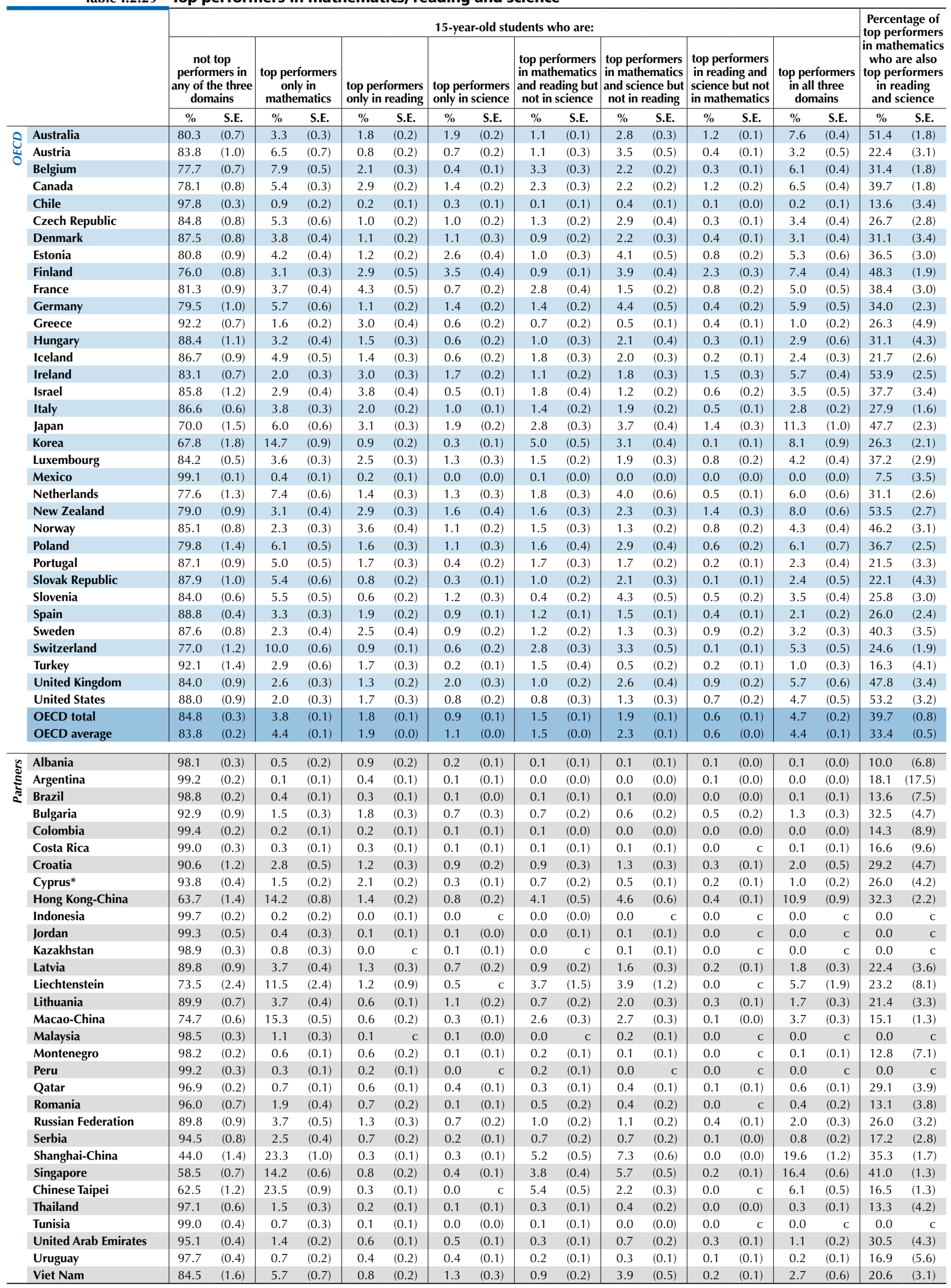

* See notes at the beginning of this Annex.

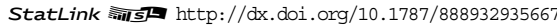


[Part 1/2]

Table I.2.30 Top performers in mathematics, reading and science, by gender

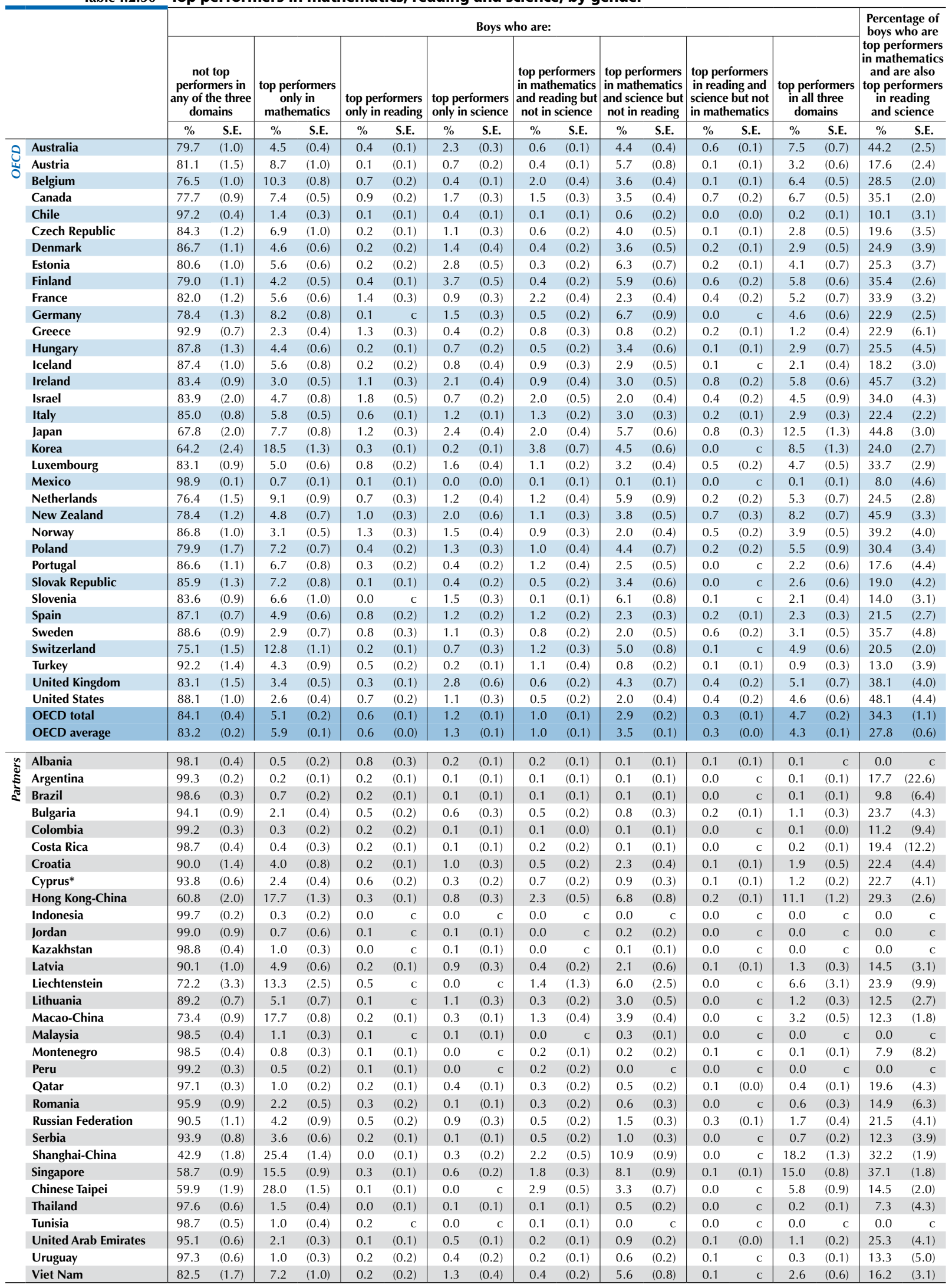

* See notes at the beginning of this Annex.

StatLink त्राजा http://dx.doi.org/10.1787/888932935667 
[Part 2/2]

Table 1.2.30 Top performers in mathematics, reading and science, by gender

\begin{tabular}{|c|c|c|c|c|c|c|c|c|c|c|c|c|c|c|c|c|c|c|c|}
\hline & \multicolumn{16}{|c|}{ Girls who are: } & \multirow{2}{*}{\multicolumn{2}{|c|}{$\begin{array}{l}\text { Percentage of } \\
\text { girls who are } \\
\text { top performers } \\
\text { in mathematics } \\
\text { and are also } \\
\text { top performers } \\
\text { in reading } \\
\text { and science }\end{array}$}} \\
\hline & & \multicolumn{2}{|c|}{$\begin{array}{c}\text { not top } \\
\text { performers in } \\
\text { any of the three } \\
\text { domains }\end{array}$} & \multicolumn{2}{|c|}{$\begin{array}{c}\text { top performers } \\
\text { only in } \\
\text { mathematics }\end{array}$} & $\begin{array}{l}\text { top pe } \\
\text { only in }\end{array}$ & $\begin{array}{l}\text { ormers } \\
\text { eading }\end{array}$ & $\begin{array}{l}\text { top pe } \\
\text { only in }\end{array}$ & \begin{tabular}{l|l} 
& $t$ \\
ormers \\
cience
\end{tabular} & $\begin{array}{l}\text { top per } \\
\text { in math } \\
\text { and rea } \\
\text { not in }\end{array}$ & $\begin{array}{l}\text { formers } \\
\text { ematics } \\
\text { ling but } \\
\text { cience }\end{array}$ & $\begin{array}{l}\text { top per } \\
\text { in math } \\
\text { and scie } \\
\text { not in }\end{array}$ & $\begin{array}{l}\text { ormers } \\
\text { ematics } \\
\text { nce but } \\
\text { eading }\end{array}$ & $\begin{array}{l}\text { top pe } \\
\text { in reac } \\
\text { scienc } \\
\text { in mat }\end{array}$ & $\begin{array}{l}\text { ormers } \\
\text { ng and } \\
\text { but not } \\
\text { ematics }\end{array}$ & $\begin{array}{r}\text { top per } \\
\text { in all } \\
\text { dom }\end{array}$ & $\begin{array}{l}\text { ormers } \\
\text { hree } \\
\text { ins }\end{array}$ & & \\
\hline & & $\%$ & S.E. & $\%$ & S.E. & $\%$ & S.E. & $\%$ & S.E. & $\%$ & S.E. & $\%$ & S.E. & $\%$ & S.E. & $\%$ & S.E. & $\%$ & S.E. \\
\hline 0 & Australia & 80.9 & (0.8) & 2.0 & $(0.3)$ & 3.2 & $(0.4)$ & 1.5 & (0.3) & 1.6 & $(0.3)$ & 1.1 & $(0.2)$ & 1.9 & $(0.3)$ & 7.7 & $(0.5)$ & 61.8 & (2.4) \\
\hline & Austria & 86.4 & (1.1) & 4.2 & (0.6) & 1.5 & (0.4) & 0.7 & $(0.2)$ & 1.8 & $(0.5)$ & 1.3 & (0.4) & 0.8 & $(0.3)$ & 3.2 & $(0.7)$ & 30.6 & (5.6) \\
\hline & Belgium & 78.9 & $(0.9)$ & 5.5 & $(0.5)$ & 3.5 & $(0.5)$ & 0.4 & $(0.1)$ & 4.6 & $(0.4)$ & 0.8 & $(0.2)$ & 0.4 & $(0.1)$ & 5.9 & $(0.4)$ & 35.3 & (2.4) \\
\hline & Canada & 78.6 & (0.9) & 3.5 & (0.4) & 4.8 & (0.4) & 1.1 & $(0.3)$ & 3.1 & $(0.3)$ & 0.9 & $(0.2)$ & 1.7 & $(0.3)$ & 6.3 & $(0.6)$ & 45.9 & (3.7) \\
\hline & Chile & 98.4 & $(0.3)$ & 0.4 & $(0.1)$ & 0.3 & $(0.1)$ & 0.3 & $(0.1)$ & 0.1 & $(0.1)$ & 0.2 & $(0.1)$ & 0.1 & $(0.1)$ & 0.2 & $(0.1)$ & 21.7 & (9.0) \\
\hline & Czech Republic & 85.3 & (1.0) & 3.6 & $(0.5)$ & 1.9 & $(0.4)$ & 0.9 & $(0.3)$ & 2.0 & $(0.4)$ & 1.7 & (0.5) & 0.5 & $(0.2)$ & 4.1 & $(0.5)$ & 36.4 & (3.5) \\
\hline & Denmark & 88.4 & $(1.0)$ & 3.0 & $(0.6)$ & 1.9 & $(0.5)$ & 0.8 & $(0.3)$ & 1.4 & $(0.4)$ & 0.7 & $(0.2)$ & 0.6 & $(0.2)$ & 3.3 & $(0.6)$ & 39.6 & (5.8) \\
\hline & Estonia & 81.1 & $(1.2)$ & 2.8 & $(0.5)$ & 2.1 & $(0.4)$ & 2.5 & (0.5) & 1.8 & $(0.5)$ & 1.9 & $(0.4)$ & 1.4 & (0.3) & 6.5 & $(0.7)$ & 50.4 & (4.4) \\
\hline & Finland & 72.9 & (1.1) & 1.9 & $(0.4)$ & 5.5 & (0.9) & 3.3 & $(0.6)$ & 1.6 & $(0.3)$ & 1.7 & $(0.4)$ & 4.1 & $(0.5)$ & 9.0 & $(0.7)$ & 63.9 & (3.0) \\
\hline & France & 80.7 & (1.1) & 1.9 & $(0.5)$ & 7.1 & $(0.8)$ & 0.4 & $(0.2)$ & 3.3 & $(0.6)$ & 0.7 & $(0.3)$ & 1.2 & $(0.3)$ & 4.7 & $(0.6)$ & 44.6 & (4.6) \\
\hline & Germany & 80.7 & $(1.2)$ & 3.2 & $(0.6)$ & 2.3 & $(0.4)$ & 1.3 & $(0.4)$ & 2.4 & $(0.4)$ & 1.9 & $(0.4)$ & 0.8 & $(0.3)$ & 7.4 & $(0.8)$ & 49.5 & (3.9) \\
\hline & Greece & 91.4 & $(1.0)$ & 0.9 & $(0.2)$ & 4.7 & (0.6) & 0.7 & $(0.3)$ & 0.7 & $(0.3)$ & 0.3 & $(0.1)$ & 0.5 & $(0.2)$ & 0.9 & $(0.2)$ & 32.6 & (8.1) \\
\hline & Hungary & 88.9 & $(1.2)$ & 2.1 & $(0.4)$ & 2.6 & $(0.5)$ & 0.6 & $(0.3)$ & 1.5 & $(0.4)$ & 0.9 & $(0.3)$ & 0.4 & $(0.2)$ & 2.9 & $(0.6)$ & 38.9 & (5.4) \\
\hline & Iceland & 85.9 & (1.4) & 4.2 & $(0.7)$ & 2.6 & (0.5) & 0.4 & $(0.3)$ & 2.7 & $(0.4)$ & 1.1 & (0.4) & 0.3 & $(0.2)$ & 2.8 & $(0.6)$ & 25.4 & (4.1) \\
\hline & Ireland & 82.9 & (1.0) & 0.9 & $(0.3)$ & 5.1 & $(0.7)$ & 1.2 & $(0.4)$ & 1.4 & $(0.3)$ & 0.5 & $(0.2)$ & 2.3 & $(0.5)$ & 5.7 & $(0.7)$ & 66.5 & (4.6) \\
\hline & Israel & 87.6 & (0.9) & 1.1 & $(0.2)$ & 5.7 & $(0.7)$ & 0.4 & $(0.2)$ & 1.5 & $(0.4)$ & 0.4 & $(0.1)$ & 0.7 & $(0.2)$ & 2.6 & $(0.4)$ & 46.2 & (5.9) \\
\hline & Italy & 88.3 & $(0.6)$ & 1.7 & $(0.2)$ & 3.5 & $(0.3)$ & 0.8 & $(0.2)$ & 1.6 & $(0.2)$ & 0.7 & $(0.1)$ & 0.7 & $(0.1)$ & 2.6 & $(0.2)$ & 39.6 & (3.7) \\
\hline & Japan & 72.4 & (1.7) & 4.0 & $(0.7)$ & 5.1 & (0.6) & 1.4 & $(0.3)$ & 3.6 & $(0.5)$ & 1.4 & $(0.5)$ & 2.0 & $(0.4)$ & 10.0 & (1.1) & 52.3 & $(4.0)$ \\
\hline & Korea & 71.9 & (2.0) & 10.2 & $(1.2)$ & 1.7 & $(0.4)$ & 0.4 & $(0.2)$ & 6.3 & $(0.8)$ & 1.6 & $(0.5)$ & 0.2 & $(0.1)$ & 7.8 & (1.1) & 30.0 & (3.1) \\
\hline & Luxembourg & 85.4 & $(0.6)$ & 2.2 & $(0.5)$ & 4.2 & (0.6) & 1.0 & $(0.4)$ & 1.9 & $(0.3)$ & 0.6 & $(0.2)$ & 1.1 & $(0.3)$ & 3.6 & $(0.5)$ & 43.4 & (6.0) \\
\hline & Mexico & 99.3 & $(0.1)$ & 0.2 & $(0.1)$ & 0.3 & $(0.1)$ & 0.0 & $(0.0)$ & 0.1 & $(0.0)$ & 0.0 & $(0.0)$ & 0.0 & c & 0.0 & $(0.0)$ & 5.9 & (4.0) \\
\hline & Netherlands & 78.8 & (1.5) & 5.6 & (0.9) & 2.2 & $(0.6)$ & 1.3 & $(0.4)$ & 2.5 & $(0.6)$ & 2.1 & $(0.6)$ & 0.8 & $(0.2)$ & 6.8 & (1.0) & 39.9 & (4.8) \\
\hline & New Zealand & 79.7 & (1.4) & 1.3 & $(0.4)$ & 5.0 & $(0.6)$ & 1.1 & $(0.3)$ & 2.1 & $(0.5)$ & 0.7 & $(0.2)$ & 2.2 & $(0.6)$ & 7.8 & $(0.9)$ & 65.4 & (5.0) \\
\hline & Norway & 83.3 & (1.3) & 1.4 & $(0.3)$ & 6.0 & (0.9) & 0.8 & $(0.2)$ & 2.1 & $(0.4)$ & 0.6 & $(0.2)$ & 1.1 & $(0.4)$ & 4.8 & $(0.7)$ & 54.4 & (4.5) \\
\hline & Poland & 79.8 & (1.5) & 5.0 & $(0.6)$ & 2.8 & $(0.5)$ & 1.0 & $(0.5)$ & 2.2 & $(0.5)$ & 1.5 & $(0.4)$ & 1.0 & $(0.3)$ & 6.7 & $(0.8)$ & 43.7 & (3.2) \\
\hline & Portugal & 87.6 & (0.9) & 3.3 & $(0.5)$ & 3.0 & $(0.5)$ & 0.4 & $(0.2)$ & 2.1 & $(0.4)$ & 0.8 & $(0.3)$ & 0.3 & $(0.1)$ & 2.4 & $(0.4)$ & 27.3 & (4.5) \\
\hline & Slovak Republic & 90.0 & (1.1) & 3.5 & $(0.7)$ & 1.5 & $(0.4)$ & 0.2 & $(0.1)$ & 1.7 & $(0.4)$ & 0.7 & $(0.3)$ & 0.2 & $(0.1)$ & 2.2 & $(0.6)$ & 27.9 & (7.0) \\
\hline & Slovenia & 84.4 & $(0.9)$ & 4.3 & $(0.7)$ & 1.2 & $(0.4)$ & 0.9 & $(0.3)$ & 0.7 & $(0.3)$ & 2.4 & $(0.6)$ & 1.0 & $(0.5)$ & 5.1 & $(0.8)$ & 40.7 & (5.9) \\
\hline & Spain & 90.5 & $(0.5)$ & 1.7 & $(0.2)$ & 3.0 & $(0.3)$ & 0.6 & $(0.1)$ & 1.1 & $(0.2)$ & 0.6 & $(0.1)$ & 0.5 & $(0.1)$ & 1.9 & $(0.2)$ & 35.0 & (3.5) \\
\hline & Sweden & 86.6 & (1.0) & 1.6 & $(0.3)$ & 4.3 & (0.6) & 0.7 & $(0.2)$ & 1.7 & $(0.4)$ & 0.5 & $(0.2)$ & 1.3 & $(0.3)$ & 3.3 & $(0.4)$ & 46.2 & (4.7) \\
\hline & Switzerland & 78.8 & (1.3) & 7.2 & $(0.8)$ & 1.7 & $(0.3)$ & 0.5 & $(0.2)$ & 4.4 & $(0.5)$ & 1.6 & $(0.4)$ & 0.2 & $(0.1)$ & 5.6 & $(0.7)$ & 29.9 & (2.8) \\
\hline & Turkey & 91.9 & (1.5) & 1.5 & $(0.5)$ & 3.0 & (0.6) & 0.1 & $(0.1)$ & 1.9 & $(0.6)$ & 0.3 & $(0.2)$ & 0.2 & $(0.2)$ & 1.0 & $(0.3)$ & 21.6 & (6.3) \\
\hline & United Kingdom & 84.8 & $(1.2)$ & 1.8 & $(0.3)$ & 2.2 & $(0.4)$ & 1.3 & $(0.4)$ & 1.4 & $(0.4)$ & 1.0 & $(0.4)$ & 1.4 & $(0.5)$ & 6.2 & $(0.8)$ & 59.9 & $(4.2)$ \\
\hline & United States & 87.8 & (1.1) & 1.4 & $(0.4)$ & 2.8 & $(0.5)$ & 0.5 & $(0.2)$ & 1.2 & $(0.5)$ & 0.6 & $(0.2)$ & 1.0 & $(0.4)$ & 4.7 & $(0.7)$ & 59.7 & (3.8) \\
\hline & OECD total & 85.6 & $(0.4)$ & 2.4 & $(0.1)$ & 3.0 & $(0.2)$ & 0.7 & $(0.1)$ & 1.9 & $(0.2)$ & 0.8 & $(0.1)$ & 0.9 & $(0.1)$ & 4.7 & $(0.2)$ & 47.5 & (1.4) \\
\hline & OECD average & 84.4 & $(0.2)$ & 2.9 & $(0.1)$ & 3.2 & $(0.1)$ & 0.9 & $(0.1)$ & 2.1 & $(0.1)$ & 1.0 & $(0.1)$ & 1.0 & $(0.1)$ & 4.6 & $(0.1)$ & 41.5 & $(0.8)$ \\
\hline 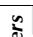 & Albania & 98.1 & (0.4) & 0.5 & $(0.2)$ & 0.9 & $(0.3)$ & 0.2 & c & 0.1 & $(0.1)$ & 0.1 & $(0.1)$ & 0.0 & c & 0.1 & $(0.1)$ & 11.1 & $(8.8)$ \\
\hline & Argentina & 99.1 & $(0.2)$ & 0.1 & $(0.1)$ & 0.6 & $(0.2)$ & 0.1 & $(0.1)$ & 0.1 & C & 0.0 & C & 0.1 & $(0.1)$ & 0.0 & C & 0.0 & c \\
\hline & Brazil & 99.0 & $(0.3)$ & 0.2 & $(0.1)$ & 0.4 & $(0.1)$ & 0.1 & $(0.1)$ & 0.1 & $(0.1)$ & 0.1 & $(0.1)$ & 0.0 & $(0.0)$ & 0.1 & $(0.1)$ & 21.6 & $(15.2)$ \\
\hline & Bulgaria & 91.7 & (1.1) & 0.8 & $(0.3)$ & 3.2 & (0.6) & 0.7 & $(0.3)$ & 0.9 & $(0.2)$ & 0.3 & $(0.1)$ & 0.8 & $(0.3)$ & 1.6 & $(0.4)$ & 44.2 & $(7.4)$ \\
\hline & Colombia & 99.6 & $(0.2)$ & 0.1 & c & 0.2 & $(0.1)$ & 0.0 & c & 0.1 & $(0.1)$ & 0.0 & c & 0.0 & $(0.0)$ & 0.0 & $(0.0)$ & 21.9 & $(20.0)$ \\
\hline & Costa Rica & 99.3 & $(0.2)$ & 0.1 & $(0.1)$ & 0.5 & $(0.2)$ & 0.1 & c & 0.1 & $(0.1)$ & 0.0 & C & 0.0 & c & 0.0 & C & 0.0 & C \\
\hline & Croatia & 91.2 & (1.3) & 1.4 & $(0.4)$ & 2.2 & (0.6) & 0.8 & $(0.2)$ & 1.3 & $(0.4)$ & 0.4 & $(0.2)$ & 0.5 & $(0.2)$ & 2.1 & $(0.7)$ & 41.2 & (7.1) \\
\hline & Cyprus* & 93.7 & (0.6) & 0.6 & $(0.2)$ & 3.6 & (0.4) & 0.2 & $(0.2)$ & 0.8 & $(0.3)$ & 0.1 & $(0.1)$ & 0.3 & $(0.1)$ & 0.7 & $(0.3)$ & 34.0 & (10.6) \\
\hline & Hong Kong-China & 67.0 & (2.0) & 10.1 & $(1.0)$ & 2.7 & $(0.4)$ & 0.8 & $(0.3)$ & 6.1 & $(0.9)$ & 1.9 & $(0.5)$ & 0.7 & $(0.2)$ & 10.7 & (1.2) & 37.1 & (3.0) \\
\hline & Indonesia & 99.7 & $(0.2)$ & 0.2 & $(0.1)$ & 0.1 & $(0.1)$ & 0.0 & c & 0.0 & c & 0.0 & c & 0.0 & c & 0.0 & c & 0.0 & c \\
\hline & Jordan & 99.6 & $(0.3)$ & 0.1 & $(0.1)$ & 0.1 & $(0.1)$ & 0.1 & $(0.1)$ & 0.2 & c & 0.0 & c & 0.0 & c & 0.0 & c & 0.0 & c \\
\hline & Kazakhstan & 99.1 & $(0.4)$ & 0.7 & $(0.3)$ & 0.0 & c & 0.1 & $(0.1)$ & 0.0 & c & 0.1 & $(0.1)$ & 0.0 & c & 0.0 & C & 0.0 & $\mathrm{C}$ \\
\hline & Latvia & 89.4 & $(1.2)$ & 2.5 & $(0.5)$ & 2.3 & (0.6) & 0.6 & $(0.2)$ & 1.3 & $(0.3)$ & 1.1 & $(0.3)$ & 0.4 & $(0.1)$ & 2.3 & $(0.5)$ & 32.1 & (5.6) \\
\hline & Liechtenstein & 74.8 & (3.6) & 9.5 & (4.8) & 2.2 & (1.9) & 0.9 & c & 6.4 & (2.9) & 1.4 & (1.4) & 0.0 & c & 4.8 & (2.7) & 21.8 & $(12.9)$ \\
\hline & Lithuania & 90.7 & $(0.9)$ & 2.2 & $(0.4)$ & 1.1 & $(0.3)$ & 1.1 & $(0.3)$ & 1.1 & $(0.4)$ & 0.9 & $(0.3)$ & 0.5 & $(0.3)$ & 2.3 & $(0.5)$ & 34.6 & (6.9) \\
\hline & Macao-China & 76.2 & $(0.8)$ & 12.9 & $(0.9)$ & 1.1 & (0.3) & 0.2 & $(0.2)$ & 4.0 & $(0.5)$ & 1.4 & $(0.4)$ & 0.1 & c & 4.1 & $(0.5)$ & 18.4 & (2.3) \\
\hline & Malaysia & 98.5 & $(0.4)$ & 1.1 & $(0.4)$ & 0.2 & c & 0.1 & $(0.1)$ & 0.0 & c & 0.1 & $(0.1)$ & 0.0 & c & 0.0 & c & 0.0 & $\mathrm{C}$ \\
\hline & Montenegro & 98.0 & (0.5) & 0.3 & $(0.2)$ & 1.1 & $(0.3)$ & 0.1 & $(0.1)$ & 0.3 & $(0.2)$ & 0.1 & c & 0.0 & c & 0.2 & $(0.1)$ & 21.9 & (14.5) \\
\hline & Peru & 99.2 & $(0.3)$ & 0.2 & $(0.1)$ & 0.4 & $(0.2)$ & 0.0 & C & 0.2 & $(0.2)$ & 0.0 & c & 0.0 & c & 0.0 & c & 0.0 & $\mathrm{C}$ \\
\hline & Qatar & 96.7 & $(0.2)$ & 0.4 & $(0.1)$ & 1.0 & $(0.2)$ & 0.3 & $(0.1)$ & 0.4 & $(0.1)$ & 0.3 & $(0.1)$ & 0.2 & $(0.1)$ & 0.8 & $(0.1)$ & 41.3 & (6.6) \\
\hline & Romania & 96.2 & $(0.7)$ & 1.6 & $(0.4)$ & 1.0 & $(0.3)$ & 0.1 & $(0.1)$ & 0.6 & $(0.2)$ & 0.2 & $(0.2)$ & 0.0 & C & 0.3 & $(0.2)$ & 10.5 & (5.2) \\
\hline & Russian Federation & 89.1 & (1.1) & 3.2 & $(0.5)$ & 2.1 & (0.5) & 0.5 & $(0.3)$ & 1.5 & $(0.4)$ & 0.8 & $(0.2)$ & 0.5 & $(0.2)$ & 2.4 & (0.4) & 30.5 & (4.5) \\
\hline & Serbia & 95.0 & $(0.9)$ & 1.3 & $(0.4)$ & 1.2 & $(0.4)$ & 0.3 & $(0.2)$ & 0.9 & $(0.3)$ & 0.3 & $(0.2)$ & 0.1 & $(0.1)$ & 0.9 & $(0.3)$ & 25.4 & (5.9) \\
\hline & Shanghai-China & 45.0 & (1.5) & 21.4 & $(1.2)$ & 0.5 & $(0.2)$ & 0.2 & $(0.1)$ & 7.9 & $(0.9)$ & 4.0 & $(0.7)$ & 0.1 & $(0.1)$ & 20.9 & (1.5) & 38.5 & (2.2) \\
\hline & Singapore & 58.3 & (1.0) & 12.9 & $(0.8)$ & 1.4 & $(0.3)$ & 0.2 & $(0.1)$ & 5.8 & $(0.7)$ & 3.1 & $(0.4)$ & 0.4 & $(0.1)$ & 17.9 & $(0.9)$ & 45.0 & $(2.1)$ \\
\hline & Chinese Taipei & 65.0 & (2.3) & 19.1 & (1.1) & 0.5 & $(0.2)$ & 0.0 & c & 7.7 & $(0.8)$ & 1.2 & $(0.3)$ & 0.0 & c & 6.4 & (1.3) & 18.7 & (3.2) \\
\hline & Thailand & 96.7 & $(0.7)$ & 1.6 & $(0.4)$ & 0.3 & $(0.2)$ & 0.1 & $(0.1)$ & 0.4 & $(0.2)$ & 0.4 & $(0.2)$ & 0.1 & $(0.1)$ & 0.5 & $(0.2)$ & 17.1 & (5.9) \\
\hline & Tunisia & 99.3 & $(0.3)$ & 0.4 & $(0.3)$ & 0.1 & $(0.1)$ & 0.2 & c & 0.0 & c & 0.0 & c & 0.0 & c & 0.0 & c & 0.0 & c \\
\hline & United Arab Emirates & 95.2 & $(0.5)$ & 0.8 & $(0.2)$ & 1.1 & $(0.3)$ & 0.6 & $(0.2)$ & 0.4 & $(0.1)$ & 0.5 & $(0.2)$ & 0.4 & $(0.1)$ & 1.0 & $(0.2)$ & 38.5 & $(7.0)$ \\
\hline & Uruguay & 98.1 & $(0.5)$ & 0.4 & $(0.2)$ & 0.6 & $(0.2)$ & 0.3 & $(0.1)$ & 0.2 & $(0.1)$ & 0.1 & $(0.1)$ & 0.2 & $(0.1)$ & 0.2 & $(0.1)$ & 24.6 & (13.0) \\
\hline & Viet Nam & 86.3 & (1.6) & 4.4 & $(0.7)$ & 1.2 & $(0.3)$ & 1.2 & $(0.4)$ & 1.2 & $(0.3)$ & 2.5 & $(0.5)$ & 0.3 & $(0.1)$ & 2.9 & $(0.7)$ & 26.1 & $(4.0)$ \\
\hline
\end{tabular}

* See notes at the beginning of this Annex.

StatLink 部 5 http://dx.doi.org/10.1787/888932935667 
[Part 1/1]

Table I.3.1 Index of opportunity to learn variables

\begin{tabular}{|c|c|c|c|c|c|c|c|}
\hline & & \multicolumn{6}{|c|}{ Opportunity to learn variables } \\
\hline & & \multicolumn{2}{|c|}{ Word problems } & \multicolumn{2}{|c|}{ Formal mathematics } & \multicolumn{2}{|c|}{ Applied mathematics } \\
\hline & & Mean & S.E. & Mean & S.E. & Mean & S.E. \\
\hline \multirow{35}{*}{ 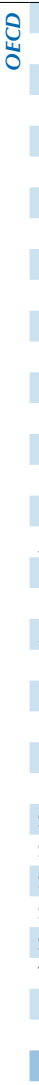 } & Australia & 1.81 & $(0.01)$ & 1.69 & $(0.01)$ & 2.03 & $(0.01)$ \\
\hline & Austria & 2.09 & $(0.02)$ & 1.54 & $(0.02)$ & 1.80 & $(0.02)$ \\
\hline & Belgium & 1.94 & $(0.02)$ & 1.83 & $(0.01)$ & 1.88 & $(0.01)$ \\
\hline & Canada & 1.99 & $(0.01)$ & 1.98 & $(0.01)$ & 2.07 & $(0.01)$ \\
\hline & Chile & 2.05 & $(0.02)$ & 1.70 & $(0.02)$ & 2.09 & $(0.01)$ \\
\hline & Czech Republic & 1.65 & $(0.02)$ & 1.80 & $(0.02)$ & 1.57 & $(0.02)$ \\
\hline & Denmark & 1.95 & $(0.02)$ & 1.62 & $(0.02)$ & 1.97 & $(0.01)$ \\
\hline & Estonia & 1.79 & $(0.02)$ & 2.00 & $(0.01)$ & 1.80 & $(0.01)$ \\
\hline & Finland & 2.06 & $(0.02)$ & 1.72 & $(0.01)$ & 1.71 & $(0.01)$ \\
\hline & France & 2.14 & $(0.02)$ & 1.87 & $(0.01)$ & 2.03 & (0.01) \\
\hline & Germany & 2.02 & $(0.02)$ & 1.66 & $(0.02)$ & 1.96 & $(0.01)$ \\
\hline & Greece & 1.33 & $(0.02)$ & 1.91 & $(0.01)$ & 1.87 & $(0.01)$ \\
\hline & Hungary & 2.01 & $(0.03)$ & 1.96 & $(0.02)$ & 1.93 & $(0.02)$ \\
\hline & Iceland & 2.37 & $(0.02)$ & 1.14 & $(0.01)$ & 2.00 & $(0.02)$ \\
\hline & Ireland & 1.81 & $(0.02)$ & 1.47 & $(0.01)$ & 1.87 & $(0.01)$ \\
\hline & Israel & 1.66 & $(0.02)$ & 1.81 & $(0.02)$ & 1.77 & $(0.02)$ \\
\hline & Italy & 1.75 & $(0.01)$ & 1.83 & $(0.01)$ & 1.77 & $(0.01)$ \\
\hline & Japan & 1.59 & $(0.02)$ & 2.05 & $(0.02)$ & 1.73 & (0.01) \\
\hline & Korea & 1.68 & $(0.02)$ & 2.07 & $(0.02)$ & 1.82 & $(0.02)$ \\
\hline & Luxembourg & 2.03 & $(0.02)$ & 1.45 & $(0.01)$ & 1.88 & $(0.01)$ \\
\hline & Mexico & 1.82 & $(0.01)$ & 1.78 & $(0.01)$ & 2.24 & $(0.01)$ \\
\hline & Netherlands & 1.58 & $(0.02)$ & 1.50 & $(0.02)$ & 2.13 & $(0.02)$ \\
\hline & New Zealand & 1.64 & $(0.02)$ & 1.51 & $(0.02)$ & 1.95 & $(0.01)$ \\
\hline & Norway & 1.82 & $(0.02)$ & $\mathrm{m}$ & m & 1.78 & $(0.02)$ \\
\hline & Poland & 2.05 & $(0.02)$ & 1.83 & $(0.02)$ & 2.02 & $(0.01)$ \\
\hline & Portugal & 1.48 & $(0.02)$ & 1.73 & $(0.02)$ & 2.16 & (0.01) \\
\hline & Slovak Republic & 1.99 & $(0.02)$ & 1.70 & $(0.01)$ & 1.87 & $(0.01)$ \\
\hline & Slovenia & 2.13 & $(0.02)$ & 1.93 & $(0.01)$ & 1.91 & $(0.01)$ \\
\hline & Spain & 2.16 & $(0.02)$ & 1.87 & $(0.01)$ & 2.01 & $(0.01)$ \\
\hline & Sweden & 1.92 & $(0.02)$ & 0.77 & $(0.01)$ & 1.73 & $(0.01)$ \\
\hline & Switzerland & 2.14 & $(0.02)$ & 1.41 & $(0.02)$ & 1.95 & $(0.01)$ \\
\hline & Turkey & 1.31 & $(0.02)$ & 1.92 & $(0.01)$ & 1.96 & $(0.02)$ \\
\hline & United Kingdom & 1.86 & $(0.02)$ & 1.63 & $(0.02)$ & 1.87 & $(0.02)$ \\
\hline & United States & 1.75 & $(0.02)$ & 2.00 & $(0.02)$ & 2.00 & $(0.01)$ \\
\hline & OECD average & 1.87 & $(0.00)$ & 1.70 & $(0.00)$ & 1.92 & $(0.00)$ \\
\hline \multirow{31}{*}{ 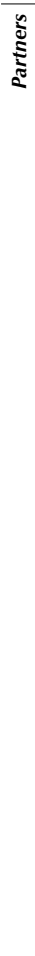 } & Albania & 1.88 & $(0.02)$ & 2.09 & $(0.01)$ & 2.18 & $(0.01)$ \\
\hline & Argentina & 1.60 & $(0.02)$ & 1.35 & $(0.03)$ & 1.89 & $(0.02)$ \\
\hline & Brazil & 1.50 & $(0.01)$ & 1.43 & $(0.02)$ & 2.03 & $(0.01)$ \\
\hline & Bulgaria & 1.55 & $(0.02)$ & 1.96 & $(0.02)$ & 1.91 & $(0.02)$ \\
\hline & Colombia & 1.88 & $(0.03)$ & 1.76 & $(0.02)$ & 2.17 & $(0.02)$ \\
\hline & Costa Rica & 1.60 & $(0.03)$ & 1.53 & $(0.03)$ & 1.72 & $(0.02)$ \\
\hline & Croatia & 2.03 & $(0.02)$ & 2.07 & $(0.01)$ & 1.83 & $(0.01)$ \\
\hline & Cyprus* & 1.68 & $(0.02)$ & 1.87 & $(0.01)$ & 1.86 & $(0.01)$ \\
\hline & Hong Kong-China & 1.35 & $(0.02)$ & 1.83 & $(0.02)$ & 1.80 & $(0.01)$ \\
\hline & Indonesia & 1.89 & $(0.02)$ & 1.60 & $(0.02)$ & 2.35 & $(0.02)$ \\
\hline & Jordan & 2.15 & $(0.02)$ & 2.15 & $(0.02)$ & 2.23 & $(0.01)$ \\
\hline & Kazakhstan & 1.85 & $(0.02)$ & 1.97 & $(0.02)$ & 2.22 & $(0.01)$ \\
\hline & Latvia & 1.73 & $(0.02)$ & 2.03 & $(0.01)$ & 1.85 & $(0.02)$ \\
\hline & Liechtenstein & 2.15 & $(0.08)$ & 1.55 & $(0.05)$ & 2.02 & $(0.05)$ \\
\hline & Lithuania & 1.63 & $(0.02)$ & 1.65 & $(0.01)$ & 1.92 & $(0.01)$ \\
\hline & Macao-China & 1.23 & $(0.01)$ & 2.20 & $(0.01)$ & 1.62 & $(0.01)$ \\
\hline & Malaysia & 1.84 & $(0.02)$ & 1.59 & $(0.02)$ & 2.03 & $(0.01)$ \\
\hline & Montenegro & 2.03 & $(0.02)$ & 1.90 & $(0.01)$ & 1.88 & $(0.01)$ \\
\hline & Peru & 1.94 & $(0.03)$ & 1.79 & $(0.02)$ & 2.06 & $(0.02)$ \\
\hline & Qatar & 1.74 & $(0.01)$ & 1.72 & $(0.01)$ & 2.02 & $(0.01)$ \\
\hline & Romania & 1.86 & $(0.02)$ & 2.02 & $(0.02)$ & 2.11 & $(0.01)$ \\
\hline & Russian Federation & 1.99 & $(0.02)$ & 2.10 & $(0.01)$ & 1.98 & $(0.02)$ \\
\hline & Serbia & 1.54 & $(0.02)$ & 2.04 & $(0.01)$ & 1.81 & $(0.02)$ \\
\hline & Shanghai-China & 1.30 & $(0.02)$ & 2.30 & $(0.01)$ & 1.62 & $(0.02)$ \\
\hline & Singapore & 1.56 & $(0.02)$ & 2.23 & $(0.01)$ & 2.00 & $(0.01)$ \\
\hline & Chinese Taipei & 1.48 & $(0.02)$ & 1.98 & $(0.01)$ & 1.75 & (0.01) \\
\hline & Thailand & 1.95 & $(0.02)$ & 1.70 & $(0.01)$ & 2.37 & $(0.01)$ \\
\hline & Tunisia & 1.64 & $(0.02)$ & 1.23 & $(0.01)$ & 2.13 & $(0.02)$ \\
\hline & United Arab Emirates & 1.82 & $(0.02)$ & 2.13 & $(0.02)$ & 2.10 & $(0.01)$ \\
\hline & Uruguay & 1.32 & $(0.02)$ & 1.64 & $(0.02)$ & 1.70 & $(0.02)$ \\
\hline & Viet Nam & 1.21 & $(0.02)$ & 1.96 & $(0.02)$ & 1.65 & $(0.02)$ \\
\hline
\end{tabular}

* See notes at the beginning of this Annex.

StatLink त्नाज् http://dx.doi.org/10.1787/888932935686 
[Part 1/1]

Estimated regression coefficients for student and school opportunity to learn variables related Table I.3.2 to achievement

\begin{tabular}{|c|c|c|c|c|c|c|c|c|c|c|c|c|c|c|c|c|c|}
\hline & & \multicolumn{8}{|c|}{ Student level } & \multicolumn{8}{|c|}{ School level } \\
\hline & & \multicolumn{2}{|c|}{ Word problems } & \multicolumn{2}{|c|}{$\begin{array}{c}\text { Applied } \\
\text { mathematics }\end{array}$} & \multicolumn{2}{|c|}{$\begin{array}{c}\text { Applied } \\
\text { mathematics } \\
\text { squared }\end{array}$} & \multicolumn{2}{|c|}{$\begin{array}{c}\text { Formal } \\
\text { mathematics }\end{array}$} & Word & roblems & $\begin{array}{r}\text { Ap } \\
\text { mathe }\end{array}$ & $\begin{array}{l}\text { lied } \\
\text { matics }\end{array}$ & $\begin{array}{r}\text { Ap } \\
\text { math } \\
\text { squ }\end{array}$ & $\begin{array}{l}\text { lied } \\
\text { matics } \\
\text { ared }\end{array}$ & $\begin{array}{l}\text { For } \\
\text { mathe }\end{array}$ & $\begin{array}{l}\text { mal } \\
\text { matics }\end{array}$ \\
\hline & & Coef. & S.E. & Coef. & S.E. & Coef. & S.E. & Coef. & S.E. & Coef. & S.E. & Coef. & S.E. & Coef. & S.E. & Coef. & S.E. \\
\hline 0 & Australia & 5.1 & $(0.8)$ & -4.2 & (5.0) & -1.8 & $(1.3)$ & 72.2 & $(1.2)$ & 16.1 & (4.1) & -17.8 & (25.8) & -0.4 & (6.7) & 118.8 & (3.7) \\
\hline 焉 & Austria & 1.8 & $(1.2)$ & 2.8 & (6.5) & -0.2 & $(1.9)$ & 35.5 & (2.4) & 22.5 & (8.4) & 75.8 & $(44.5)$ & -28.1 & (13.3) & 120.5 & (7.5) \\
\hline & Belgium & -0.1 & $(1.0)$ & -9.1 & (5.0) & 0.9 & $(1.4)$ & 30.3 & (1.7) & 4.2 & $(10.1)$ & 51.2 & (53.6) & -13.5 & (14.8) & 122.1 & (9.7) \\
\hline & Canada & 4.5 & $(0.6)$ & 4.7 & (3.9) & -3.4 & $(1.0)$ & 61.3 & (1.1) & 30.0 & (3.4) & 75.6 & $(27.8)$ & -20.1 & $(7.2)$ & 91.3 & (4.8) \\
\hline & Chile & 7.1 & $(0.9)$ & 2.2 & (5.9) & -4.9 & $(1.5)$ & 40.7 & (1.8) & 34.6 & (6.0) & 53.2 & $(50.8)$ & -27.8 & (12.4) & 143.8 & (6.4) \\
\hline & Czech Republic & 1.8 & $(1.2)$ & 3.7 & (6.0) & -3.6 & (1.9) & 49.5 & (2.5) & 15.5 & (7.1) & 45.4 & (36.8) & -22.3 & (12.2) & 155.1 & $(8.2)$ \\
\hline & Denmark & 3.5 & $(1.0)$ & -0.9 & (7.1) & -3.9 & (1.9) & 53.4 & (1.9) & 5.8 & (5.7) & 66.6 & $(41.8)$ & -25.0 & $(10.8)$ & 85.9 & (6.5) \\
\hline & Estonia & 5.6 & $(1.3)$ & -0.9 & (8.4) & -4.0 & $(2.4)$ & 58.1 & (3.0) & 33.4 & (6.5) & 53.9 & $(47.5)$ & -33.5 & (13.1) & 68.6 & (13.3) \\
\hline & Finland & 8.1 & $(1.0)$ & 1.9 & (5.1) & -3.8 & $(1.5)$ & 72.1 & (1.8) & 15.8 & (5.5) & 71.1 & (31.9) & -15.0 & (9.8) & 36.8 & (5.9) \\
\hline & France & 1.3 & $(1.2)$ & 20.9 & (8.0) & -7.1 & $(2.1)$ & 45.9 & (2.7) & 3.2 & (8.0) & 42.2 & (53.9) & -15.6 & $(14.2)$ & 177.5 & (7.8) \\
\hline & Germany & 1.9 & $(1.3)$ & 9.8 & (8.3) & -2.1 & $(2.2)$ & 44.4 & (2.5) & 18.7 & (6.9) & 64.0 & $(42.1)$ & -15.1 & (11.8) & 138.3 & (6.1) \\
\hline & Greece & -3.4 & $(1.4)$ & -12.2 & (6.6) & -0.3 & (1.9) & 31.7 & (2.3) & -22.0 & (8.9) & 6.8 & (54.5) & -19.5 & (15.2) & 135.7 & (12.1) \\
\hline & Hungary & 1.1 & $(1.1)$ & -0.2 & (6.2) & -1.2 & $(1.7)$ & 35.8 & (2.4) & 12.5 & (8.2) & -17.6 & $(57.8)$ & 0.8 & (15.3) & 167.5 & (9.8) \\
\hline & Iceland & 18.6 & $(2.0)$ & 48.6 & (10.8) & -14.5 & (2.8) & 23.8 & (3.1) & 36.2 & (9.1) & 156.0 & (55.5) & -42.7 & (14.4) & 30.3 & (14.8) \\
\hline & Ireland & 3.6 & $(1.2)$ & 0.8 & (6.8) & -4.3 & (1.9) & 62.9 & (2.1) & 8.2 & $(7.2)$ & -107.3 & (41.9) & 15.9 & (11.9) & 124.8 & (8.5) \\
\hline & Israel & 1.0 & $(1.3)$ & -4.7 & (5.7) & -2.3 & $(1.7)$ & 61.8 & (2.4) & 10.3 & (12.5) & 17.7 & $(66.0)$ & -45.2 & (19.2) & 130.9 & (13.6) \\
\hline & Italy & 2.0 & $(0.5)$ & 7.5 & (2.1) & -4.4 & $(0.6)$ & 32.3 & $(0.9)$ & 27.0 & (3.7) & 19.3 & (21.0) & -21.8 & (6.1) & 130.1 & (3.5) \\
\hline & Japan & 5.7 & $(1.0)$ & 6.6 & (4.9) & -3.1 & $(1.5)$ & 50.9 & (2.5) & 44.6 & $(11.0)$ & -9.1 & (53.6) & 1.3 & $(17.1)$ & 188.7 & (12.6) \\
\hline & Korea & 4.7 & (1.3) & -1.2 & (6.3) & -2.7 & (1.8) & 73.9 & (2.9) & 5.3 & (10.4) & -18.7 & (53.1) & -2.3 & (15.5) & 208.2 & (10.6) \\
\hline & Luxembourg & 9.0 & (1.3) & 22.5 & (6.8) & -7.8 & (1.9) & 36.1 & (2.0) & 92.8 & $(20.0)$ & 19.2 & $(127.0)$ & -29.6 & (36.8) & 148.3 & (14.5) \\
\hline & Mexico & 7.2 & $(0.4)$ & 8.6 & (3.0) & -4.3 & $(0.7)$ & 29.5 & $(0.7)$ & 24.5 & (2.9) & 63.8 & (18.5) & -24.3 & (4.6) & 87.9 & (3.0) \\
\hline & Netherlands & -4.0 & $(1.0)$ & 10.2 & (6.3) & -4.4 & (1.6) & 49.9 & $(1.8)$ & -7.0 & $(10.1)$ & 40.8 & $(61.0)$ & -13.4 & (15.7) & 155.8 & (7.1) \\
\hline & New Zealand & 6.5 & (1.6) & 21.4 & (9.0) & -7.0 & $(2.4)$ & 73.2 & (2.3) & 16.0 & (9.9) & 73.3 & $(62.0)$ & -27.6 & $(17.1)$ & 112.6 & (9.0) \\
\hline & Norway & 6.3 & (1.6) & 17.8 & (8.8) & -10.7 & $(2.5)$ & $\mathrm{m}$ & $\mathrm{m}$ & 19.6 & (8.5) & 19.8 & $(51.7)$ & -4.3 & (14.5) & $\mathrm{m}$ & $\mathrm{m}$ \\
\hline & Poland & 11.5 & $(1.4)$ & -8.8 & (9.8) & -1.5 & $(2.6)$ & 52.8 & $(2.7)$ & 23.0 & (9.5) & -13.3 & $(80.6)$ & -11.2 & $(20.7)$ & 144.6 & (14.3) \\
\hline & Portugal & 2.2 & $(1.4)$ & 2.1 & (7.9) & -2.1 & $(2.0)$ & 57.3 & $(2.2)$ & -19.9 & (11.8) & -27.0 & $(67.4)$ & 1.8 & (17.8) & 166.4 & (12.7) \\
\hline & Slovak Republic & 4.8 & $(1.3)$ & 13.4 & (8.0) & -5.1 & $(2.2)$ & 54.5 & (2.9) & 33.2 & (7.9) & 180.5 & $(45.3)$ & -57.3 & (12.5) & 153.3 & (9.1) \\
\hline & Slovenia & 1.9 & $(1.1)$ & 3.5 & (6.8) & -2.9 & $(1.8)$ & 18.7 & $(2.1)$ & 30.4 & (6.7) & -15.5 & (54.4) & -12.2 & (14.4) & 137.9 & (9.9) \\
\hline & Spain & 3.8 & $(0.6)$ & 13.3 & (3.7) & -7.0 & $(1.0)$ & 64.5 & $(0.9)$ & 11.4 & (3.5) & -32.6 & (25.5) & 4.3 & (6.9) & 109.1 & (4.1) \\
\hline & Sweden & 12.4 & $(1.6)$ & 46.6 & (8.6) & -15.3 & $(2.5)$ & 11.4 & (3.0) & 34.2 & (7.5) & 68.2 & $(46.8)$ & -25.4 & (13.4) & 40.1 & (9.5) \\
\hline & Switzerland & 3.9 & $(0.9)$ & 41.9 & (5.6) & -10.9 & $(1.5)$ & 49.7 & (1.6) & 25.3 & (7.9) & 195.1 & (52.9) & -57.3 & $(14.3)$ & 56.5 & $(6.0)$ \\
\hline & Turkey & -0.5 & $(1.2)$ & -15.4 & (5.2) & 1.5 & $(1.5)$ & 27.0 & $(2.1)$ & -8.4 & (12.5) & 47.5 & (59.1) & -21.8 & (16.5) & 156.1 & (13.9) \\
\hline & United Kingdom & 4.3 & $(0.8)$ & 4.4 & $(4.7)$ & -3.8 & $(1.3)$ & 74.5 & (1.3) & 12.1 & $(6.2)$ & 79.3 & $(38.8)$ & -32.7 & $(11.0)$ & 115.7 & $(5.7)$ \\
\hline & United States & 3.7 & $(1.3)$ & 4.9 & (7.3) & -3.4 & $(2.0)$ & 67.6 & $(2.1)$ & 24.2 & $(10.3)$ & 27.8 & $(64.2)$ & -13.3 & (17.4) & 128.9 & (10.7) \\
\hline & OECD average & 4.3 & $(0.2)$ & 7.7 & (1.2) & -4.5 & $(0.3)$ & 48.9 & $(0.4)$ & 18.6 & $(1.5)$ & 39.9 & $(9.3)$ & -19.2 & (2.6) & 124.1 & (2.1) \\
\hline$n$ & Albania & 2.7 & (1.8) & 0.9 & (10.6) & -1.3 & $(2.7)$ & -4.8 & (3.0) & 4.9 & (7.8) & -5.2 & $(50.2)$ & 5.9 & (12.3) & -8.5 & (10.7) \\
\hline & Argentina & 4.5 & $(1.0)$ & -0.5 & (4.6) & -1.8 & (1.3) & 24.1 & (1.6) & 19.5 & (7.8) & 70.3 & $(45.7)$ & -24.3 & (13.1) & 93.0 & (7.0) \\
\hline ‡ & Brazil & -0.1 & $(0.6)$ & 3.4 & (3.0) & -3.0 & $(0.8)$ & 27.5 & (0.9) & -11.9 & (4.1) & 20.1 & (21.5) & -9.7 & $(5.9)$ & 109.5 & (3.3) \\
\hline & Bulgaria & 0.4 & $(1.2)$ & 4.0 & (5.8) & -3.7 & $(1.6)$ & 31.2 & (1.9) & -5.1 & $(10.1)$ & 287.8 & $(54.1)$ & -91.3 & $(15.2)$ & 119.5 & (9.1) \\
\hline & Colombia & 3.4 & $(0.8)$ & 15.7 & $(4.7)$ & -5.7 & $(1.2)$ & 36.8 & (1.4) & 16.6 & (5.8) & 67.1 & (31.9) & -27.3 & (8.4) & 96.9 & (5.7) \\
\hline & Costa Rica & 2.6 & $(1.0)$ & 6.6 & (4.7) & -4.6 & $(1.4)$ & 25.2 & (1.6) & 13.2 & (6.3) & 83.3 & (35.9) & -32.0 & (10.8) & 92.6 & $(6.2)$ \\
\hline & Croatia & 1.6 & $(1.2)$ & 12.7 & (6.8) & -5.6 & (1.9) & 44.0 & $(2.2)$ & 16.7 & (9.5) & 76.6 & (55.0) & -28.7 & (16.1) & 191.1 & (13.1) \\
\hline & Cyprus* & 3.5 & $(1.3)$ & 2.0 & (6.4) & -4.1 & $(1.8)$ & 44.8 & $(2.2)$ & 36.0 & (12.1) & 83.4 & (61.1) & -23.9 & (16.8) & 148.6 & (12.5) \\
\hline & Hong Kong-China & -3.0 & $(1.6)$ & 2.5 & (7.6) & -3.8 & $(2.2)$ & 46.1 & (2.0) & -40.7 & (20.9) & 157.9 & (108.5) & -47.8 & $(30.2)$ & 188.3 & (18.0) \\
\hline & Indonesia & -0.3 & $(0.9)$ & 3.2 & (5.7) & -1.7 & (1.4) & 12.6 & (1.7) & -6.0 & (9.3) & 199.3 & (61.7) & -49.5 & (14.8) & 106.2 & (10.3) \\
\hline & Jordan & 7.7 & $(0.9)$ & 20.8 & (5.7) & -6.9 & $(1.4)$ & 27.2 & (1.3) & 3.5 & (10.7) & 63.8 & $(65.8)$ & -11.6 & (16.6) & 72.4 & (8.8) \\
\hline & Kazakhstan & 1.7 & (1.0) & -9.8 & (6.6) & 0.8 & $(1.7)$ & 20.5 & (1.8) & 0.3 & (8.2) & 133.4 & (57.5) & -41.6 & (14.4) & 93.4 & (12.6) \\
\hline & Latvia & 5.9 & $(1.4)$ & -2.7 & (7.8) & -3.1 & $(2.2)$ & 61.4 & (2.9) & 13.3 & $(7.2)$ & -7.7 & $(47.7)$ & -9.7 & (13.8) & 100.2 & (11.1) \\
\hline & Liechtenstein & -0.5 & $(4.1)$ & 35.6 & $(24.6)$ & -8.4 & $(6.8)$ & 25.0 & (7.4) & 59.2 & $(55.0)$ & 269.4 & (539.0) & -65.9 & (145.3) & 93.9 & (51.8) \\
\hline & Lithuania & 7.7 & (1.4) & 5.6 & (7.7) & -6.0 & $(2.1)$ & 46.0 & $(2.7)$ & 44.5 & $(10.0)$ & -3.2 & $(57.6)$ & -13.3 & (15.6) & 138.3 & (13.7) \\
\hline & Macao-China & -5.0 & (1.7) & 11.9 & (5.7) & -5.9 & (1.8) & 69.1 & (2.3) & 54.5 & $(27.0)$ & 186.0 & (115.3) & -47.0 & (36.2) & 195.7 & (16.7) \\
\hline & Malaysia & 6.6 & $(1.1)$ & 19.5 & (6.5) & -6.3 & $(1.7)$ & 48.7 & (2.0) & 5.9 & (8.4) & 41.8 & $(56.2)$ & -22.9 & (14.9) & 156.4 & (10.1) \\
\hline & Montenegro & 3.9 & $(1.2)$ & 19.3 & (5.9) & -8.0 & $(1.6)$ & 30.9 & (1.9) & 11.2 & (19.6) & -222.4 & (139.7) & 35.8 & $(36.2)$ & 172.9 & (23.8) \\
\hline & Peru & 2.9 & $(1.1)$ & 10.8 & (5.8) & -5.8 & $(1.5)$ & 36.0 & (1.7) & 23.9 & (6.6) & 67.8 & (32.7) & -23.3 & $(9.1)$ & 108.5 & (8.1) \\
\hline & Qatar & 2.4 & $(0.9)$ & 10.2 & (4.6) & -3.0 & $(1.3)$ & 31.6 & (1.3) & 29.5 & $(10.2)$ & 188.3 & $(64.0)$ & -54.6 & (16.9) & 124.9 & (7.2) \\
\hline & Romania & 3.5 & $(1.1)$ & 28.3 & (7.4) & -8.7 & $(1.9)$ & 24.9 & (1.9) & 44.6 & (8.8) & 144.4 & (60.9) & -39.5 & (15.1) & 93.1 & (9.3) \\
\hline & Russian Federation & 4.4 & $(1.3)$ & -9.9 & (7.1) & -0.5 & $(1.9)$ & 48.6 & (3.3) & 17.6 & (9.1) & -29.6 & (58.5) & -2.0 & $(15.2)$ & 93.5 & (20.8) \\
\hline & Serbia & -3.0 & $(1.3)$ & 12.7 & (6.7) & -4.3 & (1.9) & 37.7 & (2.5) & 21.2 & (12.8) & -29.6 & (51.1) & -12.6 & (16.3) & 188.1 & (17.0) \\
\hline & Shanghai-China & -5.6 & (1.5) & -10.0 & (5.0) & -0.5 & (1.5) & 53.9 & (3.0) & -44.2 & $(16.2)$ & -129.7 & (61.3) & 22.1 & (18.9) & 225.1 & (17.5) \\
\hline & Singapore & -4.8 & $(1.3)$ & 15.7 & (7.9) & -5.8 & $(2.1)$ & 84.2 & $(2.1)$ & -31.5 & $(10.1)$ & 16.6 & $(80.2)$ & -4.7 & (20.9) & 190.4 & (9.0) \\
\hline & Chinese Taipei & 2.7 & $(1.5)$ & 18.8 & (7.0) & -9.3 & $(2.0)$ & 70.5 & (2.6) & -4.5 & (15.4) & 114.4 & (79.1) & -30.4 & (22.9) & 246.4 & (12.9) \\
\hline & Thailand & 9.5 & $(1.0)$ & 28.2 & (8.0) & -7.1 & $(1.8)$ & 32.0 & (2.0) & 29.6 & $(11.0)$ & 177.2 & (98.0) & -49.2 & (22.9) & 112.9 & (13.4) \\
\hline & Tunisia & 2.7 & $(1.1)$ & 7.8 & (5.9) & -1.8 & $(1.5)$ & 5.2 & (1.9) & 52.4 & (13.9) & 187.1 & $(85.7)$ & -41.7 & $(23.0)$ & 87.6 & (22.5) \\
\hline & United Arab Emirates & 0.0 & $(0.8)$ & 2.0 & (4.7) & -1.6 & $(1.2)$ & 46.2 & $(1.2)$ & 38.7 & (5.6) & 104.0 & $(46.1)$ & -41.8 & (12.1) & 95.3 & (6.1) \\
\hline & Uruguay & -3.1 & (1.3) & -11.2 & (5.0) & -0.1 & (1.5) & 45.1 & (2.0) & -3.1 & (8.6) & 42.9 & (36.4) & -23.2 & (11.4) & 125.3 & (6.4) \\
\hline & Viet Nam & -0.1 & (1.4) & -4.9 & (5.0) & -2.3 & (1.5) & 40.2 & (2.4) & -10.8 & (12.6) & 8.3 & $(60.7)$ & -20.2 & (19.3) & 209.4 & (13.0) \\
\hline
\end{tabular}

Note: Values that are statistically significant are indicated in bold (see Annex A3).

* See notes at the beginning of this Annex.

StatLink 角鸟 http://dx.doi.org/10.1787/888932935686 
[Part 1/1]

Students' exposure to the mathematics task "using a train timetable"

Percentage of students who answered how often they have encountered the following types of mathematics tasks Table I.3.3 during their time in school

\begin{tabular}{|c|c|c|c|c|c|c|c|c|c|}
\hline & & \multicolumn{8}{|c|}{ Using a train timetable to calculate how long it would take to get from one place to another } \\
\hline & & \multicolumn{2}{|c|}{ Frequently } & \multicolumn{2}{|c|}{ Sometimes } & \multicolumn{2}{|c|}{ Rarely } & \multicolumn{2}{|c|}{ Never } \\
\hline & & $\%$ & S.E. & $\%$ & S.E. & $\%$ & S.E. & $\%$ & S.E. \\
\hline \multirow{35}{*}{ ర్ష్ర } & Australia & 15.7 & $(0.5)$ & 45.6 & $(0.6)$ & 28.3 & $(0.6)$ & 10.3 & $(0.4)$ \\
\hline & Austria & 19.0 & $(0.8)$ & 33.9 & $(0.8)$ & 29.5 & $(0.8)$ & 17.5 & $(0.8)$ \\
\hline & Belgium & 12.6 & $(0.5)$ & 33.0 & $(0.7)$ & 31.5 & $(0.7)$ & 22.9 & (0.6) \\
\hline & Canada & 13.7 & $(0.6)$ & 36.3 & $(0.6)$ & 26.2 & $(0.5)$ & 23.9 & (0.6) \\
\hline & Chile & 28.1 & $(0.8)$ & 41.1 & $(0.8)$ & 16.9 & $(0.6)$ & 14.0 & $(0.7)$ \\
\hline & Czech Republic & 11.0 & $(0.7)$ & 25.7 & $(0.9)$ & 36.8 & $(1.1)$ & 26.5 & (0.8) \\
\hline & Denmark & 25.0 & $(0.9)$ & 43.7 & $(1.0)$ & 21.1 & $(0.8)$ & 10.3 & (0.6) \\
\hline & Estonia & 18.1 & $(0.8)$ & 42.2 & $(0.9)$ & 31.2 & $(0.9)$ & 8.4 & $(0.5)$ \\
\hline & Finland & 21.1 & $(0.8)$ & 59.9 & $(0.8)$ & 15.7 & $(0.6)$ & 3.3 & (0.3) \\
\hline & France & 15.9 & $(0.7)$ & 41.1 & (0.9) & 28.2 & $(0.8)$ & 14.8 & (0.6) \\
\hline & Germany & 15.4 & $(0.8)$ & 38.8 & $(0.9)$ & 31.6 & $(1.0)$ & 14.2 & $(0.7)$ \\
\hline & Greece & 12.8 & $(0.7)$ & 20.0 & $(0.6)$ & 31.7 & $(0.9)$ & 35.6 & $(0.9)$ \\
\hline & Hungary & 19.9 & $(0.7)$ & 38.4 & (1.0) & 29.1 & $(1.0)$ & 12.7 & (0.6) \\
\hline & Iceland & 23.6 & $(1.0)$ & 35.8 & (1.1) & 23.2 & $(0.8)$ & 17.4 & (0.8) \\
\hline & Ireland & 20.0 & $(0.8)$ & 49.5 & $(1.0)$ & 24.0 & $(0.9)$ & 6.5 & (0.6) \\
\hline & Israel & 15.2 & $(0.7)$ & 27.2 & $(0.9)$ & 23.4 & $(0.9)$ & 34.2 & (1.0) \\
\hline & Italy & 11.7 & $(0.4)$ & 30.7 & $(0.4)$ & 31.1 & $(0.5)$ & 26.5 & (0.5) \\
\hline & Japan & 17.5 & $(0.7)$ & 38.7 & (0.9) & 26.6 & $(0.7)$ & 17.2 & (0.7) \\
\hline & Korea & 24.3 & $(0.8)$ & 51.6 & $(1.0)$ & 17.5 & $(0.7)$ & 6.7 & (0.5) \\
\hline & Luxembourg & 20.0 & $(0.6)$ & 32.1 & $(0.7)$ & 26.0 & $(0.7)$ & 21.9 & $(0.7)$ \\
\hline & Mexico & 17.7 & $(0.4)$ & 48.8 & $(0.5)$ & 19.5 & $(0.4)$ & 14.0 & (0.3) \\
\hline & Netherlands & 6.8 & $(0.5)$ & 32.8 & $(0.8)$ & 29.4 & $(0.9)$ & 30.9 & $(0.9)$ \\
\hline & New Zealand & 13.4 & $(0.7)$ & 46.6 & (1.1) & 26.0 & $(0.9)$ & 14.0 & $(0.7)$ \\
\hline & Norway & 17.8 & $(0.7)$ & 50.7 & $(1.0)$ & 23.7 & $(0.8)$ & 7.8 & (0.6) \\
\hline & Poland & 21.2 & $(0.9)$ & 48.8 & $(0.9)$ & 25.8 & $(0.9)$ & 4.2 & (0.4) \\
\hline & Portugal & 7.3 & $(0.5)$ & 25.6 & $(0.9)$ & 31.4 & $(0.9)$ & 35.6 & (1.0) \\
\hline & Slovak Republic & 15.4 & $(1.1)$ & 38.2 & (1.0) & 30.3 & $(0.9)$ & 16.1 & (0.7) \\
\hline & Slovenia & 17.7 & $(0.8)$ & 39.0 & (1.1) & 28.1 & $(0.9)$ & 15.2 & (0.6) \\
\hline & Spain & 17.7 & $(0.6)$ & 49.5 & $(0.7)$ & 24.2 & $(0.5)$ & 8.5 & $(0.5)$ \\
\hline & Sweden & 22.1 & $(0.7)$ & 53.2 & (1.0) & 19.8 & $(0.8)$ & 4.9 & (0.4) \\
\hline & Switzerland & 17.7 & $(0.7)$ & 44.2 & $(0.8)$ & 29.1 & $(0.7)$ & 9.0 & (0.5) \\
\hline & Turkey & 17.0 & $(0.6)$ & 31.5 & (0.9) & 25.7 & $(0.9)$ & 25.8 & (0.9) \\
\hline & United Kingdom & 18.8 & $(0.7)$ & 46.7 & $(0.8)$ & 25.6 & $(0.8)$ & 9.0 & (0.5) \\
\hline & United States & 11.4 & $(0.6)$ & 38.9 & $(0.9)$ & 29.5 & $(1.1)$ & 20.2 & (0.8) \\
\hline & OECD average & 17.1 & $(0.1)$ & 40.0 & $(0.1)$ & 26.4 & $(0.1)$ & 16.5 & (0.1) \\
\hline \multirow{31}{*}{ 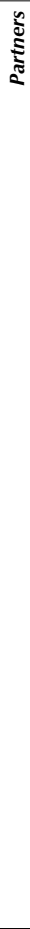 } & Albania & 16.6 & $(0.8)$ & 34.4 & (1.1) & 26.8 & (0.9) & 22.2 & (1.1) \\
\hline & Argentina & 15.7 & $(0.7)$ & 38.1 & (1.2) & 21.1 & $(0.9)$ & 25.1 & $(0.8)$ \\
\hline & Brazil & 25.7 & $(0.6)$ & 41.9 & $(0.7)$ & 18.1 & $(0.5)$ & 14.3 & (0.5) \\
\hline & Bulgaria & 19.3 & (0.8) & 36.8 & (0.8) & 31.0 & $(0.8)$ & 12.9 & $(0.7)$ \\
\hline & Colombia & 21.5 & $(0.7)$ & 41.0 & (1.1) & 17.0 & $(0.7)$ & 20.4 & $(0.8)$ \\
\hline & Costa Rica & 23.3 & (1.1) & 38.4 & (1.2) & 20.9 & $(0.9)$ & 17.5 & (0.9) \\
\hline & Croatia & 17.6 & $(0.7)$ & 32.1 & $(0.8)$ & 28.9 & $(1.0)$ & 21.4 & (0.9) \\
\hline & Cyprus* & 22.5 & $(0.8)$ & 35.6 & $(0.9)$ & 24.4 & $(0.8)$ & 17.5 & $(0.7)$ \\
\hline & Hong Kong-China & 6.5 & $(0.4)$ & 37.4 & $(1.0)$ & 47.0 & $(1.1)$ & 9.0 & (0.6) \\
\hline & Indonesia & 20.2 & $(0.9)$ & 35.6 & (1.1) & 22.0 & $(0.9)$ & 22.3 & (1.1) \\
\hline & Jordan & 24.6 & $(0.9)$ & 33.0 & $(0.8)$ & 18.7 & $(0.7)$ & 23.7 & $(0.8)$ \\
\hline & Kazakhstan & 35.9 & $(1.2)$ & 41.5 & (1.1) & 17.8 & $(0.9)$ & 4.8 & (0.5) \\
\hline & Latvia & 11.2 & $(0.7)$ & 48.1 & (1.1) & 32.2 & $(1.2)$ & 8.5 & $(0.7)$ \\
\hline & Liechtenstein & 13.8 & $(2.6)$ & 41.2 & (3.6) & 33.0 & $(3.3)$ & 12.0 & (2.4) \\
\hline & Lithuania & 16.6 & $(0.7)$ & 46.5 & (1.0) & 28.8 & $(0.9)$ & 8.1 & $(0.4)$ \\
\hline & Macao-China & 11.9 & $(0.6)$ & 47.0 & (0.8) & 34.7 & $(0.7)$ & 6.4 & (0.4) \\
\hline & Malaysia & 10.7 & $(0.6)$ & 37.2 & (1.0) & 27.7 & $(0.8)$ & 24.4 & $(0.8)$ \\
\hline & Montenegro & 30.1 & $(0.9)$ & 37.0 & $(0.9)$ & 20.4 & $(0.8)$ & 12.5 & $(0.7)$ \\
\hline & Peru & 20.9 & $(0.7)$ & 45.2 & (0.9) & 17.5 & $(0.6)$ & 16.4 & $(0.7)$ \\
\hline & Qatar & 26.1 & $(0.5)$ & 35.8 & $(0.5)$ & 19.4 & $(0.4)$ & 18.8 & $(0.4)$ \\
\hline & Romania & 19.1 & $(0.9)$ & 32.0 & $(0.9)$ & 27.7 & $(0.8)$ & 21.2 & $(0.7)$ \\
\hline & Russian Federation & 25.4 & $(0.6)$ & 44.9 & $(1.0)$ & 24.4 & $(0.9)$ & 5.3 & (0.4) \\
\hline & Serbia & 19.9 & $(0.9)$ & 30.5 & $(0.8)$ & 28.9 & $(0.8)$ & 20.7 & $(0.8)$ \\
\hline & Shanghai-China & 14.2 & $(0.6)$ & 36.2 & $(0.9)$ & 36.3 & $(0.8)$ & 13.3 & (0.6) \\
\hline & Singapore & 12.4 & $(0.6)$ & 47.3 & (0.9) & 30.1 & $(0.8)$ & 10.2 & $(0.5)$ \\
\hline & Chinese Taipei & 8.7 & $(0.4)$ & 36.3 & $(0.9)$ & 42.2 & $(0.9)$ & 12.8 & (0.6) \\
\hline & Thailand & 11.6 & $(0.6)$ & 59.5 & $(0.8)$ & 16.3 & $(0.8)$ & 12.6 & (0.7) \\
\hline & Tunisia & 14.3 & $(0.7)$ & 32.6 & (0.9) & 22.2 & $(0.8)$ & 30.9 & (1.1) \\
\hline & United Arab Emirates & 18.1 & $(0.7)$ & 36.2 & $(0.8)$ & 23.4 & $(0.6)$ & 22.4 & $(0.7)$ \\
\hline & Uruguay & 12.5 & $(0.7)$ & 29.2 & $(0.9)$ & 27.5 & $(0.8)$ & 30.8 & (1.0) \\
\hline & Viet Nam & 8.7 & $(0.6)$ & 46.6 & (1.0) & 31.0 & $(0.9)$ & 13.8 & (0.7) \\
\hline
\end{tabular}

* See notes at the beginning of this Annex.

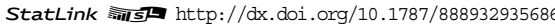


[Part 1/1]

Students' exposure to the mathematics task "calculating how much more expensive a computer would be after adding tax"

Percentage of students who answered how often they have encountered the following types of mathematics tasks Table I.3.4 during their time in school

\begin{tabular}{|c|c|c|c|c|c|c|c|c|c|}
\hline & & \multicolumn{8}{|c|}{ Calculating how much more expensive a computer would be after adding tax } \\
\hline & & \multicolumn{2}{|c|}{ Frequently } & \multicolumn{2}{|c|}{ Sometimes } & \multicolumn{2}{|c|}{ Rarely } & \multicolumn{2}{|c|}{ Never } \\
\hline & & $\%$ & S.E. & $\%$ & S.E. & $\%$ & S.E. & $\%$ & S.E. \\
\hline \multirow{35}{*}{ ত্য় } & Australia & 11.3 & $(0.4)$ & 37.6 & $(0.5)$ & 29.0 & $(0.5)$ & 22.2 & $(0.6)$ \\
\hline & Austria & 31.4 & $(1.1)$ & 36.2 & $(1.1)$ & 21.2 & $(0.9)$ & 11.2 & $(0.7)$ \\
\hline & Belgium & 10.4 & $(0.5)$ & 29.4 & $(0.6)$ & 28.6 & $(0.7)$ & 31.6 & $(0.8)$ \\
\hline & Canada & 20.1 & $(0.5)$ & 41.0 & $(0.7)$ & 24.0 & $(0.6)$ & 14.9 & $(0.5)$ \\
\hline & Chile & 19.0 & $(0.7)$ & 38.1 & $(0.8)$ & 23.1 & $(0.8)$ & 19.7 & $(0.8)$ \\
\hline & Czech Republic & 9.8 & $(0.7)$ & 32.4 & $(1.0)$ & 34.1 & $(0.8)$ & 23.8 & $(0.9)$ \\
\hline & Denmark & 20.2 & $(0.8)$ & 41.9 & $(1.0)$ & 26.3 & $(0.8)$ & 11.5 & $(0.6)$ \\
\hline & Estonia & 15.2 & $(0.7)$ & 39.5 & $(0.9)$ & 28.4 & $(0.8)$ & 16.9 & $(0.8)$ \\
\hline & Finland & 14.7 & $(0.6)$ & 45.0 & $(0.9)$ & 26.2 & (0.9) & 14.0 & $(0.7)$ \\
\hline & France & 21.0 & $(0.8)$ & 40.5 & $(1.0)$ & 21.9 & $(0.7)$ & 16.6 & $(0.7)$ \\
\hline & Germany & 22.6 & $(0.9)$ & 39.2 & $(1.0)$ & 25.0 & $(0.9)$ & 13.2 & $(0.7)$ \\
\hline & Greece & 13.4 & $(0.7)$ & 25.6 & $(0.8)$ & 32.8 & $(0.8)$ & 28.2 & (0.9) \\
\hline & Hungary & 19.1 & $(0.8)$ & 34.0 & (1.0) & 28.1 & $(0.7)$ & 18.9 & (0.8) \\
\hline & Iceland & 24.9 & $(1.0)$ & 37.2 & $(0.9)$ & 21.8 & (0.9) & 16.1 & (0.8) \\
\hline & Ireland & 29.5 & $(0.9)$ & 47.5 & $(0.9)$ & 14.5 & $(0.5)$ & 8.6 & $(0.7)$ \\
\hline & Israel & 13.5 & $(0.7)$ & 27.9 & $(0.8)$ & 22.8 & $(0.7)$ & 35.9 & (0.9) \\
\hline & Italy & 12.8 & $(0.5)$ & 23.1 & $(0.4)$ & 25.7 & $(0.6)$ & 38.4 & (0.6) \\
\hline & Japan & 11.9 & $(0.7)$ & 31.3 & $(0.7)$ & 31.0 & $(0.8)$ & 25.8 & (0.8) \\
\hline & Korea & 12.5 & $(0.7)$ & 33.8 & $(0.9)$ & 35.5 & (1.0) & 18.1 & (0.8) \\
\hline & Luxembourg & 11.4 & $(0.5)$ & 30.3 & $(0.7)$ & 27.7 & $(0.8)$ & 30.6 & (0.8) \\
\hline & Mexico & 16.9 & $(0.4)$ & 42.3 & $(0.5)$ & 24.8 & $(0.4)$ & 16.0 & (0.4) \\
\hline & Netherlands & 29.5 & $(0.9)$ & 46.1 & $(0.9)$ & 14.8 & $(0.8)$ & 9.6 & (0.6) \\
\hline & New Zealand & 19.0 & $(0.7)$ & 45.8 & $(0.9)$ & 21.6 & $(0.7)$ & 13.6 & $(0.7)$ \\
\hline & Norway & 16.1 & $(0.8)$ & 45.6 & $(1.2)$ & 25.8 & (1.0) & 12.5 & $(0.7)$ \\
\hline & Poland & 36.0 & $(1.2)$ & 44.7 & (1.1) & 15.6 & $(0.8)$ & 3.7 & $(0.4)$ \\
\hline & Portugal & 10.0 & $(0.8)$ & 29.3 & $(0.9)$ & 31.2 & (0.9) & 29.5 & (0.9) \\
\hline & Slovak Republic & 14.4 & $(0.8)$ & 38.3 & $(1.0)$ & 27.5 & $(0.8)$ & 19.7 & $(0.8)$ \\
\hline & Slovenia & 20.5 & $(0.7)$ & 37.2 & (1.1) & 25.8 & $(0.9)$ & 16.4 & (0.8) \\
\hline & Spain & 20.7 & $(0.7)$ & 47.5 & $(0.9)$ & 23.4 & $(0.6)$ & 8.5 & (0.4) \\
\hline & Sweden & 20.6 & $(0.7)$ & 46.4 & $(1.0)$ & 22.3 & $(0.8)$ & 10.7 & (0.6) \\
\hline & Switzerland & 16.4 & $(0.7)$ & 37.9 & $(0.8)$ & 26.5 & $(0.6)$ & 19.3 & (0.8) \\
\hline & Turkey & 15.0 & $(0.5)$ & 29.5 & $(0.9)$ & 27.8 & $(0.7)$ & 27.8 & (1.0) \\
\hline & United Kingdom & 22.7 & $(0.9)$ & 43.0 & $(0.8)$ & 21.3 & $(0.8)$ & 12.9 & (0.6) \\
\hline & United States & 16.9 & $(0.6)$ & 41.1 & $(0.9)$ & 27.1 & $(0.8)$ & 14.9 & $(0.6)$ \\
\hline & OECD average & 18.2 & $(0.1)$ & 37.8 & $(0.2)$ & 25.4 & $(0.1)$ & 18.6 & $(0.1)$ \\
\hline \multirow{31}{*}{ ఏ } & Albania & 16.8 & (0.9) & 34.3 & $(1.0)$ & 26.3 & (1.0) & 22.7 & (1.0) \\
\hline & Argentina & 15.2 & $(0.8)$ & 36.2 & $(0.9)$ & 24.9 & (0.9) & 23.8 & (0.9) \\
\hline & Brazil & 19.8 & $(0.5)$ & 40.7 & $(0.5)$ & 23.8 & (0.5) & 15.8 & (0.5) \\
\hline & Bulgaria & 12.4 & $(0.5)$ & 28.9 & $(0.9)$ & 33.8 & (0.9) & 24.9 & (0.9) \\
\hline & Colombia & 14.5 & $(0.7)$ & 35.5 & $(0.8)$ & 23.3 & $(0.7)$ & 26.6 & $(0.9)$ \\
\hline & Costa Rica & 13.5 & $(0.8)$ & 29.0 & $(0.9)$ & 27.6 & (0.9) & 29.9 & $(0.9)$ \\
\hline & Croatia & 18.7 & $(0.7)$ & 33.8 & $(0.8)$ & 27.5 & $(0.8)$ & 19.9 & $(0.9)$ \\
\hline & Cyprus* & 19.5 & $(0.8)$ & 33.3 & $(0.9)$ & 27.3 & $(0.8)$ & 20.0 & $(0.8)$ \\
\hline & Hong Kong-China & 8.7 & $(0.5)$ & 48.1 & $(1.0)$ & 33.5 & (0.9) & 9.7 & (0.6) \\
\hline & Indonesia & 13.0 & $(0.7)$ & 29.9 & $(1.0)$ & 25.2 & $(0.8)$ & 31.9 & $(1.2)$ \\
\hline & Jordan & 25.8 & $(0.9)$ & 35.2 & $(0.8)$ & 21.0 & $(0.7)$ & 18.0 & $(0.8)$ \\
\hline & Kazakhstan & 22.9 & $(1.0)$ & 38.1 & $(1.2)$ & 26.3 & (1.0) & 12.7 & $(0.8)$ \\
\hline & Latvia & 12.1 & $(0.7)$ & 43.2 & $(1.2)$ & 31.2 & (1.0) & 13.5 & (0.9) \\
\hline & Liechtenstein & 17.6 & $(3.0)$ & 40.4 & (3.9) & 28.9 & (3.4) & 13.1 & $(2.2)$ \\
\hline & Lithuania & 16.4 & $(0.7)$ & 43.2 & $(0.9)$ & 29.3 & $(0.7)$ & 11.1 & $(0.6)$ \\
\hline & Macao-China & 7.1 & $(0.4)$ & 33.3 & $(0.8)$ & 46.8 & (0.8) & 12.7 & $(0.5)$ \\
\hline & Malaysia & 14.6 & $(0.6)$ & 36.0 & (1.0) & 27.0 & $(0.7)$ & 22.5 & (1.0) \\
\hline & Montenegro & 24.3 & $(0.9)$ & 36.7 & $(1.0)$ & 21.2 & $(0.8)$ & 17.8 & $(0.8)$ \\
\hline & Peru & 20.7 & $(0.8)$ & 39.1 & $(0.8)$ & 20.2 & $(0.7)$ & 19.9 & $(0.8)$ \\
\hline & Qatar & 19.9 & $(0.5)$ & 37.7 & $(0.6)$ & 20.3 & $(0.4)$ & 22.0 & $(0.5)$ \\
\hline & Romania & 21.9 & $(0.7)$ & 39.7 & $(0.9)$ & 22.6 & $(0.7)$ & 15.9 & (0.6) \\
\hline & Russian Federation & 18.7 & $(0.8)$ & 36.2 & $(0.8)$ & 28.0 & $(0.8)$ & 17.1 & (0.6) \\
\hline & Serbia & 14.0 & $(0.6)$ & 32.9 & $(0.9)$ & 30.1 & (0.9) & 23.1 & $(0.7)$ \\
\hline & Shanghai-China & 20.8 & $(0.7)$ & 40.8 & $(0.9)$ & 27.6 & $(0.9)$ & 10.9 & $(0.5)$ \\
\hline & Singapore & 20.5 & $(0.6)$ & 51.0 & $(0.9)$ & 20.6 & $(0.7)$ & 7.9 & $(0.5)$ \\
\hline & Chinese Taipei & 10.7 & $(0.5)$ & 34.5 & $(0.9)$ & 36.9 & $(0.8)$ & 17.9 & $(0.6)$ \\
\hline & Thailand & 13.6 & $(0.6)$ & 53.8 & $(0.8)$ & 19.9 & $(0.7)$ & 12.7 & $(0.6)$ \\
\hline & Tunisia & 14.1 & $(0.7)$ & 34.0 & (1.0) & 20.9 & $(0.8)$ & 31.0 & (0.9) \\
\hline & United Arab Emirates & 21.3 & $(0.7)$ & 38.0 & $(0.8)$ & 21.2 & $(0.6)$ & 19.5 & $(0.8)$ \\
\hline & Uruguay & 10.5 & $(0.7)$ & 29.9 & $(1.0)$ & 28.7 & $(0.8)$ & 30.9 & (1.1) \\
\hline & Viet Nam & 3.6 & $(0.4)$ & 28.7 & $(0.8)$ & 41.4 & $(0.8)$ & 26.3 & $(0.9)$ \\
\hline
\end{tabular}

* See notes at the beginning of this Annex.

StatLink 部 
[Part 1/1]

Students' exposure to the mathematics task "calculating how many square metres of tiles you need

to cover a floor"

Percentage of students who answered how often they have encountered the following types of mathematics tasks Table I.3.5 during their time in school

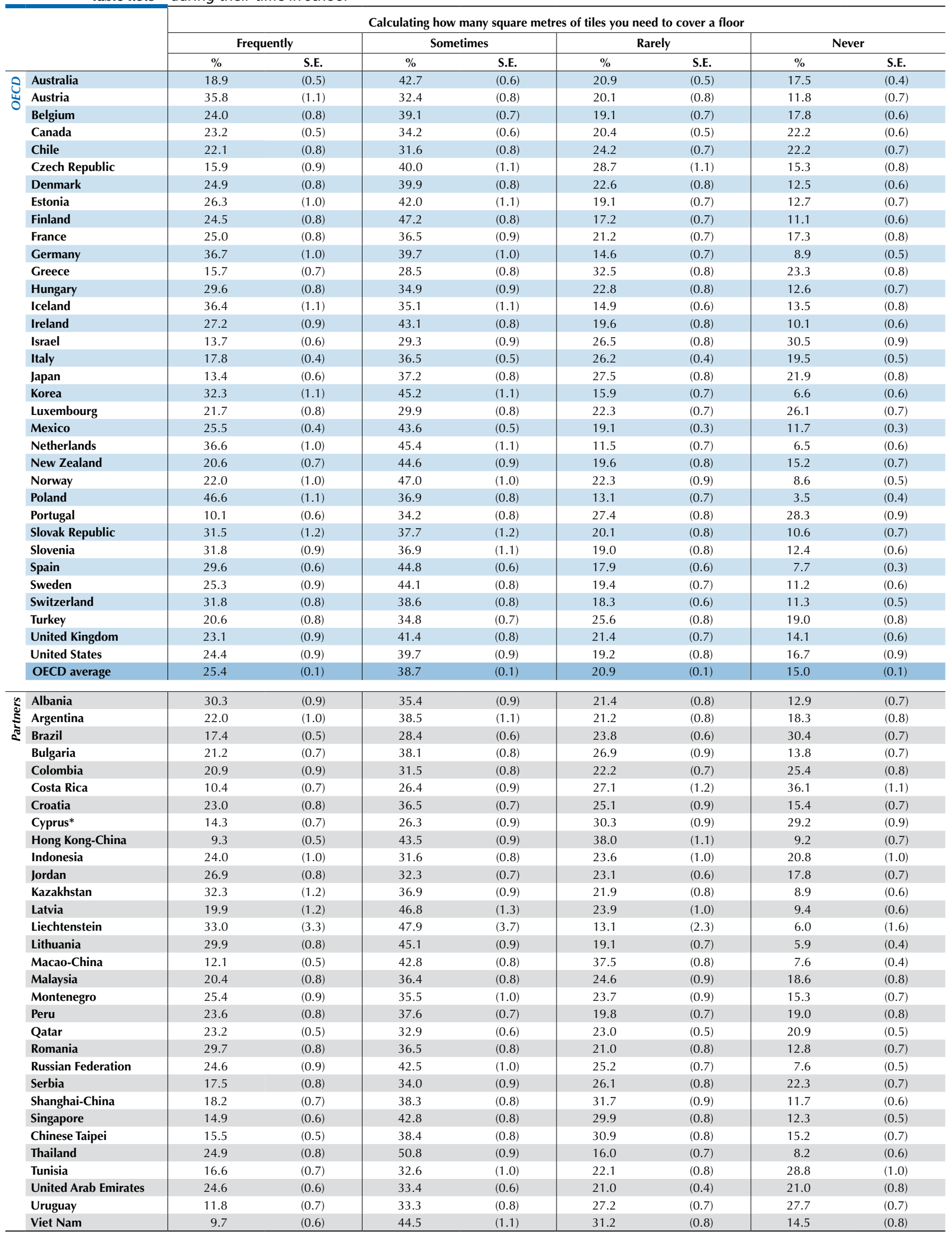

* See notes at the beginning of this Annex.

StatLink त्नाज्ञ http://dx.doi.org/10.1787/888932935686 
[Part 1/1]

Students' exposure to the mathematics task "understanding scientific tables presented in an article" Percentage of students who answered how often they have encountered the following types of mathematics tasks Table I.3.6 during their time in school

\begin{tabular}{|c|c|c|c|c|c|c|c|c|c|}
\hline & & \multicolumn{8}{|c|}{ Understanding scientific tables presented in an article } \\
\hline & & \multicolumn{2}{|c|}{ Frequently } & \multicolumn{2}{|c|}{ Sometimes } & \multicolumn{2}{|c|}{ Rarely } & \multicolumn{2}{|c|}{ Never } \\
\hline & & $\%$ & S.E. & $\%$ & S.E. & $\%$ & S.E. & $\%$ & S.E. \\
\hline \multirow{35}{*}{ I } & Australia & 10.9 & $(0.4)$ & 37.2 & $(0.6)$ & 31.6 & $(0.6)$ & 20.3 & (0.5) \\
\hline & Austria & 10.3 & $(0.6)$ & 24.6 & $(0.8)$ & 37.5 & (1.0) & 27.5 & (1.0) \\
\hline & Belgium & 14.5 & $(0.5)$ & 34.3 & $(0.7)$ & 27.1 & $(0.6)$ & 24.0 & (0.6) \\
\hline & Canada & 14.9 & $(0.5)$ & 35.2 & $(0.6)$ & 30.3 & $(0.6)$ & 19.7 & (0.5) \\
\hline & Chile & 14.2 & $(0.5)$ & 35.1 & $(0.7)$ & 30.3 & $(0.7)$ & 20.4 & $(0.8)$ \\
\hline & Czech Republic & 12.7 & $(0.9)$ & 36.7 & (1.1) & 34.7 & $(1.0)$ & 15.8 & (1.0) \\
\hline & Denmark & 13.3 & $(0.7)$ & 34.2 & $(0.8)$ & 38.8 & $(0.8)$ & 13.7 & (0.7) \\
\hline & Estonia & 17.7 & $(0.8)$ & 41.5 & $(1.0)$ & 31.2 & $(0.9)$ & 9.6 & (0.5) \\
\hline & Finland & 9.9 & $(0.5)$ & 37.3 & $(0.8)$ & 36.2 & $(0.8)$ & 16.5 & (0.6) \\
\hline & France & 18.4 & $(0.8)$ & 30.8 & $(0.8)$ & 29.6 & $(0.8)$ & 21.2 & (0.9) \\
\hline & Germany & 13.0 & $(0.6)$ & 32.8 & $(0.9)$ & 35.3 & (0.9) & 19.0 & (0.8) \\
\hline & Greece & 13.9 & $(0.6)$ & 24.6 & $(0.8)$ & 32.0 & $(0.8)$ & 29.5 & (0.9) \\
\hline & Hungary & 21.2 & $(0.8)$ & 33.8 & $(0.9)$ & 29.2 & $(0.9)$ & 15.8 & (0.9) \\
\hline & Iceland & 15.2 & $(0.8)$ & 30.0 & $(1.0)$ & 32.6 & (1.0) & 22.3 & (0.9) \\
\hline & Ireland & 12.2 & $(0.6)$ & 33.1 & $(0.9)$ & 36.0 & $(1.0)$ & 18.8 & $(0.9)$ \\
\hline & Israel & 23.5 & $(0.9)$ & 34.7 & $(0.9)$ & 20.4 & $(0.7)$ & 21.4 & (0.9) \\
\hline & Italy & 13.9 & $(0.4)$ & 32.2 & $(0.5)$ & 29.2 & $(0.4)$ & 24.7 & (0.4) \\
\hline & Japan & 6.9 & $(0.4)$ & 22.2 & $(0.8)$ & 38.0 & $(0.7)$ & 32.8 & $(0.9)$ \\
\hline & Korea & 25.8 & $(1.0)$ & 45.0 & $(0.9)$ & 22.3 & $(0.8)$ & 6.8 & (0.6) \\
\hline & Luxembourg & 13.0 & $(0.6)$ & 31.5 & $(0.8)$ & 30.3 & $(0.8)$ & 25.1 & $(0.7)$ \\
\hline & Mexico & 16.3 & $(0.3)$ & 40.9 & $(0.4)$ & 29.3 & $(0.4)$ & 13.5 & $(0.3)$ \\
\hline & Netherlands & 22.1 & $(0.9)$ & 46.0 & $(1.3)$ & 21.1 & (1.0) & 10.8 & (1.0) \\
\hline & New Zealand & 10.3 & $(0.6)$ & 36.3 & $(1.0)$ & 33.7 & (1.0) & 19.8 & $(0.8)$ \\
\hline & Norway & 10.3 & $(0.7)$ & 38.1 & $(0.9)$ & 37.2 & (1.0) & 14.3 & $(0.7)$ \\
\hline & Poland & 14.8 & $(0.7)$ & 35.7 & $(0.8)$ & 36.8 & $(0.8)$ & 12.8 & $(0.7)$ \\
\hline & Portugal & 17.0 & $(0.7)$ & 40.8 & $(0.9)$ & 23.9 & $(0.8)$ & 18.2 & (0.9) \\
\hline & Slovak Republic & 13.2 & $(0.7)$ & 32.8 & $(0.9)$ & 33.2 & (1.0) & 20.8 & $(0.7)$ \\
\hline & Slovenia & 11.6 & $(0.7)$ & 29.0 & $(0.8)$ & 35.0 & (1.0) & 24.5 & $(0.7)$ \\
\hline & Spain & 11.0 & $(0.5)$ & 29.5 & $(0.5)$ & 35.9 & $(0.7)$ & 23.6 & (0.6) \\
\hline & Sweden & 15.7 & $(0.7)$ & 42.8 & $(0.9)$ & 30.3 & $(0.8)$ & 11.1 & $(0.5)$ \\
\hline & Switzerland & 10.1 & $(0.4)$ & 30.2 & $(0.8)$ & 37.9 & $(0.6)$ & 21.7 & $(0.8)$ \\
\hline & Turkey & 18.0 & $(0.7)$ & 29.6 & $(1.1)$ & 25.2 & $(0.7)$ & 27.3 & $(0.8)$ \\
\hline & United Kingdom & 10.2 & $(0.6)$ & 32.9 & $(0.9)$ & 36.6 & $(0.8)$ & 20.4 & $(0.7)$ \\
\hline & United States & 18.9 & $(0.7)$ & 38.0 & $(0.8)$ & 26.7 & $(0.8)$ & 16.4 & (0.8) \\
\hline & OECD average & 14.6 & $(0.1)$ & 34.4 & $(0.1)$ & 31.6 & $(0.1)$ & 19.4 & $(0.1)$ \\
\hline \multirow{31}{*}{ 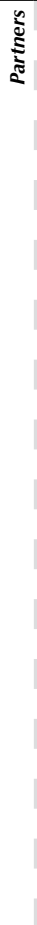 } & Albania & 32.2 & $(1.1)$ & 36.8 & $(1.1)$ & 20.5 & $(0.8)$ & 10.5 & $(0.8)$ \\
\hline & Argentina & 15.0 & $(0.7)$ & 36.7 & $(1.0)$ & 25.7 & (0.9) & 22.6 & $(0.8)$ \\
\hline & Brazil & 26.8 & $(0.7)$ & 36.2 & $(0.5)$ & 21.3 & $(0.5)$ & 15.8 & $(0.5)$ \\
\hline & Bulgaria & 18.6 & $(0.7)$ & 34.2 & $(0.8)$ & 31.5 & (0.9) & 15.7 & (0.7) \\
\hline & Colombia & 14.2 & $(0.7)$ & 31.1 & $(0.8)$ & 27.7 & $(0.8)$ & 27.0 & $(0.8)$ \\
\hline & Costa Rica & 12.3 & $(0.8)$ & 30.5 & $(0.9)$ & 27.8 & $(1.0)$ & 29.3 & (1.0) \\
\hline & Croatia & 11.6 & $(0.6)$ & 30.8 & $(0.9)$ & 34.4 & $(0.8)$ & 23.3 & (0.8) \\
\hline & Cyprus* & 15.3 & $(0.7)$ & 29.1 & $(0.9)$ & 29.5 & $(0.7)$ & 26.2 & $(0.8)$ \\
\hline & Hong Kong-China & 7.4 & $(0.4)$ & 27.4 & $(0.8)$ & 43.4 & $(0.9)$ & 21.8 & $(0.8)$ \\
\hline & Indonesia & 21.0 & $(0.9)$ & 35.0 & $(0.9)$ & 24.7 & (0.9) & 19.3 & $(0.8)$ \\
\hline & Jordan & 31.0 & $(0.8)$ & 38.1 & $(0.8)$ & 20.1 & (0.6) & 10.9 & $(0.5)$ \\
\hline & Kazakhstan & 26.0 & $(0.9)$ & 35.7 & $(1.0)$ & 25.6 & (1.0) & 12.7 & $(0.8)$ \\
\hline & Latvia & 11.3 & $(0.7)$ & 33.8 & $(1.0)$ & 37.5 & (1.0) & 17.4 & $(0.9)$ \\
\hline & Liechtenstein & 9.4 & $(2.0)$ & 33.3 & (3.3) & 36.5 & (3.5) & 20.9 & (3.0) \\
\hline & Lithuania & 15.0 & $(0.7)$ & 36.2 & $(0.9)$ & 33.6 & $(0.8)$ & 15.2 & $(0.7)$ \\
\hline & Macao-China & 8.6 & $(0.5)$ & 29.5 & $(0.7)$ & 42.2 & $(0.8)$ & 19.8 & (0.6) \\
\hline & Malaysia & 18.6 & $(0.8)$ & 38.1 & $(0.8)$ & 26.7 & $(0.8)$ & 16.6 & $(0.8)$ \\
\hline & Montenegro & 15.4 & $(0.7)$ & 32.1 & $(0.9)$ & 31.3 & $(1.1)$ & 21.2 & $(0.9)$ \\
\hline & Peru & 19.9 & $(0.8)$ & 40.6 & $(0.9)$ & 23.7 & $(0.8)$ & 15.8 & $(0.7)$ \\
\hline & Qatar & 22.5 & $(0.6)$ & 35.3 & $(0.6)$ & 24.3 & $(0.5)$ & 17.9 & (0.5) \\
\hline & Romania & 18.1 & $(0.8)$ & 34.3 & $(0.9)$ & 28.3 & $(0.7)$ & 19.2 & $(0.7)$ \\
\hline & Russian Federation & 19.2 & $(0.6)$ & 33.2 & $(0.9)$ & 31.2 & $(0.9)$ & 16.5 & $(0.7)$ \\
\hline & Serbia & 13.7 & $(0.8)$ & 29.1 & $(0.9)$ & 30.6 & $(0.7)$ & 26.5 & (0.9) \\
\hline & Shanghai-China & 25.2 & $(0.7)$ & 37.6 & $(0.7)$ & 27.6 & $(0.7)$ & 9.5 & (0.5) \\
\hline & Singapore & 14.8 & $(0.6)$ & 43.0 & $(0.8)$ & 30.7 & $(0.8)$ & 11.5 & (0.6) \\
\hline & Chinese Taipei & 15.6 & $(0.7)$ & 34.3 & $(0.9)$ & 34.1 & $(0.9)$ & 15.9 & $(0.7)$ \\
\hline & Thailand & 23.0 & $(0.9)$ & 53.1 & $(1.0)$ & 16.2 & $(0.7)$ & 7.7 & (0.6) \\
\hline & Tunisia & 24.8 & $(0.8)$ & 36.6 & $(0.9)$ & 20.6 & $(0.8)$ & 18.1 & $(0.7)$ \\
\hline & United Arab Emirates & 23.2 & $(0.6)$ & 36.6 & $(0.7)$ & 23.6 & (0.6) & 16.6 & (0.6) \\
\hline & Uruguay & 8.5 & (0.6) & 25.1 & $(0.9)$ & 28.3 & (0.8) & 38.0 & (1.0) \\
\hline & Viet Nam & 5.9 & $(0.5)$ & 28.0 & $(0.9)$ & 36.3 & $(0.8)$ & 29.8 & (0.9) \\
\hline
\end{tabular}

* See notes at the beginning of this Annex.

StatLink 部 
[Part 1/1]

Students' exposure to the mathematics task "solving an equation like $\mathbf{6 x} \mathbf{2}+\mathbf{5}=\mathbf{2 9}$ " Table 1.3.7 during their time in school

\begin{tabular}{|c|c|c|c|c|c|c|c|c|c|}
\hline & \multicolumn{8}{|c|}{ Solving an equation like $6 x^{2}+5=29$} \\
\hline & & \multicolumn{2}{|c|}{ Frequently } & \multicolumn{2}{|c|}{ Sometimes } & \multicolumn{2}{|c|}{ Rarely } & \multicolumn{2}{|c|}{ Never } \\
\hline & & $\%$ & S.E. & $\%$ & S.E. & $\%$ & S.E. & $\%$ & S.E. \\
\hline \multirow{35}{*}{ రి } & Australia & 51.1 & $(0.6)$ & 30.5 & $(0.5)$ & 10.9 & $(0.4)$ & 7.5 & $(0.3)$ \\
\hline & Austria & 63.8 & $(1.0)$ & 17.6 & $(0.8)$ & 10.7 & $(0.6)$ & 8.0 & $(0.6)$ \\
\hline & Belgium & 62.6 & $(0.7)$ & 18.3 & $(0.5)$ & 7.9 & $(0.4)$ & 11.3 & $(0.5)$ \\
\hline & Canada & 59.5 & $(0.7)$ & 23.4 & $(0.5)$ & 8.8 & $(0.4)$ & 8.2 & $(0.4)$ \\
\hline & Chile & 55.4 & $(1.2)$ & 27.0 & (1.0) & 10.6 & $(0.6)$ & 7.0 & $(0.4)$ \\
\hline & Czech Republic & 54.2 & $(1.2)$ & 29.1 & (1.1) & 10.9 & $(0.7)$ & 5.8 & (0.6) \\
\hline & Denmark & 46.3 & $(1.0)$ & 32.0 & (0.9) & 13.9 & $(0.8)$ & 7.9 & (0.6) \\
\hline & Estonia & 62.5 & (1.1) & 24.9 & $(0.9)$ & 8.3 & $(0.6)$ & 4.4 & (0.4) \\
\hline & Finland & 61.3 & (1.1) & 28.2 & $(0.8)$ & 6.8 & (0.5) & 3.7 & (0.3) \\
\hline & France & 64.9 & $(1.0)$ & 19.9 & (0.8) & 6.7 & $(0.5)$ & 8.5 & (0.6) \\
\hline & Germany & 68.9 & $(1.2)$ & 19.1 & $(0.8)$ & 7.2 & $(0.6)$ & 4.7 & (0.4) \\
\hline & Greece & 67.5 & (1.0) & 16.5 & $(0.7)$ & 8.1 & (0.6) & 7.8 & (0.6) \\
\hline & Hungary & 67.4 & $(1.2)$ & 19.5 & $(0.8)$ & 9.1 & $(0.7)$ & 4.1 & (0.5) \\
\hline & Iceland & 72.3 & $(0.9)$ & 16.7 & $(0.8)$ & 5.5 & $(0.5)$ & 5.4 & (0.5) \\
\hline & Ireland & 68.1 & $(1.0)$ & 20.6 & $(0.7)$ & 6.5 & $(0.5)$ & 4.8 & (0.4) \\
\hline & Israel & 65.4 & $(1.2)$ & 21.2 & $(0.8)$ & 7.4 & (0.6) & 6.1 & (0.5) \\
\hline & Italy & 71.7 & $(0.6)$ & 15.6 & $(0.4)$ & 6.4 & $(0.2)$ & 6.3 & (0.3) \\
\hline & Japan & 69.4 & (1.0) & 18.0 & $(0.6)$ & 6.4 & $(0.4)$ & 6.2 & (0.6) \\
\hline & Korea & 79.4 & (1.2) & 14.6 & (0.8) & 3.5 & $(0.4)$ & 2.6 & (0.4) \\
\hline & Luxembourg & 52.8 & $(0.9)$ & 24.3 & $(0.8)$ & 11.0 & $(0.5)$ & 11.9 & (0.6) \\
\hline & Mexico & 56.7 & $(0.6)$ & 31.0 & $(0.5)$ & 8.2 & $(0.3)$ & 4.1 & $(0.2)$ \\
\hline & Netherlands & 64.6 & (1.4) & 20.7 & (1.0) & 7.4 & $(0.5)$ & 7.3 & (0.6) \\
\hline & New Zealand & 48.4 & (1.1) & 30.9 & (0.9) & 11.8 & $(0.6)$ & 9.0 & (0.6) \\
\hline & Norway & 57.8 & $(1.2)$ & 31.5 & (1.0) & 6.9 & $(0.5)$ & 3.8 & (0.4) \\
\hline & Poland & 61.8 & (1.0) & 29.2 & (0.9) & 7.0 & (0.5) & 2.1 & (0.3) \\
\hline & Portugal & 48.0 & $(1.2)$ & 29.2 & (1.1) & 11.3 & $(0.7)$ & 11.5 & (0.8) \\
\hline & Slovak Republic & 57.1 & (1.4) & 27.3 & $(1.2)$ & 9.7 & $(0.6)$ & 5.9 & (0.5) \\
\hline & Slovenia & 67.2 & $(0.8)$ & 21.5 & $(0.7)$ & 7.7 & $(0.4)$ & 3.6 & (0.3) \\
\hline & Spain & 74.1 & $(0.7)$ & 18.2 & $(0.6)$ & 4.8 & $(0.3)$ & 2.9 & (0.3) \\
\hline & Sweden & 45.0 & $(1.2)$ & 37.5 & $(1.0)$ & 10.9 & $(0.6)$ & 6.7 & (0.5) \\
\hline & Switzerland & 62.7 & (1.0) & 22.3 & (0.9) & 8.5 & $(0.4)$ & 6.4 & (0.3) \\
\hline & Turkey & 58.8 & (1.3) & 21.7 & $(0.9)$ & 11.3 & $(0.6)$ & 8.2 & (0.5) \\
\hline & United Kingdom & 62.0 & $(0.9)$ & 24.9 & $(0.8)$ & 7.3 & $(0.5)$ & 5.7 & (0.4) \\
\hline & United States & 65.5 & $(1.1)$ & 23.8 & $(0.9)$ & 6.2 & $(0.5)$ & 4.5 & (0.4) \\
\hline & OECD average & 61.6 & $(0.2)$ & 23.7 & $(0.1)$ & 8.4 & $(0.1)$ & 6.3 & (0.1) \\
\hline \multirow{31}{*}{ 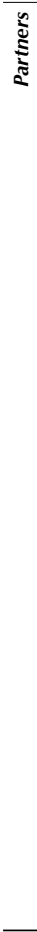 } & Albania & 69.5 & $(0.9)$ & 17.1 & $(0.7)$ & 9.2 & $(0.6)$ & 4.2 & $(0.4)$ \\
\hline & Argentina & 50.4 & $(1.1)$ & 31.2 & $(0.8)$ & 9.2 & $(0.6)$ & 9.3 & (0.6) \\
\hline & Brazil & 38.3 & $(0.8)$ & 34.5 & $(0.6)$ & 16.5 & $(0.5)$ & 10.8 & $(0.4)$ \\
\hline & Bulgaria & 65.4 & $(1.3)$ & 20.8 & $(0.8)$ & 9.2 & $(0.7)$ & 4.7 & $(0.4)$ \\
\hline & Colombia & 42.5 & $(1.0)$ & 34.8 & (1.0) & 14.2 & $(0.9)$ & 8.4 & $(0.5)$ \\
\hline & Costa Rica & 57.1 & $(1.3)$ & 28.5 & $(1.1)$ & 8.0 & $(0.5)$ & 6.5 & (0.6) \\
\hline & Croatia & 67.8 & $(1.0)$ & 21.2 & $(0.7)$ & 6.9 & $(0.5)$ & 4.1 & $(0.5)$ \\
\hline & Cyprus* & 60.4 & $(1.0)$ & 21.6 & $(0.9)$ & 10.8 & $(0.6)$ & 7.2 & $(0.5)$ \\
\hline & Hong Kong-China & 64.4 & $(1.0)$ & 28.4 & $(0.9)$ & 5.1 & $(0.5)$ & 2.1 & (0.3) \\
\hline & Indonesia & 53.5 & (1.3) & 27.4 & $(0.9)$ & 13.4 & $(0.7)$ & 5.6 & $(0.4)$ \\
\hline & Jordan & 55.2 & $(1.0)$ & 26.7 & $(0.8)$ & 12.0 & $(0.7)$ & 6.1 & (0.4) \\
\hline & Kazakhstan & 68.6 & (1.4) & 19.7 & $(0.9)$ & 9.0 & $(0.7)$ & 2.8 & (0.3) \\
\hline & Latvia & 59.9 & $(1.2)$ & 29.1 & (1.1) & 8.0 & $(0.6)$ & 3.0 & $(0.4)$ \\
\hline & Liechtenstein & 76.2 & (3.0) & 13.3 & $(2.3)$ & 4.8 & (1.8) & 5.7 & (1.6) \\
\hline & Lithuania & 65.3 & $(1.1)$ & 25.5 & (1.0) & 6.9 & $(0.5)$ & 2.3 & (0.3) \\
\hline & Macao-China & 68.3 & $(0.8)$ & 24.9 & $(0.7)$ & 5.3 & $(0.4)$ & 1.6 & $(0.2)$ \\
\hline & Malaysia & 59.8 & (1.3) & 23.4 & $(0.9)$ & 10.5 & $(0.5)$ & 6.3 & (0.5) \\
\hline & Montenegro & 59.8 & $(0.9)$ & 23.2 & $(0.8)$ & 10.7 & $(0.6)$ & 6.2 & (0.5) \\
\hline & Peru & 62.9 & (1.3) & 28.6 & (1.0) & 6.5 & $(0.5)$ & 2.0 & (0.3) \\
\hline & Qatar & 50.1 & $(0.6)$ & 27.5 & (0.6) & 12.8 & $(0.4)$ & 9.6 & (0.4) \\
\hline & Romania & 60.6 & $(1.2)$ & 23.2 & $(0.8)$ & 11.2 & $(0.6)$ & 4.9 & (0.4) \\
\hline & Russian Federation & 75.0 & $(1.1)$ & 17.4 & $(0.9)$ & 5.5 & $(0.5)$ & 2.1 & $(0.2)$ \\
\hline & Serbia & 60.5 & $(1.1)$ & 22.8 & $(0.9)$ & 10.0 & $(0.6)$ & 6.7 & (0.5) \\
\hline & Shanghai-China & 67.0 & $(1.1)$ & 20.7 & $(0.8)$ & 7.9 & $(0.5)$ & 4.5 & (0.4) \\
\hline & Singapore & 74.8 & $(0.8)$ & 19.1 & $(0.7)$ & 4.2 & $(0.3)$ & 1.9 & $(0.2)$ \\
\hline & Chinese Taipei & 59.6 & $(1.1)$ & 24.9 & $(0.6)$ & 8.8 & $(0.5)$ & 6.6 & $(0.5)$ \\
\hline & Thailand & 53.0 & $(1.3)$ & 33.4 & (1.1) & 9.2 & $(0.5)$ & 4.4 & (0.4) \\
\hline & Tunisia & 46.7 & (1.4) & 30.1 & $(0.9)$ & 12.3 & $(0.6)$ & 10.8 & $(0.7)$ \\
\hline & United Arab Emirates & 58.4 & (1.0) & 24.4 & $(0.8)$ & 10.4 & $(0.4)$ & 6.7 & (0.4) \\
\hline & Uruguay & 58.0 & (1.0) & 27.1 & $(1.0)$ & 8.2 & $(0.5)$ & 6.7 & (0.5) \\
\hline & Viet Nam & 68.0 & $(1.1)$ & 24.6 & $(0.8)$ & 5.1 & $(0.6)$ & 2.3 & $(0.3)$ \\
\hline
\end{tabular}

* See notes at the beginning of this Annex.

StatLink त्नाज्ञ http://dx.doi.org/10.1787/888932935686 
[Part 1/1]

Students' exposure to the mathematics task "finding the actual distance between two places on a map with a 1:10,000 scale"

Percentage of students who answered how often they have encountered the following types of mathematics tasks Table I.3.8 during their time in school

\begin{tabular}{|c|c|c|c|c|c|c|c|c|c|}
\hline & & \multicolumn{8}{|c|}{ Finding the actual distance between two places on a map with a 1:10 000 scale } \\
\hline & & \multicolumn{2}{|c|}{ Frequently } & \multicolumn{2}{|c|}{ Sometimes } & \multicolumn{2}{|c|}{ Rarely } & \multicolumn{2}{|c|}{ Never } \\
\hline & & $\%$ & S.E. & $\%$ & S.E. & $\%$ & S.E. & $\%$ & S.E. \\
\hline \multirow{35}{*}{ ৩) } & Australia & 12.1 & $(0.4)$ & 41.4 & $(0.6)$ & 34.4 & $(0.5)$ & 12.1 & $(0.4)$ \\
\hline & Austria & 14.3 & $(0.8)$ & 30.1 & $(1.0)$ & 37.1 & (1.1) & 18.5 & $(0.9)$ \\
\hline & Belgium & 17.5 & $(0.7)$ & 37.6 & $(0.7)$ & 31.7 & $(0.7)$ & 13.1 & $(0.5)$ \\
\hline & Canada & 13.4 & $(0.4)$ & 32.2 & $(0.6)$ & 34.9 & $(0.6)$ & 19.6 & (0.6) \\
\hline & Chile & 13.4 & $(0.7)$ & 28.6 & $(0.9)$ & 32.7 & (0.9) & 25.4 & $(0.9)$ \\
\hline & Czech Republic & 10.5 & $(0.9)$ & 34.0 & (1.3) & 41.6 & (1.3) & 14.0 & (0.8) \\
\hline & Denmark & 31.2 & $(0.9)$ & 43.7 & $(0.8)$ & 18.7 & $(0.7)$ & 6.4 & $(0.5)$ \\
\hline & Estonia & 11.8 & $(0.7)$ & 36.7 & $(0.8)$ & 43.0 & (1.0) & 8.5 & $(0.5)$ \\
\hline & Finland & 18.9 & $(0.7)$ & 51.6 & $(0.9)$ & 24.8 & (0.9) & 4.7 & (0.3) \\
\hline & France & 13.1 & $(0.7)$ & 31.4 & $(0.9)$ & 38.0 & (1.0) & 17.4 & $(0.7)$ \\
\hline & Germany & 13.6 & $(0.8)$ & 35.1 & $(0.9)$ & 39.2 & (1.0) & 12.1 & $(0.7)$ \\
\hline & Greece & 12.9 & $(0.6)$ & 20.8 & $(0.9)$ & 39.5 & (1.1) & 26.9 & (0.9) \\
\hline & Hungary & 18.8 & $(0.8)$ & 36.1 & $(1.0)$ & 34.0 & (1.0) & 11.1 & $(0.8)$ \\
\hline & Iceland & 27.5 & $(1.0)$ & 37.3 & $(1.1)$ & 25.5 & (0.9) & 9.7 & $(0.7)$ \\
\hline & Ireland & 12.3 & $(0.7)$ & 33.0 & (1.0) & 37.9 & (0.9) & 16.8 & $(0.7)$ \\
\hline & Israel & 11.6 & $(0.6)$ & 22.2 & (0.8) & 32.7 & $(0.8)$ & 33.4 & (0.9) \\
\hline & Italy & 10.5 & $(0.4)$ & 26.9 & $(0.5)$ & 38.3 & $(0.5)$ & 24.3 & $(0.4)$ \\
\hline & Japan & 30.3 & $(0.9)$ & 36.2 & $(0.8)$ & 22.0 & $(0.8)$ & 11.5 & $(0.7)$ \\
\hline & Korea & 25.6 & $(0.9)$ & 47.8 & $(0.8)$ & 21.5 & (0.8) & 5.1 & $(0.4)$ \\
\hline & Luxembourg & 14.5 & $(0.6)$ & 31.3 & $(0.8)$ & 34.4 & $(0.8)$ & 19.9 & (0.6) \\
\hline & Mexico & 18.2 & $(0.3)$ & 39.8 & $(0.4)$ & 30.1 & $(0.5)$ & 11.9 & (0.3) \\
\hline & Netherlands & 17.3 & $(1.0)$ & 45.6 & (1.1) & 28.8 & (1.0) & 8.3 & $(0.7)$ \\
\hline & New Zealand & 10.3 & $(0.7)$ & 34.6 & $(1.0)$ & 36.7 & (1.0) & 18.3 & $(0.9)$ \\
\hline & Norway & 23.9 & $(1.0)$ & 51.5 & $(0.9)$ & 20.8 & (0.9) & 3.7 & $(0.3)$ \\
\hline & Poland & 25.9 & $(1.0)$ & 44.9 & $(0.9)$ & 26.6 & (1.0) & 2.6 & $(0.3)$ \\
\hline & Portugal & 9.1 & $(0.5)$ & 29.6 & $(0.9)$ & 39.3 & (1.2) & 21.9 & (0.8) \\
\hline & Slovak Republic & 23.0 & $(0.9)$ & 41.1 & (1.0) & 27.3 & (1.0) & 8.6 & (0.6) \\
\hline & Slovenia & 19.3 & (1.0) & 36.1 & (1.0) & 34.4 & (1.0) & 10.3 & $(0.6)$ \\
\hline & Spain & 18.5 & $(0.6)$ & 38.4 & $(0.8)$ & 32.7 & $(0.8)$ & 10.3 & $(0.4)$ \\
\hline & Sweden & 24.6 & $(1.0)$ & 46.3 & $(1.0)$ & 23.4 & (1.1) & 5.6 & (0.5) \\
\hline & Switzerland & 15.0 & $(0.5)$ & 37.8 & $(0.8)$ & 36.6 & $(0.9)$ & 10.6 & $(0.6)$ \\
\hline & Turkey & 21.4 & $(0.9)$ & 30.4 & $(0.9)$ & 28.2 & $(0.8)$ & 20.1 & $(0.8)$ \\
\hline & United Kingdom & 9.6 & $(0.6)$ & 32.7 & $(0.8)$ & 40.8 & (1.0) & 16.8 & $(0.7)$ \\
\hline & United States & 12.9 & $(0.6)$ & 32.0 & $(0.9)$ & 35.6 & (1.0) & 19.5 & $(0.7)$ \\
\hline & OECD average & 17.1 & $(0.1)$ & 36.3 & $(0.2)$ & 32.5 & $(0.2)$ & 14.1 & $(0.1)$ \\
\hline \multirow{31}{*}{ 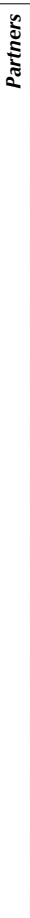 } & Albania & 23.0 & $(1.0)$ & 38.3 & (1.1) & 29.0 & (1.1) & 9.7 & (0.6) \\
\hline & Argentina & 15.8 & $(0.8)$ & 29.2 & (1.0) & 28.7 & (0.8) & 26.2 & (0.8) \\
\hline & Brazil & 17.7 & $(0.5)$ & 32.6 & $(0.7)$ & 28.6 & (0.6) & 21.2 & (0.6) \\
\hline & Bulgaria & 18.9 & $(0.9)$ & 32.0 & $(1.0)$ & 36.0 & (1.0) & 13.1 & $(0.7)$ \\
\hline & Colombia & 13.6 & $(0.9)$ & 27.0 & (1.0) & 29.5 & (1.0) & 29.9 & $(0.7)$ \\
\hline & Costa Rica & 10.6 & $(0.7)$ & 24.3 & (1.0) & 33.6 & $(0.9)$ & 31.4 & (1.0) \\
\hline & Croatia & 24.7 & $(0.8)$ & 35.2 & $(0.9)$ & 29.9 & $(0.8)$ & 10.2 & $(0.7)$ \\
\hline & Cyprus* & 19.3 & $(0.7)$ & 29.4 & $(0.8)$ & 30.2 & $(0.8)$ & 21.1 & $(0.8)$ \\
\hline & Hong Kong-China & 14.1 & $(0.6)$ & 39.1 & $(0.9)$ & 40.7 & (1.0) & 6.1 & (0.6) \\
\hline & Indonesia & 36.2 & $(1.2)$ & 36.3 & (1.1) & 19.8 & $(0.8)$ & 7.7 & $(0.5)$ \\
\hline & Jordan & 26.9 & $(0.9)$ & 34.2 & $(0.9)$ & 25.1 & $(0.7)$ & 13.8 & $(0.6)$ \\
\hline & Kazakhstan & 34.5 & $(1.1)$ & 37.2 & $(0.9)$ & 22.4 & $(0.8)$ & 5.9 & $(0.5)$ \\
\hline & Latvia & 11.2 & $(0.8)$ & 35.5 & $(0.9)$ & 44.8 & (1.1) & 8.4 & $(0.8)$ \\
\hline & Liechtenstein & 14.1 & $(2.6)$ & 30.2 & (3.3) & 45.9 & (3.5) & 9.7 & $(2.1)$ \\
\hline & Lithuania & 17.6 & $(0.7)$ & 39.2 & $(0.9)$ & 35.8 & (1.1) & 7.4 & $(0.5)$ \\
\hline & Macao-China & 9.4 & $(0.4)$ & 36.9 & $(0.8)$ & 47.1 & $(0.7)$ & 6.6 & (0.4) \\
\hline & Malaysia & 27.9 & $(0.9)$ & 38.7 & (1.0) & 24.9 & $(0.8)$ & 8.6 & $(0.7)$ \\
\hline & Montenegro & 20.2 & $(0.9)$ & 33.0 & $(0.9)$ & 29.6 & (0.9) & 17.2 & (0.8) \\
\hline & Peru & 19.0 & $(0.8)$ & 35.5 & $(0.8)$ & 26.6 & $(0.9)$ & 18.9 & $(0.6)$ \\
\hline & Qatar & 20.9 & $(0.5)$ & 30.6 & $(0.5)$ & 28.1 & $(0.4)$ & 20.4 & $(0.5)$ \\
\hline & Romania & 23.8 & $(0.9)$ & 32.9 & $(0.9)$ & 29.8 & (0.9) & 13.5 & (0.8) \\
\hline & Russian Federation & 15.2 & $(0.9)$ & 30.5 & $(0.8)$ & 39.5 & $(0.9)$ & 14.8 & (0.9) \\
\hline & Serbia & 15.0 & $(0.7)$ & 30.9 & $(0.8)$ & 34.1 & (1.1) & 20.0 & (0.8) \\
\hline & Shanghai-China & 28.0 & $(0.8)$ & 35.1 & $(0.7)$ & 29.7 & $(0.9)$ & 7.2 & $(0.5)$ \\
\hline & Singapore & 34.1 & $(0.8)$ & 43.1 & $(0.8)$ & 19.0 & (0.6) & 3.7 & $(0.3)$ \\
\hline & Chinese Taipei & 15.1 & $(0.6)$ & 38.5 & $(0.8)$ & 36.5 & $(0.8)$ & 10.0 & $(0.6)$ \\
\hline & Thailand & 25.5 & $(0.8)$ & 51.6 & $(0.9)$ & 17.2 & $(0.7)$ & 5.6 & $(0.4)$ \\
\hline & Tunisia & 16.9 & $(0.7)$ & 31.0 & $(0.9)$ & 27.6 & (1.0) & 24.5 & (1.0) \\
\hline & United Arab Emirates & 23.0 & $(0.6)$ & 33.0 & $(0.6)$ & 26.2 & (0.6) & 17.9 & $(0.6)$ \\
\hline & Uruguay & 11.6 & $(0.6)$ & 25.1 & $(0.9)$ & 30.9 & (0.9) & 32.4 & (1.0) \\
\hline & Viet Nam & 8.8 & $(0.6)$ & 41.0 & $(0.9)$ & 37.8 & $(0.9)$ & 12.3 & $(0.7)$ \\
\hline
\end{tabular}

* See notes at the beginning of this Annex.

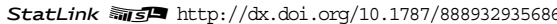


Students' exposure to the mathematics task "solving an equation like $\mathbf{2}(\mathbf{x}+\mathbf{3})=(\mathbf{x}+\mathbf{3})(\mathbf{x}-\mathbf{3})$ "

Table I.3.9 during their time in school

\begin{tabular}{|c|c|c|c|c|c|c|c|c|c|}
\hline & & \multicolumn{8}{|c|}{ Solving an equation like $2(x+3)=(x+3)(x-3)$} \\
\hline & & \multicolumn{2}{|c|}{ Frequently } & \multicolumn{2}{|c|}{ Sometimes } & \multicolumn{2}{|c|}{ Rarely } & \multicolumn{2}{|c|}{ Never } \\
\hline & & $\%$ & S.E. & $\%$ & S.E. & $\%$ & S.E. & $\%$ & S.E. \\
\hline \multirow{35}{*}{ Uి } & Australia & 51.8 & $(0.6)$ & 30.5 & $(0.5)$ & 10.6 & $(0.4)$ & 7.0 & $(0.3)$ \\
\hline & Austria & 63.3 & $(1.1)$ & 16.7 & $(0.8)$ & 11.3 & $(0.7)$ & 8.7 & $(0.6)$ \\
\hline & Belgium & 61.6 & $(0.8)$ & 18.6 & $(0.6)$ & 8.3 & $(0.4)$ & 11.5 & $(0.5)$ \\
\hline & Canada & 57.8 & $(0.6)$ & 23.0 & $(0.5)$ & 9.8 & $(0.3)$ & 9.4 & $(0.4)$ \\
\hline & Chile & 56.1 & $(1.2)$ & 25.1 & (1.0) & 11.3 & $(0.6)$ & 7.6 & $(0.4)$ \\
\hline & Czech Republic & 58.0 & $(1.2)$ & 26.3 & $(1.0)$ & 9.8 & $(0.7)$ & 5.9 & (0.6) \\
\hline & Denmark & 44.1 & $(1.1)$ & 32.8 & $(0.9)$ & 15.3 & $(0.7)$ & 7.8 & $(0.5)$ \\
\hline & Estonia & 63.3 & $(1.0)$ & 24.3 & $(0.9)$ & 8.3 & $(0.5)$ & 4.2 & $(0.4)$ \\
\hline & Finland & 50.5 & $(1.0)$ & 34.6 & $(0.9)$ & 9.9 & $(0.5)$ & 5.0 & (0.3) \\
\hline & France & 62.2 & $(0.9)$ & 20.7 & $(0.8)$ & 8.4 & $(0.5)$ & 8.7 & (0.6) \\
\hline & Germany & 66.1 & $(1.1)$ & 21.2 & $(0.8)$ & 7.8 & $(0.5)$ & 4.9 & (0.5) \\
\hline & Greece & 67.8 & (1.1) & 15.7 & $(0.7)$ & 8.8 & $(0.7)$ & 7.6 & (0.5) \\
\hline & Hungary & 69.5 & (1.1) & 17.8 & $(0.8)$ & 8.9 & $(0.6)$ & 3.8 & (0.5) \\
\hline & Iceland & 72.8 & $(0.9)$ & 17.1 & $(0.8)$ & 4.8 & $(0.5)$ & 5.2 & (0.5) \\
\hline & Ireland & 66.8 & $(1.0)$ & 21.1 & $(0.8)$ & 6.7 & $(0.4)$ & 5.4 & (0.5) \\
\hline & Israel & 65.2 & $(1.2)$ & 21.9 & $(0.7)$ & 6.4 & $(0.6)$ & 6.5 & (0.5) \\
\hline & Italy & 75.6 & $(0.6)$ & 14.2 & $(0.4)$ & 5.3 & $(0.2)$ & 4.9 & (0.3) \\
\hline & Japan & 69.8 & $(1.1)$ & 18.5 & $(0.7)$ & 6.4 & $(0.4)$ & 5.4 & (0.5) \\
\hline & Korea & 81.5 & (1.1) & 13.5 & $(0.8)$ & 2.8 & $(0.4)$ & 2.2 & (0.3) \\
\hline & Luxembourg & 53.9 & $(0.8)$ & 23.3 & $(0.8)$ & 11.3 & $(0.5)$ & 11.6 & (0.6) \\
\hline & Mexico & 56.0 & $(0.5)$ & 30.6 & $(0.5)$ & 8.9 & $(0.2)$ & 4.5 & $(0.2)$ \\
\hline & Netherlands & 59.5 & (1.5) & 23.6 & $(1.2)$ & 8.5 & $(0.7)$ & 8.4 & $(0.7)$ \\
\hline & New Zealand & 46.1 & (1.0) & 31.7 & $(0.8)$ & 12.2 & $(0.6)$ & 10.0 & $(0.7)$ \\
\hline & Norway & 53.8 & (1.3) & 33.8 & (1.1) & 8.3 & (0.6) & 4.1 & (0.4) \\
\hline & Poland & 61.8 & (1.1) & 29.5 & $(0.9)$ & 7.0 & $(0.6)$ & 1.7 & (0.3) \\
\hline & Portugal & 48.6 & (1.3) & 26.4 & (1.1) & 12.5 & $(0.7)$ & 12.6 & (0.8) \\
\hline & Slovak Republic & 58.9 & (1.3) & 26.6 & (1.0) & 9.1 & $(0.6)$ & 5.4 & (0.5) \\
\hline & Slovenia & 71.5 & $(0.9)$ & 19.3 & $(0.7)$ & 6.6 & $(0.4)$ & 2.6 & $(0.3)$ \\
\hline & Spain & 72.5 & $(0.6)$ & 19.7 & $(0.5)$ & 4.8 & $(0.3)$ & 2.9 & (0.3) \\
\hline & Sweden & 42.1 & $(1.2)$ & 38.4 & (1.1) & 12.5 & $(0.6)$ & 6.9 & (0.5) \\
\hline & Switzerland & 62.5 & (1.0) & 22.0 & (0.9) & 8.6 & $(0.4)$ & 7.0 & (0.4) \\
\hline & Turkey & 58.2 & (1.3) & 20.3 & $(0.8)$ & 12.6 & $(0.6)$ & 9.0 & (0.5) \\
\hline & United Kingdom & 58.7 & $(1.0)$ & 25.3 & (0.8) & 9.0 & $(0.4)$ & 6.9 & (0.3) \\
\hline & United States & 61.3 & $(1.2)$ & 25.7 & $(0.9)$ & 7.3 & $(0.5)$ & 5.7 & (0.5) \\
\hline & OECD average & 60.9 & $(0.2)$ & 23.8 & $(0.1)$ & 8.8 & $(0.1)$ & 6.5 & $(0.1)$ \\
\hline \multirow{31}{*}{ 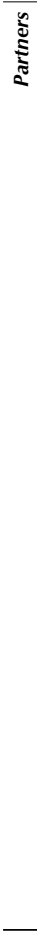 } & Albania & 70.4 & $(1.0)$ & 16.5 & (0.9) & 8.8 & (0.6) & 4.4 & $(0.5)$ \\
\hline & Argentina & 50.2 & (1.1) & 30.4 & (0.9) & 9.5 & $(0.5)$ & 9.9 & $(0.5)$ \\
\hline & Brazil & 35.9 & $(0.7)$ & 34.1 & $(0.7)$ & 18.4 & $(0.6)$ & 11.7 & $(0.5)$ \\
\hline & Bulgaria & 65.5 & $(1.2)$ & 20.9 & $(0.8)$ & 8.5 & $(0.6)$ & 5.1 & $(0.5)$ \\
\hline & Colombia & 41.5 & $(1.0)$ & 33.4 & $(1.0)$ & 15.7 & $(0.8)$ & 9.4 & (0.5) \\
\hline & Costa Rica & 57.0 & $(1.2)$ & 27.6 & (1.1) & 8.4 & $(0.6)$ & 7.0 & $(0.5)$ \\
\hline & Croatia & 70.1 & (1.0) & 18.8 & $(0.7)$ & 7.1 & $(0.5)$ & 3.9 & (0.5) \\
\hline & Cyprus* & 60.5 & $(1.0)$ & 20.8 & $(0.8)$ & 10.8 & (0.6) & 7.9 & $(0.5)$ \\
\hline & Hong Kong-China & 64.5 & (1.1) & 27.5 & $(0.9)$ & 5.7 & $(0.5)$ & 2.3 & $(0.3)$ \\
\hline & Indonesia & 53.0 & (1.4) & 29.6 & (1.0) & 12.6 & $(0.7)$ & 4.8 & $(0.5)$ \\
\hline & Jordan & 43.4 & (1.1) & 31.6 & $(0.8)$ & 16.6 & $(0.6)$ & 8.5 & $(0.5)$ \\
\hline & Kazakhstan & 70.1 & $(1.2)$ & 19.5 & $(0.9)$ & 8.2 & $(0.6)$ & 2.2 & $(0.3)$ \\
\hline & Latvia & 57.0 & $(1.3)$ & 29.6 & (1.1) & 10.3 & $(0.7)$ & 3.1 & $(0.4)$ \\
\hline & Liechtenstein & 75.9 & $(3.1)$ & 13.0 & $(2.5)$ & 4.1 & (1.4) & 6.9 & (1.8) \\
\hline & Lithuania & 65.6 & $(1.2)$ & 24.5 & $(0.9)$ & 7.2 & $(0.5)$ & 2.7 & $(0.3)$ \\
\hline & Macao-China & 69.3 & $(0.8)$ & 24.0 & $(0.9)$ & 5.0 & $(0.3)$ & 1.7 & $(0.2)$ \\
\hline & Malaysia & 60.4 & $(1.2)$ & 23.2 & $(0.8)$ & 11.0 & $(0.6)$ & 5.4 & (0.5) \\
\hline & Montenegro & 58.4 & $(0.9)$ & 24.4 & $(0.9)$ & 10.4 & $(0.6)$ & 6.8 & $(0.5)$ \\
\hline & Peru & 61.0 & $(1.2)$ & 28.7 & $(0.8)$ & 7.8 & $(0.6)$ & 2.6 & $(0.3)$ \\
\hline & Qatar & 49.4 & $(0.6)$ & 27.5 & $(0.5)$ & 13.1 & $(0.4)$ & 10.0 & $(0.4)$ \\
\hline & Romania & 57.2 & (1.3) & 25.1 & $(0.9)$ & 11.9 & $(0.7)$ & 5.8 & $(0.5)$ \\
\hline & Russian Federation & 75.5 & $(1.2)$ & 16.9 & (1.0) & 5.6 & $(0.4)$ & 2.0 & $(0.3)$ \\
\hline & Serbia & 63.3 & (1.1) & 19.3 & $(0.7)$ & 9.6 & $(0.6)$ & 7.7 & $(0.5)$ \\
\hline & Shanghai-China & 68.3 & $(1.1)$ & 19.8 & $(0.8)$ & 7.8 & $(0.6)$ & 4.2 & $(0.4)$ \\
\hline & Singapore & 76.3 & $(0.8)$ & 17.6 & $(0.7)$ & 4.2 & $(0.3)$ & 1.9 & $(0.2)$ \\
\hline & Chinese Taipei & 59.6 & $(1.1)$ & 24.7 & $(0.6)$ & 9.1 & (0.6) & 6.6 & (0.5) \\
\hline & Thailand & 52.1 & $(1.2)$ & 34.2 & $(1.0)$ & 9.8 & $(0.5)$ & 3.9 & $(0.3)$ \\
\hline & Tunisia & 49.2 & $(1.3)$ & 27.5 & $(0.9)$ & 12.8 & $(0.7)$ & 10.5 & (0.6) \\
\hline & United Arab Emirates & 54.5 & $(0.9)$ & 25.2 & $(0.7)$ & 12.1 & $(0.5)$ & 8.1 & (0.4) \\
\hline & Uruguay & 59.3 & $(1.1)$ & 24.9 & $(0.9)$ & 8.6 & $(0.5)$ & 7.2 & (0.4) \\
\hline & Viet Nam & 66.9 & (1.4) & 22.9 & (1.0) & 7.3 & $(0.7)$ & 2.8 & $(0.4)$ \\
\hline
\end{tabular}

* See notes at the beginning of this Annex.

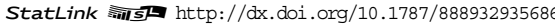


[Part 1/1]

Students' exposure to the mathematics task "calculating the power consumption of an electronic appliance per week"

Percentage of students who answered how often they have encountered the following types of mathematics tasks Table I.3.10 during their time in school

\begin{tabular}{|c|c|c|c|c|c|c|c|c|c|}
\hline & \multicolumn{8}{|c|}{ Calculating the power consumption of an electronic appliance per week } \\
\hline & & \multicolumn{2}{|c|}{ Frequently } & \multicolumn{2}{|c|}{ Sometimes } & \multicolumn{2}{|c|}{ Rarely } & \multicolumn{2}{|c|}{ Never } \\
\hline & & $\%$ & S.E. & $\%$ & S.E. & $\%$ & S.E. & $\%$ & S.E. \\
\hline \multirow{35}{*}{$\begin{array}{l}0 \\
\text { రు }\end{array}$} & Australia & 6.4 & $(0.3)$ & 29.8 & $(0.5)$ & 38.8 & $(0.6)$ & 25.1 & $(0.5)$ \\
\hline & Austria & 9.8 & $(0.5)$ & 24.1 & $(0.8)$ & 36.8 & $(0.9)$ & 29.3 & $(0.9)$ \\
\hline & Belgium & 6.3 & $(0.4)$ & 22.4 & $(0.7)$ & 35.8 & $(0.7)$ & 35.5 & $(0.8)$ \\
\hline & Canada & 11.4 & $(0.4)$ & 30.2 & $(0.5)$ & 32.4 & (0.6) & 26.0 & (0.5) \\
\hline & Chile & 15.0 & $(0.7)$ & 31.7 & $(0.8)$ & 31.9 & $(0.7)$ & 21.5 & $(0.7)$ \\
\hline & Czech Republic & 7.2 & $(0.5)$ & 28.2 & (1.1) & 39.4 & (1.1) & 25.1 & (1.0) \\
\hline & Denmark & 12.3 & $(0.6)$ & 40.6 & (0.9) & 36.0 & $(0.9)$ & 11.1 & (0.5) \\
\hline & Estonia & 9.6 & $(0.6)$ & 28.3 & $(1.0)$ & 42.5 & (0.9) & 19.6 & (0.8) \\
\hline & Finland & 10.9 & $(0.5)$ & 41.9 & $(0.8)$ & 32.6 & $(0.8)$ & 14.6 & $(0.5)$ \\
\hline & France & 10.2 & $(0.6)$ & 30.9 & $(0.8)$ & 35.8 & (0.9) & 23.1 & $(0.8)$ \\
\hline & Germany & 9.5 & $(0.6)$ & 30.6 & (0.9) & 39.9 & $(0.9)$ & 20.0 & (0.9) \\
\hline & Greece & 14.9 & $(0.7)$ & 25.8 & $(0.9)$ & 33.5 & $(0.9)$ & 25.9 & $(0.9)$ \\
\hline & Hungary & 13.6 & $(0.8)$ & 31.1 & (0.9) & 35.1 & $(1.0)$ & 20.2 & (0.9) \\
\hline & Iceland & 14.2 & $(0.8)$ & 31.4 & $(1.0)$ & 35.3 & (1.1) & 19.1 & $(0.9)$ \\
\hline & Ireland & 10.6 & $(0.5)$ & 35.4 & (1.0) & 35.5 & $(0.8)$ & 18.4 & $(0.7)$ \\
\hline & Israel & 12.9 & $(0.7)$ & 22.0 & $(0.7)$ & 28.1 & $(0.8)$ & 37.0 & (1.1) \\
\hline & Italy & 5.6 & $(0.2)$ & 18.3 & $(0.4)$ & 33.3 & $(0.5)$ & 42.8 & (0.5) \\
\hline & Japan & 10.1 & $(0.5)$ & 30.5 & $(0.8)$ & 36.6 & (0.8) & 22.9 & (0.8) \\
\hline & Korea & 13.7 & $(0.7)$ & 49.0 & $(0.9)$ & 29.9 & $(0.9)$ & 7.4 & (0.5) \\
\hline & Luxembourg & 9.1 & $(0.5)$ & 22.8 & $(0.7)$ & 33.3 & (0.8) & 34.8 & (0.8) \\
\hline & Mexico & 16.7 & $(0.4)$ & 40.0 & $(0.4)$ & 29.0 & $(0.4)$ & 14.2 & $(0.3)$ \\
\hline & Netherlands & 12.9 & $(0.6)$ & 44.3 & $(0.9)$ & 30.2 & $(0.8)$ & 12.6 & (0.8) \\
\hline & New Zealand & 9.3 & $(0.6)$ & 33.2 & $(0.9)$ & 34.6 & $(0.9)$ & 23.0 & (0.8) \\
\hline & Norway & 8.4 & $(0.6)$ & 32.9 & $(0.9)$ & 43.3 & (1.1) & 15.4 & (0.7) \\
\hline & Poland & 13.5 & $(0.7)$ & 36.4 & (1.0) & 39.4 & (1.0) & 10.7 & (0.6) \\
\hline & Portugal & 13.7 & $(0.7)$ & 32.4 & $(0.9)$ & 30.8 & $(0.9)$ & 23.2 & (0.9) \\
\hline & Slovak Republic & 13.8 & $(0.7)$ & 31.7 & $(0.8)$ & 34.6 & (1.0) & 19.9 & $(0.8)$ \\
\hline & Slovenia & 11.8 & $(0.8)$ & 30.4 & (1.0) & 36.6 & (0.9) & 21.2 & (0.9) \\
\hline & Spain & 13.2 & $(0.5)$ & 36.2 & (0.6) & 35.3 & (0.6) & 15.3 & (0.5) \\
\hline & Sweden & 11.3 & $(0.6)$ & 37.4 & (1.0) & 36.2 & (0.9) & 15.1 & (0.8) \\
\hline & Switzerland & 6.9 & $(0.4)$ & 25.5 & $(0.7)$ & 41.3 & $(0.9)$ & 26.2 & $(0.8)$ \\
\hline & Turkey & 15.0 & $(0.7)$ & 26.8 & $(0.9)$ & 30.3 & (0.8) & 27.9 & (1.0) \\
\hline & United Kingdom & 11.4 & $(0.5)$ & 36.4 & $(0.9)$ & 33.6 & $(0.9)$ & 18.7 & (0.6) \\
\hline & United States & 9.9 & $(0.6)$ & 26.3 & $(0.7)$ & 34.3 & (1.0) & 29.6 & (1.0) \\
\hline & OECD average & 11.2 & $(0.1)$ & 31.6 & $(0.1)$ & 35.1 & $(0.1)$ & 22.1 & $(0.1)$ \\
\hline \multirow{31}{*}{$\frac{n}{\vdots}$} & Albania & 22.5 & $(1.2)$ & 37.1 & (1.1) & 27.5 & (1.1) & 13.0 & (0.8) \\
\hline & Argentina & 13.5 & $(0.8)$ & 29.6 & $(0.8)$ & 29.0 & $(0.9)$ & 27.9 & (1.0) \\
\hline & Brazil & 16.0 & $(0.5)$ & 33.0 & $(0.5)$ & 26.4 & $(0.6)$ & 24.5 & (0.6) \\
\hline & Bulgaria & 15.3 & $(0.7)$ & 31.2 & $(0.8)$ & 35.1 & (1.0) & 18.4 & (0.7) \\
\hline & Colombia & 16.0 & $(0.7)$ & 33.2 & (1.1) & 26.0 & (1.0) & 24.7 & (0.8) \\
\hline & Costa Rica & 11.8 & $(0.8)$ & 25.2 & (0.9) & 31.3 & (0.9) & 31.7 & (0.9) \\
\hline & Croatia & 11.4 & $(0.5)$ & 26.9 & $(0.8)$ & 38.0 & $(0.8)$ & 23.8 & (0.8) \\
\hline & Cyprus* & 12.8 & $(0.6)$ & 24.2 & $(0.8)$ & 31.4 & (0.9) & 31.5 & (0.9) \\
\hline & Hong Kong-China & 5.9 & $(0.5)$ & 27.1 & $(0.9)$ & 49.3 & (1.1) & 17.8 & $(0.9)$ \\
\hline & Indonesia & 16.2 & $(0.9)$ & 32.8 & $(0.7)$ & 26.8 & (1.0) & 24.1 & (0.9) \\
\hline & Jordan & 26.0 & $(1.0)$ & 33.4 & $(0.8)$ & 24.8 & $(0.8)$ & 15.9 & (0.6) \\
\hline & Kazakhstan & 22.8 & $(0.8)$ & 38.5 & $(0.9)$ & 28.3 & (1.0) & 10.3 & (0.5) \\
\hline & Latvia & 12.0 & $(0.9)$ & 34.8 & $(0.8)$ & 38.1 & (1.0) & 15.1 & (0.9) \\
\hline & Liechtenstein & 4.3 & (1.5) & 28.1 & (3.1) & 42.7 & (3.6) & 24.9 & (3.2) \\
\hline & Lithuania & 13.2 & $(0.7)$ & 34.9 & $(0.9)$ & 38.3 & $(0.8)$ & 13.7 & (0.6) \\
\hline & Macao-China & 10.3 & $(0.5)$ & 30.2 & (0.8) & 41.8 & (1.0) & 17.7 & (0.6) \\
\hline & Malaysia & 12.3 & $(0.6)$ & 34.3 & (1.0) & 34.8 & (1.0) & 18.6 & $(0.8)$ \\
\hline & Montenegro & 11.9 & $(0.6)$ & 25.6 & (0.9) & 32.5 & (1.0) & 30.0 & (1.0) \\
\hline & Peru & 19.9 & $(0.6)$ & 36.4 & $(0.8)$ & 25.8 & $(0.7)$ & 17.9 & $(0.7)$ \\
\hline & Qatar & 21.2 & $(0.5)$ & 31.1 & (0.6) & 26.1 & (0.6) & 21.6 & (0.5) \\
\hline & Romania & 17.1 & $(0.7)$ & 28.3 & $(0.9)$ & 31.1 & $(0.9)$ & 23.5 & $(0.8)$ \\
\hline & Russian Federation & 16.7 & $(0.8)$ & 37.0 & $(0.9)$ & 31.8 & $(0.8)$ & 14.5 & (0.6) \\
\hline & Serbia & 9.4 & $(0.6)$ & 22.4 & $(0.8)$ & 35.1 & $(0.9)$ & 33.1 & (0.9) \\
\hline & Shanghai-China & 14.7 & $(0.7)$ & 30.1 & $(0.8)$ & 37.1 & $(0.7)$ & 18.1 & $(0.8)$ \\
\hline & Singapore & 20.6 & $(0.6)$ & 45.1 & $(0.9)$ & 25.6 & (0.8) & 8.7 & (0.5) \\
\hline & Chinese Taipei & 12.1 & $(0.6)$ & 30.1 & $(0.8)$ & 39.1 & $(0.9)$ & 18.7 & $(0.7)$ \\
\hline & Thailand & 19.6 & $(0.9)$ & 53.4 & (1.0) & 19.8 & $(0.8)$ & 7.2 & $(0.5)$ \\
\hline & Tunisia & 14.7 & $(0.7)$ & 28.8 & $(0.9)$ & 25.6 & $(0.8)$ & 30.8 & (1.0) \\
\hline & United Arab Emirates & 18.6 & $(0.6)$ & 30.2 & $(0.8)$ & 27.9 & $(0.6)$ & 23.3 & $(0.7)$ \\
\hline & Uruguay & 10.2 & $(0.6)$ & 24.6 & $(0.8)$ & 31.7 & (0.9) & 33.5 & (1.0) \\
\hline & Viet Nam & 12.5 & $(0.7)$ & 40.9 & $(0.9)$ & 31.7 & (0.9) & 14.8 & (0.8) \\
\hline
\end{tabular}

* See notes at the beginning of this Annex.

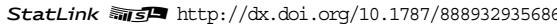


Students' exposure to the mathematics problem "solve equation; find volume"

Table I.3.11 mathematics lessons

\begin{tabular}{|c|c|c|c|c|c|c|c|c|c|}
\hline & \multicolumn{8}{|c|}{ Solve equation; find volume } \\
\hline & & \multicolumn{2}{|c|}{ Frequently } & \multicolumn{2}{|c|}{ Sometimes } & \multicolumn{2}{|c|}{ Rarely } & \multicolumn{2}{|c|}{ Never } \\
\hline & & $\%$ & S.E. & $\%$ & S.E. & $\%$ & S.E. & $\%$ & S.E. \\
\hline \multirow{35}{*}{ ర্ৰু } & Australia & 66.0 & $(0.6)$ & 28.8 & $(0.6)$ & 4.2 & $(0.2)$ & 1.0 & $(0.1)$ \\
\hline & Austria & 70.0 & $(0.9)$ & 23.2 & $(0.7)$ & 5.5 & $(0.5)$ & 1.3 & $(0.2)$ \\
\hline & Belgium & 63.4 & $(0.9)$ & 23.6 & $(0.6)$ & 7.4 & $(0.4)$ & 5.6 & $(0.4)$ \\
\hline & Canada & 72.9 & $(0.5)$ & 22.5 & $(0.5)$ & 3.5 & $(0.2)$ & 1.0 & $(0.1)$ \\
\hline & Chile & 69.6 & (1.0) & 26.3 & $(0.9)$ & 3.2 & $(0.3)$ & 0.9 & $(0.2)$ \\
\hline & Czech Republic & 68.4 & $(1.1)$ & 25.1 & $(1.0)$ & 5.3 & $(0.5)$ & 1.3 & $(0.3)$ \\
\hline & Denmark & 78.7 & $(0.8)$ & 19.0 & $(0.7)$ & 1.8 & $(0.3)$ & 0.5 & $(0.1)$ \\
\hline & Estonia & 69.9 & $(1.0)$ & 24.9 & $(0.9)$ & 4.8 & $(0.4)$ & 0.5 & $(0.1)$ \\
\hline & Finland & 78.2 & $(0.8)$ & 19.9 & $(0.8)$ & 1.3 & $(0.2)$ & 0.7 & (0.1) \\
\hline & France & 70.3 & $(0.9)$ & 23.4 & $(0.7)$ & 4.2 & (0.4) & 2.1 & (0.3) \\
\hline & Germany & 77.0 & $(0.9)$ & 18.5 & $(0.8)$ & 3.4 & $(0.3)$ & 1.2 & $(0.2)$ \\
\hline & Greece & 65.2 & $(0.9)$ & 24.4 & (0.8) & 7.5 & (0.5) & 2.8 & (0.3) \\
\hline & Hungary & 71.3 & (1.0) & 23.1 & $(0.8)$ & 4.2 & $(0.4)$ & 1.4 & (0.4) \\
\hline & Iceland & 85.4 & $(0.7)$ & 11.5 & (0.6) & 2.0 & $(0.3)$ & 1.1 & $(0.2)$ \\
\hline & Ireland & 76.9 & $(0.8)$ & 19.4 & $(0.8)$ & 3.0 & $(0.3)$ & 0.6 & $(0.2)$ \\
\hline & Israel & 55.2 & (1.0) & 29.7 & $(0.9)$ & 10.3 & $(0.6)$ & 4.8 & (0.5) \\
\hline & Italy & 63.2 & $(0.6)$ & 26.8 & $(0.5)$ & 6.6 & $(0.2)$ & 3.4 & $(0.2)$ \\
\hline & Japan & 78.7 & $(0.9)$ & 17.3 & $(0.7)$ & 2.5 & $(0.3)$ & 1.4 & $(0.2)$ \\
\hline & Korea & 60.9 & (1.0) & 30.6 & (0.9) & 6.4 & $(0.4)$ & 2.1 & (0.3) \\
\hline & Luxembourg & 68.6 & $(0.8)$ & 24.0 & $(0.7)$ & 4.6 & $(0.3)$ & 2.8 & (0.3) \\
\hline & Mexico & 61.2 & $(0.6)$ & 32.3 & $(0.5)$ & 4.8 & $(0.2)$ & 1.7 & (0.1) \\
\hline & Netherlands & 66.0 & (1.2) & 25.4 & $(1.0)$ & 5.6 & $(0.5)$ & 2.9 & (0.3) \\
\hline & New Zealand & 55.7 & (1.1) & 36.5 & (1.0) & 5.8 & $(0.5)$ & 2.0 & (0.3) \\
\hline & Norway & 60.7 & (1.1) & 33.7 & (1.0) & 4.5 & $(0.3)$ & 1.1 & $(0.2)$ \\
\hline & Poland & 65.7 & $(1.0)$ & 28.6 & $(0.8)$ & 4.7 & $(0.4)$ & 0.9 & $(0.2)$ \\
\hline & Portugal & 49.1 & (1.2) & 40.1 & (1.1) & 8.1 & $(0.5)$ & 2.8 & (0.3) \\
\hline & Slovak Republic & 73.2 & (1.1) & 21.1 & (0.9) & 4.2 & $(0.5)$ & 1.5 & (0.3) \\
\hline & Slovenia & 69.7 & $(1.0)$ & 25.0 & $(0.9)$ & 4.7 & $(0.4)$ & 0.6 & (0.1) \\
\hline & Spain & 71.7 & $(0.6)$ & 24.0 & $(0.5)$ & 3.3 & $(0.3)$ & 1.0 & (0.1) \\
\hline & Sweden & 62.9 & (1.1) & 32.3 & $(0.9)$ & 3.4 & $(0.4)$ & 1.4 & (0.3) \\
\hline & Switzerland & 73.6 & $(0.8)$ & 21.4 & $(0.6)$ & 3.6 & $(0.4)$ & 1.4 & $(0.2)$ \\
\hline & Turkey & 62.9 & $(1.0)$ & 25.8 & $(0.7)$ & 7.2 & $(0.5)$ & 4.1 & (0.5) \\
\hline & United Kingdom & 72.0 & $(0.8)$ & 24.1 & $(0.7)$ & 3.1 & $(0.4)$ & 0.9 & $(0.2)$ \\
\hline & United States & 70.5 & (1.1) & 23.3 & (0.9) & 4.7 & $(0.5)$ & 1.5 & (0.3) \\
\hline & OECD average & 68.4 & $(0.2)$ & 25.2 & $(0.1)$ & 4.7 & $(0.1)$ & 1.8 & $(0.0)$ \\
\hline \multirow{31}{*}{ ఏ } & Albania & 64.6 & (1.0) & 22.6 & $(1.0)$ & 8.9 & $(0.6)$ & 3.8 & $(0.4)$ \\
\hline & Argentina & 49.0 & $(0.9)$ & 39.3 & $(0.8)$ & 7.4 & $(0.5)$ & 4.3 & $(0.4)$ \\
\hline & Brazil & 43.2 & $(0.7)$ & 41.5 & $(0.7)$ & 11.2 & $(0.4)$ & 4.2 & $(0.3)$ \\
\hline & Bulgaria & 63.1 & (1.2) & 26.6 & (0.9) & 7.8 & $(0.6)$ & 2.4 & $(0.3)$ \\
\hline & Colombia & 59.2 & (1.2) & 32.3 & (1.1) & 5.5 & $(0.5)$ & 3.0 & $(0.4)$ \\
\hline & Costa Rica & 56.1 & (1.2) & 33.9 & $(1.0)$ & 6.7 & $(0.6)$ & 3.3 & $(0.4)$ \\
\hline & Croatia & 78.4 & $(0.9)$ & 17.3 & $(0.8)$ & 3.4 & $(0.3)$ & 0.9 & $(0.2)$ \\
\hline & Cyprus* & 62.1 & $(0.9)$ & 27.5 & $(0.9)$ & 7.6 & $(0.5)$ & 2.8 & $(0.3)$ \\
\hline & Hong Kong-China & 51.1 & (1.0) & 38.3 & (1.0) & 9.6 & $(0.6)$ & 0.9 & $(0.2)$ \\
\hline & Indonesia & 65.6 & (1.2) & 25.6 & $(0.9)$ & 6.9 & $(0.5)$ & 1.9 & $(0.3)$ \\
\hline & Jordan & 72.2 & (1.0) & 20.6 & $(0.9)$ & 4.5 & $(0.4)$ & 2.6 & $(0.3)$ \\
\hline & Kazakhstan & 65.3 & $(1.2)$ & 24.2 & (1.0) & 8.9 & $(0.6)$ & 1.7 & $(0.3)$ \\
\hline & Latvia & 66.0 & (1.2) & 27.8 & (1.1) & 5.7 & $(0.5)$ & 0.6 & $(0.2)$ \\
\hline & Liechtenstein & 77.5 & (3.1) & 18.4 & (2.8) & 2.4 & (1.1) & 1.7 & (0.9) \\
\hline & Lithuania & 65.5 & (1.1) & 28.3 & $(0.9)$ & 5.2 & $(0.4)$ & 1.1 & $(0.2)$ \\
\hline & Macao-China & 47.7 & $(0.8)$ & 36.6 & $(0.7)$ & 14.0 & $(0.6)$ & 1.7 & $(0.2)$ \\
\hline & Malaysia & 64.6 & (1.1) & 25.4 & $(0.9)$ & 6.9 & $(0.5)$ & 3.1 & (0.4) \\
\hline & Montenegro & 66.2 & (1.0) & 23.1 & $(0.9)$ & 7.1 & $(0.6)$ & 3.6 & $(0.4)$ \\
\hline & Peru & 57.2 & (1.3) & 32.2 & (1.1) & 7.5 & $(0.5)$ & 3.1 & (0.4) \\
\hline & Qatar & 53.4 & $(0.6)$ & 32.9 & $(0.6)$ & 9.3 & $(0.3)$ & 4.4 & $(0.2)$ \\
\hline & Romania & 67.3 & (1.0) & 23.6 & $(0.8)$ & 7.3 & $(0.5)$ & 1.8 & (0.3) \\
\hline & Russian Federation & 72.6 & $(1.0)$ & 21.6 & $(0.8)$ & 5.0 & $(0.5)$ & 0.8 & (0.1) \\
\hline & Serbia & 55.2 & $(1.0)$ & 30.2 & $(0.9)$ & 10.9 & $(0.6)$ & 3.7 & $(0.4)$ \\
\hline & Shanghai-China & 44.4 & $(1.0)$ & 29.2 & $(0.8)$ & 19.8 & $(0.7)$ & 6.7 & $(0.5)$ \\
\hline & Singapore & 58.5 & $(0.8)$ & 30.7 & $(0.8)$ & 9.1 & $(0.5)$ & 1.7 & $(0.2)$ \\
\hline & Chinese Taipei & 45.5 & $(0.8)$ & 36.9 & $(0.8)$ & 14.8 & $(0.7)$ & 2.7 & $(0.3)$ \\
\hline & Thailand & 65.8 & $(1.2)$ & 30.3 & (1.1) & 2.6 & $(0.2)$ & 1.3 & $(0.2)$ \\
\hline & Tunisia & 54.6 & (1.1) & 30.4 & (1.0) & 8.0 & $(0.5)$ & 7.0 & (0.5) \\
\hline & United Arab Emirates & 68.8 & $(0.7)$ & 24.1 & $(0.5)$ & 5.6 & $(0.4)$ & 1.5 & $(0.2)$ \\
\hline & Uruguay & 49.0 & $(0.9)$ & 36.8 & $(0.8)$ & 10.0 & $(0.6)$ & 4.1 & (0.4) \\
\hline & Viet Nam & 53.9 & (1.1) & 36.0 & $(0.9)$ & 8.0 & $(0.5)$ & 2.1 & $(0.3)$ \\
\hline
\end{tabular}

* See notes at the beginning of this Annex.

StatLink 部西 http://dx.doi.org/10.1787/888932935686 
[Part 1/1]

Students' exposure to the mathematics problem "word problems"

Percentage of students who answered how often they have encountered the following types of problems Table I.3.12 in their mathematics lessons

\begin{tabular}{|c|c|c|c|c|c|c|c|c|c|}
\hline & & \multicolumn{8}{|c|}{ Word problems } \\
\hline & & \multicolumn{2}{|c|}{ Frequently } & \multicolumn{2}{|c|}{ Sometimes } & \multicolumn{2}{|c|}{ Rarely } & \multicolumn{2}{|c|}{ Never } \\
\hline & & $\%$ & S.E. & $\%$ & S.E. & $\%$ & S.E. & $\%$ & S.E. \\
\hline \multirow{35}{*}{ ৩) } & Australia & 41.1 & $(0.6)$ & 49.0 & $(0.6)$ & 8.6 & $(0.3)$ & 1.2 & $(0.1)$ \\
\hline & Austria & 55.2 & $(1.0)$ & 36.3 & $(1.0)$ & 6.9 & $(0.5)$ & 1.6 & $(0.2)$ \\
\hline & Belgium & 48.7 & $(0.9)$ & 38.7 & $(0.8)$ & 9.2 & $(0.4)$ & 3.5 & $(0.3)$ \\
\hline & Canada & 50.1 & $(0.7)$ & 41.2 & $(0.6)$ & 7.2 & $(0.3)$ & 1.6 & $(0.2)$ \\
\hline & Chile & 53.0 & $(1.2)$ & 39.6 & $(1.1)$ & 6.1 & $(0.4)$ & 1.3 & $(0.2)$ \\
\hline & Czech Republic & 33.8 & $(1.0)$ & 49.6 & $(1.0)$ & 13.8 & (0.8) & 2.8 & $(0.4)$ \\
\hline & Denmark & 47.8 & $(0.9)$ & 44.4 & $(1.0)$ & 7.0 & $(0.6)$ & 0.8 & $(0.2)$ \\
\hline & Estonia & 40.0 & $(1.1)$ & 48.4 & $(1.1)$ & 10.6 & $(0.7)$ & 0.9 & $(0.2)$ \\
\hline & Finland & 53.6 & $(1.1)$ & 42.7 & $(1.0)$ & 3.0 & $(0.3)$ & 0.7 & $(0.1)$ \\
\hline & France & 57.6 & $(1.0)$ & 34.7 & $(0.8)$ & 6.3 & $(0.4)$ & 1.4 & $(0.2)$ \\
\hline & Germany & 51.5 & $(1.2)$ & 39.6 & $(1.2)$ & 7.6 & $(0.5)$ & 1.2 & $(0.2)$ \\
\hline & Greece & 21.4 & $(0.7)$ & 39.5 & $(0.9)$ & 29.6 & $(0.8)$ & 9.5 & $(0.6)$ \\
\hline & Hungary & 51.7 & $(1.2)$ & 36.5 & $(1.0)$ & 9.4 & $(0.5)$ & 2.4 & $(0.5)$ \\
\hline & Iceland & 68.7 & $(1.1)$ & 26.4 & $(1.0)$ & 3.9 & $(0.4)$ & 0.9 & $(0.2)$ \\
\hline & Ireland & 41.1 & $(1.0)$ & 46.7 & $(0.9)$ & 10.8 & (0.6) & 1.4 & $(0.2)$ \\
\hline & Israel & 35.7 & $(0.9)$ & 43.7 & $(0.9)$ & 15.4 & $(0.7)$ & 5.3 & $(0.5)$ \\
\hline & Italy & 39.9 & $(0.6)$ & 42.5 & $(0.5)$ & 12.6 & $(0.3)$ & 5.1 & $(0.3)$ \\
\hline & Japan & 32.3 & $(0.9)$ & 47.7 & $(0.8)$ & 14.3 & (0.6) & 5.7 & $(0.4)$ \\
\hline & Korea & 35.9 & $(1.0)$ & 47.6 & (1.0) & 12.3 & $(0.7)$ & 4.2 & $(0.4)$ \\
\hline & Luxembourg & 52.8 & $(0.9)$ & 37.5 & $(0.9)$ & 7.3 & $(0.5)$ & 2.4 & (0.3) \\
\hline & Mexico & 42.0 & $(0.5)$ & 48.7 & $(0.5)$ & 7.0 & $(0.2)$ & 2.4 & $(0.2)$ \\
\hline & Netherlands & 31.0 & (1.1) & 48.7 & $(1.1)$ & 15.9 & $(0.7)$ & 4.4 & (0.4) \\
\hline & New Zealand & 33.3 & $(1.0)$ & 52.3 & $(0.9)$ & 11.8 & $(0.6)$ & 2.5 & $(0.3)$ \\
\hline & Norway & 41.9 & $(1.0)$ & 49.5 & $(0.8)$ & 7.0 & (0.5) & 1.6 & $(0.2)$ \\
\hline & Poland & 52.8 & (1.1) & 40.2 & (1.0) & 6.2 & $(0.5)$ & 0.8 & $(0.2)$ \\
\hline & Portugal & 26.4 & $(0.7)$ & 51.8 & (1.0) & 17.6 & $(0.8)$ & 4.3 & $(0.4)$ \\
\hline & Slovak Republic & 50.6 & $(1.2)$ & 38.8 & (1.1) & 8.6 & (0.6) & 2.0 & (0.3) \\
\hline & Slovenia & 57.1 & $(1.0)$ & 35.7 & (1.0) & 6.4 & $(0.5)$ & 0.8 & $(0.1)$ \\
\hline & Spain & 58.7 & $(0.9)$ & 36.2 & $(0.7)$ & 4.0 & $(0.3)$ & 1.2 & $(0.1)$ \\
\hline & Sweden & 46.4 & $(1.0)$ & 46.4 & $(1.0)$ & 5.8 & $(0.4)$ & 1.3 & $(0.2)$ \\
\hline & Switzerland & 57.7 & (1.1) & 36.6 & (1.0) & 4.7 & $(0.4)$ & 1.0 & $(0.2)$ \\
\hline & Turkey & 21.9 & $(0.9)$ & 42.8 & $(0.9)$ & 22.4 & (0.9) & 12.9 & $(0.7)$ \\
\hline & United Kingdom & 43.6 & (1.0) & 45.8 & (1.1) & 9.5 & $(0.8)$ & 1.1 & $(0.2)$ \\
\hline & United States & 38.8 & (1.0) & 49.1 & $(1.1)$ & 10.0 & (0.5) & 2.1 & $(0.3)$ \\
\hline & OECD average & 44.5 & $(0.2)$ & 42.8 & $(0.2)$ & 10.0 & $(0.1)$ & 2.7 & $(0.1)$ \\
\hline \multirow{31}{*}{ 离 } & Albania & 46.3 & $(1.0)$ & 35.7 & $(0.8)$ & 12.9 & $(0.7)$ & 5.0 & $(0.4)$ \\
\hline & Argentina & 32.8 & $(1.0)$ & 49.8 & $(1.0)$ & 11.6 & $(0.7)$ & 5.8 & $(0.5)$ \\
\hline & Brazil & 28.2 & $(0.6)$ & 48.8 & $(0.7)$ & 16.8 & $(0.7)$ & 6.3 & $(0.3)$ \\
\hline & Bulgaria & 29.8 & $(0.9)$ & 43.8 & $(0.9)$ & 21.3 & $(0.7)$ & 5.0 & $(0.5)$ \\
\hline & Colombia & 45.6 & (1.3) & 41.7 & $(1.2)$ & 9.3 & (0.6) & 3.4 & $(0.4)$ \\
\hline & Costa Rica & 33.1 & $(1.2)$ & 47.4 & $(1.0)$ & 13.4 & $(0.9)$ & 6.2 & (0.6) \\
\hline & Croatia & 52.4 & $(1.2)$ & 35.6 & $(1.0)$ & 9.7 & $(0.6)$ & 2.2 & $(0.3)$ \\
\hline & Cyprus* & 36.1 & $(0.9)$ & 43.6 & $(0.9)$ & 16.1 & $(0.6)$ & 4.2 & $(0.4)$ \\
\hline & Hong Kong-China & 18.8 & $(0.7)$ & 54.0 & $(0.8)$ & 24.7 & $(0.8)$ & 2.5 & $(0.4)$ \\
\hline & Indonesia & 46.1 & $(1.1)$ & 38.3 & $(0.9)$ & 12.1 & $(0.6)$ & 3.4 & $(0.4)$ \\
\hline & Jordan & 58.9 & $(1.0)$ & 32.3 & $(0.9)$ & 6.2 & $(0.3)$ & 2.5 & $(0.3)$ \\
\hline & Kazakhstan & 43.8 & $(1.2)$ & 40.1 & $(1.0)$ & 14.1 & $(0.8)$ & 2.1 & (0.3) \\
\hline & Latvia & 37.2 & $(1.0)$ & 48.3 & $(1.1)$ & 13.1 & (0.8) & 1.3 & $(0.2)$ \\
\hline & Liechtenstein & 57.7 & (3.8) & 35.5 & (3.3) & 6.8 & (1.8) & 0.0 & c \\
\hline & Lithuania & 32.6 & $(0.9)$ & 51.6 & $(1.0)$ & 14.0 & $(0.6)$ & 1.9 & $(0.2)$ \\
\hline & Macao-China & 13.6 & $(0.6)$ & 45.2 & $(0.8)$ & 36.7 & $(0.8)$ & 4.5 & $(0.3)$ \\
\hline & Malaysia & 43.5 & $(1.1)$ & 41.9 & $(0.9)$ & 11.6 & $(0.7)$ & 3.1 & $(0.3)$ \\
\hline & Montenegro & 53.7 & $(1.0)$ & 32.7 & $(0.9)$ & 9.8 & $(0.6)$ & 3.8 & (0.4) \\
\hline & Peru & 48.8 & $(1.3)$ & 40.1 & $(1.0)$ & 7.9 & $(0.6)$ & 3.3 & $(0.4)$ \\
\hline & Qatar & 39.2 & $(0.6)$ & 46.3 & $(0.6)$ & 10.3 & $(0.3)$ & 4.2 & $(0.2)$ \\
\hline & Romania & 44.7 & $(1.0)$ & 38.8 & $(0.9)$ & 13.3 & $(0.5)$ & 3.2 & (0.3) \\
\hline & Russian Federation & 50.0 & $(1.2)$ & 37.4 & $(1.1)$ & 11.2 & (0.8) & 1.4 & $(0.2)$ \\
\hline & Serbia & 29.9 & $(1.1)$ & 43.4 & $(0.8)$ & 20.7 & $(0.9)$ & 6.0 & $(0.5)$ \\
\hline & Shanghai-China & 18.9 & $(0.8)$ & 40.3 & $(1.0)$ & 33.2 & (1.0) & 7.6 & $(0.5)$ \\
\hline & Singapore & 29.9 & $(0.8)$ & 47.3 & $(0.9)$ & 18.9 & $(0.6)$ & 3.9 & (0.3) \\
\hline & Chinese Taipei & 25.7 & $(0.7)$ & 50.4 & $(0.7)$ & 20.4 & $(0.5)$ & 3.5 & $(0.3)$ \\
\hline & Thailand & 48.3 & $(1.0)$ & 46.2 & $(0.9)$ & 3.7 & $(0.3)$ & 1.9 & (0.3) \\
\hline & Tunisia & 35.3 & $(1.0)$ & 46.2 & $(0.9)$ & 11.4 & $(0.7)$ & 7.0 & $(0.6)$ \\
\hline & United Arab Emirates & 42.4 & $(0.7)$ & 42.9 & $(0.7)$ & 11.9 & $(0.5)$ & 2.7 & $(0.2)$ \\
\hline & Uruguay & 20.7 & $(0.9)$ & 48.0 & $(0.8)$ & 21.7 & $(0.7)$ & 9.6 & (0.6) \\
\hline & Viet Nam & 14.6 & $(0.7)$ & 50.3 & $(1.0)$ & 26.7 & $(0.8)$ & 8.4 & $(0.5)$ \\
\hline
\end{tabular}

* See notes at the beginning of this Annex.

StatLink 部 St http://dx.doi.org/10.1787/888932935686 
[Part 1/1]

Students' exposure to the mathematics problem "geometrical theorems; prime number" Table I.3.13 in their mathematics lessons

\begin{tabular}{|c|c|c|c|c|c|c|c|c|c|}
\hline & & \multicolumn{8}{|c|}{ Geometrical theorems; prime number } \\
\hline & & \multicolumn{2}{|c|}{ Frequently } & \multicolumn{2}{|c|}{ Sometimes } & \multicolumn{2}{|c|}{ Rarely } & \multicolumn{2}{|c|}{ Never } \\
\hline & & $\%$ & S.E. & $\%$ & S.E. & $\%$ & S.E. & $\%$ & S.E. \\
\hline \multirow{35}{*}{ 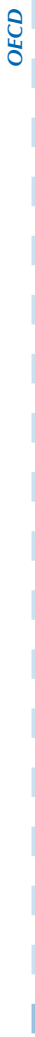 } & Australia & 30.9 & $(0.6)$ & 46.6 & $(0.6)$ & 17.5 & $(0.5)$ & 5.0 & $(0.2)$ \\
\hline & Austria & 38.3 & $(1.1)$ & 38.4 & (1.1) & 17.9 & $(0.7)$ & 5.4 & $(0.5)$ \\
\hline & Belgium & 36.2 & $(0.8)$ & 38.9 & $(0.7)$ & 15.4 & $(0.6)$ & 9.5 & (0.5) \\
\hline & Canada & 34.1 & $(0.6)$ & 42.6 & $(0.7)$ & 16.7 & $(0.5)$ & 6.6 & $(0.3)$ \\
\hline & Chile & 34.5 & $(0.9)$ & 45.5 & $(0.8)$ & 16.4 & $(0.8)$ & 3.5 & (0.4) \\
\hline & Czech Republic & 24.0 & $(1.2)$ & 43.6 & $(1.0)$ & 25.4 & $(1.0)$ & 7.0 & (0.6) \\
\hline & Denmark & 25.7 & $(0.8)$ & 49.3 & (1.0) & 21.2 & $(0.8)$ & 3.7 & (0.4) \\
\hline & Estonia & 35.7 & (1.1) & 40.4 & (1.1) & 19.5 & $(0.9)$ & 4.3 & (0.5) \\
\hline & Finland & 20.9 & $(0.7)$ & 46.9 & $(0.9)$ & 22.0 & $(0.6)$ & 10.2 & (0.6) \\
\hline & France & 42.2 & $(1.0)$ & 40.7 & $(0.9)$ & 12.8 & $(0.7)$ & 4.3 & (0.4) \\
\hline & Germany & 41.9 & $(1.2)$ & 36.9 & $(1.0)$ & 15.6 & $(0.8)$ & 5.6 & $(0.5)$ \\
\hline & Greece & 42.4 & $(0.9)$ & 36.5 & $(0.8)$ & 15.3 & $(0.6)$ & 5.8 & (0.4) \\
\hline & Hungary & 35.2 & $(1.1)$ & 42.4 & (1.0) & 17.7 & $(0.8)$ & 4.7 & (0.5) \\
\hline & Iceland & 28.0 & $(1.0)$ & 39.2 & (1.1) & 24.2 & (1.0) & 8.6 & $(0.6)$ \\
\hline & Ireland & 26.0 & $(0.8)$ & 40.8 & (0.9) & 23.6 & (0.9) & 9.6 & (0.5) \\
\hline & Israel & 30.1 & $(1.0)$ & 30.4 & $(1.0)$ & 20.0 & (0.9) & 19.6 & $(0.8)$ \\
\hline & Italy & 32.4 & $(0.5)$ & 41.9 & $(0.4)$ & 17.0 & $(0.4)$ & 8.8 & (0.3) \\
\hline & Japan & 48.3 & $(1.0)$ & 35.3 & $(0.7)$ & 10.6 & (0.6) & 5.7 & (0.4) \\
\hline & Korea & 35.5 & $(1.2)$ & 43.0 & (0.9) & 15.8 & $(0.7)$ & 5.7 & (0.5) \\
\hline & Luxembourg & 33.9 & $(0.8)$ & 41.8 & $(0.8)$ & 16.9 & $(0.6)$ & 7.4 & (0.4) \\
\hline & Mexico & 41.8 & $(0.5)$ & 44.9 & $(0.5)$ & 11.1 & $(0.3)$ & 2.2 & (0.1) \\
\hline & Netherlands & 39.6 & $(1.2)$ & 37.9 & $(0.9)$ & 13.7 & $(0.8)$ & 8.7 & (0.6) \\
\hline & New Zealand & 24.6 & $(0.9)$ & 48.2 & (1.1) & 22.0 & $(0.9)$ & 5.2 & (0.4) \\
\hline & Norway & 16.2 & $(0.8)$ & 45.6 & (1.0) & 29.5 & $(1.0)$ & 8.8 & (0.6) \\
\hline & Poland & 46.8 & (1.1) & 38.3 & (1.0) & 12.5 & (0.8) & 2.5 & (0.3) \\
\hline & Portugal & 40.9 & $(1.0)$ & 45.5 & (1.0) & 9.2 & $(0.7)$ & 4.3 & (0.4) \\
\hline & Slovak Republic & 34.8 & (1.0) & 44.1 & $(1.0)$ & 16.8 & $(0.7)$ & 4.4 & (0.4) \\
\hline & Slovenia & 33.5 & (1.0) & 48.2 & (1.0) & 16.3 & $(0.7)$ & 2.0 & $(0.2)$ \\
\hline & Spain & 35.3 & $(0.6)$ & 45.8 & $(0.8)$ & 15.2 & $(0.5)$ & 3.6 & (0.3) \\
\hline & Sweden & 14.7 & $(0.8)$ & 40.8 & $(0.8)$ & 31.8 & (0.9) & 12.7 & $(0.7)$ \\
\hline & Switzerland & 43.3 & $(0.8)$ & 39.9 & $(0.8)$ & 12.3 & $(0.5)$ & 4.5 & (0.4) \\
\hline & Turkey & 51.0 & $(1.0)$ & 33.2 & (0.9) & 9.9 & (0.6) & 5.8 & (0.6) \\
\hline & United Kingdom & 24.9 & $(1.1)$ & 45.7 & $(0.8)$ & 23.8 & $(0.8)$ & 5.6 & (0.3) \\
\hline & United States & 31.4 & $(0.9)$ & 43.0 & (1.0) & 18.4 & $(0.6)$ & 7.3 & (0.5) \\
\hline & OECD average & 34.0 & $(0.2)$ & 41.8 & $(0.2)$ & 17.8 & $(0.1)$ & 6.4 & $(0.1)$ \\
\hline \multirow{31}{*}{ ¿ } & Albania & 55.9 & (1.1) & 31.9 & (1.1) & 8.9 & (0.6) & 3.3 & $(0.3)$ \\
\hline & Argentina & 26.0 & $(0.8)$ & 43.5 & $(0.9)$ & 22.0 & $(0.7)$ & 8.5 & $(0.5)$ \\
\hline & Brazil & 33.8 & $(0.7)$ & 44.1 & $(0.7)$ & 16.2 & $(0.5)$ & 5.8 & (0.3) \\
\hline & Bulgaria & 45.4 & $(1.0)$ & 36.8 & $(0.8)$ & 13.0 & (0.6) & 4.7 & $(0.4)$ \\
\hline & Colombia & 41.7 & (1.4) & 41.0 & (1.2) & 12.4 & $(0.7)$ & 4.8 & (0.5) \\
\hline & Costa Rica & 23.3 & $(0.9)$ & 40.9 & (1.0) & 23.9 & $(0.9)$ & 11.9 & $(0.9)$ \\
\hline & Croatia & 36.8 & $(1.0)$ & 45.8 & (1.0) & 14.6 & $(0.7)$ & 2.8 & $(0.3)$ \\
\hline & Cyprus* & 31.7 & $(1.0)$ & 41.8 & (1.1) & 18.5 & $(0.7)$ & 8.0 & $(0.5)$ \\
\hline & Hong Kong-China & 33.3 & $(0.9)$ & 46.1 & $(0.7)$ & 16.8 & $(0.7)$ & 3.8 & $(0.4)$ \\
\hline & Indonesia & 61.0 & (1.3) & 30.0 & $(1.2)$ & 6.6 & $(0.6)$ & 2.3 & $(0.4)$ \\
\hline & Jordan & 46.5 & $(1.0)$ & 40.1 & $(0.8)$ & 9.9 & $(0.5)$ & 3.4 & $(0.3)$ \\
\hline & Kazakhstan & 61.8 & $(1.0)$ & 28.8 & $(0.8)$ & 7.0 & $(0.5)$ & 2.3 & (0.3) \\
\hline & Latvia & 34.6 & $(1.2)$ & 41.3 & $(0.9)$ & 16.7 & $(0.8)$ & 7.4 & $(0.7)$ \\
\hline & Liechtenstein & 54.1 & $(3.5)$ & 30.7 & (3.3) & 10.6 & $(2.2)$ & 4.6 & (1.5) \\
\hline & Lithuania & 39.5 & (1.1) & 39.7 & (1.0) & 15.8 & $(0.7)$ & 5.0 & $(0.4)$ \\
\hline & Macao-China & 29.5 & $(0.8)$ & 40.1 & $(0.8)$ & 20.4 & $(0.6)$ & 10.0 & $(0.5)$ \\
\hline & Malaysia & 43.9 & $(1.1)$ & 41.3 & $(1.0)$ & 11.6 & $(0.6)$ & 3.1 & $(0.3)$ \\
\hline & Montenegro & 42.7 & $(0.9)$ & 39.1 & (1.1) & 13.5 & $(0.6)$ & 4.7 & $(0.4)$ \\
\hline & Peru & 40.2 & $(1.2)$ & 42.3 & $(1.0)$ & 12.4 & $(0.8)$ & 5.1 & $(0.4)$ \\
\hline & Qatar & 36.3 & $(0.5)$ & 43.1 & $(0.5)$ & 15.1 & $(0.4)$ & 5.4 & $(0.3)$ \\
\hline & Romania & 57.8 & (1.1) & 32.4 & (1.0) & 8.3 & $(0.5)$ & 1.6 & $(0.2)$ \\
\hline & Russian Federation & 45.1 & $(1.0)$ & 33.5 & (0.8) & 14.5 & $(0.6)$ & 6.9 & (0.5) \\
\hline & Serbia & 35.1 & $(1.1)$ & 45.7 & (1.0) & 15.7 & $(0.8)$ & 3.6 & $(0.4)$ \\
\hline & Shanghai-China & 27.1 & $(0.8)$ & 28.1 & $(0.9)$ & 23.1 & $(0.7)$ & 21.6 & $(0.8)$ \\
\hline & Singapore & 43.0 & $(0.8)$ & 43.5 & $(0.9)$ & 11.3 & $(0.5)$ & 2.2 & (0.3) \\
\hline & Chinese Taipei & 28.1 & $(0.8)$ & 44.9 & $(0.8)$ & 21.9 & $(0.7)$ & 5.0 & $(0.3)$ \\
\hline & Thailand & 52.9 & $(1.0)$ & 42.1 & (0.9) & 3.6 & $(0.4)$ & 1.3 & $(0.2)$ \\
\hline & Tunisia & 49.4 & $(1.0)$ & 35.7 & $(0.8)$ & 9.2 & $(0.5)$ & 5.7 & (0.5) \\
\hline & United Arab Emirates & 41.0 & $(0.9)$ & 41.4 & $(0.7)$ & 13.8 & $(0.5)$ & 3.8 & (0.3) \\
\hline & Uruguay & 25.8 & $(0.8)$ & 42.2 & (1.0) & 21.3 & $(0.8)$ & 10.7 & $(0.7)$ \\
\hline & Viet Nam & 30.3 & $(0.9)$ & 47.5 & (0.8) & 15.8 & (0.6) & 6.4 & $(0.5)$ \\
\hline
\end{tabular}

* See notes at the beginning of this Annex.

StatLink त्नाज्ञ http://dx.doi.org/10.1787/888932935686 
[Part 1/1]

Students' exposure to mathematics problem requiring a real-life context (data)

Percentage of students who answered how often they have encountered the following types of problems Table I.3.14 in their mathematics lessons

\begin{tabular}{|c|c|c|c|c|c|c|c|c|c|}
\hline & & \multicolumn{8}{|c|}{ Data } \\
\hline & & \multicolumn{2}{|c|}{ Frequently } & \multicolumn{2}{|c|}{ Sometimes } & \multicolumn{2}{|c|}{ Rarely } & \multicolumn{2}{|c|}{ Never } \\
\hline & & $\%$ & S.E. & $\%$ & S.E. & $\%$ & S.E. & $\%$ & S.E. \\
\hline \multirow{35}{*}{ త్ } & Australia & 26.7 & $(0.5)$ & 52.0 & $(0.6)$ & 18.0 & (0.5) & 3.2 & $(0.2)$ \\
\hline & Austria & 13.2 & (0.9) & 36.9 & (1.1) & 36.8 & (1.1) & 13.1 & (0.8) \\
\hline & Belgium & 20.6 & $(0.7)$ & 43.9 & $(0.7)$ & 25.1 & $(0.7)$ & 10.4 & (0.5) \\
\hline & Canada & 32.1 & $(0.5)$ & 49.3 & $(0.7)$ & 15.5 & (0.5) & 3.0 & (0.3) \\
\hline & Chile & 30.0 & $(0.9)$ & 49.3 & $(0.9)$ & 17.4 & $(0.8)$ & 3.2 & (0.3) \\
\hline & Czech Republic & 6.9 & $(0.6)$ & 33.7 & $(0.9)$ & 42.4 & (1.1) & 17.0 & (0.8) \\
\hline & Denmark & 25.0 & $(0.8)$ & 51.1 & $(1.0)$ & 20.4 & $(0.8)$ & 3.4 & $(0.3)$ \\
\hline & Estonia & 10.0 & $(0.6)$ & 40.0 & $(0.9)$ & 41.5 & (1.0) & 8.5 & (0.6) \\
\hline & Finland & 12.4 & $(0.6)$ & 47.7 & $(0.8)$ & 31.3 & $(0.7)$ & 8.5 & (0.4) \\
\hline & France & 23.6 & $(0.9)$ & 45.6 & $(0.9)$ & 23.8 & (0.8) & 7.0 & (0.5) \\
\hline & Germany & 18.1 & $(0.8)$ & 47.2 & (1.0) & 28.2 & $(0.8)$ & 6.4 & (0.5) \\
\hline & Greece & 16.7 & $(0.7)$ & 37.3 & $(0.9)$ & 33.9 & (1.0) & 12.2 & (0.6) \\
\hline & Hungary & 20.5 & $(0.9)$ & 44.5 & $(1.1)$ & 27.5 & $(0.9)$ & 7.5 & (0.6) \\
\hline & Iceland & 36.7 & $(1.0)$ & 43.3 & (1.1) & 16.9 & $(0.7)$ & 3.2 & (0.4) \\
\hline & Ireland & 26.5 & $(0.8)$ & 44.2 & $(1.0)$ & 23.5 & $(0.8)$ & 5.8 & (0.5) \\
\hline & Israel & 28.6 & $(0.9)$ & 39.4 & $(0.9)$ & 19.9 & $(0.7)$ & 12.2 & $(0.7)$ \\
\hline & Italy & 15.7 & $(0.4)$ & 39.7 & $(0.4)$ & 29.2 & $(0.4)$ & 15.4 & (0.4) \\
\hline & Japan & 6.7 & $(0.4)$ & 27.8 & $(0.8)$ & 43.7 & (0.8) & 21.8 & $(0.7)$ \\
\hline & Korea & 12.2 & $(0.6)$ & 41.7 & $(0.9)$ & 35.4 & (0.9) & 10.7 & (0.5) \\
\hline & Luxembourg & 19.4 & $(0.8)$ & 44.0 & $(0.9)$ & 26.5 & (0.8) & 10.1 & (0.5) \\
\hline & Mexico & 37.6 & $(0.6)$ & 48.9 & $(0.5)$ & 11.3 & $(0.3)$ & 2.3 & $(0.1)$ \\
\hline & Netherlands & 36.4 & $(1.3)$ & 48.6 & $(1.2)$ & 12.1 & $(0.6)$ & 2.9 & $(0.3)$ \\
\hline & New Zealand & 23.9 & $(1.0)$ & 54.4 & (1.1) & 17.7 & $(0.7)$ & 4.0 & $(0.4)$ \\
\hline & Norway & 18.8 & $(0.7)$ & 54.2 & (1.0) & 22.0 & (0.9) & 5.0 & (0.4) \\
\hline & Poland & 16.2 & $(0.8)$ & 47.7 & $(1.0)$ & 31.5 & (1.0) & 4.6 & $(0.3)$ \\
\hline & Portugal & 30.5 & $(0.9)$ & 51.5 & $(0.9)$ & 14.5 & (0.8) & 3.5 & (0.3) \\
\hline & Slovak Republic & 14.6 & $(0.8)$ & 44.5 & $(1.1)$ & 31.2 & (0.9) & 9.7 & (0.6) \\
\hline & Slovenia & 15.7 & $(0.7)$ & 43.6 & $(1.0)$ & 33.9 & (1.1) & 6.8 & (0.5) \\
\hline & Spain & 22.9 & $(0.5)$ & 48.6 & $(0.5)$ & 23.5 & $(0.7)$ & 5.0 & $(0.3)$ \\
\hline & Sweden & 19.6 & $(0.8)$ & 53.6 & $(1.0)$ & 21.9 & (0.9) & 4.9 & (0.4) \\
\hline & Switzerland & 14.8 & $(0.7)$ & 45.7 & $(0.8)$ & 31.4 & (0.8) & 8.1 & (0.4) \\
\hline & Turkey & 20.2 & $(0.8)$ & 39.0 & $(0.9)$ & 24.7 & (0.6) & 16.0 & (0.9) \\
\hline & United Kingdom & 20.9 & $(0.8)$ & 47.2 & $(0.8)$ & 27.1 & $(0.8)$ & 4.8 & $(0.3)$ \\
\hline & United States & 27.8 & $(0.8)$ & 50.5 & $(1.0)$ & 17.7 & $(0.7)$ & 4.0 & (0.4) \\
\hline & OECD average & 21.2 & $(0.1)$ & 45.2 & $(0.2)$ & 25.8 & $(0.1)$ & 7.8 & $(0.1)$ \\
\hline \multirow{31}{*}{ 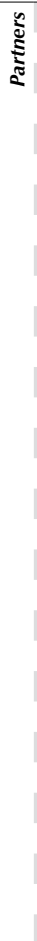 } & Albania & 28.9 & $(0.9)$ & 43.8 & $(1.0)$ & 20.5 & $(0.8)$ & 6.8 & $(0.5)$ \\
\hline & Argentina & 26.1 & $(1.0)$ & 47.0 & $(1.0)$ & 17.7 & (1.0) & 9.2 & (0.7) \\
\hline & Brazil & 29.6 & $(0.6)$ & 47.7 & $(0.7)$ & 16.3 & $(0.4)$ & 6.3 & (0.3) \\
\hline & Bulgaria & 16.6 & $(0.9)$ & 38.1 & $(0.9)$ & 32.4 & (1.0) & 12.9 & $(0.7)$ \\
\hline & Colombia & 39.1 & $(1.2)$ & 42.2 & $(1.0)$ & 12.5 & $(0.6)$ & 6.3 & (0.6) \\
\hline & Costa Rica & 18.9 & $(1.1)$ & 42.1 & $(1.3)$ & 27.6 & (1.1) & 11.4 & $(0.7)$ \\
\hline & Croatia & 12.5 & $(0.6)$ & 37.6 & $(0.9)$ & 36.1 & $(0.9)$ & 13.8 & (0.6) \\
\hline & Cyprus* & 20.9 & $(0.8)$ & 41.1 & $(1.0)$ & 29.2 & (0.8) & 8.7 & (0.5) \\
\hline & Hong Kong-China & 9.8 & $(0.7)$ & 39.2 & $(1.0)$ & 42.4 & $(0.9)$ & 8.6 & (0.6) \\
\hline & Indonesia & 44.5 & $(1.2)$ & 36.0 & $(0.9)$ & 14.0 & $(0.7)$ & 5.5 & (0.5) \\
\hline & Jordan & 39.9 & $(0.7)$ & 41.8 & $(0.8)$ & 13.5 & (0.6) & 4.7 & (0.4) \\
\hline & Kazakhstan & 28.9 & $(1.0)$ & 43.2 & $(1.1)$ & 20.3 & $(0.8)$ & 7.6 & (0.6) \\
\hline & Latvia & 14.4 & $(0.8)$ & 45.1 & $(1.0)$ & 33.4 & (1.0) & 7.1 & (0.6) \\
\hline & Liechtenstein & 14.0 & $(2.6)$ & 48.2 & $(3.6)$ & 29.5 & (3.3) & 8.3 & (2.0) \\
\hline & Lithuania & 16.5 & $(0.7)$ & 45.3 & $(0.9)$ & 31.4 & (1.0) & 6.9 & $(0.5)$ \\
\hline & Macao-China & 7.8 & $(0.4)$ & 34.3 & $(0.9)$ & 42.4 & (0.8) & 15.4 & (0.6) \\
\hline & Malaysia & 22.9 & $(0.8)$ & 43.9 & $(0.9)$ & 24.1 & $(0.7)$ & 9.1 & (0.6) \\
\hline & Montenegro & 17.3 & $(0.8)$ & 37.1 & $(1.0)$ & 29.8 & (1.0) & 15.8 & (0.6) \\
\hline & Peru & 27.6 & $(1.0)$ & 46.0 & $(1.0)$ & 18.9 & $(0.8)$ & 7.5 & (0.5) \\
\hline & Qatar & 26.6 & $(0.6)$ & 47.2 & $(0.6)$ & 19.2 & $(0.5)$ & 7.0 & (0.3) \\
\hline & Romania & 22.7 & $(1.0)$ & 40.7 & $(0.9)$ & 26.9 & $(0.9)$ & 9.7 & (0.6) \\
\hline & Russian Federation & 23.9 & $(1.1)$ & 40.5 & $(1.0)$ & 27.0 & (1.0) & 8.6 & (0.5) \\
\hline & Serbia & 14.2 & $(0.8)$ & 35.7 & $(0.9)$ & 34.9 & $(0.8)$ & 15.2 & (0.8) \\
\hline & Shanghai-China & 20.3 & $(0.8)$ & 36.8 & $(0.8)$ & 28.6 & $(0.8)$ & 14.4 & (0.7) \\
\hline & Singapore & 18.4 & $(0.7)$ & 43.7 & $(0.9)$ & 29.4 & $(0.8)$ & 8.6 & (0.4) \\
\hline & Chinese Taipei & 14.0 & $(0.7)$ & 37.2 & $(0.9)$ & 37.5 & (0.9) & 11.2 & (0.5) \\
\hline & Thailand & 40.3 & $(0.9)$ & 49.6 & $(0.9)$ & 7.7 & $(0.5)$ & 2.4 & $(0.3)$ \\
\hline & Tunisia & 35.2 & $(1.0)$ & 38.4 & $(1.0)$ & 14.4 & $(0.7)$ & 12.0 & $(0.7)$ \\
\hline & United Arab Emirates & 30.0 & $(0.7)$ & 45.7 & $(0.8)$ & 19.2 & $(0.6)$ & 5.1 & $(0.3)$ \\
\hline & Uruguay & 15.2 & $(0.7)$ & 41.4 & $(1.0)$ & 27.6 & (0.9) & 15.7 & $(0.7)$ \\
\hline & Viet Nam & 10.0 & $(0.6)$ & 34.8 & $(1.0)$ & 29.4 & $(0.7)$ & 25.8 & (1.0) \\
\hline
\end{tabular}

* See notes at the beginning of this Annex.

StatLink 部 St http://dx.doi.org/10.1787/888932935686 
[Part 1/1]

Students' exposure to the mathematics concept "exponential function"

Table I.3.15 Percentage of students who answered how familiar they are with the following mathematical concepts

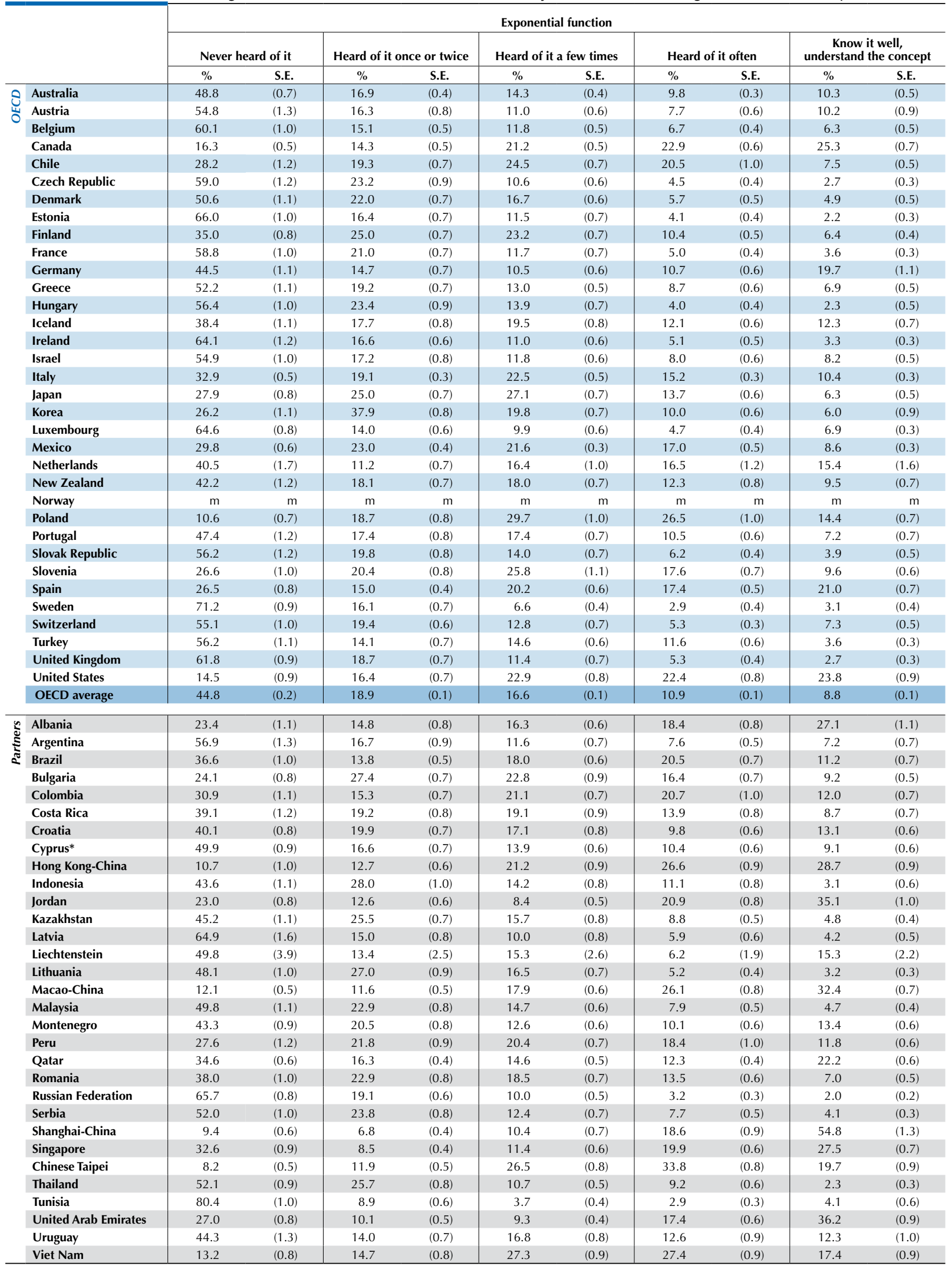

* See notes at the beginning of this Annex.

StatLink त्राज http://dx.doi.org/10.1787/888932935686 
[Part 1/1]

Students' exposure to the mathematics concept "divisor"

Table I.3.16 Percentage of students who answered how familiar they are with the following mathematical concepts

\begin{tabular}{|c|c|c|c|c|c|c|c|c|c|c|c|}
\hline & & \multicolumn{10}{|c|}{ Divisor } \\
\hline & & \multicolumn{2}{|c|}{ Never heard of it } & \multicolumn{2}{|c|}{ Heard of it once or twice } & \multicolumn{2}{|c|}{ Heard of it a few times } & \multicolumn{2}{|c|}{ Heard of it often } & \multicolumn{2}{|c|}{$\begin{array}{l}\text { Know it well, } \\
\text { understand the concept }\end{array}$} \\
\hline & & $\%$ & S.E. & $\%$ & S.E. & $\%$ & S.E. & $\%$ & S.E. & $\%$ & S.E. \\
\hline \multirow{35}{*}{ 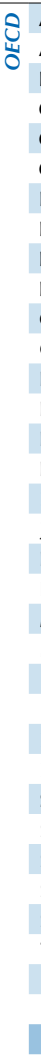 } & Australia & 33.1 & $(0.6)$ & 22.5 & $(0.5)$ & 20.3 & $(0.5)$ & 12.5 & $(0.4)$ & 11.6 & $(0.5)$ \\
\hline & Austria & 6.3 & $(0.6)$ & 7.4 & $(0.6)$ & 13.0 & $(0.6)$ & 21.7 & $(0.7)$ & 51.6 & $(1.1)$ \\
\hline & Belgium & 3.2 & $(0.3)$ & 3.8 & $(0.3)$ & 6.1 & $(0.4)$ & 15.4 & $(0.5)$ & 71.4 & $(0.7)$ \\
\hline & Canada & 13.3 & $(0.4)$ & 13.2 & $(0.4)$ & 18.0 & $(0.4)$ & 20.7 & $(0.5)$ & 34.9 & $(0.6)$ \\
\hline & Chile & 2.3 & $(0.3)$ & 5.6 & $(0.5)$ & 9.1 & $(0.6)$ & 29.6 & $(0.9)$ & 53.3 & (1.3) \\
\hline & Czech Republic & 1.5 & $(0.4)$ & 2.5 & $(0.4)$ & 8.4 & $(0.6)$ & 17.1 & $(0.8)$ & 70.5 & $(1.2)$ \\
\hline & Denmark & 25.6 & $(0.9)$ & 18.6 & $(0.7)$ & 21.0 & $(0.6)$ & 13.4 & $(0.7)$ & 21.4 & $(0.8)$ \\
\hline & Estonia & 0.8 & $(0.2)$ & 2.6 & $(0.3)$ & 6.9 & $(0.5)$ & 26.9 & $(0.9)$ & 62.9 & (1.1) \\
\hline & Finland & 6.7 & $(0.4)$ & 8.6 & $(0.5)$ & 13.4 & $(0.6)$ & 27.2 & $(0.7)$ & 44.0 & $(0.9)$ \\
\hline & France & 3.6 & $(0.4)$ & 5.7 & (0.4) & 10.2 & (0.6) & 21.5 & $(0.8)$ & 58.9 & (0.9) \\
\hline & Germany & 14.5 & $(0.8)$ & 12.0 & $(0.7)$ & 16.0 & $(0.7)$ & 17.0 & $(0.8)$ & 40.5 & (1.1) \\
\hline & Greece & 3.5 & $(0.3)$ & 6.1 & $(0.6)$ & 7.2 & $(0.5)$ & 19.6 & $(0.8)$ & 63.7 & $(1.2)$ \\
\hline & Hungary & 1.3 & $(0.3)$ & 3.8 & (0.5) & 5.4 & $(0.5)$ & 22.6 & (1.0) & 67.0 & $(1.2)$ \\
\hline & Iceland & 12.6 & $(0.7)$ & 7.1 & $(0.6)$ & 11.6 & $(0.7)$ & 19.9 & $(1.0)$ & 48.8 & $(1.2)$ \\
\hline & Ireland & 15.5 & $(0.8)$ & 16.7 & $(0.7)$ & 20.2 & $(0.9)$ & 21.8 & $(0.8)$ & 25.8 & $(0.9)$ \\
\hline & Israel & 27.5 & $(1.0)$ & 14.5 & $(0.6)$ & 12.9 & $(0.6)$ & 15.4 & $(0.7)$ & 29.8 & $(1.0)$ \\
\hline & Italy & 2.2 & $(0.2)$ & 3.6 & $(0.2)$ & 5.9 & $(0.3)$ & 20.6 & $(0.5)$ & 67.7 & $(0.7)$ \\
\hline & Japan & 2.1 & $(0.3)$ & 2.6 & $(0.3)$ & 5.7 & $(0.4)$ & 23.7 & $(0.7)$ & 65.9 & $(1.1)$ \\
\hline & Korea & 0.7 & $(0.2)$ & 2.7 & $(0.3)$ & 8.1 & $(0.5)$ & 17.8 & $(0.9)$ & 70.8 & (1.3) \\
\hline & Luxembourg & 7.0 & $(0.4)$ & 6.4 & $(0.4)$ & 11.2 & $(0.6)$ & 15.6 & $(0.6)$ & 59.8 & $(0.8)$ \\
\hline & Mexico & 5.2 & $(0.2)$ & 12.6 & $(0.3)$ & 16.2 & $(0.4)$ & 26.5 & $(0.5)$ & 39.5 & (0.6) \\
\hline & Netherlands & 24.6 & (1.3) & 12.9 & (0.9) & 16.3 & $(0.8)$ & 21.2 & $(0.9)$ & 25.0 & $(1.0)$ \\
\hline & New Zealand & 37.4 & $(1.1)$ & 23.3 & $(0.8)$ & 18.7 & $(0.8)$ & 12.0 & $(0.7)$ & 8.6 & $(0.6)$ \\
\hline & Norway & $\mathrm{m}$ & $\mathrm{m}$ & $\mathrm{m}$ & $\mathrm{m}$ & $\mathrm{m}$ & $\mathrm{m}$ & $\mathrm{m}$ & $\mathrm{m}$ & $\mathrm{m}$ & $\mathrm{m}$ \\
\hline & Poland & 3.4 & $(0.4)$ & 7.7 & (0.6) & 12.6 & $(0.7)$ & 21.6 & $(0.9)$ & 54.8 & (1.3) \\
\hline & Portugal & 2.3 & $(0.3)$ & 4.8 & $(0.5)$ & 11.1 & $(0.8)$ & 25.6 & $(0.8)$ & 56.2 & (1.4) \\
\hline & Slovak Republic & 2.7 & $(0.4)$ & 2.8 & $(0.4)$ & 8.4 & $(0.6)$ & 24.3 & $(0.8)$ & 61.8 & $(1.1)$ \\
\hline & Slovenia & 2.3 & $(0.3)$ & 2.0 & $(0.2)$ & 4.3 & $(0.4)$ & 12.6 & $(0.7)$ & 78.8 & $(0.9)$ \\
\hline & Spain & 2.1 & $(0.2)$ & 4.6 & $(0.3)$ & 11.6 & $(0.5)$ & 16.8 & $(0.5)$ & 64.9 & $(0.7)$ \\
\hline & Sweden & 53.7 & $(1.1)$ & 23.4 & $(0.9)$ & 8.6 & $(0.6)$ & 5.8 & $(0.4)$ & 8.5 & $(0.5)$ \\
\hline & Switzerland & 7.1 & $(0.5)$ & 7.6 & $(0.4)$ & 10.9 & $(0.6)$ & 16.4 & $(0.6)$ & 58.1 & $(1.3)$ \\
\hline & Turkey & 3.3 & $(0.3)$ & 6.1 & $(0.5)$ & 10.9 & $(0.6)$ & 35.4 & $(1.2)$ & 44.4 & (1.5) \\
\hline & United Kingdom & 45.8 & $(1.0)$ & 24.6 & $(0.7)$ & 15.4 & $(0.7)$ & 8.7 & $(0.6)$ & 5.4 & $(0.4)$ \\
\hline & United States & 11.8 & $(0.7)$ & 14.7 & $(0.7)$ & 20.0 & $(0.7)$ & 23.2 & $(0.7)$ & 30.3 & $(1.0)$ \\
\hline & OECD average & 11.7 & $(0.1)$ & 9.5 & $(0.1)$ & 12.0 & $(0.1)$ & 19.7 & $(0.1)$ & 47.2 & $(0.2)$ \\
\hline \multirow{31}{*}{ 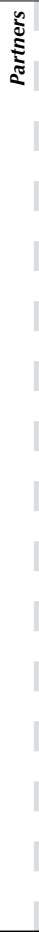 } & Albania & 3.6 & $(0.4)$ & 6.3 & (0.6) & 10.0 & $(0.7)$ & 21.1 & $(1.0)$ & 59.0 & (1.2) \\
\hline & Argentina & 6.1 & $(0.4)$ & 13.9 & $(0.9)$ & 14.1 & $(0.7)$ & 19.0 & $(0.6)$ & 46.8 & (1.5) \\
\hline & Brazil & 7.0 & $(0.3)$ & 14.0 & (0.6) & 16.0 & $(0.4)$ & 30.0 & $(0.7)$ & 33.0 & $(0.7)$ \\
\hline & Bulgaria & 6.6 & $(0.6)$ & 10.2 & $(0.7)$ & 8.8 & $(0.5)$ & 16.5 & $(0.7)$ & 57.9 & (1.5) \\
\hline & Colombia & 3.0 & $(0.3)$ & 10.2 & $(0.6)$ & 13.3 & $(0.7)$ & 31.3 & (1.0) & 42.2 & (1.0) \\
\hline & Costa Rica & 5.6 & $(0.5)$ & 9.6 & $(0.7)$ & 15.9 & $(0.8)$ & 22.2 & $(0.8)$ & 46.6 & $(1.2)$ \\
\hline & Croatia & 2.6 & $(0.3)$ & 2.9 & $(0.3)$ & 6.0 & $(0.4)$ & 10.8 & $(0.6)$ & 77.8 & $(0.9)$ \\
\hline & Cyprus* & 9.7 & $(0.5)$ & 9.8 & $(0.5)$ & 14.7 & $(0.6)$ & 23.4 & $(0.8)$ & 42.3 & $(0.8)$ \\
\hline & Hong Kong-China & 0.9 & $(0.3)$ & 1.4 & $(0.2)$ & 4.4 & $(0.5)$ & 12.4 & $(0.6)$ & 80.8 & $(0.8)$ \\
\hline & Indonesia & 2.6 & $(0.4)$ & 11.8 & $(0.7)$ & 20.4 & $(1.0)$ & 47.3 & $(0.9)$ & 17.8 & $(1.0)$ \\
\hline & Jordan & 13.2 & $(0.6)$ & 13.2 & $(0.6)$ & 9.0 & $(0.5)$ & 18.2 & $(0.7)$ & 46.4 & (1.0) \\
\hline & Kazakhstan & 4.3 & $(0.4)$ & 7.5 & $(0.6)$ & 9.9 & $(0.6)$ & 26.2 & $(0.9)$ & 52.1 & (1.3) \\
\hline & Latvia & 2.1 & $(0.3)$ & 5.8 & $(0.5)$ & 6.3 & $(0.5)$ & 18.0 & $(0.9)$ & 67.9 & $(1.2)$ \\
\hline & Liechtenstein & 4.8 & $(1.5)$ & 5.9 & (1.7) & 8.3 & $(2.0)$ & 15.0 & $(2.5)$ & 65.9 & (2.9) \\
\hline & Lithuania & 3.5 & $(0.3)$ & 8.2 & $(0.6)$ & 13.4 & $(0.6)$ & 21.6 & $(0.8)$ & 53.3 & $(1.1)$ \\
\hline & Macao-China & 2.5 & $(0.2)$ & 2.4 & $(0.3)$ & 5.1 & $(0.3)$ & 11.8 & $(0.5)$ & 78.1 & $(0.6)$ \\
\hline & Malaysia & 11.6 & $(0.8)$ & 15.4 & $(0.8)$ & 18.2 & $(0.7)$ & 31.4 & $(1.0)$ & 23.3 & (1.0) \\
\hline & Montenegro & 6.7 & $(0.4)$ & 6.8 & $(0.4)$ & 6.3 & $(0.5)$ & 14.9 & $(0.7)$ & 65.3 & $(1.0)$ \\
\hline & Peru & 3.3 & $(0.3)$ & 11.7 & $(0.6)$ & 12.0 & $(0.6)$ & 27.8 & $(0.9)$ & 45.1 & (1.3) \\
\hline & Qatar & 15.8 & $(0.5)$ & 17.7 & $(0.5)$ & 16.7 & $(0.5)$ & 13.3 & $(0.4)$ & 36.4 & (0.6) \\
\hline & Romania & 6.8 & $(0.6)$ & 13.3 & $(0.8)$ & 13.1 & $(0.8)$ & 25.7 & $(1.0)$ & 41.0 & (1.6) \\
\hline & Russian Federation & 2.8 & $(0.3)$ & 4.0 & $(0.5)$ & 5.6 & $(0.4)$ & 15.0 & $(0.6)$ & 72.6 & $(0.9)$ \\
\hline & Serbia & 3.3 & $(0.3)$ & 2.8 & $(0.4)$ & 7.4 & $(0.6)$ & 12.8 & $(0.7)$ & 73.7 & (1.1) \\
\hline & Shanghai-China & 4.74 & 0.29 & 3.7 & $(0.3)$ & 9.2 & $(0.5)$ & 15.5 & $(0.8)$ & 66.9 & $(0.8)$ \\
\hline & Singapore & 30.2 & $(0.8)$ & 12.0 & $(0.5)$ & 12.9 & $(0.6)$ & 17.1 & $(0.7)$ & 27.9 & $(0.7)$ \\
\hline & Chinese Taipei & 2.6 & $(0.3)$ & 4.9 & $(0.4)$ & 10.4 & $(0.6)$ & 26.2 & $(0.8)$ & 56.0 & $(1.0)$ \\
\hline & Thailand & 2.7 & $(0.3)$ & 11.8 & $(0.7)$ & 8.3 & $(0.5)$ & 36.8 & $(1.0)$ & 40.4 & $(1.2)$ \\
\hline & Tunisia & 11.0 & $(0.7)$ & 10.8 & $(0.7)$ & 10.4 & $(0.6)$ & 17.4 & $(0.8)$ & 50.4 & (1.5) \\
\hline & United Arab Emirates & 18.2 & $(0.5)$ & 12.1 & $(0.6)$ & 10.9 & $(0.4)$ & 18.3 & $(0.6)$ & 40.5 & $(0.9)$ \\
\hline & Uruguay & 3.8 & $(0.3)$ & 9.7 & (0.6) & 16.1 & $(0.7)$ & 25.6 & $(0.8)$ & 44.8 & $(1.0)$ \\
\hline & Viet Nam & 15.6 & $(0.9)$ & 14.6 & $(0.6)$ & 32.1 & $(1.0)$ & 20.6 & $(0.9)$ & 17.2 & $(1.1)$ \\
\hline
\end{tabular}

* See notes at the beginning of this Annex.

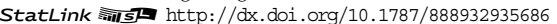


Part 1/1]

Students' exposure to the mathematics concept "quadratic function"

Table I.3.17 Percentage of students who answered how familiar they are with the following mathematical concepts

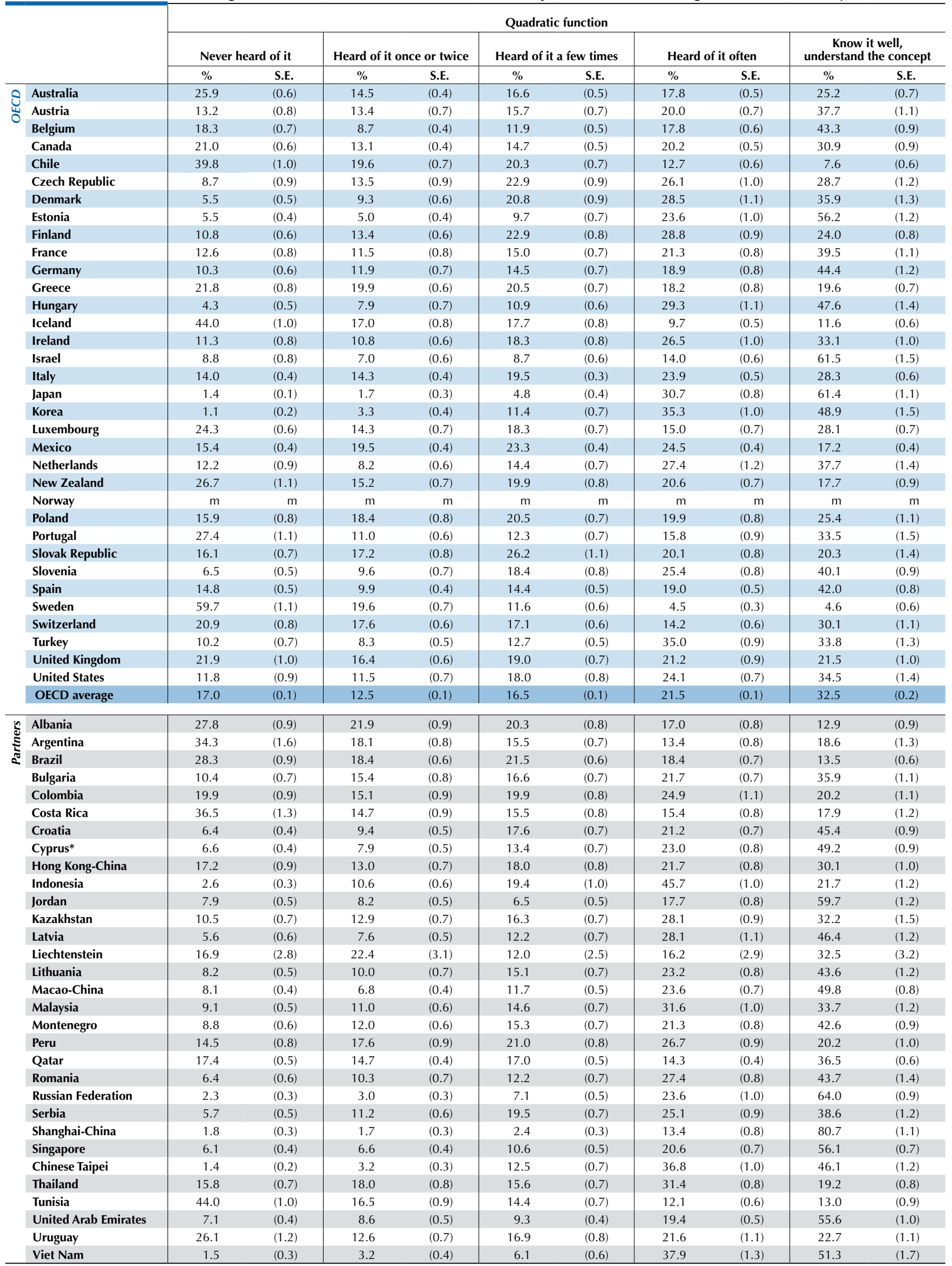

* See notes at the beginning of this Annex.

StatLink त्राज http://dx.doi.org/10.1787/888932935686 
[Part 1/1]

Students' exposure to the mathematics concept "linear equation"

Table I.3.18 Percentage of students who answered how familiar they are with the following mathematical concepts

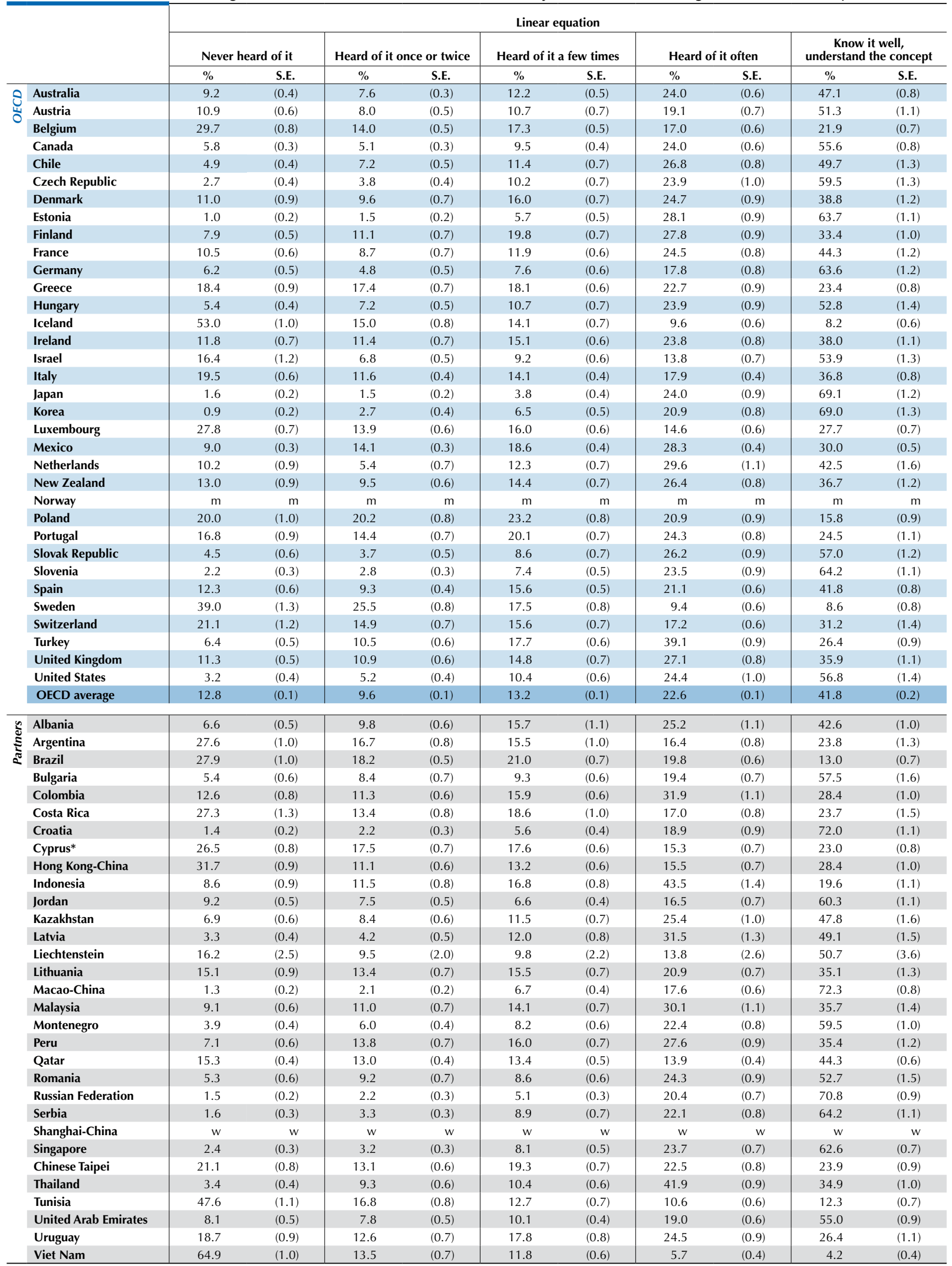

* See notes at the beginning of this Annex.

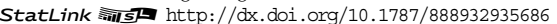


Part 1/1]

Students' exposure to the mathematics concept "vectors"

Table I.3.19 Percentage of students who answered how familiar they are with the following mathematical concepts

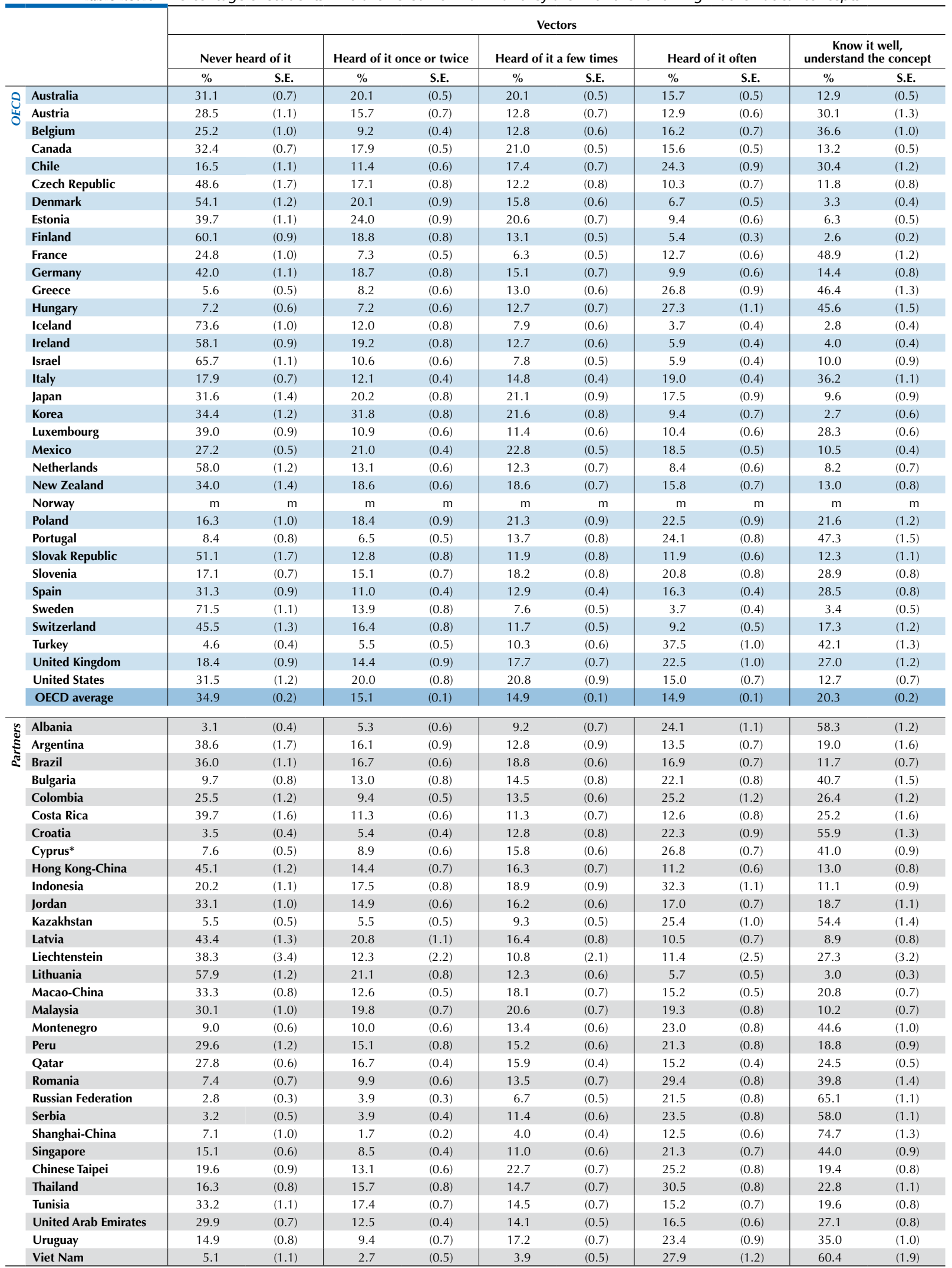

* See notes at the beginning of this Annex.

StatLink त्राज http://dx.doi.org/10.1787/888932935686 
[Part 1/1]

Students' exposure to the mathematics concept "complex number"

Table I.3.20 Percentage of students who answered how familiar they are with the following mathematical concepts

\begin{tabular}{|c|c|c|c|c|c|c|c|c|c|c|c|}
\hline & & \multicolumn{10}{|c|}{ Complex number } \\
\hline & & \multicolumn{2}{|c|}{ Never heard of it } & \multicolumn{2}{|c|}{ Heard of it once or twice } & \multicolumn{2}{|c|}{ Heard of it a few times } & \multicolumn{2}{|c|}{ Heard of it often } & \multicolumn{2}{|c|}{$\begin{array}{l}\text { Know it well, } \\
\text { understand the concept }\end{array}$} \\
\hline & & $\%$ & S.E. & $\%$ & S.E. & $\%$ & S.E. & $\%$ & S.E. & $\%$ & S.E. \\
\hline \multirow{35}{*}{ 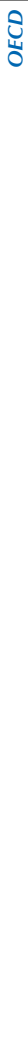 } & Australia & 18.7 & $(0.5)$ & 20.9 & $(0.4)$ & 24.7 & $(0.6)$ & 21.7 & $(0.6)$ & 14.0 & $(0.4)$ \\
\hline & Austria & 31.2 & $(1.0)$ & 21.2 & $(0.9)$ & 18.3 & $(0.7)$ & 12.9 & $(0.6)$ & 16.3 & $(0.9)$ \\
\hline & Belgium & 41.7 & $(0.9)$ & 18.5 & $(0.6)$ & 17.5 & $(0.6)$ & 11.6 & $(0.5)$ & 10.7 & $(0.5)$ \\
\hline & Canada & 20.0 & $(0.5)$ & 19.0 & $(0.5)$ & 23.1 & $(0.5)$ & 20.7 & $(0.5)$ & 17.2 & $(0.6)$ \\
\hline & Chile & 13.3 & $(0.6)$ & 16.9 & $(0.7)$ & 25.5 & $(0.7)$ & 27.5 & $(0.8)$ & 16.8 & $(0.7)$ \\
\hline & Czech Republic & 45.4 & $(1.2)$ & 27.2 & $(0.9)$ & 15.5 & $(0.8)$ & 7.7 & $(0.7)$ & 4.1 & $(0.5)$ \\
\hline & Denmark & 33.0 & $(1.0)$ & 27.4 & $(0.9)$ & 22.6 & $(0.8)$ & 10.5 & $(0.6)$ & 6.5 & $(0.5)$ \\
\hline & Estonia & 42.5 & (0.9) & 23.5 & (1.0) & 17.8 & $(0.7)$ & 9.0 & $(0.5)$ & 7.2 & (0.4) \\
\hline & Finland & 61.2 & $(0.8)$ & 22.7 & $(0.6)$ & 11.0 & $(0.5)$ & 3.6 & $(0.3)$ & 1.4 & $(0.2)$ \\
\hline & France & 30.5 & $(0.9)$ & 17.7 & $(0.7)$ & 21.3 & $(0.8)$ & 16.9 & $(0.7)$ & 13.5 & $(0.7)$ \\
\hline & Germany & 33.4 & $(1.0)$ & 24.8 & $(0.7)$ & 18.0 & $(0.7)$ & 11.3 & $(0.7)$ & 12.5 & $(0.7)$ \\
\hline & Greece & 43.5 & $(1.2)$ & 19.9 & $(0.7)$ & 15.1 & $(0.7)$ & 11.1 & $(0.6)$ & 10.4 & (0.6) \\
\hline & Hungary & 21.5 & $(0.9)$ & 20.2 & (0.8) & 22.1 & $(0.7)$ & 20.2 & $(0.8)$ & 16.0 & $(0.8)$ \\
\hline & Iceland & 72.0 & $(1.0)$ & 12.6 & $(0.8)$ & 7.9 & $(0.6)$ & 4.5 & $(0.4)$ & 3.0 & (0.4) \\
\hline & Ireland & 32.0 & $(0.9)$ & 23.1 & $(0.7)$ & 18.8 & $(0.8)$ & 14.2 & $(0.7)$ & 11.9 & $(0.7)$ \\
\hline & Israel & 37.8 & $(1.0)$ & 13.2 & $(0.6)$ & 15.8 & $(0.7)$ & 13.4 & $(0.7)$ & 19.8 & $(0.8)$ \\
\hline & Italy & 24.1 & $(0.5)$ & 17.5 & $(0.4)$ & 21.9 & $(0.4)$ & 19.6 & $(0.4)$ & 16.9 & $(0.4)$ \\
\hline & Japan & 61.2 & $(1.2)$ & 17.3 & $(0.6)$ & 11.7 & $(0.5)$ & 5.5 & $(0.5)$ & 4.2 & $(0.7)$ \\
\hline & Korea & 6.0 & $(0.7)$ & 5.1 & $(0.5)$ & 8.9 & $(0.6)$ & 23.8 & $(1.0)$ & 56.2 & (1.5) \\
\hline & Luxembourg & 30.8 & $(0.8)$ & 17.7 & $(0.7)$ & 21.5 & $(0.8)$ & 13.8 & $(0.6)$ & 16.2 & $(0.7)$ \\
\hline & Mexico & 18.2 & $(0.4)$ & 23.9 & $(0.4)$ & 24.8 & $(0.4)$ & 21.2 & $(0.4)$ & 12.0 & $(0.5)$ \\
\hline & Netherlands & 56.0 & (1.1) & 19.0 & $(0.8)$ & 14.8 & $(0.6)$ & 6.4 & $(0.6)$ & 3.8 & $(0.5)$ \\
\hline & New Zealand & 24.3 & $(0.9)$ & 23.7 & $(1.1)$ & 25.1 & $(0.9)$ & 18.3 & $(0.8)$ & 8.7 & $(0.6)$ \\
\hline & Norway & $\mathrm{m}$ & $\mathrm{m}$ & $\mathrm{m}$ & $\mathrm{m}$ & $\mathrm{m}$ & $\mathrm{m}$ & $\mathrm{m}$ & $\mathrm{m}$ & $\mathrm{m}$ & $\mathrm{m}$ \\
\hline & Poland & 40.9 & $(1.1)$ & 25.3 & $(0.7)$ & 18.1 & $(0.8)$ & 11.0 & $(0.6)$ & 4.8 & $(0.5)$ \\
\hline & Portugal & 22.6 & $(0.8)$ & 17.4 & $(0.8)$ & 23.3 & $(0.8)$ & 21.9 & $(0.8)$ & 14.9 & (0.6) \\
\hline & Slovak Republic & 46.0 & $(1.4)$ & 24.1 & $(1.1)$ & 16.8 & $(0.9)$ & 7.2 & $(0.5)$ & 5.9 & $(0.5)$ \\
\hline & Slovenia & 27.9 & $(0.8)$ & 23.6 & $(0.8)$ & 23.7 & $(0.8)$ & 15.9 & $(0.7)$ & 9.0 & $(0.5)$ \\
\hline & Spain & 26.7 & $(0.6)$ & 18.1 & $(0.5)$ & 19.0 & $(0.5)$ & 17.1 & $(0.5)$ & 19.1 & $(0.6)$ \\
\hline & Sweden & 44.4 & $(1.1)$ & 27.1 & $(0.8)$ & 16.6 & $(0.7)$ & 7.5 & $(0.5)$ & 4.3 & $(0.5)$ \\
\hline & Switzerland & 35.0 & $(0.8)$ & 22.4 & $(0.6)$ & 19.0 & $(0.6)$ & 12.0 & $(0.6)$ & 11.6 & $(0.6)$ \\
\hline & Turkey & 14.8 & $(0.7)$ & 16.3 & $(0.7)$ & 22.5 & $(0.9)$ & 30.9 & $(1.0)$ & 15.6 & $(0.8)$ \\
\hline & United Kingdom & 17.6 & $(0.6)$ & 20.5 & $(0.8)$ & 24.8 & $(0.7)$ & 21.5 & $(0.8)$ & 15.6 & $(0.7)$ \\
\hline & United States & 13.7 & $(0.8)$ & 17.5 & $(0.9)$ & 21.3 & $(0.8)$ & 22.3 & $(0.9)$ & 25.2 & $(1.2)$ \\
\hline & OECD average & 33.0 & $(0.2)$ & 20.2 & $(0.1)$ & 19.1 & $(0.1)$ & 14.9 & $(0.1)$ & 12.9 & $(0.1)$ \\
\hline \multirow{31}{*}{ 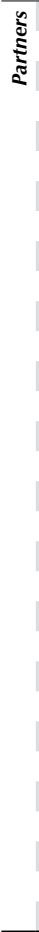 } & Albania & 23.2 & $(0.9)$ & 22.2 & (1.0) & 23.0 & $(0.8)$ & 19.5 & (1.0) & 12.1 & $(0.8)$ \\
\hline & Argentina & 26.5 & $(1.1)$ & 21.3 & $(0.8)$ & 16.1 & $(0.7)$ & 16.4 & $(0.6)$ & 19.7 & (1.1) \\
\hline & Brazil & 25.0 & $(0.6)$ & 24.2 & $(0.6)$ & 23.2 & (0.6) & 17.9 & $(0.5)$ & 9.7 & $(0.5)$ \\
\hline & Bulgaria & 29.0 & $(0.8)$ & 21.7 & $(0.8)$ & 19.9 & $(0.7)$ & 17.2 & $(0.6)$ & 12.1 & $(0.6)$ \\
\hline & Colombia & 13.7 & $(0.6)$ & 19.4 & $(0.9)$ & 23.7 & $(0.8)$ & 27.4 & (1.0) & 15.9 & $(0.9)$ \\
\hline & Costa Rica & 29.5 & $(1.2)$ & 19.8 & $(0.8)$ & 19.7 & $(0.9)$ & 16.2 & $(0.8)$ & 14.9 & $(0.8)$ \\
\hline & Croatia & 20.3 & $(0.7)$ & 19.1 & $(0.7)$ & 23.7 & $(0.7)$ & 16.2 & $(0.7)$ & 20.7 & $(0.7)$ \\
\hline & Cyprus* & 42.2 & $(0.9)$ & 15.8 & $(0.6)$ & 14.9 & $(0.7)$ & 12.5 & $(0.6)$ & 14.5 & $(0.6)$ \\
\hline & Hong Kong-China & 13.1 & $(0.8)$ & 12.8 & $(0.7)$ & 23.2 & $(0.8)$ & 23.5 & $(0.9)$ & 27.5 & (1.0) \\
\hline & Indonesia & 25.0 & $(1.3)$ & 23.3 & $(0.8)$ & 21.0 & $(0.9)$ & 24.5 & $(1.0)$ & 6.2 & $(0.5)$ \\
\hline & Jordan & 10.1 & $(0.7)$ & 10.3 & $(0.5)$ & 11.0 & $(0.6)$ & 20.1 & $(0.8)$ & 48.6 & $(1.2)$ \\
\hline & Kazakhstan & 12.9 & $(0.8)$ & 11.7 & $(0.6)$ & 15.8 & $(0.7)$ & 26.3 & $(1.0)$ & 33.4 & (1.3) \\
\hline & Latvia & 44.1 & $(1.5)$ & 23.0 & $(0.8)$ & 15.2 & $(0.8)$ & 9.6 & $(0.7)$ & 8.0 & $(0.8)$ \\
\hline & Liechtenstein & 39.1 & $(3.2)$ & 24.5 & (2.9) & 12.8 & $(2.2)$ & 10.1 & $(2.1)$ & 13.5 & (2.5) \\
\hline & Lithuania & 54.4 & $(1.1)$ & 23.1 & $(0.9)$ & 14.2 & $(0.7)$ & 5.2 & $(0.5)$ & 3.1 & $(0.3)$ \\
\hline & Macao-China & 10.9 & $(0.5)$ & 13.8 & $(0.6)$ & 24.6 & $(0.7)$ & 23.0 & $(0.7)$ & 27.6 & $(0.8)$ \\
\hline & Malaysia & 20.5 & $(0.8)$ & 22.2 & $(0.9)$ & 22.4 & $(0.6)$ & 22.7 & $(0.8)$ & 12.1 & $(0.6)$ \\
\hline & Montenegro & 17.8 & $(0.7)$ & 16.1 & $(0.7)$ & 18.2 & $(0.7)$ & 22.3 & $(0.8)$ & 25.6 & $(0.8)$ \\
\hline & Peru & 8.9 & $(0.6)$ & 19.6 & $(0.8)$ & 22.9 & $(0.8)$ & 28.5 & $(1.0)$ & 20.0 & $(0.9)$ \\
\hline & Qatar & 16.5 & $(0.5)$ & 16.7 & $(0.4)$ & 19.7 & $(0.6)$ & 17.0 & $(0.4)$ & 30.1 & (0.6) \\
\hline & Romania & 18.1 & $(0.7)$ & 19.2 & $(0.8)$ & 21.2 & $(0.8)$ & 22.2 & $(0.8)$ & 19.3 & $(0.8)$ \\
\hline & Russian Federation & 31.2 & $(0.9)$ & 20.5 & $(0.6)$ & 22.3 & (1.0) & 15.0 & $(0.5)$ & 10.9 & $(0.7)$ \\
\hline & Serbia & 15.0 & $(0.7)$ & 19.5 & $(0.8)$ & 24.3 & $(0.8)$ & 23.9 & $(0.8)$ & 17.3 & $(0.8)$ \\
\hline & Shanghai-China & 16.1 & $(0.7)$ & 11.1 & $(0.5)$ & 13.8 & $(0.5)$ & 14.9 & $(0.7)$ & 44.1 & (1.0) \\
\hline & Singapore & 19.4 & $(0.7)$ & 14.8 & $(0.7)$ & 22.8 & $(0.7)$ & 22.3 & $(0.7)$ & 20.6 & $(0.7)$ \\
\hline & Chinese Taipei & 11.3 & $(0.6)$ & 10.3 & $(0.5)$ & 18.6 & $(0.6)$ & 28.4 & $(0.8)$ & 31.4 & $(0.9)$ \\
\hline & Thailand & 12.6 & $(0.7)$ & 16.1 & $(0.7)$ & 18.8 & $(0.7)$ & 35.2 & $(0.8)$ & 17.3 & $(0.8)$ \\
\hline & Tunisia & 20.5 & $(0.9)$ & 13.8 & $(0.8)$ & 14.0 & (0.6) & 17.2 & $(0.8)$ & 34.5 & $(1.2)$ \\
\hline & United Arab Emirates & 11.3 & $(0.5)$ & 11.2 & $(0.5)$ & 14.4 & $(0.5)$ & 22.9 & $(0.6)$ & 40.2 & $(0.7)$ \\
\hline & Uruguay & 27.2 & $(0.9)$ & 20.6 & $(0.7)$ & 23.3 & $(0.8)$ & 17.4 & $(0.7)$ & 11.6 & $(0.7)$ \\
\hline & Viet Nam & 22.1 & $(1.1)$ & 18.4 & $(0.7)$ & 28.3 & $(1.0)$ & 17.3 & $(0.8)$ & 14.0 & $(0.9)$ \\
\hline
\end{tabular}

* See notes at the beginning of this Annex.

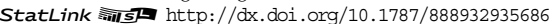


[Part 1/1]

Students' exposure to the mathematics concept "rational number"

Table I.3.21 Percentage of students who answered how familiar they are with the following mathematical concepts

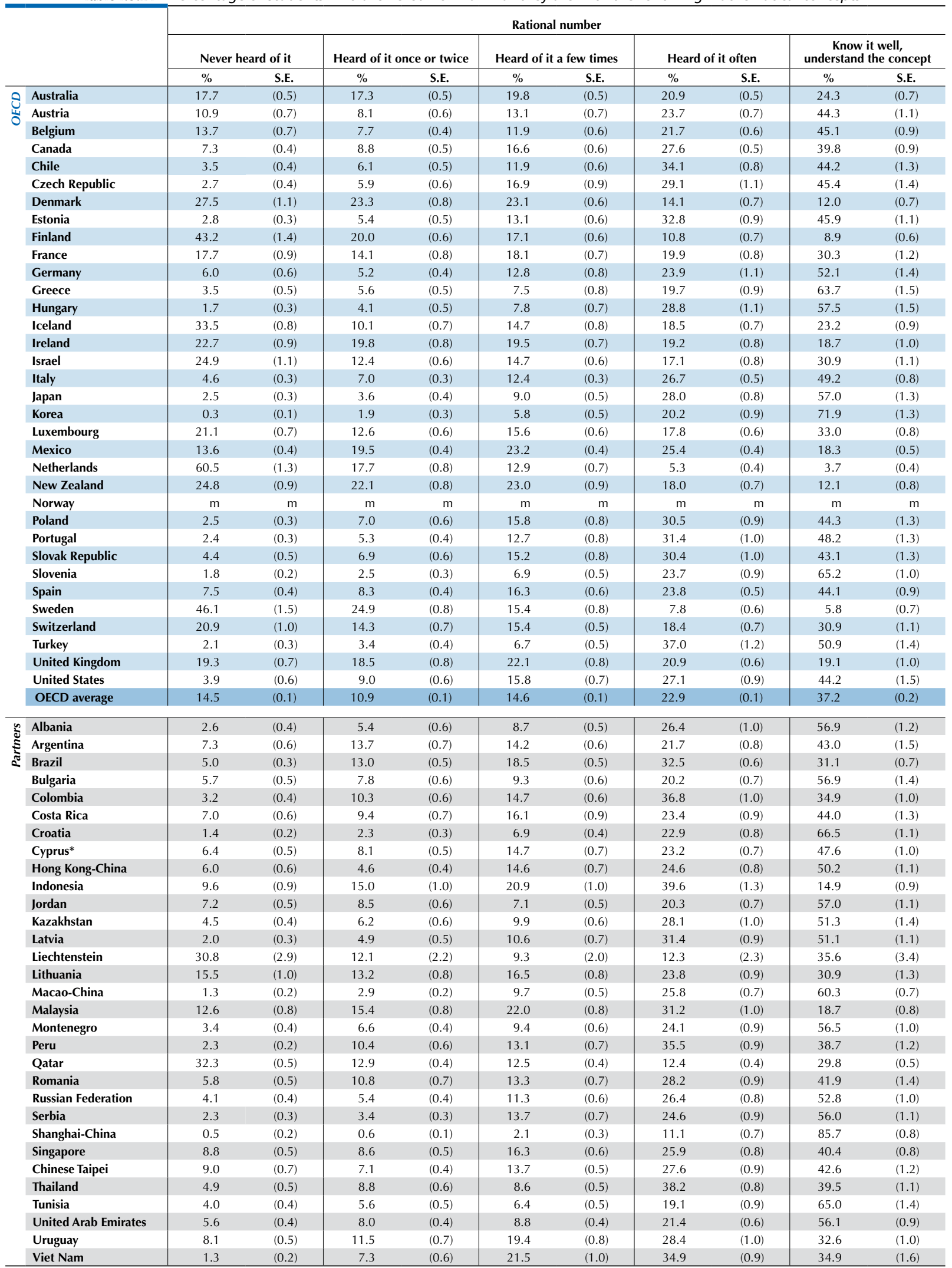

* See notes at the beginning of this Annex.

StatLink त्राज http://dx.doi.org/10.1787/888932935686 
[Part 1/1]

Students' exposure to the mathematics concept "radicals"

Table I.3.22 Percentage of students who answered how familiar they are with the following mathematical concepts

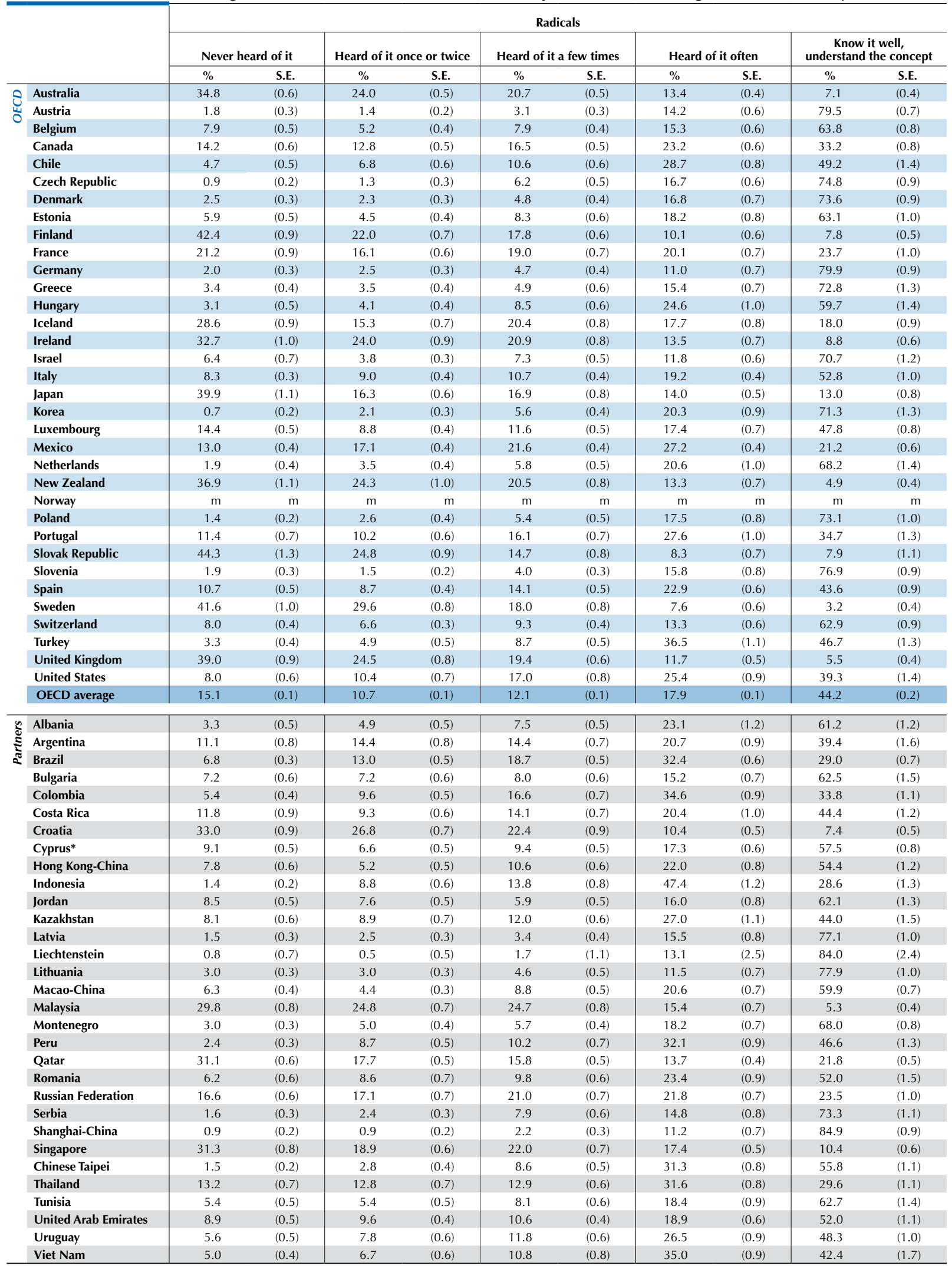

* See notes at the beginning of this Annex.

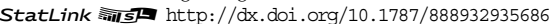


irt

Students' exposure to the mathematics concept "polygon"

Table I.3.23 Percentage of students who answered how familiar they are with the following mathematical concepts

\begin{tabular}{|c|c|c|c|c|c|c|c|c|c|c|c|}
\hline & & \multicolumn{10}{|c|}{ Polygon } \\
\hline & & \multicolumn{2}{|c|}{ Never heard of it } & \multicolumn{2}{|c|}{ Heard of it once or twice } & \multicolumn{2}{|c|}{ Heard of it a few times } & \multicolumn{2}{|c|}{ Heard of it often } & \multicolumn{2}{|c|}{$\begin{array}{l}\text { Know it well, } \\
\text { understand the concept }\end{array}$} \\
\hline & & $\%$ & S.E. & $\%$ & S.E. & $\%$ & S.E. & $\%$ & S.E. & $\%$ & S.E. \\
\hline \multirow{35}{*}{ రి } & Australia & 5.5 & $(0.3)$ & 7.4 & $(0.3)$ & 12.5 & $(0.4)$ & 22.6 & $(0.5)$ & 51.9 & (0.6) \\
\hline & Austria & 61.8 & $(1.3)$ & 16.5 & $(0.7)$ & 9.6 & $(0.5)$ & 5.0 & $(0.4)$ & 7.1 & $(0.5)$ \\
\hline & Belgium & 4.1 & $(0.3)$ & 2.9 & $(0.2)$ & 6.2 & $(0.3)$ & 14.4 & $(0.6)$ & 72.3 & (0.8) \\
\hline & Canada & 3.3 & $(0.2)$ & 3.8 & $(0.3)$ & 9.4 & $(0.4)$ & 21.0 & $(0.5)$ & 62.5 & $(0.8)$ \\
\hline & Chile & 4.4 & $(0.4)$ & 8.8 & $(0.5)$ & 18.4 & $(0.8)$ & 31.4 & $(0.9)$ & 37.0 & $(1.2)$ \\
\hline & Czech Republic & 8.6 & $(0.7)$ & 11.0 & $(0.7)$ & 19.2 & $(0.9)$ & 22.8 & $(1.0)$ & 38.5 & (1.0) \\
\hline & Denmark & 29.2 & (1.2) & 17.0 & $(0.8)$ & 15.6 & $(0.8)$ & 15.6 & $(0.9)$ & 22.6 & (1.0) \\
\hline & Estonia & 1.4 & $(0.2)$ & 1.7 & $(0.3)$ & 6.0 & $(0.5)$ & 19.9 & $(0.8)$ & 71.1 & $(0.9)$ \\
\hline & Finland & 8.0 & $(0.5)$ & 7.0 & $(0.4)$ & 11.7 & $(0.5)$ & 19.0 & $(0.6)$ & 54.2 & $(0.9)$ \\
\hline & France & 4.3 & $(0.5)$ & 4.3 & $(0.4)$ & 7.6 & $(0.6)$ & 18.5 & $(0.8)$ & 65.3 & (1.0) \\
\hline & Germany & 75.4 & $(0.9)$ & 11.8 & $(0.7)$ & 6.3 & $(0.5)$ & 2.1 & $(0.3)$ & 4.4 & (0.5) \\
\hline & Greece & 6.1 & $(0.5)$ & 7.4 & $(0.6)$ & 10.6 & $(0.7)$ & 19.2 & $(0.6)$ & 56.6 & $(1.2)$ \\
\hline & Hungary & 2.0 & $(0.4)$ & 2.7 & $(0.4)$ & 6.5 & $(0.5)$ & 19.1 & $(0.9)$ & 69.7 & (1.1) \\
\hline & Iceland & 24.0 & $(0.8)$ & 8.2 & $(0.6)$ & 11.5 & $(0.7)$ & 16.4 & $(0.8)$ & 39.9 & $(0.9)$ \\
\hline & Ireland & 36.9 & (1.0) & 15.6 & $(0.7)$ & 13.7 & $(0.5)$ & 13.7 & $(0.7)$ & 20.1 & $(0.9)$ \\
\hline & Israel & 12.5 & $(0.8)$ & 7.1 & $(0.5)$ & 14.0 & $(0.7)$ & 16.8 & $(0.6)$ & 49.7 & (1.4) \\
\hline & Italy & 4.3 & $(0.2)$ & 5.1 & $(0.2)$ & 9.5 & $(0.4)$ & 20.1 & $(0.4)$ & 61.0 & $(0.7)$ \\
\hline & Japan & 6.5 & $(0.4)$ & 3.8 & $(0.4)$ & 7.9 & $(0.5)$ & 17.6 & $(0.6)$ & 64.2 & $(1.2)$ \\
\hline & Korea & 5.8 & $(0.5)$ & 7.4 & $(0.5)$ & 13.4 & $(0.7)$ & 17.8 & $(0.7)$ & 55.5 & (1.5) \\
\hline & Luxembourg & 25.0 & $(0.8)$ & 11.4 & $(0.5)$ & 14.9 & $(0.7)$ & 17.0 & $(0.7)$ & 31.7 & $(0.8)$ \\
\hline & Mexico & 5.0 & $(0.2)$ & 10.6 & $(0.3)$ & 14.7 & $(0.3)$ & 26.3 & $(0.4)$ & 43.4 & $(0.5)$ \\
\hline & Netherlands & 57.5 & $(1.1)$ & 13.1 & $(0.7)$ & 10.9 & $(0.6)$ & 8.4 & $(0.5)$ & 10.0 & $(0.7)$ \\
\hline & New Zealand & 10.4 & $(0.8)$ & 9.7 & $(0.6)$ & 16.3 & $(0.7)$ & 24.1 & $(0.7)$ & 39.4 & (1.1) \\
\hline & Norway & $\mathrm{m}$ & $\mathrm{m}$ & $\mathrm{m}$ & $\mathrm{m}$ & $\mathrm{m}$ & $\mathrm{m}$ & $\mathrm{m}$ & $\mathrm{m}$ & $\mathrm{m}$ & $\mathrm{m}$ \\
\hline & Poland & 1.4 & $(0.2)$ & 2.9 & $(0.4)$ & 6.7 & $(0.5)$ & 16.8 & $(0.8)$ & 72.1 & (1.1) \\
\hline & Portugal & 2.3 & $(0.3)$ & 4.2 & $(0.4)$ & 10.2 & $(0.7)$ & 27.2 & $(0.9)$ & 56.1 & (1.3) \\
\hline & Slovak Republic & 13.4 & $(0.8)$ & 11.9 & $(0.7)$ & 20.3 & $(0.9)$ & 22.1 & $(0.8)$ & 32.3 & (1.1) \\
\hline & Slovenia & 30.8 & $(0.9)$ & 20.2 & $(0.8)$ & 19.3 & $(0.8)$ & 14.8 & $(0.8)$ & 14.9 & $(0.7)$ \\
\hline & Spain & 4.7 & $(0.4)$ & 6.9 & $(0.4)$ & 13.6 & $(0.5)$ & 20.0 & $(0.4)$ & 54.9 & $(0.7)$ \\
\hline & Sweden & 66.3 & $(1.2)$ & 14.6 & $(0.7)$ & 9.2 & $(0.5)$ & 5.2 & $(0.4)$ & 4.6 & $(0.6)$ \\
\hline & Switzerland & 53.4 & (1.3) & 9.1 & $(0.6)$ & 6.9 & $(0.5)$ & 7.4 & $(0.4)$ & 23.3 & $(0.9)$ \\
\hline & Turkey & 3.0 & $(0.4)$ & 3.8 & $(0.4)$ & 7.2 & $(0.5)$ & 33.3 & $(1.2)$ & 52.7 & (1.4) \\
\hline & United Kingdom & 5.8 & $(0.3)$ & 6.7 & $(0.5)$ & 10.8 & $(0.7)$ & 25.0 & $(0.9)$ & 51.8 & (1.1) \\
\hline & United States & 3.1 & $(0.4)$ & 5.5 & $(0.5)$ & 9.4 & $(0.7)$ & 18.8 & $(0.8)$ & 63.2 & (1.3) \\
\hline & OECD average & 17.8 & $(0.1)$ & 8.5 & $(0.1)$ & 11.5 & $(0.1)$ & 18.2 & $(0.1)$ & 44.1 & $(0.2)$ \\
\hline \multirow{31}{*}{ 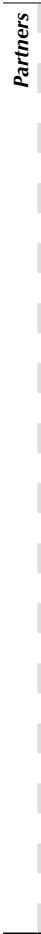 } & Albania & 3.2 & $(0.5)$ & 4.6 & $(0.6)$ & 8.0 & $(0.5)$ & 22.9 & $(1.0)$ & 61.3 & (1.1) \\
\hline & Argentina & 15.1 & $(0.9)$ & 16.5 & $(0.8)$ & 16.7 & $(0.7)$ & 20.2 & $(0.8)$ & 31.4 & $(1.2)$ \\
\hline & Brazil & 15.0 & $(0.7)$ & 17.7 & $(0.6)$ & 22.7 & $(0.6)$ & 24.2 & $(0.6)$ & 20.4 & $(0.7)$ \\
\hline & Bulgaria & 9.3 & $(0.5)$ & 9.0 & $(0.7)$ & 11.3 & $(0.6)$ & 18.4 & $(0.8)$ & 52.0 & (1.3) \\
\hline & Colombia & 5.0 & $(0.4)$ & 13.0 & $(0.7)$ & 18.9 & $(0.7)$ & 33.6 & (1.0) & 29.6 & (1.2) \\
\hline & Costa Rica & 12.0 & $(0.8)$ & 14.7 & $(0.9)$ & 19.6 & $(0.9)$ & 20.8 & $(0.9)$ & 32.9 & (1.1) \\
\hline & Croatia & 7.0 & $(0.4)$ & 6.4 & $(0.5)$ & 11.0 & $(0.6)$ & 18.3 & $(0.8)$ & 57.1 & (1.2) \\
\hline & Cyprus* & 13.0 & $(0.6)$ & 13.4 & $(0.7)$ & 16.6 & $(0.7)$ & 18.2 & $(0.8)$ & 38.8 & $(0.8)$ \\
\hline & Hong Kong-China & 0.6 & $(0.1)$ & 2.0 & $(0.2)$ & 7.9 & $(0.6)$ & 20.2 & $(0.7)$ & 69.2 & (1.0) \\
\hline & Indonesia & 38.3 & $(1.2)$ & 21.7 & $(0.8)$ & 17.4 & $(0.7)$ & 17.1 & $(0.8)$ & 5.6 & $(0.5)$ \\
\hline & Jordan & 11.0 & $(0.5)$ & 9.3 & $(0.5)$ & 10.7 & $(0.6)$ & 19.9 & $(0.6)$ & 49.0 & (0.9) \\
\hline & Kazakhstan & 3.5 & $(0.3)$ & 5.7 & $(0.5)$ & 8.0 & $(0.5)$ & 25.7 & $(1.0)$ & 57.2 & (1.3) \\
\hline & Latvia & 2.2 & $(0.3)$ & 2.5 & $(0.3)$ & 4.2 & $(0.5)$ & 14.5 & $(0.8)$ & 76.7 & $(0.9)$ \\
\hline & Liechtenstein & 67.7 & $(3.1)$ & 11.7 & (2.4) & 7.9 & (2.0) & 3.8 & $(1.4)$ & 8.8 & (1.8) \\
\hline & Lithuania & 3.4 & $(0.4)$ & 3.9 & $(0.4)$ & 6.9 & $(0.6)$ & 14.4 & $(0.7)$ & 71.4 & (1.1) \\
\hline & Macao-China & 1.6 & $(0.2)$ & 2.6 & $(0.2)$ & 8.5 & $(0.4)$ & 23.0 & $(0.7)$ & 64.3 & $(0.8)$ \\
\hline & Malaysia & 6.5 & $(0.5)$ & 9.7 & $(0.6)$ & 14.6 & $(0.6)$ & 34.1 & $(1.1)$ & 35.2 & $(1.2)$ \\
\hline & Montenegro & 8.3 & $(0.5)$ & 11.4 & $(0.6)$ & 15.3 & $(0.7)$ & 24.6 & $(0.8)$ & 40.4 & $(0.9)$ \\
\hline & Peru & 4.9 & $(0.4)$ & 12.1 & $(0.6)$ & 14.9 & $(0.8)$ & 30.2 & $(0.8)$ & 38.0 & $(1.2)$ \\
\hline & Qatar & 14.4 & $(0.5)$ & 14.8 & $(0.5)$ & 16.3 & $(0.5)$ & 16.3 & $(0.4)$ & 38.1 & $(0.6)$ \\
\hline & Romania & 10.7 & $(0.7)$ & 12.9 & $(0.7)$ & 17.0 & $(0.7)$ & 26.1 & $(1.1)$ & 33.4 & (1.3) \\
\hline & Russian Federation & 2.4 & $(0.3)$ & 1.9 & $(0.3)$ & 4.0 & $(0.3)$ & 14.0 & $(0.8)$ & 77.6 & $(0.9)$ \\
\hline & Serbia & 2.9 & $(0.4)$ & 4.9 & $(0.4)$ & 11.9 & $(0.6)$ & 20.3 & $(0.9)$ & 60.0 & (1.1) \\
\hline & Shanghai-China & 1.3 & $(0.2)$ & 1.2 & $(0.2)$ & 3.7 & $(0.4)$ & 17.1 & $(0.7)$ & 76.8 & $(0.9)$ \\
\hline & Singapore & 7.2 & $(0.4)$ & 7.4 & $(0.5)$ & 15.6 & $(0.7)$ & 28.4 & $(0.8)$ & 41.4 & $(0.8)$ \\
\hline & Chinese Taipei & 2.0 & $(0.3)$ & 4.0 & $(0.4)$ & 11.2 & $(0.6)$ & 27.1 & $(0.7)$ & 55.7 & $(1.0)$ \\
\hline & Thailand & 5.3 & $(0.4)$ & 11.7 & $(0.6)$ & 13.7 & $(0.7)$ & 35.0 & $(0.9)$ & 34.3 & $(0.8)$ \\
\hline & Tunisia & 10.2 & $(0.7)$ & 8.5 & $(0.6)$ & 11.3 & $(0.7)$ & 19.8 & $(0.8)$ & 50.2 & (1.5) \\
\hline & United Arab Emirates & 7.3 & $(0.5)$ & 7.9 & $(0.4)$ & 8.9 & $(0.4)$ & 19.6 & $(0.6)$ & 56.2 & (1.0) \\
\hline & Uruguay & 7.5 & $(0.5)$ & 11.3 & $(0.7)$ & 22.2 & $(0.7)$ & 23.9 & $(0.8)$ & 35.1 & (1.0) \\
\hline & Viet Nam & 11.3 & $(0.8)$ & 13.1 & $(0.7)$ & 24.8 & $(0.9)$ & 24.3 & $(0.9)$ & 26.5 & (1.4) \\
\hline
\end{tabular}

* See notes at the beginning of this Annex.

StatLink त्राज http://dx.doi.org/10.1787/888932935686 
[Part 1/1]

Students' exposure to the mathematics concept "congruent figure"

Table I.3.24 Percentage of students who answered how familiar they are with the following mathematical concepts

\begin{tabular}{|c|c|c|c|c|c|c|c|c|c|c|c|}
\hline & & \multicolumn{10}{|c|}{ Congruent figure } \\
\hline & & \multicolumn{2}{|c|}{ Never heard of it } & \multicolumn{2}{|c|}{ Heard of it once or twice } & \multicolumn{2}{|c|}{ Heard of it a few times } & \multicolumn{2}{|c|}{ Heard of it often } & \multicolumn{2}{|c|}{$\begin{array}{l}\text { Know it well, } \\
\text { understand the concept }\end{array}$} \\
\hline & & $\%$ & S.E. & $\%$ & S.E. & $\%$ & S.E. & $\%$ & S.E. & $\%$ & S.E. \\
\hline \multirow{35}{*}{ 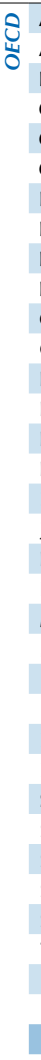 } & Australia & 35.9 & $(0.7)$ & 16.4 & $(0.5)$ & 15.6 & $(0.4)$ & 14.7 & $(0.5)$ & 17.4 & $(0.8)$ \\
\hline & Austria & 45.1 & $(1.2)$ & 15.5 & $(0.8)$ & 13.7 & $(0.7)$ & 10.5 & $(0.5)$ & 15.3 & $(0.9)$ \\
\hline & Belgium & 14.6 & $(0.7)$ & 5.2 & $(0.3)$ & 8.1 & $(0.4)$ & 15.9 & $(0.6)$ & 56.1 & (1.0) \\
\hline & Canada & 16.2 & $(0.6)$ & 10.6 & $(0.4)$ & 14.2 & $(0.4)$ & 18.2 & $(0.5)$ & 40.7 & $(0.8)$ \\
\hline & Chile & 18.1 & $(1.0)$ & 14.1 & $(0.7)$ & 19.0 & $(0.7)$ & 24.8 & $(0.8)$ & 24.1 & $(1.2)$ \\
\hline & Czech Republic & 8.5 & $(0.6)$ & 12.1 & $(0.7)$ & 19.1 & $(0.9)$ & 22.6 & $(0.9)$ & 37.7 & $(1.2)$ \\
\hline & Denmark & 28.6 & $(1.2)$ & 14.5 & $(0.7)$ & 15.4 & $(0.7)$ & 15.0 & $(0.7)$ & 26.4 & (1.0) \\
\hline & Estonia & 10.7 & $(0.6)$ & 11.5 & (0.6) & 16.0 & $(0.8)$ & 22.2 & $(0.8)$ & 39.5 & (1.1) \\
\hline & Finland & 27.1 & $(0.9)$ & 20.2 & $(0.7)$ & 20.9 & $(0.6)$ & 16.3 & $(0.8)$ & 15.4 & $(0.7)$ \\
\hline & France & 45.3 & (1.1) & 19.1 & $(0.8)$ & 15.4 & $(0.8)$ & 10.6 & $(0.6)$ & 9.7 & (0.6) \\
\hline & Germany & 30.9 & $(1.3)$ & 12.3 & (0.6) & 12.5 & $(0.7)$ & 13.2 & $(0.7)$ & 31.0 & (1.4) \\
\hline & Greece & 7.8 & $(0.6)$ & 6.7 & $(0.6)$ & 8.7 & $(0.6)$ & 17.6 & $(0.7)$ & 59.2 & (1.3) \\
\hline & Hungary & 16.6 & $(0.9)$ & 13.6 & $(0.7)$ & 16.8 & $(0.8)$ & 19.3 & $(0.9)$ & 33.7 & (1.4) \\
\hline & Iceland & 44.9 & $(1.1)$ & 13.9 & $(0.7)$ & 16.2 & $(0.9)$ & 12.4 & $(0.8)$ & 12.7 & $(0.8)$ \\
\hline & Ireland & 33.5 & $(1.0)$ & 14.3 & $(0.6)$ & 16.0 & $(0.8)$ & 16.3 & $(0.7)$ & 20.0 & $(0.8)$ \\
\hline & Israel & 16.0 & (1.1) & 6.2 & (0.4) & 9.8 & $(0.6)$ & 14.9 & $(0.6)$ & 53.1 & (1.3) \\
\hline & Italy & 14.6 & $(0.4)$ & 7.4 & $(0.3)$ & 10.1 & $(0.3)$ & 16.5 & $(0.5)$ & 51.4 & $(0.9)$ \\
\hline & Japan & 4.1 & $(0.4)$ & 3.3 & $(0.3)$ & 6.1 & $(0.5)$ & 20.6 & $(0.8)$ & 65.9 & (1.3) \\
\hline & Korea & 10.5 & $(0.7)$ & 4.9 & $(0.5)$ & 9.3 & $(0.6)$ & 13.0 & $(0.6)$ & 62.3 & (1.5) \\
\hline & Luxembourg & 38.2 & $(0.9)$ & 13.4 & $(0.6)$ & 14.6 & $(0.6)$ & 13.5 & $(0.6)$ & 20.4 & $(0.6)$ \\
\hline & Mexico & 14.4 & $(0.4)$ & 16.7 & $(0.4)$ & 18.9 & $(0.4)$ & 23.4 & $(0.4)$ & 26.6 & (0.6) \\
\hline & Netherlands & 66.7 & $(1.2)$ & 12.9 & $(0.7)$ & 9.8 & $(0.7)$ & 5.0 & $(0.5)$ & 5.7 & $(0.7)$ \\
\hline & New Zealand & 58.7 & $(1.1)$ & 18.6 & $(0.8)$ & 12.3 & $(0.7)$ & 6.9 & $(0.5)$ & 3.6 & $(0.4)$ \\
\hline & Norway & $\mathrm{m}$ & $\mathrm{m}$ & $\mathrm{m}$ & $\mathrm{m}$ & $\mathrm{m}$ & $\mathrm{m}$ & $\mathrm{m}$ & $\mathrm{m}$ & $\mathrm{m}$ & $\mathrm{m}$ \\
\hline & Poland & 6.6 & $(0.6)$ & 8.7 & (0.6) & 15.6 & $(0.7)$ & 22.9 & $(0.9)$ & 46.2 & (1.5) \\
\hline & Portugal & 52.1 & $(1.2)$ & 15.1 & $(0.6)$ & 14.5 & $(0.8)$ & 11.9 & $(0.7)$ & 6.5 & (0.6) \\
\hline & Slovak Republic & 34.5 & $(1.1)$ & 18.0 & $(0.8)$ & 18.5 & $(0.8)$ & 12.5 & $(0.6)$ & 16.5 & $(1.0)$ \\
\hline & Slovenia & 10.9 & $(0.6)$ & 6.0 & $(0.5)$ & 9.1 & $(0.5)$ & 15.7 & $(0.9)$ & 58.3 & $(1.1)$ \\
\hline & Spain & 34.1 & $(0.8)$ & 18.6 & $(0.5)$ & 18.1 & $(0.6)$ & 14.8 & $(0.5)$ & 14.4 & $(0.5)$ \\
\hline & Sweden & 71.3 & $(1.0)$ & 15.1 & $(0.7)$ & 7.5 & $(0.5)$ & 3.7 & $(0.4)$ & 2.4 & $(0.3)$ \\
\hline & Switzerland & 28.0 & $(1.1)$ & 10.6 & (0.6) & 10.5 & $(0.6)$ & 12.8 & $(0.5)$ & 38.1 & $(1.3)$ \\
\hline & Turkey & 25.9 & $(1.0)$ & 13.9 & (0.6) & 18.2 & $(0.7)$ & 21.1 & $(0.8)$ & 21.0 & $(1.2)$ \\
\hline & United Kingdom & 41.1 & $(1.0)$ & 20.4 & $(0.7)$ & 16.9 & $(0.5)$ & 12.5 & $(0.6)$ & 9.1 & $(0.6)$ \\
\hline & United States & 10.3 & $(0.8)$ & 9.0 & $(0.7)$ & 12.1 & $(0.6)$ & 18.5 & $(0.8)$ & 50.1 & $(1.3)$ \\
\hline & OECD average & 27.9 & $(0.2)$ & 12.7 & $(0.1)$ & 13.9 & $(0.1)$ & 15.5 & $(0.1)$ & 30.0 & $(0.2)$ \\
\hline \multirow{31}{*}{ 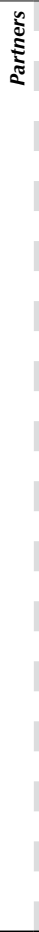 } & Albania & 6.0 & $(0.5)$ & 8.5 & (0.6) & 12.6 & $(0.7)$ & 20.4 & $(0.7)$ & 52.5 & (1.2) \\
\hline & Argentina & 50.6 & $(1.5)$ & 15.6 & $(0.7)$ & 11.9 & $(0.7)$ & 11.0 & $(0.8)$ & 10.9 & $(0.7)$ \\
\hline & Brazil & 39.1 & $(0.9)$ & 17.5 & (0.6) & 17.9 & (0.6) & 13.7 & $(0.5)$ & 11.8 & $(0.6)$ \\
\hline & Bulgaria & 13.6 & $(0.6)$ & 12.1 & $(0.7)$ & 12.8 & $(0.6)$ & 17.1 & $(0.7)$ & 44.5 & (1.3) \\
\hline & Colombia & 33.4 & $(1.2)$ & 17.8 & $(0.7)$ & 19.1 & $(0.7)$ & 17.9 & $(0.9)$ & 11.8 & $(0.7)$ \\
\hline & Costa Rica & 22.6 & $(1.1)$ & 13.6 & $(0.8)$ & 17.2 & $(0.9)$ & 18.7 & $(0.9)$ & 28.0 & $(1.2)$ \\
\hline & Croatia & 20.8 & $(0.9)$ & 13.2 & $(0.7)$ & 15.3 & $(0.7)$ & 16.6 & $(0.6)$ & 34.2 & (1.3) \\
\hline & Cyprus* & 16.7 & $(0.6)$ & 10.5 & (0.6) & 14.3 & $(0.6)$ & 18.6 & $(0.6)$ & 39.9 & $(0.9)$ \\
\hline & Hong Kong-China & 9.3 & $(0.8)$ & 7.3 & $(0.5)$ & 11.8 & $(0.6)$ & 20.1 & $(0.8)$ & 51.5 & $(1.2)$ \\
\hline & Indonesia & 13.9 & (1.0) & 13.9 & (0.8) & 19.8 & $(0.9)$ & 35.3 & $(1.0)$ & 17.1 & $(1.0)$ \\
\hline & Jordan & 9.9 & $(0.6)$ & 8.6 & $(0.5)$ & 10.1 & $(0.5)$ & 17.5 & $(0.6)$ & 53.9 & (1.1) \\
\hline & Kazakhstan & 36.0 & $(1.4)$ & 20.2 & $(1.0)$ & 16.5 & $(0.6)$ & 16.2 & $(0.8)$ & 11.0 & $(0.8)$ \\
\hline & Latvia & 2.9 & $(0.4)$ & 3.3 & $(0.4)$ & 6.4 & $(0.6)$ & 17.8 & $(0.8)$ & 69.7 & $(1.2)$ \\
\hline & Liechtenstein & 23.3 & $(2.6)$ & 8.5 & (2.1) & 9.0 & (1.9) & 11.1 & $(2.3)$ & 48.0 & (3.3) \\
\hline & Lithuania & 21.6 & $(1.1)$ & 13.9 & $(0.6)$ & 14.1 & $(0.7)$ & 17.6 & $(0.7)$ & 32.8 & $(1.0)$ \\
\hline & Macao-China & 8.2 & $(0.4)$ & 5.9 & (0.4) & 10.4 & $(0.5)$ & 17.2 & $(0.6)$ & 58.3 & $(0.7)$ \\
\hline & Malaysia & 36.6 & $(1.0)$ & 20.7 & $(0.7)$ & 18.7 & $(0.7)$ & 15.6 & $(0.8)$ & 8.4 & $(0.5)$ \\
\hline & Montenegro & 21.0 & $(0.9)$ & 16.7 & $(0.7)$ & 17.8 & $(0.8)$ & 18.9 & $(0.9)$ & 25.6 & $(0.9)$ \\
\hline & Peru & 17.2 & $(0.9)$ & 16.8 & $(0.7)$ & 19.6 & $(0.7)$ & 25.6 & $(1.0)$ & 20.8 & $(1.0)$ \\
\hline & Qatar & 23.3 & $(0.5)$ & 16.5 & $(0.5)$ & 15.5 & $(0.5)$ & 13.4 & $(0.4)$ & 31.2 & $(0.6)$ \\
\hline & Romania & 15.7 & $(0.7)$ & 13.3 & $(0.7)$ & 13.8 & $(0.8)$ & 22.5 & $(0.7)$ & 34.7 & (1.3) \\
\hline & Russian Federation & 62.5 & $(1.0)$ & 13.7 & $(0.7)$ & 11.2 & $(0.7)$ & 7.2 & $(0.5)$ & 5.4 & $(0.4)$ \\
\hline & Serbia & 9.4 & $(0.6)$ & 10.6 & $(0.8)$ & 15.3 & $(0.7)$ & 19.0 & $(0.8)$ & 45.8 & (1.3) \\
\hline & Shanghai-China & 4.0 & $(0.4)$ & 2.2 & $(0.3)$ & 3.4 & $(0.3)$ & 10.7 & $(0.7)$ & 79.7 & (1.0) \\
\hline & Singapore & 11.8 & $(0.6)$ & 6.7 & $(0.4)$ & 11.8 & $(0.6)$ & 22.1 & $(0.8)$ & 47.6 & $(0.9)$ \\
\hline & Chinese Taipei & 5.3 & $(0.4)$ & 7.2 & $(0.4)$ & 14.0 & $(0.6)$ & 24.4 & $(0.6)$ & 49.1 & $(1.0)$ \\
\hline & Thailand & 9.8 & $(0.6)$ & 15.4 & $(0.6)$ & 18.7 & $(0.8)$ & 31.2 & $(0.8)$ & 24.9 & (1.0) \\
\hline & Tunisia & 28.0 & $(0.9)$ & 15.1 & $(0.9)$ & 15.1 & $(0.7)$ & 16.3 & $(0.8)$ & 25.6 & (1.0) \\
\hline & United Arab Emirates & 14.7 & $(0.6)$ & 8.7 & $(0.4)$ & 10.4 & $(0.5)$ & 17.4 & $(0.6)$ & 48.8 & $(0.9)$ \\
\hline & Uruguay & 50.9 & $(1.0)$ & 20.0 & (0.9) & 14.1 & (0.6) & 8.4 & $(0.5)$ & 6.6 & $(0.5)$ \\
\hline & Viet Nam & 13.6 & $(0.7)$ & 11.8 & $(0.8)$ & 19.4 & $(0.7)$ & 24.2 & $(0.8)$ & 31.1 & $(1.5)$ \\
\hline
\end{tabular}

* See notes at the beginning of this Annex.

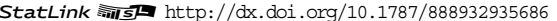


[Part 1/1]

Students' exposure to the mathematics concept "cosine"

Table I.3.25 Percentage of students who answered how familiar they are with the following mathematical concepts

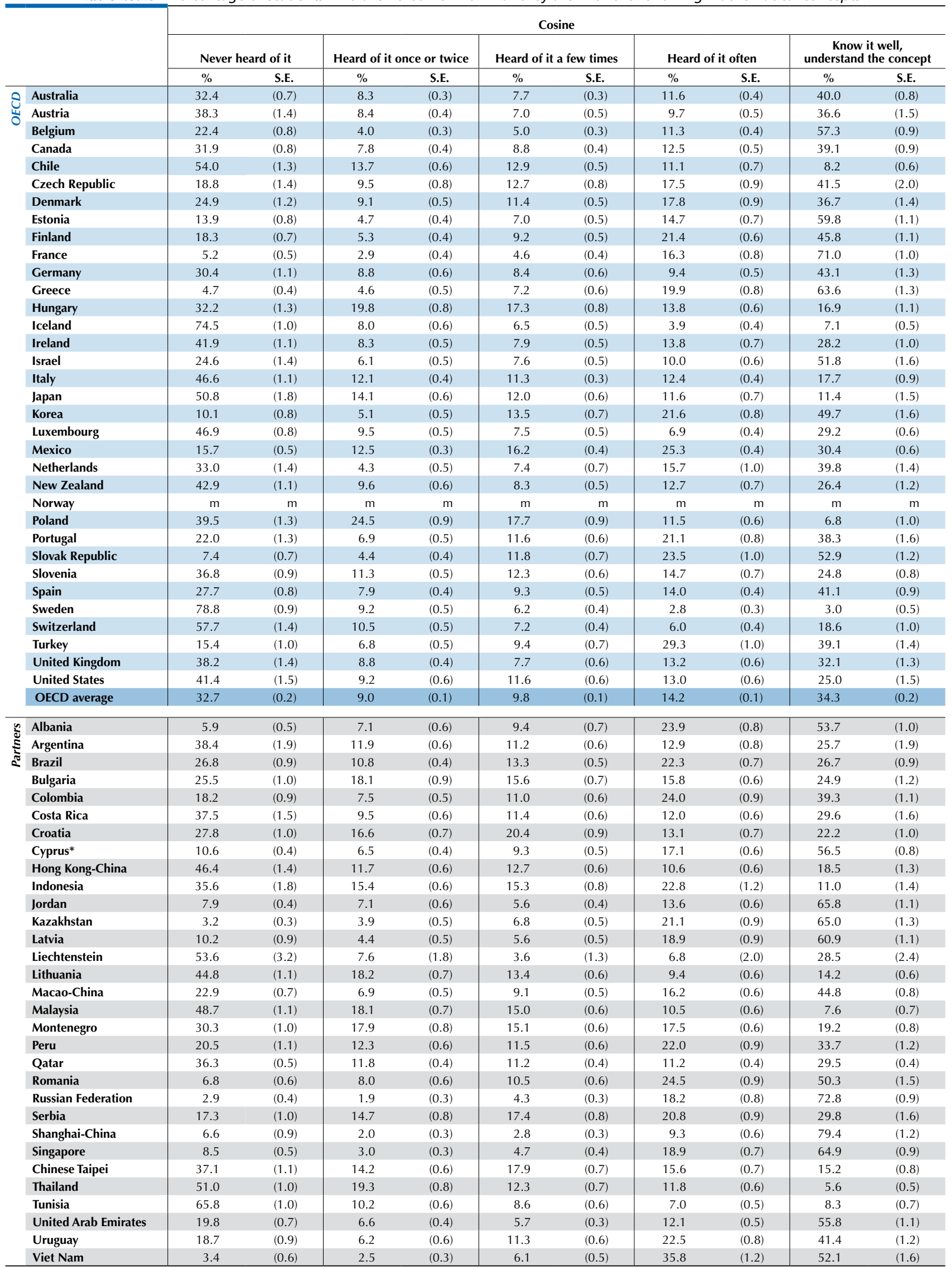

* See notes at the beginning of this Annex.

StatLink त्राज http://dx.doi.org/10.1787/888932935686 
[Part 1/1]

Students' exposure to the mathematics concept "arithmetic mean"

Table I.3.26 Percentage of students who answered how familiar they are with the following mathematical concepts

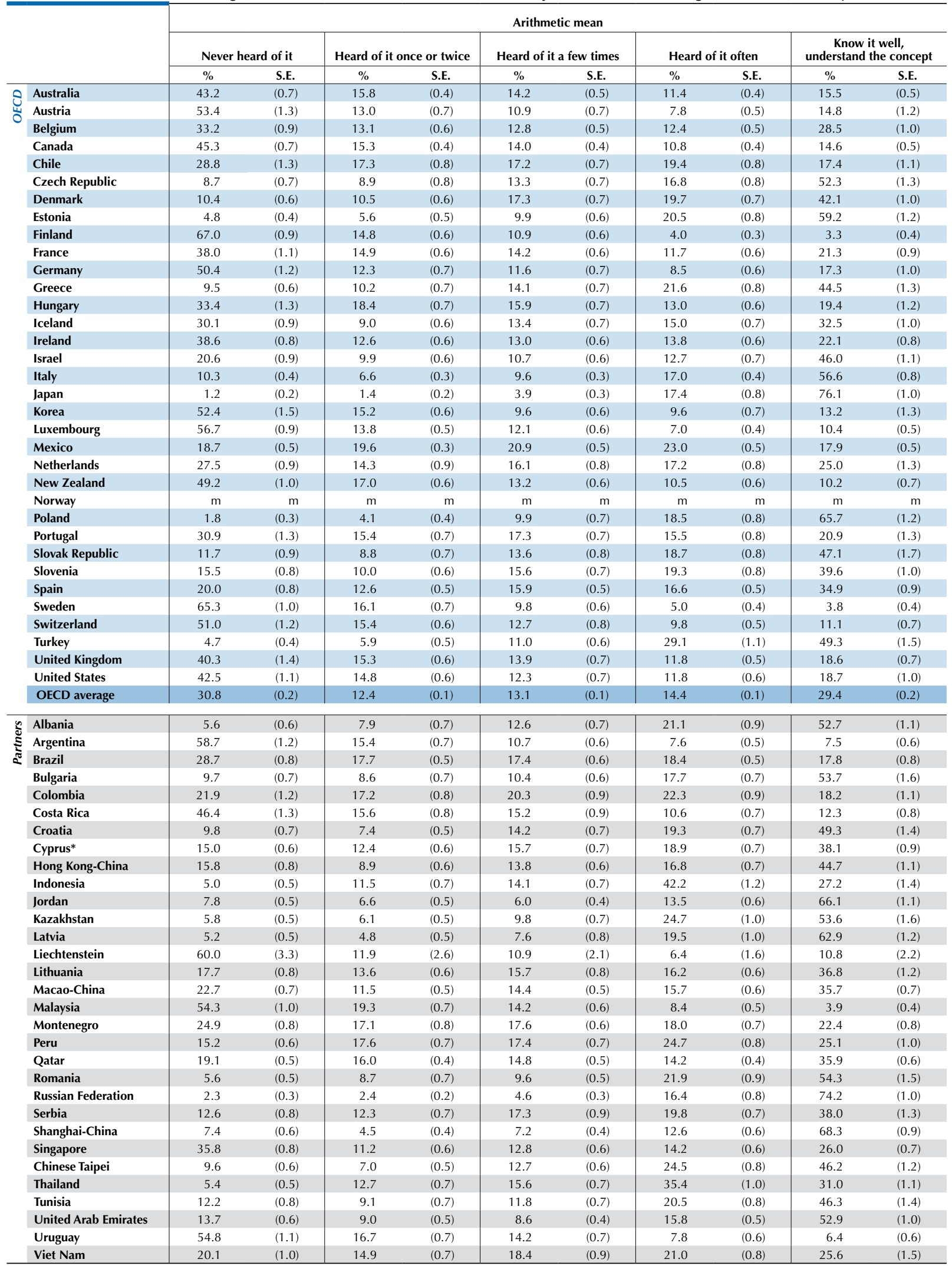

* See notes at the beginning of this Annex.

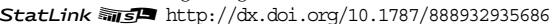


[Part 1/1]

Students' exposure to the mathematics concept "probability"

Table I.3.27 Percentage of students who answered how familiar they are with the following mathematical concepts

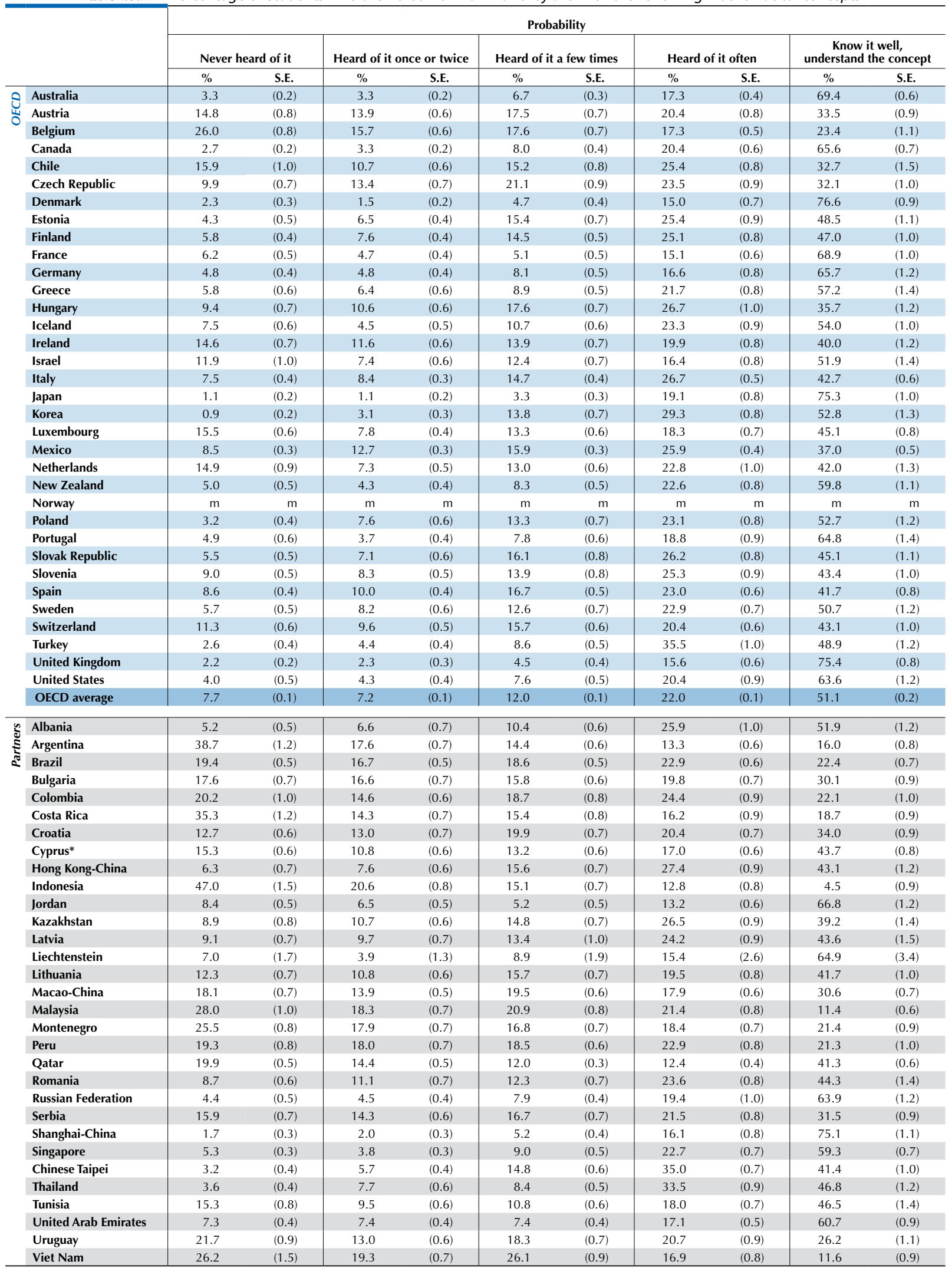

* See notes at the beginning of this Annex.

StatLink त्राज http://dx.doi.org/10.1787/888932935686 
[Part 1/1]

Familiarity with mathematics topics

Table 1.3.28 Percentage of students who «heard often» or «know well» the mathematics topics, across OECD countries

\begin{tabular}{|c|c|}
\hline $\begin{array}{l}\text { Degrees of exposure } \\
\text { with mathematics topics }\end{array}$ & Mathematics topics \\
\hline \multirow{3}{*}{$\begin{array}{l}\text { Topics with Low Exposure } \\
\text { (<40\% of students) }\end{array}$} & Exponential Function \\
\hline & Vectors \\
\hline & Complex Number \\
\hline \multirow[t]{5}{*}{ Topics with Medium Exposure } & Quadratic Function \\
\hline & Rational Number \\
\hline & Congruent Figure \\
\hline & Cosine \\
\hline & Arithmetic Mean \\
\hline \multirow{5}{*}{$\begin{array}{l}\text { Topics with High Exposure } \\
\text { ( } 660 \% \text { of students) }\end{array}$} & Divisor \\
\hline & Linear Equation \\
\hline & Radicals \\
\hline & Polygon \\
\hline & Probability \\
\hline
\end{tabular}

Source: OECD, PISA 2012 Database, Tables I.3.15 to I.3.27. 
[Part 1/1]

Table I.4.1a Percentage of students at each proficiency level in reading

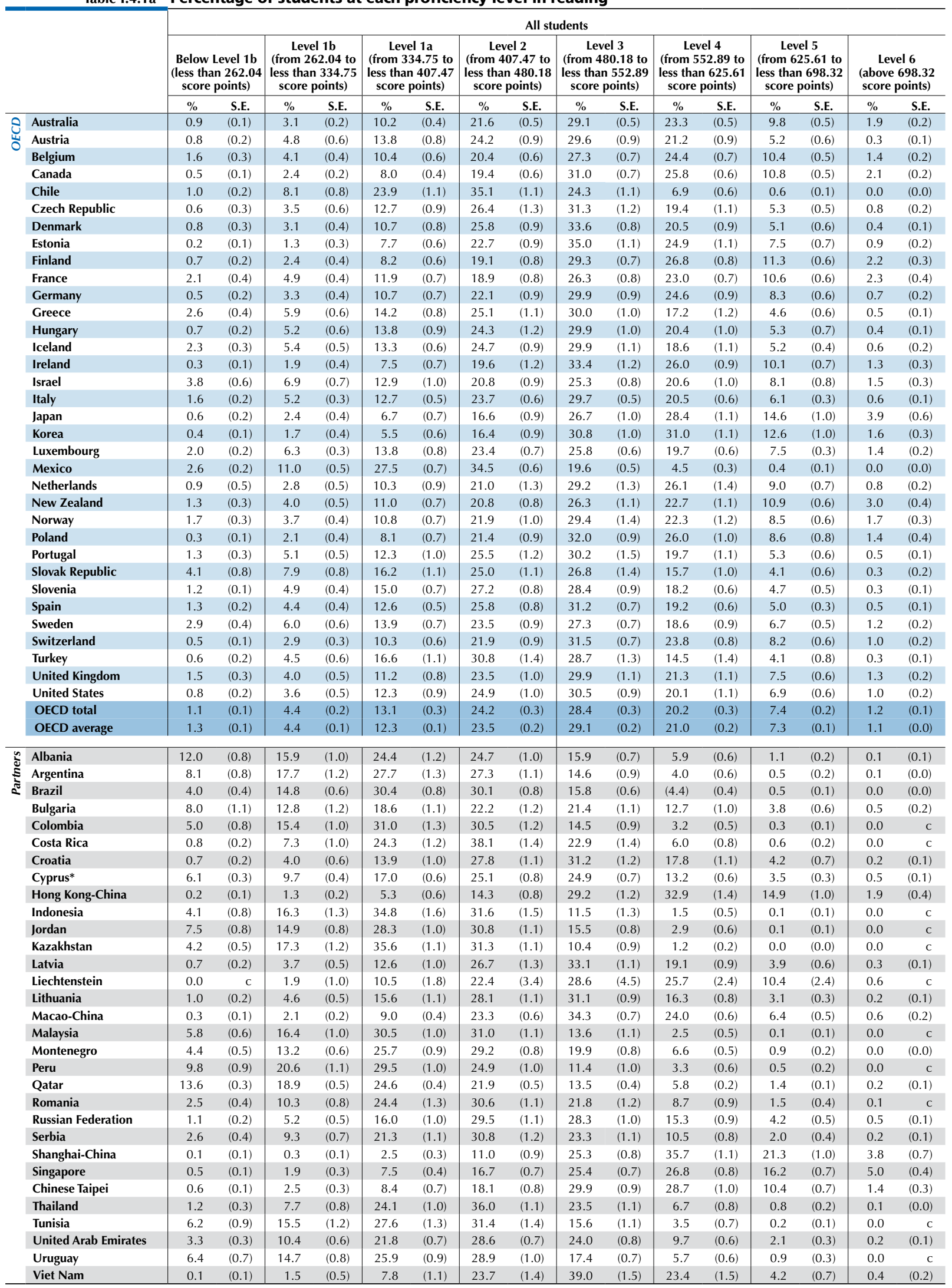

* See notes at the beginning of this Annex.

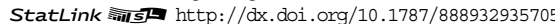


[Part 1/2]

Table I.4.1b Percentage of students below Level 2 and at Level 5 or above in reading in PISA 2000 through 2012

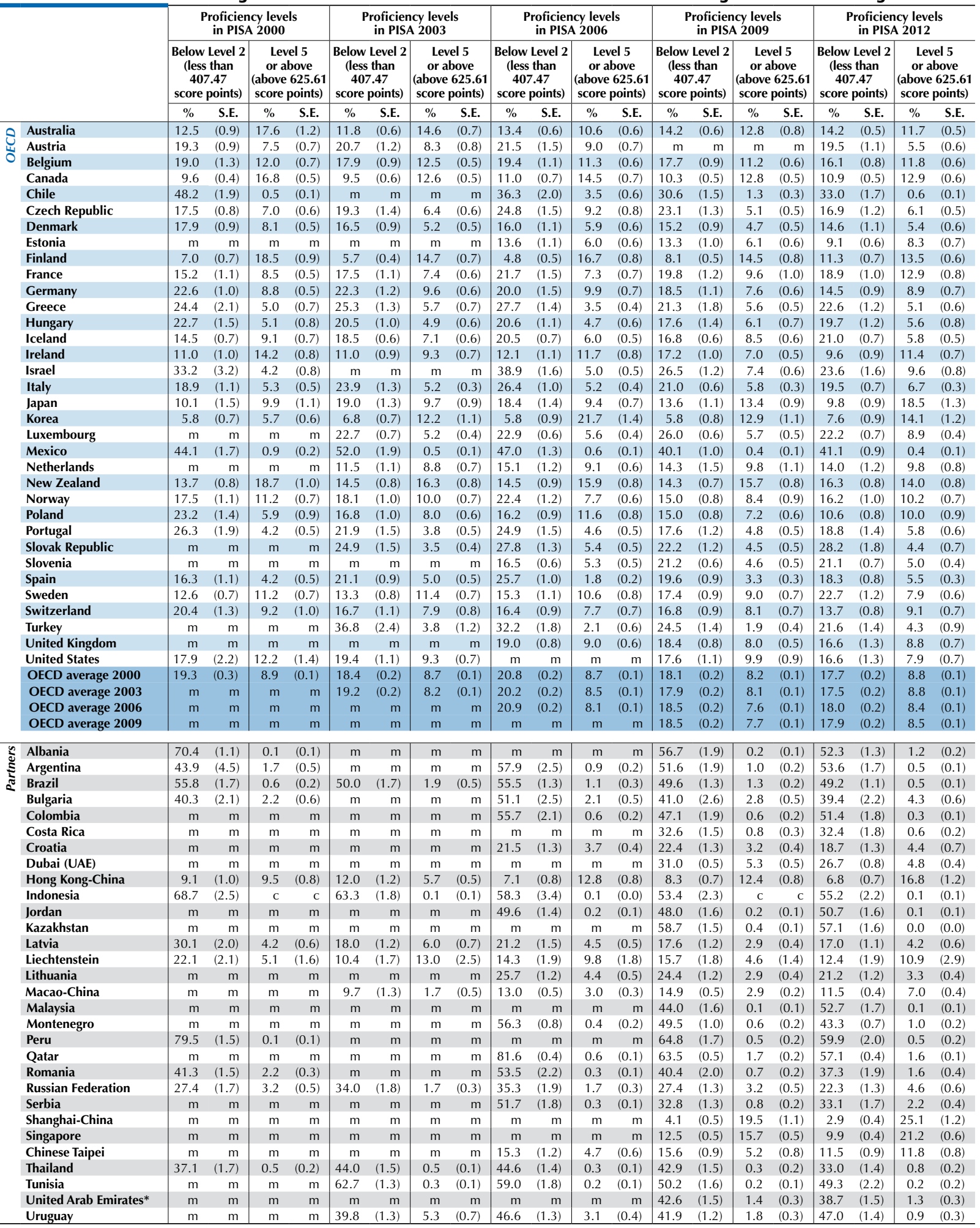

Notes: Values that are statistically significant are indicated in bold (see Annex A3).

For Chile, Albania, Argentina, Bulgaria, Indonesia, Peru and Thailand, the change between the PISA 2000 and PISA 2012 represents change between 2001 and 2012 because these countries implemented the PISA 2000 assessment in 2001 as part of PISA $2000+$

For Israel and Romania, the change between the PISA 2000 and PISA 2012 represents change between 2002 and 2012 because these countries implemented the PISA 2000 assessment in 2002 as part of PISA 2000+

For Costa Rica and Malaysia the change between PISA 2009 and PISA 2012 represents change between 2010 and 2012 because these countries implemented the PISA 2009 assessment in 2010 as part of PISA 2009

In the United Arab Emirates, Dubai took the PISA 2009 assessment in 2009 and the rest of the United Arab Emirates in 2010 as part of PISA 2009+. Results are thus reported separately. * United Arab Emirates excluding Dubai (see note above).

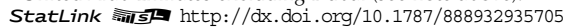


[Part 2/2]

Table I.4.1b Percentage of students below Level 2 and at Level 5 or above in reading in PISA 2000 through 2012

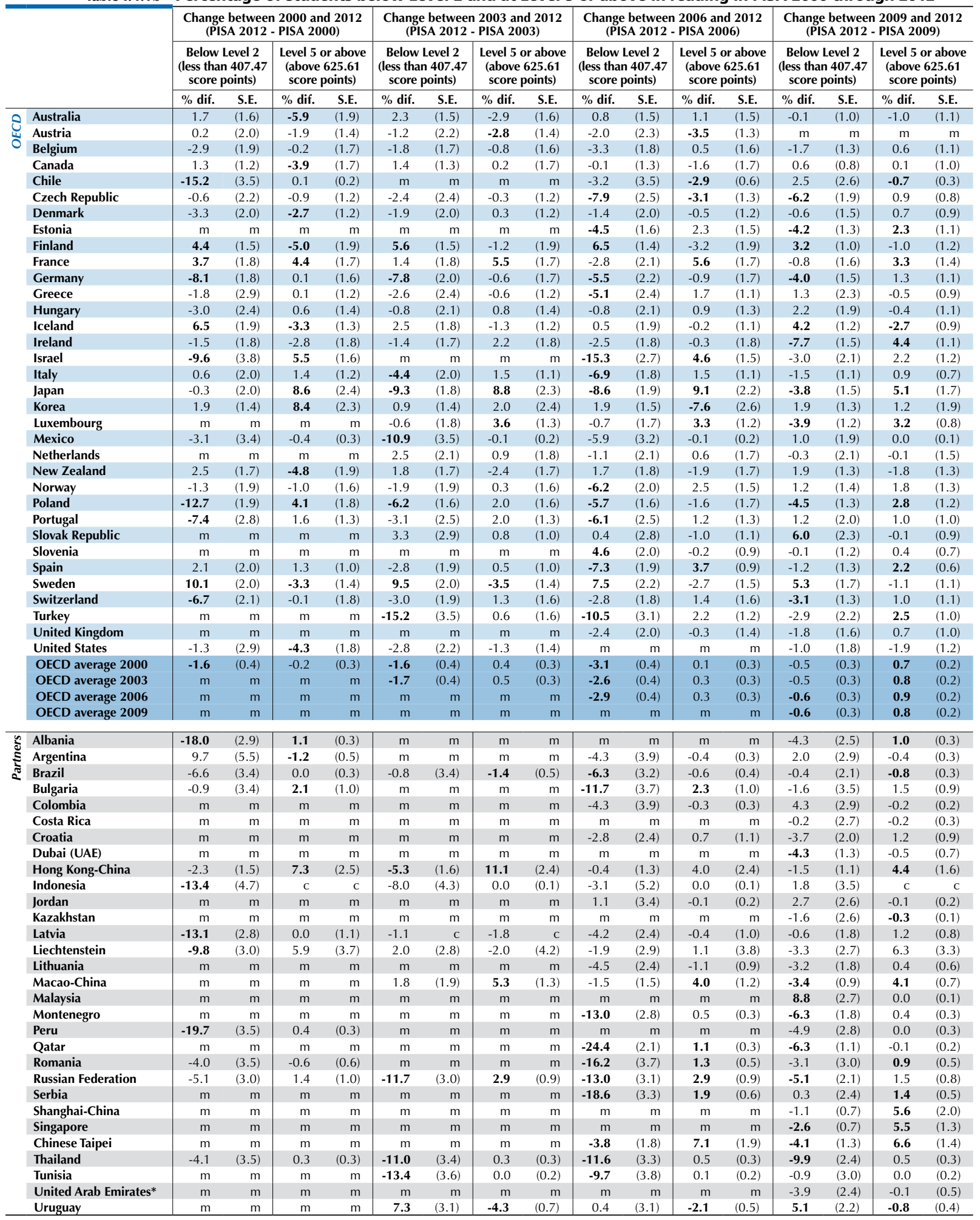

Notes: Values that are statistically significant are indicated in bold (see Annex A3).

For Chile, Albania, Argentina, Bulgaria, Indonesia, Peru and Thailand, the change between the PISA 2000 and PISA 2012 represents change between 2001 and 2012 because these countries implemented the PISA 2000 assessment in 2001 as part of PISA 2000+.

For Israel and Romania, the change between the PISA 2000 and PISA 2012 represents change between 2002 and 2012 because these countries implemented the PISA 2000 assessment in 2002 as part of PISA 2000+

For Costa Rica and Malaysia the change between PISA 2009 and PISA 2012 represents change between 2010 and 2012 because these countries implemented the PISA 2009 .

* United Arab Emirates excluding Dubai (see note above).

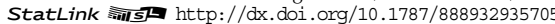


[Part 1/2]

Table I.4.2a Percentage of students at each proficiency level in reading, by gender

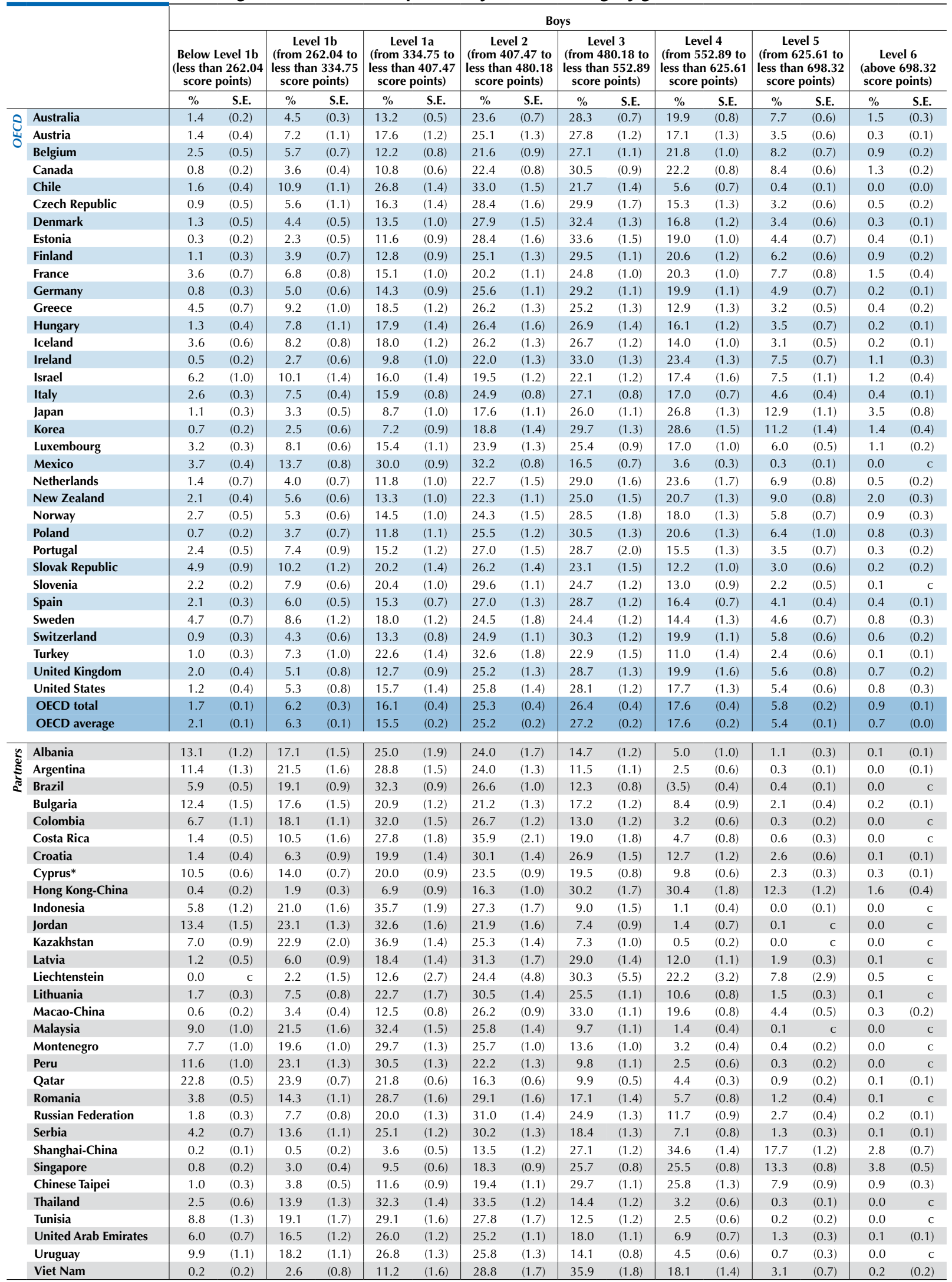

* See notes at the beginning of this Annex.

StatLink त्राजा http://dx.doi.org/10.1787/888932935705 
[Part 2/2]

Table I.4.2a Percentage of students at each proficiency level in reading, by gender

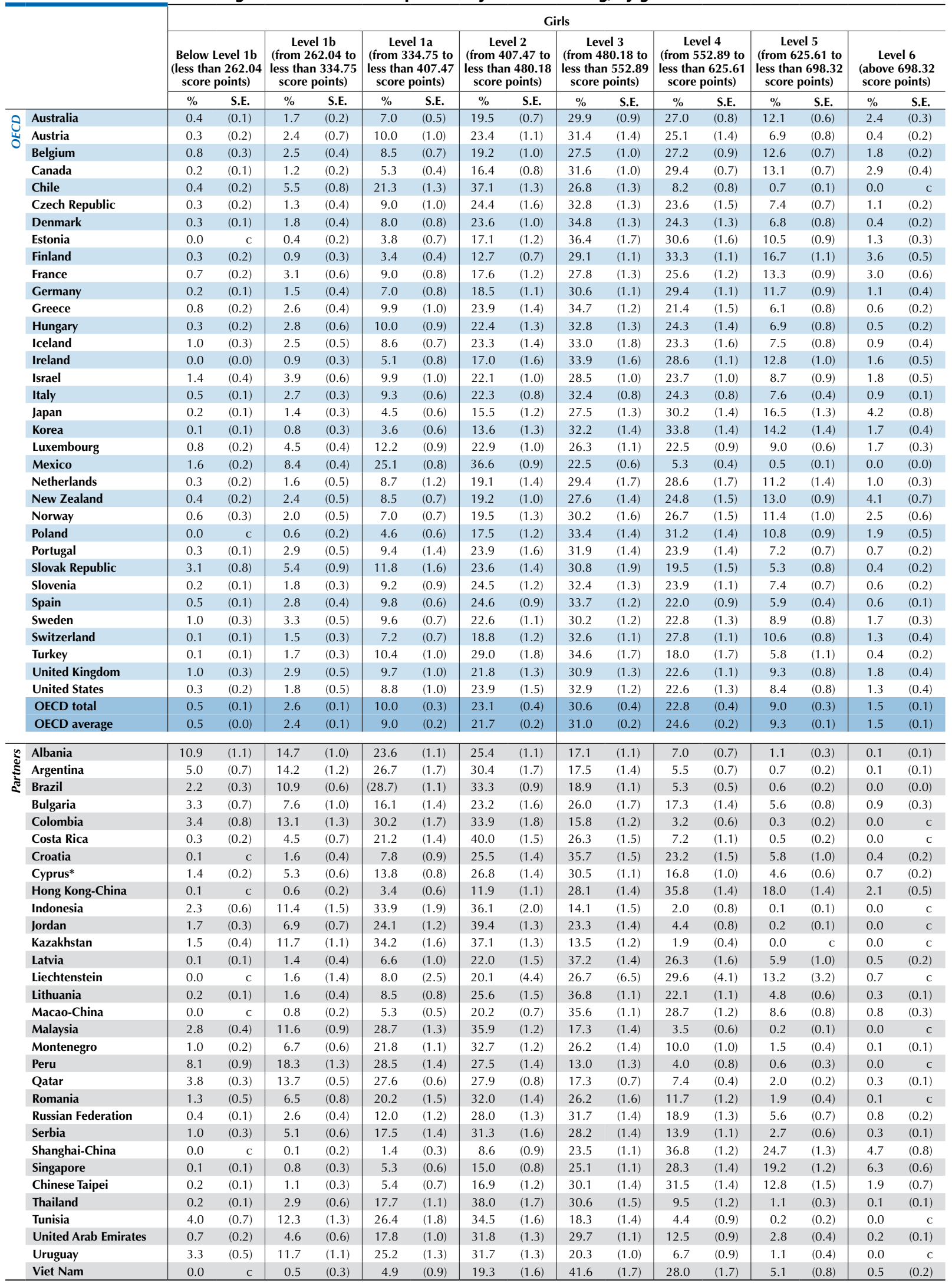

* See notes at the beginning of this Annex.

StatLink त्माजय http://dx.doi.org/10.1787/888932935705 
[Part 1/2]

Percentage of students below Level 2 and at Level 5 or above in reading in PISA 2000 and 2012 ,

Table I.4.2b by gender

\begin{tabular}{|c|c|c|c|c|c|c|c|c|c|c|c|c|c|}
\hline & & \multicolumn{12}{|c|}{ Boys } \\
\hline & & \multicolumn{4}{|c|}{ Proficiency levels in PISA 2000} & \multicolumn{4}{|c|}{ Proficiency levels in PISA 2012} & \multicolumn{4}{|c|}{$\begin{array}{c}\text { Change between } 2000 \text { and } 2012 \\
\text { (PISA 2012 - PISA 2000) }\end{array}$} \\
\hline & & \multicolumn{2}{|c|}{$\begin{array}{c}\text { Below Level } 2 \\
\text { (less than } 407.47 \\
\text { score points) }\end{array}$} & \multicolumn{2}{|c|}{$\begin{array}{l}\text { Level } 5 \text { or above } \\
\text { (above } 625.61 \\
\text { score points) }\end{array}$} & \multicolumn{2}{|c|}{$\begin{array}{c}\text { Below Level } 2 \\
\text { (less than } 407.47 \\
\text { score points) }\end{array}$} & \multicolumn{2}{|c|}{$\begin{array}{l}\text { Level } 5 \text { or above } \\
\text { (above } 625.61 \\
\text { score points) }\end{array}$} & \multicolumn{2}{|c|}{$\begin{array}{l}\text { Below Level } 2 \\
\text { (less than } 407.47 \\
\text { score points) }\end{array}$} & \multicolumn{2}{|c|}{$\begin{array}{c}\text { Level } 5 \text { or above } \\
\text { (above } 625.61 \\
\text { score points) }\end{array}$} \\
\hline & & $\%$ & S.E. & $\%$ & S.E. & $\%$ & S.E. & $\%$ & S.E. & $\%$ dif. & S.E. & $\%$ dif. & S.E. \\
\hline \multirow{28}{*}{ 䓌 } & Australia & 16.0 & $(1.3)$ & 14.2 & (1.1) & 19.0 & $(0.6)$ & 9.2 & $(0.8)$ & 3.0 & $(1.5)$ & -5.1 & $(1.3)$ \\
\hline & Austria & 23.8 & $(1.5)$ & 5.1 & $(0.7)$ & 26.2 & $(1.7)$ & 3.7 & $(0.6)$ & 2.5 & $(2.3)$ & -1.4 & $(0.9)$ \\
\hline & Belgium & 22.8 & $(1.4)$ & 9.9 & $(0.9)$ & 20.4 & $(1.2)$ & 9.1 & $(0.7)$ & -2.4 & (1.9) & -0.8 & $(1.2)$ \\
\hline & Canada & 12.7 & $(0.6)$ & 12.8 & $(0.6)$ & 15.2 & $(0.7)$ & 9.7 & $(0.7)$ & 2.5 & $(0.9)$ & -3.1 & $(0.9)$ \\
\hline & Chile & 53.6 & $(2.2)$ & 0.4 & $(0.2)$ & 39.2 & $(2.2)$ & 0.4 & $(0.1)$ & -14.4 & (3.1) & 0.1 & $(0.2)$ \\
\hline & Czech Republic & 23.6 & (1.6) & 5.3 & $(0.7)$ & 22.8 & (1.7) & 3.7 & $(0.6)$ & -0.8 & (2.4) & -1.6 & $(0.9)$ \\
\hline & Denmark & 21.8 & $(1.3)$ & 6.8 & $(0.7)$ & 19.2 & $(1.5)$ & 3.7 & (0.6) & -2.6 & (1.9) & -3.1 & $(0.9)$ \\
\hline & Finland & 11.0 & $(0.9)$ & 11.0 & $(0.9)$ & 17.7 & $(1.1)$ & 7.1 & $(0.6)$ & 6.8 & (1.5) & -3.9 & (1.1) \\
\hline & France & 19.9 & (1.5) & 6.4 & $(0.7)$ & 25.5 & (1.3) & 9.2 & $(0.9)$ & 5.6 & (2.0) & 2.8 & (1.1) \\
\hline & Germany & 26.6 & $(1.2)$ & 6.7 & $(0.8)$ & 20.1 & $(1.1)$ & 5.2 & $(0.7)$ & -6.4 & (1.6) & -1.5 & $(1.0)$ \\
\hline & Greece & 30.9 & $(2.7)$ & 3.6 & $(0.7)$ & 32.2 & (1.8) & 3.6 & $(0.6)$ & 1.3 & (3.2) & -0.1 & $(0.9)$ \\
\hline & Hungary & 27.2 & $(2.2)$ & 3.5 & $(0.8)$ & 26.9 & (1.9) & 3.8 & $(0.8)$ & -0.3 & (2.9) & 0.2 & (1.1) \\
\hline & Iceland & 20.1 & $(1.1)$ & 6.4 & $(0.9)$ & 29.8 & $(1.3)$ & 3.3 & $(0.5)$ & 9.7 & (1.7) & -3.1 & (1.1) \\
\hline & Ireland & 13.5 & (1.3) & 11.2 & (1.1) & 13.0 & (1.4) & 8.5 & $(0.7)$ & -0.5 & (1.9) & -2.7 & (1.3) \\
\hline & Israel & 36.5 & $(4.0)$ & 4.2 & (1.1) & 32.3 & (2.6) & 8.7 & (1.3) & -4.2 & (4.8) & 4.5 & $(1.7)$ \\
\hline & Italy & 24.6 & $(2.1)$ & 3.7 & (0.6) & 25.9 & $(0.9)$ & 5.0 & $(0.5)$ & 1.3 & (2.3) & 1.3 & $(0.8)$ \\
\hline & Japan & 14.2 & (2.3) & 7.5 & (1.3) & 13.1 & (1.3) & 16.4 & (1.5) & -1.1 & $(2.7)$ & 8.9 & $(2.0)$ \\
\hline & Korea & 7.3 & (1.1) & 4.4 & (0.6) & 10.4 & (1.4) & 12.6 & (1.5) & 3.1 & (1.7) & 8.2 & (1.6) \\
\hline & Mexico & 49.8 & $(2.0)$ & 0.8 & $(0.3)$ & 47.4 & $(1.1)$ & 0.3 & $(0.1)$ & -2.4 & (2.3) & -0.5 & $(0.3)$ \\
\hline & New Zealand & 18.5 & (1.4) & 13.7 & (1.2) & 21.0 & $(1.2)$ & 11.0 & (0.9) & 2.5 & (1.9) & -2.7 & (1.5) \\
\hline & Norway & 23.2 & (1.6) & 8.1 & $(0.8)$ & 22.5 & (1.4) & 6.7 & $(0.7)$ & -0.6 & (2.1) & -1.5 & (1.1) \\
\hline & Poland & 30.3 & (2.5) & 4.1 & $(0.8)$ & 16.2 & $(1.2)$ & 7.2 & (1.1) & -14.1 & (2.8) & 3.0 & (1.3) \\
\hline & Portugal & 31.3 & $(2.2)$ & 3.8 & $(0.6)$ & 25.0 & $(1.8)$ & 3.8 & $(0.8)$ & -6.3 & (2.8) & 0.0 & $(0.9)$ \\
\hline & Spain & 20.4 & (1.4) & 3.6 & $(0.7)$ & 23.4 & $(1.0)$ & 4.5 & $(0.4)$ & 3.0 & (1.7) & 0.9 & $(0.8)$ \\
\hline & Sweden & 16.8 & $(1.0)$ & 7.4 & $(0.8)$ & 31.3 & (1.8) & 5.3 & $(0.7)$ & 14.5 & (2.0) & -2.1 & $(1.1)$ \\
\hline & Switzerland & 24.6 & $(1.8)$ & 7.3 & $(0.9)$ & 18.5 & $(1.1)$ & 6.3 & $(0.7)$ & -6.1 & $(2.1)$ & -0.9 & $(1.1)$ \\
\hline & United States & 23.0 & (3.0) & 11.0 & (1.6) & 22.2 & (1.8) & 6.2 & $(0.7)$ & -0.8 & (3.5) & -4.8 & $(1.7)$ \\
\hline & OECD average 2000 & 23.8 & $(0.4)$ & 6.8 & $(0.2)$ & 23.6 & $(0.3)$ & 6.5 & $(0.1)$ & -0.3 & $(0.4)$ & -0.3 & $(0.2)$ \\
\hline \multirow{12}{*}{ 离 } & Albania & 80.6 & $(1.2)$ & 0.1 & $(0.1)$ & 55.2 & (1.9) & 1.2 & $(0.3)$ & -25.4 & (2.3) & 1.1 & $(0.3)$ \\
\hline & Argentina & 53.3 & (3.4) & 0.9 & $(0.4)$ & 61.7 & (2.0) & 0.3 & $(0.1)$ & 8.4 & (3.9) & -0.6 & $(0.4)$ \\
\hline & Brazil & 59.5 & (1.9) & 0.4 & $(0.2)$ & 57.2 & (1.3) & 0.4 & $(0.1)$ & -2.3 & (2.3) & 0.0 & $(0.3)$ \\
\hline & Bulgaria & 50.3 & $(2.4)$ & 1.2 & $(0.4)$ & 50.9 & (2.4) & 2.3 & $(0.5)$ & 0.6 & (3.4) & 1.1 & $(0.6)$ \\
\hline & Hong Kong-China & 11.9 & (1.5) & 9.0 & (1.1) & 9.1 & $(1.0)$ & 13.9 & (1.4) & -2.7 & (1.8) & 5.0 & (1.8) \\
\hline & Indonesia & 74.5 & $(2.4)$ & c & c & 62.6 & (2.6) & 0.0 & $(0.1)$ & -11.9 & (3.5) & c & c \\
\hline & Latvia & 40.3 & $(2.5)$ & 2.5 & $(0.5)$ & 25.7 & (1.9) & 2.0 & $(0.3)$ & -14.7 & (3.2) & -0.5 & $(0.6)$ \\
\hline & Liechtenstein & 27.1 & (3.9) & 3.9 & (1.9) & 14.8 & (3.0) & 8.3 & (3.1) & -12.3 & (4.9) & 4.4 & (3.7) \\
\hline & Peru & 80.7 & $(2.3)$ & 0.1 & $(0.2)$ & 65.1 & (1.9) & 0.3 & $(0.2)$ & -15.5 & (3.0) & 0.2 & $(0.3)$ \\
\hline & Romania & 44.2 & $(2.2)$ & 2.0 & $(0.4)$ & 46.8 & (2.3) & 1.2 & $(0.4)$ & 2.6 & (3.1) & -0.7 & $(0.6)$ \\
\hline & Russian Federation & 35.1 & (1.9) & 2.3 & $(0.5)$ & 29.6 & $(1.8)$ & 2.9 & $(0.5)$ & -5.5 & (2.6) & 0.6 & $(0.6)$ \\
\hline & Thailand & 51.1 & $(2.1)$ & 0.3 & $(0.2)$ & 48.6 & (1.8) & 0.3 & $(0.1)$ & -2.5 & (2.8) & 0.0 & $(0.3)$ \\
\hline
\end{tabular}

Notes: Values that are statistically significant are indicated in bold (see Annex A3).

Only countries and economies with comparable results in PISA 2000 and PISA 2012 are presented.

For Chile, Albania, Argentina, Bulgaria, Indonesia, Peru and Thailand, the change between the PISA 2000 and PISA 2012 represents change between 2001 and 2012 because these countries implemented the PISA 2000 assessment in 2001 as part of PISA 2000+.

For Israel and Romania, the change between the PISA 2000 and PISA 2012 represents change between 2002 and 2012 because these countries implemented the PISA 2000 assessment in 2002 as part of PISA 2000+.

StatLink न्ता st http://dx.doi.org/10.1787/888932935705 
[Part 2/2]

Percentage of students below Level 2 and at Level 5 or above in reading in PISA 2000 and 2012,

\begin{tabular}{|c|c|c|c|c|c|c|c|c|c|c|c|c|c|}
\hline & & \multicolumn{12}{|c|}{ Girls } \\
\hline & & \multicolumn{4}{|c|}{ Proficiency levels in PISA 2000} & \multicolumn{4}{|c|}{ Proficiency levels in PISA 2012} & \multicolumn{4}{|c|}{$\begin{array}{l}\text { Change between } 2000 \text { and } 2012 \\
\text { (PISA } 2012 \text { - PISA 2000) }\end{array}$} \\
\hline & & \multicolumn{2}{|c|}{$\begin{array}{l}\text { Below Level } 2 \\
\text { (less than } 407.47 \\
\text { score points) }\end{array}$} & \multicolumn{2}{|c|}{$\begin{array}{l}\text { Level } 5 \text { or above } \\
\text { (above } 625.61 \\
\text { score points) }\end{array}$} & \multicolumn{2}{|c|}{$\begin{array}{l}\text { Below Level } 2 \\
\text { (less than } 407.47 \\
\text { score points) }\end{array}$} & \multicolumn{2}{|c|}{$\begin{array}{l}\text { Level } 5 \text { or above } \\
\text { (above } 625.61 \\
\text { score points) }\end{array}$} & \multicolumn{2}{|c|}{$\begin{array}{l}\text { Below Level } 2 \\
\text { (less than } 407.47 \\
\text { score points) }\end{array}$} & \multicolumn{2}{|c|}{$\begin{array}{l}\text { Level } 5 \text { or above } \\
\text { (above } 625.61 \\
\text { score points) }\end{array}$} \\
\hline & & $\%$ & S.E. & $\%$ & S.E. & $\%$ & S.E. & $\%$ & S.E. & $\%$ dif. & S.E. & $\%$ dif. & S.E. \\
\hline \multirow{28}{*}{ తి } & Australia & 8.4 & $(0.9)$ & 21.6 & $(2.0)$ & 9.1 & $(0.6)$ & 14.5 & $(0.7)$ & 0.7 & $(1.1)$ & -7.1 & $(2.1)$ \\
\hline & Austria & 14.6 & $(1.0)$ & 10.0 & (1.1) & 12.8 & $(1.1)$ & 7.3 & $(0.9)$ & -1.8 & $(1.5)$ & -2.7 & (1.4) \\
\hline & Belgium & 14.1 & (1.7) & 14.5 & $(1.0)$ & 11.8 & $(0.9)$ & 14.4 & $(0.8)$ & -2.4 & (1.9) & -0.1 & (1.3) \\
\hline & Canada & 6.0 & $(0.4)$ & 21.0 & $(0.7)$ & 6.6 & $(0.4)$ & 16.0 & $(0.9)$ & 0.6 & $(0.6)$ & -5.0 & (1.1) \\
\hline & Chile & 43.4 & (2.3) & 0.6 & $(0.2)$ & 27.2 & $(1.7)$ & 0.8 & $(0.1)$ & -16.2 & $(2.9)$ & 0.1 & (0.3) \\
\hline & Czech Republic & 11.5 & $(0.8)$ & 8.6 & $(0.7)$ & 10.6 & $(1.2)$ & 8.5 & $(0.8)$ & -0.9 & (1.4) & 0.0 & (1.1) \\
\hline & Denmark & 13.3 & $(1.0)$ & 9.6 & $(0.9)$ & 10.1 & $(0.9)$ & 7.2 & $(0.9)$ & -3.3 & (1.4) & -2.4 & (1.3) \\
\hline & Finland & 3.2 & $(0.7)$ & 25.5 & (1.4) & 4.6 & $(0.6)$ & 20.3 & $(1.2)$ & 1.4 & $(0.9)$ & -5.3 & (1.8) \\
\hline & France & 10.5 & (1.1) & 10.5 & $(0.8)$ & 12.7 & $(1.1)$ & 16.4 & (1.1) & 2.2 & $(1.6)$ & 5.9 & (1.4) \\
\hline & Germany & 18.2 & (1.4) & 11.1 & $(0.8)$ & 8.7 & $(0.9)$ & 12.8 & (1.0) & -9.5 & $(1.7)$ & 1.7 & (1.3) \\
\hline & Greece & 17.7 & $(2.0)$ & 6.4 & $(0.9)$ & 13.3 & $(1.1)$ & 6.7 & $(0.9)$ & -4.4 & $(2.3)$ & 0.3 & (1.2) \\
\hline & Hungary & 17.9 & (1.7) & 6.7 & (1.0) & 13.0 & $(1.1)$ & 7.4 & (0.9) & -4.9 & $(2.0)$ & 0.7 & (1.3) \\
\hline & Iceland & 8.0 & $(0.8)$ & 11.9 & $(0.9)$ & 12.0 & $(0.8)$ & 8.4 & $(1.0)$ & 4.0 & $(1.1)$ & -3.5 & (1.3) \\
\hline & Ireland & 8.3 & (1.1) & 17.4 & $(1.2)$ & 6.1 & $(0.9)$ & 14.4 & (1.0) & -2.2 & $(1.4)$ & -3.0 & (1.6) \\
\hline & Israel & 30.6 & (3.1) & 4.2 & (1.0) & 15.1 & $(1.3)$ & 10.5 & $(0.9)$ & -15.4 & $(3.4)$ & 6.4 & (1.3) \\
\hline & Italy & 12.6 & (1.4) & 7.0 & $(0.7)$ & 12.6 & $(0.7)$ & 8.5 & $(0.5)$ & 0.0 & (1.5) & 1.5 & (0.8) \\
\hline & Japan & 6.0 & (1.2) & 12.1 & (1.4) & 6.1 & $(0.8)$ & 20.8 & (1.5) & 0.1 & (1.4) & 8.6 & (2.1) \\
\hline & Korea & 3.7 & $(0.7)$ & 7.4 & (1.0) & 4.5 & $(0.7)$ & 15.9 & (1.6) & 0.8 & (1.0) & 8.5 & (1.9) \\
\hline & Mexico & 38.9 & $(2.1)$ & 0.9 & $(0.3)$ & 35.0 & $(1.0)$ & 0.5 & $(0.1)$ & -3.9 & $(2.3)$ & -0.4 & $(0.3)$ \\
\hline & New Zealand & 8.3 & $(0.7)$ & 24.0 & (1.5) & 11.3 & $(0.9)$ & 17.1 & (1.3) & 3.0 & $(1.2)$ & -6.9 & (2.0) \\
\hline & Norway & 10.4 & $(1.0)$ & 14.7 & (1.0) & 9.6 & $(0.9)$ & 14.0 & (1.3) & -0.8 & (1.4) & -0.8 & (1.6) \\
\hline & Poland & 15.9 & (1.7) & 7.7 & (1.3) & 5.2 & $(0.7)$ & 12.7 & (1.1) & -10.7 & $(1.8)$ & 5.0 & (1.7) \\
\hline & Portugal & 21.2 & (1.9) & 4.6 & $(0.7)$ & 12.5 & $(1.5)$ & 7.8 & $(0.7)$ & -8.7 & $(2.4)$ & 3.2 & (1.0) \\
\hline & Spain & 11.5 & $(1.1)$ & 4.9 & $(0.5)$ & 13.1 & $(0.8)$ & 6.5 & $(0.4)$ & 1.6 & (1.4) & 1.7 & $(0.7)$ \\
\hline & Sweden & 7.8 & $(0.8)$ & 15.1 & (1.1) & 14.0 & $(0.9)$ & 10.5 & (1.0) & 6.2 & $(1.2)$ & -4.6 & (1.4) \\
\hline & Switzerland & 15.7 & (1.3) & 11.3 & (1.4) & 8.8 & $(0.8)$ & 11.9 & (1.0) & -6.9 & $(1.5)$ & 0.6 & (1.7) \\
\hline & United States & 13.1 & (1.7) & 13.4 & (1.6) & 10.8 & $(1.1)$ & 9.7 & (0.9) & -2.3 & $(2.0)$ & -3.7 & (1.8) \\
\hline & OECD average 2000 & 14.5 & $(0.3)$ & 11.2 & $(0.2)$ & 11.7 & $(0.2)$ & 11.2 & $(0.2)$ & -2.7 & $(0.3)$ & -0.1 & (0.3) \\
\hline \multirow{12}{*}{$\frac{n}{\vdots}$} & Albania & 60.4 & (1.4) & 0.1 & $(0.1)$ & 49.3 & (1.4) & 1.2 & $(0.4)$ & -11.2 & $(2.0)$ & 1.1 & (0.4) \\
\hline & Argentina & 36.7 & (5.6) & 2.3 & $(0.8)$ & 45.9 & (1.9) & 0.7 & $(0.2)$ & 9.2 & (5.9) & -1.6 & (0.8) \\
\hline & Brazil & 52.1 & (2.0) & 0.7 & $(0.3)$ & 41.9 & (1.3) & 0.6 & $(0.2)$ & -10.2 & (2.4) & 0.0 & $(0.4)$ \\
\hline & Bulgaria & 29.8 & (2.3) & 3.3 & (1.0) & 27.0 & $(2.1)$ & 6.5 & $(0.9)$ & -2.8 & $(3.1)$ & 3.2 & (1.4) \\
\hline & Hong Kong-China & 6.3 & (1.0) & 10.1 & $(1.2)$ & 4.1 & $(0.7)$ & 20.2 & (1.7) & -2.3 & $(1.2)$ & 10.1 & (2.1) \\
\hline & Indonesia & 63.1 & $(2.9)$ & c & c & 47.7 & $(2.4)$ & 0.1 & $(0.1)$ & -15.4 & (3.8) & c & c \\
\hline & Latvia & 19.7 & (1.8) & 5.8 & $(1.0)$ & 8.2 & $(1.1)$ & 6.4 & (1.0) & -11.5 & $(2.1)$ & 0.5 & (1.4) \\
\hline & Liechtenstein & 15.8 & (3.2) & 6.4 & (2.6) & 9.7 & $(2.8)$ & 13.9 & (3.6) & -6.1 & $(4.2)$ & 7.6 & (4.4) \\
\hline & Peru & 78.3 & $(2.0)$ & 0.1 & $(0.1)$ & 54.9 & $(2.4)$ & 0.6 & $(0.3)$ & -23.4 & $(3.2)$ & 0.5 & $(0.3)$ \\
\hline & Romania & 38.6 & (1.9) & 2.4 & (0.4) & 28.1 & (1.9) & 2.0 & $(0.5)$ & -10.5 & $(2.7)$ & -0.4 & (0.6) \\
\hline & Russian Federation & 19.6 & (1.6) & 4.1 & (0.6) & 15.0 & $(1.2)$ & 6.4 & $(0.9)$ & -4.6 & $(2.0)$ & 2.3 & (1.1) \\
\hline & Thailand & 27.3 & (1.6) & 0.6 & $(0.2)$ & 20.7 & (1.4) & 1.2 & $(0.3)$ & -6.6 & $(2.2)$ & 0.6 & $(0.4)$ \\
\hline
\end{tabular}

Notes: Values that are statistically significant are indicated in bold (see Annex A3).

Only countries and economies with comparable results in PISA 2000 and PISA 2012 are presented.

For Chile, Albania, Argentina, Bulgaria, Indonesia, Peru and Thailand, the change between the PISA 2000 and PISA 2012 represents change between 2001 and 2012 because these countries implemented the PISA 2000 assessment in 2001 as part of PISA 2000+.

For Israel and Romania, the change between the PISA 2000 and PISA 2012 represents change between 2002 and 2012 because these countries implemented the PISA 2000 assessment in 2002 as part of PISA 2000+.

StatLink 吾 St http://dx.doi.org/10.1787/888932935705 
[Part 1/1]

Table I.4.3a Mean score, variation and gender differences in student performance in reading

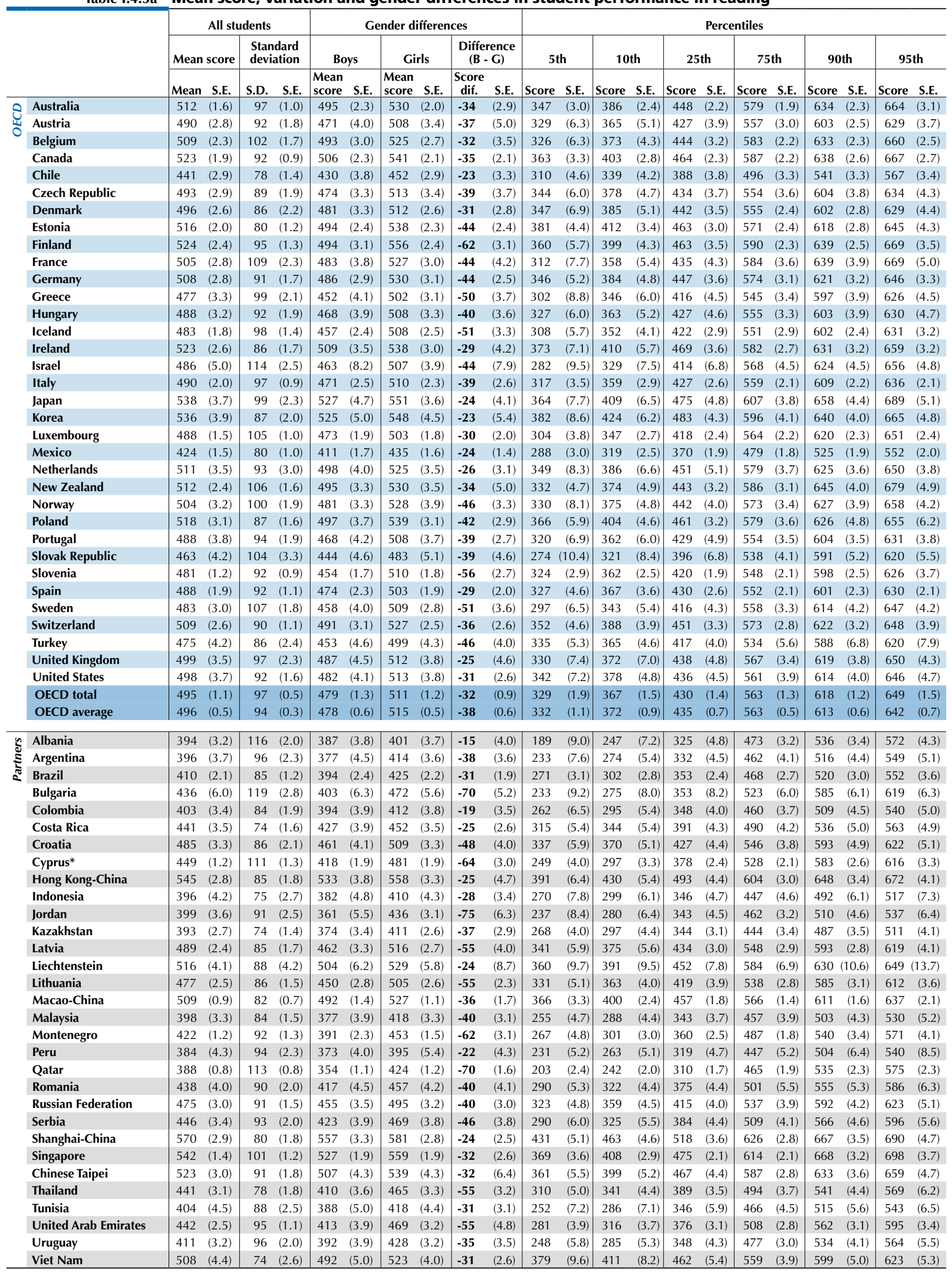

Note: Values that are statistically significant are indicated in bold (see Annex A3).

* See notes at the beginning of this Annex.

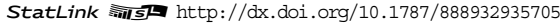


[Part 1/2]

Table I.4.3b Mean reading performance in PISA 2000 through 2012

\begin{tabular}{|c|c|c|c|c|c|c|c|c|c|c|c|}
\hline & & \multicolumn{2}{|c|}{ PISA 2000} & \multicolumn{2}{|c|}{ PISA 2003} & \multicolumn{2}{|c|}{ PISA 2006} & \multicolumn{2}{|c|}{ PISA 2009} & \multicolumn{2}{|c|}{ PISA 2012} \\
\hline & & Mean score & S.E. & Mean score & S.E. & Mean score & S.E. & Mean score & S.E. & Mean score & S.E. \\
\hline \multirow{38}{*}{ త্ } & Australia & 528 & (3.5) & 525 & $(2.1)$ & 513 & $(2.1)$ & 515 & $(2.3)$ & 512 & (1.6) \\
\hline & Austria & 492 & $(2.7)$ & 491 & (3.8) & 490 & $(4.1)$ & $\mathrm{m}$ & $\mathrm{m}$ & 490 & $(2.8)$ \\
\hline & Belgium & 507 & (3.6) & 507 & $(2.6)$ & 501 & (3.0) & 506 & $(2.3)$ & 509 & $(2.3)$ \\
\hline & Canada & 534 & (1.6) & 528 & (1.7) & 527 & (2.4) & 524 & (1.5) & 523 & (1.9) \\
\hline & Chile & 410 & (3.6) & $\mathrm{m}$ & $\mathrm{m}$ & 442 & $(5.0)$ & 449 & (3.1) & 441 & (2.9) \\
\hline & Czech Republic & 492 & (2.4) & 489 & (3.5) & 483 & $(4.2)$ & 478 & (2.9) & 493 & $(2.9)$ \\
\hline & Denmark & 497 & (2.4) & 492 & $(2.8)$ & 494 & (3.2) & 495 & $(2.1)$ & 496 & (2.6) \\
\hline & Estonia & $\mathrm{m}$ & $\mathrm{m}$ & $\mathrm{m}$ & $\mathrm{m}$ & 501 & $(2.9)$ & 501 & (2.6) & 516 & $(2.0)$ \\
\hline & Finland & 546 & (2.6) & 543 & (1.6) & 547 & $(2.1)$ & 536 & $(2.3)$ & 524 & $(2.4)$ \\
\hline & France & 505 & $(2.7)$ & 496 & $(2.7)$ & 488 & $(4.1)$ & 496 & (3.4) & 505 & $(2.8)$ \\
\hline & Germany & 484 & $(2.5)$ & 491 & (3.4) & 495 & $(4.4)$ & 497 & $(2.7)$ & 508 & $(2.8)$ \\
\hline & Greece & 474 & (5.0) & 472 & $(4.1)$ & 460 & $(4.0)$ & 483 & $(4.3)$ & 477 & (3.3) \\
\hline & Hungary & 480 & $(4.0)$ & 482 & (2.5) & 482 & (3.3) & 494 & (3.2) & 488 & (3.2) \\
\hline & Iceland & 507 & (1.5) & 492 & (1.6) & 484 & (1.9) & 500 & (1.4) & 483 & (1.8) \\
\hline & Ireland & 527 & (3.2) & 515 & $(2.6)$ & 517 & (3.5) & 496 & (3.0) & 523 & (2.6) \\
\hline & Israel & 452 & $(8.5)$ & $\mathrm{m}$ & $\mathrm{m}$ & 439 & (4.6) & 474 & (3.6) & 486 & $(5.0)$ \\
\hline & Italy & 487 & $(2.9)$ & 476 & (3.0) & 469 & $(2.4)$ & 486 & (1.6) & 490 & $(2.0)$ \\
\hline & Japan & 522 & (5.2) & 498 & (3.9) & 498 & (3.6) & 520 & (3.5) & 538 & (3.7) \\
\hline & Korea & 525 & $(2.4)$ & 534 & $(3.1)$ & 556 & $(3.8)$ & 539 & $(3.5)$ & 536 & $(3.9)$ \\
\hline & Luxembourg & $\mathrm{m}$ & $\mathrm{m}$ & 479 & (1.5) & 479 & $(1.3)$ & 472 & (1.3) & 488 & $(1.5)$ \\
\hline & Mexico & 422 & (3.3) & 400 & $(4.1)$ & 410 & (3.1) & 425 & $(2.0)$ & 424 & $(1.5)$ \\
\hline & Netherlands & $\mathrm{m}$ & $\mathrm{m}$ & 513 & (2.9) & 507 & $(2.9)$ & 508 & (5.1) & 511 & (3.5) \\
\hline & New Zealand & 529 & $(2.8)$ & 522 & (2.5) & 521 & (3.0) & 521 & $(2.4)$ & 512 & $(2.4)$ \\
\hline & Norway & 505 & (2.8) & 500 & (2.8) & 484 & $(3.2)$ & 503 & (2.6) & 504 & (3.2) \\
\hline & Poland & 479 & $(4.5)$ & 497 & (2.9) & 508 & $(2.8)$ & 500 & $(2.6)$ & 518 & (3.1) \\
\hline & Portugal & 470 & $(4.5)$ & 478 & (3.7) & 472 & (3.6) & 489 & (3.1) & 488 & (3.8) \\
\hline & Slovak Republic & $\mathrm{m}$ & $\mathrm{m}$ & 469 & (3.1) & 466 & (3.1) & 477 & (2.5) & 463 & $(4.2)$ \\
\hline & Slovenia & $\mathrm{m}$ & $\mathrm{m}$ & $\mathrm{m}$ & $\mathrm{m}$ & 494 & $(1.0)$ & 483 & $(1.0)$ & 481 & $(1.2)$ \\
\hline & Spain & 493 & $(2.7)$ & 481 & (2.6) & 461 & $(2.2)$ & 481 & $(2.0)$ & 488 & (1.9) \\
\hline & Sweden & 516 & $(2.2)$ & 514 & $(2.4)$ & 507 & (3.4) & 497 & (2.9) & 483 & (3.0) \\
\hline & Switzerland & 494 & $(4.2)$ & 499 & (3.3) & 499 & $(3.1)$ & 501 & $(2.4)$ & 509 & (2.6) \\
\hline & Turkey & $\mathrm{m}$ & $\mathrm{m}$ & 441 & $(5.8)$ & 447 & $(4.2)$ & 464 & (3.5) & 475 & $(4.2)$ \\
\hline & United Kingdom & $\mathrm{m}$ & $\mathrm{m}$ & $\mathrm{m}$ & $\mathrm{m}$ & 495 & $(2.3)$ & 494 & $(2.3)$ & 499 & (3.5) \\
\hline & United States & 504 & $(7.0)$ & 495 & $(3.2)$ & $\mathrm{m}$ & $\mathrm{m}$ & 500 & (3.7) & 498 & (3.7) \\
\hline & OECD average 2000 & 496 & $(0.7)$ & 497 & $(0.6)$ & 490 & $(0.7)$ & 496 & $(0.5)$ & 498 & $(0.6)$ \\
\hline & OECD average 2003 & $\mathrm{~m}$ & $\mathrm{~m}$ & 494 & $(0.6)$ & 492 & $(0.6)$ & 497 & (0.5) & 498 & $(0.5)$ \\
\hline & OECD average 2006 & $\mathrm{~m}$ & $\mathrm{~m}$ & $\mathrm{~m}$ & $\mathrm{~m}$ & 489 & $(0.6)$ & 494 & $(0.5)$ & 496 & $(0.5)$ \\
\hline & OECD average 2009 & $\mathrm{~m}$ & $\mathrm{~m}$ & $\mathrm{~m}$ & $\mathrm{~m}$ & $\mathrm{~m}$ & $\mathrm{~m}$ & 494 & $(0.5)$ & 497 & $(0.5)$ \\
\hline \multirow{30}{*}{ 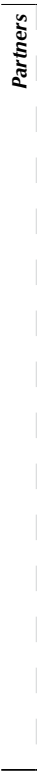 } & Albania & 349 & (3.3) & $\mathrm{m}$ & $\mathrm{m}$ & $\mathrm{m}$ & $\mathrm{m}$ & 385 & $(4.0)$ & 394 & (3.2) \\
\hline & Argentina & 418 & (9.9) & $\mathrm{m}$ & $\mathrm{m}$ & 374 & $(7.2)$ & 398 & $(4.6)$ & 396 & (3.7) \\
\hline & Brazil & 396 & (3.1) & 403 & $(4.6)$ & 393 & $(3.7)$ & 412 & (2.7) & 410 & (2.1) \\
\hline & Bulgaria & 430 & (4.9) & $\mathrm{m}$ & $\mathrm{m}$ & 402 & (6.9) & 429 & (6.7) & 436 & $(6.0)$ \\
\hline & Colombia & $\mathrm{m}$ & $\mathrm{m}$ & $\mathrm{m}$ & $\mathrm{m}$ & 385 & $(5.1)$ & 413 & (3.7) & 403 & (3.4) \\
\hline & Costa Rica & $\mathrm{m}$ & $\mathrm{m}$ & $\mathrm{m}$ & $\mathrm{m}$ & $\mathrm{m}$ & $\mathrm{m}$ & 443 & (3.2) & 441 & (3.5) \\
\hline & Croatia & $\mathrm{m}$ & $\mathrm{m}$ & $\mathrm{m}$ & $\mathrm{m}$ & 477 & $(2.8)$ & 476 & $(2.9)$ & 485 & (3.3) \\
\hline & Dubai (UAE) & $\mathrm{m}$ & $\mathrm{m}$ & $\mathrm{m}$ & $\mathrm{m}$ & $\mathrm{m}$ & $\mathrm{m}$ & 459 & (1.1) & 468 & (1.3) \\
\hline & Hong Kong-China & 525 & (2.9) & 510 & (3.7) & 536 & $(2.4)$ & 533 & (2.1) & 545 & (2.8) \\
\hline & Indonesia & 371 & $(4.0)$ & 382 & (3.4) & 393 & (5.9) & 402 & (3.7) & 396 & $(4.2)$ \\
\hline & Jordan & $\mathrm{m}$ & $\mathrm{m}$ & $\mathrm{m}$ & $\mathrm{m}$ & 401 & (3.3) & 405 & (3.3) & 399 & (3.6) \\
\hline & Kazakhstan & $\mathrm{m}$ & $\mathrm{m}$ & $\mathrm{m}$ & $\mathrm{m}$ & $\mathrm{m}$ & $\mathrm{m}$ & 390 & (3.1) & 393 & $(2.7)$ \\
\hline & Latvia & 458 & (5.3) & 491 & (3.7) & 479 & $(3.7)$ & 484 & (3.0) & 489 & $(2.4)$ \\
\hline & Liechtenstein & 483 & (4.1) & 525 & (3.6) & 510 & (3.9) & 499 & (2.8) & 516 & (4.1) \\
\hline & Lithuania & $\mathrm{m}$ & $\mathrm{m}$ & $\mathrm{m}$ & $\mathrm{m}$ & 470 & $(3.0)$ & 468 & (2.4) & 477 & (2.5) \\
\hline & Macao-China & $\mathrm{m}$ & $\mathrm{m}$ & 498 & $(2.2)$ & 492 & $(1.1)$ & 487 & $(0.9)$ & 509 & $(0.9)$ \\
\hline & Malaysia & $\mathrm{m}$ & $\mathrm{m}$ & $\mathrm{m}$ & $\mathrm{m}$ & $\mathrm{m}$ & $\mathrm{m}$ & 414 & $(2.9)$ & 398 & $(3.3)$ \\
\hline & Montenegro & $\mathrm{m}$ & $\mathrm{m}$ & $\mathrm{m}$ & $\mathrm{m}$ & 392 & $(1.2)$ & 408 & (1.7) & 422 & $(1.2)$ \\
\hline & Peru & 327 & $(4.4)$ & $\mathrm{m}$ & $\mathrm{m}$ & $\mathrm{m}$ & $\mathrm{m}$ & 370 & $(4.0)$ & 384 & $(4.3)$ \\
\hline & Qatar & $\mathrm{m}$ & $\mathrm{m}$ & $\mathrm{m}$ & $\mathrm{m}$ & 312 & $(1.2)$ & 372 & $(0.8)$ & 388 & $(0.8)$ \\
\hline & Romania & 428 & (3.5) & $\mathrm{m}$ & $\mathrm{m}$ & 396 & $(4.7)$ & 424 & (4.1) & 438 & $(4.0)$ \\
\hline & Russian Federation & 462 & $(4.2)$ & 442 & (3.9) & 440 & $(4.3)$ & 459 & (3.3) & 475 & (3.0) \\
\hline & Serbia & $\mathrm{m}$ & $\mathrm{m}$ & $\mathrm{m}$ & $\mathrm{m}$ & 401 & (3.5) & 442 & $(2.4)$ & 446 & $(3.4)$ \\
\hline & Shanghai-China & $\mathrm{m}$ & $\mathrm{m}$ & $\mathrm{m}$ & $\mathrm{m}$ & $\mathrm{m}$ & $\mathrm{m}$ & 556 & (2.4) & 570 & (2.9) \\
\hline & Singapore & $\mathrm{m}$ & $\mathrm{m}$ & $\mathrm{m}$ & $\mathrm{m}$ & $\mathrm{m}$ & $\mathrm{m}$ & 526 & (1.1) & 542 & (1.4) \\
\hline & Chinese Taipei & $\mathrm{m}$ & $\mathrm{m}$ & $\mathrm{m}$ & $\mathrm{m}$ & 496 & (3.4) & 495 & (2.6) & 523 & $(3.0)$ \\
\hline & Thailand & 431 & (3.2) & 420 & $(2.8)$ & 417 & $(2.6)$ & 421 & $(2.6)$ & 441 & $(3.1)$ \\
\hline & Tunisia & $\mathrm{m}$ & $\mathrm{m}$ & 375 & (2.8) & 380 & $(4.0)$ & 404 & (2.9) & 404 & (4.5) \\
\hline & United Arab Emirates* & $\mathrm{m}$ & $\mathrm{m}$ & $\mathrm{m}$ & $\mathrm{m}$ & $\mathrm{m}$ & $\mathrm{m}$ & 423 & (3.7) & 432 & (3.3) \\
\hline & Uruguay & $\mathrm{m}$ & $\mathrm{m}$ & 434 & (3.4) & 413 & (3.4) & 426 & (2.6) & 411 & (3.2) \\
\hline
\end{tabular}

Notes: Values that are statistically significant are indicated in bold (see Annex A3).

Annualised change is the average change between the earliest available measurement in PISA and PISA 2012. For countries and economies with more than one available measurement, the annualised change is calculated with a linear regression model. This model considers that Chile, Albania, Argentina, Bulgaria, Indonesia, Peru and Thailand implemented the 2000 assessment in 2001 and Israel and Romania in 2002 as part of the PISA 2000+ and that Costa Rica, Malaysia and the United Arab Emirates (with the

The curvilinear change is estimated by a regression of time and time-squared on reading performance. The linear term is the estimated annual increase in performance in 2012. The quadratic term is the rate at which changes in performance are accelerating (positive estimate) or decelerating (negative estimate) throughout a country/economy's participation in PISA.

For Costa Rica and Malaysia the change between PISA 2009 and PISA 2012 represents change between 2010 and 2012 because these countries implemented the PISA 2009 assessment in 2010 as part of PISA 2009+.

For Chile, Albania, Argentina, Bulgaria, Indonesia, Peru and Thailand, the change between the PISA 2000 and PISA 2012 represents change between 2001 and 2012 because these countries implemented the PISA 2000 assessment in 2001 as part of PISA $2000+$.

For Israel and Romania the change between the PISA 2000 and PISA 2012 represents change between 2002 and 2012 because these countries implemented the PISA 2000 assessment in 2002 as part of PISA 2000+.

In the United Arab Emirates, Dubai took the PISA 2009 assessment in 2009 and the rest of the United Arab Emirates in 2010 as part of PISA 2009+. Results are thus reported separately.

* United Arab Emirates excluding Dubai (see note above).

StatLink त्रोज http://dx.doi.org/10.1787/888932935705 
[Part 2/2]

Table I.4.3b Mean reading performance in PISA 2000 through 2012

\begin{tabular}{|c|c|c|c|c|c|c|c|c|c|c|c|c|c|c|c|}
\hline & \multirow{2}{*}{\multicolumn{2}{|c|}{$\begin{array}{l}\text { Change between } \\
2000 \text { and } 2012 \\
\text { (PISA 2012 - } \\
\text { PISA 2000) }\end{array}$}} & \multirow{2}{*}{\multicolumn{2}{|c|}{$\begin{array}{l}\text { Change between } \\
2003 \text { and } 2012 \\
\text { (PISA 2012 - } \\
\text { PISA 2003) }\end{array}$}} & \multirow{2}{*}{\multicolumn{2}{|c|}{$\begin{array}{l}\text { Change between } \\
2006 \text { and } 2012 \\
\text { (PISA 2012 - } \\
\text { PISA 2006) }\end{array}$}} & \multirow{2}{*}{\multicolumn{2}{|c|}{$\begin{array}{l}\text { Change between } \\
2009 \text { and } 2012 \\
\text { (PISA 2012 - } \\
\text { PISA 2009) }\end{array}$}} & \multirow{2}{*}{\multicolumn{2}{|c|}{$\begin{array}{l}\text { Annualised change } \\
\text { in reading across } \\
\text { PISA assessments }\end{array}$}} & & $\begin{array}{l}\text { Curviline } \\
\text { reading } p\end{array}$ & $\begin{array}{l}\text { ar change } \\
\text { erforman }\end{array}$ & \\
\hline & & & & & & & & & & & & $\begin{array}{l}\text { Annual } \\
2012(\mathrm{Li}\end{array}$ & $\begin{array}{l}\text { hange in } \\
\text { ear term) }\end{array}$ & $\begin{array}{r}\text { Rate of a } \\
\text { or dec } \\
\text { in perf } \\
\text { (Quadr }\end{array}$ & $\begin{array}{l}\text { eleration } \\
\text { eration } \\
\text { mance } \\
\text { ic term) }\end{array}$ \\
\hline & & Score dif. & S.E. & Score dif. & S.E. & Score dif. & S.E. & Score dif. & S.E. & $\begin{array}{l}\text { Annual } \\
\text { change }\end{array}$ & S.E. & Coef. & S.E. & Coef. & S.E. \\
\hline 0 & Australia & -16 & (7.1) & -14 & (6.2) & -1 & $(6.2)$ & -3 & $(3.8)$ & -1.4 & $(0.31)$ & -0.1 & $(0.86)$ & 0.1 & $(0.17)$ \\
\hline 島 & Austria & -2 & (7.1) & -1 & (7.3) & -1 & (7.4) & $\mathrm{m}$ & $\mathrm{m}$ & -0.2 & $(0.39)$ & 0.0 & $(1.40)$ & 0.0 & $(0.19)$ \\
\hline & Belgium & 1 & $(7.3)$ & 2 & (6.6) & 8 & (6.7) & 3 & $(4.2)$ & 0.1 & $(0.35)$ & 1.7 & $(0.97)$ & 0.1 & $(0.17)$ \\
\hline & Canada & -11 & (6.4) & -5 & $(6.2)$ & -4 & $(6.4)$ & -1 & (3.6) & -0.9 & $(0.26)$ & -0.1 & $(0.82)$ & 0.1 & $(0.16)$ \\
\hline & Chile & 32 & (7.5) & $\mathrm{m}$ & m & -1 & $(8.0)$ & -8 & $(5.0)$ & 3.1 & $(0.51)$ & -4.0 & $(1.66)$ & -0.6 & $(0.22)$ \\
\hline & Czech Republic & 1 & (7.0) & 4 & (7.2) & 10 & $(7.5)$ & 15 & $(4.8)$ & -0.5 & $(0.42)$ & 2.9 & (1.24) & 0.3 & $(0.17)$ \\
\hline & Denmark & -1 & (6.9) & 4 & (6.8) & 2 & (6.9) & 1 & $(4.3)$ & 0.1 & $(0.35)$ & 0.9 & $(0.97)$ & 0.1 & $(0.16)$ \\
\hline & Estonia & $\mathrm{m}$ & $\mathrm{m}$ & $\mathrm{m}$ & $\mathrm{m}$ & 16 & (6.6) & 15 & $(4.2)$ & 2.4 & $(0.76)$ & 7.6 & $(2.03)$ & 0.8 & $(0.57)$ \\
\hline & Finland & -22 & (6.9) & -19 & (6.3) & -23 & (6.4) & -12 & $(4.2)$ & -1.7 & $(0.31)$ & -4.8 & $(0.83)$ & -0.3 & $(0.16)$ \\
\hline & France & 1 & (7.1) & 9 & (6.8) & 18 & (7.5) & 10 & $(5.2)$ & 0.0 & $(0.37)$ & 5.1 & (1.23) & 0.4 & $(0.18)$ \\
\hline & Germany & 24 & (7.0) & 16 & (7.1) & 13 & $(7.6)$ & 10 & $(4.7)$ & 1.8 & $(0.42)$ & 2.2 & $(1.26)$ & 0.0 & $(0.17)$ \\
\hline & Greece & 3 & (8.4) & 5 & $(7.7)$ & 17 & $(7.6)$ & -6 & (6.0) & 0.5 & $(0.52)$ & 3.2 & $(1.42)$ & 0.2 & $(0.20)$ \\
\hline & Hungary & 8 & (7.8) & 7 & (6.9) & 6 & $(7.2)$ & -6 & $(5.2)$ & 1.0 & $(0.43)$ & 0.7 & (1.18) & 0.0 & $(0.18)$ \\
\hline & Iceland & -24 & (6.4) & -9 & (6.1) & -2 & $(6.2)$ & -18 & (3.5) & -1.3 & $(0.25)$ & 0.4 & $(0.64)$ & 0.1 & $(0.15)$ \\
\hline & Ireland & -3 & $(7.2)$ & 8 & (6.7) & 6 & $(7.1)$ & 28 & $(4.7)$ & -0.9 & $(0.36)$ & 4.2 & (1.19) & 0.4 & $(0.18)$ \\
\hline & Israel & 34 & (11.5) & $\mathrm{m}$ & $\mathrm{m}$ & 47 & $(8.8)$ & 12 & $(6.7)$ & 3.7 & $(0.84)$ & 10.8 & (2.19) & 0.7 & $(0.27)$ \\
\hline & Italy & 2 & $(6.9)$ & 14 & (6.7) & 21 & (6.4) & 4 & (3.6) & 0.5 & $(0.33)$ & 5.8 & $(0.98)$ & 0.4 & $(0.17)$ \\
\hline & Japan & 16 & (8.7) & 40 & (7.8) & 40 & $(7.6)$ & 18 & $(5.7)$ & 1.5 & $(0.46)$ & 12.1 & (1.39) & 0.9 & $(0.19)$ \\
\hline & Korea & 11 & (7.5) & 2 & (7.5) & -20 & $(7.8)$ & -3 & (5.9) & 0.9 & $(0.37)$ & -5.2 & $(1.29)$ & -0.5 & $(0.18)$ \\
\hline & Luxembourg & $\mathrm{m}$ & $\mathrm{m}$ & 8 & (6.0) & 8 & (5.9) & 16 & (3.3) & 0.7 & $(0.25)$ & 4.7 & $(0.66)$ & 0.5 & $(0.16)$ \\
\hline & Mexico & 2 & (7.0) & 24 & (7.1) & 13 & $(6.5)$ & -2 & (3.6) & 1.1 & $(0.34)$ & 4.8 & $(1.04)$ & 0.3 & $(0.17)$ \\
\hline & Netherlands & $\mathrm{m}$ & $\mathrm{m}$ & -2 & $(7.2)$ & 4 & $(7.2)$ & 3 & $(6.7)$ & -0.1 & $(0.55)$ & 2.2 & $(1.83)$ & 0.3 & $(0.25)$ \\
\hline & New Zealand & -17 & (7.0) & -9 & (6.6) & -9 & $(6.8)$ & -9 & $(4.2)$ & -1.1 & $(0.33)$ & -1.4 & $(0.96)$ & 0.0 & $(0.17)$ \\
\hline & Norway & -1 & (7.3) & 4 & (7.0) & 20 & $(7.2)$ & 1 & (4.9) & 0.1 & $(0.35)$ & 4.6 & $(1.27)$ & 0.4 & $(0.18)$ \\
\hline & Poland & 39 & (8.0) & 22 & (7.0) & 11 & $(7.0)$ & 18 & $(4.8)$ & 2.8 & $(0.46)$ & 0.6 & $(1.29)$ & -0.2 & $(0.19)$ \\
\hline & Portugal & 18 & (8.3) & 10 & (7.7) & 15 & $(7.6)$ & -2 & (5.5) & 1.6 & $(0.45)$ & 1.9 & $(1.47)$ & 0.0 & $(0.19)$ \\
\hline & Slovak Republic & $\mathrm{m}$ & $\mathrm{m}$ & -6 & $(7.7)$ & -4 & $(7.6)$ & -15 & $(5.5)$ & -0.1 & $(0.62)$ & -2.9 & (1.79) & -0.3 & $(0.28)$ \\
\hline & Slovenia & $\mathrm{m}$ & $\mathrm{m}$ & $\mathrm{m}$ & $\mathrm{m}$ & -13 & $(5.8)$ & -2 & (3.1) & -2.2 & $(0.53)$ & 1.0 & $(0.99)$ & 0.5 & $(0.48)$ \\
\hline & Spain & -5 & (6.8) & 7 & (6.5) & 27 & (6.3) & 7 & (3.8) & -0.3 & $(0.30)$ & 7.2 & $(0.97)$ & 0.6 & $(0.17)$ \\
\hline & Sweden & -33 & (7.0) & -31 & (6.8) & -24 & $(7.2)$ & -14 & $(4.9)$ & -2.8 & $(0.34)$ & -5.3 & (1.13) & -0.2 & $(0.17)$ \\
\hline & Switzerland & 15 & (7.7) & 10 & $(7.0)$ & 10 & (6.9) & 9 & (4.4) & 1.0 & $(0.42)$ & 1.8 & (1.05) & 0.1 & $(0.17)$ \\
\hline & Turkey & $\mathrm{m}$ & $\mathrm{m}$ & 35 & (9.1) & 28 & $(8.2)$ & 11 & $(6.1)$ & 4.1 & $(0.76)$ & 5.1 & $(2.23)$ & 0.1 & $(0.32)$ \\
\hline & United Kingdom & $\mathrm{m}$ & $\mathrm{m}$ & $\mathrm{m}$ & $\mathrm{m}$ & 4 & $(7.0)$ & 5 & $(4.9)$ & 0.7 & $(0.64)$ & 2.7 & $(2.63)$ & 0.3 & $(0.42)$ \\
\hline & United States & -7 & (9.9) & 2 & (7.5) & $\mathrm{m}$ & $\mathrm{m}$ & -2 & (5.8) & -0.3 & $(0.53)$ & 1.2 & $(2.01)$ & 0.1 & $(0.23)$ \\
\hline & OECD average 2000 & 2 & (1.5) & 4 & $(1.3)$ & 8 & $(1.3)$ & 2 & $(0.9)$ & 0.3 & $(0.08)$ & 1.9 & $(0.24)$ & 0.1 & $(0.04)$ \\
\hline & OECD average 2003 & $\mathrm{~m}$ & $\mathrm{~m}$ & 5 & (1.3) & 7 & $(1.3)$ & 2 & $(0.9)$ & 0.2 & $(0.08)$ & 1.8 & $(0.24)$ & 0.1 & $(0.04)$ \\
\hline & OECD average 2006 & $\mathrm{~m}$ & $\mathrm{~m}$ & $\mathrm{~m}$ & $\mathrm{~m}$ & 7 & $(1.2)$ & 3 & $(0.8)$ & 0.4 & $(0.08)$ & 2.1 & $(0.24)$ & 0.2 & $(0.04)$ \\
\hline & OECD average 2009 & $\mathrm{~m}$ & $\mathrm{~m}$ & $\mathrm{~m}$ & $\mathrm{~m}$ & $\mathrm{~m}$ & $\mathrm{~m}$ & 3 & $(0.8)$ & 0.4 & $(0.08)$ & 2.2 & $(0.24)$ & 0.2 & $(0.04)$ \\
\hline & Albania & 45 & (7.5) & $\mathrm{m}$ & $\mathrm{m}$ & $\mathrm{m}$ & $\mathrm{m}$ & 9 & $(5.8)$ & 4.1 & $(0.49)$ & 2.7 & $(2.28)$ & -0.1 & $(0.28)$ \\
\hline$\Xi$ & Argentina & -22 & (12.1) & $\mathrm{m}$ & $\mathrm{m}$ & 22 & $(9.8)$ & -2 & (6.5) & -1.6 & $(1.00)$ & 7.8 & $(2.70)$ & 0.8 & $(0.33)$ \\
\hline$\tilde{z}$ & Brazil & 14 & $(7.0)$ & 7 & (7.5) & 17 & $(7.0)$ & -2 & $(4.3)$ & 1.2 & $(0.35)$ & 2.2 & (1.11) & 0.1 & $(0.18)$ \\
\hline & Bulgaria & 6 & (9.8) & $\mathrm{m}$ & $\mathrm{m}$ & 34 & (10.7) & 7 & (9.4) & 0.4 & $(0.67)$ & 10.3 & $(2.77)$ & 0.8 & $(0.29)$ \\
\hline & Colombia & $\mathrm{m}$ & $\mathrm{m}$ & $\mathrm{m}$ & $\mathrm{m}$ & 18 & $(8.3)$ & -10 & (5.7) & 3.0 & (1.15) & -9.5 & (3.38) & -2.1 & $(0.72)$ \\
\hline & Costa Rica & $\mathrm{m}$ & $\mathrm{m}$ & $\mathrm{m}$ & $\mathrm{m}$ & $\mathrm{m}$ & $\mathrm{m}$ & -2 & (5.4) & -1.0 & (2.39) & $\mathrm{m}$ & $\mathrm{m}$ & $\mathrm{m}$ & $\mathrm{m}$ \\
\hline & Croatia & $\mathrm{m}$ & $\mathrm{m}$ & $\mathrm{m}$ & $\mathrm{m}$ & 7 & (7.1) & 9 & (5.1) & 1.2 & $(0.88)$ & 4.7 & $(2.85)$ & 0.6 & $(0.63)$ \\
\hline & Dubai (UAE) & $\mathrm{m}$ & $\mathrm{m}$ & $\mathrm{m}$ & $\mathrm{m}$ & $\mathrm{m}$ & $\mathrm{m}$ & 9 & (3.1) & 3.0 & $(1.02)$ & $\mathrm{m}$ & $\mathrm{m}$ & $\mathrm{m}$ & $\mathrm{m}$ \\
\hline & Hong Kong-China & 19 & $(7.2)$ & 35 & (7.3) & 9 & (6.7) & 11 & (4.4) & 2.3 & $(0.37)$ & 3.7 & $(1.05)$ & 0.1 & $(0.19)$ \\
\hline & Indonesia & 26 & (8.3) & 15 & (7.8) & 3 & (9.2) & -6 & $(6.2)$ & 2.3 & $(0.53)$ & -2.1 & (1.98) & -0.4 & $(0.25)$ \\
\hline & Jordan & $\mathrm{m}$ & $\mathrm{m}$ & $\mathrm{m}$ & $\mathrm{m}$ & -2 & $(7.4)$ & -6 & (5.5) & -0.3 & $(0.93)$ & -3.7 & $(2.94)$ & -0.6 & $(0.65)$ \\
\hline & Kazakhstan & $\mathrm{m}$ & $\mathrm{m}$ & $\mathrm{m}$ & $\mathrm{m}$ & $\mathrm{m}$ & $\mathrm{m}$ & 2 & $(4.8)$ & 0.8 & (1.59) & $\mathrm{m}$ & $\mathrm{m}$ & $\mathrm{m}$ & $\mathrm{m}$ \\
\hline & Latvia & 31 & (8.3) & -2 & (7.1) & 9 & (7.1) & 5 & (4.6) & 1.9 & $(0.53)$ & -2.9 & $(1.22)$ & -0.4 & $(0.18)$ \\
\hline & Liechtenstein & 33 & (8.3) & -10 & (7.8) & 5 & (8.0) & 16 & (5.6) & 1.3 & $(0.49)$ & -3.4 & $(1.38)$ & -0.4 & $(0.18)$ \\
\hline & Lithuania & $\mathrm{m}$ & $\mathrm{m}$ & $\mathrm{m}$ & $\mathrm{m}$ & 7 & (6.8) & 9 & $(4.3)$ & 1.1 & $(0.86)$ & 4.7 & (1.94) & 0.6 & $(0.55)$ \\
\hline & Macao-China & $\mathrm{m}$ & $\mathrm{m}$ & 11 & (6.1) & 17 & $(5.8)$ & 22 & (2.9) & 0.8 & $(0.39)$ & 7.7 & $(0.63)$ & 0.8 & $(0.23)$ \\
\hline & Malaysia & $\mathrm{m}$ & $\mathrm{m}$ & $\mathrm{m}$ & $\mathrm{m}$ & $\mathrm{m}$ & $\mathrm{m}$ & -16 & $(5.1)$ & -7.8 & $(2.19)$ & $\mathrm{m}$ & $\mathrm{m}$ & $\mathrm{m}$ & $\mathrm{m}$ \\
\hline & Montenegro & $\mathrm{m}$ & $\mathrm{m}$ & $\mathrm{m}$ & $\mathrm{m}$ & 30 & (5.8) & 15 & (3.3) & 5.0 & $(0.50)$ & 4.7 & (1.45) & -0.1 & $(0.51)$ \\
\hline & Peru & 57 & (8.6) & $\mathrm{m}$ & $\mathrm{m}$ & $\mathrm{m}$ & $\mathrm{m}$ & 14 & $(6.4)$ & 5.2 & $(0.58)$ & 4.7 & $(2.85)$ & 0.0 & $(0.31)$ \\
\hline & Qatar & $\mathrm{m}$ & $\mathrm{m}$ & $\mathrm{m}$ & $\mathrm{m}$ & 75 & (5.8) & 16 & $(2.8)$ & 12.0 & $(0.48)$ & -2.0 & $(0.82)$ & -2.4 & $(0.47)$ \\
\hline & Romania & 10 & (7.9) & $\mathrm{m}$ & $\mathrm{m}$ & 42 & $(8.3)$ & 13 & $(6.3)$ & 1.1 & $(0.58)$ & 13.8 & $(2.05)$ & 1.2 & $(0.28)$ \\
\hline & Russian Federation & 13 & (7.8) & 33 & (7.5) & 35 & $(7.7)$ & 16 & $(5.2)$ & 1.1 & $(0.48)$ & 10.7 & $(1.40)$ & 0.8 & $(0.19)$ \\
\hline & Serbia & $\mathrm{m}$ & $\mathrm{m}$ & $\mathrm{m}$ & $\mathrm{m}$ & 45 & (7.4) & 4 & $(5.0)$ & 7.6 & $(0.99)$ & -4.8 & $(2.48)$ & -2.0 & $(0.59)$ \\
\hline & Shanghai-China & $\mathrm{m}$ & $\mathrm{m}$ & $\mathrm{m}$ & $\mathrm{m}$ & $\mathrm{m}$ & $\mathrm{m}$ & 14 & $(4.5)$ & 4.6 & $(1.50)$ & $\mathrm{m}$ & $\mathrm{m}$ & $\mathrm{m}$ & $\mathrm{m}$ \\
\hline & Singapore & $\mathrm{m}$ & $\mathrm{m}$ & $\mathrm{m}$ & $\mathrm{m}$ & $\mathrm{m}$ & $\mathrm{m}$ & 16 & (3.1) & 5.4 & (1.04) & $\mathrm{m}$ & $\mathrm{m}$ & $\mathrm{m}$ & $\mathrm{m}$ \\
\hline & Chinese Taipei & $\mathrm{m}$ & $\mathrm{m}$ & $\mathrm{m}$ & $\mathrm{m}$ & 27 & $(7.2)$ & 28 & $(4.8)$ & 4.5 & $(0.86)$ & 14.1 & $(2.44)$ & 1.6 & $(0.60)$ \\
\hline & Thailand & 11 & (7.4) & 21 & $(7.0)$ & 24 & (6.9) & 20 & $(4.8)$ & 1.1 & $(0.42)$ & 8.2 & (1.18) & 0.7 & $(0.20)$ \\
\hline & Tunisia & $\mathrm{m}$ & $\mathrm{m}$ & 29 & (7.7) & 24 & $(8.2)$ & 0 & (5.9) & 3.8 & $(0.62)$ & 2.6 & $(2.20)$ & -0.1 & $(0.30)$ \\
\hline & United Arab Emirates* & $\mathrm{m}$ & $\mathrm{m}$ & $\mathrm{m}$ & $\mathrm{m}$ & $\mathrm{m}$ & $\mathrm{m}$ & 9 & (5.6) & 4.7 & (2.89) & $\mathrm{m}$ & $\mathrm{m}$ & $\mathrm{m}$ & $\mathrm{m}$ \\
\hline & Uruguay & $\mathrm{m}$ & $\mathrm{m}$ & -23 & $(7.3)$ & -1 & $(7.3)$ & -14 & $(4.8)$ & -1.8 & $(0.57)$ & -0.1 & $(1.74)$ & 0.2 & $(0.28)$ \\
\hline
\end{tabular}

Notes: Values that are statistically significant are indicated in bold (see Annex A3).

Annualised change is the average change between the earliest available measurement in PISA and PISA 2012. For countries and economies with more than one available measurement, the annualised change is calculated with a linear regression model. This model considers that Chile, Albania, Argentina, Bulgaria, Indonesia, Peru and Thailand exception of Dubai) implemented the PISA 2009 assessment in 2010 as part of PISA 2009+. Dubai implemented the PISA 2009 assessment in 2009. The curvilinear change is estimated by a regression of time and time-squared on reading performance. The linear term is the estimated annual increase in performance in
2012 . The quadratic term is the rate at which changes in performance are accelerating (positive estimate) or decelerating (negative estimate) throughout a country/economy's participation in PISA.

For Costa Rica and Malaysia the change between PISA 2009 and PISA 2012 represents change between 2010 and 2012 because these countries implemented the PISA 2009 assessment in 2010 as part of PISA 2009+.

For Chile, Albania, Argentina, Bulgaria, Indonesia, Peru and Thailand, the change between the PISA 2000 and PISA 2012 represents change between 2001 and 2012 because these countries implemented the PISA 2000 assessment in 2001 as part of PISA 2000+.

For Israel and Romania the change between the PISA 2000 and PISA 2012 represents change between 2002 and 2012 because these countries implemented the PISA 2000 assessment in 2002 as part of PISA 2000+.

In the United Arab Emirates, Dubai took the PISA 2009 assessment in 2009 and the rest of the United Arab Emirates in 2010 as part of PISA 2009+. Results are thus reported separately.

* United Arab Emirates excluding Dubai (see note above).

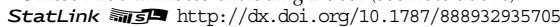


[Part 1/1]

Table I.4.3c Gender differences in reading performance in PISA 2000 and 2012

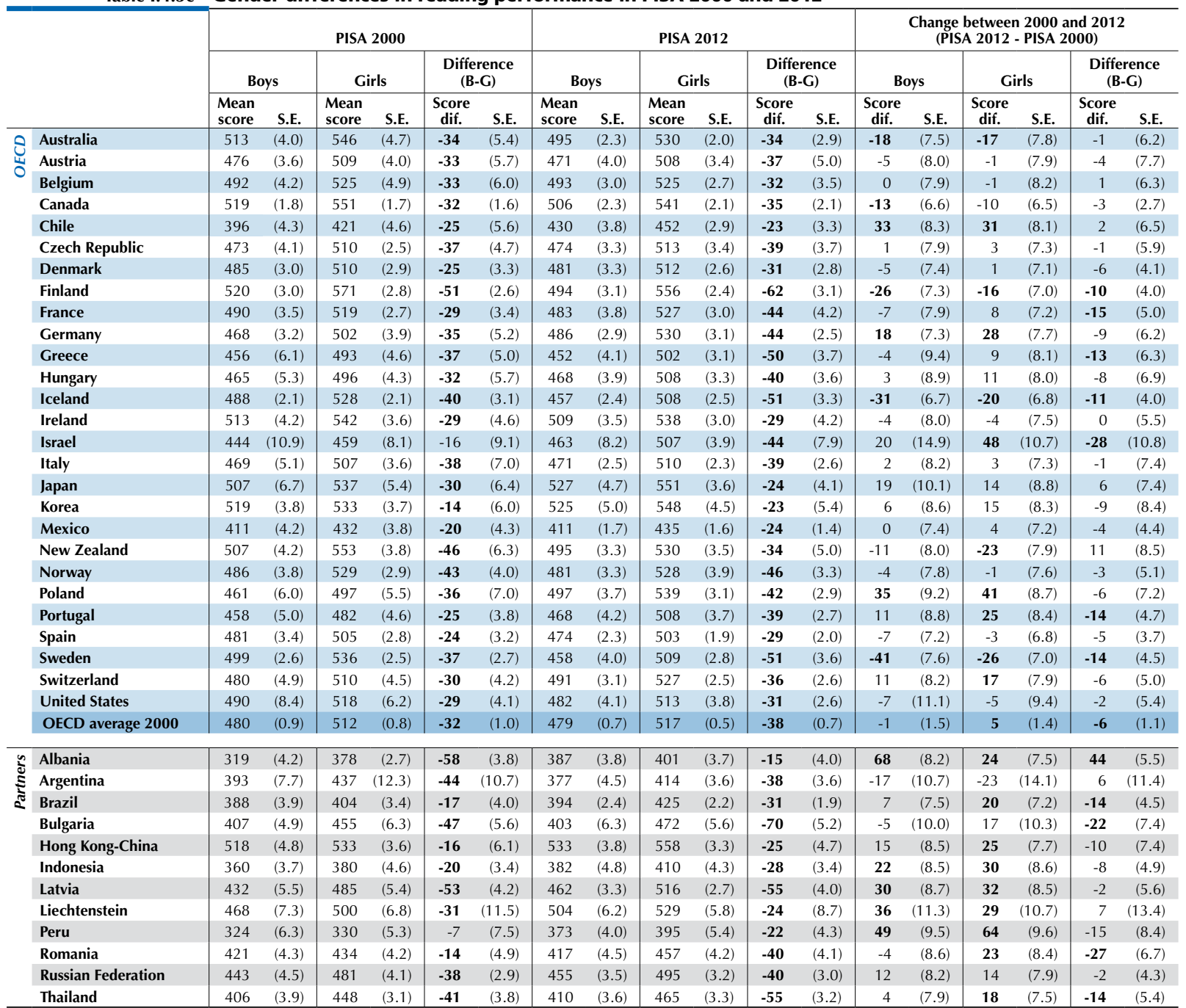

Notes: Values that are statistically significant are indicated in bold (see Annex A3).

Only countries and economies with comparable results in PISA 2000 and PISA 2012 are presented.

For Chile, Albania, Argentina, Bulgaria, Indonesia, Peru and Thailand, the change between the PISA 2000 and PISA 2012 represents change between 2001 and 2012 because these countries implemented the PISA 2000 assessment in 2001 as part of PISA 2000+.

For Israel and Romania, the change between the PISA 2000 and PISA 2012 represents change between 2002 and 2012 because these countries implemented the PISA 2000 assessment in 2002 as part of PISA $2000+$.

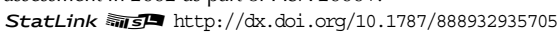


[Part 1/4]

Table I.4.3d Distribution of scores in reading in PISA 2000 through 2012, by percentiles

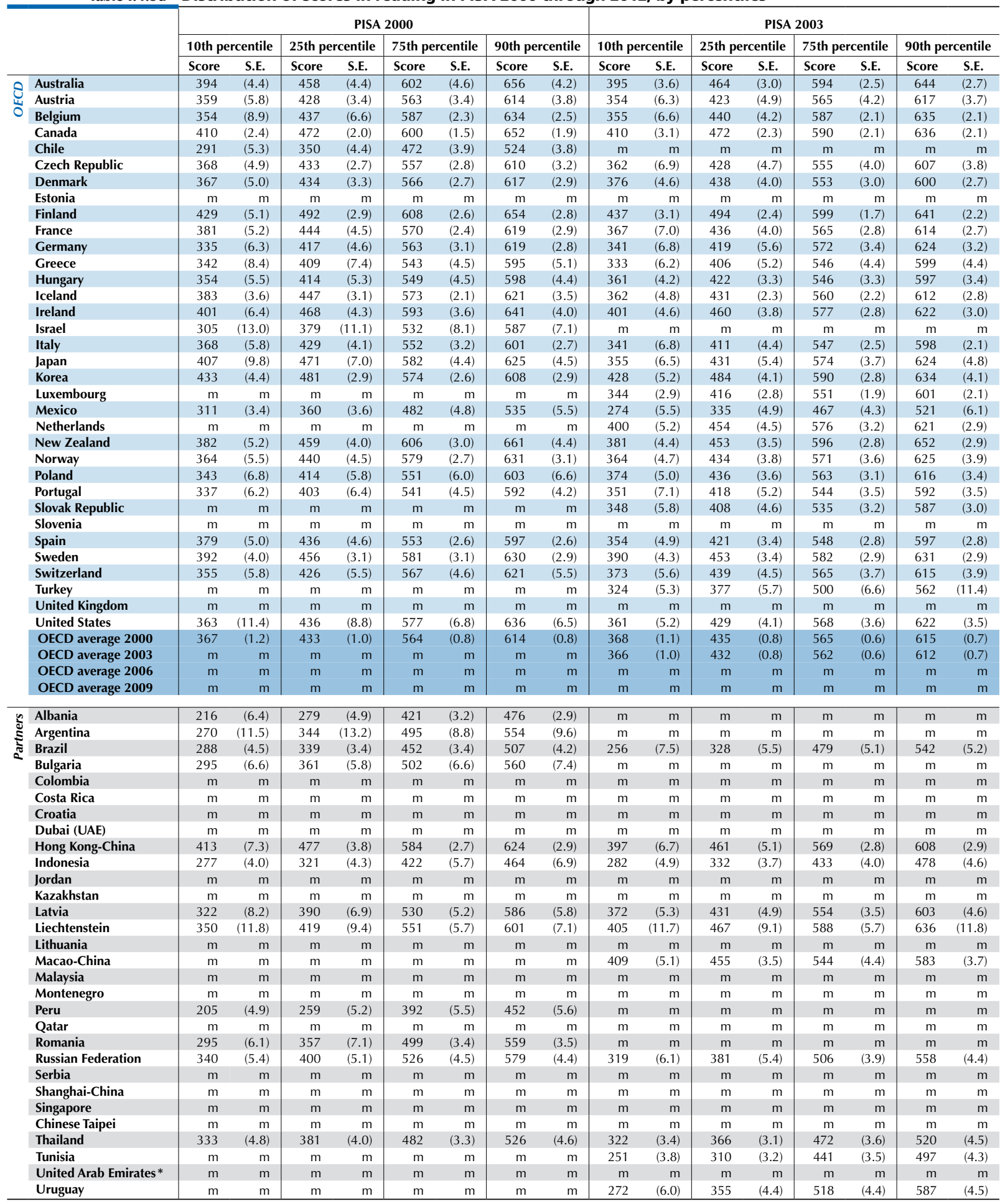

Notes: Values that are statistically significant are indicated in bold (see Annex A3).

Annualised change is the average change between the earliest available measurement in PISA and PISA 2012. For countries and economies with more than one available measurement, the annualised change is calculated with a linear regression model. This model considers that Chile, Albania, Argentina, Bulgaria, Indonesia, Peru and Thailand implemented the 2000 assessment in 2001 and Israel and Romania in 2002 as part of the PISA 2000+ and that Costa Rica, Malaysia and the United Arab Emirates (with the exception of Dubai) implemented the PISA 2009 assessment in 2010 as part of PISA 2009+. Dubai implemented the PISA 2009 assessment in 2009.

For Costa Rica and Malaysia the change between PISA 2009 and PISA 2012 represents change between 2010 and 2012 because these countries implemented the PISA 2009 assessment in 2010 as part of PISA 2009.

For Chile, Albania, Argentina, Bulgaria, Indonesia, Peru and Thailand, the change between the PISA 2000 and PISA 2012 represents change between 2001 and 2012 because these countries implemented the PISA 2000 assessment in 2001 as part of PISA $2000+$.

For Israel and Romania, the change between the PISA 2000 and PISA 2012 represents change between 2002 and 2012 because these countries implemented the PISA 2000 assessment in 2002 as part of PISA $2000+$

* United Arab Emirates excluding Dubai.

StatLink त्नाIS http://dx.doi.org/10.1787/888932935705 
[Part 2/4]

Table I.4.3d Distribution of scores in reading in PISA 2000 through 2012, by percentiles

\begin{tabular}{|c|c|c|c|c|c|c|c|c|c|c|c|c|c|c|c|c|c|}
\hline & & \multicolumn{8}{|c|}{ PISA 2006} & \multicolumn{8}{|c|}{ PISA 2009} \\
\hline & & \multicolumn{2}{|c|}{ 10th percentile } & \multicolumn{2}{|c|}{ 25th percentile } & \multicolumn{2}{|c|}{ 75th percentile } & 90th pe & rcentile & 10th pe & rcentile & 25th p & centile & 75th $p$ & centile & 90th pe & centile \\
\hline & & Score & S.E. & Score & S.E. & Score & S.E. & Score & S.E. & Score & S.E. & Score & S.E. & Score & S.E. & Score & S.E. \\
\hline$\theta$ & Australia & 388 & (3.4) & 453 & $(2.4)$ & 579 & (2.3) & 628 & (2.9) & 384 & (3.1) & 450 & $(2.9)$ & 584 & $(2.7)$ & 638 & (3.2) \\
\hline 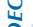 & Austria & 348 & $(9.4)$ & 421 & (5.5) & 568 & (3.7) & 621 & (3.1) & $\mathrm{m}$ & $\mathrm{m}$ & $\mathrm{m}$ & $\mathrm{m}$ & $\mathrm{m}$ & $\mathrm{m}$ & $\mathrm{m}$ & $\mathrm{m}$ \\
\hline & Belgium & 347 & (8.3) & 433 & $(4.7)$ & 581 & $(2.3)$ & 631 & $(2.2)$ & 368 & (4.3) & 436 & (3.8) & 583 & $(2.2)$ & 631 & $(2.7)$ \\
\hline & Canada & 402 & (3.9) & 468 & (3.0) & 593 & (2.6) & 644 & (2.7) & 406 & (2.7) & 464 & (1.9) & 588 & $(1.7)$ & 637 & (1.9) \\
\hline & Chile & 310 & (5.8) & 373 & $(5.4)$ & 513 & (6.4) & 575 & (6.7) & 342 & (5.0) & 393 & (4.1) & 506 & $(3.3)$ & 556 & (3.6) \\
\hline & Czech Republic & 335 & (7.0) & 408 & $(6.2)$ & 564 & (3.8) & 621 & $(4.2)$ & 357 & (4.9) & 413 & $(4.2)$ & 545 & (3.3) & 598 & (3.2) \\
\hline & Denmark & 378 & (5.0) & 437 & (3.9) & 557 & (2.9) & 604 & (3.7) & 383 & (3.7) & 440 & (2.9) & 554 & (2.8) & 599 & (3.0) \\
\hline & Estonia & 389 & (5.4) & 448 & (3.8) & 560 & (2.8) & 606 & (3.2) & 392 & (4.4) & 446 & (3.3) & 559 & $(2.8)$ & 605 & (3.6) \\
\hline & Finland & 441 & (3.8) & 494 & (2.9) & 603 & (2.2) & 649 & (2.5) & 419 & (3.6) & 481 & (2.7) & 597 & $(2.2)$ & 642 & (2.6) \\
\hline & France & 346 & (7.5) & 421 & $(6.1)$ & 564 & (3.8) & 614 & (4.0) & 352 & (7.0) & 429 & (4.7) & 572 & $(4.0)$ & 624 & (3.9) \\
\hline & Germany & 350 & (8.0) & 429 & (5.9) & 573 & (3.4) & 625 & $(3.7)$ & 367 & (5.1) & 432 & (4.5) & 567 & (2.8) & 615 & (3.2) \\
\hline & Greece & 321 & (8.5) & 398 & $(5.2)$ & 531 & (3.8) & 583 & $(4.2)$ & 355 & (8.0) & 420 & (6.3) & 550 & (3.1) & 601 & (3.7) \\
\hline & Hungary & 359 & (5.0) & 422 & $(4.8)$ & 549 & (3.6) & 595 & (4.4) & 371 & (6.9) & 435 & (4.3) & 559 & (3.6) & 607 & (3.5) \\
\hline & Iceland & 356 & $(4.1)$ & 423 & $(3.0)$ & 552 & $(2.8)$ & 603 & (3.2) & 371 & $(4.1)$ & 439 & (2.9) & 567 & $(2.0)$ & 619 & (2.6) \\
\hline & Ireland & 395 & (5.5) & 457 & $(4.7)$ & 582 & (3.9) & 633 & (3.5) & 373 & $(4.7)$ & 435 & (3.9) & 562 & (2.8) & 611 & $(2.8)$ \\
\hline & Israel & 280 & (8.0) & 356 & $(6.2)$ & 526 & $(4.8)$ & 588 & (4.9) & 322 & $(7.8)$ & 401 & (4.4) & 554 & (3.4) & 611 & $(4.0)$ \\
\hline & Italy & 325 & (4.8) & 402 & (3.6) & 546 & $(2.3)$ & 599 & (2.9) & 358 & (2.6) & 422 & (2.3) & 556 & $(1.7)$ & 604 & (1.7) \\
\hline & Japan & 361 & (6.6) & 433 & (6.1) & 569 & (3.4) & 623 & (3.5) & 386 & (7.1) & 459 & (4.8) & 590 & (3.0) & 639 & (3.6) \\
\hline & Korea & 440 & (7.9) & 503 & $(4.8)$ & 617 & (3.4) & 663 & (4.3) & 435 & (5.9) & 490 & $(4.1)$ & 595 & (3.4) & 635 & (3.0) \\
\hline & Luxembourg & 344 & (3.3) & 415 & $(2.3)$ & 552 & $(1.8)$ & 602 & (2.5) & 332 & (3.6) & 403 & (2.4) & 547 & $(1.7)$ & 600 & $(2.0)$ \\
\hline & Mexico & 285 & (6.2) & 348 & $(4.2)$ & 478 & (2.8) & 530 & (3.1) & 314 & (2.9) & 370 & (2.4) & 485 & (1.9) & 531 & $(2.2)$ \\
\hline & Netherlands & 379 & (6.4) & 446 & $(4.3)$ & 578 & (2.5) & 622 & (2.4) & 390 & (5.0) & 442 & (6.1) & 575 & $(5.4)$ & 625 & (4.6) \\
\hline & New Zealand & 381 & (4.6) & 453 & (4.5) & 595 & $(2.9)$ & 651 & $(2.8)$ & 383 & (4.5) & 452 & (3.1) & 595 & $(2.8)$ & 649 & $(2.7)$ \\
\hline & Norway & 346 & (5.5) & 416 & (4.6) & 558 & (3.0) & 613 & $(4.1)$ & 382 & (4.0) & 443 & (3.6) & 568 & $(2.9)$ & 619 & (3.9) \\
\hline & Poland & 374 & (4.6) & 441 & (3.5) & 579 & (3.2) & 633 & (3.4) & 382 & $(4.2)$ & 441 & (3.4) & 565 & $(3.2)$ & 613 & (3.3) \\
\hline & Portugal & 339 & (6.3) & 408 & (5.3) & 543 & (3.6) & 594 & (3.7) & 373 & (4.9) & 432 & (4.4) & 551 & (3.4) & 599 & (3.5) \\
\hline & Slovak Republic & 326 & (6.6) & 398 & $(4.3)$ & 542 & (3.4) & 597 & (3.8) & 358 & (5.2) & 416 & (4.1) & 543 & $(2.7)$ & 594 & (3.2) \\
\hline & Slovenia & 377 & (2.6) & 437 & $(1.8)$ & 558 & $(2.2)$ & 603 & $(2.1)$ & 359 & (2.1) & 421 & (1.9) & 550 & $(1.7)$ & 598 & (2.9) \\
\hline & Spain & 343 & (4.1) & 405 & (2.9) & 523 & $(2.3)$ & 569 & $(2.7)$ & 364 & (3.5) & 426 & (3.3) & 543 & (2.0) & 588 & $(2.0)$ \\
\hline & Sweden & 378 & (5.6) & 445 & (3.8) & 575 & (3.3) & 629 & $(4.0)$ & 368 & (5.5) & 437 & (3.3) & 565 & (3.1) & 620 & (3.7) \\
\hline & Switzerland & 373 & (5.1) & 440 & (3.5) & 566 & (3.1) & 615 & (3.6) & 374 & (4.0) & 437 & (3.6) & 569 & (3.0) & 617 & (3.3) \\
\hline & Turkey & 330 & (6.4) & 388 & (4.4) & 510 & (5.2) & 564 & (6.5) & 356 & (4.3) & 409 & (3.8) & 522 & (4.5) & 569 & $(5.2)$ \\
\hline & United Kingdom & 359 & (4.0) & 431 & $(2.8)$ & 566 & (2.5) & 621 & (3.1) & 370 & (3.1) & 430 & (2.8) & 561 & (3.2) & 616 & $(2.6)$ \\
\hline & United States & $\mathrm{m}$ & $\mathrm{m}$ & $\mathrm{m}$ & $\mathrm{m}$ & $\mathrm{m}$ & $\mathrm{m}$ & $\mathrm{m}$ & $\mathrm{m}$ & 372 & (3.9) & 433 & (4.0) & 569 & (4.6) & 625 & $(5.0)$ \\
\hline & OECD average 2000 & 358 & (1.2) & 426 & $(0.9)$ & 561 & $(0.7)$ & 613 & $(0.7)$ & 372 & (1.0) & 435 & $(0.7)$ & 563 & $(0.6)$ & 613 & $(0.6)$ \\
\hline & OECD average 2003 & 360 & (1.1) & 429 & $(0.8)$ & 562 & $(0.6)$ & 613 & $(0.7)$ & 373 & $(0.9)$ & 435 & $(0.7)$ & 563 & $(0.6)$ & 612 & $(0.6)$ \\
\hline & OECD average 2006 & 358 & (1.0) & 426 & $(0.8)$ & 559 & $(0.6)$ & 611 & $(0.6)$ & 370 & $(0.9)$ & 433 & $(0.7)$ & 560 & $(0.5)$ & 610 & $(0.6)$ \\
\hline & OECD average 2009 & $\mathrm{~m}$ & $\mathrm{~m}$ & $\mathrm{~m}$ & $\mathrm{~m}$ & $\mathrm{~m}$ & $\mathrm{~m}$ & $\mathrm{~m}$ & $\mathrm{~m}$ & 370 & $(0.8)$ & 433 & $(0.7)$ & 561 & $(0.5)$ & 610 & $(0.6)$ \\
\hline$\approx$ & Albania & $\mathrm{m}$ & $\mathrm{m}$ & $\mathrm{m}$ & $\mathrm{m}$ & $\mathrm{m}$ & $\mathrm{m}$ & $\mathrm{m}$ & $\mathrm{m}$ & 254 & (5.4) & 319 & (4.9) & 458 & $(4.8)$ & 509 & $(4.9)$ \\
\hline క & Argentina & 209 & (10.7) & 291 & (9.0) & 464 & (7.1) & 527 & $(7.0)$ & 257 & (8.3) & 329 & (5.8) & 473 & (6.3) & 535 & (7.1) \\
\hline ๘ & Brazil & 264 & $(6.0)$ & 326 & $(4.2)$ & 460 & $(4.0)$ & 523 & $(5.3)$ & 293 & (3.2) & 348 & $(2.7)$ & 474 & $(3.9)$ & 537 & $(4.2)$ \\
\hline & Bulgaria & 251 & $(9.0)$ & 321 & (8.5) & 486 & $(7.6)$ & 554 & $(7.8)$ & 276 & (7.8) & 351 & (8.6) & 512 & $(6.5)$ & 572 & (7.3) \\
\hline & Colombia & 243 & (7.0) & 316 & $(7.2)$ & 462 & (5.6) & 518 & $(5.2)$ & 302 & (5.2) & 355 & (4.4) & 473 & (3.9) & 524 & $(4.1)$ \\
\hline & Costa Rica & $\mathrm{m}$ & $\mathrm{m}$ & $\mathrm{m}$ & $\mathrm{m}$ & $\mathrm{m}$ & $\mathrm{m}$ & $\mathrm{m}$ & $\mathrm{m}$ & 339 & (4.7) & 388 & (3.7) & 498 & (3.8) & 544 & (4.4) \\
\hline & Croatia & 359 & (5.4) & 418 & (4.1) & 540 & (3.0) & 589 & (3.4) & 359 & (3.6) & 416 & (4.5) & 539 & (3.1) & 586 & (3.5) \\
\hline & Dubai (UAE) & $\mathrm{m}$ & $\mathrm{m}$ & $\mathrm{m}$ & $\mathrm{m}$ & $\mathrm{m}$ & $\mathrm{m}$ & $\mathrm{m}$ & $\mathrm{m}$ & 317 & (2.8) & 386 & (2.4) & 536 & $(2.3)$ & 596 & (2.6) \\
\hline & Hong Kong-China & 426 & (5.8) & 484 & $(3.7)$ & 594 & (2.4) & 636 & (2.9) & 418 & (4.5) & 482 & (3.0) & 592 & $(2.5)$ & 634 & (2.9) \\
\hline & Indonesia & 298 & (5.0) & 342 & $(5.3)$ & 444 & (8.4) & 490 & (8.6) & 315 & (5.0) & 357 & (4.1) & 447 & $(4.6)$ & 487 & $(5.0)$ \\
\hline & Jordan & 277 & (6.1) & 342 & (3.7) & 467 & (3.8) & 514 & (4.5) & 284 & (5.0) & 350 & (4.1) & 468 & (3.5) & 515 & (3.9) \\
\hline & Kazakhstan & $\mathrm{m}$ & $\mathrm{m}$ & $\mathrm{m}$ & $\mathrm{m}$ & $\mathrm{m}$ & $\mathrm{m}$ & $\mathrm{m}$ & $\mathrm{m}$ & 275 & (3.8) & 327 & (3.1) & 452 & $(4.2)$ & 513 & $(5.0)$ \\
\hline & Latvia & 361 & (5.4) & 419 & $(4.9)$ & 543 & (4.2) & 593 & (4.0) & 379 & (4.2) & 429 & (3.8) & 541 & (3.3) & 584 & (3.2) \\
\hline & Liechtenstein & 379 & (10.6) & 452 & (9.9) & 578 & (6.5) & 623 & (10.5) & 385 & (10.6) & 442 & (6.5) & 560 & $(4.7)$ & 599 & (7.9) \\
\hline & Lithuania & 343 & (3.9) & 405 & $(4.0)$ & 538 & (3.9) & 591 & (3.9) & 353 & $(4.2)$ & 409 & (3.3) & 530 & (3.1) & 580 & (3.4) \\
\hline & Macao-China & 394 & (2.5) & 445 & (1.9) & 545 & (1.6) & 587 & (1.8) & 388 & (1.8) & 437 & (1.4) & 540 & (1.4) & 582 & (1.8) \\
\hline & Malaysia & $\mathrm{m}$ & $\mathrm{m}$ & $\mathrm{m}$ & $\mathrm{m}$ & $\mathrm{m}$ & $\mathrm{m}$ & $\mathrm{m}$ & $\mathrm{m}$ & 304 & (4.6) & 363 & (4.0) & 470 & (2.9) & 513 & (3.1) \\
\hline & Montenegro & 276 & $(3.2)$ & 331 & $(2.1)$ & 454 & (1.9) & 506 & (2.6) & 288 & (3.8) & 345 & (2.6) & 473 & (2.4) & 526 & $(2.7)$ \\
\hline & Peru & $\mathrm{m}$ & $\mathrm{m}$ & $\mathrm{m}$ & $\mathrm{m}$ & $\mathrm{m}$ & $\mathrm{m}$ & $\mathrm{m}$ & $\mathrm{m}$ & 241 & (3.9) & 302 & (4.3) & 437 & $(5.2)$ & 496 & $(6.4)$ \\
\hline & Qatar & 181 & (2.7) & 237 & (1.8) & 380 & (1.9) & 456 & (3.6) & 228 & (2.2) & 288 & (1.3) & 450 & (1.4) & 529 & $(2.1)$ \\
\hline & Romania & 274 & (7.2) & 333 & $(7.3)$ & 461 & $(5.2)$ & 512 & (5.6) & 304 & (5.7) & 365 & (6.0) & 488 & $(4.7)$ & 537 & $(4.0)$ \\
\hline & Russian Federation & 316 & (6.0) & 377 & $(5.7)$ & 505 & $(4.2)$ & 556 & (3.6) & 344 & (5.5) & 401 & (3.6) & 519 & (3.2) & 572 & $(4.5)$ \\
\hline & Serbia & 282 & (4.6) & 339 & $(4.5)$ & 466 & (3.9) & 518 & (3.7) & 331 & (3.8) & 388 & (3.2) & 501 & $(2.5)$ & 547 & $(2.7)$ \\
\hline & Shanghai-China & $\mathrm{m}$ & $\mathrm{m}$ & $\mathrm{m}$ & $\mathrm{m}$ & $\mathrm{m}$ & $\mathrm{m}$ & $\mathrm{m}$ & $\mathrm{m}$ & 450 & (4.8) & 504 & (3.5) & 613 & $(2.8)$ & 654 & $(2.7)$ \\
\hline & Singapore & $\mathrm{m}$ & $\mathrm{m}$ & $\mathrm{m}$ & $\mathrm{m}$ & $\mathrm{m}$ & $\mathrm{m}$ & $\mathrm{m}$ & $\mathrm{m}$ & 394 & (3.1) & 460 & $(2.0)$ & 597 & $(2.1)$ & 648 & $(2.8)$ \\
\hline & Chinese Taipei & 381 & (5.9) & 442 & (4.9) & 556 & (3.0) & 598 & (3.0) & 380 & (3.9) & 439 & (3.2) & 555 & (2.9) & 600 & (4.6) \\
\hline & Thailand & 312 & (3.9) & 363 & (3.3) & 472 & (2.9) & 522 & (3.7) & 331 & (3.8) & 373 & (3.2) & 469 & (2.6) & 514 & $(4.0)$ \\
\hline & Tunisia & 252 & (5.3) & 315 & $(4.4)$ & 450 & (5.0) & 502 & (5.3) & 293 & (3.8) & 348 & (3.4) & 462 & (3.4) & 510 & $(4.8)$ \\
\hline & United Arab Emirates* & $\mathrm{m}$ & $\mathrm{m}$ & $\mathrm{m}$ & $\mathrm{m}$ & $\mathrm{m}$ & $\mathrm{m}$ & $\mathrm{m}$ & $\mathrm{m}$ & 300 & (5.4) & 359 & $(4.2)$ & 489 & (3.3) & 541 & $(5.2)$ \\
\hline & Uruguay & 253 & (5.8) & 333 & $(5.0)$ & 497 & (3.8) & 565 & (4.3) & 297 & $(4.2)$ & 359 & (3.5) & 495 & (3.1) & 552 & (3.3) \\
\hline
\end{tabular}

Notes: Values that are statistically significant are indicated in bold (see Annex A3).

Annualised change is the average change between the earliest available measurement in PISA and PISA 2012. For countries and economies with more than one available measurement, the annualised change is calculated with a linear regression model. This model considers that Chile, Albania, Argentina, Bulgaria, Indonesia, Peru and Thailand implemented the 2000 assessment in 2001 and Israel and Romania in 2002 as part of the PISA 2000+ and that Costa Rica, Malaysia and the United Arab Emirates (with the exception of Dubai) implement

For Costa Rica and Malaysia the change between PISA 2009 and PISA 2012 represents change between 2010 and 2012 because these countries implemented the PISA 2009 assessment in 2010 as part of PISA 2009+.

For Chile, Albania, Argentina, Bulgaria, Indonesia, Peru and Thailand, the change between the PISA 2000 and PISA 2012 represents change between 2001 and 2012 because these countries implemented the PISA 2000 assessment in 2001 as part of PISA $2000+$.

For Israel and Romania, the change between the PISA 2000 and PISA 2012 represents change between 2002 and 2012 because these countries implemented the PISA 2000 assessment in 2002 as part of PISA $2000+$

* United Arab Emirates excluding Dubai.

StatLink त्राज http://dx.doi.org/10.1787/888932935705 
[Part 3/4]

Table I.4.3d Distribution of scores in reading in PISA 2000 through 2012, by percentiles

\begin{tabular}{|c|c|c|c|c|c|c|c|c|c|}
\hline & \multicolumn{8}{|c|}{ PISA 2012} \\
\hline & & \multicolumn{2}{|c|}{ 10th percentile } & \multicolumn{2}{|c|}{ 25th percentile } & \multicolumn{2}{|c|}{ 75th percentile } & \multicolumn{2}{|c|}{ 90th percentile } \\
\hline & & Score & S.E. & Score & S.E. & Score & S.E. & Score & S.E. \\
\hline \multirow{38}{*}{$\begin{array}{l}\text { U్ } \\
\text { ठ }\end{array}$} & Australia & 386 & (2.4) & 448 & $(2.2)$ & 579 & (1.9) & 634 & (2.3) \\
\hline & Austria & 365 & (5.1) & 427 & (3.9) & 557 & (3.0) & 603 & (2.5) \\
\hline & Belgium & 373 & $(4.3)$ & 444 & (3.2) & 583 & $(2.2)$ & 633 & (2.3) \\
\hline & Canada & 403 & $(2.8)$ & 464 & $(2.2)$ & 587 & $(2.2)$ & 638 & (2.6) \\
\hline & Chile & 339 & $(4.2)$ & 388 & (3.8) & 496 & (3.3) & 541 & (3.3) \\
\hline & Czech Republic & 378 & $(4.7)$ & 434 & (3.7) & 554 & (3.6) & 604 & (3.8) \\
\hline & Denmark & 385 & $(5.1)$ & 442 & (3.5) & 555 & (2.4) & 602 & (2.8) \\
\hline & Estonia & 412 & (3.4) & 463 & (3.0) & 571 & (2.4) & 618 & (2.8) \\
\hline & Finland & 399 & $(4.3)$ & 463 & (3.5) & 590 & $(2.3)$ & 639 & (2.5) \\
\hline & France & 358 & (5.4) & 435 & (4.3) & 584 & (3.6) & 639 & (3.9) \\
\hline & Germany & 384 & $(4.8)$ & 447 & (3.6) & 574 & $(3.1)$ & 621 & (3.2) \\
\hline & Greece & 346 & (6.0) & 416 & (4.5) & 545 & (3.4) & 597 & (3.9) \\
\hline & Hungary & 363 & $(5.2)$ & 427 & (4.6) & 555 & (3.3) & 603 & (3.9) \\
\hline & Iceland & 352 & $(4.1)$ & 422 & (2.9) & 551 & (2.9) & 602 & (2.4) \\
\hline & Ireland & 410 & $(5.7)$ & 469 & (3.6) & 582 & $(2.7)$ & 631 & (3.2) \\
\hline & Israel & 329 & (7.5) & 414 & (6.8) & 568 & (4.5) & 624 & (4.5) \\
\hline & Italy & 359 & (2.9) & 427 & (2.6) & 559 & (2.1) & 609 & (2.2) \\
\hline & Japan & 409 & (6.5) & 475 & (4.8) & 607 & (3.8) & 658 & (4.4) \\
\hline & Korea & 424 & $(6.2)$ & 483 & $(4.3)$ & 596 & $(4.1)$ & 640 & (4.0) \\
\hline & Luxembourg & 347 & $(2.7)$ & 418 & (2.4) & 564 & $(2.2)$ & 620 & (2.3) \\
\hline & Mexico & 319 & (2.5) & 370 & (1.9) & 479 & (1.8) & 525 & (1.9) \\
\hline & Netherlands & 386 & (6.6) & 451 & (5.1) & 579 & (3.7) & 625 & (3.6) \\
\hline & New Zealand & 374 & $(4.9)$ & 443 & (3.2) & 586 & (3.1) & 645 & (4.0) \\
\hline & Norway & 375 & $(4.8)$ & 442 & (4.0) & 573 & (3.4) & 627 & (3.9) \\
\hline & Poland & 404 & (4.6) & 461 & (3.2) & 579 & (3.6) & 626 & (4.8) \\
\hline & Portugal & 362 & (6.0) & 429 & (4.9) & 554 & (3.5) & 604 & (3.5) \\
\hline & Slovak Republic & 321 & (8.4) & 396 & (6.8) & 538 & $(4.1)$ & 591 & (5.2) \\
\hline & Slovenia & 362 & (2.5) & 420 & (1.9) & 548 & $(2.1)$ & 598 & (2.5) \\
\hline & Spain & 367 & (3.6) & 430 & (2.6) & 552 & $(2.1)$ & 601 & (2.3) \\
\hline & Sweden & 343 & (5.4) & 416 & (4.3) & 558 & (3.3) & 614 & (4.2) \\
\hline & Switzerland & 388 & (3.9) & 451 & (3.3) & 573 & (2.8) & 622 & (3.2) \\
\hline & Turkey & 365 & (4.6) & 417 & (4.0) & 534 & (5.6) & 588 & (6.8) \\
\hline & United Kingdom & 372 & $(7.0)$ & 438 & (4.8) & 567 & (3.4) & 619 & (3.8) \\
\hline & United States & 378 & (4.8) & 436 & (4.5) & 561 & (3.9) & 614 & (4.0) \\
\hline & OECD average 2000 & 373 & $(0.9)$ & 437 & $(0.7)$ & 564 & $(0.6)$ & 615 & $(0.7)$ \\
\hline & OECD average 2003 & 373 & (0.9) & 437 & $(0.7)$ & 565 & $(0.6)$ & 616 & $(0.7)$ \\
\hline & OECD average 2006 & 372 & $(0.9)$ & 435 & $(0.7)$ & 563 & $(0.6)$ & 613 & $(0.6)$ \\
\hline & OECD average 2009 & 372 & $(0.9)$ & 436 & $(0.7)$ & 563 & $(0.6)$ & 614 & (0.6) \\
\hline \multirow{30}{*}{ ఏँ } & Albania & 247 & $(7.2)$ & 325 & $(4.8)$ & 473 & (3.2) & 536 & (3.4) \\
\hline & Argentina & 274 & (5.4) & 332 & (4.5) & 462 & $(4.1)$ & 516 & (4.4) \\
\hline & Brazil & 302 & (2.8) & 353 & (2.4) & 468 & $(2.7)$ & 520 & (3.0) \\
\hline & Bulgaria & 275 & $(8.0)$ & 353 & $(8.2)$ & 523 & (6.0) & 585 & (6.1) \\
\hline & Colombia & 295 & $(5.4)$ & 348 & $(4.0)$ & 460 & (3.7) & 509 & (4.5) \\
\hline & Costa Rica & 344 & (5.4) & 391 & $(4.3)$ & 490 & $(4.2)$ & 536 & (5.0) \\
\hline & Croatia & 370 & $(5.1)$ & 427 & (4.4) & 546 & (3.8) & 593 & (4.9) \\
\hline & Dubai (UAE) & 335 & (3.3) & 401 & (2.6) & 538 & $(2.7)$ & 594 & (3.4) \\
\hline & Hong Kong-China & 430 & (5.4) & 493 & (4.4) & 604 & (3.0) & 648 & (3.4) \\
\hline & Indonesia & 299 & (6.1) & 346 & $(4.7)$ & 447 & (4.6) & 492 & (6.1) \\
\hline & Jordan & 280 & (6.4) & 343 & (4.5) & 462 & $(3.2)$ & 510 & (4.6) \\
\hline & Kazakhstan & 297 & $(4.4)$ & 344 & (3.1) & 444 & (3.4) & 487 & (3.5) \\
\hline & Latvia & 375 & $(5.6)$ & 434 & (3.0) & 548 & (2.9) & 593 & (2.8) \\
\hline & Liechtenstein & 391 & (9.5) & 452 & $(7.8)$ & 584 & (6.9) & 630 & (10.6) \\
\hline & Lithuania & 363 & $(4.0)$ & 419 & (3.9) & 538 & (2.8) & 585 & (3.1) \\
\hline & Macao-China & 400 & (2.4) & 457 & (1.8) & 566 & (1.4) & 611 & (1.6) \\
\hline & Malaysia & 288 & $(4.4)$ & 343 & $(3.7)$ & 457 & (3.9) & 503 & (4.3) \\
\hline & Montenegro & 301 & (3.0) & 360 & (2.5) & 487 & (1.8) & 540 & (3.4) \\
\hline & Peru & 263 & $(5.1)$ & 319 & $(4.7)$ & 447 & $(5.2)$ & 504 & (6.4) \\
\hline & Qatar & 242 & $(2.0)$ & 310 & $(1.7)$ & 465 & (1.9) & 535 & (2.3) \\
\hline & Romania & 322 & (4.4) & 375 & (4.4) & 501 & (5.5) & 555 & (5.3) \\
\hline & Russian Federation & 359 & (4.5) & 415 & (4.0) & 537 & (3.9) & 592 & (4.2) \\
\hline & Serbia & 325 & (5.5) & 384 & (4.4) & 509 & $(4.1)$ & 566 & (4.6) \\
\hline & Shanghai-China & 463 & $(4.6)$ & 518 & (3.6) & 626 & $(2.8)$ & 667 & (3.5) \\
\hline & Singapore & 408 & (2.9) & 475 & (2.1) & 614 & $(2.1)$ & 668 & (3.2) \\
\hline & Chinese Taipei & 399 & $(5.2)$ & 467 & (4.4) & 587 & (2.8) & 633 & (3.6) \\
\hline & Thailand & 341 & (4.4) & 389 & (3.5) & 494 & (3.7) & 541 & (4.4) \\
\hline & Tunisia & 286 & (7.1) & 346 & (5.9) & 466 & (4.5) & 515 & (5.6) \\
\hline & United Arab Emirates* & 311 & (4.6) & 370 & (3.7) & 497 & (3.6) & 547 & (4.3) \\
\hline & Uruguay & 285 & (5.3) & 348 & (4.3) & 477 & (3.0) & 534 & (4.1) \\
\hline
\end{tabular}

Notes: Values that are statistically significant are indicated in bold (see Annex A3).

Annualised change is the average change between the earliest available measurement in PISA and PISA 2012. For countries and economies with more than one available measurement, the annualised change is calculated with a linear regression model. This model considers that Chile, Albania, Argentina, Bulgaria, Indonesia, Peru and Thailand implemented the 2000 assessment in 2001 and Israel and Romania in 2002 as part of the PISA 2000+ and that Costa Rica, Malaysia and the United Arab Emirates (with the exception of Dubai) implemented the PISA 2009 assessment in 2010 as part of PISA 2009+. Dubai implemented the PISA 2009 assessment in 2009.

For Costa Rica and Malaysia the change between PISA 2009 and PISA 2012 represents change between 2010 and 2012 because these countries implemented the PISA 2009 assessment in 2010 as part of PISA 2009+.

For Chile, Albania, Argentina, Bulgaria, Indonesia, Peru and Thailand, the change between the PISA 2000 and PISA 2012 represents change between 2001 and 2012 because these countries implemented the PISA 2000 assessment in 2001 as part of PISA $2000+$

For Israel and Romania, the change between the PISA 2000 and PISA 2012 represents change between 2002 and 2012 because these countries implemented the PISA 2000 assessment in 2002 as part of PISA 2000+

* United Arab Emirates excluding Dubai.

StatLink त्नाज्ञ $h t t p: / / d x . d o i . o r g / 10.1787 / 888932935705$ 
[Part 4/4]

Table I.4.3d Distribution of scores in reading in PISA 2000 through 2012, by percentiles

\begin{tabular}{|c|c|c|c|c|c|c|c|c|c|c|c|c|c|c|c|c|c|}
\hline & \multicolumn{8}{|c|}{ Change in percentiles between 2000 and 2012 (PISA 2012 - PISA 2000) } & \multicolumn{8}{|c|}{ Annualised change in percentiles across PISA assessments } \\
\hline & & \multicolumn{2}{|c|}{ 10th percentile } & \multicolumn{2}{|c|}{ 25th percentile } & 75th pe & rcentile & 90th $\mathrm{p}$ & rcentile & 10th $\mathrm{p}$ & percentile & 25th pe & ercentile & 75th p & percentile & 90th pe & jercentile \\
\hline & & $\begin{array}{c}\text { Score } \\
\text { dif. }\end{array}$ & S.E. & $\begin{array}{c}\begin{array}{c}\text { Score } \\
\text { dif. }\end{array} \\
\end{array}$ & S.E. & $\begin{array}{c}\text { Score } \\
\text { dif. }\end{array}$ & S.E. & $\begin{array}{c}\text { Score } \\
\text { dif. }\end{array}$ & S.E. & $\begin{array}{c}\begin{array}{c}\text { Score } \\
\text { change }\end{array} \\
\end{array}$ & S.E. & \begin{tabular}{|c|}
$\begin{array}{c}\text { Score } \\
\text { change }\end{array}$ \\
\end{tabular} & S.E. & \begin{tabular}{|c|}
$\begin{array}{c}\text { Score } \\
\text { change }\end{array}$ \\
\end{tabular} & S.E. & \begin{tabular}{|c}
$\begin{array}{c}\text { Score } \\
\text { change }\end{array}$ \\
\end{tabular} & S.E. \\
\hline Q & Australia & -9 & $(7.7)$ & -10 & $(7.7)$ & -23 & $(7.7)$ & -21 & (7.6) & -0.9 & $(0.19)$ & -1.3 & $(0.19)$ & -1.5 & $(0.19)$ & -1.2 & $(0.19)$ \\
\hline 밈 & Austria & 6 & (9.7) & -1 & (7.9) & -5 & (7.5) & -10 & (7.5) & -0.9 & $(0.22)$ & -1.3 & $(0.19)$ & $\mid-1.2$ & (0.19) & -1.4 & $(0.19)$ \\
\hline & Belgium & 19 & (11.5) & 7 & (9.5) & -4 & (6.7) & -1 & (6.8) & 1.8 & $(0.23)$ & 0.4 & $(0.20)$ & \begin{tabular}{|l|}
-0.4 \\
\end{tabular} & $(0.19)$ & -0.2 & (0.19) \\
\hline & Canada & -7 & $(7.0)$ & -7 & (6.7) & -14 & (6.5) & -14 & (6.7) & $\mid-0.6$ & (0.19) & -0.8 & (0.19) & $\mid-1.0$ & (0.19) & $\mid-1.0$ & (0.19) \\
\hline & Chile & 48 & (9.0) & 38 & (8.3) & 25 & (7.8) & 17 & (7.8) & 4.6 & $(0.30)$ & 3.6 & $(0.29)$ & 2.0 & $(0.29)$ & 0.9 & $(0.30)$ \\
\hline & Czech Republic & 11 & (9.0) & 0 & $(7.5)$ & -4 & (7.5) & -6 & $(7.7)$ & 0.6 & $(0.25)$ & -0.5 & $(0.24)$ & -0.6 & $(0.24)$ & -0.7 & $(0.24)$ \\
\hline & Denmark & 18 & (9.3) & 8 & $(7.6)$ & -11 & (7.0) & -15 & $(7.2)$ & 1.3 & $(0.19)$ & 0.6 & (0.19) & $\mid-0.6$ & (0.19) & $\mid-0.9$ & $(0.19)$ \\
\hline & Estonia & $\mathrm{m}$ & $\mathrm{m}$ & $\mathrm{m}$ & m & $\mathrm{m}$ & m & $\mathrm{m}$ & $\mathrm{m}$ & 4.0 & (1.97) & 2.6 & $(0.55)$ & 1.9 & $(0.48)$ & 1.9 & $(0.57)$ \\
\hline & Finland & -30 & (9.0) & -29 & (7.5) & -18 & (6.9) & -15 & $(7.0)$ & -2.9 & $(0.20)$ & -2.6 & (0.19) & $\mid-1.2$ & $(0.19)$ & \begin{tabular}{|l|}
-0.9 \\
\end{tabular} & $(0.19)$ \\
\hline & France & -23 & (9.5) & -9 & (8.6) & 14 & (7.4) & 20 & (7.6) & -2.0 & $(0.22)$ & -0.9 & $(0.21)$ & 1.0 & $(0.21)$ & 1.7 & $(0.21)$ \\
\hline & Germany & 48 & (9.9) & 30 & $(8.3)$ & 11 & (7.3) & 2 & (7.3) & 4.2 & $(0.33)$ & 2.5 & $(0.31)$ & 0.6 & $(0.31)$ & -0.2 & $(0.31)$ \\
\hline & Greece & 3 & (11.9) & 7 & (10.5) & 3 & (8.2) & 2 & (8.7) & 1.0 & $(0.34)$ & 0.9 & $(0.24)$ & 0.3 & $(0.21)$ & 0.2 & $(0.21)$ \\
\hline & Hungary & 9 & (9.6) & 12 & (9.1) & 7 & (8.2) & 5 & (8.3) & 0.9 & $(0.20)$ & 1.3 & $(0.20)$ & 0.9 & (0.19) & 0.7 & $(0.19)$ \\
\hline & Iceland & -32 & (8.0) & -26 & $(7.3)$ & -21 & (6.9) & -19 & $(7.3)$ & $\mid-1.8$ & (0.19) & -1.4 & (0.19) & \begin{tabular}{|l|}
-1.2 \\
\end{tabular} & (0.19) & -1.0 & (0.19) \\
\hline & Ireland & 9 & (10.4) & 1 & $(8.2)$ & -11 & (7.4) & -10 & (7.8) & -0.2 & $(0.20)$ & -0.5 & $(0.19)$ & -1.0 & $(0.19)$ & -0.9 & $(0.19)$ \\
\hline & Israel & 25 & (16.1) & 35 & $(14.3)$ & 36 & (11.0) & 37 & (10.2) & 2.9 & (6.08) & 3.7 & (1.92) & 3.6 & $(0.48)$ & 3.6 & $(0.30)$ \\
\hline & Italy & -8 & (8.8) & -1 & $(7.7)$ & 7 & $(7.1)$ & 8 & $(6.9)$ & 1.9 & $(0.21)$ & 1.6 & $(0.20)$ & 1.2 & $(0.20)$ & 1.0 & $(0.20)$ \\
\hline & Japan & 2 & $(13.2)$ & 4 & $(10.3)$ & 25 & (8.3) & 33 & (8.7) & 1.5 & $(0.41)$ & 1.3 & $(0.22)$ & 2.2 & $(0.20)$ & 2.7 & $(0.20)$ \\
\hline & Korea & -9 & (9.7) & 2 & $(7.8)$ & 23 & (7.7) & 32 & $(7.7)$ & -0.3 & $(0.19)$ & 0.4 & $(0.19)$ & 1.8 & $(0.19)$ & 2.2 & $(0.19)$ \\
\hline & Luxembourg & $\mathrm{m}$ & $\mathrm{m}$ & $\mathrm{m}$ & $\mathrm{m}$ & $\mathrm{m}$ & $\mathrm{m}$ & $\mathrm{m}$ & $\mathrm{m}$ & -0.1 & $(0.18)$ & 0.0 & $(0.18)$ & 1.1 & $(0.18)$ & 1.9 & $(0.18)$ \\
\hline & Mexico & 8 & (7.3) & 10 & $(7.2)$ & -3 & (7.8) & -9 & (8.3) & 4.6 & (0.19) & 3.5 & $(0.19)$ & 1.1 & $(0.19)$ & 0.1 & $(0.19)$ \\
\hline & Netherlands & $\mathrm{m}$ & $\mathrm{m}$ & $\mathrm{m}$ & $\mathrm{m}$ & $\mathrm{m}$ & $\mathrm{m}$ & $\mathrm{m}$ & $\mathrm{m}$ & $\mid-1.1$ & $(0.70)$ & -0.5 & $(0.39)$ & 0.2 & $(0.19)$ & 0.5 & $(0.19)$ \\
\hline & New Zealand & -8 & $(9.3)$ & -17 & $(7.8)$ & -20 & (7.3) & -16 & (8.4) & $\mid-0.5$ & $(0.20)$ & -1.1 & $(0.19)$ & $\mid-1.3$ & $(0.19)$ & $\mid-1.1$ & $(0.19)$ \\
\hline & Norway & 11 & (9.4) & 2 & $(8.4)$ & -6 & $(7.3)$ & -5 & $(7.7)$ & 1.5 & $(0.19)$ & 0.6 & $(0.19)$ & -0.5 & $(0.19)$ & -0.5 & $(0.19)$ \\
\hline & Poland & 61 & (10.1) & 47 & $(8.9)$ & 28 & (9.1) & 23 & (10.0) & 4.3 & $(0.26)$ & 3.2 & $(0.23)$ & 1.8 & $(0.23)$ & 1.3 & $(0.23)$ \\
\hline & Portugal & 25 & (10.5) & 26 & $(10.0)$ & 13 & (8.2) & 12 & (8.0) & 2.5 & $(0.21)$ & 2.2 & $(0.19)$ & 1.1 & $(0.19)$ & 1.1 & $(0.19)$ \\
\hline & Slovak Republic & $\mathrm{m}$ & $\mathrm{m}$ & $\mathrm{m}$ & $\mathrm{m}$ & $\mathrm{m}$ & $\mathrm{m}$ & $\mathrm{m}$ & $\mathrm{m}$ & $\mid-1.7$ & $(0.98)$ & -0.6 & $(0.44)$ & 0.4 & $(0.32)$ & 0.6 & $(0.33)$ \\
\hline & Slovenia & $\mathrm{m}$ & $\mathrm{m}$ & $\mathrm{m}$ & $\mathrm{m}$ & $\mathrm{m}$ & $\mathrm{m}$ & $\mathrm{m}$ & $\mathrm{m}$ & -2.6 & $(0.47)$ & -3.0 & $(0.46)$ & -1.9 & $(0.46)$ & -0.9 & $(0.46)$ \\
\hline & Spain & -12 & (8.6) & -7 & $(7.9)$ & -1 & (6.8) & 4 & (6.9) & 0.8 & $(0.20)$ & 0.8 & $(0.20)$ & 0.6 & $(0.20)$ & 0.8 & $(0.20)$ \\
\hline & Sweden & -49 & (9.0) & -40 & (7.9) & -24 & (7.5) & -16 & (7.8) & -4.0 & $(0.20)$ & -3.2 & $(0.19)$ & -2.1 & $(0.19)$ & -1.4 & $(0.19)$ \\
\hline & Switzerland & 33 & $(9.2)$ & 24 & $(8.7)$ & 6 & (8.0) & 1 & (8.7) & 2.1 & $(0.21)$ & 1.5 & $(0.20)$ & 0.6 & $(0.20)$ & 0.2 & $(0.20)$ \\
\hline & Turkey & $\mathrm{m}$ & $\mathrm{m}$ & $\mathrm{m}$ & $\mathrm{m}$ & $\mathrm{m}$ & $\mathrm{m}$ & $\mathrm{m}$ & $\mathrm{m}$ & 5.0 & $(0.40)$ & 4.6 & $(0.32)$ & 3.8 & $(0.61)$ & 2.8 & $(4.80)$ \\
\hline & United Kingdom & $\mathrm{m}$ & $\mathrm{m}$ & $\mathrm{m}$ & $\mathrm{m}$ & $\mathrm{m}$ & $\mathrm{m}$ & $\mathrm{m}$ & $\mathrm{m}$ & 2.2 & $(1.32)$ & 1.3 & $(0.43)$ & 0.1 & $(0.27)$ & -0.2 & $(0.40)$ \\
\hline & United States & 15 & $(13.7)$ & 0 & (11.5) & -16 & (9.8) & -22 & (9.7) & 1.5 & $(0.26)$ & 0.2 & $(0.20)$ & -1.0 & $(0.19)$ & -1.2 & $(0.19)$ \\
\hline & OECD average 2000 & 6 & (1.9) & 4 & $(1.7)$ & 1 & (1.5) & 1 & (1.5) & 0.9 & $(0.23)$ & 0.5 & $(0.08)$ & 0.2 & $(0.04)$ & 0.1 & $(0.04)$ \\
\hline & OECD average 2003 & $\mathrm{~m}$ & $\mathrm{~m}$ & $\mathrm{~m}$ & $\mathrm{~m}$ & $\mathrm{~m}$ & $\mathrm{~m}$ & $\mathrm{~m}$ & $\mathrm{~m}$ & 0.6 & $(0.06)$ & 0.4 & $(0.04)$ & 0.2 & $(0.04)$ & 0.2 & $(0.17)$ \\
\hline & OECD average 2006 & $\mathrm{~m}$ & $\mathrm{~m}$ & $\mathrm{~m}$ & $\mathrm{~m}$ & $\mathrm{~m}$ & $\mathrm{~m}$ & $\mathrm{~m}$ & $\mathrm{~m}$ & 0.9 & $(0.21)$ & 0.6 & $(0.07)$ & 0.4 & $(0.05)$ & 0.4 & $(0.15)$ \\
\hline & OECD average 2009 & $\mathrm{~m}$ & $\mathrm{~m}$ & $\mathrm{~m}$ & $\mathrm{~m}$ & $\mathrm{~m}$ & $\mathrm{~m}$ & $\mathrm{~m}$ & $\mathrm{~m}$ & 0.9 & $(0.21)$ & 0.6 & $(0.07)$ & 0.4 & $(0.05)$ & 0.4 & $(0.15)$ \\
\hline$\frac{n}{2}$ & Albania & 31 & $(11.3)$ & 45 & $\begin{array}{l}(9.1) \\
\end{array}$ & 52 & (7.4) & 60 & (7.4) & 3.3 & $(0.41)$ & 4.3 & $(0.25)$ & 4.7 & $(0.24)$ & 5.2 & $(0.24)$ \\
\hline S & Argentina & 3 & $(14.0)$ & -12 & $(15.1)$ & -33 & $(11.4)$ & -37 & $(12.1)$ & 1.7 & (1.04) & 0.0 & (1.76) & -2.7 & $(0.34)$ & -3.0 & $(0.53)$ \\
\hline ฮ & Brazil & 14 & $(8.0)$ & 14 & $(7.3)$ & 16 & (7.3) & 13 & (7.8) & 3.2 & $(0.20)$ & 2.0 & $(0.20)$ & 0.8 & $(0.20)$ & 0.2 & $(0.20)$ \\
\hline & Bulgaria & -20 & (11.9) & -7 & $(11.6)$ & 21 & $(10.7)$ & 26 & $(11.3)$ & $\mid-1.3$ & $(0.45)$ & -0.3 & $(0.44)$ & 2.1 & $(0.32)$ & 2.5 & $(0.41)$ \\
\hline & Colombia & $\mathrm{m}$ & $\mathrm{m}$ & $\mathrm{m}$ & $\mathrm{m}$ & $\mathrm{m}$ & $\mathrm{m}$ & $\mathrm{m}$ & $\mathrm{m}$ & 6.7 & $(9.02)$ & 4.0 & (2.48) & -0.8 & $(1.83)$ & -2.0 & (3.50) \\
\hline & Costa Rica & $\mathrm{m}$ & $\mathrm{m}$ & $\mathrm{m}$ & $\mathrm{m}$ & $\mathrm{m}$ & $\mathrm{m}$ & $\mathrm{m}$ & $\mathrm{m}$ & 2.6 & (436.16) & 1.2 & (112.64) & -3.9 & (162.35) & -4.2 & (399.95) \\
\hline & Croatia & $\mathrm{m}$ & $\mathrm{m}$ & $\mathrm{m}$ & $\mathrm{m}$ & $\mathrm{m}$ & $\mathrm{m}$ & $\mathrm{m}$ & $\mathrm{m}$ & 1.6 & (3.53) & 1.5 & $(1.26)$ & 0.9 & $(0.57)$ & 0.7 & $(0.77)$ \\
\hline & Dubai (UAE) & $\mathrm{m}$ & $\mathrm{m}$ & $\mathrm{m}$ & $\mathrm{m}$ & $\mathrm{m}$ & $\mathrm{m}$ & $\mathrm{m}$ & $\mathrm{m}$ & 6.0 & $(4.20)$ & 5.0 & (1.44) & 0.8 & (3.98) & -1.0 & (5.49) \\
\hline & Hong Kong-China & 16 & $(10.9)$ & 16 & $(8.3)$ & 20 & $(7.2)$ & 24 & (7.4) & 2.2 & $(0.26)$ & 2.0 & $(0.20)$ & 2.4 & $(0.20)$ & 2.6 & $(0.20)$ \\
\hline & Indonesia & 23 & (9.4) & 25 & $(8.7)$ & 26 & (9.4) & 28 & $(11.0)$ & 2.8 & $(0.27)$ & 2.7 & $(0.26)$ & 2.3 & $(0.27)$ & 2.3 & $(0.28)$ \\
\hline & Jordan & $\mathrm{m}$ & $\mathrm{m}$ & $\mathrm{m}$ & $\mathrm{m}$ & $\mathrm{m}$ & $\mathrm{m}$ & $\mathrm{m}$ & $\mathrm{m}$ & 0.5 & $(7.64)$ & 0.0 & $(0.94)$ & -0.7 & $(0.54)$ & -0.7 & (1.23) \\
\hline & Kazakhstan & $\mathrm{m}$ & $\mathrm{m}$ & $\mathrm{m}$ & $\mathrm{m}$ & $\mathrm{m}$ & $\mathrm{m}$ & $\mathrm{m}$ & $\mathrm{m}$ & 7.5 & (45.80) & 5.5 & (8.04) & -2.7 & $(17.61)$ & -8.7 & (31.65) \\
\hline & Latvia & 53 & (11.5) & 44 & (9.6) & 18 & (8.4) & 7 & (8.8) & 3.7 & $(0.28)$ & 2.6 & $(0.26)$ & 0.5 & $(0.26)$ & $\mid-0.3$ & $(0.26)$ \\
\hline & Liechtenstein & 41 & $(16.2)$ & 33 & (13.6) & 33 & $(10.8)$ & 29 & $(14.0)$ & 2.5 & $(1.54)$ & 1.3 & $(0.27)$ & 0.9 & $(0.25)$ & 0.5 & $(0.67)$ \\
\hline & Lithuania & $\mathrm{m}$ & $\mathrm{m}$ & $\mathrm{m}$ & $\mathrm{m}$ & $\mathrm{m}$ & $\mathrm{m}$ & $\mathrm{m}$ & $\mathrm{m}$ & 3.5 & (1.05) & 2.4 & $(0.95)$ & 0.0 & $(0.59)$ & $\mid-0.8$ & $(0.57)$ \\
\hline & Macao-China & $\mathrm{m}$ & $\mathrm{m}$ & $\mathrm{m}$ & $\mathrm{m}$ & $\mathrm{m}$ & $\mathrm{m}$ & $\mathrm{m}$ & $\mathrm{m}$ & -0.1 & $(0.30)$ & 0.9 & $(0.29)$ & 2.7 & $(0.29)$ & 3.3 & $(0.29)$ \\
\hline & Malaysia & $\mathrm{m}$ & $\mathrm{m}$ & $\mathrm{m}$ & $\mathrm{m}$ & $\mathrm{m}$ & $\mathrm{m}$ & $\mathrm{m}$ & $\mathrm{m}$ & -7.9 & (228.98) & -10.1 & (94.44) & -6.8 & (53.04) & -5.1 & (102.11) \\
\hline & Montenegro & $\mathrm{m}$ & $\mathrm{m}$ & $\mathrm{m}$ & $\mathrm{m}$ & $\mathrm{m}$ & $\mathrm{m}$ & $\mathrm{m}$ & $\mathrm{m}$ & 4.3 & $(0.50)$ & 4.8 & $(0.42)$ & 5.5 & $(0.42)$ & 5.6 & $(0.52)$ \\
\hline & Peru & 58 & $(9.2)$ & 60 & $(9.2)$ & 55 & (9.6) & 52 & (10.3) & 5.1 & $(0.26)$ & 5.4 & $(0.26)$ & 5.1 & $(0.27)$ & 4.9 & $(0.29)$ \\
\hline & Qatar & $\mathrm{m}$ & $\mathrm{m}$ & $\mathrm{m}$ & $\mathrm{m}$ & $\mathrm{m}$ & $\mathrm{m}$ & $\mathrm{m}$ & $\mathrm{m}$ & 9.9 & $(0.41)$ & 12.0 & $(0.41)$ & 13.0 & $(0.41)$ & 11.4 & $(0.41)$ \\
\hline & Romania & 28 & (9.6) & 19 & (10.3) & 2 & (8.8) & -4 & (8.7) & 3.4 & $(0.64)$ & 2.7 & $(0.32)$ & 0.7 & $(0.30)$ & 0.0 & $(0.29)$ \\
\hline & Russian Federation & 18 & $(9.2)$ & 15 & (8.8) & 11 & (8.4) & 13 & (8.5) & 1.9 & $(0.29)$ & 1.6 & $(0.28)$ & 1.0 & $(0.28)$ & 1.1 & $(0.28)$ \\
\hline & Serbia & $\mathrm{m}$ & $\mathrm{m}$ & $\mathrm{m}$ & $\mathrm{m}$ & $\mathrm{m}$ & $\mathrm{m}$ & $\mathrm{m}$ & $\mathrm{m}$ & 7.2 & $(1.87)$ & 7.6 & $(1.70)$ & 7.2 & $(1.66)$ & 8.0 & $(1.66)$ \\
\hline & Shanghai-China & $\mathrm{m}$ & $\mathrm{m}$ & $\mathrm{m}$ & $\mathrm{m}$ & $\mathrm{m}$ & $\mathrm{m}$ & $\mathrm{m}$ & $\mathrm{m}$ & 4.3 & (58.34) & 4.9 & (11.64) & 4.4 & (3.78) & 4.3 & (3.28) \\
\hline & Singapore & $\mathrm{m}$ & $\mathrm{m}$ & $\mathrm{m}$ & $\mathrm{m}$ & $\mathrm{m}$ & $\mathrm{m}$ & $\mathrm{m}$ & $\mathrm{m}$ & 4.9 & $(7.67)$ & 5.1 & $(1.27)$ & 5.7 & (1.24) & 6.8 & (12.83) \\
\hline & Chinese Taipei & $\mathrm{m}$ & $\mathrm{m}$ & $\mathrm{m}$ & $\mathrm{m}$ & $\mathrm{m}$ & $\mathrm{m}$ & $\mathrm{m}$ & $\mathrm{m}$ & 2.6 & (5.29) & 3.7 & (2.07) & 5.0 & $(0.43)$ & 5.4 & $(0.45)$ \\
\hline & Thailand & 8 & (8.8) & 8 & $(7.9)$ & 12 & (7.7) & 15 & (8.7) & 1.2 & $(0.21)$ & 1.1 & $(0.21)$ & 0.9 & $(0.21)$ & 1.1 & $(0.21)$ \\
\hline & Tunisia & $\mathrm{m}$ & $\mathrm{m}$ & $\mathrm{m}$ & $\mathrm{m}$ & $\mathrm{m}$ & $\mathrm{m}$ & $\mathrm{m}$ & $\mathrm{m}$ & 4.9 & $(0.48)$ & 4.7 & $(0.33)$ & 2.9 & $(0.30)$ & 2.1 & $(0.39)$ \\
\hline & United Arab Emirates* & $\mathrm{m}$ & $\mathrm{m}$ & $\mathrm{m}$ & $\mathrm{m}$ & $\mathrm{m}$ & $\mathrm{m}$ & $\mathrm{m}$ & $\mathrm{m}$ & 5.1 & (641.39) & 5.2 & (208.77) & 4.2 & (113.17) & 2.9 & (473.88) \\
\hline & Uruguay & $\mathrm{m}$ & $\mathrm{m}$ & $\mathrm{m}$ & $\mathrm{m}$ & $\mathrm{m}$ & $\mathrm{m}$ & $\mathrm{m}$ & $\mathrm{m}$ & 2.7 & $(0.50)$ & 0.1 & $(0.30)$ & -4.2 & $(0.28)$ & -5.8 & $(0.29)$ \\
\hline
\end{tabular}

Notes: Values that are statistically significant are indicated in bold (see Annex A3).

Annualised change is the average change between the earliest available measurement in PISA and PISA 2012. For countries and economies with more than one available measurement, the annualised change is calculated with a linear regression model. This model considers that Chile, Albania, Argentina, Bulgaria, Indonesia, Peru and Thailand implemented the 2000 assessment in 2001 and Israel and Romania in 2002 as part of the PISA 2000+ and that Costa Rica, Malaysia and the United Arab Emirates (with the For Costa Rica and Malaysia the change between PISA 2009 and PISA 2012 represents change between 2010 and 2012 because these countries implemented the PISA 2009 2010 as part of PISA 2009+.

For Chile, Albania, Argentina, Bulgaria, Indonesia, Peru and Thailand, the change between the PISA 2000 and PISA 2012 represents change between 2001 and 2012 because these countries implemented the PISA 2000 assessment in 2001 as part of PISA $2000+$.

For Israel and Romania, the change between the PISA 2000 and PISA 2012 represents change between 2002 and 2012 because these countries implemented the PISA 2000 * Unsessment in 2002 as part of PISA 2000+.

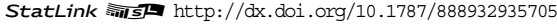


[Part 1/2]

Table I.4.4 Trends in reading performance adjusted for demographic changes

\begin{tabular}{|c|c|c|c|c|c|c|c|c|c|c|c|}
\hline & & \multicolumn{2}{|c|}{ Adjusted PISA 2000 results } & \multicolumn{2}{|c|}{ Adjusted PISA 2003 results } & \multicolumn{2}{|c|}{ Adjusted PISA 2006 results } & \multicolumn{2}{|c|}{ Adjusted PISA 2009 results } & \multicolumn{2}{|c|}{ Adjusted PISA 2012 results } \\
\hline & & Mean score & S.E. & Mean score & S.E. & Mean score & S.E. & Mean score & S.E. & Mean score & S.E. \\
\hline \multirow{38}{*}{ త్ } & Australia & 548 & (2.9) & 534 & (1.6) & 514 & (1.6) & 514 & (1.9) & 512 & (1.5) \\
\hline & Austria & 509 & (2.6) & 505 & (2.7) & 491 & (3.7) & $\mathrm{m}$ & $\mathrm{m}$ & 490 & (2.5) \\
\hline & Belgium & 521 & (3.3) & 511 & (1.9) & 504 & $(2.7)$ & 505 & (1.9) & 509 & (2.0) \\
\hline & Canada & 543 & (1.5) & 533 & (1.6) & 531 & $(2.2)$ & 524 & (1.3) & 523 & (1.7) \\
\hline & Chile & 428 & $(2.7)$ & $\mathrm{m}$ & $\mathrm{m}$ & 458 & (3.6) & 450 & (2.5) & 441 & (2.4) \\
\hline & Czech Republic & 512 & (2.1) & 486 & (2.8) & 484 & (3.7) & 477 & (2.6) & 493 & (2.5) \\
\hline & Denmark & 508 & (1.9) & 504 & $(2.1)$ & 494 & $(2.7)$ & 494 & (1.7) & 496 & (2.1) \\
\hline & Estonia & $\mathrm{m}$ & $\mathrm{m}$ & $\mathrm{m}$ & $\mathrm{m}$ & 510 & $(2.7)$ & 502 & $(2.2)$ & 516 & (1.9) \\
\hline & Finland & 560 & (2.3) & 549 & (1.5) & 550 & (1.9) & 533 & $(2.1)$ & 524 & (2.1) \\
\hline & France & 520 & (2.4) & 508 & (2.1) & 502 & (3.4) & 500 & (2.8) & 506 & (2.5) \\
\hline & Germany & 501 & (2.6) & 505 & (2.6) & 497 & (3.5) & 500 & (2.1) & 508 & (2.4) \\
\hline & Greece & 483 & (4.0) & 478 & (3.2) & 464 & (3.2) & 481 & (3.5) & 477 & (2.5) \\
\hline & Hungary & 488 & (2.5) & 486 & (1.9) & 485 & $(2.7)$ & 491 & (2.6) & 488 & (2.5) \\
\hline & Iceland & 520 & (1.8) & 496 & (1.5) & 488 & (2.0) & 501 & (1.4) & 483 & (1.8) \\
\hline & Ireland & 542 & $(2.7)$ & 528 & (2.0) & 524 & $(2.7)$ & 497 & (2.5) & 523 & (2.1) \\
\hline & Israel & 471 & (7.4) & $\mathrm{m}$ & $\mathrm{m}$ & 439 & (4.5) & 476 & (3.1) & 486 & (4.4) \\
\hline & Italy & 494 & (2.5) & 477 & (2.9) & 471 & (2.3) & 485 & (1.4) & 490 & (1.7) \\
\hline & Japan & 538 & (3.4) & 511 & (3.5) & 501 & (3.5) & 520 & (3.2) & 538 & (3.4) \\
\hline & Korea & 461 & (21.9) & 474 & $(21.5)$ & 560 & (3.2) & 540 & (2.9) & 461 & (21.9) \\
\hline & Luxembourg & $\mathrm{m}$ & $\mathrm{m}$ & 466 & (2.5) & 480 & (1.4) & 469 & $(1.3)$ & 488 & (1.6) \\
\hline & Mexico & 426 & (2.5) & 404 & (3.2) & 410 & $(2.2)$ & 423 & (1.6) & 424 & (1.3) \\
\hline & Netherlands & $\mathrm{m}$ & $\mathrm{m}$ & 524 & (2.3) & 510 & (2.5) & 512 & (4.4) & 511 & (3.1) \\
\hline & New Zealand & 529 & (2.4) & 527 & (2.1) & 514 & (2.6) & 515 & (2.0) & 512 & (2.4) \\
\hline & Norway & 512 & (2.6) & 507 & (2.6) & 487 & (2.9) & 499 & (2.5) & 504 & (2.9) \\
\hline & Poland & 497 & (4.3) & 505 & (2.4) & 523 & (2.5) & 504 & $(2.1)$ & 518 & (2.6) \\
\hline & Portugal & 481 & (3.6) & 486 & $(2.7)$ & 481 & (2.7) & 487 & $(2.2)$ & 488 & (3.0) \\
\hline & Slovak Republic & $\mathrm{m}$ & $\mathrm{m}$ & 468 & (2.0) & 471 & (2.8) & 473 & (2.4) & 463 & (3.4) \\
\hline & Slovenia & $\mathrm{m}$ & $\mathrm{m}$ & $\mathrm{m}$ & $\mathrm{m}$ & 505 & $(1.0)$ & 483 & (1.0) & 481 & $(1.2)$ \\
\hline & Spain & 506 & (1.9) & 486 & (2.0) & 468 & $(1.7)$ & 482 & (1.6) & 488 & (1.7) \\
\hline & Sweden & 518 & (2.0) & 519 & (1.9) & 507 & (3.3) & 491 & (2.3) & 483 & (2.8) \\
\hline & Switzerland & 507 & (3.6) & 511 & (2.3) & 506 & (2.6) & 503 & $(2.0)$ & 509 & (2.0) \\
\hline & Turkey & $\mathrm{m}$ & $\mathrm{m}$ & 430 & (4.0) & 443 & (3.6) & 454 & $(2.8)$ & 476 & (3.3) \\
\hline & United Kingdom & $\mathrm{m}$ & $\mathrm{m}$ & $\mathrm{m}$ & $\mathrm{m}$ & 501 & $(2.1)$ & 495 & (1.9) & 499 & (3.0) \\
\hline & United States & 520 & (4.6) & 500 & (2.5) & $\mathrm{m}$ & $\mathrm{m}$ & 498 & (2.6) & 498 & (2.9) \\
\hline & OECD average 2000 & 505 & $(1.0)$ & 501 & (1.0) & 494 & $(0.6)$ & 496 & $(0.5)$ & 495 & $(0.9)$ \\
\hline & OECD average 2003 & $\mathrm{~m}$ & $\mathrm{~m}$ & 497 & (0.9) & 495 & $(0.5)$ & 495 & $(0.4)$ & 496 & (0.9) \\
\hline & OECD average 2006 & $\mathrm{~m}$ & $\mathrm{~m}$ & $\mathrm{~m}$ & $\mathrm{~m}$ & 493 & $(0.5)$ & 493 & $(0.4)$ & 494 & $(0.8)$ \\
\hline & OECD average 2009 & $\mathrm{~m}$ & $\mathrm{~m}$ & $\mathrm{~m}$ & $\mathrm{~m}$ & $\mathrm{~m}$ & $\mathrm{~m}$ & 493 & $(0.4)$ & 494 & (0.8) \\
\hline \multirow{30}{*}{$\frac{n}{\vdots}$} & Albania & $\mathrm{c}$ & c & $\mathrm{c}$ & $\mathrm{c}$ & $\mathrm{c}$ & $\mathrm{c}$ & $\mathrm{c}$ & $\mathrm{c}$ & $\mathrm{c}$ & $\mathrm{c}$ \\
\hline & Argentina & 424 & (7.3) & $\mathrm{m}$ & $\mathrm{m}$ & 377 & (5.5) & 396 & (3.4) & 396 & (3.1) \\
\hline & Brazil & 408 & (2.7) & 415 & $(4.0)$ & 401 & (3.5) & 414 & (2.3) & 410 & (1.9) \\
\hline & Bulgaria & 435 & (3.7) & $\mathrm{m}$ & $\mathrm{m}$ & 412 & (4.6) & 429 & (4.5) & 436 & $(4.2)$ \\
\hline & Colombia & $\mathrm{m}$ & $\mathrm{m}$ & $\mathrm{m}$ & $\mathrm{m}$ & 387 & $(4.2)$ & 412 & (3.0) & 403 & (2.7) \\
\hline & Costa Rica & $\mathrm{m}$ & $\mathrm{m}$ & $\mathrm{m}$ & $\mathrm{m}$ & $\mathrm{m}$ & $\mathrm{m}$ & 444 & (4.0) & 441 & (3.0) \\
\hline & Croatia & $\mathrm{m}$ & $\mathrm{m}$ & $\mathrm{m}$ & $\mathrm{m}$ & 480 & (2.6) & 474 & (2.5) & 485 & (2.9) \\
\hline & Dubai (UAE) & $\mathrm{m}$ & $\mathrm{m}$ & $\mathrm{m}$ & $\mathrm{m}$ & $\mathrm{m}$ & $\mathrm{m}$ & 459 & (1.2) & 468 & (1.3) \\
\hline & Hong Kong-China & 539 & (3.3) & 516 & (3.3) & 539 & (2.3) & 536 & (1.9) & 544 & (2.4) \\
\hline & Indonesia & 373 & (3.4) & 390 & (4.4) & 396 & (5.8) & 402 & (3.1) & 396 & (3.7) \\
\hline & Jordan & $\mathrm{m}$ & $\mathrm{m}$ & $\mathrm{m}$ & $\mathrm{m}$ & 402 & (3.0) & 405 & (2.8) & 399 & (3.1) \\
\hline & Kazakhstan & $\mathrm{m}$ & $\mathrm{m}$ & $\mathrm{m}$ & $\mathrm{m}$ & $\mathrm{m}$ & $\mathrm{m}$ & 394 & (2.6) & 393 & (2.2) \\
\hline & Latvia & 470 & (5.3) & 490 & (3.3) & 484 & (3.1) & 484 & (2.4) & 489 & (2.0) \\
\hline & Liechtenstein & 495 & (6.9) & 540 & (5.1) & 520 & $(4.0)$ & 506 & (3.3) & 517 & (4.1) \\
\hline & Lithuania & $\mathrm{m}$ & $\mathrm{m}$ & $\mathrm{m}$ & $\mathrm{m}$ & 475 & $(2.7)$ & 472 & (2.1) & 477 & (2.0) \\
\hline & Macao-China & $\mathrm{m}$ & $\mathrm{m}$ & 502 & (2.9) & 532 & (3.1) & 487 & $(0.9)$ & 508 & $(0.9)$ \\
\hline & Malaysia & $\mathrm{m}$ & $\mathrm{m}$ & $\mathrm{m}$ & $\mathrm{m}$ & $\mathrm{m}$ & $\mathrm{m}$ & 412 & (3.6) & 398 & (2.9) \\
\hline & Montenegro & $\mathrm{m}$ & $\mathrm{m}$ & $\mathrm{m}$ & $\mathrm{m}$ & 406 & (2.0) & 413 & (1.3) & 422 & $(1.2)$ \\
\hline & Peru & 332 & (3.4) & $\mathrm{m}$ & $\mathrm{m}$ & $\mathrm{m}$ & $\mathrm{m}$ & 368 & (2.5) & 384 & (2.7) \\
\hline & Qatar & $\mathrm{m}$ & $\mathrm{m}$ & $\mathrm{m}$ & $\mathrm{m}$ & 332 & (1.3) & 379 & $(0.8)$ & 387 & $(0.9)$ \\
\hline & Romania & 460 & (6.4) & $\mathrm{m}$ & $\mathrm{m}$ & 405 & $(4.0)$ & 426 & (3.3) & 438 & (3.0) \\
\hline & Russian Federation & 486 & (3.4) & 458 & (3.1) & 457 & (3.1) & 467 & (2.7) & 475 & (2.5) \\
\hline & Serbia & $\mathrm{m}$ & $\mathrm{m}$ & $\mathrm{m}$ & $\mathrm{m}$ & 407 & (2.8) & 443 & $(2.2)$ & 446 & (3.1) \\
\hline & Shanghai-China & $\mathrm{m}$ & $\mathrm{m}$ & $\mathrm{m}$ & $\mathrm{m}$ & $\mathrm{m}$ & $\mathrm{m}$ & 559 & (1.8) & 570 & (2.3) \\
\hline & Singapore & $\mathrm{m}$ & $\mathrm{m}$ & $\mathrm{m}$ & $\mathrm{m}$ & $\mathrm{m}$ & $\mathrm{m}$ & 529 & (1.1) & 542 & $(1.2)$ \\
\hline & Chinese Taipei & $\mathrm{m}$ & $\mathrm{m}$ & $\mathrm{m}$ & $\mathrm{m}$ & 503 & $(2.7)$ & 495 & (2.1) & 523 & $(2.2)$ \\
\hline & Thailand & 444 & $(2.7)$ & 434 & (3.4) & 428 & (2.4) & 424 & (2.1) & 441 & (2.5) \\
\hline & Tunisia & $\mathrm{m}$ & $\mathrm{m}$ & 386 & (2.9) & 384 & (3.3) & 408 & (2.5) & 404 & (3.9) \\
\hline & United Arab Emirates* & $\mathrm{m}$ & $\mathrm{m}$ & $\mathrm{m}$ & $\mathrm{m}$ & $\mathrm{m}$ & $\mathrm{m}$ & 435 & (5.0) & 432 & (2.8) \\
\hline & Uruguay & $\mathrm{m}$ & $\mathrm{m}$ & 430 & (3.0) & 409 & (3.1) & 425 & (2.1) & 411 & (2.6) \\
\hline
\end{tabular}

Notes: Values that are statistically significant are indicated in bold (see Annex A3),

Annualised change is the average change between the earliest available measurement in PISA and PISA 2012. For countries and economies with more than one available measurement, the annualised change is calculated with a linear regression model. This model considers that Chile, Albania, Argentina, Bulgaria, Indonesia, Peru and Thailand exception of Dubai) implemented the PISA 2009 assessment in 2010 as part of PISA 2009+. Dubai implemented the PISA 2009 assessment in 2009.

Adjusted scores are obtained by estimating a regression of students' demographic characteristics on reading performance with demographic characteristics centred at the 2012 values. Demographic characteristics that entered the model are: students' age, gender. PISA index of economic, social and cultural status, immigrant background (first or second generation) and whether students speak a language at home which is different from the language of instruction. Adjusted values therefore represent average scores in previous assessment assuming that demographic characteristics remained unchanged. See Annex A5 for more details on the estimation of adjusted trends.

For Costa Rica and Malaysia the change between PISA 2009 and PISA 2012 represents change between 2010 and 2012 because these countries implemented the PISA 2009 assessment in 2010 as part of PISA 2009+.

For Chile, Albania, Argentina, Bulgaria, Indonesia, Peru and Thailand, the change between the PISA 2000 and PISA 2012 represents change between 2001 and 2012 because these countries implemented the PISA 2000 assessment in 2001 as part of PISA 2000+.

For Israel and Romania, the change between the PISA 2000 and PISA 2012 represents change between 2002 and 2012 because these countries implemented the PISA 2000 assessment in 2002 as part of PISA 2000+.

In the United Arab Emirates, Dubai took the PISA 2009 assessment in 2009 and the rest of the United Arab Emirates in 2010 as part of PISA 2009+. Results are thus reported separately.

* United Arab Emirates excluding Dubai (see note above).

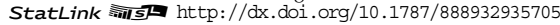


[Part 2/2]

Table I.4.4 Trends in reading performance adjusted for demographic changes

\begin{tabular}{|c|c|c|c|c|c|c|c|c|c|c|c|}
\hline & & \multicolumn{2}{|c|}{$\begin{array}{c}\text { Change between } \\
2000 \text { and } 2012 \\
\text { (PISA } 2012 \text { - PISA 2000) }\end{array}$} & \multicolumn{2}{|c|}{$\begin{array}{c}\text { Change between } \\
2003 \text { and } 2012 \\
\text { (PISA } 2012 \text { - PISA 2003) }\end{array}$} & \multicolumn{2}{|c|}{$\begin{array}{c}\text { Change between } \\
2006 \text { and } 2012 \\
\text { (PISA } 2012 \text { - PISA 2006) }\end{array}$} & \multicolumn{2}{|c|}{$\begin{array}{c}\text { Change between } \\
2009 \text { and } 2012 \\
\text { (PISA } 2012 \text { - PISA 2009) }\end{array}$} & \multicolumn{2}{|c|}{$\begin{array}{l}\text { Annualised adjusted change } \\
\text { across PISA assessments }\end{array}$} \\
\hline & & Score dif. & S.E. & Score dif. & S.E. & Score dif. & S.E. & Score dif. & S.E. & Score dif. & S.E. \\
\hline \multirow{38}{*}{ 它 } & Australia & -36 & (6.6) & -22 & $(6.0)$ & -2 & $(6.0)$ & -2 & (3.6) & -2.8 & $(0.3)$ \\
\hline & Austria & -19 & $(7.0)$ & -15 & (6.8) & -1 & $(7.2)$ & $\mathrm{m}$ & $\mathrm{m}$ & -1.6 & $(0.4)$ \\
\hline & Belgium & -12 & $(7.0)$ & -3 & $(6.1)$ & 5 & $(6.5)$ & 3 & $(3.7)$ & -1.0 & $(0.3)$ \\
\hline & Canada & -20 & (6.3) & -10 & $(6.0)$ & -8 & $(6.3)$ & -1 & (3.4) & -1.5 & $(0.3)$ \\
\hline & Chile & 13 & $(7.0)$ & $\mathrm{m}$ & $\mathrm{m}$ & -16 & $(6.9)$ & -8 & $(4.1)$ & 1.1 & $(0.4)$ \\
\hline & Czech Republic & -19 & (6.8) & 7 & (6.7) & 9 & $(7.2)$ & 16 & $(4.0)$ & -1.7 & $(0.4)$ \\
\hline & Denmark & -12 & $(6.6)$ & -8 & $(6.4)$ & 2 & (6.6) & 2 & $(3.7)$ & -1.0 & $(0.3)$ \\
\hline & Estonia & $\mathrm{m}$ & $\mathrm{m}$ & $\mathrm{m}$ & $\mathrm{m}$ & 6 & (6.4) & 14 & (3.8) & 0.7 & $(0.7)$ \\
\hline & Finland & -36 & (6.7) & -25 & $(6.2)$ & -26 & (6.1) & -9 & $(3.8)$ & -2.9 & $(0.3)$ \\
\hline & France & -14 & (6.9) & -3 & (6.5) & 3 & (7.3) & 5 & $(4.7)$ & -1.3 & $(0.3)$ \\
\hline & Germany & 7 & $(7.0)$ & 3 & (6.4) & 10 & $(7.1)$ & 8 & $(4.1)$ & 0.5 & $(0.4)$ \\
\hline & Greece & -5 & $(7.8)$ & -1 & (6.9) & 13 & (6.8) & -4 & $(5.1)$ & -0.4 & $(0.4)$ \\
\hline & Hungary & 0 & $(690.8)$ & 3 & (6.3) & 4 & $(6.7)$ & -2 & $(4.1)$ & 0.5 & $(0.4)$ \\
\hline & Iceland & -37 & (6.4) & -14 & (6.1) & -5 & (6.1) & -18 & (3.5) & -2.3 & $(0.3)$ \\
\hline & Ireland & -19 & (6.8) & -5 & (6.4) & -1 & $(6.7)$ & 26 & $(4.2)$ & -2.2 & $(0.3)$ \\
\hline & Israel & 15 & $(10.1)$ & $\mathrm{m}$ & $\mathrm{m}$ & 47 & (8.5) & 10 & $(6.0)$ & 2.4 & $(0.7)$ \\
\hline & Italy & -4 & (6.6) & 12 & (6.5) & 19 & (6.3) & 5 & $(3.4)$ & 0.0 & $(0.3)$ \\
\hline & Japan & 0 & $(761.0)$ & 27 & $(7.2)$ & 37 & $(6.8)$ & 19 & $(5.1)$ & 3.3 & $(0.5)$ \\
\hline & Korea & 0 & (652.6) & -11 & $(6.7)$ & -24 & (7.3) & -4 & $(5.4)$ & -1.9 & $(0.5)$ \\
\hline & Luxembourg & $\mathrm{m}$ & $\mathrm{m}$ & 22 & $(6.1)$ & 8 & $(5.9)$ & 19 & $(3.2)$ & 1.7 & $(0.3)$ \\
\hline & Mexico & -2 & (6.5) & 20 & $(6.6)$ & 13 & $(6.2)$ & 0 & $(3.4)$ & 0.6 & $(0.3)$ \\
\hline & Netherlands & $\mathrm{m}$ & $\mathrm{m}$ & -13 & $(7.0)$ & 2 & (6.9) & -1 & $(6.3)$ & -1.2 & $(0.5)$ \\
\hline & New Zealand & -17 & (6.8) & -15 & (6.5) & -2 & (6.5) & -2 & $(4.2)$ & -1.5 & $(0.3)$ \\
\hline & Norway & -8 & $(7.0)$ & -3 & $(6.9)$ & 17 & $(7.0)$ & 5 & $(4.3)$ & -0.8 & $(0.3)$ \\
\hline & Poland & 22 & (7.7) & 13 & (6.5) & -5 & (6.6) & 14 & $(4.3)$ & 1.5 & $(0.4)$ \\
\hline & Portugal & 7 & (7.4) & 1 & (7.1) & 6 & $(7.0)$ & 1 & $(4.6)$ & 0.6 & $(0.4)$ \\
\hline & Slovak Republic & $\mathrm{m}$ & $\mathrm{m}$ & -5 & $(6.8)$ & -8 & $(6.9)$ & -10 & $(4.9)$ & -0.5 & $(0.5)$ \\
\hline & Slovenia & $\mathrm{m}$ & $\mathrm{m}$ & $\mathrm{m}$ & $\mathrm{m}$ & -23 & $(5.8)$ & -1 & $(3.0)$ & -4.0 & $(0.5)$ \\
\hline & Spain & -18 & (6.3) & 1 & $(6.2)$ & 20 & (6.1) & 6 & $(3.5)$ & -1.3 & $(0.3)$ \\
\hline & Sweden & -34 & (6.9) & -35 & $(6.6)$ & -24 & (7.1) & -8 & $(4.4)$ & -3.2 & $(0.3)$ \\
\hline & Switzerland & 3 & (7.1) & -1 & $(6.4)$ & 3 & $(6.4)$ & 6 & (3.8) & 0.0 & $(0.3)$ \\
\hline & Turkey & $\mathrm{m}$ & $\mathrm{m}$ & 46 & $(7.5)$ & 33 & $(7.4)$ & 21 & $(5.1)$ & 5.0 & $(0.6)$ \\
\hline & United Kingdom & $\mathrm{m}$ & $\mathrm{m}$ & $\mathrm{m}$ & $\mathrm{m}$ & -2 & $(6.4)$ & 4 & $(4.6)$ & -0.3 & $(0.6)$ \\
\hline & United States & -22 & (8.0) & -3 & $(7.1)$ & $\mathrm{m}$ & $\mathrm{m}$ & 0 & $(4.6)$ & -1.2 & $(0.4)$ \\
\hline & OECD average 2000 & -10 & $(45.1)$ & -3 & $(1.2)$ & 4 & (1.3) & 3 & $(0.8)$ & -0.7 & $(0.1)$ \\
\hline & OECD average 2003 & $\mathrm{~m}$ & $\mathrm{~m}$ & -1 & $(1.2)$ & 4 & $(1.2)$ & 3 & $(0.8)$ & -0.6 & $(0.1)$ \\
\hline & OECD average 2006 & $\mathrm{~m}$ & $\mathrm{~m}$ & $\mathrm{~m}$ & $\mathrm{~m}$ & 3 & $(1.2)$ & 4 & $(0.7)$ & -0.5 & $(0.1)$ \\
\hline & OECD average 2009 & $\mathrm{~m}$ & $\mathrm{~m}$ & $\mathrm{~m}$ & $\mathrm{~m}$ & $\mathrm{~m}$ & $\mathrm{~m}$ & 3 & $(0.8)$ & -0.5 & $(0.1)$ \\
\hline \multirow{30}{*}{ } & Albania & $\mathrm{C}$ & $\mathrm{C}$ & $\mathrm{c}$ & $\mathrm{c}$ & c & c & $\mathrm{c}$ & $\mathrm{c}$ & $\mathrm{c}$ & $\mathrm{c}$ \\
\hline & Argentina & -28 & (9.8) & $\mathrm{m}$ & $\mathrm{m}$ & 19 & $(8.4)$ & 0 & $(5.1)$ & -2.3 & $(0.7)$ \\
\hline & Brazil & 3 & (6.8) & -5 & $(7.0)$ & 9 & $(6.8)$ & -4 & $(4.0)$ & 0.1 & $(0.3)$ \\
\hline & Bulgaria & 1 & $(8.0)$ & $\mathrm{m}$ & $\mathrm{m}$ & 24 & $(8.5)$ & 7 & $(6.9)$ & -0.2 & $(0.5)$ \\
\hline & Colombia & $\mathrm{m}$ & $\mathrm{m}$ & $\mathrm{m}$ & $\mathrm{m}$ & 17 & (7.6) & -9 & $(5.1)$ & 2.7 & $(1.0)$ \\
\hline & Costa Rica & $\mathrm{m}$ & $\mathrm{m}$ & $\mathrm{m}$ & $\mathrm{m}$ & $\mathrm{m}$ & $\mathrm{m}$ & -4 & (6.1) & -1.3 & $(2.0)$ \\
\hline & Croatia & $\mathrm{m}$ & $\mathrm{m}$ & $\mathrm{m}$ & $\mathrm{m}$ & 5 & $(6.8)$ & 11 & $(5.0)$ & 0.8 & $(0.8)$ \\
\hline & Dubai (UAE) & $\mathrm{m}$ & $\mathrm{m}$ & $\mathrm{m}$ & $\mathrm{m}$ & $\mathrm{m}$ & $\mathrm{m}$ & 8 & $(3.2)$ & 2.8 & $(1.0)$ \\
\hline & Hong Kong-China & 5 & (7.3) & 29 & $(7.0)$ & 6 & (6.4) & 8 & $(4.1)$ & 1.4 & $(0.4)$ \\
\hline & Indonesia & 23 & $(7.8)$ & 6 & $(7.8)$ & 0 & $(9.0)$ & -6 & $(5.0)$ & 2.0 & $(0.5)$ \\
\hline & Jordan & $\mathrm{m}$ & $\mathrm{m}$ & $\mathrm{m}$ & $\mathrm{m}$ & -3 & $(7.1)$ & -6 & $(5.1)$ & -0.7 & $(0.8)$ \\
\hline & Kazakhstan & $\mathrm{m}$ & $\mathrm{m}$ & $\mathrm{m}$ & $\mathrm{m}$ & $\mathrm{m}$ & $\mathrm{m}$ & -1 & $(4.4)$ & -0.4 & (1.4) \\
\hline & Latvia & 19 & (8.4) & -1 & $(6.9)$ & 5 & $(6.7)$ & 5 & $(4.0)$ & 1.0 & $(0.5)$ \\
\hline & Liechtenstein & 22 & $(10.1)$ & -23 & $(8.5)$ & -3 & $(7.7)$ & 10 & $(6.0)$ & -0.3 & $(0.6)$ \\
\hline & Lithuania & $\mathrm{m}$ & $\mathrm{m}$ & $\mathrm{m}$ & $\mathrm{m}$ & 2 & $(6.7)$ & 5 & $(3.9)$ & 0.3 & $(0.8)$ \\
\hline & Macao-China & $\mathrm{m}$ & $\mathrm{m}$ & 7 & (6.3) & -23 & $(6.6)$ & 22 & $(2.9)$ & -0.4 & $(0.4)$ \\
\hline & Malaysia & $\mathrm{m}$ & $\mathrm{m}$ & $\mathrm{m}$ & $\mathrm{m}$ & $\mathrm{m}$ & $\mathrm{m}$ & -13 & $(5.8)$ & -4.5 & (1.9) \\
\hline & Montenegro & $\mathrm{m}$ & $\mathrm{m}$ & $\mathrm{m}$ & $\mathrm{m}$ & 16 & (6.1) & 9 & $(3.2)$ & 2.6 & $(0.6)$ \\
\hline & Peru & 52 & (7.1) & $\mathrm{m}$ & $\mathrm{m}$ & $\mathrm{m}$ & $\mathrm{m}$ & 16 & $(4.6)$ & 4.7 & $(0.4)$ \\
\hline & Qatar & $\mathrm{m}$ & $\mathrm{m}$ & $\mathrm{m}$ & $\mathrm{m}$ & 55 & $(5.8)$ & 8 & $(2.9)$ & 8.6 & $(0.5)$ \\
\hline & Romania & -23 & (9.3) & $\mathrm{m}$ & $\mathrm{m}$ & 33 & $(7.7)$ & 12 & $(5.4)$ & 2.1 & $(0.7)$ \\
\hline & Russian Federation & -11 & (7.3) & 17 & $(6.8)$ & 18 & $(7.0)$ & 8 & $(4.5)$ & -0.5 & $(0.4)$ \\
\hline & Serbia & $\mathrm{m}$ & $\mathrm{m}$ & $\mathrm{m}$ & $\mathrm{m}$ & 39 & $(7.3)$ & 4 & $(4.8)$ & 6.6 & $(0.9)$ \\
\hline & Shanghai-China & $\mathrm{m}$ & $\mathrm{m}$ & $\mathrm{m}$ & $\mathrm{m}$ & $\mathrm{m}$ & $\mathrm{m}$ & 11 & $(3.7)$ & 3.6 & $(1.2)$ \\
\hline & Singapore & $\mathrm{m}$ & $\mathrm{m}$ & $\mathrm{m}$ & $\mathrm{m}$ & $\mathrm{m}$ & $\mathrm{m}$ & 13 & $(3.2)$ & 4.4 & $(1.0)$ \\
\hline & Chinese Taipei & $\mathrm{m}$ & $\mathrm{m}$ & $\mathrm{m}$ & $\mathrm{m}$ & 20 & $(6.6)$ & 28 & $(4.1)$ & 3.4 & $(0.7)$ \\
\hline & Thailand & -3 & $(7.0)$ & 7 & $(7.2)$ & 13 & $(6.5)$ & 17 & $(4.3)$ & -0.3 & $(0.4)$ \\
\hline & Tunisia & $\mathrm{m}$ & $\mathrm{m}$ & 18 & $(7.4)$ & 20 & $(8.0)$ & -4 & $(5.2)$ & 2.6 & $(0.6)$ \\
\hline & United Arab Emirates* & $\mathrm{m}$ & $\mathrm{m}$ & $\mathrm{m}$ & $\mathrm{m}$ & $\mathrm{m}$ & $\mathrm{m}$ & -3 & $(6.8)$ & -0.9 & $(2.5)$ \\
\hline & Uruguay & $\mathrm{m}$ & $\mathrm{m}$ & -18 & (6.7) & 2 & $(7.1)$ & -13 & $(4.0)$ & -1.3 & $(0.5)$ \\
\hline
\end{tabular}

Notes: Values that are statistically significant are indicated in bold (see Annex A3).

Annualised change is the average change between the earliest available measurement in PISA and PISA 2012. For countries and economies with more than one available measumed, the 2000 alsed change is Calculated with a rear resion exception of Dubai) implemented the PISA 2009 assessment in 2010 as part of PISA 2009+. Dubai implemented the PISA 2009 assessment in 2009.

Adjusted scores are obtained by estimating a regression of students' demographic characteristics on reading performance with demographic characteristics centred at the 2012 values. Demographic characteristics that entered the model are: students' age, gender, PISA index of economic, social and cultural status, immigrant background (first or second generation) and whether students speak a language at home which is different from the language of instruction. Adjusted values therefore represent average scores in previous assessment assuming that demographic characteristics remained unchanged. See Annex A5 for more details on the estimation of adjusted trends.

For Costa Rica and Malaysia the change between PISA 2009 and PISA 2012 represents change between 2010 and 2012 because these countries implemented the PISA 2009 assessment in 2010 as part of PISA $2009+$

For Chile, Albania, Argentina, Bulgaria, Indonesia, Peru and Thailand, the change between the PISA 2000 and PISA 2012 represents change between 2001 and 2012 because these countries implemented the PISA 2000 assessment in 2001 as part of PISA 2000+.

For Israel and Romania, the change between the PISA 2000 and PISA 2012 represents change between 2002 and 2012 because these countries implemented the PISA 2000 assessment in 2002 as part of PISA 2000+.

* United Arab Emirates excluding Dubai (see note above).

StatLink 需实 http://dx.doi.org/10.1787/888932935705 
[Part 1/1]

Table I.5.1a Percentage of students at each proficiency level in science

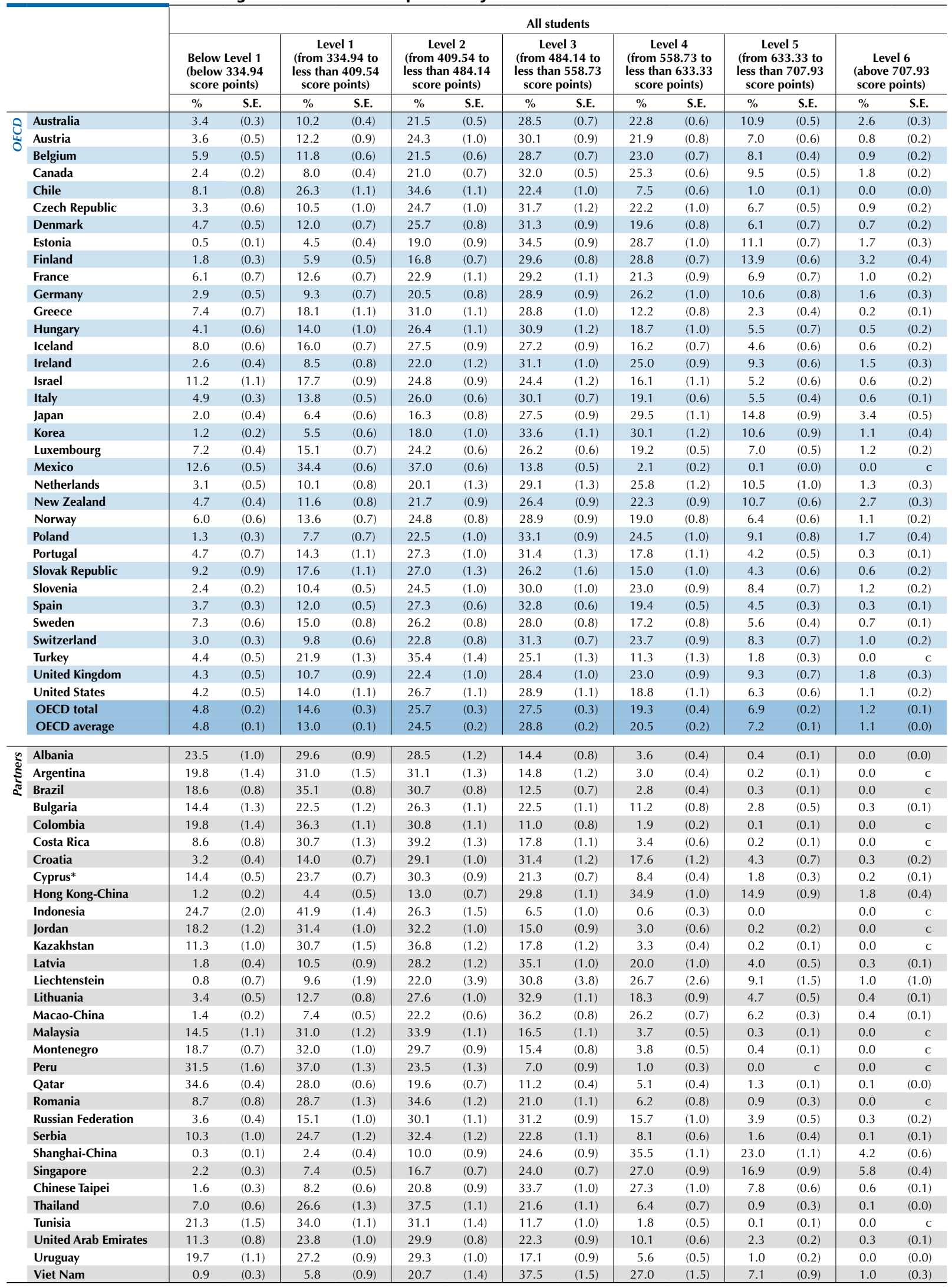

* See notes at the beginning of this Annex.

StatLink 年政 http://dx.doi.org/10.1787/888932935724 
[Part 1/1]

Table I.5.1b Percentage of students below Level 2 and at Level 5 or above in science in PISA 2006 through 2012

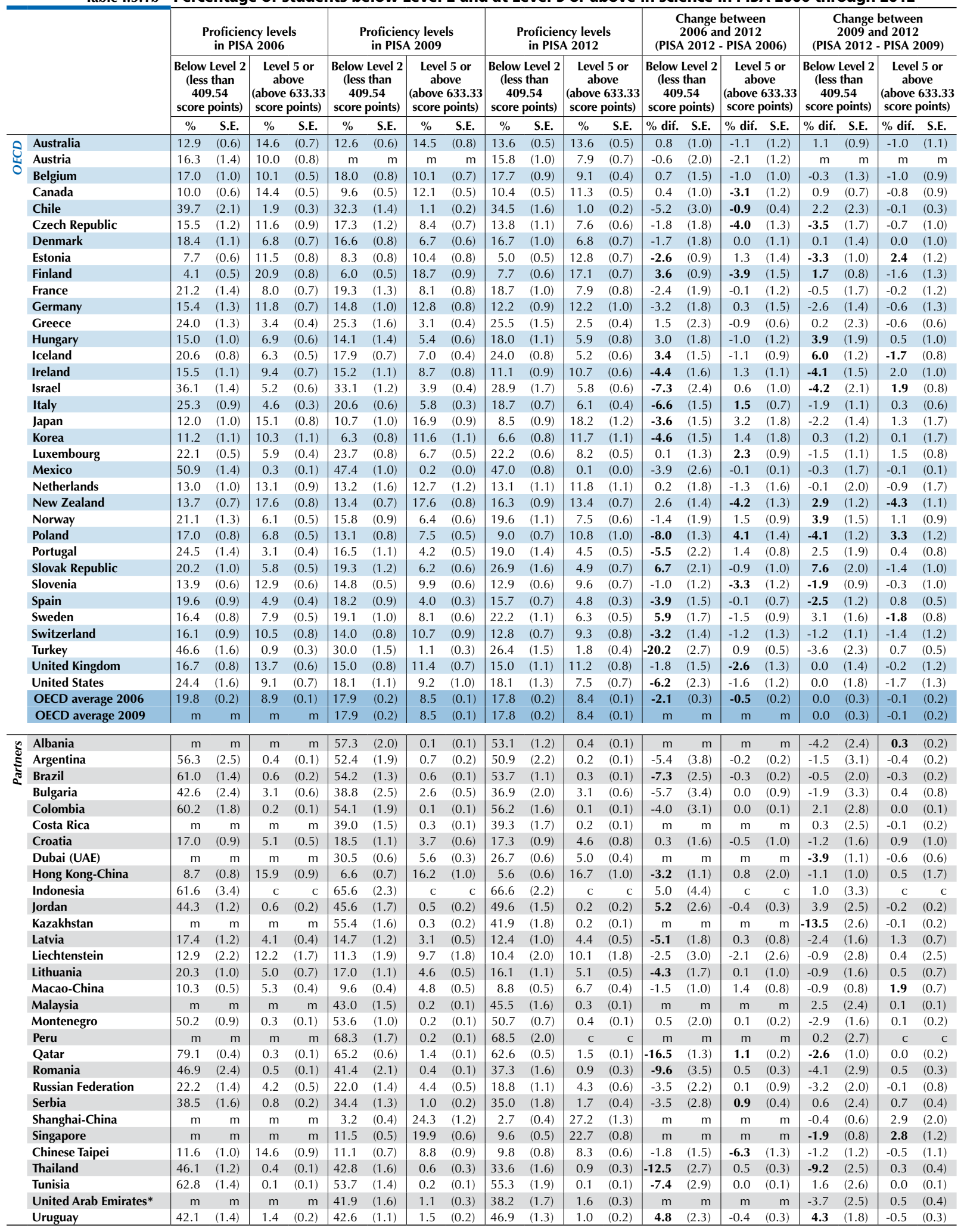

Notes: Values that are statistically significant are indicated in bold (see Annex A3).

In the United Arab Emirates, Dubai took the PISA 2009 assessment in 2009 and the rest of the United Arab Emirates in 2010 as part of PISA $2009+$. Results are thus reported separately.

For Costa Rica and Malaysia the change between PISA 2009 and PISA 2012 represents change between 2010 and 2012 because these countries implemented the PISA 2009 assessment in 2010 as part of PISA $2009+$

* United Arab Emirates excluding Dubai (see note above).

StatLink 需可 http://dx.doi.org/10.1787/888932935724 
[Part 1/2]

Table I.5.2a Percentage of students at each proficiency level in science, by gender

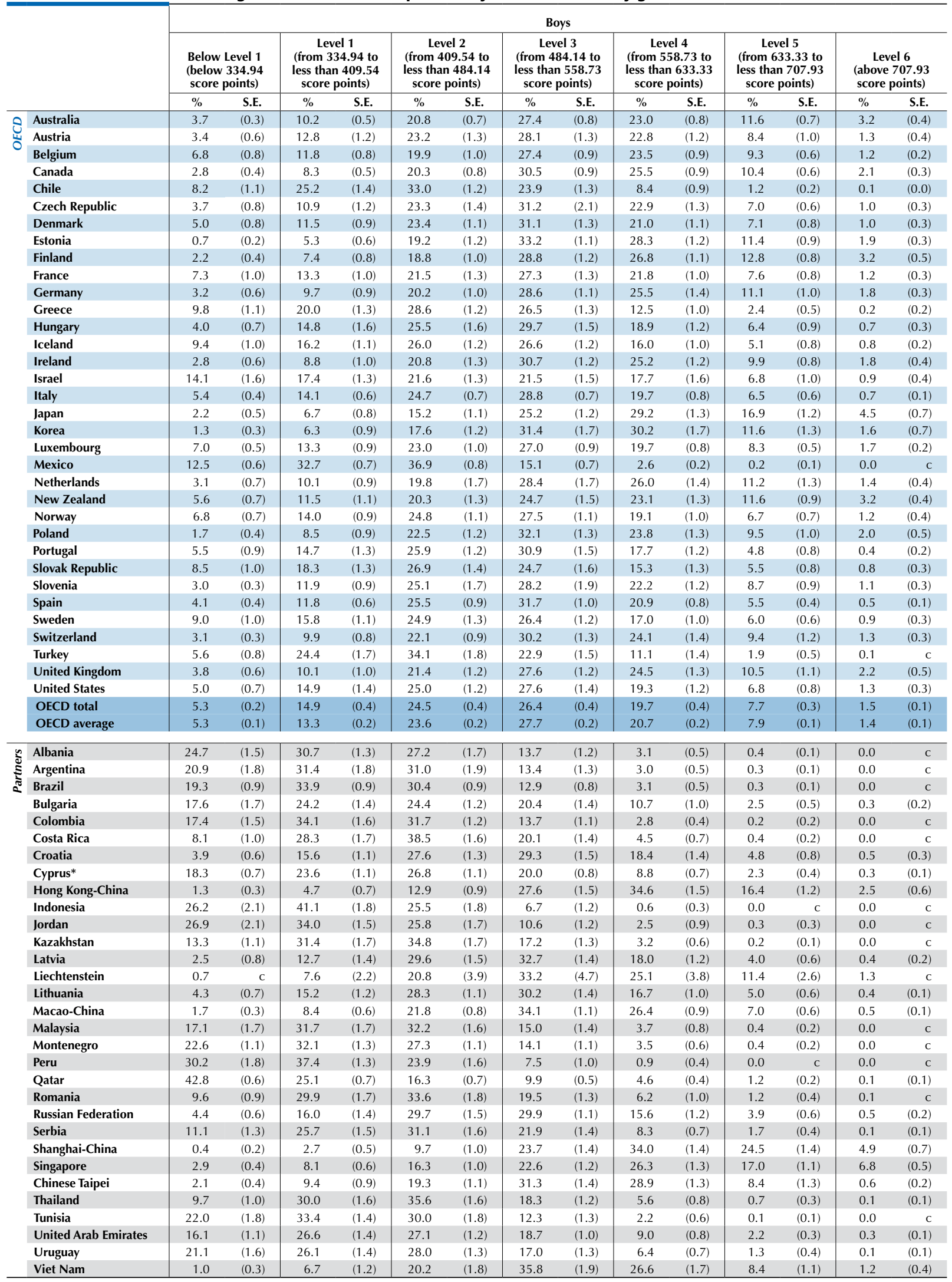

* See notes at the beginning of this Annex.

StatLink 吾Is http://dx.doi.org/10.1787/888932935724 
[Part 2/2]

Table I.5.2a Percentage of students at each proficiency level in science, by gender

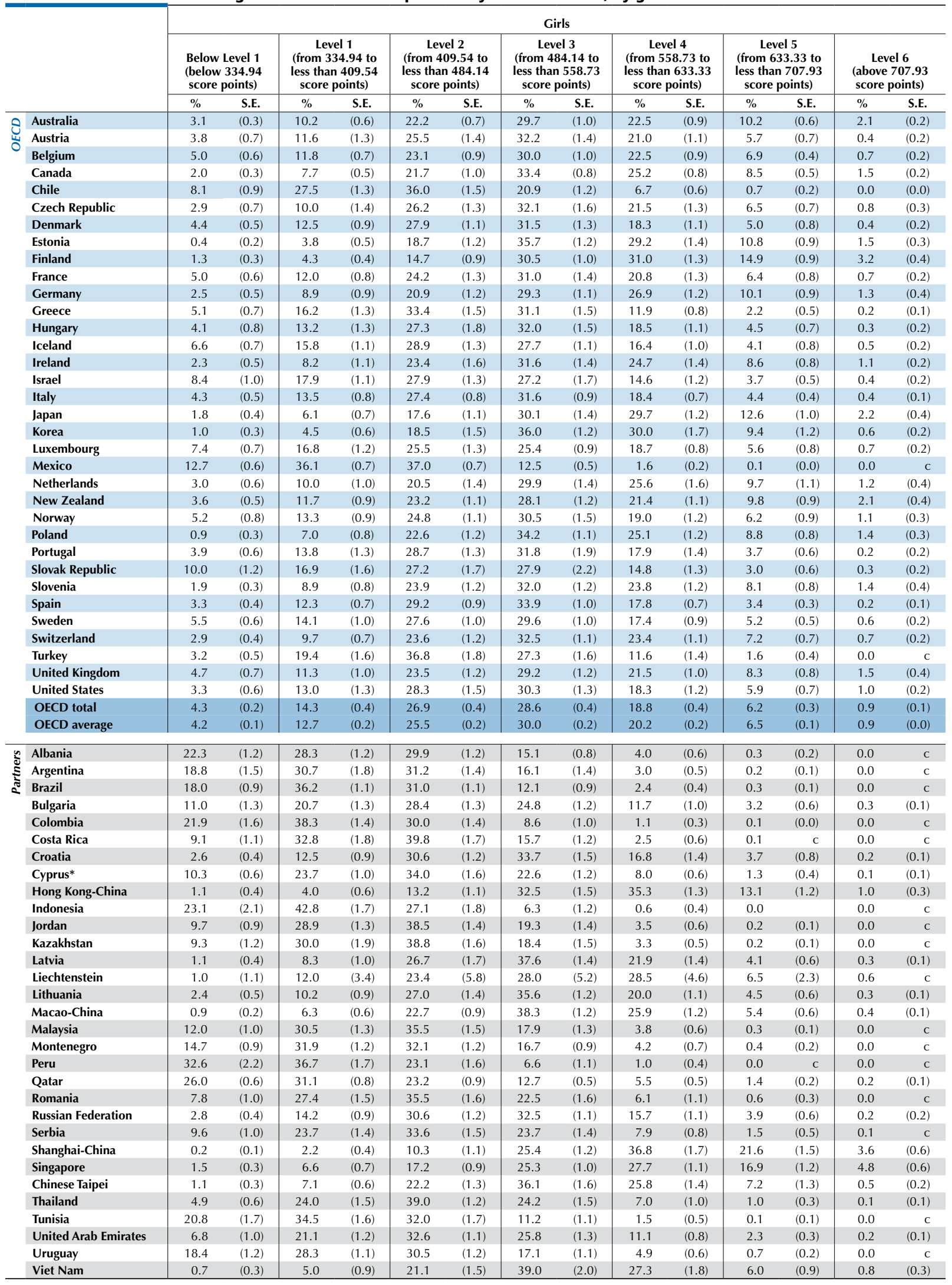

* See notes at the beginning of this Annex.

StatLink त्नाजय http://dx.doi.org/10.1787/888932935724 
[Part 1/2]

Percentage of students below Level 2 and at Level 5 or above in science in PISA 2006 and 2012

Table 1.5.2b by gender

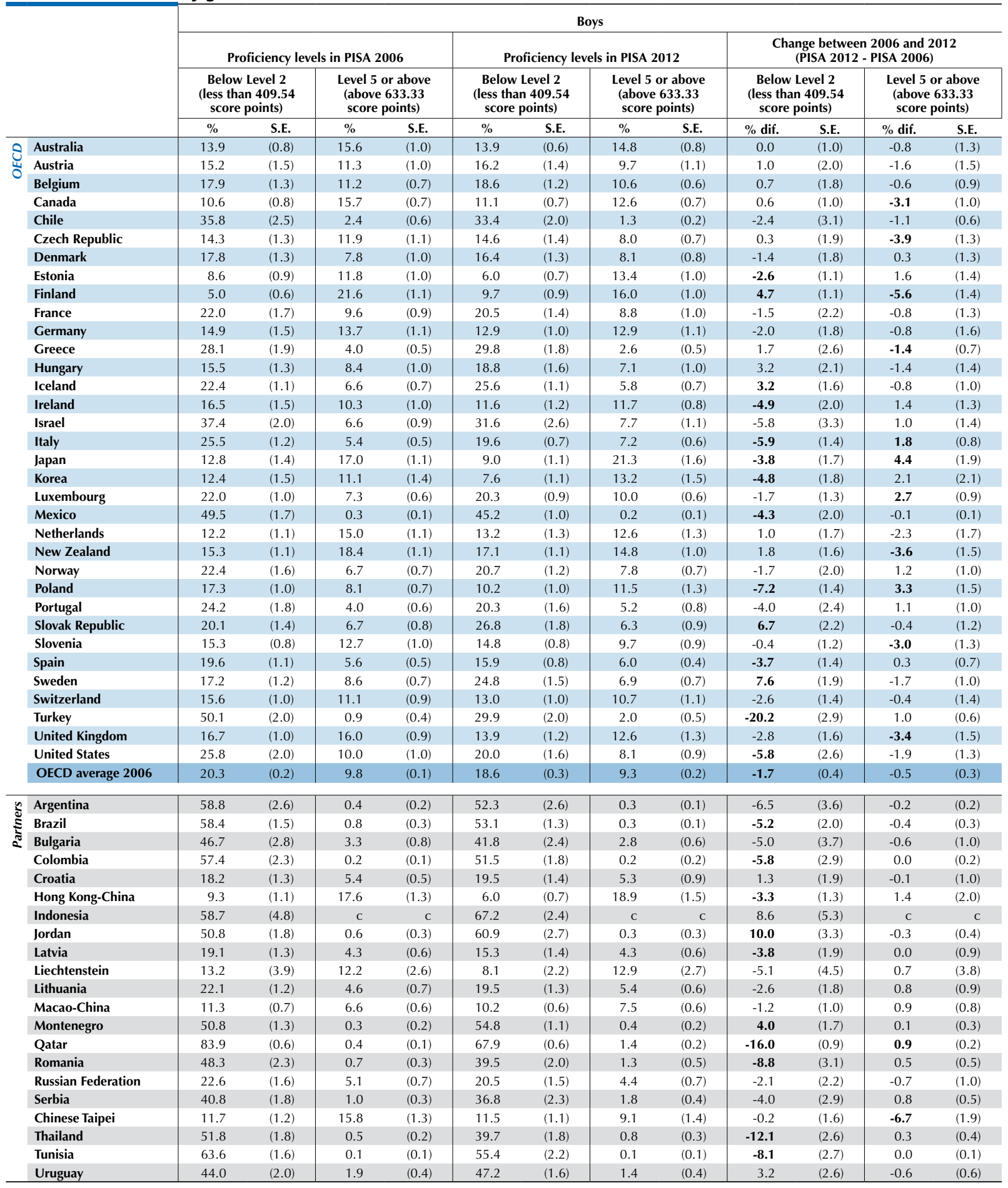

Notes: Values that are statistically significant are indicated in bold (see Annex A3).

Only countries and economies with comparable results in PISA 2006 and PISA 2012 are presented.

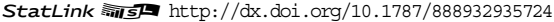


Percentage of students below Level 2 and at Level 5 or above in science in PISA 2006 and 2012,

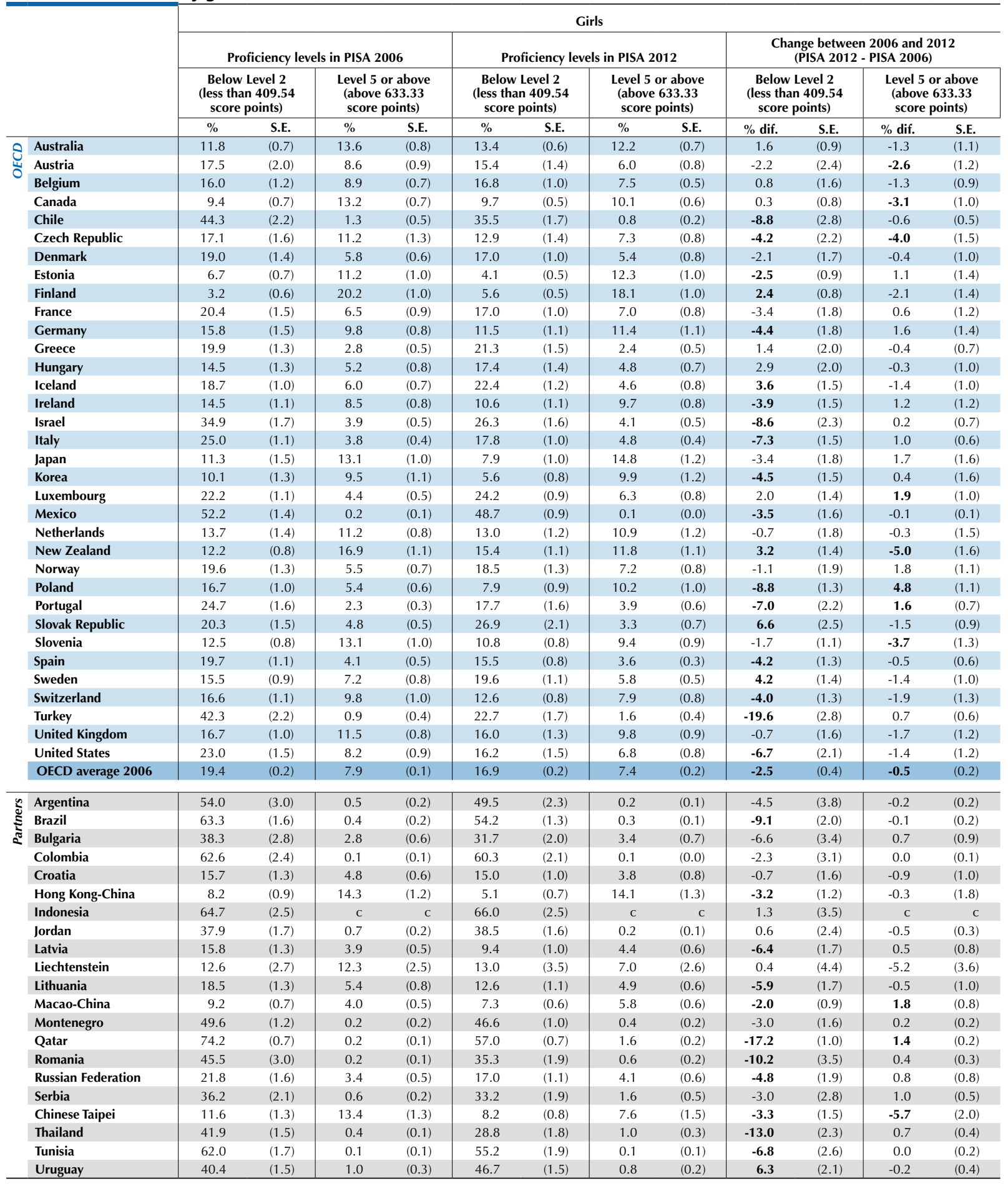

Notes: Values that are statistically significant are indicated in bold (see Annex A3).

Only countries and economies with comparable results in PISA 2006 and PISA 2012 are presented.

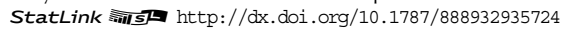


[Part 1/1]

Table I.5.3a Mean score, variation and gender differences in student performance in science

\begin{tabular}{|c|c|c|c|c|c|c|c|c|c|c|c|c|c|c|c|c|c|c|c|c|c|c|c|}
\hline & & \multicolumn{4}{|c|}{ All students } & \multicolumn{6}{|c|}{ Gender differences } & & & & & & Perce & entiles & & & & & \\
\hline & & Mean & score & $\begin{array}{l}\text { Stan } \\
\text { devi }\end{array}$ & $\begin{array}{l}\text { dard } \\
\text { ation }\end{array}$ & Во & ys & Gi & irls & $\begin{array}{c}\text { Diffe } \\
\text { (B }\end{array}$ & & $5 t$ & th & 10 & th & 25 & th & 75 & th & 90 & th & & th \\
\hline & & Mean & S.E. & S.D. & S.E. & $\begin{array}{l}\text { Mean } \\
\text { score }\end{array}$ & S.E. & $\begin{array}{l}\text { Mean } \\
\text { score }\end{array}$ & S.E. & $\begin{array}{c}\text { Score } \\
\text { dif. }\end{array}$ & S.E. & Score & S.E. & Score & S.E. & Score & S.E. & Score & S.E. & Score & S.E. & Score & S.E. \\
\hline$\theta$ & Australia & 521 & $(1.8)$ & 100 & $(1.0)$ & 524 & (2.5) & 519 & $(2.1)$ & 5 & (3.0) & 353 & (3.5) & 391 & (2.6) & 453 & (2.1) & 592 & (2.5) & 650 & (2.7) & 682 & $(2.9)$ \\
\hline & Austria & 506 & $(2.7)$ & 92 & (1.6) & 510 & (3.9) & 501 & (3.4) & 9 & (5.0) & 350 & (4.9) & 383 & (5.3) & 442 & (3.5) & 571 & (3.1) & 623 & (3.4) & 650 & (3.3) \\
\hline & Belgium & 505 & (2.2) & 101 & (1.5) & 507 & (3.0) & 503 & (2.6) & 4 & (3.6) & 326 & $(5.8)$ & 368 & (4.5) & 439 & (3.3) & 577 & (2.5) & 629 & (2.0) & 657 & (2.7) \\
\hline & Canada & 525 & (1.9) & 91 & (0.9) & 527 & (2.4) & 524 & (2.0) & 3 & (2.1) & 370 & (3.3) & 407 & (2.7) & 467 & (2.1) & 588 & (2.4) & 639 & (2.5) & 670 & (3.3) \\
\hline & Chile & 445 & (2.9) & 80 & (1.5) & 448 & (3.7) & 442 & (2.9) & 7 & (3.3) & 317 & $(4.1)$ & 343 & (3.8) & 388 & (3.3) & 500 & (3.6) & 552 & (3.7) & 581 & (3.7) \\
\hline & Czech Republic & 508 & (3.0) & 91 & (2.1) & 509 & (3.7) & 508 & (3.5) & 1 & (4.0) & 356 & $(7.2)$ & 392 & (5.5) & 449 & (4.0) & 572 & (3.2) & 622 & (3.7) & 650 & (3.1) \\
\hline & Denmark & 498 & (2.7) & 93 & (1.7) & 504 & (3.5) & 493 & (2.5) & 10 & (2.7) & 338 & (5.9) & 378 & (4.3) & 438 & (3.8) & 563 & (3.2) & 615 & (4.1) & 644 & (3.7) \\
\hline & Estonia & 541 & (1.9) & 80 & (1.1) & 540 & (2.5) & 543 & (2.3) & -2 & (2.7) & 409 & (3.0) & 439 & (3.3) & 487 & (2.7) & 597 & (2.6) & 645 & (3.1) & 672 & $(4.5)$ \\
\hline & Finland & 545 & (2.2) & 93 & (1.2) & 537 & (3.0) & 554 & (2.3) & -16 & (3.0) & 386 & $(5.7)$ & 424 & (3.9) & 486 & (2.8) & 609 & (2.4) & 662 & (2.9) & 692 & (2.6) \\
\hline & France & 499 & (2.6) & 100 & $(2.2)$ & 498 & (3.8) & 500 & (2.4) & -2 & (3.7) & 323 & (7.8) & 366 & (6.0) & 433 & (3.4) & 570 & (3.0) & 622 & (4.1) & 651 & (4.7) \\
\hline & Germany & 524 & (3.0) & 95 & (2.0) & 524 & (3.1) & 524 & (3.5) & -1 & (3.0) & 361 & (5.6) & 397 & (4.8) & 461 & (3.8) & 592 & (3.1) & 642 & (3.9) & 671 & (3.7) \\
\hline & Greece & 467 & (3.1) & 88 & (1.5) & 460 & (3.8) & 473 & (3.0) & -13 & (3.1) & 317 & (5.2) & 352 & (5.1) & 408 & (4.5) & 528 & (3.5) & 578 & (3.6) & 608 & $(4.1)$ \\
\hline & Hungary & 494 & (2.9) & 90 & (1.9) & 496 & (3.4) & 493 & (3.3) & 3 & (3.3) & 345 & (6.0) & 376 & (4.6) & 432 & (4.3) & 558 & (3.5) & 610 & $(4.7)$ & 639 & (4.0) \\
\hline & Iceland & 478 & (2.1) & 99 & (1.5) & 477 & (2.7) & 480 & (2.9) & -3 & (3.6) & 310 & (5.0) & 348 & (3.4) & 413 & (2.5) & 548 & (3.2) & 603 & (3.7) & 635 & (5.3) \\
\hline & Ireland & 522 & (2.5) & 91 & (1.6) & 524 & (3.4) & 520 & (3.1) & 4 & (4.4) & 366 & (5.8) & 404 & (4.8) & 462 & (3.1) & 586 & (2.4) & 637 & (2.6) & 666 & (3.4) \\
\hline & Israel & 470 & (5.0) & 108 & (2.1) & 470 & (7.9) & 470 & $(4.0)$ & -1 & (7.6) & 286 & $(8.7)$ & 328 & (6.4) & 396 & (5.7) & 548 & (5.7) & 608 & (5.4) & 640 & $(5.1)$ \\
\hline & Italy & 494 & (1.9) & 93 & (1.1) & 495 & (2.2) & 492 & (2.4) & 3 & (2.5) & 336 & (3.2) & 371 & (2.8) & 431 & (2.5) & 559 & (2.0) & 611 & (2.5) & 641 & (2.6) \\
\hline & Japan & 547 & (3.6) & 96 & $(2.2)$ & 552 & (4.7) & 541 & (3.5) & 11 & (4.3) & 379 & (7.0) & 421 & (6.4) & 485 & (4.5) & 614 & (3.6) & 664 & (4.3) & 693 & (4.7) \\
\hline & Korea & 538 & (3.7) & 82 & (1.8) & 539 & (4.7) & 536 & $(4.2)$ & 3 & (5.1) & 396 & (6.3) & 431 & (4.9) & 485 & (4.0) & 595 & (4.1) & 639 & (4.3) & 664 & (5.3) \\
\hline & Luxembourg & 491 & (1.3) & 103 & (1.0) & 499 & (1.7) & 483 & (1.7) & 15 & (2.2) & 318 & (3.6) & 355 & (3.1) & 419 & (2.2) & 566 & (1.9) & 624 & (2.9) & 655 & (2.9) \\
\hline & Mexico & 415 & (1.3) & 71 & (0.9) & 418 & (1.5) & 412 & (1.3) & 6 & (1.1) & 300 & (2.6) & 325 & (2.1) & 368 & (1.6) & 462 & (1.5) & 505 & (1.9) & 532 & (2.1) \\
\hline & Netherlands & 522 & (3.5) & 95 & $(2.2)$ & 524 & (3.7) & 520 & (3.9) & 3 & (2.9) & 357 & (5.9) & 393 & (5.4) & 458 & (5.0) & 591 & (3.9) & 641 & (4.1) & 667 & $(4.0)$ \\
\hline & New Zealand & 516 & (2.1) & 105 & (1.4) & 518 & (3.2) & 513 & (3.3) & 5 & (4.9) & 339 & $(4.5)$ & 377 & (4.5) & 444 & (3.0) & 591 & (3.1) & 649 & (3.0) & 682 & (3.9) \\
\hline & Norway & 495 & (3.1) & 100 & (1.9) & 493 & (3.2) & 496 & (3.7) & -4 & (3.2) & 325 & (6.6) & 365 & (5.2) & 429 & (3.7) & 564 & (3.3) & 620 & (3.4) & 651 & (3.9) \\
\hline & Poland & 526 & (3.1) & 86 & (1.5) & 524 & (3.7) & 527 & (3.2) & -3 & (3.0) & 382 & $(4.7)$ & 415 & (4.0) & 467 & (3.3) & 584 & (4.0) & 637 & (5.0) & 668 & (4.9) \\
\hline & Portugal & 489 & (3.7) & 89 & (1.6) & 488 & (4.1) & 490 & (3.8) & -2 & (2.6) & 337 & (6.0) & 372 & (5.6) & 430 & (4.8) & 551 & (3.6) & 602 & (3.6) & 630 & (4.1) \\
\hline & Slovak Republic & 471 & (3.6) & 101 & (2.8) & 475 & (4.3) & 467 & $(4.2)$ & 7 & (4.5) & 300 & (8.5) & 339 & (5.7) & 403 & (5.2) & 542 & (4.0) & 599 & (4.9) & 632 & (6.3) \\
\hline & Slovenia & 514 & (1.3) & 91 & (1.2) & 510 & (1.9) & 519 & (1.9) & -9 & (2.8) & 364 & (3.0) & 397 & (3.5) & 451 & (2.2) & 578 & (2.0) & 631 & (3.2) & 661 & (3.3) \\
\hline & Spain & 496 & (1.8) & 86 & (0.9) & 500 & (2.3) & 493 & (1.9) & 7 & (2.1) & 349 & (3.9) & 384 & (3.1) & 440 & (2.3) & 557 & (1.8) & 605 & (2.0) & 632 & $(2.0)$ \\
\hline & Sweden & 485 & (3.0) & 100 & (1.5) & 481 & (3.9) & 489 & (2.8) & -7 & (3.3) & 314 & (5.3) & 354 & (4.7) & 419 & (4.1) & 554 & (3.2) & 611 & (3.4) & 643 & (3.1) \\
\hline & Switzerland & 515 & (2.7) & 91 & (1.1) & 518 & (3.3) & 512 & (2.7) & 6 & (2.6) & 358 & (3.8) & 394 & (3.4) & 455 & (3.8) & 579 & (3.1) & 630 & (3.3) & 658 & (4.0) \\
\hline & Turkey & 463 & (3.9) & 80 & (1.9) & 458 & (4.5) & 469 & (4.3) & -10 & (4.2) & 339 & (3.6) & 363 & (3.5) & 407 & (3.5) & 518 & (5.8) & 573 & (6.3) & 602 & (5.9) \\
\hline & United Kingdom & 514 & (3.4) & 100 & (1.8) & 521 & (4.5) & 508 & (3.7) & 13 & (4.7) & 344 & (5.8) & 384 & (4.9) & 448 & (4.6) & 584 & (3.5) & 639 & (3.9) & 672 & (5.0) \\
\hline & United States & 497 & (3.8) & 94 & (1.5) & 497 & (4.1) & 498 & (4.0) & -2 & (2.7) & 344 & (5.4) & 377 & (4.9) & 431 & (4.4) & 563 & (4.2) & 619 & (4.5) & 652 & (5.5) \\
\hline & OECD total & 497 & $(1.2)$ & 98 & $(0.5)$ & 498 & (1.3) & 495 & $(1.2)$ & 3 & (1.0) & 337 & (1.6) & 371 & (1.5) & 428 & (1.5) & 566 & (1.4) & 623 & (1.4) & 655 & (1.7) \\
\hline & OECD average & 501 & $(0.5)$ & 93 & $(0.3)$ & 502 & (0.6) & 500 & $(0.5)$ & 1 & (0.6) & 344 & (0.9) & 380 & (0.8) & 439 & (0.6) & 566 & $(0.6)$ & 619 & (0.6) & 648 & $(0.7)$ \\
\hline & Albania & 397 & (2.4) & 99 & (1.8) & 394 & (3.0) & 401 & (2.9) & -7 & (3.2) & 221 & (7.0) & 271 & $(5.2)$ & 340 & (3.5) & 464 & (3.0) & 517 & (3.3) & 549 & $(5.2)$ \\
\hline & Argentina & 406 & (3.9) & 86 & $(2.2)$ & 402 & (4.5) & 409 & (4.0) & -7 & (3.4) & 262 & (7.9) & 297 & (5.1) & 350 & (4.6) & 464 & (4.7) & 513 & (4.7) & 543 & (5.2) \\
\hline ‡ & Brazil & 405 & (2.1) & 79 & (1.4) & 406 & (2.3) & 404 & (2.3) & 2 & (1.7) & 280 & (2.9) & 306 & (2.3) & 351 & (2.0) & 456 & (2.8) & 507 & (3.7) & 538 & (4.6) \\
\hline & Bulgaria & 446 & (4.8) & 102 & (2.5) & 437 & (5.6) & 457 & (4.6) & -20 & (4.5) & 280 & (7.5) & 315 & (5.3) & 374 & (5.6) & 519 & (5.1) & 580 & (6.1) & 612 & (6.2) \\
\hline & Colombia & 399 & (3.1) & 76 & (1.6) & 408 & (3.4) & 390 & (3.6) & 18 & (3.4) & 273 & (5.2) & 302 & (4.6) & 347 & (3.4) & 449 & (3.5) & 497 & $(4.0)$ & 525 & $(4.2)$ \\
\hline & Costa Rica & 429 & (2.9) & 71 & (1.6) & 436 & (3.5) & 424 & (3.2) & 12 & (3.2) & 315 & (4.1) & 341 & (3.3) & 382 & (3.6) & 476 & (3.6) & 520 & (4.9) & 546 & (5.5) \\
\hline & Croatia & 491 & (3.1) & 85 & (1.8) & 490 & (3.9) & 493 & (3.3) & -2 & (3.8) & 350 & (4.9) & 380 & (4.0) & 433 & (3.3) & 551 & $(4.2)$ & 602 & (5.2) & 630 & (5.9) \\
\hline & Cyprus* & 438 & (1.2) & 97 & (1.1) & 431 & (1.8) & 444 & (1.7) & -13 & (2.5) & 274 & (3.3) & 313 & (2.9) & 373 & (2.0) & 503 & (2.4) & 561 & (2.5) & 594 & (3.4) \\
\hline & Hong Kong-China & 555 & (2.6) & 83 & (1.8) & 558 & (3.6) & 551 & (3.1) & 7 & (4.2) & 403 & (7.1) & 446 & (5.1) & 505 & (3.8) & 613 & (3.0) & 655 & (3.4) & 679 & (3.4) \\
\hline & Indonesia & 382 & (3.8) & 68 & (2.3) & 380 & (4.1) & 383 & (4.1) & -3 & (3.1) & 271 & (5.5) & 297 & (4.9) & 336 & (3.8) & 427 & (4.7) & 471 & (6.0) & 497 & (7.3) \\
\hline & Jordan & 409 & (3.1) & 83 & (2.0) & 388 & (5.4) & 430 & (2.9) & -43 & (6.4) & 271 & (4.9) & 303 & (4.4) & 355 & (3.6) & 466 & (3.4) & 514 & $(4.2)$ & 542 & (6.5) \\
\hline & Kazakhstan & 425 & (3.0) & 74 & (1.5) & 420 & (3.4) & 429 & (3.2) & -9 & (2.9) & 303 & (4.4) & 330 & (3.6) & 375 & (3.4) & 475 & (3.5) & 521 & (3.8) & 547 & (3.8) \\
\hline & Latvia & 502 & (2.8) & 79 & (1.4) & 495 & (3.6) & 510 & (2.8) & -15 & (3.6) & 370 & (5.5) & 400 & (4.5) & 449 & (3.2) & 557 & (3.6) & 603 & (3.2) & 628 & (4.7) \\
\hline & Liechtenstein & 525 & (3.5) & 86 & (4.1) & 533 & (5.8) & 516 & (5.7) & 17 & (9.1) & 383 & (11.1) & 408 & (10.0) & 464 & (8.4) & 588 & $(8.2)$ & 635 & (9.3) & 656 & (12.2) \\
\hline & Lithuania & 496 & (2.6) & 86 & (1.7) & 488 & (3.0) & 503 & (2.6) & -15 & (2.3) & 352 & (6.3) & 383 & (4.0) & 438 & (3.2) & 555 & (3.0) & 605 & (3.6) & 634 & (3.8) \\
\hline & Macao-China & 521 & $(0.8)$ & 79 & $(0.7)$ & 520 & (1.3) & 521 & $(1.2)$ & -1 & (1.7) & 383 & (3.9) & 416 & (2.7) & 469 & (1.9) & 575 & (1.7) & 619 & (1.8) & 643 & (2.3) \\
\hline & Malaysia & 420 & (3.0) & 79 & (1.4) & 414 & (3.8) & 425 & (3.1) & -11 & (3.5) & 293 & (3.9) & 319 & (3.4) & 365 & (3.4) & 473 & (3.6) & 521 & (4.3) & 550 & (5.2) \\
\hline & Montenegro & 410 & (1.1) & 84 & $(1.0)$ & 402 & (1.6) & 419 & (1.6) & -17 & (2.4) & 274 & (3.3) & 302 & (2.9) & 352 & (1.4) & 468 & (2.2) & 522 & (2.3) & 552 & (3.5) \\
\hline & Peru & 373 & (3.6) & 78 & (1.9) & 376 & (3.5) & 370 & (4.6) & 6 & (4.0) & 248 & (4.6) & 275 & (3.8) & 321 & (3.4) & 425 & (4.4) & 475 & (5.4) & 504 & (6.5) \\
\hline & Qatar & 384 & $(0.7)$ & 106 & $(0.7)$ & 367 & $(1.2)$ & 402 & (1.1) & -35 & (1.7) & 222 & (1.9) & 254 & (1.4) & 309 & (1.3) & 453 & (1.6) & 530 & (2.4) & 573 & (2.8) \\
\hline & Romania & 439 & (3.3) & 79 & (2.0) & 436 & (3.7) & 441 & (3.5) & -5 & (3.2) & 316 & (4.0) & 340 & (3.2) & 383 & (3.4) & 492 & (4.6) & 543 & (5.1) & 573 & (5.6) \\
\hline & Russian Federation & 486 & (2.9) & 85 & (1.3) & 484 & (3.5) & 489 & (2.9) & -6 & (2.9) & 347 & (3.8) & 377 & (4.1) & 428 & (3.6) & 544 & (3.3) & 596 & (4.9) & 627 & (5.1) \\
\hline & Serbia & 445 & (3.4) & 87 & (1.9) & 443 & (4.0) & 447 & (3.8) & -4 & (3.9) & 303 & (5.6) & 333 & (5.2) & 385 & $(4.5)$ & 504 & (3.5) & 558 & (3.9) & 590 & (5.8) \\
\hline & Shanghai-China & 580 & (3.0) & 82 & (1.8) & 583 & (3.5) & 578 & (3.1) & 5 & (2.7) & 435 & (6.2) & 472 & (5.4) & 527 & (3.7) & 639 & (3.2) & 681 & (3.2) & 704 & (3.3) \\
\hline & Singapore & 551 & (1.5) & 104 & $(1.2)$ & 551 & (2.1) & 552 & (1.9) & -1 & (2.6) & 374 & (4.0) & 412 & (3.2) & 480 & (2.6) & 627 & (2.6) & 681 & (3.4) & 714 & (3.2) \\
\hline & Chinese Taipei & 523 & (2.3) & 83 & (1.4) & 524 & (3.9) & 523 & $(4.0)$ & 1 & (6.4) & 379 & (4.1) & 411 & (4.3) & 469 & (3.8) & 582 & (2.4) & 626 & $(2.2)$ & 652 & (3.1) \\
\hline & Thailand & 444 & (2.9) & 76 & (1.7) & 433 & (3.3) & 452 & (3.4) & -19 & (3.4) & 323 & (4.3) & 349 & (3.4) & 392 & (2.6) & 494 & (3.8) & 544 & (5.4) & 575 & (6.0) \\
\hline & Tunisia & 398 & (3.5) & 79 & (1.9) & 399 & (3.9) & 398 & (3.6) & 1 & (2.9) & 267 & (4.6) & 296 & (4.6) & 345 & (4.1) & 452 & (4.1) & 497 & (5.1) & 527 & (6.5) \\
\hline & United Arab Emirates & 448 & (2.8) & 94 & (1.1) & 434 & (4.1) & 462 & (3.7) & -28 & (5.1) & 299 & (3.0) & 328 & (3.2) & 382 & (3.5) & 512 & (3.5) & 572 & (3.4) & 605 & (3.7) \\
\hline & Uruguay & 416 & (2.8) & 95 & (1.7) & 415 & (3.4) & 416 & (3.1) & -1 & (3.4) & 256 & (4.8) & 293 & (4.2) & 352 & (3.8) & 480 & (3.4) & 538 & (4.3) & 572 & (5.3) \\
\hline & Viet Nam & 528 & (4.3) & 77 & (2.3) & 529 & (5.0) & 528 & (4.1) & 1 & (2.8) & 398 & (7.7) & 428 & (7.0) & 478 & (5.2) & 580 & (4.0) & 625 & (5.5) & 652 & (6.5) \\
\hline
\end{tabular}

Note: Values that are statistically significant are indicated in bold (see Annex A3)

* See notes at the beginning of this Annex.

StatLink त्नाओst http://dx.doi.org/10.1787/888932935724 
[Part 1/1]

Table I.5.3b Mean science performance in PISA 2006 through 2012

\begin{tabular}{|c|c|c|c|c|c|c|c|c|c|c|c|c|c|c|c|c|c|}
\hline & \multirow{2}{*}{\multicolumn{2}{|c|}{ PISA 2006}} & \multirow{2}{*}{\multicolumn{2}{|c|}{ PISA 2009}} & \multirow{2}{*}{\multicolumn{2}{|c|}{ PISA 2012}} & \multirow{2}{*}{\multicolumn{2}{|c|}{\begin{tabular}{|c} 
Change between \\
2006 and 2012 \\
(PISA 2012 - \\
PISA 2006)
\end{tabular}}} & \multirow{2}{*}{\multicolumn{2}{|c|}{\begin{tabular}{|c|} 
Change between \\
2009 and 2012 \\
(PISA 2012 - \\
PISA 2009)
\end{tabular}}} & & & Curv & $\begin{array}{l}\text { ilinear ch } \\
\text { perfor }\end{array}$ & $\begin{array}{l}\text { ange in } s \\
\text { rmance }\end{array}$ & cience \\
\hline & & & & & & & & & & & & $\begin{array}{r}\text { Annu } \\
\text { chan } \\
\text { scie } \\
\text { acros } \\
\text { assess }\end{array}$ & $\begin{array}{l}\text { Ialised } \\
\text { gge in } \\
\text { ence } \\
\text { s PISA } \\
\text { sments }\end{array}$ & $\begin{array}{r}\text { Annua } \\
\text { in } 201 \\
\text { te }\end{array}$ & $\begin{array}{l}\text { I change } \\
2 \text { (Linear } \\
\text { rm) }\end{array}$ & $\begin{array}{r}\text { Rat } \\
\text { acceler } \\
\text { decele } \\
\text { perfor } \\
\text { (Quadra }\end{array}$ & $\begin{array}{l}\text { e of } \\
\text { ation or } \\
\text { ation in } \\
\text { mance } \\
\text { tic term) }\end{array}$ \\
\hline & & $\begin{array}{l}\text { Mean } \\
\text { score }\end{array}$ & S.E. & $\begin{array}{l}\text { Mean } \\
\text { score }\end{array}$ & S.E. & $\begin{array}{l}\text { Mean } \\
\text { score }\end{array}$ & S.E. & $\begin{array}{c}\text { Score } \\
\text { dif. }\end{array}$ & S.E. & $\begin{array}{c}\text { Score } \\
\text { dif. }\end{array}$ & S.E. & $\begin{array}{l}\text { Annual } \\
\text { change }\end{array}$ & S.E. & Coef. & S.E. & Coef. & S.E. \\
\hline 0 & Australia & 527 & $(2.3)$ & 527 & $(2.5)$ & 521 & $(1.8)$ & -5 & $(4.5)$ & -6 & $(3.7)$ & -0.9 & $(0.77)$ & -3.0 & $(2.00)$ & -0.3 & $(0.36)$ \\
\hline 5 & Austria & 511 & (3.9) & $\mathrm{m}$ & $\mathrm{m}$ & 506 & $(2.7)$ & -5 & (5.9) & $\mathrm{m}$ & $\mathrm{m}$ & -0.8 & $(1.00)$ & $\mathrm{m}$ & $\mathrm{m}$ & $\mathrm{m}$ & $\mathrm{m}$ \\
\hline 0 & Belgium & 510 & (2.5) & 507 & $(2.5)$ & 505 & $(2.2)$ & -5 & $(4.8)$ & -2 & (3.9) & $\mid-0.9$ & $(0.82)$ & -0.2 & $(2.20)$ & 0.1 & $(0.38)$ \\
\hline & Canada & 534 & $(2.0)$ & 529 & (1.6) & 525 & (1.9) & -9 & (4.5) & -3 & (3.2) & -1.5 & $(0.76)$ & -0.7 & $(1.67)$ & 0.1 & $(0.29)$ \\
\hline & Chile & 438 & $(4.3)$ & 447 & (2.9) & 445 & (2.9) & 7 & (6.3) & -3 & (4.6) & 1.1 & (1.03) & -2.8 & $(2.26)$ & -0.7 & $(0.41)$ \\
\hline & Czech Republic & 513 & (3.5) & 500 & $(3.0)$ & 508 & (3.0) & -5 & (5.8) & 8 & $(4.7)$ & -1.0 & $(1.00)$ & 6.0 & $(2.43)$ & 1.1 & $(0.43)$ \\
\hline & Denmark & 496 & (3.1) & 499 & $(2.5)$ & 498 & $(2.7)$ & 3 & (5.4) & -1 & $(4.2)$ & 0.4 & $(0.93)$ & -1.0 & $(2.37)$ & -0.2 & $(0.40)$ \\
\hline & Estonia & 531 & $(2.5)$ & 528 & $(2.7)$ & 541 & (1.9) & 10 & $(4.7)$ & 14 & (3.9) & 1.5 & $(0.84)$ & 7.4 & (1.99) & 1.0 & $(0.36)$ \\
\hline & Finland & 563 & $(2.0)$ & 554 & $(2.3)$ & 545 & $(2.2)$ & -18 & (4.6) & -9 & (3.8) & -3.0 & $(0.77)$ & -2.8 & (1.97) & 0.0 & (0.33) \\
\hline & France & 495 & (3.4) & 498 & (3.6) & 499 & (2.6) & 4 & (5.5) & 1 & (4.9) & 0.6 & $(0.98)$ & -0.1 & $(2.71)$ & -0.1 & $(0.47)$ \\
\hline & Germany & 516 & (3.8) & 520 & $(2.8)$ & 524 & (3.0) & 8 & $(6.0)$ & 4 & (4.5) & 1.4 & (1.03) & 1.1 & (2.54) & -0.1 & $(0.46)$ \\
\hline & Greece & 473 & (3.2) & 470 & $(4.0)$ & 467 & (3.1) & -7 & (5.7) & -3 & (5.5) & -1.1 & (0.95) & -1.2 & $(3.20)$ & 0.0 & $(0.54)$ \\
\hline & Hungary & 504 & $(2.7)$ & 503 & (3.1) & 494 & (2.9) & -10 & (5.3) & -8 & $(4.8)$ & -1.6 & $(0.91)$ & -4.0 & $(2.60)$ & -0.4 & $(0.44)$ \\
\hline & Iceland & 491 & (1.6) & 496 & (1.4) & 478 & $(2.1)$ & -13 & (4.4) & -17 & (3.2) & -2.0 & $(0.71)$ & -9.5 & $(1.63)$ & -1.2 & $(0.28)$ \\
\hline & Ireland & 508 & $(3.2)$ & 508 & (3.3) & 522 & $(2.5)$ & 14 & (5.3) & 14 & (4.5) & 2.3 & $(0.91)$ & 7.1 & $(2.75)$ & 0.8 & $(0.47)$ \\
\hline & Israel & 454 & (3.7) & 455 & $(3.1)$ & 470 & $(5.0)$ & 16 & $(7.1)$ & 15 & $(6.2)$ & 2.8 & (1.18) & 7.5 & $(3.26)$ & 0.8 & $(0.51)$ \\
\hline & Italy & 475 & $(2.0)$ & 489 & (1.8) & 494 & (1.9) & 18 & (4.5) & 5 & (3.3) & 3.0 & $(0.77)$ & 0.1 & (1.64) & -0.5 & $(0.30)$ \\
\hline & Japan & 531 & (3.4) & 539 & (3.4) & 547 & (3.6) & 15 & $(6.1)$ & 7 & (5.4) & 2.6 & $(0.90)$ & 2.3 & $(3.07)$ & 0.0 & $(0.52)$ \\
\hline & Korea & 522 & (3.4) & 538 & (3.4) & 538 & (3.7) & 16 & $(6.1)$ & 0 & (5.4) & 2.6 & $(1.02)$ & -2.7 & (3.34) & -0.9 & $(0.55)$ \\
\hline & Luxembourg & 486 & $(1.1)$ & 484 & $(1.2)$ & 491 & (1.3) & 5 & (3.9) & 7 & $(2.7)$ & 0.9 & $(0.64)$ & 4.0 & $(1.04)$ & 0.5 & $(0.22)$ \\
\hline & Mexico & 410 & $(2.7)$ & 416 & (1.8) & 415 & (1.3) & 5 & $(4.6)$ & -1 & (3.0) & 0.9 & $(0.79)$ & -1.5 & $(1.52)$ & -0.4 & $(0.30)$ \\
\hline & Netherlands & 525 & $(2.7)$ & 522 & (5.4) & 522 & (3.5) & -3 & (5.7) & 0 & $(6.8)$ & -0.5 & $(0.92)$ & 0.4 & $(4.16)$ & 0.1 & (0.69) \\
\hline & New Zealand & 530 & $(2.7)$ & 532 & $(2.6)$ & 516 & $(2.1)$ & -15 & $(4.9)$ & -16 & (3.9) & -2.5 & $(0.81)$ & -8.5 & (2.18) & -1.0 & $(0.40)$ \\
\hline & Norway & 487 & $(3.1)$ & 500 & $(2.6)$ & 495 & $(3.1)$ & 8 & (5.6) & -5 & (4.5) & 1.3 & $(0.92)$ & -4.9 & $(2.41)$ & -1.0 & $(0.41)$ \\
\hline & Poland & 498 & $(2.3)$ & 508 & $(2.4)$ & 526 & (3.1) & 28 & (5.3) & 18 & (4.4) & 4.6 & $(0.90)$ & 7.2 & $(2.46)$ & 0.4 & $(0.39)$ \\
\hline & Portugal & 474 & (3.0) & 493 & $(2.9)$ & 489 & (3.7) & 15 & $(6.0)$ & -4 & (5.1) & 2.5 & (0.99) & -4.9 & (2.94) & -1.2 & $(0.49)$ \\
\hline & Slovak Republic & 488 & $(2.6)$ & 490 & (3.0) & 471 & (3.6) & -17 & (5.7) & -19 & (5.1) & -2.7 & $(0.90)$ & -9.8 & $(2.85)$ & -1.2 & $(0.47)$ \\
\hline & Slovenia & 519 & $(1.1)$ & 512 & $(1.1)$ & 514 & (1.3) & -5 & (3.9) & 2 & (2.6) & -0.8 & $(0.67)$ & 2.4 & $(1.10)$ & 0.5 & $(0.22)$ \\
\hline & Spain & 488 & $(2.6)$ & 488 & $(2.1)$ & 496 & (1.8) & 8 & $(4.7)$ & 8 & (3.4) & 1.3 & $(0.79)$ & 4.1 & $(1.92)$ & 0.5 & $(0.34)$ \\
\hline & Sweden & 503 & $(2.4)$ & 495 & $(2.7)$ & 485 & $(3.0)$ & -19 & $(5.2)$ & -10 & (4.5) & -3.1 & $(0.88)$ & -3.8 & $(2.43)$ & -0.1 & $(0.40)$ \\
\hline & Switzerland & 512 & $(3.2)$ & 517 & (2.8) & 515 & $(2.7)$ & 4 & (5.4) & -1 & (4.4) & 0.6 & $(0.91)$ & -1.5 & $(2.46)$ & -0.4 & $(0.43)$ \\
\hline & Turkey & 424 & (3.8) & 454 & (3.6) & 463 & (3.9) & 40 & (6.5) & 10 & (5.7) & 6.4 & (1.09) & -0.3 & (3.18) & -1.1 & $(0.53)$ \\
\hline & United Kingdom & 515 & $(2.3)$ & 514 & $(2.5)$ & 514 & (3.4) & -1 & (5.4) & 0 & $(4.7)$ & -0.1 & $(0.84)$ & 0.4 & $(2.60)$ & 0.1 & $(0.42)$ \\
\hline & United States & 489 & $(4.2)$ & 502 & $(3.6)$ & 497 & (3.8) & 9 & (6.7) & -5 & (5.6) & 1.4 & $(1.08)$ & -4.5 & $(3.10)$ & -1.0 & $(0.51)$ \\
\hline & OECD average 2006 & 498 & $(0.5)$ & 501 & $(0.5)$ & 501 & $(0.5)$ & 3 & $(0.9)$ & 0 & $(0.8)$ & 0.5 & $(0.15)$ & -0.5 & $(0.42)$ & -0.2 & $(0.07)$ \\
\hline & OECD average 2009 & $\mathrm{~m}$ & $\mathrm{~m}$ & 501 & $(0.5)$ & 501 & $(0.5)$ & $\mathrm{m}$ & $\mathrm{m}$ & 0 & $(0.8)$ & 0.5 & $(0.16)$ & -0.5 & $(0.44)$ & -0.2 & $(0.07)$ \\
\hline in & Albania & $\mathrm{m}$ & $\mathrm{m}$ & 391 & (3.9) & 397 & (2.4) & $\mathrm{m}$ & $\mathrm{m}$ & 7 & $(5.1)$ & 2.2 & (1.63) & $\mathrm{m}$ & $\mathrm{m}$ & $\mathrm{m}$ & $\mathrm{m}$ \\
\hline 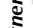 & Argentina & 391 & $(6.1)$ & 401 & $(4.6)$ & 406 & (3.9) & 14 & $(8.0)$ & 5 & (6.3) & 2.4 & $(1.35)$ & 0.8 & $(3.75)$ & -0.3 & $(0.67)$ \\
\hline & Brazil & 390 & $(2.8)$ & 405 & $(2.4)$ & 405 & $(2.1)$ & 14 & $(5.0)$ & -1 & (3.8) & 2.3 & $(0.81)$ & -2.9 & (2.09) & -0.9 & $(0.38)$ \\
\hline & Bulgaria & 434 & $(6.1)$ & 439 & $(5.9)$ & 446 & (4.8) & 12 & (8.5) & 7 & (7.8) & 2.0 & (1.46) & 2.7 & $(4.85)$ & 0.1 & $(0.85)$ \\
\hline & Colombia & 388 & $(3.4)$ & 402 & $(3.6)$ & 399 & $(3.1)$ & 11 & (5.7) & -3 & $(5.2)$ & 1.8 & $(0.97)$ & -3.8 & $(3.17)$ & -0.9 & $(0.53)$ \\
\hline & Costa Rica & $\mathrm{m}$ & $\mathrm{m}$ & 430 & $(2.8)$ & 429 & (2.9) & $\mathrm{m}$ & $\mathrm{m}$ & -1 & (4.5) & -0.6 & (2.04) & $\mathrm{m}$ & $\mathrm{m}$ & $\mathrm{m}$ & $\mathrm{m}$ \\
\hline & Croatia & 493 & $(2.4)$ & 486 & $(2.8)$ & 491 & (3.1) & -2 & $(5.3)$ & 5 & (4.7) & -0.3 & $(0.88)$ & 3.6 & $(2.73)$ & 0.7 & $(0.46)$ \\
\hline & Dubai (UAE) & $\mathrm{m}$ & $\mathrm{m}$ & 466 & $(1.2)$ & 474 & (1.4) & $\mathrm{m}$ & $\mathrm{m}$ & 8 & $(2.7)$ & 2.5 & $(0.92)$ & $\mathrm{m}$ & $\mathrm{m}$ & $\mathrm{m}$ & $\mathrm{m}$ \\
\hline & Hong Kong-China & 542 & $(2.5)$ & 549 & $(2.8)$ & 555 & $(2.6)$ & 13 & $(5.0)$ & 6 & $(4.3)$ & 2.1 & $(0.85)$ & 1.8 & $(2.28)$ & -0.1 & $(0.38)$ \\
\hline & Indonesia & 393 & $(5.7)$ & 383 & (3.8) & 382 & (3.8) & -12 & $(7.7)$ & -1 & (5.7) & -1.9 & (1.33) & 1.5 & $(2.95)$ & 0.6 & $(0.55)$ \\
\hline & Jordan & 422 & $(2.8)$ & 415 & (3.5) & 409 & (3.1) & -13 & (5.5) & -6 & $(5.1)$ & -2.1 & $(0.91)$ & -1.9 & $(2.92)$ & 0.0 & $(0.49)$ \\
\hline & Kazakhstan & $\mathrm{m}$ & $\mathrm{m}$ & 400 & $(3.1)$ & 425 & $(3.0)$ & $\mathrm{m}$ & $\mathrm{m}$ & 24 & $(4.8)$ & 8.1 & $(1.56)$ & $\mathrm{m}$ & $\mathrm{m}$ & $\mathrm{m}$ & $\mathrm{m}$ \\
\hline & Latvia & 490 & $(3.0)$ & 494 & (3.1) & 502 & $(2.8)$ & 13 & $(5.4)$ & 8 & $(4.6)$ & 2.0 & $(0.90)$ & 3.4 & $(2.68)$ & 0.2 & $(0.44)$ \\
\hline & Liechtenstein & 522 & (4.1) & 520 & (3.4) & 525 & (3.5) & 3 & $(6.5)$ & 5 & (5.3) & 0.4 & $(1.03)$ & 2.8 & (2.99) & 0.4 & $(0.51)$ \\
\hline & Lithuania & 488 & $(2.8)$ & 491 & (2.9) & 496 & $(2.6)$ & 8 & $(5.1)$ & 4 & (4.4) & 1.3 & $(0.94)$ & 1.6 & $(2.18)$ & 0.0 & $(0.39)$ \\
\hline & Macao-China & 511 & $(1.1)$ & 511 & $(1.0)$ & 521 & $(0.8)$ & 10 & (3.8) & 10 & (2.4) & 1.6 & $(0.64)$ & 4.7 & $(1.04)$ & 0.5 & $(0.22)$ \\
\hline & Malaysia & $\mathrm{m}$ & $\mathrm{m}$ & 422 & $(2.7)$ & 420 & $(3.0)$ & $\mathrm{m}$ & $\mathrm{m}$ & -3 & $(4.5)$ & -1.4 & (1.96) & $\mathrm{m}$ & $\mathrm{m}$ & $\mathrm{m}$ & $\mathrm{m}$ \\
\hline & Montenegro & 412 & $(1.1)$ & 401 & $(2.0)$ & 410 & (1.1) & -2 & (3.8) & 9 & (3.0) & -0.3 & $(0.64)$ & 6.2 & $(1.63)$ & 1.1 & $(0.29)$ \\
\hline & Peru & $\mathrm{m}$ & $\mathrm{m}$ & 369 & (3.5) & 373 & (3.6) & $\mathrm{m}$ & $\mathrm{m}$ & 4 & (5.4) & 1.3 & (1.94) & $\mathrm{m}$ & $\mathrm{m}$ & $\mathrm{m}$ & $\mathrm{m}$ \\
\hline & Qatar & 349 & $(0.9)$ & 379 & $(0.9)$ & 384 & $(0.7)$ & 34 & (3.7) & 4 & $(2.3)$ & 5.4 & $(0.61)$ & -2.9 & $(0.94)$ & -1.4 & $(0.21)$ \\
\hline & Romania & 418 & $(4.2)$ & 428 & (3.4) & 439 & (3.3) & 20 & (6.4) & 11 & (5.1) & 3.4 & $(1.08)$ & 3.7 & $(2.96)$ & 0.0 & $(0.52)$ \\
\hline & Russian Federation & 479 & (3.7) & 478 & (3.3) & 486 & (2.9) & 7 & (5.8) & 8 & $(4.8)$ & 1.0 & $(1.00)$ & 4.2 & $(2.68)$ & 0.5 & $(0.47)$ \\
\hline & Serbia & 436 & $(3.0)$ & 443 & $(2.4)$ & 445 & (3.4) & 9 & (5.8) & 2 & (4.6) & 1.5 & $(1.03)$ & -0.2 & $(2.61)$ & -0.3 & $(0.42)$ \\
\hline & Shanghai-China & $\mathrm{m}$ & $\mathrm{m}$ & 575 & $(2.3)$ & 580 & $(3.0)$ & $\mathrm{m}$ & $\mathrm{m}$ & 6 & (4.3) & 1.8 & $(1.50)$ & $\mathrm{m}$ & $\mathrm{m}$ & $\mathrm{m}$ & $\mathrm{m}$ \\
\hline & Singapore & $\mathrm{m}$ & $\mathrm{m}$ & 542 & (1.4) & 551 & (1.5) & $\mathrm{m}$ & $\mathrm{m}$ & 10 & $(2.9)$ & 3.3 & $(0.93)$ & $\mathrm{m}$ & $\mathrm{m}$ & $\mathrm{m}$ & $\mathrm{m}$ \\
\hline & Chinese Taipei & 532 & (3.6) & 520 & $(2.6)$ & 523 & $(2.3)$ & -9 & (5.5) & 3 & $(4.0)$ & -1.5 & $(0.92)$ & 3.5 & $(2.31)$ & 0.8 & $(0.42)$ \\
\hline & Thailand & 421 & $(2.1)$ & 425 & $(3.0)$ & 444 & $(2.9)$ & 23 & (5.1) & 19 & (4.6) & 3.9 & $(0.82)$ & 8.6 & $(2.76)$ & 0.8 & $(0.45)$ \\
\hline & Tunisia & 386 & $(3.0)$ & 401 & $(2.7)$ & 398 & (3.5) & 13 & (5.7) & -3 & $(4.8)$ & 2.2 & $(1.03)$ & -3.8 & $(2.54)$ & -1.0 & $(0.42)$ \\
\hline & United Arab Emirates* & $\mathrm{m}$ & $\mathrm{m}$ & 429 & (3.3) & 439 & (3.8) & $\mathrm{m}$ & $\mathrm{m}$ & 10 & (5.4) & 5.1 & $(2.75)$ & $\mathrm{m}$ & $\mathrm{m}$ & $\mathrm{m}$ & $\mathrm{m}$ \\
\hline & Uruguay & 428 & $(2.7)$ & 427 & $(2.6)$ & 416 & $(2.8)$ & -12 & $(5.2)$ & -11 & $(4.3)$ & -2.1 & $(0.91)$ & -5.5 & $(2.09)$ & -0.6 & $(0.35)$ \\
\hline
\end{tabular}

Notes: Values that are statistically significant are indicated in bold (see Annex A3).

Annualised change is the average change between the earliest available and comparable measurement in PISA and PISA 2012, taking into account all available and comparable measurement in between. This estimate considers that Costa Rica. Malaysia and the United Arab Emirates (with the exception of Dubai) implemented the PISA 2009 assessment in 2010 as part of PISA 2009+. Dubai implemented the PISA 2009 assessment in 2009.

The curvilinear change is estimated by a regression of time and time-squared on science performance. The linear term is the estimated annual increase in performance in 2012. The quadratic term is the rate at which changes in performance are accelerating (positive estimate) or decelerating (negative estimate) throughout a country/economy's participation in PISA.

For Costa Rica and Malaysia the change between PISA 2009 and PISA 2012 represents change between 2010 and 2012 because these countries implemented the PISA 2009

In the United Arab Emirates, Dubai took the PISA 2009 assessment in 2009 and the rest of the United Arab Emirates in 2010 as part of PISA 2009+. Results are thus reported separately.

* United Arab Emirates excluding Dubai (see note above).

StatLink त्राड http://dx.doi.org/10.1787/888932935724 
[Part 1/1]

Table I.5.3c Gender differences in science performance in PISA 2006 and 2012

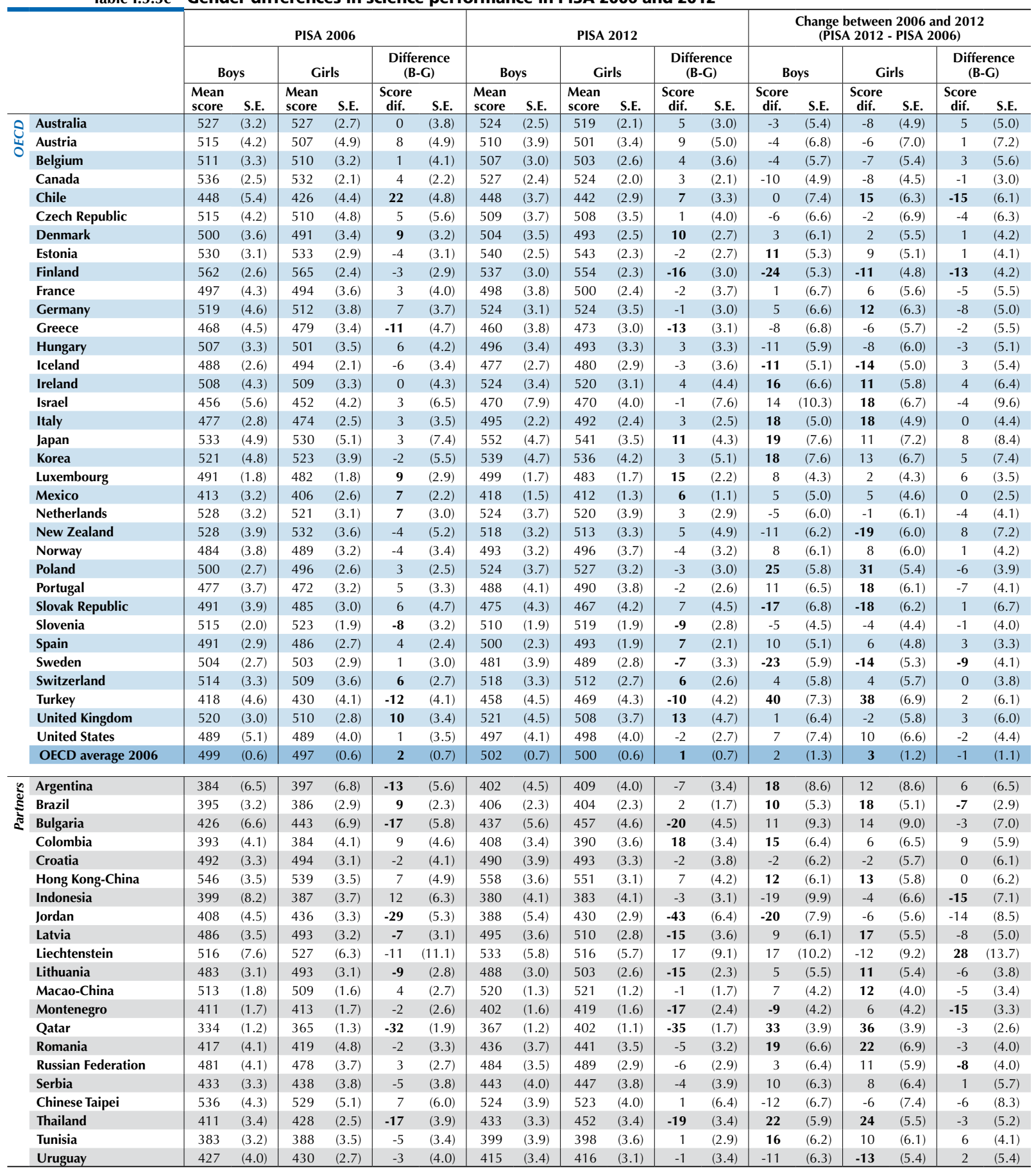

Notes: Values that are statistically significant are indicated in bold (see Annex A3).

Only countries and economies with comparable results in PISA 2006 and PISA 2012 are presented.

StatLink त्ताजय $\mathrm{http}: / / \mathrm{dx} . \mathrm{doi}$. org $/ 10.1787 / 888932935724$ 
[Part 1/3]

Table I.5.3d Distribution of scores in science in PISA 2006 through 2012, by percentiles

\begin{tabular}{|c|c|c|c|c|c|c|c|c|c|c|c|c|c|c|c|c|c|}
\hline & & \multicolumn{8}{|c|}{ PISA 2006} & \multicolumn{8}{|c|}{ PISA 2009} \\
\hline & & \multicolumn{2}{|c|}{ 10th percentile } & \multicolumn{2}{|c|}{ 25th percentile } & \multicolumn{2}{|c|}{ 75th percentile } & \multicolumn{2}{|c|}{ 90th percentile } & 10th pe & centile & 25th pe & centile & 75th pe & centile & 90th pe & centile \\
\hline & & Score & S.E. & Score & S.E. & Score & S.E. & Score & S.E. & Score & S.E. & Score & S.E. & Score & S.E. & Score & S.E. \\
\hline 0 & Australia & 395 & (3.4) & 459 & (2.6) & 598 & (2.5) & 653 & (2.9) & 395 & $(4.0)$ & 461 & (2.8) & 597 & (2.8) & 655 & (3.9) \\
\hline 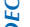 & Austria & 378 & $(6.2)$ & 443 & (5.4) & 582 & $(4.1)$ & 633 & (3.6) & $\mathrm{m}$ & $\mathrm{m}$ & $\mathrm{m}$ & $\mathrm{m}$ & $\mathrm{m}$ & $\mathrm{m}$ & $\mathrm{m}$ & $\mathrm{m}$ \\
\hline & Belgium & 374 & (5.4) & 442 & (3.8) & 584 & $(2.4)$ & 634 & $(2.3)$ & 364 & (4.8) & 438 & (3.6) & 583 & $(2.8)$ & 634 & (3.1) \\
\hline & Canada & 410 & (3.7) & 472 & $(2.5)$ & 601 & $(2.2)$ & 651 & (2.4) & 412 & (2.7) & 469 & $(2.0)$ & 593 & $(1.7)$ & 642 & (1.7) \\
\hline & Chile & 323 & (4.1) & 374 & $(4.0)$ & 501 & (5.9) & 560 & (6.5) & 343 & $(4.1)$ & 392 & (3.5) & 502 & (3.6) & 553 & (3.8) \\
\hline & Czech Republic & 385 & $(5.2)$ & 443 & $(4.6)$ & 583 & (3.9) & 641 & (4.3) & 375 & (5.6) & 437 & (3.9) & 568 & (3.4) & 624 & $(4.0)$ \\
\hline & Denmark & 373 & $(4.8)$ & 432 & $(4.3)$ & 562 & (2.9) & 615 & (3.7) & 379 & (3.9) & 438 & (3.1) & 564 & (2.9) & 615 & (3.7) \\
\hline & Estonia & 422 & (3.8) & 474 & (3.2) & 589 & (3.1) & 640 & (3.3) & 419 & (4.7) & 472 & (3.8) & 586 & (3.1) & 635 & (3.5) \\
\hline & Finland & 453 & (3.3) & 506 & (2.9) & 622 & (2.5) & 673 & (2.9) & 437 & $(4.2)$ & 496 & (3.3) & 617 & (2.9) & 665 & $(3.0)$ \\
\hline & France & 359 & (5.5) & 424 & (5.3) & 570 & $(4.0)$ & 623 & $(4.0)$ & 358 & (7.1) & 433 & $(5.6)$ & 572 & (3.8) & 624 & $(4.2)$ \\
\hline & Germany & 381 & $(7.0)$ & 447 & $(5.3)$ & 587 & (3.6) & 642 & (3.2) & 383 & $(6.2)$ & 452 & $(4.1)$ & 594 & (3.3) & 645 & (3.5) \\
\hline & Greece & 353 & (5.4) & 413 & $(4.4)$ & 537 & (3.3) & 589 & (4.1) & 353 & (6.3) & 409 & (5.3) & 535 & (3.8) & 586 & (3.6) \\
\hline & Hungary & 388 & $(4.2)$ & 442 & (3.5) & 566 & (3.3) & 617 & (3.1) & 388 & (7.6) & 446 & $(4.6)$ & 564 & (3.7) & 609 & (3.6) \\
\hline & Iceland & 364 & (3.1) & 424 & $(2.6)$ & 560 & $(2.3)$ & 614 & (2.9) & 370 & (4.3) & 435 & $(2.6)$ & 561 & $(2.2)$ & 616 & (2.9) \\
\hline & Ireland & 385 & $(4.4)$ & 444 & $(4.6)$ & 575 & (3.4) & 630 & (3.7) & 382 & (4.9) & 445 & $(3.7)$ & 576 & (3.3) & 627 & $(4.0)$ \\
\hline & Israel & 310 & $(5.2)$ & 374 & $(4.8)$ & 535 & (4.6) & 601 & (4.5) & 314 & (5.5) & 382 & $(4.5)$ & 531 & $(3.3)$ & 590 & $(4.0)$ \\
\hline & Italy & 351 & (2.8) & 409 & $(3.0)$ & 543 & (2.4) & 598 & (2.6) & 362 & (2.6) & 424 & $(2.3)$ & 557 & $(2.0)$ & 609 & $(2.0)$ \\
\hline & Japan & 396 & $(6.2)$ & 465 & $(5.1)$ & 603 & (3.1) & 654 & (3.1) & 405 & (7.3) & 477 & $(4.8)$ & 610 & $(3.2)$ & 659 & (3.5) \\
\hline & Korea & 403 & (5.7) & 462 & $(4.1)$ & 586 & (3.8) & 635 & $(4.7)$ & 431 & $(5.2)$ & 485 & $(4.2)$ & 595 & $(3.7)$ & 640 & $(3.7)$ \\
\hline & Luxembourg & 358 & (2.8) & 419 & $(2.0)$ & 556 & (2.4) & 609 & (2.8) & 345 & (3.2) & 415 & $(3.1)$ & 558 & $(2.2)$ & 615 & $(2.2)$ \\
\hline & Mexico & 306 & $(4.2)$ & 354 & $(3.6)$ & 465 & (2.9) & 516 & (3.0) & 318 & $(2.1)$ & 364 & $(1.7)$ & 468 & $(2.1)$ & 517 & $(2.8)$ \\
\hline & Netherlands & 395 & (5.4) & 456 & $(4.7)$ & 596 & (2.6) & 646 & (3.4) & 395 & (7.0) & 453 & (7.6) & 594 & (5.1) & 645 & $(4.8)$ \\
\hline & New Zealand & 389 & (4.5) & 455 & $(3.6)$ & 608 & (2.9) & 667 & (3.3) & 390 & (4.3) & 461 & $(4.1)$ & 608 & (3.0) & 667 & $(3.3)$ \\
\hline & Norway & 365 & (5.6) & 422 & (3.9) & 553 & (3.0) & 610 & (3.5) & 382 & (3.4) & 440 & (3.0) & 563 & (2.9) & 615 & (3.7) \\
\hline & Poland & 381 & (2.9) & 434 & $(2.7)$ & 562 & $(3.1)$ & 615 & (3.3) & 396 & (3.3) & 448 & $(2.7)$ & 569 & $(2.7)$ & 621 & $(2.9)$ \\
\hline & Portugal & 357 & $(4.8)$ & 411 & $(4.2)$ & 539 & $(3.0)$ & 588 & (2.9) & 384 & (3.7) & 436 & (3.7) & 551 & $(3.0)$ & 601 & (3.3) \\
\hline & Slovak Republic & 368 & $(3.7)$ & 426 & $(3.2)$ & 555 & $(4.0)$ & 609 & $(4.1)$ & 371 & (4.9) & 427 & (3.9) & 556 & (3.4) & 612 & $(4.1)$ \\
\hline & Slovenia & 391 & (2.8) & 449 & $(2.7)$ & 589 & $(2.1)$ & 647 & (3.3) & 387 & $(2.3)$ & 446 & $(2.0)$ & 580 & (2.3) & 633 & $(3.0)$ \\
\hline & Spain & 370 & (3.7) & 427 & (3.0) & 552 & (3.1) & 604 & (3.0) & 373 & (3.2) & 431 & (3.0) & 549 & $(2.2)$ & 597 & $(2.2)$ \\
\hline & Sweden & 381 & $(4.0)$ & 439 & (3.3) & 569 & (2.8) & 622 & (2.6) & 367 & (4.6) & 429 & (3.8) & 564 & (3.4) & 622 & (3.9) \\
\hline & Switzerland & 378 & $(4.9)$ & 445 & (3.9) & 584 & (3.5) & 636 & (3.8) & 388 & (3.6) & 452 & (3.5) & 585 & (3.4) & 637 & (3.8) \\
\hline & Turkey & 325 & $(3.2)$ & 366 & (2.6) & 475 & (5.8) & 540 & (9.7) & 350 & $(4.2)$ & 397 & (3.3) & 510 & $(4.6)$ & 560 & $(5.8)$ \\
\hline & United Kingdom & 376 & $(4.3)$ & 441 & (3.2) & 590 & (3.1) & 652 & (2.9) & 385 & (3.6) & 447 & $(3.7)$ & 583 & (3.1) & 640 & (3.3) \\
\hline & United States & 349 & (5.9) & 412 & (5.4) & 567 & (4.6) & 628 & (4.3) & 374 & (4.5) & 433 & (3.9) & 572 & $(4.7)$ & 629 & (5.1) \\
\hline & OECD average 2006 & 373 & $(0.8)$ & 432 & $(0.7)$ & 566 & $(0.6)$ & 620 & $(0.7)$ & 378 & $(0.8)$ & 439 & $(0.7)$ & 567 & $(0.6)$ & 619 & $(0.6)$ \\
\hline & OECD average 2009 & $\mathrm{~m}$ & $\mathrm{~m}$ & $\mathrm{~m}$ & $\mathrm{~m}$ & $\mathrm{~m}$ & $\mathrm{~m}$ & $\mathrm{~m}$ & $\mathrm{~m}$ & 378 & $(0.8)$ & 439 & $(0.7)$ & 567 & $(0.6)$ & 619 & $(0.6)$ \\
\hline 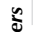 & Albania & $\mathrm{m}$ & $\mathrm{m}$ & $\mathrm{m}$ & $\mathrm{m}$ & $\mathrm{m}$ & $\mathrm{m}$ & $\mathrm{m}$ & $\mathrm{m}$ & 276 & $(4.7)$ & 331 & (4.5) & 454 & (4.8) & 504 & (4.9) \\
\hline$\stackrel{\Xi}{\Xi}$ & Argentina & 259 & $(9.0)$ & 324 & $(7.2)$ & 461 & (6.6) & 520 & (6.5) & 271 & (7.6) & 334 & (5.5) & 471 & (5.5) & 530 & $(6.6)$ \\
\hline 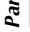 & Brazil & 281 & (3.2) & 328 & (2.3) & 447 & (4.5) & 510 & (5.6) & 302 & $(3.1)$ & 348 & $(2.3)$ & 458 & (3.4) & 517 & $(4.0)$ \\
\hline & Bulgaria & 300 & $(7.1)$ & 358 & (6.4) & 509 & $(7.8)$ & 577 & $(8.2)$ & 302 & (7.0) & 367 & (7.6) & 514 & (6.8) & 575 & $(5.7)$ \\
\hline & Colombia & 280 & $(4.5)$ & 332 & $(4.8)$ & 445 & $(4.7)$ & 496 & (4.6) & 298 & $(6.2)$ & 348 & $(4.7)$ & 457 & (3.6) & 506 & (3.6) \\
\hline & Costa Rica & $\mathrm{m}$ & $\mathrm{m}$ & $\mathrm{m}$ & $\mathrm{m}$ & $\mathrm{m}$ & $\mathrm{m}$ & $\mathrm{m}$ & $\mathrm{m}$ & 336 & (3.7) & 380 & (3.4) & 480 & (3.3) & 526 & (4.6) \\
\hline & Croatia & 383 & (3.8) & 433 & $(3.1)$ & 553 & $(2.7)$ & 604 & (3.2) & 377 & $(4.0)$ & 429 & (3.7) & 546 & (3.5) & 595 & $(4.0)$ \\
\hline & Dubai (UAE) & $\mathrm{m}$ & $\mathrm{m}$ & $\mathrm{m}$ & $\mathrm{m}$ & $\mathrm{m}$ & $\mathrm{m}$ & $\mathrm{m}$ & $\mathrm{m}$ & 330 & (2.5) & 391 & (1.6) & 542 & (1.9) & 606 & (3.0) \\
\hline & Hong Kong-China & 418 & $(6.1)$ & 482 & (3.6) & 609 & $(2.8)$ & 655 & (3.5) & 432 & (4.9) & 494 & $(3.9)$ & 610 & $(2.9)$ & 655 & (2.9) \\
\hline & Indonesia & 307 & (3.5) & 345 & $(4.2)$ & 438 & (8.0) & 488 & $(11.8)$ & 296 & $(4.0)$ & 336 & (3.7) & 428 & $(4.6)$ & 472 & $(6.2)$ \\
\hline & Jordan & 309 & (4.0) & 362 & (2.8) & 484 & (3.5) & 537 & (4.5) & 301 & (5.4) & 357 & $(4.4)$ & 477 & (3.9) & 526 & (4.4) \\
\hline & Kazakhstan & $\mathrm{m}$ & $\mathrm{m}$ & $\mathrm{m}$ & $\mathrm{m}$ & $\mathrm{m}$ & $\mathrm{m}$ & $\mathrm{m}$ & $\mathrm{m}$ & 293 & (4.3) & 342 & (3.4) & 458 & (3.8) & 515 & $(5.1)$ \\
\hline & Latvia & 380 & $(4.2)$ & 432 & (3.7) & 547 & (3.5) & 597 & (3.5) & 392 & (4.5) & 440 & $(4.1)$ & 548 & $(3.2)$ & 593 & $(4.0)$ \\
\hline & Liechtenstein & 393 & $(12.8)$ & 457 & (7.3) & 591 & (7.1) & 643 & (9.4) & 403 & (9.6) & 458 & (7.4) & 583 & $(6.0)$ & 631 & $(9.3)$ \\
\hline & Lithuania & 370 & (3.2) & 425 & (3.3) & 551 & (3.5) & 604 & $(4.2)$ & 382 & (4.9) & 434 & (3.7) & 549 & (3.2) & 600 & (3.9) \\
\hline & Macao-China & 409 & (2.5) & 458 & (1.9) & 566 & (1.8) & 611 & (1.8) & 411 & (1.9) & 461 & (2.0) & 564 & (1.7) & 608 & $(2.5)$ \\
\hline & Malaysia & $\mathrm{m}$ & $\mathrm{m}$ & $\mathrm{m}$ & $\mathrm{m}$ & $\mathrm{m}$ & $\mathrm{m}$ & $\mathrm{m}$ & $\mathrm{m}$ & 324 & (3.5) & 371 & (3.0) & 474 & (3.0) & 519 & $(4.0)$ \\
\hline & Montenegro & 312 & (2.1) & 355 & $(2.2)$ & 466 & $(2.2)$ & 517 & (3.0) & 290 & $(4.1)$ & 343 & (3.0) & 461 & (1.9) & 512 & (3.0) \\
\hline & Peru & $\mathrm{m}$ & $\mathrm{m}$ & $\mathrm{m}$ & $\mathrm{m}$ & $\mathrm{m}$ & $\mathrm{m}$ & $\mathrm{m}$ & $\mathrm{m}$ & 256 & $(4.5)$ & 310 & $(3.7)$ & 428 & $(4.2)$ & 484 & $(6.4)$ \\
\hline & Qatar & 253 & (1.4) & 292 & $(1.8)$ & 396 & (1.4) & 462 & (2.6) & 257 & $(1.7)$ & 306 & $(1.5)$ & 443 & (1.7) & 524 & (2.5) \\
\hline & Romania & 314 & $(5.0)$ & 361 & $(5.2)$ & 473 & (5.7) & 526 & $(5.7)$ & 327 & $(4.2)$ & 373 & (4.4) & 483 & $(4.0)$ & 530 & $(4.2)$ \\
\hline & Russian Federation & 364 & (5.4) & 418 & $(4.4)$ & 541 & $(4.2)$ & 596 & (3.9) & 364 & $(4.7)$ & 418 & $(4.0)$ & 539 & (3.5) & 594 & (4.6) \\
\hline & Serbia & 327 & $(4.0)$ & 377 & (3.8) & 495 & (3.9) & 545 & (3.8) & 334 & (4.4) & 387 & $(3.1)$ & 501 & $(3.0)$ & 548 & (3.3) \\
\hline & Shanghai-China & $\mathrm{m}$ & $\mathrm{m}$ & $\mathrm{m}$ & $\mathrm{m}$ & $\mathrm{m}$ & $\mathrm{m}$ & $\mathrm{m}$ & $\mathrm{m}$ & 467 & (4.3) & 523 & $(3.0)$ & 632 & $(2.8)$ & 674 & (3.4) \\
\hline & Singapore & $\mathrm{m}$ & $\mathrm{m}$ & $\mathrm{m}$ & $\mathrm{m}$ & $\mathrm{m}$ & $\mathrm{m}$ & $\mathrm{m}$ & $\mathrm{m}$ & 401 & (3.1) & 471 & $(2.0)$ & 617 & $(2.0)$ & 673 & (3.0) \\
\hline & Chinese Taipei & 402 & (5.0) & 466 & $(5.3)$ & 602 & (3.4) & 651 & $(2.7)$ & 404 & (3.6) & 464 & $(3.1)$ & 581 & (3.3) & 628 & $(4.3)$ \\
\hline & Thailand & 325 & (3.4) & 368 & $(2.8)$ & 471 & (3.3) & 524 & (3.8) & 326 & (4.8) & 373 & $(3.2)$ & 477 & (3.3) & 527 & $(4.1)$ \\
\hline & Tunisia & 283 & (3.4) & 328 & (2.9) & 440 & $(4.2)$ & 495 & (6.0) & 296 & (3.6) & 345 & (3.2) & 458 & (3.3) & 504 & $(4.5)$ \\
\hline & United Arab Emirates* & $\mathrm{m}$ & $\mathrm{m}$ & $\mathrm{m}$ & $\mathrm{m}$ & $\mathrm{m}$ & $\mathrm{m}$ & $\mathrm{m}$ & $\mathrm{m}$ & 316 & (4.6) & 368 & $(3.8)$ & 490 & $(3.8)$ & 543 & $(4.2)$ \\
\hline & Uruguay & 306 & (4.9) & 363 & $(4.1)$ & 493 & (3.3) & 550 & (3.6) & 303 & (3.6) & 362 & (3.4) & 493 & (3.5) & 551 & (3.8) \\
\hline
\end{tabular}

Notes: Values that are statistically significant are indicated in bold (see Annex A3).

Annualised change is the average change between the earliest available and comparable measurement in PISA and PISA 2012, taking into account all available and comparable measurement in between. This estimate considers that Costa Rica, Malaysia and the United Arab Emirates (with the exception of Dubai) implemented the PISA 2009 assessment in 2010 as part of PISA 2009+. Dubai implemented the PISA 2009 assessment in 2009.

For Costa Rica and Malaysia the change between PISA 2009 and PISA 2012 represents change between 2010 and 2012 because these countries implemented the PISA 2009

In the United Arab Emirates, Dubai took the PISA 2009 assessment in 2009 and the rest of the United Arab Emirates in 2010 as part of PISA 2009+. Results are thus reported separately.

* United Arab Emirates excluding Dubai (see note above).

StatLink त्राड़ http://dx.doi.org/10.1787/888932935724 
[Part 2/3]

Table I.5.3d Distribution of scores in science in PISA 2006 through 2012, by percentiles

\begin{tabular}{|c|c|c|c|c|c|c|c|c|c|}
\hline & \multicolumn{8}{|c|}{ PISA 2012} \\
\hline & & \multicolumn{2}{|c|}{ 10th percentile } & \multicolumn{2}{|c|}{ 25th percentile } & \multicolumn{2}{|c|}{ 75th percentile } & \multicolumn{2}{|c|}{ 90th percentile } \\
\hline & & Score & S.E. & Score & S.E. & Score & S.E. & Score & S.E. \\
\hline \multirow{36}{*}{$\begin{array}{l}\text { Uి } \\
\text { Oे }\end{array}$} & Australia & 391 & (2.6) & 453 & $(2.1)$ & 592 & (2.5) & 650 & (2.7) \\
\hline & Austria & 383 & (5.3) & 442 & (3.5) & 571 & $(3.1)$ & 623 & (3.4) \\
\hline & Belgium & 368 & (4.5) & 439 & (3.3) & 577 & (2.5) & 629 & (2.0) \\
\hline & Canada & 407 & (2.7) & 467 & $(2.1)$ & 588 & (2.4) & 639 & (2.5) \\
\hline & Chile & 343 & (3.8) & 388 & (3.3) & 500 & (3.6) & 552 & (3.7) \\
\hline & Czech Republic & 392 & (5.5) & 449 & (4.0) & 572 & (3.2) & 622 & (3.7) \\
\hline & Denmark & 378 & (4.3) & 438 & (3.8) & 563 & (3.2) & 615 & (4.1) \\
\hline & Estonia & 439 & (3.3) & 487 & $(2.7)$ & 597 & (2.6) & 645 & (3.1) \\
\hline & Finland & 424 & (3.9) & 486 & (2.8) & 609 & (2.4) & 662 & (2.9) \\
\hline & France & 366 & (6.0) & 433 & (3.4) & 570 & (3.0) & 622 & (4.1) \\
\hline & Germany & 397 & (4.8) & 461 & (3.8) & 592 & (3.1) & 642 & (3.9) \\
\hline & Greece & 352 & (5.1) & 408 & (4.5) & 528 & (3.5) & 578 & (3.6) \\
\hline & Hungary & 376 & (4.6) & 432 & (4.3) & 558 & (3.5) & 610 & (4.7) \\
\hline & Iceland & 348 & (3.4) & 413 & (2.5) & 548 & (3.2) & 603 & (3.7) \\
\hline & Ireland & 404 & (4.8) & 462 & (3.1) & 586 & (2.4) & 637 & (2.6) \\
\hline & Israel & 328 & (6.4) & 396 & (5.7) & 548 & (5.7) & 608 & (5.4) \\
\hline & Italy & 371 & (2.8) & 431 & (2.5) & 559 & (2.0) & 611 & (2.5) \\
\hline & Japan & 421 & (6.4) & 485 & (4.5) & 614 & (3.6) & 664 & (4.3) \\
\hline & Korea & 431 & (4.9) & 485 & (4.0) & 595 & $(4.1)$ & 639 & (4.3) \\
\hline & Luxembourg & 355 & (3.1) & 419 & (2.2) & 566 & (1.9) & 624 & (2.9) \\
\hline & Mexico & 325 & (2.1) & 368 & (1.6) & 462 & (1.5) & 505 & (1.9) \\
\hline & Netherlands & 393 & (5.4) & 458 & (5.0) & 591 & (3.9) & 641 & (4.1) \\
\hline & New Zealand & 377 & $(4.5)$ & 444 & (3.0) & 591 & (3.1) & 649 & (3.0) \\
\hline & Norway & 365 & (5.2) & 429 & (3.7) & 564 & (3.3) & 620 & (3.4) \\
\hline & Poland & 415 & $(4.0)$ & 467 & (3.3) & 584 & $(4.0)$ & 637 & (5.0) \\
\hline & Portugal & 372 & (5.6) & 430 & (4.8) & 551 & (3.6) & 602 & (3.6) \\
\hline & Slovak Republic & 339 & (5.7) & 403 & (5.2) & 542 & $(4.0)$ & 599 & (4.9) \\
\hline & Slovenia & 397 & (3.5) & 451 & (2.2) & 578 & (2.0) & 631 & (3.2) \\
\hline & Spain & 384 & (3.1) & 440 & (2.3) & 557 & (1.8) & 605 & $(2.0)$ \\
\hline & Sweden & 354 & $(4.7)$ & 419 & (4.1) & 554 & (3.2) & 611 & (3.4) \\
\hline & Switzerland & 394 & (3.4) & 455 & (3.8) & 579 & (3.1) & 630 & (3.3) \\
\hline & Turkey & 363 & (3.5) & 407 & (3.5) & 518 & (5.8) & 573 & (6.3) \\
\hline & United Kingdom & 384 & (4.9) & 448 & (4.6) & 584 & (3.5) & 639 & (3.9) \\
\hline & United States & 377 & (4.9) & 431 & (4.4) & 563 & $(4.2)$ & 619 & (4.5) \\
\hline & OECD average 2006 & 380 & $(0.8)$ & 439 & $(0.6)$ & 566 & $(0.6)$ & 619 & $(0.6)$ \\
\hline & OECD average 2009 & 380 & (0.8) & 439 & (0.6) & 566 & $(0.6)$ & 619 & $(0.7)$ \\
\hline \multirow{30}{*}{ 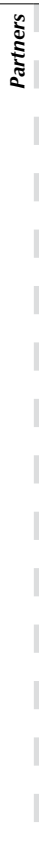 } & Albania & 271 & $(5.2)$ & 340 & (3.5) & 464 & (3.0) & 517 & (3.3) \\
\hline & Argentina & 297 & (5.1) & 350 & (4.6) & 464 & $(4.7)$ & 513 & $(4.7)$ \\
\hline & Brazil & 306 & (2.3) & 351 & (2.0) & 456 & (2.8) & 507 & (3.7) \\
\hline & Bulgaria & 315 & (5.3) & 374 & (5.6) & 519 & (5.1) & 580 & (6.1) \\
\hline & Colombia & 302 & (4.6) & 347 & (3.4) & 449 & (3.5) & 497 & $(4.0)$ \\
\hline & Costa Rica & 341 & (3.3) & 382 & (3.6) & 476 & (3.6) & 520 & (4.9) \\
\hline & Croatia & 380 & $(4.0)$ & 433 & (3.3) & 551 & $(4.2)$ & 602 & (5.2) \\
\hline & Dubai (UAE) & 348 & $(2.7)$ & 404 & (1.9) & 544 & $(2.2)$ & 600 & (2.9) \\
\hline & Hong Kong-China & 446 & (5.1) & 505 & (3.8) & 613 & (3.0) & 655 & (3.4) \\
\hline & Indonesia & 297 & $(4.9)$ & 336 & (3.8) & 427 & $(4.7)$ & 471 & $(6.0)$ \\
\hline & Jordan & 303 & (4.4) & 355 & (3.6) & 466 & (3.4) & 514 & (4.2) \\
\hline & Kazakhstan & 330 & (3.6) & 375 & (3.4) & 475 & (3.5) & 521 & (3.8) \\
\hline & Latvia & 400 & $(4.5)$ & 449 & (3.2) & 557 & (3.6) & 603 & (3.2) \\
\hline & Liechtenstein & 408 & $(10.0)$ & 464 & (8.4) & 588 & $(8.2)$ & 635 & (9.3) \\
\hline & Lithuania & 383 & $(4.0)$ & 438 & (3.2) & 555 & (3.0) & 605 & (3.6) \\
\hline & Macao-China & 416 & $(2.7)$ & 469 & (1.9) & 575 & (1.7) & 619 & (1.8) \\
\hline & Malaysia & 319 & (3.4) & 365 & (3.4) & 473 & (3.6) & 521 & $(4.3)$ \\
\hline & Montenegro & 302 & (2.9) & 352 & (1.4) & 468 & $(2.2)$ & 522 & $(2.3)$ \\
\hline & Peru & 275 & (3.8) & 321 & (3.4) & 425 & (4.4) & 475 & (5.4) \\
\hline & Qatar & 254 & (1.4) & 309 & (1.3) & 453 & (1.6) & 530 & (2.4) \\
\hline & Romania & 340 & (3.2) & 383 & (3.4) & 492 & (4.6) & 543 & (5.1) \\
\hline & Russian Federation & 377 & (4.1) & 428 & (3.6) & 544 & (3.3) & 596 & (4.9) \\
\hline & Serbia & 333 & (5.2) & 385 & $(4.5)$ & 504 & (3.5) & 558 & (3.9) \\
\hline & Shanghai-China & 472 & (5.4) & 527 & $(3.7)$ & 639 & $(3.2)$ & 681 & $(3.2)$ \\
\hline & Singapore & 412 & (3.2) & 480 & (2.6) & 627 & (2.6) & 681 & (3.4) \\
\hline & Chinese Taipei & 411 & (4.3) & 469 & (3.8) & 582 & (2.4) & 626 & $(2.2)$ \\
\hline & Thailand & 349 & (3.4) & 392 & $(2.6)$ & 494 & (3.8) & 544 & $(5.4)$ \\
\hline & Tunisia & 296 & (4.6) & 345 & (4.1) & 452 & $(4.1)$ & 497 & (5.1) \\
\hline & United Arab Emirates* & 323 & (3.9) & 376 & $(4.2)$ & 501 & (4.9) & 558 & (5.3) \\
\hline & Uruguay & 293 & $(4.2)$ & 352 & (3.8) & 480 & (3.4) & 538 & $(4.3)$ \\
\hline
\end{tabular}

Notes: Values that are statistically significant are indicated in bold (see Annex A3).

Annualised change is the average change between the earliest available and comparable measurement in PISA and PISA 2012, taking into account all available and comparable measurement in between. This estimate considers that Costa Rica, Malaysia and the United Arab Emirates (with the exception of Dubai) implemented the PISA 2009 assessment in 2010 as part of PISA 2009+. Dubai implemented the PISA 2009 assessment in 2009.

For Costa Rica and Malaysia the change between PISA 2009 and PISA 2012 represents change between 2010 and 2012 because these countries implemented the PISA 2009

In the United Arab Emirates, Dubai took the PISA 2009 assessment in 2009 and the rest of the United Arab Emirates in 2010 as part of PISA 2009+. Results are thus reported separately.

* United Arab Emirates excluding Dubai (see note above).

StatLink न्ना SD http://dx.doi.org/10.1787/888932935724 
[Part 3/3]

Table I.5.3d Distribution of scores in science in PISA 2006 through 2012, by percentiles

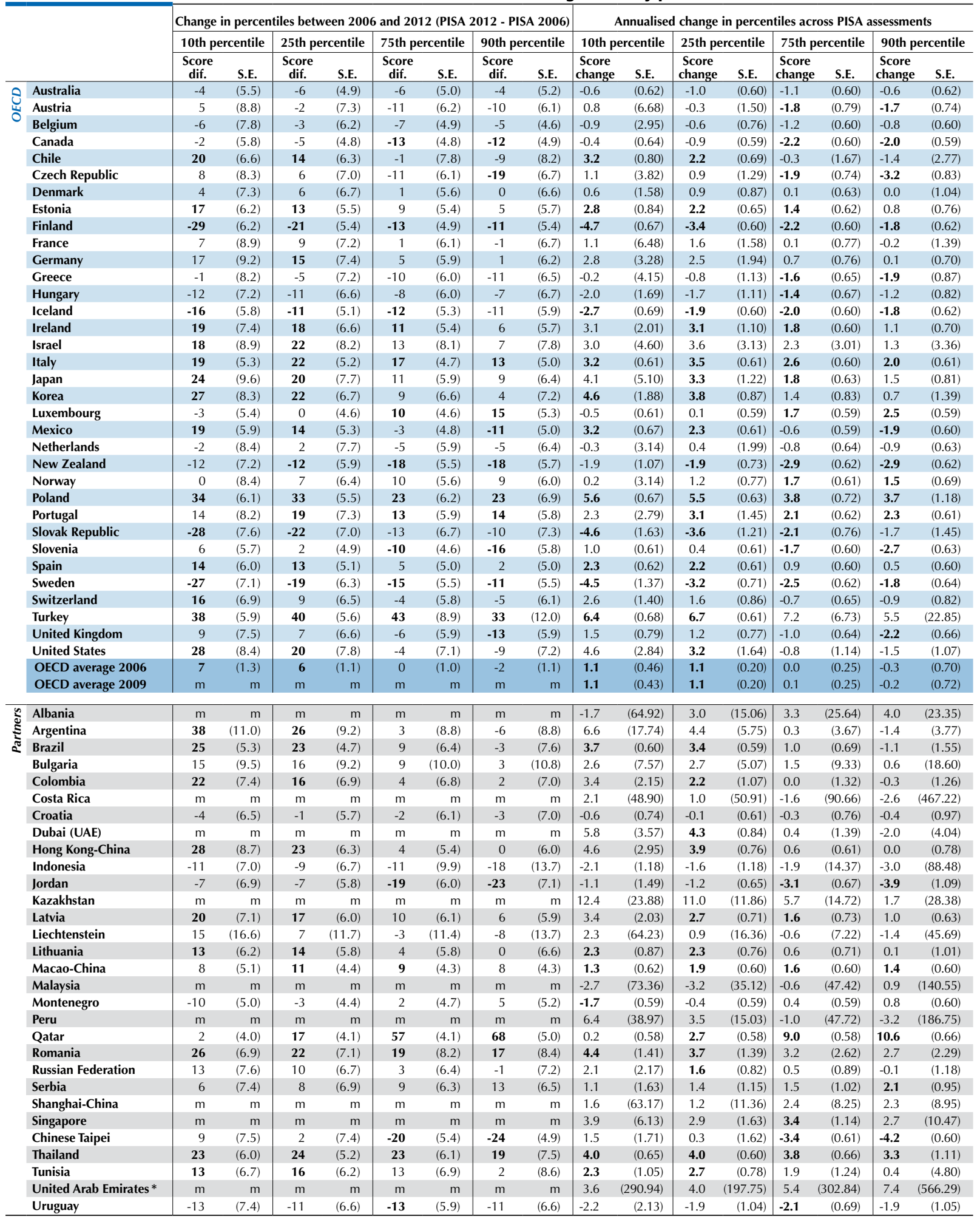

Notes: Values that are statistically significant are indicated in bold (see Annex A3).

Annualised change is the average change between the earliest available and comparable measurement in PISA and PISA 2012, taking into account all available and comparable measurement in between. This estimate considers that Costa Rica, Malaysia and the United Arab Emirates (with the exception of Dubai) implemented the PISA 2009 assessment in . Dubai implemented the PISA 2009 assessment in 2009.

For Costa Rica and Malaysia the change between PISA 2009 and PISA 2012 represents change between 2010 and 2012 because these countries implemented the PISA 2009

In the United Arab Emirates, Dubai took the PISA 2009 assessment in 2009 and the rest of the United Arab Emirates in 2010 as part of PISA 2009+. Results are thus reported separately.

* United Arab Emirates excluding Dubai (see note above).

StatLink त्नाज् http://dx.doi.org/10.1787/888932935724 
[Part 1/1]

Table I.5.4 Trends in science performance adjusted for demographic changes

\begin{tabular}{|c|c|c|c|c|c|c|c|c|c|c|c|c|c|}
\hline & \multicolumn{2}{|c|}{$\begin{array}{c}\text { Adjusted PISA } 2006 \\
\text { results }\end{array}$} & \multicolumn{2}{|c|}{$\begin{array}{c}\text { Adjusted PISA } 2009 \\
\text { results }\end{array}$} & \multicolumn{2}{|c|}{$\begin{array}{l}\text { Adjusted PISA } 2012 \\
\text { results }\end{array}$} & \multicolumn{2}{|c|}{\begin{tabular}{|c|} 
Change between \\
2006 and 2012 \\
(PISA 2012 - PISA 2006)
\end{tabular}} & \multicolumn{2}{|c|}{\begin{tabular}{|c|} 
Change between \\
2009 and 2012 \\
(PISA 2012 - PISA 2009) \\
\end{tabular}} & \multicolumn{2}{|c|}{$\begin{array}{c}\text { Annualised adjusted } \\
\text { change across } \\
\text { PISA assessments }\end{array}$} \\
\hline & & Mean score & S.E. & Mean score & S.E. & Mean score & S.E. & Score dif. & S.E. & Score dif. & S.E. & Score dif. & S.E. \\
\hline \multirow{36}{*}{ Oิ } & Australia & 528 & (1.9) & 527 & (2.2) & 522 & $(1.6)$ & -6 & $(4.3)$ & -6 & (3.4) & -1.1 & $(0.72)$ \\
\hline & Austria & 511 & (3.1) & $\mathrm{m}$ & $\mathrm{m}$ & 506 & $(2.3)$ & -5 & (5.3) & $\mathrm{m}$ & $\mathrm{m}$ & -0.9 & $(0.89)$ \\
\hline & Belgium & 512 & (2.1) & 506 & $(2.1)$ & 505 & (1.8) & -8 & (4.5) & -1 & (3.4) & -1.3 & $(0.76)$ \\
\hline & Canada & 537 & (1.8) & 527 & (1.4) & 525 & $(1.7)$ & -12 & (4.3) & -2 & (3.0) & -1.9 & $(0.72)$ \\
\hline & Chile & 452 & (2.8) & 447 & $(2.5)$ & 445 & $(2.4)$ & -7 & $(5.1)$ & -2 & $(3.7)$ & -1.0 & $(0.86)$ \\
\hline & Czech Republic & 512 & (3.1) & 498 & (2.9) & 508 & (2.6) & -3 & (5.4) & 10 & $(4.0)$ & -0.9 & $(0.94)$ \\
\hline & Denmark & 495 & (2.5) & 499 & $(2.2)$ & 499 & $(2.1)$ & 4 & (4.9) & -1 & (3.8) & 0.6 & $(0.82)$ \\
\hline & Estonia & 540 & (2.3) & 528 & (2.4) & 541 & (1.8) & 1 & (4.6) & 14 & (3.5) & 0.0 & $(0.80)$ \\
\hline & Finland & 568 & (1.8) & 552 & $(2.2)$ & 545 & (1.9) & -22 & $(4.4)$ & -7 & (3.5) & -3.7 & $(0.73)$ \\
\hline & France & 510 & (2.7) & 503 & (3.0) & 499 & $(2.4)$ & -11 & (5.3) & -4 & (4.3) & -1.8 & $(0.89)$ \\
\hline & Germany & 518 & (2.8) & 524 & $(2.1)$ & 524 & (2.6) & 7 & (5.2) & 1 & (3.9) & 1.2 & $(0.89)$ \\
\hline & Greece & 478 & (2.6) & 469 & (3.5) & 467 & (2.6) & -11 & (5.1) & -2 & $(4.7)$ & -1.8 & $(0.85)$ \\
\hline & Hungary & 504 & $(2.2)$ & 498 & (2.6) & 494 & $(2.3)$ & -10 & $(4.8)$ & -4 & (3.9) & -1.7 & $(0.81)$ \\
\hline & Iceland & 495 & (1.7) & 496 & (1.4) & 478 & $(2.1)$ & -17 & $(4.2)$ & -18 & (3.3) & -2.7 & $(0.71)$ \\
\hline & Ireland & 516 & (2.5) & 510 & (3.0) & 522 & $(2.1)$ & 6 & (4.8) & 12 & (4.3) & 1.0 & $(0.81)$ \\
\hline & Israel & 454 & (3.6) & 457 & $(2.7)$ & 470 & $(4.2)$ & 16 & (6.4) & 13 & (5.2) & 2.7 & (1.08) \\
\hline & Italy & 478 & (1.9) & 488 & (1.6) & 494 & $(1.7)$ & 15 & $(4.4)$ & 6 & (3.1) & 2.5 & $(0.75)$ \\
\hline & Japan & 535 & (3.1) & 539 & $(3.2)$ & 547 & (3.3) & 12 & (5.3) & 7 & (5.0) & 2.0 & $(0.88)$ \\
\hline & Korea & 526 & (3.0) & 539 & (3.1) & 475 & (18.7) & 11 & (5.6) & -1 & $(5.2)$ & 1.8 & $(0.94)$ \\
\hline & Luxembourg & 486 & (1.2) & 480 & (1.3) & 492 & $(1.4)$ & 5 & (3.9) & 12 & (2.6) & 0.9 & $(0.65)$ \\
\hline & Mexico & 410 & (2.0) & 414 & (1.5) & 415 & (1.1) & 5 & (4.3) & 1 & $(2.7)$ & 0.9 & $(0.71)$ \\
\hline & Netherlands & 528 & (2.1) & 527 & (4.5) & 522 & $(3.2)$ & -6 & (5.0) & -5 & (6.1) & -1.0 & $(0.85)$ \\
\hline & New Zealand & 524 & (2.5) & 525 & $(2.3)$ & 516 & $(2.1)$ & -8 & $(4.6)$ & -10 & (3.7) & -1.3 & $(0.77)$ \\
\hline & Norway & 489 & (2.8) & 495 & $(2.5)$ & 495 & (2.8) & 6 & $(5.2)$ & 0 & (4.1) & 0.9 & $(0.87)$ \\
\hline & Poland & 512 & (2.1) & 512 & (2.0) & 526 & $(2.5)$ & 14 & (4.9) & 14 & (3.9) & 2.2 & $(0.82)$ \\
\hline & Portugal & 483 & (2.3) & 491 & $(2.2)$ & 489 & $(2.9)$ & 6 & $(5.2)$ & -2 & $(4.1)$ & 0.9 & $(0.87)$ \\
\hline & Slovak Republic & 492 & (2.2) & 487 & (2.8) & 471 & $(2.7)$ & -21 & $(4.7)$ & -16 & (4.4) & -3.5 & $(0.81)$ \\
\hline & Slovenia & 531 & (1.3) & 511 & $(1.2)$ & 514 & $(1.3)$ & -17 & $(4.0)$ & 3 & (2.6) & -2.8 & $(0.68)$ \\
\hline & Spain & 496 & (1.9) & 489 & (1.7) & 496 & $(1.7)$ & 1 & (4.3) & 8 & (3.4) & 0.1 & $(0.72)$ \\
\hline & Sweden & 502 & (2.3) & 489 & $(2.2)$ & 485 & $(2.7)$ & -17 & (5.1) & -4 & (3.9) & -3.0 & $(0.86)$ \\
\hline & Switzerland & 517 & (2.7) & 518 & (2.3) & 515 & $(2.1)$ & -2 & (5.0) & -3 & (3.7) & -0.3 & $(0.84)$ \\
\hline & Turkey & 419 & (3.1) & 445 & (2.9) & 463 & (3.4) & 45 & (5.8) & 19 & $(4.8)$ & 7.4 & $(0.96)$ \\
\hline & United Kingdom & 521 & (2.1) & 515 & (2.0) & 514 & (2.9) & -7 & $(4.7)$ & 0 & $(4.1)$ & -1.1 & $(0.79)$ \\
\hline & United States & 488 & (3.2) & 500 & (2.6) & 497 & $(2.8)$ & 10 & (5.4) & -2 & (4.3) & 1.7 & $(0.91)$ \\
\hline & OECD average 2006 & 502 & $(0.4)$ & 500 & $(0.4)$ & 499 & $(0.7)$ & -1 & $(0.9)$ & 1 & $(0.7)$ & -0.2 & $(0.14)$ \\
\hline & OECD average 2009 & $\mathrm{~m}$ & $\mathrm{~m}$ & 500 & $(0.4)$ & 499 & $(0.7)$ & $\mathrm{m}$ & $\mathrm{m}$ & 1 & $(0.7)$ & -0.1 & $(0.14)$ \\
\hline \multirow{30}{*}{ 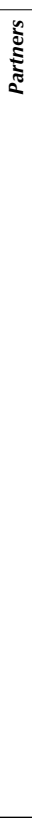 } & Albania & $\mathrm{m}$ & $\mathrm{m}$ & $\mathrm{m}$ & $\mathrm{m}$ & $\mathrm{m}$ & $\mathrm{m}$ & $\mathrm{m}$ & $\mathrm{m}$ & $\mathrm{m}$ & $\mathrm{m}$ & $\mathrm{m}$ & $\mathrm{m}$ \\
\hline & Argentina & 395 & (4.6) & 399 & (3.5) & 406 & (3.2) & 11 & (6.6) & 7 & (5.1) & 1.8 & (1.09) \\
\hline & Brazil & 398 & (2.5) & 408 & (2.0) & 405 & (1.9) & 6 & $(4.7)$ & -3 & (3.4) & 1.0 & $(0.77)$ \\
\hline & Bulgaria & 444 & (4.2) & 439 & (4.4) & 446 & $(3.7)$ & 3 & (6.8) & 7 & (6.0) & 0.3 & (1.16) \\
\hline & Colombia & 389 & (3.0) & 401 & (3.0) & 399 & $(2.6)$ & 9 & $(5.2)$ & -2 & (4.6) & 1.5 & $(0.87)$ \\
\hline & Costa Rica & $\mathrm{m}$ & $\mathrm{m}$ & 432 & (3.7) & 429 & $(2.6)$ & $\mathrm{m}$ & $\mathrm{m}$ & -2 & (5.4) & -0.7 & (1.79) \\
\hline & Croatia & 496 & (2.3) & 483 & (2.6) & 491 & $(2.9)$ & -5 & (4.9) & 8 & $(4.6)$ & -0.8 & $(0.83)$ \\
\hline & Dubai (UAE) & $\mathrm{m}$ & $\mathrm{m}$ & 467 & (1.3) & 474 & $(1.3)$ & $\mathrm{m}$ & $\mathrm{m}$ & 7 & (2.8) & 2.3 & $(0.94)$ \\
\hline & Hong Kong-China & 547 & (2.4) & 552 & (2.5) & 555 & $(2.2)$ & 8 & (4.9) & 2 & $(4.0)$ & 1.4 & $(0.82)$ \\
\hline & Indonesia & 396 & (5.4) & 383 & (3.4) & 382 & (3.3) & -15 & (7.5) & -1 & (4.6) & -2.3 & $(1.24)$ \\
\hline & Jordan & 424 & (2.6) & 416 & (3.1) & 409 & $(2.8)$ & -15 & $(5.2)$ & -6 & $(4.7)$ & -2.4 & $(0.87)$ \\
\hline & Kazakhstan & $\mathrm{m}$ & $\mathrm{m}$ & 403 & (2.9) & 425 & $(2.6)$ & $\mathrm{m}$ & $\mathrm{m}$ & 22 & (4.3) & 7.2 & (1.43) \\
\hline & Latvia & 494 & (2.7) & 494 & (2.6) & 502 & $(2.4)$ & 8 & $(5.0)$ & 8 & (4.3) & 1.2 & $(0.86)$ \\
\hline & Liechtenstein & 534 & (4.6) & 528 & (3.7) & 525 & (3.6) & -8 & (6.5) & -3 & (5.6) & -1.4 & (1.06) \\
\hline & Lithuania & 493 & (2.3) & 495 & $(2.7)$ & 496 & $(2.2)$ & 3 & (5.0) & 1 & (3.8) & 0.5 & $(0.85)$ \\
\hline & Macao-China & 538 & (3.2) & 512 & (1.1) & 520 & $(0.9)$ & -18 & (5.0) & 9 & (2.5) & -1.4 & $(0.71)$ \\
\hline & Malaysia & $\mathrm{m}$ & $\mathrm{m}$ & 416 & (3.5) & 420 & $(2.7)$ & $\mathrm{m}$ & $\mathrm{m}$ & 3 & (5.3) & 1.1 & $(1.77)$ \\
\hline & Montenegro & 423 & (1.7) & 405 & $(1.7)$ & 410 & $(1.1)$ & -12 & $(4.0)$ & 5 & (2.9) & -1.8 & $(0.68)$ \\
\hline & Peru & $\mathrm{m}$ & $\mathrm{m}$ & 368 & (2.5) & 373 & $(2.3)$ & $\mathrm{m}$ & $\mathrm{m}$ & 5 & $(4.1)$ & 1.8 & (1.38) \\
\hline & Qatar & 368 & $(0.9)$ & 387 & $(0.9)$ & 383 & $(0.8)$ & 15 & (3.7) & -4 & (2.4) & 2.0 & $(0.62)$ \\
\hline & Romania & 427 & (3.7) & 429 & (2.9) & 439 & $(2.6)$ & 12 & (5.8) & 10 & (4.5) & 2.0 & $(0.99)$ \\
\hline & Russian Federation & 497 & (2.8) & 486 & (2.9) & 486 & $(2.5)$ & -10 & (5.1) & 1 & (4.3) & -2.0 & $(0.88)$ \\
\hline & Serbia & 441 & $(2.7)$ & 443 & $(2.1)$ & 445 & $(3.1)$ & 3 & (5.7) & 1 & (4.6) & 0.6 & $(0.96)$ \\
\hline & Shanghai-China & $\mathrm{m}$ & $\mathrm{m}$ & 577 & (1.9) & 580 & $(2.5)$ & $\mathrm{m}$ & $\mathrm{m}$ & 3 & (3.8) & 1.0 & $(1.26)$ \\
\hline & Singapore & $\mathrm{m}$ & $\mathrm{m}$ & 545 & (1.4) & 551 & $(1.2)$ & $\mathrm{m}$ & $\mathrm{m}$ & 6 & $(2.7)$ & 2.1 & $(0.92)$ \\
\hline & Chinese Taipei & 538 & (2.9) & 520 & $(2.2)$ & 523 & $(1.7)$ & -15 & (4.9) & 3 & (3.5) & -2.4 & $(0.82)$ \\
\hline & Thailand & 432 & (2.1) & 428 & (2.5) & 444 & $(2.5)$ & 12 & $(4.6)$ & 16 & $(4.2)$ & 2.1 & $(0.76)$ \\
\hline & Tunisia & 389 & (2.5) & 405 & (2.4) & 398 & $(3.0)$ & 9 & (5.5) & -7 & (4.3) & 1.6 & $(0.92)$ \\
\hline & United Arab Emirates* & $\mathrm{m}$ & $\mathrm{m}$ & 440 & $(4.8)$ & 439 & (3.1) & $\mathrm{m}$ & $\mathrm{m}$ & -1 & (6.7) & -0.4 & $(2.37)$ \\
\hline & Uruguay & 424 & (2.5) & 426 & $(2.1)$ & 416 & (2.3) & -8 & (5.2) & -10 & (3.8) & -1.3 & $(0.87)$ \\
\hline
\end{tabular}

Notes: Values that are statistically significant are indicated in bold (see Annex A3).

Annualised change is the average change between the earliest available measurement in PISA and PISA 2012. For countries and economies with more than one available measurement, the annualised change is calculated with a linear regression model. This model considers that Costa Rica, Malaysia and the United Arab Emirates (with the exception of Dubai) implemented the PISA 2009 assessment in 2010 as part of PISA 2009+. Dubai implemented the PISA 2009 assessment in 2009.

Adjusted scores are obtained by estimating a regression of students' demographic characteristics on science performance with demographic characteristics centred at the 2012 values. Demographic characteristics that entered the model are: students' age, gender, PISA index of economic, social and cultural status, immigrant background (first or second generation) and whether students speak a language at home which is different from the language of instruction. Adjusted values therefore represent average scores in previous

For Costa Rica and Malaysia the change between PISA 2009 and PISA 2012 represents change between 2010 and 2012 because these countries implemented the PISA 2009 .

In the United Arab Emirates, Dubai took the PISA 2009 assessment in 2009 and the rest of the United Arab Emirates in 2010 as part of PISA 2009+. Results are thus reported separately.

* United Arab Emirates excluding Dubai (see note above).

StatLink न्नाओs http://dx.doi.org/10.1787/888932935724 
RESULTS FOR REGIONS WITHIN COUNTRIES

Table B2.I.1 Percentage of students at each proficiency level in mathematics, by region

\begin{tabular}{|c|c|c|c|c|c|c|c|c|c|c|c|c|c|c|}
\hline & \multicolumn{14}{|c|}{ All students } \\
\hline & \multicolumn{2}{|c|}{$\begin{array}{c}\text { Below Level } 1 \\
\text { (below } 357.77 \\
\text { score points) }\end{array}$} & $\begin{array}{l}\text { Le } \\
\text { (from } \\
\text { less th } \\
\text { score }\end{array}$ & $\begin{array}{l}1 \\
7.77 \text { to } \\
\mathbf{4 2 0 . 0 7} \\
\text { oints) }\end{array}$ & $\begin{array}{l}\mathrm{L} \\
\text { (from } \\
\text { less th } \\
\text { scor }\end{array}$ & $\begin{array}{l}2 \\
0.07 \text { to } \\
482.38 \\
\text { oints) }\end{array}$ & $\begin{array}{l}\text { Le } \\
\text { (from } \\
\text { less th } \\
\text { score }\end{array}$ & \begin{tabular}{|l|}
3 \\
2.38 to \\
544.68 \\
oints)
\end{tabular} & $\begin{array}{r}\text { Le } \\
\text { (from } \\
\text { less th } \\
\text { scor }\end{array}$ & $\begin{array}{l}4 \\
4.68 \text { to } \\
606.99 \\
\text { oints) }\end{array}$ & $\begin{array}{l}\text { Le } \\
\text { (from } \\
\text { less th } \\
\text { score }\end{array}$ & $\begin{array}{l}5 \\
6.99 \text { to } \\
669.30 \\
\text { oints) }\end{array}$ & $\begin{array}{r}\text { L } \\
\text { (abo } \\
\text { scor }\end{array}$ & $\begin{array}{l}\text { l } 6 \\
669.30 \\
\text { oints) }\end{array}$ \\
\hline & $\%$ & S.E. & $\%$ & S.E. & $\%$ & S.E. & $\%$ & S.E. & $\%$ & S.E. & $\%$ & S.E. & $\%$ & S.E. \\
\hline Australia & & & & & & & & & & & & & & \\
\hline Australian Capital Territory & 5.6 & $(1.0)$ & 9.9 & (1.3) & 19.8 & (1.8) & 25.2 & (1.7) & 21.0 & (1.7) & 13.3 & (1.6) & 5.2 & $(1.0)$ \\
\hline New South Wales & 6.5 & $(0.6)$ & 13.1 & $(0.9)$ & 21.0 & $(1.2)$ & 23.8 & (1.1) & 18.0 & $(0.9)$ & 11.4 & $(0.8)$ & 6.1 & $(0.9)$ \\
\hline Northern Territory & 18.1 & $(2.3)$ & 17.8 & (3.4) & 22.8 & (3.5) & 23.7 & $(3.1)$ & 11.0 & $(2.9)$ & 5.0 & $(2.1)$ & 1.5 & $(0.9)$ \\
\hline Queensland & 5.7 & $(0.8)$ & 14.0 & $(0.8)$ & 21.9 & (1.3) & 24.7 & (1.4) & 19.2 & $(1.1)$ & 10.9 & $(1.1)$ & 3.7 & $(0.5)$ \\
\hline South Australia & 7.2 & $(0.8)$ & 16.1 & $(1.2)$ & 23.8 & (1.6) & 25.1 & $(1.5)$ & 17.3 & (1.4) & 8.4 & $(1.0)$ & 1.9 & $(0.4)$ \\
\hline Tasmania & 10.2 & $(1.0)$ & 16.4 & $(1.4)$ & 25.3 & $(1.8)$ & 24.4 & (1.5) & 14.6 & (1.4) & 7.1 & $(1.1)$ & 2.0 & $(0.6)$ \\
\hline Victoria & 5.7 & $(0.8)$ & 13.7 & $(1.2)$ & 22.8 & $(1.2)$ & 26.1 & (1.3) & 19.6 & $(1.1)$ & 8.9 & $(0.9)$ & 3.2 & $(0.7)$ \\
\hline Western Australia & 4.3 & $(0.6)$ & 11.7 & $(1.0)$ & 21.0 & $(1.4)$ & 22.8 & (1.4) & 22.6 & (1.4) & 12.8 & (1.1) & 4.6 & $(0.7)$ \\
\hline Belgium & & & & & & & & & & & & & & \\
\hline Flemish Community ${ }^{\bullet}$ & 5.5 & $(0.7)$ & 9.9 & $(0.7)$ & 16.5 & $(0.8)$ & 21.5 & $(1.0)$ & 21.4 & $(0.9)$ & 16.5 & $(1.0)$ & 8.8 & $(0.7)$ \\
\hline French Community & 9.0 & $(1.0)$ & 14.8 & $(0.9)$ & 21.0 & $(1.1)$ & 23.6 & $(1.1)$ & 19.5 & $(1.0)$ & 9.4 & $(0.8)$ & 2.6 & $(0.4)$ \\
\hline German-speaking Community & 6.0 & $(0.7)$ & 10.1 & $(1.1)$ & 18.7 & (1.6) & 27.8 & (1.9) & 23.4 & (1.8) & 11.2 & (1.4) & 2.9 & $(0.7)$ \\
\hline Canada & & & & & & & & & & & & & & \\
\hline Alberta & 3.9 & $(0.7)$ & 11.3 & (1.4) & 20.6 & (1.6) & 24.9 & (1.7) & 22.4 & (1.4) & 12.5 & $(1.2)$ & 4.5 & $(0.7)$ \\
\hline British Columbia & 2.6 & $(0.6)$ & 9.6 & $(1.0)$ & 20.3 & (1.3) & 27.4 & (1.3) & 23.5 & (1.4) & 12.1 & (1.2) & 4.4 & $(0.7)$ \\
\hline Manitoba & 6.3 & $(1.0)$ & 14.9 & (1.6) & 25.5 & $(1.3)$ & 24.9 & (1.4) & 18.1 & $(1.1)$ & 7.9 & $(0.8)$ & 2.3 & $(0.5)$ \\
\hline New Brunswick & 4.2 & $(0.7)$ & 12.0 & $(1.1)$ & 23.9 & (1.5) & 29.5 & $(2.2)$ & 20.2 & (1.8) & 8.0 & $(1.4)$ & 2.1 & $(0.7)$ \\
\hline Newfoundland and Labrador & 6.4 & $(1.5)$ & 14.9 & (1.4) & 24.4 & $(1.8)$ & 27.1 & $(1.5)$ & 17.8 & (1.4) & 7.8 & $(1.1)$ & 1.6 & $(0.6)$ \\
\hline Nova Scotia & 4.3 & $(1.1)$ & 13.5 & (1.8) & 25.5 & (3.0) & 28.9 & (1.9) & 18.9 & (1.8) & 7.4 & $(1.1)$ & 1.6 & $(0.5)$ \\
\hline Ontario & 3.8 & $(0.6)$ & 10.0 & $(0.9)$ & 22.6 & $(1.5)$ & 27.3 & $(1.2)$ & 21.3 & $(1.2)$ & 11.0 & $(1.0)$ & 4.0 & $(0.7)$ \\
\hline Prince Edward Island & 6.1 & $(1.0)$ & 18.4 & (1.3) & 26.1 & $(1.7)$ & 26.8 & (1.6) & 15.8 & $(1.2)$ & 5.6 & $(0.9)$ & 1.1 & $(0.4)$ \\
\hline Quebec & 3.0 & $(0.4)$ & 8.2 & $(0.7)$ & 16.4 & $(1.0)$ & 24.2 & $(1.0)$ & 25.9 & $(1.0)$ & 16.2 & $(1.1)$ & 6.2 & (0.6) \\
\hline Saskatchewan & 3.9 & $(0.6)$ & 11.5 & $(1.0)$ & 24.4 & (1.3) & 27.2 & (1.7) & 20.9 & (1.4) & 9.9 & $(1.1)$ & 2.2 & $(0.7)$ \\
\hline Italy & & & & & & & & & & & & & & \\
\hline Abruzzo & 9.8 & $(2.0)$ & 16.9 & (1.6) & 25.8 & (1.9) & 24.8 & $(1.7)$ & 15.7 & (1.9) & 5.8 & (1.1) & 1.2 & $(0.4)$ \\
\hline Basilicata & 10.2 & $(1.3)$ & 20.4 & (1.6) & 27.4 & (1.3) & 24.5 & (1.5) & 12.7 & (1.3) & 3.6 & $(0.6)$ & 1.2 & $(0.3)$ \\
\hline Bolzano & 5.0 & $(0.6)$ & 12.6 & (1.3) & 20.1 & (1.4) & 28.7 & (1.4) & 20.3 & $(1.2)$ & 10.1 & $(0.9)$ & 3.2 & $(0.4)$ \\
\hline Calabria & 21.5 & $(2.5)$ & 24.3 & $(1.8)$ & 26.4 & $(1.8)$ & 18.3 & (1.6) & 6.9 & $(1.0)$ & 2.2 & $(0.6)$ & 0.5 & $(0.2)$ \\
\hline Campania & 14.6 & $(2.0)$ & 21.1 & $(2.3)$ & 27.8 & $(2.1)$ & 20.7 & $(2.5)$ & 11.2 & $(2.0)$ & 3.8 & $(1.0)$ & 0.7 & $(0.3)$ \\
\hline Emilia Romagna & 7.1 & $(1.2)$ & 12.8 & (1.6) & 23.3 & $(2.1)$ & 23.5 & $(1.8)$ & 19.4 & $(1.8)$ & 10.3 & (1.6) & 3.7 & $(1.0)$ \\
\hline Friuli Venezia Giulia & 3.4 & (1.1) & 9.1 & $(1.5)$ & 18.3 & (1.7) & 28.2 & (1.7) & 23.8 & (1.9) & 12.6 & $(1.6)$ & 4.5 & $(0.7)$ \\
\hline Lazio & 9.9 & (1.5) & 18.4 & (1.9) & 25.9 & (1.9) & 23.6 & $(2.0)$ & 14.2 & $(1.7)$ & 6.6 & $(1.2)$ & 1.5 & $(0.5)$ \\
\hline Liguria & 7.3 & (1.3) & 16.0 & (1.5) & 24.4 & $(1.8)$ & 25.9 & (1.7) & 16.1 & (1.8) & 7.8 & (1.3) & 2.5 & $(0.6)$ \\
\hline Lombardia & 3.2 & $(0.8)$ & 10.8 & (1.8) & 20.3 & $(2.1)$ & 27.6 & $(2.3)$ & 22.8 & (1.9) & 11.8 & (1.9) & 3.6 & $(1.0)$ \\
\hline Marche & 5.2 & (1.4) & 14.1 & $(1.5)$ & 24.5 & $(1.8)$ & 27.3 & (1.9) & 18.9 & $(1.7)$ & 8.1 & $(1.2)$ & 1.9 & (0.5) \\
\hline Molise & 9.8 & $(0.9)$ & 20.1 & (1.6) & 27.5 & (2.5) & 25.1 & $(2.2)$ & 12.4 & (1.4) & 3.9 & $(0.9)$ & 1.2 & $(0.6)$ \\
\hline Piemonte & 5.7 & $(0.8)$ & 13.6 & (1.8) & 22.4 & (1.8) & 28.3 & (1.5) & 18.6 & $(1.5)$ & 9.2 & (1.3) & 2.2 & $(0.6)$ \\
\hline Puglia & 8.2 & $(1.5)$ & 18.1 & $(1.7)$ & 25.5 & (1.8) & 24.9 & (1.6) & 16.4 & $(1.5)$ & 6.0 & $(1.1)$ & 1.0 & $(0.3)$ \\
\hline Sardegna & 12.3 & $(1.7)$ & 21.0 & $(2.0)$ & 27.4 & $(2.0)$ & 22.5 & (1.9) & 12.5 & $(1.5)$ & 3.7 & $(0.7)$ & 0.5 & $(0.2)$ \\
\hline Sicilia & 13.6 & (1.6) & 23.6 & $(2.1)$ & 29.2 & (1.9) & 21.9 & (1.8) & 9.1 & $(1.2)$ & 2.1 & $(0.6)$ & 0.4 & $(0.2)$ \\
\hline Toscana & 6.8 & $(0.9)$ & 15.3 & $(1.8)$ & 21.8 & $(2.1)$ & 25.1 & $(1.6)$ & 19.0 & (1.6) & 9.5 & $(1.2)$ & 2.5 & $(0.6)$ \\
\hline Trento & 2.3 & $(0.7)$ & 7.9 & $(1.2)$ & 20.5 & $(1.7)$ & 28.4 & (1.7) & 24.3 & (1.9) & 13.1 & $(1.2)$ & 3.4 & $(0.7)$ \\
\hline Umbria & 7.7 & $(2.2)$ & 13.1 & (1.8) & 22.9 & (1.6) & 27.6 & (1.9) & 19.4 & $(1.6)$ & 7.6 & $(1.2)$ & 1.7 & $(0.5)$ \\
\hline Valle d'Aosta & 5.1 & $(1.0)$ & 14.6 & $(1.4)$ & 26.2 & $(2.2)$ & 28.5 & $(1.7)$ & 16.6 & $(1.7)$ & 6.8 & $(0.9)$ & 2.1 & $(0.7)$ \\
\hline Veneto & 3.7 & $(1.0)$ & 9.8 & (1.6) & 19.4 & $(2.0)$ & 25.5 & $(2.3)$ & 22.9 & $(1.5)$ & 13.8 & $(2.2)$ & 4.8 & (1.5) \\
\hline Mexico & & & & & & & & & & & & & & \\
\hline Aguascalientes & 13.9 & $(2.2)$ & 28.4 & (1.9) & 32.0 & $(2.6)$ & 17.9 & $(2.0)$ & 6.2 & $(1.1)$ & 1.6 & $(0.7)$ & 0.0 & C \\
\hline Baja California & 21.4 & $(2.5)$ & 33.7 & $(2.2)$ & 27.0 & (1.9) & 13.2 & (1.9) & 4.3 & $(1.0)$ & 0.4 & $(0.4)$ & 0.0 & $\mathrm{c}$ \\
\hline Baja California Sur & 22.4 & (3.2) & 32.1 & $(2.0)$ & 27.8 & $(2.2)$ & 13.3 & $(1.7)$ & 3.9 & $(0.8)$ & 0.5 & $(0.3)$ & 0.0 & $\mathrm{c}$ \\
\hline Campeche & 29.6 & $(2.5)$ & 35.4 & $(2.2)$ & 24.4 & (1.9) & 8.1 & (1.0) & 2.0 & $(0.5)$ & 0.4 & $(0.2)$ & 0.0 & $\mathrm{C}$ \\
\hline Chiapas & 42.4 & $(4.5)$ & 32.0 & $(3.0)$ & 18.3 & (2.5) & 5.6 & $(1.2)$ & 1.2 & $(0.5)$ & 0.4 & $(0.2)$ & 0.0 & $\mathrm{C}$ \\
\hline Chihuahua & 17.4 & (2.9) & 29.1 & $(2.7)$ & 30.5 & (2.4) & 15.1 & $(2.0)$ & 6.6 & $(1.5)$ & 1.2 & $(0.6)$ & 0.1 & $\mathrm{C}$ \\
\hline Coahuila & 20.6 & (3.5) & 32.2 & (4.6) & 28.6 & $(2.8)$ & 13.6 & $(2.6)$ & 4.5 & $(1.5)$ & 0.5 & $(0.4)$ & 0.0 & $\mathrm{C}$ \\
\hline Colima & 18.1 & $(1.8)$ & 28.5 & (1.9) & 29.3 & $(2.3)$ & 17.0 & $(2.2)$ & 5.7 & $(1.1)$ & 1.2 & $(0.5)$ & 0.3 & $(0.1)$ \\
\hline Distrito Federal & 16.8 & (1.9) & 30.3 & $(2.7)$ & 30.5 & $(2.2)$ & 15.9 & $(2.3)$ & 5.6 & (1.1) & 0.9 & $(0.4)$ & 0.0 & $\mathrm{C}$ \\
\hline Durango & 18.3 & $(2.8)$ & 30.1 & $(3.0)$ & 28.6 & $(2.7)$ & 18.0 & $(2.7)$ & 4.5 & $(0.9)$ & 0.4 & $(0.3)$ & 0.0 & $\mathrm{c}$ \\
\hline Guanajuato & 24.2 & $(3.1)$ & 31.0 & $(2.2)$ & 27.2 & $(2.2)$ & 13.3 & (1.5) & 4.0 & $(1.0)$ & 0.4 & $(0.3)$ & 0.0 & $\mathrm{C}$ \\
\hline Guerrero & 46.9 & $(2.4)$ & 32.9 & $(2.3)$ & 15.1 & (1.8) & 4.3 & $(0.7)$ & 0.8 & $(0.4)$ & 0.1 & $(0.1)$ & 0.0 & c \\
\hline Hidalgo & 25.2 & $(2.8)$ & 32.7 & $(2.2)$ & 27.0 & (3.0) & 11.9 & (1.8) & 2.7 & $(0.6)$ & 0.3 & $(0.3)$ & 0.0 & $\mathrm{c}$ \\
\hline Jalisco & 13.9 & $(2.2)$ & 28.6 & $(2.4)$ & 32.3 & $(2.3)$ & 18.9 & $(2.0)$ & 5.3 & $(1.2)$ & 1.0 & $(0.4)$ & 0.1 & $\mathrm{C}$ \\
\hline Mexico & 18.1 & $(2.5)$ & 33.8 & $(2.4)$ & 32.2 & $(2.1)$ & 13.2 & $(1.7)$ & 2.1 & $(0.8)$ & 0.5 & $(0.4)$ & 0.1 & $\mathrm{C}$ \\
\hline Morelos & 20.5 & (3.5) & 31.1 & $(2.7)$ & 27.9 & $(2.6)$ & 13.6 & (1.5) & 5.1 & (1.8) & 1.5 & $(1.0)$ & 0.2 & $(0.3)$ \\
\hline Nayarit & 23.7 & $(3.0)$ & 29.8 & $(2.4)$ & 27.8 & $(2.2)$ & 13.9 & (1.5) & 4.4 & $(1.0)$ & 0.4 & $(0.3)$ & 0.0 & c \\
\hline Nuevo León & 14.7 & $(2.7)$ & 28.8 & $(2.7)$ & 30.2 & (2.4) & 18.5 & (2.9) & 6.7 & (1.5) & 1.1 & $(0.5)$ & 0.0 & $\mathrm{C}$ \\
\hline Puebla & 21.1 & $(2.6)$ & 31.9 & $(2.2)$ & 28.8 & $(2.1)$ & 13.7 & $(2.3)$ & 4.1 & $(0.8)$ & 0.4 & $(0.3)$ & 0.0 & $\mathrm{C}$ \\
\hline Querétaro & 15.1 & $(2.4)$ & 29.1 & $(2.1)$ & 30.1 & $(2.2)$ & 18.2 & $(2.7)$ & 6.1 & $(1.4)$ & 1.3 & $(0.5)$ & 0.1 & $(0.1)$ \\
\hline Quintana Roo & 23.3 & $(2.8)$ & 32.8 & (1.5) & 28.1 & $(1.7)$ & 12.6 & (1.6) & 2.7 & $(0.6)$ & 0.4 & $(0.2)$ & 0.0 & $\mathrm{C}$ \\
\hline San Luis Potosí & 25.9 & $(2.9)$ & 29.4 & $(2.6)$ & 27.1 & $(2.1)$ & 13.0 & (1.9) & 3.9 & $(1.2)$ & 0.6 & $(0.3)$ & 0.0 & $\mathrm{C}$ \\
\hline Sinaloa & 22.6 & $(2.3)$ & 34.4 & (1.8) & 27.5 & $(2.1)$ & 12.2 & (1.6) & 2.9 & $(0.6)$ & 0.4 & $(0.2)$ & 0.0 & C \\
\hline Tabasco & 38.8 & (2.7) & 35.3 & (1.8) & 18.4 & (1.7) & 6.2 & $(1.2)$ & 1.2 & $(0.4)$ & 0.1 & $(0.1)$ & 0.0 & $\mathrm{C}$ \\
\hline Tamaulipas & 23.9 & (3.0) & 32.4 & $(2.6)$ & 26.9 & $(2.3)$ & 12.3 & $(2.3)$ & 3.8 & (1.4) & 0.7 & $(0.5)$ & 0.0 & $\mathrm{c}$ \\
\hline Tlaxcala & 22.6 & $(2.5)$ & 32.9 & (1.8) & 29.1 & $(2.0)$ & 11.6 & (1.6) & 3.3 & $(0.8)$ & 0.4 & $(0.3)$ & 0.0 & $\mathrm{C}$ \\
\hline Veracruz & 28.5 & $(2.9)$ & 32.0 & $(2.2)$ & 24.7 & $(2.0)$ & 11.4 & $(2.0)$ & 2.9 & $(0.9)$ & 0.4 & $(0.4)$ & 0.0 & $\mathrm{C}$ \\
\hline Yucatán & 24.5 & $(2.7)$ & 32.7 & $(2.1)$ & 25.9 & (2.4) & 13.0 & (1.6) & 3.3 & $(0.8)$ & 0.5 & $(0.3)$ & 0.1 & C \\
\hline Zacatecas & 23.7 & $(2.2)$ & 33.7 & (1.6) & 26.5 & (1.7) & 13.4 & (1.6) & 2.5 & $(0.6)$ & 0.3 & $(0.2)$ & 0.0 & $\mathrm{C}$ \\
\hline
\end{tabular}

- PISA adjudicated region

Note: See Table I.2.1a for national data.

StatLink त्राजा http://dx.doi.org/10.1787/888932935762 
[Part 2/2]

Table B2.I.1 Percentage of students at each proficiency level in mathematics, by region

\begin{tabular}{|c|c|c|c|c|c|c|c|c|c|c|c|c|c|c|c|}
\hline & & \multicolumn{14}{|c|}{ All students } \\
\hline & & \multicolumn{2}{|c|}{$\begin{array}{l}\text { Below Level } 1 \\
\text { (below 357.77 } \\
\text { score points) }\end{array}$} & \multicolumn{2}{|c|}{$\begin{array}{c}\text { Level } 1 \\
\text { (from } 357.77 \text { to } \\
\text { less than } 420.07 \\
\text { score points) }\end{array}$} & \multicolumn{2}{|c|}{$\begin{array}{c}\text { Level } 2 \\
\text { (from } 420.07 \text { to } \\
\text { less than } 482.38 \\
\text { score points) }\end{array}$} & $\begin{array}{r}\text { L } \\
\text { (from } \\
\text { less th } \\
\text { scor }\end{array}$ & \begin{tabular}{|l|} 
I 3 \\
2.38 to \\
544.68 \\
oints)
\end{tabular} & $\begin{array}{r}\text { Le } \\
\text { (from } \\
\text { less th } \\
\text { score }\end{array}$ & \begin{tabular}{l|}
14 \\
4.68 to \\
606.99 \\
oints)
\end{tabular} & $\begin{array}{r}\mathrm{L} \\
\text { (from } \\
\text { less th } \\
\text { scor }\end{array}$ & \begin{tabular}{|l}
5 \\
6.99 to \\
669.30 \\
oints)
\end{tabular} & $\begin{array}{l}\text { Le } \\
\text { (abov } \\
\text { scor }\end{array}$ & $\begin{array}{l}16 \\
669.30 \\
\text { oints) }\end{array}$ \\
\hline & & $\%$ & S.E. & $\%$ & S.E. & $\%$ & S.E. & $\%$ & S.E. & $\%$ & S.E. & $\%$ & S.E. & $\%$ & S.E. \\
\hline 0 & Portugal & & & & & & & & & & & & & & \\
\hline ড్ & Alentejo & 7.4 & $(2.1)$ & 15.2 & (3.0) & 24.8 & $(2.2)$ & 26.0 & (3.2) & 16.9 & $(2.7)$ & 7.6 & (1.9) & 2.1 & (1.1) \\
\hline & Spain & & & & & & & & & & & & & & \\
\hline & Andalusia ${ }^{\bullet}$ & 8.5 & $(1.2)$ & 18.9 & (1.5) & 27.9 & $(2.2)$ & 24.3 & (1.8) & 14.6 & (1.4) & 4.7 & $(0.8)$ & 1.0 & $(0.3)$ \\
\hline & Aragon ${ }^{\bullet}$ & 7.9 & (1.3) & 13.4 & (1.5) & 21.2 & (1.3) & 25.3 & (1.5) & 20.8 & (1.6) & 9.5 & $(1.2)$ & 2.0 & $(0.6)$ \\
\hline & Asturias ${ }^{\bullet}$ & 6.8 & (1.3) & 11.9 & (1.4) & 22.9 & $(1.1)$ & 26.4 & (1.3) & 19.2 & (1.8) & 10.4 & (1.3) & 2.4 & $(0.7)$ \\
\hline & Balearic Islands ${ }^{\bullet}$ & 9.6 & (1.5) & 16.9 & (1.5) & 25.5 & $(1.5)$ & 25.2 & (1.6) & 17.0 & (1.5) & 5.1 & $(0.8)$ & 0.6 & $(0.3)$ \\
\hline & Basque Country ${ }^{\bullet}$ & 5.0 & $(0.5)$ & 10.5 & (0.6) & 22.0 & $(0.8)$ & 28.9 & $(0.9)$ & 23.1 & $(1.1)$ & 8.6 & $(0.6)$ & 1.9 & $(0.2)$ \\
\hline & Cantabria ${ }^{\bullet}$ & 7.2 & $(1.1)$ & 14.8 & $(1.2)$ & 24.0 & $(1.3)$ & 25.5 & $(1.2)$ & 17.9 & $(1.2)$ & 8.8 & $(0.9)$ & 1.8 & $(0.4)$ \\
\hline & Castile and Leon ${ }^{\bullet}$ & 4.3 & $(0.8)$ & 10.5 & (1.0) & 22.0 & (1.4) & 28.1 & (1.5) & 23.2 & (1.6) & 10.3 & (1.1) & 1.7 & $(0.5)$ \\
\hline & Catalonia ${ }^{\bullet}$ & 5.6 & (1.0) & 14.4 & (1.6) & 24.5 & (1.7) & 27.8 & (2.0) & 19.0 & (1.6) & 7.2 & (1.0) & 1.5 & (0.5) \\
\hline & Extremadura ${ }^{\bullet}$ & 13.9 & (1.6) & 19.1 & (1.4) & 24.9 & (1.5) & 23.4 & (1.2) & 13.1 & $(1.2)$ & 4.7 & $(0.7)$ & 1.0 & $(0.3)$ \\
\hline & Galicia• & 7.0 & (1.0) & 14.9 & (1.4) & 23.2 & (1.7) & 28.4 & (1.6) & 18.6 & (1.5) & 6.8 & $(0.9)$ & 1.2 & $(0.4)$ \\
\hline & La Rioja` & 8.3 & $(0.7)$ & 11.6 & (1.0) & 20.3 & $(1.3)$ & 24.1 & (1.3) & 20.5 & $(1.2)$ & 11.5 & (0.9) & 3.7 & $(0.5)$ \\
\hline & Madrid ${ }^{\bullet}$ & 5.3 & $(0.8)$ & 12.4 & (1.2) & 20.9 & $(1.3)$ & 27.0 & (1.4) & 22.9 & (1.8) & 9.7 & (1.4) & 1.7 & $(0.5)$ \\
\hline & Murcia ${ }^{\bullet}$ & 12.4 & $(1.3)$ & 18.6 & (1.6) & 27.9 & (1.6) & 22.9 & (1.3) & 12.6 & $(1.3)$ & 4.8 & (1.0) & 0.8 & $(0.4)$ \\
\hline & Navarre ${ }^{\bullet}$ & 3.9 & $(0.7)$ & 9.8 & $(0.9)$ & 19.4 & (1.5) & 27.6 & (1.5) & 24.8 & (1.1) & 11.9 & (1.4) & 2.7 & $(0.5)$ \\
\hline & United Kingdom & & & & & & & & & & & & & & \\
\hline & England & 8.0 & $(0.9)$ & 13.7 & (0.9) & 22.8 & $(0.9)$ & 24.5 & (1.0) & 18.7 & $(0.9)$ & 9.3 & $(0.7)$ & 3.1 & $(0.5)$ \\
\hline & Northern Ireland & 8.6 & (1.1) & 15.5 & (1.3) & 23.8 & $(1.1)$ & 24.3 & (1.4) & 17.5 & (1.0) & 8.1 & $(0.7)$ & 2.2 & $(0.4)$ \\
\hline & Scotland $\bullet^{\bullet}$ & 4.9 & (0.6) & 13.3 & (1.0) & 24.8 & (1.1) & 27.2 & (1.0) & 18.8 & (1.0) & 8.5 & $(0.7)$ & 2.4 & (0.4) \\
\hline & Wales & 9.6 & $(0.7)$ & 19.4 & $(0.7)$ & 27.5 & $(0.9)$ & 25.1 & (1.0) & 13.1 & $(0.7)$ & 4.3 & $(0.5)$ & 1.0 & $(0.2)$ \\
\hline & United States & & & & & & & & & & & & & & \\
\hline & Connecticut $^{\bullet}$ & 6.8 & $(1.2)$ & 13.8 & (1.3) & 20.0 & (1.3) & 24.3 & (1.4) & 18.6 & (1.8) & 11.5 & (1.5) & 4.9 & $(0.8)$ \\
\hline & Florida & 9.7 & (1.4) & 20.6 & (1.9) & 27.9 & (1.4) & 23.0 & (1.6) & 13.0 & (1.3) & 4.9 & (1.0) & 0.9 & $(0.4)$ \\
\hline & Massachusetts ${ }^{\bullet}$ & 5.3 & $(0.8)$ & 12.5 & $(1.2)$ & 20.4 & (1.6) & 24.3 & (1.5) & 18.9 & $(1.2)$ & 12.7 & (1.6) & 5.8 & (1.1) \\
\hline 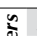 & Argentina & & & & & & & & & & & & & & \\
\hline$\stackrel{\Xi}{\Xi}$ & Ciudad Autónoma de Buenos Aires ${ }^{\bullet}$ & 23.7 & $(2.7)$ & 23.1 & (2.6) & 28.5 & $(2.3)$ & 17.1 & $(1.7)$ & 6.6 & $(1.2)$ & 1.0 & $(0.3)$ & 0.0 & c \\
\hline ฐ & Brazil & & & & & & & & & & & & & & \\
\hline & Acre & 52.2 & (3.4) & 29.5 & (2.9) & 14.8 & $(1.8)$ & 2.9 & $(1.1)$ & 0.5 & $(0.4)$ & 0.1 & c & 0.0 & c \\
\hline & Alagoas & 63.5 & (3.8) & 23.6 & (3.0) & 9.3 & $(1.9)$ & 2.9 & $(1.2)$ & 0.7 & $(0.6)$ & 0.0 & c & 0.0 & c \\
\hline & Amapá & 49.2 & (5.6) & 33.6 & $(4.7)$ & 14.2 & $(3.0)$ & 2.7 & (1.6) & 0.3 & $\mathrm{C}$ & 0.0 & c & 0.0 & c \\
\hline & Amazonas & 55.3 & (3.1) & 29.9 & (2.5) & 10.6 & $(2.0)$ & 3.2 & $(1.2)$ & 0.7 & $(0.7)$ & 0.2 & $(0.3)$ & 0.0 & c \\
\hline & Bahia & 45.4 & (5.4) & 28.6 & (3.6) & 16.5 & $(3.7)$ & 6.8 & (1.6) & 2.0 & (1.0) & 0.7 & $(0.7)$ & 0.0 & c \\
\hline & Ceará & 42.0 & $(4.0)$ & 31.5 & (3.2) & 17.0 & $(2.3)$ & 5.9 & (1.8) & 2.5 & $(1.3)$ & 1.0 & $(0.6)$ & 0.1 & c \\
\hline & Espírito Santo & 27.8 & (2.8) & 30.8 & (3.2) & 19.8 & $(2.7)$ & 12.7 & (2.3) & 6.7 & $(2.4)$ & 2.0 & $(0.9)$ & 0.2 & c \\
\hline & Federal District & 27.0 & (5.1) & 27.5 & (3.6) & 23.9 & (3.3) & 14.3 & (2.4) & 5.9 & (1.9) & 1.2 & $(0.9)$ & 0.2 & c \\
\hline & Goiás & 41.7 & $(4.1)$ & 32.9 & (3.2) & 16.6 & $(2.5)$ & 6.6 & (1.6) & 1.9 & $(0.8)$ & 0.3 & $\mathrm{C}$ & 0.0 & $\mathrm{C}$ \\
\hline & Maranhão & 61.3 & (6.9) & 23.4 & (2.8) & 10.3 & (3.8) & 3.9 & (2.4) & 1.0 & $(0.9)$ & 0.3 & $(0.3)$ & 0.0 & c \\
\hline & Mato Grosso & 46.5 & $(5.2)$ & 31.6 & (3.5) & 15.0 & $(2.6)$ & 4.2 & (1.8) & 2.4 & (1.4) & 0.3 & $(0.4)$ & 0.0 & c \\
\hline & Mato Grosso do Sul & 25.9 & $(4.0)$ & 34.0 & (2.9) & 23.5 & $(2.8)$ & 11.9 & (1.6) & 4.4 & (1.4) & 0.3 & $(0.4)$ & 0.0 & c \\
\hline & Minas Gerais & 26.5 & (3.5) & 34.4 & $(2.2)$ & 25.1 & $(2.9)$ & 11.2 & $(2.2)$ & 2.4 & $(1.0)$ & 0.4 & $(0.3)$ & 0.0 & c \\
\hline & Pará & 51.6 & (3.6) & 29.3 & (3.3) & 15.2 & $(2.0)$ & 3.4 & $(0.7)$ & 0.5 & $(0.5)$ & 0.0 & $\mathrm{C}$ & 0.0 & $\mathrm{c}$ \\
\hline & Paraiba & 33.0 & $(4.8)$ & 31.7 & (3.2) & 21.2 & $(4.3)$ & 9.9 & $(2.0)$ & 3.6 & $(1.5)$ & 0.5 & $(0.4)$ & 0.1 & c \\
\hline & Paraná & 32.0 & (3.6) & 31.3 & (3.2) & 20.5 & $(2.5)$ & 9.6 & $(1.6)$ & 4.9 & $(2.8)$ & 1.7 & $(1.8)$ & 0.1 & c \\
\hline & Pernambuco & 49.4 & $\begin{array}{l}(5.0) \\
(5.0)\end{array}$ & 32.0 & (3.6) & 14.3 & $(2.3)$ & 3.3 & $(1.0)$ & 0.9 & $\begin{array}{l}(2.0) \\
(0.7)\end{array}$ & 0.2 & $(0.2)$ & 0.0 & c \\
\hline & Piaú & 41.0 & (3.8) & $\begin{array}{l}32.0 \\
32.1\end{array}$ & (3.8) & 14.1 & (2.6) & 7.9 & (1.4) & 3.9 & $(2.1)$ & 0.7 & $(0.6)$ & 0.3 & $(0.2)$ \\
\hline & Rio de Janeiro & 34.3 & (4.1) & 35.1 & (3.2) & 20.8 & $\begin{array}{l}(2.0) \\
(2.9)\end{array}$ & 7.9 & (1.8) & 1.6 & $(0.8)$ & 0.3 & $(0.3)$ & 0.0 & $\begin{array}{r}10.27 \\
\mathrm{C}\end{array}$ \\
\hline & Rio Grande do Norte & 44.9 & (3.6) & 29.3 & (3.8) & $\begin{array}{l}20.0 \\
13.6\end{array}$ & $(2.5)$ & 7.0 & $(2.1)$ & 3.4 & $\begin{array}{l}(0.0) \\
(1.6)\end{array}$ & 1.5 & $(0.9)$ & 0.3 & $(0.4)$ \\
\hline & Rio Grande do Sul & 25.3 & $\begin{array}{l}(3.0) \\
(3.3)\end{array}$ & 33.1 & (2.4) & 27.4 & $(2.7)$ & 11.8 & $(2.3)$ & $\begin{array}{l}3.4 \\
2.1\end{array}$ & $(0.7)$ & 0.3 & $(0.3)$ & 0.0 & $\begin{array}{r}\text { (0.4) } \\
\mathrm{C}\end{array}$ \\
\hline & Rondônia & 34.9 & (3.4) & 38.4 & (2.5) & $\begin{array}{l}27.4 \\
21.2\end{array}$ & $(2.4)$ & 4.5 & $(1.2)$ & $\begin{array}{l}2.1 \\
1.0\end{array}$ & $(0.6)$ & 0.1 & $\begin{array}{r}\text { C } \\
\text { (10.J) }\end{array}$ & 0.0 & c \\
\hline & Roraima & 52.9 & (3.6) & 26.8 & $(2.5)$ & 13.7 & $(2.6)$ & 5.3 & (2.0) & 1.2 & $(0.6)$ & 0.1 & $\mathrm{c}$ & 0.0 & c \\
\hline & Santa Catarina & 23.4 & (3.6) & $\begin{array}{l}20.0 \\
30.2\end{array}$ & (2.9) & 27.4 & $(2.1)$ & 14.2 & $(2.6)$ & 4.4 & $\begin{array}{l}(0.0) \\
(1.4)\end{array}$ & 0.4 & $(0.3)$ & 0.0 & c \\
\hline & São Paulo & 29.3 & (1.7) & 32.4 & (1.7) & 22.7 & $(1.4)$ & 10.7 & $(1.2)$ & 3.8 & $(0.8)$ & 1.1 & $(0.5)$ & 0.0 & c \\
\hline & Sergipe & 38.9 & (4.8) & 32.8 & (3.6) & 18.1 & $(2.0)$ & 8.5 & (3.0) & 1.3 & $(0.8)$ & 0.3 & $(0.3)$ & 0.0 & c \\
\hline & Tocantins & 47.6 & (3.7) & 30.8 & (2.6) & 13.7 & $(1.7)$ & 6.0 & (1.5) & 1.6 & $(0.8)$ & 0.3 & C & 0.0 & c \\
\hline & Colombia & & & & & & & & & & & & & & \\
\hline & Bogotá & 29.8 & (1.9) & 37.8 & (1.5) & 23.7 & $(1.5)$ & 7.2 & (1.0) & 1.2 & $(0.6)$ & 0.3 & $(0.2)$ & 0.0 & c \\
\hline & Cali & 38.9 & (3.8) & 34.0 & (2.1) & 19.0 & $(2.7)$ & 6.8 & (1.6) & 1.2 & $(0.5)$ & 0.0 & C & 0.0 & c \\
\hline & Manizales & 27.1 & $(2.2)$ & 34.8 & (2.6) & 23.5 & $(2.2)$ & $\begin{array}{r}0.0 \\
10.8\end{array}$ & (1.6) & 3.3 & $\begin{array}{l}(0.5) \\
(0.9)\end{array}$ & 0.4 & $(0.3)$ & 0.0 & c \\
\hline & Medellín & 36.4 & (3.2) & 30.8 & (1.8) & 19.0 & $(2.1)$ & 8.8 & (1.4) & 3.5 & $(1.3)$ & $\begin{array}{l}.4 \\
1.2\end{array}$ & (0.6) & 0.4 & $(0.3)$ \\
\hline & Russian Federation & & & & & & & & & & & & & & \\
\hline & Perm Territory region & 7.4 & (1.3) & 15.6 & (1.3) & 27.2 & (1.9) & 26.0 & $(2.1)$ & 15.7 & (1.3) & 5.9 & (1.1) & 2.2 & $(1.0)$ \\
\hline & United Arab Emirates & & & & & & & & & & & & & & \\
\hline & Abu Dhabi॰ & 24.6 & (1.6) & 27.3 & $(1.2)$ & 24.4 & $(1.2)$ & 14.2 & (1.0) & 6.8 & $(0.8)$ & 2.4 & $(0.5)$ & 0.3 & $(0.2)$ \\
\hline & Ajman & 28.1 & (5.0) & 31.3 & (3.5) & 25.1 & $(2.6)$ & 12.6 & (1.8) & 2.7 & $(0.9)$ & 0.3 & $(0.3)$ & 0.0 & C \\
\hline & Dubai ${ }^{\bullet}$ & 13.6 & $(0.4)$ & 19.7 & $(0.6)$ & 24.5 & $(1.0)$ & 21.8 & $(0.8)$ & 13.6 & $(0.7)$ & 5.5 & $(0.5)$ & 1.3 & $(0.3)$ \\
\hline & Fujairah & 26.6 & $(4.0)$ & 28.2 & $(2.4)$ & 25.6 & $(3.1)$ & 14.1 & $(2.6)$ & 4.7 & $(1.4)$ & 0.7 & $(0.4)$ & 0.1 & C \\
\hline & Ras al-Khaimah & 23.5 & (3.5) & 30.5 & (2.6) & 26.9 & $(2.5)$ & 14.5 & $(1.7)$ & 3.7 & $(1.0)$ & 0.8 & $(0.5)$ & 0.0 & c \\
\hline & Sharjah & 17.1 & (2.9) & 27.2 & $(3.2)$ & 25.5 & $(2.3)$ & 18.4 & (2.5) & 9.0 & (1.9) & 2.4 & $(0.8)$ & 0.5 & $(0.4)$ \\
\hline & Umm al-Quwain & 30.6 & (3.6) & 33.8 & (3.3) & 22.7 & $(3.2)$ & 9.8 & $(2.4)$ & 1.8 & (1.1) & 1.1 & $(0.8)$ & 0.1 & $\mathrm{C}$ \\
\hline
\end{tabular}

- PISA adjudicated region.

Note: See Table 1.2.1a for national data.

StatLink त्तis http://dx.doi.org/10.1787/888932935762 
[Part 1/4]

Table B2.I.2 Percentage of students at each proficiency level in mathematics, by gender and region

\begin{tabular}{|c|c|c|c|c|c|c|c|c|c|c|c|c|c|c|c|}
\hline & & \multicolumn{14}{|c|}{ Boys } \\
\hline & & \multicolumn{2}{|c|}{$\begin{array}{c}\text { Below Level } 1 \\
\text { (below 357.77 } \\
\text { score points) }\end{array}$} & $\begin{array}{l}\text { L } \\
\text { (from } \\
\text { less th } \\
\text { scor }\end{array}$ & $\begin{array}{l}71 \\
7.77 \text { to } \\
420.07 \\
\text { oints) }\end{array}$ & $\begin{array}{r}\mathrm{L} \\
\text { (from } \\
\text { less th } \\
\text { scor }\end{array}$ & $\begin{array}{l}\text { I } 2 \\
0.07 \text { to } \\
482.38 \\
\text { oints) }\end{array}$ & $\begin{array}{r}\text { Le } \\
\text { (from } \\
\text { less th } \\
\text { scor }\end{array}$ & $\begin{array}{l}\mid 3 \\
2.38 \text { to } \\
5444.68 \\
\text { oints) }\end{array}$ & $\begin{array}{l}\mathrm{L} \\
\text { (from } \\
\text { less th } \\
\text { scor }\end{array}$ & $\begin{array}{l}14 \\
4.68 \text { to } \\
606.99 \\
\text { oints) }\end{array}$ & $\begin{array}{r}\mathrm{L} \\
\text { (from } \\
\text { less th } \\
\text { scor }\end{array}$ & $\begin{array}{l}5 \\
6.99 \text { to } \\
669.30 \\
\text { oints) }\end{array}$ & $\begin{array}{r}\mathrm{L} \\
\text { (abo } \\
\text { scor }\end{array}$ & $\begin{array}{l}16 \\
669.30 \\
\text { oints) }\end{array}$ \\
\hline & & $\%$ & S.E. & $\%$ & S.E. & $\%$ & S.E. & $\%$ & S.E. & $\%$ & S.E. & $\%$ & S.E. & $\%$ & S.E. \\
\hline 0 & Australia & & & & & & & & & & & & & & \\
\hline$u$ & Australian Capital Territory & 6.4 & $(1.5)$ & 9.8 & $(1.8)$ & 19.2 & $(2.2)$ & 24.8 & $(2.5)$ & 19.3 & $(2.8)$ & 14.0 & (2.9) & 6.4 & (1.5) \\
\hline & New South Wales & 6.9 & $(0.9)$ & 12.4 & $(1.0)$ & 21.2 & $(1.7)$ & 22.6 & $(1.3)$ & 16.8 & (1.4) & 12.7 & $(1.4)$ & 7.5 & (1.4) \\
\hline & Northern Territory & 19.2 & $(3.7)$ & 14.8 & (3.5) & 19.1 & (5.6) & 26.0 & (5.2) & 12.9 & (3.9) & 5.7 & $(3.0)$ & 2.3 & (1.6) \\
\hline & Queensland & 5.6 & $(1.0)$ & 13.1 & $(1.2)$ & 21.8 & (1.9) & 24.2 & $(1.5)$ & 19.8 & $(1.7)$ & 11.5 & $(1.5)$ & 4.1 & $(0.7)$ \\
\hline & South Australia & 7.2 & $(1.2)$ & 13.9 & $(1.8)$ & 23.6 & (2.5) & 24.9 & $(1.9)$ & 18.1 & (1.9) & 10.0 & $(1.5)$ & 2.2 & $(0.8)$ \\
\hline & Tasmania & 10.3 & $(1.5)$ & 13.3 & $(1.7)$ & 26.3 & (2.4) & 24.3 & $(2.2)$ & 15.8 & $(2.2)$ & 7.9 & $(1.7)$ & 2.1 & $(0.8)$ \\
\hline & Victoria & 5.0 & $(0.8)$ & 12.4 & (1.6) & 21.6 & $(2.0)$ & 25.6 & (1.9) & 20.6 & (1.6) & 10.0 & $(1.2)$ & 4.7 & (1.3) \\
\hline & Western Australia & 3.2 & $(0.8)$ & 9.8 & (1.2) & 20.0 & (1.9) & 21.9 & (1.9) & 24.1 & $(2.0)$ & 15.1 & $(1.6)$ & 5.9 & (1.2) \\
\hline & Belgium & & & & & & & & & & & & & & \\
\hline & Flemish Community & 5.3 & $(1.1)$ & 9.5 & $(0.9)$ & 15.5 & $(1.1)$ & 20.6 & $(1.2)$ & 20.8 & (1.3) & 17.8 & $(1.2)$ & 10.5 & $(0.9)$ \\
\hline & French Community & 9.0 & $(1.2)$ & 14.6 & $(1.5)$ & 19.1 & $(1.7)$ & 22.6 & (1.6) & 20.1 & (1.4) & 11.3 & $(1.2)$ & 3.2 & $(0.6)$ \\
\hline & German-speaking Community & 7.3 & $(1.0)$ & 11.3 & (1.7) & 17.7 & $(2.7)$ & 25.8 & (2.8) & 21.5 & $(2.0)$ & 12.5 & (1.9) & 4.0 & $(1.0)$ \\
\hline & Canada & & & & & & & & & & & & & & \\
\hline & Alberta & 3.9 & $(0.9)$ & 9.9 & $(1.9)$ & 19.9 & $(1.9)$ & 25.6 & $(2.0)$ & 21.4 & (1.9) & 13.5 & (1.5) & 5.8 & (1.1) \\
\hline & British Columbia & 2.2 & $(0.7)$ & 8.7 & (1.3) & 19.3 & (1.5) & 26.6 & (1.8) & 24.2 & (1.9) & 13.6 & $(1.7)$ & 5.3 & (1.1) \\
\hline & Manitoba & 6.4 & (1.5) & 14.4 & (3.0) & 25.2 & (2.4) & 24.4 & $(2.0)$ & 17.7 & (1.5) & 9.0 & (1.5) & 2.9 & $(0.7)$ \\
\hline & New Brunswick & 4.4 & $(0.9)$ & 12.7 & $(1.7)$ & 21.7 & (1.9) & 30.3 & (2.4) & 20.1 & $(2.2)$ & 8.3 & $(1.8)$ & 2.5 & $(0.9)$ \\
\hline & Newfoundland and Labrador & 7.2 & $(2.1)$ & 15.2 & $(2.5)$ & 22.6 & (1.9) & 26.3 & $(2.3)$ & 18.5 & (1.9) & 8.3 & $(1.7)$ & 2.0 & $(0.9)$ \\
\hline & Nova Scotia & 4.7 & $(1.5)$ & 12.2 & $(2.6)$ & 23.5 & $(3.2)$ & 27.7 & $(2.6)$ & 21.2 & $(1.8)$ & 8.8 & $(1.5)$ & 1.8 & $(0.7)$ \\
\hline & Ontario & 3.9 & $(0.8)$ & 10.0 & $(1.3)$ & 21.5 & $(1.7)$ & 25.5 & $(1.7)$ & 20.9 & (1.5) & 12.7 & $(1.5)$ & 5.5 & $(1.2)$ \\
\hline & Prince Edward Island & 6.8 & $(1.3)$ & 18.4 & $(2.0)$ & 23.8 & (2.6) & 26.0 & $(2.4)$ & 16.7 & (1.9) & 7.2 & (1.4) & 1.2 & $(0.6)$ \\
\hline & Quebec & 3.0 & $(0.8)$ & 7.5 & $(1.2)$ & 15.7 & (1.4) & 23.7 & $(1.8)$ & 24.9 & $(1.5)$ & 17.8 & $(1.4)$ & 7.5 & $(0.9)$ \\
\hline & Saskatchewan & 4.1 & $(0.7)$ & 10.6 & (1.4) & 23.9 & (1.6) & 25.5 & (2.4) & 22.7 & (2.0) & 10.6 & (1.5) & 2.6 & $(0.9)$ \\
\hline & Italy & & & & & & & & & & & & & & \\
\hline & Abruzzo & 10.0 & $(2.6)$ & 15.4 & $(2.7)$ & 25.3 & (2.6) & 23.2 & $(2.2)$ & 17.4 & $(2.2)$ & 7.0 & (1.6) & 1.7 & $(0.8)$ \\
\hline & Basilicata & 8.7 & $(1.7)$ & 18.4 & $(2.5)$ & 25.0 & (1.7) & 25.2 & $(2.2)$ & 16.0 & (2.0) & 4.9 & $(0.9)$ & 1.8 & $(0.6)$ \\
\hline & Bolzano & 4.3 & $(0.8)$ & 12.3 & $(1.8)$ & 17.7 & (1.4) & 26.2 & $(1.5)$ & 21.1 & $(2.1)$ & 13.3 & $(1.2)$ & 5.2 & $(0.8)$ \\
\hline & Calabria & 18.8 & $(2.9)$ & 23.4 & $(2.3)$ & 25.4 & (2.6) & 20.2 & $(2.2)$ & 8.2 & (1.3) & 3.2 & $(0.9)$ & 0.8 & $(0.4)$ \\
\hline & Campania & 13.6 & $(2.1)$ & 19.1 & $(2.5)$ & 27.5 & (2.3) & 21.0 & $(2.7)$ & 12.3 & (2.4) & 5.4 & $(1.3)$ & 1.0 & $(0.5)$ \\
\hline & Emilia Romagna & 7.6 & $(1.8)$ & 11.6 & $(2.7)$ & 19.8 & (2.4) & 22.3 & $(2.3)$ & 20.3 & $(2.1)$ & 13.4 & $(2.5)$ & 4.9 & (1.5) \\
\hline & Friuli Venezia Giulia & 3.4 & $(1.2)$ & 9.4 & $(2.3)$ & 15.6 & $(2.7)$ & 24.3 & $(2.4)$ & 25.0 & $(2.2)$ & 15.9 & $(2.0)$ & 6.3 & $(1.2)$ \\
\hline & Lazio & 9.3 & $(1.8)$ & 16.2 & $(2.2)$ & 24.3 & (2.1) & 23.1 & $(2.6)$ & 16.4 & (1.8) & 8.5 & (1.5) & 2.2 & $(0.7)$ \\
\hline & Liguria & 6.9 & (1.9) & 15.9 & $(2.1)$ & 23.6 & (2.4) & 25.0 & $(2.9)$ & 15.4 & $(2.2)$ & 9.4 & $(1.8)$ & 3.8 & $(0.9)$ \\
\hline & Lombardia & 3.7 & (1.1) & 9.1 & $(1.6)$ & 17.4 & (2.5) & 25.3 & $(2.8)$ & 24.3 & (2.5) & 14.7 & $(2.5)$ & 5.5 & (1.5) \\
\hline & Marche & 3.1 & $(1.2)$ & 13.5 & $(2.5)$ & 21.0 & (1.8) & 27.0 & $(2.1)$ & 21.8 & (2.6) & 10.8 & $(2.0)$ & 2.8 & $(0.9)$ \\
\hline & Molise & 9.6 & $(1.5)$ & 17.1 & $(2.4)$ & 26.2 & (3.5) & 25.5 & $(3.2)$ & 15.1 & $(2.2)$ & 4.7 & $(1.3)$ & 1.8 & $(0.8)$ \\
\hline & Piemonte & 4.8 & $(1.3)$ & 10.4 & $(1.3)$ & 20.9 & $(2.7)$ & 28.6 & $(2.3)$ & 20.8 & $(2.2)$ & 11.6 & $(1.8)$ & 3.0 & $(0.7)$ \\
\hline & Puglia & 8.2 & (1.8) & 14.6 & $(2.0)$ & 22.6 & $(2.1)$ & 26.0 & $(2.6)$ & 19.2 & $(2.0)$ & 8.2 & $(1.4)$ & 1.3 & $(0.5)$ \\
\hline & Sardegna & 12.0 & (1.6) & 20.2 & $(2.0)$ & 26.9 & $(2.7)$ & 22.0 & $(2.0)$ & 13.6 & (1.7) & 4.6 & $(1.1)$ & 0.6 & $(0.4)$ \\
\hline & Sicilia & 13.1 & $(1.8)$ & 22.0 & $(2.6)$ & 28.5 & (2.5) & 23.0 & $(2.3)$ & 9.9 & (1.8) & 2.9 & $(1.0)$ & 0.5 & $(0.4)$ \\
\hline & Toscana & 7.3 & $(1.4)$ & 15.5 & $(3.1)$ & 21.7 & (2.6) & 23.5 & $(2.3)$ & 18.5 & $(2.1)$ & 10.5 & $(1.7)$ & 3.0 & $(0.8)$ \\
\hline & Trento & 2.5 & $(1.0)$ & 8.3 & $(1.8)$ & 20.2 & (1.9) & 26.1 & $(2.6)$ & 22.8 & $(2.2)$ & 15.2 & $(1.8)$ & 4.8 & (1.1) \\
\hline & Umbria & 7.1 & $(2.6)$ & 10.9 & $(2.3)$ & 20.3 & (1.9) & 27.2 & $(2.6)$ & 22.4 & $(2.3)$ & 9.4 & $(1.9)$ & 2.7 & $(0.8)$ \\
\hline & Valle d'Aosta & 5.2 & (1.1) & 12.7 & $(1.6)$ & 24.3 & $(2.2)$ & 27.7 & $(2.5)$ & 18.6 & (2.5) & 9.0 & $(1.6)$ & 2.5 & (1.1) \\
\hline & Veneto & 3.6 & (1.1) & 9.3 & $(2.4)$ & 17.6 & $(2.2)$ & 22.1 & $(2.3)$ & 22.7 & $(2.1)$ & 17.5 & $(2.5)$ & 7.2 & (1.9) \\
\hline & Mexico & & & & & & & & & & & & & & \\
\hline & Aguascalientes & 13.0 & $(2.6)$ & 27.6 & $(3.1)$ & 30.8 & $(4.0)$ & 18.5 & $(2.9)$ & 7.9 & (1.7) & 2.2 & $(1.2)$ & 0.0 & c \\
\hline & Baja California & 18.1 & $(3.1)$ & 34.4 & $(3.5)$ & 28.1 & $(3.2)$ & 14.0 & $(2.5)$ & 4.6 & (1.1) & 0.6 & $(0.5)$ & 0.0 & C \\
\hline & Baja California Sur & 20.1 & (3.7) & 29.8 & $(2.8)$ & 30.0 & (3.3) & 14.4 & (2.4) & 5.0 & (1.1) & 0.7 & $(0.5)$ & 0.0 & C \\
\hline & Campeche & 27.1 & $(2.8)$ & 34.6 & $(3.2)$ & 26.2 & (2.6) & 8.9 & $(1.6)$ & 2.6 & $(0.9)$ & 0.5 & $(0.4)$ & 0.1 & c \\
\hline & Chiapas & 40.4 & $(4.9)$ & 33.6 & (3.8) & 18.2 & (3.1) & 5.7 & $(1.3)$ & 1.6 & $(0.6)$ & 0.6 & $(0.5)$ & 0.0 & C \\
\hline & Chihuahua & 14.4 & (3.5) & 29.0 & (3.6) & 31.1 & $(3.2)$ & 15.2 & $(2.1)$ & 8.5 & $(2.1)$ & 1.7 & $(0.9)$ & 0.2 & C \\
\hline & Coahuila & 20.0 & (3.8) & 29.7 & $(4.8)$ & 28.6 & (2.9) & 15.5 & $(2.9)$ & 5.3 & $(1.7)$ & 0.8 & $(0.6)$ & 0.0 & C \\
\hline & Colima & 17.4 & $(2.1)$ & 27.1 & $(3.0)$ & 30.0 & (2.9) & 16.7 & $(2.6)$ & 6.5 & $(1.2)$ & 1.9 & $(0.8)$ & 0.4 & $(0.2)$ \\
\hline & Distrito Federal & 12.6 & $(2.0)$ & 26.3 & $(3.7)$ & 32.3 & (3.0) & 20.1 & $(3.4)$ & 7.4 & (1.4) & 1.2 & $(0.8)$ & 0.0 & C \\
\hline & Durango & 17.1 & $(3.7)$ & 27.9 & (3.9) & 28.4 & (3.5) & 20.2 & (3.9) & 5.9 & (1.5) & 0.6 & $(0.4)$ & 0.1 & c \\
\hline & Guanajuato & 22.0 & $(3.2)$ & 28.3 & $(2.8)$ & 27.4 & $(3.1)$ & 15.5 & $(2.1)$ & 6.3 & (1.8) & 0.6 & $(0.7)$ & 0.0 & C \\
\hline & Guerrero & 44.7 & $(3.2)$ & 33.5 & (3.6) & 16.8 & $(2.7)$ & 4.0 & $(0.9)$ & 0.8 & $(0.6)$ & 0.2 & $(0.2)$ & 0.0 & c \\
\hline & Hidalgo & 22.5 & (3.1) & 31.4 & $(3.2)$ & 27.8 & (3.3) & 14.1 & $(2.4)$ & 3.5 & (1.1) & 0.6 & $(0.5)$ & 0.0 & c \\
\hline & Jalisco & 13.9 & $(2.7)$ & 26.1 & (3.3) & 30.9 & (4.3) & 20.7 & (3.5) & 7.0 & (1.6) & 1.4 & $(0.6)$ & 0.1 & c \\
\hline & Mexico & 15.5 & $(2.9)$ & 31.8 & $(3.1)$ & 33.2 & (3.3) & 15.7 & $(2.7)$ & 2.7 & $(1.2)$ & 0.9 & $(0.6)$ & 0.2 & C \\
\hline & Morelos & 20.4 & $(5.0)$ & 29.5 & $(4.1)$ & 27.3 & (3.3) & 14.8 & $(2.3)$ & 6.1 & (1.9) & 1.4 & $(1.0)$ & 0.4 & $(0.6)$ \\
\hline & Nayarit & 21.0 & (3.8) & 28.5 & $(3.5)$ & 28.9 & (3.0) & 16.0 & $(2.0)$ & 5.2 & $(1.2)$ & 0.6 & $(0.5)$ & 0.0 & C \\
\hline & Nuevo León & 11.8 & $(2.9)$ & 25.6 & $(3.2)$ & 31.6 & $(3.2)$ & 20.8 & $(3.7)$ & 8.8 & $(2.0)$ & 1.4 & $(0.9)$ & 0.0 & C \\
\hline & Puebla & 18.9 & $(3.5)$ & 28.8 & $(2.9)$ & 30.9 & (3.5) & 15.7 & $(3.2)$ & 5.0 & $(1.2)$ & 0.6 & $(0.5)$ & 0.1 & C \\
\hline & Querétaro & 12.1 & $(2.7)$ & 28.3 & $(3.7)$ & 29.1 & (3.6) & 21.1 & $(3.1)$ & 7.4 & $(2.1)$ & 1.8 & $(0.7)$ & 0.1 & $(0.2)$ \\
\hline & Quintana Roo & 21.8 & (3.5) & 31.3 & $(2.3)$ & 29.1 & (2.5) & 14.0 & $(2.1)$ & 3.2 & $(0.9)$ & 0.5 & $(0.3)$ & 0.0 & c \\
\hline & San Luis Potosí & 26.1 & (3.8) & 28.1 & (3.9) & 27.5 & $(3.0)$ & 12.7 & $(2.1)$ & 4.6 & (1.5) & 1.1 & $(0.6)$ & 0.0 & C \\
\hline & Sinaloa & 21.5 & (3.1) & 34.4 & $(3.4)$ & 27.2 & $(3.1)$ & 12.4 & $(1.9)$ & 4.0 & $(1.0)$ & 0.5 & $(0.4)$ & 0.0 & C \\
\hline & Tabasco & 37.0 & (3.3) & 33.1 & $(2.6)$ & 20.6 & (2.5) & 7.7 & $(1.8)$ & 1.3 & $(0.6)$ & 0.3 & $(0.3)$ & 0.0 & C \\
\hline & Tamaulipas & 20.6 & $(4.1)$ & 30.1 & (3.6) & 28.5 & (3.3) & 14.3 & $(3.2)$ & 5.3 & $(2.1)$ & 1.1 & $(1.0)$ & 0.0 & C \\
\hline & Tlaxcala & 21.0 & $(2.7)$ & 31.1 & (3.4) & 30.5 & (2.9) & 13.1 & (1.8) & 3.6 & $(0.9)$ & 0.7 & $(0.5)$ & 0.0 & c \\
\hline & Veracruz & 27.4 & $(3.2)$ & 29.3 & $(2.9)$ & 26.5 & (2.5) & 13.2 & (2.6) & 3.1 & (1.0) & 0.5 & $(0.6)$ & 0.0 & C \\
\hline & Yucatán & 20.3 & $(3.3)$ & 31.9 & $(3.1)$ & 26.8 & (3.5) & 15.8 & $(2.5)$ & 4.3 & $(1.1)$ & 0.7 & $(0.5)$ & 0.1 & C \\
\hline & Zacatecas & 21.4 & (2.6) & 32.4 & (2.4) & 27.2 & (2.5) & 15.7 & (2.6) & 3.0 & $(1.0)$ & 0.3 & $(0.2)$ & 0.0 & $\mathrm{C}$ \\
\hline
\end{tabular}

- PISA adjudicated region.

Note: See Table I.2.2a for national data.

StatLink 新组 http://dx.doi.org/10.1787/888932935762 
[Part 2/4]

Table B2.I.2 Percentage of students at each proficiency level in mathematics, by gender and region

\begin{tabular}{|c|c|c|c|c|c|c|c|c|c|c|c|c|c|c|c|}
\hline & & \multicolumn{14}{|c|}{ Boys } \\
\hline & & \multicolumn{2}{|c|}{$\begin{array}{l}\text { Below Level } 1 \\
\text { (below 357.77 } \\
\text { score points) }\end{array}$} & \multicolumn{2}{|c|}{$\begin{array}{c}\text { Level } 1 \\
\text { (from } 357.77 \text { to } \\
\text { less than } 420.07 \\
\text { score points) }\end{array}$} & \multicolumn{2}{|c|}{$\begin{array}{c}\text { Level } 2 \\
\text { (from } 420.07 \text { to } \\
\text { less than } 482.38 \\
\text { score points) }\end{array}$} & $\begin{array}{r}\text { L } \\
\text { (from } \\
\text { less th } \\
\text { scor }\end{array}$ & \begin{tabular}{|l|} 
I 3 \\
2.38 to \\
544.68 \\
oints)
\end{tabular} & $\begin{array}{l}\text { Le } \\
\text { (from } \\
\text { less th } \\
\text { scor }\end{array}$ & \begin{tabular}{l|}
14 \\
4.68 to \\
606.99 \\
oints)
\end{tabular} & $\begin{array}{r}\mathrm{L} \\
\text { (from } \\
\text { less th } \\
\text { scor }\end{array}$ & \begin{tabular}{|l}
5 \\
6.99 to \\
669.30 \\
oints)
\end{tabular} & $\begin{array}{l}\text { Le } \\
\text { (abov } \\
\text { score }\end{array}$ & $\begin{array}{l}16 \\
669.30 \\
\text { oints) }\end{array}$ \\
\hline & & $\%$ & S.E. & $\%$ & S.E. & $\%$ & S.E. & $\%$ & S.E. & $\%$ & S.E. & $\%$ & S.E. & $\%$ & S.E. \\
\hline 0 & Portugal & & & & & & & & & & & & & & \\
\hline ডي山ّ & Alentejo & 6.0 & $(2.1)$ & 14.1 & (3.8) & 23.1 & (3.2) & 27.3 & (4.3) & 16.6 & (3.4) & 9.9 & (3.0) & 3.0 & (1.9) \\
\hline & Spain & & & & & & & & & & & & & & \\
\hline & Andalusia ${ }^{\bullet}$ & 8.5 & (1.7) & 17.0 & (2.4) & 25.6 & (3.0) & 24.7 & (2.3) & 16.5 & (1.7) & 6.0 & (1.1) & 1.6 & (0.6) \\
\hline & Aragon ${ }^{\bullet}$ & 6.7 & (1.3) & 13.6 & (1.6) & 19.9 & (2.0) & 22.4 & (1.8) & 22.8 & $(2.2)$ & 11.9 & (1.7) & 2.7 & $(1.0)$ \\
\hline & Asturias ${ }^{\bullet}$ & 7.6 & (1.7) & 11.0 & (1.6) & 21.6 & (1.9) & 24.4 & (1.7) & 20.1 & (1.8) & 12.2 & (1.8) & 3.1 & $(0.9)$ \\
\hline & Balearic Islands ${ }^{\bullet}$ & 9.6 & (1.8) & 15.7 & (1.6) & 24.2 & $(1.7)$ & 26.2 & (2.1) & 17.7 & (1.8) & 5.8 & (1.2) & 0.9 & $(0.5)$ \\
\hline & Basque Country ${ }^{\bullet}$ & 4.6 & $(0.7)$ & 9.8 & $(0.8)$ & 20.4 & $(0.9)$ & 27.9 & $(1.3)$ & 24.5 & (1.4) & 10.4 & (0.9) & 2.3 & $(0.4)$ \\
\hline & Cantabria ${ }^{\bullet}$ & 7.5 & $(1.3)$ & 13.5 & $(1.5)$ & 20.9 & $(1.8)$ & 24.5 & (1.7) & 20.9 & (1.7) & 10.4 & (1.4) & 2.3 & $(0.6)$ \\
\hline & Castile and Leon ${ }^{\bullet}$ & 4.4 & (1.1) & 10.1 & (1.3) & 19.7 & (1.8) & 24.6 & (2.4) & 24.7 & (2.3) & 14.0 & (1.6) & 2.6 & $(0.8)$ \\
\hline & Catalonia ${ }^{\bullet}$ & 4.9 & (1.0) & 13.0 & (2.3) & 22.9 & (2.9) & 26.1 & (2.5) & 20.8 & (2.1) & 10.2 & (1.7) & 2.1 & $(0.7)$ \\
\hline & Extremadura ${ }^{\bullet}$ & 13.9 & (1.9) & 19.2 & (2.3) & 22.1 & (1.8) & 22.7 & (1.6) & 14.6 & (1.4) & 6.2 & (1.2) & 1.4 & $(0.5)$ \\
\hline & Galicia• & 7.4 & (1.3) & 15.6 & (1.6) & 21.9 & $(2.2)$ & 26.4 & (2.4) & 19.8 & (1.7) & 7.9 & (1.3) & 1.0 & $(0.5)$ \\
\hline & La Rioja` & 9.0 & $(1.2)$ & 9.8 & $(1.2)$ & 18.3 & (1.6) & 21.5 & (1.8) & 21.1 & (1.9) & 14.6 & (1.7) & 5.7 & (1.0) \\
\hline & Madrid ${ }^{\bullet}$ & 5.2 & $(0.9)$ & 12.1 & (1.7) & 18.0 & $(1.6)$ & 26.1 & (1.7) & 24.3 & $(2.6)$ & 11.6 & (2.0) & 2.6 & $(0.9)$ \\
\hline & Murcia ${ }^{\bullet}$ & 13.2 & (1.8) & 16.9 & (2.3) & 25.4 & (2.4) & 21.8 & (2.0) & 14.9 & (1.4) & 6.6 & (1.5) & 1.2 & $(0.6)$ \\
\hline & Navarre ${ }^{\bullet}$ & 4.6 & $(1.2)$ & 9.2 & (1.4) & 17.6 & (1.6) & 27.4 & (1.9) & 25.8 & (1.8) & 12.2 & (1.6) & 3.2 & $(1.0)$ \\
\hline & United Kingdom & & & & & & & & & & & & & & \\
\hline & England & 7.3 & (1.1) & 12.2 & (1.1) & 21.7 & $(1.2)$ & 25.0 & (1.4) & 19.7 & (1.3) & 10.7 & $(1.2)$ & 3.3 & $(0.7)$ \\
\hline & Northern Ireland & 8.0 & (1.3) & 14.2 & (1.7) & 23.0 & (1.7) & 25.4 & (1.8) & 18.3 & (1.5) & 8.5 & (1.1) & 2.5 & (0.6) \\
\hline & Scotland $\bullet^{\bullet}$ & 4.3 & $(0.7)$ & 11.9 & (1.2) & 23.4 & (1.3) & 27.5 & (1.6) & 20.6 & (1.4) & 9.6 & (0.8) & 2.7 & (0.5) \\
\hline & Wales & 9.4 & (1.0) & 17.5 & (1.3) & 26.8 & (1.4) & 25.8 & (1.4) & 14.2 & (1.3) & 5.1 & $(0.8)$ & 1.2 & $(0.3)$ \\
\hline & United States & & & & & & & & & & & & & & \\
\hline & Connecticut ${ }^{\bullet}$ & 5.7 & (1.3) & 13.6 & (1.9) & 19.1 & (1.6) & 23.1 & (1.8) & 19.9 & $(2.2)$ & 12.8 & (1.9) & 5.8 & (1.1) \\
\hline & Florida & 9.2 & (1.7) & 19.1 & (2.2) & 25.8 & $(2.2)$ & 24.4 & $(2.0)$ & 14.7 & $(2.0)$ & 5.6 & (1.4) & 1.1 & $(0.4)$ \\
\hline & Massachusetts ${ }^{\bullet}$ & 5.1 & (0.9) & 12.0 & (1.4) & 19.3 & (2.1) & 23.9 & (2.1) & 19.5 & (1.5) & 13.3 & (1.8) & 6.9 & (1.4) \\
\hline 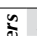 & Argentina & & & & & & & & & & & & & & \\
\hline$\stackrel{\Xi}{\Xi}$ & Ciudad Autónoma de Buenos Aires & 21.9 & $(2.8)$ & 21.3 & (3.4) & 28.7 & $(2.8)$ & 18.4 & (2.3) & 8.2 & $(2.0)$ & 1.4 & (0.6) & 0.1 & c \\
\hline ฐ & Brazil & & & & & & & & & & & & & & \\
\hline & Acre & 46.9 & (5.5) & 32.9 & $(4.1)$ & 15.7 & $(3.1)$ & 3.7 & $(1.7)$ & 0.6 & $(0.6)$ & 0.2 & c & 0.0 & c \\
\hline & Alagoas & 58.6 & $(5.4)$ & 26.5 & (3.7) & 10.4 & (3.0) & 3.7 & (1.9) & 0.8 & $(0.9)$ & 0.0 & c & 0.0 & c \\
\hline & Amapá & 42.2 & $(7.1)$ & 36.0 & (4.8) & 17.0 & $(4.5)$ & 4.5 & (2.6) & 0.4 & $\mathrm{C}$ & 0.0 & c & 0.0 & c \\
\hline & Amazonas & 50.2 & (4.9) & 31.9 & (3.9) & 11.9 & $(2.5)$ & 4.4 & (1.5) & 1.0 & (1.0) & 0.5 & $(0.6)$ & 0.0 & c \\
\hline & Bahia & 41.6 & (5.3) & 30.7 & (5.4) & 16.2 & (3.9) & 7.7 & (2.0) & 2.7 & (1.9) & 1.2 & (1.4) & 0.0 & c \\
\hline & Ceará & 37.1 & (3.9) & 33.4 & (3.9) & 16.8 & $(3.3)$ & 7.7 & (2.3) & 3.2 & $(2.0)$ & 1.8 & (1.0) & 0.1 & c \\
\hline & Espírito Santo & 23.6 & (3.3) & 30.2 & (4.5) & 21.4 & (3.9) & 14.6 & (2.5) & 7.4 & $(2.5)$ & 2.4 & $(1.2)$ & 0.3 & c \\
\hline & Federal District & 23.9 & (5.9) & 27.5 & (4.4) & 23.0 & (3.5) & 15.3 & (3.2) & 7.9 & $(2.1)$ & 2.0 & (1.1) & 0.3 & c \\
\hline & Goiás & 35.5 & (4.5) & 34.3 & (3.8) & 17.7 & $(2.5)$ & 8.5 & (2.4) & 3.5 & $(1.5)$ & 0.5 & $\mathrm{C}$ & 0.0 & c \\
\hline & Maranhão & 55.8 & (7.6) & 24.8 & (3.9) & 10.3 & (3.3) & 6.4 & (3.9) & 2.1 & $(2.0)$ & 0.7 & $(0.6)$ & 0.0 & c \\
\hline & Mato Grosso & 44.1 & (5.5) & 31.8 & (4.4) & 17.2 & (3.3) & 4.6 & (1.8) & 2.0 & $(1.5)$ & 0.3 & C & 0.0 & c \\
\hline & Mato Grosso do Sul & 21.6 & (4.6) & 31.4 & (4.4) & 26.2 & $(3.2)$ & 14.8 & (3.0) & 5.5 & $(2.3)$ & 0.5 & $(0.5)$ & 0.0 & c \\
\hline & Minas Gerais & 23.8 & (4.4) & 32.4 & (3.6) & 27.5 & $(4.0)$ & 13.1 & (3.5) & 2.5 & $(1.2)$ & 0.7 & $(0.6)$ & 0.0 & $\mathrm{c}$ \\
\hline & Pará & 46.8 & (3.7) & 31.3 & $(4.0)$ & 16.8 & $(2.7)$ & 4.1 & (1.3) & 1.0 & $(1.0)$ & 0.0 & $\mathrm{C}$ & 0.0 & c \\
\hline & Paraiba & 28.3 & $(5.2)$ & 34.0 & (4.9) & 21.3 & $(4.5)$ & 9.4 & (3.1) & 5.7 & $(2.3)$ & 1.2 & $(0.8)$ & 0.1 & $\mathrm{c}$ \\
\hline & Paraná & 27.3 & $(4.8)$ & 30.1 & (3.9) & 22.0 & $(3.1)$ & 11.5 & $(2.2)$ & 7.3 & (3.4) & 1.8 & $(2.2)$ & 0.0 & c \\
\hline & Pernambuco & 42.6 & $\begin{array}{l}(4.0) \\
(5.3)\end{array}$ & 33.2 & (4.6) & $\begin{array}{l}22.0 \\
17.2\end{array}$ & (3.7) & 5.2 & $(2.2)$ & 1.4 & (1.4) & 0.4 & $(0.4)$ & 0.0 & c \\
\hline & Piaú & $\begin{array}{l}42.0 \\
36.1\end{array}$ & (4.6) & $\begin{array}{l}53.2 \\
31.9\end{array}$ & $\begin{array}{l}(4.0) \\
(5.2)\end{array}$ & 16.8 & (4.0) & 9.2 & $(1.9)$ & 4.6 & $(2.4)$ & 0.8 & $(0.9)$ & 0.7 & $(0.4)$ \\
\hline & Rio de Janeiro & 30.5 & $\begin{array}{l}(4.0) \\
(4.2)\end{array}$ & 35.2 & (4.0) & 21.4 & $(3.3)$ & 10.0 & $(2.3)$ & 2.6 & $(1.3)$ & 0.3 & $\begin{array}{r}\text { C } \\
\text { (1). }\end{array}$ & 0.0 & $\begin{array}{r}\text { (10.4) } \\
\mathrm{C}\end{array}$ \\
\hline & Rio Grande do Norte & 38.1 & $(4.1)$ & 31.4 & $(4.3)$ & $\begin{array}{l}21.4 \\
15.4\end{array}$ & (3.5) & 7.7 & $(3.2)$ & 4.8 & $(1.9)$ & 2.3 & (2.0) & 0.3 & c \\
\hline & Rio Grande do Sul & 22.4 & $(4.0)$ & 30.8 & (3.9) & 28.9 & (3.6) & 14.8 & (3.8) & 2.7 & $(1.1)$ & 0.4 & $\begin{array}{r}(2.0) \\
\mathrm{C}\end{array}$ & 0.0 & c \\
\hline & Rondônia & $\begin{array}{l}22.4 \\
33.4\end{array}$ & $\begin{array}{l}(4.0) \\
(3.8)\end{array}$ & 37.0 & (3.9) & $\begin{array}{l}20.9 \\
22.4\end{array}$ & (3.3) & $\begin{array}{r}14.0 \\
5.4\end{array}$ & (1.9) & 1.8 & $(1.2)$ & 0.1 & c & 0.0 & c \\
\hline & Roraima & 48.8 & $(4.8)$ & 28.9 & (3.8) & 16.2 & $(4.7)$ & 5.1 & (2.6) & 0.8 & $(0.6)$ & 0.2 & $\mathrm{c}$ & 0.0 & c \\
\hline & Santa Catarina & $\begin{array}{l}40.0 \\
21.7\end{array}$ & $\begin{array}{l}(4.0) \\
(3.6)\end{array}$ & 28.8 & (3.5) & 26.4 & $(3.5)$ & 17.0 & $\begin{array}{l}(2.0) \\
(3.5)\end{array}$ & 5.7 & $\begin{array}{l}(0.0) \\
(1.7)\end{array}$ & 0.4 & $(0.3)$ & 0.0 & c \\
\hline & São Paulo & 26.2 & $(2.1)$ & 31.4 & (2.3) & 24.7 & (1.8) & 11.5 & (1.6) & 4.6 & (1.0) & 1.6 & $(0.7)$ & 0.1 & c \\
\hline & Sergipe & 32.9 & (5.7) & 32.2 & $(4.7)$ & 19.3 & $(2.6)$ & 12.2 & (4.5) & 2.6 & (1.6) & 0.7 & $(0.7)$ & 0.0 & c \\
\hline & Tocantins & 43.0 & (4.4) & 29.6 & (2.8) & 16.6 & $(2.5)$ & 8.2 & $(2.3)$ & 2.3 & $(1.3)$ & 0.3 & $\mathrm{C}$ & 0.0 & $\mathrm{c}$ \\
\hline & Colombia & & & & & & & & & & & & & & \\
\hline & Bogotá & 21.1 & (2.4) & 37.5 & (2.4) & 28.0 & (2.4) & 10.5 & (1.4) & 2.2 & (1.1) & 0.6 & $(0.5)$ & 0.0 & c \\
\hline & Cali & 35.1 & $(4.1)$ & 34.1 & (3.2) & 20.1 & $(2.9)$ & 8.8 & (2.3) & 2.0 & $(0.9)$ & 0.0 & c & 0.0 & c \\
\hline & Manizales & 21.1 & (2.5) & 32.0 & (3.3) & 25.9 & (3.1) & 14.9 & (2.5) & 5.2 & (1.6) & 0.9 & $(0.7)$ & 0.1 & $\mathrm{C}$ \\
\hline & Medellín & 29.3 & (3.6) & 31.4 & (2.6) & 22.7 & $(2.8)$ & 11.0 & (2.0) & 3.6 & $(1.3)$ & 1.5 & (1.0) & 0.6 & $(0.5)$ \\
\hline & Russian Federation & & & & & & & & & & & & & & \\
\hline & Perm Territory region & 7.7 & (1.6) & 14.9 & (1.7) & 26.1 & (2.5) & 25.1 & (2.4) & 16.4 & (1.4) & 6.9 & (1.3) & 3.0 & (1.4) \\
\hline & United Arab Emirates & & & & & & & & & & & & & & \\
\hline & Abu Dhabi & 29.7 & $(2.1)$ & 26.0 & (1.9) & 21.7 & (1.4) & 12.9 & (1.1) & 6.7 & $(1.1)$ & 2.7 & $(0.7)$ & 0.3 & $(0.2)$ \\
\hline & Ajman & 33.9 & $(8.0)$ & 31.5 & (5.7) & 22.0 & $(3.7)$ & 11.1 & (2.3) & 1.3 & $(0.8)$ & 0.1 & $\mathrm{C}$ & 0.0 & $\mathrm{C}$ \\
\hline & Dubai ${ }^{\bullet}$ & 14.6 & $(0.7)$ & 18.5 & (1.1) & 21.9 & $(1.1)$ & 21.6 & (1.1) & 14.9 & $(1.2)$ & 6.7 & (1.0) & 1.9 & $(0.4)$ \\
\hline & Fujairah & 34.9 & $(5.3)$ & 30.5 & (3.0) & 18.8 & $(4.5)$ & 10.1 & (2.6) & 4.8 & (1.8) & 0.8 & $(0.6)$ & 0.2 & C \\
\hline & Ras al-Khaimah & 27.8 & (3.6) & 31.7 & $(4.1)$ & 24.4 & (3.4) & 12.7 & $(2.2)$ & 2.9 & $(1.0)$ & 0.5 & $(0.3)$ & 0.1 & $\mathrm{c}$ \\
\hline & Sharjah & 16.2 & $(5.1)$ & 25.0 & $(4.3)$ & $\begin{array}{l}24.4 \\
25.5\end{array}$ & (4.4) & 19.0 & (3.9) & 10.3 & (3.5) & 3.0 & $(1.7)$ & 0.9 & $(0.8)$ \\
\hline & Umm al-Quwain & 41.9 & (5.5) & 33.5 & (5.2) & 16.9 & $(3.7)$ & 4.7 & $(2.7)$ & 0.0 & $\mathrm{C}$ & 1.5 & (1.3) & 1.4 & $\begin{array}{r}0.07 \\
\mathrm{C}\end{array}$ \\
\hline
\end{tabular}

- PISA adjudicated region

Note: See Table 1.2.2a for national data.

StatLink 解古 $\mathrm{http}: / / \mathrm{dx}$.doi.org/10.1787/888932935762 
[Part 3/4]

Table B2.I.2 Percentage of students at each proficiency level in mathematics, by gender and region

\begin{tabular}{|c|c|c|c|c|c|c|c|c|c|c|c|c|c|c|c|}
\hline & & \multicolumn{14}{|c|}{ Girls } \\
\hline & & \multicolumn{2}{|c|}{$\begin{array}{l}\text { Below Level } 1 \\
\text { (below 357.77 } \\
\text { score points) }\end{array}$} & $\begin{array}{l}\text { L } \\
\text { (from } \\
\text { less th } \\
\text { scor }\end{array}$ & $\begin{array}{l}\text { l } 1 \\
7.77 \text { to } \\
\mathbf{4 2 0 . 0 7} \\
\text { oints) }\end{array}$ & $\begin{array}{r}\mathrm{L} \\
\text { (from } \\
\text { less th } \\
\text { scor }\end{array}$ & $\begin{array}{l}l 2 \\
0.07 \text { to } \\
482.38 \\
\text { oints) }\end{array}$ & $\begin{array}{l}\mathrm{L} \\
\text { (from } \\
\text { less th } \\
\text { scor }\end{array}$ & \begin{tabular}{|l|}
3 \\
2.38 to \\
544.68 \\
oints)
\end{tabular} & $\begin{array}{r}L \\
\text { (from } \\
\text { less th } \\
\text { scor }\end{array}$ & $\begin{array}{l}\text { l } 4 \\
4.68 \text { to } \\
606.99 \\
\text { oints) }\end{array}$ & $\begin{array}{l}\mathrm{L} \\
\text { (from } \\
\text { less th } \\
\text { scor }\end{array}$ & $\begin{array}{l}5 \\
6.99 \text { to } \\
669.30 \\
\text { oints) }\end{array}$ & $\begin{array}{r}\mathrm{L} \\
\text { (abo } \\
\text { scor }\end{array}$ & $\begin{array}{l}6 \\
669.30 \\
\text { oints) }\end{array}$ \\
\hline & & $\%$ & S.E. & $\%$ & S.E. & $\%$ & S.E. & $\%$ & S.E. & $\%$ & S.E. & $\%$ & S.E. & $\%$ & S.E. \\
\hline 0 & Australia & & & & & & & & & & & & & & \\
\hline ( & Australian Capital Territory & 4.8 & $(1.3)$ & 9.9 & (1.8) & 20.3 & (2.6) & 25.6 & (3.4) & 22.6 & $(2.9)$ & 12.6 & $(2.2)$ & 4.0 & $(1.2)$ \\
\hline & New South Wales & 6.1 & $(0.8)$ & 13.9 & $(1.5)$ & 20.8 & (1.5) & 25.1 & $(1.5)$ & 19.3 & $(1.3)$ & 10.1 & $(1.0)$ & 4.8 & (1.1) \\
\hline & Northern Territory & 17.1 & $(2.5)$ & 20.7 & $(4.8)$ & 26.3 & (5.5) & 21.5 & (5.4) & 9.2 & $(4.0)$ & 4.4 & $(2.7)$ & 0.9 & $(0.9)$ \\
\hline & Queensland & 5.8 & $(1.0)$ & 14.8 & $(1.2)$ & 22.1 & (1.6) & 25.1 & $(2.1)$ & 18.5 & $(1.3)$ & 10.3 & $(1.3)$ & 3.2 & $(0.9)$ \\
\hline & South Australia & 7.3 & $(1.0)$ & 18.3 & $(1.7)$ & 24.1 & (2.5) & 25.4 & $(2.0)$ & 16.5 & $(2.3)$ & 6.9 & $(1.3)$ & 1.6 & (0.6) \\
\hline & Tasmania & 10.1 & $(1.5)$ & 19.8 & $(2.4)$ & 24.3 & (2.5) & 24.5 & $(2.2)$ & 13.4 & $(1.6)$ & 6.2 & $(1.7)$ & 1.8 & $(0.8)$ \\
\hline & Victoria & 6.5 & $(1.1)$ & 15.1 & (1.3) & 24.0 & (1.7) & 26.5 & $(1.8)$ & 18.5 & $(1.8)$ & 7.7 & $(1.2)$ & 1.6 & $(0.5)$ \\
\hline & Western Australia & 5.6 & $(0.9)$ & 13.8 & $(1.7)$ & 22.1 & $(2.3)$ & 23.9 & $(2.1)$ & 21.0 & $(2.1)$ & 10.4 & $(1.7)$ & 3.2 & $(0.7)$ \\
\hline & Belgium & & & & & & & & & & & & & & \\
\hline & Flemish Community• & 5.6 & $(0.8)$ & 10.3 & $(1.0)$ & 17.4 & $(1.2)$ & 22.3 & (1.3) & 22.0 & $(1.2)$ & 15.2 & $(1.2)$ & 7.1 & $(0.8)$ \\
\hline & French Community & 8.9 & $(1.1)$ & 15.0 & $(1.3)$ & 23.0 & (1.4) & 24.7 & (1.5) & 18.9 & $(1.3)$ & 7.5 & $(1.0)$ & 1.9 & $(0.3)$ \\
\hline & German-speaking Community & 4.5 & $(1.0)$ & 8.9 & (1.6) & 19.8 & (2.5) & 29.9 & (3.1) & 25.4 & $(2.9)$ & 9.8 & (1.7) & 1.7 & $(0.8)$ \\
\hline & Canada & & & & & & & & & & & & & & \\
\hline & Alberta & 3.8 & $(0.9)$ & 12.8 & $(1.7)$ & 21.4 & $(2.2)$ & 24.1 & $(2.3)$ & 23.5 & (1.9) & 11.3 & (1.5) & 3.0 & $(0.7)$ \\
\hline & British Columbia & 3.0 & $(0.6)$ & 10.6 & $(1.6)$ & 21.4 & (1.9) & 28.2 & (1.8) & 22.7 & $(1.9)$ & 10.6 & (1.6) & 3.5 & $(0.9)$ \\
\hline & Manitoba & 6.3 & $(1.4)$ & 15.4 & $(1.7)$ & 25.9 & (2.0) & 25.5 & $(2.2)$ & 18.5 & $(1.5)$ & 6.8 & $(1.0)$ & 1.7 & (0.6) \\
\hline & New Brunswick & 4.0 & $(0.9)$ & 11.4 & $(1.6)$ & 26.1 & $(2.7)$ & 28.8 & (3.4) & 20.4 & $(2.4)$ & 7.7 & (1.6) & 1.6 & $(1.2)$ \\
\hline & Newfoundland and Labrador & 5.5 & $(1.7)$ & 14.7 & $(2.0)$ & 26.3 & (3.3) & 27.9 & $(2.5)$ & 17.0 & $(1.9)$ & 7.3 & $(1.1)$ & 1.3 & $(0.7)$ \\
\hline & Nova Scotia & 3.8 & $(1.2)$ & 14.7 & $(2.3)$ & 27.5 & $(4.1)$ & 30.1 & $(2.5)$ & 16.5 & $(2.8)$ & 5.9 & $(1.4)$ & 1.5 & $(0.8)$ \\
\hline & Ontario & 3.6 & $(0.7)$ & 10.0 & $(1.1)$ & 23.7 & (1.9) & 29.0 & $(1.4)$ & 21.6 & $(1.6)$ & 9.4 & $(1.2)$ & 2.6 & $(0.7)$ \\
\hline & Prince Edward Island & 5.3 & $(1.2)$ & 18.4 & (1.8) & 28.5 & $(2.0)$ & 27.7 & $(2.2)$ & 15.0 & $(1.5)$ & 4.0 & $(1.0)$ & 1.0 & $(0.5)$ \\
\hline & Quebec & 3.0 & $(0.6)$ & 8.8 & $(0.9)$ & 17.1 & (1.3) & 24.7 & $(1.3)$ & 26.8 & (1.4) & 14.6 & $(1.1)$ & 4.9 & $(0.7)$ \\
\hline & Saskatchewan & 3.6 & $(0.9)$ & 12.4 & $(1.4)$ & 25.0 & (1.8) & 29.2 & $(2.2)$ & 18.9 & $(1.7)$ & 9.1 & (1.4) & 1.8 & $(0.8)$ \\
\hline & Italy & & & & & & & & & & & & & & \\
\hline & Abruzzo & 9.6 & $(2.0)$ & 18.3 & $(2.0)$ & 26.2 & $(2.1)$ & 26.4 & $(2.7)$ & 14.1 & $(2.4)$ & 4.6 & $(1.2)$ & 0.8 & $(0.4)$ \\
\hline & Basilicata & 11.6 & $(1.9)$ & 22.2 & $(2.1)$ & 29.8 & $(2.1)$ & 23.9 & $(1.8)$ & 9.5 & $(1.4)$ & 2.2 & $(0.7)$ & 0.7 & $(0.4)$ \\
\hline & Bolzano & 5.8 & $(0.8)$ & 12.9 & (1.6) & 22.6 & (2.4) & 31.3 & $(2.0)$ & 19.5 & $(1.7)$ & 6.9 & $(1.1)$ & 1.1 & $(0.5)$ \\
\hline & Calabria & 24.4 & $(3.8)$ & 25.1 & $(2.5)$ & 27.3 & (2.6) & 16.4 & $(2.1)$ & 5.5 & $(1.3)$ & 1.1 & $(0.5)$ & 0.1 & c \\
\hline & Campania & 15.6 & $(2.9)$ & 23.2 & $(3.7)$ & 28.0 & (3.3) & 20.4 & $(3.2)$ & 10.2 & $(2.3)$ & 2.2 & $(1.1)$ & 0.3 & $(0.3)$ \\
\hline & Emilia Romagna & 6.5 & (1.6) & 14.0 & $(2.0)$ & 27.0 & (2.6) & 24.6 & $(2.3)$ & 18.4 & $(2.4)$ & 7.1 & $(1.8)$ & 2.4 & $(0.8)$ \\
\hline & Friuli Venezia Giulia & 3.5 & $(1.7)$ & 8.8 & $(1.5)$ & 21.3 & $(2.7)$ & 32.4 & $(2.5)$ & 22.5 & $(2.4)$ & 9.1 & (1.6) & 2.5 & $(0.8)$ \\
\hline & Lazio & 10.7 & (1.9) & 21.1 & $(2.7)$ & 27.9 & (2.9) & 24.1 & $(2.2)$ & 11.4 & $(2.1)$ & 4.2 & $(1.1)$ & 0.7 & $(0.4)$ \\
\hline & Liguria & 7.7 & $(1.8)$ & 16.0 & $(1.8)$ & 25.2 & (2.4) & 26.9 & (1.9) & 16.9 & $(2.3)$ & 6.1 & $(1.3)$ & 1.2 & $(0.5)$ \\
\hline & Lombardia & 2.6 & $(0.9)$ & 12.6 & $(2.7)$ & 23.3 & (2.9) & 30.1 & $(2.9)$ & 21.2 & $(2.3)$ & 8.6 & $(1.8)$ & 1.6 & $(0.7)$ \\
\hline & Marche & 7.3 & $(2.2)$ & 14.7 & $(1.8)$ & 28.0 & (2.6) & 27.6 & $(2.3)$ & 16.0 & $(2.0)$ & 5.5 & $(1.5)$ & 1.0 & $(0.5)$ \\
\hline & Molise & 10.0 & $(1.4)$ & 23.2 & $(2.0)$ & 28.7 & (3.4) & 24.7 & $(3.0)$ & 9.6 & $(1.7)$ & 3.0 & $(1.3)$ & 0.7 & $(0.6)$ \\
\hline & Piemonte & 6.6 & $(1.5)$ & 16.8 & $(3.0)$ & 23.8 & (3.0) & 28.0 & $(2.8)$ & 16.4 & $(2.3)$ & 6.9 & $(1.4)$ & 1.5 & $(0.6)$ \\
\hline & Puglia & 8.3 & $(2.2)$ & 21.5 & $(2.4)$ & 28.4 & (2.4) & 23.8 & $(2.1)$ & 13.6 & $(2.1)$ & 3.8 & $(1.0)$ & 0.7 & $(0.4)$ \\
\hline & Sardegna & 12.5 & $(2.7)$ & 21.8 & $(3.0)$ & 28.0 & (2.8) & 23.1 & $(3.0)$ & 11.4 & $(2.0)$ & 2.8 & $(0.8)$ & 0.3 & $(0.3)$ \\
\hline & Sicilia & 14.2 & $(2.2)$ & 25.5 & $(2.7)$ & 30.1 & $(2.2)$ & 20.7 & $(2.5)$ & 8.1 & $(1.4)$ & 1.2 & $(0.5)$ & 0.2 & c \\
\hline & Toscana & 6.3 & $(1.4)$ & 15.0 & $(2.6)$ & 21.9 & (2.5) & 27.2 & $(2.8)$ & 19.6 & $(3.0)$ & 8.2 & $(1.9)$ & 1.8 & $(0.6)$ \\
\hline & Trento & 2.1 & $(1.0)$ & 7.5 & $(2.2)$ & 20.7 & (2.4) & 31.1 & $(2.6)$ & 26.2 & $(3.5)$ & 10.6 & $(1.8)$ & 1.6 & $(0.7)$ \\
\hline & Umbria & 8.2 & $(2.3)$ & 15.3 & $(2.5)$ & 25.5 & $(2.2)$ & 27.9 & $(2.2)$ & 16.5 & $(2.1)$ & 5.8 & (1.3) & 0.8 & $(0.4)$ \\
\hline & Valle d'Aosta & 5.1 & $(1.5)$ & 16.6 & $(2.4)$ & 28.3 & (3.6) & 29.3 & $(2.5)$ & 14.5 & (2.4) & 4.5 & $(1.2)$ & 1.6 & $(0.8)$ \\
\hline & Veneto & 3.8 & $(1.7)$ & 10.4 & $(2.0)$ & 21.3 & $(2.7)$ & 29.1 & $(3.0)$ & 23.0 & $(2.2)$ & 10.0 & $(2.1)$ & 2.3 & (1.0) \\
\hline & Mexico & & & & & & & & & & & & & & \\
\hline & Aguascalientes & 14.7 & $(2.8)$ & 29.3 & $(2.6)$ & 33.2 & $(2.7)$ & 17.3 & $(2.3)$ & 4.5 & (1.1) & 1.0 & $(0.8)$ & 0.0 & C \\
\hline & Baja California & 24.8 & (3.1) & 33.0 & $(3.2)$ & 25.9 & (2.5) & 12.2 & $(2.0)$ & 3.9 & $(1.5)$ & 0.3 & c & 0.0 & c \\
\hline & Baja California Sur & 24.7 & (3.6) & 34.6 & $(2.4)$ & 25.5 & (2.6) & 12.1 & $(2.1)$ & 2.8 & $(1.0)$ & 0.3 & $(0.3)$ & 0.0 & C \\
\hline & Campeche & 32.2 & $(3.2)$ & 36.2 & $(2.8)$ & 22.6 & (3.1) & 7.3 & (1.9) & 1.5 & $(0.6)$ & 0.3 & $(0.3)$ & 0.0 & C \\
\hline & Chiapas & 44.5 & $(4.8)$ & 30.4 & (3.7) & 18.5 & $(3.2)$ & 5.5 & $(1.7)$ & 0.9 & $(0.6)$ & 0.1 & c & 0.0 & C \\
\hline & Chihuahua & 20.5 & $(3.1)$ & 29.3 & (3.2) & 29.9 & (3.4) & 15.0 & $(2.7)$ & 4.6 & $(1.2)$ & 0.6 & $(0.5)$ & 0.0 & c \\
\hline & Coahuila & 21.2 & $(4.1)$ & 34.7 & $(5.5)$ & 28.7 & $(4.1)$ & 11.6 & $(3.2)$ & 3.6 & (1.9) & 0.2 & $\mathrm{C}$ & 0.0 & C \\
\hline & Colima & 18.7 & $(2.3)$ & 29.9 & $(2.1)$ & 28.6 & (2.8) & 17.3 & $(2.6)$ & 5.0 & $(1.5)$ & 0.5 & $(0.4)$ & 0.2 & C \\
\hline & Distrito Federal & 21.0 & $(3.0)$ & 34.1 & (3.4) & 28.7 & $(2.2)$ & 11.8 & $(2.0)$ & 3.9 & $(1.6)$ & 0.5 & $(0.5)$ & 0.0 & C \\
\hline & Durango & 19.4 & $(3.1)$ & 32.2 & $(3.2)$ & 28.9 & (3.7) & 15.9 & $(3.1)$ & 3.3 & $(1.1)$ & 0.3 & $(0.2)$ & 0.0 & C \\
\hline & Guanajuato & 26.2 & (3.7) & 33.5 & (3.3) & 27.0 & (2.9) & 11.2 & $(1.5)$ & 1.9 & $(0.7)$ & 0.1 & c & 0.0 & C \\
\hline & Guerrero & 49.0 & (3.0) & 32.2 & $(2.5)$ & 13.4 & (2.6) & 4.7 & $(1.1)$ & 0.7 & $(0.5)$ & 0.0 & c & 0.0 & C \\
\hline & Hidalgo & 27.5 & (3.6) & 33.9 & $(2.7)$ & 26.3 & (3.8) & 10.1 & $(2.2)$ & 2.0 & $(0.7)$ & 0.1 & C & 0.0 & C \\
\hline & Jalisco & 13.9 & (2.4) & 30.8 & $(2.3)$ & 33.5 & (2.4) & 17.2 & $(2.4)$ & 3.9 & $(1.5)$ & 0.6 & $(0.5)$ & 0.0 & C \\
\hline & Mexico & 20.6 & $(3.0)$ & 35.7 & $(2.8)$ & 31.3 & (3.4) & 10.8 & $(2.0)$ & 1.4 & $(0.9)$ & 0.2 & c & 0.0 & C \\
\hline & Morelos & 20.6 & (3.0) & 32.5 & $(3.7)$ & 28.6 & (2.9) & 12.6 & $(2.4)$ & 4.2 & $(2.2)$ & 1.5 & $(1.2)$ & 0.0 & C \\
\hline & Nayarit & 26.4 & $(3.7)$ & 31.1 & $(2.8)$ & 26.8 & (2.9) & 12.0 & $(2.0)$ & 3.6 & $(1.5)$ & 0.2 & $\mathrm{c}$ & 0.0 & C \\
\hline & Nuevo León & 18.0 & $(2.9)$ & 32.3 & $(3.0)$ & 28.5 & (2.8) & 15.9 & $(2.7)$ & 4.3 & $(1.1)$ & 0.8 & $(0.6)$ & 0.0 & C \\
\hline & Puebla & 23.1 & $(3.2)$ & 35.0 & $(3.2)$ & 26.8 & (2.8) & 11.8 & $(2.0)$ & 3.2 & $(0.8)$ & 0.1 & C & 0.0 & C \\
\hline & Querétaro & 17.9 & (3.1) & 29.8 & (3.5) & 30.9 & (3.8) & 15.5 & $(3.1)$ & 5.0 & $(1.3)$ & 0.9 & $(0.5)$ & 0.0 & C \\
\hline & Quintana Roo & 24.8 & $(3.0)$ & 34.3 & $(2.2)$ & 27.1 & (2.8) & 11.1 & $(2.0)$ & 2.3 & $(0.9)$ & 0.4 & $(0.3)$ & 0.0 & C \\
\hline & San Luis Potosí & 25.7 & $(4.1)$ & 30.6 & (3.5) & 26.9 & $(2.7)$ & 13.3 & $(2.4)$ & 3.4 & $(1.3)$ & 0.2 & c & 0.0 & c \\
\hline & Sinaloa & 23.7 & $(2.4)$ & 34.5 & $(2.9)$ & 27.7 & (3.4) & 12.1 & $(2.0)$ & 1.9 & $(0.7)$ & 0.2 & $(0.2)$ & 0.0 & C \\
\hline & Tabasco & 40.5 & $(2.9)$ & 37.3 & $(2.8)$ & 16.3 & (2.3) & 4.9 & $(1.1)$ & 1.1 & $(0.4)$ & 0.0 & c & 0.0 & C \\
\hline & Tamaulipas & 27.5 & (3.3) & 34.9 & (3.5) & 25.2 & (2.9) & 10.1 & $(2.1)$ & 2.2 & $(1.0)$ & 0.1 & $\mathrm{C}$ & 0.0 & C \\
\hline & Tlaxcala & 24.1 & $(3.0)$ & 34.7 & $(2.3)$ & 27.8 & (2.5) & 10.1 & (1.9) & 3.1 & $(1.2)$ & 0.2 & $(0.2)$ & 0.0 & C \\
\hline & Veracruz & 29.7 & (3.5) & 35.0 & $(3.0)$ & 22.8 & (3.0) & 9.5 & $(2.2)$ & 2.6 & (1.3) & 0.3 & c & 0.0 & C \\
\hline & Yucatán & 29.0 & (3.4) & 33.5 & $(2.7)$ & 24.9 & (3.0) & 10.1 & $(1.7)$ & 2.2 & $(0.9)$ & 0.3 & $(0.3)$ & 0.0 & C \\
\hline & Zacatecas & 25.9 & (2.6) & 34.9 & $(2.7)$ & 25.9 & $(2.2)$ & 11.0 & $(1.7)$ & 2.0 & $(0.6)$ & 0.3 & $\mathrm{C}$ & 0.0 & $\mathrm{C}$ \\
\hline
\end{tabular}

- PISA adjudicated region.

Note: See Table I.2.2a for national data.

StatLink त्राडs http://dx.doi.org/10.1787/888932935762 
[Part 4/4]

Table B2.I.2 Percentage of students at each proficiency level in mathematics, by gender and region

\begin{tabular}{|c|c|c|c|c|c|c|c|c|c|c|c|c|c|c|c|}
\hline & & \multicolumn{14}{|c|}{ Girls } \\
\hline & & \multicolumn{2}{|c|}{$\begin{array}{l}\text { Below Level } 1 \\
\text { (below } 357.77 \\
\text { score points) }\end{array}$} & \multicolumn{2}{|c|}{$\begin{array}{c}\text { Level } 1 \\
\text { (from } 357.77 \text { to } \\
\text { less than } 420.07 \\
\text { score points) }\end{array}$} & \multicolumn{2}{|c|}{$\begin{array}{c}\text { Level } 2 \\
\text { (from } 420.07 \text { to } \\
\text { less than } 482.38 \\
\text { score points) }\end{array}$} & $\begin{array}{l}\text { L } \\
\text { (from } \\
\text { less th } \\
\text { scor }\end{array}$ & \begin{tabular}{|l|}
3 \\
2.38 to \\
544.68 \\
oints)
\end{tabular} & $\begin{array}{l}\text { Le } \\
\text { (from } \\
\text { less th } \\
\text { scor }\end{array}$ & \begin{tabular}{|l|}
4 \\
4.68 to \\
606.99 \\
oints)
\end{tabular} & $\begin{array}{l}\text { L } \\
\text { (from } \\
\text { less th } \\
\text { scor }\end{array}$ & $\begin{array}{l}5 \\
6.99 \text { to } \\
669.30 \\
\text { oints) }\end{array}$ & $\begin{array}{l}\text { Le } \\
\text { (abov } \\
\text { scor }\end{array}$ & $\begin{array}{l}16 \\
669.30 \\
\text { oints) }\end{array}$ \\
\hline & & $\%$ & S.E. & $\%$ & S.E. & $\%$ & S.E. & $\%$ & S.E. & $\%$ & S.E. & $\%$ & S.E. & $\%$ & S.E. \\
\hline 0 & Portugal & & & & & & & & & & & & & & \\
\hline 榙 & Alentejo & 8.8 & (2.5) & 16.3 & $(2.8)$ & 26.4 & $(2.2)$ & 24.7 & (3.3) & 17.3 & (3.5) & 5.3 & (1.6) & 1.2 & $(0.8)$ \\
\hline & Spain & & & & & & & & & & & & & & \\
\hline & Andalusia ${ }^{\bullet}$ & 8.5 & (1.5) & 21.0 & $(2.0)$ & 30.5 & $(2.2)$ & 23.8 & $(2.1)$ & 12.5 & (1.9) & 3.3 & $(0.9)$ & 0.3 & $(0.4)$ \\
\hline & Aragon` & 9.0 & (1.7) & 13.2 & $(2.0)$ & 22.4 & $(2.1)$ & 28.1 & $(2.3)$ & 18.9 & $(2.1)$ & 7.1 & $(1.2)$ & 1.2 & $(0.5)$ \\
\hline & Asturias ${ }^{\bullet}$ & 5.9 & (1.3) & 12.8 & $(1.7)$ & 24.2 & (1.8) & 28.4 & $(1.9)$ & 18.4 & (2.5) & 8.6 & (1.3) & 1.8 & (0.6) \\
\hline & Balearic Islands ${ }^{\bullet}$ & 9.6 & (2.0) & 18.2 & $(2.1)$ & 26.8 & (2.3) & 24.3 & $(2.3)$ & 16.3 & $(2.1)$ & 4.4 & (1.0) & 0.4 & $(0.3)$ \\
\hline & Basque Country ${ }^{\bullet}$ & 5.5 & $(0.7)$ & 11.1 & $(0.9)$ & 23.7 & (1.3) & 29.9 & $(1.1)$ & 21.7 & (1.3) & 6.7 & $(0.7)$ & 1.4 & $(0.3)$ \\
\hline & Cantabria ${ }^{\bullet}$ & 6.9 & $(1.2)$ & 16.1 & (1.6) & 27.3 & (1.9) & 26.6 & $(2.1)$ & 14.8 & (1.7) & 7.1 & (1.0) & 1.3 & $(0.5)$ \\
\hline & Castile and Leon ${ }^{\bullet}$ & 4.2 & (1.0) & 11.0 & $(1.6)$ & 24.2 & (1.8) & 31.6 & (1.9) & 21.8 & (1.7) & 6.5 & (1.1) & 0.8 & $(0.4)$ \\
\hline & Catalonia` & 6.4 & (1.6) & 16.0 & $(2.1)$ & 26.3 & $(2.3)$ & 29.6 & $(2.4)$ & 16.9 & (1.8) & 4.0 & (1.0) & 0.8 & $(0.4)$ \\
\hline & Extremadura ${ }^{\bullet}$ & 13.9 & (1.8) & 19.0 & $(2.3)$ & 27.7 & $(2.5)$ & 24.1 & $(2.1)$ & 11.5 & (1.4) & 3.2 & $(0.8)$ & 0.6 & $(0.4)$ \\
\hline & Galicia ${ }^{\bullet}$ & 6.7 & (1.1) & 14.1 & $(2.0)$ & 24.5 & $(2.6)$ & 30.3 & $(2.3)$ & 17.3 & $(2.2)$ & 5.7 & (0.9) & 1.3 & (0.6) \\
\hline & La Rioja・ & 7.7 & $(1.0)$ & 13.2 & $(1.7)$ & 22.2 & (1.9) & 26.5 & $(1.8)$ & 19.9 & $(2.0)$ & 8.7 & (1.7) & 1.9 & $(0.8)$ \\
\hline & Madrid` & 5.3 & (1.2) & 12.8 & $(1.4)$ & 23.8 & $(2.1)$ & 27.9 & $(2.0)$ & 21.5 & (1.7) & 7.8 & (1.4) & 0.8 & $(0.4)$ \\
\hline & Murcia ${ }^{\bullet}$ & 11.6 & (1.6) & 20.3 & (1.6) & 30.4 & (2.4) & 24.0 & (1.8) & 10.4 & (1.7) & 3.0 & (0.9) & 0.4 & $(0.3)$ \\
\hline & Navarre ${ }^{\bullet}$ & 3.1 & $(0.8)$ & 10.5 & $(1.1)$ & 21.0 & $(2.2)$ & 27.8 & (1.9) & 23.8 & (1.8) & 11.6 & $(2.2)$ & 2.1 & $(0.6)$ \\
\hline & United Kingdom & & & & & & & & & & & & & & \\
\hline & England & 8.6 & (1.3) & 15.1 & (1.3) & 23.8 & $(1.3)$ & 24.1 & $(1.2)$ & 17.7 & $(1.1)$ & 7.9 & $(1.0)$ & 2.8 & $(0.7)$ \\
\hline & Northern Ireland & 9.2 & (1.4) & 17.0 & (1.9) & 24.6 & (1.7) & 23.1 & $(1.8)$ & 16.6 & (1.5) & 7.7 & $(1.2)$ & 1.8 & $(0.4)$ \\
\hline & Scotland ${ }^{\bullet}$ & 5.6 & $(0.9)$ & 14.8 & $(1.7)$ & 26.3 & (1.9) & 26.9 & $(1.3)$ & 17.0 & $(1.2)$ & 7.4 & (0.9) & 2.0 & (0.5) \\
\hline & Wales & 9.8 & (1.0) & 21.3 & (1.6) & 28.1 & (1.5) & 24.4 & (1.3) & 12.1 & (0.9) & 3.5 & $(0.5)$ & 0.8 & $(0.3)$ \\
\hline & United States & & & & & & & & & & & & & & \\
\hline & Connecticut $^{\bullet}$ & 8.0 & (1.4) & 13.9 & (1.8) & 21.0 & (1.9) & 25.5 & (1.8) & 17.3 & $(2.2)$ & 10.3 & (1.6) & 4.0 & (1.1) \\
\hline & Florida $\bullet$ & 10.3 & (1.7) & 22.3 & $(2.2)$ & 29.9 & $(2.1)$ & 21.6 & $(2.2)$ & 11.1 & (1.5) & 4.2 & (1.3) & 0.6 & $(0.5)$ \\
\hline & Massachusetts ${ }^{\bullet}$ & 5.5 & $(1.2)$ & 13.0 & (1.6) & 21.5 & $(2.1)$ & 24.7 & (1.9) & 18.4 & (1.7) & 12.2 & (1.9) & 4.8 & (1.3) \\
\hline$\tilde{2}$ & Argentina & & & & & & & & & & & & & & \\
\hline$\stackrel{\mathscr{s}}{\Xi}$ & Ciudad Autónoma de Buenos Aires $\bullet$ & 25.4 & $(3.1)$ & 24.7 & $(2.9)$ & 28.3 & $(2.4)$ & 16.0 & $(2.1)$ & 5.1 & $(1.0)$ & 0.6 & $(0.3)$ & 0.0 & c \\
\hline ‡ & Brazil & & & & & & & & & & & & & & \\
\hline & Acre & 56.9 & $(4.3)$ & 26.4 & $(3.0)$ & 14.0 & $(2.8)$ & 2.1 & $(1.3)$ & 0.5 & $(0.4)$ & 0.0 & c & 0.0 & c \\
\hline & Alagoas & 67.3 & $(3.7)$ & 21.3 & $(3.5)$ & 8.6 & $(2.1)$ & 2.3 & $(1.3)$ & 0.5 & $(0.5)$ & 0.0 & c & 0.0 & c \\
\hline & Amapá & 55.1 & $(5.4)$ & 31.6 & $(6.0)$ & 11.8 & $(3.6)$ & 1.3 & $(1.2)$ & 0.3 & c & 0.0 & c & 0.0 & c \\
\hline & Amazonas & 60.1 & (3.7) & 28.1 & $(3.2)$ & 9.4 & (2.4) & 2.0 & $(1.2)$ & 0.5 & $(0.5)$ & 0.0 & c & 0.0 & $\mathrm{C}$ \\
\hline & Bahia & 48.6 & (7.4) & 26.9 & $(4.8)$ & 16.7 & $(6.0)$ & 6.0 & $(2.5)$ & 1.5 & $(1.2)$ & 0.2 & c & 0.0 & c \\
\hline & Ceará & 46.5 & $(5.7)$ & 29.9 & $(4.0)$ & 17.2 & $(3.0)$ & 4.2 & $(1.9)$ & 1.8 & $(0.9)$ & 0.4 & $(0.3)$ & 0.0 & c \\
\hline & Espírito Santo & 31.4 & $(4.2)$ & 31.4 & (3.6) & 18.4 & $(2.7)$ & 10.9 & $(3.2)$ & 6.1 & (2.8) & 1.6 & $(1.0)$ & 0.1 & c \\
\hline & Federal District & 29.8 & $(5.1)$ & 27.6 & (3.6) & 24.6 & $(4.3)$ & 13.3 & $(2.8)$ & 4.0 & $(2.2)$ & 0.6 & C & 0.0 & c \\
\hline & Goiás & 47.2 & (4.9) & 31.7 & (3.8) & 15.5 & $(3.5)$ & 4.9 & $(1.8)$ & 0.5 & $(0.5)$ & 0.2 & c & 0.0 & c \\
\hline & Maranhão & 65.4 & $(7.1)$ & 22.3 & (3.8) & 10.3 & $(4.8)$ & 2.0 & $(1.4)$ & 0.1 & $\mathrm{C}$ & 0.0 & c & 0.0 & c \\
\hline & Mato Grosso & 48.8 & (6.0) & 31.3 & (3.9) & 13.0 & (2.9) & 3.7 & $(2.1)$ & 2.7 & (1.5) & 0.4 & c & 0.0 & c \\
\hline & Mato Grosso do Sul & 29.3 & $(4.5)$ & 35.9 & $(3.7)$ & 21.4 & $(3.3)$ & 9.7 & $(2.9)$ & 3.5 & $(1.4)$ & 0.2 & c & 0.0 & c \\
\hline & Minas Gerais & 29.0 & (3.7) & 36.3 & $(2.6)$ & 22.8 & $(3.2)$ & 9.4 & $(2.3)$ & 2.4 & $(1.2)$ & 0.1 & c & 0.0 & c \\
\hline & Pará & 55.2 & $(4.7)$ & 27.8 & $(3.7)$ & 14.0 & $(2.8)$ & 2.9 & $(1.0)$ & 0.1 & $\mathrm{C}$ & 0.0 & c & 0.0 & c \\
\hline & Paraiba & 37.0 & $(5.7)$ & 29.7 & $(4.2)$ & 21.1 & $(5.1)$ & 10.4 & $(3.5)$ & 1.8 & (1.3) & 0.0 & c & 0.0 & c \\
\hline & Paraná & 36.6 & $(4.2)$ & 32.5 & $(4.3)$ & 19.0 & $(3.4)$ & 7.7 & $(2.6)$ & 2.6 & (2.4) & 1.5 & (1.6) & 0.2 & c \\
\hline & Pernambuco & 54.9 & (5.4) & 30.9 & $(4.3)$ & 11.9 & $(2.4)$ & 1.7 & $(0.9)$ & 0.5 & $(0.5)$ & 0.1 & C & 0.0 & c \\
\hline & Piauí & 44.8 & $(4.3)$ & 32.2 & $(3.9)$ & 12.0 & $(2.2)$ & 6.9 & $(1.9)$ & 3.4 & $(2.2)$ & 0.7 & c & 0.0 & c \\
\hline & Rio de Janeiro & 37.9 & $(5.1)$ & 35.1 & $(4.4)$ & 20.2 & $(3.6)$ & 6.0 & $(2.8)$ & 0.7 & $(0.8)$ & 0.2 & $(0.3)$ & 0.0 & c \\
\hline & Rio Grande do Norte & 50.3 & $(4.8)$ & 27.7 & $(4.9)$ & 12.2 & $(2.7)$ & 6.5 & $(2.1)$ & 2.3 & (1.8) & 0.7 & $(0.6)$ & 0.3 & $(0.4)$ \\
\hline & Rio Grande do Sul & 27.9 & $(4.1)$ & 35.2 & $(3.7)$ & 26.1 & $(3.1)$ & 9.1 & $(2.2)$ & 1.6 & $(0.9)$ & 0.1 & c & 0.0 & C \\
\hline & Rondônia & 36.4 & $(4.5)$ & 39.7 & (3.8) & 20.0 & $(3.1)$ & 3.6 & $(1.8)$ & 0.3 & c & 0.0 & c & 0.0 & c \\
\hline & Roraima & 56.9 & $(4.0)$ & 24.7 & $(3.3)$ & 11.1 & $(2.6)$ & 5.6 & $(2.4)$ & 1.7 & $(1.3)$ & 0.0 & c & 0.0 & c \\
\hline & Santa Catarina & 25.0 & (4.6) & 31.6 & $(4.0)$ & 28.4 & $(3.2)$ & 11.4 & $(2.5)$ & 3.1 & $(1.4)$ & 0.5 & C & 0.0 & c \\
\hline & São Paulo & 32.3 & (2.1) & 33.3 & $(2.0)$ & 20.6 & (1.8) & 10.0 & $(1.5)$ & 3.1 & $(0.9)$ & 0.6 & $(0.5)$ & 0.0 & c \\
\hline & Sergipe & 43.7 & (6.0) & 33.2 & (5.3) & 17.1 & (3.6) & 5.6 & $(2.9)$ & 0.3 & $\mathrm{C}$ & 0.0 & C & 0.0 & c \\
\hline & Tocantins & 52.1 & $(4.1)$ & 32.1 & (3.9) & 10.9 & $(2.1)$ & 3.7 & $(1.0)$ & 1.0 & $(0.5)$ & 0.2 & c & 0.0 & c \\
\hline & Colombia & & & & & & & & & & & & & & \\
\hline & Bogotá & 37.7 & (2.3) & 38.0 & $(2.0)$ & 19.8 & (1.6) & 4.1 & (1.1) & 0.4 & $(0.3)$ & 0.0 & c & 0.0 & c \\
\hline & Cali & 41.9 & (4.4) & 34.0 & $(2.7)$ & 18.2 & (3.9) & 5.3 & $(1.7)$ & 0.7 & $(0.4)$ & 0.0 & $\mathrm{C}$ & 0.0 & c \\
\hline & Manizales & 32.6 & (3.4) & 37.4 & (3.6) & 21.4 & $(2.8)$ & 7.0 & $(2.0)$ & 1.5 & $(0.8)$ & 0.0 & c & 0.0 & c \\
\hline & Medellín & 43.2 & (4.0) & 30.2 & (2.6) & 15.4 & (2.4) & 6.7 & (1.6) & 3.5 & (1.8) & 0.8 & (0.5) & 0.3 & $(0.3)$ \\
\hline & Russian Federation & & & & & & & & & & & & & & \\
\hline & Perm Territory region` & 7.0 & (1.5) & 16.3 & $(1.7)$ & 28.5 & $(2.2)$ & 26.9 & $(2.5)$ & 15.0 & (1.7) & 4.9 & (1.1) & 1.4 & $(0.7)$ \\
\hline & United Arab Emirates & & & & & & & & & & & & & & \\
\hline & Abu Dhabi ${ }^{\bullet}$ & 19.6 & (2.3) & 28.4 & $(1.7)$ & 27.1 & $(1.8)$ & 15.6 & (1.4) & 7.0 & $(1.0)$ & 2.2 & (0.6) & 0.2 & c \\
\hline & Ajman & 22.6 & (6.2) & 31.2 & (3.3) & 27.9 & $(4.1)$ & 14.0 & $(2.8)$ & 3.9 & (1.5) & 0.4 & c & 0.0 & c \\
\hline & Dubai & 12.7 & $(0.7)$ & 21.0 & $(1.0)$ & 27.2 & (1.6) & 21.9 & $(1.4)$ & 12.2 & $(1.0)$ & 4.2 & $(0.6)$ & 0.8 & $(0.4)$ \\
\hline & Fujairah & 18.2 & (3.6) & 25.8 & $(3.7)$ & 32.5 & (3.8) & 18.2 & (3.6) & 4.7 & $(1.8)$ & 0.5 & $(0.6)$ & 0.1 & $\mathrm{C}$ \\
\hline & Ras al-Khaimah & 19.5 & (5.8) & 29.4 & $(3.4)$ & 29.3 & $(3.4)$ & 16.2 & $(2.7)$ & 4.5 & $(1.7)$ & 1.1 & $(0.9)$ & 0.0 & c \\
\hline & Sharjah & 17.8 & (3.0) & 28.9 & $(4.2)$ & 25.5 & $(2.2)$ & 18.0 & $(3.1)$ & 7.9 & $(2.4)$ & 1.8 & $(0.7)$ & 0.1 & c \\
\hline & Umm al-Quwain & 19.7 & (3.3) & 34.0 & $(4.7)$ & 28.3 & $(4.7)$ & 14.8 & (3.6) & 2.2 & (1.6) & 1.0 & $\mathrm{C}$ & 0.0 & c \\
\hline
\end{tabular}

- PISA adjudicated region.

Note: See Table 1.2.2a for national data.

StatLink 解古 $\mathrm{http}: / / \mathrm{dx}$.doi.org/10.1787/888932935762 
[Part 1/2]

Table B2.I.3 Mean score, variation and gender differences in student performance in mathematics, by region

\begin{tabular}{|c|c|c|c|c|c|c|c|c|c|c|c|c|c|c|c|c|c|c|c|}
\hline & & & All stu & Idents & & & Ge & nder di & lifferen & ices & & & & & & & Perce & entiles & \\
\hline & & Mean & score & $\begin{array}{l}\text { Stan } \\
\text { devia }\end{array}$ & $\begin{array}{l}\text { ard } \\
\text { ion }\end{array}$ & Bo & oys & & irls & $\begin{array}{c}\text { Diffe } \\
\text { (B }\end{array}$ & $\begin{array}{l}\text { rence } \\
- \text { - G) }\end{array}$ & & th & & 0th & & 5th & & 5th \\
\hline & & Mean & S.E. & S.D. & S.E. & $\begin{array}{l}\text { Mean } \\
\text { score }\end{array}$ & S.E. & $\begin{array}{l}\text { Mean } \\
\text { score }\end{array}$ & S.E. & $\begin{array}{c}\text { Score } \\
\text { dif. }\end{array}$ & S.E. & Score & S.E. & Score & S.E. & Score & S.E. & Score & S.E. \\
\hline 0 & Australia & & & & & & & & & & & & & & & & & & \\
\hline 0 & Australian Capital Territory & 518 & (3.6) & 97 & (2.9) & 518 & (5.5) & 517 & (4.6) & 1 & (7.2) & 352 & (10.3) & 391 & (7.6) & 453 & (5.8) & 586 & (5.1) \\
\hline & New South Wales & 509 & (3.6) & 102 & (2.6) & 513 & (5.6) & 505 & $(4.0)$ & 7 & $(6.7)$ & 345 & (5.4) & 380 & $(4.7)$ & 438 & (3.7) & 579 & $(5.2)$ \\
\hline & Northern Territory & 452 & (10.4) & 109 & (6.1) & 459 & (9.9) & 445 & (15.0) & 14 & (14.6) & 255 & $(20.0)$ & 310 & $(15.7)$ & 388 & (12.6) & 527 & (10.4) \\
\hline & Queensland & 503 & (2.9) & 94 & (1.8) & 507 & (3.9) & 500 & (3.6) & 7 & $(4.7)$ & 351 & (7.7) & 384 & $(5.2)$ & 436 & (4.0) & 571 & (3.9) \\
\hline & South Australia & 489 & (3.3) & 91 & $(2.0)$ & 495 & (4.3) & 483 & (3.9) & 12 & (4.7) & 341 & (8.0) & 373 & (5.4) & 424 & (4.4) & 553 & (6.1) \\
\hline & Tasmania & 478 & (3.4) & 95 & (2.4) & 482 & (4.9) & 473 & (4.9) & 10 & (7.1) & 319 & (7.8) & 357 & (7.5) & 415 & (4.6) & 541 & (5.6) \\
\hline & Victoria & 501 & (3.7) & 91 & (2.3) & 509 & (5.1) & 491 & (3.7) & 19 & (5.3) & 352 & (6.3) & 384 & (5.4) & 437 & (4.4) & 563 & (5.0) \\
\hline & Western Australia & 516 & (3.4) & 94 & $(1.8)$ & 528 & (5.3) & 504 & (4.5) & 24 & $(7.3)$ & 364 & (6.0) & 394 & (4.5) & 449 & (4.5) & 584 & (4.5) \\
\hline & Belgium & & & & & & & & & & & & & & & & & & \\
\hline & Flemish Community ${ }^{\bullet}$ & 531 & (3.3) & 104 & $(2.1)$ & 537 & (4.5) & 525 & $(4.2)$ & 12 & (5.8) & 353 & (6.9) & 392 & (4.8) & 460 & (4.8) & 608 & $(4.1)$ \\
\hline & French Community & 493 & (2.9) & 96 & (2.0) & 498 & (3.4) & 488 & (3.5) & 10 & (3.8) & 332 & (6.4) & 363 & (5.9) & 424 & (5.0) & 563 & (2.9) \\
\hline & German-speaking Community & 511 & $(2.1)$ & 90 & $(2.0)$ & 510 & (3.5) & 512 & (3.1) & -2 & (5.0) & 349 & $(7.6)$ & 389 & (6.5) & 453 & (4.4) & 572 & (3.7) \\
\hline & Canada & & & & & & & & & & & & & & & & & & \\
\hline & Alberta & 517 & (4.6) & 91 & $(1.8)$ & 522 & (5.0) & 512 & (5.1) & 11 & (4.0) & 368 & (6.0) & 398 & (6.0) & 453 & (5.6) & 582 & (5.5) \\
\hline & British Columbia & 522 & (4.4) & 86 & $(2.0)$ & 529 & (4.8) & 515 & (5.9) & 14 & $(6.1)$ & 381 & (7.0) & 410 & (5.8) & 464 & (4.1) & 582 & (5.2) \\
\hline & Manitoba & 492 & (2.9) & 89 & $(2.1)$ & 495 & (3.6) & 489 & (4.5) & 6 & (5.7) & 350 & (6.3) & 378 & (4.9) & 431 & (3.7) & 554 & (4.0) \\
\hline & New Brunswick & 502 & (2.6) & 82 & (1.9) & 504 & (3.9) & 500 & (3.8) & 3 & (5.7) & 365 & (5.7) & 396 & (4.8) & 446 & (4.1) & 559 & (5.0) \\
\hline & Newfoundland and Labrador & 490 & $(3.7)$ & 86 & $(2.2)$ & 491 & (5.2) & 490 & (3.9) & 1 & (5.6) & 346 & (9.4) & 376 & (7.1) & 431 & (6.1) & 550 & (4.8) \\
\hline & Nova Scotia & 497 & (4.1) & 81 & $(2.3)$ & 503 & (3.9) & 492 & (6.1) & 11 & (6.1) & 364 & (8.2) & 393 & $(6.8)$ & 442 & (5.6) & 552 & (5.7) \\
\hline & Ontario & 514 & (4.1) & 87 & $(1.8)$ & 520 & (4.9) & 509 & (4.0) & 10 & (3.7) & 370 & (5.6) & 401 & (5.1) & 456 & (4.0) & 574 & $(5.2)$ \\
\hline & Prince Edward Island & 481 & (2.5) & 82 & (1.8) & 484 & (3.6) & 478 & (3.3) & 6 & (4.8) & 351 & (7.6) & 376 & (4.1) & 421 & (4.5) & 538 & (3.5) \\
\hline & Quebec & 536 & (3.4) & 91 & (1.7) & 541 & (4.3) & 531 & (3.8) & 10 & (4.3) & 380 & (6.3) & 413 & (5.2) & 475 & (4.4) & 600 & (3.9) \\
\hline & Saskatchewan & 506 & (3.0) & 84 & $(2.0)$ & 510 & (3.9) & 502 & (3.6) & 8 & $(4.5)$ & 368 & (6.4) & 400 & $(4.0)$ & 448 & (3.6) & 566 & (4.8) \\
\hline & Italy & & & & & & & & & & & & & & & & & & \\
\hline & Abruzzo & 476 & (6.4) & 90 & $(4.2)$ & 481 & (7.4) & 471 & (7.1) & 9 & (7.3) & $\mid 323$ & (19.8) & 359 & (12.0) & 416 & (6.2) & 537 & (8.4) \\
\hline & Basilicata & 466 & (4.3) & 85 & (2.0) & 477 & (6.0) & 454 & (4.3) & 23 & (5.9) & 331 & (7.3) & 356 & (6.4) & 407 & (4.9) & 521 & (4.4) \\
\hline & Bolzano & 506 & $(2.1)$ & 89 & $(1.3)$ & 518 & (3.1) & 494 & (2.6) & 23 & (3.9) & 358 & (4.9) & 387 & (4.1) & 446 & $(4.0)$ & 567 & (3.2) \\
\hline & Calabria & 430 & (5.7) & 88 & (3.4) & 441 & (6.6) & 419 & $(7.0)$ & 22 & (8.0) & 286 & (9.7) & 319 & $(9.0)$ & 368 & (7.1) & 490 & (6.8) \\
\hline & Campania & 453 & (7.7) & 89 & (3.4) & 461 & (7.7) & 444 & (9.6) & 16 & (7.8) & 308 & (8.2) & 336 & (9.6) & 391 & (8.3) & 512 & (10.5) \\
\hline & Emilia Romagna & 500 & (6.4) & 97 & $(4.0)$ & 510 & (9.5) & 490 & (6.8) & 20 & $(10.7)$ & 340 & $(10.3)$ & 376 & (8.9) & 436 & (7.0) & 568 & $(9.2)$ \\
\hline & Friuli Venezia Giulia & 523 & (4.4) & 88 & $(3.2)$ & 533 & (5.6) & 512 & (5.9) & 21 & (7.9) & 374 & (12.1) & 409 & (9.5) & 465 & (7.4) & 582 & (5.3) \\
\hline & Lazio & 475 & (6.8) & 90 & $(2.9)$ & 485 & (7.5) & 462 & (7.1) & 23 & (6.7) & 328 & (7.1) & 358 & $(8.2)$ & 411 & (7.8) & 536 & (8.3) \\
\hline & Liguria & 488 & $(6.2)$ & 91 & (2.9) & 493 & (8.1) & 482 & (6.8) & 11 & (8.5) & 342 & (8.3) & 372 & $(8.2)$ & 425 & (7.0) & 548 & (7.6) \\
\hline & Lombardia & 517 & (7.6) & 86 & (3.1) & 528 & (8.9) & 505 & (7.7) & 24 & $(8.2)$ & 373 & (8.6) & 403 & (7.8) & 459 & (9.3) & 577 & (9.3) \\
\hline & Marche & 496 & (5.5) & 85 & (3.4) & 511 & (6.2) & 482 & (6.3) & 29 & $(6.2)$ & 356 & (11.8) & 386 & $(9.1)$ & 437 & (6.7) & 555 & (6.6) \\
\hline & Molise & 466 & (2.3) & 85 & (2.3) & 475 & (3.1) & 458 & (3.5) & 17 & (4.6) & 329 & (6.5) & 359 & $(4.2)$ & 407 & (4.0) & 524 & (4.0) \\
\hline & Piemonte & 499 & (5.8) & 88 & (2.6) & 512 & (5.1) & 486 & (6.9) & 25 & (5.3) & 353 & (6.5) & 384 & (6.6) & 438 & $(7.2)$ & 558 & (7.9) \\
\hline & Puglia & 478 & (6.1) & 86 & (3.2) & 489 & (6.1) & 467 & (6.5) & 22 & (5.6) & 337 & (9.6) & 366 & (7.4) & 416 & (7.1) & 540 & (7.0) \\
\hline & Sardegna & 458 & (5.3) & 87 & (2.4) & 462 & (5.5) & 454 & (7.1) & 8 & $(7.2)$ & 316 & (9.6) & 347 & (8.4) & 398 & (6.6) & 518 & (6.4) \\
\hline & Sicilia & 447 & (5.1) & 82 & (2.9) & 452 & (6.2) & 441 & (5.6) & 10 & (6.3) & 314 & (9.0) & 343 & (6.9) & 391 & (6.0) & 504 & (6.6) \\
\hline & Toscana & 495 & (4.9) & 93 & (2.5) & 496 & (7.3) & 495 & (8.3) & 2 & (12.1) & 345 & (7.4) & 373 & $(4.8)$ & 429 & (6.7) & 561 & (6.4) \\
\hline & Trento & 524 & (4.1) & 82 & (2.3) & 528 & (5.6) & 520 & (6.6) & 8 & $(9.1)$ & 385 & (9.7) & 418 & (7.2) & 469 & (6.0) & 583 & (4.1) \\
\hline & Umbria & 493 & (6.8) & 88 & $(3.8)$ & 504 & (9.7) & 482 & (6.2) & 22 & (8.5) & 340 & (13.9) & 370 & (15.4) & 435 & (11.3) & 555 & (4.8) \\
\hline & Valle d'Aosta & 492 & $(2.2)$ & 83 & $(2.1)$ & 501 & (3.6) & 482 & (3.3) & 18 & (5.3) & 356 & (10.0) & 386 & $(6.0)$ & 434 & (4.5) & 546 & (4.4) \\
\hline & Veneto & 523 & (7.6) & 91 & $(4.0)$ & 534 & (8.4) & 511 & $(8.1)$ & 23 & (7.9) & 372 & (11.6) & 405 & (8.0) & 460 & (8.0) & 587 & $(10.3)$ \\
\hline & Mexico & & & & & & & & & & & & & & & & & & \\
\hline & Aguascalientes & 437 & (4.5) & 73 & (3.0) & 442 & (5.8) & 432 & (4.8) & 10 & (5.6) & $\mid 322$ & (8.9) & 345 & (6.9) & 386 & (6.2) & $\mid 484$ & (5.2) \\
\hline & Baja California & 415 & (5.8) & 72 & (2.6) & 421 & (6.6) & 409 & (6.0) & 13 & (4.7) & 301 & (8.7) & 324 & (6.6) & 365 & (6.4) & 463 & (8.2) \\
\hline & Baja California Sur & 414 & (5.4) & 72 & (2.3) & 422 & (6.6) & 406 & (5.3) & 16 & (5.2) & 299 & (9.4) & 322 & $(8.2)$ & 364 & (7.7) & 461 & (5.1) \\
\hline & Campeche & 396 & (3.9) & 71 & (2.4) & 402 & (3.9) & 389 & (4.8) & 12 & (4.0) & 282 & (8.5) & 308 & (10.1) & 349 & (4.7) & 440 & (4.3) \\
\hline & Chiapas & 373 & (7.2) & 75 & (3.6) & 377 & (7.7) & 369 & (7.6) & 9 & (5.0) & 252 & (9.7) & 279 & (10.0) & 322 & (9.6) & 421 & (7.8) \\
\hline & Chihuahua & 428 & (7.8) & 78 & $(2.8)$ & 437 & (9.0) & 419 & (7.5) & 18 & $(6.2)$ & 304 & (11.1) & 332 & (10.0) & 376 & (8.5) & 478 & (8.1) \\
\hline & Coahuila & 418 & (8.1) & 72 & (3.6) & 424 & (8.3) & 413 & (9.4) & 11 & (6.7) & 305 & (7.0) & 328 & (7.4) & 367 & (7.8) & 465 & $(10.5)$ \\
\hline & Colima & 429 & (4.5) & 77 & (2.6) & 433 & (5.0) & 425 & (5.2) & 7 & (4.8) & 307 & (6.3) & 331 & $(6.2)$ & 373 & (5.6) & 480 & (5.6) \\
\hline & Distrito Federal & 428 & (5.0) & 73 & $(2.7)$ & 442 & (6.1) & 414 & (5.7) & 27 & (6.9) & 312 & (11.5) & 337 & (5.9) & 378 & (4.7) & 475 & (7.5) \\
\hline & Durango & 424 & (5.7) & 73 & (2.3) & 431 & (7.4) & 418 & (5.5) & 13 & (5.7) & 306 & (7.9) & 332 & (8.1) & 372 & (6.7) & 477 & (9.2) \\
\hline & Guanajuato & 412 & (5.4) & 75 & (2.6) & 421 & (5.9) & 402 & (5.7) & 19 & (4.0) & 291 & (11.0) & 316 & (8.8) & 360 & (7.3) & 463 & (5.9) \\
\hline & Guerrero & 367 & (3.4) & 67 & (2.4) & 369 & (4.0) & 365 & (4.5) & 4 & (5.3) & 265 & (10.0) & 286 & (6.4) & 321 & (5.0) & 408 & (4.7) \\
\hline & Hidalgo & 406 & (5.8) & 74 & (2.6) & 413 & (6.9) & 401 & (6.0) & 13 & (5.7) & 285 & (7.0) & 312 & (6.6) & 358 & (6.1) & 456 & (7.0) \\
\hline & Jalisco & 435 & (5.9) & 72 & $(2.2)$ & 440 & (7.6) & 430 & (5.3) & 10 & (5.2) & 316 & (9.9) & 342 & (7.4) & 386 & (6.4) & 483 & (6.6) \\
\hline & Mexico & 417 & (5.6) & 67 & (3.2) & 425 & (6.5) & 409 & (5.8) & 16 & $(5.2)$ & 307 & (6.5) & 332 & (7.1) & 373 & (6.4) & 460 & (7.5) \\
\hline & Morelos & 421 & (8.5) & 79 & (6.3) & 425 & (9.9) & 419 & (8.5) & 6 & (6.8) & 300 & $(17.7)$ & 327 & $(12.2)$ & 369 & (9.0) & 469 & (9.8) \\
\hline & Nayarit & 414 & (5.9) & 77 & (3.0) & 422 & (5.8) & 406 & $(7.2)$ & 15 & $(5.7)$ & 287 & (10.3) & 315 & (10.1) & 361 & (8.0) & 467 & (6.2) \\
\hline & Nuevo León & 436 & $(8.2)$ & 74 & $(2.2)$ & 447 & $(9.4)$ & 424 & $(7.2)$ & 23 & (5.5) & 321 & (9.8) & 342 & (8.0) & 384 & (7.8) & 486 & (10.4) \\
\hline & Puebla & 415 & (4.9) & 74 & (3.2) & 423 & $(7.0)$ & 408 & (5.2) & 15 & (7.1) & 292 & (15.8) & 321 & (9.0) & 367 & (6.2) & 464 & (5.8) \\
\hline & Querétaro & 434 & (6.4) & 75 & (3.2) & 444 & (7.4) & 426 & (6.4) & 18 & (4.5) & 314 & (9.3) & 338 & (8.0) & 384 & (8.2) & 484 & (8.2) \\
\hline & Quintana Roo & 411 & (5.4) & 71 & $(2.0)$ & 414 & (6.6) & 407 & (5.2) & 7 & (4.8) & 295 & (11.0) & 320 & (7.9) & 361 & (6.5) & 458 & (5.5) \\
\hline & San Luis Potosí & 412 & (7.4) & 75 & $(2.8)$ & 413 & (7.8) & 410 & (8.0) & 3 & (5.9) & 298 & (8.4) & 319 & (5.8) & 356 & (5.9) & 463 & (8.8) \\
\hline & Sinaloa & 411 & $(4.2)$ & 69 & (1.9) & 414 & (5.6) & 408 & (4.5) & 6 & (5.5) & 304 & (6.3) & 325 & (6.5) & 362 & (4.6) & 458 & (5.5) \\
\hline & Tabasco & 378 & (3.8) & 71 & (3.1) & 384 & (5.1) & 373 & (3.8) & 11 & (4.6) & 264 & (8.1) & 289 & (5.8) & 331 & (5.2) & 422 & (4.6) \\
\hline & Tamaulipas & 411 & (7.4) & 75 & (3.3) & 421 & $(9.8)$ & 400 & (6.5) & 21 & (7.7) & 293 & (10.0) & 317 & (9.6) & 360 & (6.3) & 460 & (9.3) \\
\hline & Tlaxcala & 411 & (5.0) & 72 & $(2.0)$ & 417 & $(5.1)$ & 406 & (5.5) & 11 & (3.7) & 295 & (9.0) & 320 & (7.0) & 364 & (6.4) & 457 & (5.0) \\
\hline & Veracruz & 402 & (6.3) & 75 & (2.8) & 407 & (6.3) & 397 & (7.8) & 10 & (6.4) & 286 & (7.5) & 308 & (7.5) & 350 & (6.1) & 452 & (7.6) \\
\hline & Yucatán & 410 & (4.6) & 74 & (2.1) & 421 & (5.6) & 399 & (5.3) & 22 & (5.9) & 294 & (5.5) & 318 & (5.9) & 359 & (6.1) & 459 & (5.2) \\
\hline & Zacatecas & 408 & (4.2) & 72 & (2.1) & 414 & (5.1) & 403 & (4.4) & 11 & (4.4) & 290 & (8.1) & 318 & (6.1) & 361 & (5.3) & 457 & (5.3) \\
\hline
\end{tabular}

- PISA adjudicated region

Notes: Values that are statistically significant are indicated in bold (see Annex A3).

See Table I.2.3a for national data.

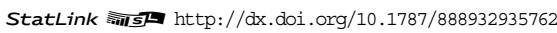


[Part 2/2]

Table B2.I.3 Mean score, variation and gender differences in student performance in mathematics, by region

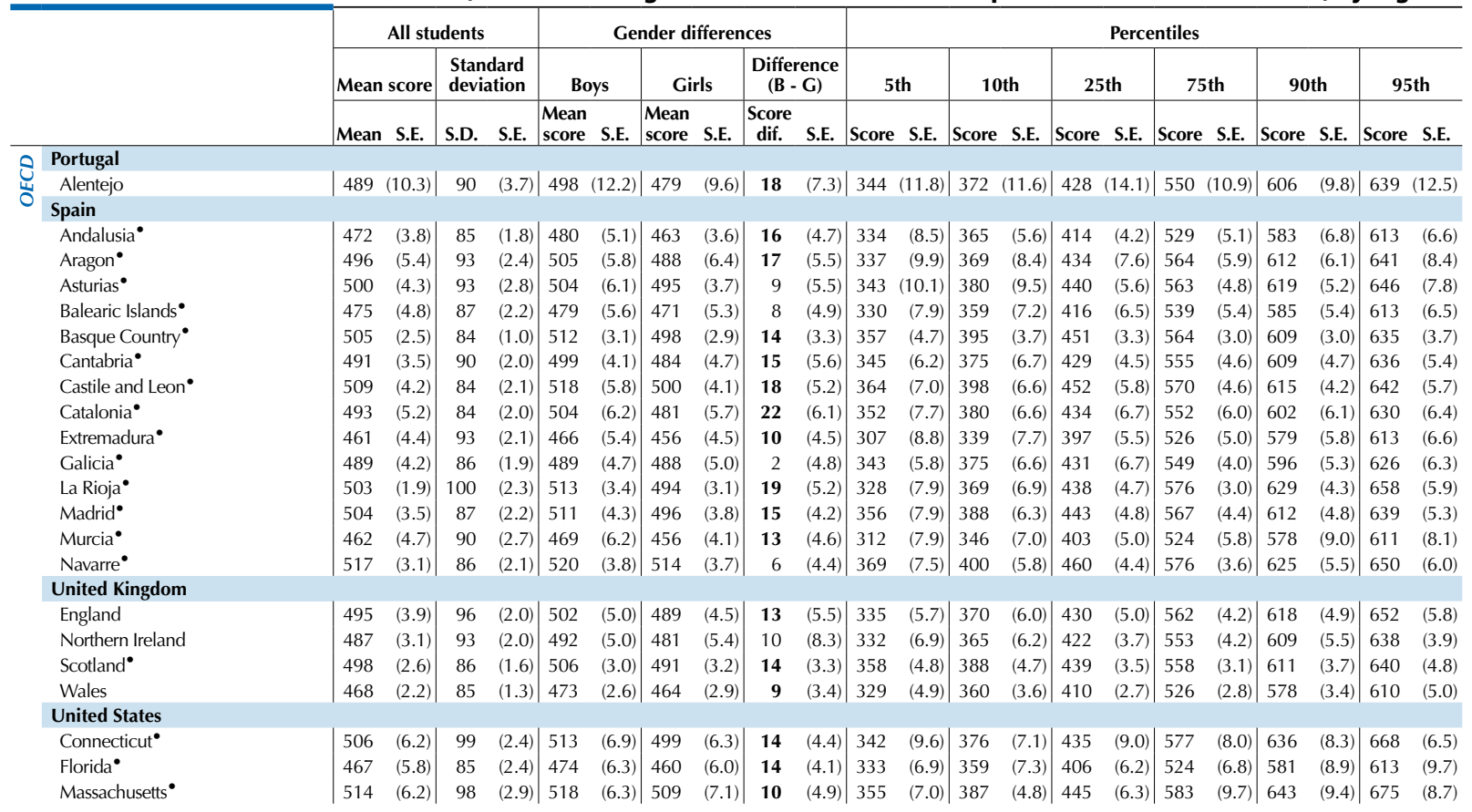

\begin{tabular}{|c|c|c|c|c|c|c|c|c|c|c|c|c|c|c|c|c|c|c|c|c|c|c|}
\hline \multicolumn{23}{|l|}{ Argentina } \\
\hline 气 Ciudad Autónoma de Buenos Aires ${ }^{\bullet}$ & $\mid 418$ & (7.3) & 95 & (7.1) & 426 & $(8.1)$ & 411 & $(7.6)$ & 15 & (5.7) & $\mid 244$ & $(23.9)$ & 296 & $(16.0)$ & $\mid 362$ & $(8.4)$ & 481 & (7.1) & $\mid 532$ & (7.9) & 561 & (8.5) \\
\hline \multicolumn{23}{|c|}{ Brazil } \\
\hline Acre & 359 & (5.6) & 67 & (3.5) & 366 & $(8.2)$ & 352 & (6.6) & 14 & (9.6) & 255 & $(8.1)$ & 277 & $(6.3)$ & 311 & $(6.8)$ & 404 & (8.6) & 446 & (8.6) & 470 & $(12.0)$ \\
\hline Alagoas & 342 & (6.0) & 70 & $(5.4)$ & 353 & (7.9) & 334 & (5.9) & 19 & (6.2) & 240 & $(10.5)$ & 261 & (9.4) & 295 & $\quad(6.2)$ & 384 & (9.5) & 433 & (14.3) & 467 & $(19.4)$ \\
\hline Amapá & 360 & (8.6) & 65 & (4.1) & 371 & $(10.3)$ & 351 & (7.9) & 21 & (6.7) & 255 & (13.5) & 279 & $(10.5)$ & 317 & $\quad(9.2)$ & 402 & (8.7) & 443 & (14.3) & 469 & (16.3) \\
\hline Amazonas & 356 & (5.5) & 65 & (6.0) & 365 & $(7.4)$ & 348 & (4.6) & 17 & (5.8) & 262 & $(7.4)$ & 281 & (6.0) & 312 & (6.4) & 392 & (6.2) & 438 & (8.6) & 469 & $(26.5)$ \\
\hline Bahia & 373 & (8.7) & 80 & (6.4) & 380 & (7.4) & 367 & (13.0) & 13 & (12.4) & 253 & $(19.7)$ & 278 & (14.9) & 321 & (10.5) & 422 & $(11.2)$ & 479 & (11.5) & 513 & $(20.1)$ \\
\hline Ceará & 378 & (8.8) & 80 & (6.9) & 389 & (10.4) & 369 & $(9.5)$ & 20 & $(9.2)$ & 258 & $(10.7)$ & 283 & (9.6) & 323 & (7.9) & 424 & (11.8) & 477 & (23.4) & 526 & $(28.7)$ \\
\hline Espírito Santo & 414 & (9.7) & 86 & (5.5) & 425 & (9.1) & 405 & (13.0) & 20 & (10.9) & 292 & (8.3) & 311 & (5.7) & 350 & $(6.9)$ & 469 & (19.0) & 539 & $(19.2)$ & 574 & $(21.4)$ \\
\hline Federal District & 416 & (9.1) & 84 & (6.8) & 425 & $(10.4)$ & 407 & (8.9) & 18 & (6.5) & 290 & $(14.9)$ & 312 & $(11.4)$ & 354 & $(10.1)$ & 472 & $(12.2)$ & 530 & $(17.5)$ & 563 & (16.3) \\
\hline Goiás & 379 & (5.9) & 72 & (3.4) & 391 & (6.8) & 369 & $(6.5)$ & 22 & (6.5) & 273 & $(10.7)$ & 294 & (8.3) & 329 & $(8.2)$ & 421 & (7.1) & 477 & 7 (8.2) & 511 & (13.0) \\
\hline Maranhão & 343 & $(13.2)$ & 77 & $(8.2)$ & 356 & $(16.0)$ & 333 & $(11.8)$ & 23 & $(7.2)$ & 228 & $(7.4)$ & 252 & (8.6) & 291 & $(7.7)$ & 388 & (19.7) & 448 & $(28.0)$ & 484 & $(29.9)$ \\
\hline Mat & 370 & $(9.0)$ & 73 & (6.8) & 373 & (8.6) & 368 & $(10.4)$ & 5 & $(6.2)$ & 263 & $(11.8)$ & 287 & $(10.2)$ & 321 & (7.8) & 411 & (12.1) & 462 & (19.1) & 503 & (32.3) \\
\hline Mato & 408 & (7.5) & 74 & (3.5) & 419 & (9.9) & 400 & $(6.6)$ & 19 & (7.9) & 295 & $(11.2)$ & 318 & $(8.8)$ & 356 & (7.6) & 456 & (8.0) & 512 & (11.7) & 543 & (12.0) \\
\hline Minas & 403 & (6.7) & 72 & (3.2) & 410 & (8.2) & 396 & (6.5) & 14 & (5.4) & 288 & $(10.7)$ & 312 & (8.7) & 354 & (7.1) & 451 & (8.1) & 498 & (11.2) & 527 & $(12.4)$ \\
\hline Pará & 360 & $(4.2)$ & 68 & (2.7) & 368 & (4.9) & 354 & (5.3) & 14 & (5.9) & 253 & (7.9) & 275 & (7.1) & 312 & (6.9) & 406 & (5.7) & 452 & (7.7) & 475 & $(9.7)$ \\
\hline Paraiba & 395 & (6.7) & 79 & (6.3) & 404 & (8.4) & 388 & (8.9) & 15 & $(10.7)$ & 274 & $(19.7)$ & 301 & $(14.3)$ & 342 & (9.3) & 443 & (8.1) & 500 & $(12.1)$ & 534 & (18.5) \\
\hline Paraná & 403 & (11.6) & 81 & (10.9) & 415 & (11.8) & 393 & $(12.7)$ & 22 & (7.0) & 290 & $(9.1)$ & 311 & (8.4) & 345 & $5 \quad(7.0)$ & 449 & (14.9) & 516 & $5(34.1)$ & 563 & $(43.1)$ \\
\hline Pernambuco & 363 & (7.5) & 67 & (4.1) & 375 & $(8.2)$ & 354 & (7.5) & 22 & (4.2) & 261 & (9.9) & 284 & $(9.7)$ & 319 & $\quad(8.2)$ & 404 & (10.6) & 449 & $(10.2)$ & 477 & $(12.1)$ \\
\hline Piauí & 385 & (7.4) & 81 & $(7.2)$ & 396 & (8.3) & 377 & (7.6) & 18 & (5.0) & 273 & (5.9) & 293 & (7.6) & 329 & (6.9) & 426 & $(9.4)$ & 504 & $+\quad(21.9)$ & 543 & $(30.0)$ \\
\hline Rio de Janeiro & 389 & (6.7) & 70 & (4.0) & 397 & (7.8) & 381 & (7.3) & 17 & (6.5) & 280 & $(8.6)$ & 302 & (8.3) & 339 & ) & 433 & (9.9) & 481 & (9.6) & 513 & (13.4) \\
\hline do Norte & 380 & (9.1) & 84 & (8.7) & 394 & (10.8) & 370 & $(8.8)$ & 24 & (6.9) & 269 & (7.3) & 286 & $(7.2)$ & 323 & $(7.5)$ & 421 & (14.5) & 501 & $(27.8)$ & 546 & (35.4) \\
\hline Rio C & 407 & (5.5) & 68 & (2.6) & 415 & (6.8) & 400 & $(5.8)$ & 16 & (5.8) & 301 & (8.0) & 321 & (6.4) & 357 & $7 \quad(6.5)$ & 453 & (6.8) & 497 & $7 \quad(6.9)$ & 520 & (9.9) \\
\hline Rondônia & 382 & (5.3) & 64 & (2.4) & 387 & (5.5) & 377 & (6.5) & 10 & (5.8) & 278 & $(6.2)$ & 299 & (8.6) & 340 & $(5.2)$ & 423 & (6.4) & 461 & (8.3) & 486 & $(10.8)$ \\
\hline Roraima & 362 & (5.7) & 72 & (3.3) & 366 & (6.5) & 358 & (7.9) & 8 & (8.8) & 256 & (8.4) & 274 & (6.9) & 313 & (5.8) & 406 & (9.6) & 462 & 2(18.4) & 496 & (14.4) \\
\hline Santa Catarina & 415 & (8.3) & 75 & (3.8) & 423 & (8.0) & 408 & $(9.7)$ & 15 & (6.8) & 299 & $(10.2)$ & 322 & (10.0) & 361 & (8.7) & 467 & $(11.5)$ & 513 & (12.1) & 542 & $(14.2)$ \\
\hline São Paulo & 404 & (4.4) & 78 & (3.4) & 411 & (4.7) & 396 & (4.8) & 15 & (3.5) & 287 & (6.1) & 310 & $(4.2)$ & 349 & (3.3) & 452 & (6.3) & 509 & $(10.2)$ & 544 & (13.8) \\
\hline Sergipe & 384 & (8.9) & 71 & (5.4) & 397 & $(11.7)$ & 373 & (8.3) & 24 & (8.2) & 279 & (10.9) & 300 & (9.5) & 335 & (7.9) & 430 & (15.0) & 483 & (19.8) & 513 & (18.1) \\
\hline Tocantins & 366 & (7.3) & 77 & (4.8) & 376 & $(9.1)$ & 355 & (6.6) & 20 & (7.1) & 248 & (8.9) & 271 & $(7.1)$ & 312 & (7.1) & 410 & (9.1) & 469 & $(15.3)$ & 503 & (18.5) \\
\hline \multicolumn{23}{|c|}{ | } \\
\hline Bogotá & 393 & (3.4) & 66 & (2.4) & 410 & (5.0) & 377 & (3.2) & 32 & (5.1) & 289 & $(4.2)$ & \begin{tabular}{|l|}
308 \\
\end{tabular} & (3.6) & 349 & (3.9) & 435 & (3.8) & 476 & $5 \quad(6.7)$ & 505 & (9.4) \\
\hline Cali & 379 & (6.1) & 70 & (2.5) & 388 & (6.4) & 372 & $(6.7)$ & 16 & (4.4) & 267 & $(6.1)$ & 291 & (6.6) & 332 & (6.3) & 425 & (8.5) & 472 & (9.1) & 499 & (9.2) \\
\hline Manizales & 404 & (4.1) & 72 & (4.0) & 421 & (6.9) & 389 & (3.4) & 32 & (7.1) & 298 & $(5.7)$ & 316 & (4.5) & 354 & $+\quad(4.0)$ & 450 & (6.7) & 503 & (10.3) & 534 & $(11.7)$ \\
\hline Medellín & 393 & (7.5 & 83 & (5.8) & 406 & $(8.2$ & 381 & $(9.7)$ & 26 & (9.7) & 275 & ; $\quad(5.9)$ & 297 & (6.6) & 335 & F & 441 & $(10.4)$ & 504 & $+(16.6)$ & 545 & $(25.1)$ \\
\hline \multicolumn{23}{|l|}{ Russian Federation } \\
\hline Perm Terri & 484 & $(5.5$ & 89 & 4.4) & 487 & $(6.6$ & 480 & (5. & 7 & (4.6) & $\mid 341$ & $(10.4)$ & $\mid 372$ & (8.0) & 425 & (4.8) & $\mid 542$ & (6.2) & $\mid 597$ & $(10.4)$ & 633 & (16.7) \\
\hline \multicolumn{23}{|l|}{ United Arab Emirates } \\
\hline Abu D & 421 & (4.0) & 88 & (2.3) & 414 & (5.1) & 429 & (5.1) & $\mid-15$ & (6.6) & 286 & (6.3) & 314 & $(4.7)$ & 359 & $(4.0)$ & 478 & (5.4) & 542 & $(7.2)$ & 578 & (8.3) \\
\hline Ajman & 403 & (7.9) & 75 & (4.4) & 391 & $(11.5)$ & 415 & $(11.4)$ & -24 & $(16.5)$ & 283 & $(14.3)$ & 305 & $(11.5)$ & 352 & $(12.7)$ & 455 & (7.3) & 502 & (8.5) & 527 & $(10.8)$ \\
\hline Dubai ${ }^{\bullet}$ & 464 & $(1.2)$ & 94 & (1.1) & 468 & (1.9) & 459 & $(1.6)$ & 9 & (2.6) & 314 & $(2.7)$ & 342 & (2.5) & 396 & (2.0) & 530 & (2.6) & 587 & $7 \quad(3.5)$ & 620 & $(4.3)$ \\
\hline Fujairah & 411 & (9.9) & 82 & (2.6) & 394 & (9.3) & 428 & (9.9) & -33 & (9.5) & 280 & (12.9) & 305 & $(11.9)$ & 352 & (11.9) & 469 & $(11.0)$ & 519 & $(12.8)$ & 549 & $(12.1)$ \\
\hline Ras al-Kh & 416 & (6.7) & 75 & (3.1) & 406 & (6.2) & 424 & (11.4) & -18 & (12.3) & 298 & $(10.7)$ & 321 & (9.5) & 362 & (9.0) & 466 & (7.5) & 514 & (7.7) & 543 & (10.6) \\
\hline Sha & 439 & (9.0) & 84 & (3.7) & 446 & (15.9) & 434 & (10.6) & 12 & $(20.4)$ & 310 & $(8.5)$ & 335 & (8.1) & 379 & (8.3) & 496 & (12.4) & 554 & (12.4) & 586 & (12.8) \\
\hline Umm al-Quwain & 398 & (4.0) & 75 & (4.1) & 379 & $(5.7)$ & 416 & (5.0) & -37 & $(7.1)$ & 284 & (8.8) & 306 & (6.7) & 347 & $7 \quad(6.4)$ & 442 & (6.9) & 497 & (11.5) & 526 & (12.3) \\
\hline
\end{tabular}

- PISA adjudicated region

Notes: Values that are statistically significant are indicated in bold (see Annex A3).

See Table I.2.3a for national data.

StatLink त्ताज http://dx.doi.org/10.1787/888932935762 
[Part 1/2]

Table B2.I.4 Percentage of students at each proficiency level on the mathematics subscale formulating, by region

\begin{tabular}{|c|c|c|c|c|c|c|c|c|c|c|c|c|c|c|c|}
\hline & & \multicolumn{14}{|c|}{ All students } \\
\hline & & \multicolumn{2}{|c|}{$\begin{array}{c}\text { Below Level } 1 \\
\text { (below } 357.77 \\
\text { score points) }\end{array}$} & $\begin{array}{l}\text { L } \\
\text { (from } \\
\text { less th } \\
\text { scor }\end{array}$ & $\begin{array}{l}\text { I } 1 \\
7.77 \text { to } \\
420.07 \\
\text { oints) }\end{array}$ & $\begin{array}{r}\mathrm{L} \\
\text { (from } \\
\text { less th } \\
\text { scor }\end{array}$ & $\begin{array}{l}l 2 \\
0.07 \text { to } \\
482.38 \\
\text { oints) }\end{array}$ & $\begin{array}{r}L \\
\text { (from } \\
\text { less th } \\
\text { scor }\end{array}$ & $\begin{array}{l}\text { l } 3 \\
2.38 \text { to } \\
544.68 \\
\text { oints) }\end{array}$ & $\begin{array}{l}\mathrm{L} \\
\text { (from } \\
\text { less th } \\
\text { scor }\end{array}$ & $\begin{array}{l}l 4 \\
4.68 \text { to } \\
606.99 \\
\text { oints) }\end{array}$ & $\begin{array}{r} \\
\text { (from } \\
\text { less th } \\
\text { scor }\end{array}$ & $\begin{array}{l}6 \\
6.99 \text { to } \\
669.30 \\
\text { oints) }\end{array}$ & $\begin{array}{r}\mathrm{L} \\
\text { (abo } \\
\text { scor }\end{array}$ & $\begin{array}{l}16 \\
669.30 \\
\text { oints) }\end{array}$ \\
\hline & & $\%$ & S.E. & $\%$ & S.E. & $\%$ & S.E. & $\%$ & S.E. & $\%$ & S.E. & $\%$ & S.E. & $\%$ & S.E. \\
\hline 0 & Australia & & & & & & & & & & & & & & \\
\hline 岙 & Australian Capital Territory & 7.9 & $(1.2)$ & 12.3 & (1.3) & 17.9 & $(1.7)$ & 21.1 & $(2.2)$ & 19.8 & (1.8) & 13.1 & (1.6) & 7.9 & (1.2) \\
\hline & New South Wales & 10.2 & $(0.8)$ & 14.9 & $(0.9)$ & 19.8 & $(0.9)$ & 20.2 & (1.0) & 15.8 & $(0.9)$ & 10.5 & $(0.7)$ & 8.7 & $(1.2)$ \\
\hline & Northern Territory & 20.3 & (2.4) & 15.8 & (3.7) & 21.2 & $(4.4)$ & 23.7 & $(4.0)$ & 11.8 & $(2.7)$ & 4.9 & (2.8) & 2.3 & (1.1) \\
\hline & Queensland & 9.2 & $(0.9)$ & 15.3 & $(1.0)$ & 20.9 & (1.1) & 21.1 & (1.1) & 17.0 & $(1.0)$ & 10.5 & $(0.9)$ & 6.0 & $(0.6)$ \\
\hline & South Australia & 11.6 & $(1.2)$ & 18.1 & (1.5) & 21.8 & (1.5) & 22.1 & $(1.3)$ & 15.0 & $(1.2)$ & 8.0 & (1.0) & 3.4 & $(0.6)$ \\
\hline & Tasmania & 13.1 & $(1.3)$ & 18.4 & (1.3) & 24.0 & $(2.0)$ & 21.2 & (1.8) & 13.6 & (1.4) & 6.8 & $(0.9)$ & 2.9 & $(0.7)$ \\
\hline & Victoria & 9.1 & $(0.8)$ & 15.2 & (1.1) & 21.8 & (1.1) & 22.7 & $(1.0)$ & 16.7 & $(1.2)$ & 9.5 & (1.1) & 5.0 & (1.0) \\
\hline & Western Australia & 7.8 & $(1.0)$ & 13.2 & $(1.2)$ & 19.7 & $(1.3)$ & 20.6 & (1.3) & 20.2 & (1.4) & 11.9 & $(0.9)$ & 6.6 & $(0.9)$ \\
\hline & Belgium & & & & & & & & & & & & & & \\
\hline & Flemish Community ${ }^{\bullet}$ & 6.3 & $(0.7)$ & 10.1 & $(0.7)$ & 16.3 & $(0.8)$ & 20.0 & $(1.0)$ & 20.6 & $(0.9)$ & 15.5 & $(0.9)$ & 11.2 & $(0.8)$ \\
\hline & French Community & 11.6 & $(1.0)$ & 15.8 & (1.1) & 21.0 & $(0.9)$ & 21.9 & $(1.0)$ & 17.1 & (1.1) & 9.2 & $(0.7)$ & 3.5 & $(0.5)$ \\
\hline & German-speaking Community & 5.8 & $(0.9)$ & 11.6 & $(1.2)$ & 19.6 & (1.4) & 25.2 & (1.8) & 21.7 & (1.9) & 11.6 & $(1.2)$ & 4.5 & $(0.8)$ \\
\hline & Canada & & & & & & & & & & & & & & \\
\hline & Alberta & 7.0 & $(1.0)$ & 12.4 & $(1.2)$ & 19.2 & $(1.2)$ & 22.4 & (1.5) & 19.8 & (1.3) & 12.5 & (1.1) & 6.8 & (1.0) \\
\hline & British Columbia & 5.9 & $(0.9)$ & 10.9 & $(0.9)$ & 20.4 & $(1.3)$ & 24.2 & $(1.1)$ & 19.5 & $(1.2)$ & 12.4 & (1.1) & 6.7 & $(0.9)$ \\
\hline & Manitoba & 9.2 & $(1.0)$ & 17.1 & (1.3) & 23.1 & (1.4) & 22.5 & (1.6) & 15.8 & $(1.0)$ & 8.8 & $(0.8)$ & 3.6 & $(0.6)$ \\
\hline & New Brunswick & 5.6 & $(0.8)$ & 12.8 & $(1.2)$ & 22.0 & $(1.7)$ & 26.8 & $(2.1)$ & 19.9 & (1.6) & 9.0 & (1.1) & 3.9 & $(0.8)$ \\
\hline & Newfoundland and Labrador & 9.3 & $(1.8)$ & 17.2 & (1.3) & 24.0 & (1.9) & 23.5 & $(2.3)$ & 15.8 & $(2.1)$ & 7.3 & (1.1) & 2.7 & $(0.8)$ \\
\hline & Nova Scotia & 6.3 & (1.4) & 15.3 & (2.9) & 23.8 & (2.9) & 25.2 & (1.6) & 18.6 & (1.9) & 7.9 & (1.3) & 2.8 & $(0.8)$ \\
\hline & Ontario & 5.8 & $(0.6)$ & 12.1 & $(0.9)$ & 22.1 & (1.4) & 23.4 & (1.3) & 19.1 & $(1.1)$ & 11.3 & $(0.9)$ & 6.2 & $(0.9)$ \\
\hline & Prince Edward Island & 9.9 & (1.0) & 17.9 & (1.7) & 25.5 & $(1.3)$ & 23.6 & (1.8) & 15.1 & (1.3) & 5.7 & (1.0) & 2.3 & $(0.5)$ \\
\hline & Quebec & 4.4 & $(0.7)$ & 8.7 & $(0.9)$ & 15.9 & $(1.0)$ & 21.7 & (1.1) & 22.7 & $(1.0)$ & 16.7 & $(0.9)$ & 9.8 & $(0.9)$ \\
\hline & Saskatchewan & 6.6 & $(0.8)$ & 13.7 & (0.9) & 22.5 & (1.3) & 24.2 & (1.6) & 18.2 & $(1.2)$ & 10.9 & (1.1) & 4.0 & $(0.8)$ \\
\hline & Italy & & & & & & & & & & & & & & \\
\hline & Abruzzo & 15.6 & (2.0) & 18.0 & (1.8) & 22.9 & $(2.1)$ & 21.0 & (1.6) & 14.0 & (1.6) & 6.6 & (1.3) & 2.0 & $(0.6)$ \\
\hline & Basilicata & 12.8 & (1.7) & 20.5 & $(2.1)$ & 26.8 & $(2.2)$ & 22.0 & (1.6) & 12.5 & $(1.2)$ & 4.1 & $(0.7)$ & 1.3 & $(0.4)$ \\
\hline & Bolzano & 5.4 & (0.6) & 11.4 & $(1.2)$ & 21.9 & (1.4) & 25.1 & $(1.3)$ & 20.0 & (1.1) & 11.4 & (1.0) & 4.8 & $(0.6)$ \\
\hline & Calabria & 23.7 & (2.3) & 25.1 & (1.5) & 26.0 & (1.6) & 16.7 & $(1.5)$ & 6.2 & $(0.9)$ & 2.0 & $(0.5)$ & 0.4 & $(0.2)$ \\
\hline & Campania & 19.0 & (2.4) & 21.1 & (2.0) & 25.9 & $(2.0)$ & 18.5 & $(2.3)$ & 10.6 & (1.5) & 3.9 & $(1.2)$ & 1.1 & $(0.5)$ \\
\hline & Emilia Romagna & 10.6 & (1.6) & 15.0 & (1.7) & 21.6 & $(1.8)$ & 22.2 & $(2.0)$ & 17.2 & (1.5) & 9.1 & (1.5) & 4.3 & (1.0) \\
\hline & Friuli Venezia Giulia & 5.7 & $(1.2)$ & 11.0 & (1.4) & 18.2 & $(1.7)$ & 25.3 & (1.5) & 21.5 & (1.6) & 11.9 & (1.4) & 6.4 & $(0.9)$ \\
\hline & Lazio & 15.4 & $(2.2)$ & 19.2 & (2.1) & 24.2 & (1.9) & 20.3 & (1.6) & 12.8 & (1.6) & 6.2 & (1.0) & 1.9 & $(0.6)$ \\
\hline & Liguria & 10.6 & (1.5) & 17.8 & (1.7) & 23.5 & (2.0) & 23.6 & $(1.8)$ & 14.6 & (1.6) & 6.6 & (1.1) & 3.3 & $(0.5)$ \\
\hline & Lombardia & 6.5 & $(1.2)$ & 12.4 & (1.9) & 22.0 & $(2.1)$ & 24.7 & $(2.0)$ & 19.6 & (2.0) & 9.6 & (1.7) & 5.2 & $(1.2)$ \\
\hline & Marche & 8.7 & (1.6) & 16.9 & (1.9) & 23.4 & $(1.7)$ & 24.3 & (1.6) & 16.6 & (1.4) & 7.7 & (1.0) & 2.4 & $(0.6)$ \\
\hline & Molise & 14.1 & (1.4) & 20.9 & (2.1) & 26.5 & $(1.8)$ & 22.4 & (1.6) & 10.8 & $(1.2)$ & 3.7 & $(0.8)$ & 1.7 & $(0.6)$ \\
\hline & Piemonte & 11.1 & (1.6) & 15.5 & (1.7) & 22.5 & $(1.8)$ & 23.0 & (1.5) & 16.1 & (1.5) & 8.5 & (1.3) & 3.3 & $(0.9)$ \\
\hline & Puglia & 13.1 & (2.1) & 18.8 & (1.8) & 25.6 & $(2.0)$ & 21.7 & (1.8) & 13.4 & (1.5) & 5.9 & (1.1) & 1.6 & $(0.5)$ \\
\hline & Sardegna & 17.3 & $(2.2)$ & 21.6 & (2.0) & 24.9 & (1.5) & 20.2 & (1.7) & 11.0 & (1.1) & 4.1 & $(0.8)$ & 0.8 & $(0.4)$ \\
\hline & Sicilia & 16.8 & (1.9) & 22.8 & (1.8) & 27.3 & (1.9) & 20.8 & (1.7) & 9.1 & (1.1) & 2.5 & $(0.6)$ & 0.6 & $(0.3)$ \\
\hline & Toscana & 11.3 & $(1.3)$ & 14.8 & (1.7) & 21.8 & (1.8) & 23.3 & (1.7) & 16.2 & (1.4) & 9.6 & $(1.2)$ & 2.9 & $(0.6)$ \\
\hline & Trento & 3.3 & $(0.6)$ & 11.0 & (1.3) & 20.2 & (1.9) & 26.5 & (1.7) & 22.0 & (1.6) & 12.5 & (1.3) & 4.6 & $(0.8)$ \\
\hline & Umbria & 11.3 & (2.4) & 14.4 & (1.6) & 23.5 & (1.4) & 24.8 & $(2.1)$ & 17.1 & (1.6) & 7.1 & (1.0) & 1.7 & $(0.4)$ \\
\hline & Valle d'Aosta & 9.7 & $(1.1)$ & 16.9 & (1.9) & 25.2 & $(1.8)$ & 23.5 & $(2.3)$ & 14.9 & $(2.2)$ & 7.3 & (1.0) & 2.4 & $(0.5)$ \\
\hline & Veneto & 6.7 & (1.1) & 11.6 & (1.5) & 20.6 & $(2.1)$ & 22.0 & $(2.1)$ & 19.8 & $(1.2)$ & 13.4 & (2.0) & 5.9 & (1.4) \\
\hline & Mexico & & & & & & & & & & & & & & \\
\hline & Aguascalientes & 17.9 & (2.9) & 27.4 & (2.6) & 27.6 & $(2.3)$ & 18.1 & $(2.0)$ & 6.8 & $(1.0)$ & 2.0 & $(0.7)$ & 0.2 & $(0.2)$ \\
\hline & Baja California & 29.0 & (2.8) & 29.0 & (2.4) & 23.2 & $(2.1)$ & 12.9 & $(2.2)$ & 4.8 & (1.0) & 0.9 & $(0.3)$ & 0.1 & c \\
\hline & Baja California Sur & 25.0 & (2.9) & 30.3 & (2.0) & 24.4 & (1.9) & 14.4 & $(2.0)$ & 5.2 & $(1.0)$ & 0.6 & $(0.3)$ & 0.0 & C \\
\hline & Campeche & 35.1 & (2.6) & 31.1 & (1.6) & 21.2 & (1.4) & 9.0 & $(1.5)$ & 2.8 & $(0.7)$ & 0.6 & $(0.3)$ & 0.1 & $(0.1)$ \\
\hline & Chiapas & 44.6 & $(4.3)$ & 27.4 & (2.2) & 18.8 & (2.3) & 7.1 & (1.5) & 1.6 & $(0.6)$ & 0.5 & $(0.3)$ & 0.1 & C \\
\hline & Chihuahua & 20.8 & (3.0) & 26.3 & (2.6) & 26.6 & (2.6) & 16.0 & $(2.1)$ & 7.9 & (1.9) & 2.1 & $(0.6)$ & 0.3 & $(0.2)$ \\
\hline & Coahuila & 24.9 & (3.4) & 28.9 & $(3.2)$ & 25.7 & (2.4) & 14.0 & (2.4) & 5.5 & (1.6) & 1.0 & $(0.6)$ & 0.0 & C \\
\hline & Colima & 23.7 & (2.0) & 25.0 & (1.6) & 26.0 & $(2.0)$ & 16.3 & (1.9) & 6.5 & $(1.2)$ & 2.2 & $(0.8)$ & 0.4 & $(0.2)$ \\
\hline & Distrito Federal & 22.3 & (2.4) & 28.9 & (2.8) & 25.6 & (1.7) & 15.7 & (1.9) & 5.9 & (1.4) & 1.4 & $(0.7)$ & 0.2 & $(0.1)$ \\
\hline & Durango & 26.4 & (3.7) & 26.7 & (3.4) & 24.4 & $(2.2)$ & 15.8 & $(2.0)$ & 5.4 & (1.6) & 1.1 & $(0.6)$ & 0.2 & $(0.1)$ \\
\hline & Guanajuato & 28.3 & (3.1) & 28.8 & (2.0) & 24.7 & (1.8) & 12.3 & (1.4) & 4.8 & (1.1) & 1.1 & (0.6) & 0.0 & c \\
\hline & Guerrero & 52.2 & (2.6) & 26.6 & $(2.2)$ & 15.4 & (1.8) & 4.5 & $(0.7)$ & 1.1 & $(0.4)$ & 0.2 & $(0.2)$ & 0.0 & c \\
\hline & Hidalgo & 30.4 & (2.9) & 28.1 & $(2.2)$ & 22.4 & $(2.8)$ & 13.8 & (1.9) & 4.2 & $(0.9)$ & 1.0 & $(0.4)$ & 0.1 & c \\
\hline & Jalisco & 18.9 & (3.1) & 25.5 & (2.3) & 28.0 & (1.9) & 18.1 & $(2.3)$ & 6.9 & $(1.0)$ & 2.3 & $(0.8)$ & 0.2 & $(0.2)$ \\
\hline & Mexico & 23.4 & (2.7) & 28.6 & (2.8) & 27.6 & $(2.7)$ & 14.2 & $(2.2)$ & 4.9 & $(1.0)$ & 1.0 & $(0.5)$ & 0.3 & $(0.2)$ \\
\hline & Morelos & 26.8 & (3.2) & 28.3 & (2.5) & 23.0 & (1.9) & 13.1 & $(2.1)$ & 5.4 & (1.4) & 2.8 & (1.6) & 0.5 & $(0.4)$ \\
\hline & Nayarit & 29.4 & (3.0) & 28.4 & (2.3) & 22.7 & $(1.7)$ & 12.9 & (1.4) & 5.2 & (1.4) & 1.1 & $(0.5)$ & 0.1 & c \\
\hline & Nuevo León & 22.1 & (3.5) & 25.6 & (2.4) & 25.1 & (1.7) & 17.3 & (2.6) & 7.2 & (1.4) & 2.4 & $(0.7)$ & 0.4 & $(0.2)$ \\
\hline & Puebla & 24.6 & (2.3) & 28.3 & (2.1) & 25.2 & $(2.2)$ & 14.7 & (1.8) & 5.8 & $(1.2)$ & 1.3 & (0.6) & 0.1 & c \\
\hline & Querétaro & 20.1 & (3.1) & 27.0 & $(2.2)$ & 24.3 & $(2.2)$ & 17.9 & $(2.2)$ & 8.1 & (1.6) & 2.0 & $(0.6)$ & 0.6 & $(0.3)$ \\
\hline & Quintana Roo & 23.9 & (2.5) & 30.5 & (2.4) & 25.7 & (1.7) & 14.2 & (1.7) & 4.7 & $(0.9)$ & 1.1 & $(0.4)$ & 0.1 & $(0.1)$ \\
\hline & San Luis Potosí & 30.4 & (3.2) & 27.2 & $(2.2)$ & 23.9 & (1.8) & 13.2 & $(2.2)$ & 4.0 & $(1.2)$ & 1.1 & $(0.6)$ & 0.2 & $(0.2)$ \\
\hline & Sinaloa & 27.3 & (2.4) & 31.4 & (1.7) & 24.9 & $(2.1)$ & 11.5 & (1.4) & 4.1 & $(0.6)$ & 0.8 & $(0.5)$ & 0.1 & C \\
\hline & Tabasco & 43.2 & (2.3) & 30.4 & (2.0) & 17.6 & (1.5) & 6.5 & (1.0) & 1.8 & $(0.4)$ & 0.3 & $(0.1)$ & 0.0 & C \\
\hline & Tamaulipas & 26.0 & (3.2) & 27.8 & (2.1) & 25.7 & (2.6) & 13.8 & $(2.2)$ & 5.4 & (1.5) & 1.1 & $(0.7)$ & 0.2 & C \\
\hline & Tlaxcala & 27.3 & (3.0) & 29.0 & (1.8) & 26.1 & (2.0) & 12.7 & (1.5) & 4.1 & $(0.8)$ & 0.7 & $(0.3)$ & 0.1 & $(0.1)$ \\
\hline & Veracruz & 29.3 & (3.1) & 30.1 & (2.3) & 23.9 & (1.7) & 11.5 & (1.9) & 4.4 & (1.0) & 0.9 & $(0.5)$ & 0.0 & C \\
\hline & Yucatán & 29.8 & (2.9) & 27.9 & (2.0) & 23.9 & $(2.3)$ & 12.5 & (1.4) & 5.0 & $(0.9)$ & 0.9 & $(0.3)$ & 0.1 & $(0.1)$ \\
\hline & Zacatecas & 27.9 & (2.4) & 29.7 & (2.0) & 24.3 & (2.4) & 13.3 & (1.5) & 3.9 & $(0.8)$ & 0.7 & $(0.3)$ & 0.1 & C \\
\hline
\end{tabular}

- PISA adjudicated region

Note: See Table I.2.5 for national data.

StatLink 完红 http://dx.doi.org/10.1787/888932935762 
[Part 2/2]

Table B2.I.4 Percentage of students at each proficiency level on the mathematics subscale formulating, by region

\begin{tabular}{|c|c|c|c|c|c|c|c|c|c|c|c|c|c|c|c|}
\hline & & \multicolumn{14}{|c|}{ All students } \\
\hline & & \multicolumn{2}{|c|}{$\begin{array}{c}\text { Below Level } 1 \\
\text { (below } 357.77 \\
\text { score points) }\end{array}$} & \multicolumn{2}{|c|}{$\begin{array}{c}\text { Level } 1 \\
\text { (from } 357.77 \text { to } \\
\text { less than } 420.07 \\
\text { score points) }\end{array}$} & \multicolumn{2}{|c|}{$\begin{array}{c}\text { Level } 2 \\
\text { (from } 420.07 \text { to } \\
\text { less than } 482.38 \\
\text { score points) }\end{array}$} & $\begin{array}{l}\text { L } \\
\text { (from } \\
\text { less th } \\
\text { scor }\end{array}$ & \begin{tabular}{|l|}
3 \\
2.38 to \\
544.68 \\
oints)
\end{tabular} & $\begin{array}{l}\text { Le } \\
\text { (from } \\
\text { less th } \\
\text { scor }\end{array}$ & \begin{tabular}{|l|}
4 \\
4.68 to \\
606.99 \\
oints)
\end{tabular} & $\begin{array}{l}\text { L } \\
\text { (from } \\
\text { less th } \\
\text { scor }\end{array}$ & \begin{tabular}{l|}
15 \\
6.99 to \\
669.30 \\
oints)
\end{tabular} & $\begin{array}{l}\text { Le } \\
\text { (abov } \\
\text { scor }\end{array}$ & $\begin{array}{l}16 \\
669.30 \\
\text { oints) }\end{array}$ \\
\hline & & $\%$ & S.E. & $\%$ & S.E. & $\%$ & S.E. & $\%$ & S.E. & $\%$ & S.E. & $\%$ & S.E. & $\%$ & S.E. \\
\hline 0 & Portugal & & & & & & & & & & & & & & \\
\hline 芩 & Alentejo & 10.9 & (3.0) & 15.8 & (3.4) & 24.0 & (3.0) & 23.0 & (3.9) & 14.2 & (2.4) & 8.2 & (1.7) & 3.7 & (1.6) \\
\hline & Spain & & & & & & & & & & & & & & \\
\hline & Andalusia ${ }^{\bullet}$ & 13.0 & (1.4) & 20.4 & (1.4) & 25.4 & (1.4) & 20.8 & $(1.7)$ & 13.7 & (1.3) & 5.3 & $(0.9)$ & 1.4 & $(0.4)$ \\
\hline & Aragon • & 9.8 & (1.4) & 14.0 & (1.4) & 20.8 & (1.9) & 22.9 & (1.5) & 19.1 & (1.3) & 9.5 & (1.1) & 3.9 & $(0.6)$ \\
\hline & Asturias ${ }^{\bullet}$ & 9.8 & (1.4) & 13.3 & $(1.2)$ & 21.4 & $(1.2)$ & 23.5 & $(1.5)$ & 17.8 & $(1.2)$ & 9.9 & (1.1) & 4.3 & $(0.8)$ \\
\hline & Balearic Islands ${ }^{\bullet}$ & 14.0 & (1.7) & 17.5 & (1.3) & 22.7 & (1.5) & 23.0 & $(2.0)$ & 15.0 & (1.6) & 6.1 & (0.9) & 1.6 & $(0.5)$ \\
\hline & Basque Country ${ }^{\bullet}$ & 6.2 & (0.6) & 11.9 & $(0.7)$ & 20.8 & (0.9) & 25.6 & $(1.0)$ & 21.0 & (0.8) & 10.7 & $(0.8)$ & 3.8 & (0.5) \\
\hline & Cantabria ${ }^{\bullet}$ & 11.6 & (1.1) & 15.8 & (1.2) & 21.5 & (1.8) & 21.9 & (1.4) & 16.7 & (1.3) & 8.8 & $(0.9)$ & 3.7 & $(0.7)$ \\
\hline & Castile and Leon ${ }^{\bullet}$ & 6.6 & $(0.9)$ & 13.1 & (1.3) & 20.0 & $(1.3)$ & 24.2 & $(1.4)$ & 21.1 & $(1.2)$ & 11.3 & (1.3) & 3.6 & (0.8) \\
\hline & Catalonia` & 10.0 & (1.3) & 15.8 & (1.3) & 22.5 & $(1.6)$ & 22.9 & $(1.3)$ & 16.6 & (1.3) & 9.2 & (1.2) & 3.0 & $(0.7)$ \\
\hline & Extremadura ${ }^{\bullet}$ & 18.0 & (1.7) & 19.6 & (1.3) & 23.1 & (1.6) & 20.8 & $(1.1)$ & 12.1 & (1.3) & 4.9 & $(0.7)$ & 1.5 & $(0.3)$ \\
\hline & Galicia ${ }^{\bullet}$ & 11.0 & (1.3) & 14.8 & (1.5) & 23.1 & $(1.3)$ & 25.0 & (1.6) & 16.7 & (1.4) & 7.2 & (1.0) & 2.3 & (0.4) \\
\hline & La Rioja・ & 10.3 & $(0.9)$ & 13.4 & (1.4) & 18.9 & $(1.1)$ & 21.1 & $(1.5)$ & 17.4 & (1.5) & 12.8 & (1.1) & 6.2 & $(0.7)$ \\
\hline & Madrid` & 9.3 & (1.1) & 14.3 & $(1.2)$ & 20.6 & $(1.2)$ & 23.0 & $(1.3)$ & 19.6 & (1.4) & 9.7 & (1.1) & 3.7 & (0.6) \\
\hline & Murcia ${ }^{\bullet}$ & 18.0 & (1.5) & 20.6 & (1.4) & 23.3 & (1.4) & 19.8 & $(1.3)$ & 11.9 & $(1.2)$ & 4.7 & (0.9) & 1.8 & $(0.7)$ \\
\hline & Navarre ${ }^{\bullet}$ & 4.8 & $(0.8)$ & 10.5 & $(1.2)$ & 18.6 & (1.6) & 25.5 & $(1.5)$ & 22.8 & (1.6) & 13.0 & (1.3) & 4.9 & $(0.8)$ \\
\hline & United Kingdom & & & & & & & & & & & & & & \\
\hline & England & 10.5 & (1.3) & 15.1 & $(0.9)$ & 21.9 & $(1.0)$ & 21.8 & $(0.9)$ & 16.4 & $(0.9)$ & 9.6 & $(0.8)$ & 4.6 & $(0.6)$ \\
\hline & Northern Ireland & 11.4 & (1.1) & 17.1 & $(1.2)$ & 22.6 & (1.4) & 22.9 & $(1.4)$ & 15.7 & $(0.9)$ & 7.2 & $(0.9)$ & 3.1 & $(0.5)$ \\
\hline & Scotland ${ }^{\bullet}$ & 8.9 & $(0.8)$ & 15.4 & $(1.2)$ & 23.3 & $(1.1)$ & 23.7 & $(1.0)$ & 16.5 & (1.0) & 8.3 & $(0.8)$ & 3.9 & $(0.5)$ \\
\hline & Wales & 14.2 & (0.9) & 20.8 & (1.0) & 26.0 & (1.0) & 21.6 & $(0.9)$ & 12.0 & $(0.9)$ & 4.3 & $(0.5)$ & 1.2 & $(0.2)$ \\
\hline & United States & & & & & & & & & & & & & & \\
\hline & Connecticut $^{\bullet}$ & 9.6 & (1.4) & 14.6 & (1.4) & 19.0 & (1.3) & 21.0 & $(1.2)$ & 17.1 & $(1.2)$ & 11.5 & (1.5) & 7.2 & (1.1) \\
\hline & Florida $\bullet$ & 14.5 & (1.8) & 21.1 & (1.8) & 25.4 & (1.8) & 21.5 & $(2.1)$ & 11.5 & (1.5) & 4.9 & $(0.9)$ & 1.1 & $(0.3)$ \\
\hline & Massachusetts ${ }^{\bullet}$ & 8.0 & (1.0) & 12.3 & (1.3) & 19.7 & (2.0) & 22.1 & (1.6) & 17.9 & (1.7) & 12.1 & (1.3) & 8.0 & (1.8) \\
\hline$\tilde{2}$ & Argentina & & & & & & & & & & & & & & \\
\hline 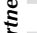 & Ciudad Autónoma de Buenos Aires ${ }^{\bullet}$ & 27.2 & (2.8) & 23.2 & $(2.2)$ & 26.1 & (1.9) & 16.1 & $(2.0)$ & 5.9 & $(1.0)$ & 1.3 & $(0.5)$ & 0.1 & $(0.2)$ \\
\hline ๘ & Brazil & & & & & & & & & & & & & & \\
\hline & Acre & 62.3 & $(3.7)$ & 24.5 & $(2.5)$ & 10.3 & $(2.2)$ & 2.3 & $(0.9)$ & 0.5 & $(0.4)$ & 0.1 & c & 0.0 & c \\
\hline & Alagoas & 62.4 & $(4.9)$ & 22.9 & (3.6) & 10.6 & $(2.3)$ & 3.2 & $(1.2)$ & 0.8 & $(0.6)$ & 0.1 & $(0.1)$ & 0.0 & c \\
\hline & Amapá & 58.7 & $(5.1)$ & 26.4 & (3.7) & 11.0 & $(2.8)$ & 3.5 & $(1.6)$ & 0.3 & c & 0.0 & c & 0.0 & c \\
\hline & Amazonas & 59.3 & (3.8) & 26.6 & (2.8) & 10.3 & (2.0) & 3.0 & $(1.2)$ & 0.8 & $(0.7)$ & 0.0 & $\mathrm{C}$ & 0.0 & c \\
\hline & Bahia & 57.1 & (4.4) & 24.6 & (3.5) & 11.6 & $(3.1)$ & 3.9 & $(1.2)$ & 1.9 & (1.0) & 0.8 & $(0.8)$ & 0.0 & c \\
\hline & Ceará & 49.4 & $(4.8)$ & 27.2 & (2.6) & 14.3 & $(2.1)$ & 5.2 & (1.9) & 3.0 & $(1.2)$ & 0.8 & $(0.6)$ & 0.1 & c \\
\hline & Espírito Santo & 35.5 & $(4.2)$ & 27.0 & $(2.7)$ & 17.3 & $(2.0)$ & 11.6 & $(2.5)$ & 6.3 & $(2.3)$ & 2.0 & $(0.7)$ & 0.3 & $(0.3)$ \\
\hline & Federal District & 35.3 & $(4.5)$ & 25.1 & (3.3) & 20.6 & $(3.3)$ & 12.2 & $(2.8)$ & 4.8 & (1.6) & 1.5 & (1.0) & 0.5 & (0.6) \\
\hline & Goiás & 50.7 & (3.8) & 26.8 & (3.1) & 13.3 & $(1.9)$ & 6.5 & $(1.2)$ & 2.1 & $(0.7)$ & 0.5 & $(0.4)$ & 0.2 & c \\
\hline & Maranhão & 73.6 & $(6.2)$ & 16.6 & (3.0) & 6.6 & $(2.6)$ & 2.3 & $(1.4)$ & 0.4 & $(0.4)$ & 0.4 & $(0.3)$ & 0.0 & c \\
\hline & Mato Grosso & 52.8 & $(5.2)$ & 25.4 & (2.8) & 14.0 & $(2.4)$ & 5.2 & $(2.0)$ & 2.0 & $(1.0)$ & 0.6 & $(0.4)$ & 0.0 & c \\
\hline & Mato Grosso do Sul & 35.3 & (3.3) & 27.9 & $(2.7)$ & 20.9 & $(2.2)$ & 11.0 & $(2.1)$ & 4.5 & $(1.3)$ & 0.4 & $(0.3)$ & 0.0 & c \\
\hline & Minas Gerais & 35.0 & (3.8) & 30.7 & (2.6) & 22.2 & $(2.5)$ & 8.9 & $(1.8)$ & 2.4 & $(1.0)$ & 0.6 & $(0.4)$ & 0.1 & c \\
\hline & Pará & 55.5 & $(4.0)$ & 26.4 & (2.5) & 15.0 & $(3.0)$ & 2.8 & $(1.2)$ & 0.4 & $(0.4)$ & 0.0 & $\mathrm{c}$ & 0.0 & c \\
\hline & Paraiba & 40.1 & $(4.8)$ & 28.5 & (3.0) & 19.9 & $(4.5)$ & 7.2 & $(1.6)$ & 3.0 & (1.5) & 1.2 & $(0.5)$ & 0.1 & c \\
\hline & Paraná & 37.5 & (3.8) & 29.9 & (2.6) & 19.0 & $(2.4)$ & 6.7 & $(1.2)$ & 4.4 & $(2.8)$ & 2.0 & (1.9) & 0.4 & c \\
\hline & Pernambuco & 53.5 & $(5.1)$ & 30.3 & (3.9) & 11.6 & $(2.5)$ & 3.4 & $(1.1)$ & 0.8 & $(0.7)$ & 0.3 & $(0.3)$ & 0.1 & c \\
\hline & Piauí & 50.1 & (3.4) & 25.6 & (2.5) & 12.0 & $(2.0)$ & 7.3 & $(1.5)$ & 3.2 & $(1.5)$ & 1.3 & $(0.9)$ & 0.5 & $(0.4)$ \\
\hline & Rio de Janeiro & 44.5 & $(3.7)$ & 29.6 & (2.9) & 17.7 & $(2.5)$ & 6.5 & $(1.7)$ & 1.4 & $(0.6)$ & 0.3 & $(0.2)$ & 0.0 & C \\
\hline & Rio Grande do Norte & 51.2 & $(4.7)$ & 22.8 & (2.9) & 14.1 & $(2.1)$ & 6.4 & $(1.8)$ & 3.2 & (1.4) & 1.7 & (1.0) & 0.5 & $(0.6)$ \\
\hline & Rio Grande do Sul & 31.2 & (3.8) & 30.3 & (3.3) & 23.8 & $(3.0)$ & 11.7 & $(2.0)$ & 2.4 & $(0.9)$ & 0.5 & $(0.4)$ & 0.1 & c \\
\hline & Rondônia & 44.8 & (2.9) & 33.4 & $(2.7)$ & 16.7 & $(2.3)$ & 4.0 & $(1.2)$ & 0.9 & $(0.5)$ & 0.2 & C & 0.0 & c \\
\hline & Roraima & 54.8 & (3.4) & 26.5 & (2.8) & 11.8 & $(1.7)$ & 5.5 & $(2.3)$ & 1.4 & $(0.6)$ & 0.1 & c & 0.0 & c \\
\hline & Santa Catarina & 29.9 & (3.9) & 29.3 & (2.8) & 23.1 & $(2.4)$ & 13.3 & $(2.7)$ & 3.8 & $(1.3)$ & 0.7 & $(0.5)$ & 0.0 & c \\
\hline & São Paulo & 37.5 & $(2.2)$ & 29.0 & (1.6) & 19.4 & $(1.3)$ & 9.2 & $(1.2)$ & 3.6 & $(0.8)$ & 1.1 & $(0.5)$ & 0.3 & $(0.2)$ \\
\hline & Sergipe & 49.6 & (4.9) & 26.6 & (2.8) & 15.7 & $(2.7)$ & 6.7 & $(1.8)$ & 1.1 & $(0.6)$ & 0.2 & c & 0.0 & c \\
\hline & Tocantins & 57.4 & (4.5) & 24.1 & (2.4) & 11.7 & $(2.1)$ & 4.9 & $(1.8)$ & 1.1 & $(0.6)$ & 0.6 & $(0.4)$ & 0.2 & $(0.2)$ \\
\hline & Colombia & & & & & & & & & & & & & & \\
\hline & Bogotá & 35.5 & (2.4) & 33.5 & (1.9) & 21.2 & $(1.7)$ & 8.1 & $(1.3)$ & 1.4 & $(0.5)$ & 0.2 & $(0.2)$ & 0.1 & $(0.1)$ \\
\hline & Cali & 44.7 & (3.7) & 29.2 & (1.6) & 18.5 & $(2.5)$ & 6.0 & $(1.3)$ & 1.5 & $(0.6)$ & 0.0 & C & 0.0 & C \\
\hline & Manizales & 29.5 & (2.3) & 32.2 & (2.8) & 23.5 & $(3.0)$ & 10.2 & (1.6) & 3.7 & (1.0) & 0.9 & (0.6) & 0.1 & c \\
\hline & Medellín & 36.8 & (3.4) & 29.3 & (2.2) & 18.6 & (1.8) & 9.0 & (1.3) & 3.9 & $(1.2)$ & 1.6 & $(0.8)$ & 0.8 & (0.4) \\
\hline & Russian Federation & & & & & & & & & & & & & & \\
\hline & Perm Territory region & 9.2 & (1.4) & 16.0 & (1.6) & 24.9 & $(1.7)$ & 24.4 & (1.7) & 15.3 & (1.3) & 6.5 & (1.0) & 3.6 & (1.4) \\
\hline & United Arab Emirates & & & & & & & & & & & & & & \\
\hline & Abu Dhabi ${ }^{\bullet}$ & 30.4 & $(1.7)$ & 25.4 & (1.0) & 20.7 & $(1.2)$ & 13.3 & $(1.0)$ & 6.6 & $(0.7)$ & 2.8 & $(0.5)$ & 0.8 & $(0.3)$ \\
\hline & Ajman & 31.1 & (4.9) & 25.7 & (3.4) & 23.3 & $(3.0)$ & 14.9 & $(1.7)$ & 4.2 & $(1.1)$ & 0.7 & $(0.4)$ & 0.0 & c \\
\hline & Dubai & 18.7 & $(0.7)$ & 20.5 & $(0.7)$ & 21.5 & $(1.0)$ & 19.3 & $(1.0)$ & 12.2 & $(0.6)$ & 5.5 & $(0.5)$ & 2.3 & $(0.3)$ \\
\hline & Fujairah & 29.3 & $(4.1)$ & 24.2 & (2.2) & 24.1 & (3.4) & 14.8 & $(2.7)$ & 6.2 & (1.9) & 1.1 & $(0.6)$ & 0.3 & $(0.3)$ \\
\hline & Ras al-Khaimah & 29.1 & (3.7) & 27.3 & (1.9) & 24.1 & $(2.5)$ & 13.4 & $(2.2)$ & 5.2 & $(1.2)$ & 0.7 & $(0.4)$ & 0.2 & $(0.3)$ \\
\hline & Sharjah & 24.3 & $(4.2)$ & 23.1 & $(2.1)$ & 22.2 & $(2.5)$ & 17.9 & $(2.6)$ & 9.2 & $(2.2)$ & 2.8 & (1.0) & 0.5 & $(0.5)$ \\
\hline & Umm al-Quwain & 32.4 & (2.9) & 30.0 & (3.1) & 21.8 & (3.7) & 11.4 & $(2.1)$ & 3.2 & (1.5) & 0.8 & $(0.6)$ & 0.6 & $\mathrm{C}$ \\
\hline
\end{tabular}

- PISA adjudicated region.

Note: See Table I.2.5 for national data.

StatLink 解古 $\mathrm{http}: / / \mathrm{dx}$.doi.org/10.1787/888932935762 
Percentage of students at each proficiency level on the mathematics subscale formulating, by gender Table B2.I.5 and region

\begin{tabular}{|c|c|c|c|c|c|c|c|c|c|c|c|c|c|c|c|}
\hline & & \multicolumn{14}{|c|}{ Boys } \\
\hline & & \multicolumn{2}{|c|}{$\begin{array}{c}\text { Below Level } 1 \\
\text { (below } 357.77 \\
\text { score points) }\end{array}$} & $\begin{array}{l}\mathrm{L} \\
\text { (from } \\
\text { less th } \\
\text { scor }\end{array}$ & $\begin{array}{l}l 1 \\
7.77 \text { to } \\
420.07 \\
\text { oints) }\end{array}$ & $\begin{array}{r}\mathrm{L} \\
\text { (from } \\
\text { less th } \\
\text { scor }\end{array}$ & $\begin{array}{l}l 2 \\
0.07 \text { to } \\
482.38 \\
\text { oints) }\end{array}$ & $\begin{array}{l}\text { Le } \\
\text { (from } \\
\text { less th } \\
\text { scor }\end{array}$ & \begin{tabular}{|l|}
3 \\
2.38 to \\
544.68 \\
oints)
\end{tabular} & $\begin{array}{l}\mathrm{L} \\
\text { (from } \\
\text { less th } \\
\text { scor }\end{array}$ & $\begin{array}{l}l 4 \\
4.68 \text { to } \\
606.99 \\
\text { oints) }\end{array}$ & $\begin{array}{l}\mathrm{L} \\
\text { (from } \\
\text { less th } \\
\text { scor }\end{array}$ & \begin{tabular}{|l|}
5 \\
6.99 to \\
669.30 \\
oints)
\end{tabular} & $\begin{array}{l}\text { Le } \\
\text { (abov } \\
\text { scor }\end{array}$ & $\begin{array}{l}16 \\
669.30 \\
\text { oints) }\end{array}$ \\
\hline & & $\%$ & S.E. & $\%$ & S.E. & $\%$ & S.E. & $\%$ & S.E. & $\%$ & S.E. & $\%$ & S.E. & $\%$ & S.E. \\
\hline 0 & Australia & & & & & & & & & & & & & & \\
\hline 4 & Australian Capital Territory & 7.6 & $(1.7)$ & 11.1 & $(2.2)$ & 18.6 & (3.4) & 21.2 & (3.1) & 19.5 & $(2.3)$ & 13.1 & (1.9) & 9.0 & (1.8) \\
\hline & New South Wales & 9.5 & $(1.0)$ & 14.7 & (1.1) & 20.2 & (1.5) & 18.7 & (1.5) & 15.5 & (1.4) & 10.8 & (1.4) & 10.6 & (1.9) \\
\hline & Northern Territory & 20.1 & $(2.7)$ & 13.7 & $(4.2)$ & 19.1 & (5.8) & 24.4 & $(5.0)$ & 14.4 & (3.4) & 4.5 & $(2.7)$ & 3.7 & (1.8) \\
\hline & Queensland & 7.8 & $(1.0)$ & 14.6 & (1.3) & 20.6 & (1.8) & 21.4 & (1.3) & 17.8 & (1.5) & 11.0 & $(1.2)$ & 6.8 & $(0.9)$ \\
\hline & South Australia & 10.1 & (1.4) & 16.1 & $(2.1)$ & 20.7 & $(1.8)$ & 23.5 & (1.9) & 16.7 & (1.9) & 8.9 & (1.4) & 4.0 & $(1.0)$ \\
\hline & Tasmania & 11.9 & (1.6) & 16.7 & (2.5) & 24.9 & (3.1) & 21.9 & $(2.1)$ & 14.0 & $(2.2)$ & 7.2 & (1.3) & 3.5 & (1.1) \\
\hline & Victoria & 7.8 & $(1.0)$ & 14.0 & $(1.3)$ & 20.6 & (1.4) & 23.1 & (1.4) & 17.5 & (1.5) & 10.3 & $(1.3)$ & 6.6 & (1.6) \\
\hline & Western Australia & 5.6 & $(1.0)$ & 12.0 & (1.5) & 18.1 & (1.6) & 20.0 & (1.9) & 21.6 & (1.9) & 14.0 & $(1.4)$ & 8.6 & (1.5) \\
\hline & Belgium & & & & & & & & & & & & & & \\
\hline & Flemish Community• & 6.2 & $(1.2)$ & 9.3 & $(0.9)$ & 15.7 & $(1.0)$ & 18.4 & $(1.1)$ & 20.7 & $(1.2)$ & 16.6 & $(1.0)$ & 13.1 & $(1.0)$ \\
\hline & French Community & 11.3 & $(1.1)$ & 14.8 & (1.5) & 19.4 & (1.4) & 21.4 & (1.6) & 17.8 & (1.3) & 10.7 & (1.1) & 4.5 & $(0.7)$ \\
\hline & German-speaking Community & 6.6 & $(1.3)$ & 11.4 & (1.8) & 19.1 & (1.8) & 24.1 & (2.6) & 20.3 & (2.6) & 12.3 & (1.7) & 6.1 & (1.4) \\
\hline & Canada & & & & & & & & & & & & & & \\
\hline & Alberta & 6.9 & (1.4) & 10.5 & (1.4) & 18.3 & $(1.7)$ & 23.0 & $(2.0)$ & 19.0 & (1.6) & 13.9 & (1.4) & 8.5 & $(1.2)$ \\
\hline & British Columbia & 4.9 & $(1.0)$ & 10.0 & $(1.5)$ & 19.4 & $(2.2)$ & 23.7 & (1.9) & 19.2 & $(2.0)$ & 14.6 & (1.4) & 8.2 & (1.2) \\
\hline & Manitoba & 8.6 & (1.4) & 16.1 & $(1.7)$ & 22.9 & $(2.0)$ & 22.6 & (1.9) & 15.6 & (1.3) & 10.1 & (1.3) & 4.1 & $(0.8)$ \\
\hline & New Brunswick & 6.1 & $(1.4)$ & 12.4 & $(2.1)$ & 21.4 & $(2.3)$ & 26.1 & $(2.5)$ & 20.3 & $(2.1)$ & 9.4 & (1.7) & 4.3 & $(1.2)$ \\
\hline & Newfoundland and Labrador & 9.7 & $(2.2)$ & 16.8 & $(2.3)$ & 22.6 & (2.0) & 22.8 & (2.6) & 17.3 & $(2.4)$ & 7.7 & (1.8) & 3.2 & $(1.2)$ \\
\hline & Nova Scotia & 5.2 & $(1.7)$ & 14.4 & $(2.9)$ & 22.4 & (3.8) & 25.2 & (2.8) & 20.2 & $(2.4)$ & 9.3 & $(2.0)$ & 3.3 & (1.0) \\
\hline & Ontario & 5.5 & $(0.9)$ & 12.7 & $(1.2)$ & 20.0 & (1.6) & 22.7 & $(1.6)$ & 18.4 & $(1.2)$ & 12.6 & $(1.1)$ & 8.1 & (1.4) \\
\hline & Prince Edward Island & 10.2 & $(1.8)$ & 16.9 & $(2.8)$ & 24.4 & $(2.1)$ & 23.4 & $(2.4)$ & 15.6 & (1.8) & 6.8 & (1.5) & 2.6 & $(0.7)$ \\
\hline & Quebec & 4.3 & $(1.0)$ & 8.3 & $(1.3)$ & 15.2 & (1.4) & 20.7 & (1.4) & 22.2 & (1.3) & 17.9 & $(1.2)$ & 11.4 & $(1.2)$ \\
\hline & Saskatchewan & 6.2 & $(1.2)$ & 12.9 & (1.4) & 21.7 & $(2.3)$ & 23.0 & (2.3) & 19.0 & (1.6) & 12.2 & (1.7) & 5.0 & (1.2) \\
\hline & Italy & & & & & & & & & & & & & & \\
\hline & Abruzzo & 14.0 & $(2.2)$ & 17.5 & $(2.0)$ & 22.7 & (2.4) & 19.5 & $(2.0)$ & 16.0 & $(2.2)$ & 7.8 & (1.7) & 2.4 & $(0.7)$ \\
\hline & Basilicata & 11.6 & $(2.3)$ & 17.8 & $(2.9)$ & 24.7 & $(2.3)$ & 23.6 & $(2.4)$ & 14.8 & (1.7) & 5.7 & (1.2) & 1.9 & $(0.7)$ \\
\hline & Bolzano & 4.3 & $(1.0)$ & 9.8 & $(1.5)$ & 19.6 & (1.5) & 23.7 & (1.5) & 20.1 & (1.5) & 15.0 & (1.5) & 7.5 & $(1.0)$ \\
\hline & Calabria & 19.5 & $(2.8)$ & 22.7 & $(1.9)$ & 26.4 & (2.8) & 19.9 & (2.3) & 8.1 & $(1.2)$ & 2.7 & $(0.8)$ & 0.6 & $(0.4)$ \\
\hline & Campania & 17.2 & $(2.5)$ & 19.7 & (2.6) & 25.6 & $(2.9)$ & 18.4 & $(2.4)$ & 12.4 & (1.8) & 5.0 & (1.4) & 1.7 & $(0.8)$ \\
\hline & Emilia Romagna & 10.6 & $(2.1)$ & 12.5 & $(2.3)$ & 19.1 & (2.0) & 21.5 & $(2.7)$ & 18.5 & $(2.1)$ & 11.9 & $(2.1)$ & 5.9 & (1.5) \\
\hline & Friuli Venezia Giulia & 5.6 & $(1.4)$ & 10.2 & $(1.9)$ & 14.7 & (1.8) & 22.5 & $(2.3)$ & 22.9 & $(2.1)$ & 14.9 & (2.5) & 9.2 & (1.7) \\
\hline & Lazio & 14.0 & (2.8) & 16.7 & $(2.4)$ & 22.9 & (1.9) & 21.0 & $(2.3)$ & 14.7 & $(2.3)$ & 8.2 & (1.6) & 2.6 & $(0.8)$ \\
\hline & Liguria & 9.7 & $(2.2)$ & 18.1 & $(2.6)$ & 22.4 & (2.6) & 22.3 & $(2.6)$ & 15.1 & (1.9) & 8.0 & (1.6) & 4.5 & $(0.8)$ \\
\hline & Lombardia & 6.2 & $(1.5)$ & 9.8 & $(1.9)$ & 18.7 & $(2.4)$ & 23.1 & $(3.0)$ & 21.6 & $(2.7)$ & 12.4 & $(2.1)$ & 8.2 & (1.8) \\
\hline & Marche & 5.5 & (1.6) & 14.9 & $(2.5)$ & 21.8 & $(2.1)$ & 24.3 & $(2.0)$ & 19.4 & (1.9) & 10.7 & (1.6) & 3.3 & $(0.9)$ \\
\hline & Molise & 12.0 & $(1.6)$ & 17.7 & $(2.1)$ & 25.9 & (3.1) & 24.8 & $(3.3)$ & 13.1 & (2.4) & 4.2 & $(1.4)$ & 2.3 & (0.9) \\
\hline & Piemonte & 8.8 & $(1.9)$ & 12.4 & $(2.2)$ & 20.7 & (1.9) & 23.6 & $(1.6)$ & 19.9 & (1.7) & 10.3 & (1.5) & 4.3 & (1.3) \\
\hline & Puglia & 10.6 & (1.9) & 16.1 & $(2.2)$ & 23.5 & $(2.1)$ & 23.3 & $(2.3)$ & 16.2 & $(2.0)$ & 8.0 & (1.9) & 2.3 & $(0.9)$ \\
\hline & Sardegna & 15.2 & (2.4) & 20.0 & $(2.7)$ & 25.7 & (2.4) & 20.7 & $(2.0)$ & 11.8 & (1.6) & 5.0 & $(1.2)$ & 1.4 & $(0.5)$ \\
\hline & Sicilia & 16.9 & $(2.2)$ & 20.7 & $(2.0)$ & 26.9 & (1.9) & 21.5 & $(2.6)$ & 9.6 & (1.5) & 3.6 & $(0.9)$ & 0.8 & $(0.5)$ \\
\hline & Toscana & 11.5 & $(2.2)$ & 13.6 & $(2.0)$ & 22.3 & (2.5) & 22.5 & $(2.3)$ & 16.3 & (1.8) & 10.5 & $(1.8)$ & 3.4 & $(0.9)$ \\
\hline & Trento & 3.2 & $(1.0)$ & 11.5 & $(1.8)$ & 18.8 & (1.9) & 25.0 & $(2.0)$ & 20.6 & $(1.7)$ & 14.4 & $(1.8)$ & 6.5 & $(1.2)$ \\
\hline & Umbria & 10.2 & $(3.2)$ & 11.9 & $(2.2)$ & 20.5 & (1.8) & 26.1 & $(3.0)$ & 19.3 & (2.4) & 9.4 & $(1.7)$ & 2.5 & $(0.9)$ \\
\hline & Valle d'Aosta & 8.4 & (1.6) & 14.5 & $(2.6)$ & 22.4 & (2.5) & 25.1 & $(2.4)$ & 17.2 & $(2.3)$ & 8.9 & (1.5) & 3.3 & $(0.8)$ \\
\hline & Veneto & 6.5 & $(1.2)$ & 10.5 & $(2.0)$ & 17.0 & $(2.1)$ & 20.3 & (2.9) & 20.2 & (1.7) & 16.7 & $(2.4)$ & 8.7 & (1.8) \\
\hline & Mexico & & & & & & & & & & & & & & \\
\hline & Aguascalientes & 16.7 & $(3.4)$ & 25.7 & $(2.7)$ & 27.0 & (3.1) & 19.3 & (2.8) & 8.2 & (1.6) & 2.8 & (1.0) & 0.4 & $(0.3)$ \\
\hline & Baja California & 24.4 & $(3.7)$ & 29.8 & $(3.0)$ & 24.4 & (3.2) & 14.5 & (2.5) & 5.8 & (1.3) & 1.0 & $(0.4)$ & 0.2 & $\mathrm{C}$ \\
\hline & Baja California Sur & 21.4 & (3.1) & 29.3 & $(2.6)$ & 25.2 & $(2.2)$ & 16.0 & $(2.9)$ & 7.1 & (1.5) & 0.9 & $(0.7)$ & 0.1 & c \\
\hline & Campeche & 30.5 & $(2.5)$ & 32.1 & $(2.4)$ & 23.4 & $(2.1)$ & 9.5 & $(2.4)$ & 3.4 & (0.9) & 1.0 & $(0.6)$ & 0.1 & C \\
\hline & Chiapas & 42.1 & $(4.9)$ & 29.0 & $(2.9)$ & 18.9 & (3.0) & 7.3 & $(1.8)$ & 1.9 & $(0.6)$ & 0.6 & $(0.5)$ & 0.1 & C \\
\hline & Chihuahua & 18.0 & $(3.7)$ & 26.6 & $(2.9)$ & 27.3 & (3.2) & 15.8 & $(2.5)$ & 9.3 & (2.2) & 2.8 & $(1.1)$ & 0.2 & C \\
\hline & Coahuila & 21.4 & $(3.7)$ & 28.5 & $(4.3)$ & 25.9 & (3.1) & 15.6 & $(2.5)$ & 6.9 & (2.3) & 1.7 & $(1.0)$ & 0.0 & C \\
\hline & Colima & 21.4 & $(2.3)$ & 24.5 & (1.9) & 26.2 & (2.6) & 17.1 & $(2.7)$ & 7.3 & (1.5) & 3.1 & $(1.1)$ & 0.5 & $(0.3)$ \\
\hline & Distrito Federal & 17.5 & (2.4) & 26.6 & $(2.9)$ & 27.4 & $(2.1)$ & 19.1 & (3.3) & 7.2 & $(2.0)$ & 1.9 & $(1.1)$ & 0.3 & $(0.3)$ \\
\hline & Durango & 24.2 & $(4.3)$ & 25.3 & $(4.1)$ & 24.6 & (2.9) & 18.2 & $(3.2)$ & 5.7 & (2.3) & 1.8 & $(1.1)$ & 0.3 & $(0.2)$ \\
\hline & Guanajuato & 25.5 & $(3.2)$ & 27.0 & $(2.8)$ & 25.1 & (2.3) & 14.3 & $(2.0)$ & 6.3 & (1.6) & 1.8 & $(0.9)$ & 0.0 & C \\
\hline & Guerrero & 49.2 & $(3.5)$ & 27.6 & (3.5) & 17.2 & (2.9) & 4.5 & $(1.1)$ & 1.2 & $(0.6)$ & 0.3 & $\mathrm{C}$ & 0.0 & C \\
\hline & Hidalgo & 27.3 & $(3.6)$ & 27.0 & $(4.0)$ & 22.4 & (3.2) & 15.9 & $(2.6)$ & 5.7 & (1.3) & 1.5 & $(0.8)$ & 0.1 & C \\
\hline & Jalisco & 17.5 & (3.3) & 21.7 & (3.1) & 27.6 & (3.1) & 21.0 & (3.4) & 8.6 & (1.5) & 3.2 & $(1.2)$ & 0.4 & $(0.3)$ \\
\hline & Mexico & 19.4 & $(2.7)$ & 27.5 & $(3.3)$ & 28.9 & (3.1) & 15.5 & $(2.5)$ & 6.7 & (1.6) & 1.5 & $(0.8)$ & 0.5 & (0.5) \\
\hline & Morelos & 25.0 & $(4.2)$ & 27.6 & $(3.6)$ & 22.5 & (3.0) & 14.4 & $(2.7)$ & 6.4 & (1.8) & 3.1 & $(1.4)$ & 1.0 & $(0.8)$ \\
\hline & Nayarit & 24.5 & $(3.0)$ & 27.3 & $(2.6)$ & 24.6 & (2.4) & 15.1 & $(1.7)$ & 6.4 & $(2.1)$ & 1.9 & $(0.7)$ & 0.2 & C \\
\hline & Nuevo León & 17.0 & $(3.3)$ & 23.1 & $(3.5)$ & 28.0 & $(2.2)$ & 19.6 & $(3.7)$ & 8.9 & (1.7) & 3.0 & $(1.0)$ & 0.4 & $(0.3)$ \\
\hline & Puebla & 20.3 & $(3.3)$ & 24.7 & $(2.4)$ & 26.6 & (3.7) & 18.7 & $(3.1)$ & 7.6 & (1.9) & 1.8 & $(1.0)$ & 0.2 & $\mathrm{C}$ \\
\hline & Querétaro & 16.0 & $(4.1)$ & 24.0 & $(4.3)$ & 24.9 & (2.9) & 21.1 & $(3.3)$ & 10.4 & (2.4) & 2.7 & $(0.9)$ & 0.9 & $(0.6)$ \\
\hline & Quintana Roo & 21.1 & $(3.2)$ & 29.5 & $(3.1)$ & 26.8 & (2.4) & 15.6 & $(2.4)$ & 5.3 & (1.3) & 1.6 & $(0.6)$ & 0.1 & c \\
\hline & San Luis Potosí & 27.8 & $(3.6)$ & 26.9 & $(2.5)$ & 24.8 & $(2.7)$ & 14.5 & $(2.5)$ & 4.3 & (1.6) & 1.4 & $(0.9)$ & 0.4 & $(0.3)$ \\
\hline & Sinaloa & 24.8 & $(2.6)$ & 30.1 & $(2.6)$ & 26.3 & (2.6) & 12.7 & (1.7) & 4.9 & (1.1) & 1.0 & $(0.9)$ & 0.2 & $\mathrm{C}$ \\
\hline & Tabasco & 37.9 & (2.9) & 31.3 & $(2.7)$ & 19.8 & (2.4) & 8.7 & (1.4) & 2.0 & $(0.7)$ & 0.2 & $(0.2)$ & 0.1 & c \\
\hline & Tamaulipas & 22.3 & $(4.4)$ & 25.4 & $(2.7)$ & 27.0 & (3.6) & 16.5 & $(2.9)$ & 6.8 & (2.4) & 1.7 & $(1.2)$ & 0.3 & C \\
\hline & Tlaxcala & 24.5 & $(2.7)$ & 28.6 & $(2.7)$ & 27.1 & (3.4) & 14.4 & $(2.5)$ & 4.4 & (1.1) & 0.7 & $(0.6)$ & 0.2 & $(0.2)$ \\
\hline & Veracruz & 27.5 & $(3.6)$ & 27.7 & (3.5) & 25.4 & (2.9) & 13.0 & (2.3) & 5.2 & (1.5) & 1.1 & $(0.7)$ & 0.0 & C \\
\hline & Yucatán & 25.4 & (3.8) & 28.0 & $(3.1)$ & 24.4 & $(2.9)$ & 14.0 & $(2.1)$ & 6.8 & (1.3) & 1.3 & $(0.6)$ & 0.1 & c \\
\hline & Zacatecas & 24.3 & (3.1) & 28.8 & $(2.8)$ & 24.8 & (3.8) & 16.5 & $(2.4)$ & 4.6 & (1.1) & 0.9 & $(0.4)$ & 0.0 & C \\
\hline
\end{tabular}

- PISA adjudicated region.

Note: See Table 1.2.6 for national data.

StatLink त्ञात्रा http://dx.doi.org/10.1787/888932935762 
Percentage of students at each proficiency level on the mathematics subscale formulating, by gender Table B2.I.5 and region

\begin{tabular}{|c|c|c|c|c|c|c|c|c|c|c|c|c|c|c|c|}
\hline & & \multicolumn{14}{|c|}{ Boys } \\
\hline & & \multicolumn{2}{|c|}{$\begin{array}{l}\text { Below Level } 1 \\
\text { (below } 357.77 \\
\text { score points) }\end{array}$} & \multicolumn{2}{|c|}{$\begin{array}{c}\text { Level } 1 \\
\text { (from } 357.77 \text { to } \\
\text { less than } 420.07 \\
\text { score points) }\end{array}$} & \multicolumn{2}{|c|}{$\begin{array}{c}\text { Level } 2 \\
\text { (from } 420.07 \text { to } \\
\text { less than } 482.38 \\
\text { score points) }\end{array}$} & $\begin{array}{r}\mathrm{L} \\
\text { (from } \\
\text { less th } \\
\text { scor }\end{array}$ & \begin{tabular}{|l|}
3 \\
2.38 to \\
544.68 \\
oints)
\end{tabular} & $\begin{array}{l}\text { L } \\
\text { (from } \\
\text { less th } \\
\text { scor }\end{array}$ & $\begin{array}{l}4 \\
4.68 \text { to } \\
606.99 \\
\text { oints) }\end{array}$ & $\begin{array}{r}\mathrm{L} \\
\text { (from } \\
\text { less th } \\
\text { scor }\end{array}$ & $\begin{array}{l}5 \\
6.99 \text { to } \\
669.30 \\
\text { oints) }\end{array}$ & $\begin{array}{l}\text { Lc } \\
\text { (abov } \\
\text { scor }\end{array}$ & $\begin{array}{l}16 \\
669.30 \\
\text { oints) }\end{array}$ \\
\hline & & $\%$ & S.E. & $\%$ & S.E. & $\%$ & S.E. & $\%$ & S.E. & $\%$ & S.E. & $\%$ & S.E. & $\%$ & S.E. \\
\hline 0 & Portugal & & & & & & & & & & & & & & \\
\hline ن & Alentejo & 9.0 & (3.0) & 14.9 & $(4.1)$ & 23.9 & $(4.0)$ & 23.7 & $(4.3)$ & 13.6 & $(2.5)$ & 8.9 & (2.3) & 5.9 & (2.6) \\
\hline & Spain & & & & & & & & & & & & & & \\
\hline & Andalusia ${ }^{\bullet}$ & 12.0 & (1.9) & 18.3 & $(2.0)$ & 24.1 & $(1.8)$ & 21.9 & $(2.1)$ & 14.9 & (1.6) & 6.4 & (1.3) & 2.4 & $(0.7)$ \\
\hline & Aragon ${ }^{\bullet}$ & 8.2 & (1.4) & 13.4 & $(1.7)$ & 19.3 & $(2.0)$ & 21.8 & (1.8) & 20.3 & (1.8) & 11.7 & (1.5) & 5.2 & $(0.9)$ \\
\hline & Asturias ${ }^{\bullet}$ & 9.9 & (1.8) & 12.0 & (1.7) & 20.9 & $(2.1)$ & 21.5 & $(2.2)$ & 18.8 & $(1.7)$ & 11.7 & (1.4) & 5.2 & (1.4) \\
\hline & Balearic Islands ${ }^{\bullet}$ & 13.5 & (1.9) & 16.6 & (1.5) & 21.9 & $(1.7)$ & 23.8 & (2.6) & 15.4 & (1.8) & 6.7 & (1.3) & 2.0 & $(0.6)$ \\
\hline & Basque Country ${ }^{\bullet}$ & 5.6 & $(0.8)$ & 10.8 & $(1.0)$ & 18.9 & $(1.3)$ & 25.0 & (1.4) & 22.6 & $(1.0)$ & 12.5 & (1.1) & 4.6 & $(0.8)$ \\
\hline & Cantabria ${ }^{\bullet}$ & 10.9 & (1.4) & 14.7 & (1.7) & 19.4 & $(2.0)$ & 20.5 & (2.0) & 19.1 & (1.8) & 10.8 & (1.6) & 4.5 & $(1.2)$ \\
\hline & Castile and Leon & 7.1 & (1.5) & 11.9 & (1.6) & 17.7 & $(1.8)$ & 21.8 & (1.9) & 22.4 & (1.8) & 14.0 & $(1.8)$ & 5.1 & $(1.2)$ \\
\hline & Catalonia ${ }^{\bullet}$ & 9.1 & $(1.7)$ & 14.7 & (2.4) & 20.4 & $(2.0)$ & 22.0 & (1.6) & 17.6 & $(1.7)$ & 11.9 & (1.6) & 4.2 & $(1.2)$ \\
\hline & Extremadura ${ }^{\bullet}$ & 17.3 & (2.3) & 18.8 & (1.9) & 21.7 & $(2.1)$ & 20.7 & $(1.7)$ & 13.6 & $(1.7)$ & 5.6 & (1.1) & 2.3 & $(0.6)$ \\
\hline & Galicia` & 12.2 & $(1.7)$ & 14.6 & (1.8) & 22.0 & $(2.2)$ & 24.9 & (2.4) & 16.9 & $(2.0)$ & 7.3 & (1.4) & 2.1 & $(0.7)$ \\
\hline & La Rioja・ & 10.4 & $(1.2)$ & 11.7 & (1.9) & 17.9 & $(2.1)$ & 17.7 & (2.1) & 17.0 & $(2.1)$ & 16.5 & (2.1) & 8.8 & $(1.2)$ \\
\hline & Madrid` & 8.5 & (1.3) & 12.5 & (1.7) & 18.6 & (1.9) & 22.9 & (1.9) & 21.0 & $(2.2)$ & 11.2 & (1.1) & 5.2 & (1.1) \\
\hline & Murcia ${ }^{\bullet}$ & 17.2 & $(2.2)$ & 18.4 & (2.0) & 22.4 & (1.6) & 19.4 & (1.6) & 13.8 & (1.4) & 6.0 & $(1.2)$ & 2.9 & (1.2) \\
\hline & Navarre ${ }^{\bullet}$ & 4.8 & (1.0) & 10.1 & (1.6) & 17.1 & (1.6) & 24.9 & (2.1) & 23.8 & $(2.3)$ & 13.9 & (1.7) & 5.5 & (1.1) \\
\hline & United Kingdom & & & & & & & & & & & & & & \\
\hline & England & 9.3 & $(1.7)$ & 14.7 & (1.4) & 21.2 & (1.4) & 22.2 & $(1.2)$ & 16.7 & (1.4) & 10.9 & $(1.2)$ & 5.0 & $(0.8)$ \\
\hline & Northern Ireland & 10.9 & (1.4) & 15.7 & (1.7) & 21.9 & $(1.6)$ & 24.2 & $(1.7)$ & 16.0 & (1.4) & 7.7 & $(1.0)$ & 3.5 & $(0.8)$ \\
\hline & Scotland ${ }^{\bullet}$ & 7.3 & (0.9) & 14.3 & (1.3) & 22.3 & $(1.2)$ & 24.1 & $(1.2)$ & 18.4 & $(1.5)$ & 9.3 & (1.1) & 4.4 & $(0.7)$ \\
\hline & Wales & 13.4 & (1.3) & 19.1 & $(1.2)$ & 26.2 & (1.6) & 21.9 & $(1.2)$ & 13.0 & $(1.1)$ & 5.1 & $(0.6)$ & 1.4 & $(0.3)$ \\
\hline & United States & & & & & & & & & & & & & & \\
\hline & Connecticut ${ }^{\bullet}$ & 8.3 & (1.6) & 13.6 & (1.9) & 18.2 & $(1.5)$ & 20.7 & (1.9) & 17.4 & $(2.1)$ & 13.2 & (2.0) & 8.6 & (1.4) \\
\hline & Florida ${ }^{\bullet}$ & 12.9 & $(2.1)$ & 19.1 & (2.4) & 24.8 & (2.9) & 22.6 & $(2.1)$ & 13.1 & $(2.3)$ & 6.0 & $(0.9)$ & 1.7 & $(0.5)$ \\
\hline & Massachusetts ${ }^{\bullet}$ & 7.2 & (1.1) & 10.8 & (1.3) & 19.4 & $(2.3)$ & 21.4 & (2.1) & 18.9 & (1.7) & 12.6 & (2.0) & 9.7 & (2.3) \\
\hline$\frac{2}{2}$ & Argentina & & & & & & & & & & & & & & \\
\hline 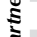 & Ciudad Autónoma de Buenos Aires ${ }^{\bullet}$ & 25.6 & $(2.9)$ & 21.3 & (2.4) & 25.3 & $(2.5)$ & 18.3 & $(2.4)$ & 7.3 & $(1.7)$ & 2.0 & $(0.9)$ & 0.2 & $(0.2)$ \\
\hline$\approx$ & Brazil & & & & & & & & & & & & & & \\
\hline & Acre & 54.0 & $(5.9)$ & 28.5 & $(4.2)$ & 12.7 & $(3.4)$ & 3.5 & (1.5) & 1.0 & $(0.9)$ & 0.2 & c & 0.0 & c \\
\hline & Alagoas & 51.6 & $(6.1)$ & 28.9 & $(5.0)$ & 14.0 & $(4.0)$ & 4.4 & (1.8) & 0.6 & $(0.6)$ & 0.4 & c & 0.0 & c \\
\hline & Amapá & 47.7 & $(5.3)$ & 29.9 & (3.3) & 15.9 & $(4.1)$ & 5.8 & (2.6) & 0.6 & $\mathrm{C}$ & 0.0 & c & 0.0 & c \\
\hline & Amazonas & 50.8 & (4.9) & 30.1 & (4.4) & 13.8 & $(2.9)$ & 4.4 & (1.9) & 1.0 & $(0.9)$ & 0.0 & C & 0.0 & c \\
\hline & Bahia & 51.5 & (5.7) & 27.5 & (4.5) & 12.9 & $(3.1)$ & 4.2 & (2.3) & 2.5 & $(1.5)$ & 1.3 & (1.5) & 0.0 & c \\
\hline & Ceará & 40.6 & (5.6) & 29.8 & (4.3) & 17.2 & $(2.7)$ & 6.7 & (2.9) & 4.2 & $(2.0)$ & 1.3 & $(0.9)$ & 0.2 & c \\
\hline & Espírito Santo & 30.7 & $(4.8)$ & 26.3 & (3.6) & 19.3 & $(3.3)$ & 12.7 & (2.8) & 7.8 & $(2.9)$ & 2.8 & (1.5) & 0.5 & $\mathrm{C}$ \\
\hline & Federal District & 30.9 & (5.6) & 24.5 & $(4.5)$ & 19.6 & $(3.6)$ & 14.5 & $(2.8)$ & 7.2 & $(2.3)$ & 2.5 & (1.5) & 0.8 & $(0.8)$ \\
\hline & Goiás & 43.9 & (5.4) & 28.2 & (4.4) & 15.1 & (3.4) & 8.3 & (1.9) & 3.2 & (1.5) & 1.0 & $(0.7)$ & 0.2 & c \\
\hline & Maranhão & 64.6 & (8.0) & 19.2 & (3.7) & 10.8 & $(4.1)$ & 3.6 & (2.8) & 1.0 & $(1.0)$ & 0.9 & $(0.7)$ & 0.0 & c \\
\hline & Mato Grosso & 48.2 & (5.5) & 27.7 & (3.8) & 15.0 & $(2.7)$ & 6.4 & $(2.1)$ & 2.2 & $(1.4)$ & 0.4 & $\mathrm{c}$ & 0.0 & c \\
\hline & Mato Grosso do Sul & 24.7 & (3.4) & 28.1 & (3.9) & 26.3 & (3.7) & 13.5 & (3.3) & 6.5 & (2.5) & 0.8 & $(0.5)$ & 0.1 & c \\
\hline & Minas Gerais & 30.0 & (4.8) & 29.2 & (4.1) & 24.4 & $(2.7)$ & 11.8 & (2.9) & 3.3 & $(1.7)$ & 1.0 & $(0.7)$ & 0.3 & $\mathrm{c}$ \\
\hline & Pará & 49.0 & (5.0) & 28.7 & (4.4) & 17.2 & $(2.5)$ & 4.2 & (1.6) & 1.0 & $(0.9)$ & 0.0 & c & 0.0 & c \\
\hline & Paraíba & 35.8 & (5.5) & 29.1 & $(5.5)$ & 20.2 & $(4.2)$ & 8.2 & $(2.7)$ & 4.3 & $(2.5)$ & 2.2 & $(1.2)$ & 0.2 & c \\
\hline & Paraná & 29.5 & $(3.2)$ & 32.2 & (3.5) & 21.2 & $(3.4)$ & 7.8 & $(2.0)$ & 6.4 & $(3.4)$ & 2.7 & (2.6) & 0.3 & c \\
\hline & Pernambuco & 44.5 & (5.3) & 33.0 & (4.8) & 15.9 & $(4.1)$ & 4.9 & $(2.2)$ & 1.1 & $(1.1)$ & 0.5 & $(0.5)$ & 0.2 & $\mathrm{c}$ \\
\hline & Piauí & 43.7 & (4.4) & 27.0 & (3.9) & 14.2 & $(4.0)$ & 8.6 & (2.5) & 4.2 & $(2.7)$ & 1.4 & (1.4) & 0.8 & $(0.5)$ \\
\hline & Rio de Janeiro & 38.5 & $(4.2)$ & 31.2 & (3.3) & 20.1 & $(3.2)$ & 7.1 & $(2.3)$ & 2.7 & $(1.1)$ & 0.4 & $(0.4)$ & 0.0 & $\mathrm{C}$ \\
\hline & Rio Grande do Norte & 42.2 & (5.9) & 25.0 & $(4.4)$ & 16.8 & $(3.1)$ & 8.1 & (2.9) & 4.7 & $(2.2)$ & 2.1 & (1.6) & 1.1 & $(1.3)$ \\
\hline & Rio Grande do Sul & 26.9 & (4.6) & 30.1 & (4.4) & 24.8 & $(3.9)$ & 14.3 & (2.4) & 2.8 & $(1.0)$ & 0.9 & $(0.6)$ & 0.2 & $\mathrm{C}$ \\
\hline & Rondônia & 40.9 & (3.8) & 33.7 & (5.4) & 18.1 & $(4.1)$ & 5.1 & (2.0) & 1.7 & $(1.1)$ & 0.5 & $\mathrm{C}$ & 0.0 & c \\
\hline & Roraima & 50.1 & $(4.2)$ & 28.3 & (3.9) & 15.6 & $(2.8)$ & 4.5 & (2.5) & 1.3 & $(1.1)$ & 0.2 & C & 0.0 & c \\
\hline & Santa Catarina & 25.0 & (3.9) & 30.3 & (4.0) & 22.5 & $(3.0)$ & 16.7 & (3.3) & 4.7 & (1.5) & 0.9 & $(0.7)$ & 0.0 & C \\
\hline & São Paulo & 32.3 & (2.5) & 29.5 & (2.3) & 21.8 & $(1.7)$ & 10.1 & (1.8) & 4.6 & $(1.2)$ & 1.3 & $(0.6)$ & 0.4 & $(0.3)$ \\
\hline & Sergipe & 38.4 & (6.0) & 28.6 & $(4.2)$ & 21.3 & (3.8) & 9.4 & (2.8) & 1.9 & $(1.4)$ & 0.5 & $\mathrm{C}$ & 0.0 & $\mathrm{C}$ \\
\hline & Tocantins & 51.7 & (5.3) & 25.1 & (3.3) & 13.9 & $(2.8)$ & 6.3 & (2.5) & 1.9 & $(1.1)$ & 0.6 & $\mathrm{C}$ & 0.5 & $(0.4)$ \\
\hline & Colombia & & & & & & & & & & & & & & \\
\hline & Bogotá & 26.3 & (3.0) & 33.2 & (2.6) & 25.3 & $(2.0)$ & 12.2 & (1.9) & 2.4 & $(0.8)$ & 0.5 & $(0.4)$ & 0.2 & $(0.2)$ \\
\hline & Cali & 40.6 & (3.6) & 29.9 & (2.5) & 19.8 & $(3.3)$ & 7.3 & $(2.1)$ & 2.3 & $(1.0)$ & 0.1 & C & 0.0 & C \\
\hline & Manizales & 23.0 & (3.1) & 29.5 & (3.2) & 26.4 & (2.9) & 13.6 & (1.9) & 5.8 & (1.6) & 1.6 & $(1.2)$ & 0.1 & $\mathrm{c}$ \\
\hline & Medellín & 28.4 & (3.7) & 30.6 & (3.1) & 22.4 & $(3.1)$ & 10.7 & (2.0) & 5.1 & (1.5) & 1.9 & (1.1) & 0.9 & $(0.6)$ \\
\hline & Russian Federation & & & & & & & & & & & & & & \\
\hline & Perm Territory region ${ }^{\bullet}$ & 8.9 & $(2.0)$ & 14.0 & (2.0) & 23.4 & $(2.4)$ & 24.9 & $(2.2)$ & 15.7 & (1.8) & 8.0 & $(1.3)$ & 5.0 & (1.9) \\
\hline & United Arab Emirates & & & & & & & & & & & & & & \\
\hline & Abu Dhabi & 32.4 & $(2.1)$ & 25.0 & (1.5) & 19.8 & $(1.5)$ & 12.2 & (1.4) & 6.6 & $(1.0)$ & 3.0 & $(0.7)$ & 1.0 & $(0.4)$ \\
\hline & Ajman & 33.1 & $(8.7)$ & 25.2 & $(5.1)$ & 22.0 & $(4.2)$ & 14.8 & $(2.8)$ & 4.3 & $(1.7)$ & 0.6 & $\mathrm{C}$ & 0.0 & $\mathrm{C}$ \\
\hline & Dubai ${ }^{\bullet}$ & 18.3 & (1.0) & 18.8 & (1.0) & 21.2 & $(1.1)$ & 19.1 & (1.1) & 13.5 & $(1.0)$ & 6.0 & $(0.7)$ & 3.0 & $(0.6)$ \\
\hline & Fujairah & 38.0 & (5.1) & 25.4 & (3.5) & 19.7 & $(4.0)$ & 10.9 & (2.4) & 5.3 & $(1.4)$ & 0.6 & $(0.3)$ & 0.1 & c \\
\hline & Ras al-Khaimah & 31.6 & (4.6) & 26.9 & (3.0) & 23.2 & (3.8) & 12.8 & $(2.8)$ & 4.6 & $(1.6)$ & 0.7 & $(0.5)$ & 0.3 & $(0.3)$ \\
\hline & Sharjah & 20.8 & $(4.5)$ & 23.0 & (3.1) & 23.6 & $(3.5)$ & 19.4 & (3.3) & 8.9 & $(3.0)$ & 3.3 & (1.9) & 1.1 & (1.1) \\
\hline & Umm al-Quwain & 38.9 & $(4.7)$ & 30.7 & $(5.1)$ & 18.9 & $(4.8)$ & 7.9 & $(2.4)$ & 2.4 & $(1.5)$ & 1.1 & $\mathrm{C}$ & 0.0 & $\mathrm{C}$ \\
\hline
\end{tabular}

- PISA adjudicated region.

Note: See Table I.2.6 for national data.

StatLink 解级 http://dx.doi.org/10.1787/888932935762 
(P/4]

Percentage of students at each proficiency level on the mathematics subscale formulating, by gender Table B2.I.5 and region

\begin{tabular}{|c|c|c|c|c|c|c|c|c|c|c|c|c|c|c|c|}
\hline & & \multicolumn{14}{|c|}{ Girls } \\
\hline & & \multicolumn{2}{|c|}{$\begin{array}{c}\text { Below Level } 1 \\
\text { (below } 357.77 \\
\text { score points) }\end{array}$} & $\begin{array}{l}\mathrm{L} \\
\text { (from } \\
\text { less th } \\
\text { scor }\end{array}$ & $\begin{array}{l}l 1 \\
7.77 \text { to } \\
420.07 \\
\text { oints) }\end{array}$ & $\begin{array}{r}\mathrm{L} \\
\text { (from } \\
\text { less th } \\
\text { scor }\end{array}$ & $\begin{array}{l}l 2 \\
0.07 \text { to } \\
482.38 \\
\text { oints) }\end{array}$ & $\begin{array}{l}\text { Le } \\
\text { (from } \\
\text { less th } \\
\text { scor }\end{array}$ & \begin{tabular}{|l|}
3 \\
2.38 to \\
544.68 \\
oints)
\end{tabular} & $\begin{array}{l}\mathrm{L} \\
\text { (from } \\
\text { less th } \\
\text { scor }\end{array}$ & $\begin{array}{l}l 4 \\
4.68 \text { to } \\
606.99 \\
\text { oints) }\end{array}$ & $\begin{array}{l}\mathrm{L} \\
\text { (from } \\
\text { less th } \\
\text { scor }\end{array}$ & \begin{tabular}{|l|}
5 \\
6.99 to \\
669.30 \\
oints)
\end{tabular} & $\begin{array}{r}\mathrm{L} \\
\text { (abo } \\
\text { scor }\end{array}$ & $\begin{array}{l}16 \\
669.30 \\
\text { oints) }\end{array}$ \\
\hline & & $\%$ & S.E. & $\%$ & S.E. & $\%$ & S.E. & $\%$ & S.E. & $\%$ & S.E. & $\%$ & S.E. & $\%$ & S.E. \\
\hline 0 & Australia & & & & & & & & & & & & & & \\
\hline $\bar{U}$ & Australian Capital Territory & 8.3 & (1.6) & 13.5 & $(2.9)$ & 17.2 & (3.2) & 20.9 & (2.5) & 20.1 & (3.2) & 13.0 & $(2.7)$ & 6.9 & (1.8) \\
\hline & New South Wales & 10.9 & (1.1) & 15.2 & (1.2) & 19.4 & (1.5) & 21.7 & (1.2) & 16.0 & (1.5) & 10.1 & (1.0) & 6.7 & (1.2) \\
\hline & Northern Territory & 20.4 & (3.3) & 17.8 & $(4.8)$ & 23.3 & (5.3) & 23.1 & $(5.0)$ & 9.3 & (3.4) & 5.2 & (3.7) & 1.0 & c \\
\hline & Queensland & 10.7 & (1.4) & 16.0 & (1.3) & 21.1 & (1.7) & 20.7 & (1.6) & 16.2 & (1.3) & 10.1 & $(1.0)$ & 5.2 & $(0.8)$ \\
\hline & South Australia & 13.1 & (1.8) & 20.0 & $(2.0)$ & 22.8 & $(2.1)$ & 20.7 & (1.9) & 13.4 & (1.6) & 7.1 & $(1.1)$ & 2.8 & $(0.8)$ \\
\hline & Tasmania & 14.5 & (1.8) & 20.3 & $(2.1)$ & 23.0 & $(2.4)$ & 20.4 & $(3.0)$ & 13.2 & (1.9) & 6.4 & (1.6) & 2.2 & $(1.0)$ \\
\hline & Victoria & 10.6 & $(1.2)$ & 16.5 & (1.5) & 23.2 & (1.6) & 22.3 & (1.9) & 15.7 & (1.4) & 8.6 & (1.4) & 3.1 & $(0.9)$ \\
\hline & Western Australia & 10.3 & (1.4) & 14.5 & (1.7) & 21.5 & $(2.0)$ & 21.2 & (1.7) & 18.6 & (1.9) & 9.6 & $(1.1)$ & 4.3 & (1.1) \\
\hline & Belgium & & & & & & & & & & & & & & \\
\hline & Flemish Community• & 6.5 & $(0.7)$ & 11.0 & $(1.0)$ & 16.8 & $(1.2)$ & 21.7 & (1.5) & 20.4 & $(1.2)$ & 14.3 & (1.3) & 9.3 & $(0.9)$ \\
\hline & French Community & 11.9 & (1.3) & 16.8 & $(1.3)$ & 22.5 & (1.3) & 22.3 & (1.6) & 16.4 & (1.4) & 7.6 & $(0.8)$ & 2.5 & $(0.5)$ \\
\hline & German-speaking Community & 5.0 & (1.3) & 11.9 & $(1.7)$ & 20.1 & $(2.2)$ & 26.3 & $(3.0)$ & 23.2 & $(3.1)$ & 10.8 & $(2.1)$ & 2.8 & $(0.9)$ \\
\hline & Canada & & & & & & & & & & & & & & \\
\hline & Alberta & 7.1 & $(1.3)$ & 14.5 & $(1.8)$ & 20.2 & $(1.7)$ & 21.7 & $(2.0)$ & 20.7 & (1.8) & 10.9 & $(1.7)$ & 4.9 & (1.1) \\
\hline & British Columbia & 6.9 & (1.3) & 11.8 & (1.3) & 21.4 & (1.9) & 24.6 & (1.8) & 19.8 & (1.7) & 10.2 & (1.6) & 5.2 & $(1.2)$ \\
\hline & Manitoba & 9.8 & (1.6) & 18.1 & (1.8) & 23.3 & (1.9) & 22.4 & $(2.0)$ & 16.0 & (1.9) & 7.4 & $(1.2)$ & 3.0 & $(0.7)$ \\
\hline & New Brunswick & 5.1 & (1.0) & 13.3 & (1.6) & 22.6 & (3.0) & 27.5 & $(2.8)$ & 19.5 & (1.9) & 8.6 & (1.3) & 3.4 & (1.4) \\
\hline & Newfoundland and Labrador & 9.0 & $(2.2)$ & 17.7 & $(2.0)$ & 25.4 & (3.0) & 24.2 & $(3.2)$ & 14.4 & $(2.5)$ & 7.0 & (1.5) & 2.3 & $(0.9)$ \\
\hline & Nova Scotia & 7.5 & $(2.1)$ & 16.2 & $(4.3)$ & 25.3 & $(4.1)$ & 25.1 & (2.4) & 17.0 & (2.8) & 6.5 & (1.4) & 2.3 & $(0.9)$ \\
\hline & Ontario & 6.1 & $(0.8)$ & 11.6 & $(1.2)$ & 24.1 & (1.9) & 24.1 & (1.8) & 19.7 & $(1.5)$ & 10.0 & $(1.1)$ & 4.4 & $(0.7)$ \\
\hline & Prince Edward Island & 9.7 & (1.1) & 18.9 & (1.8) & 26.6 & (1.9) & 23.7 & $(2.5)$ & 14.5 & (1.6) & 4.5 & $(1.1)$ & 2.0 & $(0.6)$ \\
\hline & Quebec & 4.5 & $(0.7)$ & 9.1 & $(0.9)$ & 16.6 & (1.3) & 22.6 & $(1.5)$ & 23.2 & (1.6) & 15.6 & $(1.1)$ & 8.3 & (1.1) \\
\hline & Saskatchewan & 6.9 & (1.1) & 14.6 & (1.6) & 23.4 & $(2.2)$ & 25.4 & $(2.1)$ & 17.2 & $(2.0)$ & 9.5 & (1.5) & 3.0 & $(0.9)$ \\
\hline & Italy & & & & & & & & & & & & & & \\
\hline & Abruzzo & 17.1 & (2.5) & 18.5 & $(2.3)$ & 23.0 & $(2.3)$ & 22.4 & (2.4) & 12.1 & (1.6) & 5.4 & (1.4) & 1.5 & $(0.7)$ \\
\hline & Basilicata & 14.1 & (1.9) & 23.1 & $(2.4)$ & 28.8 & (2.9) & 20.5 & (1.7) & 10.3 & (1.5) & 2.5 & $(0.7)$ & 0.7 & $(0.4)$ \\
\hline & Bolzano & 6.4 & $(0.9)$ & 13.0 & (1.8) & 24.2 & (2.3) & 26.6 & (1.9) & 19.8 & (1.5) & 7.8 & $(1.2)$ & 2.1 & $(0.5)$ \\
\hline & Calabria & 28.0 & (3.0) & 27.7 & $(2.5)$ & 25.6 & $(2.2)$ & 13.3 & (1.5) & 4.1 & $(0.9)$ & 1.3 & $(0.6)$ & 0.1 & $\mathrm{C}$ \\
\hline & Campania & 20.7 & (3.4) & 22.4 & $(2.7)$ & 26.1 & (2.6) & 18.6 & (3.2) & 8.9 & (1.8) & 2.8 & (1.5) & 0.5 & $(0.4)$ \\
\hline & Emilia Romagna & 10.6 & $(1.8)$ & 17.6 & $(2.1)$ & 24.2 & (2.5) & 23.0 & $(2.2)$ & 15.9 & $(2.0)$ & 6.2 & $(1.5)$ & 2.6 & $(0.8)$ \\
\hline & Friuli Venezia Giulia & 5.8 & (1.9) & 11.9 & $(1.9)$ & 21.8 & (2.6) & 28.3 & $(2.7)$ & 20.0 & $(2.7)$ & 8.7 & $(1.8)$ & 3.4 & (1.2) \\
\hline & Lazio & 17.1 & $(2.2)$ & 22.4 & $(2.5)$ & 25.9 & $(2.9)$ & 19.5 & $(2.8)$ & 10.5 & (1.8) & 3.7 & $(1.2)$ & 1.0 & $(0.4)$ \\
\hline & Liguria & 11.7 & (1.9) & 17.6 & $(2.1)$ & 24.6 & $(2.3)$ & 24.9 & $(2.2)$ & 14.2 & $(2.2)$ & 5.0 & (1.3) & 2.1 & $(0.7)$ \\
\hline & Lombardia & 6.8 & (1.6) & 15.2 & $(2.7)$ & 25.5 & $(2.7)$ & 26.3 & $(2.7)$ & 17.5 & (2.8) & 6.6 & (1.7) & 2.0 & $(0.8)$ \\
\hline & Marche & 12.0 & $(2.2)$ & 18.8 & (1.9) & 24.9 & $(2.5)$ & 24.3 & $(2.1)$ & 13.9 & (1.9) & 4.7 & $(1.2)$ & 1.4 & $(0.6)$ \\
\hline & Molise & 16.3 & (2.2) & 24.0 & $(3.2)$ & 27.1 & (3.5) & 19.8 & $(3.3)$ & 8.5 & (1.7) & 3.1 & $(1.1)$ & 1.1 & $(0.7)$ \\
\hline & Piemonte & 13.3 & (1.8) & 18.5 & $(2.5)$ & 24.1 & (2.6) & 22.5 & $(2.4)$ & 12.5 & (1.9) & 6.8 & (1.5) & 2.3 & $(0.8)$ \\
\hline & Puglia & 15.6 & (2.9) & 21.4 & $(2.1)$ & 27.6 & (3.0) & 20.0 & $(2.6)$ & 10.6 & (1.7) & 3.7 & $(1.1)$ & 1.0 & $(0.4)$ \\
\hline & Sardegna & 19.4 & (2.9) & 23.3 & $(2.4)$ & 24.1 & (1.8) & 19.7 & $(2.1)$ & 10.1 & (1.6) & 3.2 & $(0.7)$ & 0.3 & $(0.3)$ \\
\hline & Sicilia & 16.7 & (2.2) & 25.4 & $(2.6)$ & 27.8 & (3.1) & 20.1 & $(2.3)$ & 8.5 & (1.3) & 1.2 & $(0.7)$ & 0.3 & $(0.3)$ \\
\hline & Toscana & 11.2 & (2.3) & 16.4 & $(3.0)$ & 21.1 & $(2.1)$ & 24.4 & $(2.5)$ & 16.2 & (2.4) & 8.5 & (1.6) & 2.3 & $(0.7)$ \\
\hline & Trento & 3.3 & (1.5) & 10.3 & $(2.4)$ & 21.8 & (2.9) & 28.3 & (2.8) & 23.8 & (3.4) & 10.1 & $(2.1)$ & 2.3 & $(0.7)$ \\
\hline & Umbria & 12.3 & $(2.7)$ & 16.8 & $(2.0)$ & 26.4 & $(2.6)$ & 23.6 & $(2.3)$ & 15.0 & (1.8) & 5.0 & (1.3) & 0.9 & $(0.5)$ \\
\hline & Valle d'Aosta & 11.1 & (1.9) & 19.4 & (3.4) & 28.3 & $(2.3)$ & 21.8 & (3.4) & 12.4 & (3.0) & 5.5 & (1.4) & 1.4 & $(0.8)$ \\
\hline & Veneto & 7.0 & (1.9) & 12.7 & $(2.2)$ & 24.2 & (2.9) & 23.8 & (2.6) & 19.4 & $(2.1)$ & 10.0 & (1.9) & 3.0 & $(1.2)$ \\
\hline & Mexico & & & & & & & & & & & & & & \\
\hline & Aguascalientes & 19.1 & (3.3) & 29.2 & (3.5) & 28.1 & $(2.7)$ & 17.0 & (2.4) & 5.4 & (1.1) & 1.1 & $(0.7)$ & 0.1 & C \\
\hline & Baja California & 33.9 & (3.7) & 28.2 & $(3.7)$ & 22.0 & (2.4) & 11.4 & (2.4) & 3.8 & $(1.1)$ & 0.8 & $(0.5)$ & 0.0 & C \\
\hline & Baja California Sur & 28.8 & (3.3) & 31.3 & $(2.6)$ & 23.7 & (3.1) & 12.7 & $(2.2)$ & 3.2 & (1.0) & 0.3 & $(0.3)$ & 0.0 & c \\
\hline & Campeche & 39.7 & (3.2) & 30.2 & $(2.6)$ & 19.0 & (2.4) & 8.5 & $(1.6)$ & 2.2 & (0.9) & 0.3 & $(0.3)$ & 0.1 & c \\
\hline & Chiapas & 47.0 & (4.8) & 25.7 & $(3.2)$ & 18.7 & (3.4) & 6.9 & (1.8) & 1.3 & $(0.7)$ & 0.3 & $(0.3)$ & 0.0 & C \\
\hline & Chihuahua & 23.7 & (3.5) & 26.1 & (3.8) & 25.9 & (3.3) & 16.2 & $(2.3)$ & 6.6 & (2.4) & 1.3 & $(0.7)$ & 0.3 & $(0.3)$ \\
\hline & Coahuila & 28.4 & $(4.7)$ & 29.3 & $(4.0)$ & 25.5 & (3.4) & 12.3 & (3.4) & 4.2 & (1.8) & 0.3 & $(0.4)$ & 0.0 & c \\
\hline & Colima & 25.9 & (2.8) & 25.4 & (2.5) & 25.7 & (3.1) & 15.6 & $(2.1)$ & 5.8 & (1.5) & 1.4 & $(0.6)$ & 0.3 & $(0.3)$ \\
\hline & Distrito Federal & 27.0 & (3.6) & 31.2 & (4.4) & 23.8 & (3.3) & 12.3 & (1.9) & 4.7 & (1.6) & 1.0 & $(0.8)$ & 0.0 & c \\
\hline & Durango & 28.5 & $(4.0)$ & 28.1 & $(4.3)$ & 24.2 & (3.1) & 13.7 & $(2.3)$ & 5.1 & (1.5) & 0.4 & $(0.3)$ & 0.0 & c \\
\hline & Guanajuato & 30.9 & (3.5) & 30.4 & $(2.4)$ & 24.4 & (2.3) & 10.5 & $(2.0)$ & 3.3 & (1.0) & 0.5 & $(0.4)$ & 0.0 & C \\
\hline & Guerrero & 55.2 & (3.3) & 25.6 & $(2.3)$ & 13.6 & (2.0) & 4.4 & $(1.1)$ & 0.9 & (0.5) & 0.2 & c & 0.0 & C \\
\hline & Hidalgo & 32.9 & (4.1) & 29.1 & $(2.7)$ & 22.5 & (3.3) & 11.9 & $(2.1)$ & 2.9 & (1.1) & 0.6 & $(0.5)$ & 0.0 & C \\
\hline & Jalisco & 20.1 & (3.3) & 28.8 & (2.9) & 28.3 & $(2.7)$ & 15.6 & $(2.3)$ & 5.4 & (1.5) & 1.6 & $(0.9)$ & 0.1 & C \\
\hline & Mexico & 27.3 & (3.3) & 29.8 & (3.4) & 26.3 & (3.2) & 12.8 & $(2.5)$ & 3.3 & $(1.2)$ & 0.5 & $(0.4)$ & 0.0 & C \\
\hline & Morelos & 28.5 & (3.3) & 28.9 & (3.4) & 23.4 & (2.4) & 12.0 & $(2.1)$ & 4.5 & (1.9) & 2.6 & $(2.0)$ & 0.1 & c \\
\hline & Nayarit & 34.1 & (4.1) & 29.6 & $(3.0)$ & 21.0 & (2.3) & 10.8 & (1.9) & 4.1 & (1.2) & 0.4 & $(0.5)$ & 0.0 & C \\
\hline & Nuevo León & 27.8 & (4.5) & 28.4 & $(2.4)$ & 21.8 & $(2.7)$ & 14.7 & $(2.2)$ & 5.3 & (1.4) & 1.7 & $(0.7)$ & 0.3 & C \\
\hline & Puebla & 28.6 & (2.8) & 31.8 & $(3.7)$ & 23.7 & (3.1) & 11.0 & (1.9) & 4.1 & (1.1) & 0.8 & $(0.6)$ & 0.0 & C \\
\hline & Querétaro & 23.9 & (3.4) & 29.7 & (2.9) & 23.7 & (2.6) & 14.9 & $(2.3)$ & 6.0 & (1.6) & 1.4 & $(0.7)$ & 0.3 & $(0.2)$ \\
\hline & Quintana Roo & 26.7 & (2.9) & 31.5 & (2.9) & 24.5 & (1.8) & 12.7 & $(1.8)$ & 4.0 & (1.1) & 0.5 & $(0.5)$ & 0.1 & C \\
\hline & San Luis Potosí & 32.7 & $(4.0)$ & 27.6 & $(3.1)$ & 23.2 & (2.5) & 12.1 & $(2.6)$ & 3.6 & (1.3) & 0.9 & $(0.6)$ & 0.0 & C \\
\hline & Sinaloa & 29.5 & (3.3) & 32.5 & $(2.5)$ & 23.7 & (2.4) & 10.4 & $(2.0)$ & 3.3 & $(0.8)$ & 0.6 & $(0.5)$ & 0.0 & C \\
\hline & Tabasco & 48.3 & (3.0) & 29.6 & $(2.7)$ & 15.6 & (2.0) & 4.5 & $(1.0)$ & 1.7 & $(0.5)$ & 0.4 & $(0.3)$ & 0.0 & C \\
\hline & Tamaulipas & 30.0 & (3.3) & 30.5 & $(2.6)$ & 24.3 & (3.0) & 10.8 & $(2.2)$ & 3.9 & (1.7) & 0.5 & $(0.4)$ & 0.0 & C \\
\hline & Tlaxcala & 29.8 & (3.7) & 29.3 & $(2.7)$ & 25.2 & $(2.1)$ & 11.2 & $(2.3)$ & 3.7 & $(1.2)$ & 0.7 & $(0.4)$ & 0.0 & C \\
\hline & Veracruz & 31.2 & (3.8) & 32.7 & $(2.4)$ & 22.3 & $(2.1)$ & 9.8 & $(2.1)$ & 3.5 & (1.2) & 0.6 & $(0.5)$ & 0.0 & C \\
\hline & Yucatán & 34.3 & (4.3) & 27.7 & (3.3) & 23.4 & (3.5) & 10.8 & $(1.6)$ & 3.2 & (1.1) & 0.4 & $(0.3)$ & 0.1 & C \\
\hline & Zacatecas & 31.4 & $(2.7)$ & 30.5 & (2.6) & 23.9 & (2.9) & 10.1 & (1.7) & 3.2 & $(1.2)$ & 0.8 & C & 0.0 & C \\
\hline
\end{tabular}

- PISA adjudicated region.

Note: See Table I.2.6 for national data.

StatLink त्ञात्रा http://dx.doi.org/10.1787/888932935762 
art 4/4]

Percentage of students at each proficiency level on the mathematics subscale formulating, by gender Table B2.I.5 and region

\begin{tabular}{|c|c|c|c|c|c|c|c|c|c|c|c|c|c|c|c|}
\hline & & \multicolumn{14}{|c|}{ Girls } \\
\hline & & \multicolumn{2}{|c|}{$\begin{array}{c}\text { Below Level } 1 \\
\text { (below } 357.77 \\
\text { score points) }\end{array}$} & \multicolumn{2}{|c|}{$\begin{array}{c}\text { Level } 1 \\
\text { (from } 357.77 \text { to } \\
\text { less than } 420.07 \\
\text { score points) }\end{array}$} & \multicolumn{2}{|c|}{$\begin{array}{c}\text { Level } 2 \\
\text { (from } 420.07 \text { to } \\
\text { less than } 482.38 \\
\text { score points) }\end{array}$} & $\begin{array}{r}\mathrm{L} \\
\text { (from } \\
\text { less th } \\
\text { scor }\end{array}$ & $\begin{array}{l}3 \\
2.38 \text { to } \\
544.68 \\
\text { oints) }\end{array}$ & $\begin{array}{r}\text { Le } \\
\text { (from } \\
\text { less th } \\
\text { score }\end{array}$ & $\begin{array}{l}4 \\
4.68 \text { to } \\
606.99 \\
\text { oints) }\end{array}$ & $\begin{array}{r}\mathrm{L} \\
\text { (from } \\
\text { less th } \\
\text { scor }\end{array}$ & \begin{tabular}{l|} 
I 5 \\
6.99 to \\
669.30 \\
oints)
\end{tabular} & $\begin{array}{l}\text { Lc } \\
\text { (abov } \\
\text { scor }\end{array}$ & $\begin{array}{l}6 \\
669.30 \\
\text { oints) }\end{array}$ \\
\hline & & $\%$ & S.E. & $\%$ & S.E. & $\%$ & S.E. & $\%$ & S.E. & $\%$ & S.E. & $\%$ & S.E. & $\%$ & S.E. \\
\hline 0 & Portugal & & & & & & & & & & & & & & \\
\hline 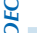 & Alentejo & 12.8 & (3.6) & 16.8 & (3.5) & 24.1 & (3.9) & 22.2 & $(4.6)$ & 14.9 & (3.4) & 7.5 & $(1.7)$ & 1.6 & (1.0) \\
\hline & Spain & & & & & & & & & & & & & & \\
\hline & Andalusia ${ }^{\bullet}$ & 14.0 & (1.4) & 22.7 & (1.9) & 26.8 & (2.5) & 19.7 & $(2.0)$ & 12.3 & (1.8) & 4.1 & $(1.0)$ & 0.4 & $(0.3)$ \\
\hline & Aragon ${ }^{\bullet}$ & 11.4 & (1.9) & 14.6 & (1.7) & 22.2 & $(2.7)$ & 24.0 & $(2.4)$ & 17.9 & $(2.0)$ & 7.3 & $(1.2)$ & 2.6 & $(0.8)$ \\
\hline & Asturias ${ }^{\bullet}$ & 9.7 & (1.4) & 14.6 & (1.8) & 21.8 & (1.7) & 25.4 & $(2.2)$ & 16.8 & (1.9) & 8.2 & $(1.2)$ & 3.5 & $(0.7)$ \\
\hline & Balearic Islands ${ }^{\bullet}$ & 14.5 & (1.9) & 18.4 & $(2.2)$ & 23.4 & $(2.3)$ & 22.2 & $(2.0)$ & 14.6 & $(2.1)$ & 5.5 & (1.1) & 1.3 & $(0.6)$ \\
\hline & Basque Country ${ }^{\bullet}$ & 6.8 & $(0.7)$ & 12.9 & (0.9) & 22.6 & $(1.2)$ & 26.2 & $(1.0)$ & 19.4 & (1.1) & 8.9 & $(0.9)$ & 3.1 & $(0.5)$ \\
\hline & Cantabria & 12.4 & (1.5) & 17.0 & (1.6) & 23.7 & $(2.2)$ & 23.4 & $(1.9)$ & 14.2 & (1.9) & 6.7 & $(1.0)$ & 2.8 & $(0.8)$ \\
\hline & Castile and Leon & 6.2 & (1.1) & 14.4 & (1.5) & 22.3 & $(1.8)$ & 26.7 & $(2.0)$ & 19.8 & $(1.7)$ & 8.5 & $(1.3)$ & 2.1 & $(0.8)$ \\
\hline & Catalonia ${ }^{\bullet}$ & 10.9 & (1.7) & 17.0 & (2.4) & 24.8 & $(2.7)$ & 23.9 & $(2.1)$ & 15.5 & $(2.0)$ & 6.2 & (1.6) & 1.7 & $(0.7)$ \\
\hline & Extremadura ${ }^{\bullet}$ & 18.7 & (1.6) & 20.4 & (2.3) & 24.6 & $(2.7)$ & 20.9 & $(2.1)$ & 10.6 & (1.6) & 4.1 & $(0.8)$ & 0.8 & $(0.4)$ \\
\hline & Galicia` & 9.8 & $(1.7)$ & 14.9 & (1.9) & 24.2 & (1.6) & 25.1 & $(2.0)$ & 16.5 & (1.8) & 7.1 & $(1.2)$ & 2.5 & $(0.6)$ \\
\hline & La Rioja・ & 10.2 & (1.4) & 15.0 & (2.1) & 19.8 & $(2.0)$ & 24.1 & (1.9) & 17.7 & (1.7) & 9.5 & (1.3) & 3.7 & $(0.9)$ \\
\hline & Madrid` & 10.1 & (1.7) & 16.0 & (1.6) & 22.5 & $(2.0)$ & 23.1 & $(2.1)$ & 18.0 & (1.6) & 8.1 & (1.6) & 2.1 & $(0.6)$ \\
\hline & Murcia ${ }^{\bullet}$ & 18.8 & (1.6) & 22.8 & (2.0) & 24.3 & $(2.4)$ & 20.1 & (1.8) & 9.9 & $(1.5)$ & 3.3 & (1.0) & 0.8 & $(0.4)$ \\
\hline & Navarre ${ }^{\bullet}$ & 4.8 & (1.0) & 11.0 & (1.5) & 20.0 & $(2.4)$ & 26.1 & $(2.3)$ & 21.8 & (1.8) & 12.1 & (1.6) & 4.2 & (1.0) \\
\hline & United Kingdom & & & & & & & & & & & & & & \\
\hline & England & 11.6 & (1.3) & 15.5 & (1.0) & 22.6 & (1.3) & 21.5 & $(1.1)$ & 16.1 & $(1.1)$ & 8.4 & (0.9) & 4.3 & $(0.8)$ \\
\hline & Northern Ireland & 11.9 & (1.6) & 18.6 & (2.0) & 23.3 & $(2.0)$ & 21.4 & (1.9) & 15.3 & $(1.5)$ & 6.7 & (1.4) & 2.7 & $(0.5)$ \\
\hline & Scotland ${ }^{\bullet}$ & 10.6 & $(1.2)$ & 16.6 & (1.5) & 24.3 & (1.6) & 23.2 & $(1.3)$ & 14.7 & $(1.2)$ & 7.3 & $(0.8)$ & 3.3 & $(0.6)$ \\
\hline & Wales & 15.0 & $(1.2)$ & 22.5 & (1.6) & 25.8 & $(1.7)$ & 21.2 & $(1.3)$ & 10.9 & $(1.0)$ & 3.5 & $(0.6)$ & 1.0 & $(0.3)$ \\
\hline & United States & & & & & & & & & & & & & & \\
\hline & Connecticut ${ }^{\bullet}$ & 10.9 & (1.6) & 15.5 & (1.9) & 19.8 & $(2.1)$ & 21.2 & $(2.2)$ & 16.8 & (1.8) & 9.9 & (1.6) & 5.9 & $(1.2)$ \\
\hline & Florida $\bullet^{\bullet}$ & 16.1 & $(2.2)$ & 23.1 & (2.0) & 26.0 & $(2.2)$ & 20.4 & $(2.6)$ & 9.9 & (1.4) & 3.9 & (1.3) & 0.6 & $(0.3)$ \\
\hline & Massachusetts & 8.7 & $(1.3)$ & 13.6 & (1.6) & 20.0 & $(2.1)$ & 22.7 & $(2.2)$ & 16.9 & $(2.3)$ & 11.6 & (1.6) & 6.5 & (1.7) \\
\hline$\stackrel{2}{2}$ & Argentina & & & & & & & & & & & & & & \\
\hline 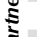 & Ciudad Autónoma de Buenos Aires ${ }^{\bullet}$ & 28.6 & (3.4) & 24.8 & (3.0) & 26.9 & $(2.7)$ & 14.1 & $(2.5)$ & 4.7 & $(1.0)$ & 0.8 & $(0.4)$ & 0.1 & c \\
\hline ¿ & Brazil & & & & & & & & & & & & & & \\
\hline & Acre & 69.8 & $(4.7)$ & 20.9 & $(3.2)$ & 8.1 & $(2.6)$ & 1.2 & $(0.8)$ & 0.1 & $(0.1)$ & 0.0 & c & 0.0 & C \\
\hline & Alagoas & 70.8 & $(5.0)$ & 18.3 & (3.9) & 7.9 & $(2.3)$ & 2.2 & $(1.3)$ & 0.9 & $(0.7)$ & 0.0 & c & 0.0 & c \\
\hline & Amapá & 67.9 & (5.6) & 23.4 & (5.3) & 6.9 & $(3.2)$ & 1.6 & $(1.3)$ & 0.1 & $\mathrm{C}$ & 0.0 & c & 0.0 & c \\
\hline & Amazonas & 67.2 & (3.9) & 23.4 & (3.9) & 7.1 & $(2.0)$ & 1.8 & $(0.8)$ & 0.6 & $(0.6)$ & 0.0 & C & 0.0 & c \\
\hline & Bahia & 61.8 & (6.6) & 22.2 & (4.3) & 10.5 & $(4.3)$ & 3.6 & $(1.5)$ & 1.5 & $(1.2)$ & 0.5 & C & 0.0 & c \\
\hline & Ceará & 57.5 & (5.5) & 24.7 & (3.4) & 11.7 & $(2.4)$ & 3.9 & $(1.5)$ & 1.9 & $(0.8)$ & 0.2 & $\mathrm{C}$ & 0.0 & c \\
\hline & Espírito Santo & 39.9 & (4.9) & 27.5 & $(4.2)$ & 15.6 & $(2.1)$ & 10.6 & $(3.6)$ & 4.9 & $(2.2)$ & 1.3 & $(0.9)$ & 0.2 & c \\
\hline & Federal District & 39.4 & (5.1) & 25.6 & (3.7) & 21.5 & $(4.0)$ & 10.0 & $(3.9)$ & 2.6 & $(1.4)$ & 0.8 & $\mathrm{C}$ & 0.0 & c \\
\hline & Goiás & 56.8 & (4.6) & 25.4 & (3.5) & 11.7 & $(2.4)$ & 4.8 & $(1.8)$ & 1.0 & $(0.6)$ & 0.2 & $\mathrm{C}$ & 0.0 & c \\
\hline & Maranhão & 80.4 & (5.4) & 14.7 & (3.5) & 3.6 & $(2.3)$ & 1.4 & $(0.8)$ & 0.0 & $\mathrm{C}$ & 0.0 & $\mathrm{C}$ & 0.0 & c \\
\hline & Mato Grosso & 57.1 & (5.8) & 23.2 & (3.3) & 13.1 & $(3.3)$ & 4.1 & $(2.6)$ & 1.8 & $(1.0)$ & 0.8 & $(0.7)$ & 0.0 & c \\
\hline & Mato Grosso do Sul & 43.6 & (4.3) & 27.7 & (3.4) & 16.6 & $(2.8)$ & 9.0 & $(2.4)$ & 2.9 & $(1.2)$ & 0.1 & $\mathrm{C}$ & 0.0 & c \\
\hline & Minas Gerais & 39.8 & (4.4) & 32.1 & $(2.8)$ & 20.1 & $(3.6)$ & 6.1 & $(1.6)$ & 1.6 & $(1.2)$ & 0.3 & $\mathrm{C}$ & 0 & c \\
\hline & Pará & 60.3 & $(4.5)$ & 24.7 & (3.4) & 13.3 & $(4.3)$ & 1.7 & $(1.5)$ & 0.0 & $\mathrm{C}$ & 0.0 & c & 0.0 & c \\
\hline & Paraíba & 43.8 & (5.5) & 28.1 & (3.8) & 19.6 & $(5.5)$ & 6.4 & $(1.8)$ & 1.8 & $(1.1)$ & 0.3 & $\mathrm{C}$ & 0.0 & c \\
\hline & Paraná & 45.5 & (5.4) & 27.7 & (2.9) & 16.9 & $(2.8)$ & 5.7 & $(2.0)$ & 2.5 & $(2.2)$ & 1.3 & (1.6) & 0.4 & c \\
\hline & Pernambuco & 60.6 & $(5.7)$ & 28.2 & $(4.7)$ & 8.2 & $(1.9)$ & 2.3 & $(1.2)$ & 0.5 & $(0.5)$ & 0.2 & $\mathrm{C}$ & 0.0 & c \\
\hline & Piauí & 55.0 & (3.8) & 24.6 & (3.5) & 10.3 & $(2.9)$ & 6.2 & $(1.8)$ & 2.4 & $(1.2)$ & 1.2 & $(0.7)$ & 0.3 & c \\
\hline & Rio de Janeiro & 50.3 & $(4.4)$ & 28.0 & $(4.1)$ & 15.4 & $(3.1)$ & 6.0 & $(1.8)$ & 0.3 & C & 0.0 & $\mathrm{C}$ & 0.0 & c \\
\hline & Rio Grande do Norte & 58.4 & $(5.0)$ & 21.1 & $(4.0)$ & 11.9 & $(2.5)$ & 5.2 & $(1.9)$ & 2.1 & $(1.5)$ & 1.3 & $(0.9)$ & 0.1 & c \\
\hline & Rio Grande do Sul & 35.1 & (4.3) & 30.5 & $(4.2)$ & 22.8 & (3.5) & 9.4 & $(2.5)$ & 2.0 & $(1.1)$ & 0.2 & $(0.2)$ & 0.0 & c \\
\hline & Rondônia & 48.5 & $(4.0)$ & 33.1 & (2.8) & 15.4 & $(2.8)$ & 2.9 & $(1.1)$ & 0.2 & C & 0.0 & C & 0.0 & c \\
\hline & Roraima & 59.4 & $(4.1)$ & 24.7 & (3.5) & 7.9 & $(2.5)$ & 6.5 & $(2.8)$ & 1.4 & $(1.0)$ & 0.0 & $\mathrm{C}$ & 0.0 & c \\
\hline & Santa Catarina & 34.6 & $(5.1)$ & 28.3 & $(3.2)$ & 23.7 & $(3.2)$ & 9.9 & $(2.9)$ & 3.0 & $(1.5)$ & 0.5 & $(0.6)$ & 0.0 & c \\
\hline & São Paulo & 42.7 & (2.8) & 28.5 & (2.3) & 17.0 & $(1.7)$ & 8.3 & $(1.4)$ & 2.5 & $(0.7)$ & 0.8 & $(0.6)$ & 0.2 & $(0.2)$ \\
\hline & Sergipe & 58.6 & $(6.1)$ & 25.0 & $(4.1)$ & 11.3 & $(3.3)$ & 4.6 & $(2.0)$ & 0.5 & $(0.5)$ & 0.0 & $\mathrm{C}$ & 0.0 & c \\
\hline & Tocantins & 63.1 & (4.4) & 23.0 & (2.5) & 9.5 & $(2.3)$ & 3.5 & $(1.2)$ & 0.3 & C & 0.6 & $(0.4)$ & 0.0 & c \\
\hline & Colombia & & & & & & & & & & & & & & \\
\hline & Bogotá & 43.8 & (2.4) & 33.8 & (2.6) & 17.5 & $(2.3)$ & 4.3 & $(1.1)$ & 0.5 & $(0.3)$ & 0.0 & c & 0.0 & c \\
\hline & Cali & 47.9 & (4.5) & 28.7 & $(2.5)$ & 17.4 & $(3.0)$ & 5.1 & $(1.5)$ & 0.9 & $(0.5)$ & 0.0 & $\mathrm{C}$ & 0.0 & c \\
\hline & Manizales & 35.4 & (3.3) & 34.7 & $(4.2)$ & 20.8 & (3.9) & 7.1 & $(2.1)$ & 1.7 & $(1.1)$ & 0.3 & $(0.4)$ & 0.0 & c \\
\hline & Medellín & 45.0 & (4.4) & 28.1 & (2.9) & 14.9 & $(2.2)$ & 7.4 & $(1.7)$ & 2.8 & $(1.5)$ & 1.3 & $(0.7)$ & 0.6 & $(0.4)$ \\
\hline & Russian Federation & & & & & & & & & & & & & & \\
\hline & Perm Territory region ${ }^{\bullet}$ & 9.5 & (1.5) & 18.3 & (2.0) & 26.6 & $(2.0)$ & 23.9 & $(2.1)$ & 14.9 & $(1.5)$ & 4.8 & (1.1) & 2.1 & $(1.0)$ \\
\hline & United Arab Emirates & & & & & & & & & & & & & & \\
\hline & Abu Dhabi & 28.5 & $(2.3)$ & 25.7 & (1.4) & 21.6 & $(1.5)$ & 14.4 & $(1.2)$ & 6.6 & $(0.9)$ & 2.6 & $(0.7)$ & 0.6 & $(0.3)$ \\
\hline & Ajman & 29.4 & (6.1) & 26.1 & $(4.0)$ & 24.6 & $(4.0)$ & 15.0 & $(2.5)$ & 4.1 & $(1.5)$ & 0.9 & $(0.6)$ & 0.0 & c \\
\hline & Dubai ${ }^{\bullet}$ & 19.1 & $(0.9)$ & 22.3 & (1.1) & 21.8 & $(1.4)$ & 19.6 & $(1.7)$ & 10.7 & $(0.9)$ & 5.0 & $(0.7)$ & 1.5 & $(0.5)$ \\
\hline & Fujairah & 20.3 & $(3.7)$ & 23.0 & (3.9) & 28.6 & $(5.3)$ & 18.8 & $(3.3)$ & 7.3 & $(2.8)$ & 1.6 & $(1.0)$ & 0.4 & c \\
\hline & Ras al-Khaimah & 26.8 & (5.3) & 27.6 & (3.3) & 25.0 & $(3.5)$ & 13.9 & $(3.0)$ & 5.8 & $(2.3)$ & 0.8 & $(0.8)$ & 0.2 & c \\
\hline & Sharjah & 27.1 & $(6.1)$ & 23.2 & $(3.2)$ & 21.0 & $(3.6)$ & 16.8 & $(3.4)$ & 9.4 & $(2.9)$ & 2.4 & $(0.9)$ & 0.1 & c \\
\hline & Umm al-Quwain & 26.0 & $(3.7)$ & 29.2 & $(4.2)$ & 24.7 & $(5.1)$ & 14.7 & $(3.5)$ & 3.9 & $(2.4)$ & 1.5 & $\mathrm{c}$ & 0.0 & $\mathrm{C}$ \\
\hline
\end{tabular}

- PISA adjudicated region.

Note: See Table I.2.6 for national data.

StatLink त्नाls http://dx.doi.org/10.1787/888932935762 
[Part 1/2]

Mean score, variation and gender differences in student performance on the mathematics Table B2.I.6 subscale formulating, by region

\begin{tabular}{|c|c|c|c|c|c|c|c|c|c|c|c|c|c|c|c|c|c|c|c|}
\hline & & & All stu & udents & & & & nder di & lifferen & ices & & & & & & & Perce & entiles & \\
\hline & & Mean & score & $\begin{array}{l}\text { Stan } \\
\text { devi }\end{array}$ & $\begin{array}{l}\text { ard } \\
\text { ion }\end{array}$ & & oys & & irls & $\begin{array}{c}\text { Diffe } \\
\text { (B. }\end{array}$ & $\begin{array}{l}\text { rence } \\
- \text { G) }\end{array}$ & & th & & 0th & & 5th & & 5th \\
\hline & & Mean & S.E. & S.D. & S.E. & $\begin{array}{l}\text { Mean } \\
\text { score }\end{array}$ & S.E. & $\begin{array}{l}\text { Mean } \\
\text { score }\end{array}$ & S.E. & $\begin{array}{c}\text { Score } \\
\text { dif. }\end{array}$ & S.E. & Score & S.E. & Score & S.E. & Score & S.E. & Score & S.E. \\
\hline & Australia & & & & & & & & & & & & & & & & & & \\
\hline & Australian Capital Territory & 515 & (4.2) & $\mid 111$ & (3.2) & 519 & (6.5) & 511 & (5.6) & 7 & (8.8) & 334 & (11.1) & 372 & (9.3) & 439 & (6.9) & 592 & (6.5) \\
\hline & New South Wales & 502 & (4.4) & 118 & (3.4) & 508 & (6.8) & 496 & $(4.7)$ & 12 & (7.8) & 316 & $(7.2)$ & 357 & $(5.2)$ & 420 & $(4.0)$ & 582 & (5.9) \\
\hline & Northern Territory & 447 & $(10.3)$ & 124 & $(9.2)$ & 454 & (9.3) & 440 & (15.6) & 14 & $(15.2)$ & 228 & $(37.2)$ & 292 & $(17.9)$ & 376 & $(14.0)$ & 525 & (13.8) \\
\hline & Queensland & 499 & (3.1) & 107 & (2.0) & 505 & (4.1) & 492 & $(4.1)$ & 13 & (5.4) & 328 & (7.4) & 361 & (5.4) & 422 & (4.4) & 575 & (4.3) \\
\hline & South Australia & 479 & (3.6) & 103 & $(2.6)$ & 489 & (4.5) & 470 & (4.4) & 18 & $(5.2)$ & 316 & $(8.8)$ & 349 & (6.8) & 407 & (4.5) & 550 & (5.9) \\
\hline & Tasmania & 470 & (3.7) & 103 & (2.8) & 477 & (5.4) & 464 & (5.1) & 13 & (7.4) & 299 & (9.7) & 340 & (8.5) & 400 & (4.3) & 539 & (5.9) \\
\hline & Victoria & 495 & (4.2) & 104 & (2.9) & 505 & (5.7) & 483 & (4.6) & 22 & (6.3) & 329 & (6.7) & 362 & (4.9) & 422 & (4.1) & 565 & (5.2) \\
\hline & Western Australia & 510 & (4.2) & 107 & $(2.3)$ & 524 & (6.6) & 494 & (5.0) & 31 & (8.4) & 336 & (7.6) & 372 & (6.5) & 434 & (4.8) & 586 & $(5.2)$ \\
\hline & Belgium & & & & & & & & & & & & & & & & & & \\
\hline & Flemish Community• & 533 & (3.7) & \begin{tabular}{|l|l|}
112 \\
$\mid$
\end{tabular} & $(2.2)$ & 540 & (5.2) & 525 & $(4.2)$ & 15 & (5.9) & 345 & (6.2) & 386 & (6.2) & 456 & (5.2) & 612 & (4.3) \\
\hline & French Community & 486 & (3.4) & 105 & (2.1) & 493 & (3.8) & 478 & (3.9) & 14 & (3.7) & 312 & (6.7) & 348 & (5.7) & 412 & (4.5) & 560 & (4.4) \\
\hline & German-speaking Community & 511 & (2.5) & 96 & (2.4) & 514 & (3.8) & 509 & (3.9) & 4 & (5.8) & 347 & (10.1) & 384 & (7.7) & 447 & (5.5) & 578 & (4.4) \\
\hline & Canada & & & & & & & & & & & & & & & & & & \\
\hline & Alberta & 514 & (5.6) & \begin{tabular}{|l|l|}
104
\end{tabular} & $(2.2)$ & 522 & (6.1) & 505 & (6.0) & 17 & (4.6) & $\mid 342$ & (10.9) & 378 & (7.1) & 441 & (6.8) & 586 & (6.6) \\
\hline & British Columbia & 517 & $(5.2)$ & 100 & (2.4) & 526 & (5.7) & 508 & (7.0) & 18 & $(7.2)$ & 351 & $(6.8)$ & 387 & (6.8) & 449 & (5.4) & 585 & (7.6) \\
\hline & Manitoba & 487 & (3.3) & 100 & $(2.3)$ & 492 & (4.3) & 482 & (4.8) & 10 & (6.3) & 328 & (7.6) & 361 & (4.9) & 417 & $(4.2)$ & 555 & (4.5) \\
\hline & New Brunswick & 504 & (2.9) & 92 & (2.4) & 505 & (4.7) & 502 & (3.9) & 3 & (6.4) & 353 & (8.0) & 385 & (5.8) & 440 & (5.8) & 564 & (4.1) \\
\hline & Newfoundland and Labrador & 482 & (4.6) & 95 & (3.1) & 485 & (5.8) & 479 & (5.1) & 6 & (6.1) & 329 & $(16.2)$ & 362 & (9.5) & 415 & (6.2) & 547 & $(6.5)$ \\
\hline & Nova Scotia & 494 & (6.4) & 90 & (2.5) & 502 & (5.4) & 486 & (8.8) & 16 & (7.1) & 350 & $(7.4)$ & 378 & (6.0) & 430 & (9.1) & 555 & (6.5) \\
\hline & Ontario & 512 & (4.7) & 99 & (2.0) & 518 & (5.6) & 506 & (4.6) & 12 & (4.1) & 350 & (6.0) & 385 & (4.9) & 444 & (4.9) & 580 & $(6.2)$ \\
\hline & Prince Edward Island & 476 & (2.8) & 92 & $(2.1)$ & 480 & (3.9) & 472 & (3.8) & 8 & (5.3) & 329 & (5.4) & 358 & (4.6) & 413 & (3.8) & 538 & (4.4) \\
\hline & Quebec & 539 & (3.9) & 102 & $(2.1)$ & 544 & (5.0) & 533 & (4.3) & 11 & (4.9) & 364 & (7.5) & 402 & (6.7) & 469 & (4.9) & 612 & (4.5) \\
\hline & Saskatchewan & 502 & (3.3) & 96 & $(2.1)$ & 508 & $(4.8)$ & 495 & (3.8) & 13 & (5.9) & 346 & $(7.2)$ & 379 & (4.9) & 435 & (3.7) & 569 & (6.1) \\
\hline & Italy & & & & & & & & & & & & & & & & & & \\
\hline & Abruzzo & 463 & (7.7) & $\mid 107$ & $(4.2)$ & \begin{tabular}{|l|}
471 \\
$\mid 71$
\end{tabular} & (8.6) & 455 & (8.6) & 15 & (8.6) & $\mid 287$ & (14.6) & 328 & (12.4) & $\mid 393$ & (8.2) & 536 & (9.8) \\
\hline & Basilicata & 460 & $(5.2)$ & 91 & (2.7) & 473 & (6.9) & 449 & (5.0) & 24 & (6.4) & 312 & (10.3) & 345 & (7.5) & 400 & (5.9) & 521 & (5.6) \\
\hline & Bolzano & 511 & $(2.2)$ & 95 & (1.5) & 526 & (2.9) & 496 & (3.0) & 30 & (3.8) & 354 & (6.7) & 389 & (4.2) & 447 & (2.8) & 577 & (3.2) \\
\hline & Calabria & 421 & (5.6) & 93 & (3.6) & 436 & (6.7) & 406 & (6.1) & 30 & (6.9) & 270 & (12.8) & 305 & $(8.7)$ & 362 & (7.7) & 483 & (6.0) \\
\hline & Campania & 444 & $(8.5)$ & 98 & $(4.1)$ & 453 & $(8.3)$ & 435 & $(10.8)$ & 18 & (8.7) & 284 & (7.6) & 319 & $(10.4)$ & 378 & (9.4) & 508 & (11.6) \\
\hline & Emilia Romagna & 490 & $(7.0)$ & 105 & (4.0) & 501 & (9.6) & 477 & $(7.7)$ & 24 & (11.0) & 315 & (12.0) & 354 & (8.6) & 418 & (8.0) & 561 & (10.1) \\
\hline & Friuli Venezia Giulia & 518 & (5.5) & 100 & (3.4) & 532 & (6.6) & 503 & (6.5) & 29 & $(8.1)$ & 349 & $(12.7)$ & 388 & (9.4) & 452 & (6.6) & 585 & (5.7) \\
\hline & Lazio & 461 & (7.9) & 100 & (3.1) & 474 & (8.8) & 446 & (8.0) & 28 & (7.6) & 299 & (10.8) & 331 & (10.6) & 392 & (9.5) & 530 & (10.5) \\
\hline & Liguria & 479 & (6.1) & 98 & (2.7) & 486 & (8.3) & 471 & (6.6) & 15 & $(8.8)$ & 324 & (7.8) & 354 & (7.3) & 410 & (7.3) & 543 & (7.6) \\
\hline & Lombardia & 506 & (8.9) & 98 & (3.3) & 522 & $(10.4)$ & 488 & (8.9) & 35 & (9.6) & 344 & (11.9) & 381 & (9.4) & 439 & (9.9) & 573 & (10.6) \\
\hline & Marche & 485 & (6.0) & 94 & (2.8) & 503 & (6.3) & 467 & (6.8) & 36 & (6.2) & 332 & (10.4) & 364 & (8.7) & 418 & (7.7) & 549 & (7.4) \\
\hline & Molise & 457 & (2.9) & 92 & $(2.8)$ & 468 & (4.3) & 445 & (3.8) & 24 & (5.6) & 308 & (9.1) & 339 & (6.3) & 394 & (5.4) & 516 & (4.6) \\
\hline & Piemonte & 485 & (7.1) & 101 & (3.4) & 501 & (6.0) & 469 & (8.4) & 32 & (6.4) & 321 & (6.9) & 352 & (9.3) & 415 & (8.3) & 555 & (8.9) \\
\hline & Puglia & 466 & (7.4) & 96 & (3.7) & 481 & (6.8) & 451 & (8.5) & 30 & (7.1) & 311 & (10.8) & 344 & (11.1) & 398 & (9.4) & 532 & (7.6) \\
\hline & Sardegna & 448 & (5.9) & 95 & (3.0) & 457 & (6.3) & 439 & $(7.2)$ & 17 & (7.0) & 297 & (9.9) & 327 & (9.6) & 382 & (7.7) & 515 & (6.3) \\
\hline & Sicilia & 443 & (5.1) & 89 & (2.4) & 447 & (6.4) & 437 & (5.5) & 10 & (6.5) & 296 & (9.7) & 329 & (7.3) & 382 & (6.4) & 503 & (6.6) \\
\hline & Toscana & 485 & (5.1) & 102 & $(2.8)$ & 488 & (7.8) & 482 & (8.7) & 6 & (12.9) & 315 & (10.0) & 351 & (6.7) & 416 & (6.6) & 557 & $(7.2)$ \\
\hline & Trento & 518 & (3.9) & 91 & (2.4) & 524 & (5.2) & 511 & $(7.2)$ & 13 & $(9.7)$ & 374 & $(7.2)$ & 402 & (5.9) & 455 & (5.8) & 581 & (4.8) \\
\hline & Umbria & 480 & (7.0) & 96 & (3.8) & 494 & (9.8) & 468 & (6.7) & 26 & (8.9) & 316 & (14.9) & 350 & (12.9) & 417 & (10.9) & 548 & (6.1) \\
\hline & Valle d'Aosta & 479 & (2.9) & 97 & (2.4) & 491 & (4.3) & 466 & (4.1) & 26 & (6.2) & 320 & (7.6) & 359 & (6.5) & 414 & (6.4) & 544 & (4.8) \\
\hline & Veneto & 512 & (8.4) & 106 & (4.4) & 525 & (9.0) & 498 & (9.3) & 27 & (9.3) & 342 & $(10.7)$ & 382 & (8.3) & 444 & (7.7) & 587 & (11.8) \\
\hline & Mexico & & & & & & & & & & & & & & & & & & \\
\hline & Aguascalientes & 433 & (5.5) & 81 & (3.1) & 440 & (6.9) & 426 & (6.2) & 15 & (7.3) & \begin{tabular}{|l|}
303 \\
$\mid$
\end{tabular} & (10.4) & 329 & (8.3) & 376 & (7.7) & 488 & (5.6) \\
\hline & Baja California & 407 & (6.2) & 84 & $(2.8)$ & 418 & (7.1) & 396 & (6.4) & 22 & (5.2) & 276 & (9.1) & 304 & $(8.2)$ & 348 & (7.2) & 463 & (7.5) \\
\hline & Baja California Sur & 413 & (5.8) & 80 & $(2.7)$ & 424 & (7.0) & 401 & (6.0) & 23 & (5.4) & 283 & (12.4) & 312 & $(9.7)$ & 357 & $(7.2)$ & 467 & (7.9) \\
\hline & Campeche & 391 & (5.2) & 80 & $(2.3)$ & 399 & (5.5) & 383 & (6.0) & 16 & (4.7) & 267 & (8.0) & 291 & (9.6) & 337 & (6.1) & 441 & (5.9) \\
\hline & Chiapas & 370 & $(8.1)$ & 87 & (3.5) & 375 & (8.8) & 365 & (8.6) & 10 & (5.9) & 227 & (8.9) & 257 & $(10.3)$ & 313 & (9.0) & 427 & (8.6) \\
\hline & Chihuahua & 429 & (9.0) & 87 & (3.2) & 436 & (10.5) & 421 & (8.9) & 15 & (7.7) & 289 & (11.0) & 319 & $(9.8)$ & 370 & (9.1) & 485 & $(10.7)$ \\
\hline & Coahuila & 415 & (8.4) & 81 & (3.2) & 424 & (8.7) & 406 & (9.9) & 18 & (7.2) & 286 & (7.8) & 312 & (6.6) & 359 & (9.3) & 470 & (11.3) \\
\hline & Colima & 424 & $(4.2)$ & 89 & (3.2) & 431 & (5.5) & 418 & (4.6) & 14 & (5.4) & 282 & (8.4) & 311 & (7.3) & 362 & (5.5) & 484 & (4.1) \\
\hline & Distrito Federal & 421 & (5.7) & 83 & $(2.9)$ & 435 & (6.6) & 407 & $(7.2)$ & 27 & (7.9) & 286 & (10.8) & 318 & (7.6) & 363 & (5.7) & 476 & (7.9) \\
\hline & Durango & 414 & (7.4) & 87 & (3.4) & 422 & (9.1) & 406 & (7.0) & 16 & (6.5) & 272 & (13.8) & 302 & $(9.2)$ & 354 & (10.6) & 475 & (8.6) \\
\hline & Guanajuato & 407 & (5.9) & 83 & (2.6) & 417 & (6.5) & 398 & (6.0) & 19 & (3.9) & 273 & (7.6) & 299 & (8.2) & 351 & (7.9) & 461 & (6.3) \\
\hline & Guerrero & 356 & (4.6) & 80 & (2.8) & 362 & (6.0) & 350 & (5.6) & 11 & (7.2) & 230 & (8.2) & 257 & (6.5) & 302 & (5.6) & 409 & (5.9) \\
\hline & Hidalgo & 401 & (6.9) & 91 & (5.3) & 411 & (7.9) & 393 & (7.7) & 17 & (7.0) & 250 & (12.9) & 289 & (8.6) & 344 & (7.7) & 462 & (9.1) \\
\hline & Jalisco & 433 & (7.7) & 85 & (3.0) & 443 & (9.4) & 424 & (6.8) & 19 & (5.7) & 294 & (13.3) & 326 & (10.6) & 376 & (9.0) & 490 & (8.2) \\
\hline & Mexico & 417 & (7.0) & 82 & (3.3) & 429 & (7.5) & 406 & (7.5) & 23 & (5.7) & 283 & (13.0) & 313 & $(9.7)$ & 362 & (7.4) & 470 & (8.2) \\
\hline & Morelos & 415 & (9.4) & 92 & (6.7) & 422 & (10.1) & 409 & (10.3) & 13 & (7.7) & 273 & (9.6) & 301 & $(10.2)$ & 353 & (8.9) & 473 & (12.8) \\
\hline & Nayarit & 406 & (5.9) & 87 & (2.6) & 420 & (5.4) & 393 & $(7.7)$ & 28 & (6.8) & 269 & (10.2) & 296 & $(6.8)$ & 347 & (7.7) & 464 & (5.7) \\
\hline & Nuevo León & 428 & (9.0) & 89 & (3.1) & 443 & (9.1) & 413 & (9.3) & 30 & (5.9) & 286 & (10.6) & 316 & (11.6) & 368 & (10.9) & 488 & $(11.0)$ \\
\hline & Puebla & 416 & (5.2) & 86 & $(2.7)$ & 430 & (8.0) & 403 & (5.2) & 26 & $(8.2)$ & 274 & (11.9) & 308 & (10.1) & 359 & (6.2) & 474 & (6.7) \\
\hline & Querétaro & 432 & (7.4) & 89 & (3.5) & 448 & (9.1) & 418 & (7.7) & 30 & (6.5) & 293 & (9.3) & 322 & (7.8) & 370 & (8.3) & 494 & (10.6) \\
\hline & Quintana Roo & 415 & (5.6) & 81 & (2.4) & 421 & (6.7) & 408 & (5.7) & 14 & (4.9) & 285 & (12.4) & 315 & (9.0) & 360 & (6.2) & 467 & (7.6) \\
\hline & San Luis Potosí & 405 & $(8.0)$ & 86 & (3.0) & 411 & (8.5) & 400 & (8.8) & 11 & (6.2) & 268 & (8.6) & 296 & (8.1) & 345 & (7.3) & 463 & (9.7) \\
\hline & Sinaloa & 405 & (4.5) & 80 & $(2.2)$ & 413 & (5.4) & 399 & (5.0) & 13 & (5.1) & 279 & (8.8) & 306 & (5.0) & 352 & (6.6) & 457 & (5.5) \\
\hline & Tabasco & 372 & (4.1) & 82 & $(2.7)$ & 382 & (4.6) & 362 & (5.5) & 21 & (5.9) & 241 & (9.6) & 272 & (10.6) & 318 & (6.3) & 423 & (4.8) \\
\hline & Tamaulipas & 413 & $(8.7)$ & 85 & (3.4) & 425 & (11.0) & 400 & (7.7) & 25 & (7.5) & 278 & (11.1) & 307 & (8.9) & 355 & (7.4) & 470 & $(10.3)$ \\
\hline & Tlaxcala & 406 & (5.6) & 84 & (3.6) & 412 & (5.3) & 400 & (6.5) & 12 & (4.1) & 263 & (12.9) & 298 & (11.0) & 351 & (8.5) & 461 & $(5.1)$ \\
\hline & Veracruz & 402 & (6.8) & 85 & (3.2) & 409 & (6.8) & 394 & (8.5) & 15 & (7.2) & 262 & (13.0) & 294 & $(10.2)$ & 347 & (6.9) & 457 & (7.7) \\
\hline & Yucatán & 404 & (5.4) & 87 & (2.4) & 416 & (5.7) & 391 & (7.4) & 25 & (7.3) & 263 & (13.6) & 294 & $(8.8)$ & 346 & (7.7) & 462 & (4.8) \\
\hline & Zacatecas & 405 & (5.1) & 85 & $(2.7)$ & 414 & (6.5) & 397 & (5.5) & 17 & (6.1) & 268 & (11.8) & 298 & (8.3) & 350 & (7.1) & 461 & (5.9) \\
\hline
\end{tabular}

- PISA adjudicated region.

Notes: Values that are statistically significant are indicated in bold (see Annex A3).

See Table 1.2.7 for national data.

StatLink त्राजी http://dx.doi.org/10.1787/888932935762 
[Part 2/2]

Mean score, variation and gender differences in student performance on the mathematics Table B2.I.6 subscale formulating, by region

\begin{tabular}{|c|c|c|c|c|c|c|c|c|c|c|c|c|c|c|c|c|c|c|c|c|c|c|c|}
\hline & & \multicolumn{4}{|c|}{ All students } & \multicolumn{6}{|c|}{ Gender differences } & \multicolumn{12}{|c|}{ Percentiles } \\
\hline & & \multicolumn{2}{|c|}{ Mean score } & \multicolumn{2}{|c|}{$\begin{array}{l}\text { Standard } \\
\text { deviation }\end{array}$} & \multicolumn{2}{|c|}{ Boys } & \multicolumn{2}{|c|}{ Girls } & \multicolumn{2}{|c|}{$\begin{array}{c}\text { Difference } \\
\text { (B - G) }\end{array}$} & \multicolumn{2}{|c|}{ 5th } & \multicolumn{2}{|c|}{ 10th } & \multicolumn{2}{|c|}{ 25th } & \multicolumn{2}{|c|}{ 75th } & \multicolumn{2}{|c|}{ 90th } & \multicolumn{2}{|c|}{ 95th } \\
\hline & & Mean & S.E. & S.D. & S.E. & $\begin{array}{l}\text { Mean } \\
\text { score }\end{array}$ & S.E. & $\begin{array}{l}\text { Mean } \\
\text { score }\end{array}$ & S.E. & \begin{tabular}{|c|}
$\begin{array}{c}\text { Score } \\
\text { dif. }\end{array}$ \\
\end{tabular} & S.E. & Score & S.E. & Score & S.E. & Score & S.E. & Score & e S.E. & Score & e S.E. & Score & S.E. \\
\hline \multirow{2}{*}{ তি } & Portugal & & & & & & & & & & & & & & & & & & & & & & \\
\hline & Alentejo & 482 & (12.4) & 102 & (4.5) & $\mid 492$ & $(14.2) \mid$ & 471 & $(11.7) \mid$ & 21 & $(7.7)$ & 312 & (17.6) & 352 & (17.3) & 414 & (16.4) & 550 & (12.6) & 619 & (13.9) & | 658 & (19.3) \\
\hline \multicolumn{24}{|c|}{ Spain } \\
\hline & Andalusia ${ }^{\bullet}$ & 463 & (4.8) & 96 & (1.8) & 472 & (6.3) & 453 & (4.5) & 18 & (5.1) & 308 & (9.7) & 343 & (7.9) & 397 & (5.7) & 529 & (6.0) & 587 & (6.1) & 621 & (8.1) \\
\hline & Aragon ${ }^{\bullet}$ & 494 & (5.8) & 102 & (2.5) & 506 & (6.1) & 482 & (6.9) & 23 & (5.8) & 320 & (9.2) & 359 & (9.7) & 424 & (7.6) & 566 & (5.9) & 622 & (7.5) & 656 & (7.6) \\
\hline & Asturias ${ }^{\bullet}$ & 494 & (4.7) & 106 & $(2.7)$ & 500 & (6.8) & 488 & (4.1) & 12 & (6.0) & 322 & (9.6) & 359 & (9.4) & 426 & (6.4) & 566 & (4.7) & 629 & (5.7) & 662 & (8.4) \\
\hline & Balearic Islands ${ }^{\bullet}$ & 468 & (5.9) & 100 & (2.5) & 472 & (6.1) & 464 & $(6.8)$ & 9 & (5.4) & 301 & (10.4) & 338 & $(8.2)$ & 399 & (6.4) & 538 & (6.8) & 592 & (7.7) & 629 & (9.7) \\
\hline & Basque Country ${ }^{\bullet}$ & 507 & (3.0) & 95 & (1.4) & 516 & (3.5) & 499 & (3.4) & 17 & (3.5) & 347 & (5.8) & 383 & $(4.2)$ & 444 & (4.0) & 573 & (3.7) & 627 & (3.8) & 658 & (4.5) \\
\hline & Cantabria ${ }^{\bullet}$ & 484 & (4.4) & 107 & (2.3) & 493 & (5.4) & 473 & (5.7) & 20 & (6.8) & 311 & (7.5) & 350 & (7.2) & 412 & (6.4) & 559 & (6.2) & 619 & (5.2) & 656 & (9.7) \\
\hline & Castile and Leon ${ }^{\bullet}$ & 505 & (5.0) & 95 & (2.3) & 515 & (7.0) & 496 & $(4.7)$ & 19 & (6.3) & 346 & (7.2) & 378 & (6.2) & 439 & (6.4) & 573 & (6.0) & 628 & (6.0) & 656 & (7.3) \\
\hline & Catalonia・ & 486 & (5.6) & 100 & (2.4) & 497 & (6.9) & 475 & (6.3) & 23 & $(7.0)$ & 319 & (9.8) & 358 & (8.5) & 417 & (6.8) & 557 & (7.7) & 619 & (5.8) & 649 & (7.9) \\
\hline & Extremadura ${ }^{\bullet}$ & 452 & (4.7) & 103 & (2.6) & 459 & (5.5) & 445 & (5.1) & 14 & (4.9) & 283 & (12.5) & 320 & (9.0) & 383 & (6.6) & 523 & (5.2) & 582 & (6.3) & 618 & (6.2) \\
\hline & Galicia $\bullet^{\bullet}$ & 481 & (4.8) & 99 & (2.4) & 479 & (5.7) & 483 & (5.7) & -4 & $(6.2)$ & 310 & (8.5) & 351 & (9.1) & 417 & (7.7) & 548 & (5.3) & 605 & (5.1) & 637 & (7.1) \\
\hline & La Rioja` & 502 & (2.1) & 112 & (2.3) & 514 & (3.8) & 491 & (3.4) & 23 & (5.9) & 317 & (9.2) & 356 & (6.3) & 424 & (4.3) & 583 & (4.4) & 645 & (5.1) & 680 & (7.4) \\
\hline & Madrid ${ }^{\bullet}$ & 495 & (4.1) & 102 & (2.6) & 505 & (5.4) & 484 & $(4.5)$ & 22 & (5.8) & 320 & (8.6) & 362 & (7.8) & 425 & (5.1) & 568 & (4.6) & 622 & (6.1) & 656 & (6.5) \\
\hline & Murcia ${ }^{\bullet}$ & 451 & (5.7) & 103 & (3.5) & 461 & (7.5) & 442 & $(4.7)$ & 19 & (5.3) & 284 & (8.7) & 318 & (8.2) & 383 & (6.4) & 521 & (6.9) & 583 & $(10.2)$ & 624 & (14.0) \\
\hline & Navarre & 519 & (3.5) & 94 & $(2.2)$ & 524 & (4.1) & 515 & (4.5) & 9 & (4.9) & 360 & (8.6) & 392 & (6.8) & 456 & (5.6) & 585 & (4.4) & 637 & (4.7) & 669 & (6.4) \\
\hline \multicolumn{24}{|c|}{ United Kingdom } \\
\hline & England & 491 & (4.4) & 105 & (2.3) & 497 & (5.6) & 485 & (5.2) & 12 & $(6.2)$ & 319 & (7.7) & 355 & (7.6) & 418 & (6.0) & 563 & (4.7) & 630 & (5.9) & 665 & (5.8) \\
\hline & Northern Ireland & 479 & (3.8) & 100 & (2.4) & 484 & (5.4) & 474 & (5.8) & 10 & $(8.2)$ & 317 & (7.2) & 350 & (6.5) & 409 & (5.8) & 548 & (4.5) & 609 & (5.8) & 648 & (7.4) \\
\hline & Scotland ${ }^{\bullet}$ & 490 & (3.3) & 99 & $(2.1)$ & 499 & (3.6) & 481 & $(4.2)$ & 18 & (4.0) & 330 & (7.4) & 364 & (5.4) & 423 & (5.3) & 557 & (3.7) & 620 & (5.1) & 658 & (5.6) \\
\hline & Wales & 457 & (2.4) & 93 & (1.4) & 463 & (2.7) & 452 & (3.2) & 11 & (3.6) & 308 & (4.3) & 339 & (3.8) & 395 & (3.3) & 521 & (3.0) & 577 & (4.1) & 612 & (5.1) \\
\hline \multicolumn{24}{|c|}{ United States } \\
\hline & Connecticut $^{\bullet}$ & 504 & (7.3) & 111 & (2.4) & 513 & (8.0) & 494 & (7.5) & 20 & (5.1) & 324 & (10.1) & 359 & (7.3) & 423 & (8.3) & 583 & (9.2) & 651 & (8.3) & \begin{tabular}{|l|}
686 \\
6
\end{tabular} & (7.3) \\
\hline & Florida ${ }^{\bullet}$ & 458 & (6.5) & 92 & $(2.2)$ & 467 & (6.7) & 448 & $(6.8)$ & 19 & $(4.0)$ & 313 & $(6.2)$ & 339 & (6.4) & 392 & (7.1) & 521 & (7.6) & 579 & (9.7) & 616 & (9.3) \\
\hline & Massachusetts ${ }^{\bullet}$ & 512 & (7.4) & 110 & $(4.3)$ & 520 & (7.4) & 504 & $(8.2)$ & 16 & $(4.8)$ & 333 & (9.0) & 373 & (8.0) & 437 & (7.0) & 587 & (10.5) & 655 & (13.7) & 696 & (15.5) \\
\hline
\end{tabular}

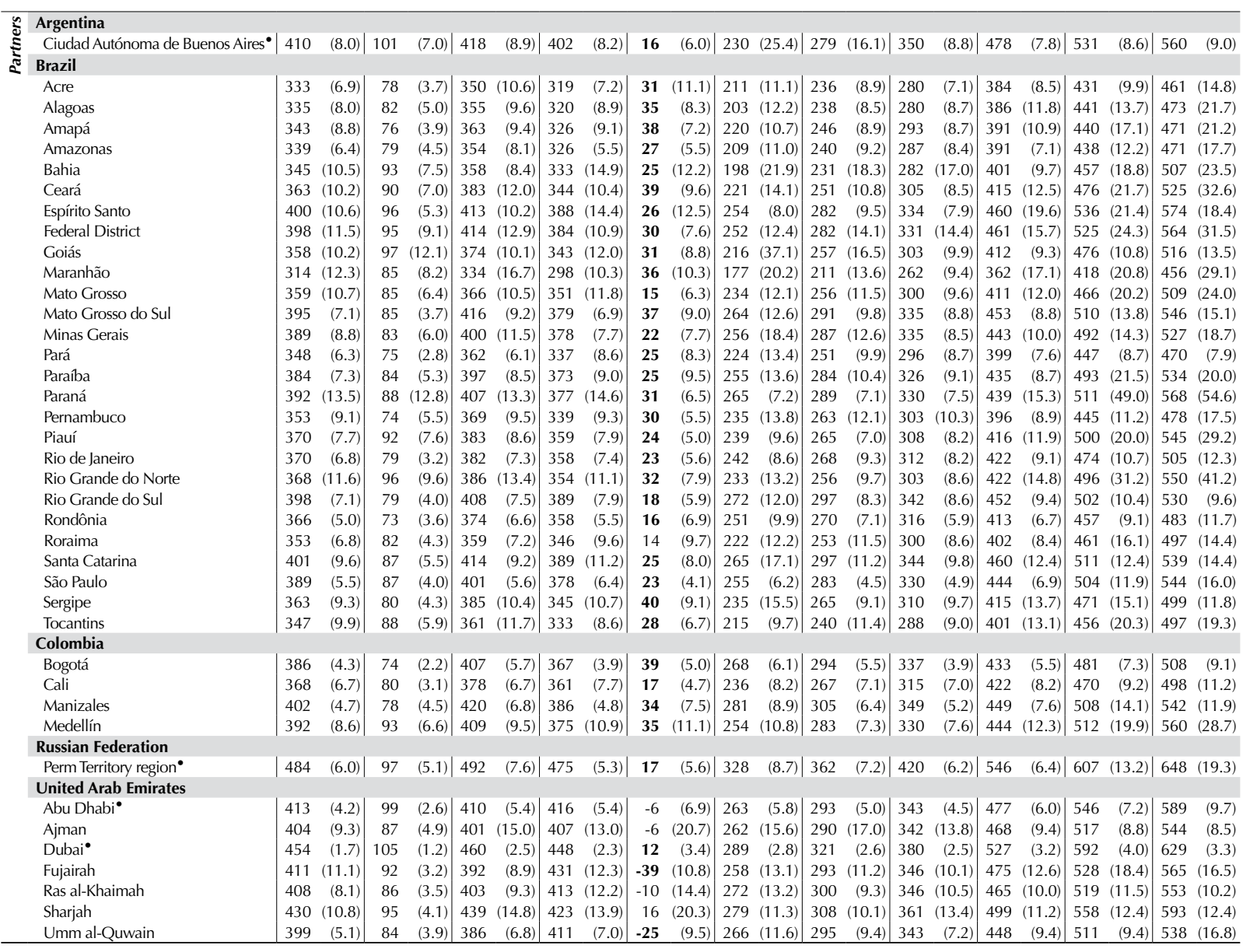

- PISA adjudicated region.

Notes: Values that are statistically significant are indicated in bold (see Annex A3).

See Table I.2.7 for national data.

StatLink 部 SL http://dx.doi.org/10.1787/888932935762 
[Part 1/2]

Table B2.I.7 Percentage of students at each proficiency level on the mathematics subscale employing, by region

\begin{tabular}{|c|c|c|c|c|c|c|c|c|c|c|c|c|c|c|c|}
\hline & & \multicolumn{14}{|c|}{ All students } \\
\hline & & \multicolumn{2}{|c|}{$\begin{array}{c}\text { Below Level } 1 \\
\text { (below 357.77 } \\
\text { score points) }\end{array}$} & $\begin{array}{r}\text { L } \\
\text { (from } \\
\text { less th } \\
\text { scor }\end{array}$ & $\begin{array}{l}11 \\
7.77 \text { to } \\
420.07 \\
\text { oints) }\end{array}$ & $\begin{array}{r}\mathrm{L} \\
\text { (from } \\
\text { less th } \\
\text { scor }\end{array}$ & $\begin{array}{l}\text { I } 2 \\
0.07 \text { to } \\
482.38 \\
\text { oints) }\end{array}$ & $\begin{array}{l}\text { Le } \\
\text { (from } \\
\text { less th } \\
\text { scor }\end{array}$ & $\begin{array}{l}3 \\
2.38 \text { to } \\
544.68 \\
\text { oints) }\end{array}$ & $\begin{array}{r}L \\
\text { (from } \\
\text { less th } \\
\text { scor }\end{array}$ & $\begin{array}{l}14 \\
4.68 \text { to } \\
606.99 \\
\text { oints) }\end{array}$ & $\begin{array}{l}\mathrm{L} \\
\text { (from } \\
\text { less th } \\
\text { scor }\end{array}$ & $\begin{array}{l}5 \\
6.99 \text { to } \\
669.30 \\
\text { oints) }\end{array}$ & $\begin{array}{l}\text { Le } \\
\text { (abov } \\
\text { scor }\end{array}$ & $\begin{array}{l}16 \\
669.30 \\
\text { oints) }\end{array}$ \\
\hline & & $\%$ & S.E. & $\%$ & S.E. & $\%$ & S.E. & $\%$ & S.E. & $\%$ & S.E. & $\%$ & S.E. & $\%$ & S.E. \\
\hline 0 & Australia & & & & & & & & & & & & & & \\
\hline U⿺辶ّ山 & Australian Capital Territory & 5.5 & $(1.1)$ & 11.0 & $(1.5)$ & 20.3 & $(2.2)$ & 24.9 & $(2.5)$ & 22.9 & (1.9) & 11.4 & (1.3) & 4.0 & $(0.9)$ \\
\hline & New South Wales & 6.5 & $(0.7)$ & 13.3 & $(0.8)$ & 21.3 & $(0.9)$ & 23.2 & (1.3) & 19.1 & (1.1) & 11.5 & $(0.9)$ & 5.1 & $(0.9)$ \\
\hline & Northern Territory & 17.6 & (1.9) & 18.6 & (3.7) & 24.2 & $(4.0)$ & 23.1 & (3.2) & 10.4 & (3.3) & 5.1 & (1.9) & 1.0 & $(0.7)$ \\
\hline & Queensland & 6.6 & $(0.9)$ & 13.8 & $(0.8)$ & 22.6 & $(1.2)$ & 24.9 & $(1.1)$ & 18.5 & $(1.2)$ & 10.6 & $(0.9)$ & 3.0 & $(0.5)$ \\
\hline & South Australia & 8.2 & $(1.0)$ & 15.8 & (1.3) & 25.2 & (1.7) & 25.0 & $(1.8)$ & 16.7 & (1.5) & 7.6 & $(0.9)$ & 1.6 & $(0.4)$ \\
\hline & Tasmania & 10.9 & $(1.2)$ & 17.2 & (1.5) & 26.0 & (1.8) & 23.6 & $(2.0)$ & 15.4 & (1.5) & 5.8 & $(1.2)$ & 1.1 & $(0.4)$ \\
\hline & Victoria & 6.4 & $(0.8)$ & 13.1 & $(0.9)$ & 24.5 & $(1.2)$ & 25.6 & $(1.5)$ & 19.4 & (1.3) & 8.3 & $(0.9)$ & 2.6 & $(0.7)$ \\
\hline & Western Australia & 4.9 & $(0.7)$ & 12.0 & $(1.2)$ & 20.5 & (1.5) & 24.7 & (1.4) & 21.8 & $(1.2)$ & 12.2 & $(1.0)$ & 3.8 & $(0.6)$ \\
\hline & Belgium & & & & & & & & & & & & & & \\
\hline & Flemish Community & 5.2 & $(0.7)$ & 9.5 & $(0.8)$ & 16.3 & $(0.9)$ & 21.5 & $(1.0)$ & 22.8 & $(1.0)$ & 16.8 & $(0.9)$ & 7.9 & $(0.6)$ \\
\hline & French Community & 8.7 & $(1.0)$ & 14.2 & $(0.9)$ & 21.4 & $(1.1)$ & 23.3 & $(1.2)$ & 20.0 & $(1.2)$ & 9.9 & $(0.8)$ & 2.6 & $(0.3)$ \\
\hline & German-speaking Community & 5.4 & $(0.8)$ & 9.6 & $(1.0)$ & 19.4 & (1.5) & 27.4 & (1.8) & 25.8 & (1.8) & 10.3 & $(1.3)$ & 2.1 & $(0.7)$ \\
\hline & Canada & & & & & & & & & & & & & & \\
\hline & Alberta & 4.1 & $(0.8)$ & 11.0 & $(1.2)$ & 20.8 & $(1.3)$ & 25.7 & $(1.2)$ & 22.8 & (1.3) & 12.1 & (1.5) & 3.6 & $(0.5)$ \\
\hline & British Columbia & 2.3 & $(0.6)$ & 9.5 & (1.3) & 20.5 & (1.8) & 28.3 & (1.5) & 23.2 & (1.3) & 12.3 & (1.3) & 3.8 & $(0.6)$ \\
\hline & Manitoba & 6.2 & (1.1) & 15.5 & $(1.1)$ & 26.5 & (1.5) & 25.3 & (1.3) & 17.0 & (1.3) & 7.3 & $(0.7)$ & 2.2 & $(0.5)$ \\
\hline & New Brunswick & 4.1 & $(0.7)$ & 12.0 & $(1.2)$ & 24.3 & (1.4) & 31.0 & $(1.7)$ & 18.6 & (1.5) & 8.5 & $(1.0)$ & 1.5 & $(0.6)$ \\
\hline & Newfoundland and Labrador & 6.6 & $(1.4)$ & 15.1 & $(2.1)$ & 24.7 & (1.7) & 26.2 & $(2.0)$ & 17.9 & $(1.3)$ & 7.7 & $(1.2)$ & 1.8 & $(0.6)$ \\
\hline & Nova Scotia & 5.1 & $(0.8)$ & 13.7 & (1.4) & 25.6 & $(2.1)$ & 28.8 & $(2.1)$ & 19.4 & $(1.3)$ & 6.2 & (1.3) & 1.3 & $(0.5)$ \\
\hline & Ontario & 4.1 & $(0.6)$ & 10.2 & $(1.1)$ & 22.4 & (1.5) & 27.6 & $(1.3)$ & 21.8 & $(1.2)$ & 10.8 & $(1.2)$ & 3.1 & $(0.6)$ \\
\hline & Prince Edward Island & 6.4 & $(0.8)$ & 18.0 & $(1.4)$ & 27.1 & (1.8) & 26.8 & $(1.3)$ & 15.3 & $(1.2)$ & 5.6 & $(0.7)$ & 0.9 & $(0.3)$ \\
\hline & Quebec & 2.9 & $(0.5)$ & 7.9 & $(0.7)$ & 16.7 & (1.0) & 24.4 & $(1.2)$ & 26.1 & (1.0) & 16.9 & $(1.0)$ & 5.3 & (0.6) \\
\hline & Saskatchewan & 3.8 & $(0.6)$ & 11.1 & $(0.9)$ & 24.3 & (1.5) & 28.4 & (1.6) & 21.3 & (1.6) & 9.5 & $(1.2)$ & 1.7 & $(0.5)$ \\
\hline & Italy & & & & & & & & & & & & & & \\
\hline & Abruzzo & 8.8 & $(1.8)$ & 15.8 & $(1.7)$ & 26.8 & (1.8) & 25.6 & (1.7) & 16.9 & (1.9) & 4.9 & $(0.9)$ & 1.2 & $(0.4)$ \\
\hline & Basilicata & 9.6 & $(1.4)$ & 20.0 & $(1.6)$ & 28.2 & (1.4) & 23.8 & (1.6) & 12.6 & (1.4) & 4.5 & $(0.7)$ & 1.3 & $(0.3)$ \\
\hline & Bolzano & 5.9 & $(0.7)$ & 11.8 & $(1.0)$ & 21.2 & (1.3) & 27.9 & (1.9) & 21.1 & $(1.2)$ & 9.5 & $(0.9)$ & 2.6 & $(0.5)$ \\
\hline & Calabria & 21.5 & $(2.1)$ & 23.2 & (1.9) & 26.7 & (1.6) & 18.6 & $(1.6)$ & 7.6 & (1.1) & 1.9 & $(0.5)$ & 0.5 & $(0.2)$ \\
\hline & Campania & 15.0 & $(2.1)$ & 21.4 & (2.4) & 26.7 & (2.0) & 21.1 & $(2.3)$ & 11.2 & $(1.7)$ & 4.0 & $(1.0)$ & 0.7 & $(0.3)$ \\
\hline & Emilia Romagna & 6.8 & $(1.2)$ & 12.8 & $(1.7)$ & 22.7 & (2.0) & 24.4 & $(2.1)$ & 19.4 & (1.7) & 9.9 & $(1.5)$ & 3.9 & $(0.9)$ \\
\hline & Friuli Venezia Giulia & 3.3 & $(1.2)$ & 9.5 & $(1.3)$ & 18.9 & (1.6) & 27.9 & (1.6) & 24.3 & (1.6) & 12.1 & $(1.6)$ & 4.0 & $(0.6)$ \\
\hline & Lazio & 9.3 & $(1.4)$ & 17.6 & $(1.8)$ & 27.4 & (1.8) & 23.8 & (1.9) & 14.2 & (1.5) & 6.4 & $(1.2)$ & 1.2 & $(0.5)$ \\
\hline & Liguria & 7.4 & $(1.4)$ & 15.4 & $(1.7)$ & 24.4 & $(2.0)$ & 26.2 & $(1.5)$ & 17.3 & $(1.7)$ & 7.1 & $(1.3)$ & 2.3 & $(0.5)$ \\
\hline & Lombardia & 3.9 & $(0.7)$ & 10.0 & $(1.5)$ & 19.7 & $(2.2)$ & 28.0 & $(2.5)$ & 22.8 & (2.3) & 12.3 & (1.9) & 3.3 & $(1.0)$ \\
\hline & Marche & 5.2 & (1.6) & 13.3 & $(1.5)$ & 24.8 & (1.8) & 27.7 & $(1.8)$ & 18.9 & (1.8) & 8.0 & $(1.1)$ & 2.1 & $(0.6)$ \\
\hline & Molise & 10.1 & $(1.2)$ & 19.4 & (1.4) & 28.9 & $(2.0)$ & 24.3 & $(2.3)$ & 12.2 & (1.8) & 4.4 & $(1.2)$ & 0.8 & $(0.3)$ \\
\hline & Piemonte & 5.6 & $(0.9)$ & 12.9 & $(1.7)$ & 22.4 & $(2.3)$ & 27.9 & $(1.9)$ & 21.3 & $(2.2)$ & 8.2 & $(1.4)$ & 1.7 & $(0.6)$ \\
\hline & Puglia & 8.2 & (1.8) & 17.3 & $(1.9)$ & 25.3 & $(2.1)$ & 24.8 & $(1.8)$ & 17.1 & $(2.1)$ & 6.6 & $(1.2)$ & 0.7 & $(0.3)$ \\
\hline & Sardegna & 13.1 & (1.9) & 21.0 & $(2.1)$ & 28.4 & (1.8) & 21.6 & $(1.6)$ & 12.1 & (1.4) & 3.4 & $(0.6)$ & 0.4 & $(0.2)$ \\
\hline & Sicilia & 14.0 & $(2.0)$ & 24.0 & $(2.2)$ & 29.1 & (1.8) & 21.5 & $(2.3)$ & 9.0 & (1.4) & 2.0 & $(0.5)$ & 0.4 & $(0.2)$ \\
\hline & Toscana & 7.5 & (1.1) & 14.8 & $(1.5)$ & 22.0 & (1.7) & 23.8 & $(1.8)$ & 19.7 & (1.7) & 9.7 & $(1.2)$ & 2.5 & $(0.6)$ \\
\hline & Trento & 2.9 & $(0.7)$ & 8.3 & $(1.3)$ & 19.2 & (1.7) & 28.7 & $(1.8)$ & 25.5 & $(2.2)$ & 12.9 & $(1.2)$ & 2.5 & $(0.5)$ \\
\hline & Umbria & 7.2 & $(2.2)$ & 13.9 & $(2.0)$ & 23.3 & (1.9) & 26.1 & $(2.1)$ & 19.4 & (1.7) & 8.2 & $(1.1)$ & 1.8 & $(0.6)$ \\
\hline & Valle d'Aosta & 4.9 & $(1.0)$ & 15.2 & $(2.1)$ & 26.2 & (1.8) & 27.9 & $(2.0)$ & 16.9 & (1.5) & 7.0 & $(1.1)$ & 1.9 & $(0.5)$ \\
\hline & Veneto & 3.6 & $(0.9)$ & 8.7 & $(1.1)$ & 19.9 & (2.3) & 25.6 & $(2.5)$ & 23.9 & $(2.0)$ & 13.4 & $(2.2)$ & 5.0 & (1.4) \\
\hline & Mexico & & & & & & & & & & & & & & \\
\hline & Aguascalientes & 16.4 & $(2.4)$ & 25.9 & $(1.5)$ & 30.5 & (2.6) & 18.4 & $(1.7)$ & 7.0 & (1.4) & 1.7 & $(0.7)$ & 0.1 & C \\
\hline & Baja California & 22.1 & $(2.3)$ & 32.6 & $(2.2)$ & 26.4 & $(2.1)$ & 13.9 & (1.6) & 4.3 & (1.3) & 0.7 & $(0.6)$ & 0.0 & C \\
\hline & Baja California Sur & 23.7 & $(3.0)$ & 30.5 & $(2.1)$ & 27.1 & $(2.2)$ & 14.0 & $(1.7)$ & 4.3 & $(0.9)$ & 0.4 & $(0.3)$ & 0.0 & C \\
\hline & Campeche & 31.8 & $(2.5)$ & 33.4 & $(2.1)$ & 23.4 & (2.4) & 8.6 & $(1.3)$ & 2.5 & $(0.6)$ & 0.3 & $(0.2)$ & 0.0 & c \\
\hline & Chiapas & 43.4 & $(4.2)$ & 29.3 & $(2.7)$ & 19.0 & (2.3) & 6.2 & $(1.4)$ & 1.6 & $(0.6)$ & 0.3 & $(0.2)$ & 0.1 & $(0.1)$ \\
\hline & Chihuahua & 17.2 & $(2.4)$ & 29.3 & $(2.5)$ & 29.1 & $(2.1)$ & 15.8 & $(2.0)$ & 7.2 & (1.6) & 1.3 & $(0.5)$ & 0.1 & C \\
\hline & Coahuila & 22.5 & $(3.1)$ & 29.7 & $(3.0)$ & 26.9 & (2.4) & 14.5 & $(2.5)$ & 5.7 & (1.9) & 0.6 & $(0.4)$ & 0.0 & C \\
\hline & Colima & 20.3 & $(2.4)$ & 26.2 & $(2.4)$ & 27.1 & (2.8) & 17.7 & $(2.4)$ & 7.4 & (1.6) & 1.1 & $(0.4)$ & 0.2 & $(0.1)$ \\
\hline & Distrito Federal & 16.7 & $(2.1)$ & 29.5 & $(2.6)$ & 28.8 & $(2.1)$ & 17.8 & $(2.2)$ & 6.0 & $(1.1)$ & 1.3 & $(0.4)$ & 0.0 & C \\
\hline & Durango & 17.7 & $(2.3)$ & 28.3 & $(2.0)$ & 28.9 & (2.6) & 18.6 & $(2.5)$ & 5.5 & (1.1) & 1.0 & $(0.4)$ & 0.0 & c \\
\hline & Guanajuato & 23.4 & $(3.1)$ & 29.0 & $(2.6)$ & 27.5 & $(2.7)$ & 14.9 & $(1.6)$ & 4.7 & $(0.8)$ & 0.5 & $(0.2)$ & 0.0 & C \\
\hline & Guerrero & 46.3 & (2.4) & 32.2 & $(2.4)$ & 16.3 & (1.3) & 4.0 & $(0.9)$ & 1.1 & $(0.4)$ & 0.1 & c & 0.0 & c \\
\hline & Hidalgo & 26.0 & $(3.0)$ & 31.8 & (2.4) & 26.4 & (2.3) & 12.6 & $(2.0)$ & 2.8 & $(0.8)$ & 0.4 & $(0.3)$ & 0.0 & c \\
\hline & Jalisco & 15.7 & $(2.4)$ & 27.0 & $(2.6)$ & 31.9 & $(2.1)$ & 18.2 & $(2.2)$ & 5.8 & $(1.1)$ & 1.3 & $(0.6)$ & 0.1 & $(0.2)$ \\
\hline & Mexico & 19.6 & $(2.9)$ & 32.9 & $(2.8)$ & 31.9 & (3.1) & 12.8 & $(1.8)$ & 2.3 & $(0.7)$ & 0.4 & $(0.4)$ & 0.1 & c \\
\hline & Morelos & 20.6 & (3.8) & 30.4 & $(2.6)$ & 27.9 & (2.5) & 13.9 & $(1.6)$ & 5.5 & $(1.7)$ & 1.6 & $(0.9)$ & 0.2 & $(0.2)$ \\
\hline & Nayarit & 25.1 & $(3.0)$ & 27.2 & $(2.0)$ & 28.6 & (1.9) & 13.7 & $(1.5)$ & 4.8 & (1.0) & 0.7 & $(0.3)$ & 0.0 & c \\
\hline & Nuevo León & 15.9 & $(2.8)$ & 27.7 & $(3.2)$ & 29.5 & (2.0) & 18.7 & $(2.7)$ & 7.2 & (1.9) & 0.9 & $(0.4)$ & 0.1 & C \\
\hline & Puebla & 21.3 & $(2.7)$ & 30.7 & $(2.2)$ & 28.1 & (1.9) & 14.4 & $(1.5)$ & 4.9 & $(0.9)$ & 0.6 & $(0.3)$ & 0.0 & C \\
\hline & Querétaro & 18.1 & $(2.3)$ & 28.0 & $(2.5)$ & 28.6 & (2.5) & 17.8 & (2.4) & 6.1 & (1.7) & 1.3 & $(0.5)$ & 0.1 & $(0.1)$ \\
\hline & Quintana Roo & 26.4 & $(2.8)$ & 30.8 & $(2.9)$ & 26.0 & (1.9) & 12.8 & $(1.5)$ & 3.5 & $(0.6)$ & 0.5 & $(0.3)$ & 0.0 & c \\
\hline & San Luis Potosí & 26.2 & $(3.2)$ & 28.5 & $(3.0)$ & 25.8 & $(2.3)$ & 14.5 & $(2.3)$ & 4.3 & (1.4) & 0.6 & $(0.5)$ & 0.1 & $(0.1)$ \\
\hline & Sinaloa & 24.5 & $(2.3)$ & 33.7 & $(2.4)$ & 26.5 & (2.5) & 11.9 & $(1.5)$ & 3.1 & $(0.7)$ & 0.3 & $(0.2)$ & 0.0 & C \\
\hline & Tabasco & 41.6 & $(2.4)$ & 31.6 & $(2.4)$ & 18.5 & $(1.7)$ & 6.7 & $(0.9)$ & 1.4 & $(0.5)$ & 0.2 & $\mathrm{C}$ & 0.0 & C \\
\hline & Tamaulipas & 27.7 & $(3.9)$ & 29.7 & $(2.4)$ & 25.8 & $(2.2)$ & 11.8 & $(2.1)$ & 4.1 & $(1.2)$ & 0.9 & $(0.7)$ & 0.0 & C \\
\hline & Tlaxcala & 24.5 & $(2.9)$ & 31.2 & $(1.8)$ & 27.3 & $(2.2)$ & 12.9 & $(1.6)$ & 3.6 & $(0.7)$ & 0.5 & $(0.4)$ & 0.0 & C \\
\hline & Veracruz & 30.1 & $(3.2)$ & 29.9 & $(2.4)$ & 23.6 & (1.7) & 12.5 & $(2.1)$ & 3.4 & $(1.0)$ & 0.5 & $(0.4)$ & 0.0 & C \\
\hline & Yucatán & 26.6 & $(2.5)$ & 30.9 & $(2.3)$ & 24.8 & $(1.7)$ & 12.6 & $(1.6)$ & 4.2 & $(0.7)$ & 0.7 & $(0.3)$ & 0.1 & $(0.2)$ \\
\hline & Zacatecas & 25.8 & $(2.5)$ & 31.5 & $(2.1)$ & 25.6 & $(1.8)$ & 13.1 & (1.4) & 3.7 & $(0.8)$ & 0.4 & $(0.2)$ & 0.0 & $\mathrm{C}$ \\
\hline
\end{tabular}

- PISA adjudicated region

Note: See Table I.2.8 for national data.

StatLink त्राड़ http://dx.doi.org/10.1787/888932935762 
[Part 2/2]

Table B2.I.7 Percentage of students at each proficiency level on the mathematics subscale employing, by region

\begin{tabular}{|c|c|c|c|c|c|c|c|c|c|c|c|c|c|c|c|}
\hline & & \multicolumn{14}{|c|}{ All students } \\
\hline & & \multicolumn{2}{|c|}{$\begin{array}{c}\text { Below Level } 1 \\
\text { (below } 357.77 \\
\text { score points) }\end{array}$} & \multicolumn{2}{|c|}{$\begin{array}{c}\text { Level } 1 \\
\text { (from } 357.77 \text { to } \\
\text { less than } 420.07 \\
\text { score points) }\end{array}$} & \multicolumn{2}{|c|}{$\begin{array}{c}\text { Level } 2 \\
\text { (from } 420.07 \text { to } \\
\text { less than } 482.38 \\
\text { score points) }\end{array}$} & $\begin{array}{l}\text { L } \\
\text { (from } \\
\text { less th } \\
\text { scor }\end{array}$ & \begin{tabular}{|l|}
3 \\
2.38 to \\
544.68 \\
oints)
\end{tabular} & $\begin{array}{l}\text { Le } \\
\text { (from } \\
\text { less th } \\
\text { scor }\end{array}$ & $\begin{array}{l}4 \\
4.68 \text { to } \\
606.99 \\
\text { oints) }\end{array}$ & $\begin{array}{l}\text { L } \\
\text { (from } \\
\text { less th } \\
\text { scor }\end{array}$ & \begin{tabular}{l|}
15 \\
6.99 to \\
669.30 \\
oints)
\end{tabular} & $\begin{array}{l}\text { Le } \\
\text { (abov } \\
\text { scor }\end{array}$ & $\begin{array}{l}16 \\
669.30 \\
\text { oints) }\end{array}$ \\
\hline & & $\%$ & S.E. & $\%$ & S.E. & $\%$ & S.E. & $\%$ & S.E. & $\%$ & S.E. & $\%$ & S.E. & $\%$ & S.E. \\
\hline 0 & Portugal & & & & & & & & & & & & & & \\
\hline 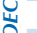 & Alentejo & 7.3 & $(1.9)$ & 14.4 & $(3.0)$ & 24.0 & $(2.0)$ & 25.3 & $(3.2)$ & 18.7 & $(2.7)$ & 8.5 & (1.7) & 1.6 & (0.8) \\
\hline & Spain & & & & & & & & & & & & & & \\
\hline & Andalusia ${ }^{\bullet}$ & 8.8 & $(1.3)$ & 19.9 & $(1.7)$ & 28.0 & $(2.2)$ & 24.5 & $(2.0)$ & 13.9 & (1.3) & 4.3 & $(0.9)$ & 0.7 & $(0.3)$ \\
\hline & Aragon • & 8.4 & (1.4) & 13.0 & (1.4) & 21.5 & (1.4) & 26.5 & (1.4) & 20.0 & (1.3) & 8.9 & (1.2) & 1.7 & $(0.6)$ \\
\hline & Asturias ${ }^{\bullet}$ & 6.6 & $(1.0)$ & 12.4 & $(1.1)$ & 23.3 & $(1.2)$ & 27.7 & $(1.2)$ & 20.0 & (1.3) & 8.2 & $(1.0)$ & 1.9 & $(0.5)$ \\
\hline & Balearic Islands ${ }^{\bullet}$ & 9.1 & $(1.4)$ & 17.3 & (1.6) & 26.0 & (1.3) & 26.8 & $(1.7)$ & 16.4 & (1.6) & 4.1 & $(0.7)$ & 0.3 & $(0.2)$ \\
\hline & Basque Country ${ }^{\bullet}$ & 4.2 & $(0.4)$ & 11.2 & $(0.7)$ & 23.1 & $(1.0)$ & 30.7 & $(0.9)$ & 22.9 & (0.9) & 7.0 & $(0.5)$ & 0.9 & $(0.2)$ \\
\hline & Cantabria ${ }^{\bullet}$ & 5.4 & $(1.0)$ & 14.3 & $(1.1)$ & 25.8 & $(1.4)$ & 26.3 & $(1.3)$ & 19.6 & (1.3) & 7.5 & (0.9) & 1.2 & $(0.3)$ \\
\hline & Castile and Leon ${ }^{\bullet}$ & 4.2 & $(0.8)$ & 10.7 & $(1.1)$ & 22.5 & $(1.5)$ & 29.0 & $(1.6)$ & 23.5 & (1.4) & 8.9 & (1.2) & 1.2 & (0.4) \\
\hline & Catalonia` & 5.9 & $(1.0)$ & 14.3 & $(1.6)$ & 23.4 & $(1.4)$ & 27.9 & $(1.3)$ & 20.1 & (1.6) & 7.3 & (1.0) & 1.2 & (0.4) \\
\hline & Extremadura ${ }^{\bullet}$ & 13.7 & (1.5) & 18.0 & $(1.1)$ & 25.5 & $(1.3)$ & 24.7 & $(1.3)$ & 13.5 & (1.4) & 4.0 & $(0.7)$ & 0.6 & $(0.3)$ \\
\hline & Galicia ${ }^{\bullet}$ & 8.4 & $(1.2)$ & 14.1 & $(1.4)$ & 24.2 & $(1.4)$ & 28.1 & $(1.4)$ & 18.6 & (1.7) & 5.7 & $(1.2)$ & 0.9 & $(0.3)$ \\
\hline & La Rioja・ & 8.5 & $(0.9)$ & 11.8 & $(1.0)$ & 20.2 & $(1.6)$ & 24.2 & $(1.6)$ & 21.6 & (1.1) & 11.5 & $(0.9)$ & 2.2 & $(0.4)$ \\
\hline & Madrid` & 6.3 & $(0.9)$ & 12.1 & $(1.1)$ & 21.5 & $(1.3)$ & 26.8 & $(1.7)$ & 23.0 & (1.8) & 8.9 & (1.3) & 1.4 & $(0.3)$ \\
\hline & Murcia ${ }^{\bullet}$ & 12.8 & (1.3) & 18.9 & $(1.7)$ & 26.5 & (1.5) & 24.4 & $(1.3)$ & 12.9 & $(1.2)$ & 3.8 & (0.9) & 0.8 & $(0.3)$ \\
\hline & Navarre ${ }^{\bullet}$ & 4.1 & $(0.7)$ & 9.4 & $(0.8)$ & 19.5 & (1.6) & 29.3 & $(1.7)$ & 24.6 & (1.5) & 11.1 & (1.0) & 1.8 & $(0.4)$ \\
\hline & United Kingdom & & & & & & & & & & & & & & \\
\hline & England & 8.0 & (0.9) & 14.6 & $(1.0)$ & 22.4 & $(1.0)$ & 25.0 & (1.1) & 18.4 & $(0.9)$ & 9.0 & $(0.7)$ & 2.7 & $(0.3)$ \\
\hline & Northern Ireland & 8.9 & $(1.0)$ & 16.1 & $(1.4)$ & 23.1 & (1.5) & 24.6 & $(1.4)$ & 17.0 & (1.1) & 8.3 & (1.1) & 2.0 & (0.4) \\
\hline & Scotland ${ }^{\bullet}$ & 6.3 & $(0.7)$ & 13.6 & $(0.9)$ & 24.3 & $(0.9)$ & 26.1 & $(0.9)$ & 18.9 & (1.0) & 8.5 & $(0.8)$ & 2.2 & $(0.3)$ \\
\hline & Wales & 10.5 & $(0.8)$ & 19.2 & $(0.8)$ & 28.0 & (1.0) & 24.3 & $(0.9)$ & 13.3 & $(0.8)$ & 4.0 & $(0.4)$ & 0.8 & $(0.3)$ \\
\hline & United States & & & & & & & & & & & & & & \\
\hline & Connecticut $^{\bullet}$ & 7.5 & (1.3) & 14.1 & (1.3) & 19.9 & (1.5) & 23.8 & (1.7) & 19.5 & (1.6) & 11.3 & (1.4) & 3.8 & $(0.7)$ \\
\hline & Florida $\bullet$ & 10.2 & $(1.3)$ & 20.5 & (1.6) & 26.9 & $(1.3)$ & 23.5 & (1.6) & 13.7 & (1.4) & 4.4 & $(0.9)$ & 0.9 & $(0.3)$ \\
\hline & Massachusetts ${ }^{\bullet}$ & 5.3 & $(0.9)$ & 12.7 & $(1.2)$ & 21.2 & (1.6) & 24.2 & (1.5) & 20.5 & (1.6) & 12.1 & (1.8) & 4.0 & (0.9) \\
\hline$\tilde{2}$ & Argentina & & & & & & & & & & & & & & \\
\hline 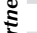 & Ciudad Autónoma de Buenos Aires ${ }^{\bullet}$ & 23.3 & $(2.5)$ & 22.5 & $(1.9)$ & 28.9 & $(2.1)$ & 17.3 & $(1.8)$ & 6.6 & $(1.2)$ & 1.3 & $(0.5)$ & 0.1 & $(0.1)$ \\
\hline ๘ & Brazil & & & & & & & & & & & & & & \\
\hline & Acre & 52.8 & (3.9) & 29.7 & $(3.0)$ & 13.7 & $(2.1)$ & 3.0 & $(1.3)$ & 0.5 & $(0.5)$ & 0.2 & $(0.2)$ & 0.0 & c \\
\hline & Alagoas & 64.8 & $(4.2)$ & 21.4 & $(3.4)$ & 10.0 & $(2.6)$ & 2.8 & $(1.2)$ & 0.8 & $(0.6)$ & 0.1 & $(0.2)$ & 0.0 & c \\
\hline & Amapá & 54.1 & (5.4) & 29.2 & $(3.9)$ & 13.2 & $(2.7)$ & 3.3 & $(1.4)$ & 0.3 & $(0.4)$ & 0.0 & c & 0.0 & c \\
\hline & Amazonas & 58.9 & (3.7) & 28.6 & (3.1) & 8.4 & (1.6) & 2.5 & $(1.0)$ & 1.4 & (1.3) & 0.1 & $\mathrm{C}$ & 0.0 & c \\
\hline & Bahia & 47.9 & $(5.7)$ & 26.3 & $(3.2)$ & 15.5 & $(3.8)$ & 7.3 & $(1.8)$ & 2.3 & (1.4) & 0.6 & $(0.5)$ & 0.0 & c \\
\hline & Ceará & 45.3 & $(4.2)$ & 29.4 & $(3.5)$ & 14.8 & $(2.1)$ & 6.3 & $(2.0)$ & 2.7 & (1.4) & 1.2 & $(0.6)$ & 0.3 & $(0.3)$ \\
\hline & Espírito Santo & 27.3 & (3.5) & 29.9 & $(3.3)$ & 20.6 & $(2.7)$ & 13.1 & $(2.6)$ & 7.3 & $(2.5)$ & 1.7 & $(0.9)$ & 0.1 & c \\
\hline & Federal District & 29.2 & $(4.2)$ & 26.7 & $(3.1)$ & 22.2 & $(2.8)$ & 14.3 & $(2.2)$ & 6.1 & $(2.2)$ & 1.3 & $(0.8)$ & 0.1 & c \\
\hline & Goiás & 40.0 & $(4.1)$ & 34.0 & (3.4) & 16.4 & $(2.2)$ & 7.6 & $(1.5)$ & 1.7 & $(0.6)$ & 0.2 & $(0.1)$ & 0.0 & c \\
\hline & Maranhão & 61.5 & $(7.2)$ & 23.7 & $(3.3)$ & 8.6 & $(3.2)$ & 4.7 & $(2.8)$ & 1.4 & $(1.2)$ & 0.1 & $\mathrm{c}$ & 0.0 & c \\
\hline & Mato Grosso & 49.2 & $(4.8)$ & 30.0 & $(3.0)$ & 14.4 & $(2.7)$ & 3.9 & $(1.8)$ & 2.1 & $(1.3)$ & 0.5 & $(0.4)$ & 0.1 & c \\
\hline & Mato Grosso do Sul & 27.9 & $(4.1)$ & 32.0 & $(3.7)$ & 24.5 & $(3.0)$ & 10.8 & $(1.4)$ & 4.2 & $(1.7)$ & 0.6 & $(0.6)$ & 0.0 & c \\
\hline & Minas Gerais & 28.8 & $(3.8)$ & 31.5 & $(2.8)$ & 25.8 & $(2.7)$ & 11.0 & $(2.0)$ & 2.4 & $(1.1)$ & 0.5 & $\mathrm{C}$ & 0.0 & c \\
\hline & Pará & 53.8 & (3.7) & 25.6 & $(3.2)$ & 16.5 & $(2.5)$ & 3.7 & $(1.6)$ & 0.4 & $(0.4)$ & 0.0 & c & 0.0 & c \\
\hline & Paraiba & 35.4 & $(4.9)$ & 31.1 & (3.8) & 20.8 & (3.9) & 9.2 & $(1.7)$ & 3.1 & (1.6) & 0.4 & $(0.4)$ & 0.1 & c \\
\hline & Paraná & 33.3 & $(3.9)$ & 29.6 & $(3.3)$ & 20.7 & $(2.8)$ & 8.9 & $(1.6)$ & 5.5 & (3.1) & 1.7 & (1.7) & 0.1 & c \\
\hline & Pernambuco & 51.3 & $(4.2)$ & 31.0 & $(2.9)$ & 13.4 & $(2.4)$ & 3.5 & $(1.2)$ & 0.7 & $(0.6)$ & 0.0 & C & 0.0 & c \\
\hline & Piauí & 41.3 & $(3.8)$ & 30.4 & $(3.1)$ & 14.6 & $(2.3)$ & 8.8 & $(1.8)$ & 3.2 & (1.4) & 1.5 & (1.3) & 0.3 & $(0.1)$ \\
\hline & Rio de Janeiro & 37.9 & $(4.1)$ & 31.9 & $(3.0)$ & 19.0 & $(2.7)$ & 8.2 & $(1.8)$ & 2.5 & $(1.0)$ & 0.4 & $(0.4)$ & 0.0 & C \\
\hline & Rio Grande do Norte & 50.3 & $(4.0)$ & 25.3 & $(3.0)$ & 11.8 & $(2.0)$ & 7.2 & $(1.6)$ & 3.1 & $(1.5)$ & 2.0 & (1.1) & 0.3 & $(0.3)$ \\
\hline & Rio Grande do Sul & 28.6 & $(3.6)$ & 31.9 & $(2.4)$ & 25.1 & $(2.6)$ & 11.9 & $(1.7)$ & 2.0 & $(0.6)$ & 0.5 & $(0.3)$ & 0.0 & c \\
\hline & Rondônia & 38.3 & $(3.3)$ & 36.6 & $(2.5)$ & 18.9 & $(2.5)$ & 5.1 & $(1.4)$ & 1.0 & $(0.5)$ & 0.1 & c & 0.0 & c \\
\hline & Roraima & 54.7 & $(3.3)$ & 26.0 & $(2.3)$ & 13.1 & $(2.1)$ & 4.6 & $(1.3)$ & 1.5 & $(0.8)$ & 0.2 & $(0.2)$ & 0.0 & c \\
\hline & Santa Catarina & 22.3 & $(3.2)$ & 30.7 & $(2.8)$ & 26.4 & $(2.3)$ & 14.3 & $(2.5)$ & 5.5 & $(1.7)$ & 0.8 & $(0.4)$ & 0.0 & c \\
\hline & São Paulo & 32.1 & $(1.6)$ & 30.6 & $(1.5)$ & 22.1 & $(1.3)$ & 10.3 & $(1.1)$ & 3.8 & $(0.9)$ & 1.0 & $(0.5)$ & 0.2 & $(0.1)$ \\
\hline & Sergipe & 38.6 & $(4.6)$ & 31.7 & (3.7) & 18.1 & $(3.2)$ & 9.3 & $(3.2)$ & 1.8 & $(1.0)$ & 0.4 & $(0.4)$ & 0.0 & c \\
\hline & Tocantins & 50.9 & (3.8) & 27.2 & $(2.7)$ & 14.5 & $(2.0)$ & 5.1 & $(1.5)$ & 1.7 & $(0.7)$ & 0.6 & $(0.4)$ & 0.0 & c \\
\hline & Colombia & & & & & & & & & & & & & & \\
\hline & Bogotá & 35.4 & (2.0) & 34.4 & (1.6) & 21.4 & (1.5) & 7.1 & (1.0) & 1.3 & $(0.6)$ & 0.2 & $(0.2)$ & 0.1 & c \\
\hline & Cali & 43.7 & (3.8) & 30.2 & $(1.6)$ & 18.3 & $(2.4)$ & 6.2 & $(1.3)$ & 1.6 & $(0.5)$ & 0.0 & C & 0.0 & c \\
\hline & Manizales & 33.7 & $(2.6)$ & 32.0 & $(2.6)$ & 21.4 & $(2.1)$ & 9.4 & (1.4) & 2.9 & $(1.0)$ & 0.6 & (0.5) & 0.0 & c \\
\hline & Medellín & 42.3 & (3.4) & 27.9 & (1.9) & 16.0 & (1.9) & 8.8 & (1.6) & 3.5 & (1.1) & 1.3 & $(0.7)$ & 0.3 & $(0.2)$ \\
\hline & Russian Federation & & & & & & & & & & & & & & \\
\hline & Perm Territory region & 7.7 & (1.3) & 14.9 & (1.3) & 25.7 & (1.4) & 25.7 & (1.8) & 17.1 & (1.6) & 6.8 & $(1.2)$ & 2.1 & $(0.8)$ \\
\hline & United Arab Emirates & & & & & & & & & & & & & & \\
\hline & Abu Dhabi ${ }^{\bullet}$ & 22.5 & (1.5) & 26.2 & $(1.2)$ & 25.3 & $(1.1)$ & 15.5 & $(1.0)$ & 7.6 & $(0.9)$ & 2.5 & $(0.5)$ & 0.4 & $(0.2)$ \\
\hline & Ajman & 28.1 & $(4.4)$ & 29.1 & $(3.0)$ & 25.6 & (2.9) & 13.4 & $(2.1)$ & 3.2 & $(1.0)$ & 0.6 & $(0.5)$ & 0.0 & c \\
\hline & Dubai & 12.4 & $(0.4)$ & 19.1 & $(1.0)$ & 23.8 & $(1.0)$ & 22.1 & $(0.9)$ & 15.4 & $(0.7)$ & 5.8 & $(0.5)$ & 1.5 & $(0.3)$ \\
\hline & Fujairah & 25.6 & $(4.4)$ & 25.9 & $(2.7)$ & 25.3 & $(2.6)$ & 15.8 & $(2.4)$ & 5.9 & $(1.2)$ & 1.2 & $(0.6)$ & 0.3 & $(0.2)$ \\
\hline & Ras al-Khaimah & 20.4 & $(3.3)$ & 28.4 & $(2.3)$ & 27.9 & $(2.9)$ & 16.0 & $(2.2)$ & 6.1 & $(1.5)$ & 1.0 & $(0.5)$ & 0.1 & c \\
\hline & Sharjah & 16.9 & $(2.9)$ & 25.0 & $(2.4)$ & 24.7 & $(2.2)$ & 19.2 & $(2.8)$ & 10.5 & $(2.0)$ & 3.1 & (1.0) & 0.6 & $(0.4)$ \\
\hline & Umm al-Quwain & 27.9 & (2.5) & 34.5 & (3.9) & 23.9 & $(3.0)$ & 9.5 & (1.8) & 3.0 & (1.0) & 1.3 & $(0.8)$ & 0.0 & $\mathrm{C}$ \\
\hline
\end{tabular}

- PISA adjudicated region.

Note: See Table I.2.8 for national data.

StatLink 解古 $\mathrm{http}: / / \mathrm{dx}$.doi.org/10.1787/888932935762 
Percentage of students at each proficiency level on the mathematics subscale employing, by gender Table B2.I.8 and region

\begin{tabular}{|c|c|c|c|c|c|c|c|c|c|c|c|c|c|c|c|}
\hline & & \multicolumn{14}{|c|}{ Boys } \\
\hline & & \multicolumn{2}{|c|}{$\begin{array}{l}\text { Below Level } 1 \\
\text { (below 357.77 } \\
\text { score points) }\end{array}$} & $\begin{array}{r}1 \\
\text { (from } \\
\text { less th } \\
\text { scor }\end{array}$ & $\begin{array}{l}11 \\
7.77 \text { to } \\
420.07 \\
\text { oints) }\end{array}$ & $\begin{array}{l}\text { Le } \\
\text { (from } \\
\text { less th } \\
\text { scor }\end{array}$ & $\begin{array}{l}l 2 \\
0.07 \text { to } \\
482.38 \\
\text { oints) }\end{array}$ & $\begin{array}{r}\mathbf{L} \\
\text { (from } \\
\text { less th } \\
\text { scor }\end{array}$ & \begin{tabular}{|l|}
3 \\
2.38 to \\
544.68 \\
oints)
\end{tabular} & $\begin{array}{r}\mathrm{L} \\
\text { (from } \\
\text { less th } \\
\text { scor }\end{array}$ & $\begin{array}{l}44 \\
4.68 \text { to } \\
606.99 \\
\text { oints) }\end{array}$ & $\begin{array}{r}\mathrm{L} \\
\text { (from } \\
\text { less th } \\
\text { scor }\end{array}$ & $\begin{array}{l}5 \\
6.99 \text { to } \\
669.30 \\
\text { oints) }\end{array}$ & $\begin{array}{r}\mathrm{L} \\
\text { (abo } \\
\text { scor }\end{array}$ & $\begin{array}{l}16 \\
669.30 \\
\text { oints) }\end{array}$ \\
\hline & & $\%$ & S.E. & $\%$ & S.E. & $\%$ & S.E. & $\%$ & S.E. & $\%$ & S.E. & $\%$ & S.E. & $\%$ & S.E. \\
\hline$\theta$ & Australia & & & & & & & & & & & & & & \\
\hline U & Australian Capital Territory & 6.3 & (1.4) & 11.6 & (1.9) & 19.0 & $(2.9)$ & 24.4 & $(3.2)$ & 21.6 & (2.4) & 12.2 & $(2.6)$ & 5.0 & (1.5) \\
\hline & New South Wales & 6.9 & $(1.1)$ & 13.7 & $(1.2)$ & 20.4 & (1.4) & 22.4 & (1.4) & 18.5 & (1.3) & 12.3 & (1.3) & 5.9 & $(1.2)$ \\
\hline & Northern Territory & 18.2 & $(2.7)$ & 17.7 & $(4.3)$ & 21.3 & $(3.7)$ & 23.3 & $(4.2)$ & 12.1 & (4.9) & 5.9 & $(2.9)$ & 1.6 & $(1.4)$ \\
\hline & Queensland & 6.0 & (1.1) & 13.1 & $(1.2)$ & 22.4 & (1.7) & 24.7 & (1.7) & 19.4 & $(1.8)$ & 11.3 & $(1.2)$ & 3.0 & $(0.6)$ \\
\hline & South Australia & 7.7 & $(1.2)$ & 14.4 & (1.6) & 24.7 & (2.6) & 24.7 & $(2.7)$ & 18.3 & $(2.1)$ & 8.4 & (1.6) & 1.7 & $(0.6)$ \\
\hline & Tasmania & 10.9 & (1.6) & 14.2 & (1.7) & 26.1 & (2.3) & 24.5 & $(2.3)$ & 16.6 & (2.5) & 6.4 & $(1.7)$ & 1.3 & $(0.6)$ \\
\hline & Victoria & 5.7 & $(0.7)$ & 11.8 & $(1.2)$ & 23.1 & (1.5) & 25.7 & $(1.7)$ & 20.9 & (1.7) & 8.9 & $(1.3)$ & 3.8 & $(1.2)$ \\
\hline & Western Australia & 3.8 & $(0.7)$ & 10.5 & (1.5) & 20.0 & $(2.0)$ & 23.6 & $(1.7)$ & 23.7 & $(1.8)$ & 14.0 & $(1.7)$ & 4.7 & (1.1) \\
\hline & Belgium & & & & & & & & & & & & & & \\
\hline & Flemish Community ${ }^{\bullet}$ & 5.0 & $(0.9)$ & 8.7 & $(1.0)$ & 15.8 & $(1.0)$ & 20.4 & $(1.2)$ & 22.5 & (1.3) & 17.5 & $(1.1)$ & 10.0 & $(0.9)$ \\
\hline & French Community & 8.7 & (1.1) & 14.0 & (1.3) & 20.4 & (1.3) & 22.1 & (1.5) & 19.9 & (1.4) & 11.5 & $(1.2)$ & 3.4 & $(0.5)$ \\
\hline & German-speaking Community & 6.5 & (1.1) & 11.2 & (1.6) & 18.4 & $(2.2)$ & 25.4 & (2.6) & 23.5 & (2.4) & 11.7 & (1.7) & 3.3 & $(0.9)$ \\
\hline & Canada & & & & & & & & & & & & & & \\
\hline & Alberta & 4.4 & $(1.2)$ & 9.6 & $(1.7)$ & 19.8 & $(1.7)$ & 26.4 & (1.7) & 22.0 & (1.8) & 13.5 & (1.7) & 4.4 & $(0.8)$ \\
\hline & British Columbia & 2.3 & $(0.8)$ & 8.3 & $(1.3)$ & 19.7 & $(2.2)$ & 27.6 & (1.9) & 23.8 & (1.9) & 13.6 & $(1.5)$ & 4.7 & $(0.9)$ \\
\hline & Manitoba & 5.7 & (1.4) & 15.1 & $(1.8)$ & 25.8 & $(2.7)$ & 25.4 & (1.8) & 16.9 & (1.7) & 8.4 & $(1.0)$ & 2.6 & $(0.8)$ \\
\hline & New Brunswick & 4.1 & (1.0) & 13.1 & $(1.8)$ & 23.4 & $(2.1)$ & 30.5 & $(2.5)$ & 18.4 & $(2.2)$ & 8.7 & (1.5) & 1.8 & $(0.5)$ \\
\hline & Newfoundland and Labrador & 7.8 & (1.9) & 15.6 & (2.4) & 23.0 & $(2.3)$ & 25.7 & $(3.3)$ & 17.3 & $(2.0)$ & 8.4 & (1.8) & 2.3 & $(1.0)$ \\
\hline & Nova Scotia & 5.8 & (1.1) & 11.8 & (1.9) & 23.3 & (2.4) & 29.3 & (2.9) & 21.4 & (2.3) & 7.0 & $(1.7)$ & 1.4 & $(0.7)$ \\
\hline & Ontario & 4.2 & $(0.8)$ & 10.0 & (1.6) & 20.7 & $(2.2)$ & 26.3 & $(2.0)$ & 21.9 & (1.7) & 12.8 & $(1.7)$ & 4.1 & $(1.0)$ \\
\hline & Prince Edward Island & 6.1 & (1.0) & 18.9 & $(2.1)$ & 25.7 & (2.6) & 25.8 & (1.9) & 16.0 & (1.6) & 6.5 & $(1.2)$ & 0.9 & $(0.5)$ \\
\hline & Quebec & 2.7 & $(0.8)$ & 7.5 & $(1.0)$ & 16.2 & (1.5) & 23.2 & (1.6) & 25.4 & (1.7) & 18.7 & (1.5) & 6.3 & $(0.9)$ \\
\hline & Saskatchewan & 3.7 & $(0.9)$ & 11.3 & (1.4) & 23.5 & (2.5) & 26.2 & (2.9) & 22.6 & (1.9) & 10.8 & (1.7) & 1.8 & $(0.8)$ \\
\hline & Italy & & & & & & & & & & & & & & \\
\hline & Abruzzo & 8.5 & (2.5) & 14.7 & $(2.7)$ & 25.1 & $(2.1)$ & 25.9 & (1.8) & 18.3 & $(2.2)$ & 5.8 & $(1.2)$ & 1.6 & $(0.6)$ \\
\hline & Basilicata & 8.4 & $(1.3)$ & 18.7 & $(2.3)$ & 24.6 & $(1.8)$ & 23.9 & $(2.1)$ & 16.0 & (1.9) & 6.4 & (1.1) & 2.0 & $(0.6)$ \\
\hline & Bolzano & 5.6 & (1.0) & 11.3 & (1.4) & 18.7 & (1.6) & 25.3 & (1.8) & 22.0 & (1.5) & 12.8 & (1.4) & 4.3 & $(0.8)$ \\
\hline & Calabria & 18.5 & $(2.5)$ & 22.6 & $(2.7)$ & 25.7 & (2.4) & 21.1 & (2.3) & 8.7 & (1.7) & 2.6 & $(0.8)$ & 0.8 & $(0.4)$ \\
\hline & Campania & 13.9 & (2.2) & 20.1 & (2.5) & 25.5 & (2.5) & 20.8 & $(2.3)$ & 13.1 & $(2.0)$ & 5.5 & (1.4) & 1.1 & $(0.5)$ \\
\hline & Emilia Romagna & 6.8 & (1.5) & 11.7 & (2.5) & 19.6 & (2.4) & 23.1 & $(2.9)$ & 21.0 & $(2.3)$ & 12.3 & $(2.1)$ & 5.4 & (1.4) \\
\hline & Friuli Venezia Giulia & 3.3 & $(1.2)$ & 9.9 & (1.9) & 16.7 & (2.3) & 24.4 & $(2.0)$ & 24.5 & (2.3) & 15.7 & $(2.1)$ & 5.5 & (1.1) \\
\hline & Lazio & 8.1 & (1.5) & 16.1 & (2.4) & 26.2 & $(2.2)$ & 23.0 & $(2.2)$ & 16.7 & (1.6) & 8.3 & $(1.5)$ & 1.7 & $(0.8)$ \\
\hline & Liguria & 6.9 & (2.0) & 15.9 & (2.6) & 23.4 & (2.3) & 24.5 & $(2.2)$ & 17.1 & $(2.1)$ & 8.7 & $(1.8)$ & 3.5 & $(0.7)$ \\
\hline & Lombardia & 4.9 & $(1.1)$ & 8.6 & (1.5) & 16.8 & (2.5) & 24.9 & $(2.7)$ & 24.6 & (3.1) & 15.3 & $(2.3)$ & 5.0 & (1.3) \\
\hline & Marche & 4.0 & (1.4) & 11.1 & $(2.1)$ & 22.2 & $(2.0)$ & 27.7 & $(2.1)$ & 21.4 & $(2.2)$ & 10.7 & $(1.8)$ & 3.1 & $(0.9)$ \\
\hline & Molise & 9.4 & $(1.2)$ & 17.2 & $(2.1)$ & 27.3 & (2.5) & 25.6 & $(3.1)$ & 14.2 & (2.3) & 5.3 & $(1.9)$ & 1.1 & (0.6) \\
\hline & Piemonte & 4.5 & $(0.9)$ & 9.4 & (1.7) & 20.8 & (2.5) & 28.9 & (3.3) & 24.1 & (3.1) & 10.3 & $(1.7)$ & 2.0 & $(0.8)$ \\
\hline & Puglia & 7.8 & (2.0) & 15.3 & $(2.3)$ & 21.1 & (2.5) & 26.5 & (2.4) & 19.8 & (2.6) & 8.7 & $(1.4)$ & 0.9 & $(0.4)$ \\
\hline & Sardegna & 13.9 & (2.0) & 19.3 & (2.3) & 27.8 & (2.5) & 21.4 & (1.9) & 13.4 & (1.6) & 3.9 & $(0.9)$ & 0.5 & $(0.3)$ \\
\hline & Sicilia & 13.5 & (2.2) & 22.9 & (2.6) & 29.0 & $(2.3)$ & 21.8 & $(2.3)$ & 9.5 & (1.7) & 2.9 & $(0.9)$ & 0.5 & $(0.3)$ \\
\hline & Toscana & 7.4 & (1.5) & 14.7 & (3.0) & 22.5 & (2.0) & 22.7 & (2.4) & 18.8 & $(2.1)$ & 10.5 & $(1.7)$ & 3.3 & $(0.9)$ \\
\hline & Trento & 3.1 & (1.0) & 8.8 & (1.6) & 19.2 & $(2.2)$ & 26.0 & $(2.1)$ & 24.0 & $(2.0)$ & 15.3 & (1.9) & 3.6 & (1.0) \\
\hline & Umbria & 7.0 & (2.7) & 12.0 & (2.6) & 21.3 & $(2.8)$ & 25.0 & (3.1) & 21.7 & $(2.7)$ & 10.3 & (1.7) & 2.8 & $(1.0)$ \\
\hline & Valle d'Aosta & 5.2 & $(1.3)$ & 12.6 & $(2.1)$ & 24.0 & (2.6) & 27.4 & (3.4) & 19.3 & (2.0) & 9.2 & $(1.4)$ & 2.3 & $(0.7)$ \\
\hline & Veneto & 4.0 & $(1.2)$ & 8.4 & (1.6) & 17.2 & (2.3) & 22.4 & (3.0) & 23.8 & (2.4) & 16.6 & $(2.3)$ & 7.7 & (1.9) \\
\hline & Mexico & & & & & & & & & & & & & & \\
\hline & Aguascalientes & 16.6 & (2.9) & 24.2 & $(2.3)$ & 28.8 & $(3.2)$ & 19.6 & (2.4) & 8.2 & (1.8) & 2.5 & $(1.0)$ & 0.2 & C \\
\hline & Baja California & 18.7 & (3.0) & 32.4 & (3.9) & 28.2 & (3.5) & 15.4 & $(2.3)$ & 4.3 & (1.3) & 0.8 & $(0.6)$ & 0.1 & C \\
\hline & Baja California Sur & 20.9 & (3.4) & 29.6 & (3.0) & 27.5 & (3.6) & 15.5 & $(2.5)$ & 5.7 & $(1.2)$ & 0.7 & $(0.5)$ & 0.1 & c \\
\hline & Campeche & 28.2 & (3.0) & 33.7 & (3.0) & 25.0 & (2.6) & 9.4 & (1.7) & 3.2 & (1.1) & 0.4 & $(0.4)$ & 0.0 & c \\
\hline & Chiapas & 41.5 & (4.8) & 30.1 & (3.6) & 19.4 & (3.3) & 6.3 & (1.5) & 2.0 & $(0.7)$ & 0.5 & $(0.3)$ & 0.2 & $(0.2)$ \\
\hline & Chihuahua & 14.9 & (3.4) & 28.0 & (3.0) & 29.7 & (3.4) & 16.2 & $(2.7)$ & 9.0 & $(2.3)$ & 1.9 & $(0.9)$ & 0.1 & c \\
\hline & Coahuila & 22.6 & $(4.2)$ & 27.2 & (3.7) & 25.5 & (3.0) & 17.2 & $(2.9)$ & 6.4 & $(2.1)$ & 1.0 & $(0.7)$ & 0.1 & c \\
\hline & Colima & 19.5 & (2.7) & 26.2 & $(2.3)$ & 26.7 & (2.9) & 17.7 & $(2.8)$ & 8.1 & (1.9) & 1.4 & $(0.7)$ & 0.4 & $(0.3)$ \\
\hline & Distrito Federal & 13.3 & (1.9) & 25.2 & (3.1) & 30.0 & (3.0) & 21.8 & $(3.2)$ & 7.7 & (1.5) & 2.0 & $(0.7)$ & 0.0 & C \\
\hline & Durango & 16.6 & $(3.0)$ & 25.4 & (3.1) & 28.6 & (2.9) & 21.3 & (3.5) & 6.8 & (1.9) & 1.3 & $(0.6)$ & 0.0 & c \\
\hline & Guanajuato & 21.3 & (3.1) & 26.3 & (3.5) & 27.9 & (3.3) & 16.7 & $(2.2)$ & 7.0 & (1.6) & 0.9 & $(0.4)$ & 0.0 & C \\
\hline & Guerrero & 44.5 & (3.7) & 32.9 & (3.7) & 17.5 & (1.9) & 3.8 & $(1.2)$ & 1.2 & $(0.6)$ & 0.1 & c & 0.0 & c \\
\hline & Hidalgo & 22.6 & (3.7) & 31.1 & (3.6) & 27.4 & $(3.2)$ & 14.6 & $(2.2)$ & 3.6 & (1.3) & 0.6 & $(0.4)$ & 0.0 & C \\
\hline & Jalisco & 15.4 & (2.9) & 25.4 & (3.5) & 30.6 & (2.9) & 19.2 & (3.1) & 7.5 & $(1.7)$ & 1.5 & $(0.6)$ & 0.3 & $(0.3)$ \\
\hline & Mexico & 18.1 & (2.9) & 31.9 & (3.0) & 31.0 & (3.3) & 15.2 & $(2.1)$ & 2.9 & (0.8) & 0.7 & $(0.6)$ & 0.2 & C \\
\hline & Morelos & 19.7 & (5.1) & 29.3 & $(3.2)$ & 27.5 & (3.7) & 14.6 & $(2.6)$ & 6.7 & $(2.1)$ & 1.8 & $(1.0)$ & 0.3 & $(0.4)$ \\
\hline & Nayarit & 23.0 & (2.9) & 25.1 & (2.3) & 30.8 & (2.4) & 15.1 & $(2.2)$ & 5.3 & (1.4) & 0.7 & $(0.5)$ & 0.0 & c \\
\hline & Nuevo León & 13.3 & (2.6) & 24.5 & (3.9) & 30.3 & (3.0) & 21.0 & $(3.7)$ & 9.5 & (3.1) & 1.3 & $(0.5)$ & 0.1 & C \\
\hline & Puebla & 20.7 & (3.7) & 27.9 & (2.6) & 28.4 & (3.0) & 15.7 & $(2.1)$ & 6.4 & (1.4) & 0.8 & $(0.5)$ & 0.0 & C \\
\hline & Querétaro & 15.6 & $(2.2)$ & 26.7 & (3.7) & 29.3 & (3.9) & 19.3 & (3.8) & 7.3 & $(2.2)$ & 1.7 & $(0.7)$ & 0.1 & $(0.1)$ \\
\hline & Quintana Roo & 24.2 & (3.4) & 31.5 & (3.8) & 25.9 & (2.4) & 13.6 & $(2.3)$ & 4.2 & (1.1) & 0.6 & $(0.4)$ & 0.0 & c \\
\hline & San Luis Potosí & 26.2 & $(4.0)$ & 27.3 & $(4.2)$ & 26.4 & (3.9) & 14.1 & $(3.1)$ & 4.8 & (1.6) & 0.9 & $(0.7)$ & 0.2 & c \\
\hline & Sinaloa & 23.3 & (3.1) & 33.1 & $(3.2)$ & 27.1 & $(2.7)$ & 12.3 & $(2.1)$ & 3.6 & (1.1) & 0.5 & $(0.3)$ & 0.0 & C \\
\hline & Tabasco & 39.8 & (3.5) & 30.6 & (3.5) & 19.0 & (2.5) & 8.6 & $(1.6)$ & 1.7 & (0.8) & 0.3 & C & 0.0 & C \\
\hline & Tamaulipas & 24.4 & (5.0) & 27.8 & $(2.8)$ & 27.3 & (3.5) & 13.2 & $(2.5)$ & 5.7 & (2.0) & 1.6 & $(1.2)$ & 0.1 & c \\
\hline & Tlaxcala & 23.2 & (2.8) & 29.1 & (2.8) & 28.7 & (2.7) & 14.2 & (1.8) & 4.3 & $(1.2)$ & 0.5 & $(0.4)$ & 0.0 & C \\
\hline & Veracruz & 29.2 & (3.3) & 27.2 & (2.5) & 25.4 & (2.7) & 13.5 & $(2.5)$ & 3.9 & (1.4) & 0.6 & $(0.5)$ & 0.1 & c \\
\hline & Yucatán & 22.5 & (3.1) & 30.6 & (2.9) & 25.5 & (2.6) & 14.5 & $(2.4)$ & 5.6 & $(1.2)$ & 1.1 & $(0.6)$ & 0.2 & c \\
\hline & Zacatecas & 24.1 & (3.4) & 29.7 & $(2.2)$ & 26.0 & (2.4) & 15.4 & $(2.1)$ & 4.3 & $(1.2)$ & 0.4 & $(0.3)$ & 0.0 & $\mathrm{C}$ \\
\hline
\end{tabular}

- PISA adjudicated region

Note: See Table 1.2.9 for national data.

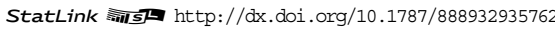


Part 2/4]

Percentage of students at each proficiency level on the mathematics subscale employing, by gender Table B2.I.8 and region

\begin{tabular}{|c|c|c|c|c|c|c|c|c|c|c|c|c|c|c|c|}
\hline & & \multicolumn{14}{|c|}{ Boys } \\
\hline & & \multicolumn{2}{|c|}{$\begin{array}{l}\text { Below Level } 1 \\
\text { (below } 357.77 \\
\text { score points) }\end{array}$} & \multicolumn{2}{|c|}{$\begin{array}{c}\text { Level } 1 \\
\text { (from } 357.77 \text { to } \\
\text { less than } 420.07 \\
\text { score points) }\end{array}$} & \multicolumn{2}{|c|}{$\begin{array}{c}\text { Level } 2 \\
\text { (from } 420.07 \text { to } \\
\text { less than } 482.38 \\
\text { score points) }\end{array}$} & $\begin{array}{r}\text { L } \\
\text { (from } \\
\text { less th } \\
\text { scor }\end{array}$ & \begin{tabular}{|l|}
3 \\
2.38 to \\
544.68 \\
oints)
\end{tabular} & $\begin{array}{l}\text { Le } \\
\text { (from } \\
\text { less th } \\
\text { scor }\end{array}$ & $\begin{array}{l}4 \\
4.68 \text { to } \\
606.99 \\
\text { oints) }\end{array}$ & $\begin{array}{r}\text { L } \\
\text { (from } \\
\text { less th } \\
\text { scor }\end{array}$ & $\begin{array}{l}5 \\
6.99 \text { to } \\
669.30 \\
\text { oints) }\end{array}$ & $\begin{array}{l}\text { Le } \\
\text { (abov } \\
\text { scor }\end{array}$ & $\begin{array}{l}\text { I } 6 \\
669.30 \\
\text { oints) }\end{array}$ \\
\hline & & $\%$ & S.E. & $\%$ & S.E. & $\%$ & S.E. & $\%$ & S.E. & $\%$ & S.E. & $\%$ & S.E. & $\%$ & S.E. \\
\hline 0 & Portugal & & & & & & & & & & & & & & \\
\hline 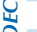 & Alentejo & 6.2 & $(2.0)$ & 13.3 & $(4.2)$ & 22.8 & (3.1) & 26.1 & (4.3) & 19.5 & (3.3) & 9.6 & (2.3) & 2.5 & (1.4) \\
\hline & Spain & & & & & & & & & & & & & & \\
\hline & Andalusia ${ }^{\bullet}$ & 8.7 & $(1.8)$ & 18.2 & (2.4) & 24.9 & $(2.4)$ & 25.4 & (2.5) & 15.8 & (1.8) & 5.9 & (1.3) & 1.2 & $(0.5)$ \\
\hline & Aragon` & 7.6 & $(1.5)$ & 12.9 & (1.7) & 20.5 & (1.8) & 24.1 & (1.7) & 21.2 & (1.7) & 11.6 & (1.8) & 2.2 & (1.1) \\
\hline & Asturias ${ }^{\bullet}$ & 7.2 & (1.5) & 11.0 & (1.4) & 22.3 & $(1.8)$ & 26.5 & (1.7) & 21.0 & (1.7) & 9.3 & (1.4) & 2.6 & $(0.9)$ \\
\hline & Balearic Islands & 8.7 & $(1.7)$ & 16.9 & $(2.2)$ & 26.0 & $(1.8)$ & 26.7 & $(2.2)$ & 16.8 & (1.9) & 4.4 & (1.0) & 0.5 & $(0.3)$ \\
\hline & Basque Country• & 4.0 & $(0.7)$ & 10.5 & $(0.9)$ & 21.2 & $(1.3)$ & 30.4 & (1.3) & 24.3 & $(1.3)$ & 8.6 & $(0.7)$ & 1.1 & $(0.3)$ \\
\hline & Cantabria• & 6.2 & $(1.3)$ & 13.4 & (1.5) & 23.1 & (1.9) & 25.0 & (1.9) & 21.8 & $(2.1)$ & 8.9 & (1.4) & 1.6 & $(0.5)$ \\
\hline & Castile and Leon ${ }^{\bullet}$ & 4.6 & $(1.2)$ & 10.1 & (1.4) & 20.1 & (1.9) & 25.1 & (2.5) & 26.3 & (2.3) & 11.9 & (1.7) & 1.9 & $(0.6)$ \\
\hline & Catalonia ${ }^{\bullet}$ & 5.3 & $(1.3)$ & 13.3 & $(2.2)$ & 22.0 & $(2.4)$ & 25.3 & $(2.1)$ & 22.4 & (2.3) & 9.9 & (1.6) & 1.8 & $(0.7)$ \\
\hline & Extremadura ${ }^{\bullet}$ & 14.3 & $(2.0)$ & 17.5 & (1.7) & 22.7 & $(2.1)$ & 24.5 & (2.0) & 14.9 & $(2.2)$ & 5.3 & (1.0) & 1.0 & (0.6) \\
\hline & Galicia• & 8.6 & (1.5) & 14.5 & (1.9) & 22.9 & $(2.2)$ & 27.7 & (2.1) & 19.2 & (1.9) & 6.0 & (1.7) & 1.0 & $(0.4)$ \\
\hline & La Rioja` & 8.9 & $(1.2)$ & 10.9 & (1.3) & 18.2 & $(1.6)$ & 21.4 & (2.1) & 22.0 & (1.7) & 15.6 & (1.6) & 3.1 & $(0.7)$ \\
\hline & Madrid` & 6.4 & (1.1) & 11.8 & (1.6) & 20.0 & (2.1) & 25.8 & (2.3) & 23.6 & (1.7) & 10.4 & (1.7) & 2.0 & $(0.7)$ \\
\hline & Murcia` & 13.0 & (1.9) & 17.9 & (2.8) & 24.1 & $(2.3)$ & 23.1 & $(2.2)$ & 15.1 & (1.8) & 5.8 & (1.4) & 1.0 & (0.6) \\
\hline & Navarre ${ }^{\bullet}$ & 4.9 & (1.1) & 9.0 & (1.1) & 16.9 & (1.8) & 29.7 & (2.0) & 25.4 & (1.9) & 11.9 & (1.5) & 2.2 & $(0.7)$ \\
\hline & United Kingdom & & & & & & & & & & & & & & \\
\hline & England & 7.2 & $(1.0)$ & 13.3 & (1.3) & 21.8 & (1.3) & 25.4 & (1.5) & 19.2 & (1.3) & 10.1 & (1.0) & 3.1 & (0.6) \\
\hline & Northern Ireland & 8.5 & $(1.3)$ & 14.2 & (1.9) & 22.8 & (2.1) & 25.9 & (2.1) & 17.6 & (1.9) & 8.8 & (1.5) & 2.2 & (0.6) \\
\hline & Scotland $\bullet^{\bullet}$ & 5.5 & $(0.8)$ & 12.3 & (1.0) & 22.6 & $(1.3)$ & 26.2 & (1.3) & 20.7 & (1.3) & 10.0 & (1.0) & 2.7 & (0.6) \\
\hline & Wales & 10.2 & $(1.0)$ & 17.1 & $(1.2)$ & 27.8 & $(1.3)$ & 25.1 & (1.3) & 14.1 & (1.1) & 4.6 & $(0.5)$ & 1.0 & $(0.3)$ \\
\hline & United States & & & & & & & & & & & & & & \\
\hline & Connecticut ${ }^{\bullet}$ & 7.1 & $(1.5)$ & 13.8 & (1.8) & 19.2 & (1.6) & 23.1 & $(2.1)$ & 21.0 & (1.9) & 11.5 & (1.5) & 4.4 & (1.0) \\
\hline & Florida ${ }^{\bullet}$ & 9.7 & (1.6) & 19.3 & (1.9) & 24.5 & $(2.2)$ & 24.7 & $(2.1)$ & 15.2 & (1.9) & 5.4 & (1.1) & 1.2 & $(0.4)$ \\
\hline & Massachusetts ${ }^{\bullet}$ & 5.5 & $(1.2)$ & 11.9 & (1.6) & 20.7 & $(1.9)$ & 23.9 & $(2.2)$ & 21.3 & (1.8) & 12.2 & (2.0) & 4.5 & $(1.2)$ \\
\hline$\frac{n}{2}$ & Argentina & & & & & & & & & & & & & & \\
\hline 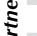 & Ciudad Autónoma de Buenos Aires $\bullet$ & 22.8 & $(2.7)$ & 20.7 & $(2.5)$ & 28.7 & $(2.7)$ & 18.2 & (2.4) & 7.9 & $(1.8)$ & 1.5 & $(0.7)$ & 0.2 & $(0.3)$ \\
\hline & Brazil & & & & & & & & & & & & & & \\
\hline & Acre & 47.6 & (5.4) & 32.7 & $(4.5)$ & 14.9 & $(2.6)$ & 3.5 & (1.6) & 1.0 & $(1.0)$ & 0.2 & c & 0.0 & c \\
\hline & Alagoas & 60.6 & $(6.1)$ & 24.5 & (4.9) & 10.8 & (3.6) & 2.8 & (1.3) & 1.2 & $(0.9)$ & 0.1 & c & 0.0 & $\mathrm{c}$ \\
\hline & Amapá & 50.2 & $(6.6)$ & 29.3 & $(5.0)$ & 15.0 & $(3.7)$ & 5.0 & $(2.5)$ & 0.5 & $\mathrm{c}$ & 0.0 & c & 0.0 & c \\
\hline & Amazonas & 52.8 & $(4.2)$ & 31.2 & (3.8) & 10.4 & $(2.2)$ & 3.8 & (1.6) & 1.5 & (1.4) & 0.3 & c & 0.0 & c \\
\hline & Bahia & 44.6 & $(6.0)$ & 27.8 & (5.8) & 16.0 & $(4.7)$ & 7.9 & (2.7) & 2.7 & $(1.7)$ & 1.0 & $(1.0)$ & 0.1 & c \\
\hline & Ceará & 41.1 & $(4.0)$ & 29.8 & (3.6) & 15.1 & $(2.9)$ & 8.0 & (2.2) & 3.9 & $(2.1)$ & 1.6 & (1.0) & 0.5 & $(0.5)$ \\
\hline & Espírito Santo & 23.5 & $(3.7)$ & 30.3 & $(4.0)$ & 21.3 & $(3.7)$ & 14.8 & (3.2) & 7.8 & $(2.7)$ & 2.2 & (1.3) & 0.1 & c \\
\hline & Federal District & 25.6 & $(4.6)$ & 27.5 & (3.8) & 21.7 & (3.6) & 14.6 & (2.8) & 8.1 & $(2.7)$ & 2.1 & (1.2) & 0.3 & c \\
\hline & Goiás & 35.9 & $(4.7)$ & 33.8 & $(4.0)$ & 17.5 & $(3.7)$ & 9.5 & (2.5) & 3.1 & $(1.0)$ & 0.3 & $(0.3)$ & 0.0 & c \\
\hline & Maranhão & 56.9 & $(7.1)$ & 24.0 & $(4.1)$ & 8.7 & $(2.9)$ & 7.6 & (4.7) & 2.6 & $(2.1)$ & 0.1 & $\mathrm{C}$ & 0.0 & c \\
\hline & Mato Grosso & 46.9 & $(5.2)$ & 31.2 & (3.6) & 15.0 & (3.1) & 5.0 & (1.8) & 1.7 & $(1.3)$ & 0.1 & C & 0.0 & c \\
\hline & Mato Grosso do Sul & 23.2 & $(5.0)$ & 29.6 & $(4.0)$ & 27.5 & (3.1) & 13.0 & (2.4) & 6.1 & $(2.8)$ & 0.6 & $(0.7)$ & 0.0 & $\mathrm{c}$ \\
\hline & Minas Gerais & 26.0 & $(5.0)$ & 30.0 & (4.4) & 28.5 & (3.8) & 11.9 & (2.7) & 2.7 & (1.6) & 1.0 & C & 0.0 & $\mathrm{c}$ \\
\hline & Pará & 49.3 & $(4.3)$ & 27.5 & $(4.3)$ & 17.7 & $(4.0)$ & 4.5 & (2.1) & 0.9 & $(1.0)$ & 0.0 & c & 0.0 & $\mathrm{c}$ \\
\hline & Paraíba & 31.4 & (5.6) & 33.8 & (6.7) & 19.3 & (3.6) & 10.1 & (3.1) & 4.5 & (2.5) & 0.7 & $(0.7)$ & 0.1 & c \\
\hline & Paraná & 29.8 & $(4.9)$ & 27.5 & (3.7) & 22.1 & (3.4) & 10.8 & (2.3) & 8.0 & (3.8) & 1.8 & (1.9) & 0.1 & c \\
\hline & Pernambuco & 45.9 & $(5.2)$ & 32.1 & $(4.0)$ & 15.4 & $(3.1)$ & 5.4 & $(2.0)$ & 1.2 & $(1.0)$ & 0.1 & C & 0.0 & C \\
\hline & Piauí & 37.6 & $(4.9)$ & 29.2 & $(4.2)$ & 17.0 & (3.5) & 9.7 & (2.5) & 4.2 & $(1.7)$ & 1.7 & (1.5) & 0.6 & $(0.3)$ \\
\hline & Rio de Janeiro & 34.6 & $(4.2)$ & 31.5 & $(4.2)$ & 19.9 & $(4.1)$ & 9.4 & (3.0) & 3.9 & (1.6) & 0.6 & (0.6) & 0.0 & $\mathrm{C}$ \\
\hline & Rio Grande do Norte & 42.2 & $(5.2)$ & 28.2 & $(4.1)$ & 14.7 & $(2.9)$ & 7.0 & (2.7) & 4.2 & $(2.3)$ & 3.0 & (1.8) & 0.7 & $(0.7)$ \\
\hline & Rio Grande do Sul & 25.8 & $(4.7)$ & 30.5 & $(4.2)$ & 26.1 & $(3.7)$ & 14.5 & (2.0) & 2.4 & $(1.1)$ & 0.8 & $(0.5)$ & 0.0 & $\mathrm{C}$ \\
\hline & Rondônia & 34.4 & $(3.6)$ & 37.4 & (3.2) & 20.8 & $(3.0)$ & 5.9 & (1.9) & 1.3 & $(0.9)$ & 0.2 & $\mathrm{C}$ & 0.0 & c \\
\hline & Roraima & 51.7 & $(4.5)$ & 27.0 & (3.9) & 15.6 & $(3.5)$ & 4.6 & (1.6) & 0.9 & $(0.8)$ & 0.2 & c & 0.0 & c \\
\hline & Santa Catarina & 21.0 & $(3.6)$ & 28.0 & (3.3) & 26.5 & $(3.2)$ & 16.5 & (3.1) & 7.2 & $(2.0)$ & 0.8 & $(0.7)$ & 0.0 & $\mathrm{c}$ \\
\hline & São Paulo & 28.3 & $(1.7)$ & 30.3 & (2.0) & 24.1 & (1.8) & 11.1 & (1.5) & 4.7 & $(1.3)$ & 1.3 & (0.6) & 0.2 & $(0.1)$ \\
\hline & Sergipe & 31.7 & $(5.2)$ & 30.3 & (5.9) & 20.7 & (3.8) & 12.8 & (4.9) & 3.4 & (1.8) & 1.0 & (1.0) & 0.1 & C \\
\hline & Tocantins & 45.8 & $(4.7)$ & 27.1 & (2.8) & 16.7 & $(2.4)$ & 7.5 & (2.2) & 2.1 & $(1.1)$ & 0.8 & (0.6) & 0.0 & C \\
\hline & Colombia & & & & & & & & & & & & & & \\
\hline & Bogotá & 26.5 & $(2.7)$ & 34.8 & (2.6) & 25.4 & $(2.3)$ & 10.5 & (1.4) & 2.3 & $(1.2)$ & 0.4 & $(0.4)$ & 0.2 & c \\
\hline & Cali & 39.1 & $(4.1)$ & 31.0 & (2.8) & 19.5 & $(3.1)$ & 8.2 & (1.9) & 2.2 & $(0.8)$ & 0.0 & c & 0.0 & c \\
\hline & Manizales & 27.1 & $(2.7)$ & 30.0 & (3.4) & 24.7 & $(2.8)$ & 12.3 & (2.2) & 4.6 & $(1.6)$ & 1.3 & (1.0) & 0.0 & C \\
\hline & Medellín & 35.5 & (3.6) & 29.1 & (3.0) & 19.0 & $(2.8)$ & 10.6 & (2.4) & 3.9 & $(1.2)$ & 1.5 & (0.9) & 0.3 & $(0.3)$ \\
\hline & Russian Federation & & & & & & & & & & & & & & \\
\hline & Perm Territory region` & 8.0 & (1.6) & 14.3 & (1.9) & 24.6 & (1.9) & 25.1 & (2.6) & 17.6 & (1.9) & 7.7 & (1.5) & 2.6 & (1.0) \\
\hline & United Arab Emirates & & & & & & & & & & & & & & \\
\hline & Abu Dhabi & 27.3 & $(1.8)$ & 25.7 & (1.6) & 23.4 & $(1.4)$ & 13.5 & $(1.2)$ & 7.0 & $(1.0)$ & 2.6 & $(0.7)$ & 0.5 & $(0.3)$ \\
\hline & Ajman & 35.0 & $(7.2)$ & 29.2 & (5.9) & 22.8 & $(5.2)$ & 11.0 & (2.4) & 1.8 & $(0.9)$ & 0.2 & $\mathrm{c}$ & 0.0 & $\mathrm{C}$ \\
\hline & Dubai & 13.2 & $(0.6)$ & 17.7 & (1.0) & 21.8 & $(1.2)$ & 21.3 & (1.1) & 16.8 & $(1.1)$ & 7.2 & $(0.9)$ & 2.1 & (0.6) \\
\hline & Fujairah & 33.5 & $(6.3)$ & 27.1 & (3.7) & 21.7 & $(4.0)$ & 9.7 & (1.8) & 6.4 & $(1.5)$ & 1.2 & $(0.7)$ & 0.4 & $(0.4)$ \\
\hline & Ras al-Khaimah & 23.8 & $(3.2)$ & 30.3 & (3.8) & 26.1 & $(2.7)$ & 14.3 & (3.1) & 4.7 & (1.9) & 0.9 & $(0.7)$ & 0.0 & $\mathrm{C}$ \\
\hline & Sharjah & 17.2 & $(4.6)$ & 23.8 & $(4.1)$ & 22.7 & $(3.5)$ & 20.4 & (3.8) & 11.1 & (3.8) & 3.6 & (1.8) & 1.2 & $(0.8)$ \\
\hline & Umm al-Quwain & 37.5 & (3.6) & 37.7 & (5.7) & 17.0 & (4.9) & 4.8 & (1.8) & 1.6 & $(1.7)$ & 1.4 & (1.3) & 0.0 & C \\
\hline
\end{tabular}

- PISA adjudicated region

Note: See Table I.2.9 for national data.

StatLink न्ताs http://dx.doi.org/10.1787/888932935762 
Pert $3 / 41$

Percentage of students at each proficiency level on the mathematics subscale employing, by gender Table B2.I.8 and region

\begin{tabular}{|c|c|c|c|c|c|c|c|c|c|c|c|c|c|c|c|}
\hline & & \multicolumn{14}{|c|}{ Girls } \\
\hline & & \multicolumn{2}{|c|}{$\begin{array}{c}\text { Below Level } 1 \\
\text { (below } 357.77 \\
\text { score points) }\end{array}$} & $\begin{array}{l}\mathrm{L} \\
\text { (from } \\
\text { less th } \\
\text { scor }\end{array}$ & $\begin{array}{l}l 1 \\
7.77 \text { to } \\
420.07 \\
\text { oints) }\end{array}$ & $\begin{array}{r}\mathrm{L} \\
\text { (from } \\
\text { less th } \\
\text { scor }\end{array}$ & $\begin{array}{l}l 2 \\
0.07 \text { to } \\
482.38 \\
\text { oints) }\end{array}$ & $\begin{array}{l}\text { Le } \\
\text { (from } \\
\text { less th } \\
\text { scor }\end{array}$ & \begin{tabular}{|l|}
3 \\
2.38 to \\
544.68 \\
oints)
\end{tabular} & $\begin{array}{l}\mathrm{L} \\
\text { (from } \\
\text { less th } \\
\text { scor }\end{array}$ & $\begin{array}{l}l 4 \\
4.68 \text { to } \\
606.99 \\
\text { oints) }\end{array}$ & $\begin{array}{l}\mathrm{L} \\
\text { (from } \\
\text { less th } \\
\text { scor }\end{array}$ & \begin{tabular}{|l|}
5 \\
6.99 to \\
669.30 \\
oints)
\end{tabular} & $\begin{array}{r}\mathrm{L} \\
\text { (abo } \\
\text { scor }\end{array}$ & $\begin{array}{l}16 \\
669.30 \\
\text { oints) }\end{array}$ \\
\hline & & $\%$ & S.E. & $\%$ & S.E. & $\%$ & S.E. & $\%$ & S.E. & $\%$ & S.E. & $\%$ & S.E. & $\%$ & S.E. \\
\hline 0 & Australia & & & & & & & & & & & & & & \\
\hline $\bar{u}$ & Australian Capital Territory & 4.7 & (1.5) & 10.3 & $(2.0)$ & 21.6 & $(2.5)$ & 25.5 & (3.2) & 24.3 & (3.3) & 10.6 & (2.8) & 2.9 & (1.1) \\
\hline & New South Wales & 6.0 & $(0.9)$ & 13.0 & (1.1) & 22.3 & (1.4) & 24.0 & (1.9) & 19.7 & (2.0) & 10.8 & (1.1) & 4.3 & (1.1) \\
\hline & Northern Territory & 17.1 & (2.8) & 19.5 & $(6.3)$ & 27.1 & (5.8) & 22.9 & (4.4) & 8.7 & (3.9) & 4.3 & $(2.7)$ & 0.4 & c \\
\hline & Queensland & 7.3 & (1.1) & 14.4 & (1.3) & 22.8 & (1.9) & 25.2 & (1.5) & 17.5 & (1.4) & 9.9 & (1.3) & 2.9 & $(0.7)$ \\
\hline & South Australia & 8.6 & (1.5) & 17.2 & (1.6) & 25.6 & $(2.3)$ & 25.4 & (1.9) & 15.1 & (1.8) & 6.8 & (1.4) & 1.4 & $(0.5)$ \\
\hline & Tasmania & 10.9 & $(1.7)$ & 20.5 & $(2.2)$ & 25.9 & (3.0) & 22.5 & (3.3) & 14.1 & (1.9) & 5.1 & (1.5) & 0.8 & $(0.5)$ \\
\hline & Victoria & 7.2 & $(1.2)$ & 14.6 & $(1.2)$ & 26.0 & $(1.7)$ & 25.4 & $(2.0)$ & 17.7 & (1.5) & 7.7 & $(1.1)$ & 1.2 & $(0.5)$ \\
\hline & Western Australia & 6.3 & (1.1) & 13.7 & (1.6) & 21.0 & (1.8) & 26.0 & $(2.0)$ & 19.8 & (1.7) & 10.2 & (1.5) & 2.9 & $(1.0)$ \\
\hline & Belgium & & & & & & & & & & & & & & \\
\hline & Flemish Community• & 5.4 & $(1.0)$ & 10.3 & $(1.2)$ & 16.8 & $(1.2)$ & 22.6 & (1.3) & 23.1 & (1.4) & 16.1 & (1.3) & 5.8 & $(0.6)$ \\
\hline & French Community & 8.6 & $(1.2)$ & 14.3 & (1.4) & 22.5 & (1.6) & 24.5 & (1.8) & 20.1 & (1.4) & 8.2 & $(0.8)$ & 1.8 & $(0.4)$ \\
\hline & German-speaking Community & 4.2 & $(1.2)$ & 7.9 & (1.4) & 20.4 & (2.4) & 29.4 & (2.8) & 28.3 & (2.5) & 8.9 & (1.9) & 0.9 & $(0.8)$ \\
\hline & Canada & & & & & & & & & & & & & & \\
\hline & Alberta & 3.7 & $(0.7)$ & 12.5 & (1.6) & 21.9 & $(2.1)$ & 25.1 & (1.7) & 23.7 & (1.5) & 10.4 & $(1.7)$ & 2.7 & $(0.8)$ \\
\hline & British Columbia & 2.2 & $(0.8)$ & 10.7 & $(1.7)$ & 21.4 & $(2.0)$ & 29.1 & $(2.1)$ & 22.6 & (1.7) & 11.1 & (1.8) & 2.9 & $(0.7)$ \\
\hline & Manitoba & 6.8 & (1.5) & 15.9 & (1.9) & 27.1 & $(2.0)$ & 25.2 & $(2.2)$ & 17.1 & (1.5) & 6.1 & $(1.0)$ & 1.8 & $(0.6)$ \\
\hline & New Brunswick & 4.0 & (1.1) & 10.9 & (1.6) & 25.3 & (1.9) & 31.6 & (3.0) & 18.8 & (1.9) & 8.3 & (1.5) & 1.2 & $(1.0)$ \\
\hline & Newfoundland and Labrador & 5.4 & $(1.5)$ & 14.7 & $(2.8)$ & 26.4 & $(2.3)$ & 26.7 & $(2.3)$ & 18.5 & $(2.2)$ & 7.0 & (1.4) & 1.2 & $(0.6)$ \\
\hline & Nova Scotia & 4.3 & (1.1) & 15.7 & $(2.5)$ & 27.9 & (3.8) & 28.2 & (3.0) & 17.3 & $(2.1)$ & 5.4 & $(1.4)$ & 1.3 & $(0.7)$ \\
\hline & Ontario & 4.1 & $(0.7)$ & 10.3 & $(1.1)$ & 24.0 & (2.0) & 28.9 & $(2.3)$ & 21.7 & $(1.7)$ & 8.9 & (1.3) & 2.1 & $(0.6)$ \\
\hline & Prince Edward Island & 6.6 & (1.1) & 17.0 & $(1.7)$ & 28.6 & (2.4) & 27.8 & (1.9) & 14.5 & (1.5) & 4.6 & $(1.1)$ & 0.8 & $(0.4)$ \\
\hline & Quebec & 3.0 & $(0.6)$ & 8.2 & $(0.9)$ & 17.1 & (1.3) & 25.6 & (1.6) & 26.7 & (1.6) & 15.1 & $(1.3)$ & 4.2 & $(0.7)$ \\
\hline & Saskatchewan & 3.8 & $(0.8)$ & 10.7 & (1.4) & 25.2 & (1.7) & 30.8 & $(2.0)$ & 19.8 & (1.9) & 8.0 & (1.5) & 1.6 & $(0.6)$ \\
\hline & Italy & & & & & & & & & & & & & & \\
\hline & Abruzzo & 9.2 & (1.6) & 16.8 & $(2.1)$ & 28.4 & (2.4) & 25.4 & $(2.5)$ & 15.6 & $(2.2)$ & 3.9 & $(0.9)$ & 0.7 & $(0.4)$ \\
\hline & Basilicata & 10.7 & $(2.0)$ & 21.3 & $(2.3)$ & 31.7 & $(2.0)$ & 23.8 & (1.9) & 9.3 & (1.5) & 2.6 & $(0.7)$ & 0.6 & $(0.4)$ \\
\hline & Bolzano & 6.3 & $(1.0)$ & 12.3 & $(1.5)$ & 23.7 & (2.4) & 30.6 & $(2.8)$ & 20.2 & (1.9) & 6.1 & $(1.2)$ & 0.9 & $(0.5)$ \\
\hline & Calabria & 24.6 & (3.4) & 23.9 & $(2.7)$ & 27.7 & $(2.2)$ & 16.0 & $(2.0)$ & 6.5 & $(1.3)$ & 1.1 & $(0.6)$ & 0.1 & $\mathrm{C}$ \\
\hline & Campania & 16.1 & (3.0) & 22.7 & (3.2) & 27.9 & $(2.6)$ & 21.4 & (3.2) & 9.2 & $(2.0)$ & 2.4 & $(1.0)$ & 0.3 & $(0.2)$ \\
\hline & Emilia Romagna & 6.8 & $(1.7)$ & 14.0 & $(2.5)$ & 26.0 & $(2.7)$ & 25.7 & $(2.2)$ & 17.8 & $(2.1)$ & 7.4 & (1.6) & 2.2 & $(0.7)$ \\
\hline & Friuli Venezia Giulia & 3.3 & (1.7) & 9.1 & $(1.4)$ & 21.3 & (2.5) & 31.6 & $(2.5)$ & 24.1 & $(2.1)$ & 8.2 & (1.6) & 2.5 & $(0.7)$ \\
\hline & Lazio & 10.9 & (1.7) & 19.5 & $(2.5)$ & 29.0 & (3.0) & 24.8 & $(2.6)$ & 11.1 & $(2.0)$ & 4.1 & (1.4) & 0.7 & $(0.4)$ \\
\hline & Liguria & 7.9 & (1.7) & 14.9 & $(1.8)$ & 25.4 & $(2.7)$ & 27.9 & $(2.0)$ & 17.4 & (2.3) & 5.3 & $(1.2)$ & 1.1 & $(0.6)$ \\
\hline & Lombardia & 2.8 & (1.1) & 11.4 & $(2.2)$ & 22.7 & (3.0) & 31.4 & $(3.1)$ & 21.0 & (2.5) & 9.2 & (1.9) & 1.5 & $(0.8)$ \\
\hline & Marche & 6.5 & $(2.1)$ & 15.4 & $(2.1)$ & 27.4 & $(2.6)$ & 27.7 & $(2.1)$ & 16.5 & $(2.2)$ & 5.3 & $(1.1)$ & 1.2 & $(0.5)$ \\
\hline & Molise & 10.7 & (2.0) & 21.7 & $(2.5)$ & 30.5 & (2.6) & 22.9 & $(3.0)$ & 10.2 & $(2.2)$ & 3.5 & $(1.3)$ & 0.4 & $(0.4)$ \\
\hline & Piemonte & 6.7 & (1.7) & 16.2 & $(2.7)$ & 24.0 & $(2.7)$ & 27.0 & $(2.6)$ & 18.6 & (2.4) & 6.2 & (1.6) & 1.4 & $(0.8)$ \\
\hline & Puglia & 8.7 & $(2.2)$ & 19.3 & $(2.6)$ & 29.6 & $(2.5)$ & 23.0 & $(2.2)$ & 14.3 & $(2.0)$ & 4.5 & $(1.2)$ & 0.6 & $(0.4)$ \\
\hline & Sardegna & 12.4 & (2.6) & 22.9 & $(2.7)$ & 29.1 & (2.4) & 21.9 & $(2.3)$ & 10.7 & (1.9) & 2.8 & $(0.7)$ & 0.2 & $(0.3)$ \\
\hline & Sicilia & 14.5 & $(2.7)$ & 25.5 & $(3.4)$ & 29.2 & (2.5) & 21.1 & $(3.3)$ & 8.5 & (1.7) & 1.1 & $(0.4)$ & 0.2 & $(0.2)$ \\
\hline & Toscana & 7.6 & (1.8) & 15.0 & $(2.5)$ & 21.4 & (2.5) & 25.2 & $(3.0)$ & 20.9 & (2.6) & 8.5 & $(1.6)$ & 1.4 & $(0.7)$ \\
\hline & Trento & 2.7 & (1.1) & 7.7 & $(2.3)$ & 19.3 & $(2.3)$ & 31.7 & (3.1) & 27.3 & (3.4) & 10.1 & $(1.8)$ & 1.1 & $(0.7)$ \\
\hline & Umbria & 7.5 & (2.1) & 15.8 & $(2.3)$ & 25.2 & (2.0) & 27.2 & $(2.1)$ & 17.2 & (2.0) & 6.2 & $(1.4)$ & 0.9 & $(0.5)$ \\
\hline & Valle d'Aosta & 4.6 & $(1.3)$ & 17.9 & $(3.0)$ & 28.6 & (3.5) & 28.4 & $(2.8)$ & 14.3 & (1.9) & 4.7 & (1.5) & 1.5 & $(0.7)$ \\
\hline & Veneto & 3.2 & (1.4) & 9.0 & $(1.5)$ & 22.7 & (3.4) & 28.9 & (2.9) & 24.0 & (2.5) & 10.0 & $(2.5)$ & 2.1 & $(0.8)$ \\
\hline & Mexico & & & & & & & & & & & & & & \\
\hline & Aguascalientes & 16.1 & (2.8) & 27.7 & $(2.0)$ & 32.1 & (2.9) & 17.2 & (2.3) & 5.9 & (1.8) & 0.8 & $(0.5)$ & 0.1 & C \\
\hline & Baja California & 25.5 & (2.6) & 32.8 & $(2.8)$ & 24.4 & (2.8) & 12.4 & $(2.1)$ & 4.2 & (1.7) & 0.6 & $(0.7)$ & 0.0 & C \\
\hline & Baja California Sur & 26.5 & (3.3) & 31.4 & $(2.5)$ & 26.8 & $(2.3)$ & 12.4 & $(1.7)$ & 2.7 & (1.0) & 0.2 & $(0.2)$ & 0.0 & c \\
\hline & Campeche & 35.5 & (3.2) & 33.0 & $(3.0)$ & 21.8 & (3.4) & 7.7 & (1.5) & 1.8 & (0.6) & 0.2 & C & 0.0 & C \\
\hline & Chiapas & 45.3 & (4.4) & 28.6 & $(2.9)$ & 18.6 & (2.4) & 6.1 & $(1.7)$ & 1.3 & $(0.6)$ & 0.2 & c & 0.0 & C \\
\hline & Chihuahua & 19.6 & (3.0) & 30.6 & $(3.4)$ & 28.5 & (3.4) & 15.3 & $(2.0)$ & 5.3 & (1.4) & 0.6 & $(0.4)$ & 0.1 & C \\
\hline & Coahuila & 22.5 & (3.5) & 32.3 & $(4.3)$ & 28.3 & (3.0) & 11.8 & (3.4) & 4.9 & (2.3) & 0.2 & $(0.3)$ & 0.0 & C \\
\hline & Colima & 21.1 & (3.1) & 26.3 & $(3.3)$ & 27.5 & (3.3) & 17.6 & $(2.7)$ & 6.8 & (1.8) & 0.7 & $(0.5)$ & 0.0 & C \\
\hline & Distrito Federal & 20.0 & (3.1) & 33.6 & (4.4) & 27.5 & (3.9) & 13.8 & $(2.2)$ & 4.4 & (1.6) & 0.6 & $(0.7)$ & 0.0 & C \\
\hline & Durango & 18.7 & (3.0) & 31.0 & $(2.6)$ & 29.3 & (3.7) & 16.0 & $(3.0)$ & 4.2 & (1.1) & 0.8 & $(0.6)$ & 0.0 & C \\
\hline & Guanajuato & 25.5 & (3.7) & 31.6 & $(3.0)$ & 27.2 & (2.9) & 13.1 & $(2.1)$ & 2.5 & $(0.8)$ & 0.1 & C & 0.0 & C \\
\hline & Guerrero & 48.2 & (3.2) & 31.5 & $(2.9)$ & 15.0 & (1.9) & 4.3 & $(1.0)$ & 1.0 & $(0.5)$ & 0.0 & c & 0.0 & C \\
\hline & Hidalgo & 28.9 & (3.9) & 32.3 & $(3.5)$ & 25.6 & $(2.7)$ & 10.9 & $(2.3)$ & 2.1 & $(0.9)$ & 0.2 & c & 0.0 & C \\
\hline & Jalisco & 16.0 & (2.5) & 28.3 & $(3.0)$ & 33.0 & (2.9) & 17.3 & $(2.1)$ & 4.3 & $(1.2)$ & 1.1 & $(0.9)$ & 0.0 & C \\
\hline & Mexico & 21.1 & (3.6) & 33.9 & $(3.8)$ & 32.7 & $(4.1)$ & 10.4 & $(2.1)$ & 1.7 & (1.0) & 0.2 & C & 0.0 & C \\
\hline & Morelos & 21.3 & (3.2) & 31.4 & $(2.8)$ & 28.2 & (2.4) & 13.2 & $(2.1)$ & 4.4 & (2.0) & 1.5 & (1.0) & 0.0 & C \\
\hline & Nayarit & 27.1 & (3.7) & 29.2 & (3.3) & 26.5 & (3.0) & 12.3 & $(2.0)$ & 4.2 & (1.4) & 0.7 & $(0.5)$ & 0.0 & C \\
\hline & Nuevo León & 18.8 & (3.4) & 31.2 & (3.5) & 28.7 & (2.9) & 16.1 & $(2.9)$ & 4.6 & (1.3) & 0.5 & $(0.4)$ & 0.1 & C \\
\hline & Puebla & 21.9 & (2.9) & 33.3 & $(3.1)$ & 27.8 & (2.5) & 13.1 & $(1.8)$ & 3.4 & (1.1) & 0.4 & $(0.3)$ & 0.0 & C \\
\hline & Querétaro & 20.5 & (3.1) & 29.3 & $(2.9)$ & 27.9 & (4.0) & 16.4 & $(2.6)$ & 4.9 & (1.4) & 1.0 & $(0.5)$ & 0.1 & C \\
\hline & Quintana Roo & 28.6 & (3.3) & 30.1 & (3.6) & 26.2 & $(2.2)$ & 12.0 & (1.6) & 2.8 & (0.9) & 0.4 & $\mathrm{C}$ & 0.0 & C \\
\hline & San Luis Potosí & 26.1 & (3.3) & 29.4 & $(2.9)$ & 25.3 & $(2.2)$ & 14.8 & $(2.5)$ & 3.9 & (1.6) & 0.4 & $(0.5)$ & 0.1 & C \\
\hline & Sinaloa & 25.5 & (2.8) & 34.1 & $(2.9)$ & 26.0 & (3.1) & 11.6 & (1.7) & 2.6 & (1.0) & 0.2 & $\mathrm{C}$ & 0.0 & C \\
\hline & Tabasco & 43.4 & (3.4) & 32.5 & $(3.2)$ & 17.9 & $(2.1)$ & 4.9 & $(0.9)$ & 1.0 & (0.5) & 0.2 & c & 0.0 & C \\
\hline & Tamaulipas & 31.4 & (3.8) & 31.8 & (3.3) & 24.1 & (2.8) & 10.2 & $(2.4)$ & 2.3 & (1.0) & 0.2 & $(0.2)$ & 0.0 & C \\
\hline & Tlaxcala & 25.7 & (3.7) & 33.2 & $(3.0)$ & 25.9 & (2.6) & 11.7 & $(2.4)$ & 2.9 & (1.0) & 0.5 & $(0.5)$ & 0.0 & C \\
\hline & Veracruz & 31.0 & (3.9) & 32.6 & (3.4) & 21.8 & (2.1) & 11.4 & $(2.3)$ & 2.8 & (1.2) & 0.5 & $(0.5)$ & 0.0 & C \\
\hline & Yucatán & 30.9 & (4.1) & 31.3 & $(3.7)$ & 24.1 & (2.3) & 10.6 & $(1.6)$ & 2.7 & (0.9) & 0.3 & $(0.2)$ & 0.1 & C \\
\hline & Zacatecas & 27.5 & (2.9) & 33.2 & (3.6) & 25.2 & (2.3) & 10.8 & (1.6) & 3.1 & $(1.2)$ & 0.3 & $(0.3)$ & 0.0 & $\mathrm{C}$ \\
\hline
\end{tabular}

- PISA adjudicated region.

Note: See Table I.2.9 for national data.

StatLink त्ञात्रा http://dx.doi.org/10.1787/888932935762 
Part 4/4]

Percentage of students at each proficiency level on the mathematics subscale employing, by gender Table B2.I.8 and region

\begin{tabular}{|c|c|c|c|c|c|c|c|c|c|c|c|c|c|c|c|}
\hline & & \multicolumn{14}{|c|}{ Girls } \\
\hline & & \multicolumn{2}{|c|}{$\begin{array}{l}\text { Below Level } 1 \\
\text { (below } 357.77 \\
\text { score points) }\end{array}$} & \multicolumn{2}{|c|}{$\begin{array}{c}\text { Level } 1 \\
\text { (from } 357.77 \text { to } \\
\text { less than } 420.07 \\
\text { score points) }\end{array}$} & \multicolumn{2}{|c|}{$\begin{array}{c}\text { Level } 2 \\
\text { (from } 420.07 \text { to } \\
\text { less than } 482.38 \\
\text { score points) }\end{array}$} & $\begin{array}{r}\mathrm{L} \\
\text { (from } \\
\text { less th } \\
\text { scor }\end{array}$ & $\begin{array}{l}3 \\
2.38 \text { to } \\
544.68 \\
\text { oints) }\end{array}$ & $\begin{array}{r}\text { Le } \\
\text { (from } \\
\text { less th } \\
\text { score }\end{array}$ & $\begin{array}{l}4 \\
4.68 \text { to } \\
606.99 \\
\text { oints) }\end{array}$ & $\begin{array}{r}\mathrm{L} \\
\text { (from } \\
\text { less th } \\
\text { scor }\end{array}$ & $\begin{array}{l}5 \\
6.99 \text { to } \\
669.30 \\
\text { oints) }\end{array}$ & $\begin{array}{l}\text { Lc } \\
\text { (abov } \\
\text { scor }\end{array}$ & $\begin{array}{l}16 \\
669.30 \\
\text { oints) }\end{array}$ \\
\hline & & $\%$ & S.E. & $\%$ & S.E. & $\%$ & S.E. & $\%$ & S.E. & $\%$ & S.E. & $\%$ & S.E. & $\%$ & S.E. \\
\hline 0 & Portugal & & & & & & & & & & & & & & \\
\hline 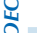 & Alentejo & 8.5 & $(2.4)$ & 15.6 & $(2.8)$ & 25.2 & (2.8) & 24.6 & $(3.7)$ & 17.9 & $(3.1)$ & 7.5 & (1.9) & 0.7 & $(0.7)$ \\
\hline & Spain & & & & & & & & & & & & & & \\
\hline & Andalusia ${ }^{\bullet}$ & 8.9 & $(1.3)$ & 21.9 & $(2.0)$ & 31.3 & $(2.9)$ & 23.6 & $(2.2)$ & 11.8 & (1.7) & 2.4 & $(0.9)$ & 0.0 & c \\
\hline & Aragon ${ }^{\bullet}$ & 9.2 & $(1.9)$ & 13.2 & $(2.1)$ & 22.6 & $(1.8)$ & 28.8 & $(2.0)$ & 18.8 & (1.9) & 6.2 & (1.3) & 1.2 & $(0.6)$ \\
\hline & Asturias ${ }^{\bullet}$ & 5.9 & $(0.9)$ & 13.7 & $(1.7)$ & 24.3 & $(1.7)$ & 28.8 & $(2.0)$ & 19.0 & (1.9) & 7.0 & $(1.2)$ & 1.2 & $(0.4)$ \\
\hline & Balearic Islands ${ }^{\bullet}$ & 9.5 & $(1.5)$ & 17.7 & (1.9) & 25.9 & $(1.7)$ & 26.9 & $(2.0)$ & 16.0 & $(2.1)$ & 3.9 & $(1.2)$ & 0.1 & $\mathrm{C}$ \\
\hline & Basque Country ${ }^{\bullet}$ & 4.4 & $(0.6)$ & 12.0 & (1.1) & 24.9 & $(1.2)$ & 31.0 & $(1.1)$ & 21.5 & (1.1) & 5.5 & $(0.6)$ & 0.7 & $(0.2)$ \\
\hline & Cantabria & 4.7 & $(1.4)$ & 15.2 & (1.8) & 28.6 & $(2.0)$ & 27.6 & $(2.0)$ & 17.2 & $(1.6)$ & 6.1 & $(1.0)$ & 0.7 & $(0.4)$ \\
\hline & Castile and Leon ${ }^{\bullet}$ & 3.9 & $(0.9)$ & 11.3 & (1.4) & 24.9 & $(2.1)$ & 33.0 & $(2.3)$ & 20.6 & $(1.7)$ & 5.9 & $(1.3)$ & 0.4 & $(0.5)$ \\
\hline & Catalonia・ & 6.4 & $(1.5)$ & 15.4 & $(2.5)$ & 24.9 & $(2.3)$ & 30.8 & $(2.0)$ & 17.6 & $(2.1)$ & 4.4 & $(1.0)$ & 0.5 & $(0.3)$ \\
\hline & Extremadura ${ }^{\bullet}$ & 13.2 & $(1.5)$ & 18.5 & (1.9) & 28.3 & $(1.9)$ & 24.9 & $(1.9)$ & 12.1 & $(1.4)$ & 2.7 & $(0.7)$ & 0.2 & $(0.2)$ \\
\hline & Galicia` & 8.2 & $(1.5)$ & 13.7 & $(2.0)$ & 25.4 & $(1.7)$ & 28.5 & $(2.1)$ & 17.9 & $(2.1)$ & 5.4 & (1.3) & 0.9 & $(0.5)$ \\
\hline & La Rioja・ & 8.1 & $(1.2)$ & 12.7 & (1.8) & 22.1 & $(2.5)$ & 26.7 & $(2.1)$ & 21.2 & $(1.8)$ & 7.8 & (1.1) & 1.4 & $(0.4)$ \\
\hline & Madrid` & 6.2 & $(1.4)$ & 12.5 & (1.5) & 23.1 & $(1.7)$ & 27.9 & $(2.3)$ & 22.3 & $(2.6)$ & 7.3 & $(1.2)$ & 0.8 & $(0.4)$ \\
\hline & Murcia ${ }^{\bullet}$ & 12.6 & $(1.5)$ & 19.9 & (1.8) & 28.9 & $(2.1)$ & 25.7 & $(2.2)$ & 10.6 & $(1.7)$ & 1.8 & $(0.6)$ & 0.5 & $(0.3)$ \\
\hline & Navarre ${ }^{\bullet}$ & 3.4 & $(0.9)$ & 9.8 & (1.1) & 22.1 & $(2.3)$ & 29.0 & $(2.2)$ & 24.0 & $(2.0)$ & 10.3 & (1.4) & 1.5 & $(0.5)$ \\
\hline & United Kingdom & & & & & & & & & & & & & & \\
\hline & England & 8.8 & $(1.1)$ & 15.8 & (1.4) & 22.9 & $(1.7)$ & 24.6 & $(1.6)$ & 17.6 & $(1.1)$ & 7.9 & $(0.8)$ & 2.3 & $(0.5)$ \\
\hline & Northern Ireland & 9.2 & $(1.4)$ & 18.1 & (2.0) & 23.4 & $(1.8)$ & 23.3 & $(1.8)$ & 16.3 & $(1.5)$ & 7.8 & (1.3) & 1.9 & $(0.6)$ \\
\hline & Scotland ${ }^{\bullet}$ & 7.2 & $(1.1)$ & 14.9 & (1.5) & 26.0 & (1.6) & 26.0 & $(1.3)$ & 17.2 & $(1.2)$ & 7.1 & $(0.8)$ & 1.6 & $(0.3)$ \\
\hline & Wales & 10.7 & $(1.0)$ & 21.3 & (1.1) & 28.1 & $(1.3)$ & 23.5 & $(1.4)$ & 12.5 & $(1.0)$ & 3.3 & $(0.6)$ & 0.6 & $(0.3)$ \\
\hline & United States & & & & & & & & & & & & & & \\
\hline & Connecticut $^{\bullet}$ & 8.0 & (1.5) & 14.4 & (1.4) & 20.6 & $(2.1)$ & 24.5 & $(2.3)$ & 18.1 & (1.9) & 11.1 & (1.8) & 3.3 & $(0.9)$ \\
\hline & Florida ${ }^{\bullet}$ & 10.6 & $(1.5)$ & 21.7 & (2.0) & 29.3 & $(2.1)$ & 22.4 & $(2.0)$ & 12.1 & $(1.5)$ & 3.4 & $(1.2)$ & 0.5 & $(0.3)$ \\
\hline & Massachusetts ${ }^{\bullet}$ & 5.1 & $(1.1)$ & 13.5 & $(1.7)$ & 21.7 & $(2.0)$ & 24.6 & (1.8) & 19.7 & $(2.4)$ & 11.9 & $(2.2)$ & 3.5 & $(1.0)$ \\
\hline$\stackrel{n}{a}$ & Argentina & & & & & & & & & & & & & & \\
\hline 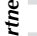 & Ciudad Autónoma de Buenos Aires & 23.7 & $(3.0)$ & 24.0 & $(2.7)$ & 29.0 & $(2.6)$ & 16.6 & $(2.3)$ & 5.5 & $(1.2)$ & 1.2 & $(0.5)$ & 0.0 & c \\
\hline & Brazil & & & & & & & & & & & & & & \\
\hline & Acre & 57.6 & $(4.9)$ & 26.9 & (3.5) & 12.6 & $(2.6)$ & 2.6 & $(1.3)$ & 0.0 & c & 0.2 & $(0.2)$ & 0.1 & c \\
\hline & Alagoas & 68.1 & $(4.1)$ & 19.1 & (3.5) & 9.3 & (2.5) & 2.8 & (1.6) & 0.5 & $(0.5)$ & 0.2 & c & 0.0 & $\mathrm{c}$ \\
\hline & Amapá & 57.3 & (5.6) & 29.1 & (4.4) & 11.6 & $(3.2)$ & 1.8 & $(1.3)$ & 0.2 & c & 0.0 & c & 0.0 & c \\
\hline & Amazonas & 64.6 & $(4.8)$ & 26.3 & $(4.7)$ & 6.5 & $(1.8)$ & 1.3 & $(0.9)$ & 1.2 & $(1.2)$ & 0.0 & $\mathrm{C}$ & 0.0 & c \\
\hline & Bahia & 50.7 & $(8.0)$ & 25.1 & (3.8) & 15.1 & $(5.7)$ & 6.7 & $(3.6)$ & 2.1 & $(1.5)$ & 0.3 & c & 0.0 & c \\
\hline & Ceará & 49.2 & $(5.8)$ & 29.1 & (5.4) & 14.6 & $(2.6)$ & 4.8 & $(2.2)$ & 1.6 & $(1.0)$ & 0.8 & $(0.3)$ & 0.0 & c \\
\hline & Espírito Santo & 30.6 & $(4.3)$ & 29.5 & $(4.0)$ & 20.1 & $(3.2)$ & 11.6 & $(3.0)$ & 6.8 & $(3.1)$ & 1.2 & $(0.9)$ & 0.1 & c \\
\hline & Federal District & 32.5 & $(4.9)$ & 26.1 & $(4.0)$ & 22.7 & $(3.3)$ & 14.0 & $(2.6)$ & 4.3 & $(2.3)$ & 0.5 & $\mathrm{C}$ & 0.0 & c \\
\hline & Goiás & 43.7 & $(4.8)$ & 34.2 & $(4.1)$ & 15.5 & $(2.8)$ & 5.8 & $(1.7)$ & 0.7 & $\mathrm{C}$ & 0.0 & $\mathrm{C}$ & 0.0 & c \\
\hline & Maranhão & 64.9 & $(7.8)$ & 23.5 & $(4.0)$ & 8.6 & $(4.1)$ & 2.5 & (1.6) & 0.5 & $(0.5)$ & 0.0 & $\mathrm{C}$ & 0.0 & $\mathrm{c}$ \\
\hline & Mato Grosso & 51.3 & (5.5) & 28.8 & (3.8) & 13.9 & (3.4) & 2.8 & $(2.1)$ & 2.4 & $(1.5)$ & 0.8 & $(0.6)$ & 0.1 & c \\
\hline & Mato Grosso do Sul & 31.5 & $(4.6)$ & 33.8 & $(5.1)$ & 22.1 & (3.9) & 9.1 & $(1.7)$ & 2.7 & $(1.3)$ & 0.7 & $(0.7)$ & 0.0 & c \\
\hline & Minas Gerais & 31.4 & (3.9) & 33.0 & (2.9) & 23.2 & (3.3) & 10.1 & (2.5) & 2.2 & $(1.0)$ & 0.1 & $\mathrm{c}$ & 0.0 & c \\
\hline & Pará & 57.1 & (4.4) & 24.2 & (3.4) & 15.6 & $(4.2)$ & 3.1 & $(2.3)$ & 0.0 & C & 0.0 & C & 0.0 & c \\
\hline & Paraíba & 38.7 & $(5.3)$ & 28.9 & $(4.2)$ & 22.0 & $(5.3)$ & 8.4 & $(2.5)$ & 1.9 & $(1.1)$ & 0.2 & C & 0.0 & c \\
\hline & Paraná & 36.8 & $(4.3)$ & 31.7 & $(4.5)$ & 19.3 & $(3.7)$ & 7.1 & $(2.4)$ & 3.2 & $(2.6)$ & 1.6 & $(1.8)$ & 0.2 & c \\
\hline & Pernambuco & 55.7 & $(5.3)$ & 30.1 & (3.9) & 11.8 & $(2.8)$ & 1.9 & $(0.9)$ & 0.4 & $(0.3)$ & 0.0 & c & 0.0 & c \\
\hline & Piauí & 44.1 & $(3.9)$ & 31.3 & (3.8) & 12.7 & $(2.6)$ & 8.1 & $(2.1)$ & 2.5 & $(1.7)$ & 1.3 & $(1.2)$ & 0.1 & c \\
\hline & Rio de Janeiro & 41.2 & $(4.8)$ & 32.3 & (3.8) & 18.1 & $(2.3)$ & 7.1 & $(1.6)$ & 1.2 & $(1.2)$ & 0.2 & c & 0.0 & c \\
\hline & Rio Grande do Norte & 56.7 & $(4.4)$ & 23.0 & (3.6) & 9.5 & $(1.9)$ & 7.3 & $(2.0)$ & 2.2 & $(1.3)$ & 1.2 & $(0.8)$ & 0.0 & c \\
\hline & Rio Grande do Sul & 31.0 & $(3.6)$ & 33.2 & (3.0) & 24.2 & $(4.1)$ & 9.6 & $(2.1)$ & 1.7 & $(0.8)$ & 0.3 & $\mathrm{C}$ & 0.0 & c \\
\hline & Rondônia & 42.0 & $(4.7)$ & 35.8 & (3.4) & 17.2 & $(3.0)$ & 4.4 & $(1.8)$ & 0.7 & $(0.6)$ & 0.0 & $\mathrm{c}$ & 0.0 & c \\
\hline & Roraima & 57.6 & $(4.0)$ & 25.1 & (2.9) & 10.7 & $(2.8)$ & 4.5 & $(2.1)$ & 2.0 & (1.8) & 0.1 & C & 0.0 & c \\
\hline & Santa Catarina & 23.6 & $(4.0)$ & 33.4 & (3.5) & 26.3 & $(3.0)$ & 12.1 & $(2.7)$ & 3.8 & (1.6) & 0.8 & $(0.7)$ & 0.0 & c \\
\hline & São Paulo & 35.8 & $(2.3)$ & 31.0 & $(2.1)$ & 20.1 & $(1.9)$ & 9.4 & $(1.5)$ & 2.8 & $(0.9)$ & 0.8 & $(0.5)$ & 0.2 & $(0.2)$ \\
\hline & Sergipe & 44.1 & $(6.1)$ & 32.8 & $(4.7)$ & 16.0 & $(4.4)$ & 6.6 & $(3.1)$ & 0.6 & $(0.6)$ & 0.0 & $\mathrm{C}$ & 0.0 & $\mathrm{C}$ \\
\hline & Tocantins & 56.1 & $(4.2)$ & 27.2 & $(3.7)$ & 12.3 & $(2.5)$ & 2.7 & $(0.9)$ & 1.3 & $(0.5)$ & 0.4 & $(0.3)$ & 0.0 & C \\
\hline & Colombia & & & & & & & & & & & & & & \\
\hline & Bogotá & 43.5 & $(2.6)$ & 34.2 & (2.9) & 17.9 & $(1.9)$ & 4.0 & $(1.0)$ & 0.5 & $(0.3)$ & 0.0 & $\mathrm{C}$ & 0.0 & c \\
\hline & Cali & 47.2 & (4.5) & 29.7 & $(2.2)$ & 17.4 & $(2.7)$ & 4.6 & (1.4) & 1.1 & $(0.5)$ & 0.0 & C & 0.0 & c \\
\hline & Manizales & 39.7 & (3.9) & 33.8 & (3.9) & 18.4 & $(2.8)$ & 6.7 & $(1.7)$ & 1.4 & $(1.0)$ & 0.0 & c & 0.0 & C \\
\hline & Medellín & 48.9 & $(4.3)$ & 26.6 & (2.6) & 13.0 & $(2.0)$ & 7.0 & $(1.8)$ & 3.2 & $(1.5)$ & 1.1 & $(0.8)$ & 0.2 & $(0.3)$ \\
\hline & Russian Federation & & & & & & & & & & & & & & \\
\hline & Perm Territory region ${ }^{\bullet}$ & 7.3 & $(1.4)$ & 15.6 & $(1.7)$ & 26.9 & $(1.8)$ & 26.3 & $(2.5)$ & 16.4 & $(2.3)$ & 5.8 & (1.5) & 1.6 & $(0.7)$ \\
\hline & United Arab Emirates & & & & & & & & & & & & & & \\
\hline & Abu Dhabi・ & 17.8 & $(2.1)$ & 26.6 & (1.4) & 27.2 & $(1.6)$ & 17.4 & $(1.5)$ & 8.2 & $(1.3)$ & 2.5 & $(0.6)$ & 0.4 & $(0.3)$ \\
\hline & Ajman & 21.6 & $(5.9)$ & 29.0 & $(2.7)$ & 28.3 & $(3.6)$ & 15.6 & $(3.1)$ & 4.5 & $(1.6)$ & 0.9 & $(0.9)$ & 0.1 & $\mathrm{C}$ \\
\hline & Dubai` & 11.5 & $(0.6)$ & 20.7 & (1.6) & 25.9 & $(1.6)$ & 22.9 & $(1.3)$ & 13.9 & $(1.0)$ & 4.3 & $(0.7)$ & 0.8 & $(0.4)$ \\
\hline & Fujairah & 17.5 & $(4.0)$ & 24.7 & $(4.1)$ & 29.0 & $(3.4)$ & 22.1 & $(3.5)$ & 5.3 & $(1.8)$ & 1.3 & $(0.9)$ & 0.2 & $\mathrm{C}$ \\
\hline & Ras al-Khaimah & 17.3 & $(5.5)$ & 26.7 & (3.4) & 29.7 & $(4.4)$ & 17.7 & $(3.2)$ & 7.5 & $(2.6)$ & 1.1 & $(0.8)$ & 0.1 & c \\
\hline & Sharjah & 16.7 & $(3.4)$ & 26.0 & (3.9) & 26.2 & $(2.6)$ & 18.2 & $(3.3)$ & 10.1 & $(2.6)$ & 2.6 & $(1.1)$ & 0.2 & c \\
\hline & Umm al-Quwain & 18.6 & $(3.4)$ & 31.4 & $(4.2)$ & 30.5 & $(4.2)$ & 14.0 & $(2.9)$ & 4.3 & $(2.1)$ & 1.1 & $(1.1)$ & 0.0 & $\mathrm{C}$ \\
\hline
\end{tabular}

- PISA adjudicated region.

Note: See Table I.2.9 for national data.

StatLink 部 SL http://dx.doi.org/10.1787/888932935762 
[Part 1/2]

Mean score, variation and gender differences in student performance on the mathematics Table B2.I.9 subscale employing, by region

\begin{tabular}{|c|c|c|c|c|c|c|c|c|c|c|c|c|c|c|c|c|c|c|c|}
\hline & & & All stu & Idents & & & & nder di & ifferen & nces & & & & & & & Perce & entiles & \\
\hline & & Mean & score & $\begin{array}{l}\text { Stan } \\
\text { devia }\end{array}$ & $\begin{array}{l}\text { dard } \\
\text { tion }\end{array}$ & & oys & Gi & & $\begin{array}{l}\text { Diffe } \\
\text { (B. }\end{array}$ & $\begin{array}{l}\text { rence } \\
- \text { G) }\end{array}$ & & th & & 0th & & 5th & & 5th \\
\hline & & Mean & S.E. & S.D. & S.E. & $\begin{array}{l}\text { Mean } \\
\text { score }\end{array}$ & S.E. & $\begin{array}{l}\text { Mean } \\
\text { score }\end{array}$ & S.E. & $\begin{array}{c}\text { Score } \\
\text { dif. }\end{array}$ & S.E. & Score & S.E. & Score & S.E. & Score & S.E. & Score & S.E. \\
\hline & Australia & & & & & & & & & & & & & & & & & & \\
\hline & Australian Capital Territory & 513 & (3.6) & 93 & (2.7) & 513 & (5.6) & 512 & (4.7) & 2 & (7.3) & 354 & $(10.2)$ & 391 & (7.0) & 449 & (6.6) & 579 & (5.3) \\
\hline & New South Wales & 507 & (3.5) & 99 & $(2.2)$ & 508 & (5.2) & 505 & (3.9) & 3 & (6.1) & 345 & $(5.3)$ & 379 & (4.4) & 438 & (3.8) & 577 & (5.0) \\
\hline & Northern Territory & 448 & $(10.1)$ & 110 & (7.9) & 452 & (9.0) & 443 & (14.6) & 8 & (13.3) & 256 & $(32.7)$ & 309 & (14.6) & 387 & $(10.0)$ & 520 & (15.4) \\
\hline & Queensland & 499 & (3.2) & 94 & $(2.2)$ & 503 & (4.1) & 496 & $(4.1)$ & 7 & (5.0) & 345 & $(7.7)$ & 378 & $(5.1)$ & 434 & (3.9) & 566 & (3.5) \\
\hline & South Australia & 484 & (3.4) & 90 & $(2.1)$ & 489 & (3.9) & 479 & (4.1) & 10 & (4.5) & 336 & (6.4) & 367 & (5.3) & 423 & (4.2) & 548 & (6.1) \\
\hline & Tasmania & 471 & (3.3) & 92 & (2.5) & 477 & (4.6) & 466 & (4.7) & 11 & (6.6) & 313 & (8.7) & 352 & (7.9) & 410 & (5.2) & 535 & (5.5) \\
\hline & Victoria & 497 & (4.0) & 90 & $(2.2)$ & 505 & (5.2) & 487 & $(4.2)$ & 18 & (5.5) & 348 & (6.6) & 380 & (4.8) & 436 & (3.5) & 559 & (5.2) \\
\hline & Western Australia & 512 & (3.7) & 92 & (1.8) & 522 & (5.2) & 501 & (4.6) & 21 & (6.5) & 358 & (6.2) & 391 & (4.8) & 448 & (5.3) & 579 & (5.3) \\
\hline & Belgium & & & & & & & & & & & & & & & & & & \\
\hline & Flemish Community• & 531 & (3.1) & 102 & (2.5) & 538 & (4.2) & 524 & $(4.3)$ & 14 & (5.8) & 356 & (7.3) & 394 & (5.9) & 462 & (5.1) & 606 & (3.4) \\
\hline & French Community & 495 & (3.0) & 96 & (1.9) & 499 & (3.4) & 491 & (3.7) & 8 & (3.8) & 330 & (6.5) & 365 & (5.9) & 429 & (4.6) & 564 & (3.2) \\
\hline & German-speaking Community & 512 & (2.0) & 88 & $(2.5)$ & 510 & (3.4) & 513 & $(3.1)$ & -3 & (5.1) & 351 & (11.6) & 393 & (5.6) & 459 & (4.7) & 572 & (3.6) \\
\hline & Canada & & & & & & & & & & & & & & & & & & \\
\hline & Alberta & 515 & (4.6) & 89 & (1.6) & 519 & $(4.7)$ & 510 & $(5.2)$ & 9 & (3.7) & 365 & (8.1) & 399 & (5.8) & 453 & (5.5) & 579 & (5.0) \\
\hline & British Columbia & 522 & (4.5) & 83 & (2.0) & 527 & (4.7) & 517 & (6.0) & 11 & (5.9) & 385 & (7.0) & 413 & (5.7) & 464 & $(4.7)$ & 580 & (5.9) \\
\hline & Manitoba & 489 & (3.2) & 88 & $(2.4)$ & 493 & (4.2) & 485 & (4.5) & 8 & (5.9) & 349 & (6.6) & 378 & (5.7) & 429 & (4.3) & 549 & $(4.2)$ \\
\hline & New Brunswick & 500 & (2.8) & 81 & $(2.2)$ & 500 & (4.1) & 500 & (3.6) & 0 & (5.4) & 366 & (6.0) & 395 & (6.3) & 447 & (5.2) & 553 & (4.6) \\
\hline & Newfoundland and Labrador & 490 & (3.8) & 88 & $(2.1)$ & 490 & (5.4) & 490 & $(4.2)$ & 0 & (5.8) & 346 & $(10.2)$ & 374 & (8.3) & 429 & (6.4) & 551 & $(5.7)$ \\
\hline & Nova Scotia & 493 & (3.1) & 81 & $(2.4)$ & 497 & (3.9) & 489 & (5.2) & 8 & (6.7) & 357 & (6.0) & 389 & (4.5) & 437 & (3.3) & 549 & (3.9) \\
\hline & Ontario & 512 & (4.3) & 86 & (1.9) & 518 & (4.8) & 507 & (4.4) & 11 & (3.7) & 367 & (6.6) & 400 & (5.9) & 454 & (4.6) & 572 & (5.4) \\
\hline & Prince Edward Island & 479 & (2.5) & 82 & (1.6) & 481 & (3.6) & 478 & (3.4) & 4 & (4.9) & 349 & $(4.0)$ & 374 & (4.1) & 422 & (4.3) & 536 & (3.9) \\
\hline & Quebec & 536 & (3.4) & 89 & (2.0) & 540 & (4.2) & 531 & (3.9) & 10 & (4.3) & 380 & (7.4) & 416 & (5.7) & 476 & (4.2) & 599 & (3.7) \\
\hline & Saskatchewan & 506 & (3.2) & 82 & (2.0) & 508 & (4.2) & 502 & (3.6) & 6 & (4.6) & 370 & (6.3) & 401 & (4.5) & 450 & (4.0) & 564 & (4.9) \\
\hline & Italy & & & & & & & & & & & & & & & & & & \\
\hline & Abruzzo & 477 & (6.0) & 89 & (3.6) & 482 & (6.8) & 471 & (6.9) & 11 & (7.3) & \begin{tabular}{|l|l|}
324 \\
$\mid$
\end{tabular} & (17.8) & 363 & (9.9) & 421 & (5.9) & 539 & (7.7) \\
\hline & Basilicata & 468 & (4.7) & 86 & (2.0) & 480 & (6.3) & 456 & (4.5) & 24 & (5.7) & 330 & (5.5) & 360 & (7.3) & 408 & (6.1) & 524 & (5.7) \\
\hline & Bolzano & 503 & $(2.2)$ & 90 & (1.5) & 514 & (3.0) & 492 & $(2.8)$ & 22 & (3.7) & 351 & (6.5) & 383 & (4.8) & 446 & (3.8) & 565 & (3.5) \\
\hline & Calabria & 431 & (5.5) & 89 & (3.3) & 442 & (5.8) & 419 & (7.1) & 23 & (7.5) & 289 & (8.8) & 316 & (6.6) & 368 & (7.1) & 492 & (6.5) \\
\hline & Campania & 453 & (7.7) & 91 & (3.5) & 462 & (7.8) & 444 & (9.6) & 18 & (7.8) & 304 & (8.3) & 337 & (8.3) & 390 & (8.2) & 514 & $(10.2)$ \\
\hline & Emilia Romagna & 501 & (6.6) & 98 & (4.1) & 510 & (9.9) & 490 & (6.6) & 20 & (10.8) & 343 & (12.2) & 377 & (8.6) & 435 & (6.8) & 568 & $(8.4)$ \\
\hline & Friuli Venezia Giulia & 521 & (4.3) & 87 & (3.1) & 529 & (5.7) & 512 & $(5.1)$ & 17 & $(6.8)$ & 375 & $(11.5)$ & 407 & $(8.3)$ & 464 & (5.8) & 580 & (5.4) \\
\hline & Lazio & 475 & (6.3) & 88 & (3.1) & 485 & (6.6) & 462 & (7.1) & 23 & (6.4) & 332 & (9.6) & 362 & $(8.9)$ & 415 & (6.7) & 534 & (8.7) \\
\hline & Liguria & 488 & (6.5) & 91 & (3.1) & 493 & (8.6) & 483 & $(7.0)$ & 10 & (9.0) & 338 & (13.8) & 374 & (8.5) & 427 & (8.0) & 549 & (7.4) \\
\hline & Lombardia & 517 & (7.6) & 87 & (3.2) & 527 & (8.9) & 507 & (7.9) & 20 & (8.0) & 367 & $(8.2)$ & 404 & (8.5) & 459 & (9.7) & 578 & (9.5) \\
\hline & Marche & 497 & (5.6) & 85 & (3.4) & 510 & (6.4) & 484 & (6.3) & 27 & (6.1) & 355 & $(15.3)$ & 388 & (9.6) & 438 & (7.1) & 555 & (6.7) \\
\hline & Molise & 466 & $(2.5)$ & 85 & $(2.2)$ & 474 & (3.2) & 457 & (3.6) & 17 & (4.5) & 329 & $(7.0)$ & 357 & (4.8) & 409 & (3.3) & 522 & $(5.0)$ \\
\hline & Piemonte & 499 & (5.8) & 86 & (2.4) & 512 & (4.5) & 487 & (7.3) & 25 & (5.5) & 353 & (7.5) & 383 & (6.9) & 442 & (6.2) & 560 & (7.1) \\
\hline & Puglia & 480 & (6.5) & 87 & (3.6) & 490 & (6.5) & 470 & (6.8) & 21 & (5.3) & 339 & $(12.1)$ & 367 & $(10.1)$ & 418 & (7.6) & 543 & (7.6) \\
\hline & Sardegna & 455 & (5.4) & 87 & $(2.8)$ & 458 & (5.5) & 451 & $(7.0)$ & 7 & (6.7) & 314 & (10.6) & 342 & $(9.1)$ & 397 & (7.0) & 516 & (6.7) \\
\hline & Sicilia & 445 & (5.4) & 83 & (3.3) & 448 & (6.6) & 442 & $(6.3)$ & 6 & $(7.1)$ & 311 & $(10.5)$ & 340 & $(9.2)$ & 391 & (5.8) & 502 & (7.4) \\
\hline & Toscana & 495 & (5.0) & 93 & (2.4) & 497 & (7.3) & 493 & (8.6) & 4 & (12.4) & 339 & (8.6) & 372 & (5.6) & 428 & (5.8) & 563 & (6.7) \\
\hline & Trento & 522 & (4.6) & 82 & (2.5) & 525 & (5.4) & 518 & (7.1) & 7 & (8.6) & 381 & (11.7) & 415 & $(7.2)$ & 468 & (7.1) & 580 & (5.5) \\
\hline & Umbria & 494 & (7.0) & 89 & (3.8) & 504 & (10.1) & 484 & $(6.2)$ & 20 & (8.7) & 342 & (12.5) & 373 & (14.3) & 433 & (11.5) & 558 & (6.1) \\
\hline & Valle d'Aosta & 491 & (2.4) & 84 & (2.1) & 500 & (3.2) & 482 & (3.7) & 18 & (4.9) & 358 & (7.6) & 389 & $(7.0)$ & 433 & (4.5) & 547 & (4.2) \\
\hline & Veneto & 524 & (7.7) & 91 & $(4.2)$ & 534 & (8.9) & 513 & (7.9) & 20 & (8.1) & 373 & (9.5) & 407 & (9.0) & 462 & (8.3) & 588 & $(10.2)$ \\
\hline & Mexico & & & & & & & & & & & & & & & & & & \\
\hline & Aguascalientes & 436 & (4.9) & 78 & (3.0) & \begin{tabular}{|l|}
441 \\
\end{tabular} & (6.5) & 432 & (4.8) & 9 & (6.2) & $\mid 311$ & (8.2) & 335 & (8.4) & 382 & (5.8) & 488 & (5.5) \\
\hline & Baja California & 416 & (5.9) & 75 & (2.8) & 423 & (6.6) & 408 & (6.0) & 15 & (4.8) & 298 & $(10.1)$ & 322 & (5.9) & 364 & (5.1) & 466 & (8.2) \\
\hline & Baja California Sur & 413 & (5.6) & 77 & (2.5) & 422 & (6.8) & 404 & (5.4) & 17 & (4.9) & 287 & (10.5) & 315 & (9.9) & 360 & (6.4) & 464 & (5.7) \\
\hline & Campeche & 393 & (4.0) & 76 & (2.6) & 400 & (4.3) & 386 & (5.0) & 14 & (4.6) & 268 & $(11.3)$ & 298 & (7.9) & 343 & (5.5) & 444 & (4.5) \\
\hline & Chiapas & 373 & (7.6) & 80 & $(4.2)$ & 378 & (8.1) & 367 & $(8.1)$ & 10 & (5.4) & 243 & (11.6) & 271 & (11.5) & 318 & $(10.2)$ & 425 & (7.4) \\
\hline & Chihuahua & 429 & (6.1) & 81 & (3.3) & 438 & (7.8) & 420 & (6.3) & 18 & (7.6) & 299 & (10.8) & 331 & $(9.7)$ & 377 & $(6.3)$ & 481 & (8.8) \\
\hline & Coahuila & 418 & (8.6) & 78 & (3.8) & 424 & (9.0) & 412 & (9.9) & 11 & (7.5) & 296 & (8.8) & 321 & (7.0) & 363 & (7.5) & 470 & (13.1) \\
\hline & Colima & 429 & (5.3) & 82 & (2.4) & 432 & (5.9) & 426 & $(6.0)$ & 6 & (5.5) & 296 & (8.8) & 323 & $(7.2)$ & 369 & (5.6) & 486 & (6.4) \\
\hline & Distrito Federal & 431 & (5.2) & 77 & (3.1) & 444 & (6.5) & 418 & (5.8) & 26 & $(7.1)$ & 308 & $(12.2)$ & 335 & (8.8) & 378 & (5.4) & 483 & $(7.8)$ \\
\hline & Durango & 430 & (5.7) & 76 & (2.2) & 437 & (7.5) & 424 & $(5.2)$ & 14 & (5.6) & 308 & (8.3) & 333 & (7.3) & 376 & (5.8) & 483 & (7.6) \\
\hline & Guanajuato & 416 & (5.8) & 77 & (2.6) & 426 & (6.5) & 406 & (6.0) & 20 & (4.3) & 290 & (10.4) & 316 & (8.0) & 361 & (7.2) & 467 & (6.4) \\
\hline & Guerrero & 366 & (3.0) & 70 & $(2.2)$ & 369 & (4.1) & 364 & (3.8) & 5 & (5.1) & 254 & $(7.1)$ & 278 & (5.6) & 318 & (5.0) & 411 & (4.6) \\
\hline & Hidalgo & 406 & (6.0) & 76 & (2.9) & 413 & (7.4) & 400 & (6.0) & 13 & (5.7) & 278 & (10.6) & 310 & (9.5) & 355 & (7.5) & 456 & (6.8) \\
\hline & Jalisco & 433 & (6.0) & 76 & (2.7) & 438 & (7.5) & 430 & (5.6) & 8 & (5.2) & 309 & (10.7) & 337 & (8.2) & 384 & (6.8) & 483 & (7.4) \\
\hline & Mexico & 415 & (5.6) & 70 & (3.4) & 421 & (6.1) & 410 & (6.3) & 11 & (5.2) & 299 & (10.1) & 326 & $(8.1)$ & 369 & (6.8) & 462 & $(7.8)$ \\
\hline & Morelos & 422 & (8.6) & 81 & (6.0) & 426 & (10.3) & 418 & (8.5) & 7 & $(7.2)$ & 291 & (16.8) & 321 & (15.4) & 368 & (9.1) & 472 & (9.2) \\
\hline & Nayarit & 413 & (6.0) & 81 & (3.0) & 420 & (5.6) & 407 & (7.6) & 13 & (6.1) & 279 & (13.0) & 309 & $(9.5)$ & 358 & (7.6) & 468 & (5.4) \\
\hline & Nuevo León & 435 & (8.5) & 76 & (3.0) & 446 & $(10.2)$ & 423 & (7.5) & 23 & (7.0) & 314 & $(9.2)$ & 337 & (9.7) & 380 & (8.9) & 488 & (10.8) \\
\hline & Puebla & 417 & (5.2) & 79 & (3.5) & 422 & (6.9) & 412 & (5.7) & 10 & (7.1) & 279 & (17.1) & 317 & (11.6) & 368 & (7.1) & 469 & (5.3) \\
\hline & Querétaro & 431 & (6.4) & 78 & (2.9) & 439 & (6.9) & 424 & (6.9) & 15 & (4.9) & 307 & (8.9) & 333 & (7.8) & 377 & (8.1) & 483 & (8.9) \\
\hline & Quintana Roo & 408 & (5.4) & 77 & (2.4) & 411 & (7.0) & 404 & (4.8) & 7 & (5.1) & 286 & (11.5) & 308 & (9.8) & 354 & (6.9) & 460 & (5.6) \\
\hline & San Luis Potosí & 412 & $(7.7)$ & 79 & (3.3) & 414 & (8.4) & 411 & $(8.1)$ & 3 & (6.1) & 287 & (7.6) & 313 & (8.4) & 355 & (8.0) & 468 & (10.8) \\
\hline & Sinaloa & 409 & (4.6) & 71 & (2.4) & 412 & (5.6) & 405 & (5.2) & 7 & (5.7) & 299 & (8.0) & 322 & (5.8) & 359 & (4.9) & 455 & (5.4) \\
\hline & Tabasco & 375 & (3.8) & 76 & (3.0) & 381 & (5.5) & 370 & (4.4) & 12 & (6.4) & 252 & (10.1) & 280 & (8.3) & 323 & (5.2) & 424 & (4.8) \\
\hline & Tamaulipas & 407 & (8.5) & 80 & (3.6) & 418 & (10.9) & 396 & $(7.2)$ & 22 & $(7.3)$ & 281 & (11.9) & 309 & (9.1) & 351 & (9.1) & 458 & (9.7) \\
\hline & Tlaxcala & 410 & (5.7) & 76 & (2.5) & 415 & (5.5) & 405 & (6.4) & 10 & (4.1) & 285 & (9.6) & 313 & (9.6) & 359 & (6.8) & 461 & (6.6) \\
\hline & Veracruz & 402 & (6.5) & 80 & (3.9) & 407 & (6.4) & 397 & (7.7) & 9 & (5.7) & 277 & (9.4) & 301 & (8.7) & 348 & (6.6) & 456 & (8.4) \\
\hline & Yucatán & 408 & (4.6) & 80 & (2.4) & 419 & (5.6) & 397 & (5.7) & 23 & (6.8) & 286 & (8.1) & 312 & (8.1) & 353 & (6.3) & 460 & (6.9) \\
\hline & Zacatecas & 407 & (4.2) & 77 & $(2.3)$ & 413 & (5.7) & 402 & (4.3) & 11 & (5.5) & 280 & (7.9) & 307 & (8.1) & 356 & (5.3) & 459 & (5.1) \\
\hline
\end{tabular}

- PISA adjudicated region.

Notes: Values that are statistically significant are indicated in bold (see Annex A3).

See Table 1.2.10 for national data.

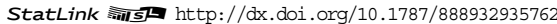


[Part 2/2]

Mean score, variation and gender differences in student performance on the mathematics Table B2.I.9 subscale employing, by region

\begin{tabular}{|c|c|c|c|c|c|c|c|c|c|c|c|c|c|c|c|c|c|c|c|c|c|c|c|}
\hline & & \multicolumn{4}{|c|}{ All students } & \multicolumn{6}{|c|}{ Gender differences } & \multicolumn{12}{|c|}{ Percentiles } \\
\hline & & \multicolumn{2}{|c|}{ Mean score } & \multicolumn{2}{|c|}{$\begin{array}{l}\text { Standard } \\
\text { deviation }\end{array}$} & \multicolumn{2}{|c|}{ Boys } & \multicolumn{2}{|c|}{ Girls } & \multicolumn{2}{|c|}{$\begin{array}{c}\text { Difference } \\
\text { (B - G) }\end{array}$} & \multicolumn{2}{|c|}{ 5th } & \multicolumn{2}{|c|}{ 10th } & \multicolumn{2}{|c|}{ 25th } & \multicolumn{2}{|c|}{ 75th } & \multicolumn{2}{|c|}{ 90th } & \multicolumn{2}{|c|}{ 95th } \\
\hline & & Mean & S.E. & S.D. & S.E. & $\begin{array}{l}\text { Mean } \\
\text { score }\end{array}$ & S.E. & $\begin{array}{l}\text { Mean } \\
\text { score }\end{array}$ & S.E. & \begin{tabular}{|c|}
$\begin{array}{c}\text { Score } \\
\text { dif. }\end{array}$ \\
\end{tabular} & S.E. & Score & S.E. & Score & S.E. & Score & S.E. & Score & S.E. & Score & S.E. & Score & S.E. \\
\hline \multirow{2}{*}{ త్ } & Portugal & & & & & & & & & & & & & & & & & & & & & & \\
\hline & Alentejo & 492 & (9.6) & 89 & (3.6) & 500 & (11.3) & 483 & (9.3) & 16 & $(7.0)$ & 343 & $(11.0)$ & 373 & (14.3) & 431 & (14.7) & 556 & (10.8) & 607 & (10.9) & 637 & $(9.8)$ \\
\hline \multicolumn{24}{|c|}{ Spain } \\
\hline & Andalusia ${ }^{\bullet}$ & 469 & (4.0) & 84 & $(2.2)$ & 477 & (5.1) & 459 & (4.1) & 18 & (4.8) & 335 & (7.9) & 362 & (5.7) & 411 & (4.8) & 526 & (5.7) & 579 & (5.6) & 606 & (5.6) \\
\hline & Aragon` & 494 & $(5.2)$ & 92 & (2.4) & 501 & (5.6) & 486 & (6.0) & 15 & (4.9) & 334 & (8.5) & 366 & (9.7) & 431 & (7.1) & 561 & (5.1) & 609 & (5.1) & 636 & $(7.7)$ \\
\hline & Asturias ${ }^{\bullet}$ & 496 & (3.9) & 89 & (2.3) & 501 & (5.6) & 491 & (3.4) & 10 & (5.1) & 345 & (8.6) & 382 & (7.8) & 440 & (5.7) & 558 & (4.6) & 607 & (6.5) & 635 & $(7.9)$ \\
\hline & Balearic Islands & 473 & (4.6) & 84 & $(2.2)$ & 475 & (5.3) & 471 & (5.1) & 4 & (4.9) & 329 & (8.7) & 362 & (6.4) & 416 & (6.5) & 534 & (4.8) & 580 & (5.7) & 603 & (5.6) \\
\hline & Basque Country & 502 & (2.4) & 78 & $(1.2)$ & 507 & (2.9) & 496 & (2.6) & 11 & (2.8) & 364 & (4.7) & 397 & (3.7) & 451 & (3.2) & 557 & (2.6) & 598 & (2.3) & 622 & (2.9) \\
\hline & Cantabria` & 492 & (3.1) & 85 & (1.9) & 498 & (4.0) & 486 & (4.4) & 11 & (5.5) & 354 & (7.8) & 384 & (5.6) & 434 & (4.1) & 553 & (4.1) & 601 & (4.1) & 628 & (5.5) \\
\hline & Castile and Leon & 506 & (4.1) & 81 & (2.0) & 514 & (5.7) & 497 & $(4.0)$ & 16 & (5.1) & 366 & (7.1) & 398 & (5.3) & 451 & (5.1) & 564 & (4.6) & 607 & (4.2) & 632 & (5.1) \\
\hline & Catalonia ${ }^{\bullet}$ & 493 & (5.3) & 84 & (2.3) & 502 & (6.4) & 483 & (5.9) & 19 & (6.3) & 351 & (8.4) & 379 & (7.5) & 435 & (7.1) & 553 & (5.4) & 600 & (5.9) & 627 & $(7.0)$ \\
\hline & Extremadura ${ }^{\bullet}$ & 461 & (4.3) & 90 & (2.0) & 465 & (5.4) & 457 & (3.8) & 8 & (3.9) & 308 & (8.4) & 340 & (7.4) & 401 & (5.9) & 525 & (4.3) & 576 & (5.1) & 603 & (5.5) \\
\hline & Galicia` & 484 & (4.6) & 88 & (2.3) & 485 & (5.1) & 484 & (5.6) & 1 & (5.4) & 333 & (7.0) & 367 & (8.0) & 428 & $(7.2)$ & 545 & (3.8) & 592 & (4.5) & 615 & (5.9) \\
\hline & La Rioja• & 500 & (2.0) & 99 & (2.5) & 508 & (3.3) & 493 & (3.0) & 15 & $(4.7)$ & 327 & (8.2) & 369 & (7.0) & 437 & (3.8) & 572 & (3.8) & 621 & (4.4) & 645 & $(4.5)$ \\
\hline & Madrid ${ }^{\bullet}$ & 500 & (3.5) & 87 & (2.3) & 505 & (4.7) & 495 & (3.9) & 10 & (5.0) & 346 & (7.5) & 383 & (6.1) & 444 & (5.0) & 564 & (4.3) & 608 & (5.2) & 634 & (6.0) \\
\hline & Murcia ${ }^{\bullet}$ & 461 & $(4.7)$ & 89 & (2.5) & 468 & (6.2) & 455 & (4.1) & 13 & (4.6) & 311 & (6.8) & 343 & (7.6) & 402 & (5.5) & 524 & (6.0) & 574 & (7.4) & 603 & $(8.2)$ \\
\hline & Navarre ${ }^{\bullet}$ & 514 & (3.0) & 83 & (2.1) & 516 & (3.6) & 511 & $(4.0)$ & 5 & (4.6) & 367 & (7.8) & 401 & (5.0) & 459 & (5.4) & 572 & (3.7) & 617 & (3.7) & 641 & (5.4) \\
\hline \multicolumn{24}{|c|}{ United Kingdom } \\
\hline & England & 493 & (3.6) & 95 & (1.8) & 499 & (4.7) & 487 & $(4.2)$ & 12 & $(5.2)$ & 335 & (5.9) & 369 & (5.5) & 428 & (5.4) & 559 & (3.8) & 615 & (4.3) & 647 & $(4.8)$ \\
\hline & Northern Ireland & 486 & (3.1) & 93 & (2.1) & 491 & (5.1) & 481 & (5.6) & 10 & (8.8) & 334 & (4.9) & 364 & (4.9) & 420 & (4.5) & 552 & (4.5) & 609 & (5.6) & 638 & (5.4) \\
\hline & Scotland ${ }^{\bullet}$ & 496 & (2.8) & 89 & (1.7) & 504 & (3.4) & 488 & (3.3) & 16 & (3.6) & 347 & (5.5) & 380 & (5.8) & 436 & (4.0) & 558 & (3.1) & 611 & (3.9) & 640 & (4.8) \\
\hline & Wales & 466 & $(2.2)$ & 85 & (1.3) & 470 & (2.7) & 461 & (2.7) & 9 & (3.2) & 325 & (4.0) & 356 & (4.1) & 408 & (3.1) & 524 & (3.0) & 574 & (3.3) & 605 & (3.9) \\
\hline \multicolumn{24}{|c|}{ United States } \\
\hline & Connecticut $^{\bullet}$ & 502 & (6.1) & 97 & (2.5) & 507 & (6.8) & 498 & (6.2) & 9 & (4.5) & 339 & (8.3) & 374 & (9.9) & 432 & (8.1) & 573 & (6.6) & 628 & (6.3) & 658 & $(7.5)$ \\
\hline & Florida ${ }^{\bullet}$ & 466 & (5.4) & 86 & (2.5) & 473 & (6.0) & 459 & (5.6) & 13 & (4.5) & 329 & (6.6) & 357 & (5.5) & 405 & (5.5) & 526 & (6.3) & 578 & (7.1) & 610 & (9.0) \\
\hline & Massachusetts ${ }^{\bullet}$ & 509 & $(5.8)$ & 94 & (2.9) & 512 & (5.7) & 507 & (6.6) & 5 & (4.4) & 354 & (9.1) & 386 & (5.0) & 443 & (5.9) & 576 & (8.3) & 632 & $(7.8)$ & 661 & (7.6) \\
\hline
\end{tabular}

\begin{tabular}{|c|c|c|c|c|c|c|c|c|c|c|c|c|c|c|c|c|c|c|c|c|c|c|c|}
\hline \multirow{3}{*}{ 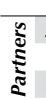 } & \multicolumn{23}{|l|}{ Argentina } \\
\hline & Ciudad Autónoma de Buenos Aires $\bullet$ & 419 & $(7.7)$ & 99 & (8.2) & 424 & $(8.2)$ & 415 & $(8.2)$ & 9 & (5.7) & 243 & $(30.1)$ & 296 & $(17.8)$ & 363 & (8.4) & 483 & (7.0) & 536 & (7.5) & $\mid 565$ & $(9.2)$ \\
\hline & \multicolumn{23}{|c|}{ Brazil } \\
\hline & Acre & 355 & (5.5) & 71 & (4.2) & 362 & (8.0) & 348 & (6.4) & 14 & (9.0) & 244 & (6.5) & 266 & $(6.2)$ & 305 & (5.3) & 403 & (7.6) & 446 & (11.4) & 475 & $(12.6)$ \\
\hline & Alagoas & 334 & $(8.4)$ & 78 & (6.0) & 344 & (10.0) & 326 & (8.4) & 18 & (6.6) & 213 & (15.9) & 242 & (10.8) & 282 & (8.9) & 382 & (10.4) & 438 & (18.7) & 473 & (19.0) \\
\hline & Amapá & 350 & (8.5) & 71 & (4.1) & 358 & (10.6) & 343 & (8.4) & 15 & (8.7) & 238 & (14.0) & 261 & (9.6) & 301 & (8.2) & 395 & (9.8) & 443 & (10.1) & 472 & (14.2) \\
\hline & Amazonas & 345 & (6.3) & 71 & (6.5) & 355 & (7.8) & 336 & (5.3) & 19 & (4.9) & 235 & (10.6) & 259 & (8.9) & 297 & (6.0) & 385 & (6.4) & 429 & (12.7) & 468 & (28.3) \\
\hline & Bahia & 370 & (10.1) & 85 & (6.9) & 376 & (8.1) & 365 & (15.7) & 12 & (15.5) & 245 & (17.1) & 271 & (12.6) & 311 & (11.7) & 423 & (15.5) & 484 & (11.8) & 513 & $(22.5)$ \\
\hline & Ceará & 373 & (8.9) & 87 & (7.4) & 383 & (11.0) & 364 & (9.0) & 20 & (9.0) & 240 & (13.5) & 267 & $(11.7)$ & 318 & (7.6) & 421 & (11.5) & 486 & (27.6) & 535 & (28.8) \\
\hline & Espírito Santo & 414 & (10.7) & 88 & (6.5) & 422 & (9.6) & 407 & (13.6) & 15 & (9.7) & 281 & (13.6) & 307 & $(10.2)$ & 353 & (8.4) & 471 & (18.6) & 538 & (21.4) & 575 & (18.4) \\
\hline & Federal District & 413 & (8.6) & 86 & (5.9) & 422 & (9.5) & 404 & (8.7) & 18 & (6.5) & 284 & (15.6) & 306 & $(10.7)$ & 348 & $(10.2)$ & 472 & $(12.8)$ & 529 & $(18.0)$ & 568 & $(20.5)$ \\
\hline & Goiás & 380 & (6.4) & 72 & (3.4) & 389 & $(7.2)$ & 371 & (7.0) & 18 & (6.6) & 271 & (11.4) & 292 & (9.4) & 331 & $(7.4)$ & 423 & $(8.2)$ & 479 & $(11.2)$ & 510 & $(9.3)$ \\
\hline & Maranhão & 342 & (13.7) & 79 & (8.8) & 355 & $(16.2)$ & 333 & (12.5) & 22 & $(6.7)$ & 221 & (11.6) & 247 & $(8.5)$ & 290 & (10.6) & 387 & $(18.0)$ & 447 & (38.7) & 493 & $(36.3)$ \\
\hline & Mato Grosso & 366 & $(9.2)$ & 74 & (7.4) & 369 & (8.6) & 364 & (10.7) & 5 & (6.2) & 258 & (12.8) & 280 & $(11.0)$ & 317 & (8.5) & 408 & (11.1) & 459 & (19.2) & 496 & $(33.3)$ \\
\hline & Mato Grosso do Sul & 406 & $(7.7)$ & 76 & (4.0) & 417 & (10.8) & 397 & (6.6) & 20 & (8.8) & 289 & $(11.7)$ & 313 & (11.5) & 352 & (8.1) & 455 & (8.3) & 510 & $(13.2)$ & 544 & $(12.0)$ \\
\hline & Minas Gerais & 402 & (7.1) & 74 & (3.1) & 408 & $(8.2)$ & 396 & $(7.2)$ & 12 & $(5.2)$ & 284 & $(8.9)$ & 308 & $(8.2)$ & 348 & (8.6) & 453 & (8.9) & 495 & (10.4) & 523 & $(14.0)$ \\
\hline & Pará & 355 & (4.4) & 72 & (3.9) & 363 & (6.3) & 350 & (4.9) & 13 & (7.0) & 245 & (9.7) & 268 & $(8.2)$ & 305 & (6.4) & 406 & (7.8) & 455 & (9.3) & 477 & $(12.8)$ \\
\hline & Paraíba & 389 & (7.1) & 81 & (6.9) & 398 & (9.7) & 382 & (8.9) & 15 & (11.6) & 261 & $(18.2)$ & 292 & $(14.0)$ & 336 & $(10.5)$ & 440 & (7.9) & 498 & (12.9) & 532 & $(15.9)$ \\
\hline & Paraná & 401 & $(11.8)$ & 86 & (11.4) & 411 & (12.3) & 391 & $(12.5)$ & 20 & (6.7) & 277 & $(12.1)$ & 300 & (11.1) & 340 & (8.3) & 449 & $(14.7)$ & 515 & $(43.9)$ & 572 & $(45.9)$ \\
\hline & Pernambuco & 358 & $(7.1)$ & 68 & (3.6) & 369 & (7.6) & 350 & $(7.6)$ & 20 & (5.2) & 248 & $(11.2)$ & 271 & (12.4) & 314 & $(7.2)$ & 403 & $(9.2)$ & 445 & $(9.5)$ & 473 & $(15.6)$ \\
\hline & Piauí & 385 & (8.1) & 86 & $(7.8)$ & 394 & $(8.3)$ & 378 & (8.5) & 17 & (4.4) & 268 & $(9.6)$ & 286 & $(9.3)$ & 324 & (7.1) & 430 & $(9.1)$ & 505 & $(21.2)$ & 544 & $(29.8)$ \\
\hline & Rio de Janeiro & 385 & (7.4) & 76 & (4.6) & 394 & $(8.2)$ & 377 & (7.5) & 18 & (5.3) & 266 & $(12.2)$ & 293 & (8.4) & 331 & (8.5) & 434 & $(11.2)$ & 487 & (15.2) & 519 & $(17.2)$ \\
\hline & Rio Grande do Norte & 373 & (9.8) & 90 & (9.0) & 389 & $(12.1)$ & 360 & (8.9) & 29 & (7.0) & 253 & (9.5) & 274 & (6.1) & 311 & (6.9) & 418 & (15.8) & 499 & (26.0) & 552 & $(38.9)$ \\
\hline & Rio Grande do Sul & 401 & (6.0) & 74 & (2.6) & 409 & (6.9) & 394 & (6.6) & 15 & (5.6) & 284 & $(11.3)$ & 308 & (8.9) & 351 & (7.1) & 453 & $(7.0)$ & 499 & (6.8) & 524 & $\quad(7.2)$ \\
\hline & Rondônia & 377 & (5.7) & 68 & (3.3) & 385 & (5.5) & 370 & (7.4) & 14 & (6.3) & 265 & (9.1) & 290 & $(9.9)$ & 333 & (6.3) & 420 & (6.8) & 461 & (8.9) & 490 & $(9.4)$ \\
\hline & Roraima & 356 & (5.9) & 76 & (3.5) & 361 & (6.2) & 352 & (8.4) & 9 & (8.8) & 240 & (8.5) & 265 & (8.5) & 304 & (5.8) & 402 & (7.6) & 458 & (12.0) & 495 & $(15.1)$ \\
\hline & Santa Catarina & 417 & (8.6) & 79 & (3.5) & 426 & (8.3) & 409 & (10.0) & 17 & (7.2) & 294 & (10.0) & 317 & (8.5) & 364 & (7.5) & 469 & (12.1) & 523 & (13.5) & 554 & $(13.7)$ \\
\hline & São Paulo & 399 & (4.5) & 83 & (3.7) & 407 & (4.7) & 391 & (5.3) & 17 & (4.0) & 274 & (4.8) & 300 & $(4.2)$ & 343 & (3.3) & 450 & (5.8) & 508 & $(11.2)$ & 545 & (15.9) \\
\hline & Sergipe & 384 & (9.4) & 75 & (5.7) & 401 & $(11.5)$ & 371 & (9.4) & 30 & (8.5) & 270 & (8.4) & 293 & (8.2) & 333 & (7.3) & 432 & (13.7) & 489 & (16.1) & 514 & $(21.2)$ \\
\hline & Tocantins & 363 & (7.4) & 80 & (4.5) & 374 & (9.1) & 351 & (6.6) & 24 & (6.7) & 238 & (10.3) & 265 & (9.8) & 310 & (8.5) & 411 & (9.9) & 467 & (13.4) & 503 & (16.7) \\
\hline \multicolumn{24}{|c|}{ 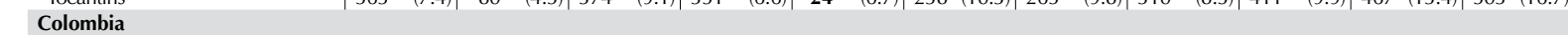 } \\
\hline & Bogotá & 384 & (3.8) & 72 & (2.4) & 402 & (5.3) & 368 & (3.6) & 34 & (5.2) & 268 & (5.6) & 294 & (4.6) & 335 & (3.8) & $\mid 431$ & (4.8) & 476 & (6.4) & \begin{tabular}{|l|}
503 \\
\end{tabular} & (8.5) \\
\hline & Cali & 371 & (7.0) & 78 & (2.9) & 382 & (7.3) & 363 & (7.7) & 19 & (5.0) & 248 & (7.9) & 272 & (6.9) & 319 & (7.3) & 423 & (9.1) & 473 & (9.7) & 503 & $(10.2)$ \\
\hline & Manizales & 394 & (4.8) & 78 & (4.2) & 410 & (8.0) & 379 & (3.7) & 31 & (7.8) & 272 & (6.1) & 297 & (5.8) & 339 & (5.8) & 443 & (6.6) & 497 & (11.1) & 532 & (12.3) \\
\hline & Medellín & 384 & (7.9) & 88 & (5.5) & 397 & (8.2) & 371 & (10.4) & 25 & (10.1) & 258 & (7.3) & 281 & $(6.2)$ & 322 & (7.0) & 436 & (12.4) & 505 & (16.7) & 545 & $(20.0)$ \\
\hline \multicolumn{24}{|c|}{ Russian Federation } \\
\hline & Perm Territory region` & 486 & (5.6) & 90 & (3.7) & 489 & (6.6) & 483 & (5.3) & 5 & (4.4) & 337 & (7.4) & 372 & (8.8) & 426 & (5.7) & $\mid 547$ & (5.8) & $\mid 601$ & (10.8) & | 632 & $(12.0)$ \\
\hline \multicolumn{24}{|c|}{ United Arab Emirates } \\
\hline & Abu Dhabi ${ }^{\bullet}$ & 428 & (3.9) & 89 & (2.3) & 419 & (5.0) & 436 & (5.1) & -17 & (6.6) & 290 & (5.6) & 317 & (4.1) & 364 & (4.1) & 486 & (5.8) & 548 & (6.9) & 584 & $(6.8)$ \\
\hline & Ajman & 406 & (7.9) & 77 & (4.2) & 391 & $(11.0)$ & 420 & (11.4) & -29 & $(16.2)$ & 284 & $(14.4)$ & 307 & $(13.0)$ & 351 & (10.6) & 460 & (9.0) & 506 & (7.3) & 531 & $(11.5)$ \\
\hline & Dubai $\bullet$ & 469 & (1.4) & 95 & (1.0) & 474 & (1.9) & 464 & (1.7) & 10 & (2.5) & 314 & (2.9) & 346 & (2.6) & 402 & (2.4) & 537 & (3.1) & 592 & (3.0) & 624 & (3.5) \\
\hline & Fujairah & 418 & $(10.2)$ & 87 & (3.0) & 402 & $(10.1)$ & 434 & (10.4) & -32 & $(10.9)$ & 275 & (14.4) & 305 & $(14.3)$ & 356 & (11.4) & 478 & (9.9) & 531 & (9.2) & 562 & $(12.7)$ \\
\hline & Ras al-Khaimah & 424 & (7.1) & 79 & (3.7) & 416 & $(5.2)$ & 432 & $(12.7)$ & -16 & $(13.1)$ & 299 & (12.4) & 324 & $(9.7)$ & 369 & (9.0) & 477 & (9.0) & 528 & $(11.0)$ & 560 & $(14.1)$ \\
\hline & Sharjah & 445 & (9.0) & 88 & (3.7) & 449 & $(16.2)$ & 441 & (11.4) & 8 & $(21.4)$ & 310 & (9.0) & 337 & $(9.1)$ & 380 & (10.0) & 505 & $(13.2)$ & 564 & (11.8) & 597 & $(11.1)$ \\
\hline & Umm al-Quwain & 402 & (4.1) & 77 & (3.6) & 382 & (5.5) & 422 & (5.5) & -39 & (7.4) & 282 & (9.7) & 308 & (7.9) & 351 & (5.4) & 450 & (8.5) & 502 & (13.3) & 539 & (14.9) \\
\hline
\end{tabular}

- PISA adjudicated region.

Notes: Values that are statistically significant are indicated in bold (see Annex A3).

See Table 1.2.10 for national data.

StatLink 部 SL http://dx.doi.org/10.1787/888932935762 
[Part 1/2]

Table B2.I.10 Percentage of students at each proficiency level on the mathematics subscale interpreting, by region

\begin{tabular}{|c|c|c|c|c|c|c|c|c|c|c|c|c|c|c|c|}
\hline & & \multicolumn{14}{|c|}{ All students } \\
\hline & & \multicolumn{2}{|c|}{$\begin{array}{c}\text { Below Level } 1 \\
\text { (below } 357.77 \\
\text { score points) }\end{array}$} & $\begin{array}{l}\text { L } \\
\text { (from } \\
\text { less th } \\
\text { scor }\end{array}$ & $\begin{array}{l}71 \\
7.77 \text { to } \\
420.07 \\
\text { oints) }\end{array}$ & $\begin{array}{r}\mathrm{L} \\
\text { (from } \\
\text { less th } \\
\text { scor }\end{array}$ & $\begin{array}{l}\text { I } 2 \\
0.07 \text { to } \\
482.38 \\
\text { oints) }\end{array}$ & $\begin{array}{r}\text { Le } \\
\text { (from } \\
\text { less th } \\
\text { scor }\end{array}$ & $\begin{array}{l}\mid 3 \\
2.38 \text { to } \\
5444.68 \\
\text { oints) }\end{array}$ & $\begin{array}{l}\mathrm{L} \\
\text { (from } \\
\text { less th } \\
\text { scor }\end{array}$ & $\begin{array}{l}14 \\
4.68 \text { to } \\
606.99 \\
\text { oints) }\end{array}$ & $\begin{array}{r}\mathrm{L} \\
\text { (from } \\
\text { less th } \\
\text { scor }\end{array}$ & $\begin{array}{l}5 \\
6.99 \text { to } \\
669.30 \\
\text { oints) }\end{array}$ & $\begin{array}{l}\text { Le } \\
\text { (abov } \\
\text { scor }\end{array}$ & $\begin{array}{l}16 \\
669.30 \\
\text { oints) }\end{array}$ \\
\hline & & $\%$ & S.E. & $\%$ & S.E. & $\%$ & S.E. & $\%$ & S.E. & $\%$ & S.E. & $\%$ & S.E. & $\%$ & S.E. \\
\hline 0 & Australia & & & & & & & & & & & & & & \\
\hline$u$ & Australian Capital Territory & 4.6 & $(0.8)$ & 9.4 & (1.4) & 16.9 & (1.5) & 21.7 & $(2.1)$ & 22.8 & (1.8) & 15.8 & (1.5) & 8.8 & $(1.2)$ \\
\hline & New South Wales & 6.4 & $(0.7)$ & 11.6 & $(0.8)$ & 19.5 & $(1.0)$ & 23.5 & $(1.3)$ & 19.6 & $(0.9)$ & 11.6 & $(0.7)$ & 7.7 & $(1.0)$ \\
\hline & Northern Territory & 18.8 & $(2.5)$ & 18.0 & $(4.0)$ & 20.5 & (3.6) & 22.1 & $(2.9)$ & 13.9 & (2.9) & 5.2 & $(2.2)$ & 1.7 & (1.1) \\
\hline & Queensland & 5.9 & $(0.8)$ & 11.6 & $(0.9)$ & 21.4 & (1.4) & 22.9 & $(1.1)$ & 19.6 & $(1.0)$ & 12.4 & $(0.8)$ & 6.2 & $(0.7)$ \\
\hline & South Australia & 7.3 & $(0.9)$ & 12.9 & $(1.2)$ & 21.7 & (1.6) & 24.2 & $(1.7)$ & 19.5 & (1.3) & 9.9 & (1.4) & 4.5 & $(0.6)$ \\
\hline & Tasmania & 9.1 & $(1.0)$ & 14.1 & (1.5) & 23.6 & (1.9) & 22.3 & $(1.7)$ & 17.0 & (1.6) & 9.3 & $(1.2)$ & 4.7 & $(0.9)$ \\
\hline & Victoria & 4.9 & $(0.7)$ & 12.0 & $(1.2)$ & 20.6 & (1.3) & 24.7 & $(1.1)$ & 21.7 & $(1.0)$ & 11.7 & $(0.9)$ & 4.4 & $(0.7)$ \\
\hline & Western Australia & 4.9 & $(0.8)$ & 10.7 & $(1.2)$ & 17.5 & $(1.2)$ & 22.0 & $(1.2)$ & 22.4 & (1.3) & 14.4 & $(1.0)$ & 8.1 & $(0.9)$ \\
\hline & Belgium & & & & & & & & & & & & & & \\
\hline & Flemish Community ${ }^{\bullet}$ & 6.4 & $(0.7)$ & 11.0 & $(0.8)$ & 17.0 & $(0.8)$ & 20.8 & $(1.0)$ & 20.5 & $(0.8)$ & 15.5 & $(0.8)$ & 8.7 & $(0.7)$ \\
\hline & French Community & 9.1 & $(1.0)$ & 14.2 & $(0.9)$ & 20.3 & $(0.9)$ & 22.0 & $(1.0)$ & 20.3 & $(1.2)$ & 10.2 & $(0.8)$ & 3.8 & $(0.4)$ \\
\hline & German-speaking Community & 7.4 & $(0.9)$ & 10.8 & (1.3) & 16.9 & (1.4) & 27.7 & (1.6) & 21.1 & (1.5) & 12.1 & $(1.2)$ & 3.9 & $(0.6)$ \\
\hline & Canada & & & & & & & & & & & & & & \\
\hline & Alberta & 4.4 & $(0.7)$ & 10.3 & $(1.0)$ & 18.8 & (1.5) & 24.8 & $(1.5)$ & 21.6 & $(1.4)$ & 14.3 & (1.4) & 5.9 & $(0.7)$ \\
\hline & British Columbia & 2.5 & $(0.6)$ & 9.0 & $(0.9)$ & 18.7 & $(1.2)$ & 26.7 & $(1.4)$ & 24.3 & $(1.2)$ & 13.0 & (1.3) & 5.7 & (1.0) \\
\hline & Manitoba & 6.4 & $(1.0)$ & 12.5 & (1.4) & 23.5 & (1.4) & 24.5 & (1.3) & 19.6 & (1.6) & 10.2 & $(1.2)$ & 3.3 & $(0.5)$ \\
\hline & New Brunswick & 5.6 & $(0.8)$ & 11.9 & $(1.1)$ & 23.2 & (1.8) & 27.3 & (1.9) & 20.1 & (1.4) & 9.0 & $(1.2)$ & 2.9 & $(0.6)$ \\
\hline & Newfoundland and Labrador & 6.1 & $(1.0)$ & 14.1 & $(1.3)$ & 22.8 & (1.4) & 25.3 & $(2.0)$ & 19.4 & (1.6) & 9.5 & (1.5) & 2.8 & $(0.7)$ \\
\hline & Nova Scotia & 5.0 & $(0.9)$ & 10.0 & $(1.0)$ & 23.2 & $(2.0)$ & 28.6 & $(2.5)$ & 21.2 & $(2.7)$ & 9.1 & $(1.2)$ & 2.8 & $(0.8)$ \\
\hline & Ontario & 4.2 & $(0.6)$ & 9.8 & $(1.0)$ & 21.2 & (1.3) & 27.2 & $(1.1)$ & 21.4 & (1.1) & 11.9 & (1.4) & 4.5 & $(0.7)$ \\
\hline & Prince Edward Island & 7.2 & $(0.9)$ & 15.9 & $(1.6)$ & 25.0 & $(1.8)$ & 25.5 & (1.4) & 17.5 & $(1.2)$ & 6.6 & $(0.9)$ & 2.2 & $(0.4)$ \\
\hline & Quebec & 4.2 & $(0.6)$ & 8.6 & $(0.7)$ & 15.8 & $(1.0)$ & 23.5 & $(0.9)$ & 24.2 & $(0.9)$ & 15.9 & $(1.0)$ & 8.0 & $(0.8)$ \\
\hline & Saskatchewan & 4.1 & $(0.6)$ & 11.1 & $(0.9)$ & 22.9 & (1.3) & 28.0 & $(1.8)$ & 21.0 & (1.3) & 10.1 & (1.1) & 2.8 & $(0.6)$ \\
\hline & Italy & & & & & & & & & & & & & & \\
\hline & Abruzzo & 11.4 & $(1.8)$ & 14.1 & $(1.6)$ & 21.8 & (1.6) & 23.1 & (1.8) & 17.9 & (1.7) & 9.1 & (1.4) & 2.6 & $(0.6)$ \\
\hline & Basilicata & 13.0 & (1.6) & 18.0 & $(1.3)$ & 24.9 & (2.1) & 20.7 & (1.9) & 14.4 & $(1.2)$ & 6.3 & $(0.8)$ & 2.7 & $(0.5)$ \\
\hline & Bolzano & 7.2 & $(0.6)$ & 11.6 & $(0.9)$ & 17.6 & $(1.7)$ & 22.5 & $(2.0)$ & 21.4 & $(1.0)$ & 12.7 & $(0.9)$ & 6.9 & $(0.7)$ \\
\hline & Calabria & 24.5 & (3.1) & 20.2 & (1.8) & 23.5 & (2.0) & 17.9 & (1.6) & 9.4 & (1.3) & 3.0 & $(0.7)$ & 1.4 & $(0.6)$ \\
\hline & Campania & 16.0 & $(2.3)$ & 18.9 & $(2.1)$ & 22.2 & (1.9) & 21.7 & (1.7) & 12.9 & (1.5) & 6.2 & (1.0) & 2.1 & $(0.7)$ \\
\hline & Emilia Romagna & 7.9 & $(1.4)$ & 10.9 & $(1.5)$ & 18.3 & (1.7) & 21.7 & (1.6) & 19.1 & (1.6) & 14.6 & (1.4) & 7.6 & (1.1) \\
\hline & Friuli Venezia Giulia & 5.5 & $(1.4)$ & 8.8 & $(1.0)$ & 14.4 & $(1.6)$ & 21.9 & $(1.8)$ & 23.7 & (1.9) & 16.5 & (1.5) & 9.2 & (1.1) \\
\hline & Lazio & 10.1 & (1.6) & 15.9 & (1.9) & 22.8 & (1.6) & 22.3 & (1.5) & 15.9 & (1.6) & 9.0 & (1.3) & 4.0 & $(0.9)$ \\
\hline & Liguria & 8.7 & $(1.3)$ & 13.7 & $(1.5)$ & 20.0 & (1.8) & 21.8 & (1.6) & 18.6 & (1.7) & 10.3 & (1.7) & 6.8 & (1.3) \\
\hline & Lombardia & 4.1 & $(0.8)$ & 8.8 & (1.5) & 16.9 & (1.8) & 22.8 & $(2.1)$ & 23.3 & (1.8) & 15.3 & (1.9) & 8.7 & (1.5) \\
\hline & Marche & 6.3 & $(1.6)$ & 11.6 & $(1.4)$ & 21.0 & $(1.7)$ & 24.7 & $(1.6)$ & 20.2 & $(1.6)$ & 11.5 & $(1.3)$ & 4.8 & (1.0) \\
\hline & Molise & 11.7 & (1.4) & 18.3 & (1.7) & 24.7 & (2.0) & 23.1 & $(2.0)$ & 14.3 & (1.5) & 5.3 & (0.9) & 2.6 & $(0.7)$ \\
\hline & Piemonte & 6.9 & $(1.0)$ & 11.9 & $(2.0)$ & 18.5 & $(1.7)$ & 23.7 & $(1.6)$ & 20.1 & (1.6) & 12.3 & (1.6) & 6.5 & (1.3) \\
\hline & Puglia & 8.6 & $(1.6)$ & 14.6 & $(2.1)$ & 24.1 & $(1.8)$ & 23.1 & (1.6) & 18.2 & (1.4) & 8.5 & $(1.2)$ & 2.9 & $(0.7)$ \\
\hline & Sardegna & 13.1 & (1.9) & 17.3 & (1.8) & 23.3 & (1.6) & 21.8 & (1.9) & 15.9 & (1.5) & 6.6 & (0.8) & 2.0 & $(0.5)$ \\
\hline & Sicilia & 15.3 & (1.9) & 19.4 & $(1.9)$ & 24.7 & (1.6) & 21.8 & $(1.8)$ & 13.2 & (1.4) & 4.4 & $(0.8)$ & 1.4 & $(0.5)$ \\
\hline & Toscana & 8.9 & $(1.7)$ & 12.8 & $(1.6)$ & 17.8 & $(1.6)$ & 22.5 & $(1.6)$ & 19.4 & (1.5) & 12.8 & (1.3) & 5.7 & $(0.9)$ \\
\hline & Trento & 3.5 & $(0.8)$ & 7.2 & $(1.1)$ & 16.4 & (1.5) & 24.9 & (1.5) & 24.6 & (1.7) & 16.2 & (1.3) & 7.3 & $(0.9)$ \\
\hline & Umbria & 8.8 & $(2.1)$ & 10.6 & (1.4) & 18.9 & (1.8) & 24.3 & $(3.2)$ & 21.5 & (2.4) & 11.1 & $(1.2)$ & 4.8 & $(0.7)$ \\
\hline & Valle d'Aosta & 6.6 & $(0.9)$ & 12.2 & $(1.5)$ & 20.9 & (1.7) & 25.8 & $(1.9)$ & 18.7 & (1.5) & 10.4 & $(1.2)$ & 5.4 & $(0.8)$ \\
\hline & Veneto & 4.5 & $(1.2)$ & 7.7 & (1.1) & 15.9 & (1.7) & 22.4 & $(1.8)$ & 23.1 & (1.8) & 16.4 & (1.6) & 10.0 & (1.8) \\
\hline & Mexico & & & & & & & & & & & & & & \\
\hline & Aguascalientes & 13.8 & $(2.2)$ & 28.5 & (1.9) & 32.2 & $(2.0)$ & 18.1 & (1.6) & 6.3 & (1.1) & 1.0 & $(0.6)$ & 0.0 & c \\
\hline & Baja California & 18.7 & $(2.9)$ & 33.8 & $(2.7)$ & 29.5 & (2.6) & 14.0 & $(2.1)$ & 3.5 & (0.9) & 0.5 & $(0.5)$ & 0.0 & C \\
\hline & Baja California Sur & 19.7 & (3.3) & 32.1 & (1.9) & 30.8 & $(2.7)$ & 13.3 & $(1.7)$ & 3.9 & $(0.9)$ & 0.3 & $(0.2)$ & 0.0 & C \\
\hline & Campeche & 27.5 & $(2.9)$ & 34.7 & $(2.5)$ & 26.0 & $(2.2)$ & 9.7 & $(1.0)$ & 1.8 & $(0.5)$ & 0.3 & $(0.2)$ & 0.0 & c \\
\hline & Chiapas & 42.4 & $(4.1)$ & 33.6 & $(2.5)$ & 18.8 & $(2.0)$ & 4.3 & $(1.1)$ & 0.7 & $(0.4)$ & 0.1 & $(0.1)$ & 0.0 & c \\
\hline & Chihuahua & 16.4 & $(2.9)$ & 29.6 & $(3.1)$ & 31.9 & $(2.2)$ & 15.7 & $(3.3)$ & 5.8 & $(2.0)$ & 0.6 & $(0.3)$ & 0.0 & C \\
\hline & Coahuila & 19.9 & $(2.9)$ & 33.2 & $(3.3)$ & 28.9 & (2.8) & 14.4 & $(2.4)$ & 3.2 & $(1.1)$ & 0.4 & $(0.3)$ & 0.0 & C \\
\hline & Colima & 16.9 & $(2.0)$ & 27.7 & $(1.9)$ & 30.7 & $(2.0)$ & 17.6 & $(1.7)$ & 6.1 & (1.3) & 0.9 & $(0.4)$ & 0.0 & C \\
\hline & Distrito Federal & 17.7 & $(2.2)$ & 29.6 & $(2.8)$ & 30.2 & $(2.2)$ & 16.2 & $(2.2)$ & 5.3 & $(1.2)$ & 1.0 & $(0.4)$ & 0.0 & C \\
\hline & Durango & 17.5 & $(2.7)$ & 29.7 & $(2.5)$ & 32.9 & $(2.7)$ & 15.6 & $(2.1)$ & 4.1 & (1.1) & 0.3 & $(0.2)$ & 0.0 & c \\
\hline & Guanajuato & 23.3 & $(3.0)$ & 32.5 & $(2.3)$ & 28.2 & (2.8) & 12.7 & $(1.7)$ & 3.0 & $(0.6)$ & 0.3 & $(0.2)$ & 0.0 & C \\
\hline & Guerrero & 44.1 & $(2.7)$ & 34.0 & $(2.3)$ & 17.4 & (1.6) & 3.7 & $(0.9)$ & 0.8 & $(0.4)$ & 0.0 & c & 0.0 & c \\
\hline & Hidalgo & 24.7 & $(2.9)$ & 33.5 & $(2.8)$ & 28.2 & (2.8) & 11.1 & (1.9) & 2.2 & $(0.8)$ & 0.2 & $(0.2)$ & 0.0 & C \\
\hline & Jalisco & 11.5 & $(2.0)$ & 29.2 & $(2.9)$ & 35.5 & (2.3) & 18.2 & $(2.1)$ & 4.8 & $(0.9)$ & 0.7 & $(0.4)$ & 0.1 & c \\
\hline & Mexico & 16.3 & $(2.2)$ & 33.6 & $(3.0)$ & 35.2 & $(2.7)$ & 12.8 & $(1.8)$ & 1.8 & $(0.7)$ & 0.3 & $\mathrm{C}$ & 0.1 & $(0.1)$ \\
\hline & Morelos & 20.0 & $(3.9)$ & 29.9 & (3.3) & 29.1 & (2.4) & 15.1 & $(2.3)$ & 4.9 & (1.9) & 0.8 & $(0.5)$ & 0.1 & C \\
\hline & Nayarit & 21.9 & $(2.9)$ & 31.2 & $(2.6)$ & 29.4 & (2.3) & 14.1 & $(1.7)$ & 3.0 & $(0.8)$ & 0.4 & $(0.3)$ & 0.0 & C \\
\hline & Nuevo León & 12.2 & $(2.8)$ & 29.0 & $(3.3)$ & 31.5 & (1.9) & 19.8 & $(3.4)$ & 6.7 & (1.7) & 0.8 & $(0.5)$ & 0.0 & C \\
\hline & Puebla & 22.1 & $(3.0)$ & 34.0 & $(2.0)$ & 29.4 & $(2.0)$ & 11.7 & $(1.4)$ & 2.6 & $(0.9)$ & 0.2 & $(0.2)$ & 0.0 & C \\
\hline & Querétaro & 12.3 & $(3.3)$ & 27.7 & $(3.8)$ & 31.7 & $(3.1)$ & 21.1 & $(3.5)$ & 6.1 & (1.4) & 1.1 & $(0.4)$ & 0.1 & C \\
\hline & Quintana Roo & 22.5 & $(3.4)$ & 32.7 & $(2.1)$ & 30.0 & (2.4) & 12.4 & $(1.8)$ & 2.2 & $(0.7)$ & 0.3 & $(0.2)$ & 0.0 & c \\
\hline & San Luis Potosí & 24.6 & (3.1) & 29.2 & $(2.7)$ & 28.7 & (2.4) & 13.9 & $(2.3)$ & 3.3 & $(1.2)$ & 0.3 & $(0.2)$ & 0.0 & C \\
\hline & Sinaloa & 21.6 & $(2.4)$ & 32.1 & $(2.2)$ & 30.0 & (2.3) & 13.7 & $(1.9)$ & 2.4 & $(0.6)$ & 0.3 & $(0.2)$ & 0.0 & C \\
\hline & Tabasco & 38.1 & $(2.8)$ & 34.5 & $(2.3)$ & 20.0 & $(2.2)$ & 6.6 & $(1.5)$ & 0.7 & $(0.4)$ & 0.1 & $(0.1)$ & 0.0 & C \\
\hline & Tamaulipas & 23.5 & $(2.5)$ & 31.4 & $(2.4)$ & 28.8 & (2.4) & 12.3 & $(2.1)$ & 3.4 & $(1.2)$ & 0.5 & $(0.3)$ & 0.1 & $(0.1)$ \\
\hline & Tlaxcala & 21.7 & $(2.9)$ & 34.0 & $(2.1)$ & 30.0 & (2.4) & 11.6 & $(1.7)$ & 2.4 & $(0.7)$ & 0.2 & $(0.2)$ & 0.0 & c \\
\hline & Veracruz & 29.7 & $(3.2)$ & 33.7 & $(2.5)$ & 23.7 & (1.9) & 10.4 & $(2.0)$ & 2.2 & $(0.9)$ & 0.3 & $(0.3)$ & 0.0 & C \\
\hline & Yucatán & 23.8 & $(2.7)$ & 32.5 & (1.9) & 26.5 & (2.5) & 13.7 & $(1.9)$ & 2.7 & $(0.8)$ & 0.6 & $(0.3)$ & 0.0 & C \\
\hline & Zacatecas & 22.6 & $(2.2)$ & 32.3 & (1.6) & 28.1 & $(1.8)$ & 14.4 & $(1.3)$ & 2.3 & $(0.6)$ & 0.3 & $(0.3)$ & 0.0 & C \\
\hline
\end{tabular}

- PISA adjudicated region.

Note: See Table I.2.11 for national data.

StatLink 新组 http://dx.doi.org/10.1787/888932935762 
[Part 2/2]

Table B2.I.10 Percentage of students at each proficiency level on the mathematics subscale interpreting, by region

\begin{tabular}{|c|c|c|c|c|c|c|c|c|c|c|c|c|c|c|c|}
\hline & & \multicolumn{14}{|c|}{ All students } \\
\hline & & \multicolumn{2}{|c|}{$\begin{array}{c}\text { Below Level } 1 \\
\text { (below } 357.77 \\
\text { score points) }\end{array}$} & \multicolumn{2}{|c|}{$\begin{array}{c}\text { Level } 1 \\
\text { (from } 357.77 \text { to } \\
\text { less than } 420.07 \\
\text { score points) }\end{array}$} & \multicolumn{2}{|c|}{$\begin{array}{c}\text { Level } 2 \\
\text { (from } 420.07 \text { to } \\
\text { less than } 482.38 \\
\text { score points) }\end{array}$} & $\begin{array}{l}\text { L } \\
\text { (from } \\
\text { less th } \\
\text { scor }\end{array}$ & \begin{tabular}{|l|}
3 \\
2.38 to \\
544.68 \\
oints)
\end{tabular} & $\begin{array}{l}\text { Le } \\
\text { (from } \\
\text { less th } \\
\text { scor }\end{array}$ & \begin{tabular}{|l|}
4 \\
4.68 to \\
606.99 \\
oints)
\end{tabular} & $\begin{array}{l}\text { L } \\
\text { (from } \\
\text { less th } \\
\text { scor }\end{array}$ & \begin{tabular}{l|}
15 \\
6.99 to \\
669.30 \\
oints)
\end{tabular} & $\begin{array}{l}\text { Le } \\
\text { (abov } \\
\text { scor }\end{array}$ & $\begin{array}{l}16 \\
669.30 \\
\text { oints) }\end{array}$ \\
\hline & & $\%$ & S.E. & $\%$ & S.E. & $\%$ & S.E. & $\%$ & S.E. & $\%$ & S.E. & $\%$ & S.E. & $\%$ & S.E. \\
\hline 0 & Portugal & & & & & & & & & & & & & & \\
\hline 芩 & Alentejo & 6.8 & (2.1) & 14.6 & (2.9) & 25.5 & $(2.1)$ & 26.8 & $(2.9)$ & 16.9 & (2.8) & 7.7 & (2.0) & 1.7 & (1.0) \\
\hline & Spain & & & & & & & & & & & & & & \\
\hline & Andalusia ${ }^{\bullet}$ & 10.2 & (1.2) & 16.0 & (1.3) & 23.4 & (1.8) & 22.8 & (1.9) & 16.3 & (1.5) & 8.2 & (1.1) & 3.1 & (0.6) \\
\hline & Aragon • & 9.0 & (1.3) & 12.9 & (1.3) & 18.7 & (1.9) & 24.6 & (1.8) & 20.2 & (1.5) & 11.0 & (1.2) & 3.6 & (0.9) \\
\hline & Asturias ${ }^{\bullet}$ & 7.4 & (1.1) & 11.6 & (1.4) & 19.8 & (1.0) & 23.9 & $(1.4)$ & 20.0 & $(1.2)$ & 11.8 & (1.4) & 5.4 & $(0.8)$ \\
\hline & Balearic Islands ${ }^{\bullet}$ & 10.6 & (1.4) & 15.4 & (1.4) & 23.2 & (1.3) & 23.3 & (1.9) & 17.8 & (1.6) & 7.7 & $(1.2)$ & 2.0 & (0.6) \\
\hline & Basque Country ${ }^{\bullet}$ & 5.1 & $(0.4)$ & 10.8 & $(0.7)$ & 19.9 & (0.8) & 25.7 & $(0.8)$ & 22.3 & (0.9) & 12.0 & $(0.7)$ & 4.1 & (0.5) \\
\hline & Cantabria ${ }^{\bullet}$ & 8.0 & (1.0) & 13.9 & (1.0) & 21.8 & $(1.2)$ & 23.2 & $(1.3)$ & 18.8 & (1.4) & 10.8 & (0.9) & 3.5 & (0.6) \\
\hline & Castile and Leon ${ }^{\bullet}$ & 4.5 & $(0.8)$ & 10.1 & (1.1) & 19.3 & (1.4) & 24.9 & $(1.7)$ & 22.5 & (1.7) & 13.7 & (1.1) & 5.1 & $(0.9)$ \\
\hline & Catalonia` & 7.3 & (1.0) & 12.5 & (1.4) & 19.6 & $(2.1)$ & 25.1 & $(2.1)$ & 20.1 & (1.6) & 10.8 & (1.2) & 4.5 & (0.9) \\
\hline & Extremadura ${ }^{\bullet}$ & 14.4 & (1.6) & 17.7 & (1.2) & 22.4 & $(2.1)$ & 21.6 & $(2.1)$ & 14.4 & (1.1) & 7.4 & (1.1) & 2.3 & $(0.7)$ \\
\hline & Galicia ${ }^{\bullet}$ & 8.4 & (1.0) & 13.0 & (1.4) & 21.1 & $(1.6)$ & 24.4 & $(1.5)$ & 20.2 & (1.4) & 9.4 & (1.0) & 3.4 & (0.5) \\
\hline & La Rioja・ & 9.9 & $(0.9)$ & 11.3 & $(1.2)$ & 18.6 & $(1.6)$ & 22.2 & $(1.2)$ & 19.4 & (1.5) & 12.6 & $(1.2)$ & 6.0 & $(0.7)$ \\
\hline & Madrid` & 5.4 & (1.0) & 10.7 & $(1.2)$ & 18.8 & $(1.3)$ & 25.5 & $(1.4)$ & 23.4 & (1.6) & 12.7 & (1.3) & 3.6 & (0.6) \\
\hline & Murcia ${ }^{\bullet}$ & 13.3 & (1.5) & 17.0 & (1.3) & 22.8 & (1.8) & 22.1 & $(1.7)$ & 15.4 & (1.3) & 7.0 & (1.1) & 2.3 & $(0.7)$ \\
\hline & Navarre ${ }^{\bullet}$ & 5.1 & $(0.8)$ & 9.4 & (1.1) & 18.9 & (1.4) & 24.7 & $(1.3)$ & 23.9 & (1.5) & 13.0 & $(1.2)$ & 5.1 & $(0.8)$ \\
\hline & United Kingdom & & & & & & & & & & & & & & \\
\hline & England & 8.5 & $(1.0)$ & 13.2 & $(0.9)$ & 20.2 & $(0.9)$ & 23.3 & $(1.2)$ & 19.2 & $(0.9)$ & 10.6 & $(0.7)$ & 4.9 & $(0.5)$ \\
\hline & Northern Ireland & 8.8 & (0.9) & 14.6 & (1.0) & 21.3 & (1.3) & 23.0 & $(1.4)$ & 18.5 & $(0.9)$ & 9.6 & $(0.9)$ & 4.2 & $(0.5)$ \\
\hline & Scotland ${ }^{\bullet}$ & 4.8 & $(0.7)$ & 10.8 & $(0.8)$ & 22.5 & $(1.3)$ & 26.7 & $(1.3)$ & 20.9 & $(1.2)$ & 10.4 & $(0.8)$ & 3.9 & $(0.5)$ \\
\hline & Wales & 9.3 & $(0.8)$ & 15.6 & (0.9) & 24.6 & (1.1) & 25.2 & $(1.0)$ & 16.1 & $(0.7)$ & 7.1 & $(0.7)$ & 2.2 & $(0.4)$ \\
\hline & United States & & & & & & & & & & & & & & \\
\hline & Connecticut $^{\bullet}$ & 7.2 & (1.3) & 11.6 & $(1.2)$ & 18.2 & (1.4) & 23.1 & (1.6) & 20.4 & (1.7) & 12.7 & (1.4) & 6.7 & (1.1) \\
\hline & Florida $\bullet$ & 10.0 & (1.4) & 18.8 & (1.6) & 25.1 & (1.7) & 23.7 & $(1.8)$ & 13.9 & (1.3) & 6.3 & (1.1) & 2.2 & $(0.8)$ \\
\hline & Massachusetts ${ }^{\bullet}$ & 5.7 & $(0.7)$ & 11.2 & (1.0) & 18.7 & (1.5) & 22.0 & (1.6) & 20.3 & (1.5) & 13.6 & (1.4) & 8.6 & (1.5) \\
\hline$\tilde{2}$ & Argentina & & & & & & & & & & & & & & \\
\hline 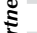 & Ciudad Autónoma de Buenos Aires ${ }^{\bullet}$ & 25.5 & (2.6) & 23.6 & $(2.0)$ & 25.5 & (1.9) & 17.6 & $(1.9)$ & 6.4 & $(1.2)$ & 1.2 & $(0.5)$ & 0.2 & $(0.2)$ \\
\hline ๘ & Brazil & & & & & & & & & & & & & & \\
\hline & Acre & 46.0 & (3.8) & 30.3 & (2.6) & 17.0 & $(2.5)$ & 5.8 & $(1.3)$ & 0.7 & $(0.5)$ & 0.1 & c & 0.2 & $(0.2)$ \\
\hline & Alagoas & 58.1 & $(4.1)$ & 25.1 & (2.8) & 12.0 & $(2.3)$ & 3.9 & $(1.4)$ & 0.9 & $(0.5)$ & 0.1 & c & 0.0 & $\mathrm{C}$ \\
\hline & Amapá & 43.3 & $(5.1)$ & 32.7 & (3.7) & 17.0 & $(2.4)$ & 6.0 & $(2.3)$ & 1.0 & $(0.9)$ & 0.1 & c & 0.0 & c \\
\hline & Amazonas & 46.5 & (3.6) & 33.0 & (2.8) & 13.6 & $(2.1)$ & 4.7 & $(1.2)$ & 1.5 & $(1.3)$ & 0.7 & $(0.8)$ & 0.0 & c \\
\hline & Bahia & 39.0 & (5.6) & 30.3 & (4.0) & 18.0 & $(3.0)$ & 9.5 & $(3.1)$ & 2.6 & (1.6) & 0.6 & $(0.6)$ & 0.0 & c \\
\hline & Ceará & 35.3 & $(4.1)$ & 32.7 & (3.3) & 20.0 & $(2.9)$ & 7.7 & $(1.7)$ & 3.4 & (1.4) & 0.8 & $(0.5)$ & 0.0 & c \\
\hline & Espírito Santo & 24.2 & (2.6) & 30.6 & (3.4) & 22.7 & $(2.1)$ & 12.5 & $(2.4)$ & 7.3 & $(2.6)$ & 2.5 & $(1.0)$ & 0.2 & c \\
\hline & Federal District & 22.6 & $(4.8)$ & 25.2 & (3.0) & 26.8 & (3.9) & 16.8 & $(2.4)$ & 7.2 & $(2.8)$ & 1.1 & $(0.6)$ & 0.2 & c \\
\hline & Goiás & 36.4 & (3.3) & 36.3 & (2.4) & 18.6 & $(2.0)$ & 6.9 & $(1.2)$ & 1.7 & $(0.6)$ & 0.1 & $\mathrm{C}$ & 0.0 & c \\
\hline & Maranhão & 55.1 & (7.4) & 23.9 & (3.5) & 13.5 & $(3.7)$ & 5.5 & $(2.8)$ & 1.8 & (1.4) & 0.2 & c & 0.0 & c \\
\hline & Mato Grosso & 40.7 & (4.9) & 32.5 & (2.8) & 17.6 & $(2.6)$ & 6.5 & $(2.2)$ & 2.2 & $(1.4)$ & 0.5 & C & 0.0 & c \\
\hline & Mato Grosso do Sul & 21.7 & (3.5) & 31.7 & (2.9) & 27.8 & $(3.3)$ & 13.3 & $(2.4)$ & 4.9 & $(2.0)$ & 0.6 & $(0.4)$ & 0.1 & c \\
\hline & Minas Gerais & 23.6 & (3.6) & 33.1 & (2.8) & 27.3 & $(2.9)$ & 12.1 & $(2.0)$ & 3.2 & $(1.4)$ & 0.7 & $(0.4)$ & 0.0 & c \\
\hline & Pará & 45.5 & (4.4) & 29.0 & (3.0) & 19.5 & $(2.2)$ & 5.2 & $(0.8)$ & 0.8 & $(0.8)$ & 0.0 & $\mathrm{c}$ & 0.0 & $\mathrm{C}$ \\
\hline & Paraiba & 29.4 & $(5.2)$ & 29.9 & (3.5) & 23.5 & $(4.2)$ & 12.8 & $(2.5)$ & 3.4 & (1.9) & 0.9 & $(0.4)$ & 0.2 & $(0.2)$ \\
\hline & Paraná & 29.1 & $(4.0)$ & 30.6 & (3.0) & 21.8 & $(2.9)$ & 11.7 & $(2.1)$ & 5.5 & (3.1) & 1.3 & (1.4) & 0.0 & $\mathrm{C}$ \\
\hline & Pernambuco & 44.6 & $(4.8)$ & 32.1 & (2.9) & 17.1 & $(2.5)$ & 5.0 & $(1.2)$ & 1.0 & $(0.7)$ & 0.3 & $(0.3)$ & 0.0 & c \\
\hline & Piauí & 37.4 & (4.6) & 32.3 & (3.1) & 17.9 & $(2.7)$ & 8.6 & $(1.7)$ & 3.0 & $(1.7)$ & 0.6 & $(0.6)$ & 0.2 & $(0.1)$ \\
\hline & Rio de Janeiro & 26.5 & $(4.1)$ & 33.3 & (3.7) & 26.6 & $(3.3)$ & 11.0 & $(1.9)$ & 2.0 & $(1.0)$ & 0.6 & (0.5) & 0.0 & c \\
\hline & Rio Grande do Norte & 36.7 & $(3.2)$ & 30.2 & (3.0) & 18.4 & $(2.3)$ & 8.7 & $(2.2)$ & 3.7 & $(1.2)$ & 1.9 & $(1.2)$ & 0.4 & $(0.4)$ \\
\hline & Rio Grande do Sul & 17.8 & $(2.7)$ & 32.2 & (2.6) & 29.3 & $(2.7)$ & 16.7 & $(2.3)$ & 3.8 & $(1.1)$ & 0.2 & c & 0.0 & C \\
\hline & Rondônia & 29.4 & $(3.7)$ & 34.8 & (2.9) & 26.0 & $(2.5)$ & 8.5 & $(1.6)$ & 1.1 & $(0.5)$ & 0.3 & $(0.2)$ & 0.0 & c \\
\hline & Roraima & 46.0 & (3.8) & 29.3 & (3.4) & 16.1 & $(2.6)$ & 6.8 & $(2.2)$ & 1.5 & $(0.8)$ & 0.2 & c & 0.0 & c \\
\hline & Santa Catarina & 22.7 & (3.6) & 27.0 & $(2.7)$ & 27.9 & $(2.2)$ & 16.6 & $(2.2)$ & 5.2 & $(1.4)$ & 0.5 & $(0.4)$ & 0.0 & $\mathrm{C}$ \\
\hline & São Paulo & 23.8 & (1.7) & 30.0 & (1.5) & 26.0 & $(1.5)$ & 14.0 & $(1.4)$ & 5.0 & $(1.1)$ & 1.0 & $(0.4)$ & 0.1 & $(0.1)$ \\
\hline & Sergipe & 35.8 & (4.6) & 33.0 & (3.0) & 18.7 & $(2.5)$ & 9.4 & $(2.9)$ & 2.6 & (1.4) & 0.4 & $(0.4)$ & 0.0 & C \\
\hline & Tocantins & 43.0 & $(4.1)$ & 31.0 & (2.6) & 16.4 & $(2.5)$ & 7.2 & $(2.0)$ & 2.0 & $(1.0)$ & 0.5 & $(0.2)$ & 0.0 & c \\
\hline & Colombia & & & & & & & & & & & & & & \\
\hline & Bogotá & 24.5 & (1.8) & 34.4 & (1.7) & 27.9 & (1.9) & 10.2 & $(1.5)$ & 2.5 & $(0.6)$ & 0.4 & $(0.3)$ & 0.1 & c \\
\hline & Cali & 33.1 & (3.0) & 31.6 & (1.9) & 24.0 & $(2.3)$ & 8.7 & $(1.5)$ & 2.1 & $(0.6)$ & 0.4 & $(0.3)$ & 0.0 & c \\
\hline & Manizales & 18.9 & (1.9) & 33.5 & (1.9) & 30.4 & $(2.4)$ & 12.9 & (1.3) & 3.7 & (1.0) & 0.6 & (0.5) & 0.0 & c \\
\hline & Medellín & 28.4 & (2.8) & 30.4 & (1.9) & 23.0 & $(2.1)$ & 11.3 & (1.8) & 4.9 & (1.3) & 1.6 & $(0.8)$ & 0.5 & (0.4) \\
\hline & Russian Federation & & & & & & & & & & & & & & \\
\hline & Perm Territory region` & 9.9 & (1.4) & 18.3 & (1.4) & 26.0 & $(2.0)$ & 24.6 & $(1.5)$ & 14.2 & $(1.2)$ & 5.3 & (1.1) & 1.7 & $(0.8)$ \\
\hline & United Arab Emirates & & & & & & & & & & & & & & \\
\hline & Abu Dhabi & 26.1 & $(1.7)$ & 28.4 & (1.2) & 24.3 & $(1.1)$ & 13.2 & $(1.1)$ & 5.9 & $(0.7)$ & 1.7 & $(0.5)$ & 0.3 & $(0.2)$ \\
\hline & Ajman & 30.5 & $(4.8)$ & 31.7 & (3.4) & 24.5 & (2.6) & 11.5 & $(2.1)$ & 1.7 & $(0.8)$ & 0.0 & c & 0.0 & c \\
\hline & Dubai & 14.3 & $(0.5)$ & 20.5 & $(0.9)$ & 24.3 & $(0.8)$ & 21.1 & $(0.8)$ & 13.3 & $(0.7)$ & 5.3 & $(0.6)$ & 1.1 & $(0.3)$ \\
\hline & Fujairah & 31.2 & $(4.3)$ & 28.3 & (2.4) & 25.5 & (3.0) & 11.3 & $(2.0)$ & 3.2 & $(0.9)$ & 0.4 & $(0.3)$ & 0.0 & $\mathrm{C}$ \\
\hline & Ras al-Khaimah & 27.8 & (3.9) & 30.2 & (2.0) & 25.0 & $(2.7)$ & 13.1 & $(2.1)$ & 3.1 & $(0.9)$ & 0.7 & $(0.3)$ & 0.0 & $\mathrm{C}$ \\
\hline & Sharjah & 19.4 & (2.6) & 26.8 & (3.2) & 25.7 & $(2.6)$ & 18.9 & $(2.6)$ & 6.9 & $(1.5)$ & 2.0 & $(0.9)$ & 0.3 & $(0.3)$ \\
\hline & Umm al-Quwain & 33.3 & (2.9) & 32.8 & (3.9) & 23.7 & $(2.8)$ & 8.2 & (1.8) & 1.5 & $(0.9)$ & 0.4 & $\mathrm{C}$ & 0.0 & $\mathrm{C}$ \\
\hline
\end{tabular}

- PISA adjudicated region.

Note: See Table I.2.11 for national data.

StatLink 解古 $\mathrm{http}: / / \mathrm{dx}$.doi.org/10.1787/888932935762 
Percentage of students at each proficiency level on the mathematics subscale interpreting, by gender Table B2.I.11 and region

\begin{tabular}{|c|c|c|c|c|c|c|c|c|c|c|c|c|c|c|c|}
\hline & & \multicolumn{14}{|c|}{ Boys } \\
\hline & & \multicolumn{2}{|c|}{$\begin{array}{l}\text { Below Level } 1 \\
\text { (below 357.77 } \\
\text { score points) }\end{array}$} & $\begin{array}{r}1 \\
\text { (from } \\
\text { less th } \\
\text { scor }\end{array}$ & $\begin{array}{l}11 \\
7.77 \text { to } \\
\mathbf{4 2 0 . 0 7} \\
\text { oints) }\end{array}$ & $\begin{array}{r}\mathrm{L} \\
\text { (from } \\
\text { less th } \\
\text { scor }\end{array}$ & $\begin{array}{l}l 2 \\
0.07 \text { to } \\
482.38 \\
\text { oints) }\end{array}$ & $\begin{array}{r}\mathbf{L} \\
\text { (from } \\
\text { less th } \\
\text { scor }\end{array}$ & \begin{tabular}{|l|}
3 \\
2.38 to \\
544.68 \\
oints)
\end{tabular} & $\begin{array}{r}\mathrm{L} \\
\text { (from } \\
\text { less th } \\
\text { scor }\end{array}$ & $\begin{array}{l}44 \\
4.68 \text { to } \\
606.99 \\
\text { oints) }\end{array}$ & $\begin{array}{r}\mathrm{L} \\
\text { (from } \\
\text { less th } \\
\text { scor }\end{array}$ & $\begin{array}{l}5 \\
6.99 \text { to } \\
669.30 \\
\text { oints) }\end{array}$ & $\begin{array}{l}\text { Le } \\
\text { (abov } \\
\text { scor }\end{array}$ & $\begin{array}{l}16 \\
669.30 \\
\text { oints) }\end{array}$ \\
\hline & & $\%$ & S.E. & $\%$ & S.E. & $\%$ & S.E. & $\%$ & S.E. & $\%$ & S.E. & $\%$ & S.E. & $\%$ & S.E. \\
\hline$\theta$ & Australia & & & & & & & & & & & & & & \\
\hline U & Australian Capital Territory & 4.7 & $(1.2)$ & 9.8 & $(2.0)$ & 16.7 & $(2.2)$ & 22.2 & (2.4) & 21.1 & (2.4) & 15.3 & $(2.2)$ & 10.2 & (1.9) \\
\hline & New South Wales & 6.9 & $(1.0)$ & 11.8 & $(1.1)$ & 18.8 & (1.4) & 22.1 & (1.5) & 19.1 & $(1.2)$ & 12.1 & $(1.1)$ & 9.2 & (1.5) \\
\hline & Northern Territory & 19.3 & (3.0) & 18.2 & $(4.7)$ & 16.2 & (4.4) & 21.7 & $(4.6)$ & 15.7 & (3.7) & 6.2 & $(3.2)$ & 2.7 & (1.7) \\
\hline & Queensland & 6.5 & $(1.2)$ & 10.8 & $(1.2)$ & 21.0 & (1.6) & 22.3 & (1.3) & 19.3 & (1.3) & 13.0 & (1.1) & 7.0 & $(1.0)$ \\
\hline & South Australia & 7.4 & $(1.2)$ & 11.4 & $(1.6)$ & 20.3 & (2.4) & 24.6 & $(2.2)$ & 19.7 & (1.6) & 11.2 & (1.4) & 5.4 & $(1.0)$ \\
\hline & Tasmania & 9.3 & (1.5) & 11.5 & $(2.0)$ & 22.9 & (2.3) & 22.8 & $(2.5)$ & 18.0 & $(2.2)$ & 10.6 & $(2.0)$ & 4.9 & (1.6) \\
\hline & Victoria & 5.1 & $(0.9)$ & 10.5 & $(1.3)$ & 19.7 & (1.7) & 24.3 & $(1.5)$ & 22.1 & $(1.2)$ & 12.7 & (1.4) & 5.6 & (1.1) \\
\hline & Western Australia & 3.4 & $(0.8)$ & 9.2 & (1.5) & 17.3 & (1.8) & 21.2 & (1.7) & 23.0 & (1.8) & 16.1 & $(1.7)$ & 9.7 & (1.6) \\
\hline & Belgium & & & & & & & & & & & & & & \\
\hline & Flemish Community ${ }^{\bullet}$ & 6.6 & $(1.0)$ & 10.5 & $(1.0)$ & 16.0 & $(0.9)$ & 20.2 & $(1.0)$ & 20.2 & (1.1) & 16.1 & $(1.0)$ & 10.4 & (1.0) \\
\hline & French Community & 9.6 & $(1.2)$ & 13.8 & $(1.3)$ & 18.7 & (1.4) & 20.7 & (1.5) & 20.7 & (1.7) & 11.6 & $(1.2)$ & 5.0 & $(0.7)$ \\
\hline & German-speaking Community & 9.1 & $(1.2)$ & 12.0 & (1.9) & 15.8 & (1.9) & 25.7 & $(2.5)$ & 19.4 & $(2.0)$ & 12.9 & (1.8) & 5.1 & (1.0) \\
\hline & Canada & & & & & & & & & & & & & & \\
\hline & Alberta & 4.5 & (1.0) & 9.3 & (1.5) & 18.3 & (1.9) & 23.6 & $(2.1)$ & 21.0 & (1.9) & 15.9 & $(2.0)$ & 7.3 & $(1.0)$ \\
\hline & British Columbia & 2.5 & $(0.8)$ & 8.3 & $(1.3)$ & 17.5 & (1.8) & 26.4 & $(2.3)$ & 23.9 & (1.7) & 14.5 & $(1.8)$ & 6.8 & $(1.5)$ \\
\hline & Manitoba & 6.2 & $(1.2)$ & 12.4 & $(1.8)$ & 22.9 & $(2.1)$ & 24.7 & (1.8) & 18.8 & $(2.2)$ & 11.3 & (1.5) & 3.7 & $(0.8)$ \\
\hline & New Brunswick & 5.9 & (1.1) & 11.6 & $(1.6)$ & 21.9 & (1.9) & 26.8 & $(2.2)$ & 20.5 & $(2.1)$ & 9.8 & (1.6) & 3.4 & $(0.9)$ \\
\hline & Newfoundland and Labrador & 7.1 & (1.6) & 13.4 & $(2.5)$ & 20.6 & $(2.8)$ & 25.3 & $(2.7)$ & 19.9 & $(2.3)$ & 9.9 & (2.4) & 3.6 & $(1.3)$ \\
\hline & Nova Scotia & 5.2 & $(1.3)$ & 9.1 & $(1.5)$ & 21.0 & (2.0) & 27.7 & $(2.3)$ & 22.4 & (2.9) & 11.0 & (1.5) & 3.6 & (1.3) \\
\hline & Ontario & 4.8 & $(0.8)$ & 10.0 & $(1.2)$ & 19.8 & (1.5) & 25.2 & (1.5) & 21.3 & (1.7) & 13.5 & $(2.1)$ & 5.4 & (1.1) \\
\hline & Prince Edward Island & 7.5 & $(1.3)$ & 15.7 & $(2.3)$ & 23.7 & (2.4) & 24.3 & $(2.2)$ & 17.8 & (1.7) & 8.2 & $(1.2)$ & 2.8 & $(0.7)$ \\
\hline & Quebec & 3.9 & $(0.9)$ & 8.3 & $(1.0)$ & 14.5 & $(1.2)$ & 22.1 & $(1.3)$ & 24.4 & (1.3) & 17.3 & $(1.2)$ & 9.5 & (1.1) \\
\hline & Saskatchewan & 4.6 & $(1.0)$ & 11.1 & $(1.2)$ & 21.4 & $(2.1)$ & 26.7 & $(2.5)$ & 22.2 & (1.9) & 10.6 & (1.6) & 3.5 & $(0.9)$ \\
\hline & Italy & & & & & & & & & & & & & & \\
\hline & Abruzzo & 12.3 & (2.5) & 13.4 & (1.8) & 19.4 & $(2.3)$ & 21.1 & $(2.2)$ & 19.4 & (2.5) & 11.1 & (1.8) & 3.2 & $(0.8)$ \\
\hline & Basilicata & 12.2 & (1.6) & 16.2 & $(2.2)$ & 22.8 & $(2.3)$ & 20.6 & (2.9) & 15.6 & $(2.2)$ & 8.7 & (1.4) & 3.8 & $(0.9)$ \\
\hline & Bolzano & 7.0 & (1.0) & 11.5 & $(1.2)$ & 15.8 & (2.4) & 20.9 & (1.8) & 22.2 & (2.0) & 13.9 & (1.4) & 8.7 & $(1.0)$ \\
\hline & Calabria & 24.1 & (3.7) & 20.2 & $(2.7)$ & 21.4 & (2.4) & 16.7 & $(2.5)$ & 11.0 & (1.9) & 4.3 & $(1.0)$ & 2.2 & $(0.9)$ \\
\hline & Campania & 15.2 & (2.3) & 17.9 & (2.4) & 20.4 & $(2.0)$ & 21.5 & $(2.5)$ & 14.4 & (1.9) & 7.6 & (1.4) & 3.0 & $(0.9)$ \\
\hline & Emilia Romagna & 8.4 & $(1.8)$ & 10.0 & $(2.0)$ & 15.8 & (1.8) & 20.2 & $(2.1)$ & 18.6 & $(2.2)$ & 16.9 & $(2.3)$ & 10.0 & (1.6) \\
\hline & Friuli Venezia Giulia & 5.0 & $(1.1)$ & 9.4 & (1.6) & 13.2 & (1.9) & 18.2 & (2.4) & 22.4 & (2.5) & 19.4 & $(1.8)$ & 12.3 & (1.8) \\
\hline & Lazio & 9.2 & (1.7) & 14.9 & $(2.2)$ & 22.0 & $(2.1)$ & 20.9 & $(2.2)$ & 16.0 & (1.6) & 11.4 & (1.7) & 5.6 & $(1.4)$ \\
\hline & Liguria & 8.0 & (1.6) & 14.4 & $(2.1)$ & 19.9 & $(2.7)$ & 19.7 & (2.5) & 17.8 & $(2.2)$ & 11.3 & (1.9) & 8.8 & (1.6) \\
\hline & Lombardia & 4.4 & $(1.1)$ & 8.0 & $(2.1)$ & 14.9 & $(2.1)$ & 20.3 & (2.4) & 22.4 & $(2.3)$ & 17.9 & $(2.3)$ & 12.1 & (2.3) \\
\hline & Marche & 5.0 & (1.8) & 9.4 & $(1.7)$ & 18.3 & $(2.2)$ & 24.2 & $(2.0)$ & 21.7 & (2.4) & 14.2 & (1.9) & 7.2 & (1.6) \\
\hline & Molise & 11.2 & (1.7) & 17.3 & (1.9) & 24.1 & $(2.2)$ & 22.5 & $(2.5)$ & 15.8 & (1.9) & 6.2 & $(1.2)$ & 2.9 & (1.0) \\
\hline & Piemonte & 6.8 & $(1.2)$ & 8.8 & $(2.0)$ & 16.3 & (1.9) & 24.4 & $(2.5)$ & 21.1 & $(2.3)$ & 14.2 & (1.9) & 8.4 & (1.6) \\
\hline & Puglia & 8.8 & (1.7) & 12.5 & $(2.0)$ & 20.4 & (1.9) & 22.1 & $(2.3)$ & 21.1 & (1.8) & 11.1 & (1.5) & 4.1 & (1.0) \\
\hline & Sardegna & 13.8 & (2.4) & 16.8 & $(2.1)$ & 22.9 & $(2.1)$ & 20.5 & $(2.2)$ & 15.3 & (1.8) & 7.5 & $(1.2)$ & 3.1 & $(0.8)$ \\
\hline & Sicilia & 14.6 & (2.3) & 18.5 & $(2.3)$ & 23.5 & (2.4) & 21.8 & $(2.1)$ & 14.3 & (1.8) & 5.4 & $(1.2)$ & 1.9 & $(0.9)$ \\
\hline & Toscana & 9.8 & (2.6) & 13.1 & $(2.3)$ & 17.1 & (2.6) & 20.7 & $(2.1)$ & 19.0 & $(2.2)$ & 13.7 & $(1.7)$ & 6.6 & $(1.2)$ \\
\hline & Trento & 3.8 & (1.0) & 7.5 & (1.5) & 16.5 & $(2.2)$ & 23.2 & $(2.2)$ & 23.0 & $(2.0)$ & 16.5 & (1.9) & 9.6 & (1.3) \\
\hline & Umbria & 9.4 & (3.1) & 7.7 & $(2.1)$ & 15.5 & $(2.1)$ & 23.5 & (3.0) & 23.7 & $(2.7)$ & 13.6 & (1.9) & 6.5 & $(1.4)$ \\
\hline & Valle d'Aosta & 6.6 & $(1.2)$ & 10.9 & (1.8) & 19.8 & (2.6) & 25.9 & $(2.8)$ & 19.6 & $(2.2)$ & 11.3 & (1.9) & 5.9 & $(1.2)$ \\
\hline & Veneto & 4.8 & (1.3) & 7.3 & (1.5) & 14.5 & $(2.2)$ & 20.0 & $(2.0)$ & 21.4 & (2.4) & 18.8 & $(2.1)$ & 13.2 & (2.3) \\
\hline & Mexico & & & & & & & & & & & & & & \\
\hline & Aguascalientes & 14.0 & (2.2) & 28.0 & (3.2) & 30.6 & (3.3) & 18.8 & (2.5) & 7.4 & (1.5) & 1.3 & $(1.0)$ & 0.0 & C \\
\hline & Baja California & 17.9 & (3.8) & 32.1 & (3.8) & 29.3 & (3.8) & 16.8 & (3.0) & 3.2 & (1.0) & 0.6 & $(0.6)$ & 0.0 & C \\
\hline & Baja California Sur & 18.0 & (3.3) & 32.0 & $(2.8)$ & 30.2 & (3.1) & 14.8 & (2.4) & 4.5 & $(1.3)$ & 0.4 & $(0.4)$ & 0.0 & c \\
\hline & Campeche & 25.6 & (3.1) & 33.7 & (3.5) & 27.8 & (3.4) & 10.4 & (1.7) & 2.1 & $(0.8)$ & 0.3 & $(0.3)$ & 0.0 & c \\
\hline & Chiapas & 40.1 & (4.7) & 35.3 & $(3.0)$ & 18.1 & (3.0) & 5.0 & (1.4) & 1.1 & (0.6) & 0.2 & $(0.2)$ & 0.1 & C \\
\hline & Chihuahua & 14.7 & (3.6) & 29.9 & (3.8) & 30.6 & $(2.7)$ & 16.1 & $(4.5)$ & 7.7 & $(3.2)$ & 1.0 & $(0.5)$ & 0.0 & c \\
\hline & Coahuila & 20.0 & (3.7) & 31.8 & (3.9) & 27.7 & $(2.7)$ & 15.6 & (2.8) & 4.2 & (1.5) & 0.7 & $(0.6)$ & 0.0 & c \\
\hline & Colima & 18.1 & (2.1) & 26.5 & $(2.3)$ & 30.9 & (2.5) & 16.9 & (1.9) & 6.4 & (1.4) & 1.2 & $(0.6)$ & 0.0 & C \\
\hline & Distrito Federal & 13.0 & (2.9) & 26.4 & $(3.3)$ & 32.4 & (2.9) & 20.1 & (2.8) & 6.6 & (1.4) & 1.4 & $(0.6)$ & 0.0 & C \\
\hline & Durango & 16.3 & (3.4) & 28.7 & $(3.0)$ & 31.5 & (3.2) & 17.2 & (2.7) & 6.0 & $(2.0)$ & 0.3 & c & 0.0 & c \\
\hline & Guanajuato & 21.4 & (3.2) & 31.4 & $(2.5)$ & 26.8 & (2.5) & 15.2 & $(2.1)$ & 4.8 & $(1.2)$ & 0.4 & $(0.4)$ & 0.0 & C \\
\hline & Guerrero & 42.9 & (3.5) & 35.0 & (3.4) & 18.0 & (2.3) & 3.2 & $(1.2)$ & 0.9 & $(0.5)$ & 0.0 & c & 0.0 & c \\
\hline & Hidalgo & 23.2 & (3.5) & 31.3 & (3.9) & 29.1 & (3.7) & 13.4 & (2.4) & 2.7 & (1.1) & 0.3 & $(0.3)$ & 0.0 & c \\
\hline & Jalisco & 12.0 & (2.5) & 27.5 & $(3.7)$ & 34.9 & (3.3) & 18.3 & (3.3) & 6.1 & (1.5) & 1.1 & $(0.7)$ & 0.2 & C \\
\hline & Mexico & 14.0 & (3.0) & 32.9 & $(3.8)$ & 35.1 & (3.5) & 14.9 & $(2.0)$ & 2.4 & $(0.9)$ & 0.5 & $\mathrm{C}$ & 0.3 & $(0.3)$ \\
\hline & Morelos & 20.9 & (5.1) & 27.3 & $(4.2)$ & 28.2 & (2.9) & 16.7 & $(2.9)$ & 5.4 & (1.6) & 1.2 & $(1.0)$ & 0.3 & C \\
\hline & Nayarit & 19.6 & (2.9) & 30.0 & (3.9) & 29.9 & $(2.7)$ & 16.5 & $(2.5)$ & 3.4 & $(0.9)$ & 0.5 & c & 0.0 & C \\
\hline & Nuevo León & 9.3 & $(2.7)$ & 26.4 & $(4.9)$ & 32.6 & $(2.7)$ & 22.0 & $(4.6)$ & 8.5 & (2.3) & 1.2 & $(0.8)$ & 0.0 & C \\
\hline & Puebla & 20.4 & (3.7) & 31.5 & $(2.7)$ & 30.9 & (2.5) & 13.4 & $(2.1)$ & 3.6 & $(1.2)$ & 0.3 & $(0.3)$ & 0.0 & C \\
\hline & Querétaro & 10.8 & (3.7) & 26.1 & $(4.3)$ & 30.4 & (3.3) & 23.0 & $(4.3)$ & 8.2 & (1.8) & 1.5 & $(0.6)$ & 0.0 & c \\
\hline & Quintana Roo & 22.5 & (3.8) & 30.9 & $(2.6)$ & 30.3 & $(2.7)$ & 13.2 & $(2.0)$ & 2.8 & $(0.8)$ & 0.3 & $(0.3)$ & 0.0 & c \\
\hline & San Luis Potosí & 27.1 & (3.8) & 27.0 & $(3.7)$ & 26.7 & (3.4) & 14.3 & $(2.9)$ & 4.3 & $(1.7)$ & 0.6 & $(0.4)$ & 0.0 & C \\
\hline & Sinaloa & 21.7 & (3.2) & 32.1 & $(2.3)$ & 29.3 & (3.7) & 13.9 & $(2.8)$ & 2.6 & (1.1) & 0.4 & $(0.3)$ & 0.0 & c \\
\hline & Tabasco & 37.5 & (3.6) & 33.2 & $(2.9)$ & 19.9 & (3.0) & 8.5 & $(2.2)$ & 0.7 & $(0.6)$ & 0.2 & $(0.2)$ & 0.1 & c \\
\hline & Tamaulipas & 22.2 & (3.2) & 29.6 & $(2.5)$ & 28.3 & (2.8) & 13.9 & $(2.7)$ & 4.9 & (1.7) & 0.9 & $(0.6)$ & 0.2 & $(0.2)$ \\
\hline & Tlaxcala & 21.0 & (2.9) & 31.9 & $(2.6)$ & 30.9 & $(2.8)$ & 13.0 & $(2.0)$ & 2.8 & $(0.9)$ & 0.4 & $(0.3)$ & 0.1 & C \\
\hline & Veracruz & 29.3 & (3.6) & 32.1 & $(3.2)$ & 24.9 & (2.5) & 11.2 & $(2.4)$ & 2.2 & $(1.0)$ & 0.0 & $\mathrm{C}$ & 0.3 & C \\
\hline & Yucatán & 20.9 & (3.3) & 32.0 & $(2.6)$ & 25.9 & (2.9) & 16.3 & $(2.5)$ & 3.6 & (1.1) & 1.2 & $(0.6)$ & 0.0 & c \\
\hline & Zacatecas & 22.3 & (2.7) & 30.8 & $(2.3)$ & 27.6 & $(2.8)$ & 16.2 & (1.9) & 2.7 & $(1.0)$ & 0.4 & $(0.3)$ & 0.0 & $\mathrm{C}$ \\
\hline
\end{tabular}

- PISA adjudicated region.

Note: See Table 1.2.12 for national data.

StatLink त्ञात्रा http://dx.doi.org/10.1787/888932935762 
Part 2/4]

Percentage of students at each proficiency level on the mathematics subscale interpreting, by gender Table B2.I.11 and region

\begin{tabular}{|c|c|c|c|c|c|c|c|c|c|c|c|c|c|c|c|}
\hline & & \multicolumn{14}{|c|}{ Boys } \\
\hline & & \multicolumn{2}{|c|}{$\begin{array}{l}\text { Below Level } 1 \\
\text { (below 357.77 } \\
\text { score points) }\end{array}$} & \multicolumn{2}{|c|}{$\begin{array}{c}\text { Level } 1 \\
\text { (from } 357.77 \text { to } \\
\text { less than } 420.07 \\
\text { score points) }\end{array}$} & \multicolumn{2}{|c|}{$\begin{array}{c}\text { Level } 2 \\
\text { (from } 420.07 \text { to } \\
\text { less than } 482.38 \\
\text { score points) }\end{array}$} & $\begin{array}{r}\mathrm{L} \\
\text { (from } \\
\text { less th } \\
\text { scor }\end{array}$ & \begin{tabular}{|l|} 
I 3 \\
2.38 to \\
544.68 \\
oints)
\end{tabular} & $\begin{array}{r}\text { Le } \\
\text { (from } \\
\text { less th } \\
\text { score }\end{array}$ & $\begin{array}{l}4 \\
4.68 \text { to } \\
606.99 \\
\text { oints) }\end{array}$ & $\begin{array}{r}\mathrm{L} \\
\text { (from } \\
\text { less th } \\
\text { scor }\end{array}$ & \begin{tabular}{l|} 
I 5 \\
6.99 to \\
669.30 \\
oints)
\end{tabular} & $\begin{array}{l}\text { Le } \\
\text { (abov } \\
\text { score }\end{array}$ & $\begin{array}{l}16 \\
669.30 \\
\text { oints) }\end{array}$ \\
\hline & & $\%$ & S.E. & $\%$ & S.E. & $\%$ & S.E. & $\%$ & S.E. & $\%$ & S.E. & $\%$ & S.E. & $\%$ & S.E. \\
\hline 0 & Portugal & & & & & & & & & & & & & & \\
\hline 氙 & Alentejo & 6.2 & $(2.1)$ & 13.0 & (3.6) & 23.5 & (3.1) & 27.4 & (3.6) & 17.4 & $(3.7)$ & 9.9 & (3.2) & 2.5 & (1.3) \\
\hline & Spain & & & & & & & & & & & & & & \\
\hline & Andalusia ${ }^{\bullet}$ & 10.2 & (1.6) & 14.0 & (1.7) & 21.0 & (2.4) & 22.4 & (2.8) & 17.9 & (1.8) & 9.9 & (1.6) & 4.5 & (1.0) \\
\hline & Aragon ${ }^{\bullet}$ & 8.9 & $(1.7)$ & 12.5 & $(2.0)$ & 17.6 & $(2.5)$ & 23.0 & $(2.8)$ & 21.5 & $(2.2)$ & 11.8 & (1.6) & 4.8 & $(1.3)$ \\
\hline & Asturias ${ }^{\bullet}$ & 8.7 & (1.6) & 11.3 & (1.6) & 18.4 & (1.6) & 22.1 & (1.7) & 20.1 & $(1.5)$ & 13.3 & (1.8) & 6.2 & $(1.1)$ \\
\hline & Balearic Islands ${ }^{\bullet}$ & 10.8 & (1.8) & 14.2 & (1.5) & 21.4 & (2.4) & 24.2 & (2.9) & 18.5 & $(2.5)$ & 8.4 & (1.8) & 2.5 & $(0.9)$ \\
\hline & Basque Country ${ }^{\bullet}$ & 4.7 & $(0.6)$ & 10.6 & $(0.9)$ & 18.2 & (1.2) & 25.2 & (1.1) & 23.0 & $(1.2)$ & 13.5 & (1.1) & 4.8 & $(0.6)$ \\
\hline & Cantabria ${ }^{\bullet}$ & 9.1 & (1.5) & 12.2 & (1.5) & 19.0 & (1.6) & 22.3 & (1.8) & 20.1 & (1.9) & 12.8 & (1.9) & 4.5 & $(1.1)$ \\
\hline & Castile and Leon • & 4.8 & $(1.2)$ & 9.4 & (1.5) & 16.8 & (1.6) & 22.4 & (1.9) & 22.8 & $(2.0)$ & 16.5 & (1.7) & 7.3 & (1.4) \\
\hline & Catalonia ${ }^{\bullet}$ & 5.6 & (1.1) & 11.0 & (1.9) & 17.6 & (2.7) & 23.3 & (2.1) & 21.3 & $(2.2)$ & 14.5 & (2.0) & 6.7 & (1.3) \\
\hline & Extremadura ${ }^{\circ}$ & 14.7 & $(2.2)$ & 16.3 & (2.0) & 20.8 & (2.6) & 20.4 & (2.5) & 15.9 & $(1.8)$ & 8.9 & (1.5) & 3.0 & (1.4) \\
\hline & Galicia• & 8.5 & (1.5) & 12.8 & $(2.0)$ & 20.7 & $(2.0)$ & 23.4 & $(2.1)$ & 21.1 & $(2.3)$ & 10.2 & (1.5) & 3.2 & $(0.8)$ \\
\hline & La Rioja ${ }^{\bullet}$ & 10.8 & (1.3) & 10.1 & (1.8) & 15.9 & (1.9) & 19.7 & (1.6) & 20.4 & $\begin{array}{l}(2.3) \\
(2.1)\end{array}$ & 14.4 & (1.4) & $\begin{array}{l}3.2 \\
8.7\end{array}$ & $\begin{array}{l}(1.0) \\
(1.1)\end{array}$ \\
\hline & Madrid $\bullet$ & 5.1 & (1.1) & 10.7 & (1.5) & 16.1 & (2.1) & 24.3 & (1.7) & 24.2 & $(2.5)$ & 15.1 & (1.6) & 4.4 & $(0.9)$ \\
\hline & Murcia ${ }^{\bullet}$ & 13.7 & (2.1) & 16.6 & (2.3) & 21.0 & (2.4) & 20.7 & (2.9) & 16.4 & $(1.8)$ & 8.6 & (1.5) & 3.0 & $(1.2)$ \\
\hline & Navarre ${ }^{\bullet}$ & 6.0 & $(1.2)$ & 9.6 & (1.4) & 16.8 & (1.6) & 23.8 & (2.1) & 23.9 & $(2.4)$ & 13.8 & (1.6) & 6.2 & (1.3) \\
\hline & United Kingdom & & & & & & & & & & & & & & \\
\hline & England & 7.9 & (1.3) & 12.0 & (1.3) & 19.2 & (1.2) & 23.1 & (1.4) & 19.9 & (1.4) & 12.2 & (1.2) & 5.8 & $(0.8)$ \\
\hline & Northern Ireland & 8.2 & (1.3) & 13.6 & (1.6) & 20.2 & (1.7) & 24.5 & (1.9) & 19.3 & $(1.5)$ & 9.4 & $(1.2)$ & 4.7 & $(0.8)$ \\
\hline & Scotland $^{\bullet}$ & 4.6 & $(0.8)$ & 10.0 & (1.0) & 21.2 & (1.5) & 25.6 & (1.5) & 22.5 & $(1.7)$ & 11.5 & $(1.2)$ & 4.6 & $(0.6)$ \\
\hline & Wales & 9.2 & (1.0) & 14.1 & $(1.2)$ & 22.8 & (1.6) & 25.9 & $(1.2)$ & 17.1 & $(0.9)$ & 8.3 & $(0.8)$ & 2.7 & $(0.5)$ \\
\hline & United States & & & & & & & & & & & & & & \\
\hline & Connecticut $^{\bullet}$ & 6.7 & (1.4) & 10.9 & $(1.7)$ & 17.2 & (1.5) & 21.7 & (1.8) & 21.3 & $(2.2)$ & 13.9 & (1.9) & 8.2 & (1.6) \\
\hline & Florida ${ }^{\bullet}$ & 9.7 & (1.8) & 17.5 & (1.8) & 22.8 & (2.0) & 23.6 & (1.8) & 16.2 & (1.9) & 7.6 & (1.7) & 2.6 & $(0.9)$ \\
\hline & Massachusetts ${ }^{\bullet}$ & 5.8 & (0.9) & 9.9 & (1.1) & 17.1 & (2.0) & 21.8 & (2.1) & 21.0 & (1.8) & 14.3 & (1.8) & 10.1 & (1.8) \\
\hline$\underline{a}$ & Argentina & & & & & & & & & & & & & & \\
\hline 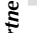 & Ciudad Autónoma de Buenos Aires & 23.3 & (2.8) & 22.1 & $(2.9)$ & 24.9 & (2.5) & 20.1 & (2.4) & 7.7 & (1.8) & 1.8 & $(0.9)$ & 0.2 & c \\
\hline 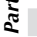 & Brazil & & & & & & & & & & & & & & \\
\hline & Acre & 43.1 & (4.9) & 32.1 & $(3.3)$ & 17.7 & (3.9) & 6.1 & $(1.7)$ & 0.7 & $(0.6)$ & 0.3 & c & 0.0 & c \\
\hline & Alagoas & 55.9 & (5.4) & 26.7 & (4.9) & 11.8 & (3.0) & 4.2 & (1.6) & 1.3 & $(0.7)$ & 0.0 & $\mathrm{C}$ & 0.0 & c \\
\hline & Amapá & 39.2 & $(6.4)$ & 34.9 & $(4.7)$ & 16.5 & $(4.0)$ & 7.9 & $(3.2)$ & 1.3 & $(1.3)$ & 0.2 & $\mathrm{C}$ & 0.0 & c \\
\hline & Amazonas & 44.7 & $(4.7)$ & 33.3 & (3.8) & 13.8 & (2.8) & 5.2 & (1.7) & 1.9 & (1.6) & 1.1 & (1.1) & 0.0 & c \\
\hline & Bahia & 36.3 & (6.0) & 29.8 & (5.5) & 19.5 & (4.1) & 11.0 & (3.9) & 2.5 & $(2.2)$ & 1.0 & (1.1) & 0.0 & c \\
\hline & Ceará & 32.8 & (4.0) & 33.4 & (3.7) & 19.7 & $(2.7)$ & 8.5 & (2.4) & 4.4 & $(2.2)$ & 1.3 & $(0.8)$ & 0.0 & c \\
\hline & Espírito Santo & 20.6 & (3.1) & 30.4 & (3.5) & 23.7 & (2.9) & 13.7 & $(2.1)$ & 8.5 & $(2.9)$ & 3.0 & (1.3) & 0.1 & c \\
\hline & Federal District & 20.8 & (5.7) & 24.1 & (3.7) & 26.0 & (4.8) & 16.9 & (2.9) & 10.2 & (3.9) & 1.8 & $(0.9)$ & 0.3 & c \\
\hline & Goiás & 32.7 & $(4.0)$ & 33.9 & (3.3) & 21.4 & (2.8) & 9.0 & $(1.7)$ & 2.7 & $(1.2)$ & 0.2 & $\mathrm{C}$ & 0.0 & c \\
\hline & Maranhão & 51.1 & (7.4) & 23.6 & $(4.7)$ & 14.4 & $(4.0)$ & 7.4 & (3.9) & 3.0 & $(2.6)$ & 0.5 & $\mathrm{C}$ & 0.0 & c \\
\hline & Mato Grosso & 41.6 & (5.3) & 32.6 & (3.8) & 16.2 & (3.0) & 7.4 & (2.5) & 1.7 & $(1.3)$ & 0.4 & $\mathrm{C}$ & 0.0 & c \\
\hline & Mato Grosso do Sul & 18.5 & (4.1) & 28.2 & (2.9) & 32.0 & (4.3) & 13.7 & (2.3) & 6.2 & $(2.7)$ & 1.1 & $(0.8)$ & 0.2 & c \\
\hline & Minas Gerais & 21.5 & (4.3) & 31.9 & (3.9) & 28.4 & (3.5) & 13.1 & (2.9) & 4.1 & $(2.1)$ & 1.1 & $(0.8)$ & 0.0 & c \\
\hline & Pará & 43.6 & $(4.2)$ & 29.9 & $(4.3)$ & 20.0 & (3.0) & 5.4 & $(1.5)$ & 1.1 & $(0.8)$ & 0.0 & $\mathrm{C}$ & 0.0 & c \\
\hline & Paraiba & 26.4 & (5.3) & 30.6 & $(4.7)$ & 25.7 & (4.5) & 10.9 & (2.8) & 4.6 & $(2.8)$ & 1.4 & (1.1) & 0.4 & $(0.4)$ \\
\hline & Paraná & 27.6 & (5.1) & 28.1 & (3.4) & 21.5 & (3.2) & 13.5 & (2.4) & 7.5 & $(4.0)$ & 1.7 & (1.8) & 0.1 & C \\
\hline & Pernambuco & 38.6 & (5.4) & 32.2 & $(4.0)$ & 20.1 & (3.1) & 7.0 & (2.0) & 1.5 & $(1.2)$ & 0.6 & $(0.6)$ & 0.0 & c \\
\hline & Piauí & 36.3 & (5.6) & 29.0 & $(5.2)$ & 20.7 & (3.9) & 9.5 & (3.0) & 3.3 & (1.9) & 0.7 & $(0.8)$ & 0.5 & $(0.3)$ \\
\hline & Rio de Janeiro & 25.5 & $(4.1)$ & 31.5 & (3.8) & 27.1 & (4.0) & 12.1 & (3.0) & 2.7 & (1.4) & 1.0 & $(0.8)$ & 0.1 & C \\
\hline & Rio Grande do Norte & 29.9 & $(3.7)$ & 32.8 & (4.5) & 19.0 & (2.6) & 10.4 & (3.8) & 4.9 & $(1.7)$ & 2.7 & (2.3) & 0.2 & c \\
\hline & Rio Grande do Sul & 16.1 & (3.8) & 31.1 & (3.7) & 29.0 & (3.8) & 18.8 & (2.8) & 4.6 & $(1.2)$ & 0.4 & $\mathrm{C}$ & 0.0 & c \\
\hline & Rondônia & 29.1 & (4.0) & 32.3 & (3.5) & 28.0 & (3.3) & 8.8 & (2.0) & 1.2 & $(0.8)$ & 0.6 & $(0.5)$ & 0.0 & c \\
\hline & Roraima & 44.6 & (5.1) & 28.7 & (3.1) & 18.5 & (3.8) & 6.9 & (2.1) & 1.0 & $(0.8)$ & 0.2 & $\mathrm{C}$ & 0.0 & c \\
\hline & Santa Catarina & 23.1 & (3.7) & 24.5 & (3.2) & 26.8 & (3.2) & 18.6 & (3.2) & 6.5 & $(1.6)$ & 0.4 & $\mathrm{C}$ & 0.0 & C \\
\hline & São Paulo & 22.6 & (2.1) & 28.3 & (2.0) & 26.8 & (2.1) & 15.2 & (2.0) & 5.6 & (1.5) & 1.3 & $(0.5)$ & 0.2 & $(0.1)$ \\
\hline & Sergipe & 31.5 & (6.4) & 32.3 & (4.8) & 18.4 & (3.5) & 12.1 & (4.1) & 4.7 & $(2.7)$ & 1.0 & (1.0) & 0.1 & c \\
\hline & Tocantins & 39.9 & (4.9) & 29.5 & (3.7) & 18.0 & (3.4) & 9.5 & (3.0) & 2.4 & $(1.5)$ & 0.7 & $(0.5)$ & 0.0 & c \\
\hline & Colombia & & & & & & & & & & & & & & \\
\hline & Bogotá & 18.5 & (2.5) & 32.3 & $(2.7)$ & 31.2 & (2.3) & 13.2 & (1.9) & 4.0 & $(1.2)$ & 0.6 & $(0.5)$ & 0.1 & c \\
\hline & Cali & 29.6 & (3.4) & 30.7 & (2.6) & 25.7 & (3.1) & 10.3 & (2.0) & 2.9 & (1.3) & 0.8 & (0.6) & 0.0 & c \\
\hline & Manizales & 14.7 & (2.0) & 29.6 & (2.5) & 32.7 & (3.3) & 15.3 & (2.0) & 6.4 & (1.9) & 1.3 & (1.1) & 0.0 & c \\
\hline & Medellín & 23.0 & (3.6) & 30.6 & (2.4) & 25.1 & (2.7) & 12.8 & (2.6) & 5.7 & (1.4) & 1.9 & (1.1) & 0.9 & $(0.8)$ \\
\hline & Russian Federation & & & & & & & & & & & & & & \\
\hline & Perm Territory region` & 11.1 & (1.9) & 19.7 & (1.8) & 23.7 & (2.3) & 23.3 & (1.9) & 13.6 & $(1.3)$ & 6.4 & (1.4) & 2.3 & (1.1) \\
\hline & United Arab Emirates & & & & & & & & & & & & & & \\
\hline & Abu Dhabi & 31.5 & (2.4) & 26.2 & (1.5) & 21.9 & (1.5) & 12.1 & (1.3) & 6.2 & $(1.1)$ & 1.6 & (0.6) & 0.5 & $(0.3)$ \\
\hline & Ajman & 37.6 & $(7.3)$ & 31.7 & (5.4) & 20.2 & (3.5) & 9.6 & (2.4) & 1.0 & $\mathrm{C}$ & 0.0 & $\mathrm{C}$ & 0.0 & $\mathrm{C}$ \\
\hline & Dubai` & 14.8 & $(0.7)$ & 19.3 & $(1.0)$ & 22.9 & (1.0) & 20.8 & $(1.1)$ & 14.3 & $(1.0)$ & 6.3 & $(0.7)$ & 1.6 & $(0.4)$ \\
\hline & Fujairah & 40.9 & (5.5) & 28.9 & $(4.1)$ & 18.3 & (2.8) & 8.3 & (1.9) & 3.2 & $(0.9)$ & 0.3 & $\mathrm{C}$ & 0.0 & C \\
\hline & Ras al-Khaimah & 34.3 & $(5.7)$ & 31.2 & (3.1) & 21.8 & (4.3) & 10.2 & (2.3) & 1.8 & $(0.8)$ & 0.7 & $(0.5)$ & 0.0 & $\mathrm{C}$ \\
\hline & Sharjah & 19.7 & (5.4) & 23.6 & $(4.1)$ & 26.2 & (4.3) & 18.6 & $(4.2)$ & 8.4 & $(3.4)$ & 2.9 & (2.0) & 0.7 & $(0.7)$ \\
\hline & Umm al-Quwain & 45.4 & (4.0) & 34.5 & (4.6) & 13.6 & (3.2) & 4.4 & (2.0) & 1.4 & (1.3) & 0.7 & C & 0.0 & C \\
\hline
\end{tabular}

- PISA adjudicated region.

Note: See Table I.2.12 for national data.

StatLink 部 SL http://dx.doi.org/10.1787/888932935762 
(Part $3 / 4$

Percentage of students at each proficiency level on the mathematics subscale interpreting, by gender Table B2.I.11 and region

\begin{tabular}{|c|c|c|c|c|c|c|c|c|c|c|c|c|c|c|c|}
\hline & & \multicolumn{14}{|c|}{ Girls } \\
\hline & & \multicolumn{2}{|c|}{$\begin{array}{c}\text { Below Level } 1 \\
\text { (below } 357.77 \\
\text { score points) }\end{array}$} & $\begin{array}{r}1 \\
\text { (from } \\
\text { less th } \\
\text { scor }\end{array}$ & $\begin{array}{l}\text { I } 1 \\
7.77 \text { to } \\
420.07 \\
\text { oints) }\end{array}$ & $\begin{array}{l}\text { Le } \\
\text { (from } \\
\text { less th } \\
\text { scor }\end{array}$ & $\begin{array}{l}l 2 \\
0.07 \text { to } \\
482.38 \\
\text { oints) }\end{array}$ & $\begin{array}{r}\mathbf{L} \\
\text { (from } \\
\text { less th } \\
\text { scor }\end{array}$ & $\begin{array}{l}3 \\
2.38 \text { to } \\
544.68 \\
\text { oints) }\end{array}$ & $\begin{array}{l}\text { Le } \\
\text { (from } \\
\text { less th } \\
\text { scor }\end{array}$ & $\begin{array}{l}44 \\
4.68 \text { to } \\
606.99 \\
\text { oints) }\end{array}$ & $\begin{array}{r}\mathrm{L} \\
\text { (from } \\
\text { less th } \\
\text { scor }\end{array}$ & $\begin{array}{l}5 \\
6.99 \text { to } \\
669.30 \\
\text { oints) }\end{array}$ & $\begin{array}{l}\text { Le } \\
\text { (abov } \\
\text { scor }\end{array}$ & $\begin{array}{l}\text { I } 6 \\
669.30 \\
\text { oints) }\end{array}$ \\
\hline & & $\%$ & S.E. & $\%$ & S.E. & $\%$ & S.E. & $\%$ & S.E. & $\%$ & S.E. & $\%$ & S.E. & $\%$ & S.E. \\
\hline 0 & Australia & & & & & & & & & & & & & & \\
\hline 遌 & Australian Capital Territory & 4.5 & $(1.2)$ & 9.0 & $(1.7)$ & 17.1 & $(2.3)$ & 21.1 & (3.3) & 24.6 & $(2.8)$ & 16.3 & (2.2) & 7.4 & (1.5) \\
\hline & New South Wales & 5.8 & $(0.8)$ & 11.5 & $(1.0)$ & 20.2 & (1.3) & 25.0 & (1.6) & 20.2 & (1.5) & 11.1 & $(1.2)$ & 6.2 & $(1.1)$ \\
\hline & Northern Territory & 18.3 & (3.7) & 17.8 & (5.9) & 24.5 & (5.5) & 22.4 & (4.6) & 12.1 & $(4.2)$ & 4.2 & $(2.2)$ & 0.6 & c \\
\hline & Queensland & 5.3 & $(0.8)$ & 12.3 & (1.1) & 21.8 & (1.7) & 23.4 & (1.6) & 19.9 & (1.5) & 11.8 & $(1.2)$ & 5.4 & $(0.8)$ \\
\hline & South Australia & 7.2 & (1.4) & 14.3 & (1.7) & 23.0 & $(2.5)$ & 23.8 & $(2.0)$ & 19.4 & $(2.0)$ & 8.7 & (2.0) & 3.6 & $(0.8)$ \\
\hline & Tasmania & 8.9 & (1.4) & 16.8 & (2.0) & 24.2 & (3.1) & 21.8 & (2.3) & 16.0 & $(2.2)$ & 7.8 & (1.6) & 4.4 & $(1.2)$ \\
\hline & Victoria & 4.7 & (1.1) & 13.6 & (1.7) & 21.8 & (1.6) & 25.1 & (1.5) & 21.2 & (1.5) & 10.6 & (1.1) & 3.0 & $(0.7)$ \\
\hline & Western Australia & 6.6 & $(1.2)$ & 12.3 & (1.7) & 17.8 & (1.5) & 22.9 & $(2.1)$ & 21.6 & $(2.0)$ & 12.4 & (1.4) & 6.5 & $(1.1)$ \\
\hline & Belgium & & & & & & & & & & & & & & \\
\hline & Flemish Community ${ }^{\bullet}$ & 6.3 & $(0.9)$ & 11.6 & $(1.0)$ & 18.0 & $(1.1)$ & 21.4 & $(1.3)$ & 20.8 & $(1.2)$ & 14.9 & $(1.2)$ & 6.9 & $(0.8)$ \\
\hline & French Community & 8.6 & (1.3) & 14.7 & (1.1) & 21.9 & (1.6) & 23.3 & (1.9) & 20.0 & (1.5) & 8.9 & $(0.9)$ & 2.6 & $(0.5)$ \\
\hline & German-speaking Community & 5.6 & $(1.2)$ & 9.6 & (1.7) & 18.1 & $(2.2)$ & 29.8 & (2.6) & 23.0 & (2.6) & 11.1 & (1.8) & 2.7 & $(1.0)$ \\
\hline & Canada & & & & & & & & & & & & & & \\
\hline & Alberta & 4.2 & $(0.7)$ & 11.4 & (1.5) & 19.4 & $(2.2)$ & 26.1 & (1.7) & 22.1 & (1.7) & 12.5 & (1.5) & 4.3 & $(0.8)$ \\
\hline & British Columbia & 2.5 & $(0.9)$ & 9.7 & (1.5) & 19.7 & (1.6) & 27.1 & (1.7) & 24.8 & (1.8) & 11.5 & (1.5) & 4.7 & $(1.1)$ \\
\hline & Manitoba & 6.7 & (1.4) & 12.7 & (2.0) & 24.1 & (1.8) & 24.2 & (1.8) & 20.5 & (1.7) & 8.9 & (1.3) & 2.8 & $(0.7)$ \\
\hline & New Brunswick & 5.2 & (1.0) & 12.3 & (1.5) & 24.7 & (2.8) & 27.7 & $(2.7)$ & 19.6 & $(2.2)$ & 8.2 & (1.6) & 2.3 & $(0.9)$ \\
\hline & Newfoundland and Labrador & 5.1 & (1.5) & 14.8 & (1.9) & 24.9 & (3.0) & 25.3 & (2.4) & 18.9 & $(2.2)$ & 9.1 & (1.3) & 1.9 & $(0.7)$ \\
\hline & Nova Scotia & 4.8 & $(1.2)$ & 11.0 & (1.7) & 25.6 & (3.4) & 29.6 & (4.2) & 20.0 & (3.6) & 7.0 & (1.6) & 2.0 & $(0.8)$ \\
\hline & Ontario & 3.6 & $(0.7)$ & 9.6 & (1.1) & 22.5 & (1.8) & 29.0 & (1.7) & 21.5 & (1.6) & 10.3 & (1.3) & 3.5 & $(0.6)$ \\
\hline & Prince Edward Island & 6.9 & $(1.1)$ & 16.2 & $(1.7)$ & 26.3 & $(2.0)$ & 26.7 & (1.7) & 17.2 & (1.7) & 5.0 & (1.1) & 1.6 & $(0.6)$ \\
\hline & Quebec & 4.4 & $(0.8)$ & 8.9 & (1.0) & 17.0 & $(1.3)$ & 24.9 & $(1.2)$ & 23.9 & $(1.2)$ & 14.5 & (1.1) & 6.5 & $(0.8)$ \\
\hline & Saskatchewan & 3.6 & $(0.9)$ & 11.2 & (1.3) & 24.5 & (1.6) & 29.4 & $(2.0)$ & 19.6 & (1.8) & 9.6 & (1.4) & 2.1 & $(0.8)$ \\
\hline & Italy & & & & & & & & & & & & & & \\
\hline & Abruzzo & 10.6 & $(1.8)$ & 14.9 & (2.4) & 24.2 & (1.9) & 25.1 & $(2.3)$ & 16.3 & (1.9) & 7.0 & (1.4) & 1.9 & $(0.8)$ \\
\hline & Basilicata & 13.7 & $(2.2)$ & 19.7 & (1.6) & 27.1 & $(2.7)$ & 20.8 & (1.8) & 13.2 & (1.7) & 3.9 & $(0.8)$ & 1.5 & $(0.6)$ \\
\hline & Bolzano & 7.5 & $(0.8)$ & 11.7 & (1.3) & 19.4 & (1.8) & 24.2 & (2.9) & 20.6 & $(2.3)$ & 11.6 & (1.6) & 5.1 & $(1.3)$ \\
\hline & Calabria & 24.9 & (4.5) & 20.2 & (2.7) & 25.6 & $(2.8)$ & 19.1 & $(2.2)$ & 7.8 & (1.3) & 1.7 & $(0.5)$ & 0.6 & $(0.4)$ \\
\hline & Campania & 16.9 & (3.2) & 19.9 & (2.8) & 24.0 & (2.6) & 21.8 & $(2.1)$ & 11.4 & (1.8) & 4.8 & $(1.2)$ & 1.2 & $(0.7)$ \\
\hline & Emilia Romagna & 7.4 & (1.8) & 11.8 & $(2.2)$ & 20.9 & (2.4) & 23.2 & $(2.1)$ & 19.6 & $(2.1)$ & 12.1 & (1.7) & 5.0 & $(1.0)$ \\
\hline & Friuli Venezia Giulia & 5.9 & (2.3) & 8.2 & (1.6) & 15.7 & $(2.2)$ & 25.7 & (2.6) & 25.1 & (2.4) & 13.3 & (1.8) & 6.0 & $(1.1)$ \\
\hline & Lazio & 11.2 & (2.2) & 17.1 & (2.4) & 23.9 & $(2.3)$ & 24.0 & $(2.3)$ & 15.8 & $(2.3)$ & 6.1 & (1.5) & 1.9 & $(0.7)$ \\
\hline & Liguria & 9.4 & (1.8) & 13.0 & (1.9) & 20.2 & $(2.8)$ & 24.0 & $(2.0)$ & 19.5 & (3.0) & 9.3 & (2.0) & 4.6 & $(1.3)$ \\
\hline & Lombardia & 3.7 & (1.0) & 9.8 & (2.0) & 19.0 & (2.4) & 25.6 & (2.6) & 24.3 & (2.6) & 12.5 & (2.5) & 5.1 & (1.5) \\
\hline & Marche & 7.5 & (2.0) & 13.8 & (2.0) & 23.6 & (2.4) & 25.2 & $(2.1)$ & 18.7 & (1.7) & 8.9 & (1.5) & 2.5 & $(0.9)$ \\
\hline & Molise & 12.3 & (1.9) & 19.3 & (2.6) & 25.2 & $(2.7)$ & 23.7 & (2.6) & 12.7 & $(2.2)$ & 4.4 & $(1.2)$ & 2.3 & $(0.8)$ \\
\hline & Piemonte & 7.0 & $(1.3)$ & 14.8 & (2.7) & 20.7 & $(2.1)$ & 23.0 & $(2.3)$ & 19.1 & (1.8) & 10.5 & (1.7) & 4.8 & $(1.2)$ \\
\hline & Puglia & 8.3 & $(2.2)$ & 16.8 & $(2.7)$ & 27.8 & (2.5) & 24.2 & $(2.5)$ & 15.3 & (1.9) & 5.9 & (1.3) & 1.7 & $(0.8)$ \\
\hline & Sardegna & 12.2 & (2.5) & 17.8 & (2.7) & 23.8 & $(2.2)$ & 23.1 & (2.4) & 16.5 & $(2.7)$ & 5.6 & (1.0) & 0.8 & $(0.4)$ \\
\hline & Sicilia & 16.1 & (2.5) & 20.4 & (2.8) & 26.1 & (1.9) & 21.8 & (2.6) & 11.9 & (1.7) & 3.1 & $(0.8)$ & 0.7 & $(0.4)$ \\
\hline & Toscana & 7.7 & (1.8) & 12.4 & (2.6) & 18.8 & $(2.2)$ & 24.8 & (2.6) & 19.9 & $(2.7)$ & 11.7 & (1.9) & 4.6 & $(1.2)$ \\
\hline & Trento & 3.2 & (1.5) & 6.9 & (1.8) & 16.3 & (2.5) & 26.8 & (2.5) & 26.4 & (2.9) & 15.7 & (2.3) & 4.6 & $(1.1)$ \\
\hline & Umbria & 8.3 & (1.8) & 13.5 & (2.1) & 22.2 & $(2.2)$ & 24.9 & (3.9) & 19.3 & (2.8) & 8.7 & (2.0) & 3.1 & $(0.7)$ \\
\hline & Valle d'Aosta & 6.6 & (1.4) & 13.6 & (2.4) & 22.0 & $(2.8)$ & 25.7 & $(2.8)$ & 17.7 & (2.4) & 9.4 & (2.1) & 4.8 & $(1.3)$ \\
\hline & Veneto & 4.1 & (1.7) & 8.1 & (1.7) & 17.3 & $(2.7)$ & 25.0 & (2.4) & 24.8 & (2.4) & 13.9 & (1.6) & 6.7 & (1.4) \\
\hline & Mexico & & & & & & & & & & & & & & \\
\hline & Aguascalientes & 13.7 & $(2.7)$ & 29.0 & $(2.3)$ & 33.8 & $(2.4)$ & 17.4 & $(2.2)$ & 5.2 & (1.3) & 0.7 & $(0.5)$ & 0.0 & c \\
\hline & Baja California & 19.6 & (2.6) & 35.5 & (3.2) & 29.6 & (2.9) & 11.0 & $(2.1)$ & 3.8 & (1.5) & 0.4 & c & 0.0 & c \\
\hline & Baja California Sur & 21.4 & $(4.0)$ & 32.2 & (2.4) & 31.3 & $(3.1)$ & 11.6 & (1.6) & 3.2 & $(1.1)$ & 0.2 & $(0.2)$ & 0.0 & c \\
\hline & Campeche & 29.4 & (3.3) & 35.7 & (3.1) & 24.2 & (3.0) & 8.9 & (1.8) & 1.4 & $(0.5)$ & 0.3 & $(0.2)$ & 0.0 & c \\
\hline & Chiapas & 44.6 & (4.3) & 31.9 & (3.0) & 19.5 & $(2.3)$ & 3.7 & (1.2) & 0.4 & $(0.3)$ & 0.0 & c & 0.0 & c \\
\hline & Chihuahua & 18.2 & (3.1) & 29.2 & (3.7) & 33.3 & $(3.2)$ & 15.2 & (3.2) & 3.8 & (1.7) & 0.2 & c & 0.0 & c \\
\hline & Coahuila & 19.7 & (3.4) & 34.6 & $(4.3)$ & 30.1 & (3.8) & 13.1 & (3.2) & 2.3 & $(0.9)$ & 0.1 & c & 0.0 & c \\
\hline & Colima & 15.8 & (2.8) & 28.9 & (2.9) & 30.6 & (2.6) & 18.3 & $(2.2)$ & 5.8 & (1.5) & 0.6 & $(0.4)$ & 0.0 & c \\
\hline & Distrito Federal & 22.2 & (2.9) & 32.8 & (3.9) & 28.0 & (2.4) & 12.4 & $(2.2)$ & 4.0 & $(1.7)$ & 0.6 & $(0.4)$ & 0.0 & c \\
\hline & Durango & 18.6 & (3.0) & 30.7 & (3.0) & 34.2 & $(3.2)$ & 14.1 & $(2.2)$ & 2.3 & $(0.9)$ & 0.2 & $(0.2)$ & 0.0 & c \\
\hline & Guanajuato & 25.2 & (3.5) & 33.4 & (3.0) & 29.5 & (3.7) & 10.4 & (1.8) & 1.4 & $(0.5)$ & 0.1 & c & 0.0 & c \\
\hline & Guerrero & 45.4 & (3.1) & 33.0 & (2.1) & 16.7 & $(2.2)$ & 4.1 & (1.3) & 0.7 & $(0.5)$ & 0.0 & c & 0.0 & c \\
\hline & Hidalgo & 26.0 & (3.4) & 35.4 & (3.1) & 27.5 & (3.6) & 9.2 & $(2.0)$ & 1.8 & $(0.9)$ & 0.1 & c & 0.0 & c \\
\hline & Jalisco & 11.1 & (2.1) & 30.6 & (2.9) & 36.1 & (2.9) & 18.2 & $(2.7)$ & 3.7 & $(0.9)$ & 0.4 & $(0.3)$ & 0.0 & C \\
\hline & Mexico & 18.5 & (2.8) & 34.2 & (3.2) & 35.2 & $(3.2)$ & 10.8 & $(2.1)$ & 1.3 & $(0.8)$ & 0.1 & c & 0.0 & c \\
\hline & Morelos & 19.2 & (3.7) & 32.3 & (4.0) & 30.0 & (3.3) & 13.7 & $(2.5)$ & 4.4 & $(2.6)$ & 0.4 & $(0.4)$ & 0.0 & c \\
\hline & Nayarit & 24.1 & (3.6) & 32.3 & (3.5) & 29.0 & (3.6) & 11.8 & $(2.1)$ & 2.5 & (1.1) & 0.2 & c & 0.0 & c \\
\hline & Nuevo León & 15.4 & (3.9) & 32.0 & (3.5) & 30.2 & $(2.8)$ & 17.3 & (3.6) & 4.7 & $(1.7)$ & 0.4 & $(0.4)$ & 0.0 & c \\
\hline & Puebla & 23.7 & (3.6) & 36.3 & $(2.7)$ & 28.1 & (3.0) & 10.1 & (1.9) & 1.8 & (1.0) & 0.0 & c & 0.0 & c \\
\hline & Querétaro & 13.6 & (3.6) & 29.2 & (4.4) & 32.8 & $(4.2)$ & 19.3 & (3.5) & 4.2 & (1.5) & 0.7 & $(0.4)$ & 0.1 & c \\
\hline & Quintana Roo & 22.4 & $(4.0)$ & 34.5 & (3.4) & 29.8 & (3.1) & 11.5 & $(2.2)$ & 1.5 & $(0.8)$ & 0.2 & $(0.2)$ & 0.0 & c \\
\hline & San Luis Potosí & 22.4 & (3.3) & 31.0 & (2.8) & 30.4 & (2.4) & 13.6 & (3.0) & 2.4 & $(1.0)$ & 0.2 & c & 0.0 & c \\
\hline & Sinaloa & 21.4 & (2.6) & 32.2 & (3.0) & 30.5 & (2.3) & 13.4 & (2.3) & 2.2 & $(0.9)$ & 0.2 & c & 0.0 & c \\
\hline & Tabasco & 38.8 & (3.1) & 35.7 & (2.9) & 20.0 & $(2.7)$ & 4.7 & $(1.2)$ & 0.8 & $(0.5)$ & 0.0 & c & 0.0 & c \\
\hline & Tamaulipas & 24.9 & (2.6) & 33.3 & (3.9) & 29.4 & (3.4) & 10.6 & $(2.3)$ & 1.8 & $(0.9)$ & 0.1 & $(0.2)$ & 0.0 & c \\
\hline & Tlaxcala & 22.4 & (3.2) & 35.9 & (2.8) & 29.2 & (3.3) & 10.3 & (2.4) & 2.0 & $(0.8)$ & 0.1 & c & 0.0 & c \\
\hline & Veracruz & 30.1 & (3.8) & 35.4 & (3.2) & 22.4 & (2.3) & 9.5 & (2.6) & 2.3 & (1.3) & 0.3 & $(0.4)$ & 0.0 & c \\
\hline & Yucatán & 26.8 & (3.0) & 33.1 & (2.4) & 27.2 & (2.9) & 11.0 & (1.9) & 1.8 & $(0.8)$ & 0.1 & c & 0.0 & c \\
\hline & Zacatecas & 22.9 & (2.4) & 33.8 & (2.4) & 28.5 & $(2.9)$ & 12.6 & $(2.1)$ & 1.9 & $(0.7)$ & 0.3 & c & 0.0 & c \\
\hline
\end{tabular}

- PISA adjudicated region.

Note: See Table 1.2.12 for national data.

StatLink त्ञात्रा http://dx.doi.org/10.1787/888932935762 
Part 4/4]

Percentage of students at each proficiency level on the mathematics subscale interpreting, by gender Table B2.I.11 and region

\begin{tabular}{|c|c|c|c|c|c|c|c|c|c|c|c|c|c|c|c|}
\hline & & \multicolumn{14}{|c|}{ Girls } \\
\hline & & \multicolumn{2}{|c|}{$\begin{array}{l}\text { Below Level } 1 \\
\text { (below 357.77 } \\
\text { score points) }\end{array}$} & \multicolumn{2}{|c|}{$\begin{array}{c}\text { Level } 1 \\
\text { (from } 357.77 \text { to } \\
\text { less than } 420.07 \\
\text { score points) }\end{array}$} & \multicolumn{2}{|c|}{$\begin{array}{c}\text { Level } 2 \\
\text { (from } 420.07 \text { to } \\
\text { less than } 482.38 \\
\text { score points) }\end{array}$} & $\begin{array}{r}\mathrm{L} \\
\text { (from } \\
\text { less th } \\
\text { scor }\end{array}$ & \begin{tabular}{l|} 
I 3 \\
2.38 to \\
544.68 \\
oints)
\end{tabular} & $\begin{array}{l}\text { Le } \\
\text { (from } \\
\text { less th } \\
\text { score }\end{array}$ & $\begin{array}{l}4 \\
4.68 \text { to } \\
606.99 \\
\text { oints) }\end{array}$ & $\begin{array}{r}\mathrm{L} \\
\text { (from } \\
\text { less th } \\
\text { scor }\end{array}$ & \begin{tabular}{|l|} 
I 5 \\
6.99 to \\
669.30 \\
oints)
\end{tabular} & $\begin{array}{l}\text { L } \\
\text { (abov } \\
\text { scor }\end{array}$ & $\begin{array}{l}16 \\
669.30 \\
\text { oints) }\end{array}$ \\
\hline & & $\%$ & S.E. & $\%$ & S.E. & $\%$ & S.E. & $\%$ & S.E. & $\%$ & S.E. & $\%$ & S.E. & $\%$ & S.E. \\
\hline 0 & Portugal & & & & & & & & & & & & & & \\
\hline 岀 & Alentejo & 7.4 & (2.5) & 16.2 & (2.8) & 27.5 & (2.6) & 26.2 & (3.4) & 16.4 & $(2.7)$ & 5.5 & (1.9) & 0.9 & (0.9) \\
\hline & Spain & & & & & & & & & & & & & & \\
\hline & Andalusia ${ }^{\bullet}$ & 10.2 & (1.4) & 18.2 & (1.9) & 26.0 & (1.9) & 23.2 & (1.9) & 14.6 & $(2.2)$ & 6.2 & (1.3) & 1.6 & (0.6) \\
\hline & Aragon ${ }^{\bullet}$ & 9.0 & (1.5) & 13.3 & (1.8) & 19.8 & (2.3) & 26.1 & (2.3) & 19.0 & $(2.3)$ & 10.2 & (1.5) & 2.6 & $(0.8)$ \\
\hline & Asturias ${ }^{\bullet}$ & 6.2 & $(1.2)$ & 11.9 & (1.8) & 21.2 & (1.6) & 25.8 & (1.9) & 19.8 & $(2.2)$ & 10.4 & (1.5) & 4.7 & $(0.9)$ \\
\hline & Balearic Islands ${ }^{\bullet}$ & 10.4 & (1.7) & 16.6 & (1.9) & 25.0 & (2.0) & 22.5 & (2.2) & 17.0 & $(2.2)$ & 7.0 & (1.4) & 1.5 & $(0.7)$ \\
\hline & Basque Country ${ }^{\bullet}$ & 5.6 & $(0.7)$ & 11.1 & $(0.9)$ & 21.6 & (1.1) & 26.3 & (1.1) & 21.6 & (1.1) & 10.5 & $(0.8)$ & 3.4 & $(0.5)$ \\
\hline & Cantabria ${ }^{\bullet}$ & 6.7 & (1.3) & 15.7 & (1.8) & 24.8 & (1.7) & 24.2 & (1.9) & 17.6 & $(2.1)$ & 8.7 & (1.6) & 2.4 & $(0.8)$ \\
\hline & Castile and Leon • & 4.2 & (1.0) & 10.7 & (1.5) & 21.8 & (2.0) & 27.5 & (2.4) & 22.1 & $(2.2)$ & 10.7 & (1.4) & 3.0 & $(0.9)$ \\
\hline & Catalonia ${ }^{\bullet}$ & 9.2 & (1.6) & 14.2 & (2.0) & 21.8 & (2.2) & 27.1 & (3.0) & 18.9 & $(2.4)$ & 6.8 & (1.3) & 2.2 & $(0.7)$ \\
\hline & Extremadura ${ }^{\circ}$ & 14.0 & (1.6) & 19.0 & $(1.5)$ & 24.0 & (2.6) & 22.8 & (2.5) & 12.8 & $(1.3)$ & 5.8 & (1.4) & 1.6 & $(0.8)$ \\
\hline & Galicia` & 8.3 & (1.1) & 13.2 & (1.9) & 21.6 & (2.1) & 25.3 & (2.0) & 19.3 & $(1.7)$ & 8.6 & $(1.2)$ & 3.6 & $(0.7)$ \\
\hline & La Rioja ${ }^{\bullet}$ & 9.0 & (1.1) & 12.3 & (1.4) & 21.1 & (1.9) & 24.5 & (1.7) & 18.5 & $(2.1)$ & 11.0 & (1.6) & 3.6 & $(0.8)$ \\
\hline & Madrid ${ }^{\bullet}$ & 5.7 & (1.3) & 10.6 & (1.6) & 21.6 & (1.6) & 26.8 & $(2.1)$ & 22.5 & $(1.7)$ & 10.1 & (1.5) & 2.7 & $(0.9)$ \\
\hline & Murcia ${ }^{\bullet}$ & 13.0 & (1.6) & 17.4 & $(1.7)$ & 24.6 & $(2.1)$ & 23.5 & (1.7) & 14.4 & (1.6) & 5.5 & (1.2) & 1.6 & $(0.6)$ \\
\hline & Navarre ${ }^{\bullet}$ & 4.2 & (1.0) & 9.2 & (1.3) & 20.9 & (2.1) & 25.6 & $(2.2)$ & 23.8 & $\begin{array}{l}(1.0) \\
(1.7)\end{array}$ & $\begin{array}{r}5.3 \\
12.2\end{array}$ & (1.4) & 4.0 & $\begin{array}{l}(0.0) \\
(0.8)\end{array}$ \\
\hline & United Kingdom & & & & & & & & & & & & & & \\
\hline & England & 9.1 & $(1.0)$ & 14.4 & (1.1) & 21.2 & (1.2) & 23.5 & (1.5) & 18.6 & (1.3) & 9.1 & $(0.8)$ & 4.1 & $(0.6)$ \\
\hline & Northern Ireland & 9.4 & $(1.2)$ & 15.5 & (1.5) & 22.5 & (1.7) & 21.3 & (1.6) & 17.7 & $(1.7)$ & 9.8 & (1.5) & 3.7 & $(0.8)$ \\
\hline & Scotland ${ }^{\bullet}$ & 5.0 & $(0.9)$ & 11.7 & (1.4) & 23.9 & (1.8) & 27.7 & (1.7) & 19.3 & $(1.3)$ & 9.3 & (1.0) & 3.1 & $(0.6)$ \\
\hline & Wales & 9.3 & (1.1) & 17.1 & (1.1) & 26.4 & (2.0) & 24.5 & (1.7) & 15.1 & $(1.0)$ & 5.9 & (1.0) & 1.6 & $(0.5)$ \\
\hline & United States & & & & & & & & & & & & & & \\
\hline & Connecticut $^{\bullet}$ & 7.8 & (1.4) & 12.3 & (1.4) & 19.2 & (1.7) & 24.5 & $(2.7)$ & 19.4 & (2.6) & 11.6 & (1.8) & 5.3 & (1.1) \\
\hline & Florida ${ }^{\bullet}$ & 10.3 & (1.7) & 20.1 & $(2.1)$ & 27.5 & (2.5) & 23.7 & (2.8) & 11.5 & (1.3) & 5.0 & (1.1) & 1.8 & $(1.0)$ \\
\hline & Massachusetts ${ }^{\bullet}$ & 5.6 & (1.1) & 12.4 & (1.5) & 20.1 & (1.8) & 22.1 & (2.1) & 19.6 & (2.0) & 13.0 & (1.7) & 7.2 & (1.6) \\
\hline 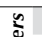 & Argentina & & & & & & & & & & & & & & \\
\hline$\cong$ & Ciudad Autónoma de Buenos Aires & 27.5 & (3.3) & 24.9 & $(2.9)$ & 26.1 & (2.3) & 15.3 & (2.4) & 5.2 & $(1.2)$ & 0.7 & $(0.5)$ & 0.2 & $(0.2)$ \\
\hline$\sqrt{\frac{2}{\pi}}$ & Brazil & & & & & & & & & & & & & & \\
\hline & Acre & 48.6 & $(4.3)$ & 28.7 & (3.9) & 16.3 & $(2.4)$ & 5.5 & $(1.7)$ & 0.7 & $(0.5)$ & 0.0 & c & 0.2 & $(0.2)$ \\
\hline & Alagoas & 59.7 & (4.4) & 23.9 & (3.8) & 12.1 & (2.5) & 3.6 & (1.6) & 0.6 & $(0.5)$ & 0.1 & c & 0.0 & c \\
\hline & Amapá & 46.7 & $(4.9)$ & 30.8 & $(4.1)$ & 17.5 & $(2.8)$ & 4.4 & (2.5) & 0.7 & $(0.8)$ & 0.0 & $\mathrm{C}$ & 0.0 & $\mathrm{C}$ \\
\hline & Amazonas & 48.2 & (3.7) & 32.7 & (3.4) & 13.4 & (2.3) & 4.3 & (1.4) & 1.1 & $(1.1)$ & 0.4 & $\mathrm{C}$ & 0.0 & c \\
\hline & Bahia & 41.3 & (6.2) & 30.8 & (5.0) & 16.7 & (5.1) & 8.3 & (3.3) & 2.7 & (1.6) & 0.2 & $\mathrm{C}$ & 0.0 & c \\
\hline & Ceará & 37.6 & (5.5) & 32.2 & (4.6) & 20.3 & (3.9) & 6.9 & (1.8) & 2.6 & $(1.1)$ & 0.3 & $(0.3)$ & 0.0 & c \\
\hline & Espírito Santo & 27.5 & (4.0) & 30.7 & $(4.7)$ & 21.7 & (2.9) & 11.5 & (3.5) & 6.2 & $(2.8)$ & 2.0 & $(1.2)$ & 0.4 & c \\
\hline & Federal District & 24.3 & (4.6) & 26.3 & (3.5) & 27.6 & (3.9) & 16.7 & (3.8) & 4.5 & $(2.2)$ & 0.6 & $\mathrm{C}$ & 0.0 & c \\
\hline & Goiás & 39.7 & (3.9) & 38.4 & (3.2) & 16.0 & (2.9) & 4.9 & (1.4) & 0.9 & $(0.4)$ & 0.0 & $\mathrm{C}$ & 0.0 & c \\
\hline & Maranhão & 58.1 & (8.0) & 24.2 & (4.6) & 12.8 & $(4.2)$ & 4.1 & (2.1) & 0.9 & $(0.6)$ & 0.0 & $\mathrm{C}$ & 0.0 & c \\
\hline & Mato Grosso & 39.9 & $(6.2)$ & 32.4 & $(4.7)$ & 18.9 & (3.8) & 5.7 & (2.3) & 2.6 & $(1.7)$ & 0.6 & $\mathrm{C}$ & 0.0 & c \\
\hline & Mato Grosso do Sul & 24.1 & $(4.1)$ & 34.5 & (3.8) & 24.4 & (4.0) & 13.0 & (3.1) & 3.9 & $(2.1)$ & 0.0 & $\mathrm{C}$ & 0.1 & c \\
\hline & Minas Gerais & 25.5 & (3.9) & 34.4 & (3.2) & 26.2 & (3.4) & 11.1 & (2.8) & 2.4 & $(1.3)$ & 0.4 & $(0.4)$ & 0.0 & c \\
\hline & Pará & 46.9 & (5.6) & 28.3 & $(4.6)$ & 19.1 & (2.9) & 5.1 & $(1.3)$ & 0.5 & $\mathrm{C}$ & 0.0 & $\mathrm{C}$ & 0.0 & c \\
\hline & Paraiba & 32.0 & (5.8) & 29.3 & $(4.2)$ & 21.7 & (4.9) & 14.3 & $(4.3)$ & 2.3 & $(1.4)$ & 0.4 & $\mathrm{C}$ & 0.0 & c \\
\hline & Paraná & 30.6 & $(4.3)$ & 33.0 & (3.9) & 22.2 & (3.3) & 9.8 & $(2.7)$ & 3.4 & $(2.5)$ & 1.0 & (1.1) & 0.0 & c \\
\hline & Pernambuco & 49.3 & (5.2) & 31.9 & (3.6) & 14.8 & (3.0) & 3.4 & (1.5) & 0.6 & $(0.5)$ & 0.1 & c & 0.0 & c \\
\hline & Piauí & 38.2 & $(4.6)$ & 34.8 & (3.5) & 15.8 & (2.7) & 7.8 & (1.9) & 2.8 & $(1.8)$ & 0.6 & $(0.6)$ & 0.0 & c \\
\hline & Rio de Janeiro & 27.3 & (4.8) & 35.1 & $(4.7)$ & 26.0 & (3.4) & 10.0 & (1.9) & 1.4 & $(1.1)$ & 0.2 & C & 0.0 & c \\
\hline & Rio Grande do Norte & 42.1 & (4.3) & 28.1 & (3.6) & 17.9 & (3.0) & 7.4 & (1.8) & 2.8 & (1.4) & 1.2 & $(0.7)$ & 0.5 & $(0.6)$ \\
\hline & Rio Grande do Sul & 19.3 & (3.5) & 33.2 & (3.2) & 29.5 & (3.3) & 14.9 & (2.9) & 3.0 & (1.3) & 0.1 & $\mathrm{C}$ & 0.0 & $\mathrm{C}$ \\
\hline & Rondônia & 29.7 & (4.0) & 37.1 & (3.8) & 24.2 & (3.3) & 8.1 & (2.2) & 0.9 & $(0.8)$ & 0.0 & c & 0.0 & c \\
\hline & Roraima & 47.5 & $(4.6)$ & 29.9 & (5.4) & 13.6 & (2.6) & 6.8 & (3.0) & 2.1 & $(1.4)$ & 0.1 & $\mathrm{c}$ & 0.0 & c \\
\hline & Santa Catarina & 22.4 & (4.9) & 29.5 & $(4.1)$ & 28.9 & (3.1) & 14.8 & (2.3) & 3.9 & $(1.8)$ & 0.6 & $(0.6)$ & 0.0 & c \\
\hline & São Paulo & 25.0 & $(2.2)$ & 31.6 & (1.8) & 25.3 & (1.7) & 12.8 & (1.4) & 4.4 & (1.1) & 0.8 & (0.5) & 0.1 & c \\
\hline & Sergipe & 39.3 & (4.9) & 33.6 & (4.0) & 18.9 & (3.3) & 7.2 & (3.0) & 1.0 & $(0.7)$ & 0.0 & $\mathrm{C}$ & 0.0 & c \\
\hline & Tocantins & 46.0 & (4.6) & 32.5 & (3.7) & 14.8 & (2.6) & 4.8 & (1.4) & 1.6 & $(0.8)$ & 0.2 & $\mathrm{C}$ & 0.0 & c \\
\hline & Colombia & & & & & & & & & & & & & & \\
\hline & Bogotá & 29.9 & (2.1) & 36.3 & (3.1) & 24.9 & (3.2) & 7.6 & (1.6) & 1.1 & $(0.5)$ & 0.1 & $(0.1)$ & 0.0 & c \\
\hline & Cali & 35.8 & (3.6) & 32.3 & (2.9) & 22.7 & (2.9) & 7.6 & (1.6) & 1.6 & $(0.6)$ & 0.1 & C & 0.0 & c \\
\hline & Manizales & 22.6 & (3.0) & 37.1 & (3.0) & 28.3 & (2.9) & 10.7 & (1.5) & 1.2 & $(0.7)$ & 0.0 & $\mathrm{C}$ & 0.0 & c \\
\hline & Medellín & 33.6 & (3.7) & 30.2 & (2.6) & 21.0 & (2.8) & 9.8 & (2.2) & 4.1 & (1.6) & 1.2 & $(0.7)$ & 0.1 & c \\
\hline & Russian Federation & & & & & & & & & & & & & & \\
\hline & Perm Territory region` & 8.7 & (1.5) & 16.8 & (1.7) & 28.5 & (2.3) & 25.9 & $(2.0)$ & 14.9 & (1.5) & 4.2 & (1.1) & 1.0 & $(0.7)$ \\
\hline & United Arab Emirates & & & & & & & & & & & & & & \\
\hline & Abu Dhabi & 20.7 & $(2.0)$ & 30.6 & (1.8) & 26.7 & (1.7) & 14.3 & $(1.7)$ & 5.7 & $(0.9)$ & 1.8 & $(0.7)$ & 0.2 & $(0.2)$ \\
\hline & Ajman & 24.0 & $(6.2)$ & 31.7 & (3.9) & 28.5 & (3.6) & 13.4 & (2.9) & 2.3 & $(1.1)$ & 0.1 & $\mathrm{C}$ & 0.0 & $\mathrm{C}$ \\
\hline & Dubai ${ }^{\bullet}$ & 13.8 & $(0.7)$ & 21.6 & (1.4) & 25.8 & (1.5) & 21.5 & (1.4) & 12.3 & $(1.1)$ & 4.3 & $(0.8)$ & 0.6 & $(0.4)$ \\
\hline & Fujairah & 21.3 & (3.8) & 27.7 & (3.4) & 32.9 & (3.9) & 14.4 & (2.8) & 3.2 & $(1.3)$ & 0.4 & $(0.4)$ & 0.0 & C \\
\hline & Ras al-Khaimah & 21.5 & (5.3) & 29.3 & (3.3) & 28.0 & (3.7) & 15.9 & (3.8) & 4.5 & $(1.7)$ & 0.7 & $(0.5)$ & 0.0 & c \\
\hline & Sharjah & 19.2 & (3.8) & 29.3 & (4.5) & 25.3 & (2.9) & 19.2 & (3.5) & 5.7 & (1.8) & 1.2 & $(0.8)$ & 0.0 & c \\
\hline & Umm al-Quwain & 21.6 & (3.6) & 31.1 & (5.7) & 33.5 & $(4.7)$ & 11.9 & (2.8) & 1.7 & (1.3) & 0.2 & C & 0.0 & c \\
\hline
\end{tabular}

- PISA adjudicated region.

Note: See Table I.2.12 for national data.

StatLink 部 SL http://dx.doi.org/10.1787/888932935762 
[Part 1/2]

Mean score, variation and gender differences in student performance on the mathematics Table B2.I.12 subscale interpreting, by region

\begin{tabular}{|c|c|c|c|c|c|c|c|c|c|c|c|c|c|c|c|c|c|c|c|}
\hline & & & All stu & udents & & & & nder di & ifferen & nces & & & & & & & Perce & entiles & \\
\hline & & Mean & score & $\begin{array}{l}\text { Stan } \\
\text { devi }\end{array}$ & $\begin{array}{l}\text { ard } \\
\text { ion }\end{array}$ & & oys & Gi & & $\begin{array}{l}\text { Diffe } \\
\text { (B. }\end{array}$ & $\begin{array}{l}\text { rence } \\
- \text { G) }\end{array}$ & & th & & 0th & & 5th & & 5th \\
\hline & & Mean & S.E. & S.D. & S.E. & $\begin{array}{l}\text { Mean } \\
\text { score }\end{array}$ & S.E. & $\begin{array}{l}\text { Mean } \\
\text { score }\end{array}$ & S.E. & $\begin{array}{c}\text { Score } \\
\text { dif. }\end{array}$ & S.E. & Score & S.E. & Score & S.E. & Score & S.E. & Score & S.E. \\
\hline & Australia & & & & & & & & & & & & & & & & & & \\
\hline & Australian Capital Territory & 533 & (3.9) & $\mid 102$ & (3.0) & 533 & (5.9) & 532 & $(5.0)$ & 1 & (7.6) & 363 & (10.4) & 399 & (8.6) & 462 & (7.8) & 606 & (5.6) \\
\hline & New South Wales & 516 & (3.7) & 105 & (2.5) & 519 & (5.6) & 513 & $(4.1)$ & 6 & (6.5) & 345 & $(6.2)$ & 382 & $(4.3)$ & 445 & (3.8) & 587 & (5.0) \\
\hline & Northern Territory & 453 & (9.5) & 110 & $(4.0)$ & 458 & (8.5) & 449 & (14.5) & 9 & $(14.1)$ & 263 & (13.6) & 304 & $(11.3)$ & 381 & $(14.3)$ & 531 & $(14.6)$ \\
\hline & Queensland & 513 & (3.3) & 101 & $(2.2)$ & 515 & (4.3) & 511 & (3.6) & 4 & (4.6) & 348 & (7.3) & 385 & $(5.1)$ & 444 & (3.7) & 585 & (4.6) \\
\hline & South Australia & 502 & (3.4) & 98 & $(2.1)$ & 508 & (4.5) & 496 & $(4.3)$ & 11 & (5.6) & 338 & (6.6) & 375 & $(8.2)$ & 435 & (4.7) & 570 & (7.0) \\
\hline & Tasmania & 493 & (3.5) & 103 & (2.6) & 498 & (4.9) & 487 & $(5.2)$ & 11 & (7.4) & 320 & (8.4) & 362 & (6.6) & 425 & (4.1) & 563 & (6.2) \\
\hline & Victoria & 512 & (3.6) & 94 & (1.8) & 518 & (4.8) & 505 & (3.6) & 13 & (4.8) & 358 & (5.2) & 389 & (5.5) & 447 & (4.7) & 579 & (4.9) \\
\hline & Western Australia & 528 & (3.3) & 102 & (1.7) & 538 & (4.8) & 516 & (5.5) & 22 & (7.9) & 359 & (7.5) & 393 & (7.3) & 456 & (6.3) & 599 & (3.9) \\
\hline & Belgium & & & & & & & & & & & & & & & & & & \\
\hline & Flemish Community• & 525 & (3.5) & \begin{tabular}{|l|l|}
108 \\
$|c|$
\end{tabular} & (2.0) & 530 & (4.9) & 520 & $(4.2)$ & 10 & (5.8) & \begin{tabular}{|l|l|}
344 \\
$\mid$
\end{tabular} & (7.4) & 383 & (5.4) & 451 & (5.0) & 605 & (3.8) \\
\hline & French Community & 497 & (3.4) & 101 & $(2.2)$ & 502 & (4.1) & 492 & (3.9) & 10 & (4.3) & 326 & (7.4) & 363 & (5.6) & 426 & (4.7) & 572 & (3.9) \\
\hline & German-speaking Community & 509 & $(2.1)$ & 99 & $(2.5)$ & 506 & (3.9) & 512 & $(3.7)$ & -6 & (6.3) & 335 & (9.9) & 376 & (8.8) & 449 & (7.3) & 576 & (3.8) \\
\hline & Canada & & & & & & & & & & & & & & & & & & \\
\hline & Alberta & 523 & $(5.2)$ & 96 & (1.9) & 529 & (6.5) & 517 & (4.9) & 12 & (5.0) & $\mid 365$ & (7.9) & 400 & (6.3) & 459 & (5.9) & 592 & (6.1) \\
\hline & British Columbia & 528 & $(4.1)$ & 88 & $(2.3)$ & 533 & (4.9) & 523 & $(5.4)$ & 10 & (6.0) & 381 & $(5.2)$ & 412 & $(5.2)$ & 469 & (5.4) & 588 & (5.3) \\
\hline & Manitoba & 502 & (3.0) & 94 & $(2.2)$ & 504 & (3.8) & 499 & $(4.7)$ & 6 & $(6.0)$ & 346 & $(7.7)$ & 381 & $(6.3)$ & 439 & (4.6) & 567 & (3.9) \\
\hline & New Brunswick & 502 & $(2.8)$ & 88 & $(2.0)$ & 504 & $(4.2)$ & 499 & (3.8) & 5 & (5.8) & 352 & (6.7) & 386 & (7.0) & 443 & (5.4) & 562 & (4.4) \\
\hline & Newfoundland and Labrador & 499 & (3.8) & 91 & $(2.3)$ & 501 & (5.3) & 496 & $(4.3)$ & 5 & (5.9) & 347 & $(10.4)$ & 379 & $(8.0)$ & 434 & (6.3) & 562 & (4.2) \\
\hline & Nova Scotia & 507 & (3.8) & 86 & (3.2) & 513 & (4.6) & 501 & $(5.1)$ & 13 & (6.0) & 358 & $(8.4)$ & 397 & (5.3) & 453 & (4.6) & 564 & (6.0) \\
\hline & Ontario & 517 & (4.4) & 90 & (1.8) & 520 & (5.1) & 513 & $(4.5)$ & 7 & (3.8) & 366 & (5.4) & 401 & (5.4) & 457 & (5.0) & 577 & (5.8) \\
\hline & Prince Edward Island & 487 & (2.9) & 89 & $(2.1)$ & 491 & (4.0) & 483 & (3.6) & 8 & (5.0) & 343 & (6.5) & 372 & (4.6) & 425 & (4.5) & 549 & (4.3) \\
\hline & Quebec & 536 & (3.4) & 98 & (1.9) & 542 & (4.3) & 529 & $(4.0)$ & 13 & (4.6) & 366 & (6.6) & 405 & (5.7) & 471 & (4.5) & 603 & (3.9) \\
\hline & Saskatchewan & 508 & (3.1) & 87 & $(2.0)$ & 511 & $(4.2)$ & 505 & $(4.0)$ & 6 & (5.3) & 365 & (6.5) & 398 & (5.3) & 452 & (3.7) & 568 & (4.0) \\
\hline & Italy & & & & & & & & & & & & & & & & & & \\
\hline & Abruzzo & 484 & $(7.0)$ & 104 & (5.4) & \begin{tabular}{|l|}
489 \\
\end{tabular} & (8.9) & 480 & $(6.8)$ & 8 & (7.7) & \begin{tabular}{|l|}
308 \\
\end{tabular} & (20.6) & 350 & (10.9) & 418 & (7.4) & 558 & (8.1) \\
\hline & Basilicata & 470 & $(5.2)$ & 103 & (2.6) & 481 & (6.7) & 460 & $(5.3)$ & 21 & (6.7) & 305 & (12.0) & 342 & (7.8) & 402 & (6.7) & 540 & (5.8) \\
\hline & Bolzano & 516 & $(2.5)$ & 106 & $(1.7)$ & 524 & (3.3) & 508 & (3.3) & 16 & (4.4) & 339 & (6.1) & 377 & (5.2) & 444 & (5.6) & 590 & (3.7) \\
\hline & Calabria & 433 & (7.8) & 102 & (4.5) & 440 & (9.9) & 426 & (8.9) & 14 & (10.6) & 270 & (10.7) & 301 & (11.4) & 359 & (11.8) & 503 & (8.2) \\
\hline & Campania & 462 & (7.9) & 105 & (3.6) & 470 & (8.2) & 453 & $(9.5)$ & 17 & $(8.1)$ & 288 & (12.5) & 330 & $(9.1)$ & 390 & (9.5) & 533 & (9.2) \\
\hline & Emilia Romagna & 516 & (6.7) & 113 & $(4.2)$ & 525 & (10.5) & 507 & $(8.2)$ & 18 & (13.5) & 325 & (16.2) & 374 & (10.4) & 442 & (8.2) & 596 & (8.6) \\
\hline & Friuli Venezia Giulia & 536 & $(6.2)$ & 104 & $(4.1)$ & 547 & $(6.1)$ & 526 & $(8.7)$ & 21 & $(9.2)$ & 354 & (13.1) & 392 & $(11.7)$ & 470 & (9.5) & 609 & (5.6) \\
\hline & Lazio & 488 & (7.9) & 101 & (3.1) & 498 & (8.5) & 476 & $(8.8)$ & 22 & (7.8) & 325 & (7.8) & 357 & $(9.5)$ & 417 & (9.3) & 558 & (9.6) \\
\hline & Liguria & 504 & (7.4) & 108 & (3.6) & 509 & $(9.2)$ & 498 & $(8.4)$ & 11 & (9.5) & 329 & (8.9) & 365 & (7.9) & 430 & (7.6) & 577 & (9.4) \\
\hline & Lombardia & 535 & (7.8) & 101 & (3.6) & 546 & (10.0) & 522 & $(8.1)$ & 24 & (10.3) & 367 & (9.3) & 406 & (9.3) & 466 & (9.5) & 604 & $(9.2)$ \\
\hline & Marche & 510 & $(6.5)$ & 97 & (3.9) & 526 & $(8.1)$ & 494 & $(6.5)$ & 32 & $(7.5)$ & 348 & $(12.2)$ & 383 & (12.0) & 443 & $(8.2)$ & 578 & $(7.3)$ \\
\hline & Molise & 471 & $(2.8)$ & 97 & (2.6) & 476 & (3.7) & 466 & $(4.5)$ & 10 & (5.8) & 315 & $(7.6)$ & 348 & $(6.5)$ & 406 & (4.4) & 535 & (6.1) \\
\hline & Piemonte & 514 & (6.4) & 103 & (3.0) & 527 & (6.1) & 503 & (7.6) & 24 & (6.5) & 344 & (6.3) & 377 & (6.3) & 443 & (8.3) & 585 & (8.3) \\
\hline & Puglia & 490 & (6.5) & 96 & (3.6) & 502 & (7.0) & 478 & $(7.1)$ & 23 & (6.6) & 334 & (10.8) & 367 & (10.3) & 425 & (7.7) & 556 & (7.7) \\
\hline & Sardegna & 472 & (5.4) & 101 & (3.2) & 474 & (6.4) & 470 & $(7.3)$ & 4 & (8.5) & 304 & (12.2) & 341 & (10.9) & 404 & (6.7) & 543 & (5.3) \\
\hline & Sicilia & 457 & $(5.8)$ & 98 & (3.5) & 462 & (7.6) & 451 & (7.0) & 12 & $(8.9)$ & 290 & (13.1) & 331 & $(10.8)$ & 392 & (7.4) & 525 & $(7.2)$ \\
\hline & Toscana & 507 & (6.0) & 109 & (4.3) & 507 & $(9.2)$ & 507 & $(9.0)$ & 0 & (13.9) & 325 & (17.6) & 364 & (10.1) & 434 & (9.5) & 584 & (6.6) \\
\hline & Trento & 537 & $(4.2)$ & 94 & $(2.5)$ & 541 & (5.6) & 533 & (7.3) & 8 & (9.9) & 375 & (10.1) & 415 & (10.0) & 476 & (6.9) & 602 & (5.3) \\
\hline & Umbria & 506 & (7.6) & 104 & (4.6) & 519 & (11.0) & 494 & $(6.8)$ & 25 & (9.8) & 316 & (20.6) & 367 & (18.6) & 441 & $(11.2)$ & 576 & (5.3) \\
\hline & Valle d'Aosta & 507 & (3.1) & 99 & (2.3) & 513 & (4.1) & 502 & $(4.5)$ & 11 & (5.9) & 346 & (6.6) & 377 & (7.6) & 440 & (5.3) & 573 & (5.7) \\
\hline & Veneto & 540 & (7.4) & 103 & (4.5) & 549 & (8.5) & 530 & $(8.4)$ & 19 & (9.0) & 364 & $(15.7)$ & 406 & (12.9) & 472 & (9.2) & 611 & (8.6) \\
\hline & Mexico & & & & & & & & & & & & & & & & & & \\
\hline & Aguascalientes & 436 & (4.6) & 71 & (2.4) & 439 & (5.5) & 434 & (5.4) & 4 & (6.1) & $\mid 323$ & (7.4) & 345 & (5.7) & $\mid 385$ & (6.1) & 483 & (5.2) \\
\hline & Baja California & 418 & (6.5) & 70 & (3.5) & 423 & (7.1) & 413 & $(6.5)$ & 9 & (4.0) & 308 & (11.4) & 331 & (9.4) & 371 & (7.1) & 463 & (8.2) \\
\hline & Baja California Sur & 418 & $(5.8)$ & 70 & (2.6) & 422 & (6.3) & 413 & (6.1) & 9 & (4.6) & 303 & (11.0) & 328 & (8.6) & 370 & (8.0) & 463 & (5.0) \\
\hline & Campeche & 400 & (4.6) & 71 & (2.6) & 404 & (4.6) & 395 & (5.9) & 9 & (5.3) & 283 & (10.7) & 309 & (8.2) & 352 & (6.4) & 446 & (4.3) \\
\hline & Chiapas & 370 & (6.6) & 72 & (3.6) & 375 & (7.3) & 365 & (6.9) & 10 & (4.9) & 253 & (9.8) & 279 & (9.6) & 322 & (8.5) & 418 & (6.1) \\
\hline & Chihuahua & 426 & (8.9) & 78 & (4.9) & 434 & (10.9) & 419 & (8.3) & 14 & (7.8) & 304 & (14.4) & 334 & (10.1) & 379 & (7.9) & 476 & (10.5) \\
\hline & Coahuila & 417 & (7.5) & 70 & (2.4) & 421 & (8.3) & 413 & (8.0) & 7 & (6.2) & 309 & (6.5) & 330 & $(6.7)$ & 370 & (6.7) & 464 & (9.4) \\
\hline & Colima & 431 & $(4.5)$ & 75 & (3.1) & 430 & (4.5) & 431 & $(5.5)$ & -1 & (4.6) & 310 & (6.1) & 334 & (6.4) & 378 & (5.6) & 481 & (5.7) \\
\hline & Distrito Federal & 427 & (5.4) & 74 & (3.1) & 440 & (6.5) & 415 & $(6.2)$ & 25 & (6.8) & 309 & (8.6) & 335 & $(6.2)$ & 376 & (6.3) & 476 & (7.7) \\
\hline & Durango & 423 & $(5.8)$ & 70 & (2.6) & 429 & (7.5) & 419 & $(5.3)$ & 10 & (5.5) & 306 & (10.8) & 331 & (8.0) & 376 & (7.5) & 471 & (6.0) \\
\hline & Guanajuato & 410 & $(5.8)$ & 73 & (2.4) & 417 & (6.4) & 403 & $(5.8)$ & 14 & (4.1) & 290 & (9.5) & 314 & $(10.2)$ & 361 & (6.6) & 460 & (5.5) \\
\hline & Guerrero & 368 & (3.7) & 67 & (2.5) & 369 & (4.0) & 368 & $(4.8)$ & 1 & (4.8) & 261 & (7.9) & 284 & (7.6) & 323 & (4.7) & 413 & (5.4) \\
\hline & Hidalgo & 405 & (5.6) & 71 & (3.0) & 410 & (6.6) & 401 & $(5.7)$ & 10 & (5.1) & 288 & (7.9) & 313 & (6.3) & 358 & (6.3) & 451 & (7.8) \\
\hline & Jalisco & 435 & (5.7) & 68 & (3.3) & 438 & (7.2) & 434 & (5.0) & 4 & (4.6) & 323 & (11.5) & 352 & $(7.7)$ & 392 & (6.3) & 480 & (7.0) \\
\hline & Mexico & 420 & (5.1) & 63 & (3.6) & 426 & (5.9) & 414 & $(5.4)$ & 12 & (5.0) & 316 & (8.8) & 339 & (7.4) & 377 & (5.7) & 460 & (6.6) \\
\hline & Morelos & 421 & $(8.7)$ & 76 & (6.1) & 423 & $(10.2)$ & 419 & (8.5) & 4 & (7.0) & 295 & (16.5) & 324 & $(15.3)$ & 372 & (10.6) & 471 & (9.5) \\
\hline & Nayarit & 414 & (5.6) & 73 & (2.7) & 421 & (6.0) & 407 & (6.5) & 14 & (5.5) & 290 & (10.3) & 318 & (8.0) & 365 & (7.1) & 466 & (6.5) \\
\hline & Nuevo León & 439 & $(9.3)$ & 71 & (2.4) & 449 & $(10.8)$ & 429 & $(8.1)$ & 20 & (6.6) & 326 & (10.4) & 349 & (9.1) & 391 & (9.4) & 488 & (11.4) \\
\hline & Puebla & 409 & $(5.3)$ & 71 & (3.8) & 414 & (7.3) & 404 & $(5.3)$ & 10 & (7.0) & 289 & (15.3) & 319 & (11.8) & 365 & (6.5) & 454 & (5.0) \\
\hline & Querétaro & 441 & (7.8) & 71 & (3.4) & 448 & (8.6) & 434 & $(8.0)$ & 14 & (4.5) & 326 & (9.9) & 349 & (10.8) & 391 & (11.1) & 491 & (9.1) \\
\hline & Quintana Roo & 410 & $(6.2)$ & 70 & (2.6) & 412 & $(7.2)$ & 409 & $(6.1)$ & 3 & (4.6) & 295 & (9.9) & 318 & (10.1) & 364 & (8.1) & 456 & (5.1) \\
\hline & San Luis Potosí & 412 & (7.4) & 74 & (3.1) & 412 & $(8.2)$ & 413 & (7.6) & -1 & (5.3) & 295 & (6.9) & 318 & (8.4) & 359 & (7.4) & 465 & (8.4) \\
\hline & Sinaloa & 414 & (4.7) & 68 & $(2.1)$ & 414 & (5.9) & 413 & (5.2) & 1 & (5.8) & 304 & (7.3) & 328 & (6.1) & 366 & (6.3) & 460 & (6.1) \\
\hline & Tabasco & 379 & (4.4) & 69 & (3.2) & 383 & (5.9) & 376 & (4.0) & 8 & (4.6) & 269 & (6.1) & 292 & (6.8) & 332 & (5.8) & 425 & (4.9) \\
\hline & Tamaulipas & 412 & (5.5) & 73 & (3.4) & 419 & (7.5) & 404 & $(5.5)$ & 15 & $(7.2)$ & 297 & $(8.2)$ & 322 & (5.9) & 361 & (7.1) & 459 & (7.6) \\
\hline & Tlaxcala & 409 & $(5.0)$ & 70 & $(2.7)$ & 413 & (5.0) & 406 & $(5.4)$ & 8 & (3.4) & 290 & (12.3) & 319 & $(8.9)$ & 365 & (6.0) & 456 & (5.2) \\
\hline & Veracruz & 398 & $(6.3)$ & 73 & (3.0) & 399 & (6.1) & 396 & $(7.7)$ & 3 & (5.7) & 283 & (7.6) & 306 & (7.6) & 348 & (6.5) & 446 & (9.0) \\
\hline & Yucatán & 411 & (5.8) & 74 & (2.4) & 420 & (7.0) & 401 & (5.8) & 19 & (5.2) & 291 & (9.7) & 319 & (8.0) & 361 & (6.4) & 460 & (6.8) \\
\hline & Zacatecas & 411 & (4.0) & 72 & (1.6) & 415 & (4.5) & 408 & (4.5) & 7 & $(4.0)$ & 292 & (8.6) & 319 & (6.8) & 363 & (4.9) & 462 & (5.4) \\
\hline
\end{tabular}

- PISA adjudicated region.

Notes: Values that are statistically significant are indicated in bold (see Annex A3).

See Table I.2.13 for national data.

StatLink त्राजा http://dx.doi.org/10.1787/888932935762 
[Part 2/2]

Mean score, variation and gender differences in student performance on the mathematics Table B2.I.12 subscale interpreting, by region

\begin{tabular}{|c|c|c|c|c|c|c|c|c|c|c|c|c|c|c|c|c|c|c|c|c|c|c|c|}
\hline & & \multicolumn{4}{|c|}{ All students } & \multicolumn{6}{|c|}{ Gender differences } & \multicolumn{12}{|c|}{ Percentiles } \\
\hline & & \multicolumn{2}{|c|}{ Mean score } & \multicolumn{2}{|c|}{$\begin{array}{l}\text { Standard } \\
\text { deviation }\end{array}$} & \multicolumn{2}{|c|}{ Boys } & \multicolumn{2}{|c|}{ Girls } & \multicolumn{2}{|c|}{$\begin{array}{c}\text { Difference } \\
\text { (B - G) }\end{array}$} & \multicolumn{2}{|c|}{ 5th } & \multicolumn{2}{|c|}{ 10th } & \multicolumn{2}{|c|}{ 25th } & \multicolumn{2}{|c|}{ 75th } & \multicolumn{2}{|c|}{ 90th } & \multicolumn{2}{|c|}{ 95th } \\
\hline & & Mean & S.E. & S.D. & S.E. & $\begin{array}{l}\text { Mean } \\
\text { score }\end{array}$ & S.E. & $\begin{array}{l}\text { Mean } \\
\text { score }\end{array}$ & S.E. & \begin{tabular}{|c|}
$\begin{array}{c}\text { Score } \\
\text { dif. }\end{array}$ \\
\end{tabular} & S.E. & Score & S.E. & Score & S.E. & Score & S.E. & Score & S.E. & Score & S.E. & Score & e S.E. \\
\hline \multirow{2}{*}{ তি } & Portugal & & & & & & & & & & & & & & & & & & & & & & \\
\hline & Alentejo & \begin{tabular}{|l|}
489 \\
\end{tabular} & $(10.2)$ & 88 & (3.8) & 498 & (12.9) & 480 & $(8.8)$ & 18 & $(8.3)$ & 342 & (16.6) & $\mid 377$ & (14.3) & 430 & $(13.7) \mid$ & 548 & (11.1) & 605 & (9.5) & 634 & $(11.2)$ \\
\hline \multicolumn{24}{|c|}{ 年 } \\
\hline & Andalusia ${ }^{\bullet}$ & 484 & (5.2) & 100 & (2.5) & 493 & (6.8) & 474 & $(5.0)$ & 20 & $(6.1)$ & 321 & (7.6) & 357 & (6.4) & 417 & (5.1) & 553 & (6.8) & 613 & (6.7) & 649 & $(10.8)$ \\
\hline & Aragon ${ }^{\bullet}$ & 500 & (6.1) & 102 & (3.2) & 506 & (6.5) & 495 & $(7.0)$ & 11 & $(6.1)$ & 323 & (9.7) & 364 & (8.6) & 432 & $(7.2)$ & 572 & (7.4) & 626 & (8.4) & 658 & (7.7) \\
\hline & Asturias ${ }^{\bullet}$ & 508 & (4.9) & 105 & (2.6) & 510 & (6.8) & 507 & $(4.5)$ & 4 & (6.1) & 333 & (10.3) & 376 & (7.7) & 443 & $(6.2)$ & 580 & (6.7) & 640 & (6.4) & 673 & (7.5) \\
\hline & Balearic Islands ${ }^{\bullet}$ & 482 & (5.4) & 98 & (2.5) & 487 & (6.1) & 477 & (6.1) & 10 & (5.6) & 321 & (9.5) & 354 & (7.9) & 417 & (6.4) & 552 & (6.1) & 606 & (5.6) & 636 & (7.2) \\
\hline & Basque Country ${ }^{\bullet}$ & 514 & (2.9) & 93 & (1.4) & 520 & (3.5) & 508 & (3.2) & 12 & (3.4) & 356 & (4.8) & 393 & (3.9) & 452 & (3.3) & 579 & (3.8) & 632 & (3.8) & 662 & (4.5) \\
\hline & Cantabria $\bullet^{\bullet}$ & 498 & (4.0) & 101 & (2.4) & 504 & (5.2) & 491 & (5.1) & 13 & (6.4) & 331 & (11.4) & 372 & $(7.7)$ & 432 & (5.3) & 569 & (4.2) & 626 & (6.1) & 656 & (5.7) \\
\hline & Castile and Leon ${ }^{\bullet}$ & 521 & (4.9) & 94 & (2.3) & 530 & (6.3) & 511 & $(5.1)$ & 20 & (5.7) & 365 & (10.3) & 400 & (7.6) & 456 & (6.6) & 588 & (5.5) & 642 & (4.7) & 671 & (7.6) \\
\hline & Catalonia・ & 506 & (6.1) & 98 & $(2.2)$ & 522 & (6.8) & 488 & $(7.2)$ & 34 & (7.1) & 338 & (8.3) & 375 & (7.3) & 439 & (8.5) & 573 & (6.7) & 631 & (8.2) & 665 & (8.4) \\
\hline & Extremadura ${ }^{\bullet}$ & 470 & (5.5) & 104 & (2.5) & 476 & (6.6) & 464 & (5.6) & 12 & (5.2) & 302 & (11.3) & 337 & (9.5) & 399 & (6.6) & 542 & (6.4) & 605 & (7.3) & 640 & (8.2) \\
\hline & Galicia ${ }^{\bullet}$ & 498 & (4.7) & 98 & (2.4) & 499 & (5.4) & 496 & (5.7) & 3 & (6.1) & 326 & (9.6) & 368 & (7.7) & 433 & (6.9) & 567 & (4.8) & 619 & (5.4) & 654 & (6.2) \\
\hline & La Rioja` & 506 & (2.2) & 110 & $(2.2)$ & 516 & (3.5) & 498 & (3.5) & 18 & (5.5) & 313 & (7.5) & 358 & (5.7) & 435 & (4.5) & 584 & (4.1) & 644 & (4.6) & 676 & (4.5) \\
\hline & Madrid ${ }^{\bullet}$ & 515 & (4.5) & 93 & (2.5) & 522 & (5.4) & 507 & (5.1) & 15 & (5.5) & 354 & (8.8) & 391 & (7.1) & 453 & (6.5) & 582 & (4.7) & 631 & (4.9) & 659 & (5.8) \\
\hline & Murcia ${ }^{\bullet}$ & 472 & (5.2) & 102 & (3.0) & 478 & (6.4) & 466 & (4.9) & 11 & (4.8) & 296 & (10.1) & 341 & (9.2) & 404 & (6.0) & 544 & (6.6) & 603 & (8.7) & 637 & (8.8) \\
\hline & Navarre ${ }^{\bullet}$ & 521 & (3.5) & 94 & (2.3) & 524 & (4.9) & 518 & (3.7) & 5 & (5.1) & 358 & (8.0) & 395 & (6.8) & 460 & (4.9) & 587 & (4.9) & 639 & (6.1) & 670 & (7.0) \\
\hline \multicolumn{24}{|c|}{ United Kingdom } \\
\hline & England & 502 & (4.2) & 103 & (2.3) & 509 & (5.5) & 495 & (4.4) & 14 & (5.6) & 331 & (7.6) & 369 & (6.3) & 432 & (5.6) & 573 & (3.9) & 634 & (4.5) & 669 & (5.5) \\
\hline & Northern Ireland & 496 & (3.5) & 102 & (2.4) & 500 & (5.2) & 491 & (5.8) & 8 & (8.4) & 328 & (8.3) & 366 & (6.0) & 425 & (4.5) & 565 & (4.1) & 628 & (6.0) & 662 & (6.3) \\
\hline & Scotland ${ }^{\bullet}$ & 510 & (2.7) & 90 & (1.9) & 516 & (3.3) & 504 & (3.2) & 12 & (3.7) & 360 & (7.3) & 396 & (5.6) & 449 & (3.9) & 571 & (3.1) & 626 & $(4.2)$ & 658 & (6.2) \\
\hline & Wales & 483 & (2.6) & 93 & (1.4) & 489 & (3.3) & 477 & (3.1) & 12 & (3.8) & 330 & (5.0) & 362 & (4.5) & 421 & (3.5) & 546 & (3.2) & 603 & (4.6) & 637 & (4.5) \\
\hline \multicolumn{24}{|c|}{ United States } \\
\hline & Connecticut $^{\bullet}$ & 515 & (6.4) & 104 & (2.9) & 523 & (7.0) & 507 & (6.6) & 16 & (4.4) & 337 & (10.1) & 376 & (9.0) & 443 & (8.9) & 589 & (6.8) & 649 & (8.5) & 682 & (7.6) \\
\hline & Florida ${ }^{\bullet}$ & 475 & (6.5) & 92 & (3.0) & 482 & (7.0) & 468 & (6.8) & 14 & (4.8) & 329 & (5.9) & 358 & (7.7) & 410 & (6.4) & 535 & (8.5) & 598 & (10.4) & 635 & (12.0) \\
\hline & Massachusetts ${ }^{\bullet}$ & 524 & (6.4) & 107 & (2.9) & 531 & (6.4) & 518 & $(7.3)$ & 13 & (4.8) & 352 & (7.0) & 388 & (5.5) & 451 & (5.9) & 597 & (8.9) & 661 & (9.0) & 699 & (10.5) \\
\hline
\end{tabular}

\begin{tabular}{|c|c|c|c|c|c|c|c|c|c|c|c|c|c|c|c|c|c|c|c|c|c|c|c|}
\hline \multirow{3}{*}{ 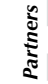 } & \multicolumn{23}{|l|}{ Argentina } \\
\hline & Ciudad Autónoma de Buenos Aires ${ }^{\bullet}$ & 415 & (7.3) & 99 & $(7.1)$ & 424 & (7.9) & 407 & (7.9) & 17 & (5.9) & 240 & $(25.8)$ & 288 & $(15.4)$ & 356 & (8.7) & 483 & (6.6) & 534 & (6.6) & 562 & (7.9) \\
\hline & \multicolumn{23}{|l|}{ Brazil } \\
\hline & Acre & 367 & (6.5) & 75 & (3.9) & 372 & (8.0) & 363 & (7.1) & 10 & (7.6) & 247 & (8.8) & 274 & $(8.7)$ & 315 & (8.7) & 417 & (8.5) & 466 & (9.6) & 492 & $(11.8)$ \\
\hline & Alagoas & 346 & (7.0) & 78 & (4.4) & 353 & (8.9) & 341 & (6.6) & 12 & (6.1) & 228 & (14.9) & 253 & $(10.0)$ & 294 & (6.9) & 395 & (10.7) & 446 & (13.3) & 481 & (17.5) \\
\hline & Amapá & 372 & (8.6) & 71 & $(4.7)$ & 379 & (10.4) & 366 & (8.3) & 13 & (7.7) & 259 & (11.0) & 284 & (9.5) & 322 & (9.4) & 418 & (9.1) & 464 & (17.6) & 495 & (16.5) \\
\hline & Amazonas & 369 & (6.0) & 74 & (6.8) & 373 & (7.9) & 365 & (5.3) & 8 & (6.1) & 258 & (11.5) & 282 & (10.1) & 320 & (5.8) & 409 & (6.7) & 462 & $(10.3)$ & 498 & (22.9) \\
\hline & Bahia & 381 & (8.9) & 85 & (6.0) & 385 & (9.2) & 378 & (11.0) & 7 & (9.9) & 240 & (23.4) & 278 & (15.9) & 326 & (13.3) & 434 & (8.6) & 495 & (11.6) & 526 & (14.7) \\
\hline & Ceará & 389 & (8.4) & 81 & (5.1) & 395 & (9.3) & 383 & (9.2) & 11 & (7.7) & 261 & (12.7) & 290 & (8.0) & 335 & (9.1) & 437 & (11.5) & 492 & (16.1) & 534 & (19.9) \\
\hline & Espírito Santo & 421 & (10.1) & 86 & (6.5) & 429 & (9.3) & 413 & (13.0) & 16 & (9.6) & 293 & (9.1) & 318 & (6.6) & 359 & (6.1) & 473 & (20.4) & 545 & $(22.2)$ & 578 & (20.9) \\
\hline & Federal District & 424 & (10.0) & 86 & (7.2) & 432 & (12.1) & 417 & (9.0) & 16 & (7.0) & 283 & (12.5) & 312 & $(15.0)$ & 365 & (15.0) & 482 & (12.2) & 540 & (14.9) & 563 & (15.7) \\
\hline & Goiás & 385 & (4.4) & 69 & $(2.7)$ & 394 & (5.7) & 376 & (5.0) & 17 & (6.1) & 279 & (9.2) & 300 & (7.7) & 338 & (5.7) & 426 & (5.5) & 475 & (6.8) & 511 & (11.3) \\
\hline & Maranhão & 351 & (14.9) & 87 & (7.4) & 359 & (17.1) & 345 & (13.8) & 14 & (6.8) & 217 & (12.3) & 245 & (9.0) & 288 & (13.1) & 409 & $(20.2)$ & 463 & (29.4) & 504 & (30.5) \\
\hline & Mato Grosso & 378 & (9.5) & 77 & (5.4) & 375 & (9.6) & 380 & (10.6) & -5 & (7.1) & 259 & (10.1) & 282 & (9.4) & 326 & (8.8) & 425 & (12.6) & 478 & (17.9) & 515 & (25.0) \\
\hline & Mato Grosso do Sul & 418 & (8.2) & 75 & (4.3) & 428 & (9.8) & 409 & (7.8) & 18 & (7.2) & 300 & (10.3) & 322 & $(10.2)$ & 365 & (7.6) & 469 & (9.4) & 522 & (18.0) & 546 & (15.6) \\
\hline & Minas Gerais & 410 & (7.3) & 75 & (4.4) & 414 & (9.3) & 406 & (6.5) & 9 & (6.3) & 287 & (11.3) & 315 & (9.7) & 360 & (8.0) & 458 & (9.4) & 504 & $(11.7)$ & 536 & (15.8) \\
\hline & Pará & 368 & (6.3) & 73 & (3.1) & 372 & (5.9) & 365 & (8.2) & 7 & (7.3) & 250 & (12.8) & 276 & (11.6) & 316 & (8.5) & 422 & (7.4) & 463 & (6.5) & 490 & (8.4) \\
\hline & Paraíba & 404 & (8.8) & 83 & (7.5) & 410 & (9.6) & 398 & $(10.2)$ & 12 & (8.9) & 271 & (26.1) & 301 & (15.4) & 348 & (12.5) & 458 & $(10.3)$ & 509 & (13.7) & 540 & (15.2) \\
\hline & Paraná & 408 & (11.4) & 83 & $(9.0)$ & 416 & (12.3) & 400 & (11.4) & 16 & (6.2) & 285 & (8.5) & 306 & $(11.7)$ & 349 & (9.0) & 460 & (16.2) & 523 & $(28.3)$ & 560 & (33.9) \\
\hline & Pernambuco & 370 & (7.9) & 73 & (5.5) & 381 & (8.9) & 361 & (7.8) & 19 & (5.0) & 258 & (10.5) & 278 & $(11.3)$ & 321 & (11.7) & 417 & (7.1) & 459 & (11.3) & 493 & (15.4) \\
\hline & Piauí & 388 & (8.2) & 79 & (6.1) & 394 & (8.7) & 383 & (8.3) & 11 & (4.0) & 273 & (7.1) & 294 & (9.4) & 332 & (6.6) & 436 & (10.8) & 495 & (20.9) & 533 & (23.5) \\
\hline & Rio de Janeiro & 404 & (7.3) & 71 & (4.5) & 409 & (8.6) & 399 & (7.4) & 9 & (6.4) & 292 & (13.3) & 315 & $(8.2)$ & 354 & (9.1) & 452 & (8.9) & 495 & (11.0) & 522 & (14.7) \\
\hline & Rio Grande do Norte & 395 & (8.4) & 85 & (7.4) & 406 & $(10.0)$ & 386 & (8.4) & 21 & (7.3) & 275 & (10.2) & 299 & (7.3) & 336 & (5.6) & 442 & (13.5) & 509 & (20.5) & 556 & $(32.7)$ \\
\hline & nde do Sul & 422 & (6.0) & 70 & (3.1) & 428 & (6.5) & 417 & (7.0) & 11 & (5.8) & 310 & (9.6) & 335 & $(11.2)$ & 374 & (7.7) & 472 & (7.5) & 515 & (6.9) & 535 & $(10.2)$ \\
\hline & Rondônia & 394 & (6.6) & 70 & (4.0) & 398 & (6.7) & 391 & (7.6) & 7 & (5.6) & 276 & (16.0) & 305 & (9.9) & 348 & $(9.2)$ & 440 & (7.6) & 482 & (10.3) & 509 & (9.7) \\
\hline & Roraima & 371 & (6.7) & 76 & (4.1) & 372 & (8.3) & 369 & (8.6) & 3 & (10.1) & 253 & (10.4) & 277 & (9.0) & 319 & (7.4) & 418 & (9.9) & 476 & (16.4) & 508 & (15.4) \\
\hline & Santa Catarina & 419 & (8.1) & 80 & (4.6) & 423 & (7.5) & 415 & $(10.2)$ & 8 & (7.7) & 285 & (21.3) & 317 & (14.1) & 366 & (11.4) & 474 & (10.0) & 523 & (9.4) & 549 & (8.1) \\
\hline & São Paulo & 416 & $(4.2)$ & 81 & $(2.4)$ & 421 & (4.5) & 411 & $(4.8)$ & 10 & (3.9) & 288 & (5.5) & 315 & (5.2) & 360 & (4.1) & 469 & (5.9) & 522 & (8.8) & 553 & (8.8) \\
\hline & Sergipe & 389 & (10.0) & 77 & (5.7) & 401 & (14.1) & 380 & (8.5) & 22 & (10.4) & 274 & (10.8) & 297 & (8.2) & 333 & (9.8) & 436 & (15.6) & 495 & (20.3) & 527 & (20.8) \\
\hline & Tocantins & 374 & (7.9) & 79 & (4.5) & 383 & (9.6) & 365 & (7.1) & 17 & (6.7) & 246 & (11.0) & 274 & (9.0) & 322 & (7.3) & 423 & $(10.1)$ & 479 & (15.0) & 515 & (17.7) \\
\hline \multicolumn{24}{|c|}{ Colombia } \\
\hline & Bogotá & 405 & (3.4) & 70 & $(2.3)$ & 420 & (5.1) & 391 & (3.4) & 29 & (5.3) & 289 & (5.6) & 315 & $(4.0)$ & 359 & (3.6) & 450 & (3.8) & 494 & (6.6) & 520 & (8.8) \\
\hline & Cali & 392 & (5.9) & 76 & (2.9) & 400 & (6.4) & 385 & (6.3) & 15 & (4.2) & 268 & (8.6) & 295 & (7.5) & 341 & (6.1) & 442 & (7.0) & 488 & (9.3) & 519 & (9.5) \\
\hline & Manizales & 418 & (3.5) & 70 & (3.3) & 433 & (5.7) & 405 & (3.7) & 28 & (6.2) & 307 & (6.9) & 331 & (5.2) & 372 & (4.6) & 461 & (4.8) & 509 & (9.0) & 539 & (11.2) \\
\hline & Medellín & 409 & (7.4) & 85 & (5.9) & 421 & (8.8) & 398 & (8.7) & 23 & (9.4) & 284 & (8.2) & 308 & (6.4) & 350 & (5.5) & 460 & (9.1) & 522 & (15.4) & 562 & (21.8) \\
\hline \multicolumn{24}{|c|}{ Russian Federation } \\
\hline & Perm Territory region ${ }^{\bullet}$ & 472 & (5.6) & 93 & (4.5) & 471 & (6.6) & 473 & (5.4) & -2 & (4.8) & 321 & (9.4) & 359 & (7.7) & 412 & (6.2) & 533 & (6.5) & 589 & (10.7) & 624 & (14.4) \\
\hline \multicolumn{24}{|c|}{ United Arab Emirates } \\
\hline & Abu Dhabi ${ }^{\bullet}$ & 415 & (4.3) & 88 & (2.5) & 407 & (6.0) & 423 & (5.1) & -15 & (7.1) & 279 & (6.1) & 307 & (4.5) & 355 & (4.4) & 470 & (5.2) & 531 & (7.5) & 567 & (8.3) \\
\hline & Ajman & 396 & (8.2) & 75 & (4.5) & 382 & (11.7) & 409 & (11.3) & -27 & (16.4) & 268 & (18.1) & 297 & (16.1) & 346 & (11.8) & 450 & (7.6) & 495 & (8.6) & 520 & (9.0) \\
\hline & Dubai ${ }^{\bullet}$ & 460 & (1.3) & 95 & (1.0) & 464 & (1.9) & 456 & (1.7) & 8 & (2.4) & 304 & (2.3) & 337 & (2.3) & 393 & (2.1) & 527 & (2.8) & 584 & (3.4) & 619 & (3.2) \\
\hline & Fujairah & 398 & (8.8) & 82 & (3.4) & 379 & (9.1) & 417 & (8.1) & -38 & (10.1) & 259 & (16.9) & 292 & (14.2) & 341 & (11.6) & 454 & (8.3) & 504 & (9.2) & 533 & (10.6) \\
\hline & Ras al-Khaimah & 405 & (7.2) & 79 & (3.4) & 391 & (9.3) & 418 & (10.8) & -28 & (13.8) & 277 & (11.8) & 304 & (11.1) & 351 & (10.5) & 460 & (8.2) & 508 & (6.4) & 535 & (10.0) \\
\hline & Sharjah & 433 & (8.8) & 84 & (3.9) & 438 & (17.3) & 428 & (10.5) & 11 & $(22.7)$ & 302 & (8.7) & 329 & (7.9) & 374 & (9.1) & 491 & (10.5) & 541 & (11.0) & 573 & (16.2) \\
\hline & Umm al-Quwain & 391 & (3.9) & 74 & (3.5) & 369 & (5.0) & 411 & (5.5) & -42 & (6.9) & 270 & (8.4) & 296 & (8.9) & 339 & (6.8) & 439 & $(7.2)$ & 483 & (9.8) & 517 & (14.3) \\
\hline
\end{tabular}

- PISA adjudicated region.

Notes: Values that are statistically significant are indicated in bold (see Annex A3).

See Table 1.2.13 for national data.

StatLink 部 SL http://dx.doi.org/10.1787/888932935762 
Percentage of students at each proficiency level on the mathematics subscale Table B2.I.13 change and relationships, by region

\begin{tabular}{|c|c|c|c|c|c|c|c|c|c|c|c|c|c|c|c|}
\hline & & \multicolumn{14}{|c|}{ All students } \\
\hline & & \multicolumn{2}{|c|}{$\begin{array}{c}\text { Below Level } 1 \\
\text { (below 357.77 } \\
\text { score points) }\end{array}$} & $\begin{array}{r}\text { L } \\
\text { (from } \\
\text { less th } \\
\text { scor }\end{array}$ & $\begin{array}{l}1 \\
7.77 \text { to } \\
420.07 \\
\text { oints) }\end{array}$ & $\begin{array}{r}\mathrm{L} \\
\text { (from } \\
\text { less th } \\
\text { scor }\end{array}$ & $\begin{array}{l}l 2 \\
0.07 \text { to } \\
482.38 \\
\text { oints) }\end{array}$ & $\begin{array}{l}\text { Le } \\
\text { (from } \\
\text { less th } \\
\text { scor }\end{array}$ & \begin{tabular}{|l|}
3 \\
2.38 to \\
544.68 \\
oints)
\end{tabular} & $\begin{array}{l}\text { L } \\
\text { (from } \\
\text { less th } \\
\text { scor }\end{array}$ & $\begin{array}{l}l 4 \\
4.68 \text { to } \\
606.99 \\
\text { oints) }\end{array}$ & $\begin{array}{l}\mathrm{L} \\
\text { (from } \\
\text { less th } \\
\text { scor }\end{array}$ & $\begin{array}{l}5 \\
6.99 \text { to } \\
669.30 \\
\text { oints) }\end{array}$ & $\begin{array}{r}\mathrm{L} \\
\text { (abo } \\
\text { scor }\end{array}$ & $\begin{array}{l}16 \\
669.30 \\
\text { oints) }\end{array}$ \\
\hline & & $\%$ & S.E. & $\%$ & S.E. & $\%$ & S.E. & $\%$ & S.E. & $\%$ & S.E. & $\%$ & S.E. & $\%$ & S.E. \\
\hline$a$ & Australia & & & & & & & & & & & & & & \\
\hline U & Australian Capital Territory & 5.9 & $(1.1)$ & 10.5 & (1.5) & 18.2 & (1.8) & 23.8 & $(2.1)$ & 20.9 & (1.7) & 14.4 & (1.8) & 6.3 & (1.5) \\
\hline & New South Wales & 7.2 & $(0.8)$ & 12.6 & $(0.9)$ & 19.5 & $(1.0)$ & 22.1 & $(1.1)$ & 18.7 & (1.1) & 12.1 & $(0.8)$ & 7.8 & (1.1) \\
\hline & Northern Territory & 18.8 & (1.9) & 16.6 & $(2.9)$ & 21.0 & $(3.2)$ & 21.7 & (3.3) & 12.7 & $(2.7)$ & 6.1 & (2.4) & 3.1 & (1.4) \\
\hline & Queensland & 6.7 & $(0.7)$ & 13.1 & $(0.8)$ & 20.9 & $(0.9)$ & 22.8 & $(1.2)$ & 18.8 & $(0.9)$ & 11.7 & $(0.9)$ & 6.0 & $(0.6)$ \\
\hline & South Australia & 9.5 & $(1.0)$ & 15.1 & $(1.2)$ & 21.2 & (1.6) & 22.8 & (1.4) & 17.6 & (1.4) & 9.4 & (1.1) & 4.3 & $(0.8)$ \\
\hline & Tasmania & 12.4 & $(1.2)$ & 15.9 & $(1.8)$ & 21.9 & (1.8) & 21.8 & $(1.8)$ & 16.0 & (1.4) & 8.6 & $(1.1)$ & 3.5 & $(0.8)$ \\
\hline & Victoria & 6.6 & $(0.7)$ & 12.5 & $(1.2)$ & 21.1 & $(1.2)$ & 24.7 & $(1.2)$ & 19.5 & (1.3) & 11.0 & $(1.0)$ & 4.5 & $(0.7)$ \\
\hline & Western Australia & 6.4 & $(0.8)$ & 11.7 & (1.1) & 19.0 & $(1.2)$ & 21.1 & (1.4) & 19.6 & (1.5) & 14.5 & (1.3) & 7.8 & (1.0) \\
\hline & Belgium & & & & & & & & & & & & & & \\
\hline & Flemish Community• & 7.2 & $(0.9)$ & 8.9 & $(0.6)$ & 15.1 & $(0.8)$ & 20.1 & $(0.8)$ & 21.7 & $(0.9)$ & 17.5 & $(0.8)$ & 9.5 & $(0.7)$ \\
\hline & French Community & 12.5 & $(1.2)$ & 12.0 & $(0.8)$ & 18.7 & $(0.9)$ & 22.4 & $(1.2)$ & 20.0 & $(1.0)$ & 10.7 & $(0.8)$ & 3.7 & $(0.5)$ \\
\hline & German-speaking Community & 7.1 & $(0.9)$ & 10.6 & (1.1) & 17.2 & (1.6) & 26.4 & (2.6) & 23.0 & (1.8) & 11.7 & (1.3) & 4.0 & $(1.0)$ \\
\hline & Canada & & & & & & & & & & & & & & \\
\hline & Alberta & 4.5 & $(0.9)$ & 9.4 & $(0.9)$ & 18.5 & (1.6) & 23.8 & (1.6) & 22.7 & $(1.1)$ & 14.7 & (1.3) & 6.5 & $(0.9)$ \\
\hline & British Columbia & 2.8 & $(0.5)$ & 8.3 & $(1.0)$ & 19.2 & (1.3) & 26.4 & (1.6) & 22.3 & (1.5) & 14.4 & (1.5) & 6.6 & $(1.0)$ \\
\hline & Manitoba & 6.6 & $(0.9)$ & 15.3 & $(1.6)$ & 21.8 & (1.5) & 23.9 & (1.3) & 19.6 & (1.1) & 9.4 & (1.0) & 3.3 & $(0.5)$ \\
\hline & New Brunswick & 5.2 & $(0.8)$ & 11.9 & $(1.0)$ & 22.5 & (1.8) & 28.3 & (1.9) & 19.7 & (1.6) & 9.3 & $(1.2)$ & 3.3 & $(0.8)$ \\
\hline & Newfoundland and Labrador & 6.5 & $(1.1)$ & 13.4 & (1.5) & 22.9 & (1.9) & 26.1 & $(2.1)$ & 17.9 & $(1.7)$ & 9.9 & (1.2) & 3.5 & $(0.8)$ \\
\hline & Nova Scotia & 5.9 & $(0.9)$ & 13.7 & (1.9) & 23.8 & $(2.1)$ & 25.1 & (1.7) & 20.4 & (1.8) & 8.3 & $(1.3)$ & 2.8 & $(0.7)$ \\
\hline & Ontario & 3.8 & $(0.6)$ & 9.0 & $(1.1)$ & 19.1 & $(1.2)$ & 27.2 & $(1.2)$ & 22.0 & $(1.2)$ & 12.9 & $(1.0)$ & 6.1 & $(0.8)$ \\
\hline & Prince Edward Island & 6.3 & $(0.8)$ & 15.6 & $(1.3)$ & 24.3 & (1.6) & 26.8 & $(1.5)$ & 18.0 & $(1.1)$ & 7.4 & $(0.9)$ & 1.6 & $(0.5)$ \\
\hline & Quebec & 4.3 & $(0.6)$ & 8.5 & $(0.7)$ & 16.2 & $(1.1)$ & 23.4 & (1.3) & 23.1 & (1.1) & 16.7 & $(0.9)$ & 7.9 & $(0.8)$ \\
\hline & Saskatchewan & 4.2 & $(0.6)$ & 9.9 & $(1.2)$ & 22.0 & (1.8) & 26.3 & (1.6) & 21.5 & $(1.2)$ & 11.9 & $(1.0)$ & 4.1 & $(0.9)$ \\
\hline & Italy & & & & & & & & & & & & & & \\
\hline & Abruzzo & 12.7 & $(2.3)$ & 17.5 & $(1.8)$ & 24.7 & $(1.8)$ & 22.5 & (1.6) & 15.0 & (1.6) & 6.2 & (1.1) & 1.5 & $(0.5)$ \\
\hline & Basilicata & 13.6 & $(1.8)$ & 19.5 & (1.6) & 28.0 & (1.9) & 20.9 & (1.6) & 11.5 & (1.3) & 4.9 & $(0.6)$ & 1.5 & $(0.5)$ \\
\hline & Bolzano & 6.8 & $(0.7)$ & 12.0 & $(1.0)$ & 20.5 & (1.6) & 25.4 & (1.1) & 21.2 & $(1.0)$ & 10.1 & $(0.9)$ & 4.0 & $(0.6)$ \\
\hline & Calabria & 25.7 & $(2.4)$ & 24.1 & $(2.0)$ & 25.4 & (1.8) & 15.8 & $(1.2)$ & 6.3 & (1.1) & 2.2 & $(0.6)$ & 0.6 & $(0.2)$ \\
\hline & Campania & 19.3 & $(2.7)$ & 22.0 & $(2.0)$ & 25.9 & $(2.0)$ & 19.2 & (1.9) & 9.8 & (1.5) & 3.1 & $(0.8)$ & 0.8 & $(0.4)$ \\
\hline & Emilia Romagna & 10.8 & $(1.5)$ & 14.0 & $(1.5)$ & 20.6 & (1.7) & 22.8 & (1.8) & 19.0 & (1.8) & 9.6 & (1.3) & 3.3 & $(0.7)$ \\
\hline & Friuli Venezia Giulia & 5.4 & $(1.2)$ & 9.4 & $(1.3)$ & 19.5 & (1.5) & 26.6 & (1.9) & 22.8 & (1.9) & 11.5 & $(1.3)$ & 4.8 & $(0.6)$ \\
\hline & Lazio & 13.8 & $(1.7)$ & 19.3 & (1.8) & 25.0 & (1.4) & 21.8 & (1.6) & 13.1 & (1.6) & 5.6 & $(1.0)$ & 1.5 & $(0.5)$ \\
\hline & Liguria & 11.6 & $(1.7)$ & 17.9 & (1.9) & 24.2 & $(2.0)$ & 23.4 & (1.9) & 14.3 & (1.8) & 6.4 & $(1.2)$ & 2.2 & $(0.5)$ \\
\hline & Lombardia & 5.1 & $(1.0)$ & 10.6 & $(1.5)$ & 21.5 & $(2.1)$ & 25.9 & (1.9) & 22.5 & (2.0) & 11.1 & $(1.7)$ & 3.5 & (1.0) \\
\hline & Marche & 7.8 & (1.6) & 15.3 & $(2.2)$ & 23.9 & $(2.1)$ & 24.5 & (1.8) & 18.7 & (1.7) & 7.7 & $(1.0)$ & 2.1 & $(0.6)$ \\
\hline & Molise & 12.4 & $(1.1)$ & 20.0 & $(1.6)$ & 28.8 & (1.7) & 23.7 & $(1.7)$ & 10.5 & (1.8) & 3.7 & $(1.1)$ & 0.9 & $(0.5)$ \\
\hline & Piemonte & 6.9 & $(0.9)$ & 13.8 & $(1.6)$ & 22.0 & (1.9) & 27.3 & $(1.4)$ & 19.4 & (1.6) & 8.4 & $(1.2)$ & 2.3 & $(0.7)$ \\
\hline & Puglia & 11.8 & $(2.2)$ & 18.2 & $(2.1)$ & 24.5 & $(2.2)$ & 23.5 & $(2.0)$ & 15.2 & (1.7) & 5.6 & $(1.2)$ & 1.2 & $(0.5)$ \\
\hline & Sardegna & 18.2 & $(2.2)$ & 20.9 & (1.7) & 25.2 & (1.8) & 20.6 & (1.6) & 10.9 & (1.4) & 3.6 & $(0.7)$ & 0.5 & $(0.2)$ \\
\hline & Sicilia & 19.8 & $(2.1)$ & 22.7 & $(1.7)$ & 26.2 & (1.5) & 20.5 & (1.9) & 8.3 & (1.3) & 2.1 & $(0.4)$ & 0.5 & $(0.2)$ \\
\hline & Toscana & 10.1 & $(1.1)$ & 14.4 & $(1.5)$ & 21.9 & (1.6) & 24.8 & (1.9) & 18.0 & (1.4) & 8.7 & (1.3) & 2.2 & $(0.6)$ \\
\hline & Trento & 4.7 & (1.3) & 9.8 & $(1.2)$ & 20.2 & (1.9) & 28.2 & (2.0) & 21.3 & (1.8) & 11.8 & $(1.1)$ & 4.0 & $(0.7)$ \\
\hline & Umbria & 10.5 & $(2.5)$ & 14.2 & $(1.9)$ & 23.4 & (1.8) & 24.9 & $(2.3)$ & 17.4 & (1.9) & 8.0 & $(0.9)$ & 1.6 & $(0.4)$ \\
\hline & Valle d'Aosta & 6.5 & $(0.9)$ & 16.7 & (1.8) & 28.1 & (2.4) & 27.1 & $(1.7)$ & 13.1 & (1.5) & 6.8 & $(0.9)$ & 1.7 & $(0.5)$ \\
\hline & Veneto & 4.9 & (1.1) & 10.6 & $(1.2)$ & 18.7 & (1.7) & 25.4 & (1.9) & 21.2 & (1.6) & 13.0 & (1.9) & 6.2 & (1.4) \\
\hline & Mexico & & & & & & & & & & & & & & \\
\hline & Aguascalientes & 19.8 & $(2.3)$ & 26.1 & $(2.1)$ & 26.8 & (2.6) & 17.9 & (1.7) & 6.8 & (1.3) & 2.5 & $(0.7)$ & 0.1 & C \\
\hline & Baja California & 28.2 & $(2.6)$ & 29.8 & $(2.7)$ & 23.3 & (2.5) & 13.1 & (1.6) & 4.6 & $(1.0)$ & 0.8 & $(0.3)$ & 0.1 & C \\
\hline & Baja California Sur & 31.2 & (3.3) & 28.3 & $(1.7)$ & 23.3 & $(2.4)$ & 11.9 & (1.5) & 4.5 & (1.0) & 0.7 & $(0.5)$ & 0.1 & C \\
\hline & Campeche & 40.7 & $(2.4)$ & 26.9 & (1.9) & 20.6 & (1.6) & 8.8 & $(1.1)$ & 2.4 & $(0.6)$ & 0.5 & $(0.4)$ & 0.1 & c \\
\hline & Chiapas & 48.1 & $(4.5)$ & 27.6 & $(2.2)$ & 16.4 & (2.3) & 5.8 & $(1.1)$ & 1.6 & $(0.5)$ & 0.4 & $(0.3)$ & 0.0 & C \\
\hline & Chihuahua & 21.9 & (3.5) & 26.0 & $(2.2)$ & 26.5 & (1.7) & 16.4 & $(2.3)$ & 7.2 & (1.7) & 1.9 & $(0.7)$ & 0.1 & $(0.1)$ \\
\hline & Coahuila & 28.7 & $(3.4)$ & 29.3 & $(2.9)$ & 23.3 & $(2.2)$ & 12.6 & $(2.4)$ & 5.0 & (1.6) & 0.9 & $(0.5)$ & 0.0 & C \\
\hline & Colima & 25.0 & $(2.5)$ & 25.0 & (1.9) & 24.8 & (2.0) & 15.8 & (1.5) & 7.4 & (1.3) & 1.6 & $(0.5)$ & 0.4 & $(0.2)$ \\
\hline & Distrito Federal & 19.5 & $(3.7)$ & 28.6 & $(3.2)$ & 27.1 & (2.3) & 16.2 & $(2.0)$ & 6.6 & (1.3) & 1.7 & $(0.7)$ & 0.3 & $(0.3)$ \\
\hline & Durango & 24.0 & $(3.0)$ & 27.9 & (1.8) & 25.2 & $(2.0)$ & 15.3 & $(2.6)$ & 6.7 & (1.3) & 0.8 & $(0.4)$ & 0.1 & $(0.1)$ \\
\hline & Guanajuato & 30.0 & (4.1) & 27.3 & $(2.3)$ & 25.2 & (2.6) & 12.0 & (1.6) & 4.4 & $(0.7)$ & 0.9 & $(0.3)$ & 0.1 & c \\
\hline & Guerrero & 52.9 & $(2.9)$ & 28.1 & $(2.1)$ & 13.6 & (1.7) & 4.1 & $(0.9)$ & 1.1 & $(0.4)$ & 0.2 & $(0.1)$ & 0.0 & C \\
\hline & Hidalgo & 29.0 & (3.7) & 31.4 & $(2.8)$ & 23.6 & (2.4) & 12.4 & $(2.1)$ & 3.1 & (1.1) & 0.5 & $(0.4)$ & 0.0 & c \\
\hline & Jalisco & 19.2 & $(3.7)$ & 26.2 & $(2.1)$ & 28.5 & (2.6) & 17.7 & $(2.3)$ & 6.5 & (1.0) & 1.6 & $(0.7)$ & 0.3 & $(0.3)$ \\
\hline & Mexico & 25.8 & (3.5) & 29.7 & $(2.6)$ & 27.9 & (2.4) & 13.0 & $(1.7)$ & 2.8 & $(0.8)$ & 0.8 & $(0.5)$ & 0.1 & $(0.1)$ \\
\hline & Morelos & 25.1 & (3.7) & 27.7 & $(2.6)$ & 26.0 & (2.4) & 14.0 & $(2.2)$ & 5.1 & (1.5) & 1.8 & $(1.0)$ & 0.4 & $(0.3)$ \\
\hline & Nayarit & 30.2 & $(2.9)$ & 27.1 & $(2.0)$ & 24.8 & (2.3) & 12.3 & (1.8) & 4.6 & $(1.2)$ & 0.8 & $(0.4)$ & 0.0 & c \\
\hline & Nuevo León & 19.2 & (3.1) & 25.9 & $(2.4)$ & 27.3 & (2.3) & 17.9 & $(3.2)$ & 7.6 & (1.8) & 2.0 & $(0.8)$ & 0.2 & $(0.2)$ \\
\hline & Puebla & 26.9 & (2.9) & 28.1 & $(2.2)$ & 24.9 & (1.8) & 13.9 & $(1.9)$ & 5.4 & (1.2) & 0.6 & $(0.4)$ & 0.2 & C \\
\hline & Querétaro & 19.1 & (3.1) & 28.2 & (3.5) & 27.2 & (3.1) & 16.2 & $(2.2)$ & 7.1 & (1.4) & 2.0 & $(0.6)$ & 0.2 & $(0.2)$ \\
\hline & Quintana Roo & 31.0 & $(2.6)$ & 26.8 & $(2.2)$ & 24.2 & (2.0) & 13.0 & $(1.6)$ & 4.2 & $(1.2)$ & 0.7 & $(0.3)$ & 0.1 & C \\
\hline & San Luis Potosí & 32.5 & (3.8) & 26.1 & $(1.7)$ & 23.5 & $(2.0)$ & 12.1 & $(1.7)$ & 4.6 & (1.3) & 1.0 & $(0.5)$ & 0.1 & $(0.1)$ \\
\hline & Sinaloa & 30.7 & $(2.5)$ & 29.1 & $(1.7)$ & 24.1 & $(2.1)$ & 12.2 & $(1.8)$ & 3.3 & (0.6) & 0.6 & $(0.3)$ & 0.1 & C \\
\hline & Tabasco & 46.0 & $(3.1)$ & 28.3 & $(2.3)$ & 17.0 & (2.0) & 6.4 & $(1.0)$ & 2.0 & $(0.5)$ & 0.3 & $(0.3)$ & 0.0 & C \\
\hline & Tamaulipas & 32.6 & (3.9) & 27.1 & $(2.1)$ & 23.8 & (2.4) & 10.7 & $(2.3)$ & 4.9 & (1.3) & 0.9 & $(0.5)$ & 0.1 & C \\
\hline & Tlaxcala & 29.8 & (3.0) & 30.2 & $(1.7)$ & 23.6 & (1.7) & 12.0 & $(1.3)$ & 3.6 & (0.8) & 0.7 & $(0.5)$ & 0.0 & C \\
\hline & Veracruz & 40.2 & $(3.0)$ & 26.8 & $(1.8)$ & 18.3 & (1.7) & 10.3 & (1.5) & 3.6 & $(0.9)$ & 0.8 & $(0.4)$ & 0.0 & C \\
\hline & Yucatán & 36.6 & $(2.6)$ & 25.1 & $(2.4)$ & 22.0 & $(2.0)$ & 11.1 & (1.4) & 3.8 & $(0.9)$ & 1.1 & $(0.4)$ & 0.2 & $(0.2)$ \\
\hline & Zacatecas & 31.6 & $(2.3)$ & 28.3 & (1.6) & 23.7 & $(2.0)$ & 12.2 & $(1.5)$ & 3.5 & $(1.0)$ & 0.5 & $(0.3)$ & 0.1 & c \\
\hline
\end{tabular}

- PISA adjudicated region.

Note: See Table I.2.14 for national data.

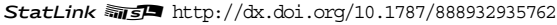


art 2/2]

Percentage of students at each proficiency level on the mathematics subscale Table B2.I.13 change and relationships, by region

\begin{tabular}{|c|c|c|c|c|c|c|c|c|c|c|c|c|c|c|c|}
\hline & & \multicolumn{14}{|c|}{ All students } \\
\hline & & \multicolumn{2}{|c|}{$\begin{array}{l}\text { Below Level } 1 \\
\text { (below 357.77 } \\
\text { score points) }\end{array}$} & \multicolumn{2}{|c|}{$\begin{array}{c}\text { Level } 1 \\
\text { (from } 357.77 \text { to } \\
\text { less than } 420.07 \\
\text { score points) }\end{array}$} & \multicolumn{2}{|c|}{$\begin{array}{c}\text { Level } 2 \\
\text { (from } 420.07 \text { to } \\
\text { less than } 482.38 \\
\text { score points) }\end{array}$} & $\begin{array}{l}\mathrm{L} \\
\text { (from } \\
\text { less th } \\
\text { scor }\end{array}$ & \begin{tabular}{|l|} 
I 3 \\
2.38 to \\
544.68 \\
oints)
\end{tabular} & $\begin{array}{r}\text { Le } \\
\text { (from } \\
\text { less th } \\
\text { score }\end{array}$ & \begin{tabular}{|l|}
4 \\
4.68 to \\
606.99 \\
oints)
\end{tabular} & $\begin{array}{l}\mathrm{L} \\
\text { (from } \\
\text { less th } \\
\text { scor }\end{array}$ & $\begin{array}{l}5 \\
6.99 \text { to } \\
669.30 \\
\text { oints) }\end{array}$ & $\begin{array}{l}\text { Le } \\
\text { (abov } \\
\text { scor }\end{array}$ & $\begin{array}{l}16 \\
669.30 \\
\text { oints) }\end{array}$ \\
\hline & & $\%$ & S.E. & $\%$ & S.E. & $\%$ & S.E. & $\%$ & S.E. & $\%$ & S.E. & $\%$ & S.E. & $\%$ & S.E. \\
\hline 0 & Portugal & & & & & & & & & & & & & & \\
\hline 氙 & Alentejo & 9.6 & (2.4) & 14.8 & (2.8) & 24.0 & (3.1) & 23.9 & (2.4) & 16.7 & (2.3) & 8.7 & (1.7) & 2.3 & $(1.0)$ \\
\hline & Spain & & & & & & & & & & & & & & \\
\hline & Andalusia ${ }^{\bullet}$ & 9.5 & (1.1) & 19.3 & (1.4) & 27.1 & (1.5) & 23.6 & (1.6) & 14.6 & (1.5) & 4.8 & $(0.7)$ & 1.1 & $(0.4)$ \\
\hline & Aragon $\bullet$ & 9.9 & (1.5) & 12.9 & (1.3) & 20.8 & (1.5) & 24.8 & (1.5) & 19.6 & (1.5) & 9.8 & $(1.2)$ & 2.2 & $(0.6)$ \\
\hline & Asturias ${ }^{\bullet}$ & 7.9 & (1.1) & 12.1 & (1.0) & 22.5 & $(1.3)$ & 25.1 & (1.1) & 19.8 & (1.3) & 9.5 & (1.0) & 3.2 & $(0.9)$ \\
\hline & Balearic Islands ${ }^{\bullet}$ & 11.7 & (1.6) & 18.5 & (1.6) & 22.1 & $(1.2)$ & 24.3 & (1.6) & 16.5 & (1.4) & 6.1 & $(0.7)$ & 0.7 & $(0.2)$ \\
\hline & Basque Country ${ }^{\bullet}$ & 5.0 & $(0.5)$ & 11.5 & $(0.7)$ & 21.9 & $(0.9)$ & 28.0 & (1.0) & 21.7 & $(0.9)$ & 9.7 & $(0.6)$ & 2.3 & $(0.3)$ \\
\hline & Cantabria ${ }^{\bullet}$ & 9.6 & $(1.1)$ & 14.8 & (1.4) & 23.7 & $(1.5)$ & 23.6 & (1.2) & 17.4 & (1.4) & 9.0 & (1.0) & 1.9 & $(0.4)$ \\
\hline & Castile and Leon ${ }^{\bullet}$ & 4.0 & $(0.7)$ & 11.4 & $(1.2)$ & 22.5 & (1.4) & 27.7 & (1.4) & 23.3 & (1.7) & 9.3 & (1.1) & 1.8 & $(0.4)$ \\
\hline & Catalonia ${ }^{\bullet}$ & 9.0 & (1.5) & 14.7 & (1.6) & 22.7 & $(1.5)$ & 25.1 & (1.7) & 18.2 & (1.5) & 8.0 & (1.2) & 2.4 & $(0.5)$ \\
\hline & Extremadura ${ }^{\bullet}$ & 16.4 & (1.6) & 17.7 & (1.3) & 23.2 & $(1.3)$ & 21.8 & (1.2) & 14.0 & $(1.2)$ & 5.5 & (1.0) & 1.4 & $(0.4)$ \\
\hline & Galicia• & 8.2 & (1.2) & 14.3 & (1.7) & 23.9 & $(1.5)$ & 28.2 & (1.6) & 17.9 & (1.3) & 6.2 & $(0.9)$ & 1.3 & $(0.4)$ \\
\hline & La Rioja’ & 9.7 & $(0.9)$ & 12.8 & (1.0) & 19.4 & (1.4) & 23.5 & (1.2) & 19.7 & (1.4) & 11.2 & (1.3) & 3.6 & $(0.5)$ \\
\hline & Madrid ${ }^{\bullet}$ & 7.0 & (1.4) & 12.6 & $(1.2)$ & 21.0 & $(1.3)$ & 25.4 & (1.3) & 22.5 & (1.5) & 9.5 & $(0.8)$ & 2.0 & $(0.4)$ \\
\hline & Murcia $\bullet$ & 14.8 & $(1.2)$ & 19.4 & (1.5) & 25.8 & $(1.6)$ & 21.0 & (1.5) & 13.0 & $(1.0)$ & 4.7 & (1.0) & 1.3 & $(0.5)$ \\
\hline & Navarre ${ }^{\bullet}$ & 3.2 & $(0.5)$ & 10.2 & (1.0) & 19.5 & (1.8) & 26.5 & (1.7) & 25.7 & $(1.2)$ & 12.1 & (1.1) & 2.8 & $(0.7)$ \\
\hline & United Kingdom & & & & & & & & & & & & & & \\
\hline & England & 8.4 & (1.0) & 13.5 & (0.9) & 21.9 & $(0.8)$ & 23.8 & (0.9) & 17.9 & (0.9) & 10.3 & (0.9) & 4.1 & $(0.5)$ \\
\hline & Northern Ireland & 10.0 & (1.3) & 16.2 & $(1.2)$ & 22.3 & (1.1) & 23.0 & (1.3) & 17.2 & (1.4) & 8.1 & $(0.9)$ & 3.2 & $(0.5)$ \\
\hline & Scotland ${ }^{\bullet}$ & 6.5 & (0.8) & 14.0 & $(0.8)$ & 23.7 & $(1.1)$ & 25.2 & (1.3) & 18.3 & $(0.9)$ & 9.2 & $(0.8)$ & 3.1 & $(0.5)$ \\
\hline & Wales & 10.8 & (0.9) & 18.3 & (0.9) & 26.1 & (1.0) & 24.3 & (0.9) & 14.5 & (0.8) & 5.1 & (0.5) & 1.1 & $(0.2)$ \\
\hline & United States & & & & & & & & & & & & & & \\
\hline & Connecticut $^{\bullet}$ & 7.0 & (1.3) & 12.5 & (1.4) & 19.7 & (1.5) & 22.3 & (1.4) & 18.2 & (1.3) & 12.8 & (1.4) & 7.6 & (1.1) \\
\hline & Florida & 9.1 & (1.3) & 18.8 & (1.5) & 26.3 & (1.5) & 23.4 & (1.3) & 14.2 & (1.5) & 6.3 & (1.2) & 2.0 & $(0.7)$ \\
\hline & Massachusetts ${ }^{\bullet}$ & 6.2 & (0.9) & 11.9 & (1.1) & 19.4 & (1.6) & 22.0 & (1.4) & 20.1 & (1.3) & 12.5 & (1.3) & 8.0 & (1.4) \\
\hline$n$ & Argentina & & & & & & & & & & & & & & \\
\hline 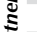 & Ciudad Autónoma de Buenos Aires ${ }^{\bullet}$ & 29.1 & (3.0) & 21.4 & (1.8) & 24.0 & $(2.0)$ & 16.2 & (1.6) & 7.0 & (1.3) & 2.2 & $(0.9)$ & 0.2 & $(0.2)$ \\
\hline ปั & Brazil & & & & & & & & & & & & & & \\
\hline & Acre & 62.1 & (3.8) & 20.6 & $(2.1)$ & 11.9 & $(2.1)$ & 4.2 & $(1.2)$ & 0.8 & $(0.6)$ & 0.4 & $(0.4)$ & 0.1 & c \\
\hline & Alagoas & 73.3 & (3.5) & 15.5 & $(2.5)$ & 6.4 & $(1.6)$ & 3.3 & $(1.3)$ & 1.0 & $(0.7)$ & 0.4 & $(0.3)$ & 0.0 & c \\
\hline & Amapá & 65.5 & (5.3) & 21.6 & $(4.1)$ & 8.8 & $(2.1)$ & 2.9 & (1.3) & 1.0 & $(0.8)$ & 0.2 & C & 0.0 & c \\
\hline & Amazonas & 68.8 & (3.4) & 18.6 & (2.4) & 7.7 & $(1.7)$ & 3.2 & (1.0) & 1.4 & $(0.8)$ & 0.4 & $(0.4)$ & 0.0 & c \\
\hline & Bahia & 57.6 & (7.4) & 19.5 & $(4.0)$ & 12.9 & $(4.5)$ & 7.2 & (3.0) & 1.9 & $(0.8)$ & 0.7 & $(0.7)$ & 0.2 & $\mathrm{C}$ \\
\hline & Ceará & 53.3 & (4.8) & 23.3 & (2.6) & 13.5 & $(2.3)$ & 5.2 & (1.4) & 3.1 & $(1.3)$ & 1.3 & $(0.8)$ & 0.4 & $(0.4)$ \\
\hline & Espírito Santo & 39.0 & (3.6) & 23.9 & (3.1) & 16.7 & $(2.7)$ & 9.6 & (1.8) & 6.8 & $(2.2)$ & 3.3 & (1.3) & 0.7 & $(0.6)$ \\
\hline & Federal District & 37.8 & $(4.3)$ & 23.2 & (2.7) & 17.2 & $(2.9)$ & 13.1 & (2.2) & 6.4 & $(2.0)$ & 2.0 & $(0.7)$ & 0.3 & $(0.2)$ \\
\hline & Goiás & 53.4 & (3.7) & 23.6 & (2.4) & 14.0 & $(2.2)$ & 6.4 & (1.4) & 1.9 & $(0.7)$ & 0.7 & $(0.4)$ & 0.0 & C \\
\hline & Maranhão & 71.9 & (7.5) & 16.5 & $(2.8)$ & 6.8 & $(2.8)$ & 2.8 & (1.9) & 1.6 & $(1.3)$ & 0.6 & $(0.5)$ & 0.0 & $\mathrm{c}$ \\
\hline & Mato Grosso & 58.6 & (4.8) & 21.8 & (2.6) & 12.6 & $(2.4)$ & 3.9 & (1.5) & 2.0 & $(1.1)$ & 0.9 & $(0.7)$ & 0.2 & $(0.2)$ \\
\hline & Mato Grosso do Sul & 39.1 & $(5.0)$ & 26.7 & $(2.7)$ & 18.9 & $(3.0)$ & 7.7 & $(1.2)$ & 6.0 & $(1.6)$ & 1.5 & $(0.7)$ & 0.1 & C \\
\hline & Minas Gerais & 36.1 & (3.9) & 26.7 & (2.4) & 22.7 & $(3.5)$ & 10.2 & (2.4) & 3.4 & (1.4) & 0.8 & $(0.7)$ & 0.2 & $(0.1)$ \\
\hline & Pará & 62.5 & (3.8) & 19.0 & (3.2) & 13.9 & $(3.1)$ & 4.0 & (1.0) & 0.5 & $(0.5)$ & 0.1 & $\mathrm{C}$ & 0.0 & $\mathrm{C}$ \\
\hline & Paraiba & 44.8 & (5.0) & 24.3 & (3.4) & 16.8 & $(3.3)$ & 9.0 & (1.7) & 3.8 & $(1.5)$ & 0.9 & $(0.8)$ & 0.4 & $(0.3)$ \\
\hline & Paraná & 43.4 & $(4.4)$ & 24.4 & $(3.1)$ & 15.7 & $(2.0)$ & 9.0 & (1.5) & 4.9 & $(2.7)$ & 2.0 & (1.5) & 0.5 & $(0.5)$ \\
\hline & Pernambuco & 61.1 & (5.2) & 23.4 & $(3.7)$ & 10.3 & $(2.9)$ & 3.9 & (1.3) & 1.0 & $(0.6)$ & 0.3 & $(0.3)$ & 0.0 & C \\
\hline & Piauí & 53.3 & (3.9) & 21.0 & $(3.1)$ & 12.5 & $(2.7)$ & 7.9 & (1.7) & 3.5 & $(1.6)$ & 1.0 & $(0.9)$ & 0.8 & $(0.4)$ \\
\hline & Rio de Janeiro & 42.6 & $(4.2)$ & 27.5 & (3.3) & 18.4 & $(2.3)$ & 8.4 & (2.0) & 2.5 & $(0.6)$ & 0.4 & $(0.3)$ & 0.2 & $(0.2)$ \\
\hline & Rio Grande do Norte & 60.7 & $(4.1)$ & 17.8 & (2.3) & 9.8 & $(1.6)$ & 6.5 & (1.9) & 3.0 & $(1.2)$ & 1.7 & $(0.9)$ & 0.4 & $\mathrm{C}$ \\
\hline & Rio Grande do Sul & 34.9 & (3.0) & 27.4 & (2.3) & 22.6 & $(2.4)$ & 11.0 & (1.7) & 3.5 & $(1.0)$ & 0.6 & $(0.4)$ & 0.0 & c \\
\hline & Rondônia & 50.8 & (3.9) & 27.2 & (2.0) & 15.1 & $(2.0)$ & 5.3 & (1.2) & 1.5 & $(0.9)$ & 0.1 & c & 0.0 & $\mathrm{C}$ \\
\hline & Roraima & 62.2 & (3.3) & 20.2 & (2.0) & 10.7 & $(1.7)$ & 5.3 & (1.8) & 1.4 & $(0.6)$ & 0.1 & c & 0.0 & $\mathrm{C}$ \\
\hline & Santa Catarina & 34.0 & (4.9) & 27.5 & (2.8) & 20.1 & $(2.4)$ & 11.3 & (2.2) & 5.5 & (1.8) & 1.5 & $(0.8)$ & 0.1 & C \\
\hline & São Paulo & 40.7 & (2.4) & 24.6 & (1.3) & 17.9 & $(1.2)$ & 10.2 & (1.3) & 4.2 & $(0.9)$ & 1.7 & (0.6) & 0.7 & $(0.4)$ \\
\hline & Sergipe & 50.4 & (5.6) & 25.1 & (2.9) & 14.0 & $(2.3)$ & 7.0 & (2.5) & 2.8 & $(1.6)$ & 0.6 & $(0.5)$ & 0.1 & $\mathrm{C}$ \\
\hline & Tocantins & 62.2 & (4.4) & 20.6 & (2.4) & 9.4 & $(1.5)$ & 5.3 & (1.5) & 1.8 & $(0.8)$ & 0.4 & $(0.3)$ & 0.1 & C \\
\hline & Colombia & & & & & & & & & & & & & & \\
\hline & Bogotá & 41.3 & (2.3) & 29.7 & $(2.2)$ & 19.7 & $(1.6)$ & 7.0 & (1.1) & 1.8 & $(0.6)$ & 0.5 & $(0.3)$ & 0.1 & c \\
\hline & Cali & 50.6 & (3.6) & 25.8 & (2.0) & 15.9 & (1.9) & 6.0 & (1.4) & 1.5 & $(0.5)$ & 0.3 & $(0.2)$ & 0.0 & c \\
\hline & Manizales & 37.9 & (3.0) & 28.4 & (2.4) & 19.0 & $(2.3)$ & 9.2 & (1.3) & 3.9 & $(0.8)$ & 1.3 & $(0.7)$ & 0.2 & $(0.3)$ \\
\hline & Medellín & 46.0 & (4.1) & 24.3 & (2.1) & 15.7 & $(1.7)$ & 8.2 & (1.4) & 3.8 & $(1.2)$ & 1.3 & (0.6) & 0.6 & $(0.4)$ \\
\hline & Russian Federation & & & & & & & & & & & & & & \\
\hline & Perm Territory region & 7.3 & (1.3) & 13.4 & (1.6) & 24.4 & (1.5) & 26.9 & (1.6) & 17.2 & (1.4) & 7.6 & (0.9) & 3.2 & $(1.2)$ \\
\hline & United Arab Emirates & & & & & & & & & & & & & & \\
\hline & Abu Dhabi` & 22.4 & (1.6) & 25.7 & (1.3) & 24.6 & $(1.1)$ & 15.8 & (1.1) & 7.1 & $(0.8)$ & 3.6 & (0.6) & 0.8 & $(0.3)$ \\
\hline & Ajman & 25.1 & $(4.7)$ & 29.1 & (2.9) & 27.2 & $(2.7)$ & 15.0 & (2.2) & 3.0 & $(1.0)$ & 0.6 & $(0.4)$ & 0.0 & c \\
\hline & Dubai ${ }^{\bullet}$ & 13.9 & $(0.5)$ & 18.1 & $(0.6)$ & 22.6 & $(0.8)$ & 21.6 & $(1.0)$ & 14.7 & $(0.8)$ & 6.8 & $(0.6)$ & 2.4 & $(0.4)$ \\
\hline & Fujairah & 23.7 & (3.9) & 27.5 & (2.4) & 25.8 & $(2.7)$ & 15.4 & (2.5) & 5.8 & $(1.3)$ & 1.7 & $(0.7)$ & 0.1 & C \\
\hline & Ras al-Khaimah & 20.1 & (3.1) & 28.5 & $(2.2)$ & 28.0 & $(2.2)$ & 17.3 & (2.0) & 5.1 & $(1.4)$ & 1.0 & $(0.6)$ & 0.0 & c \\
\hline & Sharjah & 13.9 & (3.0) & 24.6 & (3.2) & 26.7 & $(1.9)$ & 20.8 & (2.9) & 10.2 & $(2.0)$ & 2.8 & (1.1) & 1.0 & $(0.8)$ \\
\hline & Umm al-Quwain & 25.2 & $(2.5)$ & 31.5 & (3.8) & 25.8 & $(3.7)$ & 12.0 & (2.5) & 4.3 & $(1.2)$ & 1.0 & $(0.8)$ & 0.1 & $\mathrm{C}$ \\
\hline
\end{tabular}

- PISA adjudicated region.

Note: See Table 1.2.14 for national data.

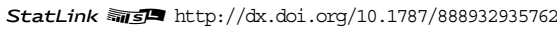


Percentage of students at each proficiency level on the mathematics subscale Table B2.I.14 change and relationships, by gender and region

\begin{tabular}{|c|c|c|c|c|c|c|c|c|c|c|c|c|c|c|c|}
\hline & & \multicolumn{14}{|c|}{ Boys } \\
\hline & & \multicolumn{2}{|c|}{$\begin{array}{c}\text { Below Level } 1 \\
\text { (below } 357.77 \\
\text { score points) }\end{array}$} & $\begin{array}{r}\text { L } \\
\text { (from } \\
\text { less th } \\
\text { scor }\end{array}$ & $\begin{array}{l}1 \\
7.77 \text { to } \\
420.07 \\
\text { oints) }\end{array}$ & $\begin{array}{l}\text { Le } \\
\text { (from } \\
\text { less th } \\
\text { scor }\end{array}$ & $\begin{array}{l}l 2 \\
0.07 \text { to } \\
482.38 \\
\text { oints) }\end{array}$ & $\begin{array}{l}\mathrm{L} \\
\text { (from } \\
\text { less th } \\
\text { scor }\end{array}$ & $\begin{array}{l}3 \\
2.38 \text { to } \\
544.68 \\
\text { oints) }\end{array}$ & $\begin{array}{l}\text { Le } \\
\text { (from } \\
\text { less th } \\
\text { scor }\end{array}$ & $\begin{array}{l}l 4 \\
4.68 \text { to } \\
606.99 \\
\text { oints) }\end{array}$ & $\begin{array}{l}\mathrm{L} \\
\text { (from } \\
\text { less th } \\
\text { scor }\end{array}$ & $\begin{array}{l}5 \\
6.99 \text { to } \\
669.30 \\
\text { oints) }\end{array}$ & $\begin{array}{r}\mathrm{L} \\
\text { (abo } \\
\text { scor }\end{array}$ & $\begin{array}{l}\text { l } 6 \\
669.30 \\
\text { oints) }\end{array}$ \\
\hline & & $\%$ & S.E. & $\%$ & S.E. & $\%$ & S.E. & $\%$ & S.E. & $\%$ & S.E. & $\%$ & S.E. & $\%$ & S.E. \\
\hline 0 & Australia & & & & & & & & & & & & & & \\
\hline 岙 & Australian Capital Territory & 6.8 & (1.5) & 10.6 & (1.6) & 18.3 & $(2.1)$ & 23.2 & (2.5) & 20.0 & $(2.3)$ & 14.6 & $(2.7)$ & 6.5 & $(2.1)$ \\
\hline & New South Wales & 7.9 & (1.0) & 12.5 & $(1.2)$ & 18.6 & (1.4) & 21.2 & (1.6) & 17.5 & (1.4) & 13.1 & (1.1) & 9.2 & (1.5) \\
\hline & Northern Territory & 18.1 & (2.3) & 16.1 & $(4.8)$ & 17.6 & (5.4) & 24.1 & $(4.3)$ & 13.5 & (3.7) & 6.3 & (3.4) & 4.3 & $(2.2)$ \\
\hline & Queensland & 6.3 & (1.0) & 12.2 & $(1.2)$ & 20.7 & (1.4) & 22.2 & (1.5) & 19.3 & (1.5) & 12.4 & (1.5) & 6.9 & $(1.0)$ \\
\hline & South Australia & 8.8 & (1.3) & 14.6 & (1.8) & 20.8 & $(2.1)$ & 21.9 & (1.9) & 18.0 & (1.5) & 10.6 & (1.5) & 5.3 & $(1.0)$ \\
\hline & Tasmania & 11.9 & (1.4) & 13.8 & (2.3) & 21.8 & $(2.5)$ & 22.4 & (3.2) & 16.3 & (1.8) & 9.6 & (1.7) & 4.2 & $(1.1)$ \\
\hline & Victoria & 6.3 & $(0.7)$ & 10.8 & (1.3) & 20.2 & $(2.0)$ & 24.1 & (1.7) & 20.3 & (1.8) & 12.1 & (1.4) & 6.0 & $(1.2)$ \\
\hline & Western Australia & 5.1 & (1.1) & 11.1 & (1.8) & 17.1 & (1.7) & 20.2 & $(2.2)$ & 21.5 & $(2.2)$ & 15.8 & (2.0) & 9.2 & (1.6) \\
\hline & Belgium & & & & & & & & & & & & & & \\
\hline & Flemish Community• & 7.3 & (1.6) & 8.4 & $(0.8)$ & 14.4 & $(1.0)$ & 18.6 & (1.3) & 21.3 & (1.3) & 18.1 & (1.1) & 11.8 & $(1.0)$ \\
\hline & French Community & 13.7 & (1.3) & 12.0 & (1.0) & 16.5 & (1.3) & 21.1 & (1.5) & 20.0 & (1.7) & 12.0 & $(1.2)$ & 4.7 & $(0.8)$ \\
\hline & German-speaking Community & 8.8 & (1.1) & 11.7 & (1.8) & 16.1 & (2.9) & 24.2 & $(4.0)$ & 21.2 & $(2.2)$ & 12.5 & (1.7) & 5.4 & $(1.7)$ \\
\hline & Canada & & & & & & & & & & & & & & \\
\hline & Alberta & 4.7 & (1.4) & 8.2 & (1.1) & 16.7 & (1.6) & 24.4 & $(2.1)$ & 22.2 & (1.5) & 15.6 & (1.7) & 8.2 & $(1.2)$ \\
\hline & British Columbia & 2.3 & $(0.7)$ & 7.5 & (1.3) & 17.8 & $(1.8)$ & 25.2 & (1.9) & 22.5 & $(2.0)$ & 16.9 & (1.9) & 7.8 & $(1.3)$ \\
\hline & Manitoba & 6.3 & (1.4) & 14.6 & $(2.2)$ & 20.0 & $(2.3)$ & 25.6 & $(2.2)$ & 19.1 & (1.9) & 10.3 & (1.4) & 4.0 & $(0.8)$ \\
\hline & New Brunswick & 5.6 & (1.1) & 12.5 & (1.8) & 20.6 & $(2.0)$ & 27.5 & (3.0) & 20.2 & (2.5) & 9.8 & (1.6) & 3.8 & $(1.0)$ \\
\hline & Newfoundland and Labrador & 7.2 & (1.8) & 13.5 & (2.4) & 22.1 & $(2.3)$ & 24.2 & (2.6) & 18.6 & $(2.1)$ & 10.0 & (1.6) & 4.4 & $(1.2)$ \\
\hline & Nova Scotia & 5.6 & (1.4) & 12.1 & (2.5) & 22.2 & $(2.3)$ & 23.8 & $(2.7)$ & 22.6 & $(2.2)$ & 10.6 & (1.8) & 3.2 & $(1.0)$ \\
\hline & Ontario & 3.5 & $(0.7)$ & 9.2 & (1.5) & 18.2 & (1.9) & 24.6 & (1.9) & 22.5 & (1.4) & 14.0 & (1.6) & 8.0 & $(1.3)$ \\
\hline & Prince Edward Island & 6.1 & $(1.2)$ & 16.1 & $(2.2)$ & 22.6 & $(2.8)$ & 26.2 & (2.5) & 18.3 & (1.5) & 8.6 & (1.3) & 2.1 & $(0.8)$ \\
\hline & Quebec & 3.7 & $(0.7)$ & 7.9 & $(0.9)$ & 14.9 & (1.4) & 22.1 & (1.4) & 22.8 & (1.3) & 18.6 & (1.3) & 10.0 & $(1.1)$ \\
\hline & Saskatchewan & 4.0 & $(0.8)$ & 9.6 & (1.5) & 20.6 & (2.5) & 25.2 & (3.0) & 22.0 & (1.9) & 13.4 & (2.0) & 5.3 & (1.4) \\
\hline & Italy & & & & & & & & & & & & & & \\
\hline & Abruzzo & 12.4 & (3.2) & 15.2 & (2.6) & 22.7 & $(2.3)$ & 22.5 & (2.3) & 17.3 & $(2.2)$ & 8.1 & (1.6) & 1.9 & $(0.6)$ \\
\hline & Basilicata & 12.3 & $(2.0)$ & 17.1 & $(2.7)$ & 26.7 & (2.4) & 21.0 & (1.9) & 14.2 & (1.9) & 6.7 & (1.1) & 2.0 & $(0.7)$ \\
\hline & Bolzano & 6.1 & $(0.8)$ & 10.7 & $(1.2)$ & 19.1 & $(2.3)$ & 23.3 & (1.6) & 22.4 & (1.7) & 12.2 & $(1.2)$ & 6.3 & $(0.9)$ \\
\hline & Calabria & 22.7 & (3.3) & 23.0 & (2.6) & 24.6 & $(2.6)$ & 17.6 & (1.6) & 7.7 & (1.6) & 3.4 & $(0.9)$ & 1.0 & $(0.5)$ \\
\hline & Campania & 18.2 & (3.0) & 20.9 & (2.1) & 24.6 & (2.5) & 19.5 & $(2.2)$ & 11.1 & (1.8) & 4.5 & (1.4) & 1.2 & $(0.7)$ \\
\hline & Emilia Romagna & 11.6 & (2.3) & 11.7 & (2.3) & 17.0 & (1.9) & 21.0 & $(2.2)$ & 22.0 & (2.8) & 12.1 & (1.9) & 4.7 & $(1.1)$ \\
\hline & Friuli Venezia Giulia & 5.1 & (1.3) & 8.4 & (1.8) & 17.0 & $(2.0)$ & 24.2 & (2.4) & 24.1 & $(2.1)$ & 14.2 & (1.9) & 7.0 & $(1.1)$ \\
\hline & Lazio & 12.7 & (1.5) & 17.7 & (2.4) & 22.4 & $(2.2)$ & 22.2 & $(2.0)$ & 15.7 & (1.9) & 7.2 & (1.3) & 2.2 & $(0.8)$ \\
\hline & Liguria & 10.6 & $(2.7)$ & 17.6 & (2.5) & 23.4 & $(2.3)$ & 22.6 & (2.4) & 14.9 & $(2.2)$ & 7.9 & (1.7) & 2.9 & $(0.9)$ \\
\hline & Lombardia & 5.3 & (1.4) & 9.5 & (1.8) & 18.8 & $(2.6)$ & 22.9 & (2.0) & 23.8 & (2.5) & 14.2 & (2.1) & 5.4 & $(1.3)$ \\
\hline & Marche & 5.1 & (1.8) & 13.7 & (3.1) & 22.4 & (2.6) & 23.8 & (2.0) & 22.3 & $(2.3)$ & 9.8 & (1.4) & 2.9 & $(1.0)$ \\
\hline & Molise & 11.5 & (1.3) & 17.5 & $(2.1)$ & 28.9 & $(2.7)$ & 24.1 & (2.3) & 12.3 & $(2.7)$ & 4.4 & (1.5) & 1.2 & $(0.7)$ \\
\hline & Piemonte & 5.4 & $(1.1)$ & 11.1 & (1.8) & 19.8 & (2.6) & 27.4 & (1.8) & 22.7 & (1.6) & 10.6 & (1.6) & 3.0 & $(0.9)$ \\
\hline & Puglia & 11.3 & $(2.3)$ & 14.8 & (2.3) & 21.3 & $(2.0)$ & 25.0 & (2.3) & 18.0 & (1.9) & 8.1 & (1.6) & 1.6 & $(0.7)$ \\
\hline & Sardegna & 18.2 & (2.3) & 19.3 & (2.1) & 24.5 & $(2.3)$ & 21.1 & (2.5) & 11.7 & (1.4) & 4.4 & (1.0) & 0.8 & $(0.4)$ \\
\hline & Sicilia & 19.8 & (2.4) & 20.3 & (2.1) & 24.8 & $(1.8)$ & 21.8 & (2.5) & 9.6 & (1.8) & 3.1 & $(0.8)$ & 0.6 & $(0.4)$ \\
\hline & Toscana & 11.3 & (1.9) & 14.8 & (1.9) & 20.1 & (1.7) & 23.7 & (2.6) & 17.6 & $(2.0)$ & 10.1 & (1.8) & 2.4 & $(0.8)$ \\
\hline & Trento & 4.7 & (1.6) & 10.1 & (1.4) & 18.9 & (2.4) & 25.7 & (2.4) & 20.8 & $(2.3)$ & 13.8 & (1.6) & 6.1 & $(1.0)$ \\
\hline & Umbria & 9.8 & (3.4) & 12.4 & (2.3) & 21.0 & (2.3) & 25.7 & (3.1) & 19.0 & (1.9) & 9.8 & (1.4) & 2.4 & $(0.8)$ \\
\hline & Valle d'Aosta & 6.8 & $(1.3)$ & 15.0 & $(2.2)$ & 25.4 & $(2.3)$ & 27.6 & (2.5) & 15.0 & $(2.0)$ & 8.2 & (1.7) & 2.0 & $(0.7)$ \\
\hline & Veneto & 4.9 & (1.3) & 10.1 & (1.6) & 15.6 & (1.9) & 21.7 & (2.5) & 22.2 & $(2.2)$ & 16.7 & (2.0) & 8.9 & $(1.8)$ \\
\hline & Mexico & & & & & & & & & & & & & & \\
\hline & Aguascalientes & 18.8 & (2.9) & 25.1 & (2.7) & 26.0 & $(3.7)$ & 18.2 & $(2.1)$ & 8.0 & $(1.7)$ & 3.8 & (1.3) & 0.2 & c \\
\hline & Baja California & 23.8 & (3.3) & 31.0 & (2.5) & 24.4 & (3.6) & 14.3 & (2.4) & 5.3 & $(1.2)$ & 1.2 & $(0.6)$ & 0.1 & c \\
\hline & Baja California Sur & 27.9 & (4.1) & 27.5 & (2.2) & 24.4 & (2.9) & 13.6 & (2.0) & 5.3 & (1.3) & 1.1 & (0.9) & 0.1 & c \\
\hline & Campeche & 38.2 & (2.6) & 25.9 & (2.8) & 23.3 & $(2.3)$ & 9.1 & (1.5) & 2.7 & $(0.8)$ & 0.7 & $(0.5)$ & 0.1 & c \\
\hline & Chiapas & 46.9 & (4.8) & 29.4 & $(2.8)$ & 15.5 & (2.9) & 6.0 & (1.6) & 1.6 & $(0.6)$ & 0.6 & $(0.4)$ & 0.1 & c \\
\hline & Chihuahua & 19.7 & (4.4) & 25.8 & (3.2) & 26.3 & (2.6) & 16.3 & (2.7) & 9.0 & $(2.3)$ & 2.7 & (1.4) & 0.1 & $(0.2)$ \\
\hline & Coahuila & 27.2 & $(4.0)$ & 27.3 & (3.3) & 23.4 & (2.6) & 14.5 & (2.6) & 6.3 & $(2.2)$ & 1.2 & $(0.7)$ & 0.1 & c \\
\hline & Colima & 23.8 & (3.0) & 24.2 & (2.5) & 24.5 & $(2.8)$ & 16.8 & $(2.1)$ & 8.0 & (1.8) & 2.0 & (1.0) & 0.7 & $(0.4)$ \\
\hline & Distrito Federal & 16.5 & $(4.2)$ & 26.0 & $(4.0)$ & 26.4 & $(2.7)$ & 19.0 & $(3.2)$ & 9.3 & (1.7) & 2.3 & (1.1) & 0.5 & $(0.5)$ \\
\hline & Durango & 23.2 & (3.7) & 25.3 & (2.8) & 26.9 & (2.6) & 15.0 & (3.2) & 8.5 & (2.3) & 0.9 & $(0.7)$ & 0.2 & $(0.2)$ \\
\hline & Guanajuato & 26.9 & $(4.1)$ & 26.4 & (3.1) & 25.8 & (3.3) & 13.6 & $(2.0)$ & 5.8 & $(1.0)$ & 1.4 & $(0.5)$ & 0.1 & C \\
\hline & Guerrero & 51.1 & (3.8) & 28.2 & (2.3) & 15.0 & (2.6) & 4.3 & (1.3) & 1.0 & $(0.6)$ & 0.3 & $(0.2)$ & 0.0 & c \\
\hline & Hidalgo & 27.5 & $(4.2)$ & 30.7 & (3.3) & 23.2 & (3.6) & 13.8 & (2.5) & 4.1 & (1.8) & 0.6 & $(0.7)$ & 0.0 & C \\
\hline & Jalisco & 19.6 & (4.6) & 23.8 & (2.4) & 28.4 & (3.3) & 18.4 & $(3.1)$ & 7.4 & (1.5) & 1.8 & $(1.0)$ & 0.6 & $(0.5)$ \\
\hline & Mexico & 23.1 & $(4.1)$ & 29.5 & (2.8) & 27.7 & $(2.8)$ & 15.2 & (2.3) & 3.1 & (1.1) & 1.1 & $(0.7)$ & 0.2 & $(0.3)$ \\
\hline & Morelos & 26.5 & (5.1) & 25.0 & (3.9) & 25.2 & (3.3) & 14.8 & $(2.7)$ & 6.3 & (1.7) & 1.8 & $(0.9)$ & 0.4 & $(0.4)$ \\
\hline & Nayarit & 29.7 & (2.9) & 25.6 & (3.0) & 24.8 & $(3.2)$ & 13.6 & $(2.2)$ & 5.1 & (1.4) & 1.2 & $(0.5)$ & 0.0 & c \\
\hline & Nuevo León & 16.8 & (3.3) & 24.1 & (3.1) & 27.7 & (4.6) & 19.0 & $(4.7)$ & 9.4 & (2.4) & 2.8 & $(1.2)$ & 0.3 & c \\
\hline & Puebla & 27.1 & $(4.1)$ & 26.5 & (3.3) & 24.3 & (3.0) & 14.5 & (2.3) & 6.5 & (1.6) & 1.2 & c & 0.0 & c \\
\hline & Querétaro & 18.4 & (3.2) & 26.2 & (3.7) & 26.5 & (3.9) & 18.6 & (3.1) & 7.5 & (1.7) & 2.6 & $(0.8)$ & 0.3 & $(0.3)$ \\
\hline & Quintana Roo & 31.2 & (2.7) & 24.9 & (2.5) & 24.0 & $(2.8)$ & 13.5 & (2.6) & 5.3 & (1.6) & 1.0 & $(0.5)$ & 0.1 & c \\
\hline & San Luis Potosí & 33.6 & (4.9) & 24.5 & (2.6) & 23.7 & (2.9) & 12.1 & $(2.0)$ & 4.6 & (1.5) & 1.4 & (1.0) & 0.2 & $(0.3)$ \\
\hline & Sinaloa & 30.7 & (3.5) & 28.8 & (2.4) & 22.9 & (2.9) & 12.6 & (2.5) & 4.0 & $(1.0)$ & 0.9 & $(0.5)$ & 0.1 & c \\
\hline & Tabasco & 45.0 & (3.6) & 26.5 & (3.0) & 17.7 & (2.5) & 8.0 & (1.4) & 2.2 & $(0.8)$ & 0.4 & $(0.4)$ & 0.1 & c \\
\hline & Tamaulipas & 29.3 & (5.0) & 25.5 & (2.9) & 24.7 & (3.4) & 12.4 & (3.0) & 6.5 & $(2.1)$ & 1.5 & (0.9) & 0.2 & C \\
\hline & Tlaxcala & 27.9 & $(2.9)$ & 29.4 & (2.8) & 24.1 & $(2.7)$ & 13.4 & (1.9) & 4.1 & (1.1) & 1.0 & (0.6) & 0.1 & C \\
\hline & Veracruz & 39.6 & (3.0) & 24.9 & (2.5) & 19.1 & (1.9) & 11.1 & (1.9) & 4.3 & (1.3) & 0.8 & $(0.5)$ & 0.0 & c \\
\hline & Yucatán & 33.0 & (3.2) & 24.1 & (2.7) & 22.5 & (3.1) & 13.2 & (2.2) & 5.3 & (1.6) & 1.6 & $(0.7)$ & 0.3 & C \\
\hline & Zacatecas & 30.1 & (3.0) & 26.7 & (2.1) & 24.8 & $(2.7)$ & 14.2 & (2.0) & 3.6 & (1.3) & 0.5 & $(0.3)$ & 0.1 & C \\
\hline
\end{tabular}

- PISA adjudicated region.

Note: See Table I.2.15 for national data.

StatLink 需可 http://dx.doi.org/10.1787/888932935762 
art 2/4]

Percentage of students at each proficiency level on the mathematics subscale Table B2.I.14 change and relationships, by gender and region

\begin{tabular}{|c|c|c|c|c|c|c|c|c|c|c|c|c|c|c|c|}
\hline & & \multicolumn{14}{|c|}{ Boys } \\
\hline & & \multicolumn{2}{|c|}{$\begin{array}{l}\text { Below Level } 1 \\
\text { (below 357.77 } \\
\text { score points) }\end{array}$} & \multicolumn{2}{|c|}{$\begin{array}{c}\text { Level } 1 \\
\text { (from } 357.77 \text { to } \\
\text { less than } 420.07 \\
\text { score points) }\end{array}$} & \multicolumn{2}{|c|}{$\begin{array}{c}\text { Level } 2 \\
\text { (from } 420.07 \text { to } \\
\text { less than } 482.38 \\
\text { score points) }\end{array}$} & $\begin{array}{r}\mathrm{L} \\
\text { (from } \\
\text { less th } \\
\text { scor }\end{array}$ & \begin{tabular}{|l|} 
I 3 \\
2.38 to \\
544.68 \\
oints)
\end{tabular} & $\begin{array}{l}\text { L } \\
\text { (from } \\
\text { less th } \\
\text { scor }\end{array}$ & $\begin{array}{l}4 \\
4.68 \text { to } \\
606.99 \\
\text { oints) }\end{array}$ & $\begin{array}{r}\mathrm{L} \\
\text { (from } \\
\text { less th } \\
\text { scor }\end{array}$ & \begin{tabular}{|l|}
5 \\
6.99 to \\
669.30 \\
oints)
\end{tabular} & $\begin{array}{l}\text { Lc } \\
\text { (abov } \\
\text { scor }\end{array}$ & $\begin{array}{l}16 \\
669.30 \\
\text { oints) }\end{array}$ \\
\hline & & $\%$ & S.E. & $\%$ & S.E. & $\%$ & S.E. & $\%$ & S.E. & $\%$ & S.E. & $\%$ & S.E. & $\%$ & S.E. \\
\hline 0 & Portugal & & & & & & & & & & & & & & \\
\hline 氙 & Alentejo & 8.4 & (2.5) & 13.7 & (3.6) & 22.7 & (3.9) & 25.1 & (3.8) & 16.7 & (3.3) & 9.7 & (2.8) & 3.7 & (1.6) \\
\hline & Spain & & & & & & & & & & & & & & \\
\hline & Andalusia ${ }^{\bullet}$ & 9.0 & (1.4) & 18.1 & $(2.0)$ & 24.0 & (2.4) & 24.5 & $(2.2)$ & 16.1 & $(2.0)$ & 6.3 & (0.9) & 1.9 & $(0.6)$ \\
\hline & Aragon ${ }^{\bullet}$ & 9.1 & (1.6) & 13.0 & (1.5) & 19.8 & $(2.0)$ & 22.9 & (1.8) & 20.5 & $(2.1)$ & 11.4 & (1.8) & 3.2 & (1.0) \\
\hline & Asturias ${ }^{\bullet}$ & 8.4 & (1.5) & 11.4 & (1.4) & 20.8 & $(1.4)$ & 24.6 & (2.0) & 20.6 & $(1.7)$ & 10.2 & (1.5) & 4.0 & $(1.2)$ \\
\hline & Balearic Islands ${ }^{\bullet}$ & 12.3 & $(2.0)$ & 17.9 & $(2.2)$ & 22.0 & $(2.1)$ & 23.7 & $(2.2)$ & 16.5 & $(1.7)$ & 6.5 & (1.1) & 1.1 & $(0.4)$ \\
\hline & Basque Country ${ }^{\bullet}$ & 4.5 & $(0.7)$ & 10.4 & $(0.9)$ & 20.2 & $(1.1)$ & 27.4 & (1.2) & 22.9 & (1.4) & 11.7 & (1.1) & 2.9 & $(0.4)$ \\
\hline & Cantabria ${ }^{\bullet}$ & 9.9 & $(1.4)$ & 13.7 & (1.8) & 22.8 & $(2.2)$ & 22.1 & (1.7) & 19.4 & (1.9) & 9.7 & (1.3) & 2.5 & $(0.7)$ \\
\hline & Castile and Leon & 4.2 & $(0.9)$ & 10.4 & (1.4) & 22.1 & $(1.8)$ & 23.7 & (1.8) & 24.1 & $(2.2)$ & 12.6 & (1.7) & 2.8 & $(0.7)$ \\
\hline & Catalonia & 8.4 & $(1.7)$ & 13.6 & (1.9) & 20.1 & (1.9) & 23.9 & (2.2) & 19.7 & $(2.1)$ & 10.6 & (2.0) & 3.7 & (1.0) \\
\hline & Extremadura ${ }^{\bullet}$ & 16.6 & $(2.2)$ & 18.3 & (1.7) & 20.6 & (1.6) & 20.4 & (1.5) & 14.9 & $(1.2)$ & 7.1 & (1.3) & 2.1 & $(0.6)$ \\
\hline & Galicia• & 8.4 & (1.5) & 15.4 & $(2.5)$ & 21.9 & $(2.7)$ & 26.8 & (2.4) & 18.7 & $(1.7)$ & 7.3 & (1.4) & 1.5 & $(0.5)$ \\
\hline & La Rioja ${ }^{\bullet}$ & 10.1 & (1.3) & 12.0 & $(1.2)$ & 16.6 & $(1.8)$ & 20.6 & (1.8) & 20.6 & $(2.0)$ & 15.0 & (1.9) & 5.1 & $(0.9)$ \\
\hline & Madrid $\bullet^{\bullet}$ & 7.4 & (1.8) & 11.9 & (1.7) & 20.4 & $(1.7)$ & 23.2 & (1.7) & 23.8 & $(2.0)$ & 10.6 & (1.3) & 2.8 & $(0.8)$ \\
\hline & Murcia ${ }^{\bullet}$ & 15.7 & (1.8) & 18.4 & (2.6) & 24.2 & $(2.5)$ & 18.9 & (2.0) & 14.4 & (1.4) & 6.2 & (1.4) & 2.1 & $(0.8)$ \\
\hline & Navarre ${ }^{\bullet}$ & 3.9 & (1.0) & 10.0 & (1.7) & 18.3 & $(2.1)$ & 25.4 & (2.4) & 26.4 & $(2.2)$ & 12.7 & (1.3) & 3.4 & $(1.1)$ \\
\hline & United Kingdom & & & & & & & & & & & & & & \\
\hline & England & 7.3 & (1.3) & 12.7 & (1.3) & 20.5 & (1.4) & 23.8 & (1.3) & 19.2 & (1.5) & 11.5 & (1.4) & 4.8 & (0.9) \\
\hline & Northern Ireland & 9.6 & (1.4) & 15.1 & (1.7) & 20.8 & (1.6) & 24.4 & (1.6) & 17.6 & (1.6) & 8.9 & $(1.2)$ & 3.6 & $(0.8)$ \\
\hline & Scotland ${ }^{\bullet}$ & 5.6 & $(0.9)$ & 12.4 & $(1.0)$ & 22.0 & $(1.2)$ & 25.6 & (1.3) & 19.8 & $(1.2)$ & 10.7 & $(1.2)$ & 3.9 & $(0.7)$ \\
\hline & Wales & 10.3 & (1.1) & 16.4 & (1.1) & 24.7 & (1.6) & 25.9 & (1.4) & 15.3 & (1.0) & 6.0 & $(0.7)$ & 1.4 & $(0.3)$ \\
\hline & United States & & & & & & & & & & & & & & \\
\hline & Connecticut ${ }^{\bullet}$ & 5.9 & (1.4) & 11.5 & (2.0) & 18.4 & (1.9) & 21.3 & (2.1) & 19.2 & (1.9) & 14.4 & (2.0) & 9.3 & (1.5) \\
\hline & Florida & 8.6 & (1.6) & 16.9 & (1.8) & 24.4 & $(2.1)$ & 23.9 & (2.1) & 16.1 & $(2.1)$ & 7.3 & (1.7) & 2.9 & $(0.9)$ \\
\hline & Massachusetts ${ }^{\bullet}$ & 5.6 & (1.1) & 10.4 & (1.7) & 18.0 & $(2.1)$ & 21.4 & (2.5) & 21.2 & (1.7) & 14.0 & (1.8) & 9.3 & (1.7) \\
\hline$n$ & Argentina & & & & & & & & & & & & & & \\
\hline 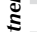 & Ciudad Autónoma de Buenos Aires & 27.8 & (3.3) & 21.0 & $(2.3)$ & 22.8 & $(2.8)$ & 18.1 & $(2.1)$ & 7.5 & (1.6) & 2.5 & $(1.0)$ & 0.2 & c \\
\hline ฐٓ & Brazil & & & & & & & & & & & & & & \\
\hline & Acre & 57.4 & (5.4) & 22.9 & (3.3) & 13.2 & $(2.8)$ & 4.4 & (1.8) & 1.3 & $(1.1)$ & 0.6 & (0.6) & 0.2 & c \\
\hline & Alagoas & 67.7 & $(5.2)$ & 18.2 & $(4.4)$ & 7.8 & $(2.1)$ & 4.2 & (1.9) & 1.5 & $(1.1)$ & 0.6 & $(0.5)$ & 0.0 & c \\
\hline & Amapá & 60.8 & (6.4) & 22.8 & $(4.3)$ & 10.1 & $(3.0)$ & 4.1 & $(2.2)$ & 1.8 & $(1.6)$ & 0.3 & $\mathrm{C}$ & 0.0 & c \\
\hline & Amazonas & 65.9 & (4.3) & 18.0 & (3.0) & 9.0 & $(2.1)$ & 4.4 & (1.4) & 1.8 & $(0.9)$ & 0.8 & $(0.9)$ & 0.0 & c \\
\hline & Bahia & 54.3 & (5.6) & 21.4 & (5.5) & 13.3 & $(4.2)$ & 7.8 & (3.1) & 2.0 & $(1.5)$ & 1.0 & (1.0) & 0.3 & $\mathrm{C}$ \\
\hline & Ceará & 50.6 & (4.5) & 21.9 & (3.2) & 14.0 & $(2.5)$ & 6.5 & (1.7) & 4.4 & $(2.2)$ & 2.0 & (1.3) & 0.7 & $(0.6)$ \\
\hline & Espírito Santo & 34.2 & $(4.2)$ & 24.5 & (3.6) & 18.4 & (3.6) & 11.2 & (2.5) & 7.0 & (1.9) & 4.0 & (1.7) & 0.8 & C \\
\hline & Federal District & 35.0 & $(4.7)$ & 23.1 & (4.0) & 16.4 & (2.6) & 13.2 & (3.2) & 8.6 & (3.1) & 3.2 & (1.2) & 0.6 & $(0.5)$ \\
\hline & Goiás & 50.2 & $(4.1)$ & 23.3 & (3.3) & 15.1 & $(2.6)$ & 7.1 & $(2.2)$ & 2.9 & $(1.1)$ & 1.4 & $(0.8)$ & 0.0 & C \\
\hline & Maranhão & 67.3 & (8.0) & 17.0 & (3.2) & 7.2 & $(2.7)$ & 4.2 & $(2.7)$ & 2.9 & $(2.4)$ & 1.3 & (1.2) & 0.0 & $\mathrm{C}$ \\
\hline & Mato Grosso & 56.8 & (5.8) & 21.9 & $(4.1)$ & 13.8 & $(2.5)$ & 5.1 & (1.8) & 1.5 & $(1.0)$ & 0.5 & C & 0.3 & $(0.3)$ \\
\hline & Mato Grosso do Sul & 34.4 & $(5.7)$ & 26.3 & $(3.2)$ & 20.6 & $(3.3)$ & 9.3 & (2.3) & 7.4 & $(2.1)$ & 2.0 & (1.0) & 0.1 & C \\
\hline & Minas Gerais & 32.8 & (4.9) & 25.7 & (3.5) & 23.9 & (3.6) & 12.1 & (3.1) & 4.4 & $(1.8)$ & 0.8 & $(0.7)$ & 0.3 & c \\
\hline & Pará & 59.3 & (3.8) & 21.8 & $(4.1)$ & 14.3 & (3.9) & 3.6 & $(1.2)$ & 0.8 & $(1.2)$ & 0.3 & $\mathrm{C}$ & 0.0 & c \\
\hline & Paraiba & 39.2 & (5.0) & 28.3 & (5.5) & 17.4 & $(4.3)$ & 8.2 & (2.9) & 4.8 & $(2.3)$ & 1.3 & $(1.2)$ & 0.8 & $(0.7)$ \\
\hline & Paraná & 39.0 & (5.1) & 22.4 & (3.9) & 17.4 & (2.4) & 11.0 & (2.5) & 7.2 & $(3.5)$ & 2.6 & (2.1) & 0.4 & c \\
\hline & Pernambuco & 56.9 & $(5.7)$ & 23.6 & $(3.7)$ & 12.7 & $(4.2)$ & 4.9 & (2.0) & 1.5 & $(1.0)$ & 0.4 & $(0.4)$ & 0.0 & c \\
\hline & Piauí & 49.1 & (4.3) & 19.6 & (3.4) & 15.2 & $(4.0)$ & 10.3 & $(2.7)$ & 3.6 & $(1.6)$ & 1.3 & (1.0) & 0.9 & $(0.6)$ \\
\hline & Rio de Janeiro & 39.3 & (4.9) & 27.8 & (3.5) & 19.0 & (3.1) & 9.9 & (2.4) & 3.1 & $(1.2)$ & 0.8 & $(0.5)$ & 0.2 & C \\
\hline & Rio Grande do Norte & 55.2 & (5.7) & 19.0 & (3.9) & 10.4 & $(2.5)$ & 8.3 & (2.8) & 4.1 & (1.6) & 2.5 & (1.3) & 0.4 & c \\
\hline & Rio Grande do Sul & 31.6 & (3.7) & 27.6 & (3.8) & 24.2 & $(3.8)$ & 11.6 & (2.9) & 4.0 & (1.6) & 1.0 & $(0.7)$ & 0.0 & c \\
\hline & Rondônia & 50.2 & (4.9) & 26.3 & (3.1) & 15.7 & $(2.8)$ & 6.3 & (1.6) & 1.3 & $(1.0)$ & 0.2 & C & 0.0 & c \\
\hline & Roraima & 59.9 & $(4.2)$ & 21.0 & (2.8) & 12.9 & $(3.1)$ & 4.7 & (2.1) & 1.4 & $(0.8)$ & 0.1 & $\mathrm{C}$ & 0.0 & c \\
\hline & Santa Catarina & 31.4 & $(4.7)$ & 26.2 & (3.3) & 20.4 & $(2.3)$ & 12.2 & (2.6) & 7.4 & $(2.4)$ & 2.3 & (1.1) & 0.0 & c \\
\hline & São Paulo & 37.2 & (2.4) & 24.6 & (1.9) & 19.0 & $(1.6)$ & 11.4 & (1.7) & 4.6 & $(0.9)$ & 2.3 & $(0.9)$ & 0.9 & $(0.4)$ \\
\hline & Sergipe & 47.0 & (6.4) & 23.0 & (4.5) & 14.0 & $(4.1)$ & 9.9 & (4.1) & 4.6 & (2.9) & 1.2 & $(0.9)$ & 0.2 & $\mathrm{C}$ \\
\hline & Tocantins & 57.7 & (5.0) & 19.6 & $(2.8)$ & 12.2 & $(2.0)$ & 7.3 & (2.5) & 2.4 & $(1.2)$ & 0.5 & $(0.5)$ & 0.2 & c \\
\hline & Colombia & & & & & & & & & & & & & & \\
\hline & Bogotá & 32.6 & $(3.2)$ & 30.1 & (3.4) & 23.6 & $(2.6)$ & 9.9 & (1.6) & 2.7 & $(1.0)$ & 1.0 & $(0.7)$ & 0.2 & c \\
\hline & Cali & 45.1 & (3.8) & 26.9 & (3.0) & 17.3 & $(2.6)$ & 8.1 & (1.9) & 2.1 & $(1.0)$ & 0.5 & $(0.4)$ & 0.0 & c \\
\hline & Manizales & 32.3 & (3.0) & 27.2 & (3.1) & 19.9 & $(2.7)$ & 12.4 & (2.3) & 5.4 & $(1.3)$ & 2.4 & (1.2) & 0.5 & $(0.5)$ \\
\hline & Medellín & 38.8 & (4.8) & 25.6 & (2.6) & 19.1 & $(2.6)$ & 9.7 & (2.0) & 4.7 & (1.4) & $\begin{array}{l}2.4 \\
1.6\end{array}$ & (1.0) & 0.6 & $(0.5)$ \\
\hline & Russian Federation & & & & & & & & & & & & & & \\
\hline & Perm Territory region ${ }^{\bullet}$ & 8.1 & $(1.7)$ & 13.5 & (1.9) & 22.5 & (1.7) & 26.3 & $(2.0)$ & 17.8 & (1.5) & 7.9 & $(1.2)$ & 4.0 & (1.5) \\
\hline & United Arab Emirates & & & & & & & & & & & & & & \\
\hline & Abu Dhabi` & 26.9 & $(2.1)$ & 25.9 & (1.8) & 22.5 & (1.4) & 13.4 & (1.3) & 6.6 & $(1.1)$ & 3.8 & $(0.8)$ & 0.9 & $(0.4)$ \\
\hline & Ajman & 29.4 & (8.4) & 28.2 & (4.4) & 26.0 & $(4.5)$ & 14.8 & (3.2) & 1.4 & $(0.8)$ & 0.2 & $\mathrm{C}$ & 0.0 & C \\
\hline & Dubai ${ }^{\bullet}$ & 15.2 & $(0.6)$ & 16.3 & $(0.9)$ & 20.7 & $(1.0)$ & 20.4 & (1.1) & 15.7 & $(1.0)$ & 8.4 & $(0.8)$ & 3.5 & $(0.5)$ \\
\hline & Fujairah & 31.3 & $(5.2)$ & 30.2 & $(2.8)$ & 19.3 & $(3.1)$ & 11.5 & $(2.4)$ & 5.4 & $(1.3)$ & 2.2 & $(0.8)$ & 0.1 & $\begin{array}{r}\mathrm{c} \\
\mathrm{C}\end{array}$ \\
\hline & Ras al-Khaimah & 24.2 & $(4.4)$ & 28.7 & (3.2) & 25.8 & $(2.6)$ & 15.7 & (3.1) & 4.5 & $(1.2)$ & 1.0 & $(0.5)$ & 0.1 & c \\
\hline & Sharjah & 13.9 & (5.2) & 23.2 & (5.0) & 23.8 & (3.4) & 21.3 & (4.3) & 11.8 & (3.8) & 4.0 & $(2.0)$ & 2.1 & (1.6) \\
\hline & Umm al-Quwain & 34.1 & (3.5) & 35.9 & (4.6) & 20.3 & $(4.0)$ & 5.8 & (2.1) & 2.5 & (1.8) & 1.1 & $(1.2)$ & 0.3 & $\mathrm{C}$ \\
\hline
\end{tabular}

- PISA adjudicated region.

Note: See Table I.2.15 for national data.

StatLink त्नाls http://dx.doi.org/10.1787/888932935762 
Percentage of students at each proficiency level on the mathematics subscale Table B2.I.14 change and relationships, by gender and region

\begin{tabular}{|c|c|c|c|c|c|c|c|c|c|c|c|c|c|c|c|}
\hline & & \multicolumn{14}{|c|}{ Girls } \\
\hline & & \multicolumn{2}{|c|}{$\begin{array}{c}\text { Below Level } 1 \\
\text { (below 357.77 } \\
\text { score points) }\end{array}$} & $\begin{array}{l}\text { L } \\
\text { (from } \\
\text { less th } \\
\text { scor }\end{array}$ & $\begin{array}{l}\text { l } 1 \\
7.77 \text { to } \\
\mathbf{4 2 0 . 0 7} \\
\text { oints) }\end{array}$ & $\begin{array}{r}\mathrm{L} \\
\text { (from } \\
\text { less th } \\
\text { scor }\end{array}$ & $\begin{array}{l}2 \\
0.07 \text { to } \\
482.38 \\
\text { oints) }\end{array}$ & $\begin{array}{r}\mathrm{L} \\
\text { (from } \\
\text { less th } \\
\text { scor }\end{array}$ & \begin{tabular}{|l|}
3 \\
2.38 to \\
544.68 \\
oints)
\end{tabular} & $\begin{array}{r}L \\
\text { (from } \\
\text { less th } \\
\text { scor }\end{array}$ & $\begin{array}{l}4 \\
4.68 \text { to } \\
606.99 \\
\text { oints) }\end{array}$ & $\begin{array}{r}\text { L } \\
\text { (from } \\
\text { less th } \\
\text { scor }\end{array}$ & $\begin{array}{l}5 \\
6.99 \text { to } \\
669.30 \\
\text { oints) }\end{array}$ & $\begin{array}{r}\mathrm{L} \\
\text { (abo } \\
\text { scor }\end{array}$ & $\begin{array}{l}16 \\
669.30 \\
\text { oints) }\end{array}$ \\
\hline & & $\%$ & S.E. & $\%$ & S.E. & $\%$ & S.E. & $\%$ & \begin{tabular}{l|l} 
S.E. & \\
\end{tabular} & $\%$ & S.E. & $\%$ & S.E. & $\%$ & S.E. \\
\hline 0 & Australia & & & & & & & & & & & & & & \\
\hline 过 & Australian Capital Territory & 4.9 & $(1.3)$ & 10.4 & $(2.1)$ & 18.1 & $(2.5)$ & 24.5 & $(3.0)$ & 21.8 & (2.6) & 14.1 & (2.6) & 6.1 & (1.7) \\
\hline & New South Wales & 6.5 & $(1.0)$ & 12.8 & $(1.2)$ & 20.5 & $(1.3)$ & 23.0 & $(1.3)$ & 19.9 & (1.3) & 11.1 & $(0.9)$ & 6.2 & (1.1) \\
\hline & Northern Territory & 19.5 & $(2.7)$ & 17.0 & $(3.9)$ & 24.2 & (6.1) & 19.3 & (5.6) & 12.0 & (3.9) & 5.9 & $(3.4)$ & 2.0 & $(2.1)$ \\
\hline & Queensland & 7.3 & $(0.9)$ & 13.9 & $(1.2)$ & 21.1 & (1.4) & 23.5 & (1.7) & 18.2 & (1.3) & 11.0 & $(1.3)$ & 5.1 & $(0.9)$ \\
\hline & South Australia & 10.3 & $(1.2)$ & 15.6 & (1.4) & 21.7 & (1.9) & 23.7 & (1.7) & 17.2 & $(2.1)$ & 8.2 & $(1.3)$ & 3.3 & $(0.9)$ \\
\hline & Tasmania & 12.9 & (1.8) & 18.1 & (2.5) & 22.0 & $(2.7)$ & 21.1 & (2.4) & 15.6 & (2.3) & 7.5 & $(2.0)$ & 2.7 & (1.1) \\
\hline & Victoria & 6.9 & $(1.1)$ & 14.5 & (1.9) & 22.0 & (2.0) & 25.3 & $(2.0)$ & 18.7 & (1.6) & 9.8 & (1.3) & 2.8 & (0.6) \\
\hline & Western Australia & 7.9 & (1.3) & 12.2 & (1.5) & 21.0 & (1.6) & 22.1 & (1.9) & 17.5 & $(2.0)$ & 13.0 & (1.7) & 6.3 & (1.4) \\
\hline & Belgium & & & & & & & & & & & & & & \\
\hline & Flemish Community ${ }^{\bullet}$ & 7.2 & $(0.8)$ & 9.3 & $(1.0)$ & 15.8 & $(1.2)$ & 21.5 & $(1.0)$ & 22.0 & (1.3) & 16.9 & $(1.2)$ & 7.2 & $(0.8)$ \\
\hline & French Community & 11.3 & $(1.2)$ & 11.9 & $(1.2)$ & 21.0 & $(1.2)$ & 23.6 & (1.6) & 20.0 & (1.7) & 9.5 & (1.3) & 2.6 & $(0.5)$ \\
\hline & German-speaking Community & 5.2 & $(1.2)$ & 9.3 & (1.6) & 18.5 & (2.3) & 28.8 & (2.5) & 24.9 & $(2.7)$ & 10.9 & (1.7) & 2.5 & $(0.8)$ \\
\hline & Canada & & & & & & & & & & & & & & \\
\hline & Alberta & 4.2 & (1.0) & 10.7 & (1.3) & 20.4 & $(2.3)$ & 23.0 & $(1.8)$ & 23.3 & (1.6) & 13.8 & (1.6) & 4.6 & $(1.0)$ \\
\hline & British Columbia & 3.3 & $(0.8)$ & 9.1 & (1.4) & 20.5 & (1.9) & 27.5 & (2.5) & 22.1 & (1.7) & 11.9 & (1.8) & 5.5 & (1.3) \\
\hline & Manitoba & 7.0 & (1.5) & 16.1 & $(2.2)$ & 23.7 & $(2.0)$ & 22.1 & $(2.2)$ & 20.1 & $(2.1)$ & 8.5 & (1.4) & 2.5 & $(0.6)$ \\
\hline & New Brunswick & 4.8 & (1.0) & 11.3 & $(1.3)$ & 24.4 & (2.8) & 29.0 & (3.1) & 19.1 & $(2.2)$ & 8.7 & (1.6) & 2.7 & $(1.0)$ \\
\hline & Newfoundland and Labrador & 5.7 & (1.9) & 13.2 & $(1.8)$ & 23.7 & (2.6) & 28.0 & $(2.8)$ & 17.1 & (2.3) & 9.7 & (1.4) & 2.6 & $(0.8)$ \\
\hline & Nova Scotia & 6.1 & (1.1) & 15.4 & $(3.1)$ & 25.5 & $(3.1)$ & 26.5 & (1.8) & 18.1 & (3.0) & 6.0 & (1.5) & 2.3 & $(0.9)$ \\
\hline & Ontario & 4.0 & $(0.8)$ & 8.8 & (1.4) & 20.0 & (1.7) & 29.6 & $(1.9)$ & 21.5 & (1.6) & 11.9 & (1.1) & 4.3 & $(0.7)$ \\
\hline & Prince Edward Island & 6.5 & (1.0) & 15.1 & $(1.6)$ & 26.1 & $(2.2)$ & 27.5 & (2.4) & 17.7 & (2.0) & 6.1 & $(1.0)$ & 1.1 & $(0.6)$ \\
\hline & Quebec & 4.8 & $(0.7)$ & 9.0 & $(0.9)$ & 17.5 & (1.4) & 24.6 & (1.8) & 23.4 & (1.6) & 14.8 & (1.2) & 5.9 & (1.1) \\
\hline & Saskatchewan & 4.4 & $(0.9)$ & 10.2 & (1.4) & 23.6 & $(2.0)$ & 27.5 & $(2.8)$ & 21.0 & (2.5) & 10.4 & (1.3) & 2.9 & $(0.9)$ \\
\hline & Italy & & & & & & & & & & & & & & \\
\hline & Abruzzo & 12.9 & (2.1) & 19.7 & $(2.3)$ & 26.6 & $(2.1)$ & 22.5 & $(2.4)$ & 12.6 & $(2.1)$ & 4.4 & (1.1) & 1.1 & $(0.6)$ \\
\hline & Basilicata & 15.0 & (2.2) & 21.8 & $(1.8)$ & 29.3 & $(2.3)$ & 20.8 & $(2.1)$ & 8.9 & (1.4) & 3.2 & $(0.8)$ & 1.0 & $(0.4)$ \\
\hline & Bolzano & 7.5 & $(1.1)$ & 13.4 & (1.3) & 22.0 & $(2.2)$ & 27.5 & (1.7) & 20.1 & (1.6) & 8.0 & $(1.2)$ & 1.6 & $(0.5)$ \\
\hline & Calabria & 28.7 & (3.5) & 25.1 & $(2.8)$ & 26.2 & (2.4) & 14.0 & (1.9) & 4.8 & $(1.2)$ & 1.0 & $(0.4)$ & 0.1 & $(0.1)$ \\
\hline & Campania & 20.3 & $(3.7)$ & 23.1 & (2.8) & 27.2 & $(2.8)$ & 18.8 & (2.9) & 8.5 & (1.8) & 1.7 & $(0.8)$ & 0.3 & $(0.2)$ \\
\hline & Emilia Romagna & 10.0 & $(2.1)$ & 16.4 & $(1.8)$ & 24.5 & (2.4) & 24.6 & (2.6) & 15.8 & (2.1) & 6.9 & $(1.5)$ & 1.8 & $(0.6)$ \\
\hline & Friuli Venezia Giulia & 5.8 & (1.9) & 10.5 & $(1.7)$ & 22.2 & (2.5) & 29.1 & $(3.1)$ & 21.3 & (3.0) & 8.7 & $(1.6)$ & 2.4 & $(0.7)$ \\
\hline & Lazio & 15.2 & (2.7) & 21.3 & $(2.7)$ & 28.3 & (2.6) & 21.2 & $(2.2)$ & 9.9 & $(1.8)$ & 3.5 & $(0.9)$ & 0.6 & $(0.3)$ \\
\hline & Liguria & 12.5 & $(2.3)$ & 18.3 & $(2.4)$ & 25.0 & (2.8) & 24.3 & (2.5) & 13.7 & $(2.1)$ & 4.8 & $(1.2)$ & 1.4 & $(0.5)$ \\
\hline & Lombardia & 4.8 & $(1.3)$ & 11.7 & $(2.0)$ & 24.4 & (2.6) & 29.1 & $(2.9)$ & 21.0 & (2.6) & 7.7 & $(1.7)$ & 1.4 & $(0.7)$ \\
\hline & Marche & 10.4 & (2.0) & 16.8 & $(2.1)$ & 25.4 & (2.5) & 25.3 & $(2.7)$ & 15.1 & $(2.0)$ & 5.7 & $(1.2)$ & 1.3 & $(0.7)$ \\
\hline & Molise & 13.5 & $(1.8)$ & 22.6 & $(2.1)$ & 28.6 & $(2.7)$ & 23.2 & $(2.2)$ & 8.7 & (1.9) & 2.8 & $(1.2)$ & 0.6 & $(0.5)$ \\
\hline & Piemonte & 8.4 & (1.3) & 16.3 & $(2.3)$ & 24.0 & (2.3) & 27.1 & $(2.1)$ & 16.3 & $(2.2)$ & 6.4 & $(1.4)$ & 1.5 & $(0.7)$ \\
\hline & Puglia & 12.2 & (2.7) & 21.6 & $(2.8)$ & 27.7 & $(3.2)$ & 22.1 & $(2.8)$ & 12.5 & (1.9) & 3.1 & $(0.9)$ & 0.8 & $(0.4)$ \\
\hline & Sardegna & 18.3 & (2.8) & 22.6 & (2.6) & 26.0 & (2.9) & 20.2 & $(2.2)$ & 10.0 & $(2.1)$ & 2.7 & $(0.7)$ & 0.3 & c \\
\hline & Sicilia & 19.8 & $(2.7)$ & 25.6 & $(2.8)$ & 27.9 & (2.3) & 18.9 & $(2.5)$ & 6.7 & (1.2) & 0.9 & $(0.4)$ & 0.3 & $(0.2)$ \\
\hline & Toscana & 8.6 & (2.1) & 13.9 & $(2.3)$ & 24.2 & (2.6) & 26.1 & (3.2) & 18.5 & $(2.2)$ & 6.9 & (1.5) & 1.9 & $(0.7)$ \\
\hline & Trento & 4.7 & $(2.0)$ & 9.5 & $(2.1)$ & 21.8 & $(2.7)$ & 31.2 & $(2.7)$ & 21.9 & (2.4) & 9.5 & $(1.3)$ & 1.5 & $(0.7)$ \\
\hline & Umbria & 11.2 & $(2.2)$ & 15.9 & $(2.3)$ & 25.8 & (2.5) & 24.1 & $(2.6)$ & 15.8 & (2.6) & 6.3 & $(1.4)$ & 0.9 & $(0.5)$ \\
\hline & Valle d'Aosta & 6.2 & $(1.3)$ & 18.5 & $(3.2)$ & 31.0 & $(4.2)$ & 26.6 & $(2.5)$ & 11.1 & $(2.2)$ & 5.3 & $(1.5)$ & 1.4 & $(0.7)$ \\
\hline & Veneto & 5.0 & (2.0) & 11.2 & (1.5) & 21.8 & (2.6) & 29.2 & (2.8) & 20.2 & (2.0) & 9.2 & $(2.0)$ & 3.4 & $(1.2)$ \\
\hline & Mexico & & & & & & & & & & & & & & \\
\hline & Aguascalientes & 20.7 & (2.4) & 27.0 & $(2.8)$ & 27.7 & (2.5) & 17.6 & $(2.2)$ & 5.6 & (1.6) & 1.2 & $(0.7)$ & 0.1 & C \\
\hline & Baja California & 32.8 & (3.7) & 28.6 & (4.4) & 22.2 & (3.3) & 11.9 & $(2.0)$ & 4.0 & (1.4) & 0.4 & $(0.3)$ & 0.0 & c \\
\hline & Baja California Sur & 34.7 & (3.1) & 29.2 & $(2.4)$ & 22.1 & (2.6) & 10.2 & (1.7) & 3.5 & (1.0) & 0.3 & $(0.3)$ & 0.0 & C \\
\hline & Campeche & 43.3 & (3.1) & 27.9 & (3.1) & 17.8 & (2.4) & 8.5 & (1.9) & 2.1 & $(0.9)$ & 0.4 & $(0.4)$ & 0.1 & c \\
\hline & Chiapas & 49.2 & $(4.9)$ & 25.8 & $(2.7)$ & 17.3 & (2.6) & 5.7 & $(1.2)$ & 1.7 & $(0.7)$ & 0.3 & $(0.3)$ & 0.0 & c \\
\hline & Chihuahua & 24.0 & (3.3) & 26.2 & $(3.2)$ & 26.6 & (3.4) & 16.6 & $(2.9)$ & 5.3 & (1.6) & 1.2 & $(0.6)$ & 0.1 & C \\
\hline & Coahuila & 30.3 & (3.9) & 31.4 & $(4.3)$ & 23.3 & (3.3) & 10.7 & $(3.0)$ & 3.7 & (1.8) & 0.6 & $(0.4)$ & 0.0 & c \\
\hline & Colima & 26.1 & (3.1) & 25.8 & $(2.4)$ & 25.0 & (2.4) & 14.8 & $(2.1)$ & 6.9 & (1.7) & 1.2 & $(0.7)$ & 0.2 & $(0.2)$ \\
\hline & Distrito Federal & 22.4 & (3.8) & 31.1 & (3.8) & 27.8 & (3.9) & 13.5 & $(2.2)$ & 3.9 & (1.4) & 1.1 & $(0.7)$ & 0.1 & c \\
\hline & Durango & 24.7 & (3.5) & 30.3 & (2.9) & 23.6 & $(3.2)$ & 15.6 & $(2.9)$ & 5.0 & $(1.2)$ & 0.6 & $(0.5)$ & 0.1 & c \\
\hline & Guanajuato & 33.0 & (4.6) & 28.2 & $(2.7)$ & 24.7 & (2.9) & 10.5 & $(1.9)$ & 3.1 & $(0.8)$ & 0.5 & $(0.4)$ & 0.0 & C \\
\hline & Guerrero & 54.8 & $(3.1)$ & 27.9 & $(3.0)$ & 12.2 & (1.9) & 4.0 & $(0.9)$ & 1.1 & $(0.5)$ & 0.0 & c & 0.0 & C \\
\hline & Hidalgo & 30.3 & (4.0) & 31.9 & (3.6) & 24.0 & (2.8) & 11.2 & (2.5) & 2.1 & (1.1) & 0.5 & $(0.3)$ & 0.0 & C \\
\hline & Jalisco & 18.8 & (3.3) & 28.4 & $(3.1)$ & 28.6 & (3.3) & 17.2 & $(2.5)$ & 5.6 & (1.6) & 1.5 & $(0.9)$ & 0.0 & C \\
\hline & Mexico & 28.3 & (4.3) & 29.8 & $(3.5)$ & 28.1 & (3.4) & 10.8 & $(2.1)$ & 2.5 & (1.2) & 0.4 & $(0.4)$ & 0.0 & C \\
\hline & Morelos & 23.8 & (3.3) & 30.0 & (3.1) & 26.7 & (3.1) & 13.3 & (2.9) & 4.1 & (1.6) & 1.7 & (1.3) & 0.4 & $(0.4)$ \\
\hline & Nayarit & 30.7 & (3.7) & 28.6 & $(2.7)$ & 24.9 & $(3.2)$ & 11.1 & $(2.3)$ & 4.2 & (1.4) & 0.4 & $(0.4)$ & 0.1 & C \\
\hline & Nuevo León & 21.9 & (3.2) & 27.9 & $(3.1)$ & 26.8 & $(2.7)$ & 16.8 & $(2.5)$ & 5.6 & (1.5) & 1.1 & $(0.6)$ & 0.1 & C \\
\hline & Puebla & 26.7 & (3.4) & 29.5 & $(2.8)$ & 25.5 & $(2.7)$ & 13.5 & $(2.3)$ & 4.3 & $(1.2)$ & 0.4 & $(0.3)$ & 0.0 & C \\
\hline & Querétaro & 19.7 & (3.8) & 30.1 & $(4.6)$ & 27.8 & (3.1) & 14.1 & $(2.3)$ & 6.7 & (1.7) & 1.4 & $(0.5)$ & 0.1 & $(0.1)$ \\
\hline & Quintana Roo & 30.8 & (3.3) & 28.7 & $(2.7)$ & 24.4 & (2.3) & 12.4 & $(1.5)$ & 3.2 & (1.0) & 0.4 & $(0.3)$ & 0.1 & C \\
\hline & San Luis Potosí & 31.6 & (3.9) & 27.6 & $(2.5)$ & 23.3 & $(2.3)$ & 12.1 & $(2.0)$ & 4.6 & (1.5) & 0.7 & $(0.6)$ & 0.0 & c \\
\hline & Sinaloa & 30.7 & $(2.7)$ & 29.3 & $(3.1)$ & 25.1 & (2.5) & 11.8 & $(2.0)$ & 2.7 & $(0.8)$ & 0.4 & $(0.3)$ & 0.1 & C \\
\hline & Tabasco & 47.0 & (3.4) & 30.0 & $(3.0)$ & 16.2 & (2.3) & 4.9 & $(1.2)$ & 1.8 & (0.6) & 0.2 & C & 0.0 & C \\
\hline & Tamaulipas & 36.1 & (3.4) & 28.7 & $(2.8)$ & 22.8 & (3.3) & 8.9 & $(2.2)$ & 3.2 & (1.6) & 0.2 & $(0.2)$ & 0.0 & C \\
\hline & Tlaxcala & 31.6 & (3.6) & 30.9 & $(2.0)$ & 23.1 & (2.3) & 10.8 & (1.8) & 3.1 & (1.1) & 0.5 & $(0.4)$ & 0.0 & C \\
\hline & Veracruz & 40.9 & (3.9) & 28.8 & $(2.7)$ & 17.4 & (3.0) & 9.5 & $(2.5)$ & 2.7 & (1.4) & 0.7 & $(0.6)$ & 0.0 & C \\
\hline & Yucatán & 40.4 & (3.3) & 26.2 & $(3.0)$ & 21.4 & (2.3) & 8.9 & $(1.7)$ & 2.3 & $(0.8)$ & 0.7 & $(0.5)$ & 0.1 & $(0.1)$ \\
\hline & Zacatecas & 33.2 & (2.4) & 30.0 & $(2.3)$ & 22.6 & $(2.5)$ & 10.3 & (1.6) & 3.5 & $(1.0)$ & 0.5 & $(0.5)$ & 0.0 & C \\
\hline
\end{tabular}

- PISA adjudicated region.

Note: See Table I.2.15 for national data.

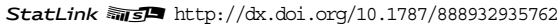


Percentage of students at each proficiency level on the mathematics subscale Table B2.I.14 change and relationships, by gender and region

\begin{tabular}{|c|c|c|c|c|c|c|c|c|c|c|c|c|c|c|c|}
\hline & & \multicolumn{14}{|c|}{ Girls } \\
\hline & & \multicolumn{2}{|c|}{$\begin{array}{l}\text { Below Level } 1 \\
\text { (below 357.77 } \\
\text { score points) }\end{array}$} & \multicolumn{2}{|c|}{$\begin{array}{c}\text { Level } 1 \\
\text { (from } 357.77 \text { to } \\
\text { less than } 420.07 \\
\text { score points) }\end{array}$} & \multicolumn{2}{|c|}{$\begin{array}{c}\text { Level } 2 \\
\text { (from } 420.07 \text { to } \\
\text { less than } 482.38 \\
\text { score points) }\end{array}$} & $\begin{array}{r}\mathrm{L} \\
\text { (from } \\
\text { less th } \\
\text { scor }\end{array}$ & \begin{tabular}{l|} 
I 3 \\
2.38 to \\
544.68 \\
oints)
\end{tabular} & $\begin{array}{l}\text { Le } \\
\text { (from } \\
\text { less th } \\
\text { score }\end{array}$ & $\begin{array}{l}4 \\
4.68 \text { to } \\
606.99 \\
\text { oints) }\end{array}$ & $\begin{array}{r}\mathrm{L} \\
\text { (from } \\
\text { less th } \\
\text { scor }\end{array}$ & \begin{tabular}{|l|} 
I 5 \\
6.99 to \\
669.30 \\
oints)
\end{tabular} & $\begin{array}{l}\text { L } \\
\text { (abov } \\
\text { scor }\end{array}$ & $\begin{array}{l}16 \\
669.30 \\
\text { oints) }\end{array}$ \\
\hline & & $\%$ & S.E. & $\%$ & S.E. & $\%$ & S.E. & $\%$ & S.E. & $\%$ & S.E. & $\%$ & S.E. & $\%$ & S.E. \\
\hline 0 & Portugal & & & & & & & & & & & & & & \\
\hline 氙 & Alentejo & 10.8 & (2.8) & 15.9 & $(2.7)$ & 25.3 & (3.3) & 22.7 & (2.5) & 16.7 & $(2.7)$ & 7.7 & (1.5) & 1.0 & $(0.6)$ \\
\hline & Spain & & & & & & & & & & & & & & \\
\hline & Andalusia ${ }^{\bullet}$ & 10.2 & $(1.5)$ & 20.6 & (1.9) & 30.5 & (1.9) & 22.6 & (2.1) & 12.9 & (1.9) & 3.1 & (0.8) & 0.2 & $(0.2)$ \\
\hline & Aragon ${ }^{\bullet}$ & 10.6 & (1.8) & 12.8 & (1.8) & 21.9 & $(2.1)$ & 26.6 & $(2.1)$ & 18.7 & $(2.1)$ & 8.2 & (1.4) & 1.3 & $(0.6)$ \\
\hline & Asturias ${ }^{\bullet}$ & 7.3 & $(1.3)$ & 12.8 & (1.5) & 24.2 & $(2.1)$ & 25.7 & (2.0) & 19.0 & $(2.1)$ & 8.8 & (1.3) & 2.3 & $(0.8)$ \\
\hline & Balearic Islands ${ }^{\bullet}$ & 11.2 & (1.8) & 19.1 & (2.0) & 22.2 & $(1.5)$ & 24.8 & (1.8) & 16.5 & $(1.8)$ & 5.8 & (1.1) & 0.3 & $(0.2)$ \\
\hline & Basque Country ${ }^{\bullet}$ & 5.6 & $(0.6)$ & 12.6 & $(0.9)$ & 23.6 & $(1.2)$ & 28.6 & (1.5) & 20.5 & $(1.2)$ & 7.6 & $(0.8)$ & 1.6 & $(0.3)$ \\
\hline & Cantabria ${ }^{\bullet}$ & 9.2 & $(1.3)$ & 16.0 & $(1.8)$ & 24.6 & (2.0) & 25.2 & (2.1) & 15.2 & (2.5) & 8.3 & $(1.7)$ & 1.4 & $(0.6)$ \\
\hline & Castile and Leon & 3.8 & $(1.0)$ & 12.3 & (1.6) & 22.8 & $(1.7)$ & 31.8 & (2.0) & 22.5 & $(2.0)$ & 6.0 & (1.1) & 0.8 & $(0.4)$ \\
\hline & Catalonia & 9.6 & $(1.8)$ & 15.9 & (2.3) & 25.5 & (2.3) & 26.3 & (2.0) & 16.7 & $(2.1)$ & 5.1 & (1.0) & 1.0 & $(0.5)$ \\
\hline & Extremadura ${ }^{\bullet}$ & 16.2 & (1.5) & 17.0 & (1.9) & 25.8 & (1.9) & 23.2 & (2.1) & 13.1 & $(1.7)$ & 3.9 & $(0.9)$ & 0.8 & $(0.4)$ \\
\hline & Galicia• & 8.0 & $(1.3)$ & 13.2 & (1.9) & 25.9 & $(2.1)$ & 29.6 & (2.4) & 17.1 & $(2.0)$ & 5.1 & (1.1) & 1.2 & $(0.5)$ \\
\hline & La Rioja` & 9.3 & $(1.1)$ & 13.6 & (1.6) & 22.0 & $(2.0)$ & 26.2 & $(1.7)$ & 18.9 & $(1.7)$ & 7.8 & (1.3) & 2.2 & $(0.6)$ \\
\hline & Madrid $\bullet^{\bullet}$ & 6.6 & $(1.6)$ & 13.3 & (1.7) & 21.6 & $(2.0)$ & 27.6 & (2.3) & 21.2 & $(2.2)$ & 8.5 & $(0.9)$ & 1.1 & $(0.4)$ \\
\hline & Murcia $\bullet$ & 13.9 & (1.5) & 20.3 & (2.3) & 27.3 & $(2.2)$ & 23.2 & (1.9) & 11.5 & $(1.6)$ & 3.2 & (0.9) & 0.6 & $(0.3)$ \\
\hline & Navarre ${ }^{\bullet}$ & 2.6 & $(0.8)$ & 10.3 & (1.4) & 20.6 & $(2.6)$ & 27.6 & (2.3) & 25.0 & $(1.8)$ & 11.6 & (1.4) & 2.4 & $(0.8)$ \\
\hline & United Kingdom & & & & & & & & & & & & & & \\
\hline & England & 9.5 & $(1.2)$ & 14.2 & (1.1) & 23.1 & (1.1) & 23.9 & $(1.2)$ & 16.6 & (1.3) & 9.2 & (1.3) & 3.5 & $(0.7)$ \\
\hline & Northern Ireland & 10.5 & (1.9) & 17.4 & (1.9) & 23.9 & (1.9) & 21.5 & (1.8) & 16.8 & (1.9) & 7.1 & (1.0) & 2.7 & $(0.5)$ \\
\hline & Scotland ${ }^{\bullet}$ & 7.5 & $(1.2)$ & 15.6 & (1.3) & 25.4 & (1.6) & 24.8 & $(2.1)$ & 16.8 & (1.4) & 7.6 & $(0.9)$ & 2.3 & $(0.6)$ \\
\hline & Wales & 11.3 & (1.0) & 20.2 & (1.4) & 27.4 & (1.4) & 22.6 & $(1.2)$ & 13.6 & (1.0) & 4.1 & (0.6) & 0.7 & $(0.2)$ \\
\hline & United States & & & & & & & & & & & & & & \\
\hline & Connecticut ${ }^{\bullet}$ & 8.1 & (1.6) & 13.5 & (1.5) & 20.9 & $(2.0)$ & 23.2 & (2.0) & 17.2 & $(1.7)$ & 11.1 & (1.5) & 6.0 & $(1.2)$ \\
\hline & Florida & 9.5 & (1.6) & 20.8 & $(2.1)$ & 28.3 & $(2.0)$ & 22.8 & (1.9) & 12.3 & (1.6) & 5.2 & (1.2) & 1.1 & $(0.6)$ \\
\hline & Massachusetts ${ }^{\bullet}$ & 6.7 & $(1.3)$ & 13.2 & (1.6) & 20.6 & (1.9) & 22.6 & (1.9) & 19.0 & $(2.2)$ & 11.2 & (1.4) & 6.7 & (1.4) \\
\hline$n$ & Argentina & & & & & & & & & & & & & & \\
\hline$\cong$ & Ciudad Autónoma de Buenos Aires & 30.2 & (3.3) & 21.7 & $(2.3)$ & 25.1 & $(2.6)$ & 14.5 & (1.9) & 6.6 & (1.6) & 1.9 & $(1.1)$ & 0.1 & c \\
\hline ๘ & Brazil & & & & & & & & & & & & & & \\
\hline & Acre & 66.3 & $(4.7)$ & 18.4 & (3.6) & 10.7 & $(3.1)$ & 4.0 & $(1.7)$ & 0.7 & c & 0.0 & c & 0.0 & c \\
\hline & Alagoas & 77.6 & (3.7) & 13.5 & $(2.4)$ & 5.4 & $(1.8)$ & 2.6 & (1.5) & 0.7 & $(0.6)$ & 0.2 & c & 0.0 & c \\
\hline & Amapá & 69.4 & $(5.4)$ & 20.6 & (5.0) & 7.7 & $(2.7)$ & 1.9 & (1.5) & 0.3 & $\mathrm{C}$ & 0.0 & c & 0.0 & c \\
\hline & Amazonas & 71.4 & $(3.2)$ & 19.1 & (3.0) & 6.4 & $(2.2)$ & 2.0 & (1.1) & 1.0 & $(0.9)$ & 0.0 & $\mathrm{C}$ & 0.0 & c \\
\hline & Bahia & 60.4 & $(10.2)$ & 17.9 & $(4.7)$ & 12.5 & $(6.4)$ & 6.7 & $(4.1)$ & 1.8 & (1.4) & 0.7 & $\mathrm{C}$ & 0.0 & c \\
\hline & Ceará & 55.6 & $(6.0)$ & 24.6 & $(4.1)$ & 13.0 & (3.3) & 4.1 & (2.0) & 1.9 & $(0.8)$ & 0.8 & $\mathrm{C}$ & 0.0 & $\mathrm{C}$ \\
\hline & Espírito Santo & 43.3 & $(4.4)$ & 23.4 & (4.6) & 15.2 & $(2.9)$ & 8.2 & (2.6) & 6.7 & $(3.2)$ & 2.6 & (1.4) & 0.6 & $(0.6)$ \\
\hline & Federal District & 40.5 & $(4.9)$ & 23.3 & (3.6) & 18.0 & $(4.0)$ & $\begin{array}{r}0.2 \\
13.0\end{array}$ & $(2.9)$ & 4.3 & $(2.2)$ & $\begin{array}{l}2.0 \\
1.0\end{array}$ & $(0.7)$ & 0.0 & $\begin{array}{r}0.0) \\
\mathrm{C}\end{array}$ \\
\hline & Goiás & 56.3 & $(4.5)$ & 23.8 & $(2.7)$ & 13.0 & $(2.9)$ & 5.8 & (1.7) & 0.9 & $(0.5)$ & 0.2 & $\mathrm{C}$ & 0.0 & c \\
\hline & Maranhão & 75.2 & $(7.8)$ & 16.0 & $(4.1)$ & 6.4 & (3.3) & 1.7 & (1.8) & 0.5 & $(0.5)$ & 0.0 & $\mathrm{C}$ & 0.0 & $\mathrm{c}$ \\
\hline & Mato Grosso & 60.2 & $(5.7)$ & 21.7 & $(4.0)$ & 11.4 & $(3.0)$ & 2.8 & (1.5) & 2.5 & (1.6) & 1.3 & (1.0) & 0.1 & c \\
\hline & Mato Grosso do Sul & 42.8 & $(5.4)$ & 27.1 & (3.4) & 17.5 & $(4.1)$ & 6.5 & $(1.3)$ & 5.0 & $(1.7)$ & 1.0 & $(0.8)$ & 0.2 & c \\
\hline & Minas Gerais & 39.2 & $(4.1)$ & 27.6 & (2.8) & 21.5 & $(4.1)$ & 8.3 & (2.4) & 2.5 & $(1.5)$ & 0.9 & $(0.9)$ & 0.1 & c \\
\hline & Pará & 64.8 & $(4.7)$ & 17.0 & (3.0) & 13.6 & $(3.7)$ & 4.4 & (1.7) & 0.3 & $\mathrm{C}$ & 0.0 & $\mathrm{C}$ & 0.0 & c \\
\hline & Paraiba & 49.6 & $(6.4)$ & 21.0 & $(4.0)$ & 16.2 & $(3.8)$ & 9.7 & (3.3) & 3.0 & $(1.7)$ & 0.4 & $\mathrm{C}$ & 0.0 & c \\
\hline & Paraná & 47.8 & (5.1) & 26.5 & (3.8) & 14.0 & $(2.7)$ & 7.1 & $(2.7)$ & 2.6 & $(2.3)$ & 1.4 & (1.5) & 0.5 & $(0.6)$ \\
\hline & Pernambuco & 64.5 & $(5.6)$ & 23.3 & $(4.7)$ & 8.3 & (3.3) & 3.0 & (1.4) & 0.6 & $(0.5)$ & 0.2 & $(0.2)$ & 0.0 & c \\
\hline & Piauí & 56.5 & $(4.6)$ & 22.1 & $(4.0)$ & 10.4 & $(3.0)$ & 6.1 & (1.6) & 3.5 & $(1.7)$ & 0.8 & (1.1) & 0.6 & $(0.3)$ \\
\hline & Rio de Janeiro & 45.8 & $(4.4)$ & 27.2 & $(4.1)$ & 17.8 & $(2.6)$ & 7.0 & (1.9) & 1.9 & $(1.0)$ & 0.3 & C & 0.0 & C \\
\hline & Rio Grande do Norte & 65.1 & $(4.0)$ & 16.9 & (2.9) & 9.4 & (1.8) & 5.1 & (1.8) & 2.2 & $(1.1)$ & 1.0 & $(0.6)$ & 0.4 & c \\
\hline & Rio Grande do Sul & 37.8 & (3.8) & 27.3 & $(4.2)$ & 21.2 & (3.4) & 10.4 & (1.9) & 3.0 & $(1.2)$ & 0.3 & $\mathrm{C}$ & 0.0 & c \\
\hline & Rondônia & 51.4 & $(5.0)$ & 28.1 & $(2.7)$ & 14.5 & $(2.7)$ & 4.3 & (1.8) & 1.6 & (1.4) & 0.1 & c & 0.0 & c \\
\hline & Roraima & 64.5 & $(4.7)$ & 19.5 & (3.1) & 8.4 & $(2.4)$ & 5.9 & (2.6) & 1.5 & $(1.0)$ & 0.1 & $\mathrm{C}$ & 0.0 & c \\
\hline & Santa Catarina & 36.6 & $(5.8)$ & 28.7 & (3.2) & 19.8 & $(4.2)$ & 10.3 & (2.9) & 3.6 & $(1.6)$ & 0.8 & $(0.6)$ & 0.2 & c \\
\hline & São Paulo & 44.1 & (3.0) & 24.6 & (1.7) & 16.9 & $(1.5)$ & 9.1 & (1.5) & 3.8 & $(1.2)$ & 1.1 & $(0.6)$ & 0.4 & $(0.4)$ \\
\hline & Sergipe & 53.1 & (5.9) & 26.8 & (3.7) & 13.9 & (3.3) & 4.7 & (1.8) & 1.3 & $(1.1)$ & 0.2 & $\mathrm{C}$ & 0.0 & $\mathrm{C}$ \\
\hline & Tocantins & 66.8 & $(4.5)$ & 21.6 & (3.1) & 6.6 & $(2.0)$ & 3.3 & (1.1) & 1.3 & $(0.6)$ & 0.4 & C & 0.0 & c \\
\hline & Colombia & & & & & & & & & & & & & & \\
\hline & Bogotá & 49.1 & $(2.4)$ & 29.4 & $(2.2)$ & 16.2 & $(1.8)$ & 4.3 & (1.0) & 0.9 & $(0.4)$ & 0.0 & C & 0.0 & c \\
\hline & Cali & 54.8 & $(4.3)$ & 24.9 & (2.6) & 14.8 & (2.3) & 4.4 & (1.6) & 1.1 & $(0.6)$ & 0.1 & c & 0.0 & c \\
\hline & Manizales & 43.0 & $(4.7)$ & 29.5 & (3.5) & 18.2 & (3.9) & 6.3 & (1.8) & 2.6 & $(0.9)$ & 0.3 & $\mathrm{C}$ & 0.0 & c \\
\hline & Medellín & 53.0 & $(4.5)$ & 23.1 & (3.2) & 12.5 & $(2.1)$ & 6.9 & (1.8) & 3.0 & $(1.6)$ & 1.0 & $(0.7)$ & 0.6 & $(0.6)$ \\
\hline & Russian Federation & & & & & & & & & & & & & & \\
\hline & Perm Territory region ${ }^{\bullet}$ & 6.4 & $(1.4)$ & 13.2 & $(2.0)$ & 26.6 & $(2.2)$ & 27.5 & $(2.0)$ & 16.7 & $(2.1)$ & 7.3 & (1.1) & 2.3 & $(1.1)$ \\
\hline & United Arab Emirates & & & & & & & & & & & & & & \\
\hline & Abu Dhabi` & 18.0 & $(2.2)$ & 25.5 & (1.6) & 26.7 & $(1.5)$ & 18.2 & (1.5) & 7.6 & $(0.8)$ & 3.3 & $(0.8)$ & 0.7 & $(0.3)$ \\
\hline & Ajman & 21.0 & $(4.7)$ & 30.0 & (3.4) & 28.4 & $(3.2)$ & 15.2 & (3.2) & 4.4 & $(1.8)$ & 0.9 & $(0.8)$ & 0.0 & C \\
\hline & Dubai ${ }^{\bullet}$ & 12.5 & $(0.6)$ & 20.0 & $(0.9)$ & 24.6 & $(1.4)$ & 22.8 & (1.5) & 13.7 & $(1.1)$ & 5.1 & $(0.7)$ & 1.3 & $(0.5)$ \\
\hline & Fujairah & 15.8 & (3.5) & 24.8 & $(4.1)$ & 32.5 & $(4.1)$ & 19.3 & (3.5) & 6.2 & (1.9) & 1.3 & $(0.9)$ & 0.1 & $\mathrm{C}$ \\
\hline & Ras al-Khaimah & 16.2 & (3.9) & 28.2 & (3.5) & 30.1 & $(3.8)$ & 18.8 & (2.6) & 5.8 & $(2.6)$ & 1.0 & (1.1) & 0.0 & c \\
\hline & Sharjah & 13.9 & $(3.2)$ & 25.7 & $(4.4)$ & 29.1 & (2.4) & 20.5 & (3.6) & 8.8 & $(2.5)$ & 1.9 & $(0.8)$ & 0.2 & c \\
\hline & Umm al-Quwain & 16.5 & (3.4) & 27.2 & $(4.7)$ & 31.2 & $(5.2)$ & 18.0 & (4.3) & 6.1 & $(2.3)$ & 0.9 & (1.1) & 0.0 & c \\
\hline
\end{tabular}

- PISA adjudicated region.

Note: See Table I.2.15 for national data.

StatLink त्नाls $h t t p: / / d x . d o i . o r g / 10.1787 / 888932935762$ 
[Part 1/2]

Mean score, variation and gender differences in student performance on the mathematics Table B2.I.15 subscale change and relationships, by region

\begin{tabular}{|c|c|c|c|c|c|c|c|c|c|c|c|c|c|c|c|c|c|c|c|}
\hline & & & All stu & udents & & & & nder di & ifferen & nces & & & & & & & Perce & entiles & \\
\hline & & Mean & iscore & $\begin{array}{l}\text { Stan } \\
\text { devi }\end{array}$ & $\begin{array}{l}\text { ard } \\
\text { ion }\end{array}$ & Bc & oys & Gi & & $\begin{array}{c}\text { Diffe } \\
\text { (B - }\end{array}$ & $\begin{array}{l}\text { rence } \\
- \text { G) }\end{array}$ & & th & & 0th & & 5th & & 5th \\
\hline & & Mean & S.E. & S.D. & S.E. & $\begin{array}{l}\text { Mean } \\
\text { score }\end{array}$ & S.E. & \begin{tabular}{|l|} 
Mean \\
score
\end{tabular} & S.E. & $\begin{array}{c}\begin{array}{c}\text { Score } \\
\text { dif. }\end{array} \\
\end{array}$ & S.E. & Score & S.E. & Score & S.E. & Score & S.E. & Score & S.E. \\
\hline 0 & Australia & & & & & & & & & & & & & & & & & & \\
\hline 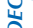 & Australian Capital Territory & 520 & $(4.1)$ & \begin{tabular}{|l|l|}
101 \\
$\mid$
\end{tabular} & (3.1) & 518 & (6.0) & 523 & (5.4) & -4 & (7.9) & 348 & (13.1) & 387 & (8.2) & 454 & (6.6) & 592 & (6.4) \\
\hline & New South Wales & 514 & (3.9) & 108 & (2.8) & 517 & (5.8) & 511 & $(4.3)$ & 6 & (6.6) & 340 & (6.1) & 376 & (5.2) & 439 & $(4.2)$ & 587 & (5.5) \\
\hline & Northern Territory & 456 & $(10.2)$ & 119 & (5.6) & 462 & (8.9) & 450 & (15.9) & 12 & (15.9) & 240 & $(23.2)$ & 302 & (15.8) & 382 & (11.7) & 534 & (15.0) \\
\hline & Queensland & 509 & $(3.1)$ & 102 & (1.9) & 514 & (4.1) & 503 & (3.7) & 10 & $(4.7)$ & 344 & (6.3) & 379 & $(5.1)$ & 437 & $(4.0)$ & 581 & (4.4) \\
\hline & South Australia & 493 & (3.4) & 102 & $(2.0)$ & 499 & (4.5) & 487 & $(4.2)$ & 12 & $(5.2)$ & 326 & (6.8) & 360 & (5.3) & 422 & (4.3) & 564 & (5.4) \\
\hline & Tasmania & 481 & (3.8) & 105 & (2.6) & 488 & (5.3) & 475 & $(5.3)$ & 13 & (7.5) & 306 & (8.7) & 344 & (7.3) & 409 & (6.4) & 554 & (5.8) \\
\hline & Victoria & 506 & (3.9) & 98 & (2.0) & 515 & (5.3) & 497 & $(4.2)$ & 18 & (5.7) & 344 & (6.8) & 378 & (4.6) & 440 & (4.8) & 573 & (4.8) \\
\hline & Western Australia & 520 & (4.3) & 107 & (2.5) & 531 & (6.3) & 509 & (5.8) & 22 & (8.6) & 345 & $(7.8)$ & 383 & $(7.0)$ & 445 & (6.2) & 597 & (5.6) \\
\hline & Belgium & & & & & & & & & & & & & & & & & & \\
\hline & Flemish Community ${ }^{\bullet}$ & 531 & (3.8) & $\mid 112$ & (3.6) & 538 & (5.5) & 525 & $(4.7)$ & 13 & (6.9) & 333 & $(10.8)$ & 381 & (7.5) & 460 & (5.1) & 613 & (3.6) \\
\hline & French Community & 490 & (4.0) & 118 & (5.4) & 491 & (4.8) & 488 & $(4.2)$ & 2 & (4.3) & 285 & (17.0) & 340 & (9.0) & 422 & (5.0) & 572 & (3.6) \\
\hline & German-speaking Community & 509 & (2.6) & 103 & (3.0) & 507 & (4.5) & 511 & (3.5) & -4 & (6.2) & 328 & (14.4) & 382 & (6.8) & 449 & (5.1) & 577 & (4.9) \\
\hline & Canada & & & & & & & & & & & & & & & & & & \\
\hline & Alberta & 526 & (4.9) & 97 & (2.4) & 533 & (5.5) & 520 & $(5.2)$ & 13 & (4.3) & 364 & (9.4) & 399 & (7.4) & 460 & (6.5) & 595 & (6.0) \\
\hline & British Columbia & 530 & (4.8) & 91 & (2.1) & 539 & (5.0) & 521 & (6.6) & 18 & (6.6) & 381 & (7.5) & 414 & (6.3) & 467 & (5.1) & 594 & (6.8) \\
\hline & Manitoba & 498 & (3.2) & 95 & $(2.2)$ & 503 & (4.1) & 493 & $(5.0)$ & 10 & (6.4) & 345 & (8.7) & 376 & (5.4) & 430 & (5.3) & 565 & (4.3) \\
\hline & New Brunswic & 505 & (3.0) & 88 & (1.9) & 507 & (4.5) & 503 & (3.6) & 4 & (5.6) & 356 & (6.4) & 390 & (5.1) & 446 & (5.1) & 562 & (4.3) \\
\hline & Newfoundland and Labrador & 500 & (3.9) & 94 & (2.3) & 500 & (5.2) & 499 & (4.4) & 1 & (5.6) & 347 & (8.3) & 379 & $(9.2)$ & 435 & (6.4) & 564 & (5.6) \\
\hline & Nova Scotia & 499 & (5.8) & 90 & (2.5) & 507 & (5.2) & 490 & $(7.7)$ & 17 & (6.2) & 351 & (7.1) & 382 & (7.0) & 437 & (5.5) & 561 & (6.1) \\
\hline & Ontario & 525 & $(4.2)$ & 92 & (1.9) & 531 & (4.9) & 519 & $(4.2)$ & 13 & (3.7) & 370 & (6.3) & 408 & (5.3) & 464 & (4.8) & 588 & (5.2) \\
\hline & Prince Edward Island & 490 & $(2.7)$ & 87 & (1.6) & 493 & (3.7) & 486 & (3.4) & 8 & (4.9) & 348 & (7.6) & 376 & $(5.2)$ & 429 & $(4.1)$ & 550 & (3.5) \\
\hline & Quebec & 535 & (3.7) & 98 & (1.8) & 545 & (4.4) & 527 & (4.3) & 18 & (4.5) & 366 & (6.8) & 405 & (5.8) & 470 & (4.6) & 606 & (4.0) \\
\hline & Saskatchewan & 516 & (3.3) & 90 & (2.3) & 521 & (4.6) & 510 & (3.6) & 12 & (5.1) & 367 & (7.1) & 402 & (5.1) & 456 & (2.7) & 580 & (5.8) \\
\hline & Italy & & & & & & & & & & & & & & & & & & \\
\hline & Abruzzo & 468 & (7.9) & $\mid 102$ & (5.9) & 476 & (9.6) & 459 & $(7.7)$ & 16 & (8.1) & 296 & (24.8) & 343 & (12.5) & 405 & (8.4) & 538 & (9.4) \\
\hline & Basilicata & 460 & (5.2) & 93 & (2.9) & 472 & (6.6) & 448 & (5.2) & 23 & (5.9) & 307 & (9.8) & 339 & (8.9) & 398 & (7.4) & 520 & (6.0) \\
\hline & Bolzano & 505 & (2.3) & 96 & (1.9) & 518 & (2.9) & 493 & (2.9) & 25 & (3.7) & 343 & (6.3) & 378 & $(5.1)$ & 441 & (4.8) & 571 & (3.4) \\
\hline & Calabria & 420 & $(5.7)$ & 96 & $(4.1)$ & 432 & (7.3) & 406 & (6.6) & 26 & (8.6) & 264 & (9.3) & 298 & (9.7) & 355 & (7.7) & 482 & (7.1) \\
\hline & Campania & 440 & (7.9) & 95 & (4.1) & 448 & (8.8) & 432 & (9.5) & 15 & (9.1) & 281 & (10.8) & 315 & (9.9) & 376 & (9.5) & 505 & $(9.2)$ \\
\hline & Emilia Romagna & 490 & $(7.3)$ & 104 & (3.7) & 501 & (10.9) & 478 & (7.6) & 23 & (12.3) & 313 & (12.1) & 354 & (7.9) & 421 & (8.8) & 564 & (8.1) \\
\hline & Friuli Venezia Giulia & 517 & (5.4) & 94 & (3.1) & 529 & (7.3) & 504 & (5.6) & 25 & (7.5) & 355 & (10.6) & 394 & (12.0) & 458 & (7.4) & 581 & (6.0) \\
\hline & Lazio & 462 & (6.6) & 98 & (3.5) & 473 & (7.0) & 449 & (7.0) & 24 & $(6.2)$ & 304 & (10.7) & 339 & $(10.1)$ & 396 & (7.7) & 529 & (8.9) \\
\hline & Liguria & 473 & (7.1) & 97 & $(3.2)$ & 479 & (9.6) & 466 & $(7.5)$ & 14 & (9.9) & 314 & $(8.9)$ & 348 & (10.1) & 406 & (8.4) & 538 & (9.2) \\
\hline & Lombardia & 511 & $(7.4)$ & 91 & $(3.2)$ & 521 & (8.9) & 500 & (8.0) & 22 & (9.1) & 358 & (9.3) & 395 & (9.3) & 451 & (8.0) & 575 & (9.1) \\
\hline & Marche & 489 & (5.7) & 91 & (3.1) & 504 & (6.4) & 474 & (6.7) & 30 & (6.6) & 338 & (13.0) & 369 & (9.5) & 426 & (7.7) & 554 & (7.0) \\
\hline & Molise & 458 & $(2.2)$ & 88 & (2.4) & 465 & (2.9) & 450 & (3.7) & 15 & (4.8) & 311 & (7.6) & 345 & (6.0) & 401 & (4.3) & 516 & (5.5) \\
\hline & Piemonte & 495 & (4.9) & 91 & (3.2) & 509 & (4.7) & 482 & (5.7) & 27 & (5.2) & 342 & (7.8) & 376 & (5.3) & 435 & (6.1) & 558 & (7.1) \\
\hline & Puglia & 470 & $(7.2)$ & 94 & (4.6) & 482 & (7.6) & 457 & $(7.2)$ & 24 & (5.9) & 315 & (14.8) & 349 & (9.9) & 406 & (7.5) & 536 & (8.1) \\
\hline & Sardegna & 444 & (5.9) & 95 & (3.0) & 449 & (6.0) & 440 & $(7.4)$ & 9 & (6.5) & 278 & $(11.2)$ & 319 & (13.6) & 380 & (8.4) & 513 & (6.6) \\
\hline & Sicilia & 435 & (6.0) & 92 & (3.3) & 441 & (7.6) & 428 & $(6.8)$ & 13 & (8.1) & 279 & (12.4) & 317 & $(9.4)$ & 374 & (8.1) & 498 & (6.3) \\
\hline & Toscana & 487 & (4.6) & 97 & (2.3) & 487 & (7.5) & 487 & (7.9) & 0 & (12.5) & 323 & (6.1) & 357 & (6.6) & 421 & (5.6) & 555 & (6.5) \\
\hline & Trento & 515 & (5.0) & 91 & (3.2) & 523 & (6.0) & 506 & $(7.8)$ & 16 & (10.0) & 362 & $(17.2)$ & 399 & $(9.3)$ & 456 & $(8.2)$ & 580 & (5.1) \\
\hline & Umbria & 483 & (7.0) & 96 & $(4.7)$ & 493 & $(10.2)$ & 473 & (6.3) & 20 & $(9.1)$ & 312 & (17.9) & 356 & (15.9) & 421 & (11.3) & 550 & (4.8) \\
\hline & Valle d'Aosta & 482 & $(2.7)$ & 86 & (2.4) & 488 & (4.1) & 475 & (3.6) & 13 & (5.5) & 345 & $(8.2)$ & 378 & (7.4) & 424 & (5.3) & 534 & (5.0) \\
\hline & Veneto & 519 & $(7.7)$ & 100 & $(4.8)$ & 532 & (8.4) & 506 & $(8.5)$ & 26 & (8.4) & 358 & $(11.7)$ & 393 & (9.3) & 457 & (8.0) & 587 & $(10.3)$ \\
\hline & Mexico & & & & & & & & & & & & & & & & & & \\
\hline & Aguascalientes & 431 & (4.9) & 85 & $(3.2)$ & 437 & (6.0) & 425 & (5.4) & 12 & (5.9) & 298 & (6.8) & ) 324 & (9.1) & 371 & (6.4) & 488 & (5.8) \\
\hline & Baja California & 407 & (5.4) & 83 & (2.6) & 416 & (6.8) & 398 & (5.7) & 18 & (6.2) & 275 & (8.8) & 303 & (7.8) & 351 & (5.4) & 463 & (6.4) \\
\hline & Baja California Sur & 401 & (6.9) & 86 & (2.7) & 409 & (8.2) & 392 & (6.3) & 18 & (4.4) & 260 & (8.9) & 288 & (11.4) & 341 & $(10.0)$ & 457 & (8.1) \\
\hline & Campeche & 381 & (4.6) & 86 & $(3.2)$ & 387 & (4.8) & 375 & (5.4) & 12 & (4.4) & 243 & (11.4) & 271 & $(7.2)$ & 325 & $(6.0)$ & 438 & (5.0) \\
\hline & Chiapas & 362 & (8.5) & 86 & (3.9) & 364 & (8.9) & 359 & (9.3) & 5 & $(6.2)$ & 220 & (10.6) & 251 & (12.4) & 304 & (11.1) & 417 & (9.9) \\
\hline & Chihuahua & 424 & (9.3) & 93 & (3.7) & 432 & (11.7) & 415 & (8.6) & 16 & (9.3) & 270 & (15.3) & 315 & (12.0) & 368 & (12.1) & 484 & (12.0) \\
\hline & Coahuila & 407 & (8.5) & 83 & (3.5) & 414 & (9.2) & 400 & (9.6) & 14 & (7.4) & 276 & (6.9) & 303 & (7.1) & 349 & (7.0) & 463 & (11.6) \\
\hline & Colima & 422 & (5.7) & 90 & (2.8) & 427 & (6.7) & 417 & $(6.2)$ & 10 & (6.0) & 276 & (9.8) & 306 & (7.1) & 358 & (7.6) & 483 & (8.0) \\
\hline & Distrito Federal & 428 & (7.1) & 83 & $(4.7)$ & 440 & (8.8) & 416 & $(7.2)$ & 25 & (7.9) & 293 & (19.8) & 326 & (12.9) & 372 & (8.0) & 482 & $(9.2)$ \\
\hline & Durango & 419 & (7.0) & 83 & (2.0) & 424 & (8.7) & 414 & (6.7) & 10 & (6.2) & 285 & (9.4) & 312 & (7.7) & 360 & (7.4) & 476 & $(10.0)$ \\
\hline & Guanajuato & 404 & (7.3) & 85 & (2.6) & 413 & (7.7) & 396 & (7.8) & 17 & (5.3) & 267 & (9.9) & 294 & (11.8) & 345 & (11.2) & 460 & (6.9) \\
\hline & Guerrero & 357 & (4.6) & 75 & (2.1) & 359 & (5.8) & 354 & $(4.7)$ & 5 & (5.3) & 238 & (8.2) & 263 & (6.3) & 306 & (6.6) & 404 & (5.4) \\
\hline & Hidalgo & 402 & (6.3) & 79 & (3.4) & 407 & (7.5) & 397 & (6.4) & 10 & (6.0) & 274 & (9.3) & 300 & (9.4) & 348 & (8.0) & 455 & (7.6) \\
\hline & Jalisco & 430 & (8.6) & 84 & (3.3) & 433 & (10.9) & 427 & $(7.2)$ & 6 & (6.3) & 292 & (13.2) & 322 & (14.1) & 374 & (11.8) & 486 & (7.5) \\
\hline & Mexico & 409 & (6.6) & 78 & (3.6) & 414 & (7.4) & 403 & (7.5) & 11 & (6.9) & 280 & (9.1) & 307 & (8.2) & 356 & (8.8) & 462 & (7.0) \\
\hline & Morelos & 415 & (9.4) & 89 & (7.1) & 416 & (11.0) & 414 & (9.4) & 2 & (7.6) & 273 & (19.3) & 305 & (16.5) & 357 & (10.1) & 472 & (11.9) \\
\hline & Nayarit & 404 & (6.2) & 86 & (3.1) & 408 & (6.3) & 400 & (7.3) & 8 & (6.0) & 262 & (14.5) & 293 & (10.2) & 344 & (7.7) & 461 & (6.0) \\
\hline & Nuevo León & 432 & (9.6) & 86 & (3.8) & 441 & (11.5) & 422 & (7.8) & 19 & (6.8) & 296 & (8.9) & 324 & (9.4) & 374 & (10.2) & 490 & (12.8) \\
\hline & Puebla & 408 & (6.4) & 89 & (4.5) & 410 & (9.7) & 407 & (6.3) & 3 & (9.9) & 259 & (16.1) & 295 & (10.6) & 353 & $(8.3)$ & 469 & (7.6) \\
\hline & Querétaro & 429 & (7.2) & 84 & (3.5) & 435 & (8.3) & 424 & (7.4) & 11 & (5.8) & 297 & (9.0) & 327 & (8.8) & 373 & (9.4) & 484 & (9.7) \\
\hline & Quintana Roo & 402 & $(5.7)$ & 87 & (3.0) & 405 & $(7.2)$ & 399 & (5.3) & 5 & (5.8) & 262 & (12.3) & 292 & (9.8) & 342 & (7.1) & 461 & (6.0) \\
\hline & San Luis Potosí & 402 & (8.9) & 87 & (2.9) & 401 & (10.3) & 403 & (8.8) & -2 & (6.7) & 265 & $(10.2)$ & 292 & (7.3) & 339 & (9.4) & 461 & (9.2) \\
\hline & Sinaloa & 400 & (5.1) & 83 & (2.5) & 402 & (6.9) & 399 & (5.1) & 3 & (6.1) & 270 & (10.6) & 294 & (7.3) & 343 & (6.1) & 457 & (5.9) \\
\hline & Tabasco & 368 & (5.7) & 84 & (3.6) & 373 & (7.0) & 363 & (6.1) & 10 & (6.3) & 234 & (10.2) & 260 & (9.3) & 310 & (7.6) & 422 & $(7.2)$ \\
\hline & Tamaulipas & 399 & (8.7) & 88 & (3.5) & 410 & (12.1) & 388 & (7.3) & 22 & (9.8) & 259 & (12.2) & 287 & (10.4) & 339 & (9.3) & 456 & (10.7) \\
\hline & Tlaxcala & 400 & (6.2) & 85 & (2.9) & 406 & (5.9) & 394 & (7.3) & 12 & (4.7) & 260 & (10.9) & 291 & (11.5) & 345 & (8.1) & 455 & (5.7) \\
\hline & Veracruz & 383 & (7.2) & 92 & (3.0) & 386 & (6.9) & 379 & $(9.0)$ & 8 & (7.0) & 235 & (8.8) & 267 & (8.6) & 318 & (7.2) & 444 & (9.4) \\
\hline & Yucatán & 393 & (5.9) & 93 & (3.0) & 405 & (6.9) & 380 & (6.7) & 25 & (6.9) & 248 & (11.5) & 280 & (8.5) & 328 & (6.3) & 454 & (5.7) \\
\hline & Zacatecas & 398 & $(5.1)$ & 86 & (2.6) & 402 & $(6.2)$ & 393 & $(5.2)$ & 9 & (5.1) & 255 & $(12.1)$ & 285 & $(7.7)$ & 340 & (6.1) & 457 & (6.1) \\
\hline
\end{tabular}

- PISA adjudicated region.

Notes: Values that are statistically significant are indicated in bold (see Annex A3).

See Table 1.2.16 for national data.

StatLink 部 SD http://dx.doi.org/10.1787/888932935762 
[Part 2/2]

Mean score, variation and gender differences in student performance on the mathematics Table B2.I.15 subscale change and relationships, by region

\begin{tabular}{|c|c|c|c|c|c|c|c|c|c|c|c|c|c|c|c|c|c|c|c|c|c|c|c|}
\hline & & & All stu & udents & & & & nder di & lifferen & nces & & & & & & & Perce & entiles & & & & & \\
\hline & & Mean & score & $\begin{array}{l}\text { Stan } \\
\text { devi }\end{array}$ & $\begin{array}{l}\text { ndard } \\
\text { iation }\end{array}$ & & oys & Gi & irls & $\begin{array}{c}\text { Diffe } \\
\text { (B }\end{array}$ & $\begin{array}{l}\text { rence } \\
\text { - G) }\end{array}$ & & th & & 0th & & 5th & & 5th & & 0th & & 5th \\
\hline & & Mean & S.E. & S.D. & S.E. & $\begin{array}{l}\text { Mean } \\
\text { score }\end{array}$ & S.E. & $\begin{array}{l}\text { Mean } \\
\text { score }\end{array}$ & S.E. & \begin{tabular}{|c}
$\begin{array}{c}\text { Score } \\
\text { dif. }\end{array}$ \\
\end{tabular} & S.E. & Score & S.E. & Score & e S.E. & Score & e S.E. & Score & e S.E. & Score & e S.E. & Score & e S.E. \\
\hline 8 & Portugal & & & & & & & & & & & & & & & & & & & & & & \\
\hline 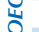 & Alentejo & \begin{tabular}{|l}
486 \\
\end{tabular} & (10.4) & 97 & (4.9) & 495 & (12.9) & 478 & (9.3) & 16 & (8.2) & \begin{tabular}{|l|}
327 \\
\end{tabular} & (16.2) & $\mid 360$ & (16.5) & 422 & $(15.4)$ & | 554 & - (12.4) & 613 & (12.4) & $\mid 648$ & (11.6) \\
\hline & Spain & & & & & & & & & & & & & & & & & & & & & & \\
\hline & Andalusia & 471 & (4.3) & 87 & (2.0) & 479 & (5.4) & 462 & (3.9) & 18 & (4.3) & 329 & (7.9) & 360 & (6.4) & 410 & (4.9) & 531 & (5.7) & 584 & (6.3) & 615 & (7.2) \\
\hline & Aragon ${ }^{\bullet}$ & 493 & (6.7) & 98 & (2.2) & 499 & (6.9) & 486 & (7.5) & 13 & (5.4) & 322 & (10.1) & 358 & (8.7) & 428 & (9.0) & 565 & (6.8) & 615 & (5.6) & 641 & (7.8) \\
\hline & Asturias ${ }^{\bullet}$ & 497 & (4.7) & 97 & (2.5) & 502 & (6.2) & 493 & (4.6) & 8 & (5.4) & 332 & (10.0) & 372 & (8.4) & 436 & (6.6) & 565 & (5.4) & 617 & (5.4) & 649 & (8.5) \\
\hline & Balearic Islands ${ }^{\bullet}$ & 471 & (4.8) & 94 & (2.3) & 472 & (5.7) & 471 & (5.4) & 2 & $(5.7)$ & 314 & (7.6) & 351 & (8.1) & 405 & (6.4) & 540 & (5.1) & 590 & (6.3) & 618 & (5.1) \\
\hline & Basque Country ${ }^{\bullet}$ & 506 & (2.6) & 87 & (1.3) & 514 & (3.1) & 498 & (3.0) & 16 & (3.0) & 358 & (4.1) & 391 & (4.2) & 448 & (3.0) & 566 & (3.1) & 615 & (2.9) & 642 & (3.5) \\
\hline & Cantabria ${ }^{\bullet}$ & 486 & (3.6) & 97 & (2.2) & 490 & (4.4) & 481 & (5.1) & 8 & $(6.2)$ & 324 & (8.6) & 361 & (6.2) & 422 & (5.2) & 555 & (4.9) & 611 & (3.8) & 636 & $(4.7)$ \\
\hline & Castile and Leon ${ }^{\bullet}$ & 507 & (4.4) & 84 & (1.7) & 514 & (5.8) & 500 & (4.5) & 14 & (5.3) & 366 & (5.5) & 398 & (6.0) & 449 & (5.4) & 567 & (5.3) & 612 & (5.6) & 638 & (4.3) \\
\hline & Catalonia ${ }^{\bullet}$ & 489 & (5.8) & 95 & (2.1) & 499 & (6.7) & 477 & (6.5) & 22 & (6.1) & 330 & (6.9) & 363 & (8.0) & 425 & (7.5) & 555 & (6.1) & 609 & (6.3) & 642 & (7.2) \\
\hline & Extremadura ${ }^{\bullet}$ & 461 & (4.6) & 100 & (2.3) & 465 & (5.6) & 456 & (4.6) & 8 & (4.6) & 292 & (9.3) & 327 & (7.4) & 390 & (6.5) & 532 & (5.5) & 588 & (6.2) & 622 & (8.1) \\
\hline & Galicia• & 485 & (4.8) & 88 & (2.1) & 487 & (5.5) & 484 & (5.5) & 2 & (5.3) & 334 & (8.0) & 368 & (7.6) & 429 & (7.3) & 546 & (4.2) & 595 & (5.3) & 624 & (6.1) \\
\hline & La Rioja• & 496 & (2.2) & 107 & (3.0) & 506 & (3.5) & 488 & (3.2) & 19 & (5.1) & 316 & (10.3) & 360 & (5.8) & 430 & (4.2) & 571 & (3.8) & 626 & (3.7) & 655 & (5.5) \\
\hline & Madrid ${ }^{\bullet}$ & 500 & (4.4) & 92 & (3.2) & 504 & (5.4) & 496 & (4.7) & 9 & (4.8) & 341 & (11.4) & 377 & (9.0) & 438 & (5.4) & 567 & $(4.2)$ & 613 & (3.9) & 638 & (4.7) \\
\hline & Murcia ${ }^{\bullet}$ & 459 & (5.2) & 97 & (2.9) & 464 & (6.5) & 454 & (4.8) & 10 & (4.9) & 301 & (9.6) & 333 & (5.5) & 396 & (5.0) & 527 & (6.5) & 584 & (8.8) & 618 & (12.4) \\
\hline & Navarre ${ }^{\bullet}$ & 519 & (3.3) & 85 & (1.8) & 520 & (4.1) & 517 & (3.9) & 3 & (4.4) & 373 & (5.9) & 405 & (5.0) & 460 & (4.9) & 579 & (3.3) & 626 & $(5.2)$ & 652 & (5.5) \\
\hline & United Kingdom & & & & & & & & & & & & & & & & & & & & & & \\
\hline & England & 498 & (4.1) & 100 & (2.1) & 506 & (5.3) & 490 & (4.6) & 15 & (5.6) & 333 & (6.2) & 368 & (6.2) & 430 & (5.3) & 568 & (4.5) & 628 & (5.1) & 662 & (5.4) \\
\hline & Northern Ireland & 486 & (3.8) & 99 & (2.3) & 491 & (5.6) & 479 & (5.8) & 12 & (8.4) & 321 & (7.4) & 358 & (6.2) & 416 & (5.1) & 555 & (5.1) & 614 & (6.3) & 651 & (5.6) \\
\hline & Scotland ${ }^{\bullet}$ & 497 & (3.1) & 93 & (2.1) & 506 & (3.5) & 487 & (3.6) & 19 & (3.5) & 344 & (7.0) & 380 & (4.9) & 434 & (4.0) & 561 & (3.3) & 618 & (4.4) & 650 & (6.8) \\
\hline & Wales & 470 & (2.5) & 90 & (1.3) & 476 & (3.0) & 463 & (3.0) & 13 & (3.3) & 321 & (4.8) & 353 & (4.9) & 409 & (3.3) & 532 & (2.9) & 584 & (3.7) & 616 & (5.2) \\
\hline & United States & & & & & & & & & & & & & & & & & & & & & & \\
\hline & Connecticut $^{\bullet}$ & 515 & (7.0) & $\mid 106$ & (2.5) & 525 & (7.7) & 504 & (7.2) & 21 & (5.4) & 343 & (10.5) & 376 & (8.8) & 439 & (8.2) & 590 & (7.4) & 653 & (8.8) & 692 & (10.4) \\
\hline & Florida• & 476 & (5.6) & 91 & (2.8) & 484 & (6.4) & 467 & (5.6) & 17 & $(4.3)$ & 334 & $(7.3)$ & 362 & (6.7) & 412 & (6.2) & 536 & (7.0) & 597 & (9.9) & 634 & $(10.9)$ \\
\hline & Massachusetts ${ }^{\bullet}$ & 518 & (6.7) & 106 & (3.3) & 527 & (6.8) & 510 & $(7.5)$ & 17 & $(5.0)$ & 346 & $(7.8)$ & 383 & (6.3) & 445 & (6.0) & 591 & (9.4) & 655 & $(10.1)$ & 693 & (11.4) \\
\hline$\frac{2}{2}$ & Argentina & & & & & & & & & & & & & & & & & & & & & & \\
\hline$\stackrel{0}{0}$ & Ciudad Autónoma de Buenos Aires $\bullet$ & 408 & $(9.7)$ & 113 & $(10.0)$ & $\mid 414$ & $(10.4)$ & 403 & $(10.1)$ & 10 & (6.5) & 209 & (37.5) & $\mid 267$ & $(17.0)$ & 342 & $(10.2)$ & 484 & (8.4) & $\mid 541$ & (9.1) & 577 & (12.5) \\
\hline$\Xi$ & Brazil & & & & & & & & & & & & & & & & & & & & & & \\
\hline & Acre & 331 & (8.6) & 96 & (6.0) & 341 & (12.0) & 322 & (9.5) & 19 & (12.6) & 177 & (12.4) & 211 & (9.1) & 267 & (7.5) & 394 & (11.8) & 453 & (17.4) & 487 & (23.3) \\
\hline & Alagoas & 304 & (9.3) & 99 & (7.6) & 323 & (12.4) & 289 & (8.4) & 34 & $(8.2)$ & 147 & (25.8) & 183 & $(16.0)$ & 241 & (9.3) & 362 & $(11.2)$ & 429 & $(24.2)$ & 476 & $(27.2)$ \\
\hline & Amapá & 323 & $(11.0)$ & 91 & (5.6) & 336 & (12.9) & 312 & (10.0) & 24 & (7.6) & 172 & (12.6) & 204 & (12.6) & 263 & (11.1) & 380 & $(12.7)$ & 435 & $(17.5)$ & 469 & (28.0) \\
\hline & Amazonas & 320 & (8.2) & 92 & $(6.2)$ & 330 & $(10.2)$ & 311 & $(7.7)$ & 19 & (7.6) & 174 & (19.0) & 211 & (10.5) & 261 & (8.3) & 374 & (9.7) & 435 & (16.0) & 483 & (26.4) \\
\hline & Bahia & 342 & (14.9) & 106 & (7.9) & 353 & (9.3) & 333 & (21.9) & 20 & (17.7) & 171 & (20.9) & 207 & (21.1) & 274 & $(18.2)$ & 412 & (22.1) & 483 & (14.1) & 513 & (18.2) \\
\hline & Ceará & 354 & (11.1) & 103 & (8.1) & 364 & (12.7) & 345 & (11.5) & 19 & (9.6) & 191 & (14.3) & 227 & (17.2) & 287 & (10.3) & 415 & (14.0) & 482 & (21.6) & 536 & (39.4) \\
\hline & Espírito Santo & 398 & (10.2) & 105 & (8.1) & 410 & (10.2) & 388 & (13.5) & 22 & (11.9) & 241 & (14.1) & 272 & (10.8) & 326 & (8.1) & 461 & (17.6) & 551 & (29.6) & 591 & $(20.2)$ \\
\hline & Federal District & 397 & (9.9) & 101 & (5.5) & 408 & $(11.7)$ & 387 & $(10.0)$ & 21 & $(8.8)$ & 241 & (12.1) & 271 & (12.9) & 323 & (12.6) & 470 & $(15.2)$ & 536 & $(17.0)$ & 570 & (12.8) \\
\hline & Goiás & 357 & (7.9) & 89 & (4.4) & 366 & (9.2) & 349 & $(8.4)$ & 17 & $(8.1)$ & 221 & (13.7) & 248 & $(11.7)$ & 296 & $(12.1)$ & 414 & $(10.4)$ & 475 & $(11.7)$ & 513 & (14.3) \\
\hline & Maranhão & 313 & $(16.2)$ & 93 & $(10.8)$ & 326 & (19.5) & 304 & $(14.8)$ & 22 & (9.6) & 172 & (11.9) & 200 & $(10.8)$ & 251 & (9.3) & 367 & $(23.4)$ & 433 & (39.5) & 482 & $(45.3)$ \\
\hline & Mato Grosso & 343 & (12.6) & 96 & $(8.4)$ & 346 & (12.6) & 340 & (13.8) & 6 & $(8.1)$ & 197 & $(24.3)$ & 227 & $(17.7)$ & 279 & (13.9) & 400 & (13.6) & 464 & $(18.2)$ & 505 & (36.5) \\
\hline & Mato Grosso do Sul & 387 & (10.8) & 97 & (5.4) & 398 & (13.2) & 378 & (9.8) & 19 & (8.5) & 235 & (13.9) & 263 & (16.6) & 322 & (13.9) & 445 & (12.5) & 520 & (19.8) & 570 & (23.1) \\
\hline & Minas Gerais & 392 & $(8.2)$ & 87 & (4.1) & 401 & (10.1) & 384 & (7.8) & 17 & (6.3) & 256 & (14.6) & 282 & (10.5) & 331 & (9.2) & 450 & (8.7) & 504 & $(12.0)$ & 539 & (15.1) \\
\hline & Pará & 333 & (6.4) & 87 & (3.3) & 340 & (7.2) & 328 & (8.0) & 11 & (8.3) & 200 & (13.4) & 226 & (11.0) & 270 & (8.6) & 393 & (11.6) & 450 & $(7.3)$ & 480 & $(10.2)$ \\
\hline & Paraíba & 375 & (9.1) & 99 & (8.8) & 383 & (11.0) & 367 & (11.2) & 16 & (12.5) & 217 & (25.4) & 253 & (18.3) & 310 & (14.9) & 441 & (9.7) & 506 & $(18.6)$ & 546 & (18.2) \\
\hline & Paraná & 384 & (13.8) & 100 & (11.1) & 397 & (14.1) & 371 & (14.9) & 26 & (8.0) & 235 & (15.2) & 266 & (12.2) & 314 & $(8.7)$ & 445 & (19.4) & 525 & (38.9) & 575 & (44.6) \\
\hline & Pernambuco & 335 & (10.5) & 86 & (4.3) & 346 & (11.3) & 327 & (10.6) & 19 & (6.0) & 199 & (13.8) & 225 & $(13.2)$ & 276 & (12.0) & 392 & (12.8) & 442 & (14.0) & 485 & (21.6) \\
\hline & Piauí & 361 & (9.9) & 104 & $(9.2)$ & 371 & (10.7) & 354 & (10.4) & 17 & $(7.2)$ & 206 & (10.6) & 237 & (9.6) & 292 & (9.3) & 422 & (13.2) & 502 & (25.1) & 548 & (30.3) \\
\hline & Rio de Janeiro & 375 & $(8.1)$ & 89 & (5.3) & 384 & (9.2) & 366 & $(8.7)$ & 18 & (7.7) & 229 & $(15.2)$ & 262 & (13.4) & 316 & $(10.5)$ & 434 & $(11.1)$ & 491 & $(12.1)$ & 525 & (10.4) \\
\hline & Rio Grande do Norte & 349 & $(10.1)$ & 103 & (7.5) & 363 & (13.0) & 337 & (9.1) & 25 & (8.5) & 201 & (12.1) & 231 & (10.3) & 280 & (7.0) & 402 & (19.4) & 494 & (23.1) & 547 & $(35.8)$ \\
\hline & Rio Grande do Sul & 393 & $(6.2)$ & 87 & (3.6) & 399 & (7.7) & 387 & (6.6) & 12 & (7.0) & 253 & (11.4) & 280 & (9.5) & 333 & (7.3) & 451 & $(8.1)$ & 505 & $(8.2)$ & 536 & (10.7) \\
\hline & Rondônia & 357 & $(8.2)$ & 84 & (4.3) & 359 & (9.0) & 356 & (9.5) & 3 & (8.6) & 220 & (15.1) & 251 & (11.4) & 301 & (9.4) & 412 & (8.2) & 465 & $(11.2)$ & 495 & (16.0) \\
\hline & Roraima & 337 & (7.1) & 90 & (4.1) & 343 & (6.5) & 332 & (10.7) & 11 & (10.5) & 200 & $(10.2)$ & 225 & (7.1) & 275 & (8.6) & 393 & (9.5) & 460 & $(15.7)$ & 497 & (18.7) \\
\hline & Santa Cat & 397 & (12.4) & 96 & (5.5) & 407 & (12.1) & 388 & (13.6) & 19 & (7.4) & 244 & (20.1) & 277 & (16.8) & 335 & (12.5) & 457 & (15.7) & 525 & $(17.5)$ & 567 & (19.9) \\
\hline & São Paulo & 387 & (6.4) & 100 & (4.2) & 395 & (6.8) & 378 & $(6.8)$ & 17 & $(4.2)$ & 233 & $(7.7)$ & 265 & (6.8) & 316 & (5.2) & 451 & $(7.7)$ & 519 & (11.4) & 559 & $(16.2)$ \\
\hline & Sergipe & 361 & (13.1) & 94 & (7.1) & 377 & (16.0) & 348 & (12.3) & 29 & (9.8) & 216 & (13.9) & 245 & (13.2) & 297 & (11.3) & 418 & (18.5) & 486 & $(29.2)$ & 529 & (27.4) \\
\hline & Tocantins & 332 & (10.8) & 99 & (5.8) & 345 & (12.4) & 319 & (9.6) & 26 & (6.8) & 176 & (15.7) & 207 & (16.4) & 265 & (11.8) & 394 & (11.4) & 463 & (21.0) & 508 & (20.7) \\
\hline & Colombia & & & & & & & & & & & & & & & & & & & & & & \\
\hline & Bogotá & 377 & (4.1) & 80 & (3.1) & 397 & (6.0) & 359 & (4.0) & 38 & (6.1) & 249 & (6.2) & 277 & (4.8) & 323 & (4.3) & 430 & (5.2) & 479 & (7.2) & 511 & (10.9) \\
\hline & Cali & 359 & (6.9) & 86 & (3.3) & 372 & (7.7) & 349 & (7.7) & 23 & (6.0) & 223 & (8.2) & 253 & (7.7) & 302 & (6.0) & 416 & (9.9) & 470 & $(9.8)$ & 503 & (11.9) \\
\hline & Manizales & 388 & (5.7) & 92 & (4.7) & 405 & (8.7) & 372 & (6.2) & 33 & (9.4) & 245 & (11.6) & 276 & (8.5) & 325 & (6.9) & 443 & (7.3) & 507 & $(12.6)$ & 550 & $(16.2)$ \\
\hline & Medellín & 375 & (9.5) & 98 & (6.0) & 391 & (10.7) & 360 & (11.3) & 31 & (11.1) & 229 & (7.9) & 256 & (9.3) & 309 & (8.6) & 436 & (13.3) & 504 & $(16.7)$ & 552 & (20.8) \\
\hline & Russian F & & & & & & & & & & & & & & & & & & & & & & \\
\hline & Perm Territory $\mathrm{r}$ & 493 & (5.9) & 93 & (4.3) & 494 & (7.1) & 491 & (5.7) & 3 & (4.9) & $\mid 337$ & (10.2) & $\mid 375$ & (9.1) & 432 & (6.5) & $\mid 553$ & (5.9) & $\mid 611$ & (9.2) & 647 & (15.6) \\
\hline & United Arab Emirates & & & & & & & & & & & & & & & & & & & & & & \\
\hline & Abu Dhabi ${ }^{\bullet}$ & 429 & (4.1) & 94 & (2.4) & 421 & (5.6) & 438 & (5.1) & -17 & (7.1) & 282 & (5.9) & $\mid 312$ & (5.7) & 365 & (4.5) & 489 & (5.2) & 555 & (8.6) & 599 & (9.2) \\
\hline & Ajman & 412 & (7.9) & 75 & (3.6) & 402 & (12.5) & 420 & (10.4) & -18 & (16.4) & 290 & (10.6) & 315 & $(11.7)$ & 357 & $(11.2)$ & 465 & (7.0) & 507 & (7.6) & 533 & (8.9) \\
\hline & Dubai ${ }^{\bullet}$ & 470 & (1.2) & 102 & (1.2) & 476 & (2.1) & 465 & (1.6) & 11 & (2.8) & 307 & (2.9) & 339 & (2.9) & 398 & (2.3) & 541 & (2.4) & 602 & (3.5) & 638 & (5.0) \\
\hline & Fujairah & 420 & (10.3) & 85 & (2.7) & 406 & $(10.2)$ & 435 & $(10.2)$ & -29 & (9.9) & 284 & (15.5) & 314 & $(13.2)$ & 361 & $(11.4)$ & 478 & (11.6) & 528 & $(10.8)$ & 564 & $(14.5)$ \\
\hline & Ras al-Khaimah & 424 & $(6.6)$ & 77 & (3.1) & 416 & (8.2) & 432 & $(9.4)$ & -16 & (10.8) & 301 & (12.6) & 326 & (8.5) & 369 & (8.3) & 479 & (7.0) & 524 & (7.5) & 552 & (11.9) \\
\hline & Sharjah & 450 & (10.4) & 86 & (4.0) & 458 & (18.9) & 444 & (10.1) & 15 & (22.0) & 319 & (13.3) & 344 & (10.4) & 388 & $(10.8)$ & 507 & (12.9) & 565 & (14.1) & 595 & (13.7) \\
\hline & Umm al-Quwain & 409 & (3.7) & 81 & (3.6) & 387 & (5.0) & 431 & (5.4) & -43 & (7.3) & 275 & (10.1) & 306 & (7.9) & 356 & (7.9) & 458 & (8.6) & 514 & (10.6) & 549 & (12.7) \\
\hline
\end{tabular}

- PISA adjudicated region.

Notes: Values that are statistically significant are indicated in bold (see Annex A3).

See Table I.2.16 for national data.

StatLink 年15 http://dx.doi.org/10.1787/888932935762 
[Part 1/2]

Percentage of students at each proficiency level on the mathematics subscale space and shape, Table B2.I.16 by region

\begin{tabular}{|c|c|c|c|c|c|c|c|c|c|c|c|c|c|c|c|}
\hline & & \multicolumn{14}{|c|}{ All students } \\
\hline & & \multicolumn{2}{|c|}{$\begin{array}{l}\text { Below Level } 1 \\
\text { (below 357.77 } \\
\text { score points) }\end{array}$} & $\begin{array}{l}\text { Le } \\
\text { (from } \\
\text { less tha } \\
\text { score }\end{array}$ & $\begin{array}{l}\text { I } 1 \\
7.77 \text { to } \\
420.07 \\
\text { oints) }\end{array}$ & $\begin{array}{l}\text { Le } \\
\text { (from } \\
\text { less th } \\
\text { score }\end{array}$ & $\begin{array}{l}2 \\
.07 \text { to } \\
482.38 \\
\text { jints) }\end{array}$ & $\begin{array}{l}\text { Le } \\
\text { (from } \\
\text { less th } \\
\text { score }\end{array}$ & $\begin{array}{l}\text { I } 3 \\
2.38 \text { to } \\
544.68 \\
\text { oints) }\end{array}$ & $\begin{array}{l}\text { Le } \\
\text { (from } \\
\text { less th } \\
\text { score }\end{array}$ & $\begin{array}{l}14 \\
4.68 \text { to } \\
606.99 \\
\text { oints) }\end{array}$ & $\begin{array}{l}\text { Le } \\
\text { (from } \\
\text { less tha } \\
\text { score }\end{array}$ & $\begin{array}{l}\text { I } 5 \\
6.99 \text { to } \\
669.30 \\
\text { oints) }\end{array}$ & $\begin{array}{l}\text { Le } \\
\text { (abov } \\
\text { score }\end{array}$ & $\begin{array}{l}6 \\
69.30 \\
\text { ints) }\end{array}$ \\
\hline & & $\%$ & S.E. & $\%$ & S.E. & $\%$ & S.E. & $\%$ & S.E. & $\%$ & S.E. & $\%$ & S.E. & $\%$ & S.E. \\
\hline 0 & Australia & & & & & & & & & & & & & & \\
\hline 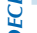 & Australian Capital Territory & 6.6 & $(1.1)$ & 12.6 & (1.4) & 19.9 & (1.8) & 23.9 & (1.7) & 19.3 & (1.6) & 12.0 & (1.4) & 5.7 & (1.1) \\
\hline & New South Wales & 8.5 & $(0.8)$ & 14.7 & $(1.0)$ & 21.2 & $(1.2)$ & 21.9 & (1.1) & 16.3 & (1.1) & 10.2 & $(0.9)$ & 7.2 & (1.1) \\
\hline & Northern Territory & 15.3 & (2.4) & 18.7 & (3.8) & 23.7 & (3.9) & 24.1 & $(4.9)$ & 12.4 & (3.2) & 4.7 & $(1.8)$ & 1.1 & $(0.7)$ \\
\hline & Queensland & 7.9 & $(0.8)$ & 15.0 & $(0.9)$ & 22.3 & (1.1) & 23.9 & $(1.0)$ & 17.1 & $(1.0)$ & 9.8 & $(0.8)$ & 4.1 & $(0.6)$ \\
\hline & South Australia & 9.5 & (1.1) & 17.6 & (1.4) & 23.3 & (1.6) & 24.5 & (1.6) & 15.6 & (1.3) & 7.0 & $(0.9)$ & 2.4 & $(0.6)$ \\
\hline & Tasmania & 11.5 & (1.4) & 18.5 & (1.4) & 25.7 & $(2.0)$ & 22.7 & (1.5) & 14.2 & (1.4) & 5.0 & $(0.9)$ & 2.5 & $(0.6)$ \\
\hline & Victoria & 8.0 & $(0.8)$ & 16.3 & $(1.3)$ & 22.2 & $(1.3)$ & 24.6 & $(1.3)$ & 17.1 & $(1.1)$ & 7.9 & $(0.8)$ & 3.9 & $(0.8)$ \\
\hline & Western Australia & 5.8 & $(0.7)$ & 12.9 & $(1.1)$ & 21.3 & $(1.2)$ & 24.6 & $(1.6)$ & 19.4 & $(1.2)$ & 11.2 & $(1.1)$ & 4.7 & $(0.8)$ \\
\hline & Belgium & & & & & & & & & & & & & & \\
\hline & Flemish Community• & 6.6 & $(0.8)$ & 10.8 & $(0.9)$ & 16.8 & $(0.9)$ & 20.8 & $(1.2)$ & 19.7 & $(1.0)$ & 15.4 & $(0.8)$ & 9.8 & $(0.7)$ \\
\hline & French Community & 10.9 & $(1.2)$ & 15.3 & $(1.1)$ & 22.9 & (1.4) & 22.8 & $(1.2)$ & 16.6 & $(1.0)$ & 8.4 & $(0.6)$ & 3.2 & $(0.5)$ \\
\hline & German-speaking Community & 5.5 & (1.3) & 12.0 & (1.5) & 20.3 & (1.6) & 26.4 & $(2.2)$ & 21.6 & (1.9) & 10.8 & (1.5) & 3.4 & $(0.8)$ \\
\hline & Canada & & & & & & & & & & & & & & \\
\hline & Alberta & 5.5 & $(0.7)$ & 11.9 & $(1.3)$ & 22.6 & $(1.7)$ & 23.9 & (1.6) & 20.6 & (1.4) & 11.0 & $(1.0)$ & 4.5 & $(0.7)$ \\
\hline & British Columbia & 4.4 & $(0.8)$ & 11.5 & $(1.1)$ & 22.6 & $(2.0)$ & 25.7 & (1.5) & 20.1 & (1.3) & 11.3 & (1.3) & 4.4 & $(0.9)$ \\
\hline & Manitoba & 8.3 & (1.3) & 16.9 & (1.6) & 25.5 & (1.5) & 23.7 & (1.8) & 15.8 & (1.4) & 7.3 & $(0.9)$ & 2.5 & $(0.5)$ \\
\hline & New Brunswick & 6.4 & $(0.8)$ & 13.0 & (1.4) & 24.3 & $(2.0)$ & 28.5 & (1.7) & 18.3 & (1.5) & 7.6 & $(1.2)$ & 1.9 & $(0.6)$ \\
\hline & Newfoundland and Labrador & 9.0 & (1.4) & 17.1 & (1.6) & 25.4 & $(2.3)$ & 26.1 & $(2.0)$ & 15.5 & (1.7) & 5.7 & $(1.0)$ & 1.1 & $(0.4)$ \\
\hline & Nova Scotia & 6.8 & (1.1) & 15.9 & $(2.0)$ & 28.7 & (3.4) & 25.1 & (1.8) & 16.5 & (1.6) & 5.2 & $(1.1)$ & 1.8 & (0.6) \\
\hline & Ontario & 5.1 & $(0.7)$ & 13.1 & $(1.0)$ & 23.2 & (1.3) & 25.6 & $(1.2)$ & 19.1 & (1.2) & 9.3 & $(0.9)$ & 4.5 & $(0.6)$ \\
\hline & Prince Edward Island & 11.7 & (1.1) & 21.0 & $(1.3)$ & 27.6 & (1.5) & 22.6 & (1.5) & 12.3 & (1.3) & 4.2 & $(0.7)$ & 0.6 & $(0.2)$ \\
\hline & Quebec & 4.7 & $(0.6)$ & 8.4 & $(0.9)$ & 16.7 & $(1.0)$ & 22.6 & (1.3) & 22.8 & $(1.0)$ & 16.2 & (1.4) & 8.6 & (1.1) \\
\hline & Saskatchewan & 5.7 & $(0.7)$ & 13.1 & $(1.1)$ & 24.8 & (1.4) & 26.1 & (1.9) & 18.9 & (1.6) & 9.0 & $(1.3)$ & 2.3 & $(0.6)$ \\
\hline & Italy & & & & & & & & & & & & & & \\
\hline & Abruzzo & 11.4 & (2.0) & 16.9 & (1.9) & 23.2 & $(1.7)$ & 21.8 & $(1.8)$ & 16.0 & (1.9) & 7.3 & (1.4) & 3.5 & $(0.9)$ \\
\hline & Basilicata & 10.9 & $(1.3)$ & 18.1 & (1.8) & 25.5 & (1.7) & 22.2 & (1.4) & 14.5 & (1.4) & 6.1 & $(1.0)$ & 2.7 & $(0.5)$ \\
\hline & Bolzano & 5.8 & $(0.7)$ & 11.8 & (1.4) & 21.8 & (1.4) & 24.7 & (1.4) & 19.5 & (1.4) & 10.9 & $(1.2)$ & 5.5 & $(0.6)$ \\
\hline & Calabria & 23.6 & $(2.3)$ & 24.0 & $(1.6)$ & 24.0 & $(1.8)$ & 17.5 & (1.7) & 7.2 & $(0.9)$ & 2.7 & $(0.7)$ & 0.9 & $(0.4)$ \\
\hline & Campania & 17.8 & $(2.2)$ & 21.2 & $(2.5)$ & 24.4 & (2.6) & 17.3 & (2.5) & 11.3 & (1.6) & 5.3 & (1.3) & 2.7 & $(1.0)$ \\
\hline & Emilia Romagna & 8.9 & (1.3) & 13.3 & $(1.5)$ & 21.1 & $(1.6)$ & 22.3 & (1.9) & 17.7 & (1.7) & 10.3 & $(1.2)$ & 6.5 & (1.5) \\
\hline & Friuli Venezia Giulia & 3.3 & $(0.8)$ & 9.6 & $(1.1)$ & 17.2 & (1.5) & 25.2 & (1.5) & 22.1 & (1.6) & 14.0 & $(1.4)$ & 8.6 & (1.1) \\
\hline & Lazio & 13.1 & (1.8) & 18.0 & (1.6) & 23.5 & $(2.1)$ & 21.9 & $(1.7)$ & 12.9 & $(1.5)$ & 7.7 & (1.3) & 3.0 & $(0.8)$ \\
\hline & Liguria & 9.1 & (1.3) & 15.8 & (1.4) & 22.9 & (1.6) & 23.3 & (1.7) & 15.6 & $(1.3)$ & 8.2 & $(1.1)$ & 5.0 & $(1.0)$ \\
\hline & Lombardia & 5.7 & (1.2) & 9.6 & (1.6) & 20.3 & $(2.4)$ & 23.5 & (2.5) & 19.8 & $(2.1)$ & 13.5 & $(2.0)$ & 7.5 & (1.6) \\
\hline & Marche & 7.2 & (1.7) & 14.8 & (1.4) & 22.7 & (1.6) & 24.9 & (1.5) & 17.6 & (1.4) & 9.1 & (1.4) & 3.7 & $(0.9)$ \\
\hline & Molise & 11.8 & (1.0) & 19.8 & $(1.4)$ & 25.7 & $(2.0)$ & 22.1 & $(2.0)$ & 12.9 & (1.3) & 5.0 & $(1.0)$ & 2.7 & $(0.7)$ \\
\hline & Piemonte & 6.7 & (1.1) & 14.8 & $(1.8)$ & 21.5 & $(1.5)$ & 23.4 & $(1.3)$ & 18.0 & $(1.8)$ & 10.4 & (1.3) & 5.2 & $(1.2)$ \\
\hline & Puglia & 10.3 & (1.5) & 17.3 & (1.8) & 23.9 & (1.8) & 22.7 & (1.9) & 15.1 & $(1.5)$ & 8.2 & $(1.2)$ & 2.6 & $(0.6)$ \\
\hline & Sardegna & 14.8 & (1.5) & 21.1 & $(1.8)$ & 25.4 & (1.9) & 21.2 & (1.9) & 11.6 & $(1.2)$ & 4.7 & $(0.9)$ & 1.2 & $(0.4)$ \\
\hline & Sicilia & 16.2 & (1.7) & 22.2 & (1.6) & 26.2 & (1.9) & 21.9 & $(1.4)$ & 9.8 & $(1.2)$ & 3.0 & $(0.7)$ & 0.7 & $(0.3)$ \\
\hline & Toscana & 9.1 & (1.3) & 14.4 & $(2.1)$ & 20.7 & $(2.0)$ & 21.2 & (1.6) & 17.9 & (1.6) & 11.1 & (1.5) & 5.7 & (1.1) \\
\hline & Trento & 2.3 & $(0.6)$ & 8.9 & $(1.3)$ & 18.8 & $(1.5)$ & 23.6 & (1.4) & 23.2 & (1.7) & 14.9 & (1.6) & 8.3 & (1.1) \\
\hline & Umbria & 9.2 & (2.4) & 13.8 & (1.8) & 21.8 & (1.5) & 22.5 & (1.9) & 18.4 & (1.8) & 10.4 & $(1.2)$ & 3.9 & $(0.7)$ \\
\hline & Valle d'Aosta & 6.8 & (1.0) & 14.2 & $(1.6)$ & 23.2 & (1.6) & 25.9 & $(1.9)$ & 17.3 & (1.9) & 7.8 & $(1.1)$ & 4.7 & $(0.8)$ \\
\hline & Veneto & 4.9 & $(0.9)$ & 10.6 & (1.1) & 18.9 & $(2.1)$ & 21.3 & $(2.2)$ & 20.8 & (1.4) & 14.3 & $(2.1)$ & 9.1 & (2.1) \\
\hline & Mexico & & & & & & & & & & & & & & \\
\hline & Aguascalientes & 13.9 & (2.1) & 26.3 & $(2.1)$ & 29.9 & (1.6) & 19.8 & $(2.2)$ & 7.3 & (1.1) & 2.8 & $(0.8)$ & 0.0 & c \\
\hline & Baja California & 24.7 & (2.7) & 31.4 & $(2.5)$ & 24.2 & (2.9) & 13.8 & (1.9) & 4.9 & (1.1) & 1.0 & $(0.4)$ & 0.0 & c \\
\hline & Baja California Sur & 21.7 & $(2.7)$ & 31.4 & $(2.5)$ & 26.5 & $(2.1)$ & 14.8 & (1.8) & 5.1 & $(0.9)$ & 0.6 & $(0.3)$ & 0.0 & $\mathrm{c}$ \\
\hline & Campeche & 29.9 & $(2.8)$ & 31.8 & (1.9) & 24.5 & $(1.6)$ & 10.1 & (1.5) & 3.0 & $(0.8)$ & 0.6 & $(0.3)$ & 0.1 & c \\
\hline & Chiapas & 44.1 & (4.6) & 28.9 & $(2.6)$ & 18.2 & $(2.3)$ & 6.7 & $(1.4)$ & 1.6 & $(0.6)$ & 0.4 & $(0.2)$ & 0.1 & c \\
\hline & Chihuahua & 19.1 & $(2.7)$ & 27.1 & $(2.2)$ & 27.2 & (1.9) & 16.1 & $(1.8)$ & 8.1 & $(2.2)$ & 2.2 & $(0.9)$ & 0.2 & $(0.2)$ \\
\hline & Coahuila & 21.2 & (3.0) & 29.1 & $(2.5)$ & 28.2 & $(2.1)$ & 14.6 & $(2.6)$ & 5.7 & (1.7) & 1.1 & $(0.5)$ & 0.1 & c \\
\hline & Colima & 18.0 & (2.3) & 28.8 & $(2.1)$ & 28.7 & $(2.2)$ & 16.7 & $(1.8)$ & 6.0 & $(0.9)$ & 1.5 & $(0.6)$ & 0.3 & $(0.3)$ \\
\hline & Distrito Federal & 21.8 & (2.8) & 29.2 & $(2.5)$ & 27.5 & $(2.3)$ & 14.9 & (1.9) & 5.5 & $(1.1)$ & 1.1 & $(0.6)$ & 0.0 & $\mathrm{c}$ \\
\hline & Durango & 20.9 & (3.0) & 28.9 & $(2.3)$ & 26.8 & $(2.7)$ & 16.8 & $(2.2)$ & 5.8 & $(1.1)$ & 0.8 & $(0.3)$ & 0.0 & c \\
\hline & Guanajuato & 24.0 & (3.4) & 28.0 & $(2.3)$ & 27.7 & $(2.3)$ & 14.5 & $(1.6)$ & 5.1 & $(0.8)$ & 0.7 & $(0.3)$ & 0.0 & c \\
\hline & Guerrero & 45.2 & (3.4) & 31.1 & $(2.8)$ & 17.1 & $(2.1)$ & 5.4 & $(1.0)$ & 1.1 & $(0.3)$ & 0.1 & $\mathrm{C}$ & 0.0 & c \\
\hline & Hidalgo & 24.9 & (2.9) & 30.6 & (1.9) & 26.0 & $(2.3)$ & 14.1 & (1.7) & 3.6 & $(0.8)$ & 0.8 & $(0.3)$ & 0.0 & c \\
\hline & Jalisco & 16.5 & (3.1) & 26.6 & $(2.8)$ & 31.3 & (3.1) & 18.1 & $(2.6)$ & 6.1 & $(1.3)$ & 1.4 & $(0.7)$ & 0.1 & c \\
\hline & Mexico & 19.7 & (2.9) & 30.7 & $(2.5)$ & 30.6 & $(2.6)$ & 15.7 & (1.8) & 2.7 & $(0.8)$ & 0.5 & $(0.4)$ & 0.1 & c \\
\hline & Morelos & 23.1 & (3.6) & 29.2 & $(2.6)$ & 25.7 & $(2.3)$ & 14.2 & $(1.8)$ & 5.4 & (1.9) & 2.0 & $(1.0)$ & 0.2 & $(0.2)$ \\
\hline & Nayarit & 27.8 & (2.8) & 26.3 & $(1.8)$ & 24.0 & $(1.7)$ & 14.8 & $(2.1)$ & 5.5 & $(0.9)$ & 1.4 & $(0.5)$ & 0.2 & $(0.2)$ \\
\hline & Nuevo León & 19.0 & $(2.7)$ & 26.3 & $(2.7)$ & 27.2 & $(2.0)$ & 16.6 & $(2.6)$ & 7.9 & (1.5) & 2.5 & $(0.7)$ & 0.3 & $(0.2)$ \\
\hline & Puebla & 24.1 & (2.6) & 28.3 & $(2.0)$ & 26.4 & $(2.0)$ & 14.3 & (1.6) & 5.9 & $(1.0)$ & 0.9 & $(0.5)$ & 0.1 & $\mathrm{c}$ \\
\hline & Querétaro & 16.8 & $(2.2)$ & 27.7 & $(2.2)$ & 26.9 & $(1.7)$ & 18.0 & $(2.2)$ & 8.2 & $(1.4)$ & 2.1 & $(0.6)$ & 0.3 & $(0.2)$ \\
\hline & Quintana Roo & 24.6 & $(2.7)$ & 31.0 & $(2.1)$ & 26.7 & $(1.8)$ & 13.1 & $(1.6)$ & 4.0 & $(0.8)$ & 0.6 & $(0.2)$ & 0.1 & c \\
\hline & San Luis Potosí & 26.8 & (3.6) & 28.3 & $(2.5)$ & 26.1 & $(2.0)$ & 12.8 & $(1.8)$ & 5.0 & $(1.4)$ & 1.0 & $(0.5)$ & 0.0 & c \\
\hline & Sinaloa & 30.6 & (2.4) & 31.0 & $(1.9)$ & 24.3 & $(1.8)$ & 10.4 & $(1.2)$ & 3.3 & $(0.7)$ & 0.5 & $(0.3)$ & 0.0 & c \\
\hline & Tabasco & 43.9 & (2.8) & 30.2 & $(1.8)$ & 18.0 & $(2.0)$ & 6.3 & $(1.0)$ & 1.4 & $(0.4)$ & 0.2 & $\mathrm{C}$ & 0.1 & $(0.1)$ \\
\hline & Tamaulipas & 23.8 & (3.3) & 30.8 & $(2.6)$ & 25.9 & $(2.2)$ & 13.7 & $(2.2)$ & 4.3 & $(1.2)$ & 1.4 & $(0.7)$ & 0.1 & c \\
\hline & Tlaxcala & 25.5 & $(2.7)$ & 30.2 & $(1.8)$ & 26.5 & $(2.0)$ & 13.6 & (1.6) & 3.4 & $(0.8)$ & 0.8 & $(0.3)$ & 0.0 & c \\
\hline & Veracruz & 27.4 & $(3.1)$ & 29.6 & $(2.1)$ & 24.9 & (1.9) & 12.7 & $(2.1)$ & 4.7 & $(1.1)$ & 0.7 & $(0.3)$ & 0.1 & c \\
\hline & Yucatán & 26.5 & (2.7) & 29.5 & $(2.3)$ & 25.5 & (2.5) & 13.5 & $(1.6)$ & 4.0 & $(0.7)$ & 0.9 & $(0.3)$ & 0.1 & c \\
\hline & Zacatecas & 26.0 & $(2.3)$ & 31.2 & (2.5) & 25.2 & $(2.1)$ & 14.0 & (1.6) & 3.3 & $(0.6)$ & 0.5 & $(0.3)$ & 0.0 & c \\
\hline
\end{tabular}

- PISA adjudicated region.

Note: See Table 1.2.17 for national data.

StatLink त्ञात्रा http://dx.doi.org/10.1787/888932935762 
Percentage of students at each proficiency level on the mathematics subscale space and shape, Table B2.I.16 by region

\begin{tabular}{|c|c|c|c|c|c|c|c|c|c|c|c|c|c|c|c|}
\hline & & \multicolumn{14}{|c|}{ All students } \\
\hline & & \multicolumn{2}{|c|}{$\begin{array}{l}\text { Below Level } 1 \\
\text { (below 357.77 } \\
\text { score points) }\end{array}$} & \multicolumn{2}{|c|}{$\begin{array}{c}\text { Level } 1 \\
\text { (from } 357.77 \text { to } \\
\text { less than } 420.07 \\
\text { score points) }\end{array}$} & \multicolumn{2}{|c|}{$\begin{array}{c}\text { Level } 2 \\
\text { (from } 420.07 \text { to } \\
\text { less than } 482.38 \\
\text { score points) }\end{array}$} & $\begin{array}{l}\text { Le } \\
\text { (from } \\
\text { less th. } \\
\text { score }\end{array}$ & $\begin{array}{l}\text { I } 3 \\
2.38 \text { to } \\
544.68 \\
\text { oints) }\end{array}$ & $\begin{array}{r}\text { Le } \\
\text { (from } 5 \\
\text { less tha } \\
\text { score }\end{array}$ & $\begin{array}{l}14 \\
4.68 \text { to } \\
606.99 \\
\text { oints) }\end{array}$ & $\begin{array}{r}\text { Le } \\
\text { (from } \\
\text { less tha } \\
\text { score }\end{array}$ & $\begin{array}{l}5 \\
5.99 \text { to } \\
669.30 \\
\text { ints) }\end{array}$ & $\begin{array}{r}\text { Le } \\
\text { (above } \\
\text { score }\end{array}$ & $\begin{array}{l}6 \\
69.30 \\
\text { ints) }\end{array}$ \\
\hline & & $\%$ & S.E. & $\%$ & S.E. & $\%$ & S.E. & $\%$ & S.E. & $\%$ & S.E. & $\%$ & S.E. & $\%$ & S.E. \\
\hline 0 & Portugal & & & & & & & & & & & & & & \\
\hline 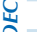 & Alentejo & 8.1 & $(2.2)$ & 15.9 & (2.8) & 23.2 & $(2.0)$ & 22.7 & $(2.8)$ & 16.0 & $(2.3)$ & 9.7 & (2.1) & 4.4 & (1.4) \\
\hline & Spain & & & & & & & & & & & & & & \\
\hline & Andalusia ${ }^{\bullet}$ & 11.3 & (1.3) & 21.9 & (1.7) & 27.3 & (1.6) & 21.8 & $(1.4)$ & 12.4 & $(1.2)$ & 4.3 & $(0.7)$ & 0.9 & $(0.3)$ \\
\hline & Aragon • & 8.8 & (1.3) & 13.8 & (1.4) & 22.6 & $(1.3)$ & 24.2 & (1.6) & 17.8 & (1.3) & 9.4 & (1.1) & 3.3 & $(0.8)$ \\
\hline & Asturias ${ }^{\bullet}$ & 8.8 & (1.3) & 13.2 & (1.3) & 23.0 & (1.0) & 24.8 & $(1.4)$ & 18.1 & (1.4) & 8.8 & $(0.9)$ & 3.4 & $(0.8)$ \\
\hline & Balearic Islands ${ }^{\bullet}$ & 10.7 & (1.4) & 21.1 & (1.8) & 25.1 & $(1.3)$ & 24.1 & $(1.4)$ & 14.1 & (1.6) & 4.1 & $(0.9)$ & 0.8 & $(0.3)$ \\
\hline & Basque Country ${ }^{\bullet}$ & 4.5 & $(0.5)$ & 12.3 & $(0.8)$ & 23.3 & $(0.9)$ & 27.6 & $(0.7)$ & 21.0 & $(0.9)$ & 9.0 & $(0.7)$ & 2.2 & $(0.3)$ \\
\hline & Cantabria & 7.5 & (1.0) & 15.1 & $(1.2)$ & 24.3 & $(1.4)$ & 24.1 & $(1.2)$ & 17.2 & (1.1) & 8.8 & $(1.2)$ & 3.0 & $(0.6)$ \\
\hline & Castile and Leon ${ }^{\bullet}$ & 5.8 & (1.0) & 12.5 & (1.3) & 21.3 & $(1.5)$ & 26.1 & $(1.2)$ & 21.4 & (1.5) & 9.9 & (1.1) & 3.0 & $(0.6)$ \\
\hline & Catalonia ${ }^{\bullet}$ & 9.0 & (1.1) & 16.5 & (1.8) & 24.1 & $(2.2)$ & 23.4 & $(1.5)$ & 16.5 & (1.5) & 8.0 & (1.4) & 2.6 & $(0.7)$ \\
\hline & Extremadura ${ }^{\bullet}$ & 14.0 & (1.4) & 21.3 & (1.4) & 25.4 & $(1.5)$ & 21.1 & $(1.5)$ & 12.6 & (1.4) & 4.6 & $(0.6)$ & 1.0 & $(0.3)$ \\
\hline & Galicia` & 10.8 & (1.4) & 16.5 & (1.4) & 22.9 & $(1.5)$ & 24.5 & (1.6) & 16.7 & (1.5) & 6.8 & (0.9) & 1.8 & $(0.5)$ \\
\hline & La Rioja・ & 8.5 & (0.9) & 12.3 & (1.0) & 18.6 & $(1.5)$ & 23.4 & $(1.2)$ & 17.8 & (1.3) & 13.3 & $(0.9)$ & 6.0 & $(0.7)$ \\
\hline & Madrid ${ }^{\bullet}$ & 8.1 & (1.1) & 13.2 & (1.1) & 21.2 & $(1.4)$ & 23.7 & $(1.8)$ & 19.2 & (1.4) & 10.7 & $(1.2)$ & 4.0 & $(0.7)$ \\
\hline & Murcia` & 14.3 & (1.4) & 21.3 & $(1.7)$ & 27.8 & $(1.5)$ & 19.8 & (1.6) & 11.2 & $(1.2)$ & 4.1 & $(0.9)$ & 1.4 & $(0.5)$ \\
\hline & Navarre ${ }^{\bullet}$ & 5.3 & $(0.7)$ & 9.4 & $(0.9)$ & 19.4 & $(1.2)$ & 26.4 & (1.5) & 21.3 & (1.1) & 13.3 & (0.9) & 4.9 & (0.6) \\
\hline & United Kingdom & & & & & & & & & & & & & & \\
\hline & England & 11.9 & (1.1) & 17.1 & $(0.9)$ & 23.5 & $(0.8)$ & 22.6 & $(1.1)$ & 14.8 & $(0.9)$ & 7.2 & $(0.7)$ & 2.9 & $(0.5)$ \\
\hline & Northern Ireland & 13.9 & (1.0) & 19.6 & (0.9) & 24.0 & $(1.1)$ & 22.0 & $(1.2)$ & 12.9 & (1.0) & 5.7 & $(0.7)$ & 1.8 & $(0.4)$ \\
\hline & Scotland ${ }^{\bullet}$ & 9.4 & (1.0) & 16.5 & (1.0) & 25.1 & $(1.1)$ & 23.7 & $(0.9)$ & 15.5 & (0.9) & 7.2 & $(0.6)$ & 2.6 & $(0.4)$ \\
\hline & Wales & 16.8 & (1.0) & 23.3 & $(0.9)$ & 26.8 & $(1.0)$ & 20.3 & $(0.9)$ & 9.2 & $(0.8)$ & 3.0 & $(0.4)$ & 0.6 & $(0.1)$ \\
\hline & United States & & & & & & & & & & & & & & \\
\hline & Connecticut ${ }^{\bullet}$ & 11.6 & (1.6) & 16.7 & (1.3) & 20.4 & $(1.4)$ & 21.1 & $(1.5)$ & 15.8 & $(1.2)$ & 9.6 & $(1.2)$ & 4.7 & $(0.8)$ \\
\hline & Florida & 16.4 & (1.9) & 22.5 & (2.0) & 26.5 & (1.4) & 20.5 & $(1.6)$ & 9.6 & (1.1) & 3.9 & (0.9) & 0.4 & $(0.2)$ \\
\hline & Massachusetts ${ }^{\bullet}$ & 9.2 & $(0.9)$ & 15.3 & (1.4) & 21.2 & $(1.5)$ & 21.4 & (1.6) & 16.4 & (1.3) & 10.5 & (1.7) & 6.0 & (1.4) \\
\hline$\tilde{a}$ & Argentina & & & & & & & & & & & & & & \\
\hline 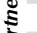 & Ciudad Autónoma de Buenos Aires ${ }^{\bullet}$ & 25.4 & (2.6) & 25.7 & $(2.2)$ & 26.4 & $(2.0)$ & 15.3 & $(2.1)$ & 5.9 & $(1.3)$ & 1.2 & $(0.4)$ & 0.1 & c \\
\hline 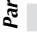 & Brazil & & & & & & & & & & & & & & \\
\hline & Acre & 55.2 & $(3.8)$ & 28.5 & $(2.7)$ & 12.2 & $(2.3)$ & 3.7 & $(1.2)$ & 0.4 & $(0.4)$ & 0.0 & c & 0.0 & c \\
\hline & Alagoas & 65.7 & $(4.0)$ & 22.4 & (2.9) & 8.5 & $(1.7)$ & 2.6 & $(1.2)$ & 0.7 & (0.6) & 0.1 & c & 0.0 & c \\
\hline & Amapá & 47.7 & $(3.7)$ & 32.3 & $(2.5)$ & 15.8 & $(2.2)$ & 3.9 & $(1.4)$ & 0.3 & $\mathrm{c}$ & 0.0 & c & 0.0 & c \\
\hline & Amazonas & 57.5 & (4.2) & 28.7 & (4.3) & 10.2 & $(2.5)$ & 2.7 & $(1.3)$ & 0.9 & $(0.9)$ & 0.0 & c & 0.0 & c \\
\hline & Bahia & 48.7 & (3.8) & 28.0 & (3.5) & 14.1 & $(2.5)$ & 5.8 & $(1.2)$ & 2.3 & $(1.1)$ & 1.0 & (1.0) & 0.0 & C \\
\hline & Ceará & 47.9 & (3.9) & 26.9 & (2.8) & 14.9 & $(2.2)$ & 6.8 & $(1.8)$ & 2.3 & $(1.1)$ & 0.9 & $(0.5)$ & 0.3 & $(0.3)$ \\
\hline & Espírito Santo & 32.2 & (3.9) & 29.1 & (3.0) & 19.4 & $(2.5)$ & 11.4 & $(3.0)$ & 6.3 & $(2.1)$ & 1.6 & $(0.8)$ & 0.1 & C \\
\hline & Federal District & 29.4 & $(4.8)$ & 28.2 & (3.8) & 22.7 & $(3.7)$ & 12.6 & $(2.1)$ & 5.5 & $(2.1)$ & 1.3 & $(0.9)$ & 0.3 & $(0.4)$ \\
\hline & Goiás & 45.0 & $(4.0)$ & 31.7 & (3.4) & 15.7 & $(2.4)$ & 6.1 & $(1.0)$ & 1.4 & $(0.7)$ & 0.2 & $(0.2)$ & 0.0 & C \\
\hline & Maranhão & 63.5 & (6.4) & 23.3 & (3.0) & 9.4 & (3.1) & 3.1 & $(2.2)$ & 0.6 & $(0.6)$ & 0.1 & C & 0.0 & c \\
\hline & Mato Grosso & 47.4 & (4.6) & 29.8 & (2.9) & 15.1 & $(2.5)$ & 4.9 & $(1.6)$ & 2.3 & (1.4) & 0.4 & C & 0.0 & c \\
\hline & Mato Grosso do Sul & 28.8 & (3.3) & 32.7 & (2.8) & 24.7 & $(2.3)$ & 8.6 & $(1.6)$ & 4.5 & $(2.1)$ & 0.7 & c & 0.0 & c \\
\hline & Minas Gerais & 36.8 & $(4.1)$ & 33.3 & (2.8) & 20.3 & $(2.6)$ & 7.6 & $(1.6)$ & 1.4 & $(0.9)$ & 0.5 & $(0.3)$ & 0.0 & c \\
\hline & Pará & 51.4 & (3.7) & 28.3 & $(2.7)$ & 14.9 & $(2.8)$ & 4.9 & $(1.3)$ & 0.4 & c & 0.0 & $\mathrm{C}$ & 0.0 & c \\
\hline & Paraíba & 39.9 & $(4.8)$ & 28.0 & (3.8) & 20.4 & $(4.5)$ & 8.1 & $(1.6)$ & 2.7 & (1.4) & 0.7 & $(0.5)$ & 0.1 & c \\
\hline & Paraná & 35.9 & (3.6) & 31.7 & (3.3) & 18.5 & $(2.6)$ & 7.4 & $(1.3)$ & 4.6 & $(2.9)$ & 1.5 & (1.6) & 0.4 & c \\
\hline & Pernambuco & 56.0 & (3.8) & 28.8 & (2.8) & 11.5 & $(2.0)$ & 2.9 & $(1.2)$ & 0.6 & $(0.5)$ & 0.2 & $(0.2)$ & 0.0 & C \\
\hline & Piauí & 43.9 & $(4.8)$ & 28.4 & (4.6) & 14.9 & $(3.2)$ & 7.7 & $(1.5)$ & 3.6 & $(1.5)$ & 1.0 & $(0.6)$ & 0.4 & $(0.2)$ \\
\hline & Rio de Janeiro & 43.9 & $(4.1)$ & 28.7 & (2.9) & 20.0 & $(2.9)$ & 5.7 & $(1.9)$ & 1.5 & $(0.7)$ & 0.1 & c & 0.0 & c \\
\hline & Rio Grande do Norte & 47.3 & (4.5) & 26.0 & (3.4) & 14.2 & $(2.7)$ & 7.1 & $(2.1)$ & 3.2 & (1.6) & 1.6 & (1.6) & 0.5 & $(0.7)$ \\
\hline & Rio Grande do Sul & 32.8 & (3.1) & 32.6 & $(2.7)$ & 23.1 & $(2.4)$ & 9.3 & $(1.8)$ & 2.0 & $(0.7)$ & 0.2 & C & 0.0 & c \\
\hline & Rondônia & 39.5 & (3.4) & 34.7 & (2.9) & 19.5 & $(2.1)$ & 5.3 & $(1.2)$ & 1.0 & $(0.5)$ & 0.1 & c & 0.0 & c \\
\hline & Roraima & 55.5 & $(4.3)$ & 26.0 & (3.5) & 12.2 & (2.0) & 4.9 & $(1.6)$ & 1.3 & $(0.6)$ & 0.1 & c & 0.0 & c \\
\hline & Santa Catarina & 23.3 & (3.2) & 34.6 & (3.2) & 27.2 & (2.5) & 11.6 & (2.4) & 3.1 & $(1.1)$ & 0.2 & $(0.2)$ & 0.0 & c \\
\hline & São Paulo & 33.2 & (2.0) & 32.3 & (1.6) & 21.7 & $(1.5)$ & 8.8 & $(1.0)$ & 3.1 & $(0.8)$ & 0.7 & $(0.5)$ & 0.2 & $(0.2)$ \\
\hline & Sergipe & 44.0 & (4.5) & 31.8 & (3.2) & 17.1 & $(2.5)$ & 6.2 & $(2.2)$ & 0.9 & $(0.6)$ & 0.1 & C & 0.0 & c \\
\hline & Tocantins & 49.5 & (3.8) & 29.9 & (2.3) & 14.4 & $(2.3)$ & 4.6 & $(1.3)$ & 1.3 & $(0.7)$ & 0.2 & $(0.2)$ & 0.0 & C \\
\hline & Colombia & & & & & & & & & & & & & & \\
\hline & Bogotá & 35.9 & $(2.7)$ & 35.0 & (1.5) & 21.0 & $(2.0)$ & 6.1 & $(1.2)$ & 1.7 & $(0.5)$ & 0.2 & $(0.2)$ & 0.0 & c \\
\hline & Cali & 43.9 & (4.3) & 30.8 & (2.3) & 18.4 & (3.0) & 5.7 & $(1.3)$ & 1.1 & $(0.5)$ & 0.0 & $\mathrm{C}$ & 0.0 & c \\
\hline & Manizales & 29.0 & (2.0) & 36.2 & (2.9) & 22.7 & $(2.2)$ & 9.0 & $(1.5)$ & 2.6 & $(1.0)$ & 0.5 & $(0.4)$ & 0.0 & C \\
\hline & Medellín & 38.3 & (3.4) & 29.6 & (1.9) & 18.8 & $(2.2)$ & 8.2 & $(1.8)$ & 3.4 & $(1.2)$ & 1.3 & $(0.7)$ & 0.4 & $(0.3)$ \\
\hline & Russian Federation & & & & & & & & & & & & & & \\
\hline & Perm Territory region ${ }^{\bullet}$ & 9.9 & (1.4) & 15.6 & (1.3) & 23.1 & $(1.5)$ & 22.9 & $(1.8)$ & 16.3 & (1.4) & 7.7 & $(0.8)$ & 4.5 & (1.6) \\
\hline & United Arab Emirates & & & & & & & & & & & & & & \\
\hline & Abu Dhabi• & 28.3 & (1.5) & 27.1 & $(1.1)$ & 22.1 & $(1.1)$ & 13.6 & $(1.1)$ & 6.1 & $(0.7)$ & 2.3 & $(0.5)$ & 0.6 & $(0.2)$ \\
\hline & Ajman & 33.7 & $(4.2)$ & 25.5 & (3.0) & 22.5 & $(3.0)$ & 14.2 & (1.9) & 3.5 & $(1.1)$ & 0.5 & $(0.5)$ & 0.0 & c \\
\hline & Dubai ${ }^{\bullet}$ & 16.7 & $(0.6)$ & 20.6 & $(0.7)$ & 23.0 & $(0.8)$ & 20.4 & $(0.8)$ & 12.8 & $(0.7)$ & 4.9 & $(0.4)$ & 1.6 & $(0.3)$ \\
\hline & Fujairah & 30.9 & (4.5) & 23.1 & (2.3) & 23.5 & $(2.2)$ & 15.5 & $(2.7)$ & 5.7 & (1.6) & 1.1 & $(0.6)$ & 0.2 & $(0.2)$ \\
\hline & Ras al-Khaimah & 28.8 & (4.5) & 27.2 & (3.2) & 24.5 & $(2.7)$ & 13.5 & $(1.8)$ & 4.9 & $(1.0)$ & 0.8 & $(0.4)$ & 0.2 & C \\
\hline & Sharjah & 27.0 & (3.6) & 24.5 & $(2.2)$ & 21.8 & $(2.6)$ & 16.0 & $(2.6)$ & 7.8 & $(2.0)$ & 2.4 & (0.9) & 0.5 & $(0.4)$ \\
\hline & Umm al-Quwain & 36.9 & (3.2) & 30.3 & (3.0) & 20.6 & (3.1) & 8.4 & $(2.0)$ & 2.8 & $(1.1)$ & 0.9 & $(0.9)$ & 0.0 & c \\
\hline
\end{tabular}

- PISA adjudicated region.

Note: See Table I.2.17 for national data.

StatLink 解古 $\mathrm{http}: / / \mathrm{dx}$.doi.org/10.1787/888932935762 
[Part 1/4]

Percentage of students at each proficiency level on the mathematics subscale space and shape, Table B2.I.17 by gender and region

\begin{tabular}{|c|c|c|c|c|c|c|c|c|c|c|c|c|c|c|c|}
\hline & & \multicolumn{14}{|c|}{ Boys } \\
\hline & & \multicolumn{2}{|c|}{$\begin{array}{c}\text { Below Level } 1 \\
\text { (below } 357.77 \\
\text { score points) }\end{array}$} & $\begin{array}{l}\text { Le } \\
\text { (from } \\
\text { less th } \\
\text { scor }\end{array}$ & $\begin{array}{l}\text { I } 1 \\
7.77 \text { to } \\
420.07 \\
\text { oints) }\end{array}$ & $\begin{array}{l}\text { Le } \\
\text { (from } \\
\text { less th } \\
\text { score }\end{array}$ & $\begin{array}{l}2 \\
.07 \text { to } \\
482.38 \\
\text { jints) }\end{array}$ & $\begin{array}{l}\text { Le } \\
\text { (from } \\
\text { less th } \\
\text { score }\end{array}$ & $\begin{array}{l}3 \\
2.38 \text { to } \\
544.68 \\
\text { oints) }\end{array}$ & $\begin{array}{l}\text { Le } \\
\text { (from } \\
\text { less th } \\
\text { score }\end{array}$ & $\begin{array}{l}14 \\
4.68 \text { to } \\
606.99 \\
\text { oints) }\end{array}$ & $\begin{array}{l}\text { Le } \\
\text { (from } \\
\text { less tha } \\
\text { score }\end{array}$ & $\begin{array}{l}5 \\
6.99 \text { to } \\
669.30 \\
\text { oints) }\end{array}$ & $\begin{array}{r}\text { Le } \\
\text { (abov } \\
\text { score }\end{array}$ & $\begin{array}{l}6 \\
69.30 \\
\text { ints) }\end{array}$ \\
\hline & & $\%$ & S.E. & $\%$ & S.E. & $\%$ & S.E. & $\%$ & S.E. & $\%$ & S.E. & $\%$ & S.E. & $\%$ & S.E. \\
\hline 0 & Australia & & & & & & & & & & & & & & \\
\hline 过 & Australian Capital Territory & 5.6 & (1.4) & 11.5 & $(2.0)$ & 19.9 & $(2.5)$ & 24.1 & (2.4) & 19.1 & $(2.5)$ & 13.3 & $(2.1)$ & 6.6 & (1.6) \\
\hline & New South Wales & 6.9 & $(0.8)$ & 14.0 & (1.1) & 21.4 & $(1.5)$ & 21.5 & (1.5) & 15.6 & (1.5) & 11.5 & (1.3) & 9.1 & (1.7) \\
\hline & Northern Territory & 14.3 & $(2.3)$ & 16.4 & $(4.2)$ & 22.8 & $(4.8)$ & 25.4 & $(4.7)$ & 15.2 & (3.8) & 4.8 & (2.6) & 1.0 & (1.1) \\
\hline & Queensland & 6.6 & (1.0) & 14.3 & $(1.3)$ & 21.7 & (1.6) & 23.7 & (1.5) & 18.9 & (1.6) & 10.1 & (1.3) & 4.7 & $(0.8)$ \\
\hline & South Australia & 8.0 & (1.6) & 15.6 & (1.6) & 23.2 & $(2.0)$ & 25.6 & (2.4) & 16.9 & (1.5) & 7.8 & (1.1) & 2.8 & $(0.8)$ \\
\hline & Tasmania & 10.1 & (1.5) & 16.7 & $(2.0)$ & 25.5 & $(2.6)$ & 24.9 & $(2.7)$ & 14.8 & $(2.7)$ & 4.9 & (1.5) & 3.1 & $(0.9)$ \\
\hline & Victoria & 6.7 & $(0.7)$ & 14.6 & $(1.6)$ & 20.8 & (1.5) & 24.9 & (1.7) & 18.7 & (1.4) & 8.7 & (1.1) & 5.4 & (1.4) \\
\hline & Western Australia & 3.9 & $(0.8)$ & 11.2 & $(1.3)$ & 20.7 & (1.9) & 23.8 & $(2.0)$ & 20.5 & $(2.0)$ & 13.9 & (1.6) & 6.0 & (1.3) \\
\hline & Belgium & & & & & & & & & & & & & & \\
\hline & Flemish Community ${ }^{\bullet}$ & 5.8 & $(1.1)$ & 9.5 & $(1.0)$ & 16.2 & $(0.9)$ & 19.6 & (1.4) & 20.2 & (1.4) & 17.2 & (1.1) & 11.4 & $(0.9)$ \\
\hline & French Community & 10.0 & (1.1) & 14.5 & $(1.3)$ & 20.9 & (1.3) & 22.7 & (1.3) & 17.6 & (1.1) & 9.7 & $(1.0)$ & 4.5 & $(0.7)$ \\
\hline & German-speaking Community & 5.5 & $(1.7)$ & 11.8 & $(2.2)$ & 18.7 & $(2.3)$ & 25.0 & (3.1) & 21.0 & $(2.1)$ & 12.9 & (1.7) & 5.0 & (1.4) \\
\hline & Canada & & & & & & & & & & & & & & \\
\hline & Alberta & 5.0 & (1.0) & 12.2 & $(1.8)$ & 21.5 & $(1.8)$ & 23.6 & (1.9) & 20.4 & (1.9) & 11.8 & (1.4) & 5.5 & $(0.9)$ \\
\hline & British Columbia & 3.8 & (1.0) & 10.7 & (1.4) & 21.5 & (2.4) & 25.4 & (2.4) & 20.8 & (1.8) & 12.5 & (1.4) & 5.4 & (1.1) \\
\hline & Manitoba & 6.6 & (1.5) & 16.6 & (1.9) & 25.3 & (2.6) & 24.5 & $(2.3)$ & 16.0 & $(1.7)$ & 8.2 & $(1.2)$ & 2.8 & $(0.7)$ \\
\hline & New Brunswick & 7.2 & $(1.2)$ & 13.6 & $(2.0)$ & 22.2 & $(2.1)$ & 28.2 & $(2.2)$ & 18.6 & $(2.3)$ & 7.7 & (1.7) & 2.5 & $(0.9)$ \\
\hline & Newfoundland and Labrador & 9.9 & $(1.8)$ & 17.3 & (3.1) & 24.3 & (3.5) & 25.4 & $(2.7)$ & 16.0 & (2.8) & 6.1 & (1.4) & 1.1 & $(0.7)$ \\
\hline & Nova Scotia & 6.7 & (1.6) & 14.6 & $(2.3)$ & 26.2 & (2.6) & 25.2 & $(2.3)$ & 18.7 & $(2.2)$ & 6.6 & (1.6) & 2.0 & (1.0) \\
\hline & Ontario & 5.1 & $(0.9)$ & 12.9 & $(1.3)$ & 22.2 & $(1.8)$ & 24.7 & $(1.7)$ & 18.8 & (1.6) & 10.5 & (1.4) & 5.9 & $(0.9)$ \\
\hline & Prince Edward Island & 11.4 & (1.4) & 20.7 & $(1.7)$ & 26.6 & $(2.2)$ & 22.8 & (1.7) & 12.9 & (1.6) & 5.0 & (1.1) & 0.5 & $(0.3)$ \\
\hline & Quebec & 4.5 & $(0.8)$ & 7.9 & $(1.2)$ & 15.6 & (1.1) & 22.3 & (1.7) & 22.3 & (1.6) & 17.4 & (1.9) & 10.0 & (1.5) \\
\hline & Saskatchewan & 5.9 & (1.0) & 12.9 & (1.4) & 24.1 & $(2.2)$ & 25.8 & $(2.7)$ & 19.2 & (2.6) & 9.9 & (1.5) & 2.2 & $(0.9)$ \\
\hline & Italy & & & & & & & & & & & & & & \\
\hline & Abruzzo & 9.2 & (2.6) & 17.2 & (2.4) & 22.4 & $(2.3)$ & 21.8 & $(2.1)$ & 17.7 & (2.3) & 7.8 & (1.6) & 3.8 & $(0.9)$ \\
\hline & Basilicata & 9.9 & (1.9) & 16.1 & $(2.5)$ & 23.5 & $(2.2)$ & 21.5 & (1.9) & 17.5 & $(2.0)$ & 7.4 & (1.6) & 4.2 & $(0.8)$ \\
\hline & Bolzano & 5.0 & $(1.1)$ & 10.4 & $(1.2)$ & 19.0 & (1.6) & 22.9 & (1.6) & 20.0 & $(1.7)$ & 14.5 & (1.6) & 8.1 & (1.0) \\
\hline & Calabria & 20.5 & (2.5) & 22.7 & (2.6) & 24.0 & $(2.7)$ & 19.2 & (2.6) & 8.9 & (1.5) & 3.5 & (1.1) & 1.3 & (0.6) \\
\hline & Campania & 14.8 & $(2.1)$ & 21.8 & (2.3) & 24.0 & (2.9) & 16.7 & (2.4) & 12.2 & $(2.2)$ & 7.1 & (1.6) & 3.5 & (1.3) \\
\hline & Emilia Romagna & 8.5 & $(1.7)$ & 11.2 & $(2.2)$ & 18.6 & $(2.4)$ & 21.8 & $(2.3)$ & 19.4 & (2.4) & 11.8 & (1.5) & 8.6 & (2.0) \\
\hline & Friuli Venezia Giulia & 2.7 & (1.0) & 8.9 & $(1.4)$ & 14.5 & (1.8) & 22.4 & $(2.2)$ & 22.4 & $(2.2)$ & 17.4 & (1.9) & 11.6 & (1.5) \\
\hline & Lazio & 11.9 & (2.1) & 15.9 & $(2.0)$ & 21.9 & $(2.8)$ & 22.5 & $(2.3)$ & 14.5 & $(2.1)$ & 9.4 & (1.6) & 4.0 & (1.1) \\
\hline & Liguria & 9.2 & $(2.2)$ & 15.9 & $(2.0)$ & 22.3 & $(1.8)$ & 21.7 & $(2.0)$ & 15.8 & (1.7) & 8.5 & (1.4) & 6.6 & (1.5) \\
\hline & Lombardia & 6.2 & $(1.8)$ & 7.4 & (2.0) & 15.4 & $(2.4)$ & 22.0 & $(2.9)$ & 21.0 & (2.6) & 16.5 & (2.3) & 11.3 & $(2.3)$ \\
\hline & Marche & 4.2 & (1.3) & 13.4 & $(1.8)$ & 20.9 & $(1.7)$ & 24.0 & $(2.2)$ & 21.2 & (1.9) & 11.2 & $(2.0)$ & 5.1 & $(1.2)$ \\
\hline & Molise & 10.1 & (1.5) & 16.3 & (2.3) & 25.6 & $(3.7)$ & 24.3 & $(2.9)$ & 13.9 & $(2.2)$ & 6.0 & (1.5) & 3.7 & (1.0) \\
\hline & Piemonte & 4.2 & (1.0) & 10.7 & (1.6) & 19.1 & (1.6) & 24.6 & $(2.2)$ & 21.5 & (2.5) & 13.4 & $(2.1)$ & 6.6 & (1.4) \\
\hline & Puglia & 10.4 & (1.7) & 15.2 & (1.8) & 20.8 & $(2.0)$ & 22.6 & $(2.0)$ & 17.8 & $(2.0)$ & 10.2 & (1.7) & 3.0 & $(1.0)$ \\
\hline & Sardegna & 14.6 & (1.8) & 19.6 & $(2.2)$ & 24.6 & $(2.4)$ & 22.2 & $(2.3)$ & 12.0 & (1.4) & 5.3 & (1.1) & 1.8 & $(0.7)$ \\
\hline & Sicilia & 15.6 & (2.0) & 20.4 & (2.5) & 26.8 & $(1.9)$ & 22.2 & (1.8) & 10.5 & (1.6) & 3.7 & (1.0) & 0.9 & $(0.5)$ \\
\hline & Toscana & 8.3 & (1.4) & 14.8 & $(2.7)$ & 21.4 & $(2.2)$ & 21.1 & $(2.0)$ & 17.3 & $(2.1)$ & 11.0 & (1.8) & 6.2 & (1.5) \\
\hline & Trento & 2.7 & $(0.8)$ & 9.2 & (1.6) & 18.2 & (1.7) & 21.6 & (2.6) & 21.7 & $(2.2)$ & 15.9 & $(2.2)$ & 10.7 & (1.5) \\
\hline & Umbria & 8.6 & (3.4) & 11.4 & (1.9) & 19.6 & $(2.2)$ & 22.8 & $(2.7)$ & 19.6 & (2.6) & 12.3 & $(2.1)$ & 5.7 & (1.1) \\
\hline & Valle d'Aosta & 6.3 & $(1.3)$ & 10.7 & $(2.1)$ & 22.0 & $(2.3)$ & 25.3 & (2.4) & 19.5 & (2.5) & 10.0 & $(2.0)$ & 6.2 & $(1.5)$ \\
\hline & Veneto & 5.7 & $(1.2)$ & 9.4 & $(1.8)$ & 16.3 & $(2.2)$ & 19.2 & (2.4) & 20.5 & (1.8) & 16.5 & $(2.1)$ & 12.4 & (2.6) \\
\hline & Mexico & & & & & & & & & & & & & & \\
\hline & Aguascalientes & 13.3 & (2.6) & 23.4 & (2.8) & 29.1 & (2.1) & 21.6 & (3.3) & 8.5 & (1.9) & 4.0 & (1.3) & 0.0 & C \\
\hline & Baja California & 19.2 & (3.2) & 31.7 & (3.3) & 26.4 & $(3.7)$ & 15.2 & (2.4) & 5.9 & (1.3) & 1.5 & $(0.7)$ & 0.0 & c \\
\hline & Baja California Sur & 18.3 & (3.2) & 28.6 & (3.4) & 28.6 & (2.9) & 17.1 & $(2.7)$ & 6.6 & (1.4) & 0.9 & $(0.6)$ & 0.0 & c \\
\hline & Campeche & 24.8 & (3.8) & 31.9 & (2.9) & 27.6 & (3.3) & 10.7 & $(2.7)$ & 3.8 & $(1.2)$ & 1.1 & $(0.5)$ & 0.1 & c \\
\hline & Chiapas & 41.7 & $(5.1)$ & 29.2 & $(3.8)$ & 19.0 & $(3.2)$ & 7.7 & (1.7) & 1.7 & $(0.7)$ & 0.5 & $(0.4)$ & 0.1 & c \\
\hline & Chihuahua & 15.2 & (3.6) & 26.3 & $(2.9)$ & 28.3 & $(3.0)$ & 17.5 & (2.6) & 9.6 & (2.8) & 3.1 & (1.5) & 0.2 & $(0.2)$ \\
\hline & Coahuila & 18.0 & (3.2) & 28.0 & $(3.1)$ & 27.7 & $(2.4)$ & 17.0 & $(3.0)$ & 7.4 & $(2.2)$ & 1.7 & $(0.9)$ & 0.2 & c \\
\hline & Colima & 14.7 & (2.2) & 28.0 & $(2.7)$ & 30.2 & $(2.9)$ & 17.1 & (3.0) & 7.2 & $(1.3)$ & 2.4 & (1.0) & 0.5 & $(0.4)$ \\
\hline & Distrito Federal & 16.5 & (3.3) & 26.1 & (3.2) & 29.5 & (3.7) & 18.9 & $(2.7)$ & 7.3 & (1.6) & 1.7 & (1.1) & 0.0 & C \\
\hline & Durango & 19.4 & (4.0) & 25.5 & (2.8) & 28.1 & $(2.6)$ & 18.4 & $(2.8)$ & 7.5 & $(2.0)$ & 1.1 & $(0.5)$ & 0.0 & c \\
\hline & Guanajuato & 21.2 & (3.5) & 25.4 & (3.3) & 28.7 & $(2.5)$ & 16.4 & $(2.0)$ & 7.3 & (1.4) & 1.2 & $(0.5)$ & 0.0 & C \\
\hline & Guerrero & 42.5 & (4.0) & 31.1 & (3.5) & 18.9 & $(3.0)$ & 6.1 & $(1.1)$ & 1.1 & (0.6) & 0.1 & c & 0.0 & C \\
\hline & Hidalgo & 20.7 & (3.0) & 29.6 & (3.0) & 26.7 & $(2.7)$ & 16.7 & (2.4) & 5.3 & (1.4) & 1.0 & $(0.5)$ & 0.0 & C \\
\hline & Jalisco & 16.2 & $(3.7)$ & 23.0 & (3.6) & 30.3 & $(3.8)$ & 20.2 & $(3.0)$ & 8.0 & (1.8) & 2.1 & $(0.9)$ & 0.2 & C \\
\hline & Mexico & 15.8 & (3.8) & 28.7 & (2.8) & 32.1 & (3.6) & 18.3 & $(2.2)$ & 4.0 & (1.4) & 0.9 & $(0.7)$ & 0.1 & C \\
\hline & Morelos & 22.2 & (4.6) & 26.3 & (3.5) & 26.8 & (3.4) & 14.4 & $(2.3)$ & 7.3 & $(2.0)$ & 2.5 & $(1.2)$ & 0.3 & $(0.3)$ \\
\hline & Nayarit & 23.2 & (3.2) & 24.1 & (2.6) & 25.3 & $(2.4)$ & 17.6 & $(2.5)$ & 7.6 & (1.4) & 1.9 & $(0.8)$ & 0.4 & $(0.4)$ \\
\hline & Nuevo León & 13.7 & (2.4) & 22.8 & (4.1) & 30.0 & $(2.7)$ & 19.9 & (3.8) & 9.4 & (2.0) & 3.7 & (1.2) & 0.5 & $(0.3)$ \\
\hline & Puebla & 19.4 & (3.5) & 24.4 & $(2.2)$ & 29.2 & $(2.9)$ & 17.3 & $(2.2)$ & 8.1 & (1.5) & 1.6 & $(0.9)$ & 0.1 & C \\
\hline & Querétaro & 11.2 & (2.5) & 26.1 & (3.9) & 27.2 & $(2.5)$ & 21.9 & (3.3) & 10.2 & (2.4) & 3.0 & $(1.2)$ & 0.4 & $(0.3)$ \\
\hline & Quintana Roo & 23.1 & (3.3) & 29.5 & (3.1) & 27.3 & $(2.6)$ & 14.8 & (2.8) & 4.5 & (1.1) & 0.7 & $(0.5)$ & 0.1 & C \\
\hline & San Luis Potosí & 25.7 & (4.4) & 27.9 & $(4.3)$ & 26.0 & (3.1) & 13.0 & $(2.1)$ & 5.8 & (2.0) & 1.4 & $(0.8)$ & 0.1 & c \\
\hline & Sinaloa & 27.2 & (2.9) & 30.4 & $(2.7)$ & 26.4 & $(2.8)$ & 11.2 & $(1.7)$ & 4.1 & $(1.1)$ & 0.8 & $(0.5)$ & 0.0 & C \\
\hline & Tabasco & 41.2 & (3.3) & 28.4 & (2.6) & 20.9 & (2.9) & 7.8 & (1.7) & 1.2 & (0.6) & 0.3 & C & 0.2 & $(0.2)$ \\
\hline & Tamaulipas & 18.1 & $(4.2)$ & 29.3 & (3.5) & 27.7 & $(2.3)$ & 16.4 & (2.8) & 6.2 & (1.7) & 2.0 & (1.1) & 0.2 & C \\
\hline & Tlaxcala & 20.9 & (2.7) & 30.0 & (3.0) & 28.8 & $(2.5)$ & 14.5 & $(2.2)$ & 4.7 & $(1.2)$ & 1.0 & $(0.5)$ & 0.1 & c \\
\hline & Veracruz & 24.8 & $(3.1)$ & 27.1 & (3.1) & 25.7 & (2.5) & 15.5 & (2.5) & 6.1 & (1.3) & 0.8 & $(0.5)$ & 0.0 & C \\
\hline & Yucatán & 20.9 & (3.2) & 28.6 & (2.8) & 27.0 & (2.6) & 16.1 & $(2.1)$ & 5.7 & (1.1) & 1.6 & $(0.6)$ & 0.1 & C \\
\hline & Zacatecas & 22.3 & (2.9) & 27.8 & (2.9) & 28.3 & $(2.3)$ & 17.2 & $(2.3)$ & 3.9 & $(1.1)$ & 0.5 & $(0.2)$ & 0.0 & $\mathrm{C}$ \\
\hline
\end{tabular}

- PISA adjudicated region

Note: See Table I.2.18 for national data.

StatLink त्ताडst http://dx.doi.org/10.1787/888932935762 
Percentage of students at each proficiency level on the mathematics subscale space and shape, Table B2.I.17 by gender and region

\begin{tabular}{|c|c|c|c|c|c|c|c|c|c|c|c|c|c|c|c|}
\hline & & \multicolumn{14}{|c|}{ Boys } \\
\hline & & \multicolumn{2}{|c|}{$\begin{array}{c}\text { Below Level } 1 \\
\text { (below } 357.77 \\
\text { score points) }\end{array}$} & \multicolumn{2}{|c|}{$\begin{array}{c}\text { Level } 1 \\
\text { (from } 357.77 \text { to } \\
\text { less than } 420.07 \\
\text { score points) }\end{array}$} & \multicolumn{2}{|c|}{$\begin{array}{c}\text { Level } 2 \\
\text { (from } 420.07 \text { to } \\
\text { less than } 482.38 \\
\text { score points) } \\
\end{array}$} & $\begin{array}{r}\text { Le } \\
\text { (from } \\
\text { less thr } \\
\text { score }\end{array}$ & $\begin{array}{l}\text { I } 3 \\
2.38 \text { to } \\
544.68 \\
\text { oints) }\end{array}$ & $\begin{array}{r}\text { Le } \\
\text { (from } \\
\text { less tha } \\
\text { score }\end{array}$ & $\begin{array}{l}14 \\
4.68 \text { to } \\
606.99 \\
\text { oints) }\end{array}$ & $\begin{array}{l}\text { Le } \\
\text { (from } \\
\text { less th } \\
\text { score }\end{array}$ & $\begin{array}{l}5 \\
5.99 \text { to } \\
669.30 \\
\text { ints) }\end{array}$ & $\begin{array}{r}\text { Le } \\
\text { (above } \\
\text { score }\end{array}$ & $\begin{array}{l}6 \\
69.30 \\
\text { ints) }\end{array}$ \\
\hline & & $\%$ & S.E. & $\%$ & S.E. & $\%$ & S.E. & $\%$ & S.E. & $\%$ & S.E. & $\%$ & S.E. & $\%$ & S.E. \\
\hline 0 & Portugal & & & & & & & & & & & & & & \\
\hline نu & Alentejo & 6.5 & $(2.1)$ & 13.6 & (3.6) & 24.3 & $(4.1)$ & 22.8 & $(5.0)$ & 15.2 & $(3.2)$ & 10.9 & (2.8) & 6.7 & (2.3) \\
\hline & Spain & & & & & & & & & & & & & & \\
\hline & Andalusia ${ }^{\bullet}$ & 10.4 & (1.6) & 18.2 & $(2.5)$ & 26.9 & $(2.3)$ & 23.0 & $(1.6)$ & 14.1 & (1.6) & 5.9 & $(1.2)$ & 1.3 & $(0.5)$ \\
\hline & Aragon` & 7.3 & (1.3) & 12.6 & $(1.8)$ & 22.0 & $(2.1)$ & 22.0 & (1.9) & 19.8 & (1.8) & 11.9 & (1.7) & 4.4 & (1.0) \\
\hline & Asturias ${ }^{\bullet}$ & 8.8 & (1.7) & 11.5 & $(1.6)$ & 22.0 & $(2.1)$ & 24.0 & $(2.2)$ & 19.5 & (1.9) & 9.9 & (1.3) & 4.2 & $(0.9)$ \\
\hline & Balearic Islands ${ }^{\bullet}$ & 9.5 & (1.8) & 19.9 & $(2.3)$ & 26.6 & $(2.0)$ & 24.9 & $(1.7)$ & 13.5 & (1.6) & 4.3 & (1.1) & 1.2 & $(0.6)$ \\
\hline & Basque Country ${ }^{\bullet}$ & 4.3 & $(0.7)$ & 11.1 & $(1.2)$ & 22.1 & (1.4) & 27.0 & $(1.1)$ & 22.7 & $(1.2)$ & 10.0 & $(1.0)$ & 2.7 & $(0.4)$ \\
\hline & Cantabria• & 6.5 & (1.1) & 13.9 & $(1.7)$ & 22.8 & (1.9) & 22.5 & $(1.5)$ & 19.8 & (1.4) & 10.4 & (1.7) & 4.1 & (1.0) \\
\hline & Castile and Leon ${ }^{\bullet}$ & 6.1 & (1.2) & 11.2 & $(1.7)$ & 19.3 & $(2.0)$ & 23.7 & $(1.7)$ & 22.7 & $(2.2)$ & 12.5 & (1.5) & 4.5 & $(1.0)$ \\
\hline & Catalonia• & 7.8 & $(1.3)$ & 15.3 & $(2.3)$ & 22.6 & $(2.3)$ & 22.5 & $(1.9)$ & 17.3 & $(2.0)$ & 10.6 & (2.0) & 3.9 & (1.1) \\
\hline & Extremadura ${ }^{\bullet}$ & 13.2 & (1.5) & 19.9 & $(1.8)$ & 23.3 & $(1.8)$ & 21.5 & $(1.8)$ & 14.6 & (1.5) & 6.2 & (1.0) & 1.3 & $(0.4)$ \\
\hline & Galicia• & 10.4 & (1.6) & 15.8 & $(1.7)$ & 22.5 & $(2.1)$ & 24.7 & $(2.2)$ & 17.8 & $(2.0)$ & 7.1 & $(1.2)$ & 1.7 & $(0.6)$ \\
\hline & La Rioja・ & 9.0 & (1.1) & 10.7 & $(1.2)$ & 17.2 & (1.8) & 21.2 & $(1.7)$ & 17.7 & $(2.0)$ & 15.4 & (1.6) & 8.7 & (1.1) \\
\hline & Madrid $\bullet$ & 7.9 & (1.5) & 12.9 & (1.6) & 19.3 & (2.0) & 22.7 & $(2.2)$ & 19.9 & (1.6) & 12.2 & (1.7) & 5.1 & (1.1) \\
\hline & Murcia` & 14.0 & (1.8) & 18.5 & $(2.1)$ & 27.0 & (2.5) & 20.2 & $(2.7)$ & 12.5 & (1.7) & 5.5 & (1.3) & 2.2 & $(0.9)$ \\
\hline & Navarre ${ }^{\bullet}$ & 5.1 & $(0.9)$ & 9.0 & $(1.1)$ & 18.0 & $(2.2)$ & 27.0 & $(2.2)$ & 21.5 & (1.8) & 13.5 & (1.4) & 5.8 & (1.1) \\
\hline & United Kingdom & & & & & & & & & & & & & & \\
\hline & England & 10.8 & (1.4) & 15.6 & $(1.2)$ & 23.5 & $(1.2)$ & 22.8 & (1.4) & 16.2 & $(1.3)$ & 8.4 & $(1.2)$ & 2.7 & $(0.7)$ \\
\hline & Northern Ireland & 13.4 & (1.6) & 18.7 & (1.6) & 24.1 & $(1.4)$ & 22.2 & $(1.6)$ & 13.4 & (1.3) & 6.1 & (1.0) & 2.1 & $(0.5)$ \\
\hline & Scotland ${ }^{\bullet}$ & 7.5 & $(1.0)$ & 15.0 & $(1.1)$ & 24.0 & $(1.8)$ & 25.1 & (1.4) & 17.1 & (1.3) & 8.0 & $(0.9)$ & 3.3 & $(0.6)$ \\
\hline & Wales & 15.2 & (1.2) & 23.0 & $(1.1)$ & 26.6 & $(1.3)$ & 21.1 & $(1.2)$ & 10.1 & (1.0) & 3.4 & $(0.6)$ & 0.7 & $(0.2)$ \\
\hline & United States & & & & & & & & & & & & & & \\
\hline & Connecticut $^{\bullet}$ & 10.9 & (1.6) & 15.6 & $(1.7)$ & 19.6 & (1.6) & 21.5 & (1.9) & 15.9 & (1.5) & 11.2 & (1.7) & 5.4 & (1.0) \\
\hline & Florida & 15.3 & $(2.2)$ & 21.0 & $(2.8)$ & 26.1 & (2.2) & 21.6 & $(2.2)$ & 11.0 & (1.4) & 4.5 & (1.1) & 0.6 & $(0.4)$ \\
\hline & Massachusetts ${ }^{\bullet}$ & 8.4 & (1.1) & 14.0 & (1.8) & 20.3 & (1.8) & 22.7 & (1.9) & 16.4 & (1.8) & 11.3 & (2.3) & 6.9 & (1.8) \\
\hline$n$ & Argentina & & & & & & & & & & & & & & \\
\hline 气 & Ciudad Autónoma de Buenos Aires ${ }^{\bullet} \mid$ & 22.7 & (2.8) & 24.2 & (3.5) & 25.9 & (2.6) & 17.8 & $(2.7)$ & 7.1 & (1.8) & 2.0 & $(0.8)$ & 0.3 & $\mathrm{c}$ \\
\hline ‡ & Brazil & & & & & & & & & & & & & & \\
\hline & Acre & 45.6 & (5.4) & 33.1 & (3.9) & 15.7 & (3.8) & 5.0 & (1.9) & 0.6 & $(0.6)$ & 0.0 & c & 0.0 & c \\
\hline & Alagoas & 59.2 & (5.0) & 26.2 & $(3.9)$ & 10.5 & $(2.9)$ & 3.4 & $(1.5)$ & 0.5 & $(0.6)$ & 0.2 & c & 0.0 & c \\
\hline & Amapá & 40.5 & (5.8) & 31.7 & $(5.1)$ & 21.1 & $(4.7)$ & 6.2 & $(2.3)$ & 0.5 & c & 0.0 & c & 0.0 & $\mathrm{c}$ \\
\hline & Amazonas & 50.0 & (5.7) & 32.7 & $(6.1)$ & 12.2 & (3.5) & 3.6 & (1.6) & 1.5 & (1.4) & 0.0 & c & 0.0 & $\mathrm{c}$ \\
\hline & Bahia & 42.4 & (5.7) & 28.1 & (4.9) & 17.8 & $(4.3)$ & 7.1 & (1.8) & 2.9 & $(0.9)$ & 1.7 & (1.5) & 0.0 & c \\
\hline & Ceará & 41.1 & (4.5) & 26.9 & $(4.4)$ & 18.2 & $(3.2)$ & 7.9 & $(2.4)$ & 3.8 & (1.8) & 1.6 & (1.0) & 0.6 & $(0.6)$ \\
\hline & Espírito Santo & 27.5 & $(4.2)$ & 28.8 & $(4.0)$ & 20.5 & (3.8) & 14.4 & $(4.1)$ & 6.9 & $(2.4)$ & 1.7 & (1.0) & 0.3 & c \\
\hline & Federal District & 25.4 & (5.1) & 28.1 & $(4.3)$ & 22.9 & $(2.8)$ & 13.7 & $(2.4)$ & 7.6 & $(2.6)$ & 1.7 & C & 0.7 & $(0.8)$ \\
\hline & Goiás & 38.5 & $(4.3)$ & 32.0 & $(3.7)$ & 18.5 & (3.4) & 8.1 & $(2.2)$ & 2.7 & (1.6) & 0.3 & $(0.3)$ & 0.0 & C \\
\hline & Maranhão & 57.1 & (7.5) & 23.4 & $(4.7)$ & 12.8 & $(4.5)$ & 5.2 & $(3.8)$ & 1.4 & $(1.5)$ & 0.2 & $\mathrm{C}$ & 0.0 & c \\
\hline & Mato Grosso & 42.6 & $(4.7)$ & 31.3 & $(3.8)$ & 17.8 & $(3.4)$ & 6.1 & $(2.3)$ & 2.0 & $(1.3)$ & 0.3 & C & 0.0 & c \\
\hline & Mato Grosso do Sul & 20.9 & (3.8) & 30.8 & (5.5) & 30.8 & $(4.2)$ & 10.7 & (2.9) & 6.2 & $(2.7)$ & 0.6 & c & 0.0 & $\mathrm{c}$ \\
\hline & Minas Gerais & 31.5 & $(4.8)$ & 34.4 & $(4.2)$ & 22.2 & $(2.8)$ & 9.2 & (2.4) & 1.7 & $(1.1)$ & 1.1 & $(0.7)$ & 0.0 & $\mathrm{c}$ \\
\hline & Pará & 47.2 & $(4.3)$ & 31.0 & (4.3) & 16.0 & (3.1) & 5.1 & (2.4) & 0.7 & C & 0.0 & c & 0.0 & c \\
\hline & Paraíba & 35.1 & (5.0) & 28.8 & $(5.1)$ & 21.9 & (5.4) & 9.4 & (3.9) & 3.3 & (1.9) & 1.3 & (1.1) & 0.2 & $\mathrm{c}$ \\
\hline & Paraná & 29.9 & (4.5) & 30.5 & (3.8) & 21.0 & (3.3) & 10.2 & $(2.0)$ & 5.8 & (2.9) & 2.2 & (2.3) & 0.3 & $\mathrm{c}$ \\
\hline & Pernambuco & 47.6 & (5.3) & 31.4 & (4.6) & 14.8 & (3.2) & 4.8 & (2.4) & 0.8 & $(0.7)$ & 0.4 & $(0.5)$ & 0.1 & c \\
\hline & Piauí & 37.8 & (5.6) & 29.0 & $(6.3)$ & 17.1 & $(3.7)$ & 9.5 & $(2.1)$ & 4.7 & $(2.4)$ & 1.2 & $(0.7)$ & 0.7 & $(0.4)$ \\
\hline & Rio de Janeiro & 40.2 & $(4.8)$ & 27.4 & $(4.3)$ & 23.5 & $(3.0)$ & 6.2 & $(2.1)$ & 2.6 & $(0.8)$ & 0.2 & c & 0.0 & C \\
\hline & Rio Grande do Norte & 42.5 & (5.3) & 25.9 & $(4.3)$ & 16.5 & $(4.2)$ & 8.1 & (3.5) & 3.8 & $(2.1)$ & 2.4 & (2.6) & 1.0 & (1.1) \\
\hline & Rio Grande do Sul & 29.6 & $(4.1)$ & 31.7 & $(4.2)$ & 24.7 & $(3.7)$ & 10.8 & $(3.3)$ & 2.8 & $(1.2)$ & 0.3 & $\mathrm{C}$ & 0.0 & C \\
\hline & Rondônia & 39.0 & $(4.1)$ & 32.3 & $(4.9)$ & 20.3 & $(2.5)$ & 6.5 & $(1.9)$ & 1.7 & $(1.0)$ & 0.2 & c & 0.0 & c \\
\hline & Roraima & 54.0 & (4.9) & 26.2 & $(4.2)$ & 14.1 & $(2.8)$ & 4.5 & $(1.6)$ & 1.2 & $(0.8)$ & 0.0 & c & 0.0 & c \\
\hline & Santa Catarina & 19.5 & (3.2) & 34.0 & $(4.0)$ & 26.7 & $(3.7)$ & 15.1 & $(3.2)$ & 4.4 & $(1.5)$ & 0.4 & $(0.4)$ & 0.0 & c \\
\hline & São Paulo & 28.0 & $(2.1)$ & 31.4 & $(2.1)$ & 25.2 & $(2.2)$ & 10.0 & $(1.3)$ & 4.2 & $(1.2)$ & 0.9 & $(0.6)$ & 0.2 & $(0.2)$ \\
\hline & Sergipe & 34.4 & (5.6) & 31.9 & $(4.9)$ & 22.8 & $(3.4)$ & 9.0 & $(3.6)$ & 1.7 & $(1.1)$ & 0.2 & C & 0.0 & C \\
\hline & Tocantins & 43.6 & $(4.1)$ & 29.9 & (3.6) & 17.3 & (2.4) & 6.7 & $(2.5)$ & 2.1 & $(1.2)$ & 0.4 & $(0.3)$ & 0.0 & c \\
\hline & Colombia & & & & & & & & & & & & & & \\
\hline & Bogotá & 25.4 & (3.3) & 36.2 & $(2.9)$ & 26.0 & $(2.7)$ & 8.9 & $(1.9)$ & 2.9 & $(1.0)$ & 0.4 & $(0.4)$ & 0.0 & $\mathrm{c}$ \\
\hline & Cali & 39.9 & (4.5) & 30.1 & $(2.6)$ & 20.2 & $(3.1)$ & 7.8 & (1.9) & 1.9 & $(1.1)$ & 0.1 & c & 0.0 & c \\
\hline & Manizales & 20.8 & (2.5) & 33.3 & (3.9) & 28.7 & $(2.7)$ & 11.7 & $(1.9)$ & 4.4 & $(1.7)$ & 1.0 & $(0.8)$ & 0.0 & C \\
\hline & Medellín & 30.8 & (3.6) & 30.2 & $(2.2)$ & 22.6 & (3.0) & 10.6 & $(2.5)$ & 4.1 & (1.4) & 1.1 & $(0.7)$ & 0.6 & $(0.6)$ \\
\hline & Russian Federation & & & & & & & & & & & & & & \\
\hline & Perm Territory region & 9.3 & (1.8) & 14.1 & $(1.5)$ & 21.9 & $(2.1)$ & 22.9 & $(2.8)$ & 16.8 & $(2.7)$ & 8.8 & (1.1) & 6.2 & $(2.1)$ \\
\hline & United Arab Emirates & & & & & & & & & & & & & & \\
\hline & Abu Dhabi & 29.5 & (2.0) & 26.6 & $(1.8)$ & 21.6 & $(1.7)$ & 13.0 & $(1.5)$ & 6.2 & (0.9) & 2.5 & $(0.7)$ & 0.7 & $(0.3)$ \\
\hline & Ajman & 38.3 & (7.6) & 24.5 & $(4.9)$ & 21.3 & $(4.9)$ & 12.3 & $(3.1)$ & 3.2 & (1.7) & 0.4 & $\mathrm{C}$ & 0.0 & c \\
\hline & Dubai ${ }^{\bullet}$ & 16.7 & $(0.9)$ & 18.5 & $(1.0)$ & 21.8 & $(1.0)$ & 20.6 & $(1.1)$ & 14.5 & $(0.9)$ & 5.6 & $(0.7)$ & 2.2 & $(0.6)$ \\
\hline & Fujairah & 38.2 & (5.7) & 24.7 & $(3.4)$ & 19.5 & (3.4) & 11.6 & $(2.9)$ & 4.8 & (1.4) & 0.9 & $(0.4)$ & 0.3 & $(0.3)$ \\
\hline & Ras al-Khaimah & 32.2 & (4.6) & 28.3 & $(4.4)$ & 23.4 & $(3.1)$ & 12.0 & $(2.5)$ & 3.6 & $(1.1)$ & 0.6 & $(0.4)$ & 0.1 & C \\
\hline & Sharjah & 28.4 & $(5.1)$ & 23.3 & $(3.4)$ & 21.5 & (3.5) & 15.7 & $(3.7)$ & 7.8 & $(2.6)$ & 2.4 & (1.6) & 0.8 & $(0.8)$ \\
\hline & Umm al-Quwain & 47.9 & (5.1) & 29.8 & $(4.8)$ & 14.4 & (4.6) & 5.5 & $(2.1)$ & 1.7 & (1.5) & 0.7 & C & 0.0 & C \\
\hline
\end{tabular}

- PISA adjudicated region

Note: See Table I.2.18 for national data.

StatLink 解古 $\mathrm{http}: / / \mathrm{dx}$.doi.org/10.1787/888932935762 
[Part 3/4]

Percentage of students at each proficiency level on the mathematics subscale space and shape, Table B2.I.17 by gender and region

\begin{tabular}{|c|c|c|c|c|c|c|c|c|c|c|c|c|c|c|c|}
\hline & & \multicolumn{14}{|c|}{ Girls } \\
\hline & & \multicolumn{2}{|c|}{$\begin{array}{c}\text { Below Level } 1 \\
\text { (below } 357.77 \\
\text { score points) }\end{array}$} & $\begin{array}{l}\text { Le } \\
\text { (from } \\
\text { less th } \\
\text { scor }\end{array}$ & $\begin{array}{l}\text { I } 1 \\
7.77 \text { to } \\
420.07 \\
\text { oints) }\end{array}$ & $\begin{array}{l}\text { Le } \\
\text { (from } \\
\text { less th } \\
\text { score }\end{array}$ & $\begin{array}{l}2 \\
.07 \text { to } \\
482.38 \\
\text { jints) }\end{array}$ & $\begin{array}{l}\text { Le } \\
\text { (from } \\
\text { less th } \\
\text { score }\end{array}$ & $\begin{array}{l}3 \\
2.38 \text { to } \\
544.68 \\
\text { oints) }\end{array}$ & $\begin{array}{l}\text { Le } \\
\text { (from } \\
\text { less th } \\
\text { score }\end{array}$ & $\begin{array}{l}14 \\
4.68 \text { to } \\
606.99 \\
\text { oints) }\end{array}$ & $\begin{array}{l}\text { Le } \\
\text { (from } \\
\text { less tha } \\
\text { score }\end{array}$ & $\begin{array}{l}5 \\
6.99 \text { to } \\
669.30 \\
\text { oints) }\end{array}$ & $\begin{array}{l}\text { Le } \\
\text { (abov } \\
\text { scor }\end{array}$ & $\begin{array}{l}6 \\
69.30 \\
\text { ints) }\end{array}$ \\
\hline & & $\%$ & S.E. & $\%$ & S.E. & $\%$ & S.E. & $\%$ & S.E. & $\%$ & S.E. & $\%$ & S.E. & $\%$ & S.E. \\
\hline 0 & Australia & & & & & & & & & & & & & & \\
\hline 过 & Australian Capital Territory & 7.6 & $(1.6)$ & 13.6 & $(2.0)$ & 20.0 & $(2.3)$ & 23.6 & (2.4) & 19.5 & $(2.3)$ & 10.7 & (1.7) & 4.9 & (1.3) \\
\hline & New South Wales & 10.1 & $(1.2)$ & 15.5 & $(1.5)$ & 21.0 & (1.6) & 22.3 & (1.5) & 17.0 & (1.4) & 8.9 & $(1.0)$ & 5.2 & (1.1) \\
\hline & Northern Territory & 16.3 & $(3.3)$ & 20.9 & $(5.4)$ & 24.7 & (6.1) & 22.7 & (6.8) & 9.6 & $(4.1)$ & 4.6 & (2.5) & 1.1 & (1.0) \\
\hline & Queensland & 9.1 & $(1.2)$ & 15.6 & $(1.4)$ & 22.9 & $(2.0)$ & 24.3 & (1.7) & 15.2 & (1.7) & 9.4 & (1.3) & 3.5 & $(0.8)$ \\
\hline & South Australia & 10.9 & $(1.3)$ & 19.6 & $(2.1)$ & 23.3 & $(2.5)$ & 23.5 & $(2.6)$ & 14.4 & (1.9) & 6.2 & $(1.2)$ & 2.1 & $(0.7)$ \\
\hline & Tasmania & 13.0 & (1.9) & 20.5 & $(1.9)$ & 25.9 & (2.9) & 20.3 & (3.0) & 13.4 & (2.4) & 5.1 & (1.5) & 1.8 & $(0.7)$ \\
\hline & Victoria & 9.4 & $(1.2)$ & 18.2 & $(1.6)$ & 23.8 & (1.6) & 24.2 & (1.7) & 15.2 & (1.5) & 6.9 & (1.1) & 2.2 & $(0.7)$ \\
\hline & Western Australia & 7.8 & $(1.2)$ & 14.9 & (1.9) & 22.0 & $(2.1)$ & 25.5 & $(2.5)$ & 18.2 & (1.8) & 8.3 & (1.4) & 3.3 & $(0.8)$ \\
\hline & Belgium & & & & & & & & & & & & & & \\
\hline & Flemish Community ${ }^{\bullet}$ & 7.4 & $(1.0)$ & 12.1 & $(1.3)$ & 17.5 & (1.4) & 22.0 & (1.3) & 19.2 & (1.3) & 13.7 & (1.0) & 8.1 & $(0.8)$ \\
\hline & French Community & 11.7 & $(1.7)$ & 16.1 & $(1.3)$ & 24.8 & (1.9) & 22.9 & (1.6) & 15.6 & (1.4) & 7.0 & $(0.9)$ & 1.8 & $(0.4)$ \\
\hline & German-speaking Community & 5.4 & (1.6) & 12.1 & (2.0) & 22.0 & $(2.7)$ & 28.0 & (2.5) & 22.3 & $(2.7)$ & 8.5 & $(2.1)$ & 1.7 & $(1.0)$ \\
\hline & Canada & & & & & & & & & & & & & & \\
\hline & Alberta & 5.9 & $(1.2)$ & 11.6 & (1.9) & 23.9 & (2.6) & 24.2 & $(2.2)$ & 20.8 & $(2.0)$ & 10.2 & (1.3) & 3.4 & $(0.8)$ \\
\hline & British Columbia & 5.1 & $(1.0)$ & 12.4 & (1.4) & 23.6 & $(2.3)$ & 25.9 & (1.8) & 19.4 & (2.0) & 10.2 & (1.7) & 3.4 & $(1.2)$ \\
\hline & Manitoba & 10.1 & (1.9) & 17.3 & $(2.5)$ & 25.7 & (1.8) & 22.8 & $(2.2)$ & 15.6 & (1.9) & 6.3 & (1.1) & 2.3 & $(0.6)$ \\
\hline & New Brunswick & 5.7 & (1.1) & 12.4 & (1.6) & 26.4 & (3.1) & 28.9 & $(2.7)$ & 17.9 & $(2.1)$ & 7.4 & (1.4) & 1.3 & $(0.7)$ \\
\hline & Newfoundland and Labrador & 8.2 & $(1.7)$ & 16.9 & (2.0) & 26.6 & (2.8) & 26.8 & $(2.3)$ & 15.0 & (2.0) & 5.4 & (1.6) & 1.0 & $(0.6)$ \\
\hline & Nova Scotia & 6.9 & $(1.5)$ & 17.2 & (3.0) & 31.2 & (5.5) & 25.0 & (2.5) & 14.2 & (2.3) & 3.7 & (0.9) & 1.6 & $(0.8)$ \\
\hline & Ontario & 5.1 & $(0.8)$ & 13.2 & $(1.3)$ & 24.3 & $(1.7)$ & 26.5 & (1.5) & 19.5 & (1.5) & 8.2 & (1.1) & 3.2 & $(0.6)$ \\
\hline & Prince Edward Island & 12.1 & $(1.5)$ & 21.3 & (1.8) & 28.6 & (2.3) & 22.3 & (2.6) & 11.6 & (1.8) & 3.3 & $(0.9)$ & 0.8 & $(0.4)$ \\
\hline & Quebec & 4.9 & $(0.7)$ & 9.0 & $(0.9)$ & 17.7 & (1.4) & 22.8 & (1.6) & 23.4 & (1.6) & 15.0 & (1.4) & 7.3 & (1.1) \\
\hline & Saskatchewan & 5.5 & $(0.9)$ & 13.4 & (1.4) & 25.6 & $(1.5)$ & 26.5 & $(2.3)$ & 18.6 & $(2.1)$ & 8.0 & (1.8) & 2.4 & $(0.9)$ \\
\hline & Italy & & & & & & & & & & & & & & \\
\hline & Abruzzo & 13.5 & $(2.1)$ & 16.5 & $(2.5)$ & 23.9 & $(2.1)$ & 21.8 & $(2.7)$ & 14.4 & $(2.1)$ & 6.8 & (1.6) & 3.1 & (1.2) \\
\hline & Basilicata & 12.0 & $(1.6)$ & 19.9 & $(2.0)$ & 27.5 & $(2.3)$ & 22.9 & (1.9) & 11.6 & (1.4) & 4.9 & $(1.1)$ & 1.3 & $(0.5)$ \\
\hline & Bolzano & 6.6 & $(1.0)$ & 13.2 & $(2.2)$ & 24.7 & $(2.2)$ & 26.5 & $(2.1)$ & 18.9 & (1.8) & 7.3 & (1.4) & 2.8 & $(0.7)$ \\
\hline & Calabria & 26.9 & $(3.3)$ & 25.4 & $(2.3)$ & 24.0 & $(2.7)$ & 15.8 & (2.4) & 5.5 & $(1.2)$ & 1.9 & $(0.6)$ & 0.4 & $(0.2)$ \\
\hline & Campania & 20.8 & (3.3) & 20.6 & (3.3) & 24.8 & $(3.2)$ & 18.0 & (3.5) & 10.5 & (1.8) & 3.5 & (1.5) & 1.8 & (1.1) \\
\hline & Emilia Romagna & 9.3 & $(1.7)$ & 15.5 & $(1.8)$ & 23.7 & (2.4) & 22.8 & (2.5) & 15.8 & $(2.1)$ & 8.6 & (1.6) & 4.4 & (1.4) \\
\hline & Friuli Venezia Giulia & 3.9 & $(1.5)$ & 10.3 & (1.8) & 20.0 & (2.4) & 28.3 & $(2.1)$ & 21.8 & (2.5) & 10.3 & (1.5) & 5.3 & (1.2) \\
\hline & Lazio & 14.7 & $(2.1)$ & 20.6 & (2.4) & 25.4 & $(2.7)$ & 21.1 & $(2.7)$ & 11.0 & (1.6) & 5.5 & (1.4) & 1.6 & $(0.7)$ \\
\hline & Liguria & 9.0 & $(1.5)$ & 15.8 & $(2.0)$ & 23.5 & $(2.1)$ & 25.0 & $(2.1)$ & 15.4 & (1.8) & 8.0 & (1.4) & 3.3 & $(0.9)$ \\
\hline & Lombardia & 5.2 & $(1.4)$ & 12.0 & (2.0) & 25.4 & $(3.2)$ & 25.1 & (2.8) & 18.5 & (2.4) & 10.3 & (1.9) & 3.4 & (1.1) \\
\hline & Marche & 10.1 & $(2.5)$ & 16.1 & $(1.7)$ & 24.4 & $(2.8)$ & 25.7 & $(2.2)$ & 14.2 & (1.6) & 7.1 & (1.4) & 2.4 & $(0.9)$ \\
\hline & Molise & 13.5 & $(1.5)$ & 23.4 & (2.5) & 25.8 & $(2.3)$ & 19.8 & $(2.1)$ & 11.9 & (1.7) & 4.0 & (1.4) & 1.7 & $(0.9)$ \\
\hline & Piemonte & 9.1 & (1.6) & 18.7 & (3.0) & 23.7 & $(1.9)$ & 22.3 & $(2.0)$ & 14.7 & (2.0) & 7.5 & (1.5) & 3.9 & (1.3) \\
\hline & Puglia & 10.3 & $(1.9)$ & 19.3 & $(2.2)$ & 26.9 & $(2.3)$ & 22.8 & $(2.5)$ & 12.4 & (1.7) & 6.2 & (1.3) & 2.1 & $(0.7)$ \\
\hline & Sardegna & 15.0 & $(2.1)$ & 22.6 & $(2.9)$ & 26.3 & $(3.1)$ & 20.1 & $(2.6)$ & 11.2 & (1.8) & 4.1 & (1.0) & 0.6 & $(0.4)$ \\
\hline & Sicilia & 16.9 & $(2.4)$ & 24.3 & $(2.0)$ & 25.5 & $(3.2)$ & 21.5 & (2.5) & 9.0 & (1.5) & 2.2 & $(0.7)$ & 0.6 & $(0.4)$ \\
\hline & Toscana & 10.1 & $(2.2)$ & 13.9 & (2.6) & 19.8 & (2.5) & 21.2 & $(2.3)$ & 18.5 & $(2.2)$ & 11.3 & (1.9) & 5.1 & (1.1) \\
\hline & Trento & 2.0 & $(0.9)$ & 8.5 & $(2.2)$ & 19.4 & $(2.1)$ & 26.0 & $(2.2)$ & 24.9 & $(2.7)$ & 13.7 & (1.9) & 5.6 & $(1.2)$ \\
\hline & Umbria & 9.7 & $(2.2)$ & 16.2 & (2.6) & 23.9 & $(2.1)$ & 22.2 & $(2.1)$ & 17.3 & (2.0) & 8.5 & (1.3) & 2.2 & $(0.8)$ \\
\hline & Valle d'Aosta & 7.3 & $(1.5)$ & 18.0 & (2.4) & 24.4 & (2.4) & 26.6 & $(2.7)$ & 15.0 & (2.6) & 5.5 & (1.7) & 3.1 & $(0.9)$ \\
\hline & Veneto & 4.2 & $(1.2)$ & 11.9 & $(1.7)$ & 21.6 & (2.9) & 23.5 & (3.4) & 21.1 & $(2.1)$ & 12.1 & (2.4) & 5.7 & (1.7) \\
\hline & Mexico & & & & & & & & & & & & & & \\
\hline & Aguascalientes & 14.4 & $(2.5)$ & 29.3 & $(2.7)$ & 30.7 & (2.3) & 18.0 & (2.3) & 6.1 & (1.3) & 1.5 & $(0.7)$ & 0.0 & C \\
\hline & Baja California & 30.5 & $(3.1)$ & 31.1 & (3.5) & 21.9 & (3.3) & 12.3 & (1.9) & 3.8 & (1.4) & 0.5 & $(0.4)$ & 0.0 & c \\
\hline & Baja California Sur & 25.2 & (3.1) & 34.2 & (2.8) & 24.4 & (2.6) & 12.4 & (1.8) & 3.6 & (1.3) & 0.2 & c & 0.0 & C \\
\hline & Campeche & 35.1 & $(3.1)$ & 31.8 & (2.9) & 21.3 & $(2.3)$ & 9.5 & (1.9) & 2.1 & $(0.8)$ & 0.3 & c & 0.0 & c \\
\hline & Chiapas & 46.5 & $(5.0)$ & 28.6 & $(3.4)$ & 17.4 & $(2.4)$ & 5.8 & (1.6) & 1.5 & (0.6) & 0.3 & $(0.3)$ & 0.0 & C \\
\hline & Chihuahua & 23.1 & (3.3) & 27.9 & $(3.1)$ & 26.2 & $(3.2)$ & 14.6 & $(2.0)$ & 6.7 & $(2.1)$ & 1.4 & $(0.8)$ & 0.2 & C \\
\hline & Coahuila & 24.4 & $(3.7)$ & 30.3 & $(3.7)$ & 28.7 & $(3.1)$ & 12.1 & $(3.4)$ & 4.0 & (1.7) & 0.5 & c & 0.0 & c \\
\hline & Colima & 21.1 & $(2.9)$ & 29.5 & (2.6) & 27.3 & (2.8) & 16.3 & $(2.0)$ & 4.9 & (1.0) & 0.7 & $(0.4)$ & 0.2 & $(0.2)$ \\
\hline & Distrito Federal & 26.9 & (3.4) & 32.2 & (3.6) & 25.6 & (3.0) & 11.0 & $(2.1)$ & 3.7 & (1.4) & 0.6 & $(0.6)$ & 0.1 & c \\
\hline & Durango & 22.4 & $(3.0)$ & 32.1 & (3.1) & 25.6 & (3.8) & 15.3 & $(2.5)$ & 4.2 & $(1.2)$ & 0.5 & $(0.3)$ & 0.0 & c \\
\hline & Guanajuato & 26.7 & $(3.9)$ & 30.5 & (3.6) & 26.9 & (3.8) & 12.7 & $(2.2)$ & 3.1 & $(0.7)$ & 0.2 & c & 0.0 & c \\
\hline & Guerrero & 47.9 & (3.7) & 31.1 & (3.2) & 15.3 & $(2.1)$ & 4.6 & (1.4) & 1.0 & (0.5) & 0.1 & c & 0.0 & C \\
\hline & Hidalgo & 28.5 & $(4.0)$ & 31.4 & (2.8) & 25.4 & $(3.2)$ & 11.8 & $(1.9)$ & 2.3 & $(0.8)$ & 0.6 & $(0.3)$ & 0.0 & C \\
\hline & Jalisco & 16.8 & $(3.2)$ & 29.8 & (2.8) & 32.1 & $(3.1)$ & 16.2 & (2.9) & 4.4 & (1.3) & 0.7 & $(0.7)$ & 0.0 & C \\
\hline & Mexico & 23.4 & (3.1) & 32.7 & (3.6) & 29.2 & $(3.4)$ & 13.1 & (2.5) & 1.3 & $(0.8)$ & 0.2 & $\mathrm{c}$ & 0.0 & C \\
\hline & Morelos & 23.9 & (3.6) & 31.9 & (3.2) & 24.7 & $(2.5)$ & 14.0 & $(2.3)$ & 3.7 & (2.3) & 1.5 & $(1.2)$ & 0.2 & $(0.2)$ \\
\hline & Nayarit & 32.2 & $(3.7)$ & 28.3 & (2.5) & 22.8 & $(2.4)$ & 12.2 & $(2.3)$ & 3.5 & $(1.2)$ & 0.9 & $(0.6)$ & 0.1 & C \\
\hline & Nuevo León & 25.0 & (3.6) & 30.3 & (3.0) & 24.2 & $(2.7)$ & 13.0 & $(2.3)$ & 6.2 & (1.7) & 1.2 & (0.6) & 0.1 & C \\
\hline & Puebla & 28.7 & $(3.3)$ & 32.1 & (3.0) & 23.8 & $(2.7)$ & 11.4 & (1.8) & 3.7 & $(1.2)$ & 0.4 & c & 0.0 & C \\
\hline & Querétaro & 22.0 & (3.1) & 29.2 & (2.7) & 26.7 & (1.9) & 14.4 & $(2.0)$ & 6.3 & (1.4) & 1.3 & $(0.6)$ & 0.2 & C \\
\hline & Quintana Roo & 26.1 & $(2.8)$ & 32.5 & $(2.7)$ & 26.1 & $(2.8)$ & 11.3 & $(1.5)$ & 3.5 & (0.9) & 0.4 & $(0.3)$ & 0.1 & C \\
\hline & San Luis Potosí & 27.8 & $(3.8)$ & 28.7 & (2.4) & 26.1 & $(2.5)$ & 12.6 & $(2.3)$ & 4.3 & (1.3) & 0.5 & $(0.4)$ & 0.0 & c \\
\hline & Sinaloa & 33.6 & $(2.9)$ & 31.6 & $(2.7)$ & 22.5 & $(2.1)$ & 9.6 & (1.9) & 2.6 & $(0.8)$ & 0.2 & c & 0.0 & C \\
\hline & Tabasco & 46.4 & (3.1) & 31.9 & (2.4) & 15.3 & (2.5) & 4.9 & $(1.0)$ & 1.5 & (0.6) & 0.0 & c & 0.0 & C \\
\hline & Tamaulipas & 30.1 & (3.5) & 32.4 & $(2.7)$ & 23.9 & $(3.2)$ & 10.6 & (2.8) & 2.3 & (1.1) & 0.7 & $(0.7)$ & 0.0 & C \\
\hline & Tlaxcala & 29.8 & $(3.2)$ & 30.3 & (2.6) & 24.4 & $(2.9)$ & 12.7 & $(2.2)$ & 2.2 & (1.0) & 0.5 & $(0.3)$ & 0.0 & C \\
\hline & Veracruz & 30.1 & $(4.0)$ & 32.2 & (2.3) & 23.9 & $(2.7)$ & 9.7 & (2.5) & 3.3 & (1.3) & 0.6 & (0.5) & 0.2 & C \\
\hline & Yucatán & 32.5 & (3.5) & 30.3 & (3.4) & 23.9 & (3.7) & 10.8 & (2.6) & 2.2 & $(1.0)$ & 0.3 & $(0.3)$ & 0.0 & C \\
\hline & Zacatecas & 29.6 & (3.4) & 34.5 & (3.2) & 22.1 & $(3.1)$ & 10.8 & (1.9) & 2.6 & $(0.9)$ & 0.4 & $(0.5)$ & 0.0 & $\mathrm{C}$ \\
\hline
\end{tabular}

- PISA adjudicated region

Note: See Table I.2.18 for national data.

StatLink त्ताडst http://dx.doi.org/10.1787/888932935762 
Percentage of students at each proficiency level on the mathematics subscale space and shape, Table B2.I.17 by gender and region

\begin{tabular}{|c|c|c|c|c|c|c|c|c|c|c|c|c|c|c|c|}
\hline & & \multicolumn{14}{|c|}{ Girls } \\
\hline & & \multicolumn{2}{|c|}{$\begin{array}{l}\text { Below Level } 1 \\
\text { (below 357.77 } \\
\text { score points) }\end{array}$} & \multicolumn{2}{|c|}{$\begin{array}{c}\text { Level } 1 \\
\text { (from } 357.77 \text { to } \\
\text { less than } 420.07 \\
\text { score points) }\end{array}$} & \multicolumn{2}{|c|}{$\begin{array}{c}\text { Level } 2 \\
\text { (from } 420.07 \text { to } \\
\text { less than } 482.38 \\
\text { score points) } \\
\end{array}$} & $\begin{array}{r}\text { Le } \\
\text { (from } \\
\text { less tha } \\
\text { score }\end{array}$ & $\begin{array}{l}\text { I } 3 \\
2.38 \text { to } \\
544.68 \\
\text { oints) }\end{array}$ & $\begin{array}{r}\text { Le } \\
\text { (from } \\
\text { less tha } \\
\text { score }\end{array}$ & $\begin{array}{l}14 \\
4.68 \text { to } \\
606.99 \\
\text { oints) }\end{array}$ & $\begin{array}{r}\text { Le } \\
\text { (from } \\
\text { less tha } \\
\text { score }\end{array}$ & $\begin{array}{l}5 \\
5.99 \text { to } \\
669.30 \\
\text { ints) }\end{array}$ & $\begin{array}{r}\text { Le } \\
\text { (above } \\
\text { score }\end{array}$ & $\begin{array}{l}6 \\
69.30 \\
\text { ints) }\end{array}$ \\
\hline & & $\%$ & S.E. & $\%$ & S.E. & $\%$ & S.E. & $\%$ & S.E. & $\%$ & S.E. & $\%$ & S.E. & $\%$ & S.E. \\
\hline 0 & Portugal & & & & & & & & & & & & & & \\
\hline نu & Alentejo & 9.8 & (2.6) & 18.1 & (3.2) & 22.1 & (3.1) & 22.5 & (3.3) & 16.7 & $(2.7)$ & 8.6 & (2.0) & 2.1 & $(0.9)$ \\
\hline & Spain & & & & & & & & & & & & & & \\
\hline & Andalusia ${ }^{\bullet}$ & 12.3 & (1.5) & 25.9 & $(2.2)$ & 27.7 & $(2.1)$ & 20.6 & $(2.3)$ & 10.6 & (1.8) & 2.6 & (0.9) & 0.3 & $(0.3)$ \\
\hline & Aragon` & 10.4 & (1.8) & 15.0 & $(1.9)$ & 23.3 & (1.6) & 26.4 & $(2.4)$ & 15.9 & (1.8) & 6.9 & $(1.2)$ & 2.2 & $(0.9)$ \\
\hline & Asturias ${ }^{\bullet}$ & 8.7 & (1.3) & 14.8 & $(1.7)$ & 23.9 & (2.0) & 25.6 & $(2.5)$ & 16.7 & (1.6) & 7.7 & (1.0) & 2.6 & $(0.9)$ \\
\hline & Balearic Islands ${ }^{\bullet}$ & 12.0 & $(2.2)$ & 22.3 & $(2.1)$ & 23.6 & $(2.1)$ & 23.3 & $(2.2)$ & 14.6 & $(2.2)$ & 3.8 & (0.9) & 0.4 & $(0.4)$ \\
\hline & Basque Country` & 4.7 & $(0.7)$ & 13.5 & (1.3) & 24.5 & (1.4) & 28.2 & $(1.1)$ & 19.3 & (1.4) & 8.0 & (1.1) & 1.8 & $(0.4)$ \\
\hline & Cantabria• & 8.6 & (1.6) & 16.4 & (1.9) & 25.9 & (1.8) & 25.7 & $(1.9)$ & 14.4 & (1.6) & 7.1 & (1.4) & 1.8 & $(0.6)$ \\
\hline & Castile and Leon ${ }^{\bullet}$ & 5.6 & (1.1) & 13.8 & (1.6) & 23.3 & (1.6) & 28.6 & $(2.1)$ & 20.0 & (1.6) & 7.2 & (1.3) & 1.4 & $(0.5)$ \\
\hline & Catalonia• & 10.3 & (1.6) & 17.8 & (2.6) & 25.6 & $(2.8)$ & 24.4 & $(2.2)$ & 15.6 & (2.6) & 5.1 & (1.5) & 1.1 & $(0.6)$ \\
\hline & Extremadura ${ }^{\bullet}$ & 14.8 & (1.6) & 22.7 & $(2.1)$ & 27.6 & $(2.0)$ & 20.7 & (1.9) & 10.6 & (1.8) & 2.9 & $(0.7)$ & 0.6 & $(0.3)$ \\
\hline & Galicia• & 11.3 & $(1.8)$ & 17.2 & $(1.9)$ & 23.3 & (1.7) & 24.3 & $(2.2)$ & 15.6 & $(2.0)$ & 6.5 & (1.1) & 1.9 & $(0.6)$ \\
\hline & La Rioja・ & 8.1 & (1.4) & 13.7 & (1.6) & 19.9 & (2.0) & 25.4 & $(1.7)$ & 17.9 & (1.9) & 11.3 & (1.7) & 3.6 & $(0.9)$ \\
\hline & Madrid $\bullet$ & 8.3 & (1.5) & 13.5 & $(1.5)$ & 23.1 & (1.9) & 24.7 & $(2.3)$ & 18.4 & (1.9) & 9.2 & (1.3) & 2.8 & $(0.8)$ \\
\hline & Murcia` & 14.6 & (1.7) & 24.1 & $(2.2)$ & 28.6 & (2.1) & 19.3 & $(1.8)$ & 10.0 & (1.9) & 2.8 & $(0.8)$ & 0.7 & $(0.4)$ \\
\hline & Navarre ${ }^{\bullet}$ & 5.4 & (1.1) & 9.7 & $(1.1)$ & 20.7 & $(2.2)$ & 25.9 & $(2.5)$ & 21.2 & (1.5) & 13.0 & (1.4) & 4.1 & $(0.8)$ \\
\hline & United Kingdom & & & & & & & & & & & & & & \\
\hline & England & 12.9 & $(1.3)$ & 18.6 & (1.3) & 23.5 & $(1.3)$ & 22.4 & (1.3) & 13.5 & $(1.1)$ & 6.1 & $(0.9)$ & 3.0 & $(0.7)$ \\
\hline & Northern Ireland & 14.6 & (1.6) & 20.6 & $(1.7)$ & 23.9 & (1.8) & 21.9 & $(2.0)$ & 12.4 & (1.6) & 5.2 & $(0.8)$ & 1.4 & $(0.4)$ \\
\hline & Scotland ${ }^{\bullet}$ & 11.4 & (1.5) & 17.9 & $(1.5)$ & 26.3 & $(1.5)$ & 22.3 & $(1.5)$ & 13.8 & $(1.1)$ & 6.3 & $(0.7)$ & 2.0 & $(0.5)$ \\
\hline & Wales & 18.3 & (1.3) & 23.7 & $(1.4)$ & 26.9 & $(1.4)$ & 19.5 & $(1.2)$ & 8.4 & (0.9) & 2.7 & $(0.6)$ & 0.4 & $(0.2)$ \\
\hline & United States & & & & & & & & & & & & & & \\
\hline & Connecticut ${ }^{\bullet}$ & 12.4 & (1.8) & 17.8 & (1.8) & 21.3 & $(2.3)$ & 20.8 & $(2.0)$ & 15.6 & (1.8) & 8.0 & (1.4) & 4.1 & $(0.9)$ \\
\hline & Florida $\bullet$ & 17.5 & (2.6) & 24.1 & $(2.0)$ & 27.0 & $(1.7)$ & 19.5 & $(1.9)$ & 8.3 & (1.1) & 3.3 & (1.1) & 0.2 & $(0.2)$ \\
\hline & Massachusetts ${ }^{\bullet}$ & 10.0 & (1.3) & 16.6 & $(2.0)$ & 22.0 & (2.5) & 20.2 & $(2.3)$ & 16.5 & (1.8) & 9.7 & (1.7) & 5.1 & (1.4) \\
\hline$\frac{2}{2}$ & Argentina & & & & & & & & & & & & & & \\
\hline$\underline{5}$ & Ciudad Autónoma de Buenos Aires $\bullet$ & 27.7 & $(3.1)$ & 27.1 & $(2.1)$ & 26.7 & $(2.5)$ & 13.0 & $(2.1)$ & 4.8 & $(1.1)$ & 0.6 & $(0.3)$ & 0.0 & c \\
\hline & Brazil & & & & & & & & & & & & & & \\
\hline & Acre & 63.9 & $(4.2)$ & 24.4 & $(3.1)$ & 9.1 & $(2.2)$ & 2.5 & $(1.0)$ & 0.2 & c & 0.0 & c & 0.0 & c \\
\hline & Alagoas & 70.7 & $(4.2)$ & 19.5 & $(3.2)$ & 7.1 & (1.9) & 2.0 & $(1.3)$ & 0.8 & $(0.7)$ & 0.0 & c & 0.0 & c \\
\hline & Amapá & 53.7 & (4.3) & 32.8 & (3.6) & 11.4 & (2.5) & 1.9 & $(1.4)$ & 0.2 & c & 0.0 & c & 0.0 & c \\
\hline & Amazonas & 64.4 & (4.5) & 24.9 & $(5.0)$ & 8.2 & (2.4) & 1.9 & $(1.2)$ & 0.5 & c & 0.0 & c & 0.0 & c \\
\hline & Bahia & 53.9 & (5.0) & 28.0 & $(4.7)$ & 11.1 & $(2.7)$ & 4.6 & $(2.1)$ & 1.8 & (1.4) & 0.6 & c & 0.0 & c \\
\hline & Ceará & 54.2 & (5.2) & 26.9 & $(3.7)$ & 11.9 & (2.9) & 5.9 & (1.6) & 1.0 & $(0.8)$ & 0.2 & c & 0.0 & c \\
\hline & Espírito Santo & 36.3 & $(5.4)$ & 29.3 & $(3.4)$ & 18.5 & $(3.5)$ & 8.8 & $(3.5)$ & 5.7 & (2.6) & 1.4 & $(1.0)$ & 0.0 & c \\
\hline & Federal District & 33.1 & $(5.7)$ & 28.3 & $(4.4)$ & 22.6 & $(5.3)$ & 11.5 & $(3.0)$ & 3.5 & $(1.9)$ & 0.9 & $(1.0)$ & 0.0 & c \\
\hline & Goiás & 50.9 & $(4.9)$ & 31.4 & $(4.5)$ & 13.1 & $(2.8)$ & 4.3 & $(1.3)$ & 0.2 & $\mathrm{C}$ & 0.0 & C & 0.0 & c \\
\hline & Maranhão & 68.3 & (6.5) & 23.3 & $(4.3)$ & 6.9 & $(2.6)$ & 1.6 & $(1.4)$ & 0.1 & c & 0.0 & c & 0.0 & c \\
\hline & Mato Grosso & 52.0 & $(6.2)$ & 28.4 & $(4.4)$ & 12.6 & (3.4) & 3.9 & $(1.7)$ & 2.6 & $(1.7)$ & 0.6 & c & 0.0 & c \\
\hline & Mato Grosso do Sul & 35.0 & $(4.1)$ & 34.1 & (3.1) & 19.9 & (2.9) & 7.0 & $(1.8)$ & 3.2 & (1.9) & 0.8 & c & 0.0 & c \\
\hline & Minas Gerais & 41.9 & $(4.8)$ & 32.2 & $(4.2)$ & 18.7 & (3.5) & 6.1 & $(1.5)$ & 1.2 & $(0.9)$ & 0.0 & C & 0.0 & $\mathrm{c}$ \\
\hline & Pará & 54.6 & $(4.8)$ & 26.3 & (3.2) & 14.1 & (3.1) & 4.8 & $(1.8)$ & 0.2 & c & 0.0 & c & 0.0 & c \\
\hline & Paraíba & 44.1 & (5.9) & 27.4 & $(4.7)$ & 19.1 & (4.6) & 7.0 & $(2.3)$ & 2.2 & $(1.7)$ & 0.2 & c & 0.0 & $\mathrm{c}$ \\
\hline & Paraná & 41.7 & $(4.1)$ & 32.9 & (3.8) & 16.1 & (3.1) & 4.7 & $(2.1)$ & 3.3 & (2.9) & 0.8 & (1.1) & 0.4 & $\mathrm{c}$ \\
\hline & Pernambuco & 62.7 & $(4.2)$ & 26.7 & (3.4) & 8.9 & (1.9) & 1.3 & $(0.9)$ & 0.4 & $(0.4)$ & 0.0 & c & 0.0 & c \\
\hline & Piauí & 48.6 & $(5.1)$ & 28.0 & $(4.7)$ & 13.3 & $(3.7)$ & 6.4 & $(1.7)$ & 2.8 & $(1.3)$ & 0.9 & $(0.8)$ & 0.1 & C \\
\hline & Rio de Janeiro & 47.5 & $(4.7)$ & 30.0 & $(3.1)$ & 16.7 & $(4.1)$ & 5.1 & $(2.5)$ & 0.6 & $(0.9)$ & 0.1 & c & 0.0 & C \\
\hline & Rio Grande do Norte & 51.2 & (5.4) & 26.1 & $(4.5)$ & 12.4 & $(2.7)$ & 6.4 & $(2.2)$ & 2.7 & $(1.8)$ & 1.1 & $(1.0)$ & 0.2 & c \\
\hline & Rio Grande do Sul & 35.7 & (3.6) & 33.5 & $(3.8)$ & 21.6 & (3.4) & 7.8 & $(1.6)$ & 1.2 & $(0.6)$ & 0.1 & $\mathrm{C}$ & 0.0 & C \\
\hline & Rondônia & 39.9 & $(4.0)$ & 37.0 & $(2.8)$ & 18.7 & $(3.0)$ & 4.1 & $(1.4)$ & 0.3 & $\mathrm{c}$ & 0.0 & c & 0.0 & C \\
\hline & Roraima & 57.0 & (5.5) & 25.8 & $(4.5)$ & 10.4 & $(2.1)$ & 5.2 & $(2.5)$ & 1.4 & $(1.0)$ & 0.2 & c & 0.0 & c \\
\hline & Santa Catarina & 26.9 & (3.9) & 35.2 & $(3.6)$ & 27.7 & (3.6) & 8.2 & $(2.2)$ & 1.9 & $(1.0)$ & 0.1 & c & 0.0 & c \\
\hline & São Paulo & 38.4 & (2.5) & 33.2 & $(2.4)$ & 18.2 & $(1.7)$ & 7.6 & $(1.4)$ & 2.0 & $(0.7)$ & 0.5 & $(0.5)$ & 0.1 & c \\
\hline & Sergipe & 51.7 & $(4.9)$ & 31.6 & $(3.4)$ & 12.5 & $(3.5)$ & 3.9 & $(1.7)$ & 0.2 & C & 0.0 & c & 0.0 & c \\
\hline & Tocantins & 55.4 & $(4.2)$ & 30.0 & $(2.7)$ & 11.4 & $(2.8)$ & 2.5 & $(0.8)$ & 0.6 & $(0.4)$ & 0.1 & c & 0.0 & c \\
\hline & Colombia & & & & & & & & & & & & & & \\
\hline & Bogotá & 45.4 & (3.0) & 34.0 & $(1.8)$ & 16.5 & $(2.2)$ & 3.6 & $(1.0)$ & 0.5 & $(0.4)$ & 0.0 & c & 0.0 & $\mathrm{c}$ \\
\hline & Cali & 47.0 & $(4.7)$ & 31.3 & $(2.9)$ & 17.0 & $(3.5)$ & 4.1 & $(1.3)$ & 0.6 & $(0.3)$ & 0.0 & c & 0.0 & c \\
\hline & Manizales & 36.5 & (2.9) & 38.8 & $(3.8)$ & 17.2 & $(3.2)$ & 6.4 & $(2.0)$ & 1.0 & $(0.8)$ & 0.1 & $\mathrm{C}$ & 0.0 & C \\
\hline & Medellín & 45.6 & $(4.3)$ & 29.1 & (2.9) & 15.0 & $(2.1)$ & 5.8 & $(2.0)$ & 2.7 & (1.6) & 1.5 & (1.1) & 0.3 & $(0.3)$ \\
\hline & Russian Federation & & & & & & & & & & & & & & \\
\hline & Perm Territory region & 10.5 & (1.8) & 17.3 & (1.9) & 24.4 & (1.9) & 22.9 & (1.9) & 15.8 & (1.4) & 6.6 & (1.3) & 2.6 & $(1.2)$ \\
\hline & United Arab Emirates & & & & & & & & & & & & & & \\
\hline & Abu Dhabi ${ }^{\bullet}$ & 27.2 & (2.5) & 27.6 & (1.6) & 22.5 & (1.4) & 14.3 & $(1.2)$ & 5.9 & $(1.0)$ & 2.1 & $(0.7)$ & 0.4 & $(0.2)$ \\
\hline & Ajman & 29.4 & (4.9) & 26.4 & $(3.1)$ & 23.7 & $(3.3)$ & 16.0 & $(3.2)$ & 3.9 & (1.6) & 0.6 & $\mathrm{C}$ & 0.0 & C \\
\hline & Dubai ${ }^{\bullet}$ & 16.7 & $(0.9)$ & 22.8 & $(1.2)$ & 24.4 & $(1.2)$ & 20.1 & $(1.5)$ & 11.1 & $(1.2)$ & 4.1 & (0.6) & 0.9 & $(0.5)$ \\
\hline & Fujairah & 23.5 & (4.6) & 21.6 & $(4.8)$ & 27.6 & (3.6) & 19.5 & $(3.2)$ & 6.5 & $(2.5)$ & 1.3 & (1.0) & 0.1 & C \\
\hline & Ras al-Khaimah & 25.7 & (6.8) & 26.3 & $(4.3)$ & 25.6 & $(4.2)$ & 15.0 & $(2.3)$ & 6.2 & (1.9) & 1.1 & $(0.7)$ & 0.2 & c \\
\hline & Sharjah & 25.9 & (5.5) & 25.4 & $(2.9)$ & 21.9 & (3.5) & 16.3 & (3.8) & 7.8 & $(3.0)$ & 2.3 & (0.9) & 0.2 & c \\
\hline & Umm al-Quwain & 26.2 & (3.7) & 30.8 & $(4.7)$ & 26.6 & (5.7) & 11.2 & (3.6) & 3.9 & $(2.0)$ & 1.2 & (1.1) & 0.0 & c \\
\hline
\end{tabular}

- PISA adjudicated region

Note: See Table I.2.18 for national data.

StatLink 解古 $\mathrm{http}: / / \mathrm{dx}$.doi.org/10.1787/888932935762 
[Part 1/2]

Mean score, variation and gender differences in student performance on the mathematics Table B2.I.18 subscale space and shape, by region

\begin{tabular}{|c|c|c|c|c|c|c|c|c|c|c|c|c|c|c|c|c|c|c|c|}
\hline & & & All stu & Idents & & & & nder di & lifferen & nces & & & & & & & Perce & entiles & \\
\hline & & Mean & iscore & $\begin{array}{l}\text { Stan } \\
\text { devia }\end{array}$ & $\begin{array}{l}\text { ard } \\
\text { ion }\end{array}$ & Bc & bys & & irls & $\begin{array}{c}\text { Diffe } \\
\text { (B - }\end{array}$ & $\begin{array}{l}\text { rence } \\
- \text { G) }\end{array}$ & & th & & 0th & & 5th & & 5th \\
\hline & & Mean & S.E. & S.D. & S.E. & $\begin{array}{l}\text { Mean } \\
\text { score }\end{array}$ & S.E. & \begin{tabular}{|l|} 
Mean \\
score
\end{tabular} & S.E. & $\begin{array}{c}\begin{array}{c}\text { Score } \\
\text { dif. }\end{array} \\
\end{array}$ & S.E. & Score & S.E. & Score & S.E. & Score & S.E. & Score & S.E. \\
\hline & Australia & & & & & & & & & & & & & & & & & & \\
\hline U & Australian Capital Territory & 511 & (3.8) & 102 & (2.8) & $\mid 517$ & (5.7) & 504 & (4.9) & 14 & (7.5) & $\mid 346$ & (9.8) & 380 & (7.1) & 438 & (5.0) & 582 & (6.5) \\
\hline & New South Wales & 503 & (4.1) & 109 & (3.2) & 512 & (6.0) & 493 & (4.4) & 19 & (6.8) & 329 & (6.4) & 366 & (4.7) & 426 & (4.1) & 575 & (5.9) \\
\hline & Northern Territory & 458 & (10.9) & 99 & (4.5) & 464 & (9.3) & 452 & (16.1) & 12 & (14.6) & 292 & (14.1) & 330 & (11.5) & 391 & (10.9) & 527 & (13.7) \\
\hline & Queensland & 496 & (3.3) & 99 & (2.0) & 502 & (4.1) & 489 & $(4.2)$ & 13 & (4.8) & 335 & (6.3) & 370 & (4.9) & 427 & (4.9) & 564 & (4.6) \\
\hline & South Australia & 481 & (3.9) & 94 & (2.4) & 489 & (5.0) & 474 & (4.4) & 15 & $(5.2)$ & 330 & (5.8) & 360 & (5.6) & 415 & (4.7) & 545 & (5.5) \\
\hline & Tasmania & 470 & (3.6) & 95 & (2.4) & 477 & (5.0) & 463 & (4.8) & 14 & (6.6) & 317 & (6.8) & 349 & (7.9) & 406 & (5.1) & 533 & (4.5) \\
\hline & Victoria & 492 & (4.1) & 98 & (2.8) & 503 & (5.5) & 479 & (4.5) & 24 & (6.0) & 336 & (5.3) & 369 & (4.1) & 422 & (5.1) & 556 & (4.8) \\
\hline & Western Australia & 508 & (4.0) & 97 & (2.4) & 522 & (6.1) & 493 & (4.1) & 29 & (6.9) & 353 & $(5.0)$ & 383 & $(5.0)$ & 440 & (5.2) & 575 & $(6.2)$ \\
\hline & Belgium & & & & & & & & & & & & & & & & & & \\
\hline & Flemish Community ${ }^{\bullet}$ & 527 & (3.5) & 109 & (2.0) & $\mid 537$ & (4.8) & 518 & (4.3) & 19 & (5.8) & 343 & (6.8) & 382 & (5.6) & 451 & (5.5) & 608 & (4.0) \\
\hline & French Community & 484 & (3.4) & 101 & (2.5) & 493 & (3.7) & 476 & $(4.2)$ & 17 & (4.1) & 317 & (7.7) & 354 & (6.1) & 416 & (5.4) & 555 & (4.3) \\
\hline & German-speaking Community & 509 & (2.8) & 91 & (2.7) & 515 & (4.6) & 501 & (3.1) & 14 & (5.7) & 354 & (9.6) & 388 & (6.7) & 445 & (4.9) & 571 & (4.4) \\
\hline & Canada & & & & & & & & & & & & & & & & & & \\
\hline & Alberta & 509 & (4.9) & 94 & (1.9) & 513 & (5.0) & 505 & (5.6) & 8 & (4.0) & $\mid 354$ & (7.8) & 388 & (5.4) & 444 & (5.2) & 575 & (6.1) \\
\hline & British Columbia & 512 & (5.0) & 91 & $(2.2)$ & 518 & (5.3) & 505 & (6.6) & 13 & (6.4) & 363 & (7.7) & 394 & (6.4) & 447 & (5.3) & 576 & (7.2) \\
\hline & Manitoba & 484 & (3.2) & 93 & (1.9) & 489 & (3.7) & 478 & (4.8) & 12 & (5.8) & 334 & (7.0) & 366 & (6.7) & 420 & (3.9) & 546 & (4.3) \\
\hline & New Brunswick & 493 & (2.7) & 87 & (1.9) & 494 & (4.3) & 493 & (3.3) & 2 & (5.6) & 345 & (5.9) & 380 & (5.6) & 436 & (4.4) & 551 & (3.6) \\
\hline & Newfoundland and Labrador & 477 & (3.7) & 88 & $(2.7)$ & 477 & (5.0) & 477 & (3.7) & 0 & (4.9) & 326 & (12.9) & 365 & (9.9) & 417 & (6.2) & 538 & (5.1) \\
\hline & Nova Scotia & 482 & $(2.7)$ & 86 & (3.1) & 490 & (4.1) & 475 & (4.0) & 15 & (6.0) & 344 & $(9.0)$ & 376 & (5.8) & 425 & (4.7) & 541 & (5.1) \\
\hline & Ontario & 505 & (4.4) & 93 & (1.9) & 509 & (5.3) & 500 & (4.5) & 10 & (4.4) & 357 & (6.5) & 387 & (5.6) & 441 & (4.7) & 567 & (5.7) \\
\hline & Prince Edward Island & 460 & (2.6) & 87 & $(1.8)$ & 463 & (3.6) & 457 & (3.4) & 6 & (4.6) & 318 & (6.5) & 350 & $(6.1)$ & 400 & (4.0) & 519 & (4.5) \\
\hline & Quebec & 535 & (4.0) & 101 & (2.0) & 541 & (4.9) & 529 & (4.4) & 12 & (4.7) & 361 & (7.5) & 402 & (6.2) & 466 & (5.0) & 606 & (4.9) \\
\hline & Saskatchewan & 497 & (3.8) & 88 & $(2.2)$ & 499 & (4.8) & 496 & (4.3) & 4 & $(5.2)$ & 353 & (5.8) & 385 & (4.3) & 438 & (3.6) & 559 & (5.7) \\
\hline & Italy & & & & & & & & & & & & & & & & & & \\
\hline & Abruzzo & 479 & $(7.7)$ & 104 & (4.5) & 485 & (8.8) & 473 & (8.7) & 13 & (9.0) & 306 & $(17.2)$ & 350 & (13.9) & 410 & (7.3) & 551 & (11.5) \\
\hline & Basilicata & 475 & (5.3) & 97 & (2.4) & 488 & (7.4) & 463 & (5.0) & 25 & (6.6) & 321 & $(8.3)$ & 353 & (7.6) & 410 & (6.2) & 540 & (6.8) \\
\hline & Bolzano & 510 & $(2.7)$ & 98 & (1.7) & 526 & (3.7) & 494 & (3.1) & 32 & (4.3) & 352 & $(4.8)$ & 385 & (5.3) & 444 & (4.2) & 577 & (4.1) \\
\hline & Calabria & 428 & (6.8) & 96 & (3.6) & 441 & (7.2) & 415 & $(8.2)$ & 26 & (7.8) & 274 & (14.4) & 308 & (9.6) & 362 & (7.2) & 493 & (8.2) \\
\hline & Campania & 453 & (9.6) & 105 & (4.9) & 464 & (9.2) & 443 & (11.8) & 21 & (8.8) & 287 & (10.1) & 323 & (9.0) & 381 & (7.9) & 522 & $(15.2)$ \\
\hline & Emilia Romagna & 502 & (7.4) & 109 & $(4.3)$ & 513 & (8.8) & 489 & $(8.5)$ & 24 & (9.9) & 325 & $(8.2)$ & 365 & (9.6) & 430 & (8.8) & 576 & (9.8) \\
\hline & Friuli Venezia Giulia & 533 & $(5.2)$ & 99 & (3.0) & 547 & (5.7) & 518 & (6.4) & 29 & (7.3) & 376 & (7.6) & 406 & (6.3) & 468 & (7.1) & 599 & (6.0) \\
\hline & Lazio & 473 & (7.8) & 103 & (3.4) & 484 & (8.7) & 458 & (8.2) & 27 & $(8.2)$ & 305 & (10.9) & 342 & (7.6) & 402 & (8.5) & 541 & (9.6) \\
\hline & Liguria & 491 & (6.5) & 102 & (3.4) & 494 & (8.9) & 487 & (6.8) & 7 & (9.3) & 328 & (10.9) & 363 & $(7.7)$ & 420 & (7.1) & 558 & (9.2) \\
\hline & Lombardia & 521 & (9.8) & 101 & (3.9) & 538 & (11.4) & 503 & (9.8) & 35 & $(10.2)$ & 351 & (11.5) & 389 & (11.9) & 454 & (9.9) & 594 & $(13.2)$ \\
\hline & Marche & 495 & (6.5) & 97 & $(4.3)$ & 512 & (6.8) & 479 & (8.1) & 33 & (7.6) & 341 & (12.3) & 374 & (11.6) & 428 & (8.2) & 561 & (7.7) \\
\hline & Molise & 469 & (2.8) & 95 & (2.7) & 480 & (3.8) & 457 & (3.7) & 24 & (4.9) & 320 & (6.0) & 349 & (5.3) & 402 & (4.4) & 530 & (5.1) \\
\hline & Piemonte & 503 & (7.5) & 101 & (3.5) & 523 & (5.9) & 483 & (8.8) & 40 & $(6.2)$ & 343 & (11.7) & 375 & (8.4) & 433 & (8.0) & 571 & (8.5) \\
\hline & Puglia & 480 & (7.1) & 98 & (3.6) & 489 & (7.4) & 472 & (7.3) & 17 & (5.8) & 321 & (11.0) & 355 & (9.5) & 412 & (7.3) & 547 & (8.6) \\
\hline & Sardegna & 455 & (5.7) & 96 & (2.9) & 460 & (6.4) & 450 & (7.0) & 9 & (7.3) & 299 & (9.7) & 336 & (6.3) & 391 & (6.5) & 520 & (5.9) \\
\hline & Sicilia & 446 & (5.3) & 92 & (2.8) & 450 & (6.7) & 441 & (5.3) & 9 & (6.2) & 289 & (9.9) & 326 & (9.4) & 387 & (5.8) & 507 & (6.3) \\
\hline & Toscana & 500 & (6.5) & 106 & (3.4) & 501 & (7.8) & 498 & (10.4) & 3 & (12.7) & 327 & (9.9) & 363 & (8.5) & 425 & (7.4) & 575 & (9.2) \\
\hline & Trento & 535 & (4.9) & 95 & (2.7) & 540 & (5.6) & 529 & (7.1) & 11 & (8.5) & 385 & (8.6) & 414 & (7.0) & 468 & (6.2) & 602 & (5.2) \\
\hline & Umbria & 496 & (8.5) & 102 & (4.4) & 507 & (12.0) & 484 & (7.8) & 23 & (10.4) & 325 & (19.7) & 363 & (16.6) & 426 & (11.3) & 569 & (7.1) \\
\hline & Valle d'Aosta & 497 & (2.8) & 97 & (2.7) & 511 & (4.3) & 483 & (4.1) & 27 & (6.3) & 342 & (9.2) & 376 & (6.7) & 433 & (4.5) & 559 & (4.6) \\
\hline & Veneto & 528 & $(8.4)$ & 105 & $(4.2)$ & 539 & (9.7) & 517 & (8.6) & 22 & (9.3) & 358 & (8.0) & 393 & (9.3) & 455 & (6.4) & 602 & $(12.7)$ \\
\hline & Mexico & & & & & & & & & & & & & & & & & & \\
\hline & Aguascalientes & 442 & (5.6) & 79 & (2.9) & 450 & (7.3) & 435 & (5.1) & 15 & (5.8) & $\mid 316$ & (8.2) & 345 & (7.4) & 387 & (7.7) & 495 & (6.7) \\
\hline & Baja California & 413 & (6.0) & 80 & (2.5) & 424 & (6.8) & 401 & (6.4) & 24 & (5.7) & 287 & (10.6) & 316 & (6.9) & 358 & (5.9) & 465 & (9.7) \\
\hline & Baja California Sur & 418 & (5.0) & 76 & (1.9) & 429 & (6.4) & 407 & (4.5) & 22 & (4.4) & 297 & (6.9) & 324 & (7.3) & 365 & (6.4) & 469 & (6.3) \\
\hline & Campeche & 399 & (5.0) & 78 & (2.3) & 410 & (5.7) & 388 & (5.1) & 22 & (4.3) & 276 & (8.1) & 301 & (6.7) & 346 & (6.1) & 449 & (5.2) \\
\hline & Chiapas & 368 & (9.3) & 86 & $(4.8)$ & 375 & (9.5) & 362 & (10.0) & 13 & (5.6) & 223 & (17.5) & 256 & (15.6) & 311 & (13.0) & 424 & (7.6) \\
\hline & Chihuahua & 432 & (8.5) & 85 & (3.0) & 443 & (10.1) & 421 & (8.0) & 22 & (6.9) & 295 & $(11.7)$ & 325 & $(8.5)$ & 374 & (7.6) & 487 & $(10.3)$ \\
\hline & Coahuila & 422 & $(8.2)$ & 78 & (3.5) & 432 & (9.1) & 411 & (8.9) & 21 & (6.5) & 298 & (7.3) & 322 & $(6.9)$ & 368 & (7.6) & 472 & (11.1) \\
\hline & Colima & 430 & (4.1) & 79 & (3.1) & 438 & (4.4) & 422 & (5.1) & 16 & (4.6) & 305 & (8.7) & 330 & (7.5) & 376 & (5.9) & 481 & (4.5) \\
\hline & Distrito Federal & 421 & (5.3) & 80 & (3.6) & 436 & (7.0) & 406 & (6.3) & 31 & $(8.2)$ & 290 & (7.5) & 320 & (7.9) & 365 & (6.3) & 473 & (5.9) \\
\hline & Durango & 423 & (6.4) & 78 & (2.8) & 431 & (8.1) & 416 & (6.1) & 15 & (6.0) & 299 & (7.1) & 323 & (10.0) & 368 & (8.0) & 478 & (9.6) \\
\hline & Guanajuato & 415 & (6.4) & 82 & (3.8) & 425 & (7.1) & 406 & (6.6) & 18 & (4.4) & 281 & (13.9) & 311 & (14.3) & 360 & (8.2) & 469 & (6.5) \\
\hline & Guerrero & 368 & (5.0) & 74 & (2.6) & 373 & (5.7) & 364 & (5.5) & 9 & (5.2) & 249 & (8.2) & 274 & $(8.7)$ & 319 & (7.6) & 417 & (5.5) \\
\hline & Hidalgo & 410 & (5.8) & 79 & $(2.7)$ & 421 & (7.0) & 401 & (6.4) & 20 & (6.5) & 282 & (8.4) & 309 & (8.5) & 357 & (7.8) & 463 & (7.3) \\
\hline & Jalisco & 433 & $(8.1)$ & 77 & $(2.7)$ & 440 & (9.6) & 426 & (7.3) & 14 & (5.5) & 305 & (9.9) & 332 & $(12.3)$ & 382 & (9.5) & 483 & (8.3) \\
\hline & Mexico & 419 & (5.8) & 72 & (3.5) & 429 & (7.3) & 408 & (6.0) & 21 & (6.7) & 299 & (12.6) & 327 & (9.0) & 371 & (8.3) & 467 & (5.4) \\
\hline & Morelos & 420 & (8.5) & 84 & (5.4) & 427 & (9.4) & 414 & (9.0) & 13 & (6.7) & 288 & (12.3) & 316 & (11.7) & 363 & (9.2) & 474 & $(11.3)$ \\
\hline & Nayarit & 412 & (6.3) & 90 & $(2.5)$ & 427 & (6.7) & 397 & (7.5) & 31 & (7.0) & 266 & (9.5) & 296 & (10.4) & 351 & (7.7) & 471 & (8.5) \\
\hline & Nuevo León & 433 & $(8.2)$ & 86 & (2.5) & 449 & (8.4) & 415 & (8.4) & 34 & (5.9) & 293 & (10.3) & 324 & (10.0) & 374 & (8.5) & 490 & (12.0) \\
\hline & Puebla & 417 & (5.3) & 84 & (3.2) & 431 & (7.5) & 402 & (5.7) & 29 & (7.5) & 282 & (15.0) & 310 & (10.0) & 361 & (7.5) & 472 & (5.2) \\
\hline & Querétaro & 436 & (6.7) & 84 & (2.7) & 453 & (8.2) & 421 & (6.9) & 33 & (5.6) & 302 & (9.1) & 332 & (8.5) & 381 & (7.6) & 491 & (8.8) \\
\hline & Quintana Roo & 411 & (5.8) & 77 & (2.6) & 415 & (7.0) & 406 & (5.5) & 9 & (4.7) & 285 & (12.5) & 314 & (8.5) & 359 & (6.0) & 462 & (6.0) \\
\hline & San Luis Potosí & 411 & (8.4) & 82 & $(2.7)$ & 415 & $(9.2)$ & 408 & (8.5) & 8 & (5.2) & 280 & (12.0) & 309 & (7.7) & 353 & (9.2) & 465 & (8.9) \\
\hline & Sinaloa & 400 & (4.4) & 77 & $(2.7)$ & 408 & (4.9) & 393 & (5.6) & 15 & (5.7) & 280 & (8.1) & 305 & (6.6) & 347 & (5.0) & 449 & (6.1) \\
\hline & Tabasco & 370 & (5.0) & 78 & (3.0) & 378 & (5.9) & 363 & (5.1) & 15 & (4.5) & 244 & (9.5) & 269 & (10.1) & 318 & (6.6) & 422 & (6.2) \\
\hline & Tamaulipas & 414 & (8.4) & 80 & (3.2) & 430 & (11.3) & 398 & (7.3) & 32 & (8.8) & 289 & (8.0) & 314 & $(8.1)$ & 360 & (7.5) & 466 & (9.4) \\
\hline & Tlaxcala & 409 & (6.1) & 80 & (3.1) & 419 & (5.6) & 400 & (7.3) & 19 & (5.0) & 278 & $(14.2)$ & 307 & (9.8) & 356 & (7.9) & 462 & (6.0) \\
\hline & Veracruz & 408 & (7.4) & 83 & $(2.7)$ & 417 & (7.6) & 398 & (8.9) & 19 & (7.3) & 276 & (10.7) & 303 & (8.3) & 352 & (7.7) & 462 & (8.8) \\
\hline & Yucatán & 410 & (5.2) & 81 & (2.5) & 424 & (6.2) & 395 & (5.7) & 28 & (6.0) & 280 & (12.6) & 309 & (8.5) & 354 & (6.5) & 463 & (5.9) \\
\hline & Zacatecas & 408 & (4.3) & 77 & $(2.2)$ & 419 & (5.1) & 397 & (5.2) & 23 & (5.6) & 281 & (10.3) & 310 & (7.5) & 356 & (5.2) & 461 & (5.5) \\
\hline
\end{tabular}

- PISA adjudicated region.

Notes: Values that are statistically significant are indicated in bold (see Annex A3).

See Table 1.2.19 for national data.

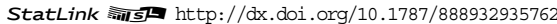


[Part 2/2]

Mean score, variation and gender differences in student performance on the mathematics Table B2.I.18 subscale space and shape, by region

\begin{tabular}{|c|c|c|c|c|c|c|c|c|c|c|c|c|c|c|c|c|c|c|c|c|c|c|c|}
\hline & & \multicolumn{4}{|c|}{ All students } & \multicolumn{6}{|c|}{ Gender differences } & \multicolumn{12}{|c|}{ Percentiles } \\
\hline & & \multicolumn{2}{|c|}{ Mean score } & \multicolumn{2}{|c|}{$\begin{array}{l}\text { Standard } \\
\text { deviation }\end{array}$} & \multicolumn{2}{|c|}{ Boys } & \multicolumn{2}{|c|}{ Girls } & \multicolumn{2}{|c|}{$\begin{array}{c}\text { Difference } \\
\text { (B - G) }\end{array}$} & \multicolumn{2}{|c|}{ 5th } & \multicolumn{2}{|c|}{ 10th } & \multicolumn{2}{|c|}{ 25th } & \multicolumn{2}{|c|}{ 75th } & \multicolumn{2}{|c|}{ 90th } & \multicolumn{2}{|c|}{ 95th } \\
\hline & & Mean & S.E. & S.D. & S.E. & $\begin{array}{l}\text { Mean } \\
\text { score }\end{array}$ & S.E. & $\begin{array}{l}\text { Mean } \\
\text { score }\end{array}$ & S.E. & \begin{tabular}{|c|}
$\begin{array}{c}\text { Score } \\
\text { dif. }\end{array}$ \\
\end{tabular} & S.E. & Score & S.E. & Score & S.E. & Score & S.E. & Score & e S.E. & Score & S.E. & Score & e S.E. \\
\hline \multirow{2}{*}{ ర్ } & Portugal & & & & & & & & & & & & & & & & & & & & & & \\
\hline & Alentejo & $\mid 493$ & (11.3) & 102 & $(4.0)$ & 505 & (13.6) & $\mid 481$ & (10.3) & 24 & $(8.0)$ & 331 & (15.7) & $\mid 367$ & (14.0) & 424 & $(13.3) \mid$ & 561 & (12.7) & 629 & (12.6) & 665 & (18.3) \\
\hline \multicolumn{24}{|c|}{ Spain } \\
\hline & Andalusia ${ }^{\bullet}$ & 461 & (4.4) & 87 & $(2.3)$ & 472 & (5.2) & 450 & $(4.2)$ & 22 & (3.9) & 322 & (7.9) & 352 & (5.4) & 401 & (4.0) & 520 & (6.0) & 578 & (5.8) & 609 & (7.2) \\
\hline & Aragon ${ }^{\bullet}$ & 493 & (6.0) & 99 & $(2.2)$ & 505 & (6.4) & 481 & (6.9) & 24 & $(5.7)$ & 324 & (11.1) & 366 & $(10.2)$ & 428 & (7.3) & 560 & (6.4) & 620 & (8.2) & 654 & (8.0) \\
\hline & Asturias ${ }^{\bullet}$ & 493 & (4.4) & 99 & (2.8) & 499 & (5.8) & 486 & (4.4) & 13 & (5.6) & 329 & (12.2) & 367 & (9.6) & 429 & (5.8) & 562 & (5.0) & 619 & (5.8) & 654 & (8.9) \\
\hline & Balearic Islands ${ }^{\bullet}$ & 465 & (5.2) & 88 & $(2.2)$ & 469 & (6.1) & 461 & $(6.0)$ & 8 & $(6.0)$ & 321 & (8.2) & 354 & (7.5) & 403 & (6.3) & 528 & (6.9) & 577 & (6.3) & 606 & (8.6) \\
\hline & Basque Country ${ }^{\bullet}$ & 503 & (2.6) & 85 & (1.4) & 509 & (3.0) & 497 & (3.1) & 12 & (3.1) & 362 & (4.2) & 392 & (3.8) & 446 & (2.8) & 563 & (3.3) & 612 & (3.8) & 640 & (4.0) \\
\hline & Cantabria ${ }^{\bullet}$ & 491 & (3.7) & 95 & (2.0) & 501 & (4.5) & 480 & (5.1) & 21 & (6.3) & 342 & (6.5) & 371 & (4.5) & 426 & (3.9) & 556 & (4.8) & 616 & (6.9) & 648 & (7.2) \\
\hline & Castile and Leon ${ }^{\bullet}$ & 504 & (4.8) & 92 & (2.4) & 513 & (6.8) & 494 & $(4.2)$ & 19 & (5.8) & 351 & (8.8) & 386 & (6.8) & 441 & (6.2) & 568 & (5.2) & 619 & (5.6) & 649 & (7.3) \\
\hline & Catalonia ${ }^{\bullet}$ & 485 & (5.8) & 94 & (2.4) & 496 & (7.1) & 473 & $(6.0)$ & 23 & (6.3) & 332 & (7.8) & 363 & (5.8) & 418 & (7.0) & 551 & (7.4) & 609 & (8.4) & 642 & (8.1) \\
\hline & Extremadura ${ }^{\bullet}$ & 457 & (4.1) & 93 & $(2.2)$ & 466 & (4.8) & 448 & (4.4) & 18 & (4.0) & 303 & (10.4) & 339 & $(8.2)$ & 393 & (4.6) & 521 & (6.1) & 578 & (6.0) & 612 & (6.4) \\
\hline & Galicia $\bullet^{\bullet}$ & 478 & (5.4) & 96 & (2.3) & 481 & (5.8) & 476 & (6.6) & 5 & $(6.2)$ & 317 & (11.1) & 354 & (7.4) & 414 & (7.3) & 545 & (5.8) & 598 & (5.3) & 631 & (6.2) \\
\hline & La Rioja• & 509 & (2.1) & 106 & (2.6) & 518 & (3.5) & 500 & (3.4) & 19 & (5.4) & 331 & (7.9) & 366 & (5.6) & 437 & (3.6) & 585 & (3.9) & 647 & (6.1) & 679 & (6.0) \\
\hline & Madrid ${ }^{\bullet}$ & 500 & (4.8) & 100 & (2.5) & 506 & (5.8) & 493 & $(5.0)$ & 14 & (5.1) & 331 & (8.4) & 373 & (9.9) & 432 & (5.5) & 570 & (7.0) & 627 & (5.4) & 659 & (7.7) \\
\hline & Murcia ${ }^{\bullet}$ & 455 & (5.2) & 94 & (3.4) & 464 & (6.7) & 446 & (4.9) & 17 & (5.3) & 307 & (9.4) & 340 & (6.8) & 393 & (5.3) & 516 & (7.1) & 578 & (8.3) & 612 & (11.8) \\
\hline & Navarre & 519 & (3.3) & 95 & $(2.2)$ & 522 & (3.9) & 515 & $(4.3)$ & 7 & (5.0) & 355 & (8.1) & 396 & (5.7) & 457 & (5.6) & 584 & (4.3) & 639 & (5.1) & 669 & (5.5) \\
\hline \multicolumn{24}{|c|}{ United Kingdom } \\
\hline & England & 477 & (4.1) & 100 & (2.0) & 484 & (5.1) & 471 & (4.9) & 13 & (5.8) & 314 & (6.6) & 348 & (5.6) & 408 & (4.8) & 544 & (5.1) & 607 & (4.8) & 643 & (5.8) \\
\hline & Northern Ireland & 463 & (3.6) & 98 & (2.5) & 467 & (5.4) & 460 & (5.4) & 7 & $(8.1)$ & 304 & (7.8) & 340 & (5.1) & 397 & (4.5) & 529 & (4.3) & 591 & (6.6) & 626 & (6.8) \\
\hline & Scotland ${ }^{\bullet}$ & 482 & (3.1) & 95 & (1.8) & 492 & (3.4) & 471 & (3.7) & 21 & (3.4) & 328 & (6.3) & 361 & (5.2) & 417 & (4.0) & 546 & (3.7) & 606 & (4.2) & 642 & (5.4) \\
\hline & Wales & 444 & (2.6) & 89 & (1.3) & 449 & (2.8) & 439 & (3.3) & 10 & (3.4) & 299 & (4.2) & 330 & $(4.2)$ & 383 & (3.1) & 505 & (3.2) & 559 & (4.4) & 592 & (5.8) \\
\hline \multicolumn{24}{|c|}{ United States } \\
\hline & Connecticut $^{\bullet}$ & 487 & (7.0) & 109 & (2.4) & 494 & (7.7) & 480 & $(7.2)$ & 14 & (5.0) & 312 & (9.4) & 348 & (9.0) & 410 & (6.9) & 563 & (9.8) & 630 & (8.8) & 667 & (9.9) \\
\hline & Florida ${ }^{\bullet}$ & 446 & (6.4) & 91 & (2.3) & 453 & (6.7) & 440 & $(6.8)$ & 13 & (4.6) & 300 & (7.1) & 332 & (6.8) & 383 & (6.9) & 507 & (7.1) & 566 & (9.3) & 600 & (8.9) \\
\hline & Massachusetts ${ }^{\bullet}$ & 498 & $(7.2)$ & 107 & (3.7) & 504 & (7.1) & 492 & $(8.2)$ & 12 & $(5.2)$ & 327 & (6.5) & 362 & (5.1) & 422 & $(6.8)$ & 572 & (11.7) & 640 & (11.3) & 678 & (13.7) \\
\hline
\end{tabular}

\begin{tabular}{|c|c|c|c|c|c|c|c|c|c|c|c|c|c|c|c|c|c|c|c|c|c|c|c|}
\hline \multirow{3}{*}{ } & \multicolumn{23}{|l|}{ Argentina } \\
\hline & Ciudad Autónoma de Buenos Aires ${ }^{\bullet}$ & 413 & (6.7) & 95 & $(4.7) \mid$ & 423 & (7.5) & 404 & (6.9) & 20 & $(5.2)$ & 246 & (19.9) & 288 & $(14.1)$ & 357 & $(8.4)$ & 475 & (7.6) & 529 & $(7.7) \mid$ & 562 & (10.1) \\
\hline & \multicolumn{23}{|l|}{ Brazil } \\
\hline & Acre & 348 & (6.6) & 76 & (3.4) & 363 & (9.0) & 335 & (6.4) & 28 & (7.6) & 224 & (11.7) & 250 & (12.8) & 298 & (8.3) & 398 & (6.3) & 441 & (10.4) & 471 & (14.1) \\
\hline & Alagoas & 329 & (7.7) & 80 & (5.7) & 346 & (7.6) & 316 & (9.0) & 30 & (6.6) & 199 & (14.4) & 232 & (11.7) & 280 & (8.6) & 379 & (8.9) & 430 & (12.8) & 464 & (18.7) \\
\hline & Amapá & 361 & (6.5) & 70 & (2.8) & 377 & (8.9) & 347 & (6.1) & 30 & (8.2) & 244 & (13.6) & 270 & (10.1) & 316 & (9.1) & 407 & (7.0) & 450 & (10.0) & 477 & $(12.3)$ \\
\hline & Amazonas & 349 & (6.4) & 70 & (5.5) & 360 & (8.4) & 339 & (5.4) & 21 & (5.7) & 240 & (9.6) & 262 & (9.6) & 302 & (8.6) & 390 & (7.4) & 436 & $(11.6)$ & 469 & (19.0) \\
\hline & Bahia & 365 & (5.5) & 87 & (6.0) & 382 & (5.9) & 351 & (9.6) & 31 & (11.8) & 229 & (17.4) & 260 & $(14.7)$ & 309 & $(10.4)$ & 413 & (8.5) & 471 & (14.9) & 522 & (20.7) \\
\hline & Ceará & 367 & (9.3) & 91 & (7.2) & 385 & (11.8) & 350 & (8.4) & 35 & (8.7) & 226 & (8.9) & 254 & (7.8) & 305 & (7.5) & 421 & (14.4) & 485 & $(23.7)$ & 526 & $(25.0)$ \\
\hline & Espírito Santo & 404 & (11.4) & 90 & (5.9) & 415 & (10.5) & 395 & (14.5) & 20 & (10.3) & 268 & (7.9) & 293 & (9.5) & 341 & (8.4) & 460 & (21.4) & 533 & (22.8) & 570 & (19.6) \\
\hline & Federal District & 409 & (9.6) & 86 & (7.8) & 421 & (10.5) & 399 & (9.8) & 23 & (7.4) & 278 & (12.5) & 306 & (12.4) & 348 & (9.4) & 467 & (12.9) & 525 & $(22.1)$ & 560 & (21.1) \\
\hline & Goiás & 372 & (5.2) & 72 & (2.4) & 385 & (6.4) & 359 & (5.8) & 26 & (6.7) & 261 & (8.6) & 284 & (8.4) & 323 & (6.6) & 416 & (7.6) & 468 & (7.7) & 506 & (8.5) \\
\hline & Maranhão & 335 & (11.6) & 78 & (7.5) & 348 & (15.3) & 326 & (9.7) & 23 & (8.1) & 214 & (18.8) & 240 & (12.8) & 284 & $(11.7)$ & 382 & (15.5) & 437 & $(25.7)$ & 472 & (24.5) \\
\hline & Mato Grosso & 369 & (9.2) & 76 & (6.8) & 375 & (8.9) & 363 & (10.8) & 12 & (6.9) & 256 & (9.6) & 279 & (6.2) & 317 & (8.9) & 413 & (12.4) & 466 & $(21.2)$ & 505 & (30.8) \\
\hline & Mato Grosso do Sul & 402 & (6.8) & 77 & (4.4) & 417 & (8.8) & 391 & (6.5) & 27 & (8.1) & 286 & (11.1) & 308 & (8.4) & 350 & (7.6) & 451 & (7.9) & 502 & (13.4) & 548 & (19.5) \\
\hline & Minas Gerais & 384 & (7.3) & 74 & (3.8) & 394 & (8.3) & 375 & (7.3) & 19 & (4.8) & 266 & (12.1) & 293 & (9.2) & 334 & (7.8) & 431 & (8.8) & 480 & $(12.2)$ & 509 & (12.0) \\
\hline & Pará & 356 & (5.1) & 76 & (3.8) & 365 & (6.1) & 350 & (7.2) & 16 & (8.6) & 232 & (10.6) & 258 & (11.6) & 306 & (7.8) & 408 & (6.6) & 457 & (7.8) & 486 & (10.6) \\
\hline & Paraíba & 383 & (6.5) & 86 & (6.5) & 395 & (7.2) & 372 & (8.9) & 23 & (9.7) & 247 & (13.0) & 276 & (13.9) & 325 & (11.8) & 438 & (7.7) & 494 & $(14.7)$ & 529 & (17.9) \\
\hline & Paraná & 394 & (11.9) & 84 & (12.1) & 409 & (12.3) & 379 & $(12.4)$ & 30 & (5.7) & 275 & (8.3) & 298 & (6.4) & 336 & (6.7) & 439 & $(14.7)$ & 511 & $(43.4)$ & 561 & $(48.2)$ \\
\hline & Pernambuco & 349 & (6.8) & 72 & (4.7) & 365 & (8.1) & 337 & (6.6) & 28 & (5.6) & 237 & (10.1) & 264 & (9.9) & 302 & (7.3) & 394 & (6.4) & 439 & (10.8) & 467 & (16.2) \\
\hline & Piauí & 381 & (8.0) & 87 & (5.6) & 395 & (9.1) & 370 & (8.1) & 25 & (4.9) & 258 & (11.1) & 283 & (7.1) & 321 & (6.1) & 429 & (13.1) & 500 & (22.1) & 543 & (20.8) \\
\hline & Rio de & 373 & (6.3) & 75 & (3.2) & 381 & (7.1) & 366 & (6.9) & 15 & (6.2) & 255 & (7.6) & 278 & (5.8) & 319 & (7.5) & 427 & (8.9) & 472 & (9.9) & 494 & (10.0) \\
\hline & do Norte & 374 & (12.2) & 93 & (11.6) & 386 & (13.3) & 364 & $(12.2)$ & 22 & (7.4) & 236 & (14.1) & 264 & (11.3) & 311 & (9.2) & 426 & (17.3) & 499 & (31.8) & 554 & (52.5) \\
\hline & Rio Grande do Sul & 393 & (5.7) & 72 & (2.4) & 401 & (6.4) & 387 & (6.4) & 15 & (5.9) & 277 & (9.7) & 304 & (8.2) & 342 & (6.0) & 444 & (8.1) & 487 & (9.0) & 514 & (9.9) \\
\hline & Rondônia & 376 & (5.0) & 70 & (3.0) & 380 & (5.6) & 373 & (6.0) & 7 & (6.0) & 263 & (5.2) & 288 & (5.8) & 329 & (7.1) & 422 & (6.8) & 466 & (6.8) & 493 & (11.2) \\
\hline & Roraima & 349 & (7.2) & 83 & (4.2) & 351 & (7.6) & 348 & (9.5) & 3 & (9.3) & 218 & $(10.2)$ & 246 & (9.4) & 294 & (8.5) & 399 & (8.6) & 457 & (12.7) & 495 & (16.9) \\
\hline & Santa & 407 & (7.3) & 73 & (3.1) & 419 & (7.2) & 395 & (8.5) & 23 & (6.5) & 285 & (12.4) & 317 & (11.0) & 361 & (7.0) & 453 & (9.1) & 501 & (12.3) & 530 & (11.9) \\
\hline & São P & 394 & (4.5) & 79 & (3.5) & 406 & (4.6) & 383 & (5.2) & 23 & (3.4) & 274 & (6.2) & 302 & (4.9) & 342 & (3.9) & 443 & (5.2) & 496 & (9.6) & 534 & (14.2) \\
\hline & Sergi & 371 & (7.2) & 72 & (4.3) & 389 & (9.8) & 356 & (6.9) & 33 & (7.2) & 258 & (10.3) & 282 & (10.6) & 323 & (7.2) & 418 & (9.1) & 466 & (16.9) & 497 & (15.0) \\
\hline & Tocantins & 361 & (7.5) & 77 & (4.7) & 373 & (8.9) & 348 & (6.3) & 25 & (5.0) & 236 & (7.9) & 266 & (6.6) & 311 & (5.9) & 408 & (10.3) & 462 & (13.8) & 491 & (16.4) \\
\hline \multicolumn{24}{|c|}{ Colombia } \\
\hline & Bogotá & 384 & (4.9) & 70 & (2.5) & 404 & (6.0) & 366 & (4.8) & 37 & (5.1) & 270 & (6.0) & 296 & (6.2) & 337 & (5.1) & 429 & (5.4) & 472 & (7.9) & 502 & (10.0) \\
\hline & Cali & 368 & (7.5) & 78 & (3.2) & 379 & (7.9) & 359 & (8.0) & 20 & (4.7) & 237 & (10.2) & 266 & (10.5) & 315 & (10.7) & 421 & (9.5) & 467 & (8.7) & 495 & (10.3) \\
\hline & Mar & 398 & (4.8) & 71 & (3.8) & 417 & (6.2) & 381 & (5.1) & 36 & (7.4) & 288 & (5.9) & 310 & (4.6) & 349 & (3.8) & 442 & (7.6) & 492 & (10.0) & 523 & (12.7) \\
\hline & Medellín & 389 & $(8.2)$ & 86 & (6.1) & 404 & $(8.0)$ & 375 & (11.4) & 29 & (10.9) & 262 & (7.9) & 288 & (8.7) & 331 & (6.4) & 439 & (10.8) & 503 & (19.1) & 546 & (24.6) \\
\hline \multicolumn{24}{|c|}{ Russian Fed } \\
\hline & Perm Territory region ${ }^{\bullet}$ & 488 & (6.3) & 104 & (5.5) & 496 & (8.1) & 479 & $(5$. & 18 & (5.9) & 319 & (10.6) & 358 & (8.0) & 418 & (6.9) & 557 & (7.0) & 621 & (13.8) & 663 & (18.9) \\
\hline \multicolumn{24}{|c|}{ United Arab Emirates } \\
\hline & Abu Dhabi & 414 & (3.8) & 93 & (2.6) & 412 & (4.9) & 415 & (5.4) & -3 & (7.0) & 270 & (5.2) & 299 & (4.6) & 350 & (3.8) & 474 & (5.5) & 537 & (7.1) & 579 & (9.4) \\
\hline & Ajman & 398 & (8.0) & 86 & (4.6) & 390 & (14.1) & 407 & (10.4) & -17 & (18.4) & 260 & (17.1) & 288 & (14.3) & 336 & (11.5) & 463 & (7.9) & 509 & (9.8) & 538 & (9.8) \\
\hline & Dubai ${ }^{\bullet}$ & 456 & $(1.2)$ & 99 & (1.3) & 462 & (1.9) & 450 & (1.8) & 12 & (2.7) & 299 & (3.4) & 330 & (2.3) & 387 & (1.7) & 525 & (3.0) & 585 & (3.9) & 620 & (5.6) \\
\hline & Fujairah & 408 & (12.2) & 95 & (2.7) & 390 & (11.5) & 427 & (12.4) & -37 & (11.1) & 252 & (16.4) & 289 & (15.7) & 340 & (13.5) & 474 & (14.1) & 528 & (13.6) & 562 & (18.9) \\
\hline & Ras al-Khaimah & 406 & (9.4) & 90 & (6.6) & 399 & (7.1) & 414 & (16.1) & -15 & (16.1) & 259 & $(24.2)$ & 294 & (17.4) & 347 & (12.5) & 467 & (8.1) & 522 & (8.6) & 551 & (10.9) \\
\hline & Sharjah & 421 & (9.0) & 96 & (4.0) & 420 & (15.2) & 422 & (12.7) & -2 & (20.6) & 272 & (8.3) & 298 & (9.3) & 352 & (9.4) & 488 & (13.0) & 548 & (15.4) & 584 & (11.6) \\
\hline & Umm al-Quwain & 388 & (4.9) & 82 & (3.7) & 367 & (6.3) & 408 & (7.1) & -41 & $(9.2)$ & 258 & (12.3) & 287 & (8.5) & 331 & $(10.0)$ & 438 & (8.0) & 496 & (12.1) & 534 & (13.1) \\
\hline
\end{tabular}

- PISA adjudicated region.

Notes: Values that are statistically significant are indicated in bold (see Annex A3).

See Table 1.2.19 for national data.

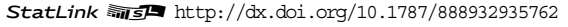


[Part 1/2]

Table B2.I.19 Percentage of students at each proficiency level on the mathematics subscale quantity, by region

\begin{tabular}{|c|c|c|c|c|c|c|c|c|c|c|c|c|c|c|c|}
\hline & & \multicolumn{14}{|c|}{ All students } \\
\hline & & \multicolumn{2}{|c|}{$\begin{array}{l}\text { Below Level } 1 \\
\text { (below } 357.77 \\
\text { score points) }\end{array}$} & $\begin{array}{l}\text { Le } \\
\text { (from } \\
\text { less tha } \\
\text { score }\end{array}$ & $\begin{array}{l}\text { I } 1 \\
7.77 \text { to } \\
420.07 \\
\text { oints) }\end{array}$ & $\begin{array}{l}\text { Le } \\
\text { (from } \\
\text { less tha } \\
\text { score }\end{array}$ & $\begin{array}{l}2 \\
.07 \text { to } \\
482.38 \\
\text { jints) }\end{array}$ & $\begin{array}{l}\text { Le } \\
\text { (from } \\
\text { less th } \\
\text { score }\end{array}$ & $\begin{array}{l}3 \\
2.38 \text { to } \\
544.68 \\
\text { oints) }\end{array}$ & $\begin{array}{l}\text { Le } \\
\text { (from } \\
\text { less th } \\
\text { score }\end{array}$ & $\begin{array}{l}4 \\
4.68 \text { to } \\
606.99 \\
\text { oints) }\end{array}$ & $\begin{array}{l}\text { Le } \\
\text { (from } \\
\text { less tha } \\
\text { score }\end{array}$ & $\begin{array}{l}\text { I } 5 \\
6.99 \text { to } \\
669.30 \\
\text { oints) }\end{array}$ & $\begin{array}{l}\text { Le } \\
\text { (abov } \\
\text { score }\end{array}$ & $\begin{array}{l}6 \\
69.30 \\
\text { jints) }\end{array}$ \\
\hline & & $\%$ & S.E. & $\%$ & S.E. & $\%$ & S.E. & $\%$ & S.E. & $\%$ & S.E. & $\%$ & S.E. & $\%$ & S.E. \\
\hline 0 & Australia & & & & & & & & & & & & & & \\
\hline క & Australian Capital Territory & 6.3 & $(1.0)$ & 10.5 & (1.4) & 20.3 & (1.9) & 24.2 & $(2.1)$ & 20.2 & $(2.0)$ & 13.1 & (1.6) & 5.6 & (1.1) \\
\hline & New South Wales & 8.7 & $(0.7)$ & 13.0 & $(0.8)$ & 20.5 & $(0.9)$ & 22.2 & $(1.0)$ & 17.7 & $(1.0)$ & 11.4 & $(1.0)$ & 6.6 & (1.0) \\
\hline & Northern Territory & 21.0 & $(2.4)$ & 17.8 & (3.5) & 19.6 & (4.5) & 24.1 & (3.5) & 11.0 & (2.8) & 4.5 & $(1.8)$ & 1.9 & $(0.9)$ \\
\hline & Queensland & 8.6 & $(0.9)$ & 14.5 & $(1.0)$ & 21.3 & (1.1) & 22.3 & $(1.0)$ & 17.7 & $(1.1)$ & 11.0 & $(1.0)$ & 4.6 & $(0.6)$ \\
\hline & South Australia & 10.1 & $(1.0)$ & 16.5 & (1.1) & 23.7 & (1.9) & 23.5 & (1.8) & 16.1 & (1.2) & 7.8 & $(0.9)$ & 2.3 & (0.5) \\
\hline & Tasmania & 13.3 & $(1.3)$ & 17.0 & (1.6) & 24.6 & $(1.7)$ & 22.5 & (1.8) & 13.4 & (1.4) & 6.9 & $(1.2)$ & 2.4 & $(0.6)$ \\
\hline & Victoria & 7.7 & $(0.8)$ & 13.7 & $(1.0)$ & 22.0 & (1.4) & 23.6 & (1.3) & 19.5 & (1.0) & 9.6 & $(0.9)$ & 3.9 & $(0.8)$ \\
\hline & Western Australia & 6.3 & $(0.8)$ & 12.6 & $(1.2)$ & 19.3 & (1.4) & 23.2 & $(1.3)$ & 20.8 & (1.3) & 12.3 & $(1.3)$ & 5.5 & $(0.9)$ \\
\hline & Belgium & & & & & & & & & & & & & & \\
\hline & Flemish Community & 5.5 & $(0.6)$ & 8.9 & $(0.7)$ & 16.2 & $(0.9)$ & 20.9 & $(0.9)$ & 21.7 & $(0.8)$ & 17.6 & $(1.0)$ & 9.2 & $(0.7)$ \\
\hline & French Community & 8.7 & $(0.9)$ & 14.2 & (1.1) & 20.1 & $(1.1)$ & 22.9 & (1.1) & 20.5 & (1.1) & 10.4 & $(0.9)$ & 3.3 & $(0.4)$ \\
\hline & German-speaking Community & 6.7 & $(0.8)$ & 9.6 & $(1.2)$ & 16.5 & (1.4) & 25.6 & (1.8) & 24.7 & (1.8) & 12.9 & (1.6) & 3.9 & $(0.9)$ \\
\hline & Canada & & & & & & & & & & & & & & \\
\hline & Alberta & 6.6 & $(1.1)$ & 12.1 & $(1.1)$ & 19.5 & (1.3) & 23.8 & (1.3) & 20.0 & (1.4) & 12.2 & $(1.2)$ & 6.0 & $(0.9)$ \\
\hline & British Columbia & 4.2 & $(0.8)$ & 9.8 & $(1.2)$ & 20.1 & (1.9) & 24.6 & (1.3) & 21.6 & (1.5) & 13.3 & (1.3) & 6.3 & (1.1) \\
\hline & Manitoba & 9.5 & $(1.0)$ & 15.6 & $(1.7)$ & 22.3 & (1.4) & 23.5 & $(1.7)$ & 17.2 & $(1.1)$ & 8.4 & $(0.8)$ & 3.5 & $(0.7)$ \\
\hline & New Brunswick & 6.4 & $(1.0)$ & 11.2 & $(1.0)$ & 22.4 & (1.5) & 27.5 & $(1.7)$ & 18.9 & (1.3) & 9.3 & $(1.3)$ & 4.3 & $(0.9)$ \\
\hline & Newfoundland and Labrador & 9.1 & $(1.3)$ & 16.3 & $(1.5)$ & 23.7 & (1.4) & 23.5 & (1.6) & 16.8 & (1.5) & 7.8 & $(1.0)$ & 2.8 & $(0.6)$ \\
\hline & Nova Scotia & 7.5 & $(1.0)$ & 14.3 & $(2.1)$ & 23.3 & $(2.1)$ & 24.9 & (2.6) & 18.4 & (1.4) & 8.6 & (1.6) & 3.1 & $(0.7)$ \\
\hline & Ontario & 6.4 & $(0.7)$ & 11.5 & $(0.8)$ & 20.5 & (1.3) & 24.7 & $(1.1)$ & 19.9 & $(1.2)$ & 11.4 & $(1.2)$ & 5.7 & $(0.8)$ \\
\hline & Prince Edward Island & 11.1 & $(1.0)$ & 17.4 & $(1.1)$ & 24.5 & (1.4) & 23.7 & (1.5) & 15.4 & $(1.2)$ & 6.2 & $(0.8)$ & 1.7 & $(0.4)$ \\
\hline & Quebec & 4.6 & $(0.6)$ & 8.0 & $(0.7)$ & 16.0 & $(1.0)$ & 23.0 & (1.3) & 24.5 & $(1.2)$ & 16.7 & $(1.0)$ & 7.1 & $(0.8)$ \\
\hline & Saskatchewan & 6.2 & $(0.8)$ & 13.4 & $(1.2)$ & 22.8 & (1.4) & 25.1 & $(1.3)$ & 18.7 & (1.3) & 10.5 & (1.1) & 3.2 & $(0.7)$ \\
\hline & Italy & & & & & & & & & & & & & & \\
\hline & Abruzzo & 11.8 & $(1.8)$ & 15.4 & $(1.5)$ & 21.9 & (1.6) & 24.4 & (1.4) & 17.2 & $(1.5)$ & 7.2 & (1.3) & 2.1 & $(0.6)$ \\
\hline & Basilicata & 11.4 & $(1.1)$ & 17.9 & $(1.5)$ & 25.1 & (1.3) & 24.3 & (1.4) & 14.6 & (1.6) & 4.9 & $(0.9)$ & 1.7 & $(0.5)$ \\
\hline & Bolzano & 6.4 & $(0.6)$ & 10.8 & $(1.2)$ & 18.5 & (1.1) & 25.9 & (1.5) & 21.6 & (1.5) & 11.4 & $(0.9)$ & 5.4 & $(0.7)$ \\
\hline & Calabria & 21.7 & $(2.6)$ & 22.1 & $(2.0)$ & 23.6 & (1.9) & 19.3 & (1.9) & 9.7 & (1.3) & 3.0 & $(0.8)$ & 0.7 & $(0.3)$ \\
\hline & Campania & 14.5 & $(2.0)$ & 20.4 & $(2.0)$ & 24.9 & (1.7) & 21.8 & $(2.2)$ & 12.5 & (1.7) & 4.6 & $(1.1)$ & 1.4 & $(0.5)$ \\
\hline & Emilia Romagna & 8.3 & $(1.3)$ & 11.4 & $(1.4)$ & 19.9 & $(1.9)$ & 23.6 & $(1.7)$ & 20.4 & $(1.9)$ & 11.3 & $(1.5)$ & 5.0 & (1.0) \\
\hline & Friuli Venezia Giulia & 5.4 & $(1.3)$ & 8.3 & $(1.1)$ & 16.4 & $(1.6)$ & 25.1 & $(1.8)$ & 24.6 & (1.4) & 13.7 & $(1.3)$ & 6.6 & $(0.8)$ \\
\hline & Lazio & 10.3 & (1.9) & 16.9 & (1.9) & 23.1 & $(1.5)$ & 23.8 & (1.6) & 15.3 & $(1.7)$ & 8.0 & $(1.2)$ & 2.5 & $(0.6)$ \\
\hline & Liguria & 8.6 & $(1.5)$ & 14.1 & (1.9) & 22.7 & (1.9) & 22.7 & $(1.5)$ & 18.7 & $(1.7)$ & 10.1 & (1.4) & 3.1 & $(0.7)$ \\
\hline & Lombardia & 4.2 & $(0.8)$ & 9.7 & $(1.3)$ & 18.4 & $(2.2)$ & 25.2 & $(1.7)$ & 23.4 & (1.9) & 14.0 & $(1.8)$ & 5.1 & (1.1) \\
\hline & Marche & 7.0 & (1.9) & 12.8 & $(1.2)$ & 21.9 & (1.8) & 24.8 & (1.7) & 20.6 & (1.6) & 9.4 & $(1.5)$ & 3.6 & (0.9) \\
\hline & Molise & 11.8 & $(1.1)$ & 16.8 & (1.6) & 25.1 & $(1.8)$ & 25.2 & $(1.7)$ & 15.3 & $(1.5)$ & 4.4 & $(1.0)$ & 1.3 & $(0.6)$ \\
\hline & Piemonte & 8.3 & $(1.3)$ & 12.7 & $(1.3)$ & 18.9 & $(1.7)$ & 24.9 & $(1.5)$ & 21.1 & $(1.8)$ & 10.6 & $(1.4)$ & 3.5 & $(0.8)$ \\
\hline & Puglia & 8.7 & (1.6) & 16.3 & $(2.0)$ & 24.3 & $(1.8)$ & 24.4 & $(1.7)$ & 17.7 & $(1.7)$ & 7.1 & $(1.0)$ & 1.5 & $(0.5)$ \\
\hline & Sardegna & 14.7 & (1.8) & 17.5 & $(1.7)$ & 24.7 & (1.8) & 22.6 & (1.6) & 13.8 & (1.3) & 5.8 & $(0.8)$ & 1.0 & $(0.4)$ \\
\hline & Sicilia & 15.3 & $(1.9)$ & 20.8 & $(2.2)$ & 26.3 & $(1.4)$ & 21.4 & $(2.0)$ & 12.0 & $(1.7)$ & 3.6 & $(0.7)$ & 0.7 & $(0.3)$ \\
\hline & Toscana & 9.0 & (1.5) & 11.9 & $(1.6)$ & 20.3 & $(1.8)$ & 23.8 & (1.4) & 19.6 & (1.9) & 10.8 & $(1.3)$ & 4.5 & $(0.6)$ \\
\hline & Trento & 4.2 & $(0.7)$ & 8.4 & $(1.0)$ & 18.1 & $(1.4)$ & 25.9 & $(1.8)$ & 24.1 & $(1.7)$ & 14.1 & $(1.6)$ & 5.2 & $(0.8)$ \\
\hline & Umbria & 7.1 & (1.6) & 12.4 & (1.9) & 22.0 & (1.6) & 25.6 & (1.8) & 21.2 & (1.5) & 9.1 & $(1.2)$ & 2.6 & $(0.6)$ \\
\hline & Valle d'Aosta & 6.6 & $(1.0)$ & 13.3 & (1.3) & 23.8 & (1.6) & 25.9 & (1.9) & 17.8 & (1.6) & 8.2 & $(1.2)$ & 4.4 & $(0.9)$ \\
\hline & Veneto & 4.4 & $(1.0)$ & 8.8 & $(1.3)$ & 18.7 & $(2.0)$ & 23.7 & $(2.1)$ & 22.0 & $(1.5)$ & 15.9 & $(2.1)$ & 6.6 & (1.7) \\
\hline & Mexico & & & & & & & & & & & & & & \\
\hline & Aguascalientes & 18.5 & (2.6) & 25.0 & $(2.4)$ & 28.6 & $(2.7)$ & 17.1 & (1.8) & 8.0 & $(0.9)$ & 2.6 & $(0.8)$ & 0.1 & C \\
\hline & Baja California & 25.2 & $(2.4)$ & 28.7 & $(2.1)$ & 24.2 & $(2.2)$ & 14.5 & (1.5) & 5.9 & $(1.1)$ & 1.5 & $(0.7)$ & 0.0 & C \\
\hline & Baja California Sur & 26.0 & $(2.7)$ & 27.5 & $(1.9)$ & 26.5 & $(2.1)$ & 13.3 & (1.5) & 5.4 & $(0.8)$ & 1.2 & $(0.5)$ & 0.2 & $\mathrm{C}$ \\
\hline & Campeche & 33.8 & $(2.8)$ & 28.7 & $(2.5)$ & 22.0 & $(1.6)$ & 11.6 & $(1.2)$ & 3.1 & $(0.7)$ & 0.7 & $(0.3)$ & 0.2 & $(0.1)$ \\
\hline & Chiapas & 47.3 & (4.0) & 26.5 & $(2.1)$ & 17.2 & $(2.2)$ & 6.5 & $(1.2)$ & 1.9 & $(0.6)$ & 0.4 & $(0.3)$ & 0.1 & $(0.1)$ \\
\hline & Chihuahua & 23.0 & $(2.7)$ & 26.1 & $(2.4)$ & 25.3 & (2.4) & 16.1 & (1.8) & 7.4 & $(1.5)$ & 1.9 & $(0.6)$ & 0.2 & $(0.2)$ \\
\hline & Coahuila & 23.5 & (3.2) & 27.8 & $(2.7)$ & 26.3 & (1.9) & 13.8 & $(2.3)$ & 6.9 & $(2.1)$ & 1.7 & $(0.9)$ & 0.0 & C \\
\hline & Colima & 22.2 & $(2.7)$ & 24.3 & $(2.2)$ & 25.5 & $(1.7)$ & 18.2 & $(1.8)$ & 7.4 & $(1.3)$ & 2.0 & $(0.7)$ & 0.4 & $(0.2)$ \\
\hline & Distrito Federal & 20.7 & $(2.1)$ & 25.4 & $(1.9)$ & 25.8 & $(1.5)$ & 17.4 & $(2.4)$ & 8.1 & $(1.5)$ & 2.3 & $(0.6)$ & 0.3 & (10.2) \\
\hline & Durango & 22.6 & (3.3) & 24.5 & $(2.4)$ & 26.2 & $(2.8)$ & 17.7 & $(2.0)$ & 6.9 & $(1.5)$ & 2.0 & $(0.9)$ & 0.2 & C \\
\hline & Guanajuato & 28.0 & $(3.2)$ & 27.8 & $(1.8)$ & 24.5 & $(2.2)$ & 13.5 & $(1.5)$ & 4.8 & $(0.7)$ & 1.3 & $(0.4)$ & 0.1 & C \\
\hline & Guerrero & 51.1 & (2.9) & 27.5 & $(2.0)$ & 14.9 & $(1.8)$ & 5.5 & $(0.9)$ & 0.9 & $(0.4)$ & 0.1 & $(0.1)$ & 0.0 & $\mathrm{C}$ \\
\hline & Hidalgo & 29.2 & (3.4) & 28.9 & $(2.2)$ & 23.4 & $(2.1)$ & 13.6 & (1.9) & 4.0 & $(1.0)$ & 0.9 & $(0.4)$ & 0.1 & c \\
\hline & Jalisco & 16.6 & (1.9) & 25.4 & $(2.1)$ & 29.6 & (2.4) & 18.4 & $(2.1)$ & 7.5 & $(1.5)$ & 2.2 & $(0.7)$ & 0.3 & $(0.2)$ \\
\hline & Mexico & 20.2 & $(2.4)$ & 28.8 & $(2.4)$ & 28.9 & $(1.9)$ & 16.6 & $(2.3)$ & 4.5 & $(1.0)$ & 0.7 & $(0.5)$ & 0.2 & $(0.2)$ \\
\hline & Morelos & 24.2 & (3.8) & 26.6 & (2.6) & 25.2 & $(2.6)$ & 14.5 & $(1.7)$ & 6.2 & $(1.7)$ & 2.6 & $(1.3)$ & 0.6 & $(0.5)$ \\
\hline & Nayarit & 22.6 & $(2.7)$ & 27.9 & $(2.1)$ & 25.7 & $(2.5)$ & 15.1 & $(2.2)$ & 6.7 & $(1.4)$ & 1.7 & $(0.6)$ & 0.2 & $(0.1)$ \\
\hline & Nuevo León & 17.5 & (3.1) & 25.4 & $(2.2)$ & 27.8 & $(1.7)$ & 19.1 & $(2.7)$ & 7.6 & $(1.6)$ & 2.1 & $(0.7)$ & 0.4 & $(0.3)$ \\
\hline & Puebla & 23.2 & $(2.5)$ & 27.1 & $(1.9)$ & 26.8 & $(1.7)$ & 15.4 & $(1.7)$ & 6.3 & $(0.9)$ & 1.0 & $(0.4)$ & 0.1 & $(0.1)$ \\
\hline & Querétaro & 17.9 & $(2.4)$ & 25.1 & $(2.3)$ & 27.6 & (1.9) & 17.7 & $(2.0)$ & 8.9 & $(1.6)$ & 2.3 & $(0.6)$ & 0.6 & $(0.3)$ \\
\hline & Quintana Roo & 26.0 & $(2.3)$ & 28.4 & $(2.0)$ & 25.2 & $(1.7)$ & 14.7 & $(1.6)$ & 4.9 & $(1.1)$ & 0.8 & $(0.3)$ & 0.1 & $(0.1)$ \\
\hline & San Luis Potosí & 26.0 & (3.4) & 27.4 & $(2.1)$ & 25.1 & $(2.0)$ & 14.8 & (1.9) & 5.3 & $(1.2)$ & 1.3 & $(0.5)$ & 0.1 & c \\
\hline & Sinaloa & 23.7 & $(2.3)$ & 30.6 & $(1.9)$ & 26.3 & $(1.8)$ & 13.6 & $(1.6)$ & 5.1 & $(0.8)$ & 0.7 & $(0.3)$ & 0.0 & C \\
\hline & Tabasco & 41.8 & $(2.8)$ & 29.3 & $(2.3)$ & 18.1 & $(1.9)$ & 8.1 & $(1.2)$ & 2.2 & $(0.6)$ & 0.4 & $(0.3)$ & 0.1 & $\mathrm{C}$ \\
\hline & Tamaulipas & 27.5 & $(2.9)$ & 28.6 & $(2.4)$ & 24.3 & (1.7) & 13.6 & $(1.8)$ & 4.6 & $(1.0)$ & 1.2 & $(0.5)$ & 0.2 & $(0.2)$ \\
\hline & Tlaxcala & 24.7 & $(2.5)$ & 29.6 & $(1.7)$ & 25.7 & $(2.1)$ & 14.4 & $(1.7)$ & 4.8 & $(0.9)$ & 0.7 & $(0.3)$ & 0.1 & $(0.1)$ \\
\hline & Veracruz & 32.6 & (3.4) & 28.4 & $(2.5)$ & 22.6 & (1.6) & 11.7 & $(2.0)$ & 4.0 & $(1.0)$ & 0.7 & $(0.4)$ & 0.1 & C \\
\hline & Yucatán & 27.6 & (3.2) & 27.5 & (1.9) & 24.9 & (1.9) & 13.8 & (1.5) & 4.9 & $(1.0)$ & 1.1 & $(0.5)$ & 0.2 & C \\
\hline & Zacatecas & 29.3 & (2.8) & 26.9 & (1.9) & 24.5 & $(2.2)$ & 14.1 & (1.5) & 4.2 & $(1.0)$ & 0.9 & $(0.5)$ & 0.1 & $(0.1)$ \\
\hline
\end{tabular}

- PISA adjudicated region.

Note: See Table I.2.20 for national data.

StatLink 完红 http://dx.doi.org/10.1787/888932935762 
[Part 2/2]

Table B2.I.19 Percentage of students at each proficiency level on the mathematics subscale quantity, by region

\begin{tabular}{|c|c|c|c|c|c|c|c|c|c|c|c|c|c|c|c|}
\hline & & \multicolumn{14}{|c|}{ All students } \\
\hline & & \multicolumn{2}{|c|}{$\begin{array}{c}\text { Below Level } 1 \\
\text { (below } 357.77 \\
\text { score points) }\end{array}$} & \multicolumn{2}{|c|}{$\begin{array}{c}\text { Level } 1 \\
\text { (from } 357.77 \text { to } \\
\text { less than } 420.07 \\
\text { score points) }\end{array}$} & \multicolumn{2}{|c|}{$\begin{array}{c}\text { Level } 2 \\
\text { (from } 420.07 \text { to } \\
\text { less than } 482.38 \\
\text { score points) }\end{array}$} & $\begin{array}{l}\text { Le } \\
\text { (from } \\
\text { less th } \\
\text { score }\end{array}$ & $\begin{array}{l}3 \\
2.38 \text { to } \\
544.68 \\
\text { oints) }\end{array}$ & $\begin{array}{r}\text { Le } \\
\text { (from } 5 \\
\text { less tha } \\
\text { score }\end{array}$ & $\begin{array}{l}14 \\
4.68 \text { to } \\
606.99 \\
\text { oints) }\end{array}$ & $\begin{array}{r}\text { Le } \\
\text { (from } \\
\text { less th } \\
\text { score }\end{array}$ & $\begin{array}{l}5 \\
6.99 \text { to } \\
669.30 \\
\text { ints) }\end{array}$ & $\begin{array}{r}\text { Le } \\
\text { (above } \\
\text { score }\end{array}$ & $\begin{array}{l}6 \\
69.30 \\
\text { ints) }\end{array}$ \\
\hline & & $\%$ & S.E. & $\%$ & S.E. & $\%$ & S.E. & $\%$ & S.E. & $\%$ & S.E. & $\%$ & S.E. & $\%$ & S.E. \\
\hline 0 & Portugal & & & & & & & & & & & & & & \\
\hline U. & Alentejo & 8.3 & (2.3) & 15.3 & (3.1) & 25.6 & $(2.8)$ & 25.4 & $(3.6)$ & 16.4 & $(2.2)$ & 7.3 & (1.7) & 1.8 & (0.9) \\
\hline & Spain & & & & & & & & & & & & & & \\
\hline & Andalusia ${ }^{\bullet}$ & 11.4 & (1.3) & 16.3 & (1.3) & 23.8 & (1.5) & 22.8 & $(1.5)$ & 16.1 & (1.3) & 7.1 & (1.0) & 2.4 & (0.5) \\
\hline & Aragon • & 9.9 & (1.4) & 12.5 & (1.3) & 18.1 & (1.4) & 22.8 & (1.3) & 20.2 & (1.3) & 12.3 & (1.3) & 4.3 & (1.1) \\
\hline & Asturias ${ }^{\bullet}$ & 7.3 & $(1.0)$ & 11.6 & (1.1) & 20.1 & (1.4) & 23.4 & $(1.2)$ & 19.4 & $(1.2)$ & 11.6 & (1.1) & 6.6 & $(0.8)$ \\
\hline & Balearic Islands ${ }^{\bullet}$ & 12.4 & (1.6) & 16.1 & (1.3) & 20.9 & $(1.2)$ & 22.9 & $(2.0)$ & 17.4 & (1.8) & 8.2 & (1.3) & 2.2 & $(0.7)$ \\
\hline & Basque Country ${ }^{\bullet}$ & 5.2 & (0.6) & 10.4 & $(0.7)$ & 20.1 & $(0.9)$ & 27.3 & $(0.9)$ & 23.0 & (0.8) & 10.8 & $(0.7)$ & 3.2 & $(0.4)$ \\
\hline & Cantabria ${ }^{\bullet}$ & 8.0 & $(0.9)$ & 14.5 & (1.0) & 21.6 & $(1.4)$ & 23.1 & $(1.3)$ & 18.3 & (1.4) & 10.4 & $(1.2)$ & 4.1 & $(0.7)$ \\
\hline & Castile and Leon ${ }^{\bullet}$ & 4.3 & $(0.8)$ & 10.5 & (1.1) & 19.1 & $(1.6)$ & 24.7 & $(1.5)$ & 24.1 & (1.6) & 12.9 & (1.1) & 4.3 & $(0.6)$ \\
\hline & Catalonia` & 6.4 & (1.0) & 13.3 & (1.4) & 21.4 & $(1.7)$ & 25.4 & $(2.1)$ & 20.5 & (1.5) & 9.7 & (1.3) & 3.3 & (0.5) \\
\hline & Extremadura ${ }^{\bullet}$ & 14.7 & (1.8) & 17.1 & (1.5) & 23.6 & $(1.3)$ & 22.2 & $(1.4)$ & 14.2 & (1.3) & 5.9 & $(0.8)$ & 2.3 & (0.4) \\
\hline & Galicia ${ }^{\bullet}$ & 7.8 & (1.1) & 12.7 & (1.4) & 21.4 & $(1.4)$ & 24.7 & $(1.5)$ & 19.8 & (1.4) & 10.3 & (1.1) & 3.3 & (0.5) \\
\hline & La Rioja・ & 9.3 & $(0.9)$ & 12.0 & (1.1) & 18.2 & $(1.3)$ & 22.1 & $(1.3)$ & 18.7 & (1.5) & 12.9 & (1.6) & 6.7 & $(0.7)$ \\
\hline & Madrid` & 7.0 & (1.1) & 11.1 & (1.1) & 17.9 & (1.5) & 23.6 & $(1.6)$ & 23.2 & (1.4) & 12.9 & (1.1) & 4.2 & $(0.6)$ \\
\hline & Murcia ${ }^{\bullet}$ & 14.1 & (1.5) & 17.3 & (1.3) & 23.5 & (2.1) & 22.8 & $(1.3)$ & 14.8 & (1.5) & 6.1 & (1.0) & 1.3 & (0.4) \\
\hline & Navarre ${ }^{\bullet}$ & 5.6 & (1.0) & 10.7 & (0.9) & 17.2 & (1.1) & 24.4 & $(1.4)$ & 25.0 & (1.5) & 12.9 & (1.1) & 4.2 & $(0.7)$ \\
\hline & United Kingdom & & & & & & & & & & & & & & \\
\hline & England & 9.6 & $(1.1)$ & 14.1 & (1.1) & 20.8 & $(1.0)$ & 22.7 & (1.1) & 18.6 & $(0.9)$ & 10.1 & $(0.7)$ & 4.1 & (0.5) \\
\hline & Northern Ireland & 9.6 & $(0.9)$ & 14.9 & $(1.2)$ & 21.1 & (1.4) & 23.5 & $(1.3)$ & 18.0 & (1.1) & 9.3 & $(0.9)$ & 3.5 & $(0.6)$ \\
\hline & Scotland ${ }^{\bullet}$ & 6.0 & $(0.7)$ & 13.1 & (1.0) & 23.0 & $(1.2)$ & 25.8 & $(1.2)$ & 19.6 & (1.1) & 9.6 & $(0.7)$ & 3.0 & (0.5) \\
\hline & Wales & 12.3 & $(0.8)$ & 19.2 & $(0.8)$ & 25.1 & (0.9) & 24.1 & $(1.0)$ & 13.4 & $(0.8)$ & 4.7 & $(0.5)$ & 1.2 & $(0.2)$ \\
\hline & United States & & & & & & & & & & & & & & \\
\hline & Connecticut $^{\bullet}$ & 9.4 & (1.4) & 13.5 & (1.3) & 19.2 & $(1.2)$ & 22.0 & $(1.2)$ & 19.4 & (1.6) & 11.5 & (1.5) & 5.1 & (1.0) \\
\hline & Florida $\bullet$ & 14.6 & (1.8) & 20.8 & (1.7) & 25.1 & $(1.3)$ & 21.4 & $(1.8)$ & 12.1 & (1.1) & 4.9 & $(1.0)$ & 1.1 & $(0.4)$ \\
\hline & Massachusetts ${ }^{\bullet}$ & 7.9 & (1.0) & 12.6 & (1.1) & 19.9 & (1.9) & 23.7 & (1.5) & 18.5 & (1.1) & 11.8 & (1.6) & 5.6 & (1.1) \\
\hline$\tilde{2}$ & Argentina & & & & & & & & & & & & & & \\
\hline 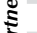 & Ciudad Autónoma de Buenos Aires ${ }^{\bullet}$ & 21.8 & (2.5) & 22.4 & $(2.1)$ & 25.8 & (1.6) & 19.3 & $(2.0)$ & 8.4 & (1.6) & 2.2 & $(0.7)$ & 0.1 & $(0.1)$ \\
\hline ‡ & Brazil & & & & & & & & & & & & & & \\
\hline & Acre & 55.0 & $(3.7)$ & 26.8 & (3.0) & 13.4 & $(2.0)$ & 4.0 & $(1.3)$ & 0.6 & $(0.4)$ & 0.2 & $(0.2)$ & 0.0 & c \\
\hline & Alagoas & 57.7 & $(4.2)$ & 23.9 & (2.6) & 12.4 & $(2.1)$ & 4.5 & $(1.5)$ & 1.4 & $(0.7)$ & 0.2 & $(0.2)$ & 0.0 & c \\
\hline & Amapá & 54.1 & (5.5) & 26.5 & (2.8) & 13.6 & $(2.9)$ & 4.8 & $(2.0)$ & 1.0 & $(0.7)$ & 0.0 & c & 0.0 & c \\
\hline & Amazonas & 56.1 & (3.5) & 26.6 & (2.5) & 11.8 & $(2.1)$ & 3.1 & $(1.3)$ & 1.6 & $(1.2)$ & 0.8 & $(0.8)$ & 0.0 & c \\
\hline & Bahia & 45.8 & $(6.8)$ & 25.2 & $(4.2)$ & 18.0 & $(4.9)$ & 7.7 & $(2.0)$ & 2.3 & (1.3) & 0.8 & $(0.7)$ & 0.1 & c \\
\hline & Ceará & 42.7 & (3.6) & 27.0 & $(2.7)$ & 17.8 & $(2.7)$ & 7.6 & $(1.8)$ & 3.0 & (1.3) & 1.6 & $(0.8)$ & 0.2 & c \\
\hline & Espírito Santo & 26.1 & $(2.8)$ & 28.1 & (2.7) & 21.4 & $(2.6)$ & 12.9 & $(1.9)$ & 8.3 & $(2.6)$ & 2.9 & (1.0) & 0.4 & $(0.3)$ \\
\hline & Federal District & 27.4 & $(5.0)$ & 25.7 & (3.6) & 22.3 & $(2.8)$ & 14.7 & $(2.6)$ & 7.1 & $(2.2)$ & 2.5 & (1.0) & 0.4 & $(0.4)$ \\
\hline & Goiás & 40.6 & $(4.1)$ & 29.3 & (2.4) & 17.2 & $(2.3)$ & 8.7 & $(1.3)$ & 3.5 & $(0.9)$ & 0.6 & $(0.4)$ & 0.1 & c \\
\hline & Maranhão & 60.7 & $(6.7)$ & 22.2 & (3.3) & 10.2 & $(3.2)$ & 5.1 & $(2.4)$ & 1.4 & (1.1) & 0.4 & $\mathrm{C}$ & 0.0 & c \\
\hline & Mato Grosso & 45.6 & $(4.0)$ & 29.7 & (3.0) & 16.0 & $(2.2)$ & 5.6 & $(1.6)$ & 2.2 & (1.4) & 0.9 & $(0.6)$ & 0.0 & c \\
\hline & Mato Grosso do Sul & 28.6 & $(4.3)$ & 29.7 & (3.1) & 22.9 & $(2.3)$ & 12.6 & $(1.6)$ & 4.9 & $(2.0)$ & 1.1 & $(0.7)$ & 0.2 & c \\
\hline & Minas Gerais & 30.0 & (3.9) & 26.8 & (2.4) & 23.9 & $(2.3)$ & 14.3 & $(2.4)$ & 3.8 & $(1.2)$ & 1.1 & $(0.5)$ & 0.0 & c \\
\hline & Pará & 53.8 & (3.0) & 26.6 & (3.0) & 14.5 & $(1.7)$ & 4.5 & $(0.7)$ & 0.5 & $(0.4)$ & 0.1 & $\mathrm{c}$ & 0.0 & c \\
\hline & Paraiba & 33.9 & $(4.9)$ & 28.3 & (3.5) & 20.9 & $(4.1)$ & 12.0 & $(1.6)$ & 3.7 & $(1.2)$ & 1.0 & $(0.6)$ & 0.1 & c \\
\hline & Paraná & 29.1 & (3.7) & 27.2 & (2.6) & 22.3 & $(2.9)$ & 11.4 & $(1.8)$ & 6.5 & (2.9) & 3.0 & (2.5) & 0.6 & (0.6) \\
\hline & Pernambuco & 45.9 & (5.4) & 30.2 & (3.9) & 16.9 & $(2.6)$ & 4.9 & $(1.1)$ & 1.7 & $(0.9)$ & 0.3 & $(0.4)$ & 0.1 & $(0.1)$ \\
\hline & Piauí & 39.1 & (3.6) & 29.5 & (2.9) & 15.9 & $(2.2)$ & 10.1 & $(1.7)$ & 3.8 & (1.6) & 1.1 & $(0.7)$ & 0.5 & $(0.4)$ \\
\hline & Rio de Janeiro & 38.0 & $(4.8)$ & 27.5 & $(3.2)$ & 21.3 & $(2.5)$ & 8.8 & $(2.0)$ & 3.5 & (1.3) & 0.8 & (0.5) & 0.1 & C \\
\hline & Rio Grande do Norte & 45.8 & (3.5) & 25.0 & (2.6) & 15.0 & $(1.9)$ & 7.7 & $(1.9)$ & 3.6 & $(1.2)$ & 2.1 & $(0.9)$ & 0.8 & (0.6) \\
\hline & Rio Grande do Sul & 27.5 & (3.5) & 27.9 & (2.1) & 25.3 & $(2.8)$ & 13.9 & $(2.2)$ & 4.4 & $(1.2)$ & 0.9 & $(0.5)$ & 0.1 & c \\
\hline & Rondônia & 39.4 & (3.1) & 30.3 & (2.0) & 21.9 & $(2.6)$ & 6.7 & $(1.5)$ & 1.5 & $(0.5)$ & 0.1 & C & 0 & c \\
\hline & Roraima & 52.8 & $(4.0)$ & 24.5 & (3.5) & 14.6 & $(2.3)$ & 6.3 & $(1.9)$ & 1.7 & $(0.7)$ & 0.1 & c & 0.0 & c \\
\hline & Santa Catarina & 23.6 & (3.5) & 22.4 & (2.4) & 26.0 & $(2.0)$ & 18.2 & $(2.3)$ & 7.8 & $(1.7)$ & 1.8 & $(0.8)$ & 0.1 & c \\
\hline & São Paulo & 31.8 & (2.0) & 27.2 & (1.6) & 21.1 & $(1.2)$ & 12.0 & $(1.3)$ & 6.0 & $(1.0)$ & 1.6 & (0.6) & 0.4 & $(0.2)$ \\
\hline & Sergipe & 38.6 & $(4.0)$ & 27.7 & (3.0) & 19.6 & $(3.0)$ & 10.0 & $(2.4)$ & 3.4 & $(1.7)$ & 0.8 & $(0.5)$ & 0.0 & c \\
\hline & Tocantins & 50.6 & (3.3) & 25.4 & (2.5) & 13.7 & $(1.7)$ & 7.2 & $(1.3)$ & 2.2 & $(0.8)$ & 0.6 & $(0.3)$ & 0.3 & (0.3) \\
\hline & Colombia & & & & & & & & & & & & & & \\
\hline & Bogotá & 34.0 & (1.6) & 30.7 & (1.7) & 22.8 & $(1.3)$ & 9.5 & $(1.2)$ & 2.5 & $(0.6)$ & 0.4 & $(0.2)$ & 0.1 & c \\
\hline & Cali & 40.5 & (3.8) & 28.4 & (1.9) & 19.5 & $(2.4)$ & 8.8 & $(1.8)$ & 2.4 & $(0.7)$ & 0.4 & $(0.2)$ & 0.0 & c \\
\hline & Manizales & 28.9 & (2.0) & 29.8 & (2.4) & 22.8 & $(2.4)$ & 11.6 & (1.5) & 5.2 & $(1.2)$ & 1.6 & $(0.7)$ & 0.2 & $(0.2)$ \\
\hline & Medellín & 38.5 & (3.3) & 25.4 & (1.9) & 17.8 & $(2.0)$ & 10.8 & (1.8) & 4.6 & $(1.2)$ & 2.0 & (0.9) & 0.9 & (0.6) \\
\hline & Russian Federation & & & & & & & & & & & & & & \\
\hline & Perm Territory region & 9.2 & (1.3) & 16.9 & (1.6) & 25.7 & (1.9) & 24.5 & (1.5) & 16.0 & (1.3) & 6.0 & $(1.2)$ & 1.8 & $(0.8)$ \\
\hline & United Arab Emirates & & & & & & & & & & & & & & \\
\hline & Abu Dhabi ${ }^{\bullet}$ & 29.4 & (1.8) & 23.8 & (1.3) & 21.4 & $(1.2)$ & 14.5 & $(1.1)$ & 7.5 & (1.0) & 2.7 & $(0.5)$ & 0.7 & $(0.3)$ \\
\hline & Ajman & 33.2 & $(4.8)$ & 28.6 & (2.7) & 21.5 & $(3.1)$ & 12.6 & $(2.5)$ & 3.5 & $(1.0)$ & 0.4 & $(0.4)$ & 0.0 & C \\
\hline & Dubai & 15.3 & $(0.6)$ & 18.1 & $(0.8)$ & 22.8 & $(1.1)$ & 21.2 & $(1.0)$ & 14.3 & $(0.7)$ & 6.4 & $(0.5)$ & 2.0 & $(0.3)$ \\
\hline & Fujairah & 30.0 & $(4.2)$ & 25.5 & (2.8) & 24.5 & $(2.8)$ & 13.5 & $(2.0)$ & 5.4 & $(0.9)$ & 0.9 & $(0.5)$ & 0.1 & $(0.1)$ \\
\hline & Ras al-Khaimah & 28.7 & (3.4) & 26.3 & (2.4) & 23.3 & $(2.5)$ & 14.6 & $(1.8)$ & 5.2 & $(1.1)$ & 1.5 & $(0.6)$ & 0.4 & $(0.3)$ \\
\hline & Sharjah & 20.7 & (3.0) & 24.1 & (3.0) & 23.2 & $(2.8)$ & 16.5 & $(2.5)$ & 10.9 & $(2.2)$ & 3.7 & (0.9) & 1.0 & (0.6) \\
\hline & Umm al-Quwain & 36.2 & $(2.7)$ & 30.6 & (3.1) & 19.5 & $(2.5)$ & 10.0 & $(2.4)$ & 2.9 & (1.4) & 0.8 & $(0.8)$ & 0.1 & $\mathrm{C}$ \\
\hline
\end{tabular}

- PISA adjudicated region

Note: See Table 1.2.20 for national data.

StatLink 解古 $\mathrm{http}: / / \mathrm{dx}$.doi.org/10.1787/888932935762 
[Part 1/4]

Percentage of students at each proficiency level on the mathematics subscale quantity, by gender Table B2.I.20 and region

\begin{tabular}{|c|c|c|c|c|c|c|c|c|c|c|c|c|c|c|c|}
\hline & & \multicolumn{14}{|c|}{ Boys } \\
\hline & & \multicolumn{2}{|c|}{$\begin{array}{l}\text { Below Level } 1 \\
\text { (below } 357.77 \\
\text { score points) }\end{array}$} & $\begin{array}{l}\mathbf{L} \\
\text { (from } \\
\text { less th } \\
\text { scor }\end{array}$ & $\begin{array}{l}\text { I } 1 \\
7.77 \text { to } \\
420.07 \\
\text { oints) }\end{array}$ & $\begin{array}{l}\text { Le } \\
\text { (from } \\
\text { less th } \\
\text { score }\end{array}$ & $\begin{array}{l}2 \\
.07 \text { to } \\
482.38 \\
\text { oints) }\end{array}$ & $\begin{array}{l}\text { Le } \\
\text { (from } \\
\text { less th } \\
\text { score }\end{array}$ & $\begin{array}{l}3 \\
2.38 \text { to } \\
544.68 \\
\text { oints) }\end{array}$ & $\begin{array}{l}\text { Le } \\
\text { (from } \\
\text { less th } \\
\text { score }\end{array}$ & $\begin{array}{l}14 \\
4.68 \text { to } \\
606.99 \\
\text { oints) }\end{array}$ & $\begin{array}{l}\text { Le } \\
\text { (from } \\
\text { less tha } \\
\text { score }\end{array}$ & $\begin{array}{l}5 \\
6.99 \text { to } \\
669.30 \\
\text { oints) }\end{array}$ & $\begin{array}{r}\text { Le } \\
\text { (abov } \\
\text { score }\end{array}$ & $\begin{array}{l}6 \\
69.30 \\
\text { ints) }\end{array}$ \\
\hline & & $\%$ & S.E. & $\%$ & S.E. & $\%$ & S.E. & $\%$ & S.E. & $\%$ & S.E. & $\%$ & S.E. & $\%$ & S.E. \\
\hline$\theta$ & Australia & & & & & & & & & & & & & & \\
\hline U & Australian Capital Territory & 7.8 & (1.4) & 10.2 & $(2.0)$ & 20.4 & $(3.2)$ & 24.9 & $(2.9)$ & 19.3 & (2.6) & 11.7 & $(2.1)$ & 5.8 & (1.3) \\
\hline & New South Wales & 9.8 & $(1.1)$ & 12.4 & $(1.1)$ & 20.0 & (1.3) & 21.2 & (1.3) & 17.4 & (1.3) & 11.8 & (1.5) & 7.4 & (1.3) \\
\hline & Northern Territory & 20.5 & (2.6) & 17.4 & $(4.7)$ & 18.1 & $(4.7)$ & 24.5 & $(4.7)$ & 11.8 & (3.0) & 4.7 & $(2.5)$ & 3.0 & (1.5) \\
\hline & Queensland & 8.3 & (1.3) & 13.9 & (1.4) & 21.7 & (1.6) & 21.7 & (1.6) & 18.3 & (1.5) & 11.1 & (1.3) & 5.0 & $(0.7)$ \\
\hline & South Australia & 9.1 & $(1.3)$ & 14.9 & (1.5) & 22.6 & $(2.1)$ & 23.9 & $(2.1)$ & 17.3 & (1.9) & 9.3 & (1.5) & 2.9 & $(0.8)$ \\
\hline & Tasmania & 12.8 & (1.7) & 13.9 & $(2.0)$ & 24.1 & $(2.4)$ & 24.2 & $(3.2)$ & 13.7 & (2.3) & 8.2 & (1.6) & 3.2 & (1.0) \\
\hline & Victoria & 7.0 & (1.1) & 12.6 & (1.5) & 20.3 & $(1.4)$ & 23.3 & (1.4) & 21.1 & (1.7) & 10.4 & (1.3) & 5.4 & (1.4) \\
\hline & Western Australia & 4.9 & $(0.9)$ & 10.6 & (1.6) & 18.7 & $(1.8)$ & 22.4 & $(1.8)$ & 22.5 & $(2.4)$ & 14.2 & $(1.8)$ & 6.7 & (1.3) \\
\hline & Belgium & & & & & & & & & & & & & & \\
\hline & Flemish Community ${ }^{\bullet}$ & 5.2 & $(0.8)$ & 8.4 & (1.1) & 16.0 & $(0.9)$ & 20.6 & $(1.2)$ & 21.2 & (1.1) & 18.0 & (1.5) & 10.6 & (1.1) \\
\hline & French Community & 8.5 & (1.0) & 13.6 & $(1.2)$ & 18.1 & $(1.4)$ & 22.4 & $(2.0)$ & 21.5 & (1.5) & 11.7 & (1.4) & 4.1 & $(0.5)$ \\
\hline & German-speaking Community & 8.0 & (1.1) & 11.3 & (1.9) & 15.0 & $(2.1)$ & 24.4 & $(2.5)$ & 22.0 & (1.9) & 13.7 & $(2.0)$ & 5.6 & (1.6) \\
\hline & Canada & & & & & & & & & & & & & & \\
\hline & Alberta & 6.5 & (1.4) & 10.4 & (1.1) & 19.0 & (1.8) & 24.0 & (1.9) & 19.4 & $(2.2)$ & 13.0 & (1.8) & 7.6 & $(1.2)$ \\
\hline & British Columbia & 4.0 & $(1.0)$ & 8.3 & $(1.3)$ & 18.9 & $(2.2)$ & 23.7 & (1.9) & 22.2 & (2.6) & 15.5 & (1.8) & 7.4 & (1.4) \\
\hline & Manitoba & 9.3 & (1.9) & 14.9 & $(2.7)$ & 21.2 & $(2.3)$ & 23.8 & $(2.3)$ & 17.8 & (1.6) & 9.1 & (1.3) & 4.0 & (1.1) \\
\hline & New Brunswick & 6.5 & (1.3) & 11.4 & (1.3) & 20.1 & (1.8) & 28.6 & (2.5) & 18.9 & (1.9) & 10.3 & (1.6) & 4.2 & $(1.2)$ \\
\hline & Newfoundland and Labrador & 9.5 & (2.1) & 15.2 & $(2.4)$ & 22.7 & $(2.3)$ & 24.2 & $(2.6)$ & 16.8 & (1.7) & 8.2 & (1.4) & 3.4 & (1.1) \\
\hline & Nova Scotia & 7.5 & (1.5) & 12.5 & $(3.0)$ & 21.3 & (3.0) & 25.3 & (2.4) & 19.4 & $(2.2)$ & 10.4 & (2.4) & 3.6 & (1.0) \\
\hline & Ontario & 6.3 & (1.0) & 11.5 & $(1.3)$ & 19.7 & (1.3) & 23.7 & (1.4) & 19.0 & (1.6) & 12.6 & (1.8) & 7.2 & (1.1) \\
\hline & Prince Edward Island & 12.8 & (1.7) & 16.6 & $(1.5)$ & 23.3 & $(2.1)$ & 22.5 & $(2.0)$ & 15.2 & (1.6) & 7.6 & (1.4) & 2.1 & $(0.7)$ \\
\hline & Quebec & 4.8 & $(0.9)$ & 7.9 & $(1.0)$ & 15.0 & (1.5) & 22.2 & (1.6) & 24.6 & (1.4) & 17.7 & (1.6) & 7.7 & (1.0) \\
\hline & Saskatchewan & 6.2 & $(1.2)$ & 13.1 & (1.8) & 21.5 & $(2.2)$ & 24.8 & (1.9) & 19.6 & $(2.1)$ & 11.1 & (1.8) & 3.7 & (1.1) \\
\hline & Italy & & & & & & & & & & & & & & \\
\hline & Abruzzo & 13.2 & (2.3) & 13.7 & $(2.0)$ & 20.4 & (2.4) & 23.5 & (2.5) & 18.6 & (2.3) & 7.9 & (1.7) & 2.8 & (0.9) \\
\hline & Basilicata & 10.4 & $(1.3)$ & 15.1 & $(2.1)$ & 22.2 & $(1.8)$ & 24.8 & $(2.1)$ & 18.1 & (2.6) & 6.9 & (1.6) & 2.6 & $(0.8)$ \\
\hline & Bolzano & 5.8 & $(0.9)$ & 10.6 & (1.5) & 16.3 & (1.8) & 23.3 & (1.8) & 21.8 & (1.8) & 14.0 & (1.5) & 8.2 & $(0.9)$ \\
\hline & Calabria & 19.3 & $(3.0)$ & 21.3 & $(2.7)$ & 22.9 & (2.6) & 20.4 & $(2.2)$ & 11.0 & (1.8) & 4.0 & (1.1) & 1.0 & (0.4) \\
\hline & Campania & 12.5 & (2.0) & 19.9 & $(2.5)$ & 22.3 & (2.4) & 22.8 & (3.2) & 14.6 & $(2.3)$ & 5.5 & $(1.2)$ & 2.3 & $(0.9)$ \\
\hline & Emilia Romagna & 8.5 & (1.8) & 11.6 & $(2.4)$ & 15.9 & $(2.2)$ & 21.4 & $(2.1)$ & 21.9 & (2.5) & 13.7 & (2.3) & 6.9 & (1.4) \\
\hline & Friuli Venezia Giulia & 5.3 & (1.6) & 9.1 & $(2.1)$ & 14.3 & $(2.3)$ & 22.4 & (2.5) & 23.5 & (1.8) & 16.2 & (1.9) & 9.2 & (1.3) \\
\hline & Lazio & 9.0 & (1.9) & 16.4 & $(2.1)$ & 21.5 & $(2.1)$ & 22.5 & $(2.1)$ & 17.3 & $(2.1)$ & 9.9 & (1.6) & 3.4 & $(0.8)$ \\
\hline & Liguria & 7.3 & (2.1) & 14.0 & $(2.5)$ & 22.8 & $(2.3)$ & 21.0 & (1.9) & 18.8 & $(2.3)$ & 11.7 & (2.0) & 4.4 & (1.0) \\
\hline & Lombardia & 4.0 & $(1.0)$ & 8.7 & (1.4) & 16.7 & (3.1) & 23.6 & $(2.7)$ & 24.1 & (2.6) & 16.0 & $(2.2)$ & 6.9 & (1.3) \\
\hline & Marche & 5.5 & (1.8) & 10.3 & $(1.8)$ & 18.8 & (2.6) & 25.0 & $(2.1)$ & 23.2 & $(2.2)$ & 11.7 & $(2.1)$ & 5.4 & (1.4) \\
\hline & Molise & 10.3 & (1.7) & 16.0 & $(2.2)$ & 23.3 & $(2.3)$ & 24.3 & $(2.4)$ & 19.1 & (2.4) & 5.2 & (1.5) & 1.7 & $(0.7)$ \\
\hline & Piemonte & 7.5 & (1.5) & 10.4 & (1.4) & 17.8 & $(1.7)$ & 24.4 & $(2.8)$ & 23.2 & (2.5) & 12.5 & (1.6) & 4.1 & $(1.0)$ \\
\hline & Puglia & 8.7 & (1.6) & 13.8 & (1.8) & 20.9 & $(1.8)$ & 24.6 & $(2.3)$ & 21.0 & $(2.3)$ & 9.1 & (1.1) & 1.8 & $(0.8)$ \\
\hline & Sardegna & 14.3 & (2.0) & 17.3 & $(2.0)$ & 24.1 & (2.5) & 22.7 & (2.4) & 14.1 & (1.5) & 6.5 & (1.0) & 1.0 & $(0.5)$ \\
\hline & Sicilia & 14.9 & (2.2) & 20.5 & (2.6) & 25.8 & (1.7) & 21.1 & (2.6) & 12.6 & $(2.0)$ & 4.1 & $(0.9)$ & 1.1 & $(0.6)$ \\
\hline & Toscana & 10.1 & (2.3) & 11.4 & $(2.3)$ & 20.0 & $(2.3)$ & 23.0 & (2.4) & 18.0 & (2.4) & 11.6 & (2.0) & 5.9 & (1.1) \\
\hline & Trento & 4.6 & $(1.2)$ & 9.0 & (1.3) & 18.2 & (1.8) & 24.8 & $(2.2)$ & 22.4 & (1.9) & 13.9 & (1.8) & 7.1 & $(1.2)$ \\
\hline & Umbria & 6.3 & (2.1) & 10.7 & $(2.5)$ & 20.1 & $(2.0)$ & 24.6 & $(2.3)$ & 22.7 & (2.4) & 11.7 & (1.7) & 3.9 & $(1.0)$ \\
\hline & Valle d'Aosta & 7.0 & $(1.3)$ & 11.0 & (1.8) & 21.3 & $(2.2)$ & 25.7 & (2.4) & 19.5 & (2.4) & 10.3 & (1.9) & 5.2 & $(1.2)$ \\
\hline & Veneto & 4.8 & (1.3) & 8.4 & (1.8) & 15.9 & $(2.3)$ & 21.2 & $(2.3)$ & 21.8 & $(2.1)$ & 18.9 & $(2.1)$ & 9.0 & (2.1) \\
\hline & Mexico & & & & & & & & & & & & & & \\
\hline & Aguascalientes & 18.6 & (3.5) & 24.4 & (2.8) & 27.0 & (3.6) & 17.1 & $(2.4)$ & 9.4 & $(1.6)$ & 3.4 & $(1.2)$ & 0.2 & c \\
\hline & Baja California & 21.6 & (3.6) & 30.2 & (3.3) & 25.2 & (3.5) & 15.0 & $(2.7)$ & 6.7 & (1.8) & 1.2 & $(0.7)$ & 0.1 & c \\
\hline & Baja California Sur & 23.8 & (3.1) & 26.9 & $(2.6)$ & 27.3 & $(3.2)$ & 13.7 & $(2.2)$ & 6.4 & $(1.2)$ & 1.7 & $(0.9)$ & 0.3 & c \\
\hline & Campeche & 31.9 & (3.6) & 26.9 & (3.4) & 23.1 & $(2.0)$ & 13.3 & $(2.1)$ & 3.7 & (1.0) & 0.9 & $(0.4)$ & 0.2 & c \\
\hline & Chiapas & 44.2 & (4.6) & 29.1 & (3.1) & 17.2 & $(2.8)$ & 6.4 & (1.8) & 2.5 & $(1.0)$ & 0.6 & c & 0.0 & c \\
\hline & Chihuahua & 20.5 & (3.4) & 25.0 & (2.9) & 25.3 & (3.6) & 17.6 & $(2.9)$ & 8.7 & (1.8) & 2.8 & $(0.9)$ & 0.1 & c \\
\hline & Coahuila & 23.3 & (3.8) & 26.0 & (3.8) & 25.1 & $(2.9)$ & 16.0 & (2.9) & 7.6 & (2.5) & 2.0 & (1.1) & 0.1 & c \\
\hline & Colima & 21.8 & (2.9) & 23.7 & $(2.3)$ & 25.4 & $(2.0)$ & 17.6 & (2.4) & 8.0 & (1.6) & 2.8 & (1.1) & 0.5 & $(0.3)$ \\
\hline & Distrito Federal & 16.0 & (2.4) & 21.7 & $(3.2)$ & 26.1 & $(3.5)$ & 21.1 & (3.3) & 11.2 & (2.6) & 3.4 & $(0.9)$ & 0.5 & c \\
\hline & Durango & 21.3 & (3.9) & 23.6 & (3.0) & 24.7 & $(3.1)$ & 18.6 & (2.7) & 9.0 & (2.5) & 2.6 & $(1.2)$ & 0.2 & c \\
\hline & Guanajuato & 24.8 & (3.3) & 26.0 & (2.9) & 24.7 & $(2.5)$ & 15.7 & $(1.9)$ & 6.8 & $(1.2)$ & 1.9 & $(0.8)$ & 0.2 & c \\
\hline & Guerrero & 49.2 & (3.1) & 27.4 & (2.6) & 16.2 & $(2.2)$ & 6.3 & (1.5) & 0.9 & $(0.6)$ & 0.2 & $(0.2)$ & 0.0 & c \\
\hline & Hidalgo & 25.9 & (4.2) & 27.1 & (3.9) & 24.1 & (2.4) & 16.1 & (2.8) & 5.2 & (1.3) & 1.4 & $(0.8)$ & 0.1 & c \\
\hline & Jalisco & 16.2 & (2.9) & 23.4 & $(2.7)$ & 28.7 & $(3.6)$ & 19.6 & (3.0) & 8.7 & (2.5) & 2.8 & (1.1) & 0.6 & $(0.5)$ \\
\hline & Mexico & 18.4 & (2.4) & 27.5 & $(2.7)$ & 27.8 & $(2.6)$ & 18.7 & (3.1) & 6.0 & (1.7) & 1.1 & $(0.7)$ & 0.5 & $(0.5)$ \\
\hline & Morelos & 24.7 & $(5.1)$ & 24.5 & (3.1) & 23.7 & (3.3) & 15.4 & (2.4) & 7.9 & (2.1) & 3.1 & (1.3) & 0.6 & (0.5) \\
\hline & Nayarit & 20.1 & (2.6) & 24.8 & (2.9) & 27.5 & (3.1) & 17.8 & $(2.6)$ & 7.6 & (1.5) & 2.0 & $(0.7)$ & 0.3 & $(0.2)$ \\
\hline & Nuevo León & 14.0 & (3.1) & 21.8 & (2.8) & 30.0 & $(2.9)$ & 21.6 & $(4.0)$ & 9.3 & (2.1) & 2.7 & (1.0) & 0.7 & (0.4) \\
\hline & Puebla & 20.4 & (3.4) & 25.2 & (2.8) & 26.8 & $(2.8)$ & 18.3 & $(2.4)$ & 7.9 & (1.4) & 1.2 & $(0.6)$ & 0.2 & $(0.2)$ \\
\hline & Querétaro & 15.5 & (2.9) & 23.2 & (3.4) & 27.3 & (3.8) & 19.7 & $(2.7)$ & 10.4 & $(2.2)$ & 3.0 & $(0.9)$ & 0.8 & $(0.4)$ \\
\hline & Quintana Roo & 25.2 & (2.7) & 27.4 & (2.4) & 25.0 & $(2.2)$ & 15.6 & (2.6) & 6.0 & (1.6) & 0.8 & $(0.4)$ & 0.1 & c \\
\hline & San Luis Potosí & 26.7 & $(4.1)$ & 25.2 & $(2.7)$ & 24.5 & $(2.5)$ & 15.8 & $(2.7)$ & 6.0 & (1.5) & 1.6 & $(0.8)$ & 0.3 & c \\
\hline & Sinaloa & 22.7 & (2.6) & 29.7 & (2.8) & 26.3 & $(2.3)$ & 14.3 & (2.3) & 5.6 & (1.3) & 1.4 & (0.6) & 0.0 & c \\
\hline & Tabasco & 38.9 & (3.8) & 28.5 & (3.1) & 18.5 & $(2.7)$ & 10.5 & $(1.8)$ & 2.8 & (1.0) & 0.7 & C & 0.0 & c \\
\hline & Tamaulipas & 23.5 & (3.7) & 27.8 & (3.1) & 24.4 & (3.1) & 15.9 & (2.4) & 6.3 & (1.7) & 1.9 & (1.0) & 0.3 & $(0.3)$ \\
\hline & Tlaxcala & 23.0 & (2.6) & 28.7 & (2.3) & 26.0 & $(2.3)$ & 16.2 & $(2.2)$ & 5.1 & (1.0) & 0.9 & $(0.4)$ & 0.1 & c \\
\hline & Veracruz & 31.7 & (3.6) & 26.2 & (3.5) & 23.9 & (2.9) & 12.4 & (2.4) & 4.9 & (1.4) & 0.8 & (0.6) & 0.1 & c \\
\hline & Yucatán & 23.4 & (3.3) & 27.1 & $(2.7)$ & 25.6 & (3.1) & 15.9 & $(2.2)$ & 5.9 & (1.4) & 1.7 & $(0.8)$ & 0.4 & c \\
\hline & Zacatecas & 27.1 & (3.7) & 27.3 & (2.4) & 23.5 & $(2.5)$ & 16.4 & $(2.1)$ & 4.3 & $(1.3)$ & 1.2 & $(0.8)$ & 0.1 & c \\
\hline
\end{tabular}

- PISA adjudicated region.

Note: See Table 1.2.21 for national data.

StatLink त्ञात्रा http://dx.doi.org/10.1787/888932935762 
rt 2/4]

Percentage of students at each proficiency level on the mathematics subscale quantity, by gender Table B2.I.20 and region

\begin{tabular}{|c|c|c|c|c|c|c|c|c|c|c|c|c|c|c|c|}
\hline & & \multicolumn{14}{|c|}{ Boys } \\
\hline & & \multicolumn{2}{|c|}{$\begin{array}{l}\text { Below Level } 1 \\
\text { (below 357.77 } \\
\text { score points) }\end{array}$} & \multicolumn{2}{|c|}{$\begin{array}{c}\text { Level } 1 \\
\text { (from } 357.77 \text { to } \\
\text { less than } 420.07 \\
\text { score points) }\end{array}$} & \multicolumn{2}{|c|}{$\begin{array}{c}\text { Level } 2 \\
\text { (from } 420.07 \text { to } \\
\text { less than } 482.38 \\
\text { score points) }\end{array}$} & $\begin{array}{r}\text { Le } \\
\text { (from } \\
\text { less tha } \\
\text { score }\end{array}$ & \begin{tabular}{|l|}
3 \\
.38 to \\
544.68 \\
ints)
\end{tabular} & $\begin{array}{r}\text { Le } \\
\text { (from } 5 \\
\text { less tha } \\
\text { score }\end{array}$ & $\begin{array}{l}4 \\
4.68 \text { to } \\
606.99 \\
\text { oints) }\end{array}$ & $\begin{array}{l}\text { Le } \\
\text { (from } \\
\text { less th } \\
\text { score }\end{array}$ & $\begin{array}{l}5 \\
.99 \text { to } \\
669.30 \\
\text { ints) }\end{array}$ & $\begin{array}{r}\text { Le } \\
\text { (above } \\
\text { score }\end{array}$ & $\begin{array}{l}6 \\
69.30 \\
\text { pints) }\end{array}$ \\
\hline & & $\%$ & S.E. & $\%$ & S.E. & $\%$ & S.E. & $\%$ & S.E. & $\%$ & S.E. & $\%$ & S.E. & $\%$ & S.E. \\
\hline 0 & Portugal & & & & & & & & & & & & & & \\
\hline 氙 & Alentejo & 7.1 & $(2.2)$ & 13.0 & $(4.0)$ & 25.3 & $(4.7)$ & 26.7 & $(4.7)$ & 15.9 & (2.3) & 9.0 & (2.3) & 2.9 & (1.4) \\
\hline & Spain & & & & & & & & & & & & & & \\
\hline & Andalusia• & 10.8 & (1.4) & 14.7 & (1.4) & 21.1 & (2.3) & 23.5 & (2.5) & 17.7 & (1.9) & 8.6 & (1.3) & 3.6 & $(0.9)$ \\
\hline & Aragon ${ }^{\bullet}$ & 9.9 & (1.6) & 11.6 & (1.6) & 16.5 & $(2.2)$ & 20.2 & (1.8) & 21.9 & (1.9) & 14.5 & (1.7) & 5.3 & (1.4) \\
\hline & Asturias ${ }^{\bullet}$ & 7.8 & (1.3) & 10.3 & (1.4) & 17.9 & $(1.6)$ & 22.4 & (1.7) & 19.4 & (1.7) & 13.1 & (1.9) & 9.0 & (1.1) \\
\hline & Balearic Islands ${ }^{\bullet}$ & 11.4 & (1.9) & 15.9 & (1.6) & 19.8 & (1.9) & 23.1 & (2.6) & 18.3 & (1.9) & 8.7 & (1.7) & 2.9 & (1.0) \\
\hline & Basque Country ${ }^{\bullet}$ & 5.0 & $(0.9)$ & 10.0 & $(0.8)$ & 18.6 & (1.4) & 26.1 & (1.3) & 23.9 & $(1.2)$ & 12.4 & $(0.9)$ & 3.9 & $(0.5)$ \\
\hline & Cantabria ${ }^{\bullet}$ & 8.3 & $(1.2)$ & 13.3 & (1.4) & 19.5 & $(2.2)$ & 21.9 & (1.7) & 19.2 & (1.8) & 13.0 & (1.5) & 4.8 & (1.0) \\
\hline & Castile and Leon ${ }^{\bullet}$ & 4.2 & (1.0) & 9.0 & (1.3) & 16.8 & (1.9) & 22.1 & (1.9) & 24.5 & $(2.8)$ & 16.7 & (1.6) & 6.7 & (1.1) \\
\hline & Catalonia ${ }^{\bullet}$ & 5.8 & (1.0) & 11.9 & (1.9) & 20.3 & $(2.8)$ & 23.4 & (2.8) & 21.7 & $(2.1)$ & 12.2 & (2.1) & 4.7 & (1.0) \\
\hline & Extremadura ${ }^{\bullet}$ & 15.1 & (2.3) & 16.2 & (2.1) & 21.8 & (1.9) & 21.8 & (1.6) & 15.1 & (1.6) & 6.8 & (1.1) & 3.3 & $(0.6)$ \\
\hline & Galicia` & 8.2 & (1.5) & 12.9 & $(2.1)$ & 20.5 & (1.6) & 24.0 & (1.7) & 21.0 & (2.3) & 10.5 & (1.6) & 2.9 & $(0.9)$ \\
\hline & La Rioja• & 9.6 & (1.2) & 10.8 & (1.5) & 15.3 & (1.6) & 19.0 & (1.8) & 20.1 & (2.5) & 15.6 & (2.2) & 9.7 & (1.3) \\
\hline & Madrid ${ }^{\bullet}$ & 6.8 & (1.3) & 10.2 & (1.5) & 15.9 & (1.9) & 21.9 & (1.9) & 24.2 & (1.5) & 14.9 & (1.3) & 6.1 & (1.0) \\
\hline & Murcia $\bullet$ & 14.5 & (2.2) & 15.6 & (1.9) & 21.1 & (3.1) & 22.2 & (2.5) & 16.3 & (2.3) & 8.4 & (1.6) & 1.9 & $(0.7)$ \\
\hline & Navarre ${ }^{\bullet}$ & 6.2 & (1.1) & 10.6 & (1.1) & 15.9 & (1.5) & 24.1 & (1.6) & 25.8 & (1.7) & 12.9 & (1.5) & 4.5 & (1.0) \\
\hline & United Kingdom & & & & & & & & & & & & & & \\
\hline & England & 8.6 & $(1.2)$ & 13.1 & (1.4) & 20.0 & (1.4) & 22.4 & (1.5) & 19.9 & (1.5) & 11.4 & (1.1) & 4.5 & $(0.8)$ \\
\hline & Northern Ireland & 9.1 & (1.4) & 13.9 & $(2.0)$ & 20.5 & $(1.5)$ & 24.3 & (1.6) & 18.3 & (1.7) & 9.8 & (1.2) & 4.0 & (1.0) \\
\hline & Scotland ${ }^{\bullet}$ & 5.4 & $(0.8)$ & 12.4 & (1.2) & 21.7 & (1.4) & 25.9 & (1.3) & 20.7 & (1.5) & 10.5 & (1.3) & 3.4 & $(0.6)$ \\
\hline & Wales & 11.8 & (1.1) & 17.8 & $(0.9)$ & 24.2 & $(1.3)$ & 24.8 & (1.4) & 14.4 & $(1.1)$ & 5.5 & $(0.7)$ & 1.4 & $(0.3)$ \\
\hline & United States & & & & & & & & & & & & & & \\
\hline & Connecticut ${ }^{\bullet}$ & 8.7 & (1.5) & 13.1 & (1.8) & 17.8 & (1.8) & 21.7 & (1.8) & 19.5 & $(2.1)$ & 13.5 & (2.3) & 5.6 & (1.3) \\
\hline & Florida & 13.4 & $(2.1)$ & 19.7 & $(2.1)$ & 23.6 & (1.9) & 22.0 & $(1.7)$ & 13.9 & (1.5) & 5.8 & $(1.2)$ & 1.7 & $(0.6)$ \\
\hline & Massachusetts & 8.0 & (1.1) & 11.9 & (1.4) & 18.8 & (2.3) & 24.6 & (2.1) & 18.2 & (1.8) & 12.6 & (2.0) & 5.9 & (1.4) \\
\hline$n$ & Argentina & & & & & & & & & & & & & & \\
\hline 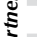 & Ciudad Autónoma de Buenos Aires & 20.7 & (2.8) & 21.6 & $(2.3)$ & 24.7 & $(2.7)$ & 19.8 & (3.5) & 10.3 & $(2.4)$ & 2.7 & $(0.9)$ & 0.1 & c \\
\hline & Brazil & & & & & & & & & & & & & & \\
\hline & Acre & 50.4 & (5.6) & 28.8 & $(4.1)$ & 15.4 & $(3.5)$ & 4.4 & (1.6) & 0.8 & $(0.5)$ & 0.4 & $(0.4)$ & 0.0 & c \\
\hline & Alagoas & 50.5 & (5.5) & 28.4 & (4.3) & 14.4 & $(3.3)$ & 4.9 & $(2.0)$ & 1.5 & (1.0) & 0.4 & $\mathrm{C}$ & 0.0 & c \\
\hline & Amapá & 49.7 & (6.0) & 25.9 & $(4.2)$ & 16.3 & $(4.7)$ & 6.7 & (3.1) & 1.4 & (1.0) & 0.0 & c & 0.0 & c \\
\hline & Amazonas & 49.9 & (5.1) & 27.9 & $(4.3)$ & 14.6 & (3.3) & 4.1 & (1.9) & 2.2 & (1.5) & 1.3 & (1.2) & 0.0 & c \\
\hline & Bahia & 44.7 & (5.5) & 27.6 & (6.0) & 16.5 & $(4.8)$ & 7.7 & (1.7) & 1.8 & (1.6) & 1.4 & (1.4) & 0.3 & c \\
\hline & Ceará & 40.3 & (3.7) & 27.0 & (3.8) & 16.9 & $(2.6)$ & 9.2 & $(2.2)$ & 3.8 & (1.9) & 2.5 & (1.4) & 0.4 & c \\
\hline & Espírito Santo & 23.1 & (3.8) & 26.9 & (3.4) & 22.7 & (3.0) & 14.9 & (2.1) & 8.8 & $(2.5)$ & 3.1 & (1.3) & 0.5 & c \\
\hline & Federal District & 24.8 & (5.6) & 26.1 & (4.5) & 21.9 & $(3.2)$ & 14.4 & (2.9) & 8.2 & (2.8) & 3.8 & (1.8) & 0.9 & $(0.9)$ \\
\hline & Goiás & 35.3 & (4.6) & 30.4 & (3.5) & 17.2 & $(2.8)$ & 11.2 & (2.6) & 5.0 & (1.0) & 1.0 & (0.5) & 0.0 & C \\
\hline & Maranhão & 54.3 & $(7.2)$ & 24.3 & (5.1) & 10.1 & (3.3) & 8.0 & (4.4) & 2.4 & (2.1) & 0.9 & $\mathrm{C}$ & 0.0 & c \\
\hline & Mato Grosso & 43.8 & (4.6) & 29.6 & (3.4) & 17.8 & (3.4) & 6.3 & (1.9) & 1.5 & $(0.9)$ & 1.0 & $(0.8)$ & 0.0 & C \\
\hline & Mato Grosso do Sul & 23.7 & $(4.8)$ & 28.6 & (3.6) & 24.9 & $(2.7)$ & 15.0 & (2.4) & 6.6 & $(3.1)$ & 1.1 & $(0.8)$ & 0.1 & c \\
\hline & Minas Gerais & 27.0 & $(4.7)$ & 26.6 & $(4.1)$ & 25.2 & (3.4) & 15.3 & (3.3) & 4.2 & $(1.3)$ & 1.5 & $(0.8)$ & 0.1 & c \\
\hline & Pará & 47.6 & $(4.0)$ & 29.0 & (5.1) & 15.8 & $(4.3)$ & 6.3 & (1.7) & 1.1 & $(1.0)$ & 0.3 & $\mathrm{C}$ & 0.0 & C \\
\hline & Paraíba & 29.4 & $(5.7)$ & 28.2 & $(5.7)$ & 23.7 & (4.9) & 11.5 & (2.2) & 5.3 & (2.4) & 1.8 & $(1.2)$ & 0.2 & c \\
\hline & Paraná & 24.3 & (4.3) & 26.8 & (2.9) & 22.6 & $(3.2)$ & 13.1 & (3.0) & 8.7 & (3.5) & 3.8 & (3.2) & 0.7 & $(0.6)$ \\
\hline & Pernambuco & 38.4 & (5.4) & 31.4 & $(4.1)$ & 19.2 & $(3.3)$ & 7.2 & (2.6) & 2.9 & $(1.9)$ & 0.6 & $(0.7)$ & 0.2 & $(0.2)$ \\
\hline & Piauí & 34.7 & $(4.8)$ & 28.9 & $(4.4)$ & 17.7 & $(3.2)$ & 11.5 & $(2.2)$ & 5.1 & $(2.4)$ & 0.1 & $\mathrm{C}$ & 1.9 & $(0.6)$ \\
\hline & Rio de Janeiro & 34.9 & (6.0) & 28.0 & (5.0) & 20.3 & $(3.0)$ & 10.2 & (2.8) & 5.1 & $(1.8)$ & 1.4 & $(0.9)$ & 0.1 & $\mathrm{C}$ \\
\hline & Rio Grande do Norte & 39.1 & $(4.3)$ & 27.0 & $(4.4)$ & 16.7 & $(3.1)$ & 8.0 & (3.0) & 4.8 & $(1.2)$ & 3.4 & (1.3) & 1.1 & (1.1) \\
\hline & Rio Grande do Sul & 23.6 & $(4.7)$ & 26.4 & $(4.2)$ & 26.3 & $(4.0)$ & 17.2 & (3.4) & 5.4 & $(1.5)$ & 1.1 & $(0.6)$ & 0.1 & $\mathrm{C}$ \\
\hline & Rondônia & 36.0 & (3.2) & 29.7 & (3.3) & 23.0 & $(3.4)$ & 8.7 & (1.9) & 2.4 & $(0.9)$ & 0.3 & $\mathrm{C}$ & 0.0 & c \\
\hline & Roraima & 49.6 & (5.4) & 25.4 & $(4.2)$ & 15.9 & $(2.8)$ & 6.9 & (2.3) & 2.1 & $(1.1)$ & 0.1 & $\mathrm{C}$ & 0.0 & c \\
\hline & Santa Catarina & 22.3 & (3.5) & 22.0 & (2.9) & 23.5 & $(3.3)$ & 20.2 & (3.1) & 9.4 & $(2.3)$ & 2.5 & $(1.2)$ & 0.2 & C \\
\hline & São Paulo & 29.3 & (2.1) & 26.4 & (1.6) & 21.8 & $(2.1)$ & 12.9 & (1.6) & 7.2 & (1.4) & 1.8 & $(0.7)$ & 0.5 & $(0.3)$ \\
\hline & Sergipe & 32.1 & $(4.7)$ & 27.0 & $(4.1)$ & 20.5 & (3.5) & 14.0 & (3.6) & 4.9 & $(3.0)$ & 1.4 & (1.0) & 0.0 & C \\
\hline & Tocantins & 47.3 & $(4.9)$ & 23.0 & $(4.0)$ & 16.0 & $(2.9)$ & 9.8 & $(1.8)$ & 2.8 & $(1.4)$ & 0.5 & $(0.5)$ & 0.5 & $(0.5)$ \\
\hline & Colombia & & & & & & & & & & & & & & \\
\hline & Bogotá & 25.5 & $(2.0)$ & 30.5 & $(2.2)$ & 26.7 & $(2.0)$ & 12.4 & (1.7) & 4.0 & $(1.3)$ & 0.8 & $(0.4)$ & 0.1 & C \\
\hline & Cali & 36.2 & (3.8) & 28.3 & (2.5) & 21.9 & $(2.9)$ & 10.1 & (2.1) & 3.1 & $(0.9)$ & 0.4 & (0.4) & 0.0 & C \\
\hline & Manizales & 22.9 & $(2.1)$ & 26.2 & (3.2) & 25.2 & $(2.7)$ & 15.7 & (2.1) & 7.3 & (1.9) & 2.5 & (1.3) & 0.3 & $(0.3)$ \\
\hline & Medellín & 32.2 & $(4.0)$ & 25.7 & (3.3) & 20.9 & $(2.4)$ & 12.7 & (2.5) & 5.2 & (1.4) & 2.2 & (1.4) & 1.1 & (1.0) \\
\hline & Russian Federation & & & & & & & & & & & & & & \\
\hline & Perm Territory region` & 9.8 & (1.8) & 15.7 & (1.7) & 23.7 & $(2.2)$ & 23.6 & (1.9) & 17.7 & (1.6) & 7.4 & (1.5) & 2.1 & $(0.9)$ \\
\hline & United Arab Emirates & & & & & & & & & & & & & & \\
\hline & Abu Dhabi & 35.1 & $(2.2)$ & 21.9 & (1.8) & 19.4 & (1.8) & 12.9 & (1.2) & 6.9 & $(1.2)$ & 3.0 & $(0.7)$ & 0.8 & $(0.4)$ \\
\hline & Ajman & 43.0 & (6.1) & 26.3 & (4.6) & 17.8 & $(3.6)$ & 11.0 & (2.9) & 1.8 & $(1.2)$ & 0.1 & $\mathrm{C}$ & 0.0 & $\mathrm{C}$ \\
\hline & Dubai ${ }^{\bullet}$ & 15.5 & (0.8) & 16.9 & $(1.0)$ & 21.3 & $(1.3)$ & 20.3 & $(1.2)$ & 15.6 & $(1.0)$ & 7.5 & (1.0) & 2.9 & $(0.5)$ \\
\hline & Fujairah & 38.7 & (5.3) & 26.1 & (3.1) & 19.4 & (3.9) & 9.2 & (2.6) & 5.3 & $(1.3)$ & 1.0 & $(0.6)$ & 0.2 & $(0.2)$ \\
\hline & Ras al-Khaimah & 31.1 & (3.5) & 28.1 & (2.9) & 22.3 & $(3.3)$ & 12.4 & (2.4) & 4.7 & (1.3) & 0.9 & C & 0.5 & $(0.4)$ \\
\hline & Sharjah & 19.0 & $(4.6)$ & 23.9 & (3.9) & 23.2 & $(4.2)$ & 16.6 & (3.1) & 11.5 & $(4.1)$ & 4.2 & (1.9) & 1.7 & (1.3) \\
\hline & Umm al-Quwain & 45.3 & $(4.2)$ & 30.3 & $(4.2)$ & 14.4 & $(4.1)$ & 7.1 & (2.9) & 2.2 & (1.9) & 0.7 & $\mathrm{C}$ & 0.0 & $\mathrm{C}$ \\
\hline
\end{tabular}

- PISA adjudicated region.

Note: See Table 1.2.21 for national data.

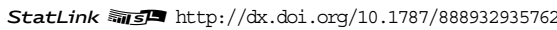


[Part 3/4]

Percentage of students at each proficiency level on the mathematics subscale quantity, by gender Table B2.I.20 and region

\begin{tabular}{|c|c|c|c|c|c|c|c|c|c|c|c|c|c|c|c|}
\hline & & \multicolumn{14}{|c|}{ Girls } \\
\hline & & \multicolumn{2}{|c|}{$\begin{array}{l}\text { Below Level } 1 \\
\text { (below } 357.77 \\
\text { score points) }\end{array}$} & $\begin{array}{l}\mathbf{L} \\
\text { (from } \\
\text { less th } \\
\text { scor }\end{array}$ & $\begin{array}{l}\text { I } 1 \\
7.77 \text { to } \\
420.07 \\
\text { oints) }\end{array}$ & $\begin{array}{l}\text { Le } \\
\text { (from } \\
\text { less th } \\
\text { score }\end{array}$ & $\begin{array}{l}2 \\
.07 \text { to } \\
482.38 \\
\text { oints) }\end{array}$ & $\begin{array}{l}\text { Le } \\
\text { (from } \\
\text { less th } \\
\text { score }\end{array}$ & $\begin{array}{l}3 \\
2.38 \text { to } \\
544.68 \\
\text { oints) }\end{array}$ & $\begin{array}{l}\text { Le } \\
\text { (from } \\
\text { less th } \\
\text { score }\end{array}$ & $\begin{array}{l}14 \\
4.68 \text { to } \\
606.99 \\
\text { oints) }\end{array}$ & $\begin{array}{l}\text { Le } \\
\text { (from } \\
\text { less tha } \\
\text { score }\end{array}$ & $\begin{array}{l}5 \\
6.99 \text { to } \\
669.30 \\
\text { oints) }\end{array}$ & $\begin{array}{l}\text { Le } \\
\text { (abov } \\
\text { score }\end{array}$ & $\begin{array}{l}6 \\
69.30 \\
\text { ints) }\end{array}$ \\
\hline & & $\%$ & S.E. & $\%$ & S.E. & $\%$ & S.E. & $\%$ & S.E. & $\%$ & S.E. & $\%$ & S.E. & $\%$ & S.E. \\
\hline$\theta$ & Australia & & & & & & & & & & & & & & \\
\hline U & Australian Capital Territory & 4.8 & $(1.2)$ & 10.8 & (1.9) & 20.1 & $(2.9)$ & 23.4 & $(3.2)$ & 21.0 & (3.0) & 14.5 & $(2.2)$ & 5.5 & (1.5) \\
\hline & New South Wales & 7.6 & $(0.8)$ & 13.6 & $(1.1)$ & 21.0 & (1.3) & 23.2 & (1.3) & 18.0 & (1.5) & 10.9 & (1.3) & 5.7 & (1.1) \\
\hline & Northern Territory & 21.5 & (3.6) & 18.3 & $(5.0)$ & 21.1 & $(9.2)$ & 23.8 & (6.5) & 10.4 & $(4.5)$ & 4.3 & (2.6) & 0.8 & c \\
\hline & Queensland & 8.8 & (1.1) & 15.2 & $(1.5)$ & 20.9 & $(2.0)$ & 23.0 & (1.7) & 17.1 & $(1.7)$ & 10.8 & (1.6) & 4.1 & $(0.9)$ \\
\hline & South Australia & 11.1 & $(1.3)$ & 18.1 & (1.7) & 24.7 & (2.4) & 23.2 & $(2.3)$ & 14.9 & (1.9) & 6.3 & $(1.2)$ & 1.8 & $(0.6)$ \\
\hline & Tasmania & 13.8 & (1.9) & 20.4 & $(2.3)$ & 25.1 & $(2.4)$ & 20.6 & $(2.8)$ & 13.0 & (2.8) & 5.5 & (1.6) & 1.5 & $(0.7)$ \\
\hline & Victoria & 8.7 & (1.1) & 15.0 & (1.3) & 24.0 & $(2.1)$ & 24.0 & (2.4) & 17.7 & (1.5) & 8.6 & $(1.2)$ & 2.2 & $(0.7)$ \\
\hline & Western Australia & 7.8 & (1.1) & 14.7 & $(2.0)$ & 20.0 & $(2.1)$ & 24.1 & (1.9) & 18.9 & (1.5) & 10.2 & (1.6) & 4.2 & (1.0) \\
\hline & Belgium & & & & & & & & & & & & & & \\
\hline & Flemish Community ${ }^{\bullet}$ & 5.8 & $(0.9)$ & 9.3 & $(0.8)$ & 16.4 & $(1.2)$ & 21.2 & $(1.2)$ & 22.3 & $(1.2)$ & 17.2 & $(1.2)$ & 7.7 & $(0.7)$ \\
\hline & French Community & 8.8 & (1.1) & 14.9 & (1.5) & 22.1 & (1.9) & 23.3 & (1.3) & 19.5 & (1.4) & 9.0 & (1.1) & 2.5 & $(0.5)$ \\
\hline & German-speaking Community & 5.4 & $(1.2)$ & 7.8 & (1.5) & 18.1 & $(2.2)$ & 26.8 & (2.5) & 27.6 & (3.1) & 12.2 & $(2.0)$ & 2.1 & $(0.9)$ \\
\hline & Canada & & & & & & & & & & & & & & \\
\hline & Alberta & 6.6 & (1.3) & 13.9 & (1.8) & 19.9 & $(2.0)$ & 23.5 & $(2.2)$ & 20.6 & $(2.0)$ & 11.2 & (1.5) & 4.2 & $(0.9)$ \\
\hline & British Columbia & 4.4 & $(1.0)$ & 11.3 & $(1.7)$ & 21.3 & $(2.3)$ & 25.5 & (1.8) & 21.1 & (1.9) & 11.1 & (1.6) & 5.3 & $(1.2)$ \\
\hline & Manitoba & 9.7 & (1.7) & 16.4 & (1.7) & 23.5 & (1.8) & 23.2 & $(2.0)$ & 16.6 & (1.5) & 7.8 & (1.1) & 3.0 & $(0.7)$ \\
\hline & New Brunswick & 6.4 & $(1.2)$ & 11.0 & (1.3) & 24.7 & $(2.8)$ & 26.4 & (2.8) & 19.0 & $(2.1)$ & 8.2 & (1.6) & 4.3 & (1.3) \\
\hline & Newfoundland and Labrador & 8.8 & (1.6) & 17.3 & $(2.5)$ & 24.8 & (2.6) & 22.7 & (2.4) & 16.8 & $(2.1)$ & 7.4 & (1.3) & 2.2 & $(0.6)$ \\
\hline & Nova Scotia & 7.5 & (1.4) & 16.2 & $(2.1)$ & 25.3 & $(4.0)$ & 24.4 & $(4.2)$ & 17.3 & (2.5) & 6.6 & (1.4) & 2.6 & $(0.9)$ \\
\hline & Ontario & 6.4 & $(0.8)$ & 11.5 & (1.1) & 21.2 & $(2.1)$ & 25.6 & (1.5) & 20.7 & (1.4) & 10.3 & (1.1) & 4.2 & $(0.8)$ \\
\hline & Prince Edward Island & 9.5 & $(1.3)$ & 18.2 & $(1.5)$ & 25.8 & $(1.8)$ & 25.0 & $(2.1)$ & 15.5 & $(2.1)$ & 4.8 & (1.1) & 1.2 & $(0.5)$ \\
\hline & Quebec & 4.4 & $(0.7)$ & 8.1 & $(0.9)$ & 17.0 & $(1.2)$ & 23.7 & (1.5) & 24.4 & (1.7) & 15.7 & (1.1) & 6.6 & (1.1) \\
\hline & Saskatchewan & 6.3 & $(1.0)$ & 13.7 & (1.7) & 24.4 & $(2.0)$ & 25.5 & $(2.1)$ & 17.7 & (1.6) & 9.9 & (1.6) & 2.6 & $(0.8)$ \\
\hline & Italy & & & & & & & & & & & & & & \\
\hline & Abruzzo & 10.4 & (1.7) & 17.1 & $(2.2)$ & 23.4 & $(2.0)$ & 25.3 & (2.5) & 15.9 & (1.8) & 6.6 & (1.4) & 1.3 & $(0.7)$ \\
\hline & Basilicata & 12.4 & $(1.7)$ & 20.8 & (1.9) & 28.1 & $(2.2)$ & 23.8 & (1.9) & 11.2 & (1.3) & 2.9 & $(0.7)$ & 0.9 & $(0.5)$ \\
\hline & Bolzano & 6.9 & $(0.9)$ & 11.0 & (1.4) & 20.7 & (1.5) & 28.6 & $(2.2)$ & 21.5 & $(2.1)$ & 8.8 & (1.1) & 2.6 & $(0.8)$ \\
\hline & Calabria & 24.1 & (3.6) & 22.8 & $(2.6)$ & 24.3 & (2.5) & 18.1 & (2.5) & 8.4 & (1.4) & 1.9 & $(0.7)$ & 0.3 & $(0.3)$ \\
\hline & Campania & 16.6 & (2.9) & 20.9 & $(2.2)$ & 27.6 & (3.0) & 20.8 & $(2.2)$ & 10.3 & (1.8) & 3.5 & $(1.2)$ & 0.4 & $(0.3)$ \\
\hline & Emilia Romagna & 8.0 & (1.6) & 11.2 & (1.5) & 24.2 & (2.6) & 26.0 & $(2.0)$ & 18.8 & $(2.2)$ & 8.7 & (1.8) & 3.0 & $(0.9)$ \\
\hline & Friuli Venezia Giulia & 5.4 & (1.9) & 7.5 & (1.3) & 18.7 & (2.6) & 27.9 & (2.4) & 25.6 & $(2.0)$ & 11.1 & (1.7) & 3.8 & $(0.9)$ \\
\hline & Lazio & 12.1 & (2.4) & 17.5 & (2.4) & 25.1 & (2.4) & 25.5 & $(2.0)$ & 12.9 & $(2.0)$ & 5.6 & $(1.2)$ & 1.4 & $(0.7)$ \\
\hline & Liguria & 9.9 & (2.0) & 14.2 & $(2.6)$ & 22.6 & $(2.9)$ & 24.5 & (1.9) & 18.6 & $(2.1)$ & 8.4 & (1.6) & 1.9 & $(0.7)$ \\
\hline & Lombardia & 4.4 & $(1.2)$ & 10.8 & $(2.1)$ & 20.1 & (2.4) & 27.0 & $(2.1)$ & 22.6 & (2.4) & 11.8 & (2.0) & 3.3 & (1.2) \\
\hline & Marche & 8.4 & (2.3) & 15.2 & (1.5) & 24.9 & (2.9) & 24.6 & $(2.3)$ & 18.1 & (1.9) & 7.1 & (1.4) & 1.8 & $(0.7)$ \\
\hline & Molise & 13.2 & (1.8) & 17.7 & (1.9) & 27.0 & (2.4) & 26.1 & $(2.3)$ & 11.5 & (1.9) & 3.6 & (1.3) & 1.0 & $(0.8)$ \\
\hline & Piemonte & 9.1 & (1.5) & 14.9 & $(2.7)$ & 19.8 & $(2.5)$ & 25.3 & $(2.3)$ & 19.1 & $(2.7)$ & 8.8 & (1.7) & 2.9 & $(1.0)$ \\
\hline & Puglia & 8.6 & $(2.2)$ & 18.9 & $(3.0)$ & 27.6 & (2.5) & 24.2 & $(2.1)$ & 14.4 & (1.9) & 5.0 & (1.3) & 1.2 & $(0.4)$ \\
\hline & Sardegna & 15.2 & (2.6) & 17.7 & (2.3) & 25.4 & (2.4) & 22.4 & $(2.2)$ & 13.3 & (2.0) & 5.0 & (1.3) & 1.0 & $(0.7)$ \\
\hline & Sicilia & 15.8 & (2.4) & 21.2 & $(2.7)$ & 26.8 & $(2.2)$ & 21.9 & (2.4) & 11.2 & (2.5) & 2.9 & $(0.9)$ & 0.3 & $(0.2)$ \\
\hline & Toscana & 7.6 & (1.6) & 12.5 & $(2.1)$ & 20.8 & $(2.8)$ & 24.7 & $(2.3)$ & 21.6 & (2.8) & 9.9 & (1.7) & 2.8 & $(0.9)$ \\
\hline & Trento & 3.8 & (1.7) & 7.7 & $(2.0)$ & 17.9 & $(2.2)$ & 27.2 & (2.5) & 26.1 & (2.6) & 14.3 & $(2.0)$ & 3.0 & $(0.9)$ \\
\hline & Umbria & 7.9 & (1.9) & 14.1 & $(2.2)$ & 23.7 & (2.4) & 26.6 & $(2.3)$ & 19.7 & $(2.0)$ & 6.7 & $(1.2)$ & 1.3 & $(0.6)$ \\
\hline & Valle d'Aosta & 6.2 & (1.4) & 15.7 & $(2.1)$ & 26.4 & (2.4) & 26.1 & (3.5) & 16.0 & $(2.3)$ & 6.0 & (1.4) & 3.7 & (1.1) \\
\hline & Veneto & 3.9 & (1.5) & 9.2 & $(2.1)$ & 21.5 & (3.1) & 26.2 & (2.5) & 22.2 & (2.8) & 12.7 & $(2.7)$ & 4.2 & (1.3) \\
\hline & Mexico & & & & & & & & & & & & & & \\
\hline & Aguascalientes & 18.4 & $(2.7)$ & 25.7 & (2.9) & 30.2 & $(2.7)$ & 17.1 & $(2.2)$ & 6.6 & $(1.3)$ & 1.9 & $(0.7)$ & 0.0 & C \\
\hline & Baja California & 28.8 & (3.1) & 27.3 & (3.4) & 23.3 & (2.5) & 13.9 & $(2.0)$ & 5.0 & $(1.2)$ & 1.8 & $(1.2)$ & 0.0 & c \\
\hline & Baja California Sur & 28.2 & (3.1) & 28.1 & $(2.5)$ & 25.8 & $(2.3)$ & 12.9 & $(2.1)$ & 4.3 & $(1.1)$ & 0.6 & $(0.3)$ & 0.0 & c \\
\hline & Campeche & 35.6 & (3.1) & 30.6 & $(2.7)$ & 20.9 & $(2.3)$ & 9.8 & (1.6) & 2.4 & $(0.7)$ & 0.5 & $(0.3)$ & 0.1 & $(0.1)$ \\
\hline & Chiapas & 50.4 & (4.6) & 24.0 & $(2.3)$ & 17.3 & $(2.7)$ & 6.5 & (1.6) & 1.4 & $(0.7)$ & 0.4 & $(0.4)$ & 0.0 & c \\
\hline & Chihuahua & 25.6 & (3.3) & 27.2 & (2.6) & 25.3 & (3.5) & 14.6 & $(2.5)$ & 6.2 & (1.7) & 0.8 & $(0.6)$ & 0.2 & c \\
\hline & Coahuila & 23.7 & (3.4) & 29.6 & $(4.0)$ & 27.5 & $(3.0)$ & 11.6 & $(2.9)$ & 6.2 & (2.5) & 1.4 & (1.1) & 0.0 & c \\
\hline & Colima & 22.6 & (3.3) & 24.8 & (3.1) & 25.5 & (2.9) & 18.8 & $(2.8)$ & 6.8 & (1.5) & 1.2 & $(0.6)$ & 0.3 & $(0.2)$ \\
\hline & Distrito Federal & 25.3 & $(2.9)$ & 28.9 & (3.0) & 25.6 & $(3.1)$ & 13.7 & (2.4) & 5.1 & (1.5) & 1.3 & $(0.8)$ & 0.0 & C \\
\hline & Durango & 23.9 & $(4.0)$ & 25.3 & $(3.1)$ & 27.5 & $(3.7)$ & 16.9 & $(2.4)$ & 4.8 & (1.5) & 1.4 & (1.0) & 0.1 & c \\
\hline & Guanajuato & 31.0 & $(4.0)$ & 29.5 & $(2.7)$ & 24.3 & (2.5) & 11.4 & $(2.2)$ & 3.0 & $(0.9)$ & 0.7 & $(0.3)$ & 0.0 & c \\
\hline & Guerrero & 53.0 & (3.9) & 27.6 & (3.0) & 13.6 & $(2.3)$ & 4.7 & $(1.1)$ & 1.0 & $(0.7)$ & 0.0 & c & 0.0 & c \\
\hline & Hidalgo & 32.0 & (4.0) & 30.3 & $(3.1)$ & 22.7 & $(2.8)$ & 11.6 & $(2.2)$ & 3.1 & (1.0) & 0.4 & c & 0.0 & c \\
\hline & Jalisco & 17.0 & (2.0) & 27.1 & (2.3) & 30.5 & $(2.3)$ & 17.4 & $(2.1)$ & 6.4 & (1.6) & 1.6 & $(0.8)$ & 0.0 & C \\
\hline & Mexico & 21.8 & (3.4) & 30.1 & (3.1) & 30.0 & $(3.2)$ & 14.6 & (2.9) & 3.0 & $(1.2)$ & 0.4 & $(0.3)$ & 0.0 & C \\
\hline & Morelos & 23.8 & (3.5) & 28.5 & (3.6) & 26.5 & (3.0) & 13.7 & $(2.1)$ & 4.7 & (2.0) & 2.1 & (1.4) & 0.7 & $(0.6)$ \\
\hline & Nayarit & 25.0 & (3.5) & 31.0 & (2.4) & 24.1 & (3.3) & 12.6 & $(2.8)$ & 5.9 & $(2.1)$ & 1.4 & $(0.9)$ & 0.1 & c \\
\hline & Nuevo León & 21.5 & (3.3) & 29.4 & $(3.7)$ & 25.3 & (3.3) & 16.3 & $(2.4)$ & 5.8 & (1.6) & 1.5 & $(0.7)$ & 0.1 & c \\
\hline & Puebla & 25.8 & (3.2) & 29.1 & (2.6) & 26.9 & $(2.6)$ & 12.6 & (1.8) & 4.8 & (1.1) & 0.8 & $(0.5)$ & 0.1 & c \\
\hline & Querétaro & 20.1 & (2.8) & 26.8 & (3.1) & 27.9 & $(2.4)$ & 15.8 & $(2.8)$ & 7.5 & (1.9) & 1.6 & $(0.6)$ & 0.3 & $(0.3)$ \\
\hline & Quintana Roo & 26.8 & (2.9) & 29.4 & (3.0) & 25.3 & $(2.6)$ & 13.8 & $(2.1)$ & 3.8 & $(1.2)$ & 0.7 & $(0.4)$ & 0.2 & c \\
\hline & San Luis Potosí & 25.3 & (3.4) & 29.3 & $(2.7)$ & 25.6 & $(2.7)$ & 13.9 & $(1.9)$ & 4.8 & (1.3) & 1.1 & $(0.6)$ & 0.0 & C \\
\hline & Sinaloa & 24.6 & (2.6) & 31.3 & (2.8) & 26.3 & (2.4) & 13.0 & $(2.2)$ & 4.6 & $(0.9)$ & 0.2 & c & 0.0 & c \\
\hline & Tabasco & 44.5 & (2.9) & 30.0 & (2.6) & 17.8 & $(2.2)$ & 5.8 & (1.1) & 1.6 & $(0.7)$ & 0.3 & $(0.2)$ & 0.0 & c \\
\hline & Tamaulipas & 31.8 & (3.3) & 29.6 & $(3.2)$ & 24.2 & (3.1) & 11.1 & $(2.2)$ & 2.9 & (1.1) & 0.5 & $(0.3)$ & 0.0 & C \\
\hline & Tlaxcala & 26.3 & (2.9) & 30.5 & (2.3) & 25.4 & $(2.5)$ & 12.7 & $(2.2)$ & 4.6 & (1.6) & 0.5 & $(0.3)$ & 0.1 & c \\
\hline & Veracruz & 33.5 & $(4.2)$ & 30.8 & $(2.8)$ & 21.2 & $(2.0)$ & 10.9 & $(2.2)$ & 3.1 & $(1.2)$ & 0.5 & $(0.5)$ & 0.0 & c \\
\hline & Yucatán & 32.0 & (4.4) & 28.0 & $(3.2)$ & 24.2 & $(2.8)$ & 11.5 & $(2.5)$ & 3.8 & (1.1) & 0.5 & c & 0.0 & c \\
\hline & Zacatecas & 31.4 & (3.3) & 26.5 & (3.0) & 25.5 & (3.0) & 11.7 & (1.6) & 4.2 & (1.1) & 0.7 & $(0.4)$ & 0.0 & $\mathrm{C}$ \\
\hline
\end{tabular}

- PISA adjudicated region.

Note: See Table 1.2.21 for national data.

StatLink त्ञात्रा http://dx.doi.org/10.1787/888932935762 
Percentage of students at each proficiency level on the mathematics subscale quantity, by gender Table B2.I.20 and region

\begin{tabular}{|c|c|c|c|c|c|c|c|c|c|c|c|c|c|c|c|}
\hline & & \multicolumn{14}{|c|}{ Girls } \\
\hline & & \multicolumn{2}{|c|}{$\begin{array}{c}\text { Below Level } 1 \\
\text { (below } 357.77 \\
\text { score points) }\end{array}$} & \multicolumn{2}{|c|}{$\begin{array}{c}\text { Level } 1 \\
\text { (from } 357.77 \text { to } \\
\text { less than } 420.07 \\
\text { score points) }\end{array}$} & \multicolumn{2}{|c|}{$\begin{array}{c}\text { Level } 2 \\
\text { (from } 420.07 \text { to } \\
\text { less than } 482.38 \\
\text { score points) }\end{array}$} & $\begin{array}{r}\text { Le } \\
\text { (from } \\
\text { less tha } \\
\text { score }\end{array}$ & $\begin{array}{l}\text { I } 3 \\
2.38 \text { to } \\
544.68 \\
\text { oints) }\end{array}$ & $\begin{array}{r}\text { Le } \\
\text { (from } 5 \\
\text { less tha } \\
\text { score }\end{array}$ & $\begin{array}{l}14 \\
4.68 \text { to } \\
606.99 \\
\text { oints) }\end{array}$ & $\begin{array}{l}\text { Le } \\
\text { (from } \\
\text { less th } \\
\text { score }\end{array}$ & $\begin{array}{l}5 \\
5.99 \text { to } \\
669.30 \\
\text { ints) }\end{array}$ & $\begin{array}{l}\text { Le } \\
\text { (above } \\
\text { score }\end{array}$ & $\begin{array}{l}6 \\
69.30 \\
\text { ints) }\end{array}$ \\
\hline & & $\%$ & S.E. & $\%$ & S.E. & $\%$ & S.E. & $\%$ & S.E. & $\%$ & S.E. & $\%$ & S.E. & $\%$ & S.E. \\
\hline 0 & Portugal & & & & & & & & & & & & & & \\
\hline 品 & Alentejo & 9.4 & (2.6) & 17.5 & (3.2) & 25.9 & $(2.4)$ & 24.0 & $(3.7)$ & 16.9 & (3.3) & 5.6 & (1.8) & 0.7 & $(0.5)$ \\
\hline & Spain & & & & & & & & & & & & & & \\
\hline & Andalusia ${ }^{\bullet}$ & 12.1 & (1.7) & 18.1 & (2.0) & 26.8 & $(2.1)$ & 22.1 & $(1.7)$ & 14.4 & (1.5) & 5.5 & (1.1) & 1.1 & $(0.4)$ \\
\hline & Aragon ${ }^{\bullet}$ & 9.9 & $(1.8)$ & 13.4 & (1.8) & 19.8 & $(1.8)$ & 25.2 & $(2.3)$ & 18.4 & (1.9) & 10.1 & (1.6) & 3.2 & $(1.2)$ \\
\hline & Asturias ${ }^{\bullet}$ & 6.7 & (1.3) & 12.8 & (1.9) & 22.2 & $(2.2)$ & 24.5 & $(1.8)$ & 19.4 & (1.5) & 10.2 & (1.3) & 4.3 & (1.0) \\
\hline & Balearic Islands ${ }^{\bullet}$ & 13.3 & (1.9) & 16.4 & (2.0) & 21.9 & $(2.0)$ & 22.7 & $(2.2)$ & 16.5 & $(2.3)$ & 7.6 & (1.4) & 1.6 & $(0.6)$ \\
\hline & Basque Country ${ }^{\bullet}$ & 5.3 & $(0.7)$ & 10.8 & (1.0) & 21.7 & $(1.2)$ & 28.5 & $(1.1)$ & 22.2 & (1.3) & 9.2 & $(0.8)$ & 2.4 & $(0.5)$ \\
\hline & Cantabria & 7.6 & $(1.2)$ & 15.8 & (1.4) & 23.7 & $(1.9)$ & 24.4 & $(2.3)$ & 17.4 & $(2.1)$ & 7.7 & (1.5) & 3.5 & (0.8) \\
\hline & Castile and Leon ${ }^{\bullet}$ & 4.5 & $(0.9)$ & 12.1 & (1.7) & 21.5 & $(2.1)$ & 27.3 & $(1.8)$ & 23.7 & (1.6) & 8.9 & (1.3) & 2.0 & $(0.7)$ \\
\hline & Catalonia ${ }^{\bullet}$ & 7.1 & (1.3) & 14.8 & (2.1) & 22.5 & $(2.3)$ & 27.6 & $(2.5)$ & 19.3 & (2.0) & 7.0 & (1.5) & 1.8 & (0.6) \\
\hline & Extremadura ${ }^{\bullet}$ & 14.3 & (1.7) & 18.0 & (2.0) & 25.5 & $(1.6)$ & 22.5 & $(2.4)$ & 13.3 & (1.9) & 5.0 & (1.0) & 1.3 & (0.5) \\
\hline & Galicia ${ }^{\bullet}$ & 7.3 & (1.2) & 12.5 & (1.5) & 22.3 & $(2.2)$ & 25.3 & $(2.2)$ & 18.6 & (1.6) & 10.2 & (1.5) & 3.8 & $(0.7)$ \\
\hline & La Rioja• & 9.0 & $(1.2)$ & 13.1 & (1.4) & 20.8 & $(1.8)$ & 25.0 & $(2.0)$ & 17.5 & (1.5) & 10.4 & (1.6) & 4.1 & (0.8) \\
\hline & Madrid ${ }^{\bullet}$ & 7.3 & (1.5) & 12.2 & (1.6) & 20.0 & $(1.7)$ & 25.2 & $(2.2)$ & 22.1 & (2.4) & 11.0 & (1.3) & 2.3 & $(0.7)$ \\
\hline & Murcia ${ }^{\bullet}$ & 13.8 & (1.6) & 19.0 & (1.7) & 25.9 & $(2.7)$ & 23.3 & (1.9) & 13.3 & (1.5) & 3.9 & (1.0) & 0.8 & (0.4) \\
\hline & Navarre ${ }^{\bullet}$ & 5.1 & (1.3) & 10.8 & (1.5) & 18.5 & $(2.0)$ & 24.7 & (2.4) & 24.3 & $(2.2)$ & 12.8 & (1.5) & 3.9 & $(0.7)$ \\
\hline & United Kingdom & & & & & & & & & & & & & & \\
\hline & England & 10.5 & (1.3) & 15.2 & (1.3) & 21.5 & $(1.2)$ & 22.9 & $(1.2)$ & 17.4 & (1.1) & 8.9 & $(0.9)$ & 3.7 & $(0.7)$ \\
\hline & Northern Ireland & 10.1 & (1.3) & 16.1 & (1.8) & 21.8 & $(2.3)$ & 22.5 & (1.6) & 17.7 & (1.5) & 8.8 & (1.4) & 3.0 & (0.6) \\
\hline & Scotland $^{\bullet}$ & 6.6 & $(1.1)$ & 13.7 & $(1.1)$ & 24.3 & $(1.8)$ & 25.6 & $(1.9)$ & 18.4 & (1.4) & 8.6 & $(0.9)$ & 2.7 & $(0.6)$ \\
\hline & Wales & 12.8 & $(1.0)$ & 20.5 & (1.4) & 26.0 & $(1.3)$ & 23.4 & $(1.5)$ & 12.4 & (1.1) & 4.0 & $(0.5)$ & 0.9 & $(0.3)$ \\
\hline & United States & & & & & & & & & & & & & & \\
\hline & Connecticut $^{\bullet}$ & 10.1 & (1.7) & 13.8 & (1.8) & 20.6 & (1.6) & 22.2 & $(1.6)$ & 19.2 & $(2.0)$ & 9.4 & (1.3) & 4.6 & (1.1) \\
\hline & Florida $\bullet^{\bullet}$ & 15.8 & $(2.1)$ & 21.9 & (2.4) & 26.7 & $(2.2)$ & 20.8 & $(2.7)$ & 10.2 & (1.5) & 4.0 & (1.2) & 0.6 & (0.5) \\
\hline & Massachusetts ${ }^{\bullet}$ & 7.9 & (1.3) & 13.1 & (1.4) & 20.9 & $(2.1)$ & 22.9 & (1.7) & 18.7 & (1.6) & 11.1 & (1.7) & 5.3 & (1.3) \\
\hline$\tilde{a}$ & Argentina & & & & & & & & & & & & & & \\
\hline$\stackrel{1}{\Sigma}$ & Ciudad Autónoma de Buenos Aires $\bullet$ & 22.8 & $(2.8)$ & 23.0 & $(2.7)$ & 26.7 & $(1.8)$ & 18.9 & $(2.0)$ & 6.7 & (1.4) & 1.8 & $(0.7)$ & 0.1 & c \\
\hline ¿ & Brazil & & & & & & & & & & & & & & \\
\hline & Acre & 59.1 & $(5.7)$ & 25.0 & (3.8) & 11.6 & $(2.4)$ & 3.7 & $(1.5)$ & 0.5 & $(0.4)$ & 0.0 & c & 0.0 & C \\
\hline & Alagoas & 63.3 & $(5.2)$ & 20.3 & $(4.0)$ & 10.8 & $(2.3)$ & 4.2 & $(1.6)$ & 1.3 & $(0.9)$ & 0.0 & c & 0.0 & c \\
\hline & Amapá & 57.7 & (5.9) & 27.0 & $(4.1)$ & 11.3 & $(2.5)$ & 3.3 & $(1.7)$ & 0.7 & $\mathrm{C}$ & 0.0 & c & 0.0 & c \\
\hline & Amazonas & 61.9 & (3.5) & 25.4 & (3.5) & 9.2 & $(2.2)$ & 2.2 & $(1.2)$ & 1.0 & $(1.0)$ & 0.3 & c & 0.0 & c \\
\hline & Bahia & 46.8 & (9.6) & 23.2 & $(4.2)$ & 19.3 & $(7.2)$ & 7.6 & $(3.1)$ & 2.7 & (1.5) & 0.4 & c & 0.0 & c \\
\hline & Ceará & 45.0 & (5.4) & 27.0 & (3.4) & 18.7 & $(3.7)$ & 6.2 & $(2.1)$ & 2.2 & $(1.0)$ & 0.9 & $(0.5)$ & 0.1 & c \\
\hline & Espírito Santo & 28.8 & (4.3) & 29.1 & (4.0) & 20.2 & (3.6) & 11.1 & $(3.0)$ & 7.8 & $(3.2)$ & 2.6 & (1.4) & 0.4 & C \\
\hline & Federal District & 29.8 & (5.4) & 25.3 & $(4.1)$ & 22.6 & $(3.3)$ & 15.0 & $(3.0)$ & 6.1 & $(2.6)$ & 1.3 & $(0.9)$ & 0.1 & c \\
\hline & Goiás & 45.4 & (4.6) & 28.4 & (2.7) & 17.2 & (2.9) & 6.5 & $(1.5)$ & 2.1 & $(1.2)$ & 0.4 & C & 0.0 & c \\
\hline & Maranhão & 65.5 & (6.9) & 20.6 & (3.3) & 10.2 & $(3.8)$ & 3.0 & $(1.5)$ & 0.7 & $(0.6)$ & 0.0 & c & 0.0 & C \\
\hline & Mato Grosso & 47.3 & $(4.7)$ & 29.8 & (3.9) & 14.4 & $(2.5)$ & 4.9 & $(2.2)$ & 2.9 & (1.9) & 0.8 & C & 0.0 & c \\
\hline & Mato Grosso do Sul & 32.5 & $(4.7)$ & 30.6 & (4.0) & 21.4 & $(3.0)$ & 10.6 & $(2.2)$ & 3.6 & $(1.5)$ & 1.1 & $(1.0)$ & 0.2 & c \\
\hline & Minas Gerais & 32.8 & (4.5) & 27.0 & (3.1) & 22.7 & $(3.1)$ & 13.3 & $(2.9)$ & 3.4 & $(1.6)$ & 0.7 & $(0.6)$ & 0.0 & c \\
\hline & Pará & 58.5 & $(4.2)$ & 24.7 & $(4.1)$ & 13.6 & $(1.8)$ & 3.1 & $(1.2)$ & 0.1 & $\mathrm{C}$ & 0.0 & $\mathrm{C}$ & 0.0 & c \\
\hline & Paraíba & 37.8 & (5.7) & 28.5 & (3.9) & 18.6 & $(4.4)$ & 12.5 & $(3.3)$ & 2.3 & (1.3) & 0.3 & $(0.4)$ & 0.0 & c \\
\hline & Paraná & 33.8 & $(4.5)$ & 27.5 & (3.3) & 22.0 & $(3.4)$ & 9.7 & $(2.2)$ & 4.4 & $(2.8)$ & 2.1 & $(2.1)$ & 0.4 & c \\
\hline & Pernambuco & 52.0 & (5.9) & 29.3 & (4.8) & 15.0 & $(3.3)$ & 3.0 & $(1.1)$ & 0.7 & $(0.5)$ & 0.1 & $\mathrm{C}$ & 0.0 & c \\
\hline & Piauí & 42.4 & (3.8) & 30.0 & (3.4) & 14.5 & $(2.4)$ & 8.9 & $(2.3)$ & 2.7 & $(1.4)$ & 1.1 & $(0.5)$ & 0.3 & $(0.5)$ \\
\hline & Rio de Janeiro & 40.9 & (4.6) & 26.9 & $(3.2)$ & 22.2 & $(3.5)$ & 7.5 & $(2.0)$ & 2.1 & $(1.2)$ & 0.4 & $\mathrm{C}$ & 0.0 & c \\
\hline & Rio Grande do Norte & 51.1 & $(4.3)$ & 23.4 & (3.4) & 13.7 & $(1.9)$ & 7.5 & $(1.9)$ & 2.6 & $(1.6)$ & 1.1 & $(0.9)$ & 0.6 & $(0.4)$ \\
\hline & Rio Grande do Sul & 31.1 & $(4.2)$ & 29.3 & (3.0) & 24.4 & (3.0) & 10.9 & $(2.1)$ & 3.4 & (1.6) & 0.8 & $(0.6)$ & 0.1 & c \\
\hline & Rondônia & 42.7 & $(4.2)$ & 30.9 & (3.4) & 21.0 & $(3.4)$ & 4.8 & $(2.0)$ & 0.7 & $(0.7)$ & 0.0 & $\mathrm{C}$ & 0.0 & c \\
\hline & Roraima & 55.9 & $(4.3)$ & 23.7 & $(4.0)$ & 13.4 & $(2.8)$ & 5.6 & $(2.4)$ & 1.4 & $(0.7)$ & 0.0 & c & 0.0 & C \\
\hline & Santa Catarina & 24.9 & (4.6) & 22.9 & (3.5) & 28.5 & (3.6) & 16.4 & $(2.7)$ & 6.2 & $(1.7)$ & 1.2 & $(1.0)$ & 0.1 & c \\
\hline & São Paulo & 34.2 & (2.5) & 28.0 & (2.6) & 20.4 & $(1.5)$ & 11.2 & $(1.5)$ & 4.7 & $(0.9)$ & 1.3 & $(0.6)$ & 0.2 & $(0.2)$ \\
\hline & Sergipe & 43.7 & (4.9) & 28.2 & (3.9) & 18.9 & (3.8) & 6.8 & $(2.3)$ & 2.3 & $(1.2)$ & 0.2 & c & 0.0 & C \\
\hline & Tocantins & 53.8 & (3.3) & 27.9 & (2.8) & 11.5 & $(2.2)$ & 4.5 & $(1.6)$ & 1.6 & $(0.8)$ & 0.7 & $(0.5)$ & 0.1 & c \\
\hline & Colombia & & & & & & & & & & & & & & \\
\hline & Bogotá & 41.8 & (2.3) & 30.9 & (2.4) & 19.4 & $(1.8)$ & 6.8 & $(1.2)$ & 1.1 & $(0.5)$ & 0.0 & c & 0.0 & c \\
\hline & Cali & 43.8 & $(4.5)$ & 28.5 & $(2.7)$ & 17.6 & $(2.6)$ & 7.8 & $(2.1)$ & 1.9 & $(0.9)$ & 0.3 & $(0.2)$ & 0.0 & C \\
\hline & Manizales & 34.4 & (3.4) & 33.1 & (3.4) & 20.6 & (3.6) & 7.8 & $(1.7)$ & 3.4 & $(1.6)$ & 0.8 & $(0.6)$ & 0.1 & c \\
\hline & Medellín & 44.5 & $(4.0)$ & 25.1 & (3.0) & 14.9 & $(2.3)$ & 8.9 & $(2.1)$ & 4.0 & (1.4) & 1.8 & (1.0) & 0.7 & (0.6) \\
\hline & Russian Federation & & & & & & & & & & & & & & \\
\hline & Perm Territory region ${ }^{\bullet}$ & 8.6 & (1.5) & 18.1 & (2.0) & 27.8 & (2.4) & 25.5 & (1.9) & 14.2 & $(1.7)$ & 4.4 & (1.3) & 1.4 & $(0.8)$ \\
\hline & United Arab Emirates & & & & & & & & & & & & & & \\
\hline & Abu Dhabi• & 23.9 & $(2.4)$ & 25.7 & $(1.7)$ & 23.3 & $(1.6)$ & 16.0 & $(1.5)$ & 8.0 & $(1.3)$ & 2.5 & $(0.6)$ & 0.6 & $(0.3)$ \\
\hline & Ajman & 24.0 & (7.4) & 30.9 & (3.6) & 25.0 & $(4.1)$ & 14.1 & (3.6) & 5.2 & $(1.7)$ & 0.8 & $(0.8)$ & 0.0 & c \\
\hline & Dubai ${ }^{\bullet}$ & 15.1 & $(0.8)$ & 19.3 & (1.1) & 24.5 & $(1.7)$ & 22.0 & $(1.9)$ & 12.9 & $(1.1)$ & 5.2 & $(0.7)$ & 1.1 & (0.4) \\
\hline & Fujairah & 21.1 & $(4.0)$ & 25.0 & (3.9) & 29.8 & $(3.2)$ & 18.0 & $(3.0)$ & 5.4 & $(1.5)$ & 0.8 & $(0.6)$ & 0.1 & c \\
\hline & Ras al-Khaimah & 26.3 & (6.4) & 24.6 & (3.7) & 24.3 & $(4.0)$ & 16.8 & $(2.6)$ & 5.6 & $(2.3)$ & 2.1 & (1.1) & 0.3 & c \\
\hline & Sharjah & 22.1 & (3.7) & 24.3 & (4.4) & 23.1 & $(3.5)$ & 16.4 & $(3.5)$ & 10.4 & $(2.7)$ & 3.2 & (1.1) & 0.4 & c \\
\hline & Umm al-Quwain & 27.3 & (3.6) & 30.8 & $(4.7)$ & 24.5 & $(4.4)$ & 12.8 & $(3.4)$ & 3.6 & (1.6) & 1.0 & $(1.0)$ & 0.0 & $\mathrm{C}$ \\
\hline
\end{tabular}

- PISA adjudicated region.

Note: See Table 1.2.21 for national data.

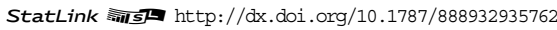


[Part 1/2]

Mean score, variation and gender differences in student performance on the mathematics Table B2.I.21 subscale quantity, by region

\begin{tabular}{|c|c|c|c|c|c|c|c|c|c|c|c|c|c|c|c|c|c|c|c|}
\hline & & & All stu & Idents & & & & nder d & differen & nces & & & & & & & Perce & entiles & \\
\hline & & Mean & score & $\begin{array}{l}\text { Stan } \\
\text { devia }\end{array}$ & $\begin{array}{l}\text { ard } \\
\text { ion }\end{array}$ & & oys & & irls & $\begin{array}{l}\text { Diffe } \\
\text { (B. }\end{array}$ & $\begin{array}{l}\text { rence } \\
- \text { G) }\end{array}$ & & th & & 0th & & 5th & & 5th \\
\hline & & Mean & S.E. & S.D. & S.E. & $\begin{array}{l}\text { Mean } \\
\text { score }\end{array}$ & S.E. & $\begin{array}{l}\text { Mean } \\
\text { score }\end{array}$ & S.E. & $\begin{array}{c}\text { Score } \\
\text { dif. }\end{array}$ & S.E. & Score & S.E. & Score & S.E. & Score & S.E. & Score & S.E. \\
\hline & Australia & & & & & & & & & & & & & & & & & & \\
\hline & Australian Capital Territory & 513 & (4.1) & 101 & (3.0) & 509 & (6.0) & 518 & (5.0) & -9 & (7.4) & $\mid 341$ & $(13.2)$ & 384 & (9.0) & 445 & (6.6) & 585 & (6.6) \\
\hline & New South Wales & 505 & (3.8) & 108 & $(2.7)$ & 505 & (5.8) & 504 & $(4.2)$ & 1 & (6.6) & 327 & $(6.3)$ & 367 & (4.8) & 431 & (3.5) & 579 & (5.9) \\
\hline & Northern Territory & 445 & $(9.7)$ & 116 & $(5.7)$ & 450 & (8.8) & 441 & $(14.9)$ & 8 & $(14.9)$ & 243 & (20.8) & 295 & $(16.3)$ & 373 & $(12.1)$ & 526 & (11.5) \\
\hline & Queensland & 498 & (3.6) & 104 & (2.3) & 500 & (4.7) & 496 & (4.3) & 4 & (5.4) & 330 & (7.3) & 366 & (5.6) & 426 & (4.4) & 571 & (4.7) \\
\hline & South Australia & 481 & (3.5) & 97 & $(2.1)$ & 489 & (4.2) & 473 & (4.4) & 16 & (4.9) & 321 & (6.3) & 357 & (5.6) & 416 & (5.1) & 548 & $(5.0)$ \\
\hline & Tasmania & 470 & (3.6) & 102 & (2.5) & 478 & (5.0) & 461 & (5.0) & 17 & (6.9) & 297 & (10.6) & 340 & (6.8) & 405 & (5.7) & 535 & (5.2) \\
\hline & Victoria & 499 & $(4.1)$ & 98 & $(2.2)$ & 507 & (5.6) & 489 & (4.2) & 19 & (5.9) & 337 & (5.9) & 371 & (4.8) & 431 & (4.7) & 566 & (5.5) \\
\hline & Western Australia & 512 & (3.9) & 101 & $(2.3)$ & 524 & (5.6) & 500 & (5.0) & 24 & (7.3) & 347 & (5.4) & 381 & (6.5) & 443 & (5.5) & 583 & $(5.8)$ \\
\hline & Belgium & & & & & & & & & & & & & & & & & & \\
\hline & Flemish Community• & 535 & (3.1) & 104 & (1.8) & 539 & (4.3) & 530 & (4.2) & 9 & (5.9) & 353 & (6.1) & 395 & (5.2) & 464 & $(4.2)$ & $\mid 612$ & (3.5) \\
\hline & French Community & 498 & (3.2) & 99 & $(2.0)$ & 504 & (3.6) & 491 & (3.8) & 13 & (3.7) & 330 & (6.2) & 366 & (5.9) & 427 & (4.9) & 570 & (3.5) \\
\hline & German-speaking Community & 516 & (2.4) & 96 & $(2.5)$ & 515 & $(4.3)$ & 517 & (3.2) & -2 & (5.8) & 342 & (9.7) & 384 & (8.0) & 458 & (6.2) & 584 & (4.6) \\
\hline & Canada & & & & & & & & & & & & & & & & & & \\
\hline & Alberta & 512 & (5.3) & 101 & $(2.2)$ & 519 & (5.7) & 505 & (5.7) & 13 & (4.5) & $\mid 347$ & (8.8) & 379 & (6.8) & 442 & (6.7) & 584 & (6.2) \\
\hline & British Columbia & 523 & (5.3) & 95 & $(2.7)$ & 531 & (5.9) & 515 & (6.6) & 16 & (6.6) & 365 & (7.8) & 401 & $(6.2)$ & 458 & (5.2) & 590 & (6.8) \\
\hline & Manitoba & 488 & (3.5) & 101 & $(2.5)$ & 492 & (4.3) & 484 & (5.1) & 7 & $(6.3)$ & 321 & (8.6) & 361 & $(6.7)$ & 420 & (4.1) & 558 & (4.5) \\
\hline & New Brunswick & 504 & (2.9) & 93 & $(2.2)$ & 507 & (4.3) & 502 & (3.9) & 5 & (6.0) & 345 & (8.8) & 382 & (7.1) & 443 & (4.2) & 564 & $(4.0)$ \\
\hline & Newfoundland and Labrador & 485 & $(4.0)$ & 96 & (2.6) & 488 & (5.9) & 482 & (4.0) & 5 & $(6.2)$ & 327 & $(10.7)$ & 362 & (5.8) & 419 & (6.1) & 552 & (5.6) \\
\hline & Nova Scotia & 494 & (4.1) & 95 & $(2.8)$ & 502 & (4.7) & 487 & (5.8) & 15 & (6.6) & 337 & (6.7) & 371 & (8.0) & 429 & (5.2) & 559 & (6.9) \\
\hline & Ontario & 511 & (4.9) & 100 & (2.1) & 516 & (5.6) & 506 & (5.0) & 9 & (4.2) & 346 & (6.5) & 381 & $(6.0)$ & 445 & (5.2) & 579 & (6.1) \\
\hline & Prince Edward Island & 475 & (2.9) & 93 & $(1.7)$ & 476 & (4.0) & 473 & (3.8) & 3 & (5.1) & 322 & (5.9) & 353 & $(5.0)$ & 409 & (4.5) & 540 & (3.4) \\
\hline & Quebec & 534 & (3.5) & 97 & $(2.0)$ & 537 & (4.5) & 531 & (3.8) & 6 & (4.5) & 363 & (7.3) & 404 & (5.9) & 471 & (4.8) & 604 & (4.3) \\
\hline & Saskatchewan & 501 & (3.5) & 93 & $(2.3)$ & 505 & (4.5) & 496 & (4.1) & 8 & $(5.2)$ & 348 & (7.0) & 382 & (5.8) & 436 & (4.1) & 564 & (5.1) \\
\hline & Italy & & & & & & & & & & & & & & & & & & \\
\hline & Abruzzo & 478 & (6.1) & 101 & (3.8) & 481 & (7.2) & 475 & (6.9) & 6 & (7.5) & 300 & (12.3) & 346 & (12.5) & 413 & (6.6) & 550 & (6.9) \\
\hline & Basilicata & 470 & (4.4) & 93 & (2.1) & 485 & (6.0) & 456 & (4.7) & 29 & (6.3) & 316 & (6.5) & 350 & $(6.1)$ & 407 & (6.0) & 533 & (4.7) \\
\hline & Bolzano & 514 & (2.3) & 100 & $(1.7)$ & 526 & (3.0) & 502 & (3.0) & 24 & (3.9) & 343 & $(6.7)$ & 383 & (5.8) & 451 & (4.4) & 582 & (2.9) \\
\hline & Calabria & 436 & (6.6) & 97 & (3.3) & 446 & $(7.0)$ & 425 & (8.4) & 21 & (8.5) & 275 & (11.9) & 310 & (8.6) & 369 & (9.4) & 504 & (7.8) \\
\hline & Campania & 458 & (7.5) & 96 & (3.5) & 468 & $(8.2)$ & 447 & (8.5) & 21 & $(7.2)$ & 301 & (9.5) & 336 & (9.2) & 394 & (7.5) & 523 & (8.9) \\
\hline & Emilia Romagna & 505 & $(7.1)$ & 105 & (3.9) & 515 & (11.0) & 495 & (6.8) & 19 & (11.7) & 327 & (13.3) & 371 & (12.1) & 438 & (8.4) & 579 & (8.6) \\
\hline & Friuli Venezia Giulia & 527 & $(4.7)$ & 98 & (3.9) & 535 & $(6.1)$ & 519 & (6.7) & 17 & $(8.8)$ & 353 & $(16.3)$ & 397 & (11.1) & 468 & (6.4) & 593 & (4.9) \\
\hline & Lazio & 481 & (7.0) & 97 & (2.9) & 491 & (7.6) & 468 & (7.9) & 23 & (7.6) & 320 & (10.4) & 356 & $(9.9)$ & 414 & (7.7) & 547 & (8.6) \\
\hline & Liguria & 494 & $(7.0)$ & 100 & (3.3) & 501 & (8.5) & 487 & (7.6) & 14 & $(8.2)$ & 332 & (14.6) & 367 & (11.0) & 427 & (7.4) & 564 & (8.1) \\
\hline & Lombardia & 523 & (7.6) & 94 & (3.0) & 531 & (8.7) & 514 & (8.3) & 17 & (8.3) & 365 & (10.1) & 401 & (9.6) & 461 & (8.8) & 588 & (8.0) \\
\hline & Marche & 501 & (6.4) & 95 & $(4.3)$ & 518 & $(7.2)$ & 485 & $(7.2)$ & 33 & (7.6) & 340 & $(17.3)$ & 377 & (12.3) & 438 & (7.6) & 568 & $(7.2)$ \\
\hline & Molise & 470 & (2.5) & 92 & $(2.3)$ & 479 & (3.4) & 461 & (3.7) & 19 & (5.1) & 317 & (7.4) & 349 & (5.3) & 409 & (3.9) & 533 & $(4.3)$ \\
\hline & Piemonte & 502 & (6.6) & 98 & (2.6) & 513 & (5.9) & 492 & (7.9) & 21 & (5.8) & 329 & (7.6) & 370 & (10.4) & 436 & (9.0) & 572 & (7.7) \\
\hline & Puglia & 483 & (6.1) & 91 & $(2.8)$ & 493 & (6.0) & 473 & (6.9) & 20 & $(6.1)$ & 330 & (11.6) & 365 & $(9.1)$ & 420 & (7.1) & 549 & (8.0) \\
\hline & Sardegna & 463 & (5.5) & 97 & $(2.8)$ & 465 & (5.9) & 461 & (7.6) & 5 & (7.9) & 300 & $(9.2)$ & 334 & $(9.0)$ & 398 & (8.6) & 530 & (5.5) \\
\hline & Sicilia & 452 & (5.9) & 93 & (3.4) & 455 & (6.7) & 449 & (6.7) & 5 & (6.5) & 298 & (11.0) & 333 & (8.5) & 392 & (7.3) & 517 & (6.3) \\
\hline & Toscana & 502 & (5.5) & 103 & (3.7) & 503 & (8.7) & 500 & (8.2) & 3 & (12.9) & 326 & (12.4) & 365 & (11.2) & 434 & (6.5) & 574 & (6.5) \\
\hline & Trento & 526 & (4.3) & 93 & $(2.2)$ & 526 & (5.6) & 525 & (7.8) & 1 & (10.4) & 365 & $(9.3)$ & 406 & $(6.2)$ & 465 & (6.6) & 591 & (5.0) \\
\hline & Umbria & 500 & (6.3) & 92 & (3.4) & 512 & (8.7) & 488 & (6.3) & 23 & $(8.2)$ & 340 & (12.3) & 377 & (12.0) & 440 & (9.7) & 564 & (5.5) \\
\hline & Valle d'Aosta & 499 & (2.8) & 96 & (2.5) & 507 & (4.2) & 490 & (4.1) & 17 & (6.0) & 342 & (8.8) & 378 & (6.9) & 435 & (5.1) & 560 & (7.0) \\
\hline & Veneto & 529 & (8.3) & 99 & (4.3) & 539 & (9.3) & 518 & (9.2) & 21 & (9.3) & 366 & (15.3) & 405 & (9.7) & 462 & (8.1) & 599 & (11.3) \\
\hline & Mexico & & & & & & & & & & & & & & & & & & \\
\hline & Aguascalientes & 435 & (5.7) & 84 & (2.9) & 439 & (7.1) & 431 & (5.7) & 8 & (5.9) & \begin{tabular}{|l|}
302
\end{tabular} & (9.8) & 326 & (9.3) & 376 & (7.6) & 491 & (6.2) \\
\hline & Baja California & 416 & (5.2) & 85 & (2.9) & 422 & (6.2) & 409 & (5.8) & 13 & (6.0) & 283 & (8.6) & 310 & (6.8) & 357 & (5.9) & 472 & (7.7) \\
\hline & Baja California Sur & 414 & $(5.7)$ & 84 & $(2.2)$ & 421 & (6.4) & 407 & (5.7) & 14 & $(4.0)$ & 279 & $(10.2)$ & 307 & (9.4) & 355 & (7.4) & 467 & (6.0) \\
\hline & Campeche & 394 & (5.0) & 86 & (3.2) & 402 & (5.4) & 387 & (5.8) & 15 & (5.1) & 257 & (12.9) & 286 & (10.7) & 337 & (7.4) & 450 & (4.5) \\
\hline & Chiapas & 364 & (8.8) & 90 & (5.1) & 371 & (8.8) & 357 & (9.8) & 14 & (5.9) & 216 & $(17.2)$ & 251 & (12.4) & 304 & (11.0) & 423 & (9.9) \\
\hline & Chihuahua & 423 & (7.0) & 91 & (4.0) & 433 & (8.3) & 413 & (7.2) & 20 & (7.0) & 277 & (13.1) & 313 & (11.0) & 362 & $(6.8)$ & 485 & (10.7) \\
\hline & Coahuila & 420 & (9.3) & 85 & (4.2) & 425 & (10.0) & 415 & (10.5) & 9 & (8.2) & 282 & (9.1) & 313 & $(7.8)$ & 362 & (8.7) & 475 & (12.8) \\
\hline & Colima & 430 & (6.1) & 89 & (3.0) & 433 & (6.5) & 427 & (6.7) & 6 & (5.1) & 285 & (10.7) & 315 & $(8.3)$ & 365 & (7.9) & 491 & (7.5) \\
\hline & Distrito Federal & 431 & (6.1) & 87 & (2.6) & 450 & (8.1) & 414 & (6.6) & 36 & (8.7) & 293 & (9.3) & 319 & (7.8) & 370 & (7.2) & 491 & (9.5) \\
\hline & Durango & 426 & (8.7) & 87 & $(2.7)$ & 434 & (10.1) & 419 & (8.5) & 15 & $(6.2)$ & 284 & (8.6) & 309 & (9.9) & 365 & (10.5) & 487 & (9.9) \\
\hline & Guanajuato & 409 & (6.4) & 88 & (2.9) & 420 & (7.0) & 398 & (6.8) & 22 & (5.4) & 268 & (14.5) & 298 & (8.8) & 349 & (8.8) & 467 & (6.3) \\
\hline & Guerrero & 357 & (4.5) & 81 & (2.6) & 362 & (4.9) & 353 & (5.9) & 9 & (6.0) & 226 & (10.9) & 255 & (8.1) & 303 & (6.1) & 409 & (5.4) \\
\hline & Hidalgo & 404 & (6.9) & 86 & (3.3) & 413 & (8.5) & 396 & (6.9) & 17 & (7.0) & 260 & (10.4) & 293 & (9.7) & 348 & (7.3) & 462 & (8.8) \\
\hline & Jalisco & 436 & (5.9) & 85 & (2.9) & 441 & (8.0) & 432 & (4.9) & 10 & (5.8) & 296 & $(12.2)$ & 329 & (8.6) & 382 & (7.6) & 490 & (6.3) \\
\hline & Mexico & 422 & (6.4) & 79 & (3.5) & 430 & $(7.0)$ & 414 & (6.9) & 15 & (5.5) & 294 & (8.1) & 323 & $(9.2)$ & 370 & (6.7) & 476 & (7.9) \\
\hline & Morelos & 421 & (10.4) & 93 & (7.6) & 424 & (12.4) & 419 & $(10.2)$ & 5 & (8.5) & 273 & (22.5) & 308 & $(15.2)$ & 360 & (9.5) & 479 & (12.4) \\
\hline & Nayarit & 421 & $(6.7)$ & 89 & (3.8) & 431 & (6.5) & 412 & (8.2) & 18 & (6.5) & 273 & (19.3) & 309 & $(14.2)$ & 364 & (7.7) & 479 & $(7.7)$ \\
\hline & Nuevo León & 438 & (8.8) & 84 & $(2.8)$ & 450 & (10.4) & 424 & (7.5) & 26 & (6.8) & 306 & (9.7) & 331 & (10.5) & 378 & (10.0) & 493 & (10.8) \\
\hline & Puebla & 419 & (5.8) & 86 & (3.8) & 427 & (8.1) & 410 & (6.1) & 17 & $(8.2)$ & 276 & (15.5) & 309 & (10.6) & 363 & (7.0) & 477 & (6.6) \\
\hline & Querétaro & 437 & (7.0) & 87 & (3.4) & 447 & (8.2) & 428 & (7.3) & 19 & (5.7) & 296 & (12.5) & 327 & (8.0) & 378 & (8.2) & 494 & (8.5) \\
\hline & Quintana Roo & 412 & $(6.0)$ & 83 & (2.4) & 415 & (7.2) & 410 & (5.8) & 6 & (5.1) & 279 & (12.4) & 306 & $(8.2)$ & 355 & (6.9) & 469 & (6.9) \\
\hline & San Luis Potosí & 415 & $(8.0)$ & 85 & (2.8) & 417 & (9.5) & 413 & (7.9) & 4 & (6.7) & 280 & (9.4) & 308 & (8.9) & 356 & (7.9) & 471 & $(10.2)$ \\
\hline & Sinaloa & 415 & (4.6) & 78 & (2.1) & 420 & (5.5) & 411 & (5.0) & 8 & (5.2) & 293 & (8.3) & 320 & (5.5) & 361 & (5.7) & 467 & (6.4) \\
\hline & Tabasco & 376 & (5.0) & 85 & (3.8) & 383 & (7.0) & 369 & (4.6) & 15 & (6.2) & 238 & (12.1) & 267 & (8.6) & 319 & (6.8) & 431 & (6.0) \\
\hline & Tamaulipas & 409 & (7.3) & 86 & (3.3) & 420 & (10.1) & 396 & (6.7) & 23 & $(9.2)$ & 268 & (13.0) & 299 & (11.0) & 352 & (6.8) & 467 & (9.8) \\
\hline & Tlaxcala & 413 & (5.6) & 82 & $(2.0)$ & 417 & (5.3) & 409 & (6.5) & 8 & (4.2) & 277 & (9.0) & 308 & $(8.1)$ & 358 & (6.8) & 469 & (6.0) \\
\hline & Veracruz & 397 & (7.1) & 87 & (3.6) & 402 & (7.1) & 393 & (8.8) & 9 & (7.1) & 256 & (12.9) & 288 & (11.5) & 339 & (9.9) & 455 & (9.3) \\
\hline & Yucatán & 410 & $(6.2)$ & 87 & (2.6) & 421 & (6.5) & 397 & (7.6) & 24 & (6.9) & 265 & (11.3) & 297 & (11.5) & 350 & (9.4) & 467 & (6.2) \\
\hline & Zacatecas & 406 & (5.8) & 87 & (3.2) & 411 & (7.3) & 401 & (5.5) & 10 & (5.8) & 259 & (11.8) & 294 & (9.6) & 347 & (7.2) & 466 & (6.0) \\
\hline
\end{tabular}

- PISA adjudicated region.

Notes: Values that are statistically significant are indicated in bold (see Annex A3).

See Table 1.2.22 for national data.

StatLink त्राजा http://dx.doi.org/10.1787/888932935762 
[Part 2/2]

Mean score, variation and gender differences in student performance on the mathematics Table B2.I.21 subscale quantity, by region

\begin{tabular}{|c|c|c|c|c|c|c|c|c|c|c|c|c|c|c|c|c|c|c|c|c|c|c|c|}
\hline & & & All stu & udents & & & & nder di & differen & nces & & & & & & & Percer & entiles & & & & & \\
\hline & & Mean & score & $\begin{array}{l}\text { Stan } \\
\text { devi }\end{array}$ & $\begin{array}{l}\text { dard } \\
\text { ation }\end{array}$ & & oys & & irls & $\begin{array}{c}\text { Diffe } \\
\text { (B }\end{array}$ & $\begin{array}{l}\text { rence } \\
\text { - G) }\end{array}$ & & th & & 0th & & 5th & & 5th & & 0th & & 5th \\
\hline & & Mean & S.E. & S.D. & S.E. & $\begin{array}{l}\text { Mean } \\
\text { score }\end{array}$ & S.E. & $\begin{array}{l}\text { Mean } \\
\text { score }\end{array}$ & S.E. & \begin{tabular}{|c}
$\begin{array}{c}\text { Score } \\
\text { dif. }\end{array}$ \\
\end{tabular} & S.E. & Score & S.E. & Score & e S.E. & Score & e S.E. & Score & S.E. & Score & e S.E. & Score & S.E. \\
\hline 8 & Portugal & & & & & & & & & & & & & & & & & & & & & & \\
\hline 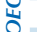 & Alentejo & 485 & (10.7) & 90 & (4.3) & 494 & (12.3) & 475 & (10.2) & 18 & (7.0) & 332 & (14.2) & $\mid 368$ & (15.0) & 424 & $(14.2)$ & 546 & (12.4) & \begin{tabular}{|l|}
602
\end{tabular} & (12.5) & | 634 & (16.9) \\
\hline & Spain & & & & & & & & & & & & & & & & & & & & & & \\
\hline & Andalusia & 478 & (4.7) & 99 & (2.2) & 488 & (5.6) & 467 & (5.2) & 21 & (5.3) & 317 & (8.4) & 350 & (6.6) & 412 & (5.3) & 547 & (5.6) & 604 & (5.4) & 636 & (6.3) \\
\hline & Aragon ${ }^{\bullet}$ & 502 & (6.2) & 105 & (2.8) & 510 & (6.8) & 494 & (6.6) & 17 & (5.3) & 320 & (11.1) & 359 & (9.6) & 432 & (9.3) & 579 & (6.2) & 631 & (6.4) & 664 & (9.5) \\
\hline & Asturias ${ }^{\bullet}$ & 510 & (4.5) & 106 & (1.9) & 519 & (6.6) & 502 & (3.8) & 17 & (5.8) & 337 & (8.8) & 377 & (7.6) & 442 & (6.0) & 583 & (5.1) & 647 & (5.9) & 682 & (6.5) \\
\hline & Balearic Islands ${ }^{\bullet}$ & 479 & (6.2) & 103 & (2.7) & 484 & (7.3) & 474 & (6.7) & 10 & (6.3) & 305 & (10.9) & 344 & (8.7) & 408 & (7.4) & 553 & (6.8) & 609 & (6.3) & 638 & (7.8) \\
\hline & Basque Country ${ }^{\bullet}$ & 511 & (2.8) & 90 & (1.7) & 517 & (3.4) & 506 & (3.1) & 11 & (3.2) & 357 & (5.8) & 394 & (4.3) & 453 & (3.6) & 573 & (3.4) & 624 & (4.0) & 652 & (4.3) \\
\hline & Cantabria ${ }^{\bullet}$ & 498 & (3.7) & 101 & (2.3) & 505 & (4.5) & 491 & (5.0) & 14 & (6.1) & 336 & (7.7) & 370 & (5.4) & 427 & (5.0) & 569 & (5.2) & 629 & (5.3) & 661 & (7.4) \\
\hline & Castile and Leon ${ }^{\bullet}$ & 519 & (4.5) & 92 & (2.4) & 532 & (5.8) & 506 & (4.2) & 26 & (4.8) & 364 & (8.2) & 395 & (7.3) & 455 & (5.4) & 585 & (4.7) & 635 & (4.8) & 663 & (6.0) \\
\hline & Catalonia ${ }^{\bullet}$ & 502 & (5.1) & 94 & (2.6) & 512 & (6.0) & 491 & (6.0) & 21 & $(6.2)$ & 343 & (9.0) & 378 & (7.3) & 438 & (7.6) & 567 & (5.4) & 620 & (6.9) & 652 & $(7.0)$ \\
\hline & Extremadura ${ }^{\bullet}$ & 466 & (5.1) & 103 & (2.8) & 471 & (6.3) & 462 & (5.1) & 9 & (5.2) & 293 & $(10.2)$ & 331 & (8.4) & 398 & $(7.2)$ & 536 & (6.3) & 597 & (6.0) & 631 & $(7.2)$ \\
\hline & Galicia• & 500 & (4.1) & 98 & (2.1) & 499 & (4.8) & 501 & (5.4) & -2 & (5.9) & 332 & (8.1) & 373 & (7.4) & 436 & (6.9) & 568 & (5.0) & 624 & (5.0) & 653 & (6.9) \\
\hline & La Rioja• & 508 & (2.4) & 113 & (3.0) & 520 & (3.7) & 496 & (3.7) & 24 & (5.7) & 318 & (8.1) & 362 & (6.3) & 434 & (4.6) & 589 & (4.0) & 648 & (4.5) & 684 & (7.1) \\
\hline & Madrid ${ }^{\bullet}$ & 512 & (4.2) & 99 & (2.9) & 522 & (4.5) & 502 & (5.1) & 20 & $(4.7)$ & 336 & (11.0) & 380 & (9.8) & 446 & (5.7) & 584 & (4.3) & 633 & (4.9) & 663 & (6.1) \\
\hline & Murcia ${ }^{\bullet}$ & 466 & (5.5) & 100 & (2.7) & 474 & (7.4) & 459 & (4.6) & 15 & (5.7) & 295 & (13.0) & 336 & (8.5) & 401 & (6.8) & 536 & (6.5) & 594 & (6.7) & 623 & (7.1) \\
\hline & Navarre ${ }^{\bullet}$ & 518 & (3.5) & 96 & (2.9) & 519 & (3.8) & 517 & (4.7) & 2 & (4.9) & 353 & (7.3) & 390 & (7.0) & 454 & (5.2) & 586 & (4.2) & 634 & $(4.7)$ & 664 & (6.1) \\
\hline & United Kingdom & & & & & & & & & & & & & & & & & & & & & & \\
\hline & England & 495 & (4.5) & $\mid 103$ & (2.2) & 502 & (5.7) & 489 & (4.8) & 14 & (5.6) & 324 & (8.9) & 361 & (8.0) & 425 & (6.5) & 569 & (4.3) & 627 & (4.2) & 661 & (4.6) \\
\hline & Northern Ireland & 491 & (3.7) & 100 & (2.6) & 495 & (5.6) & 487 & (5.9) & 8 & (8.8) & 324 & (6.4) & 360 & (5.4) & 422 & (5.4) & 561 & (4.9) & 620 & (5.3) & 653 & $(7.7)$ \\
\hline & Scotland ${ }^{\bullet}$ & 501 & (3.0) & 92 & (1.7) & 506 & (3.5) & 495 & (3.5) & 11 & (3.4) & 348 & (6.4) & 383 & (5.7) & 438 & (4.4) & 565 & (3.5) & 620 & (3.7) & 650 & (5.3) \\
\hline & Wales & 465 & (2.3) & 92 & (1.3) & 470 & (2.8) & 460 & (2.9) & 10 & (3.3) & 313 & (4.8) & 346 & (3.9) & 402 & (3.1) & 527 & (2.5) & 582 & (3.6) & 615 & (4.1) \\
\hline & United States & & & & & & & & & & & & & & & & & & & & & & \\
\hline & Connecticut $^{\bullet}$ & 502 & (6.5) & 106 & (2.9) & 509 & (7.1) & 495 & (6.9) & 14 & (5.3) & 323 & (10.1) & 362 & (9.0) & 427 & (8.8) & 577 & (7.0) & 637 & (7.8) & 671 & $(9.7)$ \\
\hline & Florida ${ }^{\bullet}$ & 458 & (6.4) & 94 & (2.6) & 466 & (6.9) & 450 & (6.8) & 16 & (5.0) & 307 & $(7.2)$ & 338 & (6.7) & 392 & $(7.2)$ & 522 & (6.9) & 582 & (8.3) & 616 & (10.7) \\
\hline & Massachusetts ${ }^{\bullet}$ & 506 & (6.0) & 105 & (3.4) & 509 & (6.2) & 504 & (6.7) & 5 & $(4.9)$ & 334 & $(9.4)$ & 372 & (7.3) & 436 & (6.3) & 578 & (8.5) & 642 & $(9.7)$ & 675 & $(9.9)$ \\
\hline$\frac{2}{2}$ & Argentina & & & & & & & & & & & & & & & & & & & & & & \\
\hline$\stackrel{0}{0}$ & Ciudad Autónoma de Buenos Aires $\bullet$ & 426 & (7.8) & $\mid 102$ & (8.1) & 432 & (8.4) & 421 & (8.1) & 11 & (5.6) & 245 & $(29.8)$ & 296 & $(15.0)$ & 369 & (8.4) & 495 & (6.9) & 549 & (8.4) & 579 & (9.0) \\
\hline$\Xi$ & Brazil & & & & & & & & & & & & & & & & & & & & & & \\
\hline & Acre & 349 & (6.0) & 78 & (3.0) & 357 & (9.1) & 342 & (8.3) & 15 & $(12.6)$ & 220 & (10.7) & 248 & (9.6) & 294 & (6.4) & 400 & (8.0) & 450 & $(12.8)$ & 481 & $(12.3)$ \\
\hline & Alagoas & 344 & (8.5) & 87 & (5.5) & 358 & (9.8) & 333 & (9.0) & 25 & $(7.2)$ & 202 & (17.1) & 237 & $(17.2)$ & 288 & (9.7) & 399 & (11.4) & 456 & $(15.1)$ & 494 & (18.7) \\
\hline & Amapá & 350 & (11.8) & 83 & (5.6) & 361 & (13.1) & 340 & (11.5) & 21 & (7.9) & 214 & (20.8) & 244 & (16.8) & 295 & $(14.0)$ & 405 & (12.7) & 458 & $(16.0)$ & 488 & (18.4) \\
\hline & Amazonas & 350 & (7.5) & 82 & (7.5) & 362 & (10.0) & 339 & (6.1) & 23 & (7.1) & 220 & (12.4) & 248 & (7.9) & 296 & (9.3) & 398 & (8.3) & 450 & $(12.2)$ & 485 & (29.1) \\
\hline & Bahia & 370 & (13.5) & 93 & (8.8) & 374 & (9.7) & 366 & (19.5) & 7 & $(16.2)$ & 225 & (19.8) & 256 & (20.5) & 310 & (15.8) & 431 & (18.2) & 489 & $(16.7)$ & 521 & (21.1) \\
\hline & Ceará & 378 & $(9.1)$ & 93 & (6.4) & 387 & (9.7) & 370 & (11.0) & 17 & (10.3) & 232 & (12.1) & 262 & (12.6) & 316 & (9.3) & 435 & (11.5) & 498 & (19.0) & 540 & (24.6) \\
\hline & Espírito Santo & 421 & (9.9) & 93 & (5.8) & 430 & (9.5) & 413 & (13.5) & 17 & (12.1) & 284 & (8.4) & 309 & (7.5) & 356 & (6.4) & 480 & (17.8) & 555 & (22.5) & 594 & (13.6) \\
\hline & Federal District & 417 & (10.5) & 95 & $(7.2)$ & 426 & $(11.2)$ & 409 & (11.1) & 16 & $(7.4)$ & 266 & $(17.8)$ & 294 & (18.4) & 352 & $(14.0)$ & 482 & (14.2) & 544 & $(15.5)$ & 584 & (20.0) \\
\hline & Goiás & 382 & $(7.8)$ & 86 & (4.0) & 395 & (7.9) & 371 & (8.9) & 24 & (7.0) & 250 & (15.8) & 277 & (8.5) & 322 & $(10.2)$ & 436 & $(10.0)$ & 499 & $(13.0)$ & 536 & (12.1) \\
\hline & Maranhão & 341 & (15.0) & 89 & (8.9) & 355 & (18.5) & 331 & (13.2) & 24 & $(9.2)$ & 205 & $(15.2)$ & 234 & $(11.2)$ & 280 & $(14.3)$ & 393 & (19.6) & 460 & $(31.3)$ & 504 & (33.2) \\
\hline & Mato Grosso & 373 & $(8.2)$ & 80 & (6.4) & 375 & (7.7) & 370 & (9.8) & 5 & (6.3) & 254 & (7.4) & 280 & $(8.3)$ & 318 & (5.9) & 420 & (11.7) & 475 & $(17.1)$ & 517 & $(28.7)$ \\
\hline & Mato Grosso do Sul & 408 & (9.4) & 85 & (4.6) & 420 & (10.6) & 398 & (9.2) & 22 & $(7.7)$ & 275 & (15.5) & 302 & (12.6) & 348 & $(11.2)$ & 462 & (10.0) & 522 & (12.6) & 557 & $(22.2)$ \\
\hline & Minas Gerais & 406 & (9.1) & 85 & (4.4) & 412 & (10.4) & 400 & (9.5) & 12 & (7.8) & 270 & (13.0) & 298 & (11.4) & 345 & (9.1) & 464 & (11.9) & 516 & (9.6) & 545 & (13.9) \\
\hline & Pará & 351 & (4.7) & 79 & (3.8) & 363 & (6.2) & 342 & (5.7) & 21 & $(7.2)$ & 227 & (14.0) & 252 & (7.3) & 295 & (8.7) & 405 & $(6.2)$ & 454 & (7.4) & 482 & (7.1) \\
\hline & Paraíba & 396 & (8.1) & 88 & (7.4) & 408 & (9.5) & 387 & (10.6) & 21 & (11.8) & 262 & (20.6) & 289 & $(14.2)$ & 337 & (13.5) & 453 & (7.3) & 514 & $(11.4)$ & 543 & (18.1) \\
\hline & Paraná & 414 & (12.7) & 92 & (10.7) & 428 & (13.0) & 401 & (13.6) & 27 & (7.4) & 283 & $(10.2)$ & 306 & (7.5) & 348 & (9.1) & 471 & (17.5) & 544 & $(41.9)$ & 590 & (41.6) \\
\hline & Pernambuco & 366 & (8.6) & 79 & (5.0) & 383 & (9.6) & 354 & (8.4) & 29 & (4.9) & 236 & (20.0) & 270 & (13.8) & 316 & $(10.1)$ & 417 & (9.0) & 463 & (12.8) & 498 & (19.3) \\
\hline & Piauí & 389 & (7.7) & 90 & (6.5) & 399 & (8.3) & 381 & (8.6) & 18 & (6.5) & 257 & (11.0) & 282 & (7.9) & 325 & $(10.7)$ & 440 & $(12.2)$ & 516 & $(16.0)$ & 552 & $(25.0)$ \\
\hline & Rio de Janeiro & 388 & (8.8) & 87 & (5.1) & 397 & $(10.2)$ & 380 & (8.4) & 17 & (6.3) & 252 & (14.3) & 278 & $(14.8)$ & 328 & $(11.5)$ & 447 & (9.5) & 498 & $(14.2)$ & 539 & (22.3) \\
\hline & Rio Grande do Norte & 380 & (9.7) & 98 & (7.8) & 396 & (11.1) & 367 & (9.8) & 29 & (7.7) & 239 & $(10.2)$ & 265 & (11.3) & 313 & (9.6) & 434 & (13.5) & 513 & (21.5) & 566 & (32.0) \\
\hline & Rio Grande do Sul & 409 & (7.0) & 84 & $(3.2)$ & 420 & (8.3) & 399 & (7.2) & 21 & (6.0) & 271 & (8.3) & 299 & (11.3) & 351 & $(10.2)$ & 466 & $(8.0)$ & 518 & $(7.5)$ & 546 & (9.7) \\
\hline & Rondônia & 378 & (5.5) & 78 & (2.4) & 387 & (5.8) & 370 & (6.9) & 16 & (6.3) & 249 & $(10.1)$ & 280 & (8.8) & 326 & (7.5) & 431 & $(7.2)$ & 474 & (8.3) & 503 & (8.4) \\
\hline & Roraima & 355 & (7.0) & 87 & $(4.3)$ & 361 & (8.5) & 349 & (7.9) & 11 & $(8.2)$ & 213 & (17.3) & 246 & $(14.7)$ & 297 & (9.5) & 413 & (10.1) & 469 & $(11.6)$ & 503 & (9.2) \\
\hline & Santa Catarina & 425 & (9.2) & 93 & (4.3) & 433 & (8.7) & 417 & (11.3) & 16 & $(8.7)$ & 266 & (13.4) & 301 & (15.5) & 364 & $(13.1)$ & 489 & (10.4) & 543 & $(11.7)$ & 578 & (14.2) \\
\hline & São Paulo & 405 & (5.0) & 92 & (2.9) & 412 & (5.3) & 397 & (5.5) & 15 & (4.3) & 262 & (8.3) & 291 & (6.1) & 341 & (5.0) & 464 & $(7.7)$ & 529 & $(9.8)$ & 567 & (10.6) \\
\hline & Sergipe & 388 & (9.5) & 85 & (5.1) & 405 & (12.0) & 375 & (9.8) & 30 & (9.6) & 257 & (12.7) & 285 & (8.9) & 330 & (8.0) & 442 & (13.8) & 504 & $(20.1)$ & 533 & (21.6) \\
\hline & Tocantins & 361 & (7.4) & 92 & (5.4) & 371 & (9.6) & 351 & (6.5) & 20 & $(7.7)$ & 217 & (11.3) & 248 & (9.6) & 298 & $(8.8)$ & 417 & (9.7) & 484 & (15.5) & 520 & (18.7) \\
\hline & Colombia & & & & & & & & & & & & & & & & & & & & & & \\
\hline & Bogotá & 391 & (3.5) & 79 & (2.4) & 410 & (4.7) & 374 & (3.9) & 36 & $(5.2)$ & 263 & (5.7) & 290 & (5.5) & 337 & (3.5) & 444 & (4.7) & 492 & (6.0) & 525 & (10.8) \\
\hline & Cali & 380 & (7.1) & 85 & (3.0) & 389 & (6.9) & 372 & (8.4) & 17 & (5.8) & 242 & $(7.7)$ & 273 & (8.2) & 323 & (6.9) & 436 & (8.5) & 490 & $(11.5)$ & 523 & $(10.2)$ \\
\hline & Manizales & 407 & (5.2) & 88 & (5.0) & 426 & (7.8) & 389 & (4.7) & 37 & (7.9) & 268 & (7.8) & 298 & (6.4) & 348 & (5.5) & 461 & (7.4) & 521 & $(14.2)$ & 563 & (15.7) \\
\hline & Medellín & 394 & (8.7) & 99 & (6.2) & 408 & (9.4) & 381 & (11.3) & 26 & (11.4) & 249 & (7.9) & 277 & (7.4) & 323 & (6.8) & 455 & (12.9) & 526 & $(18.5)$ & 572 & (24.8) \\
\hline & Russian F & & & & & & & & & & & & & & & & & & & & & & \\
\hline & Perm Territory $\mathrm{r}$ & 478 & (5.8) & 93 & (4.0) & $\mid 483$ & (6.9) & 473 & (5.6) & 10 & (5.1) & 326 & (9.1) & $\mid 362$ & (7.1) & 417 & (6.0) & $\mid 541$ & (6.6) & \begin{tabular}{|l|l}
594
\end{tabular} & (9.9) & 629 & (12.5) \\
\hline & United Arab Emirates & & & & & & & & & & & & & & & & & & & & & & \\
\hline & Abu Dhabi • & 416 & (4.8) & 100 & (2.4) & 405 & (6.3) & 425 & (5.8) & \begin{tabular}{|l|}
-20 \\
\end{tabular} & (7.8) & 260 & (5.5) & 289 & (5.1) & 344 & (4.9) & 484 & $(6.2)$ & 549 & (7.4) & 588 & $(8.2)$ \\
\hline & Ajman & 397 & (8.4) & 83 & (3.4) & 378 & (10.4) & 414 & (13.4) & -36 & (17.5) & 260 & (15.0) & 291 & $(14.1)$ & 338 & $(10.7)$ & 456 & (8.5) & 503 & (8.1) & 535 & (11.1) \\
\hline & Dubai ${ }^{\bullet}$ & 465 & (1.3) & 102 & $(1.2)$ & 471 & (2.0) & 459 & (1.7) & 11 & $(2.7)$ & 298 & (2.7) & 331 & (2.4) & 393 & (2.2) & 537 & (2.4) & 598 & (3.1) & 632 & $(5.0)$ \\
\hline & Fujairah & 406 & (9.0) & 89 & (3.8) & 389 & (9.1) & 424 & (9.3) & -35 & $(11.2)$ & 267 & (15.6) & 295 & $(11.7)$ & 344 & $(11.2)$ & 468 & (8.5) & 525 & (9.8) & 554 & $(9.3)$ \\
\hline & Ras al-Khaimah & 412 & (7.8) & 89 & (4.0) & 405 & (6.0) & 418 & (15.2) & -13 & (17.1) & 273 & (11.3) & 303 & $(10.7)$ & 348 & (8.4) & 472 & (8.1) & 528 & (9.5) & 562 & (11.8) \\
\hline & Sharjah & 439 & (9.9) & 97 & (4.4) & 446 & (17.6) & 434 & (12.4) & 12 & (23.6) & 290 & $(10.7)$ & 318 & (11.5) & 371 & (9.0) & 505 & $(14.0)$ & 576 & (15.9) & 604 & $(10.0)$ \\
\hline & Umm al-Quwain & 389 & (4.5) & 84 & (3.9) & 373 & (6.1) & 405 & (6.5) & -32 & (8.9) & 261 & (7.2) & 284 & (7.5) & 328 & (9.9) & 442 & (8.5) & 500 & (12.0) & 537 & (14.4) \\
\hline
\end{tabular}

- PISA adjudicated region.

Notes: Values that are statistically significant are indicated in bold (see Annex A3).

See Table 1.2.22 for national data.

StatLink 部 SL http://dx.doi.org/10.1787/888932935762 
[Part 1/2]

Percentage of students at each proficiency level on the mathematics subscale uncertainty and data, Table B2.I.22 by region

\begin{tabular}{|c|c|c|c|c|c|c|c|c|c|c|c|c|c|c|c|}
\hline & & \multicolumn{14}{|c|}{ All students } \\
\hline & & \multicolumn{2}{|c|}{$\begin{array}{l}\text { Below Level } 1 \\
\text { (below 357.77 } \\
\text { score points) }\end{array}$} & $\begin{array}{l}\text { Le } \\
\text { (from } \\
\text { less th } \\
\text { scor }\end{array}$ & $\begin{array}{l}\text { I } 1 \\
7.77 \text { to } \\
420.07 \\
\text { oints) }\end{array}$ & $\begin{array}{l}\text { Le } \\
\text { (from } \\
\text { less th } \\
\text { score }\end{array}$ & $\begin{array}{l}2 \\
.07 \text { to } \\
482.38 \\
\text { jints) }\end{array}$ & $\begin{array}{l}\text { Le } \\
\text { (from } \\
\text { less th } \\
\text { score }\end{array}$ & $\begin{array}{l}\text { I } 3 \\
2.38 \text { to } \\
544.68 \\
\text { oints) }\end{array}$ & $\begin{array}{l}\text { Le } \\
\text { (from } \\
\text { less th } \\
\text { score }\end{array}$ & $\begin{array}{l}14 \\
4.68 \text { to } \\
606.99 \\
\text { oints) }\end{array}$ & $\begin{array}{l}\text { Le } \\
\text { (from } \\
\text { less tha } \\
\text { score }\end{array}$ & $\begin{array}{l}\text { I } 5 \\
6.99 \text { to } \\
669.30 \\
\text { oints) }\end{array}$ & $\begin{array}{l}\text { Le } \\
\text { (abov } \\
\text { scor }\end{array}$ & $\begin{array}{l}6 \\
69.30 \\
\text { ints) }\end{array}$ \\
\hline & & $\%$ & S.E. & $\%$ & S.E. & $\%$ & S.E. & $\%$ & S.E. & $\%$ & S.E. & $\%$ & S.E. & $\%$ & S.E. \\
\hline 0 & Australia & & & & & & & & & & & & & & \\
\hline $\bar{U}$ & Australian Capital Territory & 5.0 & $(0.9)$ & 8.9 & (1.4) & 18.2 & (1.6) & 24.2 & $(2.2)$ & 21.4 & (1.6) & 15.5 & (1.5) & 6.8 & (1.3) \\
\hline & New South Wales & 6.3 & $(0.6)$ & 11.9 & $(0.8)$ & 20.8 & $(0.9)$ & 23.5 & (1.1) & 19.2 & $(0.9)$ & 12.2 & $(0.8)$ & 6.1 & (0.9) \\
\hline & Northern Territory & 19.6 & $(2.1)$ & 16.9 & $(4.0)$ & 22.6 & (4.4) & 22.0 & $(4.2)$ & 12.9 & (3.1) & 4.9 & $(2.0)$ & 1.0 & $(0.8)$ \\
\hline & Queensland & 5.6 & $(0.8)$ & 12.5 & $(0.8)$ & 22.3 & $(1.0)$ & 24.9 & $(1.2)$ & 19.7 & $(0.9)$ & 10.7 & $(0.7)$ & 4.2 & $(0.6)$ \\
\hline & South Australia & 7.0 & $(0.8)$ & 14.2 & (1.3) & 23.1 & (1.4) & 25.3 & (1.4) & 18.6 & $(1.8)$ & 9.3 & $(1.3)$ & 2.6 & $(0.4)$ \\
\hline & Tasmania & 9.3 & $(1.0)$ & 15.6 & (1.4) & 25.0 & $(2.1)$ & 24.2 & $(2.4)$ & 15.5 & (1.9) & 7.8 & $(1.1)$ & 2.7 & $(0.7)$ \\
\hline & Victoria & 5.6 & $(0.7)$ & 13.1 & $(0.9)$ & 22.2 & $(1.1)$ & 26.0 & (1.6) & 20.1 & $(1.5)$ & 9.6 & $(1.0)$ & 3.2 & $(0.8)$ \\
\hline & Western Australia & 4.6 & $(0.6)$ & 11.2 & (1.3) & 18.0 & (1.3) & 23.6 & (1.4) & 23.2 & $(1.1)$ & 13.8 & $(0.9)$ & 5.6 & $(0.7)$ \\
\hline & Belgium & & & & & & & & & & & & & & \\
\hline & Flemish Community• & 6.8 & $(1.0)$ & 10.1 & $(0.6)$ & 16.7 & (1.1) & 21.2 & $(1.2)$ & 20.1 & $(0.8)$ & 15.6 & $(0.7)$ & 9.6 & $(0.8)$ \\
\hline & French Community & 11.6 & $(1.2)$ & 14.7 & $(1.0)$ & 22.2 & $(1.0)$ & 22.5 & (1.1) & 18.0 & $(1.1)$ & 8.5 & $(0.6)$ & 2.6 & $(0.4)$ \\
\hline & German-speaking Community & 8.2 & $(1.0)$ & 11.2 & $(1.1)$ & 19.9 & (1.8) & 26.1 & (1.8) & 22.5 & (1.4) & 9.9 & (1.4) & 2.2 & $(0.6)$ \\
\hline & Canada & & & & & & & & & & & & & & \\
\hline & Alberta & 4.7 & $(0.8)$ & 10.2 & (1.4) & 19.5 & $(1.2)$ & 26.1 & $(1.3)$ & 22.3 & (1.4) & 12.6 & $(1.3)$ & 4.5 & $(0.7)$ \\
\hline & British Columbia & 2.9 & $(0.6)$ & 9.2 & $(1.0)$ & 20.5 & (1.4) & 27.5 & (1.6) & 23.2 & $(2.0)$ & 12.5 & (1.4) & 4.1 & $(0.8)$ \\
\hline & Manitoba & 6.2 & $(1.0)$ & 14.7 & (1.3) & 24.4 & (1.5) & 25.3 & (1.4) & 18.1 & (1.6) & 8.2 & $(0.8)$ & 3.1 & $(0.7)$ \\
\hline & New Brunswick & 5.3 & $(0.8)$ & 12.2 & $(1.2)$ & 24.5 & (1.5) & 28.8 & (1.5) & 20.1 & (1.5) & 7.2 & $(1.1)$ & 1.8 & $(0.8)$ \\
\hline & Newfoundland and Labrador & 8.6 & $(1.8)$ & 13.4 & $(1.7)$ & 22.3 & $(2.0)$ & 27.2 & (1.7) & 17.7 & (1.7) & 8.5 & $(1.1)$ & 2.2 & $(0.6)$ \\
\hline & Nova Scotia & 3.7 & $(0.8)$ & 12.5 & (1.7) & 26.2 & (3.2) & 25.6 & (1.8) & 20.5 & (1.9) & 9.3 & $(1.4)$ & 2.3 & (0.6) \\
\hline & Ontario & 4.2 & $(0.6)$ & 10.4 & $(1.2)$ & 22.4 & (1.4) & 28.0 & $(1.1)$ & 20.9 & $(1.1)$ & 10.9 & $(1.2)$ & 3.2 & $(0.5)$ \\
\hline & Prince Edward Island & 6.3 & $(1.0)$ & 15.7 & $(1.1)$ & 25.1 & (1.4) & 26.8 & (1.6) & 18.4 & (1.5) & 6.3 & $(0.9)$ & 1.4 & $(0.5)$ \\
\hline & Quebec & 3.3 & $(0.5)$ & 8.2 & $(0.8)$ & 17.0 & $(1.1)$ & 24.8 & $(1.2)$ & 24.4 & $(1.0)$ & 15.9 & $(1.0)$ & 6.3 & $(0.7)$ \\
\hline & Saskatchewan & 4.0 & $(0.6)$ & 10.6 & $(0.9)$ & 24.0 & (1.5) & 28.5 & (1.8) & 20.9 & (1.1) & 9.8 & (1.1) & 2.3 & $(0.7)$ \\
\hline & Italy & & & & & & & & & & & & & & \\
\hline & Abruzzo & 10.9 & $(1.5)$ & 17.2 & (1.6) & 25.7 & (1.9) & 24.9 & (1.6) & 15.6 & (1.6) & 5.0 & $(0.9)$ & 0.8 & $(0.4)$ \\
\hline & Basilicata & 14.4 & (1.6) & 20.5 & (1.3) & 27.4 & (1.5) & 21.6 & (1.4) & 11.0 & $(1.2)$ & 4.0 & $(0.7)$ & 1.2 & $(0.4)$ \\
\hline & Bolzano & 7.9 & $(0.9)$ & 12.8 & $(1.0)$ & 19.7 & $(1.2)$ & 26.1 & $(1.2)$ & 20.3 & (1.5) & 10.2 & $(1.1)$ & 3.0 & $(0.4)$ \\
\hline & Calabria & 24.3 & $(2.6)$ & 24.6 & $(1.8)$ & 24.3 & (1.4) & 16.8 & (1.5) & 7.5 & $(0.9)$ & 2.0 & $(0.5)$ & 0.5 & $(0.3)$ \\
\hline & Campania & 16.3 & $(2.4)$ & 20.9 & $(2.4)$ & 25.7 & (1.6) & 21.4 & (1.9) & 11.3 & (1.8) & 3.2 & $(0.8)$ & 1.1 & $(0.4)$ \\
\hline & Emilia Romagna & 8.3 & $(1.4)$ & 12.6 & $(1.4)$ & 21.6 & (1.9) & 23.9 & (1.8) & 19.4 & (1.6) & 10.7 & $(1.8)$ & 3.6 & $(0.9)$ \\
\hline & Friuli Venezia Giulia & 6.0 & $(1.4)$ & 10.0 & $(1.5)$ & 18.2 & $(1.6)$ & 26.6 & (1.8) & 23.5 & (1.7) & 12.2 & $(1.4)$ & 3.6 & $(0.6)$ \\
\hline & Lazio & 10.9 & $(2.0)$ & 17.7 & $(2.1)$ & 26.1 & (1.9) & 22.5 & $(1.7)$ & 14.5 & (1.6) & 6.5 & $(1.2)$ & 1.8 & $(0.5)$ \\
\hline & Liguria & 8.7 & $(1.2)$ & 16.1 & (1.6) & 23.2 & $(2.0)$ & 24.4 & (1.7) & 17.2 & (1.8) & 8.1 & (1.3) & 2.4 & $(0.6)$ \\
\hline & Lombardia & 3.9 & $(0.9)$ & 10.5 & (1.6) & 20.1 & $(2.1)$ & 27.6 & $(2.0)$ & 23.1 & (1.6) & 11.6 & $(1.7)$ & 3.3 & $(0.9)$ \\
\hline & Marche & 7.4 & $(1.5)$ & 13.6 & (1.5) & 22.5 & (1.7) & 26.8 & $(1.7)$ & 18.9 & (1.6) & 8.6 & $(1.2)$ & 2.3 & $(0.5)$ \\
\hline & Molise & 10.0 & $(1.0)$ & 21.3 & (1.7) & 28.3 & $(2.1)$ & 23.3 & (1.9) & 12.9 & $(1.4)$ & 3.4 & $(0.7)$ & 0.8 & $(0.4)$ \\
\hline & Piemonte & 6.5 & $(1.0)$ & 14.6 & (1.8) & 22.2 & (1.9) & 27.5 & (1.6) & 18.5 & $(1.7)$ & 8.6 & $(1.1)$ & 2.1 & $(0.6)$ \\
\hline & Puglia & 9.1 & $(1.7)$ & 17.4 & $(2.0)$ & 26.7 & (2.4) & 24.1 & $(2.5)$ & 16.2 & (1.9) & 5.5 & $(1.1)$ & 1.0 & $(0.4)$ \\
\hline & Sardegna & 13.4 & $(2.1)$ & 19.2 & $(2.0)$ & 26.1 & $(1.7)$ & 23.7 & $(2.0)$ & 12.5 & $(1.3)$ & 4.2 & $(0.7)$ & 0.9 & $(0.3)$ \\
\hline & Sicilia & 14.7 & $(1.7)$ & 21.8 & (1.6) & 29.5 & $(1.8)$ & 21.8 & $(1.6)$ & 9.3 & $(1.1)$ & 2.5 & $(0.6)$ & 0.4 & $(0.2)$ \\
\hline & Toscana & 9.0 & (1.1) & 14.6 & (1.6) & 21.7 & $(1.7)$ & 24.5 & $(1.7)$ & 19.0 & $(1.9)$ & 8.8 & $(1.3)$ & 2.5 & $(0.7)$ \\
\hline & Trento & 2.8 & $(0.8)$ & 8.9 & (1.5) & 21.3 & $(2.0)$ & 28.3 & (1.7) & 24.7 & $(1.7)$ & 11.3 & $(1.2)$ & 2.6 & $(0.5)$ \\
\hline & Umbria & 8.9 & $(2.1)$ & 13.5 & (1.7) & 21.4 & $(1.9)$ & 27.8 & (1.9) & 18.9 & (1.8) & 8.2 & $(1.2)$ & 1.3 & $(0.5)$ \\
\hline & Valle d'Aosta & 6.4 & $(1.0)$ & 13.9 & (1.7) & 26.1 & $(2.0)$ & 27.5 & $(2.6)$ & 17.3 & (1.9) & 6.9 & $(1.1)$ & 1.9 & $(0.5)$ \\
\hline & Veneto & 4.9 & $(1.2)$ & 10.5 & (1.5) & 19.0 & (1.8) & 26.0 & (2.3) & 22.3 & (1.8) & 12.6 & $(1.8)$ & 4.7 & (1.4) \\
\hline & Mexico & & & & & & & & & & & & & & \\
\hline & Aguascalientes & 12.5 & $(2.1)$ & 26.9 & $(2.1)$ & 35.4 & $(2.1)$ & 19.9 & $(2.2)$ & 4.9 & $(1.2)$ & 0.4 & $(0.3)$ & 0.0 & c \\
\hline & Baja California & 19.9 & (3.6) & 35.0 & (3.6) & 29.6 & (2.7) & 12.3 & (2.6) & 2.3 & $(0.9)$ & 0.8 & $(0.6)$ & 0.0 & c \\
\hline & Baja California Sur & 17.8 & (3.1) & 32.6 & $(2.3)$ & 32.8 & $(2.9)$ & 14.2 & (1.8) & 2.4 & $(0.7)$ & 0.2 & $(0.2)$ & 0.0 & $\mathrm{c}$ \\
\hline & Campeche & 25.3 & $(2.7)$ & 38.4 & (1.9) & 27.1 & $(2.1)$ & 7.6 & (1.2) & 1.4 & $(0.6)$ & 0.2 & $(0.2)$ & 0.0 & c \\
\hline & Chiapas & 36.1 & $(3.7)$ & 37.2 & (2.5) & 21.0 & $(2.2)$ & 5.0 & $(1.2)$ & 0.7 & $(0.4)$ & 0.1 & C & 0.0 & c \\
\hline & Chihuahua & 14.3 & $(2.2)$ & 30.2 & (3.3) & 33.9 & $(2.3)$ & 16.9 & $(2.8)$ & 4.3 & $(1.3)$ & 0.5 & $(0.3)$ & 0.0 & c \\
\hline & Coahuila & 18.3 & (3.3) & 33.9 & (3.3) & 31.7 & $(2.7)$ & 13.6 & $(2.4)$ & 2.1 & $(0.9)$ & 0.3 & $(0.2)$ & 0.0 & c \\
\hline & Colima & 16.5 & $(2.0)$ & 29.4 & (1.8) & 31.1 & (1.9) & 17.3 & $(2.0)$ & 5.2 & $(1.3)$ & 0.5 & $(0.3)$ & 0.0 & c \\
\hline & Distrito Federal & 17.2 & $(2.2)$ & 32.9 & $(2.7)$ & 30.4 & $(2.1)$ & 14.9 & $(2.3)$ & 4.3 & $(1.0)$ & 0.3 & $(0.2)$ & 0.0 & c \\
\hline & Durango & 14.5 & $(2.3)$ & 34.0 & (2.8) & 33.1 & $(2.4)$ & 15.6 & $(2.1)$ & 2.8 & $(0.9)$ & 0.1 & $(0.1)$ & 0.0 & c \\
\hline & Guanajuato & 21.3 & (3.3) & 33.4 & (2.0) & 30.5 & (2.9) & 12.7 & $(1.8)$ & 2.0 & $(0.5)$ & 0.1 & c & 0.0 & c \\
\hline & Guerrero & 39.0 & (3.0) & 38.9 & $(2.2)$ & 17.7 & (1.4) & 3.9 & $(0.9)$ & 0.6 & $(0.3)$ & 0.0 & c & 0.0 & c \\
\hline & Hidalgo & 24.7 & $(2.8)$ & 35.0 & (2.6) & 28.5 & $(2.6)$ & 10.6 & (1.8) & 1.2 & $(0.5)$ & 0.0 & $\mathrm{C}$ & 0.0 & c \\
\hline & Jalisco & 10.7 & (1.8) & 30.7 & (2.3) & 36.1 & $(1.8)$ & 18.1 & $(2.2)$ & 3.9 & $(0.9)$ & 0.5 & $(0.3)$ & 0.1 & $(0.1)$ \\
\hline & Mexico & 15.9 & $(1.9)$ & 37.4 & (3.1) & 34.1 & $(3.2)$ & 11.0 & (1.7) & 1.4 & $(0.8)$ & 0.2 & $(0.2)$ & 0.0 & $\mathrm{c}$ \\
\hline & Morelos & 17.4 & (3.6) & 34.5 & $(3.0)$ & 30.1 & $(2.3)$ & 13.3 & $(2.1)$ & 4.0 & $(1.8)$ & 0.7 & $(0.6)$ & 0.0 & c \\
\hline & Nayarit & 22.2 & (3.4) & 30.8 & (2.0) & 31.7 & (2.5) & 13.1 & $(1.8)$ & 2.1 & $(0.6)$ & 0.0 & c & 0.0 & c \\
\hline & Nuevo León & 11.0 & $(2.8)$ & 30.1 & (3.4) & 34.9 & $(2.3)$ & 19.3 & $(3.3)$ & 4.3 & $(1.1)$ & 0.5 & $(0.4)$ & 0.0 & c \\
\hline & Puebla & 19.8 & (3.1) & 36.6 & $(2.1)$ & 31.5 & $(2.2)$ & 10.1 & $(1.5)$ & 1.7 & $(0.8)$ & 0.3 & $(0.2)$ & 0.0 & c \\
\hline & Querétaro & 12.5 & $(2.3)$ & 29.4 & $(2.8)$ & 35.7 & (2.4) & 17.4 & $(2.1)$ & 4.4 & $(1.1)$ & 0.5 & $(0.3)$ & 0.0 & c \\
\hline & Quintana Roo & 24.0 & (3.1) & 36.0 & $(2.1)$ & 28.1 & $(2.2)$ & 10.3 & (1.8) & 1.5 & $(0.4)$ & 0.0 & C & 0.0 & c \\
\hline & San Luis Potosí & 26.8 & $(2.9)$ & 31.4 & (2.5) & 28.2 & $(2.0)$ & 10.9 & (1.9) & 2.4 & $(1.0)$ & 0.3 & $(0.2)$ & 0.0 & c \\
\hline & Sinaloa & 18.5 & $(2.7)$ & 36.1 & $(2.1)$ & 31.3 & $(2.2)$ & 12.2 & (1.7) & 1.8 & $(0.5)$ & 0.2 & $(0.2)$ & 0.0 & c \\
\hline & Tabasco & 35.5 & $(2.2)$ & 37.3 & (2.0) & 20.8 & $(2.3)$ & 5.4 & (1.0) & 0.9 & $(0.5)$ & 0.1 & c & 0.0 & c \\
\hline & Tamaulipas & 23.5 & $(3.2)$ & 34.2 & (2.8) & 28.4 & $(2.2)$ & 10.8 & $(1.8)$ & 2.8 & $(1.1)$ & 0.3 & $(0.2)$ & 0.0 & c \\
\hline & Tlaxcala & 21.1 & $(1.9)$ & 34.0 & $(2.2)$ & 31.7 & (1.9) & 10.6 & (1.3) & 2.5 & $(0.8)$ & 0.1 & $(0.1)$ & 0.0 & c \\
\hline & Veracruz & 24.3 & (3.1) & 34.8 & $(2.7)$ & 27.8 & (2.2) & 11.2 & $(2.0)$ & 1.7 & $(0.7)$ & 0.2 & $(0.1)$ & 0.0 & c \\
\hline & Yucatán & 20.1 & $(2.1)$ & 34.5 & (1.6) & 31.0 & (1.9) & 12.0 & (1.8) & 2.2 & $(0.6)$ & 0.2 & C & 0.0 & c \\
\hline & Zacatecas & 19.6 & (2.4) & 35.5 & $(2.0)$ & 30.8 & $(1.8)$ & 12.4 & (1.3) & 1.6 & $(0.5)$ & 0.0 & $\mathrm{C}$ & 0.0 & c \\
\hline
\end{tabular}

- PISA adjudicated region.

Note: See Table 1.2.23 for national data.

StatLink त्ञात्रा http://dx.doi.org/10.1787/888932935762 
Percentage of students at each proficiency level on the mathematics subscale uncertainty and data, Table B2.I.22 by region

\begin{tabular}{|c|c|c|c|c|c|c|c|c|c|c|c|c|c|c|c|}
\hline & & \multicolumn{14}{|c|}{ All students } \\
\hline & & \multicolumn{2}{|c|}{$\begin{array}{l}\text { Below Level } 1 \\
\text { (below 357.77 } \\
\text { score points) }\end{array}$} & \multicolumn{2}{|c|}{$\begin{array}{c}\text { Level } 1 \\
\text { (from } 357.77 \text { to } \\
\text { less than } 420.07 \\
\text { score points) }\end{array}$} & \multicolumn{2}{|c|}{$\begin{array}{c}\text { Level } 2 \\
\text { (from } 420.07 \text { to } \\
\text { less than } 482.38 \\
\text { score points) }\end{array}$} & $\begin{array}{r}\text { Le } \\
\text { (from } \\
\text { less tha } \\
\text { score }\end{array}$ & \begin{tabular}{|l|}
3 \\
2.38 to \\
544.68 \\
ints)
\end{tabular} & $\begin{array}{r}\text { Le } \\
\text { (from } 5 \\
\text { less tha } \\
\text { score }\end{array}$ & $\begin{array}{l}14 \\
4.68 \text { to } \\
606.99 \\
\text { oints) }\end{array}$ & $\begin{array}{r}\text { Le } \\
\text { (from } \\
\text { less tha } \\
\text { score }\end{array}$ & $\begin{array}{l}5 \\
5.99 \text { to } \\
669.30 \\
\text { ints) }\end{array}$ & $\begin{array}{r}\text { Le } \\
\text { (above } \\
\text { score }\end{array}$ & $\begin{array}{l}6 \\
69.30 \\
\text { ints) }\end{array}$ \\
\hline & & $\%$ & S.E. & $\%$ & S.E. & $\%$ & S.E. & $\%$ & S.E. & $\%$ & S.E. & $\%$ & S.E. & $\%$ & S.E. \\
\hline 0 & Portugal & & & & & & & & & & & & & & \\
\hline 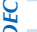 & Alentejo & 7.5 & (2.0) & 14.8 & (3.3) & 24.5 & (3.2) & 27.4 & (3.5) & 17.3 & (2.4) & 7.2 & (1.6) & 1.3 & $(0.7)$ \\
\hline & Spain & & & & & & & & & & & & & & \\
\hline & Andalusia ${ }^{\bullet}$ & 8.8 & $(1.2)$ & 18.5 & (1.3) & 25.7 & (1.3) & 24.1 & (1.4) & 14.9 & (1.3) & 6.6 & $(0.8)$ & 1.3 & $(0.4)$ \\
\hline & Aragon • & 8.3 & (1.1) & 13.0 & (1.4) & 19.3 & (2.0) & 25.3 & (1.6) & 20.5 & (1.6) & 10.4 & (1.5) & 3.2 & $(0.8)$ \\
\hline & Asturias ${ }^{\bullet}$ & 6.7 & (1.0) & 12.7 & $(1.2)$ & 22.0 & $(1.3)$ & 25.5 & (1.3) & 19.9 & (1.3) & 10.4 & (1.1) & 3.0 & $(0.8)$ \\
\hline & Balearic Islands & 10.7 & (1.5) & 16.0 & (1.7) & 23.2 & (1.4) & 27.3 & (2.0) & 15.8 & (1.9) & 6.0 & (1.1) & 1.0 & $(0.3)$ \\
\hline & Basque Country ${ }^{\bullet}$ & 4.2 & $(0.4)$ & 10.8 & $(0.8)$ & 20.9 & $(1.0)$ & 27.8 & (1.1) & 23.1 & $(0.8)$ & 10.7 & $(0.7)$ & 2.5 & $(0.3)$ \\
\hline & Cantabria $\bullet^{\bullet}$ & 8.3 & (1.1) & 14.5 & (1.0) & 22.9 & (1.4) & 23.6 & $(1.7)$ & 18.4 & (1.3) & 9.8 & (1.1) & 2.5 & (0.5) \\
\hline & Castile and Leon ${ }^{\bullet}$ & 4.9 & $(0.9)$ & 11.2 & (1.4) & 19.7 & (1.8) & 26.6 & (1.7) & 24.0 & (1.6) & 11.0 & (1.1) & 2.7 & $(0.5)$ \\
\hline & Catalonia ${ }^{\bullet}$ & 7.3 & $(1.2)$ & 14.0 & (1.6) & 22.0 & (1.6) & 25.4 & (1.7) & 19.6 & (1.4) & 9.0 & (1.4) & 2.6 & (0.6) \\
\hline & Extremadura ${ }^{\bullet}$ & 14.2 & (1.7) & 18.3 & (1.4) & 23.0 & (1.8) & 23.9 & (1.7) & 14.1 & $(1.2)$ & 5.3 & (0.9) & 1.3 & (0.4) \\
\hline & Galicia` & 8.7 & (1.0) & 14.7 & (1.5) & 22.0 & $(1.2)$ & 24.7 & (1.6) & 18.8 & (1.6) & 8.5 & $(0.8)$ & 2.6 & (0.5) \\
\hline & La Rioja` & 8.6 & (1.0) & 12.4 & (1.0) & 20.3 & (1.6) & 22.2 & (1.5) & 20.0 & (1.1) & 12.0 & (1.0) & 4.4 & $(0.7)$ \\
\hline & Madrid ${ }^{\bullet}$ & 4.7 & $(0.7)$ & 11.4 & $(1.2)$ & 22.2 & (1.4) & 27.6 & (1.3) & 23.4 & (1.6) & 8.8 & $(0.9)$ & 1.8 & (0.5) \\
\hline & Murcia ${ }^{\bullet}$ & 13.4 & $(1.2)$ & 18.5 & (1.3) & 25.4 & (1.7) & 22.2 & (1.7) & 14.5 & (1.6) & 4.8 & $(0.9)$ & 1.3 & (0.5) \\
\hline & Navarre ${ }^{\bullet}$ & 5.2 & $(0.7)$ & 10.4 & $(0.9)$ & 19.2 & (1.5) & 25.7 & (1.8) & 24.3 & (1.5) & 11.9 & $(1.2)$ & 3.3 & (0.6) \\
\hline & United Kingdom & & & & & & & & & & & & & & \\
\hline & England & 7.0 & $(0.7)$ & 13.1 & $(0.9)$ & 20.9 & $(1.2)$ & 24.2 & (1.0) & 20.1 & $(0.8)$ & 10.5 & $(0.8)$ & 4.1 & $(0.5)$ \\
\hline & Northern Ireland & 7.5 & $(0.9)$ & 14.8 & (1.1) & 21.9 & (1.3) & 23.8 & (1.4) & 19.3 & (1.5) & 9.9 & (1.1) & 2.9 & (0.6) \\
\hline & Scotland $^{\bullet}$ & 5.0 & $(0.7)$ & 11.4 & (1.0) & 23.5 & (1.1) & 27.4 & $(1.2)$ & 20.6 & (1.0) & 9.7 & $(0.8)$ & 2.4 & $(0.4)$ \\
\hline & Wales & 7.9 & $(0.7)$ & 16.0 & $(0.8)$ & 25.6 & $(1.0)$ & 26.1 & (1.1) & 16.5 & $(0.8)$ & 6.5 & $(0.6)$ & 1.5 & $(0.2)$ \\
\hline & United States & & & & & & & & & & & & & & \\
\hline & Connecticut $^{\bullet}$ & 5.8 & $(1.1)$ & 12.6 & $(1.2)$ & 20.2 & $(1.3)$ & 24.1 & (1.8) & 19.9 & (1.8) & 12.2 & (1.4) & 5.3 & (1.1) \\
\hline & Florida $\bullet$ & 7.5 & $(1.3)$ & 19.1 & (1.6) & 28.1 & (1.6) & 25.2 & (1.6) & 14.2 & (1.4) & 4.6 & $(0.9)$ & 1.3 & $(0.5)$ \\
\hline & Massachusetts & 3.9 & $(0.7)$ & 10.2 & (1.3) & 20.1 & $(1.7)$ & 25.1 & (1.3) & 21.1 & $(1.2)$ & 13.3 & (1.6) & 6.3 & $(1.2)$ \\
\hline$\stackrel{n}{2}$ & Argentina & & & & & & & & & & & & & & \\
\hline$\stackrel{\Xi}{\Xi}$ & Ciudad Autónoma de Buenos Aires ${ }^{\bullet}$ & 26.5 & $(2.8)$ & 23.8 & $(1.8)$ & 27.1 & (2.3) & 15.0 & (1.6) & 6.0 & $(1.0)$ & 1.5 & $(0.5)$ & 0.1 & C \\
\hline ¿ & Brazil & & & & & & & & & & & & & & \\
\hline & Acre & 40.7 & $(4.0)$ & 34.6 & (3.3) & 19.0 & (2.0) & 5.1 & (1.5) & 0.5 & $(0.3)$ & 0.0 & c & 0.0 & c \\
\hline & Alagoas & 54.3 & $(5.1)$ & 30.1 & (3.9) & 12.3 & $(2.1)$ & 2.9 & (0.9) & 0.4 & $(0.3)$ & 0.0 & c & 0.0 & c \\
\hline & Amapá & 37.2 & (4.5) & 36.8 & (3.3) & 20.0 & (2.9) & 5.6 & (2.3) & 0.4 & $(0.4)$ & 0.0 & c & 0.0 & c \\
\hline & Amazonas & 41.8 & (3.1) & 37.8 & (2.6) & 16.4 & (2.2) & 3.2 & (1.2) & 0.8 & $(0.5)$ & 0.1 & c & 0.0 & c \\
\hline & Bahia & 35.1 & (5.5) & 32.5 & (3.8) & 21.2 & (3.8) & 9.0 & (1.9) & 2.0 & $(1.0)$ & 0.1 & c & 0.0 & c \\
\hline & Ceará & 30.3 & (4.3) & 37.4 & (2.9) & 22.5 & (3.2) & 6.9 & (2.0) & 2.6 & $(1.2)$ & 0.2 & $(0.3)$ & 0.0 & c \\
\hline & Espírito Santo & 22.9 & (2.8) & 32.4 & (3.6) & 24.8 & (2.5) & 13.6 & (2.7) & 5.2 & (1.8) & 1.2 & $(0.6)$ & 0.0 & c \\
\hline & Federal District & 21.4 & (5.0) & 30.3 & (3.4) & 27.8 & (4.3) & 15.7 & (2.5) & 4.4 & (1.8) & 0.4 & $(0.4)$ & 0.0 & c \\
\hline & Goiás & 34.7 & (3.6) & 38.6 & $(2.8)$ & 19.8 & (2.4) & 5.7 & $(0.9)$ & 1.2 & $(0.7)$ & 0.1 & $\mathrm{C}$ & 0.0 & c \\
\hline & Maranhão & 51.6 & $(7.1)$ & 27.8 & (3.0) & 14.3 & (4.3) & 5.3 & (2.8) & 1.0 & $(0.7)$ & 0.0 & c & 0.0 & c \\
\hline & Mato Grosso & 40.7 & $(5.2)$ & 34.6 & $(3.2)$ & 17.7 & (3.3) & 5.0 & (1.9) & 1.8 & (1.0) & 0.2 & c & 0.0 & c \\
\hline & Mato Grosso do Sul & 20.5 & (3.4) & 33.3 & $(2.5)$ & 29.6 & $(3.0)$ & 12.6 & $(1.5)$ & 3.7 & $(1.0)$ & 0.3 & $(0.2)$ & 0.0 & c \\
\hline & Minas Gerais & 18.5 & $(2.8)$ & 35.6 & $(2.5)$ & 29.7 & (2.6) & 13.1 & $(2.2)$ & 2.8 & (1.4) & 0.3 & c & 0.0 & c \\
\hline & Pará & 42.1 & (3.8) & 34.2 & $(2.5)$ & 18.0 & (2.5) & 5.3 & $(1.0)$ & 0.4 & $(0.3)$ & 0.0 & c & 0.0 & c \\
\hline & Paraiba & 22.6 & (3.8) & 36.3 & (3.6) & 27.2 & $(4.2)$ & 10.7 & $(1.7)$ & 2.7 & $(1.1)$ & 0.4 & c & 0.0 & c \\
\hline & Paraná & 26.6 & (3.5) & 32.8 & (3.4) & 25.2 & (3.3) & 10.3 & $(2.3)$ & 4.0 & $(2.8)$ & 1.1 & $(1.2)$ & 0.0 & C \\
\hline & Pernambuco & 36.1 & (5.8) & 38.1 & (3.8) & 20.4 & (4.8) & 4.6 & (1.8) & 0.8 & $(0.6)$ & 0.1 & c & 0.0 & c \\
\hline & Piauí & 32.0 & (3.8) & 37.8 & $(4.0)$ & 18.1 & (2.7) & 7.9 & (1.6) & 3.1 & $(2.1)$ & 0.9 & $(0.9)$ & 0.2 & c \\
\hline & Rio de Janeiro & 25.4 & $(4.3)$ & 38.2 & (3.6) & 26.8 & (3.2) & 7.8 & (2.1) & 1.6 & $(1.2)$ & 0.1 & c & 0.0 & c \\
\hline & Rio Grande do Norte & 28.8 & (3.0) & 37.1 & (3.3) & 19.6 & (2.6) & 9.7 & (2.0) & 3.9 & $(2.1)$ & 0.8 & $(0.7)$ & 0.0 & c \\
\hline & Rio Grande do Sul & 17.1 & (3.5) & 34.7 & $(2.7)$ & 31.9 & (3.2) & 14.2 & (2.4) & 2.0 & $(0.9)$ & 0.1 & c & 0.0 & c \\
\hline & Rondônia & 24.2 & (3.4) & 38.9 & $(2.7)$ & 29.1 & (2.7) & 6.8 & (1.3) & 0.9 & $(0.4)$ & 0.1 & c & 0.0 & c \\
\hline & Roraima & 37.9 & $(4.2)$ & 34.1 & (3.2) & 18.6 & (2.5) & 7.3 & (2.0) & 2.0 & $(1.1)$ & 0.0 & c & 0.0 & c \\
\hline & Santa Catarina & 19.1 & (2.8) & 31.7 & (2.9) & 32.8 & (2.4) & 13.5 & (2.9) & 2.8 & $(1.2)$ & 0.1 & c & 0.0 & c \\
\hline & São Paulo & 20.6 & (1.6) & 35.5 & (1.9) & 28.2 & (1.7) & 11.9 & $(1.2)$ & 3.3 & $(0.9)$ & 0.4 & $(0.3)$ & 0.0 & c \\
\hline & Sergipe & 30.3 & $(4.8)$ & 37.0 & (3.2) & 22.8 & (3.1) & 8.7 & (3.0) & 1.2 & $(0.8)$ & 0.1 & $(0.1)$ & 0.0 & c \\
\hline & Tocantins & 35.7 & (3.4) & 34.8 & $(2.8)$ & 20.1 & (3.2) & 7.8 & (1.6) & 1.5 & $(0.7)$ & 0.2 & $\mathrm{C}$ & 0.0 & c \\
\hline & Colombia & & & & & & & & & & & & & & \\
\hline & Bogotá & 23.1 & (1.8) & 38.4 & (2.0) & 28.5 & (1.5) & 8.7 & $(1.2)$ & 1.2 & $(0.6)$ & 0.2 & $(0.2)$ & 0.0 & c \\
\hline & Cali & 33.3 & $(2.8)$ & 35.3 & $(1.8)$ & 23.3 & (2.2) & 7.0 & (1.4) & 1.0 & $(0.3)$ & 0.0 & c & 0.0 & c \\
\hline & Manizales & 18.5 & $(2.2)$ & 38.8 & $(2.5)$ & 29.2 & $(2.0)$ & 10.9 & (1.8) & 2.2 & $(0.8)$ & 0.3 & $(0.2)$ & 0.0 & c \\
\hline & Medellín & 28.0 & $(2.9)$ & 35.5 & $(2.4)$ & 22.7 & $(2.3)$ & 9.4 & (1.6) & 2.7 & $(1.0)$ & 1.4 & $(0.8)$ & 0.2 & $(0.2)$ \\
\hline & Russian Federation & & & & & & & & & & & & & & \\
\hline & Perm Territory region ${ }^{\bullet}$ & 10.6 & (1.6) & 18.9 & (1.4) & 28.1 & $(1.8)$ & 24.0 & (1.6) & 12.5 & (1.4) & 4.6 & (1.0) & 1.3 & $(0.7)$ \\
\hline & United Arab Emirates & & & & & & & & & & & & & & \\
\hline & Abu Dhabi・ & 23.4 & (1.6) & 28.4 & (1.4) & 25.5 & (1.3) & 14.6 & $(1.0)$ & 5.9 & $(0.8)$ & 1.8 & $(0.5)$ & 0.4 & $(0.2)$ \\
\hline & Ajman & 28.5 & (5.0) & 30.8 & (2.9) & 24.8 & (3.1) & 12.4 & $(2.1)$ & 3.2 & $(1.0)$ & 0.2 & $(0.2)$ & 0.0 & c \\
\hline & Dubai & 13.1 & $(0.4)$ & 21.6 & $(0.8)$ & 25.8 & (1.0) & 21.6 & $(0.8)$ & 12.3 & $(0.9)$ & 4.5 & (0.6) & 1.1 & $(0.2)$ \\
\hline & Fujairah & 27.9 & $(4.2)$ & 28.6 & (2.6) & 25.8 & (3.0) & 13.9 & (2.5) & 3.6 & $(1.0)$ & 0.2 & $(0.2)$ & 0.0 & c \\
\hline & Ras al-Khaimah & 23.9 & (3.5) & 30.3 & $(2.2)$ & 28.4 & (2.6) & 13.4 & (2.4) & 3.4 & $(1.2)$ & 0.5 & $(0.3)$ & 0.0 & c \\
\hline & Sharjah & 15.2 & $(2.7)$ & 28.2 & (3.7) & 27.0 & $(2.8)$ & 20.3 & (2.9) & 7.7 & $(1.7)$ & 1.5 & $(0.7)$ & 0.2 & c \\
\hline & Umm al-Quwain & 28.4 & $(2.5)$ & 33.3 & (2.8) & 26.0 & (2.9) & 9.9 & (1.8) & 2.1 & $(1.2)$ & 0.3 & C & 0.0 & C \\
\hline
\end{tabular}

- PISA adjudicated region.

Note: See Table I.2.23 for national data.

StatLink त्त्ताs http://dx.doi.org/10.1787/888932935762 
[Part 1/4]

Percentage of students at each proficiency level on the mathematics subscale uncertainty and data, Table B2.I.23 by gender and region

\begin{tabular}{|c|c|c|c|c|c|c|c|c|c|c|c|c|c|c|c|}
\hline & & \multicolumn{14}{|c|}{ Boys } \\
\hline & & \multicolumn{2}{|c|}{$\begin{array}{l}\text { Below Level } 1 \\
\text { (below } 357.77 \\
\text { score points) }\end{array}$} & $\begin{array}{l}\text { Le } \\
\text { (from } \\
\text { less th } \\
\text { scor }\end{array}$ & $\begin{array}{l}\text { I } 1 \\
7.77 \text { to } \\
420.07 \\
\text { oints) }\end{array}$ & $\begin{array}{l}\text { Le } \\
\text { (from } \\
\text { less th } \\
\text { score }\end{array}$ & $\begin{array}{l}2 \\
.07 \text { to } \\
482.38 \\
\text { jints) }\end{array}$ & $\begin{array}{l}\text { Le } \\
\text { (from } \\
\text { less th } \\
\text { score }\end{array}$ & $\begin{array}{l}\text { I } 3 \\
2.38 \text { to } \\
544.68 \\
\text { oints) }\end{array}$ & $\begin{array}{l}\text { Le } \\
\text { (from } \\
\text { less th } \\
\text { score }\end{array}$ & $\begin{array}{l}4 \\
4.68 \text { to } \\
606.99 \\
\text { oints) }\end{array}$ & $\begin{array}{l}\text { Le } \\
\text { (from } \\
\text { less tha } \\
\text { score }\end{array}$ & $\begin{array}{l}5 \\
6.99 \text { to } \\
669.30 \\
\text { oints) }\end{array}$ & $\begin{array}{l}\text { Le } \\
\text { (abov } \\
\text { score }\end{array}$ & $\begin{array}{l}6 \\
69.30 \\
\text { ints) }\end{array}$ \\
\hline & & $\%$ & S.E. & $\%$ & S.E. & $\%$ & S.E. & $\%$ & S.E. & $\%$ & S.E. & $\%$ & S.E. & $\%$ & S.E. \\
\hline 0 & Australia & & & & & & & & & & & & & & \\
\hline 岁 & Australian Capital Territory & 5.7 & $(1.4)$ & 8.9 & $(2.0)$ & 18.1 & $(2.8)$ & 23.3 & (3.4) & 20.0 & $(2.7)$ & 15.8 & $(2.5)$ & 8.2 & $(2.0)$ \\
\hline & New South Wales & 6.8 & $(1.0)$ & 12.1 & $(1.2)$ & 20.2 & (1.4) & 22.2 & (1.5) & 19.2 & (1.3) & 12.4 & (1.3) & 7.1 & (1.4) \\
\hline & Northern Territory & 20.1 & (2.9) & 16.1 & $(4.9)$ & 20.1 & (4.8) & 22.7 & (4.4) & 13.8 & (4.4) & 5.5 & (3.2) & 1.7 & (1.6) \\
\hline & Queensland & 6.1 & $(1.0)$ & 12.0 & $(1.1)$ & 22.0 & $(1.4)$ & 24.6 & (1.7) & 19.7 & (1.3) & 11.1 & $(1.2)$ & 4.5 & $(0.8)$ \\
\hline & South Australia & 7.6 & $(1.1)$ & 12.7 & (1.6) & 22.8 & (1.6) & 24.4 & $(2.3)$ & 18.6 & (2.4) & 10.7 & (1.6) & 3.3 & $(0.8)$ \\
\hline & Tasmania & 9.6 & $(1.2)$ & 12.8 & $(1.6)$ & 25.2 & (3.0) & 23.6 & (3.4) & 17.2 & (2.9) & 8.7 & $(1.7)$ & 2.8 & (1.1) \\
\hline & Victoria & 5.6 & $(0.8)$ & 12.6 & $(1.3)$ & 21.1 & (1.6) & 25.5 & $(2.2)$ & 20.3 & $(2.2)$ & 10.6 & (1.4) & 4.3 & (1.3) \\
\hline & Western Australia & 3.8 & $(0.8)$ & 9.8 & $(1.2)$ & 16.9 & $(1.7)$ & 23.1 & (1.9) & 24.8 & (1.8) & 15.3 & (1.5) & 6.4 & (1.2) \\
\hline & Belgium & & & & & & & & & & & & & & \\
\hline & Flemish Community ${ }^{\bullet}$ & 7.1 & $(1.5)$ & 9.7 & $(0.8)$ & 15.9 & $(1.2)$ & 19.9 & (1.3) & 19.7 & $(1.2)$ & 16.4 & $(0.9)$ & 11.3 & (1.0) \\
\hline & French Community & 12.4 & $(1.5)$ & 14.6 & $(1.4)$ & 20.1 & (1.3) & 21.5 & (1.4) & 18.3 & (1.5) & 9.9 & $(1.0)$ & 3.4 & $(0.7)$ \\
\hline & German-speaking Community & 10.9 & $(1.7)$ & 12.4 & (1.8) & 20.5 & $(2.5)$ & 23.3 & $(2.3)$ & 19.0 & $(2.1)$ & 11.0 & (1.6) & 3.0 & $(1.0)$ \\
\hline & Canada & & & & & & & & & & & & & & \\
\hline & Alberta & 4.4 & $(1.0)$ & 9.2 & (1.6) & 19.3 & (1.8) & 25.6 & (1.9) & 22.2 & $(2.0)$ & 13.7 & (1.5) & 5.6 & (1.0) \\
\hline & British Columbia & 2.9 & $(0.8)$ & 8.7 & (1.6) & 19.0 & (1.9) & 27.0 & $(2.2)$ & 23.6 & $(2.3)$ & 13.6 & (1.8) & 5.1 & $(1.0)$ \\
\hline & Manitoba & 6.1 & $(1.2)$ & 15.1 & $(1.6)$ & 22.8 & $(2.7)$ & 24.9 & $(2.3)$ & 18.5 & (1.9) & 9.1 & $(1.2)$ & 3.5 & $(0.9)$ \\
\hline & New Brunswick & 6.4 & $(1.2)$ & 12.9 & (1.6) & 23.9 & $(2.0)$ & 27.7 & $(2.2)$ & 19.8 & (2.6) & 7.1 & (1.9) & 2.2 & $(0.9)$ \\
\hline & Newfoundland and Labrador & 10.6 & $(2.7)$ & 13.0 & $(2.6)$ & 20.8 & (2.8) & 26.6 & $(2.5)$ & 18.4 & $(2.3)$ & 8.2 & (1.8) & 2.5 & (1.0) \\
\hline & Nova Scotia & 3.5 & $(1.0)$ & 12.5 & $(1.9)$ & 25.0 & (3.5) & 24.4 & (3.5) & 21.6 & $(2.5)$ & 10.1 & (1.9) & 2.9 & $(1.0)$ \\
\hline & Ontario & 4.5 & $(0.9)$ & 10.5 & $(1.5)$ & 20.1 & (1.7) & 26.5 & (1.9) & 20.9 & (1.3) & 13.1 & (1.8) & 4.3 & $(0.9)$ \\
\hline & Prince Edward Island & 7.5 & $(1.2)$ & 15.6 & (1.9) & 24.1 & $(2.0)$ & 25.3 & $(2.1)$ & 18.4 & (1.7) & 7.7 & (1.3) & 1.4 & $(0.6)$ \\
\hline & Quebec & 3.3 & $(0.8)$ & 8.0 & $(1.5)$ & 16.9 & (1.8) & 23.7 & (1.5) & 23.7 & $(1.2)$ & 16.9 & $(1.2)$ & 7.4 & (1.0) \\
\hline & Saskatchewan & 4.4 & $(0.8)$ & 10.6 & $(1.2)$ & 22.3 & (1.7) & 27.9 & (2.6) & 22.1 & (1.9) & 9.9 & (1.4) & 2.8 & $(1.0)$ \\
\hline & Italy & & & & & & & & & & & & & & \\
\hline & Abruzzo & 10.6 & $(1.8)$ & 16.9 & $(2.3)$ & 24.5 & $(2.1)$ & 23.7 & $(2.0)$ & 17.8 & (2.5) & 5.7 & $(1.3)$ & 0.9 & $(0.5)$ \\
\hline & Basilicata & 14.0 & $(2.0)$ & 19.7 & $(2.1)$ & 23.7 & $(2.3)$ & 22.8 & $(2.1)$ & 12.6 & (1.6) & 5.5 & (1.1) & 1.5 & $(0.6)$ \\
\hline & Bolzano & 7.9 & $(1.2)$ & 13.0 & $(1.3)$ & 17.0 & (1.4) & 24.0 & (1.5) & 21.5 & $(1.7)$ & 12.5 & (1.4) & 4.2 & $(0.7)$ \\
\hline & Calabria & 22.8 & (3.4) & 22.8 & $(2.8)$ & 23.4 & (2.6) & 17.7 & $(2.7)$ & 9.4 & (1.6) & 3.0 & (0.9) & 0.9 & $(0.6)$ \\
\hline & Campania & 16.0 & $(2.5)$ & 19.6 & $(2.3)$ & 24.9 & $(2.1)$ & 21.2 & (2.3) & 12.1 & (1.9) & 4.6 & $(1.2)$ & 1.7 & $(0.5)$ \\
\hline & Emilia Romagna & 8.6 & $(1.9)$ & 12.0 & $(2.1)$ & 19.2 & $(2.2)$ & 21.1 & (1.9) & 21.3 & (2.3) & 13.0 & $(2.7)$ & 4.8 & (1.3) \\
\hline & Friuli Venezia Giulia & 5.5 & $(1.3)$ & 10.8 & $(1.9)$ & 15.9 & $(2.2)$ & 23.3 & $(2.3)$ & 24.3 & (1.8) & 15.1 & (1.8) & 5.2 & (1.0) \\
\hline & Lazio & 10.6 & $(2.2)$ & 16.2 & $(2.7)$ & 24.3 & $(2.5)$ & 22.2 & $(2.1)$ & 16.0 & (1.9) & 8.0 & (1.4) & 2.7 & $(0.8)$ \\
\hline & Liguria & 8.2 & $(1.9)$ & 16.8 & $(2.1)$ & 23.3 & $(2.2)$ & 21.6 & $(2.2)$ & 17.1 & (2.5) & 9.8 & (1.8) & 3.1 & $(0.8)$ \\
\hline & Lombardia & 4.7 & $(1.2)$ & 8.9 & $(1.5)$ & 18.2 & $(2.1)$ & 25.6 & $(2.2)$ & 23.0 & $(2.0)$ & 14.6 & (2.0) & 5.0 & (1.3) \\
\hline & Marche & 5.3 & (1.5) & 12.1 & $(2.0)$ & 20.2 & $(2.2)$ & 26.8 & $(2.5)$ & 21.3 & $(2.2)$ & 11.0 & (1.7) & 3.4 & $(0.9)$ \\
\hline & Molise & 9.2 & $(1.2)$ & 20.7 & $(2.3)$ & 26.1 & (3.0) & 23.2 & (2.4) & 15.7 & (2.0) & 4.0 & (1.0) & 1.1 & $(0.6)$ \\
\hline & Piemonte & 5.4 & $(1.0)$ & 11.8 & $(1.6)$ & 21.1 & (1.9) & 28.1 & (1.9) & 20.2 & (1.6) & 10.8 & (1.7) & 2.7 & $(0.8)$ \\
\hline & Puglia & 8.6 & (1.7) & 14.0 & (1.9) & 24.3 & (2.3) & 25.1 & (2.9) & 19.1 & $(2.2)$ & 7.5 & (1.3) & 1.4 & $(0.5)$ \\
\hline & Sardegna & 13.2 & $(2.6)$ & 17.8 & $(2.3)$ & 26.0 & $(2.5)$ & 22.9 & $(2.3)$ & 12.8 & $(1.8)$ & 5.9 & $(1.2)$ & 1.3 & $(0.5)$ \\
\hline & Sicilia & 13.9 & $(2.0)$ & 20.4 & $(2.2)$ & 28.8 & $(2.5)$ & 22.3 & $(2.0)$ & 10.5 & $(1.2)$ & 3.5 & (1.0) & 0.7 & $(0.4)$ \\
\hline & Toscana & 10.0 & $(1.9)$ & 14.2 & $(2.4)$ & 20.6 & $(2.1)$ & 23.0 & $(2.0)$ & 19.3 & (2.4) & 9.6 & (1.6) & 3.3 & $(1.0)$ \\
\hline & Trento & 3.4 & $(1.1)$ & 9.1 & (2.4) & 19.6 & (2.9) & 26.0 & (2.6) & 24.5 & $(2.5)$ & 13.3 & (1.7) & 4.1 & $(0.9)$ \\
\hline & Umbria & 8.3 & (2.9) & 11.7 & $(1.8)$ & 17.9 & $(2.6)$ & 27.2 & (2.6) & 22.5 & (2.8) & 10.3 & (1.8) & 2.1 & $(0.9)$ \\
\hline & Valle d'Aosta & 6.3 & $(1.2)$ & 11.6 & $(2.1)$ & 22.8 & (2.4) & 28.5 & (3.1) & 20.1 & $(2.7)$ & 8.4 & (1.6) & 2.3 & $(0.8)$ \\
\hline & Veneto & 5.7 & $(1.3)$ & 8.9 & (1.8) & 16.9 & $(2.2)$ & 24.4 & $(2.5)$ & 21.9 & $(2.2)$ & 15.4 & (2.3) & 6.8 & (1.9) \\
\hline & Mexico & & & & & & & & & & & & & & \\
\hline & Aguascalientes & 12.7 & $(2.4)$ & 27.5 & $(2.4)$ & 33.7 & (3.3) & 20.4 & (2.4) & 5.0 & (1.7) & 0.6 & $(0.5)$ & 0.0 & C \\
\hline & Baja California & 19.2 & (3.9) & 34.1 & $(4.1)$ & 29.6 & (3.4) & 14.1 & (3.9) & 2.1 & $(0.8)$ & 1.1 & $(0.8)$ & 0.0 & c \\
\hline & Baja California Sur & 16.6 & $(3.2)$ & 32.9 & $(3.7)$ & 32.9 & (3.8) & 14.5 & $(2.1)$ & 2.9 & $(0.9)$ & 0.2 & $\mathrm{C}$ & 0.0 & C \\
\hline & Campeche & 25.2 & $(2.9)$ & 37.3 & $(2.5)$ & 27.3 & (3.2) & 8.4 & (1.7) & 1.7 & $(0.9)$ & 0.2 & $(0.2)$ & 0.0 & c \\
\hline & Chiapas & 32.8 & $(4.8)$ & 39.6 & (3.9) & 21.0 & $(2.9)$ & 5.6 & (1.4) & 0.9 & $(0.6)$ & 0.1 & $\mathrm{C}$ & 0.0 & C \\
\hline & Chihuahua & 11.8 & (3.0) & 29.3 & $(4.1)$ & 35.1 & $(4.3)$ & 17.2 & (3.9) & 5.9 & $(2.1)$ & 0.7 & $(0.5)$ & 0.0 & C \\
\hline & Coahuila & 18.3 & $(3.7)$ & 32.5 & (3.7) & 30.9 & $(3.2)$ & 15.1 & (3.2) & 2.6 & $(1.2)$ & 0.6 & $(0.5)$ & 0.0 & C \\
\hline & Colima & 17.7 & $(2.4)$ & 27.5 & $(2.7)$ & 31.1 & (2.5) & 17.0 & $(2.5)$ & 6.0 & (1.6) & 0.7 & $(0.5)$ & 0.0 & c \\
\hline & Distrito Federal & 13.2 & $(2.4)$ & 29.8 & $(3.6)$ & 33.4 & (2.8) & 17.7 & $(2.7)$ & 5.7 & (1.4) & 0.2 & c & 0.0 & C \\
\hline & Durango & 14.2 & $(2.6)$ & 32.8 & (3.1) & 32.2 & $(2.8)$ & 16.8 & $(2.5)$ & 3.9 & (1.4) & 0.1 & c & 0.0 & c \\
\hline & Guanajuato & 20.1 & (3.4) & 32.2 & $(3.0)$ & 29.0 & $(2.9)$ & 15.3 & $(2.3)$ & 3.2 & $(1.0)$ & 0.1 & c & 0.0 & C \\
\hline & Guerrero & 38.8 & $(3.4)$ & 38.1 & $(3.1)$ & 18.7 & $(2.5)$ & 3.7 & $(1.2)$ & 0.8 & $(0.5)$ & 0.0 & c & 0.0 & C \\
\hline & Hidalgo & 23.2 & (3.6) & 33.9 & (3.9) & 29.2 & (3.1) & 11.9 & (2.7) & 1.6 & $(0.9)$ & 0.0 & $\mathrm{C}$ & 0.0 & c \\
\hline & Jalisco & 10.9 & $(2.5)$ & 28.9 & $(3.2)$ & 35.1 & $(2.6)$ & 19.1 & (2.9) & 5.0 & (1.1) & 0.7 & $(0.5)$ & 0.3 & $(0.3)$ \\
\hline & Mexico & 15.3 & $(2.6)$ & 36.0 & $(3.7)$ & 33.1 & $(4.4)$ & 13.3 & $(2.0)$ & 1.9 & $(0.9)$ & 0.4 & $(0.4)$ & 0.0 & C \\
\hline & Morelos & 19.5 & (5.1) & 31.1 & $(3.7)$ & 29.0 & (3.1) & 15.6 & (3.1) & 4.2 & (1.7) & 0.6 & (0.6) & 0.0 & c \\
\hline & Nayarit & 20.3 & (3.2) & 30.7 & $(2.7)$ & 31.2 & (3.4) & 15.0 & $(2.7)$ & 2.8 & $(0.9)$ & 0.0 & c & 0.0 & c \\
\hline & Nuevo León & 9.2 & $(2.5)$ & 27.2 & $(4.5)$ & 36.3 & $(2.4)$ & 21.5 & (4.3) & 5.2 & (1.5) & 0.7 & $(0.5)$ & 0.0 & C \\
\hline & Puebla & 17.7 & (3.8) & 34.2 & $(3.0)$ & 33.3 & (3.8) & 11.6 & $(2.0)$ & 2.7 & (1.4) & 0.5 & $(0.5)$ & 0.0 & C \\
\hline & Querétaro & 10.6 & $(2.6)$ & 27.8 & (3.1) & 35.5 & (3.8) & 19.7 & $(2.8)$ & 5.9 & (1.5) & 0.5 & $(0.4)$ & 0.0 & c \\
\hline & Quintana Roo & 23.3 & $(4.2)$ & 34.7 & $(2.8)$ & 28.7 & $(2.4)$ & 11.3 & $(2.1)$ & 2.0 & $(0.8)$ & 0.0 & $\mathrm{C}$ & 0.0 & C \\
\hline & San Luis Potosí & 27.7 & (3.2) & 30.9 & (3.5) & 26.7 & $(2.6)$ & 11.1 & $(2.2)$ & 3.2 & (1.3) & 0.5 & $(0.5)$ & 0.0 & c \\
\hline & Sinaloa & 17.9 & $(3.2)$ & 35.0 & $(3.0)$ & 31.8 & $(3.0)$ & 12.8 & $(2.2)$ & 2.2 & $(0.8)$ & 0.3 & $(0.2)$ & 0.0 & C \\
\hline & Tabasco & 33.6 & (3.6) & 35.6 & $(3.4)$ & 22.7 & $(3.4)$ & 6.8 & (1.6) & 1.1 & $(0.7)$ & 0.1 & $\mathrm{C}$ & 0.0 & C \\
\hline & Tamaulipas & 21.9 & $(4.0)$ & 33.6 & $(2.9)$ & 28.1 & $(2.7)$ & 12.1 & $(2.2)$ & 3.8 & (1.6) & 0.6 & $(0.5)$ & 0.0 & C \\
\hline & Tlaxcala & 22.5 & $(2.3)$ & 30.9 & $(3.0)$ & 32.4 & $(2.7)$ & 11.6 & (1.7) & 2.5 & (1.1) & 0.2 & C & 0.0 & C \\
\hline & Veracruz & 24.6 & (3.4) & 34.0 & $(3.5)$ & 27.9 & (2.6) & 11.4 & (2.4) & 1.9 & $(0.7)$ & 0.2 & $(0.2)$ & 0.0 & C \\
\hline & Yucatán & 17.7 & $(2.7)$ & 32.9 & $(2.4)$ & 32.5 & (3.2) & 13.8 & (2.4) & 2.8 & (0.9) & 0.3 & C & 0.0 & C \\
\hline & Zacatecas & 18.4 & $(2.7)$ & 35.1 & $(2.4)$ & 30.7 & (2.5) & 14.0 & $(1.7)$ & 1.8 & $(0.8)$ & 0.0 & c & 0.0 & c \\
\hline
\end{tabular}

- PISA adjudicated region

Note: See Table I.2.24 for national data.

StatLink त्ताडst http://dx.doi.org/10.1787/888932935762 
Percentage of students at each proficiency level on the mathematics subscale uncertainty and data, Table B2.I.23 by gender and region

\begin{tabular}{|c|c|c|c|c|c|c|c|c|c|c|c|c|c|c|c|}
\hline & & \multicolumn{14}{|c|}{ Boys } \\
\hline & & \multicolumn{2}{|c|}{$\begin{array}{l}\text { Below Level } 1 \\
\text { (below 357.77 } \\
\text { score points) }\end{array}$} & \multicolumn{2}{|c|}{$\begin{array}{c}\text { Level } 1 \\
\text { (from } 357.77 \text { to } \\
\text { less than } 420.07 \\
\text { score points) }\end{array}$} & \multicolumn{2}{|c|}{$\begin{array}{c}\text { Level } 2 \\
\text { (from } 420.07 \text { to } \\
\text { less than } 482.38 \\
\text { score points) }\end{array}$} & $\begin{array}{l}\text { Le } \\
\text { (from } \\
\text { less th } \\
\text { score }\end{array}$ & \begin{tabular}{|l|}
3 \\
2.38 to \\
544.68 \\
ints)
\end{tabular} & $\begin{array}{r}\text { Le } \\
\text { (from } 5 \\
\text { less tha } \\
\text { score }\end{array}$ & $\begin{array}{l}4 \\
4.68 \text { to } \\
606.99 \\
\text { oints) }\end{array}$ & $\begin{array}{r}\text { Le } \\
\text { (from } \\
\text { less tha } \\
\text { score }\end{array}$ & $\begin{array}{l}5 \\
6.99 \text { to } \\
669.30 \\
\text { ints) }\end{array}$ & $\begin{array}{r}\text { Le } \\
\text { (above } \\
\text { score }\end{array}$ & $\begin{array}{l}6 \\
69.30 \\
\text { pints) }\end{array}$ \\
\hline & & $\%$ & S.E. & $\%$ & S.E. & $\%$ & S.E. & $\%$ & S.E. & $\%$ & S.E. & $\%$ & S.E. & $\%$ & S.E. \\
\hline 0 & Portugal & & & & & & & & & & & & & & \\
\hline 氙 & Alentejo & 6.8 & $(1.8)$ & 14.2 & (4.1) & 22.5 & (5.1) & 28.1 & (5.3) & 17.2 & (3.5) & 9.3 & (2.4) & 2.0 & (1.2) \\
\hline & Spain & & & & & & & & & & & & & & \\
\hline & Andalusia ${ }^{\bullet}$ & 9.1 & (1.5) & 15.3 & (1.5) & 24.5 & $(2.1)$ & 24.3 & (2.1) & 17.0 & $(2.1)$ & 7.9 & (1.4) & 1.8 & (0.6) \\
\hline & Aragon ${ }^{\bullet}$ & 7.7 & (1.4) & 12.8 & (1.6) & 17.6 & (1.6) & 23.8 & $(2.1)$ & 21.6 & (2.3) & 12.2 & (2.0) & 4.3 & (1.1) \\
\hline & Asturias ${ }^{\bullet}$ & 7.6 & (1.5) & 12.6 & (1.5) & 21.2 & (1.5) & 23.9 & (2.1) & 20.0 & (1.8) & 11.2 & (1.3) & 3.6 & (1.0) \\
\hline & Balearic Islands ${ }^{\bullet}$ & 11.7 & (1.9) & 13.0 & (2.0) & 22.4 & (2.0) & 27.7 & (2.4) & 17.3 & (2.6) & 6.7 & (1.5) & 1.2 & $(0.4)$ \\
\hline & Basque Country ${ }^{\bullet}$ & 3.7 & $(0.6)$ & 10.6 & $(1.1)$ & 19.5 & $(1.3)$ & 26.2 & (1.6) & 24.7 & $(1.2)$ & 12.2 & (1.0) & 3.1 & $(0.5)$ \\
\hline & Cantabria ${ }^{\bullet}$ & 8.5 & $(1.2)$ & 13.0 & (1.3) & 19.7 & $(2.2)$ & 22.8 & $(2.8)$ & 21.0 & (1.6) & 11.9 & (1.6) & 3.1 & $(0.7)$ \\
\hline & Castile and Leon & 5.1 & $(1.2)$ & 11.0 & (1.8) & 17.5 & $(2.1)$ & 24.5 & (1.9) & 24.1 & $(2.1)$ & 13.9 & (2.0) & 3.9 & $(0.8)$ \\
\hline & Catalonia & 6.7 & (1.4) & 11.7 & $(2.1)$ & 20.7 & (2.1) & 23.8 & (2.3) & 20.8 & (1.7) & 12.4 & (2.4) & 3.8 & (1.0) \\
\hline & Extremadura ${ }^{\bullet}$ & 14.8 & $(2.1)$ & 17.5 & $(2.2)$ & 20.0 & (2.7) & 23.2 & (2.0) & 16.1 & $(1.7)$ & 6.7 & (1.1) & 1.7 & $(0.6)$ \\
\hline & Galicia• & 9.7 & (1.5) & 14.3 & $(2.0)$ & 20.8 & (1.9) & 23.6 & (2.4) & 20.0 & $(1.7)$ & 9.8 & (1.4) & 1.8 & $(0.7)$ \\
\hline & La Rioja` & 9.3 & (1.4) & 11.7 & (1.6) & 16.7 & (2.0) & 20.8 & (1.9) & 20.3 & $(2.0)$ & 15.3 & (1.9) & 5.9 & (1.1) \\
\hline & Madrid $\bullet^{\bullet}$ & 4.4 & $(1.1)$ & 10.6 & (1.4) & 19.3 & (1.8) & 26.5 & (1.5) & 25.5 & (2.0) & 10.8 & (1.3) & 2.9 & $(0.9)$ \\
\hline & Murcia $\bullet$ & 13.2 & (1.6) & 17.6 & (2.1) & 22.6 & (2.2) & 22.0 & $(2.7)$ & 16.3 & (2.0) & 6.2 & (1.2) & 2.0 & $(0.8)$ \\
\hline & Navarre ${ }^{\bullet}$ & 5.5 & (1.1) & 9.7 & (1.1) & 17.8 & (1.8) & 24.2 & (2.5) & 25.7 & $(2.1)$ & 12.8 & (1.8) & 4.4 & (1.0) \\
\hline & United Kingdom & & & & & & & & & & & & & & \\
\hline & England & 6.3 & $(1.0)$ & 12.4 & $(1.2)$ & 19.4 & (1.9) & 24.7 & (1.4) & 20.4 & (1.4) & 11.9 & $(1.2)$ & 4.9 & $(0.9)$ \\
\hline & Northern Ireland & 7.3 & $(1.2)$ & 13.7 & (1.5) & 21.1 & (1.7) & 24.0 & (2.3) & 19.9 & $(2.1)$ & 10.8 & (1.5) & 3.4 & $(0.7)$ \\
\hline & Scotland ${ }^{\bullet}$ & 4.6 & $(0.7)$ & 10.3 & $(1.2)$ & 22.1 & (1.4) & 26.8 & (1.5) & 22.8 & (1.3) & 10.6 & (1.0) & 2.8 & $(0.5)$ \\
\hline & Wales & 7.7 & (0.9) & 15.1 & (1.1) & 23.9 & (1.4) & 27.0 & (1.6) & 17.2 & (1.1) & 7.4 & $(0.7)$ & 1.7 & $(0.4)$ \\
\hline & United States & & & & & & & & & & & & & & \\
\hline & Connecticut ${ }^{\bullet}$ & 5.5 & (1.1) & 11.1 & (1.9) & 19.7 & (2.5) & 23.2 & $(2.7)$ & 21.1 & $(2.1)$ & 13.5 & (1.6) & 6.0 & (1.4) \\
\hline & Florida & 7.2 & (1.6) & 18.1 & $(2.1)$ & 26.4 & (1.9) & 25.4 & (2.0) & 15.6 & $(2.0)$ & 5.8 & $(1.2)$ & 1.5 & $(0.6)$ \\
\hline & Massachusetts ${ }^{\bullet}$ & 3.9 & $(0.8)$ & 9.5 & (1.5) & 19.3 & $(2.1)$ & 25.0 & (1.9) & 20.9 & $(2.0)$ & 13.8 & (2.0) & 7.5 & (1.6) \\
\hline$n$ & Argentina & & & & & & & & & & & & & & \\
\hline 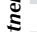 & Ciudad Autónoma de Buenos Aires & 23.9 & $(3.2)$ & 22.5 & $(2.7)$ & 27.0 & $(2.3)$ & 16.8 & $(2.1)$ & 7.5 & (1.4) & 2.0 & $(0.7)$ & 0.3 & c \\
\hline ฐٓ & Brazil & & & & & & & & & & & & & & \\
\hline & Acre & 38.0 & (5.6) & 35.7 & (5.6) & 20.4 & (3.9) & 5.4 & (2.5) & 0.4 & $(0.5)$ & 0.0 & c & 0.0 & c \\
\hline & Alagoas & 52.7 & $(6.9)$ & 30.6 & $(6.0)$ & 12.9 & $(3.2)$ & 3.5 & $(1.3)$ & 0.3 & $(0.3)$ & 0.0 & c & 0.0 & c \\
\hline & Amapá & 33.1 & (5.9) & 38.4 & $(5.1)$ & 20.8 & $(4.5)$ & 7.6 & (3.4) & 0.1 & $\mathrm{C}$ & 0.0 & $\mathrm{c}$ & 0.0 & c \\
\hline & Amazonas & 38.0 & (4.9) & 40.5 & $(5.2)$ & 16.8 & (3.0) & 3.8 & (1.6) & 0.9 & $(0.6)$ & 0.0 & $\mathrm{C}$ & 0.0 & C \\
\hline & Bahia & 33.7 & (5.9) & 33.6 & (5.1) & 19.0 & (5.0) & 11.7 & (3.3) & 1.8 & (1.9) & 0.2 & $\mathrm{C}$ & 0.0 & C \\
\hline & Ceará & 28.7 & (4.6) & 37.3 & (3.6) & 22.0 & (3.6) & 8.0 & (2.5) & 3.5 & $(1.7)$ & 0.4 & $(0.5)$ & 0.1 & C \\
\hline & Espírito Santo & 20.2 & (2.9) & 31.3 & (3.6) & 25.2 & (3.5) & 15.8 & (2.8) & 6.4 & $(2.0)$ & 1.1 & $(0.9)$ & 0.1 & C \\
\hline & Federal District & 20.4 & (6.0) & 29.7 & (4.6) & 26.0 & (3.9) & 16.8 & $(2.7)$ & 6.5 & $(2.6)$ & 0.6 & $(0.6)$ & 0.0 & C \\
\hline & Goiás & 30.2 & $(4.7)$ & 38.2 & $(4.3)$ & 21.4 & (2.8) & 8.1 & (1.4) & 1.9 & $(1.2)$ & 0.1 & C & 0.0 & C \\
\hline & Maranhão & 48.3 & (7.6) & 25.3 & (3.8) & 16.5 & $(5.1)$ & 7.6 & (4.5) & 2.1 & $(1.6)$ & 0.0 & $\mathrm{c}$ & 0.0 & c \\
\hline & Mato Grosso & 40.7 & (5.8) & 34.0 & (4.6) & 18.4 & (3.5) & 5.6 & (2.1) & 1.2 & $(1.0)$ & 0.0 & $\mathrm{C}$ & 0.0 & c \\
\hline & Mato Grosso do Sul & 18.1 & $(4.0)$ & 30.0 & (3.8) & 33.1 & (3.9) & 15.2 & (3.1) & 3.1 & $(1.0)$ & 0.4 & $(0.4)$ & 0.2 & c \\
\hline & Minas Gerais & 18.8 & (3.6) & 31.6 & (3.2) & 31.7 & (3.4) & 14.3 & (2.6) & 3.2 & $(1.7)$ & 1.3 & C & 0.0 & c \\
\hline & Pará & 37.3 & (5.2) & 36.8 & (5.1) & 19.3 & (3.2) & 5.9 & $(2.6)$ & 0.8 & $(0.6)$ & 0.0 & $\mathrm{C}$ & 0.0 & c \\
\hline & Paraiba & 21.7 & $(4.1)$ & 35.8 & $(4.9)$ & 27.6 & $(5.2)$ & 10.3 & (3.4) & 3.8 & (1.9) & 0.8 & $\mathrm{C}$ & 0.0 & c \\
\hline & Paraná & 23.6 & (3.8) & 30.9 & (3.6) & 26.5 & $(4.1)$ & 12.6 & $(2.8)$ & 5.5 & (3.4) & 0.9 & (1.0) & 0.0 & c \\
\hline & Pernambuco & 32.8 & (5.9) & 37.5 & $(4.1)$ & 22.8 & $(4.7)$ & 5.4 & (2.3) & 1.2 & $(1.1)$ & 0.2 & $\mathrm{c}$ & 0.0 & c \\
\hline & Piauí & 30.4 & $(3.7)$ & 34.4 & $(4.7)$ & 21.7 & (4.0) & 8.3 & (2.0) & 3.9 & $(2.1)$ & 0.0 & c & 1.2 & c \\
\hline & Rio de Janeiro & 22.5 & (4.4) & 38.3 & $(4.6)$ & 26.6 & $(4.0)$ & 9.9 & $(2.7)$ & 2.5 & $(1.7)$ & 0.3 & c & 0.0 & c \\
\hline & Rio Grande do Norte & 22.5 & $(4.2)$ & 36.7 & (4.9) & 22.9 & (4.6) & 10.9 & (3.5) & 6.3 & $(3.3)$ & 0.7 & $\mathrm{C}$ & 0.0 & c \\
\hline & Rio Grande do Sul & 14.6 & (3.7) & 34.4 & (3.5) & 30.1 & (3.7) & 17.6 & (3.1) & 3.1 & (1.4) & 0.0 & c & 0.2 & c \\
\hline & Rondônia & 21.8 & (3.6) & 36.8 & $(4.1)$ & 31.6 & (3.4) & 8.5 & (2.0) & 1.3 & $(0.7)$ & 0.1 & c & 0.0 & c \\
\hline & Roraima & 36.4 & (5.0) & 32.5 & (3.9) & 22.6 & $(4.2)$ & 7.0 & (2.1) & 1.5 & $(0.8)$ & 0.0 & $\mathrm{C}$ & 0.0 & C \\
\hline & Santa Catarina & 17.3 & (2.8) & 29.5 & (3.7) & 32.4 & (3.2) & 16.8 & (3.5) & 3.9 & (1.8) & 0.0 & C & 0.1 & c \\
\hline & São Paulo & 18.7 & (1.7) & 33.5 & (2.5) & 29.7 & (2.9) & 13.5 & (1.7) & 4.0 & $(1.2)$ & 0.6 & $(0.4)$ & 0.0 & c \\
\hline & Sergipe & 25.0 & (5.8) & 37.9 & $(4.7)$ & 22.6 & (3.4) & 11.8 & (4.9) & 2.3 & $(1.7)$ & 0.3 & $(0.2)$ & 0.0 & c \\
\hline & Tocantins & 32.5 & $(4.1)$ & 32.4 & (3.9) & 22.5 & (3.4) & 10.7 & (2.5) & 1.6 & $(1.0)$ & 0.4 & $\mathrm{C}$ & 0.0 & c \\
\hline & Colombia & & & & & & & & & & & & & & \\
\hline & Bogotá & 18.3 & (2.6) & 36.0 & (2.5) & 31.2 & (2.4) & 12.3 & (1.8) & 1.9 & $(1.2)$ & 0.3 & $(0.4)$ & 0.0 & c \\
\hline & Cali & 29.8 & (3.2) & 34.2 & (2.6) & 25.7 & (2.8) & 8.6 & (1.8) & 1.7 & $(0.7)$ & 0.0 & c & 0.0 & c \\
\hline & Manizales & 14.8 & (2.4) & 34.4 & (3.2) & 31.7 & $(2.7)$ & 14.5 & (3.1) & 4.1 & (1.4) & 0.6 & $(0.5)$ & 0.0 & C \\
\hline & Medellín & 24.3 & (3.5) & 34.4 & (2.9) & 24.8 & (3.1) & 11.1 & (2.3) & 3.4 & $(1.5)$ & 1.7 & (1.1) & 0.3 & $(0.3)$ \\
\hline & Russian Federation & & & & & & & & & & & & & & \\
\hline & Perm Territory region ${ }^{\bullet}$ & 11.8 & (2.4) & 19.5 & (1.7) & 26.4 & (2.5) & 22.1 & $(2.0)$ & 13.0 & $(2.0)$ & 5.6 & (1.4) & 1.6 & $(0.9)$ \\
\hline & United Arab Emirates & & & & & & & & & & & & & & \\
\hline & Abu Dhabi` & 29.3 & $(2.2)$ & 27.6 & (1.9) & 22.0 & (1.9) & 13.2 & (1.3) & 5.6 & $(1.1)$ & 1.8 & $(0.7)$ & 0.4 & $(0.3)$ \\
\hline & Ajman & 35.7 & $(7.2)$ & 30.0 & (5.5) & 19.7 & (3.6) & 11.6 & (2.8) & 2.7 & $(1.1)$ & 0.2 & C & 0.0 & $\mathrm{C}$ \\
\hline & Dubai ${ }^{\bullet}$ & 13.9 & $(0.7)$ & 21.1 & $(1.1)$ & 23.4 & (1.5) & 20.6 & $(1.1)$ & 14.2 & $(1.3)$ & 5.2 & $(0.8)$ & 1.6 & $(0.4)$ \\
\hline & Fujairah & 38.6 & (5.3) & 30.3 & $(4.0)$ & 18.2 & (3.0) & 9.5 & (2.0) & 3.2 & $(1.3)$ & 0.2 & $\begin{array}{r}10.07 \\
\mathrm{C}\end{array}$ & 0.0 & C \\
\hline & Ras al-Khaimah & 31.1 & (5.9) & 30.8 & $(2.7)$ & 24.7 & (3.5) & 10.6 & (2.8) & 2.3 & $(0.8)$ & 0.4 & $(0.3)$ & 0.0 & c \\
\hline & Sharjah & 13.0 & (3.6) & 26.2 & $(4.7)$ & 28.0 & (4.5) & 21.2 & (4.4) & 8.7 & $(2.9)$ & 2.5 & (1.6) & 0.4 & c \\
\hline & Umm al-Quwain & 39.8 & (3.5) & 32.1 & (4.8) & 20.2 & (4.6) & 6.0 & (3.0) & 1.8 & $\mathrm{C}$ & 0.0 & $\mathrm{C}$ & 0.0 & c \\
\hline
\end{tabular}

- PISA adjudicated region

Note: See Table I.2.24 for national data.

StatLink त्नाजा http://dx.doi.org/10.1787/888932935762 
[Part 3/4]

Percentage of students at each proficiency level on the mathematics subscale uncertainty and data, Table B2.I.23 by gender and region

\begin{tabular}{|c|c|c|c|c|c|c|c|c|c|c|c|c|c|c|c|}
\hline & & \multicolumn{14}{|c|}{ Girls } \\
\hline & & \multicolumn{2}{|c|}{$\begin{array}{l}\text { Below Level } 1 \\
\text { (below } 357.77 \\
\text { score points) }\end{array}$} & $\begin{array}{l}\text { Le } \\
\text { (from } \\
\text { less th } \\
\text { scor }\end{array}$ & $\begin{array}{l}\text { I } 1 \\
7.77 \text { to } \\
420.07 \\
\text { oints) }\end{array}$ & $\begin{array}{l}\text { Le } \\
\text { (from } \\
\text { less th } \\
\text { score }\end{array}$ & $\begin{array}{l}2 \\
.07 \text { to } \\
482.38 \\
\text { jints) }\end{array}$ & $\begin{array}{l}\text { Le } \\
\text { (from } \\
\text { less th } \\
\text { score }\end{array}$ & $\begin{array}{l}\text { I } 3 \\
2.38 \text { to } \\
544.68 \\
\text { oints) }\end{array}$ & $\begin{array}{l}\text { Le } \\
\text { (from } \\
\text { less th } \\
\text { score }\end{array}$ & $\begin{array}{l}4 \\
4.68 \text { to } \\
606.99 \\
\text { oints) }\end{array}$ & $\begin{array}{l}\text { Le } \\
\text { (from } \\
\text { less tha } \\
\text { score }\end{array}$ & $\begin{array}{l}5 \\
6.99 \text { to } \\
669.30 \\
\text { oints) }\end{array}$ & $\begin{array}{l}\text { Le } \\
\text { (abov } \\
\text { scor }\end{array}$ & $\begin{array}{l}6 \\
69.30 \\
\text { ints) }\end{array}$ \\
\hline & & $\%$ & S.E. & $\%$ & S.E. & $\%$ & S.E. & $\%$ & S.E. & $\%$ & S.E. & $\%$ & S.E. & $\%$ & S.E. \\
\hline 0 & Australia & & & & & & & & & & & & & & \\
\hline 岁 & Australian Capital Territory & 4.4 & $(1.2)$ & 9.0 & $(1.5)$ & 18.3 & $(2.0)$ & 25.1 & $(2.5)$ & 22.8 & $(2.7)$ & 15.2 & $(2.3)$ & 5.4 & (1.5) \\
\hline & New South Wales & 5.7 & $(0.7)$ & 11.6 & $(0.8)$ & 21.5 & $(1.1)$ & 24.9 & (1.3) & 19.2 & (1.4) & 12.0 & (1.0) & 5.1 & $(0.9)$ \\
\hline & Northern Territory & 19.1 & (2.8) & 17.8 & $(5.1)$ & 25.1 & $(6.8)$ & 21.5 & (5.6) & 12.0 & $(4.0)$ & 4.4 & (2.8) & 0.3 & c \\
\hline & Queensland & 5.1 & $(1.0)$ & 13.1 & $(1.2)$ & 22.7 & $(1.6)$ & 25.3 & (1.5) & 19.6 & (1.5) & 10.4 & (1.0) & 3.9 & $(0.9)$ \\
\hline & South Australia & 6.4 & (1.1) & 15.7 & $(1.7)$ & 23.3 & $(2.2)$ & 26.2 & $(2.0)$ & 18.6 & $(2.1)$ & 7.9 & (1.6) & 1.9 & $(0.8)$ \\
\hline & Tasmania & 8.9 & (1.8) & 18.7 & $(2.3)$ & 24.7 & $(2.6)$ & 24.9 & (2.5) & 13.6 & (2.3) & 6.8 & (1.4) & 2.5 & (1.1) \\
\hline & Victoria & 5.7 & $(1.0)$ & 13.8 & $(1.4)$ & 23.5 & (1.6) & 26.6 & (1.8) & 20.0 & (1.4) & 8.6 & (1.3) & 2.0 & $(0.7)$ \\
\hline & Western Australia & 5.5 & $(1.0)$ & 12.7 & $(2.3)$ & 19.1 & $(2.0)$ & 24.1 & $(2.2)$ & 21.5 & (1.6) & 12.2 & (1.7) & 4.8 & $(1.0)$ \\
\hline & Belgium & & & & & & & & & & & & & & \\
\hline & Flemish Community ${ }^{\bullet}$ & 6.4 & (1.1) & 10.4 & $(1.0)$ & 17.5 & (1.4) & 22.5 & (1.5) & 20.6 & $(1.2)$ & 14.7 & (1.0) & 7.8 & (0.9) \\
\hline & French Community & 10.8 & (1.6) & 14.8 & $(1.3)$ & 24.2 & (1.6) & 23.5 & (1.5) & 17.7 & $(1.2)$ & 7.1 & $(0.8)$ & 1.9 & $(0.4)$ \\
\hline & German-speaking Community & 5.3 & (1.3) & 10.0 & $(1.7)$ & 19.3 & (2.4) & 29.2 & (2.6) & 26.2 & (2.3) & 8.7 & $(2.0)$ & 1.3 & $(0.8)$ \\
\hline & Canada & & & & & & & & & & & & & & \\
\hline & Alberta & 5.1 & $(0.9)$ & 11.4 & $(2.0)$ & 19.7 & (1.8) & 26.7 & $(1.8)$ & 22.5 & (1.9) & 11.4 & (1.7) & 3.2 & $(0.7)$ \\
\hline & British Columbia & 3.0 & $(0.8)$ & 9.7 & $(1.2)$ & 22.1 & (1.9) & 28.0 & $(2.0)$ & 22.7 & $(2.2)$ & 11.5 & (1.6) & 3.1 & (1.1) \\
\hline & Manitoba & 6.2 & (1.4) & 14.4 & $(1.7)$ & 26.0 & (1.8) & 25.8 & $(2.6)$ & 17.7 & $(2.2)$ & 7.3 & $(1.0)$ & 2.6 & $(0.7)$ \\
\hline & New Brunswick & 4.2 & $(0.9)$ & 11.4 & $(1.5)$ & 25.1 & $(2.3)$ & 30.0 & $(2.6)$ & 20.5 & $(2.3)$ & 7.3 & (1.3) & 1.5 & $(0.8)$ \\
\hline & Newfoundland and Labrador & 6.6 & (1.8) & 13.9 & $(2.2)$ & 23.8 & (2.4) & 27.8 & $(2.8)$ & 17.1 & $(2.8)$ & 8.8 & (1.5) & 2.0 & $(0.7)$ \\
\hline & Nova Scotia & 3.8 & (1.6) & 12.5 & $(3.0)$ & 27.3 & $(4.1)$ & 26.9 & $(2.3)$ & 19.3 & $(2.8)$ & 8.4 & (1.8) & 1.7 & $(0.9)$ \\
\hline & Ontario & 4.0 & $(0.7)$ & 10.2 & $(1.3)$ & 24.6 & (1.6) & 29.4 & (1.5) & 20.9 & (1.6) & 8.8 & (1.3) & 2.1 & $(0.6)$ \\
\hline & Prince Edward Island & 5.1 & (1.3) & 15.8 & (1.6) & 26.1 & $(2.0)$ & 28.4 & $(2.0)$ & 18.5 & $(2.0)$ & 4.8 & $(1.0)$ & 1.4 & $(0.6)$ \\
\hline & Quebec & 3.3 & $(0.5)$ & 8.4 & $(1.0)$ & 17.1 & (1.4) & 25.9 & (1.8) & 25.1 & (1.6) & 14.9 & (1.4) & 5.2 & $(0.9)$ \\
\hline & Saskatchewan & 3.6 & $(0.9)$ & 10.6 & $(1.5)$ & 25.9 & $(2.0)$ & 29.1 & (1.9) & 19.5 & (1.8) & 9.6 & (1.6) & 1.8 & $(0.9)$ \\
\hline & Italy & & & & & & & & & & & & & & \\
\hline & Abruzzo & 11.3 & (2.0) & 17.5 & $(2.2)$ & 26.9 & $(2.5)$ & 26.1 & $(2.3)$ & 13.3 & $(1.7)$ & 4.3 & $(1.1)$ & 0.6 & $(0.5)$ \\
\hline & Basilicata & 14.7 & (1.9) & 21.3 & (1.9) & 31.0 & $(2.0)$ & 20.4 & (1.9) & 9.4 & (1.6) & 2.4 & $(0.7)$ & 0.8 & $(0.4)$ \\
\hline & Bolzano & 8.0 & (1.1) & 12.6 & $(1.5)$ & 22.4 & (1.9) & 28.2 & (1.8) & 19.0 & (2.5) & 7.9 & (1.3) & 1.9 & $(0.5)$ \\
\hline & Calabria & 25.9 & (3.7) & 26.4 & $(2.6)$ & 25.2 & $(2.6)$ & 15.8 & $(2.2)$ & 5.5 & $(0.9)$ & 1.0 & $(0.5)$ & 0.2 & $\mathrm{C}$ \\
\hline & Campania & 16.7 & (3.2) & 22.3 & (3.6) & 26.5 & $(2.5)$ & 21.6 & $(2.3)$ & 10.6 & (2.3) & 1.8 & $(0.9)$ & 0.6 & $(0.4)$ \\
\hline & Emilia Romagna & 7.9 & (1.8) & 13.3 & $(1.7)$ & 24.0 & (2.3) & 26.8 & (2.6) & 17.3 & (2.0) & 8.4 & (1.8) & 2.3 & $(0.7)$ \\
\hline & Friuli Venezia Giulia & 6.6 & (2.4) & 9.2 & $(1.8)$ & 20.5 & $(2.4)$ & 30.1 & $(2.5)$ & 22.6 & $(2.7)$ & 9.1 & (1.4) & 1.9 & $(0.8)$ \\
\hline & Lazio & 11.4 & $(2.4)$ & 19.5 & $(2.3)$ & 28.3 & $(2.1)$ & 22.9 & $(2.1)$ & 12.7 & $(2.1)$ & 4.7 & (1.4) & 0.6 & $(0.3)$ \\
\hline & Liguria & 9.3 & (1.7) & 15.4 & $(2.5)$ & 23.0 & $(2.7)$ & 27.2 & $(2.2)$ & 17.2 & $(2.1)$ & 6.3 & (1.4) & 1.6 & $(0.6)$ \\
\hline & Lombardia & 3.0 & $(1.0)$ & 12.1 & $(2.2)$ & 22.0 & $(3.0)$ & 29.6 & $(2.8)$ & 23.3 & (2.4) & 8.5 & (1.8) & 1.5 & $(0.8)$ \\
\hline & Marche & 9.4 & $(2.1)$ & 15.2 & $(1.7)$ & 24.7 & $(2.3)$ & 26.7 & $(2.5)$ & 16.5 & (1.9) & 6.3 & (1.4) & 1.2 & $(0.5)$ \\
\hline & Molise & 10.8 & (1.4) & 22.0 & $(3.0)$ & 30.5 & $(3.2)$ & 23.4 & (2.6) & 9.9 & (1.8) & 2.9 & (1.3) & 0.4 & $(0.5)$ \\
\hline & Piemonte & 7.6 & (1.5) & 17.2 & $(2.7)$ & 23.3 & $(2.6)$ & 27.0 & $(3.1)$ & 16.8 & $(2.2)$ & 6.6 & $(1.2)$ & 1.5 & $(0.7)$ \\
\hline & Puglia & 9.6 & $(2.2)$ & 20.9 & $(3.1)$ & 29.1 & (3.6) & 23.1 & (3.1) & 13.3 & $(2.0)$ & 3.4 & (1.1) & 0.6 & $(0.4)$ \\
\hline & Sardegna & 13.6 & (2.6) & 20.6 & $(2.7)$ & 26.3 & $(2.3)$ & 24.5 & $(2.6)$ & 12.1 & $(1.8)$ & 2.5 & $(0.7)$ & 0.4 & $(0.4)$ \\
\hline & Sicilia & 15.7 & $(2.2)$ & 23.5 & $(2.4)$ & 30.3 & $(2.9)$ & 21.2 & $(2.3)$ & 7.9 & (1.5) & 1.3 & $(0.4)$ & 0.1 & $\mathrm{C}$ \\
\hline & Toscana & 7.8 & $(1.8)$ & 15.0 & $(2.9)$ & 23.0 & (3.3) & 26.4 & $(3.1)$ & 18.7 & (2.6) & 7.7 & (1.7) & 1.4 & $(0.6)$ \\
\hline & Trento & 2.2 & (1.1) & 8.6 & $(1.9)$ & 23.4 & $(2.7)$ & 31.0 & (2.5) & 25.0 & (2.5) & 9.0 & (1.8) & 0.8 & $(0.4)$ \\
\hline & Umbria & 9.5 & $(2.0)$ & 15.3 & $(2.3)$ & 24.8 & $(2.3)$ & 28.4 & $(2.2)$ & 15.4 & (1.9) & 6.1 & (1.3) & 0.6 & $(0.4)$ \\
\hline & Valle d'Aosta & 6.5 & $(1.5)$ & 16.3 & (1.9) & 29.7 & $(2.8)$ & 26.4 & $(3.1)$ & 14.4 & (1.9) & 5.4 & $(1.2)$ & 1.4 & $(0.6)$ \\
\hline & Veneto & 4.2 & (1.7) & 12.2 & $(2.0)$ & 21.1 & $(2.6)$ & 27.7 & $(3.0)$ & 22.7 & (2.9) & 9.6 & (1.9) & 2.5 & (1.0) \\
\hline & Mexico & & & & & & & & & & & & & & \\
\hline & Aguascalientes & 12.2 & $(2.7)$ & 26.3 & $(3.2)$ & 37.1 & (3.3) & 19.5 & (3.4) & 4.7 & (1.6) & 0.2 & c & 0.0 & c \\
\hline & Baja California & 20.7 & (3.6) & 36.0 & (3.8) & 29.7 & $(2.9)$ & 10.5 & $(2.5)$ & 2.6 & (1.4) & 0.5 & $(0.5)$ & 0.0 & c \\
\hline & Baja California Sur & 19.1 & (3.7) & 32.3 & $(3.0)$ & 32.6 & (3.2) & 14.0 & $(2.1)$ & 1.9 & $(0.8)$ & 0.1 & $\mathrm{C}$ & 0.0 & c \\
\hline & Campeche & 25.4 & (3.5) & 39.5 & $(2.8)$ & 26.9 & $(2.7)$ & 6.9 & (1.5) & 1.2 & $(0.5)$ & 0.1 & c & 0.0 & c \\
\hline & Chiapas & 39.2 & (4.2) & 34.8 & $(2.8)$ & 21.0 & $(2.6)$ & 4.4 & (1.5) & 0.6 & $(0.4)$ & 0.0 & c & 0.0 & c \\
\hline & Chihuahua & 16.8 & (3.0) & 31.1 & $(3.8)$ & 32.6 & $(3.7)$ & 16.5 & (3.7) & 2.7 & $(0.9)$ & 0.3 & $(0.3)$ & 0.0 & c \\
\hline & Coahuila & 18.4 & (3.7) & 35.4 & $(4.4)$ & 32.6 & (3.6) & 12.1 & $(2.9)$ & 1.5 & $(0.6)$ & 0.0 & $\mathrm{C}$ & 0.0 & c \\
\hline & Colima & 15.4 & (2.4) & 31.2 & $(2.1)$ & 31.2 & (2.4) & 17.5 & $(2.3)$ & 4.4 & (1.3) & 0.3 & $(0.2)$ & 0.0 & c \\
\hline & Distrito Federal & 21.1 & (3.2) & 36.0 & $(4.0)$ & 27.4 & $(2.8)$ & 12.2 & $(2.5)$ & 2.9 & $(1.1)$ & 0.4 & $(0.3)$ & 0.0 & c \\
\hline & Durango & 14.7 & (2.8) & 35.1 & (3.8) & 33.9 & (3.3) & 14.4 & $(2.4)$ & 1.7 & $(0.8)$ & 0.2 & $(0.1)$ & 0.0 & $\mathrm{c}$ \\
\hline & Guanajuato & 22.5 & (3.8) & 34.5 & $(2.4)$ & 32.0 & $(3.6)$ & 10.3 & (1.9) & 0.8 & $(0.3)$ & 0.0 & c & 0.0 & c \\
\hline & Guerrero & 39.1 & (3.8) & 39.8 & $(3.5)$ & 16.7 & $(2.2)$ & 4.1 & $(1.0)$ & 0.4 & $(0.5)$ & 0.0 & c & 0.0 & $\mathrm{c}$ \\
\hline & Hidalgo & 26.0 & (3.2) & 35.9 & $(2.8)$ & 27.9 & $(3.2)$ & 9.5 & (1.9) & 0.8 & $(0.4)$ & 0.0 & c & 0.0 & c \\
\hline & Jalisco & 10.4 & (2.1) & 32.4 & $(2.7)$ & 36.9 & $(2.2)$ & 17.2 & (2.4) & 2.9 & (1.1) & 0.2 & c & 0.0 & C \\
\hline & Mexico & 16.5 & (2.6) & 38.7 & $(3.4)$ & 35.0 & (3.0) & 8.8 & $(2.1)$ & 1.0 & $(0.8)$ & 0.0 & $\mathrm{C}$ & 0.0 & c \\
\hline & Morelos & 15.6 & $(2.9)$ & 37.6 & (3.8) & 31.1 & $(2.6)$ & 11.2 & $(2.1)$ & 3.9 & (2.0) & 0.7 & $(0.7)$ & 0.0 & $\mathrm{c}$ \\
\hline & Nayarit & 24.0 & (4.3) & 30.9 & (2.9) & 32.2 & (3.2) & 11.4 & $(2.1)$ & 1.4 & $(0.7)$ & 0.1 & c & 0.0 & c \\
\hline & Nuevo León & 12.9 & (3.2) & 33.4 & (3.4) & 33.3 & $(3.1)$ & 16.8 & (3.1) & 3.2 & $(1.2)$ & 0.4 & $(0.4)$ & 0.0 & C \\
\hline & Puebla & 21.9 & (3.6) & 38.8 & $(2.9)$ & 29.7 & $(2.7)$ & 8.7 & (1.8) & 0.9 & $(0.5)$ & 0.0 & $\mathrm{C}$ & 0.0 & c \\
\hline & Querétaro & 14.3 & (2.8) & 30.9 & (3.6) & 35.9 & (3.1) & 15.2 & $(2.5)$ & 3.1 & $(1.0)$ & 0.6 & $(0.3)$ & 0.0 & c \\
\hline & Quintana Roo & 24.8 & (3.0) & 37.4 & $(2.7)$ & 27.5 & $(2.7)$ & 9.2 & (1.9) & 1.1 & $(0.6)$ & 0.0 & c & 0.0 & C \\
\hline & San Luis Potosí & 26.0 & (3.9) & 31.9 & (3.3) & 29.5 & $(2.8)$ & 10.8 & $(2.2)$ & 1.7 & $(0.8)$ & 0.1 & c & 0.0 & $\mathrm{c}$ \\
\hline & Sinaloa & 19.0 & (2.9) & 37.1 & $(2.8)$ & 30.8 & $(2.6)$ & 11.7 & (2.3) & 1.4 & $(0.7)$ & 0.1 & c & 0.0 & c \\
\hline & Tabasco & 37.4 & (2.6) & 39.0 & $(2.6)$ & 18.9 & $(2.0)$ & 4.1 & $(0.9)$ & 0.7 & $(0.5)$ & 0.0 & c & 0.0 & c \\
\hline & Tamaulipas & 25.3 & (3.0) & 34.9 & $(4.1)$ & 28.8 & (3.1) & 9.4 & $(2.0)$ & 1.6 & (1.0) & 0.0 & c & 0.0 & c \\
\hline & Tlaxcala & 19.8 & (2.1) & 36.9 & $(2.4)$ & 31.1 & (2.4) & 9.6 & (1.5) & 2.5 & (0.8) & 0.1 & c & 0.0 & c \\
\hline & Veracruz & 24.0 & (3.6) & 35.7 & (3.4) & 27.6 & (2.8) & 11.0 & (2.5) & 1.6 & (1.0) & 0.1 & c & 0.0 & c \\
\hline & Yucatán & 22.7 & (2.5) & 36.1 & $(3.0)$ & 29.4 & (3.0) & 10.1 & (2.3) & 1.6 & $(0.7)$ & 0.0 & c & 0.0 & c \\
\hline & Zacatecas & 20.7 & (3.0) & 35.9 & (3.4) & 31.0 & (2.4) & 10.8 & (1.6) & 1.5 & (0.6) & 0.0 & $\mathrm{C}$ & 0.0 & $\mathrm{c}$ \\
\hline
\end{tabular}

- PISA adjudicated region

Note: See Table I.2.24 for national data.

StatLink त्ताडst http://dx.doi.org/10.1787/888932935762 
Percentage of students at each proficiency level on the mathematics subscale uncertainty and data, Table B2.I.23 by gender and region

\begin{tabular}{|c|c|c|c|c|c|c|c|c|c|c|c|c|c|c|c|}
\hline & & \multicolumn{14}{|c|}{ Girls } \\
\hline & & \multicolumn{2}{|c|}{$\begin{array}{l}\text { Below Level } 1 \\
\text { (below 357.77 } \\
\text { score points) }\end{array}$} & \multicolumn{2}{|c|}{$\begin{array}{c}\text { Level } 1 \\
\text { (from } 357.77 \text { to } \\
\text { less than } 420.07 \\
\text { score points) }\end{array}$} & \multicolumn{2}{|c|}{$\begin{array}{c}\text { Level } 2 \\
\text { (from } 420.07 \text { to } \\
\text { less than } 482.38 \\
\text { score points) }\end{array}$} & $\begin{array}{l}\text { Le } \\
\text { (from } \\
\text { less th } \\
\text { score }\end{array}$ & \begin{tabular}{|l|}
3 \\
2.38 to \\
544.68 \\
ints)
\end{tabular} & $\begin{array}{r}\text { Le } \\
\text { (from } 5 \\
\text { less tha } \\
\text { score }\end{array}$ & $\begin{array}{l}4 \\
4.68 \text { to } \\
606.99 \\
\text { oints) }\end{array}$ & $\begin{array}{r}\text { Le } \\
\text { (from } \\
\text { less tha } \\
\text { score }\end{array}$ & $\begin{array}{l}5 \\
5.99 \text { to } \\
669.30 \\
\text { ints) }\end{array}$ & $\begin{array}{r}\text { Le } \\
\text { (above } \\
\text { score }\end{array}$ & $\begin{array}{l}6 \\
69.30 \\
\text { pints) }\end{array}$ \\
\hline & & $\%$ & S.E. & $\%$ & S.E. & $\%$ & S.E. & $\%$ & S.E. & $\%$ & S.E. & $\%$ & S.E. & $\%$ & S.E. \\
\hline 0 & Portugal & & & & & & & & & & & & & & \\
\hline 岀 & Alentejo & 8.1 & (2.5) & 15.3 & (3.3) & 26.5 & (3.5) & 26.8 & (3.6) & 17.4 & $(2.7)$ & 5.2 & (1.9) & 0.6 & $(0.5)$ \\
\hline & Spain & & & & & & & & & & & & & & \\
\hline & Andalusia ${ }^{\bullet}$ & 8.5 & (1.5) & 21.9 & (2.3) & 27.0 & (2.5) & 23.9 & (2.1) & 12.6 & $(1.7)$ & 5.2 & (1.0) & 0.8 & $(0.5)$ \\
\hline & Aragon ${ }^{\bullet}$ & 8.9 & (1.5) & 13.2 & $(2.2)$ & 20.9 & (3.1) & 26.7 & $(2.1)$ & 19.4 & (2.3) & 8.6 & (1.7) & 2.2 & $(0.8)$ \\
\hline & Asturias ${ }^{\bullet}$ & 5.7 & (1.0) & 12.7 & (1.6) & 22.8 & $(2.2)$ & 27.0 & (1.6) & 19.7 & $(2.0)$ & 9.6 & (1.5) & 2.4 & $(0.8)$ \\
\hline & Balearic Islands ${ }^{\bullet}$ & 9.6 & (1.8) & 18.9 & (1.9) & 24.0 & (1.8) & 27.0 & (2.6) & 14.3 & $(2.2)$ & 5.3 & $(1.2)$ & 0.8 & $(0.4)$ \\
\hline & Basque Country ${ }^{\bullet}$ & 4.7 & $(0.6)$ & 11.0 & $(0.9)$ & 22.3 & (1.3) & 29.3 & (1.4) & 21.5 & (1.1) & 9.3 & $(1.0)$ & 1.9 & $(0.4)$ \\
\hline & Cantabria ${ }^{\bullet}$ & 8.1 & $(1.5)$ & 16.1 & (1.6) & 26.3 & $(2.3)$ & 24.4 & (2.1) & 15.7 & (2.0) & 7.6 & $(1.4)$ & 1.8 & $(0.6)$ \\
\hline & Castile and Leon & 4.6 & (1.1) & 11.3 & $(2.0)$ & 22.0 & (2.6) & 28.8 & $(2.5)$ & 23.9 & $(2.1)$ & 8.0 & $(1.3)$ & 1.4 & $(0.5)$ \\
\hline & Catalonia & 7.9 & $(1.7)$ & 16.5 & (1.9) & 23.4 & $(2.1)$ & 27.3 & $(2.2)$ & 18.3 & (2.5) & 5.3 & $(1.4)$ & 1.3 & $(0.6)$ \\
\hline & Extremadura ${ }^{\bullet}$ & 13.6 & (1.9) & 19.3 & $(2.0)$ & 25.9 & $(2.7)$ & 24.6 & $(2.7)$ & 12.0 & $(1.5)$ & 3.8 & $(1.2)$ & 0.8 & $(0.4)$ \\
\hline & Galicia• & 7.8 & (1.0) & 15.2 & $(2.0)$ & 23.1 & (1.9) & 25.8 & $(2.1)$ & 17.5 & $(2.3)$ & 7.2 & $(0.9)$ & 3.3 & $(0.7)$ \\
\hline & La Rioja ${ }^{\bullet}$ & 8.1 & $(1.2)$ & 13.1 & $(1.7)$ & 23.6 & (2.0) & 23.5 & (1.9) & 19.7 & $(1.9)$ & 9.0 & $(1.3)$ & 3.0 & $(0.8)$ \\
\hline & Madrid $\bullet^{\bullet}$ & 5.0 & $(1.1)$ & 12.3 & $(1.7)$ & 25.2 & $(2.2)$ & 28.7 & $(2.2)$ & 21.3 & (1.8) & 6.8 & $(1.0)$ & 0.8 & $(0.4)$ \\
\hline & Murcia $\bullet$ & 13.5 & (1.6) & 19.4 & (1.8) & 28.2 & (2.4) & 22.3 & (1.6) & 12.6 & $(1.6)$ & 3.3 & $(0.9)$ & 0.6 & $(0.4)$ \\
\hline & Navarre ${ }^{\bullet}$ & 4.9 & $(0.9)$ & 11.1 & (1.4) & 20.5 & (2.6) & 27.2 & (2.1) & 23.0 & $(1.8)$ & 11.1 & (1.1) & 2.2 & $(0.8)$ \\
\hline & United Kingdom & & & & & & & & & & & & & & \\
\hline & England & 7.7 & (0.9) & 13.8 & $(1.2)$ & 22.4 & (1.1) & 23.8 & (1.4) & 19.7 & $(1.2)$ & 9.2 & $(1.2)$ & 3.4 & $(0.6)$ \\
\hline & Northern Ireland & 7.7 & $(1.2)$ & 15.9 & (1.8) & 22.8 & (1.8) & 23.7 & (1.9) & 18.7 & (1.8) & 8.9 & (1.3) & 2.3 & $(0.7)$ \\
\hline & Scotland ${ }^{\bullet}$ & 5.4 & (1.0) & 12.5 & (1.4) & 24.9 & (1.6) & 28.0 & (1.8) & 18.3 & (1.4) & 8.9 & (1.0) & 2.0 & (0.6) \\
\hline & Wales & 8.1 & (0.8) & 16.8 & $(1.2)$ & 27.3 & (1.3) & 25.0 & (1.6) & 15.9 & (1.3) & 5.6 & $(0.8)$ & 1.2 & $(0.3)$ \\
\hline & United States & & & & & & & & & & & & & & \\
\hline & Connecticut ${ }^{\bullet}$ & 6.1 & (1.4) & 14.0 & (2.0) & 20.7 & (1.8) & 24.9 & (1.9) & 18.7 & (1.9) & 11.0 & (1.6) & 4.6 & (1.2) \\
\hline & Florida & 7.9 & (1.7) & 20.0 & (2.4) & 29.9 & (2.4) & 25.0 & (2.4) & 12.8 & $(1.7)$ & 3.4 & (1.0) & 1.1 & $(0.7)$ \\
\hline & Massachusetts ${ }^{\bullet}$ & 3.9 & (1.0) & 10.8 & (1.6) & 20.9 & (2.1) & 25.1 & (1.7) & 21.2 & (1.9) & 12.9 & (1.9) & 5.1 & $(1.2)$ \\
\hline 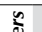 & Argentina & & & & & & & & & & & & & & \\
\hline$\cong$ & Ciudad Autónoma de Buenos Aires & 28.7 & (3.3) & 25.0 & $(2.1)$ & 27.3 & (3.0) & 13.3 & (1.8) & 4.8 & $(1.2)$ & 0.9 & $(0.6)$ & 0.0 & c \\
\hline ฮ & Brazil & & & & & & & & & & & & & & \\
\hline & Acre & 43.1 & $(4.7)$ & 33.6 & $(4.5)$ & 17.8 & $(2.7)$ & 4.8 & (1.6) & 0.6 & $(0.4)$ & 0.0 & c & 0.0 & c \\
\hline & Alagoas & 55.6 & (4.8) & 29.8 & (3.9) & 11.8 & (2.6) & 2.5 & (1.4) & 0.5 & $\mathrm{C}$ & 0.0 & c & 0.0 & c \\
\hline & Amapá & 40.7 & $(4.4)$ & 35.5 & (3.3) & 19.3 & $(3.2)$ & 3.9 & $(2.1)$ & 0.6 & $(0.7)$ & 0.0 & c & 0.0 & C \\
\hline & Amazonas & 45.3 & (3.3) & 35.2 & (3.4) & 16.0 & $(2.7)$ & 2.6 & (1.1) & 0.7 & $(0.7)$ & 0.1 & $\mathrm{c}$ & 0.0 & $\mathrm{C}$ \\
\hline & Bahia & 36.3 & (6.9) & 31.6 & (4.6) & 23.0 & $(4.0)$ & 6.8 & (1.9) & 2.3 & $(1.0)$ & 0.0 & $\mathrm{C}$ & 0.0 & C \\
\hline & Ceará & 31.8 & $(5.7)$ & 37.4 & $(4.0)$ & 23.0 & $(4.0)$ & 5.9 & (1.8) & 1.8 & $(0.9)$ & 0.1 & c & 0.0 & C \\
\hline & Espírito Santo & 25.3 & (4.3) & 33.3 & (5.4) & 24.4 & $(2.7)$ & 11.6 & (3.9) & 4.0 & (1.9) & 1.3 & $(0.9)$ & 0.0 & C \\
\hline & Federal District & 22.2 & (4.6) & 30.9 & (3.4) & 29.5 & (5.6) & 14.7 & (2.7) & 2.5 & $(1.5)$ & 0.2 & C & 0.0 & C \\
\hline & Goiás & 38.7 & $(4.5)$ & 38.8 & (3.6) & 18.4 & (3.3) & 3.4 & $(1.2)$ & 0.7 & $(0.6)$ & 0.0 & c & 0.0 & C \\
\hline & Maranhão & 54.1 & (7.5) & 29.6 & $(4.2)$ & 12.6 & (4.5) & 3.6 & $(2.2)$ & 0.1 & $\mathrm{C}$ & 0.0 & C & 0.0 & c \\
\hline & Mato Grosso & 40.7 & (6.0) & 35.2 & (4.6) & 17.0 & $(4.0)$ & 4.4 & (2.3) & 2.4 & $(1.3)$ & 0.3 & C & 0.0 & c \\
\hline & Mato Grosso do Sul & 22.4 & (3.9) & 36.0 & $(3.1)$ & 26.8 & $(3.7)$ & 10.6 & $(2.1)$ & 4.1 & $(1.3)$ & 0.1 & C & 0.0 & c \\
\hline & Minas Gerais & 18.3 & (3.2) & 39.3 & (3.5) & 27.9 & (3.2) & 11.9 & (2.8) & 2.5 & $(1.4)$ & 0.1 & C & 0.0 & c \\
\hline & Pará & 45.7 & (5.3) & 32.3 & (3.7) & 17.1 & (3.5) & 4.8 & $(1.5)$ & 0.1 & $\mathrm{C}$ & 0.0 & $\mathrm{c}$ & 0.0 & c \\
\hline & Paraiba & 23.4 & $(4.7)$ & 36.8 & (5.4) & 27.0 & (5.0) & 11.0 & $(2.1)$ & 1.8 & $(1.2)$ & 0.0 & $\mathrm{c}$ & 0.0 & c \\
\hline & Paraná & 29.4 & (4.3) & 34.6 & $(4.0)$ & 24.0 & (3.4) & 8.1 & $(2.7)$ & 2.5 & $(2.4)$ & 1.3 & $(1.5)$ & 0.1 & c \\
\hline & Pernambuco & 38.6 & (6.3) & 38.7 & $(5.2)$ & 18.4 & (5.8) & 3.9 & (1.8) & 0.4 & $(0.4)$ & 0.0 & $\mathrm{C}$ & 0.0 & c \\
\hline & Piauí & 33.2 & (5.0) & 40.4 & $(5.7)$ & 15.4 & (2.6) & 7.6 & (1.9) & 2.5 & $(2.2)$ & 0.8 & $(0.8)$ & 0.0 & c \\
\hline & Rio de Janeiro & 28.3 & (5.6) & 38.1 & (5.1) & 27.0 & $(4.0)$ & 5.8 & (2.0) & 0.8 & $(0.9)$ & 0.0 & $\mathrm{C}$ & 0.0 & c \\
\hline & Rio Grande do Norte & 33.9 & $(4.2)$ & 37.4 & (3.5) & 16.9 & (3.6) & 8.8 & $(2.7)$ & 2.0 & $(1.3)$ & 1.0 & $(0.8)$ & 0.0 & c \\
\hline & Rio Grande do Sul & 19.3 & $(4.1)$ & 35.0 & (3.4) & 33.5 & (4.3) & 11.2 & $(2.7)$ & 1.0 & $(0.9)$ & 0.0 & c & 0.0 & c \\
\hline & Rondônia & 26.5 & (4.3) & 41.0 & (2.5) & 26.7 & (3.3) & 5.2 & (1.5) & 0.5 & $(0.5)$ & 0.2 & c & 0.0 & C \\
\hline & Roraima & 39.5 & $(4.9)$ & 35.8 & $(4.4)$ & 14.6 & $(2.7)$ & 7.6 & (3.0) & 2.5 & $(1.7)$ & 0.0 & c & 0.0 & c \\
\hline & Santa Catarina & 20.9 & $(4.2)$ & 33.8 & (3.8) & 33.1 & (3.2) & 10.4 & (3.2) & 1.7 & $(0.9)$ & 0.1 & c & 0.0 & c \\
\hline & São Paulo & 22.6 & $(2.2)$ & 37.5 & $(2.2)$ & 26.7 & (1.7) & 10.3 & (1.3) & 2.6 & $(0.8)$ & 0.3 & $(0.2)$ & 0.0 & C \\
\hline & Sergipe & 34.5 & (4.9) & 36.2 & (3.8) & 22.9 & (3.8) & 6.1 & (2.6) & 0.3 & $\mathrm{C}$ & 0.0 & C & 0.0 & c \\
\hline & Tocantins & 38.9 & $(4.1)$ & 37.2 & (3.2) & 17.7 & (3.7) & 4.8 & (1.1) & 1.3 & $(0.6)$ & 0.0 & c & 0.0 & c \\
\hline & Colombia & & & & & & & & & & & & & & \\
\hline & Bogotá & 27.4 & $(2.2)$ & 40.5 & $(2.7)$ & 26.0 & (2.3) & 5.5 & (1.1) & 0.6 & $(0.4)$ & 0.0 & c & 0.0 & c \\
\hline & Cali & 36.0 & (3.3) & 36.3 & $(2.2)$ & 21.5 & $(2.7)$ & 5.8 & (1.4) & 0.5 & $(0.3)$ & 0.0 & c & 0.0 & c \\
\hline & Manizales & 22.0 & (3.1) & 42.9 & (3.2) & 27.0 & (2.2) & 7.6 & (1.3) & 0.5 & $(0.5)$ & 0.0 & c & 0.0 & c \\
\hline & Medellín & 31.6 & (3.7) & 36.6 & $(3.2)$ & 20.8 & $(2.5)$ & 7.8 & (1.6) & 2.0 & $(1.0)$ & 1.1 & $(0.6)$ & 0.1 & c \\
\hline & Russian Federation & & & & & & & & & & & & & & \\
\hline & Perm Territory region ${ }^{\bullet}$ & 9.2 & (1.5) & 18.3 & (1.9) & 29.9 & $(2.0)$ & 26.0 & $(2.1)$ & 12.0 & (1.6) & 3.5 & (0.9) & 1.0 & (0.6) \\
\hline & United Arab Emirates & & & & & & & & & & & & & & \\
\hline & Abu Dhabi` & 17.6 & $(2.1)$ & 29.2 & (1.5) & 28.9 & (1.5) & 16.0 & (1.6) & 6.1 & $(0.9)$ & 1.8 & $(0.7)$ & 0.3 & $(0.3)$ \\
\hline & Ajman & 21.9 & (6.8) & 31.5 & $(3.2)$ & 29.5 & (4.9) & 13.2 & (3.2) & 3.8 & $(1.7)$ & 0.2 & $\mathrm{C}$ & 0.0 & $\mathrm{C}$ \\
\hline & Dubai ${ }^{\bullet}$ & 12.1 & $(0.6)$ & 22.2 & $(1.1)$ & 28.2 & $(1.3)$ & 22.6 & (1.4) & 10.4 & $(1.2)$ & 3.9 & $(0.7)$ & 0.5 & $(0.3)$ \\
\hline & Fujairah & 16.9 & $(3.7)$ & 26.8 & (3.5) & 33.6 & $(4.0)$ & 18.4 & (3.5) & 4.0 & $(1.7)$ & 0.2 & $\mathrm{C}$ & 0.0 & $\mathrm{C}$ \\
\hline & Ras al-Khaimah & 17.1 & (3.6) & 29.8 & (3.2) & 32.0 & (3.9) & 16.1 & (3.5) & 4.4 & $(2.3)$ & 0.6 & $(0.6)$ & 0.0 & c \\
\hline & Sharjah & 16.9 & $(4.1)$ & 29.9 & (5.0) & 26.1 & (3.0) & 19.5 & $(4.1)$ & 6.9 & $(2.1)$ & 0.7 & $(0.4)$ & 0.0 & c \\
\hline & Umm al-Quwain & 17.4 & $(2.8)$ & 34.5 & (3.9) & 31.5 & $(4.3)$ & 13.6 & (3.1) & 2.5 & (1.5) & 0.4 & C & 0.0 & c \\
\hline
\end{tabular}

- PISA adjudicated region.

Note: See Table 1.2.24 for national data.

StatLink त्ताs http://dx.doi.org/10.1787/888932935762 
[Part 1/2]

Mean score, variation and gender differences in student performance on the mathematics Table B2.I.24 subscale uncertainty and data, by region

\begin{tabular}{|c|c|c|c|c|c|c|c|c|c|c|c|c|c|c|c|c|c|c|c|}
\hline & & & All stu & udents & & & & ender d & ifferen & nces & & & & & & & Perce & entiles & \\
\hline & & Mean & iscore & $\begin{array}{l}\text { Stan } \\
\text { devi }\end{array}$ & $\begin{array}{l}\text { ard } \\
\text { ion }\end{array}$ & Bo & ys & Gi & irls & $\begin{array}{c}\text { Diffe } \\
\text { (B - }\end{array}$ & $\begin{array}{l}\text { rence } \\
- \text { G) }\end{array}$ & & th & & 0th & & 5th & & 5th \\
\hline & & Mean & S.E. & S.D. & S.E. & $\begin{array}{l}\text { Mean } \\
\text { score }\end{array}$ & S.E. & \begin{tabular}{|l} 
Mean \\
score
\end{tabular} & S.E. & $\begin{array}{c}\begin{array}{c}\text { Score } \\
\text { dif. }\end{array} \\
\end{array}$ & S.E. & Score & S.E. & Score & S.E. & Score & S.E. & Score & S.E. \\
\hline & Australia & & & & & & & & & & & & & & & & & & \\
\hline U & Australian Capital Territory & 526 & (3.8) & 98 & (2.9) & 527 & $(5.8)$ & 525 & $(4.8)$ & 2 & (7.5) & 357 & (9.4) & .) 398 & (9.3) & 460 & (5.6) & 598 & (6.2) \\
\hline & New South Wales & 513 & (3.7) & 102 & (2.6) & 514 & (5.7) & 511 & (3.7) & 2 & (6.3) & 347 & (5.3) & 383 & (4.1) & 444 & (3.6) & 582 & (4.5) \\
\hline & Northern Territory & 447 & (10.9) & 112 & (6.1) & 451 & $(9.8)$ & 443 & (15.2) & 8 & (13.2) & 243 & $(20.2)$ & ) 300 & (15.9) & 382 & (12.0) & 526 & (15.3) \\
\hline & Queensland & 506 & (3.2) & 95 & (2.1) & 507 & $(4.3)$ & 506 & (3.8) & 1 & (4.9) & 353 & (6.8) & 387 & $(6.0)$ & 440 & (3.8) & 573 & (4.1) \\
\hline & South Australia & 495 & (3.8) & 93 & (1.9) & 499 & (4.4) & 491 & $(4.5)$ & 8 & (4.6) & 340 & (8.3) & 376 & (5.0) & 431 & (4.2) & 561 & (5.9) \\
\hline & Tasmania & 484 & (3.5) & 96 & $(2.2)$ & 488 & (4.9) & 479 & $(5.0)$ & 9 & (7.0) & 324 & (9.8) & 362 & (5.9) & 420 & (4.6) & 547 & (6.6) \\
\hline & Victoria & 503 & (3.8) & 92 & (2.3) & 509 & (5.1) & 497 & (3.9) & 12 & (5.3) & 353 & (5.6) & 384 & (4.6) & 441 & (4.7) & 566 & (5.1) \\
\hline & Western Australia & 522 & (3.2) & 96 & (2.0) & 530 & $(4.9)$ & 513 & (5.3) & 17 & (7.9) & 361 & $(5.1)$ & 394 & (5.5) & 454 & (4.8) & 590 & (4.5) \\
\hline & Belgium & & & & & & & & & & & & & & & & & & \\
\hline & Flemish Community ${ }^{\bullet}$ & 528 & (3.8) & \begin{tabular}{|l|l|}
109 \\
$\mid$
\end{tabular} & (2.8) & 532 & $(5.1)$ & 523 & $(4.6)$ & 9 & (5.9) & 341 & (9.6) & ) 382 & (8.3) & 454 & (5.0) & 607 & $(4.2)$ \\
\hline & French Community & 482 & (3.9) & 105 & (3.7) & 484 & $(4.3)$ & 480 & (4.5) & 5 & (4.3) & 300 & (15.2) & ) 347 & (8.1) & 416 & (5.5) & 556 & (3.5) \\
\hline & German-speaking Community & 500 & (2.3) & 94 & $(2.2)$ & 493 & $(4.0)$ & 508 & (3.2) & -15 & (5.6) & 333 & $(8.1)$ & 371 & (5.4) & 439 & (3.7) & 566 & (4.1) \\
\hline & Canada & & & & & & & & & & & & & & & & & & \\
\hline & Alberta & 517 & (4.8) & 93 & (1.8) & 523 & $(5.5)$ & 511 & (4.9) & 12 & (4.4) & 361 & (8.7) & 397 & (6.5) & 455 & (5.3) & 582 & (6.3) \\
\hline & British Columbia & 521 & (4.1) & 86 & $(2.0)$ & 527 & (4.9) & 516 & $(5.0)$ & 11 & (5.7) & 378 & (6.3) & 408 & $(5.7)$ & 463 & (4.7) & 581 & (5.5) \\
\hline & Manitoba & 495 & (2.9) & 91 & (2.5) & 498 & (3.7) & 493 & $(4.5)$ & 5 & $(5.7)$ & 350 & (7.0) & 379 & (6.9) & 432 & (4.0) & 559 & (4.6) \\
\hline & New Brunswick & 498 & (2.8) & 84 & (1.9) & 495 & $(4.2)$ & 501 & (3.4) & -5 & (5.3) & 355 & (7.7) & 391 & (5.2) & 441 & (4.2) & 555 & (3.8) \\
\hline & Newfoundland and Labrador & 491 & (5.0) & 94 & (3.4) & 489 & (7.3) & 494 & (4.4) & -5 & (6.8) & 328 & (13.1) & 369 & (13.7) & 431 & (6.9) & 554 & (5.4) \\
\hline & Nova Scotia & 503 & (5.5) & 84 & (2.5) & 506 & (4.9) & 500 & (7.3) & 7 & (5.8) & 370 & (6.6) & 397 & (3.9) & 444 & (5.1) & 562 & (8.7) \\
\hline & Ontario & 511 & (4.1) & 88 & $(2.0)$ & 517 & $(4.9)$ & 506 & $(4.2)$ & 11 & (3.9) & 365 & (6.9) & 400 & (5.0) & 453 & (5.2) & 572 & (5.1) \\
\hline & Prince Edward Island & 488 & $(2.7)$ & 85 & $(1.8)$ & 488 & (3.9) & 488 & (3.4) & 0 & (4.8) & 348 & (7.3) & 380 & $(5.2)$ & 428 & $(4.3)$ & 547 & (3.5) \\
\hline & Quebec & 534 & (3.5) & 92 & (1.7) & 537 & $(4.4)$ & 531 & (3.7) & 6 & (4.1) & 375 & (5.7) & 411 & (5.4) & 472 & (5.4) & 599 & (3.8) \\
\hline & Saskatchewan & 507 & (2.9) & 84 & (2.0) & 510 & $(4.0)$ & 505 & (3.3) & 5 & (4.6) & 366 & (5.9) & 400 & $(4.0)$ & 451 & (3.2) & 565 & (5.0) \\
\hline & Italy & & & & & & & & & & & & & & & & & & \\
\hline & Abruzzo & 469 & (6.0) & 93 & (3.3) & 473 & (7.0) & 465 & $(6.9)$ & 8 & (7.3) & 310 & (12.6) & 352 & (8.5) & 411 & (6.7) & 534 & (7.5) \\
\hline & Basilicata & 455 & (4.6) & 92 & (1.9) & 463 & (6.8) & 448 & (4.6) & 15 & (6.8) & 302 & (7.6) & 338 & (6.4) & 394 & (5.9) & 515 & (4.9) \\
\hline & Bolzano & 500 & $(2.2)$ & 96 & $(1.8)$ & 508 & (3.2) & 493 & (2.9) & 15 & (4.1) & 334 & (7.6) & 371 & (4.5) & 437 & (4.1) & 568 & (4.0) \\
\hline & Calabria & 423 & (5.8) & 96 & (3.5) & 432 & $(7.7)$ & 413 & $(7.2)$ & 18 & (9.5) & 265 & $(10.2)$ & 297 & (11.5) & 359 & (7.5) & 488 & (6.7) \\
\hline & Campania & 450 & (7.8) & 94 & (3.2) & 456 & (7.9) & 444 & (9.6) & 12 & (7.7) & 292 & (11.7) & 329 & (8.5) & 386 & (9.5) & 513 & (8.5) \\
\hline & Emilia Romagna & 499 & (6.0) & 101 & $(4.1)$ & 506 & (9.5) & 491 & (6.6) & 15 & (11.4) & 326 & (14.8) & 370 & (9.9) & 434 & (6.6) & 570 & (8.4) \\
\hline & Friuli Venezia Giulia & 514 & (5.3) & 93 & (3.3) & 522 & (5.6) & 505 & (7.8) & 17 & (8.8) & 347 & (12.8) & 386 & (11.8) & 454 & (8.8) & 579 & (4.9) \\
\hline & Lazio & 473 & (7.8) & 94 & (3.1) & 481 & (8.6) & 463 & (8.4) & 18 & (7.5) & 319 & (9.7) & 354 & $(9.0)$ & 410 & (9.8) & 538 & (8.7) \\
\hline & Liguria & 487 & (5.9) & 95 & (2.6) & 490 & (7.4) & 483 & (6.6) & 7 & (7.7) & 329 & (7.8) & 365 & (6.9) & 420 & (6.9) & 553 & (8.6) \\
\hline & Lombardia & 515 & (6.4) & 88 & (2.8) & 523 & $(8.0)$ & 507 & (6.6) & 15 & (7.8) & 367 & (9.6) & 403 & (6.9) & 458 & (7.0) & 576 & (8.4) \\
\hline & Marche & 494 & (5.4) & 91 & (3.3) & 509 & (6.5) & 480 & $(5.7)$ & 29 & (6.1) & 342 & (11.0) & 375 & (9.9) & 433 & (6.7) & 557 & (5.6) \\
\hline & Molise & 462 & (2.4) & 85 & $(2.2)$ & 469 & (3.1) & 455 & (3.5) & 15 & (4.4) & 318 & (7.5) & 356 & (5.3) & 405 & (3.8) & 520 & (4.6) \\
\hline & Piemonte & 495 & (6.4) & 89 & (2.7) & 506 & (5.6) & 484 & (7.6) & 22 & (5.3) & 346 & (8.0) & 379 & (7.6) & 434 & (9.5) & 557 & $(7.2)$ \\
\hline & Puglia & 475 & (6.0) & 88 & (3.4) & 487 & (5.8) & 464 & (6.6) & 23 & (5.4) & 330 & (10.6) & 362 & $(8.7)$ & 415 & (7.6) & 538 & (6.6) \\
\hline & Sardegna & 460 & (5.7) & 91 & (2.6) & 465 & (6.7) & 455 & (6.9) & 10 & (7.4) & 308 & $(11.2)$ & 341 & (9.4) & 398 & (7.2) & 523 & (5.5) \\
\hline & Sicilia & 447 & (4.8) & 87 & (3.4) & 452 & $(6.2)$ & 440 & $(5.8)$ & 12 & $(7.1)$ & 299 & (15.1) & 335 & (8.4) & 391 & (5.1) & 505 & (5.1) \\
\hline & Toscana & 491 & (5.7) & 96 & (2.9) & 492 & (8.0) & 489 & (8.5) & 3 & (11.9) & 326 & (9.0) & 363 & (6.4) & 425 & (6.6) & 560 & (7.6) \\
\hline & Trento & 518 & (4.8) & 83 & (2.6) & 523 & (6.6) & 512 & (6.0) & 11 & (8.5) & 381 & (10.9) & 412 & (8.9) & 461 & (6.3) & 576 & (4.9) \\
\hline & Umbria & 489 & (6.5) & 92 & (3.6) & 502 & (9.6) & 477 & $(6.1)$ & 24 & $(8.7)$ & 325 & (16.3) & 364 & $(14.7)$ & 429 & (10.5) & 554 & (5.4) \\
\hline & Valle d'Aosta & 489 & (2.3) & 86 & (2.3) & 498 & (3.5) & 480 & (3.3) & 18 & (5.1) & 347 & (8.0) & 381 & (5.6) & 431 & (4.9) & 548 & (4.7) \\
\hline & Veneto & 517 & $(7.4)$ & 96 & $(4.6)$ & 525 & $(8.4)$ & 508 & $(8.0)$ & 17 & $(8.0)$ & 358 & $(14.1)$ & 397 & $(12.9)$ & 455 & (9.9) & 582 & $(10.0)$ \\
\hline & Mexico & & & & & & & & & & & & & & & & & & \\
\hline & Aguascalientes & 437 & (4.9) & 67 & $(2.5)$ & 437 & (5.6) & 437 & $(6.2)$ & $\mid-1$ & (6.4) & 323 & (9.3) & ) 349 & (7.6) & 393 & (6.3) & 483 & (5.2) \\
\hline & Baja California & 414 & (8.0) & 68 & (3.7) & 417 & $(8.7)$ & 411 & $(7.7)$ & 7 & (4.0) & 306 & (7.8) & 331 & (9.6) & 369 & (8.5) & 457 & (10.0) \\
\hline & Baja California Sur & 419 & (5.5) & 65 & (2.7) & 421 & (6.4) & 416 & (5.4) & 4 & $(4.2)$ & 312 & (11.5) & 334 & (8.9) & 375 & (7.4) & 462 & (5.8) \\
\hline & Campeche & 398 & $(4.2)$ & 65 & (3.1) & 400 & $(4.1)$ & 396 & $(5.1)$ & 4 & (3.9) & 294 & $(14.7)$ & 315 & $(8.2)$ & 357 & (5.8) & 441 & (3.7) \\
\hline & Chiapas & 381 & (5.9) & 65 & (2.8) & 385 & (6.2) & 377 & (6.4) & 9 & (4.3) & 274 & (9.4) & 297 & (6.9) & 337 & (6.3) & 423 & (5.8) \\
\hline & Chihuahua & 429 & (7.3) & 69 & (2.3) & 436 & $(9.0)$ & 422 & $(6.8)$ & 14 & (6.7) & 315 & (11.9) & 343 & $(8.1)$ & 383 & (7.2) & 475 & (8.8) \\
\hline & Coahuila & 417 & (7.3) & 64 & (2.9) & 420 & (7.9) & 415 & $(7.5)$ & 5 & (4.8) & 316 & (9.1) & 336 & $(8.0)$ & 372 & (8.2) & 461 & (8.4) \\
\hline & Colima & 429 & $(4.7)$ & 71 & (2.4) & 430 & $(5.3)$ & 429 & $(5.2)$ & 1 & (4.6) & 315 & (6.7) & 336 & (7.8) & 380 & (5.8) & 477 & (6.0) \\
\hline & Distrito Federal & 422 & (4.8) & 69 & $(2.5)$ & 433 & $(5.7)$ & 412 & (5.6) & 21 & (6.1) & 311 & (7.5) & 335 & (8.0) & 375 & (5.3) & 468 & (7.1) \\
\hline & Durango & 424 & (5.3) & 63 & (2.0) & 428 & (5.9) & 421 & (5.5) & 7 & (4.1) & 318 & (7.2) & 343 & (8.2) & 380 & (6.7) & 468 & (6.0) \\
\hline & Guanajuato & 411 & (5.7) & 68 & (3.2) & 417 & $(6.1)$ & 405 & $(6.0)$ & 11 & (4.1) & 297 & (13.4) & 324 & (10.5) & 366 & (7.3) & 458 & (5.7) \\
\hline & Guerrero & 375 & (3.9) & 62 & $(2.2)$ & 376 & (4.5) & 373 & (4.5) & 2 & (4.7) & 275 & (7.8) & 296 & (7.5) & 333 & (4.9) & 414 & (3.5) \\
\hline & Hidalgo & 402 & (5.4) & 66 & (3.0) & 406 & (6.6) & 400 & (5.4) & 6 & (5.1) & 292 & $(10.2)$ & 317 & (6.5) & 359 & (6.3) & 449 & (6.7) \\
\hline & Jalisco & 435 & $(5.2)$ & 65 & $(2.5)$ & 438 & $(6.7)$ & 431 & (4.6) & 7 & (4.5) & 329 & (8.7) & 355 & (6.8) & 392 & (5.8) & 476 & (6.4) \\
\hline & Mexico & 415 & (4.5) & 59 & (3.1) & 419 & $(5.0)$ & 412 & $(5.0)$ & 7 & (4.7) & 318 & (6.9) & 341 & (6.2) & 377 & (5.1) & 453 & (5.3) \\
\hline & Morelos & 421 & (7.9) & 69 & (6.1) & 421 & $(9.2)$ & 420 & (7.7) & 0 & (6.0) & 310 & (19.5) & 337 & (12.4) & 376 & (8.0) & 463 & (8.8) \\
\hline & Nayarit & 411 & (5.6) & 70 & (3.0) & 416 & (5.8) & 406 & (6.7) & 10 & (5.8) & 290 & (10.2) & 317 & (10.8) & 365 & (9.4) & 460 & (5.8) \\
\hline & Nuevo León & 437 & $(8.2)$ & 64 & (2.1) & 443 & (9.3) & 429 & (7.5) & 14 & (5.6) & 335 & (7.9) & 354 & (8.9) & 392 & (8.5) & 480 & (9.5) \\
\hline & Puebla & 409 & (5.3) & 66 & (3.6) & 416 & (6.7) & 402 & (5.5) & 13 & (5.9) & 295 & (12.9) & 324 & (12.8) & 369 & (6.5) & 453 & (4.9) \\
\hline & Querétaro & 434 & (5.5) & 66 & (3.0) & 441 & (5.8) & 427 & (6.1) & 13 & (4.0) & 323 & (10.1) & 348 & (9.3) & 390 & (6.7) & 477 & (7.0) \\
\hline & Quintana Roo & 404 & (5.7) & 65 & (2.4) & 407 & (6.8) & 402 & (5.4) & 5 & (4.3) & 299 & (8.9) & 323 & (8.6) & 360 & (6.4) & 449 & (6.7) \\
\hline & San Luis Potosí & 406 & (6.4) & 70 & (3.3) & 406 & (6.7) & 406 & $(7.1)$ & 0 & (5.1) & 298 & (6.2) & 319 & (4.8) & 354 & (6.1) & 453 & (8.0) \\
\hline & Sinaloa & 414 & (5.1) & 63 & (2.0) & 417 & (6.1) & 412 & $(5.1)$ & 4 & (4.7) & 315 & (6.4) & 335 & (6.0) & 372 & (6.1) & 457 & (5.8) \\
\hline & Tabasco & 382 & (3.9) & 64 & (3.0) & 388 & (5.5) & 377 & (3.4) & 11 & (4.3) & 278 & (10.1) & 303 & (5.5) & 340 & (4.3) & 424 & (5.2) \\
\hline & Tamaulipas & 408 & (6.4) & 69 & (2.7) & 414 & $(8.2)$ & 402 & (5.7) & 12 & (5.9) & 299 & (9.1) & 324 & (6.8) & 361 & (7.6) & 453 & (7.7) \\
\hline & Tlaxcala & 410 & (4.3) & 66 & (2.1) & 411 & (4.4) & 410 & (4.6) & 1 & (3.0) & 300 & (8.2) & 327 & (5.5) & 366 & (4.3) & 453 & (4.5) \\
\hline & Veracruz & 405 & (5.4) & 67 & (2.8) & 405 & (5.4) & 405 & (6.6) & 1 & (5.0) & 297 & (9.0) & 318 & (6.1) & 359 & (6.6) & 450 & (6.8) \\
\hline & Yucatán & 413 & (4.0) & 66 & (1.8) & 420 & $(5.0)$ & 406 & $(4.2)$ & 14 & (4.7) & 307 & (7.9) & 332 & (6.2) & 368 & (5.3) & 457 & (5.0) \\
\hline & Zacatecas & 412 & (3.9) & 66 & $(2.4)$ & 415 & $(4.4)$ & 409 & (4.6) & 6 & (4.4) & 304 & (9.8) & 329 & (5.6) & 370 & (5.0) & 457 & (3.7) \\
\hline
\end{tabular}

- PISA adjudicated region.

Notes: Values that are statistically significant are indicated in bold (see Annex A3).

See Table 1.2.25 for national data.

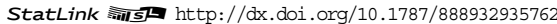


[Part 2/2]

Mean score, variation and gender differences in student performance on the mathematics Table B2.I.24 subscale uncertainty and data, by region

\begin{tabular}{|c|c|c|c|c|c|c|c|c|c|c|c|c|c|c|c|c|c|c|c|c|c|c|c|}
\hline & & \multicolumn{4}{|c|}{ All students } & \multicolumn{6}{|c|}{ Gender differences } & \multicolumn{12}{|c|}{ Percentiles } \\
\hline & & \multicolumn{2}{|c|}{ Mean score } & \multicolumn{2}{|c|}{$\begin{array}{l}\text { Standard } \\
\text { deviation }\end{array}$} & \multicolumn{2}{|c|}{ Boys } & \multicolumn{2}{|c|}{ Girls } & \multicolumn{2}{|c|}{$\begin{array}{c}\text { Difference } \\
\text { (B - G) }\end{array}$} & \multicolumn{2}{|c|}{ 5th } & \multicolumn{2}{|c|}{ 10th } & \multicolumn{2}{|c|}{ 25th } & \multicolumn{2}{|c|}{ 75th } & \multicolumn{2}{|c|}{ 90th } & \multicolumn{2}{|c|}{ 95th } \\
\hline & & Mean & S.E. & S.D. & S.E. & $\begin{array}{l}\text { Mean } \\
\text { score }\end{array}$ & S.E. & $\begin{array}{l}\text { Mean } \\
\text { score }\end{array}$ & S.E. & \begin{tabular}{|c|}
$\begin{array}{c}\text { Score } \\
\text { dif. }\end{array}$ \\
\end{tabular} & S.E. & Score & S.E. & Score & S.E. & Score & S.E. & Score & S.E. & Score & S.E. & Score & S.E. \\
\hline \multirow{2}{*}{ তি } & Portugal & & & & & & & & & & & & & & & & & & & & & & \\
\hline & Alentejo & 487 & (10.4) & 87 & (3.3) & $\mid 494$ & $(12.3) \mid$ & 479 & $(9.2)$ & 15 & $(6.5)$ & 337 & (17.1) & 372 & (11.8) & 430 & (14.6) & 547 & (9.1) & 600 & (9.6) & | 627 & (11.1) \\
\hline \multicolumn{24}{|c|}{ 年 } \\
\hline & Andalusia ${ }^{\bullet}$ & 476 & (4.6) & 92 & (2.1) & 483 & (6.0) & 468 & $(4.2)$ & 16 & (5.0) & 330 & (8.6) & 363 & (6.3) & 414 & (5.5) & 538 & (5.9) & 595 & $(6.8)$ & |628 & (6.4) \\
\hline & Aragon ${ }^{\bullet}$ & 500 & (5.0) & 98 & (2.8) & 508 & (5.7) & 492 & $(5.7)$ & 16 & (5.3) & 328 & (10.7) & 368 & $(7.7)$ & 435 & (7.6) & 568 & (5.9) & 622 & $(9.2)$ & 654 & (7.5) \\
\hline & Asturias ${ }^{\bullet}$ & 501 & (4.6) & 96 & (2.1) & 501 & (6.3) & 500 & (3.9) & 1 & (5.1) & 342 & (10.3) & 379 & (6.9) & 438 & (5.4) & 567 & $(5.7)$ & 624 & $(6.0)$ & 652 & (6.7) \\
\hline & Balearic Islands ${ }^{\bullet}$ & 476 & (5.1) & 92 & (2.6) & 480 & (5.7) & 473 & (5.7) & 7 & $(5.2)$ & 319 & (8.1) & 353 & (10.6) & 415 & (6.6) & 539 & (5.0) & 591 & $(6.2)$ & 620 & (7.3) \\
\hline & Basque Country ${ }^{\bullet}$ & 511 & (2.7) & 86 & (1.2) & 517 & (3.3) & 505 & (3.1) & 12 & (3.3) & 364 & (3.6) & 396 & $(4.0)$ & 454 & (3.4) & 572 & (3.0) & 620 & (3.4) & 647 & (3.5) \\
\hline & Cantabria $\bullet^{\bullet}$ & 492 & (4.0) & 98 & (2.3) & 500 & (4.9) & 484 & (5.3) & 17 & (6.4) & 335 & (7.5) & 368 & (7.6) & 427 & (4.9) & 562 & (6.4) & 617 & $(6.1)$ & 646 & (4.8) \\
\hline & Castile and Leon ${ }^{\bullet}$ & 511 & (4.8) & 89 & (2.5) & 518 & (5.8) & 504 & $(5.1)$ & 14 & (5.1) & 359 & (8.5) & 392 & $(7.2)$ & 451 & (6.8) & 575 & (4.8) & 621 & $(4.6)$ & 647 & (6.1) \\
\hline & Catalonia・ & 496 & (5.9) & 92 & (2.3) & 508 & (7.0) & 483 & (6.4) & 25 & (6.6) & 340 & (9.4) & 373 & $(7.7)$ & 433 & (7.8) & 561 & (6.4) & 615 & $(7.4)$ & 646 & (7.4) \\
\hline & Extremadura ${ }^{\bullet}$ & 464 & (4.6) & 98 & (2.8) & 469 & (5.3) & 458 & (4.9) & 11 & (4.4) & 298 & $(10.2)$ & 335 & (9.9) & 397 & (6.5) & 532 & (4.3) & 587 & $(5.7)$ & 619 & (6.0) \\
\hline & Galicia ${ }^{\bullet}$ & 491 & (4.7) & 97 & (2.4) & 490 & (5.9) & 491 & (5.0) & 0 & (5.7) & 325 & (12.2) & 367 & (7.9) & 426 & (7.8) & 560 & (5.2) & 613 & $(4.7)$ & 642 & (4.0) \\
\hline & La Rioja` & 503 & (2.1) & 103 & (2.4) & 513 & (3.1) & 495 & (3.2) & 18 & (4.8) & 328 & (9.3) & 366 & (5.5) & 434 & $(4.2)$ & 578 & (3.6) & 633 & $(5.7)$ & 665 & (4.9) \\
\hline & Madrid ${ }^{\bullet}$ & 505 & (3.6) & 84 & (1.8) & 514 & (4.8) & 496 & (3.6) & 18 & (4.6) & 361 & (8.3) & 395 & (5.5) & 448 & (5.3) & 566 & (4.1) & 610 & (5.1) & 638 & (6.0) \\
\hline & Murcia ${ }^{\bullet}$ & 464 & (4.9) & 96 & (2.8) & 472 & (6.1) & 456 & (4.6) & 16 & (4.7) & 301 & (9.4) & 339 & (7.9) & 400 & (5.4) & 531 & (6.9) & 586 & (6.7) & 616 & (10.4) \\
\hline & Navarre ${ }^{\bullet}$ & 515 & (3.2) & 91 & (2.1) & 520 & (4.4) & 510 & (3.4) & 10 & $(4.7)$ & 355 & $(7.2)$ & 393 & (6.8) & 456 & (4.8) & 579 & (3.7) & 626 & (4.9) & 654 & (5.9) \\
\hline \multicolumn{24}{|c|}{ United Kingdom } \\
\hline & England & 503 & (3.6) & 98 & (1.9) & 511 & (4.9) & 497 & (4.1) & 14 & (5.5) & 340 & (5.7) & 377 & (4.8) & 437 & (4.5) & 572 & (3.9) & 628 & (4.5) & 662 & (4.9) \\
\hline & Northern Ireland & 496 & (3.4) & 95 & (2.3) & 501 & (5.2) & 491 & (5.5) & 10 & $(8.2)$ & 336 & (7.1) & 373 & (5.6) & 428 & (4.9) & 564 & $(4.2)$ & 619 & $(5.5)$ & 651 & (5.9) \\
\hline & Scotland ${ }^{\bullet}$ & 504 & (2.6) & 87 & (1.7) & 510 & (2.9) & 498 & (3.5) & 12 & (3.5) & 358 & (6.3) & 393 & (4.8) & 446 & (3.7) & 565 & (3.0) & 615 & $(3.0)$ & 646 & (4.4) \\
\hline & Wales & 483 & (2.7) & 88 & (1.3) & 487 & (3.2) & 478 & (3.2) & 9 & (3.4) & 336 & (4.8) & 369 & (3.9) & 423 & (3.8) & 543 & (2.9) & 596 & $(4.1)$ & 627 & (4.4) \\
\hline \multicolumn{24}{|c|}{ United States } \\
\hline & Connecticut $^{\bullet}$ & 512 & (5.8) & 98 & (2.8) & 518 & (6.3) & 505 & (6.2) & 13 & $(4.7)$ & 353 & (8.3) & 383 & (8.6) & 442 & (7.4) & 581 & (6.7) & 640 & (8.4) & 671 & (9.8) \\
\hline & Florida ${ }^{\bullet}$ & 475 & (5.9) & 84 & (2.8) & 480 & (6.2) & 468 & (6.3) & 12 & (4.1) & 342 & (7.8) & 370 & (7.2) & 417 & (6.1) & 530 & (6.8) & 584 & $(8.4)$ & 614 & (10.7) \\
\hline & Massachusetts ${ }^{\bullet}$ & 523 & (6.4) & 96 & (3.1) & 527 & (6.5) & 518 & (7.0) & 9 & $(4.2)$ & 370 & (7.6) & 402 & $(6.1)$ & 455 & (6.8) & 589 & (9.1) & 648 & $(7.8)$ & 681 & (11.5) \\
\hline
\end{tabular}

\begin{tabular}{|c|c|c|c|c|c|c|c|c|c|c|c|c|c|c|c|c|c|c|c|c|c|c|c|}
\hline \multirow{3}{*}{ } & \multicolumn{23}{|l|}{ Argentina } \\
\hline & Ciudad Autónoma de Buenos Aires ${ }^{\bullet}$ & 411 & $(7.6) \mid$ & 101 & $(8.1)$ & 421 & (8.5) & 402 & $(8.0)$ & 19 & $(6.7) \mid$ & 234 & $(30.3)$ & 284 & $(15.3)$ & 351 & $(10.6)$ & 477 & (5.6) & 532 & $(6.3)$ & 563 & (8.7) \\
\hline & \multicolumn{23}{|l|}{ Brazil } \\
\hline & Acre & 375 & (5.1) & 66 & (2.4) & 379 & (7.2) & 372 & (5.3) & 7 & (7.2) & 275 & (10.5) & 297 & (5.5) & 330 & (5.8) & 419 & (6.9) & 463 & (7.9) & 487 & (10.4) \\
\hline & Alagoas & 352 & (7.6) & 69 & (4.4) & 355 & (8.8) & 350 & (7.6) & 5 & (5.5) & 242 & (14.5) & 268 & $(11.8)$ & 309 & (8.7) & 395 & (8.4) & 442 & (11.4) & 471 & (13.2) \\
\hline & Amapá & 378 & (7.4) & 67 & (5.5) & 383 & (9.0) & 374 & (7.0) & 9 & (6.3) & 275 & (15.5) & 298 & $(9.1)$ & 335 & (8.4) & 422 & $(8.2)$ & 463 & $(15.8)$ & 489 & $(14.1)$ \\
\hline & Amazonas & 372 & (4.8) & 64 & $(4.2)$ & 375 & (5.7) & 369 & (4.4) & 6 & (3.4) & 275 & (9.9) & 297 & $(7.1)$ & 333 & (5.5) & 410 & (5.2) & 450 & $(9.2)$ & 475 & (12.7) \\
\hline & Bahia & 386 & (8.6) & 78 & (4.9) & 387 & (9.0) & 385 & $(10.2)$ & 2 & (8.6) & 255 & (18.4) & 283 & (15.9) & 336 & (11.8) & 436 & (9.6) & 487 & (9.5) & 515 & (10.8) \\
\hline & Ceará & 393 & (8.2) & 71 & (5.7) & 397 & (9.3) & 389 & (9.2) & 8 & (8.5) & 280 & (12.7) & 305 & (12.7) & 348 & (8.1) & 435 & (11.1) & 483 & $(18.3)$ & 520 & (22.7) \\
\hline & Espírito Santo & 417 & (8.0) & 78 & (5.2) & 424 & (7.1) & 410 & (11.1) & 13 & (9.3) & 294 & (11.0) & 322 & (9.0) & 362 & (5.8) & 468 & (13.3) & 521 & (16.5) & 555 & (16.1) \\
\hline & Federal District & 418 & (8.2) & 76 & (6.8) & 423 & (10.6) & 413 & (7.4) & 10 & (7.5) & 291 & (14.7) & 321 & (18.3) & 367 & (13.4) & 470 & (8.6) & 521 & (16.1) & 544 & (17.1) \\
\hline & Goiás & 385 & (3.8) & 63 & (2.5) & 394 & (5.2) & 377 & (4.4) & 17 & (5.9) & 290 & (9.5) & 309 & (6.7) & 342 & (6.0) & 424 & (4.4) & 466 & (5.9) & 498 & (7.0) \\
\hline & Maranhão & 359 & (12.6) & 75 & (5.8) & 367 & (14.8) & 353 & (11.7) & 15 & (6.7) & 246 & (9.3) & 266 & $(10.2)$ & 304 & (9.8) & 409 & (17.5) & 458 & (23.5) & 493 & (21.6) \\
\hline & Mato Grosso & 377 & (9.0) & 70 & (5.1) & 375 & (9.2) & 378 & (9.5) & -3 & (5.6) & 270 & (10.4) & 293 & (10.4) & 330 & (9.0) & 420 & (9.9) & 464 & $(16.3)$ & 503 & (25.3) \\
\hline & Mato Grosso do Sul & 415 & (6.7) & 70 & (3.0) & 422 & (8.6) & 410 & (6.9) & 12 & (7.9) & 305 & $(12.2)$ & 326 & (11.4) & 367 & (9.9) & 459 & (6.7) & 510 & (7.4) & 536 & (9.3) \\
\hline & Minas Gerais & 416 & (5.9) & 66 & (3.8) & 419 & (7.5) & 413 & (5.6) & 7 & (5.5) & 310 & (9.3) & 334 & (7.8) & 371 & (6.2) & 460 & (8.0) & 502 & $(10.3)$ & 529 & (10.7) \\
\hline & Pará & 372 & (5.0) & 66 & (2.9) & 378 & (5.9) & 367 & (6.6) & 11 & (7.8) & 268 & (9.6) & 289 & (8.9) & 327 & $(8.2)$ & 417 & (5.9) & 459 & (5.5) & 485 & (6.9) \\
\hline & Paraíba & 408 & (6.0) & 67 & (4.8) & 413 & (6.7) & 405 & (7.9) & 8 & (8.4) & 301 & (13.2) & 327 & (11.8) & 363 & (8.1) & 453 & (6.5) & 493 & (9.7) & 526 & (12.4) \\
\hline & Paraná & 409 & (10.9) & 75 & (9.6) & 416 & (10.5) & 401 & (12.1) & 15 & (5.9) & 298 & (8.2) & 320 & (7.7) & 355 & (7.6) & 456 & (15.4) & 506 & (31.7) & 548 & (37.7) \\
\hline & Pernambuco & 380 & (8.7) & 64 & (3.4) & 386 & (9.5) & 375 & (8.6) & 11 & (4.3) & 277 & $(10.0)$ & 301 & (7.8) & 338 & (8.8) & 422 & (10.8) & 458 & (11.4) & 487 & (14.7) \\
\hline & Piauí & 394 & (7.9) & 74 & $(9.2)$ & 400 & (8.6) & 389 & (7.9) & 11 & (4.0) & 289 & (8.3) & 306 & (9.0) & 346 & (6.8) & 432 & (8.6) & 494 & (22.9) & 534 & (38.1) \\
\hline & Rio de & 400 & (7.9) & 64 & (5.0) & 407 & (8.6) & 393 & (8.0) & 14 & (4.7) & 298 & (11.0) & 319 & (9.2) & 357 & (8.5) & 442 & (9.2) & 481 & (13.1) & 510 & (15.2) \\
\hline & do Norte & 400 & (7.7) & 76 & (6.4) & 414 & (9.5) & 390 & (7.4) & 23 & (6.7) & 287 & (10.3) & 312 & (8.9) & 350 & (7.3) & 444 & (11.9) & 507 & (19.2) & 542 & (28.6) \\
\hline & nde do Sul & 418 & (6.9) & 63 & (3.7) & 425 & (7.3) & 412 & (7.6) & 14 & (5.4) & 316 & (13.1) & 338 & (11.1) & 375 & (9.1) & 462 & (7.8) & 501 & (8.0) & 520 & (8.0) \\
\hline & Rondônia & 399 & (5.7) & 61 & (3.2) & 404 & (5.9) & 393 & (6.5) & 11 & (5.0) & 292 & (11.9) & 318 & (10.9) & 359 & (7.3) & 441 & (6.4) & 475 & (6.4) & 496 & (8.3) \\
\hline & Roraima & 383 & (7.1) & 71 & (4.8) & 387 & (7.5) & 380 & (9.1) & 6 & (8.6) & 279 & (10.3) & 299 & (7.1) & 336 & (8.8) & 429 & (10.8) & 478 & (13.3) & 510 & (19.6) \\
\hline & Santa & 416 & (7.4) & 71 & (4.3) & 424 & (7.4) & 408 & (9.0) & 16 & (7.4) & 294 & (22.7) & 326 & (11.1) & 375 & (8.8) & 463 & (9.7) & 503 & (12.5) & 531 & (12.9) \\
\hline & São P & 413 & (3.8) & 69 & (2.9) & 419 & (4.2) & 407 & (4.1) & 12 & (3.1) & 304 & (6.2) & 328 & (4.7) & 367 & (3.6) & 457 & (4.9) & 505 & (8.4) & 534 & (10.0) \\
\hline & Sergi & 394 & (9.0) & 64 & (4.6) & 405 & (12.0) & 385 & (7.9) & 20 & (7.5) & 297 & (11.1) & 317 & (6.8) & 348 & (8.0) & 436 & (13.5) & 482 & (15.0) & 509 & (18.2) \\
\hline & Tocantins & 385 & (6.1) & 71 & (3.6) & 394 & (7.7) & 377 & (5.4) & 17 & (5.7) & 274 & (7.0) & 298 & (7.4) & 337 & (6.8) & 429 & (7.6) & 480 & $(10.3)$ & 505 & (10.7) \\
\hline \multicolumn{24}{|c|}{ Colombia } \\
\hline & Bogotá & 403 & (3.5) & 63 & (2.1) & 415 & (4.9) & 392 & (3.3) & 23 & (4.6) & 301 & (4.6) & 324 & (4.3) & 362 & (3.6) & 443 & (4.4) & 482 & (5.3) & 509 & (7.3) \\
\hline & Cali & 387 & (4.9) & 67 & $(2.2)$ & 395 & (5.3) & 382 & (5.4) & 13 & (4.1) & 279 & (6.7) & 302 & (5.5) & 342 & (5.4) & 431 & (5.8) & 474 & (6.9) & 500 & (7.3) \\
\hline & Mani & 412 & (3.9) & 64 & (3.4) & 425 & (6.5) & 400 & (3.6) & 24 & (6.9) & 311 & $(8.2)$ & 335 & (6.0) & 370 & (4.8) & 453 & (6.3) & 495 & (8.1) & 520 & (10.6) \\
\hline & Medellín & 402 & (6.6) & 76 & (5.5) & 412 & $(8.0)$ & 394 & (7.3) & 18 & (7.9) & 287 & (8.1) & 313 & (6.8) & 351 & (5.9) & 447 & (8.8) & 499 & (13.5) & 536 & $(24$ \\
\hline \multicolumn{24}{|c|}{ Russian Fe } \\
\hline & Perm Territory & 466 & (5.7) & 89 & (4.1) & 466 & (7.2)| & 467 & (5.1 & 0 & (5.0)| & 321 & (10.5) & 355 & (7.8) & 408 & (6.6) & 524 & (7.2) & $\mid 579$ & (9.6)| & 616 & (14.3) \\
\hline \multicolumn{24}{|c|}{ United Arab Emirates } \\
\hline & Abu Dhabi & 421 & (4.2) & 85 & (2.4) & 411 & (5.5) & 430 & (5.1) & -19 & (6.7) & 287 & (4.9) & 315 & (4.7) & 362 & (4.2) & 475 & (5.4) & 533 & (6.4) & 570 & (10.1) \\
\hline & Ajman & 404 & (8.7) & 77 & (4.5) & 392 & (11.9) & 415 & (12.4) & -23 & (17.4) & 281 & (14.9) & 304 & (13.1) & 350 & (12.5) & 458 & (10.1) & 507 & (11.5) & 535 & $(10.2)$ \\
\hline & Dubai ${ }^{\bullet}$ & 460 & (1.1) & 91 & (1.0) & 463 & (1.7) & 456 & (1.6) & 8 & (2.4) & 316 & (3.1) & 345 & (2.7) & 395 & (2.3) & 522 & (3.2) & 579 & (4.0) & 611 & $(4.0)$ \\
\hline & Fujairah & 406 & (9.3) & 80 & (3.1) & 385 & (8.9) & 427 & (8.2) & -42 & (9.1) & 274 & (15.4) & 301 & (11.8) & 350 & (10.9) & 462 & (9.9) & 506 & (8.8) & 536 & (7.4) \\
\hline & Ras al-Khaimah & 412 & (6.6) & 75 & (3.2) & 397 & (10.0) & 425 & (8.7) & -28 & (12.7) & 287 & (11.6) & 316 & (10.4) & 360 & (8.5) & 463 & (7.9) & 506 & (6.4) & 534 & (11.2) \\
\hline & Sharjal & 438 & (8.7) & 80 & (3.5) & 447 & (14.0) & 430 & (11.0) & 16 & (19.6) & 310 & (11.3) & 340 & (9.1) & 381 & (8.0) & 494 & (9.9) & 542 & (11.5) & 571 & (13.7) \\
\hline & Umm al-Quwain & 398 & (3.8) & 72 & (3.2) & 378 & (4.9) & 417 & (5.0) & -39 & (6.5) & 278 & (7.3) & 304 & (8.4) & 349 & (8.0) & 444 & (6.8) & 492 & $(11.0)$ & 514 & (13.5) \\
\hline
\end{tabular}

- PISA adjudicated region.

Notes: Values that are statistically significant are indicated in bold (see Annex A3).

See Table 1.2.25 for national data.

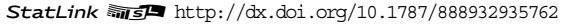


[Part 1/2]

Table B2.I.25 Percentage of students at each proficiency level in reading, by region

\begin{tabular}{|c|c|c|c|c|c|c|c|c|c|c|c|c|c|c|c|c|c|}
\hline & & \multicolumn{16}{|c|}{ All students } \\
\hline & & $\begin{array}{l}\text { Below } \\
\text { (less tha } \\
\text { score }\end{array}$ & $\begin{array}{l}\text { evel 1b } \\
\text { 262.04 } \\
\text { ooints) }\end{array}$ & $\begin{array}{l}\text { Lev } \\
\text { (from } 2 \\
\text { less tha } \\
\text { score }\end{array}$ & \begin{tabular}{|l|}
$1 \mathrm{~b}$ \\
2.04 to \\
334.75 \\
oints)
\end{tabular} & $\begin{array}{l}\text { Lev } \\
\text { (from } 3 \\
\text { less tha } \\
\text { score }\end{array}$ & $\begin{array}{l}\mid 1 \mathrm{a} \\
4.75 \text { to } \\
407.47 \\
\text { oints) }\end{array}$ & $\begin{array}{l}\text { Le } \\
\text { (from } \\
\text { less th } \\
\text { score }\end{array}$ & $\begin{array}{l}\text { el } 2 \\
7.47 \text { to } \\
480.18 \\
\text { ooints) }\end{array}$ & $\begin{array}{r}\text { Le } \\
\text { (from } 4 \\
\text { less tha } \\
\text { score }\end{array}$ & $\begin{array}{l}\text { el } 3 \\
80.18 \text { to } \\
552.89 \\
\text { points) }\end{array}$ & \begin{tabular}{|r} 
Le \\
(from 5 \\
less tha \\
score
\end{tabular} & \begin{tabular}{l|} 
el 4 \\
22.89 to \\
625.61 \\
oints)
\end{tabular} & $\begin{array}{r}\text { Le } \\
\text { (from } \\
69 \\
\text { score }\end{array}$ & $\begin{array}{l}5 \\
5.61 \text { to } \\
.32 \\
\text { ooints }\end{array}$ & $\begin{array}{l}\text { Le } \\
\text { (above } \\
\text { score }\end{array}$ & $\begin{array}{l}\text { el } 6 \\
698.32 \\
\text { oints) }\end{array}$ \\
\hline & & $\%$ & S.E. & $\%$ & S.E. & $\%$ & S.E. & $\%$ & S.E. & $\%$ & S.E. & $\%$ & S.E. & $\%$ & S.E. & $\%$ & S.E. \\
\hline 0 & Australia & & & & & & & & & & & & & & & & \\
\hline & Australian Capital Territory & 1.5 & $(0.6)$ & 3.8 & $(0.8)$ & 7.4 & (1.1) & 15.7 & (1.9) & 28.6 & (1.8) & 27.8 & $(2.6)$ & 13.1 & $(1.8)$ & 2.1 & $(0.8)$ \\
\hline & New South Wales & 1.1 & $(0.3)$ & 3.6 & $(0.5)$ & 10.2 & $(0.8)$ & 21.6 & $(1.0)$ & 27.0 & (1.0) & 23.2 & $(1.0)$ & 11.1 & $(1.0)$ & 2.3 & $(0.4)$ \\
\hline & Northern Territory & 7.4 & (1.6) & 7.3 & (1.5) & 13.8 & (3.0) & 19.9 & (3.1) & 25.6 & $(3.2)$ & 19.5 & (3.1) & 6.2 & $(2.2)$ & 0.3 & c \\
\hline & Queensland & 0.8 & $(0.2)$ & 3.1 & $(0.5)$ & 11.1 & $(0.8)$ & 23.0 & $(1.2)$ & 28.9 & (1.3) & 22.2 & (1.5) & 9.0 & $(0.9)$ & 2.0 & $(0.4)$ \\
\hline & South Australia & 0.9 & $(0.3)$ & 3.4 & $(0.7)$ & 11.4 & (1.6) & 23.8 & (1.6) & 30.6 & (1.7) & 21.8 & (1.9) & 7.4 & $(0.9)$ & 0.7 & $(0.3)$ \\
\hline & Tasmania & 2.0 & $(0.5)$ & 5.0 & $(0.9)$ & 13.9 & (1.4) & 26.3 & (1.8) & 27.2 & $(2.1)$ & 18.8 & (1.9) & 6.1 & (1.1) & 0.6 & $(0.3)$ \\
\hline & Victoria & 0.5 & $(0.1)$ & 2.4 & $(0.4)$ & 9.2 & (1.0) & 20.4 & (1.2) & 31.8 & (1.3) & 24.4 & (1.1) & 9.3 & $(0.9)$ & 2.0 & $(0.5)$ \\
\hline & Western Australia & 0.6 & $(0.2)$ & 2.4 & $(0.5)$ & 9.3 & $(0.9)$ & 20.8 & (1.1) & 29.1 & (1.3) & 25.1 & (1.3) & 10.8 & $(1.0)$ & 1.9 & $(0.5)$ \\
\hline & Belgium & & & & & & & & & & & & & & & & \\
\hline & Flemish Community• & 1.1 & $(0.3)$ & 3.3 & $(0.4)$ & 9.3 & $(0.7)$ & 19.6 & $(1.0)$ & 27.4 & (1.1) & 26.2 & $(1.0)$ & 11.7 & $(0.8)$ & 1.5 & $(0.2)$ \\
\hline & French Community & 2.3 & $(0.6)$ & 5.1 & $(0.7)$ & 11.8 & $(0.9)$ & 21.6 & $(1.0)$ & 27.1 & $(1.2)$ & 22.1 & $(1.0)$ & 8.7 & $(0.8)$ & 1.3 & $(0.3)$ \\
\hline & German-speaking Community & 1.8 & (0.6) & 4.2 & $(0.9)$ & 11.9 & (1.3) & 20.1 & $(1.7)$ & 29.6 & (1.8) & 24.6 & $(1.8)$ & 7.3 & $(1.1)$ & 0.6 & $(0.4)$ \\
\hline & Canada & & & & & & & & & & & & & & & & \\
\hline & Alberta & 0.4 & $(0.2)$ & 2.2 & $(0.5)$ & 8.0 & $(0.9)$ & 19.3 & (1.2) & 30.1 & (1.5) & 26.2 & (1.5) & 11.8 & $(1.0)$ & 2.0 & $(0.4)$ \\
\hline & British Columbia & 0.2 & $(0.2)$ & 1.7 & $(0.5)$ & 6.0 & (1.1) & 17.3 & (1.6) & 30.8 & (1.9) & 29.2 & (1.5) & 12.1 & $(1.2)$ & 2.6 & $(0.6)$ \\
\hline & Manitoba & 1.1 & $(0.4)$ & 3.8 & $(0.7)$ & 12.1 & (1.1) & 26.0 & $(2.2)$ & 28.1 & (1.4) & 21.4 & (1.5) & 6.5 & $(0.9)$ & 0.9 & $(0.3)$ \\
\hline & New Brunswick & 0.7 & $(0.3)$ & 3.7 & $(0.6)$ & 11.6 & $(1.0)$ & 25.9 & $(2.2)$ & 31.9 & $(2.0)$ & 19.2 & (1.4) & 6.1 & $(0.9)$ & 1.0 & $(0.4)$ \\
\hline & Newfoundland and Labrador & 0.9 & $(0.6)$ & 4.0 & $(1.1)$ & 11.5 & $(1.3)$ & 22.2 & $(2.0)$ & 30.9 & $(2.3)$ & 21.0 & $(1.3)$ & 7.9 & $(1.2)$ & 1.7 & $(0.5)$ \\
\hline & Nova Scotia & 0.6 & $(0.5)$ & 3.5 & $(0.6)$ & 8.2 & (1.2) & 21.7 & (1.6) & 35.2 & $(2.3)$ & 22.0 & $(2.8)$ & 7.6 & (1.7) & 1.1 & $(0.4)$ \\
\hline & Ontario & 0.4 & $(0.2)$ & 2.2 & $(0.4)$ & 7.2 & $(0.8)$ & 18.3 & (1.1) & 31.2 & (1.1) & 26.6 & (1.4) & 11.6 & $(1.2)$ & 2.5 & $(0.4)$ \\
\hline & Prince Edward Island & 0.7 & $(0.3)$ & 4.4 & $(0.9)$ & 13.9 & (1.6) & 25.7 & (1.9) & 30.2 & $(1.8)$ & 19.8 & $(1.1)$ & 4.8 & $(0.8)$ & 0.4 & $(0.3)$ \\
\hline & Quebec & 0.6 & $(0.2)$ & 2.4 & $(0.4)$ & 8.8 & $(0.8)$ & 19.6 & (1.0) & 31.0 & (1.5) & 25.4 & $(1.2)$ & 10.4 & $(0.9)$ & 1.8 & $(0.5)$ \\
\hline & Saskatchewan & 0.5 & $(0.2)$ & 3.0 & $(0.5)$ & 10.3 & (1.2) & 23.4 & (1.2) & 33.1 & (1.6) & 21.2 & (1.3) & 7.5 & $(0.9)$ & 1.0 & $(0.3)$ \\
\hline & Italy & & & & & & & & & & & & & & & & \\
\hline & Abruzzo & 1.9 & $(0.7)$ & 6.3 & (1.2) & 14.1 & (1.7) & 23.7 & (1.5) & 30.4 & $(2.1)$ & 18.5 & (1.7) & 4.8 & (1.1) & 0.3 & $(0.2)$ \\
\hline & Basilicata & 0.9 & $(0.4)$ & 5.2 & (1.2) & 14.6 & (1.7) & 30.0 & (1.9) & 31.5 & $(2.2)$ & 14.7 & (1.5) & 2.9 & $(0.6)$ & 0.1 & $(0.1)$ \\
\hline & Bolzano & 1.3 & $(0.5)$ & 4.3 & $(0.6)$ & 10.8 & $(0.9)$ & 22.8 & (1.8) & 32.5 & $(1.5)$ & 21.8 & (1.1) & 6.1 & $(0.7)$ & 0.4 & $(0.2)$ \\
\hline & Calabria & 4.4 & $(1.8)$ & 11.7 & (1.5) & 21.2 & $(2.0)$ & 28.2 & $(2.1)$ & 23.9 & (1.9) & 8.9 & $(1.2)$ & 1.5 & $(0.5)$ & 0.0 & c \\
\hline & Campania & 1.7 & $(0.6)$ & 8.1 & (1.5) & 18.4 & (2.1) & 26.6 & $(2.3)$ & 26.3 & $(2.0)$ & 15.8 & $(3.0)$ & 3.0 & $(0.9)$ & 0.2 & $(0.1)$ \\
\hline & Emilia Romagna & 2.1 & $(0.6)$ & 5.4 & (1.2) & 10.5 & (1.7) & 20.4 & (1.8) & 30.4 & $(2.2)$ & 22.3 & (1.5) & 8.0 & (1.1) & 1.0 & $(0.4)$ \\
\hline & Friuli Venezia Giulia & 0.9 & $(0.4)$ & 2.8 & $(1.2)$ & 8.7 & (1.6) & 18.1 & (1.5) & 31.6 & $(2.0)$ & 27.4 & (1.6) & 9.4 & $(0.9)$ & 1.1 & $(0.3)$ \\
\hline & Lazio & 1.1 & $(0.6)$ & 5.3 & (1.4) & 14.5 & $(2.4)$ & 27.2 & $(2.0)$ & 29.0 & $(2.1)$ & 17.8 & $(2.3)$ & 4.7 & $(1.0)$ & 0.3 & $(0.1)$ \\
\hline & Liguria & 1.4 & $(0.5)$ & 5.7 & (1.5) & 12.8 & (1.5) & 23.6 & (1.9) & 28.4 & $(2.1)$ & 20.9 & $(2.0)$ & 6.7 & $(1.2)$ & 0.6 & $(0.3)$ \\
\hline & Lombardia & 0.6 & $(0.2)$ & 2.6 & $(0.6)$ & 7.2 & $(1.2)$ & 19.2 & $(2.1)$ & 31.8 & $(2.4)$ & 28.1 & $(2.2)$ & 9.4 & (1.6) & 0.9 & $(0.3)$ \\
\hline & Marche & 0.5 & $(0.3)$ & 3.9 & $(1.2)$ & 11.9 & (1.6) & 24.9 & (1.8) & 31.2 & $(2.0)$ & 21.2 & (1.8) & 5.9 & (1.0) & 0.5 & $(0.2)$ \\
\hline & Molise & 1.9 & $(0.5)$ & 5.5 & $(0.9)$ & 14.3 & (1.8) & 26.3 & (2.8) & 32.5 & (1.9) & 15.8 & (1.4) & 3.4 & $(0.8)$ & 0.3 & $(0.2)$ \\
\hline & Piemonte & 0.8 & $(0.4)$ & 2.5 & $(0.8)$ & 9.6 & $(1.2)$ & 24.0 & (1.9) & 32.9 & $(1.8)$ & 22.4 & $(1.5)$ & 7.1 & (1.3) & 0.8 & $(0.3)$ \\
\hline & Puglia & 1.2 & $(0.5)$ & 4.6 & (1.1) & 10.8 & (1.3) & 24.3 & $(2.1)$ & 32.7 & $(2.3)$ & 20.2 & $(2.1)$ & 5.6 & (1.0) & 0.5 & $(0.2)$ \\
\hline & Sardegna & 3.3 & $(0.9)$ & 7.2 & (1.4) & 16.8 & (1.7) & 26.3 & $(2.0)$ & 27.4 & $(2.2)$ & 15.7 & $(1.7)$ & 3.1 & $(0.6)$ & 0.2 & $(0.1)$ \\
\hline & Sicilia & 2.9 & $(0.9)$ & 7.5 & (1.1) & 19.3 & $(2.1)$ & 29.6 & (1.9) & 26.7 & $(2.0)$ & 12.0 & (1.5) & 1.9 & (0.4) & 0.2 & $(0.1)$ \\
\hline & Toscana & 2.1 & $(0.6)$ & 5.9 & $(1.3)$ & 13.3 & $(1.8)$ & 21.4 & (2.3) & 29.5 & $(1.7)$ & 20.4 & (1.9) & 6.6 & $(1.2)$ & 0.6 & $(0.3)$ \\
\hline & Trento & 0.9 & $(0.4)$ & 2.8 & $(1.0)$ & 8.0 & $(1.1)$ & 20.4 & $(2.1)$ & 27.7 & $(2.3)$ & 27.1 & $(1.8)$ & 11.7 & (1.2) & 1.4 & $(0.4)$ \\
\hline & Umbria & 1.8 & $(0.8)$ & 4.3 & (1.4) & 11.9 & (1.4) & 22.3 & (1.9) & 32.6 & (1.9) & 21.9 & (1.9) & 4.8 & $(0.6)$ & 0.4 & $(0.2)$ \\
\hline & Valle d'Aosta & 1.1 & $(0.5)$ & 2.7 & $(0.8)$ & 10.3 & (1.7) & 24.7 & (2.3) & 32.1 & $(2.2)$ & 22.0 & (1.5) & 6.3 & (0.8) & 0.9 & $(0.4)$ \\
\hline & Veneto & 1.4 & $(0.6)$ & 2.7 & $(0.8)$ & 7.6 & $(1.2)$ & 18.3 & (1.5) & 30.1 & $(2.3)$ & 27.6 & $(1.7)$ & 10.5 & (1.6) & 1.8 & $(0.5)$ \\
\hline & Mexico & & & & & & & & & & & & & & & & \\
\hline & Aguascalientes & 1.5 & $(0.8)$ & 6.8 & (1.4) & 21.8 & $(2.2)$ & 35.3 & $(2.1)$ & 26.2 & $(2.3)$ & 7.5 & $(1.2)$ & 0.9 & $(0.4)$ & 0.0 & c \\
\hline & Baja California & 1.5 & $(0.7)$ & 9.7 & $(2.2)$ & 29.2 & (2.8) & 34.6 & $(2.6)$ & 19.0 & $(2.3)$ & 5.4 & (1.2) & 0.7 & $(0.5)$ & 0.0 & c \\
\hline & Baja California Sur & 1.6 & $(0.8)$ & 10.5 & (2.6) & 28.1 & $(2.2)$ & 37.9 & $(2.1)$ & 18.4 & $(2.0)$ & 3.5 & $(1.0)$ & 0.1 & c & 0.0 & c \\
\hline & Campeche & 2.5 & (1.1) & 13.2 & $(2.1)$ & 31.0 & (2.5) & 34.6 & $(2.3)$ & 15.1 & $(1.7)$ & 3.2 & $(0.8)$ & 0.3 & $(0.3)$ & 0.1 & C \\
\hline & Chiapas & 9.1 & $(2.3)$ & 23.5 & $(2.9)$ & 34.8 & (3.1) & 23.6 & (2.6) & 7.7 & $(1.4)$ & 1.2 & $(0.6)$ & 0.1 & c & 0.0 & $\mathrm{C}$ \\
\hline & Chihuahua & 2.2 & $(0.8)$ & 7.4 & $(1.7)$ & 21.7 & (3.1) & 34.9 & (1.9) & 24.5 & $(3.1)$ & 8.7 & $(2.1)$ & 0.5 & $(0.4)$ & 0.0 & c \\
\hline & Coahuila & 1.1 & $(0.6)$ & 10.3 & $(2.1)$ & 26.4 & (2.9) & 35.2 & $(2.2)$ & 21.9 & $(3.0)$ & 4.8 & $(1.5)$ & 0.3 & $(0.3)$ & 0.0 & c \\
\hline & Colima & 1.5 & $(0.7)$ & 8.7 & (1.7) & 23.7 & $(2.1)$ & 34.1 & $(2.0)$ & 23.4 & $(1.7)$ & 7.6 & (1.1) & 0.9 & $(0.4)$ & 0.0 & c \\
\hline & Distrito Federal & 1.1 & $(0.6)$ & 6.4 & (1.5) & 20.7 & $(2.2)$ & 38.2 & (2.3) & 25.9 & $(2.5)$ & 6.7 & (1.4) & 1.0 & $(0.4)$ & 0.1 & c \\
\hline & Durango & 1.4 & $(0.4)$ & 8.5 & (1.9) & 25.7 & $(2.4)$ & 34.0 & (1.9) & 24.2 & (3.1) & 5.7 & $(1.2)$ & 0.5 & $(0.3)$ & 0.0 & c \\
\hline & Guanajuato & 3.6 & (1.1) & 13.6 & $(2.0)$ & 29.6 & $(2.6)$ & 31.5 & $(2.5)$ & 17.3 & $(2.5)$ & 4.2 & (1.1) & 0.1 & $(0.2)$ & 0.0 & C \\
\hline & Guerrero & 9.2 & (1.5) & 24.6 & $(2.2)$ & 35.5 & (2.6) & 22.9 & $(2.0)$ & 7.0 & (1.3) & 0.9 & $(0.3)$ & 0.0 & c & 0.0 & C \\
\hline & Hidalgo & 3.9 & (1.1) & 12.1 & $(1.8)$ & 29.5 & (3.0) & 33.3 & (2.6) & 17.4 & $(2.4)$ & 3.7 & $(0.8)$ & 0.1 & $(0.1)$ & 0.0 & C \\
\hline & Jalisco & 1.8 & $(0.7)$ & 7.9 & (1.3) & 25.9 & (2.8) & 34.4 & (2.3) & 23.6 & $(2.5)$ & 5.7 & (1.4) & 0.7 & $(0.5)$ & 0.0 & c \\
\hline & Mexico & 1.0 & $(0.5)$ & 6.9 & (1.3) & 25.6 & $(2.8)$ & 38.3 & (2.9) & 23.3 & (2.6) & 4.3 & (1.3) & 0.6 & $(0.5)$ & 0.1 & c \\
\hline & Morelos & 4.0 & $(2.1)$ & 10.2 & $(2.1)$ & 25.1 & $(2.4)$ & 34.5 & $(2.9)$ & 20.2 & $(2.4)$ & 5.2 & (1.8) & 0.8 & $(0.6)$ & 0.0 & c \\
\hline & Nayarit & 3.2 & (1.1) & 11.6 & $(2.1)$ & 29.8 & $(2.7)$ & 33.2 & (2.0) & 17.8 & $(2.4)$ & 4.0 & $(1.0)$ & 0.3 & $(0.3)$ & 0.0 & c \\
\hline & Nuevo León & 1.2 & $(0.7)$ & 6.8 & $(2.3)$ & 23.6 & $(3.2)$ & 37.4 & (2.5) & 24.4 & $(2.8)$ & 6.0 & (1.7) & 0.5 & (0.4) & 0.0 & c \\
\hline & Puebla & 2.6 & $(1.1)$ & 10.2 & $(1.9)$ & 26.6 & $(2.2)$ & 37.0 & $(2.7)$ & 19.5 & $(2.3)$ & 3.9 & (1.1) & 0.1 & c & 0.0 & C \\
\hline & Querétaro & 1.0 & $(0.6)$ & 5.7 & (1.5) & 22.1 & (3.1) & 35.2 & $(2.4)$ & 26.3 & (3.9) & 8.8 & (1.8) & 0.9 & $(0.6)$ & 0.0 & c \\
\hline & Quintana Roo & 1.9 & $(0.9)$ & 9.4 & (1.5) & 25.8 & (2.3) & 35.8 & (1.7) & 22.6 & $(2.0)$ & 4.2 & $(0.9)$ & 0.2 & $(0.3)$ & 0.0 & c \\
\hline & San Luis Potosí & 2.8 & (1.0) & 11.2 & $(2.1)$ & 26.6 & (2.8) & 33.2 & $(2.0)$ & 20.7 & $(2.5)$ & 5.1 & (1.5) & 0.3 & $(0.3)$ & 0.0 & c \\
\hline & Sinaloa & 1.9 & $(0.8)$ & 12.9 & (1.8) & 29.7 & (1.9) & 34.4 & (2.4) & 18.1 & $(2.3)$ & 2.7 & $(0.7)$ & 0.2 & $(0.2)$ & 0.0 & C \\
\hline & Tabasco & 3.8 & $(0.9)$ & 17.3 & (1.9) & 34.8 & (2.3) & 31.7 & $(2.2)$ & 11.0 & (1.6) & 1.4 & $(0.7)$ & 0.1 & c & 0.0 & c \\
\hline & Tamaulipas & 2.8 & $(0.9)$ & 10.5 & (1.7) & 28.0 & (2.6) & 36.6 & (2.6) & 18.1 & $(2.0)$ & 3.7 & (1.0) & 0.2 & $(0.2)$ & 0.0 & c \\
\hline & Tlaxcala & 3.4 & $(0.8)$ & 12.7 & (1.8) & 28.5 & (2.5) & 32.0 & (1.8) & 18.2 & (2.4) & 5.0 & (1.1) & 0.2 & $(0.2)$ & 0.0 & c \\
\hline & Veracruz & 3.0 & $(0.8)$ & 14.8 & $(2.1)$ & 30.6 & $(2.1)$ & 32.1 & $(2.3)$ & 16.0 & (1.8) & 3.3 & $(0.9)$ & 0.3 & $(0.3)$ & 0.0 & c \\
\hline & Yucatán & 1.7 & $(0.7)$ & 10.8 & (1.9) & 27.6 & (2.0) & 35.7 & $(2.2)$ & 19.2 & (1.7) & 4.7 & $(1.0)$ & 0.4 & $(0.2)$ & 0.0 & C \\
\hline & Zacatecas & 3.1 & $(0.9)$ & 12.5 & (1.8) & 31.3 & $(2.1)$ & 34.6 & (1.9) & 15.4 & (1.8) & 3.1 & $(0.7)$ & 0.1 & C & 0.0 & C \\
\hline
\end{tabular}

- PISA adjudicated region.

Note: See Table I.4.1a for national data.

StatLink 需s http://dx.doi.org/10.1787/888932935762 
[Part 2/2]

Table B2.I.25 Percentage of students at each proficiency level in reading, by region

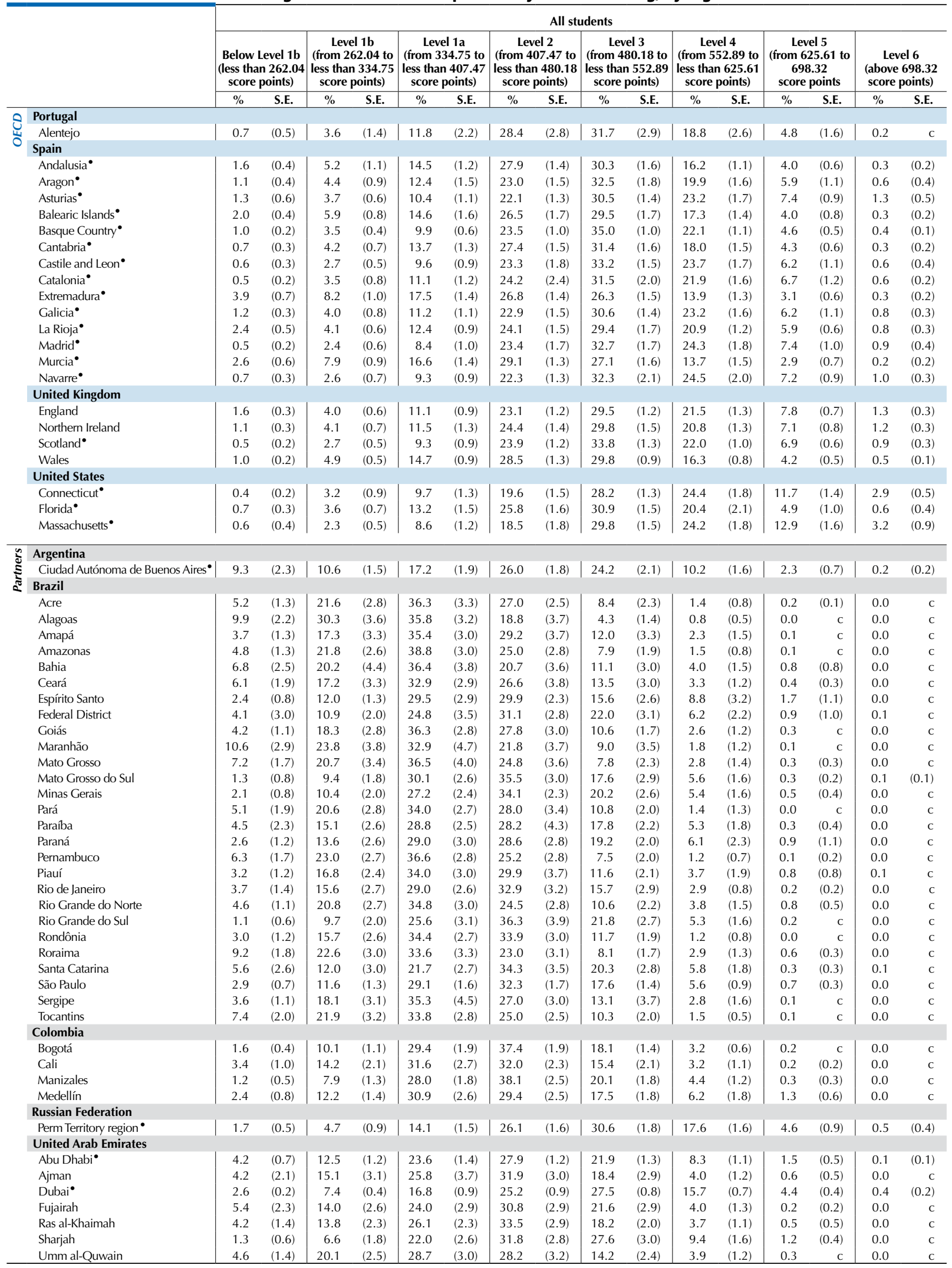

- PISA adjudicated region.

Note: See Table I.4.1 a for national data.

StatLink 需政 http://dx.doi.org/10.1787/888932935762 
[Part 1/4]

Table B2.I.26 Percentage of students at each proficiency level in reading, by gender and region

\begin{tabular}{|c|c|c|c|c|c|c|c|c|c|c|c|c|c|c|c|c|c|}
\hline & & \multicolumn{16}{|c|}{ Boys } \\
\hline & & $\begin{array}{l}\text { Below } \\
\text { (less th } \\
\text { score }\end{array}$ & $\begin{array}{l}\text { evel 1b } \\
262.04 \\
\text { oints) }\end{array}$ & $\begin{array}{l}\text { Le } \\
\text { (from } \\
\text { less th } \\
\text { score }\end{array}$ & $\begin{array}{l}1 \mathrm{~b} \\
2.04 \text { to } \\
334.75 \\
\text { oints) }\end{array}$ & $\begin{array}{l}\text { Lev } \\
\text { (from } \\
\text { less tha } \\
\text { score }\end{array}$ & $\begin{array}{l}11 \mathrm{a} \\
34.75 \text { to } \\
407.47 \\
\text { oints) }\end{array}$ & $\begin{array}{r}\text { Lev } \\
\text { (from } 4 \\
\text { less tha } \\
\text { score }\end{array}$ & $\begin{array}{l}\mid 2 \\
7.47 \text { to } \\
480.18 \\
\text { oints) }\end{array}$ & \begin{tabular}{|} 
Le \\
(from 4 \\
less tha \\
score
\end{tabular} & $\begin{array}{l}\text { el } 3 \\
30.18 \text { to } \\
552.89 \\
\text { oints) }\end{array}$ & $\begin{array}{r}\text { Lev } \\
\text { (from } 5 \\
\text { less tha } \\
\text { score }\end{array}$ & $\begin{array}{l}4 \\
2.89 \text { to } \\
625.61 \\
\text { oints) }\end{array}$ & $\begin{array}{r}\text { Le } \\
\text { (from } \\
69 \\
\text { score }\end{array}$ & $\begin{array}{l}\text { l } 5 \\
5.61 \text { to } \\
.32 \\
\text { ooints }\end{array}$ & $\begin{array}{l}\text { Le } \\
\text { (above } \\
\text { score }\end{array}$ & $\begin{array}{l}\text { l } 6 \\
698.32 \\
\text { oints) }\end{array}$ \\
\hline & & $\%$ & S.E. & $\%$ & S.E. & $\%$ & S.E. & $\%$ & S.E. & $\%$ & S.E. & $\%$ & S.E. & $\%$ & S.E. & $\%$ & S.E. \\
\hline 0 & Australia & & & & & & & & & & & & & & & & \\
\hline & Australian Capital Territory & 2.4 & (1.1) & 6.2 & (1.4) & 10.3 & $(1.8)$ & 18.6 & (3.0) & 28.8 & $(2.6)$ & 22.6 & (3.0) & 9.9 & $(2.0)$ & 1.3 & $(0.7)$ \\
\hline & New South Wales & 1.8 & $(0.5)$ & 5.3 & $(0.7)$ & 14.0 & $(1.2)$ & 23.9 & (1.4) & 24.8 & $(1.6)$ & 19.2 & (1.3) & 9.0 & $(1.2)$ & 1.9 & $(0.6)$ \\
\hline & Northern Territory & 9.2 & (1.9) & 8.8 & $(2.5)$ & 15.2 & $(4.1)$ & 21.7 & $(5.7)$ & 23.5 & $(5.8)$ & 16.4 & $(4.1)$ & 5.1 & $(2.6)$ & 0.0 & c \\
\hline & Queensland & 1.3 & $(0.4)$ & 4.5 & $(0.9)$ & 14.2 & $(1.3)$ & 24.5 & (1.9) & 28.1 & (1.9) & 19.2 & $(2.3)$ & 7.0 & (1.4) & 1.2 & $(0.4)$ \\
\hline & South Australia & 1.6 & $(0.6)$ & 4.5 & (1.1) & 14.6 & $(2.1)$ & 25.6 & $(2.2)$ & 30.3 & $(2.0)$ & 17.7 & $(2.0)$ & 5.4 & $(0.9)$ & 0.4 & $(0.3)$ \\
\hline & Tasmania & 3.0 & $(0.9)$ & 7.1 & (1.3) & 15.2 & $(1.6)$ & 27.6 & (2.4) & 27.7 & $(2.3)$ & 15.0 & $(2.8)$ & 4.0 & $(1.1)$ & 0.3 & $(0.2)$ \\
\hline & Victoria & 0.7 & $(0.3)$ & 3.4 & $(0.6)$ & 12.0 & (1.5) & 22.4 & (1.8) & 31.7 & (1.8) & 21.0 & (1.5) & 7.0 & (1.3) & 1.8 & $(0.7)$ \\
\hline & Western Australia & 0.8 & $(0.3)$ & 3.5 & $(0.7)$ & 10.6 & $(1.5)$ & 22.7 & (2.0) & 29.8 & (1.9) & 22.8 & (1.9) & 8.6 & (1.9) & 1.3 & $(0.6)$ \\
\hline & Belgium & & & & & & & & & & & & & & & & \\
\hline & Flemish Community ${ }^{\bullet}$ & 1.6 & $(0.5)$ & 4.6 & $(0.8)$ & 11.2 & $(1.1)$ & 21.4 & $(1.2)$ & 27.3 & $(1.4)$ & 23.4 & (1.4) & 9.5 & $(0.9)$ & 1.0 & $(0.3)$ \\
\hline & French Community & 3.6 & $(0.9)$ & 7.1 & $(1.2)$ & 13.4 & (1.1) & 22.0 & (1.4) & 26.9 & $(1.7)$ & 19.6 & (1.5) & 6.6 & (1.0) & 0.9 & $(0.4)$ \\
\hline & German-speaking Community & 3.4 & $(1.2)$ & 6.7 & (1.7) & 17.0 & $(2.0)$ & 21.6 & (2.4) & 26.5 & $(2.4)$ & 18.7 & $(2.8)$ & 5.6 & (1.4) & 0.6 & $(0.5)$ \\
\hline & Canada & & & & & & & & & & & & & & & & \\
\hline & Alberta & 0.7 & $(0.4)$ & 3.2 & $(0.9)$ & 9.8 & (1.4) & 21.8 & (1.7) & 29.9 & (2.6) & 23.0 & (1.9) & 10.0 & (1.3) & 1.4 & $(0.4)$ \\
\hline & British Columbia & 0.4 & $(0.3)$ & 2.6 & $(0.8)$ & 7.8 & (1.3) & 19.6 & $(2.3)$ & 31.0 & $(2.5)$ & 26.5 & (1.9) & 10.4 & (1.6) & 1.6 & $(0.6)$ \\
\hline & Manitoba & 1.8 & $(0.7)$ & 5.7 & (1.1) & 15.7 & $(1.8)$ & 28.0 & (2.5) & 26.3 & $(2.0)$ & 17.0 & (1.6) & 4.8 & $(1.2)$ & 0.5 & $(0.3)$ \\
\hline & New Brunswick & 1.2 & $(0.7)$ & 6.0 & (1.1) & 16.2 & $(2.0)$ & 28.9 & (3.0) & 29.6 & $(2.1)$ & 13.8 & $(2.0)$ & 3.9 & $(0.9)$ & 0.4 & $(0.3)$ \\
\hline & Newfoundland and Labrador & 1.6 & $(1.1)$ & 7.1 & $(2.0)$ & 16.0 & $(2.4)$ & 24.5 & (2.6) & 28.8 & $(3.0)$ & 16.3 & $(2.1)$ & 4.9 & $(1.4)$ & 0.8 & $\mathrm{C}$ \\
\hline & Nova Scotia & 1.0 & $(0.8)$ & 5.5 & (1.1) & 11.3 & (1.6) & 24.3 & $(2.7)$ & 33.8 & (3.1) & 18.3 & (3.7) & 5.2 & $(2.1)$ & 0.5 & $(0.5)$ \\
\hline & Ontario & 0.7 & $(0.3)$ & 3.4 & $(0.8)$ & 10.0 & (1.3) & 21.9 & (1.6) & 30.3 & (1.6) & 22.8 & $(1.7)$ & 9.2 & $(1.2)$ & 1.7 & $(0.5)$ \\
\hline & Prince Edward Island & 1.3 & $(0.6)$ & 7.2 & $(1.7)$ & 19.2 & (2.5) & 27.2 & $(2.7)$ & 27.3 & (3.0) & 14.8 & (1.6) & 3.0 & $(0.9)$ & 0.1 & $\mathrm{c}$ \\
\hline & Quebec & 0.9 & $(0.4)$ & 3.4 & $(0.6)$ & 11.8 & $(1.1)$ & 22.5 & (1.3) & 31.2 & $(1.7)$ & 21.8 & (1.8) & 7.5 & $(1.1)$ & 0.9 & $(0.3)$ \\
\hline & Saskatchewan & 0.8 & $(0.4)$ & 4.6 & $(0.9)$ & 14.2 & (1.9) & 25.8 & (1.9) & 30.6 & $(2.2)$ & 18.0 & (1.5) & 5.6 & (1.1) & 0.4 & $(0.4)$ \\
\hline & Italy & & & & & & & & & & & & & & & & \\
\hline & Abruzzo & 3.0 & (1.1) & 9.9 & (1.9) & 18.9 & $(2.7)$ & 26.3 & $(2.1)$ & 25.7 & $(2.4)$ & 12.8 & $(2.2)$ & 3.3 & (1.1) & 0.1 & $\mathrm{C}$ \\
\hline & Basilicata & 1.6 & $(0.9)$ & 7.9 & (1.9) & 17.6 & (1.8) & 31.2 & (2.6) & 26.9 & $(2.7)$ & 12.3 & (1.6) & 2.4 & $(0.7)$ & 0.1 & C \\
\hline & Bolzano & 1.9 & $(0.9)$ & 5.9 & $(1.1)$ & 13.2 & $(1.7)$ & 26.1 & (2.6) & 29.8 & $(2.2)$ & 17.3 & (1.4) & 5.4 & $(0.9)$ & 0.4 & $(0.3)$ \\
\hline & Calabria & 5.9 & $(2.7)$ & 14.9 & $(2.2)$ & 25.9 & $(3.0)$ & 26.2 & (2.8) & 19.2 & $(2.3)$ & 6.4 & (1.3) & 1.3 & $(0.5)$ & 0.0 & $\mathrm{C}$ \\
\hline & Campania & 2.8 & $(1.0)$ & 11.5 & $(2.1)$ & 22.0 & $(2.7)$ & 26.7 & (2.5) & 21.7 & (2.4) & 13.0 & $(2.2)$ & 2.2 & $(0.8)$ & 0.1 & c \\
\hline & Emilia Romagna & 3.7 & $(1.0)$ & 7.9 & $(2.0)$ & 13.8 & $(2.8)$ & 22.2 & (2.5) & 27.4 & $(3.2)$ & 19.1 & (2.6) & 5.4 & $(1.1)$ & 0.5 & $(0.4)$ \\
\hline & Friuli Venezia Giulia & 1.5 & $(0.7)$ & 4.3 & (1.7) & 11.0 & (1.8) & 22.7 & (1.9) & 31.6 & $(3.0)$ & 21.9 & $(2.0)$ & 6.5 & $(1.0)$ & 0.4 & $(0.3)$ \\
\hline & Lazio & 1.9 & $(1.0)$ & 7.6 & $(2.1)$ & 17.4 & (3.0) & 27.5 & (2.6) & 25.9 & $(2.3)$ & 15.8 & (2.5) & 3.8 & (1.1) & 0.2 & $(0.2)$ \\
\hline & Liguria & 2.6 & $(0.9)$ & 8.2 & (2.4) & 16.6 & (1.9) & 26.5 & (2.4) & 26.3 & $(2.5)$ & 14.9 & $(2.3)$ & 4.7 & $(1.1)$ & 0.3 & $(0.2)$ \\
\hline & Lombardia & 1.1 & $(0.5)$ & 4.0 & (1.0) & 10.3 & $(2.1)$ & 20.7 & (3.2) & 30.2 & (3.3) & 25.0 & (2.9) & 8.1 & (1.7) & 0.6 & $(0.4)$ \\
\hline & Marche & 0.6 & $(0.5)$ & 5.1 & $(1.7)$ & 14.9 & $(2.2)$ & 26.1 & $(2.0)$ & 30.6 & $(2.5)$ & 17.7 & $(2.1)$ & 4.6 & $(1.0)$ & 0.3 & $(0.2)$ \\
\hline & Molise & 3.2 & $(0.8)$ & 8.4 & $(1.2)$ & 18.4 & $(2.7)$ & 28.9 & (3.4) & 27.0 & $(2.7)$ & 11.4 & (1.6) & 2.3 & $(0.9)$ & 0.5 & $(0.3)$ \\
\hline & Piemonte & 1.5 & $(0.8)$ & 3.7 & $(1.0)$ & 12.4 & $(2.1)$ & 27.5 & (2.4) & 32.1 & $(2.3)$ & 17.5 & (1.6) & 4.9 & $(1.2)$ & 0.4 & $(0.3)$ \\
\hline & Puglia & 2.3 & (1.1) & 7.7 & (2.0) & 14.1 & (1.6) & 24.7 & (2.2) & 29.8 & (2.4) & 16.7 & $(2.1)$ & 4.5 & $(1.2)$ & 0.2 & $(0.2)$ \\
\hline & Sardegna & 4.7 & (1.4) & 9.0 & (2.3) & 20.6 & (2.8) & 27.6 & (2.3) & 23.5 & (3.1) & 12.0 & (1.7) & 2.5 & $(0.8)$ & 0.1 & c \\
\hline & Sicilia & 4.5 & (1.3) & 9.9 & (1.9) & 20.9 & (2.3) & 29.2 & $(2.2)$ & 23.9 & $(2.1)$ & 9.9 & (1.8) & 1.6 & $(0.6)$ & 0.1 & c \\
\hline & Toscana & 3.4 & $(0.9)$ & 8.4 & (1.9) & 16.7 & $(2.7)$ & 22.8 & (2.4) & 28.2 & (2.5) & 15.8 & (1.9) & 4.3 & (1.2) & 0.4 & $(0.3)$ \\
\hline & Trento & 1.4 & $(0.7)$ & 4.7 & (1.8) & 11.5 & (1.7) & 24.7 & (3.0) & 27.5 & $(3.1)$ & 21.7 & $(2.7)$ & 7.6 & (1.6) & 0.8 & $(0.5)$ \\
\hline & Umbria & 2.9 & (1.3) & 7.4 & $(2.2)$ & 13.9 & $(2.3)$ & 23.0 & (2.5) & 29.9 & $(2.7)$ & 18.6 & $(2.7)$ & 3.9 & $(1.1)$ & 0.4 & $(0.3)$ \\
\hline & Valle d'Aosta & 1.5 & $(0.8)$ & 3.9 & (1.1) & 13.6 & (2.1) & 25.7 & (3.5) & 31.4 & (3.0) & 18.7 & (1.8) & 4.9 & (1.3) & 0.4 & c \\
\hline & Veneto & 1.9 & $(0.9)$ & 4.5 & (1.4) & 11.0 & (1.9) & 21.5 & (2.4) & 29.5 & (3.3) & 22.5 & $(2.7)$ & 7.9 & $(2.0)$ & 1.1 & $(0.6)$ \\
\hline & Mexico & & & & & & & & & & & & & & & & \\
\hline & Aguascalientes & 2.5 & (1.3) & 9.3 & (1.9) & 25.5 & $(3.1)$ & 34.7 & (3.0) & 20.9 & (2.4) & 6.4 & (1.3) & 0.7 & $(0.5)$ & 0.0 & c \\
\hline & Baja California & 2.0 & (1.4) & 12.5 & (3.1) & 31.7 & (3.6) & 32.7 & (3.1) & 16.9 & $(2.7)$ & 3.9 & (1.4) & 0.2 & c & 0.0 & c \\
\hline & Baja California Sur & 2.3 & $(1.2)$ & 12.8 & (3.3) & 30.0 & $(2.9)$ & 36.5 & (2.8) & 15.8 & $(2.3)$ & 2.7 & $(1.0)$ & 0.0 & c & 0.0 & c \\
\hline & Campeche & 3.0 & $(1.2)$ & 15.7 & (3.0) & 34.5 & $(4.1)$ & 31.3 & $(3.2)$ & 13.0 & (1.6) & 2.4 & $(0.8)$ & 0.2 & $(0.2)$ & 0.0 & c \\
\hline & Chiapas & 12.3 & (3.0) & 26.9 & (3.3) & 35.8 & $(3.7)$ & 18.9 & (2.8) & 5.0 & (1.6) & 1.1 & $(0.8)$ & 0.2 & c & 0.0 & c \\
\hline & Chihuahua & 2.5 & (1.4) & 9.3 & $(2.2)$ & 26.2 & $(4.4)$ & 33.5 & (2.8) & 20.1 & $(3.7)$ & 8.0 & $(2.6)$ & 0.4 & $(0.5)$ & 0.0 & $\mathrm{C}$ \\
\hline & Coahuila & 1.8 & $(0.8)$ & 14.1 & (3.1) & 29.8 & $(3.4)$ & 30.4 & (2.8) & 19.1 & (3.2) & 4.3 & (1.6) & 0.4 & $(0.4)$ & 0.0 & $\mathrm{C}$ \\
\hline & Colima & 2.7 & (1.1) & 12.9 & $(2.8)$ & 26.1 & $(2.7)$ & 33.5 & $(3.2)$ & 18.9 & $(2.2)$ & 5.2 & $(1.2)$ & 0.7 & $(0.4)$ & 0.0 & c \\
\hline & Distrito Federal & 1.8 & $(1.0)$ & 7.8 & (2.4) & 21.0 & (3.7) & 37.6 & $(2.7)$ & 25.3 & (3.5) & 5.6 & (1.5) & 0.9 & $(0.6)$ & 0.0 & c \\
\hline & Durango & 2.3 & $(0.7)$ & 11.0 & (2.5) & 29.8 & (3.0) & 31.4 & (2.3) & 21.6 & $(4.2)$ & 3.5 & $(1.2)$ & 0.4 & $(0.3)$ & 0.0 & c \\
\hline & Guanajuato & 4.3 & (1.7) & 16.7 & (2.5) & 32.6 & (3.0) & 27.9 & (3.0) & 14.4 & $(2.0)$ & 3.9 & (1.0) & 0.3 & c & 0.0 & c \\
\hline & Guerrero & 12.3 & $(2.3)$ & 27.3 & (3.4) & 35.2 & $(3.7)$ & 19.7 & (2.6) & 4.9 & $(1.1)$ & 0.6 & $(0.3)$ & 0.0 & c & 0.0 & $\mathrm{C}$ \\
\hline & Hidalgo & 5.4 & $(2.3)$ & 13.4 & (2.4) & 32.3 & (3.8) & 30.6 & (3.2) & 15.0 & $(2.3)$ & 3.2 & (1.1) & 0.1 & c & 0.0 & C \\
\hline & Jalisco & 2.8 & $(1.2)$ & 11.1 & $(2.2)$ & 30.1 & $(4.0)$ & 32.5 & (3.0) & 18.1 & (2.6) & 4.6 & $(1.2)$ & 0.7 & $(0.5)$ & 0.0 & C \\
\hline & Mexico & 1.3 & $(0.7)$ & 7.9 & (1.9) & 28.5 & $(3.2)$ & 38.2 & (3.7) & 20.3 & (3.1) & 3.1 & (1.1) & 0.6 & $(0.5)$ & 0.1 & $\mathrm{C}$ \\
\hline & Morelos & 6.9 & (3.8) & 12.9 & (3.0) & 25.0 & (3.8) & 33.1 & (4.6) & 17.6 & (2.6) & 3.9 & (1.5) & 0.5 & $(0.4)$ & 0.0 & $\mathrm{C}$ \\
\hline & Nayarit & 4.1 & (1.5) & 13.6 & $(2.7)$ & 32.4 & (2.9) & 32.9 & (2.7) & 13.9 & $(2.8)$ & 2.6 & (1.0) & 0.4 & $(0.4)$ & 0.0 & $\mathrm{C}$ \\
\hline & Nuevo León & 1.9 & (1.3) & 9.1 & (3.5) & 25.6 & (3.6) & 36.9 & (2.9) & 20.7 & (3.3) & 5.4 & (2.0) & 0.4 & $(0.4)$ & 0.0 & c \\
\hline & Puebla & 3.9 & (1.8) & 12.5 & (2.9) & 30.6 & (3.3) & 34.2 & (3.6) & 16.0 & $(2.7)$ & 2.9 & $(1.1)$ & 0.0 & $\mathrm{C}$ & 0.0 & $\mathrm{C}$ \\
\hline & Querétaro & 1.1 & $(0.7)$ & 7.4 & (2.1) & 26.5 & (3.9) & 33.9 & (3.4) & 22.7 & (4.1) & 7.9 & (1.8) & 0.4 & $(0.3)$ & 0.0 & c \\
\hline & Quintana Roo & 3.5 & (1.6) & 13.7 & (2.3) & 29.1 & (3.0) & 32.4 & (2.5) & 18.8 & (2.5) & 2.5 & $(0.7)$ & 0.1 & c & 0.0 & c \\
\hline & San Luis Potosí & 4.6 & (1.9) & 16.4 & (3.6) & 31.3 & (3.4) & 29.3 & (3.0) & 14.7 & (2.8) & 3.7 & (1.3) & 0.1 & c & 0.0 & C \\
\hline & Sinaloa & 3.3 & (1.4) & 18.7 & (2.5) & 34.6 & (2.4) & 29.0 & (3.0) & 13.1 & (2.4) & 1.3 & $(0.6)$ & 0.0 & c & 0.0 & C \\
\hline & Tabasco & 6.2 & (1.4) & 22.2 & (3.2) & 38.0 & (4.3) & 24.5 & (2.5) & 8.3 & $(1.7)$ & 0.8 & $(0.7)$ & 0.1 & C & 0.0 & C \\
\hline & Tamaulipas & 3.7 & (1.3) & 12.4 & (2.5) & 30.3 & (3.9) & 33.7 & (3.4) & 16.2 & $(2.3)$ & 3.6 & (1.3) & 0.1 & $(0.2)$ & 0.0 & $\mathrm{C}$ \\
\hline & Tlaxcala & 5.2 & (1.4) & 16.0 & (2.8) & 30.5 & (4.4) & 29.2 & (2.4) & 14.9 & $(2.7)$ & 4.1 & (1.2) & 0.2 & c & 0.0 & c \\
\hline & Veracruz & 3.9 & (1.3) & 18.4 & (3.0) & 31.5 & (3.1) & 30.2 & (3.1) & 14.0 & $(2.5)$ & 2.0 & $(0.8)$ & 0.1 & c & 0.0 & c \\
\hline & Yucatán & 2.1 & $(1.0)$ & 12.7 & (2.8) & 29.2 & $(2.9)$ & 32.9 & (3.1) & 17.5 & $(2.6)$ & 5.1 & (1.3) & 0.6 & $(0.4)$ & 0.0 & c \\
\hline & Zacatecas & 4.2 & $(1.4)$ & 15.9 & $(2.6)$ & 34.7 & (3.4) & 30.5 & $(3.0)$ & 12.4 & $(2.0)$ & 2.3 & $(1.0)$ & 0.0 & C & 0.0 & c \\
\hline
\end{tabular}

- PISA adjudicated region.

Note: See Table I.4.2a for national data.

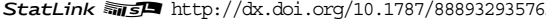


[Part 2/4]

Table B2.I.26 Percentage of students at each proficiency level in reading, by gender and region

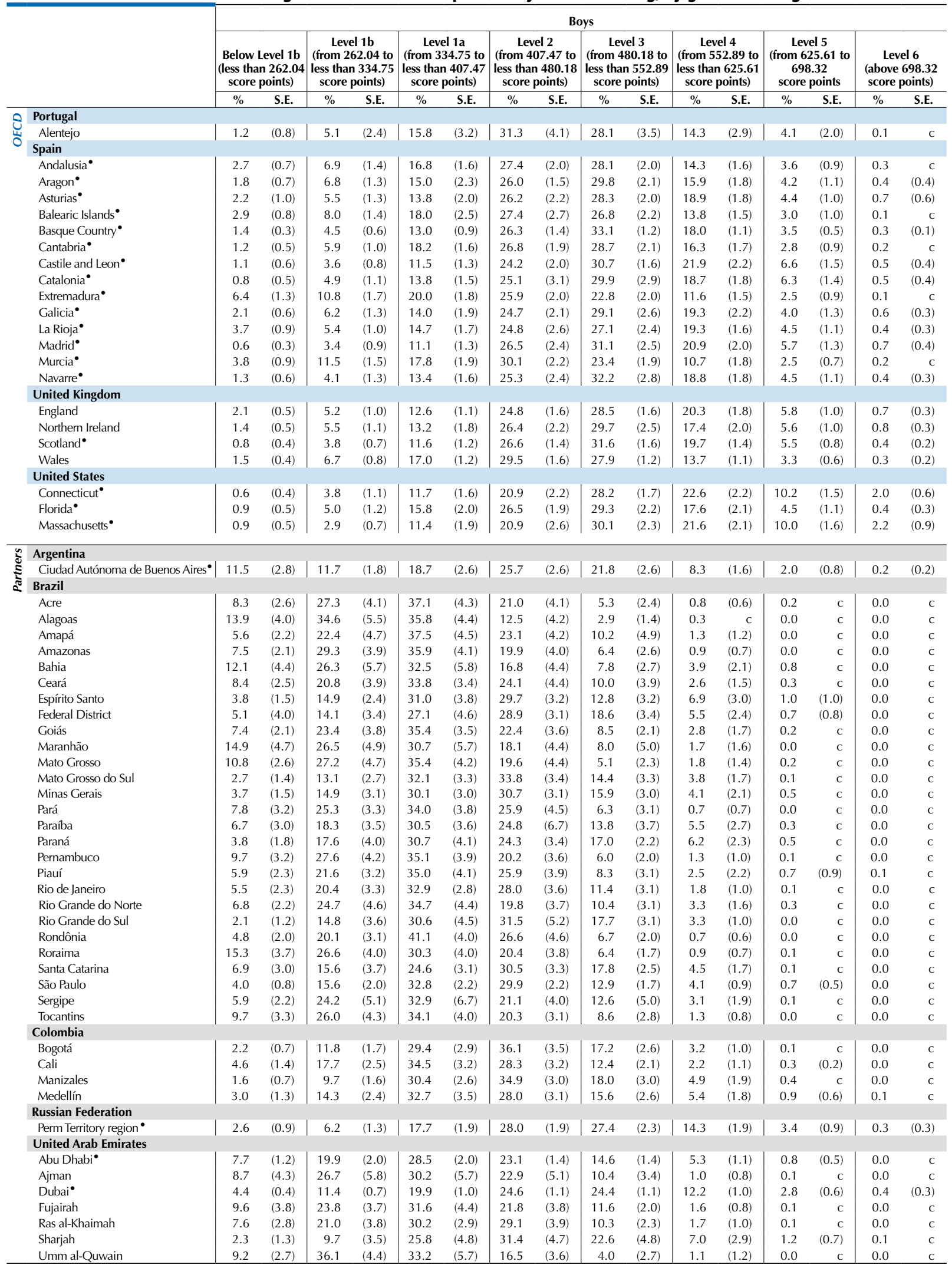

- PISA adjudicated region.

Note: See Table I.4.2a for national data.

StatLink न्तार्य http://dx.doi.org/10.1787/888932935762 
[Part 3/4 ]

Table B2.I.26 Percentage of students at each proficiency level in reading, by gender and region

\begin{tabular}{|c|c|c|c|c|c|c|c|c|c|c|c|c|c|c|c|c|c|}
\hline & & \multicolumn{16}{|c|}{ Girls } \\
\hline & & $\begin{array}{l}\text { Below } \\
\text { (less th } \\
\text { score }\end{array}$ & $\begin{array}{l}\text { evel 1b } \\
262.04 \\
\text { oints) }\end{array}$ & $\begin{array}{r}\text { Lev } \\
\text { (from } 2 \\
\text { less tha } \\
\text { score }\end{array}$ & $\begin{array}{l}\mid 1 \mathrm{~b} \\
2.04 \text { to } \\
334.75 \\
\text { oints) }\end{array}$ & $\begin{array}{l}\text { Lev } \\
\text { (from } \\
\text { less tha } \\
\text { score }\end{array}$ & $\begin{array}{l}11 \mathrm{a} \\
34.75 \text { to } \\
407.47 \\
\text { oints) }\end{array}$ & $\begin{array}{l}\text { Le } \\
\text { (from } 4 \\
\text { less tha } \\
\text { score }\end{array}$ & $\begin{array}{l}\text { l } 2 \\
7.47 \text { to } \\
480.18 \\
\text { oints) }\end{array}$ & \begin{tabular}{|} 
Le \\
(from 4 \\
less tha \\
score
\end{tabular} & $\begin{array}{l}\text { el } 3 \\
30.18 \text { to } \\
552.89 \\
\text { oints) }\end{array}$ & $\begin{array}{r}\text { Lev } \\
\text { (from } 5 \\
\text { less tha } \\
\text { score }\end{array}$ & $\begin{array}{l}4 \\
2.89 \text { to } \\
625.61 \\
\text { oints) }\end{array}$ & $\begin{array}{r}\text { Le } \\
\text { (from } \\
69 \\
\text { score }\end{array}$ & $\begin{array}{l}\text { l } 5 \\
5.61 \text { to } \\
.32 \\
\text { ooints }\end{array}$ & $\begin{array}{l}\text { Le } \\
\text { (above } \\
\text { score }\end{array}$ & $\begin{array}{l}\text { l } 6 \\
698.32 \\
\text { oints) }\end{array}$ \\
\hline & & $\%$ & S.E. & $\%$ & S.E. & $\%$ & S.E. & $\%$ & S.E. & $\%$ & S.E. & $\%$ & S.E. & $\%$ & S.E. & $\%$ & S.E. \\
\hline$\theta$ & Australia & & & & & & & & & & & & & & & & \\
\hline & Australian Capital Territory & 0.6 & $(0.5)$ & 1.4 & $(0.9)$ & 4.4 & $(1.4)$ & 12.7 & $(2.2)$ & 28.4 & $(2.7)$ & 33.1 & $(4.0)$ & 16.5 & $(2.8)$ & 2.9 & (1.4) \\
\hline & New South Wales & 0.3 & $(0.2)$ & 1.8 & $(0.5)$ & 6.1 & $(0.8)$ & 19.2 & (1.3) & 29.3 & $(1.8)$ & 27.3 & (1.6) & 13.3 & (1.3) & 2.8 & $(0.5)$ \\
\hline & Northern Territory & 5.7 & $(1.8)$ & 5.8 & $(1.7)$ & 12.4 & (3.0) & 18.2 & (3.9) & 27.6 & $(4.2)$ & 22.5 & $(4.7)$ & 7.3 & (3.7) & 0.6 & c \\
\hline & Queensland & 0.3 & $(0.2)$ & 1.7 & $(0.5)$ & 8.0 & $(1.1)$ & 21.5 & $(1.5)$ & 29.7 & (1.9) & 25.2 & $(1.7)$ & 11.0 & $(1.3)$ & 2.7 & $(0.7)$ \\
\hline & South Australia & 0.3 & $(0.3)$ & 2.3 & $(0.6)$ & 8.2 & (1.4) & 22.0 & $(2.0)$ & 30.9 & $(2.4)$ & 25.8 & $(2.3)$ & 9.3 & $(1.3)$ & 1.1 & $(0.5)$ \\
\hline & Tasmania & 0.9 & $(0.7)$ & 2.8 & (1.3) & 12.5 & $(2.0)$ & 24.8 & (2.8) & 26.7 & $(2.9)$ & 22.9 & (2.5) & 8.4 & (1.9) & 1.0 & $(0.6)$ \\
\hline & Victoria & 0.3 & $(0.2)$ & 1.2 & $(0.5)$ & 6.1 & $(0.9)$ & 18.0 & (1.4) & 32.0 & (1.6) & 28.2 & (1.5) & 12.0 & $(1.2)$ & 2.2 & $(0.5)$ \\
\hline & Western Australia & 0.4 & $(0.2)$ & 1.3 & $(0.5)$ & 8.0 & $(1.1)$ & 18.6 & (1.4) & 28.3 & $(2.2)$ & 27.6 & $(2.2)$ & 13.2 & (1.9) & 2.7 & $(0.8)$ \\
\hline & Belgium & & & & & & & & & & & & & & & & \\
\hline & Flemish Community ${ }^{\bullet}$ & 0.5 & $(0.3)$ & 2.1 & $(0.6)$ & 7.3 & $(0.8)$ & 17.7 & $(1.4)$ & 27.6 & $(1.5)$ & 29.0 & (1.3) & 13.9 & $(1.1)$ & 2.0 & $(0.4)$ \\
\hline & French Community & 1.1 & $(0.5)$ & 3.0 & $(0.6)$ & 10.2 & $(1.3)$ & 21.2 & (1.6) & 27.3 & $(1.5)$ & 24.7 & (1.3) & 10.9 & (1.1) & 1.7 & $(0.4)$ \\
\hline & German-speaking Community & 0.1 & c & 1.5 & $(1.0)$ & 6.4 & (1.6) & 18.4 & $(2.2)$ & 32.9 & $(2.8)$ & 31.0 & (2.6) & 9.1 & (1.6) & 0.6 & $(0.6)$ \\
\hline & Canada & & & & & & & & & & & & & & & & \\
\hline & Alberta & 0.1 & c & 1.0 & $(0.4)$ & 6.0 & (1.1) & 16.5 & (1.6) & 30.4 & $(2.1)$ & 29.8 & (1.9) & 13.7 & (1.5) & 2.6 & $(0.7)$ \\
\hline & British Columbia & 0.0 & c & 0.9 & $(0.5)$ & 4.3 & (1.3) & 15.0 & (1.7) & 30.6 & $(2.7)$ & 31.9 & $(2.0)$ & 13.9 & (1.7) & 3.5 & $(1.2)$ \\
\hline & Manitoba & 0.3 & $(0.3)$ & 1.7 & $(0.8)$ & 8.2 & (1.6) & 23.9 & $(3.0)$ & 29.9 & $(2.1)$ & 26.1 & $(2.2)$ & 8.4 & (1.3) & 1.4 & $(0.5)$ \\
\hline & New Brunswick & 0.2 & $(0.2)$ & 1.4 & $(0.6)$ & 6.8 & $(1.1)$ & 22.7 & $(2.1)$ & 34.3 & $(3.2)$ & 24.8 & $(2.2)$ & 8.4 & (1.5) & 1.5 & $(0.7)$ \\
\hline & Newfoundland and Labrador & 0.2 & c & 1.0 & $(0.5)$ & 7.1 & $(1.4)$ & 19.9 & (2.6) & 32.9 & (3.4) & 25.5 & (2.4) & 10.8 & (1.8) & 2.7 & $(0.9)$ \\
\hline & Nova Scotia & 0.2 & c & 1.4 & $(0.6)$ & 5.1 & (1.6) & 19.1 & (2.5) & 36.7 & (3.1) & 25.9 & (3.1) & 10.1 & $(2.2)$ & 1.6 & $(0.7)$ \\
\hline & Ontario & 0.1 & $(0.1)$ & 1.1 & $(0.4)$ & 4.5 & $(0.7)$ & 14.8 & (1.6) & 32.0 & $(1.7)$ & 30.2 & $(1.7)$ & 13.9 & (1.6) & 3.4 & $(0.7)$ \\
\hline & Prince Edward Island & 0.1 & $\mathrm{c}$ & 1.6 & $(0.6)$ & 8.5 & (1.4) & 24.2 & (1.9) & 33.2 & $(2.1)$ & 25.0 & $(2.1)$ & 6.7 & $(1.2)$ & 0.7 & $(0.5)$ \\
\hline & Quebec & 0.3 & $(0.2)$ & 1.4 & $(0.4)$ & 6.0 & $(0.9)$ & 16.8 & (1.4) & 30.7 & $(2.0)$ & 29.0 & (1.8) & 13.2 & (1.4) & 2.6 & $(0.8)$ \\
\hline & Saskatchewan & 0.2 & c & 1.3 & $(0.4)$ & 6.1 & $(0.9)$ & 20.9 & (1.6) & 35.7 & $(2.1)$ & 24.6 & $(2.0)$ & 9.7 & $(1.2)$ & 1.6 & $(0.6)$ \\
\hline & Italy & & & & & & & & & & & & & & & & \\
\hline & Abruzzo & 0.9 & $(0.5)$ & 2.7 & $(0.9)$ & 9.5 & $(1.7)$ & 21.2 & $(2.0)$ & 35.0 & $(3.2)$ & 24.0 & (2.5) & 6.3 & (1.6) & 0.4 & $(0.3)$ \\
\hline & Basilicata & 0.2 & $(0.2)$ & 2.6 & $(0.9)$ & 11.6 & $(2.3)$ & 28.9 & $(2.3)$ & 35.9 & $(2.4)$ & 17.1 & $(2.1)$ & 3.4 & $(0.8)$ & 0.2 & $(0.2)$ \\
\hline & Bolzano & 0.6 & $(0.4)$ & 2.6 & $(0.6)$ & 8.4 & $(1.1)$ & 19.5 & $(1.8)$ & 35.3 & $(1.7)$ & 26.4 & $(2.0)$ & 6.8 & $(0.9)$ & 0.4 & $(0.3)$ \\
\hline & Calabria & 2.9 & (1.9) & 8.4 & (1.9) & 16.3 & (2.4) & 30.3 & (3.0) & 28.9 & $(2.8)$ & 11.5 & (1.8) & 1.7 & $(0.5)$ & 0.0 & c \\
\hline & Campania & 0.6 & $(0.3)$ & 4.6 & (1.4) & 14.9 & (2.4) & 26.4 & (3.7) & 31.0 & $(2.7)$ & 18.6 & $(4.5)$ & 3.7 & (1.4) & 0.3 & $(0.2)$ \\
\hline & Emilia Romagna & 0.4 & $(0.3)$ & 2.7 & $(0.9)$ & 7.1 & (1.5) & 18.4 & (2.5) & 33.5 & $(2.5)$ & 25.6 & (2.5) & 10.8 & $(1.7)$ & 1.6 & $(0.6)$ \\
\hline & Friuli Venezia Giulia & 0.2 & c & 1.2 & $(1.0)$ & 6.3 & $(2.3)$ & 13.3 & (3.0) & 31.7 & (3.3) & 33.2 & (2.9) & 12.4 & (1.9) & 1.8 & $(0.6)$ \\
\hline & Lazio & 0.2 & $(0.2)$ & 2.4 & $(0.9)$ & 10.9 & $(2.7)$ & 26.9 & (3.4) & 32.9 & (3.1) & 20.4 & $(2.7)$ & 5.9 & (1.3) & 0.4 & $(0.3)$ \\
\hline & Liguria & 0.2 & c & 3.0 & $(1.2)$ & 8.8 & $(2.1)$ & 20.5 & $(2.3)$ & 30.6 & $(2.9)$ & 27.2 & (3.0) & 8.7 & (1.9) & 1.0 & $(0.6)$ \\
\hline & Lombardia & 0.1 & c & 1.2 & $(0.7)$ & 3.9 & (1.3) & 17.7 & $(2.2)$ & 33.6 & $(3.0)$ & 31.4 & (2.6) & 10.9 & (2.4) & 1.3 & $(0.7)$ \\
\hline & Marche & 0.4 & $(0.4)$ & 2.7 & $(1.2)$ & 9.0 & (1.8) & 23.8 & (2.6) & 31.7 & $(2.2)$ & 24.7 & (2.4) & 7.2 & (1.5) & 0.6 & $(0.4)$ \\
\hline & Molise & 0.6 & $(0.4)$ & 2.5 & (1.3) & 10.1 & (1.7) & 23.8 & (2.9) & 38.1 & (3.5) & 20.3 & $(2.1)$ & 4.5 & (1.5) & 0.1 & c \\
\hline & Piemonte & 0.2 & c & 1.3 & $(0.9)$ & 6.9 & (1.7) & 20.6 & $(3.2)$ & 33.7 & $(2.3)$ & 27.2 & $(2.3)$ & 9.1 & (1.9) & 1.1 & $(0.6)$ \\
\hline & Puglia & 0.1 & c & 1.6 & $(0.8)$ & 7.5 & (1.7) & 23.9 & (3.1) & 35.6 & (3.3) & 23.8 & (3.0) & 6.6 & (1.6) & 0.9 & $(0.4)$ \\
\hline & Sardegna & 1.9 & (1.4) & 5.3 & $(2.0)$ & 12.8 & $(2.0)$ & 24.9 & (3.0) & 31.5 & $(2.8)$ & 19.6 & (2.4) & 3.9 & (1.0) & 0.3 & $(0.2)$ \\
\hline & Sicilia & 0.9 & $(0.7)$ & 4.6 & (1.5) & 17.3 & (3.2) & 30.0 & (2.9) & 30.1 & $(3.2)$ & 14.6 & (2.1) & 2.3 & $(0.6)$ & 0.3 & $(0.2)$ \\
\hline & Toscana & 0.5 & $(0.6)$ & 2.8 & (1.3) & 9.0 & $(2.1)$ & 19.7 & (3.4) & 31.0 & (3.0) & 26.4 & (3.0) & 9.6 & (2.1) & 1.0 & $(0.5)$ \\
\hline & Trento & 0.3 & c & 0.5 & $(0.6)$ & 3.9 & (1.6) & 15.2 & $(2.7)$ & 27.9 & $(2.7)$ & 33.5 & (3.0) & 16.6 & (2.0) & 2.1 & $(0.7)$ \\
\hline & Umbria & 0.8 & $(0.5)$ & 1.3 & $(1.0)$ & 9.9 & (1.5) & 21.5 & (2.5) & 35.1 & $(2.3)$ & 25.1 & (2.3) & 5.8 & $(1.1)$ & 0.4 & $(0.3)$ \\
\hline & Valle d'Aosta & 0.6 & c & 1.5 & $(1.0)$ & 6.7 & (1.9) & 23.6 & (2.6) & 32.9 & (2.8) & 25.6 & (2.6) & 7.7 & (1.6) & 1.4 & $(0.7)$ \\
\hline & Veneto & 0.8 & $(0.5)$ & 0.9 & $(0.6)$ & 4.1 & (1.3) & 15.0 & $(2.1)$ & 30.6 & (3.0) & 32.8 & (2.4) & 13.2 & (1.7) & 2.6 & $(0.7)$ \\
\hline & Mexico & & & & & & & & & & & & & & & & \\
\hline & Aguascalientes & 0.0 & c & 4.3 & $(1.1)$ & 18.0 & $(2.0)$ & 35.8 & (2.5) & 31.5 & (3.1) & 8.7 & (1.7) & 1.2 & $(0.7)$ & 0.5 & c \\
\hline & Baja California & 1.0 & $(0.7)$ & 6.7 & (1.8) & 26.6 & $(2.9)$ & 36.5 & (3.4) & 21.1 & $(2.5)$ & 7.1 & (1.7) & 1.1 & $(0.7)$ & 0.0 & c \\
\hline & Baja California Sur & 0.8 & $(0.8)$ & 8.1 & (2.4) & 26.1 & $(2.7)$ & 39.3 & $(2.5)$ & 21.1 & $(2.4)$ & 4.3 & (1.7) & 0.2 & c & 0.0 & c \\
\hline & Campeche & 2.0 & (1.4) & 10.6 & $(2.3)$ & 27.5 & $(2.9)$ & 38.0 & $(2.9)$ & 17.2 & $(2.8)$ & 4.1 & $(1.2)$ & 0.5 & c & 0.0 & c \\
\hline & Chiapas & 6.0 & $(2.1)$ & 20.2 & (3.3) & 33.8 & (3.6) & 28.3 & (3.3) & 10.3 & $(1.8)$ & 1.3 & $(0.7)$ & 0.1 & c & 0.0 & c \\
\hline & Chihuahua & 2.0 & (1.1) & 5.6 & $(1.8)$ & 17.2 & $(2.7)$ & 36.3 & $(2.5)$ & 29.0 & $(3.7)$ & 9.4 & $(2.1)$ & 0.6 & $(0.6)$ & 0.0 & C \\
\hline & Coahuila & 0.0 & c & 6.5 & (1.8) & 22.9 & $(3.9)$ & 40.1 & $(4.1)$ & 24.7 & (3.8) & 5.3 & (1.9) & 0.5 & c & 0.0 & c \\
\hline & Colima & 0.4 & c & 4.5 & (1.4) & 21.5 & (2.6) & 34.7 & (2.4) & 27.8 & $(2.6)$ & 10.0 & $(1.8)$ & 1.1 & $(0.7)$ & 0.0 & c \\
\hline & Distrito Federal & 0.5 & $(0.4)$ & 5.0 & (1.7) & 20.4 & $(2.6)$ & 38.8 & (3.4) & 26.5 & (3.1) & 7.6 & $(2.2)$ & 1.1 & $(0.6)$ & 0.1 & c \\
\hline & Durango & 0.6 & $(0.4)$ & 6.1 & (1.8) & 21.9 & (3.1) & 36.5 & $(3.7)$ & 26.6 & (4.4) & 7.7 & $(2.1)$ & 0.6 & $(0.4)$ & 0.0 & c \\
\hline & Guanajuato & 2.9 & (1.3) & 10.7 & (2.3) & 26.8 & (3.0) & 35.0 & (3.9) & 20.0 & $(4.1)$ & 4.6 & (1.6) & 0.1 & c & 0.0 & c \\
\hline & Guerrero & 6.0 & (1.5) & 21.8 & $(2.8)$ & 35.7 & $(2.9)$ & 26.2 & $(2.3)$ & 9.2 & $(2.0)$ & 1.1 & $(0.6)$ & 0.0 & c & 0.0 & C \\
\hline & Hidalgo & 2.6 & $(0.9)$ & 11.0 & (2.4) & 27.1 & (3.2) & 35.6 & (3.2) & 19.4 & (3.4) & 4.1 & (1.0) & 0.2 & c & 0.0 & c \\
\hline & Jalisco & 0.9 & $(0.4)$ & 5.0 & $(1.2)$ & 22.2 & (2.8) & 36.1 & (3.5) & 28.5 & (2.9) & 6.6 & (1.9) & 0.7 & (0.6) & 0.0 & c \\
\hline & Mexico & 0.6 & $(0.6)$ & 6.0 & (1.5) & 22.7 & (3.5) & 38.4 & (3.4) & 26.3 & $(3.0)$ & 5.4 & $(2.0)$ & 0.6 & $(0.6)$ & 0.0 & c \\
\hline & Morelos & 1.3 & $(0.7)$ & 7.8 & (1.8) & 25.1 & $(3.2)$ & 35.8 & (3.7) & 22.4 & (3.3) & 6.4 & (2.4) & 1.1 & (1.0) & 0.0 & c \\
\hline & Nayarit & 2.3 & (1.3) & 9.7 & $(2.3)$ & 27.4 & (3.9) & 33.5 & (2.4) & 21.5 & (3.3) & 5.5 & (1.5) & 0.2 & c & 0.0 & c \\
\hline & Nuevo León & 0.5 & $(0.7)$ & 4.3 & (1.6) & 21.4 & (3.5) & 37.9 & (3.5) & 28.6 & (3.5) & 6.7 & (1.9) & 0.7 & $(0.6)$ & 0.0 & c \\
\hline & Puebla & 1.5 & $(0.9)$ & 8.0 & $(2.3)$ & 22.7 & (2.8) & 39.7 & (3.3) & 22.9 & $(3.2)$ & 4.9 & (1.5) & 0.2 & c & 0.0 & c \\
\hline & Querétaro & 0.9 & $(0.6)$ & 4.1 & (1.8) & 17.9 & (3.3) & 36.4 & (3.3) & 29.6 & $(4.0)$ & 9.7 & $(2.2)$ & 1.4 & (1.0) & 0.0 & c \\
\hline & Quintana Roo & 0.7 & c & 5.0 & (1.4) & 22.5 & (3.1) & 39.3 & (2.5) & 26.6 & (2.5) & 6.0 & (1.4) & 0.0 & c & 0.0 & c \\
\hline & San Luis Potosí & 1.1 & $(0.6)$ & 6.7 & (1.4) & 22.6 & (3.3) & 36.7 & (2.4) & 26.0 & (2.9) & 6.4 & (2.0) & 0.5 & $(0.5)$ & 0.0 & c \\
\hline & Sinaloa & 0.6 & $(0.5)$ & 7.9 & $(2.0)$ & 25.5 & (2.4) & 39.0 & (3.0) & 22.5 & (2.9) & 3.9 & $(1.2)$ & 0.4 & $(0.3)$ & 0.1 & c \\
\hline & Tabasco & 1.5 & $(0.8)$ & 12.7 & $(1.7)$ & 31.8 & (2.6) & 38.5 & $(2.7)$ & 13.5 & $(2.3)$ & 2.0 & (0.9) & 0.1 & c & 0.0 & c \\
\hline & Tamaulipas & 2.0 & (1.3) & 8.4 & (1.6) & 25.5 & $(2.2)$ & 39.9 & $(2.9)$ & 20.3 & $(2.7)$ & 3.8 & (1.3) & 0.2 & c & 0.0 & c \\
\hline & Tlaxcala & 1.7 & $(0.9)$ & 9.7 & (1.9) & 26.7 & $(3.0)$ & 34.6 & $(2.7)$ & 21.2 & (3.1) & 5.7 & (1.4) & 0.2 & $(0.2)$ & 0.0 & c \\
\hline & Veracruz & 2.1 & $(0.9)$ & 10.9 & $(2.2)$ & 29.7 & $(2.8)$ & 34.2 & (2.6) & 18.1 & $(2.0)$ & 4.6 & (1.9) & 0.4 & $(0.5)$ & 0.0 & c \\
\hline & Yucatán & 1.2 & $(0.9)$ & 8.7 & $(2.2)$ & 26.0 & $(2.5)$ & 38.7 & $(2.5)$ & 21.0 & $(2.5)$ & 4.2 & $(1.3)$ & 0.2 & c & 0.0 & C \\
\hline & Zacatecas & 2.0 & $(0.8)$ & 9.2 & $(1.7)$ & 27.9 & $(2.5)$ & 38.6 & $(2.4)$ & 18.5 & $(2.2)$ & 3.8 & $(0.9)$ & 0.1 & C & 0.0 & c \\
\hline
\end{tabular}

- PISA adjudicated region.

Note: See Table I.4.2a for national data.

StatLink त्तार्य http://dx.doi.org/10.1787/888932935762 
[Part 4/4]

Table B2.I.26 Percentage of students at each proficiency level in reading, by gender and region

\begin{tabular}{|c|c|c|c|c|c|c|c|c|c|c|c|c|c|c|c|c|c|}
\hline & & \multicolumn{16}{|c|}{ Girls } \\
\hline & & \multicolumn{2}{|c|}{$\begin{array}{l}\text { Below Level 1b } \\
\text { (less than 262.04 } \\
\text { score points) }\end{array}$} & \multicolumn{2}{|c|}{\begin{tabular}{|c|} 
Level 1b \\
(from 262.04 to \\
less than 334.75 \\
score points) \\
\end{tabular}} & $\begin{array}{r}\text { Lev } \\
\text { (from } 3 \\
\text { less tha } \\
\text { score }\end{array}$ & $\begin{array}{l}1 \mathrm{a} \\
34.75 \text { to } \\
407.47 \\
\text { oints) }\end{array}$ & $\begin{array}{r}\text { Lev } \\
\text { (from } 4 \\
\text { less tha } \\
\text { score }\end{array}$ & \begin{tabular}{l|} 
el 2 \\
7.47 to \\
480.18 \\
oints)
\end{tabular} & $\begin{array}{r}\text { Lev } \\
\text { (from } 4 \\
\text { less thar } \\
\text { score }\end{array}$ & \begin{tabular}{l|} 
el 3 \\
0.18 to \\
552.89 \\
oints)
\end{tabular} & $\begin{array}{r}\text { Le } \\
\text { (from } 5 \\
\text { less tha } \\
\text { score }\end{array}$ & $\begin{array}{l}24 \\
2.89 \text { to } \\
625.61 \\
\text { oints) }\end{array}$ & $\begin{array}{r}\text { Le } \\
\text { (from } 6 \\
69 \\
\text { score }\end{array}$ & $\begin{array}{l}\text { el } 5 \\
5.61 \text { to } \\
.32 \\
\text { ooints }\end{array}$ & $\begin{array}{c}\text { Le } \\
\text { (above } \\
\text { score }\end{array}$ & $\begin{array}{l}\text { l } 6 \\
698.32 \\
\text { oints) }\end{array}$ \\
\hline & & $\%$ & S.E. & $\%$ & S.E. & $\%$ & S.E. & $\%$ & S.E. & $\%$ & S.E. & $\%$ & S.E. & $\%$ & S.E. & $\%$ & S.E. \\
\hline 0 & Portugal & & & & & & & & & & & & & & & & \\
\hline 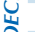 & Alentejo & 0.5 & c & 2.1 & (1.0) & 7.7 & $(2.5)$ & 25.6 & $(3.4)$ & 35.4 & (3.8) & 23.3 & $(4.0)$ & 5.5 & (2.5) & 0.0 & C \\
\hline & Spain & & & & & & & & & & & & & & & & \\
\hline & Andalusia ${ }^{\bullet}$ & 0.4 & $(0.4)$ & 3.3 & $(1.2)$ & 12.0 & (1.7) & 28.4 & (1.6) & 32.7 & (2.5) & 18.2 & $(1.7)$ & 4.5 & $(0.9)$ & 0.4 & $(0.3)$ \\
\hline & Aragon ${ }^{\bullet}$ & 0.4 & $(0.4)$ & 2.1 & $(0.8)$ & 9.8 & $(1.5)$ & 20.1 & $(2.2)$ & 35.2 & $(2.7)$ & 23.9 & (2.4) & 7.6 & $(2.1)$ & 0.9 & $(0.6)$ \\
\hline & Asturias ${ }^{\bullet}$ & 0.4 & $(0.3)$ & 1.9 & $(0.7)$ & 7.1 & $(1.2)$ & 18.1 & $(1.8)$ & 32.8 & (1.9) & 27.5 & (2.4) & 10.3 & $(1.5)$ & 1.9 & $(0.8)$ \\
\hline & Balearic Islands ${ }^{\bullet}$ & 1.2 & $(0.6)$ & 3.8 & $(0.8)$ & 11.2 & (1.6) & 25.5 & $(2.3)$ & 32.1 & (2.5) & 20.8 & (1.8) & 5.0 & $(1.3)$ & 0.4 & $(0.4)$ \\
\hline & Basque Country & 0.6 & $(0.2)$ & 2.4 & $(0.5)$ & 6.8 & $(0.7)$ & 20.7 & $(1.1)$ & 37.0 & (1.4) & 26.2 & (1.6) & 5.7 & $(0.6)$ & 0.6 & $(0.2)$ \\
\hline & Cantabria ${ }^{\bullet}$ & 0.2 & c & 2.4 & $(0.8)$ & 8.9 & $(1.7)$ & 28.1 & $(2.3)$ & 34.2 & $(2.2)$ & 19.7 & (2.3) & 5.8 & $(1.2)$ & 0.5 & $(0.5)$ \\
\hline & Castile and Leon ${ }^{\bullet}$ & 0.2 & c & 1.8 & $(0.6)$ & 7.7 & $(1.2)$ & 22.4 & (2.6) & 35.9 & $(2.3)$ & 25.5 & $(2.2)$ & 5.8 & (1.6) & 0.7 & $(0.5)$ \\
\hline & Catalonia $\bullet$ & 0.1 & c & 2.1 & $(0.8)$ & 8.1 & $(1.7)$ & 23.3 & $(2.7)$ & 33.3 & $(2.4)$ & 25.3 & (2.5) & 7.2 & $(2.0)$ & 0.7 & $(0.5)$ \\
\hline & Extremadura ${ }^{\bullet}$ & 1.3 & $(0.5)$ & 5.6 & $(1.2)$ & 15.0 & $(1.8)$ & 27.7 & (1.9) & 29.8 & $(1.9)$ & 16.3 & (1.6) & 3.8 & $(0.9)$ & 0.5 & $(0.4)$ \\
\hline & Galicia` & 0.3 & $(0.3)$ & 1.9 & $(0.7)$ & 8.4 & $(1.2)$ & 21.1 & $(2.3)$ & 32.0 & $(1.8)$ & 27.1 & (2.0) & 8.3 & (1.6) & 0.9 & $(0.5)$ \\
\hline & La Rioja• & 1.2 & $(0.4)$ & 2.9 & $(0.7)$ & 10.4 & (1.3) & 23.4 & (1.8) & 31.4 & $(2.8)$ & 22.4 & (2.1) & 7.2 & $(1.0)$ & 1.2 & $(0.4)$ \\
\hline & Madrid ${ }^{\bullet}$ & 0.3 & $(0.2)$ & 1.3 & (0.6) & 5.6 & $(1.4)$ & 20.1 & $(2.6)$ & 34.3 & $(1.8)$ & 27.9 & (2.4) & 9.2 & $(1.3)$ & 1.2 & $(0.6)$ \\
\hline & Murcia ${ }^{\bullet}$ & 1.3 & $(0.5)$ & 4.2 & (0.9) & 15.3 & (1.9) & 28.1 & (1.8) & 30.8 & $(2.2)$ & 16.8 & (1.7) & 3.3 & $(1.1)$ & 0.3 & $(0.3)$ \\
\hline & Navarre ${ }^{\bullet}$ & 0.2 & $(0.2)$ & 1.2 & $(0.5)$ & 5.4 & $(1.0)$ & 19.5 & $(2.2)$ & 32.3 & $(2.2)$ & 30.0 & $(3.2)$ & 9.8 & $(1.6)$ & 1.6 & $(0.5)$ \\
\hline & United Kingdom & & & & & & & & & & & & & & & & \\
\hline & England & 1.1 & $(0.4)$ & 3.0 & $(0.6)$ & 9.8 & (1.1) & 21.5 & $(1.5)$ & 30.5 & (1.5) & 22.6 & $(1.3)$ & 9.6 & $(0.9)$ & 1.9 & $(0.5)$ \\
\hline & Northern Ireland & 0.8 & $(0.4)$ & 2.6 & $(0.7)$ & 9.7 & $(1.7)$ & 22.3 & (1.9) & 29.9 & $(2.0)$ & 24.4 & $(2.0)$ & 8.8 & $(1.0)$ & 1.6 & $(0.5)$ \\
\hline & Scotland ${ }^{\bullet}$ & 0.1 & $(0.1)$ & 1.7 & (0.6) & 6.8 & $(1.2)$ & 21.3 & (1.6) & 35.9 & $(2.1)$ & 24.2 & (1.3) & 8.4 & $(1.0)$ & 1.5 & $(0.4)$ \\
\hline & Wales & 0.5 & $(0.2)$ & 3.0 & $(0.6)$ & 12.5 & $(1.1)$ & 27.5 & $(1.7)$ & 31.8 & (1.4) & 19.0 & (1.3) & 5.1 & $(0.8)$ & 0.7 & $(0.2)$ \\
\hline & United States & & & & & & & & & & & & & & & & \\
\hline & Connecticut ${ }^{\bullet}$ & 0.2 & $(0.2)$ & 2.5 & $(0.8)$ & 7.7 & (1.4) & 18.2 & (1.6) & 28.3 & $(2.0)$ & 26.2 & $(2.1)$ & 13.2 & (1.9) & 3.7 & $(0.8)$ \\
\hline & Florida $\bullet^{\bullet}$ & 0.4 & $(0.2)$ & 2.2 & (0.6) & 10.5 & (1.7) & 25.1 & $(2.2)$ & 32.5 & $(1.7)$ & 23.2 & (2.5) & 5.2 & (1.1) & 0.9 & $(0.6)$ \\
\hline & Massachusetts ${ }^{\bullet}$ & 0.4 & $(0.2)$ & 1.7 & $(0.8)$ & 6.0 & $(1.0)$ & 16.2 & (1.8) & 29.5 & $(2.2)$ & 26.6 & (2.4) & 15.6 & (1.9) & 4.1 & (1.1) \\
\hline$\frac{2}{3}$ & Argentina & & & & & & & & & & & & & & & & \\
\hline 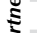 & Ciudad Autónoma de Buenos Aires ${ }^{\bullet}$ & 7.3 & $(2.1)$ & 9.6 & (1.8) & 15.9 & $(2.1)$ & 26.2 & $(2.1)$ & 26.3 & $(2.9)$ & 11.8 & $(2.3)$ & 2.6 & $(0.9)$ & 0.3 & c \\
\hline ‡ & Brazil & & & & & & & & & & & & & & & & \\
\hline & Acre & 2.4 & $(1.2)$ & 16.4 & (3.3) & 35.6 & $(4.8)$ & 32.4 & (3.9) & 11.2 & (3.0) & 2.0 & $(1.5)$ & 0.1 & c & 0.0 & c \\
\hline & Alagoas & 6.8 & $(2.7)$ & 27.0 & (3.9) & 35.8 & $(4.0)$ & 23.8 & $(4.1)$ & 5.4 & $(2.0)$ & 1.2 & $(0.7)$ & 0.0 & c & 0.0 & c \\
\hline & Amapá & 2.1 & (1.3) & 13.0 & $(4.0)$ & 33.7 & $(4.6)$ & 34.4 & $(5.0)$ & 13.6 & (2.8) & 3.2 & (2.4) & 0.1 & c & 0.0 & c \\
\hline & Amazonas & 2.3 & (1.5) & 15.0 & (2.3) & 41.5 & $(4.2)$ & 29.8 & $(3.2)$ & 9.3 & $(2.5)$ & 2.0 & (1.1) & 0.2 & $\mathrm{c}$ & 0.0 & c \\
\hline & Bahia & 2.4 & (1.9) & 15.1 & $(4.1)$ & 39.6 & $(4.4)$ & 24.1 & $(4.1)$ & 13.9 & $(4.8)$ & 4.1 & (1.5) & 0.8 & $(0.9)$ & 0.0 & c \\
\hline & Ceará & 3.9 & (2.4) & 13.9 & (3.7) & 32.1 & $(4.2)$ & 28.9 & (3.8) & 16.8 & (3.4) & 3.9 & (1.4) & 0.6 & $(0.4)$ & 0.0 & c \\
\hline & Espírito Santo & 1.2 & $(0.7)$ & 9.4 & (2.0) & 28.3 & $(4.0)$ & 30.1 & (3.4) & 18.2 & $(2.9)$ & 10.4 & (4.0) & 2.4 & (1.5) & 0.1 & c \\
\hline & Federal District & 3.1 & (2.5) & 7.9 & (1.9) & 22.7 & $(3.4)$ & 33.1 & $(3.2)$ & 25.1 & $(4.0)$ & 6.8 & (2.5) & 1.1 & $(1.3)$ & 0.2 & c \\
\hline & Goiás & 1.4 & $(0.7)$ & 13.8 & (3.0) & 37.1 & $(4.3)$ & 32.6 & (3.8) & 12.6 & (2.4) & 2.3 & (1.1) & 0.3 & c & 0.0 & c \\
\hline & Maranhão & 7.5 & (2.4) & 21.7 & (4.3) & 34.5 & $(5.2)$ & 24.6 & $(4.2)$ & 9.7 & (2.9) & 1.8 & (1.1) & 0.1 & c & 0.0 & C \\
\hline & Mato Grosso & 3.8 & (1.5) & 14.6 & (3.1) & 37.5 & $(5.4)$ & 29.7 & $(4.5)$ & 10.3 & $(3.2)$ & 3.7 & (1.6) & 0.5 & $(0.5)$ & 0.0 & C \\
\hline & Mato Grosso do Sul & 0.2 & $\mathrm{c}$ & 6.5 & (1.8) & 28.6 & (3.5) & 36.9 & $(4.0)$ & 20.2 & (3.6) & 7.0 & (2.0) & 0.4 & $(0.3)$ & 0.2 & $(0.2)$ \\
\hline & Minas Gerais & 0.6 & $(0.6)$ & 6.2 & (1.4) & 24.5 & (3.5) & 37.3 & (3.5) & 24.2 & (3.8) & 6.6 & (1.8) & 0.5 & $(0.5)$ & 0.0 & c \\
\hline & Pará & 3.1 & (1.3) & 17.1 & (3.8) & 34.1 & (3.8) & 29.6 & $(4.0)$ & 14.1 & (3.6) & 2.0 & (2.2) & 0.0 & c & 0.0 & c \\
\hline & Paraíba & 2.6 & (1.8) & 12.4 & (3.0) & 27.3 & (3.5) & 31.1 & (3.8) & 21.1 & (4.9) & 5.2 & (2.4) & 0.3 & c & 0.0 & c \\
\hline & Paraná & 1.4 & (0.9) & 9.7 & (2.2) & 27.4 & $(3.1)$ & 32.8 & (3.8) & 21.3 & (2.8) & 6.0 & (2.7) & 1.4 & (1.5) & 0.0 & c \\
\hline & Pernambuco & 3.6 & (1.4) & 19.4 & (3.8) & 37.8 & (4.4) & 29.2 & $(4.3)$ & 8.6 & (3.0) & 1.2 & $(0.7)$ & 0.1 & $(0.2)$ & 0.0 & c \\
\hline & Piauí & 1.2 & $(0.8)$ & 13.1 & (3.6) & 33.2 & $(4.0)$ & 32.9 & (4.6) & 14.0 & $(2.2)$ & 4.6 & (2.3) & 0.8 & (1.0) & 0.1 & c \\
\hline & Rio de Janeiro & 2.1 & (1.4) & 11.0 & (2.9) & 25.2 & $(4.0)$ & 37.6 & $(4.2)$ & 20.0 & (4.5) & 3.9 & (1.5) & 0.3 & $(0.3)$ & 0.0 & c \\
\hline & Rio Grande do Norte & 2.9 & (1.1) & 17.7 & (2.9) & 34.9 & (3.7) & 28.3 & (3.5) & 10.7 & $(2.7)$ & 4.3 & (1.9) & 1.3 & $(0.6)$ & 0.0 & c \\
\hline & Rio Grande do Sul & 0.0 & c & 5.1 & (2.0) & 21.0 & (3.3) & 40.7 & (3.6) & 25.7 & $(3.2)$ & 7.2 & (2.6) & 0.4 & c & 0.0 & c \\
\hline & Rondônia & 1.3 & $(0.8)$ & 11.5 & $(2.8)$ & 28.0 & (3.5) & 40.9 & (3.5) & 16.5 & $(3.1)$ & 1.8 & (1.5) & 0.0 & c & 0.0 & c \\
\hline & Roraima & 3.2 & (1.8) & 18.6 & (3.2) & 36.9 & (3.9) & 25.6 & (3.8) & 9.8 & (2.4) & 5.0 & (2.6) & 1.0 & $(0.7)$ & 0.0 & c \\
\hline & Santa Catarina & 4.3 & (2.6) & 8.4 & (3.2) & 18.8 & $(3.9)$ & 37.9 & $(5.2)$ & 22.8 & (4.4) & 7.0 & (2.4) & 0.5 & $(0.5)$ & 0.2 & c \\
\hline & São Paulo & 1.9 & $(0.8)$ & 7.7 & (1.3) & 25.5 & $(2.0)$ & 34.8 & $(2.1)$ & 22.3 & (1.9) & 7.1 & (1.3) & 0.8 & $(0.4)$ & 0.0 & c \\
\hline & Sergipe & 1.8 & $(0.8)$ & 13.2 & (3.0) & 37.1 & $(4.5)$ & 31.7 & $(3.9)$ & 13.5 & $(4.1)$ & 2.6 & (1.6) & 0.1 & c & 0.0 & c \\
\hline & Tocantins & 5.0 & (1.4) & 17.8 & (2.9) & 33.5 & (3.8) & 29.6 & $(3.0)$ & 12.1 & $(2.4)$ & 1.7 & $(0.7)$ & 0.2 & c & 0.0 & c \\
\hline & Colombia & & & & & & & & & & & & & & & & \\
\hline & Bogotá & 1.0 & $(0.5)$ & 8.5 & (1.4) & 29.3 & (2.5) & 38.7 & $(2.9)$ & 19.0 & (2.0) & 3.3 & $(0.8)$ & 0.2 & c & 0.0 & C \\
\hline & Cali & 2.5 & $(0.9)$ & 11.5 & (2.4) & 29.4 & (3.3) & 34.8 & (3.0) & 17.6 & $(2.5)$ & 3.9 & (1.4) & 0.2 & c & 0.0 & c \\
\hline & Manizales & 0.8 & $(0.6)$ & 6.1 & (1.7) & 25.8 & $(2.1)$ & 41.0 & (3.6) & 22.1 & (1.9) & 3.9 & $(1.7)$ & 0.3 & $(0.3)$ & 0.0 & C \\
\hline & Medellín & 1.8 & $(0.7)$ & 10.2 & (1.5) & 29.2 & $(2.9)$ & 30.7 & $(3.1)$ & 19.4 & (1.9) & 7.0 & (2.3) & 1.7 & (1.0) & 0.0 & c \\
\hline & Russian Federation & & & & & & & & & & & & & & & & \\
\hline & Perm Territory region ${ }^{\bullet}$ & 0.8 & $(0.4)$ & 3.0 & $(0.9)$ & 10.3 & (1.5) & 24.0 & $(2.4)$ & 34.1 & $(2.1)$ & 21.3 & (2.3) & 5.9 & $(1.2)$ & 0.7 & $(0.6)$ \\
\hline & United Arab Emirates & & & & & & & & & & & & & & & & \\
\hline & Abu Dhabi• & 0.8 & $(0.4)$ & 5.2 & (1.1) & 18.8 & (1.6) & 32.5 & $(2.1)$ & 29.1 & (1.9) & 11.2 & (1.5) & 2.2 & $(0.7)$ & 0.1 & $(0.1)$ \\
\hline & Ajman & 0.0 & c & 4.2 & (2.0) & 21.7 & $(5.4)$ & 40.3 & $(4.5)$ & 25.8 & $(5.1)$ & 6.7 & $(2.1)$ & 1.1 & $(0.9)$ & 0.1 & C \\
\hline & Dubai ${ }^{\bullet}$ & 0.6 & $(0.2)$ & 3.3 & (0.6) & 13.5 & $(1.3)$ & 25.9 & $(1.2)$ & 30.8 & $(1.3)$ & 19.3 & (1.3) & 6.1 & $(0.7)$ & 0.5 & $(0.3)$ \\
\hline & Fujairah & 1.0 & $(0.8)$ & 4.0 & (1.9) & 16.3 & $(3.1)$ & 40.1 & (3.6) & 31.8 & $(3.2)$ & 6.5 & (1.8) & 0.3 & C & 0.0 & C \\
\hline & Ras al-Khaimah & 0.9 & $(0.9)$ & 7.0 & $(2.7)$ & 22.1 & (3.4) & 37.7 & $(4.5)$ & 25.7 & (3.8) & 5.6 & (1.8) & 0.9 & $(1.0)$ & 0.0 & C \\
\hline & Sharjah & 0.0 & c & 4.2 & (1.6) & 18.9 & $(4.0)$ & 32.1 & $(4.2)$ & 31.6 & (4.0) & 11.4 & (3.0) & 1.3 & $(0.7)$ & 0.5 & C \\
\hline & Umm al-Quwain & 0.7 & c & 4.6 & (1.9) & 24.4 & (3.9) & 39.5 & $(5.2)$ & 24.1 & (5.5) & 6.6 & (2.5) & 0.0 & c & 0.0 & c \\
\hline
\end{tabular}

- PISA adjudicated region.

Note: See Table 1.4.2a for national data

StatLink त्नात्रा http://dx.doi.org/10.1787/888932935762 
[Part 1/2]

Table B2.I.27 Mean score, variation and gender differences in student performance in reading, by region

\begin{tabular}{|c|c|c|c|c|c|c|c|c|c|c|c|c|c|c|c|c|c|c|c|}
\hline & & & All stu & Idents & & & & nder di & lifferen & nces & & & & & & & Perce & entiles & \\
\hline & & Mean & score & $\begin{array}{l}\text { Stan } \\
\text { devia }\end{array}$ & $\begin{array}{l}\text { ard } \\
\text { ion }\end{array}$ & Bo & oys & & irls & $\begin{array}{c}\text { Diffe } \\
\text { (B }\end{array}$ & $\begin{array}{l}\text { rence } \\
- \text { - G) }\end{array}$ & & th & & 0th & & 5th & 75 & th \\
\hline & & Mean & S.E. & S.D. & S.E. & $\begin{array}{l}\text { Mean } \\
\text { score }\end{array}$ & S.E. & $\begin{array}{l}\text { Mean } \\
\text { score }\end{array}$ & S.E. & $\begin{array}{c}\begin{array}{c}\text { Score } \\
\text { dif. }\end{array} \\
\end{array}$ & S.E. & Score & S.E. & Score & S.E. & Score & S.E. & Score & S.E. \\
\hline 0 & Australia & & & & & & & & & & & & & & & & & & \\
\hline 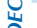 & Australian Capital Territory & 525 & (3.6) & 102 & (3.1) & 501 & (5.5) & 550 & (4.8) & -49 & (7.5) & 329 & (15.8) & $\mid 385$ & (9.7) & 467 & (5.9) & 597 & (5.1) \\
\hline & New South Wales & 513 & (3.3) & 101 & $(2.1)$ & 493 & (5.5) & 533 & (3.7) & -41 & (6.5) & 339 & $(7.0)$ & 382 & (4.9) & 446 & (4.3) & 584 & (4.4) \\
\hline & Northern Territory & 466 & $(8.3)$ & 123 & (5.8) & 449 & $(10.1)$ & 482 & (11.4) & -33 & (14.1) & 224 & (23.5) & 293 & $(18.7)$ & 395 & (11.3) & 556 & (8.6) \\
\hline & Queensland & 508 & (3.4) & 97 & $(2.1)$ & 491 & (4.3) & 525 & (4.0) & -34 & (4.8) & 346 & $(6.2)$ & 384 & (5.9) & 443 & (3.8) & 575 & (4.1) \\
\hline & South Australia & 500 & (4.0) & 92 & $(2.0)$ & 484 & (4.4) & 517 & (4.5) & -33 & (4.3) & 343 & $(8.0)$ & 380 & $(6.2)$ & 441 & (4.8) & 566 & (6.0) \\
\hline & Tasmania & 485 & (3.6) & 98 & $(2.9)$ & 468 & (4.8) & 503 & (5.1) & -35 & (6.8) & 312 & (11.4) & 359 & (7.7) & 420 & (5.1) & 555 & $(5.7)$ \\
\hline & Victoria & 517 & (3.5) & 92 & (1.8) & 502 & (5.1) & 534 & (3.5) & -31 & (5.1) & 360 & (7.2) & 395 & (4.9) & 459 & (4.4) & 579 & (4.7) \\
\hline & Western Australia & 519 & (3.1) & 94 & $(2.1)$ & 507 & (5.3) & 533 & (4.4) & -26 & (7.5) & 360 & (6.5) & 395 & (5.0) & 458 & (4.8) & 585 & (3.3) \\
\hline & Belgium & & & & & & & & & & & & & & & & & & \\
\hline & Flemish Community ${ }^{\bullet}$ & 518 & (3.0) & 99 & $(2.2)$ & 503 & (4.4) & 532 & (3.8) & -30 & (5.7) & 342 & (8.0) & 1) 385 & $(5.7)$ & 454 & (4.3) & 590 & (3.4) \\
\hline & French Community & 497 & (3.9) & 105 & (2.9) & 480 & (4.3) & 514 & (4.4) & -34 & (4.0) & 306 & $(10.9)$ & 357 & (7.3) & 430 & (5.9) & 573 & $(4.0)$ \\
\hline & German-speaking Community & 499 & $(2.3)$ & 98 & (2.6) & 474 & (3.8) & 526 & $(3.2)$ & -52 & (5.3) & 323 & (11.1) & 365 & $(9.3)$ & 438 & $(4.8)$ & 571 & (4.6) \\
\hline & Canada & & & & & & & & & & & & & & & & & & \\
\hline & Alberta & 525 & (4.1) & 92 & $(1.8)$ & 511 & (4.6) & 541 & (4.3) & -29 & (3.7) & 370 & (8.9) & 405 & (6.9) & 466 & (5.3) & 590 & (4.4) \\
\hline & British Columbia & 535 & $(4.5)$ & 89 & $(2.7)$ & 522 & (5.1) & 548 & (5.5) & -26 & (6.1) & 382 & (11.4) & 418 & (7.3) & 479 & (5.4) & 595 & (4.6) \\
\hline & Manitoba & 495 & (3.3) & 94 & (2.6) & 475 & $(4.2)$ & 517 & (4.6) & -41 & (5.9) & 336 & $(8.7)$ & 374 & (5.6) & 433 & (5.0) & 563 & (4.4) \\
\hline & New Brunswick & 497 & (2.6) & 90 & (2.6) & 473 & $(4.2)$ & 521 & (3.7) & -49 & (6.0) & 342 & (7.6) & 378 & (5.6) & 440 & (4.1) & 557 & (5.0) \\
\hline & Newfoundland and Labrador & 503 & (3.7) & 96 & (2.4) & 476 & $(5.2)$ & 529 & (4.0) & -53 & (5.5) & 335 & $(10.7)$ & 378 & (6.3) & 442 & (6.6) & 567 & $(5.2)$ \\
\hline & Nova Scotia & 508 & (3.1) & 89 & (2.8) & 489 & (4.4) & 529 & (4.4) & -40 & (6.5) & 350 & (10.9) & 394 & $(9.8)$ & 454 & (6.5) & 569 & (5.5) \\
\hline & Ontario & 528 & $(4.4)$ & 92 & (1.8) & 510 & (5.4) & 546 & $(4.2)$ & -36 & (3.9) & 366 & $(7.7)$ & 408 & $(5.7)$ & 471 & (5.5) & 592 & (5.0) \\
\hline & Prince Edward Island & 488 & $(2.7)$ & 90 & $(2.0)$ & 465 & $(4.2)$ & 512 & (3.2) & -48 & (5.1) & 333 & (9.5) & 369 & (6.0) & 427 & $(4.2)$ & 553 & (3.8) \\
\hline & Quebec & 520 & (3.6) & 93 & $(2.1)$ & 502 & (4.0) & 537 & (4.0) & -36 & (4.1) & 358 & (6.4) & 397 & (5.3) & 461 & (4.5) & 585 & (3.9) \\
\hline & Saskatchewan & 505 & (2.8) & 89 & $(2.0)$ & 487 & (3.9) & 525 & (3.4) & -37 & (4.6) & 353 & (6.8) & 389 & (6.6) & 448 & (4.1) & 566 & $(4.2)$ \\
\hline & Italy & & & & & & & & & & & & & & & & & & \\
\hline & Abruzzo & 480 & (5.8) & 97 & (3.8) & 454 & (8.0) & 506 & (6.0) & -53 & (7.3) & \begin{tabular}{|l|}
309 \\
$\mid$
\end{tabular} & (14.3) & 347 & (10.8) & 417 & (8.1) & 549 & (5.7) \\
\hline & Basilicata & 474 & (5.4) & 85 & (3.1) & 459 & (7.2) & 490 & (5.0) & -31 & (6.4) & 325 & (11.5) & 361 & (10.7) & 421 & (8.1) & 534 & (4.9) \\
\hline & Bolzano & 497 & (2.4) & 92 & (1.8) & 481 & (3.4) & 513 & (2.9) & -32 & $(4.2)$ & 329 & (6.9) & 371 & (6.5) & 440 & (3.9) & 561 & (3.6) \\
\hline & Calabria & 434 & $(7.2)$ & 98 & (5.8) & 415 & (9.0) & 454 & (8.7) & -39 & (10.4) & 268 & (17.5) & 306 & (15.5) & 365 & (11.0) & 505 & $(6.2)$ \\
\hline & Campania & 464 & (9.3) & 95 & (3.7) & 444 & (8.2) & 483 & (11.2) & -39 & (9.1) & 301 & (10.2) & 336 & (8.9) & 397 & (9.7) & 533 & (12.4) \\
\hline & Emilia Romagna & 498 & (6.5) & 102 & (4.5) & 474 & (10.5) & 523 & $(7.5)$ & -49 & (13.3) & 312 & (12.9) & 356 & (15.0) & 435 & $(11.7)$ & 571 & (6.6) \\
\hline & Friuli Venezia Giulia & 518 & (4.1) & 92 & $(4.1)$ & 497 & $(5.2)$ & 541 & (7.7) & -45 & $(9.0)$ & 352 & (18.6) & 394 & (11.0) & 462 & $(8.8)$ & 583 & (3.3) \\
\hline & Lazio & 480 & $(7.2)$ & 92 & (3.8) & 465 & $(8.2)$ & 499 & $(8.2)$ & -34 & (7.2) & 321 & (14.4) & 358 & (11.3) & 418 & (10.1) & 546 & (7.6) \\
\hline & Liguria & 490 & (6.9) & 98 & (3.9) & 466 & (8.4) & 516 & (7.7) & -51 & (9.2) & 319 & (13.3) & 357 & (13.2) & 425 & (7.5) & 562 & (7.9) \\
\hline & Lombardia & 521 & (5.9) & 89 & (3.2) & 506 & (8.2) & 537 & (6.4) & -31 & (7.8) & 363 & (9.6) & 404 & (9.6) & 467 & (8.5) & 583 & (6.9) \\
\hline & Marche & 497 & (6.3) & 89 & (3.9) & 484 & (6.8) & 509 & (7.1) & -25 & (6.2) & 341 & (16.3) & 378 & (11.3) & 438 & (8.3) & 559 & (6.2) \\
\hline & Molise & 476 & (2.6) & 91 & $(2.2)$ & 455 & (3.6) & 499 & (3.4) & -44 & (4.8) & 310 & (7.7) & 355 & $(8.0)$ & 419 & (6.2) & 539 & (3.8) \\
\hline & Piemonte & 506 & (4.8) & 87 & (2.8) & 487 & (5.1) & 523 & (6.1) & -36 & (4.9) & 356 & (9.7) & 393 & (8.9) & 450 & (5.9) & 565 & (6.4) \\
\hline & Puglia & 493 & (5.9) & 92 & (3.8) & 473 & (7.1) & 513 & (6.8) & -40 & (7.2) & 326 & (14.5) & 371 & (12.2) & 439 & (8.6) & 556 & (6.3) \\
\hline & Sardegna & 464 & (7.0) & 100 & $(4.1)$ & 445 & $(7.2)$ & 483 & (9.3) & -38 & (8.4) & 285 & (16.2) & 331 & (14.9) & 400 & (9.5) & 535 & (7.0) \\
\hline & Sicilia & 455 & (5.7) & 93 & (2.8) & 440 & (6.9) & 472 & (7.4) & -32 & (8.2) & 291 & (11.9) & 333 & $(9.2)$ & 394 & (7.1) & 520 & (6.4) \\
\hline & Toscana & 488 & (5.8) & 102 & $(4.1)$ & 465 & (7.8) & 517 & $(8.2)$ & -52 & (12.1) & 303 & (15.6) & 347 & (11.4) & 422 & (8.9) & 560 & (6.5) \\
\hline & Trento & 521 & (5.2) & 94 & (4.0) & 496 & (7.7) & 550 & (7.8) & -54 & (11.9) & 359 & (19.2) & 400 & (9.7) & 458 & (9.6) & 589 & (5.7) \\
\hline & Umbria & 492 & (7.0) & 94 & (5.2) & 474 & (10.8) & 510 & (5.2) & -36 & (10.8) & 320 & (23.9) & 366 & (16.8) & 434 & (10.3) & 558 & (5.4) \\
\hline & Valle d'Aosta & 502 & (2.5) & 90 & (2.5) & 486 & (3.9) & 519 & (3.5) & -32 & (5.6) & 351 & (10.6) & 388 & (8.3) & 444 & (3.6) & 564 & (4.7) \\
\hline & Veneto & 521 & (6.0) & 97 & (4.8) & 499 & (8.5) & 544 & (6.4) & -45 & (8.3) & 349 & (14.3) & 394 & (13.3) & 464 & (7.9) & 588 & (5.5) \\
\hline & Mexico & & & & & & & & & & & & & & & & & & \\
\hline & Aguascalientes & 447 & (4.9) & 79 & (3.0) & 432 & (6.2) & 462 & (4.5) & -30 & (5.3) & $\mid 313$ & (10.8) & 345 & (10.4) & $\mid 395$ & (6.6) & 503 & (4.5) \\
\hline & Baja California & 428 & $(7.2)$ & 79 & (3.6) & 416 & (8.4) & 440 & (6.8) & -24 & (5.2) & 305 & (15.0) & 330 & $(10.7)$ & 372 & (9.6) & 481 & (8.4) \\
\hline & Baja California Sur & 423 & (5.8) & 73 & $(2.8)$ & 413 & (6.6) & 434 & (5.7) & -20 & (4.6) & 298 & (10.5) & 326 & (11.1) & 375 & (8.6) & 474 & (4.8) \\
\hline & Campeche & 413 & (5.1) & 78 & (3.3) & 402 & (4.9) & 424 & (6.1) & -22 & (4.4) & 285 & (11.7) & 311 & (11.8) & 360 & (6.4) & 466 & (4.9) \\
\hline & Chiapas & 371 & (8.6) & 82 & $(4.1)$ & 357 & (9.1) & 386 & (8.7) & -30 & (5.7) & 234 & (11.7) & 266 & (11.8) & 318 & (11.5) & 426 & (7.3) \\
\hline & Chihuahua & 444 & (9.4) & 83 & $(2.7)$ & 432 & (12.4) & 455 & (7.9) & -23 & (8.6) & 302 & (13.7) & 336 & (13.4) & 392 & (10.4) & 500 & $(10.3)$ \\
\hline & Coahuila & 431 & (8.6) & 76 & (3.1) & 419 & (10.0) & 443 & (7.8) & -25 & (6.6) & 304 & $(8.7)$ & 329 & $(9.7)$ & 379 & (8.9) & 485 & (10.5) \\
\hline & Colima & 440 & $(4.1)$ & 82 & (2.9) & 423 & (5.5) & 457 & $(4.2)$ & -34 & (6.0) & 303 & (9.1) & 333 & (8.6) & 384 & (6.4) & 497 & (5.5) \\
\hline & Distrito Federal & 448 & (5.5) & 76 & (3.4) & 441 & (7.5) & 454 & (5.8) & -13 & $(7.2)$ & 317 & (13.6) & 352 & $(10.1)$ & 401 & (6.2) & 498 & $(6.2)$ \\
\hline & Durango & 436 & (7.0) & 77 & (2.6) & 422 & (8.2) & 449 & (6.9) & -27 & (6.5) & 306 & (9.4) & 335 & (8.7) & 385 & (8.1) & 492 & (7.7) \\
\hline & Guanajuato & 414 & (6.7) & 82 & (3.0) & 403 & (6.9) & 424 & (7.6) & -22 & (6.1) & 273 & $(12.2)$ & 305 & $(10.7)$ & 359 & (8.8) & 471 & $(7.2)$ \\
\hline & Guerrero & 368 & $(5.2)$ & 79 & (2.9) & 355 & (5.8) & 381 & (5.7) & -26 & (5.2) & 238 & (10.2) & 265 & (6.8) & 314 & (7.0) & 422 & (7.6) \\
\hline & Hidalgo & 414 & (6.3) & 81 & (3.4) & 404 & (7.5) & 422 & (6.4) & -19 & (6.0) & 273 & $(13.2)$ & 309 & (9.9) & 361 & (7.6) & 470 & (8.3) \\
\hline & Jalisco & 436 & (6.2) & 79 & (3.2) & 421 & (6.7) & 450 & (6.3) & -29 & (4.7) & 306 & (12.1) & 336 & (6.8) & 383 & (8.4) & 492 & (6.9) \\
\hline & Mexico & 437 & (6.3) & 73 & (4.2) & 428 & (6.8) & 445 & (7.3) & -17 & (6.3) & 317 & (8.5) & 344 & (8.6) & 388 & (7.1) & 487 & (7.5) \\
\hline & Morelos & 425 & $(9.7)$ & 86 & (6.5) & 410 & (11.8) & 439 & (8.8) & -30 & (8.8) & 272 & $(27.4)$ & 315 & (18.1) & 371 & (13.6) & 482 & (8.3) \\
\hline & Nayarit & 418 & (7.4) & 81 & (3.0) & 406 & (6.8) & 429 & (8.9) & -23 & (5.8) & 281 & (11.9) & 314 & (9.6) & 364 & (9.4) & 473 & (8.1) \\
\hline & Nuevo León & 442 & (7.3) & 75 & $(4.1)$ & 431 & (8.4) & 453 & (7.4) & -22 & (4.9) & 317 & (15.6) & 346 & (12.3) & 393 & (9.4) & 494 & (7.6) \\
\hline & Puebla & 423 & (6.6) & 78 & (4.1) & 409 & (7.0) & 436 & (7.4) & -27 & (6.8) & 288 & (15.1) & 322 & (13.2) & 374 & (9.5) & 477 & (7.2) \\
\hline & Querétaro & 451 & $(9.1)$ & 78 & (2.8) & 440 & (9.9) & 461 & (8.6) & -21 & (5.2) & 321 & (13.5) & 350 & $(9.7)$ & 398 & (10.0) & 503 & (9.9) \\
\hline & Quintana Roo & 430 & (5.9) & 77 & (2.6) & 412 & (7.0) & 449 & (5.3) & -37 & (5.0) & 296 & $(16.7)$ & 328 & $(10.0)$ & 379 & $(6.8)$ & 486 & (5.6) \\
\hline & San Luis Potosí & 425 & (6.9) & 82 & (3.7) & 402 & (7.5) & 444 & (6.6) & -42 & (5.4) & 286 & (11.7) & 316 & (10.0) & 369 & (8.0) & 484 & (8.4) \\
\hline & Sinaloa & 417 & (5.4) & 76 & (2.8) & 395 & (6.2) & 436 & (5.7) & -41 & (5.5) & 295 & (7.5) & 318 & (5.9) & 363 & (7.2) & 470 & (7.6) \\
\hline & Tabasco & 395 & (4.5) & 74 & (2.9) & 378 & (5.4) & 411 & (4.3) & -34 & (4.0) & 273 & (7.7) & 298 & (6.9) & 345 & (5.6) & 446 & (5.5) \\
\hline & Tamaulipas & 421 & (6.0) & 77 & (3.3) & 413 & (7.2) & 429 & (6.6) & -16 & (6.8) & 287 & (13.5) & 317 & (9.4) & 369 & (6.9) & 473 & (7.1) \\
\hline & Tlaxcala & 418 & (6.4) & 82 & $(2.7)$ & 404 & (6.5) & 431 & (7.1) & -26 & $(4.2)$ & 276 & (9.4) & 310 & (9.4) & 364 & (8.2) & 476 & (7.6) \\
\hline & Veracruz & 410 & (5.3) & 79 & (3.0) & 399 & (5.6) & 423 & (6.8) & -24 & (6.6) & 281 & (8.2) & 310 & (6.8) & 356 & (7.3) & 465 & (6.0) \\
\hline & Yucatán & 426 & (6.5) & 77 & $(2.2)$ & 420 & (8.1) & 432 & (6.0) & -11 & (6.1) & 300 & (8.8) & 326 & (7.8) & 372 & (8.0) & 478 & (6.5) \\
\hline & Zacatecas & 412 & (5.6) & 77 & (2.2) & 398 & (6.5) & 425 & $(5.2)$ & -26 & (4.6) & 280 & (10.8) & 313 & (8.9) & 360 & (6.8) & 463 & (5.7) \\
\hline
\end{tabular}

- PISA adjudicated region.

Notes: Values that are statistically significant are indicated in bold (see Annex A3).

See Table I.4.3a for national data.

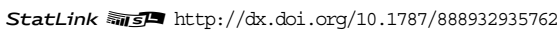


[Part 2/2]

Table B2.I.27 Mean score, variation and gender differences in student performance in reading, by region

\begin{tabular}{|c|c|c|c|c|c|c|c|c|c|c|c|c|c|c|c|c|c|c|c|c|c|c|c|}
\hline & & \multicolumn{4}{|c|}{ All students } & \multicolumn{6}{|c|}{ Gender differences } & \multicolumn{12}{|c|}{ Percentiles } \\
\hline & & \multicolumn{2}{|c|}{ Mean score } & \multicolumn{2}{|c|}{$\begin{array}{l}\text { Standard } \\
\text { deviation }\end{array}$} & \multicolumn{2}{|c|}{ Boys } & \multicolumn{2}{|c|}{ Girls } & \multicolumn{2}{|c|}{$\begin{array}{c}\text { Difference } \\
\text { (B - G) }\end{array}$} & \multicolumn{2}{|c|}{ 5th } & \multicolumn{2}{|c|}{ 10th } & \multicolumn{2}{|c|}{ 25th } & \multicolumn{2}{|c|}{ 75th } & \multicolumn{2}{|c|}{ 90th } & \multicolumn{2}{|c|}{ 95th } \\
\hline & & Mean & S.E. & S.D. & S.E. & $\begin{array}{l}\text { Mean } \\
\text { score }\end{array}$ & S.E. & $\begin{array}{l}\text { Mean } \\
\text { score }\end{array}$ & S.E. & $\begin{array}{c}\text { Score } \\
\text { dif. }\end{array}$ & S.E. & Score & S.E. & Score & S.E. & Score & S.E. & Score & S.E. & Score & S.E. & Score & S.E. \\
\hline \multicolumn{24}{|c|}{ " } \\
\hline 㟧 & Alentejo & 490 & (8.5) & 86 & (4.6) & 472 & $(10.2)$ & $\mid 507$ & $(8.3)$ & \begin{tabular}{|l|}
-35 \\
-35
\end{tabular} & (7.6) & 342 & (16.5) & 376 & (14.8) & 437 & (11.0) & 549 & (10.7) & $\mid 598$ & (10.5) & 626 & (13.8) \\
\hline \multicolumn{24}{|c|}{ | } \\
\hline & Andalusia ${ }^{\bullet}$ & 477 & $(4.2)$ & 92 & (2.4) & 464 & (5.5) & 490 & (4.5) & -26 & (5.4) & 317 & (11.0) & 356 & (10.4) & 419 & (5.8) & 540 & (4.0) & 586 & (4.5) & 619 & (5.7) \\
\hline & Aragon • & 493 & (5.8) & 92 & (3.0) & 474 & (6.4) & 512 & (6.1) & -38 & (5.3) & 330 & (11.0) & 369 & (9.8) & 434 & (8.9) & 556 & (5.5) & 607 & $(6.7)$ & 635 & (7.9) \\
\hline & Asturias ${ }^{\bullet}$ & 504 & $(5.2)$ & 96 & (3.6) & 481 & (7.0) & 527 & (4.7) & -46 & (6.3) & 335 & (12.1) & 382 & (9.1) & 444 & (6.6) & 570 & (4.5) & 620 & (5.5) & 649 & (8.6) \\
\hline & Balearic Islands` & 476 & (4.5) & 95 & (2.1) & 459 & (5.0) & 493 & (5.4) & -34 & $(5.7)$ & 308 & $(7.2)$ & 348 & (6.0) & 416 & (6.9) & 543 & (4.9) & 594 & (6.5) & 621 & (6.6) \\
\hline & Basque Country & 498 & (2.8) & 86 & (1.4) & 483 & (3.4) & 513 & (2.8) & -30 & (3.1) & 342 & (6.8) & 384 & $(5.2)$ & 448 & (3.3) & 557 & (2.8) & 600 & $(2.7)$ & 626 & (3.4) \\
\hline & Cantabria` & 485 & (3.5) & 88 & (2.0) & 470 & (3.9) & 501 & (4.3) & -31 & (4.4) & 336 & (7.3) & 369 & (6.7) & 428 & (5.1) & 547 & (3.7) & 596 & (4.5) & 623 & (5.4) \\
\hline & Castile and Leon ${ }^{\bullet}$ & 505 & (5.5) & 86 & $(2.2)$ & 498 & (6.7) & 513 & (5.5) & -15 & (5.5) & 353 & (10.4) & 391 & (7.8) & 451 & (5.9) & 567 & (5.9) & 610 & (6.7) & 637 & (6.8) \\
\hline & Catalonia• & 501 & $(4.7)$ & 89 & (1.8) & 489 & (5.5) & 514 & (5.7) & -24 & $(6.1)$ & 346 & (9.0) & 383 & (5.9) & 443 & (5.3) & 563 & (5.6) & 612 & (7.1) & 640 & (7.3) \\
\hline & Extremadura ${ }^{\bullet}$ & 457 & (4.9) & 102 & (2.4) & 438 & (6.0) & 477 & (4.8) & -39 & (5.4) & 276 & $(10.2)$ & 322 & (9.1) & 393 & (6.7) & 530 & (4.9) & 581 & (6.3) & 609 & (8.4) \\
\hline & Galicia• & 499 & $(4.7)$ & 94 & (2.6) & 480 & (5.8) & 518 & (5.1) & -38 & (5.5) & 332 & (11.4) & 375 & (9.8) & 441 & (6.5) & 566 & (5.4) & 612 & (6.0) & 638 & (7.7) \\
\hline & La Rioja ${ }^{\bullet}$ & 490 & (2.4) & 101 & $(2.7)$ & 475 & (3.6) & 504 & (3.0) & -29 & (4.7) & 312 & (9.5) & 364 & (6.3) & 430 & (3.7) & 559 & (3.4) & 610 & (4.3) & 639 & (5.0) \\
\hline & Madrid• & 511 & (4.8) & 86 & (2.3) & 497 & (5.6) & 526 & (4.9) & -30 & (4.4) & 364 & (11.1) & 401 & (6.4) & 455 & (5.7) & 572 & (5.6) & 618 & (5.4) & 647 & (6.4) \\
\hline & Murcia ${ }^{\bullet}$ & 462 & (5.0) & 95 & (2.4) & 445 & (6.3) & 479 & (4.4) & -34 & $(4.2)$ & 291 & (8.8) & 332 & (9.5) & 401 & (6.8) & 529 & (5.0) & 580 & $(7.2)$ & 607 & (7.0) \\
\hline & Navarre ${ }^{\bullet}$ & 509 & (3.2) & 89 & $(2.1)$ & 487 & $(4.2)$ & 531 & (3.9) & -44 & (4.8) & 354 & (6.9) & 391 & (6.3) & 454 & (4.4) & 571 & (4.7) & 617 & (4.9) & 646 & (5.8) \\
\hline \multicolumn{24}{|c|}{ United Kingdom } \\
\hline & England & 500 & $(4.2)$ & 98 & (2.6) & 487 & (5.4) & 512 & (4.5) & $\mid-24$ & (5.4) & 328 & (8.5) & $\mid 371$ & (8.3) & 438 & (5.8) & 568 & (3.8) & 621 & (4.5) & 652 & (5.2) \\
\hline & Northern Ireland & 498 & (3.9) & 95 & $(2.7)$ & 484 & (5.4) & 512 & $(5.2)$ & -27 & (7.6) & 333 & (9.6) & 373 & (7.1) & 436 & (5.0) & 565 & (5.7) & 618 & (5.3) & 646 & (5.9) \\
\hline & Scotland ${ }^{\bullet}$ & 506 & (3.0) & 87 & (1.8) & 493 & (3.2) & 520 & (3.5) & -27 & (3.4) & 357 & $(7.2)$ & 394 & (5.1) & 450 & (3.9) & 565 & (3.6) & 614 & (3.8) & 645 & (4.8) \\
\hline & Wales & 480 & $(2.7)$ & 90 & (1.7) & 466 & (3.2) & 493 & (3.2) & -27 & (3.5) & 325 & (6.3) & 365 & $(4.7)$ & 421 & (3.7) & 541 & (3.2) & 593 & (3.9) & 624 & (4.6) \\
\hline \multicolumn{24}{|c|}{ United States } \\
\hline & Connecticut $^{\bullet}$ & 521 & (6.5) & 99 & $(2.7)$ & 510 & (7.1) & 532 & (6.7) & \begin{tabular}{|l|}
-22 \\
-2
\end{tabular} & (5.0) & 352 & (10.2) & 388 & (9.6) & 456 & (7.5) & 590 & (6.0) & 645 & (7.3) & 674 & (8.8) \\
\hline & Florida ${ }^{\bullet}$ & 492 & (6.1) & 89 & (2.6) & 481 & (7.0) & 503 & (5.9) & -22 & (4.1) & 342 & (10.4) & 377 & $(7.2)$ & 433 & (7.1) & 555 & (7.0) & 602 & (7.4) & 630 & (7.6) \\
\hline & Massachusetts ${ }^{\bullet}$ & 527 & (6.1) & 98 & (2.9) & 511 & (6.2) & 542 & (6.6) & -32 & $(4.2)$ & 359 & $(10.0)$ & 399 & (7.7) & 464 & (7.1) & 595 & (7.7) & 652 & (7.3) & 682 & (8.2) \\
\hline
\end{tabular}

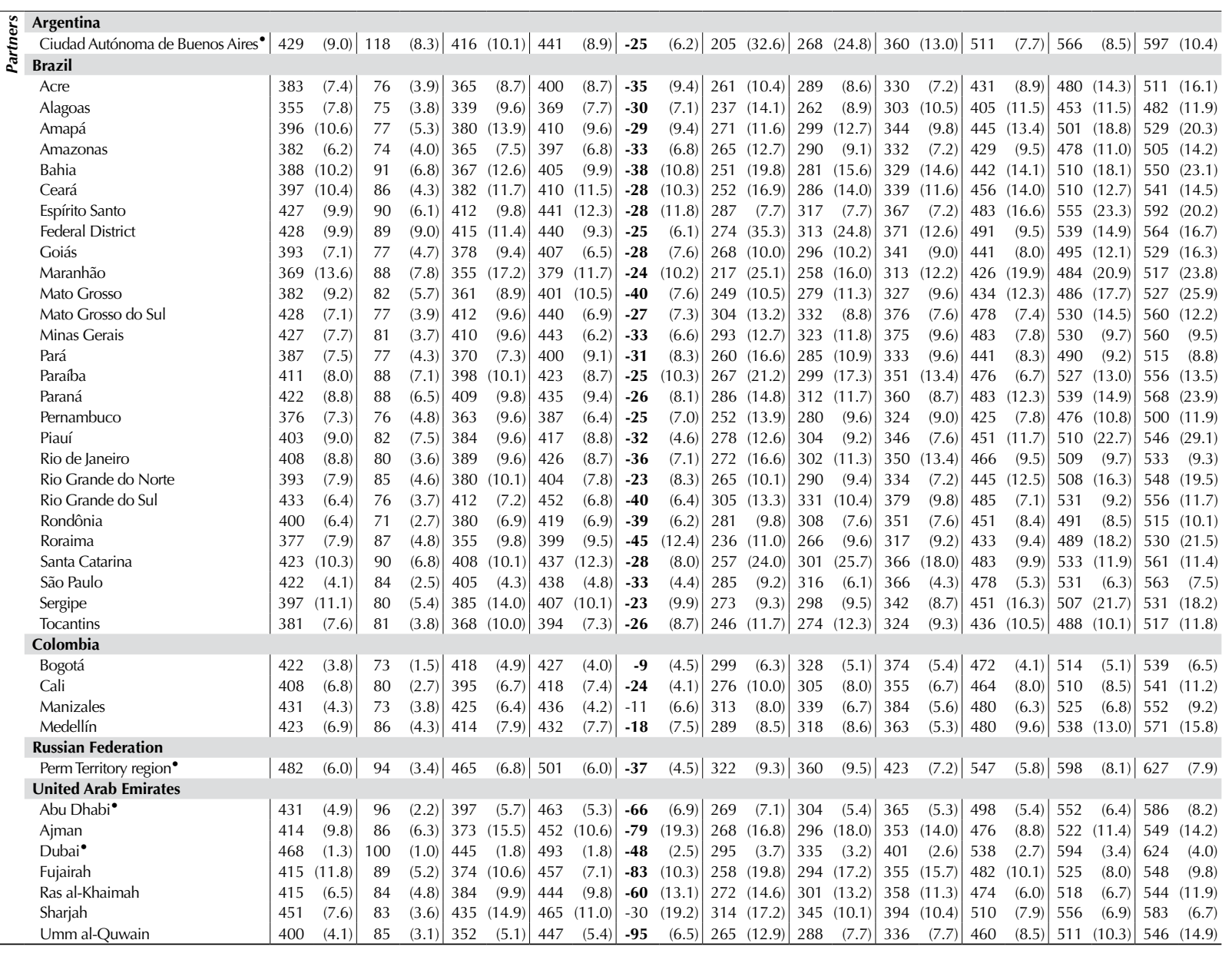

- PISA adjudicated region.

Notes: Values that are statistically significant are indicated in bold (see Annex A3).

See Table I.4.3a for national data.

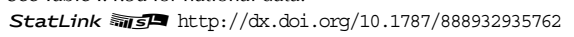


[Part 1/2]

Table B2.I.28 Percentage of students at each proficiency level in science, by region

\begin{tabular}{|c|c|c|c|c|c|c|c|c|c|c|c|c|c|c|c|}
\hline & & \multicolumn{14}{|c|}{ All students } \\
\hline & & \multicolumn{2}{|c|}{$\begin{array}{c}\text { Below Level } 1 \\
\text { (below } 334.94 \\
\text { score points) }\end{array}$} & $\begin{array}{l}\mathrm{L} \\
\text { (from } \\
\text { less th } \\
\text { scor }\end{array}$ & $\begin{array}{l}1 \\
.94 \text { to } \\
409.54 \\
\text { ints) }\end{array}$ & $\begin{array}{l}\mathrm{Le} \\
\text { (from } \\
\text { less th } \\
\text { scor }\end{array}$ & $\begin{array}{l}2 \\
9.54 \text { to } \\
484.14 \\
\text { pints) }\end{array}$ & $\begin{array}{r}\mathrm{L} \\
\text { (from } \\
\text { less th } \\
\text { scor }\end{array}$ & $\begin{array}{l}3 \\
.14 \text { to } \\
558.73 \\
\text { ints) }\end{array}$ & $\begin{array}{l}\text { Le } \\
\text { (from } \\
\text { less th } \\
\text { scor }\end{array}$ & $\begin{array}{l}4 \\
3.73 \text { to } \\
633.33 \\
\text { oints) }\end{array}$ & $\begin{array}{l}\text { L } \\
\text { (from } \\
\text { less th } \\
\text { scor }\end{array}$ & $\begin{array}{l}5 \\
.33 \text { to } \\
707.93 \\
\text { ints) }\end{array}$ & $\begin{array}{l}\text { Le } \\
\text { (abov } \\
\text { scor }\end{array}$ & $\begin{array}{l}6 \\
07.93 \\
\text { ints) }\end{array}$ \\
\hline & & $\%$ & S.E. & $\%$ & S.E. & $\%$ & S.E. & $\%$ & S.E. & $\%$ & S.E. & $\%$ & S.E. & $\%$ & S.E. \\
\hline 0 & Australia & & & & & & & & & & & & & & \\
\hline 岙 & Australian Capital Territory & 4.1 & $(0.8)$ & 8.0 & (1.1) & 17.3 & $(1.5)$ & 27.7 & (1.9) & 25.9 & $(2.1)$ & 13.7 & (1.5) & 3.2 & $(0.9)$ \\
\hline & New South Wales & 3.9 & $(0.5)$ & 10.1 & $(0.8)$ & 20.4 & $(0.9)$ & 27.1 & $(1.1)$ & 22.2 & $(0.9)$ & 12.8 & (1.0) & 3.6 & $(0.6)$ \\
\hline & Northern Territory & 12.5 & (1.7) & 13.1 & $(2.3)$ & 19.3 & $(3.0)$ & 27.3 & (3.6) & 19.0 & (3.4) & 6.2 & (2.1) & 2.6 & $(1.2)$ \\
\hline & Queensland & 3.1 & $(0.5)$ & 10.3 & $(0.8)$ & 22.7 & $(1.0)$ & 29.0 & (1.4) & 22.8 & $(1.2)$ & 10.0 & $(0.8)$ & 2.1 & $(0.4)$ \\
\hline & South Australia & 3.8 & $(0.7)$ & 10.7 & $(1.2)$ & 24.2 & (1.4) & 28.5 & $(1.7)$ & 21.9 & (1.3) & 9.4 & (1.4) & 1.5 & $(0.6)$ \\
\hline & Tasmania & 6.3 & $(0.8)$ & 13.6 & $(1.2)$ & 22.9 & (1.8) & 26.4 & $(2.0)$ & 20.8 & (1.6) & 8.2 & $(1.2)$ & 1.7 & $(0.6)$ \\
\hline & Victoria & 2.9 & $(0.4)$ & 10.5 & $(0.9)$ & 22.5 & $(1.3)$ & 30.1 & $(1.5)$ & 22.7 & (1.3) & 9.2 & $(1.0)$ & 2.0 & $(0.5)$ \\
\hline & Western Australia & 2.1 & $(0.4)$ & 8.7 & $(0.9)$ & 19.0 & $(1.3)$ & 29.0 & $(1.5)$ & 25.3 & (1.7) & 12.7 & $(1.0)$ & 3.2 & $(0.6)$ \\
\hline & Belgium & & & & & & & & & & & & & & \\
\hline & Flemish Community ${ }^{\bullet}$ & 4.8 & $(0.5)$ & 10.4 & $(0.7)$ & 19.3 & $(0.8)$ & 28.0 & $(1.0)$ & 25.4 & $(0.9)$ & 10.7 & $(0.7)$ & 1.5 & $(0.3)$ \\
\hline & French Community & 7.3 & $(0.9)$ & 13.7 & $(1.0)$ & 24.5 & $(1.1)$ & 29.7 & $(1.1)$ & 19.7 & (1.1) & 4.8 & $(0.5)$ & 0.3 & $(0.1)$ \\
\hline & German-speaking Community & 5.0 & $(1.0)$ & 10.0 & (1.3) & 20.6 & (1.8) & 34.4 & (2.5) & 23.7 & $(2.2)$ & 5.8 & (1.0) & 0.5 & $(0.3)$ \\
\hline & Canada & & & & & & & & & & & & & & \\
\hline & Alberta & 1.9 & $(0.5)$ & 6.9 & $(1.0)$ & 18.1 & (1.4) & 29.9 & (1.5) & 26.9 & (1.5) & 13.4 & (1.3) & 2.9 & $(0.6)$ \\
\hline & British Columbia & 1.4 & $(0.4)$ & 5.7 & $(0.9)$ & 17.4 & (1.4) & 30.0 & $(1.7)$ & 29.8 & (1.6) & 12.8 & (1.3) & 2.9 & $(0.6)$ \\
\hline & Manitoba & 3.9 & $(0.8)$ & 12.3 & (1.1) & 24.9 & (2.0) & 30.6 & (1.9) & 20.6 & (1.3) & 6.9 & $(0.8)$ & 0.9 & $(0.4)$ \\
\hline & New Brunswick & 2.7 & $(0.6)$ & 11.1 & $(1.0)$ & 25.4 & (1.9) & 33.3 & $(1.8)$ & 20.3 & (1.4) & 6.4 & (1.1) & 0.9 & $(0.6)$ \\
\hline & Newfoundland and Labrador & 3.2 & $(0.7)$ & 10.0 & (1.6) & 22.0 & $(1.8)$ & 33.2 & $(2.3)$ & 21.6 & (1.7) & 8.7 & (1.2) & 1.3 & $(0.4)$ \\
\hline & Nova Scotia & 2.2 & $(0.6)$ & 8.3 & $(1.5)$ & 23.8 & (2.5) & 34.5 & (2.6) & 22.9 & (2.5) & 7.4 & (1.3) & 0.8 & $(0.4)$ \\
\hline & Ontario & 2.7 & $(0.5)$ & 8.2 & $(0.8)$ & 20.3 & (1.4) & 31.5 & $(1.2)$ & 25.2 & (1.3) & 9.9 & (1.0) & 2.2 & $(0.5)$ \\
\hline & Prince Edward Island & 3.3 & $(0.7)$ & 13.9 & $(1.3)$ & 27.5 & $(1.8)$ & 31.8 & $(1.8)$ & 18.3 & (1.5) & 4.8 & (1.0) & 0.5 & $(0.3)$ \\
\hline & Quebec & 2.4 & $(0.5)$ & 8.2 & $(0.8)$ & 23.3 & $(1.3)$ & 34.5 & (1.4) & 24.7 & $(1.2)$ & 6.2 & $(0.7)$ & 0.6 & $(0.2)$ \\
\hline & Saskatchewan & 2.6 & $(0.4)$ & 8.3 & $(0.8)$ & 24.3 & $(1.1)$ & 32.7 & $(2.0)$ & 22.9 & (1.5) & 8.4 & $(1.2)$ & 0.8 & $(0.4)$ \\
\hline & Italy & & & & & & & & & & & & & & \\
\hline & Abruzzo & 5.5 & (1.4) & 14.7 & $(1.7)$ & 29.9 & $(2.3)$ & 30.1 & $(2.3)$ & 16.0 & $(1.7)$ & 3.4 & $(0.8)$ & 0.4 & $(0.3)$ \\
\hline & Basilicata & 4.9 & $(1.0)$ & 20.7 & (1.5) & 34.4 & $(1.5)$ & 26.5 & $(1.8)$ & 11.3 & (1.4) & 2.1 & $(0.5)$ & 0.1 & $(0.2)$ \\
\hline & Bolzano & 2.7 & $(0.6)$ & 9.8 & $(0.9)$ & 21.7 & $(1.3)$ & 31.3 & (1.4) & 24.6 & $(1.2)$ & 8.9 & $(0.9)$ & 1.1 & $(0.3)$ \\
\hline & Calabria & 14.1 & $(2.1)$ & 26.0 & (1.9) & 32.4 & $(2.1)$ & 20.4 & $(1.8)$ & 6.2 & $(1.0)$ & 0.9 & $(0.3)$ & 0.0 & c \\
\hline & Campania & 8.5 & $(2.0)$ & 21.2 & $(2.7)$ & 32.2 & $(1.8)$ & 25.8 & (2.4) & 10.6 & (1.8) & 1.7 & (0.6) & 0.1 & c \\
\hline & Emilia Romagna & 3.5 & $(0.9)$ & 10.4 & $(1.6)$ & 22.3 & (2.1) & 32.0 & $(2.2)$ & 23.6 & (2.3) & 7.3 & $(1.3)$ & 0.8 & $(0.4)$ \\
\hline & Friuli Venezia Giulia & 1.9 & (1.0) & 7.3 & (1.6) & 18.0 & (1.4) & 34.1 & $(2.2)$ & 27.5 & $(2.0)$ & 9.8 & $(1.0)$ & 1.4 & $(0.4)$ \\
\hline & Lazio & 4.0 & (1.1) & 16.3 & (2.4) & 29.6 & $(2.2)$ & 30.1 & (1.9) & 15.6 & (1.7) & 4.2 & (1.0) & 0.3 & $(0.2)$ \\
\hline & Liguria & 3.7 & $(0.9)$ & 13.4 & $(1.6)$ & 24.4 & $(1.8)$ & 31.0 & $(1.9)$ & 20.5 & (1.9) & 6.0 & (1.1) & 0.9 & $(0.4)$ \\
\hline & Lombardia & 1.7 & $(0.5)$ & 7.1 & $(1.2)$ & 19.9 & $(2.7)$ & 32.8 & $(2.2)$ & 28.0 & (2.3) & 9.7 & (1.7) & 0.9 & $(0.4)$ \\
\hline & Marche & 2.8 & (1.1) & 10.6 & (1.6) & 24.9 & (1.7) & 33.6 & $(2.2)$ & 21.5 & (1.8) & 6.0 & $(0.8)$ & 0.5 & $(0.2)$ \\
\hline & Molise & 5.5 & $(0.8)$ & 16.6 & (1.5) & 34.3 & (1.9) & 32.2 & (1.8) & 9.7 & (1.4) & 1.5 & (0.5) & 0.1 & c \\
\hline & Piemonte & 3.0 & $(0.6)$ & 10.3 & $(1.2)$ & 23.3 & (1.8) & 34.0 & $(2.1)$ & 22.7 & (1.8) & 5.9 & (1.0) & 0.7 & $(0.3)$ \\
\hline & Puglia & 5.0 & (1.3) & 14.8 & (1.8) & 29.0 & (2.1) & 31.3 & $(2.1)$ & 16.8 & (1.7) & 2.9 & (0.6) & 0.1 & $(0.1)$ \\
\hline & Sardegna & 6.3 & (1.3) & 16.0 & (1.8) & 31.3 & (1.9) & 29.4 & (1.8) & 14.3 & (1.6) & 2.6 & (0.6) & 0.1 & C \\
\hline & Sicilia & 8.9 & (1.6) & 21.6 & $(2.2)$ & 31.7 & (1.8) & 26.4 & $(2.1)$ & 9.6 & (1.3) & 1.6 & $(0.5)$ & 0.1 & $(0.1)$ \\
\hline & Toscana & 4.7 & $(0.9)$ & 12.4 & (1.1) & 24.2 & (2.2) & 29.7 & (1.8) & 22.6 & (1.9) & 6.0 & $(0.8)$ & 0.4 & $(0.2)$ \\
\hline & Trento & 1.5 & $(0.6)$ & 6.5 & $(1.2)$ & 19.3 & (1.7) & 33.0 & (1.9) & 27.7 & (1.9) & 10.8 & (1.2) & 1.1 & $(0.4)$ \\
\hline & Umbria & 4.1 & (1.5) & 11.3 & (1.9) & 23.1 & (1.5) & 35.5 & (2.1) & 21.0 & $(2.0)$ & 4.6 & (1.1) & 0.4 & $(0.2)$ \\
\hline & Valle d'Aosta & 2.7 & $(0.7)$ & 10.1 & (1.3) & 24.2 & (1.8) & 35.4 & (1.8) & 21.7 & (1.9) & 5.4 & (0.9) & 0.5 & $(0.4)$ \\
\hline & Veneto & 2.5 & $(0.9)$ & 7.1 & (1.4) & 19.6 & (1.7) & 31.1 & $(2.3)$ & 26.4 & (2.0) & 11.3 & (1.8) & 2.1 & $(0.6)$ \\
\hline & Mexico & & & & & & & & & & & & & & \\
\hline & Aguascalientes & 8.0 & (1.4) & 28.7 & $(2.2)$ & 39.6 & (2.5) & 19.4 & $(2.2)$ & 3.6 & $(1.0)$ & 0.6 & $(0.3)$ & 0.0 & c \\
\hline & Baja California & 11.6 & $(2.2)$ & 35.2 & $(3.2)$ & 36.5 & $(2.0)$ & 14.0 & $(1.8)$ & 2.4 & $(0.9)$ & 0.2 & c & 0.0 & c \\
\hline & Baja California Sur & 10.7 & (1.6) & 34.0 & $(2.3)$ & 38.8 & $(2.2)$ & 14.2 & $(1.7)$ & 2.2 & $(0.7)$ & 0.1 & c & 0.0 & C \\
\hline & Campeche & 15.6 & $(2.7)$ & 37.2 & (2.4) & 34.5 & (2.3) & 10.8 & (1.3) & 1.8 & $(0.6)$ & 0.2 & $(0.2)$ & 0.0 & C \\
\hline & Chiapas & 28.0 & $(4.2)$ & 40.1 & $(2.5)$ & 25.6 & (3.1) & 5.6 & $(1.3)$ & 0.7 & $(0.4)$ & 0.0 & c & 0.0 & C \\
\hline & Chihuahua & 9.9 & $(2.2)$ & 29.6 & (3.7) & 37.4 & (2.8) & 18.8 & $(4.0)$ & 3.9 & (1.4) & 0.3 & $(0.5)$ & 0.0 & c \\
\hline & Coahuila & 11.5 & (2.6) & 31.1 & $(3.1)$ & 38.5 & $(2.8)$ & 16.4 & (2.9) & 2.3 & $(0.7)$ & 0.1 & $(0.1)$ & 0.0 & C \\
\hline & Colima & 10.5 & (1.5) & 29.6 & $(1.8)$ & 37.0 & $(2.2)$ & 18.3 & $(1.8)$ & 4.0 & $(1.2)$ & 0.6 & $(0.3)$ & 0.0 & c \\
\hline & Distrito Federal & 8.4 & $(2.1)$ & 30.8 & $(2.7)$ & 41.9 & $(2.8)$ & 16.0 & $(2.1)$ & 2.8 & $(0.9)$ & 0.2 & C & 0.0 & c \\
\hline & Durango & 9.3 & (1.9) & 32.4 & (3.0) & 40.9 & (3.3) & 15.9 & (2.4) & 1.5 & $(0.5)$ & 0.1 & $(0.1)$ & 0.0 & C \\
\hline & Guanajuato & 16.5 & (2.9) & 35.7 & (2.6) & 34.8 & (2.8) & 11.2 & (1.3) & 1.6 & $(0.6)$ & 0.0 & c & 0.0 & c \\
\hline & Guerrero & 27.9 & (3.1) & 43.8 & $(2.3)$ & 23.5 & (2.2) & 4.4 & $(0.9)$ & 0.4 & $(0.2)$ & 0.0 & c & 0.0 & c \\
\hline & Hidalgo & 15.0 & $(2.1)$ & 33.3 & (3.1) & 36.2 & (2.5) & 13.7 & (1.8) & 1.7 & $(0.6)$ & 0.0 & C & 0.0 & C \\
\hline & Jalisco & 6.8 & (1.4) & 29.6 & (2.9) & 39.5 & (1.9) & 20.1 & (2.8) & 3.9 & $(0.9)$ & 0.2 & $(0.2)$ & 0.0 & C \\
\hline & Mexico & 8.2 & (1.4) & 35.3 & $(2.7)$ & 41.9 & (2.7) & 12.8 & (2.6) & 1.6 & $(0.6)$ & 0.2 & $(0.2)$ & 0.0 & c \\
\hline & Morelos & 10.8 & (3.6) & 31.7 & $(3.2)$ & 37.0 & (3.2) & 16.3 & (2.5) & 3.7 & (1.3) & 0.5 & $(0.5)$ & 0.0 & C \\
\hline & Nayarit & 15.8 & (2.6) & 35.7 & (2.6) & 34.9 & $(2.7)$ & 12.3 & (1.8) & 1.4 & $(0.7)$ & 0.0 & C & 0.0 & C \\
\hline & Nuevo León & 6.8 & (1.8) & 28.8 & (3.4) & 41.0 & (3.6) & 19.1 & (3.3) & 4.0 & $(0.9)$ & 0.2 & $(0.2)$ & 0.0 & C \\
\hline & Puebla & 11.3 & $(2.8)$ & 28.9 & (2.0) & 40.8 & (3.1) & 16.0 & (2.0) & 2.9 & $(0.9)$ & 0.1 & C & 0.0 & c \\
\hline & Querétaro & 8.2 & (1.7) & 29.7 & (3.4) & 39.4 & (3.5) & 18.6 & (2.3) & 3.9 & (1.1) & 0.2 & $(0.2)$ & 0.0 & c \\
\hline & Quintana Roo & 12.2 & $(2.4)$ & 33.1 & $(2.0)$ & 38.3 & (2.8) & 14.6 & (2.4) & 1.7 & $(0.7)$ & 0.1 & c & 0.0 & c \\
\hline & San Luis Potosí & 12.5 & (1.8) & 34.6 & (2.9) & 35.5 & (1.8) & 15.0 & $(2.7)$ & 2.4 & $(0.9)$ & 0.0 & c & 0.0 & c \\
\hline & Sinaloa & 13.4 & $(2.1)$ & 39.2 & (2.4) & 34.6 & $(2.2)$ & 11.5 & $(1.8)$ & 1.3 & $(0.5)$ & 0.1 & c & 0.0 & c \\
\hline & Tabasco & 19.9 & $(2.5)$ & 42.6 & $(3.1)$ & 29.0 & (2.6) & 7.9 & $(1.3)$ & 0.6 & $(0.4)$ & 0.0 & c & 0.0 & c \\
\hline & Tamaulipas & 12.8 & $(2.3)$ & 34.5 & $(3.2)$ & 36.2 & (2.5) & 14.2 & $(2.3)$ & 2.2 & $(0.9)$ & 0.1 & $(0.2)$ & 0.0 & C \\
\hline & Tlaxcala & 13.4 & (1.8) & 34.6 & $(2.5)$ & 37.3 & (2.4) & 13.3 & $(1.7)$ & 1.3 & $(0.4)$ & 0.0 & C & 0.0 & C \\
\hline & Veracruz & 16.7 & $(2.3)$ & 37.6 & (2.9) & 33.6 & (2.6) & 11.2 & (2.4) & 0.9 & $(0.6)$ & 0.0 & c & 0.0 & c \\
\hline & Yucatán & 13.1 & $(2.3)$ & 33.8 & $(2.2)$ & 36.3 & (2.5) & 14.3 & (1.6) & 2.3 & $(0.7)$ & 0.1 & c & 0.0 & c \\
\hline & Zacatecas & 17.1 & $(2.2)$ & 36.0 & $(2.2)$ & 34.4 & (2.2) & 11.5 & (1.4) & 1.0 & $(0.4)$ & 0.0 & C & 0.0 & C \\
\hline
\end{tabular}

- PISA adjudicated region.

Note: See Table I.5.1 a for national data.

StatLink 新组 http://dx.doi.org/10.1787/888932935762 
[Part 2/2]

Table B2.I.28 Percentage of students at each proficiency level in science, by region

\begin{tabular}{|c|c|c|c|c|c|c|c|c|c|c|c|c|c|c|c|}
\hline & & \multicolumn{14}{|c|}{ All students } \\
\hline & & \multicolumn{2}{|c|}{$\begin{array}{c}\text { Below Level } 1 \\
\text { (below } 334.94 \\
\text { score points) }\end{array}$} & \multicolumn{2}{|c|}{$\begin{array}{c}\text { Level } 1 \\
\text { (from } 334.94 \text { to } \\
\text { less than } 409.54 \\
\text { score points) }\end{array}$} & \multicolumn{2}{|c|}{$\begin{array}{c}\text { Level } 2 \\
\text { (from } 409.54 \text { to } \\
\text { less than } 484.14 \\
\text { score points) }\end{array}$} & $\begin{array}{r}\text { Le } \\
\text { (from } \\
\text { less tha } \\
\text { score }\end{array}$ & $\begin{array}{l}\text { I } 3 \\
4.14 \text { to } \\
558.73 \\
\text { oints) }\end{array}$ & $\begin{array}{r}\text { Le } \\
\text { (from } 5 \\
\text { less tha } \\
\text { score }\end{array}$ & $\begin{array}{l}14 \\
8.73 \text { to } \\
633.33 \\
\text { oints) }\end{array}$ & $\begin{array}{r}\text { Le } \\
\text { (from } 6 \\
\text { less tha } \\
\text { score }\end{array}$ & $\begin{array}{l}5 \\
53 \text { to } \\
707.93 \\
\text { ints) }\end{array}$ & $\begin{array}{r}\text { Le } \\
\text { (above } \\
\text { score }\end{array}$ & $\begin{array}{l}6 \\
07.93 \\
0 \text { ints) }\end{array}$ \\
\hline & & $\%$ & S.E. & $\%$ & S.E. & $\%$ & S.E. & $\%$ & S.E. & $\%$ & S.E. & $\%$ & S.E. & $\%$ & S.E. \\
\hline 0 & Portugal & & & & & & & & & & & & & & \\
\hline ن & Alentejo & 2.7 & (0.9) & 12.0 & $(2.8)$ & 29.2 & (2.4) & 35.5 & $(3.3)$ & 16.4 & (2.5) & 4.0 & (1.3) & 0.2 & C \\
\hline & Spain & & & & & & & & & & & & & & \\
\hline & Andalusia ${ }^{\bullet}$ & 4.5 & (0.9) & 14.1 & (1.4) & 30.3 & (1.9) & 30.9 & (1.6) & 15.8 & (1.4) & 4.1 & (0.8) & 0.3 & $(0.2)$ \\
\hline & Aragon ${ }^{\bullet}$ & 3.9 & (1.0) & 11.9 & $(1.4)$ & 23.9 & (1.6) & 31.5 & (1.9) & 21.2 & (1.4) & 6.8 & (1.1) & 0.8 & $(0.3)$ \\
\hline & Asturias ${ }^{\bullet}$ & 2.7 & $(0.7)$ & 8.9 & $(1.2)$ & 23.7 & $(1.7)$ & 31.1 & $(1.6)$ & 24.2 & $(1.7)$ & 8.1 & (1.2) & 1.2 & $(0.4)$ \\
\hline & Balearic Islands ${ }^{\bullet}$ & 4.2 & $(0.9)$ & 14.9 & $(1.4)$ & 30.2 & $(1.7)$ & 32.0 & $(1.6)$ & 16.2 & (1.6) & 2.4 & $(0.5)$ & 0.1 & C \\
\hline & Basque Country ${ }^{\bullet}$ & 2.9 & $(0.4)$ & 8.9 & $(0.6)$ & 25.3 & $(0.9)$ & 36.8 & $(0.9)$ & 21.4 & (1.0) & 4.4 & $(0.4)$ & 0.3 & $(0.1)$ \\
\hline & Cantabria ${ }^{\bullet}$ & 3.4 & $(0.7)$ & 11.6 & $(1.1)$ & 27.2 & (1.8) & 31.8 & (1.9) & 19.9 & (1.7) & 5.6 & $(0.8)$ & 0.6 & $(0.3)$ \\
\hline & Castile and Leon ${ }^{\bullet}$ & 1.6 & $(0.5)$ & 7.1 & $(0.9)$ & 23.3 & $(1.5)$ & 35.6 & $(1.8)$ & 25.8 & (1.6) & 6.3 & (0.9) & 0.4 & $(0.2)$ \\
\hline & Catalonia $\bullet$ & 2.9 & $(0.7)$ & 12.6 & $(1.3)$ & 29.6 & $(1.7)$ & 34.5 & $(2.3)$ & 17.0 & (1.9) & 3.2 & $(0.7)$ & 0.2 & $(0.1)$ \\
\hline & Extremadura ${ }^{\bullet}$ & 6.0 & $(0.9)$ & 15.1 & $(1.3)$ & 28.7 & (1.4) & 29.3 & $(1.4)$ & 16.0 & (1.4) & 4.2 & $(0.7)$ & 0.6 & $(0.3)$ \\
\hline & Galicia• & 2.8 & $(0.6)$ & 9.7 & $(1.1)$ & 23.3 & $(1.7)$ & 33.9 & (1.6) & 23.4 & (1.5) & 6.4 & (1.1) & 0.5 & $(0.3)$ \\
\hline & La Rioja• & 4.3 & $(0.7)$ & 8.9 & $(0.8)$ & 23.0 & $(1.2)$ & 31.5 & $(1.3)$ & 25.3 & $(1.3)$ & 6.6 & $(0.9)$ & 0.4 & $(0.2)$ \\
\hline & Madrid• & 2.2 & $(0.6)$ & 8.2 & $(1.1)$ & 22.7 & (1.6) & 34.3 & $(1.5)$ & 25.3 & $(1.7)$ & 6.8 & $(0.8)$ & 0.5 & $(0.3)$ \\
\hline & Murcia $\bullet$ & 5.3 & $(1.0)$ & 15.6 & $(1.3)$ & 30.4 & (1.6) & 30.8 & $(1.6)$ & 14.5 & $(1.7)$ & 3.1 & $(0.6)$ & 0.3 & $(0.2)$ \\
\hline & Navarre ${ }^{\bullet}$ & 2.6 & $(0.7)$ & 8.2 & $(1.2)$ & 23.8 & $(1.7)$ & 34.5 & $(1.5)$ & 23.2 & (1.4) & 7.0 & (1.1) & 0.7 & $(0.2)$ \\
\hline & United Kingdom & & & & & & & & & & & & & & \\
\hline & England & 4.3 & $(0.6)$ & 10.6 & $(1.0)$ & 21.9 & (1.1) & 28.0 & $(1.1)$ & 23.4 & (1.1) & 9.8 & $(0.8)$ & 1.9 & $(0.4)$ \\
\hline & Northern Ireland & 4.7 & $(0.7)$ & 12.1 & (1.3) & 23.7 & $(1.5)$ & 27.8 & $(1.5)$ & 21.4 & (1.3) & 8.3 & $(0.9)$ & 2.0 & $(0.5)$ \\
\hline & Scotland ${ }^{\bullet}$ & 2.7 & $(0.4)$ & 9.4 & $(0.7)$ & 24.9 & $(1.2)$ & 32.4 & $(1.2)$ & 21.8 & (1.0) & 7.5 & $(0.7)$ & 1.3 & $(0.3)$ \\
\hline & Wales & 5.2 & $(0.6)$ & 14.2 & $(0.8)$ & 27.1 & $(1.3)$ & 29.5 & $(1.3)$ & 18.4 & (0.9) & 4.9 & (0.6) & 0.8 & $(0.2)$ \\
\hline & United States & & & & & & & & & & & & & & \\
\hline & Connecticut ${ }^{\bullet}$ & 3.3 & $(0.8)$ & 10.2 & (1.4) & 21.4 & (1.6) & 29.4 & (1.7) & 22.8 & (1.5) & 10.7 & (1.1) & 2.2 & $(0.6)$ \\
\hline & Florida ${ }^{\bullet}$ & 5.1 & $(1.0)$ & 16.1 & $(1.6)$ & 28.4 & (1.6) & 28.2 & $(2.0)$ & 16.6 & $(1.6)$ & 4.9 & (1.0) & 0.6 & $(0.4)$ \\
\hline & Massachusetts ${ }^{\bullet}$ & 2.6 & $(0.6)$ & 8.9 & $(1.0)$ & 21.2 & $(2.0)$ & 29.4 & (1.5) & 23.8 & (1.8) & 11.3 & (1.5) & 2.9 & $(0.7)$ \\
\hline 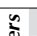 & Argentina & & & & & & & & & & & & & & \\
\hline$\stackrel{\varrho}{\Xi}$ & Ciudad Autónoma de Buenos Aires $\bullet$ & 19.3 & $(2.4)$ & 21.4 & $(2.0)$ & 27.3 & (1.9) & 22.3 & $(2.1)$ & 8.1 & (1.4) & 1.4 & $(0.6)$ & 0.0 & c \\
\hline & Brazil & & & & & & & & & & & & & & \\
\hline & Acre & 24.6 & $(3.2)$ & 43.1 & $(2.9)$ & 26.3 & $(3.3)$ & 5.6 & $(1.4)$ & 0.3 & $(0.3)$ & 0.1 & c & 0.0 & c \\
\hline & Alagoas & 46.1 & $(5.2)$ & 36.4 & $(3.1)$ & 14.1 & $(3.1)$ & 3.1 & $(1.6)$ & 0.4 & $(0.4)$ & 0.0 & $\mathrm{c}$ & 0.0 & c \\
\hline & Amapá & 25.3 & $(5.0)$ & 40.4 & $(4.1)$ & 26.2 & $(4.2)$ & 7.3 & $(3.3)$ & 0.7 & $(0.7)$ & 0.0 & $\mathrm{C}$ & 0.0 & c \\
\hline & Amazonas & 27.2 & $(3.2)$ & 43.7 & (3.5) & 23.0 & $(2.8)$ & 5.2 & $(1.6)$ & 0.9 & $(0.8)$ & 0.0 & $\mathrm{C}$ & 0.0 & c \\
\hline & Bahia & 24.8 & $(5.2)$ & 38.3 & $(3.8)$ & 24.1 & $(4.7)$ & 9.8 & $(2.6)$ & 2.7 & $(1.2)$ & 0.4 & $(0.4)$ & 0.0 & c \\
\hline & Ceará & 25.2 & $(4.3)$ & 37.8 & (3.6) & 26.1 & $(3.7)$ & 8.5 & $(2.2)$ & 2.1 & $(1.0)$ & 0.2 & C & 0.0 & c \\
\hline & Espírito Santo & 12.7 & $(1.9)$ & 31.3 & $(3.0)$ & 31.7 & (3.4) & 15.4 & $(2.0)$ & 7.7 & (3.1) & 1.1 & $(0.5)$ & 0.0 & c \\
\hline & Federal District & 13.3 & (3.6) & 31.3 & $(3.1)$ & 33.0 & $(2.9)$ & 17.8 & $(2.1)$ & 4.1 & $(1.2)$ & 0.5 & $(0.6)$ & 0.0 & c \\
\hline & Goiás & 20.9 & $(3.7)$ & 38.2 & $(3.0)$ & 28.2 & $(3.0)$ & 10.6 & $(1.8)$ & 2.0 & $(0.6)$ & 0.1 & $(0.1)$ & 0.0 & c \\
\hline & Maranhão & 41.9 & $(6.1)$ & 33.4 & $(4.0)$ & 17.0 & $(3.5)$ & 6.3 & $(3.4)$ & 1.4 & $(1.2)$ & 0.0 & C & 0.0 & c \\
\hline & Mato Grosso & 26.1 & $(3.7)$ & 42.0 & $(3.8)$ & 23.4 & $(3.1)$ & 5.8 & $(1.6)$ & 2.5 & $(1.5)$ & 0.2 & $(0.3)$ & 0.0 & c \\
\hline & Mato Grosso do Sul & 12.5 & $(2.6)$ & 35.9 & $(2.6)$ & 34.4 & $(3.5)$ & 14.9 & $(3.4)$ & 2.2 & $(0.5)$ & 0.1 & $\mathrm{C}$ & 0.0 & c \\
\hline & Minas Gerais & 13.9 & $(2.9)$ & 30.5 & $(2.9)$ & 35.5 & (3.0) & 16.2 & $(2.8)$ & 3.3 & $(1.0)$ & 0.6 & $(0.4)$ & 0.0 & c \\
\hline & Pará & 28.7 & (3.4) & 39.4 & $(3.3)$ & 25.0 & $(2.3)$ & 6.6 & $(1.1)$ & 0.3 & $\mathrm{C}$ & 0.0 & $\mathrm{C}$ & 0.0 & c \\
\hline & Paraíba & 16.3 & $(4.2)$ & 33.8 & $(2.7)$ & 31.4 & $(4.1)$ & 14.7 & $(1.5)$ & 3.5 & $(1.2)$ & 0.4 & $\mathrm{C}$ & 0.0 & c \\
\hline & Paraná & 15.1 & $(2.9)$ & 35.2 & $(3.1)$ & 30.9 & (3.5) & 13.0 & $(2.2)$ & 5.2 & $(3.0)$ & 0.8 & (1.0) & 0.0 & c \\
\hline & Pernambuco & 31.1 & $(4.1)$ & 38.7 & (3.0) & 22.6 & (3.8) & 6.6 & $(1.9)$ & 0.9 & $(0.7)$ & 0.1 & $(0.2)$ & 0.0 & c \\
\hline & Piauí & 19.3 & $(3.1)$ & 37.3 & $(4.2)$ & 29.5 & (3.4) & 10.2 & $(1.8)$ & 3.0 & $(2.0)$ & 0.7 & $(0.6)$ & 0.0 & c \\
\hline & Rio de Janeiro & 19.6 & (3.4) & 34.8 & $(2.9)$ & 32.0 & $(2.7)$ & 12.2 & $(2.2)$ & 1.4 & $(0.7)$ & 0.0 & C & 0.0 & c \\
\hline & Rio Grande do Norte & 26.8 & (3.5) & 37.8 & $(3.3)$ & 23.2 & $(3.2)$ & 9.4 & $(2.4)$ & 2.7 & $(1.4)$ & 0.1 & $\mathrm{C}$ & 0.0 & c \\
\hline & Rio Grande do Sul & 10.7 & (1.8) & 33.9 & $(2.9)$ & 37.4 & $(3.2)$ & 16.2 & $(2.5)$ & 1.7 & $(0.8)$ & 0.0 & $\mathrm{c}$ & 0.0 & c \\
\hline & Rondônia & 20.3 & $(3.2)$ & 42.2 & $(3.5)$ & 30.1 & $(3.3)$ & 6.5 & $(1.5)$ & 0.8 & $(0.4)$ & 0.0 & $\mathrm{c}$ & 0.0 & c \\
\hline & Roraima & 33.4 & (3.1) & 34.8 & $(3.1)$ & 22.3 & $(2.8)$ & 6.4 & $(1.8)$ & 2.8 & $(1.7)$ & 0.3 & $\mathrm{c}$ & 0.0 & c \\
\hline & Santa Catarina & 13.5 & (3.9) & 30.5 & $(3.1)$ & 37.4 & (3.0) & 16.0 & $(2.9)$ & 2.6 & $(0.9)$ & 0.1 & c & 0.0 & c \\
\hline & São Paulo & 13.1 & $(1.3)$ & 34.1 & $(1.7)$ & 34.1 & (1.6) & 14.8 & $(1.4)$ & 3.5 & $(0.8)$ & 0.3 & $(0.2)$ & 0.0 & c \\
\hline & Sergipe & 19.8 & $(3.2)$ & 41.5 & $(4.0)$ & 28.0 & $(3.8)$ & 9.0 & $(3.4)$ & 1.6 & $(1.1)$ & 0.0 & C & 0.0 & c \\
\hline & Tocantins & 28.7 & $(3.3)$ & 39.7 & $(3.3)$ & 23.1 & $(2.9)$ & 7.3 & $(1.7)$ & 1.1 & $(0.5)$ & 0.1 & $\mathrm{c}$ & 0.0 & c \\
\hline & Colombia & & & & & & & & & & & & & & \\
\hline & Bogotá & 13.5 & (1.8) & 36.3 & $(2.2)$ & 35.6 & $(2.0)$ & 12.6 & $(1.6)$ & 1.9 & $(0.5)$ & 0.2 & $(0.2)$ & 0.0 & c \\
\hline & Cali & 18.9 & $(2.9)$ & 35.8 & $(2.9)$ & 31.4 & $(2.6)$ & 11.8 & $(2.2)$ & 2.0 & $(0.8)$ & 0.1 & C & 0.0 & c \\
\hline & Manizales & 8.8 & $(1.2)$ & 33.4 & $(2.5)$ & 35.8 & $(2.3)$ & 17.3 & $(2.1)$ & 4.3 & $(1.1)$ & 0.3 & $(0.2)$ & 0.0 & c \\
\hline & Medellín & 13.9 & (1.8) & 34.8 & $(2.8)$ & 31.9 & $(2.4)$ & 14.3 & $(2.1)$ & 4.2 & $(1.5)$ & 0.8 & $(0.5)$ & 0.0 & c \\
\hline & Russian Federation & & & & & & & & & & & & & & \\
\hline & Perm Territory region & 4.8 & $(1.0)$ & 15.2 & (1.5) & 31.0 & (1.8) & 31.3 & (1.8) & 14.5 & (1.5) & 3.1 & $(1.0)$ & 0.2 & $(0.2)$ \\
\hline & United Arab Emirates & & & & & & & & & & & & & & \\
\hline & Abu Dhabi & 14.3 & (1.3) & 24.2 & $(1.4)$ & 29.0 & $(1.5)$ & 21.2 & $(1.3)$ & 9.0 & $(1.0)$ & 2.1 & $(0.5)$ & 0.2 & $(0.1)$ \\
\hline & Ajman & 17.1 & (4.3) & 27.6 & (3.5) & 31.8 & (3.5) & 18.8 & $(2.4)$ & 4.6 & $(1.3)$ & 0.2 & C & 0.0 & (10.1) \\
\hline & Dubai & 7.7 & $(0.4)$ & 19.0 & $(0.6)$ & 27.3 & $(0.8)$ & 25.7 & $(0.8)$ & 15.2 & $(0.7)$ & 4.3 & $(0.4)$ & 0.7 & $(0.2)$ \\
\hline & Fujairah & 12.8 & $(3.0)$ & 30.4 & $(2.8)$ & 33.9 & (3.1) & 17.8 & $(2.8)$ & 4.8 & $(1.2)$ & 0.4 & $(0.3)$ & 0.0 & $\mathrm{C}$ \\
\hline & Ras al-Khaimah & $\begin{array}{l}12.0 \\
10.6\end{array}$ & (2.8) & 29.3 & $\begin{array}{l}(2.0) \\
(2.7)\end{array}$ & 35.6 & (3.0) & 19.4 & $(2.3)$ & 4.4 & $(0.8)$ & 0.6 & $(0.4)$ & 0.0 & c \\
\hline & Sharjah & 8.7 & $\begin{array}{l}(2.0) \\
(2.2)\end{array}$ & 24.8 & $(3.7)$ & 32.0 & $(2.2)$ & 23.2 & (3.3) & $\begin{array}{l}4.4 \\
9.9\end{array}$ & $\begin{array}{l}(0.0) \\
(2.5)\end{array}$ & 1.3 & $(0.6)$ & 0.0 & c \\
\hline & Umm al-Quwain & 16.8 & $(2.5)$ & $\begin{array}{l}2.0 \\
32.4\end{array}$ & (4.3) & 31.0 & $(4.1)$ & $\begin{array}{l}2.2 \\
15.0\end{array}$ & (2.4) & 4.5 & (1.4) & 0.4 & $\begin{array}{r}(0.0) \\
\mathrm{C}\end{array}$ & 0.0 & c \\
\hline
\end{tabular}

- PISA adjudicated region.

Note: See Table I.5.1 a for national data.

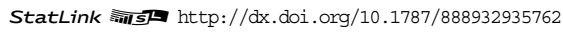


[Part 1/4]

Table B2.I.29 Percentage of students at each proficiency level in science, by gender and region

\begin{tabular}{|c|c|c|c|c|c|c|c|c|c|c|c|c|c|c|c|}
\hline & & \multicolumn{14}{|c|}{ Boys } \\
\hline & & \multicolumn{2}{|c|}{$\begin{array}{c}\text { Below Level } 1 \\
\text { (below } 334.94 \\
\text { score points) }\end{array}$} & $\begin{array}{l}\text { Le } \\
\text { (from } \\
\text { less tha } \\
\text { score }\end{array}$ & $\begin{array}{l}\text { I } 1 \\
4.94 \text { to } \\
409.54 \\
\text { oints) }\end{array}$ & $\begin{array}{l}\text { Le } \\
\text { (from } \\
\text { less th } \\
\text { score }\end{array}$ & $\begin{array}{l}2 \\
.54 \text { to } \\
484.14 \\
\text { jints) }\end{array}$ & $\begin{array}{l}\text { Le } \\
\text { (from } \\
\text { less th } \\
\text { score }\end{array}$ & $\begin{array}{l}3 \\
4.14 \text { to } \\
558.73 \\
\text { oints) }\end{array}$ & $\begin{array}{l}\text { Le } \\
\text { (from } \\
\text { less th } \\
\text { score }\end{array}$ & $\begin{array}{l}14 \\
8.73 \text { to } \\
633.33 \\
\text { oints) }\end{array}$ & $\begin{array}{l}\text { Le } \\
\text { (from } \\
\text { less th } \\
\text { score }\end{array}$ & $\begin{array}{l}5 \\
3.33 \text { to } \\
707.93 \\
\text { oints) }\end{array}$ & $\begin{array}{l}\text { Le } \\
\text { (abov } \\
\text { score }\end{array}$ & $\begin{array}{l}6 \\
07.93 \\
0 i n t s)\end{array}$ \\
\hline & & $\%$ & S.E. & $\%$ & S.E. & $\%$ & S.E. & $\%$ & S.E. & $\%$ & S.E. & $\%$ & S.E. & $\%$ & S.E. \\
\hline 0 & Australia & & & & & & & & & & & & & & \\
\hline U్山 & Australian Capital Territory & 5.1 & $(1.2)$ & 8.3 & (1.8) & 16.3 & (1.9) & 26.6 & $(2.8)$ & 24.8 & (2.9) & 15.5 & (2.6) & 3.3 & (1.4) \\
\hline & New South Wales & 4.6 & $(0.8)$ & 10.8 & $(1.0)$ & 20.2 & $(1.3)$ & 25.6 & $(1.4)$ & 21.2 & (1.4) & 13.2 & (1.5) & 4.3 & $(1.0)$ \\
\hline & Northern Territory & 13.0 & $(2.5)$ & 14.1 & $(4.0)$ & 17.9 & $(4.4)$ & 22.6 & $(5.0)$ & 23.3 & $(5.1)$ & 5.1 & $(2.3)$ & 4.0 & $(2.4)$ \\
\hline & Queensland & 3.5 & $(0.7)$ & 10.1 & $(1.0)$ & 22.3 & (1.4) & 27.5 & $(2.2)$ & 23.7 & $(2.0)$ & 10.6 & (1.3) & 2.3 & $(0.6)$ \\
\hline & South Australia & 4.0 & $(0.9)$ & 9.9 & $(1.4)$ & 24.3 & $(2.0)$ & 28.1 & $(2.0)$ & 21.4 & (2.4) & 10.4 & (2.3) & 1.9 & $(0.9)$ \\
\hline & Tasmania & 6.8 & $(1.1)$ & 12.5 & $(1.5)$ & 22.4 & $(2.3)$ & 27.6 & $(2.8)$ & 21.0 & $(2.2)$ & 7.9 & (1.8) & 1.8 & (1.1) \\
\hline & Victoria & 2.8 & $(0.5)$ & 10.5 & $(1.1)$ & 21.3 & (1.5) & 29.0 & (1.7) & 23.5 & (1.5) & 10.1 & (1.4) & 2.7 & $(0.8)$ \\
\hline & Western Australia & 2.0 & $(0.5)$ & 7.7 & $(1.0)$ & 17.6 & $(1.7)$ & 28.7 & $(2.2)$ & 26.8 & $(2.2)$ & 13.7 & (1.6) & 3.7 & $(0.9)$ \\
\hline & Belgium & & & & & & & & & & & & & & \\
\hline & Flemish Community• & 5.4 & $(0.9)$ & 10.7 & $(1.0)$ & 18.1 & $(1.0)$ & 26.7 & $(1.2)$ & 25.3 & $(1.2)$ & 12.1 & $(1.0)$ & 1.9 & $(0.4)$ \\
\hline & French Community & 8.6 & $(1.1)$ & 13.4 & (1.4) & 22.3 & $(1.8)$ & 28.4 & $(1.5)$ & 21.1 & (1.4) & 5.7 & $(0.8)$ & 0.4 & $(0.2)$ \\
\hline & German-speaking Community & 6.5 & $(1.3)$ & 11.9 & $(2.1)$ & 19.3 & $(2.0)$ & 30.2 & $(2.7)$ & 23.9 & (2.6) & 7.3 & (1.9) & 0.9 & $(0.6)$ \\
\hline & Canada & & & & & & & & & & & & & & \\
\hline & Alberta & 2.3 & $(0.7)$ & 6.6 & (1.5) & 17.5 & $(1.8)$ & 30.0 & (1.9) & 25.5 & (1.7) & 14.6 & (1.6) & 3.5 & $(0.8)$ \\
\hline & British Columbia & 1.6 & $(0.6)$ & 5.7 & $(1.0)$ & 17.0 & (2.0) & 28.0 & (2.5) & 30.2 & (2.9) & 14.4 & (2.3) & 3.2 & (1.2) \\
\hline & Manitoba & 4.6 & $(1.3)$ & 12.8 & $(1.6)$ & 23.4 & $(2.0)$ & 29.6 & (2.9) & 21.1 & (1.9) & 7.5 & (1.1) & 1.0 & $(0.6)$ \\
\hline & New Brunswick & 3.1 & $(0.8)$ & 12.3 & $(1.8)$ & 25.0 & $(2.7)$ & 32.5 & (2.6) & 19.5 & (1.9) & 6.9 & (1.4) & 0.6 & $(0.5)$ \\
\hline & Newfoundland and Labrador & 4.4 & $(1.2)$ & 11.4 & $(2.9)$ & 21.5 & (2.6) & 31.2 & (3.8) & 21.4 & (3.0) & 9.0 & (1.8) & 1.2 & $(0.8)$ \\
\hline & Nova Scotia & 2.8 & $(0.9)$ & 9.3 & $(2.0)$ & 21.1 & $(2.8)$ & 33.8 & (2.9) & 24.1 & (3.4) & 8.1 & $(2.2)$ & 0.8 & $(0.6)$ \\
\hline & Ontario & 3.1 & $(0.9)$ & 8.7 & $(1.2)$ & 19.5 & $(1.8)$ & 29.7 & (1.8) & 25.4 & (1.6) & 10.9 & (1.3) & 2.6 & $(0.7)$ \\
\hline & Prince Edward Island & 3.9 & $(1.0)$ & 16.3 & $(1.8)$ & 25.8 & (2.3) & 29.9 & (2.4) & 17.5 & (1.8) & 6.0 & (1.3) & 0.6 & $(0.5)$ \\
\hline & Quebec & 2.7 & $(0.8)$ & 8.2 & $(1.0)$ & 23.1 & (1.6) & 33.3 & (1.7) & 25.2 & (1.7) & 6.8 & $(0.8)$ & 0.7 & $(0.3)$ \\
\hline & Saskatchewan & 3.2 & $(0.7)$ & 9.3 & (1.4) & 23.0 & (1.7) & 31.4 & (2.2) & 23.6 & (2.5) & 8.5 & (1.6) & 1.0 & $(0.5)$ \\
\hline & Italy & & & & & & & & & & & & & & \\
\hline & Abruzzo & 7.2 & $(2.1)$ & 15.5 & $(2.4)$ & 29.4 & $(3.2)$ & 28.0 & $(2.5)$ & 15.7 & (1.9) & 3.7 & (1.1) & 0.5 & $(0.4)$ \\
\hline & Basilicata & 5.5 & (1.4) & 20.3 & $(2.1)$ & 32.5 & (2.8) & 26.5 & $(2.6)$ & 12.5 & $(1.7)$ & 2.6 & $(0.7)$ & 0.1 & c \\
\hline & Bolzano & 2.9 & $(0.7)$ & 9.8 & $(1.2)$ & 21.0 & $(2.1)$ & 29.3 & $(2.2)$ & 24.5 & (1.4) & 10.6 & $(1.2)$ & 1.9 & $(0.5)$ \\
\hline & Calabria & 14.4 & $(2.6)$ & 26.2 & $(2.6)$ & 30.3 & $(3.0)$ & 20.8 & $(2.2)$ & 6.9 & (1.5) & 1.3 & $(0.6)$ & 0.0 & C \\
\hline & Campania & 9.0 & $(2.0)$ & 21.5 & $(2.4)$ & 30.8 & $(2.2)$ & 25.0 & $(2.1)$ & 11.1 & $(2.1)$ & 2.4 & $(0.8)$ & 0.1 & C \\
\hline & Emilia Romagna & 4.0 & (1.3) & 11.4 & $(2.2)$ & 20.5 & $(2.5)$ & 30.3 & (2.6) & 24.6 & (3.0) & 8.2 & (1.6) & 1.0 & $(0.6)$ \\
\hline & Friuli Venezia Giulia & 1.9 & $(1.1)$ & 8.0 & $(1.8)$ & 18.0 & $(2.2)$ & 30.8 & (2.8) & 27.5 & (3.0) & 12.1 & (1.7) & 1.8 & $(0.7)$ \\
\hline & Lazio & 4.3 & (1.4) & 15.3 & $(2.8)$ & 28.0 & $(2.7)$ & 29.7 & $(2.3)$ & 17.2 & $(2.1)$ & 5.2 & (1.4) & 0.3 & $(0.2)$ \\
\hline & Liguria & 4.2 & (1.4) & 14.0 & $(2.5)$ & 24.4 & (1.9) & 30.3 & $(2.8)$ & 19.5 & $(2.3)$ & 6.7 & $(1.3)$ & 1.0 & $(0.5)$ \\
\hline & Lombardia & 2.3 & $(0.7)$ & 7.5 & (1.4) & 17.9 & (3.0) & 30.4 & (2.4) & 28.2 & $(2.7)$ & 12.4 & $(2.3)$ & 1.2 & $(0.5)$ \\
\hline & Marche & 2.1 & $(1.0)$ & 9.0 & $(1.7)$ & 24.4 & (2.4) & 33.1 & $(2.7)$ & 23.2 & (2.3) & 7.4 & (1.5) & 0.7 & $(0.4)$ \\
\hline & Molise & 6.7 & $(1.1)$ & 17.9 & $(2.0)$ & 32.5 & $(2.2)$ & 30.7 & (2.5) & 10.5 & (1.7) & 1.7 & (0.6) & 0.2 & C \\
\hline & Piemonte & 3.0 & $(0.9)$ & 8.9 & $(1.4)$ & 22.2 & $(2.4)$ & 34.3 & $(3.1)$ & 24.2 & (1.9) & 6.6 & (1.2) & 0.9 & $(0.4)$ \\
\hline & Puglia & 6.8 & (1.9) & 14.5 & $(2.3)$ & 25.1 & $(2.3)$ & 31.5 & $(2.5)$ & 18.3 & (2.1) & 3.7 & (1.0) & 0.1 & $(0.1)$ \\
\hline & Sardegna & 6.8 & $(2.0)$ & 16.7 & $(2.4)$ & 30.3 & (2.6) & 28.2 & $(2.4)$ & 15.1 & (1.9) & 2.7 & $(0.8)$ & 0.1 & c \\
\hline & Sicilia & 9.2 & $(1.9)$ & 22.8 & $(2.5)$ & 30.3 & $(2.2)$ & 25.6 & (2.5) & 10.3 & (1.5) & 1.8 & $(0.7)$ & 0.0 & c \\
\hline & Toscana & 5.8 & $(1.3)$ & 13.4 & $(2.0)$ & 25.1 & $(2.3)$ & 27.5 & $(2.5)$ & 22.2 & (2.4) & 5.5 & (1.0) & 0.4 & $(0.3)$ \\
\hline & Trento & 1.9 & $(0.9)$ & 7.9 & (1.7) & 20.1 & (2.4) & 31.5 & $(2.6)$ & 25.3 & $(2.6)$ & 11.7 & $(1.7)$ & 1.5 & $(0.6)$ \\
\hline & Umbria & 5.4 & $(2.2)$ & 11.1 & $(2.6)$ & 20.4 & (1.9) & 34.3 & $(3.0)$ & 22.6 & (2.4) & 5.6 & (1.5) & 0.4 & $(0.4)$ \\
\hline & Valle d'Aosta & 3.5 & $(1.1)$ & 11.2 & $(2.0)$ & 23.6 & $(2.5)$ & 33.4 & $(3.2)$ & 21.7 & (2.6) & 6.0 & (1.3) & 0.6 & $(0.5)$ \\
\hline & Veneto & 2.6 & $(1.0)$ & 8.6 & (1.8) & 19.9 & (2.5) & 27.0 & $(2.2)$ & 26.8 & (3.0) & 12.4 & (2.6) & 2.8 & $(0.8)$ \\
\hline & Mexico & & & & & & & & & & & & & & \\
\hline & Aguascalientes & 7.8 & $(1.8)$ & 28.4 & (2.9) & 38.3 & $(2.8)$ & 20.5 & (2.8) & 4.4 & (1.6) & 0.6 & $(0.4)$ & 0.0 & C \\
\hline & Baja California & 10.9 & $(2.6)$ & 34.0 & $(4.5)$ & 37.3 & $(3.1)$ & 15.0 & (2.5) & 2.5 & $(1.0)$ & 0.3 & c & 0.0 & c \\
\hline & Baja California Sur & 8.3 & (1.9) & 32.4 & (3.3) & 40.3 & (2.8) & 16.1 & (2.6) & 2.8 & (1.3) & 0.1 & c & 0.0 & c \\
\hline & Campeche & 13.5 & $(3.1)$ & 36.3 & (3.5) & 36.8 & (3.3) & 10.9 & (1.6) & 2.3 & $(1.1)$ & 0.2 & c & 0.0 & c \\
\hline & Chiapas & 28.8 & $(4.9)$ & 39.4 & $(2.9)$ & 25.4 & $(4.3)$ & 5.3 & $(1.4)$ & 1.0 & $(0.6)$ & 0.1 & c & 0.0 & c \\
\hline & Chihuahua & 9.2 & $(3.0)$ & 29.3 & $(4.4)$ & 36.6 & (3.4) & 19.6 & $(4.7)$ & 5.0 & (1.6) & 0.4 & $(0.5)$ & 0.0 & C \\
\hline & Coahuila & 12.1 & $(3.4)$ & 30.1 & $(4.3)$ & 34.0 & $(4.1)$ & 19.9 & $(4.2)$ & 3.7 & (1.3) & 0.2 & $(0.3)$ & 0.0 & C \\
\hline & Colima & 11.3 & $(2.3)$ & 28.3 & $(3.4)$ & 35.1 & $(3.2)$ & 20.0 & $(2.4)$ & 4.6 & (1.5) & 0.7 & $(0.3)$ & 0.0 & C \\
\hline & Distrito Federal & 7.4 & $(2.3)$ & 27.0 & (3.6) & 43.6 & $(3.4)$ & 18.6 & (2.9) & 3.1 & $(1.2)$ & 0.2 & c & 0.0 & C \\
\hline & Durango & 10.5 & $(2.5)$ & 31.1 & (3.6) & 39.2 & $(4.3)$ & 17.1 & (3.5) & 2.0 & $(0.9)$ & 0.1 & $(0.1)$ & 0.0 & c \\
\hline & Guanajuato & 17.3 & $(2.9)$ & 33.1 & $(3.2)$ & 34.5 & (3.4) & 12.7 & (2.0) & 2.5 & (0.9) & 0.1 & c & 0.0 & C \\
\hline & Guerrero & 27.8 & (3.4) & 43.3 & $(3.0)$ & 23.8 & (2.4) & 4.8 & (1.3) & 0.4 & $(0.3)$ & 0.0 & c & 0.0 & C \\
\hline & Hidalgo & 14.5 & (2.9) & 31.1 & $(4.1)$ & 36.0 & (3.4) & 16.1 & $(2.1)$ & 2.2 & $(0.9)$ & 0.1 & c & 0.0 & c \\
\hline & Jalisco & 7.9 & $(2.0)$ & 28.4 & $(3.4)$ & 38.4 & $(3.0)$ & 20.4 & $(3.5)$ & 4.6 & (1.4) & 0.4 & $(0.3)$ & 0.0 & C \\
\hline & Mexico & 7.4 & $(1.8)$ & 32.3 & $(4.2)$ & 43.5 & $(5.2)$ & 14.4 & $(3.7)$ & 2.0 & (0.9) & 0.4 & $(0.4)$ & 0.0 & C \\
\hline & Morelos & 11.9 & $(5.3)$ & 29.4 & (3.8) & 36.9 & $(3.6)$ & 17.0 & $(3.2)$ & 4.2 & (1.3) & 0.6 & $(0.6)$ & 0.0 & C \\
\hline & Nayarit & 13.0 & $(2.8)$ & 34.8 & $(4.4)$ & 36.9 & $(3.6)$ & 13.9 & (3.1) & 1.3 & $(1.0)$ & 0.0 & $\mathrm{C}$ & 0.0 & C \\
\hline & Nuevo León & 6.5 & $(1.9)$ & 26.0 & (3.6) & 40.7 & $(3.7)$ & 21.4 & $(4.0)$ & 5.2 & $(1.3)$ & 0.2 & $(0.2)$ & 0.0 & c \\
\hline & Puebla & 10.2 & $(3.2)$ & 26.9 & $(2.7)$ & 40.4 & $(4.3)$ & 18.8 & $(2.8)$ & 3.5 & (1.2) & 0.2 & c & 0.0 & C \\
\hline & Querétaro & 7.7 & $(2.2)$ & 26.3 & (4.3) & 40.4 & $(5.2)$ & 20.3 & (3.0) & 4.9 & (1.5) & 0.4 & $(0.3)$ & 0.0 & c \\
\hline & Quintana Roo & 13.6 & $(3.0)$ & 32.1 & $(2.5)$ & 37.0 & (3.7) & 15.2 & $(2.9)$ & 2.0 & $(1.1)$ & 0.0 & c & 0.0 & c \\
\hline & San Luis Potosí & 14.9 & $(2.5)$ & 34.4 & $(3.9)$ & 33.3 & $(2.9)$ & 14.2 & $(3.0)$ & 3.2 & (1.5) & 0.1 & c & 0.0 & C \\
\hline & Sinaloa & 14.3 & $(3.2)$ & 38.0 & (3.8) & 34.1 & (2.9) & 12.1 & $(2.1)$ & 1.3 & (0.6) & 0.1 & c & 0.0 & C \\
\hline & Tabasco & 18.4 & (3.3) & 43.9 & $(4.1)$ & 28.1 & (3.3) & 8.6 & $(2.0)$ & 0.9 & $(0.6)$ & 0.1 & $\mathrm{C}$ & 0.0 & c \\
\hline & Tamaulipas & 13.3 & (3.3) & 32.3 & $(4.0)$ & 35.6 & (3.8) & 15.4 & $(3.0)$ & 3.2 & (1.5) & 0.2 & $(0.4)$ & 0.0 & C \\
\hline & Tlaxcala & 13.4 & $(2.1)$ & 32.8 & (3.8) & 37.3 & $(3.2)$ & 15.0 & $(2.1)$ & 1.5 & $(0.9)$ & 0.1 & c & 0.0 & c \\
\hline & Veracruz & 17.5 & $(3.0)$ & 37.3 & $(3.4)$ & 33.0 & $(2.7)$ & 11.3 & $(2.2)$ & 0.9 & $(0.6)$ & 0.0 & c & 0.0 & C \\
\hline & Yucatán & 12.3 & $(3.0)$ & 32.4 & (3.4) & 36.8 & $(3.0)$ & 15.6 & $(2.2)$ & 2.7 & (1.1) & 0.2 & c & 0.0 & C \\
\hline & Zacatecas & 16.8 & $(2.7)$ & 37.3 & (3.0) & 33.2 & $(2.7)$ & 11.6 & $(2.0)$ & 1.1 & $(0.6)$ & 0.0 & C & 0.0 & C \\
\hline
\end{tabular}

- PISA adjudicated region

Note: See Table I.5.2a for national data.

StatLink 新细 http://dx.doi.org/10.1787/888932935762 
[Part 2/4]

Table B2.I.29 Percentage of students at each proficiency level in science, by gender and region

\begin{tabular}{|c|c|c|c|c|c|c|c|c|c|c|c|c|c|c|c|}
\hline & & \multicolumn{14}{|c|}{ Boys } \\
\hline & & \multicolumn{2}{|c|}{$\begin{array}{c}\text { Below Level } 1 \\
\text { (below } 334.94 \\
\text { score points) }\end{array}$} & \multicolumn{2}{|c|}{$\begin{array}{c}\text { Level } 1 \\
\text { (from } 334.94 \text { to } \\
\text { less than } 409.54 \\
\text { score points) }\end{array}$} & \multicolumn{2}{|c|}{$\begin{array}{c}\text { Level } 2 \\
\text { (from } 409.54 \text { to } \\
\text { less than } 484.14 \\
\text { score points) } \\
\end{array}$} & $\begin{array}{l}\text { Le } \\
\text { (from } \\
\text { less th } \\
\text { score }\end{array}$ & $\begin{array}{l}3 \\
5.14 \text { to } \\
558.73 \\
\text { ints) }\end{array}$ & $\begin{array}{r}\text { Le } \\
\text { (from } 5 \\
\text { less tha } \\
\text { score }\end{array}$ & $\begin{array}{l}14 \\
8.73 \text { to } \\
633.33 \\
\text { oints) }\end{array}$ & $\begin{array}{r}\text { Le } \\
\text { (from } 6 \\
\text { less tha } \\
\text { score }\end{array}$ & $\begin{array}{l}5 \\
53 \text { to } \\
707.93 \\
\text { ints) }\end{array}$ & $\begin{array}{r}\text { Le } \\
\text { (above } \\
\text { score }\end{array}$ & $\begin{array}{l}6 \\
07.93 \\
0 \text { ints) }\end{array}$ \\
\hline & & $\%$ & S.E. & $\%$ & S.E. & $\%$ & S.E. & $\%$ & S.E. & $\%$ & S.E. & $\%$ & S.E. & $\%$ & S.E. \\
\hline 0 & Portugal & & & & & & & & & & & & & & \\
\hline 닌 & Alentejo & 3.1 & $(1.2)$ & 11.9 & (3.5) & 28.6 & (3.5) & 34.2 & $(4.7)$ & 16.5 & (3.8) & 5.4 & $(2.0)$ & 0.2 & c \\
\hline & Spain & & & & & & & & & & & & & & \\
\hline & Andalusia ${ }^{\bullet}$ & 5.3 & (1.1) & 13.2 & (1.5) & 26.9 & (1.9) & 31.7 & (2.0) & 17.2 & (1.9) & 5.4 & $(1.2)$ & 0.3 & $(0.3)$ \\
\hline & Aragon` & 4.2 & (1.3) & 12.5 & (1.8) & 23.5 & $(1.8)$ & 29.3 & (2.4) & 22.0 & (2.0) & 7.5 & (1.3) & 1.1 & $(0.4)$ \\
\hline & Asturias ${ }^{\bullet}$ & 3.6 & $(0.9)$ & 9.7 & (1.4) & 21.9 & $(1.7)$ & 30.0 & (2.1) & 24.9 & $(2.1)$ & 8.4 & (1.7) & 1.5 & $(0.7)$ \\
\hline & Balearic Islands & 3.9 & (1.1) & 14.8 & (1.9) & 29.4 & $(2.3)$ & 32.0 & (2.0) & 17.0 & (1.9) & 2.8 & $(0.8)$ & 0.1 & c \\
\hline & Basque Country• & 2.8 & (0.6) & 8.7 & $(0.9)$ & 24.1 & $(1.2)$ & 35.1 & (1.5) & 23.5 & $(1.3)$ & 5.4 & $(0.6)$ & 0.5 & $(0.2)$ \\
\hline & Cantabria` & 3.7 & (1.0) & 11.3 & (1.5) & 24.0 & $(2.5)$ & 30.8 & (2.6) & 23.1 & (2.5) & 6.3 & (1.0) & 0.8 & $(0.4)$ \\
\hline & Castile and Leon ${ }^{\bullet}$ & 2.0 & $(0.8)$ & 7.3 & (1.4) & 21.6 & $(2.0)$ & 33.0 & (1.9) & 27.3 & (1.9) & 8.1 & (1.3) & 0.6 & $(0.3)$ \\
\hline & Catalonia• & 2.2 & $(0.9)$ & 12.8 & $(1.7)$ & 28.6 & $(2.5)$ & 32.5 & (2.4) & 19.3 & (2.4) & 4.4 & (1.1) & 0.3 & $(0.2)$ \\
\hline & Extremadura ${ }^{\bullet}$ & 6.8 & (1.3) & 14.7 & (1.9) & 26.7 & $(2.5)$ & 27.7 & (1.9) & 17.7 & $(2.1)$ & 5.5 & (1.0) & 0.9 & $(0.5)$ \\
\hline & Galicia ${ }^{\bullet}$ & 3.2 & (0.9) & 10.3 & (1.7) & 22.5 & $(2.0)$ & 32.4 & (2.3) & 24.2 & (1.9) & 7.0 & (1.4) & 0.4 & $(0.3)$ \\
\hline & La Rioja・ & 4.9 & (1.0) & 9.8 & (1.3) & 21.6 & $(1.7)$ & 27.9 & (1.9) & 26.7 & (1.9) & 8.5 & (1.4) & 0.7 & $(0.5)$ \\
\hline & Madrid` & 2.7 & (0.6) & 8.1 & (1.1) & 21.7 & $(1.9)$ & 32.3 & (1.9) & 26.4 & $(2.1)$ & 8.1 & $(1.2)$ & 0.7 & $(0.4)$ \\
\hline & Murcia $\bullet$ & 6.5 & (1.3) & 16.0 & (1.9) & 29.0 & $(2.0)$ & 28.7 & $(2.2)$ & 15.6 & (1.9) & 3.8 & (1.0) & 0.4 & $(0.3)$ \\
\hline & Navarre ${ }^{\bullet}$ & 3.3 & $(0.9)$ & 9.6 & (1.6) & 21.5 & $(2.3)$ & 33.4 & (2.3) & 23.9 & $(2.2)$ & 7.5 & (1.5) & 0.7 & $(0.4)$ \\
\hline & United Kingdom & & & & & & & & & & & & & & \\
\hline & England & 3.8 & $(0.7)$ & 10.0 & $(1.2)$ & 20.8 & (1.4) & 27.1 & (1.4) & 25.0 & (1.5) & 11.0 & (1.3) & 2.3 & $(0.6)$ \\
\hline & Northern Ireland & 4.4 & (1.0) & 11.8 & (1.5) & 22.4 & $(2.0)$ & 28.9 & (2.3) & 22.2 & (2.1) & 7.9 & (1.1) & 2.3 & $(0.6)$ \\
\hline & Scotland ${ }^{\bullet}$ & 2.6 & $(0.5)$ & 9.4 & (0.9) & 23.9 & $(1.4)$ & 30.9 & (1.7) & 23.4 & $(1.2)$ & 8.3 & $(0.8)$ & 1.4 & $(0.4)$ \\
\hline & Wales & 5.3 & $(1.0)$ & 12.7 & $(1.0)$ & 26.0 & (1.6) & 29.8 & (1.5) & 19.4 & (1.3) & 5.8 & $(0.8)$ & 1.0 & $(0.3)$ \\
\hline & United States & & & & & & & & & & & & & & \\
\hline & Connecticut ${ }^{\bullet}$ & 2.8 & $(0.8)$ & 10.1 & (1.5) & 20.3 & (1.9) & 27.5 & (2.1) & 24.1 & (1.9) & 12.5 & (1.4) & 2.7 & $(0.6)$ \\
\hline & Florida $\bullet$ & 5.6 & (1.3) & 14.9 & (1.8) & 25.9 & $(1.7)$ & 28.2 & (1.8) & 18.3 & $(2.2)$ & 6.3 & $(1.2)$ & 0.7 & $(0.6)$ \\
\hline & Massachusetts & 2.8 & $(0.7)$ & 9.2 & $(1.2)$ & 20.1 & $(2.0)$ & 28.4 & (1.9) & 24.7 & $(2.0)$ & 11.6 & (1.8) & 3.2 & (1.0) \\
\hline$\frac{2}{2}$ & Argentina & & & & & & & & & & & & & & \\
\hline 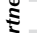 & Ciudad Autónoma de Buenos Aires $\bullet$ & 19.0 & (2.6) & 19.7 & $(2.8)$ & 28.4 & $(2.5)$ & 22.2 & $(2.8)$ & 9.1 & (1.9) & 1.6 & $(0.7)$ & 0.0 & c \\
\hline & Brazil & & & & & & & & & & & & & & \\
\hline & Acre & 22.1 & (3.3) & 44.0 & $(4.1)$ & 28.0 & (4.5) & 5.4 & (2.0) & 0.4 & c & 0.0 & c & 0.0 & c \\
\hline & Alagoas & 43.3 & $(6.0)$ & 37.1 & (3.6) & 15.4 & $(4.6)$ & 3.8 & $(1.7)$ & 0.4 & c & 0.0 & c & 0.0 & C \\
\hline & Amapá & 22.6 & (5.4) & 40.0 & (6.4) & 28.0 & $(5.5)$ & 8.4 & (3.9) & 1.0 & $(1.1)$ & 0.0 & c & 0.0 & c \\
\hline & Amazonas & 27.0 & (4.4) & 42.7 & $(5.2)$ & 23.3 & $(4.2)$ & 5.6 & (1.8) & 1.4 & $(1.1)$ & 0.0 & $\mathrm{C}$ & 0.0 & c \\
\hline & Bahia & 27.0 & $(6.0)$ & 34.7 & (4.6) & 23.8 & (6.9) & 10.7 & (4.2) & 3.2 & $(1.3)$ & 0.6 & (0.6) & 0.0 & c \\
\hline & Ceará & 23.7 & $(4.7)$ & 39.9 & (4.6) & 24.0 & $(4.2)$ & 9.2 & (2.6) & 2.9 & (1.6) & 0.4 & $\mathrm{C}$ & 0.0 & c \\
\hline & Espírito Santo & 11.1 & (2.6) & 31.7 & (3.1) & 31.0 & (3.3) & 17.0 & $(2.2)$ & 8.1 & (3.2) & 1.0 & $(0.7)$ & 0.0 & $\mathrm{c}$ \\
\hline & Federal District & 14.5 & $(4.2)$ & 30.3 & (3.8) & 31.3 & $(4.0)$ & 17.2 & (2.7) & 6.3 & (1.9) & 0.5 & c & 0.0 & c \\
\hline & Goiás & 19.9 & $(4.2)$ & 37.9 & $(4.7)$ & 27.6 & (3.8) & 11.5 & (2.1) & 3.0 & $(0.8)$ & 0.1 & $\mathrm{C}$ & 0.0 & c \\
\hline & Maranhão & 39.4 & $(7.2)$ & 32.0 & $(5.8)$ & 18.4 & (4.4) & 7.6 & (4.3) & 2.6 & $(2.5)$ & 0.0 & $\mathrm{c}$ & 0.0 & $\mathrm{c}$ \\
\hline & Mato Grosso & 28.9 & (4.3) & 39.8 & $(4.0)$ & 23.6 & (3.8) & 5.6 & (1.6) & 2.0 & $(1.5)$ & 0.1 & c & 0.0 & c \\
\hline & Mato Grosso do Sul & 13.7 & (3.6) & 33.9 & (4.3) & 34.6 & (3.2) & 15.5 & (3.8) & 2.2 & $(0.8)$ & 0.2 & $\mathrm{c}$ & 0.0 & c \\
\hline & Minas Gerais & 17.5 & (4.3) & 26.5 & (3.1) & 35.5 & (4.4) & 17.0 & (3.2) & 2.8 & (1.3) & 0.8 & $(0.5)$ & 0.0 & c \\
\hline & Pará & 31.4 & (4.4) & 36.6 & (3.6) & 26.7 & (3.7) & 5.0 & (1.9) & 0.2 & $\mathrm{c}$ & 0.0 & $\mathrm{c}$ & 0.0 & c \\
\hline & Paraíba & 17.3 & (4.6) & 32.7 & $(4.0)$ & 30.7 & $(5.6)$ & 13.6 & (3.9) & 4.9 & $(2.1)$ & 0.8 & $\mathrm{C}$ & 0.0 & c \\
\hline & Paraná & 14.7 & (3.5) & 34.2 & (3.3) & 29.6 & $(4.0)$ & 14.8 & (2.7) & 6.5 & (3.4) & 0.2 & c & 0.0 & c \\
\hline & Pernambuco & 31.4 & $(5.2)$ & 36.8 & $(5.1)$ & 22.9 & $(5.5)$ & 7.4 & (2.7) & 1.4 & $(1.1)$ & 0.2 & c & 0.0 & c \\
\hline & Piauí & 20.6 & (4.8) & 36.9 & (6.9) & 28.5 & $(5.7)$ & 10.9 & (2.2) & 2.1 & $(2.2)$ & 1.0 & $(0.7)$ & 0.0 & C \\
\hline & Rio de Janeiro & 21.5 & (4.3) & 34.6 & (3.4) & 30.1 & (3.6) & 12.3 & (2.6) & 1.5 & $(0.8)$ & 0.0 & $\mathrm{c}$ & 0.0 & c \\
\hline & Rio Grande do Norte & 26.4 & (4.5) & 37.9 & (4.3) & 22.5 & $(4.2)$ & 9.4 & (3.3) & 3.7 & $(2.2)$ & 0.1 & $\mathrm{c}$ & 0.0 & c \\
\hline & Rio Grande do Sul & 12.7 & (2.5) & 32.6 & $(3.7)$ & 36.4 & (3.4) & 16.2 & (2.3) & 2.0 & (1.0) & 0.1 & $\mathrm{c}$ & 0.0 & c \\
\hline & Rondônia & 21.3 & (3.8) & 42.5 & $(4.5)$ & 28.9 & $(4.2)$ & 6.2 & (1.6) & 1.1 & $(0.7)$ & 0.0 & c & 0.0 & c \\
\hline & Roraima & 35.7 & (4.3) & 33.2 & (3.9) & 23.2 & (3.7) & 5.9 & (2.3) & 2.1 & (1.5) & 0.0 & $\mathrm{c}$ & 0.0 & c \\
\hline & Santa Catarina & 12.7 & $(4.0)$ & 30.3 & (3.1) & 36.5 & (3.8) & 18.0 & (3.6) & 2.4 & $(0.9)$ & 0.1 & $\mathrm{c}$ & 0.0 & c \\
\hline & São Paulo & 13.8 & (1.8) & 33.6 & (2.1) & 33.9 & $(2.1)$ & 14.4 & (1.7) & 3.8 & $(1.1)$ & 0.4 & $(0.4)$ & 0.0 & C \\
\hline & Sergipe & 19.5 & (4.3) & 39.1 & (5.9) & 27.7 & $(5.2)$ & 11.2 & (5.2) & 2.4 & (1.5) & 0.1 & $\mathrm{C}$ & 0.0 & C \\
\hline & Tocantins & 29.6 & (4.4) & 36.8 & (4.7) & 24.3 & $(4.0)$ & 8.0 & (2.2) & 1.1 & $(0.6)$ & 0.1 & c & 0.0 & C \\
\hline & Colombia & & & & & & & & & & & & & & \\
\hline & Bogotá & 10.0 & (2.1) & 32.6 & (2.9) & 37.7 & $(2.7)$ & 16.4 & (2.5) & 2.8 & (0.9) & 0.4 & (0.5) & 0.0 & C \\
\hline & Cali & 17.0 & (3.2) & 34.2 & (3.5) & 31.6 & (3.0) & 14.3 & (2.8) & 2.8 & $(1.2)$ & 0.2 & C & 0.0 & C \\
\hline & Manizales & 7.5 & (1.2) & 28.9 & (2.5) & 34.6 & $(2.7)$ & 21.7 & (2.6) & 6.7 & (1.6) & 0.5 & (0.5) & 0.1 & c \\
\hline & Medellín & 10.9 & (2.0) & 33.3 & (3.4) & 34.4 & (3.4) & 15.4 & (2.4) & 5.0 & (2.0) & 0.9 & $(0.8)$ & 0.0 & c \\
\hline & Russian Federation & & & & & & & & & & & & & & \\
\hline & Perm Territory region ${ }^{\bullet}$ & 5.8 & (1.4) & 15.5 & (1.8) & 28.7 & $(2.3)$ & 30.1 & (2.5) & 15.6 & (1.9) & 4.0 & (1.4) & 0.3 & c \\
\hline & United Arab Emirates & & & & & & & & & & & & & & \\
\hline & Abu Dhabi ${ }^{\bullet}$ & 21.8 & (2.0) & 27.6 & (1.9) & 25.2 & $(1.6)$ & 16.5 & (1.3) & 7.2 & $(1.2)$ & 1.6 & $(0.6)$ & 0.1 & $(0.1)$ \\
\hline & Ajman & 26.4 & $(8.1)$ & 31.9 & $(4.4)$ & 24.8 & $(4.9)$ & 14.3 & (3.0) & 2.5 & $(1.5)$ & 0.0 & $\mathrm{C}$ & 0.0 & C \\
\hline & Dubai ${ }^{\bullet}$ & 10.3 & $(0.6)$ & 20.9 & $(1.0)$ & 25.4 & $(1.4)$ & 23.2 & (1.1) & 14.6 & $(0.9)$ & 4.7 & $(0.6)$ & 0.9 & $(0.4)$ \\
\hline & Fujairah & 20.2 & $(4.7)$ & 36.5 & (3.8) & 26.3 & (4.9) & 11.3 & (2.8) & 5.1 & $(1.3)$ & 0.5 & $(0.5)$ & 0.0 & $\mathrm{c}$ \\
\hline & Ras al-Khaimah & 14.1 & (4.6) & 34.4 & $(4.7)$ & 34.2 & (4.4) & 13.9 & (2.8) & 2.9 & (1.1) & 0.5 & $(0.3)$ & 0.0 & c \\
\hline & Sharjah & 8.6 & (3.0) & 25.6 & (5.8) & 32.4 & $(4.8)$ & 22.2 & (5.1) & 9.6 & (3.9) & 1.5 & $(0.9)$ & 0.1 & C \\
\hline & Umm al-Quwain & 29.1 & (4.9) & 41.4 & (6.7) & 21.9 & (5.7) & 5.1 & (2.4) & 2.3 & $(1.2)$ & 0.1 & c & 0.0 & c \\
\hline
\end{tabular}

- PISA adjudicated region.

Note: See Table 1.5.2a for national data.

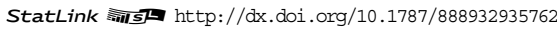


[Part 3/4]

Table B2.I.29 Percentage of students at each proficiency level in science, by gender and region

\begin{tabular}{|c|c|c|c|c|c|c|c|c|c|c|c|c|c|c|c|}
\hline & & \multicolumn{14}{|c|}{ Girls } \\
\hline & & \multicolumn{2}{|c|}{$\begin{array}{c}\text { Below Level } 1 \\
\text { (below } 334.94 \\
\text { score points) }\end{array}$} & $\begin{array}{l}\text { Le } \\
\text { (from } \\
\text { less tha } \\
\text { score }\end{array}$ & $\begin{array}{l}\text { I } 1 \\
4.94 \text { to } \\
409.54 \\
\text { oints) }\end{array}$ & $\begin{array}{l}\text { Le } \\
\text { (from } \\
\text { less th } \\
\text { score }\end{array}$ & $\begin{array}{l}2 \\
.54 \text { to } \\
484.14 \\
\text { jints) }\end{array}$ & $\begin{array}{l}\text { Le } \\
\text { (from } \\
\text { less th } \\
\text { score }\end{array}$ & $\begin{array}{l}3 \\
4.14 \text { to } \\
558.73 \\
\text { oints) }\end{array}$ & $\begin{array}{l}\text { Le } \\
\text { (from } \\
\text { less th } \\
\text { score }\end{array}$ & $\begin{array}{l}14 \\
8.73 \text { to } \\
633.33 \\
\text { oints) }\end{array}$ & $\begin{array}{l}\text { Le } \\
\text { (from } \\
\text { less tha } \\
\text { score }\end{array}$ & $\begin{array}{l}5 \\
3.33 \text { to } \\
707.93 \\
\text { oints) }\end{array}$ & $\begin{array}{l}\text { Le } \\
\text { (abov } \\
\text { score }\end{array}$ & $\begin{array}{l}6 \\
07.93 \\
0 i n t s)\end{array}$ \\
\hline & & $\%$ & S.E. & $\%$ & S.E. & $\%$ & S.E. & $\%$ & S.E. & $\%$ & S.E. & $\%$ & S.E. & $\%$ & S.E. \\
\hline 0 & Australia & & & & & & & & & & & & & & \\
\hline U్山 & Australian Capital Territory & 3.1 & $(1.0)$ & 7.7 & $(1.7)$ & 18.3 & $(2.2)$ & 28.8 & $(3.1)$ & 27.1 & (2.6) & 11.9 & $(2.2)$ & 3.0 & (1.1) \\
\hline & New South Wales & 3.2 & (0.6) & 9.3 & $(1.1)$ & 20.5 & $(1.2)$ & 28.6 & $(1.7)$ & 23.2 & (1.6) & 12.3 & $(1.2)$ & 2.8 & $(0.5)$ \\
\hline & Northern Territory & 12.0 & $(2.0)$ & 12.1 & $(3.3)$ & 20.7 & $(4.7)$ & 31.8 & (5.6) & 14.9 & (3.6) & 7.2 & (3.9) & 1.2 & c \\
\hline & Queensland & 2.7 & $(0.6)$ & 10.6 & $(1.2)$ & 23.2 & (1.4) & 30.5 & (1.6) & 21.8 & (1.4) & 9.3 & (1.1) & 1.8 & $(0.4)$ \\
\hline & South Australia & 3.5 & $(0.9)$ & 11.5 & $(1.5)$ & 24.1 & $(2.0)$ & 28.8 & $(2.2)$ & 22.5 & (2.3) & 8.4 & (1.5) & 1.2 & (0.6) \\
\hline & Tasmania & 5.7 & (1.3) & 14.9 & $(1.9)$ & 23.5 & (2.8) & 25.2 & $(2.8)$ & 20.6 & $(2.1)$ & 8.5 & $(2.1)$ & 1.6 & $(0.7)$ \\
\hline & Victoria & 3.0 & (0.6) & 10.5 & $(1.2)$ & 23.9 & $(1.7)$ & 31.4 & $(2.5)$ & 21.7 & (2.3) & 8.2 & (1.3) & 1.2 & $(0.4)$ \\
\hline & Western Australia & 2.2 & $(0.6)$ & 9.9 & (1.4) & 20.5 & $(2.2)$ & 29.3 & $(2.3)$ & 23.7 & $(2.2)$ & 11.6 & (1.8) & 2.8 & $(0.9)$ \\
\hline & Belgium & & & & & & & & & & & & & & \\
\hline & Flemish Community• & 4.2 & $(0.7)$ & 10.1 & $(1.0)$ & 20.5 & (1.3) & 29.2 & (1.3) & 25.6 & $(1.3)$ & 9.2 & $(0.9)$ & 1.1 & $(0.3)$ \\
\hline & French Community & 6.1 & $(1.0)$ & 14.1 & (1.3) & 26.7 & $(1.7)$ & 30.9 & $(1.7)$ & 18.3 & (1.7) & 3.8 & $(0.6)$ & 0.2 & c \\
\hline & German-speaking Community & 3.4 & $(1.1)$ & 7.9 & (1.4) & 22.0 & (3.0) & 39.0 & (3.5) & 23.6 & $(2.9)$ & 4.2 & $(1.2)$ & 0.0 & C \\
\hline & Canada & & & & & & & & & & & & & & \\
\hline & Alberta & 1.5 & $(0.6)$ & 7.2 & $(1.1)$ & 18.7 & $(2.1)$ & 29.9 & $(2.7)$ & 28.4 & $(2.1)$ & 12.0 & (1.6) & 2.3 & $(0.8)$ \\
\hline & British Columbia & 1.3 & $(0.5)$ & 5.7 & $(1.2)$ & 17.9 & (1.7) & 31.9 & $(2.0)$ & 29.4 & $(2.1)$ & 11.2 & (1.5) & 2.6 & $(0.8)$ \\
\hline & Manitoba & 3.1 & $(1.0)$ & 11.9 & $(1.8)$ & 26.4 & (3.0) & 31.6 & (2.5) & 20.1 & $(2.2)$ & 6.2 & (1.0) & 0.8 & $(0.4)$ \\
\hline & New Brunswick & 2.3 & $(0.7)$ & 9.8 & $(1.4)$ & 25.7 & $(2.4)$ & 34.1 & $(2.2)$ & 21.1 & (2.0) & 5.9 & (1.4) & 1.1 & (1.3) \\
\hline & Newfoundland and Labrador & 2.1 & $(0.7)$ & 8.7 & $(1.8)$ & 22.6 & (2.3) & 35.2 & $(3.0)$ & 21.7 & $(2.0)$ & 8.3 & (1.5) & 1.4 & $(0.7)$ \\
\hline & Nova Scotia & 1.5 & $(0.7)$ & 7.3 & $(1.5)$ & 26.6 & $(4.5)$ & 35.3 & (3.8) & 21.8 & (2.5) & 6.7 & (1.6) & 0.8 & $(0.7)$ \\
\hline & Ontario & 2.3 & $(0.5)$ & 7.6 & $(0.9)$ & 21.1 & $(1.8)$ & 33.3 & (1.4) & 24.9 & (1.5) & 9.0 & (1.0) & 1.8 & $(0.5)$ \\
\hline & Prince Edward Island & 2.7 & $(0.9)$ & 11.4 & $(1.8)$ & 29.2 & (2.3) & 33.7 & $(2.1)$ & 19.1 & $(2.1)$ & 3.6 & (1.1) & 0.3 & $(0.3)$ \\
\hline & Quebec & 2.1 & $(0.5)$ & 8.2 & $(1.0)$ & 23.5 & (1.9) & 35.8 & $(2.0)$ & 24.2 & (1.9) & 5.6 & (1.1) & 0.6 & $(0.2)$ \\
\hline & Saskatchewan & 2.0 & $(0.6)$ & 7.3 & (1.4) & 25.6 & (2.0) & 34.0 & (3.2) & 22.2 & (1.7) & 8.3 & (1.3) & 0.6 & $(0.4)$ \\
\hline & Italy & & & & & & & & & & & & & & \\
\hline & Abruzzo & 3.8 & $(1.2)$ & 13.9 & $(2.2)$ & 30.3 & (2.6) & 32.2 & $(3.0)$ & 16.3 & (2.3) & 3.2 & (1.1) & 0.3 & $(0.3)$ \\
\hline & Basilicata & 4.3 & $(1.2)$ & 21.0 & $(2.3)$ & 36.3 & (2.6) & 26.5 & $(2.1)$ & 10.1 & (1.6) & 1.6 & $(0.6)$ & 0.2 & $(0.2)$ \\
\hline & Bolzano & 2.5 & (0.6) & 9.7 & $(1.3)$ & 22.4 & (1.9) & 33.4 & $(2.0)$ & 24.7 & (1.9) & 7.1 & (1.1) & 0.4 & $(0.3)$ \\
\hline & Calabria & 13.8 & (3.2) & 25.9 & $(2.2)$ & 34.6 & $(2.9)$ & 19.9 & (2.4) & 5.4 & (1.0) & 0.4 & $(0.3)$ & 0.0 & C \\
\hline & Campania & 7.9 & (2.5) & 20.9 & (3.7) & 33.6 & $(2.2)$ & 26.7 & (3.8) & 10.0 & (1.9) & 1.0 & $(0.5)$ & 0.1 & C \\
\hline & Emilia Romagna & 3.0 & $(1.1)$ & 9.4 & (1.8) & 24.3 & $(2.7)$ & 33.9 & $(2.3)$ & 22.5 & $(2.8)$ & 6.4 & (1.3) & 0.6 & $(0.5)$ \\
\hline & Friuli Venezia Giulia & 1.9 & (1.1) & 6.5 & $(2.3)$ & 18.0 & $(2.4)$ & 37.7 & (3.1) & 27.6 & (2.6) & 7.4 & (1.1) & 1.0 & $(0.4)$ \\
\hline & Lazio & 3.6 & (1.4) & 17.6 & (2.9) & 31.6 & $(3.1)$ & 30.6 & (2.5) & 13.6 & $(2.1)$ & 2.9 & $(0.9)$ & 0.2 & c \\
\hline & Liguria & 3.2 & $(1.2)$ & 12.8 & $(2.2)$ & 24.5 & $(2.5)$ & 31.8 & $(2.7)$ & 21.6 & (2.9) & 5.3 & (1.5) & 0.7 & $(0.6)$ \\
\hline & Lombardia & 1.0 & $(0.4)$ & 6.6 & $(1.6)$ & 21.9 & (3.9) & 35.4 & $(2.9)$ & 27.8 & (3.0) & 6.7 & (1.6) & 0.5 & $(0.5)$ \\
\hline & Marche & 3.5 & (1.5) & 12.1 & $(2.3)$ & 25.4 & $(2.0)$ & 34.1 & (2.6) & 19.9 & (2.0) & 4.7 & $(1.2)$ & 0.3 & $(0.2)$ \\
\hline & Molise & 4.3 & $(1.1)$ & 15.4 & $(2.9)$ & 36.1 & $(3.5)$ & 33.7 & (2.5) & 9.0 & (2.0) & 1.4 & $(0.7)$ & 0.1 & C \\
\hline & Piemonte & 3.0 & $(0.7)$ & 11.7 & $(1.8)$ & 24.4 & $(2.5)$ & 33.8 & (2.5) & 21.3 & (2.3) & 5.3 & (1.3) & 0.5 & $(0.3)$ \\
\hline & Puglia & 3.3 & $(1.2)$ & 15.2 & $(2.5)$ & 32.9 & (3.2) & 31.1 & $(2.8)$ & 15.2 & $(2.1)$ & 2.1 & $(0.8)$ & 0.1 & c \\
\hline & Sardegna & 5.8 & (1.5) & 15.2 & $(2.6)$ & 32.4 & $(2.6)$ & 30.7 & (2.8) & 13.5 & (2.3) & 2.4 & (0.9) & 0.1 & C \\
\hline & Sicilia & 8.6 & (1.9) & 20.2 & $(3.1)$ & 33.3 & $(2.7)$ & 27.3 & (3.2) & 8.9 & (1.6) & 1.4 & $(0.8)$ & 0.3 & $(0.2)$ \\
\hline & Toscana & 3.2 & (1.1) & 11.1 & $(2.4)$ & 23.1 & $(3.0)$ & 32.6 & $(2.5)$ & 22.9 & (3.2) & 6.6 & (1.6) & 0.4 & $(0.3)$ \\
\hline & Trento & 1.0 & $(0.6)$ & 4.8 & (1.9) & 18.4 & (2.9) & 34.9 & (3.4) & 30.5 & (3.2) & 9.7 & $(2.0)$ & 0.7 & $(0.4)$ \\
\hline & Umbria & 2.8 & $(1.3)$ & 11.4 & $(2.3)$ & 25.7 & (2.4) & 36.6 & $(2.3)$ & 19.5 & (2.4) & 3.7 & $(1.3)$ & 0.3 & $(0.2)$ \\
\hline & Valle d'Aosta & 1.8 & $(0.7)$ & 8.9 & $(1.7)$ & 24.7 & $(2.6)$ & 37.5 & $(2.5)$ & 21.8 & (2.8) & 4.8 & (1.5) & 0.4 & c \\
\hline & Veneto & 2.3 & (1.5) & 5.5 & (1.5) & 19.3 & $(2.2)$ & 35.3 & $(3.1)$ & 26.0 & (2.3) & 10.2 & (1.8) & 1.3 & $(0.5)$ \\
\hline & Mexico & & & & & & & & & & & & & & \\
\hline & Aguascalientes & 8.2 & (1.8) & 29.0 & $(2.7)$ & 41.0 & $(3.4)$ & 18.3 & $(2.5)$ & 2.9 & (0.9) & 0.6 & $(0.5)$ & 0.0 & C \\
\hline & Baja California & 12.4 & (2.8) & 36.5 & (3.4) & 35.7 & (2.5) & 13.1 & $(2.2)$ & 2.3 & (1.1) & 0.1 & c & 0.0 & c \\
\hline & Baja California Sur & 13.3 & (2.4) & 35.7 & $(2.6)$ & 37.3 & $(2.7)$ & 12.2 & (1.7) & 1.5 & $(0.6)$ & 0.0 & c & 0.0 & c \\
\hline & Campeche & 17.7 & (3.4) & 38.1 & (3.8) & 32.1 & (3.3) & 10.6 & $(2.0)$ & 1.2 & $(0.7)$ & 0.3 & $(0.2)$ & 0.0 & c \\
\hline & Chiapas & 27.2 & $(4.2)$ & 40.9 & (3.5) & 25.8 & (3.1) & 5.8 & $(1.6)$ & 0.3 & $(0.3)$ & 0.0 & c & 0.0 & c \\
\hline & Chihuahua & 10.6 & $(2.7)$ & 29.9 & $(4.0)$ & 38.3 & $(3.8)$ & 18.1 & (3.9) & 2.9 & (1.5) & 0.2 & c & 0.0 & C \\
\hline & Coahuila & 10.9 & (2.3) & 32.1 & (3.8) & 43.1 & (3.4) & 12.9 & $(2.7)$ & 0.9 & (0.6) & 0.0 & c & 0.0 & C \\
\hline & Colima & 9.7 & (1.7) & 30.9 & $(3.3)$ & 38.9 & (2.9) & 16.6 & $(2.3)$ & 3.4 & (1.4) & 0.4 & $\mathrm{c}$ & 0.0 & C \\
\hline & Distrito Federal & 9.4 & (2.0) & 34.4 & (3.3) & 40.2 & $(3.7)$ & 13.4 & (2.4) & 2.5 & (1.1) & 0.1 & c & 0.0 & C \\
\hline & Durango & 8.2 & (2.0) & 33.5 & (3.4) & 42.5 & $(4.0)$ & 14.8 & (3.0) & 1.0 & $(0.7)$ & 0.0 & c & 0.0 & c \\
\hline & Guanajuato & 15.8 & (3.5) & 38.3 & $(3.1)$ & 35.1 & (3.5) & 9.9 & (1.9) & 0.8 & (0.4) & 0.0 & c & 0.0 & C \\
\hline & Guerrero & 28.0 & (3.6) & 44.3 & $(2.7)$ & 23.1 & (3.3) & 4.1 & $(1.1)$ & 0.4 & $(0.4)$ & 0.0 & c & 0.0 & C \\
\hline & Hidalgo & 15.4 & (2.2) & 35.2 & (3.7) & 36.4 & $(3.7)$ & 11.7 & $(2.5)$ & 1.3 & $(0.7)$ & 0.0 & c & 0.0 & c \\
\hline & Jalisco & 5.7 & (1.9) & 30.6 & $(4.0)$ & 40.4 & $(3.0)$ & 19.8 & $(3.3)$ & 3.4 & $(1.2)$ & 0.1 & $\mathrm{C}$ & 0.0 & C \\
\hline & Mexico & 9.1 & (1.7) & 38.2 & $(3.7)$ & 40.4 & (3.4) & 11.1 & $(2.6)$ & 1.1 & (0.6) & 0.0 & $\mathrm{c}$ & 0.0 & C \\
\hline & Morelos & 9.9 & (2.6) & 33.7 & (3.9) & 37.2 & $(3.6)$ & 15.6 & $(3.1)$ & 3.2 & (1.8) & 0.5 & $(0.5)$ & 0.0 & C \\
\hline & Nayarit & 18.4 & (3.4) & 36.5 & $(2.9)$ & 32.9 & $(3.2)$ & 10.7 & $(1.9)$ & 1.4 & $(0.8)$ & 0.0 & c & 0.0 & C \\
\hline & Nuevo León & 7.1 & $(2.2)$ & 32.0 & $(4.1)$ & 41.3 & $(5.1)$ & 16.6 & (3.1) & 2.7 & (1.0) & 0.3 & c & 0.0 & c \\
\hline & Puebla & 12.3 & (3.0) & 30.8 & $(2.5)$ & 41.1 & (2.9) & 13.4 & $(2.0)$ & 2.3 & (1.1) & 0.0 & c & 0.0 & C \\
\hline & Querétaro & 8.7 & $(1.8)$ & 32.7 & (3.4) & 38.5 & (2.9) & 17.0 & $(2.9)$ & 2.9 & $(1.2)$ & 0.1 & c & 0.0 & c \\
\hline & Quintana Roo & 10.7 & (2.7) & 34.1 & $(3.2)$ & 39.7 & $(4.1)$ & 13.9 & $(2.7)$ & 1.4 & $(0.6)$ & 0.1 & c & 0.0 & c \\
\hline & San Luis Potosí & 10.4 & (2.0) & 34.9 & (3.6) & 37.5 & $(2.4)$ & 15.6 & $(3.3)$ & 1.6 & $(0.7)$ & 0.0 & c & 0.0 & C \\
\hline & Sinaloa & 12.6 & (2.3) & 40.3 & (3.5) & 34.9 & $(2.8)$ & 11.0 & $(2.1)$ & 1.2 & $(0.7)$ & 0.0 & c & 0.0 & C \\
\hline & Tabasco & 21.3 & (3.1) & 41.4 & (3.5) & 29.8 & $(3.2)$ & 7.2 & $(1.2)$ & 0.4 & $(0.4)$ & 0.0 & c & 0.0 & C \\
\hline & Tamaulipas & 12.2 & (2.1) & 36.8 & $(4.0)$ & 36.9 & $(2.8)$ & 12.9 & $(2.5)$ & 1.2 & $(0.7)$ & 0.0 & c & 0.0 & C \\
\hline & Tlaxcala & 13.5 & (1.8) & 36.3 & (2.4) & 37.4 & $(2.6)$ & 11.7 & (1.8) & 1.1 & $(0.8)$ & 0.0 & c & 0.0 & c \\
\hline & Veracruz & 15.9 & (2.9) & 37.8 & $(3.8)$ & 34.3 & (3.7) & 11.1 & (3.2) & 0.8 & (0.8) & 0.1 & c & 0.0 & C \\
\hline & Yucatán & 14.0 & (2.6) & 35.3 & $(3.3)$ & 35.8 & (3.9) & 13.0 & $(2.1)$ & 1.8 & $(0.8)$ & 0.0 & c & 0.0 & C \\
\hline & Zacatecas & 17.3 & (2.9) & 34.8 & $(2.5)$ & 35.6 & (3.0) & 11.3 & $(1.6)$ & 0.9 & $(0.7)$ & 0.0 & C & 0.0 & C \\
\hline
\end{tabular}

- PISA adjudicated region

Note: See Table I.5.2a for national data.

StatLink 新细 http://dx.doi.org/10.1787/888932935762 
[Part 4/4]

Table B2.I.29 Percentage of students at each proficiency level in science, by gender and region

\begin{tabular}{|c|c|c|c|c|c|c|c|c|c|c|c|c|c|c|c|}
\hline & & \multicolumn{14}{|c|}{ Girls } \\
\hline & & \multicolumn{2}{|c|}{$\begin{array}{c}\text { Below Level } 1 \\
\text { (below } 334.94 \\
\text { score points) }\end{array}$} & \multicolumn{2}{|c|}{$\begin{array}{c}\text { Level } 1 \\
\text { (from } 334.94 \text { to } \\
\text { less than } 409.54 \\
\text { score points) }\end{array}$} & \multicolumn{2}{|c|}{$\begin{array}{c}\text { Level } 2 \\
\text { (from } 409.54 \text { to } \\
\text { less than } 484.14 \\
\text { score points) }\end{array}$} & $\begin{array}{r}\text { Le } \\
\text { (from } \\
\text { less tha } \\
\text { score }\end{array}$ & $\begin{array}{l}3 \\
5.14 \text { to } \\
558.73 \\
\text { ints) }\end{array}$ & $\begin{array}{r}\text { Le } \\
\text { (from } 5 \\
\text { less tha } \\
\text { score }\end{array}$ & $\begin{array}{l}14 \\
8.73 \text { to } \\
633.33 \\
\text { oints) }\end{array}$ & $\begin{array}{r}\text { Le } \\
\text { (from } 6 \\
\text { less tha } \\
\text { score }\end{array}$ & $\begin{array}{l}5 \\
53 \text { to } \\
707.93 \\
\text { ints) }\end{array}$ & $\begin{array}{r}\text { Le } \\
\text { (above } \\
\text { score }\end{array}$ & $\begin{array}{l}6 \\
07.93 \\
0 \text { ints) }\end{array}$ \\
\hline & & $\%$ & S.E. & $\%$ & S.E. & $\%$ & S.E. & $\%$ & S.E. & $\%$ & S.E. & $\%$ & S.E. & $\%$ & S.E. \\
\hline 0 & Portugal & & & & & & & & & & & & & & \\
\hline ن & Alentejo & 2.4 & (1.2) & 12.1 & (3.0) & 29.7 & (3.4) & 36.7 & $(4.1)$ & 16.3 & (2.6) & 2.6 & (1.5) & 0.1 & C \\
\hline & Spain & & & & & & & & & & & & & & \\
\hline & Andalusia ${ }^{\bullet}$ & 3.7 & (1.1) & 15.1 & (2.6) & 34.0 & $(2.7)$ & 30.1 & (2.0) & 14.1 & (1.5) & 2.8 & $(0.9)$ & 0.3 & $(0.3)$ \\
\hline & Aragon ${ }^{\bullet}$ & 3.7 & (1.1) & 11.2 & (1.8) & 24.3 & $(2.2)$ & 33.6 & (2.3) & 20.5 & (1.9) & 6.0 & (1.3) & 0.6 & $(0.4)$ \\
\hline & Asturias ${ }^{\bullet}$ & 1.8 & $(0.7)$ & 8.1 & (1.5) & 25.6 & $(2.6)$ & 32.1 & (2.1) & 23.4 & $(2.0)$ & 7.9 & (1.2) & 1.0 & $(0.4)$ \\
\hline & Balearic Islands ${ }^{\bullet}$ & 4.5 & (1.1) & 15.0 & (1.7) & 31.0 & $(2.2)$ & 32.0 & (2.4) & 15.5 & $(2.2)$ & 2.0 & $(0.6)$ & 0.0 & C \\
\hline & Basque Country ${ }^{\bullet}$ & 2.9 & (0.5) & 9.0 & (0.9) & 26.6 & $(1.4)$ & 38.5 & (1.3) & 19.4 & (1.1) & 3.3 & $(0.4)$ & 0.2 & $(0.1)$ \\
\hline & Cantabria ${ }^{\bullet}$ & 3.0 & $(0.8)$ & 11.9 & (1.6) & 30.4 & $(2.7)$ & 32.9 & (2.2) & 16.5 & (1.8) & 4.8 & (1.0) & 0.5 & $(0.3)$ \\
\hline & Castile and Leon ${ }^{\bullet}$ & 1.2 & $(0.5)$ & 6.8 & (1.1) & 24.9 & (1.8) & 38.2 & (2.6) & 24.3 & $(2.2)$ & 4.4 & (0.9) & 0.1 & C \\
\hline & Catalonia $\bullet$ & 3.6 & (0.9) & 12.3 & (1.9) & 30.7 & $(3.0)$ & 36.7 & (3.3) & 14.6 & $(2.1)$ & 2.0 & (0.6) & 0.1 & C \\
\hline & Extremadura ${ }^{\bullet}$ & 5.2 & (1.0) & 15.5 & (1.6) & 30.8 & $(2.0)$ & 31.0 & (2.1) & 14.3 & (1.8) & 2.8 & (0.9) & 0.4 & $(0.2)$ \\
\hline & Galicia• & 2.4 & $(0.7)$ & 9.1 & (1.6) & 24.1 & $(2.3)$ & 35.4 & (2.4) & 22.7 & $(2.0)$ & 5.8 & (1.1) & 0.6 & $(0.4)$ \\
\hline & La Rioja• & 3.7 & $(0.9)$ & 8.1 & $(1.2)$ & 24.3 & $(2.0)$ & 34.9 & $(2.2)$ & 24.0 & $(1.7)$ & 4.9 & (1.2) & 0.2 & $\mathrm{C}$ \\
\hline & Madrid• & 1.7 & $(0.7)$ & 8.3 & (1.4) & 23.7 & $(2.1)$ & 36.4 & (2.6) & 24.2 & $(2.2)$ & 5.6 & $(0.9)$ & 0.2 & c \\
\hline & Murcia $\bullet$ & 4.0 & (1.1) & 15.2 & (2.0) & 31.8 & $(2.4)$ & 32.9 & (2.2) & 13.5 & $(2.1)$ & 2.3 & (0.6) & 0.3 & $(0.2)$ \\
\hline & Navarre ${ }^{\bullet}$ & 2.0 & $(0.7)$ & 6.9 & (1.3) & 26.0 & $(2.0)$ & 35.5 & (2.3) & 22.4 & (1.9) & 6.6 & (1.4) & 0.7 & $(0.3)$ \\
\hline & United Kingdom & & & & & & & & & & & & & & \\
\hline & England & 4.8 & $(0.8)$ & 11.2 & $(1.2)$ & 22.9 & (1.4) & 28.9 & (1.4) & 21.9 & $(1.2)$ & 8.7 & (0.9) & 1.6 & $(0.4)$ \\
\hline & Northern Ireland & 5.0 & (0.9) & 12.4 & (2.0) & 25.1 & $(2.0)$ & 26.6 & (2.1) & 20.6 & (1.9) & 8.7 & (1.4) & 1.7 & $(0.6)$ \\
\hline & Scotland ${ }^{\bullet}$ & 2.7 & (0.6) & 9.3 & (1.1) & 25.9 & (1.8) & 33.9 & (1.5) & 20.2 & (1.5) & 6.7 & (1.1) & 1.2 & $(0.4)$ \\
\hline & Wales & 5.0 & $(0.7)$ & 15.7 & (1.3) & 28.3 & (1.6) & 29.2 & (1.7) & 17.4 & $(1.2)$ & 3.9 & $(0.7)$ & 0.6 & $(0.2)$ \\
\hline & United States & & & & & & & & & & & & & & \\
\hline & Connecticut ${ }^{\bullet}$ & 3.7 & (1.1) & 10.4 & (1.7) & 22.5 & (2.3) & 31.2 & (2.3) & 21.6 & (1.7) & 8.8 & (1.6) & 1.8 & (1.0) \\
\hline & Florida ${ }^{\bullet}$ & 4.7 & (0.9) & 17.4 & (1.9) & 31.0 & (2.3) & 28.2 & (3.0) & 14.8 & (1.7) & 3.4 & (1.2) & 0.5 & $(0.5)$ \\
\hline & Massachusetts ${ }^{\bullet}$ & 2.4 & (0.9) & 8.5 & (1.2) & 22.2 & (2.3) & 30.3 & (2.2) & 22.9 & (2.3) & 11.0 & (1.6) & 2.6 & $(0.8)$ \\
\hline 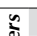 & Argentina & & & & & & & & & & & & & & \\
\hline$\stackrel{\varrho}{\Xi}$ & Ciudad Autónoma de Buenos Aires $\bullet$ & 19.6 & $(2.7)$ & 23.0 & $(2.4)$ & 26.4 & $(2.3)$ & 22.4 & (2.5) & 7.3 & (1.6) & 1.3 & $(0.7)$ & 0.1 & c \\
\hline & Brazil & & & & & & & & & & & & & & \\
\hline & Acre & 26.9 & $(4.8)$ & 42.3 & (3.9) & 24.8 & $(3.6)$ & 5.7 & (1.8) & 0.3 & c & 0.0 & c & 0.0 & c \\
\hline & Alagoas & 48.3 & (5.4) & 35.7 & $(4.3)$ & 13.1 & $(2.9)$ & 2.6 & (1.8) & 0.4 & $(0.5)$ & 0.0 & c & 0.0 & c \\
\hline & Amapá & 27.6 & (5.5) & 40.8 & $(5.3)$ & 24.8 & $(4.4)$ & 6.5 & (3.7) & 0.4 & $\mathrm{C}$ & 0.0 & $\mathrm{C}$ & 0.0 & C \\
\hline & Amazonas & 27.4 & (3.4) & 44.6 & (3.7) & 22.7 & $(3.2)$ & 4.7 & (1.8) & 0.6 & c & 0.0 & $\mathrm{C}$ & 0.0 & C \\
\hline & Bahia & 23.1 & (6.3) & 41.3 & (5.7) & 24.3 & $(4.4)$ & 9.0 & (2.2) & 2.2 & $(1.5)$ & 0.2 & $\mathrm{C}$ & 0.0 & C \\
\hline & Ceará & 26.7 & (5.3) & 35.9 & (3.8) & 28.0 & $(4.2)$ & 7.9 & (2.4) & 1.4 & $(0.8)$ & 0.0 & $\mathrm{C}$ & 0.0 & C \\
\hline & Espírito Santo & 14.2 & $(2.7)$ & 30.9 & (3.8) & 32.4 & (4.9) & 13.9 & (3.0) & 7.4 & (3.5) & 1.2 & $(0.9)$ & 0.1 & C \\
\hline & Federal District & 12.2 & (3.5) & 32.2 & (3.2) & 34.6 & $(3.2)$ & 18.4 & (3.5) & 2.1 & $(1.1)$ & 0.5 & $(0.5)$ & 0.0 & C \\
\hline & Goiás & 21.8 & $(4.2)$ & 38.4 & $(4.2)$ & 28.8 & $(3.7)$ & 9.8 & (2.4) & 1.1 & $(0.7)$ & 0.1 & $\mathrm{C}$ & 0.0 & C \\
\hline & Maranhão & 43.7 & (6.4) & 34.4 & (4.5) & 16.0 & $(3.7)$ & 5.4 & (3.1) & 0.4 & $\mathrm{C}$ & 0.0 & $\mathrm{C}$ & 0.0 & c \\
\hline & Mato Grosso & 23.5 & $(4.1)$ & 44.1 & $(5.2)$ & 23.3 & (3.8) & 5.9 & (2.2) & 2.9 & $(1.8)$ & 0.3 & $\mathrm{C}$ & 0.0 & C \\
\hline & Mato Grosso do Sul & 11.5 & (2.4) & 37.5 & (3.6) & 34.3 & $(4.7)$ & 14.4 & (3.7) & 2.2 & $(0.9)$ & 0.1 & $\mathrm{C}$ & 0.0 & C \\
\hline & Minas Gerais & 10.6 & $(2.2)$ & 34.2 & (3.9) & 35.5 & $(2.8)$ & 15.6 & (3.8) & 3.7 & $(1.5)$ & 0.4 & $(0.4)$ & 0.0 & c \\
\hline & Pará & 26.8 & (3.4) & 41.5 & $(4.1)$ & 23.7 & (3.3) & 7.7 & (1.9) & 0.3 & $\mathrm{C}$ & 0.0 & $\mathrm{C}$ & 0.0 & c \\
\hline & Paraíba & 15.4 & $(4.3)$ & 34.7 & (3.8) & 31.9 & $(4.0)$ & 15.5 & (2.9) & 2.4 & (1.6) & 0.0 & $\mathrm{C}$ & 0.0 & c \\
\hline & Paraná & 15.5 & (3.2) & 36.1 & (4.4) & 32.1 & $(4.1)$ & 11.2 & $(2.4)$ & 3.8 & $(3.0)$ & 1.3 & (1.7) & 0.0 & c \\
\hline & Pernambuco & 31.0 & $(4.8)$ & 40.2 & (3.1) & 22.3 & (3.6) & 5.9 & $(1.9)$ & 0.6 & $(0.6)$ & 0.1 & $(0.2)$ & 0.0 & c \\
\hline & Piauí & 18.2 & (3.0) & 37.6 & $(4.0)$ & 30.2 & $(2.9)$ & 9.7 & (2.3) & 3.8 & $(2.0)$ & 0.4 & $(0.6)$ & 0.0 & c \\
\hline & Rio de Janeiro & 17.7 & $(3.7)$ & 35.0 & $(4.4)$ & 33.8 & $(4.2)$ & 12.1 & (2.6) & 1.3 & $(0.8)$ & 0 & C & 0.0 & c \\
\hline & Rio Grande do Norte & 27.0 & (4.0) & 37.8 & $(4.2)$ & 23.7 & (3.6) & 9.4 & $(2.4)$ & 1.9 & $(1.1)$ & 0.2 & $\mathrm{C}$ & 0.0 & c \\
\hline & Rio Grande do Sul & 8.8 & $(2.2)$ & 35.1 & (3.5) & 38.4 & $(4.1)$ & 16.2 & (3.4) & 1.5 & $(0.9)$ & 0.0 & $\mathrm{c}$ & 0.0 & c \\
\hline & Rondônia & 19.3 & $(4.1)$ & 42.0 & $(4.9)$ & 31.3 & (3.6) & 6.8 & $(2.4)$ & 0.6 & $(0.6)$ & 0.0 & $\mathrm{c}$ & 0.0 & c \\
\hline & Roraima & 31.2 & (3.5) & 36.5 & $(4.0)$ & 21.4 & (3.4) & 6.8 & $(2.3)$ & 3.6 & $(2.3)$ & 0.5 & $\mathrm{c}$ & 0.0 & c \\
\hline & Santa Catarina & 14.2 & (4.6) & 30.6 & $(4.2)$ & 38.3 & $(4.1)$ & 14.1 & (3.1) & 2.7 & $(1.3)$ & 0.1 & c & 0.0 & c \\
\hline & São Paulo & 12.4 & $(1.8)$ & 34.6 & $(2.9)$ & 34.3 & $(2.2)$ & 15.2 & (2.0) & 3.2 & $(0.9)$ & 0.3 & $(0.2)$ & 0.0 & c \\
\hline & Sergipe & 20.0 & (3.6) & 43.4 & $(4.3)$ & 28.3 & $(4.1)$ & 7.3 & $(2.9)$ & 1.0 & $(1.0)$ & 0.0 & C & 0.0 & c \\
\hline & Tocantins & 27.8 & (3.7) & 42.5 & (3.5) & 21.9 & $(3.7)$ & 6.7 & (1.7) & 1.1 & $(0.6)$ & 0.0 & $\mathrm{c}$ & 0.0 & c \\
\hline & Colombia & & & & & & & & & & & & & & \\
\hline & Bogotá & 16.6 & $(2.1)$ & 39.6 & $(2.8)$ & 33.6 & $(2.7)$ & 9.2 & (1.4) & 1.0 & $(0.5)$ & 0.0 & c & 0.0 & c \\
\hline & Cali & 20.3 & (3.3) & 37.1 & (3.7) & 31.2 & (3.4) & 10.0 & $(2.3)$ & 1.4 & $(0.6)$ & 0.0 & $\mathrm{C}$ & 0.0 & C \\
\hline & Manizales & 10.0 & $(2.0)$ & 37.6 & (3.8) & 37.0 & (3.4) & 13.3 & (3.0) & 2.1 & $(1.3)$ & 0.0 & $\mathrm{C}$ & 0.0 & c \\
\hline & Medellín & 16.8 & $(2.6)$ & 36.2 & (3.8) & 29.6 & $(2.8)$ & 13.2 & (2.9) & 3.5 & $(1.6)$ & 0.8 & $(0.6)$ & 0.0 & c \\
\hline & Russian Federation & & & & & & & & & & & & & & \\
\hline & Perm Territory region ${ }^{\bullet}$ & 3.8 & $(1.0)$ & 14.8 & (1.8) & 33.3 & (2.4) & 32.5 & (2.6) & 13.3 & $(1.8)$ & 2.0 & $(0.8)$ & 0.1 & c \\
\hline & United Arab Emirates & & & & & & & & & & & & & & \\
\hline & Abu Dhabi ${ }^{\bullet}$ & 7.0 & (1.5) & 21.0 & $(1.7)$ & 32.7 & $(1.8)$ & 25.9 & (2.1) & 10.7 & $(1.2)$ & 2.6 & $(0.7)$ & 0.2 & $(0.2)$ \\
\hline & Ajman & 8.4 & (2.9) & 23.6 & (5.1) & 38.2 & $(4.4)$ & 23.0 & (3.7) & 6.5 & $(2.1)$ & 0.3 & $\mathrm{C}$ & 0.0 & $\mathrm{C}$ \\
\hline & Dubai & $\begin{array}{l}0.7 \\
4.9\end{array}$ & $(0.4)$ & 17.1 & $(1.0)$ & 29.4 & $(1.5)$ & 28.3 & (1.4) & 15.9 & $(1.0)$ & 3.9 & (0.6) & 0.4 & $(0.3)$ \\
\hline & Fujairah & 5.2 & (1.9) & 24.1 & $(4.1)$ & 41.6 & $(3.7)$ & 24.5 & (3.3) & 4.4 & $(1.5)$ & 0.2 & $\mathrm{C}$ & 0.0 & $\mathrm{C}$ \\
\hline & Ras al-Khaimah & $\begin{array}{l}3.2 \\
7.3\end{array}$ & (3.5) & 24.5 & $\begin{array}{l}(4.1) \\
(3.3)\end{array}$ & 37.0 & $(4.2)$ & 24.6 & (3.6) & 5.7 & $(1.2)$ & 0.8 & $(0.7)$ & 0.1 & c \\
\hline & Sharjah & 8.8 & (2.8) & 24.2 & (4.7) & 31.6 & $(3.9)$ & $\begin{array}{l}24.0 \\
24.0\end{array}$ & (4.0) & 10.1 & $(3.2)$ & $\begin{array}{l}0.0 \\
1.2\end{array}$ & $(0.8)$ & 0.0 & c \\
\hline & Umm al-Quwain & 4.8 & (1.3) & 23.6 & (3.6) & 39.8 & $(4.8)$ & 24.5 & (4.0) & 6.5 & $(2.4)$ & 0.8 & $\mathrm{C}$ & 0.0 & c \\
\hline
\end{tabular}

- PISA adjudicated region.

Note: See Table 1.5.2a for national data.

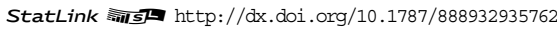


[Part 1/2]

Table B2.I.30 Mean score, variation and gender differences in student performance in science, by region

\begin{tabular}{|c|c|c|c|c|c|c|c|c|c|c|c|c|c|c|c|c|c|c|c|}
\hline & & & All stu & Idents & & & & nder di & lifferen & ices & & & & & & & Perce & entiles & \\
\hline & & Mean & score & $\begin{array}{l}\text { Stan } \\
\text { devia }\end{array}$ & $\begin{array}{l}\text { ard } \\
\text { ion }\end{array}$ & & oys & & irls & $\begin{array}{c}\text { Diffe } \\
\text { (B . }\end{array}$ & $\begin{array}{l}\text { rence } \\
- \text { - G) }\end{array}$ & & th & & 0th & & 5th & 75 & th \\
\hline & & Mean & S.E. & S.D. & S.E. & $\begin{array}{l}\text { Mean } \\
\text { score }\end{array}$ & S.E. & $\begin{array}{l}\text { Mean } \\
\text { score }\end{array}$ & S.E. & $\begin{array}{c}\text { Score } \\
\text { dif. }\end{array}$ & S.E. & Score & S.E. & Score & S.E. & Score & S.E. & Score & S.E. \\
\hline 0 & Australia & & & & & & & & & & & & & & & & & & \\
\hline 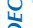 & Australian Capital Territory & 534 & (3.9) & 104 & (3.1) & 534 & (5.5) & 533 & (5.2) & 1 & (7.4) & 346 & (11.1) & 395 & (8.3) & 470 & (6.8) & 608 & (6.5) \\
\hline & New South Wales & 526 & (3.6) & 105 & $(2.1)$ & 525 & (5.6) & 527 & (4.1) & -2 & $(6.7)$ & 347 & $(7.0)$ & 389 & (4.7) & 454 & (3.7) & 600 & $(5.7)$ \\
\hline & Northern Territory & 483 & $(10.2)$ & 124 & $(4.8)$ & 486 & $(10.7)$ & 480 & (14.3) & 6 & (14.7) & 255 & (14.5) & 308 & $(17.3)$ & 406 & (12.8) & 566 & (12.4) \\
\hline & Queensland & 519 & (3.1) & 97 & (1.7) & 521 & (4.0) & 517 & (3.7) & 4 & (4.5) & 356 & (6.2) & 392 & (4.9) & 453 & (3.6) & 587 & (4.2) \\
\hline & South Australia & 513 & (3.7) & 97 & $(2.2)$ & 515 & (4.4) & 510 & (4.6) & 5 & (5.0) & 348 & (6.8) & 386 & (5.9) & 448 & (4.5) & 582 & (5.4) \\
\hline & Tasmania & 500 & (3.8) & 105 & (3.0) & 501 & (5.2) & 499 & (5.8) & 2 & (7.9) & 322 & (10.6) & 363 & (6.6) & 430 & (5.8) & 573 & (5.4) \\
\hline & Victoria & 518 & (3.8) & 96 & (2.0) & 523 & (5.3) & 512 & (3.7) & 11 & (5.4) & 359 & (5.8) & 393 & (5.0) & 454 & (5.2) & 583 & (4.3) \\
\hline & Western Australia & 535 & (3.7) & 98 & $(1.8)$ & 541 & (5.7) & 528 & $(5.2)$ & 13 & $(8.1)$ & 375 & $(7.0)$ & 405 & (5.4) & 467 & (5.1) & 602 & (4.7) \\
\hline & Belgium & & & & & & & & & & & & & & & & & & \\
\hline & Flemish Community ${ }^{\bullet}$ & 518 & (3.2) & 102 & $(2.0)$ & 520 & (4.8) & 516 & (3.9) & 4 & (5.9) & 337 & (6.3) & 380 & (5.8) & 453 & (5.1) & 592 & (3.5) \\
\hline & French Community & 487 & (3.3) & 97 & (2.3) & 489 & (3.8) & 485 & (3.9) & 4 & (4.1) & 315 & $(7.2)$ & 354 & (7.3) & 424 & (5.3) & 558 & (3.4) \\
\hline & German-speaking Community & 508 & (2.4) & 91 & (2.6) & 506 & $(4.0)$ & 510 & (3.3) & -4 & (5.6) & 338 & (13.5) & 380 & (7.3) & 453 & (5.4) & 570 & $(4.2)$ \\
\hline & Canada & & & & & & & & & & & & & & & & & & \\
\hline & Alberta & 539 & (4.7) & 94 & (1.9) & 542 & (4.9) & 537 & (5.1) & 5 & (3.6) & $\mid 377$ & (7.8) & 417 & (6.2) & 478 & (5.8) & 604 & (5.5) \\
\hline & British Columbia & 544 & (3.9) & 90 & (2.4) & 548 & (4.7) & 541 & (5.4) & 7 & (6.3) & 392 & (8.8) & 430 & (5.7) & 485 & (5.3) & 605 & (5.4) \\
\hline & Manitoba & 503 & (3.2) & 93 & (2.4) & 503 & $(4.2)$ & 502 & (4.6) & 1 & (5.9) & 347 & (8.6) & 381 & (6.5) & 438 & (4.6) & 568 & (4.5) \\
\hline & New Brunswick & 507 & (2.6) & 87 & (2.3) & 504 & (4.0) & 510 & (4.1) & -6 & $(6.2)$ & 360 & (5.1) & 392 & (6.6) & 451 & (4.0) & 565 & (4.5) \\
\hline & Newfoundland and Labrador & 514 & (3.6) & 93 & $(2.1)$ & 510 & (5.0) & 518 & (4.0) & -8 & (5.5) & 357 & $(9.7)$ & 393 & $(7.0)$ & 455 & (5.6) & 575 & (4.9) \\
\hline & Nova Scotia & 516 & (3.0) & 85 & (2.6) & 518 & $(4.8)$ & 515 & (4.3) & 3 & $(6.7)$ & 371 & (9.4) & 407 & (9.4) & 460 & (4.4) & 574 & (5.9) \\
\hline & Ontario & 527 & (4.3) & 93 & (1.9) & 528 & (5.4) & 525 & (4.0) & 3 & (4.1) & 367 & $(6.1)$ & 405 & (5.8) & 467 & (4.9) & 590 & (5.3) \\
\hline & Prince Edward Island & 495 & (3.0) & 86 & $(2.0)$ & 492 & (4.3) & 497 & (3.6) & -5 & (5.2) & 352 & (7.4) & 381 & (5.4) & 436 & (4.9) & 555 & (4.3) \\
\hline & Quebec & 516 & (3.3) & 84 & (1.9) & 516 & (3.9) & 515 & (3.5) & 2 & (3.7) & 371 & (7.3) & 406 & $(5.7)$ & 462 & (4.1) & 575 & (3.6) \\
\hline & Saskatchewan & 516 & (2.9) & 89 & $(2.0)$ & 516 & $(4.0)$ & 517 & (3.5) & -2 & $(4.8)$ & 366 & (7.8) & 405 & (5.3) & 458 & (3.7) & 579 & $(5.3)$ \\
\hline & Italy & & & & & & & & & & & & & & & & & & \\
\hline & Abruzzo & 482 & (5.6) & 89 & (4.0) & 478 & (7.0) & 487 & (6.1) & -9 & (6.5) & 330 & (13.5) & 367 & (10.7) & 425 & $(7.2)$ & 544 & (7.1) \\
\hline & Basilicata & 465 & (3.9) & 83 & $(1.8)$ & 467 & (5.5) & 463 & (4.6) & 4 & (6.4) & 335 & (7.8) & 361 & (5.8) & 408 & (5.1) & 521 & (4.3) \\
\hline & Bolzano & 519 & $(2.2)$ & 90 & $(1.7)$ & 523 & (3.0) & 515 & (2.6) & 8 & (3.5) & 364 & (5.2) & 396 & $(4.2)$ & 459 & (4.6) & 583 & (3.7) \\
\hline & Calabria & 431 & $(5.7)$ & 89 & (3.7) & 433 & (6.4) & 428 & (8.0) & 4 & (8.8) & 282 & (15.5) & 318 & (9.3) & 372 & (8.0) & 491 & (6.6) \\
\hline & Campania & 457 & (7.7) & 87 & (3.3) & 457 & (7.1) & 456 & (10.0) & 1 & $(8.1)$ & 311 & (11.4) & 342 & (10.4) & 398 & (8.6) & 516 & (8.9) \\
\hline & Emilia Romagna & 512 & $(6.2)$ & 92 & (3.2) & 513 & (8.8) & 510 & (7.1) & 3 & $(10.3)$ & 350 & (8.5) & 389 & (10.5) & 452 & (8.2) & 577 & (7.1) \\
\hline & Friuli Venezia Giulia & 531 & $(4.7)$ & 86 & $(4.3)$ & 535 & (4.0) & 528 & (7.1) & 7 & $(7.0)$ & 379 & $(15.0)$ & 414 & (12.9) & 478 & (6.9) & 589 & $(4.2)$ \\
\hline & Lazio & 484 & (6.6) & 86 & (2.4) & 488 & (6.7) & 478 & (8.1) & 10 & (6.9) & 343 & (9.6) & 373 & $(8.4)$ & 423 & (8.5) & 543 & (7.5) \\
\hline & Liguria & 501 & (6.2) & 92 & (3.5) & 500 & (8.3) & 502 & (7.1) & -2 & (9.4) & 346 & (9.1) & 379 & (9.9) & 438 & (9.7) & 566 & (7.1) \\
\hline & Lombardia & 529 & (6.8) & 86 & $(2.8)$ & 534 & (8.2) & 524 & (7.4) & 9 & (7.8) & 383 & $(9.2)$ & 416 & (7.3) & 474 & (9.1) & 589 & (7.4) \\
\hline & Marche & 507 & $(5.2)$ & 86 & $(4.2)$ & 514 & (5.5) & 499 & (6.1) & 15 & (5.4) & 359 & (14.5) & 392 & (12.9) & 450 & (7.8) & 566 & (4.8) \\
\hline & Molise & 468 & (2.3) & 79 & $(2.2)$ & 466 & (3.5) & 470 & (3.2) & -4 & (5.0) & 331 & $(9.0)$ & 365 & (5.9) & 417 & (3.9) & 520 & (3.6) \\
\hline & Piemonte & 509 & (4.4) & 87 & (2.6) & 515 & (4.4) & 503 & (6.3) & 12 & (6.8) & 355 & $(8.1)$ & 391 & (7.9) & 453 & (6.4) & 570 & (5.8) \\
\hline & Puglia & 483 & (5.0) & 86 & (3.5) & 484 & (5.9) & 483 & (6.0) & 2 & (6.5) & 334 & (13.2) & 367 & $(10.2)$ & 426 & (8.8) & 545 & (5.6) \\
\hline & Sardegna & 473 & (5.4) & 87 & (3.2) & 472 & (6.3) & 475 & (7.1) & -3 & $(7.7)$ & 325 & (11.4) & 360 & (10.7) & 417 & (6.8) & 533 & (6.0) \\
\hline & Sicilia & 454 & (6.2) & 89 & (3.5) & 453 & (6.6) & 456 & (8.4) & -3 & (8.4) & 308 & (12.2) & 340 & (8.4) & 394 & (8.0) & 518 & (6.6) \\
\hline & Toscana & 501 & (4.4) & 93 & (2.9) & 495 & (5.9) & 508 & (8.4) & -13 & (11.3) & 337 & (8.5) & 375 & (8.3) & 438 & (5.6) & 568 & (5.7) \\
\hline & Trento & 533 & (3.9) & 85 & (2.3) & 529 & (5.7) & 537 & (7.1) & -7 & (9.9) & 386 & (10.5) & 420 & (7.0) & 478 & $(6.7)$ & 592 & (3.6) \\
\hline & Umbria & 501 & (6.3) & 87 & (4.1) & 504 & (9.5) & 499 & (5.5) & 4 & (9.0) & 344 & (15.9) & 383 & (12.9) & 448 & (10.7) & 562 & (5.8) \\
\hline & Valle d'Aosta & 508 & (2.5) & 84 & $(2.5)$ & 505 & (3.8) & 511 & (3.6) & -5 & (5.3) & 361 & (8.6) & 396 & (6.3) & 452 & (4.4) & 565 & (4.5) \\
\hline & Veneto & 531 & (6.1) & 92 & $(4.2)$ & 532 & $(7.7)$ & 531 & (7.0) & 1 & (8.3) & 372 & (12.9) & 412 & (11.0) & 473 & (7.5) & 595 & (7.7) \\
\hline & Mexico & & & & & & & & & & & & & & & & & & \\
\hline & Aguascal & 435 & (3.9) & 72 & (2.5) & \begin{tabular}{|l|l|}
437 \\
|
\end{tabular} & (5.1) & 432 & (4.0) & 5 & (5.0) & $\mid 320$ & (8.7) & 343 & (5.6) & 385 & (4.8) & 481 & (4.8) \\
\hline & Baja California & 417 & $(5.7)$ & 70 & $(2.7)$ & 421 & (6.4) & 414 & (5.9) & 7 & (4.6) & 307 & $(7.2)$ & 329 & (8.0) & 371 & (5.9) & 465 & (7.1) \\
\hline & Baja California Su & 418 & $(4.7)$ & 68 & $(2.3)$ & 425 & (5.6) & 411 & $(5.2)$ & 14 & (5.0) & 309 & (9.9) & 332 & $(6.0)$ & 372 & $(6.2)$ & 463 & (5.4) \\
\hline & Campeche & 405 & (4.6) & 70 & (2.4) & 410 & (4.8) & 400 & (5.5) & 10 & $(4.7)$ & 292 & (9.5) & 315 & $(8.7)$ & 357 & (6.0) & 451 & (4.5) \\
\hline & Chiapas & 377 & (7.5) & 71 & (3.6) & 377 & (8.7) & 376 & (7.0) & 1 & (4.8) & 263 & (13.3) & 286 & (10.4) & 328 & (9.0) & 425 & (9.1) \\
\hline & Chihuahua & 429 & (9.3) & 75 & (3.0) & 434 & (10.8) & 425 & (8.5) & 9 & (6.1) & 308 & (11.6) & 335 & (10.4) & 379 & (9.6) & 481 & (9.7) \\
\hline & Coahuila & 421 & $(7.2)$ & 70 & (2.6) & 426 & (9.3) & 417 & (6.4) & 9 & (6.8) & 304 & (9.5) & 329 & (10.2) & 373 & (8.9) & 470 & (9.6) \\
\hline & Colima & 429 & (4.8) & 75 & (3.6) & 431 & (5.5) & 428 & (5.4) & 4 & (5.0) & 309 & (7.6) & 332 & $(7.2)$ & 378 & (5.9) & 478 & (6.2) \\
\hline & Distrito Federal & 427 & (5.3) & 68 & (3.6) & 434 & (7.0) & 420 & (4.9) & 13 & (6.1) & 316 & (13.7) & 341 & (8.5) & 381 & (5.7) & 470 & (6.5) \\
\hline & Durango & 423 & (6.0) & 65 & (2.9) & 424 & (6.9) & 422 & (6.0) & 2 & $(4.7)$ & 312 & (11.0) & 339 & (8.7) & 378 & (7.2) & 468 & (6.6) \\
\hline & Guanajuato & 404 & (5.8) & 73 & (3.2) & 408 & (6.1) & 400 & (6.5) & 8 & (4.8) & 284 & (14.4) & 311 & (10.7) & 356 & (7.7) & 454 & (5.3) \\
\hline & Guerrero & 372 & (5.3) & 68 & (3.8) & 373 & (5.4) & 371 & (6.2) & 2 & (4.8) & 260 & (12.6) & 286 & (10.5) & 329 & (6.0) & 417 & (5.4) \\
\hline & Hidalgo & 411 & (5.4) & 72 & $(2.2)$ & 415 & (6.4) & 406 & (5.7) & 9 & (5.1) & 289 & (8.8) & 316 & (7.3) & 362 & (7.6) & 460 & (6.7) \\
\hline & Jalisco & 436 & (6.0) & 69 & (2.6) & 437 & (7.0) & 435 & (6.2) & 2 & (5.1) & 325 & (8.1) & 349 & (7.9) & 390 & (6.7) & 482 & (8.8) \\
\hline & Mexico & 421 & (5.4) & 62 & (3.1) & 427 & (5.9) & 415 & (5.7) & 11 & (4.7) & 319 & (7.1) & 343 & (6.8) & 378 & (5.4) & 461 & (6.3) \\
\hline & Morelos & 425 & (8.9) & 76 & (6.6) & 426 & $(11.0)$ & 424 & (8.4) & 1 & (7.5) & 304 & (23.3) & 332 & (16.1) & 376 & (8.4) & 473 & (8.8) \\
\hline & Nayarit & 407 & (5.5) & 70 & (2.6) & 412 & (5.5) & 402 & (6.8) & 11 & (5.7) & 292 & $(9.2)$ & 318 & (8.6) & 359 & (7.3) & 454 & (6.9) \\
\hline & Nuevo León & 435 & (7.4) & 69 & (2.8) & 441 & (7.8) & 429 & $(7.2)$ & 13 & (4.0) & 324 & (11.8) & 348 & (9.0) & 388 & (8.5) & 481 & (8.1) \\
\hline & Puebla & 423 & (6.1) & 73 & (4.5) & 429 & (7.9) & 417 & (5.9) & 12 & (6.5) & 295 & (17.5) & 329 & (13.7) & 378 & $(8.2)$ & 471 & (5.3) \\
\hline & Querétaro & 432 & (6.5) & 71 & (3.1) & 439 & (7.8) & 426 & (6.4) & 13 & (4.9) & 317 & (10.3) & 342 & (8.4) & 386 & (8.9) & 479 & (7.6) \\
\hline & Quintana Roo & 416 & (6.4) & 69 & (1.9) & 416 & (7.5) & 417 & (6.2) & -1 & (5.0) & 300 & (13.1) & 326 & (8.1) & 370 & $(7.2)$ & 463 & (6.1) \\
\hline & San Luis Potosí & 416 & (6.3) & 71 & $(2.7)$ & 413 & (6.9) & 419 & (6.9) & -5 & $(6.1)$ & 303 & (9.0) & 327 & (5.5) & 366 & (5.4) & 465 & (8.6) \\
\hline & Sinaloa & 408 & (4.3) & 66 & (2.3) & 407 & (4.7) & 408 & (5.1) & -1 & (4.7) & 301 & (6.1) & 324 & (7.2) & 362 & (4.8) & 453 & (5.6) \\
\hline & Tabasco & 391 & $(4.3)$ & 66 & (2.9) & 393 & (5.1) & 388 & (4.3) & 5 & (4.1) & 284 & (7.8) & 307 & $(7.2)$ & 346 & (5.6) & 433 & (5.9) \\
\hline & Tamaulipas & 414 & (6.8) & 72 & (3.6) & 417 & (9.1) & 411 & (5.4) & 6 & (6.7) & 297 & (11.1) & 325 & $(9.2)$ & 366 & (6.9) & 463 & (7.8) \\
\hline & Tlaxcala & 412 & (4.4) & 69 & (2.1) & 415 & (4.9) & 410 & (4.7) & 5 & (3.9) & 295 & (8.7) & 321 & $(7.2)$ & 367 & (5.8) & 460 & (4.9) \\
\hline & Veracruz & 401 & (5.5) & 70 & (3.0) & 400 & (5.3) & 403 & (7.1) & -3 & (5.9) & 285 & (10.4) & 312 & (8.5) & 356 & (6.1) & 448 & (6.9) \\
\hline & Yucatán & 415 & (5.5) & 72 & (2.6) & 420 & (6.5) & 411 & (5.6) & 9 & (4.9) & 299 & (10.5) & 323 & (8.8) & 368 & (6.8) & 462 & (5.2) \\
\hline & Zacatecas & 402 & (4.6) & 70 & (2.1) & 401 & (5.0) & 403 & $(5.2)$ & -2 & $(4.7)$ & 285 & (11.8) & 313 & (8.4) & 355 & (6.0) & 451 & (5.5) \\
\hline
\end{tabular}

- PISA adjudicated region

Notes: Values that are statistically significant are indicated in bold (see Annex A3).

See Table I.5.3a for national data.

StatLink 需细 http://dx.doi.org/10.1787/888932935762 
[Part 2/2]

Table B2.I.30 Mean score, variation and gender differences in student performance in science, by region

\begin{tabular}{|c|c|c|c|c|c|c|c|c|c|c|c|c|c|c|c|c|c|c|c|c|c|c|c|}
\hline & & \multicolumn{4}{|c|}{ All students } & \multicolumn{6}{|c|}{ Gender differences } & \multicolumn{12}{|c|}{ Percentiles } \\
\hline & & \multicolumn{2}{|c|}{ Mean score } & \multicolumn{2}{|c|}{$\begin{array}{l}\text { Standard } \\
\text { deviation }\end{array}$} & \multicolumn{2}{|c|}{ Boys } & \multicolumn{2}{|c|}{ Girls } & \multicolumn{2}{|c|}{$\begin{array}{c}\text { Difference } \\
\text { (B - G) }\end{array}$} & \multicolumn{2}{|c|}{ 5th } & \multicolumn{2}{|c|}{ 10th } & \multicolumn{2}{|c|}{ 25th } & \multicolumn{2}{|c|}{ 75th } & \multicolumn{2}{|c|}{ 90th } & \multicolumn{2}{|c|}{ 95th } \\
\hline & & Mean & S.E. & S.D. & S.E. & $\begin{array}{l}\text { Mean } \\
\text { score }\end{array}$ & S.E. & $\begin{array}{l}\text { Mean } \\
\text { score }\end{array}$ & S.E. & $\begin{array}{c}\text { Score } \\
\text { dif. }\end{array}$ & S.E. & Score & S.E. & Score & S.E. & Score & S.E. & Score & S.E. & Score & S.E. & Score & S.E. \\
\hline \multicolumn{24}{|c|}{ 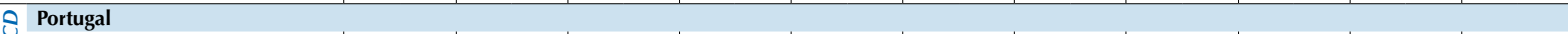 } \\
\hline 㟧 & Alentejo & 494 & $(8.2)$ & 81 & (3.3) & 495 & (10.0) & $\mid 492$ & (7.9) & 3 & (7.5) & 356 & (13.0) & $\mid 391$ & $(11.2)$ & 443 & (11.7) & 548 & (8.3) & $\mid 595$ & (11.0) & 626 & (11.8) \\
\hline \multicolumn{24}{|c|}{ 每 } \\
\hline & Andalusia ${ }^{\bullet}$ & 486 & (4.3) & 87 & (2.0) & 491 & (5.5) & 481 & $(4.2)$ & 10 & (4.9) & 339 & (8.8) & 375 & (6.4) & 429 & (4.8) & 544 & (5.6) & 599 & (6.5) & 628 & (6.6) \\
\hline & Aragon • & 504 & $(5.2)$ & 93 & $(4.2)$ & 504 & (6.1) & 504 & (5.8) & 1 & (5.8) & 348 & $(12.0)$ & 381 & (8.1) & 443 & (7.0) & 569 & (5.4) & 622 & (6.3) & 648 & (7.4) \\
\hline & Asturias ${ }^{\bullet}$ & 517 & (4.7) & 91 & (2.4) & 516 & (6.5) & 517 & (4.3) & -1 & $(5.7)$ & 364 & (10.2) & 402 & (7.6) & 457 & (5.4) & 580 & (5.5) & 631 & (4.8) & 658 & (6.9) \\
\hline & Balearic Islands` & 483 & (4.5) & 83 & (2.3) & 486 & (5.0) & 480 & (5.5) & 7 & (5.4) & 342 & $(8.2)$ & 376 & (6.9) & 427 & (6.8) & 543 & (4.7) & 588 & (4.4) & 612 & (4.5) \\
\hline & Basque Country & 506 & (2.4) & 82 & (1.4) & 510 & (3.2) & 501 & (2.5) & 10 & (3.2) & 364 & (5.1) & 400 & $(4.2)$ & 455 & (2.8) & 561 & (2.6) & 605 & (3.4) & 631 & (3.5) \\
\hline & Cantabria` & 501 & (3.7) & 88 & (1.9) & 506 & (3.8) & 495 & (5.0) & 11 & (4.8) & 353 & (9.9) & 387 & (5.5) & 443 & (5.1) & 562 & (4.7) & 612 & (4.4) & 641 & (5.2) \\
\hline & Castile and Leon ${ }^{\bullet}$ & 519 & $(4.2)$ & 79 & (1.9) & 523 & (5.8) & 515 & (3.7) & 9 & (5.0) & 385 & (8.5) & 417 & (6.3) & 466 & (5.2) & 574 & (4.1) & 619 & (4.3) & 643 & (4.0) \\
\hline & Catalonia• & 492 & $(4.2)$ & 80 & (2.0) & 498 & (5.3) & 486 & (4.9) & 12 & (5.8) & 355 & (8.4) & 388 & (5.4) & 436 & (5.2) & 547 & $(4.8)$ & 594 & (5.8) & 620 & (5.9) \\
\hline & Extremadura ${ }^{\bullet}$ & 483 & (4.5) & 93 & (2.0) & 487 & (5.4) & 479 & $(4.7)$ & 8 & $(4.7)$ & 325 & (7.8) & 363 & (8.8) & 421 & (4.8) & 546 & (5.1) & 600 & (5.4) & 631 & (7.8) \\
\hline & Galicia• & 512 & (4.8) & 86 & (2.3) & 511 & (5.6) & 512 & $(5.7)$ & 0 & (5.8) & 363 & (9.3) & 397 & (7.6) & 455 & (6.0) & 573 & (5.3) & 619 & (6.2) & 644 & (5.9) \\
\hline & La Rioja• & 510 & (2.1) & 92 & $(2.2)$ & 512 & (3.2) & 507 & (3.2) & 5 & (4.8) & 346 & (12.1) & 392 & (6.6) & 454 & (3.4) & 576 & (3.3) & 620 & (5.0) & 644 & (4.0) \\
\hline & Madrid• & 517 & (4.0) & 84 & (2.3) & 520 & (4.7) & 515 & (4.3) & 6 & $(4.2)$ & 376 & (8.9) & 407 & (7.1) & 463 & (5.6) & 576 & $(4.2)$ & 622 & (4.5) & 647 & (5.8) \\
\hline & Murcia ${ }^{\bullet}$ & 479 & $(4.7)$ & 87 & (2.6) & 479 & (6.0) & 480 & (4.3) & -1 & (4.3) & 333 & (8.8) & 365 & (6.4) & 422 & (5.5) & 539 & (6.0) & 589 & $(8.7)$ & 620 & (7.0) \\
\hline & Navarre ${ }^{\bullet}$ & 514 & (3.5) & 86 & (2.6) & 514 & (4.4) & 514 & $(4.2)$ & -1 & (4.8) & 369 & (9.5) & 406 & (5.8) & 460 & (3.9) & 573 & (4.6) & 622 & (5.3) & 650 & (5.7) \\
\hline \multicolumn{24}{|c|}{ United Kingdom } \\
\hline & England & 516 & (4.0) & 101 & $(2.2)$ & 523 & (5.4) & 509 & (4.3) & 14 & (5.5) & 343 & (7.0) & $\mid 384$ & (5.9) & 449 & (5.6) & 587 & (4.1) & 642 & (4.2) & 674 & (5.6) \\
\hline & Northern Ireland & 507 & (3.9) & 101 & $(2.7)$ & 510 & (6.3) & 504 & (5.8) & 5 & $(9.2)$ & 338 & (7.6) & 375 & (7.3) & 438 & (5.2) & 578 & $(5.2)$ & 635 & (6.5) & 669 & (7.4) \\
\hline & Scotland ${ }^{\bullet}$ & 513 & (3.0) & 89 & (2.0) & 517 & (3.3) & 510 & (3.6) & 7 & (3.3) & 365 & (6.9) & 400 & (4.5) & 454 & (3.7) & 574 & (3.2) & 627 & (4.2) & 658 & (5.3) \\
\hline & Wales & 491 & (3.0) & 94 & (1.6) & 496 & (3.4) & 485 & (3.5) & 11 & (3.5) & 334 & (6.2) & 370 & (4.5) & 428 & (4.1) & 556 & (3.4) & 609 & (3.9) & 639 & (5.4) \\
\hline \multicolumn{24}{|c|}{ United States } \\
\hline & Connecticut $^{\bullet}$ & 521 & (5.7) & 98 & (2.8) & 528 & (6.2) & 514 & (6.1) & 14 & (4.5) & 354 & (10.8) & 389 & (9.5) & 455 & (8.5) & 588 & (5.7) & 647 & (6.0) & 679 & (7.5) \\
\hline & Florida ${ }^{\bullet}$ & 485 & (6.4) & 92 & (2.4) & 491 & (7.4) & 478 & (6.2) & 13 & (4.8) & 334 & (8.5) & 366 & (7.2) & 421 & (7.5) & 549 & (8.2) & 604 & (7.3) & 637 & (7.6) \\
\hline & Massachusetts ${ }^{\bullet}$ & 527 & (6.0) & 98 & (3.0) & 529 & (6.1) & 526 & (6.8) & 3 & (4.6) & 367 & (7.1) & 403 & (5.6) & 460 & (6.5) & 594 & (7.9) & 654 & (9.4) & 685 & (7.7) \\
\hline
\end{tabular}

\begin{tabular}{ll}
\hline \multirow{2}{*}{ Argentina } \\
Brazil Aud
\end{tabular}

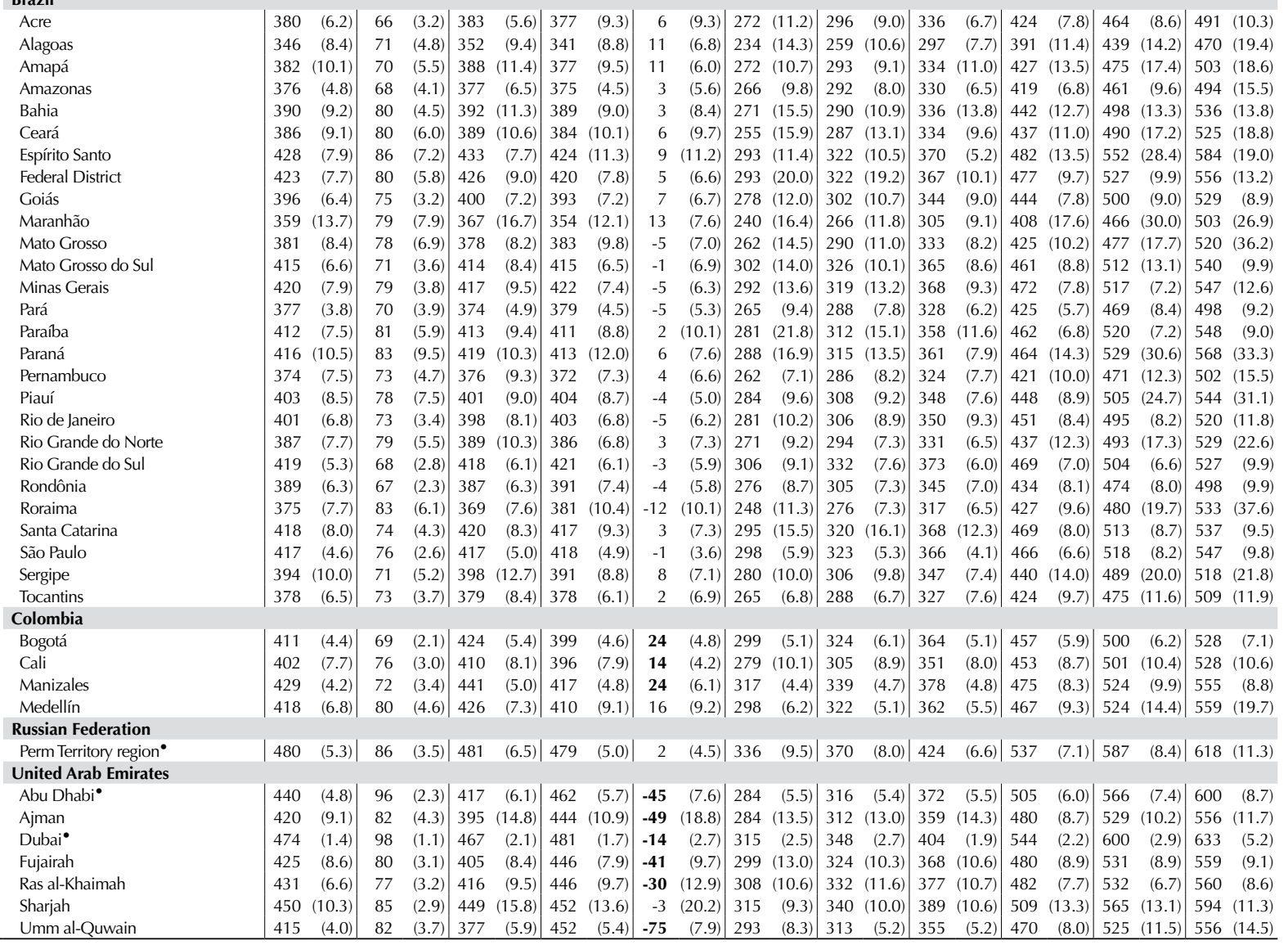

- PISA adjudicated region.

Notes: Values that are statistically significant are indicated in bold (see Annex A3).

See Table I.5.3a for national data.

StatLink त्नात्र http://dx.doi.org/10.1787/888932935762 
[Part 1/2]

Table B2.I.31 Top performers in mathematics, reading and science, by region

\begin{tabular}{|c|c|c|c|c|c|c|c|c|c|c|c|c|c|c|c|c|c|c|c|}
\hline & & & & & & & & 15-yea & -old stud & Idents w & ho are: & & & & & & & Percen & tage of \\
\hline & & $\begin{array}{r}\text { not } \\
\text { perfo } \\
\text { in any } \\
\text { three d }\end{array}$ & $\begin{array}{l}\text { top } \\
\text { cmers } \\
\text { of the } \\
\text { omains }\end{array}$ & $\begin{array}{r}\text { top per } \\
\text { onl } \\
\text { mathe }\end{array}$ & $\begin{array}{l}\text { formers } \\
y \text { in } \\
\text { matics }\end{array}$ & $\begin{array}{r}\text { top per } \\
\text { onl } \\
\text { rea }\end{array}$ & $\begin{array}{l}\text { ormers } \\
\text { in } \\
\text { ling }\end{array}$ & $\begin{array}{r}\text { top per } \\
\text { onl } \\
\text { scie }\end{array}$ & $\begin{array}{l}\text { ormers } \\
\text { in } \\
\text { nce }\end{array}$ & $\begin{array}{r}\text { top per } \\
\text { in math } \\
\text { and } r \\
\text { but } \\
\text { in sc }\end{array}$ & $\begin{array}{l}\text { formers } \\
\text { ematics } \\
\text { ading } \\
\text { not } \\
\text { ence }\end{array}$ & $\begin{array}{r}\text { top per } \\
\text { sin math } \\
\text { and s } \\
\text { but } \\
\text { in re }\end{array}$ & $\begin{array}{l}\text { ormers } \\
\text { ematics } \\
\text { ience } \\
\text { not } \\
\text { iding }\end{array}$ & $\begin{array}{c}\text { stop per } \\
\text { s } \\
\text { in re } \\
\text { and s } \\
\text { but } \\
\text { in math }\end{array}$ & $\begin{array}{l}\text { ormers } \\
\text { ding } \\
\text { ience } \\
\text { not } \\
\text { ematics }\end{array}$ & $\begin{array}{c}\text { top per } \\
\text { in } \\
\text { three } d\end{array}$ & $\begin{array}{l}\text { formers } \\
\text { all } \\
\text { omains }\end{array}$ & $\begin{array}{r}\text { who a } \\
\text { top per } \\
\text { in re } \\
\text { and sc }\end{array}$ & $\begin{array}{l}\text { rematics also } \\
\text { roormers } \\
\text { cieng } \\
\text { cience }\end{array}$ \\
\hline & & $\%$ & S.E. & $\%$ & S.E. & $\%$ & S.E. & $\%$ & S.E. & $\%$ & S.E. & $\%$ & S.E. & $\%$ & S.E. & $\%$ & S.E. & $\%$ & S.E. \\
\hline & Australia & & & & & & & & & & & & & & & & & & \\
\hline 总 & Australian Capital Territory & 76.5 & $(2.1)$ & 3.4 & $(0.9)$ & 2.1 & $(0.7)$ & 1.3 & $(0.5)$ & 1.2 & $(0.6)$ & 3.5 & (0.9) & 1.5 & $(0.8)$ & 10.5 & (1.4) & 56.5 & (6.1) \\
\hline & New South Wales & 77.9 & (1.5) & 3.4 & $(0.5)$ & 1.4 & $(0.5)$ & 1.9 & $(0.4)$ & 1.0 & $(0.2)$ & 3.4 & $(0.5)$ & 1.2 & $(0.2)$ & 9.8 & $(1.0)$ & 56.1 & (3.0) \\
\hline & Northern Territory & 89.2 & (2.7) & 1.1 & $(0.8)$ & 0.9 & $(0.9)$ & 2.2 & (1.1) & 0.0 & c & 0.9 & $(0.9)$ & 0.0 & c & 4.5 & (1.9) & 68.9 & (15.7) \\
\hline & Queensland & 81.1 & $(1.2)$ & 3.8 & $(0.6)$ & 1.7 & $(0.4)$ & 1.7 & $(0.3)$ & 1.4 & $(0.4)$ & 2.5 & $(0.5)$ & 1.0 & $(0.3)$ & 6.9 & $(0.8)$ & 47.5 & (3.8) \\
\hline & South Australia & 84.3 & $(1.3)$ & 2.7 & $(0.7)$ & 1.4 & $(0.5)$ & 2.4 & $(0.5)$ & 0.7 & $(0.3)$ & 2.6 & $(0.9)$ & 1.5 & $(0.4)$ & 4.4 & $(0.7)$ & 42.5 & (5.6) \\
\hline & Tasmania & 86.9 & (1.4) & 2.1 & $(0.7)$ & 0.7 & $(0.4)$ & 1.9 & $(0.7)$ & 0.3 & $(0.2)$ & 2.3 & $(0.7)$ & 1.5 & $(0.5)$ & 4.3 & $(0.9)$ & 47.3 & (8.9) \\
\hline & Victoria & 82.4 & (1.4) & 2.6 & $(0.7)$ & 2.6 & $(0.5)$ & 1.6 & $(0.5)$ & 1.2 & $(0.3)$ & 2.1 & $(0.6)$ & 1.2 & $(0.3)$ & 6.2 & $(1.0)$ & 51.3 & $(5.2)$ \\
\hline & Western Australia & 76.7 & (1.5) & 4.4 & $(0.8)$ & 1.7 & $(0.5)$ & 2.5 & $(0.5)$ & 1.2 & $(0.4)$ & 3.7 & $(0.7)$ & 1.6 & $(0.4)$ & 8.1 & (1.1) & 46.5 & (4.8) \\
\hline & Belgium & & & & & & & & & & & & & & & & & & \\
\hline & Flemish Community• & 72.7 & (1.3) & 10.5 & $(0.9)$ & 1.2 & $(0.3)$ & 0.5 & $(0.1)$ & 3.5 & $(0.4)$ & 3.2 & $(0.4)$ & 0.3 & $(0.1)$ & 8.1 & $(0.7)$ & 32.1 & $(2.0)$ \\
\hline & French Community & 84.2 & $(0.9)$ & 4.5 & $(0.6)$ & 3.2 & $(0.5)$ & 0.3 & $(0.1)$ & 3.0 & $(0.4)$ & 1.0 & $(0.3)$ & 0.3 & $(0.1)$ & 3.5 & $(0.5)$ & 29.4 & (3.5) \\
\hline & German-speaking Community & 83.4 & $(1.3)$ & 6.5 & $(1.1)$ & 1.8 & $(0.5)$ & 0.3 & C & 2.0 & $(0.5)$ & 1.9 & $(0.8)$ & 0.4 & $(0.3)$ & 3.7 & $(0.6)$ & 26.0 & (4.4) \\
\hline & Canada & & & & & & & & & & & & & & & & & & \\
\hline & Alberta & 76.5 & $(1.7)$ & 3.6 & $(0.6)$ & 2.1 & $(0.4)$ & 2.8 & $(0.7)$ & 1.5 & $(0.4)$ & 3.4 & $(0.8)$ & 1.7 & $(0.4)$ & 8.4 & $(0.8)$ & 49.9 & (2.8) \\
\hline & British Columbia & 76.4 & (1.9) & 3.9 & $(0.7)$ & 2.7 & $(0.6)$ & 2.4 & (0.6) & 1.3 & $(0.4)$ & 2.6 & $(0.6)$ & 1.9 & $(0.4)$ & 8.8 & $(1.0)$ & 53.2 & (3.9) \\
\hline & Manitoba & 85.7 & (1.3) & 3.6 & $(0.7)$ & 2.1 & $(0.5)$ & 1.2 & $(0.4)$ & 0.8 & $(0.2)$ & 1.9 & $(0.6)$ & 0.7 & $(0.3)$ & 3.9 & $(0.7)$ & 37.8 & (6.3) \\
\hline & New Brunswick & 86.0 & (1.3) & 3.9 & $(1.0)$ & 2.0 & $(0.6)$ & 1.2 & $(0.7)$ & 0.9 & $(0.5)$ & 1.9 & $(0.6)$ & 0.8 & $(0.4)$ & 3.4 & $(0.7)$ & 33.8 & (5.9) \\
\hline & Newfoundland and Labrador & 84.5 & (1.5) & 2.2 & $(0.8)$ & 2.7 & $(0.6)$ & 2.0 & $(0.8)$ & 0.8 & $(0.5)$ & 1.7 & $(0.6)$ & 1.4 & $(0.5)$ & 4.7 & $(0.9)$ & 50.4 & $(8.2)$ \\
\hline & Nova Scotia & 85.3 & $(1.2)$ & 2.8 & $(0.7)$ & 2.6 & $(1.1)$ & 1.7 & $(0.8)$ & 1.0 & $(0.4)$ & 1.5 & $(0.6)$ & 1.4 & (1.3) & 3.7 & $(0.9)$ & 41.0 & (7.4) \\
\hline & Ontario & 78.6 & (1.7) & 3.8 & $(0.5)$ & 3.5 & $(0.6)$ & 1.3 & $(0.5)$ & 2.0 & $(0.4)$ & 2.2 & $(0.4)$ & 1.5 & $(0.4)$ & 7.2 & $(1.0)$ & 47.6 & (3.5) \\
\hline & Prince Edward Island & 90.2 & $(1.2)$ & 2.4 & $(0.5)$ & 1.5 & $(0.5)$ & 1.0 & $(0.3)$ & 0.7 & $(0.3)$ & 1.2 & $(0.5)$ & 0.6 & $(0.3)$ & 2.4 & $(0.5)$ & 36.4 & (6.4) \\
\hline & Quebec & 74.5 & (1.5) & 11.3 & $(0.9)$ & 2.6 & $(0.5)$ & 0.3 & $(0.2)$ & 4.7 & $(0.7)$ & 1.7 & $(0.3)$ & 0.2 & $(0.1)$ & 4.7 & $(0.7)$ & 20.8 & (2.7) \\
\hline & Saskatchewan & 83.8 & $(1.3)$ & 4.0 & $(0.7)$ & 1.7 & $(0.4)$ & 1.6 & $(0.4)$ & 1.3 & $(0.5)$ & 2.0 & $(0.7)$ & 0.7 & $(0.2)$ & 4.9 & $(0.8)$ & 40.4 & (5.2) \\
\hline & Italy & & & & & & & & & & & & & & & & & & \\
\hline & Abruzzo & 90.2 & (1.5) & 2.9 & $(0.7)$ & 1.9 & $(0.6)$ & 0.5 & $(0.2)$ & 1.2 & $(0.6)$ & 1.3 & $(0.5)$ & 0.4 & $(0.2)$ & 1.7 & $(0.7)$ & 23.5 & (8.8) \\
\hline & Basilicata & 93.4 & $(0.8)$ & 2.4 & $(0.5)$ & 1.1 & $(0.4)$ & 0.4 & $(0.2)$ & 0.8 & $(0.4)$ & 0.7 & $(0.3)$ & 0.2 & $(0.2)$ & 0.9 & $(0.3)$ & 18.7 & (5.7) \\
\hline & Bolzano & 82.7 & (1.1) & 4.8 & $(0.5)$ & 1.2 & $(0.3)$ & 2.4 & $(0.5)$ & 1.2 & $(0.3)$ & 3.6 & $(0.6)$ & 0.4 & $(0.2)$ & 3.6 & $(0.5)$ & 27.3 & $(2.9)$ \\
\hline & Calabria & 96.6 & $(0.8)$ & 1.5 & $(0.5)$ & 0.6 & $(0.3)$ & 0.1 & $(0.1)$ & 0.4 & $(0.3)$ & 0.2 & $(0.2)$ & 0.0 & c & 0.5 & $(0.2)$ & 17.2 & $(6.0)$ \\
\hline & Campania & 93.5 & (1.4) & 2.5 & $(0.8)$ & 1.4 & $(0.6)$ & 0.4 & $(0.3)$ & 0.8 & $(0.4)$ & 0.4 & $(0.2)$ & 0.2 & $(0.1)$ & 0.8 & $(0.4)$ & 17.0 & $(8.7)$ \\
\hline & Emilia Romagna & 81.8 & (2.3) & 5.9 & (1.1) & 2.6 & $(0.6)$ & 0.9 & $(0.4)$ & 1.6 & $(0.5)$ & 2.4 & $(0.8)$ & 0.7 & $(0.3)$ & 4.1 & $(0.9)$ & 29.5 & (4.3) \\
\hline & Friuli Venezia Giulia & 77.7 & (1.4) & 6.7 & $(1.1)$ & 2.8 & $(0.7)$ & 1.4 & $(0.4)$ & 1.6 & $(0.4)$ & 3.8 & $(0.8)$ & 1.0 & $(0.3)$ & 4.9 & $(0.7)$ & 28.9 & (3.2) \\
\hline & Lazio & 89.3 & (1.6) & 3.5 & $(0.9)$ & 1.6 & $(0.5)$ & 0.8 & $(0.5)$ & 1.2 & $(0.4)$ & 1.3 & $(0.4)$ & 0.2 & $(0.2)$ & 2.0 & $(0.6)$ & 24.9 & (6.1) \\
\hline & Liguria & 85.9 & (1.9) & 4.1 & $(0.7)$ & 2.2 & $(0.7)$ & 1.0 & $(0.3)$ & 1.0 & $(0.3)$ & 1.8 & $(0.5)$ & 0.7 & $(0.4)$ & 3.5 & $(0.8)$ & 33.9 & (5.4) \\
\hline & Lombardia & 79.4 & (2.8) & 4.9 & (1.0) & 2.8 & $(0.7)$ & 1.8 & $(0.5)$ & 2.4 & $(0.7)$ & 3.5 & (0.9) & 0.6 & $(0.4)$ & 4.6 & (1.0) & 29.8 & (4.4) \\
\hline & Marche & 86.7 & (1.7) & 3.8 & $(0.8)$ & 1.9 & (0.6) & 1.0 & $(0.3)$ & 1.1 & $(0.4)$ & 2.2 & $(0.5)$ & 0.4 & $(0.2)$ & 2.9 & $(0.6)$ & 29.4 & $(4.0)$ \\
\hline & Molise & 93.3 & (1.0) & 2.5 & $(0.6)$ & 1.4 & $(0.5)$ & 0.2 & $(0.2)$ & 1.1 & $(0.5)$ & 0.4 & $(0.2)$ & 0.0 & c & 1.1 & $(0.4)$ & 21.5 & (7.2) \\
\hline & Piemonte & 84.7 & (2.0) & 4.6 & $(0.8)$ & 2.3 & $(0.7)$ & 1.1 & $(0.4)$ & 1.8 & $(0.5)$ & 1.7 & $(0.4)$ & 0.4 & $(0.2)$ & 3.3 & $(0.8)$ & 29.2 & (4.6) \\
\hline & Puglia & 89.9 & (1.4) & 2.9 & (0.6) & 2.3 & $(0.8)$ & 0.4 & $(0.3)$ & 1.9 & $(0.7)$ & 0.7 & (0.4) & 0.4 & $(0.3)$ & 1.5 & $(0.5)$ & 22.1 & (7.6) \\
\hline & Sardegna & 93.1 & (1.0) & 1.9 & $(0.5)$ & 1.7 & $(0.5)$ & 0.8 & $(0.4)$ & 0.7 & $(0.3)$ & 0.9 & $(0.3)$ & 0.2 & $(0.2)$ & 0.7 & $(0.3)$ & 17.2 & (5.4) \\
\hline & Sicilia & 95.8 & $(0.9)$ & 1.1 & $(0.5)$ & 1.0 & $(0.2)$ & 0.6 & $(0.3)$ & 0.4 & $(0.2)$ & 0.4 & $(0.3)$ & 0.2 & $(0.1)$ & 0.6 & $(0.2)$ & 24.7 & (10.9) \\
\hline & Toscana & 84.3 & (1.6) & 5.4 & $(1.0)$ & 2.3 & $(0.8)$ & 0.8 & $(0.3)$ & 1.6 & $(0.4)$ & 2.2 & $(0.6)$ & 0.6 & $(0.3)$ & 2.8 & $(0.5)$ & 23.6 & $(4.0)$ \\
\hline & Trento & 76.3 & (1.6) & 5.3 & (1.0) & 4.0 & $(0.9)$ & 2.0 & $(0.5)$ & 2.5 & $(0.8)$ & 3.3 & $(0.5)$ & 1.2 & $(0.4)$ & 5.5 & $(0.8)$ & 33.1 & $(4.5)$ \\
\hline & Umbria & 87.8 & (1.4) & 4.3 & $(0.7)$ & 1.7 & (0.6) & 0.9 & $(0.4)$ & 1.2 & $(0.5)$ & 1.7 & $(0.7)$ & 0.3 & $(0.2)$ & 2.1 & $(0.6)$ & 22.2 & (5.9) \\
\hline & Valle d'Aosta & 87.2 & (1.4) & 3.1 & $(0.7)$ & 2.4 & $(0.7)$ & 1.1 & $(0.5)$ & 1.4 & $(0.4)$ & 1.5 & $(0.5)$ & 0.4 & $(0.3)$ & 2.9 & $(0.6)$ & 32.7 & (6.1) \\
\hline & Veneto & 75.8 & (2.9) & 5.8 & (1.4) & 2.6 & $(0.5)$ & 1.9 & $(0.5)$ & 2.3 & $(0.8)$ & 4.1 & (1.1) & 1.0 & $(0.3)$ & 6.4 & (1.4) & 34.4 & $(4.2)$ \\
\hline & Mexico & & & & & & & & & & & & & & & & & & \\
\hline & Aguascalientes & 97.5 & $(0.7)$ & 1.1 & (0.6) & 0.5 & $(0.3)$ & 0.0 & c & 0.3 & $(0.2)$ & 0.0 & c & 0.0 & C & 0.0 & c & 0.0 & c \\
\hline & Baja California & 98.9 & $(0.6)$ & 0.0 & c & 0.5 & $(0.3)$ & 0.0 & c & 0.0 & c & 0.0 & c & 0.0 & c & 0.0 & c & 0.0 & c \\
\hline & Baja California Sur & 99.4 & $(0.3)$ & 0.4 & $(0.2)$ & 0.0 & c & 0.0 & c & 0.0 & c & 0.0 & c & 0.0 & c & 0.0 & c & 0.0 & c \\
\hline & Campeche & 99.2 & $(0.4)$ & 0.3 & $(0.2)$ & 0.0 & c & 0.1 & $(0.1)$ & 0.1 & $(0.1)$ & 0.0 & c & 0.0 & c & 0.0 & c & 0.0 & c \\
\hline & Chiapas & 99.6 & $(0.2)$ & 0.3 & $(0.2)$ & 0.0 & c & 0.0 & c & 0.0 & c & 0.0 & C & 0.0 & C & 0.0 & c & 0.0 & c \\
\hline & Chihuahua & 98.3 & $(0.9)$ & 0.9 & $(0.5)$ & 0.3 & $(0.3)$ & 0.0 & c & 0.2 & $(0.2)$ & 0.0 & c & 0.0 & c & 0.0 & c & 0.0 & c \\
\hline & Coahuila & 99.3 & $(0.5)$ & 0.3 & $(0.3)$ & 0.0 & c & 0.0 & c & 0.0 & c & 0.0 & c & 0.0 & c & 0.1 & $(0.1)$ & 19.4 & (17.9) \\
\hline & Colima & 97.9 & $(0.7)$ & 0.8 & $(0.3)$ & 0.4 & $(0.3)$ & 0.0 & c & 0.3 & $(0.2)$ & 0.0 & c & 0.0 & $\mathrm{c}$ & 0.2 & $(0.1)$ & 16.3 & (7.6) \\
\hline & Distrito Federal & 98.3 & $(0.6)$ & 0.5 & $(0.3)$ & 0.7 & (0.4) & 0.0 & c & 0.3 & $(0.2)$ & 0.0 & c & 0.0 & c & 0.0 & c & 0.0 & c \\
\hline & Durango & 99.2 & $(0.3)$ & 0.3 & $(0.2)$ & 0.3 & $(0.2)$ & 0.0 & c & 0.0 & c & 0.0 & c & 0.0 & c & 0.1 & $(0.1)$ & 15.4 & (14.6) \\
\hline & Guanajuato & 99.5 & $(0.3)$ & 0.3 & $(0.2)$ & 0.0 & c & 0.0 & c & 0.0 & c & 0.0 & c & 0.0 & c & 0.0 & c & 0.0 & $\mathrm{c}$ \\
\hline & Guerrero & 99.9 & $(0.1)$ & 0.1 & $(0.1)$ & 0.0 & c & 0.0 & c & 0.0 & c & 0.0 & c & 0.0 & c & 0.0 & c & 0.0 & c \\
\hline & Hidalgo & 99.5 & $(0.3)$ & 0.0 & c & 0.0 & c & 0.0 & c & 0.0 & c & 0.0 & c & 0.0 & C & 0.0 & c & 0.0 & c \\
\hline & Jalisco & 98.5 & $(0.7)$ & 0.7 & $(0.4)$ & 0.4 & $(0.3)$ & 0.0 & c & 0.2 & $(0.2)$ & 0.0 & c & 0.0 & c & 0.1 & $(0.1)$ & 11.9 & $(10.2)$ \\
\hline & Mexico & 99.1 & $(0.7)$ & 0.3 & $(0.2)$ & 0.3 & $(0.3)$ & 0.0 & c & 0.2 & $(0.2)$ & 0.0 & c & 0.0 & c & 0.1 & $(0.2)$ & 25.6 & (25.0) \\
\hline & Morelos & 97.9 & (1.1) & 1.1 & $(0.6)$ & 0.3 & $(0.2)$ & 0.0 & c & 0.0 & c & 0.1 & $(0.2)$ & 0.0 & c & 0.2 & $(0.3)$ & 14.9 & $(13.2)$ \\
\hline & Nayarit & 99.3 & $(0.4)$ & 0.3 & $(0.2)$ & 0.3 & $(0.3)$ & 0.0 & c & 0.0 & c & 0.0 & c & 0.0 & c & 0.0 & c & 0.0 & c \\
\hline & Nuevo León & 98.4 & $(0.7)$ & 0.9 & $(0.4)$ & 0.3 & $(0.3)$ & 0.1 & $(0.1)$ & 0.1 & $(0.1)$ & 0.0 & c & 0.0 & C & 0.0 & c & 0.0 & c \\
\hline & Puebla & 99.4 & $(0.3)$ & 0.4 & $(0.3)$ & 0.0 & C & 0.0 & C & 0.0 & c & 0.0 & c & 0.0 & c & 0.0 & c & 0.0 & C \\
\hline & Querétaro & 97.9 & $(0.8)$ & 1.0 & $(0.4)$ & 0.6 & $(0.5)$ & 0.0 & c & 0.2 & $(0.2)$ & 0.0 & $\mathrm{C}$ & 0.0 & C & 0.1 & $(0.1)$ & 7.4 & (5.8) \\
\hline & Quintana Roo & 99.4 & $(0.3)$ & 0.4 & $(0.2)$ & 0.0 & c & 0.0 & c & 0.0 & c & 0.0 & c & 0.0 & c & 0.0 & c & 0.0 & c \\
\hline & San Luis Potosí & 99.2 & $(0.5)$ & 0.5 & $(0.3)$ & 0.2 & $(0.2)$ & 0.0 & c & 0.0 & c & 0.0 & c & 0.0 & c & 0.0 & c & 0.0 & c \\
\hline & Sinaloa & 99.5 & $(0.2)$ & 0.2 & $(0.2)$ & 0.1 & $(0.2)$ & 0.0 & c & 0.1 & $(0.1)$ & 0.0 & c & 0.0 & c & 0.0 & c & 0.0 & c \\
\hline & Tabasco & 99.8 & $(0.2)$ & 0.1 & $(0.1)$ & 0.0 & c & 0.0 & c & 0.0 & c & 0.0 & c & 0.0 & c & 0.0 & c & 0.0 & C \\
\hline & Tamaulipas & 99.2 & $(0.6)$ & 0.5 & $(0.5)$ & 0.0 & c & 0.0 & c & 0.1 & $(0.1)$ & 0.0 & C & 0.0 & C & 0.0 & c & 0.0 & c \\
\hline & Tlaxcala & 99.4 & $(0.3)$ & 0.4 & $(0.3)$ & 0.2 & $(0.1)$ & 0.0 & c & 0.0 & C & 0.0 & c & 0.0 & C & 0.0 & c & 0.0 & c \\
\hline & Veracruz & 99.4 & $(0.4)$ & 0.3 & $(0.3)$ & 0.1 & $(0.1)$ & 0.0 & c & 0.0 & c & 0.0 & c & 0.0 & c & 0.0 & c & 0.0 & c \\
\hline & Yucatán & 99.2 & $(0.4)$ & 0.4 & $(0.3)$ & 0.0 & c & 0.0 & c & 0.1 & $(0.1)$ & 0.0 & c & 0.0 & c & 0.0 & c & 0.0 & c \\
\hline & Zacatecas & 99.7 & $(0.2)$ & 0.3 & $(0.2)$ & 0.0 & C & 0.0 & c & 0.0 & C & 0.0 & C & 0.0 & C & 0.0 & C & 0.0 & C \\
\hline
\end{tabular}

- PISA adjudicated region.

Note: See Table I.2.29 for national data.

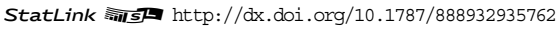


[Part 2/2]

Table B2.I.31 Top performers in mathematics, reading and science, by region

\begin{tabular}{|c|c|c|c|c|c|c|c|c|c|c|c|c|c|c|c|c|c|c|c|}
\hline & & \multicolumn{16}{|c|}{ 15-year-old students who are: } & \multirow{2}{*}{\multicolumn{2}{|c|}{$\begin{array}{c}\text { Percentage of } \\
\text { top performers } \\
\text { in mathematics } \\
\text { who are also } \\
\text { top performers } \\
\text { in reading } \\
\text { and science }\end{array}$}} \\
\hline & & \multicolumn{2}{|c|}{$\begin{array}{c}\text { not top } \\
\text { performers } \\
\text { in any of the } \\
\text { three domains }\end{array}$} & \multicolumn{2}{|c|}{$\begin{array}{c}\text { top performers } \\
\text { only in } \\
\text { mathematics }\end{array}$} & \multicolumn{2}{|c|}{$\begin{array}{c}\text { top performers } \\
\text { only in } \\
\text { reading }\end{array}$} & \multicolumn{2}{|c|}{$\begin{array}{l}\text { top performers } \\
\text { only in } \\
\text { science }\end{array}$} & \multicolumn{2}{|c|}{$\begin{array}{c}\text { top performers } \\
\text { in mathematics } \\
\text { and reading } \\
\text { but not } \\
\text { in science }\end{array}$} & \multicolumn{2}{|c|}{$\begin{array}{c}\text { top performers } \\
\text { in mathematics } \\
\text { and science } \\
\text { but not } \\
\text { in reading }\end{array}$} & \multicolumn{2}{|c|}{$\begin{array}{c}\text { top performers } \\
\text { in reading } \\
\text { and science } \\
\text { but not } \\
\text { in mathematics }\end{array}$} & \multicolumn{2}{|c|}{$\begin{array}{c}\text { top performers } \\
\text { in all } \\
\text { three domains }\end{array}$} & & \\
\hline & & $\%$ & S.E. & $\%$ & S.E. & $\%$ & S.E. & $\%$ & S.E. & $\%$ & S.E. & $\%$ & S.E. & $\%$ & S.E. & $\%$ & S.E. & $\%$ & S.E. \\
\hline \multirow{26}{*}{ త్ } & Portugal & & & & & & & & & & & & & & & & & & \\
\hline & Alentejo & 88.5 & (2.3) & 4.4 & (1.3) & 1.3 & $(0.9)$ & 0.2 & $(0.2)$ & 1.6 & $(0.6)$ & 1.8 & $(0.8)$ & 0.0 & c & 1.9 & $(1.0)$ & 19.8 & $(8.9)$ \\
\hline & Spain & & & & & & & & & & & & & & & & & & \\
\hline & Andalusia ${ }^{\bullet}$ & 91.6 & (0.9) & 1.9 & $(0.5)$ & 1.3 & $(0.4)$ & 0.9 & $(0.3)$ & 0.8 & $(0.3)$ & 1.3 & $(0.5)$ & 0.5 & $(0.2)$ & 1.8 & $(0.5)$ & 31.1 & $(7.6)$ \\
\hline & Aragon $\bullet$ & 85.6 & $(1.7)$ & 4.1 & $(0.9)$ & 1.3 & $(0.4)$ & 1.1 & $(0.4)$ & 1.4 & (0.5) & 2.6 & $(0.6)$ & 0.5 & $(0.4)$ & 3.4 & $(0.8)$ & 29.3 & $(4.6)$ \\
\hline & Asturias ${ }^{\bullet}$ & 82.9 & (1.5) & 4.0 & $(0.7)$ & 2.3 & $(0.5)$ & 1.3 & $(0.4)$ & 1.5 & (0.5) & 3.1 & $(0.9)$ & 0.7 & $(0.2)$ & 4.2 & $(0.9)$ & 33.1 & $(6.3)$ \\
\hline & Balearic Islands` & 91.2 & (1.0) & 3.1 & $(0.7)$ & 2.2 & $(0.8)$ & 0.6 & $(0.3)$ & 1.0 & $(0.3)$ & 0.7 & $(0.3)$ & 0.2 & $(0.2)$ & 0.9 & $(0.3)$ & 15.1 & (5.1) \\
\hline & Basque Country & 87.4 & $(0.8)$ & 5.2 & $(0.5)$ & 1.3 & $(0.2)$ & 0.7 & $(0.2)$ & 1.4 & $(0.3)$ & 1.7 & $(0.2)$ & 0.2 & $(0.1)$ & 2.2 & $(0.3)$ & 20.7 & $(2.7)$ \\
\hline & Cantabria• & 87.0 & (1.1) & 4.7 & $(0.8)$ & 0.9 & $(0.5)$ & 1.3 & $(0.4)$ & 1.2 & $(0.3)$ & 2.3 & (0.6) & 0.2 & $(0.2)$ & 2.4 & $(0.4)$ & 22.2 & (3.7) \\
\hline & Castile and Leon ${ }^{\bullet}$ & 84.6 & (1.5) & 5.1 & $(0.8)$ & 1.7 & $(0.5)$ & 1.3 & $(0.4)$ & 2.0 & $(0.5)$ & 2.2 & $(0.6)$ & 0.4 & $(0.3)$ & 2.7 & $(0.5)$ & 22.6 & (3.9) \\
\hline & Catalonia・ & 87.5 & (1.7) & 3.9 & (1.0) & 3.3 & $(0.9)$ & 0.4 & $(0.3)$ & 2.0 & $(0.5)$ & 0.9 & $(0.3)$ & 0.1 & $(0.1)$ & 2.0 & $(0.6)$ & 22.7 & (6.9) \\
\hline & Extremadura ${ }^{\bullet}$ & 91.6 & (1.0) & 2.0 & $(0.5)$ & 0.9 & $(0.3)$ & 1.5 & $(0.4)$ & 0.6 & (0.3) & 1.4 & $(0.4)$ & 0.2 & $(0.1)$ & 1.6 & $(0.4)$ & 28.8 & $(6.6)$ \\
\hline & Galicia` & 86.6 & (1.4) & 2.8 & (0.5) & 2.7 & $(0.5)$ & 1.8 & $(0.5)$ & 0.9 & (0.3) & 1.9 & $(0.6)$ & 0.9 & $(0.5)$ & 2.3 & $(0.5)$ & 29.1 & $(4.7)$ \\
\hline & La Rioja• & 82.4 & (0.9) & 7.3 & $(0.7)$ & 1.2 & $(0.3)$ & 1.0 & $(0.3)$ & 2.1 & (0.4) & 2.6 & $(0.4)$ & 0.3 & $(0.2)$ & 3.2 & $(0.6)$ & 20.9 & (3.8) \\
\hline & Madrid• & 83.9 & (1.6) & 4.3 & (1.0) & 2.8 & $(0.5)$ & 1.5 & $(0.4)$ & 1.8 & (0.4) & 2.0 & $(0.5)$ & 0.4 & $(0.3)$ & 3.4 & $(0.6)$ & 29.5 & $(4.8)$ \\
\hline & Murcia ${ }^{\bullet}$ & 92.6 & (1.3) & 2.4 & (0.8) & 1.0 & $(0.5)$ & 0.7 & $(0.3)$ & 0.6 & (0.3) & 1.2 & $(0.4)$ & 0.0 & c & 1.4 & $(0.4)$ & 26.0 & $(7.3)$ \\
\hline & Navarre ${ }^{\bullet}$ & 82.3 & (1.5) & 6.3 & $(0.8)$ & 1.7 & $(0.4)$ & 0.9 & $(0.3)$ & 1.9 & (0.6) & 2.2 & $(0.6)$ & 0.5 & $(0.2)$ & 4.1 & $(0.8)$ & 28.2 & $(4.5)$ \\
\hline & \multicolumn{19}{|l|}{ United Kingdom } \\
\hline & England & 83.4 & (1.1) & 2.6 & (0.4) & 1.3 & $(0.3)$ & 2.1 & $(0.4)$ & 1.0 & (0.3) & 2.8 & $(0.5)$ & 0.9 & $(0.3)$ & 6.0 & $(0.7)$ & 48.2 & (3.8) \\
\hline & Northern Ireland & 85.6 & $(1.2)$ & 2.3 & $(0.5)$ & 1.2 & $(0.3)$ & 2.0 & $(0.4)$ & 0.7 & $(0.3)$ & 1.8 & $(0.4)$ & 0.9 & $(0.3)$ & 5.5 & $(0.7)$ & 53.7 & (4.5) \\
\hline & Scotland ${ }^{\bullet}$ & 85.4 & $(0.8)$ & 3.1 & (0.5) & 1.5 & $(0.3)$ & 1.6 & $(0.3)$ & 1.3 & (0.3) & 2.1 & $(0.3)$ & 0.7 & $(0.2)$ & 4.5 & $(0.6)$ & 41.2 & $(4.2)$ \\
\hline & Wales & 91.6 & (0.6) & 1.2 & $(0.2)$ & 1.1 & $(0.3)$ & 1.3 & $(0.4)$ & 0.5 & $(0.2)$ & 1.2 & $(0.2)$ & 0.7 & $(0.2)$ & 2.5 & $(0.4)$ & 46.2 & $(4.7)$ \\
\hline & \multicolumn{19}{|l|}{ United States } \\
\hline & Connecticut $^{\bullet}$ & 77.6 & (2.0) & 3.6 & $(0.7)$ & 3.4 & $(0.6)$ & 1.6 & $(0.4)$ & 2.5 & (0.6) & 2.7 & $(0.6)$ & 1.0 & $(0.4)$ & 7.6 & (1.1) & 46.5 & $(4.2)$ \\
\hline & Florida & 90.8 & (1.5) & 1.4 & $(0.4)$ & 1.6 & $(0.4)$ & 1.3 & $(0.4)$ & 0.7 & (0.3) & 1.0 & $(0.3)$ & 0.6 & $(0.2)$ & 2.6 & $(0.7)$ & 45.6 & $(5.8)$ \\
\hline & Massachusetts & 76.4 & (2.5) & 3.8 & $(0.8)$ & 2.9 & $(0.6)$ & 1.2 & $(0.4)$ & 2.6 & $(0.8)$ & 2.6 & $(0.7)$ & 1.0 & $(0.3)$ & 9.5 & $(1.5)$ & 51.1 & $(3.6)$ \\
\hline
\end{tabular}

\begin{tabular}{|c|c|c|c|c|c|c|c|c|c|c|c|c|c|c|c|c|c|c|}
\hline \multicolumn{19}{|l|}{ Argentina } \\
\hline$\Xi$ Ciudad Autónoma de Buenos Aires $\bullet$ & 96.1 & $(0.8)$ & 0.4 & $(0.2)$ & 1.8 & $(0.6)$ & 0.8 & $(0.4)$ & 0.3 & $(0.2)$ & 0.1 & $(0.1)$ & 0.4 & $(0.2)$ & 0.1 & $(0.1)$ & 14.4 & $(10.1)$ \\
\hline \multicolumn{19}{|l|}{ Brazil } \\
\hline Acre & 99.8 & $(0.1)$ & 0.0 & $\mathrm{C}$ & 0.0 & c & 0.0 & c & 0.0 & $\mathrm{C}$ & 0.0 & c & 0.0 & c & 0.0 & $\mathrm{C}$ & 0.0 & C \\
\hline Alagoas & 99.9 & $(0.1)$ & 0.0 & $\mathrm{c}$ & 0.0 & c & 0.0 & c & 0.0 & c & 0.0 & c & 0.0 & c & 0.0 & $\mathrm{c}$ & 0.0 & c \\
\hline Amapá & 99.9 & $(0.2)$ & 0.0 & $\mathrm{C}$ & 0.0 & c & 0.0 & c & 0.0 & $\mathrm{c}$ & 0.0 & c & 0.0 & c & 0.0 & $\mathrm{C}$ & 0.0 & C \\
\hline Amazonas & 99.6 & $(0.3)$ & 0.2 & $(0.3)$ & 0.0 & c & 0.0 & c & 0.0 & $\mathrm{C}$ & 0.0 & c & 0.0 & c & 0.0 & $\mathrm{C}$ & 0.0 & C \\
\hline Bahia & 98.8 & $(1.1)$ & 0.0 & $\mathrm{C}$ & 0.0 & c & 0.0 & c & 0.0 & c & 0.0 & c & 0.0 & c & 0.0 & $\mathrm{C}$ & 0.0 & C \\
\hline Ceará & 98.5 & $(0.8)$ & 0.9 & $(0.5)$ & 0.3 & $(0.3)$ & 0.0 & c & 0.0 & c & 0.0 & c & 0.0 & c & 0.0 & $\mathrm{c}$ & 0.0 & c \\
\hline Espírito Santo & 96.8 & (1.4) & 1.0 & $(0.6)$ & 0.6 & $(0.6)$ & 0.0 & c & 0.4 & $(0.3)$ & 0.0 & c & 0.0 & c & 0.6 & $(0.4)$ & 28.6 & $(17.9)$ \\
\hline Federal District & 98.2 & (1.4) & 0.7 & $(0.5)$ & 0.4 & $(0.5)$ & 0.0 & c & 0.0 & c & 0.0 & c & 0.0 & c & 0.3 & $(0.4)$ & 24.3 & (19.6) \\
\hline Goiás & 99.4 & $(0.5)$ & 0.0 & c & 0.0 & $\mathrm{C}$ & 0.0 & c & 0.0 & $\mathrm{c}$ & 0.0 & c & 0.0 & c & 0.0 & $\mathrm{C}$ & 0.0 & C \\
\hline Maranhão & 99.7 & $(0.3)$ & 0.3 & $(0.3)$ & 0.0 & c & 0.0 & c & 0.0 & c & 0.0 & c & 0.0 & c & 0.0 & $\mathrm{c}$ & 0.0 & c \\
\hline Mato Grosso & 99.3 & $(0.5)$ & 0.0 & $\mathrm{c}$ & 0.2 & $(0.3)$ & 0.0 & c & 0.0 & $\mathrm{c}$ & 0.0 & c & 0.0 & c & 0.0 & $\mathrm{C}$ & 0.0 & c \\
\hline Mato Grosso do Sul & 99.3 & $(0.5)$ & 0.0 & $\mathrm{C}$ & 0.3 & $(0.2)$ & 0.0 & c & 0.0 & $\mathrm{c}$ & 0.0 & c & 0.0 & c & 0.0 & $\mathrm{C}$ & 0.0 & c \\
\hline Minas Gerais & 98.9 & $(0.6)$ & 0.0 & $\mathrm{c}$ & 0.0 & c & 0.0 & c & 0.0 & c & 0.0 & c & 0.0 & c & 0.0 & $\mathrm{c}$ & 0.0 & c \\
\hline Pará & 100.0 & $(0.0)$ & 0.0 & c & 0.0 & c & 0.0 & c & 0.0 & c & 0.0 & c & 0.0 & c & 0.0 & c & 0.0 & c \\
\hline Paraiba & 98.9 & $(0.5)$ & 0.4 & $(0.3)$ & 0.3 & $(0.3)$ & 0.0 & c & 0.0 & c & 0.0 & c & 0.0 & c & 0.0 & c & 0.0 & C \\
\hline Paraná & 97.8 & $(2.1)$ & 0.9 & $(1.0)$ & 0.3 & $(0.3)$ & 0.0 & c & 0.0 & $\mathrm{c}$ & 0.0 & c & 0.0 & c & 0.0 & $\mathrm{c}$ & 0.0 & C \\
\hline Pernambuco & 99.7 & $(0.3)$ & 0.0 & $\mathrm{C}$ & 0.0 & C & 0.0 & c & 0.0 & $\mathrm{c}$ & 0.0 & c & 0.0 & c & 0.0 & $\mathrm{c}$ & 0.0 & C \\
\hline Piauí & 98.4 & $(1.1)$ & 0.4 & $(0.4)$ & 0.3 & $(0.4)$ & 0.2 & $(0.2)$ & 0.0 & $\mathrm{c}$ & 0.0 & c & 0.0 & c & 0.4 & $(0.5)$ & 37.3 & (30.6) \\
\hline Rio de Janeiro & 99.7 & $(0.3)$ & 0.0 & c & 0.0 & $\mathrm{c}$ & 0.0 & C & 0.0 & $\mathrm{c}$ & 0.0 & c & 0.0 & c & 0.0 & $\mathrm{C}$ & 0.0 & $\mathrm{C}$ \\
\hline Rio Grande do Norte & 97.9 & $(1.0)$ & 1.3 & $(0.9)$ & 0.4 & $(0.2)$ & 0.0 & c & 0.0 & $\mathrm{c}$ & 0.0 & c & 0.0 & c & 0.0 & $\mathrm{c}$ & 0.0 & c \\
\hline Rio Grande do Sul & 99.6 & $(0.4)$ & 0.2 & $(0.2)$ & 0.0 & c & 0.0 & c & 0.0 & $\mathrm{c}$ & 0.0 & c & 0.0 & c & 0.0 & $\mathrm{c}$ & 0.0 & C \\
\hline Rondônia & 99.9 & $(0.2)$ & 0.0 & c & 0.0 & c & 0.0 & c & 0.0 & c & 0.0 & c & 0.0 & c & 0.0 & c & 0.0 & C \\
\hline Roraima & 99.2 & $(0.3)$ & 0.0 & $\mathrm{C}$ & 0.4 & $(0.4)$ & 0.0 & C & 0.0 & $\mathrm{c}$ & 0.0 & c & 0.0 & c & 0.0 & $\mathrm{C}$ & 0.0 & c \\
\hline Santa Catarina & 99.3 & $(0.5)$ & 0.3 & $(0.2)$ & 0.0 & c & 0.0 & c & 0.0 & $\mathrm{c}$ & 0.0 & c & 0.0 & c & 0.0 & $\mathrm{C}$ & 0.0 & c \\
\hline São Paulo & 98.3 & $(0.6)$ & 0.7 & $(0.4)$ & 0.5 & $(0.2)$ & 0.0 & c & 0.2 & $(0.1)$ & 0.1 & $(0.1)$ & 0.0 & c & 0.0 & $\mathrm{c}$ & 0.0 & c \\
\hline Sergipe & 99.6 & $(0.3)$ & 0.3 & $(0.3)$ & 0.0 & c & 0.0 & c & 0.0 & c & 0.0 & c & 0.0 & c & 0.0 & $\mathrm{C}$ & 0.0 & c \\
\hline Tocantins & 99.6 & $(0.3)$ & 0.0 & c & 0.0 & c & 0.0 & c & 0.0 & c & 0.0 & c & 0.0 & c & 0.0 & $\mathrm{c}$ & 0.0 & c \\
\hline \multicolumn{19}{|l|}{ Colombia } \\
\hline Bogotá & 99.5 & $(0.3)$ & 0.0 & c & 0.0 & c & 0.0 & c & 0.0 & c & 0.1 & $(0.2)$ & 0.0 & c & 0.0 & C & 0.0 & C \\
\hline Cali & 99.7 & $(0.2)$ & 0.0 & c & 0.2 & $(0.1)$ & 0.0 & c & 0.0 & c & 0.0 & c & 0.0 & c & 0.0 & c & 0.0 & c \\
\hline Manizales & 99.2 & $(0.4)$ & 0.2 & $(0.2)$ & 0.2 & $(0.2)$ & 0.0 & c & 0.0 & c & 0.0 & c & 0.0 & c & 0.0 & c & 0.0 & c \\
\hline Medellín & 97.7 & $(1.1)$ & 0.6 & $(0.4)$ & 0.6 & $(0.4)$ & 0.1 & $(0.1)$ & 0.3 & $(0.2)$ & 0.2 & $(0.2)$ & 0.0 & c & 0.4 & $(0.3)$ & 28.3 & (10.4) \\
\hline \multicolumn{19}{|l|}{ Russian Federation } \\
\hline Perm Territory region ${ }^{\bullet}$ & 89.4 & $(2.0)$ & 3.7 & $(0.8)$ & 1.8 & $(0.5)$ & 0.5 & $(0.2)$ & 1.7 & $(0.6)$ & 1.3 & $(0.5)$ & 0.1 & $(0.1)$ & 1.4 & $(0.7)$ & 17.5 & (5.5) \\
\hline \multicolumn{19}{|l|}{ United Arab Emirates } \\
\hline Abu Dhabi• & 96.0 & $(0.8)$ & 1.1 & $(0.2)$ & 0.5 & $(0.2)$ & 0.6 & $(0.2)$ & 0.2 & $(0.1)$ & 0.7 & $(0.3)$ & 0.2 & $(0.1)$ & 0.7 & $(0.3)$ & 26.3 & (8.9) \\
\hline Ajman & 99.2 & $(0.6)$ & 0.0 & $\mathrm{c}$ & 0.4 & $(0.4)$ & 0.0 & c & 0.0 & $\mathrm{c}$ & 0.0 & c & 0.0 & c & 0.0 & $\mathrm{c}$ & 0.0 & c \\
\hline Dubai • & 90.6 & $(0.7)$ & 2.6 & $(0.4)$ & 1.3 & $(0.3)$ & 0.7 & $(0.2)$ & 0.4 & $(0.2)$ & 1.3 & $(0.3)$ & 0.6 & $(0.2)$ & 2.5 & $(0.3)$ & 36.5 & (5.0) \\
\hline Fujairah & 99.0 & $(0.5)$ & 0.5 & $(0.4)$ & 0.0 & c & 0.0 & c & 0.0 & C & 0.0 & c & 0.0 & c & 0.0 & C & 0.0 & C \\
\hline Ras al-Khaimah & 98.7 & $(0.6)$ & 0.3 & $(0.2)$ & 0.0 & c & 0.3 & $(0.2)$ & 0.0 & c & 0.2 & $(0.1)$ & 0.0 & c & 0.0 & $\mathrm{c}$ & 0.0 & c \\
\hline Sharjah & 96.5 & (1.1) & 1.5 & $(0.7)$ & 0.3 & $(0.2)$ & 0.4 & $(0.4)$ & 0.3 & $(0.3)$ & 0.4 & $(0.3)$ & 0.0 & c & 0.6 & $(0.3)$ & 21.7 & (7.3) \\
\hline Umm al-Quwain & 98.5 & $(0.9)$ & 0.9 & $(0.7)$ & 0.0 & c & 0.0 & $\mathrm{C}$ & 0.0 & $\mathrm{c}$ & 0.0 & $\mathrm{c}$ & 0.0 & $\mathrm{c}$ & 0.0 & $\mathrm{C}$ & 0.0 & C \\
\hline
\end{tabular}

- PISA adjudicated region.

Note: See Table 1.2.29 for national data.

StatLink त्नाls $h t t p: / / d x . d o i . o r g / 10.1787 / 888932935762$ 
[Part 1/4]

Table B2.I.32 Top performers in mathematics, reading and science, by gender and region

\begin{tabular}{|c|c|c|c|c|c|c|c|c|c|c|c|c|c|c|c|c|c|c|c|}
\hline & & & & & & & & & Boys wh & ho are: & & & & & & & & & tage of \\
\hline & & $\begin{array}{r}\text { not } \\
\text { perfo } \\
\text { in any } \\
\text { three d }\end{array}$ & $\begin{array}{l}\text { top } \\
\text { mers } \\
\text { of the } \\
\text { omains }\end{array}$ & $\begin{array}{c}\text { top per } \\
\text { onl } \\
\text { mathe }\end{array}$ & $\begin{array}{l}\text { formers } \\
\text { in } \\
\text { matics }\end{array}$ & $\begin{array}{r}\text { top per } \\
\text { on } \\
\text { rea }\end{array}$ & $\begin{array}{l}\text { ormers } \\
\text { in } \\
\text { ling }\end{array}$ & $\begin{array}{r}\text { top pe } \\
\text { on } \\
\text { sci }\end{array}$ & $\begin{array}{l}\text { ormers } \\
\text { in } \\
\text { nce }\end{array}$ & $\begin{array}{r}\text { top per } \\
\text { in math } \\
\text { and } r \\
\text { but } \\
\text { in sc }\end{array}$ & $\begin{array}{l}\text { formers } \\
\text { ematics } \\
\text { eading } \\
\text { not } \\
\text { ience }\end{array}$ & $\begin{array}{r}\text { top per } \\
\text { in math } \\
\text { and s } \\
\text { but } \\
\text { in re }\end{array}$ & $\begin{array}{l}\text { ormers } \\
\text { ematics } \\
\text { ience } \\
\text { not } \\
\text { ding }\end{array}$ & $\begin{array}{r}\text { top per } \\
\text { in re } \\
\text { and } s \\
\text { but } \\
\text { in math }\end{array}$ & $\begin{array}{l}\text { formers } \\
\text { ading } \\
\text { cience } \\
\text { not } \\
\text { ematics }\end{array}$ & $\begin{array}{c}\text { top per } \\
\text { in } \\
\text { three o }\end{array}$ & $\begin{array}{l}\text { formers } \\
\text { all } \\
\text { lomains }\end{array}$ & $\begin{array}{l}\text { in math } \\
\text { and a } \\
\text { top per } \\
\text { in re } \\
\text { and sc }\end{array}$ & $\begin{array}{l}\text { hematics } \\
\text { re also } \\
\text { rformers } \\
\text { cading } \\
\text { cience }\end{array}$ \\
\hline & & $\%$ & S.E. & $\%$ & S.E. & $\%$ & S.E. & $\%$ & S.E. & $\%$ & S.E. & $\%$ & S.E. & $\%$ & S.E. & $\%$ & S.E. & $\%$ & S.E. \\
\hline 0 & Australia & & & & & & & & & & & & & & & & & & \\
\hline 0 & Australian Capital Territory & 76.7 & $(2.8)$ & 4.0 & (1.4) & 0.2 & $(0.2)$ & 2.0 & $(0.8)$ & 0.0 & c & 6.0 & (1.6) & 0.7 & $(0.7)$ & 10.0 & (1.8) & 49.3 & (8.4) \\
\hline & New South Wales & 77.1 & $(2.2)$ & 4.6 & $(0.8)$ & 0.0 & c & 2.2 & $(0.5)$ & 0.6 & $(0.2)$ & 5.2 & $(0.8)$ & 0.4 & $(0.2)$ & 9.7 & (1.5) & 48.2 & (4.0) \\
\hline & Northern Territory & 88.9 & (3.3) & 1.9 & (1.6) & 0.0 & c & 3.0 & (1.7) & 0.0 & c & 1.0 & (1.5) & 0.0 & c & 5.0 & (2.6) & 63.9 & $(25.2)$ \\
\hline & Queensland & 80.9 & (1.6) & 4.9 & $(0.9)$ & 0.6 & $(0.4)$ & 2.2 & $(0.5)$ & 0.7 & (0.3) & 3.7 & $(1.0)$ & 0.7 & $(0.3)$ & 6.3 & (1.1) & 40.3 & (5.4) \\
\hline & South Australia & 83.7 & $(2.0)$ & 3.5 & $(0.9)$ & 0.3 & $(0.2)$ & 3.0 & $(0.9)$ & 0.3 & $(0.2)$ & 4.1 & (1.5) & 0.8 & $(0.4)$ & 4.4 & $(0.9)$ & 35.8 & (6.9) \\
\hline & Tasmania & 87.1 & $(2.1)$ & 2.9 & $(1.1)$ & 0.0 & c & 2.2 & $(0.9)$ & 0.0 & $\mathrm{C}$ & 3.5 & (1.4) & 0.4 & $(0.6)$ & 3.6 & (1.3) & 36.8 & $(14.2)$ \\
\hline & Victoria & 82.1 & $(2.1)$ & 3.6 & $(1.0)$ & 0.6 & $(0.4)$ & 2.0 & $(0.7)$ & 0.8 & $(0.3)$ & 3.5 & $(1.0)$ & 0.6 & $(0.3)$ & 6.8 & (1.5) & 46.2 & $(6.2)$ \\
\hline & Western Australia & 75.2 & (2.3) & 6.4 & $(1.2)$ & 0.5 & $(0.3)$ & 2.7 & $(0.8)$ & 0.6 & $(0.4)$ & 5.9 & (1.3) & 0.7 & $(0.4)$ & 8.0 & (2.1) & 38.1 & (7.4) \\
\hline & Belgium & & & & & & & & & & & & & & & & & & \\
\hline & Flemish Community• & 70.8 & (1.5) & 13.1 & $(1.2)$ & 0.3 & $(0.2)$ & 0.5 & $(0.2)$ & 1.8 & (0.4) & 5.1 & $(0.7)$ & 0.1 & $(0.1)$ & 8.3 & $(0.8)$ & 29.3 & (2.3) \\
\hline & French Community & 83.8 & (1.4) & 6.6 & $(1.1)$ & 1.2 & $(0.5)$ & 0.3 & $(0.2)$ & 2.3 & (0.6) & 1.8 & $(0.6)$ & 0.2 & $(0.1)$ & 3.8 & $(0.6)$ & 26.4 & (4.1) \\
\hline & German-speaking Community & 82.1 & (1.9) & 8.3 & (1.6) & 0.7 & $(0.5)$ & 0.5 & c & 0.8 & $(0.5)$ & 3.0 & (1.4) & 0.2 & c & 4.4 & (1.1) & 27.0 & (6.7) \\
\hline & Canada & & & & & & & & & & & & & & & & & & \\
\hline & Alberta & 75.9 & $(2.0)$ & 4.5 & $(0.9)$ & 0.6 & $(0.4)$ & 3.3 & $(0.9)$ & 0.9 & (0.4) & 4.9 & (1.1) & 1.0 & $(0.5)$ & 9.0 & (1.1) & 46.5 & $(4.2)$ \\
\hline & British Columbia & 75.7 & $(2.3)$ & 5.1 & $(1.0)$ & 0.9 & $(0.5)$ & 3.3 & (1.0) & 0.8 & (0.6) & 3.9 & $(1.2)$ & 1.3 & $(0.5)$ & 9.1 & (1.4) & 48.1 & (5.4) \\
\hline & Manitoba & 85.5 & (1.8) & 4.8 & (1.1) & 0.8 & $(0.5)$ & 1.4 & $(0.5)$ & 0.4 & (0.3) & 3.0 & $(1.0)$ & 0.4 & $(0.5)$ & 3.7 & (1.0) & 31.2 & (7.7) \\
\hline & New Brunswick & 87.2 & $(2.0)$ & 4.6 & (1.3) & 0.0 & c & 1.4 & $(0.8)$ & 0.5 & $(0.5)$ & 2.5 & $(0.9)$ & 0.3 & $(0.4)$ & 3.3 & (1.0) & 30.5 & $(8.2)$ \\
\hline & Newfoundland and Labrador & 85.6 & $(2.1)$ & 3.1 & (1.4) & 0.7 & $(0.5)$ & 2.8 & $(1.2)$ & 0.0 & $\mathrm{c}$ & 2.8 & $(1.0)$ & 0.7 & $(0.5)$ & 4.0 & $(1.2)$ & 38.9 & $(10.8)$ \\
\hline & Nova Scotia & 85.3 & (1.7) & 4.1 & (1.3) & 0.8 & $(0.9)$ & 2.4 & (1.7) & 0.9 & (0.5) & 2.5 & $(1.2)$ & 0.9 & (1.6) & 3.1 & (1.1) & 29.5 & (9.4) \\
\hline & Ontario & 78.3 & (1.9) & 5.6 & $(0.9)$ & 1.2 & $(0.4)$ & 1.6 & $(0.6)$ & 1.3 & (0.4) & 3.6 & $(0.9)$ & 0.7 & $(0.3)$ & 7.6 & $(1.2)$ & 41.8 & (4.6) \\
\hline & Prince Edward Island & 89.4 & (1.5) & 3.6 & $(0.8)$ & 0.0 & c & 1.7 & $(0.6)$ & 0.0 & $\mathrm{c}$ & 2.2 & $(0.9)$ & 0.3 & $(0.2)$ & 2.4 & $(0.8)$ & 28.4 & (8.7) \\
\hline & Quebec & 73.6 & (1.8) & 15.0 & (1.4) & 0.7 & $(0.3)$ & 0.3 & $(0.2)$ & 3.1 & $(0.9)$ & 2.7 & $(0.5)$ & 0.1 & $(0.1)$ & 4.5 & $(0.7)$ & 17.7 & (2.3) \\
\hline & Saskatchewan & 83.9 & (1.8) & 5.4 & $(1.2)$ & 0.6 & $(0.3)$ & 1.9 & $(0.8)$ & 0.6 & $(0.3)$ & 2.8 & $(1.0)$ & 0.4 & $(0.3)$ & 4.4 & $(1.0)$ & 33.4 & (6.5) \\
\hline & Italy & & & & & & & & & & & & & & & & & & \\
\hline & Abruzzo & 89.8 & (1.9) & 4.4 & $(1.1)$ & 0.7 & $(0.4)$ & 0.6 & $(0.3)$ & 0.9 & $(0.7)$ & 1.8 & $(0.7)$ & 0.2 & $(0.2)$ & 1.6 & $(0.9)$ & 19.0 & $(10.0)$ \\
\hline & Basilicata & 92.2 & $(1.2)$ & 3.8 & $(1.0)$ & 0.5 & $(0.3)$ & 0.6 & $(0.4)$ & 0.8 & $(0.6)$ & 1.0 & $(0.5)$ & 0.0 & c & 1.1 & $(0.6)$ & 15.6 & $(8.0)$ \\
\hline & Bolzano & 78.6 & (1.5) & 7.6 & $(0.9)$ & 0.3 & $(0.3)$ & 2.5 & $(0.8)$ & 1.0 & $(0.4)$ & 5.5 & (1.1) & 0.2 & $(0.2)$ & 4.4 & $(0.7)$ & 23.8 & (3.5) \\
\hline & Calabria & 95.7 & $(1.2)$ & 2.4 & $(0.9)$ & 0.0 & c & 0.2 & $(0.2)$ & 0.4 & $(0.5)$ & 0.4 & $(0.3)$ & 0.0 & C & 0.8 & $(0.4)$ & 19.7 & (7.1) \\
\hline & Campania & 92.3 & (1.8) & 4.0 & $(1.2)$ & 0.5 & $(0.4)$ & 0.7 & $(0.6)$ & 0.8 & $(0.4)$ & 0.8 & $(0.3)$ & 0.0 & c & 0.9 & (0.5) & 14.2 & (8.1) \\
\hline & Emilia Romagna & 79.6 & (3.0) & 9.2 & (1.9) & 0.5 & $(0.3)$ & 1.3 & $(0.6)$ & 1.4 & $(0.6)$ & 4.0 & $(1.2)$ & 0.3 & $(0.2)$ & 3.7 & $(0.8)$ & 20.1 & (3.5) \\
\hline & Friuli Venezia Giulia & 74.9 & $(1.8)$ & 9.8 & (1.6) & 0.0 & c & 1.6 & $(0.7)$ & 0.8 & $(0.4)$ & 6.7 & (1.4) & 0.6 & $(0.4)$ & 4.9 & $(0.9)$ & 22.1 & (3.5) \\
\hline & Lazio & 87.4 & (1.9) & 5.4 & (1.3) & 0.7 & $(0.4)$ & 1.1 & $(0.8)$ & 1.0 & $(0.4)$ & 2.1 & $(0.7)$ & 0.1 & $(0.2)$ & 2.1 & $(0.7)$ & 20.3 & $(6.0)$ \\
\hline & Liguria & 85.2 & (2.3) & 5.9 & $(1.2)$ & 0.4 & $(0.3)$ & 0.9 & $(0.4)$ & 0.8 & $(0.6)$ & 3.0 & $(0.8)$ & 0.3 & $(0.3)$ & 3.5 & (1.1) & 26.2 & (6.7) \\
\hline & Lombardia & 76.3 & (3.1) & 7.2 & (1.6) & 0.9 & $(0.4)$ & 2.3 & $(0.8)$ & 2.0 & $(0.8)$ & 5.6 & (1.5) & 0.0 & C & 5.4 & (1.3) & 26.9 & (5.5) \\
\hline & Marche & 84.5 & (2.2) & 5.9 & (1.6) & 0.5 & $(0.3)$ & 1.2 & $(0.5)$ & 1.0 & $(0.5)$ & 3.4 & $(0.8)$ & 0.2 & $(0.2)$ & 3.3 & $(0.8)$ & 24.7 & $(5.4)$ \\
\hline & Molise & 92.7 & $(1.2)$ & 3.9 & $(1.2)$ & 0.7 & $(0.6)$ & 0.0 & c & 0.9 & $(0.6)$ & 0.6 & $(0.4)$ & 0.0 & c & 1.1 & $(0.6)$ & 17.3 & $(8.1)$ \\
\hline & Piemonte & 83.6 & (2.1) & 7.1 & (1.3) & 0.4 & $(0.3)$ & 1.2 & $(0.6)$ & 1.5 & $(0.6)$ & 2.7 & $(0.8)$ & 0.0 & c & 3.3 & (1.1) & 22.7 & $(7.1)$ \\
\hline & Puglia & 88.7 & (1.8) & 4.7 & (1.1) & 1.0 & $(0.5)$ & 0.7 & $(0.5)$ & 1.8 & $(0.8)$ & 1.2 & $(0.7)$ & 0.2 & $(0.2)$ & 1.7 & $(0.8)$ & 18.0 & (8.6) \\
\hline & Sardegna & 93.0 & (1.4) & 2.5 & (1.0) & 0.9 & $(0.4)$ & 0.8 & $(0.5)$ & 0.8 & $(0.4)$ & 1.1 & $(0.5)$ & 0.0 & $\mathrm{C}$ & 0.8 & $(0.4)$ & 15.1 & $(7.3)$ \\
\hline & Sicilia & 95.3 & (1.5) & 1.8 & $(0.8)$ & 0.7 & $(0.4)$ & 0.6 & $(0.3)$ & 0.5 & $(0.4)$ & 0.6 & $(0.4)$ & 0.0 & $\mathrm{c}$ & 0.6 & $(0.4)$ & 17.5 & $(10.5)$ \\
\hline & Toscana & 84.7 & (2.3) & 7.3 & (1.5) & 0.8 & $(0.4)$ & 0.8 & $(0.4)$ & 1.3 & $(0.6)$ & 2.5 & $(0.6)$ & 0.2 & $(0.2)$ & 2.4 & $(0.7)$ & 18.0 & $(4.4)$ \\
\hline & Trento & 76.4 & (2.3) & 7.7 & (1.6) & 1.1 & $(0.7)$ & 2.2 & $(0.6)$ & 1.6 & $(0.7)$ & 5.3 & $(1.0)$ & 0.0 & c & 5.5 & $(1.2)$ & 27.5 & $(5.0)$ \\
\hline & Umbria & 85.9 & (2.1) & 6.1 & $(1.2)$ & 0.7 & $(0.4)$ & 1.1 & $(0.6)$ & 1.3 & $(0.8)$ & 2.7 & (1.1) & 0.0 & c & 2.0 & $(0.7)$ & 16.8 & (5.4) \\
\hline & Valle d'Aosta & 86.3 & (1.9) & 4.8 & (1.3) & 0.9 & $(0.6)$ & 1.1 & $(0.7)$ & 1.4 & $(0.8)$ & 2.5 & $(1.0)$ & 0.3 & $(0.3)$ & 2.7 & $(0.8)$ & 23.6 & $(6.1)$ \\
\hline & Veneto & 73.0 & (3.5) & 9.4 & (1.9) & 0.3 & $(0.3)$ & 1.7 & $(0.5)$ & 2.1 & $(1.2)$ & 6.9 & (1.7) & 0.2 & $(0.3)$ & 6.3 & (1.5) & 25.5 & (4.7) \\
\hline & Mexico & & & & & & & & & & & & & & & & & & \\
\hline & Aguascalientes & 97.0 & (1.1) & 1.9 & (1.1) & 0.4 & $(0.4)$ & 0.0 & c & 0.0 & c & 0.0 & c & 0.0 & c & 0.0 & c & 0.0 & c \\
\hline & Baja California & 99.1 & $(0.6)$ & 0.0 & $\mathrm{C}$ & 0.0 & C & 0.0 & c & 0.0 & c & 0.0 & c & 0.0 & c & 0.0 & c & 0.0 & c \\
\hline & Baja California Sur & 99.2 & $(0.5)$ & 0.7 & $(0.5)$ & 0.0 & c & 0.0 & c & 0.0 & c & 0.0 & c & 0.0 & c & 0.0 & c & 0.0 & c \\
\hline & Campeche & 99.4 & $(0.4)$ & 0.4 & $(0.3)$ & 0.0 & c & 0.0 & c & 0.0 & c & 0.0 & c & 0.0 & c & 0.0 & c & 0.0 & $\mathrm{c}$ \\
\hline & Chiapas & 99.4 & $(0.5)$ & 0.4 & $(0.4)$ & 0.0 & c & 0.0 & c & 0.0 & c & 0.0 & c & 0.0 & c & 0.0 & c & 0.0 & c \\
\hline & Chihuahua & 97.9 & $(1.0)$ & 1.4 & $(0.8)$ & 0.0 & c & 0.0 & c & 0.1 & $(0.2)$ & 0.0 & c & 0.0 & c & 0.0 & c & 0.0 & c \\
\hline & Coahuila & 99.0 & $(0.7)$ & 0.5 & $(0.5)$ & 0.0 & c & 0.0 & c & 0.0 & c & 0.0 & C & 0.0 & c & 0.2 & $(0.2)$ & 22.6 & $(22.7)$ \\
\hline & Colima & 97.6 & $(0.8)$ & 1.4 & $(0.7)$ & 0.0 & c & 0.0 & c & 0.0 & c & 0.0 & c & 0.0 & C & 0.4 & $(0.3)$ & 16.6 & (11.5) \\
\hline & Distrito Federal & 98.1 & $(0.8)$ & 0.9 & $(0.6)$ & 0.5 & $(0.4)$ & 0.0 & c & 0.0 & c & 0.0 & c & 0.0 & c & 0.0 & c & 0.0 & c \\
\hline & Durango & 99.2 & $(0.4)$ & 0.0 & c & 0.0 & c & 0.0 & c & 0.0 & c & 0.0 & c & 0.0 & c & 0.1 & $(0.1)$ & 24.5 & $(22.0)$ \\
\hline & Guanajuato & 99.2 & $(0.6)$ & 0.4 & $(0.4)$ & 0.0 & c & 0.0 & c & 0.0 & c & 0.0 & c & 0.0 & c & 0.0 & c & 0.0 & c \\
\hline & Guerrero & 99.8 & $(0.2)$ & 0.2 & $(0.2)$ & 0.0 & c & 0.0 & c & 0.0 & c & 0.0 & c & 0.0 & c & 0.0 & c & 0.0 & c \\
\hline & Hidalgo & 99.4 & $(0.5)$ & 0.0 & c & 0.0 & c & 0.0 & c & 0.0 & c & 0.0 & c & 0.0 & c & 0.0 & c & 0.0 & c \\
\hline & Jalisco & 98.1 & $(0.8)$ & 0.9 & $(0.6)$ & 0.3 & $(0.3)$ & 0.0 & c & 0.2 & $(0.2)$ & 0.0 & c & 0.0 & c & 0.2 & $(0.2)$ & 12.7 & (11.5) \\
\hline & Mexico & 98.8 & $(0.8)$ & 0.5 & $(0.4)$ & 0.0 & c & 0.0 & c & 0.2 & $(0.3)$ & 0.0 & c & 0.0 & c & 0.3 & $(0.4)$ & 29.6 & (28.3) \\
\hline & Morelos & 97.7 & (1.1) & 1.4 & $(0.8)$ & 0.0 & c & 0.0 & c & 0.0 & c & 0.0 & c & 0.0 & c & 0.0 & c & 0.0 & c \\
\hline & Nayarit & 99.0 & $(0.6)$ & 0.6 & $(0.5)$ & 0.4 & (0.4) & 0.0 & c & 0.0 & c & 0.0 & c & 0.0 & c & 0.0 & c & 0.0 & c \\
\hline & Nuevo León & 98.2 & (1.1) & 1.2 & $(0.7)$ & 0.0 & c & 0.0 & c & 0.0 & c & 0.0 & c & 0.0 & c & 0.0 & c & 0.0 & c \\
\hline & Puebla & 99.2 & $(0.5)$ & 0.6 & $(0.5)$ & 0.0 & c & 0.0 & c & 0.0 & c & 0.0 & c & 0.0 & c & 0.0 & c & 0.0 & c \\
\hline & Querétaro & 97.8 & $(0.8)$ & 1.5 & $(0.7)$ & 0.0 & c & 0.0 & c & 0.0 & c & 0.0 & c & 0.0 & c & 0.1 & $(0.2)$ & 7.7 & (7.8) \\
\hline & Quintana Roo & 99.5 & $(0.3)$ & 0.4 & $(0.3)$ & 0.0 & c & 0.0 & c & 0.0 & c & 0.0 & c & 0.0 & C & 0.0 & c & 0.0 & c \\
\hline & San Luis Potosí & 98.9 & $(0.6)$ & 0.9 & $(0.5)$ & 0.0 & c & 0.0 & c & 0.0 & c & 0.0 & c & 0.0 & C & 0.0 & c & 0.0 & c \\
\hline & Sinaloa & 99.5 & $(0.4)$ & 0.4 & $(0.3)$ & 0.0 & c & 0.0 & c & 0.0 & c & 0.0 & c & 0.0 & c & 0.0 & c & 0.0 & c \\
\hline & Tabasco & 99.7 & $(0.3)$ & 0.2 & $(0.2)$ & 0.0 & c & 0.0 & c & 0.0 & c & 0.0 & c & 0.0 & c & 0.0 & C & 0.0 & c \\
\hline & Tamaulipas & 98.8 & (1.0) & 0.9 & $(0.8)$ & 0.0 & c & 0.0 & c & 0.1 & (0.1) & 0.0 & c & 0.0 & C & 0.0 & c & 0.0 & c \\
\hline & Tlaxcala & 99.2 & $(0.5)$ & 0.6 & $(0.4)$ & 0.0 & c & 0.0 & c & 0.0 & C & 0.0 & C & 0.0 & c & 0.0 & c & 0.0 & c \\
\hline & Veracruz & 99.4 & $(0.5)$ & 0.4 & $(0.4)$ & 0.0 & c & 0.0 & c & 0.0 & c & 0.0 & C & 0.0 & c & 0.0 & c & 0.0 & c \\
\hline & Yucatán & 98.7 & $(0.6)$ & 0.6 & $(0.4)$ & 0.0 & c & 0.0 & c & 0.0 & c & 0.0 & c & 0.0 & c & 0.0 & c & 0.0 & c \\
\hline & Zacatecas & 99.7 & $(0.3)$ & 0.3 & $(0.2)$ & 0.0 & C & 0.0 & C & 0.0 & c & 0.0 & C & 0.0 & C & 0.0 & c & 0.0 & C \\
\hline
\end{tabular}

- PISA adjudicated region.

Note: See Table I.2.30 for national data.

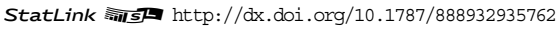


[Part 2/4]

Table B2.I.32 Top performers in mathematics, reading and science, by gender and region

\begin{tabular}{|c|c|c|c|c|c|c|c|c|c|c|c|c|c|c|c|c|c|c|c|}
\hline & & \multicolumn{16}{|c|}{ Boys who are: } & \multirow{2}{*}{\multicolumn{2}{|c|}{$\begin{array}{l}\text { Percentage of } \\
\text { boys who are } \\
\text { top performers } \\
\text { in mathematics } \\
\text { and are also } \\
\text { top performers } \\
\text { in reading } \\
\text { and science }\end{array}$}} \\
\hline & & $\begin{array}{r}\text { not } \\
\text { perfo } \\
\text { in any } \\
\text { three } d\end{array}$ & $\begin{array}{l}\text { top } \\
\text { mers } \\
\text { of the } \\
\text { omains }\end{array}$ & $\begin{array}{c}\text { top perf } \\
\text { only } \\
\text { mather }\end{array}$ & $\begin{array}{l}\text { ormers } \\
\text { in } \\
\text { matics }\end{array}$ & $\begin{array}{r}\text { top per } \\
\text { on } \\
\text { rea }\end{array}$ & $\begin{array}{l}\text { ormers } \\
\text { in } \\
\text { ing }\end{array}$ & $\begin{array}{r}\text { top per } \\
\text { onl } \\
\text { scie }\end{array}$ & ormers & $\begin{array}{l}\text { top perf } \\
\text { in math } \\
\text { and re } \\
\text { but } \\
\text { in sci }\end{array}$ & $\begin{array}{l}\text { ormers } \\
\text { ematics } \\
\text { ading } \\
\text { not } \\
\text { ence }\end{array}$ & $\begin{array}{l}\text { top per } \\
\text { in math } \\
\text { and so } \\
\text { but } \\
\text { in re }\end{array}$ & $\begin{array}{l}\text { ormers } \\
\text { ematics } \\
\text { ience } \\
\text { not } \\
\text { ding }\end{array}$ & $\begin{array}{r}\text { top per } \\
\text { in re } \\
\text { and s } \\
\text { but } \\
\text { in math }\end{array}$ & $\begin{array}{l}\text { ormers } \\
\text { ding } \\
\text { ience } \\
\text { not } \\
\text { ematics }\end{array}$ & $\begin{array}{l}\text { top per } \\
\text { in } \\
\text { three } d\end{array}$ & $\begin{array}{l}\text { ormers } \\
\text { all } \\
\text { omains }\end{array}$ & & \\
\hline & & $\%$ & S.E. & $\%$ & S.E. & $\%$ & S.E. & $\%$ & S.E. & $\%$ & S.E. & $\%$ & S.E. & $\%$ & S.E. & $\%$ & S.E. & $\%$ & S.E. \\
\hline 0 & Portugal & & & & & & & & & & & & & & & & & & \\
\hline 氹 & Alentejo & 86.5 & (3.3) & 6.1 & $(2.1)$ & 0.4 & $(0.4)$ & 0.0 & c & 1.5 & $(1.2)$ & 2.9 & (1.5) & 0.0 & c & 2.4 & (1.4) & 18.4 & (9.6) \\
\hline & Spain & & & & & & & & & & & & & & & & & & \\
\hline & Andalusia ${ }^{\bullet}$ & 90.1 & (1.5) & 2.8 & $(0.8)$ & 0.6 & $(0.3)$ & 1.3 & $(0.5)$ & 0.9 & $(0.5)$ & 2.0 & $(0.9)$ & 0.3 & $(0.2)$ & 2.0 & $(0.7)$ & 26.5 & (7.8) \\
\hline & Aragon` & 83.6 & (1.9) & 6.4 & (1.3) & 0.2 & $(0.2)$ & 1.4 & $(0.7)$ & 1.1 & $(0.6)$ & 3.9 & $(1.1)$ & 0.0 & c & 3.2 & (0.9) & 21.8 & (5.3) \\
\hline & Asturias ${ }^{\bullet}$ & 82.5 & (1.9) & 6.2 & $(1.0)$ & 0.5 & $(0.3)$ & 1.6 & $(0.5)$ & 1.0 & (0.6) & 4.7 & (1.3) & 0.0 & c & 3.5 & $(1.2)$ & 22.7 & (7.1) \\
\hline & Balearic Islands ${ }^{\bullet}$ & 91.2 & (1.3) & 3.7 & $(1.0)$ & 1.2 & $(0.8)$ & 0.8 & $(0.5)$ & 0.9 & $(0.5)$ & 1.1 & $(0.5)$ & 0.0 & c & 1.0 & $(0.5)$ & 14.7 & (7.6) \\
\hline & Basque Country ${ }^{\bullet}$ & 85.6 & (1.0) & 7.0 & $(0.7)$ & 0.5 & $(0.2)$ & 1.0 & $(0.3)$ & 1.0 & $(0.3)$ & 2.5 & $(0.4)$ & 0.0 & c & 2.2 & $(0.5)$ & 16.9 & (3.2) \\
\hline & Cantabria ${ }^{\bullet}$ & 85.5 & (1.5) & 6.5 & (1.4) & 0.0 & $\mathrm{c}$ & 1.6 & $(0.6)$ & 0.8 & $(0.4)$ & 3.5 & $(1.0)$ & 0.0 & c & 2.0 & $(0.7)$ & 15.8 & (5.5) \\
\hline & Castile and Leon ${ }^{\bullet}$ & 80.2 & (1.9) & 7.7 & $(1.1)$ & 1.0 & $(0.5)$ & 1.8 & $(0.7)$ & 2.2 & $(0.7)$ & 3.2 & (1.1) & 0.4 & $(0.3)$ & 3.4 & $(0.8)$ & 20.6 & (4.7) \\
\hline & Catalonia ${ }^{\bullet}$ & 85.2 & (2.6) & 5.9 & $(1.7)$ & 1.7 & (0.9) & 0.6 & $(0.4)$ & 2.5 & $(0.7)$ & 1.5 & (0.5) & 0.0 & C & 2.4 & $(0.9)$ & 20.0 & (7.5) \\
\hline & Extremadura ${ }^{\bullet}$ & 90.0 & (1.3) & 2.9 & $(0.9)$ & 0.0 & c & 2.0 & $(0.6)$ & 0.4 & $(0.3)$ & 2.6 & $(0.7)$ & 0.2 & $(0.2)$ & 1.7 & $(0.6)$ & 22.7 & (7.9) \\
\hline & Galicia• & 86.6 & (1.7) & 3.8 & $(0.8)$ & 1.4 & $(0.5)$ & 2.4 & $(0.7)$ & 0.7 & $(0.4)$ & 2.6 & (1.0) & 0.7 & $(0.5)$ & 1.8 & $(0.6)$ & 19.9 & (6.3) \\
\hline & La Rioja• & 78.5 & (1.5) & 10.9 & (1.7) & 0.0 & $\mathrm{c}$ & 0.9 & $(0.4)$ & 1.1 & $(0.5)$ & 4.6 & $(0.8)$ & 0.0 & c & 3.6 & $(1.0)$ & 17.7 & (5.1) \\
\hline & Madrid ${ }^{\bullet}$ & 82.8 & $(2.2)$ & 6.0 & (1.4) & 0.9 & $(0.5)$ & 1.8 & $(0.7)$ & 1.5 & $(0.6)$ & 3.0 & $(0.9)$ & 0.2 & $(0.3)$ & 3.7 & $(0.9)$ & 26.2 & (6.0) \\
\hline & Murcia ${ }^{\bullet}$ & 91.0 & (1.9) & 3.7 & $(1.2)$ & 0.5 & $(0.3)$ & 0.8 & $(0.5)$ & 0.8 & (0.6) & 1.9 & $(0.7)$ & 0.0 & C & 1.4 & $(0.7)$ & 18.6 & (8.0) \\
\hline & Navarre ${ }^{\bullet}$ & 82.5 & (1.6) & 7.9 & (1.5) & 0.4 & $(0.3)$ & 1.3 & $(0.6)$ & 0.9 & $(0.5)$ & 3.3 & $(0.9)$ & 0.3 & $(0.3)$ & 3.2 & $(1.0)$ & 21.1 & (6.4) \\
\hline & United Kingdom & & & & & & & & & & & & & & & & & & \\
\hline & England & 82.4 & (1.7) & 3.5 & $(0.6)$ & 0.2 & $(0.2)$ & 2.9 & $(0.7)$ & 0.5 & $(0.3)$ & 4.6 & $(0.8)$ & 0.4 & $(0.2)$ & 5.4 & $(0.9)$ & 38.2 & (4.5) \\
\hline & Northern Ireland & 86.1 & (1.6) & 3.0 & $(0.8)$ & 0.3 & $(0.2)$ & 2.2 & $(0.7)$ & 0.4 & $(0.3)$ & 2.4 & $(0.7)$ & 0.4 & $(0.4)$ & 5.2 & (0.9) & 47.7 & (5.3) \\
\hline & Scotland $^{\bullet}$ & 84.7 & $(0.9)$ & 4.1 & $(0.7)$ & 0.5 & $(0.3)$ & 2.2 & $(0.4)$ & 0.9 & $(0.4)$ & 3.2 & $(0.5)$ & 0.3 & $(0.2)$ & 4.1 & $(0.6)$ & 33.1 & (4.0) \\
\hline & Wales & 90.9 & $(0.8)$ & 1.6 & $(0.4)$ & 0.3 & $(0.2)$ & 2.0 & $(0.7)$ & 0.4 & $(0.2)$ & 1.9 & $(0.4)$ & 0.5 & $(0.2)$ & 2.4 & $(0.5)$ & 37.8 & (5.5) \\
\hline & United States & & & & & & & & & & & & & & & & & & \\
\hline & Connecticut $^{\bullet}$ & 76.7 & (2.4) & 4.6 & (1.1) & 1.9 & $(0.6)$ & 2.3 & $(0.7)$ & 1.6 & (0.6) & 4.2 & $(1.1)$ & 0.5 & $(0.4)$ & 8.2 & (1.3) & 44.1 & (5.5) \\
\hline & Florida $\bullet$ & 90.1 & $(1.7)$ & 1.7 & $(0.7)$ & 0.7 & $(0.4)$ & 1.9 & $(0.7)$ & 0.0 & c & 1.4 & $(0.5)$ & 0.6 & $(0.4)$ & 3.2 & $(0.8)$ & 46.6 & (7.4) \\
\hline & Massachusetts ${ }^{\bullet}$ & 76.6 & $(2.8)$ & 5.6 & $(1.3)$ & 1.3 & $(0.6)$ & 1.6 & $(0.7)$ & 1.8 & $(0.7)$ & 4.0 & $(1.1)$ & 0.4 & $(0.3)$ & 8.8 & $(1.5)$ & 43.4 & $(4.2)$ \\
\hline$n$ & Argentina & & & & & & & & & & & & & & & & & & \\
\hline$\cong$ & Ciudad Autónoma de Buenos Aires ${ }^{\bullet}$ & 96.3 & (1.1) & 0.6 & $(0.3)$ & 1.2 & $(0.6)$ & 0.7 & $(0.5)$ & 0.3 & $(0.4)$ & 0.3 & $(0.3)$ & 0.0 & c & 0.3 & $(0.2)$ & 18.0 & (12.3) \\
\hline & Brazil & & & & & & & & & & & & & & & & & & \\
\hline & Acre & 99.8 & $(0.3)$ & 0.0 & c & 0.0 & c & 0.0 & c & 0.0 & c & 0.0 & c & 0.0 & c & 0.0 & c & 0.0 & c \\
\hline & Alagoas & 99.9 & $(0.3)$ & 0.0 & c & 0.0 & c & 0.0 & c & 0.0 & c & 0.0 & c & 0.0 & c & 0.0 & c & 0.0 & c \\
\hline & Amapá & 100.0 & $(0.0)$ & 0.0 & c & 0.0 & c & 0.0 & c & 0.0 & c & 0.0 & c & 0.0 & c & 0.0 & c & 0.0 & c \\
\hline & Amazonas & 99.5 & $(0.6)$ & 0.5 & $(0.6)$ & 0.0 & c & 0.0 & c & 0.0 & c & 0.0 & c & 0.0 & c & 0.0 & c & 0.0 & c \\
\hline & Bahia & 98.3 & (1.6) & 0.0 & c & 0.0 & c & 0.0 & c & 0.0 & c & 0.0 & $\mathrm{c}$ & 0.0 & c & 0.0 & c & 0.0 & c \\
\hline & Ceará & 98.0 & (1.3) & 1.5 & $(0.9)$ & 0.0 & c & 0.0 & c & 0.0 & c & 0.0 & c & 0.0 & c & 0.0 & c & 0.0 & c \\
\hline & Espírito Santo & 96.8 & (1.3) & 1.8 & $(1.0)$ & 0.0 & c & 0.0 & c & 0.0 & c & 0.0 & c & 0.0 & c & 0.5 & $(0.6)$ & 20.3 & $(22.1)$ \\
\hline & Federal District & 97.7 & (1.2) & 1.4 & $(1.0)$ & 0.0 & c & 0.0 & c & 0.0 & c & 0.0 & c & 0.0 & c & 0.0 & c & 0.0 & c \\
\hline & Goiás & 99.3 & $(0.7)$ & 0.0 & c & 0.0 & c & 0.0 & c & 0.0 & c & 0.0 & c & 0.0 & c & 0.0 & c & 0.0 & c \\
\hline & Maranhão & 99.3 & $(0.6)$ & 0.7 & $(0.6)$ & 0.0 & c & 0.0 & c & 0.0 & c & 0.0 & c & 0.0 & c & 0.0 & c & 0.0 & c \\
\hline & Mato Grosso & 99.7 & $(0.4)$ & 0.0 & c & 0.0 & c & 0.0 & c & 0.0 & c & 0.0 & c & 0.0 & c & 0.0 & c & 0.0 & c \\
\hline & Mato Grosso do Sul & 99.4 & $(0.5)$ & 0.0 & c & 0.0 & c & 0.0 & c & 0.0 & c & 0.0 & c & 0.0 & c & 0.0 & c & 0.0 & c \\
\hline & Minas Gerais & 98.6 & $(0.8)$ & 0.0 & c & 0.0 & c & 0.0 & c & 0.0 & c & 0.0 & c & 0.0 & c & 0.0 & c & 0.0 & c \\
\hline & Pará & 100.0 & $(0.0)$ & 0.0 & c & 0.0 & c & 0.0 & c & 0.0 & c & 0.0 & c & 0.0 & c & 0.0 & c & 0.0 & c \\
\hline & Paraíba & 98.1 & $(0.8)$ & 0.8 & $(0.7)$ & 0.0 & c & 0.0 & c & 0.0 & c & 0.0 & c & 0.0 & c & 0.0 & c & 0.0 & c \\
\hline & Paraná & 98.0 & (2.3) & 1.4 & (1.9) & 0.0 & c & 0.0 & c & 0.0 & c & 0.0 & c & 0.0 & c & 0.0 & c & 0.0 & c \\
\hline & Pernambuco & 99.5 & $(0.5)$ & 0.0 & c & 0.0 & $\mathrm{c}$ & 0.0 & c & 0.0 & c & 0.0 & c & 0.0 & c & 0.0 & c & 0.0 & c \\
\hline & Piauí & 98.2 & (1.3) & 0.6 & $(0.6)$ & 0.0 & c & 0.0 & c & 0.0 & c & 0.0 & c & 0.0 & c & 0.7 & $(0.6)$ & 47.0 & $(37.0)$ \\
\hline & Rio de Janeiro & 99.7 & $(0.5)$ & 0.0 & c & 0.0 & c & 0.0 & c & 0.0 & c & 0.0 & c & 0.0 & c & 0.0 & c & 0.0 & c \\
\hline & Rio Grande do Norte & 97.4 & $(2.0)$ & 2.3 & $(1.8)$ & 0.0 & c & 0.0 & c & 0.0 & c & 0.0 & c & 0.0 & c & 0.0 & c & 0.0 & c \\
\hline & Rio Grande do Sul & 99.6 & $(0.5)$ & 0.0 & c & 0.0 & c & 0.0 & c & 0.0 & c & 0.0 & c & 0.0 & c & 0.0 & c & 0.0 & c \\
\hline & Rondônia & 99.9 & $(0.4)$ & 0.0 & c & 0.0 & c & 0.0 & c & 0.0 & c & 0.0 & c & 0.0 & c & 0.0 & c & 0.0 & c \\
\hline & Roraima & 99.8 & $(0.3)$ & 0.0 & c & 0.0 & c & 0.0 & c & 0.0 & c & 0.0 & c & 0.0 & c & 0.0 & c & 0.0 & c \\
\hline & Santa Catarina & 99.6 & $(0.4)$ & 0.3 & $(0.3)$ & 0.0 & c & 0.0 & c & 0.0 & c & 0.0 & c & 0.0 & c & 0.0 & c & 0.0 & c \\
\hline & São Paulo & 98.0 & $(0.9)$ & 1.0 & $(0.5)$ & 0.3 & $(0.3)$ & 0.0 & c & 0.3 & $(0.2)$ & 0.2 & $(0.2)$ & 0.0 & c & 0.0 & c & 0.0 & c \\
\hline & Sergipe & 99.3 & $(0.7)$ & 0.6 & (0.6) & 0.0 & c & 0.0 & c & 0.0 & c & 0.0 & c & 0.0 & c & 0.0 & c & 0.0 & c \\
\hline & Tocantins & 99.7 & $(0.4)$ & 0.0 & c & 0.0 & c & 0.0 & c & 0.0 & c & 0.0 & c & 0.0 & c & 0.0 & c & 0.0 & c \\
\hline & Colombia & & & & & & & & & & & & & & & & & & \\
\hline & Bogotá & 99.3 & (0.6) & 0.0 & c & 0.0 & c & 0.0 & c & 0.0 & c & 0.3 & (0.4) & 0.0 & c & 0.0 & c & 0.0 & c \\
\hline & Cali & 99.6 & $(0.3)$ & 0.0 & c & 0.2 & $(0.2)$ & 0.0 & c & 0.0 & c & 0.0 & c & 0.0 & c & 0.0 & c & 0.0 & c \\
\hline & Manizales & 98.7 & $(0.8)$ & 0.5 & (0.5) & 0.0 & c & 0.0 & c & 0.0 & c & 0.0 & c & 0.0 & c & 0.0 & c & 0.0 & c \\
\hline & Medellín & 97.7 & (1.3) & 0.9 & $(0.7)$ & 0.0 & c & 0.0 & c & 0.3 & $(0.3)$ & 0.0 & c & 0.0 & c & 0.6 & (0.5) & 26.0 & (12.9) \\
\hline & Russian Fede & & & & & & & & & & & & & & & & & & \\
\hline & Perm Territory region ${ }^{\bullet}$ & 88.7 & $(2.4)$ & 4.9 & $(1.2)$ & 0.8 & $(0.5)$ & 0.6 & $(0.3)$ & 1.3 & (0.6) & 2.1 & $(0.8)$ & 0.0 & c & 1.6 & $(0.9)$ & 15.9 & (6.4) \\
\hline & United Arab Emirates & & & & & & & & & & & & & & & & & & \\
\hline & Abu Dhabi & 96.5 & $(0.9)$ & 1.6 & $(0.4)$ & 0.0 & c & 0.4 & $(0.3)$ & 0.2 & $(0.2)$ & 0.7 & (0.4) & 0.0 & c & 0.6 & $(0.3)$ & 19.1 & (7.7) \\
\hline & Ajman & 99.9 & $(0.2)$ & 0.0 & c & 0.0 & $\mathrm{c}$ & 0.0 & $\mathrm{c}$ & 0.0 & $\mathrm{c}$ & 0.0 & $\mathrm{c}$ & 0.0 & c & 0.0 & c & 0.0 & $\mathrm{c}$ \\
\hline & Dubai ${ }^{\bullet}$ & 90.2 & $(0.8)$ & 3.8 & (0.6) & 0.3 & $(0.2)$ & 0.9 & $(0.3)$ & 0.0 & c & 2.0 & $(0.5)$ & 0.2 & $(0.2)$ & 2.6 & $(0.5)$ & 30.4 & (6.3) \\
\hline & Fujairah & 98.8 & $(0.5)$ & 0.6 & $(0.5)$ & 0.0 & c & 0.0 & c & 0.0 & c & 0.0 & c & 0.0 & c & 0.0 & c & 0.0 & c \\
\hline & Ras al-Khaimah & 99.2 & $(0.4)$ & 0.3 & $(0.3)$ & 0.0 & c & 0.2 & $(0.2)$ & 0.0 & c & 0.2 & $(0.2)$ & 0.0 & c & 0.0 & c & 0.0 & c \\
\hline & Sharjah & 95.8 & $(2.2)$ & 2.2 & (1.5) & 0.0 & c & 0.0 & c & 0.0 & c & 0.5 & $(0.4)$ & 0.0 & c & 0.9 & (0.6) & 22.1 & (7.7) \\
\hline & Umm al-Quwain & 98.4 & (1.3) & 1.5 & (1.3) & 0.0 & c & 0.0 & $\mathrm{c}$ & 0.0 & $\mathrm{c}$ & 0.0 & c & 0.0 & c & 0.0 & C & 0.0 & \\
\hline
\end{tabular}

- PISA adjudicated region.

Note: See Table 1.2.30 for national data.

StatLink 部 
[Part 3/4]

Table B2.I.32 Top performers in mathematics, reading and science, by gender and region

\begin{tabular}{|c|c|c|c|c|c|c|c|c|c|c|c|c|c|c|c|c|c|c|c|}
\hline & & & & & & & & & Girls w & vho are: & & & & & & & & & tage of \\
\hline & & $\begin{array}{r}\text { not } \\
\text { perfo } \\
\text { in any } \\
\text { three d }\end{array}$ & $\begin{array}{l}\text { top } \\
\text { mers } \\
\text { of the } \\
\text { omains }\end{array}$ & $\begin{array}{c}\text { top per } \\
\text { onl } \\
\text { mathe }\end{array}$ & $\begin{array}{l}\text { formers } \\
\text { in } \\
\text { matics }\end{array}$ & $\begin{array}{r}\text { top per } \\
\text { on } \\
\text { rea }\end{array}$ & $\begin{array}{l}\text { ormers } \\
\text { in } \\
\text { ling }\end{array}$ & $\begin{array}{r}\text { top pe } \\
\text { on } \\
\text { sci }\end{array}$ & $\begin{array}{l}\text { ormers } \\
\text { in } \\
\text { nce }\end{array}$ & $\begin{array}{l}\text { top per } \\
\text { in math } \\
\text { and re } \\
\text { but } \\
\text { in sc }\end{array}$ & $\begin{array}{l}\text { formers } \\
\text { ematics } \\
\text { eading } \\
\text { not } \\
\text { ience }\end{array}$ & $\begin{array}{r}\text { top per } \\
\text { in math } \\
\text { and s } \\
\text { but } \\
\text { in re }\end{array}$ & $\begin{array}{l}\text { ormers } \\
\text { ematics } \\
\text { ience } \\
\text { not } \\
\text { iding }\end{array}$ & $\mid \begin{array}{r}\text { top per } \\
\text { in re } \\
\text { and s } \\
\text { but } \\
\text { in math }\end{array}$ & $\begin{array}{l}\text { formers } \\
\text { ading } \\
\text { cience } \\
\text { not } \\
\text { ematics }\end{array}$ & $\begin{array}{c}\text { top per } \\
\text { in } \\
\text { three }\end{array}$ & $\begin{array}{l}\text { formers } \\
\text { all } \\
\text { omains }\end{array}$ & $\begin{array}{l}\text { in math } \\
\text { and ar } \\
\text { top per } \\
\text { in re } \\
\text { and sc }\end{array}$ & $\begin{array}{l}\text { ematics } \\
\text { re also } \\
\text { rformers } \\
\text { ading } \\
\text { cience }\end{array}$ \\
\hline & & $\%$ & S.E. & $\%$ & S.E. & $\%$ & S.E. & $\%$ & S.E. & $\%$ & S.E. & $\%$ & S.E. & $\%$ & S.E. & $\%$ & S.E. & $\%$ & S.E. \\
\hline 0 & Australia & & & & & & & & & & & & & & & & & & \\
\hline 0 & Australian Capital Territory & 76.3 & (3.0) & 2.7 & $(1.1)$ & 4.0 & (1.4) & 0.7 & $(0.6)$ & 2.1 & (1.1) & 1.0 & $(0.7)$ & 2.4 & (1.6) & 11.0 & $(1.8)$ & 65.6 & (6.3) \\
\hline & New South Wales & 78.8 & (1.6) & 2.1 & $(0.5)$ & 2.7 & $(0.9)$ & 1.7 & $(0.5)$ & 1.4 & $(0.5)$ & 1.4 & $(0.4)$ & 2.0 & $(0.5)$ & 10.0 & (1.1) & 67.2 & $(4.0)$ \\
\hline & Northern Territory & 89.4 & (4.6) & 0.0 & c & c & c & 1.5 & (2.0) & 0.0 & c & 0.0 & c & 0.0 & c & 4.0 & $(2.5)$ & 78.4 & $(17.0)$ \\
\hline & Queensland & 81.3 & (1.5) & 2.7 & $(0.8)$ & 2.7 & $(0.6)$ & 1.1 & $(0.4)$ & 2.1 & (0.6) & 1.2 & (0.4) & 1.3 & $(0.4)$ & 7.6 & $(1.1)$ & 55.9 & (5.6) \\
\hline & South Australia & 84.9 & (1.8) & 1.9 & $(1.0)$ & 2.5 & $(0.9)$ & 1.9 & $(0.8)$ & 1.1 & (0.6) & 1.0 & $(0.6)$ & 2.2 & $(0.7)$ & 4.4 & $(0.9)$ & 52.6 & (8.6) \\
\hline & Tasmania & 86.7 & $(2.2)$ & 1.4 & $(0.6)$ & 1.1 & $(0.6)$ & 1.6 & $(0.8)$ & 0.7 & (0.4) & 1.0 & $(0.8)$ & 2.6 & $(1.1)$ & 5.0 & $(1.3)$ & 61.9 & (9.2) \\
\hline & Victoria & 82.7 & (1.5) & 1.3 & $(0.6)$ & 4.9 & $(1.0)$ & 1.2 & $(0.5)$ & 1.7 & $(0.5)$ & 0.6 & $(0.4)$ & 1.9 & $(0.5)$ & 5.6 & (1.1) & 60.5 & $(7.2)$ \\
\hline & Western Australia & 78.4 & (2.4) & 2.3 & $(0.8)$ & 3.1 & (1.1) & 2.3 & $(0.8)$ & 1.9 & $(0.6)$ & 1.2 & $(0.7)$ & 2.7 & $(0.8)$ & 8.2 & (1.4) & 60.7 & (5.6) \\
\hline & Belgium & & & & & & & & & & & & & & & & & & \\
\hline & Flemish Community• & 74.5 & (1.6) & 7.8 & $(1.0)$ & 2.2 & $(0.5)$ & 0.5 & $(0.2)$ & 5.2 & (0.6) & 1.3 & $(0.3)$ & 0.5 & $(0.2)$ & 8.0 & $(0.7)$ & 35.7 & (2.6) \\
\hline & French Community & 84.7 & $(1.2)$ & 2.3 & $(0.6)$ & 5.3 & $(0.9)$ & 0.2 & $(0.2)$ & 3.8 & (0.6) & 0.2 & $\mathrm{c}$ & 0.4 & $(0.2)$ & 3.2 & $(0.6)$ & 34.0 & (4.7) \\
\hline & German-speaking Community & 84.9 & (1.9) & 4.6 & $(1.2)$ & 3.0 & $(1.0)$ & 0.1 & c & 3.3 & (0.9) & 0.7 & $(0.5)$ & 0.6 & $(0.5)$ & 2.8 & $(0.8)$ & 24.4 & (6.7) \\
\hline & Canada & & & & & & & & & & & & & & & & & & \\
\hline & Alberta & 77.1 & $(2.1)$ & 2.6 & $(0.8)$ & 3.9 & $(0.9)$ & 2.2 & $(0.8)$ & 2.1 & (0.8) & 1.8 & (0.6) & 2.4 & $(0.7)$ & 7.9 & (1.1) & 54.9 & (4.9) \\
\hline & British Columbia & 77.2 & (2.5) & 2.7 & $(0.8)$ & 4.6 & (1.1) & 1.6 & $(0.6)$ & 1.8 & (0.6) & 1.2 & $(0.5)$ & 2.5 & $(0.7)$ & 8.5 & (1.6) & 60.0 & (5.1) \\
\hline & Manitoba & 86.0 & (1.5) & 2.3 & $(0.8)$ & 3.5 & $(0.7)$ & 1.1 & $(0.6)$ & 1.3 & (0.3) & 0.8 & $(0.5)$ & 1.1 & $(0.5)$ & 4.0 & $(0.9)$ & 47.9 & (8.5) \\
\hline & New Brunswick & 84.7 & (1.9) & 3.2 & (1.4) & 3.8 & (1.1) & 0.9 & (1.0) & 1.3 & $(0.6)$ & 1.3 & $(0.8)$ & 1.3 & $(0.7)$ & 3.5 & $(1.3)$ & 38.0 & $(12.7)$ \\
\hline & Newfoundland and Labrador & 83.3 & (1.7) & 1.2 & $(0.6)$ & 4.6 & (1.4) & 1.3 & $(0.7)$ & 1.1 & $(0.8)$ & 0.8 & $(0.4)$ & 2.2 & $(0.8)$ & 5.5 & $(1.0)$ & 64.1 & $(9.6)$ \\
\hline & Nova Scotia & 85.4 & (2.4) & 1.5 & $(0.7)$ & 4.5 & (1.7) & 0.9 & $(0.5)$ & 1.1 & $(0.5)$ & 0.5 & $(0.4)$ & 1.8 & (1.1) & 4.3 & $(1.2)$ & 58.5 & $(10.8)$ \\
\hline & Ontario & 78.9 & (1.9) & 2.0 & $(0.5)$ & 5.7 & $(0.9)$ & 1.1 & $(0.5)$ & 2.5 & (0.6) & 0.8 & $(0.3)$ & 2.2 & $(0.6)$ & 6.7 & $(1.1)$ & 56.2 & $(6.7)$ \\
\hline & Prince Edward Island & 90.9 & (1.4) & 1.1 & $(0.5)$ & 2.9 & $(0.9)$ & 0.3 & $(0.2)$ & 1.2 & $(0.5)$ & 0.0 & c & 0.9 & $(0.5)$ & 2.5 & $(0.8)$ & 50.3 & (12.4) \\
\hline & Quebec & 75.5 & (1.8) & 7.7 & (1.1) & 4.4 & $(0.9)$ & 0.3 & $(0.2)$ & 6.3 & $(1.0)$ & 0.7 & $(0.3)$ & 0.3 & $(0.2)$ & 4.8 & (1.1) & 24.7 & (5.1) \\
\hline & Saskatchewan & 83.8 & (1.5) & 2.6 & $(0.8)$ & 2.8 & $(0.8)$ & 1.4 & $(0.7)$ & 1.9 & $(0.9)$ & 1.0 & $(0.6)$ & 1.1 & $(0.4)$ & 5.5 & (1.1) & 49.6 & (7.3) \\
\hline & Italy & & & & & & & & & & & & & & & & & & \\
\hline & Abruzzo & 90.6 & (1.8) & 1.4 & (0.6) & 3.0 & $(1.0)$ & 0.5 & (0.4) & 1.4 & (0.7) & 0.8 & (0.4) & 0.5 & $(0.4)$ & 1.7 & $(0.7)$ & 31.0 & $(12.6)$ \\
\hline & Basilicata & 94.7 & $(1.0)$ & 0.9 & $(0.5)$ & 1.8 & $(0.6)$ & 0.3 & $(0.2)$ & 0.8 & $(0.7)$ & 0.4 & $(0.3)$ & 0.0 & c & 0.7 & $(0.4)$ & 26.1 & $(14.8)$ \\
\hline & Bolzano & 86.8 & (1.5) & 2.1 & $(0.6)$ & 2.2 & $(0.6)$ & 2.3 & $(0.9)$ & 1.5 & 0.5 & 1.6 & $(0.6)$ & 0.7 & $(0.3)$ & 2.8 & $(0.7)$ & 35.6 & $(7.7)$ \\
\hline & Calabria & 97.5 & $(0.6)$ & 0.6 & $(0.4)$ & 1.0 & $(0.4)$ & 0.0 & c & 0.4 & $(0.4)$ & 0.0 & c & 0.0 & $\mathrm{C}$ & 0.0 & c & 0.0 & c \\
\hline & Campania & 94.8 & (1.6) & 1.0 & $(0.7)$ & 2.4 & $(1.0)$ & 0.2 & $(0.2)$ & 0.8 & $(0.7)$ & 0.0 & c & 0.0 & c & 0.6 & $(0.5)$ & 24.4 & $(17.2)$ \\
\hline & Emilia Romagna & 84.1 & (2.4) & 2.3 & $(0.8)$ & 4.8 & (1.0) & 0.6 & $(0.3)$ & 1.8 & $(0.7)$ & 0.7 & $(0.5)$ & 1.0 & $(0.5)$ & 4.6 & $(1.2)$ & 48.7 & $(7.6)$ \\
\hline & Friuli Venezia Giulia & 80.5 & $(2.1)$ & 3.3 & (1.1) & 5.2 & $(1.2)$ & 1.2 & $(0.4)$ & 2.6 & $(0.7)$ & 0.8 & $(0.4)$ & 1.5 & $(0.4)$ & 4.9 & $(0.9)$ & 42.8 & (6.5) \\
\hline & Lazio & 91.7 & (1.8) & 1.2 & $(0.7)$ & 2.6 & $(0.9)$ & 0.5 & $(0.3)$ & 1.5 & $(0.6)$ & 0.4 & $(0.3)$ & 0.0 & $\mathrm{c}$ & 1.8 & $(0.6)$ & 37.6 & (9.9) \\
\hline & Liguria & 86.7 & (2.5) & 2.1 & $(0.8)$ & 4.0 & (1.3) & 1.0 & $(0.5)$ & 1.2 & $(0.5)$ & 0.4 & $(0.3)$ & 1.1 & $(0.7)$ & 3.5 & $(0.9)$ & 48.7 & (9.0) \\
\hline & Lombardia & 82.7 & (3.1) & 2.5 & $(0.9)$ & 4.8 & (1.4) & 1.4 & $(0.7)$ & 2.7 & $(1.0)$ & 1.3 & $(0.5)$ & 0.9 & $(0.6)$ & 3.7 & $(1.0)$ & 36.1 & (8.3) \\
\hline & Marche & 88.8 & (1.9) & 1.6 & $(0.7)$ & 3.3 & $(0.9)$ & 0.7 & $(0.3)$ & 1.3 & $(0.5)$ & 1.0 & (0.4) & 0.7 & $(0.4)$ & 2.6 & $(0.9)$ & 39.4 & (9.6) \\
\hline & Molise & 93.9 & (1.4) & 1.2 & $(0.9)$ & 2.1 & (1.0) & 0.3 & $(0.3)$ & 1.4 & $(1.0)$ & 0.0 & c & 0.0 & c & 1.1 & $(0.7)$ & 29.3 & (16.0) \\
\hline & Piemonte & 85.8 & (2.4) & 2.3 & $(0.7)$ & 4.1 & (1.3) & 1.0 & $(0.7)$ & 2.0 & $(0.7)$ & 0.7 & (0.3) & 0.7 & $(0.4)$ & 3.4 & (1.1) & 40.3 & $(8.8)$ \\
\hline & Puglia & 91.1 & (1.6) & 1.1 & $(0.6)$ & 3.6 & (1.2) & 0.0 & c & 1.9 & $(0.7)$ & 0.0 & c & 0.7 & $(0.5)$ & 1.4 & $(0.6)$ & 30.6 & (12.1) \\
\hline & Sardegna & 93.2 & (1.4) & 1.2 & $(0.8)$ & 2.5 & $(0.9)$ & 0.9 & (0.6) & 0.6 & $(0.5)$ & 0.6 & (0.5) & 0.0 & c & 0.7 & $(0.3)$ & 21.1 & (10.2) \\
\hline & Sicilia & 96.5 & (1.0) & 0.4 & $(0.3)$ & 1.3 & $(0.5)$ & 0.5 & $(0.5)$ & 0.2 & $(0.2)$ & 0.0 & c & 0.4 & $(0.3)$ & 0.6 & $(0.4)$ & 47.6 & $(24.2)$ \\
\hline & Toscana & 83.9 & (2.5) & 2.9 & (1.0) & 4.3 & (1.6) & 0.8 & $(0.7)$ & 1.9 & $(0.8)$ & 1.8 & $(0.8)$ & 1.1 & $(0.6)$ & 3.3 & $(0.9)$ & 33.5 & $(10.2)$ \\
\hline & Trento & 76.3 & (2.6) & 2.3 & $(1.0)$ & 7.4 & (1.8) & 1.8 & $(0.9)$ & 3.7 & (1.6) & 0.9 & $(0.5)$ & 2.3 & $(0.8)$ & 5.4 & $(1.5)$ & 44.2 & (11.0) \\
\hline & Umbria & 89.6 & (1.5) & 2.7 & $(0.9)$ & 2.7 & (1.1) & 0.8 & $(0.5)$ & 1.1 & 0.5 & 0.8 & $(0.7)$ & 0.4 & $(0.3)$ & 2.1 & $(0.8)$ & 32.0 & (11.0) \\
\hline & Valle d'Aosta & 88.1 & (2.1) & 1.3 & (1.0) & 4.1 & (1.5) & 1.1 & $(0.5)$ & 1.3 & $(1.0)$ & 0.4 & (0.4) & 0.6 & $(0.5)$ & 3.1 & $(1.0)$ & 50.8 & (12.3) \\
\hline & Veneto & 78.8 & (2.9) & 2.1 & $(0.9)$ & 5.1 & $(0.9)$ & 2.0 & $(0.8)$ & 2.4 & $(0.9)$ & 1.2 & (0.6) & 1.8 & $(0.6)$ & 6.5 & (1.6) & 52.7 & (6.7) \\
\hline & Mexico & & & & & & & & & & & & & & & & & & \\
\hline & Aguascalientes & 98.1 & $(0.7)$ & 0.0 & c & 0.6 & $(0.5)$ & 0.0 & c & 0.0 & c & 0.0 & c & 0.0 & c & 0.0 & c & 0.0 & c \\
\hline & Baja California & 98.7 & $(0.8)$ & 0.0 & $\mathrm{C}$ & 0.9 & $(0.7)$ & 0.0 & c & 0.0 & c & 0.0 & c & 0.0 & c & 0.0 & c & 0.0 & c \\
\hline & Baja California Sur & 99.6 & $(0.3)$ & 0.0 & c & c & c & 0.0 & $\mathrm{c}$ & 0.0 & c & 0.0 & c & 0.0 & c & 0.0 & c & 0.0 & c \\
\hline & Campeche & 99.1 & $(0.5)$ & 0.0 & c & c & c & 0.0 & c & 0.0 & c & 0.0 & c & 0.0 & C & 0.0 & c & 0.0 & $\mathrm{c}$ \\
\hline & Chiapas & 99.9 & $(0.2)$ & 0.0 & $\mathrm{c}$ & c & c & 0.0 & $\mathrm{c}$ & 0.0 & c & 0.0 & c & 0.0 & c & 0.0 & c & 0.0 & c \\
\hline & Chihuahua & 98.8 & $(0.8)$ & 0.4 & $(0.3)$ & 0.4 & $(0.3)$ & 0.0 & c & 0.0 & c & 0.0 & c & 0.0 & c & 0.0 & c & 0.0 & c \\
\hline & Coahuila & 99.6 & $(0.5)$ & 0.0 & c & C & c & 0.0 & c & 0.0 & c & 0.0 & $\mathrm{C}$ & 0.0 & c & 0.0 & c & 0.0 & c \\
\hline & Colima & 98.3 & $(0.9)$ & 0.0 & c & 0.8 & $(0.6)$ & 0.0 & $\mathrm{c}$ & 0.0 & $\mathrm{C}$ & 0.0 & $\mathrm{C}$ & 0.0 & $\mathrm{C}$ & 0.0 & c & 0.0 & c \\
\hline & Distrito Federal & 98.5 & $(0.8)$ & 0.0 & c & 0.8 & $(0.4)$ & 0.0 & c & 0.3 & $(0.3)$ & 0.0 & c & 0.0 & c & 0.0 & c & 0.0 & c \\
\hline & Durango & 99.3 & $(0.4)$ & 0.2 & $(0.2)$ & 0.4 & $(0.3)$ & 0.0 & $\mathrm{c}$ & 0.0 & $\mathrm{c}$ & 0.0 & c & 0.0 & c & 0.0 & c & 0.0 & c \\
\hline & Guanajuato & 99.8 & $(0.2)$ & 0.0 & c & c & c & 0.0 & c & 0.0 & c & 0.0 & c & 0.0 & c & 0.0 & c & 0.0 & c \\
\hline & Guerrero & 100.0 & $(0.0)$ & 0.0 & $\mathrm{c}$ & c & c & 0.0 & c & 0.0 & c & 0.0 & c & 0.0 & c & 0.0 & c & 0.0 & c \\
\hline & Hidalgo & 99.7 & $(0.4)$ & 0.0 & c & c & c & 0.0 & c & 0.0 & c & 0.0 & c & 0.0 & c & 0.0 & c & 0.0 & c \\
\hline & Jalisco & 98.9 & $(0.8)$ & 0.4 & $(0.4)$ & 0.5 & $(0.4)$ & 0.0 & c & 0.0 & c & 0.0 & c & 0.0 & c & 0.0 & c & 0.0 & c \\
\hline & Mexico & 99.3 & $(0.6)$ & 0.0 & c & 0.5 & $(0.5)$ & 0.0 & c & 0.0 & c & 0.0 & c & 0.0 & c & 0.0 & c & 0.0 & c \\
\hline & Morelos & 98.0 & (1.4) & 0.8 & $(0.6)$ & c & c & 0.0 & c & 0.0 & c & 0.0 & c & 0.0 & c & 0.0 & c & 0.0 & c \\
\hline & Nayarit & 99.7 & $(0.3)$ & 0.0 & c & c & c & 0.0 & c & 0.0 & c & 0.0 & c & 0.0 & c & 0.0 & c & 0.0 & c \\
\hline & Nuevo León & 98.6 & $(0.7)$ & 0.6 & $(0.4)$ & 0.4 & $(0.4)$ & 0.0 & c & 0.0 & c & 0.0 & c & 0.0 & c & 0.0 & c & 0.0 & c \\
\hline & Puebla & 99.7 & $(0.4)$ & 0.0 & c & c & c & 0.0 & c & 0.0 & c & 0.0 & c & 0.0 & c & 0.0 & c & 0.0 & c \\
\hline & Querétaro & 98.0 & (1.0) & 0.6 & $(0.5)$ & 1.1 & (1.0) & 0.0 & c & 0.3 & $(0.3)$ & 0.0 & c & 0.0 & c & 0.0 & c & 0.0 & c \\
\hline & Quintana Roo & 99.2 & $(0.5)$ & 0.3 & $(0.3)$ & c & c & 0.0 & c & 0.0 & c & 0.0 & c & 0.0 & C & 0.0 & c & 0.0 & c \\
\hline & San Luis Potosí & 99.4 & $(0.5)$ & 0.0 & c & 0.4 & $(0.4)$ & 0.0 & c & 0.0 & c & 0.0 & c & 0.0 & c & 0.0 & c & 0.0 & c \\
\hline & Sinaloa & 99.5 & (0.4) & 0.0 & c & 0.3 & $(0.3)$ & 0.0 & c & 0.2 & 0.2 & 0.0 & c & 0.0 & c & 0.0 & c & 0.0 & c \\
\hline & Tabasco & 99.9 & $(0.1)$ & 0.0 & c & C & c & 0.0 & c & 0.0 & c & 0.0 & c & 0.0 & c & 0.0 & C & 0.0 & c \\
\hline & Tamaulipas & 99.7 & $(0.3)$ & 0.0 & C & c & c & 0.0 & c & 0.0 & c & 0.0 & c & 0.0 & C & 0.0 & c & 0.0 & c \\
\hline & Tlaxcala & 99.6 & $(0.3)$ & 0.0 & C & 0.2 & $(0.2)$ & 0.0 & c & 0.0 & C & 0.0 & C & 0.0 & C & 0.0 & c & 0.0 & c \\
\hline & Veracruz & 99.4 & $(0.6)$ & 0.0 & $\mathrm{c}$ & 0.2 & $(0.3)$ & 0.0 & C & 0.0 & c & 0.0 & C & 0.0 & c & 0.0 & c & 0.0 & c \\
\hline & Yucatán & 99.6 & (0.4) & 0.0 & c & c & c & 0.0 & c & 0.0 & c & 0.0 & c & 0.0 & c & 0.0 & c & 0.0 & c \\
\hline & Zacatecas & 99.7 & (0.4) & 0.0 & c & c & c & 0.0 & c & 0.0 & c & 0.0 & c & 0.0 & c & 0.0 & c & 0.0 & c \\
\hline
\end{tabular}

- PISA adjudicated region.

Note: See Table I.2.30 for national data.

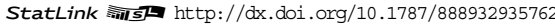


[Part 4/4]

Table B2.I.32 Top performers in mathematics, reading and science, by gender and region

\begin{tabular}{|c|c|c|c|c|c|c|c|c|c|c|c|c|c|c|c|c|c|c|c|}
\hline & & \multicolumn{16}{|c|}{ Girls who are: } & \multirow{2}{*}{\multicolumn{2}{|c|}{$\begin{array}{l}\text { Percentage of } \\
\text { girls who are } \\
\text { top performers } \\
\text { in mathematics } \\
\text { and are also } \\
\text { top performers } \\
\text { in reading } \\
\text { and science }\end{array}$}} \\
\hline & & $\begin{array}{c}\text { not } \\
\text { perfor } \\
\text { in any } \\
\text { three d }\end{array}$ & $\begin{array}{l}\text { top } \\
\text { mers } \\
\text { of the } \\
\text { omains }\end{array}$ & $\begin{array}{r}\text { top per } \\
\text { onl } \\
\text { mathe }\end{array}$ & $\begin{array}{l}\text { ormers } \\
\text { in } \\
\text { natics }\end{array}$ & $\begin{array}{r}\text { top per } \\
\text { onl } \\
\text { reac }\end{array}$ & $\begin{array}{l}\text { formers } \\
y \text { in } \\
\text { ling }\end{array}$ & $\begin{array}{r}\text { top perf } \\
\text { onl } \\
\text { scie }\end{array}$ & ormers & $\begin{array}{l}\text { top per } \\
\text { in math } \\
\text { and re } \\
\text { but } \\
\text { in sci }\end{array}$ & $\begin{array}{l}\text { ormers } \\
\text { ematics } \\
\text { ading } \\
\text { not } \\
\text { ence }\end{array}$ & $\begin{array}{l}\text { top per } \\
\text { in math } \\
\text { and sc } \\
\text { but } \\
\text { in re }\end{array}$ & $\begin{array}{l}\text { ormers } \\
\text { ematics } \\
\text { ience } \\
\text { not } \\
\text { ding }\end{array}$ & $\begin{array}{l}\text { top perf } \\
\text { in rea } \\
\text { and sc } \\
\text { but } \\
\text { in math }\end{array}$ & $\begin{array}{l}\text { formers } \\
\text { ading } \\
\text { cience } \\
\text { not } \\
\text { ematics }\end{array}$ & $\begin{array}{c}\text { top per } \\
\text { in } \\
\text { three } \mathrm{d}\end{array}$ & $\begin{array}{l}\text { ormers } \\
\text { all } \\
\text { omains }\end{array}$ & & \\
\hline & & $\%$ & S.E. & $\%$ & S.E. & $\%$ & S.E. & $\%$ & S.E. & $\%$ & S.E. & $\%$ & S.E. & $\%$ & S.E. & $\%$ & S.E. & $\%$ & S.E. \\
\hline 0 & Portugal & & & & & & & & & & & & & & & & & & \\
\hline 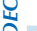 & Alentejo & 90.6 & (2.9) & 2.7 & (1.0) & C & c & 0.0 & c & 1.7 & (1.0) & 0.7 & $(0.7)$ & 0.0 & c & 1.4 & $(0.8)$ & 22.1 & $(11.1)$ \\
\hline & Spain & & & & & & & & & & & & & & & & & & \\
\hline & Andalusia ${ }^{\bullet}$ & 93.3 & (1.2) & 1.0 & $(0.4)$ & 2.1 & (0.8) & 0.4 & $(0.3)$ & 0.6 & $(0.5)$ & 0.5 & $(0.4)$ & 0.6 & (0.4) & 1.5 & $(0.6)$ & 41.8 & (13.0) \\
\hline & Aragon ${ }^{\bullet}$ & 87.6 & (2.0) & 1.8 & (0.9) & 2.3 & $(0.7)$ & 0.8 & $(0.4)$ & 1.7 & $(0.8)$ & 1.3 & $(0.6)$ & 1.0 & $(0.7)$ & 3.5 & (1.0) & 42.5 & (9.8) \\
\hline & Asturias ${ }^{\bullet}$ & 83.3 & (1.7) & 1.8 & $(0.7)$ & 4.1 & (0.8) & 1.1 & $(0.4)$ & 2.0 & $(0.7)$ & 1.6 & $(0.7)$ & 1.2 & $(0.4)$ & 5.0 & $(1.0)$ & 48.3 & (7.9) \\
\hline & Balearic Islands ${ }^{\bullet}$ & 91.2 & (1.4) & 2.5 & $(0.7)$ & 3.1 & (1.1) & 0.5 & $(0.3)$ & 1.2 & $(0.5)$ & 0.4 & $(0.3)$ & 0.3 & $(0.3)$ & 0.8 & $(0.5)$ & 15.7 & (9.8) \\
\hline & Basque Country ${ }^{\bullet}$ & 89.2 & (0.8) & 3.4 & $(0.5)$ & 2.1 & (0.4) & 0.3 & $(0.2)$ & 1.8 & $(0.4)$ & 0.8 & $(0.2)$ & 0.3 & $(0.2)$ & 2.2 & $(0.4)$ & 26.5 & (3.7) \\
\hline & Cantabria・ & 88.6 & (1.3) & 2.9 & $(0.8)$ & 1.7 & (0.9) & 1.0 & $(0.5)$ & 1.6 & $(0.6)$ & 1.2 & $(0.5)$ & 0.4 & $(0.4)$ & 2.7 & $(0.7)$ & 32.6 & (7.8) \\
\hline & Castile and Leon ${ }^{\bullet}$ & 89.0 & (2.0) & 2.4 & (0.9) & 2.4 & (1.1) & 0.9 & $(0.5)$ & 1.6 & $(0.7)$ & 1.2 & $(0.5)$ & 0.5 & (0.4) & 2.0 & $(0.7)$ & 27.2 & (9.0) \\
\hline & Catalonia • & 89.9 & (2.0) & 1.7 & $(0.8)$ & 5.0 & (1.4) & 0.0 & C & 1.4 & (0.6) & 0.0 & c & 0.0 & C & 1.5 & $(0.5)$ & 30.6 & (9.8) \\
\hline & Extremadura ${ }^{\bullet}$ & 93.2 & (1.2) & 1.2 & $(0.4)$ & 1.6 & (0.5) & 1.1 & $(0.6)$ & 0.8 & $(0.5)$ & 0.0 & c & 0.3 & $(0.2)$ & 1.6 & $(0.5)$ & 41.3 & $(11.2)$ \\
\hline & Galicia` & 86.6 & (1.6) & 1.9 & (0.6) & 4.0 & $(1.0)$ & 1.2 & $(0.5)$ & 1.2 & (0.5) & 1.1 & $(0.6)$ & 1.2 & $(0.6)$ & 2.9 & $(0.7)$ & 40.8 & (7.3) \\
\hline & La Rioja` & 85.9 & (1.4) & 4.0 & (1.1) & 2.1 & $(0.6)$ & 1.1 & $(0.6)$ & 3.0 & $(0.7)$ & 0.7 & $(0.5)$ & 0.5 & $(0.4)$ & 2.8 & $(0.7)$ & 26.7 & (5.8) \\
\hline & Madrid• & 85.0 & (1.6) & 2.5 & (1.0) & 4.6 & $(0.9)$ & 1.1 & $(0.5)$ & 2.1 & 0.8 & 1.0 & $(0.5)$ & 0.0 & C & 3.0 & $(0.7)$ & 35.3 & (6.5) \\
\hline & Murcia ${ }^{\bullet}$ & 94.3 & (1.3) & 1.2 & (0.6) & 1.6 & $(0.9)$ & 0.6 & $(0.4)$ & 0.4 & $(0.3)$ & 0.4 & $(0.3)$ & 0.0 & c & 1.4 & $(0.6)$ & 43.5 & (16.3) \\
\hline & Navarre ${ }^{\bullet}$ & 82.2 & $(2.2)$ & 4.8 & (1.4) & 2.9 & $(0.8)$ & 0.5 & $(0.3)$ & 2.8 & (1.1) & 1.1 & $(0.5)$ & 0.7 & $(0.4)$ & 4.9 & $(1.3)$ & 35.8 & (6.4) \\
\hline & United Kingdom & & & & & & & & & & & & & & & & & & \\
\hline & England & 84.3 & (1.4) & 1.8 & $(0.3)$ & 2.2 & $(0.4)$ & 1.4 & $(0.5)$ & 1.4 & $(0.4)$ & 1.0 & $(0.4)$ & 1.4 & $(0.6)$ & 6.5 & $(0.9)$ & 60.6 & (4.7) \\
\hline & Northern Ireland & 85.0 & (1.6) & 1.5 & $(0.4)$ & 2.2 & $(0.6)$ & 1.9 & $(0.5)$ & 0.9 & $(0.4)$ & 1.2 & $(0.7)$ & 1.4 & $(0.4)$ & 5.8 & $(0.9)$ & 61.4 & $(7.2)$ \\
\hline & Scotland $\bullet^{\bullet}$ & 86.1 & (1.3) & 2.0 & (0.6) & 2.4 & $(0.7)$ & 1.0 & $(0.4)$ & 1.6 & $(0.4)$ & 0.9 & $(0.3)$ & 1.0 & $(0.3)$ & 4.9 & $(0.8)$ & 51.9 & $(7.0)$ \\
\hline & Wales & 92.3 & $(0.8)$ & 0.7 & $(0.3)$ & 1.8 & $(0.5)$ & 0.7 & $(0.3)$ & 0.6 & $(0.2)$ & 0.5 & $(0.2)$ & 0.8 & $(0.3)$ & 2.5 & $(0.5)$ & 58.6 & (6.9) \\
\hline & United States & & & & & & & & & & & & & & & & & & \\
\hline & Connecticut $^{\bullet}$ & 78.4 & (2.3) & 2.6 & $(0.7)$ & 5.0 & (1.2) & 0.9 & $(0.4)$ & 3.4 & $(0.9)$ & 1.2 & $(0.6)$ & 1.4 & $(0.8)$ & 7.1 & (1.4) & 49.7 & (5.9) \\
\hline & Florida• & 91.5 & (1.7) & 1.1 & $(0.5)$ & 2.5 & (0.6) & 0.7 & $(0.6)$ & 0.9 & $(0.5)$ & 0.6 & $(0.3)$ & 0.6 & $(0.3)$ & 2.1 & $(0.7)$ & 44.4 & (9.6) \\
\hline & Massachusetts ${ }^{\bullet}$ & 76.2 & $(2.7)$ & 2.2 & $(0.7)$ & 4.5 & $(1.1)$ & 0.7 & $(0.4)$ & 3.5 & $(1.1)$ & 1.2 & $(0.6)$ & 1.6 & $(0.5)$ & 10.1 & $(1.7)$ & 59.7 & (5.3) \\
\hline$n$ & Argentina & & & & & & & & & & & & & & & & & & \\
\hline$\Xi$ & Ciudad Autónoma de Buenos Aires $\bullet$ & 95.9 & $(0.9)$ & 0.3 & $(0.3)$ & 2.3 & $(0.9)$ & 0.9 & $(0.6)$ & 0.0 & c & 0.0 & c & 0.4 & $(0.3)$ & 0.0 & c & 0.0 & c \\
\hline ฐँ & Brazil & & & & & & & & & & & & & & & & & & \\
\hline & Acre & 99.9 & (0.1) & 0.0 & C & c & c & 0.0 & c & 0.0 & c & 0.0 & c & 0.0 & c & 0.0 & c & 0.0 & c \\
\hline & Alagoas & 100.0 & $(0.0)$ & 0.0 & c & c & c & 0.0 & c & 0.0 & c & 0.0 & c & 0.0 & c & 0.0 & c & 0.0 & c \\
\hline & Amapá & 99.9 & $(0.3)$ & 0.0 & C & c & c & 0.0 & c & 0.0 & c & 0.0 & c & 0.0 & c & 0.0 & c & 0.0 & c \\
\hline & Amazonas & 99.7 & $(0.3)$ & 0.0 & C & $\mathrm{C}$ & c & 0.0 & c & 0.0 & c & 0.0 & c & 0.0 & c & 0.0 & c & 0.0 & c \\
\hline & Bahia & 99.2 & (0.9) & 0.0 & c & $\mathrm{C}$ & c & 0.0 & c & 0.0 & c & 0.0 & c & 0.0 & c & 0.0 & c & 0.0 & c \\
\hline & Ceará & 99.1 & $(0.5)$ & 0.3 & $(0.3)$ & 0.5 & $(0.4)$ & 0.0 & c & 0.0 & c & 0.0 & c & 0.0 & c & 0.0 & c & 0.0 & c \\
\hline & Espírito Santo & 96.8 & (1.8) & 0.0 & c & 1.0 & $(0.7)$ & 0.0 & c & 0.5 & $(0.4)$ & 0.0 & c & 0.0 & c & 0.7 & $(0.6)$ & 42.0 & $(23.6)$ \\
\hline & Federal District & 98.6 & (1.6) & 0.0 & c & 0.8 & $(1.0)$ & 0.0 & c & 0.0 & c & 0.0 & $\mathrm{c}$ & 0.0 & c & 0.0 & c & 0.0 & c \\
\hline & Goiás & 99.5 & (0.6) & 0.0 & C & $\mathrm{C}$ & C & 0.0 & c & 0.0 & c & 0.0 & c & 0.0 & c & 0.0 & c & 0.0 & c \\
\hline & Maranhão & 99.9 & $(0.3)$ & 0.0 & c & c & c & 0.0 & c & 0.0 & c & 0.0 & c & 0.0 & c & 0.0 & c & 0.0 & c \\
\hline & Mato Grosso & 99.0 & (0.9) & 0.0 & c & c & c & 0.0 & c & 0.0 & c & 0.0 & c & 0.0 & c & 0.0 & c & 0.0 & c \\
\hline & Mato Grosso do Sul & 99.2 & (0.6) & 0.0 & c & 0.5 & $(0.3)$ & 0.0 & c & 0.0 & c & 0.0 & c & 0.0 & c & 0.0 & c & 0.0 & c \\
\hline & Minas Gerais & 99.2 & (0.8) & 0.0 & c & C & C & 0.0 & c & 0.0 & c & 0.0 & c & 0.0 & c & 0.0 & c & 0.0 & c \\
\hline & Pará & 100.0 & $(0.0)$ & 0.0 & c & C & c & 0.0 & C & 0.0 & c & 0.0 & c & 0.0 & c & 0.0 & c & 0.0 & c \\
\hline & Paraíba & 99.7 & (0.5) & 0.0 & C & $\mathrm{C}$ & c & 0.0 & C & 0.0 & c & 0.0 & c & 0.0 & c & 0.0 & c & 0.0 & c \\
\hline & Paraná & 97.7 & (2.3) & 0.0 & c & $\mathrm{C}$ & c & 0.0 & $\mathrm{C}$ & 0.0 & c & 0.0 & c & 0.0 & c & 0.0 & c & 0.0 & c \\
\hline & Pernambuco & 99.8 & $(0.2)$ & 0.0 & c & $\mathrm{C}$ & c & 0.0 & $\mathrm{C}$ & 0.0 & c & 0.0 & c & 0.0 & c & 0.0 & c & 0.0 & c \\
\hline & Piauí & 98.6 & (1.2) & 0.0 & c & 0.5 & $(0.6)$ & 0.0 & C & 0.0 & c & 0.0 & c & 0.0 & c & 0.0 & c & 0.0 & c \\
\hline & Rio de Janeiro & 99.7 & (0.4) & 0.0 & c & C & c & 0.0 & C & 0.0 & c & 0.0 & c & 0.0 & c & 0.0 & c & 0.0 & c \\
\hline & Rio Grande do Norte & 98.3 & $(0.8)$ & 0.0 & c & 0.6 & $(0.3)$ & 0.0 & c & 0.0 & c & 0.0 & c & 0.0 & c & 0.0 & c & 0.0 & c \\
\hline & Rio Grande do Sul & 99.5 & $(0.5)$ & 0.0 & c & c & c & 0.0 & c & 0.0 & c & 0.0 & c & 0.0 & c & 0.0 & c & 0.0 & c \\
\hline & Rondônia & 100.0 & $(0.0)$ & 0.0 & c & $\mathrm{c}$ & c & 0.0 & c & 0.0 & c & 0.0 & c & 0.0 & c & 0.0 & c & 0.0 & c \\
\hline & Roraima & 98.7 & $(0.8)$ & 0.0 & c & 0.8 & $(0.7)$ & 0.0 & c & 0.0 & c & 0.0 & c & 0.0 & c & 0.0 & c & 0.0 & c \\
\hline & Santa Catarina & 99.0 & (0.9) & 0.0 & C & $\mathrm{C}$ & c & 0.0 & c & 0.0 & c & 0.0 & c & 0.0 & c & 0.0 & c & 0.0 & c \\
\hline & São Paulo & 98.6 & (0.6) & 0.4 & (0.3) & 0.6 & $(0.3)$ & 0.0 & c & 0.0 & c & 0.0 & c & 0.0 & c & 0.0 & c & 0.0 & c \\
\hline & Sergipe & 99.9 & $(0.3)$ & 0.0 & c & C & c & 0.0 & c & 0.0 & c & 0.0 & c & 0.0 & c & 0.0 & c & 0.0 & c \\
\hline & Tocantins & 99.6 & $(0.3)$ & 0.0 & c & c & c & 0.0 & c & 0.0 & c & 0.0 & c & 0.0 & c & 0.0 & c & 0.0 & c \\
\hline & Colombia & & & & & & & & & & & & & & & & & & \\
\hline & Bogotá & 99.8 & $(0.3)$ & 0.0 & c & c & c & 0.0 & c & 0.0 & c & 0.0 & c & 0.0 & c & 0.0 & c & 0.0 & c \\
\hline & Cali & 99.8 & $(0.2)$ & 0.0 & c & $\mathrm{C}$ & c & 0.0 & c & 0.0 & c & 0.0 & c & 0.0 & c & 0.0 & c & 0.0 & c \\
\hline & Manizales & 99.7 & $(0.3)$ & 0.0 & c & 0.3 & $(0.3)$ & 0.0 & c & 0.0 & c & 0.0 & c & 0.0 & c & 0.0 & c & 0.0 & c \\
\hline & Medellín & 97.6 & $(1.2)$ & 0.0 & c & 1.0 & $(0.7)$ & 0.0 & c & 0.3 & $(0.2)$ & 0.0 & c & 0.0 & c & 0.3 & $(0.4)$ & 30.2 & $(23.7)$ \\
\hline & Russian Federation & & & & & & & & & & & & & & & & & & \\
\hline & Perm Territory region ${ }^{\bullet}$ & 90.2 & (1.8) & 2.5 & $(0.7)$ & 3.0 & $(1.0)$ & 0.4 & $(0.3)$ & 2.2 & (1.1) & 0.4 & $(0.3)$ & 0.0 & c & 1.3 & $(0.6)$ & 20.3 & (6.0) \\
\hline & United Arab Emirates & & & & & & & & & & & & & & & & & & \\
\hline & Abu Dhabi ${ }^{\bullet}$ & 95.5 & (0.9) & 0.6 & $(0.3)$ & 0.9 & $(0.5)$ & 0.8 & $(0.3)$ & 0.2 & $(0.2)$ & 0.7 & $(0.4)$ & 0.4 & $(0.2)$ & 0.8 & $(0.4)$ & 35.2 & (13.6) \\
\hline & Ajman & 98.6 & $(1.2)$ & 0.0 & c & 0.8 & $(0.7)$ & 0.0 & c & 0.0 & c & 0.0 & c & 0.0 & c & 0.0 & c & 0.0 & c \\
\hline & Dubai & 91.1 & $(0.9)$ & 1.3 & (0.4) & 2.5 & $(0.7)$ & 0.5 & $(0.4)$ & 0.8 & (0.3) & 0.5 & (0.3) & 1.0 & $(0.3)$ & 2.4 & $(0.4)$ & 47.8 & (8.2) \\
\hline & Fujairah & 99.2 & $(0.7)$ & 0.4 & (0.5) & C & c & 0.0 & C & 0.0 & c & 0.0 & c & 0.0 & c & 0.0 & c & 0.0 & c \\
\hline & Ras al-Khaimah & 98.3 & (1.2) & 0.3 & $(0.3)$ & c & c & 0.0 & c & 0.0 & c & 0.0 & c & 0.0 & c & 0.0 & c & 0.0 & c \\
\hline & Sharjah & 97.1 & (1.3) & 0.9 & (0.6) & 0.5 & $(0.5)$ & 0.4 & $(0.6)$ & 0.4 & (0.4) & 0.0 & c & 0.0 & c & 0.4 & $(0.3)$ & 21.7 & (18.0) \\
\hline & Umm al-Quwain & 98.5 & (1.3) & 0.0 & $\mathrm{C}$ & $\mathrm{C}$ & c & 0.0 & $\mathrm{c}$ & 0.0 & c & 0.0 & c & 0.0 & c & 0.0 & $\mathrm{c}$ & 0.0 & c \\
\hline
\end{tabular}

- PISA adjudicated region.

Note: See Table 1.2.30 for national data.

StatLink 解古 $\mathrm{http}: / / \mathrm{dx}$.doi.org/10.1787/888932935762 


\section{ANNEX B3}

\section{RESULTS FOR THE COMPUTER-BASED AND COMBINED SCALES FOR MATHEMATICS AND READING}

PISA 2012 supplemented the paper-based assessment with an optional computer-based assessment in mathematics and reading in which 32 of the 65 countries and economies participated. In addition, PISA 2012 included an optional computer-based assessment of problem solving (Volume $\mathrm{V}$, forthcoming) in which 44 of the countries and economies participated.

Fourty-one specially designed computer-based items were developed for the assessment. Future PISA surveys will feature more sophisticated computer-based items as developers and item writers become more fully immersed in the computer-based assessment and as delivery of the computer-based assessment becomes more sophisticated.

There were two reasons for including a computer-based mathematics assessment in PISA 2012. First, computer-based items can be more interactive, authentic and engaging than paper-based items. They can be presented in new formats (e.g. drag-and-drop), include real-world data (such as a large, sortable dataset), and use colour, graphics and movement to aid comprehension. Students may be presented with a moving stimulus or representations of three-dimensional objects that can be rotated, or have more flexible access to relevant information. New item formats can expand response types beyond verbal and written, giving a more rounded picture of mathematical literacy (Stacey and Wiliam, 2013).

Second, computers have become essential tools for representing, visualising, exploring, and experimenting with all kinds of mathematical objects, phenomena and processes, not to mention for realising all types of computations - at home, at school, and at work. In the workplace, mathematical literacy and the use of computer technology are inextricably linked (Hoyles et al., 2002).

The design of the computer-based assessment ensured that mathematical reasoning and processes take precedence over mastery of using the computer as a tool. Each computer-based item involves three aspects:

- the mathematical demand (as for paper-based items);

- the general knowledge and skills related to information and communication technologies (ICT) that are required (e.g. using a keyboard and mouse, and knowing common conventions, such as arrows to move forward). These are intentionally kept to a minimum; and

- competencies related to the interaction of mathematics and ICT, such as making a pie chart from data using a simple "wizard", or planning and implementing a sorting strategy to locate and collect desired data in a spreadsheet.

Similarly, in response to the increasing presence of digital texts in personal, social and economic life, and the digital world's demand for reading proficiency digital reading was included in the PISA 2009 assessment, an acknowledgement of the fact that any definition of reading in the 21 st century needs to encompass both printed and digital texts (OECD, 2011). An assessment of digital reading was also included in PISA 2012, based on the PISA 2009 framework (OECD, 2009).

The results of the computer-based assessments are reported separately, but are also reported together with the paper-based assessment results in a combined scale, for both mathematics and reading, as shown at the end of this annex.

In general, there is a high degree of consistency in student performance on items delivered on paper and by computer. However, there are important exceptions.

In the field of mathematics, one participant (Shanghai-China) saw a large difference, of around 50 score points, in favour of the paperbased format. Three other countries and economies showed substantial differences in the same direction - Poland (28-point difference), Chinese Taipei (22-point difference) and Israel (20-point difference). Conversely, there are also countries for which computer delivery of the assessment appears to have been advantageous. The largest difference, of about 30 score points, was seen in Brazil. Colombia also saw a difference of about 20 points in the same direction. The United States, the Slovak Republic and Italy also saw marked, albeit smaller, differences in favour of the computer delivery of the assessment. Across OECD countries, the performance advantage of the computer-based assessment is slightly higher for boys than for girls.

Further analyses are needed to explore the extent to which these differences are driven by the different nature of the tasks, by the differences in the mode of delivery, or by student familiarity with computers.

The situation is similar for reading. There are also exceptions to the overall high degree of consistency in student performance on items delivered on paper and by computer. Shanghai-China, Hungary, the United Arab Emirates, Israel and Spain show a significant advantage in favour of the paper-based assessment. Conversely, the advantage for the computer-based assessment is significant in Singapore, Brazil, Korea and Sweden.

As in PISA 2009, in all participating countries and economies, the gender gap in performance is narrower in digital reading than in print reading. Across the participating OECD countries, girls outperform boys in digital reading by an average of 26 score points, compared to an average of 37 score points in print reading. 


\section{References}

Hoyles, C., A. Wolf, S. Molyneux-Hodgson and P. Kent (2002), Mathematical Skills in the Workplace: Final Report to the Science Technology and Mathematics Council, London.

OECD (2011), PISA 2009 Results: Students On Line Digital Technologies and Performance (Volume VI), PISA, OECD Publishing. http://dx.doi.org/10.1787/9789264112995-en

OECD (2009), PISA 2009 Assessment Framework Key Competencies in Reading, Mathematics and Science, PISA, OECD Publishing. http://dx.doi.org/10.1787/9789264062658-en

Stacey, K. and D. Wiliam (2013), Technology and Assessment in Mathematics, Springer International Handbooks of Education, Vol.27, pp. 721-751. 
[Part 1/1]

Table B3.I.1 Percentage of students at each proficiency level on the computer-based mathematics scale

\begin{tabular}{|c|c|c|c|c|c|c|c|c|c|c|c|c|c|c|c|}
\hline & & \multicolumn{14}{|c|}{ All students } \\
\hline & & \multicolumn{2}{|c|}{$\begin{array}{l}\text { Below Level } 1 \\
\text { (below 357.77 } \\
\text { score points) }\end{array}$} & \multicolumn{2}{|c|}{$\begin{array}{c}\text { Level } 1 \\
\text { (from } 357.77 \text { to } \\
\text { less than } 420.07 \\
\text { score points) }\end{array}$} & \multicolumn{2}{|c|}{$\begin{array}{c}\text { Level } 2 \\
\text { (from } 420.07 \text { to } \\
\text { less than } 482.38 \\
\text { score points) }\end{array}$} & \multicolumn{2}{|c|}{$\begin{array}{c}\text { Level } 3 \\
\text { (from } 482.38 \text { to } \\
\text { less than } 544.68 \\
\text { score points) }\end{array}$} & \multicolumn{2}{|c|}{$\begin{array}{c}\text { Level } 4 \\
\text { (from } 544.68 \text { to } \\
\text { less than } 606.99 \\
\text { score points) }\end{array}$} & \multicolumn{2}{|c|}{$\begin{array}{c}\text { Level } 5 \\
\text { (from } 606.99 \text { to } \\
\text { less than } 669.30 \\
\text { score points) }\end{array}$} & \multicolumn{2}{|c|}{$\begin{array}{c}\text { Level } 6 \\
\text { (above } 669.30 \\
\text { score points) }\end{array}$} \\
\hline & & $\%$ & S.E. & $\%$ & S.E. & $\%$ & S.E. & $\%$ & S.E. & $\%$ & S.E. & $\%$ & S.E. & $\%$ & S.E. \\
\hline \multirow{25}{*}{ రి } & Australia & 5.0 & $(0.4)$ & 11.6 & $(0.5)$ & 22.1 & $(0.7)$ & 26.8 & $(0.6)$ & 20.9 & $(0.6)$ & 10.2 & $(0.4)$ & 3.4 & $(0.3)$ \\
\hline & Austria & 5.1 & $(0.7)$ & 12.3 & $(0.9)$ & 20.4 & $(0.9)$ & 26.2 & $(1.0)$ & 23.2 & $(1.0)$ & 10.4 & $(0.9)$ & 2.4 & (0.4) \\
\hline & Belgium & 6.8 & $(0.5)$ & 11.0 & $(0.6)$ & 18.9 & $(0.6)$ & 24.5 & $(0.8)$ & 21.9 & $(0.6)$ & 12.4 & $(0.6)$ & 4.5 & (0.4) \\
\hline & Canada & 4.1 & $(0.3)$ & 8.6 & (0.4) & 18.8 & (0.6) & 26.9 & (0.6) & 24.3 & $(0.8)$ & 12.8 & $(0.7)$ & 4.5 & (0.5) \\
\hline & Chile & 18.2 & (1.4) & 26.9 & $(1.2)$ & 28.0 & $(1.0)$ & 18.3 & (1.1) & 7.1 & $(0.6)$ & 1.4 & $(0.2)$ & 0.2 & $(0.1)$ \\
\hline & Denmark & 6.0 & $(0.6)$ & 13.0 & (0.8) & 23.4 & (1.0) & 27.5 & $(1.2)$ & 20.8 & $(0.9)$ & 7.7 & (0.6) & 1.6 & $(0.3)$ \\
\hline & Estonia & 2.9 & $(0.4)$ & 9.3 & $(0.5)$ & 22.1 & $(0.8)$ & 29.1 & (1.0) & 23.3 & (1.0) & 10.6 & $(0.7)$ & 2.8 & $(0.4)$ \\
\hline & France & 5.6 & $(0.8)$ & 10.8 & $(0.7)$ & 20.1 & (0.9) & 27.1 & $(0.9)$ & 23.3 & (0.9) & 10.5 & $(0.8)$ & 2.5 & $(0.4)$ \\
\hline & Germany & 6.5 & $(0.7)$ & 11.4 & $(0.8)$ & 19.7 & $(0.9)$ & 25.3 & $(1.0)$ & 21.7 & $(0.8)$ & 11.5 & $(0.8)$ & 4.0 & $(0.5)$ \\
\hline & Hungary & 11.3 & $(1.2)$ & 17.4 & (1.0) & 26.0 & $(1.2)$ & 24.4 & (1.1) & 14.4 & (1.0) & 5.5 & $(0.7)$ & 1.0 & $(0.3)$ \\
\hline & Ireland & 5.3 & $(0.7)$ & 12.5 & $(0.8)$ & 25.2 & $(0.9)$ & 30.3 & (1.1) & 19.5 & (1.0) & 6.1 & $(0.5)$ & 0.9 & $(0.2)$ \\
\hline & Israel & 20.7 & (1.6) & 18.0 & (1.1) & 21.9 & $(0.9)$ & 20.1 & $(0.9)$ & 13.0 & (1.0) & 5.3 & $(0.8)$ & 1.1 & $(0.3)$ \\
\hline & Italy & 4.8 & $(0.8)$ & 12.8 & (1.1) & 24.1 & $(1.3)$ & 28.8 & $(1.2)$ & 20.3 & $(1.1)$ & 7.5 & $(0.9)$ & 1.8 & $(0.4)$ \\
\hline & Japan & 2.4 & $(0.4)$ & 6.6 & (0.6) & 16.3 & $(0.8)$ & 26.5 & (1.2) & 26.9 & (1.1) & 14.8 & $(0.9)$ & 6.6 & $(0.9)$ \\
\hline & Korea & 1.8 & $(0.3)$ & 5.4 & (0.6) & 14.3 & (1.0) & 23.9 & (1.0) & 26.9 & (1.3) & 18.7 & $(1.2)$ & 9.0 & $(1.2)$ \\
\hline & Norway & 5.5 & $(0.6)$ & 13.2 & (0.8) & 24.4 & $(0.9)$ & 27.0 & (1.0) & 19.7 & $(0.8)$ & 8.3 & $(0.6)$ & 2.0 & $(0.3)$ \\
\hline & Poland & 6.6 & $(0.8)$ & 14.3 & $(0.9)$ & 25.7 & $(1.0)$ & 27.2 & $(0.9)$ & 18.0 & $(1.0)$ & 6.8 & $(0.7)$ & 1.5 & $(0.3)$ \\
\hline & Portugal & 6.4 & $(0.6)$ & 14.9 & (0.9) & 25.2 & $(0.9)$ & 27.2 & (1.0) & 18.4 & (1.0) & 6.5 & $(0.6)$ & 1.5 & $(0.2)$ \\
\hline & Slovak Republic & 6.1 & $(0.8)$ & 11.8 & $(0.9)$ & 23.0 & (1.1) & 29.1 & (1.3) & 20.9 & $(1.1)$ & 7.6 & $(0.8)$ & 1.5 & $(0.4)$ \\
\hline & Slovenia & 7.1 & $(0.4)$ & 15.8 & $(0.7)$ & 25.3 & $(0.8)$ & 25.3 & $(1.0)$ & 17.9 & $(0.8)$ & 7.4 & $(0.5)$ & 1.3 & $(0.3)$ \\
\hline & Spain & 8.5 & $(0.9)$ & 16.4 & $(0.9)$ & 27.1 & $(1.0)$ & 27.7 & (1.0) & 15.9 & $(0.9)$ & 4.0 & $(0.4)$ & 0.4 & $(0.1)$ \\
\hline & Sweden & 6.2 & $(0.5)$ & 14.7 & $(0.8)$ & 25.2 & $(0.8)$ & 28.0 & $(0.8)$ & 17.5 & $(0.8)$ & 6.8 & $(0.6)$ & 1.6 & $(0.3)$ \\
\hline & United States & 5.9 & $(0.8)$ & 12.4 & (1.0) & 24.7 & $(1.1)$ & 26.9 & $(0.9)$ & 19.3 & $(1.1)$ & 8.2 & $(0.8)$ & 2.5 & $(0.5)$ \\
\hline & OECD total & 5.7 & $(0.3)$ & 11.7 & $(0.4)$ & 22.1 & $(0.4)$ & 26.4 & $(0.4)$ & 20.9 & $(0.4)$ & 9.8 & $(0.3)$ & 3.3 & $(0.2)$ \\
\hline & OECD average & 6.9 & $(0.2)$ & 13.1 & $(0.2)$ & 22.7 & $(0.2)$ & 26.3 & $(0.2)$ & 19.8 & $(0.2)$ & 8.7 & $(0.1)$ & 2.6 & $(0.1)$ \\
\hline \multirow{9}{*}{ 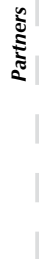 } & Brazil & 22.6 & $(1.9)$ & 28.4 & $(1.2)$ & 27.3 & (1.7) & 13.9 & $(1.0)$ & 6.0 & $(1.1)$ & 1.6 & $(0.5)$ & 0.2 & $(0.1)$ \\
\hline & Colombia & 28.9 & (1.6) & 35.5 & $(1.2)$ & 23.8 & $(1.0)$ & 9.2 & $(0.8)$ & 2.2 & $(0.4)$ & 0.3 & $(0.1)$ & 0.1 & $(0.1)$ \\
\hline & Hong Kong-China & 2.6 & $(0.5)$ & 5.2 & $(0.8)$ & 12.1 & $(0.8)$ & 24.5 & $(1.0)$ & 30.3 & $(1.1)$ & 18.7 & $(1.0)$ & 6.7 & $(0.7)$ \\
\hline & Macao-China & 1.7 & $(0.2)$ & 5.9 & $(0.4)$ & 15.3 & $(0.5)$ & 26.4 & $(0.7)$ & 28.5 & $(0.8)$ & 16.6 & $(0.6)$ & 5.6 & $(0.4)$ \\
\hline & Russian Federation & 5.2 & $(0.5)$ & 13.8 & $(0.8)$ & 27.3 & $(0.9)$ & 29.3 & $(1.1)$ & 17.7 & $(0.9)$ & 5.7 & $(0.5)$ & 1.1 & $(0.2)$ \\
\hline & Shanghai-China & 1.8 & $(0.3)$ & 5.1 & $(0.6)$ & 13.2 & $(0.8)$ & 20.8 & $(0.9)$ & 25.8 & $(1.0)$ & 21.0 & $(1.0)$ & 12.3 & $(0.9)$ \\
\hline & Singapore & 2.0 & $(0.3)$ & 5.7 & $(0.4)$ & 12.4 & $(0.5)$ & 19.7 & $(0.6)$ & 24.7 & $(1.0)$ & 21.2 & $(0.9)$ & 14.4 & $(0.6)$ \\
\hline & Chinese Taipei & 2.8 & $(0.4)$ & 7.5 & $(0.6)$ & 16.2 & $(0.9)$ & 25.0 & $(0.9)$ & 26.4 & $(1.0)$ & 16.1 & $(0.9)$ & 6.0 & $(0.6)$ \\
\hline & United Arab Emirates & 18.2 & $(0.9)$ & 25.5 & $(0.8)$ & 28.5 & $(0.8)$ & 18.3 & $(0.7)$ & 7.3 & $(0.5)$ & 2.0 & $(0.3)$ & 0.2 & $(0.1)$ \\
\hline
\end{tabular}

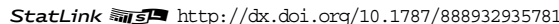


[Part 1/2]

Table B3.I.2 Percentage of students at each proficiency level on the computer-based mathematics scale, by gender

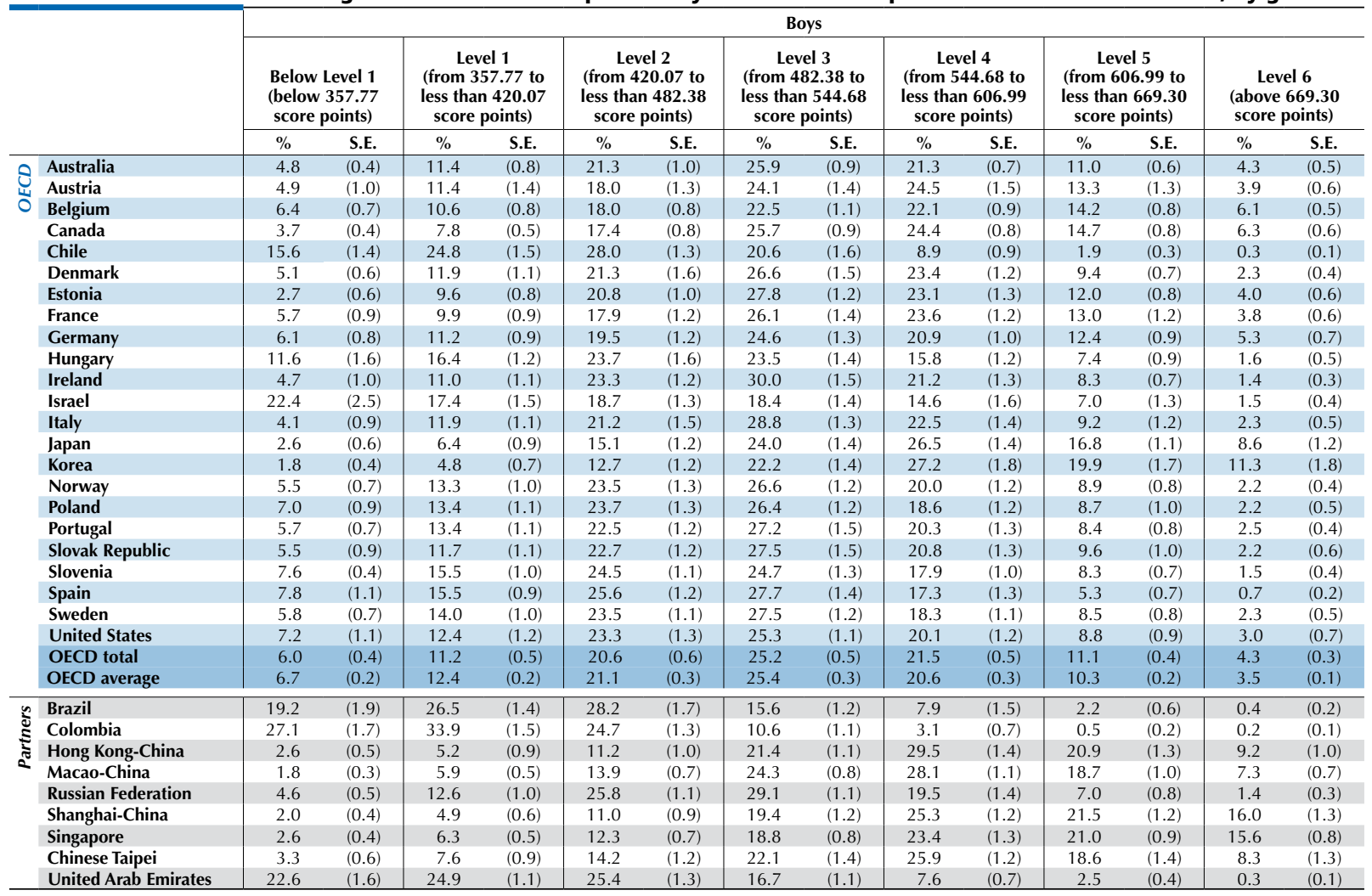

[Part 2/2]

Table B3.I.2 Percentage of students at each proficiency level on the computer-based mathematics scale, by gender

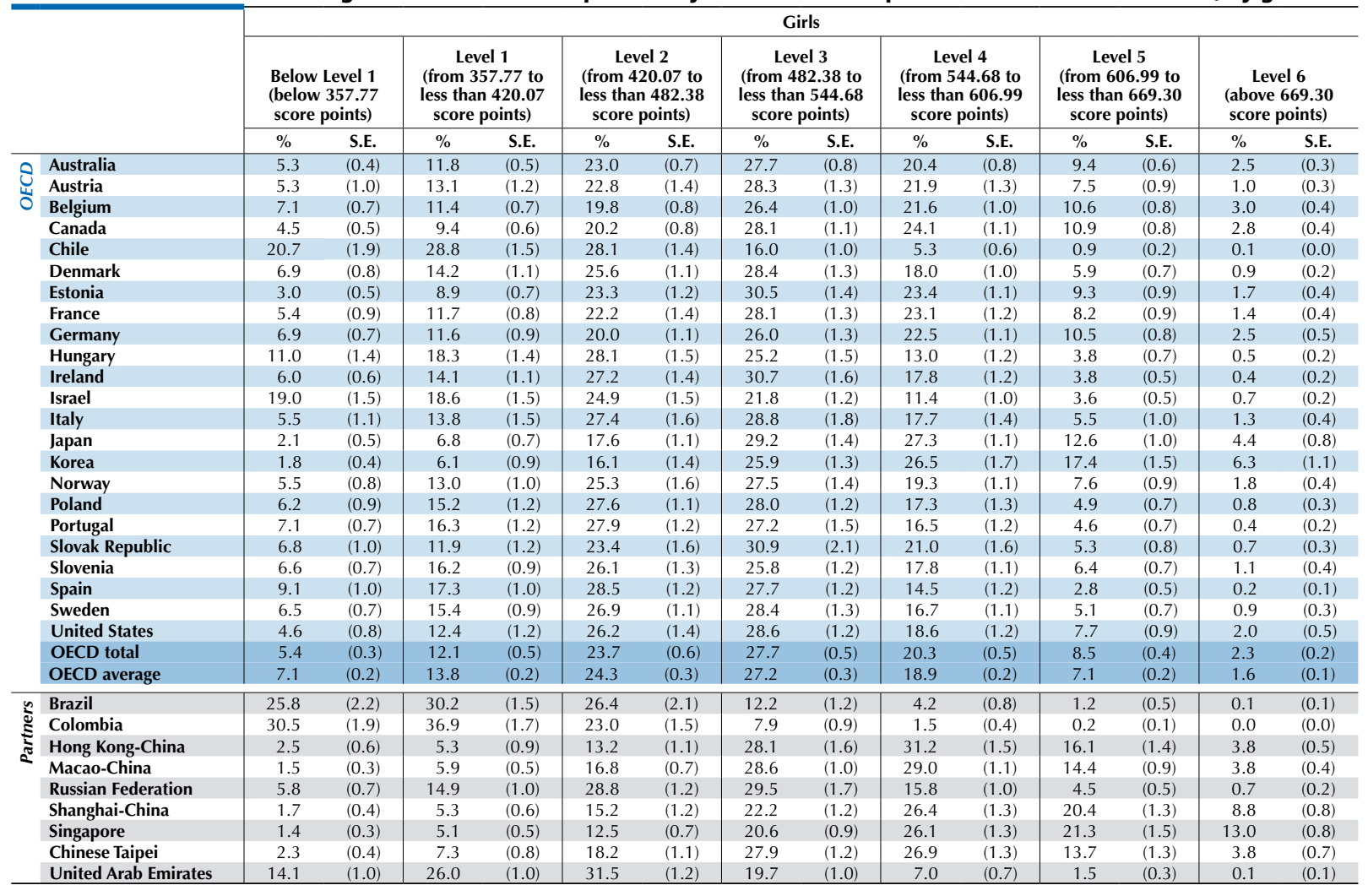

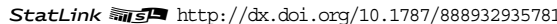


[Part 1/1]

Mean score, variation and gender differences in student performance on the computer-based Table B3.I.3 mathematics scale

\begin{tabular}{|c|c|c|c|c|c|c|c|c|c|c|c|c|c|c|c|c|c|c|c|c|c|c|c|}
\hline & & \multicolumn{4}{|c|}{ All students } & \multicolumn{6}{|c|}{ Gender differences } & \multicolumn{12}{|c|}{ Percentiles } \\
\hline & & \multicolumn{2}{|c|}{ Mean score } & \multicolumn{2}{|c|}{$\begin{array}{l}\text { Standard } \\
\text { deviation }\end{array}$} & \multicolumn{2}{|c|}{ Boys } & \multicolumn{2}{|c|}{ Girls } & \multicolumn{2}{|c|}{$\begin{array}{l}\text { Difference } \\
\quad(B-G)\end{array}$} & \multicolumn{2}{|c|}{ 5th } & \multicolumn{2}{|c|}{ 10th } & \multicolumn{2}{|c|}{ 25th } & \multicolumn{2}{|c|}{ 75th } & \multicolumn{2}{|c|}{ 90th } & \multicolumn{2}{|c|}{ 95th } \\
\hline & & Mean & S.E. & S.D. & S.E. & $\begin{array}{l}\begin{array}{l}\text { Mean } \\
\text { score }\end{array} \\
\end{array}$ & S.E. & $\begin{array}{l}\text { Mean } \\
\text { score }\end{array}$ & S.E. & $\begin{array}{c}\begin{array}{c}\text { Score } \\
\text { dif. }\end{array} \\
\end{array}$ & S.E. & Score & S.E. & Score & S.E. & Score & S.E. & Score & S.E. & Score & S.E. & Score & S.E. \\
\hline \multirow{25}{*}{ ত্ডি } & Australia & 508 & (1.6) & 91 & $(1.2)$ & 512 & $(2.2)$ & 503 & $(2.1)$ & 9 & $(2.8)$ & 357 & (3.3) & 391 & (2.9) & 447 & $(2.1)$ & 570 & (2.0) & 623 & $(2.7)$ & 654 & (3.3) \\
\hline & Austria & 507 & (3.5) & 89 & (2.2) & 518 & $(4.7)$ & 497 & (3.7) & 21 & (4.9) & 357 & (6.2) & 388 & (6.1) & 447 & $(5.0)$ & 571 & (3.7) & 619 & $(4.8)$ & 646 & (5.1) \\
\hline & Belgium & 512 & $(2.5)$ & 99 & (1.6) & 519 & (2.9) & 505 & (2.9) & 14 & $(3.1)$ & 342 & (5.0) & 382 & (4.1) & 447 & (3.8) & 582 & (2.8) & 637 & (3.4) & 666 & (3.3) \\
\hline & Canada & 523 & $(2.2)$ & 92 & (1.5) & 532 & (2.5) & 514 & (2.3) & 17 & (1.9) & 369 & (4.3) & 406 & (3.3) & 465 & (2.4) & 585 & (2.5) & 635 & (3.1) & 666 & (3.9) \\
\hline & Chile & 432 & (3.3) & 81 & (1.6) & 442 & (3.9) & 423 & (3.7) & 19 & (3.9) & 301 & (5.3) & 330 & (4.5) & 376 & $(4.1)$ & 488 & (4.0) & 538 & (4.3) & 567 & (3.6) \\
\hline & Denmark & 496 & $(2.7)$ & 86 & (1.4) & 506 & (3.2) & 486 & (2.8) & 20 & (2.5) & 349 & (5.4) & 383 & (4.5) & 439 & (3.7) & 557 & (2.9) & 604 & (3.3) & 633 & (4.1) \\
\hline & Estonia & 516 & $(2.2)$ & 82 & (1.4) & 521 & (2.6) & 512 & (2.5) & 9 & $(2.5)$ & 380 & (4.7) & 411 & (3.4) & 462 & (3.1) & 573 & (2.5) & 621 & (3.2) & 650 & (3.8) \\
\hline & France & 508 & (3.3) & 92 & (4.1) & 516 & (3.7) & 501 & (3.5) & 15 & (3.0) & 353 & (8.3) & 390 & (5.8) & 450 & (3.7) & 572 & (3.3) & 620 & $(4.0)$ & 647 & (4.4) \\
\hline & Germany & 509 & (3.3) & 95 & (2.0) & 514 & (3.7) & 504 & (3.5) & 10 & (2.7) & 345 & (5.6) & 382 & (6.1) & 446 & (4.5) & 577 & (4.0) & 629 & $(4.0)$ & 660 & $(5.4)$ \\
\hline & Hungary & 470 & (3.9) & 93 & (2.6) & 476 & (4.5) & 464 & $(4.1)$ & 12 & (3.8) & 313 & (7.3) & 350 & (7.3) & 410 & (4.8) & 534 & (4.5) & 587 & (6.0) & 619 & (6.1) \\
\hline & Ireland & 493 & (2.9) & 81 & (2.0) & 502 & (3.9) & 484 & (3.0) & 19 & (3.7) & 355 & (6.2) & 388 & (4.6) & 442 & (3.8) & 548 & (2.8) & 594 & (3.0) & 619 & (3.2) \\
\hline & Israel & 447 & (5.6) & 111 & (3.5) & 448 & (9.2) & 445 & (4.3) & 3 & (8.9) & 252 & (10.4) & 299 & (9.2) & 375 & (6.7) & 525 & (5.7) & 586 & (6.9) & 617 & (7.0) \\
\hline & Italy & 499 & (4.2) & 83 & (2.6) & 507 & (4.6) & 489 & $(4.9)$ & 18 & (5.0) & 360 & (6.9) & 391 & (6.3) & 443 & $(5.2)$ & 556 & (5.1) & 604 & (5.8) & 631 & $(6.5)$ \\
\hline & Japan & 539 & (3.3) & 88 & (2.4) & 546 & (4.4) & 531 & (3.0) & 15 & (3.8) & 391 & (6.0) & 426 & (5.0) & 482 & (4.1) & 597 & (3.7) & 649 & $(4.7)$ & 682 & (6.1) \\
\hline & Korea & 553 & (4.5) & 90 & (2.3) & 561 & (6.0) & 543 & $(5.2)$ & 18 & $(6.7)$ & 403 & (5.3) & 437 & (5.4) & 494 & (5.0) & 615 & (5.3) & 665 & (5.9) & 695 & $(8.2)$ \\
\hline & Norway & 498 & $(2.8)$ & 87 & (1.6) & 499 & (3.1) & 496 & (3.1) & 3 & $(2.8)$ & 354 & (5.4) & 386 & (4.2) & 439 & $(4.0)$ & 557 & (3.4) & 608 & (3.3) & 637 & (4.3) \\
\hline & Poland & 489 & $(4.0)$ & 86 & (2.0) & 495 & $(4.4)$ & 484 & $(4.2)$ & 11 & (3.2) & 345 & (5.9) & 380 & (5.5) & 432 & $(4.2)$ & 548 & (4.1) & 599 & (5.1) & 628 & (5.3) \\
\hline & Portugal & 489 & (3.1) & 85 & (1.6) & 499 & (3.5) & 479 & (3.1) & 20 & (2.3) & 347 & (4.9) & 378 & $(4.7)$ & 431 & (4.3) & 549 & (3.3) & 598 & (3.7) & 626 & $(4.6)$ \\
\hline & Slovak Republic & 497 & (3.5) & 86 & (2.4) & 503 & $(4.0)$ & 491 & $(4.0)$ & 11 & (3.9) & 348 & (7.5) & 384 & (6.5) & 443 & $(4.7)$ & 557 & (3.9) & 603 & $(4.0)$ & 630 & (5.0) \\
\hline & Slovenia & 487 & $(1.2)$ & 88 & (1.0) & 488 & (1.9) & 486 & (1.8) & 3 & $(3.0)$ & 341 & (3.1) & 375 & (2.4) & 426 & (2.3) & 549 & (1.7) & 601 & $(2.8)$ & 629 & (2.9) \\
\hline & Spain & 475 & (3.2) & 82 & (1.5) & 481 & (3.4) & 469 & (3.4) & 12 & (2.5) & 335 & (6.3) & 367 & (5.2) & 421 & $(4.2)$ & 533 & (3.1) & 577 & (3.4) & 603 & (3.6) \\
\hline & Sweden & 490 & (2.9) & 86 & (1.6) & 497 & (3.4) & 483 & (3.0) & 13 & $(2.8)$ & 349 & (4.2) & 380 & (4.1) & 432 & (3.6) & 548 & (3.3) & 600 & $(3.7)$ & 629 & (5.1) \\
\hline & United States & 498 & $(4.1)$ & 89 & (2.2) & 498 & (4.4) & 498 & $(4.2)$ & 0 & (3.0) & 350 & (7.7) & 386 & (5.5) & 440 & (4.5) & 558 & (4.3) & 611 & (5.9) & 643 & (6.3) \\
\hline & OECD total & 505 & $(0.2)$ & 92 & (0.1) & 510 & $(0.3)$ & 500 & $(0.6)$ & 10 & $(0.8)$ & 351 & (1.2) & 387 & $(0.8)$ & 445 & (1.4) & 568 & $(0.4)$ & 622 & $(0.6)$ & 653 & (1.0) \\
\hline & OECD average & 497 & $(0.7)$ & 89 & (0.4) & 503 & $(0.8)$ & 491 & $(0.6)$ & 13 & $(0.7)$ & 348 & (1.0) & 382 & (0.9) & 439 & $(0.8)$ & 559 & $(0.7)$ & 609 & $(0.8)$ & 638 & (1.0) \\
\hline \multirow{9}{*}{ ఏँ } & Brazil & 421 & $(4.7)$ & 84 & (3.1) & 432 & $(5.0)$ & 410 & $(4.7)$ & 22 & $(2.4)$ & 291 & $(6.2)$ & 319 & (4.7) & 364 & (4.9) & 473 & (5.4) & 530 & (9.0) & 567 & (10.9) \\
\hline & Colombia & 397 & (3.2) & 73 & (1.8) & 403 & (3.5) & 391 & (3.6) & 12 & (3.3) & 280 & (5.8) & 307 & (4.4) & 350 & (3.5) & 443 & (3.8) & 490 & $(4.5)$ & 521 & (5.9) \\
\hline & Hong Kong-China & 550 & (3.4) & 87 & (2.3) & 558 & (4.4) & 540 & (3.5) & 17 & (4.3) & 394 & (9.1) & 435 & (6.3) & 499 & $(4.8)$ & 608 & (3.2) & 654 & (3.8) & 680 & (3.8) \\
\hline & Macao-China & 543 & (1.1) & 83 & $(0.8)$ & 549 & (1.3) & 536 & (1.7) & 13 & (2.0) & 401 & (3.5) & 433 & $(2.7)$ & 489 & $(2.0)$ & 600 & (1.5) & 647 & (2.3) & 674 & $(2.4)$ \\
\hline & Russian Federation & 489 & (2.6) & 80 & (1.5) & 496 & (3.0) & 482 & (2.9) & 14 & (2.8) & 356 & (4.3) & 387 & (3.8) & 436 & (3.0) & 544 & (2.9) & 590 & (3.8) & 619 & $(4.1)$ \\
\hline & Shanghai-China & 562 & (3.4) & 94 & (2.1) & 572 & (4.1) & 553 & (3.3) & 18 & $(2.9)$ & 404 & (5.9) & 439 & (5.3) & 500 & (5.1) & 628 & (3.5) & 679 & (3.5) & 708 & $(4.7)$ \\
\hline & Singapore & 566 & $(1.3)$ & 98 & (1.0) & 566 & (1.8) & 566 & (1.6) & 1 & $(2.3)$ & 399 & (3.7) & 434 & (2.9) & 500 & (2.6) & 635 & (2.0) & 689 & (2.9) & 717 & (2.5) \\
\hline & Chinese Taipei & 537 & $(2.8)$ & 89 & (1.9) & 545 & (4.6) & 530 & $(4.1)$ & 15 & $(6.7)$ & 386 & (6.1) & 419 & (4.6) & 478 & (3.9) & 600 & (3.1) & 649 & (3.8) & 676 & $(4.2)$ \\
\hline & United Arab Emirates & 434 & (2.2) & 84 & (1.5) & 428 & (3.6) & 440 & (2.6) & -13 & (4.4) & 297 & (3.8) & 327 & (3.2) & 378 & (2.8) & 490 & (2.7) & 542 & (3.4) & 575 & $(4.2)$ \\
\hline
\end{tabular}


[Part 1/1]

Table B3.I.4 Percentage of students at each proficiency level on the combined mathematics scale

\begin{tabular}{|c|c|c|c|c|c|c|c|c|c|c|c|c|c|c|c|}
\hline & & \multicolumn{14}{|c|}{ All students } \\
\hline & & \multicolumn{2}{|c|}{$\begin{array}{c}\text { Below Level } 1 \\
\text { (below 357.77 } \\
\text { score points) }\end{array}$} & \multicolumn{2}{|c|}{$\begin{array}{c}\text { Level } 1 \\
\text { (from } 357.77 \text { to } \\
\text { less than } 420.07 \\
\text { score points) }\end{array}$} & \multicolumn{2}{|c|}{$\begin{array}{c}\text { Level } 2 \\
\text { (from } 420.07 \text { to } \\
\text { less than } 482.38 \\
\text { score points) }\end{array}$} & \multicolumn{2}{|c|}{$\begin{array}{c}\text { Level } 3 \\
\text { (from } 482.38 \text { to } \\
\text { less than } 544.68 \\
\text { score points) }\end{array}$} & \multicolumn{2}{|c|}{$\begin{array}{c}\text { Level } 4 \\
\text { (from } 544.68 \text { to } \\
\text { less than } 606.99 \\
\text { score points) }\end{array}$} & \multicolumn{2}{|c|}{$\begin{array}{c}\text { Level } 5 \\
\text { (from } 606.99 \text { to } \\
\text { less than } 669.30 \\
\text { score points) }\end{array}$} & \multicolumn{2}{|c|}{$\begin{array}{c}\text { Level } 6 \\
\text { (above 669.30 } \\
\text { score points) }\end{array}$} \\
\hline & & $\%$ & S.E. & $\%$ & S.E. & $\%$ & S.E. & $\%$ & S.E. & $\%$ & S.E. & $\%$ & S.E. & $\%$ & S.E. \\
\hline \multirow{25}{*}{ రి } & Australia & 4.9 & $(0.3)$ & 12.6 & $(0.5)$ & 22.7 & $(0.6)$ & 26.2 & $(0.6)$ & 19.8 & $(0.6)$ & 10.3 & $(0.4)$ & 3.4 & $(0.3)$ \\
\hline & Austria & 4.7 & $(0.6)$ & 12.7 & (1.0) & 21.7 & $(0.8)$ & 25.6 & (1.0) & 22.6 & $(0.9)$ & 10.4 & $(0.8)$ & 2.3 & $(0.3)$ \\
\hline & Belgium & 5.9 & $(0.5)$ & 11.9 & $(0.7)$ & 19.2 & $(0.7)$ & 24.1 & $(0.8)$ & 21.6 & $(0.7)$ & 12.6 & $(0.5)$ & 4.6 & $(0.3)$ \\
\hline & Canada & 3.0 & $(0.3)$ & 9.1 & (0.4) & 20.5 & $(0.6)$ & 27.8 & $(0.6)$ & 23.9 & $(0.7)$ & 12.0 & $(0.6)$ & 3.7 & (0.3) \\
\hline & Chile & 18.5 & (1.3) & 30.4 & (1.1) & 27.5 & $(1.1)$ & 16.4 & $(0.9)$ & 6.0 & $(0.6)$ & 1.1 & $(0.2)$ & 0.1 & $(0.0)$ \\
\hline & Denmark & 4.4 & $(0.5)$ & 13.0 & $(0.7)$ & 24.4 & $(0.8)$ & 29.3 & (1.4) & 20.1 & $(1.0)$ & 7.5 & $(0.5)$ & 1.3 & $(0.2)$ \\
\hline & Estonia & 1.9 & $(0.3)$ & 8.7 & (0.6) & 22.3 & (1.0) & 30.4 & (1.0) & 23.6 & $(0.9)$ & 10.5 & $(0.7)$ & 2.6 & (0.3) \\
\hline & France & 6.5 & $(0.7)$ & 12.4 & $(0.7)$ & 21.7 & $(1.0)$ & 25.8 & $(1.0)$ & 21.1 & $(0.9)$ & 10.0 & $(0.6)$ & 2.4 & (0.4) \\
\hline & Germany & 5.4 & $(0.5)$ & 11.5 & $(0.8)$ & 20.6 & $(0.8)$ & 24.8 & $(0.9)$ & 22.1 & $(0.8)$ & 12.0 & $(0.8)$ & 3.7 & (0.4) \\
\hline & Hungary & 9.8 & $(0.9)$ & 18.2 & (1.1) & 26.6 & $(1.2)$ & 23.6 & (1.1) & 14.6 & $(0.9)$ & 6.0 & $(0.7)$ & 1.2 & (0.4) \\
\hline & Ireland & 4.5 & $(0.5)$ & 11.8 & $(0.7)$ & 25.6 & $(0.8)$ & 30.1 & (1.0) & 20.2 & $(0.9)$ & 6.8 & $(0.5)$ & 1.1 & $(0.2)$ \\
\hline & Israel & 17.7 & $(1.4)$ & 18.2 & (1.0) & 22.3 & $(0.9)$ & 20.7 & $(1.0)$ & 14.1 & (1.0) & 5.9 & $(0.7)$ & 1.2 & (0.3) \\
\hline & Italy & 5.5 & $(0.8)$ & 13.7 & (1.0) & 25.1 & (1.3) & 28.1 & $(1.3)$ & 19.3 & (1.1) & 7.0 & $(0.8)$ & 1.4 & (0.3) \\
\hline & Japan & 2.3 & $(0.4)$ & 6.8 & (0.6) & 16.8 & $(0.9)$ & 26.3 & (1.0) & 26.0 & $(1.0)$ & 15.4 & $(0.9)$ & 6.3 & (0.8) \\
\hline & Korea & 1.8 & $(0.3)$ & 5.7 & $(0.6)$ & 14.5 & $(0.9)$ & 23.5 & $(1.0)$ & 25.4 & $(1.0)$ & 19.3 & $(0.9)$ & 9.8 & (1.2) \\
\hline & Norway & 5.6 & $(0.5)$ & 14.1 & $(0.7)$ & 25.2 & $(0.9)$ & 27.2 & (1.1) & 19.0 & (1.1) & 7.6 & $(0.6)$ & 1.5 & (0.3) \\
\hline & Poland & 4.2 & $(0.5)$ & 12.4 & $(0.8)$ & 24.5 & $(1.0)$ & 27.3 & $(0.9)$ & 19.9 & $(0.9)$ & 8.9 & $(0.8)$ & 2.6 & $(0.5)$ \\
\hline & Portugal & 6.6 & $(0.7)$ & 16.0 & (1.0) & 24.5 & $(0.8)$ & 26.4 & $(0.9)$ & 17.9 & (1.1) & 7.3 & (0.6) & 1.3 & $(0.2)$ \\
\hline & Slovak Republic & 7.9 & (0.9) & 14.2 & (1.0) & 24.3 & (1.4) & 25.4 & $(1.2)$ & 18.9 & (1.1) & 7.5 & $(0.6)$ & 1.9 & (0.5) \\
\hline & Slovenia & 5.4 & $(0.4)$ & 15.6 & (0.6) & 24.7 & $(0.9)$ & 25.1 & $(0.8)$ & 18.1 & (1.0) & 9.0 & $(0.6)$ & 1.9 & (0.3) \\
\hline & Spain & 6.6 & $(0.6)$ & 16.5 & $(1.0)$ & 27.4 & $(0.9)$ & 28.5 & $(0.9)$ & 16.3 & $(0.8)$ & 4.3 & $(0.4)$ & 0.4 & $(0.1)$ \\
\hline & Sweden & 6.5 & $(0.5)$ & 16.9 & $(0.8)$ & 25.8 & $(1.0)$ & 26.4 & $(0.8)$ & 17.1 & $(0.8)$ & 6.1 & $(0.4)$ & 1.2 & $(0.2)$ \\
\hline & United States & 6.0 & $(0.7)$ & 15.2 & (1.0) & 26.5 & $(1.0)$ & 25.9 & $(1.0)$ & 17.4 & $(1.0)$ & 7.1 & $(0.7)$ & 2.0 & $(0.3)$ \\
\hline & OECD total & 5.5 & $(0.3)$ & 13.1 & $(0.4)$ & 23.1 & $(0.4)$ & 25.8 & $(0.4)$ & 19.8 & $(0.4)$ & 9.6 & $(0.3)$ & 3.1 & $(0.2)$ \\
\hline & OECD average & 6.3 & $(0.1)$ & 13.8 & $(0.2)$ & 23.2 & $(0.2)$ & 25.9 & $(0.2)$ & 19.3 & $(0.2)$ & 8.9 & $(0.1)$ & 2.5 & (0.1) \\
\hline \multirow{9}{*}{ ఏँ় } & Brazil & 26.3 & $(1.8)$ & 32.8 & $(1.3)$ & 24.0 & $(1.3)$ & 11.7 & $(1.0)$ & 4.1 & $(0.7)$ & 0.9 & $(0.3)$ & 0.1 & $(0.1)$ \\
\hline & Colombia & 34.9 & (1.6) & 35.9 & (1.1) & 20.7 & $(1.0)$ & 6.8 & $(0.6)$ & 1.5 & $(0.3)$ & 0.2 & $(0.1)$ & 0.0 & $(0.0)$ \\
\hline & Hong Kong-China & 2.2 & $(0.3)$ & 5.1 & $(0.7)$ & 11.9 & $(0.7)$ & 22.7 & $(1.0)$ & 29.4 & $(1.1)$ & 20.5 & $(1.1)$ & 8.2 & $(0.8)$ \\
\hline & Macao-China & 2.1 & $(0.2)$ & 6.5 & $(0.4)$ & 15.8 & $(0.5)$ & 26.0 & $(0.6)$ & 27.1 & $(0.7)$ & 16.7 & $(0.6)$ & 5.8 & (0.3) \\
\hline & Russian Federation & 5.3 & $(0.6)$ & 15.0 & $(0.9)$ & 28.4 & $(0.9)$ & 28.3 & $(0.9)$ & 16.6 & $(0.9)$ & 5.4 & $(0.6)$ & 0.9 & $(0.2)$ \\
\hline & Shanghai-China & 1.0 & $(0.2)$ & 3.5 & $(0.5)$ & 9.7 & $(0.7)$ & 17.1 & $(0.8)$ & 24.3 & $(0.9)$ & 24.6 & $(1.0)$ & 19.8 & (1.0) \\
\hline & Singapore & 1.9 & $(0.2)$ & 5.7 & $(0.4)$ & 12.3 & $(0.7)$ & 19.0 & $(0.6)$ & 23.5 & $(0.8)$ & 21.5 & $(0.7)$ & 16.2 & (0.5) \\
\hline & Chinese Taipei & 3.1 & $(0.4)$ & 8.0 & (0.6) & 14.7 & $(0.6)$ & 20.4 & $(0.8)$ & 23.9 & $(0.9)$ & 19.2 & $(0.9)$ & 10.7 & (0.8) \\
\hline & United Arab Emirates & 18.2 & $(0.8)$ & 27.4 & $(0.8)$ & 26.9 & $(0.7)$ & 17.5 & $(0.7)$ & 7.6 & $(0.5)$ & 2.0 & $(0.3)$ & 0.3 & $(0.1)$ \\
\hline
\end{tabular}

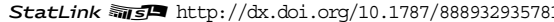


[Part 1/2]

Table B3.I.5 Percentage of students at each proficiency level on the combined mathematics scale, by gender

\begin{tabular}{|c|c|c|c|c|c|c|c|c|c|c|c|c|c|c|c|}
\hline & \multicolumn{14}{|c|}{ Boys } \\
\hline & & \multicolumn{2}{|c|}{$\begin{array}{l}\text { Below Level } 1 \\
\text { (below } 357.77 \\
\text { score points) }\end{array}$} & \multicolumn{2}{|c|}{$\begin{array}{c}\text { Level } 1 \\
\text { (from } 357.77 \text { to } \\
\text { less than } 420.07 \\
\text { score points) }\end{array}$} & \multicolumn{2}{|c|}{$\begin{array}{c}\text { Level } 2 \\
\text { (from } 420.07 \text { to } \\
\text { less than } 482.38 \\
\text { score points) }\end{array}$} & \multicolumn{2}{|c|}{$\begin{array}{c}\text { Level } 3 \\
\text { (from } 482.38 \text { to } \\
\text { less than } 544.68 \\
\text { score points) }\end{array}$} & \multicolumn{2}{|c|}{$\begin{array}{c}\text { Level } 4 \\
\text { (from } 544.68 \text { to } \\
\text { less than } 606.99 \\
\text { score points) }\end{array}$} & \multicolumn{2}{|c|}{$\begin{array}{c}\text { Level } 5 \\
\text { (from } 606.99 \text { to } \\
\text { less than } 669.30 \\
\text { score points) }\end{array}$} & \multicolumn{2}{|c|}{$\begin{array}{c}\text { Level } 6 \\
\text { (above } 669.30 \\
\text { score points) }\end{array}$} \\
\hline & & $\%$ & S.E. & $\%$ & S.E. & $\%$ & S.E. & $\%$ & S.E. & $\%$ & S.E. & $\%$ & S.E. & $\%$ & S.E. \\
\hline \multirow{25}{*}{ ড్ } & Australia & 4.7 & $(0.4)$ & 12.1 & $(0.6)$ & 22.0 & (0.9) & 25.4 & $(0.7)$ & 20.2 & $(0.7)$ & 11.2 & $(0.5)$ & 4.4 & (0.6) \\
\hline & Austria & 4.2 & $(0.8)$ & 11.4 & $(1.2)$ & 19.6 & (1.3) & 24.2 & (1.3) & 23.8 & $(1.2)$ & 13.1 & (1.1) & 3.6 & (0.6) \\
\hline & Belgium & 5.7 & $(0.7)$ & 11.8 & $(0.9)$ & 17.6 & (1.0) & 22.9 & (1.0) & 21.7 & $(0.9)$ & 14.2 & $(0.9)$ & 6.0 & (0.5) \\
\hline & Canada & 2.7 & $(0.3)$ & 8.4 & $(0.5)$ & 19.3 & $(0.7)$ & 26.5 & $(0.8)$ & 24.2 & $(0.8)$ & 13.8 & $(0.8)$ & 5.1 & (0.6) \\
\hline & Chile & 15.0 & $(1.3)$ & 27.9 & (1.3) & 28.3 & (1.2) & 19.2 & $(1.2)$ & 7.9 & $(0.9)$ & 1.6 & $(0.3)$ & 0.2 & (0.1) \\
\hline & Denmark & 3.8 & (0.5) & 11.5 & $(0.9)$ & 22.6 & $(1.2)$ & 29.0 & (1.7) & 22.5 & (1.3) & 8.7 & $(0.7)$ & 1.9 & $(0.3)$ \\
\hline & Estonia & 1.7 & $(0.4)$ & 9.1 & $(0.8)$ & 21.2 & (1.3) & 29.1 & (1.4) & 23.5 & (1.1) & 11.9 & $(0.8)$ & 3.5 & (0.5) \\
\hline & France & 6.7 & $(0.8)$ & 11.5 & $(1.0)$ & 20.8 & (1.3) & 24.0 & (1.3) & 21.3 & (1.1) & 12.3 & $(0.9)$ & 3.4 & (0.6) \\
\hline & Germany & 5.2 & $(0.6)$ & 10.7 & $(0.9)$ & 19.9 & $(1.2)$ & 24.2 & (1.0) & 21.7 & $(1.0)$ & 13.5 & $(0.9)$ & 4.8 & (0.6) \\
\hline & Hungary & 9.9 & $(1.1)$ & 17.1 & (1.4) & 25.4 & (1.5) & 22.4 & (1.4) & 15.7 & (1.1) & 7.6 & $(0.9)$ & 1.8 & (0.6) \\
\hline & Ireland & 4.1 & $(0.8)$ & 10.3 & $(1.0)$ & 22.8 & (1.1) & 30.5 & (1.5) & 22.1 & $(1.2)$ & 8.4 & $(0.9)$ & 1.8 & $(0.3)$ \\
\hline & Israel & 20.0 & $(2.1)$ & 16.8 & (1.5) & 19.0 & (1.3) & 18.5 & (1.5) & 15.6 & (1.6) & 8.2 & (1.3) & 1.8 & (0.5) \\
\hline & Italy & 5.2 & $(0.9)$ & 13.0 & $(1.2)$ & 23.2 & (1.7) & 27.2 & (1.7) & 20.9 & (1.4) & 8.7 & (1.0) & 1.8 & (0.5) \\
\hline & Japan & 2.6 & $(0.5)$ & 6.6 & $(0.8)$ & 15.2 & (1.0) & 23.6 & (1.1) & 26.0 & (1.3) & 17.6 & $(1.2)$ & 8.4 & (1.2) \\
\hline & Korea & 1.8 & $(0.4)$ & 5.5 & $(0.7)$ & 12.9 & (1.0) & 21.7 & (1.4) & 25.1 & (1.5) & 20.4 & $(1.2)$ & 12.6 & (1.8) \\
\hline & Norway & 5.8 & $(0.6)$ & 14.1 & $(0.9)$ & 24.3 & $(1.2)$ & 26.3 & $(1.3)$ & 20.1 & (1.6) & 7.7 & $(0.8)$ & 1.8 & $(0.3)$ \\
\hline & Poland & 4.7 & $(0.7)$ & 12.1 & $(0.9)$ & 23.2 & $(1.2)$ & 26.4 & (1.1) & 19.8 & $(1.3)$ & 10.3 & $(1.0)$ & 3.6 & $(0.8)$ \\
\hline & Portugal & 6.8 & $(0.8)$ & 14.1 & (1.3) & 22.0 & (1.3) & 26.6 & $(1.2)$ & 19.7 & (1.3) & 8.7 & $(0.7)$ & 2.1 & $(0.4)$ \\
\hline & Slovak Republic & 7.2 & $(0.9)$ & 14.5 & $(1.3)$ & 24.2 & (1.6) & 23.4 & $(1.5)$ & 18.7 & $(1.3)$ & 9.4 & $(1.0)$ & 2.6 & (0.6) \\
\hline & Slovenia & 5.6 & $(0.5)$ & 15.5 & $(0.9)$ & 24.1 & (1.1) & 24.9 & (1.4) & 17.7 & (1.6) & 9.9 & $(1.0)$ & 2.2 & $(0.5)$ \\
\hline & Spain & 6.1 & $(0.8)$ & 15.5 & $(1.1)$ & 26.3 & (1.4) & 27.5 & $(1.2)$ & 18.2 & (1.1) & 5.8 & $(0.6)$ & 0.6 & $(0.2)$ \\
\hline & Sweden & 7.0 & $(0.8)$ & 16.7 & $(1.2)$ & 24.6 & $(1.2)$ & 25.5 & $(1.2)$ & 17.5 & (1.1) & 7.3 & $(0.6)$ & 1.6 & $(0.4)$ \\
\hline & United States & 6.9 & $(0.9)$ & 15.6 & $(1.2)$ & 24.5 & (1.1) & 24.3 & $(1.1)$ & 18.8 & $(1.2)$ & 7.6 & $(0.7)$ & 2.3 & $(0.5)$ \\
\hline & OECD total & 5.8 & $(0.4)$ & 12.7 & $(0.5)$ & 21.6 & (0.5) & 24.4 & $(0.4)$ & 20.6 & $(0.5)$ & 10.9 & $(0.3)$ & 4.1 & (0.3) \\
\hline & OECD average & 6.2 & $(0.2)$ & 13.1 & $(0.2)$ & 21.9 & $(0.3)$ & 24.9 & $(0.3)$ & 20.1 & $(0.3)$ & 10.3 & $(0.2)$ & 3.4 & $(0.1)$ \\
\hline \multirow{9}{*}{ 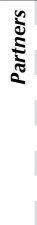 } & Brazil & 21.9 & $(2.0)$ & 31.8 & $(1.5)$ & 25.3 & (1.5) & 14.0 & (1.4) & 5.5 & (0.9) & 1.3 & $(0.4)$ & 0.2 & $(0.2)$ \\
\hline & Colombia & 30.7 & (1.9) & 34.5 & $(2.1)$ & 23.3 & (1.5) & 8.7 & $(1.0)$ & 2.4 & $(0.6)$ & 0.3 & $(0.1)$ & 0.0 & $(0.0)$ \\
\hline & Hong Kong-China & 2.2 & $(0.4)$ & 5.2 & $(0.8)$ & 11.5 & (1.1) & 19.5 & $(1.1)$ & 27.9 & $(1.4)$ & 22.6 & $(1.3)$ & 11.1 & (1.2) \\
\hline & Macao-China & 2.3 & $(0.4)$ & 6.9 & $(0.6)$ & 14.5 & $(0.7)$ & 24.3 & $(0.8)$ & 26.5 & $(1.0)$ & 18.2 & $(1.2)$ & 7.1 & (0.6) \\
\hline & Russian Federation & 5.2 & $(0.6)$ & 14.5 & (1.1) & 27.5 & (1.4) & 28.3 & $(1.2)$ & 17.3 & $(1.1)$ & 6.2 & $(0.7)$ & 1.0 & $(0.3)$ \\
\hline & Shanghai-China & 1.0 & $(0.2)$ & 3.7 & $(0.6)$ & 9.0 & $(0.8)$ & 15.8 & $(1.0)$ & 23.1 & $(1.0)$ & 24.6 & $(1.2)$ & 22.9 & (1.5) \\
\hline & Singapore & 2.5 & $(0.4)$ & 6.3 & $(0.5)$ & 12.5 & $(0.8)$ & 17.9 & $(0.8)$ & 22.0 & $(1.0)$ & 21.3 & $(0.8)$ & 17.5 & $(0.8)$ \\
\hline & Chinese Taipei & 3.7 & $(0.7)$ & 8.7 & $(0.8)$ & 13.2 & $(0.8)$ & 17.4 & $(1.1)$ & 23.2 & $(1.2)$ & 20.6 & $(1.0)$ & 13.1 & (1.6) \\
\hline & United Arab Emirates & 22.2 & $(1.5)$ & 26.6 & $(1.2)$ & 24.0 & $(1.2)$ & 15.9 & $(1.0)$ & 8.3 & $(0.9)$ & 2.6 & $(0.4)$ & 0.4 & $(0.1)$ \\
\hline
\end{tabular}

[Part 2/2]

Table B3.I.5 Percentage of students at each proficiency level on the combined mathematics scale, by gender

\begin{tabular}{|c|c|c|c|c|c|c|c|c|c|c|c|c|c|c|c|}
\hline & \multicolumn{14}{|c|}{ Girls } \\
\hline & & \multicolumn{2}{|c|}{$\begin{array}{l}\text { Below Level } 1 \\
\text { (below } 357.77 \\
\text { score points) }\end{array}$} & \multicolumn{2}{|c|}{$\begin{array}{c}\text { Level } 1 \\
\text { (from } 357.77 \text { to } \\
\text { less than } 420.07 \\
\text { score points) }\end{array}$} & \multicolumn{2}{|c|}{$\begin{array}{c}\text { Level } 2 \\
\text { (from } 420.07 \text { to } \\
\text { less than } 482.38 \\
\text { score points) }\end{array}$} & \multicolumn{2}{|c|}{$\begin{array}{c}\text { Level } 3 \\
\text { (from } 482.38 \text { to } \\
\text { less than } 544.68 \\
\text { score points) }\end{array}$} & \multicolumn{2}{|c|}{$\begin{array}{c}\text { Level } 4 \\
\text { (from } 544.68 \text { to } \\
\text { less than } 606.99 \\
\text { score points) }\end{array}$} & \multicolumn{2}{|c|}{$\begin{array}{c}\text { Level } 5 \\
\text { (from 606.99 to } \\
\text { less than } 669.30 \\
\text { score points) }\end{array}$} & \multicolumn{2}{|c|}{$\begin{array}{c}\text { Level } 6 \\
\text { (above } 669.30 \\
\text { score points) }\end{array}$} \\
\hline & & $\%$ & S.E. & $\%$ & S.E. & $\%$ & S.E. & $\%$ & S.E. & $\%$ & S.E. & $\%$ & S.E. & $\%$ & S.E. \\
\hline \multirow{25}{*}{ 仓ي } & Australia & 5.2 & $(0.4)$ & 13.2 & $(0.6)$ & 23.5 & $(0.8)$ & 27.0 & $(0.9)$ & 19.4 & $(0.8)$ & 9.3 & $(0.7)$ & 2.4 & $(0.4)$ \\
\hline & Austria & 5.2 & (0.9) & 14.0 & (1.4) & 23.7 & (1.3) & 27.1 & (1.3) & 21.4 & $(1.2)$ & 7.6 & (1.1) & 1.0 & $(0.3)$ \\
\hline & Belgium & 6.0 & $(0.7)$ & 12.0 & $(0.7)$ & 20.9 & $(0.9)$ & 25.3 & (1.1) & 21.6 & $(1.0)$ & 11.0 & $(0.7)$ & 3.2 & $(0.3)$ \\
\hline & Canada & 3.2 & $(0.4)$ & 9.8 & $(0.5)$ & 21.7 & $(0.8)$ & 29.1 & $(0.9)$ & 23.6 & $(0.8)$ & 10.2 & $(0.6)$ & 2.4 & $(0.3)$ \\
\hline & Chile & 21.9 & (1.7) & 32.7 & (1.4) & 26.7 & (1.6) & 13.8 & (1.0) & 4.2 & $(0.5)$ & 0.7 & $(0.1)$ & 0.0 & $(0.0)$ \\
\hline & Denmark & 5.0 & $(0.6)$ & 14.5 & $(0.9)$ & 26.2 & (1.3) & 29.6 & (1.6) & 17.7 & $(1.2)$ & 6.2 & $(0.7)$ & 0.8 & $(0.2)$ \\
\hline & Estonia & 2.0 & $(0.4)$ & 8.3 & $(0.8)$ & 23.3 & (1.1) & 31.7 & (1.3) & 23.8 & $(1.2)$ & 9.1 & $(0.9)$ & 1.8 & $(0.4)$ \\
\hline & France & 6.4 & $(0.9)$ & 13.2 & $(0.8)$ & 22.6 & (1.3) & 27.6 & (1.3) & 20.9 & (1.2) & 7.9 & $(0.7)$ & 1.5 & $(0.3)$ \\
\hline & Germany & 5.6 & $(0.6)$ & 12.4 & $(1.0)$ & 21.2 & (1.1) & 25.4 & $(1.2)$ & 22.5 & $(1.2)$ & 10.4 & $(0.9)$ & 2.5 & $(0.5)$ \\
\hline & Hungary & 9.6 & (1.1) & 19.1 & (1.4) & 27.7 & (1.5) & 24.8 & (1.4) & 13.5 & (1.1) & 4.6 & $(0.7)$ & 0.7 & $(0.2)$ \\
\hline & Ireland & 4.9 & $(0.6)$ & 13.2 & $(0.9)$ & 28.4 & (1.1) & 29.6 & (1.3) & 18.3 & (1.2) & 5.1 & $(0.6)$ & 0.5 & $(0.2)$ \\
\hline & Israel & 15.4 & (1.3) & 19.6 & $(1.1)$ & 25.4 & $(1.1)$ & 22.8 & $(1.1)$ & 12.5 & $(1.1)$ & 3.6 & $(0.5)$ & 0.6 & $(0.2)$ \\
\hline & Italy & 5.9 & (1.1) & 14.5 & (1.4) & 27.3 & (1.5) & 29.1 & (1.6) & 17.4 & (1.4) & 4.9 & $(0.8)$ & 0.9 & $(0.3)$ \\
\hline & Japan & 2.0 & $(0.4)$ & 7.1 & $(0.8)$ & 18.6 & $(1.2)$ & 29.3 & (1.5) & 26.0 & (1.1) & 13.0 & (1.0) & 3.9 & $(0.7)$ \\
\hline & Korea & 1.8 & (0.4) & 5.9 & $(0.8)$ & 16.3 & (1.4) & 25.7 & (1.2) & 25.7 & (1.4) & 18.1 & (1.3) & 6.5 & (1.0) \\
\hline & Norway & 5.3 & $(0.6)$ & 14.1 & $(1.0)$ & 26.1 & $(1.2)$ & 28.1 & (1.6) & 17.7 & $(1.0)$ & 7.5 & $(0.9)$ & 1.2 & $(0.3)$ \\
\hline & Poland & 3.7 & $(0.6)$ & 12.8 & (1.1) & 25.8 & (1.3) & 28.2 & $(1.2)$ & 20.0 & (1.3) & 7.7 & (1.0) & 1.7 & $(0.4)$ \\
\hline & Portugal & 6.5 & $(0.7)$ & 17.8 & $(1.2)$ & 26.9 & (1.1) & 26.3 & $(1.2)$ & 16.2 & (1.3) & 5.9 & $(0.6)$ & 0.4 & $(0.2)$ \\
\hline & Slovak Republic & 8.8 & $(1.1)$ & 13.8 & $(1.2)$ & 24.3 & $(1.7)$ & 27.6 & (1.6) & 19.1 & (1.5) & 5.4 & $(0.7)$ & 1.0 & $(0.4)$ \\
\hline & Slovenia & 5.2 & $(0.7)$ & 15.8 & $(0.9)$ & 25.4 & $(1.2)$ & 25.3 & $(1.2)$ & 18.6 & $(1.2)$ & 8.1 & $(0.8)$ & 1.6 & $(0.5)$ \\
\hline & Spain & 7.1 & $(0.8)$ & 17.5 & (1.3) & 28.5 & (1.1) & 29.6 & (1.1) & 14.4 & (1.1) & 2.8 & $(0.4)$ & 0.1 & $(0.1)$ \\
\hline & Sweden & 6.1 & $(0.7)$ & 17.1 & (1.1) & 27.1 & (1.4) & 27.4 & $(1.0)$ & 16.8 & $(1.1)$ & 4.8 & $(0.6)$ & 0.8 & $(0.2)$ \\
\hline & United States & 5.1 & $(0.9)$ & 14.9 & (1.3) & 28.5 & (1.3) & 27.5 & (1.3) & 15.8 & $(1.2)$ & 6.5 & $(0.8)$ & 1.7 & $(0.4)$ \\
\hline & OECD total & 5.3 & $(0.3)$ & 13.4 & $(0.5)$ & 24.8 & $(0.5)$ & 27.2 & $(0.5)$ & 18.9 & $(0.5)$ & 8.2 & $(0.3)$ & 2.1 & $(0.2)$ \\
\hline & OECD average & 6.4 & $(0.2)$ & 14.5 & $(0.2)$ & 24.6 & $(0.3)$ & 26.9 & $(0.3)$ & 18.6 & $(0.2)$ & 7.4 & $(0.2)$ & 1.6 & $(0.1)$ \\
\hline \multirow{9}{*}{ 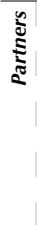 } & Brazil & 30.4 & $(2.1)$ & 33.7 & $(1.7)$ & 22.9 & $(1.6)$ & 9.6 & $(1.2)$ & 2.8 & $(0.7)$ & 0.6 & $(0.2)$ & 0.0 & $(0.0)$ \\
\hline & Colombia & 38.7 & $(2.0)$ & 37.1 & $(1.5)$ & 18.3 & (1.4) & 5.1 & $(0.8)$ & 0.8 & $(0.2)$ & 0.1 & $(0.1)$ & 0.0 & $(0.0)$ \\
\hline & Hong Kong-China & 2.2 & $(0.5)$ & 5.0 & $(0.9)$ & 12.3 & $(1.0)$ & 26.5 & $(1.6)$ & 31.1 & (1.4) & 18.1 & $(1.5)$ & 4.9 & $(0.8)$ \\
\hline & Macao-China & 1.9 & $(0.2)$ & 6.0 & $(0.5)$ & 17.1 & $(0.8)$ & 27.8 & $(0.9)$ & 27.7 & $(1.1)$ & 15.0 & $(0.9)$ & 4.5 & $(0.5)$ \\
\hline & Russian Federation & 5.5 & $(0.8)$ & 15.4 & $(1.2)$ & 29.3 & $(1.1)$ & 28.4 & $(1.2)$ & 16.0 & $(1.0)$ & 4.7 & $(0.6)$ & 0.8 & $(0.2)$ \\
\hline & Shanghai-China & 0.9 & $(0.2)$ & 3.3 & $(0.5)$ & 10.4 & $(0.9)$ & 18.3 & $(1.1)$ & 25.6 & $(1.3)$ & 24.6 & $(1.1)$ & 16.9 & $(1.1)$ \\
\hline & Singapore & 1.2 & $(0.3)$ & 5.0 & $(0.5)$ & 12.0 & $(0.9)$ & 20.1 & $(0.9)$ & 25.2 & $(1.0)$ & 21.7 & (1.1) & 14.8 & $(0.6)$ \\
\hline & Chinese Taipei & 2.6 & $(0.4)$ & 7.4 & $(0.7)$ & 16.0 & $(1.0)$ & 23.2 & $(1.2)$ & 24.5 & $(1.2)$ & 17.8 & $(1.3)$ & 8.4 & (1.4) \\
\hline & United Arab Emirates & 14.4 & $(1.0)$ & 28.1 & $(1.0)$ & 29.7 & (1.1) & 19.1 & $(1.0)$ & 7.0 & $(0.7)$ & 1.5 & $(0.3)$ & 0.2 & $(0.1)$ \\
\hline
\end{tabular}

StatLink 泀ist http://dx.doi.org/10.1787/88893293578 
[Part 1/1]

Mean score, variation and gender differences in student performance on the combined Table B3.I.6 mathematics scale

\begin{tabular}{|c|c|c|c|c|c|c|c|c|c|c|c|c|c|c|c|c|c|c|c|c|c|c|c|}
\hline & & \multicolumn{4}{|c|}{ All students } & \multicolumn{6}{|c|}{ Gender differences } & \multicolumn{12}{|c|}{ Percentiles } \\
\hline & & \multicolumn{2}{|c|}{ Mean score } & \multicolumn{2}{|c|}{$\begin{array}{l}\text { Standard } \\
\text { deviation }\end{array}$} & \multicolumn{2}{|c|}{ Boys } & \multicolumn{2}{|c|}{ Girls } & \multicolumn{2}{|c|}{$\begin{array}{c}\text { Difference } \\
(\mathbf{B}-\mathbf{G})\end{array}$} & \multicolumn{2}{|c|}{ 5th } & \multicolumn{2}{|c|}{ 10th } & \multicolumn{2}{|c|}{ 25th } & \multicolumn{2}{|c|}{ 75th } & \multicolumn{2}{|c|}{ 90th } & \multicolumn{2}{|c|}{ 95th } \\
\hline & & Mean & S.E. & S.D. & S.E. & $\begin{array}{l}\text { Mean } \\
\text { score }\end{array}$ & S.E. & $\begin{array}{l}\text { Mean } \\
\text { score }\end{array}$ & S.E. & \begin{tabular}{|c}
$\begin{array}{c}\text { Score } \\
\text { dif. }\end{array}$ \\
\end{tabular} & S.E. & Score & S.E. & Score & S.E. & Score & S.E. & Score & S.E. & Score & S.E. & Score & S.E. \\
\hline \multirow{25}{*}{ త్రి } & Australia & 506 & $(1.5)$ & 91 & $(1.2)$ & 511 & $(2.2)$ & 500 & (1.9) & 11 & $(2.9)$ & 358 & (2.7) & 390 & (2.3) & 443 & (1.7) & 568 & (2.1) & 624 & $(2.7)$ & 654 & $(3.1)$ \\
\hline & Austria & 506 & $(2.8)$ & 88 & (1.8) & 517 & $(4.0)$ & 496 & $(3.2)$ & 21 & $(4.7)$ & 360 & $(5.1)$ & 390 & (3.8) & 444 & (3.7) & 570 & (3.4) & 618 & (3.5) & 646 & $(4.3)$ \\
\hline & Belgium & 513 & $(2.2)$ & 96 & (1.4) & 520 & $(2.7)$ & 507 & (2.6) & 13 & $(3.1)$ & 350 & $(4.3)$ & 385 & (3.3) & 448 & (3.2) & 582 & (2.6) & 637 & (2.9) & 666 & $(2.7)$ \\
\hline & Canada & 520 & (1.9) & 85 & (0.9) & 527 & $(2.2)$ & 514 & $(2.0)$ & 14 & (1.9) & 378 & (2.9) & 410 & (2.6) & 462 & $(2.2)$ & 580 & $(2.1)$ & 629 & $(2.3)$ & 657 & (3.2) \\
\hline & Chile & 427 & (2.9) & 77 & (1.4) & 439 & (3.6) & 417 & (3.1) & 22 & (3.6) & 309 & (3.6) & 332 & (3.3) & 373 & (3.1) & 479 & (3.7) & 530 & (4.0) & 559 & $(4.0)$ \\
\hline & Denmark & 498 & (2.3) & 81 & (1.2) & 507 & (2.8) & 490 & (2.3) & 17 & (2.3) & 363 & (4.4) & 393 & (3.2) & 443 & (3.2) & 554 & $(2.7)$ & 602 & (3.2) & 629 & (3.7) \\
\hline & Estonia & 518 & (1.9) & 78 & (1.1) & 522 & (2.3) & 515 & (2.1) & 7 & $(2.4)$ & 390 & (3.7) & 418 & (2.8) & 465 & (2.7) & 572 & (2.3) & 620 & (3.1) & 649 & $(4.0)$ \\
\hline & France & 502 & (2.5) & 91 & (1.8) & 508 & (3.2) & 496 & $(2.7)$ & 12 & (3.0) & 346 & (5.8) & 379 & (4.6) & 440 & (3.0) & 566 & (2.9) & 617 & (3.4) & 645 & (4.5) \\
\hline & Germany & 511 & (2.9) & 93 & (1.6) & 517 & (3.2) & 506 & (3.2) & 12 & $(2.6)$ & 354 & (5.4) & 388 & (4.6) & 448 & (3.6) & 578 & (3.3) & 630 & $(4.0)$ & 659 & (4.1) \\
\hline & Hungary & 473 & (3.3) & 90 & $(2.3)$ & 479 & (3.8) & 468 & (3.7) & 10 & (3.5) & 328 & (5.1) & 359 & $(4.4)$ & 412 & $(4.4)$ & 535 & $(4.4)$ & 592 & $(6.3)$ & 624 & (7.7) \\
\hline & Ireland & 497 & (2.3) & 79 & (1.4) & 506 & (3.3) & 489 & (2.3) & 17 & (3.4) & 362 & (4.7) & 395 & $(4.2)$ & 445 & (2.9) & 552 & $(2.2)$ & 597 & $(2.3)$ & 624 & (2.4) \\
\hline & Israel & 457 & $(5.0)$ & 104 & (2.4) & 460 & (8.3) & 453 & (3.6) & 7 & $(8.0)$ & 281 & (7.1) & 320 & (6.7) & 385 & (5.4) & 532 & (5.7) & 590 & $(6.3)$ & 623 & (5.5) \\
\hline & Italy & 493 & (3.7) & 82 & $(2.2)$ & 500 & (4.4) & 486 & $(4.2)$ & 14 & $(4.7)$ & 354 & (6.3) & 386 & (5.3) & 437 & $(4.1)$ & 552 & (4.4) & 600 & (4.7) & 626 & (5.7) \\
\hline & Japan & 538 & (3.3) & 87 & (2.3) & 545 & (4.4) & 529 & $(3.1)$ & 16 & (3.9) & 391 & (6.9) & 424 & $(4.8)$ & 480 & $(4.1)$ & 598 & (3.9) & 648 & (4.4) & 678 & (5.6) \\
\hline & Korea & 553 & $(4.4)$ & 91 & $(2.1)$ & 561 & $(5.7)$ & 544 & $(4.9)$ & 18 & $(6.2)$ & 401 & (5.6) & 434 & $(5.0)$ & 491 & $(4.8)$ & 618 & (4.4) & 668 & $(5.7)$ & 696 & (6.8) \\
\hline & Norway & 493 & (2.4) & 85 & (1.2) & 495 & (2.6) & 492 & (3.0) & 3 & (2.8) & 354 & $(4.0)$ & 384 & (4.0) & 435 & (3.1) & 552 & (3.3) & 603 & (3.1) & 631 & (3.6) \\
\hline & Poland & 503 & (3.6) & 85 & (1.7) & 507 & $(4.1)$ & 500 & (3.7) & 7 & $(3.2)$ & 364 & $(4.2)$ & 395 & (3.6) & 445 & (3.5) & 562 & (4.7) & 614 & (5.5) & 644 & (6.9) \\
\hline & Portugal & 488 & $(3.2)$ & 86 & (1.3) & 496 & (3.6) & 480 & $(3.2)$ & 16 & $(2.2)$ & 347 & $(4.7)$ & 376 & (3.8) & 427 & (4.6) & 549 & (3.5) & 600 & (3.7) & 627 & $(4.2)$ \\
\hline & Slovak Republic & 489 & (3.3) & 90 & $(2.2)$ & 494 & (3.9) & 484 & (3.8) & 10 & $(4.1)$ & 337 & (5.8) & 371 & (6.1) & 429 & (4.3) & 553 & (3.6) & 604 & $(4.3)$ & 635 & (5.1) \\
\hline & Slovenia & 494 & $(1.2)$ & 87 & (1.0) & 495 & (1.9) & 493 & (1.9) & 3 & (3.0) & 355 & $(2.8)$ & 382 & $(2.8)$ & 431 & $(2.0)$ & 557 & (2.1) & 610 & (2.1) & 639 & (4.1) \\
\hline & Spain & 479 & $(2.4)$ & 79 & (1.1) & 485 & (2.8) & 473 & (2.6) & 13 & $(2.4)$ & 347 & $(4.2)$ & 375 & (3.4) & 425 & (3.0) & 535 & (2.7) & 580 & $(2.7)$ & 605 & $(2.8)$ \\
\hline & Sweden & 484 & $(2.2)$ & 85 & (1.3) & 487 & (2.9) & 481 & $(2.4)$ & 5 & $(2.8)$ & 348 & (3.7) & 375 & (2.9) & 425 & $(2.7)$ & 543 & (2.9) & 593 & $(3.2)$ & 622 & (3.6) \\
\hline & United States & 490 & $(3.7)$ & 86 & (1.6) & 491 & (3.9) & 488 & (3.9) & 2 & $(2.7)$ & 350 & $(5.0)$ & 380 & $(4.6)$ & 430 & (3.9) & 549 & (4.5) & 602 & (5.1) & 635 & $(5.2)$ \\
\hline & OECD total & 502 & $(0.4)$ & 90 & $(0.4)$ & 507 & $(0.5)$ & 497 & $(0.3)$ & 10 & $(0.5)$ & 354 & (1.6) & 385 & $(0.8)$ & 440 & $(0.9)$ & 565 & $(0.7)$ & 619 & $(0.7)$ & 651 & (1.9) \\
\hline & OECD average & 497 & $(0.6)$ & 87 & $(0.3)$ & 503 & $(0.7)$ & 491 & $(0.6)$ & 12 & $(0.6)$ & 353 & $(0.9)$ & 384 & $(0.8)$ & 438 & $(0.7)$ & 558 & $(0.7)$ & 609 & $(0.7)$ & 638 & $(0.8)$ \\
\hline \multirow{9}{*}{ 苋 } & Brazil & 409 & (3.9) & 77 & (2.5) & 420 & (4.3) & 398 & (3.9) & 22 & $(2.3)$ & 292 & (4.5) & 315 & (3.4) & 355 & $(4.0)$ & 457 & (5.0) & 512 & $(8.1)$ & 545 & $(9.0)$ \\
\hline & Colombia & 387 & $(2.7)$ & 68 & (1.6) & 397 & $(3.2)$ & 378 & $(3.1)$ & 19 & $(3.1)$ & 281 & $(4.3)$ & 304 & (3.4) & 341 & $(2.7)$ & 429 & (3.3) & 475 & $(4.4)$ & 505 & $(6.8)$ \\
\hline & Hong Kong-China & 555 & (3.0) & 87 & (1.9) & 563 & $(4.2)$ & 547 & (3.5) & 16 & (4.9) & 398 & $(7.4)$ & 438 & $(6.2)$ & 502 & (4.3) & 615 & (3.1) & 661 & (3.2) & 687 & (3.9) \\
\hline & Macao-China & 541 & $(0.9)$ & 85 & $(0.7)$ & 544 & (1.3) & 537 & (1.3) & 8 & (1.8) & 394 & (3.7) & 428 & (2.6) & 484 & (1.5) & 601 & (1.4) & 648 & $(2.1)$ & 675 & $(2.2)$ \\
\hline & Russian Federation & 486 & $(2.5)$ & 79 & (1.3) & 489 & (3.1) & 483 & (2.8) & 6 & $(2.8)$ & 355 & (3.9) & 385 & (3.6) & 432 & (3.0) & 539 & $(3.2)$ & 588 & (3.6) & 616 & (3.5) \\
\hline & Shanghai-China & 587 & $(3.1)$ & 93 & $(2.0)$ & 594 & (3.8) & 582 & $(3.1)$ & 12 & (2.9) & 426 & $(7.0)$ & 462 & $(5.1)$ & 524 & (4.6) & 654 & (2.9) & 703 & $(3.2)$ & 731 & $(4.6)$ \\
\hline & Singapore & 570 & $(1.3)$ & 100 & $(0.9)$ & 569 & (1.8) & 570 & (1.6) & -1 & $(2.4)$ & 400 & (3.8) & 436 & $(2.6)$ & 501 & $(2.7)$ & 641 & (1.7) & 695 & $(2.7)$ & 723 & (2.5) \\
\hline & Chinese Taipei & 549 & $(2.8)$ & 99 & (1.8) & 554 & $(4.8)$ & 543 & $(4.7)$ & 10 & $(7.7)$ & 379 & $(5.5)$ & 414 & $(4.4)$ & 479 & $(4.2)$ & 620 & (2.8) & 673 & (3.9) & 702 & (4.3) \\
\hline & United Arab Emirates & 434 & $(2.1)$ & 82 & $(1.2)$ & 430 & $(3.5)$ & 438 & $(2.5)$ & -9 & $(4.2)$ & 306 & (3.3) & 331 & $(2.5)$ & 376 & $(2.5)$ & 489 & $(2.9)$ & 544 & (3.4) & 577 & $(3.5)$ \\
\hline
\end{tabular}


[Part 1/1]

Table B3.I.7 Percentage of students at each proficiency level on the digital reading scale

\begin{tabular}{|c|c|c|c|c|c|c|c|c|c|c|c|}
\hline & & \multicolumn{10}{|c|}{ All students } \\
\hline & & \multicolumn{2}{|c|}{$\begin{array}{l}\text { Below Level } 2 \\
\text { (less than } 407.47 \\
\text { score points) } \\
\end{array}$} & \multicolumn{2}{|c|}{$\begin{array}{c}\text { Level } 2 \\
\text { (from } 407.47 \text { to less than } \\
480.18 \text { score points) } \\
\end{array}$} & \multicolumn{2}{|c|}{$\begin{array}{c}\text { Level } 3 \\
\text { (from } 480.18 \text { to less than } \\
552.89 \text { score points) }\end{array}$} & \multicolumn{2}{|c|}{$\begin{array}{c}\text { Level } 4 \\
\text { (from } 552.89 \text { to less than } \\
625.61 \text { score points) }\end{array}$} & \multicolumn{2}{|c|}{$\begin{array}{c}\text { Above Level } 4 \\
\text { (above } 625.61 \text { score points) }\end{array}$} \\
\hline & & $\%$ & S.E. & $\%$ & S.E. & $\%$ & S.E. & $\%$ & S.E. & $\%$ & S.E. \\
\hline \multirow{25}{*}{ Uి } & Australia & 12.5 & (0.5) & 19.8 & $(0.5)$ & 29.4 & (0.6) & 24.9 & $(0.7)$ & 13.4 & $(0.7)$ \\
\hline & Austria & 20.2 & (1.4) & 26.3 & (1.2) & 30.0 & (1.3) & 18.4 & (1.0) & 5.1 & $(0.7)$ \\
\hline & Belgium & 17.2 & (0.9) & 20.2 & $(0.7)$ & 29.3 & (0.9) & 24.4 & (0.8) & 9.0 & $(0.6)$ \\
\hline & Canada & 8.5 & (0.5) & 17.3 & $(0.6)$ & 31.3 & $(0.7)$ & 29.4 & $(0.8)$ & 13.6 & $(0.7)$ \\
\hline & Chile & 29.3 & (1.7) & 32.9 & $(1.2)$ & 27.1 & (1.2) & 9.6 & $(0.8)$ & 1.1 & $(0.2)$ \\
\hline & Denmark & 14.2 & (1.0) & 26.7 & $(0.9)$ & 34.2 & (1.0) & 20.3 & (1.3) & 4.5 & (0.6) \\
\hline & Estonia & 11.4 & (0.9) & 19.8 & $(0.9)$ & 30.0 & (1.0) & 25.7 & (1.1) & 13.1 & (0.9) \\
\hline & France & 13.8 & (1.2) & 19.6 & $(0.9)$ & 30.6 & (1.3) & 26.3 & (1.0) & 9.7 & $(1.0)$ \\
\hline & Germany & 19.1 & (1.5) & 21.7 & (1.0) & 29.9 & (1.3) & 21.9 & (1.2) & 7.4 & $(0.8)$ \\
\hline & Hungary & 32.5 & (1.4) & 24.6 & $(1.2)$ & 24.8 & (1.1) & 14.1 & (1.0) & 4.0 & $(0.6)$ \\
\hline & Ireland & 9.4 & (0.9) & 19.8 & (0.9) & 34.9 & (0.8) & 26.8 & (1.0) & 9.0 & $(0.7)$ \\
\hline & Israel & 31.0 & (1.8) & 22.3 & $(1.2)$ & 23.5 & $(1.2)$ & 16.9 & (1.3) & 6.2 & $(0.9)$ \\
\hline & Italy & 15.7 & (1.4) & 20.9 & (1.3) & 31.4 & (1.3) & 23.8 & (1.3) & 8.2 & $(0.9)$ \\
\hline & Japan & 4.9 & (0.8) & 14.4 & $(1.0)$ & 32.3 & (1.2) & 34.1 & $(1.2)$ & 14.2 & (1.1) \\
\hline & Korea & 3.9 & $(0.5)$ & 11.7 & $(0.8)$ & 30.8 & (1.3) & 35.3 & (1.2) & 18.3 & (1.6) \\
\hline & Norway & 16.6 & (1.1) & 22.0 & $(0.8)$ & 29.9 & $(1.0)$ & 22.8 & $(0.9)$ & 8.6 & $(0.7)$ \\
\hline & Poland & 22.4 & (1.5) & 26.3 & (1.0) & 29.4 & (1.1) & 17.4 & (1.3) & 4.5 & $(0.7)$ \\
\hline & Portugal & 19.2 & (1.6) & 25.7 & (1.1) & 31.3 & (1.4) & 19.7 & (1.3) & 4.1 & $(0.6)$ \\
\hline & Slovak Republic & 22.6 & (1.5) & 25.9 & (1.1) & 31.1 & (1.4) & 16.9 & (1.0) & 3.5 & $(0.6)$ \\
\hline & Slovenia & 25.1 & $(0.7)$ & 26.1 & $(1.0)$ & 26.9 & $(1.2)$ & 17.6 & $(0.8)$ & 4.3 & $(0.5)$ \\
\hline & Spain & 26.2 & (1.5) & 27.1 & (1.1) & 27.9 & (1.1) & 15.2 & (0.9) & 3.7 & $(0.4)$ \\
\hline & Sweden & 16.7 & (1.1) & 23.2 & $(0.9)$ & 30.2 & (1.0) & 21.8 & $(0.9)$ & 8.1 & $(0.7)$ \\
\hline & United States & 12.6 & (1.4) & 22.3 & $(1.2)$ & 31.5 & $(1.0)$ & 24.6 & (1.3) & 9.0 & $(0.9)$ \\
\hline & OECD total & 13.8 & $(0.6)$ & 20.9 & $(0.5)$ & 30.8 & $(0.4)$ & 25.0 & $(0.5)$ & 9.5 & $(0.4)$ \\
\hline & OECD average & 17.6 & $(0.3)$ & 22.5 & $(0.2)$ & 29.9 & $(0.2)$ & 22.1 & $(0.2)$ & 7.9 & $(0.2)$ \\
\hline \multirow{9}{*}{ 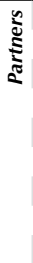 } & Brazil & 37.2 & $(2.2)$ & 30.4 & (1.3) & 22.8 & (1.4) & 8.3 & (1.0) & 1.4 & $(0.4)$ \\
\hline & Colombia & 54.9 & (1.8) & 27.5 & (1.1) & 13.4 & (0.9) & 3.7 & $(0.5)$ & 0.5 & $(0.2)$ \\
\hline & Hong Kong-China & 7.6 & $(0.8)$ & 13.8 & $(0.8)$ & 26.5 & (1.1) & 31.0 & (1.2) & 21.1 & (1.3) \\
\hline & Macao-China & 7.0 & $(0.5)$ & 22.8 & $(0.7)$ & 39.8 & $(0.7)$ & 25.3 & (0.8) & 5.1 & $(0.5)$ \\
\hline & Russian Federation & 24.6 & (1.6) & 31.2 & $(1.2)$ & 28.5 & $(1.0)$ & 13.0 & $(1.0)$ & 2.6 & $(0.4)$ \\
\hline & Shanghai-China & 7.9 & (1.1) & 18.1 & $(1.1)$ & 32.6 & (1.4) & 28.9 & (1.4) & 12.5 & $(1.2)$ \\
\hline & Singapore & 4.3 & $(0.3)$ & 12.5 & $(0.5)$ & 26.0 & $(0.7)$ & 30.3 & $(0.7)$ & 26.8 & $(0.7)$ \\
\hline & Chinese Taipei & 11.1 & (0.9) & 19.3 & $(0.8)$ & 31.8 & (1.0) & 27.6 & (1.1) & 10.3 & $(0.9)$ \\
\hline & United Arab Emirates & 50.5 & $(1.4)$ & 24.2 & $(0.8)$ & 15.7 & $(0.8)$ & 7.3 & $(0.5)$ & 2.3 & $(0.3)$ \\
\hline
\end{tabular}

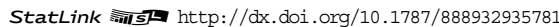


[Part 1/2]

Table B3.I.8 Percentage of students at each proficiency level on the digital reading scale, by gender

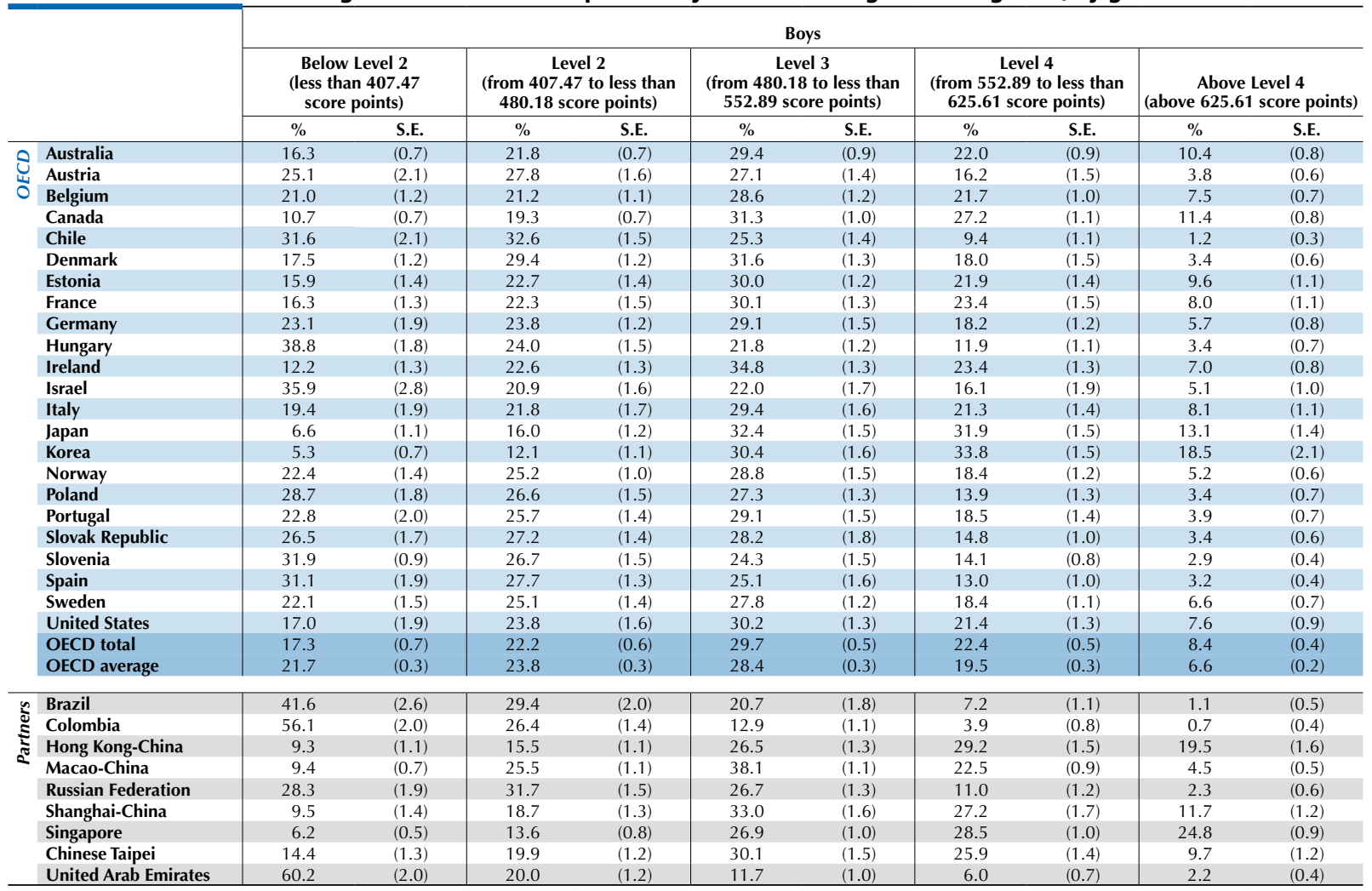

[Part 2/2]

Table B3.I.8 Percentage of students at each proficiency level on the digital reading scale, by gender

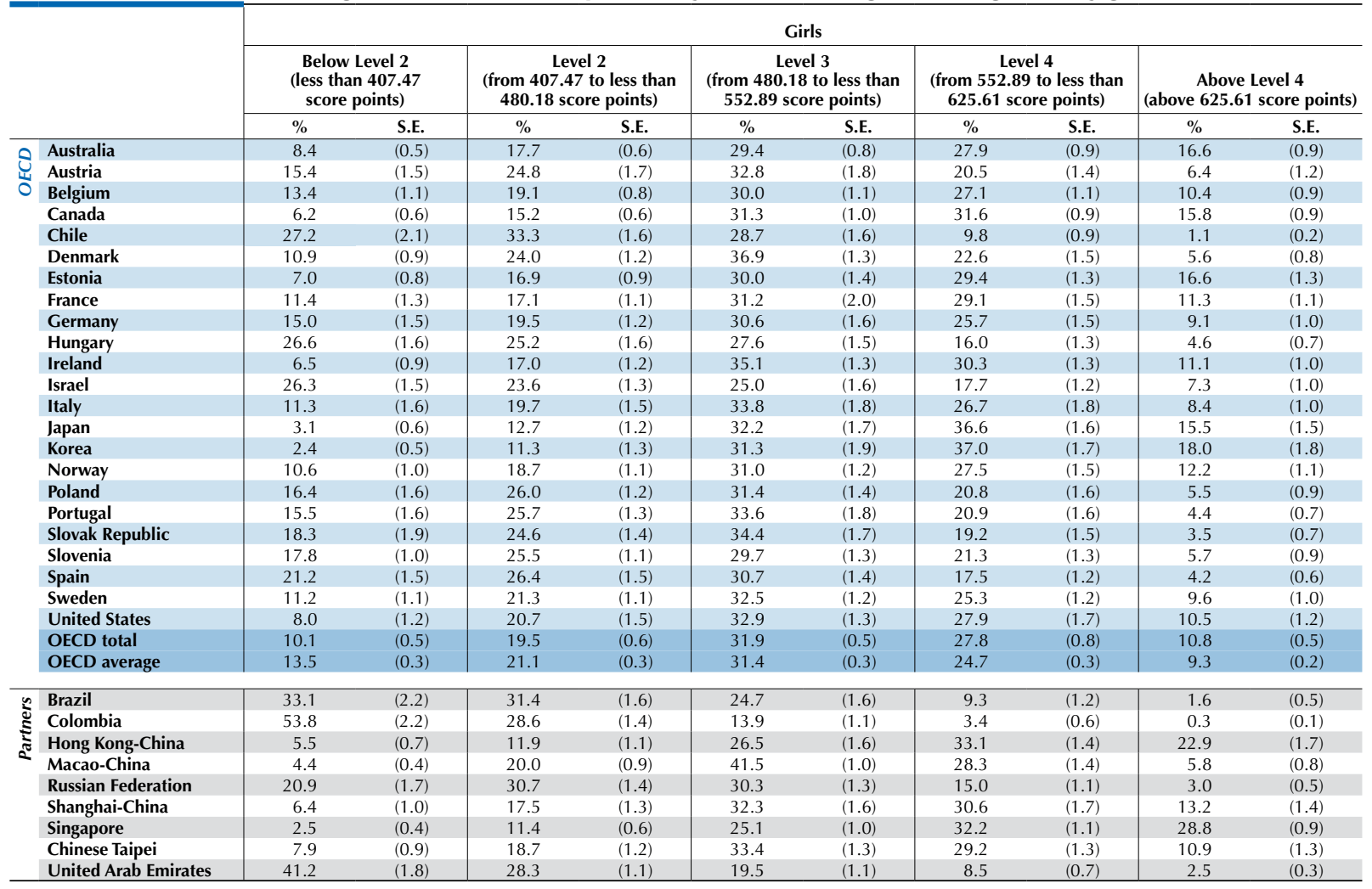

StatLink त्तोIs http://dx.doi.org/10.1787/888932935781 
[Part 1/1]

Table B3.I.9 Mean score, variation and gender differences in student performance on the digital reading scale

\begin{tabular}{|c|c|c|c|c|c|c|c|c|c|c|c|c|c|c|c|c|c|c|c|c|c|c|c|}
\hline & & \multicolumn{4}{|c|}{ All students } & \multicolumn{6}{|c|}{ Gender differences } & \multicolumn{12}{|c|}{ Percentiles } \\
\hline & & \multicolumn{2}{|c|}{ Mean score } & \multicolumn{2}{|c|}{$\begin{array}{l}\text { Standard } \\
\text { deviation }\end{array}$} & \multicolumn{2}{|c|}{ Boys } & \multicolumn{2}{|c|}{ Girls } & \multicolumn{2}{|c|}{$\begin{array}{c}\text { Difference } \\
\quad(B-G)\end{array}$} & \multicolumn{2}{|c|}{ 5th } & \multicolumn{2}{|c|}{ 10th } & \multicolumn{2}{|c|}{ 25th } & \multicolumn{2}{|c|}{ 75th } & \multicolumn{2}{|c|}{ 90th } & \multicolumn{2}{|c|}{ 95th } \\
\hline & & Mean & S.E. & S.D. & S.E. & $\begin{array}{l}\text { Mean } \\
\text { score }\end{array}$ & S.E. & $\begin{array}{l}\text { Mean } \\
\text { score }\end{array}$ & S.E. & $\begin{array}{c}\text { Score } \\
\text { dif. }\end{array}$ & S.E. & Score & S.E. & Score & S.E. & Score & S.E. & Score & S.E. & Score & S.E. & Score & S.E. \\
\hline \multirow[t]{25}{*}{8} & Australia & 521 & (1.7) & 97 & (1.1) & 506 & $(2.5)$ & 536 & $(2.0)$ & -31 & (2.9) & 354 & (3.1) & 394 & (2.6) & 458 & $(2.2)$ & 588 & $(2.2)$ & 642 & (3.0) & 672 & (3.0) \\
\hline & Austria & 480 & (3.9) & 104 & (4.3) & 467 & (5.3) & 493 & (4.6) & -27 & (6.1) & 314 & (11.3) & 361 & (6.8) & 424 & $(4.7)$ & 549 & $(4.2)$ & 600 & (4.5) & 626 & $(4.9)$ \\
\hline & Belgium & 502 & (2.6) & 100 & (1.8) & 490 & (3.4) & 515 & (3.3) & -25 & $(4.0)$ & 323 & (5.9) & 367 & (4.5) & 441 & (4.3) & 574 & $(2.5)$ & 621 & (3.0) & 648 & (3.1) \\
\hline & Canada & 532 & (2.3) & 89 & (1.2) & 522 & (2.5) & 543 & (2.5) & -21 & (1.8) & 379 & (4.1) & 418 & (3.3) & 478 & (2.8) & 592 & (2.5) & 639 & (2.3) & 667 & (3.1) \\
\hline & Chile & 452 & (3.6) & 82 & (1.8) & 447 & $(4.4)$ & 457 & $(4.1)$ & -9 & (4.4) & 312 & (5.8) & 346 & (5.6) & 397 & $(4.2)$ & 509 & $(4.2)$ & 556 & (3.8) & 581 & (3.7) \\
\hline & Denmark & 495 & (2.9) & 83 & (1.5) & 483 & (3.3) & 506 & (2.9) & -23 & (2.4) & 352 & (5.4) & 386 & (5.1) & 442 & (3.6) & 553 & (3.3) & 597 & (3.2) & 622 & (4.5) \\
\hline & Estonia & 523 & (2.8) & 93 & (1.9) & 504 & (3.2) & 541 & (3.0) & -37 & (2.8) & 365 & (5.9) & 400 & (5.6) & 462 & (3.9) & 589 & (3.5) & 640 & (4.0) & 667 & $(4.0)$ \\
\hline & France & 511 & (3.6) & 98 & $(4.2)$ & 499 & $(4.0)$ & 522 & $(4.0)$ & -22 & (3.6) & 334 & (13.1) & 384 & (8.1) & 455 & $(4.5)$ & 579 & (3.6) & 624 & (4.1) & 650 & (5.5) \\
\hline & Germany & 494 & (4.0) & 99 & (3.4) & 479 & $(4.3)$ & 509 & (4.1) & -30 & (3.0) & 318 & (8.5) & 358 & (7.8) & 431 & (6.1) & 564 & (3.9) & 613 & (4.4) & 639 & $(4.4)$ \\
\hline & Hungary & 450 & (4.4) & 112 & (3.9) & 433 & (5.2) & 466 & $(4.7)$ & -33 & (4.9) & 247 & (13.2) & 297 & (10.6) & 378 & (5.5) & 531 & (4.8) & 586 & (5.6) & 617 & (5.7) \\
\hline & Ireland & 520 & (3.0) & 82 & (1.8) & 508 & $(4.0)$ & 533 & (3.3) & -25 & (4.3) & 375 & (6.6) & 412 & (5.5) & 469 & (3.7) & 578 & (3.4) & 622 & (3.1) & 647 & (3.7) \\
\hline & Israel & 461 & (5.1) & 117 & (3.2) & 447 & (7.1) & 474 & $(4.7)$ & -27 & (6.4) & 257 & (9.0) & 304 & (7.9) & 384 & (6.7) & 547 & (5.6) & 604 & (6.5) & 633 & (5.7) \\
\hline & Italy & 504 & (4.3) & 95 & (2.8) & 494 & (5.4) & 516 & (5.0) & -21 & $(6.0)$ & 334 & (10.3) & 375 & (8.3) & 446 & (6.1) & 571 & $(4.2)$ & 618 & (4.0) & 644 & $(4.4)$ \\
\hline & Japan & 545 & (3.3) & 78 & (2.1) & 537 & (4.2) & 553 & (3.3) & -16 & (3.8) & 409 & (7.8) & 444 & (5.5) & 496 & (3.9) & 599 & (3.0) & 640 & (4.1) & 663 & $(4.2)$ \\
\hline & Korea & 555 & (3.6) & 81 & (2.0) & 552 & (4.8) & 559 & (3.9) & -7 & (5.1) & 420 & (5.9) & 456 & (4.4) & 508 & (3.6) & 609 & (4.4) & 652 & (5.0) & 677 & (5.9) \\
\hline & Norway & 500 & (3.5) & 100 & (2.6) & 477 & (3.9) & 523 & (3.6) & -46 & (3.1) & 321 & (10.2) & 370 & (6.9) & 440 & (4.4) & 569 & (3.2) & 619 & (3.8) & 647 & $(4.9)$ \\
\hline & Poland & 477 & (4.5) & 96 & (2.5) & 459 & $(4.7)$ & 493 & $(4.7)$ & -34 & (3.4) & 305 & (8.8) & 349 & (7.3) & 416 & (5.0) & 545 & (4.3) & 593 & (5.0) & 622 & (5.5) \\
\hline & Portugal & 486 & (4.4) & 89 & (2.3) & 477 & (4.9) & 495 & $(4.2)$ & -17 & (3.0) & 330 & (7.7) & 367 & (6.3) & 427 & (5.8) & 550 & (4.5) & 595 & $(4.2)$ & 619 & (5.0) \\
\hline & Slovak Republic & 474 & (3.5) & 95 & (2.8) & 465 & (3.8) & 484 & (4.5) & -19 & (4.3) & 301 & (8.0) & 344 & (9.1) & 417 & $(5.8)$ & 541 & (3.2) & 587 & $(4.1)$ & 613 & (5.8) \\
\hline & Slovenia & 471 & (1.3) & 99 & (1.1) & 452 & (1.3) & 492 & $(2.2)$ & -39 & $(2.7)$ & 297 & (3.7) & 340 & (3.3) & 407 & (2.4) & 543 & $(2.3)$ & 593 & (3.4) & 621 & (4.7) \\
\hline & Spain & 466 & (3.9) & 98 & $(2.4)$ & 453 & $(4.7)$ & 480 & (3.6) & -27 & (3.1) & 294 & (9.2) & 336 & (7.3) & 404 & (5.0) & 535 & (3.7) & 586 & (3.8) & 615 & (3.9) \\
\hline & Sweden & 498 & (3.4) & 96 & (1.7) & 482 & (4.3) & 515 & (3.2) & -33 & (3.3) & 329 & (7.8) & 373 & (5.2) & 438 & (4.1) & 566 & (3.3) & 616 & (3.7) & 644 & $(4.2)$ \\
\hline & United States & 511 & (4.5) & 89 & $(2.2)$ & 497 & $(4.8)$ & 526 & (4.5) & -28 & (2.6) & 358 & (8.8) & 394 & (8.3) & 454 & (5.8) & 573 & $(4.2)$ & 621 & (4.5) & 649 & (5.1) \\
\hline & OECD total & 510 & $(0.2)$ & 94 & $(0.9)$ & 499 & $(0.4)$ & 522 & $(0.4)$ & -23 & $(0.7)$ & 344 & (1.7) & 386 & (3.2) & 452 & (1.4) & 576 & $(0.5)$ & 624 & (1.6) & 651 & (2.0) \\
\hline & OECD average & 497 & (0.6) & 94 & (0.4) & 484 & $(0.7)$ & 510 & $(0.7)$ & -26 & (0.6) & 332 & (1.3) & 373 & (1.2) & 438 & $(0.8)$ & 563 & $(0.7)$ & 611 & (0.8) & 638 & $(0.9)$ \\
\hline \multirow{9}{*}{ 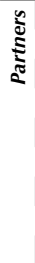 } & Brazil & 436 & (4.9) & 92 & $(2.7)$ & 426 & (5.6) & 445 & $(4.7)$ & -19 & (3.2) & 280 & (9.3) & 316 & (7.1) & 375 & (6.2) & 501 & (5.6) & 552 & (5.4) & 581 & (6.1) \\
\hline & Colombia & 396 & (4.0) & 92 & (2.9) & 393 & $(4.7)$ & 398 & $(4.4)$ & -4 & $(4.3)$ & 247 & (6.8) & 280 & (5.7) & 336 & $(4.8)$ & 457 & $(4.3)$ & 512 & (5.0) & 546 & $(6.0)$ \\
\hline & Hong Kong-China & 550 & (3.6) & 94 & $(2.4)$ & 541 & $(4.4)$ & 560 & $(4.2)$ & -19 & (5.0) & 381 & (7.8) & 427 & (6.0) & 493 & (5.0) & 615 & $(4.1)$ & 663 & $(4.1)$ & 690 & $(4.2)$ \\
\hline & Macao-China & 515 & $(0.9)$ & 70 & $(0.8)$ & 506 & (1.4) & 525 & (1.1) & -18 & (1.7) & 395 & (2.9) & 424 & (2.5) & 469 & (1.5) & 564 & (1.6) & 604 & (2.0) & 627 & (3.5) \\
\hline & Russian Federation & 466 & (3.9) & 86 & (1.6) & 457 & $(4.2)$ & 474 & (4.1) & -18 & (3.0) & 321 & (6.3) & 354 & (5.7) & 409 & $(4.8)$ & 525 & (4.0) & 576 & $(4.2)$ & 604 & (4.4) \\
\hline & Shanghai-China & 531 & (3.7) & 84 & $(2.4)$ & 526 & (4.3) & 536 & (3.7) & -10 & (2.8) & 385 & (7.8) & 420 & (7.1) & 477 & $(4.8)$ & 590 & (3.8) & 635 & $(4.7)$ & 662 & (4.9) \\
\hline & Singapore & 567 & $(1.2)$ & 90 & $(0.9)$ & 558 & (1.8) & 576 & (1.6) & -18 & $(2.2)$ & 415 & (3.4) & 449 & (2.6) & 508 & (1.8) & 631 & $(2.2)$ & 681 & (2.0) & 711 & (3.1) \\
\hline & Chinese Taipei & 519 & (3.0) & 89 & (1.9) & 511 & $(4.2)$ & 528 & (3.8) & -17 & (5.3) & 361 & (7.3) & 401 & (5.3) & 464 & (3.5) & 582 & (3.2) & 627 & $(4.1)$ & 651 & $(4.4)$ \\
\hline & United Arab Emirates & 407 & (3.3) & 110 & $(2.0)$ & 381 & $(5.2)$ & 431 & (3.9) & -50 & (6.5) & 226 & (5.6) & 265 & (4.8) & 331 & $(4.1)$ & 481 & (4.3) & 550 & $(4.8)$ & 591 & (5.4) \\
\hline
\end{tabular}

Note: Values that are statistically significant are indicated in bold (see Annex A3).

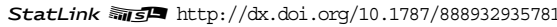


[Part 1/1]

Table B3.I.10 Percentage of students at each proficiency level on the combined reading scale

\begin{tabular}{|c|c|c|c|c|c|c|c|c|c|c|c|c|c|c|c|c|c|}
\hline & & \multicolumn{16}{|c|}{ All students } \\
\hline & & \multicolumn{2}{|c|}{\begin{tabular}{|} 
Below Level 1b \\
(less than 262.04 \\
score points)
\end{tabular}} & \multicolumn{2}{|c|}{$\begin{array}{c}\text { Level 1b } \\
\text { (from 262.04 to } \\
\text { less than } 334.75 \\
\text { score points) }\end{array}$} & \multicolumn{2}{|c|}{\begin{tabular}{|c|} 
Level 1a \\
(from 334.75 to \\
less than 407.47 \\
score points)
\end{tabular}} & \multicolumn{2}{|c|}{\begin{tabular}{|c|} 
Level 2 \\
(from 407.47 to \\
less than 480.18 \\
score points) \\
\end{tabular}} & \multicolumn{2}{|c|}{$\begin{array}{c}\text { Level } 3 \\
\text { (from } 480.18 \text { to } \\
\text { less than } 552.89 \\
\text { score points) }\end{array}$} & \multicolumn{2}{|c|}{$\begin{array}{c}\text { Level } 4 \\
\text { (from } 552.89 \text { to } \\
\text { less than } 625.61 \\
\text { score points) }\end{array}$} & \multicolumn{2}{|c|}{$\begin{array}{l}\text { Level } 5 \\
\text { (from } 625.61 \\
\text { to } 698.32 \\
\text { score points) }\end{array}$} & \multicolumn{2}{|c|}{$\begin{array}{c}\text { Level } 6 \\
\text { (above } 698.32 \\
\text { score points) }\end{array}$} \\
\hline & & $\%$ & S.E. & $\%$ & S.E. & $\%$ & S.E. & $\%$ & S.E. & $\%$ & S.E. & $\%$ & S.E. & $\%$ & S.E. & $\%$ & S.E. \\
\hline \multirow{25}{*}{ రి } & Australia & 0.6 & $(0.1)$ & 2.7 & $(0.2)$ & 9.2 & (0.4) & 21.1 & $(0.5)$ & 30.5 & (0.6) & 24.3 & (0.5) & 10.0 & $(0.5)$ & 1.7 & $(0.2)$ \\
\hline & Austria & 1.9 & $(0.5)$ & 3.9 & $(0.5)$ & 13.8 & (0.9) & 25.3 & $(1.1)$ & 31.2 & (1.1) & 19.5 & (1.0) & 4.2 & $(0.6)$ & 0.2 & $(0.1)$ \\
\hline & Belgium & 1.2 & $(0.2)$ & 4.1 & $(0.4)$ & 10.6 & $(0.7)$ & 20.8 & $(0.6)$ & 29.0 & (0.8) & 25.5 & $(0.7)$ & 8.3 & $(0.5)$ & 0.6 & $(0.1)$ \\
\hline & Canada & 0.3 & $(0.1)$ & 1.4 & $(0.2)$ & 6.5 & $(0.4)$ & 18.6 & $(0.6)$ & 33.1 & (0.6) & 29.0 & $(0.7)$ & 9.9 & $(0.5)$ & 1.3 & $(0.2)$ \\
\hline & Chile & 0.7 & $(0.2)$ & 6.6 & $(0.7)$ & 22.4 & (1.2) & 36.6 & $(1.2)$ & 26.0 & $(1.2)$ & 7.2 & $(0.7)$ & 0.5 & $(0.1)$ & 0.0 & c \\
\hline & Denmark & 0.4 & $(0.1)$ & 2.5 & $(0.3)$ & 10.7 & $(0.7)$ & 26.7 & (0.9) & 35.5 & (1.1) & 20.0 & (0.9) & 4.0 & $(0.5)$ & 0.1 & (0.1) \\
\hline & Estonia & 0.2 & $(0.1)$ & 1.2 & $(0.2)$ & 7.9 & (0.6) & 21.7 & $(0.9)$ & 33.4 & (0.9) & 26.0 & (0.9) & 8.5 & $(0.6)$ & 1.0 & $(0.2)$ \\
\hline & France & 1.5 & $(0.3)$ & 4.0 & (0.5) & 10.2 & $(0.7)$ & 19.7 & (0.9) & 29.0 & (1.2) & 25.3 & (0.9) & 9.2 & $(0.7)$ & 1.0 & (0.3) \\
\hline & Germany & 0.7 & $(0.2)$ & 3.7 & (0.5) & 11.7 & $(0.9)$ & 22.3 & (0.9) & 30.5 & (1.1) & 24.3 & (1.1) & 6.4 & $(0.6)$ & 0.4 & $(0.1)$ \\
\hline & Hungary & 2.3 & $(0.5)$ & 7.9 & (0.9) & 16.1 & (1.2) & 24.7 & (1.5) & 28.1 & (1.1) & 17.2 & (0.9) & 3.6 & $(0.6)$ & 0.2 & (0.1) \\
\hline & Ireland & 0.2 & $(0.1)$ & 1.3 & $(0.3)$ & 7.1 & $(0.6)$ & 19.9 & $(0.9)$ & 35.6 & (1.1) & 26.9 & (1.1) & 8.2 & $(0.7)$ & 0.7 & $(0.2)$ \\
\hline & Israel & 3.6 & $(0.5)$ & 7.6 & (0.8) & 15.5 & (1.1) & 22.0 & (1.0) & 25.9 & (1.1) & 19.1 & $(1.2)$ & 5.8 & $(0.6)$ & 0.5 & $(0.1)$ \\
\hline & Italy & 1.1 & $(0.3)$ & 3.9 & $(0.7)$ & 11.7 & (0.9) & 23.1 & $(1.2)$ & 32.0 & (1.3) & 22.7 & $(1.2)$ & 5.2 & $(0.7)$ & 0.3 & $(0.1)$ \\
\hline & Japan & 0.2 & $(0.1)$ & 1.3 & $(0.3)$ & 5.0 & (0.6) & 15.6 & (0.9) & 30.4 & (1.0) & 32.7 & (1.2) & 13.1 & (1.0) & 1.7 & (0.3) \\
\hline & Korea & 0.2 & $(0.1)$ & 1.0 & $(0.2)$ & 3.5 & $(0.5)$ & 13.5 & (1.0) & 32.7 & (1.3) & 35.0 & (1.1) & 12.9 & $(1.2)$ & 1.2 & (0.3) \\
\hline & Norway & 1.4 & $(0.3)$ & 3.6 & (0.4) & 10.6 & $(0.7)$ & 22.1 & $(0.7)$ & 31.5 & (1.0) & 22.8 & (1.0) & 7.1 & $(0.7)$ & 0.9 & $(0.2)$ \\
\hline & Poland & 0.7 & $(0.2)$ & 3.4 & (0.5) & 10.6 & (0.9) & 24.9 & $(1.2)$ & 33.0 & (1.0) & 21.5 & (1.1) & 5.3 & $(0.7)$ & 0.5 & $(0.2)$ \\
\hline & Portugal & 0.8 & $(0.2)$ & 4.3 & (0.5) & 13.0 & (1.0) & 26.2 & (1.0) & 32.2 & (1.3) & 19.8 & (1.1) & 3.5 & $(0.4)$ & 0.1 & (0.1) \\
\hline & Slovak Republic & 2.5 & $(0.6)$ & 7.3 & $(0.8)$ & 15.3 & $(0.9)$ & 25.6 & (1.0) & 30.1 & (1.5) & 16.1 & $(1.0)$ & 3.0 & $(0.5)$ & 0.1 & $(0.1)$ \\
\hline & Slovenia & 1.3 & $(0.1)$ & 5.6 & $(0.4)$ & 15.6 & (0.6) & 27.4 & (0.9) & 28.5 & (1.1) & 18.0 & (0.6) & 3.5 & $(0.4)$ & 0.2 & (0.1) \\
\hline & Spain & 1.2 & $(0.2)$ & 5.1 & $(0.5)$ & 15.1 & $(0.7)$ & 28.3 & (0.9) & 31.2 & (0.9) & 16.2 & $(0.8)$ & 2.9 & $(0.4)$ & 0.1 & $(0.1)$ \\
\hline & Sweden & 1.4 & $(0.3)$ & 4.8 & $(0.5)$ & 12.4 & $(0.8)$ & 24.4 & (0.9) & 30.0 & $(0.8)$ & 20.3 & (0.9) & 6.1 & $(0.5)$ & 0.6 & $(0.2)$ \\
\hline & United States & 0.4 & $(0.2)$ & 2.8 & $(0.5)$ & 10.1 & (1.0) & 24.6 & (1.3) & 32.0 & (1.1) & 22.5 & $(1.2)$ & 6.8 & $(0.6)$ & 0.8 & $(0.2)$ \\
\hline & OECD total & 0.7 & $(0.1)$ & 3.1 & $(0.2)$ & 9.9 & $(0.4)$ & 22.3 & $(0.5)$ & 31.2 & $(0.4)$ & 24.3 & $(0.5)$ & 7.7 & $(0.3)$ & 0.8 & $(0.1)$ \\
\hline & OECD average & 1.1 & $(0.1)$ & 3.9 & $(0.1)$ & 11.5 & $(0.2)$ & 23.3 & $(0.2)$ & 30.9 & $(0.2)$ & 22.3 & $(0.2)$ & 6.4 & $(0.1)$ & 0.6 & $(0.0)$ \\
\hline \multirow{9}{*}{ ఏँ } & Brazil & 2.9 & (0.6) & 11.5 & (1.1) & 27.4 & (1.4) & 32.4 & (1.6) & 19.8 & (1.3) & 5.5 & $(0.8)$ & 0.5 & $(0.2)$ & 0.0 & $(0.0)$ \\
\hline & Colombia & 4.7 & $(0.7)$ & 16.6 & (1.0) & 32.7 & $(1.2)$ & 29.7 & (1.1) & 13.1 & (0.9) & 2.9 & $(0.4)$ & 0.2 & $(0.1)$ & 0.0 & c \\
\hline & Hong Kong-China & 0.2 & $(0.1)$ & 1.3 & $(0.2)$ & 4.9 & $(0.6)$ & 13.5 & $(0.8)$ & 28.8 & (1.1) & 34.5 & (1.1) & 15.2 & $(0.9)$ & 1.7 & $(0.3)$ \\
\hline & Macao-China & 0.1 & $(0.0)$ & 1.1 & $(0.2)$ & 6.8 & (0.5) & 23.0 & (0.8) & 39.2 & $(0.7)$ & 25.2 & $(0.6)$ & 4.4 & $(0.4)$ & 0.1 & $(0.1)$ \\
\hline & Russian Federation & 0.5 & $(0.1)$ & 4.6 & $(0.5)$ & 17.0 & (1.0) & 32.2 & $(1.2)$ & 29.8 & $(1.0)$ & 13.5 & (1.0) & 2.4 & $(0.3)$ & 0.1 & $(0.1)$ \\
\hline & Shanghai-China & 0.1 & $(0.0)$ & 0.5 & $(0.1)$ & 3.8 & (0.6) & 13.9 & (1.0) & 30.4 & (1.1) & 34.7 & (1.3) & 14.9 & $(1.0)$ & 1.7 & $(0.5)$ \\
\hline & Singapore & 0.1 & $(0.1)$ & 1.0 & $(0.2)$ & 4.9 & $(0.4)$ & 14.8 & $(0.6)$ & 26.6 & $(0.8)$ & 29.7 & $(0.7)$ & 17.8 & $(0.6)$ & 5.1 & $(0.4)$ \\
\hline & Chinese Taipei & 0.4 & $(0.1)$ & 2.3 & (0.4) & 7.7 & $(0.6)$ & 18.9 & (0.9) & 32.0 & (1.1) & 28.8 & (1.1) & 9.0 & $(0.7)$ & 0.8 & $(0.2)$ \\
\hline & United Arab Emirates & 4.8 & $(0.4)$ & 13.8 & $(0.7)$ & 24.5 & $(0.8)$ & 28.0 & $(0.7)$ & 19.2 & $(0.8)$ & 8.0 & $(0.6)$ & 1.6 & $(0.2)$ & 0.1 & $(0.1)$ \\
\hline
\end{tabular}

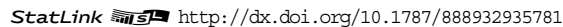


[Part 1/2]

Table B3.I.11 Percentage of students at each proficiency level on the combined reading scale, by gender

\begin{tabular}{|c|c|c|c|c|c|c|c|c|c|c|c|c|c|c|c|c|c|}
\hline & & \multicolumn{16}{|c|}{ Boys } \\
\hline & & \multicolumn{2}{|c|}{$\begin{array}{c}\text { Below Level 1b } \\
\text { (less than 262.04 } \\
\text { score points) }\end{array}$} & \multicolumn{2}{|c|}{\begin{tabular}{|c|} 
Level $1 \mathrm{~b}$ \\
(from 262.04 to \\
less than 334.75 \\
score points)
\end{tabular}} & \multicolumn{2}{|c|}{\begin{tabular}{|c|} 
Level 1a \\
(from 334.75 to \\
less than 407.47 \\
score points)
\end{tabular}} & \multicolumn{2}{|c|}{\begin{tabular}{|c|} 
Level 2 \\
(from 407.47 to \\
less than 480.18 \\
score points)
\end{tabular}} & \multicolumn{2}{|c|}{\begin{tabular}{|c|} 
Level 3 \\
(from 480.18 to \\
less than 552.89 \\
score points)
\end{tabular}} & \multicolumn{2}{|c|}{\begin{tabular}{|c|} 
Level 4 \\
(from 552.89 to \\
less than 625.61 \\
score points)
\end{tabular}} & \multicolumn{2}{|c|}{$\begin{array}{c}\text { Level } 5 \\
\text { (from } 625.61 \\
\text { to } 698.32 \\
\text { score points) }\end{array}$} & \multicolumn{2}{|c|}{$\begin{array}{c}\text { Level } 6 \\
\text { (above 698.32 } \\
\text { score points) }\end{array}$} \\
\hline & & $\%$ & S.E. & $\%$ & S.E. & $\%$ & S.E. & $\%$ & S.E. & $\%$ & S.E. & $\%$ & S.E. & $\%$ & S.E. & $\%$ & S.E. \\
\hline \multirow{25}{*}{ ర్ష్ర } & Australia & 0.9 & $(0.2)$ & 3.9 & $(0.3)$ & 12.0 & $(0.6)$ & 23.3 & $(0.7)$ & 30.0 & $(0.8)$ & 21.0 & $(0.7)$ & 7.7 & $(0.6)$ & 1.3 & $(0.3)$ \\
\hline & Austria & 2.0 & $(0.6)$ & 5.6 & $(0.9)$ & 17.9 & (1.4) & 26.4 & (1.5) & 28.9 & (1.2) & 15.9 & (1.3) & 3.0 & $(0.6)$ & 0.2 & $(0.1)$ \\
\hline & Belgium & 1.9 & $(0.4)$ & 5.5 & $(0.6)$ & 12.5 & (1.0) & 22.1 & $(0.9)$ & 28.6 & (1.1) & 22.3 & (0.9) & 6.8 & $(0.6)$ & 0.4 & $(0.1)$ \\
\hline & Canada & 0.4 & $(0.1)$ & 2.2 & $(0.3)$ & 8.7 & $(0.5)$ & 21.6 & $(0.9)$ & 33.1 & (0.9) & 25.4 & (0.8) & 7.7 & $(0.5)$ & 0.9 & $(0.2)$ \\
\hline & Chile & 1.1 & $(0.3)$ & 8.7 & (1.1) & 24.7 & (1.5) & 35.1 & (1.6) & 23.6 & (1.5) & 6.4 & $(0.8)$ & 0.4 & $(0.1)$ & 0.0 & c \\
\hline & Denmark & 0.7 & $(0.2)$ & 3.6 & $(0.5)$ & 13.1 & $(0.9)$ & 30.0 & (1.3) & 33.0 & (1.5) & 16.8 & (1.1) & 2.7 & $(0.4)$ & 0.1 & $(0.1)$ \\
\hline & Estonia & 0.3 & $(0.1)$ & 2.2 & $(0.4)$ & 11.6 & (1.0) & 26.3 & (1.3) & 32.8 & (1.3) & 20.9 & (1.4) & 5.6 & $(0.7)$ & 0.5 & $(0.1)$ \\
\hline & France & 2.5 & (0.6) & 5.1 & $(0.7)$ & 12.2 & $(0.9)$ & 22.5 & (1.3) & 27.7 & (1.3) & 22.3 & (1.3) & 6.8 & $(0.9)$ & 0.8 & $(0.4)$ \\
\hline & Germany & 1.1 & $(0.4)$ & 5.2 & $(0.8)$ & 14.9 & (1.1) & 24.8 & (1.2) & 30.4 & (1.2) & 19.6 & (1.1) & 3.9 & $(0.5)$ & 0.2 & $(0.1)$ \\
\hline & Hungary & 3.4 & $(0.7)$ & 10.6 & (1.3) & 19.3 & (1.9) & 25.6 & $(2.0)$ & 24.3 & (1.3) & 14.1 & (1.1) & 2.6 & $(0.6)$ & 0.1 & $(0.1)$ \\
\hline & Ireland & 0.3 & $(0.2)$ & 2.0 & $(0.4)$ & 9.4 & (1.0) & 22.8 & (1.2) & 35.5 & (1.3) & 23.4 & (1.2) & 6.1 & $(0.8)$ & 0.4 & $(0.2)$ \\
\hline & Israel & 5.6 & $(0.8)$ & 10.7 & (1.5) & 17.7 & (1.6) & 20.0 & (1.4) & 23.1 & (1.6) & 17.4 & (1.8) & 5.1 & $(0.9)$ & 0.4 & $(0.2)$ \\
\hline & Italy & 1.6 & (0.5) & 5.8 & $(0.9)$ & 14.9 & (1.3) & 24.6 & (1.5) & 29.7 & (1.7) & 19.0 & $(1.2)$ & 4.3 & $(0.7)$ & 0.2 & $(0.1)$ \\
\hline & Japan & 0.3 & $(0.2)$ & 2.0 & $(0.6)$ & 6.6 & $(0.8)$ & 17.4 & (1.2) & 29.8 & (1.3) & 30.6 & (1.4) & 11.8 & (1.3) & 1.5 & $(0.4)$ \\
\hline & Korea & 0.4 & $(0.1)$ & 1.5 & $(0.3)$ & 4.8 & $(0.7)$ & 15.4 & (1.3) & 32.0 & (1.6) & 32.8 & (1.6) & 12.0 & (1.5) & 1.3 & $(0.4)$ \\
\hline & Norway & 2.2 & $(0.5)$ & 5.2 & $(0.6)$ & 14.3 & $(1.0)$ & 25.1 & $(1.0)$ & 30.6 & (1.3) & 18.1 & (1.1) & 4.3 & $(0.6)$ & 0.3 & $(0.1)$ \\
\hline & Poland & 1.3 & $(0.4)$ & 5.3 & $(0.8)$ & 14.6 & (1.1) & 27.6 & (1.5) & 29.9 & (1.3) & 17.4 & (1.3) & 3.7 & $(0.7)$ & 0.3 & $(0.2)$ \\
\hline & Portugal & 1.4 & $(0.4)$ & 6.2 & $(0.9)$ & 15.5 & $(1.2)$ & 27.4 & $(1.2)$ & 30.0 & (1.4) & 16.8 & (1.2) & 2.7 & $(0.5)$ & 0.1 & $(0.1)$ \\
\hline & Slovak Republic & 2.8 & $(0.7)$ & 8.8 & $(1.0)$ & 19.0 & $(1.1)$ & 27.3 & (1.3) & 26.3 & (1.7) & 13.0 & (1.0) & 2.6 & $(0.6)$ & 0.1 & c \\
\hline & Slovenia & 2.2 & $(0.2)$ & 8.6 & $(0.6)$ & 20.0 & $(0.8)$ & 29.2 & (1.3) & 24.7 & (1.6) & 13.3 & $(1.0)$ & 2.0 & $(0.4)$ & 0.0 & c \\
\hline & Spain & 1.9 & $(0.3)$ & 7.1 & $(0.8)$ & 17.9 & $(0.9)$ & 29.7 & (1.3) & 27.5 & (1.4) & 13.3 & $(0.9)$ & 2.5 & $(0.4)$ & 0.1 & $(0.1)$ \\
\hline & Sweden & 2.4 & $(0.4)$ & 7.1 & $(0.8)$ & 16.4 & (1.3) & 25.9 & (1.4) & 27.5 & $(1.2)$ & 15.9 & (1.1) & 4.3 & $(0.6)$ & 0.4 & $(0.2)$ \\
\hline & United States & 0.8 & $(0.3)$ & 4.2 & $(0.8)$ & 13.5 & (1.4) & 26.3 & (1.5) & 29.3 & $(1.2)$ & 20.1 & (1.3) & 5.4 & $(0.7)$ & 0.4 & $(0.2)$ \\
\hline & OECD total & 1.1 & $(0.1)$ & 4.4 & $(0.3)$ & 12.6 & $(0.6)$ & 24.0 & $(0.5)$ & 29.4 & $(0.5)$ & 21.6 & (0.5) & 6.3 & $(0.3)$ & 0.6 & $(0.1)$ \\
\hline & OECD average & 1.6 & $(0.1)$ & 5.5 & $(0.2)$ & 14.4 & $(0.2)$ & 25.1 & $(0.3)$ & 29.0 & $(0.3)$ & 19.0 & $(0.2)$ & 5.0 & $(0.1)$ & 0.4 & $(0.0)$ \\
\hline \multirow{9}{*}{ ఏ } & Brazil & 4.3 & $(0.9)$ & 13.6 & $(1.3)$ & 30.0 & $(1.8)$ & 30.4 & $(1.9)$ & 16.4 & $(1.4)$ & 4.9 & $(0.9)$ & 0.4 & $(0.2)$ & 0.0 & $\mathrm{c}$ \\
\hline & Colombia & 5.9 & $(1.0)$ & 18.9 & (1.1) & 32.5 & (1.5) & 27.1 & (1.4) & 12.1 & (1.1) & 3.1 & $(0.6)$ & 0.3 & $(0.2)$ & 0.0 & c \\
\hline & Hong Kong-China & 0.3 & $(0.1)$ & 1.8 & $(0.3)$ & 5.9 & $(0.8)$ & 16.2 & (1.1) & 28.8 & (1.3) & 32.4 & (1.3) & 13.2 & (1.1) & 1.4 & $(0.4)$ \\
\hline & Macao-China & 0.2 & $(0.1)$ & 1.8 & $(0.3)$ & 9.7 & $(0.6)$ & 26.4 & $(0.9)$ & 37.5 & $(0.9)$ & 21.0 & $(0.8)$ & 3.3 & $(0.4)$ & 0.1 & c \\
\hline & Russian Federation & 0.8 & $(0.3)$ & 6.4 & $(0.7)$ & 20.5 & $(1.3)$ & 33.5 & (1.7) & 26.8 & (1.3) & 10.2 & $(1.0)$ & 1.7 & $(0.4)$ & 0.1 & c \\
\hline & Shanghai-China & 0.1 & $(0.1)$ & 0.7 & $(0.2)$ & 4.8 & $(0.7)$ & 16.2 & (1.3) & 31.2 & (1.5) & 32.3 & (1.7) & 13.2 & (1.1) & 1.4 & $(0.5)$ \\
\hline & Singapore & 0.2 & $(0.1)$ & 1.7 & $(0.4)$ & 6.7 & $(0.6)$ & 16.4 & $(0.9)$ & 26.9 & (1.0) & 28.3 & (0.9) & 15.5 & $(0.8)$ & 4.2 & $(0.5)$ \\
\hline & Chinese Taipei & 0.7 & $(0.2)$ & 3.4 & $(0.7)$ & 10.6 & $(0.9)$ & 19.7 & (1.3) & 30.9 & $(1.5)$ & 26.8 & (1.4) & 7.3 & $(0.9)$ & 0.6 & $(0.2)$ \\
\hline & United Arab Emirates & 8.6 & $(0.9)$ & 20.4 & $(1.2)$ & 26.5 & (1.2) & 23.2 & $(1.2)$ & 14.0 & (1.0) & 6.0 & $(0.7)$ & 1.3 & $(0.3)$ & 0.1 & $(0.1)$ \\
\hline
\end{tabular}

[Part 2/2]

Table B3.I.11 Percentage of students at each proficiency level on the combined reading scale, by gender

\begin{tabular}{|c|c|c|c|c|c|c|c|c|c|c|c|c|c|c|c|c|c|}
\hline & & \multicolumn{16}{|c|}{ Girls } \\
\hline & & \multicolumn{2}{|c|}{$\begin{array}{c}\text { Below Level 1b } \\
\text { (less than } 262.04 \\
\text { score points) } \\
\end{array}$} & \multicolumn{2}{|c|}{ 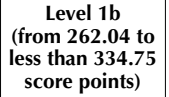 } & \multicolumn{2}{|c|}{$\begin{array}{c}\text { Level } 1 \mathrm{a} \\
\text { (from } 334.75 \text { to } \\
\text { less than } 407.47 \\
\text { score points) }\end{array}$} & \multicolumn{2}{|c|}{$\begin{array}{c}\text { Level } 2 \\
\text { (from } 407.47 \text { to } \\
\text { less than } 480.18 \\
\text { score points) }\end{array}$} & \multicolumn{2}{|c|}{\begin{tabular}{|c|} 
Level 3 \\
(from 480.18 to \\
less than 552.89 \\
score points) \\
\end{tabular}} & \multicolumn{2}{|c|}{$\begin{array}{c}\text { Level } 4 \\
\text { (from } 552.89 \text { to } \\
\text { less than } 625.61 \\
\text { score points) }\end{array}$} & \multicolumn{2}{|c|}{$\begin{array}{c}\text { Level } 5 \\
\text { (from } 625.61 \\
\text { to } 698.32 \\
\text { score points) }\end{array}$} & \multicolumn{2}{|c|}{$\begin{array}{c}\text { Level } 6 \\
\text { (above } 698.32 \\
\text { score points) }\end{array}$} \\
\hline & & $\%$ & S.E. & $\%$ & S.E. & $\%$ & S.E. & $\%$ & S.E. & $\%$ & S.E. & $\%$ & S.E. & $\%$ & S.E. & $\%$ & S.E. \\
\hline \multirow[t]{25}{*}{8} & Australia & 0.3 & $(0.1)$ & 1.4 & $(0.2)$ & 6.2 & $(0.5)$ & 18.7 & $(0.7)$ & 31.1 & $(1.0)$ & 27.8 & (1.0) & 12.5 & $(0.9)$ & 2.1 & $(0.3)$ \\
\hline & Austria & 1.7 & $(0.5)$ & 2.1 & $(0.6)$ & 9.6 & $(1.0)$ & 24.2 & (1.4) & 33.6 & (1.6) & 23.1 & (1.4) & 5.5 & (0.8) & 0.2 & $(0.1)$ \\
\hline & Belgium & 0.5 & $(0.1)$ & 2.7 & $(0.5)$ & 8.6 & $(0.8)$ & 19.4 & $(0.8)$ & 29.5 & $(1.0)$ & 28.7 & (1.0) & 9.8 & $(0.7)$ & 0.8 & $(0.2)$ \\
\hline & Canada & 0.1 & $(0.0)$ & 0.7 & $(0.2)$ & 4.3 & $(0.4)$ & 15.6 & $(0.7)$ & 33.0 & $(1.0)$ & 32.5 & (1.0) & 12.0 & $(0.7)$ & 1.7 & $(0.3)$ \\
\hline & Chile & 0.4 & $(0.3)$ & 4.7 & $(0.7)$ & 20.2 & (1.4) & 38.0 & (1.5) & 28.2 & (1.5) & 8.0 & $(0.8)$ & 0.5 & $(0.1)$ & 0.0 & c \\
\hline & Denmark & 0.1 & $(0.1)$ & 1.3 & $(0.3)$ & 8.4 & $(0.7)$ & 23.5 & (1.1) & 38.0 & $(1.2)$ & 23.3 & (1.1) & 5.3 & $(0.8)$ & 0.1 & $(0.1)$ \\
\hline & Estonia & 0.1 & $(0.1)$ & 0.3 & $(0.2)$ & 4.4 & $(0.6)$ & 17.1 & (1.1) & 34.0 & (1.4) & 31.0 & (1.2) & 11.5 & $(0.9)$ & 1.6 & $(0.4)$ \\
\hline & France & 0.4 & $(0.2)$ & 2.9 & $(0.6)$ & 8.4 & $(0.9)$ & 17.1 & $(1.0)$ & 30.3 & (1.7) & 28.2 & (1.3) & 11.5 & $(0.9)$ & 1.3 & $(0.4)$ \\
\hline & Germany & 0.3 & $(0.2)$ & 2.2 & $(0.4)$ & 8.4 & $(0.9)$ & 19.7 & (1.2) & 30.7 & (1.5) & 29.2 & (1.4) & 8.9 & $(0.9)$ & 0.5 & $(0.2)$ \\
\hline & Hungary & 1.2 & $(0.4)$ & 5.3 & $(0.9)$ & 13.1 & (1.1) & 23.8 & (1.6) & 31.6 & (1.4) & 20.2 & (1.1) & 4.5 & $(0.7)$ & 0.2 & $(0.1)$ \\
\hline & Ireland & 0.1 & $(0.1)$ & 0.7 & $(0.3)$ & 4.7 & $(0.6)$ & 16.9 & (1.3) & 35.8 & (1.6) & 30.6 & (1.5) & 10.4 & $(0.9)$ & 0.9 & $(0.3)$ \\
\hline & Israel & 1.7 & $(0.5)$ & 4.7 & $(0.6)$ & 13.3 & (1.0) & 23.9 & (1.1) & 28.7 & (1.2) & 20.6 & (1.2) & 6.4 & $(0.7)$ & 0.7 & $(0.2)$ \\
\hline & Italy & 0.4 & $(0.3)$ & 1.8 & $(0.6)$ & 8.1 & (1.0) & 21.3 & (1.6) & 34.6 & (1.8) & 26.9 & (1.7) & 6.3 & (1.0) & 0.4 & $(0.2)$ \\
\hline & Japan & 0.0 & c & 0.6 & $(0.3)$ & 3.2 & $(0.5)$ & 13.6 & $(1.1)$ & 31.0 & (1.4) & 34.9 & (1.4) & 14.7 & $(1.2)$ & 2.0 & $(0.4)$ \\
\hline & Korea & 0.0 & c & 0.5 & $(0.2)$ & 2.1 & $(0.5)$ & 11.4 & (1.3) & 33.5 & (1.8) & 37.5 & (1.6) & 13.8 & (1.5) & 1.1 & $(0.4)$ \\
\hline & Norway & 0.5 & $(0.2)$ & 1.9 & $(0.4)$ & 6.7 & $(0.7)$ & 19.0 & $(1.0)$ & 32.6 & $(1.3)$ & 27.9 & (1.3) & 10.1 & (1.1) & 1.4 & $(0.4)$ \\
\hline & Poland & 0.1 & $(0.1)$ & 1.6 & $(0.4)$ & 6.8 & $(0.9)$ & 22.4 & (1.5) & 36.0 & $(1.3)$ & 25.5 & (1.5) & 6.8 & $(0.9)$ & 0.7 & $(0.3)$ \\
\hline & Portugal & 0.2 & $(0.1)$ & 2.3 & $(0.5)$ & 10.4 & $(1.1)$ & 25.1 & $(1.3)$ & 34.5 & (1.5) & 23.0 & (1.4) & 4.4 & $(0.5)$ & 0.1 & $(0.1)$ \\
\hline & Slovak Republic & 2.2 & $(0.6)$ & 5.6 & $(1.0)$ & 11.3 & $(1.2)$ & 23.7 & $(1.5)$ & 34.2 & (1.9) & 19.5 & (1.5) & 3.4 & $(0.7)$ & 0.1 & $(0.1)$ \\
\hline & Slovenia & 0.3 & $(0.1)$ & 2.4 & $(0.4)$ & 10.9 & $(0.8)$ & 25.5 & $(1.1)$ & 32.5 & (1.1) & 22.9 & (1.0) & 5.1 & $(0.8)$ & 0.3 & $(0.2)$ \\
\hline & Spain & 0.4 & $(0.2)$ & 3.0 & $(0.5)$ & 12.2 & $(0.8)$ & 26.8 & $(1.2)$ & 34.9 & (1.6) & 19.1 & $(1.2)$ & 3.3 & $(0.5)$ & 0.2 & $(0.1)$ \\
\hline & Sweden & 0.4 & $(0.2)$ & 2.4 & $(0.4)$ & 8.3 & $(0.7)$ & 22.9 & $(1.1)$ & 32.5 & $(1.2)$ & 24.8 & (1.1) & 7.8 & $(0.7)$ & 0.8 & $(0.2)$ \\
\hline & United States & 0.0 & $(0.0)$ & 1.4 & $(0.4)$ & 6.7 & (1.0) & 22.9 & (1.5) & 34.7 & (1.4) & 24.9 & (1.5) & 8.2 & $(0.9)$ & 1.1 & $(0.3)$ \\
\hline & OECD total & 0.2 & $(0.0)$ & 1.7 & $(0.2)$ & 7.1 & $(0.4)$ & 20.5 & $(0.6)$ & 33.1 & $(0.5)$ & 27.1 & $(0.6)$ & 9.2 & $(0.4)$ & 1.0 & $(0.1)$ \\
\hline & OECD average & 0.5 & $(0.1)$ & 2.3 & $(0.1)$ & 8.5 & $(0.2)$ & 21.4 & $(0.3)$ & 32.8 & $(0.3)$ & 25.7 & $(0.3)$ & 8.0 & $(0.2)$ & 0.8 & $(0.1)$ \\
\hline \multirow{9}{*}{ 离 } & Brazil & 1.6 & $(0.5)$ & 9.5 & $(1.2)$ & 25.0 & $(1.8)$ & 34.2 & $(2.0)$ & 22.9 & $(1.6)$ & 6.1 & $(0.9)$ & 0.7 & $(0.2)$ & 0.0 & $(0.0)$ \\
\hline & Colombia & 3.6 & $(0.6)$ & 14.6 & (1.3) & 32.9 & (1.5) & 32.0 & (1.4) & 14.0 & (1.1) & 2.7 & (0.4) & 0.2 & $(0.1)$ & 0.0 & $\mathrm{C}$ \\
\hline & Hong Kong-China & 0.1 & c & 0.6 & $(0.2)$ & 3.7 & $(0.5)$ & 10.5 & $(1.0)$ & 28.7 & (1.6) & 36.9 & (1.4) & 17.5 & (1.4) & 2.0 & $(0.5)$ \\
\hline & Macao-China & 0.0 & c & 0.4 & $(0.2)$ & 3.8 & $(0.6)$ & 19.5 & (1.1) & 41.0 & $(1.0)$ & 29.6 & (1.0) & 5.6 & $(0.7)$ & 0.2 & $(0.1)$ \\
\hline & Russian Federation & 0.2 & $(0.1)$ & 2.7 & $(0.4)$ & 13.5 & $(1.3)$ & 30.8 & (1.3) & 32.7 & (1.4) & 16.7 & (1.5) & 3.2 & $(0.5)$ & 0.1 & $(0.1)$ \\
\hline & Shanghai-China & 0.0 & c & 0.3 & $(0.2)$ & 2.8 & $(0.5)$ & 11.7 & $(1.0)$ & 29.6 & (1.4) & 37.0 & (1.5) & 16.6 & $(1.2)$ & 2.0 & $(0.7)$ \\
\hline & Singapore & 0.0 & c & 0.3 & $(0.1)$ & 3.1 & $(0.4)$ & 13.1 & $(0.7)$ & 26.2 & (1.1) & 31.1 & (1.1) & 20.2 & $(0.9)$ & 6.1 & $(0.6)$ \\
\hline & Chinese Taipei & 0.2 & $(0.1)$ & 1.3 & $(0.3)$ & 4.9 & $(0.5)$ & 18.1 & (1.1) & 33.1 & (1.4) & 30.7 & (1.6) & 10.7 & (1.4) & 1.0 & $(0.3)$ \\
\hline & United Arab Emirates & 1.2 & $(0.3)$ & 7.5 & $(0.8)$ & 22.7 & (1.0) & 32.7 & $(1.0)$ & 24.2 & $(1.1)$ & 9.9 & $(0.8)$ & 1.8 & $(0.3)$ & 0.1 & $(0.1)$ \\
\hline
\end{tabular}

StatLink 部 St http://dx.doi.org/10.1787/888932935781 
[Part 1/1]

Table B3.I.12 Mean score, variation and gender differences in student performance on the combined reading scale

\begin{tabular}{|c|c|c|c|c|c|c|c|c|c|c|c|c|c|c|c|c|c|c|c|c|c|c|c|}
\hline & & \multicolumn{4}{|c|}{ All students } & \multicolumn{6}{|c|}{ Gender differences } & \multicolumn{12}{|c|}{ Percentiles } \\
\hline & & \multicolumn{2}{|c|}{ Mean score } & \multicolumn{2}{|c|}{$\begin{array}{l}\text { Standard } \\
\text { deviation }\end{array}$} & \multicolumn{2}{|c|}{ Boys } & \multicolumn{2}{|c|}{ Girls } & \multicolumn{2}{|c|}{$\begin{array}{l}\text { Difference } \\
\quad(B-G)\end{array}$} & \multicolumn{2}{|c|}{ 5th } & \multicolumn{2}{|c|}{ 10th } & \multicolumn{2}{|c|}{ 25th } & \multicolumn{2}{|c|}{ 75th } & \multicolumn{2}{|c|}{ 90th } & \multicolumn{2}{|c|}{ 95th } \\
\hline & & Mean & S.E. & S.D. & S.E. & $\begin{array}{l}\text { Mean } \\
\text { score }\end{array}$ & S.E. & $\begin{array}{l}\text { Mean } \\
\text { score }\end{array}$ & S.E. & $\begin{array}{c}\text { Score } \\
\text { dif. }\end{array}$ & S.E. & Score & S.E. & Score & S.E. & Score & S.E. & Score & S.E. & Score & S.E. & Score & S.E. \\
\hline \multirow[t]{25}{*}{ G } & Australia & 516 & (1.5) & 93 & (1.0) & 500 & $(2.2)$ & 533 & (1.8) & -33 & (2.8) & 355 & (3.0) & 394 & (2.5) & 456 & (1.9) & 581 & (2.0) & 633 & (2.4) & 662 & $(2.7)$ \\
\hline & Austria & 485 & (3.0) & 92 & (2.4) & 469 & (4.3) & 501 & (3.7) & -32 & (5.3) & 325 & (9.5) & 366 & (5.7) & 427 & (4.2) & 550 & (3.0) & 597 & (3.4) & 622 & (3.9) \\
\hline & Belgium & 506 & (2.2) & 96 & (1.4) & 491 & (2.9) & 520 & (2.8) & -29 & (3.6) & 332 & (4.5) & 375 & (4.4) & 444 & (3.7) & 576 & (2.1) & 621 & (2.4) & 646 & (2.6) \\
\hline & Canada & 528 & (1.8) & 84 & $(0.9)$ & 514 & (2.1) & 542 & (1.9) & -28 & (1.9) & 381 & (3.1) & 418 & (2.5) & 475 & (2.1) & 586 & (1.9) & 630 & (2.1) & 657 & (2.9) \\
\hline & Chile & 447 & (3.0) & 75 & (1.6) & 439 & (3.8) & 454 & (3.2) & -16 & (3.7) & 319 & (5.5) & 348 & (4.5) & 396 & (3.7) & 500 & (3.6) & 543 & $(3.2)$ & 568 & (3.4) \\
\hline & Denmark & 495 & (2.5) & 79 & (1.4) & 482 & (3.0) & 509 & (2.4) & -27 & (2.4) & 358 & (5.6) & 391 & (4.4) & 444 & (3.2) & 551 & (2.3) & 594 & (2.9) & 619 & (3.8) \\
\hline & Estonia & 520 & $(2.2)$ & 82 & (1.3) & 499 & (2.5) & 539 & (2.4) & -40 & (2.5) & 380 & (5.3) & 410 & (3.5) & 464 & (3.1) & 578 & (2.4) & 623 & (3.1) & 649 & (3.7) \\
\hline & France & 508 & (2.8) & 99 & (2.5) & 491 & (3.6) & 524 & (3.1) & -33 & $(3.7)$ & 330 & $(8.2)$ & 374 & (5.9) & 445 & (4.4) & 579 & (3.0) & 627 & (3.8) & 652 & (4.9) \\
\hline & Germany & 501 & (3.1) & 90 & (2.1) & 483 & (3.3) & 519 & (3.3) & -37 & (2.5) & 341 & (6.7) & 377 & (6.3) & 440 & (4.7) & 567 & (3.0) & 612 & (3.2) & 635 & (4.1) \\
\hline & Hungary & 469 & (3.5) & 98 & (2.4) & 451 & (4.2) & 487 & (3.7) & -36 & $(4.0)$ & 296 & (8.1) & 334 & (6.7) & 403 & (5.5) & 542 & (3.7) & 589 & $(4.2)$ & 616 & (5.2) \\
\hline & Ireland & 522 & (2.4) & 80 & (1.6) & 508 & (3.2) & 535 & (2.8) & -27 & (3.8) & 383 & (5.3) & 416 & (4.8) & 471 & (3.5) & 577 & (2.5) & 622 & (2.7) & 645 & (3.0) \\
\hline & Israel & 473 & (4.8) & 109 & (2.7) & 455 & (7.4) & 491 & (3.9) & -36 & (6.9) & 281 & (8.1) & 326 & (7.8) & 401 & $(7.2)$ & 554 & (4.8) & 606 & (4.5) & 634 & (5.0) \\
\hline & Italy & 496 & (3.8) & 90 & (2.5) & 480 & (4.8) & 514 & (4.5) & -33 & $(5.3)$ & 335 & (9.6) & 374 & (7.5) & 438 & (5.3) & 561 & (3.6) & 606 & (3.3) & 629 & (4.5) \\
\hline & Japan & 541 & (3.3) & 83 & (2.0) & 532 & (4.2) & 552 & (3.2) & -20 & $(3.7)$ & 393 & (8.2) & 432 & (5.8) & 489 & (4.4) & 600 & (3.2) & 643 & (3.6) & 667 & (4.2) \\
\hline & Korea & 545 & (3.5) & 77 & (1.8) & 538 & (4.6) & 554 & (3.9) & -15 & (4.9) & 410 & $(8.2)$ & 448 & $(5.7)$ & 499 & (4.0) & 599 & (3.7) & 639 & $(4.2)$ & 660 & (5.1) \\
\hline & Norway & 502 & $(2.8)$ & 95 & (1.7) & 479 & (3.1) & 525 & $(3.2)$ & -46 & (3.0) & 335 & (6.5) & 377 & (5.4) & 444 & (3.8) & 568 & (2.6) & 617 & (3.1) & 644 & (3.4) \\
\hline & Poland & 498 & (3.5) & 87 & (1.7) & 478 & (3.9) & 516 & (3.6) & -38 & (3.0) & 344 & (5.8) & 383 & (5.5) & 442 & (4.2) & 558 & (3.5) & 604 & (4.9) & 631 & (5.4) \\
\hline & Portugal & 487 & (3.8) & 86 & (1.8) & 473 & (4.3) & 501 & (3.7) & -28 & $(2.7)$ & 335 & (6.6) & 370 & (5.9) & 431 & (5.1) & 549 & (3.4) & 592 & (3.6) & 616 & (3.8) \\
\hline & Slovak Republic & 469 & (3.7) & 96 & (2.9) & 455 & (4.0) & 484 & $(4.6)$ & -29 & $(4.2)$ & 292 & (9.0) & 336 & (7.6) & 407 & (5.6) & 537 & (3.4) & 585 & (4.9) & 610 & (4.8) \\
\hline & Slovenia & 476 & (1.1) & 91 & (0.9) & 453 & (1.3) & 501 & (1.9) & -48 & (2.5) & 318 & (2.4) & 355 & (2.4) & 416 & (2.0) & 543 & (2.2) & 592 & (2.3) & 617 & (2.8) \\
\hline & Spain & 476 & $(2.7)$ & 87 & (1.6) & 461 & (3.4) & 491 & (2.5) & -29 & (2.6) & 324 & (5.1) & 360 & (4.9) & 419 & (3.4) & 538 & (2.6) & 585 & (3.2) & 610 & (3.0) \\
\hline & Sweden & 491 & (2.9) & 95 & (1.5) & 470 & (3.8) & 512 & $(2.7)$ & -42 & (3.3) & 322 & (6.4) & 364 & (4.8) & 430 & (3.9) & 558 & (2.9) & 608 & (3.3) & 637 & (2.9) \\
\hline & United States & 504 & (3.9) & 87 & (1.7) & 490 & $(4.2)$ & 519 & $(4.0)$ & -30 & (2.5) & 356 & $(7.2)$ & 391 & (6.2) & 446 & (4.5) & 565 & (3.7) & 614 & (3.8) & 641 & $(4.7)$ \\
\hline & OECD total & 508 & $(0.2)$ & 90 & $(0.6)$ & 494 & $(0.4)$ & 522 & $(0.3)$ & -28 & $(0.5)$ & 349 & (1.0) & 388 & (1.3) & 449 & $(0.7)$ & 572 & (0.6) & 619 & $(0.6)$ & 646 & $(1.2)$ \\
\hline & OECD average & 498 & $(0.5)$ & 89 & $(0.3)$ & 482 & $(0.6)$ & 514 & $(0.6)$ & -32 & $(0.5)$ & 341 & $(1.2)$ & 379 & (1.0) & 440 & $(0.7)$ & 562 & $(0.5)$ & 608 & $(0.7)$ & 633 & $(0.8)$ \\
\hline \multirow{9}{*}{ 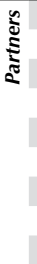 } & Brazil & 424 & (4.3) & 84 & $(2.2)$ & 412 & (4.9) & 435 & $(4.0)$ & -23 & (2.8) & 283 & (7.0) & 315 & (6.5) & 367 & (5.1) & 482 & (5.1) & 532 & $(5.2)$ & 560 & $(6.1)$ \\
\hline & Colombia & 400 & (3.4) & 82 & (1.9) & 394 & (4.0) & 405 & $(3.7)$ & -11 & $(3.7)$ & 265 & (5.6) & 294 & (4.8) & 344 & (4.1) & 455 & (3.8) & 504 & $(4.2)$ & 536 & (5.0) \\
\hline & Hong Kong-China & 547 & (2.8) & 84 & (1.9) & 537 & (3.8) & 559 & (3.4) & -22 & $(4.6)$ & 394 & (6.8) & 435 & (6.1) & 496 & (4.0) & 606 & (2.9) & 647 & (3.3) & 670 & (3.2) \\
\hline & Macao-China & 512 & $(0.8)$ & 72 & $(0.7)$ & 499 & (1.2) & 526 & (1.0) & -27 & (1.4) & 387 & (3.3) & 417 & (2.6) & 466 & (1.2) & 562 & (1.6) & 602 & (1.7) & 623 & (2.3) \\
\hline & Russian Federation & 470 & (3.1) & 81 & (1.3) & 456 & (3.4) & 485 & (3.3) & -29 & (2.8) & 334 & (4.5) & 365 & (4.5) & 416 & (3.9) & 527 & (3.9) & 576 & (3.9) & 602 & (4.1) \\
\hline & Shanghai-China & 550 & (3.1) & 78 & (1.9) & 542 & (3.6) & 559 & (3.0) & -17 & (2.5) & 414 & (6.9) & 446 & (5.1) & 500 & (4.1) & 606 & (3.1) & 647 & (3.4) & 669 & (3.9) \\
\hline & Singapore & 555 & (1.3) & 92 & (1.0) & 542 & (1.8) & 567 & (1.6) & -25 & $(2.3)$ & 398 & (3.4) & 433 & (2.3) & 494 & (1.8) & 619 & (1.9) & 670 & (2.6) & 699 & (2.6) \\
\hline & Chinese Taipei & 521 & (2.9) & 87 & (1.8) & 509 & (4.1) & 533 & (3.9) & -25 & (5.8) & 365 & (6.1) & 405 & (4.5) & 468 & (3.8) & 583 & (3.0) & 625 & (3.2) & 649 & (4.6) \\
\hline & United Arab Emirates & 424 & $(2.7)$ & 97 & (1.4) & 397 & $(4.2)$ & 450 & (3.2) & -53 & $(5.2)$ & 264 & (4.0) & 297 & (3.5) & 356 & (3.4) & 491 & (3.3) & 551 & (3.7) & 584 & (3.6) \\
\hline
\end{tabular}

Note: Values that are statistically significant are indicated in bold (see Annex A3)

StatLink न्ताइ http://dx.doi.org/10.1787/888932935781 
Part 1/2

Percentage of students at each proficiency level on the computer-based mathematics scale, Table B3.I.13 by region

\begin{tabular}{|c|c|c|c|c|c|c|c|c|c|c|c|c|c|c|c|}
\hline & & \multicolumn{14}{|c|}{ All students } \\
\hline & & \multicolumn{2}{|c|}{$\begin{array}{l}\text { Below Level } 1 \\
\text { (below 357.77 } \\
\text { score points) }\end{array}$} & \multicolumn{2}{|c|}{$\begin{array}{c}\text { Level } 1 \\
\text { (from } 357.77 \text { to } \\
\text { less than } 420.07 \\
\text { score points) }\end{array}$} & \multicolumn{2}{|c|}{$\begin{array}{c}\text { Level } 2 \\
\text { (from } 420.07 \text { to } \\
\text { less than } 482.38 \\
\text { score points) }\end{array}$} & \multicolumn{2}{|c|}{$\begin{array}{c}\text { Level } 3 \\
\text { (from } 482.38 \text { to } \\
\text { less than } 544.68 \\
\text { score points) }\end{array}$} & \multicolumn{2}{|c|}{$\begin{array}{c}\text { Level } 4 \\
\text { (from } 544.68 \text { to } \\
\text { less than } 606.99 \\
\text { score points) }\end{array}$} & \multicolumn{2}{|c|}{$\begin{array}{c}\text { Level } 5 \\
\text { (from } 606.99 \text { to } \\
\text { less than } 669.30 \\
\text { score points) } \\
\end{array}$} & \multicolumn{2}{|c|}{$\begin{array}{c}\text { Level } 6 \\
\text { (above } 669.30 \\
\text { score points) }\end{array}$} \\
\hline & & $\%$ & S.E. & $\%$ & S.E. & $\%$ & S.E. & $\%$ & S.E. & $\%$ & S.E. & $\%$ & S.E. & $\%$ & S.E. \\
\hline a & Australia & & & & & & & & & & & & & & \\
\hline 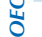 & Australian Capital Territory & 5.7 & $(0.9)$ & 9.4 & $(1.4)$ & 20.9 & (2.6) & 26.6 & $(2.7)$ & 22.2 & $(2.2)$ & 11.8 & (1.5) & 3.5 & $(0.7)$ \\
\hline & New South Wales & 5.7 & $(0.7)$ & 12.1 & $(1.1)$ & 21.9 & $(1.1)$ & 25.6 & $(1.0)$ & 20.0 & $(1.1)$ & 10.6 & $(0.8)$ & 4.2 & $(0.8)$ \\
\hline & Northern Territory & 14.5 & $(2.2)$ & 14.2 & $(3.5)$ & 21.3 & (3.6) & 26.9 & $(4.3)$ & 16.3 & (3.1) & 5.5 & $(2.1)$ & 1.3 & $(1.0)$ \\
\hline & Queensland & 4.7 & $(0.6)$ & 11.8 & $(0.8)$ & 22.7 & (1.3) & 27.5 & $(1.2)$ & 20.4 & (1.0) & 10.1 & $(0.9)$ & 2.8 & $(0.5)$ \\
\hline & South Australia & 6.1 & $(1.2)$ & 11.9 & $(1.0)$ & 23.4 & (1.3) & 28.2 & (1.5) & 20.0 & (1.5) & 8.5 & (1.1) & 2.1 & $(0.5)$ \\
\hline & Tasmania & 10.2 & $(1.1)$ & 16.3 & $(1.4)$ & 24.6 & $(1.7)$ & 24.1 & (1.6) & 16.0 & (1.5) & 6.5 & $(1.2)$ & 2.3 & $(0.6)$ \\
\hline & Victoria & 3.3 & $(0.6)$ & 10.9 & $(1.0)$ & 22.4 & (1.7) & 28.2 & (1.4) & 22.2 & $(1.2)$ & 9.9 & $(1.0)$ & 3.1 & $(0.8)$ \\
\hline & Western Australia & 5.1 & $(1.1)$ & 10.8 & (1.3) & 19.7 & (1.4) & 25.2 & (1.6) & 22.8 & (1.4) & 12.3 & $(1.0)$ & 4.0 & $(0.8)$ \\
\hline & Belgium & & & & & & & & & & & & & & \\
\hline & Flemish community• & 5.5 & $(0.7)$ & 9.6 & $(0.9)$ & 16.2 & (0.9) & 21.7 & (0.9) & 24.0 & (0.9) & 16.3 & $(0.9)$ & 6.8 & $(0.6)$ \\
\hline & French community & 8.6 & $(0.9)$ & 12.8 & $(0.8)$ & 22.5 & (0.9) & 28.0 & (1.3) & 19.1 & (1.0) & 7.4 & (0.8) & 1.6 & $(0.4)$ \\
\hline & German-speaking community & 3.7 & $(0.8)$ & 10.3 & $(1.5)$ & 21.2 & (1.8) & 30.4 & (1.9) & 21.2 & (1.8) & 10.4 & $(1.1)$ & 2.8 & $(0.6)$ \\
\hline & Canada & & & & & & & & & & & & & & \\
\hline & Alberta & 5.7 & $(1.1)$ & 9.2 & $(0.9)$ & 20.1 & (1.5) & 25.5 & (1.4) & 22.5 & (1.4) & 12.2 & $(1.4)$ & 4.8 & $(0.9)$ \\
\hline & British Columbia & 2.6 & $(0.6)$ & 7.9 & $(1.0)$ & 18.7 & (1.5) & 26.5 & (1.4) & 24.5 & (1.4) & 13.3 & (1.6) & 6.4 & $(1.1)$ \\
\hline & Manitoba & 7.0 & $(1.1)$ & 13.3 & $(1.3)$ & 23.8 & (1.6) & 27.0 & (1.4) & 19.2 & (1.3) & 7.8 & $(0.7)$ & 1.9 & $(0.5)$ \\
\hline & New Brunswick & 6.1 & $(0.8)$ & 10.5 & $(1.0)$ & 23.7 & (1.3) & 30.9 & $(1.5)$ & 20.4 & (1.6) & 7.4 & $(1.2)$ & 0.9 & $(0.3)$ \\
\hline & Newfoundland and Labrador & 4.0 & $(0.9)$ & 8.6 & $(1.2)$ & 22.0 & $(1.7)$ & 29.4 & (1.9) & 24.9 & (1.6) & 9.1 & (1.3) & 2.0 & $(0.5)$ \\
\hline & Nova Scotia & 5.1 & $(1.0)$ & 11.3 & $(1.7)$ & 22.0 & (1.3) & 29.1 & (1.6) & 20.9 & $(2.1)$ & 10.0 & (1.0) & 1.6 & $(0.6)$ \\
\hline & Ontario & 3.2 & $(0.7)$ & 7.6 & $(0.9)$ & 17.8 & (1.3) & 27.3 & (1.5) & 25.1 & (1.7) & 13.8 & $(1.2)$ & 5.2 & $(1.0)$ \\
\hline & Prince Edward Island & 8.4 & $(0.9)$ & 13.7 & $(1.2)$ & 23.4 & (1.5) & 26.4 & (1.5) & 18.3 & (1.3) & 7.1 & $(1.0)$ & 2.7 & $(0.5)$ \\
\hline & Quebec & 4.6 & $(0.6)$ & 8.5 & $(0.8)$ & 17.2 & (1.0) & 26.2 & (1.3) & 25.7 & (1.3) & 13.8 & (1.1) & 4.0 & $(0.6)$ \\
\hline & Saskatchewan & 5.8 & $(0.8)$ & 12.0 & (1.1) & 23.0 & (1.5) & 28.0 & (1.3) & 20.8 & (1.6) & 8.7 & (1.0) & 1.8 & $(0.5)$ \\
\hline & Italy & & & & & & & & & & & & & & \\
\hline & Abruzzo & 2.8 & $(2.0)$ & 13.0 & $(8.2)$ & 28.1 & (7.6) & 34.2 & (7.8) & 18.1 & (8.7) & 3.5 & (1.8) & 0.4 & c \\
\hline & Basilicata & 4.4 & (3.5) & 16.3 & (4.5) & 28.6 & $(4.7)$ & 30.8 & (6.0) & 16.5 & (3.6) & 3.0 & (1.6) & 0.3 & c \\
\hline & Bolzano & 0.0 & $\mathrm{c}$ & 6.5 & $(2.0)$ & 17.4 & (5.3) & 33.4 & $(4.1)$ & 30.7 & (6.3) & 11.4 & (3.5) & 0.6 & $(0.7)$ \\
\hline & Calabria & 7.6 & $(4.0)$ & 16.6 & (6.6) & 33.4 & $(5.2)$ & 31.6 & (8.0) & 8.2 & (3.0) & 2.5 & (2.3) & 0.0 & c \\
\hline & Campania & 10.9 & $(4.7)$ & 21.5 & (3.8) & 27.8 & (3.6) & 26.4 & $(4.1)$ & 10.1 & (2.6) & 2.9 & $(1.1)$ & 0.4 & $(0.3)$ \\
\hline & Emilia Romagna & 4.6 & $(2.0)$ & 11.5 & (3.1) & 25.8 & $(4.1)$ & 29.3 & (5.4) & 18.2 & (3.5) & 7.4 & (3.4) & 3.2 & (2.6) \\
\hline & Friuli Venezia Giulia & 4.2 & (2.3) & 8.5 & (3.7) & 19.8 & $(11.0)$ & 28.6 & (6.0) & 29.8 & (12.5) & 7.8 & (6.1) & 1.2 & (1.1) \\
\hline & Lazio & 3.8 & $(2.2)$ & 14.2 & (3.5) & 22.2 & $(4.8)$ & 29.1 & (3.1) & 22.6 & (3.2) & 6.5 & $(2.0)$ & 1.6 & $(0.7)$ \\
\hline & Liguria & 1.7 & $(1.3)$ & 6.3 & (3.5) & 16.3 & (6.5) & 26.4 & $(8.2)$ & 19.0 & $(4.2)$ & 15.7 & (8.6) & 14.6 & $(9.8)$ \\
\hline & Lombardia & 1.2 & $(0.7)$ & 5.1 & $(1.5)$ & 19.5 & $(4.0)$ & 32.1 & (2.8) & 27.0 & (2.9) & 12.4 & (3.0) & 2.5 & (1.4) \\
\hline & Marche & 2.1 & $(2.0)$ & 9.3 & $(4.8)$ & 22.0 & (6.8) & 31.9 & (5.6) & 26.3 & $(7.4)$ & 6.8 & $(4.3)$ & 1.5 & (1.3) \\
\hline & Molise & 3.4 & $(2.4)$ & 16.4 & $(9.3)$ & 25.3 & $(4.7)$ & 40.1 & $(9.7)$ & 12.2 & (4.4) & 1.2 & c & 1.4 & $(0.9)$ \\
\hline & Piemonte & 5.1 & $(3.0)$ & 11.9 & $(2.5)$ & 22.1 & (4.6) & 26.4 & $(4.2)$ & 24.3 & (3.5) & 8.0 & (3.5) & 2.2 & (1.6) \\
\hline & Puglia & 7.6 & (3.5) & 16.0 & (3.8) & 26.5 & (3.7) & 24.8 & $(4.1)$ & 20.9 & (4.5) & 3.8 & (1.1) & 0.5 & c \\
\hline & Sardegna & 8.6 & $(6.3)$ & 17.5 & (6.3) & 40.5 & $(6.0)$ & 27.8 & (6.3) & 5.2 & (3.0) & 0.4 & C & 0.0 & c \\
\hline & Sicilia & 3.1 & $(1.5)$ & 13.1 & (3.9) & 28.7 & (4.4) & 34.1 & (3.8) & 17.2 & (3.9) & 3.3 & (1.6) & 0.5 & $(0.4)$ \\
\hline & Toscana & 4.9 & (3.4) & 14.8 & (5.0) & 21.9 & (5.5) & 26.0 & (3.6) & 22.6 & (5.6) & 9.1 & (3.4) & 0.8 & c \\
\hline & Trento & 1.3 & $(1.2)$ & 6.3 & $(2.9)$ & 12.3 & (2.1) & 23.2 & (3.3) & 33.4 & (5.3) & 19.4 & $(4.7)$ & 4.1 & (2.9) \\
\hline & Umbria & 4.5 & (2.6) & 11.2 & (3.4) & 26.9 & $(7.0)$ & 34.3 & (6.1) & 20.0 & (5.1) & 2.3 & (1.5) & 0.8 & $(0.8)$ \\
\hline & Valle d'Aosta & 1.4 & $(1.7)$ & 9.7 & (5.6) & 25.4 & (5.5) & 37.3 & (6.0) & 21.9 & (7.4) & 3.3 & (2.3) & 0.9 & (1.0) \\
\hline & Veneto & 4.3 & (1.3) & 13.0 & (4.3) & 20.1 & (3.3) & 23.0 & (4.5) & 21.7 & (3.5) & 14.2 & (5.5) & 3.7 & (1.9) \\
\hline & Portugal & & & & & & & & & & & & & & \\
\hline & Alentejo & 8.6 & (2.3) & 13.7 & $(2.8)$ & 22.9 & (2.4) & 31.2 & (3.0) & 17.2 & (2.3) & 4.9 & (1.5) & 1.5 & (1.1) \\
\hline & Spain & & & & & & & & & & & & & & \\
\hline & Andalusia ${ }^{\bullet}$ & 11.8 & $(2.5)$ & 20.6 & (2.6) & 31.1 & (2.4) & 23.7 & (2.6) & 9.9 & (2.1) & 2.3 & $(0.8)$ & 0.5 & $(0.3)$ \\
\hline & Aragon • & 12.5 & (5.4) & 15.9 & (5.8) & 17.7 & (4.6) & 24.3 & $(4.2)$ & 19.3 & (5.8) & 9.1 & (4.9) & 1.2 & (1.7) \\
\hline & Asturias ${ }^{\bullet}$ & c & $\mathrm{c}$ & c & c & c & c & $\mathrm{c}$ & c & c & c & c & c & c & c \\
\hline & Balearic Islands ${ }^{\bullet}$ & c & c & c & c & c & c & c & c & c & c & c & c & c & c \\
\hline & Basque Country ${ }^{\bullet}$ & 6.0 & $(0.7)$ & 12.8 & $(0.9)$ & 24.8 & $(0.9)$ & 30.1 & (0.9) & 20.0 & (1.0) & 5.6 & $(0.5)$ & 0.6 & $(0.1)$ \\
\hline & Cantabria & c & c & c & c & c & c & c & c & c & c & c & c & c & c \\
\hline & Castile and Leon ${ }^{\bullet}$ & 0.0 & c & 8.2 & $(2.2)$ & 20.6 & (3.5) & 36.6 & (5.0) & 25.3 & (4.4) & 7.5 & (3.1) & 1.7 & c \\
\hline & Catalonia $\bullet$ & 6.4 & (1.9) & 13.9 & (1.6) & 27.6 & (1.9) & 30.8 & $(2.1)$ & 16.6 & (2.1) & 4.4 & (1.1) & 0.3 & $(0.2)$ \\
\hline & Extremadura ${ }^{\bullet}$ & 11.1 & $(4.5)$ & 15.6 & $(2.7)$ & 19.2 & (4.6) & 29.2 & $(5.2)$ & 19.5 & (5.8) & 5.4 & $(2.2)$ & 0.1 & c \\
\hline & Galicia• & 10.4 & (8.0) & 14.8 & $(4.7)$ & 23.1 & (3.8) & 29.7 & $(4.8)$ & 20.0 & (5.7) & 1.9 & (1.5) & 0.1 & c \\
\hline & La Rioja• & c & $\mathrm{c}$ & c & c & c & c & c & c & c & c & c & c & c & c \\
\hline & Madrid• & 4.2 & (1.4) & 13.1 & $(2.3)$ & 25.8 & (3.2) & 31.4 & (2.9) & 20.4 & (2.7) & 4.9 & (1.4) & 0.3 & c \\
\hline & Murcia ${ }^{\bullet}$ & 14.5 & $(4.2)$ & 23.8 & (3.9) & 26.8 & (5.3) & 24.1 & (4.8) & 9.5 & (3.2) & 1.3 & (1.1) & 0.0 & c \\
\hline & Navarre ${ }^{\bullet}$ & C & c & C & c & C & c & C & C & C & c & c & C & $\mathrm{C}$ & C \\
\hline
\end{tabular}

- PISA adjudicated region.

Note: See Table B3.I.1 for national data.

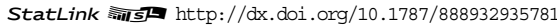


Part 2/2]

Percentage of students at each proficiency level on the computer-based mathematics scale, Table B3.I.13 by region

\begin{tabular}{|c|c|c|c|c|c|c|c|c|c|c|c|c|c|c|c|}
\hline & & \multicolumn{14}{|c|}{ All students } \\
\hline & & \multicolumn{2}{|c|}{$\begin{array}{l}\text { Below Level } 1 \\
\text { (below 357.77 } \\
\text { score points) }\end{array}$} & \multicolumn{2}{|c|}{$\begin{array}{c}\text { Level } 1 \\
\text { (from } 357.77 \text { to } \\
\text { less than } 420.07 \\
\text { score points) }\end{array}$} & \multicolumn{2}{|c|}{$\begin{array}{c}\text { Level } 2 \\
\text { (from } 420.07 \text { to } \\
\text { less than } 482.38 \\
\text { score points) }\end{array}$} & \multicolumn{2}{|c|}{$\begin{array}{c}\text { Level } 3 \\
\text { (from } 482.38 \text { to } \\
\text { less than } 544.68 \\
\text { score points) }\end{array}$} & \multicolumn{2}{|c|}{$\begin{array}{c}\text { Level } 4 \\
\text { (from } 544.68 \text { to } \\
\text { less than } 606.99 \\
\text { score points) }\end{array}$} & \multicolumn{2}{|c|}{$\begin{array}{c}\text { Level } 5 \\
\text { (from } 606.99 \text { to } \\
\text { less than } 669.30 \\
\text { score points) }\end{array}$} & \multicolumn{2}{|c|}{$\begin{array}{c}\text { Level } 6 \\
\text { (above } 669.30 \\
\text { score points) }\end{array}$} \\
\hline & & $\%$ & S.E. & $\%$ & S.E. & $\%$ & S.E. & $\%$ & S.E. & $\%$ & S.E. & $\%$ & S.E. & $\%$ & S.E. \\
\hline \multirow{41}{*}{ ఏँ๊ } & Brazil & & & & & & & & & & & & & & \\
\hline & Acre & 8.4 & (4.5) & 37.0 & (8.0) & 40.3 & (7.1) & 13.2 & (7.1) & 1.0 & (1.4) & 0.1 & c & 0.0 & c \\
\hline & Alagoas & 37.1 & $(16.6)$ & 30.0 & (9.4) & 20.2 & $(10.6)$ & 8.6 & (2.9) & 3.4 & $(2.2)$ & 0.7 & $(0.8)$ & 0.0 & C \\
\hline & Amapá & 22.5 & $(9.0)$ & 37.9 & (10.5) & 28.5 & $(5.7)$ & 9.4 & (5.3) & 1.7 & (2.6) & 0.0 & c & 0.0 & c \\
\hline & Amazonas & 25.6 & (8.4) & 51.4 & (13.7) & 17.7 & (7.3) & 3.1 & (3.1) & 1.7 & (2.8) & 0.6 & (1.0) & 0.0 & c \\
\hline & Bahia & 50.1 & (6.8) & 22.2 & (5.4) & 14.9 & (5.6) & 8.7 & $(2.7)$ & 2.8 & (2.1) & 1.3 & (1.6) & 0.0 & c \\
\hline & Ceará & 34.1 & $(10.3)$ & 26.2 & (5.5) & 16.8 & (5.0) & 12.5 & $(6.0)$ & 7.8 & $(4.9)$ & 2.2 & $(1.7)$ & 0.4 & c \\
\hline & Espírito Santo & 10.3 & (3.7) & 30.1 & (6.3) & 34.5 & (7.6) & 15.7 & (3.9) & 5.8 & (2.9) & 2.8 & (2.6) & 0.7 & (0.6) \\
\hline & Federal District & c & c & c & c & c & c & c & c & c & c & c & c & c & c \\
\hline & Goiás & 34.5 & $(10.4)$ & 31.8 & (4.9) & 21.1 & (6.1) & 9.7 & (3.6) & 2.6 & $(1.7)$ & 0.3 & c & 0.0 & C \\
\hline & Maranhão & 60.3 & $(10.9)$ & 23.7 & (8.9) & 9.6 & (5.5) & 3.7 & (2.9) & 2.4 & $(2.2)$ & 0.3 & c & 0.0 & c \\
\hline & Mato Grosso & c & c & c & c & c & c & c & c & c & c & c & c & c & c \\
\hline & Mato Grosso do Sul & 7.6 & (3.5) & 30.5 & (7.4) & 29.7 & (4.3) & 16.4 & $(4.7)$ & 13.6 & (4.3) & 2.0 & (1.7) & 0.2 & c \\
\hline & Minas Gerais & 17.5 & (5.9) & 25.9 & (5.2) & 30.0 & (5.2) & 15.1 & (3.3) & 7.8 & $(5.7)$ & 3.2 & (2.5) & 0.5 & $(0.5)$ \\
\hline & Pará & 37.8 & $(10.0)$ & 30.4 & (9.0) & 19.0 & (5.7) & 10.8 & $(7.0)$ & 1.7 & (1.9) & 0.3 & c & 0.0 & c \\
\hline & Paraíba & c & c & c & c & c & c & c & c & c & c & c & c & c & c \\
\hline & Paraná & 21.2 & (3.4) & 36.4 & (3.5) & 23.8 & (3.5) & 10.7 & (2.3) & 5.9 & (2.6) & 1.7 & (1.5) & 0.2 & c \\
\hline & Pernambuco & 12.7 & $(4.7)$ & 35.0 & (5.7) & 35.4 & (6.2) & 11.2 & (2.5) & 5.2 & (3.7) & 0.6 & c & 0.0 & c \\
\hline & Piauí & c & c & c & c & c & c & c & c & c & c & c & c & c & c \\
\hline & Rio de Janeiro & 18.3 & (6.3) & 23.7 & (3.9) & 30.1 & $(10.0)$ & 18.2 & (4.9) & 8.8 & (3.8) & 0.9 & $(1.2)$ & 0.1 & c \\
\hline & Rio Grande do Norte & c & c & c & c & c & c & c & c & c & c & c & c & c & c \\
\hline & Rio Grande do Sul & 7.7 & (2.3) & 28.7 & (6.1) & 37.0 & (5.3) & 21.5 & (3.8) & 4.7 & (1.4) & 0.4 & c & 0.0 & c \\
\hline & Rondônia & 22.1 & (4.7) & 38.3 & (6.7) & 27.7 & (5.7) & 9.9 & $(4.8)$ & 2.0 & (1.5) & 0.0 & c & 0.0 & c \\
\hline & Roraima & 17.6 & (13.8) & 41.3 & (6.7) & 25.6 & $(12.2)$ & 12.6 & (5.3) & 2.8 & $(2.1)$ & 0.2 & c & 0.0 & c \\
\hline & Santa Catarina & 19.3 & (15.6) & 21.2 & (6.9) & 31.6 & (9.7) & 21.5 & (4.4) & 5.5 & (2.5) & 0.8 & (0.9) & 0.0 & c \\
\hline & São Paulo & 18.2 & (3.2) & 27.9 & (1.8) & 29.7 & (2.7) & 15.1 & (1.9) & 6.4 & (1.5) & 2.2 & (1.0) & 0.4 & (0.3) \\
\hline & Sergipe & 11.1 & (6.0) & 37.3 & (8.5) & 36.4 & (8.7) & 12.2 & (4.4) & 2.5 & (1.1) & 0.4 & c & 0.0 & c \\
\hline & Tocantins & 18.2 & (5.4) & 37.0 & $(7.2)$ & 33.1 & (7.8) & 9.0 & (3.6) & 2.7 & (2.4) & 0.0 & c & 0.0 & c \\
\hline & \multicolumn{15}{|l|}{ Colombia } \\
\hline & Bogota & 23.1 & (2.2) & 32.8 & (1.8) & 28.5 & (1.8) & 13.0 & (1.6) & 2.0 & $(0.6)$ & 0.5 & $(0.4)$ & 0.1 & $(0.1)$ \\
\hline & Cali & 30.8 & (4.3) & 31.7 & (3.0) & 23.8 & (3.0) & 10.2 & (2.3) & 3.1 & (1.3) & 0.4 & $(0.4)$ & 0.0 & c \\
\hline & Manizales & 21.2 & (1.9) & 36.8 & (2.0) & 28.7 & (2.1) & 10.9 & (1.5) & 2.2 & (1.0) & 0.2 & $(0.2)$ & 0.0 & c \\
\hline & Medellin & 25.6 & (3.2) & 30.1 & (2.0) & 25.7 & (2.2) & 12.5 & $(2.0)$ & 4.5 & (1.3) & 1.4 & $(0.7)$ & 0.3 & $(0.2)$ \\
\hline & \multicolumn{15}{|l|}{ United Arab Emirates } \\
\hline & Abu Dhabi & 23.2 & (1.8) & 26.6 & (1.3) & 25.9 & (1.2) & 16.1 & $(1.2)$ & 6.2 & $(0.8)$ & 1.7 & $(0.6)$ & 0.3 & $(0.2)$ \\
\hline & Ajman & 32.7 & (4.3) & 33.8 & (2.7) & 24.5 & (3.0) & 8.2 & (1.8) & 0.8 & $(0.6)$ & 0.0 & c & 0.0 & c \\
\hline & Dubai $\bullet$ & 12.7 & $(0.5)$ & 19.8 & $(0.7)$ & 26.5 & $(0.9)$ & 23.1 & $(0.8)$ & 13.0 & $(0.8)$ & 4.4 & $(0.4)$ & 0.5 & $(0.2)$ \\
\hline & Fujairah & 18.8 & (2.3) & 26.3 & (3.1) & 31.5 & (2.3) & 18.7 & (2.5) & 4.6 & (1.5) & 0.1 & c & 0.0 & c \\
\hline & Ras Al Khaimah & 20.4 & (3.6) & 31.3 & (2.7) & 31.1 & (2.3) & 13.9 & (1.7) & 2.9 & (1.0) & 0.3 & $(0.3)$ & 0.0 & c \\
\hline & Sharjah & 10.5 & (2.3) & 26.5 & (2.5) & 36.5 & (2.9) & 20.2 & (2.3) & 5.5 & (1.6) & 0.7 & $(0.4)$ & 0.0 & c \\
\hline & Umm Al Quwain & 33.8 & (3.1) & 32.1 & (3.4) & 25.1 & (3.2) & 7.9 & (1.9) & 1.1 & (0.6) & 0.0 & c & 0.0 & C \\
\hline
\end{tabular}

- PISA adjudicated region.

Note: See Table B3.I.1 for national data.

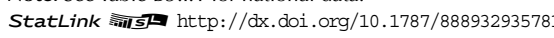


Percentage of students at each proficiency level on the computer-based mathematics scale, Table B3.I.14 by gender and region

\begin{tabular}{|c|c|c|c|c|c|c|c|c|c|c|c|c|c|c|c|}
\hline & & \multicolumn{14}{|c|}{ Boys } \\
\hline & & \multicolumn{2}{|c|}{$\begin{array}{c}\text { Below Level } 1 \\
\text { (below } 357.77 \\
\text { score points) }\end{array}$} & \multicolumn{2}{|c|}{$\begin{array}{c}\text { Level } 1 \\
\text { (from } 357.77 \text { to } \\
\text { less than } 420.07 \\
\text { score points) }\end{array}$} & \multicolumn{2}{|c|}{$\begin{array}{c}\text { Level } 2 \\
\text { (from } 420.07 \text { to } \\
\text { less than } 482.38 \\
\text { score points) }\end{array}$} & \multicolumn{2}{|c|}{$\begin{array}{c}\text { Level } 3 \\
\text { (from } 482.38 \text { to } \\
\text { less than } 544.68 \\
\text { score points) }\end{array}$} & \multicolumn{2}{|c|}{$\begin{array}{c}\text { Level } 4 \\
\text { (from } 544.68 \text { to } \\
\text { less than } 606.99 \\
\text { score points) }\end{array}$} & \multicolumn{2}{|c|}{$\begin{array}{c}\text { Level } 5 \\
\text { (from } 606.99 \text { to } \\
\text { less than } 669.30 \\
\text { score points) }\end{array}$} & \multicolumn{2}{|c|}{$\begin{array}{c}\text { Level } 6 \\
\text { (above } 669.30 \\
\text { score points) }\end{array}$} \\
\hline & & $\%$ & S.E. & $\%$ & S.E. & $\%$ & S.E. & $\%$ & S.E. & $\%$ & S.E. & $\%$ & S.E. & $\%$ & S.E. \\
\hline$\theta$ & Australia & & & & & & & & & & & & & & \\
\hline 엉 & Australian Capital Territory & 6.9 & $(1.3)$ & 9.9 & $(1.7)$ & 19.8 & $(3.7)$ & 25.5 & $(4.2)$ & 21.6 & (3.3) & 13.2 & $(2.2)$ & 3.0 & $(0.8)$ \\
\hline & New South Wales & 6.2 & $(0.9)$ & 12.8 & (2.0) & 21.4 & (1.8) & 24.2 & (1.4) & 19.4 & (1.5) & 11.1 & (1.1) & 4.9 & (1.2) \\
\hline & Northern Territory & 12.8 & (3.0) & 13.8 & (4.5) & 21.3 & (3.7) & 26.0 & (6.4) & 17.7 & (4.8) & 6.2 & (2.9) & 2.3 & (2.0) \\
\hline & Queensland & 4.3 & $(0.8)$ & 11.7 & (1.1) & 22.5 & $(1.5)$ & 25.4 & (1.4) & 21.5 & (1.5) & 11.3 & (1.3) & 3.3 & $(0.7)$ \\
\hline & South Australia & 6.2 & $(1.2)$ & 10.9 & (1.3) & 21.5 & $(1.7)$ & 28.1 & (2.4) & 21.3 & (2.4) & 9.5 & (1.5) & 2.6 & $(0.7)$ \\
\hline & Tasmania & 9.7 & $(1.5)$ & 15.6 & (1.8) & 24.7 & $(2.3)$ & 23.8 & (2.3) & 16.4 & (2.0) & 7.4 & (1.5) & 2.4 & $(0.9)$ \\
\hline & Victoria & 2.7 & $(0.7)$ & 10.0 & (1.3) & 21.3 & $(2.3)$ & 28.5 & $(2.2)$ & 22.5 & (1.5) & 10.6 & (1.4) & 4.4 & (1.5) \\
\hline & Western Australia & 3.9 & $(1.2)$ & 10.0 & $(1.7)$ & 18.0 & $(1.7)$ & 24.9 & (1.9) & 24.3 & (1.8) & 13.4 & $(1.4)$ & 5.5 & (1.7) \\
\hline & Belgium & & & & & & & & & & & & & & \\
\hline & Flemish community ${ }^{\bullet}$ & 5.2 & $(0.8)$ & 9.1 & $(1.1)$ & 16.1 & $(1.1)$ & 20.0 & (1.3) & 23.0 & (1.4) & 17.8 & $(1.1)$ & 8.8 & $(0.7)$ \\
\hline & French community & 8.1 & $(1.1)$ & 12.5 & $(1.0)$ & 20.6 & (1.4) & 25.7 & $(1.7)$ & 20.8 & (1.4) & 9.6 & $(1.2)$ & 2.6 & $(0.7)$ \\
\hline & German-speaking community & 3.5 & $(1.2)$ & 9.5 & (1.9) & 18.7 & $(2.2)$ & 30.0 & $(2.7)$ & 23.5 & (2.6) & 11.1 & (1.6) & 3.8 & (1.1) \\
\hline & Canada & & & & & & & & & & & & & & \\
\hline & Alberta & 4.7 & $(1.1)$ & 8.9 & $(1.2)$ & 20.2 & $(2.3)$ & 25.2 & (1.9) & 22.0 & $(1.7)$ & 12.8 & $(1.7)$ & 6.2 & (1.3) \\
\hline & British Columbia & 2.2 & $(0.7)$ & 6.5 & (1.4) & 16.7 & $(2.1)$ & 24.6 & (1.9) & 25.5 & (1.9) & 15.3 & (1.9) & 9.2 & (1.9) \\
\hline & Manitoba & 6.5 & $(1.3)$ & 12.3 & (1.8) & 21.7 & $(2.0)$ & 26.0 & $(2.1)$ & 21.0 & (1.8) & 9.6 & $(1.2)$ & 2.9 & $(0.8)$ \\
\hline & New Brunswick & 6.8 & $(1.2)$ & 10.2 & (1.5) & 22.4 & (1.8) & 31.0 & (2.4) & 19.4 & (2.4) & 9.1 & $(1.7)$ & 1.1 & $(0.4)$ \\
\hline & Newfoundland and Labrador & 5.0 & $(1.4)$ & 8.9 & (2.5) & 19.5 & $(2.7)$ & 28.9 & (3.5) & 25.1 & $(2.2)$ & 10.3 & (1.8) & 2.3 & $(0.7)$ \\
\hline & Nova Scotia & 4.6 & $(1.2)$ & 10.6 & $(2.2)$ & 20.1 & $(2.5)$ & 27.9 & (2.4) & 23.2 & $(2.2)$ & 11.6 & $(1.8)$ & 2.0 & $(0.9)$ \\
\hline & Ontario & 2.6 & $(0.8)$ & 6.5 & $(0.9)$ & 16.2 & (1.5) & 25.7 & (1.8) & 24.9 & (1.9) & 16.5 & (1.5) & 7.6 & (1.5) \\
\hline & Prince Edward Island & 10.0 & $(1.3)$ & 13.4 & (1.7) & 24.1 & (1.8) & 26.7 & (2.0) & 18.1 & (1.6) & 5.2 & (1.1) & 2.5 & (0.6) \\
\hline & Quebec & 4.2 & $(0.7)$ & 8.3 & $(1.0)$ & 15.9 & $(1.2)$ & 25.0 & (1.4) & 26.3 & (1.6) & 15.4 & (1.3) & 4.9 & (0.9) \\
\hline & Saskatchewan & 6.6 & (1.0) & 10.4 & (1.4) & 21.9 & (1.6) & 28.0 & $(2.2)$ & 20.7 & $(2.2)$ & 10.0 & (1.6) & 2.3 & (0.6) \\
\hline & Italy & & & & & & & & & & & & & & \\
\hline & Abruzzo & 2.0 & $(2.0)$ & 8.4 & (5.4) & 21.5 & (9.4) & 34.3 & $(9.2)$ & 27.3 & $(10.0)$ & 5.7 & $(2.7)$ & 0.8 & c \\
\hline & Basilicata & 6.4 & $(6.3)$ & 15.0 & (5.9) & 26.1 & (5.6) & 31.4 & (10.1) & 17.2 & (5.5) & 3.2 & (1.8) & 0.6 & c \\
\hline & Bolzano & 0.0 & c & 4.5 & (3.4) & 12.3 & $(4.9)$ & 29.0 & (4.1) & 33.2 & (4.5) & 19.6 & (5.9) & 1.4 & (1.6) \\
\hline & Calabria & 5.7 & $(4.9)$ & 15.1 & $(6.0)$ & 29.4 & $(8.5)$ & 31.7 & (6.4) & 13.6 & (5.5) & 4.5 & $(5.0)$ & 0.0 & C \\
\hline & Campania & 11.8 & $(5.6)$ & 21.2 & (3.6) & 24.4 & $(4.3)$ & 25.7 & (3.9) & 11.8 & (2.8) & 4.8 & (1.8) & 0.4 & C \\
\hline & Emilia Romagna & 3.6 & $(2.1)$ & 10.7 & $(4.2)$ & 20.1 & $(6.0)$ & 31.9 & (7.1) & 19.8 & (2.9) & 9.5 & (4.4) & 4.3 & (3.3) \\
\hline & Friuli Venezia Giulia & 6.6 & $(4.8)$ & 10.2 & (5.4) & 11.6 & (7.4) & 26.6 & (5.6) & 37.2 & $(13.2)$ & 6.6 & (5.3) & 1.3 & (1.5) \\
\hline & Lazio & 4.8 & (3.1) & 15.5 & (5.6) & 19.0 & (5.1) & 28.6 & (4.1) & 24.0 & (4.5) & 6.6 & (2.0) & 1.5 & $(0.6)$ \\
\hline & Liguria & 2.2 & $(1.6)$ & 6.4 & (3.8) & 14.7 & (5.3) & 26.2 & (9.0) & 20.5 & (4.8) & 15.1 & (8.6) & 14.9 & $(10.2)$ \\
\hline & Lombardia & 1.2 & $(1.1)$ & 5.4 & (1.9) & 16.1 & (3.8) & 31.1 & (3.6) & 29.0 & (3.3) & 13.8 & (3.8) & 3.3 & (1.7) \\
\hline & Marche & 0.0 & c & 8.8 & $(4.0)$ & 20.2 & $(7.2)$ & 35.2 & $(7.2)$ & 26.5 & (6.4) & 5.9 & (4.4) & 3.4 & (2.0) \\
\hline & Molise & 4.9 & $(4.1)$ & 25.6 & $(11.1)$ & 23.5 & (5.6) & 30.9 & (10.3) & 12.1 & $(4.8)$ & 0.3 & c & 2.8 & (2.6) \\
\hline & Piemonte & 1.9 & (1.1) & 10.1 & (3.2) & 19.9 & (6.4) & 29.3 & (5.4) & 25.2 & (4.9) & 10.4 & (5.4) & 3.2 & (2.0) \\
\hline & Puglia & 5.3 & $(2.0)$ & 14.0 & (6.5) & 28.4 & $(4.6)$ & 23.0 & $(6.7)$ & 24.2 & (6.8) & 4.3 & $(2.0)$ & 0.7 & C \\
\hline & Sardegna & 5.5 & (6.6) & 22.3 & (6.5) & 38.5 & (5.1) & 27.0 & (6.3) & 6.2 & (3.2) & 0.6 & c & 0.0 & c \\
\hline & Sicilia & 2.8 & (1.9) & 11.1 & (3.8) & 26.8 & (5.9) & 36.4 & (4.4) & 19.0 & (3.6) & 3.6 & (1.8) & 0.3 & c \\
\hline & Toscana & 1.7 & $(1.3)$ & 9.1 & (3.2) & 17.0 & (6.5) & 26.5 & (5.3) & 30.3 & (6.7) & 13.9 & $(4.8)$ & 1.4 & c \\
\hline & Trento & 1.2 & $(1.2)$ & 7.6 & (3.9) & 11.3 & (3.2) & 22.8 & (3.1) & 32.0 & (6.5) & 20.2 & (5.8) & 4.9 & (3.8) \\
\hline & Umbria & 6.0 & $(4.3)$ & 10.6 & $(3.2)$ & 29.0 & $(9.4)$ & 32.4 & (5.3) & 16.8 & (6.6) & 3.6 & (2.6) & 1.5 & (1.8) \\
\hline & Valle d'Aosta & 1.1 & (1.4) & 7.7 & (4.4) & 20.9 & (7.4) & 35.3 & (7.6) & 28.6 & (9.4) & 4.8 & (3.2) & 1.6 & (1.7) \\
\hline & Veneto & 3.8 & $(1.2)$ & 10.8 & (3.3) & 17.0 & $(5.2)$ & 19.9 & (3.6) & 23.4 & (3.1) & 20.9 & $(6.8)$ & 4.3 & (2.2) \\
\hline & Portugal & & & & & & & & & & & & & & \\
\hline & Alentejo & 7.7 & $(2.3)$ & 11.9 & (3.0) & 19.3 & $(4.0)$ & 32.1 & (4.3) & 19.0 & (3.0) & 8.0 & (2.6) & 2.0 & (1.7) \\
\hline & Spain & & & & & & & & & & & & & & \\
\hline & Andalusia ${ }^{\bullet}$ & 11.6 & $(3.4)$ & 19.0 & (3.0) & 28.6 & (2.6) & 25.9 & (2.8) & 11.1 & $(2.7)$ & 3.1 & (1.1) & 0.7 & (0.4) \\
\hline & Aragon • & 8.6 & $(4.4)$ & 17.3 & (5.8) & 17.0 & $(5.2)$ & 24.4 & (4.5) & 21.5 & (6.4) & 9.4 & (3.9) & 1.8 & (2.6) \\
\hline & Asturias ${ }^{\bullet}$ & $\mathrm{C}$ & c & c & c & c & c & c & c & C & c & c & c & c & C \\
\hline & Balearic Islands ${ }^{\bullet}$ & c & c & c & c & c & c & c & c & c & c & c & c & c & c \\
\hline & Basque Country ${ }^{\bullet}$ & 5.9 & $(1.0)$ & 11.9 & $(1.2)$ & 22.7 & (1.3) & 29.3 & $(1.2)$ & 22.2 & $(1.2)$ & 7.0 & $(0.7)$ & 0.9 & (0.3) \\
\hline & Cantabria • & C & c & c & c & c & c & c & c & c & c & c & c & c & c \\
\hline & Castile and Leon ${ }^{\bullet}$ & 0.0 & c & 11.3 & (2.9) & 18.3 & $(4.8)$ & 32.9 & $(8.1)$ & 25.5 & (5.4) & 10.1 & $(4.1)$ & 2.0 & $\mathrm{c}$ \\
\hline & Catalonia $\bullet$ & 6.0 & $(2.3)$ & 13.6 & $(2.2)$ & 24.1 & $(2.5)$ & 29.7 & (2.6) & 19.6 & (2.9) & 6.3 & (1.5) & 0.6 & (0.3) \\
\hline & Extremadura ${ }^{\bullet}$ & 9.1 & $(3.7)$ & 18.0 & (3.6) & 21.0 & $(5.0)$ & 26.7 & (4.7) & 18.7 & (7.9) & 6.4 & (2.5) & 0.1 & C \\
\hline & Galicia• & 12.4 & $(8.7)$ & 16.3 & (4.9) & 23.3 & $(6.0)$ & 29.0 & (6.6) & 15.5 & (5.4) & 3.2 & (2.5) & 0.2 & c \\
\hline & La Rioja• & c & c & c & c & c & c & c & c & C & c & c & c & c & c \\
\hline & Madrid• & 3.9 & (1.6) & 11.9 & (3.4) & 23.8 & $(4.1)$ & 32.3 & (4.4) & 21.3 & (3.2) & 6.3 & $(2.2)$ & 0.5 & c \\
\hline & Murcia ${ }^{\bullet}$ & 9.8 & $(4.2)$ & 21.7 & $(4.7)$ & 25.8 & (6.6) & 26.8 & (4.5) & 13.4 & (3.7) & 2.5 & (2.0) & 0.0 & c \\
\hline & Navarre ${ }^{\bullet}$ & $\mathrm{C}$ & $\mathrm{C}$ & $\mathrm{C}$ & C & c & c & c & c & C & C & c & c & c & C \\
\hline
\end{tabular}

- PISA adjudicated region.

Note: See Table B3.I.2 for national data.

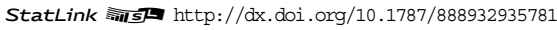


Part 2/4]

Percentage of students at each proficiency level on the computer-based mathematics scale, Table B3.I.14 by gender and region

\begin{tabular}{|c|c|c|c|c|c|c|c|c|c|c|c|c|c|c|c|}
\hline & & \multicolumn{14}{|c|}{ Boys } \\
\hline & & \multicolumn{2}{|c|}{$\begin{array}{l}\text { Below Level } 1 \\
\text { (below 357.77 } \\
\text { score points) }\end{array}$} & \multicolumn{2}{|c|}{$\begin{array}{c}\text { Level } 1 \\
\text { (from } 357.77 \text { to } \\
\text { less than } 420.07 \\
\text { score points) }\end{array}$} & \multicolumn{2}{|c|}{$\begin{array}{c}\text { Level } 2 \\
\text { (from } 420.07 \text { to } \\
\text { less than } 482.38 \\
\text { score points) }\end{array}$} & \multicolumn{2}{|c|}{$\begin{array}{c}\text { Level } 3 \\
\text { (from } 482.38 \text { to } \\
\text { less than } 544.68 \\
\text { score points) }\end{array}$} & \multicolumn{2}{|c|}{$\begin{array}{c}\text { Level } 4 \\
\text { (from } 544.68 \text { to } \\
\text { less than } 606.99 \\
\text { score points) }\end{array}$} & \multicolumn{2}{|c|}{$\begin{array}{c}\text { Level } 5 \\
\text { (from } 606.99 \text { to } \\
\text { less than } 669.30 \\
\text { score points) }\end{array}$} & \multicolumn{2}{|c|}{$\begin{array}{c}\text { Level } 6 \\
\text { (above } 669.30 \\
\text { score points) }\end{array}$} \\
\hline & & $\%$ & S.E. & $\%$ & S.E. & $\%$ & S.E. & $\%$ & S.E. & $\%$ & S.E. & $\%$ & S.E. & $\%$ & S.E. \\
\hline \multirow{41}{*}{ ฏ. } & Brazil & & & & & & & & & & & & & & \\
\hline & Acre & 7.9 & (3.5) & 33.4 & (6.7) & 40.7 & (9.7) & 15.7 & (11.7) & 2.1 & (3.2) & 0.2 & c & 0.0 & c \\
\hline & Alagoas & 36.9 & (19.3) & 33.3 & $(14.2)$ & 19.2 & $(13.2)$ & 7.3 & (4.3) & 2.6 & (2.0) & 0.6 & c & 0.0 & C \\
\hline & Amapá & 9.0 & (9.8) & 37.0 & $(14.7)$ & 39.6 & (10.3) & 12.3 & (5.5) & 2.1 & (3.2) & 0.0 & c & 0.0 & c \\
\hline & Amazonas & 30.0 & (10.4) & 43.6 & (15.4) & 19.8 & (8.5) & 3.7 & $(4.2)$ & 1.9 & (3.0) & 0.9 & c & 0.0 & c \\
\hline & Bahia & 41.8 & $(10.3)$ & 23.1 & $(7.5)$ & 17.1 & (7.6) & 11.7 & (3.7) & 5.0 & (3.9) & 1.4 & c & 0.0 & c \\
\hline & Ceará & 29.1 & (8.1) & 26.5 & (7.5) & 15.8 & (5.4) & 14.2 & (6.2) & 9.5 & (5.2) & 4.2 & (3.0) & 0.7 & C \\
\hline & Espírito Santo & 10.4 & (6.1) & 30.0 & (8.6) & 32.4 & (8.1) & 16.1 & (5.0) & 7.6 & (3.2) & 2.5 & (2.1) & 0.9 & (1.0) \\
\hline & Federal District & c & c & c & c & c & c & c & c & c & c & c & c & c & c \\
\hline & Goiás & 29.5 & (9.5) & 29.9 & (7.0) & 24.1 & (8.4) & 12.0 & (3.6) & 3.9 & (2.0) & 0.5 & c & 0.0 & c \\
\hline & Maranhão & 59.9 & $(10.8)$ & 21.6 & (9.6) & 7.3 & (6.0) & 5.9 & (4.4) & 4.8 & (4.6) & 0.6 & c & 0.0 & c \\
\hline & Mato Grosso & c & c & c & c & c & c & c & c & c & c & c & c & c & c \\
\hline & Mato Grosso do Sul & 6.7 & $(4.0)$ & 22.8 & (11.5) & 33.7 & (6.1) & 17.8 & (8.6) & 15.6 & (5.3) & 2.9 & (2.8) & 0.4 & c \\
\hline & Minas Gerais & 14.9 & (6.7) & 24.0 & (6.5) & 29.9 & (6.5) & 15.9 & (4.1) & 10.5 & (7.8) & 3.6 & (2.5) & 1.1 & (1.1) \\
\hline & Pará & 36.2 & $(14.8)$ & 32.2 & (11.5) & 21.3 & (11.9) & 7.2 & (5.6) & 3.2 & c & 0.0 & c & 0.0 & c \\
\hline & Paraíba & c & c & c & c & c & c & c & c & c & c & c & c & c & c \\
\hline & Paraná & 15.9 & (3.4) & 37.8 & $(5.2)$ & 25.2 & (5.4) & 11.6 & (3.3) & 7.4 & (3.3) & 2.1 & (1.8) & 0.0 & c \\
\hline & Pernambuco & 11.2 & (5.7) & 31.2 & $(6.0)$ & 34.1 & (6.5) & 11.7 & (5.6) & 10.6 & (8.3) & 1.3 & c & 0.0 & c \\
\hline & Piauí & c & c & c & c & c & c & c & c & c & c & c & c & c & c \\
\hline & Rio de Janeiro & 15.1 & (5.7) & 21.2 & (5.6) & 30.9 & (8.6) & 19.9 & (7.4) & 11.6 & (5.5) & 1.2 & c & 0.0 & c \\
\hline & Rio Grande do Norte & c & c & c & c & c & c & c & c & c & c & c & c & c & c \\
\hline & Rio Grande do Sul & 4.8 & (3.0) & 20.7 & (7.0) & 38.7 & (7.6) & 27.6 & (7.1) & 7.3 & (2.8) & 0.9 & c & 0.0 & c \\
\hline & Rondônia & 11.7 & (7.1) & 30.2 & (5.6) & 33.5 & (7.3) & 20.1 & (9.6) & 4.3 & (3.4) & 0.1 & c & 0.0 & c \\
\hline & Roraima & 9.6 & (9.6) & 35.9 & $(10.2)$ & 32.4 & (13.2) & 20.0 & (9.5) & 2.2 & c & 0.0 & c & 0.0 & c \\
\hline & Santa Catarina & 19.7 & (16.6) & 18.4 & (5.4) & 29.9 & $(10.9)$ & 25.3 & (5.7) & 5.9 & (2.5) & 0.8 & $(0.8)$ & 0.0 & c \\
\hline & São Paulo & 15.3 & (3.3) & 26.2 & (2.2) & 31.1 & (3.2) & 16.4 & (2.4) & 7.7 & (1.9) & 2.9 & (1.3) & 0.6 & $(0.4)$ \\
\hline & Sergipe & 7.3 & (7.3) & 31.9 & (8.4) & 39.0 & (7.0) & 15.7 & (8.5) & 5.1 & (1.6) & 0.9 & c & 0.0 & c \\
\hline & Tocantins & 19.9 & $(12.1)$ & 28.4 & (15.5) & 33.2 & $(16.1)$ & 14.2 & (9.4) & 4.3 & $(5.2)$ & 0.0 & c & 0.0 & c \\
\hline & \multicolumn{15}{|l|}{ Colombia } \\
\hline & Bogota & 17.9 & (2.6) & 31.0 & (2.8) & 30.4 & $(2.2)$ & 16.6 & (2.4) & 2.8 & $(1.0)$ & 1.1 & $(0.9)$ & 0.3 & (0.3) \\
\hline & Cali & 28.2 & $(4.2)$ & 30.6 & (3.2) & 24.1 & (3.2) & 11.5 & (2.5) & 4.7 & $(2.2)$ & 0.9 & (1.0) & 0.1 & c \\
\hline & Manizales & 18.7 & (2.0) & 34.7 & (3.0) & 29.2 & (2.7) & 13.9 & (2.3) & 3.2 & (2.0) & 0.3 & c & 0.0 & c \\
\hline & Medellin & 22.3 & (3.5) & 29.8 & (2.4) & 27.2 & (2.9) & 14.8 & (2.5) & 4.2 & (1.3) & 1.4 & $(0.9)$ & 0.3 & $(0.4)$ \\
\hline & \multicolumn{15}{|l|}{ United Arab Emirates } \\
\hline & Abu Dhabi & 27.6 & (2.9) & 26.2 & (1.6) & 23.2 & (1.8) & 14.4 & (1.5) & 6.5 & (1.1) & 1.7 & $(0.7)$ & 0.3 & $(0.2)$ \\
\hline & Ajman & 46.1 & (4.7) & 34.0 & (4.3) & 17.5 & (3.7) & 2.4 & (1.1) & 0.0 & c & 0.0 & c & 0.0 & c \\
\hline & Dubai $\bullet$ & 14.8 & $(0.8)$ & 18.9 & (1.1) & 24.5 & (1.1) & 22.1 & (1.3) & 13.0 & $(1.2)$ & 5.9 & $(0.7)$ & 0.7 & $(0.2)$ \\
\hline & Fujairah & 26.0 & (3.0) & 27.5 & (3.1) & 27.8 & $(2.7)$ & 14.2 & $(2.2)$ & 4.3 & (1.3) & 0.2 & c & 0.0 & c \\
\hline & Ras Al Khaimah & 28.3 & (7.3) & 31.3 & (4.3) & 27.4 & (4.0) & 11.0 & (2.2) & 2.0 & $(0.9)$ & 0.1 & $(0.1)$ & 0.0 & c \\
\hline & Sharjah & 13.1 & (4.8) & 26.4 & (4.3) & 32.7 & (5.1) & 20.2 & (4.6) & 6.6 & (2.9) & 0.9 & (0.8) & 0.1 & c \\
\hline & Umm Al Quwain & 43.7 & (3.7) & 25.5 & (3.9) & 22.9 & (4.5) & 7.1 & (2.6) & 0.8 & c & 0.0 & c & 0.0 & C \\
\hline
\end{tabular}

- PISA adjudicated region.

Note: See Table B3.I.2 for national data.

StatLink त्नाls http://dx.doi.org/10.1787/888932935781 
Percentage of students at each proficiency level on the computer-based mathematics scale, Table B3.I.14 by gender and region

\begin{tabular}{|c|c|c|c|c|c|c|c|c|c|c|c|c|c|c|c|}
\hline & & \multicolumn{14}{|c|}{ Girls } \\
\hline & & \multicolumn{2}{|c|}{$\begin{array}{c}\text { Below Level } 1 \\
\text { (below } 357.77 \\
\text { score points) }\end{array}$} & \multicolumn{2}{|c|}{$\begin{array}{c}\text { Level } 1 \\
\text { (from } 357.77 \text { to } \\
\text { less than } 420.07 \\
\text { score points) }\end{array}$} & \multicolumn{2}{|c|}{$\begin{array}{c}\text { Level } 2 \\
\text { (from } 420.07 \text { to } \\
\text { less than } 482.38 \\
\text { score points) }\end{array}$} & \multicolumn{2}{|c|}{$\begin{array}{c}\text { Level } 3 \\
\text { (from } 482.38 \text { to } \\
\text { less than } 544.68 \\
\text { score points) }\end{array}$} & \multicolumn{2}{|c|}{$\begin{array}{c}\text { Level } 4 \\
\text { (from } 544.68 \text { to } \\
\text { less than } 606.99 \\
\text { score points) }\end{array}$} & \multicolumn{2}{|c|}{$\begin{array}{c}\text { Level } 5 \\
\text { (from } 606.99 \text { to } \\
\text { less than } 669.30 \\
\text { score points) }\end{array}$} & \multicolumn{2}{|c|}{$\begin{array}{c}\text { Level } 6 \\
\text { (above } 669.30 \\
\text { score points) }\end{array}$} \\
\hline & & $\%$ & S.E. & $\%$ & S.E. & $\%$ & S.E. & $\%$ & S.E. & $\%$ & S.E. & $\%$ & S.E. & $\%$ & S.E. \\
\hline$\theta$ & Australia & & & & & & & & & & & & & & \\
\hline 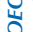 & Australian Capital Territory & 4.5 & $(1.1)$ & 8.8 & (1.8) & 22.0 & (3.3) & 27.6 & (3.6) & 22.9 & (2.8) & 10.3 & $(2.0)$ & 3.9 & $(1.0)$ \\
\hline & New South Wales & 5.0 & $(0.8)$ & 11.3 & (1.1) & 22.3 & (1.4) & 27.0 & (1.5) & 20.7 & (1.6) & 10.1 & $(1.2)$ & 3.5 & $(0.9)$ \\
\hline & Northern Territory & 16.2 & (2.6) & 14.6 & (4.7) & 21.4 & (5.4) & 27.7 & (6.4) & 14.8 & $(4.0)$ & 4.8 & (3.4) & 0.4 & c \\
\hline & Queensland & 5.1 & $(0.9)$ & 11.9 & (1.3) & 22.9 & (1.7) & 29.7 & (1.8) & 19.2 & (1.5) & 9.0 & (1.4) & 2.2 & $(0.5)$ \\
\hline & South Australia & 5.9 & $(1.4)$ & 12.8 & $(1.7)$ & 25.2 & (2.0) & 28.2 & (2.1) & 18.7 & $(1.7)$ & 7.5 & (1.4) & 1.6 & $(0.7)$ \\
\hline & Tasmania & 10.7 & (1.6) & 16.9 & (2.1) & 24.5 & $(2.2)$ & 24.4 & (2.3) & 15.7 & (2.0) & 5.6 & (1.9) & 2.2 & $(0.8)$ \\
\hline & Victoria & 4.1 & $(0.8)$ & 11.9 & $(1.2)$ & 23.7 & (1.8) & 27.9 & (2.0) & 21.8 & (1.8) & 9.0 & (1.1) & 1.6 & $(0.5)$ \\
\hline & Western Australia & 6.5 & (1.4) & 11.7 & (1.8) & 21.6 & (2.2) & 25.6 & (2.5) & 21.1 & (2.4) & 11.0 & (1.5) & 2.4 & $(0.8)$ \\
\hline & Belgium & & & & & & & & & & & & & & \\
\hline & Flemish community ${ }^{\bullet}$ & 5.8 & $(1.0)$ & 10.1 & $(1.1)$ & 16.3 & $(1.2)$ & 23.4 & $(1.2)$ & 24.9 & (1.3) & 14.8 & $(1.2)$ & 4.7 & $(0.7)$ \\
\hline & French community & 9.0 & $(1.0)$ & 13.1 & (1.0) & 24.5 & $(1.2)$ & 30.3 & $(1.7)$ & 17.3 & (1.4) & 5.1 & $(0.9)$ & 0.7 & $(0.3)$ \\
\hline & German-speaking community & 4.0 & $(1.1)$ & 11.2 & (1.8) & 23.9 & (2.6) & 30.9 & (2.5) & 18.6 & $(2.1)$ & 9.7 & (1.5) & 1.7 & $(0.6)$ \\
\hline & Canada & & & & & & & & & & & & & & \\
\hline & Alberta & 6.8 & (1.6) & 9.6 & (1.6) & 19.9 & (1.5) & 25.8 & (2.0) & 23.1 & (2.6) & 11.6 & $(1.7)$ & 3.3 & $(0.8)$ \\
\hline & British Columbia & 3.0 & $(0.8)$ & 9.2 & (1.3) & 20.7 & (1.8) & 28.4 & (1.9) & 23.6 & (1.9) & 11.4 & $(1.7)$ & 3.7 & $(0.9)$ \\
\hline & Manitoba & 7.6 & $(1.4)$ & 14.3 & (2.0) & 26.0 & (2.4) & 28.1 & (2.4) & 17.2 & (1.6) & 5.9 & $(0.9)$ & 0.9 & $(0.3)$ \\
\hline & New Brunswick & 5.4 & $(1.0)$ & 10.8 & (1.4) & 25.0 & (2.0) & 30.8 & (2.3) & 21.4 & (1.8) & 5.8 & (1.6) & 0.8 & $(0.7)$ \\
\hline & Newfoundland and Labrador & 3.0 & $(0.8)$ & 8.4 & (1.7) & 24.5 & (2.6) & 29.9 & $(2.2)$ & 24.7 & (2.0) & 7.8 & (1.4) & 1.7 & $(0.6)$ \\
\hline & Nova Scotia & 5.6 & (1.7) & 12.1 & (2.6) & 24.0 & (3.0) & 30.2 & (2.4) & 18.6 & (2.9) & 8.3 & (1.7) & 1.2 & $(0.6)$ \\
\hline & Ontario & 3.7 & $(0.8)$ & 8.7 & $(1.2)$ & 19.4 & (1.7) & 28.8 & $(2.2)$ & 25.4 & (2.0) & 11.1 & (1.5) & 2.8 & $(0.9)$ \\
\hline & Prince Edward Island & 6.6 & $(1.1)$ & 14.1 & (1.6) & 22.7 & (2.0) & 26.1 & $(2.1)$ & 18.4 & (2.0) & 9.1 & (1.5) & 3.0 & $(0.6)$ \\
\hline & Quebec & 5.1 & $(0.7)$ & 8.6 & (1.0) & 18.5 & (1.4) & 27.3 & (1.8) & 25.2 & (1.6) & 12.3 & (1.3) & 3.0 & $(0.6)$ \\
\hline & Saskatchewan & 4.9 & (1.4) & 13.7 & (2.5) & 24.1 & $(2.2)$ & 28.0 & (1.7) & 20.9 & (2.3) & 7.3 & (1.3) & 1.2 & $(0.6)$ \\
\hline & Italy & & & & & & & & & & & & & & \\
\hline & Abruzzo & 3.4 & (3.2) & 16.3 & (11.6) & 32.9 & (8.1) & 34.2 & (11.6) & 11.4 & $(9.7)$ & 1.8 & (1.8) & 0.0 & c \\
\hline & Basilicata & 1.9 & $(1.4)$ & 18.0 & (7.4) & 31.7 & (9.5) & 30.0 & (7.4) & 15.7 & (4.8) & 2.7 & c & 0.0 & c \\
\hline & Bolzano & 0.0 & $\mathrm{C}$ & 7.8 & (2.0) & 20.9 & (7.0) & 36.5 & (5.5) & 29.0 & (9.3) & 5.6 & $(4.0)$ & 0.1 & c \\
\hline & Calabria & 9.2 & $(4.0)$ & 17.9 & $(8.2)$ & 36.8 & (5.3) & 31.5 & (12.4) & 3.7 & (2.3) & 0.9 & $(0.7)$ & 0.0 & c \\
\hline & Campania & 10.1 & $(4.3)$ & 21.9 & (4.8) & 31.1 & (3.8) & 27.2 & (5.4) & 8.4 & (3.1) & 1.0 & $(1.0)$ & 0.3 & c \\
\hline & Emilia Romagna & 5.8 & $(4.1)$ & 12.4 & (4.6) & 32.5 & (6.1) & 26.2 & (6.5) & 16.3 & (5.9) & 4.8 & (2.9) & 2.0 & $(2.1)$ \\
\hline & Friuli Venezia Giulia & 2.3 & (2.4) & 7.0 & (4.5) & 26.6 & (14.5) & 30.3 & (9.0) & 23.7 & $(13.7)$ & 8.8 & (8.8) & 1.2 & $(1.2)$ \\
\hline & Lazio & 2.2 & $(1.4)$ & 12.2 & (3.0) & 27.2 & (7.5) & 29.7 & (5.3) & 20.4 & $(3.2)$ & 6.5 & $(2.7)$ & 1.7 & $(1.2)$ \\
\hline & Liguria & 0.0 & c & 6.1 & $(4.2)$ & 19.3 & (9.9) & 26.6 & (8.8) & 16.4 & (6.2) & 16.7 & (9.1) & 14.9 & (9.7) \\
\hline & Lombardia & 1.2 & $(0.5)$ & 4.8 & (1.6) & 23.1 & $(6.2)$ & 33.2 & $(4.0)$ & 24.9 & (4.5) & 11.0 & (3.9) & 1.7 & (1.3) \\
\hline & Marche & 4.1 & $(5.1)$ & 10.7 & (9.4) & 26.4 & (9.3) & 23.7 & (6.3) & 25.9 & $(12.1)$ & 9.2 & $(4.8)$ & 0.0 & c \\
\hline & Molise & c & c & c & c & c & c & c & c & c & c & c & c & c & c \\
\hline & Piemonte & 8.2 & $(5.5)$ & 13.7 & (4.1) & 24.3 & (4.8) & 23.5 & (5.4) & 23.5 & $(4.1)$ & 5.7 & $(2.7)$ & 1.1 & (1.3) \\
\hline & Puglia & 10.3 & $(6.2)$ & 18.5 & (5.3) & 24.1 & (4.8) & 26.9 & (5.4) & 16.8 & (4.6) & 3.1 & $(1.0)$ & 0.3 & c \\
\hline & Sardegna & c & c & c & c & c & c & c & c & c & c & c & c & c & c \\
\hline & Sicilia & 3.6 & $(2.3)$ & 16.6 & (6.0) & 32.2 & (5.4) & 29.9 & $(5.2)$ & 14.1 & (5.2) & 2.9 & (1.9) & 0.7 & $(0.8)$ \\
\hline & Toscana & 7.8 & $(6.1)$ & 19.9 & (6.7) & 26.2 & (5.9) & 25.5 & (5.4) & 15.7 & (5.5) & 4.8 & (2.9) & 0.1 & c \\
\hline & Trento & 1.6 & $(1.3)$ & 4.4 & (2.3) & 13.9 & (2.9) & 23.7 & (8.8) & 35.7 & (6.3) & 18.1 & $(6.2)$ & 2.8 & $(2.7)$ \\
\hline & Umbria & 2.6 & $(1.7)$ & 11.9 & (5.7) & 24.3 & (9.5) & 36.6 & (11.6) & 23.9 & (8.0) & 0.7 & c & 0.0 & c \\
\hline & Valle d'Aosta & 1.9 & $(2.2)$ & 12.7 & (7.4) & 32.1 & (5.7) & 40.3 & (8.3) & 11.9 & (3.9) & 1.2 & $(1.2)$ & 0.0 & c \\
\hline & Veneto & 4.9 & (2.3) & 15.4 & (7.4) & 23.6 & (4.4) & 26.4 & (6.3) & 19.8 & (5.6) & 6.9 & (3.9) & 3.0 & (1.9) \\
\hline & Portugal & & & & & & & & & & & & & & \\
\hline & Alentejo & 9.6 & $(2.7)$ & 15.5 & (3.4) & 26.6 & (2.8) & 30.2 & (3.2) & 15.4 & (3.1) & 1.8 & $(0.8)$ & 0.9 & $(0.6)$ \\
\hline & Spain & & & & & & & & & & & & & & \\
\hline & Andalusia ${ }^{\bullet}$ & 12.0 & $(2.5)$ & 22.4 & (3.1) & 33.9 & (3.1) & 21.4 & (2.9) & 8.5 & (2.1) & 1.5 & $(0.7)$ & 0.2 & c \\
\hline & Aragon` & 15.8 & $(6.8)$ & 14.7 & (8.1) & 18.3 & (6.6) & 24.3 & (6.6) & 17.4 & (7.5) & 8.8 & $(7.1)$ & 0.7 & c \\
\hline & Asturias ${ }^{\bullet}$ & c & c & c & c & c & c & c & c & c & c & c & c & c & c \\
\hline & Balearic Islands ${ }^{\bullet}$ & c & c & c & c & c & c & c & c & c & c & c & c & c & c \\
\hline & Basque Country ${ }^{\bullet}$ & 6.2 & $(0.8)$ & 13.6 & $(1.2)$ & 26.9 & $(1.2)$ & 31.0 & $(1.2)$ & 17.9 & (1.4) & 4.2 & $(0.6)$ & 0.3 & $(0.2)$ \\
\hline & Cantabria ${ }^{\bullet}$ & c & $\mathrm{C}$ & c & c & c & c & c & c & c & c & c & c & c & c \\
\hline & Castile and Leon ${ }^{\bullet}$ & 0.0 & c & 5.4 & (2.1) & 22.7 & (4.6) & 40.0 & (5.1) & 25.2 & $(6.2)$ & 5.2 & $(2.7)$ & 1.5 & c \\
\hline & Catalonia $\bullet$ & 6.8 & $(1.9)$ & 14.2 & (2.3) & 31.3 & (2.3) & 32.0 & (2.8) & 13.3 & $(2.1)$ & 2.4 & $(1.1)$ & 0.0 & c \\
\hline & Extremadura ${ }^{\bullet}$ & 12.9 & $(6.0)$ & 13.6 & (5.6) & 17.6 & (5.8) & 31.4 & (6.7) & 20.2 & (5.3) & 4.4 & (3.1) & 0.0 & c \\
\hline & Galicia• & 8.9 & $(7.9)$ & 13.7 & (5.8) & 23.0 & (3.9) & 30.2 & (6.1) & 23.4 & (7.5) & 0.9 & c & 0.0 & c \\
\hline & La Rioja• & c & C & c & c & c & c & c & c & c & c & c & c & c & c \\
\hline & Madrid ${ }^{\bullet}$ & 4.5 & $(1.7)$ & 14.3 & (2.4) & 27.8 & (3.3) & 30.5 & (3.0) & 19.4 & (3.5) & 3.5 & (1.4) & 0.0 & c \\
\hline & Murcia ${ }^{\bullet}$ & 19.9 & $(4.7)$ & 26.1 & (5.4) & 27.9 & $(7.2)$ & 21.0 & (7.9) & 3.1 & c & 2.0 & c & 0.0 & c \\
\hline & Navarre ${ }^{\bullet}$ & $\mathrm{C}$ & $\mathrm{C}$ & $\mathrm{C}$ & $\mathrm{C}$ & $\mathrm{c}$ & $\mathrm{c}$ & $\mathrm{C}$ & $\mathrm{C}$ & $\mathrm{C}$ & $\mathrm{C}$ & $\mathrm{c}$ & $\mathrm{C}$ & $\mathrm{C}$ & C \\
\hline
\end{tabular}

- PISA adjudicated region.

Note: See Table B3.1.2 for national data.

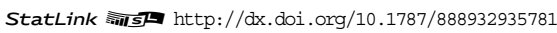




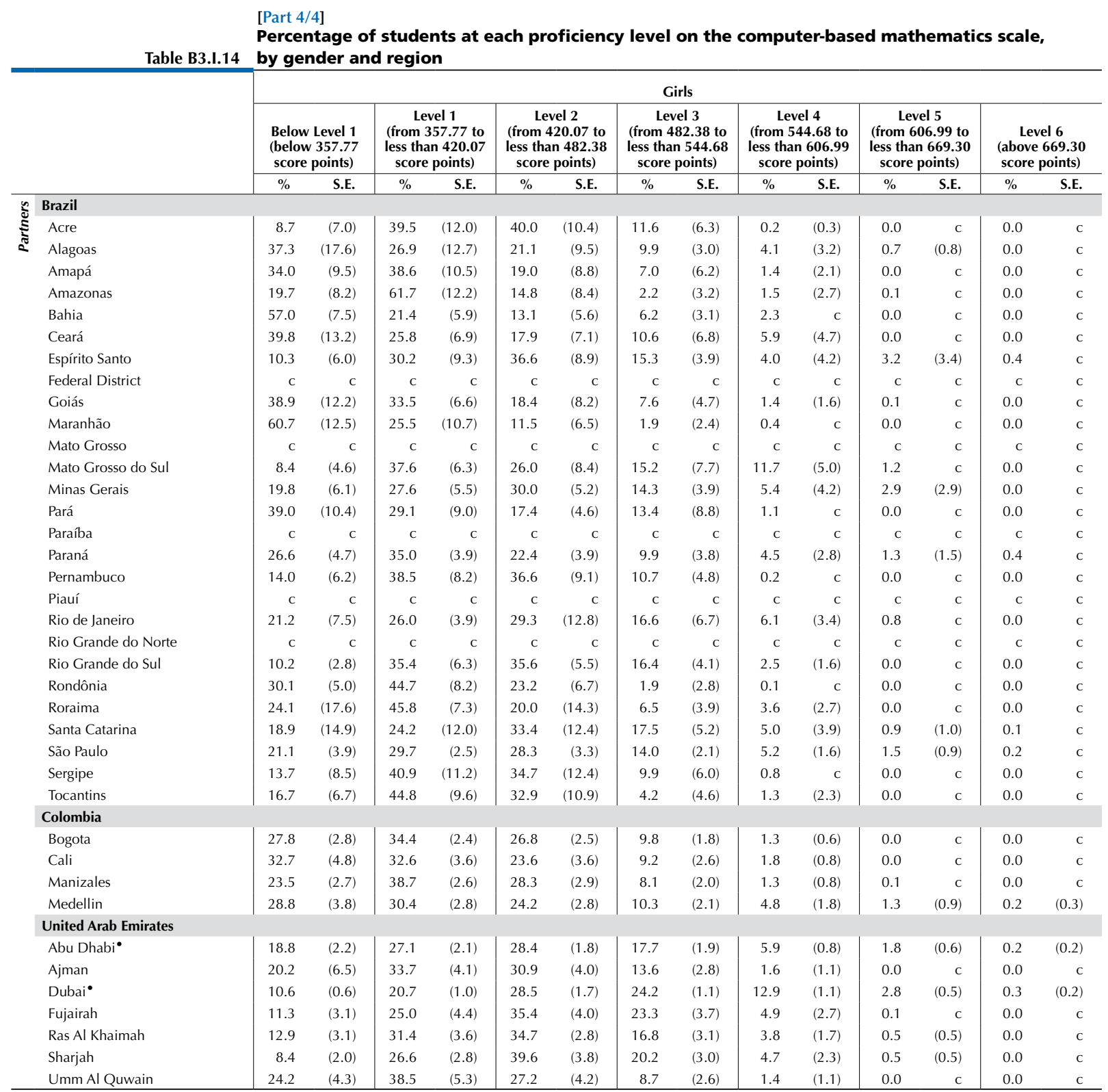

- PISA adjudicated region.

Note: See Table B3.I.2 for national data.

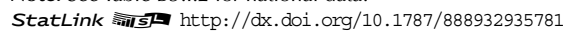


[Part 1/2]

Mean score, variation and gender differences in student performance on the computer-based Table B3.I.15 mathematics scale, by region

\begin{tabular}{|c|c|c|c|c|c|c|c|c|c|c|c|c|c|c|c|c|c|c|c|c|c|c|c|}
\hline & & \multicolumn{4}{|c|}{ All students } & \multicolumn{6}{|c|}{ Gender differences } & \multicolumn{12}{|c|}{ Percentiles } \\
\hline & & \multicolumn{2}{|c|}{ Mean score } & $\begin{array}{l}\text { Stanc } \\
\text { devia }\end{array}$ & $\begin{array}{l}\text { dard } \\
\text { ation }\end{array}$ & BC & oys & & iirls & $\begin{array}{c}\text { Diffe } \\
\text { (B }\end{array}$ & $\begin{array}{l}\text { erence } \\
\text { - G) }\end{array}$ & & 5th & & 0th & & 5th & & 5 th & & oth & & 5th \\
\hline & & Mean & S.E. & S.D. & S.E. & $\begin{array}{l}\text { Mean } \\
\text { score }\end{array}$ & S.E. & $\begin{array}{l}\text { Mean } \\
\text { score }\end{array}$ & S.E. & $\begin{array}{c}\text { Score } \\
\text { dif. }\end{array}$ & S.E. & Score & e S.E. & Score & e S.E. & Score & e S.E. & Score & e S.E. & Score & e S.E. & Score & S.E. \\
\hline 0 & Australia & & & & & & & & & & & & & & & & & & & & & & \\
\hline & Australian Capital Territory & 512 & (3.2) & 92 & (2.6) & 510 & (5.0) & 515 & $(4.2)$ & -5 & (6.8) & 350 & $\begin{array}{ll}0 & (9.2)\end{array}$ & 394 & $4 \quad(6.8)$ & 455 & $(5.0)$ & 577 & $7 \quad(6.3)$ & 628 & $(6.1)$ & 658 & $(6.9)$ \\
\hline & New South Wales & 508 & (3.6) & 95 & (2.4) & 507 & $(5.2)$ & 508 & (4.3) & 0 & (6.3) & 351 & $1 \quad(7.8)$ & 387 & $7 \quad(4.5)$ & 445 & (4.1) & 572 & $2 \quad(4.4)$ & 630 & $(6.2)$ & 663 & $(7.1)$ \\
\hline & Northern Territory & 470 & (8.3) & 103 & (3.9) & 477 & (8.0) & 463 & (13.0) & 15 & (13.8) & 276 & $6(14.1)$ & 330 & $(13.2)$ & 405 & (11.0) & 539 & $9(12.6)$ & 591 & $(14.0)$ & 622 & $(22.5)$ \\
\hline & Queensland & 506 & (3.3) & 87 & (1.9) & 511 & (3.8) & 502 & (4.0) & 9 & (4.0) & 360 & $\begin{array}{ll}0 & (5.3)\end{array}$ & 392 & (5.5) & 449 & $(4.1)$ & 566 & $5 \quad(4.7)$ & 619 & (4.8) & 650 & (6.0) \\
\hline & South Australia & 498 & (4.4) & 89 & (3.5) & 504 & $(4.9)$ & 493 & (4.9) & 10 & (4.2) & 346 & $6(13.2)$ & 385 & (7.2) & 442 & (4.7) & 557 & $7 \quad(4.7)$ & 609 & (5.1) & 638 & $(7.6)$ \\
\hline & Tasmania & 479 & (3.4) & 95 & (2.6) & 482 & (4.6) & 476 & (4.9) & 6 & (6.5) & 318 & 8 (6.1) & 357 & (6.7) & 416 & (4.6) & 545 & $5 \quad(4.5)$ & 601 & (7.5) & 638 & (10.5) \\
\hline & Victoria & 512 & (4.0) & 86 & (3.0) & 519 & (5.5) & 504 & (3.6) & 15 & (5.2) & 373 & $\begin{array}{ll}3 & (5.3)\end{array}$ & 403 & (4.6) & 454 & $(4.0)$ & 570 & (4.6) & 620 & $(6.0)$ & 650 & (8.8) \\
\hline & Western Australia & 515 & (4.6) & 94 & (3.7) & 525 & (6.4) & 504 & (5.9) & 21 & (8.4) & 356 & $6(13.2)$ & 393 & $(7.6)$ & 453 & $(6.3)$ & 580 & (5.4) & 631 & (5.4) & 661 & (7.6) \\
\hline & Belgium & & & & & & & & & & & & & & & & & & & & & & \\
\hline & Flemish community ${ }^{\bullet}$ & 529 & (3.6) & 101 & $(2.2)$ & 535 & $(4.2)$ & 522 & (4.5) & 13 & (5.1) & 353 & (6.9) & 393 & (5.0) & 461 & (5.8) & 602 & (4.1) & 654 & (3.9) & 680 & (3.8) \\
\hline & French community & 490 & (3.7) & 92 & (2.6) & 498 & (4.2) & 482 & (3.9) & 16 & (3.5) & 329 & (8.3) & 369 & $(7.2)$ & 433 & (4.4) & 554 & (4.6) & 603 & (5.5) & 632 & (6.7) \\
\hline & German-speaking community & 512 & (2.5) & 84 & (2.3) & 519 & (3.8) & 504 & (3.8) & 15 & (5.9) & 369 & $(8.2)$ & 402 & (5.0) & 458 & $(5.0)$ & 569 & (4.3) & 620 & (5.8) & 647 & (6.2) \\
\hline & Canada & & & & & & & & & & & & & & & & & & & & & & \\
\hline & Alberta & 516 & (5.2) & 97 & (4.5) & 522 & (4.9) & 510 & (6.3) & 12 & $(4.2)$ & 350 & $(14.9)$ & 393 & (10.1) & 455 & (5.1) & 582 & (6.0) & 637 & (6.7) & 669 & (8.4) \\
\hline & British Columbia & 532 & (4.7) & 90 & (3.2) & 545 & (6.1) & 519 & (5.0) & 26 & (6.0) & 385 & (8.4) & 418 & (5.7) & 471 & (4.8) & 591 & (6.1) & 645 & (8.8) & 681 & (11.1) \\
\hline & Manitoba & 493 & (3.2) & 89 & (2.7) & 502 & $(4.1)$ & 484 & (4.3) & 18 & (5.4) & 344 & (8.6) & 374 & (7.4) & 436 & (6.1) & 555 & (3.4) & 606 & (4.3) & 633 & (6.3) \\
\hline & New Brunswick & 496 & (2.8) & 85 & (2.6) & 498 & (4.5) & 494 & (3.5) & 4 & (5.8) & 347 & $7 \quad(9.0)$ & 389 & (7.3) & 447 & (3.9) & 553 & (4.0) & 599 & (6.5) & 627 & (5.2) \\
\hline & Newfoundland and Labrador & 511 & (3.2) & 83 & (1.8) & 512 & $(5.0)$ & 510 & (3.2) & 2 & (5.4) & 369 & (14.6) & 408 & $(9.7)$ & 457 & (4.8) & 568 & $(4.0)$ & 612 & (5.8) & 639 & (6.6) \\
\hline & Nova Scotia & 503 & (5.9) & 88 & (3.0) & 510 & (4.0) & 495 & (9.3) & 15 & (8.1) & 354 & $+(16.1)$ & 392 & (9.3) & 449 & (8.6) & 562 & (5.6) & 614 & (5.8) & 642 & (5.1) \\
\hline & Ontario & 530 & (5.5) & 90 & (3.1) & 542 & $(6.1)$ & 519 & (5.5) & 23 & (3.8) & 382 & $(8.2)$ & 416 & $(7.3)$ & 473 & (5.6) & 590 & (5.1) & 642 & (7.0) & 671 & (8.5) \\
\hline & Prince Edward Island & 491 & (3.0) & 95 & (2.1) & 484 & (4.0) & 497 & (3.6) & -13 & (4.7) & 326 & $5 \quad(7.0)$ & 369 & $(6.7)$ & 429 & (3.9) & 553 & (2.8) & 606 & (5.5) & 642 & (6.1) \\
\hline & Quebec & 523 & (3.8) & 93 & (2.0) & 529 & (4.5) & 517 & (4.2) & 12 & (4.1) & 361 & $(7.9)$ & 403 & (5.8) & 467 & (4.5) & 587 & (4.5) & 634 & (5.4) & 662 & (5.2) \\
\hline & Saskatchewan & 499 & (3.3) & 92 & (2.0) & 502 & (3.9) & 496 & (3.9) & 6 & (4.4) & 352 & (5.6) & 387 & (5.3) & 443 & $(4.2)$ & 561 & (4.6) & 610 & (5.7) & 638 & (5.9) \\
\hline & Italy & & & & & & & & & & & & & & & & & & & & & & \\
\hline & Abruzzo & 491 & (23.4) & 68 & (4.9) & 513 & (20.0) & 476 & (30.0) & 37 & $(24.5)$ & 374 & $+(21.8)$ & 400 & (34.2) & 443 & (30.4) & 540 & $(22.6)$ & 581 & $(16.2)$ & 601 & (12.9) \\
\hline & Basilicata & 481 & (11.7) & 71 & (6.8) & 482 & (23.0) & 479 & (10.3) & 3 & (28.6) & 362 & $(27.4)$ & 386 & (21.9) & 430 & (16.0) & 533 & $(10.2)$ & 573 & (8.7) & 599 & (15.5) \\
\hline & Bolzano & 529 & (12.2) & 66 & (3.6) & 547 & (13.0) & 516 & (13.4) & 31 & (9.3) & 411 & (11.9) & 438 & (13.4) & 484 & (16.4) & 577 & (13.4) & 614 & (11.3) & 632 & (12.0) \\
\hline & Calabria & 463 & (16.7) & 75 & (8.6) & 476 & (19.9) & 452 & (15.2) & 24 & (10.0) & 334 & $(43.2)$ & 377 & (28.8) & 421 & (21.8) & 508 & (11.4) & 546 & (22.8) & 581 & (27.6) \\
\hline & Campania & 459 & (13.6) & 81 & (5.8) & 463 & (15.9) & 454 & (12.0) & 9 & (8.4) & 319 & $(25.2)$ & 354 & (24.3) & 405 & (16.3) & 511 & (9.8) & 562 & $(17.2)$ & 596 & (11.5) \\
\hline & Emilia Romagna & 501 & (14.8) & 84 & (9.4) & 514 & (17.6) & 486 & (19.6) & 28 & $(22.1)$ & 361 & $(15.2)$ & 393 & (19.4) & 445 & (13.8) & 557 & (19.9) & 612 & (33.1) & 645 & (34.7) \\
\hline & Friuli Venezia Giulia & 512 & (28.6) & 81 & (10.1) & 514 & (33.3) & 511 & (35.2) & 3 & $(37.2)$ & 372 & $(34.5)$ & 404 & (26.4) & 467 & (32.5) & 570 & (28.9) & 604 & (29.0) & 629 & (33.1) \\
\hline & Lazio & 500 & (8.6) & 80 & $(4.2)$ & 499 & (11.2) & 500 & (10.6) & -1 & (13.9) & 369 & $(18.7)$ & 397 & $(12.2)$ & 442 & $(10.2)$ & 557 & (11.1) & 600 & (11.6) & 621 & (8.7) \\
\hline & Liguria & 552 & (36.8) & 96( & (11.3) & 552 & (35.7) & 552 & (40.5) & 1 & $(15.2)$ & 397 & $(29.4)$ & 431 & $(27.2)$ & 484 & $(27.0)$ & 624 & (69.9) & 685 & (41.8) & 716 & (39.4) \\
\hline & Lombardia & 530 & (10.9) & 72 & (4.0) & 536 & (10.8) & 524 & (13.3) & 13 & $(10.7)$ & 412 & $(12.3)$ & 439 & (9.8) & 480 & (10.1) & 581 & (12.9) & 623 & (13.1) & 648 & (21.3) \\
\hline & Marche & 513 & (20.9) & 73 & (6.3) & 516 & (18.5) & 504 & (32.3) & 11 & (19.4) & 379 & (26.6) & 411 & (31.5) & 467 & (22.8) & 568 & (25.3) & 598 & (26.8) & 630 & (35.0) \\
\hline & Molise & 482 & (19.6) & 69 & (4.8) & 470 & (25.2) & c & & c & c & 364 & $4(17.2)$ & 383 & (25.5) & 436 & (31.2) & 526 & (11.8) & 557 & (10.2) & 585 & (28.5) \\
\hline & Piemonte & 504 & (11.6) & 87 & (9.0) & 520 & (12.7) & 488 & (18.6) & 31 & (24.4) & 357 & $7(29.8)$ & 382 & (17.4) & 449 & (17.9) & 566 & $(14.7)$ & 608 & (18.1) & 636 & (23.5) \\
\hline & Puglia & 480 & (10.7) & 81 & (7.3) & 487 & (14.3) & 471 & (16.1) & 16 & (23.7) & 340 & (32.8) & 374 & (20.4) & 424 & $(17.2)$ & 544 & (11.8) & 580 & (8.6) & 601 & (8.4) \\
\hline & Sardegna & 453 & (17.5) & 66 & (6.6) & 455 & (15.2) & c & c & c & c & 324 & $4(41.7)$ & 366 & (34.2) & 418 & (35.6) & 499 & (19.3) & 529 & (11.7) & 549 & (19.6) \\
\hline & Sicilia & 491 & (10.5) & 68 & (4.6) & 496 & (9.0) & 481 & (13.8) & 15 & (9.2) & 372 & (22.6) & 402 & (16.0) & 445 & (13.6) & 537 & $(11.3)$ & 573 & (15.3) & 600 & (15.8) \\
\hline & Toscana & 498 & (17.9) & 86 & (9.4) & 527 & (17.7) & 472 & (21.4) & 55 & (26.7) & 358 & (26.8) & 385 & (19.8) & 438 & (24.4) & 564 & (20.5) & 607 & (14.2) & 629 & (16.5) \\
\hline & Trento & 548 & (12.0) & 79 & (8.7) & 550 & (14.9) & 547 & (12.6) & 3 & (14.5) & 406 & (19.3) & 440 & (26.7) & 496 & (16.6) & 604 & (11.6) & 645 & (15.7) & 664 & (19.9) \\
\hline & Umbria & 490 & (11.7) & 71 & (6.6) & 487 & (13.9) & 494 & (15.2) & -7 & (17.8) & 362 & $(23.4)$ & 392 & (20.2) & 445 & (15.0) & 542 & (10.1) & 573 & (11.3) & 595 & (12.5) \\
\hline & Valle d'Aosta & 502 & (19.3) & 67 & (5.1) & 515 & (20.4) & 483 & (15.4) & 32 & (7.5) & 394 & (22.6) & 415 & (22.5) & 461 & (26.8) & 547 & (15.3) & 580 & (17.6) & 604 & (20.8) \\
\hline & Veneto & 515 & (15.7) & 92 & (7.4) & 530 & (16.9) & 498 & (20.1) & 32 & (22.7) & 363 & $(8.7)$ & 392 & (11.9) & 445 & (21.0) & 584 & $(24.3)$ & 635 & $(22.8)$ & 658 & (14.7) \\
\hline & Portugal & & & & & & & & & & & & & & & & & & & & & & \\
\hline & Alentejo & 485 & (11.0) & 87 & (5.2) & $\mid 497$ & (12.7) & 472 & (10.2) & 26 & (6.7) & $\mid 327$ & (16.8) & 367 & (14.4) & 430 & (15.4) & 541 & (10.0) & 587 & (11.1) & 620 & (23.6) \\
\hline & Spain & & & & & & & & & & & & & & & & & & & & & & \\
\hline & Andalusia ${ }^{\bullet}$ & 455 & (8.3) & 79 & (2.8) & 462 & (10.3) & 448 & (7.1) & 13 & (6.5) & 323 & (10.4) & 351 & (9.6) & 402 & (10.0) & 508 & (8.6) & 555 & (10.5) & 586 & (11.5) \\
\hline & Aragon ${ }^{\bullet}$ & 483 & (28.4) & 98 & (3.5) & 492 & (23.2) & 476 & (34.0) & 16 & (14.3) & 319 & (19.8) & 349 & (17.9) & 405 & (40.5) & 559 & $(33.2)$ & 609 & (34.0) & 628 & (26.0) \\
\hline & Asturias ${ }^{\bullet}$ & c & c & c & c & c & c & c & c & c & c & c & c & c & c & c & c & c & c & c & c & c & c \\
\hline & Balearic Islands ${ }^{\bullet}$ & c & c & c & c & c & c & c & c & c & c & c & c & c & c & C & c & c & c & c & c & c & c \\
\hline & Basque Country ${ }^{\bullet}$ & 490 & (3.1) & 82 & (2.1) & 496 & (3.6) & 484 & (3.5) & 11 & (3.4) & 348 & (6.8) & 383 & (4.2) & 439 & (3.9) & 547 & $(3.0)$ & 590 & (3.0) & 614 & (3.2) \\
\hline & Cantabria ${ }^{\bullet}$ & c & c & c & c & c & c & c & c & c & c & & & c & c & c & c & c & c & c & c & c & c \\
\hline & Castile and Leon ${ }^{\bullet}$ & 513 & (5.9) & 67 & (4.9) & 514 & (7.6) & 512 & (5.3) & 2 & (5.6) & 388 & (11.3) & 420 & $(17.1)$ & 475 & $(10.2)$ & 559 & (13.9) & 598 & (13.6) & 622 & (14.5) \\
\hline & Catalonia ${ }^{\bullet}$ & 483 & (6.8) & 77 & (4.2) & 491 & (7.6) & 474 & (6.9) & 16 & (5.5) & 347 & $7(15.2)$ & 382 & (13.3) & 435 & (8.3) & 536 & (6.9) & 579 & $(8.2)$ & 605 & (8.1) \\
\hline & Extremadura ${ }^{\bullet}$ & 479 & (13.4) & 89 & (3.9) & 480 & (12.6) & 478 & (15.7) & 2 & (10.0) & 321 & $(24.9)$ & 352 & (30.3) & 416 & (13.3) & 544 & (17.4) & 591 & (17.4) & 608 & (6.0) \\
\hline & Galicia• & 474 & (25.1) & 85 & (11.2) & 467 & (24.7) & 479 & (26.2) & -13 & (9.1) & 317 & $7(42.6)$ & 355 & (46.8) & 418 & $(44.3)$ & 538 & $(16.0)$ & 570 & (12.3) & 587 & (16.8) \\
\hline & La Rioja $\bullet$ & c & & c & & c & c & c & c & c & c & c & c & c & & c & c & c & c & c & c & c & c \\
\hline & Madrid ${ }^{\bullet}$ & 493 & (7.1) & 74 & (3.2) & 499 & (8.3) & 486 & (7.4) & 13 & (6.7) & 364 & $4(10.4)$ & 391 & (12.5) & 443 & (9.0) & 546 & (7.3) & 584 & $(8.2)$ & 607 & (8.8) \\
\hline & Murcia ${ }^{\bullet}$ & 447 & (10.7) & 80 & (4.6) & 465 & (9.9) & 426 & (13.0) & 39 & (12.5) & 317 & $7(23.1)$ & 342 & (15.0) & 387 & (14.3) & 508 & $(11.0)$ & 547 & (10.5) & 569 & (6.5) \\
\hline & Navarre & $\mathrm{c}$ & $\mathrm{c}$ & $\mathrm{C}$ & C & C & C & c & $\mathrm{C}$ & c & C & C & $\mathrm{c}$ & C & c & $\mathrm{C}$ & c & C & c & C & c & c & C \\
\hline
\end{tabular}

- PISA adjudicated region.

Notes: Values that are statistically significant are indicated in bold (see Annex A3).

See Table B3.I.3 for national data.

StatLink त्नाज्ञा http://dx.doi.org/10.1787/888932935781 
[Part 2/2]

Mean score, variation and gender differences in student performance on the computer-based Table B3.I.15 mathematics scale, by region

\begin{tabular}{|c|c|c|c|c|c|c|c|c|c|c|c|c|c|c|c|c|c|c|c|c|c|c|c|}
\hline & & \multicolumn{4}{|c|}{ All students } & \multicolumn{6}{|c|}{ Gender differences } & \multicolumn{12}{|c|}{ Percentiles } \\
\hline & & \multicolumn{2}{|c|}{ Mean score } & \multicolumn{2}{|c|}{$\begin{array}{l}\text { Standard } \\
\text { deviation }\end{array}$} & \multicolumn{2}{|c|}{ Boys } & \multicolumn{2}{|c|}{ Girls } & \multicolumn{2}{|c|}{$\begin{array}{c}\text { Difference } \\
(B-G)\end{array}$} & \multicolumn{2}{|c|}{ 5th } & \multicolumn{2}{|c|}{ 10th } & \multicolumn{2}{|c|}{ 25th } & \multicolumn{2}{|c|}{ 75th } & \multicolumn{2}{|c|}{ 90th } & \multicolumn{2}{|c|}{ 95th } \\
\hline & & Mean & S.E. & S.D. & S.E. & $\begin{array}{l}\text { Mean } \\
\text { score }\end{array}$ & S.E. & $\begin{array}{l}\text { Mean } \\
\text { score }\end{array}$ & S.E. & $\begin{array}{c}\text { Score } \\
\text { dif. }\end{array}$ & S.E. & Score & S.E. & Score & e S.E. & Score & S.E. & Score & S.E. & Score & e S.E. & Score & e S.E. \\
\hline \multirow{41}{*}{ 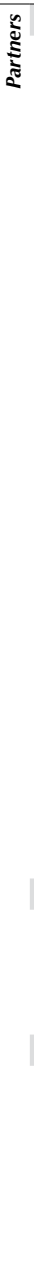 } & Brazil & & & & & & & & & & & & & & & & & & & & & & \\
\hline & Acre & 428 & (5.5) & 54 & (3.5) & 435 & (7.4) & 423 & (8.4) & 12 & (11.8) & 336 & (14.7) & $\mid 364$ & (18.3) & 392 & (8.2) & 466 & (9.2) & 492 & $(16.4)$ & 519 & $(19.4)$ \\
\hline & Alagoas & 391 & (23.1) & 78 & (10.6) & 389 & $(23.2)$ & 393 & (25.1) & -4 & (15.0) & 273 & (42.5) & 301 & (29.8) & 335 & $(27.0)$ & 442 & (30.3) & 495 & $(20.9)$ & 535 & $(35.0)$ \\
\hline & Amapá & 407 & (14.1) & 58 & (7.9) & 428 & (11.3) & 390 & (16.7) & 38 & (10.4) & 324 & (9.8) & 341 & (13.0) & 362 & (13.5) & 443 & $(27.8)$ & 489 & $(25.1)$ & 508 & $(37.6)$ \\
\hline & Amazonas & 394 & (13.4) & 53 & (14.5) & 395 & (16.8) & 392 & (11.7) & 3 & (13.0) & 320 & (22.6) & 339 & (20.6) & 361 & (10.8) & 417 & (19.4) & 454 & (39.1) & 481 & (75.9) \\
\hline & Bahia & 372 & (10.9) & 91 & (12.7) & 389 & (18.0) & 357 & (10.0) & 33 & (15.7) & 244 & (38.4) & 269 & (18.7) & 305 & (9.2) & 436 & (26.4) & 494 & $(23.8)$ & 529 & $(47.2)$ \\
\hline & Ceará & 408 & (27.6) & 96 & (12.1) & 423 & (25.1) & 391 & (29.0) & 32 & (8.7) & 266 & $(20.2)$ & 296 & (16.5) & 339 & (18.5) & 474 & (48.5) & 545 & $(45.1)$ & 589 & $(36.6)$ \\
\hline & Espírito Santo & 443 & (11.6) & 74 & (10.4) & 446 & (9.2) & 440 & (17.6) & 7 & (14.8) & 333 & $(17.0)$ & 358 & (13.7) & 392 & $(14.7)$ & 482 & (18.5) & 545 & (45.6) & 582 & $(46.9)$ \\
\hline & Federal District & c & & C & & c & c & c & c & $\mathrm{C}$ & $\mathrm{c}$ & C & c & c & C & C & c & c & $\mathrm{c}$ & c & c & c & c \\
\hline & Goiás & 393 & (16.7) & 76 & (9.6) & 404 & (15.5) & 383 & (18.8) & 21 & (11.4) & 281 & (41.9) & 307 & (21.6) & 339 & (19.0) & 442 & (14.9) & 494 & (29.5) & 530 & $(18.9)$ \\
\hline & Maranhão & 340 & (25.0) & 89 & $(17.2)$ & 349 & (30.5) & 333 & (21.4) & 16 & (13.4) & 193 & (53.6) & 231 & (51.1) & 285 & (28.4) & 389 & (34.4) & 448 & (43.6) & 510 & $(61.2)$ \\
\hline & Mato Grosso & c & & C & c & c & & c & c & $\mathrm{C}$ & $\mathrm{c}$ & C & C & c & C & c & C & C & c & c & 4 & c & c \\
\hline & Mato Grosso do Sul & 455 & (6.8) & 76 & (2.1) & 466 & $(10.2)$ & 445 & (8.8) & 21 & (13.3) & 352 & (11.0) & 365 & $(11.2)$ & 397 & (8.0) & 511 & (13.6) & 574 & $(18.5)$ & 590 & (9.7) \\
\hline & Minas Gerais & 437 & (21.5) & 86 & (12.9) & 450 & $(24.2)$ & 426 & (19.5) & 24 & (7.9) & 307 & (18.7) & 335 & (16.6) & 379 & (19.0) & 488 & (31.5) & 556 & (51.8) & 591 & $(43.8)$ \\
\hline & Pará & 386 & (21.5) & 77 & (13.5) & 388 & (25.9) & 385 & (22.1) & 3 & (17.9) & 267 & (39.1) & 294 & (30.5) & 335 & (19.7) & 435 & (34.4) & 493 & $(33.7)$ & 519 & $(33.2)$ \\
\hline & Paraíba & C & & C & & C & & C & $c$ & $\mathrm{C}$ & c & C & & c & C & c & c & C & & C & $\mathrm{c}$ & c & c \\
\hline & Paraná & 418 & $(10.2)$ & 76 & (9.7) & 427 & (10.1) & 410 & (12.5) & 17 & (8.8) & 314 & (8.6) & 331 & (6.9) & 364 & (5.9) & 461 & (16.5) & 526 & $(35.2)$ & 566 & $(31.3)$ \\
\hline & Pernambuco & 426 & $(13.7)$ & 68 & (6.6) & 438 & $(17.0)$ & 415 & (13.5) & 23 & (10.6) & 315 & (28.6) & 345 & (22.0) & 386 & (9.0) & 465 & $(14.8)$ & 509 & $(23.9)$ & 546 & $(40.2)$ \\
\hline & Piauí & c & & C & & C & & C & c & c & $\mathrm{c}$ & c & & c & c & c & c & c & & c & c & c & c \\
\hline & Rio de Janeiro & 434 & (12.6) & 79 & (10.1) & 445 & $(12.3)$ & 423 & (13.9) & 22 & (5.7) & 304 & (16.4) & 333 & (18.3) & 377 & $(20.2)$ & 488 & $(14.7)$ & 543 & $(20.9)$ & 567 & $(19.5)$ \\
\hline & Rio Grande do Norte & c & & c & & c & & c & c & $\mathrm{C}$ & c & c & & c & c & c & c & C & c & c & c & c & c \\
\hline & Rio Grande do Sul & 444 & (6.5) & 61 & (3.5) & 461 & (9.2) & 431 & (6.8) & 30 & (8.2) & 345 & (12.9) & 363 & (12.6) & 402 & (8.1) & 486 & (9.1) & 523 & $(10.5)$ & 546 & $(11.0)$ \\
\hline & Rondônia & 407 & (6.9) & 61 & (4.3) & 434 & $(10.1)$ & 386 & (9.6) & 48 & (15.9) & 310 & (18.4) & 329 & (23.6) & 366 & (11.8) & 446 & (11.5) & 491 & (14.3) & 521 & $(22.6)$ \\
\hline & Roraima & 414 & $(21.2)$ & 62 & (4.6) & 432 & (14.1) & 399 & (25.4) & 33 & (15.8) & 319 & $(42.7)$ & 343 & (27.4) & 370 & (27.1) & 454 & (25.6) & 504 & (20.8) & 530 & $(23.2)$ \\
\hline & Santa Catarina & 419 & (38.5) & 106 & (33.5) & 426 & (39.1) & 412 & (38.3) & 14 & (11.8) & 182 & $(84.8)$ & 218 & (185.0) & 380 & $(57.2)$ & 488 & (15.0) & 528 & $(14.2)$ & 553 & $(25.2)$ \\
\hline & São Paulo & 431 & (7.2) & 81 & (4.7) & 440 & (7.5) & 421 & (7.8) & 19 & (4.7) & 305 & (11.2) & 331 & (9.1) & 376 & (9.0) & 480 & (8.0) & 536 & $(16.1)$ & 578 & $(16.4)$ \\
\hline & Sergipe & 426 & (9.1) & 58 & (4.1) & 440 & (9.7) & 416 & (12.3) & 24 & (12.2) & 337 & (18.1) & 356 & (12.2) & 385 & (18.6) & 458 & $(11.7)$ & 504 & $(15.7)$ & 529 & $(19.4)$ \\
\hline & Tocantins & 413 & (11.1) & 64 & (4.5) & 423 & (31.9) & 404 & (12.1) & 19 & $(42.2)$ & 311 & (13.4) & 333 & (13.6) & 374 & (16.9) & 454 & (16.5) & 495 & $(30.1)$ & ) 531 & (24.9) \\
\hline & Colombia & & & & & & & & & & & & & & & & & & & & & & \\
\hline & Bogota & 410 & (4.7) & 72 & (3.1) & 424 & (6.8) & \begin{tabular}{|l}
398 \\
398
\end{tabular} & (4.6) & 25 & (6.7) & 293 & (6.9) & 320 & (6.1) & 363 & (5.4) & 458 & (5.0) & 500 & (6.0) & )) 525 & (7.7) \\
\hline & Cali & 396 & (9.8) & 80 & (5.8) & 405 & (10.3) & 389 & (10.2) & 16 & (6.2) & 262 & (18.5) & 295 & (14.9) & 344 & (10.4) & 448 & (10.6) & 498 & (14.6) & 531 & (18.3) \\
\hline & Manizales & 410 & (4.2) & 66 & (3.5) & 418 & (7.0) & 402 & (3.5) & 16 & (7.0) & 306 & (4.5) & 327 & (5.2) & 367 & (4.7) & 453 & (5.9) & 496 & (9.1) & 521 & (11.9) \\
\hline & Medellin & 412 & (8.0) & 82 & (4.5) & 419 & (8.3) & 406 & (9.8) & 14 & (8.7) & 282 & (11.3) & 313 & (8.0) & 357 & (7.3) & 464 & (9.6) & 520 & $(14.1)$ & 555 & (16.5) \\
\hline & United & & & & & & & & & & & & & & & & & & & & & & \\
\hline & Abu Dhabi` & 423 & (4.6) & 87 & (3.2) & 415 & (6.6) & 431 & (5.5) & $\mid-16$ & (8.1) & 286 & (6.6) & 314 & (5.6) & 363 & (5.2) & 480 & (5.8) & 535 & (7.6) & 569 & $(10.3)$ \\
\hline & Ajman & 389 & (7.8) & 71 & $(3.2)$ & 363 & (7.0) & 412 & (11.8) & -49 & (14.0) & 268 & $(17.5)$ & 300 & (12.6) & 341 & (8.9) & 437 & $(7.7)$ & 478 & $(8.8)$ & ) 507 & $(10.3)$ \\
\hline & Dubai` & 460 & (1.1) & 90 & (1.0) & 460 & (1.8) & 461 & (1.4) & -1 & (2.4) & 309 & (3.4) & 344 & (2.9) & 401 & (2.0) & 522 & (2.4) & 576 & (2.8) & 607 & (3.5) \\
\hline & Fujairah & 426 & (6.8) & 75 & (2.7) & 411 & (5.4) & 441 & (9.3) & -30 & (9.7) & 295 & (8.6) & 324 & (8.6) & 375 & (8.6) & 480 & (8.3) & 520 & $(10.0)$ & ) 543 & $(10.8)$ \\
\hline & Ras Al Khaimah & 415 & (6.7) & 73 & (6.2) & 398 & (12.9) & 431 & (7.4) & -33 & (14.9) & 291 & (18.7) & 321 & (14.0) & 371 & (9.8) & 463 & (6.3) & 505 & (8.8) & 531 & (8.5) \\
\hline & Sharjah & 442 & (6.1) & 66 & (3.1) & 441 & (13.4) & 443 & (6.0) & -3 & (15.7) & 330 & (9.8) & 356 & (11.2) & 398 & (6.9) & 486 & (7.2) & 527 & $(11.5)$ & 552 & $(10.0)$ \\
\hline & Umm Al Quwain & 389 & (3.5) & 70 & (2.7) & 375 & (4.8) & 403 & (4.6) & -28 & (6.3) & 275 & $(9.2)$ & 301 & (8.2) & 340 & (6.4) & 437 & (6.3) & 478 & (8.2) & 503 & $(10.0)$ \\
\hline
\end{tabular}

- PISA adjudicated region.

Notes: Values that are statistically significant are indicated in bold (see Annex A3).

See Table B3.1.3 for national data.

StatLink त्ताज् http://dx.doi.org/10.1787/888932935781 
[Part 1/2] Table B3.I.16 Percentage of students at each proficiency level on the combined mathematics scale, by region

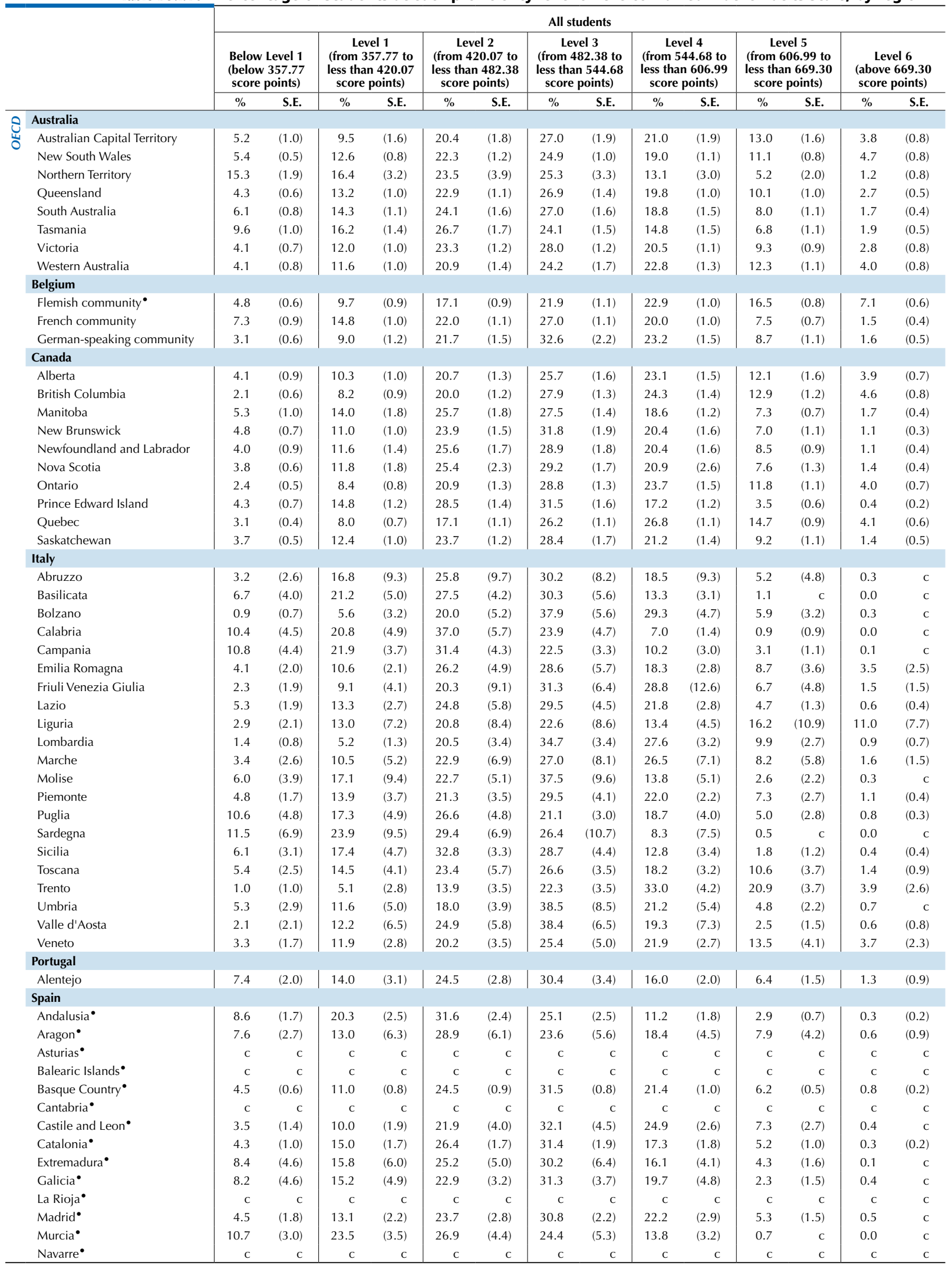

- PISA adjudicated region.

Note: See Table B3.I.4 for national data.

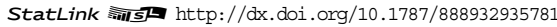


[Part 2/2]

Table B3.I.16 Percentage of students at each proficiency level on the combined mathematics scale, by region

\begin{tabular}{|c|c|c|c|c|c|c|c|c|c|c|c|c|c|c|c|}
\hline & & \multicolumn{14}{|c|}{ All students } \\
\hline & & \multicolumn{2}{|c|}{$\begin{array}{l}\text { Below Level } 1 \\
\text { (below 357.77 } \\
\text { score points) }\end{array}$} & \multicolumn{2}{|c|}{$\begin{array}{c}\text { Level } 1 \\
\text { (from } 357.77 \text { to } \\
\text { less than } 420.07 \\
\text { score points) }\end{array}$} & \multicolumn{2}{|c|}{$\begin{array}{c}\text { Level } 2 \\
\text { (from } 420.07 \text { to } \\
\text { less than } 482.38 \\
\text { score points) }\end{array}$} & \multicolumn{2}{|c|}{$\begin{array}{c}\text { Level } 3 \\
\text { (from } 482.38 \text { to } \\
\text { less than } 544.68 \\
\text { score points) }\end{array}$} & \multicolumn{2}{|c|}{$\begin{array}{c}\text { Level } 4 \\
\text { (from } 544.68 \text { to } \\
\text { less than } 606.99 \\
\text { score points) }\end{array}$} & \multicolumn{2}{|c|}{$\begin{array}{c}\text { Level } 5 \\
\text { (from } 606.99 \text { to } \\
\text { less than } 669.30 \\
\text { score points) }\end{array}$} & \multicolumn{2}{|c|}{$\begin{array}{c}\text { Level } 6 \\
\text { (above } 669.30 \\
\text { score points) }\end{array}$} \\
\hline & & $\%$ & S.E. & $\%$ & S.E. & $\%$ & S.E. & $\%$ & S.E. & $\%$ & S.E. & $\%$ & S.E. & $\%$ & S.E. \\
\hline \multirow{41}{*}{ ఏँ } & Brazil & & & & & & & & & & & & & & \\
\hline & Acre & 13.6 & $(4.7)$ & 43.2 & (7.4) & 35.6 & (6.8) & 7.0 & (3.8) & 0.5 & $(1.1)$ & 0.1 & c & 0.0 & C \\
\hline & Alagoas & 52.2 & $(14.8)$ & 26.9 & $(11.2)$ & 12.9 & (5.0) & 5.5 & $(1.1)$ & 2.4 & (1.8) & 0.1 & c & 0.0 & C \\
\hline & Amapá & 24.3 & (5.1) & 44.5 & (6.3) & 24.2 & (4.4) & 6.4 & (4.9) & 0.6 & $(0.9)$ & 0.0 & c & 0.0 & c \\
\hline & Amazonas & 56.6 & $(10.2)$ & 33.0 & $(6.2)$ & 5.8 & $(4.1)$ & 2.6 & (3.3) & 1.5 & $(2.7)$ & 0.5 & $(0.8)$ & 0.0 & C \\
\hline & Bahia & 50.6 & (8.6) & 24.3 & (7.3) & 13.7 & (4.8) & 7.8 & (2.6) & 2.6 & $(2.2)$ & 0.9 & (1.1) & 0.0 & c \\
\hline & Ceará & 38.1 & $(10.5)$ & 27.5 & (5.1) & 15.1 & $(4.7)$ & 10.1 & $(5.2)$ & 6.3 & (3.9) & 2.7 & (2.0) & 0.2 & C \\
\hline & Espírito Santo & 12.3 & (3.0) & 28.8 & (7.0) & 34.3 & (6.4) & 17.0 & $(5.0)$ & 5.1 & $(3.1)$ & 2.1 & $(2.0)$ & 0.4 & C \\
\hline & Federal District & $\mathrm{C}$ & $\mathrm{C}$ & $\mathrm{c}$ & c & c & c & $\mathrm{c}$ & c & c & c & c & c & c & C \\
\hline & Goiás & 32.0 & (8.6) & 38.3 & (7.1) & 18.5 & (3.8) & 8.0 & $(2.3)$ & 2.8 & (1.5) & 0.4 & c & 0.0 & c \\
\hline & Maranhão & 61.2 & $(10.8)$ & 25.8 & (9.6) & 7.2 & (4.4) & 4.4 & $(2.8)$ & 1.1 & (1.4) & 0.3 & c & 0.0 & c \\
\hline & Mato Grosso & $\mathrm{C}$ & $\mathrm{C}$ & $\mathrm{c}$ & c & c & c & c & c & c & c & c & c & c & C \\
\hline & Mato Grosso do Sul & 12.1 & (3.4) & 31.3 & (9.3) & 29.9 & (7.5) & 15.8 & (3.7) & 9.8 & $(4.2)$ & 1.0 & (1.1) & 0.0 & c \\
\hline & Minas Gerais & 17.5 & (4.6) & 32.0 & (5.7) & 29.8 & (3.9) & 15.1 & $(4.6)$ & 4.8 & (3.5) & 0.5 & $(0.5)$ & 0.3 & c \\
\hline & Pará & 50.6 & (9.5) & 23.8 & (5.6) & 18.6 & (5.5) & 6.4 & $(4.2)$ & 0.6 & c & 0.0 & c & 0.0 & C \\
\hline & Paraíba & $\mathrm{c}$ & $\mathrm{c}$ & $\mathrm{c}$ & c & c & c & c & c & c & c & c & c & c & C \\
\hline & Paraná & 24.9 & (5.3) & 38.2 & (4.8) & 20.7 & (3.4) & 9.5 & (1.5) & 4.8 & $(3.1)$ & 1.7 & $(1.7)$ & 0.1 & C \\
\hline & Pernambuco & 22.6 & (7.1) & 43.0 & $(4.2)$ & 24.3 & $(5.2)$ & 8.5 & $(2.7)$ & 1.5 & $(1.2)$ & 0.0 & c & 0.0 & C \\
\hline & Piauí & c & c & c & c & c & c & c & c & c & c & c & c & c & c \\
\hline & Rio de Janeiro & 23.0 & (7.5) & 31.2 & (6.8) & 26.8 & (6.5) & 14.4 & (3.6) & 3.9 & (3.4) & 0.7 & $(1.0)$ & 0.0 & c \\
\hline & Rio Grande do Norte & $\mathrm{C}$ & $\mathrm{c}$ & $\mathrm{C}$ & c & c & c & c & c & c & c & c & c & c & C \\
\hline & Rio Grande do Sul & 11.4 & (3.7) & 32.6 & (5.1) & 35.0 & $(4.8)$ & 18.0 & $(4.9)$ & 2.9 & $(1.5)$ & 0.2 & c & 0.0 & c \\
\hline & Rondônia & 27.6 & $(5.2)$ & 44.5 & (6.0) & 19.7 & (4.9) & 6.6 & $(2.3)$ & 1.6 & (1.6) & 0.0 & c & 0.0 & C \\
\hline & Roraima & 23.1 & $(4.1)$ & 43.0 & (4.9) & 22.1 & (5.5) & 10.3 & $(2.7)$ & 1.4 & $(1.0)$ & 0.1 & c & 0.0 & C \\
\hline & Santa Catarina & 19.8 & $(13.8)$ & 28.9 & (6.8) & 30.4 & (8.3) & 16.9 & (5.1) & 3.5 & (1.8) & 0.4 & $(0.4)$ & 0.0 & c \\
\hline & São Paulo & 21.8 & (2.9) & 33.2 & (2.5) & 26.2 & (2.3) & 12.3 & $(1.9)$ & 5.0 & $(1.3)$ & 1.4 & $(0.7)$ & 0.1 & $(0.1)$ \\
\hline & Sergipe & 17.6 & (3.8) & 46.9 & (5.4) & 22.5 & (4.3) & 9.8 & $(3.7)$ & 2.6 & $(1.1)$ & 0.6 & $(0.5)$ & 0.0 & C \\
\hline & Tocantins & 30.5 & $(11.8)$ & 40.1 & (7.0) & 19.6 & (5.4) & 6.9 & $(4.9)$ & 2.8 & $(1.7)$ & 0.0 & c & 0.0 & c \\
\hline & \multicolumn{15}{|l|}{ Colombia } \\
\hline & Bogota & 24.7 & (1.8) & 37.6 & (1.5) & 27.9 & (1.5) & 8.1 & $(1.2)$ & 1.3 & $(0.5)$ & 0.3 & $(0.3)$ & 0.0 & c \\
\hline & Cali & 33.6 & (3.8) & 36.1 & (2.5) & 20.9 & (2.5) & 8.2 & (1.8) & 1.2 & $(0.5)$ & 0.0 & c & 0.0 & c \\
\hline & Manizales & 22.3 & $(2.2)$ & 39.0 & $(2.1)$ & 26.2 & (1.6) & 10.1 & (1.4) & 2.2 & $(1.0)$ & 0.2 & $(0.2)$ & 0.0 & c \\
\hline & Medellin & 29.9 & $(3.2)$ & 32.9 & $(2.1)$ & 22.2 & (2.3) & 9.9 & (1.7) & 3.5 & $(1.2)$ & 1.2 & $(0.7)$ & 0.3 & $(0.2)$ \\
\hline & \multicolumn{15}{|l|}{ United Arab Emirates } \\
\hline & Abu Dhabi & 22.7 & (1.5) & 29.2 & (1.3) & 25.1 & $(1.2)$ & 15.3 & (1.1) & 5.9 & $(0.8)$ & 1.7 & $(0.5)$ & 0.2 & $(0.2)$ \\
\hline & Ajman & 30.6 & (4.9) & 33.0 & (3.5) & 26.0 & (3.1) & 8.8 & (1.8) & 1.5 & $(0.9)$ & 0.0 & c & 0.0 & c \\
\hline & Dubai ${ }^{\bullet}$ & 12.2 & $(0.5)$ & 20.7 & (0.6) & 26.2 & (1.0) & 22.5 & $(0.8)$ & 13.3 & $(0.8)$ & 4.4 & $(0.4)$ & 0.8 & $(0.2)$ \\
\hline & Fujairah & 22.3 & (3.4) & 27.5 & (2.4) & 30.6 & $(2.7)$ & 15.1 & $(2.3)$ & 4.3 & (1.4) & 0.2 & $(0.3)$ & 0.0 & c \\
\hline & Ras Al Khaimah & 20.6 & (3.5) & 33.9 & (2.7) & 28.6 & (2.8) & 14.0 & $(2.1)$ & 2.5 & $(0.9)$ & 0.4 & $(0.3)$ & 0.0 & c \\
\hline & Sharjah & 12.2 & (2.4) & 28.8 & (2.7) & 30.9 & (2.4) & 19.5 & (2.6) & 7.7 & (2.0) & 0.9 & $(0.6)$ & 0.1 & c \\
\hline & Umm Al Quwain & 30.8 & (2.5) & 36.4 & (3.4) & 22.6 & (3.0) & 8.3 & (2.0) & 1.5 & $(0.9)$ & 0.3 & c & 0.0 & c \\
\hline
\end{tabular}

- PISA adjudicated region.

Note: See Table B3.I.4 for national data.

StatLink न्नाज्ञ http://dx.doi.org/10.1787/888932935781 


\begin{tabular}{|c|c|c|c|c|c|c|c|c|c|c|c|c|c|c|c|}
\hline & & \multicolumn{14}{|c|}{ Boys } \\
\hline & & \multicolumn{2}{|c|}{$\begin{array}{l}\text { Below Level } 1 \\
\text { (below } 357.77 \\
\text { score points) }\end{array}$} & \multicolumn{2}{|c|}{$\begin{array}{c}\text { Level } 1 \\
\text { (from } 357.77 \text { to } \\
\text { less than } 420.07 \\
\text { score points) }\end{array}$} & \multicolumn{2}{|c|}{$\begin{array}{c}\text { Level } 2 \\
\text { (from } 420.07 \text { to } \\
\text { less than } 482.38 \\
\text { score points) }\end{array}$} & \multicolumn{2}{|c|}{$\begin{array}{c}\text { Level } 3 \\
\text { (from } 482.38 \text { to } \\
\text { less than } 544.68 \\
\text { score points) }\end{array}$} & \multicolumn{2}{|c|}{$\begin{array}{c}\text { Level } 4 \\
\text { (from } 544.68 \text { to } \\
\text { less than } 606.99 \\
\text { score points) }\end{array}$} & \multicolumn{2}{|c|}{$\begin{array}{c}\text { Level } 5 \\
\text { (from } 606.99 \text { to } \\
\text { less than } 669.30 \\
\text { score points) }\end{array}$} & \multicolumn{2}{|c|}{$\begin{array}{c}\text { Level } 6 \\
\text { (above 669.3 } \\
\text { score points) }\end{array}$} \\
\hline & & $\%$ & S.E. & $\%$ & S.E. & $\%$ & S.E. & $\%$ & S.E. & $\%$ & S.E. & $\%$ & S.E. & $\%$ & S.E. \\
\hline 0 & Australia & & & & & & & & & & & & & & \\
\hline 밈 & Australian Capital Territory & 6.6 & (1.4) & 9.1 & $(2.2)$ & 20.1 & (2.9) & 26.9 & (2.8) & 19.1 & (3.6) & 14.4 & (2.9) & 3.9 & $(1.2)$ \\
\hline & New South Wales & 5.8 & $(0.7)$ & 12.7 & (1.1) & 22.2 & (1.6) & 23.7 & (1.4) & 18.0 & (1.8) & 11.8 & (1.4) & 5.8 & $(1.3)$ \\
\hline & Northern Territory & 14.4 & $(2.5)$ & 15.9 & (3.3) & 22.0 & $(4.7)$ & 24.6 & $(4.5)$ & 15.3 & (3.7) & 5.9 & (2.5) & 1.8 & (1.4) \\
\hline & Queensland & 3.9 & $(0.8)$ & 13.0 & (1.3) & 22.4 & $(1.7)$ & 25.6 & $(1.5)$ & 20.7 & (1.5) & 11.0 & (1.5) & 3.2 & $(0.6)$ \\
\hline & South Australia & 6.2 & $(1.1)$ & 12.9 & (1.8) & 23.0 & $(2.1)$ & 26.5 & $(2.2)$ & 20.2 & (2.5) & 9.2 & (1.8) & 2.0 & $(0.7)$ \\
\hline & Tasmania & 9.3 & $(1.4)$ & 15.0 & (1.9) & 26.8 & (2.4) & 23.7 & (2.3) & 15.8 & (2.0) & 7.4 & (1.5) & 2.0 & $(0.7)$ \\
\hline & Victoria & 3.4 & $(0.8)$ & 10.9 & $(1.2)$ & 22.0 & (1.5) & 27.9 & $(1.7)$ & 21.1 & (1.4) & 10.3 & (1.3) & 4.3 & (1.3) \\
\hline & Western Australia & 2.8 & $(0.9)$ & 10.6 & (1.4) & 19.0 & (1.7) & 23.7 & (1.9) & 24.9 & $(2.1)$ & 13.8 & (1.4) & 5.3 & (1.6) \\
\hline & Belgium & & & & & & & & & & & & & & \\
\hline & Flemish community ${ }^{\bullet}$ & 4.7 & $(0.8)$ & 9.4 & $(1.2)$ & 16.1 & (1.1) & 21.1 & (1.4) & 22.0 & (1.5) & 17.7 & $(1.2)$ & 9.0 & $(0.8)$ \\
\hline & French community & 7.1 & $(1.0)$ & 15.0 & (1.3) & 19.5 & (1.5) & 25.2 & (1.5) & 21.3 & (1.3) & 9.7 & (1.0) & 2.2 & $(0.6)$ \\
\hline & German-speaking community & 3.5 & $(0.9)$ & 9.5 & (1.8) & 18.9 & $(2.2)$ & 31.8 & $(3.2)$ & 23.7 & (2.3) & 10.4 & $(2.2)$ & 2.3 & $(0.8)$ \\
\hline & Canada & & & & & & & & & & & & & & \\
\hline & Alberta & 3.7 & $(1.0)$ & 8.9 & $(1.3)$ & 20.7 & $(2.0)$ & 25.8 & (1.9) & 22.7 & $(1.7)$ & 12.8 & (1.6) & 5.2 & $(1.0)$ \\
\hline & British Columbia & 1.4 & $(0.7)$ & 7.3 & $(1.2)$ & 18.7 & $(1.7)$ & 25.7 & $(2.3)$ & 25.4 & $(2.2)$ & 15.0 & (1.8) & 6.5 & (1.3) \\
\hline & Manitoba & 5.0 & $(1.3)$ & 13.6 & (2.4) & 24.3 & $(2.2)$ & 26.4 & $(2.1)$ & 19.5 & $(1.7)$ & 8.8 & $(1.2)$ & 2.4 & $(0.6)$ \\
\hline & New Brunswick & 5.3 & $(1.1)$ & 11.5 & $(1.8)$ & 21.3 & (1.9) & 32.3 & $(2.1)$ & 20.2 & $(2.1)$ & 8.2 & (1.6) & 1.2 & $(0.5)$ \\
\hline & Newfoundland and Labrador & 5.2 & $(1.2)$ & 11.1 & (1.6) & 23.8 & $(2.0)$ & 28.9 & (2.5) & 20.3 & $(2.0)$ & 9.3 & (1.6) & 1.3 & $(0.7)$ \\
\hline & Nova Scotia & 3.5 & $(1.2)$ & 10.7 & (2.0) & 24.4 & (2.3) & 27.8 & $(2.6)$ & 22.9 & $(2.9)$ & 9.3 & $(2.3)$ & 1.5 & $(0.6)$ \\
\hline & Ontario & 2.1 & $(0.6)$ & 7.8 & $(1.1)$ & 19.1 & (1.5) & 27.3 & $(1.7)$ & 23.9 & $(2.1)$ & 14.0 & (1.6) & 5.8 & $(1.2)$ \\
\hline & Prince Edward Island & 5.5 & $(1.1)$ & 15.2 & $(1.7)$ & 26.7 & (2.0) & 32.4 & $(2.2)$ & 16.4 & (1.8) & 3.4 & $(0.9)$ & 0.4 & $(0.3)$ \\
\hline & Quebec & 2.8 & $(0.6)$ & 7.5 & $(1.2)$ & 16.4 & (1.3) & 24.8 & (1.5) & 27.0 & (1.6) & 16.4 & $(1.2)$ & 5.1 & $(0.8)$ \\
\hline & Saskatchewan & 4.4 & $(0.8)$ & 11.2 & (1.3) & 22.9 & (1.9) & 27.1 & $(2.1)$ & 22.1 & (1.8) & 10.7 & (1.5) & 1.6 & $(0.7)$ \\
\hline & Italy & & & & & & & & & & & & & & \\
\hline & Abruzzo & 0.0 & c & 12.7 & (7.4) & 21.5 & $(6.2)$ & 29.5 & (9.5) & 26.4 & $(10.1)$ & 7.2 & (7.0) & 2.7 & c \\
\hline & Basilicata & 8.3 & $(7.0)$ & 18.3 & (7.1) & 26.5 & (6.0) & 28.3 & (8.4) & 16.7 & (3.7) & 2.0 & c & 0.0 & c \\
\hline & Bolzano & 0.0 & c & 4.2 & (1.8) & 13.2 & $(5.2)$ & 34.4 & (5.6) & 38.7 & (6.8) & 8.4 & (4.3) & 1.2 & c \\
\hline & Calabria & 8.9 & $(5.5)$ & 24.6 & (6.3) & 29.0 & (5.9) & 25.2 & (4.9) & 10.3 & (4.5) & 2.1 & (2.1) & 0.0 & c \\
\hline & Campania & 10.7 & $(5.1)$ & 21.9 & (4.5) & 28.5 & (4.5) & 21.6 & (4.4) & 12.7 & (3.8) & 4.4 & (1.6) & 0.2 & c \\
\hline & Emilia Romagna & 3.8 & (3.4) & 9.2 & (4.1) & 17.8 & (5.0) & 31.3 & (7.4) & 22.1 & $(5.2)$ & 11.3 & (4.4) & 4.5 & (3.2) \\
\hline & Friuli Venezia Giulia & 4.1 & $(4.4)$ & 9.7 & (5.9) & 17.7 & (9.9) & 25.9 & $(5.7)$ & 32.4 & $(10.3)$ & 8.6 & (5.6) & 1.7 & $(2.0)$ \\
\hline & Lazio & 6.3 & $(3.2)$ & 12.3 & (2.9) & 24.7 & (7.9) & 29.6 & $(7.0)$ & 21.6 & $(3.3)$ & 5.1 & (1.7) & 0.5 & $(0.3)$ \\
\hline & Liguria & 3.6 & (2.6) & 10.9 & $(6.1)$ & 19.7 & $(7.8)$ & 26.3 & $(10.0)$ & 11.0 & (3.5) & 17.0 & $(12.4)$ & 11.5 & (8.4) \\
\hline & Lombardia & 2.0 & $(1.7)$ & 6.3 & (1.9) & 18.6 & $(4.7)$ & 31.3 & $(5.1)$ & 28.5 & $(4.1)$ & 12.0 & (2.9) & 1.3 & (1.0) \\
\hline & Marche & 0.0 & $\mathrm{c}$ & 9.7 & (5.4) & 21.2 & (6.7) & 31.6 & (10.7) & 26.2 & (6.3) & 7.2 & (5.5) & 4.0 & (2.3) \\
\hline & Molise & 9.4 & $(6.8)$ & 24.2 & (12.4) & 22.9 & $(7.2)$ & 25.3 & $(8.2)$ & 14.3 & (6.3) & 3.9 & c & 0.0 & c \\
\hline & Piemonte & 3.8 & $(1.7)$ & 8.8 & $(3.2)$ & 21.4 & (4.1) & 32.4 & (4.4) & 22.2 & (2.8) & 9.2 & (4.7) & 2.2 & $(0.9)$ \\
\hline & Puglia & 7.1 & $(2.7)$ & 17.5 & $(7.1)$ & 27.8 & (5.0) & 18.7 & (5.7) & 20.8 & $(6.2)$ & 7.7 & (3.9) & 0.4 & c \\
\hline & Sardegna & 10.7 & $(7.7)$ & 30.7 & (10.9) & 26.7 & (9.7) & 24.5 & (10.3) & 4.5 & c & 3.0 & c & 0.0 & c \\
\hline & Sicilia & 5.6 & (2.9) & 16.0 & (4.4) & 34.1 & (3.9) & 28.1 & (4.5) & 14.0 & (4.0) & 2.0 & (1.5) & 0.2 & c \\
\hline & Toscana & 2.9 & $(2.7)$ & 9.4 & (3.0) & 22.2 & (6.6) & 25.1 & $(4.2)$ & 22.8 & (3.7) & 15.2 & (4.5) & 2.3 & (1.9) \\
\hline & Trento & 0.0 & c & 7.0 & (3.9) & 13.2 & (4.5) & 22.6 & (3.7) & 30.5 & $(5.2)$ & 21.1 & (6.4) & 5.5 & (3.7) \\
\hline & Umbria & 6.7 & $(4.5)$ & 10.9 & $(6.2)$ & 19.1 & $(6.0)$ & 35.2 & (9.5) & 20.6 & (6.9) & 6.3 & $(5.2)$ & 1.2 & c \\
\hline & Valle d'Aosta & 2.2 & $(2.5)$ & 12.2 & (7.9) & 19.5 & $(8.2)$ & 36.4 & $(7.1)$ & 24.5 & (9.5) & 4.1 & (2.4) & 1.0 & (1.3) \\
\hline & Veneto & 3.9 & (1.8) & 10.3 & (3.2) & 16.7 & (4.9) & 21.6 & (3.6) & 24.0 & (5.0) & 18.7 & (4.5) & 4.9 & (2.4) \\
\hline & Portugal & & & & & & & & & & & & & & \\
\hline & Alentejo & 6.3 & (1.9) & 12.7 & (3.2) & 21.7 & (3.9) & 30.9 & (4.5) & 16.9 & (3.0) & 9.5 & (2.4) & 1.9 & (1.5) \\
\hline & Spain & & & & & & & & & & & & & & \\
\hline & Andalusia ${ }^{\bullet}$ & 8.5 & (2.4) & 18.8 & (2.7) & 29.0 & (2.8) & 25.7 & (3.2) & 13.3 & (2.5) & 4.3 & (1.1) & 0.4 & $(0.3)$ \\
\hline & Aragon • & 3.4 & $(2.0)$ & 14.8 & $(7.1)$ & 33.7 & $(10.2)$ & 19.0 & (6.5) & 19.7 & (6.6) & 8.1 & (5.7) & 1.3 & (2.0) \\
\hline & Asturias ${ }^{\bullet}$ & c & $\mathrm{c}$ & c & c & c & c & c & c & c & c & c & c & $\mathrm{c}$ & c \\
\hline & Balearic Islands ${ }^{\bullet}$ & c & c & c & c & c & c & c & c & c & c & c & c & c & c \\
\hline & Basque Country ${ }^{\bullet}$ & 4.2 & $(0.8)$ & 10.6 & $(0.8)$ & 22.3 & (1.1) & 30.9 & $(1.2)$ & 23.3 & $(1.2)$ & 7.7 & $(0.8)$ & 1.1 & $(0.3)$ \\
\hline & Cantabria ${ }^{\bullet}$ & c & c & c & c & c & c & c & c & c & c & c & c & c & c \\
\hline & Castile and Leon ${ }^{\bullet}$ & 4.4 & (2.9) & 12.2 & (3.4) & 19.1 & (3.1) & 27.3 & (5.4) & 25.7 & (5.5) & 10.5 & $(4.1)$ & 0.8 & c \\
\hline & Catalonia ${ }^{\bullet}$ & 3.9 & $(1.2)$ & 14.1 & (2.1) & 23.4 & (2.3) & 29.8 & (2.0) & 20.2 & (2.3) & 8.0 & (1.6) & 0.5 & $(0.3)$ \\
\hline & Extremadura ${ }^{\bullet}$ & 7.9 & (3.6) & 12.7 & (8.0) & 32.3 & $(7.2)$ & 26.3 & (5.9) & 15.2 & (5.5) & 5.5 & (2.6) & 0.1 & c \\
\hline & Galicia• & 10.3 & $(4.8)$ & 16.9 & (5.5) & 24.7 & (6.9) & 28.0 & (6.4) & 16.3 & (4.9) & 2.8 & (2.6) & 1.0 & c \\
\hline & La Rioja• & c & $\mathrm{c}$ & c & c & c & c & c & c & c & c & c & c & $\mathrm{c}$ & c \\
\hline & Madrid ${ }^{\bullet}$ & 3.8 & $(1.7)$ & 12.2 & (2.8) & 22.5 & (3.5) & 29.6 & (3.0) & 25.1 & (3.8) & 5.9 & (1.9) & 0.9 & c \\
\hline & Murcia ${ }^{\bullet}$ & 8.0 & (3.3) & 22.1 & (3.8) & 27.0 & (8.3) & 25.5 & (7.6) & 16.2 & (4.7) & 1.3 & c & 0.0 & c \\
\hline & Navarre ${ }^{\bullet}$ & $\mathrm{c}$ & $\mathrm{c}$ & $\mathrm{c}$ & $\mathrm{c}$ & $\mathrm{C}$ & $\mathrm{c}$ & $\mathrm{c}$ & $\mathrm{c}$ & $\mathrm{c}$ & $\mathrm{c}$ & $\mathrm{c}$ & $\mathrm{c}$ & $\mathrm{c}$ & $\mathrm{c}$ \\
\hline
\end{tabular}

- PISA adjudicated region.

Note: See Table B3.I.5 for national data.

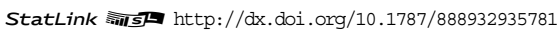




\begin{tabular}{|c|c|c|c|c|c|c|c|c|c|c|c|c|c|c|c|}
\hline \multirow{4}{*}{\multicolumn{2}{|c|}{ Table B3.I.17 }} & \multicolumn{14}{|c|}{$\begin{array}{l}\text { [Part } 2 / 4] \\
\text { Percentage of students at each proficiency level on the combined mathematics scale, by gender } \\
\text { and region }\end{array}$} \\
\hline & & \multicolumn{14}{|c|}{ Boys } \\
\hline & & \multicolumn{2}{|c|}{$\begin{array}{c}\text { Below Level } 1 \\
\text { (below 357.77 } \\
\text { score points) }\end{array}$} & \multicolumn{2}{|c|}{$\begin{array}{l}\text { Level } 1 \\
\text { (from } 357.77 \text { to } \\
\text { less than } 420.07 \\
\text { score points) }\end{array}$} & \multicolumn{2}{|c|}{$\begin{array}{l}\text { Level } 2 \\
\text { (from } 420.07 \text { to } \\
\text { less than } 482.38 \\
\text { score points) }\end{array}$} & \multicolumn{2}{|c|}{$\begin{array}{c}\text { Level } 3 \\
\text { (from } 482.38 \text { to } \\
\text { less than } 544.68 \\
\text { score points) }\end{array}$} & \multicolumn{2}{|c|}{$\begin{array}{c}\text { Level } 4 \\
\text { (from } 544.68 \text { to } \\
\text { less than } 606.99 \\
\text { score points) }\end{array}$} & \multicolumn{2}{|c|}{$\begin{array}{c}\text { Level } 5 \\
\text { (from } 606.99 \text { to } \\
\text { less than } 669.30 \\
\text { score points) }\end{array}$} & \multicolumn{2}{|c|}{$\begin{array}{c}\text { Level } 6 \\
\text { (above 669.30 } \\
\text { score points) }\end{array}$} \\
\hline & & $\%$ & S.E. & $\%$ & S.E. & $\%$ & S.E. & $\%$ & S.E. & $\%$ & S.E. & $\%$ & S.E. & $\%$ & S.E. \\
\hline \multirow{41}{*}{ ఏँ় } & Brazil & & & & & & & & & & & & & & \\
\hline & Acre & 9.9 & (4.6) & 39.8 & (12.5) & 38.0 & (13.3) & 11.1 & $(7.2)$ & 1.2 & c & 0.0 & c & 0.0 & c \\
\hline & Alagoas & 53.9 & (17.5) & 28.1 & $(12.1)$ & 11.7 & $(7.4)$ & 3.5 & (2.6) & 2.7 & (1.8) & 0.1 & c & 0.0 & c \\
\hline & Amapá & 11.9 & (6.8) & 48.4 & $(12.1)$ & 30.3 & (9.6) & 8.5 & (5.3) & 0.9 & (1.5) & 0.0 & c & 0.0 & c \\
\hline & Amazonas & 60.5 & (10.1) & 26.5 & (5.6) & 7.6 & (5.4) & 3.0 & (3.7) & 1.6 & (2.9) & 0.8 & (1.4) & 0.0 & c \\
\hline & Bahia & 42.2 & $(12.7)$ & 24.6 & (8.7) & 17.1 & (7.5) & 10.6 & (4.6) & 4.0 & (3.2) & 1.4 & (1.7) & 0.0 & c \\
\hline & Ceará & 31.1 & $(8.1)$ & 29.3 & $(7.7)$ & 14.4 & (5.1) & 12.2 & (5.5) & 8.6 & (4.5) & 3.9 & (2.6) & 0.5 & c \\
\hline & Espírito Santo & 13.5 & (5.1) & 28.5 & (8.9) & 29.7 & (7.0) & 20.3 & $(7.0)$ & 5.4 & (2.8) & 2.0 & (1.7) & 0.5 & c \\
\hline & Federal District & c & c & c & c & c & c & $\mathrm{c}$ & c & c & c & C & c & $\mathrm{C}$ & c \\
\hline & Goiás & 24.6 & $(7.7)$ & 39.1 & $(9.7)$ & 19.8 & (6.5) & 11.4 & (2.5) & 4.5 & (2.4) & 0.6 & c & 0.0 & c \\
\hline & Maranhão & 57.4 & $(11.7)$ & 26.4 & (12.9) & 5.8 & (5.1) & 7.7 & $(4.2)$ & 2.1 & (3.0) & 0.6 & c & 0.0 & c \\
\hline & Mato Grosso & c & c & c & c & c & c & $\mathrm{c}$ & c & c & c & C & c & $\mathrm{C}$ & c \\
\hline & Mato Grosso do Sul & 7.5 & $(4.2)$ & 29.3 & (11.5) & 29.7 & (9.3) & 19.6 & $(7.2)$ & 12.2 & $(4.7)$ & 1.8 & $(2.2)$ & 0.0 & c \\
\hline & Minas Gerais & 15.3 & (5.6) & 29.5 & $(6.6)$ & 30.1 & (5.6) & 17.7 & (5.5) & 5.8 & (3.7) & 0.9 & (1.0) & 0.7 & c \\
\hline & Pará & 49.6 & $(17.0)$ & 27.7 & $(10.9)$ & 16.6 & (7.4) & 5.0 & (4.3) & 1.0 & c & 0.0 & c & 0.0 & c \\
\hline & Paraíba & c & c & c & c & c & c & $\mathrm{c}$ & c & c & c & c & $\mathrm{c}$ & $\mathrm{c}$ & c \\
\hline & Paraná & 19.5 & (6.3) & 40.0 & (5.6) & 22.7 & (4.5) & 9.1 & $(2.7)$ & 6.9 & (3.8) & 1.9 & (1.9) & 0.0 & c \\
\hline & Pernambuco & 18.7 & (6.1) & 40.4 & (8.0) & 25.6 & (8.4) & 12.0 & (5.3) & 3.2 & (2.6) & 0.0 & c & 0.0 & c \\
\hline & Piauí & c & c & c & c & c & $\mathrm{c}$ & $\mathrm{c}$ & c & c & $\mathrm{c}$ & c & $\mathrm{C}$ & $\mathrm{c}$ & c \\
\hline & Rio de Janeiro & 17.0 & (5.9) & 31.9 & (7.7) & 26.5 & (6.7) & 17.8 & (7.6) & 6.2 & (5.4) & 0.6 & c & 0.0 & c \\
\hline & Rio Grande do Norte & c & c & c & c & c & c & $\mathrm{c}$ & c & c & c & c & c & $\mathrm{c}$ & c \\
\hline & Rio Grande do Sul & 7.2 & (3.3) & 27.5 & (6.3) & 36.6 & (5.7) & 23.4 & (7.6) & 5.0 & $(2.7)$ & 0.4 & c & 0.0 & c \\
\hline & Rondônia & 18.4 & (8.4) & 32.8 & $(11.0)$ & 31.1 & (7.5) & 14.1 & (4.8) & 3.7 & (3.7) & 0.0 & c & 0.0 & c \\
\hline & Roraima & 15.5 & (10.4) & 38.8 & (9.4) & 32.4 & $(11.0)$ & 12.1 & $(5.7)$ & 1.0 & $(1.0)$ & 0.2 & c & 0.0 & c \\
\hline & Santa Catarina & 20.2 & (13.4) & 25.5 & (5.8) & 29.9 & (11.5) & 19.6 & (6.9) & 4.3 & $(2.7)$ & 0.5 & c & 0.0 & c \\
\hline & São Paulo & 18.2 & (3.2) & 31.4 & (2.8) & 28.6 & (3.0) & 13.6 & $(2.7)$ & 6.1 & (1.8) & 1.9 & (1.0) & 0.3 & $(0.2)$ \\
\hline & Sergipe & 11.8 & (5.9) & 45.7 & (7.9) & 21.1 & (9.9) & 14.6 & (8.5) & 5.2 & (1.9) & 1.5 & (1.3) & 0.0 & c \\
\hline & Tocantins & 30.5 & (20.8) & 29.5 & (8.0) & 23.9 & $(14.0)$ & 11.8 & $(11.2)$ & 4.3 & (3.9) & 0.0 & c & 0.0 & c \\
\hline & \multicolumn{15}{|l|}{ Colombia } \\
\hline & Bogota & 18.1 & $(2.2)$ & 34.7 & (2.4) & 33.5 & (2.4) & 10.8 & (2.0) & 2.2 & (1.1) & 0.7 & $(0.7)$ & 0.0 & c \\
\hline & Cali & 29.3 & (3.8) & 36.8 & (3.4) & 21.0 & (2.9) & 10.5 & (2.6) & 2.3 & $(1.2)$ & 0.0 & c & 0.0 & c \\
\hline & Manizales & 18.1 & (2.3) & 35.1 & (3.0) & 29.1 & (2.8) & 13.6 & (2.3) & 3.7 & (2.0) & 0.4 & $(0.5)$ & 0.0 & c \\
\hline & Medellin & 24.2 & (3.5) & 33.5 & (2.8) & 25.3 & (2.8) & 11.6 & (2.3) & 3.5 & (1.4) & 1.5 & (1.1) & 0.3 & $(0.3)$ \\
\hline & \multicolumn{15}{|l|}{ United Arab Emirates } \\
\hline & Abu Dhabi ${ }^{\bullet}$ & 27.8 & $(2.2)$ & 28.6 & (1.6) & 21.9 & (1.7) & 13.5 & (1.3) & 6.4 & (1.1) & 1.7 & $(0.7)$ & 0.2 & $(0.2)$ \\
\hline & Ajman & 41.6 & (7.3) & 32.3 & (5.9) & 21.4 & (3.6) & 4.5 & (1.3) & 0.2 & c & 0.0 & c & 0.0 & c \\
\hline & Dubai • & 13.6 & $(0.7)$ & 19.8 & $(1.2)$ & 24.2 & (1.3) & 21.4 & (1.1) & 14.0 & (1.1) & 5.9 & $(0.8)$ & 1.1 & $(0.4)$ \\
\hline & Fujairah & 30.9 & $(4.2)$ & 29.1 & (2.8) & 24.7 & (3.6) & 10.8 & (1.9) & 4.3 & (1.3) & 0.2 & c & 0.0 & c \\
\hline & Ras Al Khaimah & 27.5 & (6.4) & 34.2 & (4.9) & 25.5 & (4.1) & 10.6 & (2.5) & 2.0 & (0.8) & 0.2 & $(0.2)$ & 0.0 & c \\
\hline & Sharjah & 12.8 & (5.0) & 28.0 & (4.3) & 29.2 & (5.1) & 19.2 & (4.0) & 9.4 & (3.9) & 1.4 & $(1.2)$ & 0.1 & c \\
\hline & Umm Al Quwain & 42.6 & (3.2) & 31.7 & $(4.7)$ & 17.8 & $(4.7)$ & 6.0 & (2.3) & 1.7 & (1.3) & 0.2 & $\mathrm{C}$ & 0.0 & c \\
\hline
\end{tabular}

- PISA adjudicated region.

Note: See Table B3.I.5 for national data.

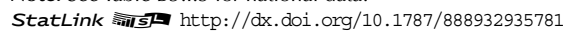




\begin{tabular}{|c|c|c|c|c|c|c|c|c|c|c|c|c|c|c|c|}
\hline & & \multicolumn{14}{|c|}{ Girls } \\
\hline & & \multicolumn{2}{|c|}{$\begin{array}{l}\text { Below Level } 1 \\
\text { (below } 357.77 \\
\text { score points) }\end{array}$} & \multicolumn{2}{|c|}{$\begin{array}{c}\text { Level } 1 \\
\text { (from } 357.77 \text { to } \\
\text { less than } 420.07 \\
\text { score points) }\end{array}$} & \multicolumn{2}{|c|}{$\begin{array}{c}\text { Level } 2 \\
\text { (from } 420.07 \text { to } \\
\text { less than } 482.38 \\
\text { score points) }\end{array}$} & \multicolumn{2}{|c|}{$\begin{array}{c}\text { Level } 3 \\
\text { (from } 482.38 \text { to } \\
\text { less than } 544.68 \\
\text { score points) }\end{array}$} & \multicolumn{2}{|c|}{$\begin{array}{c}\text { Level } 4 \\
\text { (from } 544.68 \text { to } \\
\text { less than } 606.99 \\
\text { score points) }\end{array}$} & \multicolumn{2}{|c|}{$\begin{array}{c}\text { Level } 5 \\
\text { (from } 606.99 \text { to } \\
\text { less than } 669.30 \\
\text { score points) }\end{array}$} & \multicolumn{2}{|c|}{$\begin{array}{c}\text { Level } 6 \\
\text { (above } 669.30 \\
\text { score points) }\end{array}$} \\
\hline & & $\%$ & S.E. & $\%$ & S.E. & $\%$ & S.E. & $\%$ & S.E. & $\%$ & S.E. & $\%$ & S.E. & $\%$ & S.E. \\
\hline$\theta$ & Australia & & & & & & & & & & & & & & \\
\hline 밈 & Australian Capital Territory & 3.7 & $(1.1)$ & 10.0 & (2.0) & 20.7 & $(2.1)$ & 27.2 & (3.6) & 23.0 & (3.6) & 11.7 & $(2.2)$ & 3.7 & $(1.0)$ \\
\hline & New South Wales & 5.0 & $(0.7)$ & 12.5 & (1.1) & 22.4 & (1.7) & 26.2 & (1.5) & 19.9 & (1.5) & 10.4 & (1.1) & 3.5 & $(0.9)$ \\
\hline & Northern Territory & 16.2 & $(2.7)$ & 16.8 & (4.9) & 25.0 & (5.6) & 26.0 & (5.6) & 10.9 & (3.9) & 4.4 & (3.3) & 0.6 & c \\
\hline & Queensland & 4.8 & $(0.8)$ & 13.3 & (1.3) & 23.3 & (1.3) & 28.3 & $(2.0)$ & 18.9 & (1.5) & 9.1 & (1.5) & 2.3 & $(0.6)$ \\
\hline & South Australia & 6.0 & $(1.1)$ & 15.7 & (1.5) & 25.1 & (2.4) & 27.6 & $(2.2)$ & 17.4 & (1.9) & 6.8 & (1.3) & 1.4 & $(0.6)$ \\
\hline & Tasmania & 9.8 & $(1.5)$ & 17.5 & (1.8) & 26.5 & (2.3) & 24.5 & $(2.2)$ & 13.8 & (1.9) & 6.2 & (1.7) & 1.7 & $(0.7)$ \\
\hline & Victoria & 4.8 & $(0.9)$ & 13.2 & $(1.2)$ & 24.8 & (1.7) & 28.0 & $(1.7)$ & 19.8 & (1.5) & 8.3 & (1.1) & 1.2 & $(0.5)$ \\
\hline & Western Australia & 5.5 & $(1.1)$ & 12.6 & (1.5) & 23.0 & (2.7) & 24.8 & (2.4) & 20.6 & $(2.2)$ & 10.8 & $(1.7)$ & 2.6 & $(0.8)$ \\
\hline & Belgium & & & & & & & & & & & & & & \\
\hline & Flemish community ${ }^{\bullet}$ & 5.0 & $(0.9)$ & 10.0 & (1.1) & 18.1 & $(1.2)$ & 22.7 & (1.4) & 23.7 & (1.5) & 15.4 & (1.1) & 5.1 & $(0.6)$ \\
\hline & French community & 7.4 & $(1.0)$ & 14.7 & $(1.2)$ & 24.5 & (1.3) & 28.7 & (1.6) & 18.6 & (1.3) & 5.3 & $(0.8)$ & 0.8 & $(0.3)$ \\
\hline & German-speaking community & 2.7 & $(1.2)$ & 8.6 & (2.0) & 24.7 & (2.6) & 33.6 & (2.6) & 22.7 & (2.6) & 6.8 & (1.3) & 1.0 & $(0.5)$ \\
\hline & Canada & & & & & & & & & & & & & & \\
\hline & Alberta & 4.4 & $(1.1)$ & 11.9 & $(1.5)$ & 20.7 & $(1.7)$ & 25.6 & $(2.2)$ & 23.5 & $(2.7)$ & 11.3 & $(2.1)$ & 2.5 & $(0.8)$ \\
\hline & British Columbia & 2.7 & $(0.8)$ & 9.2 & $(1.1)$ & 21.2 & (1.9) & 30.0 & $(2.0)$ & 23.3 & $(2.4)$ & 10.8 & $(2.0)$ & 2.8 & $(0.9)$ \\
\hline & Manitoba & 5.6 & $(1.4)$ & 14.3 & (2.0) & 27.2 & $(2.2)$ & 28.6 & $(2.0)$ & 17.6 & (1.6) & 5.7 & $(0.9)$ & 1.0 & $(0.5)$ \\
\hline & New Brunswick & 4.3 & $(0.8)$ & 10.6 & (1.3) & 26.6 & $(2.1)$ & 31.2 & (2.6) & 20.6 & $(2.2)$ & 5.7 & $(1.7)$ & 1.0 & $(0.7)$ \\
\hline & Newfoundland and Labrador & 2.8 & $(0.9)$ & 12.0 & (2.0) & 27.4 & (3.3) & 29.0 & (3.0) & 20.4 & (2.6) & 7.6 & $(1.2)$ & 0.8 & $(0.4)$ \\
\hline & Nova Scotia & 4.2 & $(1.1)$ & 13.0 & $(3.1)$ & 26.4 & (3.3) & 30.6 & $(2.1)$ & 18.9 & $(3.2)$ & 5.7 & $(1.2)$ & 1.2 & $(0.6)$ \\
\hline & Ontario & 2.7 & $(0.6)$ & 9.0 & $(1.0)$ & 22.6 & (1.8) & 30.3 & (1.6) & 23.6 & (1.6) & 9.6 & $(1.0)$ & 2.2 & $(0.7)$ \\
\hline & Prince Edward Island & 3.0 & $(0.8)$ & 14.3 & (1.4) & 30.3 & $(2.2)$ & 30.6 & $(2.5)$ & 17.9 & $(1.7)$ & 3.6 & $(0.8)$ & 0.4 & $(0.3)$ \\
\hline & Quebec & 3.4 & $(0.6)$ & 8.5 & (1.0) & 17.9 & (1.5) & 27.5 & (1.9) & 26.6 & (1.5) & 13.0 & $(1.2)$ & 3.2 & $(0.7)$ \\
\hline & Saskatchewan & 3.0 & $(0.6)$ & 13.7 & $(1.7)$ & 24.6 & (1.9) & 29.7 & (2.4) & 20.3 & (2.3) & 7.7 & (1.6) & 1.1 & $(0.6)$ \\
\hline & Italy & & & & & & & & & & & & & & \\
\hline & Abruzzo & 3.6 & (3.3) & 19.7 & (13.8) & 28.9 & $(15.2)$ & 30.7 & (14.8) & 12.7 & (11.4) & 3.7 & (5.0) & 0.6 & c \\
\hline & Basilicata & 4.6 & (3.3) & 25.0 & (8.3) & 28.7 & (7.1) & 32.8 & (9.4) & 8.9 & (6.2) & 0.0 & c & 0.0 & c \\
\hline & Bolzano & 0.0 & c & 6.6 & (4.4) & 24.8 & (7.5) & 40.4 & $(7.0)$ & 22.7 & (4.6) & 4.1 & (3.3) & 1.4 & c \\
\hline & Calabria & 11.7 & $(5.2)$ & 17.6 & (4.3) & 43.7 & (8.4) & 22.8 & $(5.7)$ & 4.2 & (2.9) & 0.0 & c & 0.0 & c \\
\hline & Campania & 10.9 & $(4.0)$ & 21.8 & $(4.4)$ & 34.3 & $(5.7)$ & 23.4 & $(4.0)$ & 7.8 & $(3.2)$ & 1.9 & $(0.9)$ & 0.0 & c \\
\hline & Emilia Romagna & 4.5 & $(2.3)$ & 12.4 & (2.7) & 36.1 & (5.6) & 25.3 & (5.5) & 13.8 & $(2.7)$ & 5.6 & (3.7) & 2.3 & (2.1) \\
\hline & Friuli Venezia Giulia & 0.8 & $(0.8)$ & 8.6 & (5.6) & 22.5 & $(11.6)$ & 35.8 & $(8.4)$ & 25.9 & $(17.0)$ & 5.1 & (5.5) & 1.3 & c \\
\hline & Lazio & 3.8 & (1.9) & 14.8 & (3.9) & 24.9 & $(6.7)$ & 29.3 & (5.5) & 22.2 & (3.5) & 4.2 & (1.9) & 0.7 & $(0.6)$ \\
\hline & Liguria & 1.7 & $(1.6)$ & 16.9 & (10.6) & 22.9 & $(10.6)$ & 15.8 & $(9.0)$ & 17.8 & (9.3) & 14.8 & (9.3) & 10.2 & $(7.7)$ \\
\hline & Lombardia & 0.7 & $(0.4)$ & 3.9 & (1.3) & 22.5 & (3.8) & 38.2 & (3.7) & 26.6 & $(4.4)$ & 7.6 & (3.2) & 0.4 & c \\
\hline & Marche & 7.6 & $(7.6)$ & 12.3 & (9.6) & 27.1 & $(10.9)$ & 15.3 & (5.6) & 27.1 & $(15.1)$ & 10.5 & (7.9) & 0.0 & c \\
\hline & Molise & c & c & c & c & $\mathrm{C}$ & c & c & c & c & c & c & c & c & c \\
\hline & Piemonte & 5.8 & $(3.2)$ & 19.0 & (6.1) & 21.3 & $(5.2)$ & 26.6 & (5.9) & 21.9 & (4.1) & 5.3 & $(2.1)$ & 0.1 & c \\
\hline & Puglia & 14.9 & $(8.7)$ & 17.0 & (5.9) & 25.2 & (6.7) & 24.0 & (3.8) & 16.0 & (3.7) & 1.7 & (1.6) & 1.2 & $(0.5)$ \\
\hline & Sardegna & c & c & c & c & $\mathrm{C}$ & c & c & c & c & c & c & c & $\mathrm{c}$ & c \\
\hline & Sicilia & 6.9 & $(4.1)$ & 19.7 & (6.8) & 30.6 & (5.3) & 29.9 & (6.7) & 10.8 & (4.0) & 1.4 & $(1.2)$ & 0.7 & $(0.8)$ \\
\hline & Toscana & 7.6 & $(4.3)$ & 19.1 & (7.4) & 24.4 & $(7.0)$ & 27.8 & (5.9) & 14.0 & (4.6) & 6.5 & (3.4) & 0.5 & c \\
\hline & Trento & 1.6 & (1.3) & 2.0 & (1.3) & 15.1 & (3.2) & 21.8 & (5.1) & 36.8 & (5.6) & 20.6 & (5.3) & 2.2 & (2.6) \\
\hline & Umbria & 3.7 & $(2.3)$ & 12.5 & (5.3) & 16.6 & (4.8) & 42.5 & (11.8) & 21.8 & (8.5) & 2.9 & $(2.7)$ & 0.0 & c \\
\hline & Valle d'Aosta & 2.0 & $(2.2)$ & 12.1 & $(7.1)$ & 33.1 & (5.9) & 41.2 & $(7.2)$ & 11.4 & (4.7) & 0.2 & c & 0.0 & c \\
\hline & Veneto & 2.6 & $(2.2)$ & 13.8 & (4.9) & 24.1 & (5.9) & 29.7 & $(8.0)$ & 19.6 & (3.6) & 7.8 & (3.5) & 2.5 & (2.3) \\
\hline & Portugal & & & & & & & & & & & & & & \\
\hline & Alentejo & 8.6 & (2.4) & 15.2 & (3.7) & 27.3 & (3.3) & 29.8 & (4.3) & 15.0 & (2.3) & 3.2 & (1.3) & 0.8 & $(0.7)$ \\
\hline & Spain & & & & & & & & & & & & & & \\
\hline & Andalusia ${ }^{\bullet}$ & 8.7 & (1.6) & 21.9 & (3.0) & 34.4 & (2.7) & 24.5 & (2.7) & 8.9 & (1.8) & 1.4 & $(0.8)$ & 0.3 & c \\
\hline & Aragon • & 11.3 & $(5.2)$ & 11.4 & (6.0) & 24.7 & (6.6) & 27.6 & (6.8) & 17.4 & (6.9) & 7.7 & (4.6) & 0.0 & c \\
\hline & Asturias ${ }^{\bullet}$ & c & $\mathrm{c}$ & c & c & c & c & c & c & c & c & c & c & $\mathrm{c}$ & c \\
\hline & Balearic Islands ${ }^{\bullet}$ & c & c & c & c & c & c & c & c & c & c & c & c & c & c \\
\hline & Basque Country ${ }^{\bullet}$ & 4.9 & $(0.7)$ & 11.5 & $(1.2)$ & 26.8 & (1.5) & 32.2 & $(1.2)$ & 19.5 & (1.3) & 4.7 & (0.6) & 0.5 & $(0.2)$ \\
\hline & Cantabria ${ }^{\bullet}$ & c & c & c & c & c & c & c & c & c & c & c & c & c & c \\
\hline & Castile and Leon ${ }^{\bullet}$ & 2.6 & (1.3) & 7.9 & (3.9) & 24.5 & (6.1) & 36.6 & (6.0) & 24.1 & $(5.2)$ & 4.4 & (2.6) & 0.0 & c \\
\hline & Catalonia $\bullet^{\bullet}$ & 4.7 & (1.1) & 16.0 & (2.4) & 29.7 & $(2.2)$ & 33.2 & (2.7) & 14.1 & (1.9) & 2.2 & $(0.9)$ & 0.1 & c \\
\hline & Extremadura ${ }^{\bullet}$ & 8.8 & $(6.2)$ & 18.5 & $(7.3)$ & 18.9 & (4.1) & 33.7 & (7.9) & 16.9 & (6.8) & 3.2 & (2.4) & 0.0 & c \\
\hline & Galicia• & 6.5 & $(5.1)$ & 13.8 & (5.4) & 21.6 & (4.0) & 33.8 & (5.0) & 22.3 & (7.6) & 2.0 & (1.3) & 0.0 & c \\
\hline & La Rioja• & c & $\mathrm{c}$ & c & c & c & c & c & c & c & c & c & c & $\mathrm{c}$ & c \\
\hline & Madrid ${ }^{\bullet}$ & 5.2 & $(2.3)$ & 14.0 & $(2.7)$ & 24.9 & (3.6) & 32.0 & (3.2) & 19.2 & (3.1) & 4.7 & (1.9) & 0.1 & c \\
\hline & Murcia ${ }^{\bullet}$ & 13.8 & $(4.7)$ & 25.0 & $(6.2)$ & 26.8 & (8.2) & 23.2 & (7.8) & 11.2 & $(4.7)$ & 0.0 & c & 0.0 & c \\
\hline & Navarre ${ }^{\bullet}$ & $\mathrm{c}$ & $\mathrm{c}$ & $\mathrm{c}$ & $\mathrm{c}$ & $\mathrm{C}$ & $\mathrm{c}$ & $\mathrm{c}$ & $\mathrm{c}$ & $\mathrm{c}$ & $\mathrm{c}$ & $\mathrm{c}$ & $\mathrm{c}$ & $\mathrm{c}$ & $\mathrm{c}$ \\
\hline
\end{tabular}

- PISA adjudicated region.

Note: See Table B3.I.5 for national data.

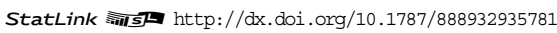




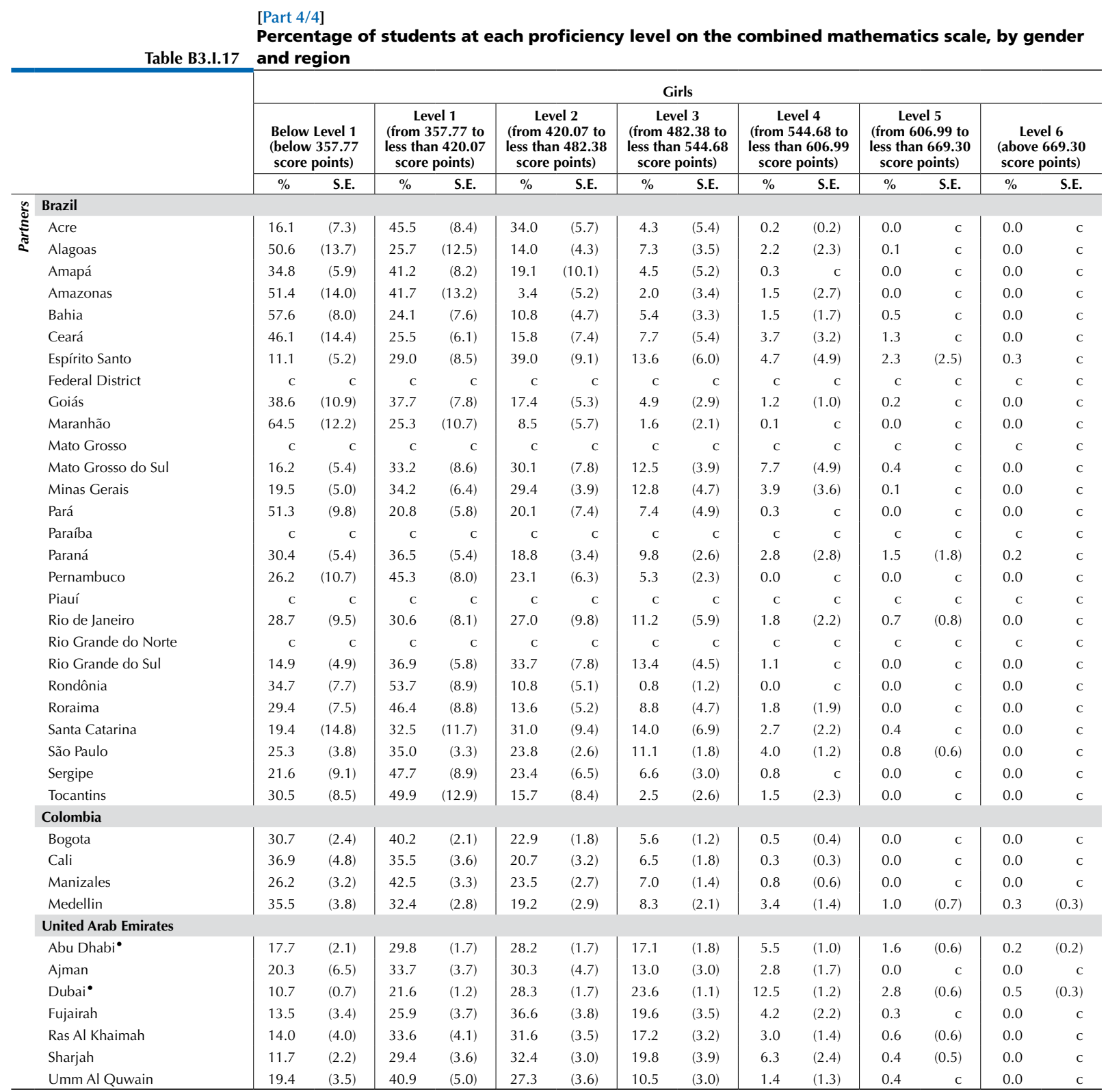

- PISA adjudicated region.

Note: See Table B3.I.5 for national data.

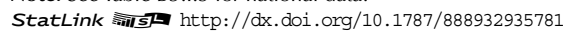


[Part 1/2]

Mean score, variation and gender differences in student performance on the combined Table B3.I.18 mathematics scale, by region

\begin{tabular}{|c|c|c|c|c|c|c|c|c|c|c|c|c|c|c|c|c|c|c|c|c|c|c|}
\hline & & \multicolumn{4}{|c|}{ All students } & \multicolumn{6}{|c|}{ Gender differences } & \multicolumn{11}{|c|}{ Percentiles } \\
\hline & & \multicolumn{2}{|c|}{ Mean score } & \multicolumn{2}{|c|}{$\begin{array}{l}\text { Standard } \\
\text { deviation }\end{array}$} & & oys & & irls & $\begin{array}{c}\text { Diffe } \\
\text { (B }\end{array}$ & $\begin{array}{l}\text { erence } \\
\text { - G) }\end{array}$ & 5th & & 0th & & 5th & & 5th & & oth & & 5th \\
\hline & & Mean & S.E. & S.D. & S.E. & $\begin{array}{l}\text { Mean } \\
\text { score }\end{array}$ & S.E. & $\begin{array}{l}\text { Mean } \\
\text { score }\end{array}$ & S.E. & $\begin{array}{c}\text { Score } \\
\text { dif. }\end{array}$ & er.E. & Score S.E. & Score & S.E. & Score & e S.E. & Score & e S.E. & Score & e S.E. & Score & S.E. \\
\hline 8 & Australia & & & & & & & & & & & & & & & & & & & & & \\
\hline 님 & Australian Capital Territory & 515 & (3.3) & 92 & (2.6) & 514 & (5.2) & 516 & $(4.2)$ & -2 & (6.8) & $357(10.5)$ & 395 & (7.8) & 456 & $(5.1)$ & 579 & $9 \quad(5.0)$ & 634 & $+\quad(6.1)$ & 659 & $(7.6)$ \\
\hline & New South Wales & 508 & (3.4) & 96 & $(2.4)$ & 510 & (5.3) & 506 & (3.9) & 4 & (6.4) & $354 \quad(4.9)$ & 388 & $(3.7)$ & 442 & (3.4) & 575 & $5 \quad(5.4)$ & 634 & (6.4) & 667 & $(6.8)$ \\
\hline & Northern Territory & 461 & $(9.2)$ & 103 & (4.6) & 468 & (8.8) & 454 & (13.8) & 14 & $(14.0)$ & $270(15.4)$ & 321 & $(15.2)$ & 400 & (11.3) & 529 & $9(13.7)$ & 583 & $(15.1)$ & 622 & $(19.5)$ \\
\hline & Queensland & 505 & (2.8) & 87 & (1.6) & 509 & (3.5) & 501 & (3.5) & 8 & $(4.2)$ & $364 \quad(5.3)$ & 393 & $(5.6)$ & 443 & (3.9) & 566 & $5 \quad(3.7)$ & 619 & (4.4) & 648 & $(4.3)$ \\
\hline & South Australia & 494 & (3.4) & 86 & (1.9) & 499 & (4.1) & 488 & (3.9) & 11 & $(4.2)$ & $347 \quad(7.8)$ & 382 & $(6.2)$ & 434 & $(4.2)$ & 554 & $4 \quad(5.2)$ & 606 & $(6.2)$ & 634 & $(6.0)$ \\
\hline & Tasmania & 479 & (3.3) & 92 & (2.4) & 482 & (4.6) & 475 & (4.8) & 8 & (6.7) & $326 \quad(8.6)$ & 360 & (4.9) & 418 & $(5.2)$ & 540 & (4.7) & 601 & (7.3) & 633 & $(8.4)$ \\
\hline & Victoria & 506 & (3.6) & 86 & (2.6) & 514 & (5.0) & 497 & (3.4) & 17 & (5.0) & $366 \quad(5.5)$ & 397 & (4.3) & 446 & (3.3) & 564 & $4 \quad(4.4)$ & 617 & (6.1) & 647 & $(7.1)$ \\
\hline & Western Australia & 516 & (3.5) & 91 & (2.4) & 526 & (5.5) & 504 & (4.8) & 23 & (7.7) & $367 \quad(8.3)$ & 397 & (5.7) & 453 & $(4.8)$ & 580 & (4.5) & 631 & (5.4) & 659 & $(7.5)$ \\
\hline & Belgium & & & & & & & & & & & & & & & & & & & & & \\
\hline & Flemish community $^{\bullet}$ & 530 & (3.2) & 99 & (2.0) & 536 & (4.1) & 523 & (4.2) & 13 & (5.3) & $359 \quad(6.2)$ & 395 & (6.3) & 462 & $(4.7)$ & 603 & (3.6) & 656 & (3.4) & 682 & (3.1) \\
\hline & French community & 492 & (2.9) & 88 & $(2.2)$ & 498 & (3.4) & 485 & (3.3) & 13 & (3.4) & $342 \quad(7.0)$ & 374 & (5.1) & 431 & (4.6) & 555 & $(3.4)$ & 603 & (3.8) & 631 & (4.9) \\
\hline & German-speaking community & 511 & $(2.1)$ & 77 & $(2.0)$ & 514 & (3.3) & 508 & (3.2) & 7 & (5.0) & $374 \quad(7.8)$ & 409 & $(6.7)$ & 463 & (3.7) & 565 & (3.6) & 608 & $(4.0)$ & 631 & (6.8) \\
\hline & Canada & & & & & & & & & & & & & & & & & & & & & \\
\hline & Alberta & 517 & (4.5) & 90 & (2.6) & 522 & (4.4) & 511 & (5.4) & 11 & (3.8) & $369 \quad(9.4)$ & 401 & $(5.7)$ & 455 & (5.8) & 578 & (5.5) & 632 & (5.5) & 660 & (6.2) \\
\hline & British Columbia & 527 & (4.2) & 84 & (2.3) & 537 & (5.1) & 517 & (5.1) & 20 & (5.9) & $388 \quad(7.3)$ & 419 & (4.7) & 469 & (5.0) & 585 & (5.2) & 635 & (6.3) & 666 & (7.5) \\
\hline & Manitoba & 493 & (2.9) & 85 & (2.3) & 499 & (3.7) & 487 & (4.2) & 12 & (5.4) & $357 \quad(6.3)$ & 384 & (7.6) & 436 & (4.3) & 551 & (2.9) & 602 & (4.5) & 630 & (6.9) \\
\hline & New Brunswick & 499 & (2.5) & 79 & (1.9) & 501 & (4.0) & 497 & (3.4) & 4 & (5.4) & $360 \quad(7.1)$ & 395 & (5.5) & 447 & (4.4) & 552 & (4.2) & 599 & (6.4) & 625 & (6.5) \\
\hline & Newfoundland and Labrador & 501 & (3.3) & 80 & (1.9) & 501 & (4.9) & 500 & (3.4) & 1 & (5.2) & $367(11.2)$ & 400 & (10.0) & 445 & (4.9) & 555 & (4.4) & 605 & (5.1) & 631 & $(7.9)$ \\
\hline & Nova Scotia & 500 & (4.8) & 80 & (1.9) & 506 & (3.6) & 494 & (7.6) & 13 & (6.8) & $367 \quad(8.0)$ & 396 & $(7.2)$ & 445 & (6.6) & 556 & (5.4) & 602 & (5.2) & 630 & $(7.1)$ \\
\hline & Ontario & 522 & (4.5) & 84 & $(2.0)$ & 531 & $(5.1)$ & 514 & (4.4) & 17 & (3.6) & $383 \quad(5.4)$ & 416 & (5.4) & 466 & (5.6) & 580 & (5.4) & 629 & (5.0) & 659 & (8.1) \\
\hline & Prince Edward Island & 485 & (2.3) & 73 & (1.6) & 483 & (3.2) & 487 & (2.8) & -5 & (3.9) & $364 \quad(5.1)$ & 390 & (4.3) & 435 & (3.6) & 536 & $(2.8)$ & 577 & (4.4) & 599 & (5.1) \\
\hline & Quebec & 530 & (3.3) & 87 & (1.5) & 535 & (4.1) & 524 & (3.7) & 11 & (4.0) & $379 \quad(6.0)$ & 414 & (5.7) & 473 & (4.8) & 590 & (3.9) & 638 & (3.3) & 663 & (4.5) \\
\hline & Saskatchewan & 502 & (2.9) & 83 & (1.7) & 506 & (3.6) & 499 & (3.4) & 7 & (4.0) & $368 \quad(5.8)$ & 397 & (5.0) & 446 & (4.1) & 561 & (4.1) & 609 & (5.4) & 634 & (6.5) \\
\hline & Italy & & & & & & & & & & & & & & & & & & & & & \\
\hline & Abruzzo & 490 & (32.4) & 73 & (4.8) & 506 & (22.9) & 479 & (42.6) & 27 & (30.2) & $372(28.0)$ & $\mid 395$ & (22.5) & 432 & $(42.1)$ & 544 & (32.9) & 585 & (33.9) & 611 & (33.7) \\
\hline & Basilicata & 467 & (9.0) & 70 & $(6.2)$ & 472 & (19.7) & 460 & (9.6) & 12 & $(26.0)$ & $347(24.1)$ & 373 & (20.0) & 413 & (12.4) & 522 & (7.5) & 556 & (7.2) & 576 & (18.7) \\
\hline & Bolzano & 519 & $(10.2)$ & 61 & (3.7) & 536 & (10.6) & 507 & (11.5) & 29 & (9.6) & $410(16.8)$ & 438 & (18.9) & 479 & (12.0) & 563 & (9.7) & 593 & (16.1) & 613 & (15.6) \\
\hline & Calabria & 449 & (12.8) & 72 & (6.1) & 456 & (18.1) & 443 & (11.6) & 13 & (12.8) & $324(29.3)$ & 356 & (19.8) & 407 & (20.6) & 493 & (9.0) & 537 & (10.9) & 562 & (9.9) \\
\hline & Campania & 456 & (12.6) & 78 & (5.4) & 461 & (15.1) & 451 & (10.9) & 9 & (7.8) & $329(16.3)$ & 354 & (18.5) & 403 & $(18.2)$ & 506 & $(12.2)$ & 564 & $(20.2)$ & 596 & (11.8) \\
\hline & Emilia Romagna & 506 & (11.3) & 86 & $(9.2)$ & 522 & (16.3) & 487 & (14.1) & 35 & (19.4) & 368 (25.7) & 403 & (13.4) & 450 & (7.6) & 563 & (18.4) & 618 & (32.0) & 656 & (30.8) \\
\hline & Friuli Venezia Giulia & 513 & (27.1) & 76 & (8.4) & 516 & (30.8) & 511 & (33.3) & 5 & $(34.7)$ & $381(25.9)$ & 414 & $(23.2)$ & 463 & (33.9) & 566 & $(30.3)$ & 602 & (23.4) & 622 & (28.0) \\
\hline & Lazio & 492 & (7.8) & 77 & (2.4) & 491 & (10.2) & 494 & (11.2) & -3 & (14.6) & 355 (23.7) & 389 & (10.7) & 437 & (6.7) & 550 & (8.7) & 588 & (9.2) & 608 & (11.4) \\
\hline & Liguria & 530 & (43.8) & 103 & (14.3) & 533 & (43.0) & 525 & (47.4) & 8 & (18.7) & $377(22.1)$ & 397 & (22.9) & 452 & (33.6) & 617 & (91.7) & 676 & (45.7) & 708 & (37.4) \\
\hline & Lombardia & 522 & (8.0) & 68 & $(4.1)$ & 526 & (10.0) & 519 & (8.4) & 7 & (9.5) & 411 (13.5) & 435 & (10.7) & 479 & (8.9) & 569 & (7.6) & 609 & (11.4) & 633 & (12.5) \\
\hline & Marche & 509 & (22.2) & 78 & (7.8) & 514 & (18.5) & 497 & (37.6) & 17 & (23.9) & 386 (40.5) & 404 & (22.3) & 454 & (27.6) & 567 & (20.8) & 607 & (31.2) & 627 & (24.0) \\
\hline & Molise & 480 & (20.0) & 73 & (7.5) & 466 & (29.0) & c & & c & c & 352 (21.4) & 372 & (24.7) & 432 & $(47.0)$ & 530 & (10.7) & 563 & (14.6) & 589 & (17.2) \\
\hline & Piemonte & 499 & (7.5) & 82 & (5.7) & 511 & (10.7) & 487 & (14.6) & 23 & (22.0) & 357 (18.0) & 389 & $(10.2)$ & 444 & (15.5) & 557 & $(8.2)$ & 603 & (12.6) & 628 & (18.8) \\
\hline & Puglia & 474 & (13.1) & 87 & (8.3) & 484 & (17.6) & 463 & (15.5) & 21 & (24.2) & $334(17.6)$ & 356 & (18.5) & 413 & (17.3) & 542 & $(18.2)$ & 589 & $(17.2)$ & 611 & (15.7) \\
\hline & Sardegna & 450 & (23.4) & 71 & (5.7) & 444 & (19.0) & c & c & c & c & 337 (21.3) & 355 & (25.5) & 393 & (28.0) & 506 & $(31.7)$ & 539 & $(26.2)$ & 556 & (19.6) \\
\hline & Sicilia & 471 & (13.4) & 70 & (5.7) & 473 & (12.2) & 468 & (17.3) & 6 & (10.7) & $349(27.5)$ & 381 & (17.9) & 424 & (18.7) & 521 & (12.4) & 560 & (11.8) & 583 & (16.1) \\
\hline & Toscana & 498 & (12.2) & 86 & (8.0) & 519 & (13.8) & 478 & (17.8) & 41 & $(25.3)$ & $354(26.3)$ & 384 & (18.1) & 438 & (17.3) & 561 & (21.6) & 615 & (16.0) & 630 & (11.6) \\
\hline & Trento & 549 & (9.7) & 76 & (7.6) & 549 & (13.2) & 550 & (7.8) & -2 & (12.1) & $414(25.7)$ & 449 & (20.3) & 496 & (13.2) & 607 & (5.8) & 635 & (11.7) & 659 & (17.4) \\
\hline & Umbria & 497 & (12.5) & 75 & (8.4) & 497 & (17.0) & 497 & (9.8) & 1 & (13.0) & $358(28.4)$ & 393 & (29.6) & 456 & $(30.2)$ & 548 & $(8.2)$ & 586 & (11.5) & 609 & (14.1) \\
\hline & Valle d'Aosta & 496 & (20.0) & 65 & (4.6) & 506 & (22.9) & 480 & (14.3) & 26 & (11.5) & 381 (29.5) & 409 & $(22.2)$ & 446 & (27.8) & 541 & (15.1) & 575 & (20.1) & 597 & (16.9) \\
\hline & Veneto & 517 & (12.0) & 89 & (6.9) & 530 & (14.8) & 502 & (16.5) & 28 & $(22.0)$ & $371(14.4)$ & 402 & (8.3) & 448 & (11.5) & 583 & $(20.5)$ & 634 & (21.6) & 661 & (19.7) \\
\hline & Portugal & & & & & & & & & & & & & & & & & & & & & \\
\hline & Alentejo & 487 & (10.0) & 85 & (4.1) & 498 & (11.9) & 476 & (9.1) & 22 & (6.8) & $\mid 339$ (12.9) & $\mid 373$ & (14.1) & 432 & (14.5) & 542 & (8.9) & $\mid 593$ & (12.8) & 624 & (13.5) \\
\hline & Spain & & & & & & & & & & & & & & & & & & & & & \\
\hline & Andalusia ${ }^{\bullet}$ & 463 & (6.8) & 77 & (2.4) & 470 & (8.9) & 456 & (5.4) & 14 & (5.8) & $337 \quad(8.3)$ & 364 & (8.6) & 412 & (7.8) & 515 & (8.3) & 562 & (9.1) & 592 & (10.8) \\
\hline & Aragon • & 486 & (20.8) & 85 & (5.9) & 491 & (20.7) & 481 & (22.7) & 10 & (10.6) & 336 (21.4) & 375 & (27.9) & 431 & (20.0) & 550 & $(26.8)$ & 603 & (28.1) & 620 & (15.4) \\
\hline & Asturias ${ }^{\bullet}$ & c & c & c & c & c & c & c & c & c & c & c & c & c & c & c & c & c & c & c & c & c \\
\hline & Balearic Islands & $\mathrm{c}$ & c & c & c & c & c & c & c & c & c & c & c & c & c & c & c & c & c & c & c & c \\
\hline & Basque Country ${ }^{\bullet}$ & 498 & (2.6) & 78 & (1.5) & 504 & (3.1) & 492 & (3.0) & 12 & (3.1) & $363 \quad(5.5)$ & 397 & (3.8) & 448 & (3.0) & 552 & (2.9) & 595 & (2.5) & 618 & (3.5) \\
\hline & Cantabria • & $\mathrm{c}$ & c & c & c & c & c & c & c & c & c & $\mathrm{c}$ & c & c & c & c & c & c & c & c & c & c \\
\hline & Castile and Leon • & 505 & (7.8) & 75 & (4.3) & 506 & (9.7) & 504 & (7.4) & 1 & (7.1) & $372(17.7)$ & 400 & $(12.2)$ & 458 & (11.0) & 558 & (9.5) & 600 & (12.3) & 621 & (14.6) \\
\hline & Catalonia ${ }^{\bullet}$ & 488 & (5.2) & 75 & (2.3) & 497 & (6.3) & 478 & (5.4) & 19 & (5.5) & $363 \quad(7.9)$ & 387 & $(7.3)$ & 436 & (6.6) & 540 & (5.3) & 585 & $(7.7)$ & 610 & (7.0) \\
\hline & Extremadura ${ }^{\bullet}$ & 477 & (2.4) & 80 & (8.3) & 479 & (6.7) & 476 & (5.3) & 4 & (11.1) & 341 (19.4) & 367 & (23.2) & 424 & (11.0) & 533 & $(11.7)$ & 582 & (13.5) & 603 & (11.7) \\
\hline & Galicia• & 480 & (18.4) & 81 & (5.3) & 472 & (16.9) & 487 & (20.8) & -15 & (11.4) & $334(31.2)$ & 367 & (28.1) & 426 & (28.3) & 540 & $(12.3)$ & 576 & $(12.2)$ & 594 & (12.8) \\
\hline & La Rioja• & c & c & $\mathrm{c}$ & c & c & c & c & c & c & C & c & c & c & c & c & c & c & c & c & c & c \\
\hline & Madrid ${ }^{\bullet}$ & 495 & (7.6) & 77 & (3.8) & 502 & (8.7) & 488 & (8.0) & 14 & (6.8) & 361 (14.4) & 391 & (12.0) & 444 & (9.1) & 551 & (7.8) & 591 & (7.8) & 612 & (7.2) \\
\hline & Murcia• & 456 & $(7.2)$ & 77 & (3.1) & 465 & (10.9) & 445 & (9.4) & 21 & (13.9) & $328(16.9)$ & 355 & (12.9) & 395 & (12.2) & 515 & $(12.4)$ & 557 & (10.8) & 578 & (11.8) \\
\hline & Navarre ${ }^{\bullet}$ & $\mathrm{c}$ & $\mathrm{c}$ & $\mathrm{C}$ & c & $\mathrm{c}$ & $\mathrm{c}$ & $\mathrm{c}$ & $\mathrm{c}$ & $\mathrm{c}$ & $\mathrm{c}$ & c & $\mathrm{c}$ & $\mathrm{c}$ & $\mathrm{C}$ & $\mathrm{c}$ & $\mathrm{C}$ & $\mathrm{c}$ & $\mathrm{C}$ & C & c & C \\
\hline
\end{tabular}

- PISA adjudicated region.

Notes: Values that are statistically significant are indicated in bold (see Annex A3).

See Table B3.I.6 for national data.

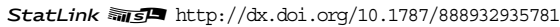


[Part 2/2]

Mean score, variation and gender differences in student performance on the combined Table B3.I.18 mathematics scale, by region

\begin{tabular}{|c|c|c|c|c|c|c|c|c|c|c|c|c|c|c|c|c|c|c|c|c|c|c|c|}
\hline & & \multicolumn{4}{|c|}{ All students } & \multicolumn{6}{|c|}{ Gender differences } & \multicolumn{12}{|c|}{ Percentiles } \\
\hline & & \multicolumn{2}{|c|}{ Mean score } & \multicolumn{2}{|c|}{$\begin{array}{l}\text { Standard } \\
\text { deviation }\end{array}$} & \multicolumn{2}{|c|}{ Boys } & \multicolumn{2}{|c|}{ Girls } & \multicolumn{2}{|c|}{$\begin{array}{c}\text { Difference } \\
\text { (B - G) }\end{array}$} & \multicolumn{2}{|c|}{5 th } & \multicolumn{2}{|c|}{ 10th } & \multicolumn{2}{|c|}{ 25th } & \multicolumn{2}{|c|}{ 75th } & \multicolumn{2}{|c|}{ 90th } & \multicolumn{2}{|c|}{ 95th } \\
\hline & & Mean & S.E. & S.D. & S.E. & $\begin{array}{l}\text { Mean } \\
\text { score }\end{array}$ & S.E. & $\begin{array}{l}\text { Mean } \\
\text { score }\end{array}$ & S.E. & \begin{tabular}{|c}
$\begin{array}{c}\text { Score } \\
\text { dif. }\end{array}$ \\
\end{tabular} & S.E. & Score & S.E. & Score & S.E. & Score & S.E. & Score & S.E. & Score & e S.E. & Score & e S.E. \\
\hline \multirow{41}{*}{ 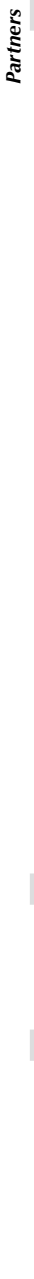 } & Brazil & & & & & & & & & & & & & & & & & & & & & & \\
\hline & Acre & 410 & (5.9) & 53 & (3.1) & 421 & (6.4) & 403 & (8.6) & 18 & (10.8) & 322 & (17.8) & 345 & (12.9) & 376 & $(7.9)$ & 445 & (11.8) & 472 & (19.0) & 496 & $(16.4)$ \\
\hline & Alagoas & 364 & $(18.7)$ & 77 & (9.5) & 363 & (19.9) & 365 & (20.3) & -2 & $(15.1)$ & 261 & (48.6) & 283 & $(22.2)$ & 309 & (18.6) & 407 & $(22.3)$ & 471 & $(18.4)$ & 513 & $(30.9)$ \\
\hline & Amapá & 398 & (9.4) & 52 & (7.1) & 412 & (8.5) & 386 & (10.9) & 26 & (7.9) & 325 & (12.6) & 335 & (8.5) & 360 & $(8.0)$ & 433 & $(14.4)$ & 471 & $(25.7)$ & 495 & $(33.5)$ \\
\hline & Amazonas & 361 & (15.4) & 56 & (18.7) & 360 & (18.6) & 362 & (13.3) & -1 & $(12.2)$ & 295 & (20.0) & 306 & (15.8) & 327 & (8.6) & 379 & (22.5) & 423 & $(80.9)$ & ) 459 & $(94.3)$ \\
\hline & Bahia & 368 & (13.6) & 90 & (12.8) & 386 & (19.4) & 353 & (12.5) & 33 & (11.8) & 236 & (39.6) & 265 & (28.1) & 308 & $(17.7)$ & 421 & $(26.3)$ & 489 & $(21.7)$ & 525 & $(39.5)$ \\
\hline & Ceará & 398 & $(27.0)$ & 94 & (12.5) & 415 & $(24.7)$ & 378 & $(28.2)$ & 37 & $(10.2)$ & 268 & (15.2) & 288 & (15.4) & 331 & (16.4) & 460 & $(50.1)$ & 539 & $(45.8)$ & 584 & $(48.8)$ \\
\hline & Espírito Santo & 439 & (10.1) & 71 & (8.5) & 441 & (7.1) & 437 & (16.3) & 4 & $(14.2)$ & 328 & (11.1) & 351 & (14.3) & 390 & (15.6) & 482 & (16.3) & 531 & (31.3) & 564 & $(42.4)$ \\
\hline & Federal District & c & & C & C & C & & C & c & $\mathrm{C}$ & $\mathrm{c}$ & C & C & C & C & C & c & c & c & c & c & c & c \\
\hline & Goiás & 392 & (11.8) & 72 & $(7.2)$ & 406 & (10.4) & 380 & (14.2) & 26 & $(10.7)$ & 287 & (30.5) & 312 & $(17.7)$ & 346 & $(19.1)$ & 433 & (10.4) & 489 & $(23.3)$ & 531 & (16.5) \\
\hline & Maranhão & 343 & $(21.1)$ & 77 & (15.9) & 354 & (25.5) & 334 & (18.2) & 20 & (10.3) & 225 & (42.4) & 250 & $(34.1)$ & 296 & $(24.0)$ & 382 & $(26.7)$ & 440 & $(45.4)$ & 498 & $(67.1)$ \\
\hline & Mato Grosso & c & & c & & c & & $\mathrm{c}$ & & c & & C & & c & & c & c & c & & c & c & c & c \\
\hline & Mato Grosso do Sul & 441 & $(10.1)$ & 71 & (2.8) & 454 & (14.5) & 429 & (8.8) & 26 & $(13.2)$ & 342 & (12.3) & 355 & (7.4) & 386 & $(15.1)$ & 486 & $(15.0)$ & 551 & (18.5) & 571 & (10.5) \\
\hline & Minas Gerais & 425 & (15.5) & 73 & (8.0) & 434 & (18.6) & 416 & (13.4) & 18 & (7.7) & 312 & $(11.0)$ & 333 & $(11.2)$ & 375 & $(12.4)$ & 471 & (22.8) & 522 & (29.7) & 550 & $(32.1)$ \\
\hline & Pará & 368 & (16.0) & 71 & (9.1) & 370 & (20.7) & 366 & (16.3) & 3 & (16.5) & 259 & (39.3) & 283 & (20.6) & 317 & $(15.7)$ & 420 & (23.8) & 466 & $(23.7)$ & 490 & $(20.2)$ \\
\hline & Paraíba & c & & C & & C & & C & & c & & C & C & c & & c & c & c & c & c & c & c & c \\
\hline & Paraná & 410 & (11.2) & 75 & (11.2) & 418 & (11.8) & 401 & (12.6) & 17 & (8.5) & 308 & (9.6) & 325 & (12.0) & 358 & $(9.8)$ & 451 & $(14.7)$ & 516 & (37.4) & 560 & $(37.8)$ \\
\hline & Pernambuco & 399 & (11.2) & 61 & (5.0) & 410 & (13.8) & 389 & (11.5) & 21 & (9.3) & 300 & (19.2) & 325 & (16.9) & 361 & (11.8) & 437 & (12.5) & 484 & (21.1) & ) 505 & $(24.7)$ \\
\hline & Piauí & c & & C & C & c & c & C & & C & C & C & c & C & C & C & c & C & C & C & c & c & c \\
\hline & Rio de Janeiro & 416 & (10.5) & 73 & (11.6) & 430 & (10.0) & 404 & (12.5) & 25 & (6.1) & 302 & (15.2) & 322 & (12.7) & 364 & (20.4) & 467 & (15.3) & 514 & (29.1) & ) 541 & (30.3) \\
\hline & Rio Grand & c & & C & C & C & & C & C & c & C & C & c & C & C & C & c & c & c & C & c & c & c \\
\hline & Rio Grande do Sul & 431 & (9.1) & 60 & (3.4) & 445 & (10.6) & 418 & (9.8) & 27 & (6.9) & 336 & (12.9) & 353 & (8.8) & 386 & $(12.3)$ & 473 & (12.6) & 509 & (13.4) & 535 & $(16.1)$ \\
\hline & Rondônia & 391 & (4.7) & 61 & (4.4) & 418 & (8.4) & 369 & (6.5) & 48 & (12.4) & 294 & $(22.3)$ & 315 & (26.5) & 355 & $(15.0)$ & 427 & (9.9) & 471 & (17.8) & 501 & $(17.9)$ \\
\hline & Roraima & 403 & (6.3) & 59 & (2.1) & 418 & (9.3) & 391 & (10.4) & 27 & (16.6) & 322 & (21.3) & 334 & (11.5) & 361 & (7.6) & 437 & (17.0) & 487 & $(17.3)$ & ) 515 & $(15.2)$ \\
\hline & Santa Catarina & 418 & (23.6) & 80 & (18.4) & 422 & $(24.7)$ & 413 & (23.0) & 9 & (8.3) & 261 & (50.4) & 286 & $(88.0)$ & 377 & $(44.4)$ & 473 & (17.6) & 515 & (18.6) & 540 & $(12.4)$ \\
\hline & São Paulo & 418 & (6.3) & 76 & (4.5) & 428 & (6.6) & 409 & (7.0) & 19 & (4.5) & 304 & (5.6) & 325 & (7.0) & 365 & $(6.7)$ & 464 & (8.0) & 521 & (14.3) & 558 & $(17.0)$ \\
\hline & Sergipe & 411 & (4.3) & 61 & (2.5) & 426 & (9.7) & 400 & (8.6) & 27 & (16.0) & 325 & (12.0) & 343 & (8.5) & 368 & $(7.3)$ & 447 & (13.4) & 496 & $(17.2)$ & 524 & $(19.1)$ \\
\hline & Tocantins & 393 & $(18.2)$ & 64 & (3.5) & 404 & $(40.6)$ & 383 & $(7.5)$ & 21 & (44.5) & 289 & (26.4) & 315 & $(22.5)$ & 349 & $(23.0)$ & 426 & $(18.4)$ & 481 & (50.6) & ) 522 & $(34.5)$ \\
\hline & Colombia & & & & & & & & & & & & & & & & & & & & & & \\
\hline & Bogota & 401 & (3.6) & 64 & (2.9) & 417 & (5.6) & 388 & (3.3) & 29 & (5.7) & 300 & (7.1) & 321 & (3.5) & 358 & (3.5) & 443 & (3.8) & 481 & (6.2) & 504 & (8.9) \\
\hline & Cali & 388 & (6.8) & 68 & (2.9) & 397 & (7.1) & 381 & (7.3) & 16 & (4.6) & 280 & (7.2) & 302 & (6.8) & 341 & (7.5) & 433 & (9.4) & 480 & (9.6) & 504 & $\quad(9.4)$ \\
\hline & Manizales & 407 & (3.9) & 63 & (4.0) & 420 & (6.8) & 396 & (2.8) & 24 & (6.7) & 312 & (5.4) & 331 & (3.9) & 363 & (4.5) & 446 & (6.2) & 493 & (9.3) & 520 & $(12.0)$ \\
\hline & Medellin & 403 & (7.3) & 78 & (5.3) & 413 & (7.8) & 393 & (9.4) & 20 & (9.0) & 289 & $(7.2)$ & 312 & (6.3) & ) 348 & (5.8) & 450 & (10.3) & 505 & (15.0) & )) 544 & $(23.5)$ \\
\hline & United $A$ & & & & & & & & & & & & & & & & & & & & & & \\
\hline & Abu Dhabi` & 422 & $(4.0)$ & 82 & (2.6) & 414 & (5.4) & 430 & (4.7) & -16 & (6.5) & 297 & (5.8) & 321 & (4.2) & 363 & (3.8) & 477 & (5.4) & 532 & (7.0) & ) 567 & $(9.0)$ \\
\hline & Ajman & 396 & (7.4) & 67 & (3.0) & 377 & (8.3) & 414 & (11.5) & -37 & (14.5) & 291 & (12.6) & 310 & (10.1) & 346 & $(8.8)$ & 443 & (7.9) & 483 & (7.7) & ) 508 & $(10.0)$ \\
\hline & Dubai ${ }^{\bullet}$ & 462 & (1.1) & 88 & (1.0) & 464 & (1.8) & 460 & (1.4) & 4 & (2.4) & 319 & (2.1) & 348 & (2.2) & 399 & (1.7) & 524 & (2.5) & 578 & (2.8) & 609 & $(4.2)$ \\
\hline & Fujairah & 418 & (8.1) & 73 & (2.4) & 403 & (6.6) & 434 & (9.3) & -32 & (8.9) & 300 & (9.5) & 325 & (8.0) & 365 & (9.3) & 469 & (8.8) & 511 & (8.0) & 539 & (14.1) \\
\hline & Ras Al Khaimah & 415 & (6.0) & 68 & (3.5) & 402 & (8.8) & 428 & (8.8) & -26 & (12.0) & 305 & (10.6) & 329 & (9.4) & 367 & $(8.3)$ & 462 & (7.1) & 506 & (6.8) & 530 & $(9.4)$ \\
\hline & Sharjah & 441 & (6.9) & 71 & (3.2) & 443 & (14.0) & 439 & (7.5) & 5 & (17.0) & 330 & (9.2) & 350 & (7.1) & 392 & (6.5) & 489 & (8.0) & 536 & $(13.1)$ & ) 563 & (8.9) \\
\hline & Umm Al Quwain & 393 & (3.5) & 68 & (3.2) & 377 & (4.7) & 409 & (4.5) & -33 & (6.1) & 285 & (8.2) & 309 & (7.6) & 347 & (6.0) & ) 436 & (7.0) & 482 & (7.8) & 511 & (12.8) \\
\hline
\end{tabular}

- PISA adjudicated region.

Notes: Values that are statistically significant are indicated in bold (see Annex A3).

See Table B3.I.6 for national data.

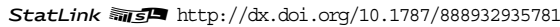


[Part 1/2] Table B3.I.19 Percentage of students at each proficiency level on the digital reading scale, by region

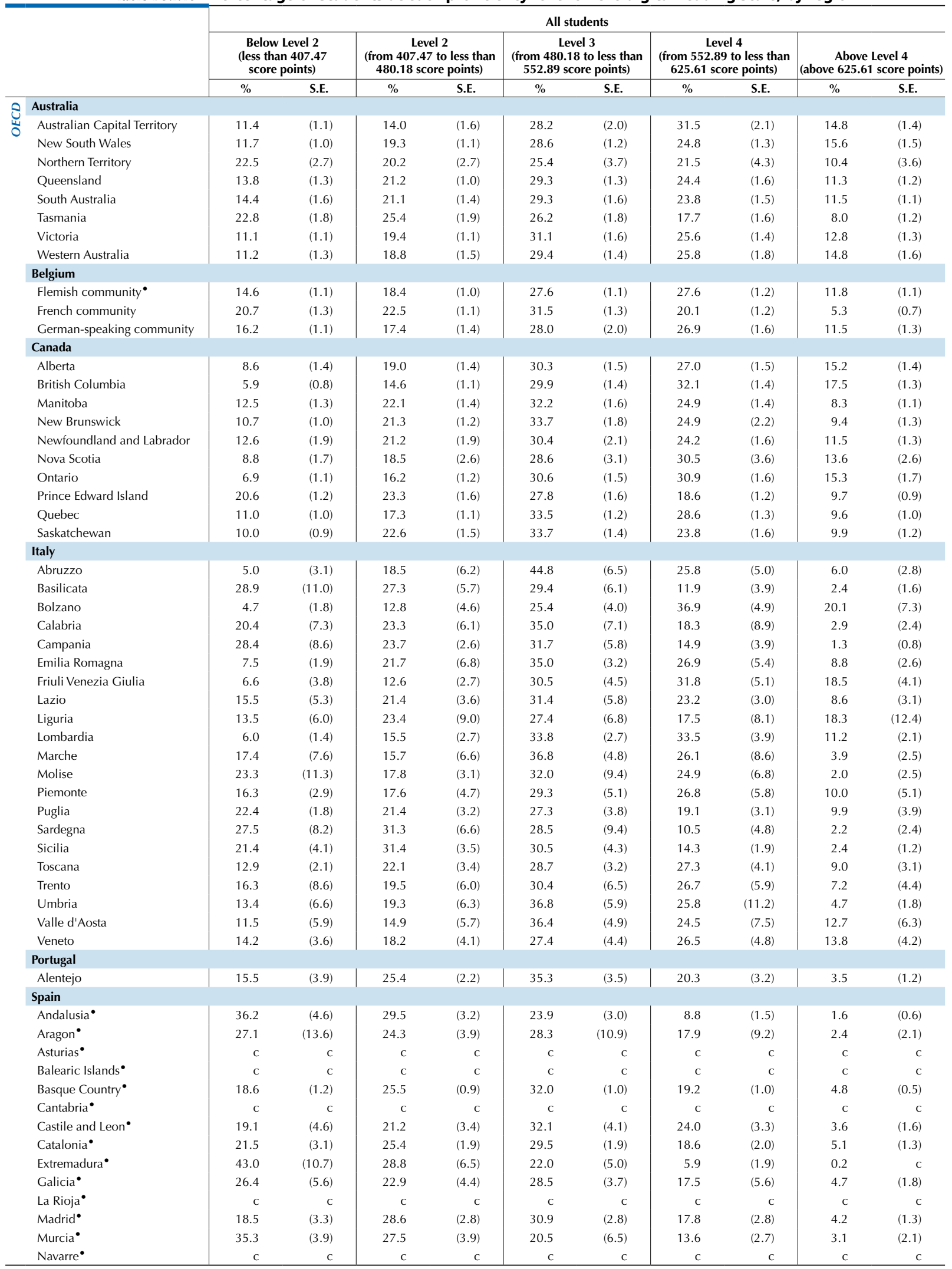

- PISA adjudicated region.

Note: See Table B3.I.7 for national data.

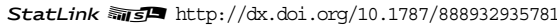


Table B3.I.19 Percentage of students at each proficiency level on the digital reading scale, by region

\begin{tabular}{|c|c|c|c|c|c|c|c|c|c|c|c|}
\hline & & \multicolumn{10}{|c|}{ All students } \\
\hline & & \multicolumn{2}{|c|}{$\begin{array}{l}\text { Below Level } 2 \\
\text { (less than } 407.47 \\
\text { score points) }\end{array}$} & \multicolumn{2}{|c|}{$\begin{array}{c}\text { Level } 2 \\
\text { (from } 407.47 \text { to less than } \\
480.18 \text { score points) }\end{array}$} & \multicolumn{2}{|c|}{$\begin{array}{c}\text { Level } 3 \\
\text { (from } 480.18 \text { to less than } \\
552.89 \text { score points) }\end{array}$} & \multicolumn{2}{|c|}{$\begin{array}{c}\text { Level } 4 \\
\text { (from } 552.89 \text { to less than } \\
625.61 \text { score points) }\end{array}$} & \multicolumn{2}{|c|}{$\begin{array}{c}\text { Above Level } 4 \\
\text { (above } 625.61 \text { score points) }\end{array}$} \\
\hline & & $\%$ & S.E. & $\%$ & S.E. & $\%$ & S.E. & $\%$ & S.E. & $\%$ & S.E. \\
\hline \multirow{41}{*}{ 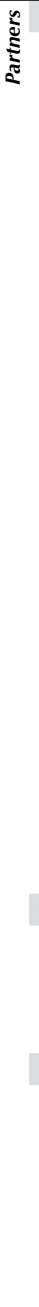 } & Brazil & & & & & & & & & & \\
\hline & Acre & 21.3 & $(4.7)$ & 40.2 & (8.7) & 29.8 & (7.6) & 8.1 & (4.9) & 0.7 & (1.3) \\
\hline & Alagoas & 76.2 & (7.0) & 14.0 & $(7.7)$ & 7.8 & (1.6) & 2.0 & $(0.5)$ & 0.1 & c \\
\hline & Amapá & 22.6 & (7.3) & 40.0 & (6.4) & 29.6 & (6.4) & 7.7 & (3.4) & 0.1 & c \\
\hline & Amazonas & 82.3 & $(10.5)$ & 11.4 & (5.4) & 5.3 & (5.8) & 1.0 & (1.4) & 0.0 & $\mathrm{C}$ \\
\hline & Bahia & 51.6 & (8.9) & 23.7 & (7.5) & 16.2 & (5.7) & 6.6 & (4.4) & 1.9 & (1.9) \\
\hline & Ceará & 52.0 & $(19.7)$ & 24.0 & (8.8) & 14.5 & (6.9) & 8.0 & (4.9) & 1.5 & (1.6) \\
\hline & Espírito Santo & 22.5 & (5.8) & 34.3 & (6.9) & 30.8 & (6.2) & 8.7 & (3.3) & 3.8 & (3.4) \\
\hline & Federal District & c & c & c & c & c & c & C & c & c & c \\
\hline & Goiás & 34.0 & (4.1) & 35.2 & (4.9) & 23.6 & $(4.2)$ & 6.7 & (1.6) & 0.5 & c \\
\hline & Maranhão & 69.8 & (13.6) & 18.8 & (11.7) & 9.2 & (5.6) & 2.0 & (2.4) & 0.2 & c \\
\hline & Mato Grosso & c & c & c & c & c & c & c & c & c & c \\
\hline & Mato Grosso do Sul & 25.6 & $(11.3)$ & 32.5 & (7.1) & 28.8 & (7.0) & 12.2 & (1.9) & 0.9 & (1.0) \\
\hline & Minas Gerais & 33.5 & (6.7) & 33.8 & $(4.7)$ & 23.3 & (4.4) & 8.3 & (5.0) & 1.0 & $(0.9)$ \\
\hline & Pará & 54.7 & $(11.2)$ & 22.8 & (6.7) & 13.1 & (5.1) & 7.2 & (5.9) & 2.2 & $(2.1)$ \\
\hline & Paraíba & c & c & c & c & c & c & c & c & c & c \\
\hline & Paraná & 33.1 & (5.9) & 31.1 & (3.9) & 24.1 & (3.6) & 9.5 & (3.1) & 2.2 & (1.1) \\
\hline & Pernambuco & 38.9 & (8.0) & 34.8 & (5.0) & 20.3 & (5.8) & 5.7 & (4.5) & 0.3 & c \\
\hline & Piauí & c & c & c & c & c & c & c & c & c & c \\
\hline & Rio de Janeiro & 27.4 & (5.5) & 29.1 & (5.6) & 30.2 & $(4.7)$ & 12.0 & (3.2) & 1.2 & c \\
\hline & Rio Grande do Norte & c & c & c & c & c & c & c & c & c & c \\
\hline & Rio Grande do Sul & 28.6 & (4.6) & 35.8 & (6.8) & 25.0 & (6.3) & 8.1 & (4.3) & 2.6 & $(2.1)$ \\
\hline & Rondônia & 57.9 & $(11.2)$ & 30.4 & (4.0) & 8.4 & (8.7) & 3.1 & (4.6) & 0.1 & c \\
\hline & Roraima & 42.7 & (5.8) & 39.7 & $(8.2)$ & 12.6 & $(4.1)$ & 4.2 & $(2.2)$ & 0.7 & $(0.7)$ \\
\hline & Santa Catarina & 44.6 & $(14.6)$ & 29.0 & (9.7) & 19.9 & (9.8) & 5.6 & (4.0) & 0.9 & $(0.8)$ \\
\hline & São Paulo & 27.9 & (3.0) & 32.9 & (2.0) & 27.5 & (2.5) & 10.3 & (2.0) & 1.4 & $(0.7)$ \\
\hline & Sergipe & 48.5 & (8.8) & 30.6 & (8.7) & 16.5 & (3.3) & 3.4 & (1.2) & 1.0 & $(1.2)$ \\
\hline & Tocantins & 62.1 & (10.5) & 29.8 & (9.7) & 6.9 & (3.1) & 1.1 & (1.3) & 0.1 & $(0.1)$ \\
\hline & \multicolumn{11}{|l|}{ Colombia } \\
\hline & Bogota & 45.0 & $(4.2)$ & 35.2 & (2.4) & 15.4 & $(2.1)$ & 3.8 & (1.1) & 0.6 & $(0.4)$ \\
\hline & Cali & 46.2 & (4.4) & 28.1 & (2.6) & 18.9 & (2.9) & 6.2 & (1.7) & 0.5 & $(0.3)$ \\
\hline & Manizales & 44.3 & (3.1) & 33.2 & (3.1) & 18.3 & (2.0) & 3.9 & (1.0) & 0.3 & $(0.2)$ \\
\hline & Medellin & 42.4 & (3.6) & 29.3 & (2.0) & 19.7 & $(2.2)$ & 7.3 & (1.5) & 1.3 & $(0.5)$ \\
\hline & \multicolumn{11}{|l|}{ United Arab Emirates } \\
\hline & Abu Dhabi` & 57.7 & (2.4) & 23.6 & (1.4) & 13.0 & $(1.2)$ & 4.5 & $(0.8)$ & 1.1 & $(0.5)$ \\
\hline & Ajman & 68.3 & (3.8) & 19.8 & (2.6) & 10.1 & (1.9) & 1.7 & $(0.7)$ & 0.1 & c \\
\hline & Dubai $\bullet$ & 33.3 & $(0.8)$ & 24.3 & (1.3) & 21.7 & $(0.9)$ & 14.8 & $(0.8)$ & 5.8 & $(0.4)$ \\
\hline & Fujairah & 66.1 & (4.1) & 23.0 & $(2.1)$ & 8.8 & (2.3) & 1.9 & $(0.9)$ & 0.2 & $(0.2)$ \\
\hline & Ras Al Khaimah & 68.8 & (3.0) & 23.6 & (2.3) & 6.2 & (1.5) & 1.2 & $(0.5)$ & 0.2 & $(0.2)$ \\
\hline & Sharjah & 44.4 & (4.8) & 27.1 & (2.3) & 19.3 & (3.1) & 7.4 & (1.8) & 1.9 & (1.0) \\
\hline & Umm Al Quwain & 69.6 & $(2.0)$ & 19.7 & (1.9) & 8.6 & (1.6) & 1.6 & (0.6) & 0.4 & $(0.5)$ \\
\hline
\end{tabular}

- PISA adjudicated region.

Note: See Table B3.I.7 for national data.

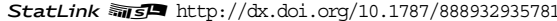


[Part 1/4]

Table B3.I.20 Percentage of students at each proficiency level on the digital reading scale, by gender and region

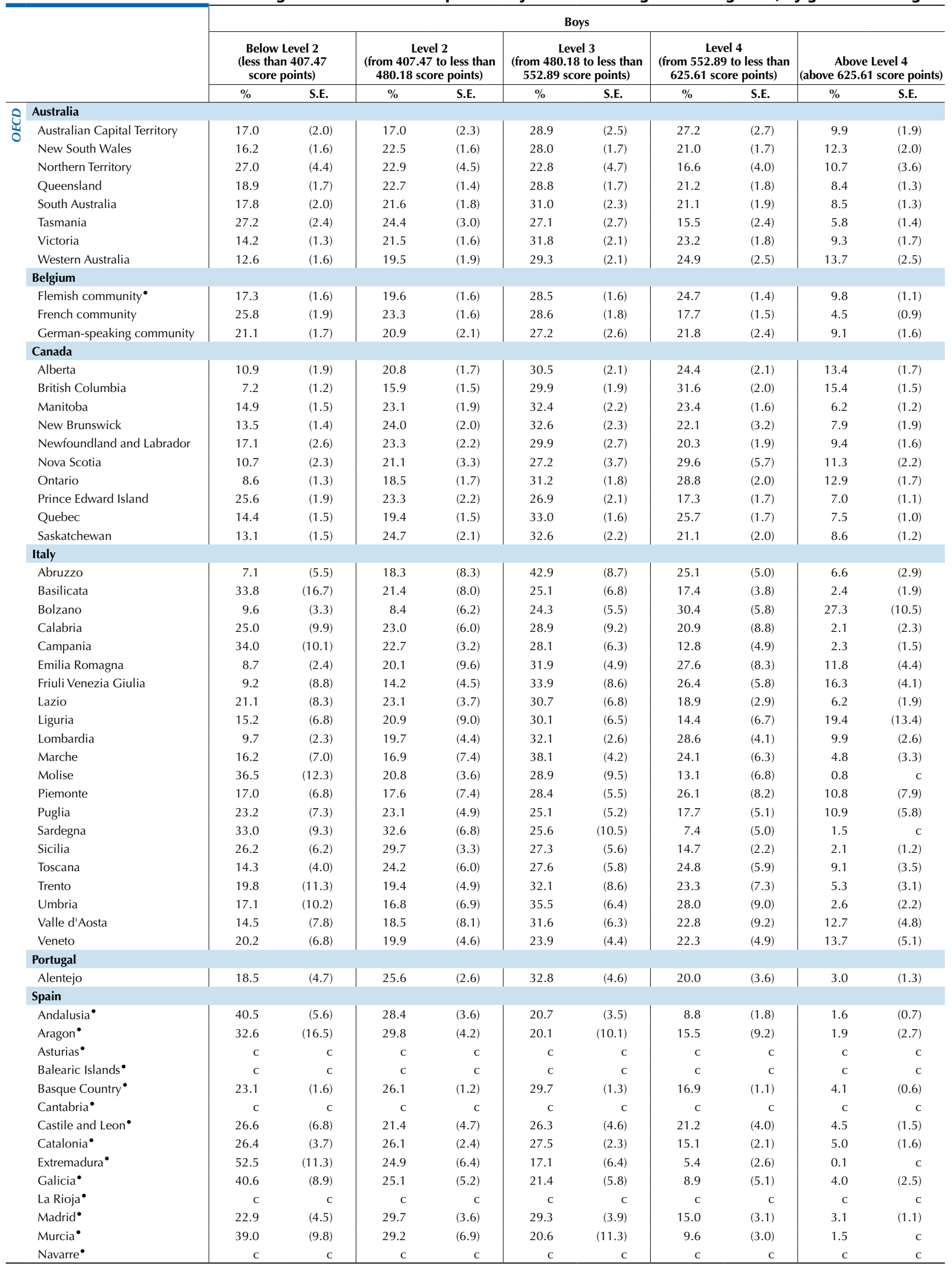

- PISA adjudicated region.

Note: See Table B3.I.8 for national data.

StatLink 部 
[Part 2/4]

Table B3.I.20 Percentage of students at each proficiency level on the digital reading scale, by gender and region

\begin{tabular}{|c|c|c|c|c|c|c|c|c|c|c|c|}
\hline & & \multicolumn{10}{|c|}{ Boys } \\
\hline & & \multicolumn{2}{|c|}{$\begin{array}{l}\text { Below Level } 2 \\
\text { (less than 407.47 } \\
\text { score points) }\end{array}$} & \multicolumn{2}{|c|}{$\begin{array}{c}\text { Level } 2 \\
\text { (from } 407.47 \text { to less than } \\
480.18 \text { score points) }\end{array}$} & \multicolumn{2}{|c|}{$\begin{array}{c}\text { Level } 3 \\
\text { (from } 480.18 \text { to less than } \\
552.89 \text { score points) }\end{array}$} & \multicolumn{2}{|c|}{$\begin{array}{c}\text { Level } 4 \\
\text { (from } 552.89 \text { to less than } \\
625.61 \text { score points) }\end{array}$} & \multicolumn{2}{|c|}{$\begin{array}{c}\text { Above Level } 4 \\
\text { (above } 625.61 \text { score points) }\end{array}$} \\
\hline & & $\%$ & S.E. & $\%$ & S.E. & $\%$ & S.E. & $\%$ & S.E. & $\%$ & S.E. \\
\hline \multirow{41}{*}{ 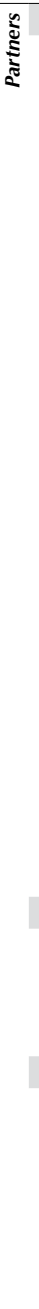 } & Brazil & & & & & & & & & & \\
\hline & Acre & 25.9 & (8.4) & 46.6 & (8.7) & 23.5 & (11.1) & 3.8 & (3.8) & 0.2 & c \\
\hline & Alagoas & 84.1 & (6.3) & 10.4 & (5.8) & 4.7 & (1.5) & 0.8 & $\mathrm{c}$ & 0.0 & c \\
\hline & Amapá & 31.8 & (7.6) & 43.6 & (9.3) & 23.6 & (8.1) & 1.0 & c & 0.0 & c \\
\hline & Amazonas & 84.1 & $(10.7)$ & 11.4 & (6.8) & 4.2 & (5.8) & 0.3 & c & 0.0 & c \\
\hline & Bahia & 53.0 & (7.8) & 22.0 & (7.4) & 15.0 & (6.5) & 8.0 & (5.6) & 2.1 & (2.3) \\
\hline & Ceará & 49.1 & (19.9) & 23.5 & $(9.2)$ & 16.8 & (7.5) & 9.0 & $(5.5)$ & 1.6 & c \\
\hline & Espírito Santo & 28.5 & (5.8) & 39.1 & (6.6) & 25.8 & (6.2) & 4.3 & $(2.2)$ & 2.2 & (1.6) \\
\hline & Federal District & c & c & c & c & c & c & c & c & c & c \\
\hline & Goiás & 32.3 & (4.4) & 37.5 & (7.8) & 22.5 & (6.8) & 7.2 & (2.8) & 0.6 & c \\
\hline & Maranhão & 83.1 & (9.1) & 6.1 & (4.3) & 7.8 & (4.6) & 2.7 & (3.8) & 0.3 & c \\
\hline & Mato Grosso & c & c & c & c & c & c & c & c & c & c \\
\hline & Mato Grosso do Sul & 23.4 & $(14.8)$ & 34.7 & (13.1) & 28.7 & (9.0) & 12.3 & $(3.1)$ & 1.0 & c \\
\hline & Minas Gerais & 38.8 & (8.5) & 32.7 & (6.9) & 19.6 & (5.6) & 8.2 & $(5.4)$ & 0.7 & c \\
\hline & Pará & 60.8 & $(16.1)$ & 23.4 & $(11.0)$ & 10.5 & (6.3) & 5.3 & $(5.4)$ & 0.0 & c \\
\hline & Paraíba & c & c & c & c & c & c & c & c & c & c \\
\hline & Paraná & 41.9 & (8.0) & 28.7 & (6.8) & 19.2 & $(4.2)$ & 8.6 & $(3.2)$ & 1.6 & $(0.8)$ \\
\hline & Pernambuco & 50.2 & $(10.2)$ & 29.9 & $(10.2)$ & 16.1 & $(6.2)$ & 3.8 & $(4.0)$ & 0.0 & c \\
\hline & Piauí & c & c & c & c & c & c & c & c & c & c \\
\hline & Rio de Janeiro & 31.4 & $(6.2)$ & 29.5 & (7.7) & 29.1 & (6.1) & 9.1 & (3.8) & 0.9 & c \\
\hline & Rio Grande do Norte & c & c & c & c & c & c & c & c & c & c \\
\hline & Rio Grande do Sul & 35.4 & (6.1) & 30.8 & (8.4) & 23.9 & $(7.2)$ & 8.1 & $(5.5)$ & 1.7 & (1.5) \\
\hline & Rondônia & 48.5 & (5.8) & 36.9 & (8.4) & 11.2 & (7.1) & 3.1 & (3.8) & 0.3 & c \\
\hline & Roraima & 44.5 & $(10.2)$ & 39.1 & $(10.3)$ & 13.9 & (4.3) & 2.3 & $(1.2)$ & 0.3 & c \\
\hline & Santa Catarina & 55.5 & $(14.2)$ & 24.9 & $(8.2)$ & 16.6 & (10.4) & 3.0 & (3.0) & 0.0 & c \\
\hline & São Paulo & 32.2 & (3.7) & 33.1 & (3.0) & 24.6 & $(2.7)$ & 8.7 & $(2.4)$ & 1.4 & (1.1) \\
\hline & Sergipe & 55.1 & (11.5) & 21.8 & (11.6) & 17.5 & (6.8) & 3.6 & $(2.3)$ & 2.0 & (2.5) \\
\hline & Tocantins & 64.9 & (17.4) & 24.8 & $(11.1)$ & 8.7 & (7.0) & 1.6 & $(2.6)$ & 0.0 & c \\
\hline & \multicolumn{11}{|l|}{ Colombia } \\
\hline & Bogota & 47.1 & (4.8) & 33.2 & (3.5) & 14.8 & (2.7) & 4.0 & (1.5) & 1.0 & $(0.8)$ \\
\hline & Cali & 52.2 & (4.0) & 28.9 & (3.3) & 14.8 & (2.7) & 4.0 & (1.4) & 0.2 & c \\
\hline & Manizales & 46.3 & (3.4) & 30.9 & (3.4) & 18.0 & (2.3) & 4.5 & $(1.1)$ & 0.3 & $(0.3)$ \\
\hline & Medellin & 45.9 & (4.3) & 28.5 & (3.2) & 18.4 & (2.6) & 6.6 & (1.6) & 0.6 & $(0.4)$ \\
\hline & \multicolumn{11}{|l|}{ United Arab Emirates } \\
\hline & Abu Dhabi` & 68.8 & (3.1) & 17.3 & (1.9) & 9.2 & (1.3) & 3.6 & $(1.0)$ & 1.0 & (0.6) \\
\hline & Ajman & 82.6 & (3.0) & 13.5 & $(2.7)$ & 3.6 & (1.8) & 0.4 & c & 0.0 & c \\
\hline & Dubai $\bullet$ & 40.0 & $(0.9)$ & 23.4 & (1.3) & 18.7 & $(1.1)$ & 12.4 & $(0.9)$ & 5.4 & (0.6) \\
\hline & Fujairah & 80.0 & (3.5) & 14.4 & (3.0) & 4.3 & (1.4) & 1.0 & $(0.8)$ & 0.3 & $(0.3)$ \\
\hline & Ras Al Khaimah & 73.9 & (3.3) & 21.1 & (3.3) & 4.2 & (1.4) & 0.6 & $(0.4)$ & 0.2 & $(0.1)$ \\
\hline & Sharjah & 54.9 & (8.5) & 24.1 & $(4.2)$ & 13.4 & (4.3) & 6.0 & $(3.0)$ & 1.6 & (1.6) \\
\hline & Umm Al Quwain & 91.6 & (1.7) & 5.9 & (1.8) & 2.0 & (1.0) & 0.5 & c & 0.0 & c \\
\hline
\end{tabular}

- PISA adjudicated region.

Note: See Table B3.I.8 for national data.

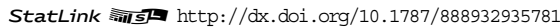


[Part 3/4]

Table B3.I.20 Percentage of students at each proficiency level on the digital reading scale, by gender and region

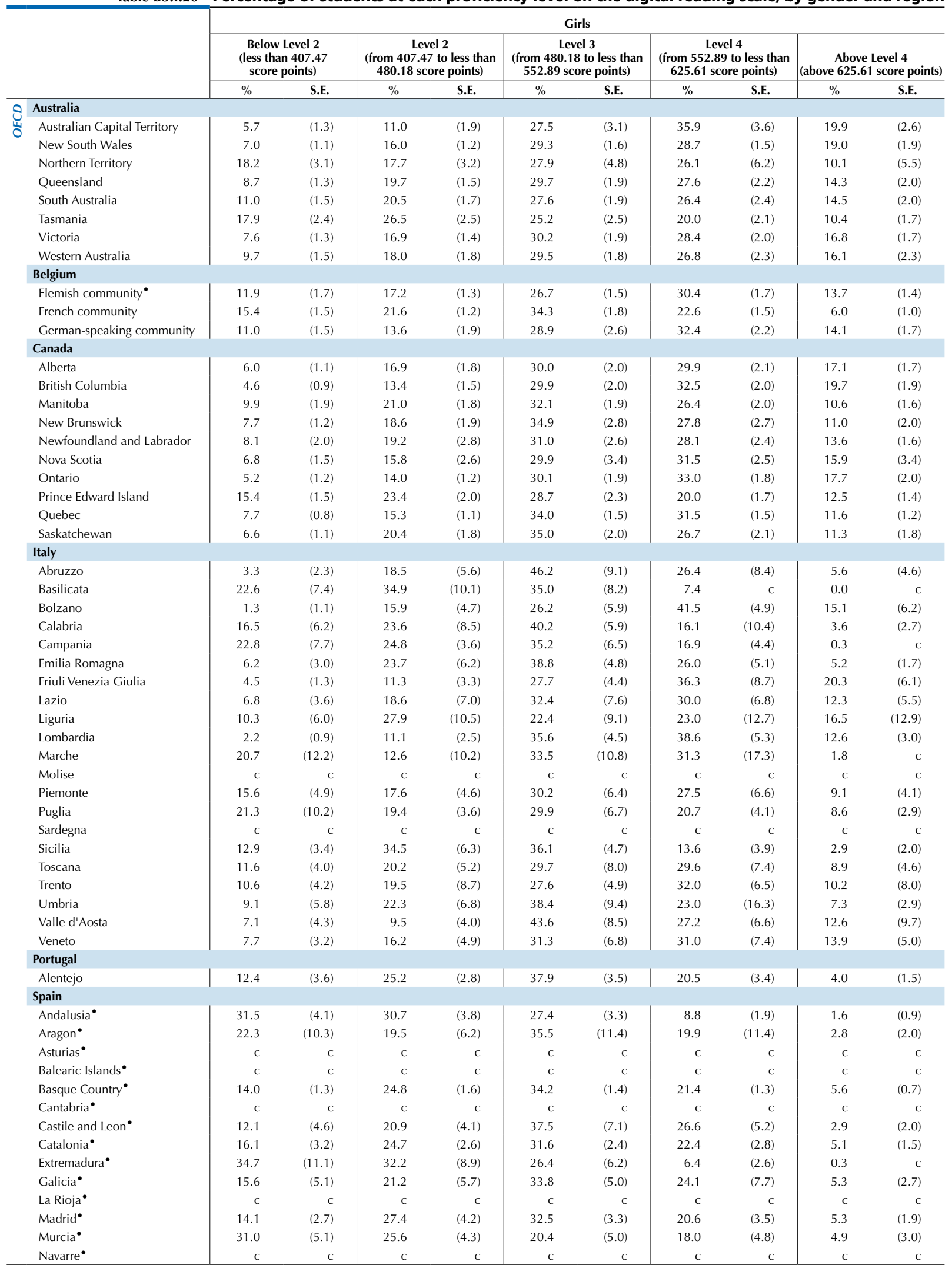

- PISA adjudicated region.

Note: See Table B3.I.8 for national data.

StatLink 敞SL http://dx.doi.org/10.1787/888932935781 
[Part 4/4]

Table B3.1.20 Percentage of students at each proficiency level on the digital reading scale, by gender and region

\begin{tabular}{|c|c|c|c|c|c|c|c|c|c|c|c|}
\hline & & \multicolumn{10}{|c|}{ Girls } \\
\hline & & \multicolumn{2}{|c|}{$\begin{array}{l}\text { Below Level } 2 \\
\text { (less than } 407.47 \\
\text { score points) }\end{array}$} & \multicolumn{2}{|c|}{$\begin{array}{c}\text { Level } 2 \\
\text { (from } 407.47 \text { to less than } \\
480.18 \text { score points) }\end{array}$} & \multicolumn{2}{|c|}{$\begin{array}{c}\text { Level } 3 \\
\text { (from } 480.18 \text { to less than } \\
552.89 \text { score points) }\end{array}$} & \multicolumn{2}{|c|}{$\begin{array}{c}\text { Level } 4 \\
\text { (from } 552.89 \text { to less than } \\
625.61 \text { score points) }\end{array}$} & \multicolumn{2}{|c|}{$\begin{array}{c}\text { Above Level } 4 \\
\text { (above } 625.61 \text { score points) }\end{array}$} \\
\hline & & $\%$ & S.E. & $\%$ & S.E. & $\%$ & S.E. & $\%$ & S.E. & $\%$ & S.E. \\
\hline \multirow{41}{*}{ 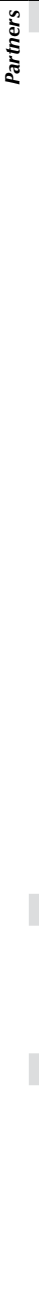 } & Brazil & & & & & & & & & & \\
\hline & Acre & 18.1 & (3.6) & 35.8 & $(12.0)$ & 34.0 & (9.6) & 10.9 & (7.1) & 1.1 & c \\
\hline & Alagoas & 68.4 & (7.5) & 17.4 & (9.9) & 10.9 & (2.9) & 3.1 & (1.3) & 0.1 & c \\
\hline & Amapá & 14.7 & (8.1) & 36.9 & (7.3) & 34.8 & (9.1) & 13.5 & (5.9) & 0.1 & c \\
\hline & Amazonas & 79.9 & (11.1) & 11.5 & (5.0) & 6.8 & (7.3) & 1.9 & (2.4) & 0.0 & c \\
\hline & Bahia & 50.4 & (11.4) & 25.2 & $(11.0)$ & 17.3 & (7.9) & 5.4 & (3.7) & 1.7 & (1.9) \\
\hline & Ceará & 55.2 & (19.9) & 24.5 & (9.7) & 12.0 & (7.5) & 6.8 & (5.6) & 1.5 & c \\
\hline & Espírito Santo & 16.3 & $(7.8)$ & 29.4 & (11.1) & 35.8 & (11.0) & 13.2 & (5.7) & 5.3 & (5.4) \\
\hline & Federal District & c & c & c & c & c & c & c & c & c & c \\
\hline & Goiás & 35.6 & (5.8) & 33.2 & (5.5) & 24.6 & (7.1) & 6.2 & (2.0) & 0.4 & c \\
\hline & Maranhão & 58.3 & $(21.8)$ & 29.9 & $(21.5)$ & 10.4 & (7.0) & 1.4 & (1.9) & 0.1 & c \\
\hline & Mato Grosso & c & c & c & c & c & c & c & c & c & c \\
\hline & Mato Grosso do Sul & 27.6 & (9.9) & 30.5 & (5.4) & 28.9 & (9.7) & 12.2 & (3.2) & 0.9 & c \\
\hline & Minas Gerais & 28.7 & (5.4) & 34.8 & (4.9) & 26.8 & (5.0) & 8.3 & (5.0) & 1.4 & c \\
\hline & Pará & 50.1 & $(12.7)$ & 22.3 & (7.7) & 15.0 & (5.8) & 8.7 & (6.7) & 3.9 & (3.5) \\
\hline & Paraíba & c & $\mathrm{C}$ & c & c & c & c & C & c & c & c \\
\hline & Paraná & 24.3 & (4.9) & 33.5 & (5.5) & 28.9 & (4.5) & 10.5 & (3.8) & 2.8 & (1.8) \\
\hline & Pernambuco & 28.6 & (7.3) & 39.3 & (7.4) & 24.1 & (8.1) & 7.5 & (6.1) & 0.5 & c \\
\hline & Piauí & c & c & c & c & c & c & c & c & c & c \\
\hline & Rio de Janeiro & 23.8 & (5.9) & 28.8 & (5.6) & 31.2 & (5.2) & 14.7 & (3.6) & 1.5 & c \\
\hline & Rio Grande do Norte & c & c & c & c & c & c & c & c & c & c \\
\hline & Rio Grande do Sul & 22.9 & (4.8) & 40.0 & (6.5) & 25.8 & (5.9) & 8.1 & (4.3) & 3.3 & (2.9) \\
\hline & Rondônia & 65.3 & $(17.2)$ & 25.4 & (4.3) & 6.3 & $(11.1)$ & 3.0 & (5.7) & 0.0 & c \\
\hline & Roraima & 41.2 & (7.1) & 40.3 & (8.3) & 11.6 & (5.6) & 5.8 & (3.8) & 1.1 & (1.0) \\
\hline & Santa Catarina & 33.1 & $(16.8)$ & 33.3 & (14.5) & 23.4 & $(10.5)$ & 8.3 & (5.9) & 1.9 & (1.5) \\
\hline & São Paulo & 23.7 & (3.3) & 32.7 & (3.2) & 30.4 & (3.1) & 11.9 & (2.1) & 1.3 & (0.6) \\
\hline & Sergipe & 44.0 & $(10.5)$ & 36.6 & $(10.1)$ & 15.9 & (4.6) & 3.3 & (2.3) & 0.3 & c \\
\hline & Tocantins & 59.6 & (7.8) & 34.3 & $(10.3)$ & 5.2 & (4.3) & 0.7 & $(0.2)$ & 0.1 & $(0.1)$ \\
\hline & \multicolumn{11}{|l|}{ Colombia } \\
\hline & Bogota & 43.2 & (4.3) & 37.0 & (2.8) & 16.0 & (2.6) & 3.6 & (1.3) & 0.2 & $(0.2)$ \\
\hline & Cali & 41.7 & (5.4) & 27.6 & (3.0) & 22.1 & (3.9) & 7.9 & (2.3) & 0.8 & $(0.4)$ \\
\hline & Manizales & 42.4 & (3.6) & 35.3 & (3.9) & 18.6 & (2.5) & 3.4 & (1.5) & 0.2 & $(0.2)$ \\
\hline & Medellin & 39.1 & (4.1) & 30.1 & (2.9) & 20.9 & (3.1) & 7.9 & (1.9) & 2.0 & $(0.9)$ \\
\hline & \multicolumn{11}{|l|}{ United Arab Emirates } \\
\hline & Abu Dhabi` & 46.9 & (3.2) & 29.7 & (1.9) & 16.8 & (1.9) & 5.4 & (1.0) & 1.1 & $(0.4)$ \\
\hline & Ajman & 55.0 & (5.0) & 25.7 & (3.8) & 16.2 & (2.5) & 3.0 & (1.1) & 0.1 & c \\
\hline & Dubai • & 26.3 & (1.1) & 25.3 & (1.8) & 24.9 & $(1.2)$ & 17.2 & (1.2) & 6.3 & $(0.7)$ \\
\hline & Fujairah & 51.7 & $(5.2)$ & 31.8 & (3.1) & 13.5 & (3.3) & 2.9 & $(1.2)$ & 0.1 & c \\
\hline & Ras Al Khaimah & 63.9 & (5.0) & 25.9 & (3.3) & 8.1 & $(2.3)$ & 1.9 & $(0.9)$ & 0.2 & c \\
\hline & Sharjah & 35.8 & (5.8) & 29.6 & (2.6) & 24.1 & (4.3) & 8.5 & (2.3) & 2.0 & $(1.2)$ \\
\hline & Umm Al Quwain & 48.3 & $(4.0)$ & 33.1 & (3.8) & 15.0 & (3.2) & 2.8 & (1.3) & 0.8 & $(0.9)$ \\
\hline
\end{tabular}

- PISA adjudicated region.

Note: See Table B3.I.8 for national data.

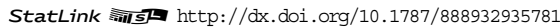


[Part 1/2]

Mean score, variation and gender differences in student performance on the digital reading scale, Table B3.I.21 by region

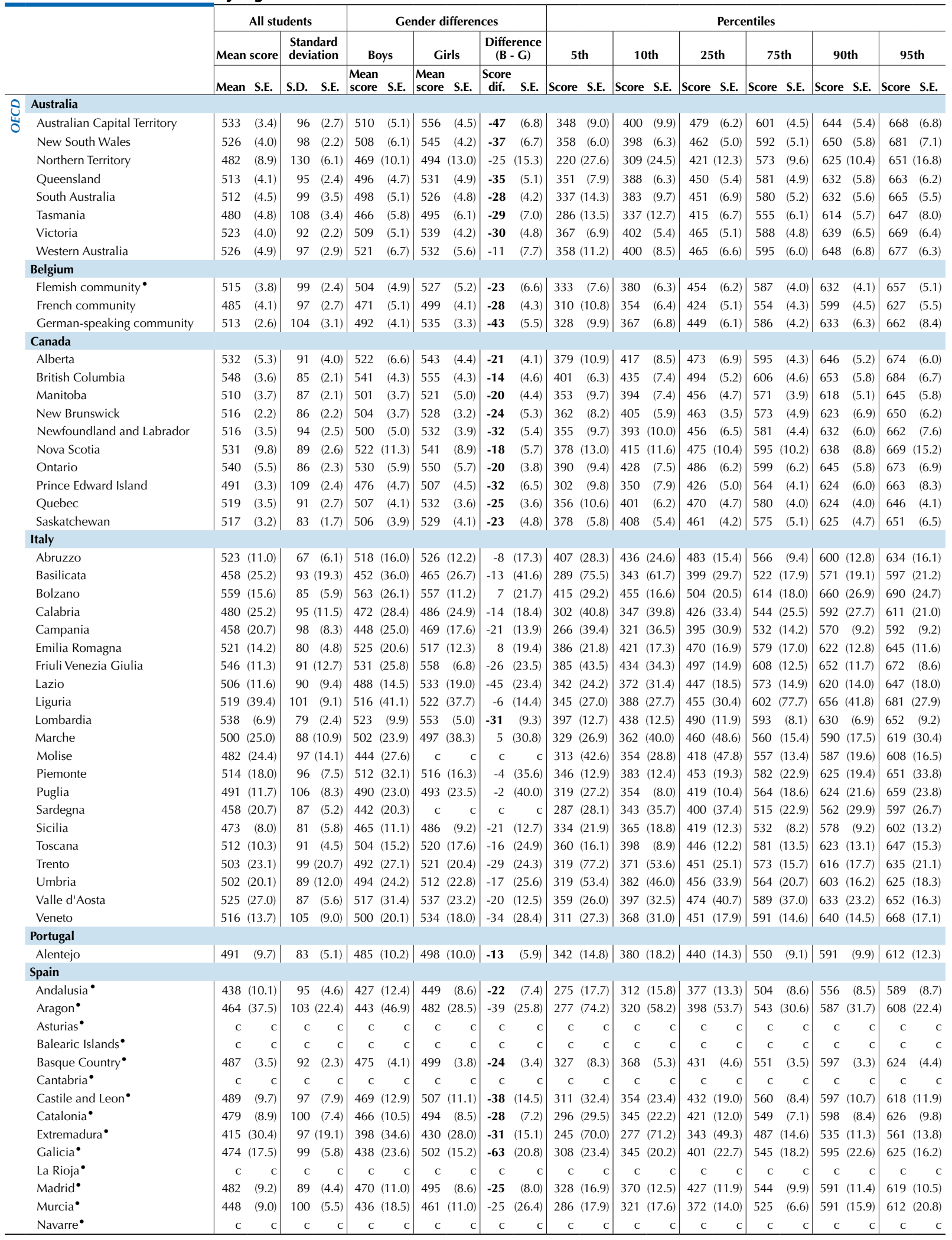

- PISA adjudicated region.

Notes: Values that are statistically significant are indicated in bold (see Annex A3).

See Table B3.I.9 for national data.

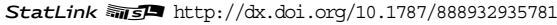


[Part 2/2]

Mean score, variation and gender differences in student performance on the digital reading scale, Table B3.I.21 by region

\begin{tabular}{|c|c|c|c|c|c|c|c|c|c|c|c|c|c|c|c|c|c|c|c|c|c|c|c|}
\hline & & \multicolumn{4}{|c|}{ All students } & \multicolumn{6}{|c|}{ Gender differences } & \multicolumn{12}{|c|}{ Percentiles } \\
\hline & & \multicolumn{2}{|c|}{ Mean score } & \multicolumn{2}{|c|}{$\begin{array}{l}\text { Standard } \\
\text { deviation }\end{array}$} & \multicolumn{2}{|c|}{ Boys } & \multicolumn{2}{|c|}{ Girls } & \multicolumn{2}{|c|}{$\begin{array}{c}\text { Difference } \\
\text { (B - G) }\end{array}$} & \multicolumn{2}{|c|}{ 5th } & \multicolumn{2}{|c|}{ 10th } & \multicolumn{2}{|c|}{ 25th } & \multicolumn{2}{|c|}{ 75th } & \multicolumn{2}{|c|}{ 90th } & \multicolumn{2}{|c|}{ 95th } \\
\hline & & Mean & S.E. & S.D. & S.E. & $\begin{array}{l}\text { Mean } \\
\text { score }\end{array}$ & S.E. & $\begin{array}{l}\text { Mean } \\
\text { score }\end{array}$ & S.E. & \begin{tabular}{|c}
$\begin{array}{c}\text { Score } \\
\text { dif. }\end{array}$ \\
\end{tabular} & S.E. & Score & S.E. & Score & S.E. & Score & S.E. & Score & S.E. & Score & e S.E. & Score & e S.E. \\
\hline \multirow{41}{*}{ 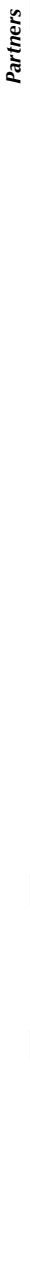 } & Brazil & & & & & & & & & & & & & & & & & & & & & & \\
\hline & Acre & 459 & (11.1) & 72 & (7.3) & 442 & (11.6) & 472 & (13.5) & -30 & (10.4) & 335 & (15.9) & 375 & $(16.0)$ & 418 & $(13.1)$ & 502 & (22.3) & 546 & $(34.2)$ & 574 & $(36.5)$ \\
\hline & Alagoas & 341 & (22.2) & 98 & (5.7) & 320 & (24.6) & 363 & (18.3) & -43 & (16.7) & 199 & $(27.7)$ & 219 & $(33.2)$ & 278 & $(27.7)$ & 406 & (38.8) & 482 & $(14.8)$ & 521 & (9.0) \\
\hline & Amapá & 460 & (12.6) & 65 & (9.5) & 439 & $(11.2)$ & 478 & (16.0) & -39 & (12.4) & 355 & (23.2) & 375 & $(20.2)$ & 413 & $(15.0)$ & 506 & $(14.0)$ & 542 & $(19.6)$ & 570 & $(33.9)$ \\
\hline & Amazonas & 345 & (21.5) & 81 & (10.1) & 325 & (23.5) & 371 & (19.8) & -45 & (11.9) & 170 & (94.8) & 257 & $(30.3)$ & 301 & (13.3) & 388 & (29.6) & 437 & (76.6) & 494 & $(53.6)$ \\
\hline & Bahia & 401 & $(27.3)$ & 117 & (20.4) & 397 & $(23.8)$ & 405 & (31.6) & -8 & (15.1) & 183 & $(74.5)$ & 254 & (72.0) & 330 & $(41.5)$ & 480 & (30.1) & 543 & $(36.2)$ & 584 & $(48.1)$ \\
\hline & Ceará & 398 & (44.9) & 114 & (15.3) & 400 & (48.5) & 396 & (42.5) & 4 & (18.8) & 214 & (58.8) & 254 & $(47.5)$ & 318 & $(52.0)$ & 477 & $(47.8)$ & 550 & $(39.2)$ & ) 583 & $(33.0)$ \\
\hline & Espírito Santo & 466 & (15.5) & 86 & (13.0) & 445 & $(12.7)$ & 488 & (21.5) & -43 & (19.1) & 317 & (41.4) & 361 & $(27.5)$ & 414 & $(20.7)$ & 520 & $(17.2)$ & 566 & $(32.0)$ & 605 & $(56.9)$ \\
\hline & Federal District & c & & C & & C & & C & & C & $\mathrm{c}$ & C & c & C & C & C & c & c & c & c & c & c & c \\
\hline & Goiás & 436 & (8.1) & 84 & (4.9) & 433 & (8.5) & 438 & (11.7) & -5 & (12.3) & 284 & (18.4) & 318 & (18.6) & 386 & $(16.1)$ & 490 & (8.8) & 541 & $(10.2)$ & 566 & (14.9) \\
\hline & Maranhão & 357 & $(50.7)$ & 101 & (29.6) & 340 & (45.7) & 373 & (55.7) & -33 & (14.4) & 184 & $(71.2)$ & 227 & $(85.2)$ & 303 & $(87.9)$ & 422 & $(50.2)$ & 489 & $(53.3)$ & 520 & $(48.6)$ \\
\hline & Mato Grosso & C & & C & & C & & C & & c & & C & & c & & c & c & c & & c & c & c & \\
\hline & Mato Grosso do Sul & 460 & (15.6) & 80 & (10.7) & 461 & $(19.2)$ & 460 & (12.8) & 2 & (8.4) & 325 & (37.4) & 357 & $(41.4)$ & 406 & $(30.7)$ & 516 & $(12.8)$ & 565 & $(7.5)$ & 583 & $(20.1)$ \\
\hline & Minas Gerais & 442 & (16.6) & 83 & (8.1) & 433 & (18.4) & 451 & (15.3) & -19 & (6.2) & 303 & (19.8) & 337 & (16.5) & 387 & $(16.0)$ & 501 & (22.8) & 552 & $(26.1)$ & ) 578 & $(29.4)$ \\
\hline & Pará & 408 & (28.8) & 99 & (16.5) & 381 & (29.6) & 428 & $(30.2)$ & -47 & (28.7) & 268 & $(21.0)$ & 294 & (23.8) & 336 & $(22.9)$ & 469 & $(54.2)$ & 546 & $(55.8)$ & 584 & $(44.4)$ \\
\hline & Paraíba & c & & c & & c & & c & & c & & c & & c & & c & & c & & c & c & c & c \\
\hline & Paraná & 445 & (13.8) & 92 & (10.7) & 426 & (18.4) & 463 & (10.9) & -37 & (15.2) & 283 & (42.6) & 322 & (40.7) & 391 & $(16.3)$ & 509 & (13.6) & 561 & (19.5) & ) 593 & $(20.8)$ \\
\hline & Pernambuco & 428 & (16.3) & 82 & (9.6) & 410 & (16.2) & 444 & (15.6) & -34 & (6.2) & 288 & (33.0) & 320 & (29.6) & 373 & $(24.4)$ & 483 & (15.8) & 536 & $(20.6)$ & 555 & (18.9) \\
\hline & Piauí & c & & C & c & c & c & c & & c & $\mathrm{c}$ & C & c & c & c & c & c & c & c & c & c & c & c \\
\hline & Rio de Janeiro & 462 & (8.9) & 82 & (6.9) & 454 & (8.6) & 469 & (10.6) & -15 & (7.8) & 323 & $(21.2)$ & 351 & (18.7) & 401 & (16.6) & 520 & (12.6) & 569 & $(10.9)$ & )) 591 & (13.6) \\
\hline & Rio Grand & c & & C & c & c & c & c & C & c & c & C & c & C & C & C & c & c & & c & c & c & c \\
\hline & Rio Grande do Sul & 454 & (13.2) & 80 & (9.0) & 444 & (14.0) & 462 & (13.2) & -18 & (5.7) & 327 & (9.0) & 351 & (16.8) & 397 & $(11.7)$ & 508 & (21.0) & 557 & $(29.7)$ & 590 & $(37.2)$ \\
\hline & Rondônia & 386 & (26.9) & 84 & (11.8) & 396 & $(18.7)$ & 378 & (34.8) & 18 & $(22.7)$ & 240 & (30.6) & 274 & $(21.0)$ & 332 & $(22.7)$ & 435 & (41.6) & 492 & $(68.3)$ & 527 & $(56.1)$ \\
\hline & Roraima & 417 & (7.7) & 76 & (8.0) & 409 & $(13.1)$ & 424 & (10.2) & -15 & (17.9) & 303 & (39.3) & 323 & (19.4) & 368 & $(22.8)$ & 462 & $(14.0)$ & 511 & (21.0) & ) 553 & (38.9) \\
\hline & Santa Catarina & 422 & $(27.7)$ & 85 & (8.3) & 398 & $(27.3)$ & 448 & (26.9) & -51 & (9.5) & 276 & $(33.4)$ & 311 & (30.4) & 364 & (32.6) & 487 & (39.9) & 528 & (31.8) & 562 & (36.8) \\
\hline & São Paulo & 455 & $(7.2)$ & 82 & (3.5) & 446 & $(8.0)$ & 465 & $(7.2)$ & -18 & (5.2) & 318 & (12.6) & 349 & $(11.2)$ & 400 & $(7.7)$ & 512 & (7.4) & 559 & (9.6) & 588 & $(10.6)$ \\
\hline & Sergipe & 412 & (15.7) & 82 & (12.9) & 408 & (23.8) & 414 & (13.3) & -6 & (18.0) & 279 & (36.8) & 306 & (43.7) & 355 & $(32.3)$ & 465 & $(14.7)$ & 518 & $(14.4)$ & ) 548 & (14.4) \\
\hline & Tocantins & 383 & (21.3) & 73 & (8.4) & 375 & (39.0) & 391 & (7.0) & ) & (33.7) & 257 & (34.7) & 290 & $(47.4)$ & 336 & $(35.9)$ & 437 & $(26.4)$ & 468 & $(12.5)$ & 499 & (8.6) \\
\hline & Colombia & & & & & & & & & & & & & & & & & & & & & & \\
\hline & Bogota & 415 & (8.1) & 82 & (3.7) & 411 & (9.5) & 418 & (7.7) & -6 & (5.7) & 279 & (12.1) & 309 & $(10.2)$ & 361 & (8.6) & 467 & (7.7) & 516 & $(10.8)$ & 548 & $(12.4)$ \\
\hline & Cali & 415 & (10.5) & 95 & (5.9) & 401 & (8.6) & 425 & (12.6) & ) -24 & (7.4) & 251 & (25.4) & 294 & (20.5) & 356 & $(10.2)$ & 482 & $(12.3)$ & 533 & (11.5) & 564 & $(10.4)$ \\
\hline & Manizales & 417 & (4.6) & 82 & (3.4) & 414 & (6.0) & 420 & (4.5) & -6 & (5.3) & 278 & (9.7) & 310 & (9.4) & 361 & $(7.1)$ & 474 & (5.2) & 524 & (6.1) & ) 547 & (7.5) \\
\hline & Medellin & 429 & (7.7) & 89 & (3.4) & 421 & (8.4) & 436 & $(8.7)$ & ) & (7.6) & 286 & $(10.0)$ & 318 & (8.1) & ) 366 & (8.4) & 490 & (9.8) & 546 & (9.5) & 578 & (9.8) \\
\hline & United & & & & & & & & & & & & & & & & & & & & & & \\
\hline & Abu Dhabi & 385 & (6.3) & 107 & (3.9) & 355 & (8.6) & 415 & $(7.2)$ & ) -61 & (10.2) & 208 & $(9.2)$ & 248 & (8.3) & 312 & $(7.2)$ & 458 & (7.3) & 521 & (9.6) & ) 560 & $(11.6)$ \\
\hline & Ajman & 357 & (12.7) & 100 & (6.6) & 322 & (13.4) & 390 & (16.9) & -68 & (20.5) & 186 & $(22.0)$ & 220 & (24.0) & 291 & $(16.7)$ & 430 & (11.4) & 488 & (8.0) & 517 & $(12.0)$ \\
\hline & Dubai` & 456 & (1.2) & 111 & (1.1) & 439 & (1.9) & 474 & (1.6) & ) -35 & (2.5) & 269 & (3.8) & 310 & (2.9) & 379 & (2.8) & 537 & (2.8) & 601 & (3.1) & ) 632 & (3.9) \\
\hline & Fujairah & 362 & (8.8) & 96 & (3.9) & 325 & (6.7) & 401 & (9.9) & ) -76 & (12.9) & 200 & (11.0) & 234 & (7.6) & 295 & (8.4) & 431 & (11.6) & 485 & $(14.7)$ & 515 & (15.4) \\
\hline & Ras Al Khaimah & 364 & (6.7) & 87 & (5.8) & 343 & (11.2) & 384 & (8.6) & ) & (13.1) & 217 & (22.4) & 250 & (16.3) & 307 & (9.8) & 424 & (8.8) & 469 & (8.1) & ) 499 & $(10.1)$ \\
\hline & Sharjah & 422 & (11.5) & 99 & (5.9) & 400 & (21.4) & 439 & (12.9) & -39 & (26.3) & 260 & (19.7) & 294 & (15.9) & 351 & (12.5) & 491 & (13.6) & 549 & $(14.8)$ & ) 585 & (17.1) \\
\hline & Umm Al Quwain & 336 & (3.9) & 117 & (4.2) & 266 & (6.0) & 405 & (5.3) & ) -139 & (8.1) & 140 & (26.0) & 177 & (12.5) & 247 & (9.5) & 421 & (6.4) & 484 & (8.4) & ) 510 & $(10.0)$ \\
\hline
\end{tabular}

- PISA adjudicated region.

Notes: Values that are statistically significant are indicated in bold (see Annex A3).

See Table B3.1.9 for national data.

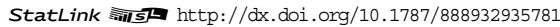


[Part 1/2] Table B3.I.22 Percentage of students at each proficiency level on the combined reading scale, by region

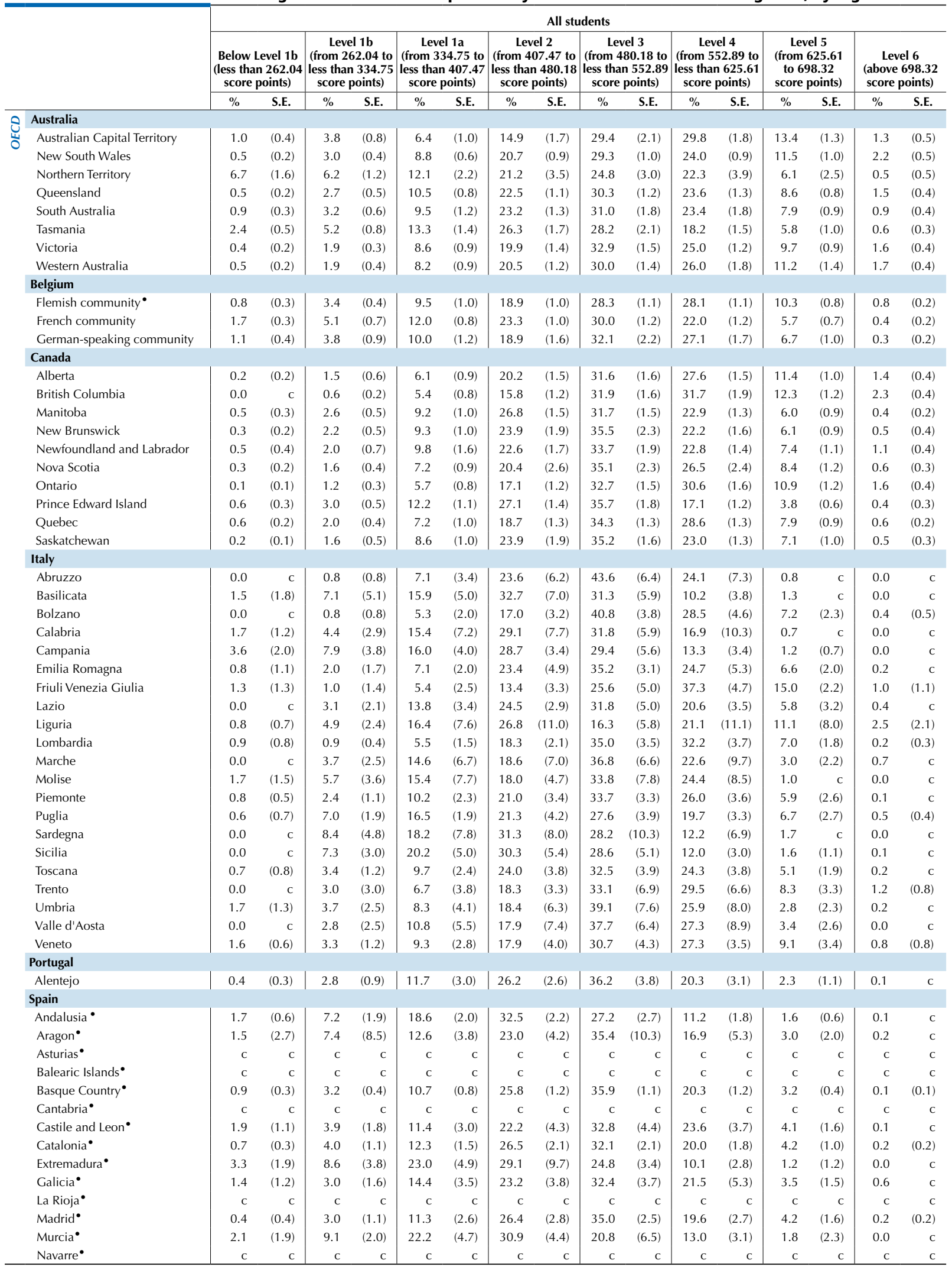

- PISA adjudicated region.

Note: See Table B3.I.10 for national data.

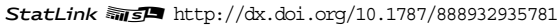


[Part 2/2]

Table B3.I.22 Percentage of students at each proficiency level on the combined reading scale, by region

\begin{tabular}{|c|c|c|c|c|c|c|c|c|c|c|c|c|c|c|c|c|c|}
\hline & & \multicolumn{16}{|c|}{ All students } \\
\hline & & \multicolumn{2}{|c|}{$\begin{array}{l}\text { Below Level 1b } \\
\text { (less than } 262.04 \\
\text { score points) }\end{array}$} & \multicolumn{2}{|c|}{\begin{tabular}{|c|} 
Level $1 \mathrm{~b}$ \\
(from 262.04 to \\
less than 334.75 \\
score points)
\end{tabular}} & \multicolumn{2}{|c|}{\begin{tabular}{|c|} 
Level 1a \\
(from 334.75 to \\
less than 407.47 \\
score points)
\end{tabular}} & \multicolumn{2}{|c|}{\begin{tabular}{|c|} 
Level 2 \\
(from 407.47 to \\
less than 480.18 \\
score points)
\end{tabular}} & \multicolumn{2}{|c|}{\begin{tabular}{|c|} 
Level 3 \\
(from 480.18 to \\
less than 552.89 \\
score points)
\end{tabular}} & \multicolumn{2}{|c|}{\begin{tabular}{|c|} 
Level 4 \\
(from 552.89 to \\
less than 625.61 \\
score points)
\end{tabular}} & \multicolumn{2}{|c|}{$\begin{array}{c}\text { Level } 5 \\
\text { (from } 625.61 \\
\text { to } 698.32 \\
\text { score points) }\end{array}$} & \multicolumn{2}{|c|}{$\begin{array}{c}\text { Level } 6 \\
\text { (above 698.32 } \\
\text { score points) }\end{array}$} \\
\hline & & $\%$ & S.E. & $\%$ & S.E. & $\%$ & S.E. & $\%$ & S.E. & $\%$ & S.E. & $\%$ & S.E. & $\%$ & S.E. & $\%$ & S.E. \\
\hline \multirow{41}{*}{ ఏ } & Brazil & & & & & & & & & & & & & & & & \\
\hline & Acre & 0.8 & $(0.4)$ & 5.1 & $(2.3)$ & 22.5 & (10.6) & 41.9 & (7.9) & 26.1 & $(9.1)$ & 3.4 & (3.3) & 0.1 & $\mathrm{c}$ & 0.0 & c \\
\hline & Alagoas & 17.2 & $(7.8)$ & 29.2 & $(6.2)$ & 32.9 & $(8.0)$ & 12.3 & $(4.7)$ & 7.3 & $(1.9)$ & 1.0 & $(0.8)$ & 0.0 & $\mathrm{c}$ & 0.0 & C \\
\hline & Amapá & 0.2 & $(0.4)$ & 7.3 & (2.5) & 24.8 & $(9.8)$ & 51.1 & $(11.2)$ & 13.5 & $(4.8)$ & 3.0 & (3.8) & 0.1 & $\mathrm{c}$ & 0.0 & c \\
\hline & Amazonas & 8.2 & (3.7) & 41.2 & (5.7) & 33.9 & (5.5) & 10.8 & (3.7) & 4.7 & (5.1) & 1.1 & (1.3) & 0.0 & $\mathrm{C}$ & 0.0 & C \\
\hline & Bahia & 9.5 & (5.5) & 18.4 & (8.1) & 26.3 & $(5.2)$ & 24.0 & $(8.2)$ & 13.9 & (3.9) & 6.5 & (3.9) & 1.4 & (1.4) & 0.0 & c \\
\hline & Ceará & 8.3 & (5.6) & 19.6 & (8.9) & 29.5 & (7.5) & 21.8 & (7.4) & 12.7 & $(7.0)$ & 7.6 & $(4.8)$ & 0.5 & c & 0.0 & c \\
\hline & Espírito Santo & 1.9 & (2.0) & 7.1 & $(4.2)$ & 19.3 & (6.5) & 36.8 & $(8.2)$ & 25.0 & $(5.5)$ & 7.3 & (3.2) & 2.1 & $(2.1)$ & 0.4 & $(0.5)$ \\
\hline & Federal District & c & c & c & c & $\mathrm{C}$ & c & C & c & C & c & c & c & c & c & C & C \\
\hline & Goiás & 2.4 & (1.1) & 8.9 & $(2.2)$ & 29.5 & (3.9) & 39.7 & (5.0) & 15.3 & (2.9) & 4.1 & (1.4) & 0.1 & $\mathrm{c}$ & 0.0 & C \\
\hline & Maranhão & 10.2 & (11.6) & 23.7 & (12.9) & 36.1 & $(14.3)$ & 18.9 & (10.5) & 9.3 & $(5.2)$ & 1.7 & $(2.1)$ & 0.0 & c & 0.0 & C \\
\hline & Mato Grosso & C & c & c & c & $\mathrm{C}$ & c & c & c & c & c & c & c & c & c & c & c \\
\hline & Mato Grosso do Sul & 0.0 & c & 5.1 & $(4.3)$ & 25.5 & (7.9) & 33.4 & $(7.7)$ & 26.9 & $(6.3)$ & 8.3 & (2.5) & 0.9 & $\mathrm{c}$ & 0.0 & c \\
\hline & Minas Gerais & 1.4 & (1.1) & 6.9 & (2.1) & 24.6 & $(4.7)$ & 37.2 & (4.6) & 23.1 & (5.6) & 6.3 & (3.9) & 0.4 & $\mathrm{C}$ & 0.0 & C \\
\hline & Pará & 6.7 & (6.9) & 23.8 & $(8.7)$ & 28.6 & (8.9) & 22.3 & (6.0) & 14.8 & $(7.5)$ & 3.6 & (2.9) & 0.1 & $\mathrm{c}$ & 0.0 & c \\
\hline & Paraíba & $\mathrm{c}$ & c & c & c & c & c & $\mathrm{c}$ & c & c & c & c & c & c & c & c & $\mathrm{c}$ \\
\hline & Paraná & 3.0 & (3.0) & 9.0 & $(4.0)$ & 27.3 & $(5.1)$ & 32.4 & (5.3) & 20.2 & $(4.0)$ & 7.2 & (3.0) & 1.0 & $(1.0)$ & 0.0 & c \\
\hline & Pernambuco & 2.6 & (1.8) & 13.5 & (4.6) & 36.1 & $(8.3)$ & 33.7 & (6.4) & 13.2 & $(4.5)$ & 0.9 & (1.3) & 0.0 & $\mathrm{c}$ & 0.0 & c \\
\hline & Piauí & $\mathrm{C}$ & c & c & C & $\mathrm{C}$ & c & $\mathrm{c}$ & c & c & c & $\mathrm{C}$ & c & c & $\mathrm{c}$ & $\mathrm{c}$ & c \\
\hline & Rio de Janeiro & 1.4 & (1.3) & 8.9 & (4.3) & 24.1 & (5.8) & 34.3 & (7.9) & 25.1 & $(4.7)$ & 5.9 & (2.4) & 0.4 & $\mathrm{C}$ & 0.0 & C \\
\hline & Rio Grande do Norte & C & c & c & c & $\mathrm{C}$ & c & $\mathrm{c}$ & c & c & c & $\mathrm{c}$ & c & c & c & $\mathrm{c}$ & c \\
\hline & Rio Grande do Sul & 0.0 & c & 5.9 & (2.7) & 24.6 & (5.4) & 37.4 & $(4.8)$ & 25.5 & (6.4) & 6.0 & (3.6) & 0.5 & $(0.6)$ & 0.1 & c \\
\hline & Rondônia & 4.4 & (1.9) & 19.5 & $(4.0)$ & 32.8 & (5.3) & 35.1 & (6.9) & 7.6 & (5.8) & 0.6 & (1.0) & 0.0 & $\mathrm{c}$ & 0.0 & c \\
\hline & Roraima & 1.3 & (1.6) & 7.5 & $(4.1)$ & 33.2 & (5.2) & 38.7 & (4.8) & 14.9 & (6.3) & 4.2 & (2.1) & 0.2 & c & 0.0 & C \\
\hline & Santa Catarina & 3.6 & $(4.7)$ & 17.2 & $(12.4)$ & 20.6 & $(7.0)$ & 32.4 & (10.4) & 20.4 & $(9.5)$ & 5.6 & (3.5) & 0.1 & C & 0.0 & C \\
\hline & São Paulo & 1.0 & $(0.5)$ & 7.8 & (1.4) & 26.3 & (2.0) & 34.8 & $(2.0)$ & 23.3 & $(2.3)$ & 6.3 & (1.5) & 0.5 & $(0.4)$ & 0.0 & C \\
\hline & Sergipe & 0.0 & c & 18.5 & $(8.9)$ & 32.8 & (6.0) & 28.1 & $(10.0)$ & 15.4 & $(4.0)$ & 3.6 & (1.4) & 0.5 & $(0.6)$ & 1.1 & C \\
\hline & Tocantins & 4.1 & (4.1) & 19.7 & $(12.1)$ & 38.4 & (6.1) & 30.3 & (10.9) & 7.1 & (3.1) & 0.4 & $(0.2)$ & 0.0 & $\mathrm{C}$ & 0.0 & c \\
\hline & \multicolumn{17}{|l|}{ Colombia } \\
\hline & Bogota & 1.5 & $(0.5)$ & 10.9 & (1.5) & 31.0 & $(2.2)$ & 38.0 & (2.5) & 16.0 & $(2.2)$ & 2.6 & $(0.8)$ & 0.2 & $(0.2)$ & 0.0 & c \\
\hline & Cali & 3.3 & (1.1) & 13.7 & $(2.6)$ & 31.7 & (2.8) & 30.6 & $(2.3)$ & 16.8 & $(2.6)$ & 3.7 & $(1.1)$ & 0.2 & $(0.2)$ & 0.0 & c \\
\hline & Manizales & 1.4 & $(0.5)$ & 9.3 & (1.3) & 29.9 & (1.9) & 37.6 & (3.1) & 18.3 & $(2.0)$ & 3.4 & (1.1) & 0.2 & $(0.2)$ & 0.0 & C \\
\hline & Medellin & 1.6 & $(0.6)$ & 10.9 & (1.6) & 31.0 & (2.4) & 31.8 & $(2.2)$ & 17.7 & $(2.2)$ & 6.0 & (1.6) & 1.1 & $(0.6)$ & 0.0 & C \\
\hline & \multicolumn{17}{|l|}{ United Arab Emirates } \\
\hline & Abu Dhabi $\bullet$ & 6.5 & $(1.0)$ & 16.3 & (1.3) & 26.2 & $(1.2)$ & 27.8 & (1.3) & 16.7 & (1.4) & 5.6 & (1.0) & 0.8 & $(0.3)$ & 0.1 & $(0.1)$ \\
\hline & Ajman & 7.9 & $(2.7)$ & 21.6 & (3.3) & 28.8 & (2.9) & 27.1 & (3.3) & 13.2 & $(2.2)$ & 1.3 & $(0.7)$ & 0.0 & $\mathrm{c}$ & 0.0 & C \\
\hline & Dubai • & 2.7 & $(0.2)$ & 8.4 & $(0.4)$ & 18.3 & $(0.8)$ & 26.1 & $(0.8)$ & 24.2 & $(0.9)$ & 15.8 & $(0.8)$ & 4.1 & $(0.4)$ & 0.3 & $(0.1)$ \\
\hline & Fujairah & 7.6 & (1.5) & 20.5 & (2.8) & 28.4 & (2.5) & 28.3 & (2.9) & 13.5 & (2.6) & 1.8 & $(0.9)$ & 0.1 & $\mathrm{c}$ & 0.0 & C \\
\hline & Ras Al Khaimah & 6.2 & (1.8) & 18.2 & (2.1) & 32.5 & $(2.7)$ & 31.7 & (2.6) & 9.6 & (1.8) & 1.7 & $(0.7)$ & 0.2 & $(0.3)$ & 0.0 & C \\
\hline & Sharjah & 1.8 & $(1.0)$ & 10.5 & $(2.3)$ & 25.2 & (3.4) & 30.4 & (2.5) & 23.9 & $(3.0)$ & 7.4 & (1.6) & 0.8 & $(0.5)$ & 0.0 & c \\
\hline & Umm Al Quwain & 13.4 & (1.9) & 26.9 & (2.9) & 23.0 & (2.6) & 24.0 & $(2.7)$ & 10.5 & $(2.0)$ & 2.0 & $(0.9)$ & 0.2 & c & 0.0 & c \\
\hline
\end{tabular}

- PISA adjudicated region.

Note: See Table B3.I.10 for national data.

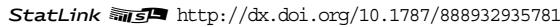


Part 1/4]

Percentage of students at each proficiency level on the combined reading scale, by gender Table B3.I.23 and region

\begin{tabular}{|c|c|c|c|c|c|c|c|c|c|c|c|c|c|c|c|c|c|}
\hline & & \multicolumn{16}{|c|}{ Boys } \\
\hline & & \multicolumn{2}{|c|}{$\begin{array}{l}\text { Below Level 1b } \\
\text { (less than 262.04 } \\
\text { score points) }\end{array}$} & \multicolumn{2}{|c|}{\begin{tabular}{|c|} 
Level $1 \mathrm{~b}$ \\
(from 262.04 to \\
less than 334.75 \\
score points)
\end{tabular}} & \multicolumn{2}{|c|}{$\begin{array}{c}\text { Level 1a } \\
\text { (from } 334.75 \text { to } \\
\text { less than } 407.47 \\
\text { score points) }\end{array}$} & \multicolumn{2}{|c|}{\begin{tabular}{|c|} 
Level 2 \\
(from 407.47 to \\
less than 480.18 \\
score points)
\end{tabular}} & \multicolumn{2}{|c|}{\begin{tabular}{|c|} 
Level 3 \\
(from 480.18 to \\
less than 552.89 \\
score points) \\
\end{tabular}} & \multicolumn{2}{|c|}{\begin{tabular}{|c|} 
Level 4 \\
(from 552.89 to \\
less than 625.61 \\
score points)
\end{tabular}} & $\begin{array}{r}\text { Le } \\
\text { (from } \\
\text { to } 6 \\
\text { score }\end{array}$ & $\begin{array}{l}\text { l } 5 \\
25.61 \\
8.32 \\
\text { oints) }\end{array}$ & $\begin{array}{r}\text { Le } \\
\text { (above } \\
\text { score }\end{array}$ & $\begin{array}{l}\text { l } 6 \\
698.32 \\
\text { oints) }\end{array}$ \\
\hline & & $\%$ & S.E. & $\%$ & S.E. & $\%$ & S.E. & $\%$ & S.E. & $\%$ & S.E. & $\%$ & S.E. & $\%$ & S.E. & $\%$ & S.E. \\
\hline 0 & Australia & & & & & & & & & & & & & & & & \\
\hline 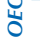 & Australian Capital Territory & 1.7 & $(0.7)$ & 6.1 & (1.3) & 9.2 & $(1.7)$ & 17.9 & $(2.7)$ & 30.0 & $(2.7)$ & 25.2 & (2.9) & 9.3 & (1.9) & 0.7 & $(0.4)$ \\
\hline & New South Wales & 0.8 & $(0.4)$ & 4.7 & $(0.8)$ & 12.2 & $(1.0)$ & 23.5 & (1.4) & 28.0 & $(1.5)$ & 19.9 & (1.5) & 9.1 & $(1.3)$ & 1.8 & $(0.6)$ \\
\hline & Northern Territory & 7.4 & (1.8) & 7.6 & $(2.0)$ & 15.4 & (3.3) & 22.0 & $(4.9)$ & 22.5 & $(4.3)$ & 19.3 & $(4.0)$ & 4.9 & $(2.7)$ & 0.8 & c \\
\hline & Queensland & 0.8 & $(0.3)$ & 4.1 & $(0.8)$ & 13.9 & (1.3) & 24.2 & $(1.3)$ & 29.3 & $(1.5)$ & 20.5 & (1.7) & 6.5 & $(1.0)$ & 0.8 & $(0.3)$ \\
\hline & South Australia & 1.6 & $(0.6)$ & 4.1 & $(1.0)$ & 11.7 & (1.8) & 24.7 & (1.6) & 31.9 & $(2.4)$ & 19.9 & $(2.2)$ & 5.5 & $(1.0)$ & 0.6 & $(0.5)$ \\
\hline & Tasmania & 3.6 & $(0.9)$ & 6.4 & (1.1) & 15.6 & (2.0) & 27.4 & (2.5) & 27.1 & $(2.7)$ & 15.8 & (2.0) & 3.9 & $(1.2)$ & 0.3 & $(0.3)$ \\
\hline & Victoria & 0.5 & $(0.3)$ & 2.7 & $(0.6)$ & 11.2 & $(1.2)$ & 22.5 & (1.5) & 33.1 & $(1.7)$ & 21.6 & (1.4) & 7.0 & $(1.2)$ & 1.5 & $(0.7)$ \\
\hline & Western Australia & 0.6 & $(0.3)$ & 2.5 & $(0.5)$ & 9.2 & $(1.2)$ & 22.7 & (1.8) & 29.5 & $(2.0)$ & 25.0 & (2.1) & 9.4 & (1.8) & 1.2 & $(0.5)$ \\
\hline & Belgium & & & & & & & & & & & & & & & & \\
\hline & Flemish community $^{\bullet}$ & 1.2 & $(0.4)$ & 4.3 & $(0.6)$ & 11.2 & (1.5) & 20.7 & (1.4) & 28.5 & $(1.4)$ & 24.9 & (1.4) & 8.7 & $(0.9)$ & 0.4 & $(0.2)$ \\
\hline & French community & 2.7 & $(0.6)$ & 7.0 & (1.1) & 14.2 & (1.1) & 24.0 & (1.6) & 28.7 & $(1.7)$ & 18.9 & (1.3) & 4.3 & $(0.7)$ & 0.3 & $(0.2)$ \\
\hline & German-speaking community & 1.9 & $(0.7)$ & 6.0 & (1.3) & 14.7 & $(2.0)$ & 21.6 & (2.5) & 28.6 & (2.6) & 22.2 & (1.9) & 4.8 & $(1.2)$ & 0.2 & c \\
\hline & Canada & & & & & & & & & & & & & & & & \\
\hline & Alberta & 0.4 & $(0.4)$ & 2.3 & $(0.9)$ & 7.7 & $(1.4)$ & 22.8 & (1.9) & 31.8 & $(2.1)$ & 24.2 & (2.5) & 9.6 & $(1.4)$ & 1.1 & $(0.6)$ \\
\hline & British Columbia & 0.0 & c & 1.0 & $(0.5)$ & 6.7 & $(0.9)$ & 18.3 & (1.9) & 32.1 & (2.4) & 29.5 & $(2.1)$ & 10.4 & $(1.3)$ & 2.0 & $(0.6)$ \\
\hline & Manitoba & 0.9 & $(0.6)$ & 3.7 & $(0.8)$ & 11.6 & (1.3) & 29.6 & (2.0) & 30.6 & $(2.2)$ & 19.0 & (1.6) & 4.3 & $(1.0)$ & 0.2 & $(0.1)$ \\
\hline & New Brunswick & 0.4 & $(0.3)$ & 3.4 & $(0.8)$ & 13.0 & (1.8) & 27.7 & (2.6) & 33.3 & $(3.1)$ & 18.1 & $(2.7)$ & 4.0 & $(0.9)$ & 0.2 & c \\
\hline & Newfoundland and Labrador & 1.0 & $(0.8)$ & 3.4 & (1.5) & 14.1 & (2.3) & 25.6 & $(2.2)$ & 32.0 & (2.3) & 18.6 & $(2.0)$ & 4.7 & $(1.2)$ & 0.7 & $(0.6)$ \\
\hline & Nova Scotia & 0.4 & $(0.2)$ & 2.1 & $(0.7)$ & 10.5 & (1.3) & 23.5 & (3.4) & 33.5 & $(3.1)$ & 23.4 & $(4.1)$ & 6.2 & $(1.7)$ & 0.3 & $(0.3)$ \\
\hline & Ontario & 0.2 & $(0.1)$ & 1.8 & $(0.4)$ & 7.8 & (1.1) & 20.5 & $(1.7)$ & 33.1 & (1.8) & 27.1 & (1.9) & 8.5 & $(1.2)$ & 1.0 & $(0.3)$ \\
\hline & Prince Edward Island & 1.1 & $(0.6)$ & 4.8 & (0.9) & 16.4 & (1.7) & 28.6 & $(2.2)$ & 32.9 & (2.3) & 13.4 & (1.4) & 2.6 & $(0.9)$ & 0.2 & c \\
\hline & Quebec & 0.7 & $(0.3)$ & 2.9 & $(0.6)$ & 9.8 & (1.4) & 21.4 & (1.8) & 34.7 & (1.6) & 24.5 & (1.7) & 5.6 & $(0.9)$ & 0.4 & $(0.2)$ \\
\hline & Saskatchewan & 0.3 & $(0.2)$ & 2.4 & $(0.7)$ & 11.9 & (1.5) & 26.7 & (3.1) & 33.1 & (2.3) & 19.9 & (1.7) & 5.3 & $(1.2)$ & 0.3 & $(0.3)$ \\
\hline & Italy & & & & & & & & & & & & & & & & \\
\hline & Abruzzo & 0.0 & c & 1.8 & (1.8) & 11.5 & $(6.7)$ & 26.2 & $(7.2)$ & 37.7 & (9.5) & 22.1 & (7.8) & 0.2 & c & 0.4 & c \\
\hline & Basilicata & 2.6 & $(3.1)$ & 12.1 & $(8.0)$ & 17.5 & (8.8) & 27.4 & $(10.5)$ & 26.2 & $(6.2)$ & 12.3 & $(4.0)$ & 0.0 & c & 1.8 & c \\
\hline & Bolzano & 0.0 & c & 1.2 & (1.5) & 7.1 & $(2.3)$ & 17.7 & (5.6) & 36.1 & $(5.0)$ & 28.6 & (8.6) & 8.4 & $(4.5)$ & 0.9 & c \\
\hline & Calabria & 1.9 & $(1.7)$ & 4.9 & (3.2) & 23.7 & $(10.2)$ & 28.8 & $(8.2)$ & 25.0 & $(8.0)$ & 14.5 & $(7.3)$ & 1.2 & c & 0.0 & c \\
\hline & Campania & 5.0 & $(2.8)$ & 11.2 & $(5.0)$ & 20.0 & (4.9) & 26.6 & (4.4) & 23.6 & (5.6) & 12.5 & $(4.0)$ & 1.0 & $(0.7)$ & 0.0 & c \\
\hline & Emilia Romagna & 1.5 & (1.9) & 3.3 & (3.0) & 6.4 & (2.7) & 23.0 & $(7.0)$ & 31.8 & $(5.0)$ & 26.6 & (8.5) & 6.9 & $(2.9)$ & 0.4 & c \\
\hline & Friuli Venezia Giulia & 2.9 & $(3.1)$ & 0.0 & c & 7.7 & (5.6) & 16.6 & $(4.7)$ & 31.0 & (8.4) & 31.3 & (7.0) & 8.9 & $(4.1)$ & 1.7 & c \\
\hline & Lazio & 0.0 & c & 4.5 & (3.6) & 18.9 & (5.0) & 27.0 & (3.3) & 31.6 & (6.5) & 14.8 & $(3.2)$ & 3.0 & (1.9) & 0.3 & c \\
\hline & Liguria & 1.0 & $(0.9)$ & 6.3 & (3.1) & 16.4 & (7.9) & 27.9 & (11.7) & 15.9 & (5.9) & 19.0 & (11.4) & 11.3 & (8.4) & 2.2 & c \\
\hline & Lombardia & 1.8 & (1.6) & 1.4 & $(0.7)$ & 9.3 & (2.9) & 24.1 & (3.7) & 33.2 & (3.7) & 25.2 & (3.9) & 4.8 & (1.4) & 0.2 & c \\
\hline & Marche & 0.0 & c & 3.9 & (3.1) & 14.6 & (6.8) & 18.7 & (6.5) & 41.0 & (8.3) & 18.7 & (6.7) & 2.0 & (1.8) & 1.0 & c \\
\hline & Molise & $\mathrm{C}$ & c & $\mathrm{C}$ & c & c & c & $\mathrm{C}$ & c & C & c & c & C & $\mathrm{C}$ & $\mathrm{C}$ & c & c \\
\hline & Piemonte & 1.6 & $(1.0)$ & 3.8 & $(2.1)$ & 10.7 & $(4.0)$ & 22.5 & (5.1) & 33.0 & (4.4) & 23.2 & (5.5) & 5.0 & (3.0) & 0.1 & C \\
\hline & Puglia & 1.0 & $(1.2)$ & 8.6 & (3.5) & 17.7 & (5.4) & 20.5 & (5.3) & 27.7 & (6.4) & 17.3 & (6.5) & 7.0 & (3.7) & 0.2 & c \\
\hline & Sardegna & $\mathrm{C}$ & c & $\mathrm{C}$ & c & c & c & C & c & c & c & c & c & c & c & c & $\mathrm{C}$ \\
\hline & Sicilia & 0.0 & c & 11.1 & (4.7) & 22.9 & (6.6) & 29.0 & (6.7) & 26.2 & (5.5) & 9.5 & (2.6) & 1.2 & $(1.0)$ & 0.2 & C \\
\hline & Toscana & 1.5 & (1.7) & 4.8 & (2.4) & 10.5 & (4.3) & 28.3 & (5.7) & 28.7 & (4.9) & 20.6 & (4.6) & 5.2 & $(2.3)$ & 0.3 & $\mathrm{C}$ \\
\hline & Trento & 0.0 & c & 3.4 & (3.7) & 9.6 & (5.9) & 21.9 & (3.4) & 33.9 & (6.8) & 26.3 & (7.5) & 3.9 & $(3.2)$ & 1.1 & c \\
\hline & Umbria & 3.1 & $(2.4)$ & 5.3 & $(4.1)$ & 11.0 & (6.4) & 15.3 & (6.6) & 43.0 & $(11.9)$ & 20.5 & $(8.1)$ & 1.7 & $(1.9)$ & 0.0 & c \\
\hline & Valle d'Aosta & 0.0 & c & 3.9 & (3.7) & 13.8 & (7.8) & 18.8 & $(7.1)$ & 35.6 & $(8.1)$ & 23.9 & $(10.0)$ & 3.9 & $(3.1)$ & 0.0 & c \\
\hline & Veneto & 2.3 & (1.1) & 5.0 & (2.1) & 12.9 & (5.0) & 19.8 & (3.4) & 27.2 & (6.0) & 24.1 & $(5.2)$ & 8.4 & (3.6) & 0.2 & c \\
\hline & Portugal & & & & & & & & & & & & & & & & \\
\hline & Alentejo & 0.8 & $(0.4)$ & 3.9 & (1.4) & 14.9 & (4.1) & 27.9 & (3.2) & 32.3 & (4.5) & 18.5 & (3.4) & 1.8 & (1.4) & 0.0 & c \\
\hline & Spain & & & & & & & & & & & & & & & & \\
\hline & Andalusia ${ }^{\bullet}$ & 2.7 & $(0.9)$ & 10.3 & $(2.7)$ & 20.3 & (2.6) & 31.1 & (2.9) & 23.5 & (3.1) & 10.4 & (2.0) & 1.6 & $(0.8)$ & 0.0 & c \\
\hline & Aragon • & 2.4 & (3.8) & 9.4 & (8.5) & 16.3 & (5.8) & 30.4 & $(4.8)$ & 25.2 & (10.4) & 14.4 & (7.6) & 1.8 & $(2.5)$ & 0.2 & c \\
\hline & Asturias ${ }^{\bullet}$ & c & c & c & c & c & c & c & c & c & c & c & c & c & c & c & c \\
\hline & Balearic Islands ${ }^{\bullet}$ & c & c & c & c & c & c & c & c & c & c & c & c & c & c & c & c \\
\hline & Basque Country ${ }^{\bullet}$ & 1.2 & $(0.5)$ & 4.4 & $(0.6)$ & 14.0 & (1.1) & 27.6 & (1.4) & 33.7 & (1.6) & 16.7 & (1.3) & 2.5 & $(0.5)$ & 0.0 & c \\
\hline & Cantabria • & c & c & c & c & c & c & c & c & c & c & c & c & c & c & c & c \\
\hline & Castile and Leon • & 4.0 & $(2.2)$ & 7.0 & (3.2) & 14.8 & (4.9) & 22.8 & (5.4) & 27.3 & (5.0) & 19.1 & (4.3) & 5.0 & $(2.7)$ & 0.0 & c \\
\hline & Catalonia ${ }^{\bullet}$ & 1.2 & $(0.6)$ & 5.7 & (1.7) & 15.2 & (2.0) & 26.6 & (2.6) & 30.7 & $(2.7)$ & 16.4 & (2.0) & 4.0 & (1.5) & 0.2 & c \\
\hline & Extremadura ${ }^{\bullet}$ & 5.1 & (1.5) & 10.5 & (5.4) & 29.9 & (9.0) & 27.6 & (12.1) & 19.1 & $(7.2)$ & 7.2 & (2.3) & 0.6 & c & 0.0 & c \\
\hline & Galicia• & 2.8 & $(2.1)$ & 5.1 & $(3.0)$ & 23.3 & $(4.7)$ & 26.8 & (4.5) & 25.1 & (3.7) & 12.7 & $(4.8)$ & 3.4 & $(2.2)$ & 0.8 & c \\
\hline & La Rioja• & c & c & c & c & c & c & c & c & c & c & c & c & c & c & c & c \\
\hline & Madrid ${ }^{\bullet}$ & 0.8 & $(0.6)$ & 3.7 & $(2.0)$ & 13.9 & $(4.2)$ & 30.0 & (4.5) & 32.1 & (4.3) & 16.4 & (3.4) & 3.0 & (1.3) & 0.0 & c \\
\hline & Murcia ${ }^{\bullet}$ & 0.0 & c & 11.9 & (3.3) & 24.2 & (7.6) & 31.9 & (6.9) & 21.3 & $(9.2)$ & 7.4 & (2.6) & 3.2 & c & 0.0 & c \\
\hline & Navarre ${ }^{\bullet}$ & $\mathrm{c}$ & $\mathrm{c}$ & $\mathrm{c}$ & $\mathrm{c}$ & $\mathrm{c}$ & $\mathrm{c}$ & $\mathrm{c}$ & $\mathrm{c}$ & $\mathrm{c}$ & $\mathrm{c}$ & c & $\mathrm{c}$ & $\mathrm{c}$ & $\mathrm{c}$ & c & $\mathrm{c}$ \\
\hline
\end{tabular}

- PISA adjudicated region.

Note: See Table B3.I.11 for national data.

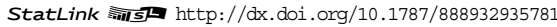




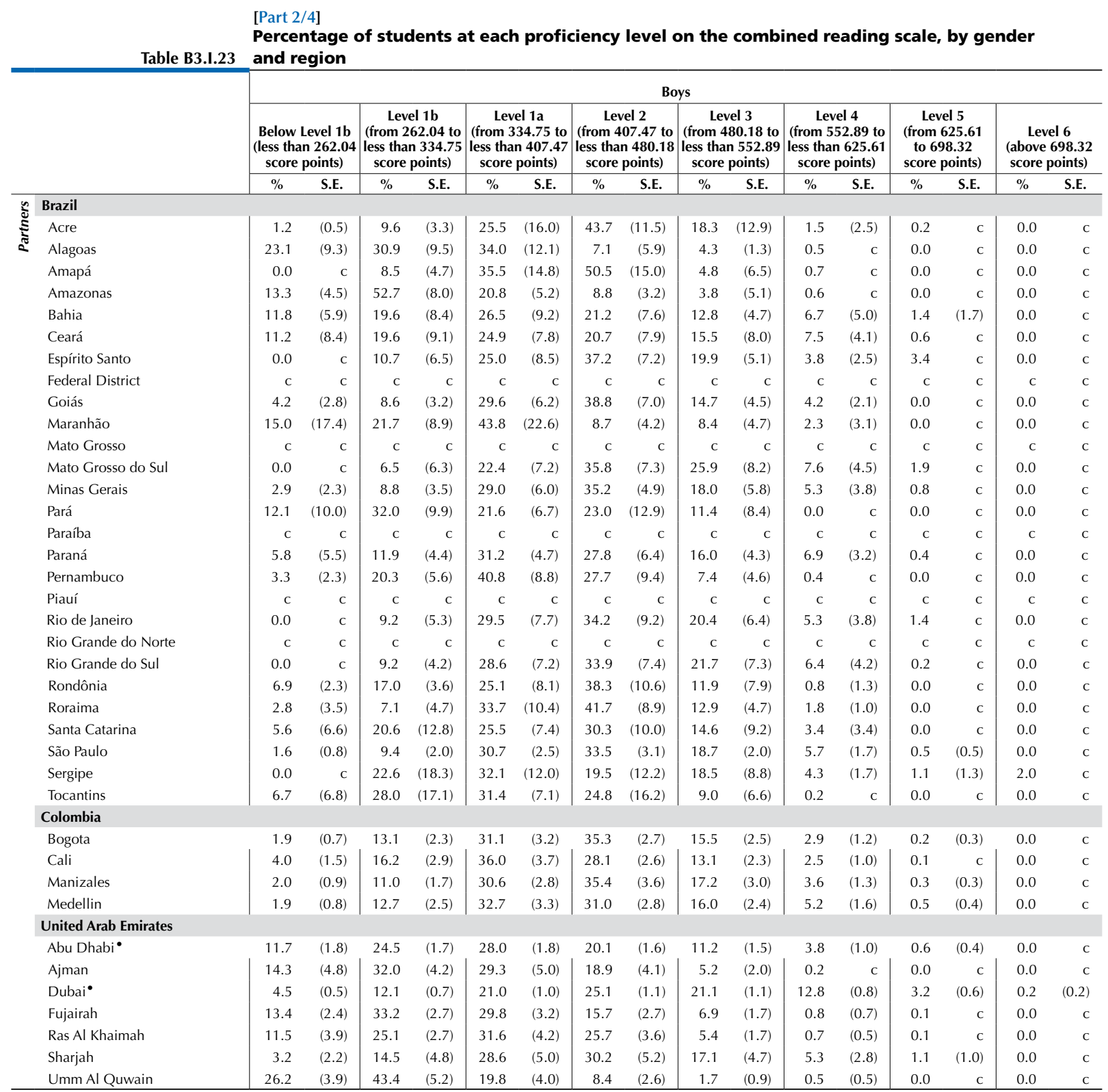

- PISA adjudicated region.

Note: See Table B3.I.11 for national data.

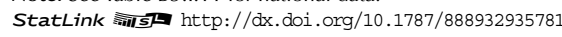


Part 3/4]

Percentage of students at each proficiency level on the combined reading scale, by gender Table B3.I.23 and region

\begin{tabular}{|c|c|c|c|c|c|c|c|c|c|c|c|c|c|c|c|c|c|}
\hline & & \multicolumn{16}{|c|}{ Girls } \\
\hline & & \multicolumn{2}{|c|}{$\begin{array}{c}\text { Below Level 1b } \\
\text { (less than } 262.04 \\
\text { score points) }\end{array}$} & \multicolumn{2}{|c|}{\begin{tabular}{|c|} 
Level $1 \mathrm{~b}$ \\
(from 262.04 to \\
less than 334.75 \\
score points)
\end{tabular}} & \multicolumn{2}{|c|}{\begin{tabular}{|c|} 
Level $1 \mathrm{a}$ \\
(from 334.75 to \\
less than 407.47 \\
score points)
\end{tabular}} & \multicolumn{2}{|c|}{\begin{tabular}{|c|} 
Level 2 \\
(from 407.47 to \\
less than 480.18 \\
score points)
\end{tabular}} & \multicolumn{2}{|c|}{\begin{tabular}{|c|} 
Level 3 \\
(from 480.18 to \\
less than 552.89 \\
score points)
\end{tabular}} & \multicolumn{2}{|c|}{\begin{tabular}{|c|} 
Level 4 \\
(from 552.89 to \\
less than 625.61 \\
score points)
\end{tabular}} & $\begin{array}{r}\text { Le } \\
\text { (from } \\
\text { to } 6 \\
\text { score }\end{array}$ & $\begin{array}{l}5 \\
25.61 \\
8.32 \\
\text { oints) }\end{array}$ & $\begin{array}{l}\text { Le } \\
\text { (abov } \\
\text { score }\end{array}$ & $\begin{array}{l}\text { el } 6 \\
698.32 \\
\text { oints) }\end{array}$ \\
\hline & & $\%$ & S.E. & $\%$ & S.E. & $\%$ & S.E. & $\%$ & S.E. & $\%$ & S.E. & $\%$ & S.E. & $\%$ & S.E. & $\%$ & S.E. \\
\hline 9 & Australia & & & & & & & & & & & & & & & & \\
\hline$y$ & Australian Capital Territory & 0.4 & $(0.4)$ & 1.4 & $(0.6)$ & 3.6 & $(1.2)$ & 11.9 & (1.9) & 28.7 & (3.0) & 34.6 & (3.0) & 17.6 & $(2.5)$ & 1.9 & $(0.9)$ \\
\hline & New South Wales & 0.1 & $(0.1)$ & 1.3 & $(0.4)$ & 5.2 & $(0.8)$ & 17.9 & (1.3) & 30.6 & (1.7) & 28.2 & (1.5) & 14.0 & $(1.4)$ & 2.7 & $(0.7)$ \\
\hline & Northern Territory & 6.0 & (1.8) & 4.9 & (1.7) & 9.0 & $(2.6)$ & 20.4 & $(4.2)$ & 27.0 & (4.1) & 25.2 & $(5.2)$ & 7.3 & $(4.0)$ & 0.2 & C \\
\hline & Queensland & 0.2 & $(0.1)$ & 1.2 & $(0.4)$ & 7.0 & $(1.1)$ & 20.8 & (1.5) & 31.3 & (1.7) & 26.7 & (1.9) & 10.7 & $(1.4)$ & 2.2 & $(0.7)$ \\
\hline & South Australia & 0.3 & $(0.2)$ & 2.3 & $(0.7)$ & 7.3 & (1.3) & 21.8 & (1.9) & 30.1 & (2.1) & 26.9 & $(2.7)$ & 10.3 & (1.6) & 1.1 & $(0.6)$ \\
\hline & Tasmania & 1.1 & $(0.6)$ & 3.9 & (1.1) & 10.8 & $(1.7)$ & 25.1 & (2.4) & 29.4 & (3.2) & 20.8 & (2.9) & 7.9 & (1.8) & 0.9 & $(0.5)$ \\
\hline & Victoria & 0.3 & $(0.1)$ & 1.0 & (0.5) & 5.6 & $(1.2)$ & 17.0 & (2.0) & 32.7 & $(2.2)$ & 29.0 & (1.9) & 12.7 & $(1.7)$ & 1.7 & $(0.5)$ \\
\hline & Western Australia & 0.5 & $(0.3)$ & 1.3 & (0.6) & 7.1 & $(1.2)$ & 18.2 & (1.6) & 30.5 & (2.3) & 27.1 & (2.6) & 13.1 & $(2.1)$ & 2.2 & $(0.7)$ \\
\hline & Belgium & & & & & & & & & & & & & & & & \\
\hline & Flemish community ${ }^{\bullet}$ & 0.4 & $(0.2)$ & 2.4 & $(0.7)$ & 7.7 & (1.1) & 17.0 & (1.3) & 28.0 & (1.6) & 31.4 & (1.6) & 11.9 & $(1.0)$ & 1.2 & $(0.3)$ \\
\hline & French community & 0.6 & $(0.2)$ & 3.1 & $(0.7)$ & 9.8 & $(1.1)$ & 22.6 & (1.3) & 31.3 & (1.5) & 25.1 & (1.7) & 7.1 & $(1.1)$ & 0.4 & $(0.3)$ \\
\hline & German-speaking community & 0.2 & $\mathrm{c}$ & 1.4 & $(0.8)$ & 4.9 & $(1.2)$ & 16.1 & (2.0) & 35.8 & (3.2) & 32.5 & (2.9) & 8.7 & (1.6) & 0.4 & $(0.3)$ \\
\hline & Canada & & & & & & & & & & & & & & & & \\
\hline & Alberta & 0.0 & c & 0.6 & $(0.5)$ & 4.3 & $(1.1)$ & 17.3 & $(2.2)$ & 31.5 & (1.9) & 31.3 & $(2.0)$ & 13.4 & $(1.6)$ & 1.6 & $(0.6)$ \\
\hline & British Columbia & 0.0 & c & 0.1 & $(0.2)$ & 4.1 & $(0.8)$ & 13.4 & (1.3) & 31.7 & $(2.0)$ & 33.9 & (2.4) & 14.1 & (1.8) & 2.6 & $(0.7)$ \\
\hline & Manitoba & 0.0 & c & 1.3 & $(0.6)$ & 6.6 & (1.4) & 23.7 & (1.9) & 32.8 & (2.0) & 27.1 & (1.9) & 7.8 & $(1.2)$ & 0.6 & $(0.3)$ \\
\hline & New Brunswick & 0.0 & c & 1.0 & $(0.4)$ & 5.6 & $(0.9)$ & 20.0 & $(2.2)$ & 37.8 & (3.6) & 26.4 & (2.8) & 8.3 & (1.6) & 0.9 & $(0.9)$ \\
\hline & Newfoundland and Labrador & 0.0 & c & 0.6 & $(0.3)$ & 5.7 & (1.5) & 19.6 & $(2.2)$ & 35.4 & (3.1) & 27.0 & $(2.2)$ & 10.1 & (1.6) & 1.6 & $(0.6)$ \\
\hline & Nova Scotia & 0.0 & c & 1.0 & $(0.4)$ & 3.8 & $(1.0)$ & 17.1 & (2.8) & 36.8 & (3.6) & 29.7 & $(2.1)$ & 10.7 & $(1.5)$ & 0.9 & $(0.4)$ \\
\hline & Ontario & 0.0 & $(0.0)$ & 0.6 & $(0.4)$ & 3.7 & $(0.7)$ & 13.9 & (1.3) & 32.4 & $(2.2)$ & 34.1 & (2.1) & 13.1 & (1.4) & 2.2 & $(0.6)$ \\
\hline & Prince Edward Island & 0.0 & c & 1.1 & $(0.5)$ & 7.9 & (1.3) & 25.5 & (1.8) & 38.6 & $(2.2)$ & 21.0 & (2.1) & 5.1 & $(0.9)$ & 0.8 & $(0.6)$ \\
\hline & Quebec & 0.5 & $(0.2)$ & 1.0 & $(0.3)$ & 4.8 & $(0.9)$ & 16.1 & (1.4) & 33.9 & (1.7) & 32.6 & (1.8) & 10.3 & (1.4) & 0.8 & $(0.3)$ \\
\hline & Saskatchewan & 0.0 & c & 0.6 & (0.6) & 5.0 & $(1.0)$ & 20.9 & (1.8) & 37.6 & (2.4) & 26.4 & $(2.2)$ & 8.9 & (1.3) & 0.6 & $(0.5)$ \\
\hline & Italy & & & & & & & & & & & & & & & & \\
\hline & Abruzzo & 0.0 & c & 0.0 & c & 3.9 & (2.6) & 21.7 & (7.9) & 48.0 & $(7.2)$ & 25.5 & $(9.7)$ & 0.9 & c & 0.0 & c \\
\hline & Basilicata & 0.0 & c & 0.0 & c & 13.8 & $(4.9)$ & 39.6 & $(12.3)$ & 37.8 & (8.5) & 7.4 & $(7.8)$ & 1.4 & c & 0.0 & c \\
\hline & Bolzano & 0.0 & c & 0.0 & c & 4.0 & $(2.7)$ & 16.5 & $(4.0)$ & 44.1 & (5.0) & 28.4 & $(4.7)$ & 6.4 & (3.4) & 0.6 & c \\
\hline & Calabria & 1.5 & (1.5) & 4.0 & (3.5) & 8.4 & $(4.5)$ & 29.3 & (10.5) & 37.6 & (6.7) & 18.9 & (14.2) & 0.3 & c & 0.0 & c \\
\hline & Campania & 2.2 & (1.8) & 4.6 & (3.1) & 11.9 & $(4.1)$ & 30.8 & $(4.2)$ & 35.2 & (6.3) & 14.0 & (3.7) & 1.3 & $(1.2)$ & 0.0 & c \\
\hline & Emilia Romagna & 0.0 & c & 0.6 & $(0.8)$ & 7.9 & (3.7) & 23.8 & $(5.2)$ & 39.2 & $(4.0)$ & 22.3 & (5.0) & 6.1 & (1.9) & 0.0 & c \\
\hline & Friuli Venezia Giulia & 0.0 & c & 0.4 & $(0.5)$ & 3.5 & (1.7) & 10.8 & $(4.2)$ & 21.1 & (6.4) & 42.3 & (8.5) & 20.1 & (3.8) & 1.8 & $(2.0)$ \\
\hline & Lazio & 0.0 & c & 0.0 & c & 5.9 & $(3.0)$ & 20.6 & $(6.1)$ & 32.2 & (7.3) & 29.6 & $(7.0)$ & 10.1 & (5.5) & 1.6 & C \\
\hline & Liguria & 0.0 & C & 2.2 & (2.0) & 16.4 & $(9.0)$ & 24.8 & (12.0) & 17.0 & (8.9) & 24.9 & (12.7) & 10.9 & (9.5) & 3.8 & C \\
\hline & Lombardia & 0.0 & c & 0.0 & c & 1.5 & $(0.7)$ & 12.3 & (2.8) & 36.9 & (5.4) & 39.4 & $(4.7)$ & 9.3 & (2.9) & 0.6 & c \\
\hline & Marche & 0.0 & c & 3.2 & (3.4) & 14.6 & (9.6) & 18.2 & (11.2) & 26.3 & (5.8) & 32.4 & (17.5) & 5.5 & (4.6) & 0.0 & c \\
\hline & Molise & c & c & c & c & c & c & c & c & c & c & c & c & c & c & c & c \\
\hline & Piemonte & 0.0 & c & 1.0 & (0.9) & 9.6 & (4.1) & 19.4 & $(4.2)$ & 34.3 & (4.8) & 28.8 & (5.6) & 6.8 & (3.8) & 0.0 & c \\
\hline & Puglia & 0.0 & c & 5.1 & (5.1) & 14.9 & (5.1) & 22.3 & (4.3) & 27.5 & (5.5) & 22.6 & (4.0) & 6.4 & (2.4) & 1.1 & c \\
\hline & Sardegna & c & c & c & c & c & c & c & c & c & c & c & c & c & c & c & c \\
\hline & Sicilia & 0.0 & c & 0.0 & c & 15.3 & (6.8) & 32.5 & (5.9) & 32.9 & (7.8) & 16.4 & (6.0) & 2.3 & (2.4) & 0.6 & c \\
\hline & Toscana & 0.0 & c & 2.2 & (1.8) & 9.0 & (2.8) & 20.1 & (5.9) & 35.9 & (6.4) & 27.7 & $(7.0)$ & 5.0 & (2.9) & 0.1 & c \\
\hline & Trento & 0.0 & c & 2.4 & (2.3) & 2.2 & $(2.2)$ & 12.5 & (4.3) & 31.8 & (10.5) & 34.5 & (8.1) & 15.2 & $(5.0)$ & 1.4 & c \\
\hline & Umbria & 0.0 & c & 1.7 & (1.2) & 5.0 & (3.0) & 22.1 & (7.9) & 34.4 & (5.4) & 32.4 & (9.5) & 4.0 & $(4.1)$ & 0.4 & c \\
\hline & Valle d'Aosta & 0.0 & c & 0.0 & c & 6.3 & (4.6) & 16.4 & (9.8) & 41.0 & (5.7) & 32.4 & (9.6) & 2.7 & (2.6) & 1.2 & c \\
\hline & Veneto & 0.7 & $(0.8)$ & 1.4 & (1.4) & 5.3 & $(2.1)$ & 15.9 & (6.3) & 34.6 & (7.6) & 30.9 & (7.1) & 9.8 & (4.8) & 1.4 & (1.5) \\
\hline & Portugal & & & & & & & & & & & & & & & & \\
\hline & Alentejo & 0.0 & c & 1.7 & $(1.0)$ & 8.4 & (2.6) & 24.6 & (3.6) & 40.1 & (4.6) & 22.2 & (4.0) & 2.8 & (1.1) & 0.3 & c \\
\hline & Spain & & & & & & & & & & & & & & & & \\
\hline & Andalusia ${ }^{\bullet}$ & 0.5 & $(0.4)$ & 3.9 & (1.4) & 16.8 & $(2.4)$ & 33.9 & (3.0) & 31.2 & (2.9) & 12.0 & (2.1) & 1.6 & $(0.7)$ & 0.1 & c \\
\hline & Aragon $\bullet$ & 0.0 & c & 5.7 & (9.1) & 9.3 & $(4.2)$ & 16.7 & (4.9) & 44.2 & (10.1) & 19.0 & $(7.2)$ & 4.1 & $(2.4)$ & 1.0 & C \\
\hline & Asturias ${ }^{\bullet}$ & c & c & c & c & c & c & c & c & c & c & c & c & c & c & c & c \\
\hline & Balearic Islands ${ }^{\bullet}$ & c & c & c & c & c & c & c & c & c & c & c & c & c & c & c & c \\
\hline & Basque Country ${ }^{\bullet}$ & 0.5 & $(0.2)$ & 2.0 & $(0.5)$ & 7.4 & $(0.8)$ & 24.0 & (1.5) & 38.1 & (1.2) & 24.0 & (1.6) & 3.9 & $(0.6)$ & 0.2 & $(0.2)$ \\
\hline & Cantabria ${ }^{\bullet}$ & c & c & c & c & c & c & c & c & c & c & c & c & c & c & c & c \\
\hline & Castile and Leon ${ }^{\bullet}$ & 0.0 & c & 1.1 & $(0.7)$ & 8.2 & (3.1) & 21.6 & (5.1) & 38.0 & (5.0) & 27.8 & (5.5) & 3.2 & (1.6) & 0.2 & c \\
\hline & Catalonia ${ }^{\bullet}$ & 0.0 & c & 2.1 & $(0.8)$ & 9.2 & (1.7) & 26.3 & (2.8) & 33.6 & (3.0) & 24.0 & (2.5) & 4.4 & $(1.2)$ & 0.4 & $(0.3)$ \\
\hline & Extremadura ${ }^{\bullet}$ & 1.7 & $(2.7)$ & 6.9 & (5.3) & 16.9 & $(6.2)$ & 30.4 & (8.5) & 29.8 & $(4.7)$ & 12.6 & (5.2) & 1.8 & c & 0.0 & c \\
\hline & Galicia $\bullet$ & 0.0 & c & 1.4 & (1.2) & 7.5 & (3.8) & 20.5 & (6.4) & 38.0 & (6.5) & 28.3 & (6.9) & 3.6 & $(2.0)$ & 0.7 & c \\
\hline & La Rioja• & c & c & c & c & c & c & c & c & c & c & c & c & c & c & c & C \\
\hline & Madrid ${ }^{\bullet}$ & 0.0 & c & 2.3 & (1.0) & 8.7 & (1.8) & 22.7 & (2.6) & 37.8 & (3.7) & 22.7 & (3.3) & 5.4 & $(2.3)$ & 0.4 & $(0.4)$ \\
\hline & Murcia ${ }^{\bullet}$ & 0.0 & c & 6.0 & (3.4) & 20.0 & (6.0) & 29.7 & (7.9) & 20.4 & (6.7) & 19.2 & (4.4) & 4.8 & c & 0.0 & c \\
\hline & Navarre ${ }^{\bullet}$ & c & $\mathrm{c}$ & c & c & c & C & $\mathrm{c}$ & c & c & c & c & c & c & $\mathrm{c}$ & c & c \\
\hline
\end{tabular}

- PISA adjudicated region.

Note: See Table B3.I.11 for national data.

StatLink 䨛 SD http://dx.doi.org/10.1787/888932935781 


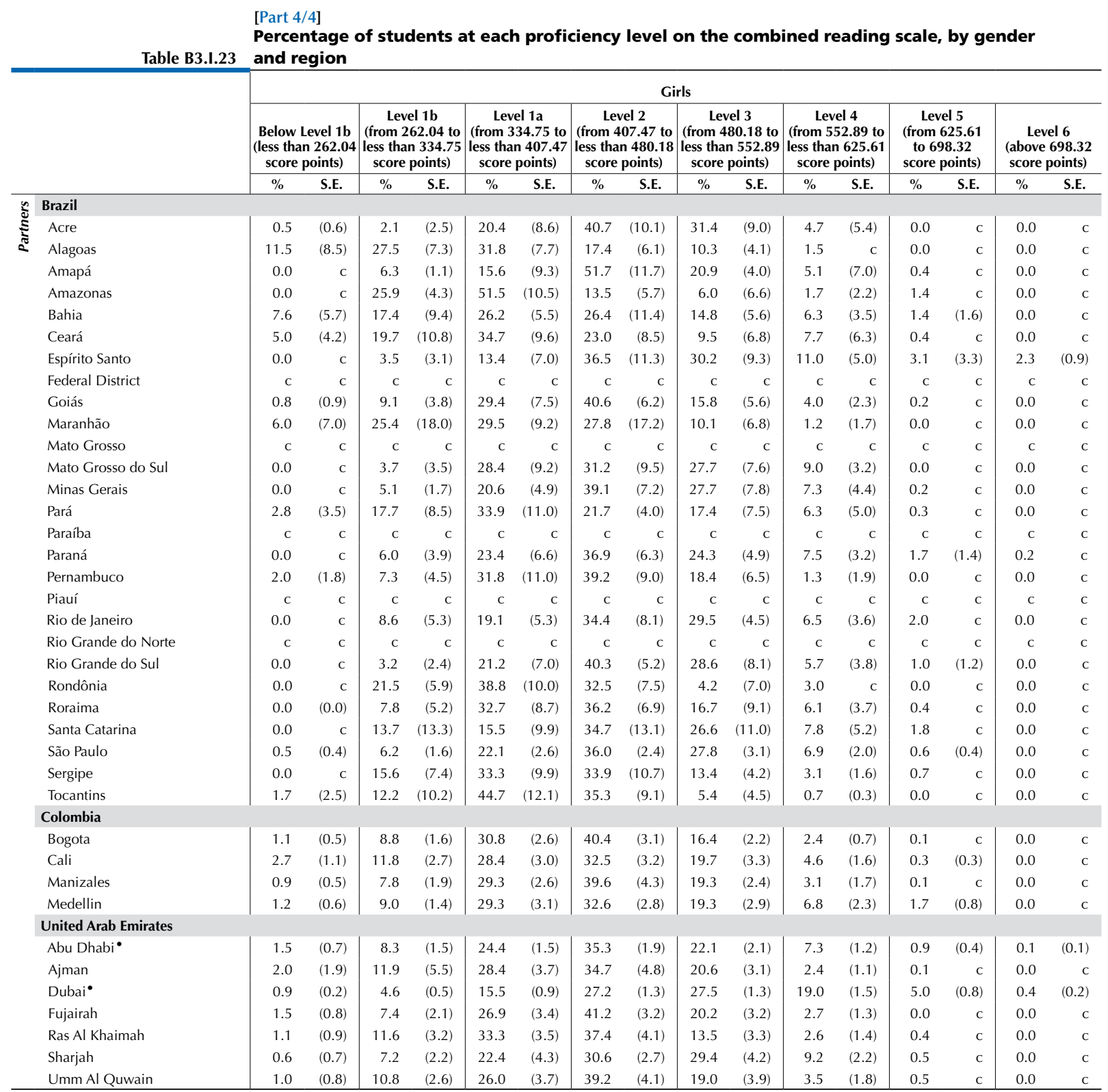

- PISA adjudicated region.

Note: See Table B3.I.11 for national data.

StatLink 青市D http://dx.doi.org/10.1787/888932935781 
[Part 1/2]

Mean score, variation and gender differences in student performance on the combined reading scale, Table B3.I.24 by region

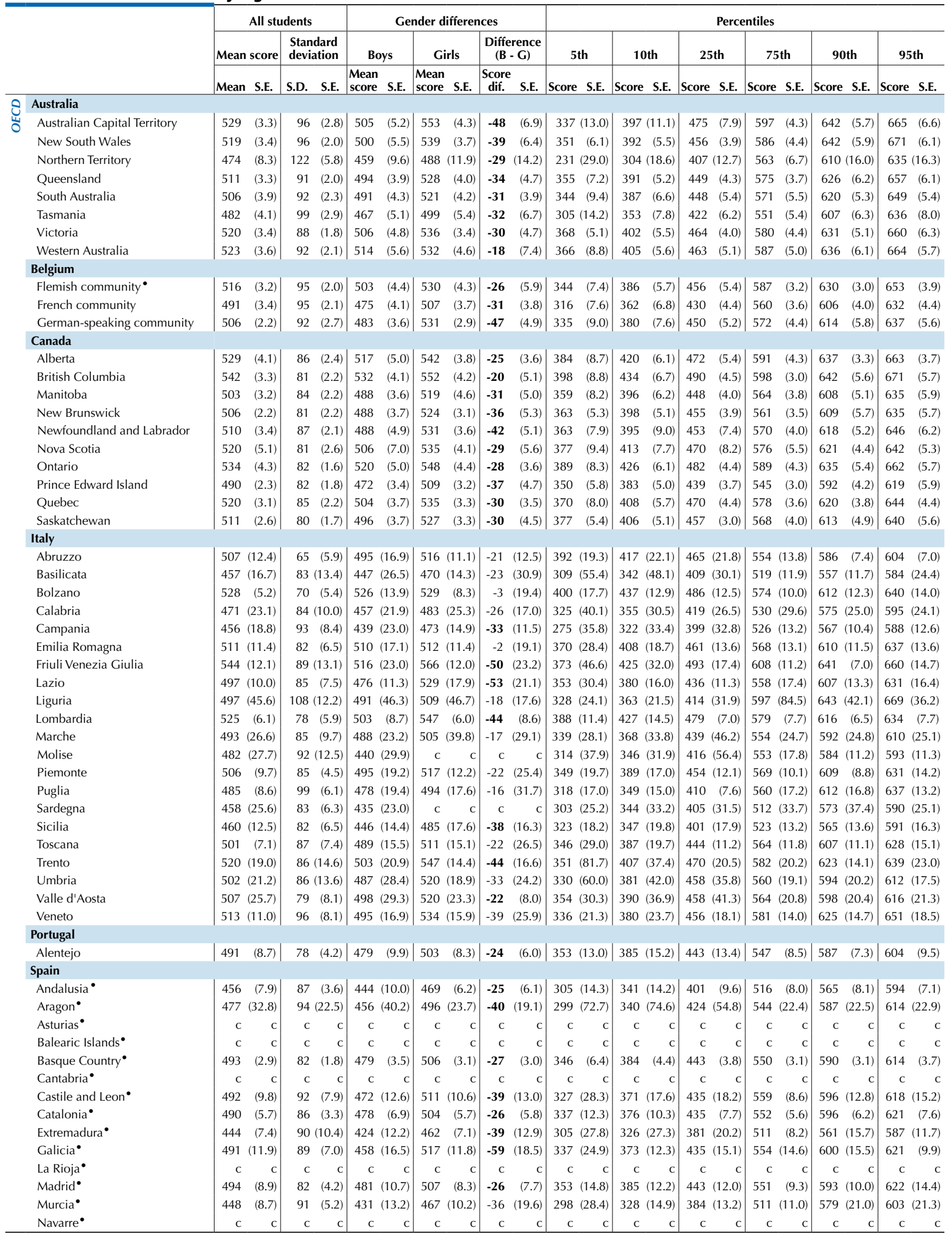

- PISA adjudicated region.

Notes: Values that are statistically significant are indicated in bold (see Annex A3).

See Table B3.I.12 for national data.

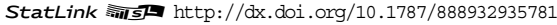


[Part 2/2]

Mean score, variation and gender differences in student performance on the combined reading scale, Table B3.I.24 by region

\begin{tabular}{|c|c|c|c|c|c|c|c|c|c|c|c|c|c|c|c|c|c|c|c|c|c|c|c|}
\hline & & \multicolumn{4}{|c|}{ All students } & \multicolumn{6}{|c|}{ Gender differences } & \multicolumn{12}{|c|}{ Percentiles } \\
\hline & & \multicolumn{2}{|c|}{ Mean score } & \multicolumn{2}{|c|}{$\begin{array}{l}\text { Standard } \\
\text { deviation }\end{array}$} & \multicolumn{2}{|c|}{ Boys } & \multicolumn{2}{|c|}{ Girls } & \multicolumn{2}{|c|}{$\begin{array}{c}\text { Difference } \\
\text { (B - G) }\end{array}$} & \multicolumn{2}{|c|}{ 5th } & \multicolumn{2}{|c|}{ 10th } & \multicolumn{2}{|c|}{ 25th } & \multicolumn{2}{|c|}{ 75th } & \multicolumn{2}{|c|}{ 90th } & \multicolumn{2}{|c|}{ 95th } \\
\hline & & Mean & S.E. & S.D. & S.E. & $\begin{array}{l}\text { Mean } \\
\text { score }\end{array}$ & S.E. & $\begin{array}{l}\text { Mean } \\
\text { score }\end{array}$ & S.E. & \begin{tabular}{|c|} 
Score \\
dif.
\end{tabular} & S.E. & Score & S.E. & Score & S.E. & Score & S.E. & Score & e S.E. & Score & e S.E. & Score & S.E. \\
\hline \multirow{41}{*}{ 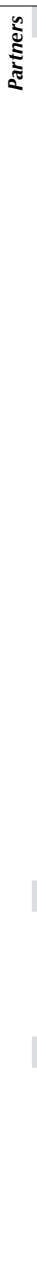 } & Brazil & & & & & & & & & & & & & & & & & & & & & & \\
\hline & Acre & 443 & (19.7) & 66 & (4.8) & 424 & (21.3) & 456 & (20.9) & -32 & (10.9) & 330 & (10.1) & 361 & (18.8) & 403 & (23.4) & 491 & $(27.7)$ & 530 & (35.3) & 549 & (27.6) \\
\hline & Alagoas & 345 & (14.4) & 86 & (5.9) & 323 & (17.2) & 366 & (11.0) & -43 & (15.1) & 219 & (23.1) & 240 & (30.4) & 286 & (24.5) & 395 & (18.5) & 470 & (13.7) & 504 & (9.9) \\
\hline & Amapá & 428 & (10.9) & 61 & (10.9) & 408 & (11.2) & 445 & (14.6) & -36 & (13.5) & 321 & (30.7) & 350 & (26.8) & 394 & (13.6) & 462 & (20.3) & 517 & (41.4) & 538 & (32.1) \\
\hline & Amazonas & 347 & (16.6) & 73 & (11.0) & 326 & (17.9) & 375 & (16.1) & -49 & $(10.2)$ & 213 & (64.8) & 272 & (15.4) & 303 & (9.9) & 382 & (32.1) & 441 & (61.4) & 492 & $(63.2)$ \\
\hline & Bahia & 397 & (22.9) & 106 & (15.6) & 388 & (23.1) & 405 & (23.4) & -17 & (11.5) & 234 & (33.0) & 269 & (39.3) & 327 & (35.0) & 466 & (24.0) & 539 & (28.9) & 575 & (39.1) \\
\hline & Ceará & 395 & (33.0) & 101 & (13.3) & 394 & (35.9) & 396 & (32.1) & -2 & (16.7) & 230 & (47.9) & 273 & (36.3) & 327 & (33.1) & 463 & (48.6) & 537 & $(45.2)$ & 574 & (28.5) \\
\hline & Espírito Santo & 448 & (16.4) & 83 & (12.4) & 427 & (13.6) & 470 & (21.9) & -44 & (17.8) & 302 & (52.5) & 343 & (30.8) & 396 & (18.6) & 499 & (16.5) & 550 & (28.8) & 584 & $(54.0)$ \\
\hline & Federal District & c & & c & & c & & c & & c & c & c & & c & $\mathrm{c}$ & c & c & c & c & c & C & c & C \\
\hline & Goiás & 422 & $(6.7)$ & 74 & (3.2) & 419 & (6.0) & 425 & (10.0) & -7 & (9.6) & 291 & (24.3) & 328 & (14.0) & 378 & (10.4) & 466 & (5.6) & 517 & (13.1) & 546 & (16.2) \\
\hline & Maranhão & 366 & (36.9) & 87 & (19.7) & 350 & (34.5) & 380 & (40.0) & -30 & (14.0) & 220 & (58.9) & 258 & (58.5) & 312 & (52.7) & 421 & (41.2) & 486 & $(37.5)$ & 506 & (34.9) \\
\hline & Mato Grosso & c & & c & c & c & & c & & c & c & c & c & c & $\mathrm{c}$ & c & c & c & c & c & c & c & c \\
\hline & Mato Grosso do Sul & 447 & (16.5) & 76 & (9.7) & 445 & (19.9) & 450 & (14.3) & -5 & (9.0) & 325 & (42.8) & 352 & (29.1) & 398 & (25.7) & 500 & (11.7) & 545 & $(12.2)$ & 574 & (19.6) \\
\hline & Minas Gerais & 439 & (14.3) & 76 & (5.5) & 426 & (17.4) & 451 & (11.6) & -25 & (7.5) & 315 & (19.5) & 344 & (12.7) & 390 & (15.3) & 493 & (20.9) & 539 & $(21.6)$ & 562 & $(24.0)$ \\
\hline & Pará & 389 & (26.7) & 90 & $(14.7)$ & 361 & (32.3) & 410 & (23.5) & -49 & (31.4) & 257 & (28.4) & 277 & (29.8) & 320 & (37.9) & 450 & $(44.7)$ & 517 & (33.6) & 541 & (33.5) \\
\hline & Paraíba & c & & c & c & c & c & c & c & c & & c & c & c & c & c & 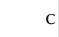 & c & c & c & c & c & c \\
\hline & Paraná & 432 & (14.3) & 87 & (10.9) & 413 & (18.7) & 450 & $(11.2)$ & -36 & (14.4) & 285 & (43.9) & 322 & $(38.2)$ & 375 & (15.9) & 491 & (14.7) & 546 & $(20.1)$ & 576 & $(24.5)$ \\
\hline & Pernambuco & 403 & (11.6) & 70 & (8.6) & 385 & (10.7) & 419 & (13.2) & -34 & (8.8) & 289 & (24.8) & 312 & (22.5) & 355 & (16.3) & 449 & (15.7) & 498 & (17.9) & 517 & $(24.8)$ \\
\hline & Piauí & c & & c & c & c & c & c & & c & & C & & c & $\mathrm{c}$ & c & & c & c & c & c & c & C \\
\hline & Rio de Janeiro & 438 & $(10.0)$ & 79 & (8.7) & 427 & (8.9) & 448 & (11.8) & -21 & $(7.2)$ & 301 & (30.3) & 335 & $(24.5)$ & 379 & (18.8) & 495 & (15.4) & 541 & (5.9) & 559 & $(14.0)$ \\
\hline & Rio Grande do Norte & c & & c & c & c & & c & & c & c & c & & c & c & c & & c & c & c & & c & c \\
\hline & Rio Grande do Sul & 446 & (12.0) & 71 & (6.9) & 433 & (12.0) & 456 & (12.0) & -23 & $(4.2)$ & 327 & (13.9) & 352 & (13.3) & 396 & (11.5) & 498 & (16.2) & 539 & (20.8) & 565 & $(27.9)$ \\
\hline & Rondônia & 389 & (12.7) & 71 & (4.6) & 395 & (10.1) & 384 & (17.9) & 11 & (16.5) & 265 & (38.8) & 292 & (16.3) & 338 & (15.1) & 438 & (16.2) & 473 & (28.5) & 503 & (40.8) \\
\hline & Roraima & 422 & (8.8) & 72 & (5.2) & 415 & (7.8) & 429 & (15.1) & -14 & (16.5) & 311 & (16.0) & 340 & (10.7) & 372 & (13.6) & 469 & (17.9) & 518 & $(21.4)$ & 549 & (25.6) \\
\hline & Santa Catarina & 419 & (31.1) & 87 & (14.0) & 399 & (30.3) & 440 & (31.7) & -42 & (8.1) & 262 & (35.6) & 295 & (44.8) & 354 & (55.4) & 483 & (33.8) & 530 & $(29.0)$ & 554 & (28.6) \\
\hline & São Paulo & 438 & (5.5) & 77 & (2.9) & 427 & (6.0) & 450 & (6.0) & -23 & $(5.2)$ & 314 & (8.6) & 340 & (7.4) & 385 & (5.4) & 492 & (7.9) & 537 & $(10.2)$ & 565 & $(10.2)$ \\
\hline & Sergipe & 409 & (13.8) & 81 & (9.3) & 404 & (25.6) & 413 & (11.4) & -9 & (24.5) & 292 & (21.6) & 307 & (25.0) & 347 & (24.9) & 467 & (16.7) & 522 & (11.2) & 546 & (12.5) \\
\hline & Tocantins & 386 & (22.7) & 69 & (7.0) & 376 & $(40.4)$ & 395 & (8.5) & -18 & (33.7) & 265 & (30.8) & 290 & (39.8) & 339 & (38.3) & 435 & (23.4) & 469 & (15.7) & 500 & (29.6) \\
\hline & Colombia & & & & & & & & & & & & & & & & & & & & & & \\
\hline & Bogota & 419 & (5.4) & 71 & (2.1) & 415 & (6.6) & 422 & (5.3) & -8 & (4.8) & 300 & (9.8) & 325 & (7.2) & 371 & (6.5) & 466 & (5.3) & 507 & (6.5) & 534 & (8.6) \\
\hline & Cali & 412 & (7.8) & 81 & (3.0) & 398 & (7.0) & 422 & (8.8) & -24 & (5.2) & 279 & (11.3) & 309 & (10.3) & 357 & (8.2) & 468 & (8.8) & 516 & (9.6) & 544 & (9.6) \\
\hline & Manizales & 424 & (4.0) & 72 & (3.4) & 420 & (5.6) & 428 & (3.8) & -8 & (5.4) & 305 & (8.3) & 332 & (6.2) & 376 & (6.6) & 472 & (5.5) & 518 & (7.0) & 541 & (10.3) \\
\hline & Medellin & 426 & (6.6) & 82 & (3.6) & 417 & (7.1) & 434 & (7.6) & -17 & (6.8) & 299 & (7.8) & 325 & (8.1) & 369 & (5.8) & 480 & (10.1) & 536 & (12.4) & 568 & (13.6) \\
\hline & United Arab Emirates & & & & & & & & & & & & & & & & & & & & & & \\
\hline & Abu Dhabi• & 408 & (5.3) & 96 & (2.9) & 376 & $(6.7)$ & 439 & (5.9) & -63 & (8.0) & 249 & (8.0) & 282 & (5.9) & 342 & (5.7) & 475 & (5.8) & 531 & (7.5) & 564 & (8.7) \\
\hline & Ajman & 386 & $(10.2)$ & 86 & $(4.7)$ & 348 & (11.8) & 421 & (13.4) & -73 & (17.6) & 242 & $(16.2)$ & 273 & (13.0) & 324 & (12.1) & 449 & $(10.5)$ & 499 & $(10.3)$ & 522 & (7.4) \\
\hline & Dubai $\bullet$ & 462 & (1.2) & 101 & (1.0) & 442 & (1.7) & 483 & (1.5) & -42 & (2.3) & 289 & (2.9) & 328 & $(2.2)$ & 393 & (2.3) & 536 & (2.9) & 591 & (3.9) & 622 & (3.0) \\
\hline & Fujairah & 389 & (9.9) & 87 & (3.3) & 350 & (6.1) & 429 & (8.4) & -79 & (8.9) & 245 & (10.8) & 273 & (9.0) & 325 & (11.8) & 453 & (10.6) & 499 & $(10.1)$ & 525 & $(11.3)$ \\
\hline & Ras Al Khaimah & 389 & (5.9) & 79 & (4.4) & 363 & (9.3) & 414 & (8.4) & -51 & $(11.2)$ & 255 & (13.5) & 284 & (10.9) & 336 & (8.1) & 444 & (5.7) & 486 & (7.8) & 511 & (7.7) \\
\hline & Sharjah & 437 & (8.5) & 85 & (4.4) & 418 & (16.9) & 452 & $(10.2)$ & -34 & (20.6) & 297 & (14.1) & 325 & (12.4) & 377 & (9.9) & 498 & (8.7) & 545 & (8.8) & 572 & (10.6) \\
\hline & Umm Al Quwain & 368 & (3.8) & 95 & (3.3) & 309 & (5.1) & 426 & (5.0) & -117 & (6.7) & 219 & (11.8) & 250 & (12.5) & 296 & (8.7) & 439 & (7.0) & 491 & (9.2) & 524 & $(14.0)$ \\
\hline
\end{tabular}

- PISA adjudicated region.

Notes: Values that are statistically significant are indicated in bold (see Annex A3).

See Table B3.I.12 for national data.

StatLink 部 
ANNEX B4

TRENDS IN MATHEMATICS, READING AND SCIENCE PERFORMANCE

- Figure B4.1 [Part 1/9] -

Trends in mathematics, reading and science performance: OECD countries

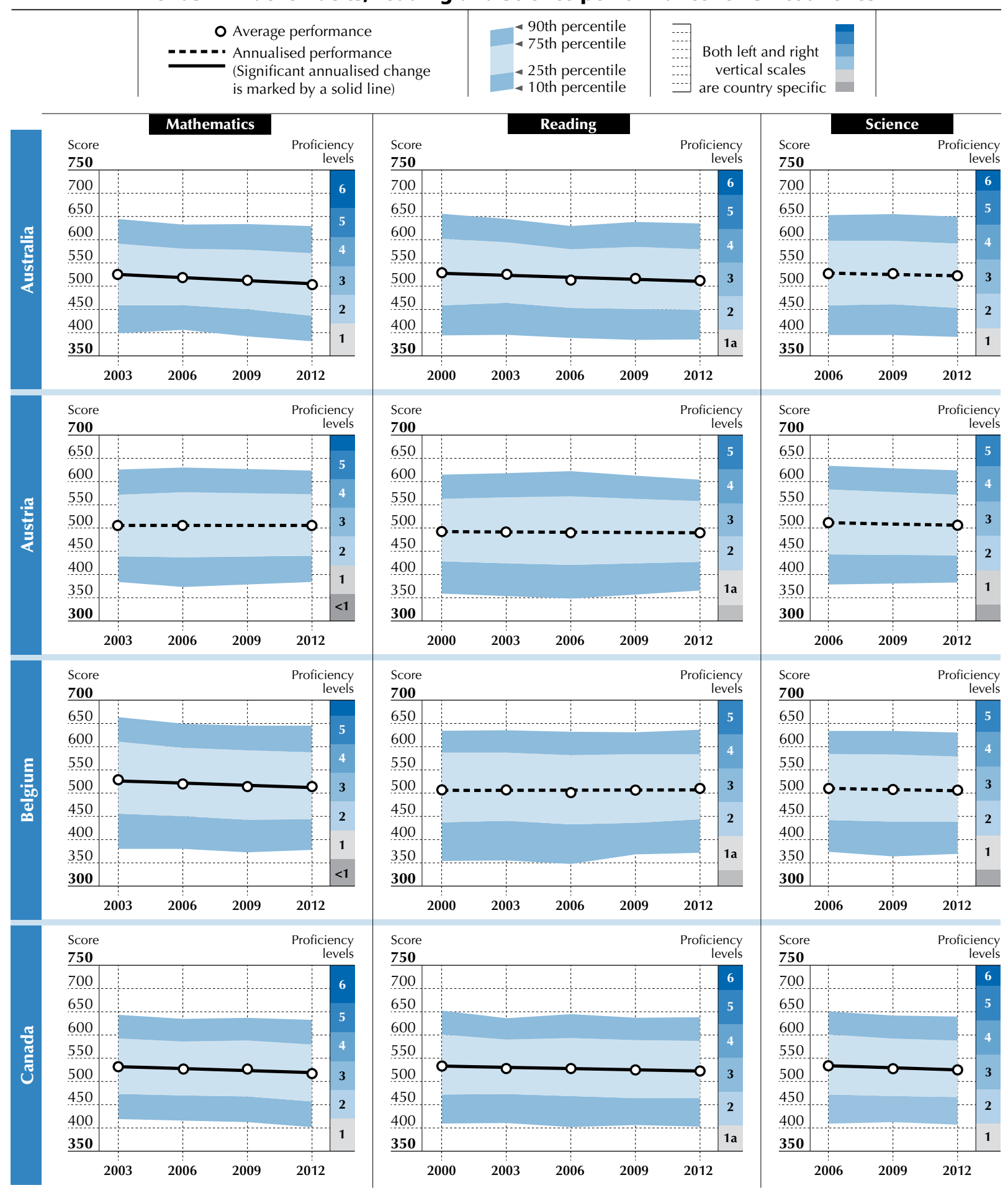

Notes: The slope of the annualised performance is the annualised change, or the average change between the earliest available measurement in PISA and PISA 2012. For countries and economies with more than one available measurement, the annualised change is calculated with a linear regression model. The line marks the values predicted by the regression model. For more details on the calculation of the annualised change, see Annex A5.

Years in the figure represent PISA assessments.

Source: OECD, PISA 2012 Database, Tables I.2.3b, I.2.3d, I.4.3b, I.4.3d, I.5.3b and I.5.3d

StatLink त्राजा http://dx.doi.org/10.1787/888932935648 
- Figure B4.1 [Part 2/9]

Trends in mathematics, reading and science performance: OECD countries

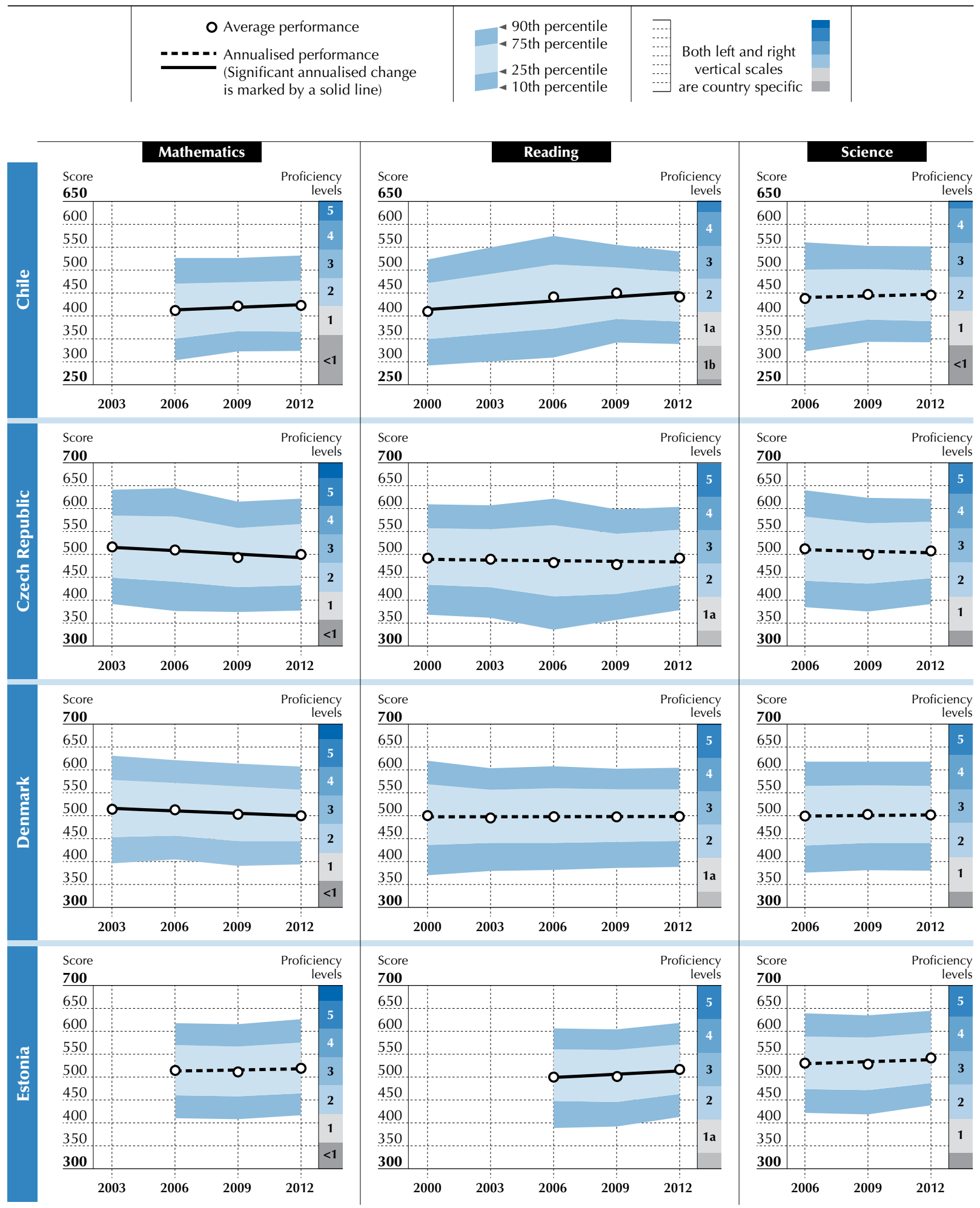

Notes: The slope of the annualised performance is the annualised change, or the average change between the earliest available measurement in PISA and PISA 2012. For countries and economies with more than one available measurement, the annualised change is calculated with a linear regression model. The line marks the values predicted by the regression model. For more details on the calculation of the annualised change, see Annex A5.

Years in the figure represent PISA assessments.

Source: OECD, PISA 2012 Database, Tables I.2.3b, I.2.3d, I.4.3b, I.4.3d, I.5.3b and I.5.3d.

StatLink त्नाI 
- Figure B4.1 [Part 3/9]

\section{Trends in mathematics, reading and science performance: OECD countries}

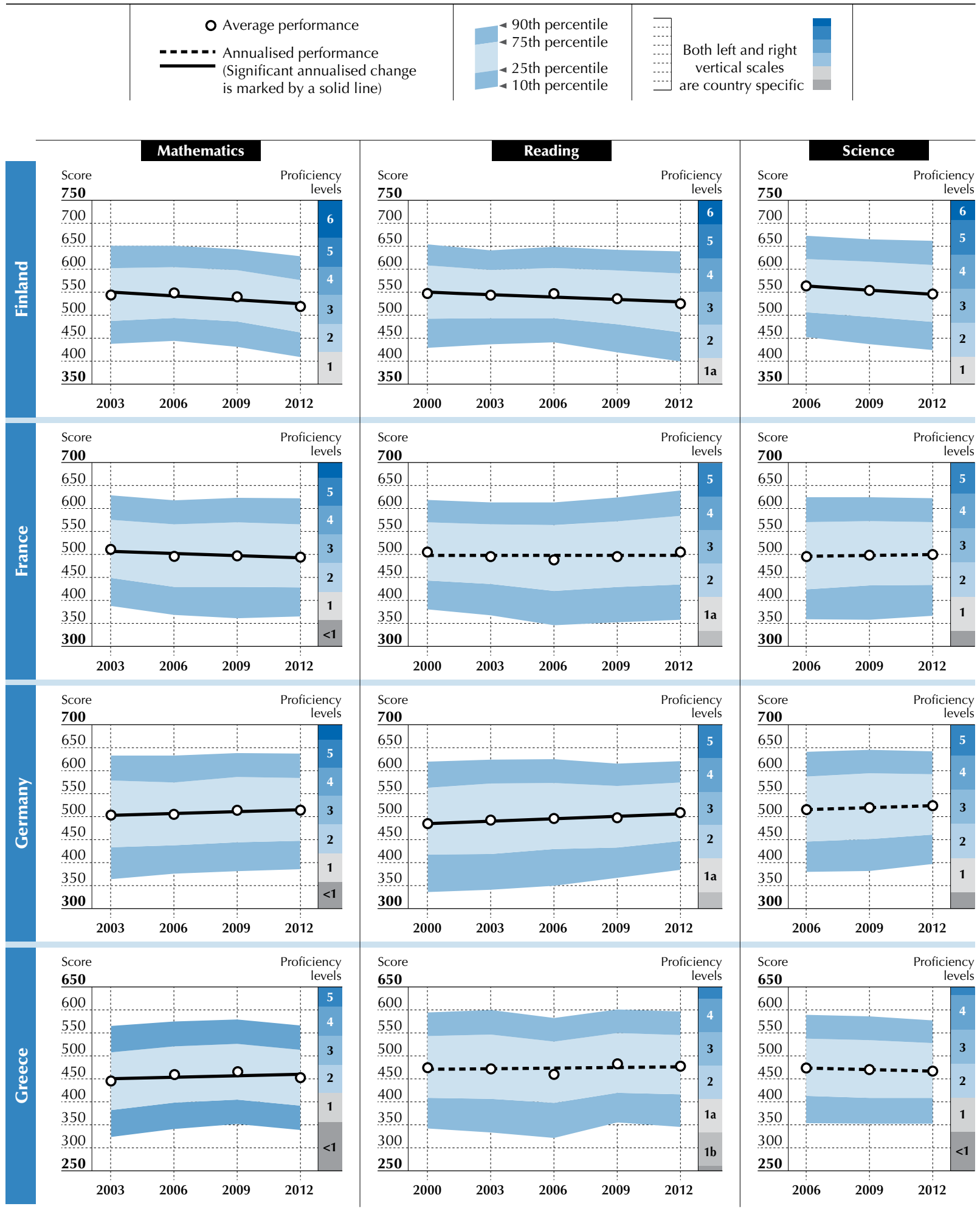

Notes: The slope of the annualised performance is the annualised change, or the average change between the earliest available measurement in PISA and PISA 2012. For countries and economies with more than one available measurement, the annualised change is calculated with a linear regression model. The line marks the values predicted by the regression model. For more details on the calculation of the annualised change, see Annex A5.

Years in the figure represent PISA assessments.

Source: OECD, PISA 2012 Database, Tables I.2.3b, I.2.3d, I.4.3b, I.4.3d, I.5.3b and I.5.3d

StatLink 需可 http://dx.doi.org/10.1787/888932935648 
- Figure B4.1 [Part 4/9] -

Trends in mathematics, reading and science performance: OECD countries

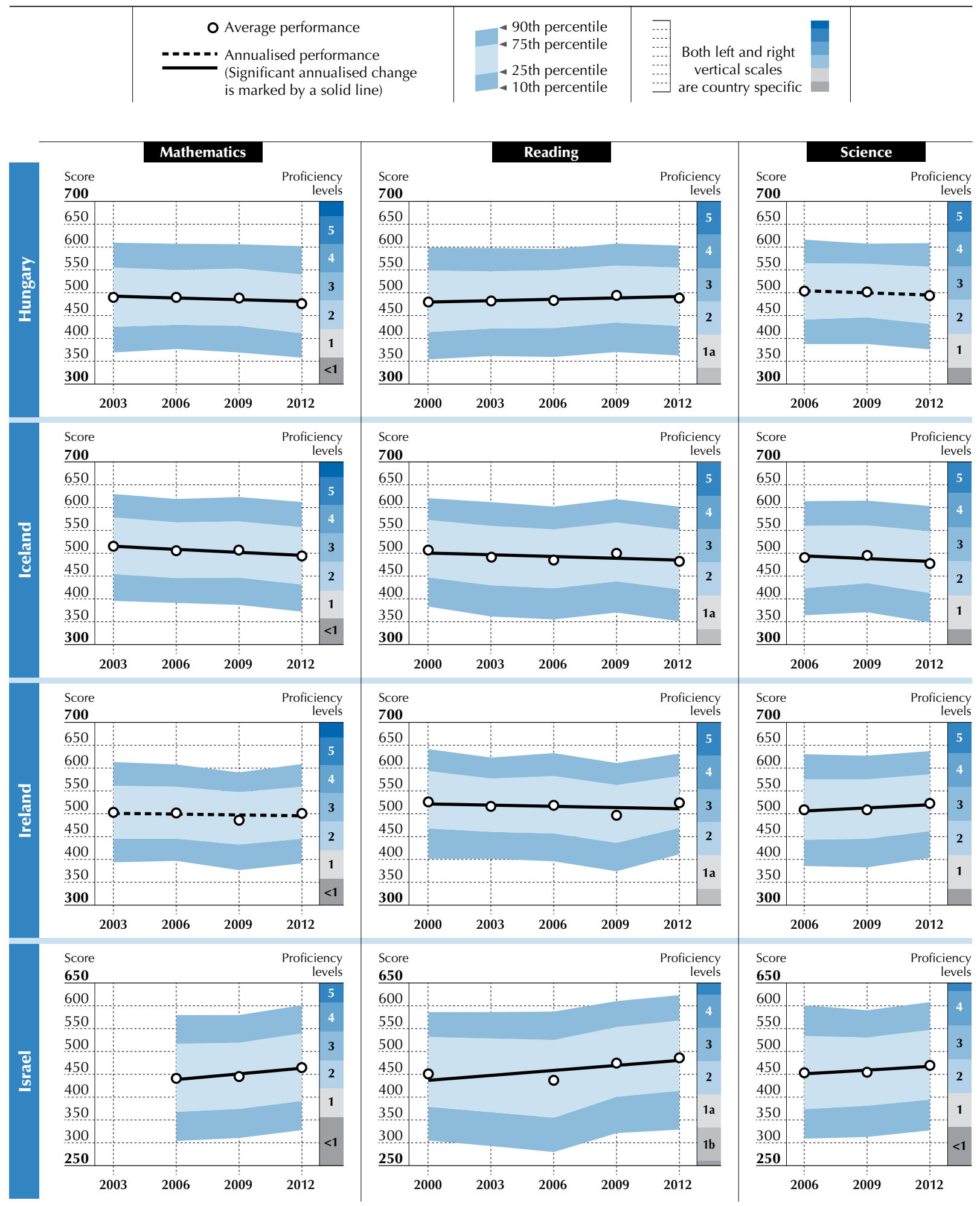

Notes: The slope of the annualised performance is the annualised change, or the average change between the earliest available measurement in PISA and PISA 2012. For countries and economies with more than one available measurement, the annualised change is calculated with a linear regression model. The line marks the values predicted by the regression model. For more details on the calculation of the annualised change, see Annex A5.

Years in the figure represent PISA assessments.

Source: OECD, PISA 2012 Database, Tables I.2.3b, I.2.3d, I.4.3b, I.4.3d, I.5.3b and I.5.3d.

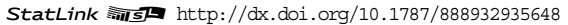


- Figure B4.1 [Part 5/9]

\section{Trends in mathematics, reading and science performance: OECD countries}

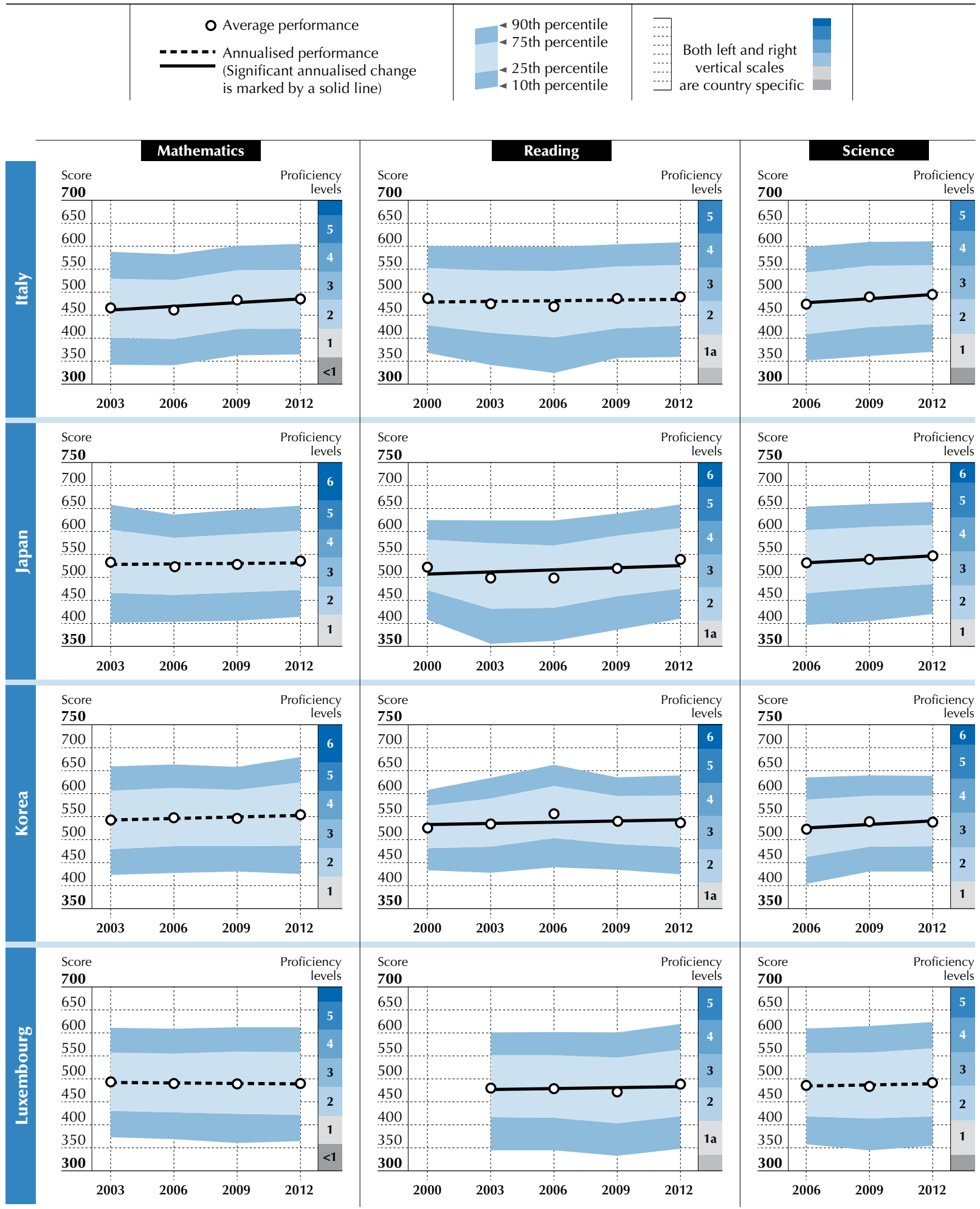

Notes: The slope of the annualised performance is the annualised change, or the average change between the earliest available measurement in PISA and PISA 2012. For countries and economies with more than one available measurement, the annualised change is calculated with a linear regression model. The line marks the values predicted by the regression model. For more details on the calculation of the annualised change, see Annex A5.

Years in the figure represent PISA assessments.

Source: OECD, PISA 2012 Database, Tables I.2.3b, I.2.3d, I.4.3b, I.4.3d, I.5.3b and I.5.3d.

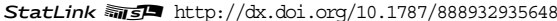


- Figure B4.1 [Part 6/9] -

Trends in mathematics, reading and science performance: OECD countries

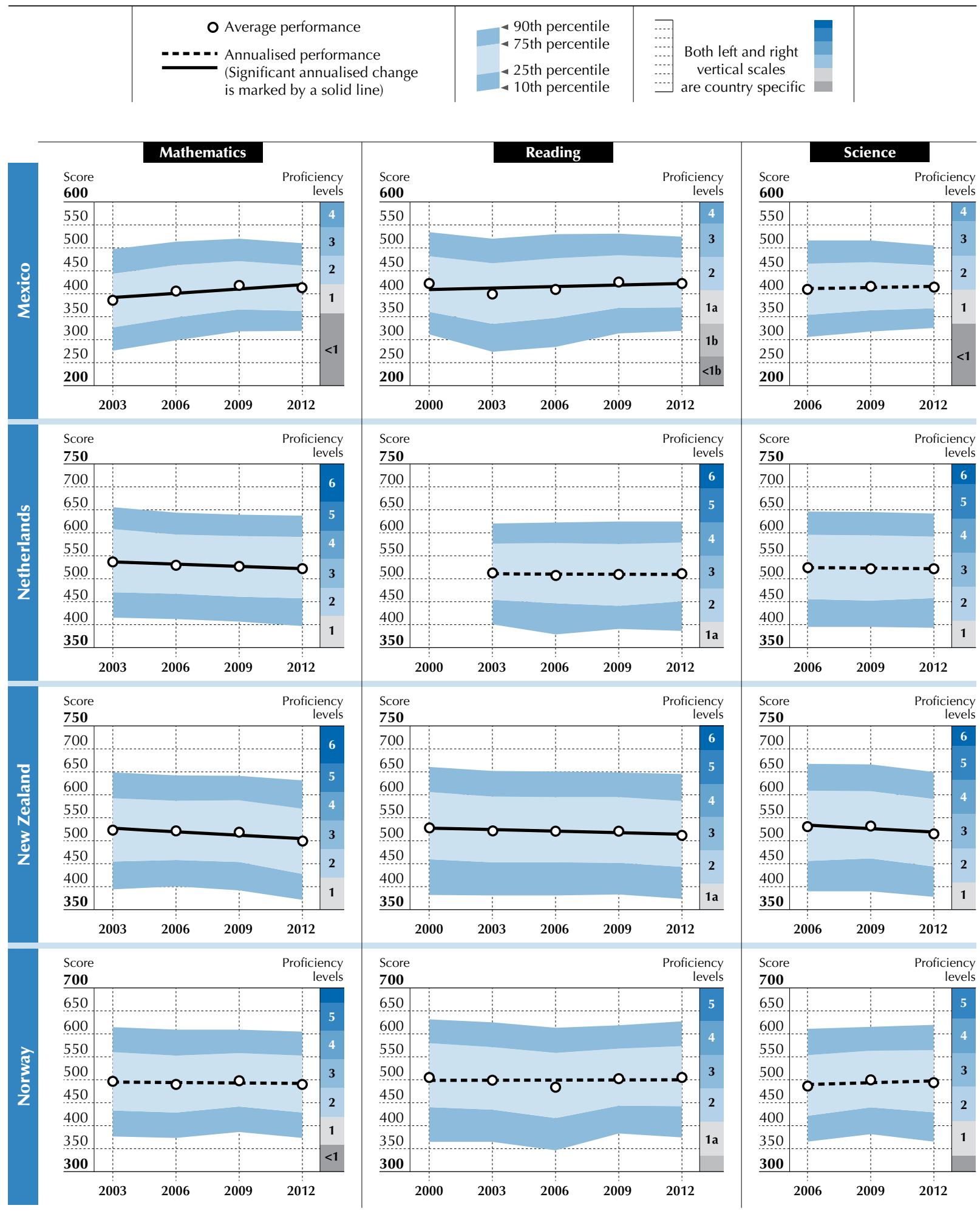

Notes: The slope of the annualised performance is the annualised change, or the average change between the earliest available measurement in PISA and PISA 2012. For countries and economies with more than one available measurement, the annualised change is calculated with a linear regression model. The line marks the values predicted by the regression model. For more details on the calculation of the annualised change, see Annex A5.

Years in the figure represent PISA assessments.

Source: OECD, PISA 2012 Database, Tables I.2.3b, I.2.3d, I.4.3b, I.4.3d, I.5.3b and I.5.3d.

StatLink त्नारा http://dx.doi.org/10.1787/888932935648 
- Figure B4.1 [Part 7/9]

\section{Trends in mathematics, reading and science performance: OECD countries}

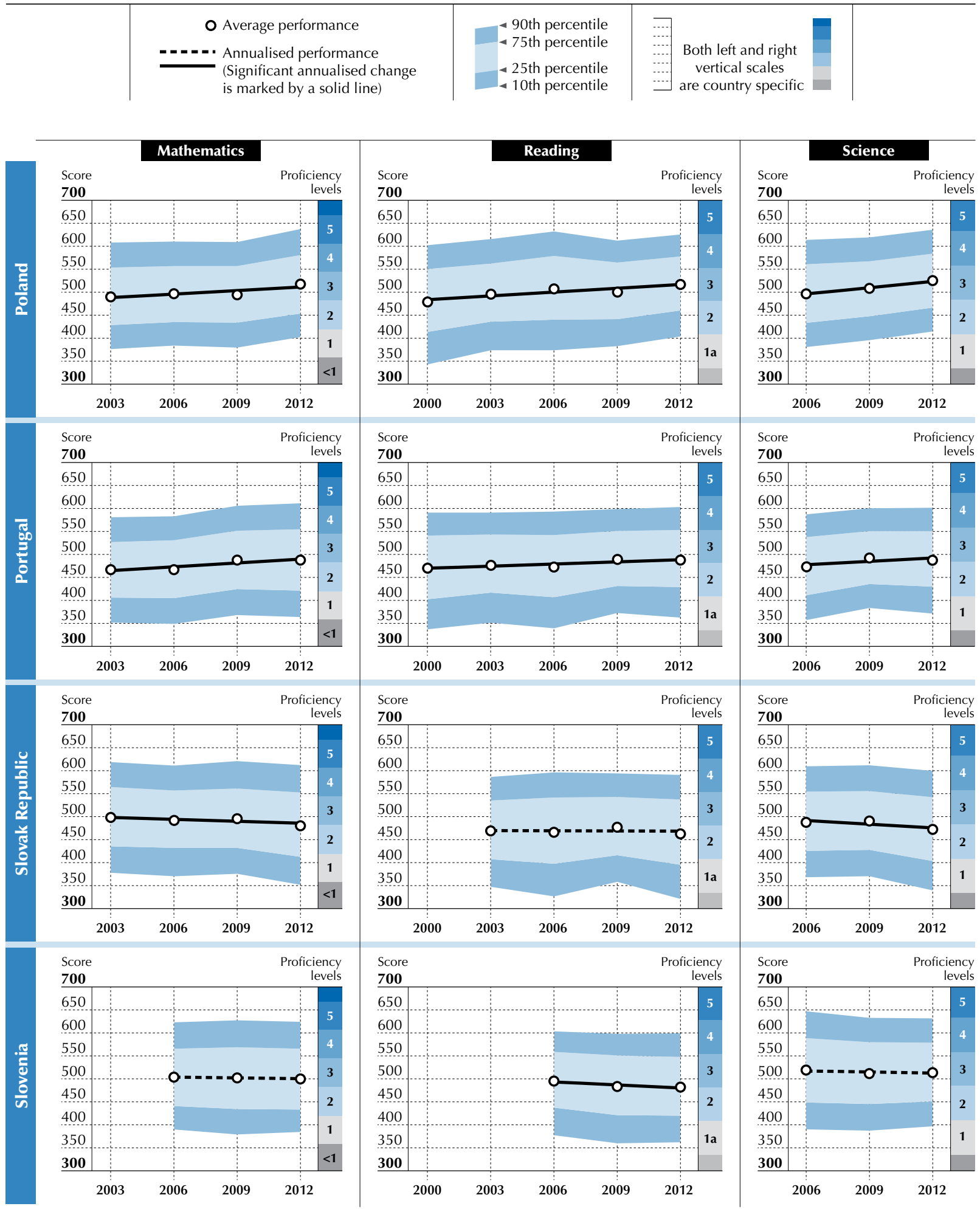

Notes: The slope of the annualised performance is the annualised change, or the average change between the earliest available measurement in PISA and PISA 2012. For countries and economies with more than one available measurement, the annualised change is calculated with a linear regression model. The line marks the values predicted by the regression model. For more details on the calculation of the annualised change, see Annex A5.

Years in the figure represent PISA assessments.

Source: OECD, PISA 2012 Database, Tables I.2.3b, I.2.3d, I.4.3b, I.4.3d, I.5.3b and I.5.3d.

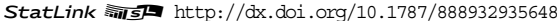


- Figure B4.1 [Part 8/9]

Trends in mathematics, reading and science performance: OECD countries

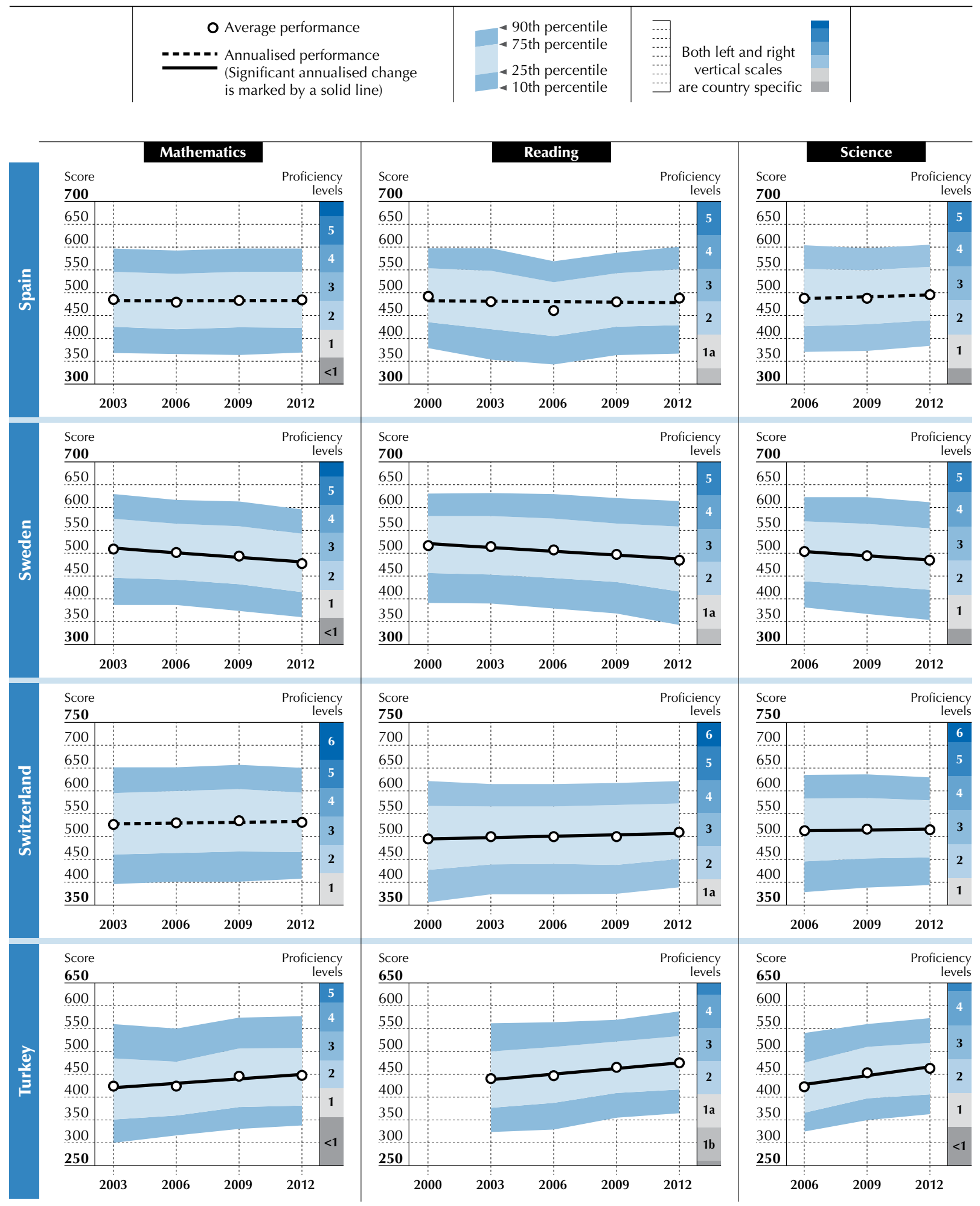

Notes: The slope of the annualised performance is the annualised change, or the average change between the earliest available measurement in PISA and PISA 2012. For countries and economies with more than one available measurement, the annualised change is calculated with a linear regression model. The line marks the values predicted by the regression model. For more details on the calculation of the annualised change, see Annex A5.

Years in the figure represent PISA assessments.

Source: OECD, PISA 2012 Database, Tables I.2.3b, I.2.3d, I.4.3b, I.4.3d, I.5.3b and I.5.3d.

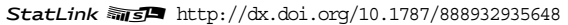


- Figure B4.1 [Part 9/9]

Trends in mathematics, reading and science performance: $O E C D$ countries

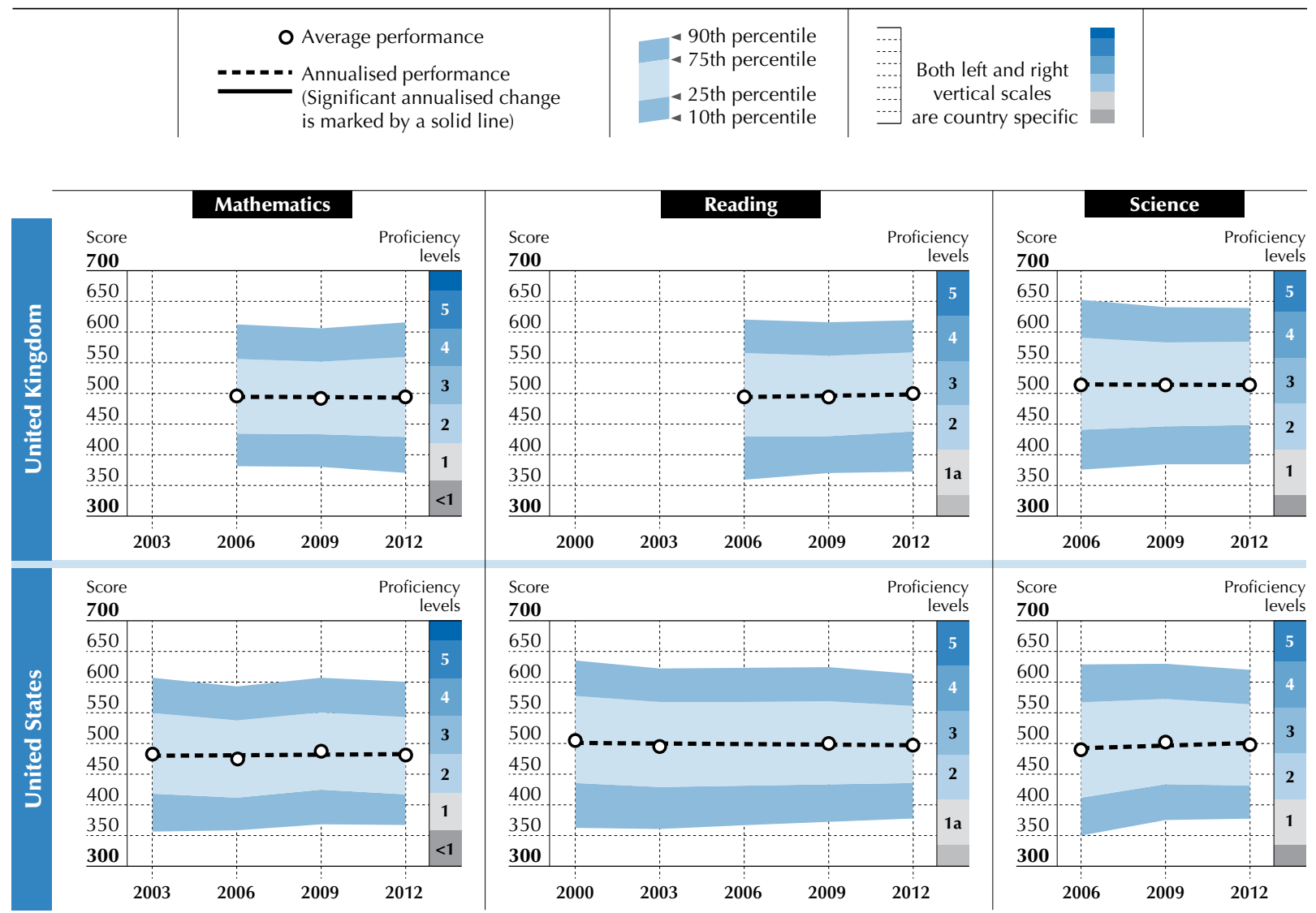

Notes: The slope of the annualised performance is the annualised change, or the average change between the earliest available measurement in PISA and PISA 2012. For countries and economies with more than one available measurement, the annualised change is calculated with a linear regression model. The line marks the values predicted by the regression model. For more details on the calculation of the annualised change, see Annex A5. Years in the figure represent PISA assessments.

Source: OECD, PISA 2012 Database, Tables I.2.3b, I.2.3d, I.4.3b, I.4.3d, I.5.3b and I.5.3d

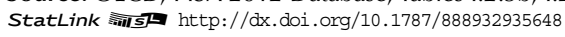


- Figure B4.2 [Part 1/8]

Trends in mathematics, reading and science performance: Partner countries and economies

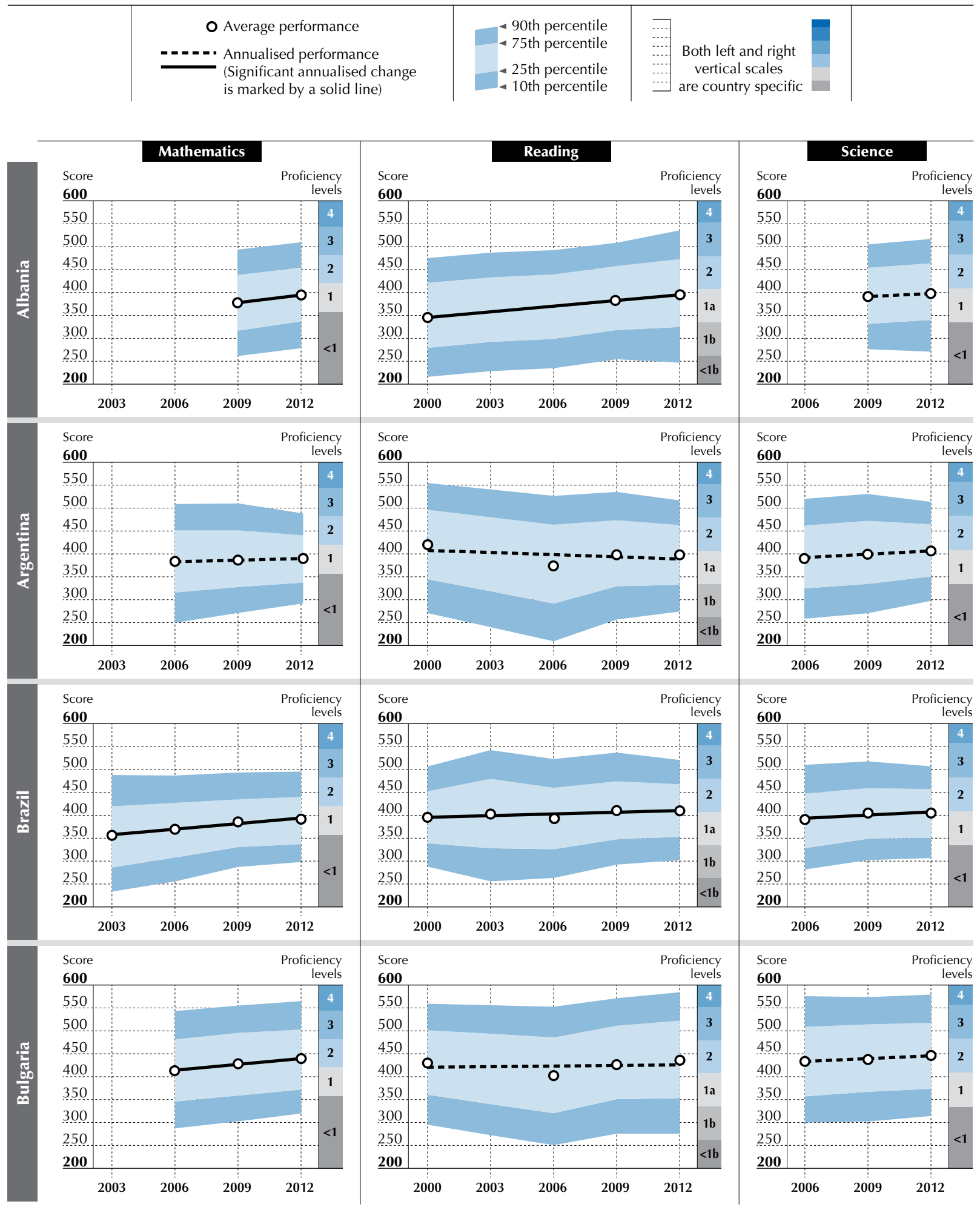

Notes: The slope of the annualised performance is the annualised change, or the average change between the earliest available measurement in PISA and PISA 2012. For countries and economies with more than one available measurement, the annualised change is calculated with a linear regression model. The line marks the values predicted by the regression model. For more details on the calculation of the annualised change, see Annex A5.

Years in the figure represent PISA assessments.

Source: OECD, PISA 2012 Database, Tables I.2.3b, I.2.3d, I.4.3b, I.4.3d, I.5.3b and I.5.3d.

StatLink त्नाज्ञ http://dx.doi.org/10.1787/888932936446 
- Figure B4.2 [Part 2/8] "

Trends in mathematics, reading and science performance: Partner countries and economies

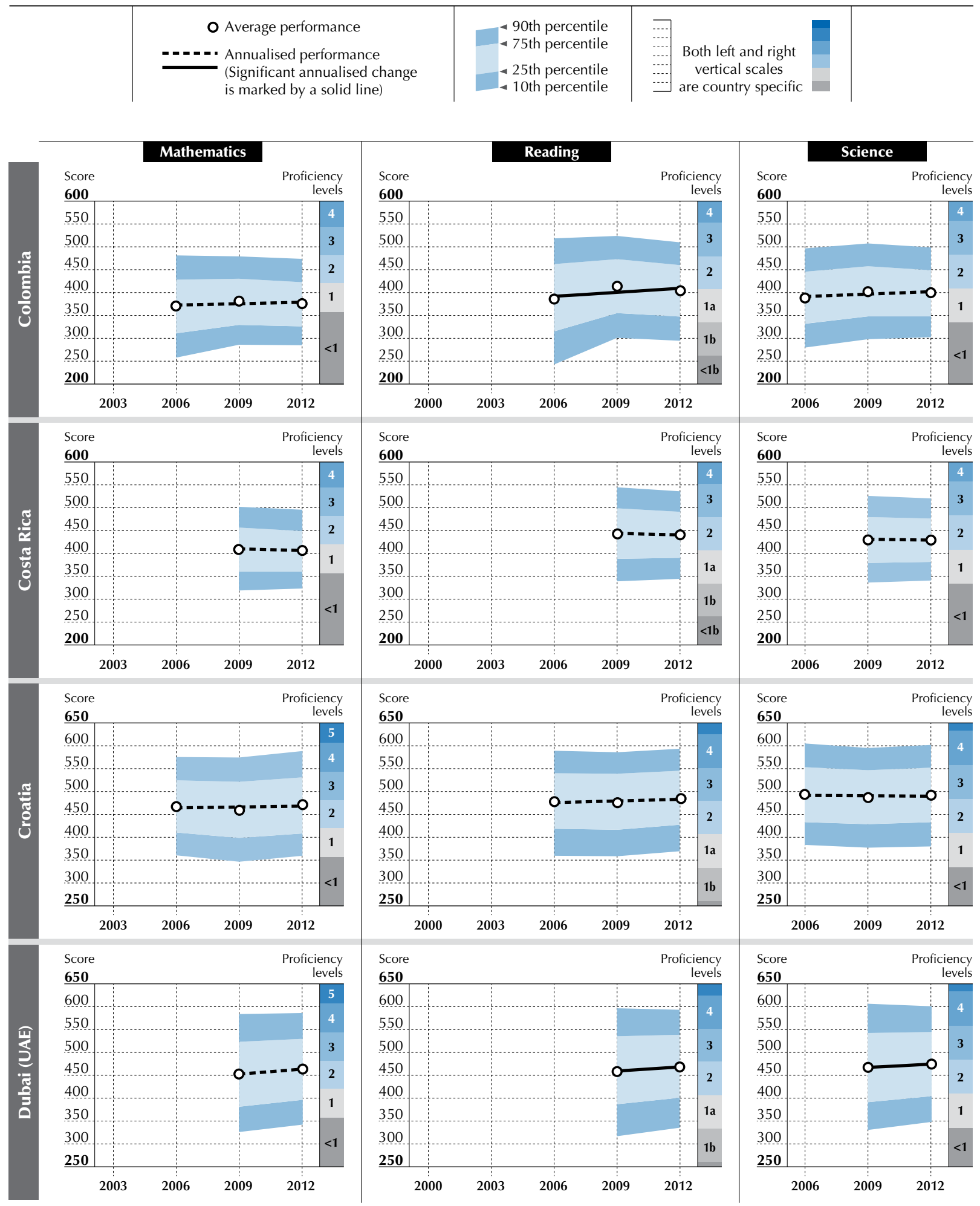

Notes: The slope of the annualised performance is the annualised change, or the average change between the earliest available measurement in PISA and PISA 2012. For countries and economies with more than one available measurement, the annualised change is calculated with a linear regression model. The line marks the values predicted by the regression model. For more details on the calculation of the annualised change, see Annex A5.

Years in the figure represent PISA assessments.

Source: OECD, PISA 2012 Database, Tables I.2.3b, I.2.3d, I.4.3b, I.4.3d, I.5.3b and I.5.3d

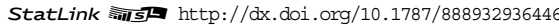


- Figure B4.2 [Part 3/8] -

Trends in mathematics, reading and science performance: Partner countries and economies

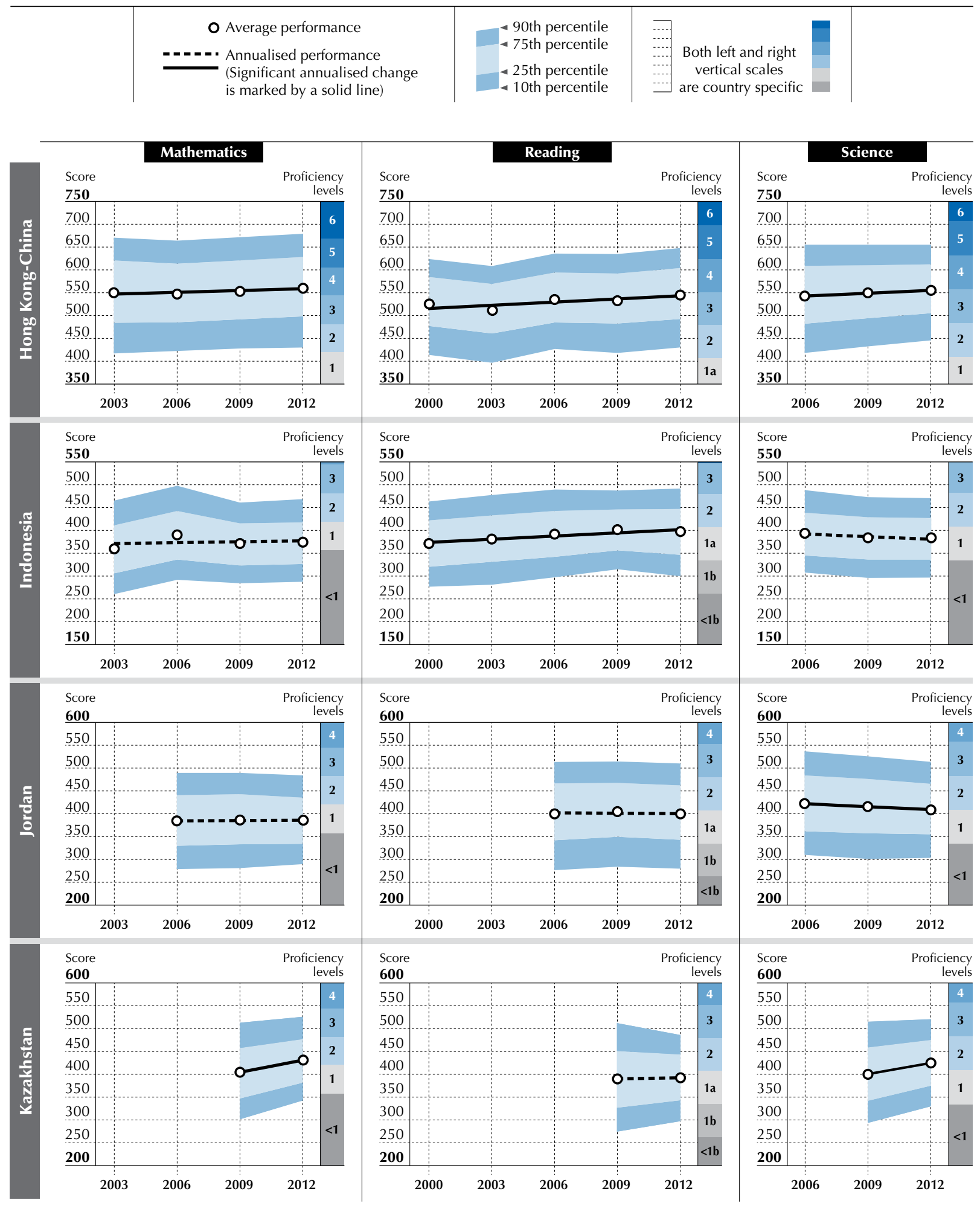

Notes: The slope of the annualised performance is the annualised change, or the average change between the earliest available measurement in PISA and PISA 2012. For countries and economies with more than one available measurement, the annualised change is calculated with a linear regression model. The line marks the values predicted by the regression model. For more details on the calculation of the annualised change, see Annex A5.

Years in the figure represent PISA assessments.

Source: OECD, PISA 2012 Database, Tables I.2.3b, I.2.3d, I.4.3b, I.4.3d, I.5.3b and I.5.3d.

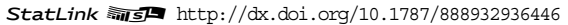


- Figure B4.2 [Part 4/8] "

Trends in mathematics, reading and science performance: Partner countries and economies

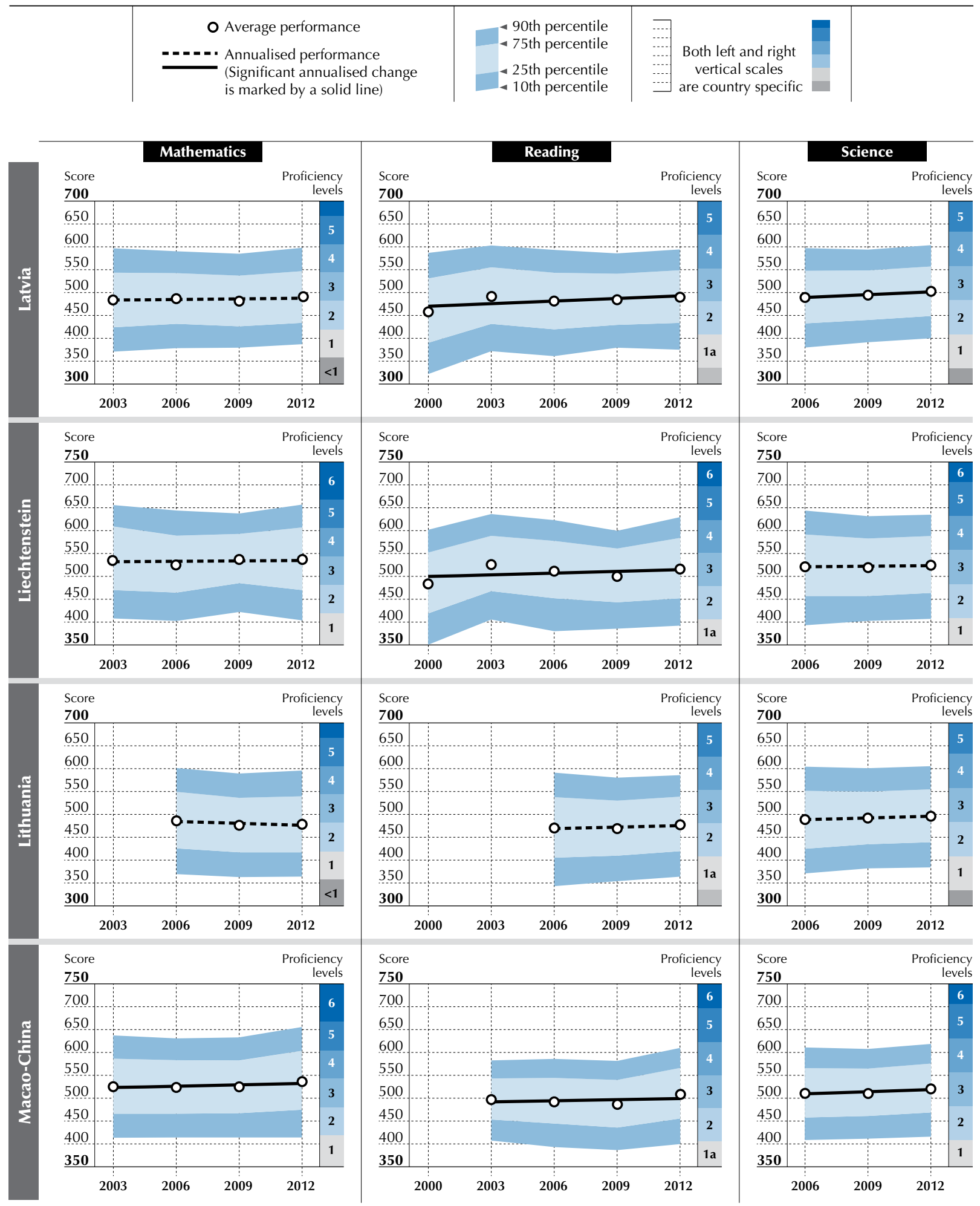

Notes: The slope of the annualised performance is the annualised change, or the average change between the earliest available measurement in PISA and PISA 2012. For countries and economies with more than one available measurement, the annualised change is calculated with a linear regression model. The line marks the values predicted by the regression model. For more details on the calculation of the annualised change, see Annex A5.

Years in the figure represent PISA assessments.

Source: OECD, PISA 2012 Database, Tables I.2.3b, I.2.3d, I.4.3b, I.4.3d, I.5.3b and I.5.3d

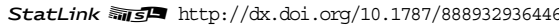


- Figure B4.2 [Part 5/8] -

Trends in mathematics, reading and science performance: Partner countries and economies

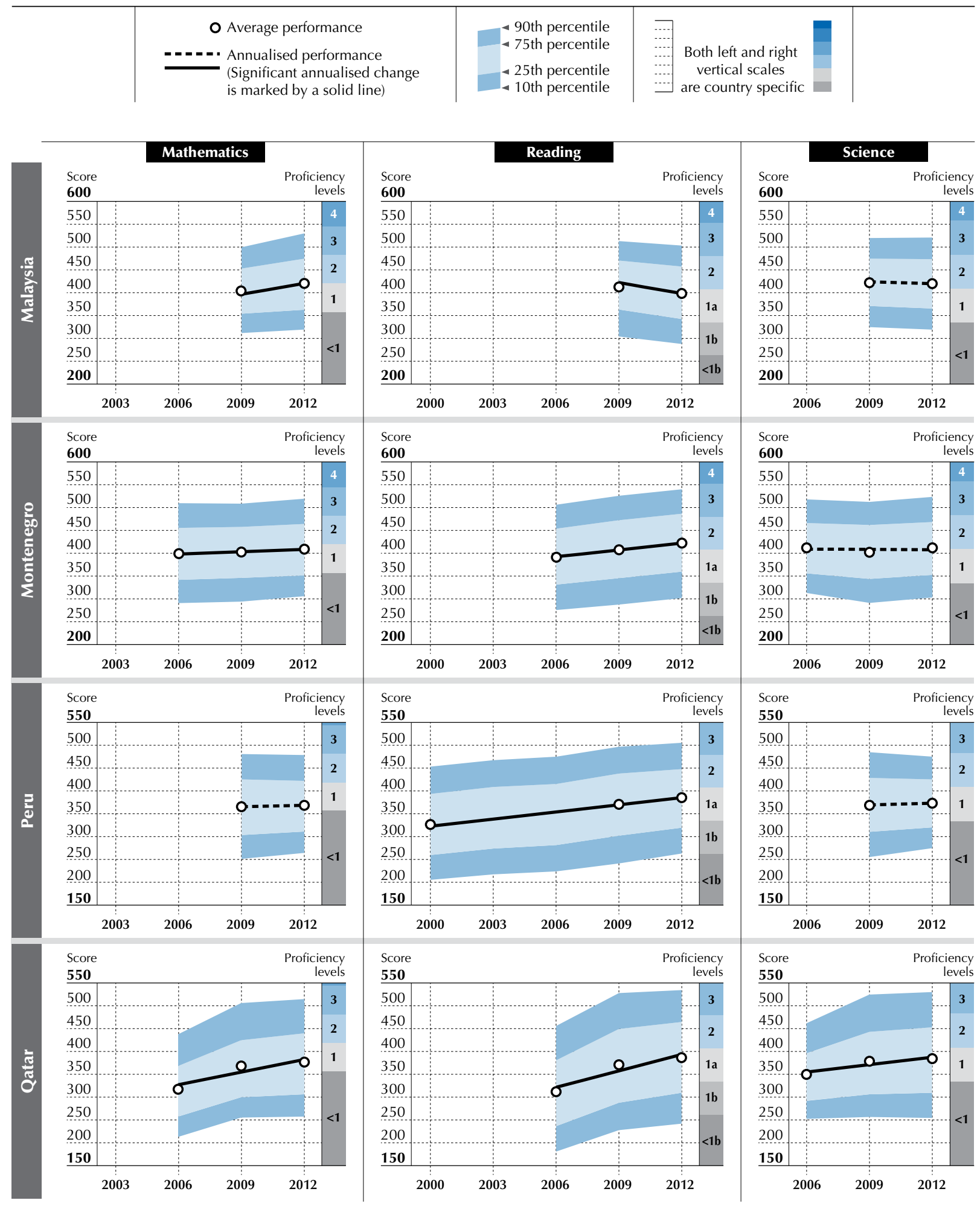

Notes: The slope of the annualised performance is the annualised change, or the average change between the earliest available measurement in PISA and PISA 2012. For countries and economies with more than one available measurement, the annualised change is calculated with a linear regression model. The line marks the values predicted by the regression model. For more details on the calculation of the annualised change, see Annex A5.

Years in the figure represent PISA assessments.

Source: OECD, PISA 2012 Database, Tables I.2.3b, I.2.3d, I.4.3b, I.4.3d, I.5.3b and I.5.3d.

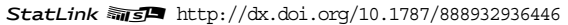


- Figure B4.2 [Part 6/8] "

Trends in mathematics, reading and science performance: Partner countries and economies

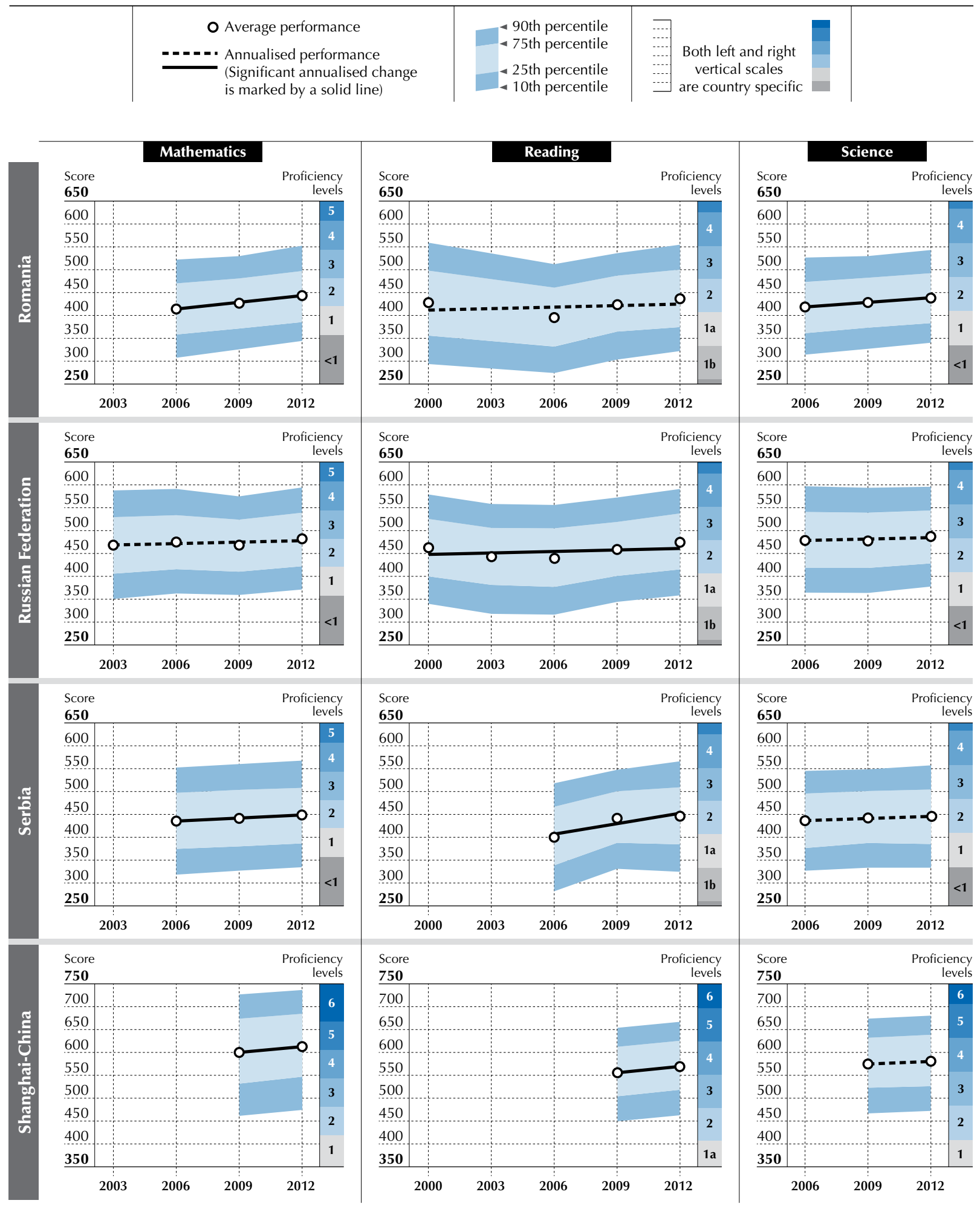

Notes: The slope of the annualised performance is the annualised change, or the average change between the earliest available measurement in PISA and PISA 2012. For countries and economies with more than one available measurement, the annualised change is calculated with a linear regression model. The line marks the values predicted by the regression model. For more details on the calculation of the annualised change, see Annex A5.

Years in the figure represent PISA assessments.

Source: OECD, PISA 2012 Database, Tables I.2.3b, I.2.3d, I.4.3b, I.4.3d, I.5.3b and I.5.3d

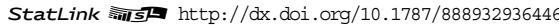


- Figure B4.2 [Part 7/8]

Trends in mathematics, reading and science performance: Partner countries and economies

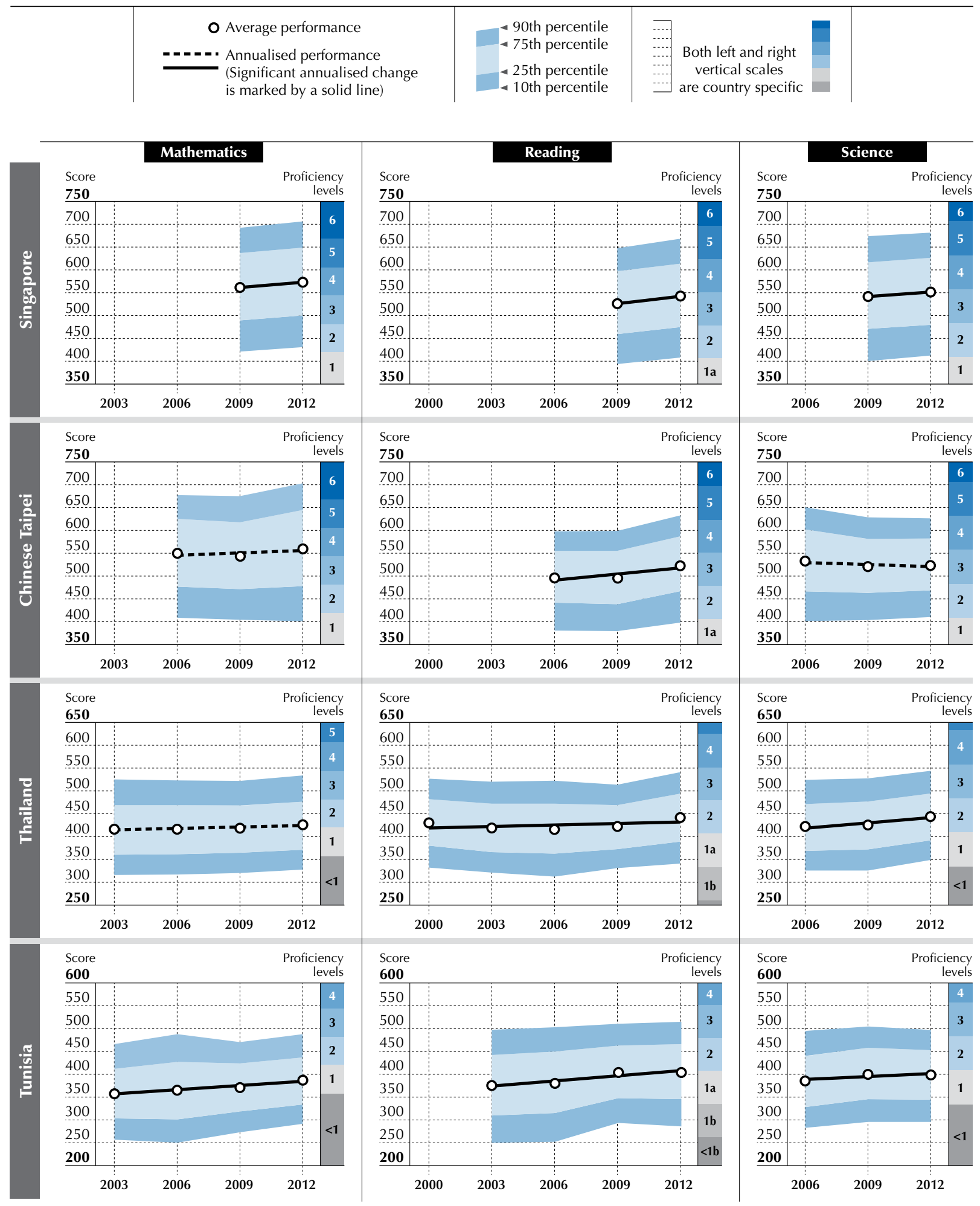

Notes: The slope of the annualised performance is the annualised change, or the average change between the earliest available measurement in PISA and PISA 2012. For countries and economies with more than one available measurement, the annualised change is calculated with a linear regression model. The line marks the values predicted by the regression model. For more details on the calculation of the annualised change, see Annex A5.

Years in the figure represent PISA assessments.

Source: OECD, PISA 2012 Database, Tables I.2.3b, I.2.3d, I.4.3b, I.4.3d, I.5.3b and I.5.3d.

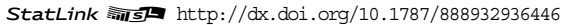


- Figure B4.2 [Part 8/8] -

Trends in mathematics, reading and science performance: Partner countries and economies

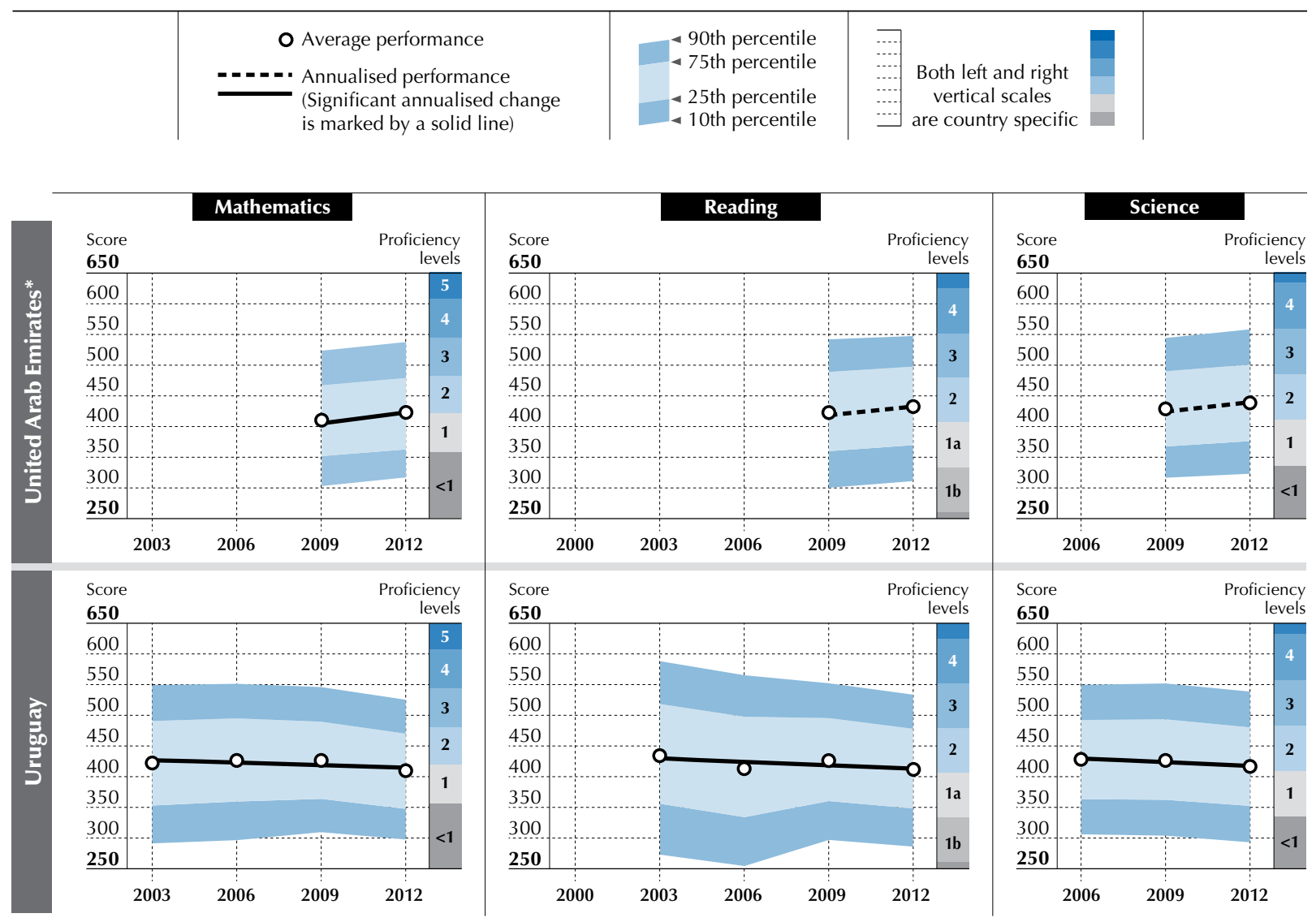

* United Arab Emirates excluding Dubai. Dubai took the PISA 2009 assessment in 2009 and the rest of the United Arab Emirates in 2010 as part of PISA $2009+$ Notes: The slope of the annualised performance is the annualised change, or the average change between the earliest available measurement in PISA and PISA 2012. For countries and economies with more than one available measurement, the annualised change is calculated with a linear regression model. The line marks the values predicted by the regression model. For more details on the calculation of the annualised change, see Annex A5.

Years in the figure represent PISA assessments.

Source: OECD, PISA 2012 Database, Tables I.2.3b, I.2.3d, I.4.3b, I.4.3d, I.5.3b and I.5.3d.

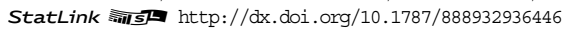





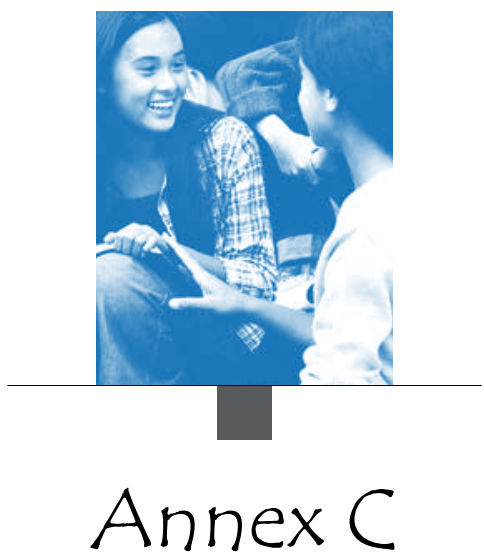

THE DEVELOPMENT AND IMPLEMENTATION OF PISA A COLLABORATIVE EFFORT 
PISA is a collaborative effort, bringing together experts from the participating countries, steered jointly by their governments on the basis of shared, policy-driven interests.

A PISA Governing Board, on which each country is represented, determines the policy priorities for PISA, in the context of OECD objectives, and oversees adherence to these priorities during the implementation of the programme. This includes setting priorities for the development of indicators, for establishing the assessment instruments, and for reporting the results.

Experts from participating countries also serve on working groups that are charged with linking policy objectives with the best internationally available technical expertise. By participating in these expert groups, countries ensure that the instruments are internationally valid and take into account the cultural and educational contexts in OECD member and partner countries and economies, that the assessment materials have strong measurement properties, and that the instruments place emphasise authenticity and educational validity.

Through National Project Managers, participating countries and economies implement PISA at the national level subject to the agreed administration procedures. National Project Managers play a vital role in ensuring that the implementation of the survey is of high quality, and verify and evaluate the survey results, analyses, reports and publications.

The design and implementation of the surveys, within the framework established by the PISA Governing Board, is the responsibility of external contractors. For PISA 2012, the development and implementation of the cognitive assessment and questionnaires, and of the international options, was carried out by a consortium led by the Australian Council for Educational Research (ACER). Other partners in this Consortium include cApStAn Linguistic Quality Control in Belgium, the Centre de Recherche Public Henri Tudor (CRP-HT) in Luxembourg, the Department of Teacher Education and School Research (ILS) at the University of Oslo in Norway, the Deutsches Institut für Internationale Pädagogische Forschung (DIPF) in Germany, the Educational Testing Service (ETS) in the United States, the Leibniz Institute for Science and Mathematics Education (IPN) in Germany, the National Institute for Educational Policy Research in Japan (NIER), the Unité d'analyse des systèmes et des pratiques d'enseignement ( $\mathrm{aSPe}$ ) at the University of Liège in Belgium, and WESTAT in the United States, as well as individual consultants from several countries. ACER also collaborated with Achieve, Inc. in the United States to develop the mathematics framework for PISA 2012.

The OECD Secretariat has overall managerial responsibility for the programme, monitors its implementation daily, acts as the secretariat for the PISA Governing Board, builds consensus among countries and serves as the interlocutor between the PISA Governing Board and the international Consortium charged with implementing the activities. The OECD Secretariat also produces the indicators and analyses and prepares the international reports and publications in co-operation with the PISA Consortium and in close consultation with member and partner countries and economies both at the policy level (PISA Governing Board) and at the level of implementation (National Project Managers).

\section{PISA Governing Board}

Chair of the PISA Governing Board: Lorna Bertrand

\section{OECD countries}

Australia: Tony Zanderigo

Austria: Mark Német

Belgium: Christiane Blondin and Isabelle Erauw

Canada: Pierre Brochu, Patrick Bussiere and Tomasz Gluszynski

Chile: Leonor Cariola Huerta

Czech Republic: Jana Paleckova

Denmark: Tine Bak and Elsebeth Aller

Estonia: Maie Kitsing

Finland: Tommi Karjalainen

France: Bruno Trosseille

Germany: Elfriede Ohrnberger and Susanne von Below

Greece: Vassilia Hatzinikita and Chryssa Sofianopoulou

Hungary: Benõ Csapó

Iceland: Júlíus Björnsson

Ireland: Jude Cosgrove and Gerry Shiel

Israel: Michal Beller and Hagit Glickman

Italy: Paolo Sestito

Japan: Ryo Watanabe

Korea: Sungsook Kim and Keunwoo Lee

Luxembourg: Amina Kafai
Mexico: Francisco Ciscomani and Eduardo Backhoff Escudero

Netherlands: Paul van Oijen

New Zealand: Lynne Whitney

Norway : Anne-Berit Kavli and Alette Schreiner

Poland: Stanislaw Drzazdzewski and Hania Bouacid

Portugal: Luisa Canto and Castro Loura

Slovak Republic: Romana Kanovska and Paulina Korsnakova

Slovenia: Andreja Barle Lakota

Spain: Ismael Sanz Labrador

Sweden: Anita Wester

Switzerland: Vera Husfeldt and Claudia Zahner Rossier

Turkey: Nurcan Devici and Mustafa Nadir Çalis

United Kingdom: Lorna Bertrand and Jonathan Wright

United States: Jack Buckley, Dana Kelly and Daniel McGrath

Observers

Albania: Ermal Elezi

Argentina: Liliana Pascual

Brazil: Luiz Claudio Costa

Bulgaria: Neda Kristanova

Chinese Taipei: Gwo-Dong Chen and Chih-Wei Hue

Colombia: Adriana Molina

Costa Rica: Leonardo Garnier Rimolo

Croatia: Michelle Bras Roth 
Hong Kong-China: Esther Sui-chu Ho

Indonesia: Khairil Anwar Notodiputro

Jordan: Khattab Mohammad Abulibdeh

Kazakhstan: Almagul Kultumanova

Latvia: Andris Kangro, Ennata Kivrina and Dita Traidas

Lithuania: Rita Dukynaite

Macao-China: Leong Lai

Montenegro: Zeljko Jacimovic

Panama: Arturo Rivera

Peru: Liliana Miranda Molina

Qatar: Hamda Al Sulaiti

Romania: Roxana Mihail

Russian Federation: Isak Froumin and Galina Kovaleva

Serbia: Dragica Pavlovic-Babic

Shanghai-China: Minxuan Zhang

Singapore: Khah Gek Low

Thailand: Precharn Dechsri

United Arab Emirates: Moza al Ghufly and Ayesha G. Khalfan Almerri

Uruguay: Andrés Peri and Maria Helvecia Sanchez Nunez

Viet Nam: Le Thi My Ha

PISA 2012 National Project Managers

Albania: Alfonso Harizaj

Argentina: Liliana Pascual

Australia: Sue Thomson

Austria: Ursula Schwantner

Belgium: Inge De Meyer and Ariane Baye

Brazil: João Galvão Bacchetto

Bulgaria: Svetla Petrova

Canada: Pierre Brochu and Tamara Knighton

Chile: Ema Lagos Campos

Colombia: Francisco Reyes

Costa Rica: Lilliam Mora

Croatia: Michelle Bras Roth

Czech Republic: Jana Paleckova

Denmark: Niels Egelund

Estonia: Gunda Tire

Finland: Jouni Välijärvi

France: Ginette Bourny

Germany: Christine Sälzer and Manfred Prenzel

Greece: Vassilia Hatzinikita

Hong Kong-China: Esther Sui-chu Ho

Hungary: Ildikó Balazsi

Iceland: Almar Midvik Halldorsson

Indonesia: Yulia Wardhani Nugaan and Hari Setiadi

Ireland: Gerry Shiel and Rachel Perkins

Israel: Joel Rapp and Inbal Ron-Kaplan

Italy: Carlo Di Chiacchio

Japan: Ryo Watanabe

Jordan: Khattab Mohammad Abulibdeh

Kazakhstan: Gulmira Berdibayeva and Zhannur Azmagambetova
Korea: Ji-Min Cho and Mi-Young Song

Latvia: Andris Kangro

Liechtenstein: Christian Nidegger

Lithuania: Mindaugas Stundza

Luxembourg: Bettina Boehm

Macao-China: Kwok Cheung Cheung

Malaysia: Ihsan Ismail and Muhamad Zaini Md Zain

Mexico: María Antonieta Díaz Gutierrez

Montenegro: Divna Paljevic Sturm

Netherlands: Jesse Koops

New Zealand: Kate Lang and Steven May

Norway: Marit Kjaernsli

Peru: Liliana Miranda Molina

Poland: Michal Federowicz

Portugal: Ana Sousa Ferreira

Qatar: Aysha Al-Hashemi and Assad Tounakti

Romania: Silviu Cristian Mirescu

Russian Federation: Galina Kovaleva

Scotland: Rebecca Wheater

Serbia: Dragica Pavlovic-Babic

Shanghai-China: Jing Lu and Minxuan Zhang

Singapore: Chew Leng Poon and Sean Tan

Slovak Republic: Julia Miklovicova and Jana Ferencova

Slovenia: Mojca Straus

Spain: Lis Cercadillo Pérez

Sweden: Magnus Oskarsson

Switzerland: Christian Nidegger

Chinese Taipei: Pi-Hsia Hung

Thailand: Sunee Klainin

Tunisia: Mohamed Kamel Essid

Turkey: Serdar Aztekin

United Arab Emirates: Moza al Ghufly

United Kingdom: Rebecca Wheater

United States: Dana Kelly and Holly Xie

Uruguay: Maria Helvecia Sánchez Nunez

Viet Nam: Thi My Ha Le

\section{OECD Secretariat}

Andreas Schleicher (Strategic development)

Marilyn Achiron (Editorial support)

Francesco Avvisati (Analytic services)

Brigitte Beyeler (Administrative support)

Simone Bloem (Analytic services)

Marika Boiron (Translation support)

Francesca Borgonovi (Analytic services)

Jenny Bradshaw (Project management)

Célia Braga-Schich (Production support)

Claire Chetcuti (Administrative support)

Michael Davidson (Project management and analytic services)

Cassandra Davis (Dissemination co-ordination)

Elizabeth Del Bourgo (Production support)

Juliet Evans (Administration and partner country/economy relations) 
Tue Halgreen (Project management)

Miyako Ikeda (Analytic services)

Tadakazu Miki (Analytic services)

Guillermo Montt (Analytic services)

Giannina Rech (Analytic services)

Diana Tramontano (Administration)

Sophie Vayssettes (Analytic services)

Elisabeth Villoutreix (Production co-ordination)

Pablo Zoido (Analytic services)

\section{PISA 2012 mathematics expert group}

Kaye Stacey (Chair) (University of Melbourne, Australia)

Caroline Bardini (University of Melbourne, Australia)

Werner Blum (University of Kassel, Germany)

Joan Ferrini-Mundy (Michigan State University, United States)

Solomon Garfunkel (COMAP, United States)

Toshikazu Ikeda (Yokohama National University, Japan)

Zbigniew Marciniak (Warsaw University, Poland)

Mogens Niss (Roskilde University, Denmark)

Martin Ripley (World Class Arena Limited, United Kingdom)

William Schmidt (Michigan State University, United States)

\section{PISA 2012 problem solving expert group}

Joachim Funke (Chair) (University of Heidelberg, Germany)

Benő Csapó (University of Szeged, Hungary)

John Dossey (Illinois State University, United States)

Arthur Graesser (The University of Memphis United States)

Detlev Leutner (Duisburg-Essen University, Germany)

Romain Martin (Université de Luxembourg FLSHASE, Luxembourg)

Richard Mayer (University of California, United States) Ming Ming Tan (Ministry of Education, Singapore)

\section{PISA 2012 financial literacy expert group}

Annamaria Lusardi (Chair) (The George Washington University School of Business, United States)

Jean-Pierre Boisivon (Université de Paris II Panthéon-Assas, France)

Diana Crossan (Commission for Financial Literacy and Retirement Income, New Zealand)

Peter Cuzner (Australian Securities and Investments Commission, Australia)

Jeanne Hogarth (Federal Reserve System, United States)

Dušan Hradil (Ministry of Finance, Czech Republic)

Stan Jones (Consultant, Canada)

Sue Lewis (Consultant, United Kingdom)

\section{PISA 2012 questionnaire expert group}

Eckhard Klieme (Chair) (Deutsches Institut für Internationale Pädagogische Forschung (DIPF), Germany)

Eduardo Backhoff (University of Baja California at the Institute of Educational Research and Development, Mexico)

Ying-yi Hong (Nanyang Business School of Nanyang Technological University, Singapore)

David Kaplan (University of Wisconsin - Madison, United States) Henry Levin (Columbia University, United States)
Jaap Scheerens (University of Twente, Netherlands)

William Schmidt (Michigan State University, United States)

Fons van de Vijver (Tilburg University, Netherlands)

\section{Technical advisory group}

Keith Rust (Chair) (Westat, United States)

Ray Adams (ACER, Australia)

Cees Glas (University of Twente, Netherlands)

John de Jong (Language Testing Services, Netherlands)

David Kaplan (University of Wisconsin - Madison, United States)

Christian Monseur (University of Liège, Belgium)

Sophia Rabe-Hesketh (University of California - Berkeley,

United States)

Thierry Rocher (Ministry of Education, France)

Norman Verhelst (CITO, Netherlands)

Kentaro Yamamoto (ETS, United States)

Rebecca Zwick (University of California, United States)

\section{PISA 2012 Consortium}

\section{Australian Council for Educational Research}

Ray Adams (International Project Director)

Susan Bates (Project administration)

Alla Berezner (Data management and analysis)

Yan Bibby (Data processing and analysis)

Phillipe Bickham (IT services)

Esther Brakey (Administrative support)

Robin Buckley (IT services)

Mark Butler (Financial literacy instruments and test development)

Wei Buttress (Project administration and quality monitoring) Renee Chow (Data processing and analysis)

John Cresswell (Reporting and dissemination)

Alex Daraganov (Data processing and analysis)

Jorge Fallas (Data processing and analysis)

Kate Fitzgerald (Data processing and sampling)

Kim Fitzgerald (IT Services)

Paul Golden (IT and helpdesk support)

Jennifer Hong (Data processing and sampling)

Nora Kovarcikova (Survey operations)

Winson Lam (IT services)

Petra Lietz (Questionnaire development)

Tom Lumley (Reading instruments and test development)

Greg Macaskill (Data management and processing and sampling)

Ron Martin (Science instruments and test development)

Barry McCrae (Problem solving and science instruments and test development)

Louise McDonald (Graphic design)

Juliette Mendelovits (Reading and financial literacy instruments and test development)

Martin Murphy (Field operations and sampling)

Thoa Nguyen (Data processing and analysis)

Stephen Oakes (IT management and support)

Elizabeth O'Grady (Questionnaire development and project support) 
Penny Pearson (Administrative support)

Ray Peck (Mathematics and financial literacy instruments and test development)

Fei Peng (Quality monitoring and project support)

Ray Philpot (Problem Solving instruments and test development) Anna Plotka (Graphic design)

Dara Ramalingam (Reading instruments and test development) Sima Rodrigues (Data processing and analysis)

Alla Routitsky (Data management and processing)

James Spithill (Mathematics instruments and test development)

Rachel Stanyon (Project support)

Naoko Tabata (Survey operations)

Stephanie Templeton (Project administration and support)

Mollie Tobin (Questionnaire development and project support)

David Tout (Mathematics instruments and test development)

Ross Turner (Management, mathematics instruments and test development)

Maryanne Van Grunsven (Project support)

Charlotte Waters (Project administration, data processing and analysis)

Maurice Walker (Management, computer-based assessment)

Louise Wenn (Data processing and analysis)

Yan Wiwecka (IT services)

\section{cApStAn Linguistic Quality Control (BELGIUM)}

Raphael Choppinet (Computer-based verification management) Steve Dept (Translation and verification operations)

Andrea Ferrari (Linguistic quality assurance and quality control designs)

Musab Hayatli (Right-to-left scripts, cultural adaptations)

Elica Krajceva (Questionnaire verification co-ordinator)

Shinoh Lee (Cognitive test verification co-ordinator)

Irene Liberati (Manuals verification co-ordinator)

Laura Wayrynen (Verifier training and verification procedures)

\section{Educational Testing Service (ETS)}

Jonas Bertling (Questionnaire instruments and test development) Irwin Kirsch (Reading Components)

Patricia Klag (Problem-solving instruments and test development)

Patrick Kyllonen (Questionnaire instruments and test development)

Marylou Lennon (Questionnaire instruments and test development)

Richard Roberts (Questionnaire instruments and test development)

Matthias von Davier (Questionnaire instruments and test development)

Kentaro Yamamoto (Member TAG, problem-solving instruments and test development)

\section{Deutches Institut für Internationale Pädagogische Forschung} (DIPF, GERMANY)

Frank Goldhammer (Test developer, problem solving)

Eckhard Klieme (Chair of Questionnaire Expert Group)

Silke Hertel (Questionnaire development)

Jean-Paul Reeff (International Consultant)

Heiko Rolke (Software Design \& Software Development
Management [Delivery System, Translation System])

Brigitte Steinert (Questionnaire development)

Svenja Vieluf (Questionnaire development)

\section{Institutt for Lærerutdanning Og Skoleutvikling (ILS, NORWAY)}

Bjornar Alseth (Mathematics instruments and test development)

Ole Kristian Bergem (Mathematics instruments and test development)

Knut Skrindo (Mathematics instruments and test development)

Rolf V. Olsen (Mathematics instruments and test development)

Arne Hole (Mathematics instruments and test development)

Therese Hopfenbeck (Problem-solving instruments and test development)

\section{Leibniz Institute for Science and Mathematics Education (IPN, GERMANY)}

Christoph Duchhardt (Mathematics instruments and test development)

Aiso Heinze (Mathematics instruments and test development)

Eva Knopp (Mathematics instruments and test development)

Martin Senkbeil (Mathematics instruments and test development)

\section{National Institute for Educational Policy Research (NIER, JAPAN)}

Keiichi Nishimura (Mathematics instruments and test development)

Yuji Surata (Mathematics instruments and test development)

\section{The TAO Initiative: Henry Tudor Public Research Centre, University of Luxembourg (LUXEMBOURG)}

Joel Billard (Software Engineer, School Questionnaire) Marilyn Binkley (Project Consultant, Assessment Expert) Jerome Bogaerts (Software Engineer, TAO Platform)

Gilbert Busana (Electronic Instruments, Usability)

Christophe Henry (System Engineer, School Questionnaire and Hosting)

Raynald Jadoul (Technical Lead, School Questionnaire and Electronic Instruments)

Isabelle Jars (Project Manager)

Vincent Koenig (Electronic Instruments, Usability)

Thibaud Latour (Project Leader, TAO Platform)

Lionel Lecaque (Software Engineer, Quality)

Primael Lorbat (Software Engineer, Electronic Instruments)

Romain Martin (Problem Solving Expert Group Member)

Matteo Melis (Software Engineer, School Questionnaire)

Patrick Plichart (Software Architect, TAO Platform)

Vincent Porro (Software Engineer, Electronic Instruments)

Igor Ribassin (Software Engineer, Electronic Instruments)

Somsack Sipasseuth (Software Engineer, Electronic Instruments)

\section{Unité d'analyse des Systèmes et des Pratiques d'enseignement} (ASPE, BELGIUM)

Isabelle Demonty (Mathematics instruments and test development)

Annick Fagnant (Mathematics instruments and test development) Anne Matoul (French source development)

Christian Monseur (Member of Technical Advisory Group) 


\title{
WESTAT
}

Susan Fuss (Sampling and weighting)

Amita Gopinath (Weighting)

Jing Kang (Sampling and weighting)

Sheila Krawchuk (Sampling, weighting and quality monitoring)

Thanh Le (Sampling, weighting and quality monitoring)

John Lopdell (Sampling and weighting)

Keith Rust (Director of the PISA Consortium for sampling and

weighting)

Erin Willey (Sampling and weighting)

Shawn Lu (Weighting)

Teresa Strickler (Weighting)

Yumiko Sugawara (Weighting)

Joel Wakesberg (Sampling and weighting)

Sergey Yagodin (Weighting)

\section{Achieve Inc.}

Michael Cohen (Mathematics framework development)

Kaye Forgione (Mathematics framework development)

Morgan Saxby (Mathematics framework development)

Laura Slover (Mathematics framework development)

Bonnie Verrico (Project support)

\section{HallStat SPRL}

Beatrice Halleux (Consultant, translation/verification referee, French source development)

\section{University of Heidelberg}

Joachim Funke (Chair, Problem Solving Expert Group)

Samuel Greiff (Problem-solving instruments and test development)

\section{University of Melbourne}

Caroline Bardini (Member Mathematics Expert Group) John Dowsey (Mathematics instruments and test development) Derek Holton (Mathematics instruments and test development) Kaye Stacey (Chair Mathematics Expert Group)

\section{Other experts}

Michael Besser (Mathematics instruments and test development, University of Kassel, Germany)

Khurrem Jehangir (Data analysis for TAG, University of Twente, Netherlands)

Kees Lagerwaard (Mathematics instruments and test development, Institute for Educational Measurement of Netherlands, Netherlands)

Dominik Leiss (Mathematics instruments and test development, University of Kassel, Germany)

Anne-Laure Monnier (Consultant French source development, France)

Hanako Senuma (Mathematics instruments and test development, Tamagawa University, Japan)

\section{Publication layout}

\author{
Fung Kwan Tam
}




\section{ORGANISATION FOR ECONOMIC CO-OPERATION AND DEVELOPMENT}

The OECD is a unique forum where governments work together to address the economic, social and environmental challenges of globalisation. The OECD is also at the forefront of efforts to understand and to help governments respond to new developments and concerns, such as corporate governance, the information economy and the challenges of an ageing population. The Organisation provides a setting where governments can compare policy experiences, seek answers to common problems, identify good practice and work to co-ordinate domestic and international policies.

The OECD member countries are: Australia, Austria, Belgium, Canada, Chile, the Czech Republic, Denmark, Estonia, Finland, France, Germany, Greece, Hungary, Iceland, Ireland, Israel, Italy, Japan, Korea, Luxembourg, Mexico, the Netherlands, New Zealand, Norway, Poland, Portugal, the Slovak Republic, Slovenia, Spain, Sweden, Switzerland, Turkey, the United Kingdom and the United States. The European Union takes part in the work of the OECD.

OECD Publishing disseminates widely the results of the Organisation's statistics gathering and research on economic, social and environmental issues, as well as the conventions, guidelines and standards agreed by its members. 


\section{PISA 2012 Results: \\ What Students Know and Can Do \\ STUDENT PERFORMANCE IN MATHEMATICS, READING AND SCIENCE VOLUME I}

The OECD Programme for International Student Assessment (PISA) examines not just what students know in mathematics, reading and science, but what they can do with what they know. This is one of six volumes that present the results of the 2012 PISA survey, the fifth round of the triennial assessment.

Volume I, What Students Know and Can Do: Student Performance in Mathematics, Reading and Science, summarises the performance of students in PISA 2012.

Volume II, Excellence through Equity: Giving Every Student the Chance to Succeed, defines and measures equity in education and analyses how equity in education has evolved across countries between PISA 2003 and 2012.

Volume III, Ready to Learn: Students' Engagement, Drive and Self-Beliefs, explores students' engagement with and at school, their drive and motivation to succeed, and the beliefs they hold about themselves as mathematics learners.

Volume IV, What Makes Schools Successful? Resources, Policies and Practices, examines how student performance is associated with various characteristics of individual schools and school systems.

Volume V, Skills for Life: Student Performance in Problem Solving, presents student performance in the PISA 2012 assessment of problem solving, which measures students' capacity to respond to non-routine situations.

Volume VI, Students and Money: Financial Literacy Skills for the 21st Century, examines students' experience with and knowledge about money.

\section{Contents of this volume}

Chapter 1. What is PISA?

Chapter 2. A profile of student performance in mathematics

Chapter 3. Measuring opportunities to learn mathematics

Chapter 4. A profile of student performance in reading

Chapter 5. A profile of student performance in science

Chapter 6. Policy implications of student performance in PISA 2012

Consult this publication on line at: $\boldsymbol{h t t p : / / d x . d o i . o r g / 1 0 . 1 7 8 7 / 9 7 8 9 2 6 4 2 0 8 7 8 0 - e n ~}$

This work is published on the OECD iLibrary, which gathers all OECD books, periodicals and statistical databases. Visit www.oecd-ilibrary.org and do not hesitate to contact us for more information.

\section{4}

